Historic, Archive Document

Do not assume content reflects current

scientific knowledge, policies, or practices. 

ENOMOLOGY ELAS-CRAM WOH
UNITED STATES DEPARTMENT OF AGRICULTURE LIBRARY

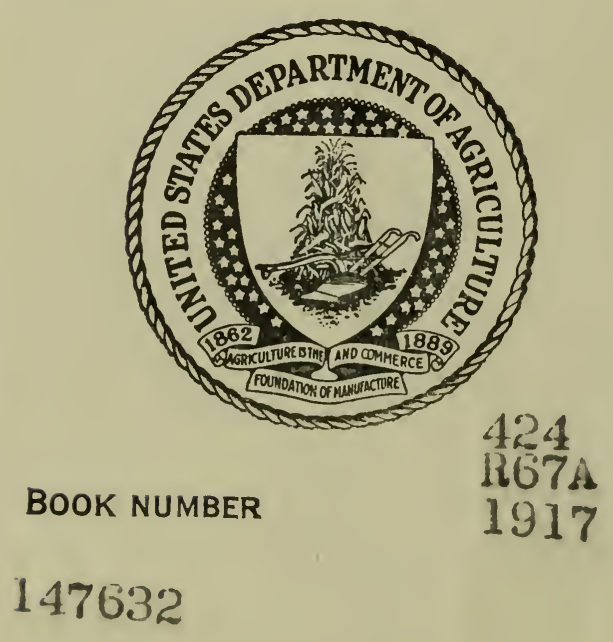




To the throng of eager questioning brother's and sisters in the art of bee culture, in our own and other countries, this work is especially dedicated. The Authors. 



\section{THE}

A B C and $\mathrm{X}$ Y Z

$\mathrm{OF}$

BEE CULTURE

A Cyclopedia of Everything Pertaining to the Care of the Honey - bee; Bees; Hives, Honey, Implements, Honeyplants, etc. Facts Gleaned from the Experience of Thousands of Beekeepers, and Afterward Verified in Our Apiary.

By A. I. and E. R. Root

161st Thousand

MEDINA, OHIO

THE A. I. ROOT COMPANY

1917 


\section{7 \\ MAR 3! 1917}

(C) CIAH60109

2uo 2 


\section{I877 Preface}

In preparing this work I have been much indebted to the books of Langstroth, Moses Quinby, Prof. A. J. Cook, King, and some others, as well as to all of the bee-journals; but, more than to all these, have I been indebted to the thousands of friends scattered far and wide who have so kindly furnished the fullest particulars in regard to all the new improvements as they have come up in our beloved branch of rural industry. Those who questioned me so much a few years ago are now repaying by giving me such long kind letters in answer to any inquiry I may happen to make that I often feel ashamed to think what meager answers $\mathrm{I}$ have been obliged to give them under similar circumstances. A great part of this A B C book is really the work of the people; and the task that devolves on me is to collect, condense, verify, and utilize what has been scattered thru thousands of letters for years past. My own apiary has been greatly devoted to testing carefully each new device, invention, or process as it came up. The task has been a very pleasant one, and if the perusal of the following pages affords you as much pleasure I shall feel amply repaid.

November, 1877.

A. I. Root.

\section{Preface to the I9I7 Edition}

Nearly forty years have elapsed since the original edition of this work, then consisting of 200 pages, was placed before the public. Since that time great changes have taken place in the beekeeper's world. Beekeeping was hardly known then as a business; but now it has grown to enormous proportions. Thousands of colonies are today handled by single individuals and by syndicates, and honey is shipped by the carload and almost by the shipload to various parts of the world. The wonderful and almost startling strides in commercial beekeeping have brought about new methods of management as well as new appliances. While the fundamental methods of keeping bees are the same, the details have been materially modified.

The remarkable growth of the industry has called for numerous editions of this work. Failing health and cares of a rapidly growing business made it impossible for the original author, A. I. Root, to make the revisions necessitated by the newer conditions. That task, since the second edition, has devolved principally on his oldest son, the author and reriser, who has been ably assisted by his brother, H. H. Root.

Little did A. I. Root dream in 1879 that his work would continue to grow, not only in the size of the book itself, but in the size of the editions, until a grand total of 161,000 copies have come off the press. The original work consisted of 212 pages, while the present rolume contains 850 . Altho it was originally intended as a work for the beginner only, it has continued to develop in size and maturity until it is now the $\mathrm{X} \mathrm{Y} \mathrm{Z}$ as well as the A B C of bee culture-admittedly the largest work from the standpoint of actual matter that has erer been issued on bees in any language. While it is more than ever a work for be- 


\section{PREFACE}

ginners, it is likewise more than ever a work for the advanced beekeeper. For the former class it contains more articles than it ever has had before; and for the latter class almost every known method that has proved successful in the hands of our best producers has been incorporated in the present rolume.

In 1885 the author and reviser, owing to the ill health of his father, gradually assumed the editorial work on Gleanings in Bee Culture, and at the same time the revision of the A B C of Bee Culture, then a modest work of only 250 pages. Since that time he has prepared most of the matter on the practical management of bees for the last twelve editions. In order that he might be the better fitted to do this work he traveled extensively over the Inited States, with camera and note book, visiting some of the best beekeepers in the United States and Canada. This, together with voluminous correspondence in connection with bee culture, has enabled him to present, as he hopes, in this volume the very latest practices to be found in this country.

In addition to all this, the author and reviser has thought it adrisable to call in the help of other's. Foremost among them has been Dr. C. C. Miller, the veteran comb-honey producer, now 86 years old-a man who bridges the past and present, and one who is well known in Europe. He rendered important and valuable aid in the preparation of the articles on comb-honey production and swarming, with which he is so intimately familiar.

In the line of the scientific and technical, the author acknowledges his indebtedness to Dr. E. F. Phillips, Apicultural Expert in the Bureau of Entomology, Washington, D. C. $\mathrm{He}$ is a trained entomologist-one who likewise has traveled extensively over the United States. He is also author of the book "Beekeeping," published by the McMillan Co., New York. Mr. G. F. Demuth, his assistant in the Bureau, one who is a practical combhoney producer as well as an expert on the subject of swarming, has rendered helpful advice in both subjects.

A younger brother, $\mathrm{H} . \mathrm{H}$. Root, who has done special work in the matter of extracting honey in a large way, and has conducted a long series of experiments in wax-rendering, lias written the articles on Buildings, Extracting, and Wax. Besides this he has read much of the proof.

Mr. John W. Love, of the Cleveland Plain Dealer, besides writing the articles on Alfalfa and Sweet Clover, for which he was eminently fitted, also offered many suggestions that were adopted.

The technical articles on Honey, Glucose, Invert Sugar, Sugar and Honey Analysis. were prepared by A. Hugh Bryan, formerly of the Bureau of Chemistry, Washington, D. C. While in the Bureau he specialized on the subject of honey; so it is safe to say that what Mr. Bryan has written is technically correct.

Articles on bee botany required some one who was not only a botanist, entomologist. and naturalist but one who was also a beekeeper. That rare combination was found in Mr. John H. Lovell, of Waldoboro, Maine, who prepared nearly all the articles on honey-plants. He was assisted in his work by Prof. Edwin G. Baldwin, of DeLand University, Florida.

In the matter of laws relating to bees and beekeeper's' rights, it seemed necessary to have one who was not only a beekeeper but a lawyer. Mr. Leslie Burr. who has kept bces in several states of the Union, who is now a practicing attorney in Honolulu, wrote the article entitled "Laws Relating to Bees."

The articles on the Anatomy of the Honeybee and the Sense Organs of the Honeybee have been witten by government experts in the Bureau of Entomology, Washington, D. ('., reference to whom is made later in this preface.

Last, but by $n 0$ means least, the writer acknowledges his indebtedness to his fathor, A. I. Rout, with whom he was associated in his early experimental work from the late 60 \% up to 1885, when ill health ampelled the senior Mr. Root to take up other matters. It was $A$. I. Root who wonceived the idea of an A B C book for the beginner, on the plan 


\section{PREFACE}

of an encyclopedia that could be frequently reviser. To that end he had it set up originally in standing type. It was he who looked far enough ahead to see that beekeeping was a rapidly advancing industry, and that any book on the subject would soon be out of date unless it were frequently revised. That his rision was not an idle one is attested by the fact that some fifteen editions, consisting of 161,000 copies in all, have come from the press. The matter for the book is now set up on a modern linotype, and the whole of this edition has been reset.

While A. I. Root's name does not appear in any individual article, yet much of his original matter is scattered thruout the work. Some of it will never be stricken out, because it was fundamentally right for all time. His Preface and Introduction of 1877 , for example, will always be retained.

Taking it all in all, it will be seen that this work is the product of many minds. While the reviser has written probably four-fifths of the matter, yet he feels that it is only right that he should acknowledge his indebtedness to all of those who have so kindly assisted him during the forty years that have made the A B C and $\mathrm{X} \mathrm{I} \mathrm{Z} \mathrm{of} \mathrm{Bee} \mathrm{Culture} \mathrm{what} \mathrm{it}$ is and has been.

This edition differ's also from its predecessor's in that it has more elementary articles on bees and beekeeping than ever before. The A B C of Beekeeping, for example, at the rery beginning of the work, assumes that the reader has had practically no knowledge of bees; and it proceeds, therefore, to give him a general scope of the fundamentals of the industry before he plunges into the general articles. All thru the work there are articles for beginners, such as Beginning with Bees, Backlot Beekeepers, The Farmer Beekeeper, Transferring, and almost every article starts out with a definition of the subject in hand, so that the novice may more readily understand that which follows.

Each article is a complete monograph, or a little text-book in itself, on the subject of which it treats. While there are numerous cross-references from one article to another, an effort was made to get almost everything pertaining to any one subject under that subject's particular head. The numerous cross-references in the articles themselves, together with a very complete index, will enable the intelligent reader to develop each subject thoroly if he will carry the work into the beeyard and test out every teaching. Herein he will soon have a thoro knowledge of the business.

As in the former editions, so in this one, many old articles have been reclassified, and some of them have been divided into shorter articles in order to facilitate reference. For example, Comb Honey appears as three subjects, namely: Comb Honey; Comb Honey, Appliances for; and Comb Honey, Production of. In a like manner, Wintering has been split up as follows: Wintering; Wintering Outdoors; Wintering in Cellars; Wintering in the South. Formerly all these were comprised under one head-Wintering; and when the reader was referred to that head it was like trying to find a reedle in a haystack to find the paragraph looked for.

The following is the list of the entirely new articles that were written for this edition:

Foreword; A B C of Beekeeping; Breeding Stock; Brood and Brood-rearing; Building; Bumblebees; Comb; Cucumbers; Dandelion; Drifting; Dzierzon; Dzierzon Theory; Farmer Beekeepers; Frames; Honey, Analysis of ; Inventions Relating to Bee Culture; Inspectors; Invert Sugar; Isle of Wight Disease; Playsspells of Young Bees; Sense Organs of the Honeybee; Shipping Bees; Solitary Bees; Temperature.

The following subjects have been entirely rewritten or greatly revised for this edition :

Adulteration; Alfalfa; Apiary; Aster; Bottling Honey; Box Hives; Clover; Cotton; Comb Foundatiou; Diseases of Bees; Extracted Honey; Extracting; Feeding and Feeders; Feeding Outdoors; Foul Brood; Fruit-bloom; Gallberry; Glucose; Grading Comb Honey; Granulated Honey; Hives; Honey; Honey as a Food; Horsemint; Hybrids; Introducing; Italian Bees; Laws Relating to Bees; Laws, Foul-brood; Locust; Manipulation of Colonies; Marketing Honey; Milkweed; Nectar; Nucleus; Observation Hives; Out-apiaries; Overstocking; Pollen; Queens; Queen-rearing; Robbing; Sage; Spacing Frames; Stings; Swarming; Sweet Clover; Transferring; Uniting; Water for Bees; Wax; Wintering Outdoors: Wintering in Cellars; Wintering in the South. 
In order that the reader may be able to trace authorship, the following has been prepared, emphasizing the statement that this book is the result of the work of many minds.

ARTICLES WRITTEN BY E. R. ROOT.

Foreword; A B C of Beekeeping; Apiary; Artificial Fertilization; Backlot Beekeeping; Barrels; Beespaces; Bees and Fruit-growing; Bees and Poultry; Bees and Truck Gardening; Bees as a Nuisance; Bees Attacking Fruit; Bees on Shares; Beginning with Bees; Bleaching Comb Honey; Bottling Honey; Box Hives; Breeding; Comb Honey; Comb Honey, to Produce; Combs; Contraction; Diseases of Bees; Dividing; Drifting; Drones; Dysentery; Enemies of Bees; Entrances of Hives; Farmer Beekeepers; Feeding and Feeders; Feeding Back; Feeding Outdoors; Flight of Bees; Foul Brood; Gloves for Handling Bees; Grading Comb Honey; Granulated Honey; Hermaphrodite Bees; Hive-making; Hives; Honey and its Colors; Honey-dew; Honey-exhibits; Honey-peddling; Hybrids; Increase; Inspectors; Introducing; Inventions Relating to Bees; Italianizing; Laying Workers; Locality; Manipulation of Colonies; Marketing Honey; Migratory Beekeeping; Moth-miller; Moving Bees; Nucleus; Overstocking; Playspells of Young Bees; Poisonous Honey; Profits in Bees; Propolis; Queen-rearing; Queens; Races of Bees; Rats; Recordkeeping of Hives; Reversing; Robbing; Sage; Scale Hive; Shipping Bees; Shipping cases for Comb Honey; Skeps; Spacing Frames; Specialty in Bees; Specific Gravity of Honey; Spreading Brood; Spring Dwindling; Spring Management; Statistics of the Bee and Honey Business; Stings; Swarming; Temperature; Transferring; Uniting Bees; Veils; Ventilation; Vinegar; Wintering; Wintering Outdoors; Wintering in Cellars; Wintering in the Southern States.

Articles written conjointly by E. R. Root and A. I. Root.-Absconding Swarms; After-swarming; Age of Bees; Ants; Anger of Bees; Artificial Heat; Artificial Pasturage, Bee-hunting; Brood-rearing; Candy for Bees; Italians.

Articles written conjointly by E. R. Root and H. H. Root.-Smoke and Smokers; Comb Honey, Appliances for; Honey-comb; Honey as a Food.

Articles written conjointly by E. R. Root and Dr. C. C. Miller.-Langstroth; Out-apiaries.

Articles written by J. W. Love.-Alfalfa; Sweet Clover.

Articles written conjointly by E. R. Root and Arthur C. Miller.-Observatory Hives.

Articles written conjointly by E. R. Root and J. H. Lovell.-Buckwheat; Clover; Dzierzon Theory; Fruit-blossoms; Pollen; Pollination of Flowers; Tupelo.

Articles written conjointly by E. R. Root and W. K. Morrison.-Ants.

Articles written by H. H. Root.-Buildings; Extracted Honey; Extracting Honey; Wax.

Articles written by L. C. Root.-Quinby.

Articles written by J. H. Lovell.-Bumblebees; Campanilla; Canada Thistles; Carpet Grass; Catclaw ; Catnip; Cotton; Cucumber; Dandelion; Figwort; Gallberry; Goldenrod; Heartsease; Holly; Honey-plants ; Hoarhound; Horsemint; Huajilla ; Locust; Logwood; Marigold; Mesquite; Milkweed; Mustard; Poplar-tree; Raspberry; Solitary Bees; Sourwood; Spanish Needle; Sumac; Sunflower; Willow.

Articles written by Prof. E. G. Baldwin, Deland University, Florida.-Magnolia; Mangrove; Orange; Palmetto; Partridge Pea; Pennyroyal; Phacelia; Titi; Wild Cherry.

Articles written by A. Hugh Bryan. formerly of Bureau of Chemistry, Washington, D. C.-Cane Sugar; Glucose; Honey, Analysis of ; Honey; Invert Sugar; Labels for Honey; Sugar.

Anatomy of the Bee by R. E. Snodgrass, Bureau of Entomology, Washington.

Bee Behavior, by A. C. Miller.

Beekeeping for Women, by Mrs. J. H. Comstock.

Development of Bees, by James A. Nelson, Bureau of Entomology, Washington, D. C.

Dzierzon, British Bee Journal.

Eye; Parthenogenesis, by Dr. E. F. Phillips, Bureau of Entomology, Washington, D. C.

Laws Relating to Bees, by Leslie Burr.

Sense Organs of the Bee, by McIndoo, Bureau of Entomology, Washington.

April 1, 1917.

E. R. Root. 


\title{
Introduction to the First Edition
}

\author{
BY A. I. ROOT.
}

About the year 1865, during the month of August, a swarm of bees passed overhead where we were at work, and my fellow-workman, in answer to some of my inquiries respecting their habits, asked what I would give for them. I, not dreaming he could by any means call them down, offered him a dollar, and he started after them. To my astonishment, he, in a short time, returned with them, hived in a rough box he had hastily picked up, and, at that moment, I commenced learning my A B C in bee culture. Before night I had questioned not only the bees but every one I knew, who could tell me anything about these strange new acquaintances of mine. Our books and papers were overhauled that evening; but the little that I found only puzzled me the more, and kindled anew the desire to explore and follow out this new hobby of mine; for, dear reader, I have been all my life much given to hobbies and new projects.

Farmers who had kept bees assured me that they once paid, when the country was new, but of late years they were no profit, and everybody was abandoning the business. I had some headstrong views in the matter, and in a few days I visited Cleveland, ostensibly on other business, but I had really little interest in anything until I could visit the bookstores and look over the books on bees. I found but two, and I very quickly chose Langstroth. May God reward and for ever bless Mr. Langstroth for the kind and pleasant way in which he unfolds to his readers the truths and wonders of creation to be found inside the beehive.

What a gold-mine that book seemed to me as I looked it over on my journey home! Nerer was romance so enticing-no, not even Robinson Crusoe; and, best of all, right at my own home I could live out and verify all the wonderful things told therein. Late as it was, I yet made an observatory hive and raised queens from worker eggs before winter, and wound up by purchasing a queen of Mr. Langstroth for $\$ 20.00$. I should, in fact, have wound up the whole business, queen and all, most effectually, had it not been for some timely advice toward Christmas, from a plain practical farmer near by. With his assistance, and by the purchase of some more bees, I brought all safely thru the winter. Thru Mr. Langstroth I learned of Mr. Wagner, who shortly afterward was induced to recommence the publication of the American Bee Journal, and thru this I gave accounts monthly of my blunders and occasional successes.

In 1867, news came across the ocean from Germany, of the honey-extractor; and by the aid of a simple home-made machine I took $1000 \mathrm{lbs}$. of honey from 20 stocks, and increased them to 35 . This made quite a sensation, and numbers embarked in the new business; but when I lost all but 11 of the 35 the next winter, many said, "There! I told you how it would turn out."

I said nothing, but went to work quietly and increased the 11 to 48 during the one season, not using the extractor at all. The 48 were wintered entirely without loss, and I think it was mainly because I took care and pains with each individual colony. From the 48 I secured $6162 \mathrm{lbs}$. of extracted honey, and sold almost the entire crop for 25 cents per lb. This capped the climax, and inquiries in regard to the new industry began to come in from all sides. Beginners were eager to know what hives to adopt, and where to get honeyextractors. As the hives in use seemed very poorly adapted to the use of the extractor, 


\section{INTRODUCTION}

and as the machines offered for sale were heavy and poorly adapted to the purpose, besides being "patented," there really seemed to be no other way before me than to manufacture these implements. Unless I did this I should be compelled to undertake a correspondence that would occupy a great part of my time without affording any compensation of any account. The fullest directions I knew how to give for making plain simple hives, ete., were from time to time published in the American Bee Journal; but the demand for further particulars was such that a circular was printed, and, shortly after, a second edition; then another, and another. These were intended to answer the greater part of the queries; and from the cheering words received in regard to them it seemed that the idea was a happy one.

Until 1873 all these circulars were sent out gratuitously; but at that time it was deemed best to issue a quarterly at 25 cents per year, for the purpose of answering these inquiries. The very first number was received with such favor that it was immediately changed to a monthly at 75 cents. The name of it was Gleanings in Bee Culture, and it was gradually enlarged until, in 1876 , the price was changed to $\$ 1.00$. During all this time it has served the purpose excellently of answering questions as they came up, both old and new ; and even if some new subscriber should ask in regard to something that had been discussed at length but a short time before, it is an easy matter to refer him to it or send him the number containing the subject in question.

When Gleanings was about commeneing its fifth year, inquirers began to dislike being referred to something that was published half a dozen years before. Besides, the decisions that were then arrived at perhaps needed to be considerably modified to meet present wants. Now you can see whence the necessity for this A B C book, its office, and the place we propose to have it fill.

December, 1878.

A. I. Root. 



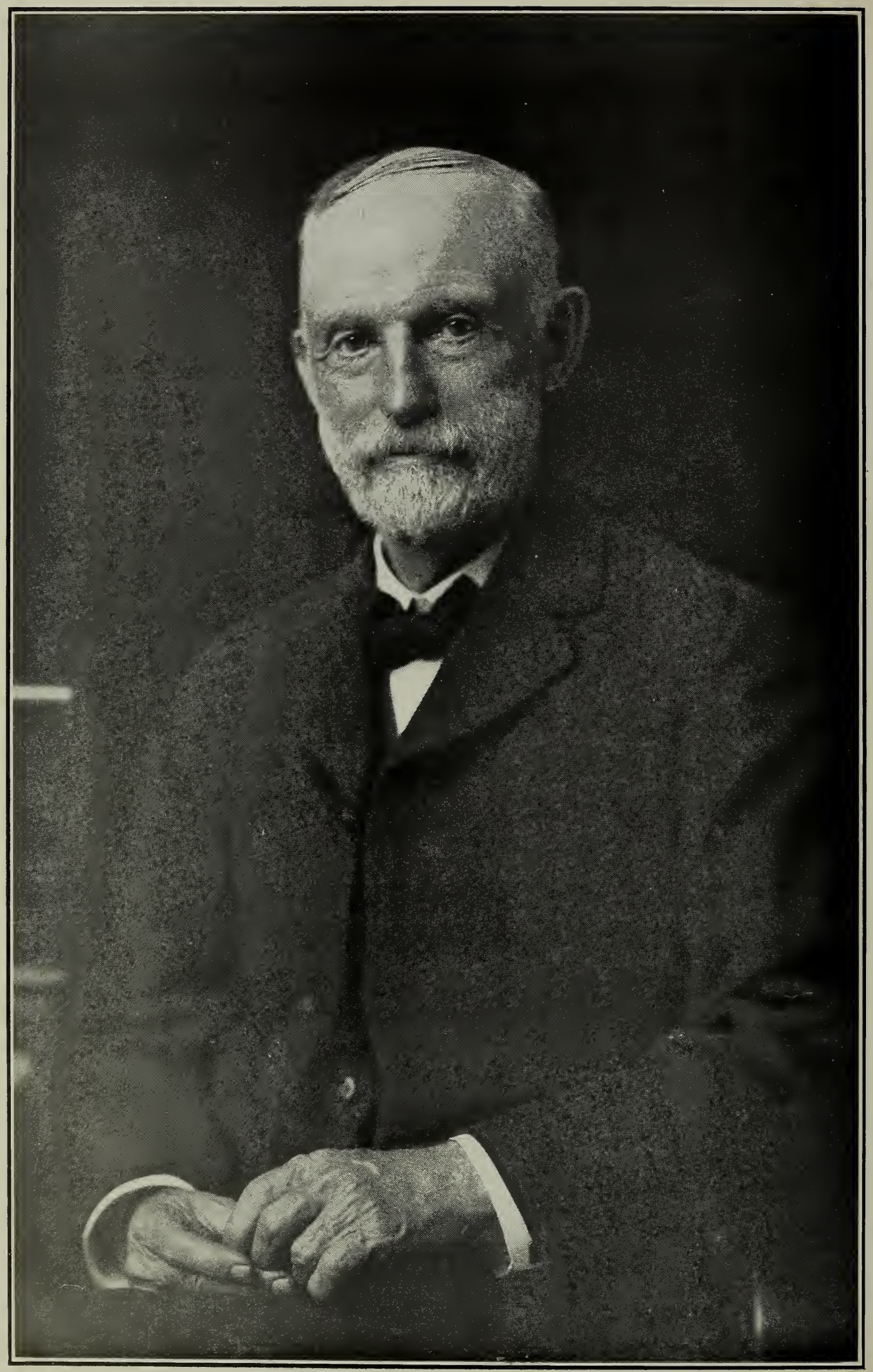

A. I. ROOT. 


\section{Foreword}

It is hardly necessary to remind the reader that this is an encyclopaedia on bees. It should not therefore be read consecutively, but taken up subject by subject in the order indicated later. A preliminary statement should first be made in order that the beginner, at least, may be able to form at the very outset some idea of the scope and character of the industry which he is to study.

Bees have been kept from time almost immemorial. Reference to bees and "honey in the honeycomb" appear all thru ancient history. Honey, aside from the sugar in fruit, was the only sweet then known, and hence was always highly prized. Bees were kept in caves, earthen jars, old logs, straw baskets or skeps. When man contrived the art of making boards out of trees he constructed rude boxes which were called gums or hives. The skeps were made of braided straw, and these are still used to a considerable extent in Europe among the peasant classes who cannot afford modern equipments, and who lack, even more, the mental capacity to put into effect modern metbods. See "Skeps."

The keeping of bees in the old days was but little more than an avocation or sideline in connection with some other business or profession. While the great majority of the beekeepers of today are probably amateurs or back-lotters, those who keep a few bees for pleasure and profit, there are now thousands upon thousands who make beekeeping a vocation; that is, their sole means of livelihood. Their colonies are numbered by the hundreds and even thousands, and their annual production of honey is measured by the ton and carload. While there were a few, both in Europe and America, who had as many as two or three hundred colonies, and produced honey by the ton, beekeeping as a specialty and as an exclusive business was scarcely known until after the advent of the movable-frame hive of Langstroth and the honey-extractor of Hruschka. See "Hives" and "Extractors." These inventions revolutionized the industry to such an extent that it is now possible for the beekeeper so to manipulate his colonies that he can produce tons where he could produce only pounds before.

The time was when Moses Quinby, in the 50's, and that was before the invention of the movable-frame hive by Langstroth, sent a canalboat-load of honey to the city of New York. This was more than the metropolis had ever seen before-so much honey, indeed, that it "broke down the market," and the honey went begging for a customer. Now, in these latter days that same market is able to dispose of hundreds and hundreds of carloads of honey that has been shipped in from all over the United States, but mainly from the irrigated regions of the West.

In addition to the specialist class of beekeepers there are many hundreds of thousands who keep a few bees in the back yard in cities and towns. There is also another large class, the farmer beekeepers, who keep a few bees on the farm, not only for the purpose of pollinating their fruit trees, the clovers and buckwheat, but to supply the family table with honey, the purest and best sweet in the world.

A conservative estimate would place the total number of persons who keep bees, either as a rocation or as an avocation, anywhere from 750,00 to $1,000,000$ in the United States alone. If we estimate that the average beekeeper owns ten colonies, we shall have $10,000,000$ hives of bees. 
On a very conservative estimate, based on United States statistics and on the record of sales of the largest bee-supply factories in the United States, there is at least $\$ 20,000,000$ worth of honey produced annually in the United States, and something like $\$ 2,000,000$ worth of beeswax. The business of keeping bees has grown to be so enormous that there are several large bee-supply manufacturers who send out carloads of hives and honey-boxes all over the United States and to foreign countries. The aggregate capital of these factories would run over a million dollars.

Nearly every agricultural paper contains some matter on bees; and every now and then there will appear in the standard magazines an article on honey as a food; how to use honey for baking, cooking, and canning; why honey as a sweetener is superior to ordinary cane sugar. See "Honey" and "Honey as a Food.'

Modern appliances and modern methods have now made it possible for specialists, backlotters, and farmers, to handle bees with few or no stings; to take the honey away without destroying the hives, combs, or bees-indeed, they all alike find both pleasure and profit in the study and in the handling of these wonderful little insects, that, in the language of the day, "work for nothing and board themselves." While this is not literally true, of course, the little fellows will toil day in and day out and allow their owner to take the product of their toil before their very eyes, and rob them day after day, without so much as offering a single sting, that is, provided, of course, their owner knows how. It is the province of this work to show "how" all these things can be done and are being done by many thousands scattered all over the United States.

The modern movable frame, as already mentioned, has made it possible for the owner of bees to go clear thru his hives, remove the combs, inspect every portion of the hives and the bees. After learning their condition he can put the combs back, close the hive up, and, if he follows directions, he will probably receive no stings.

The use of the bee-smoker and bee-veil to protect the face, and sometimes gloves for the hands of the more timid, has made it also possible for the owner to play with bees as he might with kittens; to rob them of their honey whenever he sees fit; to invade their homes; to take away their queen; to take everything they have, if he is so minded, without a protest and without a sting.

In this connection it would be unfair to state that the modern beekeeper never receives any stings. He certainly does; but when he knows the modern methods that are taught in this work or any other standard book on bees, the bugaboo of stings fades away.

As a matter of fact the beekeeper receives comparatively few stings, and what he does receive leave no after-effect in swelling, because his system soon becomes immune to the poison, and, beyond the sharp prick of pain which lasts for a full minute, there is no local fever or swelling.

The modern bee-smoker (see "Smokers") will quiet bees, and, when necessary, and that is not often, drive them down thru the combs in utter confusion. In fact, smoke so diverts their attention from the thought of defense and offense that they become passive and tractable. While the smoker may be used as a means of control, it also in the hands of an ignorant or careless person may be used as an instrument of torture. If instructions are followed there will be no need of causing any pain, much less of killing any bees by its use. See "Stings" and "Smokers.",

Reference has already been made to the fact that honey is being used as a food as it never was before. See "Honey," "Honey as a Food," "Extracted Honey," and "Comb Honey.' Honey is now found in our best hotels and restaurants, on dining-cars of the great trunk line railroads, and in all of our leading groceries. It is now being put up attractively in comb and liquid form. 
Traveling men are out buying and selling it as a regular commodity. Sometimes they will contract for ten or even twenty carloads at a time. It is then repacked, put up in small packages, and sold to the consuming trade, either direct or at the large wholesale or retail groceries. See " Bottling Honey."

Some of the darker and stronger-flavored honeys are being used by the large baking concerns in making their cakes and cookies. As high as one hundred carloads have been bought at a time for the purpose. Honey is an invert sugar, and as such it keeps the cakes, cookies, and jumbles soft and moist for months at a time. The cakes that contain the most honey are known as "honey jumbles," some of which have kept for a period of twelve years, and were found to be still as good, almost, as the day they were made. See "Honey as a Food.'

The question might be raised at this point whether there are not too many beekeepers already or whether the ten million colonies are not using all the honey or nectar there is in the flowers. The facts are, more nectar goes to waste than is gathered. It has been estimated that from 50 to 80 per cent of it is lost simply because there are no bees in the vicinity to gather it. It is at least conservative, says Dr. Phillips, Apicultural Expert of the Department of Agriculture, in his book, "Beekeeping," to say that ten times as much honey could be produced in localities where there are now no bees or an insufficient number, as is now produced. In other words, the resources of this country could furnish $\$ 200,000,000$ worth of honey. If that much were produced next year the market would certainly be glutted. But experience shows that the increase in the number of beekeepers keeps at about an even pace with the increase in the number of honey consumers, so that by the time the bees produce $\$ 200,000,000$ worth of honey there will be a market for every pound.

The farmers of this country are just beginning to discorer the value of sweet clover as a forage plant for cattle and hogs (see "Sweet Clover"). In many localities it is nearly if not quite the equal of alfalfa. Unlike it, it will grow on poor land, and restores poor soil as almost nothing else will do. The farm papers all over the country are already proclaiming the virtues of sweet clover. The experiment stations extol it everywhere. So far from being a "noxious weed," it is one of the most raluable legumes ever known. Now, sweet clover is a honey-plant-one of the best in this country. When the acreage of this plant is increased, as it is sure to be in the near future, it will be possible to produce not only $\$ 200,000,000$ worth of honey, but even $\$ 500,000,000$ worth. No beekeeper need be alarmed, however, as it may be centuries perhaps before that amount will be secured. We simply mention the resources for honey so that the reader will see there is plenty of room for him in every town and on every farm.

But there is another big factor that will make an enormous increase in the amount of nectar. We made the statement that about $\$ 20,000,000$ worth of honey is produced in the United States alone. If that were all the bees do in this country it would be a fine record. From an economic standpoint they do far more than this. There is no other agency in the world that does such perfect work in pollimation-that is, bringing the pollen of one blossom to that of another-as the honeybees. There are countless thousands of them at a time of the year when comparatively few other insects are present. They therefore make it possible to produce more and better fruit. See "Fruit Blossoms," also "Pollination."

If a limb of an ordinary apple tree, the blossoms of which are sterile to their own pollen, be covered with mosquito netting, before the tree comes to bloom, effectually excluding all insects, including bees, it will be found that not much over two or three per cent of the fruit so covered will mature. The blcssoms will drop as soon as they come into bloom, while those on the uncovered portions of the tree will remain and develop the usual amount of fruit. 
Experiments show that bees are about the only insects that will make a $\ddot{n}$ enormous increase in the amount of fruit. The largest fruit-growers find that they cannot get their full quota of fruit unless they have bees in their orchards, and the growers of bees are now having calls for them as they never did before.

Briefly we have given a general survey of the industry, and now it will be proper to refer the reader to the series of subjects which he should take up. Each will be found in its appropriate alphabetical order; and when these have been read, the reader can then take up the other subjects as he chooses. But we may suggest that, if he can possibly secure a hive of bees, he should do so in order that he may study them intelligently and apply the teachings of this book as he goes along. The following course of reading is suggested:

A B C of Beekeeping; Beginning with Bees ; Anger of Bees ; Manipulation of Colonies ; Apiary ; Smoke and Smokers ; Stings; Hives ; Transferring; Robbing ; Feeding; Backlot Beekeeping; Swarming; Comb Honey; Extracting; Spring Management; Uniting; Wintering. The other subjects may be taken up in any order that may seem best. 


\section{A}

A B C OF BEEKEEPING. - In this article we shall assume that the reader knows absolutely nothing about bees or beekeeping except that "bees sting, and are ready to sting anywhere at any time any one who approaches within a hundred yards of their hive." By reading this article and the one on Stixgs the reader will see that nothing can be furtber from the truth.

Before we proceed further it is important that we take a general birdseye view of the whole industry; and to do that we shall make a brief résumé of the entire contents of this work. The reader, having a comprehensive view of the business, the ways and means and wherefores, will then be able to take up specifically a course of reading as suggested at the close of the Foreword.

There are two different kinds of beessolitary bees (see Solitari BeEs) and social bees, those that live in colonies or communities. There are many species of both kinds; but for the purpose of this work we shall concern ourselves with the social bees and mainly the species known as Apis mellifica, or "honey-makers." This name comes from three Latin words-apis, meaning bee; mel, honey, and faceo, I make. Putting the words together we have Apis mellifica. Some scientists designate them as A pis mellifera, or "honey-bearers," from Apis, a bee, and fero, I bear or carry. But the great majority accept the former name. and we accept it because it is more accurate.

There are three classes of individuals in each colony-namely, the queen bee or true female, the drones, and the worker, or neuter bees as some call them, but more correctly undeveloped females. Each worker-bee is functionally the same as a queenbee except that her tongue, mouth parts, pollen-gathering bristles on the legs, and the sting are more fully developed than the same organs in the only true female, known as the "queen." See Pollen.

A colony of bees may contain anywhere from 25,000 to 75,000 individuals, and in rare cases as high as 100,000 , all the daughters of one queen-bee. But the average good colony for producing honey will run anywhere from 35,000 to 50,000 workers. During the winter this number will be reduced, possibly a half; for Nature apparently goes on the assumption that it is wise not to produce a lot of unnecessary consumers for winter.

The duties of the worker-bees are quite varied. Primarily their business is to gather nectar or honey; but in reality bees gather nectar, and by some mechanical process which no one seems to understand fully, change the nectar, or sucrose, into invert sugar or honey. As a matter of fact, they gather nectar and make it over into honey; hence it comes about that bees actually "make honey."

Bees also gather pollen from the flowers, and store it in combs the same as they store honey. The pollen is used for making a milky-white nitrogenous food into which enters honey to feed the larræ. This food is very much like thin condensed milk. As the larræ derelop this same food or "pap" is made richer and stronger. See DevelopMENT OF BEES.

Bees also gather a kind of glue for making up what we call bee-glue, or propolis. This is used to seal up all cracks that might let cold air into the hive. The word "propolis" is derived from two Greek wordspro, meaning in front, and polis, a city. In ancient times, especially with some strains of Apis mellifica, the bees used this substance in front of the hive to contract the entrance in order to keep out rodents and other insects, hence the name, in front of the city, or propolis.

Torker-bees naturally fall into two divisions-young bees for taking care of young brood, building comb, protecting the entrance against robbers, and in other ways performing the inside work of the hive. The older bees, or "fielders," are those that gather the nectar, pollen, and bee-glue. 
When there are few or no young bees the older ones can and do assume the duties of nurse bees. See BRoOd.

The fully developed, or true female, is what we call the "queen." As already stated, she functionally is much the same as the workers with this difference: Her mouth parts, pollen-gathering apparatus, as well as her sting, are atrophied or aborted, while her ovaries are highly developed. She is capable of laying as many as 5000 eggs in a day, but usually 3000 is the limit. During the height of the season she will not average, probably, over 1500 eggs a day. At the close of the active season she lets up on her egg-laying, sometimes stopping altogether. This seems to be wise provision in nature to prevent the rearing of a lot of useless consumers that would simply use up all the stores before winter comes on. Along in the fall, if there should be a fall flow, egg-laying will start again, and a lot of fresh bees will be reared to make up a colony that will go into winter quarters. The bees that gather the crop luring an active honey season very seldom if ever live to go into winter quarters. The fruit of their toil goes to their successors.

Only one queen-bee, under normal conditions, is allowed in the hive at a time. The worker bees, apparently, are willing to tolerate one or more queens; but evidently the queens themselves are jealous of each other, and, when they meet, a mortal combat follows, during which one of them receives a fatal sting. The reigning queen-bee, then, is often the survival of the fittest. Sometimes mother and daughter will get along very nicely together, but along toward fall the mother disappears. Whether the daughter helps to make away with her, whether she dies of old age, or whether the bees take a hand in the matter, we do not pcsitively know.

Two strange queens, therefore, cannot, as a rule, be put in a hive. (See IntroducING.) The moment they meet they elinch each other in mortal combat, and the one that is successful enough to sting her antagonist comes out the victor. As soon as the vanquished receives her wound she quivers a moment and dies. This is about the only time a queen uses her sting, for she rarely stings a human being, altho she may at times sting a worker.

The average queen-bee will remain the mother of a colony for from two to three years. She may live to be as old as five or six years, but these cases are very rare. Usually a queen over two years old is not worth much, and some believe that a queen over a year should be replaced by younger blood. See AGE of BeEs.

The other individuals in the hive are male bees or drones. Their mouth parts and pollen-gathering apparatus are all very much aborted, and they have no sting. They are completely at the mercy of their sisters, and their only function is to fecundate the queen-bee. This act takes place in the air, for apparently Nature has designed to prerent in-breeding. After the main honeyflow is over, the drones are rudely pushed out at the entrance by their sisters, where they soon starve to death. See Drones.

The average young queen, when she sallies forth in the air on her wedding trip, may or may not find her consort from the same hive, but the probabilities are she will find a drone from some other hive. As soon as the act of copulation has taken place her mate dies. The two whirl around in the air until they drop, when the queen tears herself loose, carrying with her the drone organs. Soon after she enters her hive these are removed by the worker bees, but the spermatic fluid is retained in the spermatheca, where a supply sufficient to last the rest of her life is held. The queen is from that time on able to lay fertilized eggs that will produce bees, and infertile eggs that produce only drones. See BEEs and Drierzon Theory.

The same egg that produces a worker-bee will also produce a queen-bee. The question of whether an egg shall be developed into a queen or an ordinary worker depends almost entirely on conditions. If the bees desire to raise a queen, or several of them, they will build one or more large cells, and feed the baby grubs a special food. (See QueENs and QUEEN-REARING.) In sixteen days a perfect queen will emerge; while in the case of the worker, fed on a coarser food, 21 days elapse.

Such, in brief, is a statement concerning the inmates of the hive and their duties. Before we proceed further it will be proper for us now to say something about the hive. In doing this we shall start with the old box hive of our forefather's, working up to the modern hive which has made it possible for 
us to handle bees with such infinite pleasure and profit.

\section{THE OLD IVAY OF KEEPING BEES.}

The old primitive box hives of our grandfathers, consisting of a rude box (hence the name), was about 12 inches square, and from two to three feet deep. Thru the center were secured two cross-cleats at right angles to each other, to help support the combs. See Box Hrves. This box hive standing on a board or slab usually had a notch at the bottom in front, to provide an entrance and exit for the bees. The bees, when building their combs in such a hive, fastened them to the sides and ends over and around the cross-cleats before mentioned. The combs, when so built, would, of course, permit of no examination nor handling, as do the modern hives; and when it was desired to take the honey, the bees of the heaviest hives in the fall were brimstoned, while those of the lightest were allowed to live over until the next season, to provide for swarms to replace those brimstoned. The honey taken from box hives was mixed with bee-bread and brood, and was of inferior quality. The combs were cut out of the hive and dumped into buckets to be used as necessity required.

The modern hive has long since eliminated these crude and cruel methods, and in their stead we have accessibility to every part; and, so far from destroying our little servants, we can take their honey without a sting if we follow directions. Every comb is now built in movable frames that permit of easy examination. (See Frances.) TVe can open the hive and remove the frames, playing with our pets by the hour if we know how. There is no more alluring pastime for the tired business or professional man or the overworked housewife than the keeping of bees. They all say it's just fun, and it's "fun" that makes money. (See BACKLOT BeEKeEPING.)

THE MODERN HIVE FOR THE PRODUCTION OF COMB AND EXTRACTED HONEY.

The modern hive, or exterior housing, in its simplest form consists of a floor or bottom-board; a hive body (box without cover or bottom) to hold the brood-frames; of supers (shallow box rims) to hold section-holders for the sections or extractingframes for extracted honey; a thin wooden lid, or "super cover," and over the whole a "telescope cover," as shown, to shield the hive from the weather. In addition there's an entrance-contracting cleat that can be remored so that a wide or narrow entrance may be used, depending on the season. In the best-regulated apiaries, hive-stands are used for holding the hives. These protect the bottom and hive proper from unnecessary exposure to the ground and rot, and at the same time provide an easy grade or alighting-board for the convenience of heavily laden bees as they come in from the field. When a bee is filled with honey it nery often drops down a foot or two from the hive. It is, therefore, very important to have an easy runway into the hive proper, and hence the hive-stand provided with an alighting-board, as shown.

Each of the hive parts hele enumerated is separable. One part can be piled on top of another in such a way as to accommodate the largest colonies and the largest yields of honey that may be secured. The modern hive, therefore, is capable of all degrees of expansion, to accommodate any colony or any honey crop. Some large colonies will store enough honey to make a hive four and even five stories high.

\section{BROOD-FRAMES}

Movable frames to hold the combs are called "brood-frames." The tops of these have projections resting upon rabbets cut in the upper ends of the hive. (See diagram, lower right hand.) The end-bars of the frames have, near the top, projecting ends just wide enough so that the combs will be spaced the correct distance apart. Such self-spacing frames for holding the combs are called "Hoffman brood-frames," and any one of them can be removed and replaced. Another set of frames of the same pattern, but shallower, are used for the storage of the surplus honey. These are hung in shallow hives, or "supers," as they are technically called. The honey may be cut out of them and stored in tin cans, or it may be "extracted" from the combs by means of a honey-extractor. See Extract$\mathrm{OR}$.

Every comb has a series of honey-cells on each side, which, when filled with honey, are capped over with a thin film of wax. This capping is sliced off with a sharp-bladed knife made for the purpose, called an "un- 


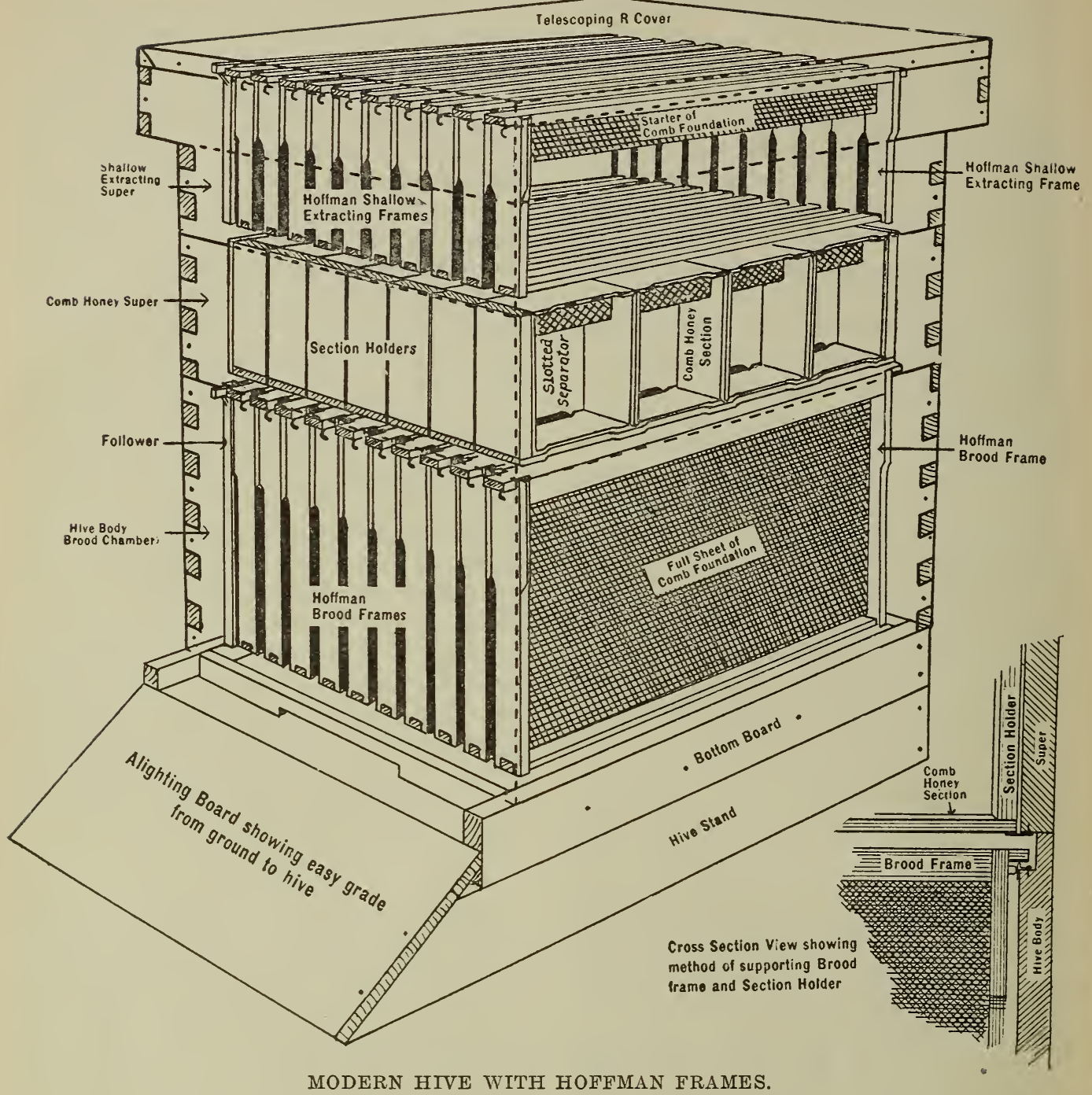

capping-knife." The combs, with the cappings removed, are then placed in the baskets of a centrifugal honey-extractor. These baskets are geared to run at a relatively high rate of speed inside of a metal can. The honey is thrown out by centrifugal force from the side of the comb next to the can. The machine is stopped; the combs are reversed, when the reel is started revolving, throwing the honey out from the other side also. When emptied the combs are put back into the hive and refilled with honey, when they are again extracted as before. This process may be repeated one or more times during the season, or as long: as the honey-flow lasts.

Extracted honey can be produced for less money than that in the comb, because the empty combs can be used over and over again, year after year. As it takes anywhere from 5 to $10 \mathrm{lbs}$. of honey to make a pound of wax, the extracted honey, or honey separated from the comb, saves the bees making comb each time. As a matter of fact, the market price for extracted is but a little more than half that of comb honey.

\section{SECTIONS AND SEPARATORS AS USED IN COMB-} HONEY PRODUCTION.

The production of honey in the comb involves a different set of fixtures. Comb honey is produced in little square boxes technically called "sections." These are usually either $4 \times 5 \times 13 / 8$ inches wide, or $41 / 4$ square by $17 / 8$ wide. These sections, four in number, are placed in a sort of 
frame called a "section-holder." Between each row of sections, when placed on the hive, is a wooden separator consisting of a thin piece of veneer wood a little narrower than the section is deep. Sometimes a series of thin slats, fastened together by cross-cleats technically called "fences," are used in place of separators. The function of the separator or fence is to separate the rows of sections from each other. Without them the bees would build the comb in these sections too fat or too lean. So far as possible it is highly important, from the marketing point of view, to have each comb in each section approximately the same weight -something between 12 and 14 ounces. While the sections will hold an eren pound when filled clear full, ic is very seldom that the producer of comb honey can get his bees to make his sections run uniformly one pound in weight. The arerage market permits and expects that comb-honey sections shall run slightly less than one pound. See Comb HoNey.

\section{COMB FOUNDATION.}

In order to start the bees building their combs centrally in the section, a product known as "comb foundation" (quite generally abbreviated "fdn.") is used. This consists of a thin sheet or sheets of pure beeswax embossed or favosed, so that the surface shall be an exact duplicate of the midrib or center of the honeycomb with the cells sliced off. In other words, comb foundation is a duplicate of the foundation of the natural comb, and hence the name. The artificial product has more wax in the initial cells than the natural product. This surplus is used by the bees in building out their combs. In modern apiculture it is almost an indispensable article. It is used either in narrow strips called "foundation starters," or in full sheets. The latter are preferable, because the bees will build more nearly perfect combs-combs that are flat as a board and a duplicate of the article built wholly by the bees. Without comb foundation the bees will show a tendency to build their own product in all kinds of fantastic shapes, crosswise of the section honey-boxes or the brood-frames. Practically all the combs in modern apiculture today are built on comb foundation. This is filled with honey by the bees, and capped over, and in all respects is equal and even superior to that made by the bees without the use of starters. See Comb Foundation.

\section{TOOLS FOR HANDLING BEES.}

The tools required by a beekeeper for opcning his hives and doing other necessary work in the production of honey are not elaborate. The total outlay need not go above $\$ 3.00$. First and foremost, there must be a bee-smoker-a derice consisting of a store and bellows for blowing smoke from some slow-burning fuel on the bees. Without smoke, many manipulations would be very difficult; and the norice, at least. would be inclined to give up the business after his first experience in trying to handle a colony of bees, especially if weather conditions were unfarorable. But with smoke, and an instrument for applying it, one can, if he knows how, perform all pos-

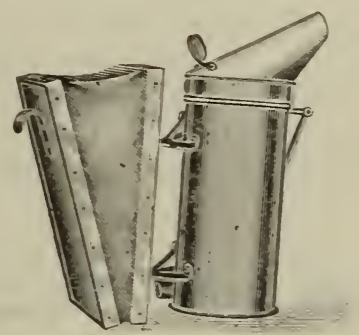

sible manipulations with bees when weather conditions are right. In fact, a large number of beekeepers, except during a time when the wcather is bad, do not use a reil, glores, nor anything else, because an intelligent use of the bee-smoker will often put the bees on their good behavior, to an extent that the use of protectors is rendered useless. Perhaps a majority of honey-producers work with a reil on the hat, but not drawn down except when an angry bee seems disposed to show fight.

The other tool, if it may be so regarded, is designed for face protection. This may be in the form of a wire-cloth cylinder with suitable cape to protect the neck and shoulders, or it may be made of some sort of netting, preferably black, so as to obscure the rision as little as possible. The higherpriced veils of silk Brussels netting offer practically no obstruction to the eres but at the same time give the wearer a sense of security that he cannot otherwise have.

Some beekeepers, wishing to get thru with as large an amount of work as possi- 
ble, and knowing that rapid manipulation has a tendency, in spite of smoke, to make bees sting, wear both bee-reil and gloves; and a few of the careless bunglers go so far as to wear cowhide boots in addition, tucking the trousers into the boots. We do not

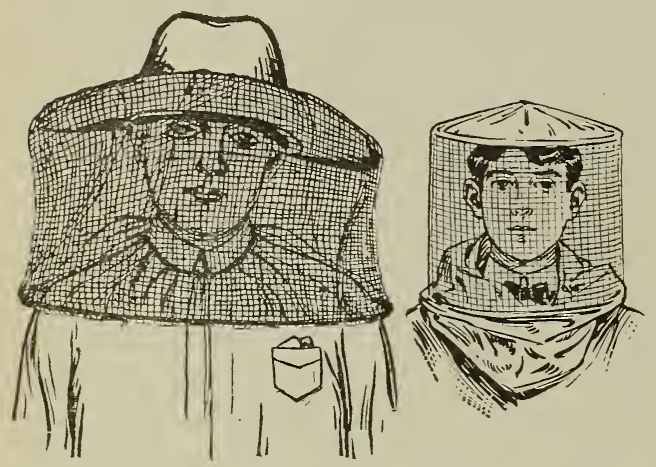

approve of šch bungling slam-bang methods, that only irritate the bees. One will accomplish as much or more in a day, provided he works cautiously and deliberately, using his brains to save making a multiplicity of quick moves. A few slow movements carefully planned will accomplish much with bees.

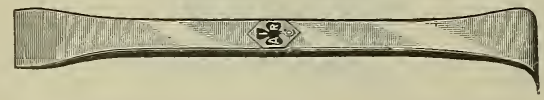

Almost the only other tool required is a strong screwdriver, a knife with a good stiff blade, or, better still, a specially constructed hive-tool made of spring steel with a broad blade for the purpose of a pry or seraper. A tool of some sort is indispensable for separating the frames and the parts

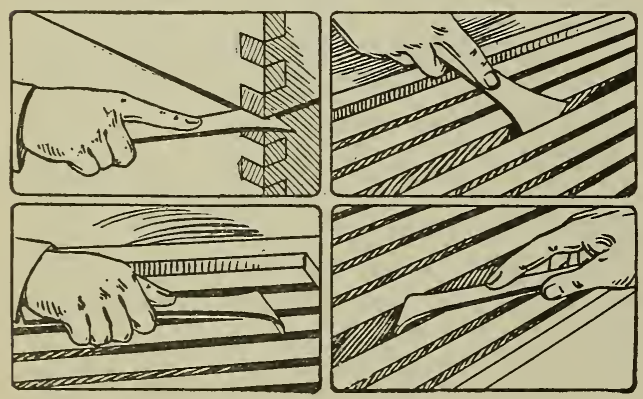

of a hive, because the bees make use of what is known as bee-glue, cementing the frames together. In warm or lot weather this bee-glue does not cause as much trouble in handling the hives as during cold weath- er, when it is stiff and hard. Ordinarily bees should not be handled at such times.

One more tool is sometimes used, and that is a swarming-box or a swarm-basketa device invented by the late A. E. Manum. A wire basket is mounted on the end of a long pole so that a majority of the swarms can be reached and captured from the

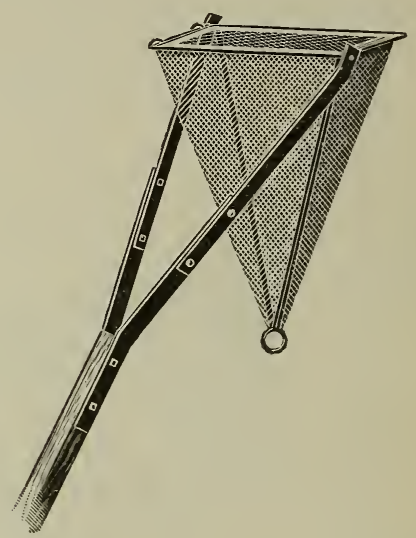

ground. Where the wings of the queen are clipped, as explained under QueEns and Swarming, no such appliance is needed except in instances where a second swarm comes off with a virgin queen.

\section{MANIPULATING A COLONY OF BEES.}

Having now considered the inmates of a hive, the hive itself, and the several parts and the tools for manipulating the same, it is now in order to take up the manipulation of the hive, or the handling of a colony of bees.

The average beginner at this point may feel that he has a job on his hands. He may get stung, when his face will be disfigured so that he will not be presentable to company. While we do not deny he may get stung, the one who tries for the first time to handle bees should protect his hands with gloves and his face with a veil, not because they are absolutely essential, but because it will take away that feeling of fear that might cause him to make a false move and thus incite the bees to sting.

If he will follow the directions that we are now about to give he should not receive a single sting even in his clothing. First of all, it is important that he select a warm day, between ten and three o'clock. After having lighted his smoker (see Srokers), he should put on his veil and gloves and approach his hive. He shculd be sure that 
the smoker delivers a good smoke. The best fuel we have found is old rags or greasy waste, which can be had for the asking at almost any machine shop. The smoke of this is not pungent, but is a bluish white and quite opaque. Care should be taken not to work the smoker bellows too hard, as otherwise the fuel will burst into fiame.

With the smoker just right, blow three or four puffs of smoke into the entrance, and in doing it be careful not to blow in too much smoke, otherwise you will start the bees in the hive on a stampede, especially if they are blacks or hybrids. While bees will not sting in this condition it renders subsequent manipulation exceedingly difficult.

The next movement is to take the screwdriver or hive tool and pry the cover up about a sixteenth of an inch-not wider, because the bees would escape. Thru the gap so made between the cover and hive itself blow in a couple of puffs of smoke. Next gently lift up the cover, following the movement with perhaps two or three light puffs of smoke. It is just as important not to use too much smoke as not enough.

One may now proceed to lift out individual frames. If they are stuck together on account of the bee-glue a little smoke may be required to follow each operation in separating the frames; but usually the smoker can be set down alongside the hive, and frame after frame be lifted out without receiring a single sting.

Care should be taken not to pinch any bees. Always place the fingers at some point where there are no bees. If they are very numerous gently brush them over to one side by pushing the fingers down between them, being careful not to pinch them in doing it.

After one has opened a hive a few times he will be able to discard the gloves, and later he can dispense with the veil at times, because he will find that an intelligent use of the smoker will do more to eliminate stings than any other one thing. After one has acquired a sense of freedom and knows the bees will not sting, he can work over them for hours at a time, getting more real joy out of his pets than from anything else on the place, See MANIPULATION OF COLONIES.
ABNORMALITIES IN BEES. - S e e Hermaphrodite BeEs; also "Drones with Heads of Different Colors," under Drones.

ABSCONDING SWARMS.-No part of animated creation exhibits a greater love of home than do the honeybees. No matter how humble or uninviting the surroundings they seem very much attached to their home; and as they parade in front of their doorway after a hard day's work, they plainly indicate that they have a keen idea of the rights of ownership and exhibit a willingness to give their lives freely, if need be, in defense of their hard-earned stores. It is difficult to understand how they can ever be willing to abandon it altogether, and with such sudden impulse and common consent. No matter if they have never seen or heard of such a thing as a hollow tree, and have for innumerable bee generations been domesticated in hives made by human hands, none the less they have that instinctive longing that prompts them to seek the forest or rocks in mountainous country as soon as they get loose from the chains of civilized man. It is probable that the bees as they go out foraging keep an eye out for desirable places for starting new homes. Indeed, we positively know that they generally have the hollow trees picked out some time before deciding to leave. Many incidents have been reported that prove this beyond question.

We once found our bees working strongly on a particular locality about a mile and a half from the apiary, where the white clover was blooming with most unusual luxuriance. Very soon after, a colony swarmed, and the bces, after pouring out of the hive, took a direct line for a tree in this clover-field, without so much as making any attempt to cluster at all. Did they not figure out the advantage of having only a few rods instead of over a mile to carry their honey, after having patiently gathered it from the blossoms, little by little?

It is very unusual for a swarm to go to the woods without clustering; the bees usually hang from fifteen minutes to an hour, and many times several hours; in fact, we have known them to hang over night, and sometimes stay and build comb; but usually it is better to take care of them inside of fifteen or twenty minutes to make sure of them. Long before sivarming-time, 
hives should all be in readiness, and they should also be located near where the new colony is to stand. If one is going to have a model apiary, he should not think of waiting until the bees swarm before he lays it out, but take time by the forelock, and with careful deliberation decide where every hive shall be before it is stocked with bees, if he would keep ahead and prevent his bees from taking " French leave."

But they sometimes leave, even after they have been carefully hived in modern hives on frames of foundation. If the swarming mania gets under way in a beeyard, a swarm is more apt to come out the second time, even when hived in a new location in a different hive, than where there is only a very little swarming. It was once thought that giving a frame of unsealed brood to these second-time absconders would hold them. While this, no doubt, acts as a restraincr, yet when a swarm leaves its new quarters we would recapture it, hive it back into the hive, and then carry hive, bees, and all down cellar and keep them there several days until they get over their mania. They may then be set out on their permanent summer stands.

How are we to avcid losing the occasional swarm that goes off without clustering at all? or the quite frequent cases of coming out unobserved, or when no one is at home? There is a very certain and safe remedy for all cases of first swarming, in having the wings of the queen clipped, or using an Alley trap so she cannot fly. See QueEns, subhead "How to Clip the Queen's Wings." Wing-clipping is in very general use, and answers excellently for all first swarms; but, alas! the after-swarms are the very ones that are most apt to abscond, and we cannot clip the wings of their queens, because they have not yet taken their wedding flight. What shall we do? In the first place, second or after swarms should not be allowed. If the parent hive, after it has cast its first swarm, is treated as recommended under the head of AFTER-SWARMING, there will be no further swarming from that colony for that season. We recommend the Heddon method, given at the close of AFTER-SWARMING.

Clipping the wings of the queen (or putting on drone-traps-see Drones) will prevent losing first swarms by absconding, it is true; but it does not always prevent losing the queen. She goes out with the bees as usual, and, after hopping about in front of the hive, sometimes gets ready to go back at about the same time that the bees do, after having discovered she is not in the crowd. Even if she gets some little distance from the hive, the loud hum they make as they return will guide her home many times; but unless the apiarist is at hand to look after affairs, many queens will be lost, and the bees will rear a lot of young queens and go into after-swarming in good earnest, making even the first swarm an "after-swarm." A friend, who knows little of bee culture, once told us our bees were swarming, and if we did not ring the bells, etc., they would certainly go to the woods. As we quietly picked up the queen in passing the hive, we told him if they staried to go away we would call them back. Sure enough they did start for the woods, and had gone so far that we really began to be frightened ourselves, when, away in the distance, we saw them suddenly wheel about, and then return to the hive at our very feet. While he gave us the credit of having some supernatural power over bees, we felt ex tremely glad we had taken precautions to clip all our queens' wings but a few days before. After this we felt a little proud of our control over these wayward insects, until a fine swarm of Italians started off under similar circumstances, and, despite our very complacent, positive remarks, to the effect that they would soon come home, they went off and stayed "off." In a humbler, and, we dare say, wiser frame of mind, we investigated, and found they had joined with a very small third swarm of black bees that had just come from one of the neighbor's hives. We tried to "explain," but it required a five-dollar bill to make matters.so clear that we could carry back our rousing swarm of yellow bees, and sort out the black unfertile queen, that they might be made to accept their own.

\section{ABSCONDING FOR WANT OF FOOD.}

Perhaps bees oftener desert their hives because they are short of stores than from any other cause; and many times, in the spring, they seemed to desert because they were nearly out. They issue from the hive, and alight in a tree very much like a normal swarm during the swarming season. The remedy, or, rather, preventive, for this 
state of affairs, is so plain we hardly need discuss $i^{2}$. Aftar they have swarmed out, and are put back into the hire, gire a heavy comb of sealed stores; if that cannot be obtained, feed them a little at a time, until they have plenty, and be sure that they have brood in the combs. If necessary, give them a comb of unsealed larvæ from some other hive, and then feed them until they have a great abundance of food. One should be ashamed of having bees abscond for want of food.

\section{ABSCONDING NUCLEUS SWARMIS.}

A very small nucleus-if it contains no more than a couple of hundred bees-is liable to swarm out. Queen-breeders, in attempting to mate queens in baby nuclei containing only one or two section boxes, had considerable trouble in keeping the bees in the hive, especially when the young queen went out to mate. Accordingly it was found necessary to make the baby hives much larger, with frames $55 \% 8 \times 8$ inches, and two nuclei to a hive. See QUEEN-REARING.

With these there is not much trouble from swarming out, provided that they are well supplied with bees, some brood and honey, and provided also the young queen is taken out as soon as she is laying.

\section{ABSCONDING FOR MORE SATISFACTORY QUARTERS.}

There is still another kind of absconding that seems to be for no other reason than that the bees are displeased with their hive, or its surroundings, and, at times, it seems rather difficult to assign any good reason for their having suddenly deserted. We have known a colony to swarm out and desert their hive because it was too cold and open, and we have known them to desert because the combs were soiled and filthy from dysentery in the spring. They very often swarm out because they are out of stores. and this generally happens about the first day in spring that is sufficiently warm and sunny. We have known them to swarm out because their entrance was too large, and, if we are not mistaken, because it was too small.

We have also known them to swarm out because they were so "pestered" with a neighboring ant-hill-see ANTs-that they evidently thought patience ceased to be a virtue.
ABSCONDING IN THE SPRING.

They often swarm out in the spring where no other cause can be assigned than that they are weak and discouraged, and in such cases they usually try to make their way into other colonies. While it may not always be possible to assign a reason tosuch behavior with medium or fair colonies, we may rest assured that good strong colonies, with ample supplies of sealed stores, seldom, if ever, go into any such foolishness.

It seems to occur just at a time when we can ill afford to lose a single bee, and, worse still, only when our stocks are, generally, rather weak, so that we dislike the idea of losing any of them. In this case they do not, as a general thing, seem to care particularly for going to the woods, but rather take a fancy to pushing their way into some of the adjoining hives, and, at times, a whole apiary will seem so crazy with the idea as to become utterly demoralized.

A neighbor, who made a hobby of small hives-less than half the usual size-one fine April day had as many as 40 colonies leave their hives and cluster together in all sorts of promiscuous combinations. To say that their owner was perplexed, would be stating the matter very mildly.

Similar cases, tho perhaps not as bad, have been reported from time to time, ever since novices commenced to learn the science of bee culture; and altho cases of swarming out in the spring were known once in a great while before the recent improvements, they are nothing like the mania that has seemed to possess entire apiaries-small ones-since the time of artificial swarming, honey-extractors, etc. We would by no means discourage these improvements, but only warn beginners against experimenting before they have had sufficient experience. We would not commence dividing our. bees until they are abundantly strong. They should go into winter quarters with an abundance of sealed honey in tough old combs as far as may be; and should have hives with walls thick and warm, of some porous material, such as chaff or straw, with a good thickness of the same above, then we shall have little cause to fear any trouble from bees absconding in the spring. 
SUMMARY.

If you would not lose your bees by natural swarming, clip the wings of all queens as soon as they commence laying; then look to the hives often, but not necessarily into them, and know what is going on in the apiary every day during the swarming season. If you would not liave runaway swarms in the spring, and while queens are being fertilized, confine your experiments to pecks of bees instead of pints.

ACTIVITIES OF BEES.-See BeE BEHAVIOR.

ADULTERATION OF HONEY. - The adulteration of this product dates back many years, but the methods of detecting the same are of comparatively recent date. Accum, in his "Treatise on Adulterations of Fnod and Culinary Provisions" (one of the earliest works devoted to food adulteration) published in London in 1820, does not cover the subject of honey. Hassall in his "Adulteration Detected," published about 1855, mentions honey. His examinations were made with the microscope, and he was able from the pollen to tell the kinds of flowers visited by the bees. He also noted crystals of sucrose intermingled with those of dextrose when a honey was evaporated to a crystallization point. In his later editions he gives methods for the detection of sucrose and also commercial glucose. The two works cited above were written in England. Hoskins in his book "What to Eat," possibly the first book on food adulteration written by an American, and published in Boston about 1861, states that "Factitious and adulterated honey is very common in our markets. The substances used are generally ordinary sugar, made into a syrup with water, and flavored with different articles. This preparation is usually mixed with genuine honey, and so extensive is this practiced that very little 'Strained Honey' can be found which is pure. The only really injurious adulteration as regards health which I have found in such honey is alum." He noted "Glucose and starch sugar among the adulterants of honey," but never verified their presence. Later work has brought forth the same statements as above, viz., that "If one wants pure honey, he should purchase it in the comb." This statement was possibly true up to the passage of the National Pure-food Law, which went into effect January 1, 1907. Altho just previous to this time extracted honey was not as much adulterated as formerly, due in part to the many state food laws and also, in greater part, to the fact that chemical methods had advanced to a point where adulterations with glucose, sugar syrup, etc., were easily recognized. Part 6 , Bulletin 13, of the Division of Chemistry, U. S. Department of Agriculture (a report of investigations made under direction of Dr. H. W. Wiley about 1890), contains some 75 pages devoted to honey. In this are given numerous analyses of honey. The adulterants noted were glucose, cane sugar, and invert sugar. The number of samples containing glucose were very large (see Glucose, Cane Sugar, Invert Sugar for descriptions of the substances; also ANaLYSIS OF HoNEY for methods of their detection.

Examining the first 4000 Notices of Judgment given pursuant to Section 4 of the Food and Drug Act, published from the office of the Secretary, United States Department of Agriculture, which represents the whole published information on prosecutions under this act up to October 21, 1.15, one finds 12 notices referring to honey.

In one, No. 1123, the product was labeled as containing 8 ounces of honey, but examination showed that the containers were short some 4.86 per cent. In another, No. 352 , the label stated the contents as "one pint," but examination showed much less to be present. Both cases resulted in favor of the Government.

In one, No. 269, the product was labeled "Compound Pure Comb and Strained Honey and Corn Syrup." Analysis revealed that the product was largely composed of corn syrup (commercial glucose) with some comb honey and strained honey. The case was lost by the Government in that it was held that "it was impossible to say what portion of the label as printed would signify greater percentage of the product." In opposition to this, some state laws require that the substances composing a compound should be stated on the label in the order in which they predominate in the finished product.

In the other cases, the adulteration was with invert sugar (see Invert Sugar). Nos: 
18, 19, 20, and 21 refer to shipments in barrels where the only mark was a capital $\mathrm{H}$ enclosed in a square, but this product had been consigned as a pure strained honey. Examination showed it to contain invert sugar and some glucose. The case was not fought in court, the claimant failing to answer a decree of seizure, and condemnation was rendered by the court.

In the other cases, Nos. 3401, 2, 3, 4, and 6 , evidence was introduced on each side, with the result that the jury returned a verdict in favor of the United States. This being' an important case, it is well to give it with some detail. The trial came off in Philadelphia on November 20-25, 1913. The product was placed on the market in 36 and 60 pound cans labeled "Excelsior Choice Pure Strained Honey."

The manufacturer claimed that the mix. ture in the cans consisted of Cuban and buckwheat honey, and that he boiled and strained this. It was koshered for the purpose of selling to the Jewish trade. On direct testimony the manufacturer stated that the skimming was the koshering, but on being recalled to the stand he stated that the boiling and the straining-in fact, the whole process, was the koshering. The judge in his charge to the jury says on this point: "He boils this article that is here in question (the cans of honey), and whether it was for the purpose of koshering it or not is not very clear in his statement, because honey is cleaned by straining it, and it is heated to a certain point, but he says he boils and skims the top off and then strains it, and then he calls it koshered honey." The chemist for the manufacturer gave an analysis similar to the Government chemists', but not as full as theirs. The Government chemists showed that no Cuban nor any buckwheat honey ever contained less than .07 per cent ash. (The chemist for the manufacturer also claimed this.). The sample in question contained only .028 per cent. ash, hence there could be only 40 parts of these honeys in every 100 parts of the mixture, and the other 60 was commercial invert sugar which had no ash. They also showed that the honey in question responded to all the color tests indicative of commercial invert sugar (the manufacturer's chemists claimed that these color tests were produced by the boiling of the pure honey, a point not held by the government chem- ists). The government chemists also showed that the sample under question contained 0.08 per cent tartaric acid, an acid not hitherto found in pure honey, and the acid that is used in making commercial invert sugar (see INvert SugAr). It was also shown that Cuban honey at $4 \frac{1}{2}$ cts. a pound and buckwheat honey at $71 / 2$ cts. a pound used in the mixture in the proportion of 80 parts Cuban to 20 parts buckwheat would cost $\$ 5.10$ a huindred pounds, while with sugar at $61 / 2$ cts. a pound 100 parts of invert sugar would cost $\$ 4.55$ a hundred pounds. Hence a possible motive for the use of the invert sugar.

In the course of his charge to the jury the judge says:

"Every man, woman, and child in the United States when hungry needs food, and when sick needs drugs, but the individual citizen is unable to see to it that the food purchased or the drugs he must purchase are pure, and the Government has taken on itself the work of performing that for the whole people. So that this is a contest for pure food, for the protection of the individual citizen who has not the facilities or the information to protect himself, and it is a very beneficial and commendatory act, because we all know that impure foods are manufactured and sold, and it is against the manufacturer and vendor of these impure foods and the manufacturer and vendor of these impure drugs that this act is aimed, and it has no terrors for the man who manufactures or sells a pure article and brands it what it is. Notwithstanding the attempt to throw a very great deal of doubt and uncertainty over the work of the experts in this case, chemistry has been brought to such a high point of efficiency that it can be told with certainty, or, at any rate, with that degree of certainty which should authorize us to act, what is contained in almost any substance you put into the possession of the expert chemist. They can tell whether or not honey is pure, or whether it has some substance mixed in it, and it may be that they cannot tell it with the same degree of certainty that you can work a geometrical demonstration, but they can say, with a degree of certainty that should authorize us to act, in the examination of questions which come before courts as to whether foods or drugs of a specific kind are pure or adulterated or 
misbranded....... Now you will notice, gentlemen of the jury, that an article is adulterated if any substance has been substituted wholly or in part for the article. It is not the dictionary definition of adulteration. You must take the statutory definition. It makes no difference what the article is, if any substance has been substituted wholly or in part it is an adulteration. There is no question as to whether it is deleterious or injurious to health; it may or may not be; the substitution may be as beneficial or more beneficial than the original article. What the law aims at is to guarantee to the consumer that when he desires to purchase a certain article, and goes to a manufacturer or vendor for that article, and states what he wants, he shall know that he gets what he pays for..... The evidence upon which you will have to rely to ascertain whether it was pure or adulterated, and, if adulterated, misbranded, is the evidence adduced upon the stand by the experts for the Government, and by the experts and the defendant for the defendant."

The jury retired and returned a verdict in favor of the United States Government. On May 13, 1915, final judgment of condemnation and forfeiture was entered, the court finding the product adulterated ard misbranded, and it was ordered that the product should be sold by the United States Marshal, and the owners should pay all costs of the proceedings.

The winning of this case by the Government has stopped much of the adulteration of honey with commercial invert sugar. Furthermore, since the passage and general enforcement of federal and state pure-food laws, honey adulteration, instead of being common, is becoming exceedingly rare.

AFTER-SWARIMING.-We might define this by saying that all swarms that come out, or are led out by a virgin queen, or a plurality of them are generally termed after-swarms; and all swarms after the first swarm are accompanied by such queens. There may be from one all the way up to a half-dozen or even more, depending on the yield of honey, amount of brood or larvæ, and the weather; but whatever the number, they are all led off by queens reared from one lot of queen-cells, and the number of bees accompanying them is, of necessity, less each time. The last ones frequently contain no more than a pint of bees, and, if hived in the old way, would be of little use under almost any circumstances; yet when supplied with combs already built and filled with honey, such as every enlightened apiarist should always keep in store, they may be made the very best of colonies, for they have young and vigorous queens, and often are equal to any in the apiary the next season.

It has been said that when a colony has decided to send out no more swarms, all the young queens in the hive are sent out, or, it may be, allowed to go out with the last one. Whether this is true or not, we cannot say; but every few days during the swarming season, some "new hand" writes us about the wonderful fact of his having found three or four, or it may be half a dozen queens in one swarm. On one occasion, a friend, who weighed something over 200 , ascended to the top of an apple tree during a hot July day to hive a small third swarm. He soon came down, in breathless haste, to inform us that the swarm was all queens; and, in proof of it, he brought two or three in his closed-up hands.

Years ago after-swarming was considered a sort of necessary evil that had to be tolerated because it could not be obviated; but in no well-regulated apiary should it be allowed. Many consider it good practice to permit one swarm-the first one. After that all others are restrained. Cutting out all the queen-cells but one may have the effect of preventing a second swarm; but the practice is objectionable-chiefly because one cannot be sure that he destroys all buit one. If there are two cells the occupant of one of them, when she hatches, is likely to bring out an after-swarm; indeed, we may say that, as long as there are young queens to hatch, there are likely to be after-swarms up to the number of three or four.

But many practical honey-producers consider cell cutting for the prevention of these little swarms as waste of time, altho they may and do cut out cells to prevent prime or first swarms. There are some who deem it advisable to prevent swarming. The plan usually adopted to prevent second swarms is about as follows:

The wings of all queens in the apiary should be clipped, or else there should be 
entrance guards over the colonies. As soon as the first swarm comes forth, aid while the bees are in the air, the queen, if clipped, is found in front of the entrance of the old hive. She is eaged, and the old hive is lifted off the old stand, and an empty one containing frames of foundation or empty combs is put in its place. A perforated zinc honey-board is then put on top, and finally the supers, now on the old stand. The queen in her cage is placed in front of the entrance, and the old hive is next carried to an entirely new location. In the mean time the swarm returns to find the queen at the old stand; and when the bees are well started to running into the entrance she is released, and allowed to go in with them. Most of the old or flying bees that happen to be left in the old colony, now on the new location, will go back to the old stand to strengthen further the swarm. This will so depopulate the parent colony that there will hardly be bees enough left to cause any after-swarming, and the surplus of young queens will have to fight it out among themselves-the "survival of the fittest" being, of course, the only one left. She will be mated in the regular way, and the few bees with her will not, of course, follow her. In a short time comparatively the old parent colony will be strong enough for winter.

\section{HEDDON'S METHOD.}

The first swarm is allowed to come forth; and while it is in the air the parent colony is removed from its stand and placed a few inches to one side, with its entrance pointing at right angles to its former position. For instance, if the old hive faced the east, it will now look toward the north. Another hive is placed on the old stand, filled with frames of wired foundation. The swarm is put in this hive, and at the end of two days the parent hive is turned around so that its entrance points in the same direction as the hive that now has the swarm. Just as soon as young queens of the parent colony are likely to hatch it is carried to a new location during the middle of the day or when the bees are flying thickest. The result is, these flying bees will go back to the hive having the swarm. This, like the other method described, so depletes the parent hive that any attempt at after-swarming is effectually forestalled.
A variation from this plan makes it easier and just as good. Hive the swarm on the old stand and set the old hive close beside it, both facing the same way. A week later, when most bees are out, remove the old hive to a new stand. That leaves the old colony just as much depleted as the longer way; and the depletion coming more suddenly will more thoroly discourage all thought of further swarming.

AGE OF BEES.-It may be rather diffcult to decide how long a worker bee would live if kept from wearing itself out by the active labors of the field; six months certainly, and perhaps a year; but the average life during the summer time is not over three months, and perhaps during the height of the clorer bloom not over six or eight weeks. The matter is easily determined by introducing Italian queens to hives of black bees at different periods of the year. If done in May or June, we shall have all Italians in the fall; and if we note when the last black bees hatch out, and the time when no black bees are to be found in the colony, we shall have a pretty accurate idea of the age of the blacks. The Italians will perhaps hold out under the same circumstances a half longer. If we introduce the Italian queen in September in the northern states, we shall find black bees in the hive until the month of May following -they may disappear a little earlier, or may be found a little later, depending upon the time they commence to rear brood largely. The bees will live considerably longer if no brood is reared, as has been sereral times demonstrated in the case of strong queenless colonies. It has been said that black bees will live longer in the spring than Italians-probably because the latter are more inclined to push out into the fields when the weather is too cool for them to do so with safety; they seldom do this, however, unless a large amount of brood is on hand, and they are suffering for pollen or water.

During the summer months, the life of the worker bee is cut short by the wearingout of its wings, and we may, at the close of a warm day, find hundreds of these heavily laden, ragged-winged reterans making their way into the hives slowly and painfully, as compared with the nimble and perfect-winged young bees. If we examine 
the ground around the apiary at nightfall, we may see numbers of these old bees hopping about, evidently recognizing their own inability to be of any further use to the community. We have repeatedly picked them up and placed them in the entrance, but they usually seem only bent on crawling and hopping off out of the way where they can die without hindering the teeming rising generation. During the height of a honey-flow workers probably do not live more than six weeks.

\section{AGE OF DRONES.}

It is somewhat difficult to decide upon the age of drones, because the poor fellows are so often hustled out of the way, for the simple reason that they are no longer wanted; but we may be safe in assuming it is something less than the age of a worker. If kept constantly in a queenless hive they might live for three or four months. Occasionally some live over winter, say from September to April.

\section{AGE OF THE QUEEN.}

As the queen does little or no outdoor work, and is seldom killed by violence as are the drones, we might expect her to live to a good old age, and this she does, despite her arduous egg-laying duties. Some queens die, seemingly, of old age, the second season, but generally they live thru the second or third, and we have had them lay very well even during the fourth year. They are seldom profitable after the second or third year, and the Italians will sometimes have a young queen "helping" mother before she becomes unprofitable. Some good beekeepers think it profitable to requeen yearly.

ALFALFA (Medicago sativa L.). - $\Lambda$ lfalfa belongs to the pulse family, or Leguminosae, which includes more than 5000 species. Many of the species are very abundant, and valuable for fodder or edible seeds or dyes, as white and yellow sweet clover, the true clovers, sanfoin, and the vetches, peas, beans, and lentils, and indigo. The cassias and acacias are also placed in this family by Gray. Alfalfa is a perennial, herbaceous plant with trifoliate leaves; violet-purple, irregular flowers in short racemes; and spirally twisted pods, each containing several kidney-shaped seeds. A most important character of alfalfa is the taproot, which may extend downward to a depth of fifteen feet, enabling the plant to obtain food materials and water inaccessible to other field crops. The genus Medicago contains more than 100 species and varieties, natives of the Caucasus and western Siberia, the Mediterranean region and northern Africa. One species (M. arborea L.) is a shrub growing in the vicinity of the Mediterranean Sea ten feet tall and producing a hard dark wood resembling ebony.

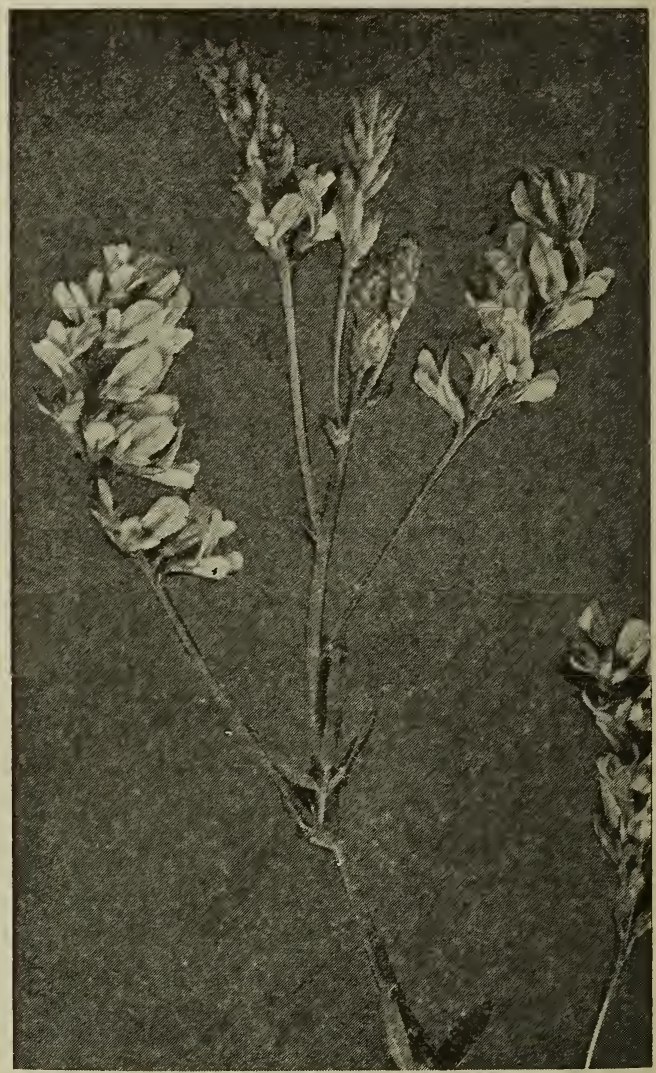

Alfalfa blossom.

The foliage furmishes excellent forage for cattle and sheep. In California it is cultivated as an ornamental shrub for its bright yellow flowers.

\section{HISTORY.}

The common alfalfa is probably of Asiatic origin, as it has been found growing wild in Afghanistan, Persia, and the region south of the Caucasus. In China it has been under cultivation from a very early date. The plant was brought into Greece at the time of the Persian war, 470 B.C., from Media whence the scientific name Medicago. 
In Italy it has been cultivated from about the first century, and is well described by Virgil and Pliny. During the Middle Ages it received the remacular name of lucerne from the Valley of Luzerne in Piedmont. northern Italy. It was long popularly known under this name in Europe outside of Spain, and in eastern North America.

This species was also very early introduced into northern Africa, where it was called alfalfa, a word of Arabic origin signifying "the best fodder." During the Moorish inrasion it was carried into Spain, and later was brought by the Spaniards to Mexico and Soutl America; and finally, in 1854, was carried from Chile to California. It is first heard of in England about 1650 . Under the name of lucerne the early colonists introduced it into eastern Nortl America, where it still grows spontaneously in fields and waste places; but the first attempts to cultivate it proved unsuccessful. Other common names are Spanish trefoil. Burgundy, Brazilian, and Chilian clover. It is also known as purple medick from the color of the flowers and the Latin word medica (Media); and snail clover from its twisted pods.

Other and more hardy strains have been discovered in Siberia and northern Europe. and brought to this country by Hansen and other agricultural explorers. They found alfalfa growing under cultivation and also growing wild in the extreme northern parts of Siberia. From these high latitudes we get a type of plant called the Hardy or Northern Alfalfa, as distinguished from the Southern or Non-hardy Alfalfa.

The culture of the plant has become established in every state in the Union and every province in Canada. Its claim to the attention of beekeepers lies in its extreme importance as a honey-plant in the West. To discuss alfalfa from the standpoint of the beekeeper, this article will first consider the nature of alfalfa honey; second. alfalfa as bee pasturage; and, finally, conditions and methods of its culture.

\section{ALFALFA HONEX.}

Most alfalfa honey has a pleasant slightly minty taste. The best alfalfa honey, thick, rich, and delicious, has proved a favorite with the public where the honey can be eaten before granulation commences. Altho difficult to handle on that account, dealers hesitate to discard so well-flavored an article. It runs twelve to thirteen pounds to the gallon while other honeys seldom exceed twelve pounds, its thickness making it difficult to extract.

The great drawback of alfalfa honey is its tendency to granulate, especially in that from certain localities. In examining a given lot of alfalfa honey it is impossible to say when granulation will be likely to set in. If kept in a warm room some alfalfa honey will last in good shape for an entire season; but, on the other hand, it may be solid in a rery few weeks. When granulated it is fine and creamy, hence is often retailed in the solid form, in cartons. See Granulated Hoxey.

As with other honey, low temperature, and especially variable temperature, have the same effect in hastening granulation. and higher and uniform temperatures in retarding. In tests conducted by the Bureau of Chemistry. alfalfa samples shown to be purer than the other's (that is, freer from other honeys) granulated solid. The statement has been made that pure alfalfa honey will scarcely granulate at all. and what solidifies early is usually mixed with honey from wild flowers. In view. howerer, of the uniform granulation of samples of known purity tested by the gorernment. this statement is apparently not generally true. Moreorer, tests made by the Bureau with other honeys show that impure samples, those with a high percentage of dextrose and undetermined matter do not candy readily. A hard white lard seems to be the ultimate state of even the best of alfalfa honey.

The color of alfalfa honey varies from so-called "water-white" to light amber, according to the humidity, the season, and the character of the soil. In localities of little rainfall or where the soil is sandy the color is white. In allurial soils where the water is close to the surface the honey is amber and eren darker after extracting. To the percentage of water in the honey itself is largely due directly the shade of color. as slown in the gorernment tests alluded to above. Parts of California and Arizona produce a darker alfalfa honey. Alfalfa honey from Inyo County, California, east of the Sierra Nevadas, and from country around Reno, Nevada, both rery dry regions, is water-white. Imperial 
County, California, and Yuma County, Arizcna, yield a darker honey. Usually honey from the second and third crops of alfalfa is lighter in color than that from the first crop, the reason, of course, being the greater amount of water present in the plants at the opening of the season.

The content of nitrogen, protein, dextrine, and undetermined matter in alfalfa honey is low. Conversely, the sucrose content is higher than in most other honeys.

\section{BEE PASTURAGE.}

Alfalfa is one of the most important honey-plants in the West, in some localities easily the most important. The San Joaquin and the Imperial Valley in California, and parts of Colorado, Arizona, and $\mathrm{Ne}$ vada produce the most alfalfa honey. In irrigated regions it is the most reliable as bee pasturage, in dry seasons contributing more than the sage.

In the West the plant starts to blossom and yield nectar in April and continues intermittently until October. Those fields which are allowed to go to seed yield abundantly for weeks. Ordinarily the second and third crops give nectar, the first and last very little. Alfalfa (except the trees yielding honey like basswood, tupelo, and logwood) will support more colonies of bees to a given acreage than any other plant in the world. In some localities 5000 to 7000 can be counted in a circle of ten miles diameter. Beekeepers have rushed so thickly to favored spots like the Imperial Valley that the best are overstocked, making it impossible for apiaries to contain for effective work more than a couple hundred colonies.

After four or five days of hot weather and no wind, the honey-flow will be astonishing. Fortunate indeed is the beekeeper who is located near where alfalfa is raised for seed, as in parts of the Southwest; the flow lasts until the blossoms are all gone. Some years ago alfalfa ranges were largely used for grazing and made valuable apiary sites. As the country becomes more settled these are disappearing before cultivated ranches and diversified farms.

Where the alfalfa is cut for hay, the usual purpose of its growth, the beekeeper can realize upon only a part, and often a very small part of the nectar. Farmers as a rule cut when the plants are coming well into bloom. With this practice in view, beekeepers can forecast the length of the honey-flow, and provide the bees with no more sections than they can fill.

Unfortunately alfalfa seldom yields nectar east of the Mississippi River. Beekeepers in several states have occasionally reported a honey-flow in New York and Wisconsin, for example, but nothing can be expected from alfalfa fields in localities where the seed cannot be grown.

\section{THE CULTIVATION OF ALFALFA.}

When the conditions for its growth are favorable, alfalfa is a sturdy plant, and, unlike its near relative, sweet clover, which is a biennial, it is a perennial. Some fields have been reported half a century old. While it draws on the fertility of the soil it keeps the ground well supplied with nitrogen for the use of later crops. Its ability to survive dry periods which would kill other plants except sweet clover adapts it to arid and semi-arid regions. Nothing is superior to it as a forage crop. Not only is the food value high, but crop after crop can be taken off in a season.

While alfalfa is better adapted to all parts of the United States than was generally imagined, the varieties thrive best where there is plenty of hot sunshine and deep, rich soils, and make their richest growth in the hottest weather. To the entire range of elevation in this country, it seems to be equally adapted. One can find a Southern variety flourishing in the Imperial Valley, 100 feet below sea level, and the San Luis Valley, 7500 feet above. In Colorado, the Grimm, Baltic, and Hardy Turkestan grow in altitudes higher than 8000 feet. While alfalfa has been most extensively planted in the West, particularly in the regions opened to cultivation by irrigation projects, its culture has been found highly profitable of late years in the older soils of the East, in places where its habits are understood. It does almost equally well in the hilly and gravelly land of New England, and the clay and loam of the corn belt.

Most pronounced advantages of its cultivation have been observed in alkaline soils in the West. Here the long tap-root piercing layers of sub-soil to a depth of ten to twenty feet, leave millions of openings for air and moisture and bring up stores of 


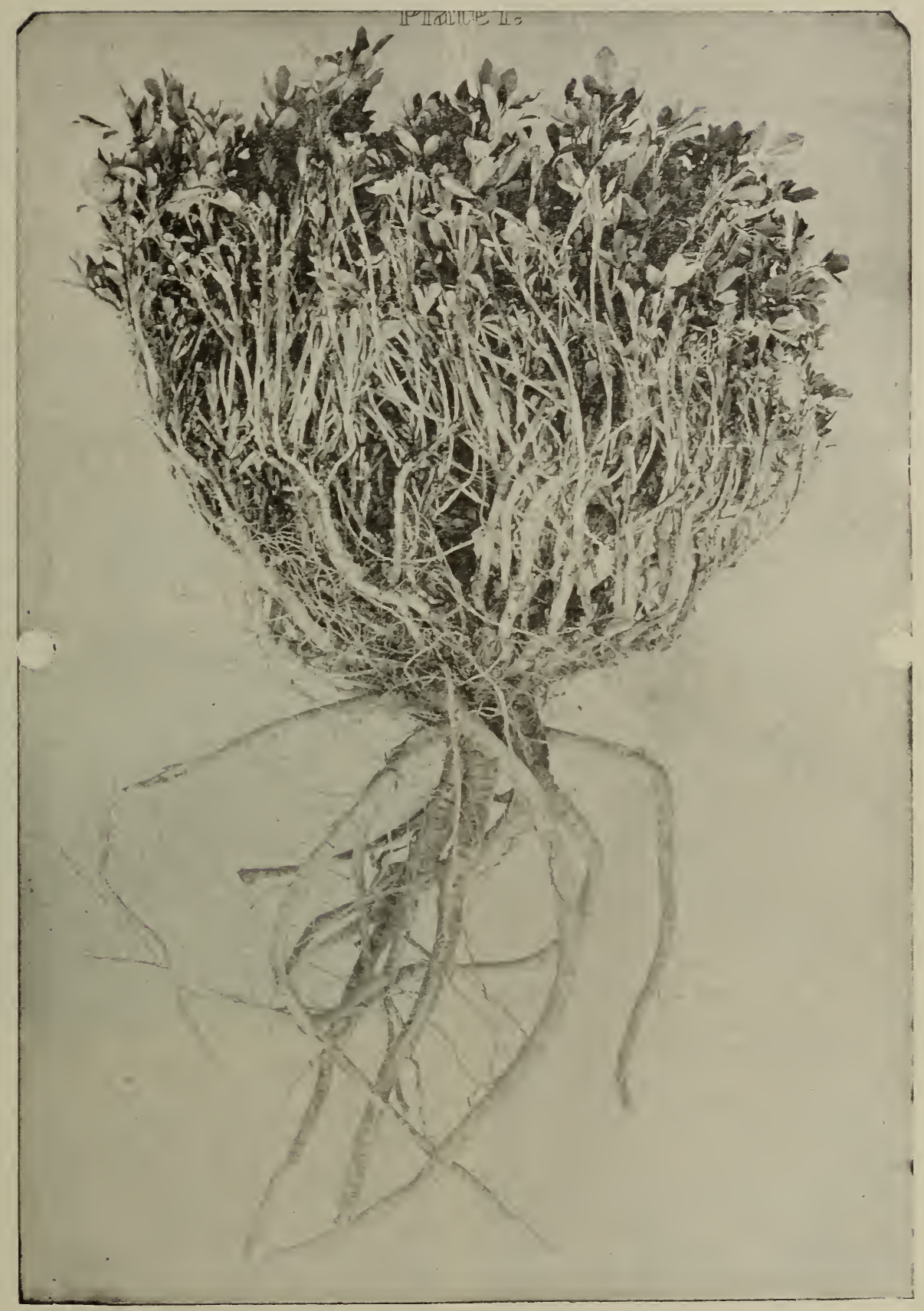

THE CELEBRATED ALFALFA PLANT AND ROOT.

The plant represented in this plate grew in rich, loose soil, with a heavy clay subsoil and an abundant supply of water, the water level ranging from 4 to 8 feet from the surface at different seasons of the year. The diameter at the top was 18 inches, and the number of stems 360 . The plate shows how these crowns gather soil around them, for the length of the underground stems is seen to be several inches, and this represents the accumulation of nearly this much material about it.

This is one of the largest plants that I have yet found. The specimen, as photographed, was dug April 30, 1896.-Dr. Headden, in Bulletin No. 35, "Alfalfa."

plant food to enrich the soil: the roots themselves when they decay furnish a heavy store of nitrogen. Naturally rich in potash, lime, and phosphate, the soils lack the nitro- gen and organic matter, both of which are liberally supplied by the growth of alfalfa. The same is also true of sweet clover. See Siveet Clover. 
WELL-DRAINED，WELL-LIMED， FERTILE SOIL.

On the other hand, wide as the range of alfalfa seems to be, there are some distinct conditions which must be met before its cultivation can be successful. It demands well-drained land, a sweet fertile soil, the right kind of bacteria in the soil, and freedom from weeds. To get a successful stand, a firm, fine seed bed is necessary. After this it demands little attention. In general any soil that grows corn or red clover successfully will grow alfalfa.

Wet and soggy land, land where the ground water stands within three or four feet of the surface, or where water stands half a day at a time, are not suitable. In springy, seepy soil in the northern parts of the country, the alternate freezing and thawing heaves out the plant and completely destroys the stand. In this respect a sandy loam is a little better than a clay loam. Properly drained soil is again necessary on account of the great depth to which the tap-root plunges. The roots must get nitrogen from the air, but they cannot do this if surrounded by water. The plant cannot take nitrogen in any other way than thru the roots; in fact, alfalfa needs more thoro drainage than any other crop. Not only must the soil be well drained, but a second and equally important essential is that it be free from acidity and even have an alkaline reaction. Alfalfa would never grow on an acid soil. In the East especially, where very few soils are not acid, it is necessary to sweeten very heavily with lime. As with drainage, it requires more than any other forage crop. It demands not only a neutral soil but one with an excess of lime for its own use.

Before sowing alfalfa be sure of the state of the soil in this respect. One good way is to wrap a moist piece of earth in blue litmus paper; if the paper shows a tendency to redden, the soil is doubtless badly in need of lime. This may be applied in two ways. Either the ground unburned limestone (carbonate of lime), two to four tons to the acre, or burned lime, one or two tons. See Clover. Since the lime stays where it is put, thoroly harrow it in. Often it is well to apply the lime the year before putting in alfalfa, say with corn or potatoes.

Whether carbonate of lime absorbs some exhalation of the plant which would otherwise be destructive to its life, or for some other reason not yet known, it is necessary for the health of the alfalfa. Humus can not be formed from decaying organic matter without lime. It prevents the loss of the nitrogen in the soil thru the leaching of rains; in fact, carbonate of lime seems to be the foundation of fertility itself.

Except in the wonderfully rich land of the West, one's treatment of the soil can not stop here. While alfalfa has been much touted as a restorer of fertility, it is nevertheless true that it makes heavy drafts upon the phosphates and potash in the soil. As with lime, when these are not present they must be supplied. Unlike sweet clover, it requires a fertile soil to start with. On worn-out fields, phosphorus should be supplied; 400 to 600 pounds of steamed bone meal to the acre or natural rock phosphate mixed with manure has been recommended. Give plenty of well-rotted stable manure, or, lacking that, cow peas, crimson clover, and soy beans can be planted for green manure. When potash may be lacking in the soil, apply wood ashes or commercial potash. Summing up, it is more important, as the late J. E. Wing pointed out in his book on alfalfa, to fill the soil with plant food than to get the seed bed right.

\section{SOIL INOCULATION.}

A third essential for successful alfalfa cultivation is that the right kind of bacteria be present in the soil. Only in comparatively recent years has this been understood. Minute vegetable organizations inhabit the small pale nodules which can be seen with the eye about the roots of the plant; their function is to gather nitrogen from the air and convert it into a form in which it can be assimilated by the plant. If the soil is wet or acid they will not thrive. Where they are not present in the soil already they have to be put there. This process. known as inoculation, is universally demanded where alfalfa and sweet clover have not been grown before.

One of the two or three satisfactory methods of inoculation is the soil-transfer. Gaiher soil from a field in which alfalfa has been grown before or from about the roots of sweet clover (the sweet clover and alfalfa bacteria are identical), pulverize and screen thoroly, mix with the alfalfa 
seed, and sow three hundred or four hundred pounds to the acre. Since the sun's rays are fatal to these germs the mixing should be done in the shade and the sowing in the evening or on a cloudy day. If the earth is broadcasted it should be harrowed in immediately. A smaller quantity of earth is required by wetting the seed with water in which enough glue has been dissolved to make the water sticky; mix the seed with fine earth from another field.

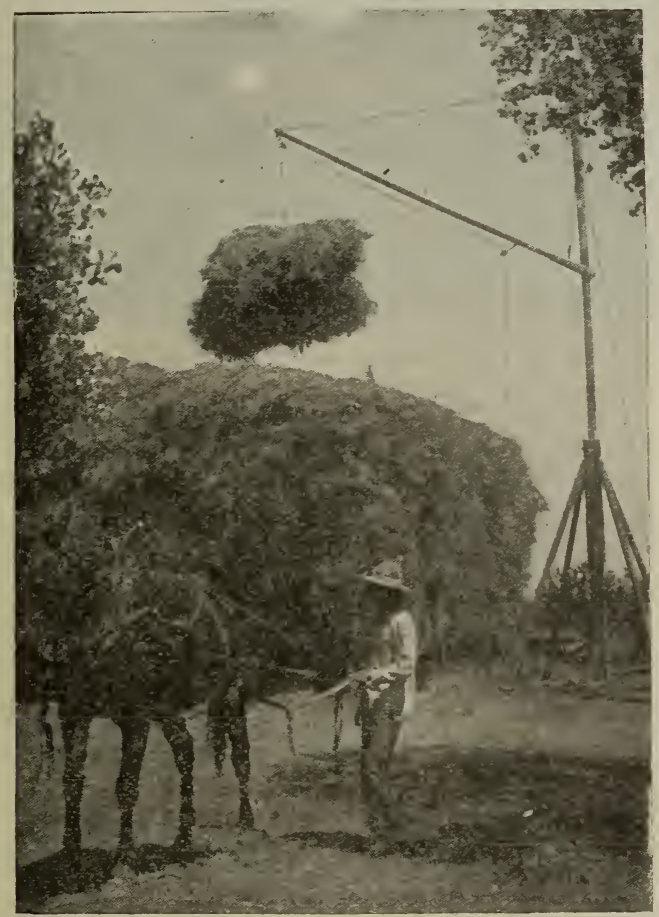

Method of stacking alfalfa hay.

The Department of Agriculture sends out pure cultures of the bacteria in tubes, making inoculation convenient where soil is not readily obtained. Simply follow directions.

In the humid regions of the country, weeds are very troublesome, in many localities the worst enemy of alfalfa. If the soil is fertile, has been well limed, and has been placed in proper condition before the alfalfa is sown, little need be feared from weeds. After alfalfa once gets a start it can kill out most of the weeds naturally. A clean field can usually be secured by preceding alfalfa with some clean cultivation crop. By seeding in the late summer the alfalfa plants by spring will have the start of the weeds. If weeds threaten to injure an old stand their stalks can some- times be burned out in the spring before the alfalfa starts.

Dodder is one of a few weeds to be feared. Especial care should be taken to get seed free from dodder. The stems come up with the alfalfa, twine around it, and finally wither away. From that time until the death of both plants the dodder lives parasitically on the juices of the alfalfa. If dodder makes its appearance in a field the infected plant should be rooted out when it has become well established. The only effective cure is to use the field for some other crop for several years. Wild barley often ruins the first crop in irrigated regions of the West. Quack or couch g'rass, Kentucky blue grass, and foxtail grass are weeds dangerous in other regions.

\section{PUTTING IN THE SEED.}

A great many facts have been collected on seeding alfalfa, not all of which apply to a particular locality by any means, nor even agree with one another in some cases. The time of sowing varies widely between one part of the country and another. Midsummer sowing is probably most popular in the North and East. If the seed is put in between June and the first of September, the young plants are usually strong enough to resist winter killing. Some advise spring sowing-the last of May and early June, but this is not best where weeds are likely to disturb the roung plants. In the hot irrigated portions seed may be sown any time between April and August. Fall seeding is most common-September, October, or November.

Early-maturing crops do well to precede alfalfa. The clean culture of potatoes and garden truck rids the land of weeds, aerates the soil, and makes an introductory application of nitrogen unnecessary. Corn in the North and cotton in the South are both suitable. A crop of crimson clover cut for hay builds up the soil and gives plenty of time to get the land ready for alfalfa.

Too much care can hardly be given to the selection of seed. Not only thru carelessness in this respect do weeds get their foothold, but failure often comes from adulterated seed or seed of poor quality. The average quality of alfalfa seed in the market is low. A considerable quantity of dead seed has been sold and it is sometimes adulterated with trefoil. Test samples for 


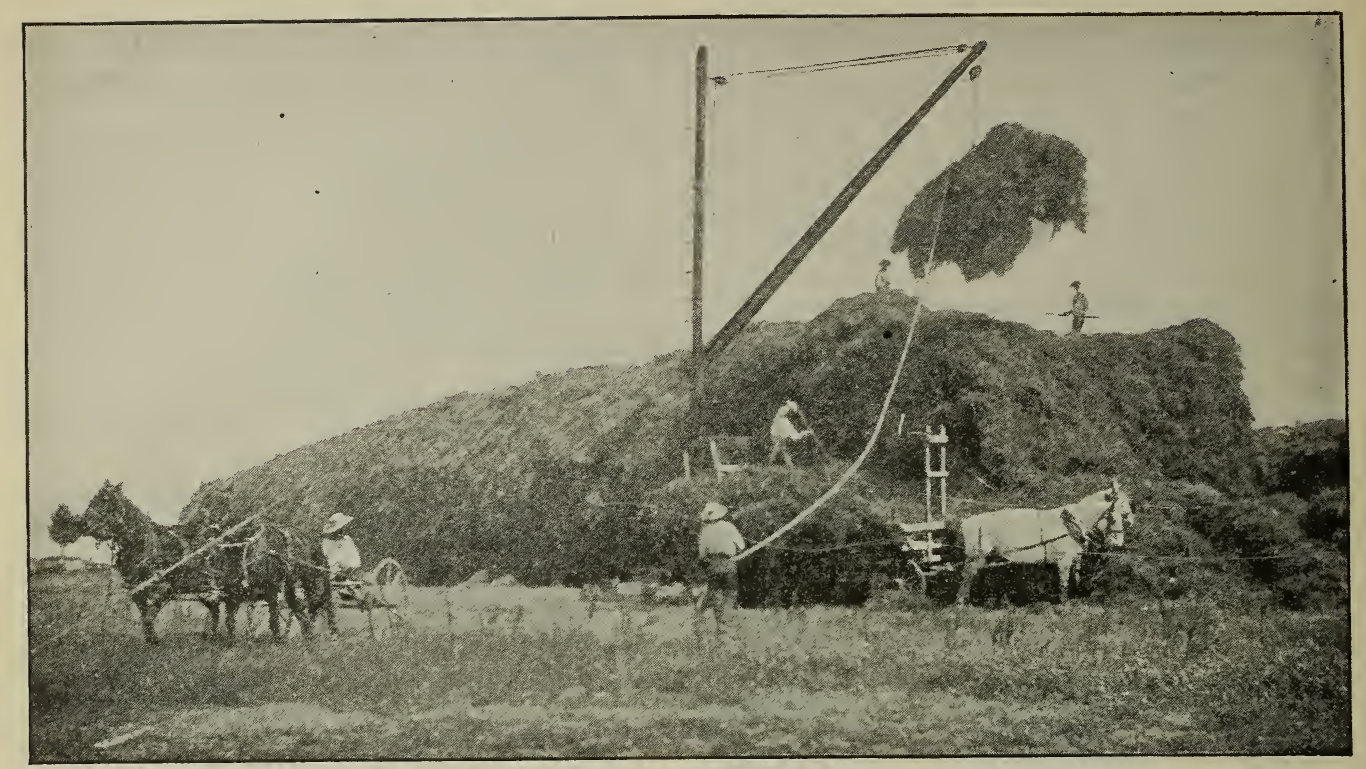

An a'fa'fa hay-stack on a 5000-acre farm assumes enormous proportions.

germination in every case before buying, either by a home testing-plate or sending to the seed laboratory of the Department of Agriculture, which does this free of charge. A home test should show a germination of at least 95 per cent. If the germination is low, sow a larger quantity than if the germination is high.

Seed grown in the Northern States may be planted with success in the Southern, but the reverse is not true. It is always well to get seed grown in the same latitude in which it is to be sown. While ordinary alfalfa is very satisfactory, certain kinds have local advantages. Superior resistance to the cold as well as greater tonnage to the acre are claimed for the Grimm alfalfa and the commercial sand lucerne. The Baltic has also been found a superior strain.

Plow deeply for alfalfa. The roots need all the moisture they can get, and the ground should be thoroly stirred up, so that air can penetrate to the nodules. The seed bed should be fine on top, but thoroly settled; for this reason it is well to let the land rest for six weeks after plowing, and then to give it a light disking. If plowing is done on hot days, follow immediately with a harrow to break up clods before they harden. Pulverize with a drag, disk, and smoothing harrow. For spring sowing it is not so necessary to have a perfect seed bed: the plants have a long start by winter.

Seeding alfalfa in irrigated regions re- quires an entirely different procedure. Inoculation is unnecessary; so is fertilizer. Level the land, plow deeply, follow with the disk and harrow immediately, and let stand a month. Irrigate before and after seeding, and irrigate again if the young plants seem to be suffering for lack of water. They should be watered after each cutting. Upon the irrigation of alfalfa Mr. Kezer of the Colorado Experiment Station writes as follows:

Different soils, different climates, and different sources of water supply would all be causes of different methods. In some sections it is necessary to irrigate two or three times for each cutting; in other sections, one irrigation to the cutting is sufficient, in which case the best practice is to irrigate a week or ten days prior to the cutting or the expected time of cutting, and then cut as soon as the ground is settled enough to bear the weight of the haying machinery. This water puts the soil in good condition for the succeeding crop and causes it to start forward more quickly and more vigorously. Irrigation practice varies quite widely and must vary quite widely because of the diversity of conditions. A complete statement covering the most of the known conditions would require several pages. Suffice it to say, that in some regions best results are obtained by a flooding method, others by a furrow method, and in some regions the basin methods give the best results. Climatic and soil conditions chiefly govern.

The amount of seed to the acre likewise raries with the locality. For honey production in the West ten pounds gives a good 
AVERAGE PERCENTAGE COMPOSITION OF ALFAIFA AND OTHER FORAGE CROPS.*

\begin{tabular}{|c|c|c|c|c|c|c|c|}
\hline Kind of forage & $\begin{array}{c}\text { Number } \\
\text { of analy- } \\
\text { ses. }\end{array} \mid$ & Water & Ash & Protein & $\begin{array}{l}\text { Crude } \\
\text { fiber }\end{array}$ & $\begin{array}{l}\text { Nitrogen } \\
\text { free } \\
\text { extract }\end{array}$ & $\begin{array}{l}\text { Ether } \\
\text { extract } \\
\text { (fat) }\end{array}$ \\
\hline Fresh alfalfa. & $23 \mid$ & $71.8 \%$ & $2.7 \%$ & $4.8 \%$ & $7.4 \%$ & $12.3 \%$ & $1.0 \%$ \\
\hline Fresh clover ... & 43 & 70.8 & 2.1 & 4.4 & 8.1 & 13.5 & 1.1 \\
\hline Alfalfa hay ... & 21 & 8.4 & 7.4 & 14.3 & 25.0 & 42.7 & 2.2 \\
\hline Clover hay.... & 38 & 15.3 & 6.2 & 12.3 & 24.8 & 38.1 & 3.3 \\
\hline Timothy hay.. & 68 & 13.2 & 4.4 & 5.9 & 29.0 & 45.0 & 2.5 \\
\hline Cowpea hay ... & 8 & 10.7 & 7.5 & 16.6 & 20.1 & 42.2 & 2.2 \\
\hline
\end{tabular}

stand; in the Atlantic and Southern States, 24 to 28 pounds; between the Apalachian Mountains and the Mississippi, slightly less than this. Wing estimates 15 to 20 pounds under ordinary circumstances and with ordinary soils. One plant to the square foot is enough under the best of conditions, but they must stand more thickly as a rule. Since more come up than can exist, only the strongest plants survive.

Alfalfa may be sown either broadcast or with a wheelbarrow seeder or a drill. Broadcasting requires more seed than drilling, and must be followed with a harrow or some other implement to cover the seed almost an inch deep. In arid lands it is covered about an inch and a half. In drilling it is advisable to sow across field in one direction and then at right angles. No further treatment need be given the rest of the year except for the appearance of dodder. Carefully keep wagons and stock off the field.

After seeding in the late summer, the stand will usually be eight or ten inches high by fall. With the spring sowing a clipping may need to be given in the late summer, but no hay can be taken off until the next season. Should the plants show a lack of vitality or trace of disease, cutting them will often prove salutary, and in the East a top dressing of nitrate of soda is effective. In a great portion of the West this would not be beneficial. If weeds are troublesome the field may be disked with the disks set upright. This hinders the growth of weed and grass and lets air and water into the soil.

Alfalfa is seldom successful with a nurse crop except in irrigated land, for the reason that the nurse crop often chokes out the young plants just as weeds do. Barley grown for hay, and hay only, can be made a success with spring sowing of alfalfa, and gives a larger return to the acre, but to let it grow until it is ready to harvest as grain seriously injures the forage stand. In irri- gated sections with good water rights, alfal$\mathrm{fa}$ is usually successful with a nurse crop, altho more vigorous growth can usually be obtained without it. Mixtures of alfalfa with certain of the grasses are successful, the grasses seemingly more vigorous than when alone, and the alfalfa almost as good.

\section{ALFALFA AS HAY.}

Alfalfa is one of the most palatable and highly nutritious of all forage crops, either green or as hay. One estimate gives alfalfa hay slightly more than double the food value of timothy. No other forage crop is so rich in digestible protein. Wheat bran which runs $\$ 25$ to $\$ 30$ a ton is about as rich, tho more easily fed. While protein is hard to get and expensive it is the one thing absolutely necessary for the production of stock or milk. While dairymen are bankrupting themselves buying bran and cottonseed meal to get this necessary protein, they could feed just as much and make enormous saving by growing alfalfa on their own farms. Alfalfa has three times as much protein as corn, but in fat and carbohydrates is decidedly inferior.

The market price of alfalfa hay, governed simply by supply and demand, runs about $\$ 12$ a ton. The number of cuttings a season which may be made has been as high as eight and even nine in the Southwest. In favorable years in the North three are possible, but two are most common in the eastern part of the country. Thirty or forty days of hot weather are usually all that are necessary to mature a crop. A good yield amounts to two tons to the acre.

\section{CUTTING BEFORE IT BLOOMS.}

Shall the farmer cut the alfalfa before it comes to bloom, or while it is in bloom, or wait until the blossoms are all gone? This is a matter of decided concern to the beekeeper, since his crop of honey depends upon it. If the stand is mown before

\footnotetext{
* In part from Henry's "Feeds and Feeding," appendix.
} 
bloom, the bees get no nectar at all, and the beekeeper may find his colonies starving in the midst of miles of alfalfa.

The old rule with alfalfa growers was to cut for hay when the stand was about one tenth in blossom. Arizona growers claimed that the alfalfa is richer for milk production at that time than any other, but for loorses and mules it is more nourishing if cut in full bloom. The Utah Experiment Station after a series of investigations reached this conclusion: "To insure a large yield of dry matter and the largest amount of albuminoids, lucerne should be cut not earlier than the period of medium bloom, and not much later than the first full flower. .... It is a more serious matter to cut too early than to cut too late." On the same point the national bulletin writes, "The general rule is to cut alfalfa just as it is coming into bloom. Feeding experiments show that the feeding value is highest when alfalfa is cut in early bloom."

Of late years a new rule has taken the place of the old. Authorities now advise alfalfa growers to mow when the shoots of the new growth at the base of the plant are just showing. In Ohio this comes about June 1. When the shoots appear it is time to cut immediately. If this is done too soon the second growth is retarded; if too late a great many of the leaves are lost, and in them lies much of the food value. Danger of winter-killing is also increased. The net result so far as the beekeeper is concerned is often more favorable under the new plan.

Another fact to his advantage is the habit of men, whatever the rule, of being just a little late. In some places the practice is to cut while the fields are well into bloom. The growers fear that if cut too early it will cause bloat in cattle, and is likely to powder in curing. The state of growth at which to mow the alfalfa also varies between one crop and another: the third cutting is often made when the plants are in full flower.

Immediately after cutting, fields look brown and bare for the first few lours, but the plants soon rally, and are flourishing again in a surprisingly short time. The field should not be disturbed until the time for the second cutting.

Making hay with alfalfa in the West is a struggle to get it stacked before the leaves dry so much they drop off. In the East is a similar struggle to get it cured beween showers. On the ranches the farmers harvest a green hay which is practically impossible to get in humid regions. It is esteemed highly as horse feed, altho for cows a brown hay is quite as good. Stacks of this green hay keep their color indefinitely. To the Easterner it is surprising to cut into a stack and find the interior as green as the field itself.

Curing in windrows is better than in the swath. The hay is raked the same day it is cut, and as soon as cured is cocked and stacked, or baled directly from the cocks. The tedder is of little value since it shatters the leaves too much. Most of the protein is contained in the leaves which are somewhat richer than bran. Where showers are frequent the alfalfa should be raked into windrows soon after being eut, in order to avoid damage by rains. Special alfalfa rakes are on the market. Of the ordinary machinery the side-delivery rake is very useful. If the hay is put into the barn too green, it may ignite.

\section{ALFALFA AS PASTURE AND SOILING; SEED PRODUCTION.}

Alfalfa pastures, while not uncommon, must be grazed sparingly if a good stand of the plants is to be maintained. Fields should never be used for this purpose the first season or two. Horses and sheep graze more closely than cattle do, and are therefore more destructive to the stand. Hogs on alfalfa pasturage should be ringed. In the autumn stock should be taken off in order to give the plants a start for winter. The tendency of cattle and sheep to bloat when turned on an alfalfa field can be overcome, it has been suggested, by feeding before turning them in, and then keeping them on the pasture all the time, altho there are few places east of the Rocky Mountains where either sheep or cattle can be pastured on alfalfa with safety, except when the plants are in a dormant state. In the West are great alfalfa ranches for horses, cattle, and even ostriches.

Alfalfa land will support three times as many animals by soiling as by pasturing. Let the crop mature and then carry it to them. A better way even is to combine both pasturing and soiling-feed the animals with alfalfa, then give them access to the pasture. Alfalfa makes silage if prop- 
erly handled, but the silage is inferior to corn, kafir, feterita, milo, or sorghum.

In the arid regions of the country where seed can be grown, there are great opportunities for profit. Seed now brings $\$ 10$ to $\$ 12$ a bushel, but the culture would be worth while with seed at half the price. The crop which matures in the driest season is always the one saved. A thin stand is necessary; for best results the plants are set in long rows about trenty inches apart and cultivated just as corn. East of the Mississippi very little seed has been produced.

\section{POLLINATION.}

The form of the flower is papilinnac:ous. or butterfly-shaped, bearing a general r'esemblance to the flower of the garden pea. The manner of pollination is of great interest both to beekeeper's and seed-growers. The flower's are known as explosive flowers. The anthers and stigma are held in the keel under elastic tension, which resides in the staminal column formed by the union of the filaments of 9 of the 10 stamens. When a bee presses down the wings and keel, says Burkill, it pulls two triggers and fires off the flower, that is, the two processes which restrain the staminal column in the carina separate, and permit the stamens and pistil to fly forcibly uprard, bringing the pollen in contact with the under side of the bea's body. A slight clicking sound may sometimes be heard when the stigma strikes against the standard, and a little cloud of pollen is visible. The stigma stands a little in advance of the anthers, and strikes the pollen-brush of the bee first; if the latter is covered with pollen from another flower. previously visited, cross-pollination is effected. Both of these organs then more upward against the erect petal called the standard, where they are out of the way. and do not again come in contact with insects. A single normal visit is sufficient to effect pollination, and all subsequent visits are useless. After the flowers have been exploded, or "tripped," they still continue, howerer, to secrete nectar and receive insect visits. This is clearly an imperfection. since the attraction of risitors is no longer an adrantage.

In different seasons and different localities there is a wide difference in the quantity of seed produced by alfalfa. In the
Milk River Talley of Montana a vield of from 10 to 12 bushels per acre has been obtained in farorable years, while in others it was almost a complete failure. Contradictory assertions have been repeatedly made by various observer's that the flowers were self-fertile or self-sterile in the $a b$ sence of insects. For the purpose of settling this question definitely numerous experiments were conducted by Piper and his assistants, the results of which were published by the Bureau of Plant Industry in 1914.

More than 24 species of wild bees, b?sides many butterflies, flies, and beetles. have been observed on the flowers; but many of these are useless as pollinators. In localities where alfalfa is nectarless it is almost entirely ignored by honeybees, but where it secretes nectar freely they are attracted in great numbers. Usually they obtain the nectar thru a hole in the side of the flower without tripping it. Out of 500 visits observed by Westgate a flower was tripped in only one instance. In California, according to McKee, few flowers are tripped by honeybees; but in England, Burkill saw them tripping the flower's in great numbers. Fren if an individual honeybee tripped a flower only occasionally the aggregate exploded in a day orer a large area of alfalfa would be large. Bumblebees are more important than honeybees, and trip the flowers frequently-in Washington and Montana about 30 per cent of the flowers visited. But the leaf-cutting bees (Megachile) are the most efficient pollinator's. MI. latimanus trips 9 out of every 10 flowers visited, and three of these bees were observed to trip flowers at the rate of 552 per hour. Butterflies are common visitors, especially in California, where the alfalfa butterfly ( $E u$ rymus eurytheme) is abundant; but they obtain the nectar thru the orifice in the side of the flower without depressing the carina. In South America small birds called honeysuckers risit the flower for nectar. Pollination by the wind does not occur.

Untripped flowers seldom produce seed, but in the absence of insects a large percentage may explode automatically. At Chinook, Montana, 33 out of 57 marked flowers on one plant became self-tripped, and set 21 pods; and on a second plant 36 fiowers out of 64 tripped automatically, and produced 16 pods. In the first case 
63 per cent of the self-pollinated flowers produced pods, and in the second 44 per cent. In rare instances flowers develop pods without tripping. Variability in self-tripping is strongly influenced by climatic factors, as temperature, humidity, and bright sunshine. A single alfalfa plant was screened from insects for ten days or longer until it was in full bloom. The screen was then removed for 15 minutes on a very warm clear day. The flowers quickly began exploding with a snapping sound, at times 3 or 4 being heard simultaneously. It was estimated that more than one-half of the flowers were self-tripped before the screen was replaced. In the West, automatic selftripping probably results in the production of as many pods as insect pollination. This observation is important since it explains the production of a large crop of seed in the absence of insects.

A series of experiments was conducted to test the comparative effects of self-pollination and cross-pollination of alfalfa flowers. Nine thousand and seventy-four flowers were artificially tripped, and consequently self-pollinated, and set 2784 pods. The different plants on which the flowers were thus self-pollinated varied greatly in the production of pods, 68 per cent of the flowers in one instance setting pods, while others yielded none. Pollination from a different flower on the same plant is of little advantage over self-pollination. Five hundred and thirteen self-pollinated flower's set 165 pods, or 32 per cent; while 437 flowers pollinated from another flower on the same plant set 134 pods, or 30 per cent. When 446 flowers were each cross-pollinated with pollen from another plant 206 pods were produced, or 46 per cent. The average number of seeds per pod of the self-pollinated flowers was 1.4 ; of the flowers pollinated from another flower on the same plant, 2.02; and of the cross-pollinated flowers 2.38. Cross-pollination is, therefore, more potent than self-pollination, and consequently pollination by insects is an advantage.

It is now well-established that the production of seed is greatly influenced by climate; and practical experience has shown that it can be raised in paying quantities only in those states which possess a hot dry season. Too much moisture is injurious, and consequently the eastern portion of the country with its larger rainfall is not well adapted for this purpose; while in the irrigated sections one irrigation is usually omitted. It is of interest to beekeepers to know that most of the seed is raised in Arizona, California, Utah, Colorado, Kansas, and Idaho. The best results are obtained with a thin stand of alfalfa, or where it is cultivated in rows. The domestic supply is far below the demand, and millions of pounds are annually imported.

\section{AUTHORITIES.}

While certain general principles can be laid down regarding alfalfa for all parts of the United States, it has not been possible in this article to go into those local details with which the well-informed grower should be familiar. Any one interested in the plant should first find out what his state experiment station has published on alfalfagrowing in his locality. The literature is thoro and comprehensive.

The best work in the subject is J. E. Wing's "Alfalfa in America" (1912). A somewhat more extensive work is F. D. Coburn's "The Book of Alfalfa" (1906). The Department of Agriculture, Washington, publishes Farmers' Bulletin No. 339, entitled "Alfalfa," by J. M. Westgate. Of the various publications by state experiment stations, those by the Colorado, Illinois, Utah, and Kentucky stations are especially valuable. All of the works cited were used in the preparation of this article. Grateful acknowledgment is made to $\mathrm{Mr}$. Alvin Kezer, Chief Agronomist at the Colorado State Experiment Station, for reading and making suggestions to the manuscript.

ALGAROBA.-See Mesquite.

\section{ALSIKE CLOVER.-See ClOVER.}

AMATEUR BEEKEEPING . - S e e Backlot Befkeeping; also A B C of BeeKEEPING.

ANALYSIS OF HONEY.-See HONEY and Honey ANaLYSIS.

ANATOMY OF THE BEE.-The three parts of the body of the bees are well separated by constrictions. The head carries the eyes, antennæ, and mouth parts; the thorax, the wings and legs; and the abdomen, the wax-glands and sting. 


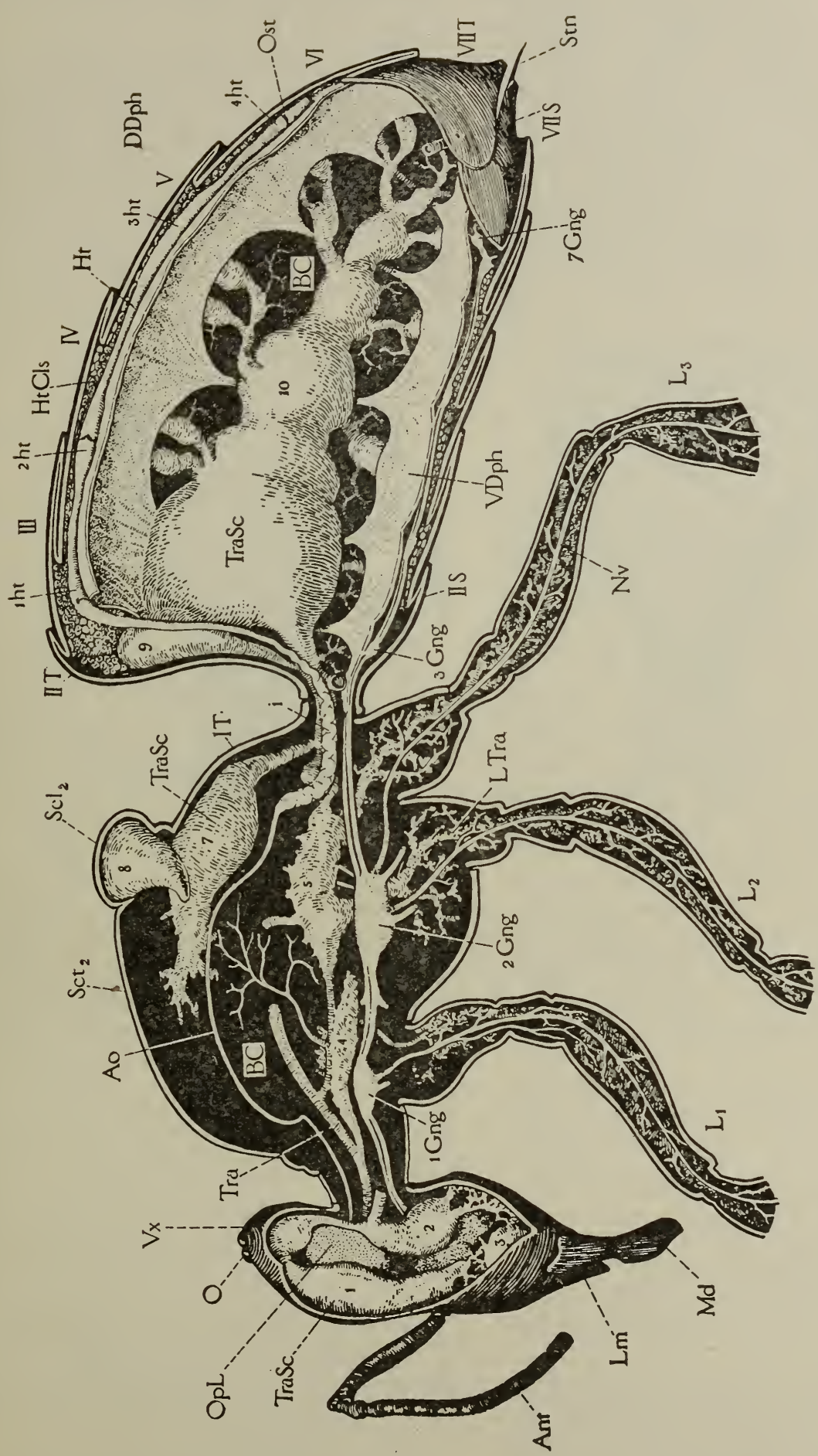

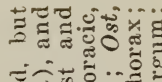

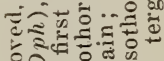

A

छक्य

० ช.

Q

है चَّ

है

औ.

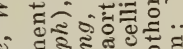

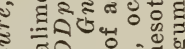

"⿵人一

ฮี

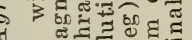

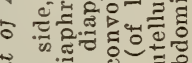

है चี

密

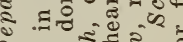

- ⿵人一兀

..

(5)

过

a br

$\therefore$.

今ँ

है

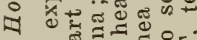

$\approx$ \&

त

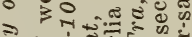

है क्षे हैं की

ङ

章

:

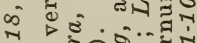

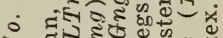

$z_{1}$

है और

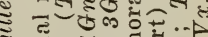

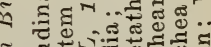

₹

ह-

T记

-

ic of  
The head is flattened and triangular, being widest crosswise thru the upper corners, which are capped by the large compound eyes. It carries the antennae, or feelers, on the middle of the face (Fig. 2, A, Ant); the large compound eyes $(E)$ laterally; three small simple eyes or ocelli $(O)$, at the top of the face, and the mouth parts ( $M d$, $I I x$, and $L b$ ) ventrally. Each antenna consists of a long basal joint and of a series of small ones hanging downward from the end of the first. The antennæ are very sensitive to touch, and contain the organs of smell. At the lower edge of the face is a loose flap (Fig. 2, A, Lm) forming an upper lip called the labrum. On its under surface is a small soft lobe called the epipharynx on which are located the organs of taste. At the sides of the labrum are the two heavy jaws, or mandibles $(M d)$, which work sidewise. They are spoon-shaped at their ends in the worker, but sharp-pointed and toothed in the queen and drone. Those of the queen are largest, those of the drone smallest. Behind the labrum and mandibles is a bunch of long appendages, usually folded back beneath the head, which together constitute the proboscis (Fig. 2, A, Prb). These organs correspond with the second pair of jaws, or maxillae, and the lower lip, or labium, of other insects. In Fig. 2 they are cut off a short distance from their bases, but are shown detached from the head and flattened out in Fig. 3, D. The middle series of pieces $(S m t-L b l)$ constitutes the labium, the two lateral series $(C d-M I x)$ the maxillæ. The labium consists of a basal submentum $(S m t)$, and a mentum $(M t)$, which supports distally the slender, flexible, tonguelike glossa ( $G l s)$, the two delicate paraglossae $(P g l)$, and the two lateral, jointed labial palpi $(L b P l p)$. Each maxilla is composed of a basal stalk, the cardo $(C d)$; a main plate, the stipes $(S t)$, and a wide terminal blade $(M x)$ called the galea. At the base of the galea is a rudimentary maxillary palpus (MxPlp), representing a part which in most insects consists of several slender joints.

As before stated, the part of the maxillæ and the labium together constitute the probescis, which, as shown in Fig. 2, B, is suspended from a deep cavity (PrbFs) on the lower part of the back of the head having a membranous floor. The nasal stalks $(C d)$ of the maxillæ are hinged to knobs on the sides of this cavity, while the labium is attached to the maxillary stalks by means of a flexible band called the lorum (Fig. 3, D, $L r)$.

When the bee wishes to suck up any liquid, especially a thick liquid like honey or syrup, provided in considerable quantity, the terminal lobes of the labium and maxillæ are pressed close together so as to make a tube between them. The labium is then moved back and forth between the maxillæ with a pump-like motion produced by muscles within the head. This brings the liquid up to the mouth, which is situated above the base of the proboscis, between the mandibles and beneath the labrum. The food is then taken into the mouth by a sucking action of the pharynx, produced by its muscles.

A more delicate apparatus is probably necessary, however, for sucking up minute drops of nectar from the bottom of a flower. Such a structure is provided within the glossa. This organ (Fig. 3, D, Gls), ordinarily called the "tongue," is terminated by a delicate, sensitive, spoonlike lobe known as the labella (Fig. 3, A, B, and D, $L b l$ ), and has a groove (k) running along its entire length on the ventral side. Within the glossa this groove expands into a double-barreled tube (Fig. 3, E, Lum). A flexible chitinous rod $(r)$ lies along the dorsal wall of this channel, which is itself provided with a still finer groove $(l)$ along its ventral surface. Thus the very smallest quantity of nectar may find a channel suited to its bulk thru which it may run up to the base of the glossa by capillary attraction. But since the glossal channels are ventral the nectar must be transferred to the dorsal side of the labium by means of the paraglossæ, the two soft lobes (Fig. 3, $\mathrm{D}$ and $\mathrm{F}, P g l)$ whose bases are on the upper side of the mentum, but whose distal ends underlap the base of the glossa, and thus afford conduits for the nectar around the latter to the upper side of the labium. The glossa is highly extensible and retractile by means of muscles attached to the base of its rod, and its movements when a bee is feeding are very conspicuous, and interesting to watch.

The thorax of an insect carries the wings and the legs. The two wing's of the bee on each side are united to each other by a series of minute hooks so that they work 
together, and the four wings are thus practically converted into two. Each wing is hinged at its base to the back, and pivoted from below upon a small knob of the side wall of the thorax. The up-and-down motion of the wings is produced, not by muscles attached to their bases, but by two sets of enormous musciles, one rertical and the other horizontal, attached to the walls of the thorax, whose contractions elevate and depress the back plates of the thorax. Since the fulcrum of each wing is outside of its attachment to the back, the depres-

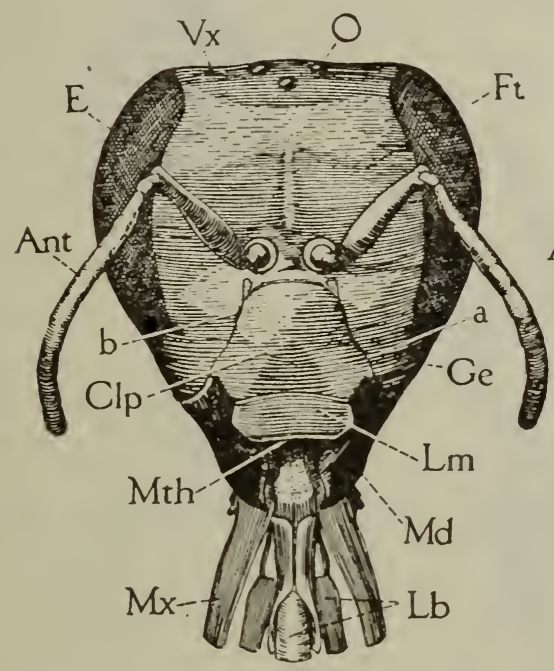

A

Prb and brushes on the last, are illustrated in Fig. 4. The tarsi are each provided with a pair of terminal claws $(E, C l a)$, by means of which the bee clings to rough objects, while between the claws is a sticky pad, the empodium ( $E m p)$, which is brought into play when the bee alights on or walks over any smooth surface like glass.

The hind part of the thorax of bees, wasps, and their allies is composed of a segment, which, in other insects, is a part of the abdomen. It is known as the propodeum. The middle division of the body of

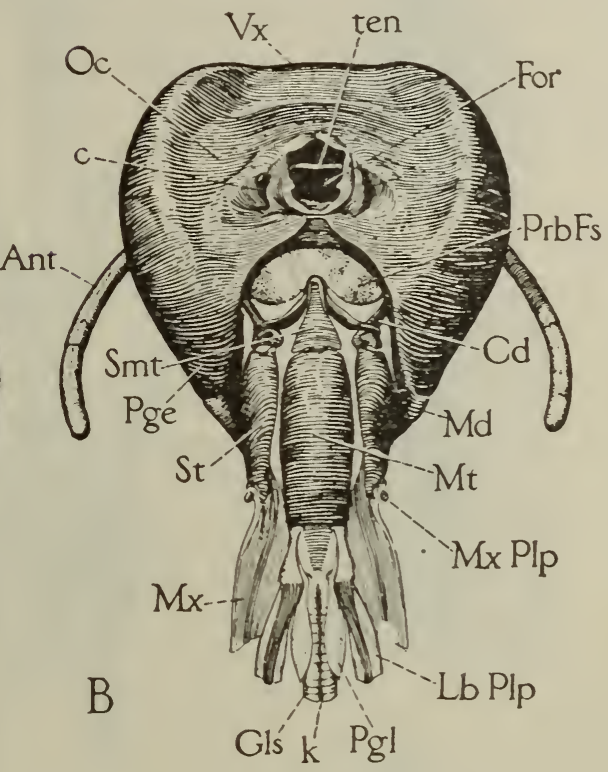

From Bulletin No. 18, "The Anatomy of the Honeybee," by Snodgrass, Dept. of Ag., Washington, D. C.

FIG. 2.-Head of worker with parts of proboscis cut off a short distance from their bases. A, anterior; B, posterior; a, clypeal suture; Ant, antenna; $b$, pit in clypeal suture marking anterior end of internal bar of head; $c$, pit on occipital surface of head, marking posterior end of internal bar; $C d$, cardo; $C l p$, clypeus; $E$, compound eye; For, foramen magnum; Ft, front; Ge, gena ; Gls, glossa, or "tongue;" $k$, rentral groose

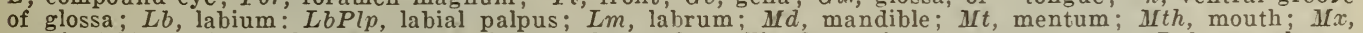
terminal blade of maxilla; $M I x P l p$, maxillary palpus; $O$, ocelli; Oc, occiput; Pge, postgena ; Pgl, paraglossa; Prb, base of proboscis; PrbFs, fossa of proboscis; Smt, submentum; St, stipes; ten, small bar of tentorium arching over foramen magnum; $T x$, vertex.

sion of the latter elerates the wings, and an elevation of the back lowers the wing. But the bee flies by a propeller-like action, or figure- 8 motion of the wings. This is produced by two other sets of much smaller muscles acting directly upon the wing bases, one before and the other behind the fulcrum of each. The combined result of all these muscles is that the down stroke of the wing is accompanied by a forward movement and a deflection of the anterior edge, while the up stroke reverses this.

The legs of the bee are too familiar to need any extensive description here. Their special characters, such as the antennæcleaners on the first and pollen-baskets a bee, wasp, or ant, therefore, is not exactly the equiralent of the thorax of a grasshopper, fly, or butterfly.

The abdomen of the bee has no appendages corresponding with those of the head or thorax; but it bears two important organs, viz., the wax glands and the sting. The wax glands are simply specially developed cells of the skin on the ventral surfaces of the last four visible abdominal segments of the worker. There are only six segments visible in the apparent abdomen; but remembering that the propodeum of the thorax is really the first, the wax glands occur, therefore, on segments four to seven inclusive (Fig. 1, IV-VII). The wax se- 
creted by the glands is discharged thru minute pores in the ventral plate of each segment, and accumulates in the form of a little scale in the pocket above the underlapping ventral plate of the segment next in front.

The sting is such a complicated organ that it is very difficult to describe it clearly in a few words. Fundamentally it consists of three slender, closely appressed pieces forming the sharp piercing organ that projects from the tip of the abdomen (Fig. 1, $S t n)$, and of two soft fingerlike lobes, sometimes also visible, all of which arise from three pairs of plates belonging to the eighth and ninth segments of the abdomen, but which are concealed within the seventh segment.

Fig. 5 shows, somewhat diagrammatically, all the parts of the left side. Th : ite
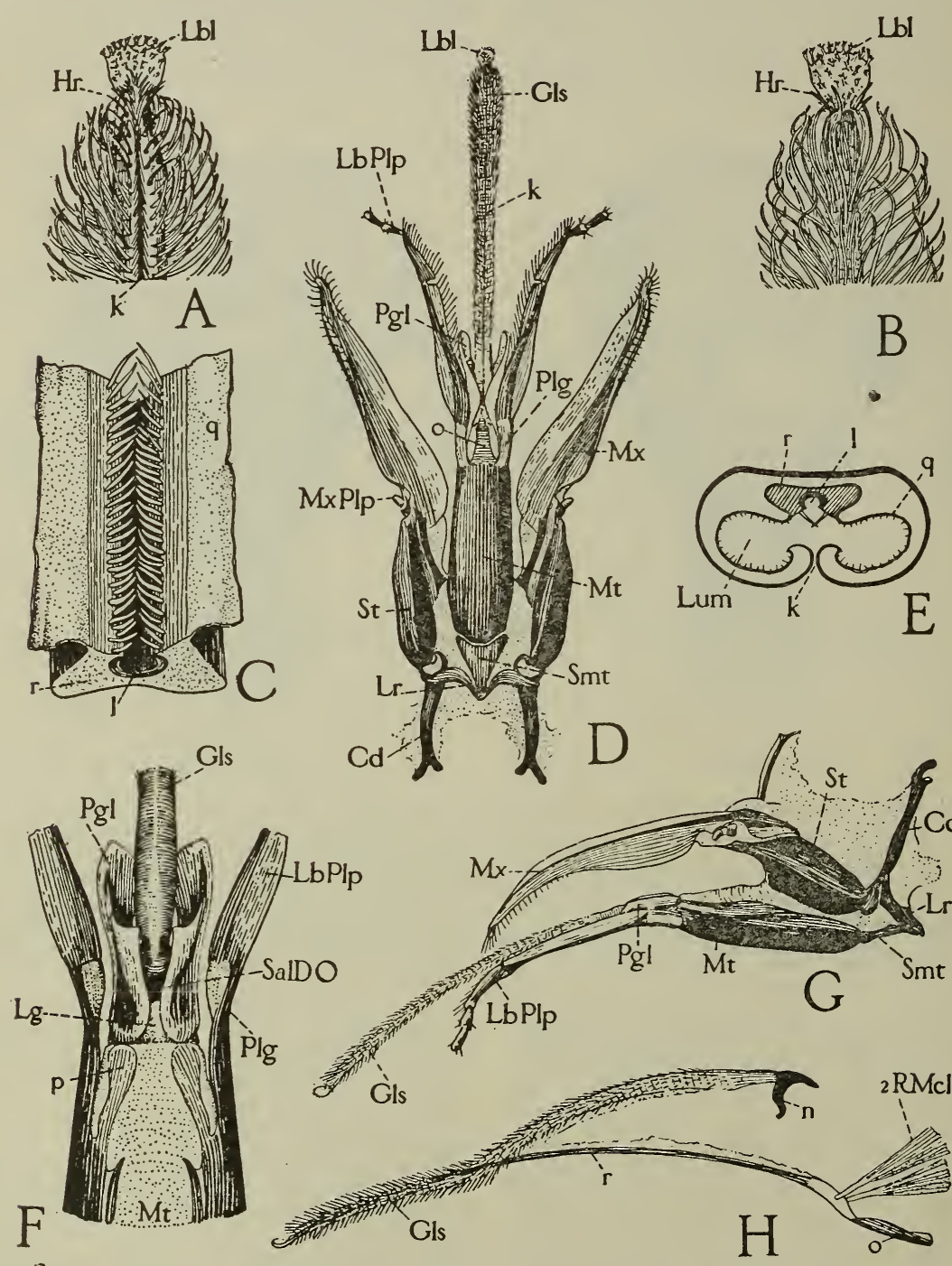

$\mathrm{Lbl}$
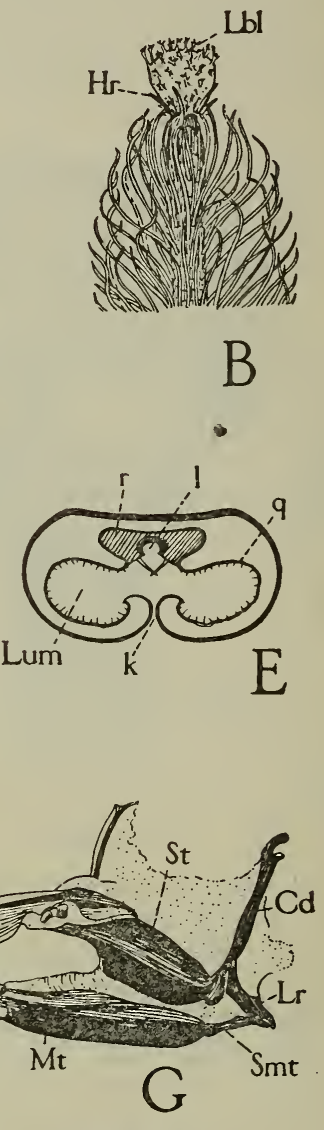

LbPlp

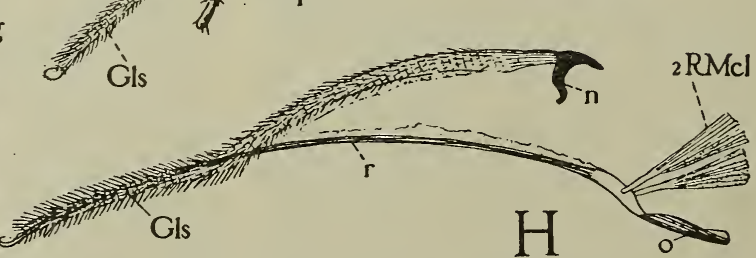

From Bulletin No. 18, "The Anatomy of the Honeybee," by Snodgrass, Dept. of Ag., Washington, D. C.

FIG. 3.-Details of mouth parts of worker. $A$, tip of glossa, ventral; $B$, tip of glossa, dorsal; $C$, piece of glossal rod $(r)$ showing ventral groove $(l)$ with parts of wall $(q)$ of glossal channel attached; $D$, parts of proboscis (maxillæ and labium) flattened out in ventral view; $E$, cross-section of glossa, showing its channel $(L u m)$ open below along the groove $(k)$, the internal rod $(r)$ in roof of channel, and its groove $(l) ; F$, distal end of mentum ( $M I t)$, dorsal, showing opening of salivary duct (SalDO) on base of ligula; $G$, lateral view of left half of proboscis; $H$, glossa $(G l s)$ with its rod $(r)$ partly torn away, showing retractor muscles $(2 R M c l)$ attached to its base; $C d$, cardo; $H r$, long stiff hairs near tip of glossa; $k$, ventral groove of glossa; $l$, ventral groove of glossal rod; $L b l$, labella; $L b P l p$, labial palpus; $L g$, ligula; $L r$, lorum; $L u m$, channel in glossa; $M t$, mentum; $M x$, terminal blade of maxilla; $M x P l p$, maxillary palpus; $n$, basal process of glossal rod; 0 , ventral plate of ligula, carrying base of glossal rod; $p$, dorsal plates of mentum; Pgl, paraglossa; Plg, palpiger; $q$, inner wall of glossal channel; $r$, rod of glossa; 2 RMcl, retractor muscle of glossal rod; SalDO, opening of salivary duct; Smt, submentum; St, stipes. 
;haft swells basally into a large 3) which is connected by a basal ach side with wo lateral plates [ri). The fingerlike lobes, called If the sting $(S t n P l p)$ are carried 3 lower of these two plates $(O b)$ ipper (Tri) carries the third and te $(Q d)$ which partially overlaps $\mathrm{Ob})$.

examination of the sting proper both the bulb and the tapering ormed of three pieces. One is 3 and $S h S)$ while the other two (Lct) art rentral (of course only one of the latter shows in side view). Furthermore, the basal arm on each side is formed of two pieces, one of which ( $S h A$ ) is continuous with the dorsal piece of the sting, while the other ( $L c t)$ is continuous with the ventral rod of the same side. Since these ventral rods are partially enclosed within a hollow on the under side of the dorsal piece, the latter is called the sheath of the sting. It consists of the terminal shaft of the sheath $(S h S)$, the bulb $(S h B)$, and of a basal $\operatorname{arm}(S h A)$ on each side. The rentral pieces $(L c t)$ are slender sharp-pointed rods having barbed extremities, and are known as the lancets. The shaft of the sheath is grooved along the entire $1 \mathrm{~nm}$, th of its ventral surface. the pom roing

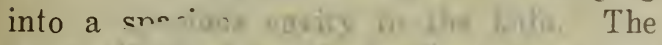

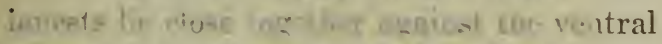

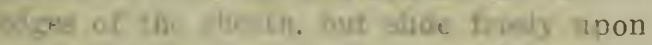

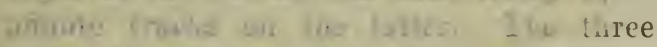

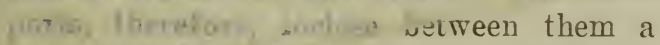
curiey wist is tubular in the shaft. but wiarged into a wide chamber in the bulb. The great poison-sac (Fig. 8. PsrSc) of the acid glands of the sting opens into the base of the bulb along with the smaller, tubular, alkaline gland $(B G l)$. By morements of the triangular plates (Fig. 5, Tri) the lancets slide back and forth against the sheath while the poison exudes in tiny drops from an opening. between them near the tips. The poison-sac has no muscles in its walls, and, hence, cannot force the poison thru the sting. The poison, in fact, is driven out of the latter by a force pump inside of the bulb. This consists of two pouchlike lobes situated on the upper edges of the lancets, having their cavities open posteriorly. When the lancets move forward the walls of these pouches collapse; but when the motion is reversed they flare apart and drive the poison contained in the bulb back thru the shaft and out at the end.

The poison is an acid liquid formed by the glands (Fig. 8, $A G l, A G l$, and $B G l$ ). Two of these ( $A G l$ and $A G l$ ) are simply small enlargements at the ends of two long coiled tubes $(A G l D)$, which latter unite into a short single tube that opens into the anterior end of the great poison-sac (Psn $S c$ ). The secretion of these glands is acid. The third gland $(B G l)$ is a short, somewhat $t$ wisted tube opening into the bulb of the sting along with the poison-sac. Its secretion is alkaline. Carlet has shown that it is only the mixture of these two secretions that has the full strength in stinging properties.

The alimentary canal (Fig. 6) consists of a tube extending thru the entire bcdy, and coiled somewhat in the abdomen. The first part above the mouth in the head is widened to form the pharynx (Phy). Then follows the long slender oesophagus $(E)$, running clear thru the thorax and into the front of the abdomen, where it enlarges into a thin-walled bag, called, in general, the crop, but which is known as the honeystomach (HS) in the bee. Back of the honey-stomach is a short narrow proventriculus (Pvent), which is followed by the large U-shaped stomach, or ventriculus (Vent). Then comes the slender small intestine (SInt) with the circle of Malpighian tubules ( $M a l$ ) arising from its anterior end. Finally, forming the terminal part of the alimentary canal, is the large intestine, or rectum (Rect), consisting of an enormous sac, varying in size according to its contents, but often occupying a large part of the abdominal carity. Six opaque longitudinal bands on its anterior end are known as the rectal gland $(R G l)$.

The honey-stomach is of special interest in the worker because the nectar gathered from the flowers is held in it, instead of being swallowed on down into the stomach. and is regurgitated into the cells of the comb, or given up first to another bee in the hive. The upper end of the proventriculus sticks up into the lower end of the honeystomach as a small cone with an $\mathrm{X}$-shaped opening in its summit. This opening is called the stomach mouth. Its four lips are rery active, and take whatever food the ventriculus requires from the hrney-stom- 
ach, for it must all go into the latter first, while at the same time it affords the bees a means of retaining nectar or honey in the honey-stomach.

The natural food of bees consists of pollen, nectar, and honey. The first contains the nitrogen of their diet, and the other two the hydrogen, carbon, and oxygen. Observations made by the writer indicate that the pollen is not digested until it gets
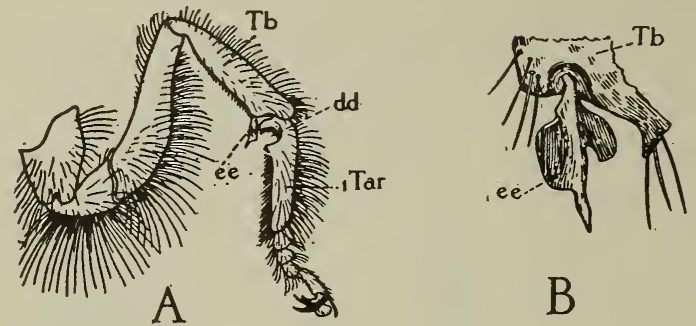

B
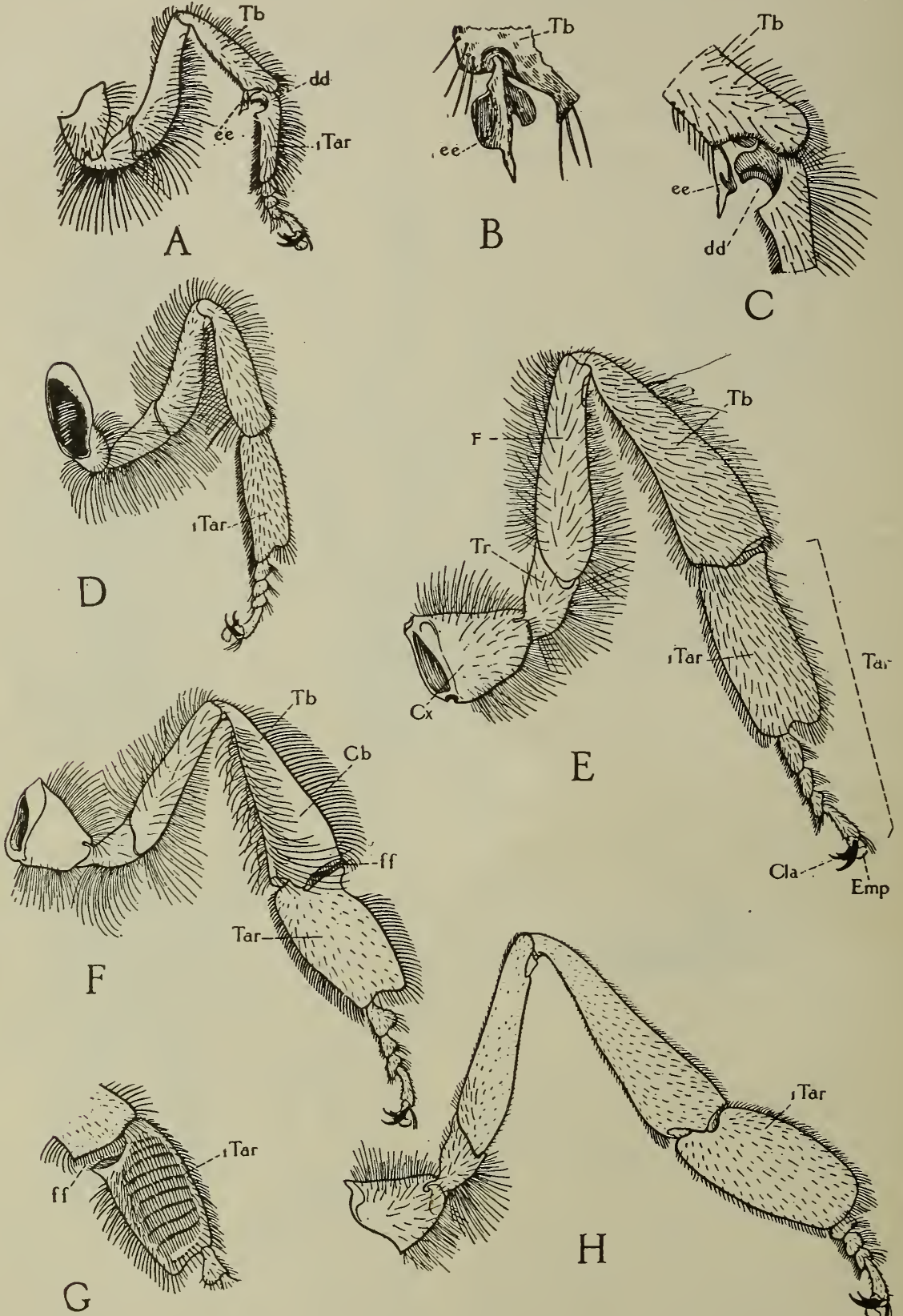

$\mathrm{Tb}$
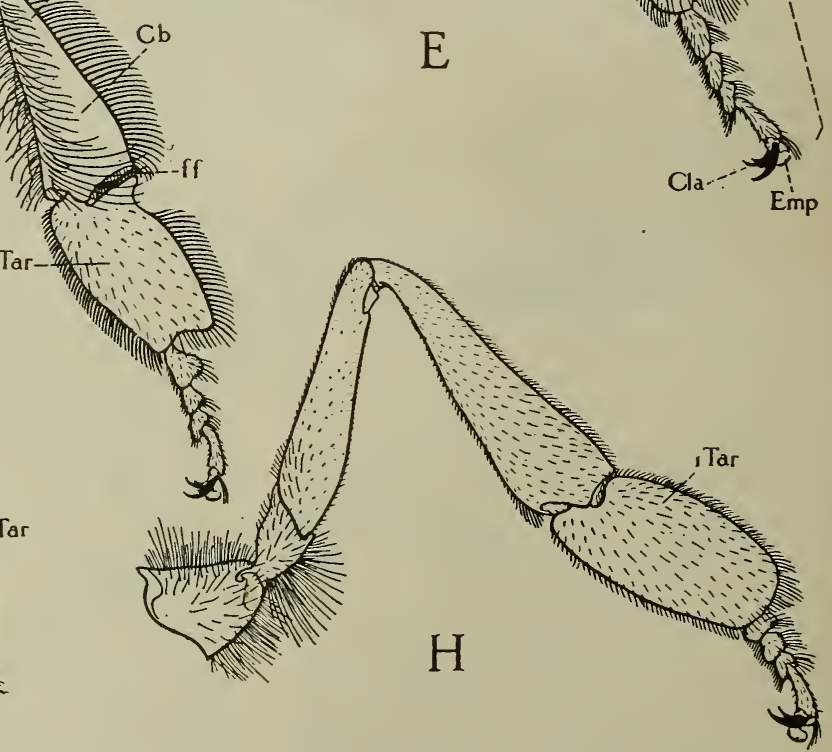

From Bulletin N'o. 18, "The Anatomy of the Honeybee," by Snodgrass, Dept. of Ag., Washington, D. C.

FIG. 4.-Details of legs. $A$, front leg of worker, showing position of antenna-cleaner ( $d d d$ and $e e$ ); $B$, end of tibia of front leg showing spine $(e e)$ of antenna-cleaner; $C$, antenma-cleaner, more enlarged; $D$, middle leg of worker; $E$, hind leg of queen; $F$, hind leg of worker, showing pollen-basket $(C b)$ on outer surface of tibia; $G$, inner view of basal joint of hind tarsus of worker, showing the brush of pollen-gathering hairs; $H$, hind leg of drone; $C b$, corbiculum, or pollen-basket; $C l a$, claws; $C x$, coxa; $d d$, notch of antenna= cleaner on basal joint of first tarsus; $e$, spine of antenna-cleaner on distal end of tibia; $E m p$, empodium, sticky pad between the claws for walking on smooth surfaces; $F$, femur; ff, "wax shears;" Tar, tarsus; 1 Tar. first joint of tarsus; $T b$, tibia. 
into the intestine, for masses of fresh-looking grains nearly always appear in the rear part of the ventriculus, which is otherwise filled with a brownish slime. On the other hand, the nectar and honey are very probably digested in the rentriculus, and in large part absorbed from it.

The salivary glands, located in the back part of the head (Fig. 6, 2Gl) and in the fiont part of the thorax $(3 G l)$ open upon the upper part of the labium (Fig. 3, F, SalDo). The saliva can thus affect the liquid food before the latter enters the mouth, or it can be allowed to run down the proboseis upon hard sugar in order to dissolve it, for the latter is eaten with the proboscis, not with the mandibles.

The largc glands (Fig. 6, 1Gl) situated heart consists of four consecutive chambers $(1 \mathrm{ht}=\mathrm{h} \mathrm{ht})$, which are merely swellings of the tube, each having a vertical slit or ostium (Ost) opening into each side. The blood is the colorless liquid that fills the spaces about the viscera of the body cavity. The dorsal diaphragm and the heart pulsate forward. The blood in the cavity above the former enters the ostia of the heart, and is pumped forward thru the aorta and out into the cavity of the head. From here it percolates back thru the thorax and enters the space beneath the ventral diaphragm $(V D p h)$ of the abdomen. This membrane pulsates backward, and the blood is driven posteriorly and upward, thru the lateral openings, around the abdominal viscera, and again into the dorsal or pericardial

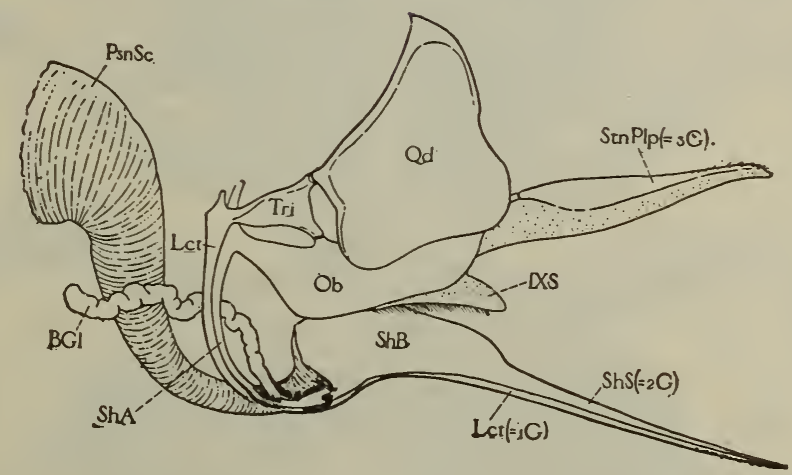

From Bulletin No. 18, "The Anatomy of the Honeybee," by Snodgrass, Dept. of Ag., Washington, D. C.

FIG. 5.-Left side of sting and its accessory plates, with alkaline gland $(B G l)$ and base of poison-sac $(P s n S c)$ attached. $B G l$, alkaline-poison gland; Lct, lancet; Ob, oblong plate; PsnSc, base of poison-sac, holding secretion from acid-gland (see Fig. 8); Qd, quadrate plate; IXS, median part of ninth abdominal sternum; ShA, arm of sheath; ShB, bulb of sheath; ShS, shaft of sheath; StnPlp; palpus of sting; Tri, triangular plate.

in the front part of the head are supposed, by some students of the bee, to form the white pasty brood food and the royal jelly. Others think that these substances come from the stomach. More investigation of the subject must be made, however, before the question can be decided; but the contents of the stomachs of the workers have no resemblance to the brood food.

The circulatory system is very simple, consisting of a delicate, tubular, pulsating heart (Fig. 1, Ht), in the upper part of the abdomen, of a single long blood-vessel, the aorta $(A o)$, extending forward from the heart thru the thorax into the head, and of two pulsating membranes, the diaphragms $(D D p h$ and $V D p h)$, stretched across the dorsal and ventral walls of the abdomen, but leaving wide openings along their sides between the points of attachment. The cavity of the abdomen, where it begins its circulation anew. In insects the principal function of the blood is to distribute the food which dissolves into it from the alimentary canal.

The respiratory system is very highly developed in the bee, consisting (Fig. 1) of large air-sacs (TraSc, 1-10) in the head, thorax, and abdomen, and of tubes called tracheæ given off from them (Tra, LTra). Fig. 1 shows principally the parts in only the right side of the body. In the abdomen a large sac (10) lies on each side connected with the exterior by short tubes opening on the sides of the first seven segments. Three other pairs of such openings occur in the thorax; but the last of these, being in the propodeum, really belongs to the abdomen. Thus there are in all ten pairs of breathing apertures, and they are called the 


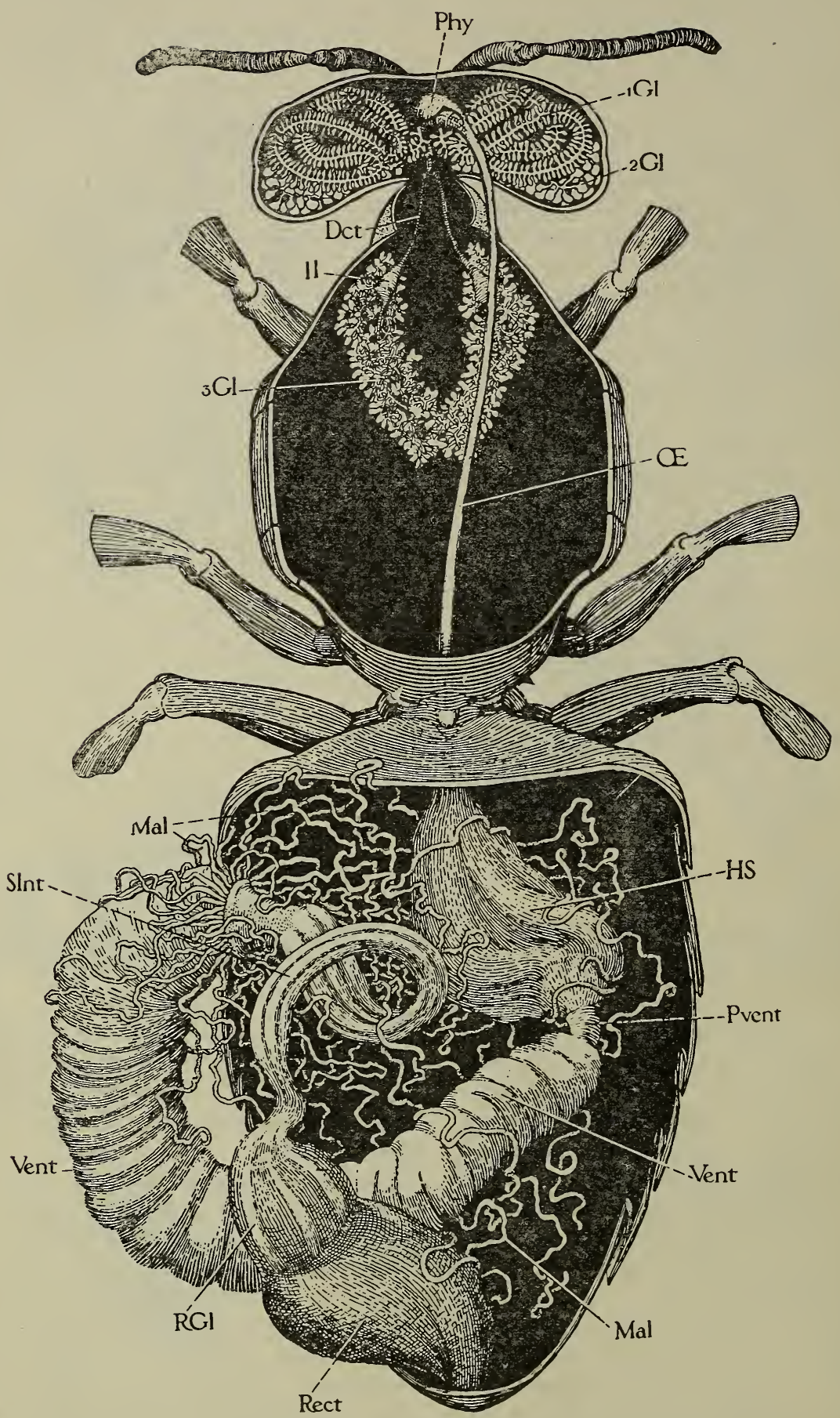

From Bulletin No. 18, "The Anatomy of the Honeybee," by Snodgrass, Dept. of Ag., Washington, D. C.

FIG. 6-Alimentary canal and salivary glands of worker, dorsal. Dct, salivary duct; $1 G l$, pharyngeal glands of head (supracerebral glands): $2 G l$, salivary glands of head (postcerebral glands); $3 G l$, salivary glands of the thorax; $H S$, honevstomach; $l l$, reservoir of thoracic salivary gland; Mal, Malpighian tubules; (F), cesophagus; Phy, pharynx; Pvent, proventriculus; Rect, rectum; Rgl, rectal glands; SInt, small intes tine; Vent, ventriculus. 


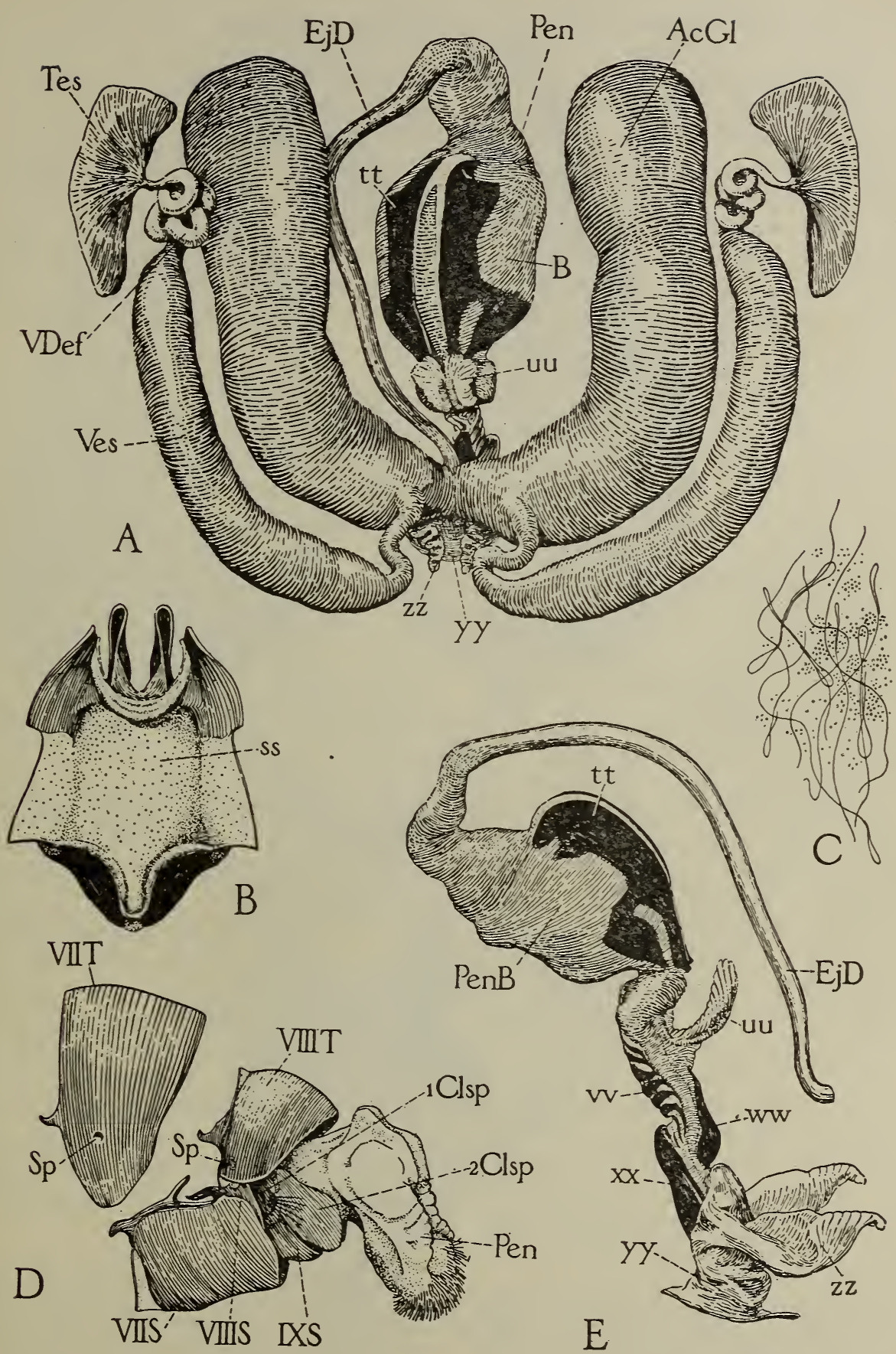

From Bulletin No. 18, "The Anatomy of the Honeybee," by Snodgrass, Dept. of Ag., Washington, D.C.

FIG, 7-A, reproductive organs of drone, dorsal; $B$, inner view of dorsal wall of penis; $C$, group of spermatozoa; $D$, terminal segments of drone, lateral, showing penis $(P e n)$ partly protruded; $E$, lateral view of penis and ejaculatory duct $(E j D) ; A c G l$, accessory mucous gland; $B$, bulb of penis; 1 Clsp, $2 C l s p$, clasping organs of ninth abdominal sternum; Pen, penis; PenB, bulb of penis; $\nabla I I S-I X S$, serenth to ninth abdominal sterna; ss, gelatinous mass of inner wall of bulb of penis: VIIT-VIIIT, seventh and eighth abdominal terga; $t$, dorsal plates of bulb of penis; Tes, testis; $u$, fimbriated lobe at base of bulb of penis; $v v$, ladder-like plates of penis; $\nabla D e f$, vas deferens; Ves, seminal vesicle; $w w, x x$, dorsal and ventral plates in wall of penis; $y y$, terminal chamber of penis thru which the rest is everted; $z z$, copulatory pouches of penis. 
spiracles. None occur on the head. The tracheal tubes given off from the air-sacs branch minutely to all parts of the body and penetrate into most of the tissues. Hence oxygen is carried directly to the cells that use it, and the blood of insects is thus relieved of the work of distributing itone of its principal functions in vertebrate animals. The respiratory movements are produced by muscles of the abdomen.

The life processes of the cells of the body result in the formation of products excreted by the cells into the surrounding blood. These products are poisonous to the system unless immediately changed into simpler substances. This change is effected partly by the inhaled oxygen combining with the waste products, resulting in the formation of compounds of nitrogen which dissolve in the blood, and of carbonic acid gas which diffuses into the tracheal tubes and is exhaled. The nitrogen compounds are supposed to be removed by the Malpighian tubules (Fig. 6, Mal), which are regarded as the kidneys of insects.

The nervous system consists of a series of small masses of nerve tissue called ganglia, lying along the median ventral line of the body cavity (Fig. 1, 1Gng-rGng), the two of the thorax being much larger than those of the abdomen. Each two are connected by a pair of cords called commissures. Nerves are given off from these ganglia to the various organs and parts of the body, and to the legs and wings. In the head there are two ganglionic masses. One is called the brain $(O p L)$, and is situated above the rosophagus, where it gives off nerves to the eyes, the antennæ, the front, and the labrum. The other, called the suboesophageal ganglion, lies in the lower part of the head, and innervates the mouth parts, while it is connected by commissures with both brain and the first thoracic ganglion.

The reproductive system consists of those organs that produce the spermatozoa in the male and the eggs in the female and their accessory parts.

The spermatozoa are formed in the testes of the male (Fig. 7, A, Tes), a pair of small bodies in the front part of the abdomen, said to be developed at their highest in the pupal stage. Each is connected by a coiled tube, the vas defferens ( $V D e f)$, with a long sac, the seminal vesicle ( $V e s)$ in which the spermatozoa are stored during the adult stage of the drone's life. The two vesicles open into the bases of two enormous mucous glands $(A c G l)$ which come together in a narrow muscular tube, the ejaculatory duct $(E j D)$. This opens into the anterior end of the penis (Pen). This is a complicated organ, shown at E, Fig. 7. It is ordinarily contained within the cavity of the abdomen; but during copulation it is entirely everted, and its basal pouches $(z z)$ lock into corresponding pouches of the oviduct of the queen.

The eggs are formed by the ovaries of the female (Fig. 8, Ov), each of which consists of a thick mass of tubules called the ovarioles $(o v)$, within which the eggs grow from simple cells at their upper ends into the mature eggs found at their lower ends. The ovarioles of each ovary open into an oviduct $(O v D)$, which two unite into a wide median tube called the vagina ( $\mathrm{rag}$ ) that swells posteriorly into a large pouch known as the bursa copulatrix $(B C p x)$, opening to the exterior in the eighth segment beneath the base of the sting.

During copulation the drone ejects the spermatozoa into the upper end of the ragina of the queen. The spermatozoa consist of minute vibratory threads (Fig. 7, C), which, probably, by their own motion, make their way up thru a small tube opening into the dorsal wall of the vagina, and so reach a globular sac (Fig. 7, Spm) called the spermatheca. Here they are held during the rest of the lifetime of the queen, to be extruded in small bundles, of about a hundred each, according to Breslaw, upon the eggs passing out of the vagina. Thus are the female eggs fertilized, the drone eggs developing' without the addition of the male element.

ANGER OF BEES.-We do not like the term " anger," when applied to bees, and it almost makes us angry when we hear people speak of their being " mad," as if they were always in a towering rage, and delight to inflict severe pain on everything and everybody coming near them. Bees are, on the contrary, the pleasantest, most sociable, genial, and good-natured little beings we meet in all animated creation, when we understand them. Why, we can tear their beautiful comb all to bits right before their 


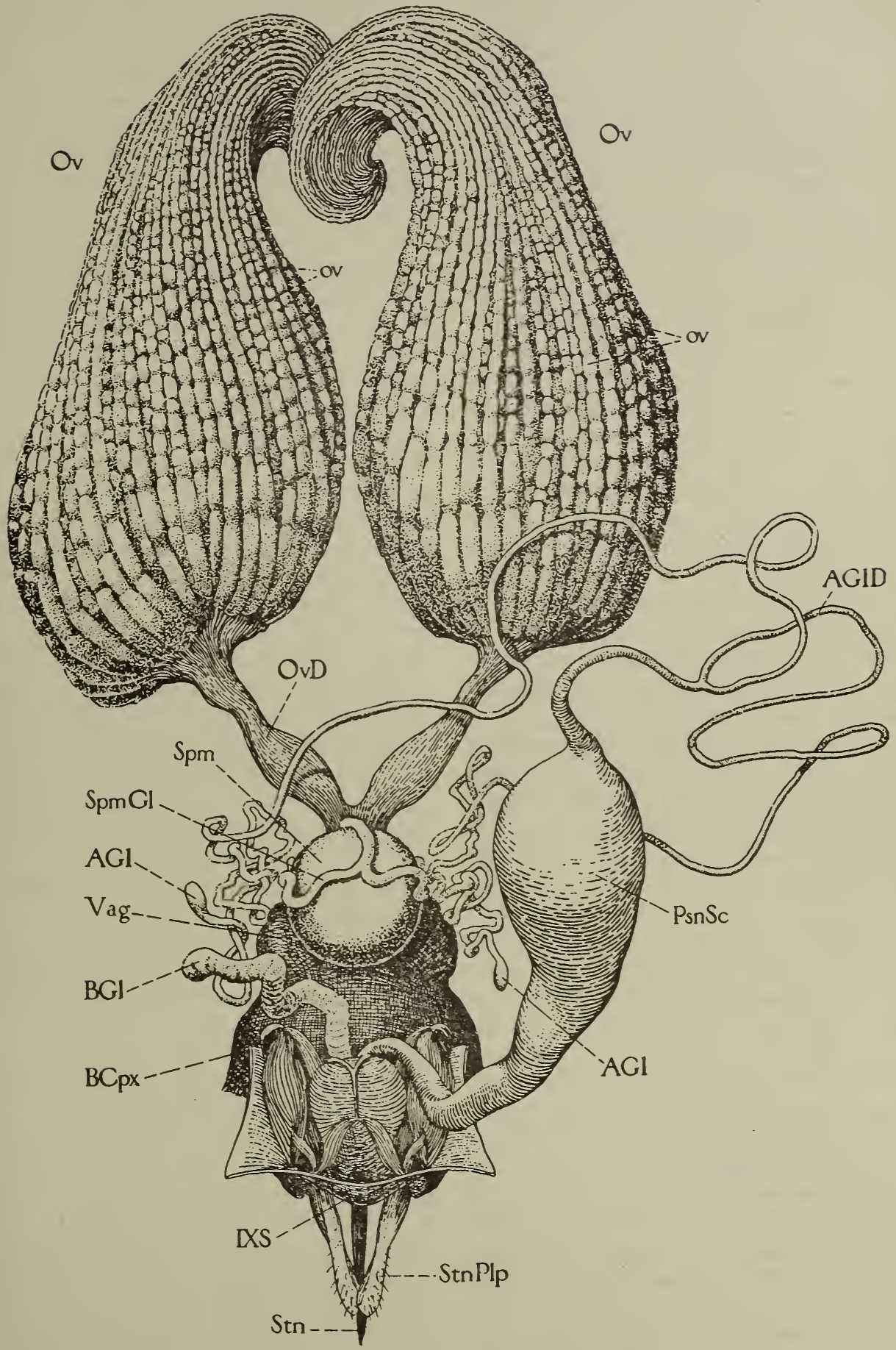

From Bulletin No. 18, "The Anatomy of the Honeybee," by Snodgrass, Dept. of Ag., Trashington, D. C.

FIG. 8.-Reproductive organs of queen, dorsal, together with sting, its muscles, glands, and poison-sac. $A G l$, acid-glands of sting: $A G L D$, duct of acid-glands. $B C p x$, bursa copulatrix; $B G l$, alkaline gland of sting; $O v$, ovaries; $o v$, orarioles; $O v D$. oriduct; $P s n S c$, poison-sac; $I X s$, median part of ninth abdominal sterum : Spm, sac of spermatheca; SpmGl, spermathecal gland; Stn, sting; StnPlp, palpus of sting; Tag, ragina. 
very eyes, and without a particle of resentment; but with all the patience in the world they will at once set to work to repair it, and that, too, without a word of remonstrance. If they are pinched they will sting; and anybody who has energy enough to take care of himself would do as much had he the weapon.

How to open hives in such a way as to avoid stings, see Manipulation of ColoNIES, and STINGS.

In order that the reader may better understand that which follows, it may be well to set forth two or three fundamental conditions under which bees become cross or nervous and unpleasant to handle. First, a slackening or a shutting-off of the supply of food obtained either from the fields in a natural way, or from exposed sweets, always has a tendency to make bees ill-natured. If the honey-flow is unusually strong, and then slackens up very rapidly, the bees in the whole yard become cross. This is particularly noticeable at the closing of basswood or after the drying up of certain honey-dews deposited on the leaves of trees. When the bees are robbing, and combs or syrup is carelessly exposed, and these combs or the syrup is suddenly put under cover, so that not another drop can be secured, bees will usually sting furiously, when, if their supply were allowed to stand and gradually diminish, they will be much better-natured.

If some one carelessly exposes sweets in quantities during a dearth of honey when bees are disposed to rob, this will have a tendency to stir up the whole apiary. The roar of the excitement may be heard some distance from the apiary. Thousands and thousands of bees will be found flying around everywhere to discover where this new supply is located; but, as a general thing, bees are not cross when trying to find the source of the sweet. The real trouble begins about the time the supply gives out.

During the middle hours of the day, when the bees are going into the fields when the air is warm and balmy, they are generally very gentle. But if a sudden rainstorm comes up, shutting off the supply of nectar they will usually be quite cross, and this bad temper will last until the normal supply begins to come in again.

Bees are apt to be cross on cool or chilly days. When all are at home, and the hives are opened unceremoniously, they may resent the intrusion. It is then that beginners discover, much to their sorrow, that bees should not be handled during cool or chilly weather, right after a rain, nor at night.

By keeping these facts carefully in mind, one will more readily discover why bees are cross when the following incidents are related:

A few years ago a very intelligent man procured some Italians, an extractor, etc., and commenced bee culture. He soon learned to handle them, and succeeded finely; when it came time to extract, the whole business went on so easily that he was surprised at what had been said about experienced hands being needed to do the work. $\mathrm{He}$ had been in the habit of doing his work as directed, toward the middle of the day, while the great mass of the bees were in the fields; but in the midst of a heavy yield of clover honey, when the hives were full to overflowing, they were one day stopped by a heavy thunder-shower. This, of course, drove the bees home, and at the same time washed the honey out of the blossoms so completely that they had nothing to do but remain in the hives until more was secreted. Not so with their energetic and enthusiastic owner. As soon as the rain had ceased, the hives were again opened, and an attempt made to take out the frames, as but a few hours before; but the bees that were all gentleness then, seemed now possessed of the very spirit of mischief; and when all the operators had been severely stung, they concluded that prudence was the better part of valor and stopped operations for the day. While loads of honey were coming in all the while, and every bee rejoicing, none was disposed to be cross; but after the shower, the bees were standing around idle; and when a hive was opened, each was ready to take a grab from its neighbor, and the result was a free fight in a very short time.

There is nothing in the world that will induce bees to sting with such wicked recklessness as to have them get to quarreling over combs or honey left exposed when they have nothing to do. When the supply is exhausted their frenzy reaches its height. From a little carelessness in this respect, and nothing else, whole apiaries have been so demoralized that people were stung when passing along the street several rods distant. During the middle of the day, when 
bees were busily engaged on the flowers during a good yield, we have frequently left filled combs standing on the top of a hive from noon until supper time without a bee touching them; but to do this after a hard rain, or at a time when little or no honey is to be gathered in the fields, might result in the ruin of several colonies, and the bees being voted a nuisance by the whole neighborhood.

Almost every season we get more or less letters complaining that the bees have suddently become so cross as to be almost unmanageable, and those letters come along in July, after the clover and linden have begun to slacken. As already pointed out, and at the beginning of this article, it is the slackening or stoppage of the flow that makes the bees irritable.

Bees are not so very unlike mankind after all, and all one has to do is to avoid opening the hive for a few days, until they get used to the sudden disappointments of having avenues thru which they were getting wealth so rapidly, cut off. After a week or ten days they will be almost as gentle as in times when they gathered half a gallon of honey daily, if care is taken about leaving hives open too long or leaving any bits of honey or comb about.

It is not easy to explain why bees sting so remorselessly and vindictively after having had a taste of stolen sweets, yet nearly all the instances where there is trouble with stinging have been from this very cause. Bees from colonies that have a habit of robbing will buzz about one's ears and eyes for hours, seeming to delight in making one nervous and fidgety if they succeed in so doing, and they not only threaten, but often times inflict, the most painful stings, and then buzz about in an infuriated way, as if frantic because unable to sting one a dozen times more after their stings are lost. The colonies that furnish this class of bees are generally hybrid, or perhaps black bees having just a trace of Italian blood. These bees seem to have a perfect passion for following one about, and buzzing before the nose from one side to the other (until one gets cross-eyed in trying to follow their erratic oscillations), in a way that is most decidedly provoking. One such colony annoyed us so much while extracting that we killed the queen, altho she was very prolific, and substituted a pure Italian. It is seidom an Italian follows one about in the manner mentioned, yet an occasional colony may contain bees that do it; at least we have found such, where the workers were all three-banded. That it is possible to have an apiary without any such disagreeable bees, we have several times demonstrated; but oftentimes it will be necessary to discar'd some of the very best honey-gatherers, to be entirely rid of them. On occasions like this it is advisable to use robber-traps. See RobBers.

With a little practice the apiarist will tell as soon as he comes very near the apiary whether any angry bees are about, by the high keynote they utter when on the wing. It is well known that with meal feeding (sie POLLEN) we have perfect tranguillity altho bees from every hive in the apiary may be working on a square yard of meal. Now, should we substitute honey for the meal, we should have a perfect uproar, for a taste of honey found in the open air during a dearth of pasturage, or at a time when our bees have learned to get it by stealing instead of honest industry, seems to have the effect of setting every bee crazy. In some experiments to determine how and why this result came about, we had considerable experience with angry bees. After they had been robbing and had become tranquil, we tried them with dry sugar; the quarrelsome bees fought about it for a short time, but soon resumed their regular business of hanging about the well-filled hives, trying to creep into every crack and crevice, and making themselves generally disagreeable all around. If a hive was to be opened, they were into it almost before the cover was raised, and then resulted a pitched battle between them and the inmates; the operator was sure to be stung by one or both parties, and, pretty soon, some of the good people indoors would be asking what in the world made the bees so awfully cross, saying that they even came indoors and tried to sting. Now, why could they not work peaceably on the sugar as they do on the meal, or the clover blossoms in June? We dampened the sugar with a sprinkler. and the bees that were at work on it soon started for home with a load; then began the high keynote of robbing, faint at first, then louder and louder, until we began to be almost frightened at the mischief that might ensue. When the dampness was all 
licked up they soon subsided into their usual condition. The effect of feeding honey in the open air is very much worse than that of feeding any kind of syrup.

HOW THE SOURCE FROM WHICH BEES ARE GATHERING AFFECTS THEIR TEMPER.

It has been found that bees are crosser when working on some blossoms than on others. For example they seem to be more inclined to sting when working on buckwheat than on clover. This is probably due to the fact that the latter yields nectar all day while the former will in most localities yield an hour or two in the morning and again toward night. The stoppage of the flow seems to affect the bees adversely.

In the same way they are cross when working on honey-dew from hickory and oaks. This yields heavily in the morning and lets up and stops during the middle hours of the day. The morning dews soften the saccharine matter secreted on the leaves of these trees, and when it dries up again the nectar supply is cut off and the bees are cross. During 1909, when there was so much honey-dew from oaks and hickories from all over the country, bees that year were reported to be exceptionally cross.

To make bees good-natured, a honeyplant must be a continuous yielder all day. So long as it keeps up its supply, there is quiet.

HOW THE PRESENCE OR ABSENCE OF SHRUB-

BERY OR TREES AFFECTS THE TEMPER OF THE BEES IN THE YARD.

It has been shown time and time again that the same bees that are ciocile as kittens in the home yard, with plenty of shrubbery to shut off the view of individual colonies, will often be as cross as hornets when placed in an out-apiary on a level piece of ground where their hive is in view of every other hive, without any obstructing shrubbery or trees. The reason of it is plain. If there are any cross bees in the air, and they see a moving object like a beekeeper, for example, going thru the yard they will immediately come buzzing about him with that peculiar angry scream that a mad bee always has. Those same bees when located in a yard where there is plenty of shrubbery, and where they cannot see moving objects as readily, will forget all about the source of their irritability, and either go to the fields or into their own hives.
Several times we have been tempted to kill all the queens in a certain yard because their bees were so very cross, only to discover later on that when we moved them to the home yard, where there were grapevines shutting off the view of their colony or hive, that there was nothing the matter with the bees but only with their previous environment. For that reason alone, some of the crossest bees we have ever known have become very tractable when placed in a small orchard or piece of woods. The crossest bees will also become very docile when put into a house-apiary. When the owner is inside he cannot be seen, of course, and he can work inside of the building without hindrance.

How to make bees good-natured by feeding, see Feeding Outdoors; also see Robbing, Stings, and Manipulation of ColoNIES.

ANTS.-Altho we have given the matter considerable attention, we cannot find that ' ants are guilty of anything in the North that should warrant the apiarist in waging any great warfare against them. Some years ago a visitor frightened us by saying that the ants about our apiary would steal every drop of honey as fast as the bees could gather it. Accordingly we prepared ourselves with a tea-kettle of boiling water, and not only killed the ants but some graperines growing near. Afterward there came a spring when the bees, all but about eleven colunies, dwindled away and died, and the hives filled with honey, scattered about the apiary unprotected, seemed to be as fair a chance for the ants that had not "dwindled" a particle, as they could well ask for. We watched to see how fast they would carry away the honey, but, to our astonishment, they seemed to care more for the hives that contained bees than for those containing only honey. We soon determined that it was the warmth from the cluster that especially attracted them; and as the hives were directly on the ground, the ants soon moved into several that contained a small cluster only, and for a while both used one common entrance. As the bees increased, they began to show a decided aversion to having two families in the same house, altho the ants were evidently inclined to be peaceable enough until the bees tried to "push" matters, when they 
turned about and showed themselves fully able to hold possession. The bets seencel to be studying orer the matter for a while. and finally we found them one day taking the ants. one by one. and carrying them high up in the air. and letting them drop at such a distance from their home that they would surely nerer be able to walk back again. The bees. as fast as they became st ong rolrnies, drove the ants ont: and our experience erer since has been. that a guod clony of bees in the North is nerer in any danger of being troubled in the least by ants. One weak colony. after battling a while with a sirong rest of the ants. swarmed out: but they might have done this any way. so we do not lay much blame to the ants.

But ants do prove to be rery amoring in those apiariss where there is any attempt to keep the grass down with a lawn-mower. The little hillocks that they make all over the rard disfigure it to some extent. as well as forming more or less obstruction to the scrthe and lawn-mower. While. as we have already said. ants do little if any damage to hives in the North. ret as it is so easy to eradicate them it mar be well to consider methods for their extermination.

\section{HOW TO DESTROT ANTS NESTS.}

With a crowbar or a short stick and a mallet make a hole an inch or so in diameter. and about a foot deep. down thru the center of the nest. Around this hole make two or three other similar ones. or more if the nest is a large one. Go to the drugstore and get about a dime's rorth of bisulphide of carbon. Be careful with the stuff. for it is rery explosive, and the fumes of it should not be allowed to collect in the room where there is a gasoline flame or any store or lamp burning. From this bottle pour about a tablespoonful of the liquid in each hole: then immediately stop each up with a plug of earth. fre it is desired to have the fumes of the bisulphide penetrate all the galleries of the nest. thus destroving ants. larræ. and exgs. In a dar or so it will be found that everything formerly animate in and about the nest is dead.

But if the nests are not rery large. one can secure almost as good results by using coal oil or gasoline in place of the bisulphide. But in using these. about twice or three times the quantity should be poured in each hole. Tre have tried both gasoline and kerosene. and have found each effective in destroring the nest. Of the two, the kerc sone (or coal oil. as some call it) seems to be preferable. In using bisulphide of carbon. gasoline. or kerosene. be careful about spilling or pouring any of it on the top of the nest. as that will kill the grass. learing a brown spot right where it should be greeu. The bisulphide is more apt to kill the grass than the gasoline or coal oil. as it is much more porrerful.

The best time to destroy ants nests is to go early in the spring. before the ants have had an opportumity to make much of a hill ck: then there will be less liability of killing the grass: or, rather, a better opportunity for the grass to recover from its " dose" during the early spring rains.

\section{ANTS IN THE SOLTH.}

These insects are much more troublesome in the Southern States, and all warm climates, in fact, than in the North. Sometimes ther are so large and porrerful that they even set about to destroy the colony. Tre would first find the nest. and proceed to destroy by the use of kerosene or gasoline. If these do not prove to be potrerful enough. use bisulphide of carbon, making three or four holes to the square foot of nest: but in the case of bisulphide. one must be careful to have each hole stopper up tight with plugs of earth, otherwise the gas will escape. and the effect of the liquid will be largely lost.

But there is a species of ants in warm climates that hare nests in trees that are inaccessible. Other ants are so small. and come such long distances, that it is almost impossible to find their nest. In such cases it has been recommended to place within their reach some syrup or honey mixed with arsenic. Paris green. London purple. or strychmine. It is unnecessary to say that all ressels containing such poisonous mixtures should be placed in a bos corered with screen just fine enough to keep out bees. and coarse enough to admit the ants. They will work on these poisonous mixtures, and carry them home to their ronng. with the result that both mature insects as well as larræ will be destroyed, no matter where the nest may be.

The box containing the poisonous sweet should be put in the trail of the ants. It is 
usually necessary to get the ants started on something that they like that is not poisonous-a piece of fat chicken meat, for instance, then add the poison when they are well started.

When it does not seem practicable to destroy the pests they may be kept away from the hive temporarily by pouring a little narrow trail of kerosene clear around the hive or hives. The ants will come up to the oily line, and there stop.

Mr. Poppleton, of Florida, has graphically described in Gleanings the carnivorous ants.

With one exception these ants are the worst enemies bees have here in Florida, and only constant vigilance from September to December inclusive will prevent the loss of many colonies every season. These ants are usually found in our hummock lands, and only occasionally in clean pine woods; are red in color; of very large size; frequently measuring nearly or quite half an inch in length; are strictly nocturnal in their habits, being seldom seen in daytime except when disturbed or waging battle with a colony of bees; are usually found in decayed wood, thru which they cut out galleries for use as living-apartments. A favorite place is in a saw-palmetto root in the ground. Nearly every cabbage-palmetto tree contains a colony of them among the boots near its top, and for this reason a thick palmetto grove is one of the worst places where an apiary can be located. They are also found in piles of old boards, and on the ground under boards or logs. They alsu like to enter our houses and locate in trunks, boxes, drawers, and in almost any place where they can find a few inches of space to occupy. They are frequently found in the tops of our hives if there is sufficient space above the bees under the cover.

At sundown they start on their nightly quest for food; and if near an apiary a few of them will usually be seen running on some of the hives. As long as only two or three can be seen on any one hive, no special attention need be given them; but if a dozen or more are seen it means that they have probably selected that hive for their own use, and it needs close watching. They will continue their regular attentions to that one hive, gradually increasing in numbers until they decide they are strong enough, when nearly the entire colony of ants will boldly attack the bees by biting off their wings and legs, and crippling them so they are of no more use. Bees fight back courageously, the battle continuing for hours, and sometimes a day or two, according to the relative strength of the two belligerents. The inside of the hive and the ground near by will be strewn with dead ants and dead and crippled bees; but it always ends with the destruction of all the bees, and the moving in and occupation of the hive by the ant colony. When ants have once chosen a certain colony of bees to work on, the beemaster has to destroy the ants, roo' and branch, or they will in time destroy the bees. If a part only of the ants are destroyed they will simply bide their time until they have built up strong enough, and then do the work. I know of few or no living creatures more persistent in evil works than are these bee-killing ants. They also, in certain localities, do great damage to queen-rearing nuclei.

During the fall months I make it a practice almost every evening after dark in my home apiary, and as often as possible in the out-apiaries, to see by the light of a lantern the front of every hive; and any one on which I see three or four or more ants running over has a mark placed on it. If the number of ants on any one of these marked hives increases each night I give that hive special attention until the ants get numerous enough to begin to worry the bees. When this occurs, bees commence to whine, as I call it-that is, utter a fine sharp note with their wings. As the ants get bolder the cry of the bees becomes louder and more frequent-so much so that I have frequently heard it fifty feet away. The ants usually worry the bees continually for several nights, when suddenly the whole colony of ants starts in on a battle royal, which continues for hours or even a day or two, until every bee is disabled or driven out. A great many of the ants will also be killed; but how the bees do this is a mystery to me.

When the battle has once been joined, the beekeeper has a difficult task to save the bees; but this condition is preventable. When the ants become plentiful enough at the hive to begin worrying the bees, there is usually a trail of going and returning ants from their nest to the hive, and this can usually be located and traced to their nest, which, when found, should be left undisturbed until the following day, when all the ants will be at home. If the nest cannot be found the first time trying, I search again until it is found. As soon as the nest is found, or search for it is given up for that night, I sprinkle some insect powder on their trail near the hive; also wherever on or around the hive I can do so to worry the ants and not injure the bees. This will usually keep the ants from doing any more harm that night.

The next day when all the ants are at home, I take a kettle of boiling water, tear open the nest, and, if possible, kill every ant and egg. If a few of them are left they are likely to gather together, increase in time to their former strength, and again attack that same colony of bees. Whenever the nest is found in a box or piece of wood that can be easily moved with all the ants, the easiest and best plan is to carry them into the chicken-yard, break open the nest, and the hens will gladly do the rest of the business. 
They are very fond of both ants and eggs; and they not only find them good to eat, but give their owner lots of fun watching the old rooster especially, kick and scold every time an ant bites one of his feet. I have had many a hearty laugh watching this performance.

The ants are a great pest here in Florida. They destroy in the aggregate a great many colonies every tall. I know of one apiary which was entirely lost, largely, I judge, from what I hear, by these ants. At the best they are a great nuisance because they compel the beekeeper to remain at home watching them at a season of the year when nothing is doing in the apiary, and the apiarist could, but for them, be away on a holiday, or have some outside business.

Stuart, Fla.

O. O. Poppleton.

Ants are a serious pest to bees in many tropical countries, notably in South America, where they are omnipresent and almost omnipotent. A species similar to that described by Mr. Poppleton in Florida exists all over tropical America, and particularly in the Southern continent. $\mathrm{He}$ has so graphically described it, there is no necessity to enlarge on it further. The worst feature of these ants is their readiness to travel, so that, when one does destroy their

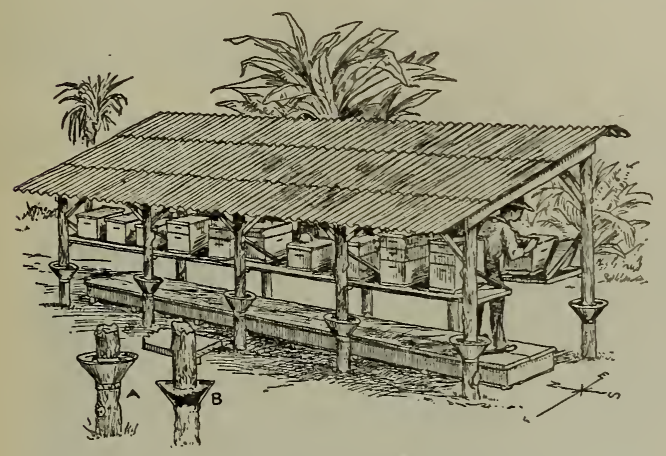

Morrison's ant-proof beehive shed.

nests, there is no assurance the apiary is safe from their attacks. Another bad feature is their habit of traveling by night; in fact, nearly all their depredations are made in the dark.

To circumvent them it is necessary to destroy all their nests within a radius of 100 yards of the apiary by the application of bisulphide of carbon to their nests. But this precaution alone will not suffice, and it will be necessary to adopt further measures. Luckily it is not difficult to do this, as tropical beekeepers are obliged to keep their hives under a shed, for excellent reasons.
In erecting a shed, therefore, we can take measure to prevent effectually the ants having access to the hives at all. All we have to do is to add cups to all the posts used to support the structure. The illustration preceding shows very clearly how this is accomplished with but little expense or trouble. The cups are filled with coaltar, creosote, or crude petroleum, all of which the ants positively dislike for two reasons-they stick to their feet and the smell is vile. No ant will attempt to cross such a mess as this, hence the bees are secure. The warm climate keeps the tar, etc., always soft; and if some rain falls into the cups it does no harm, as the water also tastes of the tar.

In working with the bees care should be taken to see nothing is left which will form a "bridge" whereby the ants will manage to reach the beehives while the apiarist is absent. One of the worst things that can happen is to allow the ants to get a taste of the bees; for once they do they are sure to linger around waiting for an opportunity to get into the hive.

APIARIST.-One who keeps bees, or a beekeeper; and a plot of ground including hives, bees, etc., is called an

APIARY.-A place where bees are kept, a beeyard; may consist of an indefinite number of colonies in hives.

\section{LOCATION.}

There is scarcely a spot on the surface of the earth where mankind finds sustenance that will not, to some extent, support bees, altho they may do much better in some localities than in others. A few years ago it was thought that only localities especially favored would give big honey crops; but since the introduction of modern races, and the new methods of management, we are each year astonished to hear of great yields here and there, and from almost every quarter of the globe. It will certainly pay to try a colony or two of bees, no matter where you may be located.

Beekeeping is profitable, even in the heart of some of our large cities. In this case the apiary is usually located on the roof of the building, that the bees may be less likely to frighten nerrous people and those unacquainted with their habits 


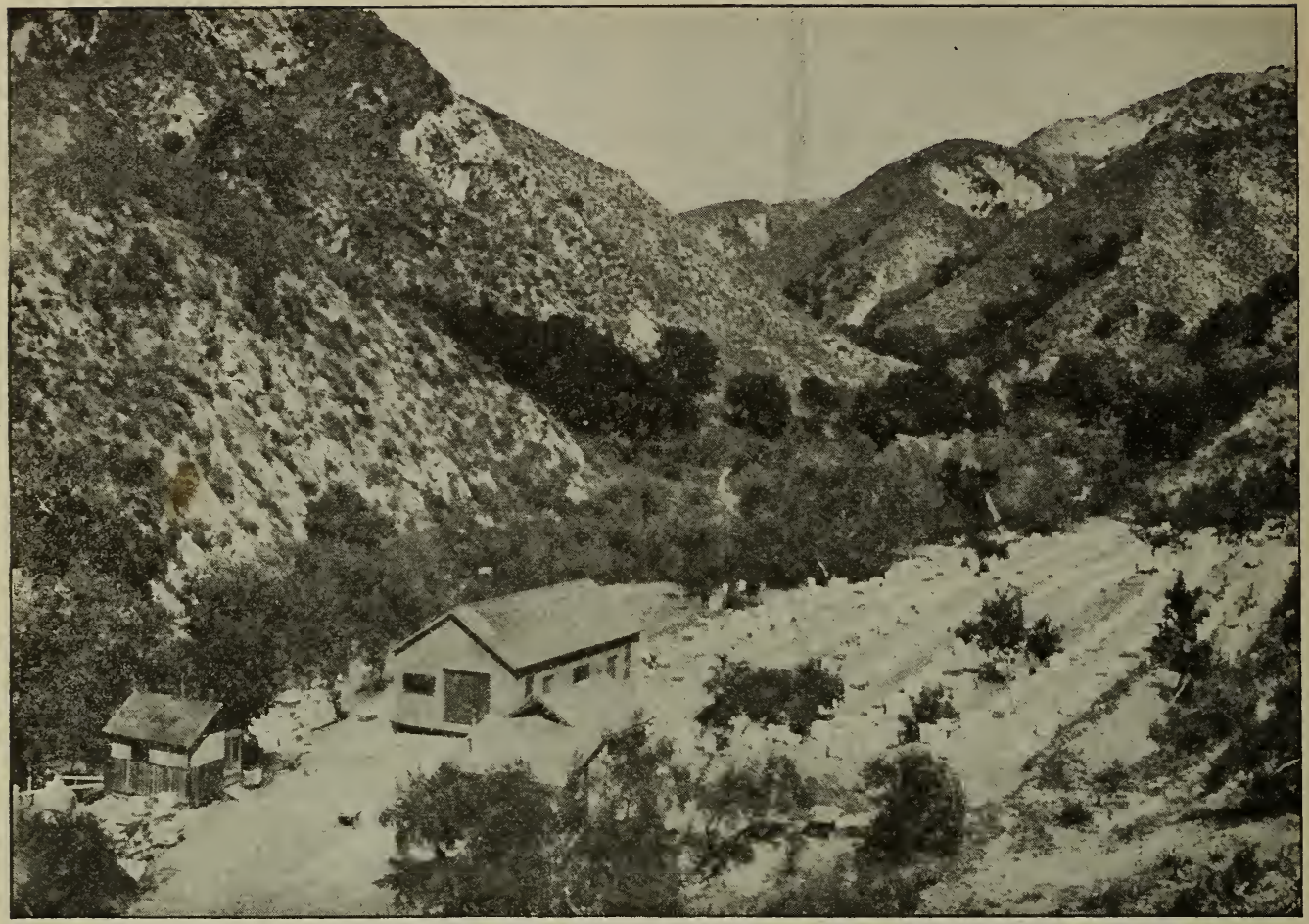

APIARY OF M. H. MENDLESON.

This apiary occupies a very unique position down in the bottom of the canyon, where it is well protected. The ground has been leveled off and terraced, and the rows of hives are straight and parallel. This is one of the most picturesque spots for an apiary in the world. From it some of the best sage honey of California is obtained, and no wonder; for the mountain sage is always in sight and in reach of the bees. The patches of white, black, and button sage on the mountain-sides can be plainly seen.

When the author visited this yard in 1901, he considered it one of the best-located yards in all California -well protected, and the bee-pasturage at close range. But for the fact that there is only about one good yield of honey in five years, this would be a veritable bee-paradise indeed.

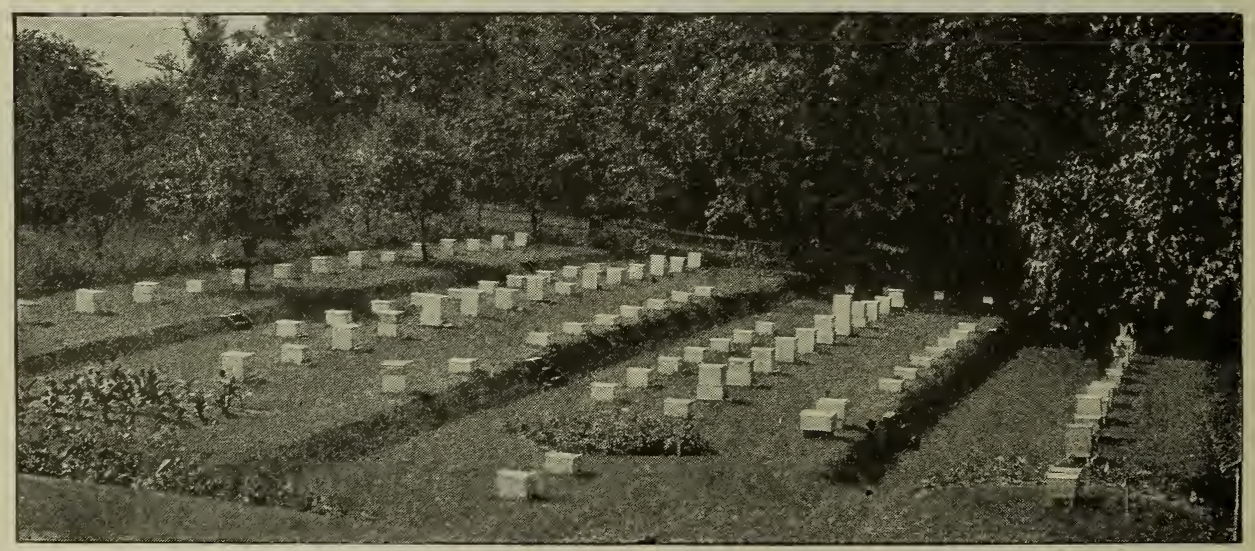

THE AUTHORS' APIARY AT JENKINTOWN, PA.

'This was an exhibition apiary in the suburbs of Philadelphia, used to demonstrate the various processes and methods of handling bees. Here were also shown to the visitors the various races, their characteristics and markings.

This yard, at the time, was a model one in every respect, and was so pronounced. The ground was nicely terraced, and here and there were flower-gardens so arranged as to give a pleasing effect.

In June, 1905, and again in 1906, a general field-day of beekeepers was held at this apiary. Experts were present to describe and illustrate their various methods of handling bees, to the crowds that assembled from all over the country. At the field meet of 1906 there were somewhat over 1000 beekeepers present making by all odds the largest gathering of beekeepers the cquntry has ever seen. The location was only leased, and has since been sold, and is used for other purposes. 


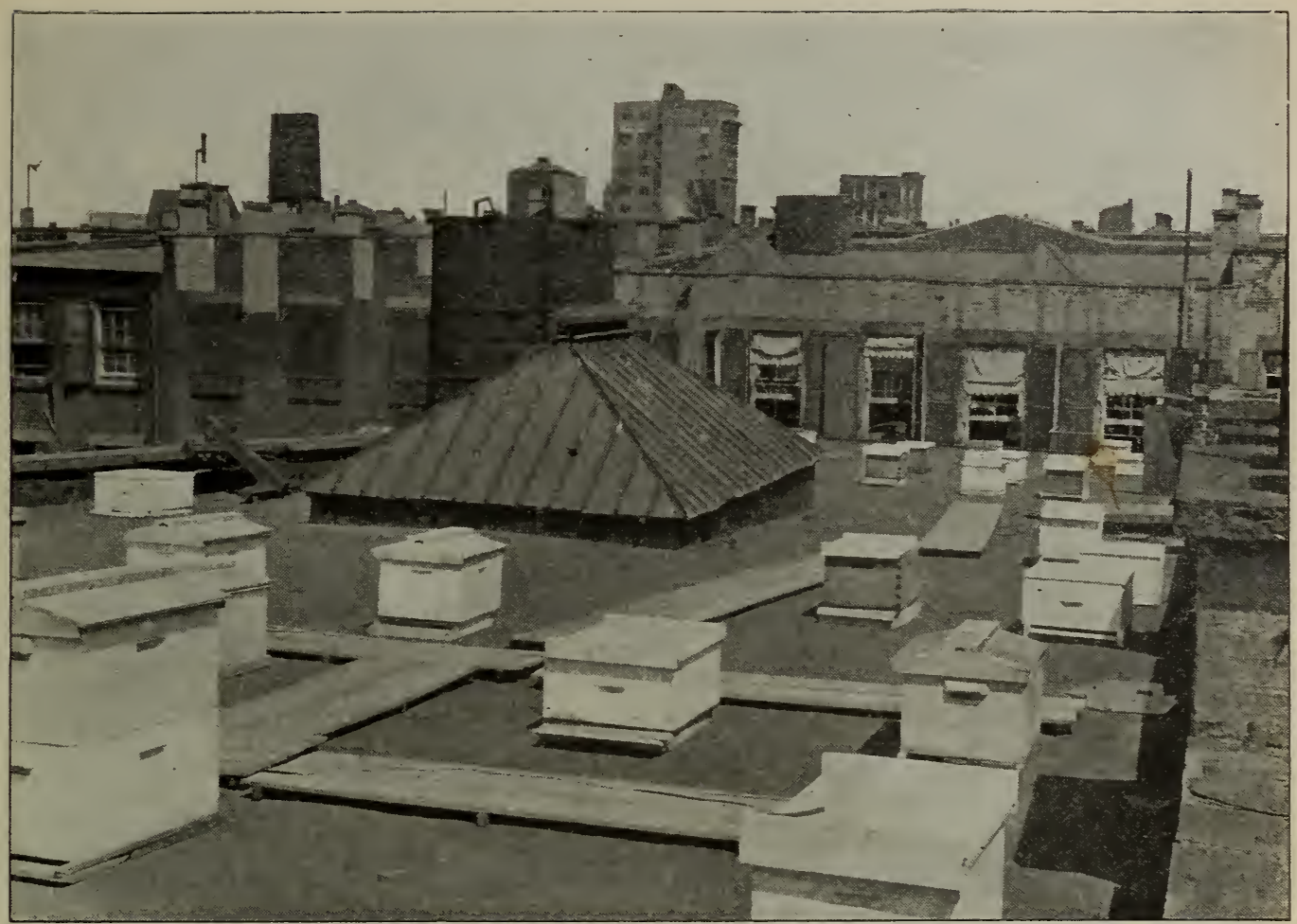

AUTHORS' APIARY IN NEW YORY CITY AS IT WAS SOME YEARS AGO.

In sereral cities tees are kept on the roofs of buildings in tile heart of cities and towns. If the building is high enough there will usually be enough breezes to keep the bees from getting too hot and combs from melting down. If the roofs are not high, shade-boar ds will have to he prorided.

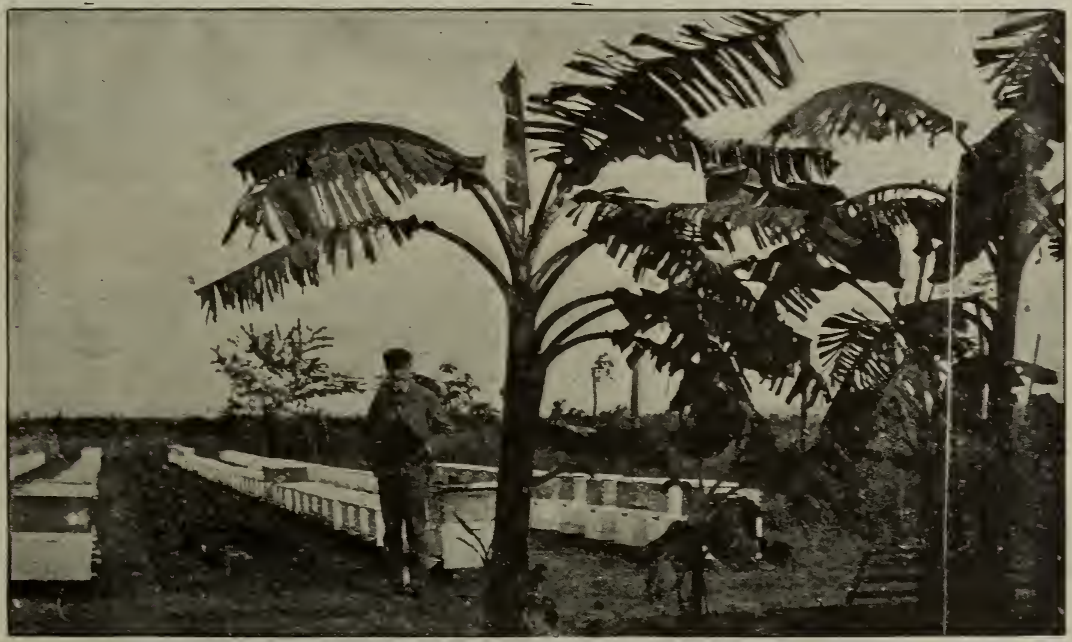

'T'HE AUTHORS' APIARY IN CUBA.

Some eight or ten years ago we owned and operated an apiary in Cuba, the same run for honey as well as bees and queens; but the poor seasons finally compelled us to abandon it. . . The hires here shown are in straight rows and close together. Experience showed that this was a mistake, for there were no distinguishing objects by which the bees could mark their homes, and as a result there was more or less confusion and robbing.

Such an apiary should be established like those on the ground in all essential points.

It is not always possible to select just the location for an apiary that we might like, and we are therefore compelled to take what we can get; but where conditions permit it is advisable to select the rear of a village lot: or, if located on a farm, back 


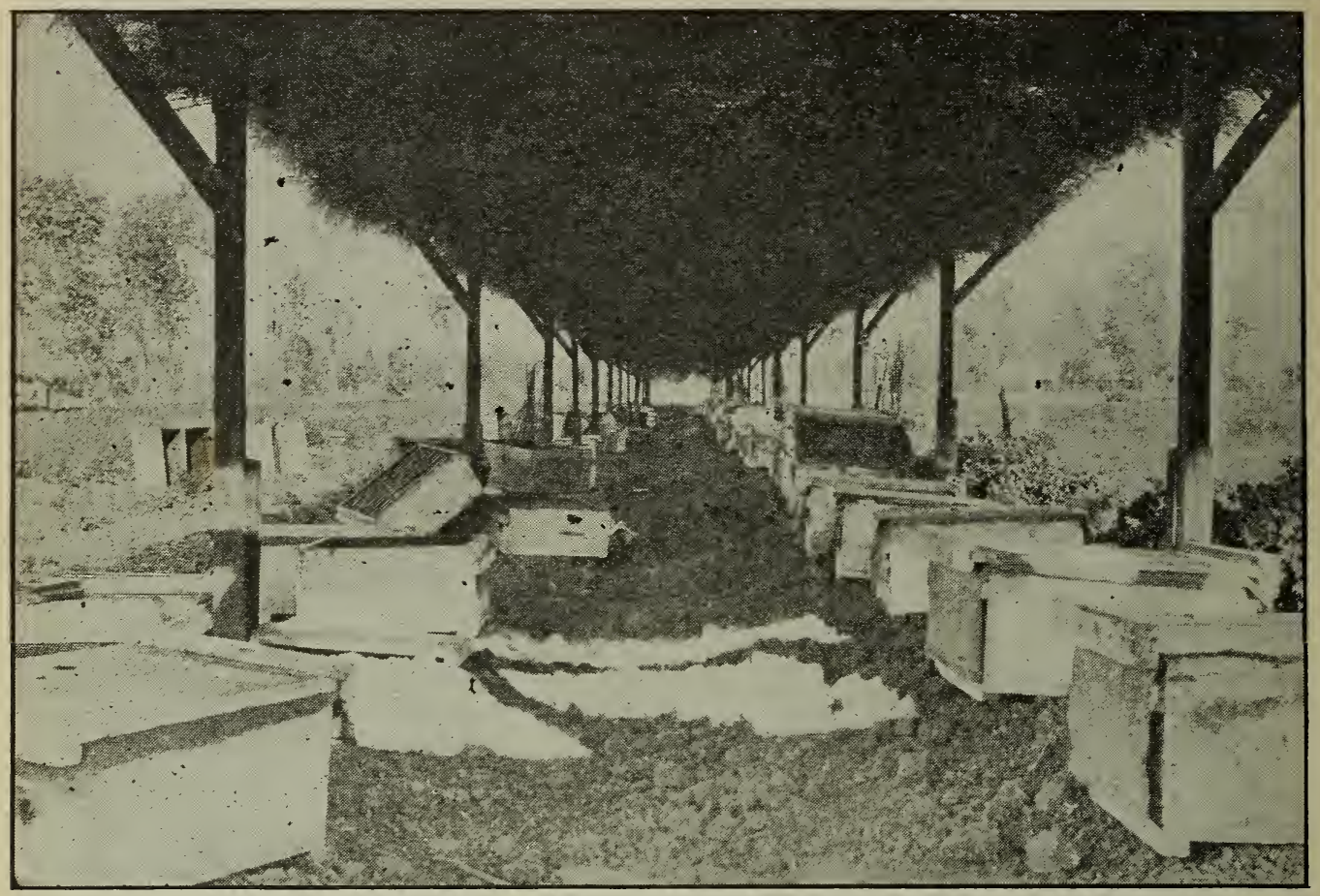

CULVER APIARY AT CALEXICO, CALIFORNIA.

This method of shading an apiary in New Mexico, Arizona, and the Imperial Valley, Southern California, where the temperature during the hottest weather often goes above 100 degrees, is almost universal. The roof consists of dried grass or leaves laid on top, and secured by wires laid over the whole.

of the house in an orchard. The ground should be rolled and smoothed down so that a lawnmower can run over every portion of it, as the grass should be kept down around the hives. Moreover, a smooth plot of ground renders the use of a wheelbarrow or handear for handling loads much more pleasant and convenient. An ideal spot would be an orchard of young trees seventy-five or a hundred feet from the road or highway. Usually the rear end of a village lot just back of the house will answer very

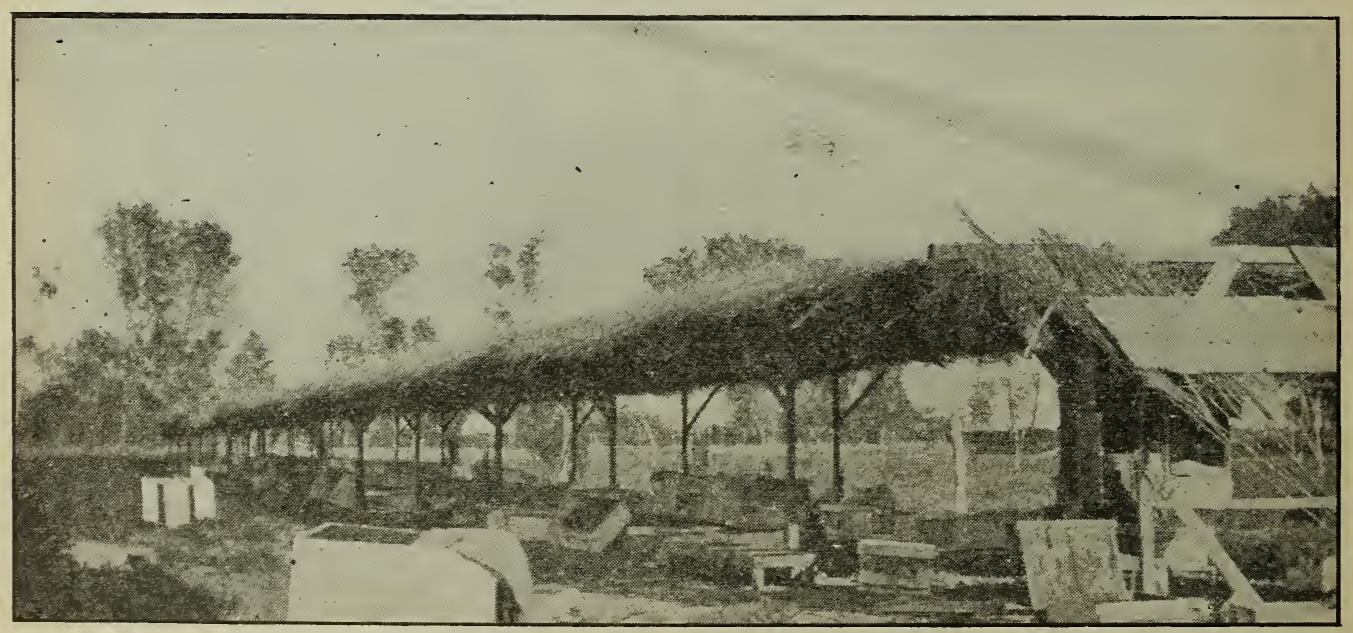

SIDE AND FND VIEW OF THE SAME APIARY.

The climate in this valley is very hot in summer, the same as it is in Arizona. Shade is very necessary. 


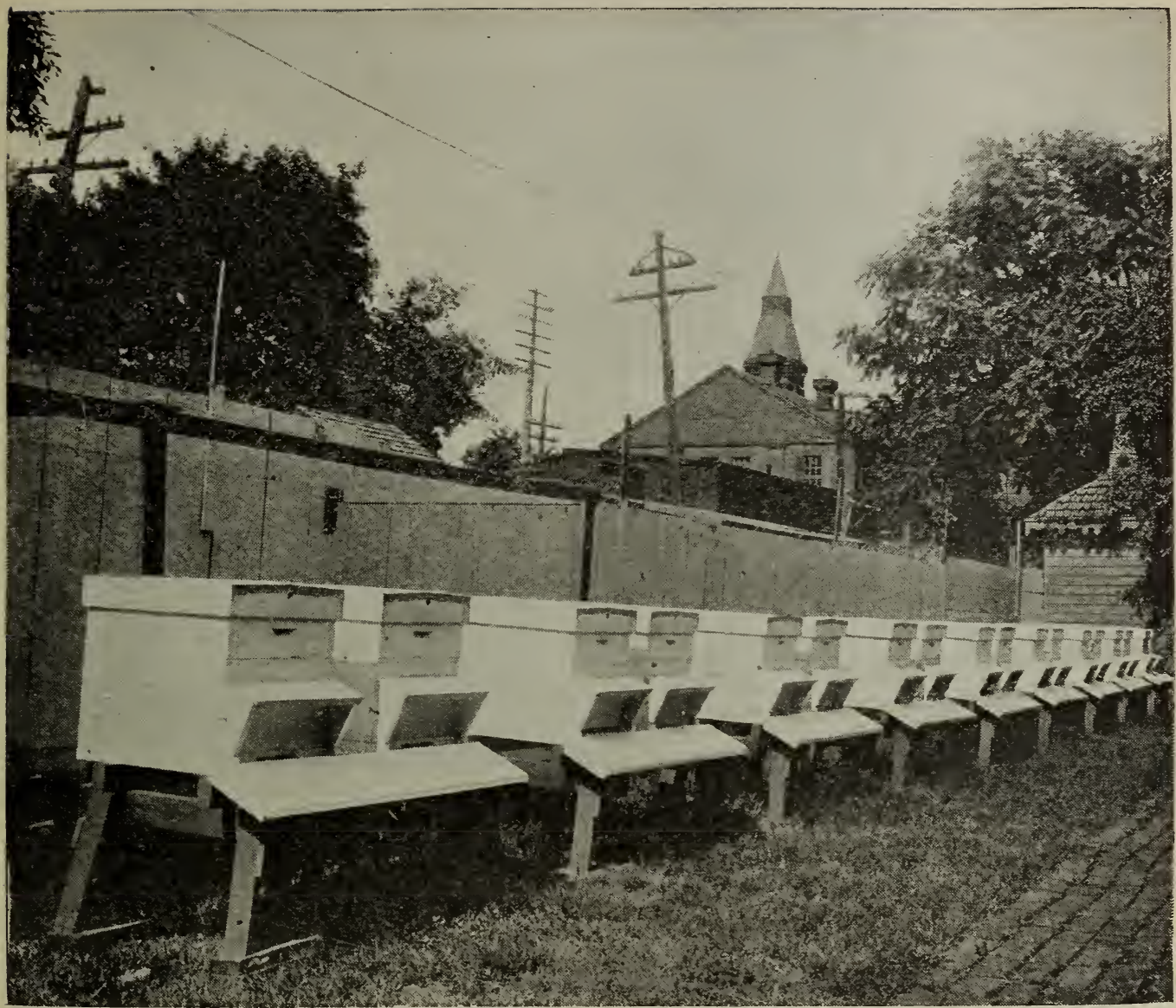

APIARY OF CHA.S. Y. HAKE, YORK, P.l.

This is a backlot apiary that is well screened from prerailing winds as most yards of this kind are. It therefore follows that such yards winter ketter than the large apiaries out in the open. Mr. Hake has his colonies elevated on hive-stands for convenience in handling. The objection is that during bad chilly weather some bces drop short of the entrance. If they were on or near the ground the bees could crawl in and le sared. The arrangement used by Robert Peschko, shown at the close of this article, is much better.

nicely. If the apiary must be located close to the highway, then a high board fence should be placed between the bees and the street. A hedge of osage orange, or evergreens; a trellis of some sort of vine; trees, shrubbery, or anything that will cause the bees to raise their flight to a height of ten or twelve feet above the traflic of the street should be used. In any case, the bees should never be allowed to go direct from their hives on a line that would encounter vehicles or pedestrians: otherwise their owner may have a lawsuit on his hands for alleged damages from bee-stings. See BeEs as a Nuisance.

\section{THE IMPORTANCE OF SHRUBBERY OR SMALL TREES IN THE BEEYARD.}

Under the head of ANGER OF BEEs, at the close of the article we call attention to the value of small shrubbery or trees to shut off the views of individual colonies from each other. The matter is so important that we deem it wise to mention it again here in order that the reader may wisely locate his bees.

The same bees that are gentle at the home yard where they are well screened or located, sometimes become rery cross when placed out in the open field without shrubbery or trees. A little shade on hot days is of great value in protecting the hive from the direct rays of the sun. Aside from the value of the shade, if the shrubbery is tall enough it adds a great deal to the comfort of the apiarist himself. In an open yard it usually becomes necessary to wear a veil to prevent the bees from stinging the face without warning. In a yard that has shrubbery, one can often work all day without 


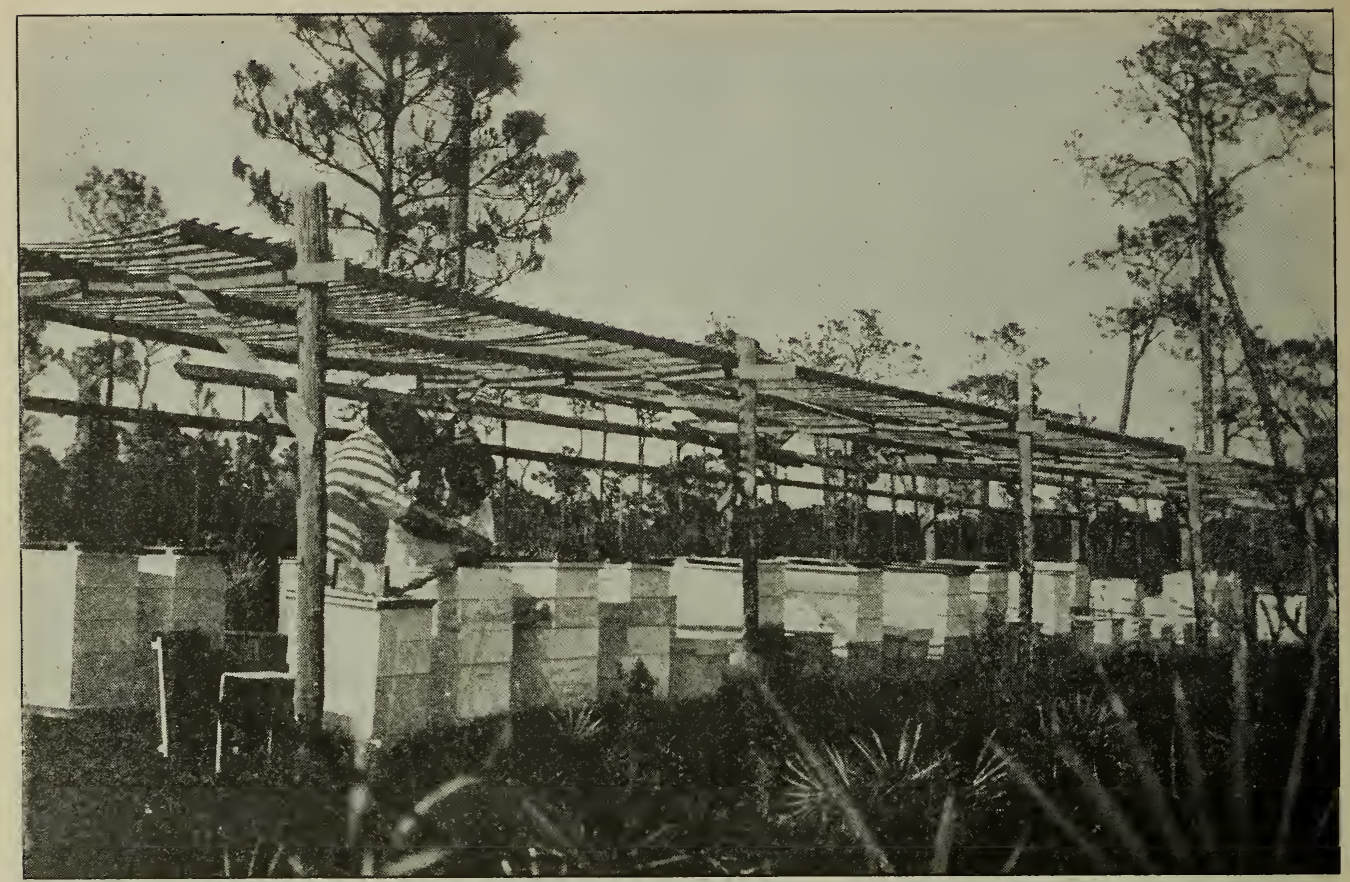

APIARY OF FARRY DUBOIS ON THE LOXAHATCHIE RIVER, FLORIDA.

The idea of a screen of slats overhead is not to shut off the sun's rays entirely, but to break them up. Too inuch shade does as much harm as too little in this country. The same general scheme of semi-shading could be carried out elsewhere to advantage in many localities. It would not answer in Arizona, New Mexico, and the Imperial Valley, California, because the sun is too hot and the climate too dry.

a veil, and sometimes with but very little smoke. It is not always possible to locate a beeyard in the midst of shrubbery or small trees; and one, therefore, has to take what he can find, which very often is an open space in one corner of a lot.

Shrubbery consisting of small bushes or trees has an additional value in that it enables the bees to locate their entrances a little better. When the hives are placed together without any space between, there is more or less drifting - that is to say, the bees make mistakes and go into the wrong hives. The unfortunate part of it is that the strong colonies will draw from the weaker, because the young bees, in their initial flight, are quite inclined to join the place where there are the most bees flying. At the home yard, a view of which is shown several pages ahead, it will be noted that the individual colonies are placed on the north side of individual grapevine trellises. These trellises are between six and seven feet high. They are all very carefully trimmed; and we usually estimate that the amount of fruit pays for the labor of keeping the vines in order. Strangers at any time are permitted to go thru this yard, and it is rery seldom that any one is stung, because an occasional cross bee, or dozens of them, on account of the obstructions to the general view by the vines, are unable to see any moving object, and therefore they do not offer attack.

\section{TOO MUCH SHADE DETRIMENTAL.}

If the orchard where the bees are to be located is made up of old trees, then there can be from four to five hives grouped under each tree. If, on the other hand, it consists of young ones, then not more than one or two hives should be placed at a tree, and in that case always on the north side, to be in the shade. The hives should be so located that they will get the morning sun up to eight or nine o'clock, and the afternoon sun from three to four o'clock on. Too much shade is detrimental, and too much hot sun pouring directly on the hives is equally bad. Experience has shown eonclusively that a very dense shade over bees in the morning hours is detrimental. Colonies located on the west side of a building or barn, or under densely foliaged trees, so that they do not get the morning sun, will not, as a rule, be as far along by the time 


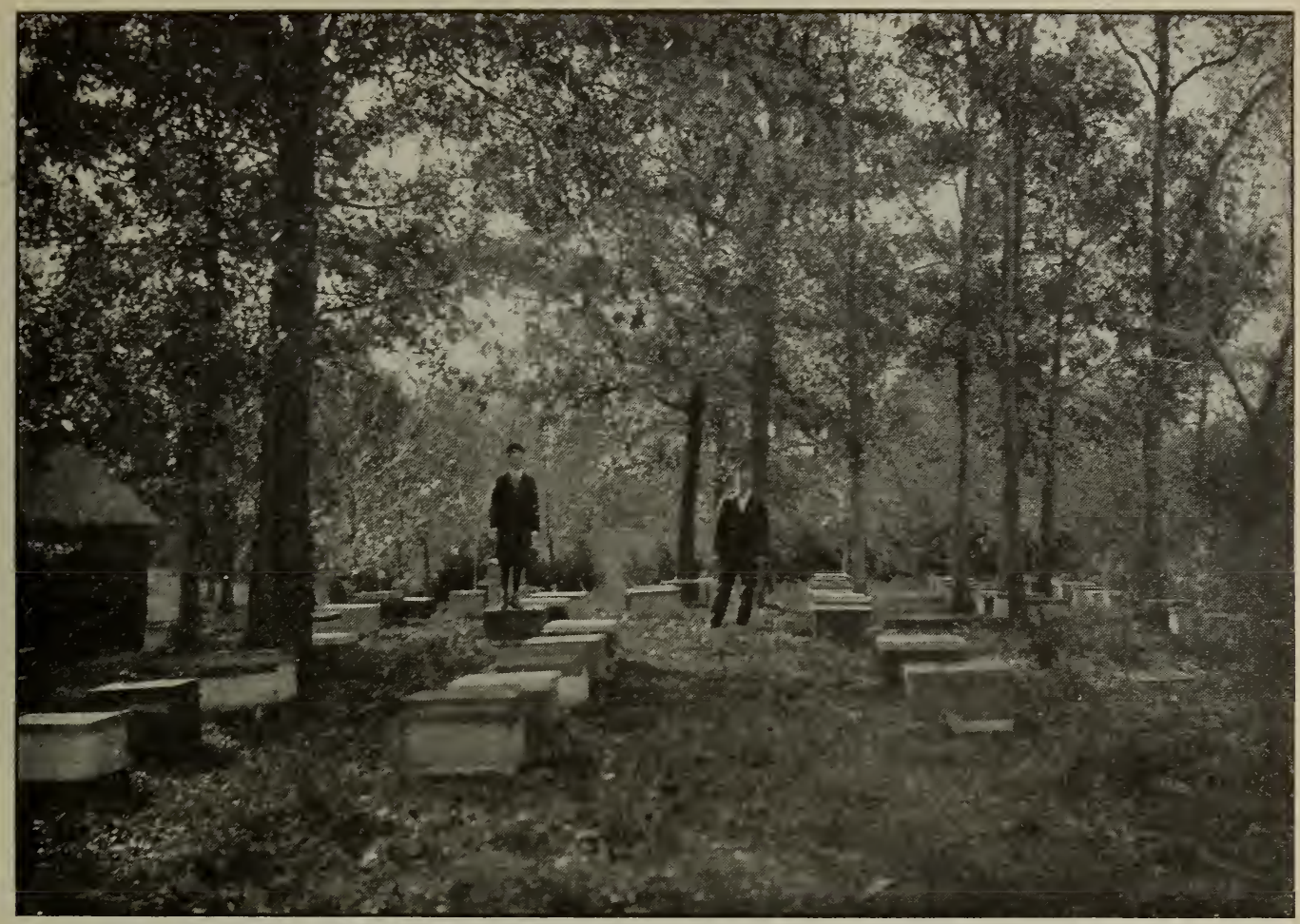

P.ART OF THE OLD APIARY OF E. A. DUAX, CHIPPEWA FALLS, WIS.

This rard is sheitered on the west and north by a cedar hedge; but the shade is a little too dense. Too much shade does as much harm as too little.

the honey-flow comes on as those that have only moderate shade. On the other hand, an afternoon shade does not do as much harm as one in the forencon.

Well. suppose one does not have trees of any sort in his yard-what shall he do? One of four courses lies open: First, to use double-walled hives: second, singlewalled hives with shade-boards: third, single-walled hives having on the south side of them some sort of rine that can be reared up within a year or two. A graperine trellis, say 8 feet high and 10 or 12 feet long, ruming from east to wes!.** well corered with a vine, can be made to protect anywhere from five to ten hives. On this trellis, graperines or any other quick-growing vine may be reared to provide shade during the heat of the day. The fourth and last plan is to use overhead trellis, making' use of straw, dried grass, or brush for covering such as is used in Arizona and Cuba. Thes? trellises are about 7 feet high, and

* In Cuba or other humid countries the sheds should run north and south, for the hives need the sun in the morning and late afternoon to dry them. protection is required only during the heat of the day when the sun is overhead. run from east to west, so that the sun, nearly orerhead as it is in Arizona and southern California, never strikes the hives from morning till night. These trellised

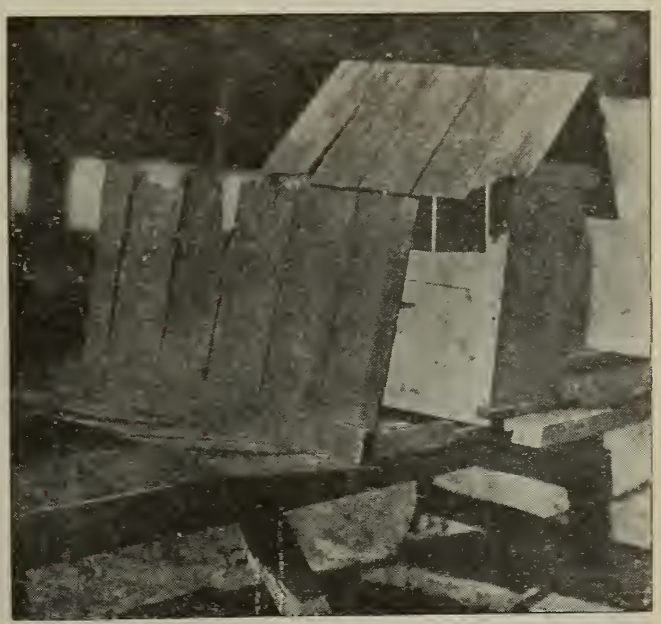

Marcliant's shade-board. This provides better ventilation than the ordinary flat shade-board.

shares, if there are no trees, are indispensable in hot localities. They thoroly protect the bees, prevent combs melting down. and render work of the apiarist pleasant. 


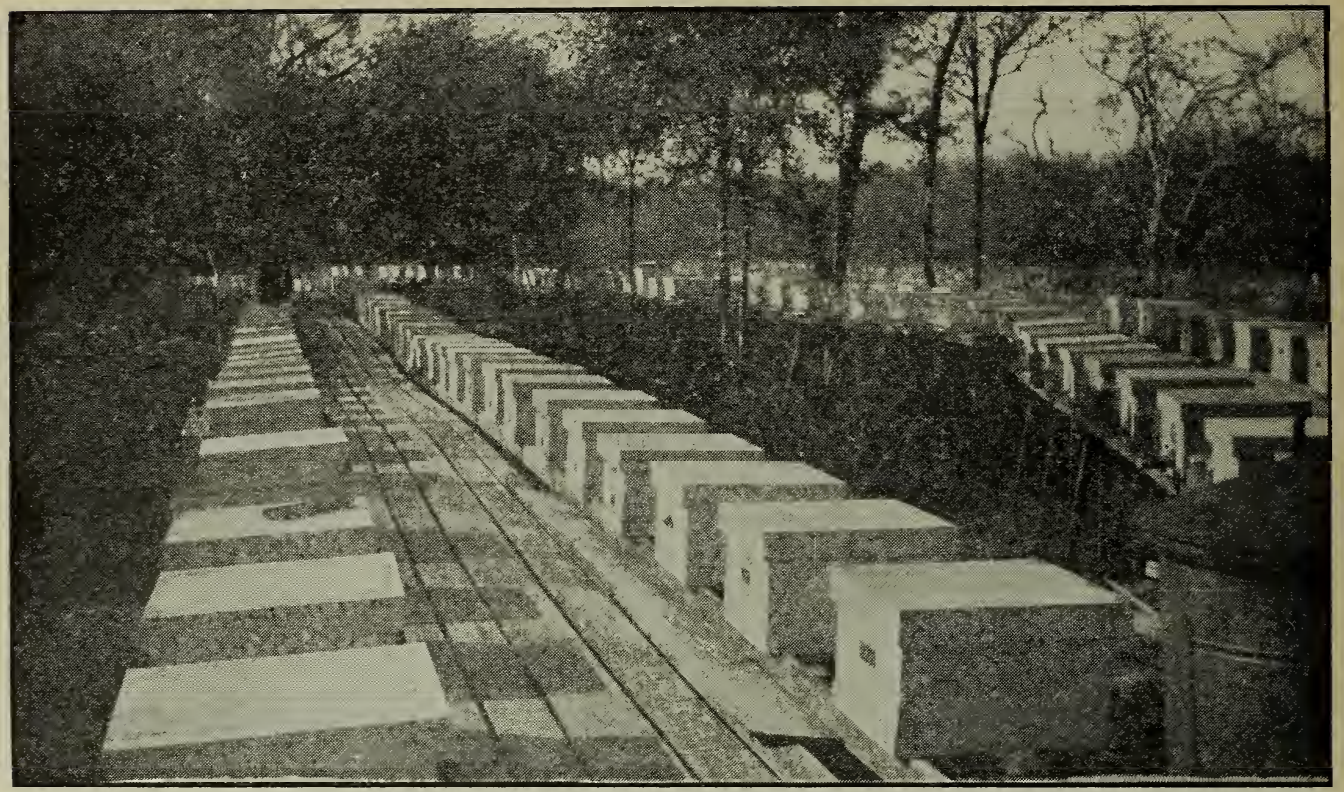

APIARY OF THE A. I. ROOT CO., ON THE APALACHICOLA RTVEP, FI,ORIDA, IN 1914.

This shows a general view of 300 colonies placed on raised platforms or scaffolding five or six feet high, or above high-water mark. While these platforms are somewhat expensive, they are very convenient in affording easy access to all colonies. There is no uneven ground, no shrubbery nor weeds to interfere with the flight of the bees, and a wheelbarrow has good wheeling to every hive. It would have been better if the hives had been arranged in groups of twos, threes, and fours, as explained under the engraving and apiary of Mr. L. F. Howden.

Some beekeepers prefer to use shadeboards. These may be made of large covers cleated at the ends, and made of two or three boards of the cheapest lumber that can be had, or they may be made of common shingles in the manner shown in the illustrations. Some will, perhaps, prefer them nailed up as Mr. Marchant uses them. Others would prefer to put them together

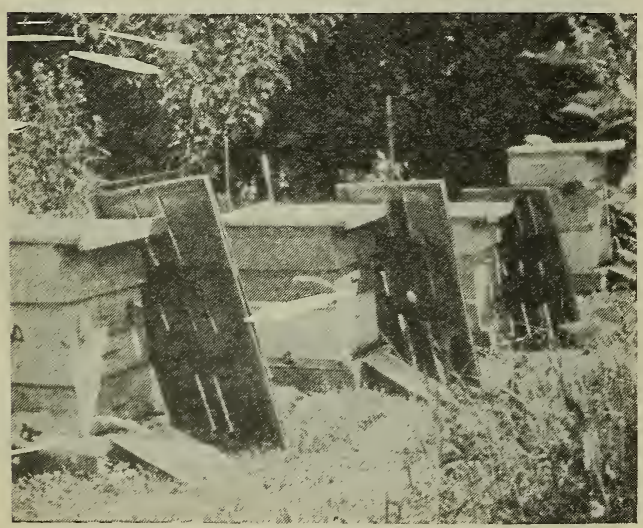

Robertson method of shading the hives and the entrances in the morning.

as Mr. Robertson makes them. In some cases it may be advisable to lean them up against the hives rather than to place them on top. When used on top they should be large enough to project a foot over the front and rear, and an equal distance on each side. They are then held securely in place by a stone weighing 15 or 20 pounds.

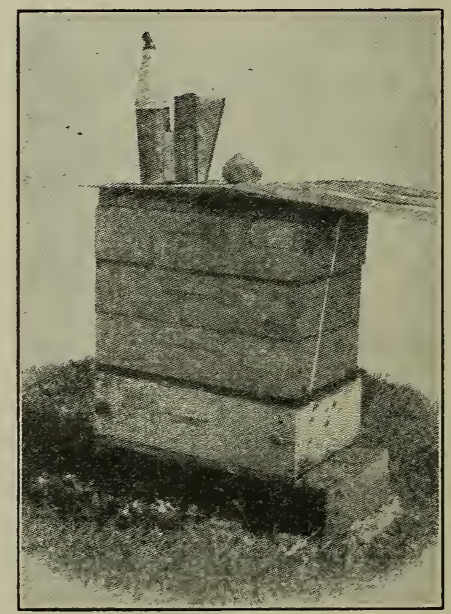

Shading tops and fronts of hives during the hottest part of the day.

But whenever one manipulates these hives he is required to lift a heavy stone and remove an awkward shade-board before he can do any work with the bees. 


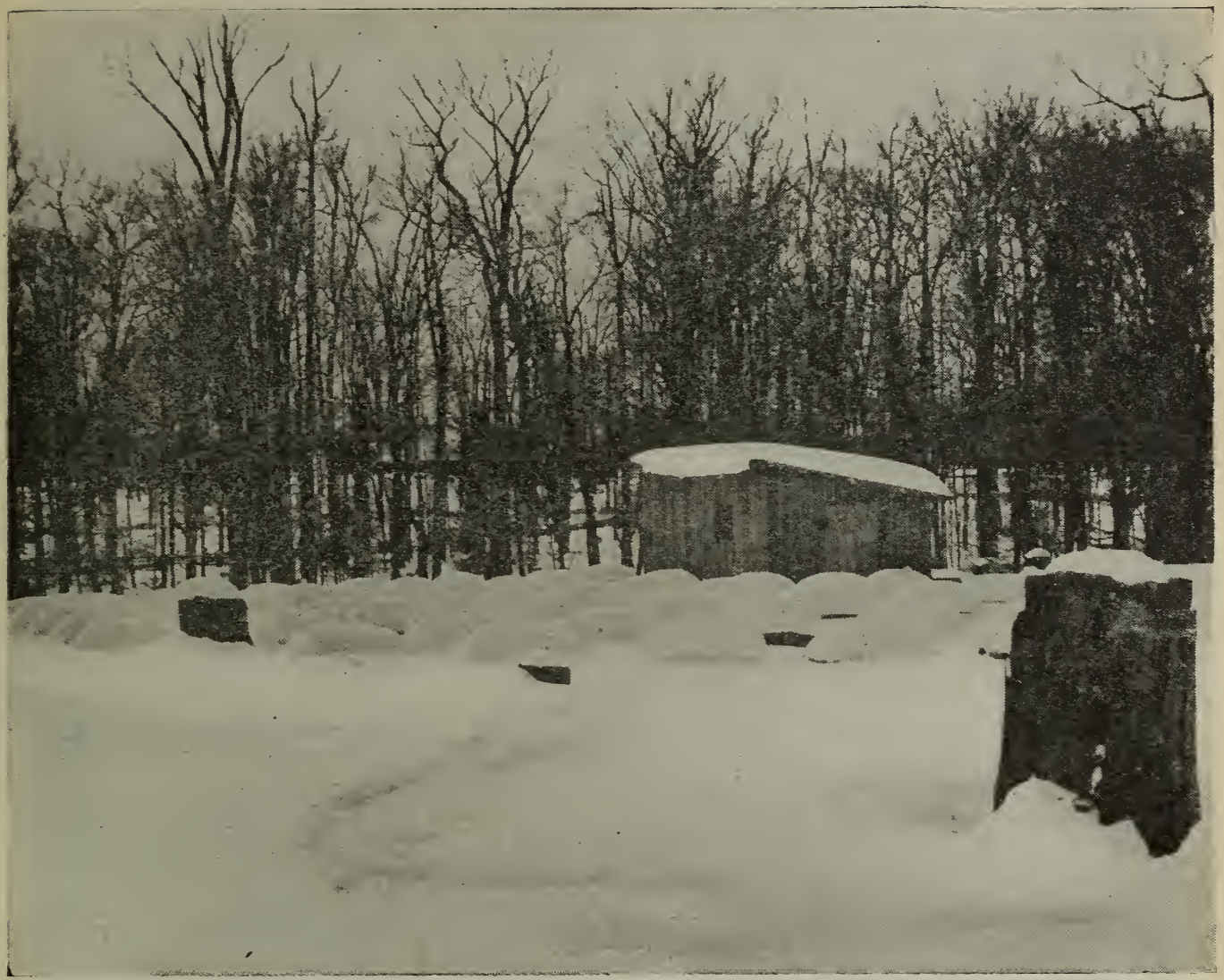

J. L. BYER'S APIARY, MARKHAM, ONTARIO, CANADA.

This has windbreaks on all four sides; elevation to the north, and woods on the three other sille's The hives are completely covered with snow. No harm results from this, provided the climate is cold and provided the snow does not become wet and soggy, and freeze.

When hives are placed in long rows close together, as under a shed or on a roof, it is very essential that they differ from each other in appearance so that the bees may distinguish their own hive from all the rest. The differentiation may be accomplished in various ways; first, by painting the hives different colors; second, by using a different entrance or alighting-board; third, by laying a stone or brick on some boards and not on others; fourth, by placing a piece of brush on the front of some hives, etc. The idea is to place some distinctive mark by which each hive may be quickly recognized by its tenants. The best way to make such mark is at the entrance so that all the bees can see it, both on leaving and returning. See ARRANGEMENT of Hives.

\section{WINDBREAKS.}

The most perfect windbreak is an inclosure of woods on three sides, with an opening to the south. This, however, is not available to all. An apiary so situated that there is a clump of woods on one side and building on the other two sides, leaving only a southern aspect, is well sheltered from the prevailing winds. But, as already stated, if there are woods or buildings around the east side of the beeyard, enough so as to shade the hives until about noon, the bees will not build up as fast in the spring as those that can get the morning sun up to ten or eleven o'clock. In the $a b-$ sence of any natural or accidental protection whatever, it is highly important that some sort of windbreak be provided. If it is desirable to put up something permanent, and something that will not rot out or require repairs, outskirt the apiary with rows of hardy-growing evergreens, such as are seen in our own apiary in the preceding pages. These, for the first few years, would afford but a scanty protection; bnt in ten years' time they answer their purpose admirably. In 1879 we enclosed our apiary 


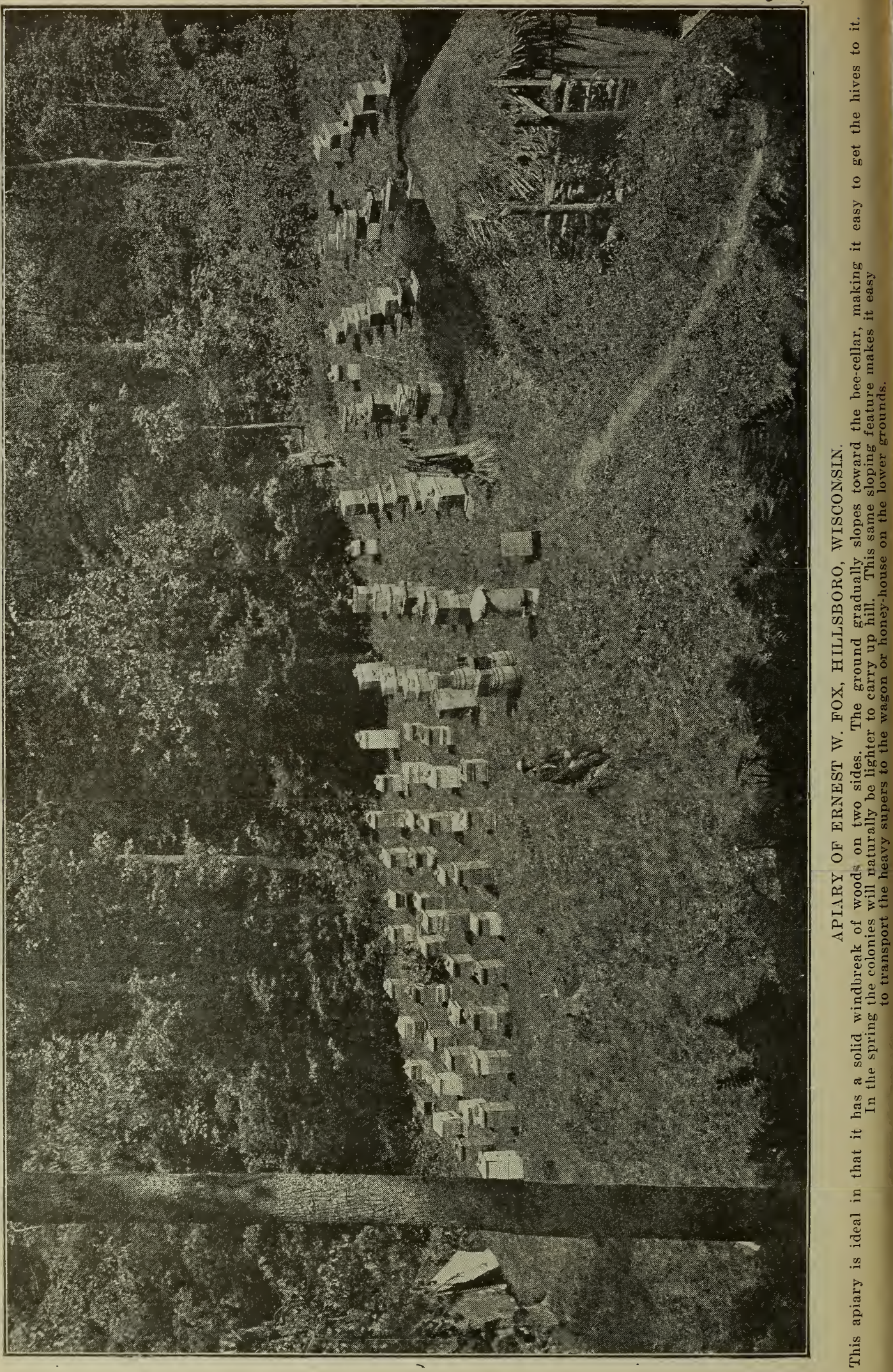




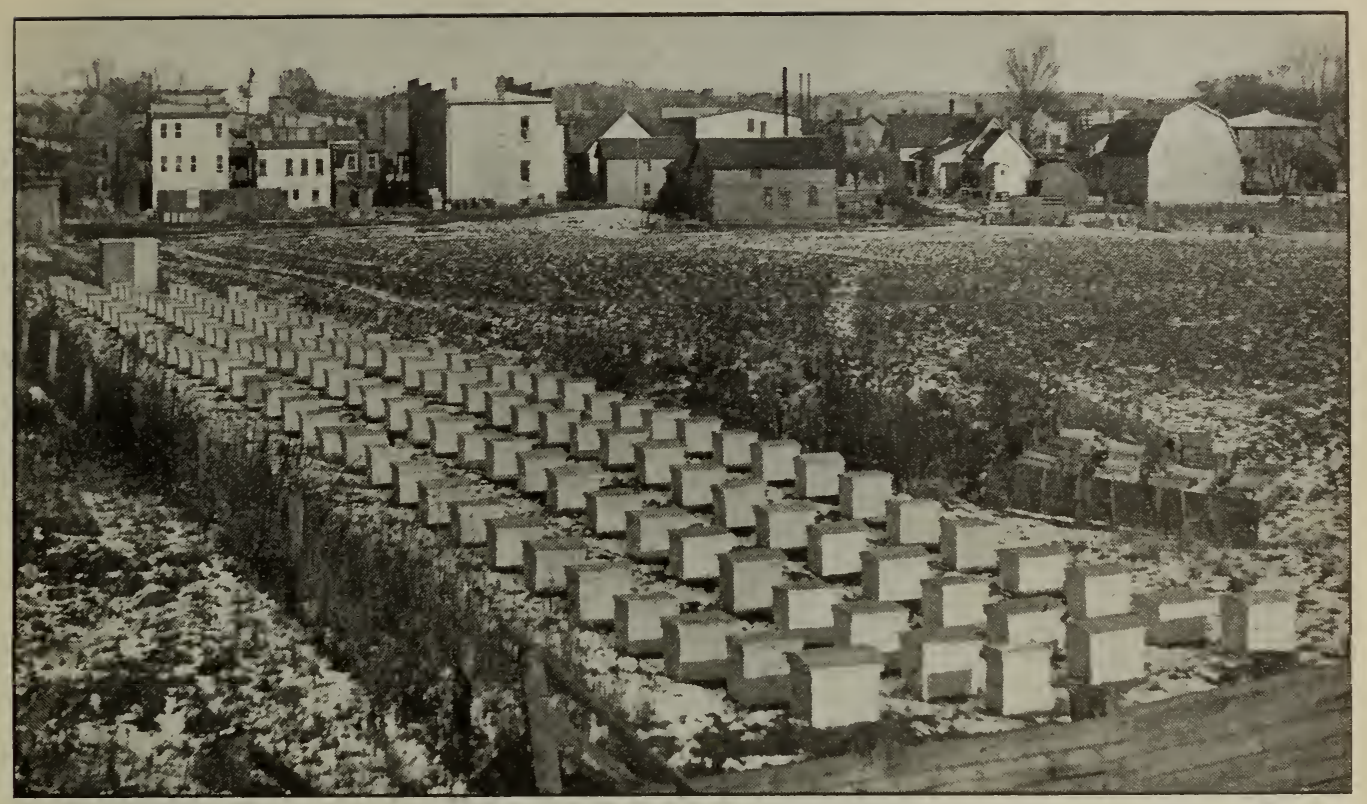

IPIARY OF 190 COIONIES OWNED BY L. F. HOWDEN IN THE TOWN OF FILLMORE, N. Y.

This apiary, while located in town, is apparently on one side of it. and remote from any highway or driveway and off in the cormer of the lot. The first criticism is that the hires are in long straight rows, one hive to a spot. There would be considerable confusion in the flight of the bees and more or less drifting. It would be better to put the hives in irregular groups of twos, threes, and fours, so that the bees can better recognize their entrances. Fvery hive should have an identity of its own. Otherwise there will be danger of robbing and drifting. The second criticism is that it has no windbreaks.

with evergreens. They have proved to be very hardy and thrifty, and now are fullsized trees.

A good windbreak is now regardeā, for winter protection, as about as important (and some think more important) for outdoor-rvintered bees, as packing and doublewalled hives. Of course, it is better still to have hives packed as well as protected from the prevailing winds. Experience has shown that colonies, even tho well packed, but placed where there are sharp wind exposures on an elevation, will often die before spring, or become so weakened as to be practically worthless, when colonies of the same strength in single-walled hives screened against the wind will winter comparatively well.

In a location on a prairie, especially if it is permanent throughout the year, care should be taken to see that it is protected on the north and west especially. Sometimes an apiary can be placed at the bottom of a hill lying at the north; but it would be far better if shrubbery were placed at the brow of the hill to prevent the wind from diving down and striking the colonies with full force.
The best windbreak we have found consists of trees or shrubbery of some sort. A solid fence is not as good, because the wind will strike it squarely and glance upward, when the on-rushing blast will cause it to roll and dive downward.

At one of our outyards we had a high board fence on the north, and it was distinctly noticeable that the third row of colonies from the fence would come out in much weaker condition than the rows either to the north or south. Many colonies in the third row died outright. This happened several winters. Finally an investigation showed that, during a blow with fine particles of snow, the wind would strike the fence, glance upward, and this upward blast striking the wind from the north would roll like a sort of horizontal whirlwind. This would gradually sag until it struck the entrances full force facing south in the third row. This horizontal whirlwind apparently seemed to spend all its fury on this row of hives, while the other rows were left comparatively free. Had it not been for the fine snow we should never have known the exact course of the wind.

An ideal location is the center of a large orchard. The outside rows of trees will 


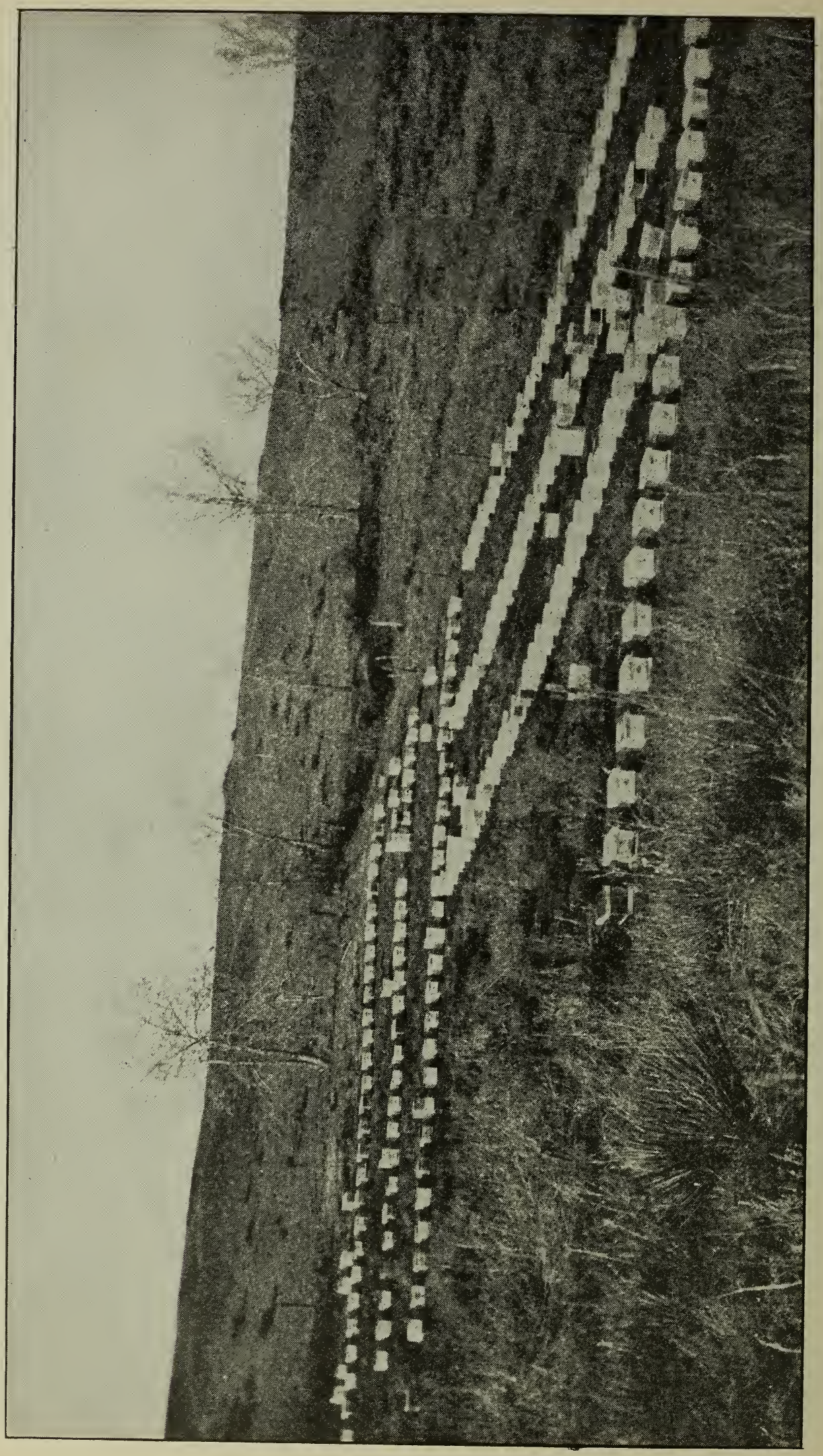




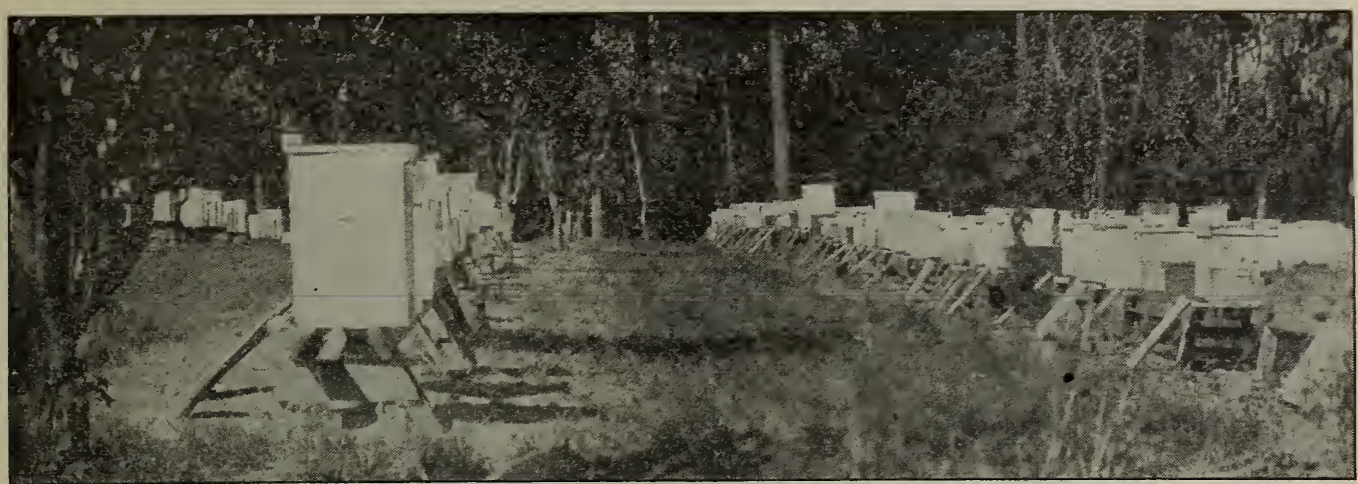

Marchant's home yard of 400 colonies. Along the Apalachicola River as many as 500 colonies can sometimes be supported in one yard. He has had as many as 600 .

break the force of the wind so that the blast of air will not strike any particular hive; or, in other words, the wind as it attempts to pass thru among the trees encounters so much friction that its force is expended. If the hives are placed near the outside trees, the wind will sometimes dive under the tops.

A common fence made of rails, pickets, or boards, will help to break the force of the wind; but in these latter days barbed wire is used almost exclusively. It is best, therefore, to locate the hives either in the center of the orchard, or, if the orchard is small, in an enclosure of low shrubbery or bushes under trees. Berry-vines, grapevines, or trimmings from the trees in the form of brush, sometimes answer as a very good substitute.

The apiary may often be located advantageously behind barns and other outbuildings on the farm; but as a general thing an enclosure of this kind is used for wintering and feeding stock.

Where the bees are located out on a prairie in the North with a wind-sweep for miles it is quite essential that there be a barrier of some sort to cut off the wind. Quick-growing shrubbery should be placed around the yard. In the mean time a screen of brush may be used. If a fence is erected, one made of pickets, so that the wind can filter thru and not glance upward and downward, as explained, will be better. A vertical trellis may be made for quick-growing vines; but the vines should be of such a nature that its intertwining branches will make a filtering screen even when the summer leaves are off. Evergreens make the best windbreak of all, but it takes years to get them.

\section{HIVE-STANDS.}

It will be next in order to consider whether we shall put the hives directly on the ground or on some sort of stand. Many beekeepers use four half-bricks, so arranging them that they come directly under the four corners of the bottom-board. To secure a proper level, it will be necessary to use a spade or pickax to cut down the soil in spots sufficiently to let one or more bricks come down to the grade of the others. It is desirable, however, to have the forward bricks a little lower than the rear in order that the water may run out of the entrances. Other beekeepers use short strips of old boards or pieces of scantling, cut off in lengths equal to the width of the hive, and leveled in the same manner as the bricks. But the bricks and old boards allow the hives to come too near the groundenough so to cause dampness, and, sometimes, when the bricks settle, the rotting of the under side of the bottom-board.

Mr. R. C. Hollins, of Sladenville, Ky., drives four notched stakes into the ground, made of stuff three inches wide, one inch thick, and one or two feet long. The part driven into the ground should be dipped in creosote, linseed oil, or, better still, carbolineum, a kind of wood preservative used by railway companies to preserve ties. The illustration on page 58 will show the idea. The stakes should project up above the ground from one to six inches. Four inches will ordinarily be high enough. In that case the stakes need not be more than 18 inches long. The length of them, however, will depend a good deal on the character of the soil and the preference of operatorwhether the hive shall be high or low. 
The stakes should be driven by line, and accurately measured off, and afterward leveled with a bottom-board and spirit-level. If the stakes stick up six inches above the ground it will add greater convenience to the handling of the bees; but in cool spring whole should be securely nailed and made to conform to a level floor. When a sufficient number have been made they can be spaced off and leveled up in the yard ready to receive pairs of hives, or even three if thought necessary.

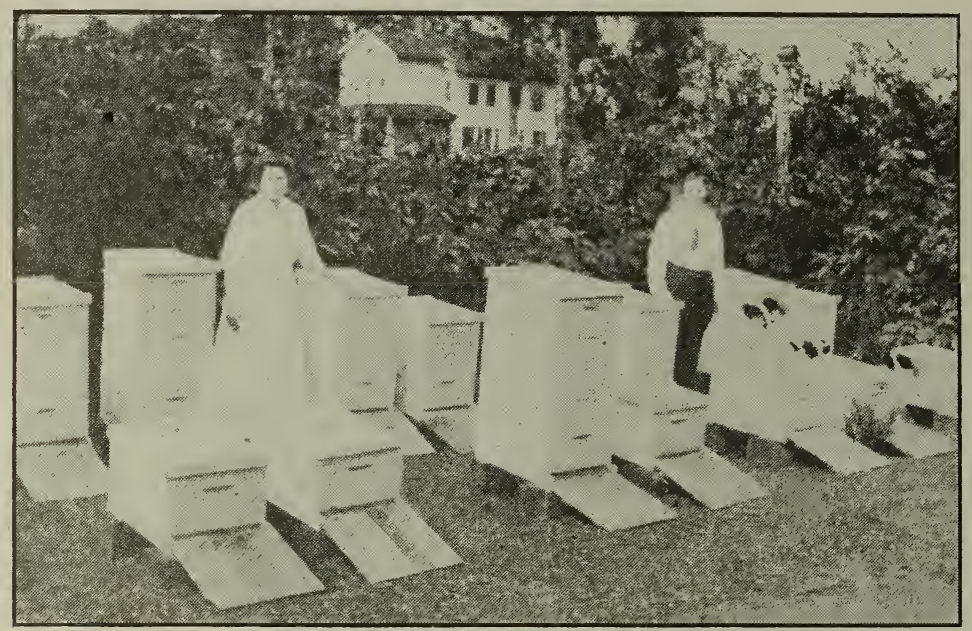

BACKLOT APIARY OF ROBERT PESCHKO, DANBURY, CT.

This yard, like other backlot apiaries where there is a small number of colonies, has given a large yield per colony. One can judge by the height of the hives. As explained in the text, a small apiary will give larger yields in proportion than a large yard, providing, of course, there are no other bees in the immediate locality. While Mr. Peschko puts his hives up on stands, he realizes the importance of having easy runways from the ground up to the entrance. In cool or chilly weather this saves the lives of a good many bees.

weather there should be some sort of board reaching from the ground up to the alighting-board, so that the bees coming in somewhat chilled may crawl from the ground up into the hive.

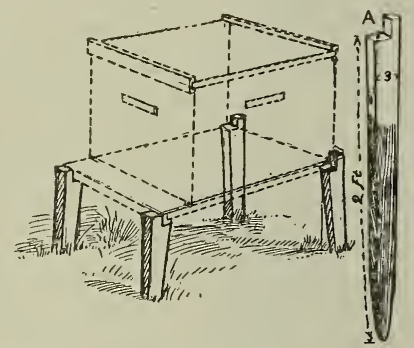

Hive-stand made of four stakes.

Another arrangement that is favored by a good many is a double hive-stand made as shown in the illustration on this page. The legs should not be less than two inches square, and the ends to come in contact with the ground should be dipped in tar, or some sort of wood preservative. The sideboards, if the legs are a foot long, may be anywhere from three to six inches widefour inches will be a nice compromise. The
These arrangements have much to recommend them. They permit keeping the hives in groups of two or three, so they may be operated at convenient distance from the ground. They also allow earrying out the general plan of shaking swarms, as explained further under the head of ARTIFICIAL SWARMING; of forming nuclei, or doubling

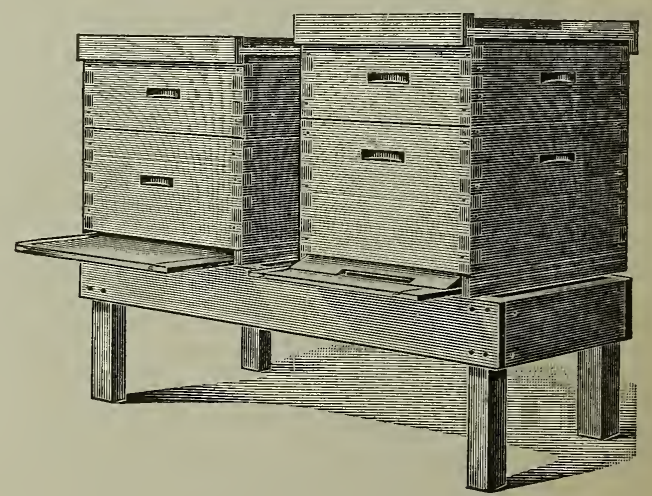

Double hive-stand.

up in the fall. Say there are two hives on the same stand, and both of them weak, and neither of them strong enough to go thru the 


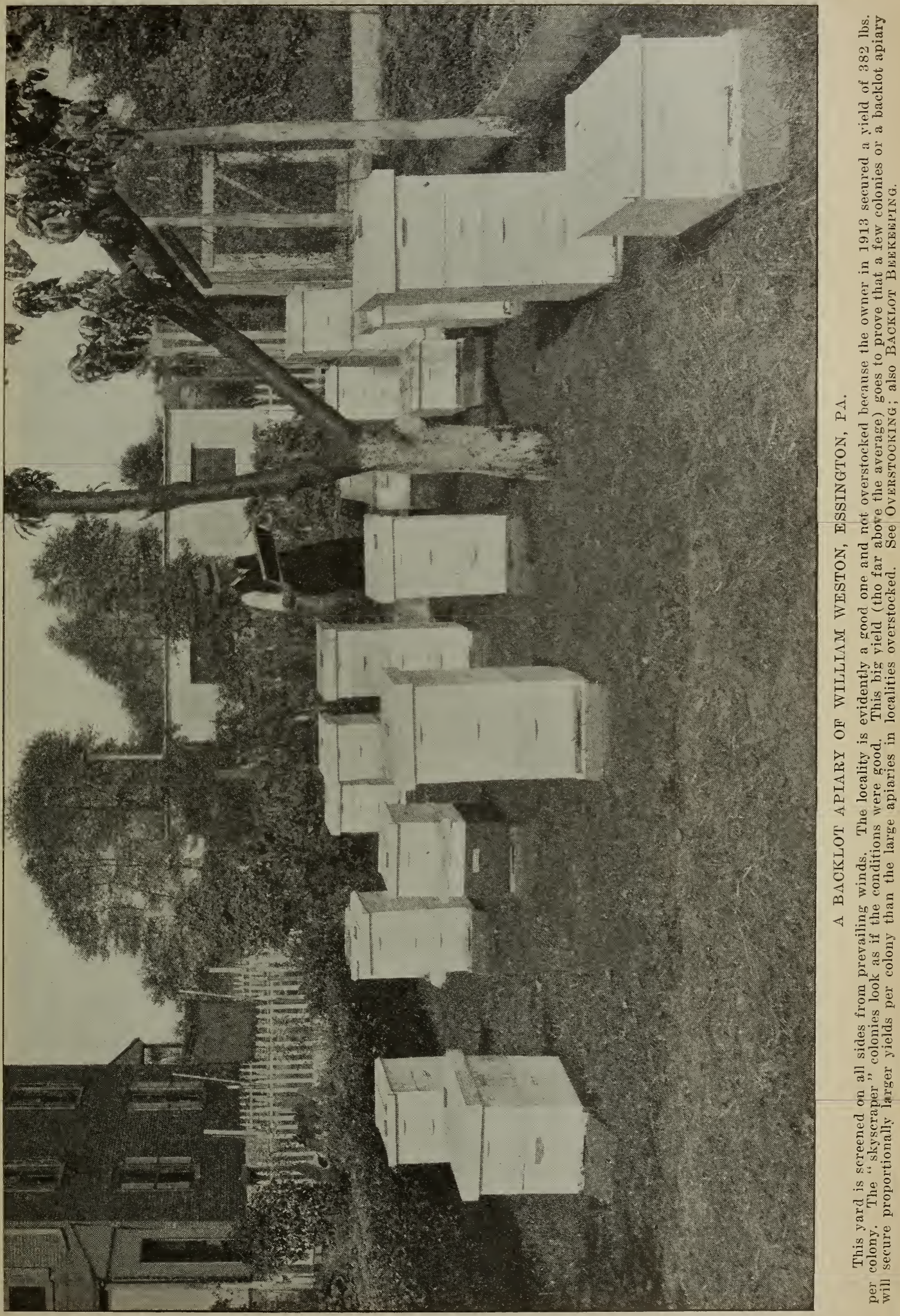




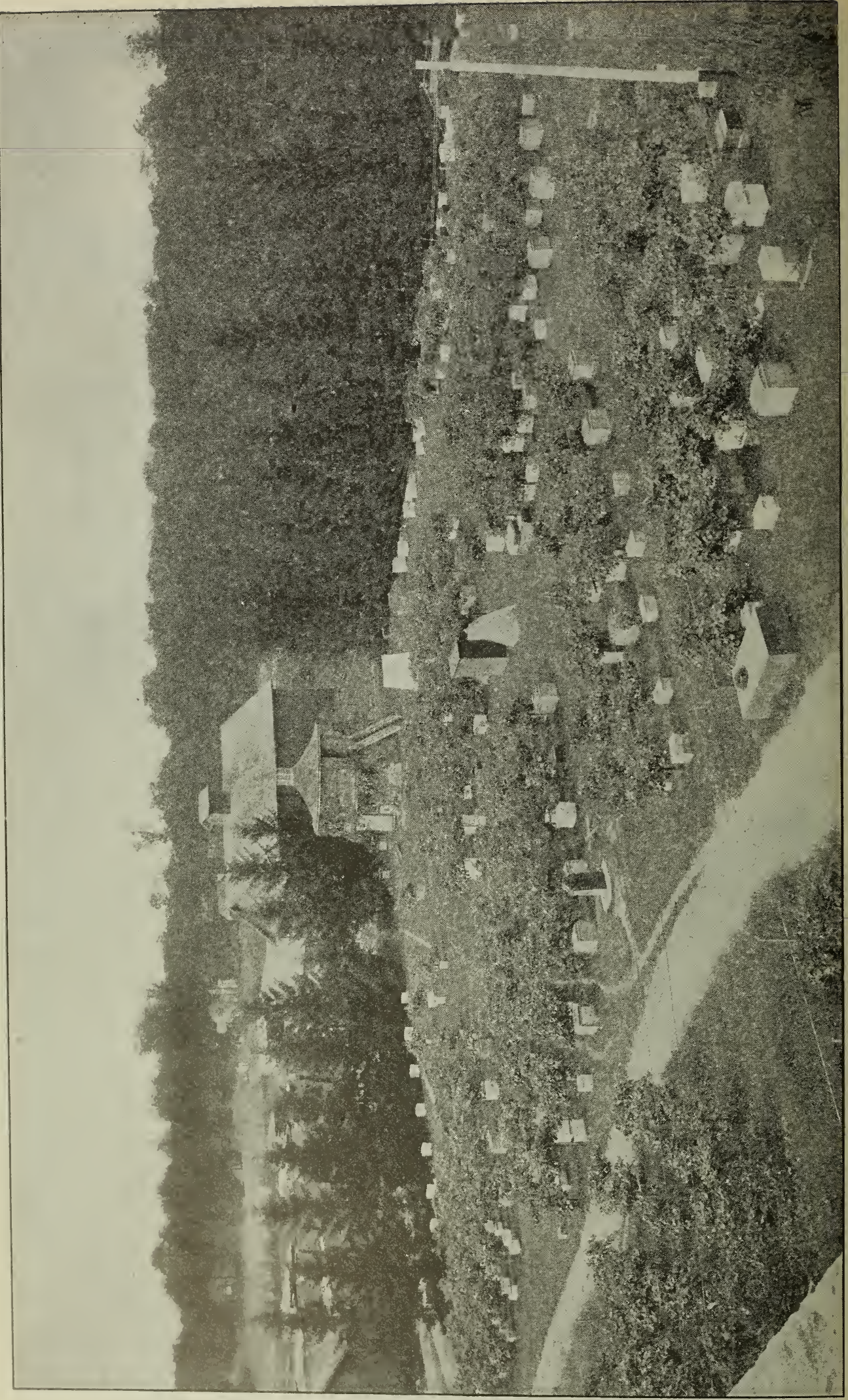




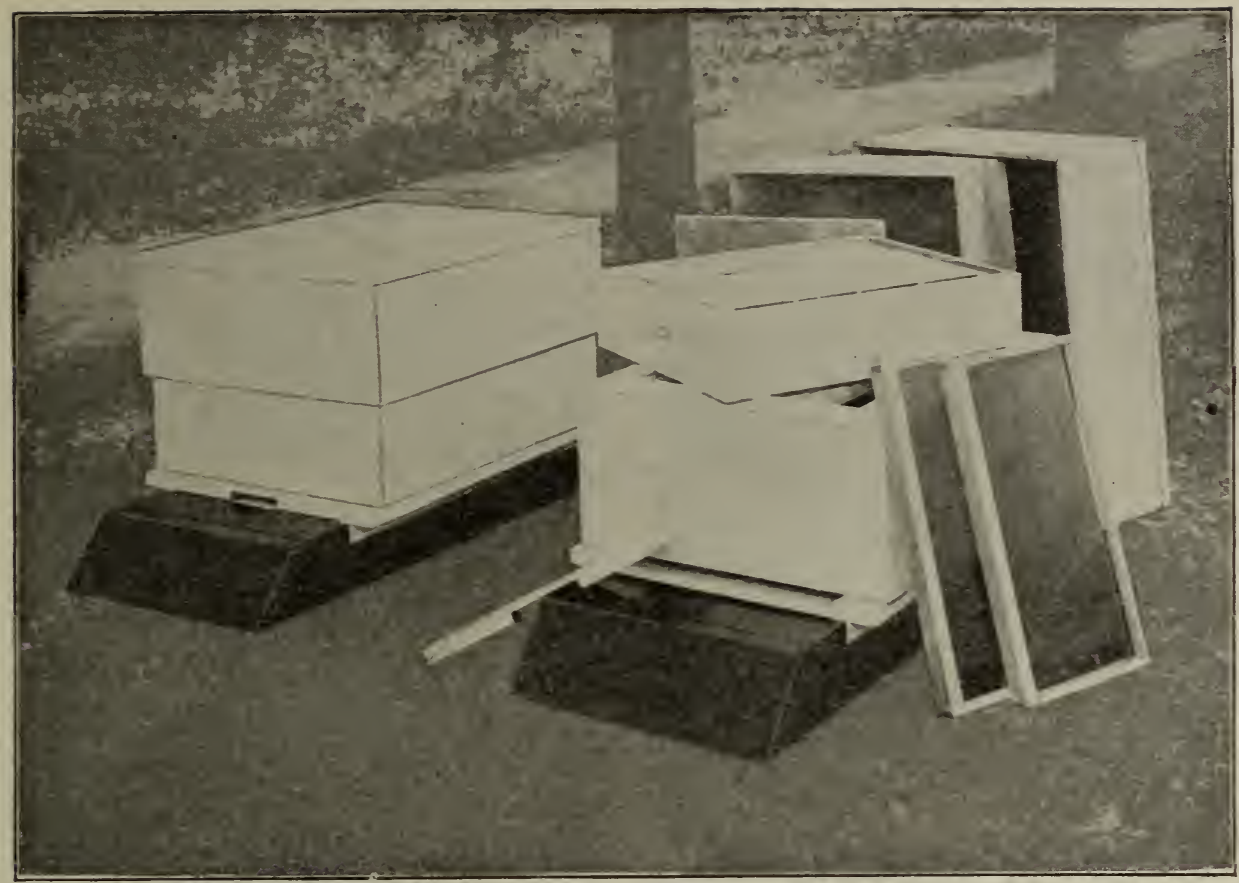

Buckeye double-walled hive with a slanting-front hire-stand.

winter. Place all the combs and bees in one hive, and put it in the space exactly between where the two stood. Now move the other hive away entirely. The flying bees of both hives will go back to the one now at a point midway between where the other two stood.

Another important feature of this hivestand is that it permits of being moved from one out-apiary to another without "pulling up stakes;" and a stand that will hold two or tinee hives is cheaper than two or three separate stands.

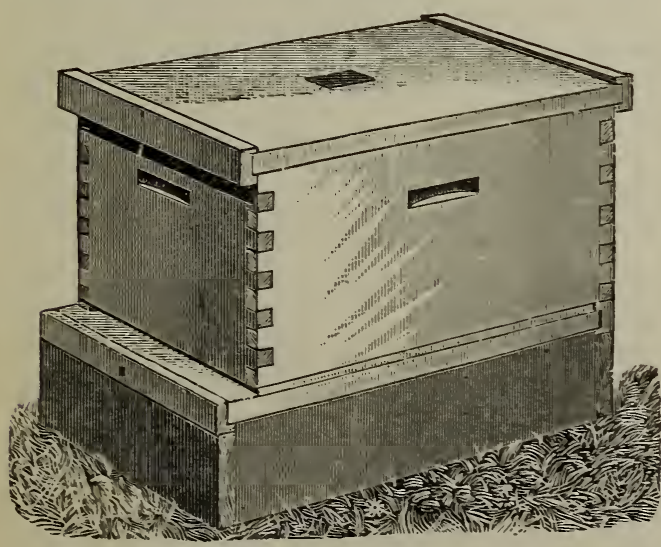

Heddon hive-stand.

If the entrances of the hives are less than a foot above ground it is desirable to have some sort of board leading from the ground up to the entrance, unless the alightingboard itself is of good size, as shown at the top of the previous page, in which case the incoming bees will be able to land without difficulty.

Another arrangement that has been used to a considerable extent is what is known as the Heddon hive-stand. It is made of four rough boards of cheap lumber from four to

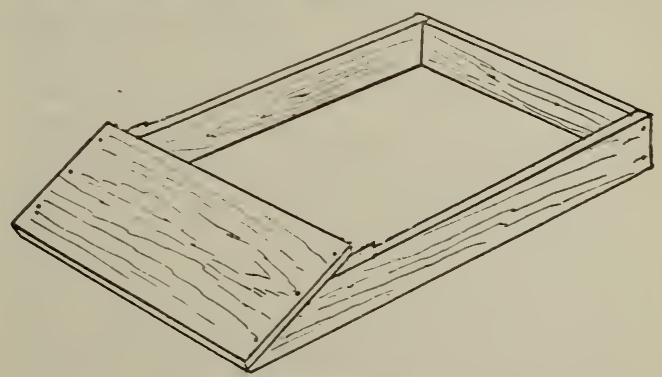

Hive-stand with slanting front.

six inches wide, and one inch thick. The dimensions should, of course, be of the size of the bottom-board. The manner of putting together will be plain from the cut on the left. This stand is preferred by a large number of beekeepers.

A modified form, and a much better one, is shown in the above two cuts. It has the obrious adrantage of a slanting front from the ground to the bottom-board. 
A few use slabs of concrete. The objections to these are the expense and difficulty of moving.

\section{ARRANGEMENT OF HIVES.}

Having decided upon the location, kind of shade, windbreaks, and hive-stands, how shall we arrange the hives in the apiary? This question can best be answered by studying the plans adopted by some of the prominent apiarists. The lay of the land and exposure to high winds will, of course, have to be taken into consideration.

The usual plan is to arrange the hives in long straight rows, each hive so many feet distant from its neighbor, and on an exact line drawn by a string. While such an arrangement is pretty, it has its objectionable features. When hives all face in the same direction, and in straight rows, each hive by itself, the bees are apt to become mixed up at the entrances, especially if the hives are only two or three feet apart. When the young bees are out at their playspells, they are liable to join the group where the bees are flying the thickest. The result is, their own colony is depleted while the one that makes the biggest demonstration for the time being is getting more bees than it can easily take care of. This causes some colonies to be too strong, and swarm too early, while the others are too weak, and do nothing all summer. See Drifting.

It very often happens, also, that when bees are taken out of the cellar and put into regular rows they will drift in the same way; and this drifting, as we call it-bees going into the wrong hives-makes trouble. While, as a rule, a colony will not take bees that belong to other hives, yet when bees are flying strong in front of the entrances, they are not expecting robbers; and when young or other bees enter their hives by mistake, as if they belonged there, no objection is made.

This whole drifting difficulty can be corrected by giving each hive or group of hives an individuality of its own. We would, therefore, advise putting hives in groups of two, three, or five; two here; three there; five there, and so on. They may be in regular groups of two or groups of three, but in either case there should be a bush or tree at or near each group to enable the bees to distinguish one group from another.
The following plans have been suggested where great economy of space is desired; but instead of following any one of the plans, we would adopt a combination so that the groups will be irregular in size and number of hives, especially if there is no distinguishing shrubbery or trees.

C. A. Hatch, of Ithaca, Wis., a prominent and extensive beekeeper, arranges his hives on the plan shown below, which, as will be seen, will work nicely in connection with the double hive-stand shown on a previous page.

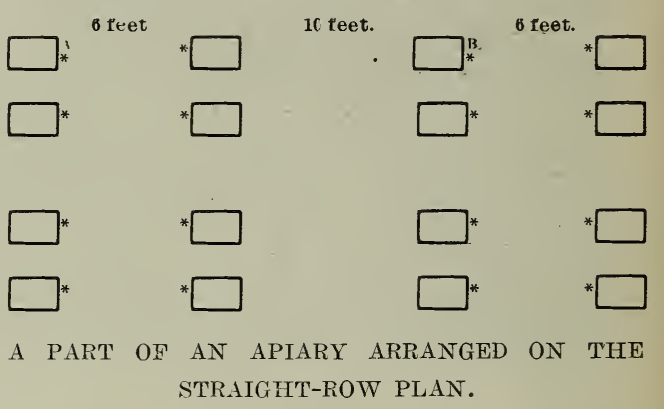

The stars in the preceding diagram indicate the entrances. There are two lanes, or alleyways, one six feet wide, for the bees, and one ten feet wide, for the apiarist, and his horse and wagon, ete. It will be noticed that the hives are arranged in pairs, in such a way that they face each other with entrances six feet apart. In the next alley their backs are toward each other, with plenty of room for a roadway.

DR. C. C. MILLER'S SCHEME FOR PLACING HIVES.

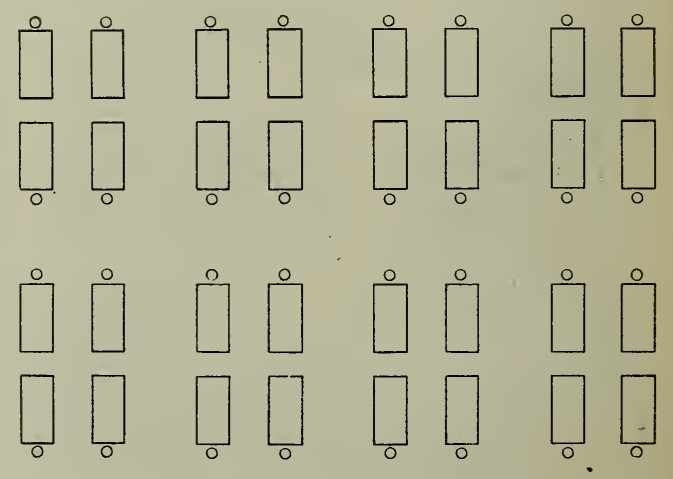

Dr. C. C. Miller prefers this arrangement. It certainly works well for him.

S. E. MILLER'S PLAN OF AN APIARY.

This plan is similar to the one used by $\mathrm{Mr}$. Hatch, but is arranged with a view of 
still greater economy of space, not losing sight of the scheme of a highway for bees, and an alley for the apiarist. Instead of being in pairs they are arranged in groups of five each. Little circles in front of the hives indicate the entrances. The hives should be 18 inches apart to give room for a lawn-mower. It would hardly do to put them closer than 12 inches, for long timothy grass will grow between them, and then it is difficult to clean it out; and if not cut out it is in the way of putting on the supers. The groups can be from 10 to 20 feet

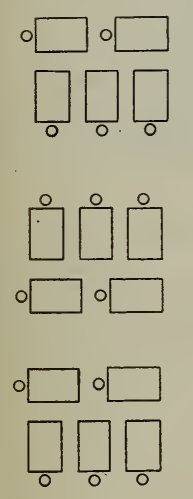

ALLEY FOR APIARIST.
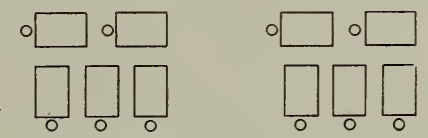

HIGHWAY FOR BEES.

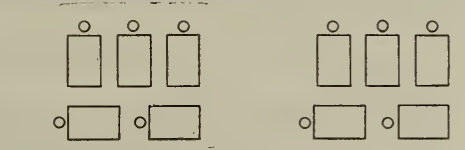

ALCEY FOR APIARIST.

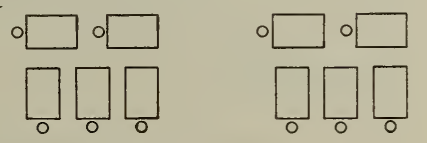

HIGHWAY FOR BEES.

apart; but if put exactly 16 feet apart, and the hives in the group 18 inches apart, an apiary of 80 colonies can be accommodated on a plot 75 feet square, or in the back yard of an ordinary town lot. One advantage of this grouping plan is, that the apiarist can sit on one hive while he is working on another; and his tools, such as smoker, honey-knives, bee-brushes, etc., are right at hand for the whole five hives. Where there is only one hive on a stand, the tools have to be carried to each hive.

The objection to this and the Hatch arrangement is that one row of hives may have to face prevailing winds, or a north or west exposure. In the northern climates this should be avoided. We recommend, therefore, putting hives in pairs and threes, and facing either the south or east.

One can crowd more colonies on a given area on the S. E. Miller plan shown (and yet leave room to run wagons or carts among the hives), than with any other. It is specially well adapted to a location in a grove; but as trees often vary in size the foliage is sometimes lopsided or scant on some of the trees, and hence it is neither practicable nor advisable to put five hives at each tree. It is our practice to place in front of the smallest trees only one hive; in front of those a trifle larger, two hives; those still larger, three hives, and, when they are of fair size, five, as in the Miller plan. Arranging the hives thus gives each group of one, two, three, or five, as the case may be, an individuality of its own, thus affording the bees a better chance to distinguish their own group; but in every case the precaution must be observed of placing the hives on the north side of the tree. Where there are two and three in a group, one can have the entrances facing toward the south; or if there are only two in a group he can have one hive with its entrance pointing toward the south, and the other hive toward the east. In any case aroid having hives face the north and west. This is very important from the standpoint of wintering.

The following diagram shows how the hives on the three-and-two plan may be arranged, considering, of course, that the tree is just south of the hive, and one, two, three, or four feet from it.
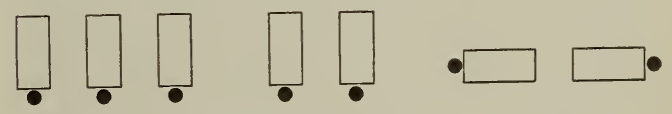

In some apiaries in California we found double rows of hives, with a double alleyway between them, instead of being parallel, diverge from a common center, like the spokes of a wheel.

KEEPING GRASS DOWN AROUND THE HIVES.

Having decided on the location and plan of the apiary, the next question that would naturally arise is: Shall grass be allowed to grow and be kept down to an even height with a lawnmower or shall the sod be cut off entirely, and the hives be placed on a smooth plot of clay leveled off like a brickyard? In favor of this arrangement it may be said that queens can be easily found, and that, when the sod is once removed, all that is necessary is to go around the hives with a hoe or scraping-knife to shave off the weeds as fast as they come. If they are kept down thus, and the plot is sprinkled with a thin layer of sawdust raked over evenly, we have an almost ideal spot for bees. While ground floors of this kind are nice and pretty to look at, it 
means a great deal of labor and expense, because there is almost constant warfare against weeds. They will crowd their heads up thru the sawdust; and at the present low prices at which honey sells, it may be doubted whether it pays. The great majority of beekeepers, however, after having leveled the plot, leaving the sod, consider it sufficient to keep the grass down with a lawn-mower. If it is mown once or twice a week, the yard not only looks pretty but practically there is no inconvenience resulting from the short grass. A lawn apiary is much prettier, and about as convenient in every way as one with a brickyard bottom.

\section{KEEPING DOWN THE GRASS AT ENTRANCES} OF THE HIVES.

It is not practicable to run a lawn-mower any closer than about two inches to a hive; and some sprinkle salt in front of the entrances and around the hives. This kills all vegetation up to a point where the lawnmower can reach it.

But a good many apiarists do not even have the time to use a lawn-mower. As it would be a great task to keep the grass down in front of the hives where it would obstruct bees returning heavily laden from the fields, it is a very common practice to use a board little longer than the entrance, and a foot or 18 inches wide. This board should be cleated on the back, and attached to the hive so that the bees may have an easy runway clear up to the entrance. These boards may be planed and painted; but ordinarily we would recommend rough unplaned stuff - the cheaper the better. This gives the bees a good foothold, and at the same time saves some expense. See ENTRANCES.

SHEEP FOR KEEPING DOWN GRASS IN THE APIARY.

One of our neighbors lets loose a few sheep in his apiary occasionally. It is well known that our wooly friends can gnaw the grass closer than any other stock. If a few of them be turned into an apiary for a day or two they will cut down all the vegetation close to the hives, not leaving a sprig of any sort. One would naturally suppose that the bees would sting the animals, with the pcssible result that a hive or two would be overturned; but in actual practice no trouble results. Once in a gre: sheep is stung; but instead of ru bellowing like a calf, or kicking a like a horse, these animals quietl: to a bush and plunge their hear and keep them there until all is bee cannot possibly hurt them exce the eyes and nose. But it is so st they are attacked that one canno it cruelty to animals to use then mowers. If one does not care to stung at all he can turn them apiary just at night, and before drive them out again. But we har a yard where two or three sheep lowed to graze the season thru, $\varepsilon$ that time they were not stung $\mathrm{n}$ once or twice, and yet the grass down automatically over every $s q$ of the apiary.

One would suppose the droppir be somewhat offensive; but our assures us that this is not the eas manure very soon sun-dries, and such a nature that it makes no $t$ the first place.

\section{THE HOUSE-APIARY.}

This is a term that is used to de structure enclosing a whole apia: hives are usually arranged on she? to the outside walls and having di munication with the outside.

As a general thing, an outdoor : cheaper and more satisfactory tha a building. For the house-apiary, ital to put up the building must nished at the outset; and one that . 50 colonies will cost much more same number of hives intended for use. But there are conditions und the house-apiary may be and is advantage-in fact, affords the only of keeping bees at all. Where lan uable, such as in or near the cit: localities occasionally visited by where bees, honey, and everything as possible, must be kept under 1 key, it is a necessity. A small k also, to accommodate 35 or 40 colon when these conditions do not exi often be used very advantageously nection with the regular apiary 0 When robbers are bad, or when the rainy, the work can continue right 


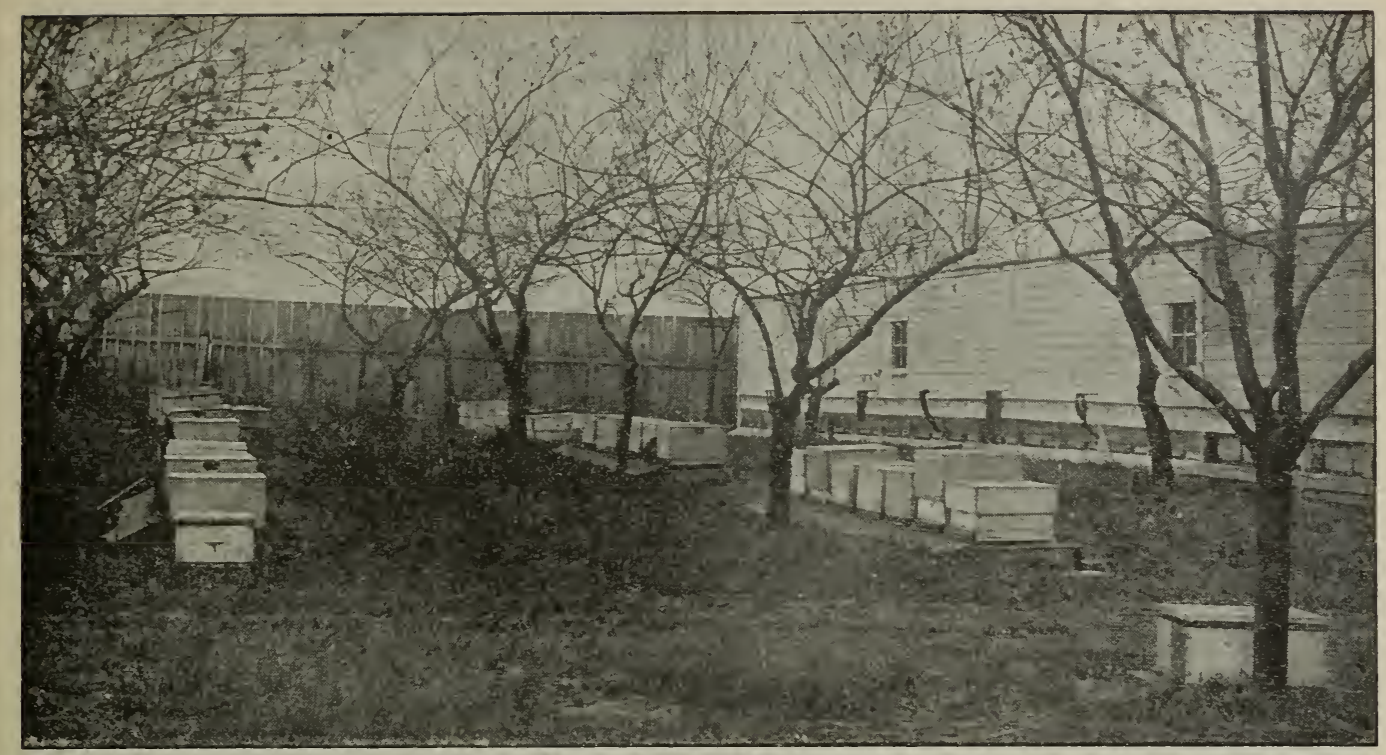

Outdoor colonies sheltered on the north by the house-apiary, and on the west by a high board fence.

cause the apiarist can leave the outdoor bees and resume operations inside, free from robbers in the one case, or protected from inclement weather in the other.

Until very recently house-apiaries have not been regarded with very much faror among practical beekeepers, principally on account of faulty construction, and because bee-escapes, when house-apiaries began to come into use in certain quarters, were not known; but since the advent of these laborsaving devices, the troubles arising from bees leaving the hives, and crawling over the floor to die, or to be trampled on if not already dead, at the first visit of the apiarist, are eliminated. These and other inconveniences have been almost wholly removed; and perhaps the only reason why the house-apiary is not more generally used is the expense or first cost.

\section{HOW TO CONSTRUCT A HOUSE-APIARY.}

The building may be oblong, square, octagonal, or round. The round or octagonal form will. perhaps, save steps during the operation of extracting; because, if the building is only 12 or 14 feet in diameter, the extractor may be put in the center of the room, and every hive will be equally distant, or practically so, and the combs may be transferred from hive to extractor, and vice versa, without taking more than one step; whereas, if the building is oblong some hives will be further from the seat of operations. The house-apiary building we formerly used was octagonal: but we found it a rery expensive thing to make, and we were greatly annoyed by a leaky roof; and the only way to make it tight, with its many angles, was to corer it with tin. We would, therefore, construct a plain square building. say 12 feet across. For a roof we would adopt the plain gable, covering it with shingles. Where the winters are cold the building should by all means be doublevalled; and sawdust or some sort of packing-material should be poured in between the two walls. Unless it is warmly packed there will be bad wintering. Our own building is lined on the inside with tarred paper, and re-covered with manilla paper; but we are not sure that we would recommend it for any one else, because holes are constantly being punched thru it. A better way would be to line it with wood-some cheap flooring would be good enough. If the joints are made tight, so that the packing-material will not leak, plain No. 2 barnboards would answer. Thru the roof, and extending thru the center of the ceiling, we would have a ventilator-shaft, made of wood, about a foot square, and so arranged that it can be closed at will. During summer weather the smoker should be set directly beneath the shaft, and the ventilator opened for the escape of smoke. It sho:id always be closed before learing the building, because it is desirable to hare the room 


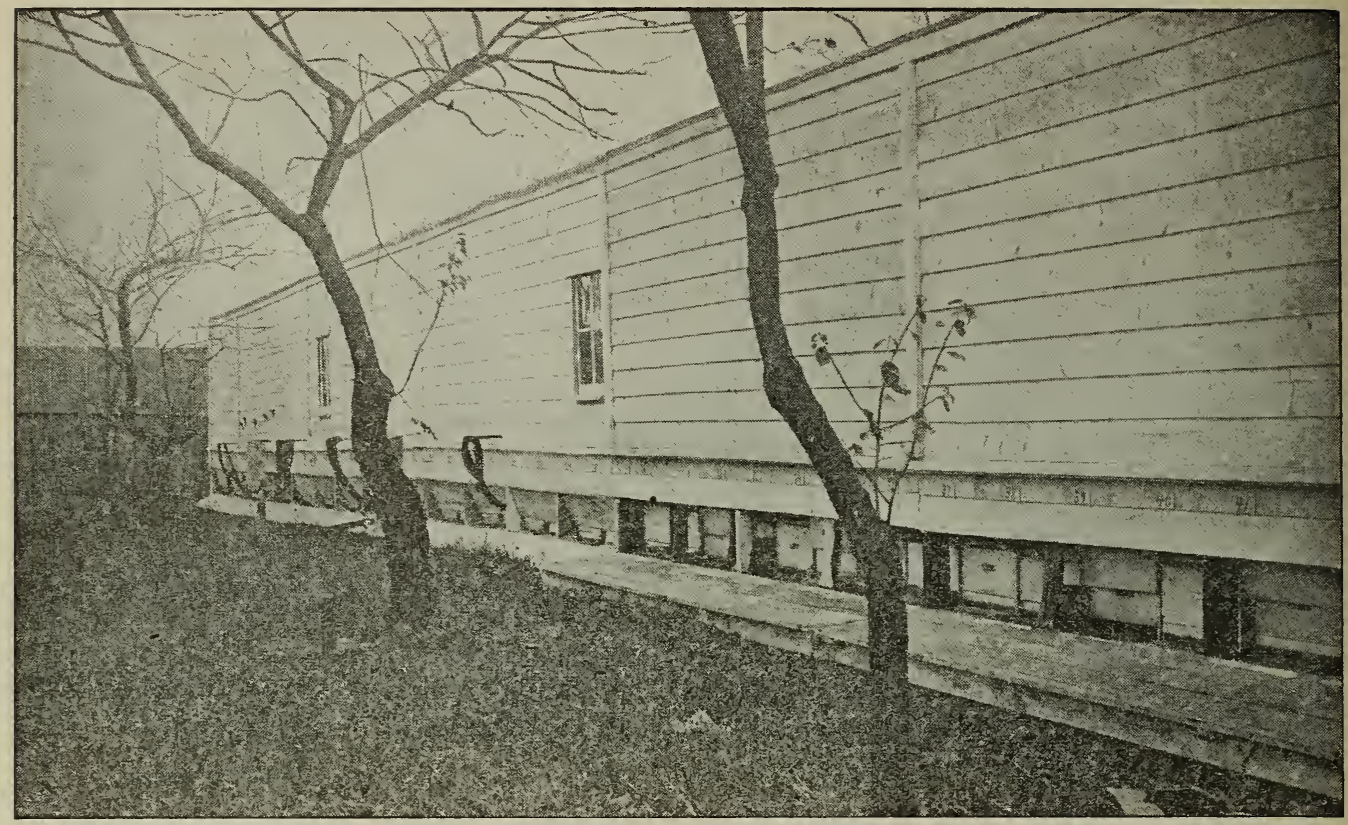

W. C. Sorter's house-apiary. The rags of different colors are used to enable the bees to mark their own entrances more easily.

perfectly dark, except at the small openings, where bee-escapes are to be placed, as we shall soon explain.

As to doors and windows there should be only one window, and that opposite the door, so as to allow a draft to pass directly thru, because the building at best becomes very sultry in hot summer weather. An ordinary tight-fitting door should be used, hinged in the usual way. To the outside of the door-frame there should be a wire-cloth screen door. At the top of the door the wire cloth should extend up as seen in the cut below; that is to say, it should be nailed on the outside, and should extend four or five inches beyond the bottom inside edge of the

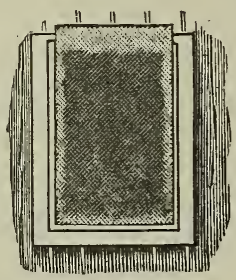

frame, leaving a bee-space between the frame and cloth. This is to allow the bees that collect in the room during the time of working, as, for instance, during extracting time, to escape in accordance with the natural instinct that prompts them to crawl upward. The window should have wire cloth nailed on the outside in like manner, the same extending above the window-casing as in the figure.

A better method is that shown in the larger cut, where the edges of the wire cloth are formed into bee-escapes.

A better arrangement still, and the expense is but slight, is ordinary screen win-

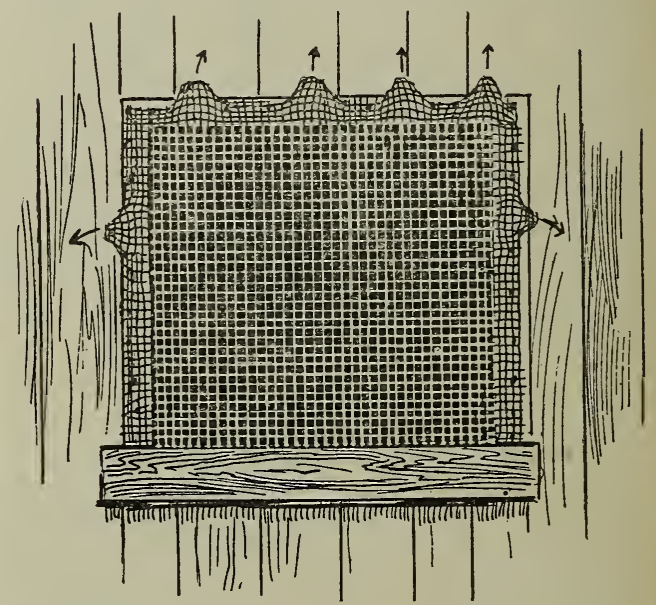

dows. At two of the upper corners attach Porter honey-house bee-escapes as shown in the engraving in the next column. This will be more reliable, as the robbers cannot by any possibility return thru the Porter, while they may learn the way back thru the projecting screen. 


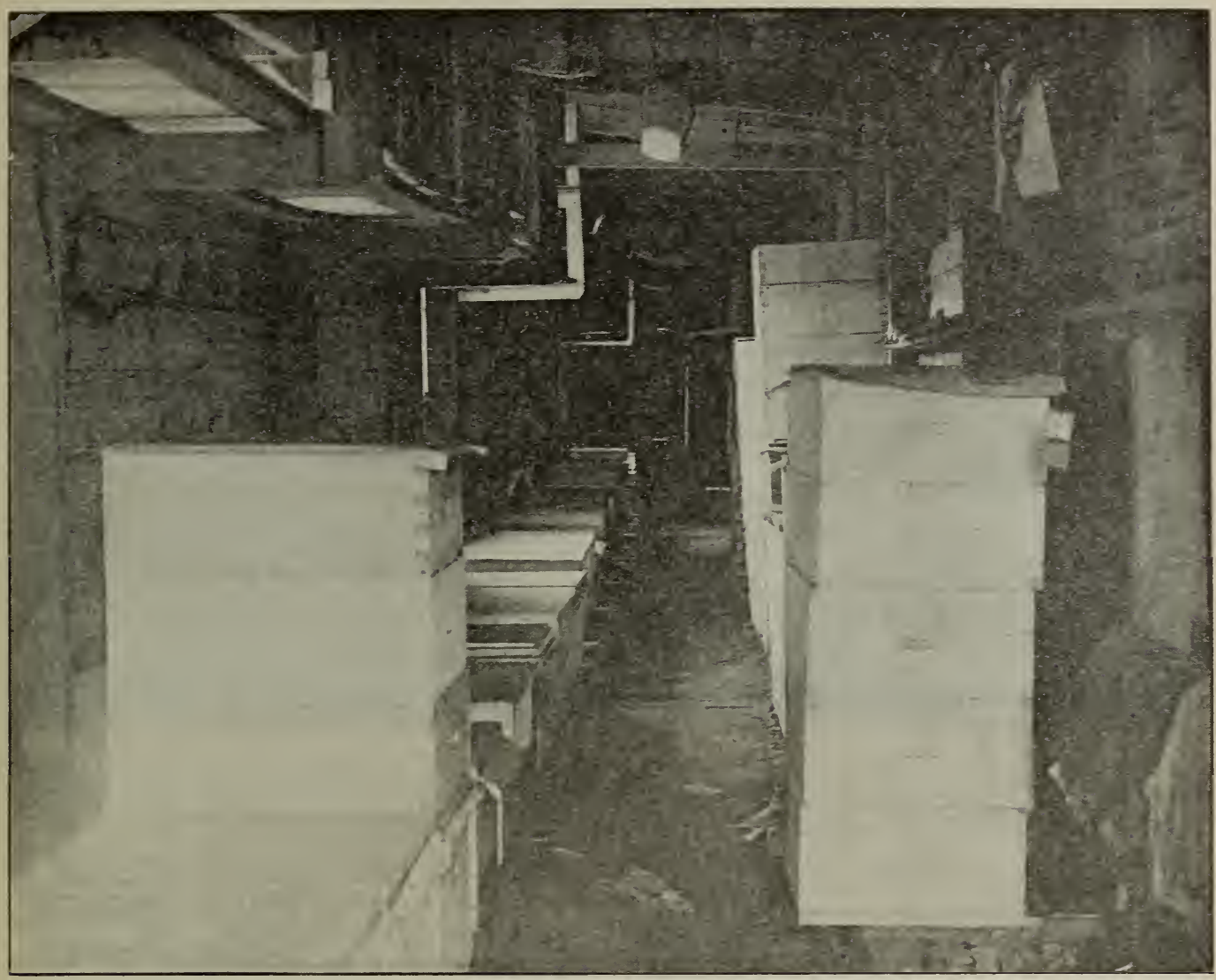

Interior of Sorter's house-apiary. The colonies are arranged along the south wall on the left side. The rest of the building is used for empty supers, supplies, etc.

At several points, close on a line with the floor, should be one-inch holes, on the out-

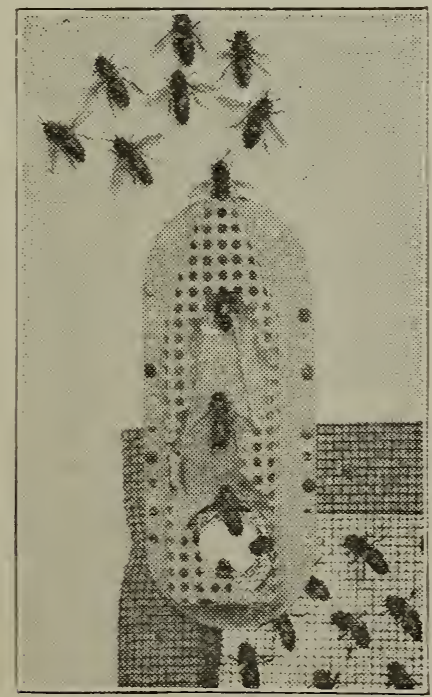

Porter honey-house bee-escape.

side of which should be more Porter honeyhouse bee-escapes. The purpose of the opening in thesa escapes is to let the bees that happen to be inside after working crawl out toward the light; and, once outside, they will enter their own hives, with the possible exception of a few young ones, and they will be accepted at any of the entrances.

A few years ago it was not deemed necessary to have anything but end boards to hold up the frames. These boards resting on the floor or shelf were secured against the side of the building. It remained then to close up the open side with a tight-fitting division-board, and the top with a quilt. But this practice was found to be very objectionable; and those who manage houseapiaries now prefer to use ordinary outdoor hires instead, primarily because the bees can be more easily confined to the hires; and, secondarily, because the indoor and outdoor hives are one and the same, and interchangeable.

The hire entrances should be so arranged that they communicate with openings thru the side of the building; and then ordinary 


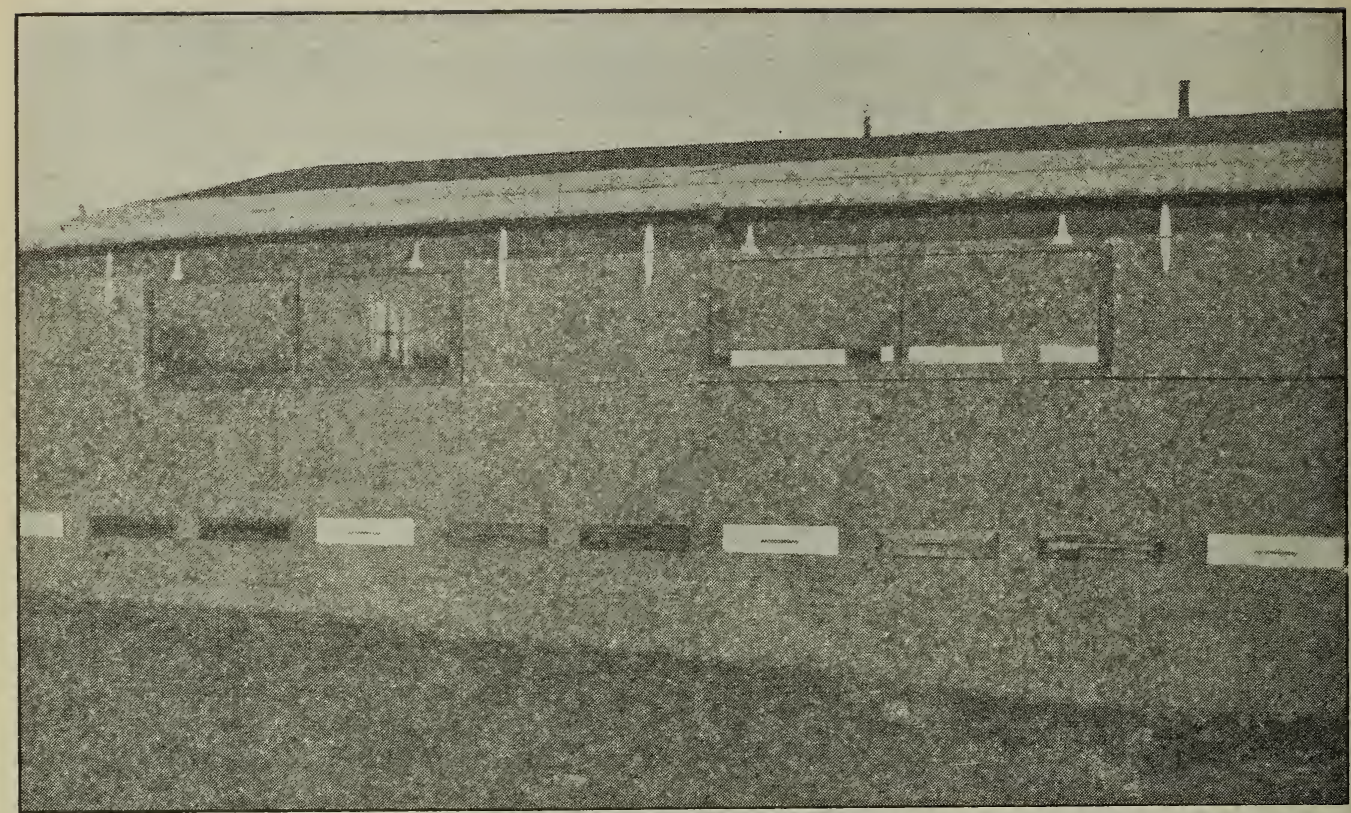

Addition built on the south side of E. C. Barber's shop, 20 feet long and 5 feet wide. It is covered with two-ply paper, granite finish. Cost for material and labor, $\$ 22.50$. Ten colonies are wintered inside this building, temperature 45 to $50 \mathrm{Fahr}$. In hot weather the side can be opened to give plenty of ventilation. There is also a door in each end.

covers should be used to confine the bees strictly within the hives. In lieu of a cover a thin $3 / 8$ board, or something of that sort, may answer just as well; but so far as possible we would so construct the houseapiary that everything outdoors may be moved inside, and vice versa, whenever requirements make it necessary. The dimensions of the house-apiary inside should be just large enough to take a row of hives without wasting space.

When the building of a house-apiary is double-walled, it is necessary to provide some sort of bridgework or housing to cover the runway between the entrances of the hives inside and the openings outside. In our original house-apiary we used a twoinch round hole, because it was easier to insert a tube than to make a narrow rectangular box or housing. But a round hole as large as this is not desirable, and we therefore recommend a covered runway thru the building to the regular entrance of the hive of about the usual dimensions.

On account of convenience in handling frames, many prefer to have the hive sides against the building. In that case there will have to be a slot in the side of the bottomboard instead of in the end. Others prefer, on account of economy of space, to place the front end of the hive against the building. When this is done it involves no change in the structure of the bottomboard; but it makes the handling of the frames a little awkward as will readily be seen by the illustrations of the Sorter house-apiary.

To economize still further the space of the building, there should be another tier of hives about four feet above the floor; and these should be supported by shelving that reaches clear around the room. The same arrangement with regard to entrances may be employed as described for the bottom tier.

Now let us urge again. Do not get the idea that you can build hives cheaper, and have them a part of the building. The ordinary outdoor hives are in every way much more handy. And another thing, do not be satisfied to put just a mere quilt on top of the frames. It is essential that the bees be confined strictly to their own hives, otherwise they will be crawling from one hive to another, killing queens occasionally, getting on the floor, and getting mashed, to say nothing of the inconvenience to the apiarist when he desires to work inside.

PUTTING CROSS COLONIES IN HOUSE-APIARY.

We have always observed that the crossest bees are but little inclined to sting 
inside of a building. When they fly from the combs that you are handling, they find themselves inclosed; and this so disconcerts them that they immediately fly to the screen windows and escape. James Heddon said, "If you have a cross colony, put it in the house-apiary and see how tame it will become."

\section{HOUSE-APIARIES FOR WINTERING.}

As the building is double-walled, and is (or ought to be) packed, colonies will require less protection than outdoors. Indeed, about all that is necessary to put them into winter quarters will be to put on an extra comb-honey super, tuck in a chaff cushion, replace the cover, when the bees will be prepared. In very severe cold weather, a small fire, or heat from a large lamp in the room, may, perhaps, be used to advantage; but artificial heat in wintering should be used sparingly and with care, for oftentimes it does more harm than good.

Mr. E. C. Barber, of Framingham, Mass., whose house-apiary we show, thus summarizes the adrantages of keeping bees inside of a building:

I prefer the house apiary instead of the outside yard for several reasons. First, you can work at your bees and not be among those flying in the air, especially if the windows in the house are closed. What few bees fly from any hive you are working on inside of the house, instead of trying to frighten or sting you will fly to the window to get out. Second, you do not have to carry the hives in and out of the cellar in the spring and fall, or move them to their winter quarters. Third, your bees' are always protected from the snow, rain, and winds. Fourth, they are at leisure for a flight in the winter any time when it is warm enough, such as the past few days have been, when the thermometer was around 70. Fifth, in this house-apiary I can see a big difference in spring brood-rearing; also protection during cold nights, when bees are working in sections during the summer.

Mr. Barber is entirely correct. The only serious objection to a house-apiary is its non-portability and its expense. In these days of out-apiaries, colonies may occupy a location for only one season. Of course a house-apiary can be made comparatively small and light; but the expense of moving it even then would be considerable.

APIARY, OUT.-See OUT-APIARIES.

APIS DORSATA.-See RACES OF BEES.
ARTIFICIAL FERTILIZATION.-After the reader has read the subjects of Drones, Queens, and QueEn-Rearing, he will fully understand that the mating of the drone and queen in a state of nature takes place on the wing in the air, and never occurs inside the hive. Nature has seemed to design, for the purpose of avoiding inbreeding, that the queen shall find her mate in the open air, where, according to the law of chance, she will in all probability meet some drone not directly related to her. Attempts have been made at various times to bring about fertilization within the hive or within some small tent connected with the hive entrance. But all such attempts have resulted in failure, because the drones and queens, as soon as they find they are confined in a small inclosure, will bump against the sides of the mosquito netting or wire cloth, vainly seeking to escape.

A good many years ago Mr. J. S. Davitt, of Aragon, Ga., put up a tent of mosquito netting, 30 feet tall and 30 feet in diameter. Hives of bees containing select drones were placed around the bottom edge of the tent, each hive having two entrances-one opening into the inclosure and the other into the outer air. The latter were covered with perforated zine in order to compel the queen and drones, when seeking flight, to pass out of the other entrance into the enclosure. This inside entrance was kept closed for about a week; then on some favorable day, from 11 A. x. to $1: 30$ P. xr., it was opened and the drones and the queens were allowed to go into the tent. Mr. Davitt reported that a very pretty school of drones would be found flying at the top, and that he was successful in mating many queens. It will be noticed that the worker bees, accustomed as they are to the outside entrance, which is always open, do not go into the inside of the tent during the mating hours, so that the drones and queens are largely by themselves.

Unfortunately this general plan has been tried by one or two others, but without success. So far no one else has had the nerve to try it. One man reported having tried taking a drone of mating age and pressing him until the drone organs were distended. The spermatozoa were then injected into the body of a queen of mating age. He stated that, altho the wings of the queen had been clipped when she was one 
cay old. she began to lay and the eggs developed into worker brood. The experiment is worth trying, and the author suggests that some of our A B C scholars try it out and report results.

So far the only feasible plan for mating queens with select drones is to put perforated zinc over the entrances of all colonies not having choice drones, leaving only select drones to have the freedom of the air. If there are no other bees in the locality except those liaving screened entrances, the chances will be largely in favor of having the rueens mated to the drones of the colony selected. A still better plan is to take the queen-mating nuclei to an island where there is a colony of select drones, or several of them. This island should be located at least five miles from the mainland. See Quenns, Queen-Rearing, and Drones.

ARTIFICIAL HEAT.-As strong colonies early in the season are the ones that get the honey and furnish the early swarms as well, and are in fact the real source of profit to the beekeeper, it is not to be wondered at that much time and money have been spent in devising ways and means whereby all might be brought up to the desired strength in time for the first yield of clover honey. As market gardeners and others hasten early vegetables by artificial leat, or by taking advantage of the sun's rays by greenhouses, etc., it would seem that something of the kind might be done with bres; in fact, we have, by the aid of glass and the heat of a stove, succeeded in rearing young bees every month in the year, even while the weather was at zero, or lower, outside; but as nearly as we can learn, all artificial work of this kind has resulted in failure, so far as profit is concerned. The bees, it is true, learned to fly under the glass and come back to their hives; but for every bee that was raised in confinement, two or three were sure to die, from one cause or another, and we at length decided that it was best to wait until summer weather, and then take full advantage of it. See Pollen.

Later we made experiments with artificial heat while the bees were allowed to fly out at pleasure; and altho it seemed at first to have the desired effect, so far as hastening brood-rearing was concerned, the result was, in the end, just about as before; more bees were hatched, but the unseasonable activity, or something else, killed off twice as many as were reared, and the stocks that were let alone in the good old way came out ahead. Since then we have rather endeavored to check very early brood-rearing, and with better results.

A few experiments with artificial heat have apparently succeeded, and it may be that it will eventually be made a success; but our impression is, that we had much better turn our energies to sometling else, until we have warm settled weather. Packing the hives with chaff, sawdust, or any other warm, dry, porous material, so as to economize the natural heat of the cluster, seems to answer the purpose much better, and such treatment seems to have none of the objectionable features of working with artificial heat. The packing needs to be as close to the bees as possible; and to this end we would have all the combs removed except such as are needed to lold their stores. Bees thus prepared seem to escape the ill effects of frosty nights in the early part of the season, and we accomplish for brood-rearing exactly what was hoped for by the use of artificial heat.

For the benefit of thcse who may be inclined to experiment, we would state that we covered almost our entire apiary with manure, on the plan of a hot-bed, one spring, and had the mortification of seeing almost all die of spring dwindling. Another time we kept the houss-apiary warmed up to a summer temperature with a large oil-lamp, for several weeks, just to have them beat those out of doors. The investment resulted in losing nearly all in the house-apiary with spring dwindling, while those outside stayed in their hives as honest bees should, until settled warm weather, and then did finely, just because we were "too busy to take care of them"(?) as we used to express it.

\section{WINTERING BEES IN A WARM ROOM.}

But a number have wintered single colonies of bees in the living-room of a house where the temperature was kept between 65 and 72 , night and day, with very good results. In the cases mentioned, the colonies were placed on a shelf next to a window, with the entrance communicating with the outside. All old and superannuated bees can thus escape at any time; and when the 
weather is suitable the bees can fly. We had one colony of bees in one of our offices that was there for at least three years. Some years it seemed to winter very nicely; but taking one year with another, we notice that these indoor colonies do not seem to get ahead like those outdoors. The warmer atmosphere in which the hive is placed has a tendency to start brood-rearing. This forces the bees out on unfavorable days, with the result that they never return. The slight amount of brood hatched does not compensate for the number lost in this way; and the result is, the colony gradually goes down. By the time spring comes on, the queen is not ready for the actire duties of the hive, for the simple reason that she has been laying more or less all winter; and we presume if she were a human being she would say she was "all petered out." At all erents, we have never known such colonies to build up like those that have been well packed outdonrs or put in the cellar.

\section{ARTIFICIAL PASTURAGE. - Altho} there used to be quite a trade in seeds and plants to be cultivated for their honey alone, we can give little encouragement to those who expect to realize money by such investments. There is certainly a much greater need of taking care of the honey that is almost constantly wasting just for lack of bees to gather it.* A field of buckwheat will perhaps occasionally yield enough honey to pay the expense of sowing, as it comes in at a time when the bees in many places would get little else; and if it does not pay in honey, it certainly will in grain. If one has the money, and can afford to run the risk of a failure, it would be a fine thing to make some accurate experiments, and it may be that a farm of one or two hundred acres, judiciously stocked with honey-bearing plants, trees, and grains, would be a success financially. It has been much talked about, but none, so far as we know, have ever put the idea in practice.

Of course, alfalfa at the present time affords the best example of artificial pasturage of anything we have. But alfalfa will not grow everywhere, or at least not until the soil has been put in the right condition with proper inoculation. See Alfalfa. In the West, where it grows under irrigation, it yields as much or more

\footnotetext{
* See Foreword.
}

honey than any of the natural or wild sources of the country.

Sweet clover furnishes an artificial as well as wild pasturage, and is now being grown as a regular farm crop. In many portions of the West where the land is too dry to grow alfalfa, sweet clover will thrive. In many parts of Kentucky sweet clover is coming to be a very profitable crop. It often does well on land that will not grow anything else, especially on rocky hillsides. There thousands of cattle are fed on the legume, and there thousands of colonies of bees yield handsome returns in the way of fine honey. See StweEt Clover.

Alsike also furnishes artificial pasturage in the eastern states. It often takes the place of ordinary red clover that fails to do well. Alsike can stand wet feet, but red clover will not. This discorery has caused many farmers to g'row it either with timothy or exclusively, and the result is that wherever it is extensirely grown the keeping of bees is profitable.

To beginners we would say: Plant and sow all you can that will be sure to pay aside from the honey crop, and then, if the latter is a success, "you will be so much ahead; but beware of investing much in seeds that are for plants producing nothing of value except honey. Alsike, white Dutch clover, buckwheat, rape, alfalfa, and the like, it will do to invest in; but catnip, mignonette, Rocky Mountain bee-plant, etc., we would at present handle rather sparingly.

The question, "How many acres of a good honey-bearing plant would be needed to keep 100 colonies busy?" has often been asked. If ten acres of buckwheat would answer in full bloom, we should need perhaps ten other similar fields sown with rape, mustard, catnip, etc., blossoming at as many different periods, to keep them going the entire warm season. It would seem 500 acres should do nicely, even if nothing were obtained from other sources, but at present we can only conjecture. A colony of bees will frequently pay for itself in ten days during a good yield from natural pastrirage; and if we could keep up this state of affairs during the whole of the summer mon!hs, it would be quite an item. Alfalfa, sainfoin, sweet clover, buckwheat, rape, alsike clover, crimson and red clover, cow peas of the South, and some others, are 
the only cultivated plants that have given paying crops of honey, without question, so far as we have been informed. See HONEY-PLANTS.

ARTIFICIAL SWARMING. - Before the reader takes up this subject he should first read carefully the article on SwARMING in order that he may understand the conditions that bring about swarming in a natural way. He will then be in a better position to understand the principles involved in artificial swarming.

In the first place, the natural swarm, when it starts forth, is fully prepared to abandon its old home; and, no matter where it may be placed, its individual members have no thought of going back to the old stand. If, therefore, we would succeed with artificial swárming, we must practice some scheme that will remove the home-loving: instincts to such an extent that the swarm that we have made up artificially will stay in the new location; and, not only that, will be in such a condition that it is, to all intents and purposes, a natural swarm. As it is somewhat difficult, however, to remove entirely the home-loving instinct, we are obliged to cater somewhat to it, and we therefore so far as possible hive our artificial swarm in the old location, so that, if the home-loving instinct has not been removed, or only in part, we shall still hold bees that would otherwise have been "homesick," and go back.

The swarm that goes out naturally, for a few days prior to its issuance begins to become logy. The bees show a disposition to hang out in front of the entrance, and there seems to be a general letting-up in their activities. Swarming cells are started. Whenever this condition begins to manifest itself, it is time to act. Instead of letting the colony go on and finally swarm unexpectedly at their convenience when we may be away, we anticipate their action and force them to swarm at our convenience. The plan in brief is as follows:

After the honey-flow has begun, and perhaps three or four days (not earlier)* before the colony is expected to cast a swarm, the hive is moved to one side of the

* Reports show that, if the colony is shaken or brushed from one week to ten days before a swarm would otherwise issue, no good will be accomplished and that the bees will re likely to swarm. The shaking should not take place before the bees feel and show the desire to swarm. stand, and an empty one, just like it, is put in its place. In this hive are placed frames having foundation starters or frames with full sheets-preferably the latter. But if neither is available, combs may be used. The bees of the parent colony are then shaken or brushed in front of the entrance of the new hive on the old stand. Some go so far as to brush all the bees out of the old hive; and this can be done if the weather is hot and nights warm; for young hatching brood will soon be out to take care of the young brood. The practice is not to be recommended as it is too risky. The supers from the parent hive are next put on the new one. The parent colony is then moved to a new location or left by the side of the new hive with its entrance facing in the same direction. In either case the entrance should be contracted.

If work is already partly begun in the super, the bees will continue work, and rush the honey above. In some cases it may be advisable to use perforated zinc between the super and brood-nest to keep the queen below.

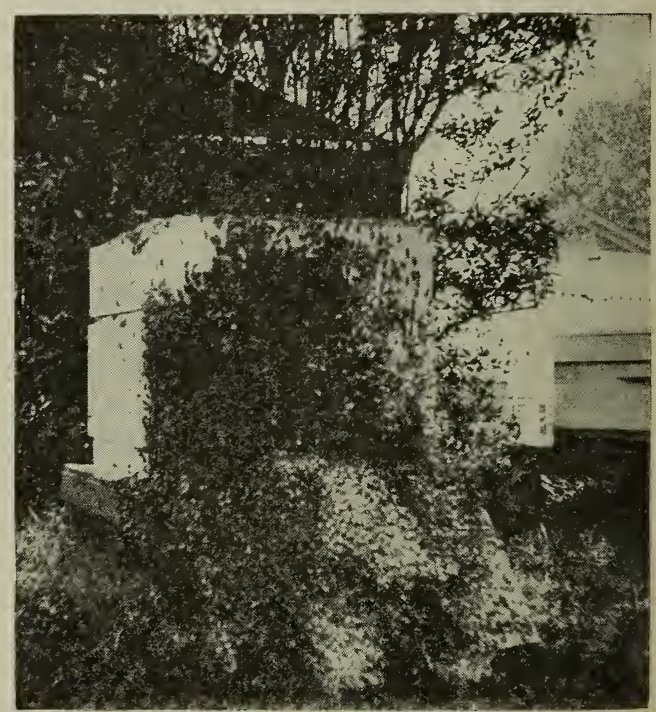

Swarm shaken on the alighting-board of the new hive.

The plan will meet favor, especially with those in localities where the season is short and the honey-flow rapid; and it will doubtless enable many who usually get no comb honey at all to secure a good crop.

The question may be asked, "What is done with the parent hive and all its brood?" If left beside the new colony, the brood, 
when hatched out, is shaken in front of the new hive, so that at the last drive all the bees that would have been hatched in the original colony are now given to the brushed swarm. after which the hive is moved away. In this respect a brushed or "shook" swarm, as some call it, will secure more comb honey than a natural swarm because it has the additional strength of the young bees. The queen from the old hive (if one has been raised or introduced) should, of course, be remored befure the last drive, and given to some other colony.

While this plan of forcing the swarm ahead of time at the convenience of the apiarist generally gives satisfaction among beekeepers, some do not make it work; but so many have reported favorably thru the bee journals that we are satisfied that, if details are carefully followed, it will prove successful with most people.

Another plan has been suggested that is somewhat similar to that already described; but instead of shaking all the bees at once the operation is performed at two different times. For example, a colony in an eightframe hive has four combs of brood taken out of the center of the brood-nest and in their place is put an equal number of frames of full sheets of foundation. The combs removed are now shaken one by one in front of the entrance. Two or three days afterward, when work gets nicely started on the first frames of foundation the remaining old combs with their brood and honey are removed and a second set of frames are put in their place. The combs of brood are then shaken in front of the entrance as before. The beeless brood should, of course, be given to other colonies that can use it to advantage.

This involves the principle of the brushed or shaken swarm idea, and has the further advantage that the bees are not liable to swarm out as when they are shaken all at one drive on nothing but foundation.

\section{DOOLITTIE MODIFIED SHAKEN SWARMI METHOD.}

This plan involves some of the principles of the shaken-swarm method; and in certain localities it can be employed to very good advantage. The method in brief is as follows: Sets of partly filled extractingframes from weak colonies the year before, as will be explained later, are kept over winter in the honey-house, until the spring or early summer, when upper stories are filled with them, and placed on all strong colonies. The idea of this procedure is to make the colony below feel rich in stores so there will be no curtailment of brood-rearing. If any honey should come in from fruit-bloom or other sources before the main flow it is promptly carried upstairs without crowding the queen below.

A week or two prior to the expected honey-flow or swarming season this upper story is lifted off and the old colony moved to one side. On the old stand is placed another empty hive. The set of combs, all save one, that were originally in the upper story, containing more or less honey, are now put down in the empty hive on the old stand. One comb is left out in the center, and replaced by a frame partly filled with brood from another hive. On this hive, at the parent stand thus prepared, is placed a comb-honey super containing sections filled with full sheets of foundation, and having at the center ten or twelve other sections with partly drawn comb. On this super is placed another of sections with only full sheets of foundation. Last of all the cover is put on. The frames of brood put in the old hive removed to one side are now taken out and shaken in front of the entrance of this newly prepared hive at the old stand. The brood is then stacked up on the few weak colonies not run for comb honey. As the bees hatch, the combs are more or less filled with honey during the season, thus furnishing the sets of extracting-frame to be used for the comb-honey colonies the next year. The queen in the comb-honey hive will have the one frame of brood partly filled where she can begin laying. The large amount of honey in the brood-nest the bees will begin carrying upstairs to the supers in order to give the queen more room in which to lay. Thus work is started in filling the sections before the honey-flow actually begins; and when honey does come in, the bees continue to store it above without any swarming. In the meantime the queen occupies every available cell in the lower part of the hive.

Mr. G. M. Doolittle, the author of this system, has tested it most thoroly several seasons; and one year in particular, when the season was only fair, secured an average of $114 \frac{1}{2}$ pninds of comb honey per colony, with no swarms at any outyard. 
While the first sections will contain a little old honey, yet if it be buckwheat or other good honey it does not impair the flavor, for there are many who like a little buckwheat flavor in comb honey; and such sections, Mr. Doolittle says, sell at the highest market price. For further particulars see Doolittle's book, "A Year's Work in an Out-apiary," put out by the publishers of this work.

We tried what was known as the Sibbald method of swarm control at one of our out$y$ ards. It involved the idea of having the colonies arranged in pairs, one very much stronger than the other. When the stronger colony began to show evidence of its intention to swarm, it was slifted over to the place occupied by the weaker one, and the weaker one placed on its stand. The supers on the strong colony were given to the weak one. Theoretically, all of the flying bees would go to the old stand; the cells that were built in the colony preparing to swarm would be destroyed because it would be robbed of all its flying bees. But the scheme worked only partially. Some strains of bees would go back to their old stand in spite of the change of position.

So far we have discussed various methods of artificial swarming. Under the head of INCREASE we take up the question of various methods for increasing the number of our colonies by dividing or otherwise. The reader should understand that "artificial swarming" is one thing, and "increase by dividing" is entirely another. The former is used to prevent natural swarming, or, rather, put it at a time to suit our convenience and yet get a crop of honey. The latter does not contemplate the idea of securing honey, but rather an increase in the number of colonies.

ASTER.-(Aster, the Greek word for star.) Asters are also called starworts, and in England Christmas daisies from their late period of blooming. This is a genus of the Compositae, the largest and most important plant family, to which also belong the goldenrods, sunflowers, thistles, and daisies. There are about 142 species of asters in North America, and about half that number in northeastern America. The species are very difficult to distinguish, as there are numerous rarieties and hybrids. Asa Gray declares in one of his letters that the asters threatened to reduce him to blank despair. The so-called flower of an aster is in reality a compact cluster, or composite, of many small sessile flowers subtended by scale-like bracts, termed a head or capitulum. The marginal or ray-flowers have strap-shaped corollas, and are blue, purple, or white, but never yellow. The central or dise flowers are tubular, and range in color from dark to golden yellow, changing in some species in the later stages of the flower to crimson purple, brown purple, or purple. The ge-

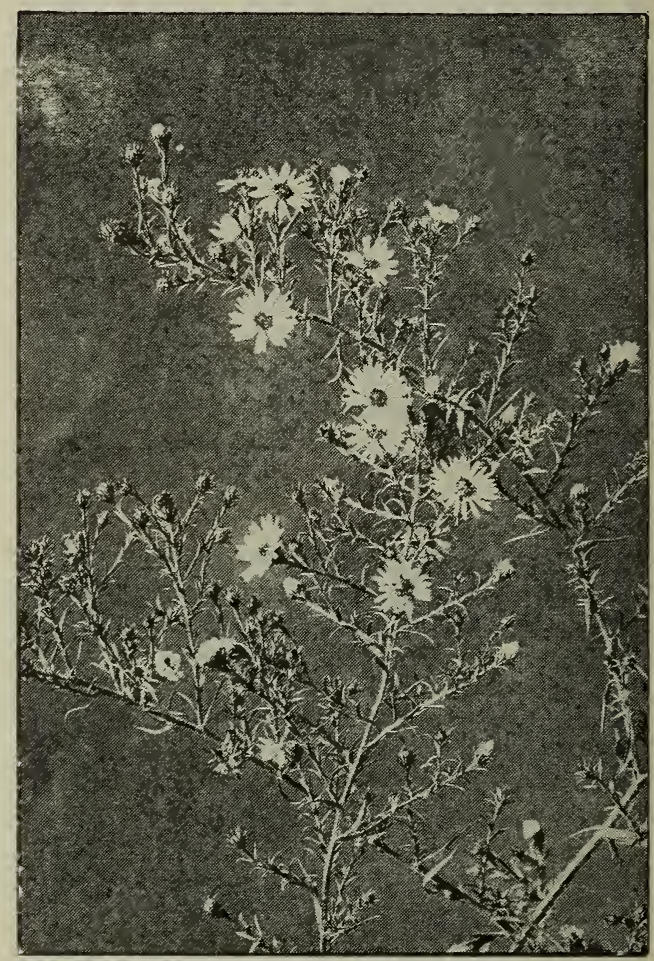

Aster.

nus is represented by a larger number of species in North $\Lambda$ merica than in any other continent.

The asters are visited by many insects besides honeybees, such as bumblebees, wasps, butterflies, and flies. On the New England aster there have been collected 46 different kinds of insects, and on the common A. puniceus, or purple-stemmed aster, 77 different visitors. Thus the honeybee has many competitors for the nectar which is secreted at the bottom of the tubular flowers.

Aster honey is gathered chiefly from the very common species $A$. multiflorus, $A$. vimineus, A. lateriflorus, A. tradescanti, 
and A. paniculatus, all of which produce dense clusters of small white-rayed heads, except $A$. multiflorus, which has the rays white or purplish. Over large areas in Kentucky, Indiana, and other states the bloom is so abundant that the fields look as if covercd with snow. The plants are often rery bushy, growing from six inches to three feet tall. When the weather is favorable colonies will pack their combs with aster honey, or if the combs have already been filled from an earlier source a surplus is often stored. One season at Underwood, Indiana, there were hundreds of acres of white aster in bloom, and 100 pounds of comb honey per live is reported to have been obtained. At Langnau, Kentucky, the scales showed a gain of 25 pounds in four days from Oct. 2 to 5 . Forty-eight colonies harvested 3000 pounds, of which one-half was surplus. There were ninety-five acres of white aster within reach of the bees. During twelve days of hot weather in September, 1914, J. L. Byer reports that 250 colonies, 100 miles north of Toronto, Can., simply jammed the brood-nests solid with aster honey.

Pure aster honey is white-as white, according to beekeepers familiar with it, as white-clover honey; but it is seldom obtained pure. Usually it is colored amber or yellow by honey from goldenrod or other late-blooming autumnal flowers. The asters, however, remain in bloom longer than the goldenrcds. When newly gathered it has a rank odor, but this disappears when it has ripened. It has a pleasant aromatic taste. and is so thick that at times it is extracted with difficulty. It crystallizes quickly with a finer grain than goldenrod. It has been stated to be unsuitable for table use, but 0 . $\mathrm{H}$. Townsend writes that in Michigan he sells aster honey for the same price as red raspberry, and that it has a fine flavor and good body. Other beekeepers also describe the flavor as agreeable.

Many beekeepers have complained that their colonies suffered more or less loss when wintering on aster honey. So strong has been the opposition to it for this purpose that its removal and the replacing of the stores by feeding sugar syrup has been repeatedly advised. It is not improbable that aster honey gathered so late that it only partially ripens and remains unsealed is liable to deteriorate and become deleterious before spring; but any other honey or even sugar syrup under similar conditions would be open to objection. Its tendency to candy quickly and solidly has also added to its poor reputation as a winter food which is only partly available. Mismanagement on the part of the apiarist seems likewise in some instances to have been laid to the fault of aster honey. But if this honey possessed properties that were actually injurious to bees, they would appear - uniformly everywhere, but this is not the case. The experience of scores of beekeepers, continued thru many years, proves that aster honey well ripened and sealed is an excellent winter focd for bees. And why should it not be? The asters are bland innocuous herbs, which are readily eaten by domestic animals, either dried as hay or green in the pastures. The 250 colonies of J. L. Byer, which packed their hives with aster honey, survived the winter in fine condition. In a symposium, published in Gleanings in Bee Culture, August 15, 1915, many beekeepers testified that they had wintered bees successfully year after year on aster honey with very little loss. It has been suggested that perhaps different species of aster yield different kinds of honey; but there is no ground for such a supposition. On the contrary, the nectar of the various species, as in the case of the goldenrods, is very similar.

In Georgia several species of aster (the most common are $A$. adnatus and $A$. squarrosus) grow all over the state, and in many places are the main reliance for winter stores. In a few localities a surplus is obtained. The honey is medium in quality, of fair color, but candies quickly in the comb if not sealed. The blooming time is from September to November.

Several widely distributed and abundant species of aster are well worthy of cultivation for their handsome flowers. A very common form is $A$. patens, or purple daisy, which has bright blue-purple flowers. The New England aster (A. novae-angliae) has stout hairy stems, eight feet tall, with violet-purple rays, rarely white, or in a variety pink. Very common along the Atlantic Coast, especially in swampy marshes, is $A$. novi-belgii. The purple-stemmed aster, cocash, or meadow scabish (A. puniceus), which is common in swamps, is a tall hairy species with purple stems and flowers. 


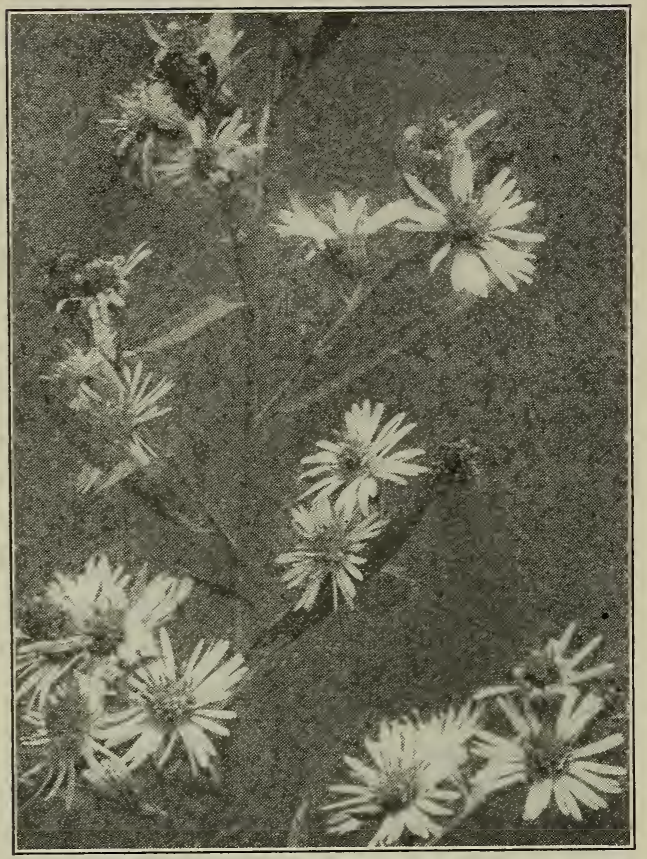

Aster paniculatus.

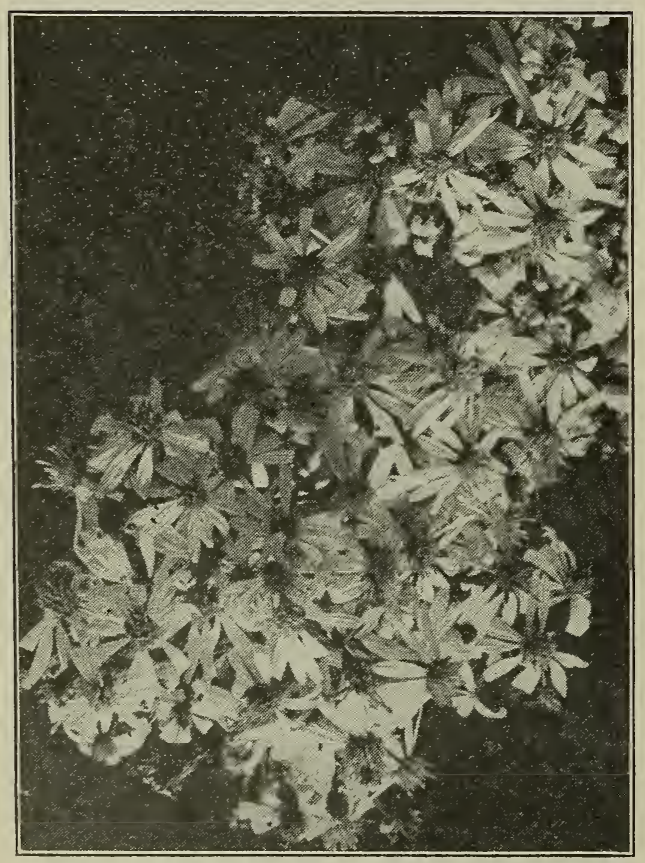

Aster multiflorus.

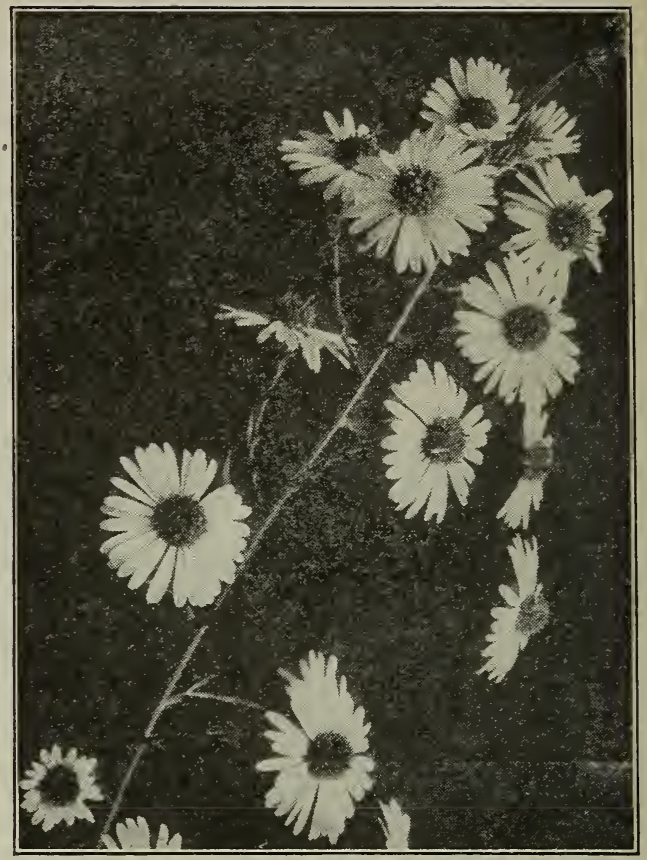

Aster Tradescanti.

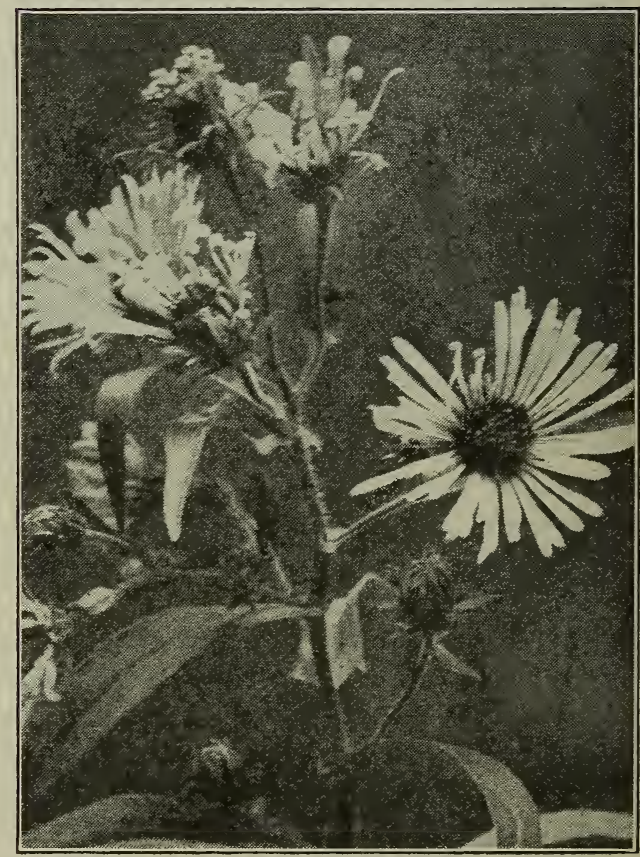

Aster puniceus. 


\section{B}

BACKLOT BEEKEEPING. - A very large number of those who keep bees are those who might properly be called backlotters-those who live in cities and towns who keep a few bees in connection with a few chickens or a little garden. The backlotters comprise professional men, business men, and women and children of the two classes mentioned. We might include in this class also the farmers' wives who have a few colonies to pollinate fruit-trees, and who likewise desire recreation, amusement, and a little money on the side for the family. Bees will earn as much money as chickens and often do much better.

Backlot beekeeping does not differ greatly from the keeping of bees on a large scale except that there will be no outyards, no expensive moving-truck and elaborate extracting-outfits, and no hired help. The backlotter, primarily, whether man, woman, or child, is one who desires to take up some form of amusement or recreation-something that will keep one outdoors and something that will take up his time while he is out of the store, office, or shop. If the backlotter happens to be an orerworked business or professional man he will surely need some line of diversion-something that will rest the mind, and take it off from his business or profession, and allow it to rest and recuperate in new lines of thought. Why not beekeeping? See BeEkeEPING FOR WOMEN.

While there are those who take up the hobby of kodaking or taking pictures, of running a little garden, or keeping a few chickens. the number of those who are taking up bees is increasing very rapidly. The average back lot in the city will not permit of a very extensire garden -in fact. in most cases no garden at all. The chicken business is liable to cause trouble with the neighbors, especially if the chickens fly orer the fence and scratch up Mrs. Neighbor's posy-bed. While bees will not scratch up gardens they may soil Mrs. Neighbor's wash on the line; but a box or two of honey in advance will so sweeten her up that she will tolerate any inconvenience of this kind, which fortunately occurs only about once a rear. After bees have been confined for the winter, on their first flight, they discharge their liquid feces on the white linen if it happens to be on the line at the time; but a rinsing of the clothes will make them as clean as before, and the pail or box of honey will do wonders in advance by sireetening up feelings that would otherwise be sour.

But the objection may be made that bess mar sting Mrs. Neighbor's children. While this may happen, such occurrences are not common. If one will follow the plain and simple directions with regard to handling bees there will be no trouble. Indeed, there are backlot apiaries in all of our large cities (and even on the roofs of some large office buildings)-Lundreds and hundreds of them: and when we consider the backlot apiaries in the smaller towns, their number can be measured by the thousands; and yet out of all these thousands of little apiaries it is only about once in four or five years that we hear of a single case of trouble, and only once in about ten or fifteen years that resort is had to the courts. (See LAtrs Reiatista to BeEs and Bees as a NutSATCE.)

The danger from stings may be arerted by reading carefully the articles on APIaries, Robbing, Stivgs, BeE-Sarokers, and MLaxiptlation of Colonies-particularly the last named. There is no good reason why any backlotter should stir up his colonies to a furious stinging. If he will carefully inform himself by reading the articles mentioned, his next-door neighbors will never know he has any bees except as they may see the hives and the bees flying out to the fields. If he will take the further precaution to give those neighbors a box of honey now and then they will be willing to overlook any occasional annorance resulting from a lack of experience and mismanagement. 


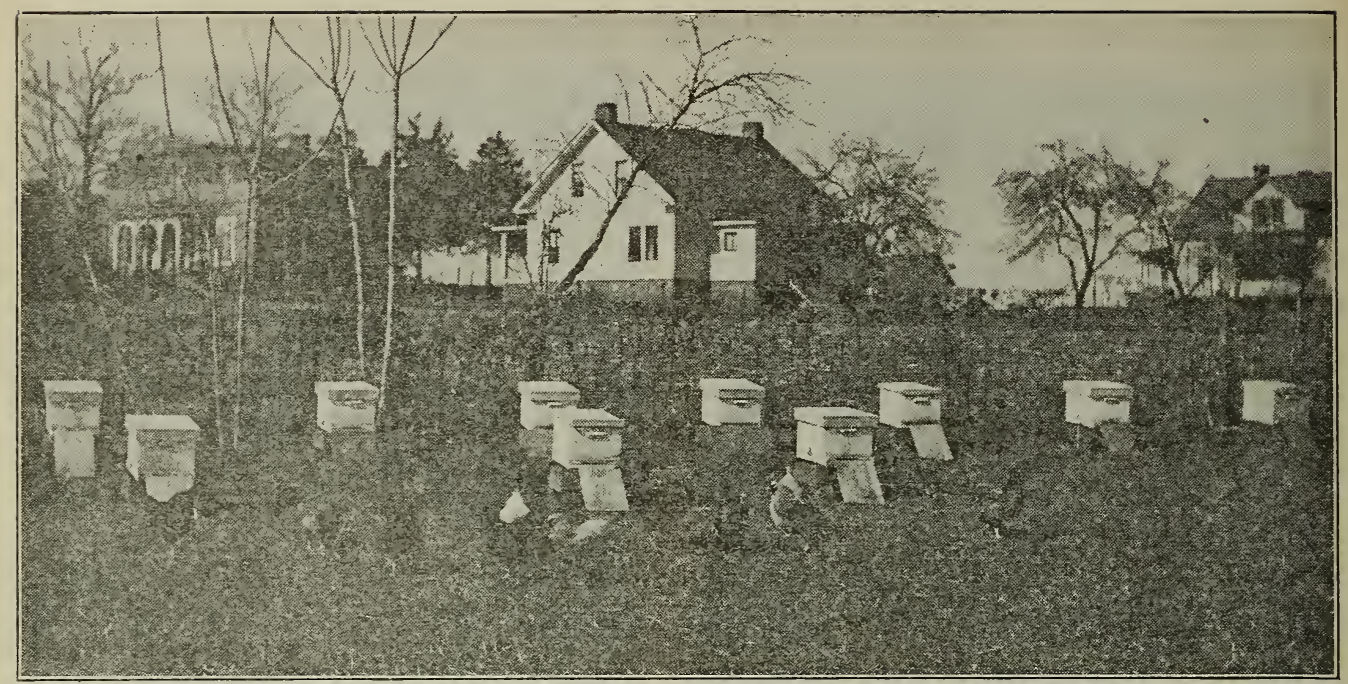

APIARY OF E. L. WEBB, IN THE CENTER OF MORGANTOWN, N. C., A TOWN OF 5000 PEOPLE.

Outside of the clover pastures and the lawns, these bees have to fly from $2 \frac{1}{2}$ to 5 miles to get sourwood honey. It is apparent in this case that bees and chickens go well together.

Every backlotter should, if possible, visit some practical beekeeper. He can get more information in an hour of a practical sort by seeing some good beekeeper open up a hive than he can get from a book in several days. In fact, it would pay Mr. Backlotter well to take a trolley trip off into the country, hunt up some person who is keeping bees, and, if he approaches his man with the idea of purchasing a colony or two, he will be able to get all the information he desires; and in this connection we may say it is usually cheaper for one to make a start by buying a few bees than to send away to some supply-factory unless he buys them in pound-package form. (See BegrnNing WITH BEES.)

Besides the allurements of a restful hobby, of diversion from the cares of the office, shop, factory, and of the home for the wife, backlot beekeeping affords in addition a profit, provided, of course, that one follows directions, and provided further that there is something in the locality on which bees

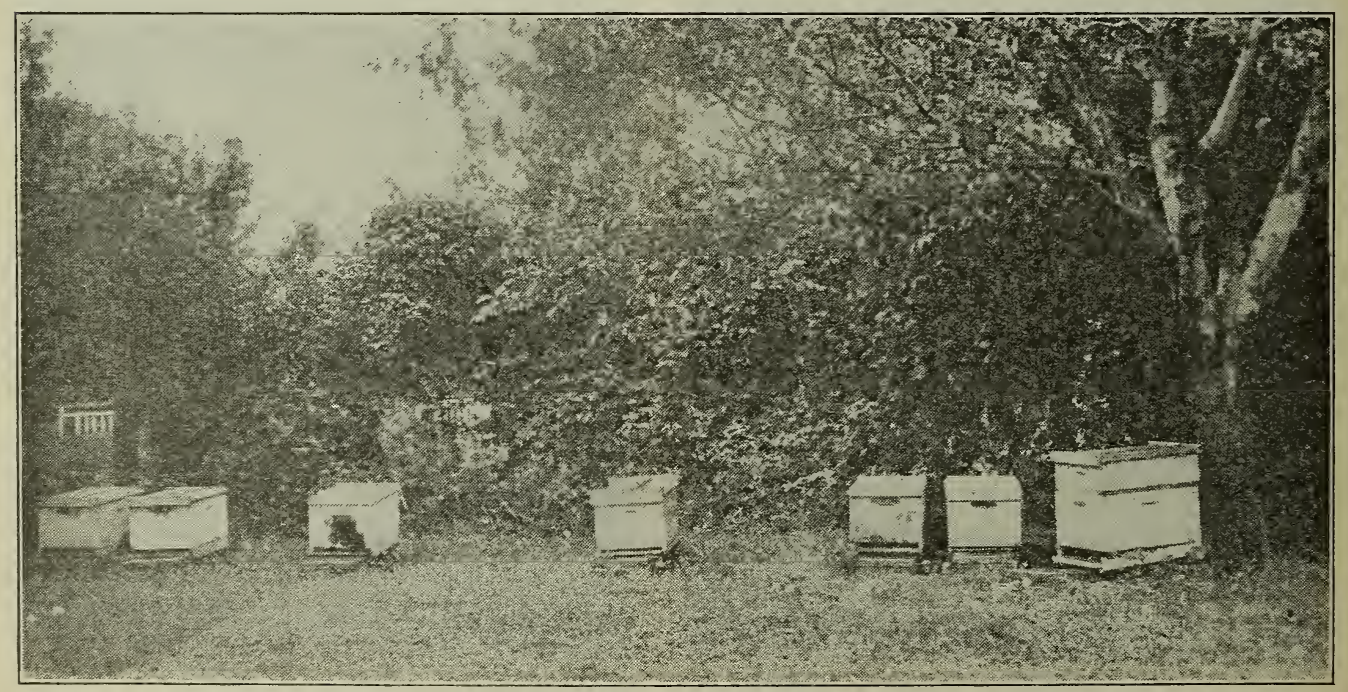

APIARY OF E. S. BRINTON, WEST CHESTER, PA.

The apiary is well protected in the back lot by apple-trees and shrubbery. It appears to be an ideal place for wintering bees; but the colonies should, of course, be packed in winter cases in order to get the best results. 
can work. In most of our cities white clover thrives on lawns. No matter how dry the season, the constant sprinkling and mowing keeps white clover in bloom for a much longer period than the average pasture lot. Besides white clover, sweet clover is being grown extensively along railroad embankments, in waste fields, and lots unoccupied, and which are being held until a suitable price can be secured.

The growing of small-fruit trees in the back yards of our cities affords abundant pasturage in the spring when they are in bloom. The ever present dandelions, a nuisance on almost all lawns, irrepressible, also afford pollen and a little honey. (See DANDELION.)

The conditions for keeping a few bees in a city or town are usually very favorable. As stated under the head of APIARY and under the head of Overstockirg, a few colonies of bees-five, ten, or twenty-five, will give much larger yields per colony than a larger number-say fifty or a hundred. Of course, if there are any considerable number of persons in the city who adopt the beekeeping hobby, the yield per colony will be less in proportion; but as a general rule these backlot yards will not be closer than one or two miles, and the yield should be fairly good even then.

By referring to Profits in Bees one can get some idea of the returns; but it can be safely stated that our backlot beekeeper will do even better than there stated, for the reason he will have the field all his own.

We have known some backlotters to secure two to three hundred pounds of honey per colony. (See some of the legends under the cuts in APIARY.) As the market is right at hand much of the honey can be sold at retail without sharing the profits with middlemen. Backlot beekeeping, therefore, offers exceptional opportunities for making a little money on the side as well as securing an unlimited amount of pleasure and a new field for thought in the realm of nature.

It is safe to say that any man or woman who takes up the pleasurable pastime of beekeeping will be bigger and broader, and will live longer. The great trouble with the American people today, especially with the residents of our cities, is the awful rush after the "almighty dollar," and in this scramble to get ahead the mind and body wear out. If more of our city folks would have side lines of diversion and ride hobbies-if you please, the hobby of keeping bees-they would live longer, live happier, and in the end make a little money.

BAIT SECTIONS.-See COMв HONEYHOW TO PRODUCE.

BALLING OF QUEENS.-See QUEENS, QUEEN-REARING, and INTRODUCING.

\section{BANAT BEES.-See RACES of BeEs.}

BARRELS.-The regular size used for the storage and shipping of extracted honey is about 31 or 32 gallons. Barrels of 45 to 50 gallons capacity are a little too heavy, and being rery unwieldy they are liable to be broken or jammed by freight-handlers in shipping. As to the kind of barrel, second-hand alcohol or whisky barrels that can be obtained at the drugstores may be used, providing they are not charred on the inside. The ordinary alcohol-barrel is gummed or glazed on the inside with a preparation of glue that does not dissolve. As a general rule, whisky-barrels are charred, and therefore unsuitable. Before taking barrels of any kind it is very necessary to determine what the character of the lining is on the inside. Molasses or syrup barrels may be used, if they be thoroly cleansed; but barrels that have a sour or musty smell should not be considered; for, even if cleaned, they might taint and ruin the honey.

After the barrel has been cleansed it should be put in a dry place, so that it will dry thoroly inside and out. One should never use barrels, the wood of which has become soaked with water; for honey has the quality of absorbing moisture from the wood; that is to say, a wet barrel filled with honey will actually become dry. The staves shrink, and then, of course, the honey leaks out. If one does a large business in shipping honey in barrels he should buy new ones. The stares should be made of sound kiln-dried lumber; and iron hoops, not wooden ones, should be used. The barrels should be kept in a dry place, and then, before using, they should be well coopered and tested, as will be explained.

\section{KEGS.}

Wooden packages holding from 100 to 150 lbs. are used quite extensively in some parts of the East. They are usually constructed of cypress, and, when well made, make a very 
good package. The general directions that apply to barrels apply also to kegs.

\section{BARRELS THE FREQUENT CAUSE OF COMPLAINT.}

It may be said that no slovenly, careless, or slipshod beekeeper should use barrels. He will be too careless to see that they are tight. He will put his honey into them, ship them, and in all probability the barrels will begin to leak en route; and he will receive a complaint from the consignee that "the honey arrived in bad condition," "half of it gone." There have been more ill feelings and hard words because of inexcusable carelessness or lack of proper knowledge concerning this matter of shipping honey in barrels than, perhaps, any other thing connected with the marketing of extracted honey. If the directions we have given are carefully followed, and good barrels are selected, there will be little or no trouble.

Another frequent source of complaint arises from the fact that the barrels are filled too full. Honey, during the process of granulating, will expand. If it is put into the barrel long before it is candied, the barrel should not be filled quite full. Just before shipping put in a little more and then ship. We have received several consignments of honey that had candied in barrels. The barrels had been filled full; the honey candied, and burst the barrel.

HOW TO TEST BARRELS FOR LEAKS.

Barrels that are intended for the storage of honey should not be kept in a cellar but in a dry place. Before filling, the hoops should be driven down tight all around. To test for leakage, Mr. N. E. France, Platteville, Wis., a beekeeper of large experience, recommends the following plan:

Drive one of the bungs in, and then with the mouth* placed tightly over the other bunghole blow in until there is quite a pressure in the barrel. To do this, place the mouth over the hole, exhaust the lungs, draw in a fresh supply thru the nose, exhaust the lungs again, and so on until you have forced in all the air possible. Place the side of the palm next to the mouth, then with a quick sliding motion move the mouth simultaneously with the palm, and close the opening. Now listen for air-leaks. If there are any,

* On account of the danger of transmitting disease A. C. Miller suggests the use of a tire pump and a special bung. His point is well taken. there will be a hissing in one or more places. Dip the free hand into some water, and push it along to where the air seems to be hissing out. This will prove beyond a doubt whether there is a leak at that point. If there is one, there will be a sputtering or bubbling. Note the place, and then hunt for other leaks. But all this time, of course, the palm of one hand should be held over the bung thru which the air was forced. Wherever the air is found leaking thru, drive the hoops down still further until the openings are closed. Then, again, force air into the barrel and try for leaks as before.

Do not, under any circumstances, test a barrel for leakage with water, as it soaks up the wood, and the latter would swell up and close the leak. After the honey is put into the barrel it would absorb the water, and the barrel would leak just at the time it could be least afforded-when it would be half way on its journey.

\section{THE NEED OF PARAFFINING OR WAXING BAR-} RELS.

We are well aware that some of our best honey-producers say it is not necessary to wax or paraffine barrels inside; but our experience shows that it is very important, not so much so for the purpose of closing up any possible leaks as to prevent the honey from soaking into the wood of the barrel or the wood itself from giving a taint to the honey. The average person has little idea of the amount of honey that can be soaked up inside of an unwaxed barrel, and be charged up to the shipper. After having tested the barrels for leaks by the air-pressure plan recommended, and made them tight, wax or paraffine the inside of the barrels; don't depend on the waxing to close up the leaks-the barrel should be tight before.

Paraffine, being a good deal cheaper than beeswax, and melting at a lower temperature, is, therefore, to be recommended. Melt up about 10 or $12 \mathrm{lbs}$, and when hot pour it thru a large funnel into one bunghole of the barrel. Quickly drive in the bung, roll it around, twirl it on each head; then give it another spin so as to cover perfectly all around the chime. This operation will warm the air inside to such an extent that the liquid will be forced into every crevice. As soon as the inside is covered, loosen the 
bung with a hammer; and if the work is well done the bung will be thrown into the air with a loud report. Pour out the remaining liquid, warm it up again, and treat the other barrels in a like manner.

The operation as a whole takes but very little time; and if one has taken pains to prove the barrel tight by the air-pressure plan, the coating of paraffine on the inside will make it doubly secure. Second-hand barrels especially should be paraffined; and even new barrels should be so treated to prevent a great loss of honey that would necessarily soak into the wood. Steel barrels are not recommended.

\section{SLIPPING HOOPS.}

It is very important that the barrels be made tight before honey is put into them. If they once begin to leak en route, driving the hoops down will not do much good, for the simple reason that the leaking honey makes a sort of lubricant, causing the hoops to slide up immediately after receiving a blow from a hammer.

We have had some very unsatisfactory experience with shipping honey in barrels; and on arriving at Medina the honey was leaking over the sides of the barrels. This honey came with a carload of bees, and the man in charge who saw the leaks attempted to drive the hoops downward; but the more he drove, he said the more they slipped back again. If it were possible to exert pressure enough on all sides of the barrels at once, and then drive nails above the hoops, something might be done to stop the leaks.

The barrels in the first place should be bone-dry before they are paraffined; and just before the waxing the hoops should be driven down as far as they will go. If there is any danger of the barrels leaking, tacks should be driven above the hoops to prevent their slipping. But it is penny wise and pound foolish to use any barrel that is not perfect. The difference between the cost of a good barrel and a poor one is only a few cents; while a barrel of honey may cost from $\$ 20.00$ to $\$ 50.00$.

\section{BARREL OR SQUARE CANS.}

In California, Colorado, and other hot or dry states, barrels and kegs should never be used. The ordinary 60-pound tin cans, described under Extracted Honer, are the only suitable shipping-packages. Indeed, they are the only package that nine-tenths of the beekeepers of this land can use safely. While they cost considerably more per pound, yet the honey is nearly always reported as going thru in good order. Even if one has a hole punched in it, only 60 pounds of honey is lost; while in the case of a leak or break in a barrel, anywhere from five to eight times that amount is wasted. Thru the entire West-and that is where the great bulk of the extracted honey in the United States is produced-the square tin can, two in a case, is used exclusively; and we would strongly urge the average beekeeper to use them in preference to barrels. While the tin package costs a little more per pound, it also brings a little more on the market; for the buyer can take as large or small a quantity as he needs. Where the purchaser hesitates to buy a whole barrel of honey for his own local trade, he will readily take one or more cans of $60 \mathrm{lbs}$. each.

\section{REMOVING CANDIED HONEY FROMI BARRELS.}

Good thick honey will usually become solid at the approach of frosty weather, and perhaps the readiest means of getting it out of the barrel in such cases is to remove one of the heads and take it out with a scoop. When it is quite hard, you may at first think it difficult to force a scoop down into it; but if you press steadily and keep moving the scoop slightly, you will soon get down its whole depth. If the barrel is kept for some time near the stove, or in a very warm room, the honey will become liquid enough to be drawn out thru a largesized honey-gate.

A more wholesale way of removing candied honey is to set the barrel or keg in a tub or wooden tank of water, the latter being kept hot by a small steam-pipe. In 24 or 36 hours the honey in the barrel will be melted, and can then be drawn out in the usual way.

BASSWOOD.-Of the twelve described species three are indigenous to the United States. The most common species is Tilia americana L., a tall tree growing in forests from New Brunswick to Nebraska and Texas, and especially abundant in the Alleghanies. T. Michauxii Nutt. (T. pubescens is a synonym) extends from Connecticut to Florida and Texas; and T. heterophylla 


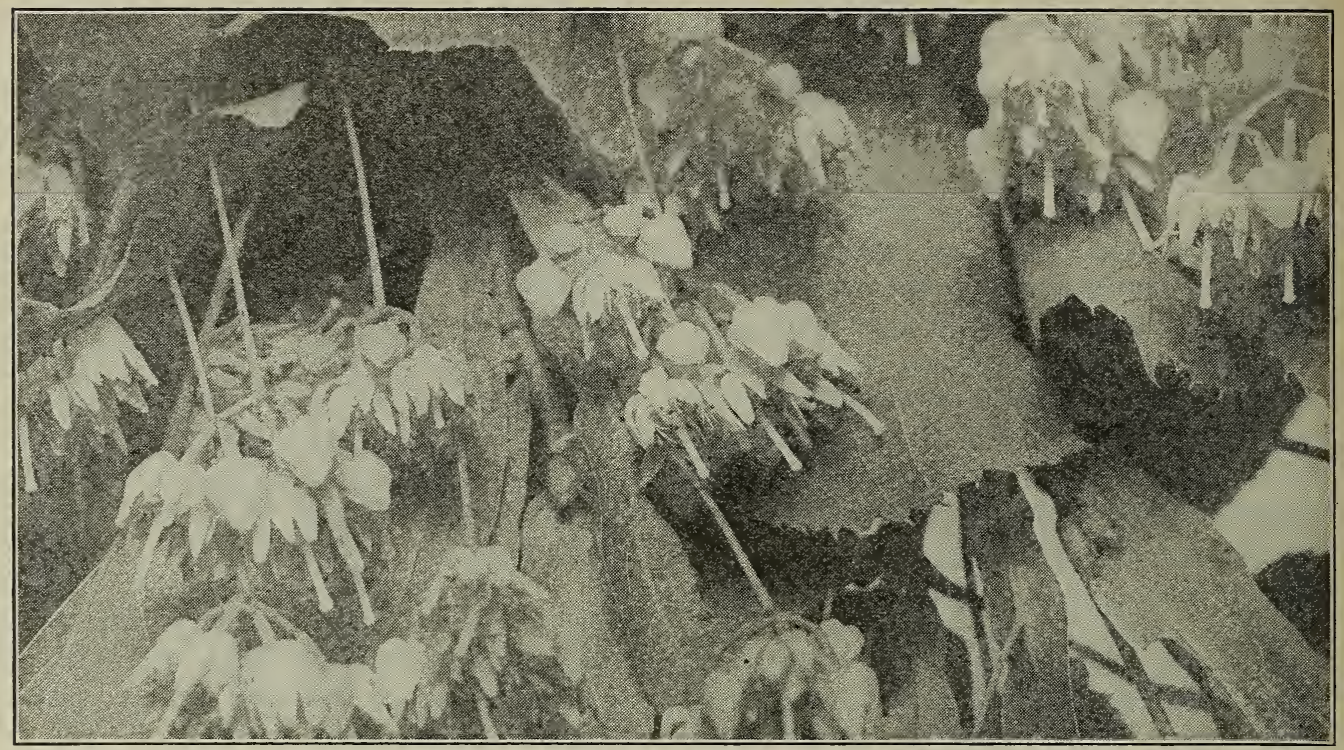

Basswood in full bloom.

Vent. from Pennsylvania to southern Illinois and Alabama, but is most common in limestone regions. The three species may be separated by the following leaf characters: T. americana has the leaves smooth on both sides; in $T$. Michauxii the leaves are smooth above, but pubescent beneath; and in T. heterophylla smooth above and silvery white below. The European linden ( $T$. Europaea L.) is widely cultivated in this country as an ornamental tree. Other vernacular names are linden, lime-tree, bsetree, whitewood, and whistle-wood.

Excepting, perhaps, alfalfa, sage, and white clover, basswood furnishes more honey than any other plant or tree known in this country. It is a variable source of honey, but it is seldom that it fails entirely to yield nectar. Rarely in eastern New York, late in the spring, a drop in temperature sufficient to freeze ice has been known to kill all the flower-buds in low ground, and greatly injure those on the hills. Even when the trees are laden with flowers if the weather is cold, cloudy, and windy, no surplus will be obtained. Hot clear weather and a humid atmosphere are the conditions most favorable for the active secretion of nectar. Small drops may then be seen sparkling in the bloom, and a bee may at times obtain a load from a single blossom. During a favorable season; when the atmosphere and temperature were both propitious, nine tons of basswood honey have been obtained as surplus at Delanson, N. Y. The best yield of honey at Medina, Ohio, ever secured from a single hive was from basswood bloom, the quantity being 43 pounds in three days. The best ever recorded from clover was 10 pounds in one day. At Orchard, Iowa, a yield of 600 pounds from a single colony in thirty days was once secured, an average of 20 pounds per day. A colony at Borodino, N. Y., stored 302 pounds in ten days, and an average of about 55 pounds per colony has been obtained for thirty years. The length of the honey-flow from basswood may vary from five to twenty-five days; while the date of blooming is influenced by locality, altitude, and temperature. From 10 to 15 days may intervene between the opening of the flowers in a cold season and a hot one. In localities where basswood grows both in the valleys and on high hills the bees will have a much longer time to gather the nectar, since the trees in the lowlands will bloom earlier than those at a greater height. It has been suggested that a beekeeper might with advantage follow the blooming of basswood, beginning at some southern point, and moving his hives northward to meet the requirements of the harvest.

Basswood honey is white and has a strong aromatic or mint-like flavor, and it is easy to tell when the blossoms are out by the odor about the hives. The taste of the honey also indicates to the beekeeper the 
very day the bees begin to work on the flowers. The honey, if extracted before it is sealed over, has so strong and distinctive a flavor as to be disagreeable to some persons. The smell and taste have been likened to that of turpentine or camphor-rery disagreeable when just gathered; but when sealed orer and fully ripened in the hive almost every one considers it delicious. A pure basswood extracted honey, on account of its strong flavor, should be blended with some honey of milder flaror, as for example, that of mountain sage.

The illustration shows the appearance of basswood flowers and leaves. The clusters of from six to fifteen flowers are drooping, thus protecting the nectar from the rain. The stem of the cluster is adnate to an oblong membranous bract. The nectar is secreted and held in the fleshy sepals; and it is often so abundant that it appears like dewdrops in the sunlight. The blossoms are small, light yellow, and exhale a honeylike fragrance. The stamens are numerous, and the anthers contain a small amount of pollen, but honeybees seldom gather it when the nectar is abundant; if, however, the nectar supply is scanty then both honeybees and bumblebees may be seen with little balls of pollen on their thighs. In England basswood seldom sets seed. The inner bark is tough and fibrous, and is largely used by agriculturists and florists for binding purposes.

\section{CUltivation.}

If a beekeeper is content to wait, say ten or fifteen years for the realization of his hopes, or if he has an interest in providing for the beekeepers of a future generation, it will pay him to plant basswood. A tree that was set out about ten years ago on one of our streets now furnishes a profusion of blossoms almost every year; and from the way the bees work on them we should judge that they furnish considerable nectar. A hundred such trees in the ricinity of an apiary would be, without doubt, of great value. In the spring of 1872 we set out 4000 trees, and in 1877 many of them were bearing fair loads of blossoms. While seedlings may be obtained by planting the seeds by far the better and cheaper way is to get small trees from the forest. They can be bought for about a cent each. These can be obtained in almost any quantity from any piece of woodland from which all stock has been excluded. Cattle feed upon the young basswouds with great avidity, and pasturing the woodlands will eventually cut short the growth of young trees from our forests, and also of many other kinds which are valuable. Trees all the way from one to ten feet tall were planted, but the larger ones as a general rule did the best.

The growth of basswood is strongly influenced by climatic conditions. Among the hills of New York the leares assume mammoth proportions. IVe measured one from a small tree that was 14 inches long. While this leaf was among the largest, yet the leaves were, on the average, about twice the size of those in our locality. In Illinois we noticed that the basswoods seemed to be less thrifty than in Ohio.

The European basswood, which is fully as good a honey-producer as the American species, is famous as an arenue tree. The famous street in Berlin, Unter-den-Linden, is shaded by this species. It is known in England as "the lime tree," and is there a great favorite for street planting. The famous "Lime-tree Walk" of Cambridge is well known. It is also an excellent tree for street planting in the northern United States. It is to be regretted that basswood is not more abundant since where it grows it is one of the mainstays of the honeyproducer, and is also a most valuable wood for manufacturing purposes. It will hardly do for outside exposure to the weather, but is admirably adapted for packing-boxes and for furniture, forming the bottom and sides of drawers, the backs of bureaus and dressing-cases. It is also employed extensively in the manufacture of paper.

As large quantities of the timber are used in making section honey-boxes, the question has been raised, "Why do the manufacturers of supplies use the tree that produces so much honey and of such fine quality?" Is it a case of "killing the goose that lays" the golden egg?" The answer is, that the amount used by the makers of sections is only a drop in the bucket as compared with that used in the other arts. Even if all the bee-supply manufacturers should discontinue the use of basswood, the difference in the amount of honey produced from that valuable tree would never be noticed. For the making of section honey-boxes there is no timber available that has the same de- 
gree of toughness to stand the fold at the $\mathrm{V}$ edge in the ordinary one-piece section. The four-piece section has now practically dropped out of the market on account of the expense and time taken in preparing them for the hive.

After all, there is one redeeming feature: The basswood is a very rapid grower. If basswood will replace itself in ten or even twenty years, so that it is again large enough for lumber, there is yet hope that it will continue to bless the beekeeper. Over against this is the stubborn fact that our basswoods are disappearing rapidly over the whole country. During 1899, when there was such a great adrance in pine lumber, basswood was used very largely for housebuilding, with the consequence that millions of feet were consumed.

Basswood, and perhaps most other forest trees, require shade, especially when young. Much to our surprise young trees that were planted directly under large white-oak trees did better than any of the rest. We would plant the trees rot more than 12 feet apart.

BEE BEHAVIOR.-Behavior is a term used to describe the activities of animal life whether induced by external or internal stimuli. Under this head will be described some of the various life activities of the bees, particularly those which have more or less to do with the practices of bee culture.

\section{THE LARVAL BEE.}

On the hatching of the egg the tiny larva wriggles and twitches much as does a caterpillar when poked with a straw. Almost at once it is supplied with food by a "nurse" bee. This part of the life of a larva has not received sufficient study to warrant any definite statements as to the frequency of the feeding, the amount supplied, its possible varying quality, etc. It must suffice now to say that the periods of feeding seem to be irregular and the amount of food received by different larvæ varies largely.

When the larva has completed its feeding period and has stretched out to its full length in the cell, the bees proceed to seal the cell. There are some exceptions to this when the larvæ are left unsealed, tho usually the cell walls are slightly extended and the opening contracted. Beekeepers speak of this as "bareheaded brood" and it often causes the novice much concern. See Bro0D and BroOd-REARING. The condition has been ascribed to excessive heat; but as it occurs at other times than during the hot weather, and as some colonies seldom or never have brood in such condition while others almost always do, it is reasonable to look upon it as a congenital trait. In some cases uncovered brood is due to the work of the waxmoth.

After a brief rest the larva begins spinning its cocoon. Slowly the head turns from side to side and back and forth, gradually reaching the middle of the cell; and slowly doubling on itself, the larva extends its work to the base and lies at full length reversed in the cell. Before its labors cease, however, it usually resumes the former position of its head toward the outer end.

In the case of the queen larva, the spinning begins and proceeds in the same way, but when she is reversed in the cell she reaches as far up as she can, but that is not to the base; and as she cannot climb, there is no silken web on that part of the cell.

When spinning has ceased, the larva turns on its back and lies still. The changes which follow take place so slowly that only after considerable intervals are the results noticeable. When the metamorphosis is virtually complete (see Development of BeEs), there is seen in place of the larva a bluishwhite bee lying motionless on its back.

The only appendages seemingly missing are the wings. Careful examination will reveal each pair folded up in a little case (pellicle) which lies against the side of the thorax between first and second pair of legs.

The first sign of coloring is seen on the ends of the antennæ, then on the eyes and feet, and gradually it extends over the whole body. As the time approaches for the bee to emerge from the cell slight tremors are to be seen in the feet and legs, or an antenna moves. About the beginning of the last day the encased wings begin to quiver and move. Slowly they turn until they lie under the bee and at once they unfold. As soon as this occurs, the bee turns over and begins to cut its way out.

\section{THE YOUNG BEE.}

Almost as soon as out, it begins to move over the surface of the combs; and when it comes to a cell of honey it enter's and eats. Just when it begins to eat pollen, is unde- 
termined. After eating, the young bee commences to comb itself and this procedure continues more or less steadily for a day or more. At this tender age the insect's vision seems to be rery imperfect. Also, it is unable to fly; and if tossed into the air makes no attempt to use its wings. This function appears only at a later age. Drones, queens, and workers all spend the early hours of their life in much the same way, except that queens seem to be able to fly sooner than workers. Probably queens most precocious in this way have been held in the cells longer than normally and have matured in there.

The color of the young bee deepens with age. When they first emerge they are much lighter in color than a day or so later. This difference is more noticeable with queens than with workers or drones.

\section{HOME LAROR OF BEES.}

The first duty of the worker is the feeding of the larvæ, and then a little at a time it extends to pollen-packing, propolizing, comb-cleaning and repairing, honey-ripening, and comb-building.

\section{THE FIRST POLLEN OF THE SEASON.}

When a bee comes in from the field with a load of pollen, she is often surrounded by other bees, all trying to get a bite of the coveted food. This is especially noticeable in the spring when fresh pollen first appears. It is amusing to watch a pollen-laden bee side step, whirl, shake, and go thru all sorts of actions to save her lcad. It is no unusual thing in the spring for such bees to be completely stripped of their loads before they can get near a comb.

\section{THE UNLOADING OF THE POLLEN.}

On their return to the hive with their loads of pollen the bees differ widely in their behavior. A part walk slowly orer the combs, while a part, presumably the younger bees, appear greatly excited, shaking their bodies and moving their wings. A cell may be selected with little hesitation or many may be examined before one is found satisfactory to the bee. The pollen may be stored in an empty cell, or in one already partly filled with pollen, either of the same kind or of different kinds; but drone comb is seldom used, altho this occasionally happens.
The way in which the bee unloads the masses of pollen has been fully described by Casteel. Grasping one edge of the cell with its fore legs, it arches its abdomen so that its apex rests on the opposite side of the cell. The hind legs hang down freely in the cell with the pollen-masses about level with its edge. The planta (metatarsus) of the middle leg on each side is then raised and thrust downward between the pollen-mass and the tibia so that the mass is shored outward and falls into the cell. The middle legs are now rested on the edge of the cell. Casteel was unable to determine definitely whether the spurs were of any aid in dislodging the pollen, as asserted by Cheshire, or not.

The bee usually departs without any further attention to the pollen masses, and another worker shortly afterward attends to the packing. Entering the cell head first, the bee breaks up the pellets of pollen, mashes them down on the bottom of the cell, and adds sugar and perhaps other secretions which change the chemical constitution of the pollen.

\section{PROPOLIS: HOW GATHERED AND USED.}

Propolis is brought in on the pollen-baskets. When it is gathered fresh from the buds, it looks like a glistening bead in the pollen-baskets; but when it is gathered from old frames, hives, etc., the pellets are more irregular. Propolis is always packed while the bee is standing, while pollen which is packed and carried in the same baskets is adjusted while the bee is flying. This difference in the way of using the same limbs for different materials is rery interesting.

Propolis is taken from the legs of the field bees and stuck into all sorts of places and is moved and reworked as suits the vagaries of the bees. Much of the propolis is spread with the tongue. Whether or not the bee rarnishes the inside of brood-cells with propolis is unknown. Certainly they spend much time polishing the inside of such cells, going over and over the surface with their tongues: and when they have finished, the cell walls shine as if varnished. This is not done to new combs used for honey only; but let such be once used for brood, then it gets its polishing before being used for anything else.

Comb repairing and building seems to be a haphazard job, and the work of one bee 
is often at once undone by another. Propolis is used in the construction of new comb, sometimes as much as one-half to three-quarters of an ounce being added to a pound of wax. It adds to the strength of the comb and makes its fastening to the wood more secure.

HOW BEES DEPOSIT THEIR LOADS OF NECTAR.

The honey-ladeu bee on return from the field is not at all in a hurry to get rid of her load, and it is not at all unusual for her to keep her load fur half an hour or more before depositing it. She may walk aimlessly about or settle quietly down somewhere and seemingly forget the world, or she may, after an extended journey over the combs, select a cell for her lcad. She enters the cell with her back down and feet up. If the cell has no honey in it, she goes in until her mandibles touch the upper and rearmost angle. The mouth and mandibles are opened and a drop of nectar appears, welling up until it touches the cell wall. Slowly the bee turns her head from side to side, spreading the nectar against the upper part of the cell. All this time the mandibles are kept in motion; and as the nectar covers their gland openings, it is possible that the secretions of those glands is being added to the nectar.

When the bee is adding her load to honey already in a cell, the proceeding is the same, except that the mouth parts are submerged in the honey already there. The mandibles are kept in motion as before. The tongue in neither case takes any part in the proceeding, but is $k \in p t$ folded behind the head.

THE RESTING PERIODS OF BEES.

When rid of her load, the worker may at once return to the field, but usually she loiters about the hive for anywhere from a few minutes to half a day. So commonly do such bees crawl into a cell and go to sleep for a half-hour or so that it is reasonable to assume that such is the customary proceeding. By sleeping is meant as nearly a complete suspension of movement as possible. The customary pulsation of the abdomen nearly, if not.quite, ceases, or is suspended for minutes at a time, and the occasional pulsation is very slow.

When the nap is over, the bee backs out, combs off her head just as if "scratching for a thought," and starts off in more or less of a hurry.
All the bees of a colony do a lot of this sleeping, and drones and queen are no exeeption; but in the case of the latter two, the sleeping is not usually done in cells.

When bees are getting stolen sweets, a very different condition arises, and a feverish excitement is noticeable in the returning workers, and it is not long before the whole colony is in a more or less disturbed state. Sleeping then is not in evidence. Why a load or several loads of honey should cause so marked a difference from several loads of nectar is unknown, and until we know more about the bee it is idle to speculate.

\section{HOW BEES RIPEN HONEY.}

Honey-ripening is a slow but interesting process. After the day's work is about over, almost the whole colony spreads out over all available surface, and nearly every bee has her sac full of honey. All the bees hang vertically with head up and all seem to prefer not to be crowded too closely by the other bees. Then each bee opens her mandibles and mouth and forces up a drop of nectar. This drop fills the mouth and extends up over the upper lip and fills the space between the mandibles, covering the openings of the glands connected therewith. The tongue meantime is kept folded behind the head. Next the bee begins a chewing motion with the lower "jaw" and this causes the drop to pulsate. The mandibles are held still. They are not moved as in depositing nectar.

For about ten minutes this operation is continued; then the drop is swallowed, and after a few moments' pause another drop appears and the process is renewed. This is continued by the colony until about 11 P. M., or sometimes later, and then work stops and all hands go to sleep.

While the work is in process, the heavy hum so pleasant to the ears of beekeepers is continuous; but after the work ceases, the hive becomes almost silent. This varies with the amount of honey gathered during the day. Sometimes the humming lasts almost all night and sometimes it ceases early in the evening.

COMB-BUILDING AND ITS RELATION TO THE RIPENING OF HONEY.

Comb-building is rapid when most of the bees are ripening nectar. If the flow is good and many bees have to retain their 
loads for awhile, as with a recently hived swarm, wax secretion is rapid. Or if the flow is heavy and nearly all have to work at the ripening process, wax secretion is forced. The bees cannot help producing it then. Its production seems to be closely connected with the conversion of nectar into honey. If this view is correct, it affords an explanation of the failure to obtain satisfactory results in feeding back ripe honey to have sections completed. Honey extracted "raw" or. "green" and fed to comb-building colonies gives much better results.

\section{VARIATION IN COMIB-BUILDING.}

No satisfactory explanation has been found to account for the construction of the two sizes of cells. Several theories have been advanced, but so far are only interesting.

Great rariation in comb work is found between bees of different strains or of different colonies closely related. Some colonies build comb of wonderful smoothness and uniformity, and others never produce good combs. 'One will rarely use a brace or a burr, while another sticks them everywhere. By selection the beekeeper can weed out the stock with undesirable traits and perpetuate the others.

The difference in capping is well recognized, and selection is as effective in this case as in the former. The difference between colonies in building out to frame or section sides and down to bottom-bars or of rounding off the edges has often been remarked. Ft may be stated in a general way that the bees which build clear to the wood usually leave the cuter cells unsealed, while those bees which round off the edges of the combs seal all cells. (This was first defined by Mr. Allen Latham.) Of course, there are all gradations, but fundamentally the law holds good.

\section{THE ARRANGEMENT OF BROOD, POLLEN, AND HONEY.}

The arrangement of brood, pollen, and honey, the first in the center, then the others in order about it, is interesting, and with rare exceptions is always the arrangement. As the brood increases in the spring, we may say the pollen is forced outward and the honey forced beyond that. In the closing of the season the process is reversed, and under what we may be permitted to call natural conditions, as in a tree, box, or undisturbed frame hive, the brood is slowly worked downward and forward, so that at the end of the season the cluster is down by the entrance with the stores at each side of, above, and behind it. This is not always the location of the cluster in our frame hives; but if man has not meddled after mid-summer, it will generally be found to be so.

\section{THE QUEEN.}

This individual is unquestionably the most interesting member of the bee community, and more talked of and written about than any other, and perhaps more misunderstood. From earliest infancy she is subject to more vagaries than any of the other bees.

The presence or absence of the functional odor may have something to do with the introduction of alien queens, or it may be wholly their behavior.

After handling a laying queen, bees from any hive will run over one's hand, apparently eagerly seeking the queen, and the behavior of all workers is the same whether they are from the queen's hive or from another.

There is much difference in the temperament of queens. Some are very timid, and will run on the slightest disturbance, and, if handled or anointed with any foreign substance, seem to become really frantic. Such queens are very apt to be balled or killed by the bees. Other queens will passively submit to all sorts of treatment, and, as soon as let alone, will quietly resume their duties.

Virgin queens are almost always nervous or timid; and if put into a strange colony, large or small, very often, or perhaps it would be more accurate to say generally, run out and fly away, by no means always returning.

Before mating, a queen hunts up her own food from the combs; but after she begins to lay she turns to the workers for virtually all her food. Once in a great while she will dip her tongue into a cell of honey, but not often. As she passes about her duties, she from time to time crosses antennæ with workers. Finally one is found with a supply of food; the worker's mouth opens and the queen inserts her tongue and begins to eat. The worker's tongue is kept folded behind the head. It is quite common to see 
several other workers extend their tongues and try to get a taste of the food, and sometimes one will succed in putting her tongue in with the queen's. It is not at all unusual to see two workers getting food thus from another worker, and the drones obtain their food in the same way.

Egg production is influenced by several factors. Queens differ in fecundity, and egg development is dependent on food. The food supply comes chiefly from the younger bees; and if they are not numerous the queen cannot produce eggs in abundance. If honey and pollen are scarce or temperature is low, food is not prepared freely.

If the queen is young and vigorous and the colony small, she may deposit several eggs in each cell. If comb surface is insufficient and bees abundant, she will use cells of any shape, deep, shallow, or crooked, and will put in each one an egg which will produce a worker. Under some conditions a normal queen will put into worker cells eggs which will produce drones. She may be laying in shallow drone comb; and, coming to a queen-cell cup, will put into it an egg which will produce a female.

So many are the vagaries of a queen that only by observation and experience can most of them be learned, and the seasoned veteran not infrequently runs across some new peculiarity.

After an egg is put in a cell a worker is pretty sure to pop in and inspect it, and it has been supposed that possibly they did something to it. Inspection of thousands of bees occupied in examining eggs has failed to find a single one that louches an egg in any way. Bees often take their nap in cells containing eggs or larvæ.

During a heavy flow of nectar, the bees often deposit it in cells containing eggs, sometimes filling the cells half full. Such nectar is removed within a few hours, and the eggs hatch as usual.

\section{DRONES.}

Drones have many interesting habits, and are well worth closer study than they have yet received. They are much slower to mature after emergence from cells than the workers. They are very fond of warmth, and may often in cool weather be found massed shoulder to shoulder on outlying sealed brood.

It seems to take a lot of preparation on the drone's part before he can take wing. Drones pay no attention to a virgin queen among them in the hive, no matter what her age.

\section{SWARMING.}

Swarming apparently starts with a bee here and there. Such a bee suddenly begins to run a few steps one way, then a few another, then spins around and finally appears to work itself into a veritable frenzy. Other bees take it up and soon a rush is made, and is quite as apt to be from as toward the entrance. As soon, however, as part of the flood begins to emerge from the entrance the tide turns that way.

BEE-BREAD.-A term in common use, applied to pollen when stored in the combs. In olden times, when bees were killed with sulphur to get at the honey, more or less pollen was usually found mixed with the honey; it has something of a "bready" taste, and hence, probably, came its name. Since the advent of the extractor and section boxes, it is very rare to find pollen in the honey designed for table use. See Pollen.

\section{BEE-DRESS.-See VEILS.}

BEE-ESCAPES.-See Сомв Honex, also Extracting.

BEE-HUNTING.-We are giving the warning so often, against leaving sweets of any kind about the apiary, and about being careful not to let the bees get to robbing each other, that it may seem strange for us to tell how best to encourage and develop this very robbing propensity in these little friends of ours.

The only season in which we can trap bees is when they will rob briskly at home; for while honey is to be found in the flowers in plenty, they will hardly deign to notice our bait of even honey in the comb. Before starting out, it will be policy to inform yourself of all bees kept in the vicinity, for you might otherwise waste much time in following lines that lead into the hives of your neighbors. You should be at least a mile from any one who has a hive of bees when you commence operations, and it is safer to be two miles. We do not mean by this to say that there are no bee-trees near large apiaries, for a number have been 
found within half a mile of our own, and an experienced hand would have but little trouble in finding more, in all probability; but those who are just learning would, very likely, be much perplexed and bothered by domesticated bees mixing with the wild ones.

Perhaps the readiest means of getting a line started is to catch bees that will be found on the flowers, especially in the early part of the day. Get them to take a sip of the honey you have brought for that purpose, and they will, true to their instinctive love of gain, speed homeward with their load, soon to return for another. To find the tree, you have only to watch and see where they go. Very simple, is it not? It certainly is on paper, but usually inrolves much hard work when carried out in practice. You can get along with very simple implements; but if your time is valuable, it may pay to go out fully equipped. For instance, a small glass tumbler will answer to catch bees with; and after you have caught one, you can set the glass over a piece of honeycomb. Now cover it with your handkerchief to stop its buzzing against the glass, and it will soon discover the honey and load up. Keep your eye on it; and as soon as it is really at work on the honey gently raise the glass and creep away, where you may get a good view of the proceedings. As soon as it takes wing it will circle about the honey, as a young bee does in front of the hive, that it may know where to return; for a whole "chunk" of honey, during the dry autumn days, is quite a little gold-mine in its estimation. There may be a thousand or more hungry mouths to feed, away in the forest at its leafy home, for aught we know.

If you are quick enough to keep track of the bee's eccentric circles and oscillations, you will see that these circles become larger and larger, and that each time the bee comes round it sways to one side; that is, instead of making the honey the center of its circles, it makes it almost on one edge, so that the last few times the bee comes round it simply comes back after it has started home, and throws a loop, as it were, about the honey to make sure of it for the last time. Now you can be pretty sure which way its home lies almost the rery first circuit it makes, for it has its home in mind all the time, and bears more and more toward it.
If you can keep your eye on it until it finally takes the "bee-line" for home, you do pretty well, for a new hand can seldom do this. After the bee is out of sight, you hare only to wait until it comes back, which it will surely do, if honey is scarce. Of course, if its home is near by it will get back soon; and to determine how far it is by the length of time the bee is gone, brings in another very important point. The honey that bees get from flowers is rery thin; in fact, it is nearer sweetened water than honey, and if you wish a bee to load up and fly at about a natural "gait," you should give it honey diluted with water to about this consistency. Unless you do, it will not only take a great deal more time in loading up, but the thick honey is so much heavier the bee will very likely stagger under the load, and make a very crooked bee-line of its homeward path. Besides it will take much more time to unload. Sometimes, after circling about quite a time, the bee will stop to take breath before going home, which is apt to mislead the hunter unless he is experienced; all this is avoided by filling your honeycomb with honey and water, instead of with honey alone.

Now, it takes quite a little time to get a bee caught and started at work; and that we may get busy, we will have several bees started at the same time. To do this expeditiously, we will use a bee-hunting box made as in the following cut.

\section{BOX FOR BEE-HUNTING.}

This is simply a light box about $4 \frac{1}{4}$ inches square; the bottom is left open, and the top closed with a sheet of glass that slides easily in saw-cuts made near the upper edge. About a half-inch below the glass is a small feeder quite similar to the one figured in FeEdixg and Feeders.

\section{HOW TO USE THE HUNTING-BOX.}

Take with your box about a pint of diluted honey in a bottle. If you fill the bottle half full of thick honey, and then fill it up with warm water, you will have it about right. In the fall of the year you will be more likely to find bees on the flowers in the early part of the day. When you get on the ground, near some forest, where you suspect the presence of wild bees. pour a little of your honey into the feeder, and cautiously set the box over the 
first bee you find upon the flowers. As soon as the box is well over the flower, close the bottom with your hand, and the bee will buzz up against the glass. Catch as many as you wish, in the same way, and they will soon be sipping the honey. Before any have filled themselves, ready to fly, place the box on some elevated point, such as the top of a stump in an open space in the field, and draw back the glass slide. Stoop down now, and be ready to keep your eye on one bee whichever way it may turn. If you keep your head low, you will be more likely to have the sky as a background. If you fail in following one, you must try the next; and as soon as you get a sure line on a bee as it bears finally for home, be sure to mark it by some object that you can remember. If you are curious to know how long they are gone, you can, with some

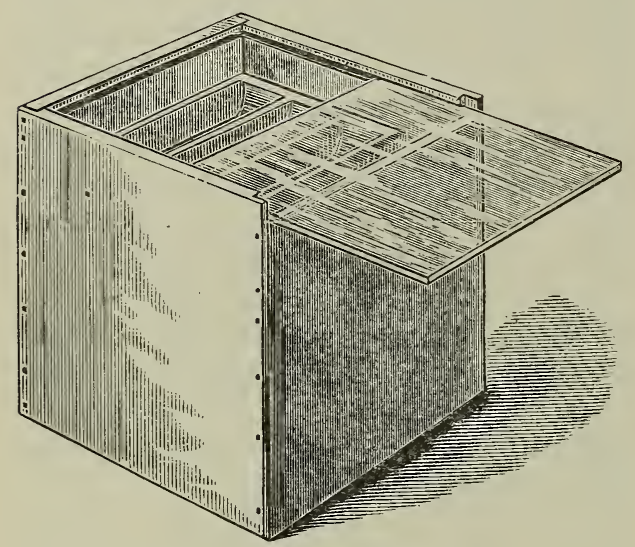

white paint in a little vial, and a pencilbrush, mark one of them on the back." This is quite a help where you have two or more lines working from the same bait. When a bee comes back, you will recognize it by the peculiar inquiring hum, like robbers in front of a hive where they have once had a taste of spoils. If the tree is near by, each one will bring others along in its wake, and soon your box will be humming with a throng so eager that a further filling of the

\footnotetext{
* Since this was written, an A B C scholar says: "Bees vary in their flight. But we have found that on an average they will fly a mile in five minutes, and spend about two minutes in the hive or tree. Of course, they will spend more time in a tree when they have to crawl a long distance to get to the brood-nest, hence we may deduce the rule: Subtract two from the number of minutes absent, and divide by ten. The auotient is the number of miles from the stand to the tree. This applies to a partially wooded country. Perhaps in a clearing they could make better time. On a very windy day it takes them longer to make trips,"
}

feeder from the bottle will be needed. As soon as you are pretty well satisfied in which direction they are located, you can close the glass slide and move along on the line, nearer the woods. Open the box, and you will sson have them just as busy again; mark the line and move again, and you will very soon follow them to their home. To aid you in deciding just where they are, you can move off to one side and start a cross-line.* Of course the tree will be found just where these lines meet; when you get where you think they should be, examine the trees carefully, especially all the knot-holes, or any place that might allow bees to enter and find a cavity. If you place yourself so that the bees will be between you and the sun, you can see them plainly, even if they are among the highest branches. Remember you are to make a careful and minute examination of every tree, little and big, body and limbs, even if it does make your neck ache. If you do not find them by carefully looking the trees over, go back and get your hunting-box, bring it up to the spot, and give them feed until you get a quart or more at work. You can then sae pretty clearly where they enter. If you do not find them the first day, you can readily start them again almost any time, for they are very quick to start, when they have once been at work, even tho it is several days afterward. Bees are sometimes started by burning what is called a "smudge." Get some old bits of comb containing bee-bread as well as honey, and burn them on a small tin plate, by setting it over a little fire. The bees will be attracted by the odor of the burning honey and comb, and, if near, will sometimes come in great numbers.

A telescope is very convenient in finding where the bees go in, especially if the tree is very tall; even the toy telescopes sold for 50 cents or a dollar are sometimes quite a help. The most serviceable, however, are the achromatic opera-glasses that cost from

* The same writer says further: "It is a waste of time to look for the bee-tree, or to make cross-lines, until you get beyond the tree. When the bees fly back on the line you may rest assured that you are beyond the tree. Move your last two stands closer together (lining the bees carefully), so that they are only ten or fifteen rods apart. Now, as you have bees flying from two directions into the tree you will probably discover where they are immediately. But if you fail to find them easily, take a stand at one side, eight or ten rods, and cross-line. This is the only place that I find a cross-line of any advantage." 
$\$ 3.00$ to $\$ 5.00$. With these we can use both eyes, and the field is so broad that no time is lost in getting the glass instantly on the spot. We can, in fact, see bees with them in the tops of the tallest trees almost as clearly as we can see them going into hives placed on the ground.

After you have found the tree, probably you will be in a hurry to get the bees that you know are there, and the honey that may be there. Do not fix your expectations too high, for you may not get a single pound of the latter. Of two trees that we took a few years ago, one contained just about as much honey as we had fed them, and the other contained not one visible cell full. The former were fair hybrids, and the latter well-marked Italians. If the tree is not a valuable one, and stands where timber is cheap and plentiful, perhaps the easiest way is to cut it down. This may result in a smashed heap of ruins, with combs, honey, and bees all mixed up with dirt and rubbish, or it may fall so as to strike on the limbs or small trees, and thus ease its fall in such a way as to do very little injury to the tree or contents. The chances are rather in favor of the former, and on many accounts it is safer to climb the tree and let the bees' part down witl a rope. If the hollow is in the body of the tree, or so situated that it cannot be cut off above and below, the combs may be taken out and let down in a pail or basket; for the broodcombs, and such as contain but little honey, the basket will be rather preferable. The first thing, however, will be to climb the tree; and as we would be very sorry to give any advice in this book that might in any way lead to loss of life, we will, at the outset, ask you not to attempt climbing unless you are, or can be, a very careful person. An old gentleman who has been out with us remarked that he once knew a very expert climber who took all the bees out of the trees for miles around, but was finally killed instantly by letting his hands slip as he was getting above a large knot in the tree. We do not wish to run any risks where human life is at stake.

\section{CLIMBERS FOR BEE-HUNTERS.}

For climbing trees 12 or 18 inches in diameter, a pair of climbers should be used, such as can be obtained at any telephone office.

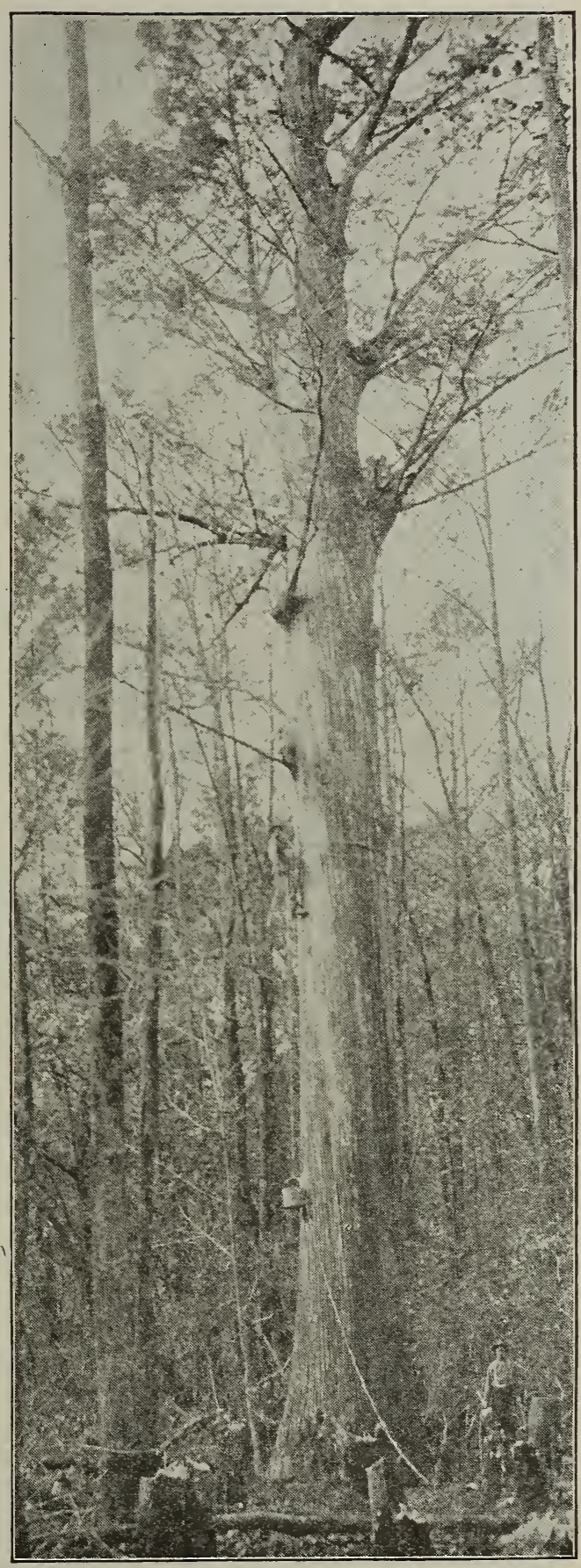

A bee-tree eleven feet in diameter climbed by Green Derrington.

If the tree is large, the climber provides himself with a withe or whip, of some tough green bough, and bends this so it will go around the trunk, while an end is held in each hand. As he climbs upward, this is hitched up the tree. If he keeps a sure and firm hold on this whip, and strikes his 
climbers into the trunk firmly, he can go up the most forbidding trees rapidly and safely. Some light cord, a clothes-line, for instance, should be tied around his waist, so he can draw up such tools as he may need. Those needed are a sharp ax, a hatchet, saw, and an auger to bore in to see just how far the hollow extends. If the bees are to be saved, the limb or tree should be cut off above the hollow, and allowed to fall. A stout rope can be then tied about the log hive, passed over some limb above, the end brought down and wrapped about a tree until the hive is cut off ready to lower. After it is down, let it stand an hour or two, or until sundown, when all the bees will have found and entered the hive; then cover the entrance with wire cloth, and take it home.

There are some trees, indeed, so large that it would be impossible to climb them with the implements already given. A very ingenious plan, however, has been put into execution by Mr. Green Derrington, of Poplar Bluff, Mo. We give his description, together with an engraving made from a photograph which he sent.

I send you a photograph of a very large tree, which I climbed by means of spikes and staples. To prevent the possibility of falling I put a belt under my arms. To this I attached two chains. At the end of each chain is a snap. My method of climbing is as follows: After ascending the ladder as far as I can go I drive into the side of the tree a large bridge spike, far enough into the wood to hold my weight. A little further up I drive another spike. In between the spikes I drive the first staple, and to this I attach the first chain by means of the snap, and ascend by the nails as far as the chain will allow me; I then drive another staple, and attach the other chain, and next loosen the lower snap. After driving in more spikes, I again ascend as high as the chain will allow me, and attach the other chain to another staple. In this manner I can make my ascent with perfect security.

The tree stands close to the Black River, in a graveyard, and from it I obtained 50 lbs. of honey. Regular climbers are excellent for small trees, say from two to three feet in diameter; but the tree illustrated has such a rough and uneven bark, and is so large that it would be difficult to climb it without the aid of spikes and the staples I have mentioned. On account of the large knots it would be impossible to use a rope, or something similar, to hitch up by climbers. Knots are not in the way when I use spikes and staples. Green Derrington.
HOW TO GET BEES OUT OF BEE-TREES OR FROM BETWEEN THE SIDINGS OF A HOUSE WITHOUT MUTILATING EITHER THE TREE OR THE HOUSE.

It sometimes happens that a colony of bees will take their abode in some fine shade tree in a park, which the authorities will not allow to be cut; or they will domicile in the woods of some farmer, who, while he will allow the bee-hunter to get the bees, will not let him cut the tree; or, as it often happens, a colony will make its home between the plaster and the clapboarding of a house. How, then, can such bees and their

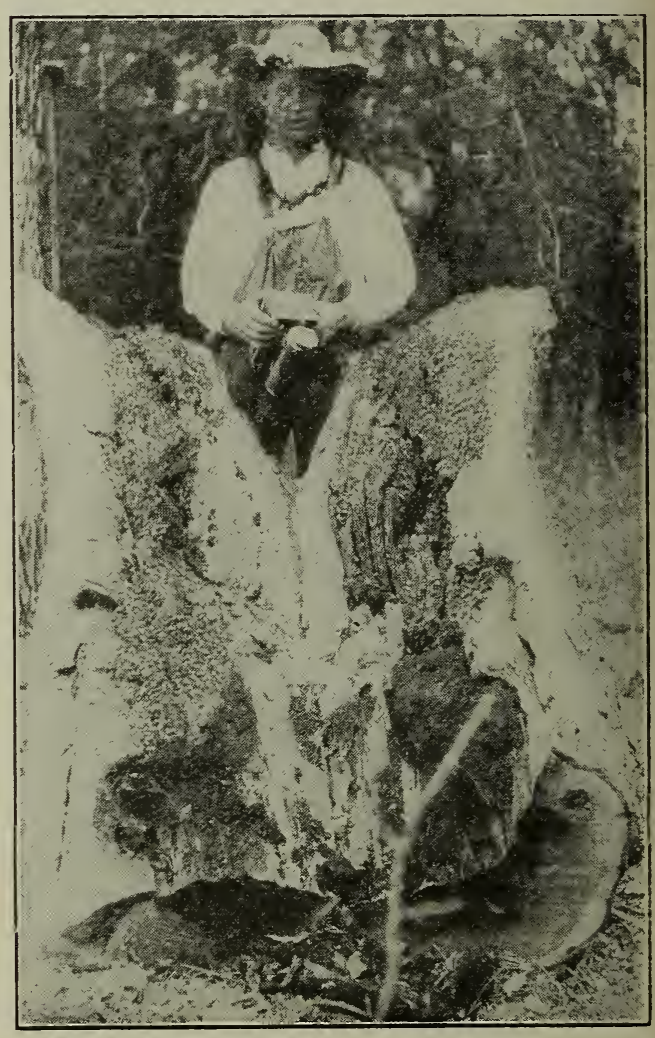

Two-foot $\log$ split open, exposing large colony of bees.

honey be secured without doing any damage to the tree or the building that gives them a home and protection? The matter is made very easy by the use of the modern beeescape. For particulars regarding this device, see COMb Honey and Extracted HONEY.

Having the bees located in the bee-tree, the hunter prepares a small colony of bees or a nucleus, putting it into a light hive or box which can be carried to the scene of 


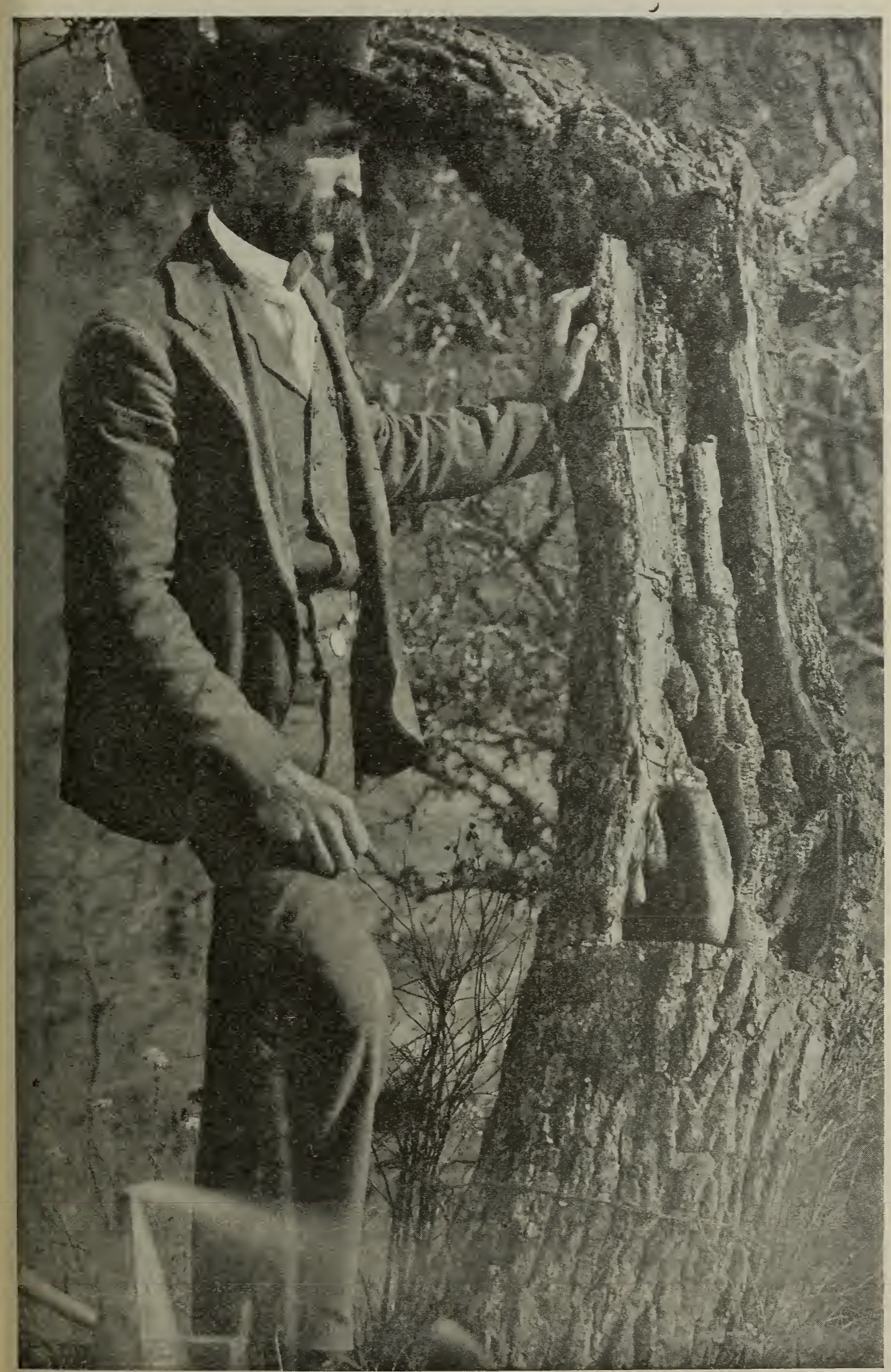

A dissected bee-tree. This shows the general arrangement of combs in the cavity. Fortunately in this case the swarm was accommodating enough to make the nest close to the ground where easily captured. 
operations. He takes along with him a hammer, a saw, some nails, and lumber, with which he can make a temporary platform. On arriving on the spot he lights his smoker and then prepares to set up this platform directly opposite or in front of the flight-hole of the bee-tree, or the knot-hole of the dwelling. The platform he constructs out of the lumber he has brought. Before doing so it will be necessary for him to blow smoke into the flight-hole, in order to prevent bees from interfering with the building of the temporary hive-stand. He next puts a Porter bee-escape over the flight-

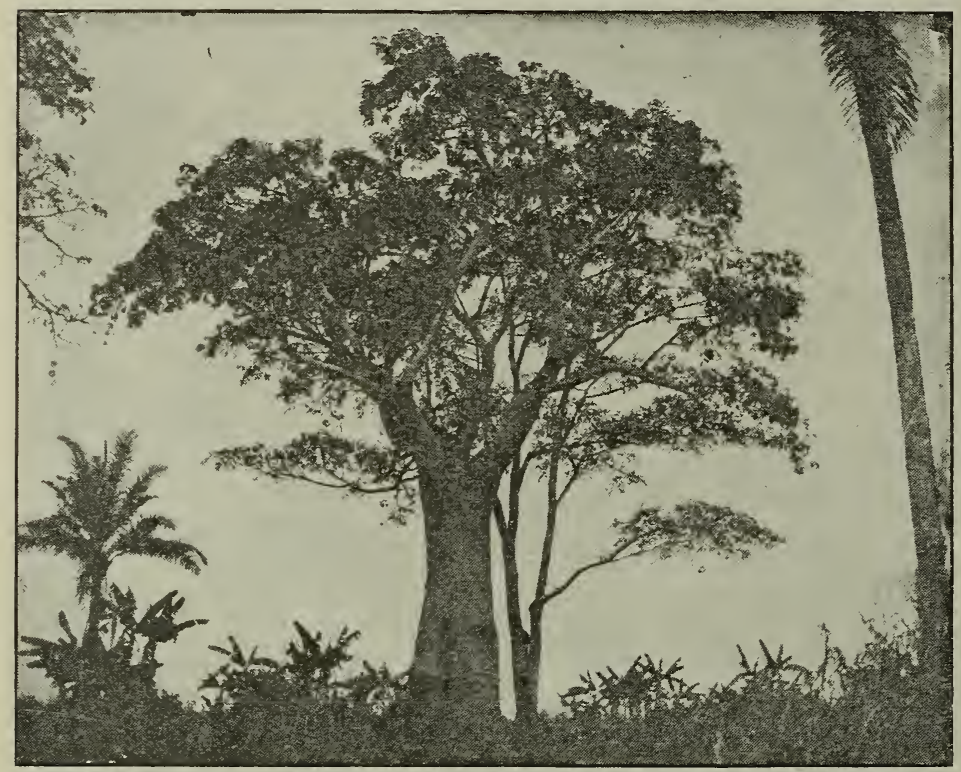

The largest bee-tree in the world-65 feet in circumference. rized platform. the scene. He loads his smoker with fuel (brimstone), removes the bee-escape and brimstones the old colony, or what is left, which by this time is probably not more than a handful of bees with the queen.

Again he leaves the scene of operation; but the bee-escape is not replaced. What happens now? The bees in the hive, including those that were captured, rob all the honey out of the old nest in the tree or house in the course of three or four days, carrying it into the hive on the extempo-

The bee-hunter now takes away the hive, removes the temporary hive-stand and carries the bees home. If they be taken a mile or a mile and a half they will stay where placed.

In the meantime, no damage has been done either to tree or building, as the case may be. All that will be left in the tree will be some old dry combs which, in the form of wax, probably would not amount to fifty cents, if the time of rendering be taken into account.

This method of taking bees could not very well be practiced where the bees are located in inaccessible positions, as in

hole of the tree, in such a way that the bees can come out but not go back in. Last of all he places his hive with the bees which he has brought, with its entrance as near the bee-escape (now placed over the old entrance) as he can.

His work is now complete, and he leaves the bees to work out their own salvation.

The bees from the tree, as fast as they come out, are, of course, unable to return. These, one by one, find their way into the hive on the temporary platform. At the end of four or five weeks the queen in the tree or dwelling will have very few bees left, and there will also be but little brood for that matter, thru lack of bees to take care of it, for her subjects are nearly all in the hive on the outside.

At this time Mr. Bee-hunter appears on high trees; but it will be found very useful where a colony is located in some building or shade-tree in a park.

We are indebted for the general principles here set forth to Mr. Ralph Fisher, of Great Meadows, N. J., who has practiced this plan with great success.

\section{DOES BEE-HUNTING PAY?}

If you can earn a dollar per day at some steady employment, we do not think it would, as a rule; yet there are doubtless localities where an expert would make it pay well in the fall of the year. With the facilities we now have for rearing bees, a beekeeper could stock an apiary much quicker by rearing bees than he would by bringing them home from the woods, and transferring. In the former case he would 


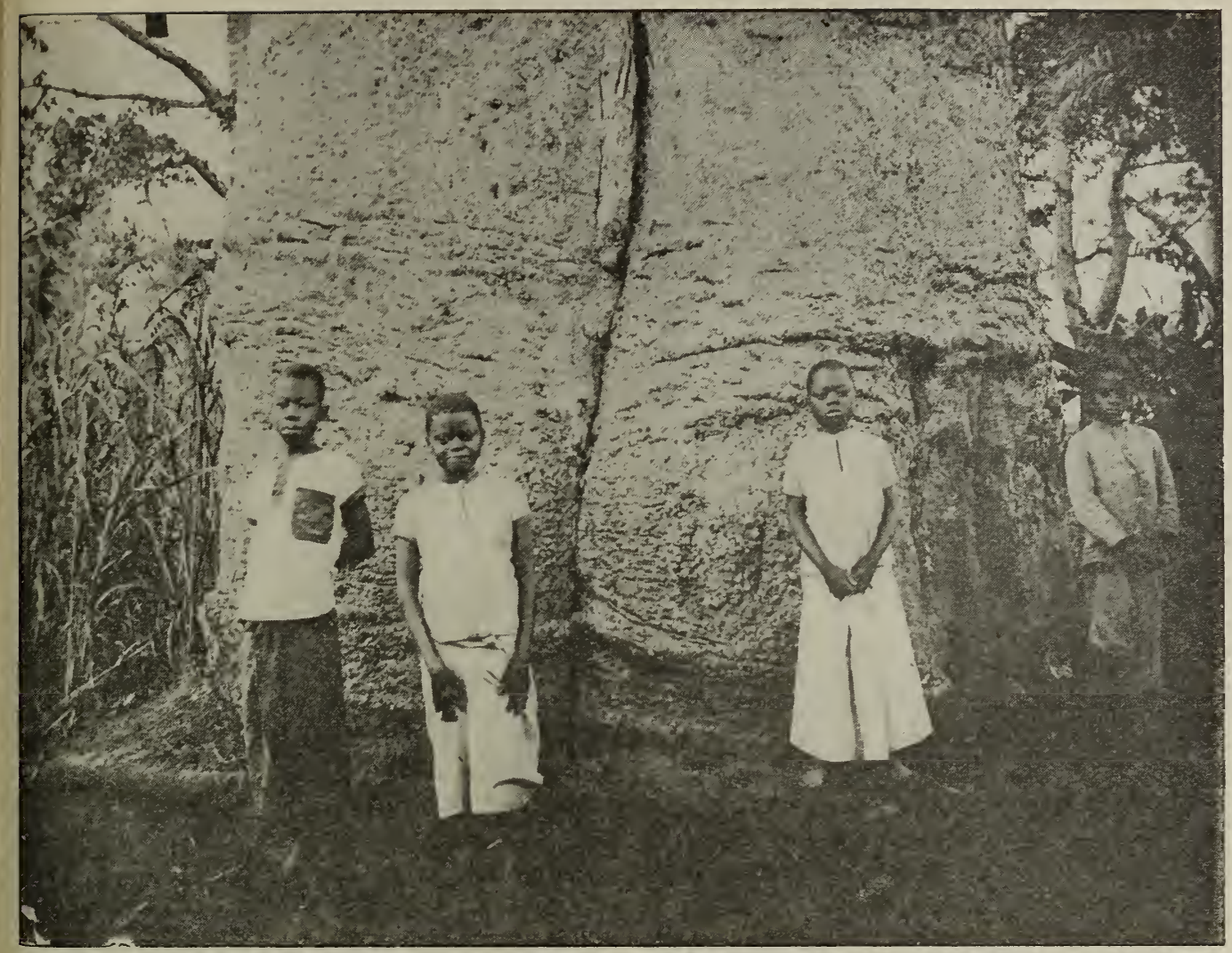

Closer view of largest bee-tree in the world. Natice children in foreground gire an idea of its size.

have nice straight combs, especially if he used foundation; but the combs from the woods would require a great deal of fussing, and yet would never be nearly as nice as those built on foundation, even then. So much by way of discouragement. On the other hand, a ramble in the woods, such as bee-hunting furnishes, is one of the most healthful forms of recreation one can find, because it gives one a chance to study, not only the habits of the bees, but the flowers as well; for in hunting for a bee to start with we find many plants that are curious and many that we would not otherwise know bees frequent.

\section{GETTING OUT BLACK BEES FOR QUEEN- REARING.}

It may also be mentioned that if one is trying to Italianize his apiary the presence of black bees in the woods will seriously interfere with pure mating. When bees build their combs naturally in trees they build an excessive amount of drone comb. The blacks will, therefore, raise drones all out of proportion to the number raised in hives of Italians where only combs from foundation are used. Indeed, it is not any exaggeration to say that one colony of blacks on natural combs will raise as many drones as forty or fifty colonies of Italians whose combs are built from all-worker foundation. It would, therefore, pay and pay well to get all the bee-trees of blacks or mismated bees, even if there were no financial gain in the honey or bees so secured.

BEEKEEPING AS A SPECIALTY.See Beginning with Bees and Profits in BeEs; also Specialty in Bees.

\section{BEEKEEPING FOR WOMEN.}

[It is presumed, of course, that no ordinary man would be entirely competent to write on a subject of this kind. In looking about for some woman to do this, the authors could think of no one more able than Mrs. Anna B. Comstock, author of a charming work for beginners on "How to Keep Bees." Mrs. Comstock is the wife of Prof. J. Henry Comstock, of Cornell University, and both of them entomologists. We engaged her to write the following article:]

Two questions invariably pop up at us when this matter of feminine beekeeping is discussed: One is, "Why shouldn't a wo- 
man keep bees?" and the other is: "Why should a woman keep bees?" Like most other questions these may be answered more or less rationally with proper consideration.

Taking the "why shouldn't" question first, we are bound to confess that nowadays there is no effective reason why a woman should not do almost any thing that she takes into her enterprising little head to do. But quite aside from the consideration of woman's prowess, there are one or two reasons that might deter some of the faint-hearted fair from undertaking beekeeping. There is no use trying to gloss over the fact that there is a great deal of hard work and heavy lifting in the care of a profitable apiary. The hard work is really no objection, as most women of whatever class are at it any way. But lifting heavy hives is certainly not particularly good exercise for any woman, altho I must confess that $I$ have never lifted half so strenuously when caring for the bees as I used to on the farm when we moved the cook-stove into the summer kitchen, accomplishing this feat by our feminine selves, rather than to bring to the surface any of the latent profanity which seems to be engendered in the masculine bosom when taking part in this seasonal hegira.

There are at least two ways of obviating this feminine disability in beekeeping. One, practiced successfully by several women, is thru the use of a Boardman hivecart, which almost solves the problem if the bees are wintered out of doors, and do not have to be carried up and down cellar stairs; the other method is to get some man to do the lifting and carrying.* It may be the husband, the father, the brother, the son, or the hired man; but as this work can be done at a time which can be planned for, it is not so difficult for the men of the establishment to give the help needed. I am sure my husband would say that I am quite enthusiastically in faror of the man solution of this problem; but his opinion does not count for much, because he loves the bees so enthusiastically I have to beg for a chance to work with them at all, altho he virtuously points out the hives to people as "Mrs. Comstock's bees."

Another "shouldn't" reason might be

* Some frail women remove all honey, one comb at a time. that women are afraid of bee-stings. This falls flat, from the fact that women are not a bit more nervous than men in this respect. This year when I was struggling to hive a swarm from a most difficult position, an interested man stood off at a safe distance in a most pained state of mind. He was a courteous gentleman, and he felt that it was outrageous for me to have to do the work alone, but he did not dare to come to my aid, and I think he considered my temerity in dealing with the swarm as almost scandalous.

Thus having disposed of all the reasons I can think of why women shouldn't keep bees, I turn gladly to the more interesting reasons why she should look upon the apiary as one of her legitimate fields of labor. There are so many reasons for this that I could not enumerate them even if a complete number of a bee journal were given me for the purpose. So I shall speak of just a few of the most cogent reasons. I should put first of all, and as embracing all other reasons, that beekeeping may be made an interesting avocation which can be carried on coincidentally with other employments; it is an interesting study in natural history; it cultivates calmness of spirit, self-control, and patience; it is a "heap" of fun; incidentally it may supply the home table with a real luxury; and it may add a very considerable amount to any woman's spendingmoney. It can also be carried on as a regular business, to support a family.

But it is as an avocation that I am especially interested in the apiary. Any woman who keeps house needs an avocation to take the mind and attention completely off her household cares at times. There is something about the daily routine of housekeeping that wears mind and body full of ruts, even in the case of those who love to do housework better than anything else. Talk about the servant question! It is not the servant question, but the housework question. If some means could be devised by which housework could be performed with inspiration, zeal, and enthusiasm, the servant problem would solve itself; but this ideal way of doing housework can be carried on only when the spirit is freed from the sense of eternal drudgery. I am not a wizard to bring about this change; but I know one step toward it, and that is the establishment of some permanent interest 
for woman that will pull her out of the ruts and give her body and mind a complete change and rest. Embroidery, lace-making, weaving, painting, and sereral other like occupations, may serve this purpose in a measure; and, perhaps, if carried on in the right way, may achieve more in this line than they do at present. But these are all indoor occupations; and what a woman needs is something to take her out of doors where she can have fresh air. Excess of perspiration induced by the cook-stove is weakening; but honest sweat called forth in the open air by the application of generous sunshine is a source of health and strength.

Beekeeping is orre of the best of these life-saring, nerve-healing avocations; it takes the mind from household cares as completely as would a trip to Europe, for one cannot work with bees and think of anything else. Some of the attributes which make beekeeping an interesting avocation I will mention: First of all, bees are such wonderful creatures, and so far beyond our comprehension, that they have for us always the fascination of an unsolved problem. I never pass our hive without mentally asking, "Well, you dear little rascals, what will you do next?" Bees are of particular interest to every woman for several reasons: if she likes good housekeeping, then the bee is a model; if she likes a woman of business, again is the bee a shining light; if she is interested in the care of the young, then is the bee-nurse an example of perfection; if she believes in the political rights of woman, she will find the highest feminine politicai wisdom in the constitu. tion of the bee commune. In fact, it is only as a wife that the bee is a little too casual 'n pose as ideal, altho as a widow she :certainly remarkable and perhaps even notorious.

Another phase which makes beekeeping a pleasing avocation for women is that much of the work is interesting and attractive. I never sit down to the "job" of folding sections and putting in. starters without experiencing joy at the prettiness of the work. And if there is any higher artistic happiness than comes from cleaning up a section holding a pound of well-capped amber honey and putting the same in a dainty carton for market, then I have never experienced it; and the making of pictures has been one of my regular avocations. By the way, woman has never used her artistic talent rightly in this matter of cartons. Each woman beekeeper ought to make her own colored design for the carton, thus securing something so individual and attractive as to catch at once the eye of the customer.

As a means of cultivating calmness, patience, and self-control the bee is a wellrecognized factor. Bees can be, and often are, profoundly exasperating; and yet how worse than futile it is to evince that exasperation by word or morement! No creature reacts more quickly against irritation than the bee. She cannot be kicked nor spanked; and if we smoke her too much, we ourselves are the losers. There is only one way to manage exasperation with beesthat is, to control it; and this makes the apiary a means of grace.

The money-making side of beekeeping is a very important phase in arousing and continuing' the woman's interest in her work. I think woman is by birth and training a natural gambler, and the uncertainty of the nectar supply and of the honey market adds to rather than detracts from her interest in her apiary. I know of several women who have made comfortable incomes and supported their families by beekeeping: but, as yet, I think such instances are few. However, I believe there are a large number of women who have added a goodly sum yearly to their amount of spending money, and have found the work a joy instead of drudgery. Personally, I hare had very little experience with the commercial side of beekeeping. Once when our maddeningly successful apiary grew to forty hives when we did not want more than a dozen at most, and the neighborhood was surfeited with our: bounty, we were "just naturally" obliged to sell honey. TVe enjoyed greatly getting the product ready for market, and were somehow surprised that so much fun could be turned into ready cash. As a matter of fact, both my husband and myself have absorbing vocations and arocations in plenty, so that our sole reason for keeping bees is because we love the little creatures, and find them so interesting that we would not feel that home was really home without them; the sight of our busy little co-workers adds daily to our psychic income. We are so very busy that we have but very little time to spend with them, and have finally formulated our ideal for 
our own beekeeping, and that is to keep bees for honey and for "fun." We shall have plenty of honey for our own table, and iust enough to bestow on the neighbors so they will not get tired of it; and fun enough to season life with an out-of-door interest and the feeling that no summer day is likely to pass without a surprise.

BEEKEEPERS' SOCIETIES. - See Organizations of Beekeepers.

BEE LEGISLATION.-See LEGISLATION OX BeEs.

\section{BEE-MOTH.-See MOTH-MILLER.}

\section{BEE PARAIJYSIS.-See Diseases of BeEs.}

BFE-SPACE.-This term is applied to sraces left by the bees both between combs they build and between the parts of the hive and the combs. It varies all the way from $3-16$ to $3-8$; but $5-16$ is considered the correct average. But in hive-construction it has been found that a space of $1 / 4$ inch will be more free from the building of bits of comb and the depositing of propolis than a little wider spacing. Any less space than 3-16 will be plugged up with propolis and wax. See Frames.

Father Langstroth, in the great invention which he gave to the world-the first practical movable frame-made the discovery that bees recognize and protect passageways which we now call bee-spaces. Taking advantage of this fact he made a frame for holding comb bee-space all around. All who preceded him had failed to grasp the fact that bees would leave such spaces unfilled with wax or propolis. Before Langstroth's time it was necessary to pull out frames stuck fast to the hives with propolis, or tear or cut loose the combs with a thin-bladed knife, before they could be removed for the purpose of inspection.

By bringing out his bee-spaced frame the " father of modern apiculture" solved, with one great master-stroke, a problem that had been puzzling the minds of beekeepers for centuries.

In later years, manufacturers of hives have been compelled to recognize this great principle, that there are certain parts inside hives that must be bee-spaced from every other part or elsa they will be stuck or glued together in a way that will make them practically inseparable. For example, the bottoms of supers containing the sections must be $5 / 16$ inch above the tops of the brood-frames in the lower part of the hive. The sections themselves must be held a beespace away from the separators or fences. It has come to be a general practice to put the bee-space in the bottom-board, leaving the bottoms of the frames jri the brood-nest nearly flush with the botiom of the hive. This makes it necessary to have the sides and ends of the hive project above the general level of the frames about $5 / 16$ inch. In tke same way the supers have a bee-space or: top but not on the bottom. If a super b? removed, and a hive-cover be put in its place, there will still be a space between the cover and the brood-frames.

\section{BEES.-See RaCes of BeEs.}

BEES AND FRUIT-GROWING.-Under head of Fruit-bLossoms and also under Pollen we have shown the very intimate relations between the beekeeping industry and the business of growing fruit. Most fruit, especially the finer varieties, requires the aid of the bees in scattering pollen from flower to flower when the fruit is in embryo or just started. If, therefore, the two industries are so intimately con. nected, why should not the business of growing fruit combine nicely with the busi. ness of producing honey? Fruit-growers all over the country have come to recognize: the valuable work performed by the bees. As they consider their little friends indis. pensable, they have been buying one lot of bees after another, until now a number of the fruit-growers have quite large apiaries; and, while they were induced to put in bees to help out their fruit-growing, they also found the bee business was a very profitable side line to run in connection with fruitgrowing. It is very seldom that the two industries conflict. The result is, that one man or a force of men can work the bees a part of the time and the fruit-trees the other part. We know of a large number of orange-growers who are also at the same time quite extensive beekeepers. There are also many fruit-growers in California, Wisconsin, and New York, who keep a good many colonies of bees. They are, therefore, able to furnish two of the finest sweets in 


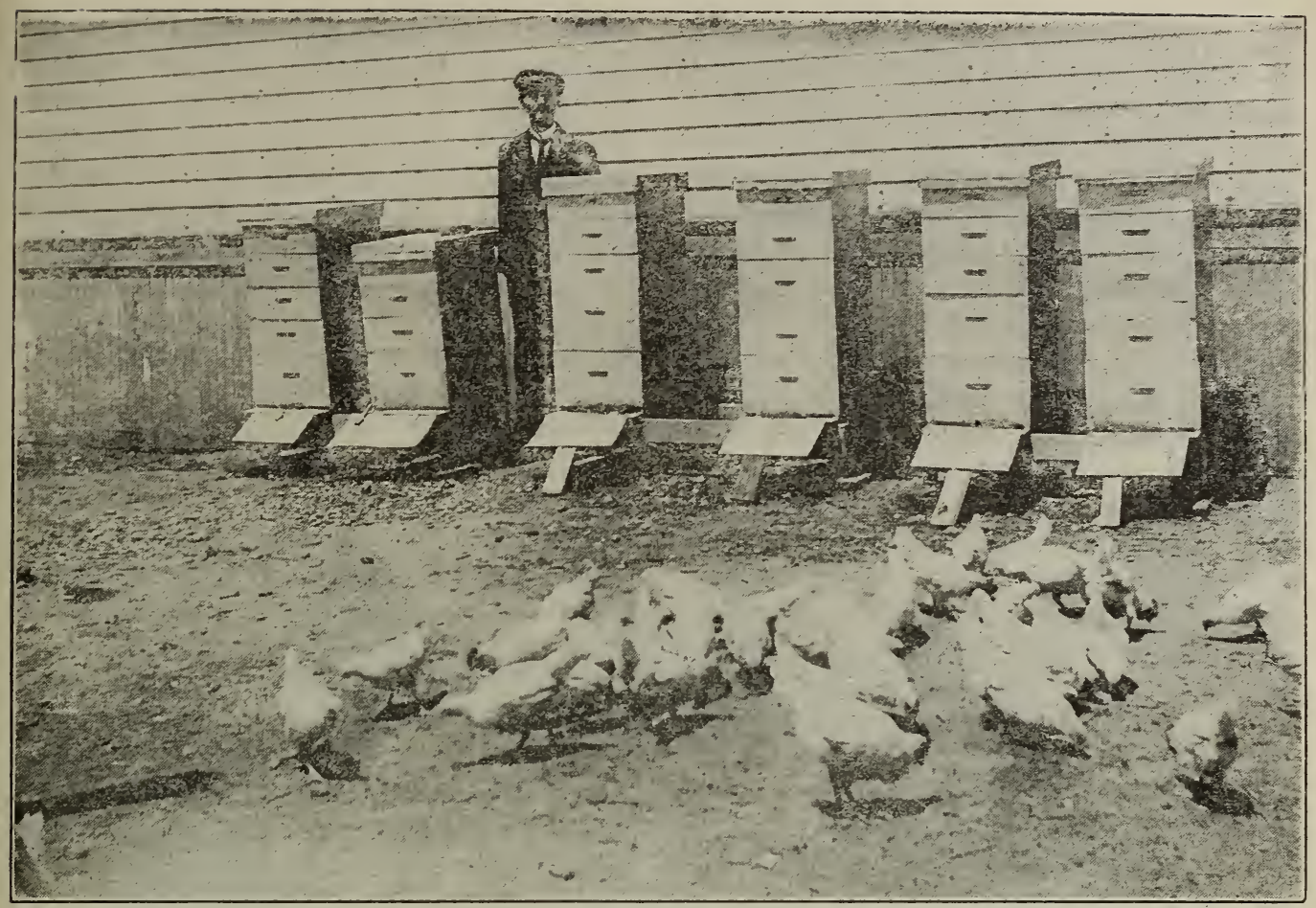

Bees and chickens in the same back lot, Detroit, Mich.

the world-the sugar in fruit and the natural sugar as we find it in the nectar of the blossoms themselves.

Within the last few years the citrus growers of California and in the southern states, and particularly in Florida and the Isle of Pines, are finding that at least a few bees are necessary to insure a proper fruitage. But it should be understood that not nearly so many colonies are required per acre in a citrus grove as in an ordinary fruit-orchard in the North. We have estimated that at least one colony to the acre is necessary in a northern orchard. The reason of this is because seasonal conditions are often unfavorable, so that the bees may have only a few hours in which to do their work. It follows, therefore, that a much larger proportion of bees is required to cover a given acreage in the northern states. In the South, in the orange and grapefruit groves, the trees are in bloom for a long pericd of time, and hence only about a fifth the number of bees, probably, are needed. But in view of the fact that beekeeping and orange-growing in the South go well together it is probably wise to make the proportion of bees much larger than indicated.

See Frutt Brossons, also Pollen, for a further discussion of the relation of bees to fruit.

BEES AND POULTRY.-Under the head of BEes AND Fruit we show how beekeeping and fruit-growing go well together. If there is any industry, aside from that of growing fruit, that combines nicely with the keeping of bees, it is poultry. When the bees require the most attention, the poultry needs the least. When chickens demand the most time, the bees are taking their long winter sleep, and, of course, require no attention, or very little. In the more northern states, at least, the bees are put into winter quarters along in the fall, and require almost no attention until the following spring, along in April or May. During this time the chickens require considerable care. If one would have early broilers in the spring, he must start his incubator going early. He must feed his chickens so that they will lay during the winter, and not only that, but give him fertile eggs so that he can start his incubator. Incubator work and the brooding of chickens go on along until spring. The bees at that time require a little attention in the way of feeding and going over to see 
whether any of them need uniting: but, beyond that, they will not reguire very much care until about the middle of Nay or the first of June. In the mean time, the cleaning-out of the poultry-houses, gathering of eggs, marketing, all require considerable time on the part of the owner of the chickens. Just about the time the bees begin to require considerable attention the hens will begin to lessen their laying, and the weather will be such that they will not require such careful feeding; for usually they can get a good deal of their green food directly from the ground. At that time the beekeeper will begin either extracting or putting on his comb-honey supers. If the chickens require a good deal of his time then, he can simply put on extra supers, piling them one on top of the other, until he has the hives stacked up three or four stories high. If he practices artificial swarming, as described under that head, he will not have much trouble with swarms. He can even go further, and prevent swarms from coming out to a very great extent by practicing the methods given under head of SwARMIING and ARTIFICIAI Swarming. Taking it all in all, he can postpone the greater part of his bee work until his chickens do not require very much attention, and then he can take off his honey, scrape his sections, or extract if necessary.

The great majority of those who keep bees in the United States work them in connection with some profession or some other industry, like fruit-growing or poultry-keeping, etc. Some localities do not make it feasible to make beekeeping the sole means of livelihocd. While it is true there are a great many specialists, especially in the West, they are in localities that are particularly favorable for the keeping of bees in a large way. One can scarcely make a living from one or two hundred colonies; but that number in connection with poultry-keeping or the growing of fruit helps to make up the general income of the family. For a further consideration of the question whether bees can be made the sole means of livelihood, see Profits IN Bees, Backlot Beekeeping, Specialti in BeEs, and the Foreword.

BEES AND TRUCK GARDENING.Beekeeping can be managed in connection with truck gardening, but it does not make nearly as good a combination as bees and poultry. The difficulty in combining bees with gardening is that the latter requires its greatest attention when the bees also need a large amount of care. There are times and circumstances, however, when beekeeping, fruit-growing, and poultrykeeping might all three be worked together; but in most cases we fear the man who attempted this would be a "Jack of all trades and master of none."

BEES AS A NUISANCE.-It would seem almost out of place to discuss this question in a work intended for perusal and study by those who believe (and rightly, too) that bees are not a nuisance; but, as we shall show, there are very good reasons why we should calmly discuss this question in order to avoid trouble that may arise in the future. Certain difficulties have arisen between the keepers of bees and their neighbors. Perhaps the bees, after a long winter confinement, have taken a flight and soiled the washing hung on a line in a neighbor's yard, or after several days' confinement at any time, if the clothes are within a short distance. Possibly some of his children have been stung, or there have been times when he has been greatly annoyed while in the peaceable possession of his own property by bees coming on his premises and sinelling around, as they sometimes do during the fruit-canning season whell the aroma of sugar and juicy fruits penetrates thru the doors and windows of the kitchen. Possibly the offended neighbor keeps chickens, and members of his feathered tribe have trespassed on the grounds of the beekeeper. The result of all this is that bad feelings arise. Complaint is made to the village officers; an ordinance is proposed declaring bees within the limits of the corporation to be a nuisance, and requiring the keeper to remove them at once or suffer the penalty of fine or imprisonment, or both. See Laws Relating to Bees.

In some instances, live stock has been stung; a cow or a calf or a horse may get near the entrances of the hives, which, we will say, are within a foot of a dividing line between the two properties. Perhaps the stock is stung nearly to death. Damage is claimed and a lawsuit follows, with the result that a feeling of resentment is stirred up against the beekeeper. But this is not 
all. Possibly the beekeeper has an apiary in his front yard, bordering on the common highway. A nucleus may be robbed out, with the result that the bees go on the warpath, and begin to sting passersby. Perhaps a span of horses is attacked; a runaway follows; damages are claimed, and another lawsuit is begun.

In the foregoing we have supposed possible instances. It is proper to state that they are only types of what has occurred and may occur again, so it behoores us to be careful. strongly from the hives, send word to your neighbors and ask them not to hang cut their washing, if it is a wash-day, for a few hours. Send along a few boxes of honey. and keep the folks across the way "sweetened up." Ninety-nine neighbors out of a hundred will puiv up with a great deal of inconrenience, and say, "Oh! that is all right. It won't take long to rinse out the clothes again."

Take, for example, more serious caseswhere horses or cattle have been stung. If you have been foolish enough to place hivcs

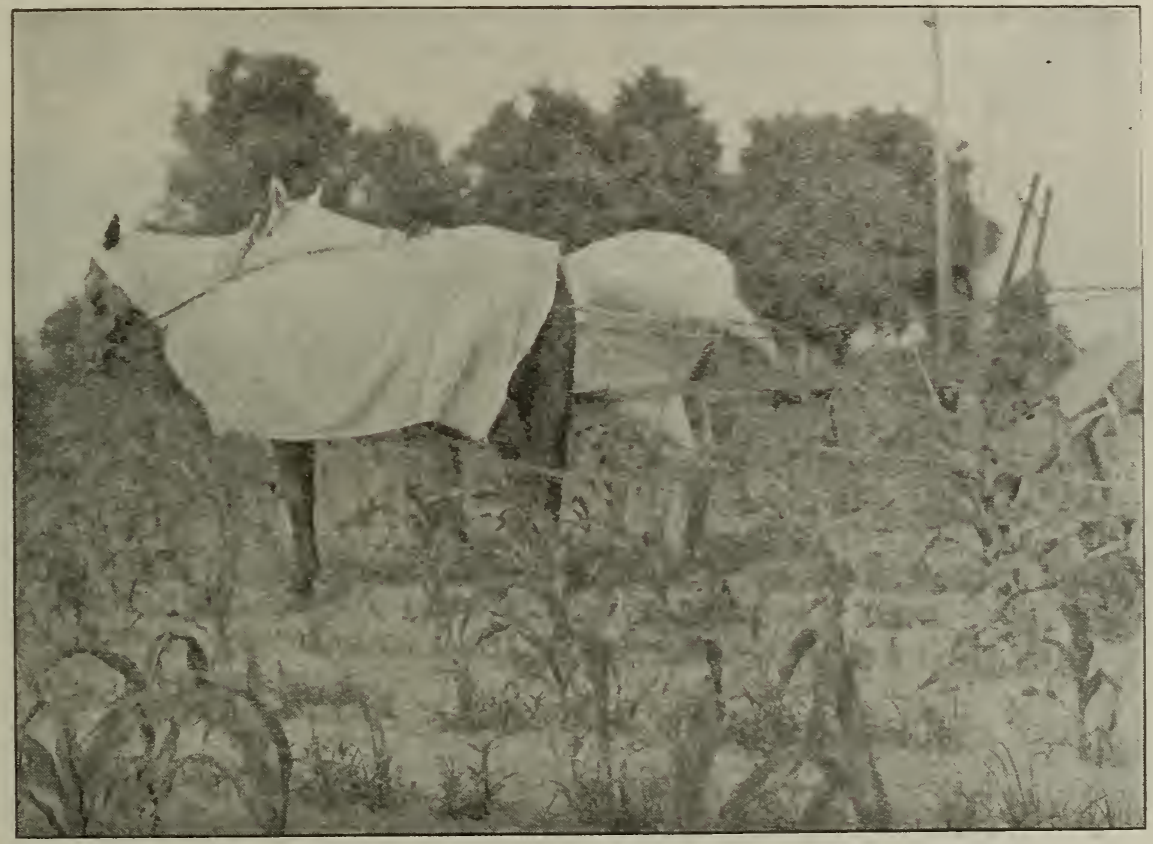

Scheme for protecting horses while cultirating a field next to a bee-sard.

In the first case mentioned (the aggrieved neighbor's washing soiled by the stains from bees affected with dysentery), it is well for the beekeeper to send over sereral nice sections of honey, or to offer to pay for the damage done to the washing. Nothing makes a woman more angry than to have her nice clean white linen, after she has scrubbed, rinsed, and hung it out to dry, daubed with nasty, ill-smelling brown stains. But if our beekeeping friend will take pains to offer an apology before the woman makes complaint and shows a disposition to make the matter good, trouble will in most cases be averted. And right here it should be said, if the bees are in the cellar do not set them out on a wash-day: or if they are outdoors, and the sun comes out bright so they begin to fly near the highway or your neighbor's line fence where he has loose stock, you may have to pay pretty dearly for it before you get thru. The remedy is prevention. Alwars put bees in a back yard, and not too close to your neighbor's line fence. Be careful, also, to prevent robbing. See that there are no weak nuclei with entrances too large. As soon as the honey-flow stops, contract the entrances of all the weaker colonies. If extracting is done after the honey-flow, great caution needs to be exercised. The extracting-room should be screened off, and bee-escapes provided. Whenever possible, take off all surplus by the use of bee-escapes rather than by shaking. See Robbing and Extracting.

Under the head of ANGer of BeEs, in the 
latter part of the article, and under the head of APIARIES, we emphasize the importance of placing the hives so that they shall be screened by shrubbery or small trees, from other hives and objects in the yard. Nothing is more conducive to insuring good temper on the part of bees than to place the individual hives so that the inmates cannot from their own doorsteps see moving objects in the immediate vicinity. When the space where the apiary is placed is open, without shrubbery or trees to screen the hires, the bees are much crosser than when placed behind obstructing objects. The average backlot beekeeper will have much better bees to handle, and no trouble with neighbors if he will put his hives among the he came to cut the crop the horses would cccasionally be stung while drawing the mower. In one case there came very near being a serious mixup, as the team nearly ran away with the mowing-machine.

Two years later corn was planted in this same field. When the horses were cultivating up and down the rows they were attacked again by the bees, for they were going in great droves across this field to a patch of clover byond. Notwithstanding we had a high board fence to raise the flight of the bees above the team when near our yard, there was more or less trouble. On one occasion the driver was stung pretty sererely, and the animals became unmanageable. Fortunately the driver got them

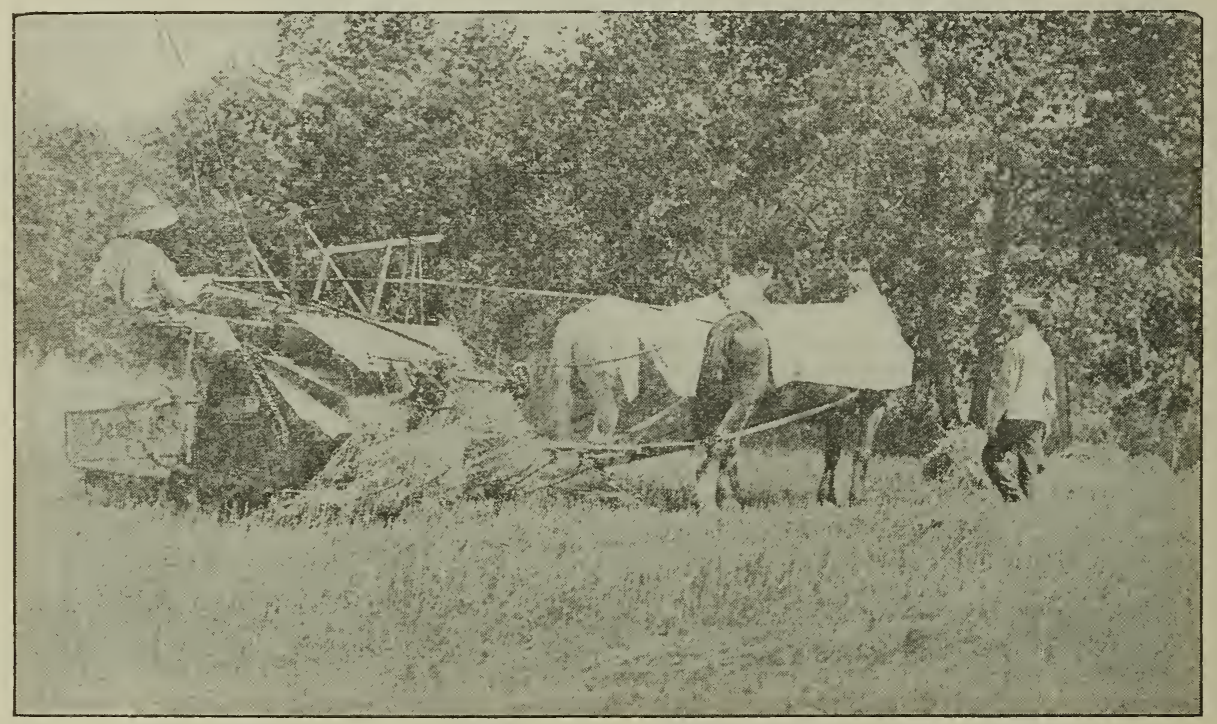

When the team was in the flight of the bees the smoker was held in readiness should the horses be stung.

bushes. If he has a high board fence, or a hedge of evergreens to shut off the little apiary from passing teams, pedestrians, or children that play in the next yard, the conditions will be much better. See BackLOT BeEKeEping.

\section{WHAT TO DO WHEN THE BFES ATTACK NEIGH- BORS' HORSES.}

But it sometimes happens that something must be done at once to avert an attack upon teams or horses working in fields adjoining a bee-yard. We have one outyard located near a field where our neighbor's horses have been attacked by the bees on sereral occasions. We supplied our neighbor with clover seed for this field; and when under control without any serious consequences.

Now, our neighbor is a kindly man; and when he telephoned what had happened we saw that something would have to be done. We told him to go to the harness-shop and secure some large horse-blankets that would cover the necks and backs of the horses, and we would pay the bill. We then directed him to secure some large squares of mosquito netting and fold this around the horses' heads. In the meantime we supplied him with veils for himself and man.

When the next day came for cultivating, the blankets were put on and we went down to watch developments. We found that the blankets helped very materially, as they 
protected the animals from the onslaught of bees around their backs and necks where they could not brush or switch them off. Our neighbor did not think it was necessary to put the mosquito netting orer their heads, as he said his horses did not mind bees on the face, as they could be brushed off on the fore-legs. With these large blankets the horses went up and down the rows with rery little trouble.

We found upon investigation that the bees were not disposed to be cross, but in going to and from the fields in.search of honey they were interrupted in their flight. The switching of the tails of the horses angered them with the result as stated.

In cases of this kind we find it an adrantage to have an experienced beeman, and also an experienced horseman, if the two can be combined in one person. We happened to have just such a man in our employ, and sent him along around with the mower and reaper with a lighted smoker. If he found the bees were flying around the horses' heads he used a little smoke and drove them away. It was not necessary for him to follow the machine clear around the field, but only along that side next to the flight of the bees.

But suppose your neighbor is unreasonable and ugly, and he bring's suit for damages; or suppose that your bees are located in a city or village, and that the town council has declared your bees a nuisance.

Do not move the bees if you have used reasonable precaution, but write at once to the authors.

Well, we will say the attorneys have been retained. Any number of decisions have been handed down to prove that bees are not a nuisance per se; that, when they are properly kept, and due precautions are used, they cannot be driven out of the corporation. There are several precedents from various courts, even from the Supreme Court of Arkansas, to show that bees have the right to be kept within a corporation like any live stock, so that any ordinance not in conformity with these decisions can be declared unconstitutional. Several ordinances declaring bees to be a nuisance have been repealed. See Laws Relating to BEEs.

BEES ATTACKING(?) FRUIT.-Occasionally we hear complaints of how bees will attack and eat up fruit; and to a casual observer, at least, they apparently do bite thru the skin, and extract the juices until the specimen is shriveled up to a mere semblance of its former shape and size. Careful investigation has shown repeatedly that bees never attack sound fruit no matter how soft the skin nor how juicy and pulpy the contents within the skin.

Some years ago, Prof. N. W. McLain, then in the employ of the Department of Agriculture, Washington, D. C., conducted an elaborate series of experiments in which he placed sound fruit, consisting of grapes, peaches, apricots, and the like, in hires containing bees that were brought to the rerge of starration. This fruit was left in the hives day after day, but it was never once molested. Then he tried breaking some of

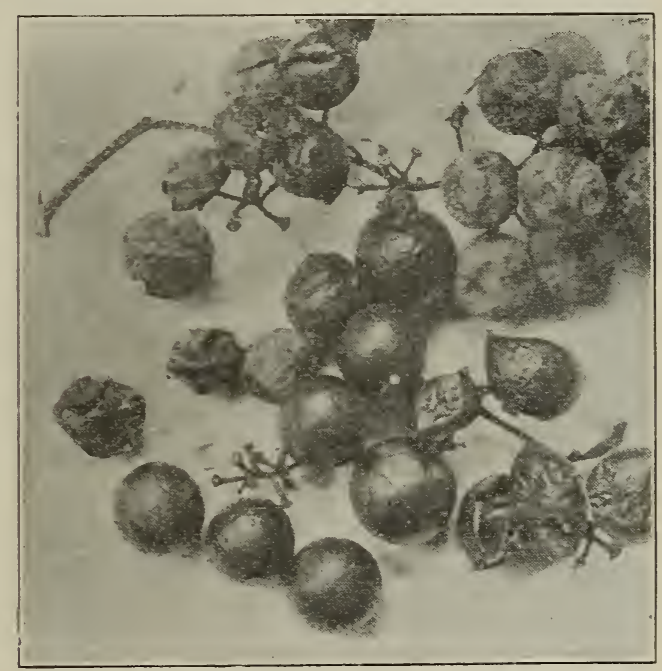

Grapes punctured by birds and despoiled by bees.

the fruit, and in erery case all such specimens were attacked by the bees sucking up the juices until nothing but a dried skin and the stones or seeds were left.

Years later, Prof. H. A. Surface, economic zoologist at Harrisburg, Pa., tried a similar experiment, but in no case did the bees attack the sound fruit, altho they partook freely of that which he had broken.

At the Wilmington State Fair, held Sept., 1208, in Delaware, Mr. Joel Gilfillan, of Newark, Del., had on exhibition a threestory observation hive containing two combs of bees. In the third story was hung a peach, a pear, and a bunch of grapes. This was kept on exhibition during the entire fair where the general public could see it. 
As is shown, this fruit was never once visited by the bees. The general verdict of those who saw it, fruit-men and farmers alike, was that bees could not injure sound fruit.

The authors have had, during the past thirty years, between three and four hundred colonies located in a vineyard at their home apiary. Notwithstanding hundreds and hundreds of pounds of grapes are raised every year, the bunches hanging within three or four feet of the entrance of the hives, the sound fruit is never attacked; but during a dearth of honey, a broken or otherwise bruised bunch of grapes will often be visited by a few bees.

The writer of this article has attended various horticultural and pomological conventions, both state and national. Among the progressive fruit-growers and horticulturists there is a general acknotvledgment that bees do not attack sound fruit; that the little harm they do to damaged fruit is compensated for a hundred times over by the indispensable service they perform in pollinating fruit-blossoms early in the season when no other insects or means of mingling the pollen exists. Indeed, our best fruit-growers are now keeping a few hives of bees in each of their orchards. Often they invite beekeepers to locate yards of bees either in the orchards or as near as it is practicable to put them.

But a casual observer might easily get the impression that bees not only suck damaged fruit dry, but actually puncture and eat up sound fruit. Some years ago a neighbor sent word to us that he would like to have us come up to his vineyard and he would give us indisputable proof that our bees were actually puncturing his grapes and sucking out the juice. We looked at the luscious bunches as they were hanging down, and, sure enough, there were small needlelike holes in almost every berry that the bees were working on. It looked like a clear case of "caught in the act" evidence against them. For the time being we were unable to offer a satisfactory explanation. We brought the matter to the attention of an old farmer who had been a beekeeper for many years. Finally one morning he sent word to us that he had found the culprit, and that if we would come down to his place early some morning he would point him out. This we did. He showed us a little bird, quick of flight, and almost never to be seen around the vines when any human being was present. This bird, about the size of a sparrow, striped, and called the Cape May warbler (Dendroica tigrina) has a long sharp needlelike beak. It will alight on a bunch, and, about as fast as one can count them, will puncture grape after grape. After his birdship has done his mischief he leaves, and then com'e the innocent bees during the later hours of the day and finish up the work of destruction by sucking the juices and the pulp of the grape until it becomes a withered skin over

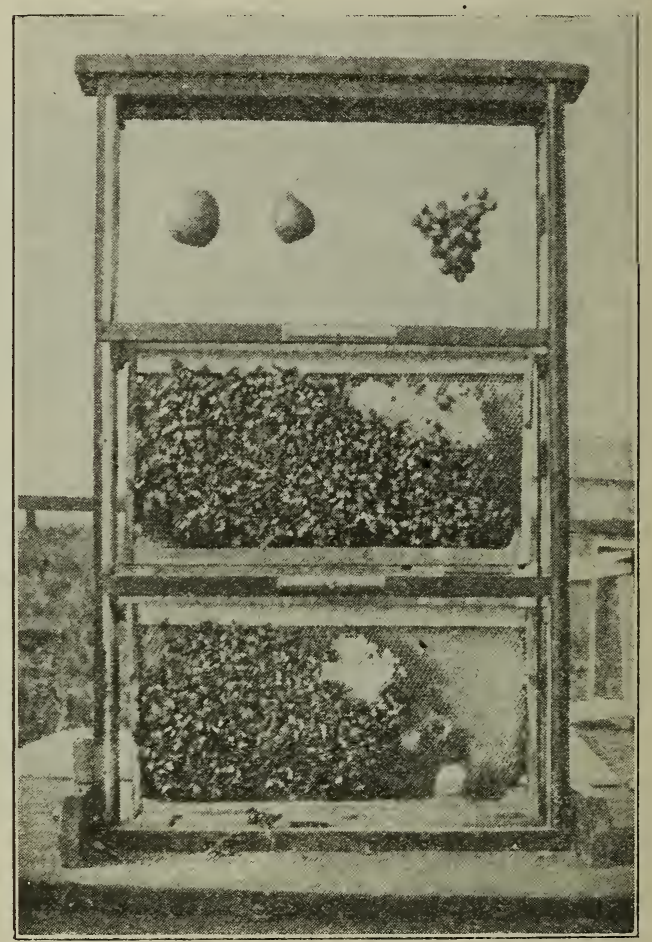

One of the exhibits of bees at the Grange Fair, in Wilmington, Delaware, held in September, 1908. A card in the hive read, "Bees do not injure sound fruit."

a few seeds. It is thus the birds during the early hours of the day are never seen; but the bees, coming on later, receive all the credit for the mischief. The Cape May warbler is not the only bird guilty of puncturing grapes. There are many other species of small birds that learn this habit, and among them we may name the ever present sparrow and the beautiful Baltimore oriole, the sweet singer that is sometimes called the swinging bird, from its habit of building its nest on some overhanging limb. 


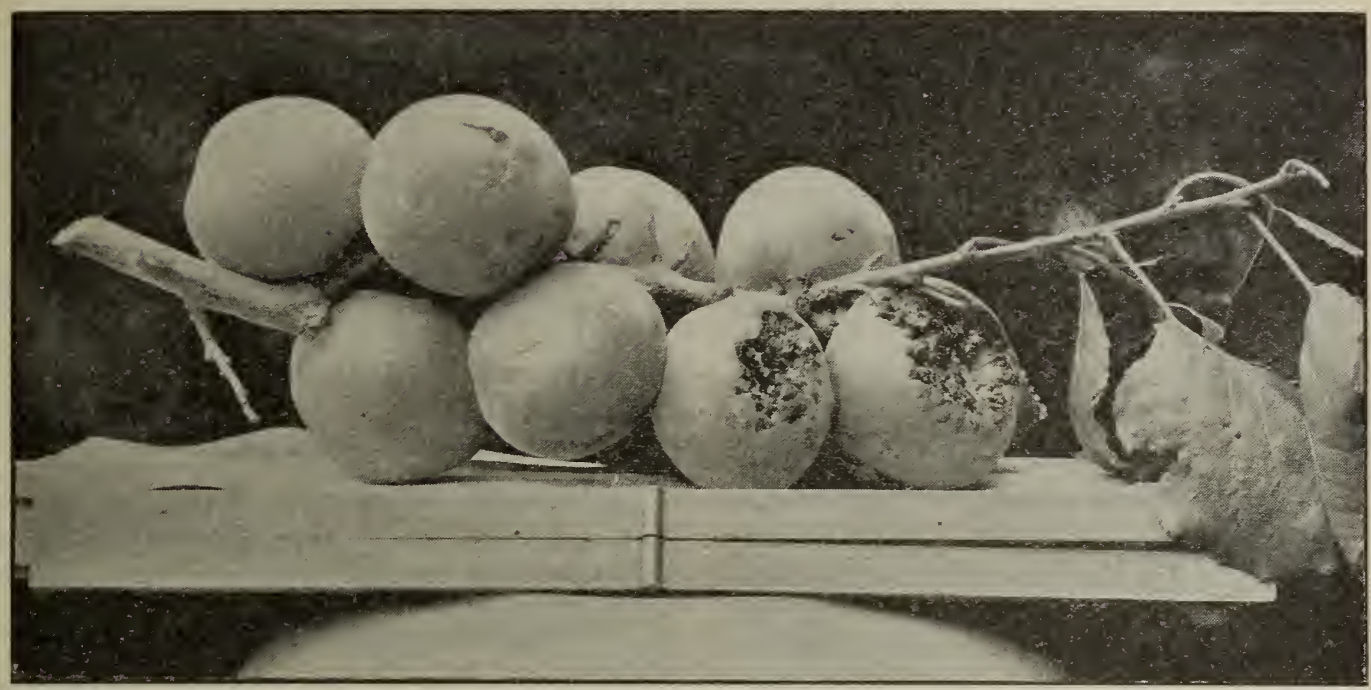

Apricots damaged by birds; fruits thus injured are sucked dry by bees, which store the juice as honey.

Some seasons the insect visitor's are much more numerous than others. Several years may pass before any complaint is made, and then the next thing the beekeeper knows he will have angry people in the vicinity of his bees calling him up on the telephone, saying the bees are eating up their grapes. The only thing to do is to call on each complainant, and prove that the birds are the ones that do the mischief in the first place, and that it is only by careful watching at intervals that they can be seen at their work.

In order to determine their presence the observer should go away from the grapevine about fifty or perhaps a hundred feet. The early morning hours are the most favorable for catching the miscreant at work. The Cape May warbler is a shy little fellow, and he will not usually show limself if any one is near the vines. It is for that reason that the bird is seen on the grapes only at brief intervals; and the bees, working on the bunches all the day, get the blame for all the damage.

For further information regarding grapepuncturing birds, refer to bulletins by Dr. Merriam, of the United States Department of Agriculture, Washington, D. C.

\section{WHEN BEES MAY DAMAGE FRUIT.}

But there are times when bees are a nuisance, and it is then that their owner should compromise; or, better still, seek means to avoid trouble in the first place. In the fruit-drying ranches of California, apricots and peaches are cut up into small pieces and laid upon trays exposed to the sun's rays. If there is a dearth of honey at this time, and a large number of bees in the locality, this fruit may be attacked. The bees may visit it in such large numbers that they suck out the juices, leaving nothing but the shriveled form of the fruit. The property is, of course, damaged, and its sale ruined. Before anything of this kind can happen, the beekeeper should move his whole yard to a point three or four miles distant from any fruit-drying operations. Failing to do so the fruit-grower, if the bees caused trouble, might enter suit for damages, and possibly recover the value of his crop.

Years ago we had trouble with a cidermaker. He claimed that our bees would lick up the cider from the press as fast as he could make it. We easily adjusted this difficulty by screening his building with mosquito netting.

In every case of this sort the owner of bees should avoid trouble. If he is a member of the National Beekeepers' Association he might put up a stiff defense, it is true; but in the case of the fruit-drying ranches and the cider-mills, the beekeeper had better err on the safe side by avoiding suit for damages, because no beekeepers' union nor any other organization, nor lawyers either, for that matter, would be able to give much assistance where it was clearly proven that the bees were doing an actual damage. 


\section{BEES EXONERATED BY A JURY.}

In 1900, trouble arose between two brothers named Utter, at Amity, N. Y. One was a beekeeper and the other a fruit-grower. The latter averred that the former's bees punctured his peaches. and that, in consequence of their alleged damage, he claimed he was unable to raise any fruit. There had not been very good feeling between the brothers for years. The fruit-grower brought suit against the beekeeper, and the case was tried on December 17, 18, and 19, 1899, at Goshen. There was no lack of legal talent on either side. The case was a very hard-fought one from beginning to end. Among some thirty odd witnesses examined, the Government expert, Mr. Frank Benton, formerly of the United States Department of Agriculture, Washington, D. C., gave his testimony to the effect that bees never puncture sound fruit; that it is practically impossible for them to do so, owing to the fact that they have no cutting jaws like those found in the wasp and other insects of that character. He also showed how wasps and birds will, under some conditions, puncture fruit; that these minute holes they make will, during a dearth of honey, be visited by bees. Other expert testimony was offered, nearly all of which exonerated the bees. After all the evidence was in and the pleas were made, the jury returned a verdict for the defendant.

For further particulars regarding this, the reader is referred to the publishers of this work.

In case trouble arises, the owner of the bees will do well to read BeEs as a NUISANCE, and also the other subject found in its alphabetical order, Laws Relating тo BEEs.

\section{BEES, CROSS.-See ANger of BeES.}

\section{BEES, CROSSES OF.-See HyBRIDS.}

BEES, HANDLING.-See A B C OF Beekheping, Manipulation of Colonies; also Exhibits.

BEES ON SHARES.-In some localities, notably in California, Colorado, and the great West, bees are often kept on shares. While this method of doing business has usually been conducted quite successfully and satisfactorily to both parties, yet nevertheless many disputes and troubles have arisen, perhaps because there was a lack of contract; or if there was one there was nothing in it to cover the point in dispute.

The following form of contract was very carefully drawn by an attorney, and it is hoped it will meet every condition.

\section{ARTICLES OF AGREEMENT}

This agreement, made and entered into at - , this — day of - $19-$, by and between - of - party of the first part, and hereinafter called the owner, and of -, party of the second part, and hereinafter called the employee.

Witnesseth: First, that said owner has agreed, and in consideration of the covenants and agreements herein contained and to be performed by said employee, does hereby agree to provide a good location for keeping bees, at or near put thereon, on or before the - day of - 19-, not less than colonies of healthy bees, and then and thereafter at such times as needed during the continuance of this contract, to provide and furnish at his own cost and expense, all hives, tools, implements, machinery, and buildings necessary to enable said employee to carry on successfully the business of producing and securing honey and wax from said bees; and further to pay one-half of the cost and expense of all sections, cans, bottles, shippingcases, and packages that may be required to put the honey and wax into marketable shape; and in case it shall be necessary to feed said bees, to provide and furnish feeders and the sugar for making the syrup; and said owner further agrees to give and deliver on the said premises, to said employee, as and for his compensation for labor done and provided by him in caring for said bees and securing honey and wax, the full one-half of all marketable honey and wax produced and secured from said bees.

Second: In consideration of the above covenants and agreements, the said- - employee, hereby agrees to enter the employ of said owner on said-day of- $19-$, and at once care for said bees in a proper manner; do, perform, and provide all labor necessary to carry on successfully the business of producing and securing honey and wax ready for market; pay one-half the cost and expense of all sections, cans, bottles, shipping-cases, and packages that may be required to put the honey and wax into marketable shape; feed the bees, when necessary that they shall be fed, and deliver on the premises to the said owner the full onehalf of all the marketable honey and wax produced and secured from said bees, and to accept the remaining half as and for his full compensation for labor done and provided by him in the care of said bees and the production and securing of honey and wax.

Provided, and it is mutually agreed and understood by and between the parties here- 
to, that said employee shall double up all of said hives at the close of the season or leave them reasonably strong and well supplied with stores and prepared for the winter; and if any of said colonies of bees are lost thru the carelessness or negligence of said employee, said owner may recover from said employee as damages an amount not greater than one-half what it would cost to replace said bees and queens; all increase of swarms (artificial or natural) to belong to said owner. It is further mutually agreed and understood that in case no honey is secured, or the amount runs below ten (10) pounds per colony, said. owners shall pay to said employee, as and for his compensation for all labor done and provided by him on and about said bees, an amount not exceedingcents per hour for each and every hour of labor so performed, and provided by said employee on and about said bees, and in such case all honey to belong to said owner.

Signed in duplicate by said parties, the day and year first above written.

Signed in presence of

The foregoing comprises the essential features of a contract; but local conditions may render it necessary to make some modifications.

The last clause in the contract is inserted as a matter of fairness to the employee. If no honey should be secured, he has performed his part of the contract in good faitl, and, moreover, has improved the apiary-perhaps increased it--so that it will be in better condition the following year for a honey crop. For this betterment it is no more than right that the owner should pay his man a reasonable sum, whatever amount may be agreed on; or, if preferred, a certain number of colonies. One can readily see that, in case the honey season was an absolute failure, the employee would suffer a total loss except for a provision of this kind, and that the owner would still have his bees, his implements, and everything necessary to carry on the business for another season.

By the above contract it is to the interest of both parties to keep down increase. The employee must know, if he is a practical beekeeper, that, the greater the increase, the less the honey; and he will, therefore, bend all his efforts and skill to keep the colonies in the best condition to obtain a crop of honey.

Keeping bees on shares is practiced quite extensively in Colorado and California. It rery often happens that a beekeeper lately arrived from the East desires to try a locality to determine whether it will be suited to his health, and whether or not he can make the keeping of bees a success. He accordingly finds a beekeeper whose other business leads him to desire some one competent to manage them for him. But where one is well settled in a locality, and has the means whereby he can purchase the bees, he should do so.

The business of keeping bees on shares has not always been an unqualified success; and where one can buy bees outright, paying for them out of his earnings, he would better do so. But the owner of the bees should, of course, be secured by a chattel mortgage until the last payment is made.

BEES, STINGLESS.-Their habitat extends from the boundary between the United States and Mexico down to Buenos Aires in Argentina, embracing an area of 8,000,000 square miles. One comparatively unimportant species inhabits most of the West India islands. There are a few species in Asia and Africa.

By entomologists these bèes are usually classed under two great genera-Melipona. and Trigona; but some naturalists are disposed to add another, Tetrasoma. There is an extraordinary variety of these bees, which is supposed to embrace at least 100 species, whereas there are not more than 8 species of Apis. The variation in size is also great, for some are no larger than a mosquito, while others are considerably larger than the hive bee. A number of naturalists are at work studying them with a view to their proper classification and arrangement by species.

There is an equal variation in the number of bees per colony, for some consist of only a few (100) individuals while others are supposed to contain not less than 100,000 bees.

Some build only small nests, not much larger than an orange; others, again. construct a home as large as an ordinary flourbarrel. Some build in a hole in the ground; others in the open air, as wasps and hornets do, while quite a number build their nests in the hollows of forest-trees.

Early travelers in South and Central America did not fail to notice the stingless bees, and they are quite frequently referred 
to by them. Capt. Basii Hall, in the 18th century, noticed apiaries of them in Peru; and Koster, in his Travels in Brazil, carefully mentions them. Spanish writers on Central America casually noted them in the sixteenth century; but no European seems to have been interested enough in them to make a comprehensive study of their lifehistory and habits. The work was left for now been taken up in earnest. White men have been inclined to dismiss them as worthless for practical purposes; but the natives of South America are certainly not of that opinion. On the contrary, they regard them as superior to the "stinging" fly" of the white man. In Southern Mexico, Central America, and South America, they are quite frequently kept in a domesticated state by

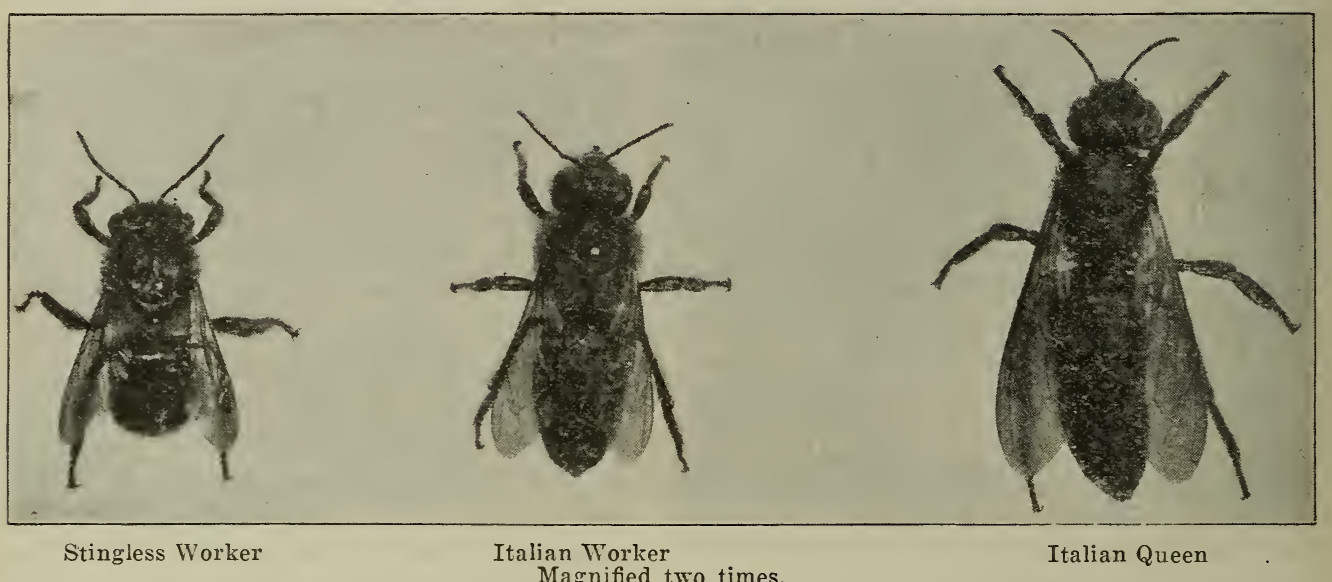

the twentieth-century naturalists. Geoffrey St. Hilaire, a naturalist-explorer, did something to awaken interest by his now classical observations on honey-gathering wasps of Paraguay, of which he furnished a complete account in 1825 (Paris). Azara, a similar explorer, also called attention to them in his travel thru Paraguay. He de-

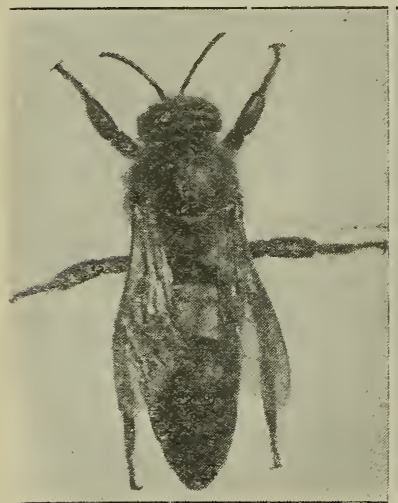

Italian Queen
Magnified two times.

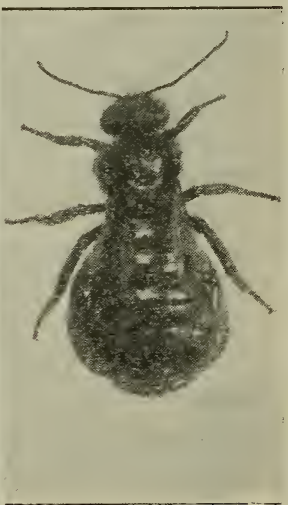

scribes a species twice as large as Apis mellifica.

Other explorers have mentioned them from time to time, but nothing of real value was elicited until lately. Their study has the native inhabitants-that is to say, they have them in hollow logs which have been brought from the forests. These "hives" are generally hung up by ropes around their dwellings to protect the bees from their chief enemy, the lizard. The logs are robbed at stated intervals, the keeper being well satisfied if he can secure a gallon of honey per hive at a robbing, depending somewhat on the species used for domestication.

Apparently no effort has ever been made to invent a hive suitable to their wants. It is noticeable that the natives use only those species whose homes are made in hollow trees, no effort being made to utilize the many other species whose nests are made in holes in the ground or on tree-branches.

The quality of the honey and wax varies rery much, some of it being quite good and some quite the opposite. The wax is apt to be mixed with propolis to a great extent; but at least one species inhabiting the upper tributaries of the Orinoco, in Colombia. furnishes a desirable wax which has been frequently sold in this country.

While the stingless bees cannot sting they bite and worry in a way to surpass bees possessed of a sting. At the Philadelphia field-day meeting at which a thousand beekeepers were present, in June, 1906, two 


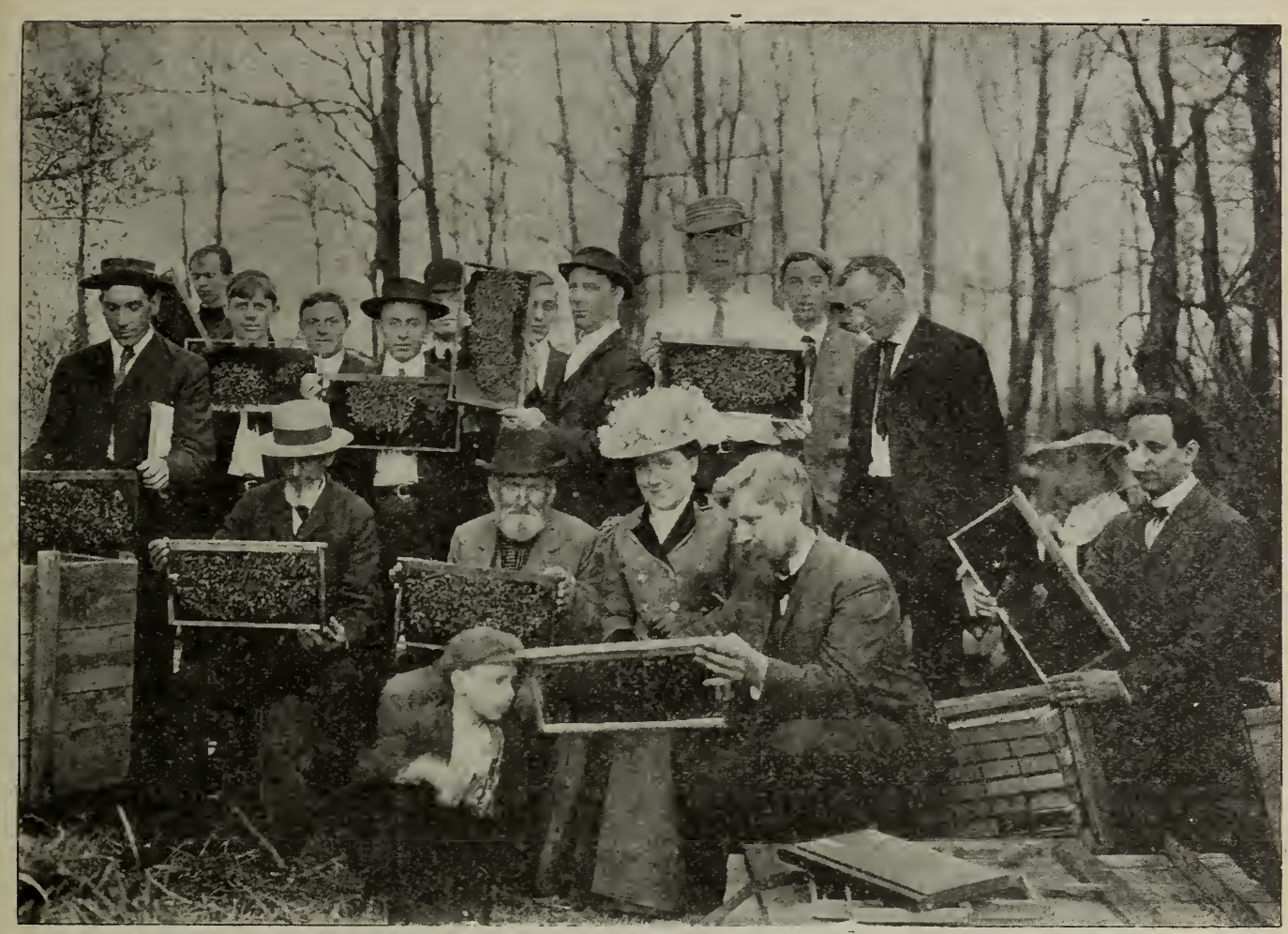

Prof. H. A. Surface, Zoologist, at Harrisburg, Pa., with his beginners' class in beekeeping.

colonies of a large species of stingless bee were exhibited. A hive of them was torn apart and opened for inspection. Did those stingless bees take such intrusion without making any objections? Not at all. They attacked their despoilers in a way they will not soon forget. They would bite, grasp the hair, eye-lashes, twist and pull, and even crawl into the ears and noses of their tormentors. So vicious was their onslaught that they drove one man, who had a hand in breaking up their home, from the scene of action. While the pain of their bite is infinitesimal, yet the high-note hissing sound, getting into the hair, pulling at the eyes and eye-lashes, and crawling into the nostrils and ears, almost makes one crazy.

It is fair to state that stingless bees do not offer such attack unless provoked to fury; ordinarily they can be handled without any protection whatever.

BEGINNING WITH BEES.-The beginner should, first of all, read the A B C of Beereepixg, the initial article of this work. He should also visit some well-known beekeeper. He will then find that he will be able to understand the articles and appliances in this work much more readily. If he can afford it, it would be well for him even to go some distance to see some progressive beekeeper, and spend a whole day where he will be able to pick up tricks of the trade, and a fund of information that might take him weeks or months to dig out of textbooks. Even if he knows of no one but an old-fashioned box-hive beekeeper, he should see him; but, far better, visit some practical man who will be able to point out the queen, and illustrate the modus operandi of opening a hive and handling the frames-in short, make a practical demonstration of many of the manipulations here explained. If there is no beekeeper he can visit he should send to his nearest dealer and get a one or two frame nucleus with a queen. Let him follow carefully the directions on the outside of the shipping-box; then, with the bees before him, read and study his A B C's. Having seen the bees and learned how to open a hive, what next?

The importance of a small beginning with as little expense as possible cannot be urged too strongly, for nothing is more discouraging after having plunged into the business extensively (blindfolded as it were) than to lose a large portion of the bees, either thru 


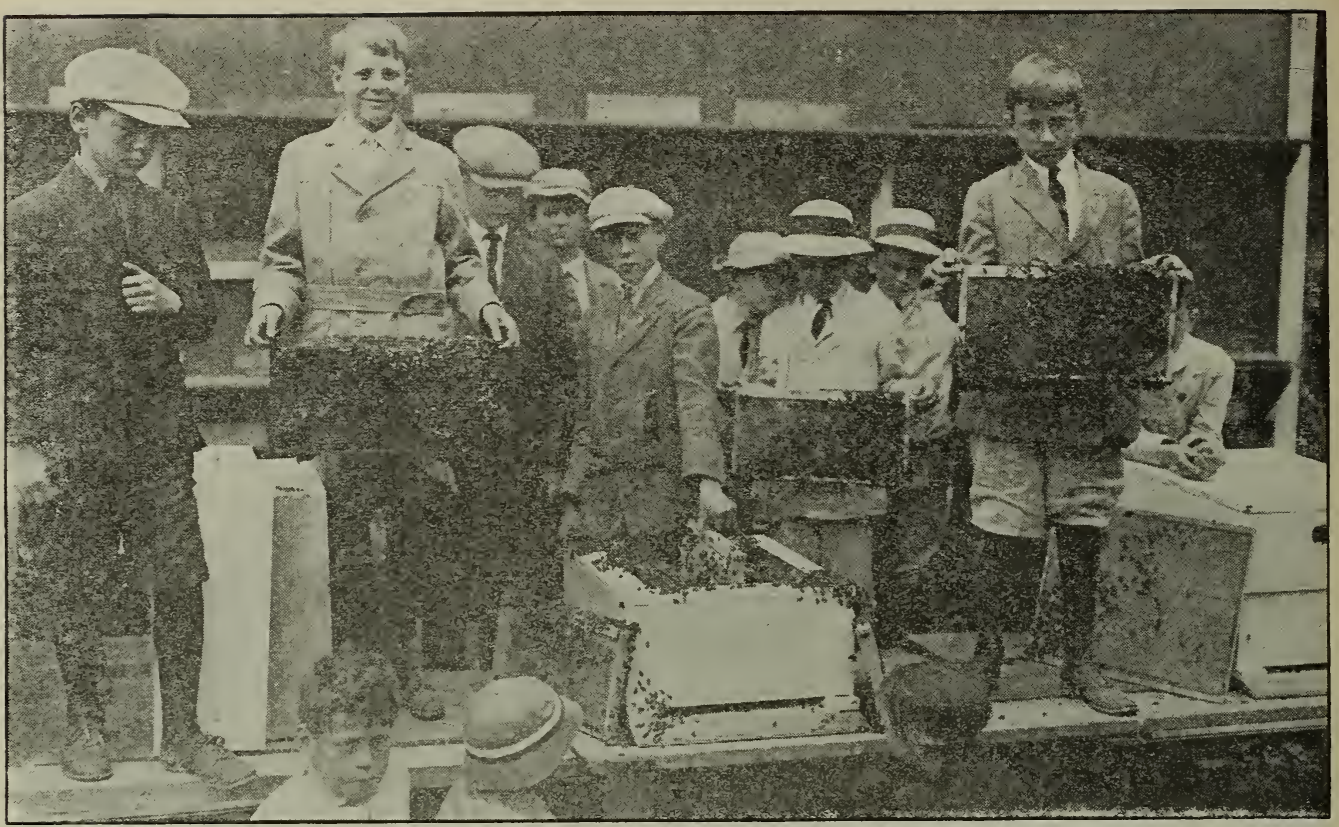

A group of boys who here found out that bees can be "tamed."

bad wintering or from some other causeall for the want of a little practical experience, or even a theoretical knowledge. Many a person has met with disaster from starting out with bees on altogether too large a scale. Sometimes one is offered a bargain of 50 or 100 colonies including. hives, bees, implements, smokers, etc., at a ridiculously low price, and the temptation becomes strong to buy. He'd better not invest unless he has read the several articles indicated at the close of the Foreword at the beginning.

After investing $\$ 25.00$, put no more into the business until the bees bring in some returns. In other words, make the bees pay their way. It is a very easy matter to throw some good money into the venture and get no returns; because beekeeping as a business is something that depends as much upon the weather, perhaps, as any other. For this reason we do not advise any one to rely on bees as a sole means of livelihood. True it is that there are many beekeeping specialists; but they are men who have gradually grown into the business, and as a general rule have an especially favorable location, keeping from 500 to 1000 colonies.

The keeping of bees is generally more successfully carried on in connection with some other business. (See BeEkEEPING AND FruIt-growiNg; also BeEs and Poultry.
Many a professional man desires some sort of light recreation, and a few bees will afford him just the diversion he needs. Farmers, fruit-growers, or horticulturists, may keep from 50 to 100 colonies without greatly interfering with any other work; and nearly every one, as explained under APIARY, can keep a few colonies in his back yard. Ten or twenty colonies will yield almost a certain return of a much larger revenue, per colony, than ten times that number. See BACKrot BeEKeEping.

Having considered some of the difficulties and uncertainties of beekeeping, we may now inquire whether we desire to go into the business at all. With the knowledge that from 10 to 20 colonies can usually be handled successfully, and at a good profit, the beginner will naturally desire to try his hand at it. How shall he make his start? Whenever possible, bees should be purchased in one's own vicinity. A strong colony of Italian bees, with a tested queen, in a new Dovetailed hive, or in any modern hive, in fact, might be worth $\$ 10.00$. If bees are bought of a dealer from a distance it will cost more. Usually bees that are hybrids or blacks, in movable-frame hives, second hand, sell from $\$ 3.00$ to $\$ 5.00$ per stock, including hive. If there are no modern beekeepers in the vicinity he may have to purchase a box hive or two with the combs all built 


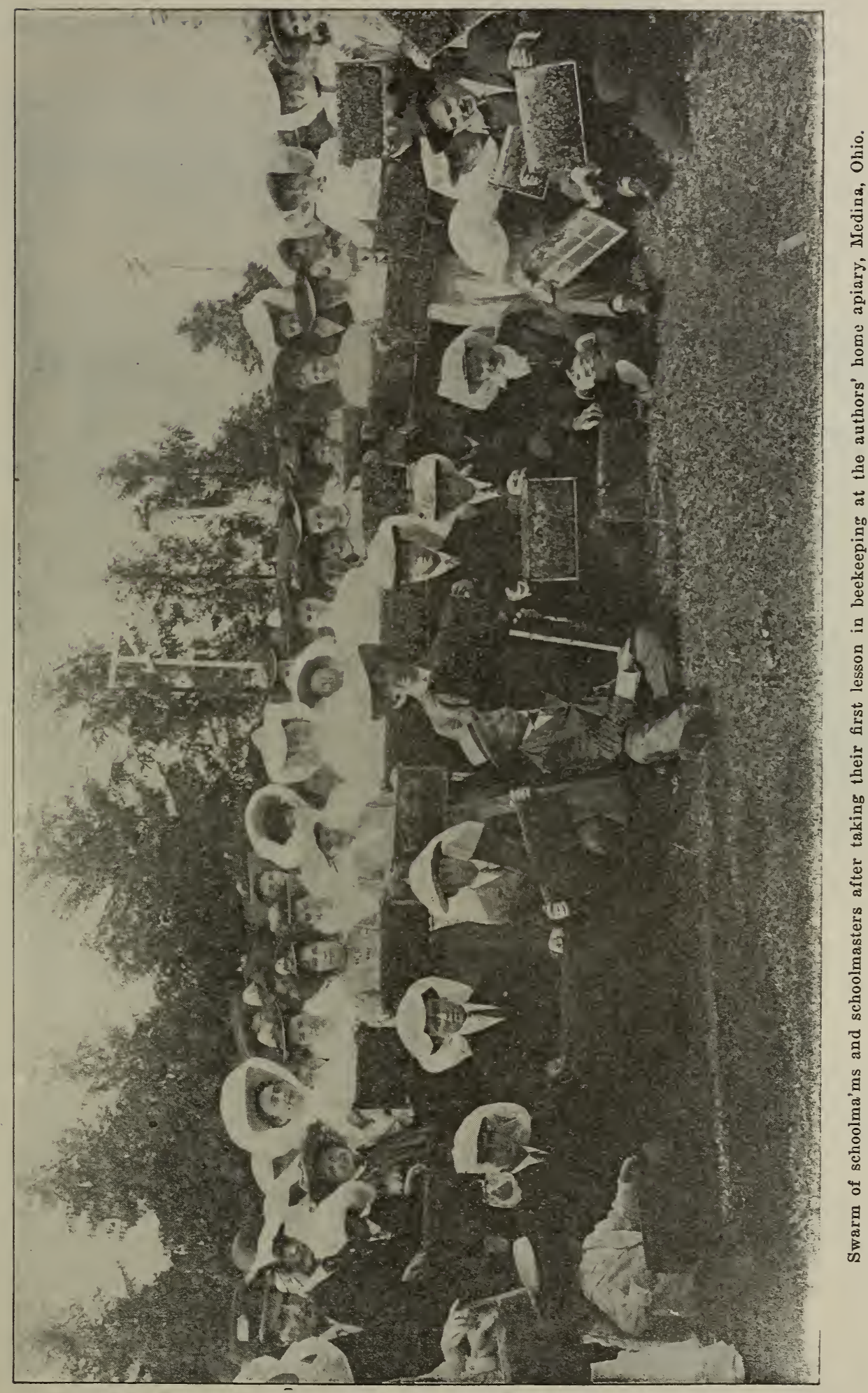


solidly into the hive-see Box Hives. The price of these, if they are blacks or hybrids, is generally from $\$ 1.00$ to $\$ 3.00$ per hive.

To move colonies in box hives, turn the hive upside down, and tie over the end a piece of cheese-cloth. The moving should be done at night, or at least on a cool day, carrying them a distance of at least a mile and a half, otherwise many of the bees will return to their old location, unless they are much bumped and jounced in moving. See Moving BeEs.

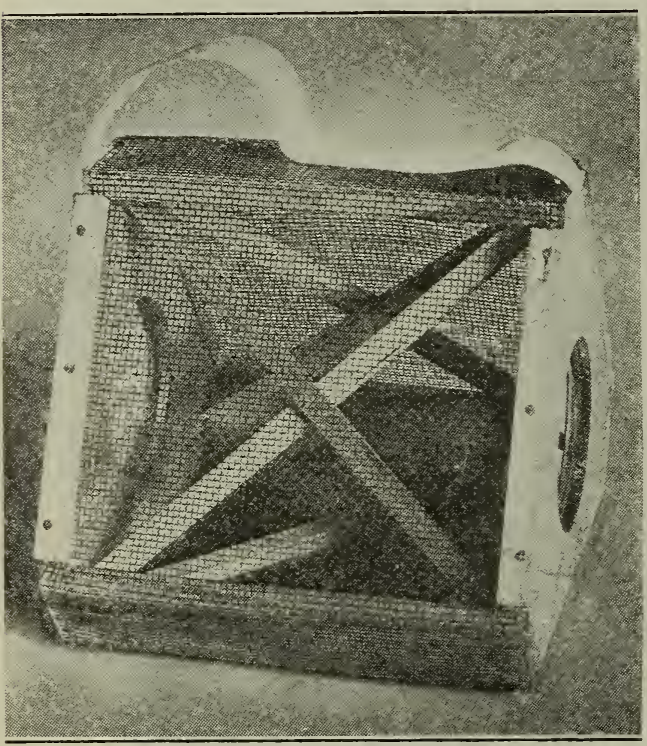

Half-pound cage for shipping bees. The triangular construction adds to the strength and insures abundant ventilation.

In some localities it may not be possible to buy bees of any one. Send to the nearest dealer for a half-pound or a pound of bees, or a one or two frame nucleus with a queen. If one doesn't mind expense, let him purchase four or five pound packages or nuclei and then proceed to build them up as described under Nucleus and FeEding.

On account of the danger of spreading bee disease we advise the purchase of bees in pound packages without combs. They come much cheaper this way, and the expense is very much less. See SHIPping BEEs.

Before purchasing any bees one should get of his dealer or manufacturer five or ten modern hives in the flat. As there are several such hives on the market, all of them fairly good, the beginner may be at a loss to know which of them to choose. For comb honey we would recommend the Dovetailed hive. For particulars see Hives. They are sold by all the dealers; and as these hives

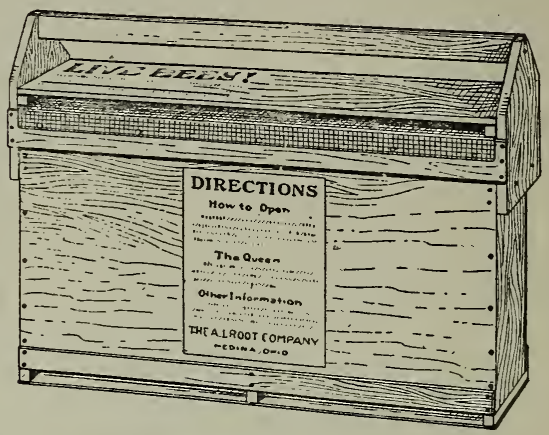

A two-frame nucleus shipping-box.

are used largely by expert beekeepers who carry on the business quite extensively with good results, the novice will not go far astray by adopting them.

As soon as the hives are received in the flat, nail them up and paint them. With every lot of hives there will be sufficient nails of the right kind to put them together. If one cannot afford to take the time himself, let him employ some carpenter, who, with the printed directions, will be able to put them together in a workmanlike manner. ( $A$ carpenter is not needed, however.)

Having the hives all in readiness, five or ten, as the case may be, one can, with his pound of bees or two or three nuclei, build them up by feeding, and then divide as recommended under Nuclueus and FeEding.

If the beginner is successful thus far, he may then, with some assurance, purchase of his dealer one or two Italian queens, which he can easily introduce to the nuclei. See INTRODUCING. In dividing or forming nuclei, he should, of course, give the new queen he just purchased to the bees that are made queenless. After he has had a little more experience in watching and studying bees he may then be able to do something at queen-rearing. See QUEENS and QuEENREARING. To avoid trouble with robbers he should then read very carefully the subject of Stings and Robbing. Toward the close of the season he should next take up WiNTERING, as found in its alphabetical order, reading this carefully; for more disasters in apiculture result from failure to winter bees properly than from any other cause.

BELLFLOWER.-See Campanilla. 
BLACK BROOD.-See FOUL BROOD.

BLACK LOCUST.-See LocUST.

BLEACHING COMB HONEY.-Under head of Coms Honey, and Grading Comb HoNer, will be found something concerning the fact that a good many sections have soiled surfaces. This discoloration of cappings may go clear thru, or it may be upon the surface itself. If the reader will look

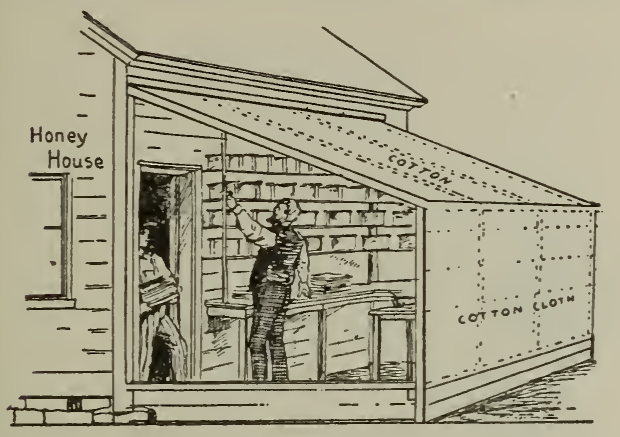

White's bleaching-house for soiled comb honey.

over the unsold odds and ends of the grocer's he will be able to find samples of all these classes, and the fall of the year is a good time to find them, as they are the last to sell.

A knowledge of how to make dark or soiled sections No. 1 white, thus putting them at the top of the market, may be worth hundreds of dollars to some beekeepers; and while it is probably not possible to make water-soaked and certain kinds of travel-stained sections white, there is a probability that a very large class of the soiled boxes can be rendered No. 1 .

The late Byron Walker, a honey-merchant of Chicago, accidentally placed some yellow or pollen-stained sections in his show-window, where they were subjected to the direct rays of sunlight. A short time after he noticed that the faces of these sections that were next to the light were bleached white, while those on the reverse side retained the old color. Instantly grasping at the suggestion he placed other sections of the same kind in the same window, and was gratified to learn that these were likewise bleached as were the first; but so far as we know, Mr. Walker was successful in bleaching pollen-stained or yellow-faced combs only. The real travel-stained and water-soaked ones he considered beyond redemption. The time required to bleach the yellow sections was anywhere from two to three days, depending on weather and sunlight.

Mr. A. E. White, of Pala, California, apparently goes one step further; for in connection with sunlight he uses sulphur, which is known to be a powerful bleaching agent. His method is described as follows:

"We first fumigate with sulphur, the: place the combs where the sun will shine on them, and that is the whole process.

"I build a frame on the south side of my honey-house, and cover the same with cotton cloth. A door opens from the honeyhouse into this room. I place shelres on the sides and ends of this room, the bottom shelf being a wide board to be used as a table. I place the combs on these shelves so that the sunlight will strike them. Dark combs will require several hours. This plan will whiten dark combs here in California. If you fumigate a few combs, then place them on a window-sill where the sun will shine on them, you will be convinced.

"In placing the sections on shelves in the morning, I find the following plan good: On the shelves at the east and west end of the room I place sections end to end lengthwise of the shelves, two rows on each shelf, one row on the outer and the other on the

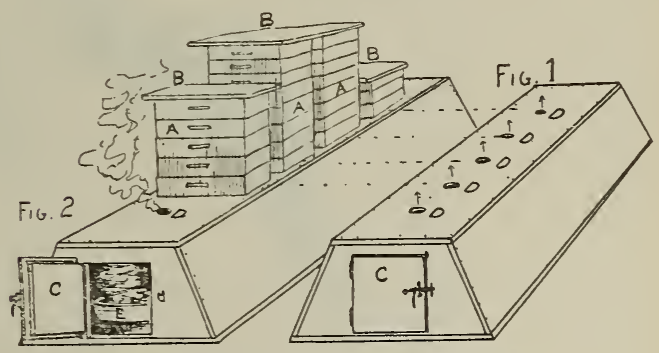

White sulphur-box for bleaching.

inner edge. The morning sun strikes one side, and the afternoon sun the cther side. On the front shelves, I set them crosswise of the shelf, far enough apart so as not to shade each other.

"I pack them away every evening; all not white I put out again next morning. Some of them will bleach quite slowly, but I have been able to whiten the worst ones by perseverance."

BORAGE (Borago officinalis L.).-The common borage, introduced from Europe, is cultivated as a honey-plant and for ornament. The rotate or wheel-shaped flowers 
are sky-blue with a black cone of anthers in the center. Under the dome formed by the anthers nectar is freely secreted by the pale yellow base of the ovary. The more or less inverted position of the flowers which face the earth protects them from rain. The anthers mature long before the stigmas. Each anther contains about 120,000 grains of pollen.

Honeybees constantly visit the flowers for both nectar and pollen. Two groups of conical chamber between them. On each anther there is a tooth-like projection. When a bee grasps with its claw the handle on the lower anther it is pulled downward and the pollen is sprinkled over its body. As soon as released the anther springs back in place, and later more pollen collects in the conical chamber. The stigmas are at first concealed beneath the anthers; but after all the pollen has been removed they g'row out and become receptive. The flow-

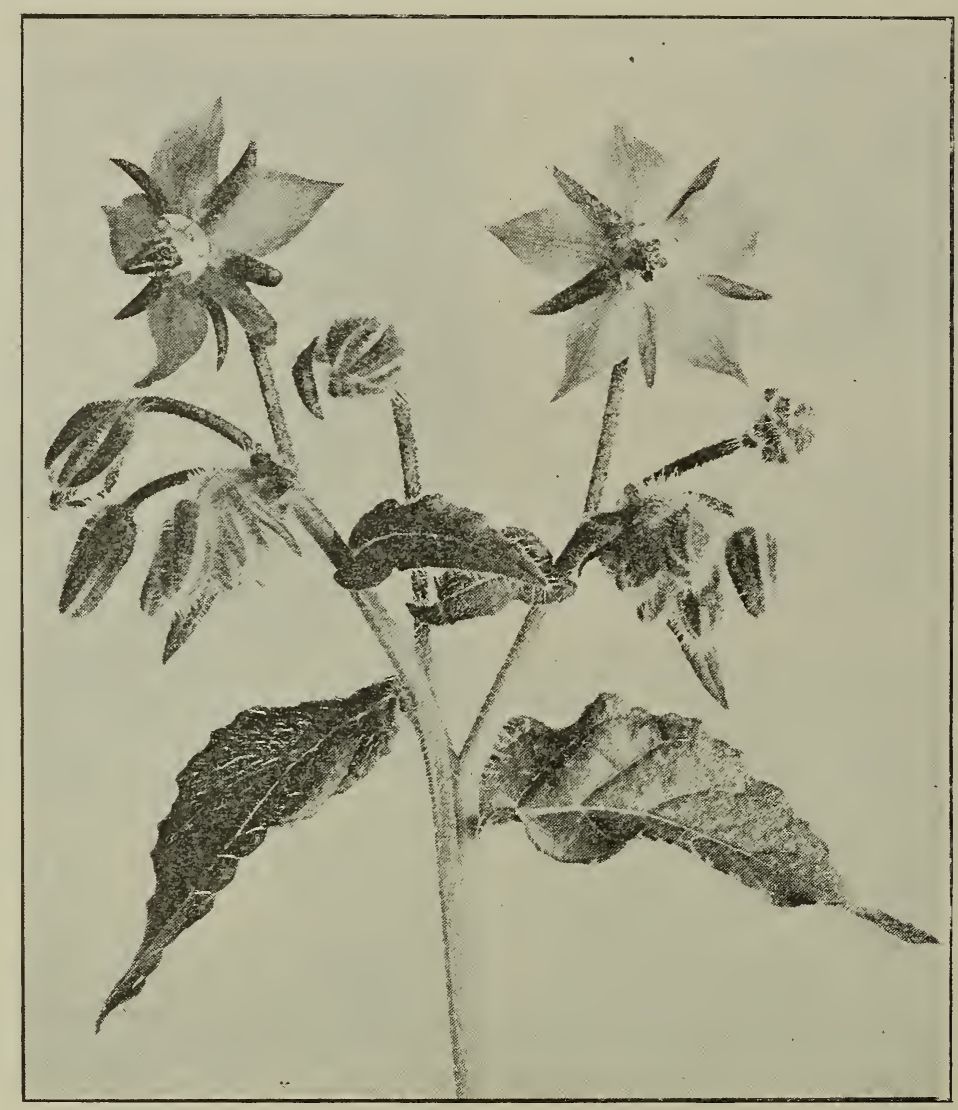

Common borage.

flowers, one containing five and the other four flowers, were watched for ten minutes. The first received 15 and the second 13 visits from honeybees. The value of the blue corollas in attracting bees was shown by the following experiment. When they were all removed from the flowers of the first group the visits of the bees ceased entirely. To reach the nectar a bee hangs under the flower and inserts its tongue between the stamens. The anthers open slowly and the free pollen falls out into the ers are also visited by bumblebees and solitary bees.

The eagerness with which bees visit the borage blossoms shows that it possesses a fine flavor, and the honey is reported to be excellent. The plants can be easily grown from seed, and produce a profusion of flowers from mid-summer until frost. It will not, however, be found profitable to cultivate borage for honey alone. The leaves are sometimes used as a salad and in medicine. 
BOTTLING HONEY.-Under BARRELS we have given some general directions on how to put up honey in wood so that it may be sent to market. Under Extracted HoNEY we have shown the styles of containers made of tin. Under Granulated Honey we tell how to liquefy; but here we wish to give some details on putting up honey in glass. One who can bottle honey and put it up in neat and attractive form so it will nct granulate for at least a year can get geod prices and do a good business.

With one or two exceptions all extracted honey, unless especially treated, will granulate toward the approach of cooler weather -especially when the temperature begins to vary from 70 to 80 to near freezing or below it. As a general thing, granulated honey in glass is unsalable; and we shall attempt to show how to keep the honey liquid until it is sold.

Two methods are used to accomplish this. One is, to heat the honey and seal it while hot; and the other, to sterilize it by exposing it to the sun's rays. We will discuss this later.

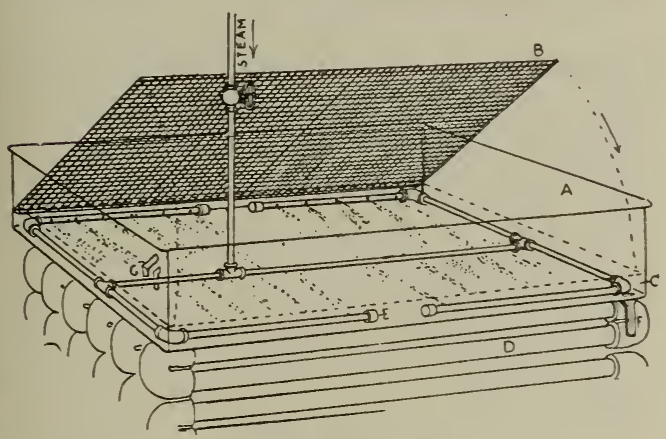

HEATING-TRAY.

Instead of using a gasoline-stove to beat the water in the tray, $3 / 8$-inch steam-pipes connected as in the manner shown can be used. The outside pipes should be perforated with loles that blow a jet of steam transversely across the bottom of the pan. The coil of steam-pipes below serves no purpose but to keep the large filling-tank of honey warm.

Steam from a boiler is, of course, the most convenient of anything for heating that we can employ; but as the average reader of this work probably cannot get it he must use something else. While the ordinary cooking-range or cook-stove, using either wood or coal, may be used for heating honey, a gas or gasoline stove with three burners is far better-better, because the heat can be perfectly controlled. A wood or coal fire is apt to burn too strongly at one time or ga down at another. If the honey be orerheated it will be injured, both in color and flaror. It may be scorched, or the flavor so impaired that it will sell at only a moderate price.

There are two methods for heating honey to put in glass or tin. One is, to draw it off from a large can while cold, in bottles or tumblers, and, before they are sealed, heating the honey while the bottles are standing up to their necks in hot water. The other plan, and the one generally used, is to heat in bulk and then draw off into bottles while hot, and seal. This method has the advantage that warm or hot honey flows more freely, and, of course, can be handled more rapidly. On the other hand, heating honey in the retail glass packages has the advantage of being better adapted to a small business.

\section{HEATING HONEY IN BOTTLES, OR BOTTLING FOR A LOCAL TOIVN TRADE.}

Proride a square or oblong galvanizediron pan as large as the top of the stove, with perpendicular sides, and about six or seven inches deep. If a gasoline-stove is used, the pan should be as long and as broad as the top; and if the three burners are on the same level, all the better. The pan should be just about the depth of an ordinary Mason jar; or, rather, a little deeper than the deepest package to be used. A false bottom of coarse wire cloth should be secured about half an inch above the bottom proper by means of proper stars. This is for the purpose of providing a circulation of water under the bottoms of the bottles, for otherwise they might break from the direct heat of the stove. Fill the pan about half full of water, and set it on the store.

When the water registers about 180 according to the thermometer, set the bottles of cold honey into the tray, on the false bottom of wire cloth. When the pan is full of bottles placed close together. the water should be raised to within an inch of the top of the bottles. Let them stand in the hot water until the honey in one of the bottles register's about 160 . They may now be taken out and corked or. sealed. A fresh supply of filled bottles of honey should next be put back to replace the first lot, and the operation of heating and sealing can be continued indefinitely. 
There are several advantages of this method, aside from the one of first cost for apparatus; viz.:

1. One can fill a small order at any time, and it is not necessary to heat a great bulk of honey in order to put up a dozen bottles or so of honey. In heating a large quantity of honey one necessarily has to keep it hot for a considerable time. The longer the honey is kept hot the greater the liability to discolor and impair its flavor.

2. Bottles that are submerged in hot water can be easily wiped off with a cloth; and as soon as they are corked or sealed they are ready for labeling.

3. Any honey that has been poured from a honey-gate into the vessels cold will have a tendency to collect air-bubbles; and it is these particles of air that hasten granulation. When the honey is heated gradually in the bottles aftei' filling, the process expels the bubbles; and by the time the honey is clear it is ready for sealing and labeling.

4. If any honev should candy, one can unseal, and set the bottles in the tray of hot water, and reheat and seal without emptying.

Honey bottled in this way will retain more of the original flavor than when it is heated in bulk and then bottled.

Where one has a little larger trade, and takes care of one or two towns outside of his own community, the foregoing will be a little too slow; and, besides, it has the decided disadvantage that honey bottled in this way will granulate more quickly than honey heated in bulk, and kept hot for a considerable length of time. A large quantity of honey in a tank can be kept hot for five or six hours at a temperature of 130 degrees Fahr. This low temperature long continued will keep honey in a liquid condition longer than a higher temperature for a shorter period. But, as already stated, a long-hot honey will not have quite as fine a flavor as the quicker heated and quickly cooled article. But this difference will be noted, not by the ordinary consumer, but by the bottler or honey connoisseur. We shall consider, therefore, convenience and low cost of production, even if we do have to sacrifice slightly in flavor.

Mr. Chalon Fowls, of Oberlin, O., has used a method of bottling that requires but very little outlay for apparatus, and is quite inexpensive, Outside of two large pails and a filling-tank he utilizes only what can be found in the ordinary home.

As stated, Mr. Fowls makes use of a gasoline-stove and a couple of large cans which he puts on each of the top burners. These are partially filled with water, then a square can of honey is let down in each until it is completely submerged. After the contents are all melted, a thermometer is let down, as will be ssen; and when the

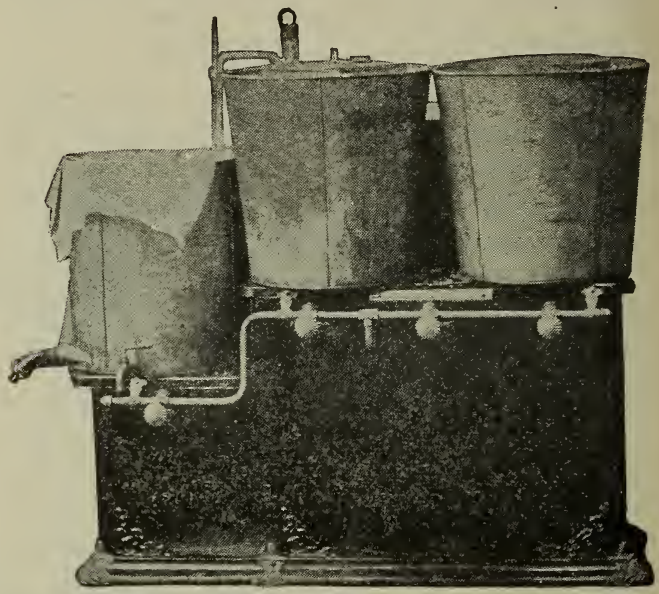

Mr. Fowls' melting-tanks, siphon, and gasolinestove.

mercury rises to about 150 (not higher than 160 ), the honey is drawn off by means of a siphon into a filling-tank that stands on a lower step of the stove. The siphon may be of glass or flexible tubing. The latter is to be preferred, because it is more convenient to handle. While the honey is hot the tubing should be immersed in the honey until it is filled. To do this, attach a string at both ends, and submerge it. Draw out one end and run it over into the filling-tank, which is lower down. The hot honey will now immediately run out; and as the can is emptied, the water surrounding the can should be drawn off or else the can will float and tip over. From the filling-tank the honey is drawn off while hot, or about as near 140 as possible, into honey-tumblers, Mason jars, Muth jars, or any of the packages already described. When filled they should be sealed while hot; after which, as soon as they are sponged off in warm water, they may be labeled, when they are ready for market.

BOTTLING ON A LARGE SCALE.

The Fowls plan will take care of several towns of two or three thousand inhabifants 
cach; but it is not well adapted to a general business, taking a whole state or a series of them. An ordinary store or a gas-stove is not well adapted to take care of a large business; hence it will be necessary to purchase a five or ten horsc-power boiler and install it in a room or basement where the bottling is to be carried on. Steam is by all odds the best heating agent in a general bottling establishment. It is more convenient, cheaper, and there is but very little clanger of overheating the honey, if the thermometer is used to register the temperature.

The great bulk of the honey for bottling purposes will come in 60-lb. square cans. While some of it may be secured in kegs or barrels, producers and buyers generally prefer to sell and buy honey in large square cans, eren at an extra price of half a cent; so we may as well figure that in a bottling business the honey will be received in the tin containers. Much of this honey will be granulated before the bottling season comes un.

There are two ways of melting honey in square cans. One is, to submerge them three-fourths their depth in a large tank of water heated by steam until all the honey is melted. But this is objectionable, in that the melted portion has to remain with the portion still granulated until the whole bulk has been brought to a liquid condition. This impairs the flavor, for the longer honey is kept hot the more its delicate aroma and color are sacrificed. The plan also necessitates the lifting of heary cans of honey out of their bath of hot water and emptying them into the filling-tank.

A far better plan is to heat these cans with hot air, while inverted, in a steamoven. The caps are, of course, removed, and as fast as the honey melts it rums out and is caught in a receiving-trough beneath. Thence it flows immediately into another container, or is pumped out with an ordinary honey-pump, such as is used in connection with power-driven honey-extractors. See Extractors and Extractixg.

Illustrations showing a honey-heating oren will be found under GranuLATED Honer. See Figs. 1 and 2, Pouder's method.

While Mr. Pouder uses a gas jet, it is preferable to use steam-pipes, so placed as to be out of the way of the honey that runs out of the screw tops into the bottom of the oren or tank. Enough steam radiation should be provided to bring the temperature of the air in the oven up to 180 or 190 degrees.

When steam is used as a heating agent for these honey-melting orens, it is not necessary to use a metal box, but a large double-walled wooden box with lid, with packing material between the walls, and a galvanized tray or trough in the bottom to catch the honey. The melted honey should not be allowed to accumulate in the oren, but should be drawn or pumped out into a receiving or filling tank immediately. This is important, as it is not practicable to have 11:e oren placed on a level above the fillingtank; a honey-pump to deliver the honey to the tank is much more satisfactory than a lank and honey-melting oren placed at difforent elevations.

The receiring-tank is made on the doubleboiler principle-one tank inside of the other. The outer one should be at least two inches larger in diameter. and the space of about one inch between the tanks should be filled with water heated by steam. The inner tank to hold the honey should have a tube at the bottom, passing thru the hot water to the outer tank, to which is attached a honey-gate. This gate may be used for filling the bottles direct, or the tank may be used for making up the blend referred to further on, as practically all bottled honeys nowadays are made up of two or three different flavors. When a blend is used it is customary to run the honey from the receiving-tank into a separate fillingtank. From the filling-tank there should be attached a three-quarter steam hose fire or six feet long. On the end of this hose is attached a specially made honey-gate, with a snout long enough to reach down to the bottom of the bottles or glass jars. Thile packages can be filled from a honeygate attached directly to the tank, it is much more convenient and better to use rubber hose with a gate on the end. The bottles should be placed in groups of one or two dozen in a tray; and by means of the flexible hose and honey-filling gate, each package is filled without handling. Moreover a long snout on the gate enables one to direct the stream of honey clear down to the bottom of the jar, thus avoiding the accumulation of air-bubbles that make the honey look frothy on top, and, besides, 
hasten granulation. In filling, the snout should be put clear to the bottom of the jar; and as the jar fills, the gate should be lifted slowly until the jar is full. This feature is important. The process is repeated with the next jar until all are filled. Another tray of jars is placed within reach of the rubber hose, and the process repeated. After the jars are filled they are sealed while hot, then labeled and wrapped, ready to be put in paper cartons.

\section{A BLEND OF SEVERAL KINDS OF HONEY FOR BOTTLING PURPOSES.}

The seasons for honey production are so uncertain at times that one finds himself unable to supply his trade with the honey he produces from his own yard. If, for example, his honey is almost exclusively from clover, with little or no basswood or fall flow, the trade will become educated to like that particular flavor, and will reject all other honeys of other flavors on the ground that they are impure. To provide against a contingency of this kind it is advisable to use from the start for bottling purposes a honey that can always be furnished year after year. It is usually customary to make a blend of white clover. basswood, alfalfa, and mountain sage, and if the trade is supplied with this blend from the very start it will become accustomed to it. Such a blend can be made up of honeys that one can purchase when local honey fails; whereas if one puts up only white clover at the beginning, he will find it difficult to purchase a strictly pure clover except at highest prices. Where one lives in a clover locality he will do well to make up a blend of 50 per cent of clover, 25 per cent of sage, and 25 per cent of alfalfa. It may be assumed, for example, that he has a season of failure, and yet the bottling trade keeps up just the same. He usually buys a mixture of clover and basswood. His taste will become educated so he can determine the percentage of the one to the other. Then by putting in a small amount of alfalfa, which he can always procure, he will be able to supply his trade with the proper blend.

If one lives in a locality where alfalfa is produced extensively, there will be no need of having a special blend, because the pure alfalfa can usually be obtained in sufficient quantity.
In mixing the different flavors of honey it will be necessary after putting into the tank the requisite amount of each kind, to stir them slightly while heating. This is to prevent overheating a part of the honey, and to bring about a thoro blend. The stirring may be done with a paddle; but a better arrangement is a sort of extractorreel having blades that will thoroly mix the honey. The reel should revolve four or five times a minute. Faster than this will not be necessary. The little motor that is used to operate the honey-pump can also run a counter-shaft geared back so that the mixing-reel inside of the blending-tark will not revolve faster than the time stated.

\section{USING THE SUN'S RAYS IN SOLAR WAX-EX-} TRACTORS TO PREVENT HONEY IN BOT-

\section{TLES FROM GRANULATING.}

The late H. R. Boardman, of Collins, Ohio; E. B. Rood, of Bradentown, Florida, and some others, have been placing their bottled honey in solar wax-extractors, to "sterilize" the honey. Under some conditions the temperature would reach 150 degrees Fahrenheit. When this is maintained for a good part of the day the heat alone apparently goes a good way toward preventing granulation; but apparently, at least, the actinic rays of the sun have some chemical effect, in addition to the heat. Mr. Boardman, who has been a pioneer in the art of sterilizing honey in bottles by the use of the heat, and light of the sun, wrote an article for Gleanings in Bee Culture, Vol. XXXVII., page 769 . This is what he says :

During the last ten years I have kept, perhaps, an average of one hundred colonies of bees, and have run them mostly for extracted honey. Nearly all of this I have put in glass packages, sterilized in my solar sterilizer, and furnished to the grocery trade or sold in my home market. So entirely satisfactory has this honey been found that I now have very little, if any, other. I am seriously contemplating cutting out comb-honey production entirely in the near future.

I started my experiments with the rays of the sun by placing granulated honey in a solar-extractor to restore it to the liquid state. So well pleased was I with the results that I continued the experiments further. In the mean time I discovered that there were some properties besides heat in the sun's rays which were being imparted to my honey that made it act differently from any honey that I had warmed artificially. These results led me to treat liquid honey, as soon 
as I extracted it, in the same way, and I found that it came out bright and sparkling, with the delicate original flavor unimpaired.

LAST YEAR'S CROP.

Some of my honey from last year I carried over. It was in two-quart jars, and all that was thoroly treated to the sun I found remained bright and sparkling, and in perfect condition in every way. Some that had been treated hurriedly, on acount of a lack of capacity of my sterilizer, crystallized more or less, but I was not disappointed in this. Honey that is often disturbed will soon show a tendency to granulate. Moisture will cause honey to granulate. Some of the jars showed some granulation. A little water got into these jars after the honey was sterilized last year. This honey grained and settled down into the elear liquid, and remained suspended in fantastic shapes.

In 1902 I sent the editor some samples of honey put up in jelly-glasses, and taken from a lot prepared for market the year previous. At that time, as it showed no signs of granulating, I supposed it would remain liquid indefinitely. This was put to a strenuous test during the winter, and it granulated as reported at the time. I am entirely satisfied, however, from further experiments, that this granulating was caused by frequent handling and disturbing. I have some of this same lot of samples yet that have remained undisturbed, and there is no granulation even tho seven years liave elapsed.

In the light of these experiments I think it is conservative to say that honey thoroly and properly sterilized will remain from year to year unchanged, and, under favorable conditions, will remain indefinitely without granulating. If, for any reason, the honey is not thoroly treated, it may sooner or later show a tendency to crystallize.

In this connection I would say that I have found full sunshime absolutely essential to perfect sterilization. Unfortunately, this is a feature which we cannot control. In the sunny South I know of no reason why a solar sterilizer of honey should not be eminently successful, and, to some extent, be utilized in putting up bulk comb honey.

The honey to which $\mathrm{Mr}$. Boardman refers, and which he desired us to test, was placed on the window-sill just outside of the office. This honey stood outdoors during the following winter, subject to extremes of temperature; and if there is any thing that will make honey granulate, it is alternate warming and cooling. The temperature during the summer would probably go up to 90 in the shade, and in winter anywhere from 50 degrees above to 10 below zero. Certainly the conditions were favorable for making this honey granulate; but it remained liquid thruout the winter and all the following summer; but by the middle of the following winter it began to show slight traces of granulation. We do not know cf any honey that has been subjected to heat alone that has stood this extreme difference of temperature for so long a period, and therefore we conclude that there must be something in the chemical effect of the sunlight itself.

The question naturally arises why large bottlers of honey do not use the sun's rays rather than artificial heat alone. Principally because the solar wax-extractor, for commercial purposes, is too slow; and because, further, in the northern states there are too many days without direct sunlight, especially at that time of the year when the bottling trade should be at its height. But for a local demand, the solar wax-extractor in the matter of convenience and effectiveness is probably much ahead of artificial heat alone.

\section{WASHING AND CLEANING BOTTLES.}

Prepare several tubs of water-one of them with strong suds-and then have on hand a few ounces of shot-No. 6 is about right. If particles of glass or dirt cling to the inside of the bottles, pour in four or five ounces of shot and give the bottle a shaking. This will dislodge all particles, when the shot may be poured into another bottle, to be similarly treated. In rinsing, use clear soft water. Hard water is liable to leave traces of sediment. Any glass packag'e used for honey designed for table purpcses should be spotlessly clean.

\section{HOW TO INSERT CORKS IN BOTTLES.}

Two or three methods are employed. One is, to use a rubber mallet, which can be purchased at any of the rubber-stores. The ends of the mallet being soft, a cork that is barely entered can be driven into the bottle with a blow.

Another plan is to use a lever, as shown at $\mathrm{D}$, in cut. This lever should have a projection on the under side so the cork can be forced down into the bottle about a sixteenth of an inch. It is important, after corking, to pour a layer of paraffine or wax over the top of the cork. Some go so far as to dip the corks into hot paraffine, then pour a hot layer on top after they are inserted in the bottles. Nay, some go even further. After the corks have been paraffined they put on a neat tinfoil top. If the honey has been heated above 160 , and sealed 
while hot, and the cork is made impervious, it will remain liquid for months; as we have seen samples of honey put up in Muth jars that have been kept in a refrigerator six months, and yet it would remain perfectly clear all the time. But the grocer customers should not be advised to put honey in a cold place. The bottles should not be handled more than is necessary, but be kept in a warm place at as uniform a temperature as possible.

Assuming that no directions are necessary for sealing packages using rubber rings, it is important that the sealing be made as tight as possible. In the case of Mason jars, the tops should be screwed down with a wrench, and screwed down tight.

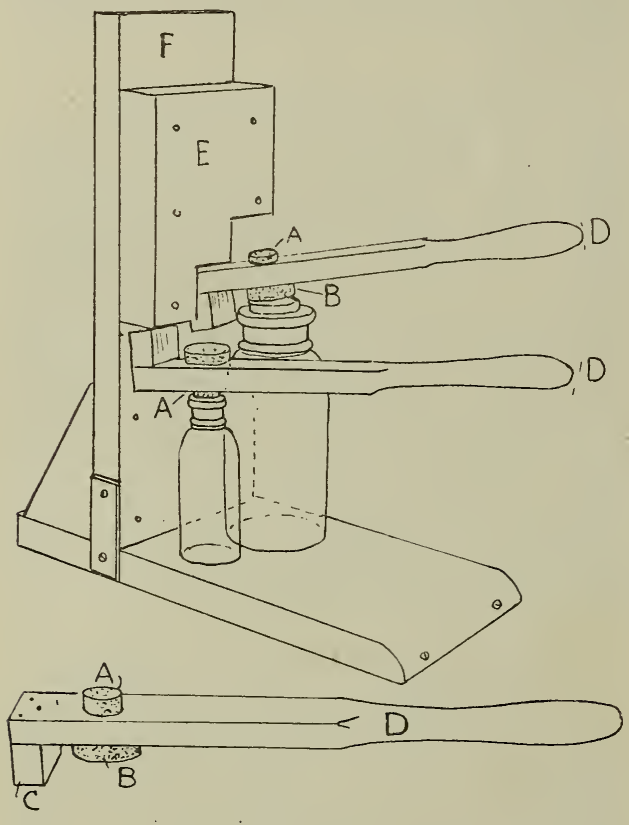

In sealing jelly-tumblers, cut circles of paper (preferably paraffined paper) about the size of the top of the tumbler. When the jar is filled, put the paper on top of the jar, and squeeze the top down with the palm of the hand, putting a large part of the weight of the body on it. If the top

goes down too easily, use thicker paper or two thicknesses.

\section{REQUIREMENTS OF THE LAW AS TO LABELS.}

It will be well to state that the national pure-food law, and in. some cases state laws, require that the label shall indicate the exact contents of a package; and therefore it would not be advisable to call a blend, such as we have described, a pure clover. It will be perfectly proper to say "pure extracted honey bottled by John Jones;" but John Jones must not say "pure extracted honey from the apiary of John Jones" unless such honey did actually come from his apiary.

Allusion has already been made to the fact that the federal laws, and in some instances state laws, require that the exact quantity by weight or measure of the contents for retail purposes shall show on the label. It should be stated, in this connection, that the Bureau of Chemistry has ruled that anything under one pound should be stated in ounces. Anything above a pound should be stated in terms of pounds and ounces. It is contrary to the ruling to make a label read " 36 ounces, net weight," when it should read "two pounds and four ounces, net weight." The purpose of this is to prevent confusing of the consumer by making a statement which may be at the same time misleading. If the package states, for example, that the package contains 60 ounces, the consumer has to make a mental calculation to determine how much honey or other food product he is getting. The purpose of the law is to give the consumer an opportunity to know just what he is getting, and the exact weight in terms that are the most easily understood.

\section{LABELING BOTTLED HONEY.}

As a general rule, use small circular labels. The big ones that cover up the whole jar do not usually afford as pretty an effect as the small neat tasty labels that give the customer an opportunity to see the honey. It is the honey that sells; and if it is a fine quality, get the grocer to display it in such a way in his window that the light will sparkle thru it, and we will guarantee it will sell. See LABELS FOR HoNEY.

BOX HIVES.-It seems as if any description of box hives in a work to teach modern apiculture would be out of place; but the facts are, there are thousands upon thousands of colonies kept in these old gums in the South Atlantic states where there are more bees and beekeepers to the square mile than anywhere else in the United States. 


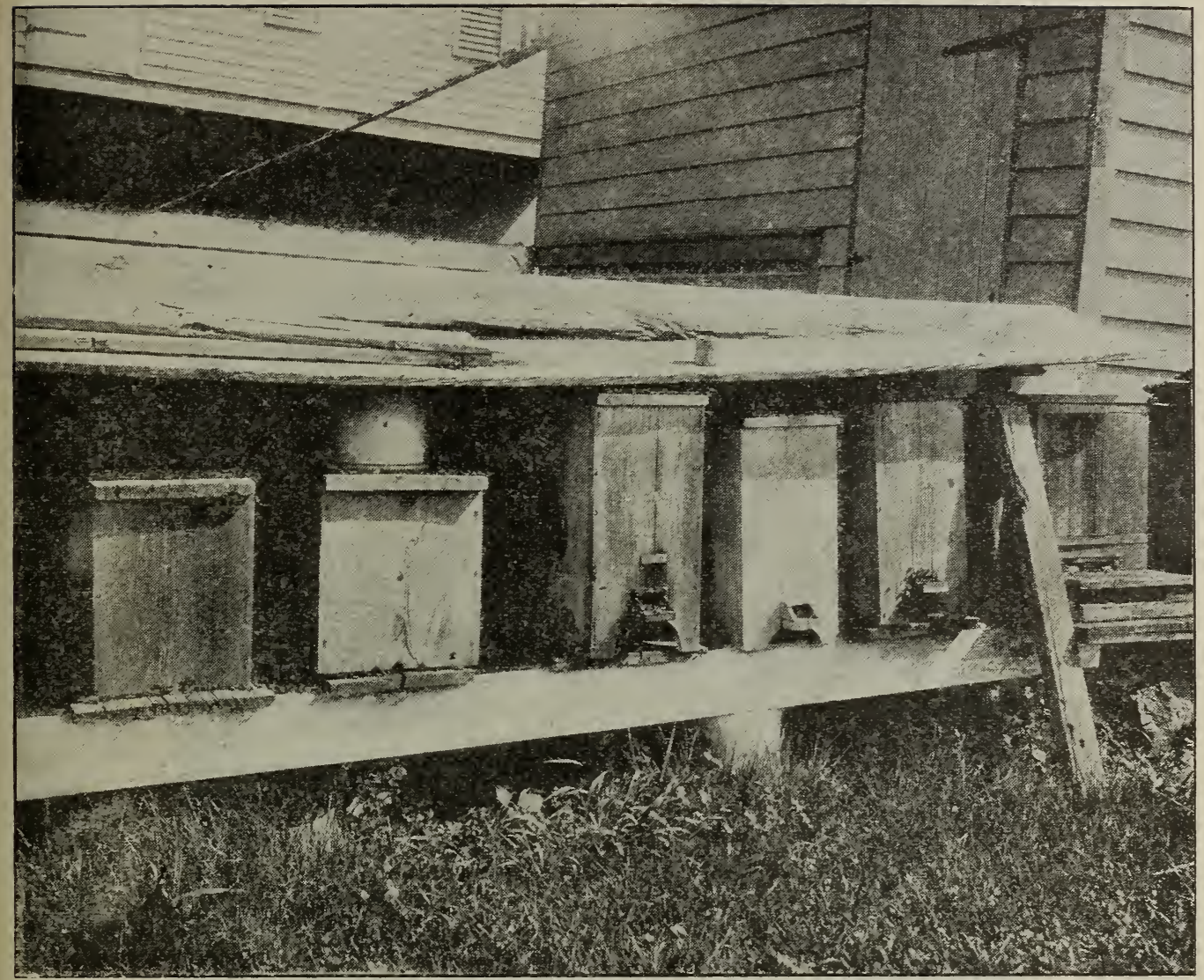

A typical backlot box-hire apiary under a shed.

These hives, as the name indicates, are merely boxes containing neither broodframes nor movable fixtures. They usually consist of a rude rough box about a foot square, and from 18 to 24 inches high. Thru the center there are two cross-sticks, the purpose of which is to help sustain the weight of the combs built in irregular sheets within the hive.

At the close of the season it was and is the custom for the apiarist to go around and "heft" his hives. Those that are heavy are marked to be brimstoned; and those that were light were left to winter over for next season if they can. The bees of the first named were destroyed with sulphur fumes, and then the bee-bread, honey, and everything were cut out.

In the more modern box hives there were boxes with glass ends that could be drawn out from an upper part, leaving the lower intact. In this case the bees were not destroyed. In any case there was no opportunity to inspect combs, hunt queens, divide, nor perform any of the hundred and one operations peculiar to modern apiculture.

As stated at the outset, in some of the southern states, particularly the south Atlantic - Virginia, North Carolina, South Carolina, Alabama, and Georgia-box hives or log gums are used very largely. Indeed, there are very few modern hives or modern beekeepers. The mountaineers in some of those states are of the purest of pure Anglo-Saxon blood. Their ancestors came from England three hundred years ago. As their isolation up in the mountains shuts them out completely from the outside world, many of the old customs and modes of speech still cling to them. At all events, they appear to be keeping bees in box hives or gums just as it was done in England 300 years ago. They have no knowledge of modern methods. The moth-miller, swarming, and wintering, are the handicaps that prevent them from getting much honey. The most of them, for example, know nothing of hiving the first swarm on the old stand, and placing the parent colony to one 
side or in an entirely new location in order to catch all the flying bees with the swarm. They leave the parent colony on the old stand, and, of course, it continues to swarm itself weak. In the mean time the mothmiller and winter get in their destructive work. The result is that little or no increase is made, and the prime swarms are the only ones that yield any return. If foul brood ever gets a foothold here the business, such as it is, will be wiped out.

No matter what the season is, even tho the crop has been only half harvested, the it is to be hoped that the United States will some day send experts down into this country to teach modern methods; for statistics show that there are more bees and beekeepers in this Southland than in any other portion of the United States. The country is exceedingly favorable for the keeping of bees, and the day should not be far distant when modern apiculture will supplant the old box-hive system, coupled as it is with ignorance and superstition.

It is cnly fair to state, however, that the class of box-hive beekeepers here described

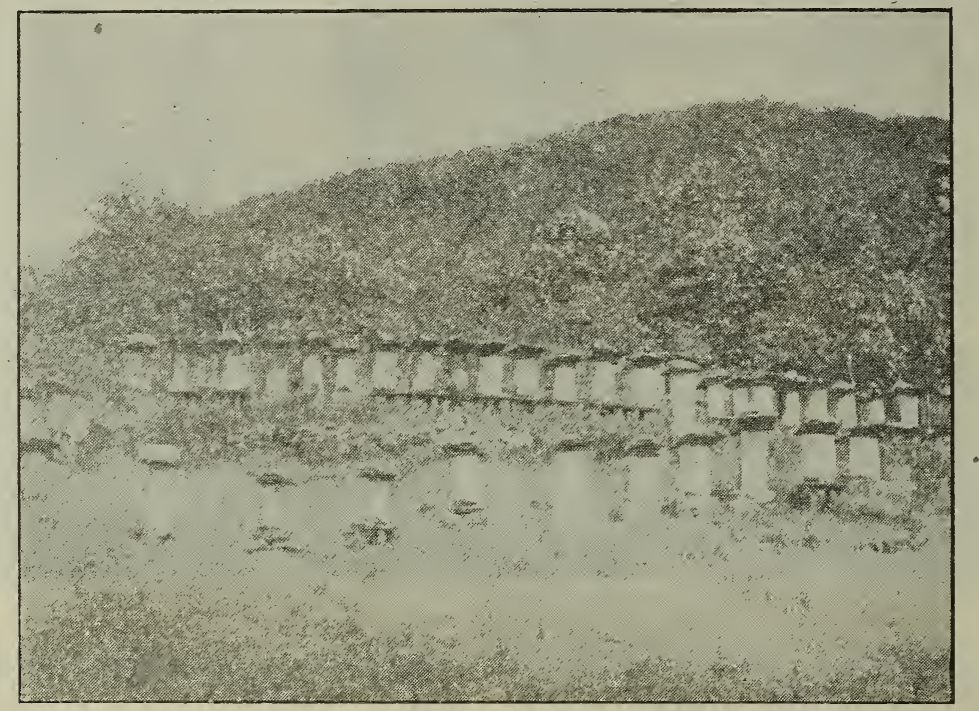

A TYPICAL LOG-GUM APIARY IN THE MOUNTAINS OF GEORGIA.

There are many log apiaries all thru the South. The hollow logs are better because the walls are thicker than those of the regular box hives.

colony must be brimstoned and the honey taken off at some particular phase of the moon.

Whenever there is a death in the family the bees must be notified by pounding on the gum and telling it that So and So is dead. On Washington's birthday, Feb. 22, the gums must be moved an inch or two or the bees will all die. If a visitor calls to see the bees, and the owner is asked how many gums he has, he always says he does not know exactly. If the visitor proceeds to count he is stopped immediately; for to count the colonies and know the exact number would invite calamity; and so common superstition seems to have gotten hold of these splendid highlanders, the purest of the pure descendants of our forefathers.

Possibly here is a case showing that if ignorance is bliss 'tis folly to be wise; but does not represent all of this Southland; but there are enough of them to require the earnest attention of the extension workers or county agents sent out by the general Government.

Some of these people live in almost absolute poverty when they might just as well get a fair living if they could but know of the modern methods of handling even box hives.

Moses Quinby, in the early '50's, handled box hives so that he made money; and if these people cannot afford movable-frame hives, they could, by the simple expedient of hiving a swarm back on the parent stand, and, removing the parent colony, vastly increase their resources. Father Quinby did not brimstone his bees; and neither will these purest of pure Anglo-Saxons up in the mountains of the South Atlantic states 
be compelled to do so. Quinby's old book of 1853-a reprint of which the publishers of this rolume are now making, will be available very soon. This explains how
BR.EEDING STOCK.-Every well-regulated apiary or series of apiaries should have one or more choice queens from which to breed. Such queens should, of course, be

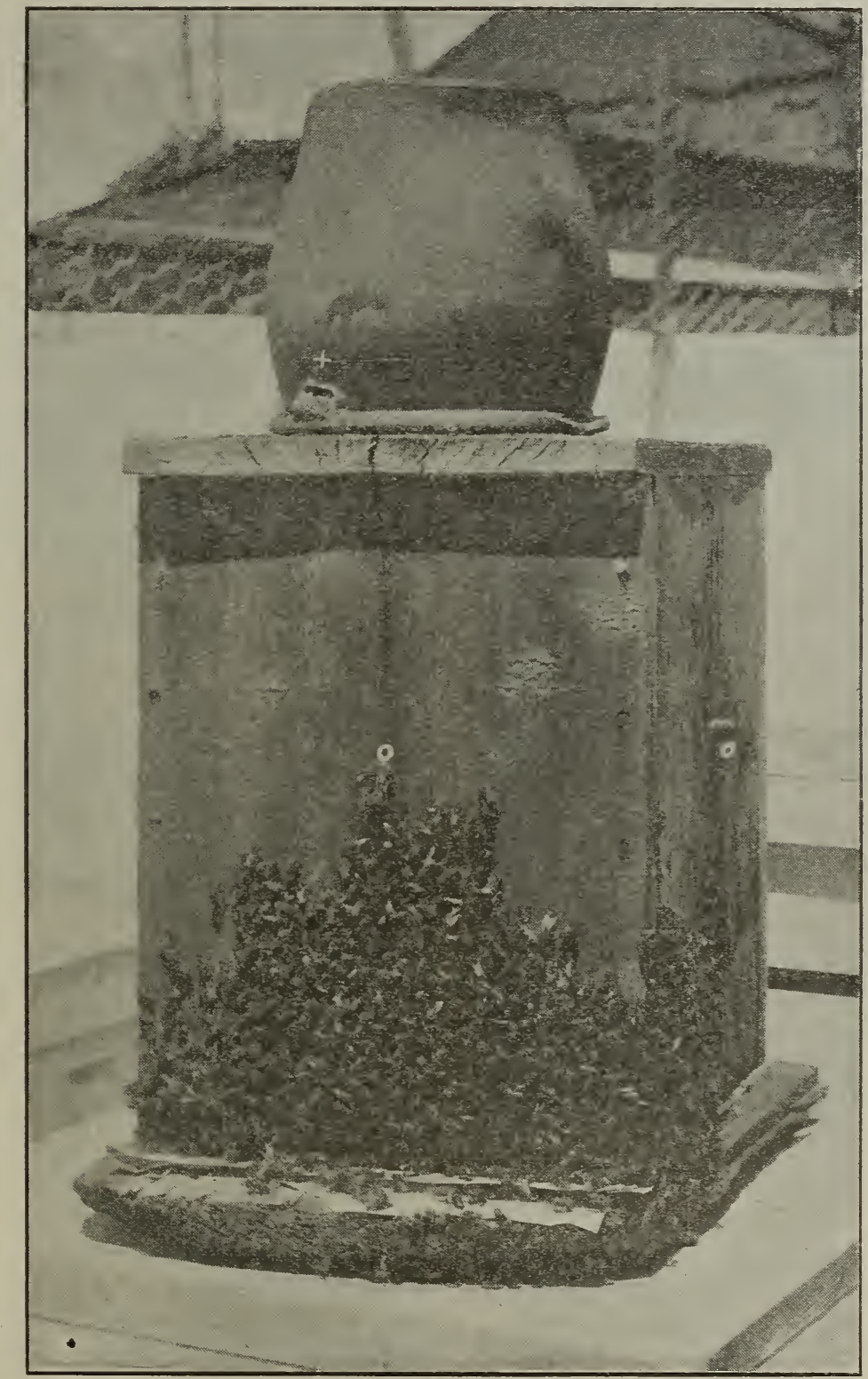

A TYPICAL BOX HITE WITH AN EARTHEN CROCK FOR A COMBHONEY SUPER.

These crocks would be cold, but when once filled would keep the honey safe from leaking after taking off the gum.

bees can be kept on the box-hive system without the use of brimstone. While the tricks of the trade taught in this old work of Quinby would enable the highlanders to increase their yields per colony, the modern hire with movable frames would enable them to do still better. the very best in the apiary, or, better still, the best out of a series of outyards including the home apiary. Such queens should not only be prolific but be the mothers of workers that are energetic and good workers - that is, bees that will store more honey than any others. It is important, also, that 
they be of pure stock in order that they may the better transmit their qualities. While gentleness is desirable, we sometimes have to sacrifice this desirable quality in order to get bees for business.

When using Italian stock do not be misled by the fad of a bright golden or yellow color. If it comes about accidentally without the sacrifice of business qualities, we are that much ahead. As a rule, the darker strains of Italians will show more desirable points than the bright-colored ones.

Ability to stand a severe winter is a. necessary quality. It usually follows that

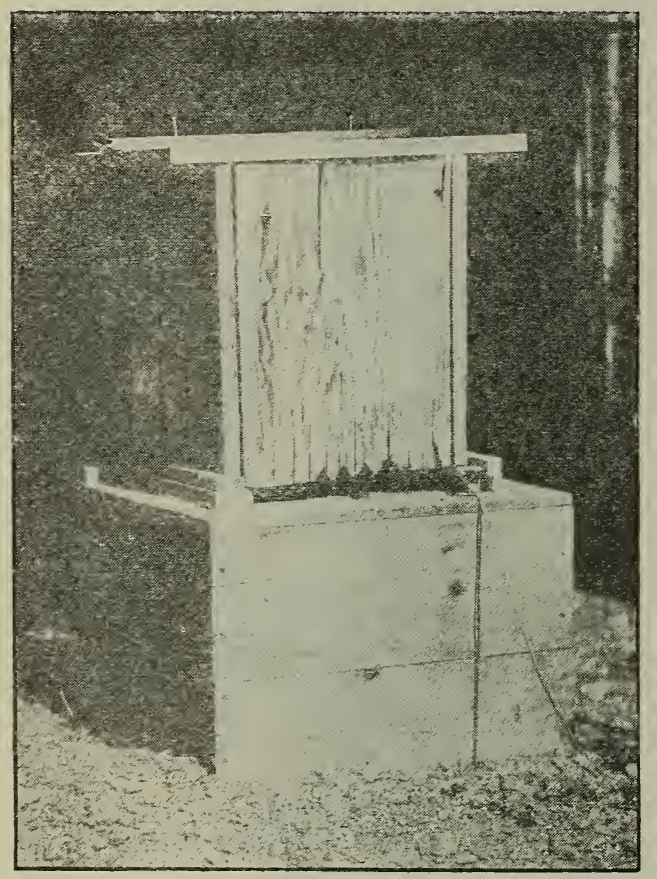

A type of box hive largely used 50 years ago, and still found in old-fashioned apiaries.

a strain that will breed up early in the spring, and prove to be good workers, are also good winterers. Bees that will not stand a cold winter will be too weak, if they survive, to be good for anything in the season. It, therefore, follows as a natural corollary that a colony of bees that can pile up super after super of honey are also good for wintering.

It has been proven that some strains of bees will resist disease much better than others. While no stock is immune, there are some that will not contract disease while others will fall easy victims. If possible a breeding queen should be one whose bees have demonstrated their ability to ward off disease, and there are some that have show: great superiority in this respect.

In this connection, good breeding drones should not be forgotten. It is generally accepted that a male is more potent to transmit his good or bad qualities than the female; and the same rule holds good in bee culture. Therefore, in selecting breeding queens we not only select those that will produce good daughters but those that will beget good sons. It very often and generally happens that, in order to prevent inbreeding, one must go to some other breeder to get stock for crossing with his own.

The average beginner should buy his breeding-stock, especially if he has only a few colonies; and even after he becomes fairly expert, if he has only one apiary it will be advisable for him to buy a breedingqueen of two or three of the best breeders in the country. A good queen is worth from $\$ 5.00$ to $\$ 10.00$ - usually the latter figure. Sometimes as much as $\$ 25.00$ is paid. When one buys a breeder he should always have her sent to him in a nucleus rather than thru the mails. Usually a breeding-queen is not less than one year old, for it takes at least a year, unless the season is exceedingly favorable, to measure up her value. A queen one or two years old will not stand transmission thru the mails like an untested queen that has just begun to lay.

After one receives a breeder he should give her the utmost care, not expecting that she will live more than a year, especially if she is already two years old. He must keep her in a small nucleus, for no breedingqueen during the active season should be the mother of a powerful colony. She should be kept down, and given as little egg-laying as possible; and then in the winter, when the active season is over, her colony should be gradually built up with combs of hatching brood. Keep on giving young brood in this way until she is the mother of a large colony, and then give her every advantage by housing her colony in a large double-walled hive in a protected location. Or if one has a good cellar where he can control conditions, place her colony indoors. See Wintering Outdoors and Wintering in Special Repositories.

The use of a good breeding-queen may mean the difference between profit and loss in a year's business. It is folly to keep scrub cows on the farm when good cows on 


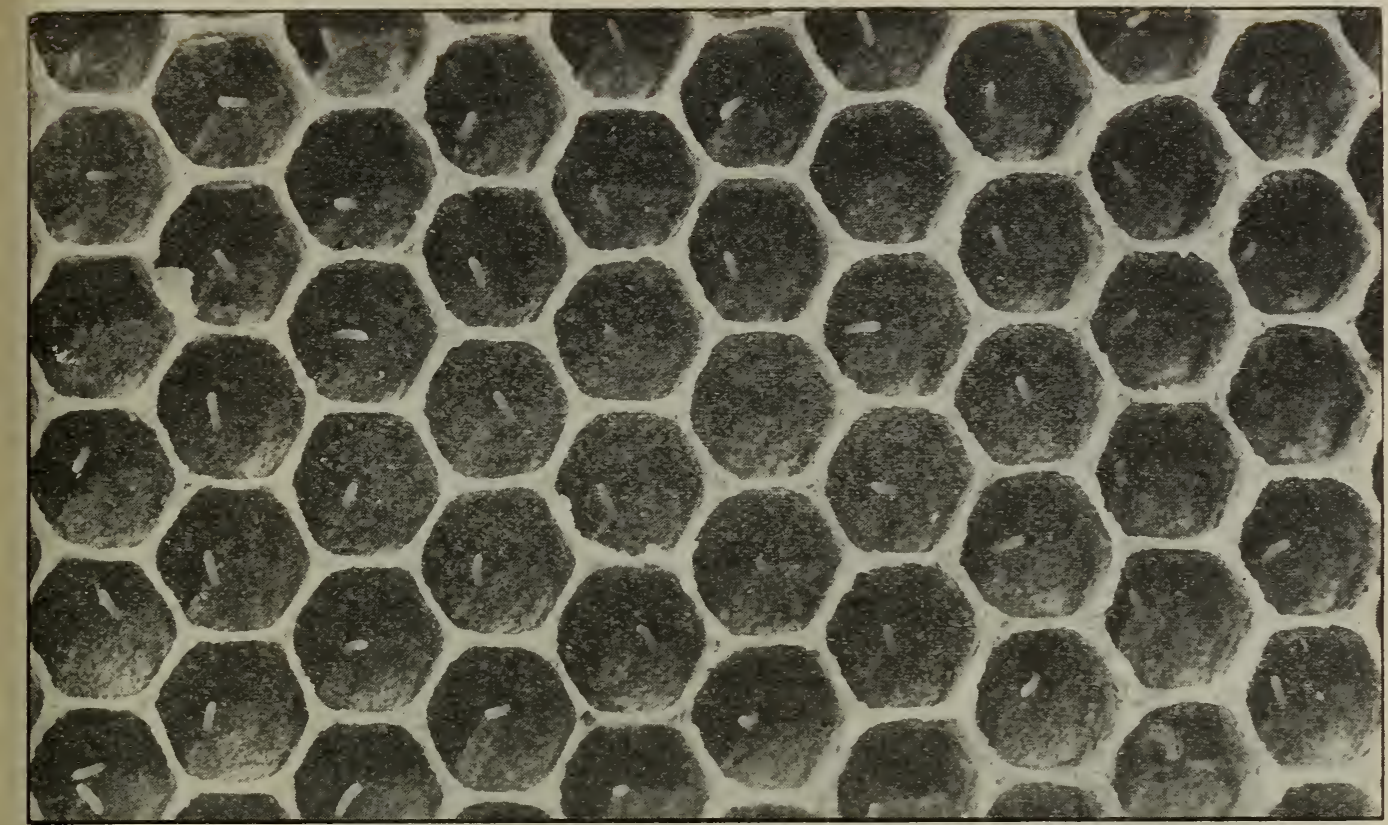

Close view of eggs. Notice the cell in the lower left-hand corner contains two eggs, while that at the right-hand corner has a larra.

the same feed will furnish two or three times the milk. It is equally foolish to breed from anything but the best queen stock obtainable. A good strain of bees will produce anywhere from two to three times as much honey as a poor one. See QUEENS AND QUEEN-RÉARING.

\section{BROOD AND BROOD - REARING. -} "Brood" is a term commonly used to designate the young of the bees in the cells that have not hatched out. It may be young bees just before they have emerged from the cells, the larvæ in various stages of growth, or even the egg's.

Very often the beginner is confused because he is not able to disting'uish capped honey from capped brood; nor does he know the difference between drone and worker brocd. Sealed brood is of a light to dark brown color, depending on the age and color of the comb itself. In ordinary worker brood, in cells five to the inch, the cappings are made up of wax and fibrous material, smooth and slightly convex if the brood is not diseased. The cappings over honey are white, bluish-white, or yellow, are more or less irregular, and somewhat flattened. By comparing the illustrations of brood shown on next page, together with the cappings of comb honey under Сомв
Honey, the beginner will easily make the distinction.

The average beginner may not be able to see eggs at first. One trouble is, he does not know where to look nor what to expect. When he peers down into the bottoms of the cells and sees tiny little objects standing on end at an angle he hardly knows what they are. The accompanying photo shows the eggs in the bottoms of the cells. But photography is not able to show the depth of the cell, altho with a stereoscope using two pictures the relative position of the egg in the bottom will show better. The other view shows brood in rarious stages of development.

HOW THE PRESENCE OR ABSENCE OF BROOD REVEALS THE REAL CONDITION OF THE COLONY.

It is the presence of eggs or young larræ that shows that the bees have a queen and are beginning to rear brood. This may take place even during mid-winter if the weather has been warm for a few days; or it may occur as it usually does in early spring. Brood will be found in all stages of growth as the season progresses.

On the other hand, the absence of unsealed brood, and especially the absence of egg's, may be an indication that the colony is 


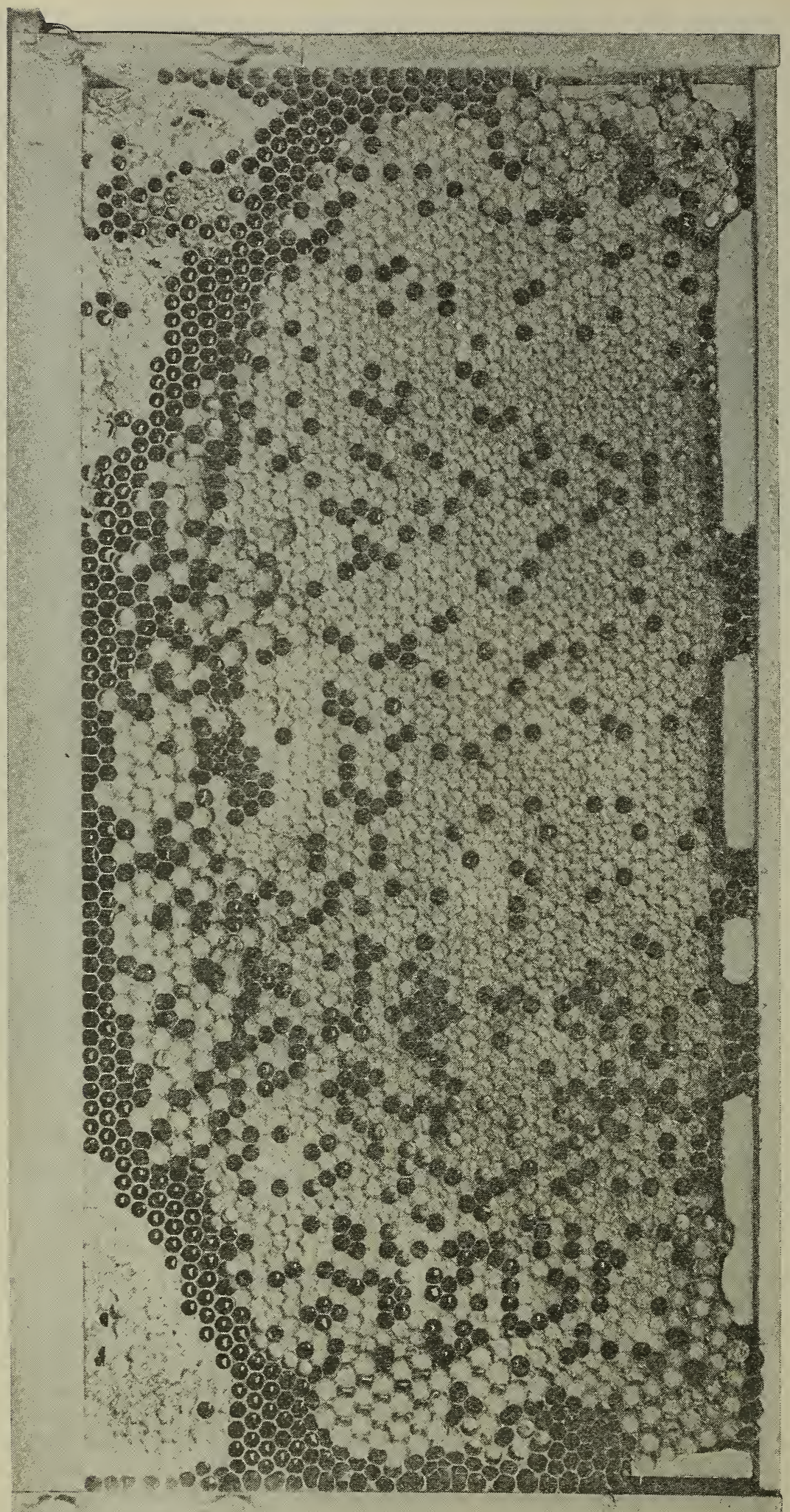

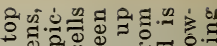

ॠ

उ.

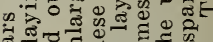

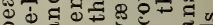

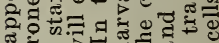

$70=0$

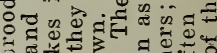

\% 때

5.

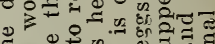

急

들

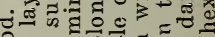

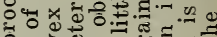

记实的

\& 8.0.

๘

च.

0 का

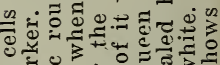

कo

政

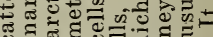

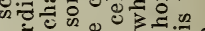

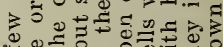

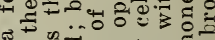

उี

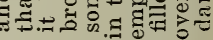

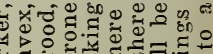

잉

०

品

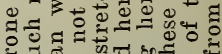

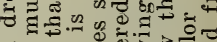

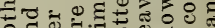

2 \%

of

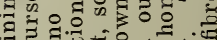

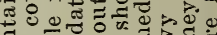

ơ

o 0

西势

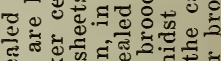

on

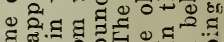

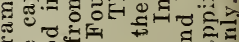

DE

正

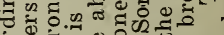

o है है

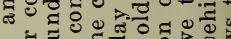

ñ

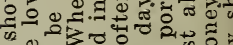

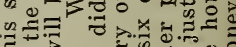

Fै

ซึ 
queenless. During spring and early summer there will be, or should be, brood in all stages, including eggs. Such a condition indicates general prosperity, and the beekeeper can feel that his pets are doing well. But if there are no eggs nor young larvæ, and the queen cannot be found, and if, also, there are initial queen-cells during spring and the fore part of summer, the strong probabilities are that the queen has recently died or that a swarm has issued. We may go further and say that the absence of eggs and the presence of initial queen-cells during the active season is fairly good proof either that the queen is not in the hive, or that the one that is there is good for nothing and should be replaced. It will be seen, then, that the presence or absence of brood in various stages of growth, and especially young brood and eggs, gives one a pretty accurate idea of the condition of the colony.

After the main honey-flow, which usually occurs in the northern states from July 1 to August 1, the queen will let up on egglaying, and the amount of brood, even in a normal colony, will be very much less than at any time preceding the honey-flow. Sometimes there will be almost no larvæ nor eggs, and but very little sealed brood. The beginner will be inclined to think the queen is failing, when, as a matter of fact, she and her colony are pursuing a normal course. Nature evidently works on the plan that there is no use in producing a lot of worker bees and consumers when they can be of no possible help to the colony; so she husbands her forces until another honeyflow comes on toward fall. At that time brood-rearing will start up again, and possibly the hives may have as much brood as at any time during spring or early summer. But if cool or frosty nights come on, the amount, probably, will not go beyond one or two frames; for if a severe cool or cold spell should come on, it would cause a lot of brood to chill.

Sometimes. during the flow during aster and goldenrod, the bees and queen apparently become excited and begin breeding heavily. A chilly rainy spell may come on for four or five days, but not cold enough to kill the blossoms in the fields. During the interim the cluster contracts, especially at night. The young brocd outside of the cluster chills and dies. In a day or two these larvæ will be found scattered around the entrance of the hive, and the beginner is inclined to come to the conclusion that something is wrong-that some bee disease like foul brood is in the larvæ or hives.

We made the statement that egg-laying would begin to let up after the main honeyflow. That is true with all except young laying queens. A queen reared in June will probably continue laying all thru the summer, and the colony will contain brood in all stages. One reared in September will begin laying immediately, no matter what the conditions, and she will keep it up till cool or cold weather shuts it off.

In some localities it is an advantage to use young queens in order that there may be a large force of bees for the honey-flow that will follow the main one. The secondary flow, we will say, will be from buckwheat, aster, goldenrod, or all of them. It is important to have a strong force of bees for it. Brood-rearing should, therefore, be continued from the first flow either by having young queens or by stimulative feeding, if honey is not coming in from ratural sources. (See FEeding, subhead "Stimulative Feeding.")

"BY THEIR FRUITS YE SHALL KNOW THEM."

The amount of brood, the manner in which the eggs are laid-whether in scattering or irregular patches-also give one a fair idea, even tho he has not seen her, of the kind of queen he has in the hive. If there is only a scant amount of brood, and eggs are scattering when other colonies are well supplied, the presumption is that the queen is poor, and that something better should be put in her place. After she is found, the probabilities are that she will be so small that she will be no larger than a worker.

If, on the other hand, we find brood in six or seven frames in all stages of growth, from eggs to the hatching bees in a tenframe colony, we may draw the conclusion that the queen is a good one, even tho we have not seen her. "By their fruits ye shall know them." When we locate her we shall probably discover a large, handsome, long, or full-bodied queen. If we wait a moment we may have the pleasure of seeing her lay an egg, for such a queen is usually on the job night and day. 
As already stated, after the main honeyflow egg-laying may almost entirely cease. One is more apt to find this condition at the close of the general harvest where the queen is one or two years old. A young queen reared in spring will usually continue to lay on thru the season. But usually any queen will begin laying when new honey begins to come in or when the colony is given stimulative feeding. But late in the fall such feeding will fail to produce brood-rearing, because the bees and the queen have more sense than their owner. Brood at such times will do more harm than good, because winter is close at hand. There should be no brood in the hives during winter in the North until about February or March, and then in only small patches and in outdoor colonies.

Too early brood-rearing during winter may or may not be a good omen. Much will depend on the climate and the winter. A mild winter or a mild climate will start breeding, especially if the bees can fly; but if a sharp cold snap follows, much of the brood will die, and the colony will suffer. In the South, brood-rearing on account of the mildness of the climate may or may not progress every month in the year. Breeding always requires a large amount of stores, and this explains why bees in the southern states consume more stores during winter than those in the North.

\section{BROOD-REARING DURING MID-TINTER.}

Mention has been made of the fact that brood may be found in the hive during midwinter, particularly with bees outdoors. If the weather is mild, or if bees are located in a southern climate, brood will be found in the hive every month in the year. Ordinarily, in the northern states no brood will be found before January; but breeding may be started both in the cellar and outdoors by giving slabs of hard candy laid flat on top of the brood-nest with a couple of $3 / 8$ cleats to hold it up from the top of the frames. (See CANDY, particularly HARD Candy.) Disturbance of the brood-nest in or out of the cellar will often start breeding also. The average beginner would do well not to hasten things before the bees commence themselves. If brood-rearing: begins too early, there is danger of dysentery setting in. In order to maintain broodrearing, the temperature of the colony. must be up to about blood heat-97. This stimulates the activities of the colony, causing a large consumption of stores; but if the bees are not able to make winter flights the retention of the feces may cause dysentery. When this starts in January or February it will probably mean the loss of the colony before spring. (See Dysentery.) But an experienced beekeeper may start brood-rearing sometimes by giving slabs of candy, in the northern states, and the result will be that the colony will be stronger by spring than in the fall. But the arerage beginner should let the bees severely alone provided he is sure they have plenty of stores and are well housed.

For a further discussion of brood and brood-rearing, see Feeding, subhead Stimulative Feeding; Candy; Spreading Brood; Quefns and Queen-Rearing. For a discussion of brood diseases, chilled brood, and neglected brood, see Foul Brood.

\section{DRONE BROOD.}

This has the general characteristics of worker brood, except that the cells are larger and the cappings more convex. While worker brood hatches out in from 20 to 21 days from the laying of the egg, drone brood emerges in from 23 to 24 days. See large half-tone plate.

A drone-laying queen or a laying worker (see LAYING WORKERS) may lay drone eggs in worker-cells. In that case the brood will be worker. size, but the cappings will be more convex than ordinary' worker.

Drone brood will often die from neglect. It will smell like foul brood, but lack the characteristics of either European or American foul brood. Beginners sometimes suppose it to be a disease. But dead drone brood usually means nothing serious, especially if the worker brood in the hive is normally healthy.

Tinder the head of BeE BeHavion and Development of Bees we have taken up the scientific side of the growth of the bee from the egg to the fully developed worker; but as there may be some who do not care to go into the science of this, we present here something that will enable one to follow out for himself the entire development of the bee, from the egg up to the time that it hatches, and even after it begins to perform some of the duties of the hive. 
THE DEVELOPJIENT OF BROOD."

During warm weather, while bees are gathering honey, open the hive about noon, and put in the center a frame containing a sheet of foundation; examine it every morning, noon, and evening, until eggs can be seen in the cells. By inserting it between two combs already containing brood, eggs will be found in the cells the next day.

If one has never seen an egg that is to produce a bee, he may have to look rery sharp the first time, for they are white like polished ivory, and scarcely larger than one of the periods in this print. They will be seen in the center of the cells attached to the comb by one end. The egg under the microscope much resembles the cut. It is covered, as will be noted, with a sort of lacelike penciling, or net-work it might properly be called. Immediately on discorering

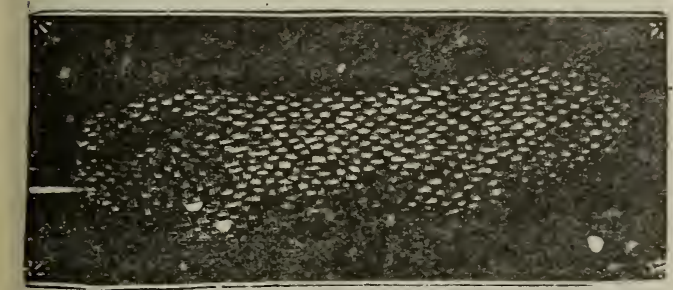

A queen's egg under the microscope.

eggs, the date should be marked. If the weather is favorable, these egg's will hatch out in about three days or a little more, when, in place of the egg, we will, if we look sharp enough, see a tiny white worm or grub floating in a minute drop of milky fluid. If we watch we will find bees incessantly poking their heads into these cells; and very likely the milky fluid is placed on and about the egg a little before the inmate breaks its way out of the shell. We infer this, because we have never been able to get the egg's to hatch when taken away from the bees, $\uparrow$ altho we have carefully kept the temperature at the same point as in the hive. These worms are really young bees in their larval state, and we shall in future call them larvæ. They thrive and grow very rapidly on their bread-and-milk diet, as we can see if we look at them rery often. They will more than double in size in a single half-day. This seems almost incred-

* See also Developirent of Bees.

t Since this was written it has been proved that eggs, removed from the hive, when subjected to proper temperature will hatch if supplied artificially with the milky food, otherwise not. ible; but there they are, right before our eyes. We presume it is owing to the highly concentrated nature of this "bread-andmilk" food that the workers are so constantly giving them that they grow so rapidly. If we take the comb away from the bees for a little while we shall see the larræ opening their mouths to be fed, like a nest of young birds.

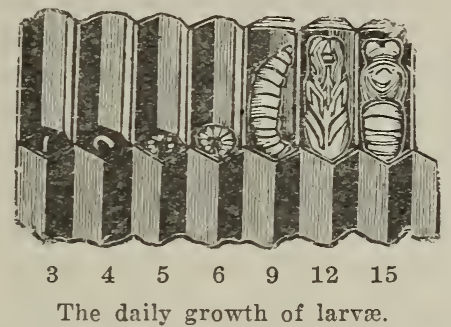

Figures under the cut represent the age in days from the laying of an egg. First the larva just having broken the egg-shell on the third day; next, a larra on the fourth day. During the fifth and sixth days they grow very rapidly, but it is difficult to fix any precise mark in regard to size. On the ninth day, the larva, having straightened itself out, worker-bees cap it orer. See Developarent of Bees. ITe have made a pretty accurate experiment on this point, and it was just six days and seven hours after the first egg hatched that the bees completely capped it orer. To determine when larræ begin to have legs and eyes, see Developirext of Bees; but we found that the wings derelop toward the last of the growth.

After the larræ are 6 days old, or between 9 and 10 days from the time the egg was laid, one will find the bees sealing up some of the largest. This sealing is done with a porous-like substance in which we find wax shreds, old silk, bee hair, and sometimes pollen; and while it shuts the young bee up, it still allows it a chance to breathe thru the pores of the capping. It is given its last food, and the nurses seem to say, "There! you have been fed enough; spin your cocoon, and take care of yourself." See Developarent of Bees.

After this, as a general thing, the young bee is left corered up until it gnaws off the capping and comes out a perfect bee. This will be in about 21 days from the time the egg was laid, or it may be 20 if the weather is very favorable; therefore it is shut up 11 
or 12 days. Now, there is an exception to this last statement, and it has caused not a little trouble and solicitude to beginners. During very warm summer weather, the bees, for one reason or another, decide to let a part of their children go "barebeaded," and therefore we find, on opening a hive, whole patches of immature bees looking like silent corpses with their white heads in tiers just about on a level with the surface of the comb.* At this stage of growth they are motionless, of course, and so the young beekeeper sends a postal card, telling us the brood in his hive is all dead. Some have imagined that the extractor killed them, others that it was foul brood (see Foul Brood); and we often think, when reading these letters, of the family which mored from the city into the country. When their beans began to come up, they thought the poor things had made a mistake by coming up wrong end first; so they pulled them all up, and replanted them with the bean part in the ground, leaving the proper roots sprawling in the air. We can rest assured that the bees always know when it is safe to let the children's heads go uncovered.

It is very important, many times, to discover just when a queen was lost or a colony swarmed; hence we should learn these data thoroly: The development of a bee occupies 3 days in the egg, 6 in the larval state, and 12 days sealed up.

The capping of worker-brood is nearly flat; that of the drones so much raised or convexed that we can at a giance tell when drones are reared in worker-cells, as is sometimes the case. See large plate.

\section{BROOD AFTER IT HATCHES.}

The young bee, when it gnaws its way out of the cell, commences to rub its own nose, straighten out its feathers, and then push its way among the busy throng, doubtless rejoicing to become one of that vast commonwealth. Nobody says a word, nor, apparently, takes any notice of the youngster; but for all that, they, as a whole, we are well convinced, feel encouraged, and rejoice in their own way at a house full of young folks. Keep a colony without young bees for a time and we shall see a new

\footnotetext{
* This seems to be peculiar to the offspring of some queens or strains, and is sometimes so pro nounced that almost no brood is perfectly sealed at any season.
}

energy infused into all hands just as soon as young bees begin to gnaw out.

If we vary our experiment by putting a frame of Italian eggs into a colony of black bees, we shall be better able to follow the newly emerged young bee as it matures. The first day it does little but crawl around; but about the next day it will be found dipping greedily into the cells of unsealed honey, and so on for a week or more. After about the first day it will also begin to look after the wants of the unsealed larvæ, and very soon assists in furnishing the milky food for them. While so doing, a large amount of pollen is used, and it is supposed that this larval food is pollen and honey, partially digested by these young nurses. Bees of this age or a little older supply royal jelly for the queen-cells, which is the same, probably, as the food given very small larvæ. Just before they are sealed up, larvæ to produce worker-bees and drones are fed on a coarser, less perfectly digested mixture of honey and pollen." Young bees have a white downy look until they are a full week old, and continue a peculiar young aspect until they are quite two weeks old. At about this latter age they are generally active comb-builders of the hive. When a week or ten days old they take their first flight out of doors; we know no prettier sight in the apiary than a host of young Italians taking a playspell in the open air, in front of their hive. Their antics and gambols remind one of a lot of young lambs at play. See Play Spells.

It is also very interesting to see these little chaps bringing their first load of pollen from the fields. If there are plenty of other bees in the hive of the proper age, they will not usually take up this work until about two weeks old. The first load of pollen is to a young bee just about what the first pair of pants is to a boy baby. Instead of going straight into the hive with its load, as the veterans do, a vast amount of circling round the entrance must be done; and even after the young bee has once alighted it takes wing again before rushing all thru the hive, to jostle nurses, drones, and perhaps the queen too, saying as plainly as could words, "Look! Here

* Very possibly the only difference is the addi. tion of honey with its contained pollen, to the food previously given by some other nurses, perhaps younger ones. 
am I. I gathered this, all myself. Is it not nice?"

We might imagine some old veteran, who had brought thousands of such loads, answering gruffly, "Well, suppose you did; what of it? You had better put it in a cell and start off after more, instead of making all this row and wasting time, when there are so many mouths to feed." WVe said we might imagine this, for we have never been able to find any indication of unkindness inside a beehive. No one scolds or finds fault, and the children are never forced to work, unless they wish. If they are improvident, and starvation comes, they all suffer alike, and, we do believe, without any hard feeling or censure toward any one. They all work together, just as the right hand assists the left; and if we would understand the economy of the beehive, it were well to bear this point in mind.

Shortly following the impulse for pollencollecting, comes that for honey-gathering; and the bee is probably in its prime as a worker when a montl old. At this age it can. like a man of forty, "turn its hand" to almost any domestic duty; but if the bive is well supplied with workers of all ages, it now probably does most effective service in the fields. See Bee Behavior; also Age of BEEs.

When a colony is formed of young bees entirely, they will sometimes go out into the fields for pollen when but five or six days old. Also when a colony is formed wholly of adult bees they can build comb, feed the larvæ, construct queen-cells, and perform work generally that is usually done by younger bees; yet it is probably better economy to have bees of all ages in the bive.

\section{BROOD, SPREADING.-See SPREADING BROOD.}

BUCKWHEAT (Fagopyrum esculentum Moench.).-This, in certain sections, is one of the most important honey-plants. It is grown principally on the hillsides of Eastern New York, Pennsylvania, and some in Michigan, Wisconsin, and Ontario, Can.; and in those localities where there are thousands of acres within a radius of a few miles, immense quantities of buckwbeat honey are annually produced. On one hilltop in Schoharie Co., N. Y., near Gallupville, where we stood, we were told that within a radius of three miles the bees had access to 5000 acres of buckwheat, all of which was within the range of the eye. So great is the acreage of it in New York that anywhere from 2000 to 3000 colonies can be kept in some counties; and this means hundreds of beekeepers who are specialist honey-growers and farmers, almost all of whom keep at least a few colonies. The latter class reason this way: That the growing of buckwheat as a grain is one of the most profitable branches of farming; that the nectar in the blossoms properly belongs to them, and if they keep a ferv colonies they will virtually get two crops from one fieldhoney and buckwheat grain.

We have ridden a bicycle thru the buckwheat region of New York, traveling all day, without losing sight of buckwheat fields that seemed to cover every available piece of ground on both sides of the road. So immense were the fields that the atmosphere seemed to be hearily charged with the aroma of the bloom, and if one is not a lover of buckwheat honey the odor is somewhat sickening.

One beekeeper in the heart of the buckwheat country (IT. L. Coggshall, of Groton), who lives near Cayuga Lake, harrested one year with his 1000 colonies 78,$000 \mathrm{lbs}$. of honey; another year $50,000 \mathrm{lbs}$; and for a good many years his crops have ranged along into the carloads. The late E. W. Alexander, of Delanson, N. Y., also produced immense quantities of this honey. So much buckwheat grew around that he maintained 700 colonies in one yard for years. While the honey produced by these men was not all buckwheat honey by considerable, yet a good big portion of it was.

But the growing of buckwheat is by no means confined to the East. It is grown in small acreages of, say, one to five acres, in most of the North Central States. It is grown quite largely in parts of Ontario, Canada. It also is a paying crop for seed and honey in the South, being grown to some extent in South Carolina and Texas. But it is in Eastern New York, on the hillsides, that it seems to thrive best. Stalks of the celebrated Japanese variety that would measure two feet high in Ohio will reach five or six feet in length in the more farored locations in New York. There is something in the climate and soil of those hills that makes the growing of this plant 
much more profitable in the East than in the West, altho it is always a paying crop for the grain in nearly every locality where ordinary grain crops can be grown.

\section{THE QUALITY OF BUCKWHEAT HONEY.}

Buckwheat honey itself is of a deep dark purplish tint, and looks much like the old New Orleans or sorghum molasses. It is usually of heavy body; and the flavor, to one who is a lover of clover and basswood, and who has never been accustomed to buckwheat honey, is more or less sickish; and yet those who have always been used to

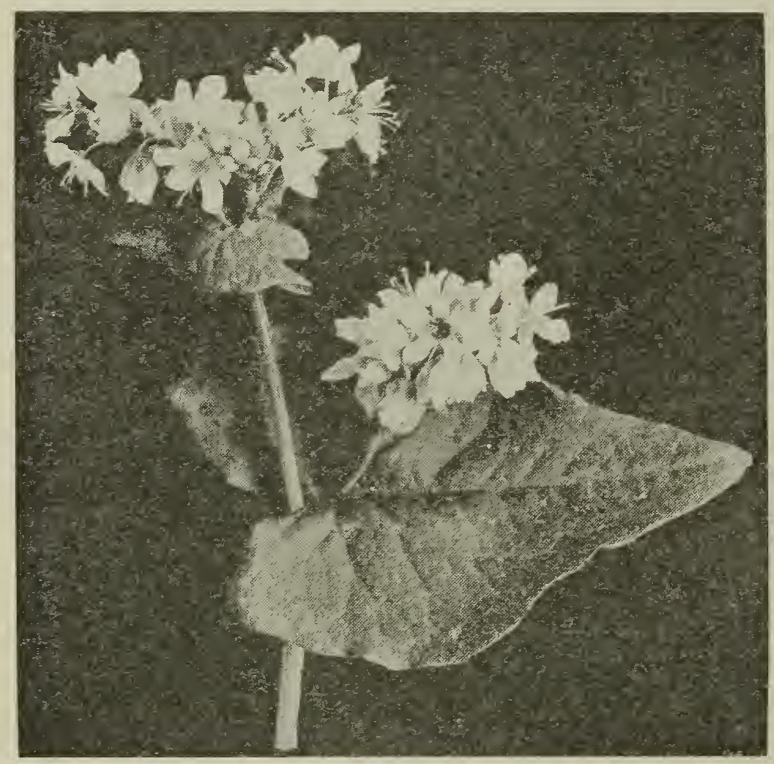

Buckwheat blossom.

buckwheat honey, or at least a good many of them, prefer it even to clover or basswood.

A lady from the East once called at our store and looked over our honey. We showed her several samples of choice clover and basswood comb honey.

"I do not like this," she said. "It looks like manufactured sugar honey. Haven't you any buckwheat honey?"

"Yes, but we did not suppose you would like that, because such honey rarely sells in our locality."

We then placed before her some sections of buckwheat honey, and these suited her exactly.

"That is real bee honey," said she, with a look of satisfaction, and she carried home several sections.
It seems that her father had been a beekeeper, and about all the honey she ever saw was buckwheat; and unless it had the strong flavor and dark color of the honey with which she was familiar in her childhood days it was not honey to her, and there are thousands like her in the East.

Yes, there is a fancy trade that prefers buckwheat; and this trade is so large that buckwheat honey in New York and Albany brings almost as high a price as the fancy grades of white; but in the Western markets, principally in Chicago, "the stuff" goes begging a purchaser, and sells as an off grade of honey.

Notwithstanding the color of buckwheat honey itself is purplish, the cappings of the combs, especially if made by black bees, are almost pearly white. Some of it at least is very pretty, and especially when it is put up by practical beekeepers who know how to produce a firstclass grade of any honey.

\section{IS BUCKWHEAT A RELIABLE SOURCE FOR HONEY, AND WHEN?}

In York State, buckwheat can be depended upon almost every year for a crop of honey, but in the West it is rather uncertain, some years yielding no honey, and others doing fairly well. But when it does yield, the bees work on it almost entirely in the morning, the nectar supply lasting until about 10 or 11 o'clock. There are, however, exceptions.

In the East, on account of the immense acreage, the bees are kept busy gathering honey from morning until about 2 o'clock in the afternoon; and owing to the fact that it can be depended on almost absolutely for a yield of honey-when even basswood or clover fails, as it does sometimes in any locality-the beekeeper is able to make at least expenses and something besides. Indeed, some years when there is almost a total failure of white honey, the York State honey-producers are enabled to make a fair living from buckwheat alone.

\section{DIFFERENT VARIETIES OF BUCKWHEAT.}

The first buckwheat of which very much became known was designated as the black and the gray. Later on, the silverhull came into prominence, and still later the Japan- 
ese. As this latter had a larger stalk and a larger grain or berry, it was supposed that it was much superior to any other variety. For a number of years it was grown very extensively. While it might grow more bushels of grain to the acre, it didn't necessarily follow that it would grow more flour to the acre. It was also discovered that it did not yield honey quite so honey-plant unless the seed will pay the expense of the crop. In this case, buckwheat, as we have shown, is one of the most profitable grains that can be grown; and outside of any honey it may yield, there is " good money in it." In our own locality the yield of nectar from buckwheat is so irregular and so scant from season to season that we do not get very much honey; and

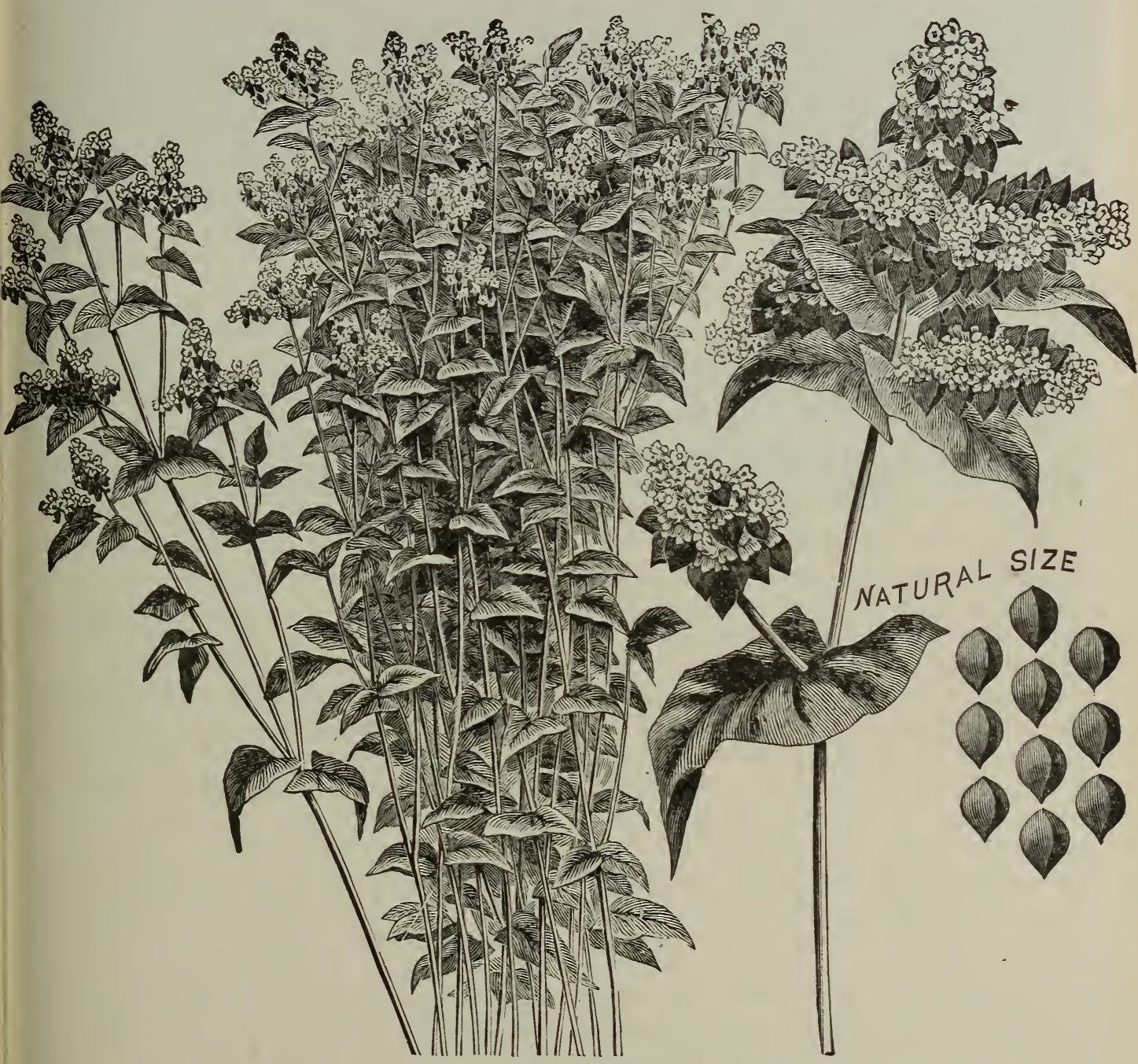

Japanese Buckwheat.

well as the old-fashioned varieties; namely, the black, gray, and the silverhull. In New York, where buckwheat is grown so very largely, the Japanese has been dropped almost altogether; and the gray and the silver hull are now being used as formerly.

\section{BUCKWHEAT A PAYING FARM CROP.}

We have set it down as a rule in this work that it is not profitable to grow any yet when it does yield it affords an excellent diversion for the bees, keeping them out of mischief when there would be an absolute dearth of honey from every other source; hence even in Ohio it pays to grow it.

\section{CONDITIONS UNDER WHICH BUCKIVHEAT YIELDS NECTAR.}

Probably no beekeeper has ever had a more extended experience with buckwheat 


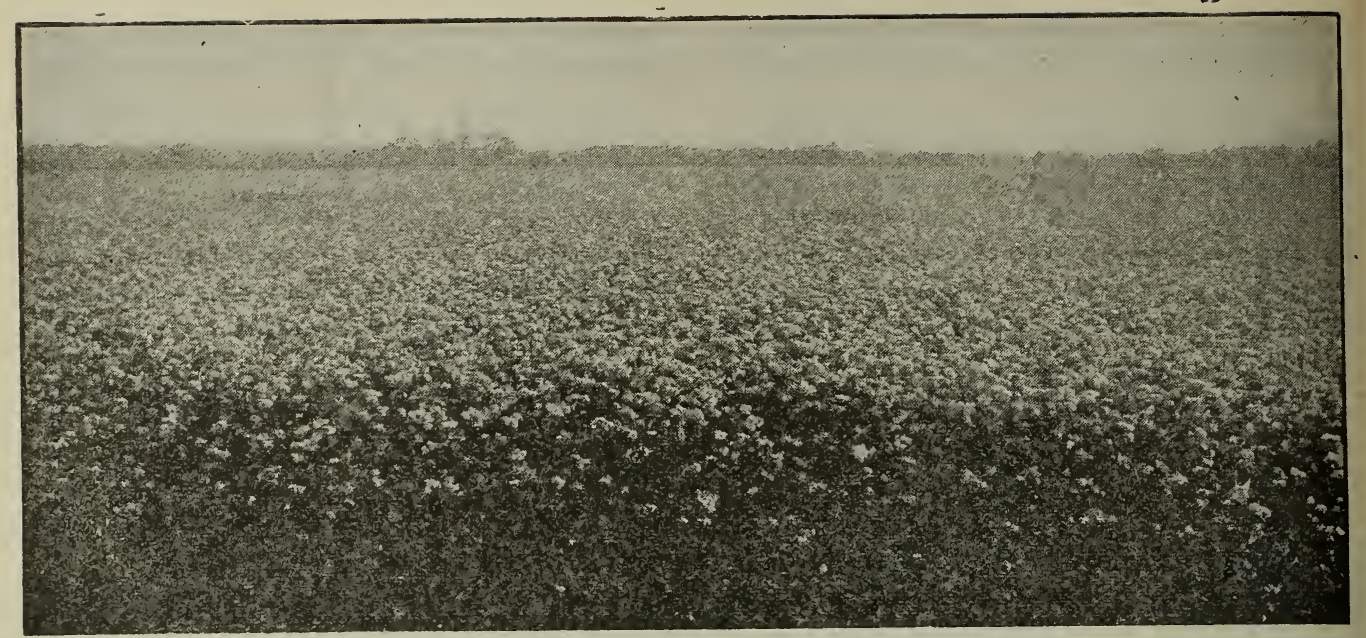

Japanese luckwheat thirty-four inches high in a little over three weeks from the time the seed was planted.

as a honey-plant than the late E. W. Alexander. He observed that the secretion of nectar varied greatly with the temperature and with clear or cloudy weather. He said: "Several years ago I kept nearly 200 colonies in a location where there was barely 100 acres of buckwheat within reach of my bees-that is, within four miles, or in a circle eight miles in diameter. Still, with this small acreage per colony it was no uncommon thing to harvest a surplus of 15 to $20 \mathrm{lbs}$. of nice buckwheat section honey per colony. This caused me to feel very anxious to keep bees in a buckwheat location where thousands of acres were raised annually; so I moved to this place (Delanson, N. Y.). But I soon found, to my sorrow, that the amount of bloom had but little bearing on the amount of surplus I obtained; and in this respect buckwheat is no exception to other flowers, aside from the fact that it does its best when we have quite cool nights followed by a clear sky and a bright hot sun with little or no wind; then from about 9 o'clock in the morning until 2 in the afternoon it secretes nectar very fast. We seldom find a bee at work on it much earlier or later in the day. Buckwheat does not amount to much in cloudy weather, even if the day is warm. With a temperature below 70 degrees on a cloudy day, bees will waste away fast on either goldenrod or buckwheat. They simply crawl around, unable to fly; and unless they get a bright sun the next day they soon die. A few years ago, at the beginning of our August harvest, when there wern at least 1500 acres of buckwheat in bloom, and the bees were bringing in nectar very fast, a heavy thunder-shower came down from the north about 2 P. M., which caused the mercury to drop 21 degrees in less than half an bour. A low temperature of about 65 degrees, with windy cloudy weather, lasted some 11 days, during which the flowers ceased entirely to secrete nectar, and the bees were compelled to destroy large quantities of their brood."

\section{HOW TO PREPARE THE SOIL FOR GROWING BUCKWHEAT, AND WHEN TO SOW.}

Two crops of buckwheat can be grown in a season, but usually they do not pay. In such case the first must be sown very early - so early that it is liable to be killed by frosts after it comes up. Very hot weather coming on while it is in bloom proves unfavorable to the maturing of the seed. Buckwheat ordinarily should be sown after some other crop, anywhere from July 1 to the middle of August, depending on the locality. Almost any soil can be used for growing it; but the better the soil, the larger the crop, of course. Some recommend loose mellow ground, or clover sod turned under. Others say plow immediately after sowing oats or planting corn, as by thus working the soil early it becomes settled and holds the moisture which buckwheat demands; and the result is, the seed fills better. After plowing, the ground should be thoroly harrowed, and then the seed sown with a drill. If a fertilizer is used, it should be put in at the same time with the seed and run thru the drill. One experienced grower says the 


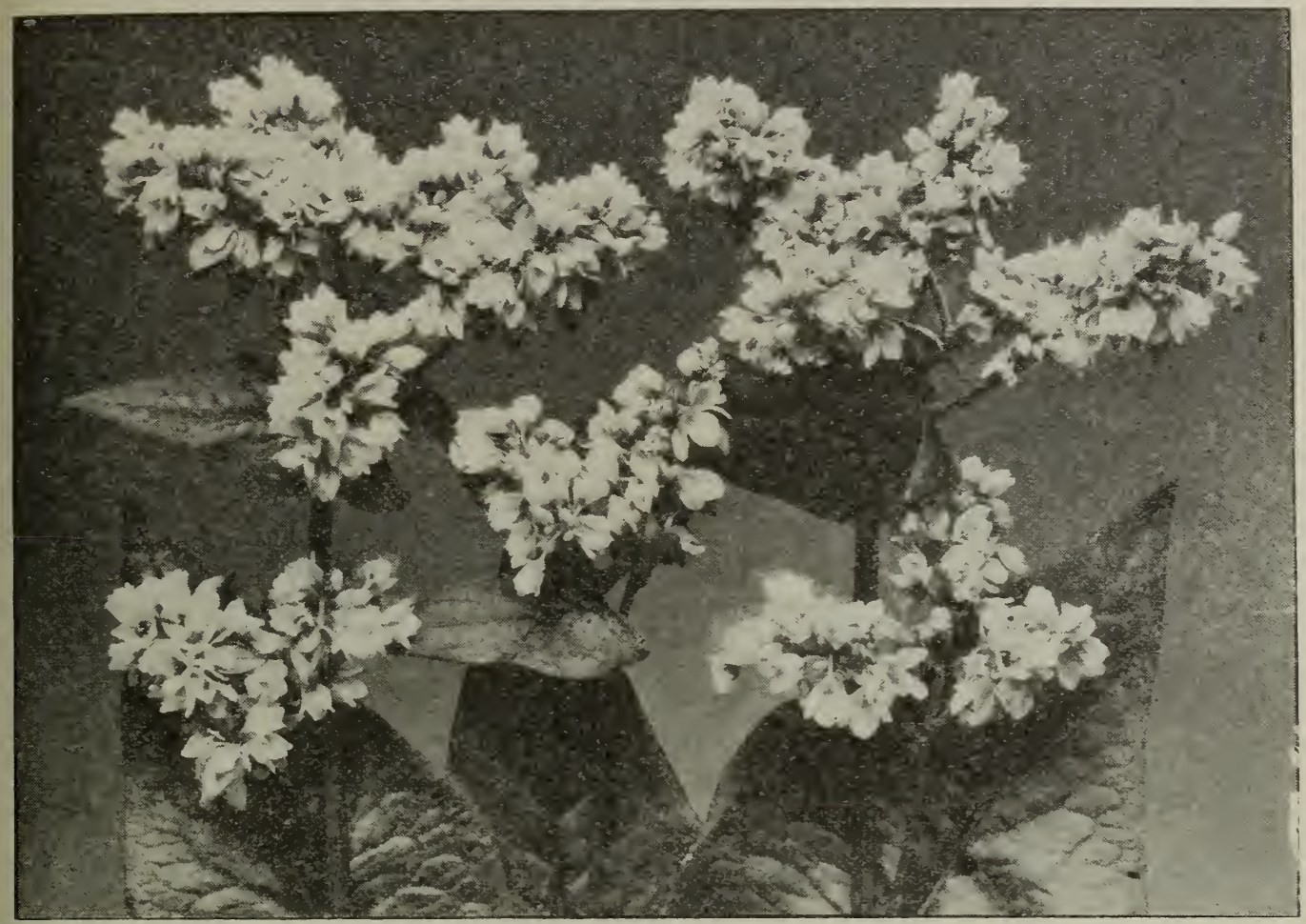

Honey for the bees, seed for harvest, fertilizer for the ground-buckwheat should be planted extensively.

soming should be done while the ground is dry and dusty, and never immediately after a rain. After sowing, the surface should be immediately rolled to compact the soil, as the grain sprouts more quickly, sometimes showing above in less than four days.

Mr. J. H. Kennedy, of Quenamo, Kan., tells us of a crop of 116 bushels of Japanese buckwheat that cost him next to nothing. After turning under his oat stubble in July, as it was too early to put in wheat he sowed the ground to buckwheat with a drill. This came off so soon that the ground was in almost as good condition, apparently, for sowing wheat as it was when first prepared. He then put the drill right on to the buckwheat stubble, and next season reported that the wheat sown on this stubble looked exactly as well as the rest sown on other ground. It is probable that a plant so different in its habits from wheat will take little if any of the necessary plant food for wheat from the soil; and it is a common remark that nothing fits the ground so nicely for a succeeding crop as buckwheat.

The amount of seed to the acre varies according to the locality. On good land, two pecks per acre is recommended as enough; on thin soil, three pecks. Mr. Mc-
Gowan, as will be seen by his article further on, doubles these figures; but we have found that two and three pecks are enough on our soil. One can increase the yield on thin soils by the use of $50 \mathrm{lbs}$. of phosphate and $50 \mathrm{lbs}$. of plaster mixed and drilled in, according to W. L. Coggshall, of Groton, N. Y., to whom we have already referred. The same authority estimates that buckwheat is one of the best crops to subdue rough land, and that it always leares the ground in gnod condition for potatoes and oats, and almost any crop except corn.

\section{SOWING BUCKWHEAT IN THE SPRING.}

Buckwheat can sometimes be grown in the spring, provided one is lucky enough to get it out just after the last frost. Buckwheat likes warm or hot weather; and if the spring is favorable a spring crop can sometimes be grown. But, as a general rule, it is much more profitable to grow it after some other crop, as recommended.

\section{BUCKIVHEAT FOR TURNING UNDER.}

Buckwheat as a fertilizer of soil is one of the best. Sometimes after late sowing, early frosts nip the stalks. In such cases we would always recommend plowing it under 
before the plants wilt. It will more than pay for its cost as a fertilizer, and some buckwheat-growers, we understand, enrich their soil every so often in this way, even when the frost does not come in to spoil the crop. In this case they wait till after the blooming to get the honey and then plow under. Indeed, several prominent men recommend plowing in two or even three crops of buckwheat, one after another, if short of manure, when it is desired to get the ground into a high state of cultivation.

The best crop of buckwheat we ever had was after plowing under a crop of red clover. The influence of clover and abundant rains matured the grain in just 65 days after the sowing; and as the seed was not sown in the first place till after the 15th of August, our experiments showed that, under favorable circumstances, buckwheat is a very speedy crop. There was no killing frost that season until the last of October, but this, of course, is unusual.

\section{SOWING BUCKWHEAT AND CRIMSON CLOVER} AT THE SAME TIME.

During the last two or three years we have had excellent success in sowing crimson clover with buckwheat, especially where both were put in along the last of July or first of August. They come up together; but the buckwheat, being stronger, takes the ground, and the crimson clover makes but little showing until after the buckwheat is harvested. Then the crimson clover, during cool moist fall weather, rapidly covers the ground. If frost should kill the buckwheat, the crimson clover will rise up above it and hide its black unsightliness in a very brief period; and the dead buckwheat seems to be just the sort of mulching that the clover needs. The finest crop of crimson clover we ever grew or saw was sown in this way, and turned under the following June, for planting potatoes. See "Crimson Clover," under Clover.

\section{HOW TO MAKE BUCKWHEAT A PAYING CROP.}

Our neighbor, H. B. Harrington, has grown buckwheat for years. He writes:

Buckwheat is the best, and, in fact, the only artificial honey-pasture that a beekeeper can supply himself with at a profit, from the middle of July, when basswood and clover are past, up to the middle of September, when the fall bloom of wild flowers commences. There are no arbitrary rules that can be laid down as to its culture, because buckwheat, probably more than any other grain, will adapt itself to seasons and conditions. Very hot weather will sometimes blight it if you sow too early, and early frosts destroy if you sow too late in the season; so you see you have a seed time from the 20th of June to August 1; and we once harvested over 40 bushels of very fine buckwheat per acre from a crop drilled on the 4th of August; but we used over 300 pounds of first-class blood-and-bone phosphate per acre.

It is a strong point in favor of buckwheat that it is a quick grower, and can succeed another crop. That crop was on the ground only 51 days from the time it was sown until the day it was thrashed; and the next day we drilled the same field to wheat without even the use of a dray and but very little extra fertilizer. The buckwheat left the land so mellow that it was the finest kind of summer fallow. We always raise our largest crops of wheat when we sow after buckwheat.

It is easy to see where the profit comes in from two crops where you have to plow and fit the land only once. If the buckwheat comes off too late for wheat, sow the field to rye.

In this section rye is the surest crop that can be raised. Never sow rye before the middle of October; and if you get the crop in by the first or even the 10th of November you run no great risk. Rye ground fine is the cheapest feed that we ever fatted hogs with. Small potatoes cooked and mixed in were used. It is still better to let the rye meal soak in water at least two days before feeding.

Now to beekeepers who want the crop for honey. Plant the crop at three different times to prolong the honey-flow, and you will be sure to hit the lucky time for a good field of grain. Buckwheat, on an average, will occupy the land about sixty days. It will commence to yield honey in fifteen or twenty days from the time it is planted, and take about ten days to mature after the honey-flow ceases.

Sow the first crop on the 20 th of June; the second crop on the 4 th of July, and the third on the 18th of July. We pick the 18th because the best crop we ever raised was sown on that day.

Now, what is the grain worth? The best home-grown feed for dairy cows that we ever tried, and we have fed lots of this, is one-third buckwheat, one-third corn, and onethird oats. Rye is a good substitute for the corn in this mixture. Thirty-two bushels of buckwheat is equal in value to fifty bushels of oats, and it is just as good feed for a horse as it is for a cow.

Buckwheat is the greatest weed exterminator that a farmer can use. Plow in June and till well, and two crops will exterminate and clear any field of Canada thistles.

Now one word to potato-raisers. Plow under your best crop of clover about the frst 


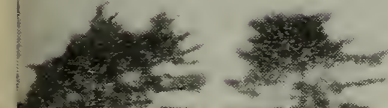

$2+\frac{1}{2}=20$

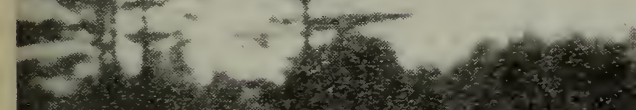

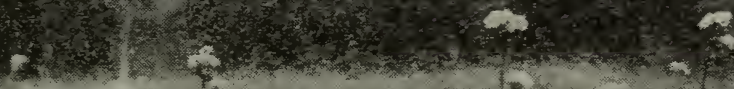

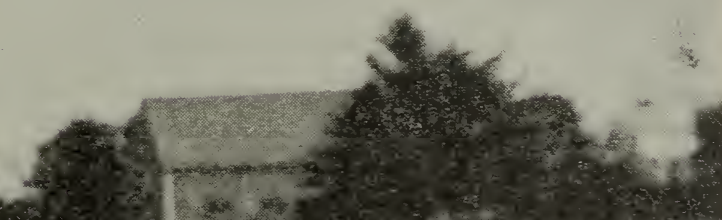

3

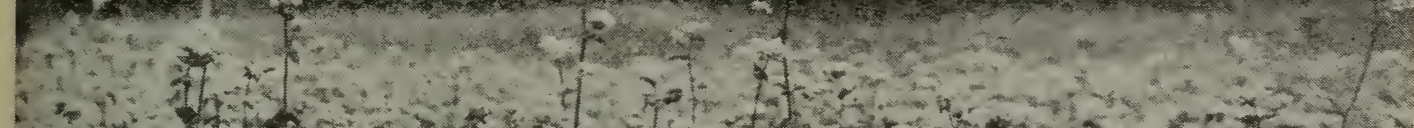

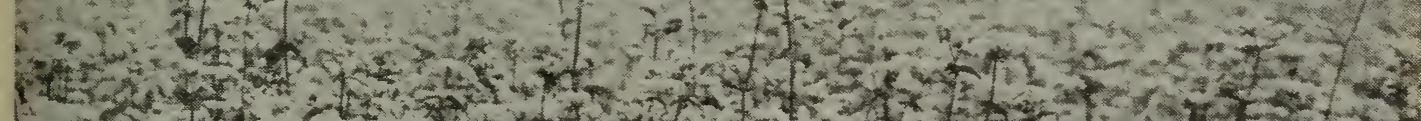

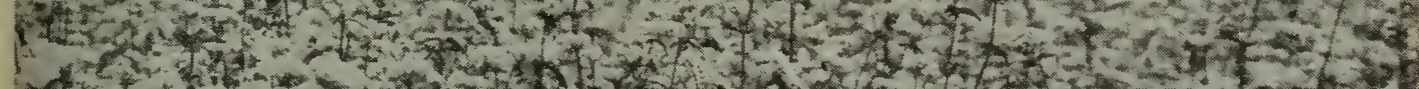

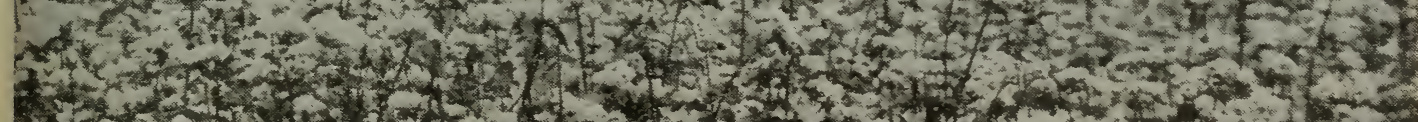

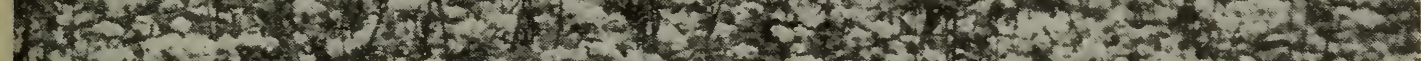

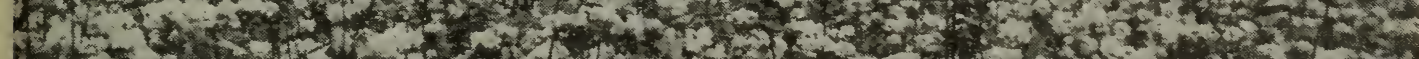

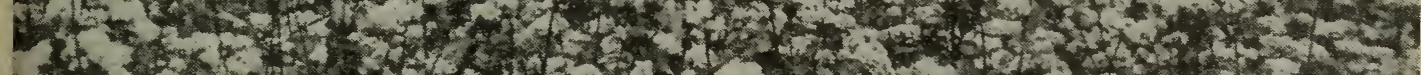

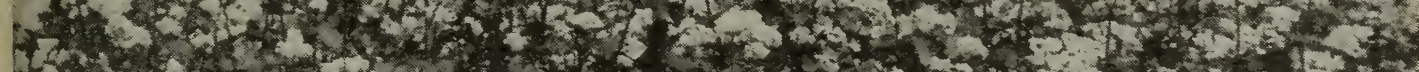

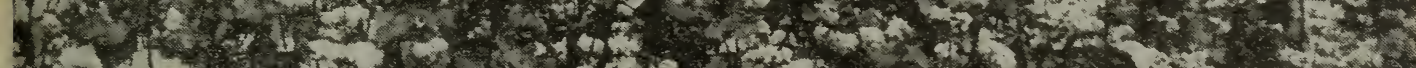

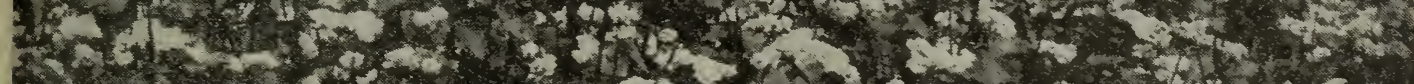

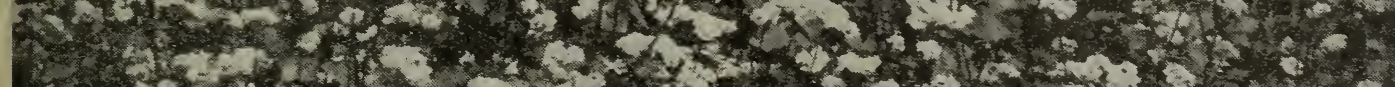

\section{(6)}

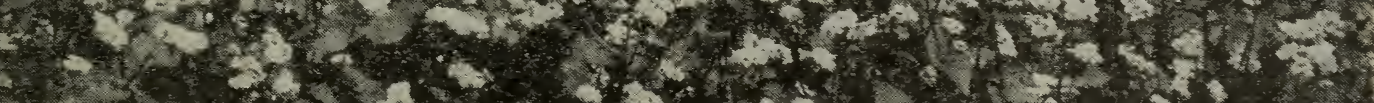

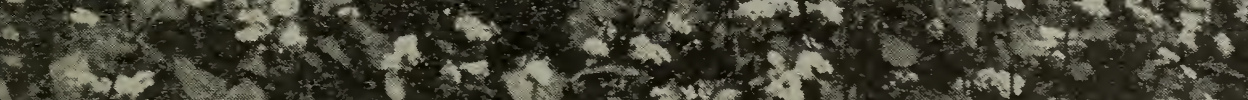

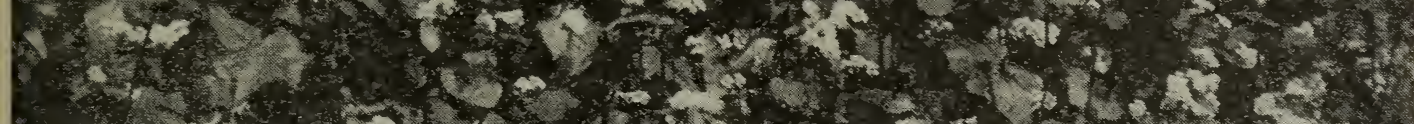

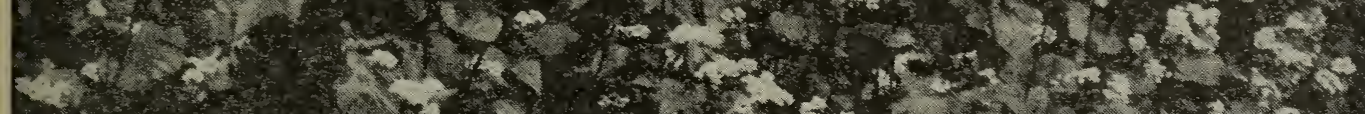

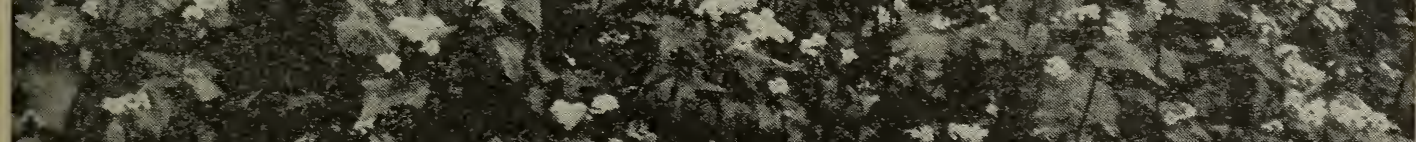

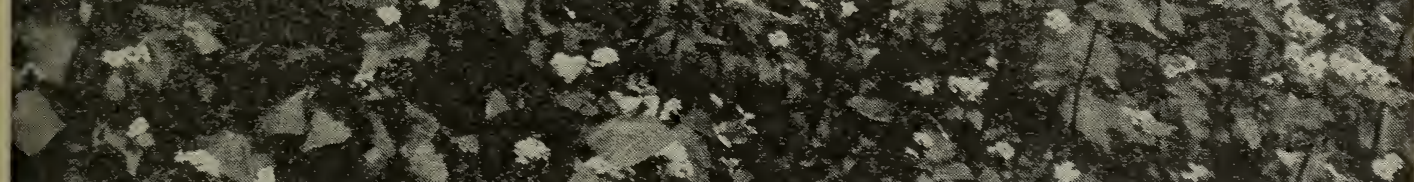

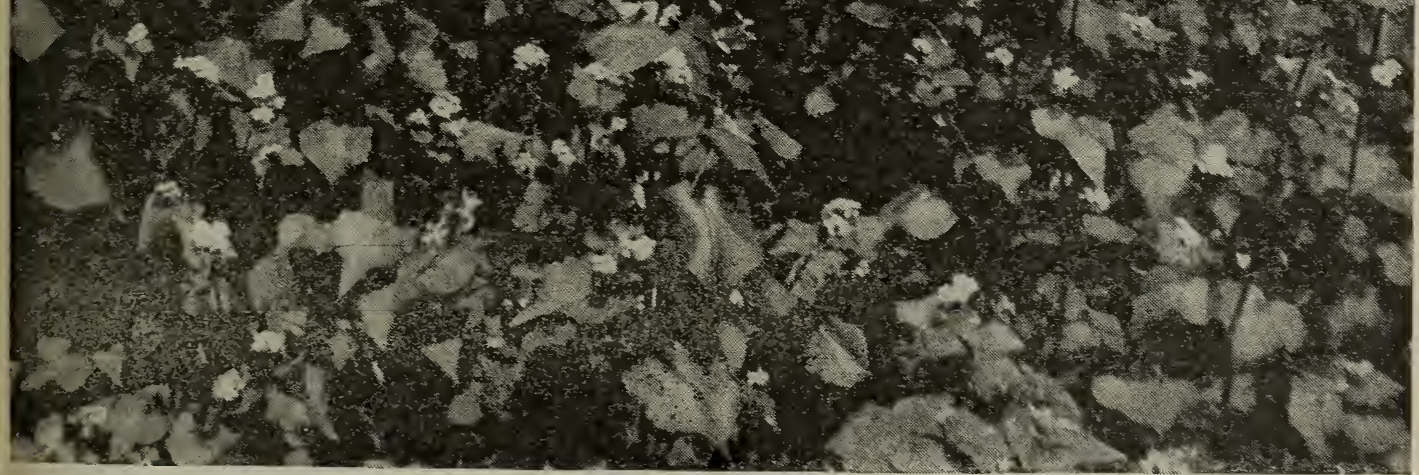




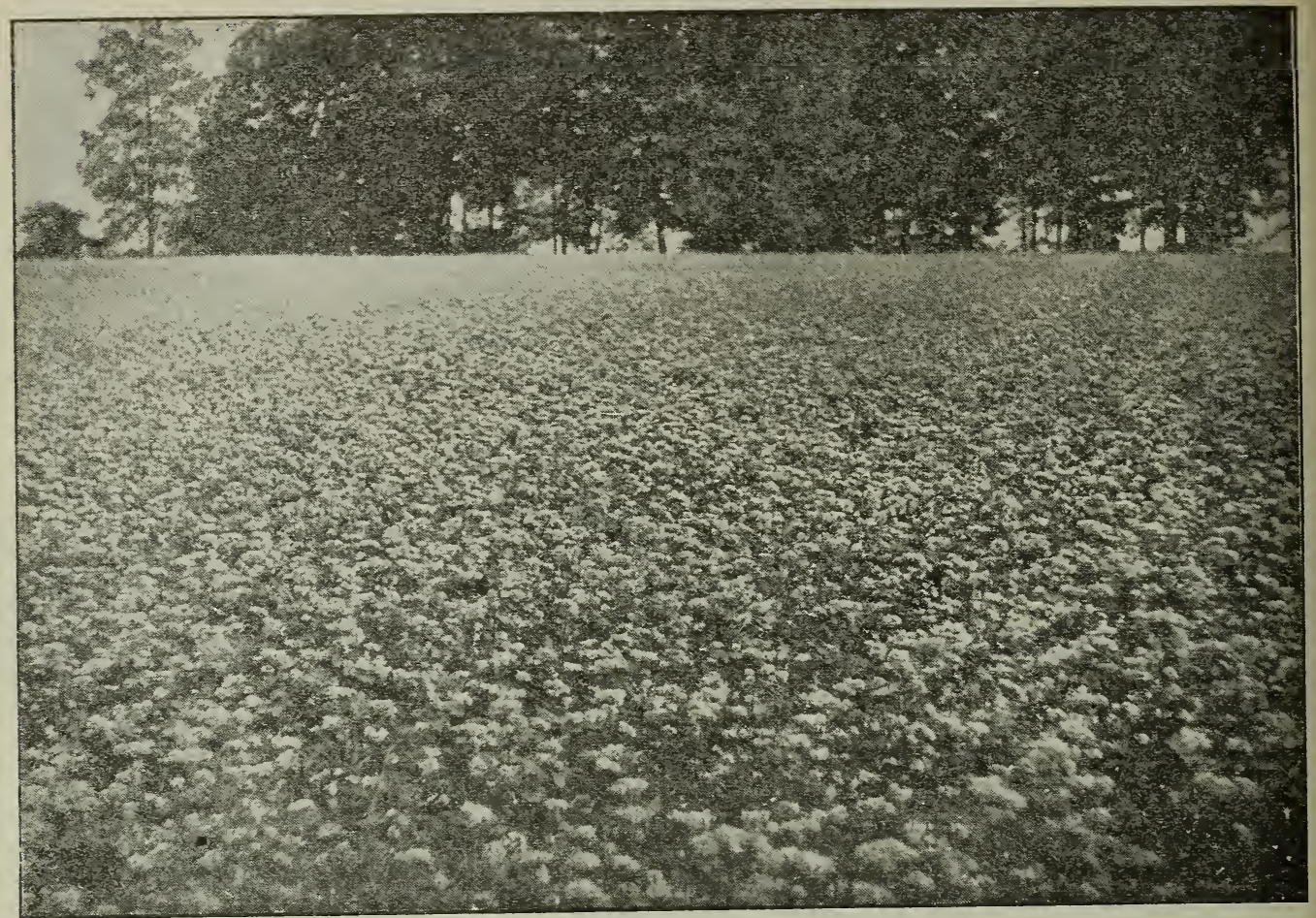

McGowan's buckwheat in full bloom in Butler Co., Pa. Mr. McGowan, by a close study of the details, prevents failures and makes the crop a very reliable one.

of July. Sow the land to buckwheat and to rye in the fall. The following June turn the rye under and you have the best conditions for potatoes that we ever tried.

Buckwheat will thrive on any kind of land, and pays well for the good phosphate that may be used. Don't be afraid to use a roller on the newly plowed land. Make a fine seed-bed. On heavy clay soil sow three or four days before a rain if you can. If a heavy rain crusts the soil before the plant comes up, it is apt to weaken it.

Again, Mr. J. H. McGowan, of Prospect, $\mathrm{Pa}$, sent an article for Gleanings in Bee Culture, Vol. XXXVIII., page 151, that is worth giving here in full.

I send a snapshot of a buckwheat field in full bloom. The growing of this crop here is considered by some an uncertainty, while others call it a "sorry crop;" that is, they are sorry, when it is good, that they did not sow more, and sorry, when it is bad, they sowed so much. But in this article I will try to tell how one may be almost sure of getting plenty of bloom (what the beekeeper likes to see) and plenty of straw and grain.

THE KIND OF SOIL.

To grow this crop to its best, several things must be taken into consideration. First, the soil. Any kind of well-drained land will answer. Buckwheat will not grow on ground that is wet and heavy or where the water stands and gradually dries up, leaving the soil in a hard, lifeless condition. It does best where the land is naturally dry, or made so by proper draining.

\section{PLOWING AND PREPARING THE LAND.}

Here in Butler Co., we begin to plow just as soon as corn is planted-about May 25. Each day's plowing is rolled or dragged down in the evening. This is important, as one should keep in the soil all the moisture that is already there. We follow this plan until plowing is all done.

\section{HARROWING AND SEEDING.}

Now, then, the work is only partly done, as it is necessary to keep after this field with a good spring-tooth harrow or disk and roller alternately until seeding time, when the seed-bed should be perfectly clean, fine, and solid. It is now ready to drill in (never broadcast), providing the proper time is at hand. Here we drill from July 1 to 20 . Early sowing insures a large yield of straw and bloom, while late sowing usually fills the best, as the sun is then not nearly so hot during the time of bloom. I have seen fields sown early turn brown in two days on account of the hot sun.

\section{HOW MUCH SEED TO SOW PER ACRE.}

One and a half bushels of Japanese, and one bushel of silverhull or little black is about right. In the Japanese variety the grain is larger and the stalk does not branch out as much as the other two varieties mentioned. This is the reason why more Japan- 
ese should be sown per acre; but if honey is a consideration I would advise sowing the little black or silverhull, as it blooms until cut or killed by frost.

\section{THE USE OF FERTILIZER.}

There is another important factor in the raising of this crop; and that is the use of fertilizer. We never think of growing it without using from 100 to $150 \mathrm{lbs}$. per acre of acid fertilizer, costing from $\$ 10.00$ to $\$ 12.00$ per ton. It just seems to make it boom-makes both grain and straw, and a much larger yield. Last year I sowed three fields to buckwheat. The first one was drilled in July 6; the straw was medium, and yielded 16 bushels per acre. The second was drilled in July 11; straw heavier than that in the first field, and yielded 22 bushels per acre. The third was drilled in July 19. straw like the first field, but yielded 25 bushels per acre. As a rule, early sowing gives large straw and a poor yield in bushels, while late sowing is the opposite.

Here buckwheat is grown for the following reasons: It comes quick; is easily harvested; is a splendid bee pasture; in fact, it is all we have to depend on. The straw is valuable on the farm. The flour has a ready sale at good prices on account of its national reputation. Nothing is quite so good as buckwheat for poultry; and when ground in connection with corn and oats it makes the best kind of feed for milch cows.

I would urge every beekeeper, if at all possible, to put in at least a few acres for the bees, and to furnish some of those good warm cakes which we all like for breakfast.

Caution.-It is a fact that buckwheat honey occasionally contains 33 per cent of water, and is, therefore, too thin, according to the formula of the national pure-food law passed June 30, 1906, which limits the amount of water in honey to 25 per cent. It will be necessary, therefore, to eraporate thin honey to make it conform to the law.

This may be done by means of a honeyevaporator, or by storing it for a while in a hot dry room. Beekeepers need not hesitate to go to the extra trouble involved by the law, since the honey is really so much improved, and ought to command a higher price.

GIVING AWAY BUCKWHEAT SEED TO FARMIERS.

This may sometimes be done profitably in localities where buckwheat is not grown at all. By furnishing seed to farmers for one or two years free a beekeeper may thereby be able to get the farmers to put it in as a regular crop, year in and year out. We would not advise giving arvay the seed free after the second rear. During the third or fourth year, furnish it at half price. We never give it away nor furnish it free to any one more than a quarter of a mile from the bees.

For further particulars on the question of whether it pays to give away seed like this, see "Alsike" under head of ClOvER.

BUILDINGS.-It is manifestly impossible to recommend any standard design of buildings for beekeepers' use that would suit all requirements. Some beekeepers require a room that can be used for extracting only; others sereral rooms for workshop, storage room, and extracting. The same room may often be used for different purposes at different times of the year, but, nerertheless, the purpose for which the building is to be used principally should be taken into consideration when it is planned.

The construction and materials for these buildings also rary greatly from the light framework covered with canvas to the most substantial concrete structure. Except the buildings erected at home apiaries, temporary or demountable or take-downable buildings are the rule for the reason that out-apiaries often have to be moved about.

Some use small buildings that can be easily loaded on a low wagon and hauled about from place to place. Still others use buildings made in sections, bolted together. so that the rarious sections may be taken apart and loaded on a wagon in the flat. Mr. E. D. Townsend, of Michigan, has used such buildings for years. Such a construction costs a little more than the usual type built solid from the ground up, but the convenience, provided there is a likelihood of frequent moves, more than offsets the extra cost.

In order to make the rarious sections strong enough to hold together after being unbolted, $2 \times 4$ material is used for the framework. There are six sections in allnot counting the floor-the two ends, the two sides, and the two halves of the roof. Before nailing on the siding of the sections Mr. Townsend tacks on a good grade of tar paper which is proof against depredations of mice, and makes the building more beeproof as well, certainly an essential feature when extracting has to be done after the boney-flow when bees are inclined to rob. 


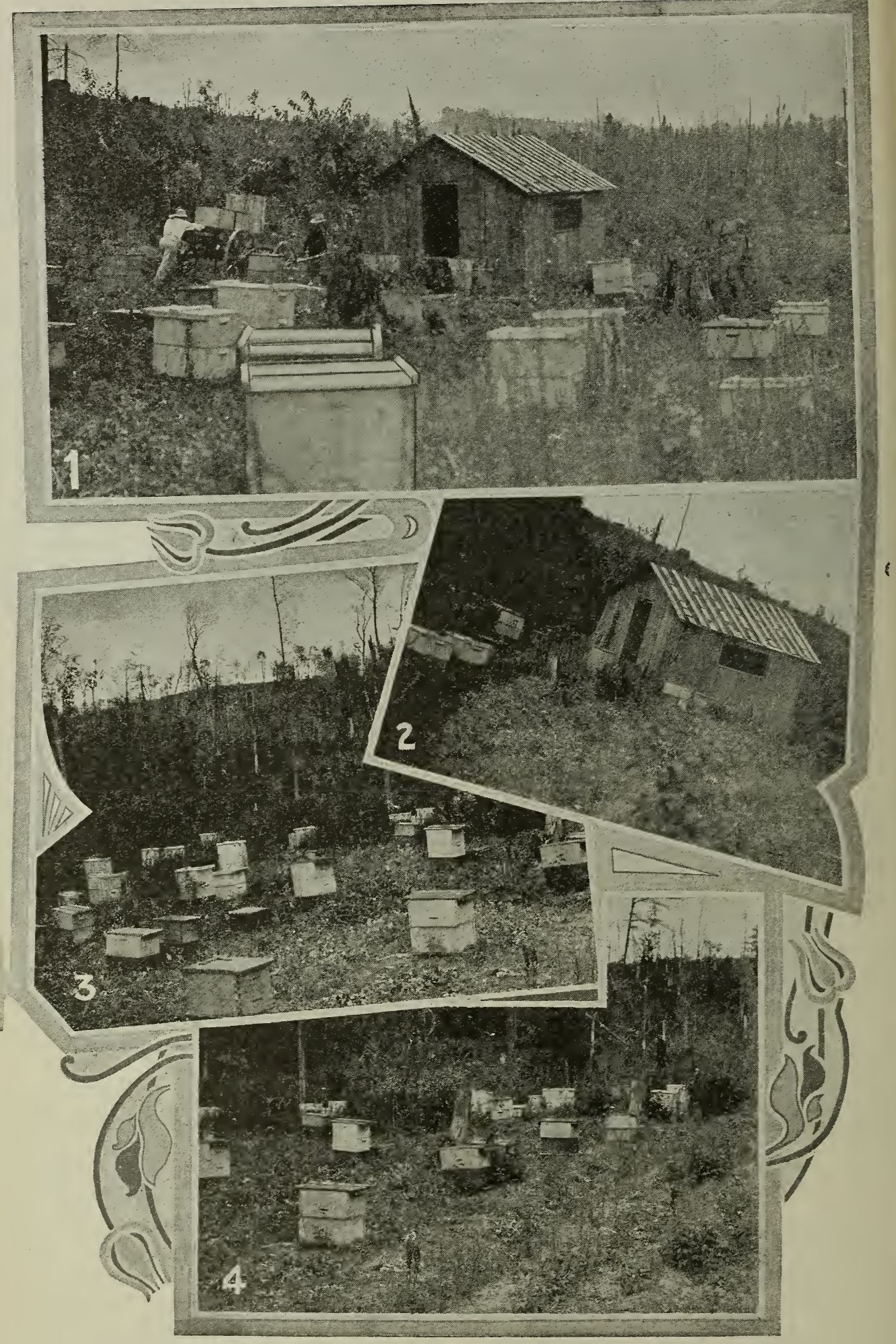

E. D. Townsend's Spring Brook Apiary and sectional extracting-house. This building is made in six separate panels or sections beside the floor, which bolt together at the corners, making it perfectly rigid. If desired, it may be quickly taken apart and moved on a wagon. 
In locating a building the most convenient place to the apiary must be taken into consideration; but if the lay of the ground permits, a downhill grade to the building makes it much easier to wheel or cart stuff to the building. In many instances it is of advantage to have a two-story building, the second floor, where the extracting is done, on a level with the apiary. The honey can then be piped into a tank in the lower story, the floor of which should be on a level, say, with the bed of a wagon on the ground at the lower end of the building.

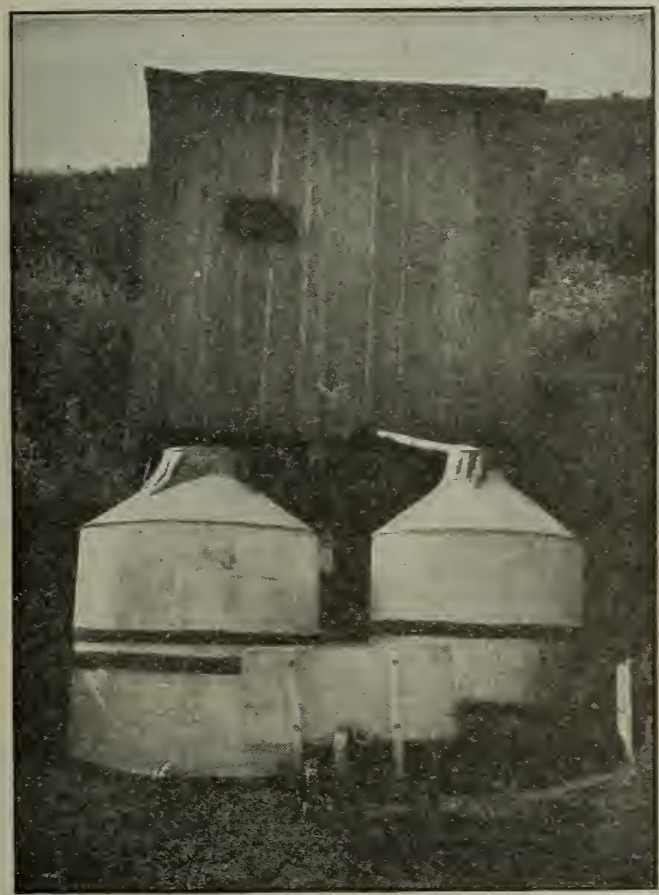

Typical side-hill Oalifornia honey-house. The honey runs by gravity from the extractor thru pipes into the large tanks located below the building on the outside.

When there is no side hill and the "gravity plan" is, therefore, impractical a honeypump is a real necessity to elevate the honey so that the lifting and consequent loss of time are avoided. See Extracting. In hilly or mountainous countries, however, there is no difficulty in selecting a side hill. If desired, as is the custom in many parts of California, large honey-tanks may be located out of doors on the lower side of the building, the honey running from the extractingroom direct to the tank.

The late E. W. Alexander, of Delanson, N. Y., a beekeeper who had 750 colonies all in one apiary, used for many years a small extracting-house just large enough to receive an extractor, uncapping-box, and space to receive and pass out combs thru openings in the side of the building, ordinarily covered with sliding doors. A tin pipe conveyed the honey by gravity to a large tank in another building on lower ground.

E. S. Miles, of Dunlap, Iowa, has a very. conveniently arranged building having two large rooms, the floors of which are on different levels, the floor of the ell being $31 / 2$ feet below that of the main room. Needless to say, Mr. Miles has room for a work-bench where he nails shipping-cases, cases for comb honey, hives, and other stuff. Each room has an outer door with a platform just about the height of a wagon-bed. These two doors are on a side of the building opposite from the bees so that there is little danger in driving right up with a team of horses.

The sides of the building are of $2 \times 4$ studding, 24 inches apart, boarded with shiplap, then papered, and finally sided with regular 6-inch house siding. The roof is made of $2 \times 4$ rafters, 24 inches apart, corered with sheathing and shingled. The material for the whole building cost about $\$ 300$. The main room is $16 \times 48$ feet; the addition, or ell, 12 by 18 feet. A building of this size is ample for all the work in connection with the handling of 300 colonies. By using a cheap shed for additional storage it would be large enough for 500 colonies.

VENTILATION AND IVINDOWS.

A common fault of beekeepers' buildings is that the ceilings are too low and there is inadequate ventilation so that the temperature on a hot day becomes almost unbearable. A ceiling three or four feet higher than it would actually have to be adds but very little to the general cost and at the same time permits a wide shelf, perhaps seven feet from the floor, running the entire length on either side of the building. Such shelves not only help to keep the room cooler, but furnish much additional space for temporary storage.

For light and ventilation a very good plan is to cut out long horizontal windows in each side and perhaps in one end also, having hinged wooden shutters which can be lowered to keep out the storm in bad weather. A tight-fitting frame covered with 


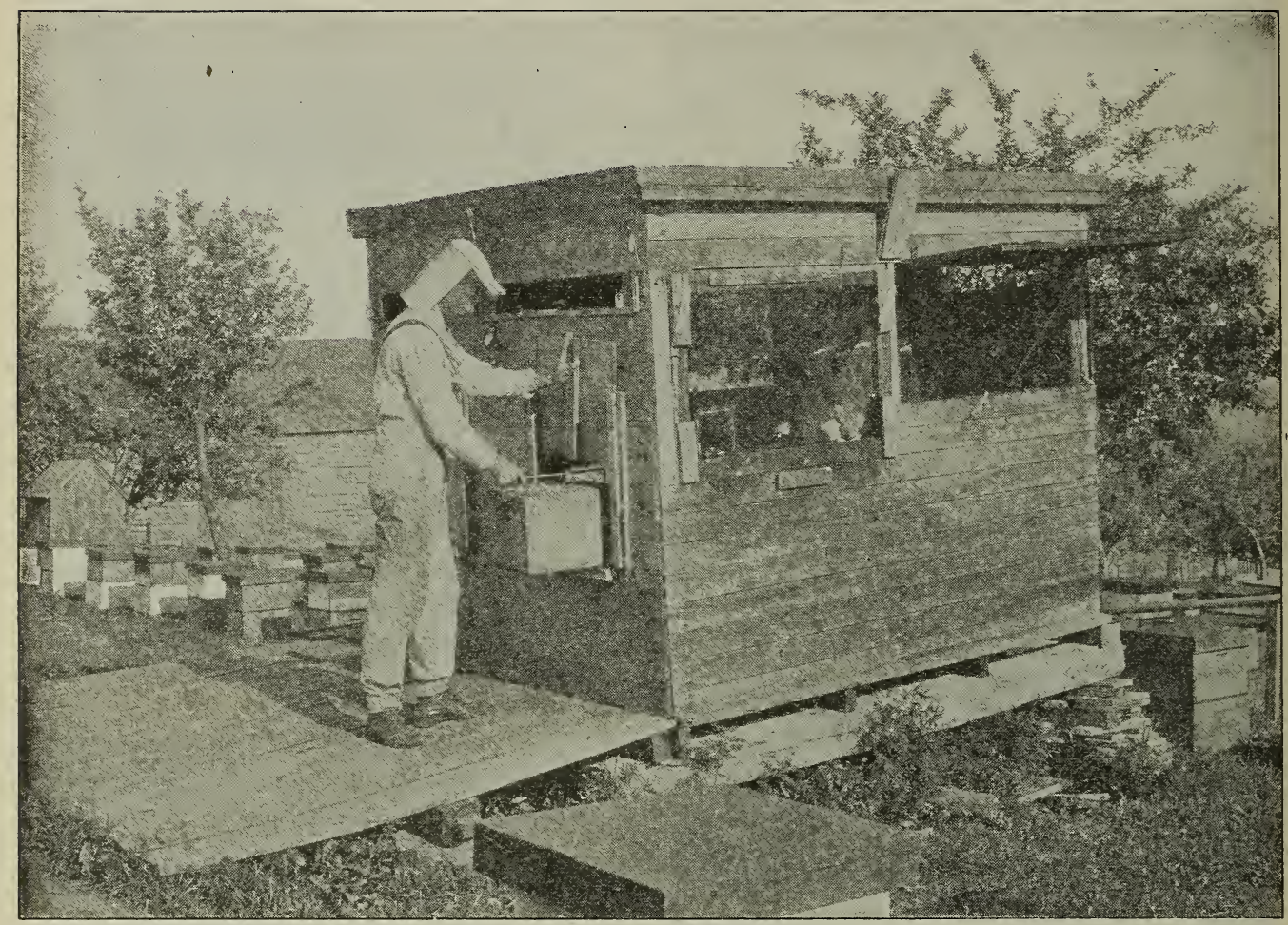

A small inexpensive extracting-room as formerly used by E. W. Alexander, of Delanson, N. Y. There are two openings in the end of the building that close with sliding doors. The full combs are put in thru one door, and the empty ones taken out the other one. A pipe conveys the honey from the extractor to a tank in another building down the hill.

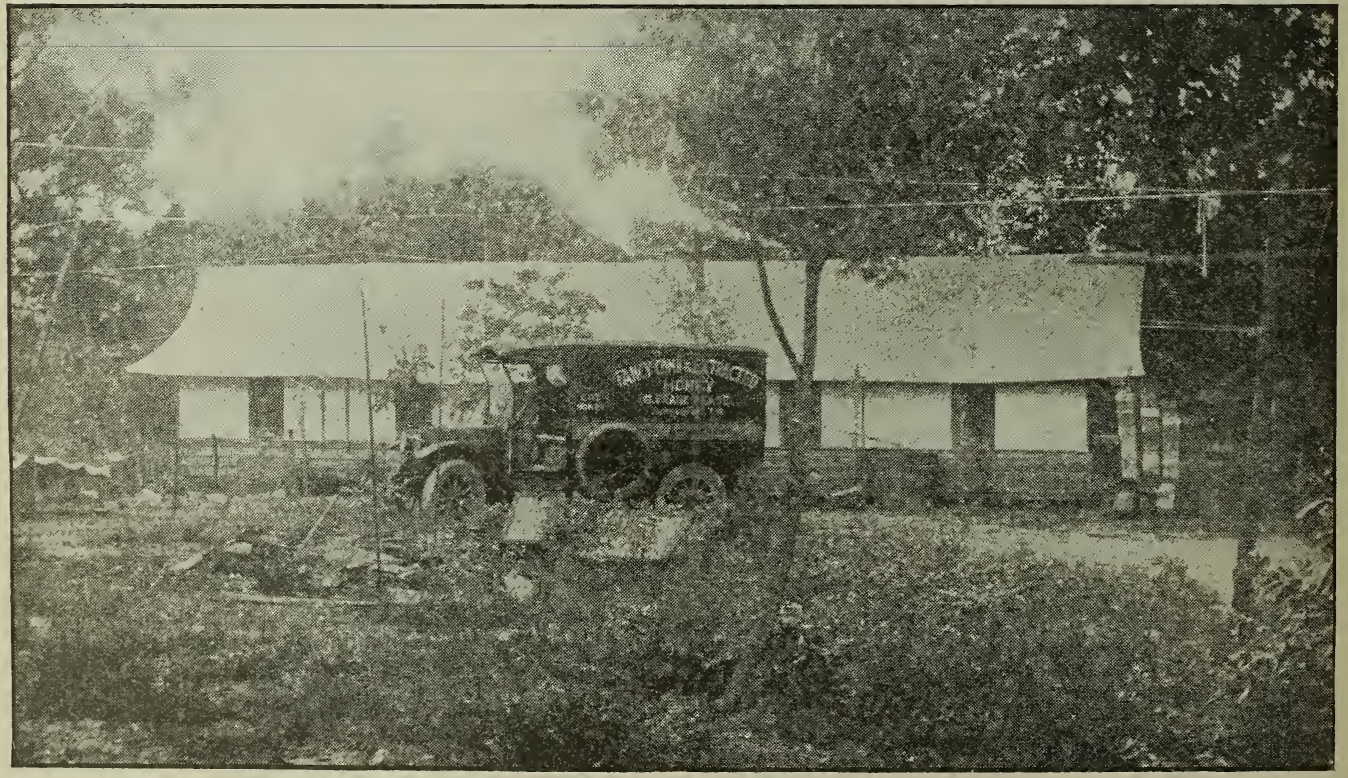

An inexpensive and quickly constructed building that answers every requirement. Walls and floor of wood, roof of canvas. A good canvas roof gives a better light inside and is cooler than a solid roof. 
galranized wire cloth makes the opening bee-tight. There ought to be one or two glass windows as well to permit of interior work in stormy weather when it would be best to have the shutters closed. All screened openings should be provided with several honey-house bee-escapes at the top to let out bees that are bound to get inside during extracting time. A screened door is a positive disadvantage for the bees keep hovering around the door, and when it is opened many of them get in. A solid door or one having glass in the upper part is to be preferred.

During a time when robbers are bad, allowing the bees to escape to the outside as fast as they get in the room is bad practice. A number of large beekeepers, instead of using bee-escapes, have the window-screens remorable or hinged at the bottom. The bees collect on the screens during the day; and after the work is finished, or late in the afternoon, the screens are removed or swung out at the top so that all the bees escape at once to their hives. The building thus acts as a robber-trap until the bees are released when flying is nearly over for the day. By morning the excitement will be over.

Mr. C. F. Hochstein, of Cuba, leaves an opening three feet wide all around his building. This he covers with heavy galvanized wire cloth. Ingeniously made beeescapes are located along the upper edge, constructed of wedge-shaped blocks of wood between the wire cloth and the siding. For a tropical climate this construction is all right, but in other localities smaller openings which can be entirely closed by means of hinged shutters are to be preferred. All honey-house bee-escapes which operate on the "cone" principle ought to be so constructed that the openings can be entirely closed in case the bees should get to robbing and should find the small exits.

A substantially constructed tent makes a light, cool, and easily moved structure. $\mathrm{Mr}$. G. Frank Pease, of Marshall, Mich., has a rery comfortable four-room work tent. The floors and side walls are of wood, making a rery substantial construction and yet inexpensive.

\section{EXTRACTING-HOUSES ON WHEELS.}

There are many ingenious portable extracting-rooms consisting of a canvas or screen-covered framework on an extended wagon-bed. W. D. Jefferson, of Safford, Ariz., uses a low wagon with small widetired wheels. The platform is wide enough to extend out eren with the outer edges of the wheels and long enough to give suffcient room for extracting purposes. Under

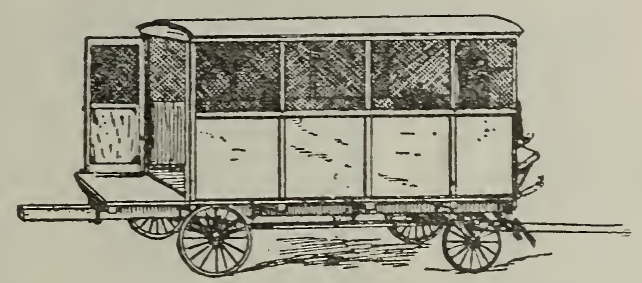

Jefferson's portable extracting-house. A 200-gallon honey-tank is located under the floor between the axles.

the platform is a shallow tank hanging between the front and rear axles which holds 200 gallons. The screen for the honey is in the floor orer the tank where it can be changed easily as often as it becomes clogged up. The honey, of course, runs from the extractor on to the screen and then into the tank.

This portable outfit is hauled from yard to yard, and the honey as fast as extracted is hauled home so that none of it is left at the outyard.

Earl C. Biddick, Meridian, Idaho, has a portable extracting-outfit 16 feet long, 8 feet wide, and 6 feet high. On the platform is built a framework of $2 \times 4$ 's corered with a light canvas. Such a building is large enough to hold an eight-frame extractor, gasoline-engine, uncapping-box, etc. The honey runs from the extractor thru a pipe to a separate tank outside the building, the honey itself not being handled at all while the extracting is going on.

Mr. Biddick screens one end of the framework and has canvas curtains which may be rolled up, thus providing plenty of light and rentilation. A very desirable feature of an outfit of this kind is that as soon as the springs are blocked the extracting may begin. Regular two-ton wagon springs are used.

THE SUBSTANTIAL BUILDING FOR THE HOME YARD OR CENTRAL EXTRACTING-PLANT.

As has been mentioned, the building suitable for an out-apiary is usually inadeguate for the home yard where there must be room for considerable storage, for making sup- 


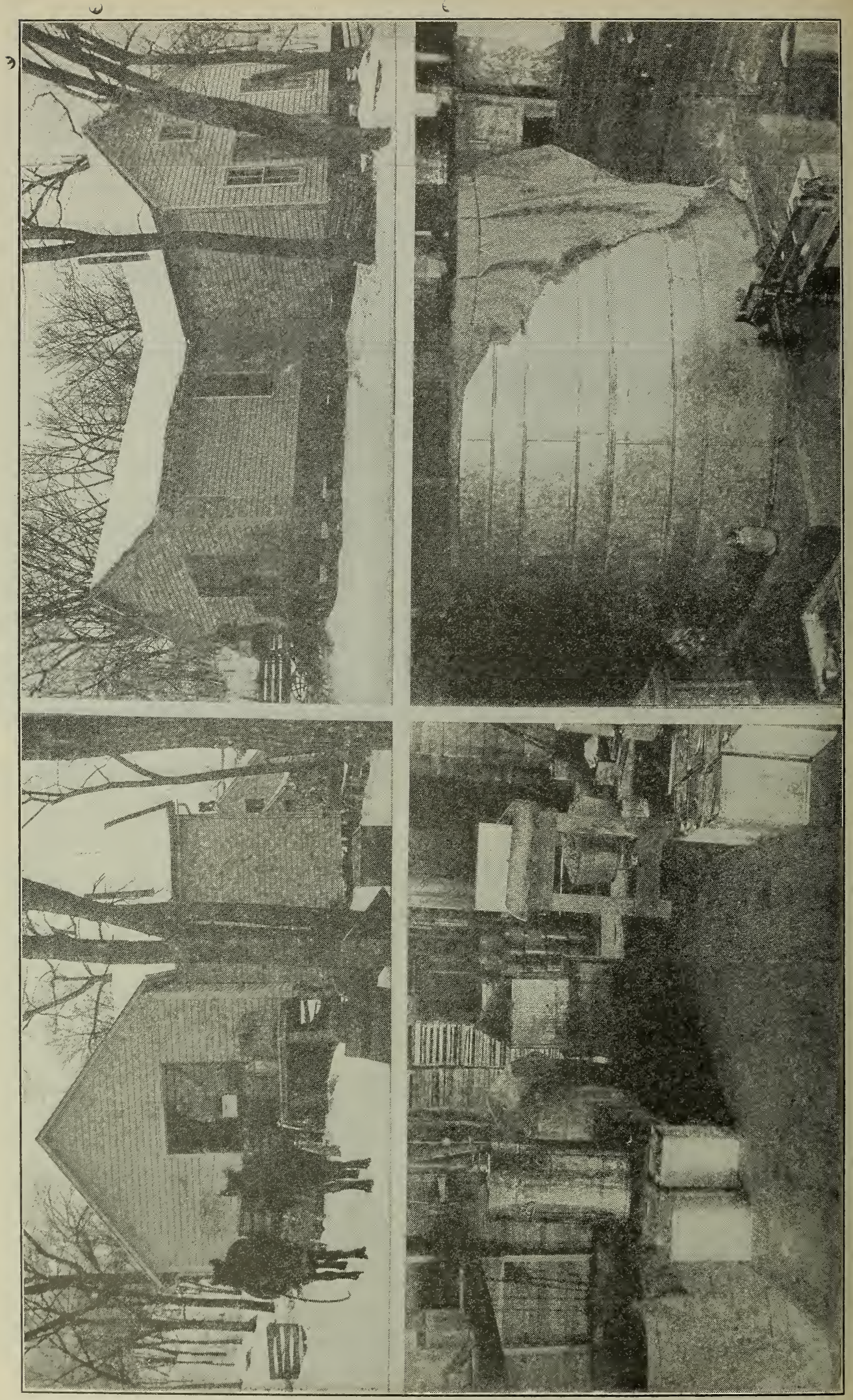




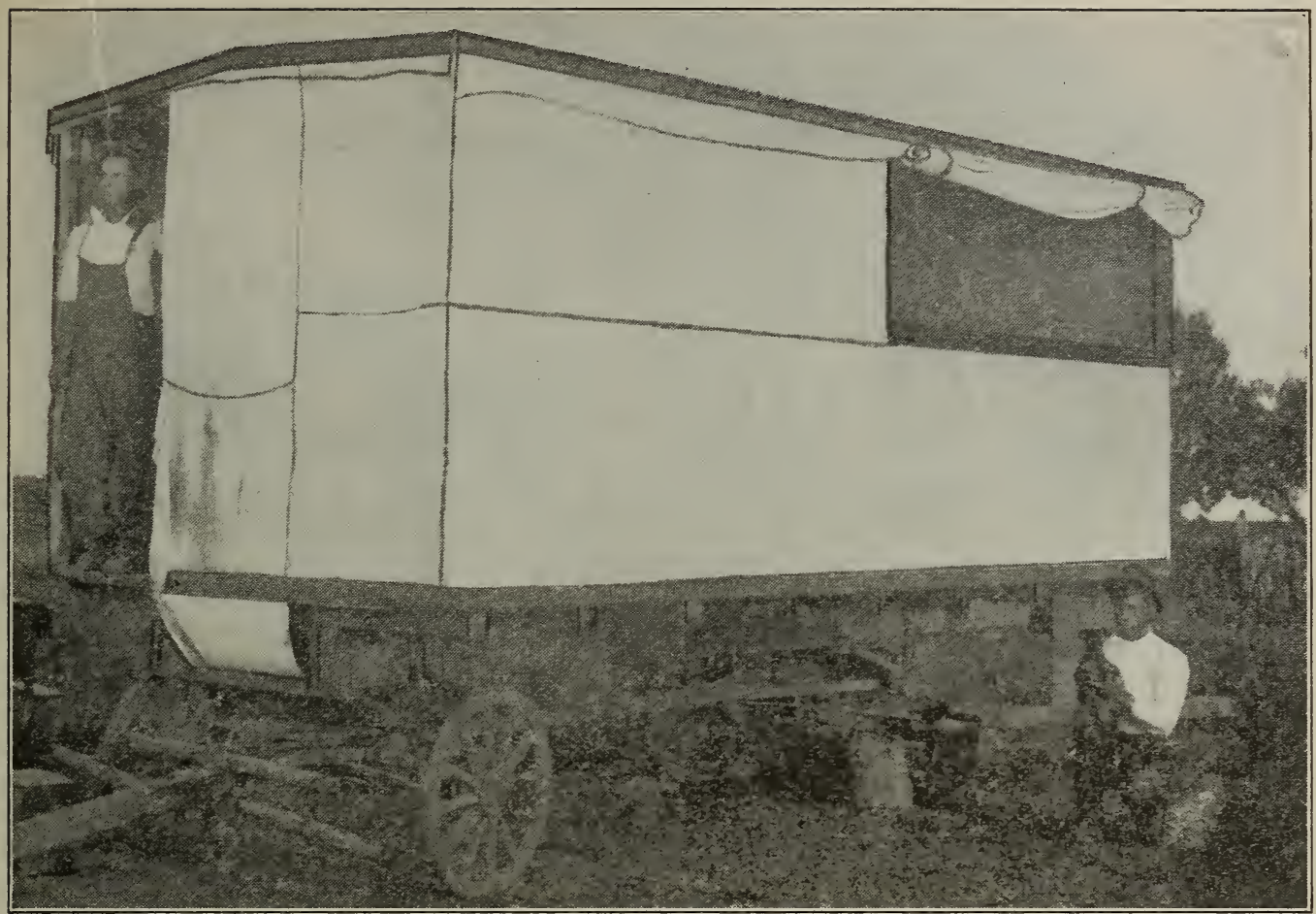

Earl Biddick's portable extracting tent. This gives a floor space of $8 \times 16$ feet, large enough to hold an eight-frame extractor, engine, uncapping-box, etc. The honey runs thru a pipe to a separate tank on the outside. A room built on a wagon need not be cramped, necessarily.

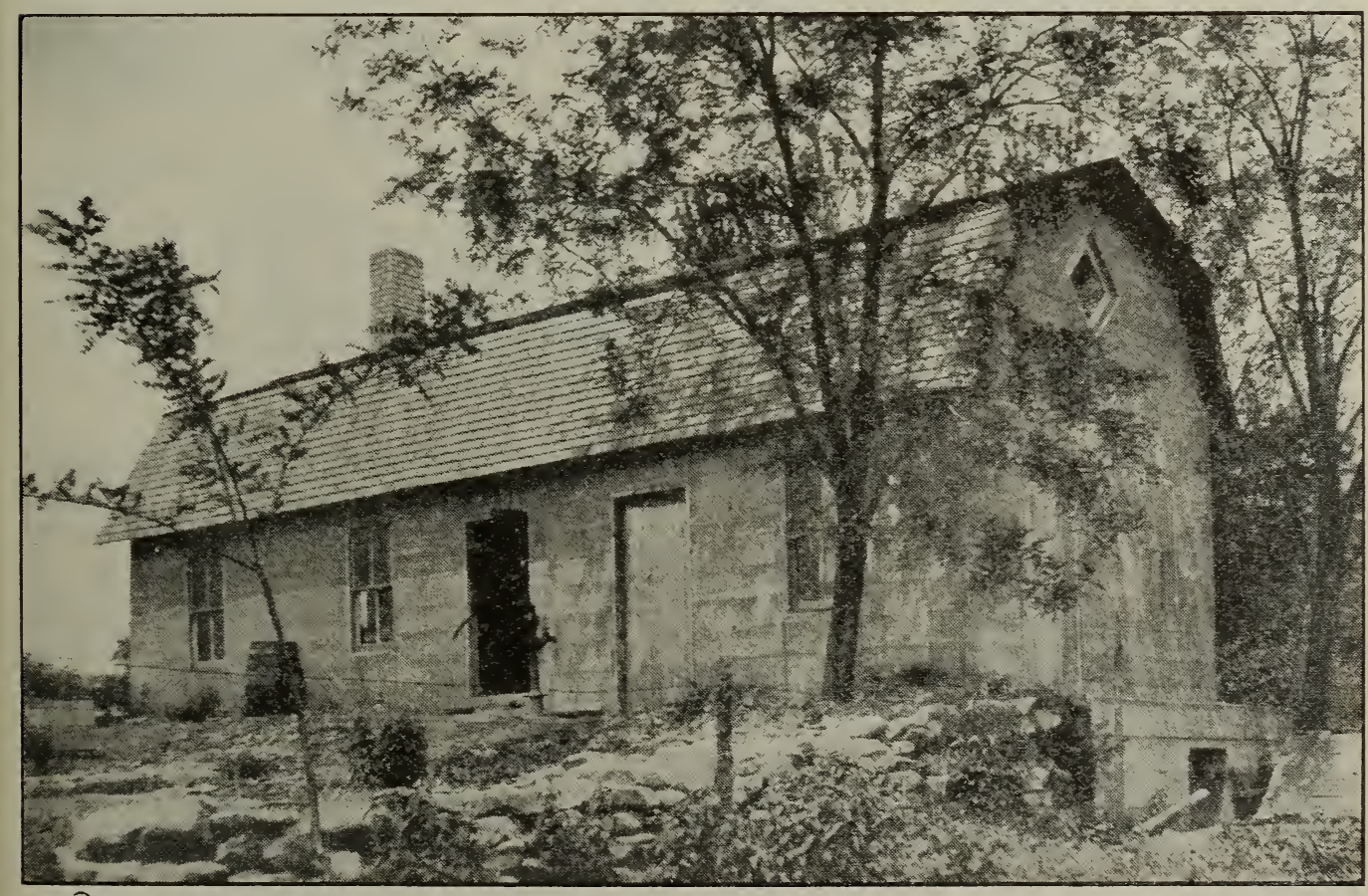

David Running's $16 \times 40$-foot concrete building. There are two different floors besides the cellar where the bees are wintered. The cellar has a capacity for nearly 350 colonies. Where gravel is cheap, concrete is cheaper than lumber in the long run. 


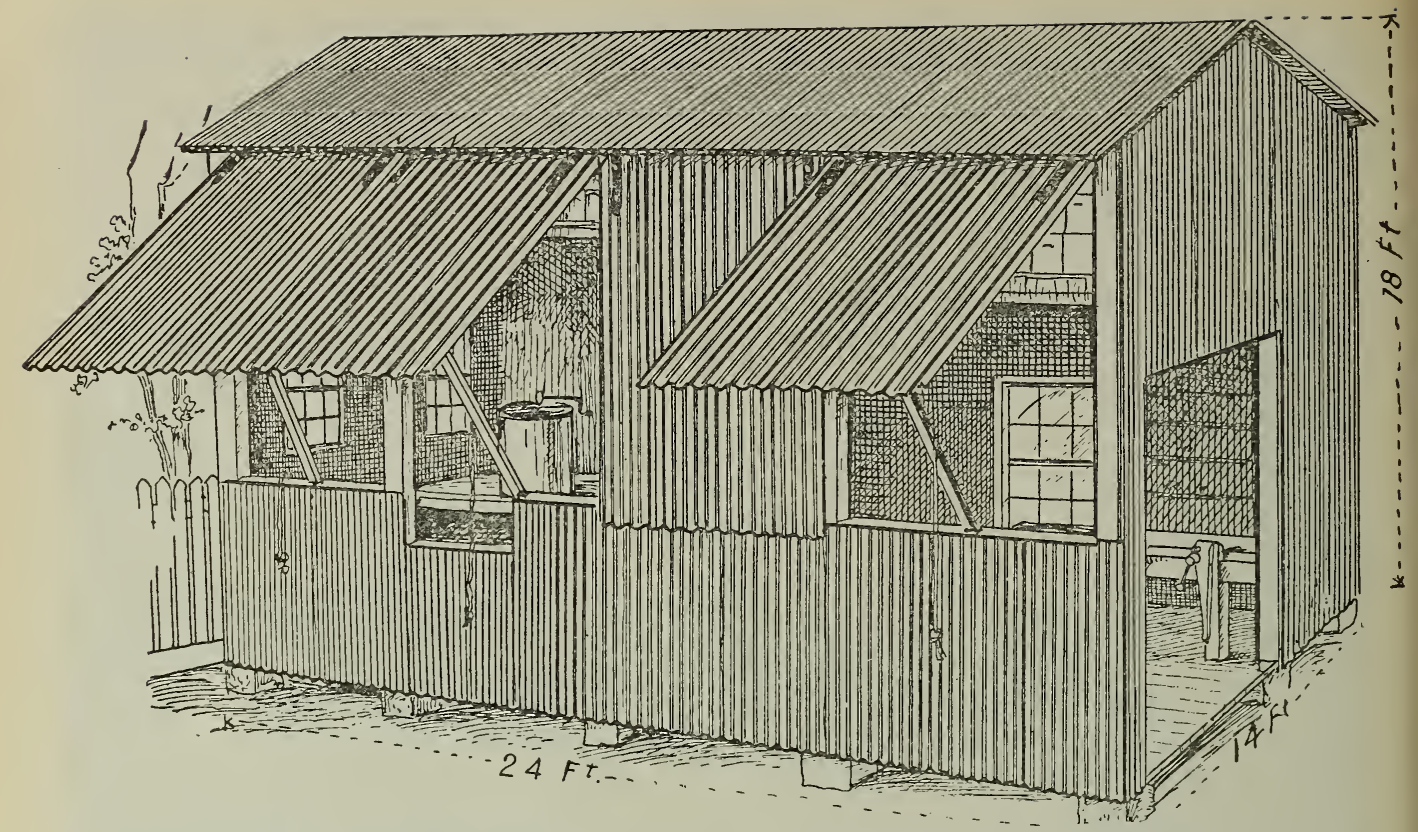

Louis Scholl's corrugated-iron honey-house and work-shop. As shown in the sectional view there are four different floors in this building which are used for carpenter work, extracting honey, storage, etc.

plies, and for all the inside work, in fact, in connection with the business. For this reason expensive conveniences are usually out of place in a building in an outyard. At home it pays to erect a larger and more substantial building, including such conveniences as are time and labor savers. David Running, of Filion, Mich., has one of the best and most completely equipped concrete buildings in the country. Concrete, so far as the cost of material is concerned, the roof.

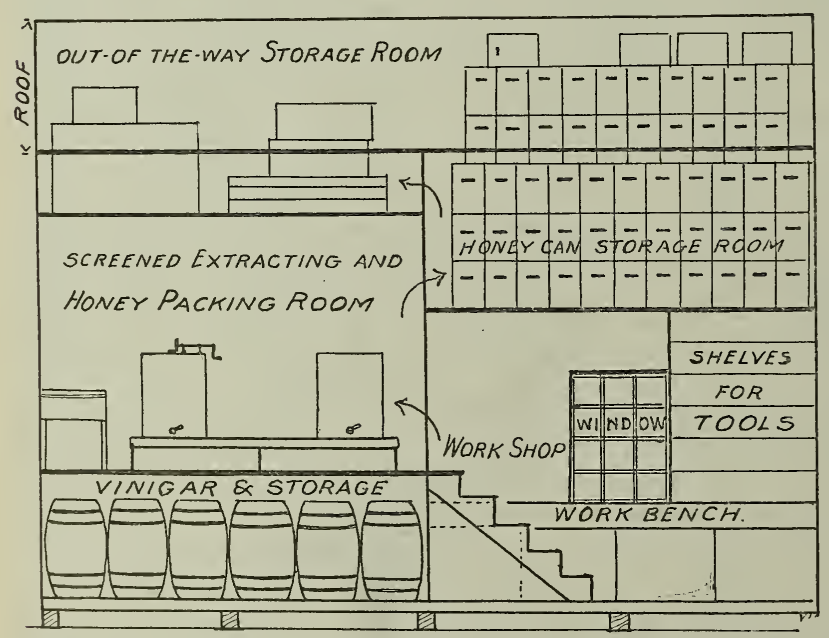

sides the basement used as a bee-cellar, and yet the material cost only $\$ 206.75$. A large number of stones, to save the cost of cement, were used and cost nothing but the labor of picking up. The walls, moreover, are only six inches thick. In most instances eight inches for solid concrete is thin enough. The lumber used for making the forms is not wasted, for it can all go into

More and more beekeepers are using automobiles or auto trucks in their business. While it is not always possible nor desirable it is oftentimes convenient if the honeyhouse and work-shop includes also the garage. Mr. Henry Hograve, of Wauketa, Wis., has such a building, which he finds a distinct advantage. Mr. Hograve has a driveway thru the center of his apiary, and he uses the auto for carrying full supers right into the garage. From there they are pushed thru an opening on to a platform in the extracting-room. It would doubtless facilitate loading and unloading and save considerable lifting if especially where gravel is cheap, often costs less than lumber. Mr. Running's building is $16 \times 40$ feet, has two different floors be- the floor of the garage could be two or three feet lower than the door of the adjoining room. 


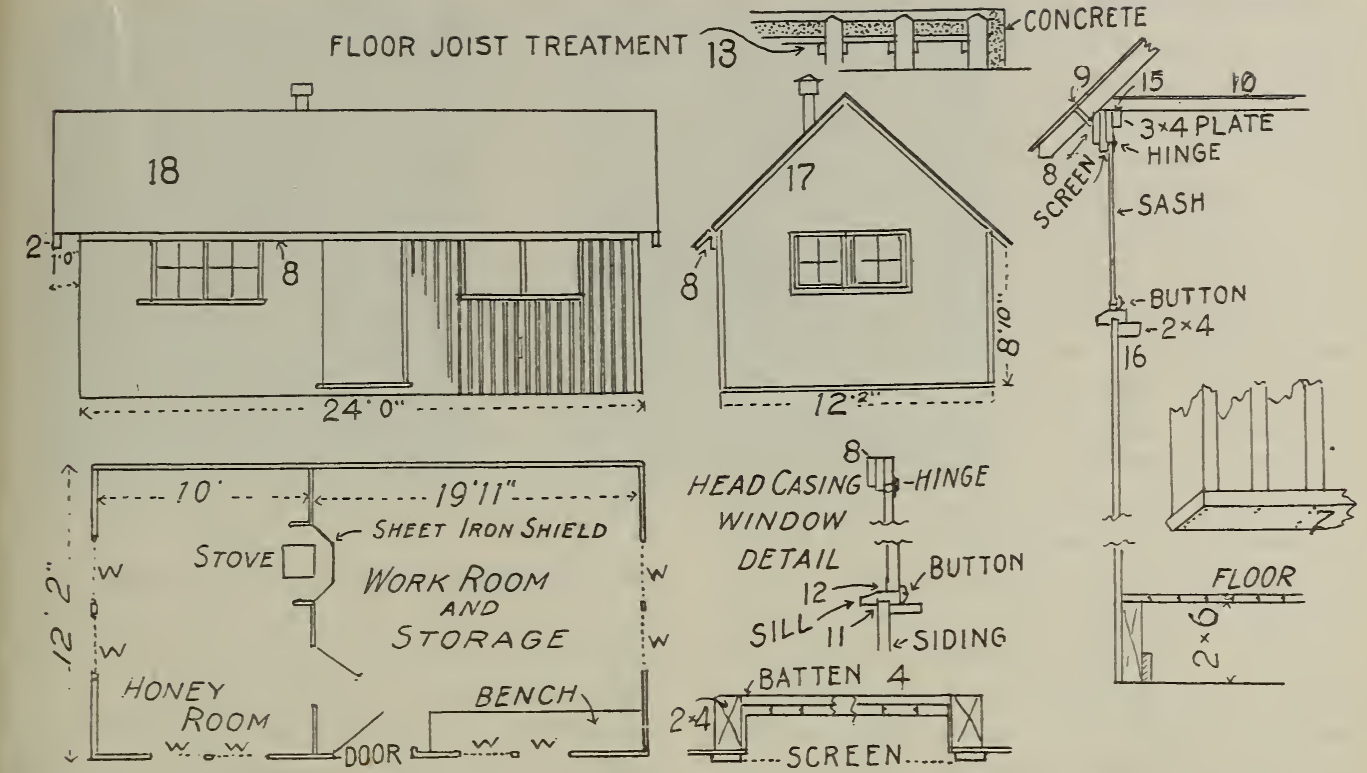

Neat design for both workshop and honey-room.
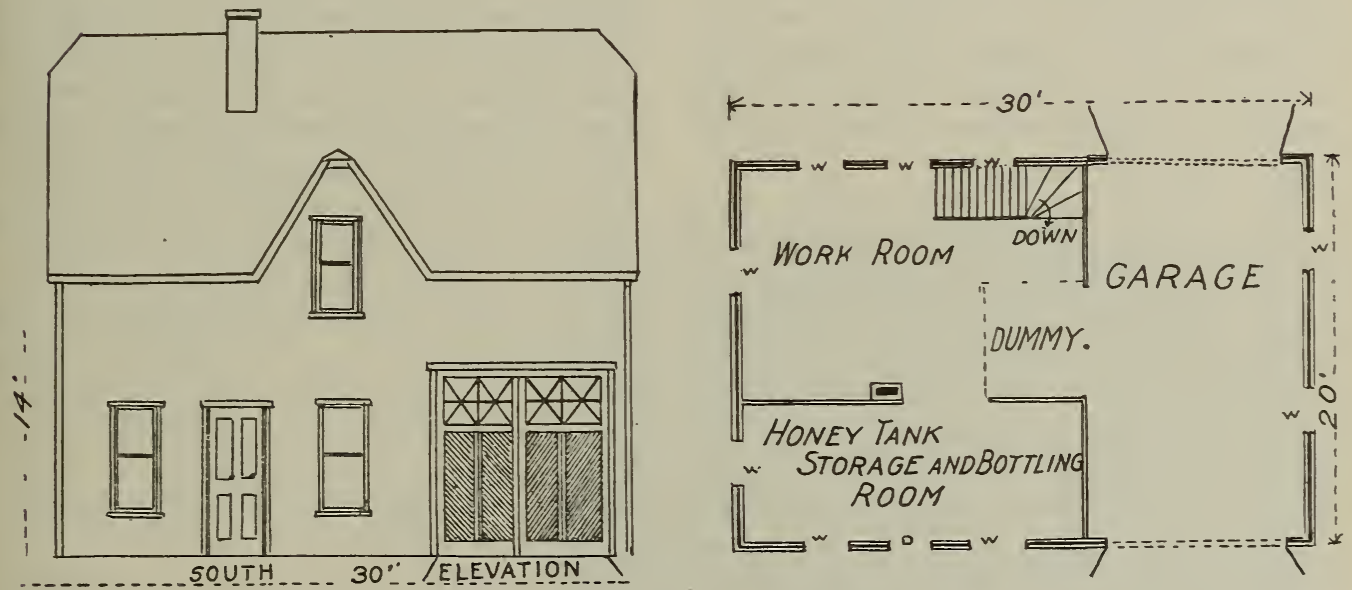

Garage and honey-house combined. The load may be taken off the auto and set directly on to the platform in the work room thru an opening in the wall.

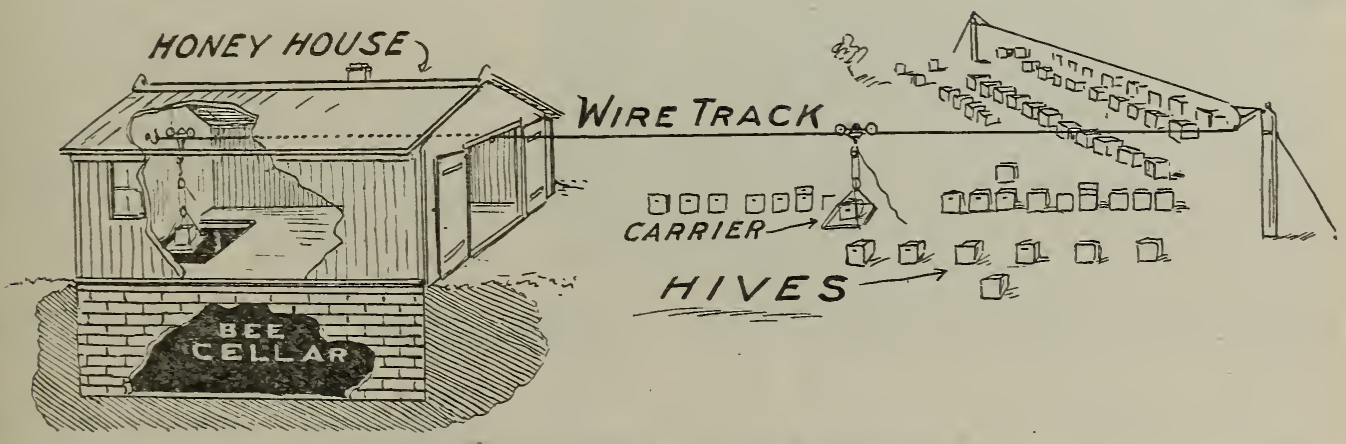

Very little carrying, lifting, or wheeling in this apiary. 


\section{BUILDING UP COLONIES.-Under the} heads of Spring Dwindling, Spring ManAGEMENT, and UNITING, will be found hints on building up colonies in the spring and fall; but this article will confine itself to the question of building up colonies so that they will be ready for the honey-flow.

There is no more important matter in this whole volume than having colonies ready for harvest-not only strong, but bees of the right flying age to secure a crop. Colonies of only half strength, or below par, will come far short of the strongest colonies in honey production. A beginner would naturally suppose that a half or twothirds strength stock would gather proportionally as much honey as one of full strength. But this is far from being the case. In the production of comb honey, at least, the half and medium sized colonies possibly might not go up into the supers at all, while the full colonies might store 50,100 , or even 200 pounds each. In the production of extracted honey the relative difference between the different sizes of colonies is not so marked, but great enough to make it very important that all colonies should be regular boomers in size, full to overflowing with bees.

The average novice would readily suppose that the proper thing would be to equalize the strength of the various colonies by the interchange of brood a month or six weeks before the main harvest; but if the weak colonies are strengthened at the expense of the strong, the danger is that all the colonies will be below par, and that the yield of honey will be light. Of course if there are any colonies that are very strong so that in early spring their hives are overflowing with bees, they can be drawn on to help the weak or subnormal.

Some of our best beekeepers are unanimous in the opinion that the process should be reversed. If the colony is strong, it is only necessary to see that it has plenty of stores. Of the two, four, and six frame colonies, the strongest should be selected, and built up by taking broor and bees from the weak and extra strong. By this process the nuclei will be absorbed and all colonies be brought to honey-gathering strengtb.

In uniting it is best not to take too much brood at a time, as the reinforced colony may have more than it can take care of properly. If that is the case, some of the brood would be chilled or neglected if unsealed. So far as possible it is advisable to use hatching brood, or near hatching brood, in the early part of the season. Later on, when the weather is settled and warm, the younger brood can be used. Indeed, we advise at that time taking brood, bees, and all, of the weak nuclei, and giving them to the stronger of the sub-normal colonies. In honey production, either comb or extracted, the weakling colony in the spring is usually good for nothing except to use for making increase. But a better rule by far is to unite in the manner here explained, on the principle that "to him that hath shall be given, and he shall have more abundance; but from him that hath not, shall be taken away even that which he seemeth to have." See UNiting.

But the reinforcing with brood, as already explained, will not accomplish much unless the bees have plenty of stores in reserve, and natural pollen in the combs early in the spring. Of course, after the bees can get pollen from the fields there is no danger of a shortage; but before this time there will be bad weather early in the spring when the bees will not breed readily unless provided with combs containing pollen. Without it they will not do much. It should be borne in mind that in the early spring pollen is nearly as important as stores of sugar syrup or honey. Every good beekeeper will see that combs of it are gathered up in the fall and kept in reserve, and then slipped into the hives early in the spring on the first favorable day." There is no better capital in the beeyard than combs of natural pollen.

Under PoLLen we explain how artificial substitutes can be given; and while these answer the purpose to a limited extent they by no means take the place of the natural article, for the simple reason that the nitrogenous food element that the bees so urgently need is not supplied in proper form.

For particulars on how to unite flying bees with a colony on another stand, see UNiting. Also read carefully the article on SPRing Management as well as Spring Dwindling, and Feeding.

\section{BULK COMB HONEY.-See COMB HoNEY.}

* It is not advisable to have such combs in the hive during mid-winter. 


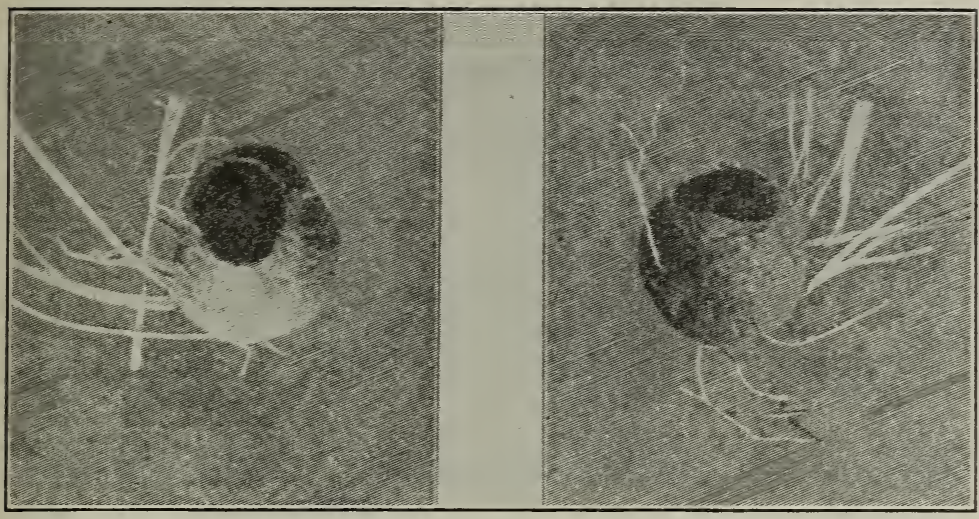

FIG. 1.-Two views of honey-pot of Bombus lapidarius. (After Sladen.) wise very helpful in pollinating many blueberries, cranberries, gooseberries, and currants. While leaf - cutting bees (Megachile) are the chief pollinators of alfalfa, many flowers are tripped by bumblebees. The flowers of the squash, cucumber, and pumpkin are also rery attractive to them. As

BUMBLEBEES.-The bumblebee family, or Bombidae, includes only two genera, Bombus, or the nest-building bumblebees, and Psithyrus, or the parasitic bumblebees. About 234 species and varieties of Bombus hare been described in the world and 57 of Psithyrus. Bumblebees are found thruout North and South America, extending northward to McCormack Bay 77 degrees north latitude, Greenland, and to an altitude of 13,600 feet at Cuzco, Peru. They are also widely distributed in Europe, Asia, and North Africa, but the great Saharan deserts offer an effectual barrier to their southward extension. Australia and New Zealand have no natire species, but three species were introduced into New Zealand from England in 1884.

\section{BUMBLEBEES AND FLOWER POLLINATION.}

As agents in the pollination of flowers bumblebees are second in importance only to honeybees. Many flowers are adapted wholly to their risits and are called bumblebee flowers, as the larkspurs, aconites, columbines, red clover, jewelweed, turtlehead, Linaria, snapdragon, the closed and fringed gentians, besides a number of orchids. While they generally avoid rery small flowers with a scanty supply of nectar, they resort to a great variety of blossoms, many of which yield valuable fruits. Altho seldom seen on the inflorescence of the pear, they seek the apple bloom in large numbers. They are like- in these plants the stamens and pistils are in separate blossoms, their productiveness is largely dependent upon bees.

But their numbers, wide distribution, and industry enable the bumblebees to perform a serrice of the greatest value in the pollination of red clover, onle of the most important of fodder plants. As there were no native bumblebees in New Zealand redclover seed could not be profitably raised for market until after the introduction of European species. They now annually benefit these islands to the extent of thousands of dollars. In one prorince alone, in 1912 ,

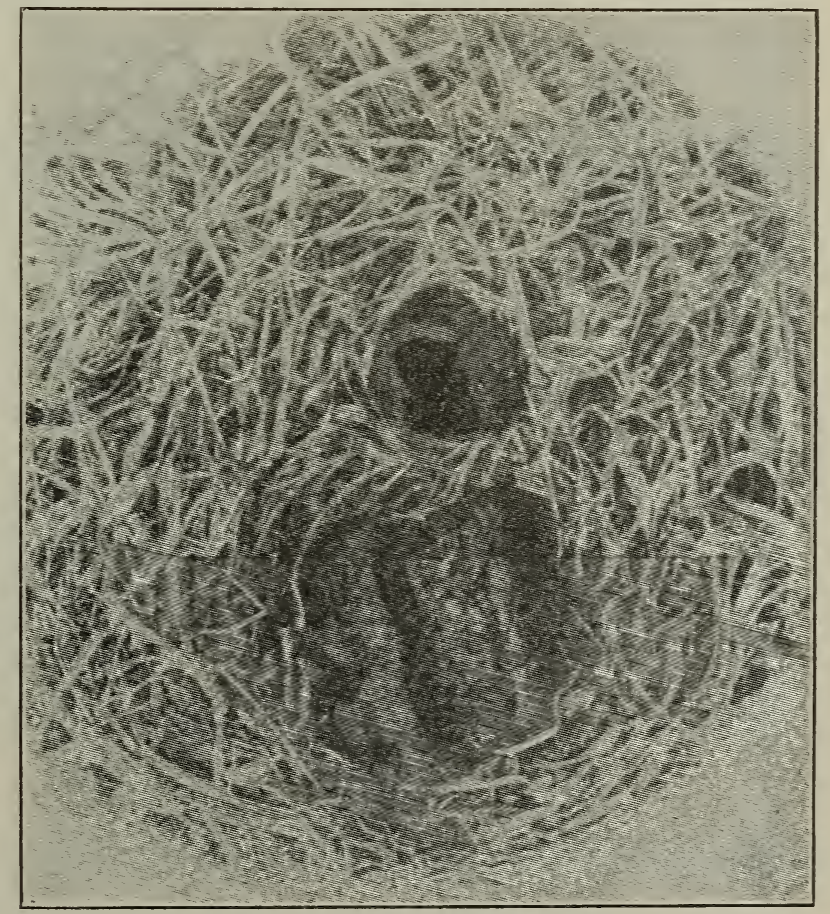

FIG. 2.-Nest of Bombus terrestris showing cluster of cocoons with groore in the center in which the queen sits, and honey-pot. (After Sladen.) 


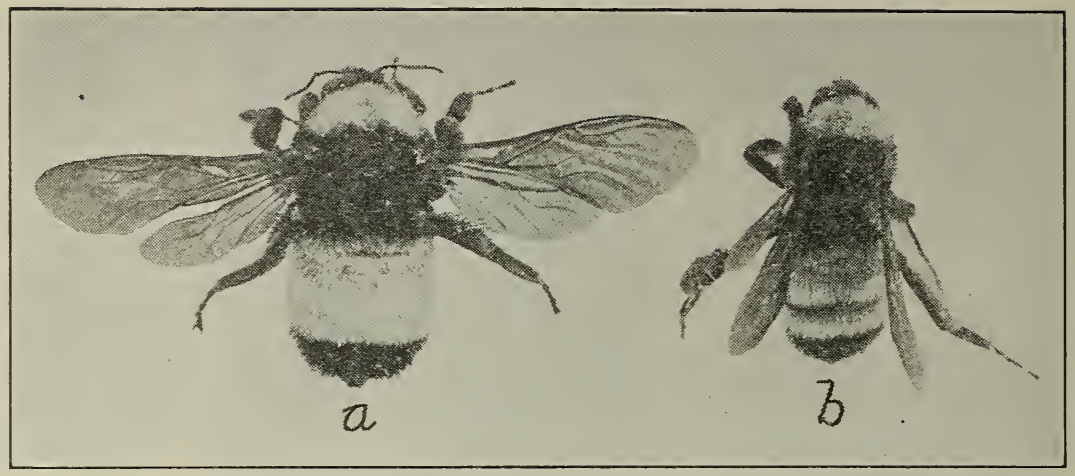

Fig. 5.-Bombus pennsylvanicus; $a$, queen; $b$, worker.

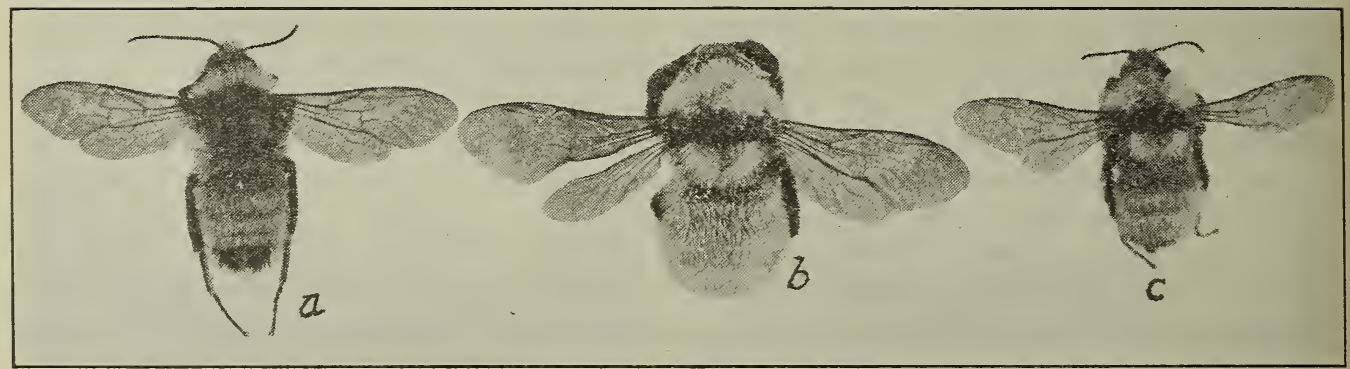

FIG. 6.-Bombus fervidus; $a$, male; $b$, queen; $c$, worker.

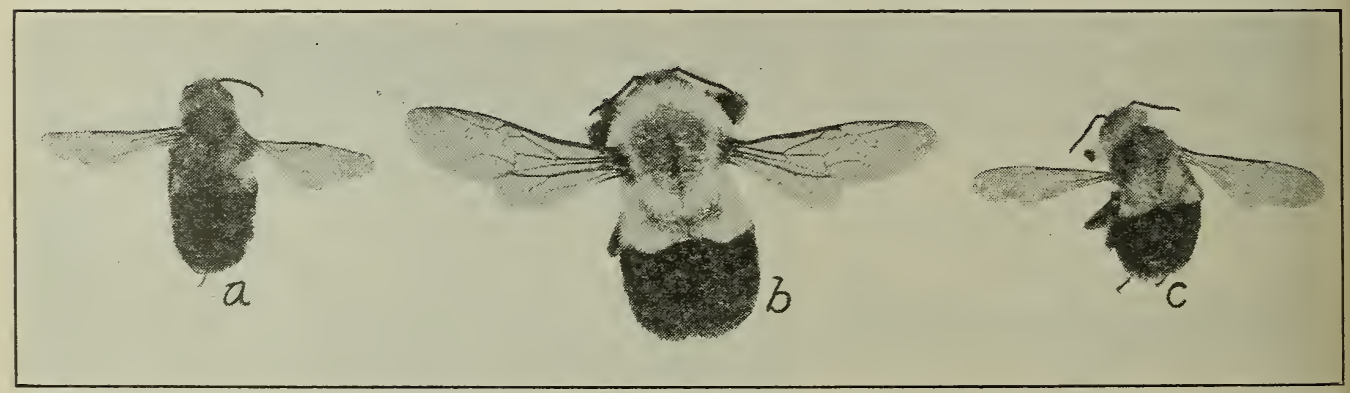

FIG. 7.-Bombus impatiens; $a$, male; $b$, queen; $c$, worker.

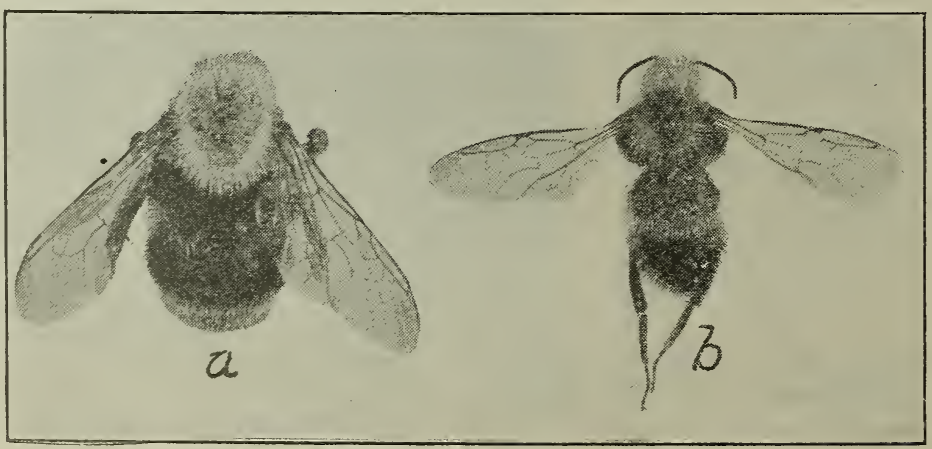

Frg. 8-Psithyrus laboriosus; $a$, queen; $b$, male. 


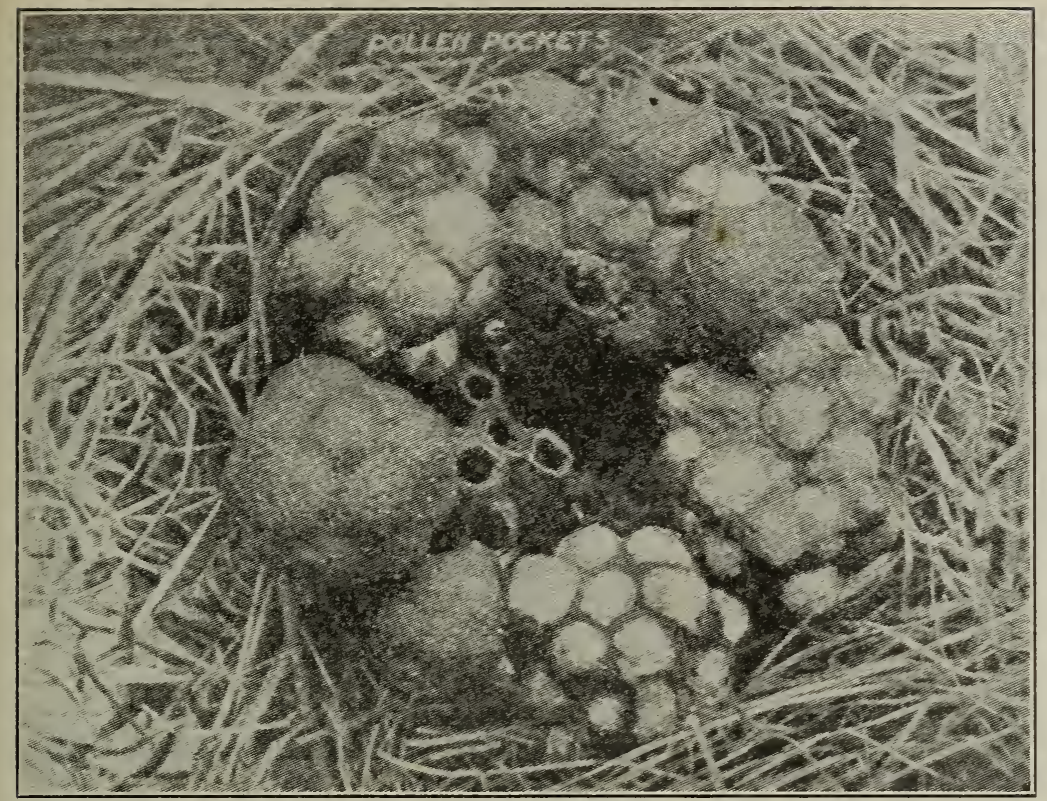

FIG. 3.-Nest of Bombus agrorum, showing symmetrical arrangement of comb; $a$, pollen-pockets. After Sladen.
LIFE HISTORY AND HABITS.

In mid-summer or early autumn a bumblebee colony produces $\mathrm{males}$ and queens. The males, which are about the size of the workers, are pleasantly scented and make long flights over the meadows and the o $\mathrm{p}$ e $\mathrm{n}$ lands in search of the less a ctive females. Before leaving the nest, to which they seldom return, the virgin queens fill the honey-sac with honey; and very 6610 acres were sown with red clover, which, it is estimated, yielded an average of 158 pounds to the acre. Fields which were almost barren in the absence of bumblebees produced a perfect mass of seed after their advent. At Canterbury 26 acres of red clover was the resort of thousands of burablebees and yielded 400 to 500 pounds of seed to the acre. The Bureau of Plant Industry reports that from 757 heads of red clover, covered with tarlatan to exclude insects, an average of only one-tenth of a seed per head was ob ta in ed ; while from 311 heads visited by bumblebees there was an average of 30 seeds per head. Bumblebees visit as many as 30 to 35 flowers a minute. They are less abundant in the great central plain of the United States than in the Atlantic and Pacific highlands. soon after impregnation conceal themselves in moss or leaves, or burrow in the ground, where they remain till the following season. The period of hibernation is about nine months, species which begin sleeping in July awaking in March, while later species do not fly until May or June. The economy of American bumblebees is little known, and this account is based largely on Sladen's observations of the English species.

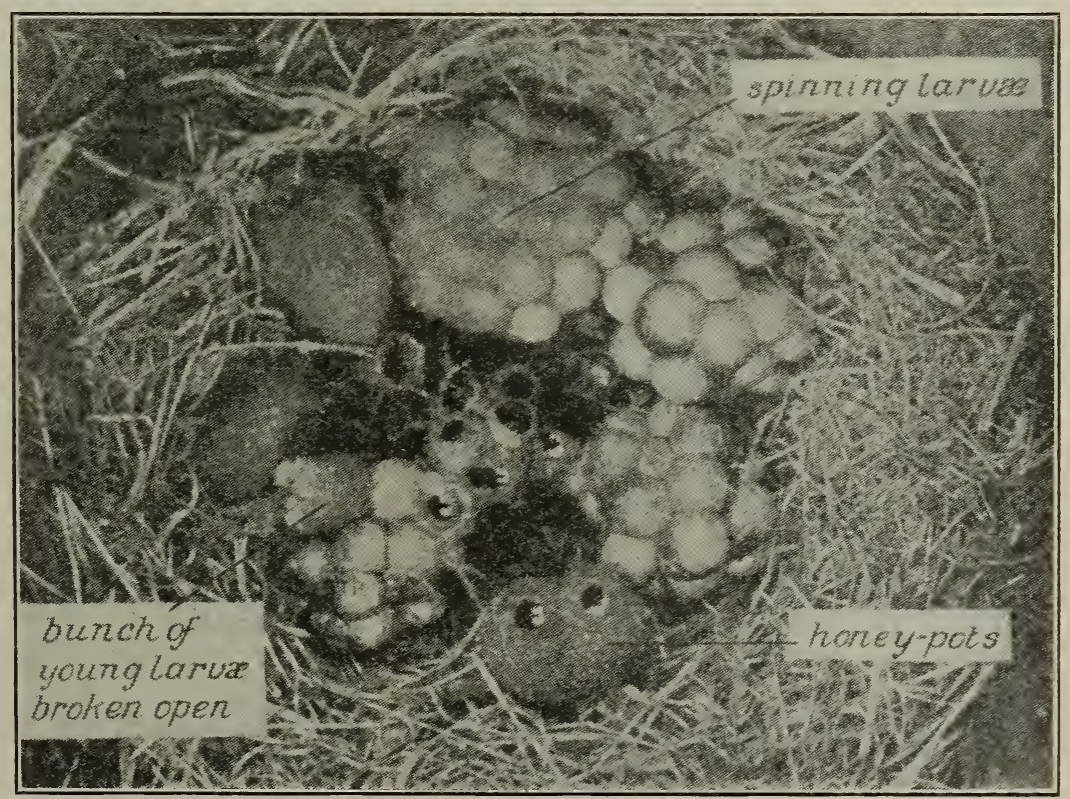

FIG. 4.-Nest of Bombus lapidarius. (After Sladen.) 
Soon after the warmer weather of spring permits the queen to leave permanently her place of hibernation she begins to search for the nest of a mouse or mole in which to rear her colony. A mouse nest consists usually of a mass of soft dried grass with a hollow in the center. Many species of bumblebees prefer nests which are underground, while others select those which are on the surface. Access to the subterranean nests is gained thru a tunnel usually not far from two feet in length and about an inch in diameter. Queens may often be seen examining the ground in fields in search of the openings to these tunnels. In the center of the nest a small cavity is formed about an inch in diameter and a little less in height, with an entrance about the size of the queen's body. Before she departs for the field, the queen forms a memory picture of the location by describing above it a series of gradually widening circles.

On the center of the floor of this cavity she stores a small mass of pollen gathered from flowers and moistened with honey. In a round cell of wax about the size of a pea built on top of the pollen from six to twelve eggs are laid and the top of the cell is then sealed over. According to Sladen the wax is much softer than that of the honeybee, and exudes from between the segments on the upper side of the abdomen instead of being excreted in little pockets on the rentral side of the abdomen as in the honeybee. A honey-pot is built in the entrance to the cavity and filled with honey, which the queen uses in the night time and in rainy weather. It is about the size and shape of a small marble, with open mouth, and, altho very thin and fragile, it remains intact for a month, which is as long as it is needed (Fig. 1). The supply of honey is frequently corsumed and renewed and is, consequently, much thinner than that of the honeybee.* In large colonies additional honey-pots are built near the edge of the comb, and many of the cocoons are filled with honey, the number of which may amount to three or four hundred.

Except when she leaves the nest to procure food the queen incubates the cell constantly to keep the eggs warm. They hatch

* The queen's honey-pot in a nest of B. fervidus examined at Ottawa, Canada, in 1915, was found to be complctely closed, possibly a provision of nature, preventing ants, etc., from discovering the honey when the queen is absent from the nest.F. W. L. S. in four days. The larvæ feed on the mass of pollen and also on a milky food of partially digested pollen and honey prepared by the queen. This liquid is injected into the wax cell thru a minute hole in the top. At first the larvæ are provided with a common supply, but later each is fed separately. When the larvæ are five days old they begin to grow very rapidly, and the cell expands into a large globular bunch or bag, in which the position of each can easily be discerned. On the eleventh day they reach their full size, and each larva spins about itself a thin papery but very tough cocoon. The cocoons stand upright and form a compact cluster with a smooth concave groove in the center, in which the queen sits to furnish the warmth needed to mature the first brood of workers (Fig. 2). On the $22 d$ or $23 d$ day the perfect workers emerge from the cocoons by cutting a hole in the top either alone or with the aid of the queen. The newly hatched bees are a dull gray and move about very feebly, but by the third day they have acquired their natural colors and strength and are ready to depart for the field. The life of a worker bumblebee in mid-summer is about four weeks.

As soon as the larvæ of the first brood spin their cocoons, the queen begins to build a row of cells on the outer edge of one side of the cluster of cocoons parallel with the central groove, and later a second row on the outer side of the cluster. She then lays a variable number of eggs, but usually from six to twelve in each cell. As soon as the workers become sufficiently numerous to provide supplies for the colony the queen no longer leaves the nest and may lay a new lot of eggs daily. The history of the eggs in the later cells is similar to those in the first cell except that the larvæ are fed largely or wholly by the workers, and the cluster of cocoons is convex without a central groove. The structure of the cocoon clusters varies with different species. Those of the English Bombus terrestris are loose and irregular, while those of $B$. agrorum are compact and globular and are arranged symmetrically in a ring around the nest (Fig. 3). Underground species may protect the top of the comb by a roof of wax; but this in surface dwellers is reduced to a mere dise or is entirely wanting. On very hot days the nest is rentilated by one or more 
workers standing on the comb or in the entrance and rapidly fanning with their wings. Night brings no rest to the colony. Its activity even increases, for now the entire population are at home and busily engaged in caring for the brood and comb (Fig. 4).

Pollen is never put in cells containing honey, but is stored in empty cocoons or in tall columnar cells, which may be over an inch high and half an inch in diameter, near the center of the nest. A few species store it in little pockets on the side of the maxcorered bunches of larræ, called by Sladen pocket-makers to distinguish them from the pollen-storers. The workers gather the pollen and load it in the pollen-baskets in the same manner as described for the honeybee.

The culminating erent in the history of a bumblebee colony is the production of males and queens, for it is upon this act that the life of the species depends. This is not undertaken until the old queen has laid from 200 to 400 worker eges, according to the species, and the colony is in a high state of prosperity. Both sexes may oceur in the same cluster of cocoons, or it may consist wholly of males or females. In exceptional cases a colony produces exclusirely males or queens. The males appear earlier and are about twice as numerous as the females. One hundred to fire hundred males and queens may be raised, according to the strength of the colony. As in the case of the honeybee the bumblebee queens are probably fed on a different kind of food than the workers, altho no difference has yet been observed. The males live for about three weeks, and, like the queens, after once learing the nest seldom return.

With the departure of the males and virgin queens from the nest, the purpose of the colony has been attained in providing for the continuance of the species another year, and the closing days of its existence are now fast approaching. The old queen begins to fail, her body becomes denuded of hair, and her productiveness decreases. There are not sufficient eggs to keep the colony busy, and laying workers appear, which, however, produce only males. Finally brood-rearing ceases, and the comb begins to mold. There is no longer an abundance of flowers, and the surplus of boney is consumed; then the older workers die one by one and the dozen or more re- maining become idle. "One night, a little cooler than usual," says Sladen, "finding her food supply exhausted, the queen grows torpid, as she has done many a time before in the early part of her career, but on this occasion, her life work finished, there is no arakening."

There are 47 species of bumblebees known in America north of Mexico, and 40 species ${ }^{\circ}$ in America south of Mexico, one species (B. dahlbomii) being common on the Straits of Magellan. A large and common species east of the Rocky Mountains is Bombus pennsylvanicus, Geer., which has a tongue $14 \mathrm{~mm}$. long (Fig. 5). The colonies live in deserted mouse-nests both underground and on the surface. $B$. fervidus is another common species found in nearly every state in the Union and in Canada (Fig. 6). This species is a surface dweller, and its nests may be found in a variety of locations. Putnam found on July 27 a nest of paper and rags under the floor of a shed, which contained 70 bees, 150 cells with brood, and 200 larrx in various stages of growth in the pollen masses, besides 50 cells of honey. $B$. impatiens $\mathrm{Cr}$. occurs thruout the eastern United States (Fig. 7). It is a subterranean species. A nest taken by Franklin, Aug. 31, contained 340 bees, of which 4 were aueens and 15 males. It was $21 / 2$ feet below the surface of the ground. There were 330 unbroken cells, the majority of which were queen-cells. Another rery common species of bumblebee, east of the Rocky Mountains, and from coast to coast in Canada, is $B$. vagans $\mathrm{Sm}$. According to Franklin the honey-pots of American species appear to be made not of wax but of pollen grains cemented with propolis.

\section{THE PARASITIC BUMBLEBEES.}

Many bumblebee colonies are destrored by parasitic or false bumblebees belonging to the genus Psithyrus. They are also called inquiline or guest bumblebees. They closely resemble bumblebees in appearance and are no doubt descended from common ancestors. About ten species are known in America north of Mexico, and three or four more in Mexico and Central America. It is a singular fact that not a single species is certainly known from South America. A common species widely distributed in the United States is Ps. latoriosus F. (Fig. 8). The worker caste is entirely absent and ouly 
males and females are produced. They do not build combs or gather pollen and nectar for their young, but live in the nests of the true bumblebees, at whose expense their brood is reared.

They were long supposed to be commensals living with the bumblebees but doing little harm or possibly some benefit; but much information in regard to the habits of two English species has been gained thru the observations of Sladen.* Like the bumblebees they hibernate during the wintei', but begin to fly a little later in the spring. A Psithyrus queen seeks to enter the nest of the host bumblebee soon after the first brood of workers have appeared. Little opposition is then offered by the doomed colony, which soon becomes accustomed to her presence. So long as the workers are too few to provide ample food supplies the intruder with instinctive cunning waits until they have become numerous enough to care for herself and her brood. As soon as the nest has become populous a crisis is precipitated by the Psithyrus queen preparing to lay eggs. Aroused by this invasion of her rights, the bumblebee queen apparently attacks the usurper, altho she is doomed beforehand to defeat. Protected by a thick tough integument and armed with a larger and more curved sting, the parasitic queen invariably kills the bumblebee queen. The Psithyrus queen is at first compelled to protect her eggs from the Bombus workers, but they soon care for her brood as faithfully as for their own. In Austria two species of Psithyrus $\dagger$ are reported to live amicably with their hosts, both producing males and females.

If the Psithyrus queen waits too long and then enters a colony of the host bumblebee which has a strong company of workers, she is at once furiously assailed by overpowering numbers; and, altho fighting valiantly, is finally slain. Before she is destroyed, however, a dozen or more of her assailants are sometimes killed. If two Psithyrus queens enter the same nest they

\footnotetext{
* One of these is Ps. vestalis, which dwells in the nest of $B$. terrestris. Ps. ashtoni, the representative of $P s$. vestalis in Eastern Canada, possibly ascoriates in the same way with $B$. terricola.-F. W. I. S

* Represented in North America by Ps. laboriosus, Ps. insularis, and Ps. jernaldae.-F. W. L. S.
}

seem never to fight with each other, but one soon goes away. The parasitic bumblebees visit a variety of flowers, but they show a preference for Composites like the thoroughwort and goldenrod which are rich in nectar. Their visits are made in a leisurely way very unlike those of the bumblebees.

The two genera, Bombus and Psithyrus, have doubtless been derived from a common stock. Psithyrus shows evidence of degeneration in the loss of the pollen-baskets, the smaller eyes, and the untoothed mandibles. In explanation of the origin of the parasitic habit Sladen points out that the queens of several common species of Bombus often enter the nests of their own species, fight a duel to the death with the queen, and, if successful (which is unusual) lay their eggs and assume the duties of the foundress of the colony. $B$. terrestris behaves in this way in the nest of the nearly-related species $B$. lucorum, but with the difference that she usually succeeds by means of her greater alertness and ferocity in killing the lucorum queen, and, lucorum being an early species, she frequently does not enter the lucorum nest until the first workers are beginning to emerge. If this practice were to become habitual, an inquiline bee similar to Psithyrus would be likely to result.

Bumblebee nests are destroyed by mice, and Darwin suggested that in the vicinity of towns their numbers were partly determined by the number of cats. The comb and brood are devoured by the larvæ of wax-moths and of several species of flies. Ants destroy nests in the early stages. Among other insects found in the nests are flies belonging to the genus Volucella, which mimic bumblebees in their appearance and habits of flight so closely that they are often mistaken for them. Two of these fiies were collected and sent to the writer as bumblebees by an entomologist of great experience. Like the bumblebees they visit flowers for pollen and nectar.

For further information on bumblebees see "Habits of Some Species of Humble Bees," F. W. Putnam; "The Bombidæ of the New World," H. J. Franklin; and "The Humble-bee," F. W. L. Sladen, Macmillan \& Co. 


\section{C}

CAGES FOR QUEENS.-See INTRODUCING.

CAMPANILLA.-There are two species of Convolvulaceae, or morning-glory family, which are of great importance to the beekeepers of Cuba as honey-plants; namely, Ipomoea sidaefolia Choisy, and I. trilola L. Popular English and Spanish names of $I$. sidaefolia are white bellflower, campanilla blanca, campanilla, Christmas pop, and aguinaldo de pascuas. It is a perennial, the
PINK BELIFLOWER.

The pink bellflower, I. triloba, is also known as Campanilla morada, aguinaldo rosado, and marrullero. It blooms during the months of October and November. It is found principally in western Cuba, in the region known as the "vuelta abaja," the great tobacco region; and it is the growing of tobacco that makes possible the great amount of this particular variety of the bellflower, for tobacco seed is, as a rule,

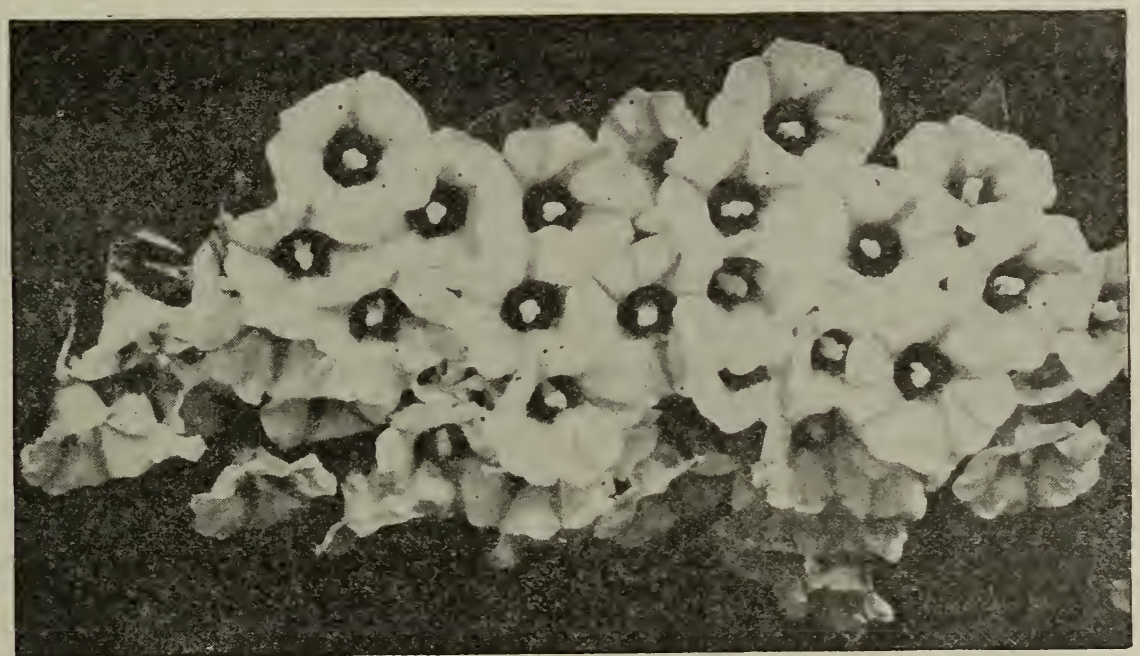

Campanilla or bellflower.

vines sometimes obtaining the size of from two or three inches in diameter, and is generally found growing among trees and shrubs or along fences and stone walks. The height of bloom is about Christmas, for which reason it is also called the "aguinaldo de pascuas," and at this season of the year it is a common sight to see almost every tree, shrub, and fence along the road one solid mass of white aguinaldo bloom. The odd feature about this plant is its irregular blooming. It will bloom only every other day, and then, again, several days in succession. The days of blooming are always universal. One day every vine is in full bloom; the next day not a single vine is to be seen in bloom in miles of travel. always sown on virgin soil. Large tracts of land, on both mountain and coast, are cleared every year, just to grow one crop of tobacco-plants. When the plants are big enough to be transplanted they are pulled and shipped by railroad, ox-cart, or muletrain, to where the tobacco is to be grown. These tobacco-seed beds are, by the next year, and for years to come, covered by the vines of the campanilla morada, which in western Cuba, springs up wherever the land has been cultivated.

The honey from the bellflowers, in color and flavor, is equal to alfalfa or sage. The comb built during the bellflower flow is pearly white, and when melted it produces wax as white as tallow. 
CAMPECHE.-See LOGWOOD.

CANADA THISTLE (Cirsium arvense (L.) Scop.).-Altho this troublesome weed, naturalized from Europe, is condemned by agriculturists and is outlawed everywhere, it is the source of a small quantity of honey in parts of Canada. Like most pernicious weeds it belongs to the family Compositae. The heads are small but very numerous, each head composed of about 100 rose-purple tubular florets. The nectar is secreted so freely that it rises in the corolla tubes to a point where it can be reached by nearly all insects. Honeybees gather both nectar and pollen. The honey is light colored, of very fine quality with a delightful flavor, and is fully equal to the best clover or basswood honey in the market.

Canada thistles will live in a great variety of conditions, but they luxuriate in rich bottom lands where they take almost complete possession of the soil. It is a commercial asset to the beekeeper chiefly in those localities where it has become a pest to farmers who would gladly exterminate it root and branch. Beekeepers should also do everything in their power to destroy it; but the Canada thistle is difficult to eradicate since it multiplies by underground creeping rootstocks and roots, a small fragment of these if left in the soil will give rise to a new plant.

\section{CANDIED HONEY.-See GRANUlated HONEY.}

CANDY FOR BEES.-There is just one kind of candy that is used universally by beekeepers for queen-cages. While excellent for this purpose it should not be used as winter food unless in pans, where, if it becomes soft, it will not run down and kill the bees.

It is none other than what is popularly termed the "Good" candy, after I. R. Good, of Nappanee, Indiana, who introduced it into this country. It was, however, first made by a German named Scholz, many years before. See "Langstroth on the Honpybee," p. 274, 1875 edition. By Europeans it is, therefore, called the Scholz candy.

HOW TO MAKE.

Make a stiff dough with a first quality of extracted honey and powdered sugar. A thick well-ripened clover should be used when it can be obtained. The powdered sugar must have no starch in it. There are two kinds of frosting sugar-one with starch and the other without. The latter should be specified, and to determine whether the right article has been secured, a small particle should be rubbed between the fingers. If it has a granular feeling it probably contains no starch. If, on the other hand, it contains starch the sugar will have a smooth soft touch. While starch is not necessarily fatal to queen-cage candy, experience shows that queens can be sent only short distances on a food containing it.

Having secured the right ingredients, heat the honey to a temperature of 140 degrees F.; then stir in the pulverized sugar with a big strong spoon or stick. After adding all that it is possible for the honey to absorb, and when the stick or spoon cannot stir any more, spread some powdered sugar on a molding-board. Remove the mixture from the pan to the board, and proceed to knead the dough the same as ordinary bread dough, adding sugar to prevent sticking. The candy should be worked until all the sugar has been incorporated that it is possible to get in, and yet not have it too stiff nor too soft and moist. Right here is a very nice point: If too much sugar is worked in, the candy will become dry and hard; if not enough, it will be soft, sticky, and shiny. If the candy has been handled properly it should hold its shape or form at a temperature of 90 degrees* and not be sticky. It may then be set away in a closed tin pan and used as a food to fill cages.

During very hot moist weather, it may be necessary, before filling the eages, to knead in a little more sugar.

The holes for holding the candy in queencages should be lined with paraffine or beeswax. The object of this is to prevent the moisture of the candy from being absorbed into the wood. This absorption would make the bee-feed dry and hard. It should be maintained slightly moist and soft, but never sticky to the journey's end.

If it is impossible to make Good candy by following these directions, either the honey is wrong or the pulverized sugar. And this suggests the wisdom of trying a

* Summer weather will seldom exceed this, and if it holds its shape at this temperature it will do so when it is colder. 
few pounds of the sugar before making a large batch of candy.

Recent postal regulations in the United States require on the part of every queenbreeder who sends queens by mail one of two things-a certificate of inspection from a duly authorized bee inspector certifying that no bee disease has been discovered in the yard from which the queens are reared. A copy of this must go on every package. In the event that there is no bee-inspection law, and, of course, no inspector, the postal authorities require a statement, duly attested before a notary, that the honey of which the candy has been made has been boiled twenty minutes in a closed vessel.

But experience shows that boiled honey does not make good queen-cage candy. The character of the honey is so changed by boiling that the queens die on it in the space of a short time.

The real intent of the regulation, which is to prevent the dissemination of bee disease, can be subserved by using invert sugar in place of honey. See Invert Sugar. This is a syrup having a good many of the chemical characteristics of honey, but it lacks some of the food elements of nature's product. However, it makes a better candy and is safer. Of course, invert sugar could not contain disease of any kind, as it has not been in contact with bees.

Invert sugar can usually be obtained of any large candy-maker. A very good article is sold under the name of nullomoline by the Nullomoline Co., of New York.

Some queen-breeders have been very successful in the use of fondant, such as is used for filling the inside of ordinary chocolate candy. Inasmuch as the ingredients do not involve the use of honey, some may prefer it.

HOW TO MAKE FONDANT.

Take of granulated sugar $12 \mathrm{lbs}$; glucose, such as the candy-makers use, $11 / 2$ lbs.; water, 11/4 quarts; cream of tartar, $1 / 3$ teaspoonful. The cream of tartar, water, and glucose, are put together in a kettle and heated. As soon as the mixture comes to a boil, the sugar is added little by little until it is all incorporated. During the process of adding the sugar the candy is continually stirred. When the boiling-point is reached again, the stirring is discontinued. When the temperature reaches 238 by a candy- mixer's thermometer, the mixture is removed from the stove and allowed to cool. When it cools to 120 it is stirred again until it begins to "cream." As soon as it looks like paste or starch, it is ready to use.

This candy has been used quite successfully as a winter food. It is put in shallow trays, and placed over the top of a cluster of bees. It has also been used for supply queen-cages.

HARD CANDY FOR WINTER AND SPRING FEEDING; HOW TO MAKE IT.

Into a dish of hot water on the stove slowly pour an equal amount of sugar, stirring constantly. Make sure that the sugar is all dissolved before boiling commences. If this precaution is not observed, some of the undissolved sugar is likely to burn, injuring the flavor of the candy and almost surely causing trouble with the bees later. If one has a candy thermometer, watch the temperature, and do not let it go above 275 to 280 degrees. 'Test frequently by dropping a very little of the syrup into cold water (about 50 to 55 degrees F.). When the boiling has continued long enough the drop of candy, when cooled in the water, should be hard and brittle when taken out; but when placed in the mouth it should soften slightly, so that it is tough. When this time has arrived, pour the syrup immediately on to paraffined or waxed paper on a table. Have the table perfectly level, and around the outside of the paper put wooden sticks $1 / 4$ inch high to confine the syrup and prevent it from running off. When the candy is nearly hard, crease it or cut it with a heavy knife so that it may be broken up into right-sized squares when hard.

The color of the candy when cold should be about that of light basswood honey. If it is darkened very much it is scorched and unfit for the bees. To prevent the scorching, reduce the fire toward the last so that the syrup will boil but slowly.

When the candy is first made, it is hard and glassy, and perfectly transparent; but after it stands for a little time it becomes somewhat watery and crystalline; but this is all the better so far as the bees are concerned, for they are enabled to take it more easily.

The thin cakes of candy being only $1 / 4$ inch thick may be placed over the frames 
and under the regular cover, and in this way a colony may be saved that would be lost. The feeding of syrup, especially in the spring, is apt to cause great excitement and possibly robbing, and for this reason the candy is safer as it is taken slowly.

Caution.-Whoever makes the candy should clearly understand that if the mixture is scorched, even the slightest, it will make unfit food for spring or winter feeding. When the syrup is cooked nearly enough, there is great danger of burning, and it is then that the greatest care should be exercised.

CANE SUGAR.-This is the common name applied to the sugar-sucrose. Sucrose is made from the sugar-cane and also from the sugar-beet. When derived from the beet it should go under the name of beet sugar. Sucrose is found in pure honey in amounts varying from nothing up to 8 per cent. Only in a very few cases has pure honey been found which showed the higher figures. The standards for pure honey allow 8 per cent to be present. New honey generally contains more sucrose than old honey. There are present in honey before heating some enzymes (unorganized ferments) which have the power to invert the sucrose. Hence on ageing, if heat has not been applied to kill this action the per cent of sucrose decreases. Sucrose on hydrolysis or inversion forms equal parts of dextrose and levulose, these latter being the predominant sugars of honey. See Sugar; INverT Stgar; also Honey, Analysis of.

\section{CANS FOR HONEY.-See EXTRACTED HONEY.}

CARNIOLANS.-See RACES OF BeEs.

\section{CARPENTER BEES. - See SOLITARY BEEs.}

CARPET GRASS (Lippia nodiflora (L.) Michx.).-Other vernacular names are fogfruit and mat grass - a prostrate, creeping, herbaceous perennial, only a few inches high, which forms dense mats in damp soil and on river banks. It is of great value in preventing the erosion of sandy land and is in consequence known as a "sand-binder." In Florida it would be a boon for that purpose alone. Stock will eat it; and it holds up its head when everything else is burned up by the sun. The flowers are small, white, resembling those of the sweetscented garden verbena from China, which belongs to the same genus. Both species belong to the Verbenaceae, or Verbena family. Common carpet grass is widely distributed in the warmer regions of North America, extending from Central America and the West Indies to Florida, Georgia, and Texas. It is very abundant in Sutter County and in the Sacramento Valley, California, carpeting the slopes of the Sacramento River, where it produces a large amount of honey. It blooms from May until September. The honey is white, of the mildest flavor, and crystallizes with a very fine grain. In Texas carpet grass grows along rivers and small streams, but is of little importance as a honey-plant.

\section{OTHER SPECIES OF CARPET GRASS.}

The carpet grasses, of which there are about one hundred species, belong chiefly to the warmer regions of the Old and New Worlds; but are most abundant in tropical and subtropical America. They yield much nectar in Central America and are also valuable honey-plants in the West Indies and the Bermudas. There are about nine species in the United States distributed over an area extending from New Jersey to Nebraska and Kansas, southward to Georgia and Texas, and west to Arizona and California.

In 1900 Lippia repens Hort. was introduced from Italy into California, where it now covers thousands of acres. Because of its thickly matted growth it is widely used for covering lawns and tennis courts. Only one or two cuttings are required during the summer. It thrives in the poorest soils, smothers weeds, requires but little water, and looks as well as any grass; but during two or three months it turns brown and ceases to grow, when its appearance is less pleasing. A new growth appears in early spring. The small flowers are visited by many honeybees and probably the honey does not differ from that of the common carpet grass.

Lippia lanccolata Michx. grows in New Jersey, Texas, Mexico, and California, and is also vâlued as a honey-plant.

CATCLAW (Acacia Greggii, Gray).Known also as paradise flower and devil's claws. The acacia-trees are most abundant 
in Australia and Africa; but 16 species occur in the Southern States, chiefly in Texas. Sereral species are raluable for both honey and pollen: A. Greggii Gray and A. Berlandiera Benth. are two of the most important honey-plants of Texas, and rield immense quantities of excellent honey that ranks with the best white honey of the North. Sereral species of acacia are culti-

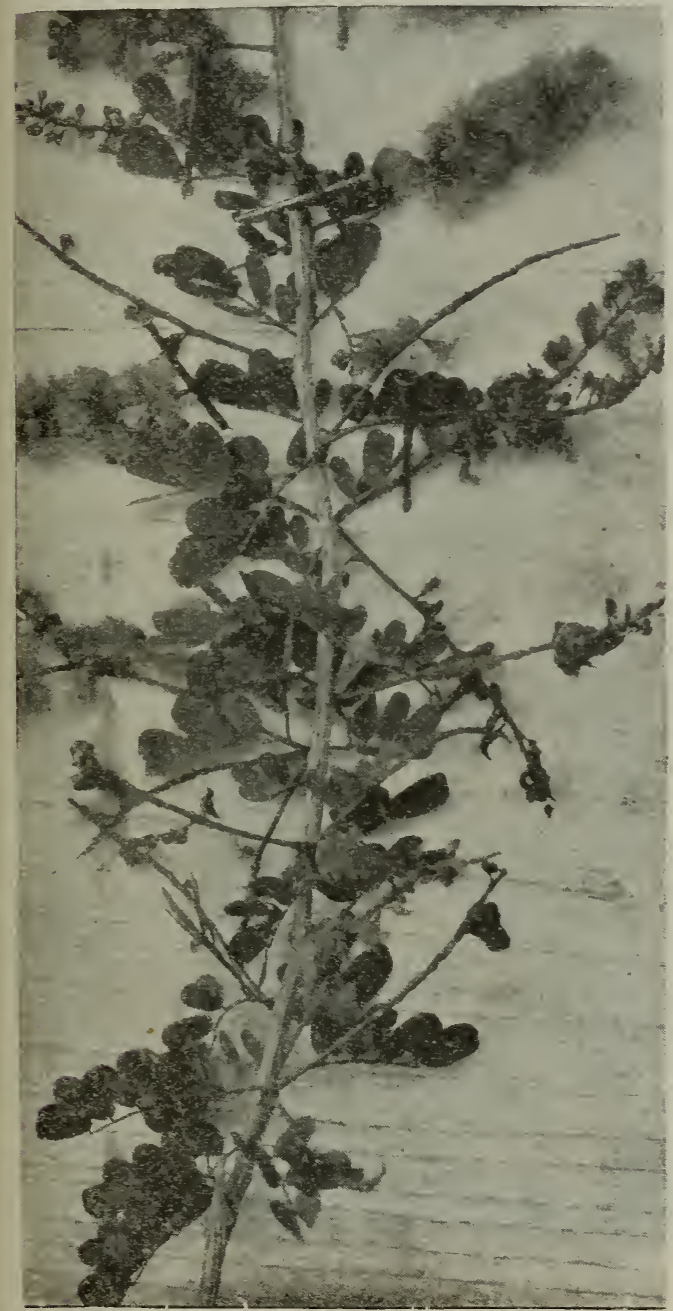

Catclaw leaf, twig, and blossoms; life-size.

vated in Califcrnia, and rield much honey. Thile fossibly it would not sell alongside of our clovers, ret in localities where it is produced it is praised rery highly for table use, no honey being classed higher except that from the "huajilla," which see.

The catclaw is a bushy tree with lowspreading branches, attaining a height of anywhere from 15 to 20 feet. It derives its name from the bushy and fuzzy blossoms sugoestire of the furry ccat of a cat, and the peculiar kind of claws or hooks, shaped very much like the claw of a common house cat. If one tries to push thru the bushes or among the branches he will conclude that, unless he "backs up," he may "remain hooked." Perhaps he will anyhow.

The illustration in the column opposite shows a small twig, life size. The leares are small and in clusters while the blossoms have a cottony or downy look. One of the seed-pods, after the blossoms hare been cast off, is shown at the upper left-hand corner of the plate.

The tree comes into bloom about the first of May, and yields honey for a considerable length of time before going out of bloom. In July there is a second crop.

Like the huajilla and mesquite it grows in the semi-desert regions of Texas and Arizona where it would be impossible to carry on farming without irrigation. There are vast areas in both states mentioned that will probably nerer be used for anything more useful to man than catclaw, huajilla. and mesquite: so that the onward march of civilization will not displace these honeytrees with more profitable farm crops. We may reasonably conclude that catclaw will remain one of the permanent sources of honey supply.

TVe are not sure but it would pay to introduce these valuable honey-bearing trees in other semi-arid regions. It has been introduced into Southern Europe, whence large quantities of its flowers are exported to France and England. It is there known as mimosa.

CATNIP (Nepeta Cataria L.).--Often called catmint. Flowers bilabiate, nearly white spotted with purple. The late Moses Quinby once said that, if he were to grow any plant extensirely for the honey it produces, that plant would be catnip; and very likely he was not far from right. But as we hare nerer yet had any definite report from a sufficient field of it to test it alone, either as to quality or quantity of the honey, we remain almost as much in the dark in regard to it as we were at the time he made the statement many years ago. Sereral have cultirated it in small patches, and hare reported that in a state of cultiration it apparently yielded more honey than in its wild state, for bees were found on it almost con- 
stantly, during several months in the year, but rarely one gets a full load. It has been called the "bees' bar-room," as they are so constantly hanging around it. Yet no one, we believe, is prepared to say positively that it would pay to cultivate it for honey only.
CLOVER (Trifolium). - No class of plants yields more or better honey than the clovers. When we say "clover" we mean the common red, common white, alsike, and crimson clover. Alfalfa, sweet clover, sainfoin, and pin clover we do not include under this head, because they belong to a different

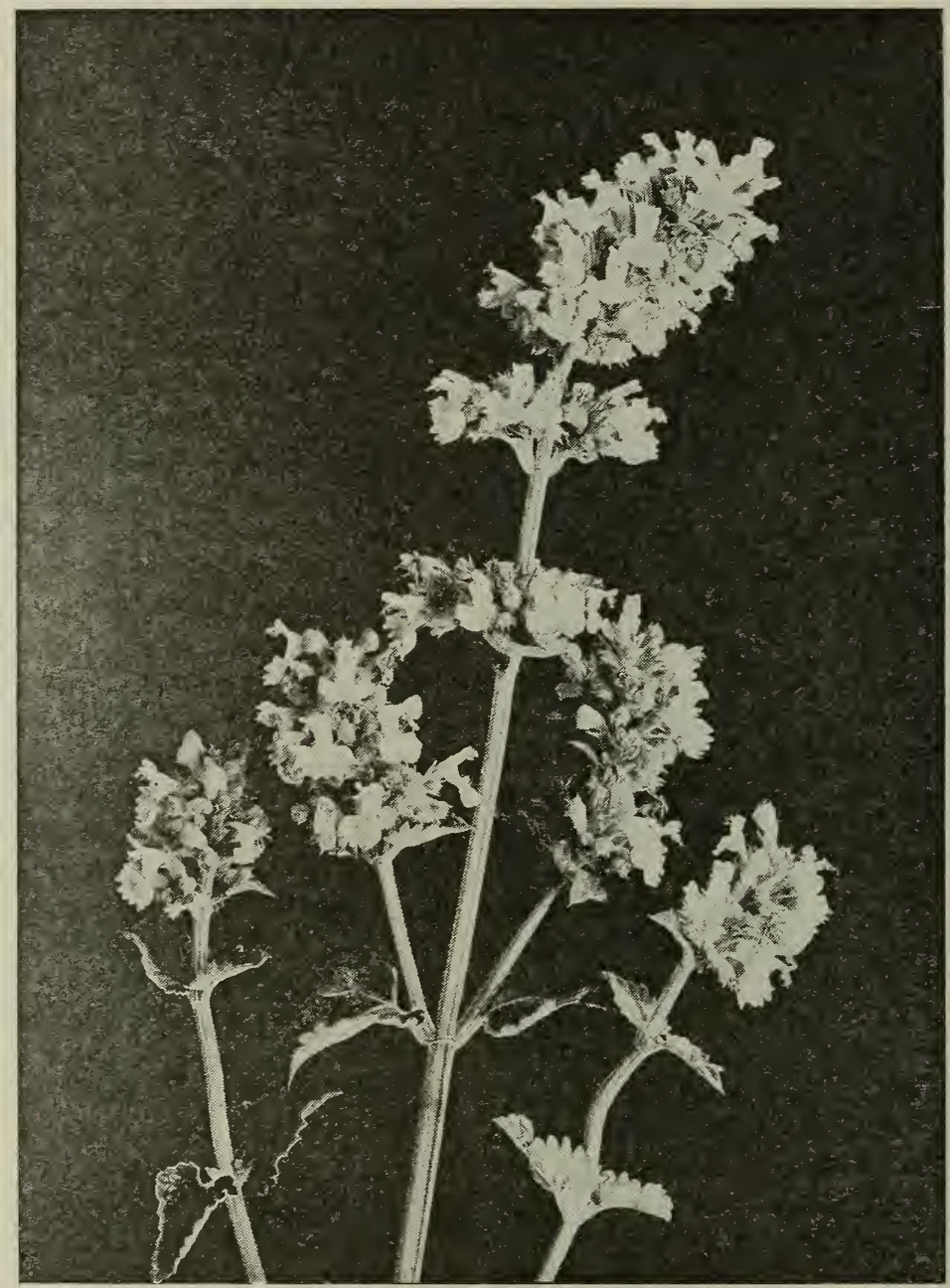

Catnip.

CAUCASIANS.-See RACES Of BeEs.

CELLAR WINTERING.-See WinteRING IN REPOSITORIES.

CELLS, QUEEN. - See QueENS and QUEEN-REARING.

CHUNK HONEY. - See "Bulk Comb Honey," under head of Comb Honer.

CLIPPING.-See QUEENS. genus, and in one case to a different family. However, if we include all these clovers under one general head we might say that clover in its broadest sense includes a class of plants that yield by far the most and finest table honey in the world. Years ago, when we spoke of clover honey we had in mind the common white clover and sometimes a little red-clover honey mixed with it. But in later years alfalfa and sweet clover have come to be grown so largely in the West 
that our great source of table honey is not from white clover, but from alfalfa, sweet clover, and sage.

Some thirty or forty years ago a failure in a crop of clover honey was almost unknown. But during later years intensive agriculture has crowded the white clover out of our fields to a certain extent, and we find it now only in fence-corners and in some stray pastures that have not been plowed up. In its place have come alsike and red clover; but during the last few years the farmers have begun to notice that some of their lands were what they call " clover-sick." Lands that formerly yielded clover in abundance would produce it only sparingly, if at all, during these later years. In the meantime, they began to discover that alsike clover would grow where the red clover did not seem to do well. During the last two or three years the real reason for this has been discovered. It is now known that red clover will not thrive unless there is plenty of lime in the soil. In later years, the constant cropping of clover and other legumes has so exhausted the natural lime in the soil that red clover often does not grow as it did in former days, and the land is then considered " clover-sick."

Alsike clover can stand a much more acid soil than red clover, and for that reason has been taking the place of red clover all over the country. But the time will soon come, at the present rate, when the soil will be too acid for alsike. The obvious remedy is to put lime in the soil.

In general, we may say that, where sorrel or red-top is seen to grow, where alsike thrives better than red clover, it may be safely assumed that there is a lack of lime in the soil. It therefore behooves the beekeeper to look into this matter very carefully in his own locality at least; and if the farmers around him are not posted on this subject he should look the matter up, study the clover-fields very carefully, and where he finds usual evidences of lack of lime in the soil he should induce those not posted to get in touch with the nearest experiment station to advise how much lime should be used. Sometimes $500 \mathrm{lbs}$. to the acre will suffice; but usually it will take $1000 \mathrm{lbs}$; and sometimes 2000 to sweeten the soil.

Again, the beekeeper should call the attention of his farmer friend to the part that clover plays in imparting nitrogen to the soil. If he does not already know it, explain to him that there are little nodules clinging to the roots of the clovers, and these nodules contain bacteria. These bacteria gather the nitrogen, and impart it to the clover and to the soil itself. If the farmer is not growing clover, particularly alsike, or if he says his soil is "cloversick," it is to the interest of the beekeeper to inform him, in order that his bees may gather clover honey as in former days.

In one respect, at least, this lack of lime in the soil is helping out the beekeeper, be-

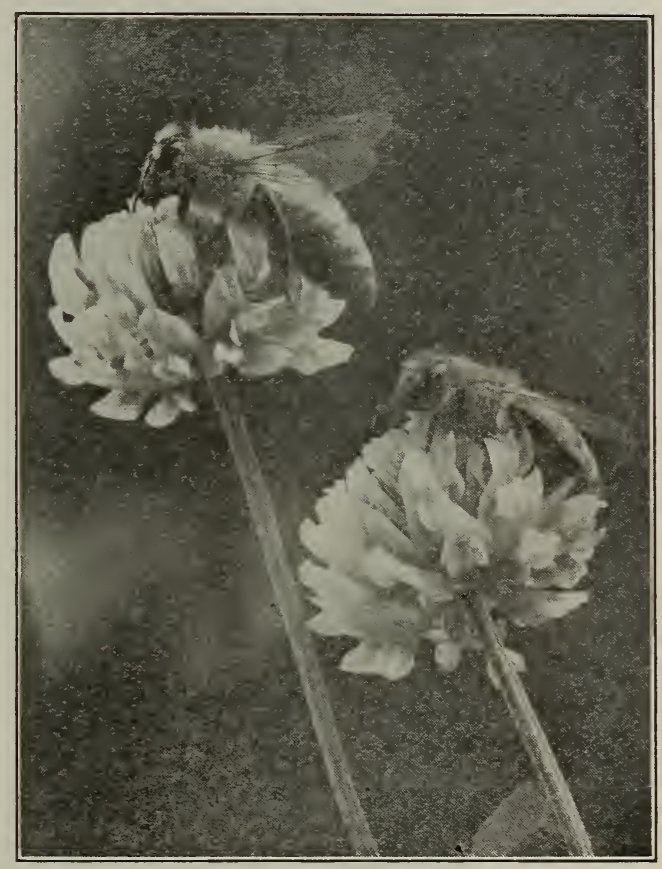

What is sweeter than honey?

cause the farmer is putting in alsike clover to grow on land that would not grow red clover as formerly. If alsike would continue to thrive year in and year out on such land, when red clover would not grow, or at least not very satisfactorily, the beekeeper could have no interest in urging the use of lime in the soil to make it grow red clover, which only at certain seasons has its nectar accessible to honeybees. But the difficulty comes right here: The soil will continue to grow more and more acid until it will not grow even alsike.

We do not know as yet whether white clover can resist acid soils as well as alsike or not. Mr. Alva Agee, one of the best authorities on the growing of clover and 


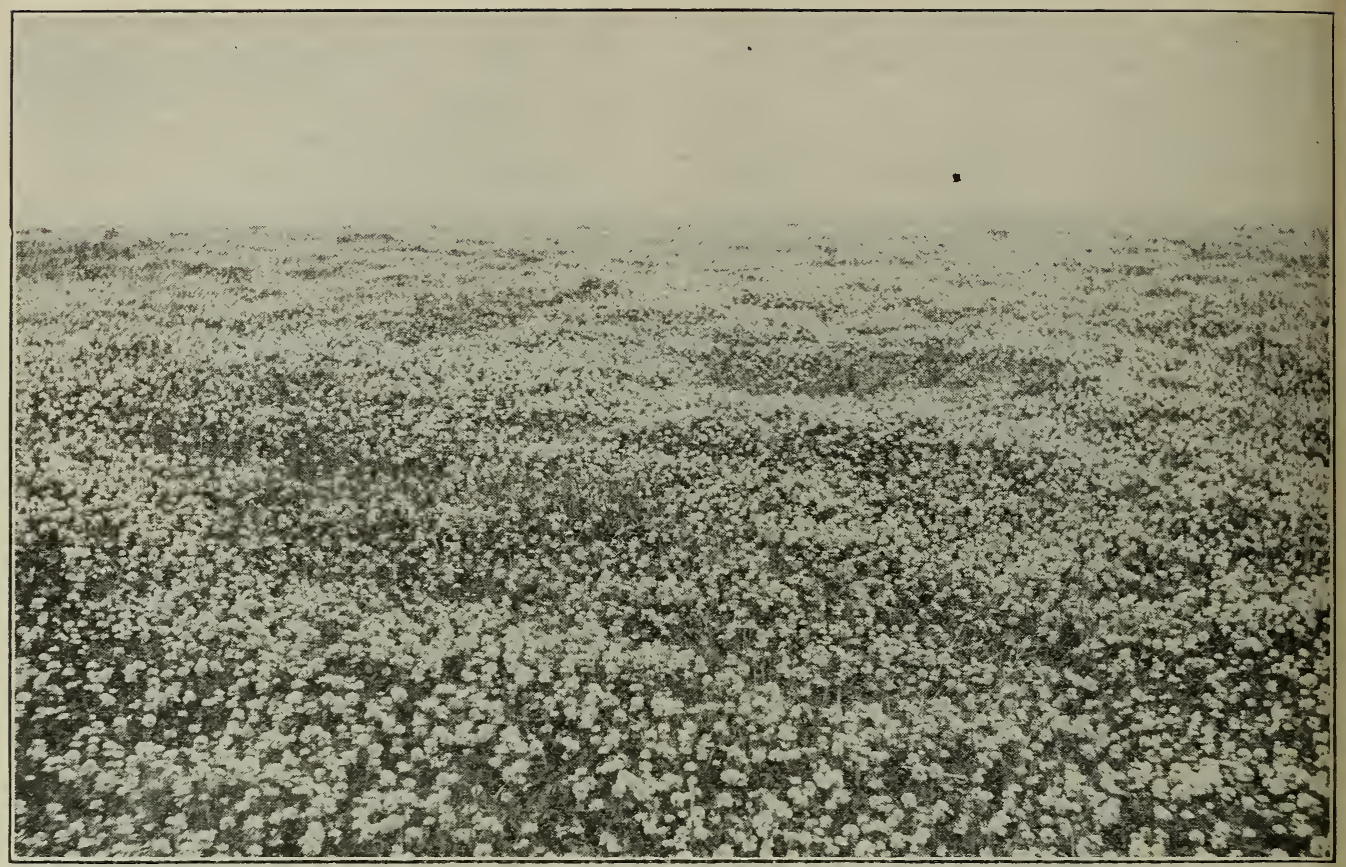

A fine field of white clover in Iowa.

liming the soil, says that white clover thrives best where blue grass thrives best, and blue grass loves a soil rich in lime. The natural inference, then, would be that white clover has been going out, not only because of intensive agriculture, but because the soil is becoming too acid for it to grow. We do know this: Years ago there was no difficulty in getting crops of honey from white clover. But in late years white clover for some reason has failed time and again, even when the season was favorable. This may be due to the fact that the soil is too acid for even white clover to do well. If this be the fact, and white clover seems to be our main dependence for clover honey, it would be well for the beekeeper to urge upon his farmer friends, if they are not already so informed, the importance of liming the soil.

Don't infer from what we have said that the land may be too acid in every case. There are certain sections of the United States where it has been discovered that clovers will not grow as formerly, yet there is plenty of lime in the soil, and, of course, no good would come from putting any more lime in the land.

WHITE CLOVER (Trifolium repens L.).--In the central and eastern states no other honey-plant is so universally known as white clover, and white-clover honey is the honey par excellence-the honey with which all other honeys are compared. It is a delicious white honey of the finest quality. While not so thick and heavy as goldenrod nor so pronounced in flavor as buckwheat or basswood, it yet possesses the qualities which satisfy the largest number of consumers and fills most perfectly the demand for a table honey of the highest grade. It is given the preference by most purchasers, and the highest encomium which can be bestowed on any honey is to pronounce it equal to that of white clover. As a confectionery its appearance is most attractive, while for medicinal purposes it is unsurpassed.

In general in America where it is sufficiently abundant white clover usually yields excellent honey harvests, which are not far from surpassing all records. In 1913, at Marengo, Illinois, Dr. C. C. Miller obtained from 72 colonies, spring count, 19,186 sections of chiefly white-clover honey, or an average of 266.47 sections per colony. The three best colonies yielded 390, 395, and 4.02 sections respectively. This phenomenal surplus was largely due to a most favorable season consisting of a succession of hot humid days, altho the strain of bees and the care they received were important factors. 
The flow began about June 1 and continued until the last of August, the bees then gradually changing to sweet clover and heartsease. During this long even flow there were up to September 1 only two rainy days. At other times the rain came during the night, the weather becoming clear again before the bees were ready to begin work in the morning. In central Kentucky, in 1906, 115 colonies stored 12,000 pounds of white-clorer honey and increased to 240 colonies. From secrete nectar and are bent backward and downward against the stem. By preventing useless visits this change in position is beneficial to both flowers and insects. When they expand the flowers are white, but they often turn reddish after they are reflexed. The calyx is only three millimeters long so that not only honeybees, but many other insects are able to reach the nectar. Honeybees also often gather loads of greenish pollen, altho this is not abundant.

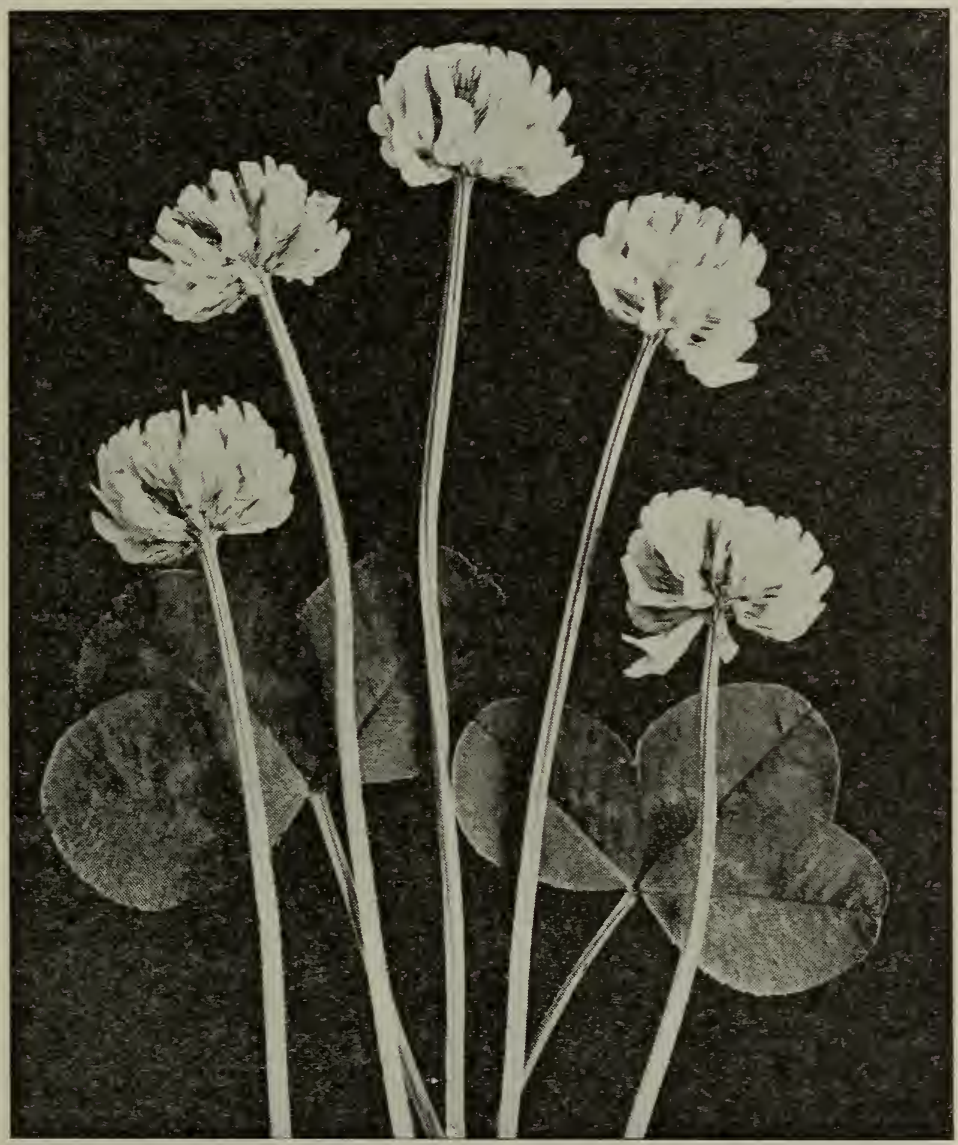

White-clover blossom-first stage.

the same apiary in the following year the product was 30,000 pounds, while in 1908 drouth reduced the crop to 15,000 pounds.

The flowers of white clover are familiar to every one since the plant finds a congenial habitat in the vicinity of human dwellings. It carpets the lawns, fringes the paths and roads, and is common in the fields and pastures. There are in each head or flower-cluster from 57 to 89 small florets. At first all the florets stand erect, but as the marginal ones are pollinated they cease to
DISTRIBUTION OF WHITE CLOVER.

White clover is very widely distributed in the north temperate zone of both hemispheres. The factors controlling the secretion of nectar are very imperfectly understood. While in the United States and England it is usually a good honey-plant, in France and Switzerland, in fact, thruout continental Europe, one may travel for several kilometers and not see a bee on it. At Rouen, France, during one day of whiteclover bloom a hive on scales actually lost 
300 grams in weight. In various localities in the United States it is also reported to be an almost total failure. At Plainfield, N. J., altho the ground is often white with the bloom a good flow is obtained only about once in ten years. One beekeeper says: "As an actual fact, the amount of clover honey is not measured by the quantity of bloom; for I have seen the fields white with an abundance of it, but only a fair crop. I can remember one year when we had a great scarcity of bloom, and yet clover belt"-that is, in the blue-grass region of Kentucky, in Ohio, Indiana, Illinois, Missouri, Iowa, southern Minnesota, and southern Wisconsin, Iowa and southern Illinois being in the heart of the belt. Even here the nectar yield is often very variable. In some years it is enormous. In others no surplus is stored. At Richmond, Kentucky, according to Virgil Weaver, a normal year comes only once in every five years, viz., $1897,1902,1906$, and 1910. Two full crops obtained in succession are often followed

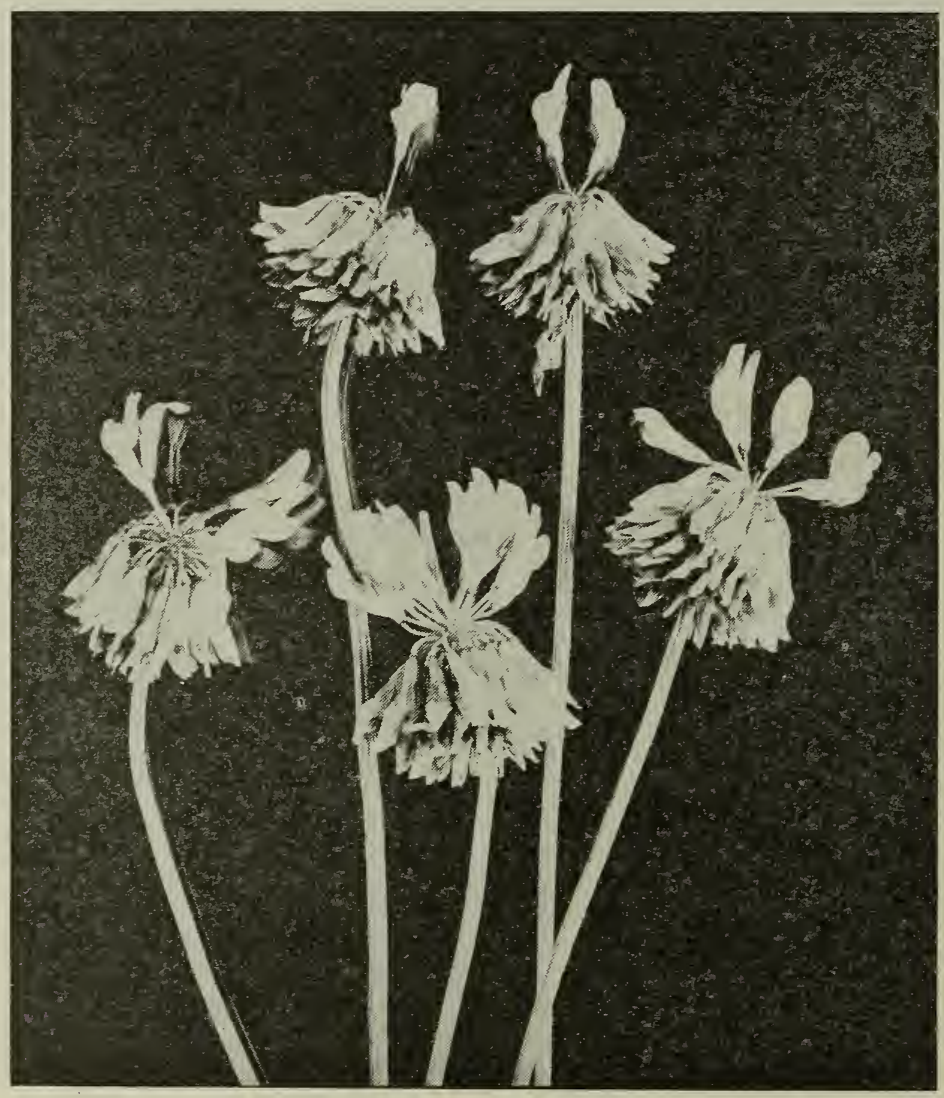

White-clover blossom-second stage.

we had a good crop of clover honey. I have also seen fields white with clover but no honey." In the southern and extreme western states white clover is of little importance to the beekeeper, not so much because it does not secrete nectar as because it is not sufficiently common. In many districts the climate is too dry. The nectar secretion also varies greatly from day to day according to weather conditions.

White clover is at its maximum as a honey-plant in what is known as the "white- by several years when the yield is less satisfactory. This difference is largely determined by soil and climate. In wet clay ground in regions where the winters are severe the roots may be much broken and drawn out upon the surface, or the plants killed outright by repeated "lifting" caused by the alternate thawing and freezing of the soil. The destructive work of the frost, however, is much lessened by the natural mulch afforded by the dead vegetation found in waste places and in meadows, which have 
not been cropped too closely. Snow also offers excellent protection, and, when it covers the ground for most of the winter clover suffers little cr no damage. Winterkilling from freezing in well-drained sandy soils or in warmer climate is practically unknown.

In Kentucky, Iowa, and the surrounding territory, where there are light soils, it seems to be well established that there will be a very small honey-flow if the preceding season has been very dry. If there is no rain after July 1 the drouth destroys the old the absence of sufficient moisture in the soil. But if there is a good stand of white clover in early spring, a drouth in May or June, if copious rains follow, will only retard the bloom and delay the harvest. I have seen clover parched by drouth in June, says a beekeeper, and not a blossom in sight. Then came a succession of soaking rains, and, presto! bloom and a crop of honey. Similar results have been described at London, Canada. An exceptionally dry fall after August 15 was followed by a dry spring until the last of May, when a series of warm

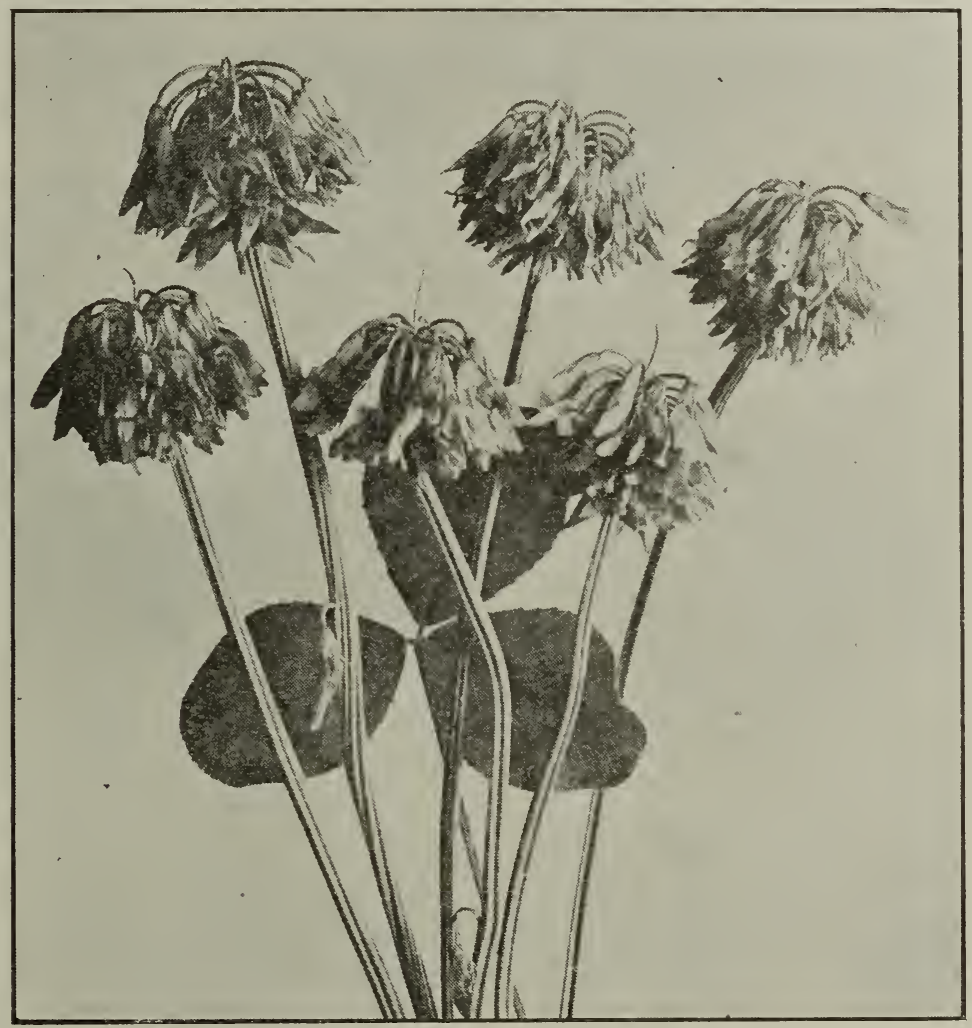

White-clover blossom-third stage.

plants of feeble vitality, checks the growth of offshoots, prevents the germination of seedlings, and retards the formation of an extensive root system with the result that there are few blossoms and little nectar the following season. This statement does not call for discussion since all herbaceous plants growing in porous sandy soil suffer if there is a large decrease in the normal rainfall. Altho the injury wrought by the drouth does not become apparent until the next season, it should not be attributed to winter-killing, but to the correct cause- rains commenced which continued almost daily until about the twentieth of June. The effect was marvelous. July found the fields and roadsides a beautiful mass of white and alsike clover, and the honey crop was the best that memory can recall. A very cold spring may also cause failure, even if there is a normal rainfall. In 1907 in parts of New York the average temperature of April, May, and June was four degrees below the respective means for these months in other years, and there was no white-clover honey. 
Cold rainy weather during the honey-flow will both lessen the quantity of nectar and prevent the bees from working on the bloom; for the best results there must be a series of warm humid days. Finally, where white clover has been grown indefinitely in the same fields the soil conditions may become deleterious. Microscopic protozoa may multiply until they destroy a large part of the beneficial bacteria, or the soil may become acid and require a liberal application of lime. Such land is said to be "cloversick," as explained at the beginning of the general article on Clover. Nearly all of northeastern Ohio and the major part of Pennsylvania show a deficiency of lime. This is also true of Massachusetts where very little white-clover honey is produced. The remedy, of course, is to apply lime as previously explained.

WHITE CLOVER, HOW PROPAGATED.

There is no more important or interesting subject to the beekeepers of "the whiteclover belt" than the life history of white clover and its problems. The plant is propagated both by seeds and runners which root at the nodes and finally become inde. pendent stocks. As in the case of the strawberry, a single plant may in a favorable season cover with its runners a circle of ground one or two feet in diameter. If these new plants winter uninjured they will bloom the following season in the same manner as strawberry-runners. The older plants, as is again true of the strawberry, exhausted by multiplying both sexually and vegetatively, are easily killed by drouth or cold. When the ground is densely covered with an old growth there will be little op. portunity for runners to root or seed to germinate. Consequently there may come years when there are few new plants to bloom.

White clover seeded in the spring will produce, if there is sufficient rain, a heavy crop of bloom in July and a fair amount of seed. Much depends upon locality. Clover raised from seed is more valuable for nectar the second season than during the first.

RED CLOVER (Trifolium pratense L.). -Red clover is pollinated chiefly by bumblebees, and is therefore called a bumblebee flower. This reciprocal relation will be made clear by a brief history of the intro- duction of red clover into New Zealand. There were neither bumblebees nor honeybees in those islands at the time of their discovery; consequently, when the colonists attempted to grow this valuable fodder plant it failed to produce seed. To remedy this difficulty about 100 bumblebees, belonging to three different species, were imported from Europe, and subsequently the red-clover heads became fertile. It seems to have been supposed that any bumblebee would answer for this purpose, as one of the species brought from Europe was Bonzbus terrestris, which has too short a tongue,

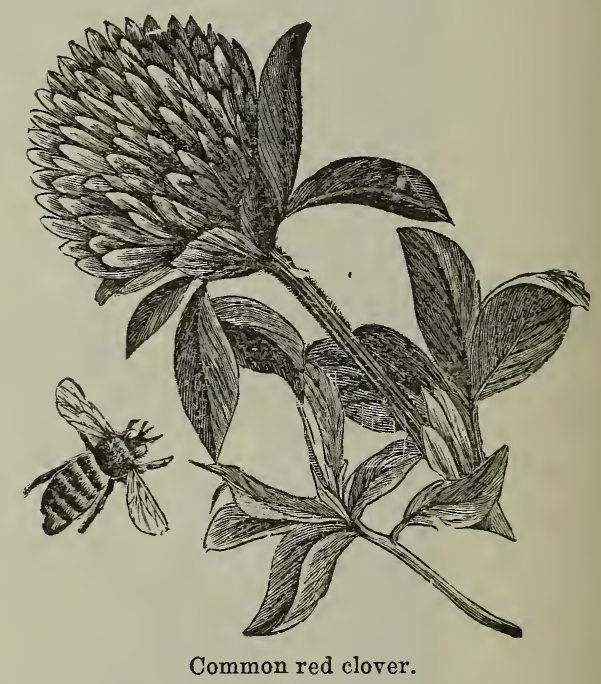

and has formed the habit of biting holes in the corolla tubes and robbing the flowers of their nectar without rendering any service in return. After the holes have once been made, other insects, which are themselves unable to puncture the corolla, use them to abstract the nectar. Thus, so far as the red clover is concerned, it would have been better if this bumblebee had never been brought to New Zealand. In the course of time this fact was learned by experience; and as recently as 1905 the New Zealand government wrote to an experiment station in Canada inquiring in regard to the bumblebees useful in pollinating red clover in that country. As has been pointed out by Dr. Graenicher, two of the common and hardy bumblebees (Bombus americanorum and $B$. fervidus), which have tongues 14 millimeters long, would be well adapted for this work. See BumblebeEs.

In a favorable season, when there is an abundant rainfall, and the flowers of the 


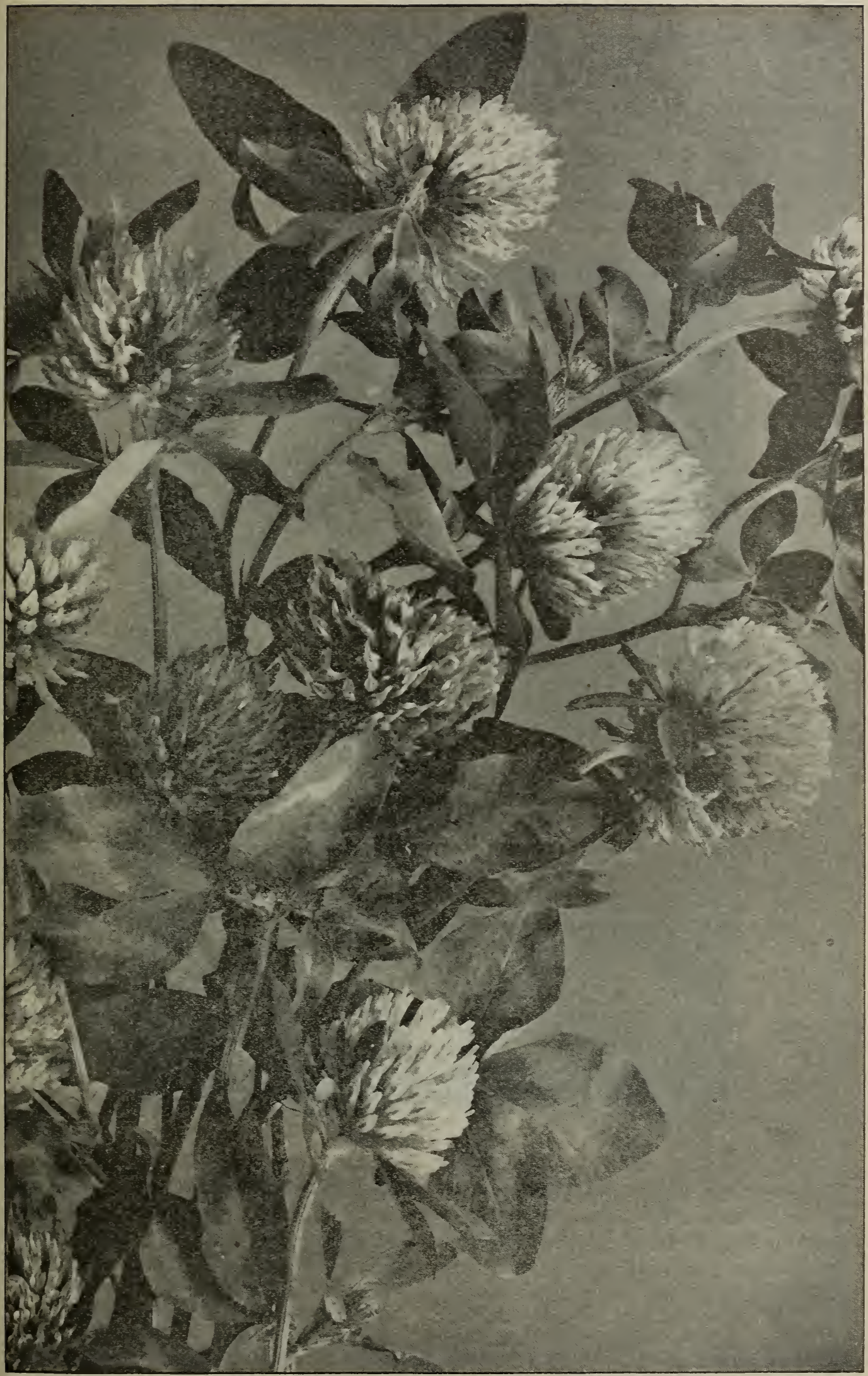

Peavine, or mammoth red clover; life size. 
red clover are fully developed, a bee can not reach the nectar unless it has a tongue 9 millimeters long. As the tongue of the Italian bee is only $61 / 4$ millimeters in length, the nectar is then wholly inaccessible to it. This has been the cause of much regret among beekeepers, for these flowers not only secrete nectar very freely but the nectaries are much less influenced by weather conditions than those of many other plants. Repeated attempts have been made to develop a permanent strain of red-clover bees; but all such attempts have proved unsuccessful. It is no easy matter to lengthen the tongue of the honeybee $23 / 4$ millimeters. The production of a race of red clover with shorter floral tubes has also received consideration.

But the second crop of red clover usually has shorter corolla tubes, and occasionally in very dry seasons the tubes are so short that large yields of honey are obtained. G. M. Doolittle says that two or three times in thirty years at Borodino, N. Y., the red clover has been a very valuable source of honey; and that one year he obtained fully sixty pounds to the colony on the average. W. Z. Hutchinson stated that he remembered one year when his bees stored 500 pounds of pure red-clover honey, as surplus, in the section honey-boxes. It was when the second crop had been stunted by drouth. The blacks stored none of the honey, the hybrids stored a little, but the bulk of the 500 pounds was furnished by the pure Italians.

A remarkable illustration of the correlation existing between the weather and the length of the corolla tubes of the red clover was observed by us in 1906 . There was almost a drouth during the latter part of the season at the nortl beeyard, two miles north of Medina. Adjoining this yard were several fields of red clover, for the farmers were furnished with seed of red clover and alsike free of charge. Owing to the dry weather the corolla tubes of the red-clover beads were shorter than usual, and great numbers of bees were attracted by the nectar which was now within their reach. When one of the farmers began to cut his red clover that season there came near being a bad stinging-fracas; for when the cutterknives of the mower went thru the field they stirred up the bees, with the result that they attacked the horses and the man on the mower. So greedily did the bees work on that field that it looked as tho they were not going to let anybody cut off their honey-supply. Other farmers in the vicinity also had considerable trouble in cutting their red clover because the heads were so covered with bees.

Singularly enough, at Medina, and the south beeyard, only two miles away, there was plenty of rain. When we went over a big field of rank clover at our south yard, scarcely a bee could be found; while quite the reverse had been true the whole season on the fields at the north yard, where there had been a drouth. The clover at the home and south yard, by reason of the plentiful rains, had attained a rank growth. The corolla tubes were so long that the bees could not get any nectar from them, and consequently there were no bees on the heads. Thus two beekeepers living only two miles apart might have arrived at diametrically opposite conclusions as to the value of red clover as a honey-plant.

THE PEAVINE, OR MAMMOTH CLOVER (Trifolium pratense perenne), is the largest kind of red clover known, as its name indicates; and it does, many seasons, furnish a very large amount of honey. As a rule, however, like the red clover mentioned above, it is seldom visited by the common bees; but nearly every season it is visited more or less by Italians; which some seasons (where very large fields are near by) store remarkably large amounts of very fine honey from this one source alone. In bloom principally thru the months of $\mathrm{Au}$ gust and September, it is a very important honey-plant. Altho the hay is hardly equal to that from common red clover, it is, perhaps, the best forage-plant known to plow under. Once well started it will grow on almost any soil; and let a good stand be secured and plowed under, the ground gets in condition to furnish a fair crop of almost anything.

ALSIKE CLOVER (Trifolium hybridum L.), so called Alsatian or Swedish clover. This was formerly supposed to be a hybrid, since it appeared so nearly intermediate between the white and red clovers; hence it is named Trifolium hybridum. It is now known to be a distinct species.

Alsike yields fully as much honey, and of as good a quality, as the ordinary white 
clover; and since many soils have become too acid for the growth of red clover, alsike is now taking its place. It is also being sown with timothy. The greatly increased acreage of alsike has, to a great extent, in some places at least, made up for the loss of white clover which formerly was so abundant. In Michigan and some other states nary coarser red clorer does not possess. The statement has been made by dairymen over and orer again, that, acre for acre, alsike will yield more milk or more butter than red clorer or timothy hay. When the farmers over the country come to discover this fact, there will be, of course, increased acreages of alsike. It may, therefore, come

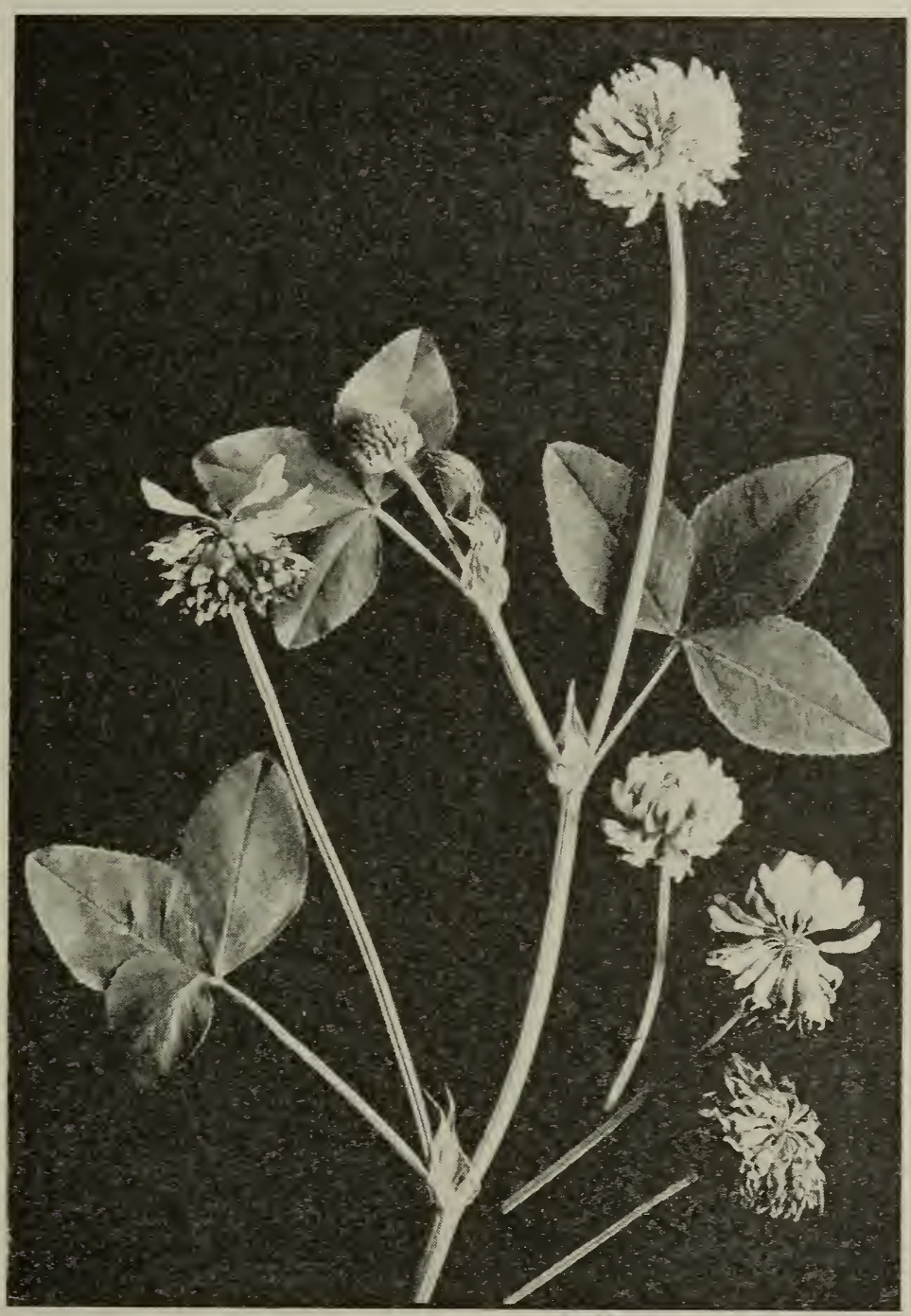

Alsike clover.

there would have been no clover honey had it not been for alsike. White clover has disappeared to a great extent; but alsike, which has been grown so generally, is yielding a large quantity of fine clover honey.

In the meantime, farmers have come to learn that alsike clorer has a peculiar quality and food value to stock that the ordi- to pass that acidity in the soil is going to prove a blessing in disguisa; for after the soils hare been brought back to their former sweetness, so that they will grow red clorer, there is a possibility and eren a probability that farmers will see that alsike is so much better that they will continue to grow it as they have grown it in the past when they 
could not grow the ordinary coarser red clover.

Another thing that has been discovered is that, if alsike is cut or pastured off just before it comes into bloom, it will give a crop of clover honey just when we are most in need of it. One of our leading honeymen said that this fact alone, learned at a convention, has been worth more than $\$ 50.00$ to him.

The following from the United States Department of Agriculture, Bureau of Plant Industry, is so valuable that we give it entire.

Alsike Clover (Trifolium hybridum).-A perennial clover, intermediate in size and general appearance between the common red clover and white clover. The branching and leafy stems, while not growing as large as those of red clover, commonly reach a height of 18 inches, and even 3 feet or more, on slough land. The fragrant blossoms have a pinkish tint, and furnish large quantities of honey, the plant being often sown for that purpose by beekeepers.

Distribution.-In general alsike clover will grow well where red clover grows, but is best adapted to a cool, humid climate. It produces maximum yields near the boundary lines between the United States and Canada, in the regions of the Great Lakes and the Atlantic and Pacific oceans. It is also grown very successfully in some of the irrigated Rocky Mountain valleys, and in certain portions of Kentucky, Tennessee, and other sections where red clover now fails to produce satisfactorily.

Soil Requirements.-The most suitable soil for alsike clover is a deep, moist, clay loam, with a high percentage of lime. Slough soils that have been deposited by the action of water are also well adapted to alsike. Good erops are also grown on sandy loam soils well supplied with humus, but this clover will not succeed well on dry, sandy, or porous, gravelly soils. It will succed on soils too wet for red clover.

Sowing.-Like red clover, alsike clover may be sown either alone or in small grain crops in early spring in the North, and early spring or autumn in the southern regions. When sown in the spring in small-grain crops the common practice is to allow the action of the weather to cover the seeds. Very often, however, better results are obtanied if the seed is given a slight covering with a smoothing harrow or weeder. When sown alone the seed-bed should be well settled and finely pulverized on top, and the seed given a light covering. On strong, moist soil it should be sown with a grass, such as timothy, orchard grass, or redtop, to prevent lodging. It matures about the same time as these grasses, and improves the quality of the hay. On lighter soils where the growth is not heavy, successful crops are grown when sown with a grain crop or alone. When sown alone for seed or hay from 5 to 8 pounds to the acre are usually required. When sown with a mixture of grasses the amounts vary with local conditions, but a fair average for most conditions is alsike 4 pounds, and timothy 8 pounds per acre, or alsike 5 pounds and 10 pounds of ordinary redtop seed. A favorite mixture in the southern tier of states of 5 pounds of orchard grass, 10 pounds of tall meadow oat-grass, 4 pounds of redtop, and 4 pounds of alsike. Some farmers use a mixture of red clover and alsike, since the latter is a perennial, and will cover the ground when the red clover runs out.

Alsike is often used to good advantage in pasture mixtures, especially on wet land and in regions where red clover is not successful. Where alsike is used for pasture exclusively for horses and mules, it sometimes causes a skin disease. When cut for hay it should be cut just after it has passed full bloom, and it should be handled the same as red clover.

\section{SAVING THE HAY.}

Raised for hay and honey, without any reference to saving the seed, it gives at least two good crops every season; in this case it is cut when in full bloom. In our locality it usually blooms the last of June, and sometimes furnishes considerable honey before the white clover is out. The hay is admitted by all to be equal to any of the grasses or clovers in use, while pasturage, after the clover is cut, is most excellent for all kinds of stock.

Its value for milch cows is shown by the following, taken from Gleanings in Bee Culture, Vol. XIII., page 161:

As a forage plant it has no superior, producing a large flow of very rich milk. June 15 , when I shut the stock out of the alsike, I allowed them to run in a field of red clover that was just coming into blossom, and at the end of the third day the five cows had shrunk their milk to the amount of 9 quarts to the milking. Then, in October, to test it further for feed, as there was quite a growth of leaves on the ground I again allowed the cows in the field. You may imagine my surprise when I found, at the end of a week, they had made a gain of 10 quarts to the milking.
Millington, Mich.
M. D. York.

\section{SAVING THE SEED.}

The seed is always saved from the first crop of blossoms, and it should be allowed to stand about two weeks longer than when cut for hay. If you wish to get a good price for your seed, it must be very nicely cleaned. It is thrashed out with a clover-huller, 
made expressly for clover seed, and then cleaned with a fanning-mill with appropriate sieves. Timothy seed is very nearly the same size, making it difficult to remove it all, unless by a fanning-mill having the proper blast arrangement. As the alsike weighs $60 \mathrm{lbs}$. to the bushel, and timothy only 45 , there is no great difficulty in doing it effectually.

We need scarcely add, that whoever raises seed for sale should exercise the most scrupulous care to aroid sending out foul seeds of any kind; and where Canada thistles or weeds of that class prevail, we would. under no circumstances, think of raising seed to be sent all over the land. If they are in your neighborhood, raise hay and honey, and let seed be furnished by some one who is differently situated.

\section{FURNISHING THE SEED FREE.}

Some beekeepers are beginning to find that it pays to furnish alsike-clover seed free of charge to their neighbors within a mile or a mile and a half of their beeyards. They arer that, when the seed is once in the soil, the plant continues to reseed itself so it will spread all thru the farming country. This enriches the farmer, giving him a better quality of hay when mixed with other clovers and timothy, and at the same time increases the annual honey crop of the beekeeper. One or two years after the free giving of seed, the farmers will begin to find out its value, and will then want it and be willing to pay for it. Some beekeepers then furnish it at half price.

We have for several years been furnishing alsike-clover seed to farmers at half price provided that the fields where it was to be sown were within half a mile of some one of our yards. We have also furnished it free to those who would sow it in fields within a few rods of the yards.

By continuing this policy we have enormously increased the alsike-clover acreage within half a mile of our yards. Our men observed that the amount of clover honey gathered has noticeably increased, and that less feeding of sugar syrup in the fall has been found necessary. After the alsike is once introduced it will keep on self-sowing, and, what is more, the farmers will discover that it will take root where the ordinary red clovers fail to make any satisfactory showing. Whenever the ground becomes "clover-sick," or whenever there is any ground on which ordinary red clovers do not seem to make a satisfactory growth, the alsike will usually do much better.

After a few years it will not be necessary to furnish seed free and at half price, for the farmer will find the crop so valuable that he will pay full price for it; but he must be educated at first by giving him a bonus.

WINTER-KILLING AND ITS EFFECT ON THE CLOVERS.

There are two kinds of winter-killing. One is known as the "heaving-out" process, by which the alternate freezing and thawing of a water-soaked soil breaks the roots of the clovers, dismembering them until there seems to be but little of them left. The other kind of winter-killing is from what might be called the dry process. In this the ground is frozen to a great depth, freezing the roots and plants solid. Thile it may thaw and freeze somewhat, it is claimed "that the severe cold wind blowing over the surface when the ground is not protected, if it continues for any length of time, will kill almost any clover." It follows that, when the ground is covered with snow for most of the winter, clover suffers little or no damage.

But on the other hand it is claimed that white clorer suffers less from winter-killing than any of the clovers. Unlike the common red, peavine, and alsike, it has no great tap-root. It is essentially a vine like the strawberry, having shallow roots at frequent intervals shooting down into the ground for short distances. During the heaving process of winter-killing, the white clovers are lifted up and down, and apparently are but little harmed by the process except in cases where there is very severe cold without snow that attacks root and branch alike.

CRIMSON CLOVER (Trifolium incarnatum L.).-Sometimes called Italian or carnation clover. Grown in middle and southern states, but not hardy north. This species, if grown largely, would certainly have one special advantag'e orer any of the other clovers, in that it comes into bloom before any other, and very soon after appleblossoms; in fact, it fills the gap between apple-bloom and white clover. The color of the bloom is quite distinct from that of the 


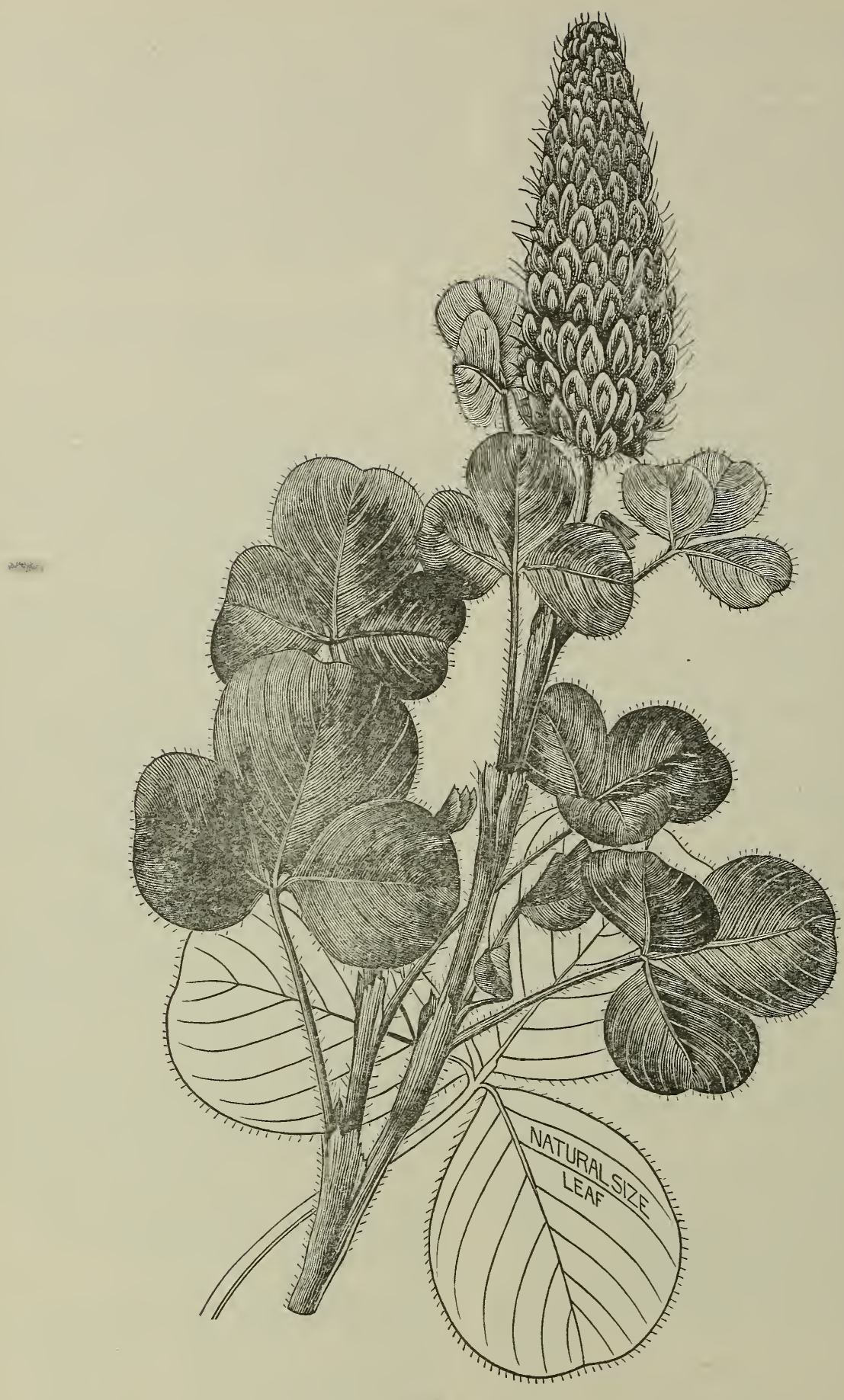

Crimson clover.

common red clover; in fact, it looks more like a great tapering strawberry than anything else. Almost every season, while ours is in bloom, people stop their teams and look at it and inquire about it; and on Decoration Day sometimes they come for miles just to get huge bouquets of these great crimson blossoms that almost startle one by their beauty and brightness. In visiting other beekeepers where they have succeeded in growing it, we found a similar report; and one who has never seen an acre 
of crimson clover in bloom can scarcely comprehend the beauty, not only of its gorgeous blossoms, but of the beautiful brightgreen foliage which, with the color of the blossoms, distinguishes it from any other plant.

While this variety is not exactly new, the idea that it can be sown during July or August, and yet winter over as far north as Ohio, is a comparatively new discovery. In states south of the Ohio River it may be sown in September, October, and even November. In our locality we obtain excellent results by sowing it the same time we do buckwheat (for particulars see BuckWHEAT) ; or it may be sown with all sorts of garden crops, especially those that are to come off soon, all thru the months of July and August. With very favorable fall weather it may succeed, or partially succeed, thru the month of September. Some of our best crops have been secured by broadcasting it among early corn, just before it is cultivated the last time. If you want to raise some nice turnips without any additional expense, mix thoroly an ounce of turnip seed with 5 pounds of erimson clover before the clover is sown. In sowing it among corn, as mentioned above, we use a broad-cast seed-sower, the operator sitting on the back of a horse so as to get him above the tops of the corn.

\section{SOWING CRIMSON CLOVER IN THE SPRING.}

As the clover is a hardy cold-weather plant, sowing it in the spring is not, so far as we can learn, a success. The trouble is, when put in in the spring, even if put in quite early, the blooming time is quite apt to come just when the weather is hot and dry; and a drouth is almost sure to cause failure. If, however, the seed is put in quite early, and the spring months happen to be cool, with plenty or rain clear into July and even August, it sometimes makes an excellent crop. When sown as above, it naturally makes a large amount of feed, equal to any of the clovers; and some of our experiment stations have estimated that a good stand plowed under while in bloom is equivalent to ten tons per acre of the best stable manure.

As it comes in bloom a little before any of the other clovers (when wintered over), it may be plowed under for almost any crop. On our grounds we sow regularly four or five acres each year, and have had no failure.

\section{MANY FAILURES}

It is no more than fair to state, however, that in our locality, the northern part of Ohio, there have been many failures. In fact, one of our standard writers on agriculture says thousands of dollars have been wasted by farmers trying to grow crimson clover. The reason of our success was, we think, first, our ground was all thoroly underdrained; second, it had large amounts of stable manure, and is comparatively rich.

The best stand we ever had, we think, was in the spring of 1899 . We had several acres of wheat the year before that lodged badly. The consequence was, enough wheat rattled out and was left on the ground to make pretty thoro seeding. This wheat grew up in the fall so rank as to fall down before winter. The crimson clover was sown right on the wheat stubble in August; and when the wheat fell over, the clover pushed up thru and was thus well mulched thru the winter. The consequence is, we had, on April 25, a tremendous growth of clover and wheat together. This was turned under as soon as the clover was in full bloom. We have grown excellent crops of potatoes on crimson clover turned under in this way, for several years past; and, in fact, we have secured a splendid stand of crimson clover by sowing it after potatoes were dug that were planted comparatively early. One year we sowed crimson clover as fast as the potatoes were got out of the ground; that is, as fast as we dug fifteen or twenty rows we worked up the ground with a cutaway and Acme harrow, and sowed the clover. The first put in (in August) wintered splendidly. That put in along the fore part of September did fairly; but where we did not get the seed in until the last of September or fore part of October, it was mostly a failure. Perhaps one other reason why we succeeded is that our seed of late years has been of our own growing. It is an easy matter to grow seed; and where it is worth only $\$ 2.50$ a bushel, the ordinary price, we think the seed can be grown profitably in our locality-that is, on good ground with the conditions mentioned.

In conclusion it is but fair to state that crimson clover has not come into general use-mainly on account of winter-killing. 
QUALITY OF CRIMSON-CLOVER HONEY.

The quality of the honey from crimson clover ranks fairly with that of any of the clovers. Some have called it superior: There has not been enough of it in our locality to make a perceptible difference in the honey-yield; but when in bloom there are as many bees on the same area as we ever saw, even in a buckwheat-field. As we plow it under while in full bloom, the bees are gradually crowded down to the last heads standing; and after the last head goes under, for some time there will be quite a lot of bees swarming over the ground, apparently wondering what has become of their abundant pasturage in so short a space of time. We have as yet had no reports, to our knowledge, from hundreds of acres or more in blossom at the same time, as is often the case with alfalfa, white clover, and sometimes red clover. A fair-sized apiary needs many acres of any plant to give a good yield of honey.

Another great advantage it has over almost everything else for poultry is that it is green and luxuriant thru the winter when almost every other plant is killed by the frost. If it is desired to give poultry green feed, with but little trouble, crimson clover should be got in as soon as a crop is off.

SAINFOIN CLOVER (Onobrychis sativa Lam.).-This excellent farm crop has been grown for ages in Europe, and at the present day is raised very extensively, more particularly in England, France, and Belgium, where it is a standby. The name "sainfoin" literally means healthy hay, presumably because it does not bloat stock to which it is fed. It certainly makes fine hay-possibly the very best known. It also produces choice honey in liberal quantities - the honey almost identical with whiteclover honey. Grown and cultivated very much as alfalfa is with us it has this difference-it is not suited to a semi-arid country. It has been grown quite successfully at the Ottawa, Ontario, experiment station, and thruout all Ontario. Sainfoin does not yield as much hay as alfalfa, being finer in the vine, and not so tall. It commences to bloom shortly after fruit-blossoms fall, and stays in bloom long enough to allow bees ample time to gather a crop. The blossoms do not come all together, but in succession, hence it is not practical to cut it just before blooming time, as is now done with alfalfa. It would seem to be a grand crop for those who raise fine horses and cattle, also poultrymen who feed cut clover. It is not likely it will ever yield so large a crop as alfalfa, but in every other respect it is probably superior.

ALFILERILLA (Erodium cicutarium (L.) L'Her).--Alfilerilla is derived from the Spanish word for pin, also known as alfilaria, pin-clover, musk clover, storksbill, heron's bill, and pin-grass. The fruit resembles a heron's bill, whence the name of the genus Erodium, the Greek for heron. Naturalized from Europe, and widely distributed; one of the leading honey and pollen yielders of California and Arizona. It is regarded as an excellent forage plant by stockmen, quite equal in feeding value to alfalfa, and probably more palatable, because much less woody in character. An analysis by the chemist of the Arizona Experiment Station shows it is quite equal to any clover for feeding. It is being rapidly spread by sheep and cattle in the extreme Southwest, for it is easily disseminated, and requires no particular cultivation. In this respect it resembles sweet clover; but animals do not have to be educated to eating it; on the contrary they are fond of it from the start. As a honey and pollen plant it ranks very high, both as regards quantity and quality.

COLOR OF HONEY.-See HoNEY, COLOR OF.

COMB FOUNDATION,-The invention of the movable frame by Langstroth; the honey-extractor by Hruschka; the bellows smoker by Quinby, and last, but not least, comb foundation by Mehring, made it possible to keep bees on a commercial scale never before attempted.

Comb foundation is just what its name signifies. It is the base, midrib, or foundation of honeycomb. If we take a piece of comb and slice it down on both sides nearly to the bottom of the cells we shall have the foundation of the comb, with initial cell walls, and hence the name. The comb foundation of commerce is much the same thing except that it is artificial, made of pure beeswax, with walls enough heavier so that the bees can use the surplus in drawing out and extending the cells. 
Comb foundation is made by passing a thin sheet of pure beeswax between a set of rolls or dies, the surfaces of which have been stamped or engraved in such a way as to give the imprint of the natural base of the honeycomb itself. The invention or discovery, rather, lay in the fact that the bees would utilize this article made by man, and construct it into perfect all-worker comb inside of the space of 24 or 48 hours when honey is coming in at a good rate.

\section{THE HISTORY OF THE INVENTION OF COMB FOUNDATION.}

To Mr. J. Mehring, of Frankenthal, Germany, is accorded the credit of having invented comb foundation in 1857; but his product was very crude, having only the indentation of the bottoms of the cells with

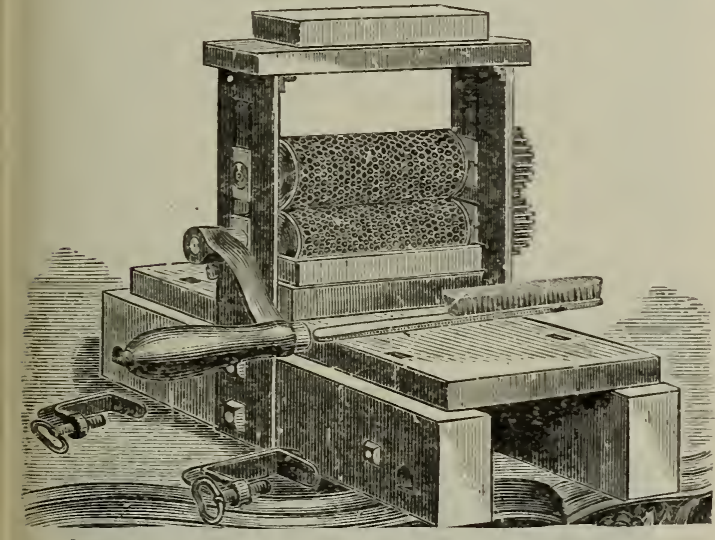

Washburn foundation-mill.

no cell walls. In $1861 \mathrm{Mr}$. Samuel Wagner, the first editor of the American Bee Journal, improved the foundation of Mehring by adding shallow cell walls. This, besides giving the bees wax to build the cells, also strengthened the sheet itself. Up to this time the article had been made between engraved flat metal plates; but Wagner was the first to conceive the idea of turning out the product between a pair of suitably engraved or stamped rolls operated on the principle of a mangle or a common laundry wringer. But, evidently, he never developed the principle.

\section{FOUNDATION-ROLLS.}

In 1866 the King brothers, of New York, and in 1874 Frederic Weiss, made foundation-rolls; but, apparently, the product that they turned out from these rolls was very crude. It was not until 1875 that A. I.
Root, in collaboration with a friend of his, Mr. A. Washburn, a fine mechanic, brought out a machine on the mangle principle that turned out sheets good enough and rapidly enough to be of commercial importance. Indeed, this old original Washburn machine was so searly perfect that its product was the equal of any made on any modern machine today.

About this time, also, or perhaps a little later, Frances Dunham and J: Vandevort, of New York, built rolls that turned out an excellent product. In the mean time Mr. J. E. Van Deusen, also of New York, built a machine that made foundation having flat bases, and incorporated in it fine wires. While the flat bases were not natural, of course, yet the purpose was to get a thinner base and to use wire. The bees, it is true, would reconstruct the bases, but they apparently did not take to flat-bottomed foundation as well as to the article having natural bases, and it subsequently disappeared from the market.

In later years Mr. Charles Ohlm, of Wisconsin, built a machine for engraving rolls with natural bases by the use of cutting-knives or gravers. This reduced the price so that machines are now within the reach of all.

\section{FLAT-PLATE FOUNDATION-MACHINES.}

About the time that the Root-Washburn comb-foundation rolls were being developed, the Given press using flat die-plates was brought out. Some few preferred the product from that machine, because, as they said, the foundation could be made right on the wires of a frame, and because the bees could work the wax a little more readily. The reason of this last point was because no press could exert as great a pressure as that given by a pair of rolls; and the result was, there was a large waste of wax in the bases. The foundation made good combs, and the bees worked it readily; but the individual sheets were too expensive as compared with the product turned out on rolls by the manufacturers, and so the Given press disappeared from the market.*

In the early 80 's various flat-plate machines were brought out. Among the number was one using flat dies made of plaster

* No foundation-press using flat plates can ever compete with rolls, any more than a Washington hand printing-press can compete with a cylinder press. 
of Paris. By taking a perfect sheet of comb foundation it was possible to take off molds in plaster. But these molds would not stand pressure, and therefore it was necessary to pour melted wax over them

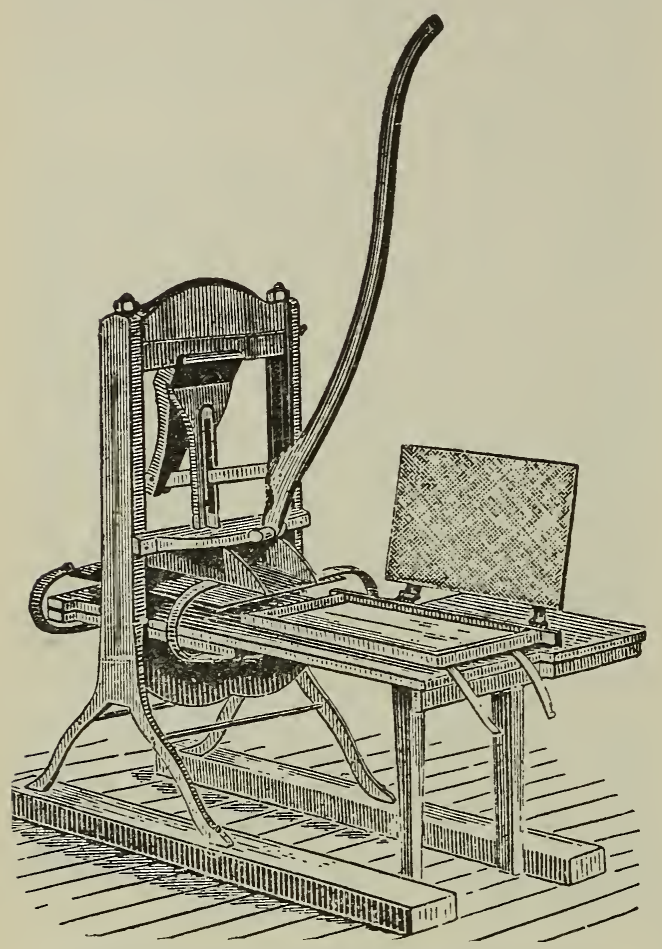

Given Foundation-press.

and close the dies. As soon as the wax cooled, the dies were opened and the sheet removed. But difficulty was experienced in getting this cast foundation (for that is just what it was) from the plaster molds. About this time, also, electrotype plates were taken off from a perfect sheet of foundation-a process that was comparatively simple, and one that any electrotype founder could readily carry thru. Various patterns of these copper-faced machines appeared on the market; but the only one that has survived is the Rietsche press, made in Germany. A good many thousand of these have been sold; but the objection to this and to all other presses is the waste of wax left in the cell bases. None of the Rietsche presses or flat-plate machines of any sort are sold in the United States, and the only foundation-rolls that have survived in this country, or in the whole world, are the Root rolls built by automatic machines employing the principle of the engravingknives of Charles Ohlm.

\section{WEED SHEETED FOUNDATION.}

Up till 1895, practically all the sheeted wax used in making comb foundation was made by dipping a thin board into melted wax and then into cold water. The thickness of the sheet was regulated by the number of dippings. For thin foundation a single dip was sufficient; for brood foundation, two or three dips were required. But the objection to this was that the wax sheet was thicker at the bottom than at the top. This was overcome somewhat by reversing the ends of the board.

Many efforts had been made to make wax sheets in continuous rolls; but it was not till 1895 that E. B. Weed built a waxsheeting machine that would turn out wax sheets any length desired, and of any thickness. The quality and quantity of this product was such that every manufacturer of comb foundation in the world, with one or two exceptions, has abandoned the old sheeting methods and adopted the Weed process. Probably 90 per cent of all the comb foundation made in the world turned out by manufacturers is first sheeted on the Weed machine and then put thru embossing-rolls generally called "comb-foundation machines."

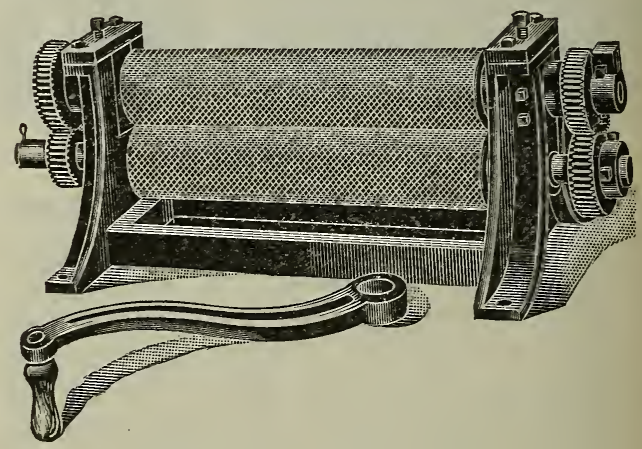

\section{FOUNDATION MADE BY LARGE FACTORIES.}

The art of making foundation is very complicated, and its manufacture has now gravitated into the hands of the large supply manufacturers who are able to turn out a product which for quality and thinness of base is far superior to that made by individual beekeepers. It is a trade in itself to make foundation having thin bases; and an arerage beekeeper does not possess the requisite skill to make foundation without wasting wax and ruining the delicate die faces of the comb-foundation rolls. 
WHAT FOUNDATION HAS ACCOMPLISHED.

Before we discuss the economic uses of comb foundation as now used in modern apiculture it is proper at this time to make a statement of what can be accomplished by the use of the invention. Its introduction has solved many difficult problems of the earlier days. Our forefathers had difficulty, for example, in getting the bees to build their combs straight and all worker. Before this invention, drones were reared in enormous numbers because there was so much drone comb. In modern apiculture only a rery ferv, and those the most select for breeding, are reared. By the use of allworker foundation there will be but very few drones in a hive. The rearing of so many useless consumers not only involved a serious drain on the resources of the colony, but it took the labor of the nurse-bees. The elimination of drones by the use of comb foundation materially increases the worker force in a colony, and this has made it possible to increase the actual yield of honey per colony proportionally. See Brood AND BROOD-REARING.

Mention is made of the fact that our forefather's were unable to secure straight combs in their movable frames. The combs, besides having an excess of drone-cells, were more or less wary, and it was not a little difficult to get the bees to build their product on a straight line, and parallel with and directly underneath the top-bar of the frame. (See Frames.) V-shaped combguides, or narrow strips of wood, the edges of which projected downward, were used as a coaxer to get the bees to build their combs parallel with the top-bar. But every now and then they would build their combs crosswise, zigzagwise, and every other wise except the right way. The use of even a narrow strip of foundation compels the bees to start the comb on a center medial line beneath the top-bar of the frame; and when a full sheet is used, the comb built from it is not only true and stright, but it will be all worker, as before explained.

THE EVOLUTION OF THE SECTION HONEY-BOX.

The old box hive of our fathers contained combs built irregularly in small boxes holding from five to ten pounds, the ends of these boxes being glassed. But such a package was too large for retail purposes. The time came when there was a demand for a small package, or one holding about a pound. Comb foundation made it possible for the beekeeper to compel his bees to build combs straight and even in little boxes holding approximately a pound. Without comb foundation, comb honey in sections would be impossible; and therefore the invention of foundation paved the way for the one-pound honey-section box that sprang into use shortly after comb foundation was introduced on a commercial scale. (See Comb Honey.)

\section{FOUNDATION AND ITS ECONOMIC USES.}

Having discussed the value of comb foundation we may now take up its specific uses.

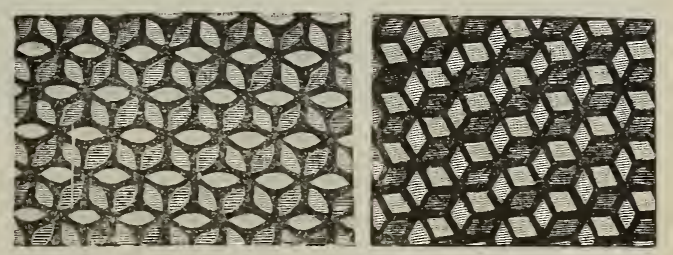

Heavy and medium brood

Light brood

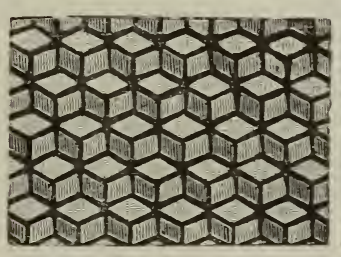

Thin super

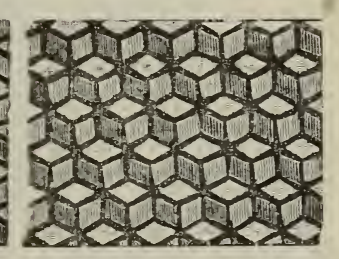

Extra-thin super
Comb foundation may be divided into two general classes: That designed for the brood-chamber and that for the supers, or where the surplus honey is stored. Each of these general classes is subdivided still further, viz., "thin super," running 10 to 11 square feet to the pound; "extra thin," 12 to 13; "light brood," used only in the brood-nest, running 8 to 9 feet; "medium brood," 7 to 8 feet. Thin super is generally used for sections, and medium brood for the brood-frames.

The four illustrations used above represent the different grades. The medium had what was called the round cell. This foundation has been used for the brood-nest, because of its tendency to resist sag while the bees are drawing it out into comb; stronger, because there is more wax in the corners of the hexagons. It has been found that bees will utilize all the wax in the walls, and draw it out into cells. The more wax we can give 
them in the wall, the quicker they will draw it out into comb. The objection to the medium brood is the expense.

\section{WHAT WEIGHT OF FOUNDATION TO USE.}

The light brood is now generally used for the brood-nest where frames are wired. As will be seen by comparison of illustrations, there is less of wax in the wall and less strength to the sheet. On this account it is not recommended that light brood foundation be put into brood-frames that are not wired. The thin super has lighter walls still than the light brood; and the extra-thin super lighter walls still and a thinner base.

The ordinary thin super is generally preferred because the bees are less inclined to gnaw it down; and when they do begin work on it they draw it out more readily. The extra-thin is preferred by some because it is believed it makes less midrib.

It was formerly supposed that the heavier grades of foundation used in sections would cause the bees to build too heavy a midrib in the combs; that such heavy midrib would be very objectionable to the consumer, in that it would give rise again to the stories about manufactured comb honey. (See Comb Honer.) But late experience seems to indicate that the bees will thin down the heavier grades, and, what is more, will accept the foundation much more readily than the extra-thin grades. But the real objection to heavy foundation is the expense. Then there is also the fear that the bees may not thin down the extra-heavy wax at times, thus making it objectionable in the mouth of the consumer.

Owing to the tendency of foundation to cause midrib in comb honey, some think that using a starter would remove the objectionable feature. They argue that nearly all the comb would have to be natural, and it would, therefore, be delicate and friable like the old comb honey on the farm. But it has been shown in a majority of cases that the natural-built will be store or drone, the cells being larger so the bees can build them more readily. Some recent tests seem to show that natural-built drone comb has as much or more wax to the cubic inch than worker comb built from full sheets of thin worker foundation. If the bees, on the other hand, would make their natural comb all worker, then we should have a comb, the delicacy and friableness of which would be all that we could desire. Drone-comb cappings do not have nearly the pleasing appearance of worker. If for no other reason, full sheets of worker foundation should be used.

With ordinary brood-frames, at least, or shallow extracting-frames, it is quite important to use some sort of support for the foundation; and unless these supports are used, the wax stretches in drawing out into comb. What is of still more importance, the finished comb will have no stability in the frame. When colonies are hauled over rough roads to out-apiaries the frames get some severe jolts. They also receive more or less rough handling at extracting time. They are often shaken to remove the bees, and in the extractor are subjected to severe centrifugal force which throws the honey out of the cells. On account of all this it is very important to have the foundation held by means of horizontal wires of a fine gauge, these wires being strung across the frames before the foundation is inserted.

\section{FASTENING FOUNDATION IN BROOD-FRAMES.}

Some beekeepers secure the foundation to the top-bar without using any stays or wires to hold the sheet in place; but the great majority seem to prefer to have all their

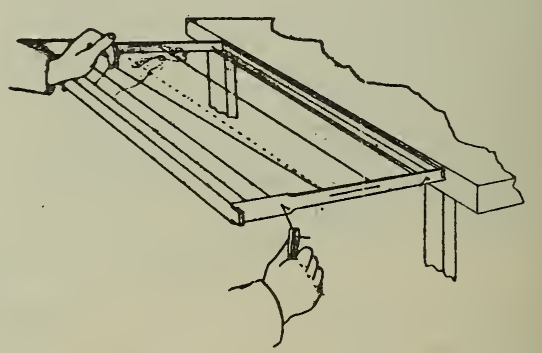

Method of drawing the wire preparatory to fastening.

frames wired-that is to say, strands of No. 30 wire stretched vertically or horizontally across the frame; these are then imbedded into a sheet of foundation which fills the frame. The combs, therefore, are firmly enough anchored to stand the rough usage of the extractor, and to stand shipment when colonies are sent by express or freight or hauled over rough roads to outyards.

Most beekeepers say that the expense of the wiring is so slight in comparison with the great benefits secured that they could 


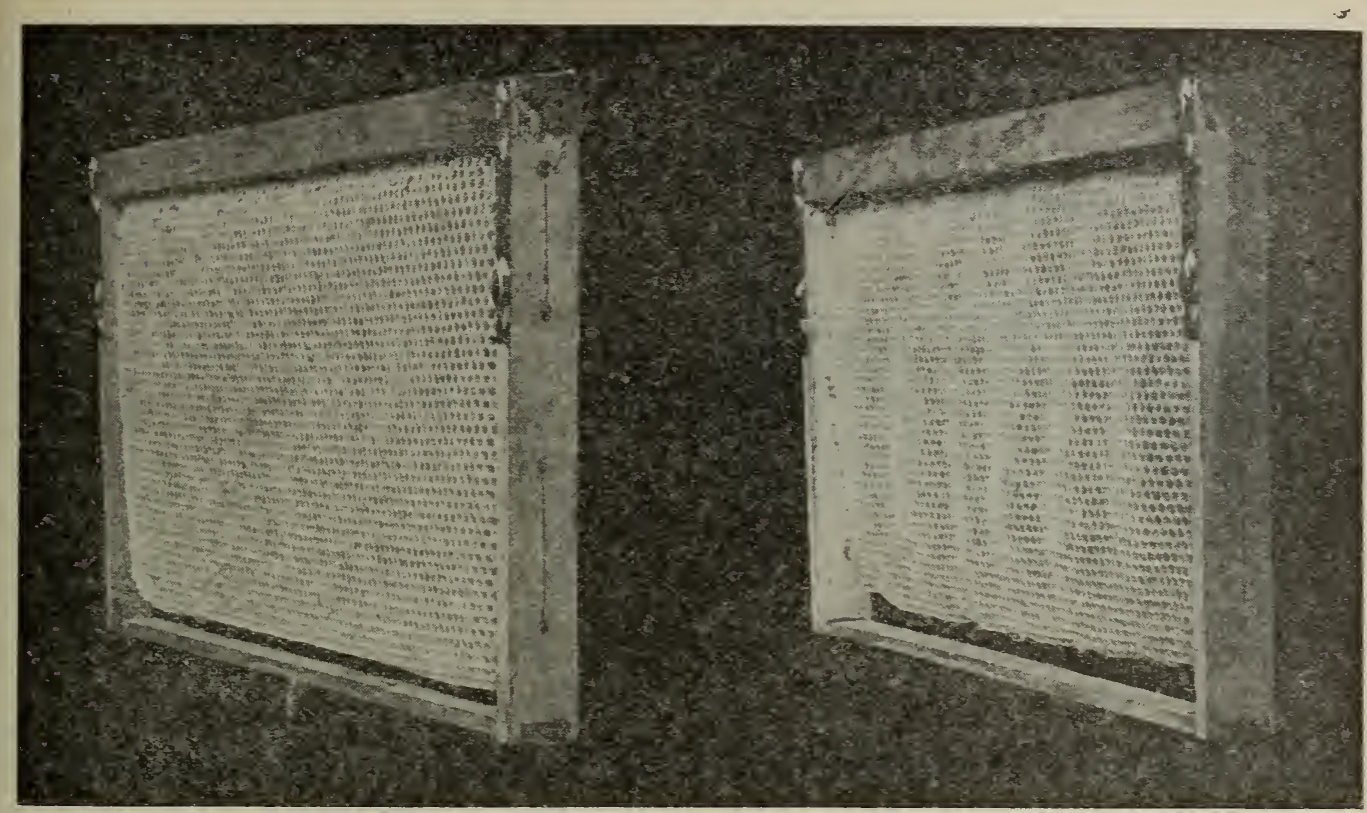

Horizontal and vertical wiring compared. Note that the comb at the left, built from horizontally wired foundation, is perfect except for the slight sagging. The comb at the right, built from foundation reinforced with seven vertical wires and two horizontal wires, is very irregular.

not think of dispensing with it; and, what is of coissiderable importance, during the process of drawing out the foundation the wires tend to reduce materially the stretching of the wax; and such stretching, unless restrained by stays of some sort, results in

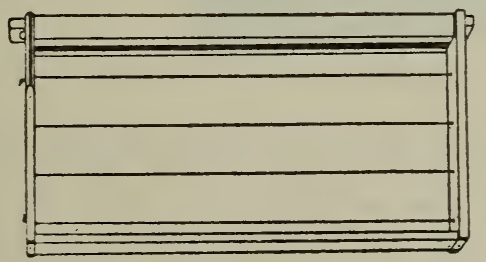

Brood-frame horizontally wired.

elongated cells in which the queen will lay drone eggs or she will not lay at all. This one item alone pays for the expense of wiring. The usual method is to pierce the endbars about two inches apart, threading the wires thru these holes back and forth as shown in the illustrations on the previous page. The sheet of wax is laid on and wires imbedded as shown on the following pages.

While this is the usual method, some prefer the vertical wiring, arguing that the horizontal strands are liable to sag to some extent, allowing a slight stretching of the wax. If the top-bars are thin the wires are threaded thru the top and bottom bars, when the process of fastening the foundation is the same as before described.

It is true that the vertical wiring permits of a thinner and therefore cheaper grade of foundation; for when the horizontal strands are used, nothing lighter than that known as light brood should be used, running from 9 to 10 sheets, Langstroth size, to the pound.

But there are two difficulties in wiring frames perpendicularly. One is the thickness of the top-bars and the other is the

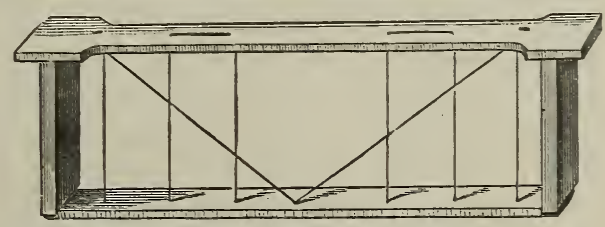

tendency of the foundation to expand between the vertical wires. The only practical way to use them in thick-top frames (see FraMres) is to use staples driven on a medial line on the under side of the top-bar and the top side of the bottom-bar. But as these interfere with the double-wedge-andgroove plan described further on, which has come to be so popular among beekeepers, rertical wiring of thick-top frames has not come into general use. The other objection is the tendency of the foundation to expand between the lines of support. This will be seen by referring to the illustration at the 
top of the previous page. The frame at the left is wired with four horizontal wires, while the one at the right has five vertical wires and two horizontal ones. Notice how the foundation is bulged out between the vertical wires. This, of course, would make the combs somewhat wavy, and therefore, to a certain extent, imperfect. While foundation expands in drawing out the comb between horizontal wires, the wires themselves sag just enough to take up this expansion, and therefore it does not show. See illustration at the left. At the present time, it seems more feasible to use a heavier grade of foundation, using horizontal wires, than to attempt to use vertical wires, especially as it is so difficult to fasten them to the top-bar and bottom-bar when the top-bars are thick. The reason for such thick tops is explained under Frames. froth up because of the moisture frying out of them. When frothing ceases, and the splints are saturated with wax, they are ready for use. The frame of foundation is laid on the board as before. With a pair of pliers a splint is lifted out of the wax (kept just hot enough over a gasoline-stove), and placed upon the foundation so that the splint shail be perpendicular when the frame is hung in the hive. As fast as a splint is laid in place, an assistant immediately presses it down into the foundation with the wetted edge of a board. About 11/2 inches from each end-bar is placed a splint, and between these two splints three others at equal disstance. When these are built out they make beautiful combs, and the splints do not seem to be at all in the way.

A little experience will enable one to judge, when putting in the splints, how hot to keep the wax. If too hot there will be too light a coating of wax.

It must not be understood that the mere use of these splints will under any and all circumstances result in faultless combs built

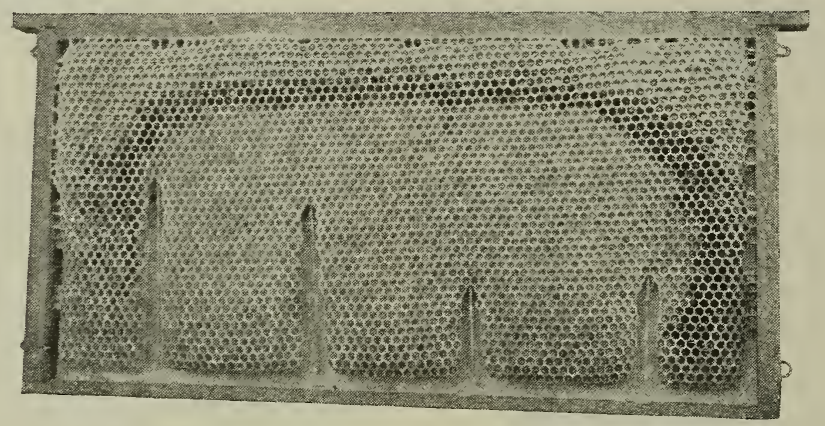

In some cases wooden splints are gnawed by bees.

The elongated cells complained of in horizontal wiring usually take place, not while the foundation is being drawn out, but a year or so after the combs have been in use. It appears that a slight stretch takes place after the combs are filled with honey; and the weight of the honey during hot weather has a tendency to stretch the cells somewhat, making them somewhat elongated near the top.

\section{THE WOOD-SPLINT PLAN.}

Dr. C. C. Miller, of Marengo, Illinois, has overcome the difficulty of fastening vertical wires to the top-bar by using wooden splints instead of wires. These he secures in the manner described in his "Fifty Years among the Bees."

The splints should be about 1-16 inch square and about $1 / 4$ inch shorter than the inside depth of the frame. A bunch of them should be thrown into a square shallow tin pan that contains hot beeswax, They will securely down to the bottom-bar. It seems to be the natural thing for bees to leave a free passage under the comb, no matter whether the thing that comes next below the combs be the floor-board of the hive or the bottom-bar of the frames. So if a frame be given when little storing is going on, the bees will deliberately dig away the foundation at the bottom; and even if it has been built down, but the cells not very fully drawn out, they will do more or less at gnawing a passage. To make a success the frames should be given at a time when work goes on uninterruptedly until full-depth cells reach the bottom-bar.

Under some conditions the bees will gnaw around the wooden stays, as shown by the illustration. This occurs more particularly when bees have not much to do; and when they run across anything which is fibrous they will at such times show a disposition to remove the object.

The suggestion has been made that in no case should the splints be allowed to project 
beyond the edge of the foundation; or, better still, the sheet should reach clear to the bottom-bar.

But we see no reason why the foundation should not expand between the vertical splints the same as it expands between the vertical wires. While $\mathrm{Dr}$. Miller says that he has had no trouble of that sort, it is because he uses foundation heavy enough so that he overcomes this stretching or expanding. As the wooden supports prevent the sagging of the foundation or the comb only after it is drawn out, and do not secure the comb to the frame, it may be a question whether it is not safer and more satisfactory all around to use four horizontal wires, especially if one is going to do very much extracting or intends to ship or move bees to any extent. The splints only prevent the sagging of the foundation while placed over the top of a common lamp, is drawn over the wires, the operator exerting a slight pressure as he does so, causing the

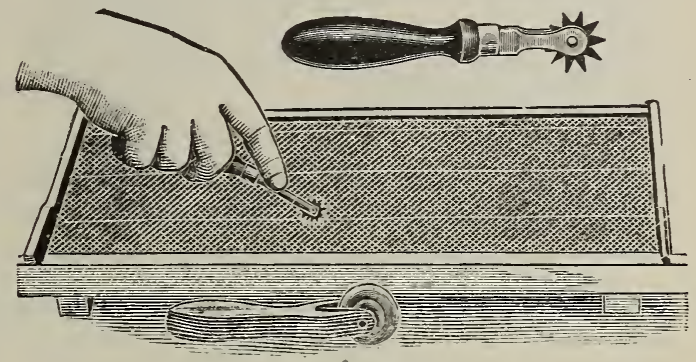

Spur wire-imbedder.

wires to be imbedded in the foundation. The hot teeth as they pass over the wire cause a little bridge of melted wax to form across a wire. The sheet is, therefore, tied at intervals between each of the teeth.

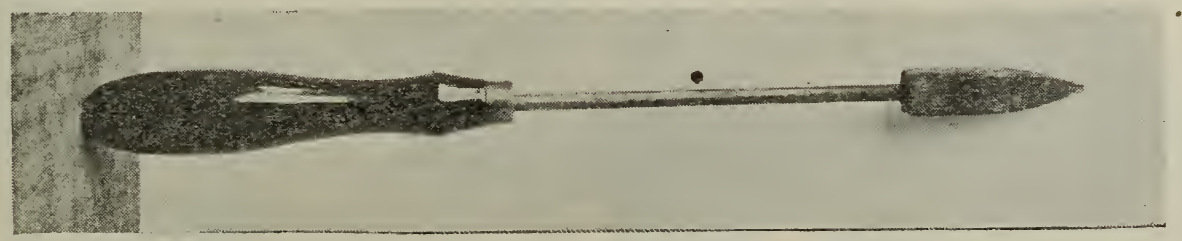

A. C. Miller's soldering-iron with the point grooved so that it may be used for imbedding wires.

being drawn out, but do not hold the comb securely like wires threaded thru the endbars as shown on previous pages.

\section{PAPER AS A BASE FOR FOUNDATION.}

Other devices have been used, such as paper imbedded in the center of the foundation; but this is very objectionable because the bees soon discover that this is a foreign substance, and proceed to tear out the paper bit by bit, utterly ruining the foundation. They do not always do this; but sooner or later they will; when they have nothing else to do they will begin to tear out the paper, thinking, perhaps, that the fiber is a part of the silken gallery of the moth-worm.

\section{IMBEDDING THE WIRE.}

Various methods of imbedding the wire have been used; but one of the simplest is the spur wire-imbedder.

A sheet of foundation is laid on a board of such size that it will just go inside of the frame. A frame with wires stretched across it is laid on top. The wide-toothed spur imbedder, after being heated by being
Another tool that has found favor with quite a number, including $\mathrm{Mr}$. A. C. Niller, of Providence, R. I., and Dr. Burton N. Gates, Apicultural Instructor, Amherst, Mass., is a small soldering-iron with a fine groove just wide enough to ride over a 30 gauge wire, such as is used for wiring the frames. This little tool, after heating over a common lamp, is drawn slowly over the wires, one by one. As it passes over, it heats the wire, causing it to imbed itself in the foundation as it cools. The tool is heated again, and applied to the other wires in like manner.

Those having access to an electric-lighting current will find it convenient to do their imbedding by electricity. The fine wire threaded back and forth in the frame becomes hot when a current of electricity passes thru it and readily melts its way down into the foundation. A little pressure from the hand or wooden roller facilitates the work. If the electricity is shut off at the right instant the wire will be in the center of the foundation, and it will be almost impossible to tell which side it melted thru, so perfectly is the work done. 


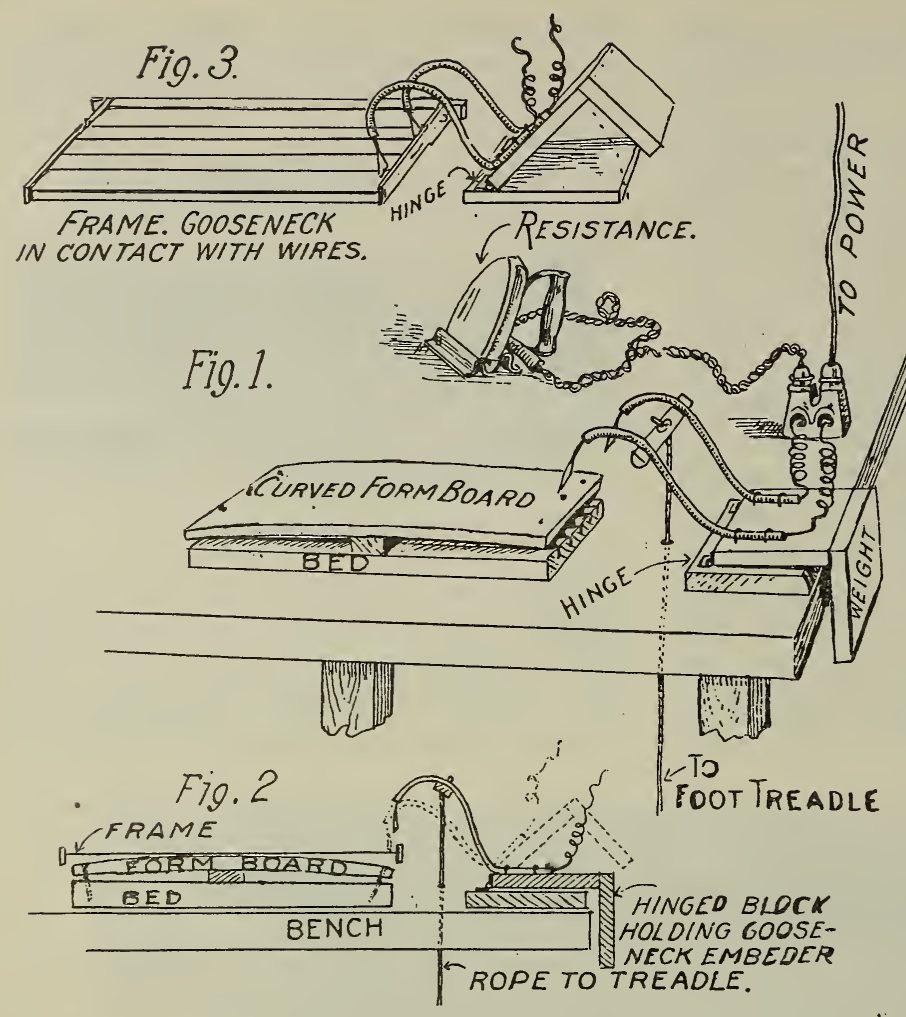

Most of the supply-factories furnish these kinds of top-bars now because beekeepers -generally prefer them. There is a double groove, one of which is in the center of the top-bar. In this groove is inserted the sheet of foundation, as at D. The wedge-shaped strip of wood B is then driven into the other groove as far as it will go, crowding the central partition firmly against the foundation. It is very important that it be driven below the surface of the wood, as otherwise it may work out, allowing the foundation to fall out. When the work is properly done it is thus held firmly in place without any special tools or fussing with melted wax.

It is not possible to use the whole current as the wire would get too hot-redhot, in fact. The current must be reduced by being run first thru coils of iron wire called resistance. Select some iron wire, about No. 14 or 16, and wind it in tight regular turns (one layer only) on a broomstock. Withdraw the stick and you will have a long coiled spring, perhaps three feet long. Run the current thru this coil before it passes thru the fine wire of the frame. If the latter gets hot too quick, or gets too hot, use more of the coiled wire. If it does not get hot enough use less. Mr. E. L. Sechrist finds that an electrical flatiron furnishes just about the right amount of resistance, and he uses it, therefore, instead of the coiled wire. He simply runs the current thru the flatiron before it passes into the fine wire of the frame.

FASTENING FOUNDATION TO THE TOP-BARS OF BROOD-FRAMES.

After the frames have been wired, but before the wires are imbedded, the foundation is fastened to the top-bars, either with the Van Deusen wax-tube or double-grooveand-wedge "plan shown next.

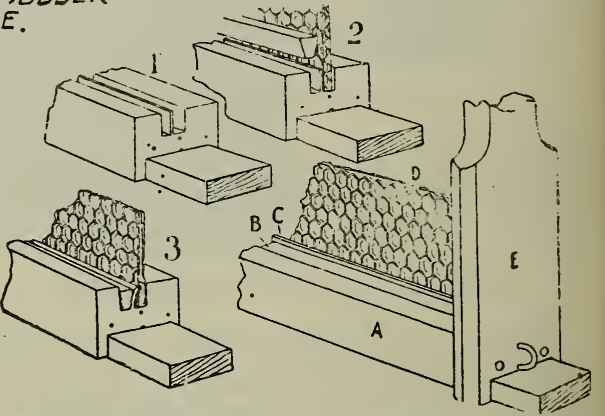

Wedge-top-bar method of fastening foundation.

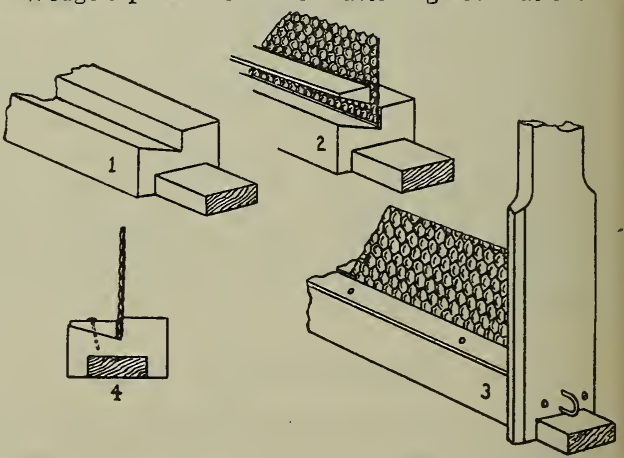

Corner-cut top-bar method of fastening foundation.

Another top-bar known as the corner-cut top-bar is used considerably, especially in the West. The loose triangular strip, when toe-nailed as shown in the illustration just above, grips the foundation firmly. 
There are few who prefer the meltedwax plan of fastening foundation. Where the under side of the top-bar is plain without grooves or molded edge, this is perhaps

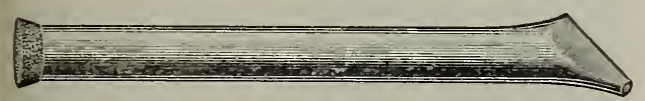

the best. The best tool for depositing a hot stream of wax along the edge of the foundation is undoubtedly the Van Deusen waxtube fastener. It is simply a tube tapering, and at the apex a small hole. On one side is bored another small hole which may be opened or closed with the thumb. When the tube is stood up in a cup of hot wax the air will escape from the upper hole, and the wax flow in at the other small hole at the bottom. The thumb is closed over the upper one; the instrument is drawn out of the wax, and the point is then slowly drawn along the edge of the foundation in contact with the top-bar, leaving a fine stream of hot wax to cement it. While doing this the thumb should be lifted from the upper hole.

\section{FASTENING FOUNDATION IN SECTIONS.}

Foundation starters, or full sheets, are used also in comb-honey sections. There are two different ways for fastening the foundation to the sections, by pressure and by melted wax. The pressure method is little nsed now, because it takes longer and the wax is not so firmly secured to the sections. Moreover, it wastes foundation.

By far the best plan of securing foundation in sections is with melted wax, either by the use of additional wax applied with the Van Deusen wax tube or by the hotplate method which melts a small quantity of the wax on the edge of the foundation. If full sheets of foundation are used instead of starters the former plan is to be recommended, for the foundation may then be fastened on the top and two-thirds the way down each side. It is not a good plan to fasten the full length on each side, as this would have a little more tendency to cause the foundation to buckle. On the other hand, if a full sheet if fastened at the top only the bees by clustering on one side sometimes swing the sheet away from the center of the section.

To do rapid work with the Van Deusen wax tube, make a rack to hold four sections at a time. On a board nail four blocks a little less than half as thick as the section is wide and of a size that will just fit inside the section. The blocks should be so spaced that four sections slipped over them will be close together. Crowd a section-holder around the four sections, place the foundation in position, and you are ready for the wax tube. If one desires to apply the melted wax to the sides of the foundation as well as the top the wax should be started on the side of the section, allowed to run down to the corner, then across the bottom or what is really the top of the section, then two-thirds the way up the other side. Of course, as the tube is moved along the rack should be turned accordingly so that the wax may run downhill, thus facilitating the work. As soon as one section is finished the tool is moved to the next, and so on.

\section{THE HOT-PLATE FASTENER.}

The hot-plate type of fastener, originally devised by Arthur C. Miller, melts a small amount of wax on the edge of the founda-

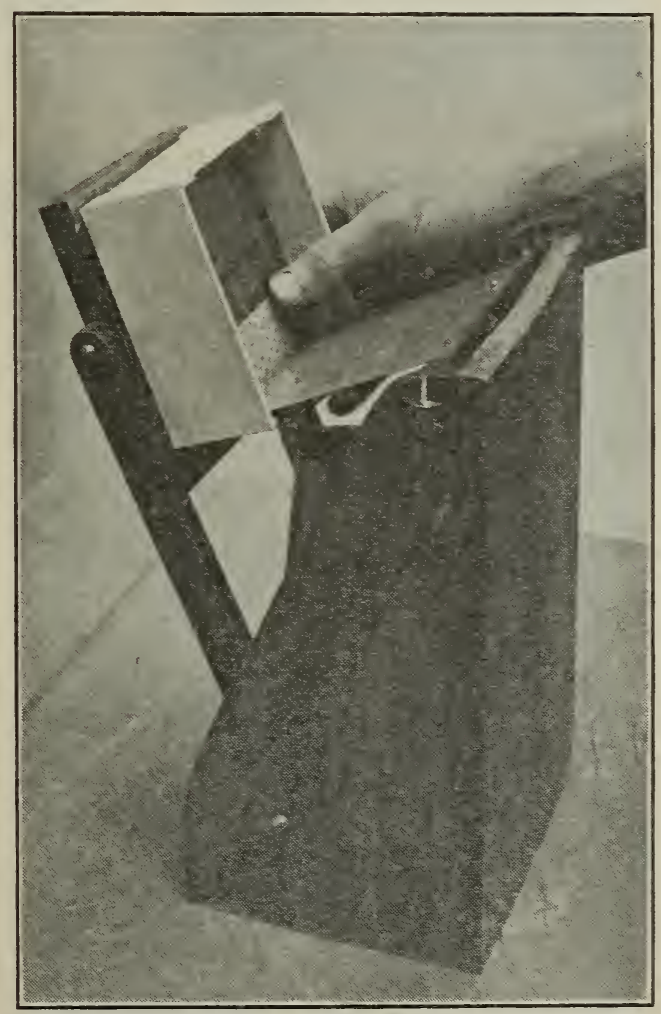

Bjard fastener.

tion-starter so that it adheres instantly to the wood. This is used more than any other method, principally on account of the neatness and the strength of the work. More- 
over, this method of fastening is the most rapid of any plan. There are a number of these fasteners on the market, all of which do good work. Some of them fold the sections as well as fasten the foundation. This is quite an advantage.

In most of these hot-plate fasteners the heat is furnished by a small alcohol or kerosene lamp placed directly under the plate to be heated. This plan is sometimes over them. Put the foundation in place and, while pressing lightly on the upper edge with the fingers of the left hand, slide the hot blade under the edge of the wax as it rests against the wood. All surplus melted wax will be wiped off on to the wood so that the foundation will be most firmly attached. The tool will remain hot long enough to fasten all four starters.

The Root steam foundation-fastener has

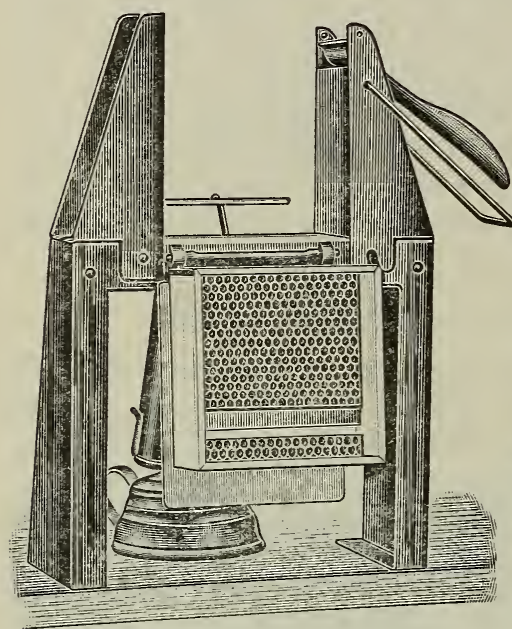

Woodman combined folder and foundation-fastener. This tool is constructed of metal and does fine work.

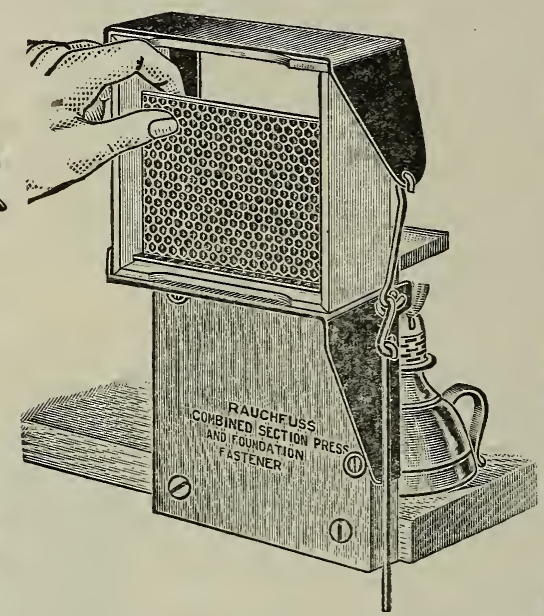

Rauchfuss combined section folder and fastener. One of the simplest and best combined tools on the market.

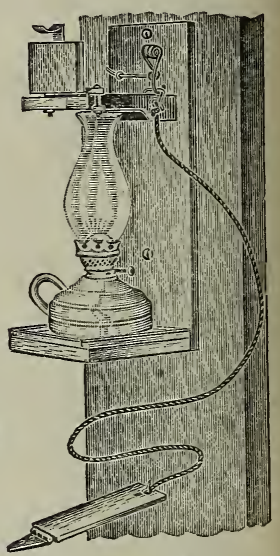

Lewis foundationfastener. A simple and rapid outflt. objectionable, owing to the difficulty of maintaining a constant temperature. In case of the kerosene lamp there is always more or less soot which sometimes gets on to the sections, spoiling their appearance. In the Rauchfuss fastener this difficulty is overcome by the use of an alcohol lamp, which is much cleaner, altho the heat is not quite as casily controlled.
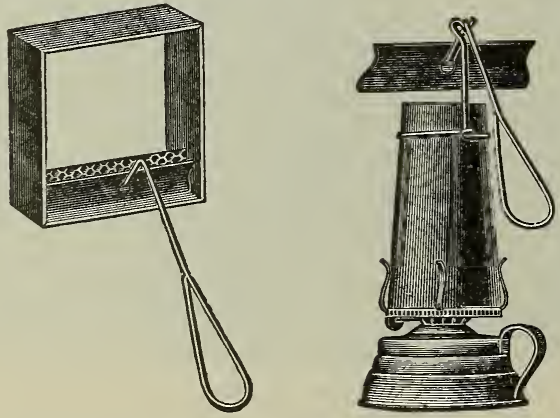

The Root fastener is a small hand tool hung over a lamp to be heated. To use it make a rack to hold four sections as described above and slip the section-holder a hot plate kept at a constant temperature by means of steam. There is no troublesome lamp to work over, no soot, and, of course, absolutely no danger of fire from wax dropping into the lamp. Moreover, the steam is also used for dampening the sections, for this device is a folder as well as a foundation-fastener, a most desirable feature. Sections dampened by steam are not easily broken and there is no danger that the wood may swell so that the section when folded is diamond-shaped.

When the foot-treadle is pushed forward the notched ends of the section are firmly crowded together. The same movement brings the steam-heated plate into position. The starter is dropped into place and held for an instant, until enough wax is melted to hold it firmly. The same backward movement of the foot that releases the section causes the hot plate to move out of the way so that the finished section with its starter is ready to be placed in the super. It is impossible to remove a starter so fastened without actually tearing the sheet. 


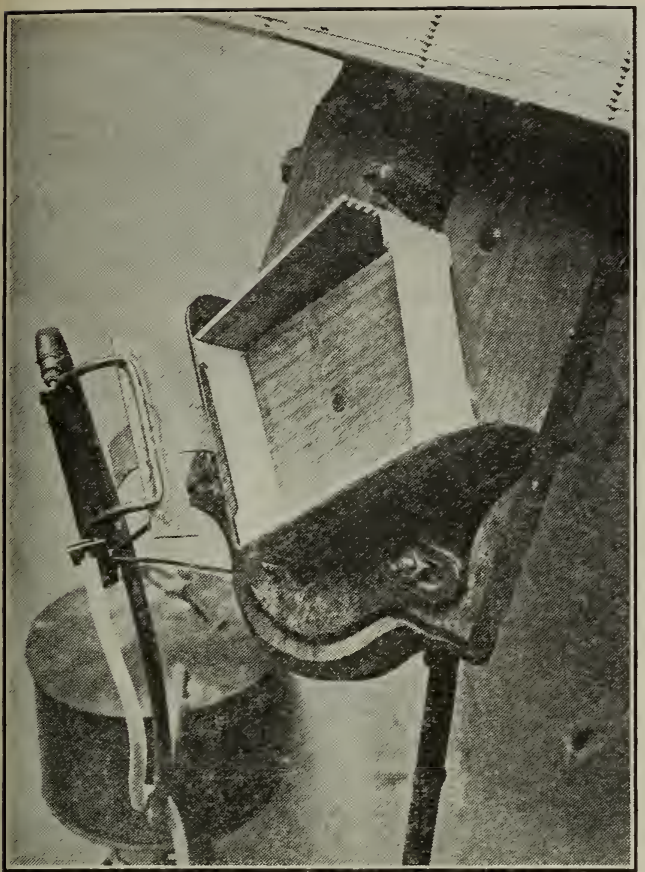

When the foot is in the back position the hot plate is out of the way-nothing to interfere with putting the section in position ready to fold.

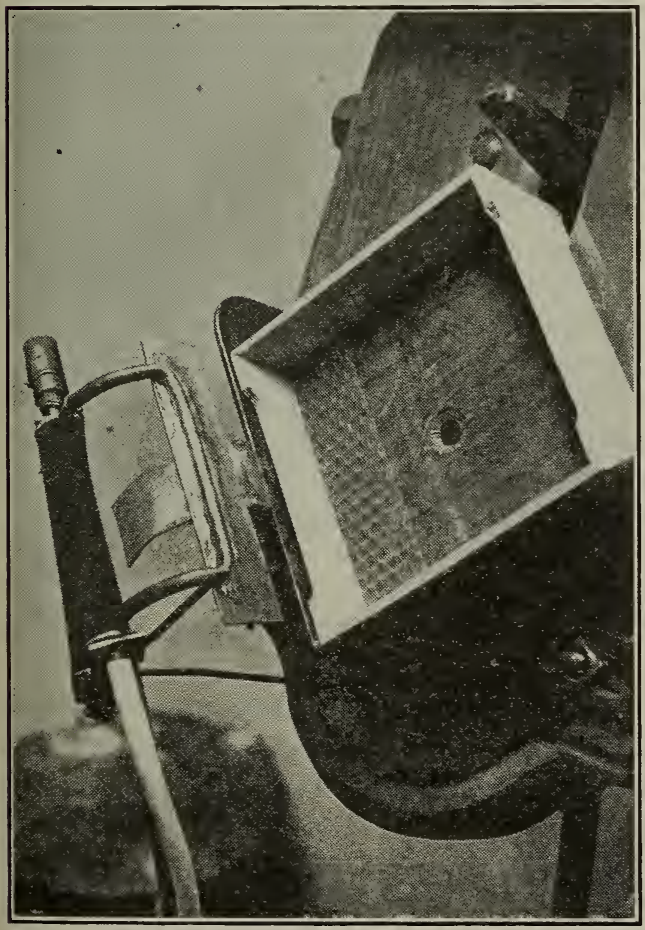

The movement of the foot backward slowly withdraws the hot plate. The wax is all wiped off on to the section and the foundation is firmly "cemented" in place.

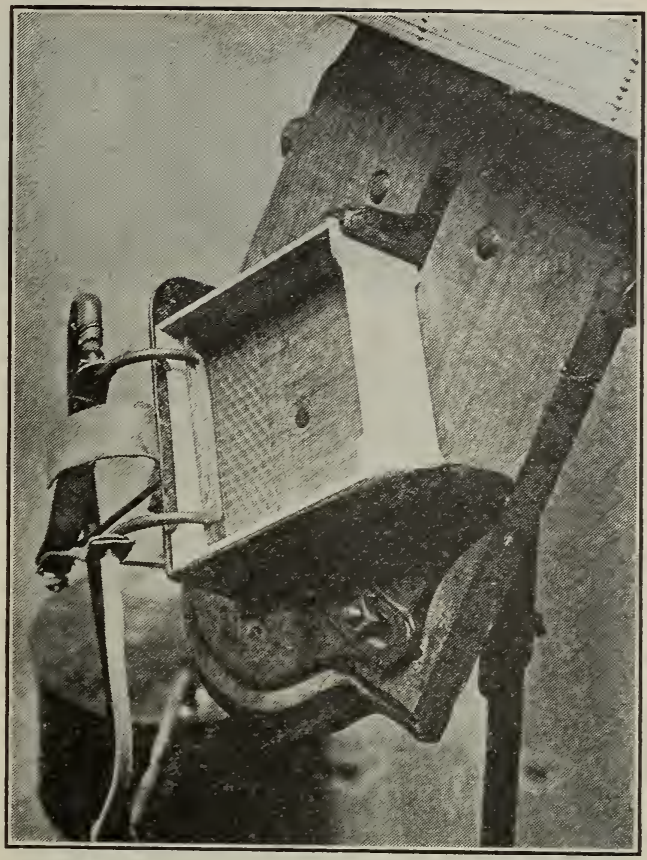

As the foot swings forward, the corners of the section are forced together and at the same time the hot plate slides into position ready for the starter or full sheet of foundation ts be applied.

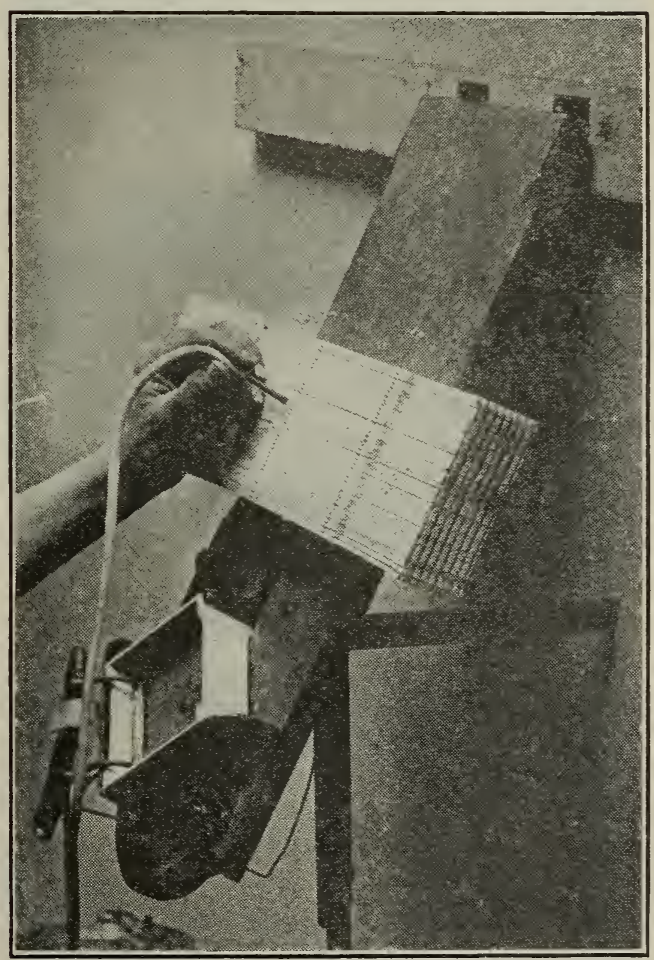

Fifty or seventy-five sections may be thoroly dampened in a few seconds' time by allowing the steam to blow thru the V grooves. Steam-dampened sections almost never break, and the sections remain true and square. 


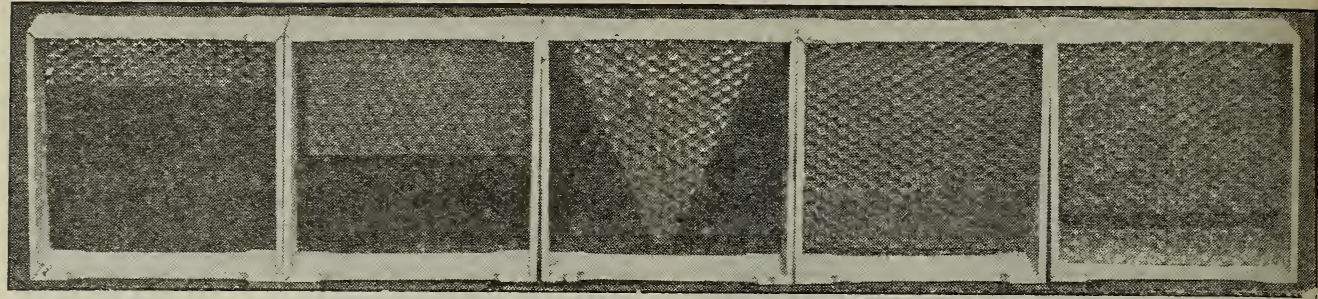

The different methods of cutting foundation for the sections.

STARTERS VS. FULL SHEETS FOR SECTIONS:

In the illustrations under Coмr Honex, showing the supers, only narrow sheets of foundation (or starters) are shown in the sections. The expert comb-honey producer will never be content with a starter. $\mathrm{He}$ will buy his foundation of such size that he can cut it to suit his own individual notions.

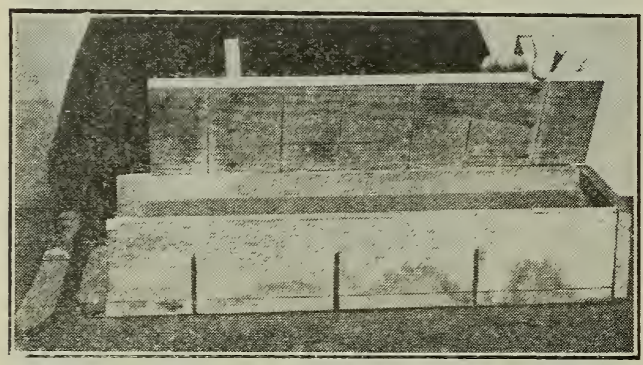

Long sheets of foundation laid in the box ready to cut. (The distance between the saw cuts determines the size of the starters.)

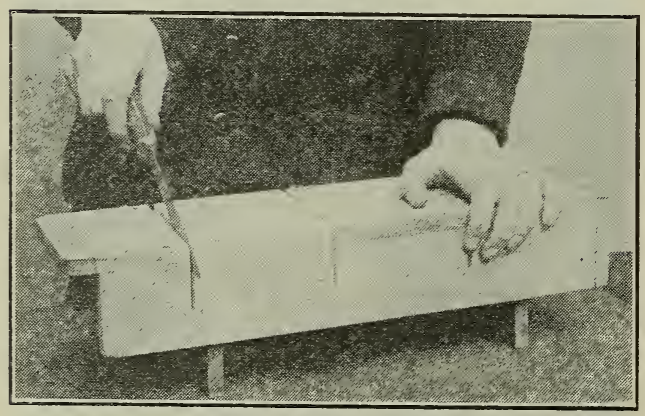

Box turned over for cutting. Use sharp thin knife wet with soap suds, and cut on drawing stroke only.

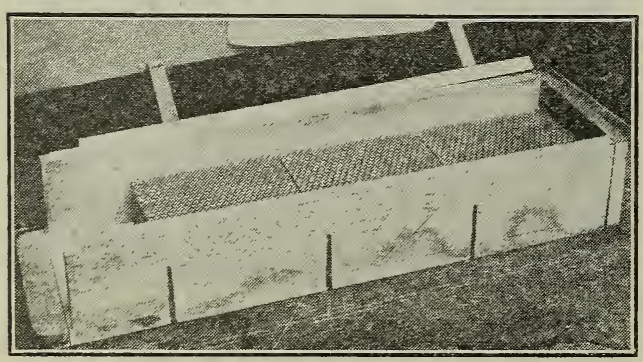

The box reversed to original position with foundation cut to size ready to take out.
Some of our comb-honey producers cut it in sheets one-fourth of an inch narrower and half an inch shorter than the inside of the section. It is then fastened to the top as shown previously, with any one of the several styles of foundation-fasteners. Others cut the sheets in the shape of a letter $\mathrm{V}$; still others use half a sheet.

But the great majority of producers prefer to use two pieces-a large one secured to the top and a strip about $5 / 8$ inch wide fastened to the bottom. The larger sheet is so cut as to reach within $1 / 8$ or $1 / 4$ inch of the bottom starter when in place to allow for stretching.

During the subsequent process of drawing out, the bees will make one complete comb, the same being fastened to the top and bottom. Where only a starter or even one large sheet is put into a section, the fastening will be at the top and part way down on each side; but when the bottom starter is used in connection with a large sheet of foundation, there surely will be a fastening at the bottom as well as at the outer edges. The result is a comb fastened to all four sides, one that is neater in its general filling, and, in consequence, will command a higher price; and last, but not least, a section that will stand shipping. -A nice super of sections with combs not fastened at the bottom is liable to arrive at destination in bad condition-many of the combs broken out; and it is, therefore, always advisable to use a bottom starter.

A few beekeepers advise cutting the foundation so it will just neatly fill the section on all four sides. A section is then slipped over a block a little less than half its thickness so that when one of these just-rightsize sheets of foundation is laid on the block, the foundation will be perfectly centered in the section. With the Van Deusen wax-tube shown on a previous page the sheet is then secured to all four sides by the stream of hot wax. 
It has been found that very fine comb honey can be secured by this plan, the resulting sections having but few pop-holes. However, there are two disadvantages. For instance, some find it difficult to cut the foundation just the right size and still do the work rapidly. It can be seen at once

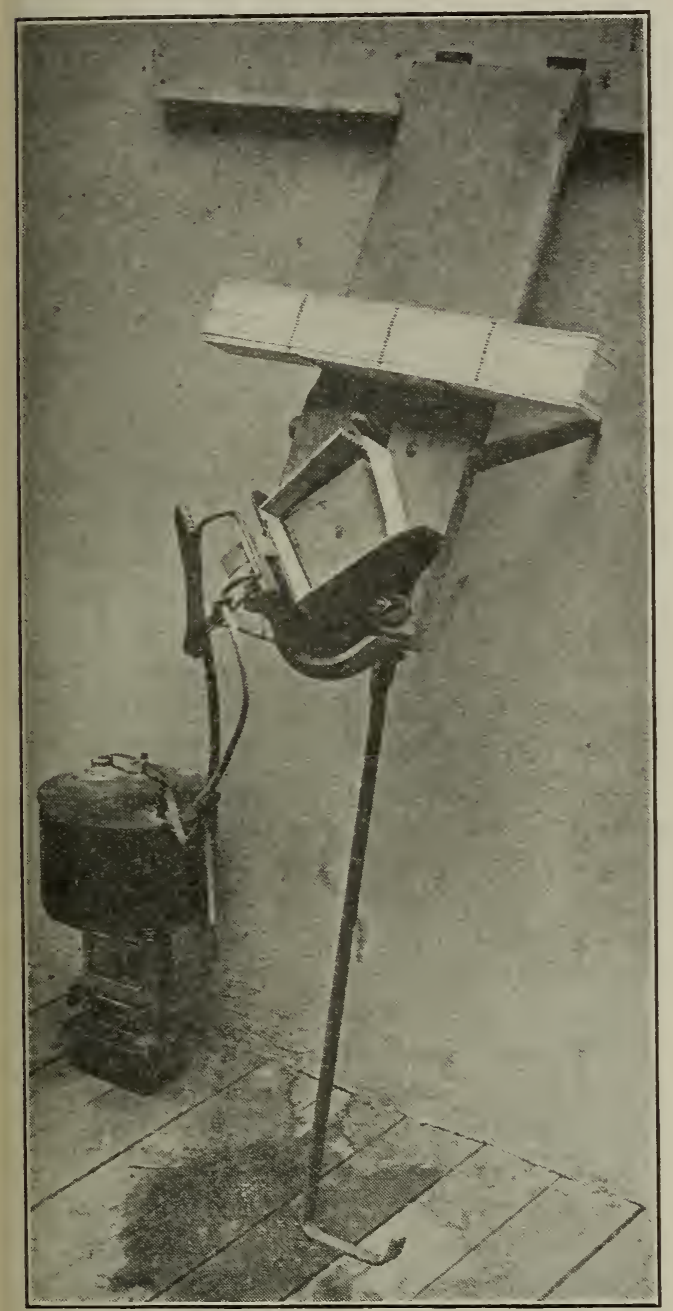

The Root section-folder and steam foundationfastener. Steam is generated in the small boiler, rises thru the tube and keeps the plate at a constant and uniform temperature.

that there must be but little variation in the size of the sheets. The best arrangement for cutting the foundation that we know of is the miter-box. This device can be quickly made by almost any one, the construction being plain from the illustrations. The box should be placed on a table with the saw-cuts down as in Fig 1 , and from five to twenty sheets of foundation laid in, care to be taken to see that the ends are even.
Then the cleated board should be put on top of the sheets of foundation, and the box turned over so that it rests on the cleats, as shown in Fig. 2. For cutting, a keen-edged butcher-knife should be used. It need not be hot, if kept well lubricated with soapy water. The knife should be held at an angle as shown, and moved rapidly but lightly back and forth, cutting only on the drawing stroke. If the saw-cuts are carefully spaced and the whole box put together in a square workmanlike manner, the sheets can be quickly and accurately cut.

COMB HONEY,-While all honey in the comb is what may be called "comb honey," yet the term as ordinarily used refers to small squares of comb, built into frames of wood technically called section honey-boxes, or "sections" for short; therefore all references to comb honey, whether in the market quotations or in the ordinary literature relating to bees is understood to apply to the article built in sections.

More recently, little chunks of sealed comb honey about an inch and a half square are being put up in paraffine paper, the whole slipped into a neat little carton. This is what is called the "individual comb-honey service," and may be found in some of our best restaurants, hotels, and dining-cars.

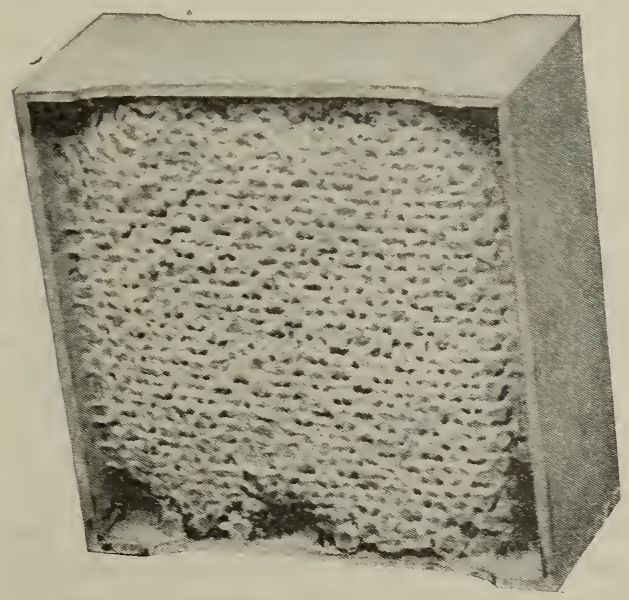

In the southern states there is another article called chunk or "bulk comb honey." The combs are built usually in shallow extracting-frames, and cut out in rarioussized chunks of a size that will fit tin buckets or glass jars. The spaces between the combs and around them are filled with a good quality of extracted honey. They are 
sealed or covered with the ordinary cover of the tin bucket. Bulk comb honey is produced very largely, particularly in the South, and where bulk honey is sold, very little comb honey in sections is produced Bulk comb honey has the advantage that it does not require as much skill to produce it as the ordinary comb honey in sections; neither is it necessary that every piece of comb be as perfect as to capping, filling, or shape. In localities where there is any suspicion of manufactured comb honey, bulk comb honey is readily sold. Generally. speaking, its sale is confined to the southern states-Texas and the Southwest, while in the North, and practically all the rest of the United States, comb honey is put up in sections.

The time may come, however, when consumers everywhere will learn to appreciate bulk or chunk comb honey, especially after they learn that it costs less to produce and at the same time retains all the fine eating qualities of the article in sections. It may also come to pass that cut comb honey wrapped in paraffine paper, and further protected with a neat carton, will take the place of section comb honey. There is no doubt that such honey will ship better than comb honey built solid in sections.

The greatest objection to the use of bulk comb honey in the northern states is the danger of the liquid portion granulating. When this takes place the whole will have to be melted up in a wax-extractor, even tho the comb honey is not candied.

A few years ago, when the extractor was first invented, it was supposed that nothing but honey out of the comb would be sold for the reason that it could be produced more cheaply. But our best connoisseurs now know that even our very best extracted honey seldom has the fine delicate aroma of honey that is held in the comb, just as nature gives it to us. The latter holds the flavor and the delicate aroma from the individual flowers from which it was gathered much better than after it is removed from the comb. The flavors of honey, it is said, are made up of ethel alcohols that are very volatile. It follows that, when the honey has been removed from its original container, on exposure to air, it loses some of its flavor, especially if it be heated to prevent granulation. See Extracted Honer, Bottuing Honer, and Granulated Honey. If ever a majority of consumers prefer comb honey it will be because to them it has more flavor, and because, probably, the crushing of the delicate cells in the mouth gives the eater a certain degree of satisfaction because he has something to "chew." Extracted honey on the other hand is swallowed, while comb honey is masticated, or "chewed," as food should be. Of course the little pellets of wax, after the honey has been eaten, are generally expelled. To some this very accumulation of wax in the mouth is an objection, and we therefore find there are many who prefer extracted honey, because they prefer to have something they can chew on bread and butter and biscuit, without having wax mixed with the food.

Unfortunately of late years, many honeydealers have refused to handle comb honey because of the amount of breakage and leakage and the tendency to granulate after cold weather has set in. The result is that the demand for extracted has increased while the call for comb honey has become less and less. This is wrong. So long as it is admitted that comb honey has a little finer flavor than the same honey out of the comb, beekeepers should cater to the demands of all classes of consumers. When we remember that comb honey, as a rule, retails at twice the price of extracted, it goes to show that there are thousands and thousands of consumers who prefer honey in that form, even if they have to pay double price. It therefore behooves us to see that our shipping-cases and comb-honey carriers are properly constructed in the first place. (See SHIPPING-CASES FOR COMB Honey; also MARKeting.)

In the early ' 80 's the statement was made that comb honey could be manufactured" combs made out of paraffine, filled with glucose, and capped over with appropriate machinery." This canard went like wildfire over the country; and even to this day there are some who believe that honey in sections is manufactured, because it is unlike the honey they saw on the old farm. Except in a very small way it is impossible to make honeycomb as perfect and delicate as the bees do. On a commercial basis it is an utter impossibility. Dies could be made that would press wax in a semi-melted condition in the shape of a honeycomb. So far, so good; but it is utterly impossible to make any dies that will free themselves 
from the comb after it is pressed into shape without tearing the comb to pieces. Talk with any mechanic or die-maker, and he will tell you the idea is utterly absurd. Even if we could construct the combs it would be impossible to fill them with glucose, and equally impossible to spread a film of wax over the filled cells that would come anywhere near imitating the appearance of comb produced by the bees. Any consumer who has a suspicion that combs in sections are manufactured has only to look over a dozen or more sections at any grocery. $\mathrm{He}$ will find no two of them alike. If combs were built from dies, they would appear all alike, like the common rough-faced cement blocks which are made in one mold. But a comparison of any two boxes of comb honey will show that bees make each section totally different from all others. The attachments at the sides of the sections vary as well as the surfaces of the cappings.

It is hardly necessary to tell the reader of this work that combs are not manufactured; but sometimes he will meet prospective customers who will tell him in the most brazen way that the product he is trying to sell them is "manufactured." Therefore he should be reinforced with arguments and reasons to show them their mistake. Nay, he can go even further, and say that the authors of this work will pay ten thousand dollars if they will furnish any proof showing that such a thing as manufactured comb honey is or ever was on the market that even approximates the natural product.

COMB HONEY, APPLIANCES FOR.Years ago, all comb honey was produced in glass boxes. These were about five inches square, fifteen or sixteen inches long, glassed on both ends. They were not altogether an attractive package, and were never put upon the market without being more or less soiled with burr-combs and propolis. As they held from ten to fifteen pounds of honey each, they contained a larger quantity than most families cared to purchase at once. To obviate these and other difficulties, what is popularly known as the "section honey-box" was invented, holding little less than a pound.

It was what was wanted-a small package for comb honey. Thus was accomplished, not only the introduction of a smaller package for comb honey, but one attractive and readily marketable. The retailer is at once able to supply his customer with a small quantity of comb honey without daubing, or fussing with plates. The housewife, in turn, has only to lay the package upon a plate, pass a common table knife around

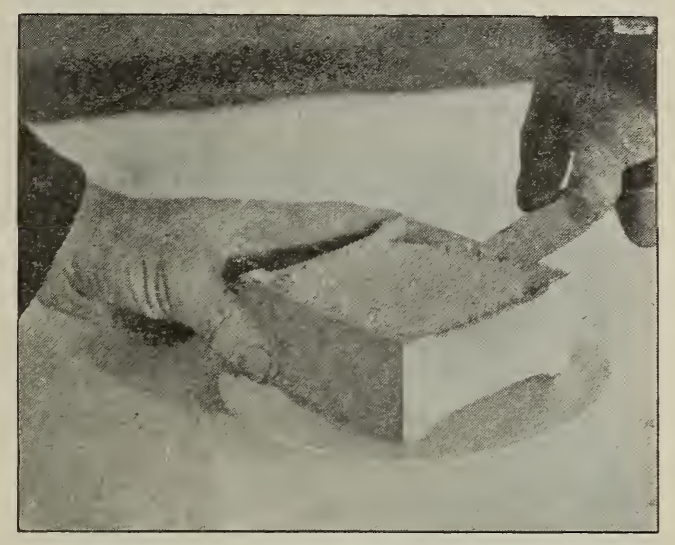

the comb, to separate the honey from the section proper, and the honey is ready for the table, without drip.

DEVICES FOR HOLDING SECTIONS WHILE BEING FILLED ON THE HIVE.

Sections cannot very well be placed on the hive without some sort of arrangement to hold them. There are a score of different sorts of wide frames, racks, trays, boxes,

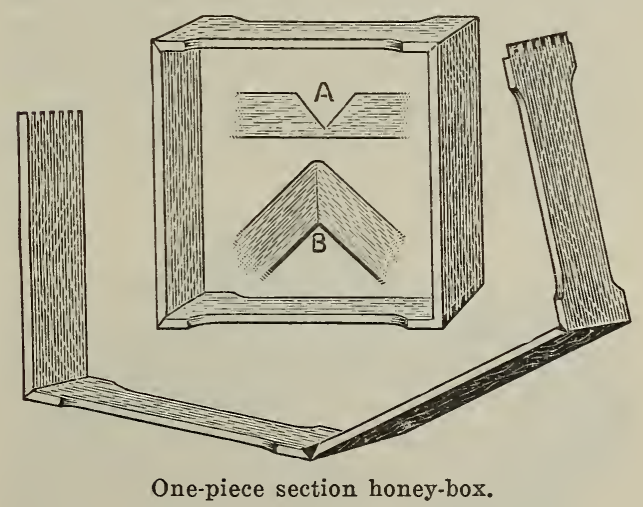

clamps, all of which possess some special features. It would be impracticable to show all of them; but for the sake of illustrating some principles it may be well to mention some of those that were used most largely.

What was known as the double-tier wide frame was perhaps the first device for holding sections in the hive. This consisted of a frame of the same inside depth and length as the ordinary brood-frame, but of the 
same width as the section, eight sections to the frame. This was used very largely at one time; but in the course of time it was discovered that it had several objectionable features. First, a whole hiveful of them gave the bees too much capacity to start on; and, as a consequence, this discouraged them from beginning work. Second, they did not permit tiering up to advantage.

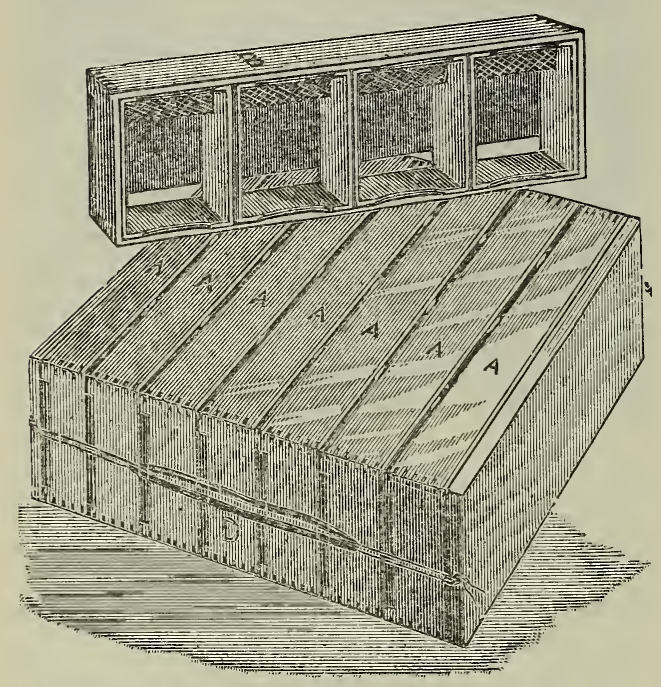

Doolittle's single-tier wide frames.

The Doolittle surplus arrangement consisted of a series of single-tier wide frames having no projections to the top-bars, altho shallow wide frames have been made with such projections. Both the double and single tier wide frames had the merit of protecting the surfaces of the sections from travel-stain and bee-glue.

\section{SEPARATORS.}

Before we proceed it may be well to say that all the devices for holding sections on the hives, with one exception, require what is called a separator or fence between the rows of sections. The separator may consist of a sheet of tin a little narrower than the depth of the section, or a thin piece of wood veneering.

Both of the devices already described made use of what is known as the old tin separator; but on account of the expense and the coldness to the bees, tin separators have almost entirely disappeared, and in their place have come the wood separators or fences. These latter will be described a little later on, in connection with the supers that take plain sections.

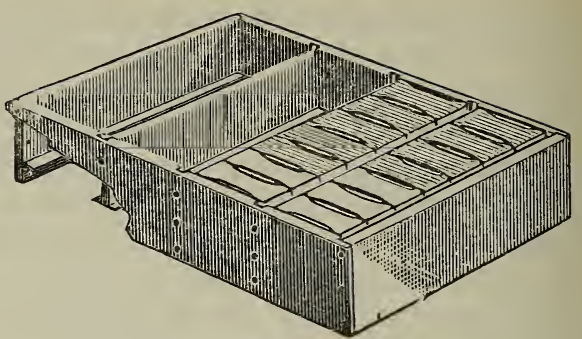

Moore (or Heddon) crate.

This uses neither separators nor fences. We do not include it here because we consider it a practical device, for indeed it has practically gone out of use altogether, for the simple reason that commission men and honey-merchants generally will not buy honey unless it has been produced with separators or fences. Or, if they take it at all, they will take it at greatly reduced prices.

\section{T SUPER.}

This, at one time, was one of the most popular forms of section-crates, and a few

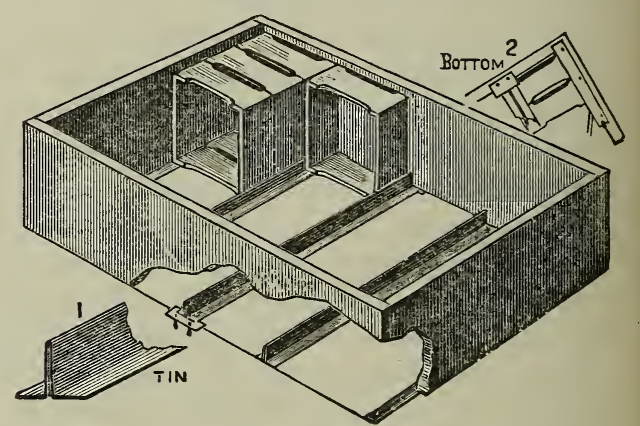

prefer it to anything else. It is so named for the $T$ tins that support the sections. The tins are folded in the form of a letter

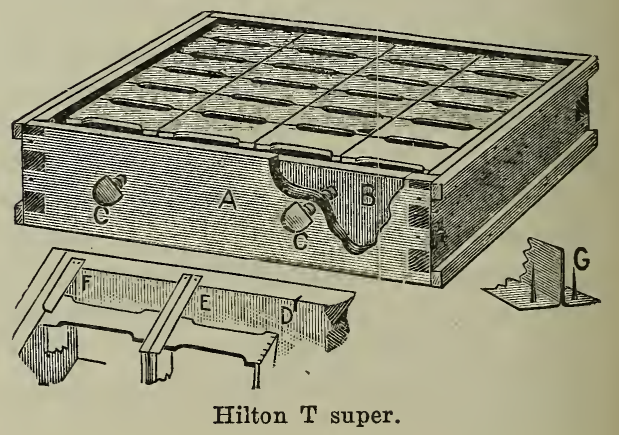

$\mathrm{T}$ inverted, such construction making a very stiff and rigid support.

Some prefer, like Dr. Miller, to have the $\mathrm{T}$ tins rest loosely on a little piece of strap 
iron, or bent staple, both for conrenience in filling the supers, and in emptying the same after the sections are filled. But there are others, like the late George E. Hilton, of Fremont, Mich., who objected to loose pieces, and preferred the super with stationary tins, the tins being nailed to the bottom inside edges of the super.

But the $\mathrm{T}$ super has its objections. If the sections are inclined to be a little out of square, or diamond-shaped, when folded, they will not be squared up in the $\mathrm{T}$ super unless an extra set of $\mathrm{T}$ tins or strips of wood are used to fill up the gaps between the rows on top. And, again, it is not practicable to alternate the several rows of sections. Sometimes, in a poor honey-flow, it is desirable to move the center row of sections to the outside, and the outside to the center.

It will be noticed also that he preferred having compression-a feature which he accomplished by means of wooden thumbscrews and a follower.

\section{SUPER SPRINGS.}

In the illustration of the Hilton super, it will be noted that thumbscrews are used to crowd a follower up against the sections. In the other form of $\mathrm{T}$ super a super spring between the side of the super and the follower performs the same office. Indeed, this spring is used nowadays in nearly all modern section-supers.

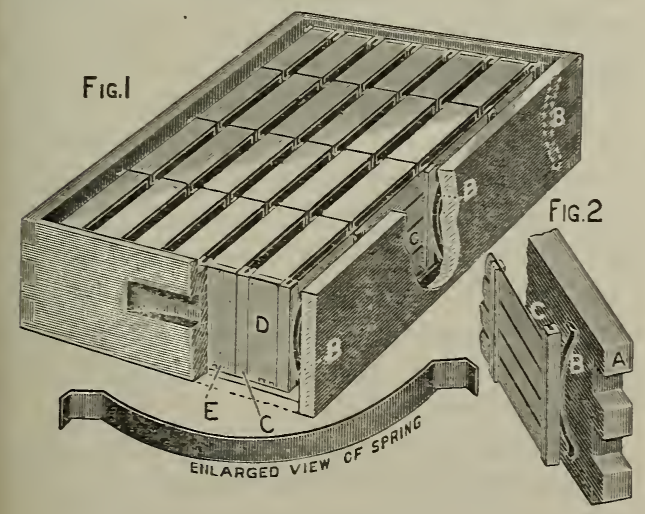

Super-springs.

There is no denying the fact that in any form of surplus arrangement the sections and separators should be squeezed together to reduce accumulations of propolis. Formerly, thumbscrews were used to some extent for this purpose in place of some sort of wooden wedge or tightening-strip. An objection to anything of this kind is that if the sections in a super become swelled by dampness the rigid screw or strip becomes stuck and this sticking makes it hard to remore the sections. Sections, however, do not often swell in a super. But they do shrink quite often-indeed, quite generally. The joints of the sections have been moistened to prerent breakage when the sections are folded, and then when the super is put on the hive there is a slight shrinkage. That shrinkage makes more trouble than swelling, for the contents of the super become so loose that the wooden wedges fall down, leaving the sections very loose in the super. Of course the bees improre the opportunity to crowd a lot of propolis into all the cracks.

To remedy all this trouble the steel super spring has come as a boon. Its pressure is constant. It adapts itself to any swelling that may occur, and equally adapts itself to any shrinking, so as to press the parts together at all times enough to prevent the bees from crowding in propolis.

In the illustration it will be seen at B, B, $B$, that a spring is crowded vertically between the side of the super and the middle post of the fence, and also between the side of the super and the two end posts of the fence. When a follower is used, two springs (one at each end) are crowded vertically or diagonally between the side of the super and the follower. Some use only a single spring at the middle of the follower.

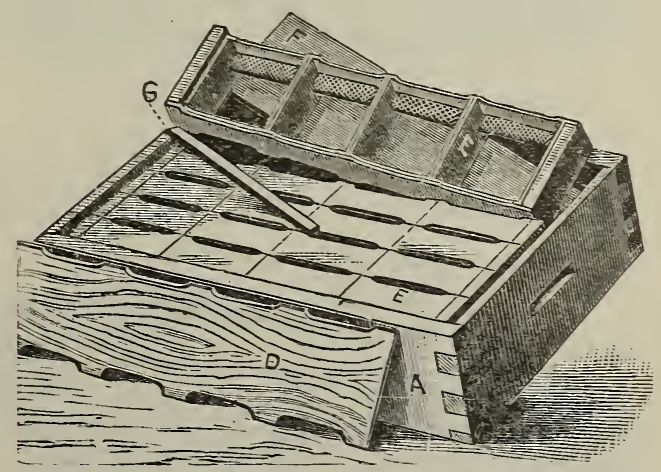

DOVETAILED SUPER WITH SECTION-HOLDERS FOR BEEWAY SECTIONS.

This is the form of super that has been, perhaps, used more largely than any other. It is a sort of compromise between the old- 
style wide frames and the $\mathrm{T}$ super. It consists of a series of section-holders that are open at the top. Each holder is supported at the end by a strip of tin nailed on the inner edge of the ends of the super.

Four sections in each section-holder are held snugly and squarely in position with no spaces between the rows of sections as in the case of the $T$ super. When beeway sections are used the bottom-bars of the sections are scored out to correspond with the beeways. Between the rows of sections is dropped a wooden separator, as shown at $\mathrm{D}$ on the previous page.

\section{THE FENCE AND PLAIN-SECTION SYSTEM.}

The sections and section-supers shown heretofore have been mostly of the beeway type. Brood-frames, when in the hive must be placed a bee-space apart; so also must the sections. Almost the first honey-boxes that were introduced had the bee-space cut out of the top and bottom of the sections

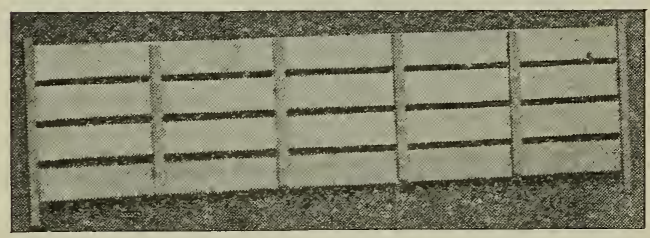

themselves, so that they could be placed directly in contact with each other or the separator. This kind of section continued almost up to 1897, when there was introduced a section without beeways, having plain straight edges all around. This had

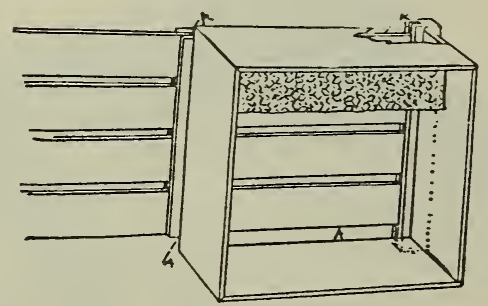

been used for some ten or twelve years previously by various beekeepers who found it to be in every way satisfactory. But plain sections (even width all around, without beeways) necessitate some scheme for holding them a bee-space apart while on the hive. Accordingly, a separator or fence was devised, having transverse cleats at regular intervals on both sides, binding the series of slats together-cleats so spaced as to come opposite the uprights in the sections. It will be seen at once that the fence system provides for a narrower section, and yet this same section holds as much honey as one $3 / 8$ inch wider, because the extra width is taken up by the thickness of the cleats on the fences, as shown at A A A in previous cut or what would be in the old section two beeways of 3-16 inch each. In the cuts shown below there are specimens of beeway sections and no-beeway, the last
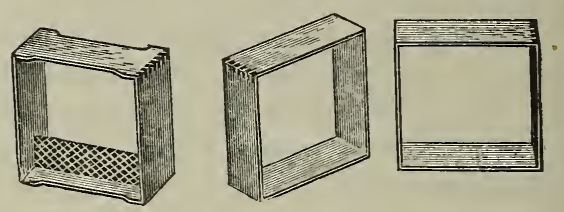

Beeway and no-beeway sections.

being generally termed plain sections. It will be seen that they save quite a little wood, and consequently take somewhat less room in shipping-cases. In other words, the twelve and twenty-four pound shippingcases can be made somewhat smaller, because it is not necessary to have each comb bee-spaced apart in the marketing-cases, the same as while on the hive. Moreover, the plain straight edges of plain sections offer special advantages in the matter of scraping. There are no insets, often roughly cut (as in beeway sections), to work into and around with a scraping-knife. A single sweep of the knife on each of the four edges will remove the propolis, or, better still, if the blade of the knife is long enough, one can scrape two edges at a time. Weight for weight, and of the same filling, a comb in a plain section looks prettier than one having beeways. The illustration on the next page shows beeway sections in one shipping-cases, and plain sections in the other. Compare also other cuts under head of Marketing.

But there is one more point to be taken into consideration. The fences are made up of a series of slats having a scant beespace between each slat; and as the crosscleats, or posts, are $1 / 2$ inch shorter than the length of the section, the beeway is very much wider. Instead of being a narrow opening thru the top as in the old section, the opening is clear across the top, and part way down and up each of the sides. This 
gives the bees much freer communication, and, in consequence, has a tendency to reduce the size of the corner holes in each on the fences. But one would lose many of the advantages of plain sections if he were to adopt the open-corner boxes. They

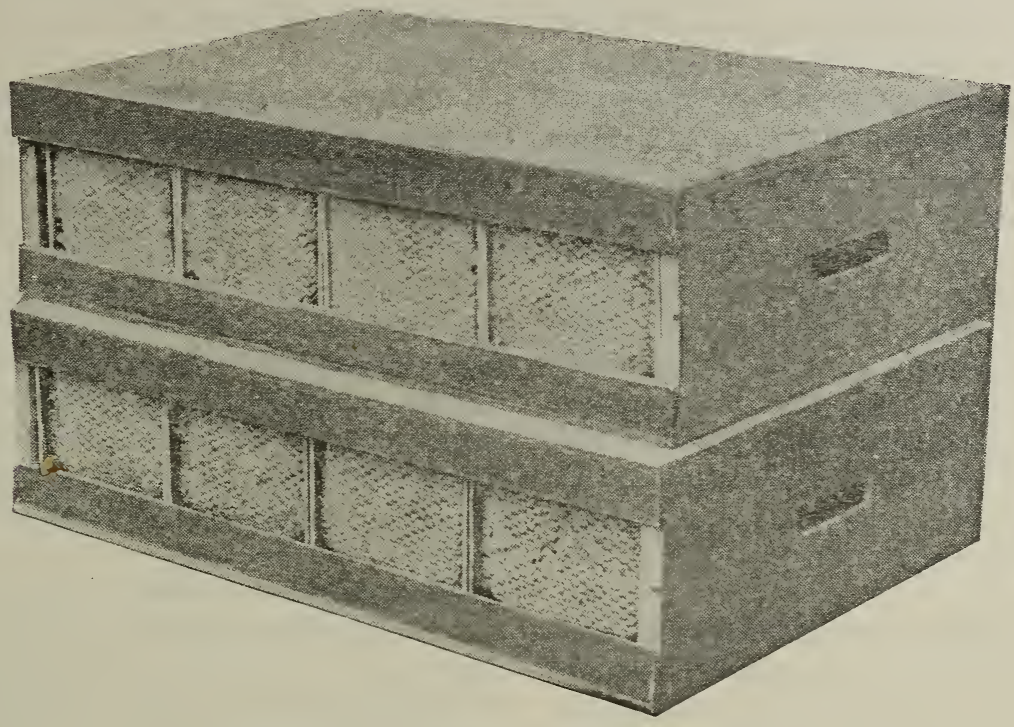

Shipping-cases with beeway and plain sections.

section. Then there is that factor, namely, horizontal openings between each of the slats. This allows free communication from one section to another, not only crosswise but lengthwise of the super. On account of this a good many have already testified that they secured much better and more perfect filling of combs in plain sections than in the old style with solid separators; that the bees enter plain sections sooner, and that in some markets better prices are secured. There are others who say they can see no difference.

Under the same conditions the plain sections will be filled no better than the beeway. If there is any difference in the filling it is because the one offers special advantages in the way of freer communication; for in the ordinary old-style, with solid separators, each section, so to speak, is shut off in a little box by itself, and it has been proven that bees are disinclined to work in little compartments almost completely shut off from the rest. Open-corner sections, divided off by means of slatted separators, without eleats, ought to be and would be filled just as well as plain sections divided off by fences; for the conditions will be precisely the same, because the beeways, made part and parcel of these sections, exactly correspond to the beeways (cleats) would not look, with even filling, as pretty as plain sections.

SUPERS FOR PLAIN SECTIONS.

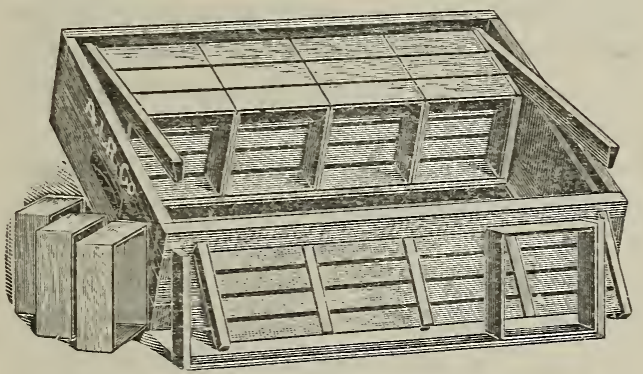

In the main, these differ very little from the section-holder super already shown and described for the old-style sections. The

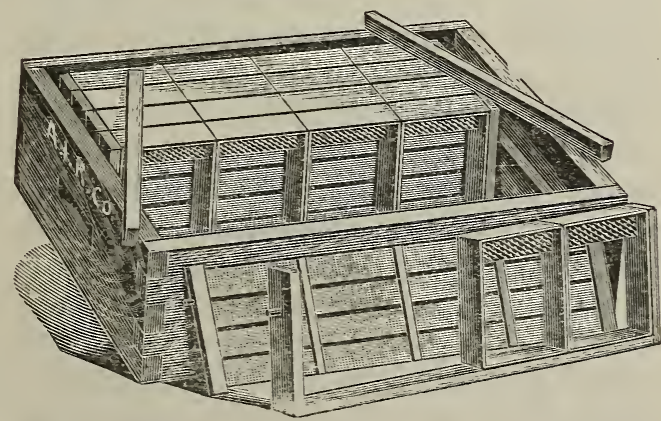

section-holders themselves are the same width as the sections. Between each row 
of sections in a section-holder is placed a fence, the end-post of the fence resting upon the strip of tin nailed on the bottom inside edge of the end of the super. There is a fence on the outside of each outside row of sections, because it was demonstrated by S. T. Pettit that a perforated divider, or what is exactly the same thing in principle, the fence, when placed between the outside rows and the super sides will result in having those outside rows of sections filled, in many instances, as well as those in the center. The reason of this is, that it places a wall of bees on each side of the fence, between the comb honey and the super side; and these walls of bees, so to speak, help to conserve the heat so they can draw out the comb and complete the sections on the outside as well as in the center.

COMB HONEY, TO PRODUCE. - In order to secure comb honey the colonies must be very strong - that is to say, the hives must be fairly boiling over with bees - so strong, indeed, that some of the colonies will be inclined to swarm as soon as the honey-flow starts. But of this, mention will be made later on.

In the early part of the season it may be an advantage if one brood-nest is crowded to use a second story and breed in that also. As soon as the harvest begins this upper story is lifted off, and a super of sections is put on instead. The hatching brood in the mean time of the two stories is put in the lower hive, and the rest of the brood given to colonies that can take care of it. This procedure is practiced by some of our best beekeepers because it insures powerful colonies that will go into the supers.

There is not much use in trying to produce comb honey if the colonies are only two-thirds or one-half strength. In order to bring all of these up to honey-gathering pitch the reader should turn to the general subject of BUILDING UP COLONIES found in its alphabetical order. Be sure that the directions that are given are carefully followed. Assuming that this has been or will be done, it is also important that there should be the proper proportion of bees of flying age-that is, fielders. A colony, for example, might have enough bees, but an insufficiency of bees old enough to go to the fields. Many a beginner fails right here. The bees should not be younger than ten days or two weeks. It will, therefore, require that eggs that have been laid to produce bees for the field should be laid from a month to six weeks ahead of the expected harvest.

If it is not practicable to build up the colonies by uniting, or if it is desirable to run for both comb honey and extracted, the medium colonies may be left as they are, and run for extracted honey, and those of proper strength run for comb honey. The weak colonies-that is, those of two and three frame size - should be united to the medium-strength colonies; for even in the production of extracted, more honey, relatively, will be secured per 1000 bees than from a comparatively small or medium force.

The medium colonies ean be built to proper comb-honey pitch without. uniting, provided the weather conditions are such that the bulk of the eggs can be laid from a month to six weeks ahead of the harvest. If that is not possible it will be necessary to unite, perhaps.

Colonies that are very strong in the spring will build up faster, relatively, than the weaker ones; and these can sometimes supply frames of hatching brood and bees to the stocks that are below par, or put in an upper story as explained at the outset.

In order that the colonies may build up properly in early spring, they should be well housed-preferably in double-walled hives. If they are in winter packing-cases as described under WINTERING OUTDOORS, leave the packing on until settled warm weather has arrived. Cool or frosty nights will quickly penetrate the walls of hives having only a single-board thickness. This necessarily cuts down the brood-rearing, and consequently reduces the amount of honey, either comb or extracted, that will be secured.

There should also be a liberal supply of stores in the hives the previous fall, not only to prevent starvation, but to make brood-rearing possible. If the supply is scant, the amount of brood and bees in the brood-nest will be correspondingly small, and then it may be necessary to resort to stimulative feeding. See FeEding to StimULATE. But experience has shown over and over again that the feeding should be done in the fall if possible. If it is done in the 
early spring it has a tendency to over-stimulate. It forces the bees out of the hive on cool days when they ought to be inside; and therefore it is highly important that all colonies be liberally supplied with stores, either natural or artificial, in late fall.

Having gotten our colonies up to combhoney pitch, it will be found that some of them, as soon as the harvest opens up, will be inclined to swarm. This may be shown by the building of initial queen-cells or clustering out in front of the entrance. Cells should be cut out every ten days; and while this practice does not entirely stop swarming it goes a long way toward checking and preventing it entirely in most of the colonies. There will be some other stocks that will make no effort to swarm at all. These should be carefully noted, and queens from them be used for breeding. The swarming nuisance can be very materially reduced by breeding from the queen whose colonies keep on storing honey without swarming. This is the practice of $\mathrm{Dr}$. C. C. Miller, one of the best comb-honey producers in the United States.

Just as the harvest opens up, or a little before, as may be shown by the combs whitening and bulging near the top, the hive should be lifted up on four blocks as illustrated and described under the head of Swarming, How to Control. It has been proven that the giving of a large amount of bottom ventilation in this way will check swarming to a very great extent. This ventilation should be supplied a little before the harvest opens up, to prevent queen-cells in colonies that are not inclined to swarm, and discourage the building of such cells in colonies that show a disposition to swarm.

Swarming may also be discouraged by the use of a super of shallow extracting combs, and, after the bees are started in this, substituting a super of sections. Extracting-combs may also be put in the side of a comb-honey super, as explained further on, or partially built sections from the previous season, called bait sections, may be used. A couple of these placed in the center of each super on the hives will do much to discourage swarming and get the bees up into the super.

The reader may find it necessary and advantageous to practice artificial swarming; but he should not do this unless initial queen-cells have been started. See ARTI-
FICIAL Swarming, especially the brushed or shake-swarming plan. This is usually very effective, but it involves a large amount of work.

Where one is at home, or can be near his comb-honey-producing bees, we would advise the preventive measures already described; but if for any reason the producer must be away from his bees thru the middle hours of the day or if he operates outyards it is advisable to shake the swarm so that the work can be performed at the convenience of the apiarist. The shake-swarm plan has been used to a considerable extent, and usually with a fair degree of success, altho it should be said that the majority of comb-honey producers, where they can do so, allow the first swarm to come off naturally, hive it on empty combs on the old stand, carrying the parent colony to another stand, or allowing it to stand beside the new hive, but with the entrance at right angles. The comb-honey super, if there was one on the old hive, is given to the swarm. As soon as most of the brood hatches, the parent colony is removed, when the flying bees join the swarm. This keeps down increase, and at the same time boosts the swarm so that it produces a large crop if the season hangs on long enough. For particulars regarding any or all of these methods, see Swarming, How to Control; also Artificial Swaraming.

In all the foregoing we assume that the main harvest of nectar comes on at the time expected. Sometimes clover or other sources furnishing the main crop will be out in abundance, and yet not yield a drop of nectar. At other times there will not be much of it in sight, and the bees will gather a large amount of honey.

When the season is poor, it is better to run for extracted, and that is why we advocate the production of both comb and extracted honey at the same time. Either the Barber or the Townsend plan will commend itself at such times. If the season starts in well, and the colonies are strong, practically all comb honey can be produced if desired. But we would advocate the use of bait sections to start the bees going above. We shall have more to say about this further on.

At this point the reader will do well to turn back to BuILdiNG UP Colonies, found in its alphabetical place. Many stocks in 
spring will be somewhat weak, and some will be of medium strength. Neither of these two classes will be fit for the production of comb honey. How to handle them, see BuILding up Colonies.

\section{WHEN AND HOW TO PUT ON SUPERS.}

If the colony is in one story and the bees begin to come in from the field, and combs are whitened near the tops, frames fairly well filled with brood and with honey, we put on supers. If we have supers containing half-depth extracting-combs, we prefer to put these on first, even if we desire to produce comb honey, for the bees will enter them much more readily, and begin storing above. Then when they are once well start$e d$ we raise the extracting-super up and place under it a comb-honey super containing sections filled with full sheets of foundation.

The usual practice is to put the combhoney super on at the start; but in our experience, Italians especially are loath to enter the boxes. If they once get into the habit of going above, they will keep it up, even if the super is changed. The extracting super can remain on top of the same hive on which it was put in the first place, but we would put it on some other colony to give it the "upstair fever," after which it should be replaced by a comb-honey super. After a little there will be some filled extracting-supers as well as those of comb. By proceeding on this plan we have found that we can produce just about as much comb honey as we should if we put the comb-honey supers on in the first place, with the additional advantage that the extracted honey obtained is just so much clear gain.

Two of our correspondents sent to Gleanings in Bee Culture their method of using extracting-combs to bait the bees above. One uses a whole super of shallow extracting-combs, and the other uses both sections and extracting-combs in the same super. We have thought best to give them both here. The first mentioned writes:

I have been, for several years, very much interested in trying and comparing different methods of handling bees for honeycomb. I have been in the business for eight years, and have had fair success. For the first five years I tried a different method each year. Three years ago I tried an experiment that succeeded so well I have followed it up, and have in a measure overcome the two greatest difficulties that I had to contend with-loafing and swarming. We use the eight-frame Dovetailed hives with sectionholders for $41 / 4 \times 41 / 4$ sections. Our bees would always begin to loaf or hang out on the front of the hives when we put on the sections, and most of them would do but little in the sections until they had lost several days, and then would swarm, thus losing several days of the first alfalfa bloom.

I had sixty colonies of Italians in my outapiary, and in trying my experiment I tried to be fair. I took 30 supers of half-depth extracting-frames full of comb from the home apiary, and put them on 30 hives in the out-apiary at the same time that I put sections on the other 30 hives. In four or five days the extracting-combs were full of new honey, and the bees excited and busy at their work, while most of those having sections were loafing, and some had swarmed.

I raised the combs by putting a super of sections between them and the brood-nest. At the end of two weeks from putting on the combs those sections under the combs were better filled than those on the hives that had no combs. As soon as the combs were sealed, I put them away to extract, having that amount of honey extra, and the bees started nicely in their work. I had only about a third as many swarms from those hives as from the ones with sections and no combs.

I liked the plan so well that last year I had enough of those little combs built to furnish a super of them to every colony that was to be run for section honey.

I tried the plan again this year, and from 75 colonies at the out-apiary I had 8000 fine white marketable sections, about $500 \mathrm{lbs}$. of unfinished and imperfect sections, 1500 lbs. of extracted honey, and $60 \mathrm{lbs}$. of beeswax, and two barrels of vinegar. We got short of fixtures, and I had to cut out some of my little combs, and have the bees build them again to keep them at work. I forgot to mention that we sell a lot of those combs to families for home use as we can sell them cheaper than sections. When we cut them out we do so after extracting, and then the washings make good vinegar, and the wax goes into the solar extractor, and is of the best quality. We leave half an inch of comb at the top of the frame, to save putting in foundation. I do not believe we shall ever be able to overcome swarming entirely, but I believe my plan stops the loafing better than anything else I know of. We had 57 swarms this year, but no loafing in the outapiary. We have bought an extractor for that apiary, and will continue to run on that plan to start them to work. After the first super of sections is well started there is no more trouble about loafing. My neighbor's bees loafed and swarmed thru all the best of the season, while mine worked hard.

Mancos, Col.
Mrs. A. J. Barber. 


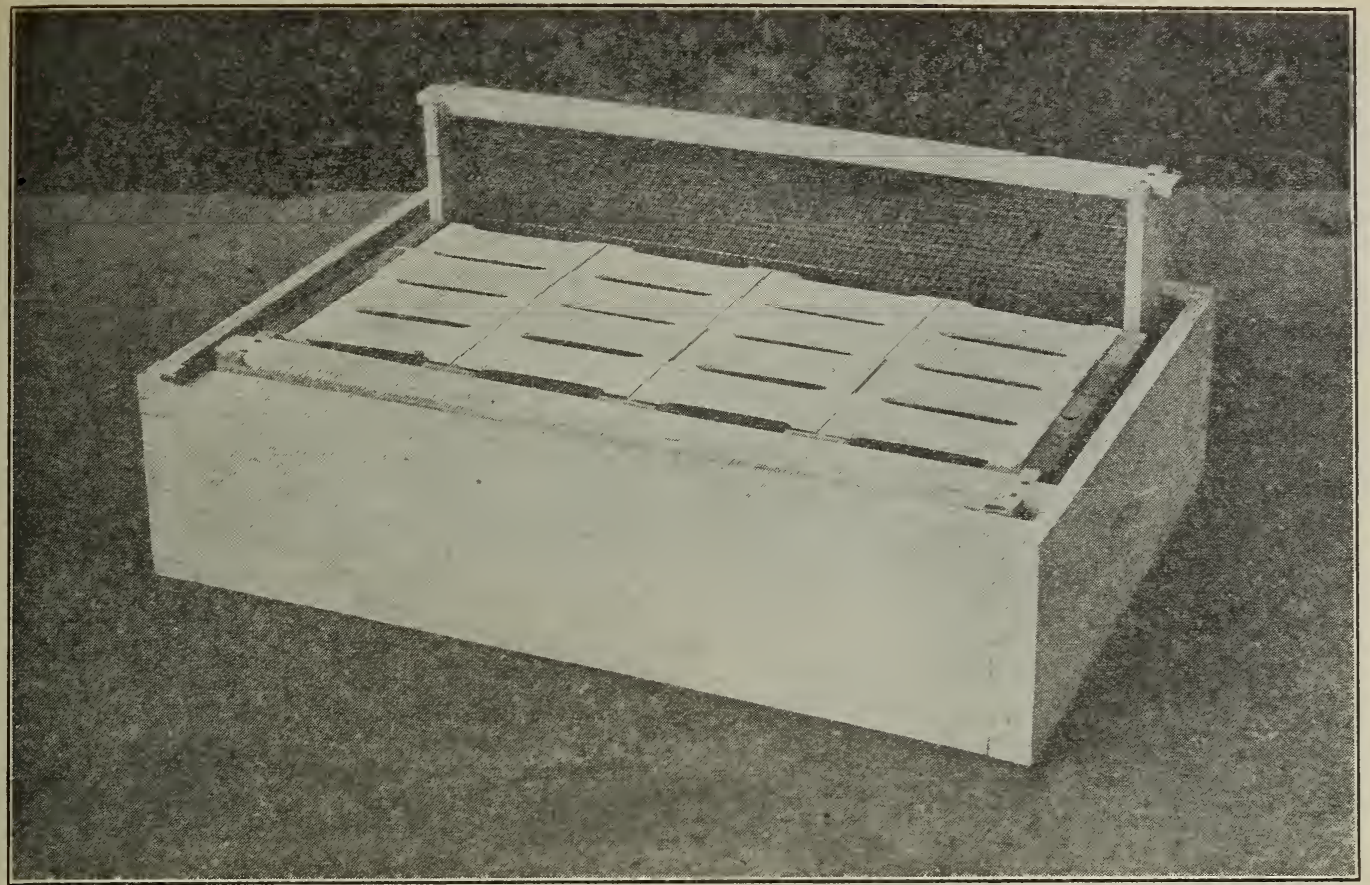

T super containing two extracting-frames with wide end-bars, so that they take up the same amount of room as a section-holder.

Other correspondents to Gleanings in Bee Culture have reported good results from following the same methods. It is particularly applicable where both comb and extracted are called for.

Mr. E. D. Townsend, of Northstar, Mich., the other correspondent, goes one step further than the Barber plan by producing comb and extracted honey in the same super. Instead of putting on a case of extracting-combs, and afterward substituting therefor one containing sections, he has a special super which contains both extracting-combs and sections.

The illustration given here shows a combhoney super containing 4 x 5 sections. This is equipped precisely the same as any other super for sections except that it has extracting-combs with closed-end frames on each outside. When a super of this kind is placed on a hive the bees immediately occupy the drawn comb at the sides of the super and begin their storing. The combs already drawn out are very inviting places in which the bees can begin storing honey. Having made a nice start in the two side extracting-combs they work toward the center-that is to say, they begin to draw out the full sheets of foundation in $4 \times 5$ sections next to the combs, and store in them. When work is once in full progress in the side sections of the super, the center ones will take care of themselves with the result that every section is finished about the same time, and of about equal fullness. When the super is completed, the two extracting-combs will be filled and capped as well as the section honey-boxes. The former can be extracted and used again.

It will be seen that the extracting-combs serve the purpose of excellent baits; and Mr. Townsend draws attention to the fact that, when such baits are placed at the sides instead of in the center, they cause an even filling of the entire super; whereas by the old plan of putting bait combs in the middle of the super the storing begins around the baits, gradually working from the center to the outside. This naturally brings about a better filling of the center sections, leaving those toward the sides at a much later stage of comb-building and filling. The result of this is that the center sections will be filled in advance of the outside ones; and by the time these latter are filled, all the former will be travel-stained, and may induce swarming in the mean time.

When Mr. Townsend first began this scheme of comb and extracted honey production from the same super he had in 


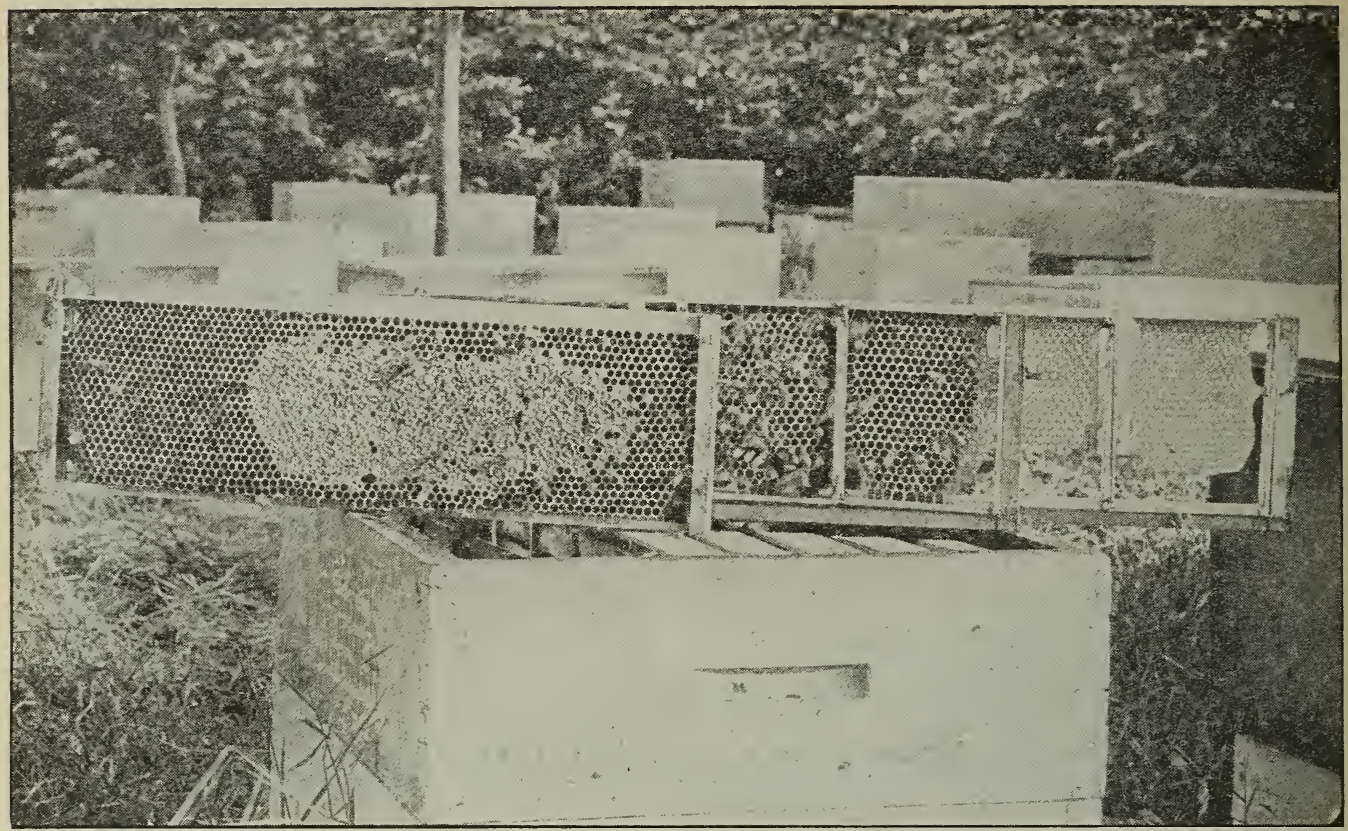

The work well started in the extracting-combs at the side of the comb-honey super. Note that the row of sections just back of the extracting-frame is well along and that the second row back is started.

mind only baiting the bees up into the sections; but he incidentally discovered that, inasmuch as the bees would enter such supers without hesitation, he thereby almost entirely overcame swarming.

Comb-honey producers well know that the ordinary section-super placed on a hive is very often not readily entered by the bees. The series of little compartments (the sections) cause the bees to sulk, and before they actually enter the super they may swarm in disgust.

It is well known, also, that after bees are once started going above, there is less inclination on their part to swarm. Mr. Townsend finds that the two side extracting-combs that he puts in every comb-super start the bees into the super about as readily as they would if containing extractingcombs only. The whole effect of this procedure is such that swarming is reduced to a minimum-almost brought under control.

For the local markets, the side extractingcombs can be cut out and sold for chunk honey at about the same price as that in the sections; so that there need be practically no loss; or when there is a call for liquid honey it can be extracted.

The deep super, already described, with its $4 \times 5$ sections and section-holders, is well suited to carry out the Townsend plan.
Even the shallower supers using $41 / 4 \times 41 / 4$ sections can be similarly arranged.

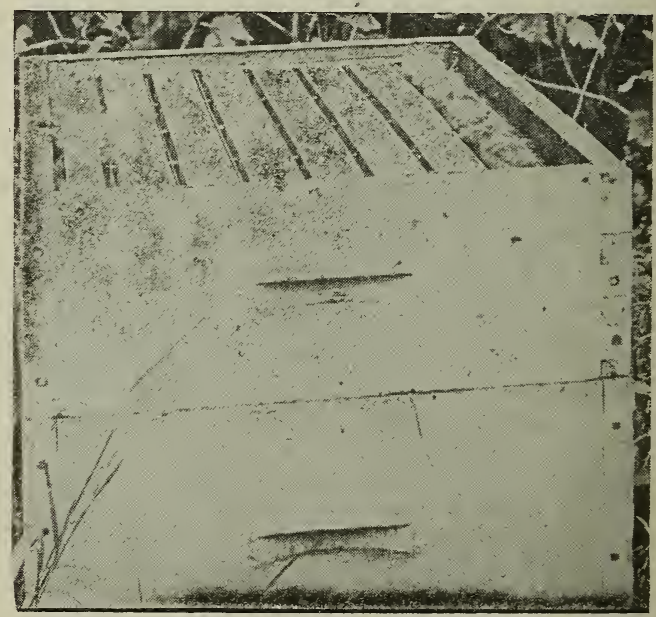

One of Jay Smith's hives, showing extracting-combs at the side of the super, $a$ la Townsend.

Mr. Jay Smith, of Vincennes, Ind., among many others who have been using the Townsend plan with good success, writes:

I have been using Mr. Townsend's plan of putting extracting-combs at the outside of the sections, and feel that in this Mr. Townsend has given the bee fraternity a most valuable kink. In the engraving will be seen a super just set on the hive. The bees immediately take possession to clean it up. They will at once go to work and store hon- 
ey in the comb. The other picture shows the work as it progresses. The outside extracting-frame is partly capped. The comb-honey section next to it has honey in it, while the third has work just commenced. After the bees begin in the center ones, they will push the work there a little faster, with the result that the entire super is finished at once and can be set aside for market without sorting.

I am running eighty colonies on this plan this year, and I have never had a single case of loafing, and the bees work with all the energy they possess. When I read of some who let the hive-body get clogged with honey, and the bees cluster out, and they "shake" energy into them, I thought the beekeeper was the one who needed shaking instead of the bees. With the above system I usually have about six per cent of swarms. This was the worst year for swarms I ever had, and the percent of swarms was ten.

\section{BAIT SECTIONS.}

Some beekeepers, howerer, while admitting the excellenee of the plans given for those who want part of their crop in extracted honey, say that there is no need to use extracting-frames to start the bees at work in supers, since the same thing can be accomplished by means of what are called "bait sections," thus securing the entire crop in sections.

A bait section is one which has been partly filled with honey, which honey is afterward emptied out by the bees, generally in the fall. It is thus a section containing drawn comb, but having no honey in it, to all intents and purposes an extracting-comb on a small scale. Bait sections thus prepared are kept over winter, to be used at the beginning of the next honeyharvest.

If a single bait section is put in the middle of the first super that is given to a colony, it is claimed that the bees will begin work in it as promptly as they will begin work in an extracting-comb. Some use more than a single bait in a super, but there may be no great advantage in this, and the number of baits should be limited as much as possible, for when a section is thus filled the second time it is not so beautiful as one filled the first time. A bait section is not needed in any super after the first.

One serious objection to bait sections is their tendency to granulate early; and on account of this they should never be put into a shipping-case with other sections of comb honey. They are never as nice, and should always be sold around home as soon as possible after they are taken off the hive.

Some producers have made the serious mistake of putting their bait sections when completed in with other sections and sending them in one case to the city market. As these baits granulate very quickly, the city dealer is quick to discover it, and he will, therefore, conclude that the whole case of sections is just as bad.

\section{WHAT TO DO WHEN THE BEES REFUSE TO ENTER THE SECTIONS.}

We have already given some general suggestions that should enable the producer to get the bees up into the supers. One is, to give the bees a super of empty extractingcombs; and then when they have once started in them, place a super of sections between it and the hive. The other is, to use the extracting-combs as well as sections in the same super, a la Townsend; and still another is, to use bait sections. When all of these devices fail, it may indicate that the weather is too cold, even tho there is plenty of bloom, or the colony is not strong enough to go into the supers. We sometimes find it an advantage to run our colonies two story during the breeding season, then remove the other story, and put on a super of sections as explained elsewhere. If the weather is cool or chilly or colony not strong enough, no amount of "baiting" will get the bees above. The weather conditions must be right, and honey must be coming in at a fairly good pace, even if the colony is strong enough, before the bees will go above. But when they are once started they will keep it up as long as anything is coming in.

If some colonies are storing in the supers, and others are not, it indicates that the weather conditions must be right; and the presumption is that the laggards are not strong enough to go above. If they have plenty of bees, it is sometimes advisable to give those that will not work in the supers, a super from some other hive in which the bees have already started building comb and storing honey. In other cases, we would use either baits or empty combs on the sides. We would also make sure that the bees in hot weather are not driven out of the supers by the direct rays of the sun. In some localities, at least, shade must be pro- 
vided, so that the bees will be protected during the middle hours of the day. See APIARY, and especially "Shade-boards."

If the bees hang out in front of the entrance, colonies are strong, and bees are storing honey in other hives, enlarging the entrance or putting the hive up on four blocks, as shown and illustrated under SwARMING, may serve the purpose of getting the bees inside at work in the supers.

It sometimes happens that the brood-nest is not filled with brood and honey. Until that takes place, there will not be much work done in the supers unless the colony is very strong or honey coming in rapidly.

\section{TIERING UP.}

If honey is coming in at a good rate, one may expect (if the bees have started above) that the super, or case of sections, will soon be filled about half full of honey-with the sections in different stages of completion. When the super is about half filled with honey, raise it up and place another empty super under it. About the time this reaches the condition of about half completion, raise both supers and put under another empty. one on. This process of "tiering up," or "storifying," as it is called by the English, may be continued until it is three, four, or more high, depending upon the length of the honey-flow and the amount of nectar coming in daily. In the mean time the ripening process of the honey in the first super continues. In most localities it is not practicable to tier up more than two supers.

\section{CAUTION.}

Care must be exercised in tiering up, or a lot of unfinished sections will be the result. When the honey-flow is drawing to a close, and it is discovered that there is an evident decrease in the amount of nectar coming in, no more empty supers should be given. The bees should complete what they have on hand, which they will do if one is fortunate enough in his calculations as to when the nectar flow will end. If uncertain whether another super is needed or not toward the close of the harvest, it is often adrisable to put another super on top. The bees are not likely to commence on this till they really need it. It is impossible to give general rules on tiering up; but with the assistance of the foregoing one is to exercise his own discretion.

\section{WHEN AND HOW TO TAKE OFF SECTIONS.}

Usually it is not practicable to wait till every section in a super is completed; that is, until every cell is capped over. Those sections most liable to be unfinished will be in the two outside rows, and these the bees will be long in completing. If the honeyflow is over we would not wait for them to be completed, but would take the whole super off at once. The longer it remains on the hive, the more travel-stained the honey will become, and the more it will be soiled with propolis. However, if one desires a really fine, delicious article of comb honey, one more pleasing to the tongue than to the eye, and is not particular about the white marketable appearance of the cappings, the super should be left on the hive for two or three months. Most beekeepers agree that comb honey left on the hive acquires a certain richness of flavor not found in honey just capped over. Altho such honey is really better, it is not quite so marketable because the cappings in the mean time become more or less travel-stained.

If one is producing very much comb honey he can scarcely afford to get along without a scale hive. See Scale Hive, found in alphabetical order.

\section{HOW TO GET BEES OUT OF THE SECTIONS WITHOUT BEE-ESCAPES.}

There is one danger in leaving honey on till after the honey-flow. As soon as the hive is opened, the bees, especially hybrids, possibly may uncap and carry some of the honey down. Whether it is left on the hive or whether it is removed as soon as capped, the methods of taking off and getting the bees out will be much the same. In the latter case, some supers may not be filled with honey, altho a glance at the top may show nice white capped combs. If capped below, it may be removed. To take off, smoke should be blown into the top of the super for a minute or so, to drive most of the bees down. The super should be lifted off and set on end near the entrance or on top of the hive (not as it rests on the hive, or it will kill bees). If honey is coming in freely, robbers will not molest, and in two or three hours the bees will have left the super and gone into the hive.

Until one has some experience, perhaps his safest plan is, never to set a super of 


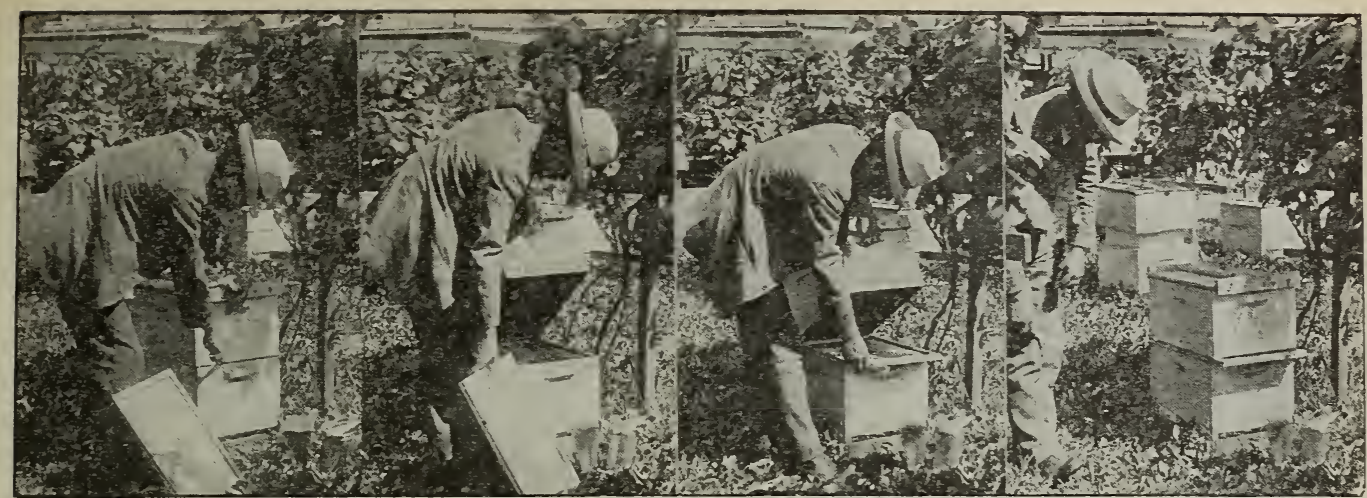

Method of inserting the escape-board.

honey by the hive. Sometimes it may be safe to let it stand there all day when the bees have more than they can do on the flowers: but, again, all at once it may start the bees to robbing and demoralize them generally.

If the honey-flow has stopped or is tapering off, to aroid the possibility of robbing it would, perhaps, be better, after smoking the bees out as far as possible, to give the

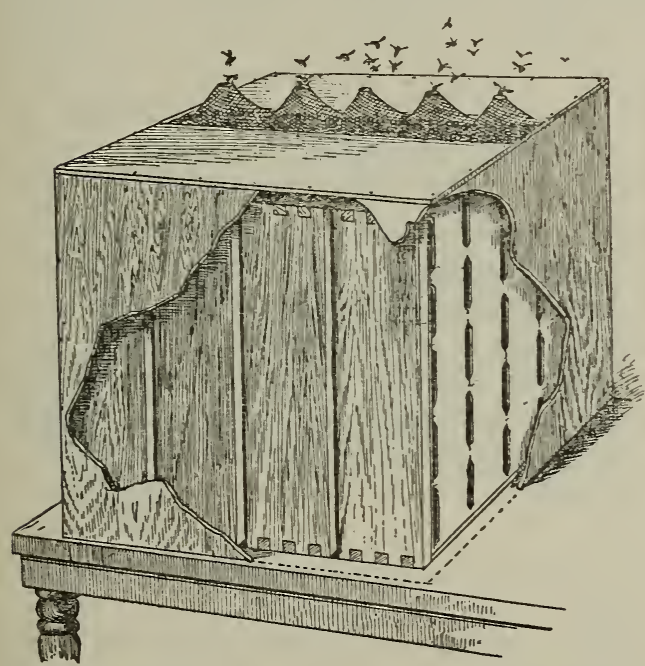

The Whitney bee-escape case for clearing the bees from comb-honey supers.

super a vigorous shaking in front of the hive; then with the bee-brush clean off the bottom and top of the super; this will clean out nearly all the bees. The super should then be placed inside of a building. What few remain will desert, fly to the windowscreens, and get out thru the bee-escape, which shoula be provided in all well-regulated honey-houses. But a better plan, perhaps, would be to shake out most of the bees as before described, then stand the supers on end, and set over a case with beeescapes on top, like that shown in the engraving above. This is used by W. M. Whitney, of Lake Geneva, Wis.

By far the most satisfactory arrangement for getting bees out of supers is the doubleend Porter bee-escape. This is mounted in

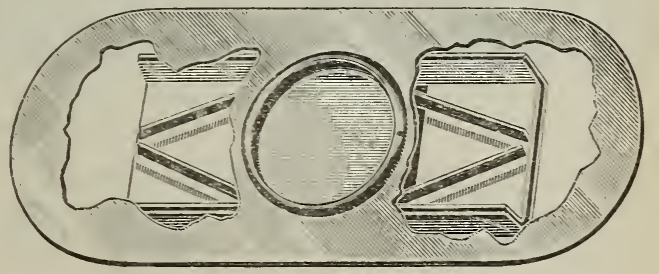

Porter double-end bee-escape.

a board, cleated at the ends and sides, in such a way as to provide a bee-space on one side, so that it can be placed between the supers and the brood-nest beneath. But care slould be taken that it be placed right side up-lhat is, the side up as shown in

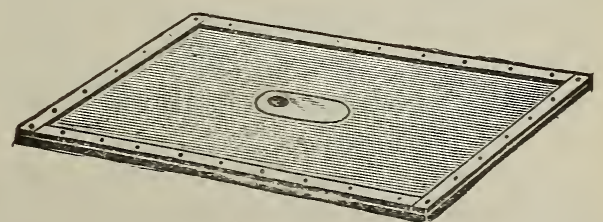

the illustration. If the device be put on toward night, or, better, along in the afternoon, by the next morning practically all the bees will be out of the super and in the brood-nest below; or in some cases will have gone from the finished super into one partly finished.

Our method of putting on one of these escape-boards is as follows: With a hivetool. screw-driver, putty-knife, or pry, loosen the super so that propolis connections will be severed or broken. Now with one 


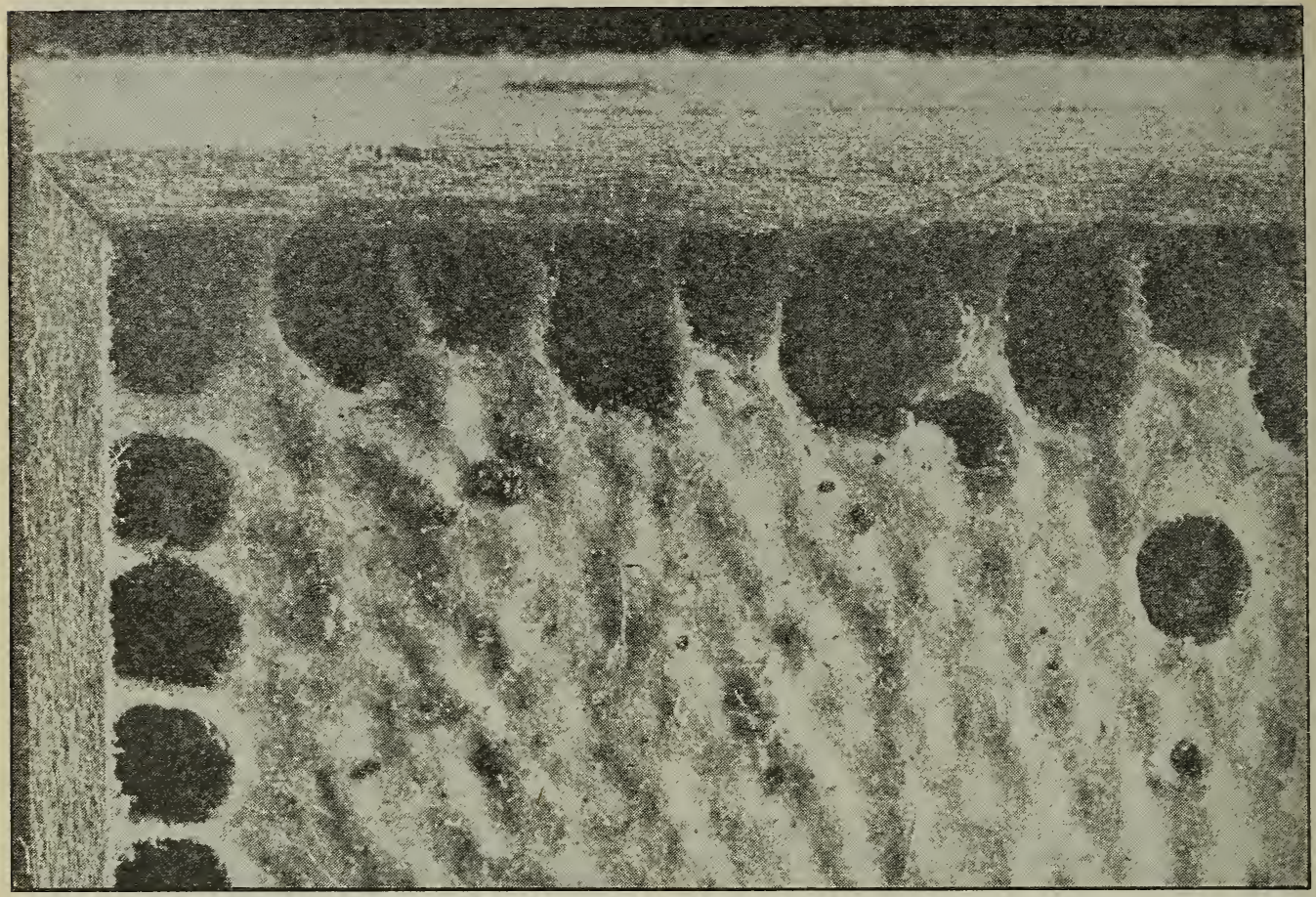

A corner of a section of honey enlarged to show the dust of wood and propolis scattered over the surface of the cappings. This trouble is caused by carelessness in cleaning the propolis from the wood.

hand tilt up the super at one end enough to make a gap, and with the other hand take the smoker and blow in two or three whiffs of smoke to drive the bees back.

Next lift the same end of the super up a little further so that it will stand say at an angle of nearly 45 degrees. With the free hand set down the smoker and pick up the escape-board, which should be leaning conveniently against the leg. Slide this on top of the hive as far as it will go, beespace side up. Let the super down on the escape-board gently, and, last of all, bring the escape-board and super into alignment with the hive.

This method eliminates hard lifting, saves time, prevents angering the bees, and avoids killing them.

The best time to put on Porter escapes is at night. If thirty or forty of them are put on, the next morning about nine o'clock there will be about thirty or forty supers ready to come off, with but few bees in them. If there are three or four bees left, or say a dozen, they will usually take wing as soon as the super is uncovered.

SCRAPING SECTIONS.

In order to make sections present a clean and marketable appearance all the propolis should be scraped off. Some and perhaps most beekeepers prefer for this purpose a common caseknife, and others a sharp jackknife. Sometimes the edge of a scrapingknife is ground square, and the scraping is done with a corner of the knife. But the general practice seems to favor the ordinary edge. Others, including Dr. C. C. Miller and Allan Latham, prefer to use No. 2 sandpaper. A sheet of it is laid flat on the table; and the section, edges down, is rubbed back and forth on the rough surface. If the day is not too warm, nor the propolis soft, the sandpaper will do faster work than a knife. But the edges of the sections are a little roughened, and more or less fine dust at times gets on to the surface of the comb. Sometimes a dealer on receiving such honey objects to this dust, thinking it to be the excrement of the moth-worm. See cut.

The objection is also made that the sandpaper fills up with bee-glue, and that is true. But sandpaper is cheap, says Mr. Latham. When one sheet is filled, another can be used, and so on.

Where one has a large amount of comb honey the work can be done with sandpaper more expeditiously by fastening it on a 
revolving cylinder or on the flat surface of a revolving disk operated by foot power or a small motor. Where one has a gasolineengine for a large power-driven honeyextractor, he can use that as a motor power.

We stated that rubbing the section on a flat sheet of sandpaper by hand leaves the edges rough, and dust on the surface of the comb. The illustration (preceding page) enlarged to illustrate the details, shows how the fine dust lodges on the comb, and how the edges of the sections are roughened, leaving hairs or fibers of wood clinging to the edges. Our experience is, however, that a power-driven cylinder or disk on account of the high speed, does not scratch the sections nor leave the surfaces of the comb covered with dust.

\section{BOOMHOTER KNIFE-SCRAPING TABLE.}

Mr. Frank Boomhower, of Gallupville, N. Y., has a section-scraping table like the one shown herewith. As will be seen, two scrapers can work at a time, the sides of

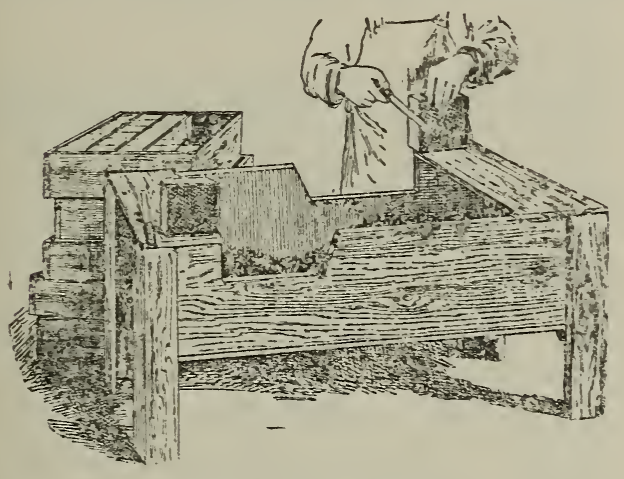

Knife-scraping table.

the box or tray being cut away in such a way as to allow a knife to scrape down clear past the edge of the section. Each section, as it is scraped, is put into the shipping-case. We have seen this table in operation and know that it is just the thing for knife-scraping.

Those with only a few sections will not be likely to have such a table, and some large producers might not prefer to use it. Any ordinary table may be used for the work, or a board on the lap will answer. It is easier to do the work sitting. A block 2 inches thick, more or less, and 4 inches square, the size not being important, lies on the table, or on the board on the lap. When the section is placed upon this block, pro- jecting over one side, it allows free play for the knife. If the super is of such character that the sections may be taken out en masse, the work may be greatly shortened by cleaning all the tops at one operation, and the bottoms in the same way. Indeed, no matter what the super, one may shorten in this way: Make a rim, or box without top or bottom, whose depth is an inch or less than the height of the sections to be cleaned, and an inch or so wider and longer than the superful of sections. Hare two boards as large as or a little larger than the rim mentioned. Lay a board on the table, set the rim on the board, and then fill the rim with sections. Put into one end a thin board as a follower and wedge it up. Do the same at one side. Now, with a cabinetmaker's scraper or some other tool scrape the propolis off the entire surface. Follow this up with No. 2 sandpaper. Now lay the other board on top of the sections. Turn the whole thing upside down. Take the top board off the sections. Loosen the wedges as much as necessary to let the rim drop down on the board and then wedge tight again. Scrape and sandpaper as before. The sections may now be taken out and finished on the little blocks as before mentioned. It is a convenience to have a large table and a number of boards. Each board may be slid along on the table out of the way, or it may be piled up on another boardful of sections.

Both scraping and sandpapering will work better when it is so cool that the glue is brittle. Indeed, sandpaper will not work on soft glue.

\section{UNFINISHED SECTIONS.}

The more carefully the apiary is manipulated in the matter of working for comb honey, the fewer will be the number of unfinished sections; but all such are not always the result of improper working of the colonies. With the best of care a sudden stoppage of the honey-flow will throw on the beekeeper a lot of these sections: and such cessation of the nectar supply, no one can foresee in some localities. In the alfalfa regions, and other places, it can be told within a few days when the honey will stop: it is then possible so to arrange the supply of sections on the hives as to leare rery few of them unfinished when the season does finally close. 
HOW DR. MILLER PREVENTS AN OVERSUPPLY OF UNFINISHED SECTIONS.

Dr. Miller takes off his supers as soon as a majority of the sections in the super are finished. The latter are set aside to be scraped and cased for market, while those unfinished are set back into the supers-the supers to go back on the hives immediately, and that is before the honey-flow stops. $\mathrm{By}$ proceeding thus, he manages to have few unfinished sections at the end of the season. Those that are returned to the hive he fittingly styles "go-backs." These, as fast as they accumulate in the honey-room, are put into the regular hive-supers. Part of these go-back supers may be placed on colonies that show a special aptitude* for finishing up work already begun in sections, and a part may be placed on the regular colonies already at work on their own sections. The great advantage of this plan is that it allows the sections to be taken off before all in the super are finished, consequently before any of the central nnes have lost their virgin whiteness.

Such a plan of procedure is possible only in localities where the honey-flow lasts sufficiently long, not only to fill two-thirds of the sections full in the supers, but enough longer to finish out supers of go-backs placed on hives afterward. Bees can be made to finish partly filled sections even when the natural honey-flow has ceased altogether by feeding back a thinned honey. See FEeDING BACK.

In any case, some unfinished sections will be on hand at the close of the season; for if the surplus be all stored in sections it is not possible to give the exact number of sections that will be finished.

\section{WHAT TO DO WITH UNFINISHED SECTIONS.}

Some prefer to dispose of unfinished sections by selling them around home for less money, or using them exclusively for home consumption. The honey, for eating purposes, is practically just as good; and it is the practice, in many beekeepers' families, to consume all such sections if they can, reserving those that are marketable and well finished to be sold.

Some beekeepers consider them very valuable for baits; that is, they place one of

* Some colonies are better at finishing up work already begun than at starting it from the raw foundation. these in the center of a super to bait the bees above, as has already been explained. Others place them in stacked-up supers a few rods from the apiary. A very small entrance at the bottom of the pile, large enough for one or two bees to pass at a time, is provided. By this slow method of robbing, the bees will empty out the honey and carry it to the hives much more cheaply than the beekeeper himself can afford to do it by means of the extractor. While this slow robbing may cause a little disturbance in the yard at the time, it does no particular harm. But mark this: Never give the bees a wide entrance at the bottom. It should be only wide enough to allow one or two bees to pass at a time. This is known as the Miller plan, having been, we believe, originated by Dr. C. C. Miller. Taking everything into consideration it is the safer one to follow; but where one is an expert beekeeper, and has a large lot of unfinished sections for the bees to empty out, a plan originated by the late $\mathrm{B}$. Taylor is perhaps better. Dr. Miller, who uses the plan, thus speaks of it:

For a number of years I have used the Taylor plan at the close of every season. All sections that are less than half-filled are put in supers in the shop cellar, and the doors kept closed till the whole business is over, and all that are to be emptied are in the cellar. The supers stand on end so as to be all open, or piled in piles erossing each other. When no more are to be taken into the cellar I open the door and say to the bees, "Go in.", They go in, I assure you. The air is black with bees at the door, and they do more or less sailing about in the vicinity. Sometimes they do a little tearing of the sections, but not much. There is too large a surface for them to cover. Gradually they give up the job as the supply ceases, but the supers are not taken away till a week or two after the bees have stopped working on them. They might as well be put in the open air, only they are safe from rain in the cellar. Please remember that this is what I do at the end of every harvest after the flow has stopped.

As a matter of fact, I use the Taylor oftener than the Miller plan. It depends on the number of sections to be emptied in proportion to the number of bees. Whether little or much is to be emptied, I am not afraid of a rampage. I will set a super of sections on top of a hive and let the bees rob it out, and there will be no rampage. But I will be exceedingly careful not to take away the super until all honey is cleaned out, and until at least 24 hours after the bees have stopped trying to find any more 


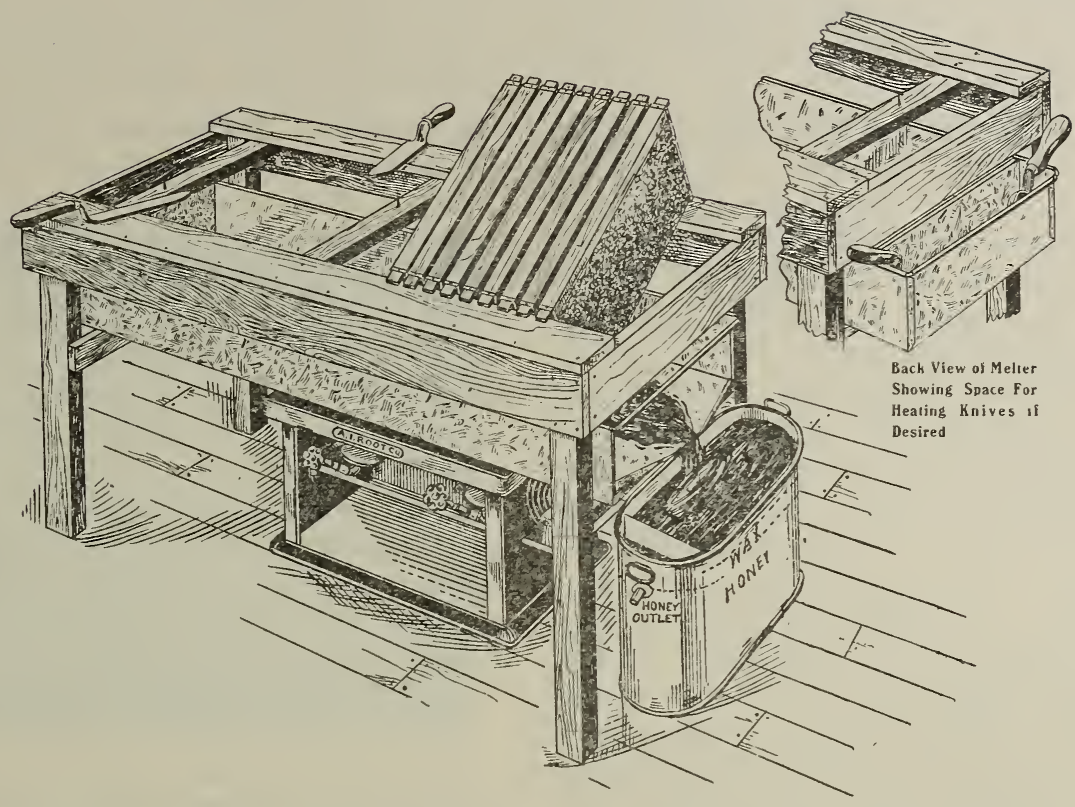

The Pelerson capping-melter and wax-separator here recommended for liquefying candied honey. Altho designed for melting cappings as explained under EXTRACTED HONEY, it may be used as a liquefier if a screen is put across the open end to prevent the solid portions from sliding out. As soon as the honey is melted, it runs out, away from the heat.

honey there. Take away the super while the bees are at work at it, and wholesale destruction would follow.

Since foul brood has become so generally distributed over the United States, there would be great danger of spreading it among the bees if we practice the plan above described. Certainly it would not be advisable, in case any of our neighbors had disease among their bees; nor could it be recommended if foul brood ever had been among the bees within the last year or so. There would be danger that some colonies had the germs of the disease; and altho they showed no evidence of it during the preceding season they might spread disease thruout the entire apiary. For this reason we would advise our A B C scholars at least to use almost any other plan than letting the bees rob out the supers.

\section{GRANULATED COMB HONEY; WHAT TO DO WITH IT.}

If dealers are not suspicious regarding comb honey nor have had their heads filled with stories of artificial comb honey, they can probably sell granulated comb honey at very near the same price as that which is still in the liquid form; for granulated honey in the comb is fine for table use. Some explanation should be made, however, to the effect that the honey going "back to sugar" does not indicate at all that the bees were fed sugar syrup, and that nearly all kinds of pure honey will granulate in time. See Granulation.

The Jews, in their religious festivals, at certain seasons of the year, use considerable granulated comb honey. The honey and wax make up the right combination for their purpose, and very often granulated comb honey can be sold to the Jews at fair prices.

If it is impossible to sell granulated comb honey at a reasonable figure, it may be melted up in a capping-melter, and the liquid honey and wax saved and sold separately. If there is any great amount of honey to melt up in this way a large capping-melter should be used, for it is important to have a good-sized heating surface so that the melted honey and wax may be separated as soon as possible. If a small melter is used and overloaded, much of the honey is likely to be confined in close contact with the heated surface for some time; and this, in connection with the wax, imparts to it a flavor that, while not disagree- 
able, distinguishes it from honey not so treated. On this account the outlet of the melter must not be allowed to dam up so as to confine the honey.

A framework should be made to fit the top of the melter, on which a wide board may be secured directly over the melter.

Use a sharp butcher-knife or steam uncapping-knife to cut the comb out of the section, then strike the notched or dovetailed corner of the section, causing it to fly open allowing three sides of the section to lie flat on the board. Beginning at the right-hand end, move the edge of the knife with a scraping motion toward the left, holding the section in the left hand by the fourth side, which should be at right angles to the other three sides lying flat on the board. Then use the other edge of the knife; and, beginning at the top of the fourth side, cut down to the board, thus removing quickly all the wax adhering to the wood. With a little practice the honey may be cut out of the sections very rapidly - perhaps faster than the melter can handle it; but in the intervals the heaps of scraped sections may be removed, new cases of honey set on the bench ready, etc.

The melted honey and wax as it comes from the melter should pass directly into a separator made on the principle of the Aikin separator. The large cut shows the whole melter, separator, etc. At the end of the day, or when the work is finished, the honey should be drawn off as close as possible to the wax, so that the smallest amount will be left to cool with it. The reason for this is that any honey is given a slightly waxy flavor if allowed to cool under wax. As soon as the honey is drawn off, and while it is still warm, it should be strained thru a cheese-cloth, so that it will be ready for market.

\section{SHALL WE USE SEPARATORS?}

Ten or fifteen years ago a good many comb-honey producers thought they could dispense with separators. Some few claimed they could produce just as good comb honey, as evenly filled and perfect in every way as that produced with separators. But after having looked over a good many carloads of comb honey it is our candid opinion that most if not all of the unseparatored article is totally unfit to go to market. While it may look very neat and pretty, the difficulty lies right here: Some combs will be over full-that is, too fat, and others will be too thin. The trouble comes in crating such uneven combs in an ordinary shipping-case. While such honey can be crated if one takes a good deal of time.

Many of our commission houses and honey-buyers today positively refuse to take unseparatored comb honey at any price. A few will take it at greatly reduced prices. The average honey-producer who thinks he can dispense with separators will probably have to make up his mind to sell for less money or sell it to his neighbors.

Since the net-weight law went into effect (see Labels; also Grading Comb Honey) unseparatored comb honey cannot be graded satisfactorily. The law has in effect made the use of separators imperative.

\section{WHAT SIZE OF SECTION TO USE.}

A few years ago there were a good many varieties and sizes and styles of sections on the market. For instance, there were the two-pound prize sections, the half-pound sections, and three-quarter-pound sections; but at the present time everything has been

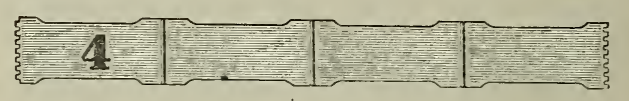

reduced down to practically three styles: viz., the $41 / 4 \times 41 / 4 \times 17 / 8$ beeway sections, the plain $41 / 4 \times 4 \frac{1}{4} \times 1 \frac{1}{2}$; and the $4 \times 5 \times 13 / 8$ plain sections. All of these three hold a scant pound of honey, section included; but under the federal net-weight law (see LABELS) and some state laws it is not permissible to include the square of wood around it and therefore the section will be sold in weights from 10 ounces for the lightest to 14 ounces for the heaviest. While it might be desirable to have something holding an even pound, yet no two sections will run exactly the same weight. See Grading COMB HoNEY.

TALL VS. SQUARE SECTIONS.

The standard section for a good many years has been and is $4 \frac{1}{4}$ inch square; but, notwithstanding, during all this time, a good many beekeepers, principally in New York, have been using a section taller than broad. The late Capt. J. E. Hetherington, who had the reputation of being the most extensive apiarist in the world, used a section $37 / 8 \times 5$. Other beekeepers in New 
PASTEBOARD CARTONS FOR ONE-POUND SECTIONS OF COMB HONEY.

While sections with glass panels have been practically eliminated from the market, comb honey in paper cartons is becoming more and more popular. In some cities a definite ordinance requires that all food packages be kept sealed to keep out insects, and especially flies, that carry the germs of disease. It is evident that legislation of this kind will go from city to city and from state to state. But suppose there is or will be no legislation the housewife sometimes has troublo with a section of honey breaking and leaking over her groceries when delivered. She will thereafter buy her comb honey put up in neat cartons* that specify the exact weight of the boney, not including the section, as it is not allowable to sell the section by weight, section and all.

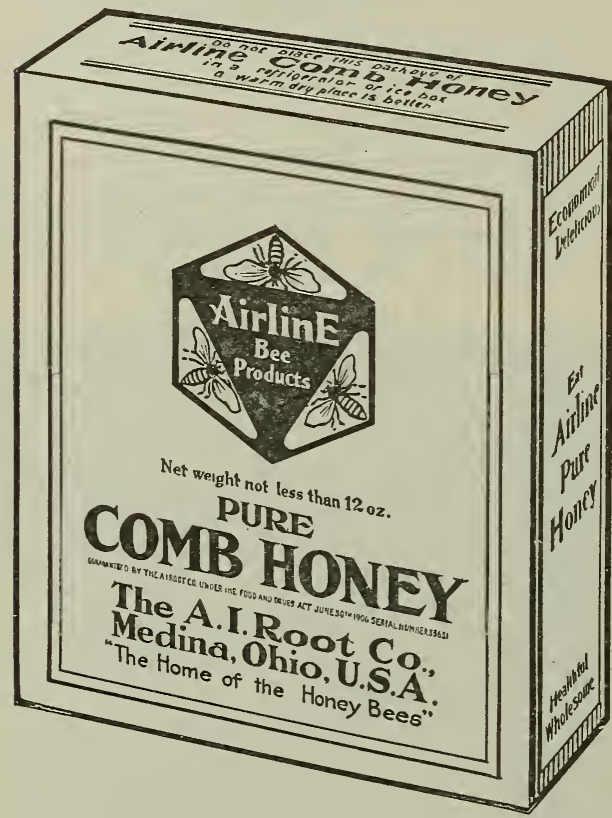

Several attractive designs of cartoned comb lioney are now on the market; and the fact that the demand for comb honey in this shape is growing, even where there is no legislation requiring sealed packages, shows that not many years hence comb honey will have to be put up in that form, if for no other reason than to shut out the typhoid house-fly.

Some beekeepers sell their honey in folding cartons, the top and bottom sliding into

* The paper cartons are comparatively cheap and can be given away with the honey. The glass-panel scheme protects the honey, but it is too expensive to furnish with the honey. slits provided. But such cartons do not seal the package hermetically.

The publishers of this work have for several years back put out a package sealed with glue under the name of "Airline," such name being drawn from the name of A. I. Root, the original author of this work, and president of the company. Airline means beeline; and the fact that the A. I. Root Co. is selling comb honey in these sealed packages-tens of thousands of dollars of it-shows that the demand for comb honey put up in attractive form, and sealed from the typhoid fly and other insects, is on the increase.

For hints on marketing, see Extracted Honey, Bortuling Honey, Peddling HoNEY, and particularly MaRKeting HoNeY, found in their alphabetical order.

\section{HOW TO KEEP COMB HONEY AND AT THE SAME TIME PREVENT IT FROM \\ GRANULATING.}

It is sometimes desirable to keep comb honey for a better market, or hold it so we may have a supply the year round. To keep it with unimpaired flavor it must not be subjected to dampness. If water condenses on the surface of the comb it soon dilutes the honey, and then it sours. On this account the honey should never be put into a cellar or other damp room. Better put it upstairs; and that there may be a free circulation of air, without admitting bees or flies, the windows should be covered with painted wire cloth. We are accustomed to keeping comb honey the year round, and rarely have it deteriorate in the least. The same plan will, in the main, apply to keeping extracted honey. During damp and rainy weather, the doors and windows of the honey-room or honey-house should be closed and opened again when the air is dry.

Comb honey should under no circumstances be stored where it is likely to freeze, as freezing contracts the wax so as to break the combs and let the honey run. It should be kept as nearly as possible between 80 and 90 degrees F. It should never go down to the freezing-point at any time-nay, rather, it should never go below 70 if it is possible to avoid it. Varying degrees of temperature have a strong tendency to make honey granulate; and nothing ruins comb honey quicker than this. 
Perhaps one in a small way might be able to maintain a room hot by the use of a hard-coal stove, from which a regular heat will be given off. In some instances one might use furnace heat. This latter would, perhaps, be advantageous in that it would provide for ventilation and thus hasten the eraporation of any unripe or thin honey. Where natural gas is arailable and cheap enough, gas-stoves will furnish a more regular heat than anything else. But certain it is, there must be some sort of automatic regulation of the heat. While the heater can be controlled to a certain extent, it seems more feasible to let the surplus heat escape.

THE TEMIPERATURE TO ARREST GRANULATION AFTER IT BEGINS.

We made some experiments to see how hot we could keep the room and not have the combs melt down. We find the temperature must not go higher than $103 \mathrm{~F}$. While this may seem excessively high, yet if the honey begins to candy the only way to arrest the process of granulation is to bring the temperature up to 103, and maintain it there. Aye, there is the difficulty. WVe accomplish it by putting steam-coils in the room with sufficient radiation so that the temperature can be held between 101 and 103. If it goes above the high point, an automatic regulator, something on the plan of an incubator-valve, allows the heat to escape. As the temperature drops, this ralve closes.

We kept some $2000 \mathrm{lbs}$. of honey in this room for two months. Some of the honey had already begun to granulate, and it was our hope that we could not only arrest the granulation but bring the granulation back to a liquid condition. In this last we were disappointed, but we succeeded admirably in stopping the process that would have soon ruined this whole lot of honey.

We are not sure but a temperature of 100 F. might do as well, and possibly such a degree would be safer for the average person to use, because, if the thermometer shors higher than 103, there is great danger that the combs will be overheated, sag, and set the honey to leaking. It should be stated that a temperature of $100 \mathrm{~F}$., while it will stop granulation will cause the honey to become very thick and waxy. This is objectionable to some of the trade.
COMBS.-Under HoNeYCOMB, further on, we discuss the article as a rehicle or container to hold the honey gathered by the bees, its general structure, how the bees build it without artificial aid, and the so called artificial comb, which does not exist, and never did. Under Comb Foundation we describe particularly how combs are built by the use of artificial aids; under Maxipulation of Colonies, how combs or frames are handled; and under this head we shall discuss the economic and comparative ralue of good and poor combs when used in brood-frames.

In the olden days, before foundation was known, there was a much larger proportion of inferior and bad combs than there is today when, in a well-regulated apiary, they are built almost entirely from full sheets of foundation. (See Comis Foundation.) By the use of the last mentioned and selfspacing in frames, it is possible to have every comb in the hive a good one-all of them uniform, with little or no drone comb, and as flat as a board, containing very few drone-cells.

The beekeeper who has good modern hives well painted, and yet who has the arerage natural built or poor combs, will lose a large part of the value of his investment. The rearing of drones means a big waste to the colony; and while one can, as we shall explain further on, make the bees build all-worker combs without any artificial aids, the problem is far easier if he uses full sheets of foundation well wired, as explained and illustrated in Coмr FourDation, subhead "Fastening Foundation in Brond-frames."

There is not a better asset in the beeyard than a full quota of nice perfect combs. If one has only just enough to fill the hives at the approach of the honey-flow, he will lose a large amount of honey if he is producing extracted, by not having an extra supply on hand. Inserting frames containing full sheets of foundation will help out some in an emergency. While the bees may draw these out into combs, it absorbs a large force of bees that might otherwise be occupied in the field gathering honey. Nor is this all. The beekeeper who has a large stnck of good straight combs on hand can control swarming to a great extent as well as secure a larger crop of honey. (See Swarming.) In the production of extracted 


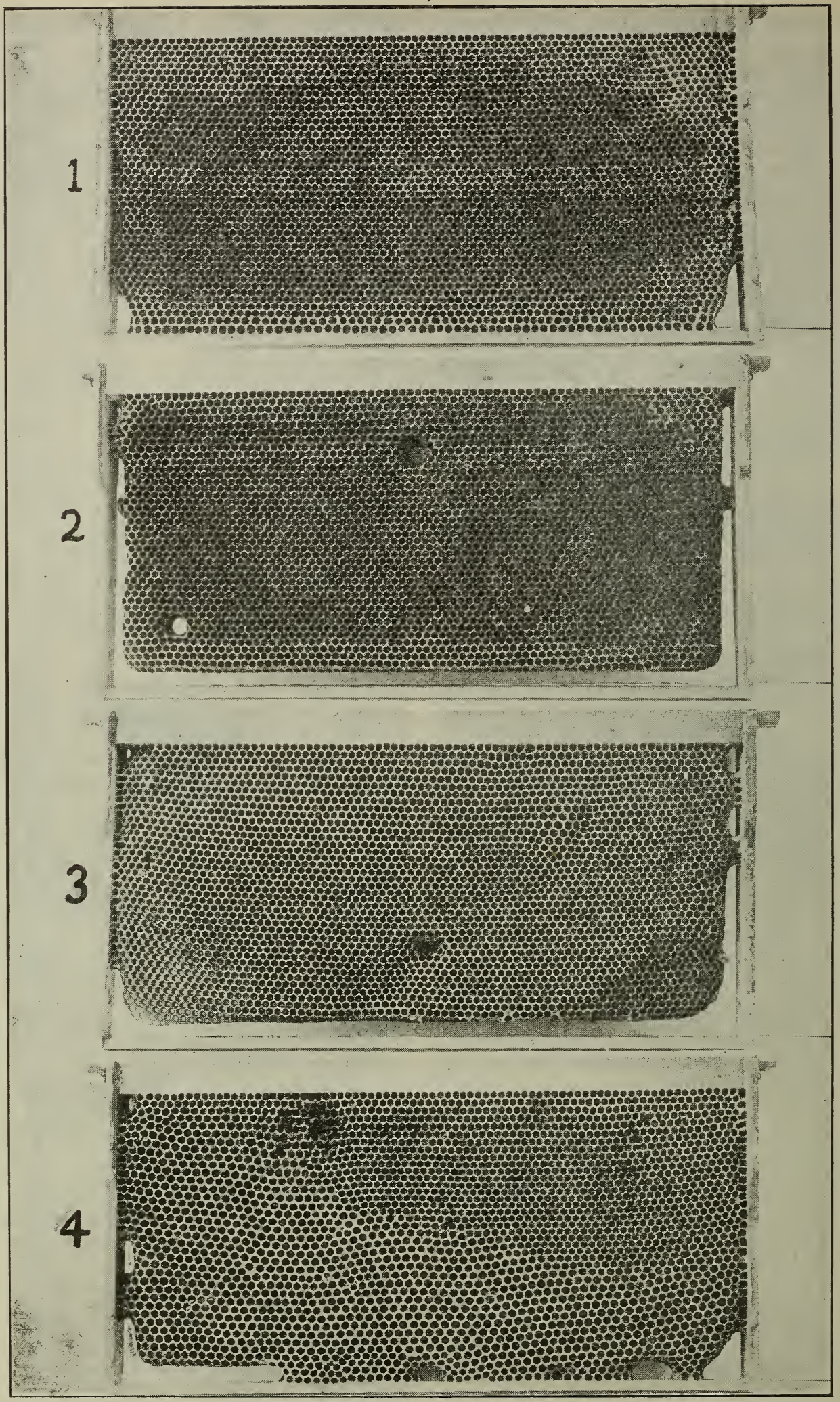

1, perfect; 2 , good; 3 , medium; 4, poor combs. 
honey there should be at least one if not two or three extra supers of drawn combs in reserve. These should be kept carefully stored in empty supers or hive-bodies bee and moth tight, awaiting the harvest.

Some years ago, when we were operating our outyards for extracted honey we got along without any swarming until we ran out of drawn combs. The only thing we could give the bees was full sheets of foundation in brood-frames. As soon as we supplied them with these, swarming commenced. They acted as if they were disgusted because they had to stop and build combs, and then they proceeded to swarm. While we could have extracted the filled combs already on the hives and returned them, such combs were not entirely sealed, and, of course, the honey was not thoroly ripened. As explained under ExTRACTED HONEY, the quality of the honey is, as a rule, very greatly improved by leaving it on the hives until every cell is sealed, and many times it is better to leave it on a week or two after they are sealed.

The novice will see, then, the importance of having a large stock of empty combs on hand. If one does not have the combs, how can he get them? This can be done by giving the bees frames of foundation in the fall, when they are gathering an inferior honey. They may then be extracted and held in reserve until the following season, until the main crop of white table honey comes on. Of course, one can have the combs drawn out during the main honeyflow; but that will mean probably some swarming and a decrease in the crop. The swarming nuisance can be materially reduced by alternating the frames containing brood with frames of full sheets of foundation. Bees will quickly draw out the combs, and the queen will enter them. This will usually check swarming; but it means increasing the force of bees that will come on at a time of year when they will be consumers. This, so far from being a detriment, will be an advantage provided it is in the fall.

\section{THE ECONOMIC WASTE FROM THE USE OF POOR COMIBS.}

At the outset we spoke of the economic difference between good and poor combs. The accompanying illustration will give one an idea of what constitutes a good comb, a medium one, and a poor one. First of all, the combs should be well wired to stand rapid handling, moving full colonies from one yard to another, and more or less rough usage in and out of the extractor. (See Comb Foundation and Extractors.) When the honey is thick the extractor must be revolved at full speed; and unless the combs are well wired they are liable to break out of the frame.

It is essential, also, that the comb be well fastened to the end-bars, and built clear down to the bottom-bar. No. 1 is an illustration of a fairly good comb. No. 2 is fair. No. 3 is a bad one, and both 2 and 3 are defective in that they are only partially attached to the end-bars. In a year or two perhaps, especially during a good honeyflow, the combs may be extended and attached to the end-bars. If the flow is an extra heavy one the bees may build them down in contact with the bottom-bars as shown in No. 1 . If the comb is attached only to the top-bar as in No. 2 there will be a bee-space between the end-bars and the bottom-bars-just the nicest place for a queen to hide when one desires to locate Her Majesty.

Attachments to the bottom-bars can be made very quickly by turning a super upside down, and leaving it so for a week or two, or even twenty days, during which the bees will probably build the comb upward and attach to the bottom-bar, but now the top-bar. (See Reversing.) No. 4, while fairly well fastened, is very bad on account of the presence of so much drone comb. It may be used for the production of extracted honey; but the objection to it is that the queen, unless excluding zine is used, will go on it and fill it with drone eggs. Fixtracted honey can be produced in it as well as in all-worker comb, but the average beekeeper will do well to cut out any comb like No. 4 and melt it up. There will be very few or no drone-cells provided a full sheet of foundation is used and the frame is well wired as shown in No. 1.

The ideally perfect comb is one that is attached to all four sides of the frame, and which has no holes like No. 2. In a good honey-flow these holes will be filled up, but probably with drone-cells; and the presence of these is as bad as the holes themselves.

There are about 132 square inches in a standard Langstroth frame, and this will 


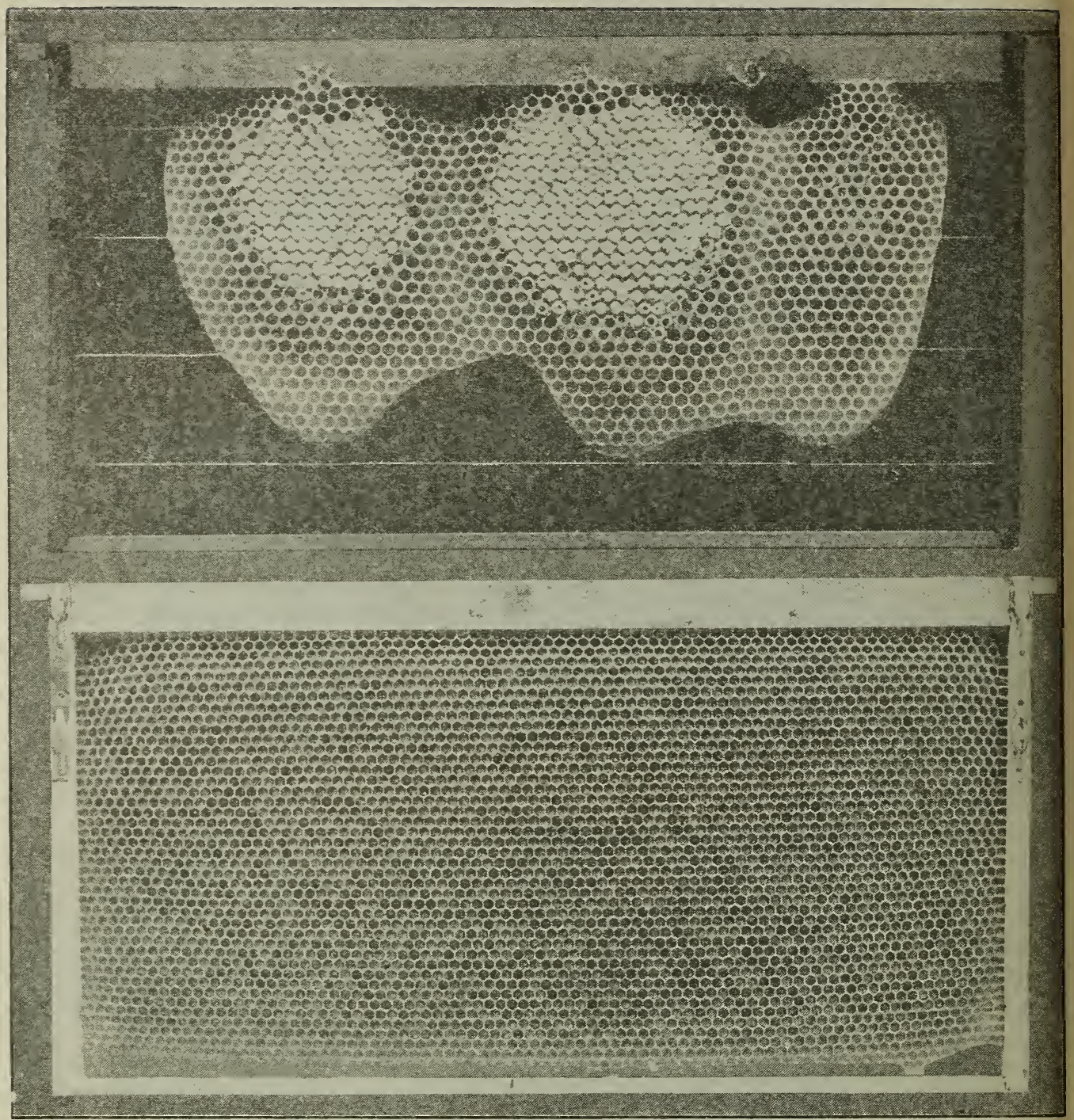

The upper frame, by mistake, contained no foundation, altho it was wired. Note the drone-cells. The lower frame contained a full sheet of foundation, and every cell is worker.

make the average comb contain approximately 6500 worker-cells on the two surfaces, provided the comb is perfect. If the combs are like No. 4, it will be seen there is a big loss in the breeding capacity for worker brood. One may, therefore, have a ten-frame hive and still have only fifty or sixty per cent capacity for worker brood. It is one thing to have good hives, and it is another thing to have good combs; but better yet a combination of the two.

HOW TO MAKE BEES BUILD ALL-WORKER COMB TVHEN ONLY STARTERS ARE USED.

Where one cannot afford the expense of full sheets of foundation it is well to know how to make the bees eliminate all drone combs. Mr. E. D. Townsend, of Northstar, Mich., tells in Gleanings in Bee Culture how this may be accomplished.

The secret seems to be in having just the right number of workers and just the right amount of honey coming in, so that the bees will draw out the combs no faster than the queen can occupy them with brood. As long as this condition lasts we should expect the bees to build worker combs. From this we see that, in order to get good results in comb-building from a natural swarm, this swarm should be of just the right size, and there should be a honey-flow of, say, three or four pounds a day.

We will suppose a large swarm is hived during a period when honey is coming in 
freely. At this time there is too much honey coming in for the best results in comb-build. ing in the brood-nest, if the whole force of workers is compelled to do all their work in the brood-nest. The remedy is to put most of the workers at work in the supers. Most beginners fail in doing this; but the principle is to make the surplus receptacles more inviting to the workers than the brood-nest, and the bees will immediately go up into the supers on being hived. Our comb-honey super with extracting-combs at the sides makes an ideal arrangement for this very thing.

It is plain to see that, if most of the honey being carried in is placed in the sections, where it should be, the queen will not be hurried to keep pace with the workers, consequently nearly all-worker comb will be built. The brood-nest should be filled with comb during the first 23 days after the swarm is hived, for the queen must keep up with the workers and lay in nearly every cell as fast as it is drawn out, or the bees will begin to store honey in the cells. When this condition arrives, the bees, on the supposition that the queen has reached her limit, and that the rest of the combs will be used for storing honey, begin to build the storage size or the drone-cells in the broodnest. This is likely to occur in about 23 days after the swarm is hived; for by this time the brood is beginning to hatch out in that part of the hive where the laying began. From this time on the queen has nearly all she can do to keep the cells filled with eggs where the young bees are hatching. This means that the comb-building part of the hive is neglected, and that the bees build store or drone comb to a great extent until the hive is filled.

There are artificial ways of handling bees so that they will build good worker combs. I refer to the plan of shaking the bees into an empty hive, in the same way that a swarm is hived. If a colony is divided into nuclei of, say, two or three combs each, and each nucleus given a young queen reared the same year, such little colonies will build very nice worker combs; but the beginner will not be interested in this artificial way of making increase, for he should stick to the natural-swarming plan for his increase until such time as he has had experience and made a success of getting a crop of honey. In fact, there are many things to be learned before a beginner should take up artificial ways of making increase.

CONTRACTION. - Along in the '80's contraction of the brood-nest seemed to be all the rage. It was argued that most colonies, Italians especially, after they had put a little honey in the brood-nest, would be disinclined to go above into the supers; and to force them above, some beekeepers took out three or four of the brood-frames below and contracted the brood-nest and then placed supers on top. This was very pretty in theory, and in practice it did force things. It forced the bees into the supers, but more often forced swarming.

Another set of contractionists argued in faror of hiving swarms in a contracted brood-chamber. They did not believe in contracting the brood-nest in an established colony; and, therefore, when they contracted at all they did so only during swarming time. This form of contraction will certainly be better than the other; but as the years go by we hear less and less about contraction and more and more about expansion-how to get stocks strong-big. rousing, powerful colonies. (See ComB Honey, How to Produce; also Building uP Colonies.) An eight-frame brood-nest is usually small enough. Indeed, a ten-frame may be none too big. See Hrves, Size of, elsewhere, for the further consideration of this subject.

COTTON (Gossypium herbaceum L.).It is but a few years, comparatively, since cotton came into prominence as a honeyplant. Years ago cotton honey was hardly known, probably because the honey that bees obtained from cotton was attributed to some other source. But more recently, especially when it is grown in rich alluvial soil, in valleys and rirer bottoms where the growth is luxuriant, cotton is generally recognized as one of the most raluable of honey-plants. In the United States the cultiration of cotton is confined chiefly to "the cotton belt," which includes the states of North and South Carolina, Georgia. Tennessee, Alabama, Mississippi, Arkansas, Louisiana. and Texas, altho thousands of bales are produced in other states. In this vast area there grow annually millions of acres of cotton offering a bee pasture, which in extent and richness can be equaled by few other economic plants.

The cotton plant possesses both floral and extra-floral nectaries. The floral nectaries attract various insects, as bees, wasps, and butterflies, which effect cross pollination. The fire sepals form a cup-like calyx, around the base of which on the inner side there is a narrow band of papilliform cells which secrete nectar. Just abore the nectary there is a fringe or fence of long stiff hairs, which exclude small insects and the 
wet; but the larger bees are able easily to thrust their longer tongues thru this belt of hairs. On the first day after expanding the flowers are pure white or tinged with red, changing on the second day to dark red.

The extra-floral nectaries are of two kinds, one occurring on the involucral bracts and the other on the under side of the leaves. Below the flower there are three leaf-like heart-shaped bracts, each of which has at its base on both the inner and outer side a round nectary. In some varieties of cotton the outer involucral glands are wanting. The leaf nectaries are on the under side of the leaves on the center rib and may vary in number from one to three. In form they are oval or arrow-shaped. Besides bees the extra-floral glands attract many ants and are also visited by humming-birds. The leaf nectaries seem to be most active at the time the leaf reaches full maturity. When atmospheric conditions are just right nectar will collect on these glands in such large drops that one can readily taste it, and a bee can obtain a load in a very few visits. At such times honeybees neglect the blossoms, and the honey comes in very rapidly.

The honey-flow may last from July until long after the first frosts, yielding in some localities as much surplus as all other sources combined. Often a hundred pounds or more per colony is stored in favorable seasons. Even after the first frosts, if there is pleasant weather, the bees may continue for two weeks longer to work upon the plants and make a large increase in the honey crop.

The surplus obtained depends largely upon locality, the soil, the season, and atmospheric conditions. There are many factors which influence the nectar-flow and cause it to vary in aifferent places and at different times. Cotton yields best when the atmosphere is warm and damp. On poor soil or sandy land it does not secrete nectar plentifully, and in some cases not at all. In an average season a good yield may be expected from cotton in the black-land districts and in the river valleys. Under favorable conditions it is not excelled by any other nectar-yielding plant in the cotton belt.

The yield is most abundant in the early morning, and it decreases toward the middle of the day as the atmosphere becomes drier. In the afternoon unless the season is very dry and hot the yield begins to increase again. During cloudy days or when the atmosphere is damp, nectar is secreted abundantly thruout the entire day. The flow has also been observed to increase toward the close of the season.

Cotton honey is very light in color and mild in flavor when thoroly ripened, and it compares favorably with the very best grades of honey. Honey from upland cotton or that which is grown on poorer soil has a light amber color. When first gathered cotton honey has a flavor which is very characteristic of the sap of the cotton plant itself, but this disappears as the honey ripens. During a heavy flow there is a strong odor in the apiary like that produced by brusing cotton leaves.

At Trenton, Texas, in 1909, during a very long drouth a very fine and pure grade of cotton honey was, obtained from cotton growing on rich bottom land. It was so thick that it was almost impossible to extract it and entirely out of the question to strain it thru even a single thickness of cheese-cloth. It was light in color, mild in flavor, and very heavy, and compared well with even the famous huajilla honey. Ordinarily cotton honey granulates easily and in the granulated form is almost pure white and very fine grained.

Cotton furnishes the clothing of the larger part of the human race, and the manufacture of the white fibrous hair on the seeds into cotton cloth is one of the most ancient as well as one of the most important of human industries. Fortunately cotton plants grow in nearly all subtropical and in many temperate regions of the world. They were cultivated in India 500 years before the Christian era, and the Spanish discoverers of America found cotton garments among the natives of Mexico and Peru. Unlike all other fibers cotton can at once, even with the fingers, be spun into yarn without any preliminary preparation. The number of species has been placed all the way from five to fifty; but conservative authority admits of only seven valid species, the other forms being regarded as varietal. Barbadoes, or sea-island cotton (Gossypium Barbadense L.) is cultivated in Georgia, South Carolina, and Florida, but is of comparatively little importance as a honeyplant. 


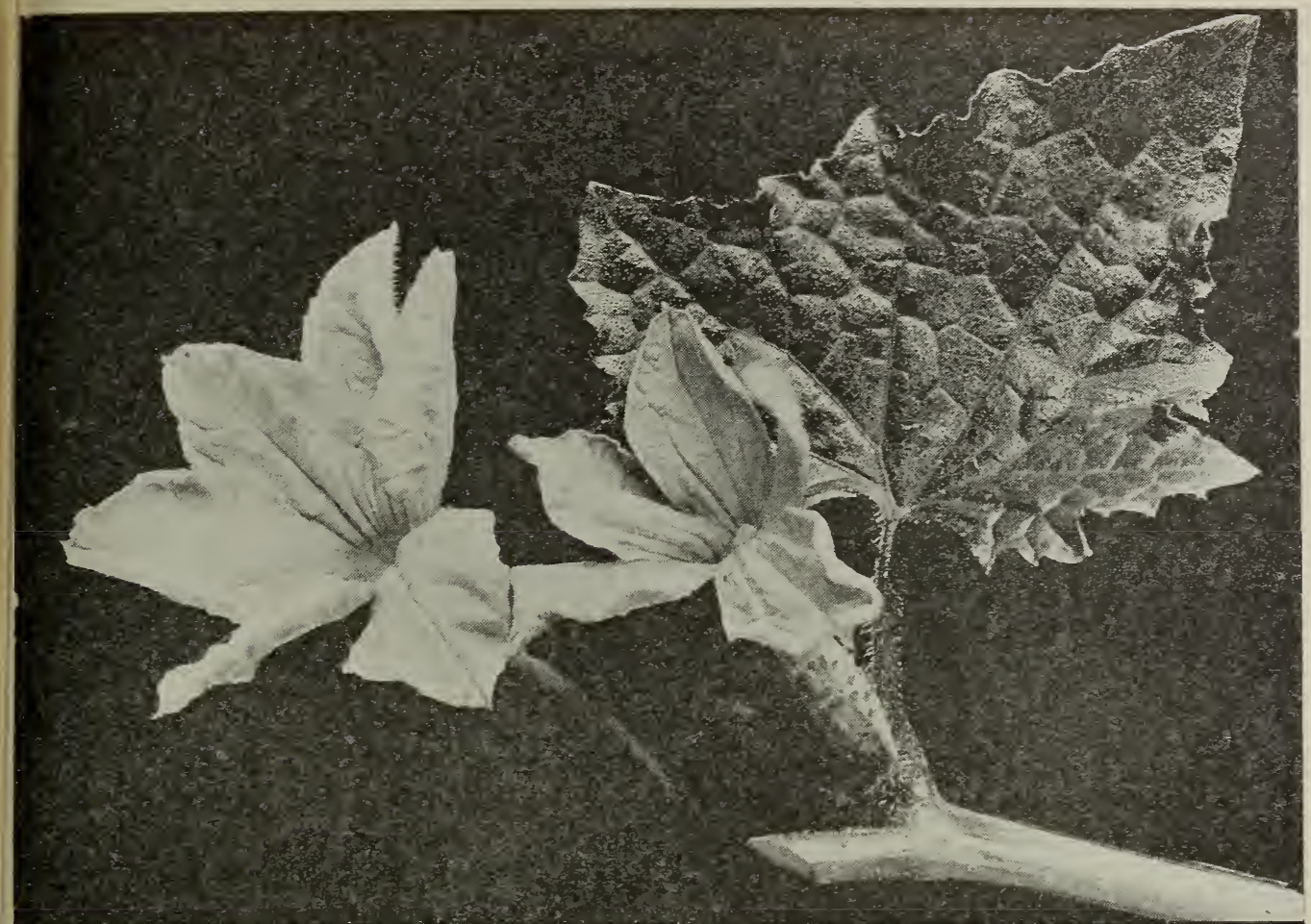

Cucumber.

CRIMSON CLOVER.-See CLOVER.

CROSS BEES.-See ANger of BeEs.

CROSSES OF BEES.-See Hybrids.

CUCUMBER (Cucumis sativus L.).-In the vicinity of pickle-factories large areas are devoted to growing cucumbers. Two factories at Marengo, Illinois, are supplied by 600 acres, which yield from seventy-five to one hundred thousand bushels of pickles annually. The fields vary in size from half an acre to three or four acres, and the ground is completely corered by the large heart-shaped leaves. The total number of acres cultivated for cucumbers thruout the country must be very large. As many as 300,000 cucumbers have been produced on a single acre, but this is more than double the average crop.

In the absence of bees cucumber-blossoms whether in the field or hothouse, remain barren. The stamens and pistils are in different flowers on the same vine, the staminate flowers being more abundant on the main stems and the pistillate on the lateral branches. The former are sometimes incorrectly called "male" and the latter "female" blossoms. The nectar is secreted in the bottom of a cup formed by the fusion of the floral leaves at base. In the staminate flowers this cup is covered by the fleshy expanded stamens, and access to the nectar is gained thru three narrow lateral passages between the anthers. When an insect inserts its tongue in one of these passages both sides of its head are dusted with pollen. In the pistillate flowers the pistil rises from the center of the cup. The staminate flowers are the larger and open first.

In order that the pistillate flower may be fruitful, pollen from the staminate flowers must be brought to the stigmas; and in the fields this work is chiefly performed by honeybees, other insects than bees being of little importance. A market gardener in Manitoba states that during three years he was unable, without colonies of the domestic bee, to obtain more than a dozen cucumbers, and in the case of these exceptions the flowers were pollinated by hand. A colony of honeybees was bought, and subsequently the number was increased to eleven, and that year cucumbers to the ralue of $\$ 55$ were sold. It may be regarded as an axiom in cucumber growing: No bees, no fruit. 
Cucumbers raised under glass must either be pollinated by hand or by hives of bees placed at each end of the hothouse. In Massachusetts cucumbers are grown very extensively in hothouses, and more than 2000 colonies of bees are required annually to pollinate the blossoms. A single grower is reported to have forty acres under glass. Many colonies are also required for the same purpose in New Jersey. Pollination was formerly effected by hand, but the bees have provea most efficient pollinators, and enormous crops of cucumbers are obtained. Unfortunately they often beat against the glass in their efforts to escape into the open until they fall exhausted to the floor and die by hundreds. Many also perish from lack of sufficient stores, so that, as a matter of course, new colonies are required each year.

The honey obtained from cucumber-blossoms is pale yellow or amber, and has at first a rather strong flavor, apparently suggestive of the fruit; but this probably largely disappears in time. In localities where there are pickle-factories beekeepers find the cucumber a valuable addition to the honey flora. Sufficient honey for wintering is often secured besides a small surplus.

The cucumber has been in cultivation in India for over 3000 years and was known to the Greeks and Romans. According to De Candolle it was one of the fruits of Egypt regretted by the Israelites in the desert.

CYPRIAN BEES.-See ItALIANS.
DANDELION ( Taraxicum officinale Weber).-Other English names are lion's tooth, blowball, yellow gowan, and priest's crown. Widely distributed over Europe, Asia, North America, the Arctic regions, and in many other parts of the civilized world. At Medina, as is shown in the photograph, and in many other localities the flowers are in some years so abundant that the fields and lawns are an almost unbroken sheet of golden yellow. The effect is most cheerful and pleasing, and in its season there is no other wild flower that can vie with the dandelion for ornamental purposes on a large scale. Coming as it does in early spring, preceding fruit-bloom, it is a most valuable plant for bees. Altho it yields but little honey, it affords a large amount of pollen at a time when bees require a rich, nitrogenous food for broodrearing.

The dandelion belongs to the Compositae, and is related to the hawkweed and chicory. The head or capitulum consists of from 100 to 200 florets. The corolla of each floret is strap-shaped, but at base unites to form a short tube which holds the nectar. At night and in damp weather the head closes so that there is little visible except a protecting whorl of green bracts. The pollen and nectar are thus completely sheltered from dew and rain. In fair weather the hour of opening in the morning varies from 6 to 8 or 9 o'clock, and the time of closing from 2 till sunset, according to the month and latitude. The flowers open much later in September than in mid-summer, and in northern regions than in the United States. The dandelion often blooms a second time in the fall, but much less freely than in spring.

As the nectar and pollen are readily accessible a great variety of insects are attracted, and more than one hundred different species of bees and flies have been observed seeking the flower food of this species. The supply of nectar is usually scanty; and, while honeybees are very frequently present, the number of visits is not excessive. The pollen is abundant and a special source of attraction. The grains are large, many-sided, and spinose, and so firm- 


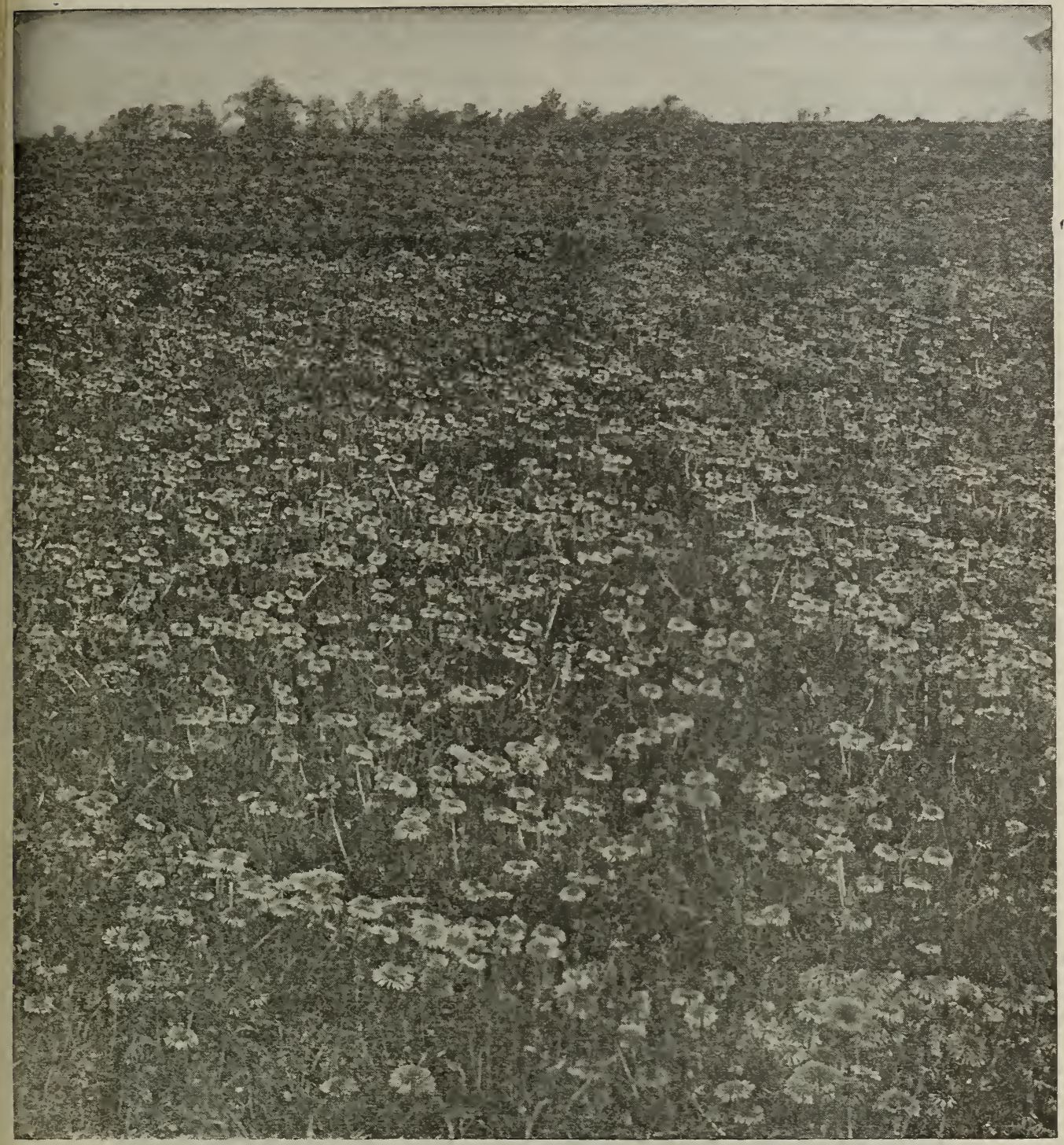

A part of a field of dandelion in full bloom at Medina. This, and other fields like it near Medina, furnish considerable honey and pollen in early spring - just when they can do the most good. We do not find that the plant hurts the hay or pastures in the least.

ly do they hold together that bees can carry large packets of them.

While there is no such thing as dandelion honey on the market and probably never will be, yet the little that is gathered is valuable for brood-rearing. A beekeeper in Illinois, however, reports that one season about ten pounds of dandelion honey per colony was stored in the supers. The flow in May lasts for about two weeks. The honey is a deep yellow, and after extracting crystallizes in a week or two. It has a strong, not to say rank, flavor, and probably would not be liked by persons accustomed to a mild honey. It keeps well and seems to improve with age. Owing to its viscosity and tendency to granulate it would not be desirable for winter food; but since it is gathered so early there is doubtless none left in the fall. It would be well worth while to endeavor to obtain by selection or breeding a variety of this species which would yield nectar more freely.

There are several species of dandelion which, like the honeybee, possess the power of reproduction by parthenogenesis. The upper half of the unopened heads of $T$. vulgare, T. intermedium, T. obovatum, and of several other species, has been cut off with a razor, and all the anthers and stig- 
mas removed before they had ripened, so that fertilization was impossible, yet the plants developed perfect fruits.

The dandelion has both beauty and utility, and an attempt to exterminate it, even if this were possible, would be a grave mis- flow of milk and improves its quality. 'Tons of the leaves, both wild and cultivated, are boiled as "greens" and afford a most palatable and wholesome food-to be had for the gathering. Large quantities are also salted for winter use. The roots serve as a

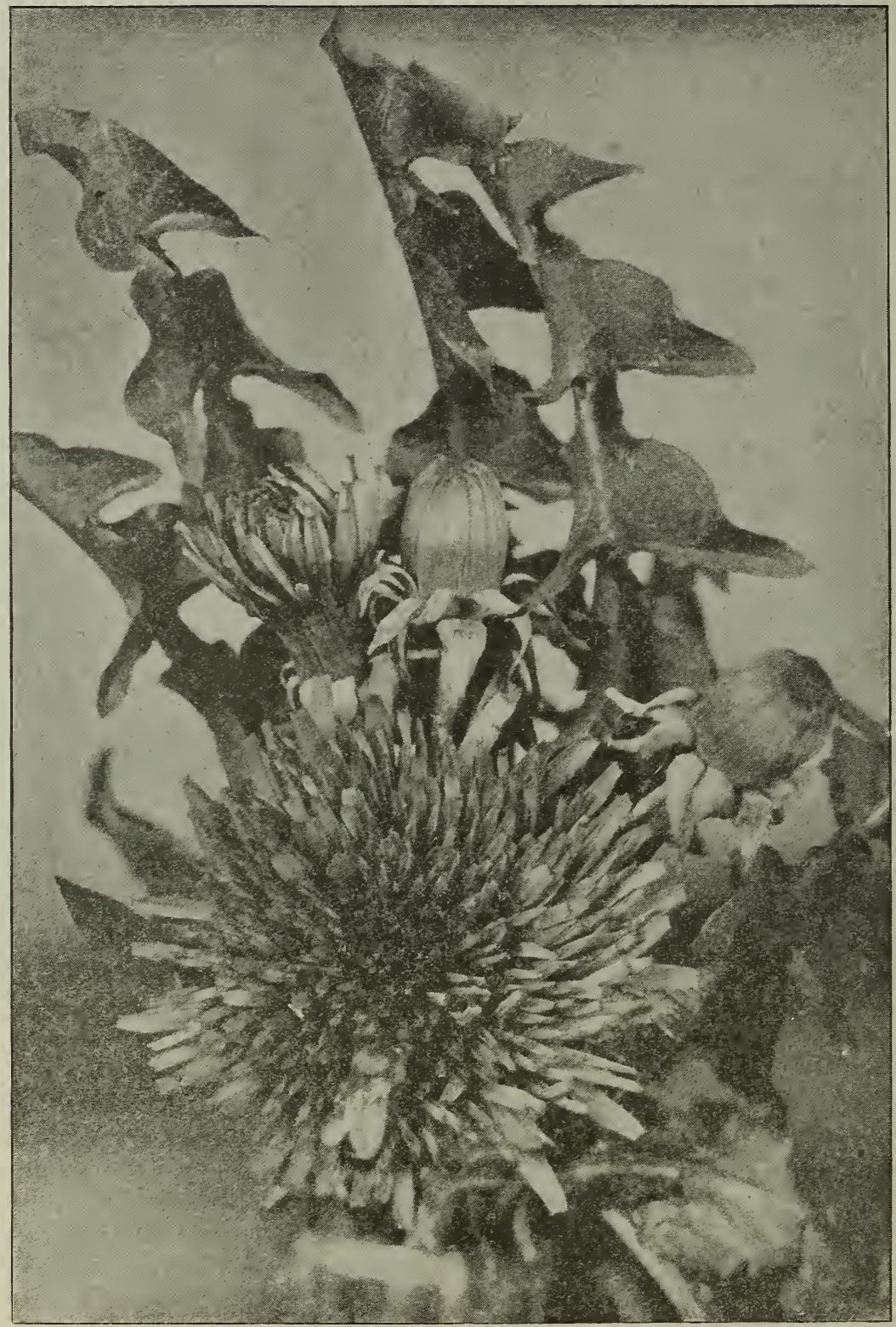

A large specimen of dandelion blossom, buds, and leaves-life size. The blossom here shown is larger than the average. The usual size is about two inches across.

take. "Of the attractiveness of the bloom there can be no doubt. Attentively considered it will be seen that it is a model of symmetry." It is of no injury in the hay fields, and as a pasture feed it increases the tolerable substitute for coffee, and are reputed to be of medicinal value in cases of disordered liver. The sceds are eaten by poultry, and even the flowers are occasionally utilized. 
But more than one futile crusade has been organized against the dandelion based on the complaint that it is a pestiferous weed in lawns. This is, of course, a matter of individual opinion; but personally we hold that its masses of golden bloom in early spring, when there is a scarcity of other flowers, more than compensate for any detriment it may cause in midsummer. A rich soil and a dense turf will do much to eradicate or exclude it; but happily nature has made its wholesale extermination difficult. Contrary to general belief, it can be killed in most cases if it be cut off level with the ground. If this is not effective a drop of kerosene applied with a spring-top oil-can will do it. If the dandelion is not invulnerable, it is invincible. Says A. I. Root: "This plant has been called only a pest, but it is one of God's greatest and most precious gifts in making our northern Ohio clay soil 'a land flowing with milk and honey,' and both at the same time."

\section{DAISY.-See Asters.}

DEVELOPIENT OF BEES.-The literature on the development of the honeybee available to the beekeeper is scant. This is specially true as regards the development in the egg (embryology) and the metamorphosis. The origin of drones from unfertilized egg's has been much discussed in the journals devoted to beekeeping, but such discussion has as a rule contributed but little to our knowledge of the facts. This condition of affairs is somewhat surprising, considering the attention which has been given to anatomy of the honeybee, and also that the development in the egg is well known, having been described by the following investigators: Butschli (Germany) in 1870, Kowalevsky (Russia) in 1871, and Grassi (Italy) in 1884. The metamorphosis was described in detail by Anglas (France) in 1900 .

Before taking up a description of the development of the bee, a few words should be said in regard to what the student of plant or animal life knows as a cell. This word has several meanings, but is used here in a restricted and special sense. All plants and animals are, without exception, composed of one or more cells. The cell is the unit of structure, as the brick is the unit of structure of the chimney or the soldier of the army. Cells are commonly micro- scopic in size, so that it requires many millions of them to make up even so small an animal as a bee. A group of typical tissue cells is shown in Fig. 1. A cell may be defined as "a mass of protoplasm (living material) containing a nucleus." Both nucleus and protoplasm are interdependent; reither is capable of continued existence without the other. The nucleus $(\mathrm{N})$ is a body usually more or less rounded in form, containing within it a substance commonly believed to be the bearer of the hereditary qualities of the individual and of the race. Every cell is to a certain extent independent, carrying on its own vital functions, such as the assimilation of nourishment and

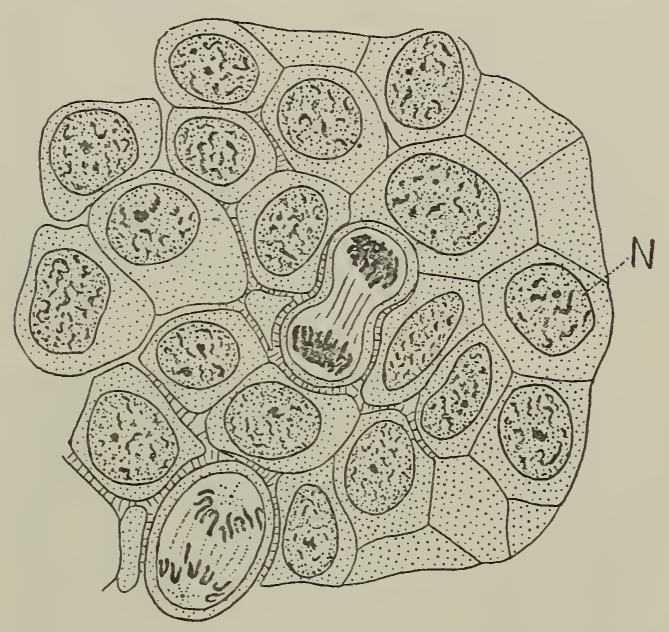

Fig. 1.-Group of tissue cells from the skin of a roung salamander (greatly magnified). $N$, nucleus. Two cells are shown in process of division, and are indicated by their lighter shade.

the elimination of waste. In addition, in the higher organisms, it usually has a special function; for example, the special function of the liver cell is to secrete bile, that of the nerve cell to transmit nerve impulses. All the cells in an organism are, however, so co-ordinated that the sum total of their activities is a unified whole, that is, an individual, capable, under the proper conditions, of maintaining itself and contributing to the reproduction of its kind. One of the protoplasm and nucleus of a typical cell is that of multiplying by self-division. This division always affects daughter cells, thus each receiving a part of both. In Fig. 1 two cells are in process of division.

On beginning its development every egg' is essentially a single cell. In addition to the protoplasm and nucleus of a typical 
eell, tho egre contains also a certain amonnt of non-living material, yolk, which serves as a store of food for the developing enbryo. Before it can begin development, the mifertilized egg or female cell must usually be first united with a inuch smaller and more condensed eell, the spermalozoon, or male cell. 'This eell supplies the male half of the inherited character's and also stimulates the egre into developtnent. This phenomenon is ferlitization. In certain cases egrgs may develop withont the stimnlus of the spermatomoon, and they therefore inherit their characters only thru the mother; this is parlhenogenesis.

'The development of the egrer or eell formed by the union of the male and female cells consists in its repeated division, by which many cells, united together, are formed; the shifting and rearangement of these to form organs and tissues; the gradual appearanee of differences between the cells forming the varions tissnes and organs, so that the cells berome changed or modified in accordance with the function which they are to assume.

'The corge of the honeybee is shaped somewhat like a banana and is about 6-100 of an iuch long. One end is slightly langer than the other, the eger arlhering to the bottom of the rell by the sinaller end. The embryo is always formed on the longer or comvex side of the eger, its lower or ventral surface directed oulward, the head at the larger end. The ego is in appearance pearly white, and slightly transhucent. It is covcred extemally by a very thin but tough membrane whose surface is eovered by a delicate network of ridges. The egre of the bee contains a relatively large quantity of yolk, the protoplasm being eomparatively small in amomnt. On this aceount eell division is restricted to the interior of the ego, the eells thus formed later rising to its surface to form a layer from which all the parts of the future larva are formed.

The first conspicuous evidence of the future embryo is the appearance, during the second half of the second day, of a bandlike thickening on the long side of the egg (Fig. 2). On this thickenirg, at the larger end of the egre the appendages begin to appear als rounded protuberances, the antema $(\Lambda n t)$ and the mouth parts (mandibles and maxillie, Md. $1 \mathrm{Mx}, 2 \mathrm{Mx}$ ) being the first to appear. Behind them are the rudiments of the three pairs of legg (L 1 , L. 2, I, 3). At about the same time the rudiments of the stignata and tracheal system appear as a single row of pits on each side $(S p)$. The rudiments of the silk or spinning glauds (SlkG) also appear as pits just behind the second maxillse. On the upper or dorsal side of the head are also seen two pairs of swellings (Br) which constitute the rudiments of the brain. At this stage therefore nearly all of the important organs of the larva are outlined. The changes leading to the completed larva are illustrated by Figs. $2 c$ and $2 d$. In Fig. 2c a number of important changes are seen to have taken place. The bandlike embryo has widened, growing toward the dorsal or concave side of the egg. The mouth $(M t h)$ and anus $(\Lambda n)$ appear as deep pits at the two opposite ends of the embryo. They join with cell masses on the interior to form the alimentary canal, the parts forming the fore and hind intestines, the cell masses the mid intestine (Fig. 3, MLnt). The mouth parts have changed little, but the upper lip (Len) is now represented by a flap-like outgrowth. The Malpighian tubules, MT, the exeretory organs of the larva, have arisen as out growths of the hind intestine. The pits constituting the tracheal invaginations have enlarged to form sac's, and each of these in turn sends out three hollow outgrowths, two of which extend forward and backward to meet those of the neighboring segrnents, and one of which extends downward to join the corresponding branch in the same segment on the opposite side (Fig. 2, Er). The pit-like rudiments of the silk-glands (Slk-Gl) have growe backward to form long tubes. The rings or segments of the borly are now marked off by constrictions, as they are in the larra. In Fig. $2 d$ the development in the egr is practically completed. 'The important elanges to be noted are: The disappearance of the rudiments of the antenno and legs, the joining together of the second maxillas to form the lower lip; the completion of the tracheal loops ('Tr); and the development of the nervous system. The embryo has by this time completely surrounded the egg, closing up the gap on the back, as seen in Fig. 2b. The embryo next breaks the egg shell and becomes a larva, the development in the egg laving lasted a trifle over three days. 


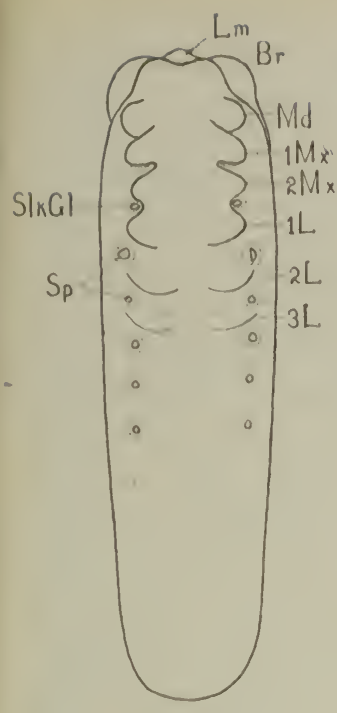

a

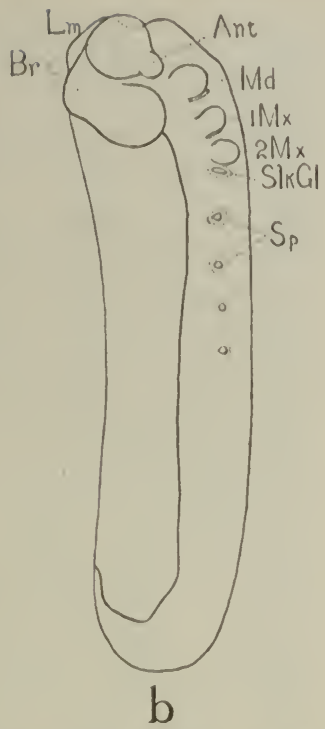

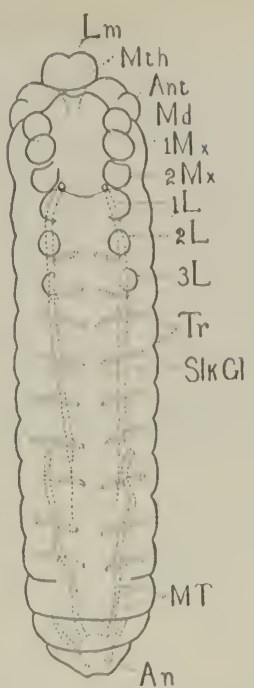

$\mathrm{C}$

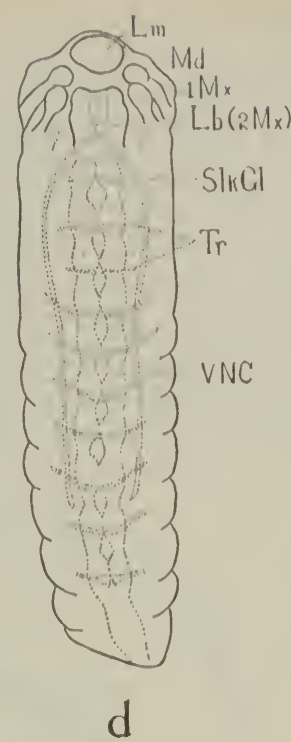

Fra.2. - Three stages to the developrnent of the ege (greatly magnified). The carliest stage at which the rudiments of the appendiges are seen is represented by a und b; $a$, egg seen from the ventral (lower) side; b, from the right side: c, later stage, showing the development of the mouth parts, silk glands, etc.; d, embryo just prior to hatehing, the development withing the egg leing completed; 入u, nums; Ant, untenna; Br, lirain; $1 \mathrm{~L}, 2 \mathrm{I}, 3 \mathrm{~J}$, thoracic legs; 1.h, labium (lower lip)); Lm, labrum (upper lip); Md, mandilie; M'I', malpighian tubules; 1Mx, 2Mx, first and second maxilus: Slk(t), silk gland; Sp, rualiment of spiracle; 'Tr, trachea; VNC, ventral nerve cord.

It is interesting to note that cleavage and in general what may be ealled "the preparation of the materials," from which the parts of the embryo are formed, consumes from 42 to 44 liours, or over half of the entire period of development. Afler this the embryo develops very rapidly, as shown by the three embryos represented in Fig. 2. The embryo represented by Fig. $2, a$ and $b$, is about 45 hours old; Fig. 2e, about 56 hours old; while that shown by Fig. $2 d$ is completely developed.

The yolk, which forms the greater part of the egg, remains in the interior of the egg, the embryo being formed on the exterior and then gradnally surrounding the yolk, the lateral edges of the embryo finally uniting in the dorsal mid-line. The yolk meanwhile is being used up by the growth processes and undergoes considerable shrinkage. 'Toward the end of development it becomes enclosed in the mid-intestine and is finally digested there.

In respect to their later development insects are usually divided into two elasses -those with a complete metamorphosis and those with an incomplete metamorphosis. The honeybee is an excellent illustration of the first class, while the grasshopper is an illustration of the second. When the young grasshopper hatches from the exge it is elearly recognizable as a grasshopper and would never be mistaken for anotler insect, since it resembles the adnlt in every important particular exeept that its wings are only short pad-like structures. Moreover, its food and habits of life are those of the adnlt, and it faces the same difficulties and dangers. Its development into the adult is simple; it is little more than an increase in size. The honeybee, on hatching from the erg, is, however, quite a different creature from the adnlt, being without organs of locomotion (legs), touch (antenna), or sight (eyes). Moreover, its integnment is thin and not hardened as in the adult. The larval stage in insects with complete metamorphosis is a short eut in development, by which the young insect is enabled to obtain food more advantageonsly and to grow more rapidly, and, in the case of the bee, is also protected from enemies. The bee larva is especially adapted by nature for rapidly digesting and assimilatiner food. $\Lambda$ s Fier. 3 slows, its mid-intestine or stomach ocempies the greater portion of the bodly of the larve. As one beekeper expressed it, "a larva is all stomach." For this reason and because of the rich and easily digested food supplied by the worker 
bees, and also because the young or larval bee is not required to use up any energy in escaping enemies or in obtaining food, all its energies being bent on eating and growing, it is enabled to complete its growth in a short space of time. This is accomplished in the case of the worker bee in a little less than five days. When the larva is first hatched it lies bent in the form of the letter $\mathrm{C}$ on the bottom of the cell. As it increases in size it becomes more tightly curled until, when about three days old or a trifle older,

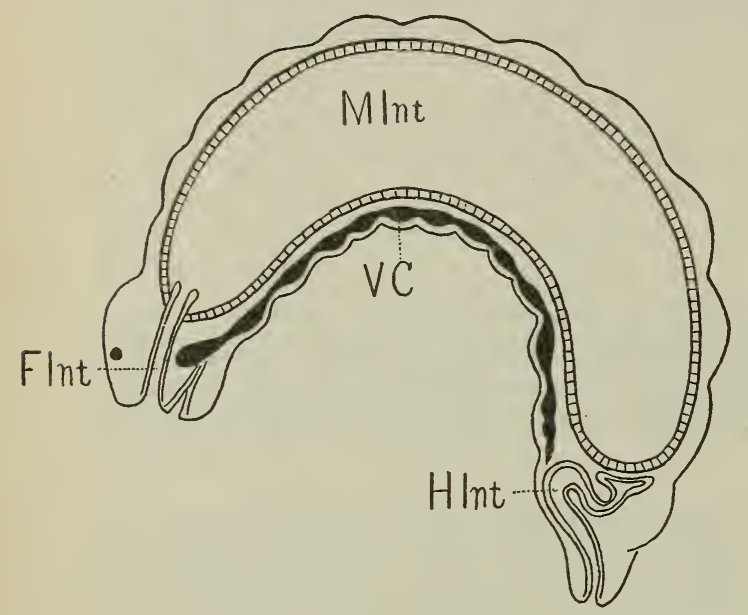

FIG. 3.-Diagram of a longitudinal section through a larva. Flnt, fore intestine; HInt, hind intestine; MInt, mid intestine; VNC, ventral nerve cord.

it is so large that it covers the bottom of the cell with its back against the wall of the cell and its two ends close together. It should be noted that a larva of this age is actually much larger than those commonly supposed by beekeepers to be three days old and is much too large to be used in queen-rearing. Notwithstanding its cramped position the larva does not alter its position in the cell, but remains curled on the bottom. Since the walls of the cell prevent further expansion in that direction the larva grows in the only other direction possible-that is, toward the mouth of the cell. When a larva is nearly full grown it fits the cell like a tight plug, and if it could be frozen or otherwise fixed in this position, when taken out it would present a veritable cast of the lower half of the cell, reproducing its rounded bottom and its six flat sides. In fact, during the fourth and fifth days, the larva fits the cell so snugly that its removal is scarcely possible without severe damage to either larva or cell. It is thus evident that, during the later stages of growth, the larva is greatly distorted. When removed from the cell, however, it presents the appearance shown in Fig. 4c, and it is scarcely conceivable that such a plump-looking creature could ever have occupied such narrow quarters. During the first three days of the larval stage of the worker bee, and during all of the larval stage of the queen, it is fed a highly nitrogenous food produced by the nurse bees. The origin of this food, whether it is a secretion from special glands of the nurse bees, or is regurgitated from their stomachs, is not at present known. After the first three days, however, the worker bees are fed honey and pollen. When the larva has attained its full size, which in the case of the worker bee occurs after about five days, it is sealed up in its cell by the worker bees, which place a thin cap of porous wax and pollen over the muuth of the cell. Next the entire interior of the cell is lined with a delicate but tough silken cocoon spun by the larva and secreted by special glands which become active at this time-the silk-glands (Fig. 2, $c$ and $d$, SlkGl). To accomplish this task the larva has to turn lengthwise of the cell at least twice. At the time of

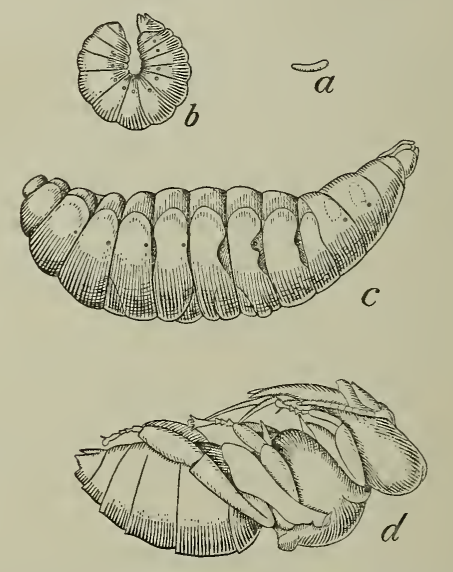

FIG. 4.-Four stages in the development of the honeybee. a, egg; b, young larva; c, old larva; $d$, pupa.

spinning the cocoon a connection between the mid and hind intestines (Fig. 2, MInt, HInt) becomes established, and the darkcolored residue of the food digested during the feeding period is evacuated on the bottom of the cell, usually in its angles. Soon after the spinning of the cocoon, which consumes about one day's time, the larva 
gradually becomes motionless, lying extended on its back, with its head toward the mouth of the cell. The larva now becomes a scmi-pupa or pronymph. Its form is much like that of an old larra, but its color seems paler and less glistening. If touched a semi-pupa seems soft and pulpy, and if an attempt is made to remove it from the cell it will be found very delicate and easily ruptured. After about three days in this stage, or four days after capping, the semipupa moults its larral skin and becomes a pupa, with the form and all the parts of an adult bee (Fig. 4d). These-legs, antennæ, etc.-hare been dereloping rapidly during the semi-pupal stage, but were covered and therefore hidden from view by the larral skin. On the eleventh day after hatching, the eyes begin to turn from white to pink, which color later turns to reddish brown and finally, on the sisteenth day, to black; the thorax at the same time becomes a light yellowish brown. On the nineteenth day after hatching the development is complete, the roung bee sheds its pupal skin and gnaws its way out of the cell. The duration of the larval and pupal stages in the development of queens and drones is different from those of the worker. (See Bee Metamorphoses, in "Reekeepers' Dictionary," in the back part of this work.)

It is evident that, during the period after the larva is sealed up in the cell, the developmental changes which it undergoes must be active and radical indeed in order to bring forth a creature as different from the larva as is the adult bee. The following is only a brief sketch of these complex processes. In general they inrolve a tearing down and rebuilding of many of the tissues of the bee as well as the coming into activity of portions of the larra which have been dormant ever since it left the egg, or even before this time. To the former category belongs in particular the alimentary tract. which is literally torn down and cast away, being replaced by new cells. To the latter category belong the legs, wings, and eyes, which are developed from groups of cells whose activities have been held in abeyance during the larral period. These are formed from growth centers of the body wall which are formed before the larra hatches from the egg, but which are quiescent during the growing period of the larva. After the larva is sealed up these rudiments are roused into actirity. The legs and wings are formed in pockets of the body wall, and, after the moult of the prepupal skin, are pushed out by blood pressure from the interior, as the fingers of a glove may be pushed out by blowing into them. The muscles of the larva are partly torn down and replaced by new muscles, and partly persist as the muscles of the adult. The changes undergone by the nerrous system and the trachæ are much less radical. All these changes consume energy, which is shown by the fact that there is a considerable loss of weight during the pupal period. This energy is stored up in the larva largely in the form of fat contained in the fatbody which surrounds the mid-intestine.

DISEASES OF BEES.-A few years ago it was considered that bees were freer from disease than perhaps any other class of animated nature, for the reason that individual members of the colonies were so constantly giving way to the younger ones. But this has been shown to be, to some extent at least, a mistake; for apparently there are at least three or four distinct diseases with which the beekeeper has to contend; and it is well for the beginner to have an idea, at least, of what they are like; for the time to cure a disease of a contagious character is to take it at the start, or, better still, take precautionary measures such as will prerent its making eren a beginning.

\section{HOT TO AVOID DISEASE.}

Contagious diseases spread very rapidly among bees, just as they make rapid headway in crowded centers of the human family. Unfortunately, bees are disposed to rob from each other during a dearth of honey; and if the germs of disease or infection reside in the honey they may be scattered orer the entire apiary in a few days. An infected colony is naturally weakened and discouraged, and as a result the bees do not make the defense that they would under normal conditions. During a dearth of honey the healthy bees all over the yard are quite disposed to rob the weak or sick ones, so that the infection is scattered right and left.

One of the best precautions against disease is good food, and keeping all colonies strong. A healthy human being is much 
more able to resist the germs of infection than one who is " all run down." A person, for instance, is not likely to come down with typhoid unless his system is greatly reduced.

TWO CLASSES OF DISEASES.

The diseases with which the beekeeper has to contend may be divided into two classes-those that affect the mature flying bees, and those that attack the brood. The latter are considered under Foun Brood.

Among the diseases that attack the mature bees may be mentioned "spring dwindling." This, perhaps, should hardly be considered a disease, but it is a malady with which one has to deal. For particulars regarding it see Spring DwINDLING. Still another trouble is dysentery. This in some cases may be a germinal disease; and in most cases assumes the nature of an ordinary diarrhea. See Drsentery.

\section{BEE-PARALYSIS.}

This is a disease that is much more prevalent and virulent in warm than in cold climates. Almost every apiarist in the North has noticed at times perhaps one or two colonies in his apiary that would show bees affected with it. Yet it seldom spreads or makes any great trouble; but, unfortunately, this is not true in some parts of the South and West. In the South it is known to affect whole apiaries, and seems to be contagious. It may be Isle of Wight disease described later.

\section{SYMIPTOMS.}

In the early stages an occasional bee will be found to be running from the entrance, with the abdomen greatly swollen, and in other respects the bee has a black, greasy appearance. While these sick bees may be scattered thru the hive, they will sooner or later work their way toward the entrance, evidently desiring to rid the colony of their miserable presence. The other bees also seem to regard them as no longer necessary to the future prosperity of the colony. In fact, they will tug and pull at them about as they would at a dead bee until they succeed in getting them out in the grass, where the poor bees seem willing to go and die alone.

Another symptom is, that the bees often show a shaking or trembling motion. Along with this is an effort to scratch or tug at their bodies with their legs as if there was an itching or irritation. The other bees tug and pull at the affected bees, apparently trying to get them out of the hive.

\section{TREATMENT AND CURE.}

In most cases, destroying the queen of the infected colony, and introducing another from a healthy stock, effects a cure. This would seem to indicate that paralysis is constitutional, coming from the queen; but in the South, where the disease is much more prevalent and destructive, destroying the queen seems to have but little effect. Spraying the combs with a solution of salt and water, or of carbolic acid and water, has been recommended; but these do little or no good. One writer recommends removing the diseased stock from its stand, and putting in its place a strong healthy one. The affected colony is then removed to the stand formerly occupied by the healthy bees. He reports that he tried this in many cases and found that an absolute cure followed in every instance. The rationale of the treatment seems to be that the bees of the ordinary colony having beeparalysis are too much discouraged to remove the sick: as a consequence, the source of infection-that is, the swollen, shiny bees-are allowed to crawl thru the hive at will. But when the colonies are transposed, the healthy vigorous bees of the sound stock carry the diseased bees entirely away from the hive. The sick and the dying removed, the colony recovers.

Mr. O. O. Poppleton, of Stuart, Florida, has had a large experience. One plan that he uses is as follows:

$\mathrm{He}$ sprinkles sulphur over the affected bees and combs, but not until all the brood in the diseased colony has been removed and put into a strong healthy one; for Mr. Poppleton says the sulphur kills all unsealed brood and eggs; that no harm results in putting the brood among healthy bees, as be finds the source of the malady is not in the brood or combs; for he has put combs from paralysis colonies repeatedly into healthy ones and never (but once) did the disease develop in any such colony, and that was a year afterward.

At first, says Mr. Poppleton, the disease seems to get worse instead of better. The colony will dwindle, but in two weeks there 
will be a decided improvement, and finally the colony will be cured and will stay cured. In many cases, he thinks, it may be necessary to repeat the application of the sulphur about ten days after the first time. This makes sure that every bee has received a curative quantity of the sulphur, even if it were not in the hive at the first dose.*

While the foregoing has worked well, yet because it is attended with a rapid reduction of the strength of the colony so treated, and because the disease has a tendency to run in certain strains that are very susceptible to it, Mr. Poppleton thinks that, in the long run, it may be better to use the following plan: He forms as many nuclei from strong healthy stocks as there are sick colonies to be treated. $\Lambda$ s soon as the nuclei have young laying queens, he gives to each, as fast as they can take care of them, one or two frames of the oldest capped brood from each of the paralytic colonies, and thereafter till all the brood of such colonies is used up. The diseased bees and queen he next destroys with sulphur fumes, fumigating the hives at the same time.

BEE PARALYSIS IN AUSTRALIA; DEVELOPING A STRAIN OF BEES IMMUNE TO IT.

As already mentioned, bee paralysis seems to be more virulent in hot climates than in cold ones; and it also appears that some strains of bes are less immune to it than others. Mr. F. R. Beulne, of Tooberac, Australia, one of the most extensive beekeepers of that country, has had a very large experience with it. In some parts it is very destructive. But Mr. Beuhne has it well under control by developing and propagating a strain of vigorous leather-colored Italians. The yellow strains he does not find to be very resistant to the disease. It appears that, by paying careful attention to breeding, the tendency to contract this disease may be almost entirely eliminated, and Mr. Beuhne has succeeded. On one occasion he had shipped into his locality 50 colonies, and almost immediately every one of them became badly affected. By killing off the queens and introducing his own stock he cured the disease.

Repeated tests have shown that paralysis is never transmitted by the brood or combs, but that it is carried by the read or sick

* Always dust the sulphur on in the evening.

bees. It is, therefore, important that, in giving the combs to the nuclei, there be no dead bees in the cells.

\section{ISLE OF WIGHT DISEASE.}

This is a condition that was first described from the Isle of Wight, south of Great Britain, in 1904. It continued on from year to year until it came very near wiping out all the bees on the island. It was feared that it might get on the mainland of England, and in 1907 it did make a start there. At first but little attention was paid to it; but the beekeepers of the British Isles learned that it was something very serious -much more so than European or American foul brood.

SYMPTOMS AND DIFFERENTIATION BETWEEN ISLE OF WIGHT DISEASE AND BEE PARALYSIS.

The symptoms are very similar to those of bee paralysis, and it may be a modified form of that disease. It is both endemic and epidemic. A careful reading of the reports in the British Bee Journal for the last ten years seems to indicate the symptoms as follows:

A few bees will be crawling out of the hives the same as when attacked by bee paralysis, crawling up spears of grass; and if they can fly at all, it is but a few feet. In some cases the abdomens are distended by fecal accumulations. In other cases there is no distension. Sometimes the smaller or the larger wings in some specimens seem to be out of joint. In bee paralysis the wings appear normal, but show a tremulous motion; but very little of this tremulous condition has been seen in the Isle of Wight disease. The bees sometimes lose the use of one or more pair of legs or drag their hind legs, tho the others may be more or less vigorous. The bees with Isle of Wight disease become listless, and cluster in bunches around the entrance of the hive. In bee paralysis there may be somewhat similar clustering; but the bees are more scattered. The affected bees of the Isle of Wight disease, from reports, are not black and shiny as in the other disease. In fact, in many cases they seem to be quite normal in their appearance, differing only in their behavior. As the disease advances, the crawling bees will rlag their distended abdomens on the ground, seeming not to have the power to 
carry them as they ordinarily do, owing to their inability to take the cleansing flight. As it progresses further, every bee in the hive will be involved, and finally the cluster will be reduced to just a very few in the hive centering around the queen. The queen seems to be the last one affected.

The intestines of some of the infected bees are said by some writers to contain a large amount of undigested pollen. When this disease is contracted, the bees, it is stated, seem to have an unusual fondness for nitrogenous food, even gorging themselves with pollen of all kinds without collecting any in their pollen-baskets. This is doubtless what causes the abdomens of some of the bees to be swollen. So distended at times are they that it appears to interfere with the proper action of the breathingspiracles.

Sometimes, more especially in early spring, the affected bees seem to lose control of the muscles of the bowel and discharge a liquid looking very much like that of ordinary dysentery. Whether this is one of the symptoms of Isle of Wight disease, or whether it is another disease, or just common dysentery that attacks the colony weakened by the malady, does not seem to be clearly shown.

Dr. Zander, of Germany, found in the chyle stomach of affected bees that soiled their hives and combs with the discharges of fecal matter a nosema which he called Nosema apis. Referring to this, an elaborate report on the Isle of Wight bee disease published in Great Britain in the Journal of the Board of Agriculture, Vol. XIX., No. 2, May, 1912, says:

Since no method of cultivating Nosema apis outside the body of the bee has yet been devised, spores of Nosema, obtained from the bodies of diseased bees, were used. It is shown that the disease can be produced in healthy bees by feeding with syrup or honey containing spores, by contaminating their food with infected excrement, by allowing them to feed on candy previously used by infected bees, by placing bees dead of the disease in the cages occupied by healthy bees, and by confining healthy bees in cages in which diseased bees had traveled. By observations on infected stocks kept in captivity the variations in the symptoms were studied. Some of the experiments seemed to indicate that partially immune stocks exist, which can be caused to suffer from the disease only with difficulty, but which may harbor the parasite and act as centers of infection for susceptible stocks.
A nosema is often found in other insects, and it is said to be quite destructive, especially to silkworms. As Nosema apis is a member of the group named Microsporidia the term Microsporidiosis has been suggested to denote the cases due to infection with Nosema apis.

The later researches of Drs. GrahamSmith, Malden, Fantham \& Porter, all of Cambridge, have confirmed the findings of Dr. Zander, and agree that the so-called Isle of Wight disease is caused by the presence in the walls of the chyle-stomach and intestine of the bee of vast numbers of the microscopic animal parasite or protozoon Nosema apis. This belongs to the group called Microsporidia, hence the disease is now known in Britain by the scientific name of Microsporidiosis.

As in the case of bee paralysis, the Isle of Wight disease seems to be much worse during a wet and foggy season than during a warm dry one. Similarly a moist climate is more favorable to their propagation than a dry one.

\section{HAS THERE BEEN ANY ISLE OF WIGHT DISEASE IN AMERICA ?}

A malady very similar to the condition described in the Isle of Wight disease has been found in several portions of the United States. Whether it is bee paralysis, whether it is the Isle of Wight disease, or whether they are one and the same thing, at this writing is not known. In 1915 (which was unusually wet) there was a scourge of bee disease in this country, particularly around Portland, Oregon. Many of the symptoms were the same as those described for the Isle of Wight disease and bee paralysis. In the disease reported from the Northwest, it was stated that the brood itself was sometimes involved. But if the colony becomes listless it is apparent that the brood would be neglected, and therefore die of starvation.

A condition similar in many respects was noticed down in the Mississippi Valley, in parts of Texas, California, and in some of the West Indies in 1915, and in the '90's in Florida; but as soon as settled warm dry weather came on it disappeared.

There are many puzzling things about that peculiar condition that developed in the Northwest in 1915 and disappeared. The symptoms were not quite like those of 
bee paralysis, nor entirely similar to the Isle of Wight disease. The malady, in some cases, seemed to be helped somewhat by the application of sulphur sprinkled over the combs as recommended by 0 . O. Poppleton for bee paralysis; but sulphur seems to be of but little value with a similar disease which has wrought such havoe in the British Isles.

\section{SOME STRAINS MORE RESISTANT THAN OTHERS.}

In the United States, Italian bees and their crosses are predominant among our most successful apiarists; and since the Italians are found to be more resistant to European foul brood, the best beekeepers are introducing them as rapidly as possible, especially if they have hybrids. In Great Britain black bees are predominant; and as this race is not nearly as resistant to European foul brood, it is to be presumed it is a more easy prey to this peculiar malady than a vigorous strain of leather-colored Italians. Indeed, there are some reports in the British Bee Journal showing that the leather-colored Italians are more resistant to the Isle of Wight disease than the ordinary blacks. It is equally true that some strains of Italians, as with bee paralysis, have appeared to be much more resistant to the disease in Oregon than other strains of Italians. It is hoped that immune strains can be found for the Isle of Wight disease in Great Britain.

\section{THE MAAY DISEASE.}

In Europe, in Germany, and in France, there has been reported a disease not unlike the Isle of Wight trouble, except that it is never seen after early summer. In France it has been called mal de mai; in Great Britain, "May disease;" in Germany, Maikrankheit. They all refer, of course, to the same condition; but apparently the symptoms of this disease are not the same as those of the Isle of Wight disease. It comes on in May and June, and then disappears. It is more the nature of dysentery, and warm weather seems to abate it. It is probable that it is not the same condition as described for the destructive Isle of Wight disease.

TREATMENT OF ISLE OF WIGHT DISEASE.

The best authorities in Great Britain seem to feel that the only thing they can do is to destroy bees and combs, and disinfect the hives and everything connected with the bees. The dead bees in the grass and hives, some believe, are also a source of infection. This may or may not be true. Some even go so far as to say that every colony should be burned in the yard, and that other hives, even several miles away, should receive like treatment.

Experiments have been carried out to test the efficacy of various medicaments; but up to the present without success, and medicated syrup has hitherto proved valueless. The danger of the spread of the disease is from what have been termed "parasite-carriers" -that is, bees in which the parasite is present without causing the discase.

The weather conditions in the United States are probably such that the Isle of Wight disease would not make very much headway here; still, we had best take no chances. There should be no importation of any bees into this country from any of the British Isles or from any other territory where it finds lodgment.

DISTANCES BEES FLY.-See FLIGHT OF BEES.

DIVIDING.-Under the head of ARTIficial Swariming, Increase, Nucleus, and SwARMING, we show various methods of dividing. But dividing, as it is ordinarily understood, has to do with the operation of increasing the number of colonies or stocks by taking part of the frames and adhering bees, with or without a queen, and putting them in another hive on another stand. Generally speaking, dividing is unscientific and wasteful, while artificial swarming or division on the plans described under NUCLEUS and INCREASE are scientific and profitable because they are worked in such a way as to secure a honey crop as well as an increase in the number of bees or colonies. Dividing may be performed so as to ruin all chances of a honey crop and in addition leave the apiary with a lot of weak nuclei in a totally unfit condition to go into winter quarters, for it is an axiom in beekeeping that one good strong colony will secure more honey than that some colony unintelligently split into halves and put on two different stands.

DOMESTIC ECONOMY O F TH E HIVE.-See BeE Behavior, BRoOd AND 
Brood-Rearing; also Developaient of the BEE.

DRIFTING.-This is a word that has been coined by beekeeper's referring to a lot of bees in the air that have by mistake gone into the wrong hive. Young bees in their playspells referred to under "Play Spells of Young Bees," under RoBbing, not haring thoroly learned the location of their homes, will drift to a hive or hives where many bees are flying strongest, and go in just as if it were their regnlar home. Even the old bees, when all the lives are set out of the cellar, will very frequently drift into the wrong' hive. 'The colonies that are making' the biggest hubbub in front of the entrance will attract flying bees from their weaker neighbors.

Drifting also takes place when a large number of hives all alike are placed together in one row. When the conditions at each entrance are practically the same, the bees become more or less confused. Sometimes drifting under conditions like this results in robbing; and if there is any disease in any hive it will be carried all up and down the row. Under the head of APIARY we emphasize the importance of so placing the lives in a yard that each set of bees can recognize their own entrances. The hives should face different points of the compass, and near some distinguishing object. Slirubs or bushes of different sizes, a tree, a stump here and a building there, all serve the purpose of giving each hive a location and an identity all its own.

When the hives are placed in pairs there is not much danger of the bees of the weaker colonies drifting into the stronger ones, for the bees seem to know the difference between right and left in going back home; but they do not readily distinguish their own individual entrances when the hives are painted the sanie color, and when each hive looks exactly like other hives in the row.

The arrangement of the hives in our Cuban apiary, as illustrated under APIARIEs, which see, is very bad, and decidedly favorable for drifting. The hives would not have been so placed except that our apiarist was very much cramped for room. But it would have been far better if he had reversed the entrances and placed the hives, some zigzagwise and some square with the world.

Drifting when taking bees out of the cellar can be avoided somewhat if the directions are followed under Winterixg in Special Repositories, subhead "Setting" Bees Out of the Cellar." Drifting can also be avoided when locating bees at outyards by moving them toward night, and placing. them on their stands when it is too late for them to fly, being careful to place the individual hives so that each will have a location peculiar to itself. Next morning they will mark their entrances.

\section{WHY ARE NOT DRIFTING BEES STUNG LIKE ROBBERS ?}

The novice will, perhaps, ask the question why, when bees drift into the wrong hive. they are not instantly killed by the guards at the entrance, the same as happens in a case of robbing. When bees drift, as already explained, it is because a new condition has been created, or because the young bees when at play have not yet thoroly learned their location. When, therefore, they go by mistake into the hive, they enter right in as tho it were their own hive. Robber bees (see RobBing) show by their actions that they are afraid of being grabbed by the guards of the hive they propose invading. Their guilty actions, seeking by stealth or quick dodging to get into the hive, betray them at once. On the other hand, the drifting bees show no such actions, and of course go right into the hive as if they belonged there.

Take the case of bees just out of the cellar or a lot of bees moved to an outyard. The conditions are entirely different. When they rush out into the air, many bees scarcely know whence they came, and the result is they will join the entrance of the strongest flyers, or where the greatest demonstration is being made in front of the entrance, and so go in without arousing suspicion.

When bees are out for a playspell there will be a big liubbub in front of the hive whence they came. Other young bees in the air, or in nearby hives, attracted by their anties in the air, are quite inclined to join in the fun, for fun it evidently is. When the frolic is over, nothing can be more natural than for the whole bunch of them to go into the hive whether they belong there or not. If the hives are properly located, as explained on the preceding page, and under APIARY, there will be very little drifting as a result of playspells. 
DRONES.-These are large noisy bees that do a great amount of buzzing, but never sting anybody, for the very good reason that they have no sting. The beekeeper who has learned to recognize them, both by sight and sound, never pays any attention to their noise, but visitors are many times frightened by their loud buzzing.

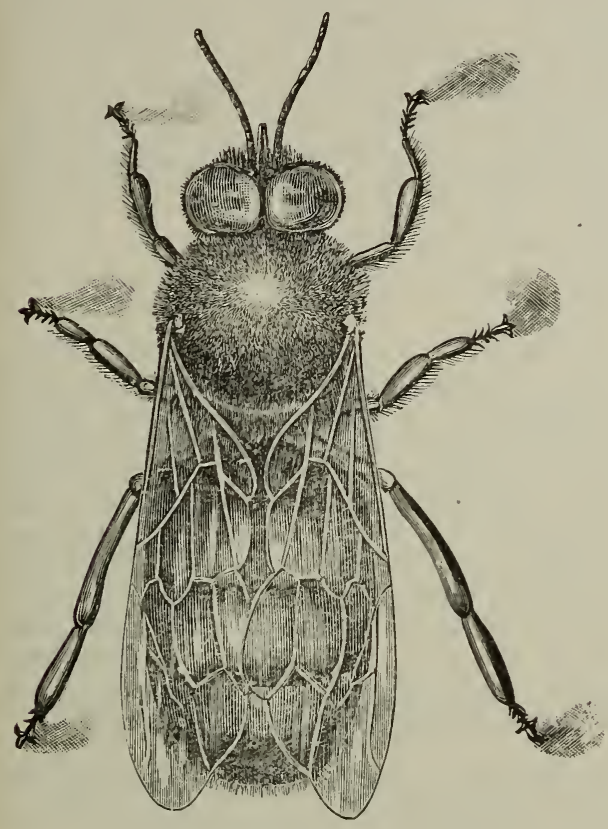

Drone bee enlarged four times.

If our colonies are prosperous, we may find eggs in the drone comb of some of the best hives as early as March, but not, as a general thing, until April. The drone-cells can be told from the worker at a glance by the size, and by looking at HoNercons; also Brood and Brood-REaring, large cut. Whenever eggs are seen in the large cells, it may be assumed they are drone eggs. It is not meant by this that the eggs that produce drones look any different from any other eggs that the queen lays, for in looks they are precisely the same. They are almost the same in every respect, for the only difference is that the eggs that produce the worker-bees have been impregnated, while the others have not; but more of this anon. The egg, like those producing workers, remains brooded over by the bees until it is about three days old, and then by one of nature's wonderful transformations is gone, and a tiny worm appears, a mere speck in the bottom of the cell. This worm is fed as before, until it is about a week old, and is then sealed over like a worker larva, except that the cap to the cell is raised considerably more; in fact, the cappings very much resemble a lot of bullets laid closely together on a board. See Brood AND BroodREARING. The young drones will begin to cut the caps of these cells in about 24 or 25 days; the caps come off in a round piece, very much like those from a queen-cell.

The body of a drone is hardly as long as that of a queen, but he is so much thicker thru than either queen or worker that no one will ever mistake him for either. He has no baskets on his legs in which to carry pollen, and his tongue is so unsuited to the gathering of honey from flowers that he might starve to death in the midst of a clover-field in full bloom.

THE COST OF REARING TOO MANY DRONES.

Since the life of every colony depends on the mating of its queen, nature is very lavish in providing a great number of drones in order that the virgin may be successful in her bridal flight, even tho there are very few bees in the immediate vicinity. But where several colonies are kept in one apiary, and especially where they are run for honey production, the rearing of so many drones is an unnecessary expense, the cost of which is nicely shown in an article written by G. M. Doolittle, in which he says:

Taken in round numbers, a square foot of comb will give 8000 workers or about 5000 drones. It takes 24 days to perfect the drones while the workers will emerge in 21 days from the laying of the egg. And it will take about the same amount of food for the rearing of each, since both occupy the same space; and when all these 8000 workers have emerged from this foot of comb we have a fair-sized swarm of honey-gatherers added to the other forces of the hive, which will almost if not quite turn failure into a successful surplus.

\section{THE IIATING OF QUEEN AND DRONE.}

The young drones are ready to leave their hive after they are about two weeks old, and they do this shortly after noon of a warm pleasant day. They come out with the young bees as they play, and first try their wings; but their motions are far from being graceful and easy, and they frequently tumble about so awkwardly that, as they strike against one's face, he might almost think them either drunk or crazy. It is not 
easy to decide how old a drone must be to fulfill the sole purpose of his existence, the fertilization of the queen, but it may be guessed anywhere from three weeks to as many months. Perhaps he seldom lives so long as the last period named.

Many facts seem to indicate that drones, as well as the queen, fly long distances from the hive-perhaps two miles or more. We have now satisfactory evidence that the meeting between queens and drones takes place not very high up from the ground. Several observers have reported having seen this meeting not far from the hives, during the swarming season. The queens and drones sally forth during the middle of the day, or afternoon, and in from fifteen minutes to an hour, or possibly a couple of hours, the queen returns with a white appendage attached to the extremity of her body, that microscopic examination shows to be the generative organs of the drone. These facts have been observed by hundreds of beekeepers, and are well authenticated. In attempts to have queens fertilized in wire-cloth houses, we have, after letting the queens out, seen the drones pursue them until both vanished from sight. Still another fact: If one takes a drone in his hand some warm afternoon just as he has sallied from the hive, and press him in a certain way, he will burst open something like the popping of a grain of corn, extruding the very same organ we find attached to the queen, and dying instantly.

The manner in which the meeting of the drone and queen takes place has been witnessed a great many times. We give here the statements of a few observers.

The Rev. Mr. Millette, of Whitemarsh, $\mathrm{Pa}$, appears to have been the first who witnessed the actual encounter. The following communication from his pen, which we copy from the Farmer and Gardener for November, 1899, settles the important fact, as it came under his observation in the preceding summer :

\section{DRONE AND QUEEN BEE.}

In the month of June, an old stock threw off a second swarm in which there were four queens. During the process of hiving, one of the queens was observed on the wing, and in a moment was seized by a drone. After flying about a rod they both came to the ground in close contact; the writer instantly followed them up; and as the drone was about departing (having broken loose), seized both the bees, the queen in one hand and the drone in the other. They were taken into the house and left at liberty to fly, when the queen flew to the closed window; but the drone, after erawling about on the hand, was laid upon the window-seat, and in a very few minutes expired. Both the queen and drone had a milky-white fluid upon the extremity of the abdomen, and upon pressing the drone there was no indieation of his possessing the specialty of his sex.

To this we append the following extract of a letter written by Mr. S. B. Parsons, of Flushing, New York, confirmatory of the foregoing. He was the introducer of the Italian bee into this country.

\section{He says (American Bee Journal) :}

One fact in our last summer's experience will interest the readers of the Journal. The copulation of an Italian drone and queen, upon the wing, was witnessed in my apiary by Mr. Carey and Mr. Otis. They saw the queen issue from the hive, and circle round, when the drone struck her (both being upon the wing). A sharp snap ensued; the drone fell to the ground, and was picked up dead. The queen fell in the grass, rose again, and entered the hive. Mr. Carey soon searched for her, found the workers cleaning her off, and the male organs attached to her body.

Later Mr. Carey related his own account of the occurrence, which we submit in his own words :

About three o'clock p. m., on the 8th of July, I saw a young Italian queen enter her hive without any sign of impregnation. She came out again in a few minutes, and I closed the entrance to the hive. During her absence, which lasted thirteen minutes, three drones came in front of the hive, and, finding the entrance closed, kept on the wing most of the time. When the returning queen was about three feet from the entrance, one of the drones very rapidly flew to her, and, clasping his legs about her, caused her to settle a little, and to come in contact with a long spear of grass. At the same time an explosion was distinctly heard, and they immediately separated-the drone falling to the ground perfectly dead, and having his abdomen very much contracted. The queen, after making a few circles in the air, entered the hive with the male organs of the drone attached to her. All these facts were witnessed by myself and Mr. R. C. Otis, of Kenosha, Wis., as we were seated on opposite sides of the hive, not more than six feet apart, so that there can be no possible ground of mistake.

In later times a correspondent in Gleanings in Bee Culture thus describes the act: 
MATING OF THE QUEEN AND DRONE ON THE WIXG, AS SEEN BY AN EYE-WITNESS.

On June 21, 1888, I saw this mating take place. The queen issued from the hive, took two circles, and came within five feet of my face, and was there met by a drone. They seemed to face each other, clinging by their fore legs, their bodies being perpendicular, and in this shape flew from my sight. It happened so unexpectedly that I hardly knew what was going on before it was too late to follow them. I could have easily kept up with them. I have described this because rour book says they have not been seen, only as they were whirling about each other. I saw these fasten; and as they did so they turned and came together, square up and down; and as they flew away their bodies inclined like this / and each bee was using its wings.
Myrtle, Pa.
E. A. Pratt.

One of our iormer apiarists, now Dr. W. I. Mood, lately told us he had seen the drone and queen come in contact face to face, exactly as Mr. Pratt describes.

Another correspondent reported the one thing yet unobserved; viz., the manner of separation of the queen and drone. He described it as follows:

I was going out to my bees one day, when two bees came whirling down in front of me and fell on a pumpkin leaf. It proved to be a queen and drone. The drone acted as if he had been stung by a worker. He held fast to the leaf with his feet, and the queen kept whirling over and over, about as a fly would if caught in a spider's web, until she freed herself, then she flew out of sight in an instant, and the drone remained where he was on the leaf, but showed life for only about three minutes.

Onawa City, Ia.

S. R. Fletcher.

The late E. L. Pratt, of Swarthmore, Pa., a queen-breeder of note, in Gleanings in Bee Culture for 1904 thus wrote:

I have this day witnessed the act of copulation between a queen and a drone. About 2:30 o'clock on the afternoon of Thursday, July 2, I was standing near a fertilizing-box filling a feeder when my attention was attracted by an unusual commotion in the way of extra loud buzzing, as of drones on the wing. I looked and saw a queen rapidly flying toward the fertilizing-box, evidently her home. She was closely followed by two drones, one of which turned and flew off, bnt the other remained in pursuit. They were flying rot six inches from the ground, and were not over eight feet from the fertilizing-box when the act took place. It was done so quickly that I marveled at it, and I wish here to record the facts as I witnessed them. I could not see that the queen was flying in any but the usual way when return- ing to her hive, but the drone was unusually swift of wing. They were both flying rapidly; and as they flew the drone made two circles about the queen as tho to head her off; and as these circles were made about the queen she rose slightly each time. Directly after making the second circle about the queen the drone flew at her as a worker with the intention of stinging in earnest. His abdomen was curved, and his wings rattled in about the same manner. Directly the drone was in contact with the queen there was a sudden lurch sidewise, and they went together some distance into the field until I lost sight of them. As they flew together they much resembled workers when they attempt jointly to bear off their dead. I remained by the fertilizing-box perhaps three minutes, and saw the queen return and enter, bearing the marks of having met a drone. I still lingered by the box, and soon saw a worker bear out the telltale white speck. I later opened the box, and saw the queen bearing the usual thread from the male contact. A queen-bee is very swift of wing; but I am convinced that a drone is ten times swifter; for to be able to encircle the queen in the manner this one did, such must be the fact.

Our head queen-breeder, who, during the iast ten rears, raised for us 20,000 queens, has had exceptional opportunities for obserring the mating of queens and drones, says :

I find that the meeting usually takes place not more than 15 feet from the ground.

During the warmest part of the day the drones congregate in sheltered locations in such large numbers as to make a loud humming noise. This attracts virgin queens out seeking their mates. In one instance in particular about 3 o'clock in the afternoon a loud humming was heard near our Basswood apiary. Investigation showed that it was made by an unusually large collection of drones in the air. Unfavorable weather had kept them in the hives for two days back, but now the sun was out bright, and both virgins and drones were coming out in astonishing numbers. When a virgin came from under the tree tops a number of drones (in some instances apparently twenty or more) would circle close about her, the bunch resembling a small but very active swarm. They would dash high and low for a few seconds when one of the drones would clasp her and they would fall together, the rest of the drones following them nearly to the ground. Four such swarms of drones were seen at one time after a queen.

On two occasions I have seen drones meet with the queen close to the entrance of the hive. In both of these instances they met facing each other, clinging by their fore legs, their bodies being perpendicular. Simultaneously a sharp sound like a miniature explosion was distinctly heard when they dropped to the ground. 
The manner in which the queen frees herself from the drone is similar to that of a fly caught in a spider web, whirling around and around, while the drone clings to anything he can grasp. In this way the male organs are torn from him and carried away by the queen.

DOES THE DRONE HAVE ONLY ONE PARENT?

One of the most wonderful things about the drone, or male bee, is that it is hatched from an egg that is unimpregnated. So wonderful indeed is this that the matter was for ages disputed, and is even now, by many who have not looked into the matter and examined the evidence. What we mean by unimpregnated is, that queens that have never met the male bee at all will lay eggs, and these eggs will hatch, but they always produce drones, and never workers. Those who have had the care of poultry are well aware that the hens will lay eggs right along, if no cock is kept in the yard at all; and a pullet will lay her full quota of eggs, even if she has never seen a male bird.

Nearly the same is true with regard to the queen-bees. If she fails to meet a drone during the first thirty days of her life (if the bees do not kill her before) she usually begins to lay eggs; but she seldom lays as many, or with the same regularity, as a fertile queen. The eggs a hen lays, if she is allowed to sit, never produce any chicks at all. The eggs laid by a queen, under the same circumstances, as we have said before, always produce drones. There is one more fact connected with the common fowl: If a male bird is put into the yard with the hen for one day only, good fertile eggs will be laid for many days, possibly a whole laying. If a Black-Spanish cock should get among a flock of white hens for a single day, all the eggs laid for many days afterward will produce chicks with more or less black feathers on them. We give these statements from actual facts. The point we wish you to observe is that the eggs of even the common fowl are fertilized as they are laid by the hen, or possibly a few days before. With the fowls, one meeting with the male bird suffices for the fertilization of an egg daily, for a week or more; with the queen-bee, for her whole life of three or even four years.

We do not know whether the hen has the power of laying fertile or unfertile eggs at will or not; probably not; but we do know that a queen-bee lays both fertilized and unfertilized eggs, alternating from one kind to the other in rapid succession. Skillful microscopists have carefully dissected eggs from worker-cells, and found the living spermatozoa in numbers from one to five. These living spermatozoa were precisely identical with those found in dissecting a mature drone. Again: Every egg a queen lays passes a little sac containing a minute quantity of some fluid; the microscope shows that this fluid contains thousands of these spermatozoa. Is it not wonderful that these spermatozoa should live four years or more in this little sac, awaiting their turn to be developed into a higher life whenever they should be required to fertilize the egg that is to produce a worker-bee?

Again, the egg that is taken from a dronecell contains no trace of spermatozoa. Therefore it, like the unimpregnated egg of the common fowl, should never hatch. Strange to say, it does hatch, and produce the drone. The first glimpse we get of the little bit of animated nature is the tiny speck alive at the bottom of the cell. Does he grow out of nothing, without parentage, at least on the paternal side? If his mother was an Italian, he is also an Italian; if a black queen, he is also a black. We shall have to conclude, perhaps, that he is the son of his mother, and nothing more. The egg that has never been impregnated in the usual way, must, after all, have some living germ incorporated in its make-up, and this germ must come only from the mother. The great skill and proficiency with the microscope required to make these minute examinations is such that but one or two have ever succeeded in exploring as far as we lave mentioned, and it is somewhat like our investigations in the polar regions. Who among us will educate himself for the work and carry it along?

\section{DRONES FROM WORKER BEES.}

Drones are also hatched from eggs laid by worker-bees. These drones are usually smaller in size than those from a queen because they are generally reared in workercells, and the question as to whether they are capable of fertilizing queens, so as to be of some value, like other drones, is one that we believe has never been decided. Some facts have been brought to light that seem to be pretty good evidence on both sides of the question; but, so far as we 
know, nothing very definite. We confess that we should not want to make use of them, even if they were good, for we want the strongest, healthiest, and largest drones we can get. For a further account of the mothers of these queer drones, see LAFING WORKERS.

After what we hare said, the reader will see how clear it is that drones are in no way affected by the fertilization of the queen; or, in other words, that all daughters of a purely fertilized Italian queen produce drones absolutely pure whether they have been fertilized by a black drone or not.

Until the invention and general adoption of foundation we had no easy way of repressing the production of drones in far greater numbers than could ever be desirable. (See Comb Foundation.) Since the introduction of that article, it is found to be quite an easy matter to make almost every cell in the hive a worker-cell. On the other hand, if we choose, we can have a hive entirely filled with drone comb, and a good queen could, we think, be induced to raise nearly, if not quite. a full quart of drones at a time. $\mathrm{By}$ this means we can have our drones raised from such stock as we choose, and we can sare the rast amount of honey that has so long been wasted by rearing and feeding drones that we do not need. While extracting, we have found as many as several pounds of drone larvæ in a single hive; and, to save the honey they would consume as soon as hatched, we used to shave their heads off with a very sharp knife. This is certainly rather expensive business, for it must take more than a pound of honey, to say nothing of the value of the pollen, to get up a pound of sealed brood. If all this labor and material had been utilized in the production of worker-brood, it would doubtless have been equivalent to a swarm of bees. All-worker comb would have insured this without trouble.

This general subject is covered in a more technical article entitled PARThenogeneSIS elsewhere in this book, and also under hearl of QueENs.

\section{REARING DRONES OUT OF SEASON.}

This is quite a difficult matter to accomplish, especially in the spring; and altho we have many times fed colonies with this end in view, we have always found some other colony that would have drones flying just as soon, without any artificial aid. Drones may be kept almost any length of time by making the colonies containing' them queenless, or by putting them into queenless colonies. During warm dry weather in the summer or fall, drones may be procured by feeding, but the feeding must be regular, and given every day for several days or weeks. By feeding one colony a barrel of sugar in the fall, we succeeded in getting a nice lot of drones in October. Of course their combs were taken away and empty ones given them, to give the queen room. Before we can raise drones we must get worker brood under good headway, and then, if we put a drone comb right in the center of the nest, the queen will, if all thing's are farorable, begin at once to fill it with eggs; but it should be observed that a two or three year-old queen is better for the work than a young one. The feeding must be kept up, however, for bees are very easily discouraged; and if a stoppage occurs in the daily supplies, they will not hesitate to pull the young drones out of their cells and sacrifice them without mercy.

\section{DRONES FROM DRONE-LAYERS.}

Queen-breeders find that one or more drone-layers of good stock. rearing fully developed drones, if supplied with plenty of worker brood, will furnish a fine lot of nice drones in and out of season; but drones from laying workers, or from queens that have never been fertilized, are to be avoided. Drones from queens that have once laid worker eggs, and then failed, are as good as the drones from any queen.

\section{DESTRUCTION OF DRONES IN THE FALL.}

This does not necessarily occur in the fall, but may take place at any time in the summer; and we have several times known the drones killed off between apple-bloom and white clover, only because supplies ceased, causing the bees to become discouraged and give up swarming for the time being. We know of no way in which one can tell so well that the yield of honey has ceased as by the behavior of the bees toward their drones. When, in the midst of the honey season, we see a worker buzzing along on the back of a drone that seems to be doing his best to get aray from the hive, 


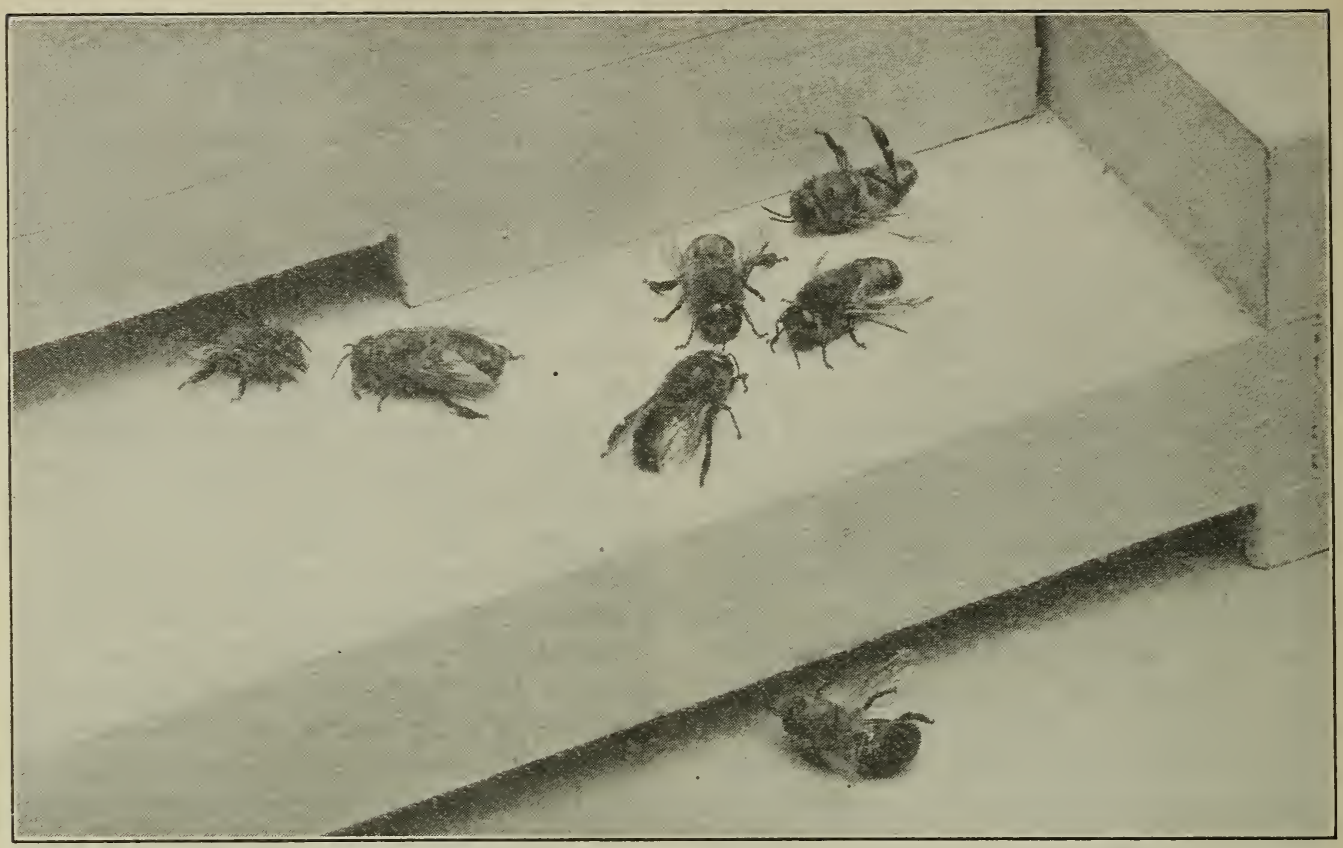

THE LAMENT OF THE DRONES.

Grace Allen, Nashville, Tenn.

No more?

Not ever ever more within the hive No more to feel its friendly shelter 'round?

No more to share its pulsing peace, alive

With vibrant hum of motion and of sound? And we so powerful-winged and light of heart!

Of all this life we love are we a part

No more?

No more.

Not ever ever more within the hive. An unimaginable end has come.

The things are turning dead that were alive And all the singing voices turning dumb

And Life herself, who one time bade us be,

Has turned away her eyes, which we shall see No more.

we may take warning that the yield of honey is failing, and that we had better stop making artificial swarms, and prepare for uniting, if it is our intention to do so. We do not know that we ever saw bees sting drones, but they sometimes pretend to do so. It is probable that it is only a feint to drive them away. The poor drone, at such times, after vainly trying to go back into the hive, will sometimes take wing and soar away off in the air, only to return after a time to be repulsed again, until, thru weakness perhaps, and want of food, he flutters hopelessly in the dust, and so submits to the fate that seems to be a part of the inexorable law of nature and of his being.

To preserve drones for late queen-rearing, we have been in the habit of carrying all frames containing drone brood to some queenless hive, knowing they would be safe
And this the end?

No end but this for those uncounted days Of banquetting, or those mad hours of bliss

We went careening, careless thru the ways of miracle and light? No end but this?

No end but this. No proud sustaining thought Of deed with rapture or with patience wroughtNo end but this.

More and more

The dripping night that stalks without the hive Draws round us dread and ghostly, grim and stark; Within, the deepest shadows are alive.

With warmth and fragrance, and the very dark Dreams day to come. But tho the great sun burns A million dawns awake, the day returns I'o us, no more-no more.

there as long as wanted, even if it were al winter. We believe drones have been, under such circumstances, wintered over; but whether they are of any value in the spring or not, we are unable to say. We should fear they would not be by the time queens could be reared. We usually have drones in some of our colonies as soon as April, and that is as early as we should care to undertake to rear queens, in ordinary seasons. We have several seasons reared queens and had them successfully fertilized, even after all the drones had been gone some time, so far as we could discover; and as they proved to be purely fertilized, we have been not a little perplexed.

DRONES WITH HEADS OF DIFFERENT COLORS.

This is a queer feature in natural history. Almost every summer some one writes or 
sends us specimens of drones with heads of different colors. The matter has been reported and commented on at different times in Gleanings in Bee Culture. Not only do we occasionally find drones with white heads, but we find them with heads of a cherry-color; again, of a bright green, and at other times yellow. Why should this peculiarity show itself in the drones more than in the queens and workers? Again, why should heads be the subject of these bright rainbow colors? Is there really any purpose or design in it? or is it just because it happened so? We presume there are very few among our readers but will say there is a purpose and a design in it; and the next thing is to decide why it should be so. Here is a conundrum. See Hermaphrodite Bees.

\section{RESTRAINING UNDESIRABLE DRONES.}

Drones undesirable for breeding purposes may be prevented from going out to meet the queens, by keeping them from going out of the hive, or by letting them go out into a cage thru which workers can pass and they cannct. This is done by taking adrantage of the fact that a worker-bee will pass readily thru slots in perforated metal (or between bars properly spaced) where a drone cannot. In the figure shown we give the form of the perforated metal.

THE PROPER SIZE FOR THE PERFORATIONS.

The oblong holes, as shown, must be of such a size as to permit the easy passage of workers, but exclude not only drones but even queens (see ExTracted HoNer and SwARMING). It is no great task to make the perforations drone-excluding; but to make them queen-excluding at the same

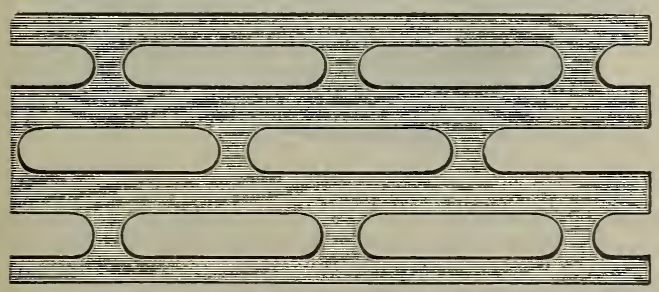

Perforated zinc.

time, and yet not hinder the easy passage of workers, requires a very nice adjustment in the width of the perforations. The first sheet of perforated zinc was cut in England, and imported to this country. This had perforations 18-100 of an inch in width. While this ansivered a most excellent purpose, a few claimed that queens would occasionally get thru it. To obviate this, zinc was made with the perforations a little narrower.

The width of this was $5-32$ or $16-100$ of an inch. While no queen succeeded in getting thru this, reports, as well as our own experience, convinced us that this size was too narrow. It not only proved to be a great hindrance to the workers when their honey-saes were empty, but, when gorged

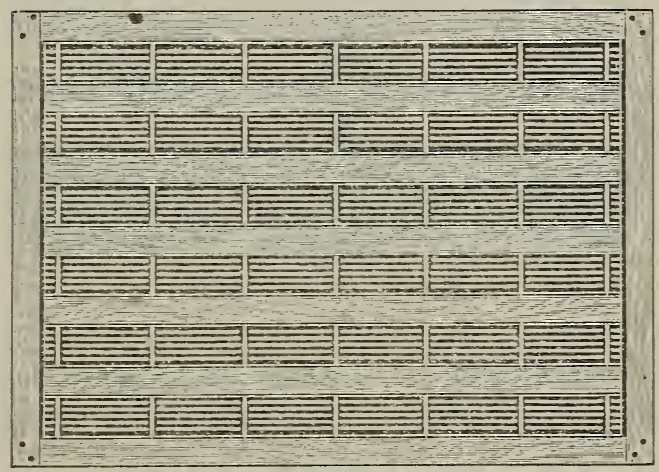

Wood and wire honey-board.

with honey, they were scarcely able, if at all, to pass thru. Later, perforated zinc was made in this country on a different pattern, but with perforations exactly 1631000 of an inch in width, or a trifle smaller than the foreign. The reports, as well as our own experience in regard to the perforated zinc as so made, have led us to believe that this size of perforations is about right.

In 1908 there was put on the market a new form of queen-excluder* consisting of wire bars held at the required distances apart by means of soft-metal cross-ties at every two or three inches. These bars consist of No. 14 hard-drawn galvanized wire that has been straightened in a wirestraightener so that it is true as a die. Contrary to what one might expect, the spaces between these bars are more exact than the width of the various perforations in sheet metal. In the process of making, the bars are laid in metal forms having grooves that are spaced exactly right, and then a soft metal in a molten state is made to flow in certain cross-grooves of the metal form. As

* Invented by Frank G. Marbach, formerly of Medina, Ohio. 
in such a way that this water would run down on the bees and their unsealed stores, it would be very apt to produce unhealthiness, to say nothing further.

There is a kind of dysentery in Great Britain which is thought to be contagious. One is mild, and comes on in the spring, and disappears soon at the approach of warm weather. The other one (Nosema apis) is either a part of the Isle of Wight disease or entirely distinct from it. (See ISLE OF WIGHT Disease under the head of Diseases of Bees.)

\section{THE AGENCY OF THE APHIDES IN PRODUCING DYSENTERY.}

The poorest winter food is, without doubt, the honey gathered from the aphides (see HONEY-DEW) ; or, at least, most complaints have been made of this honey. As bees seldom touch this, except during drouths or unfavorable seasons, it no doubt has been the cause of some of the mischief. If the early honey is all extracted from the broodcombs, and the bees left with nothing but this bad honey, gathered in the summer, the matter is much worse; and many cases have been reported of colonies dying where the extractor has been used, while those untouched had been free from the disease. The moral is, refrain from extracting too closely from the brond-apartment. Wie. would at least let the bees fill their broodchamber with a good quality of honey, just before the yield ceases, extracting toward the close of the harvest, only from the combs in the upper story, unless we choose to feed them up for winter on sugar syrup or candy. We have had one or two favorable reports of wintering on the aphidian honey, from which we may conclude it is not always deleterious.

\section{PREVENTION OF DYSENTERY.}

There are two important factors-protection against extremes of cold during winter. and good food. Under the head of WINTERING OUtdoons, WINTERING IN RePOSItories, Spring Dwindling, and Spring MANAGEMENT, full particulars are given on how to house bees properly.

Good food may be in the form of good honey or sugar-syrup stores well ripened. Any of the good table honeys make suitable food; and there are many of the fall honeys that do very well. Aster honey, unless well ripened and sealed in the combs, sometimes brings on dysentery. Some winters it is worse than others (see Asters). Honeydew usually should not be used. It is generally dangerous (see HONEY-DEW).

\section{CURE FOR DYSENTERY OUTDOORS.}

If the affected colonies are outdoors, about the only real remedy is settled warm weather. Even one good warm day will often serve to alleviate the trouble, as it gives the bees a chance to void their excrement out in the open air, away from the hives and the combs. Otherwise the continued confinement during an extended cold spell sometimes compels the bees to retain their fæces or excreta so long that they are finally forced to void it over the combs and over the hives. In such cases, where one has good clean combs of sealed honey he may take out the combs and replace with the clean ones. At the same time the broodnest should be contracted to a space the bees can fill. This work should never be done on a cool day-only when it is warm and balmy, as we have explained. But the practical beekeeper of today does not make it a rule to fuss with colonies affected with dysentery; for he knows that, as soon as warm weather comes on, the trouble will disappear of itself, in all such colonies as are not too far gone and too weak to recover.

Combs taken out of the hive in cold weather, and stained with dysentery, may be given to strong colonies in late spring or summer to clean up. Indeed, there is no danger in hiving swarms in hives where colonies have died with dysentery during the previous winter. They will quickly clean up and use the stores that are left.

\section{DYSENTERY IN BEE-CELLARS.}

After a long and cold winter, if the temperature in the cellar goes much below 40 degrees Fahr., or if the stores are of poor quality, there is a liability of some colonies being affected with dysentery. The best remedy is prevention. The cellar should be dry, and the temperature should be between 45 and $50 \mathrm{~F}$. It should never go below 40 for a longer period than ten or twelve hours. If the temperature of the cellar can not be kept up, a small stove with a connection to a chimney should be 
used to keep the temperature up to the requisite point.

Some authorities think that dampness has nothing to do with causing dysentery in the cellar; but dampness in combination with a temperature below 40 degrees for several weeks, we are satisfied, is the most potent cause of dysentery in cellar repositories. We Lave one cellar that is perfectly dry, and where we control the temperature. In this we have but very little dysentery-in fact, almost none. At our outyards we have had damp cellars, and where, too, the temperature went down below 40 degrees. It was a most noticeable fact that in these cellars we had so much dysentery we had to abandon them.

But what are we going to do if the bees do get dysentery? Suppose the food is bad, and the cellar one where it is not practicable to use artificial heat, say at an outyard. If there are days during mid-winter when the bees can fly (and some localities do afford such weather for one day and possibly two), take the diseased colonies out on one such day and let them have a flight, then at night put them back in the cellar. A cleansing flight will do a world of good. We are well aware that some authorities disagree with us here; but our own experience has shown conclusively, over and over again, that it does pay. If the bees are suffering from an over-accumulation of poisonous fecal matter, why will there not be almost instantaneous relief as soon as it can be voided? If the food is bad, give the bees better next year. Some recommend taking away all fall stores and feeding sugar syrup. For further consideration of this subject, see WINTERING IN REPOSITORIES.

DZIERZON.*-The life of Dr. Dzierzon was a simple, uneventful one, similar to that of many clergymen in Germany. He was born on Jan. 16, 1811, at Lowkowitz, near Kreuzburg, Upper Silesia. He attended the school of Lowkowitz till his tenth year, and was afterward transferred to the University of Breslau, where he attained such excellence in his studies that, after having finished his course, he had been first in every class in his college, and left

* From the British Bee Journal, Dec 20, 1906. the University in the autumn of 1830 with a certificate as having passed No. 1.

From early childhood young Dzierzon had a great partiality for bees. His father kept a few colonies in log hives, mostly placed in an upright position; these were at that time the kind in general use in Silesia. He always found the greatest pleasure in the contemplation of the indefatigable industry of bees, and while studying at the University he was in the habit of taking his walks near to an apiary, or where a colony of bees occupied a hollow
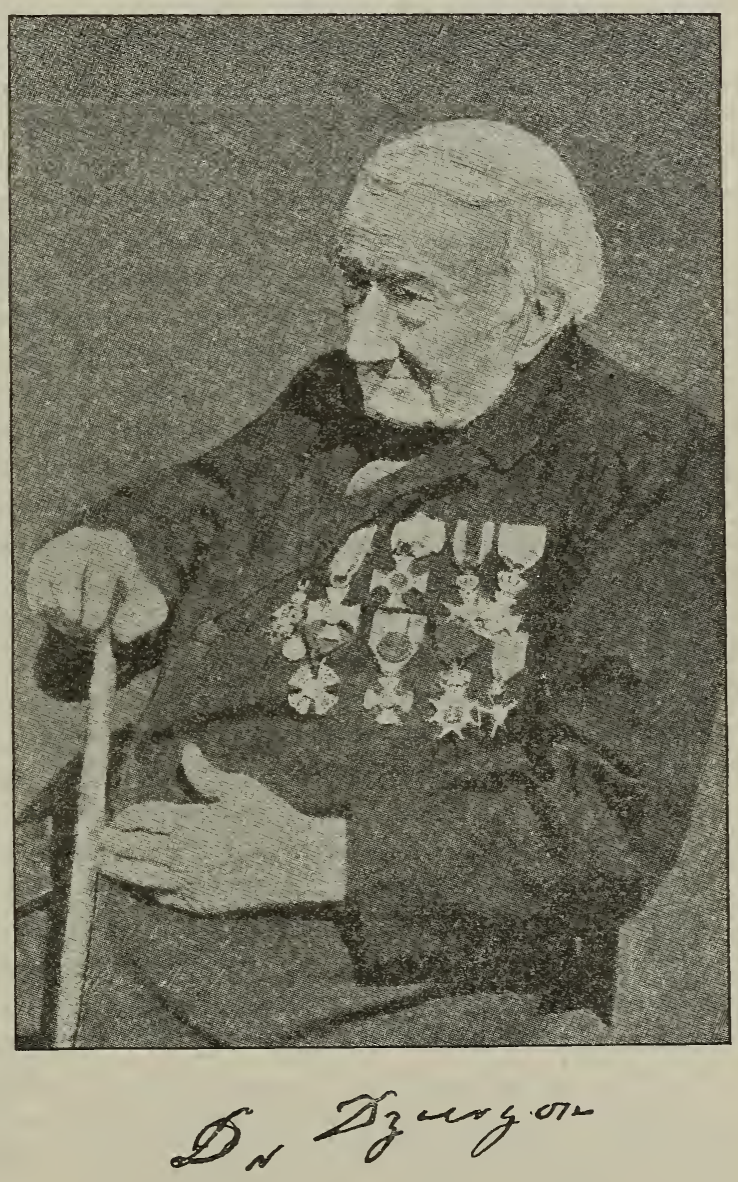

tree, so that he might enjoy the sight of the industrious insects and listen to their joyful humming.

His fondness for bees made him choose a calling in which it would be possible for him to follow the bent of his inclination.

Dzierzon was ordained on March 16, 1834, and having acted as chaplain in the Schalkowitz District of Oppeln till July, 1835, he received a clerical appointment at Karls- 
markt. This brought him a very small income; but as in succeeding years it suited him entirely, it never occurred to him to seek a more richly endowed living. The garden of his parsonage was a tolerably large one, and his first care was to arrange a place for bees. $\mathrm{He}$ soon stocked it with some colonies from his father's apiary in the old-fashioned hives mentioned above. His bees did very well in them. He, however, was not content with these primitive hives, but proceeded to make various changes in them, so that he might have a more perfect control over his bees. These changes gradually led to the invention of movable combs, which enabled him to take out a full brood-comb, or honeycomb, and insert it in another hive. $\mathrm{He}$ introduced bars, to which the bees built the combs, and as these were usually attached to the sides of the hives (there being no side bars) Dzierzon conceived the idea of opening the hive at the back so as to enable him to cut the attachments. At the commencement Dzierzon used single hives called "Lagers" and "Standers," but afterward constructed hives to hold two, three, six, or eight colonies, in order to economize material and space. Owing to the advantages thus gained the number of his colonies increased in a few years to four hundred, and he was constantly making new hives and planting out-apiaries in the neighboring villages. He had twelve of them, but his apiary at Karlsmarkt was chiefly used for observations and experiments, and after his introduction of the Italian race,* for breeding these bees and keeping them pure. This apiary was visited by numerous people desirous of increasing their knowledge in beekeeping, especially by schoolmasters, many of whom came by desire and at the cxpenset of the

* Captain Baldenstein, when stationed in Italy, was the first to notice the exceeding industry of the was the first to notice the exceeding industry of the
Italian bee. When he retired from the army he settled in Swityerland, and procured a colony from Italy in September, 1843. His observations im. pelled Dzierzon to make an effort to procure the Italian bee; and by the aid of the Austrian Agricultural Society he succeeded in obtaining, late in February, 1853, a colony from Mira, near Venice. Dzierzon bestowed much pains in maintaining the purity of his Italian bees, and thirty years after the first introduction he exhibited at Neustadt, near Vienna, a perfectly pure descendant from his original stock.

$\dagger$ Several of the governments of Europe took great interest in spreading among their people a knowledge of Dzierzon's system of beekeeping. Prussia furnished monthly a number of persons from different parts of the kingdom with the means of acquiring a knowledge of this system; while the Bavarian government prescribed instruction in Dzierzon's theory and practice of bee culture as a part of the regular course of studies in its teachers' seminaries.
Government. He was at all times ready to communicate the results of his experience to his visitors; he also made known his views in the Frauendorf Journal, which enjoyed a large circulation at that time. These articles were afterward collected and published in the form of a pamphlet entitled "Pfarrer Dzierzon's Improved Method of Beekeeping." This pamphlet was very incomplete, and induced Dr. Dzierzon to publish his views in a more complete form, which work, after passing thru several editions, was published under the title of "Rational Beekeeping," the latest and most complete edition of which appeared in the year 1878. In 1880 this edition was translated into English by Messrs. H. Dieck and S. Studderd, and edited by Mr. C. N. Abbott, who then introduced it to British beekeepers. The last book he wrote, "Der Zwillingstock," was published in 1890 . From 1854 to 1856 he published the "The Bee Master of Silesia," but the greater part of his observations and experiences appeared in the Bienenzeitung. In this publication appeared his views on parthenogenesis, and for eight years, from 1845 to 1853 , he had to fight hard to defend his theory, which met with the most strenuous opposition, and it was not until he introduced Italian bees in 1853 that he was clearly able to demonstrate the correctness of his statements. Baron von Berlepsch at first vigorously opposed it, but was at length convinced of his mistake, acknowledged his error, and openly declared he would come into Dzierzon's camp "with bag and baggage. " Dzierzon's theory, according to which drones originate from unfertilized eggs, and all impregnated eggs produce females, gradually found adherents and recognition among men of science; and its correctness was proved by the microscopical and physiological researches by Professors Dr. von Siebold and Leuckart.

In recent years M. Dickel made a violent attack on this theory, and stated that all eggs laid by the queen were fecundated, and that the bees themselves determined the sex of the eggs by means of a secretion from special glands. Dickel and Dzierzon met at the annual congress of beekeeper's in Salzburg in 1898, where they vigorously defended their theories in the presence of a large gathering of beekeepers. Dzierzon's arguments were so forceful that they con- 
stintly elicited applause. He has had his partisans and detractors; some, like M. Perez, have discussed the theory most courteously; a few others have done so with extreme rudeness, especially to a man of his age. It is gratifying to find that Dzierzon lived long enough to see his theory triumphantly vindicated before he passed away from amongst us.

From all parts of the continent, and from many of the reigning sovereigns, Dzierzon has received distinetions and honors. One of the first which he received was that signed by Archduke John in his capacity as president of the Agricultural Society of Graz. The honorary title of "Doctor" was conferred on him by the University of Munich. At the Beekeepers' Congress at Darmstadt, the then reigning Grand Duke of Hesse invested him with the order of Ludwig, and from the Emperor of Austria he received the Order of Francis Joseph. The Emperor of Russia conferred upon him the Order of St. Anne, and the King of Sweden the Order of Wasa. The photograph we reproduce from the Bienen-vater shows the venerable old man decorated with these orders. He has also been made an honorary member of a great many societies, and his name is known in every portion of the globe.

To Dr. Dzierzon we are indebted for the various artificial substitutes for pollen. With his eye ever open to discover any means that would be of assistance to his bees, he observed them bringing from a neighboring mill rye-meal, before they were able to secure a natural supply for the food of the larvæ; and ever since beekeepers have been in the habit of supplying the bees with artificial pollen in the spring.

Dr. Dzierzon, like many other beekeepers, has had sad experiences of the virulence of foul brood. In 1848 this plague broke out in his apiary, destroying several hundred stocks, and leaving only ten untouched.

So vigorous was his fight against the disease that three years later, in 1851, he was able with pride to point to the four hundred colonies of healthy bees which he had worked up from the ten survivors of the disaster.

His apiary passed thru several troubles. At one time seventy hives were stolen, then twenty-four were lost in a flood, and sixty were destroyed by fire.
In consequence of various ecelesiastical troubles which occurred at Karlsmarkt, he decided to leave the place where he had lived forty-nine years. He remored to Lowkowitz, the place of his birth, in 1884 , and took up his abode with his nephew, tlie youngest son of his brother, whose wife accompanied him to the last in his visits to conventions of beekeepers. At Lowkowitz he lived a happy, peaceful, contented life, his time being wholly taken up with his bees.

About a year ago Dzierzon was taken ill. and the worst was feared, but his vigorous constitution enabled him to rally, and during the spring he got better. Toward the autumn, however, his strength began to give away, and he sank rapidly, until the end came on October 26, 1906. To beekeepers his loss is great, and his name will always stand out prominently in the history of beekeeping in the nineteenth century.

DZIERZON THEORY.-In 1845 the Rev. John Dzierzon enunciated what is now known as the "Dzierzon Theory," and thus in reality laid the foundation for much of our scientific and practical knowledge of bees. While he was not original in the discovery of parthenogenesis, he threw a great deal of light on the subject. (See PARTHENOGENESIS, elsewhere, and sketch of his life just preceding.) That the reader may know just what the theory was, we give below the the several propositions as given by Dzierzon.

I. A colony of bees, in its normal condition, consists of three characteristically different kinds of individuals-the queens, the workers, and (at certain periods) the drones.

II. In the normal condition of a colony, the queen is the only perfect female present in the hive, and lays all the eggs found therein. These eggs are male and female. From the former proceed the drones; from the latter, if laid in narrow cells, proceed the workers, or undeveloped females; and from them also, if laid in wider acorn-shaped and vertically suspended, so-called royal cells, lavishly supplied with a peculiar pabulum or jelly, proceed the queens.

III. The queen possesses the ability to lay male or female eggs at pleasure, as the particular cells she is at any time supplying may require.

IV. In order to become qualified to lay both male and female eggs, the queen must be fecundated by a drone or male bee.

$\mathrm{V}$. The fecundation of the queen is alwars effected outside of the hive, in the open air, 
and while on the wing. Consequently, in order to become fully fertile, that is, capable of laying both male and female eggs, the queen must leave her hive at least once.

VI. In the act of copulation the genitalia of the drone enter the vulva of the queen, are there retained, and the drone simultaneously perishes.

VII. The fecundation of the queen, once accomplished, is efficacious during her life, or so long as she remains healthy and vigorous; and, when once become fertile, she never afterward leaves her hive except when accompanying a swarm.

VIII. The ovaries of the queen are not impregnated in copulation; but a small vesicle or sac which is situated near the termination of the oviduct, and communicating therewith, becomes charged with the semen of the drone.

IX. All eggs germinated in the ovary of the queen develop as males, unless impregnated by the male sperm while passing the mouth of the seminal sac or spermatheca, when descending the oviduct. If they be thus impregnated in their downward passage (which. impregnation the queen can effect or omit at pleasure), they develop as females.

$X$. If a queen remain unfecundated, she ordinaryily does not lay eggs. Still, exceptional cases do sometimes occur; and the eggs then laid produce drones only.

$\mathrm{XI}$. If, in consequence of superannuation, the contents of the spermatheca of a fecundated queen become exhausted; or, if from enervation or accident, she lose the power of using the muscles connected with that organ, so as to be unable to impregnate the passing egg, she will thenceforward lay drone eggs only, if she lay at all.

XII. As some unfecundated queens occasionally lay drone eggs, so also in queenless colonies, no longer having the requisite means of rearing a queen, common workers are sometimes found that lay eggs from which drones only proceed. These workers are likewise unfecundated, and the eggs are uniformly laid by some individual bee, regarded and treated more or less by her companions as their queen.

XIII. So long as a fertile queen is present in the hive, the bees do not tolerate a fertile worker. Nor do they tolerate one while cherishing the hope of being able to rear a queen. In rare instances, however, exceptional cases occur. Fertile workers are sometimes found in the hive immediately after the death or removal of the queen, and even in the presence of a young queen, so long as she has not herself become fertile.

When this was put out originally in the Bienenzeitung, it called forth most strenuous opposition. Even the Baron von Berlepsch opposed it; but later on, when Italian bees were introduced, and the theory could be demonstrated, Berlepsch became its most staunch supporter. Indeed, he published a series of articles defending it; but there has been more or less opposition to it ever since. In $1895 \mathrm{Mr}$. Dickel made a violent attack on the theory, stating that all eggs laid by the queens were fecundated, and that the bees themselves determined the sex of the eggs by means of a secretion from the glands. For a number of years the European journals were filled with discussion, some supporting Dickel and some Dzierzon. Finally, in 1898 the Dickel theory was shown to be untenable.

The Dzierzon theory, in the main, still stands; but Dr. E. F. Phillips, in his book "Beekeeping," published in 1915, while not taking exception to the fact that drone eggs are unfertilized, says :

The determination of sex is one of the most earnestly debated questions in zoology. $\mathrm{Nu}$ merous theories have been proposed, most of which are not now seriously considered. From the observations and conclusions of Dzierzon and other observers it was long held that sex in bees and similar forms (ants and wasps) is determined by the presence or absence of fertilization. These species were seemingly an exception to the phenomenon observed in most species. Of recent years, sex determination has been the object of numerous investigations, and it is now quite generally accepted that sex is inherited in accordance with the same laws which govern other phenomena of inheritance. It is, of course, impossible to attempt to record here or even to outline the observations which lead to this theory or to elaborate the theory, as has been done by various authors. It is now held that one of the chromosomes (the bearers of hereditary characters) of the sex cells bears the sex-determining character. If we take into consideration the important fact that not all the eggs of an unfertilized (drone-laying) queen hatch, then the bee does not appear as an exception in Nature. It seems clear, however, that the statement of Dzierzon that all the eggs in the ovary are male eggs cannot be accepted; and it is, in fact, not improbable that the eggs destined to be females die for want of fertilization, while the eggs destined to be males, not requiring fertilization, are capable of development. It should be understood that the casting of doubt on Dzierzon's theory of sex determination does not invalidate his theory in so far as it pertains to the development of males from unfertilized eggs.

In view of the fact that drone eggs are usually deposited in the larger cells, the theory has been advanced that the pressure on the abdomen of the queen when she is about to lay an egg in a worker cell, by some reflex, causes the spermatheca to open, 
thereby enabling the egg to be fertilized. This is known among American beekeepers as the Wagner theory. Since fertilized eggs may be laid in comb foundation when the side walls are only started, and since drone eggs are often laid in worker cells, this simple explanation can not be accepted.

From the various phenomena observed in connection with parthenogenetic development, it appears that fertilization of the egg serves two purposes: It brings to the egg the hereditary characters of the male parent and also stimulates the egg-cell to develop by cell division. If development can occur without this stimulation, the resulting individual contains the hereditary characters from one parent only. It should, perhaps, be mentioned that in plant-lice both males and females sometimes develop from unfertilized eggs, while in certain Lepidoptera only females develop from unfertilized eggs. The male sex is not a necessary result of parthenogenetic development.

The theory that drones develop from unfertilized eggs has not been accepted without protest. From the beginning it has been assailed by the publication of evidence and arguments which were supposed to contradict the theory. In the author's paper, to which reference has been made, the various contrary views are outlined, and the interested reader is referred to this paper for references to the literature on the subject up to the date of publication (1903). Of recent critics, none is so insistent as Dickel, a German beekeeper, who claims that fertile queens can not lay unfertilized eggs, and that sex is determined by secretions of the nurse bees. These fantastic theories with others of a similar character have been adequately overthrown by Dickel's critics and need not be discussed at length here.

Those who desire to see the original arguments in support of the theory will be interested in reading the booklet entitled "The Dzierzon Theory," by the Baron ron Berlepsch, published by The A. I. Root Co. In the mean time the reader is referred to PARTHENOGENESIS, where more information is given on the subject. Some recent work by Nachtsheim seems to make Dzierzon's position still stronger.

\section{RECENT EVIDENCE IN PFOOF OF DZIERZON} THEORY.

Any reliable evidence either for or against Dzierzou's theory, that the drones of the honeybee are produced from unfertilized eggs, is at the present time of more than usual interest to beekeepers. In the January number of the American Naturalist T. H. Morgan describes some experiments made by Newell at Houston, Texas, in mating Italian and Carniolan bees. It had been established by observations extending over several years that the stocks were pure. When yellow virgin Italian queens were mated with grayish Carniolan drones, both the workers and queens, which come from fertilized eggs, were yellow, from which it appears that yellow is dominant over gray. The drones were also yellow, like the Italian mother, which would be expected if they inherited from the mother; but since the maternal color (yellow) is here dominant the hybrid drones would be yellow eren if the egg's producing them were fertilized by the gray Carniolan drones. The experiment therefore, as Morgan points out, is not decisive.

The reciprocal experiment was, however, decisive. When gray Carniolan queens were crossed with yellow Italian drones, the workers and queens were yellow as before, due to the dominant yellow of the father. But the drones were gray like the gray Carniolan mother and the pure stock of Carniolan drones. That is, they inherited from the mother alone. Otherwise, they would have been yellow. This proves that they came from unfertilized eggs. Prof. Morgan characterizes these crosses as furnishing the long-sought evidence demonstrating the drones inherit only the characters of their mother in accordance with Dzierzon's theory.

According to Fabre's observations parthenogenesis also occurs among the solitary bees in the genus Halictus. The males of this genus do not appear until fall. After mating with the females they fly about among the flowers for a week or so and then all perish, none surviving the winter. The fecundated females hibernate in their old nests, or in the crevices in stone walls, or other retreats. With the return of warm weather they reappear, dig new burrows, and provision their cells with little masses of pollen and honey, on each of which they lay on egg. From these eggs come only females, and at this season of the year theire are no males of this genus in existence with which they can mate. This first generation of females soon build new groups of cells, the daughters of a single mother extending the old nest, and all using the old entrancetunnel in common. The eggs of these unimpregnated females give birth to both males and females; thus in the second generation both sexes are produced by parthen- 
ogenesis. After mating the males die, and the females survive the winter and the cycle is repeated as before.

Fabre sums up as follows: "The Halicti have two generations a year; one in the spring, issuing from the mothers who have lived thru the winter after being fecundated in the autumn; the other in the summer, the fruit of parthenogenesis; that is to say, of reproduction by the powers of the mother alone. Of the union of the two sexes females alone are borne. Parthenogenesis gives birth at the same time to females and males."
FGGS.-See Brood and Brood-REaring.

ELEMENTARY BEEKEEPING. - See A B C of Beekeeping.

EMBRYOLOGY OF BEES.-See DEvelopment of Bees.

ENEMIES OF BEES.-King-birds and bee-martins, and a few other insectivorous birds prey on bees. We once saw a single king-bird capture six or eight bees in as many trips, on the wing. It would alight on the peak of the barn near the apiary, and then make a dive thru the air, grab one bee on the wing, return to its perch to dispose of its morsel, and then catch another.

There have been a number of conflicting reports as to whether king-birds do or do not swallow their victims. Some have asserted that they do, and afterward expelled the ball of bees. At one experiment station a number of kind-birds were shot, and the conclusion, after examining their crops, was that they did not swallow bees. From observations that have been made since, it appears that the king-bird does not generally swallow worker-bees. It grabs the bee, flies away, and, after it alights on some perch with its victim in its beak, bites away until it absorbs the honey or juices, when it drops the carcass, and flies away for another, which it treats in the same way. Observers have reported seeing these carcasses of bees below the birds' favorite perches.

There are other birds that do swallow bees. Cases are on record where they throw up the dead carcasses of the bees after they have absorbed the honey.
The loss of a few bees which the birds might kill would amount to nothing; but in large queen-rearing yards, if the birds are allowed to go unmolested there is quite likely to be a loss of young queens; for no doubt the birds select the largest and noisiest-flying bees, and these, of course, will be queens and drones. If such be the case, the owner of a queen-rearing yard would do well to use his shotgun until everything in the way of bee-killing birds is destroyea.

\section{MICE.}

Mice do harm only when they get into the hives, and this part of the subject will be sufficiently noticed under the head of Entrances. Mice sometimes make sad havoc among surplus combs, when stored away with small patches of honey in them. The combs will be completely riddled during the winter time, if they are left where mice can get at them. On this account the honeyhouse should be mouse-proof; and for fear that a stray one may by accident get in, it is well to keep a trap ready, baited with toasted cheese. If one does not have a tight room, he should make a tight box, large enough to hold all the surplus combs which have honey in them. (See EntrancEs.)

\section{PARASITES.}

The only parasite we have ever seen is the Braula coeca, or Italian bee louse, and we have never seen them except on bees just imported from Italy.

The following from M. Lucien Iches, in "L'abeille domestique," Paris, 1905, quotes from J. Perez, Notes d'apiculture, and is 


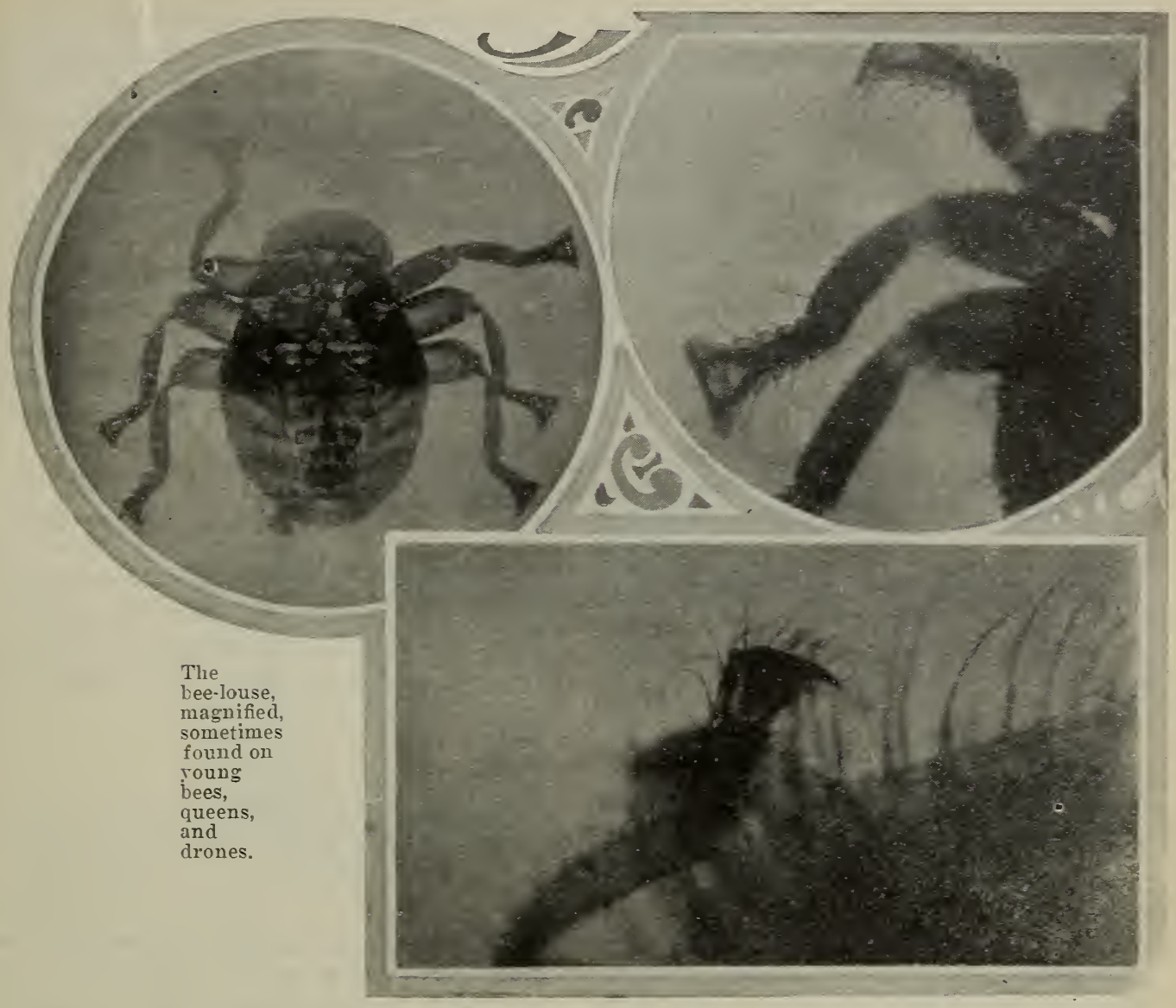

about as authoritative as anything we have soen :

One dar, having captured a bee with one of these lice I fixed its head with a pair of pincers sufficiently to keep it unmovable, and to capture the small parasite easily. Both it and the bee were left for a while on the table in my studio, under a glass.

When I returner to them I was not a little puzzled to see the parasite in the most vivacious and strange agitation. Seated on the fore part of the bee's head it was moving about with incredible vivacity, as tho possessed of veritable rage. Now it would go to the margin of the bee's cap, with its fore feet raised, stamp and scratch as hard as its weakness would allow at the base of the bee's lip; then it would suddenly run back to the insertion of the antemnæ to renew its impetuous attack immediately. I was quite taken up by my first surprise, when I suddenly saw all this fury turned to perfect calmness, and the little animal squatted on the edge of the eap and bent down its head to the bee's mouth, which was slightly trembling, and sucked up a drop of moisture.

I instantly understood. The movements I had just witnessed were preparatory to the animal's meals. When the louse wishes to feed it goes to the bee's mouth, where the motions of its feet, armed with bent claws. produces a tickling sensation, perhaps disagreeable to its host, but at least provoking some morement of the bucal organs, which slightly open and release a small drop of honey which the louse at oilce licks up.

Thus the Braula coeca is not a real parasite of the bee in the true sense of the word. It is rather a guest-queer, if you like thus to consider it, like so many others existing among animals.

\section{SKUNKS.}

Skunks have been known to approach the hive at night time, and by scratching on or near the alighting-board, entice the bees out where they could "gobble them up." It would seem a little strange that these animals* liave no fear of stings, but they. doubtless, are guided by a sort of instinct that enables them to divine how to get hold

* A correspondent in Gleanings in Bee Culture, page 866 , Vol. XV., writes that she effectually got rid of skunks by the use of Rough on Rat stirred in an egg. This mixture was placed at the entrance of hires preriously risited by skunks. After the doses had been repeated two erenings in succession the skunks nerer again came back. 
of the bee with its sweet morsel of honey in its honey-sac without being stung.

\section{ANTS.}

Certain ants in the more southern states, particularly in Florida and Texas, will attack a colony of bees and utterly ruin it. For further particulars see ANTs, subhead "Ants in the South."

\section{SPIDERS.}

Spiders as well as toads seem to have a rare appreciation of a heavily laden bee as it returns to the hive; we should therefore be careful that all spider-webs be faithfully kept brushed away from the hives, and that they have no corners or crevices about them to harbor such insects. Be sure there is no place which the broom will not clear out at one sweep; for where we have a hundred hives we cannot well spend a great amount of time on each one.

We are inclined to think that many of these so-called enemies take up the destruction of bees only as a chance habit, and that it is not always to be looked for nor expected. Common fowls sometimes get a habit of eating their own eggs; but it is so unusual an occurrence that we can hardly regard it as a matter of any very serious importance. It may be well at times to look out for the enemies that prey on bees; but, as a general thing, we think they are quite capable of fighting their own battles if we give them the proper care and suitable hives.

It was Mr. L. L. Langstroth, just before he died, who showed how spiders may be of value to the beekeeper. If, he said, they have access freely to the combs stored in stacked-up hives in the apiary, there never need be any fear that moth-worm or mothmiller will be able to do any damage, for the spiders will shortly destroy them.

\section{WASPS.}

Wasps and hornets sometimes capture and carry off honeybees; but unless they should take part in the work in great numbers, we would have no solicitude in regard to them.

\section{MOSQUITO-HAWKS.}

Mosquito-hawks, sometimes called "devil's darning-needles," and "bee-hawks," at certain seasons of the year, are very destructive to bees in some of the southern states, particularly in Florida. They give more trouble along the Florida rivers, especially along the marshy lands, where they breed very rapidly. In April and May they will come in such countless numbers that the sky will be black with them. As the habits of these insects are predatory, they will attack any insects, including mosquitoes and bees. When they are very numerous, the bees have learned the trick of staying in the hives, so it is said, realizing that the mosquito-hawks are their natural enemies. These insect hawks are so destructive at times that they will weaken a whole apiary.

One year, when the authors of this work had some 300 to 400 colonies on the Apalachicola River, their apiarist there estimated that the mosquito-hawks did damage to the extent of a thousand dollars in four or five days. We were preparing to move the bees north to escape this pest, but we did not move them soon enough.

\section{THIEVES.}

Thieves are sometimes troublesome at outyards, and once in a while at the home yard. The best way to put a stop to their depredations is to put up a sign or two offering fifty or a hundred dollars reward for the arrest and conviction of the guilty parties. The thief is immediately warned that a price is upon his head, and that he had best, if he knows when he is well off, stop stealing. It is seldom that the reward money is ever called for, and further annoyance is stopped.

\section{THE WORST ENEMY.}

By all odds the most serious enemy to the bees and beekeeping is the careless or ignorant beekeeper himself who harbors disease in his hives, either because he does not care or because he does not know any better. Such a man places in jeopardy the interests of every other beekeeper for miles around. While bees do not ordinarily fly over a mile and a half (see FLIGHT of BEES), and one is usually safe if he is that far from a foul-broody apiary, yet in the course of a year or two the colonies in the diseased yard will die. Bees a mile and a half away will rob out the honey from these dead colonies, and carry the infection to their own yards. They in turn become diseased, forming new centers of infection reaching out a mile further or perhaps two 
miles. This, in fact, is the way bee disease proceeds from yard to yard by robbing. To prevent this spread arises the need of foulbrood laws and bee inspectors. See LAwS Relating to Foul Brood; also Inspectors.

\section{ENTRANCE GUARDS.-See DRONES.}

ENTRANCES TO HIVES.-We do not know that it makes any great difference to the bees, or with the amount of honey gathered, where the entrance is; whether at the warm air generateed by the cluster, rising by its lightness, compared with the colder air outdoors, has a much less chance for escape than if the opening were nearer the top of the hive. If it is a little below the bottom-board, cold winds and storms are not so readily admitted.

An entrance part way up is not so liable to become clogged with dead bees. On the other hand, the lives ones will not be able nearly so easily to remove the dead if they have to tug them up the perpendicular sides

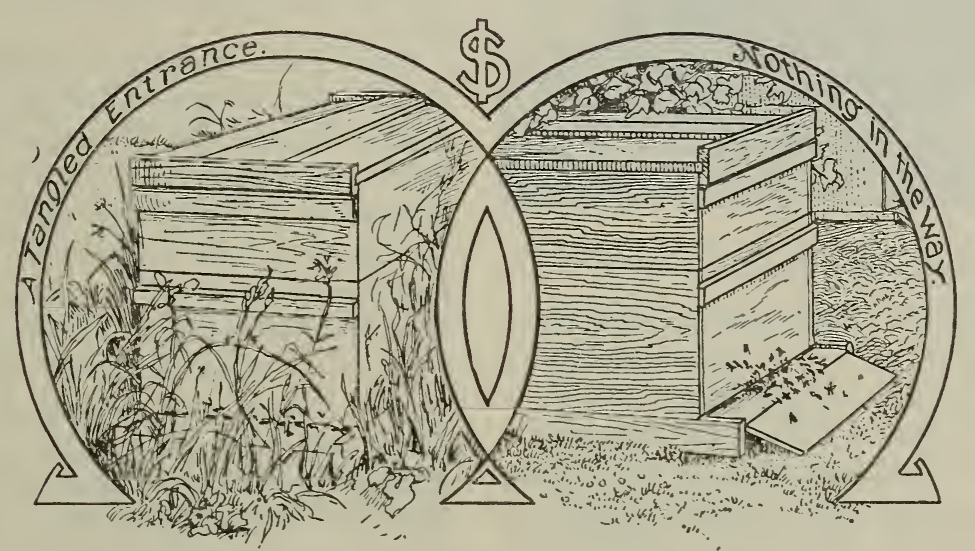

very lowest part of the hive, or right in the top. We have had them do well with their entrance in almost all positions. On many accounts, an entrance even with, or a little below, the bottom-board of the hive would be most desirable. This gives the bees every

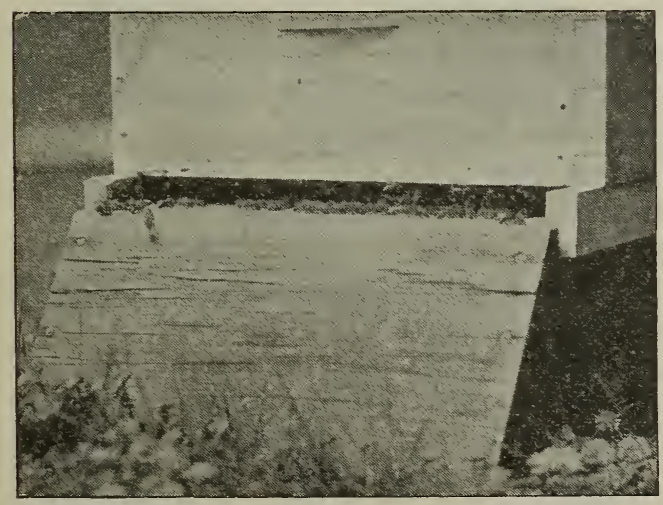

facility for removing dirt or dead bees; also bits of refuse comb, capping's from the cells, dust, etc., for this all falls to the bottom of the hive, and is naturally carried toward the entrance by the passage, out and in, of the inmates. There is another advantage in having the entrance at the bottom. The until they reack the opening; nor can the apiarist himself assist in the process. Where the entrance is on a level with the bottom of the hive, he can reach in with a hooked wire and rake out all the dead bees that may have accumulated during the winter. Indeed, he should, if the accumulation is enough to clog the entrance, clear it out once or twice during the winter, with a wire.

There is still another objection to a high entrance. During cool weather many of the flying bees on returning will become chilled in their efforts to crawl up the perpendicular side, and thus fail to get into the hiye; so, all things considered, an entrance that is handy for the bees is also best for the beekeeper.

On account of the tendency of returning bees to chill in cool weather, there should be a large alighting-board if the hive is raised off the ground; or if on the ground, there should be an easy slanting grade or doorstep to the entrance. All grass and weeds should be kept down within at least a foot of the front of the hive; and it would be better if there were a full yard of clear space. Bees that come in heavily laden are often knocked down by bumping into tall 
weeds or sprigs of grass. While they ultimately take wing, making another attempt, and finally land in the hive, such obstructions, if hindering to the bees, cause a loss to their owner.

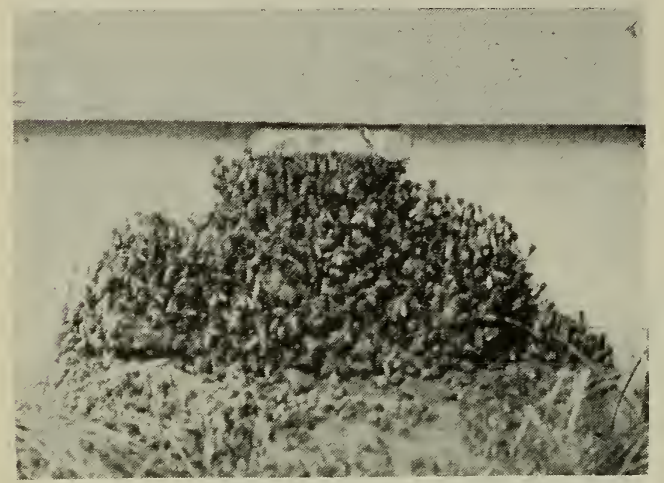

A colony with an entrance too small where the bees have formed the loafing habit.

It is impossible to estimate just how much the loss in honey is; but if the actual figures could be secured the producer would be surprised. When it is such an easy matter to cut away the weeds, or keep them away from the entrance with a little sprinkling of salt or with a wide board, it is " penny wise and pound foolish" to wear out the wings of our little servants trying to pass this obstruction, at the same time delaying them when every moment counts. Farmer beekeepers especially seem to have the idea that bees will work for nothing and board themselves, and in three cases out of five one will find the entrances of their hives, what few they may have, all tangled up with grass and weeds. On mornings when there is a heavy dew such obstruction is very considerable.

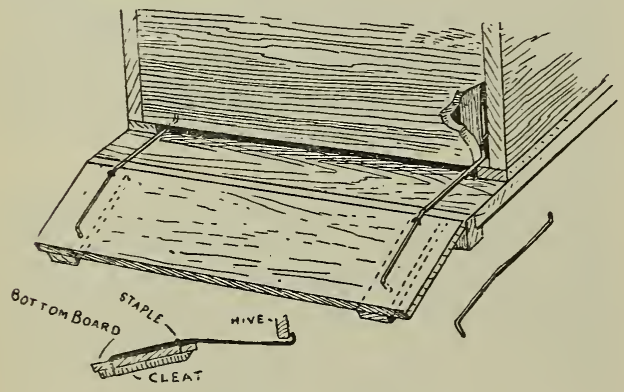

Very many use a scythe, lawn-mower, or a common sickle, to cut down the grass. Others keep it down with a small handful of salt scattered around the front of the hive. Still others prefer to use a piece of board about a foot wide or more, and as long as the hive is wide. Rough unplaned lumber of the cheapest kind is better than clear planed stuff, as the bees can cling to it better. The boards should be cleated and laid directly on the ground, abutting up close to the bottom-board if it rests on or close to the ground. No grass or weed can grow, of course, where these boards are laid; and general practice shows it is cheaper and better to use such boards than to be compelled to use salt or cut down the obstructions every few days in front of the hive.

One of the drawings contains a suggestion which can be very easily applied to the cleated boards just described. Bend some iron wires, about No. 8, as shown with hook at each end. Drive one of the hooks into the board as here illustrated, and secure in position by means of a common blind-staple near the other edge. If the wires are cut right, this alighting-board can be easily hooked into the entrance and make a nice easy grade from the ground up to the hive. At any time these alighting-boards can be unhooked so that the grass can be cut down with a lawn-mower and then replaced.

\section{SIZE OF ENTRANCES.}

This depends on the season of the year, the size of the colony, and whether the bees are wintered indoors or out. During the height of the honey-flow the aperture should be as large as the bottom-board or hive will permit-not less than $7 / 8$ inch deep by the width of the hive. Experience has shown that a contracted opening does not give the bees sufficient ventilation; and, as a consequence, the great mass of bees are forced out of the hive, where they will loaf day after day, doing nothing. When they once get into the loafing habit they will be much inclined to swarm, to say nothing about wasting valuable time during that part of the season when, if ever, they should bring in money in return for all the labor expended on them.

Where one uses hives of the loose-bottom type, he can usually cure this clustering out and loafing by raising the brood-chamber off the bottom, placing four blocks $7 / 8$ of an inch thick on the bottom-board and setting the brood-chamber back again. This will provide an opening on all four sides. While the bees will use the front or main entrance 
mainly, they will fly out from the others. With so much rentilation the bees, unless the colonies are extraordinarily strong. will go back into the hive and go to work. Some beekeepers go so far as to claim that the procedure will almost entirely eliminate swarming. For further particulars on this subject see STARMIng, to Control. See also the illustrations on the prerious page.

Nuclei or weak colonies must have no larger entrances than they can easily defend. They should be as small as possible after the regular honey-flow, for then it is that robbers are liable to rush in pell-mell and overpower the guards of the little colony. depriving it of the scanty store it may hare. See Robbing. A two-frame nucleus should not have an opening larger than will admit two or three bees at a time if it is during the robbing season. When the honer-flow is on, it may be larger: but it should be contracted as soon as it eases up.

\section{ENTRANCE CONTRACTORS.}

When cool weather comes on the entrances of all colonies should be contracted, both

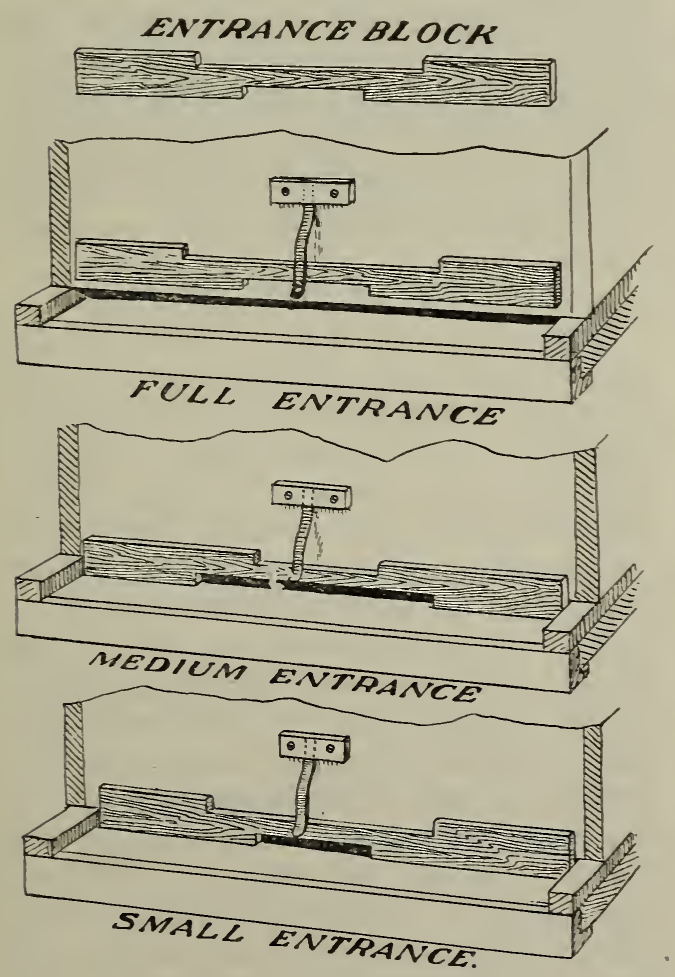

strong and weak, and kept so during the entire winter if bees are left outdoors. Formerly the practice was to allow the full size: but experience has shown in many localities that this - is a serious mistake. There is no more reason why the bees should hare their doors wide open in mid-winter. letting chilling drafts blow in. than that we should leare our doors open. An ordinary eight-frame Langstroth hive should have an entrance not much larger than 8 inches wide by $1 / 1$ deep. During rery serere weather it might be still further closed. Some of the rery strongest colonies may hare an opening of 8 or 10 inches: but with this contracted entrance it may be necessary for the apiarist to hook the dead bees out with a wire two or three times during the winter, and possibly once in the spring: for in no case must the opening be clogged up.

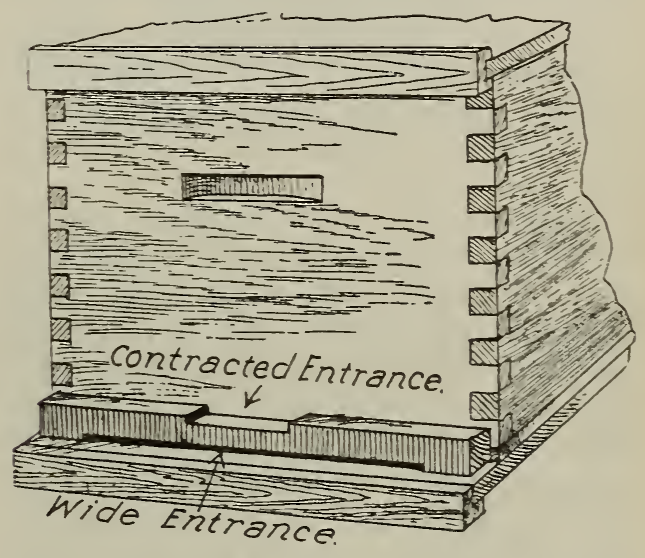

It is customary to have some sort of cleat to reduce a wide entrance to a small slot on one side $1_{4}$ by 5 or 6 inches. This, when inserted slot side down, reduces the opening to the proper size for outdoor-wintered bees. In cleaning out the dead bees the entrance-stop should be remored entirely. making the entrance itself the full size. Any dead bees that may have accumulated should be raked out and the stop put back. If it is discorered that the colony is weak. the slot should be reduced to one inch in width. At the same time the frames should be contracted to the number that the bees can reasonably occupy or corer. If they are compelled to keep a large room warm. they may die from cold.

The illustrations show rery simple cleats which can be made at any planing-mill, or wan be cut at home, using nothing but a common hand-saw and a chisel. These cleats give rarious-sized entrances according to the way they are attached. When 
the cleats are removed entirely the full opening of the hive is provided.

Under the heading ENEmies of BeEs we referred to the depredations of mice during the winter. It often becomes necessary to screen the entrances of hives put in the cellar or out on their summer stands if wintered outdoors. Mr. W. D. Keyes, of

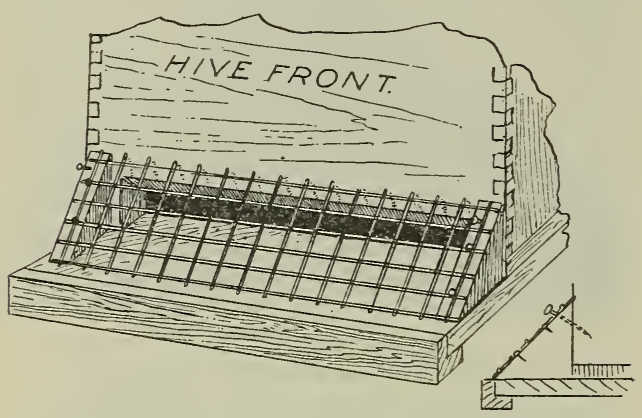

Coarse wire mesh that will let bees through but exclude mice.

Wilkinsburg, Pa., uses a very simple device, consisting of two triangular blocks and a strip of coarse-mesh cloth, just coarse enough to let bees thru it and yet exclude the mice. It is very quickly applied; and if there is one to each hive in the apiary it will make very little expense, especially when we remember that a mouse on even one frame of young brood may do enough mischief in a single colony to pay the expense of these excluders for the whole apiary. They will seldom gnaw wider a slot $1 / 4$ inch deep in an entrance-contracting cleat. Ordinarily they serve the purpose quite as well as the wire-cloth guards.

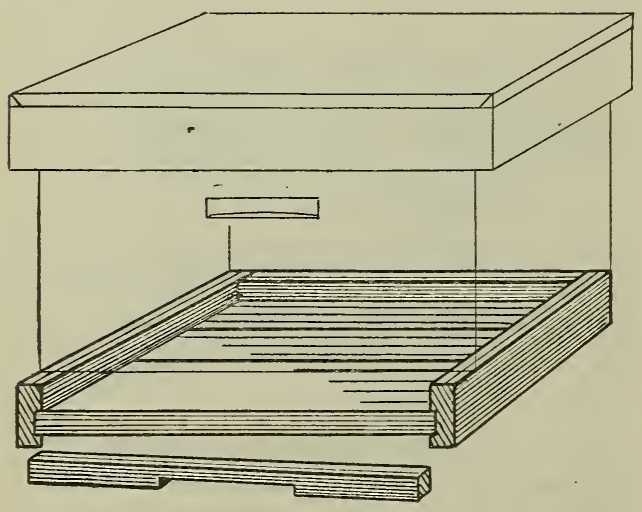

The accompanying illustrations show how the entrance is provided for in a modern dovetailed hive. The bottom is made up of an outside rim or framework, into which is inserted the floor-boards $7 / 8$ inch thick. These slide into grooves so cut that on one side the bottom-board provides a $3 / 8$ space, and on the other side $7 / 8$. The usual practice is to use the deep side up, and an entrance-contracting cleat as shown.

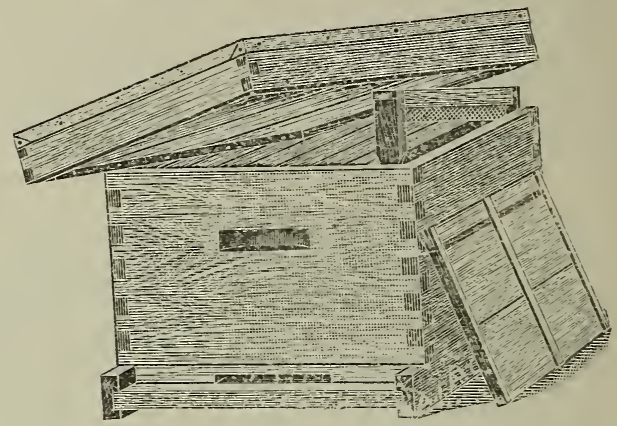

While some prefer to use the shallow side of the bottom-board the year round, it is better to use the deep side, and then make the necessary contraction of entrance with the contracting cleat as shown. During the warm part of the year, when bees need an abundance of ventilation, spoken of under Comb Honey, how to Produce, and Swarming, How to Control, the wide or deep entrance is used without the entrancecleat. As cooler weather comes on, or if the colony is not strong, the cleat is inserted as shown in the above engraving.

\section{A PLURALITY OF ENTRANCES.}

While it is true that a plurality of entrances may be a detriment in a broodchamber, it does not necessarily hold good during the honey season when the hive is tiered up two or three stories high. It then becomes difficult, and wasteful of bee energy that might be better employed, to ventilate the whole hive from one entrance, however large it is in the lower story, for the bees have to maintain a current of air rushing in, and another going out at the same aperture. If queen-excluders are used the case is made worse. It almost goes without saying, that, during the period in which the honey is evaporated while in the combs, there ought to be more than one entrance to the hive-at least two, and, during very hot weather, more, one to each story, with the cover or roof slightly raised at the back to furnish additional means for the bad air to escape at the top of the hive. 
PLURALITY OF ENTRANCES FOR THE CONTROL OF SIVARMING.

It is said by those who have tried this method of air control that it is a great prerentive of swarming, and it looks reasonable. The brood-chamber is far less crowded, since the field workers arrive and depart from the upper entrance to a great extent, saving overcrowding of the brood-chamber, which surely leads to swarming. On the other hand, there is danger of the honeychambers being rendered too cool by so many entrances; but if this is the case, it is also too cool for honey-gathering, and the upper stories should be removed. If the colony is weak, upper entrances are unnecessary; and in that case, also, the honeychambers should be removed, since such a colony does not gather a surplus in any event. It is too weak.

Some of our well-known writers on bee culture heartily recommend upper entrances -notably so Dr. C. C. Miller, C. P. Dadant, R. F. Holtermann, and, in early times, Adam Grimm, who, with the money he made with his bees, established a bank.

Dr. C. C. Miller, writing in Gleanings in Bee Culture for June 1, 1907, writes: "Prof. Cook says, p. 312, that bees ventilate so effectively at the entrance that it is best to have only one opening to the hive, evidntly meaning at all times; and $\mathrm{W}$. K. Morrison, page 686, asks if I subscribe to that doctrine. Emphatically, no. If running for extracted honey I would generally have one more opening than the number of stories in use-the regular entrance and an opening at the top of each story. Each year for years I have had one or more piles thus ventilated, and none has ever swarmed. Many years ago I learned from Adam Grimm to have an opening for ventilation at the top of the brood-chamber at the back end when running for comb honey. I gave it up because it interfered with the finishing of the sections near such openings. But I have gone back to it again, believing that such disadvantage is overbalanced by the gain in ventilation. You can't make me believe that it is not easier for the bees to have one hole for the air to go out and another for it to come in than to make the air go both ways in the same hole."* The

* It is a rery interesting experiment to light a match and hold it in front of the entrance while the eraporation of nectar is going on in the hive. On practical beekeeper will soon discover for himself when and how to use a plurality of entrances, for much depends on the climate. Evidently it does not work so well with comb-honey production as it does extracted; yet even this may be satisfactorily arranged. It looks now as if plural entrances were a long step toward swarm prevention by causing the field workers to leave the brood and confine their energies to storing honey in the upper chambers. See SWARMING.

ENTRANCES FOR INDOOR WINTERING.

Authorities differ as to the size of entrance that should be used for indoor wintering. Some argue that, the larger the openings, the better. A few go even so far as to urge that the bottom-boards be removed entirely, one hive piled upon two others, leaving an opening between the two lower hives of about one-third of the size of the entire
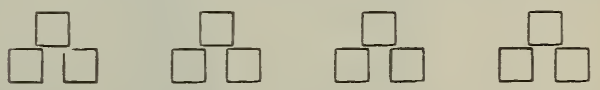

bottom of the hive. Others advise a regular. bottom-board, but an entrance two inches deep by the full width of the hive; while others recommend no larger entrance than the bees have during the summer.

The preponderance of evidence seems to be in favor of the last-mentioned size. Too much ventilation, eren in a cellar where the temperature is reasonably under control, has a tendency to induce too large a consumption of stores. Over-feeding causes dysentery. When that happens in a beecellar the colony is doomed unless it can be given a flight on a warm day, as recommended under the head of IVINTERING IN REPOsITORIES in the latter part of this work.

Our practice has been to use the same entrance that we have in the summer for our indoor-wintered hives; and so long as we used that size we had excellent results in wintering. But one winter, for the purpose of experiment, we raised each individual hive off its bottom-board and inserted a rim three inches deep and of the same outside

one side the flame will be sucked into the entrance and on the other side the flame will be blown away from it. So strong is the current that the match will be sucked out in one case and blown out in the other. It shows that bees, like a series of little electric fans, are sucking fresh air in one side and forcing the air laden with moisture from evaporation on the other side. The direction of the air current can also be determined by the use of a little smoke or a light and fluffy feather. 
dimensions as the hive. The sides of these lims were open, but covered with wire cloth. The result was that we lost over 100 colonies out of the 230 odd put into the cellar, and the rest came out in a very weakened condition.

The bee is essentially a warm-blooded animal. Experience has shown that a temperature of 45 to 50 degrees Fahrenheit in a cellar gives the best results. An ordinary colony with ordinary summer entrance in such cellar temperature will be able to warm become very valuable sources of timber and other commercial products, and are likewise very effective as avenue and landscape trees. A part of the species are popularly known as gum-trees because a resinous gum flows from incisions in the bark; others are called iron-bark trees from their very hard bark, and still others from their fibrous bark are termed stringy-bark trees. To this genus belongs the tallest tree in the world, $E$. amygdalina, which attains the height of 480 feet.

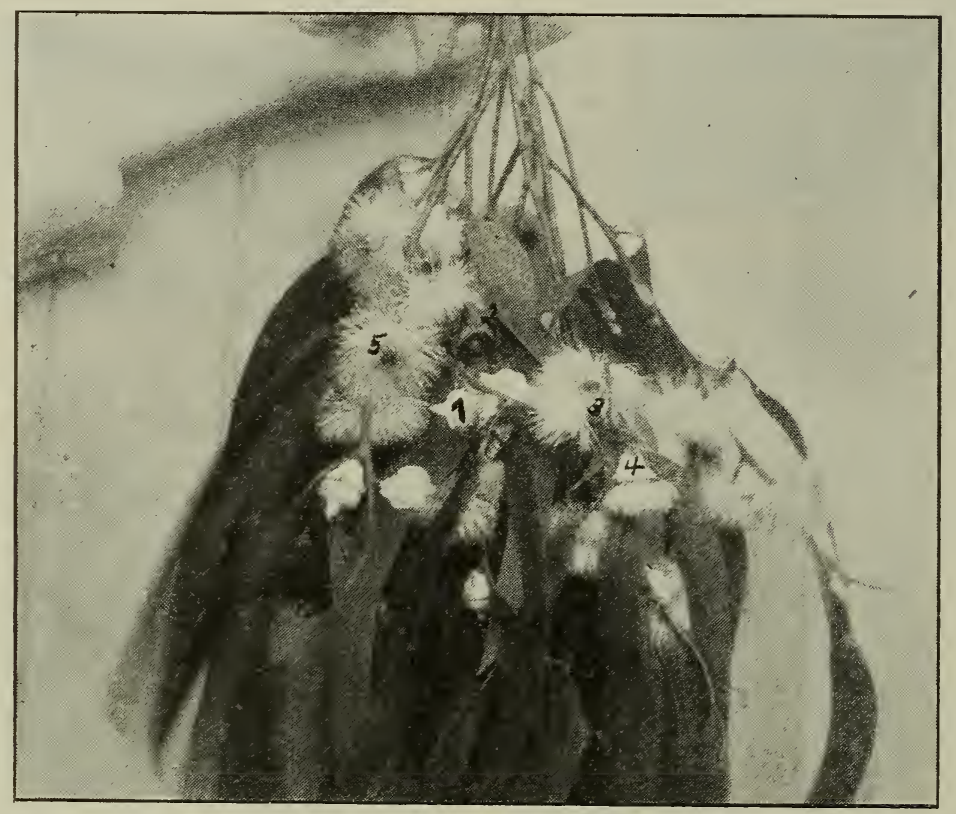

The eucalyptus is of vast importance in California.

the interior of its hive without too much expenditure of animal heat. When the bees are too cold they will eat largely of their stores, and in doing so bring on disease.

EUCALYPTUS.-A large genus of evergreen trees growing chiefly in the coast region of Australia and New Guinea. About 150 species have been described, of which not far from 100 have been introduced into California. At the Forestry Station at Santa Monica there have been planted nearly 70 species and varieties, the qualities of which are being tested and compared. To a much smaller extent they have been planted in Arizona and the Gulf region of Texas. Few eucalypts will endure a temperature below 20 degrees, or above 120 degrees F. They grow very rapidly and promise to
By far the most widely planted and probably the best adapted to the climatic conditions of California is the blue gum, or $E$. globulus, which is found in almost every town in the state from San Francisco to San Diego, and inland as far as the edge of the Imperial Desert region. It is apparently as vigorous in California as in its native Australia. It is claimed to be the fastest growing tree in the world. Seedlings will average a growth of 50 feet in height in six years and 100 feet in ten years; and under favorable conditions a seedling may reach a height of 35 feet in eight months, and in three years a height of 70 feet. In Australia old trees grow 375 feet tall. The wood is very heavy, hard, and strong, and is valued at the same price as oak. It is used for innumerable purposes from tele- 
graph-poles, railroad-ties, and ship-building to cabinet work and wagon-wheels, as well as for fuel; while the leaves yield large quantities of medicinal oil. Windbreaks of two or three rows of blue gum afford excellent protection to orchards. The cost of setting out and cultivating a plantation for two years is about $\$ 25$ per acre, while the returns at the end of ten years will usually not exceed $\$ 160$ per acre.

The bark of the blue gum is smooth and pale brown. The leaves are sword-shaped, 6 to 12 inches long, tough, leathery, and bluish-green in young trees, but dark green in older trees. The flowers are solitary (in most other species they are in small clusters), in the axils of the leaves and appear from December to June. The flower-bud expands by the top of the calyx dropping off, when there is a "veritable starburst" of some 100 creamy-white stamens. A flower consists of the cup-shaped lower portion of the calyx, which is well adapted to hold the very abundant supply of nectar, and a ring of stamens, with the pistil in the center-there are no petals. The seed-cases are round, top-shaped, or in the blue gum angular, and a pound of seed will produce over 10,000 plants. E. globulus was introduced into California in 1856.

Other species of eucalyptus, which are promising commercially, are the sugar gum (E. corynocalyx), the red gum (E. rostra$t a)$, and the gray gum (E. tereticornis); but none of them are comparable to $E$. globulus in rapid growth, value of timber, and ability to flourish over a wide range of conditions in California. The sugar gum is much used in southern California as a street tree and for windbreaks. It strongly resists drouth, but succumbs easily to frosts. The red g'um has been largely planted in the Sacramento and San Joaquin Valleys, and also withstands well the intense heat of the Imperial Valley. The gray gum endures drouth and cold better than many species, and can, therefore, be planted over a wide range of the state. The timber of all three species is strong and valuable.

All of the species yield nectar, but most of them are so rare outside of experimental grounds that their value as honey-producers remains to be determined. The blooming time of the various species varies so widely that there are, at least, from three to seven species in flower during every month of the year, and a species may even bloom twice in the same year. The blue gum ( $E$. globulus) is the only species which is yet sufficiently abundant to be of much importance to apiarists. There is a fair flow of nectar which is but little affected by the weather; but the amber-colored honey, which is very heary and crystallizes in a few weeks is so sour that it is in little demand for table use. Several species are reputed to yield fine honeys with exquisite flavors. The sugar gum ( $E$. corynocalyx) secretes nectar copiously, and two or three bees may often be seen around a single blossom seeking a load of nectar. The flowers, which are in pretty white elusters about two inches broad, exhale a most agreeable odor suggestive of a ripe cantalope. The mahogany gum ( $E$. robusta) which thrives in swampy localities is also very valuable. White iron bark ( $E$. leucoxylon) with a vanilla-like fragrance, and the honey-scented gum (E. mellilodora) are reported to be wonderful yielder's of nectar and to be very eagerly visited by bees. They all bloom during the earlier half of the year when their value in stimulating brood-rearing is almost beyond estimate.

But encalyptus honey in America probably belongs chiefly to the future. The commercial importance of eucalyptus culture, which has now passed the experimental stage. will lead to the planting of thousands of trees, which will offer a bee pasture of extraordinary richness. The Santa Fe Railroad Company, for example, expects to cover 8000 acres in San Diego County with eucalyptus trees for ties and timber. If the nectar production of these immense plantations equals expectation the possibilities of bee culture in California can hardly be overestimated. It is, however, unfortunate that the blue gum, which financially is the most promising species, should yield a honey of inferior quality. For descriptions and illustrations of the more important species of eucalyptus and the methods of cultivation see Bulletins No. 196 and No. 225, Agriculture Experiment Station, Berkeley, Cal., and Circular 59 of Forest Service. United States Department of Agriculture.

EXTRACTED HONEY.-Up to the year 1865 all liquid honey obtainable was pressed and strained from the combs-hence the term "strained" honey. Such a product is 


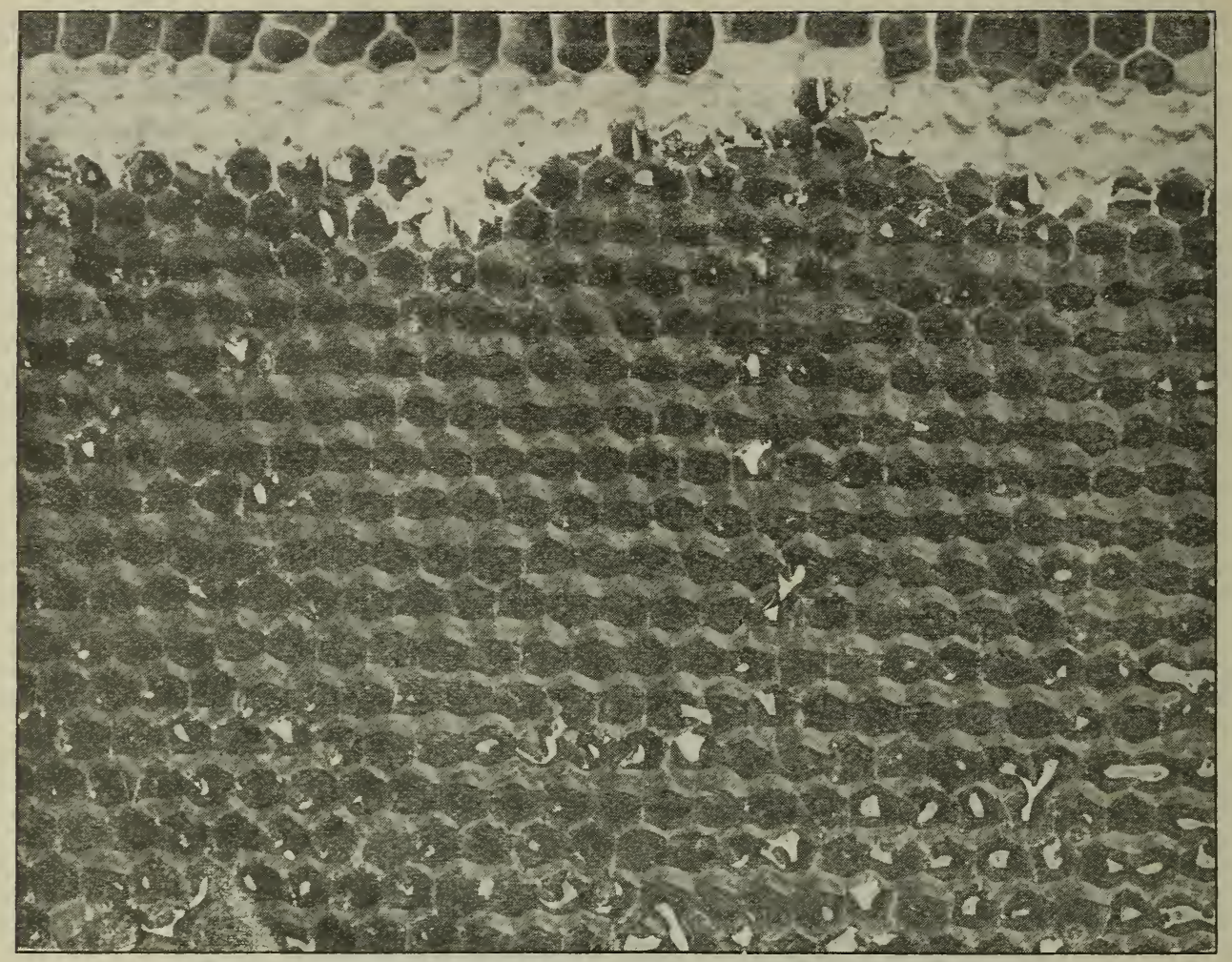

A comb of honey with the cappings shaved off by a sharp knife.

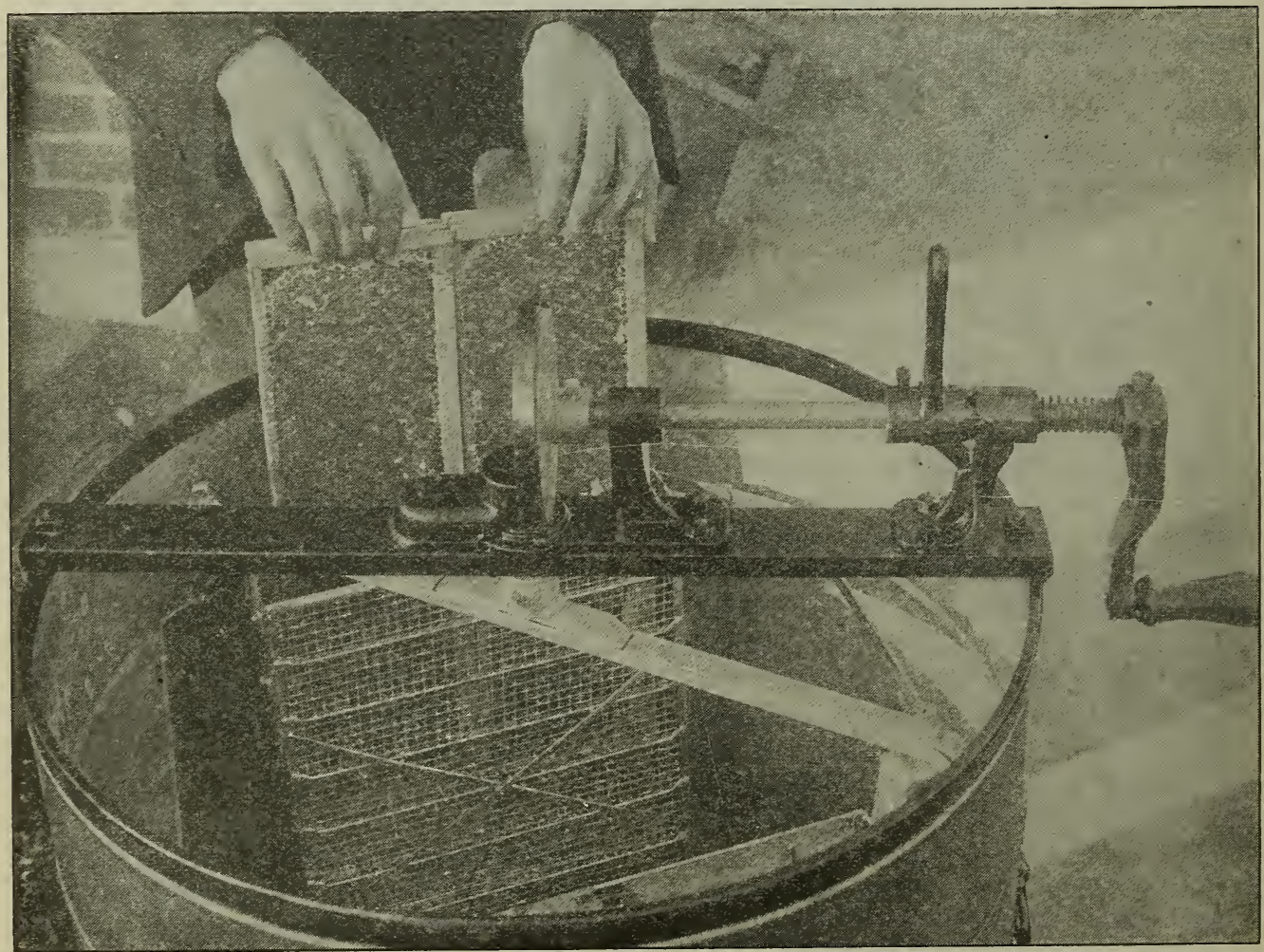

Uncapped combs being lowered into a honey-extractor. 


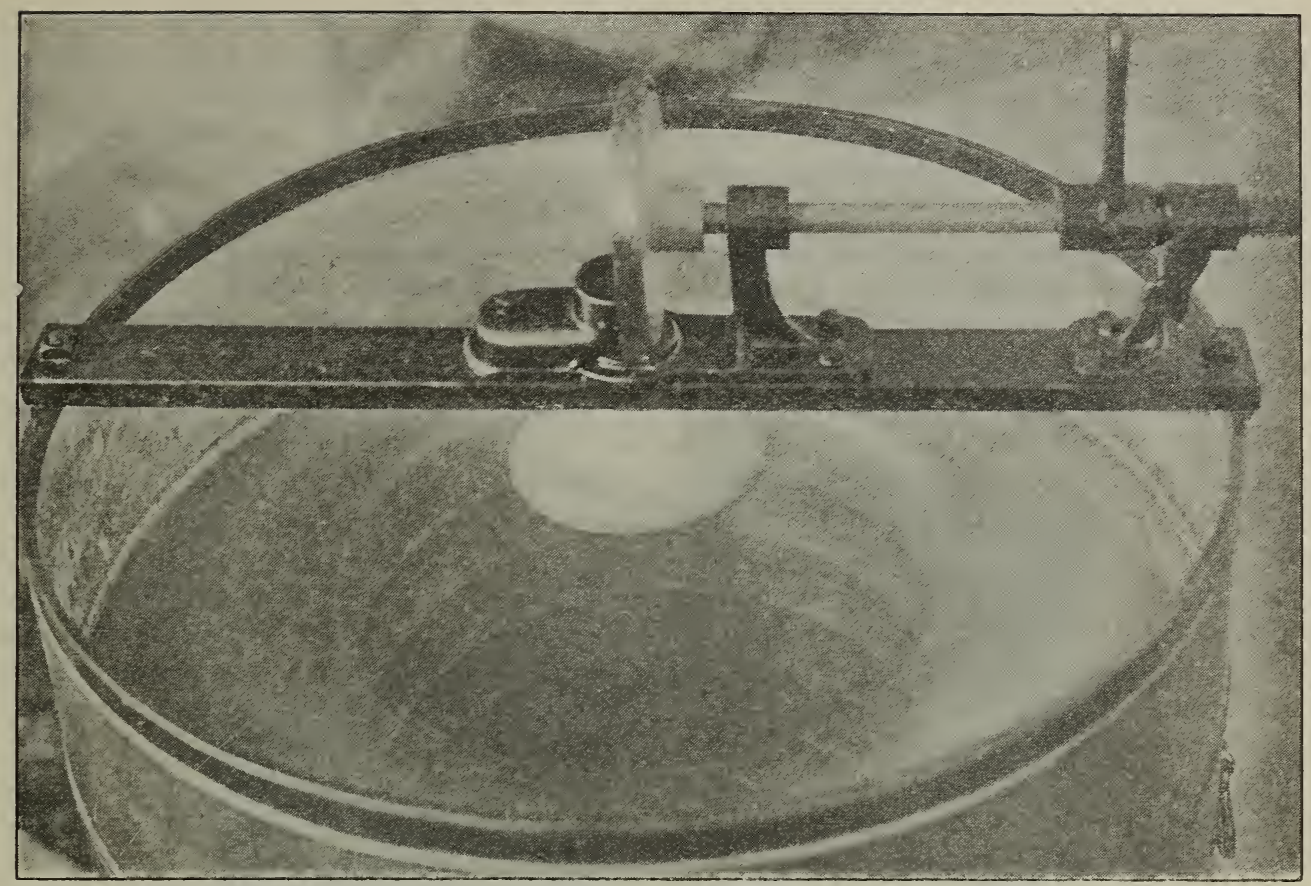

When the combs are whirled rapidly, the centrifugal force throws the honey out of the cells against the side of the can.

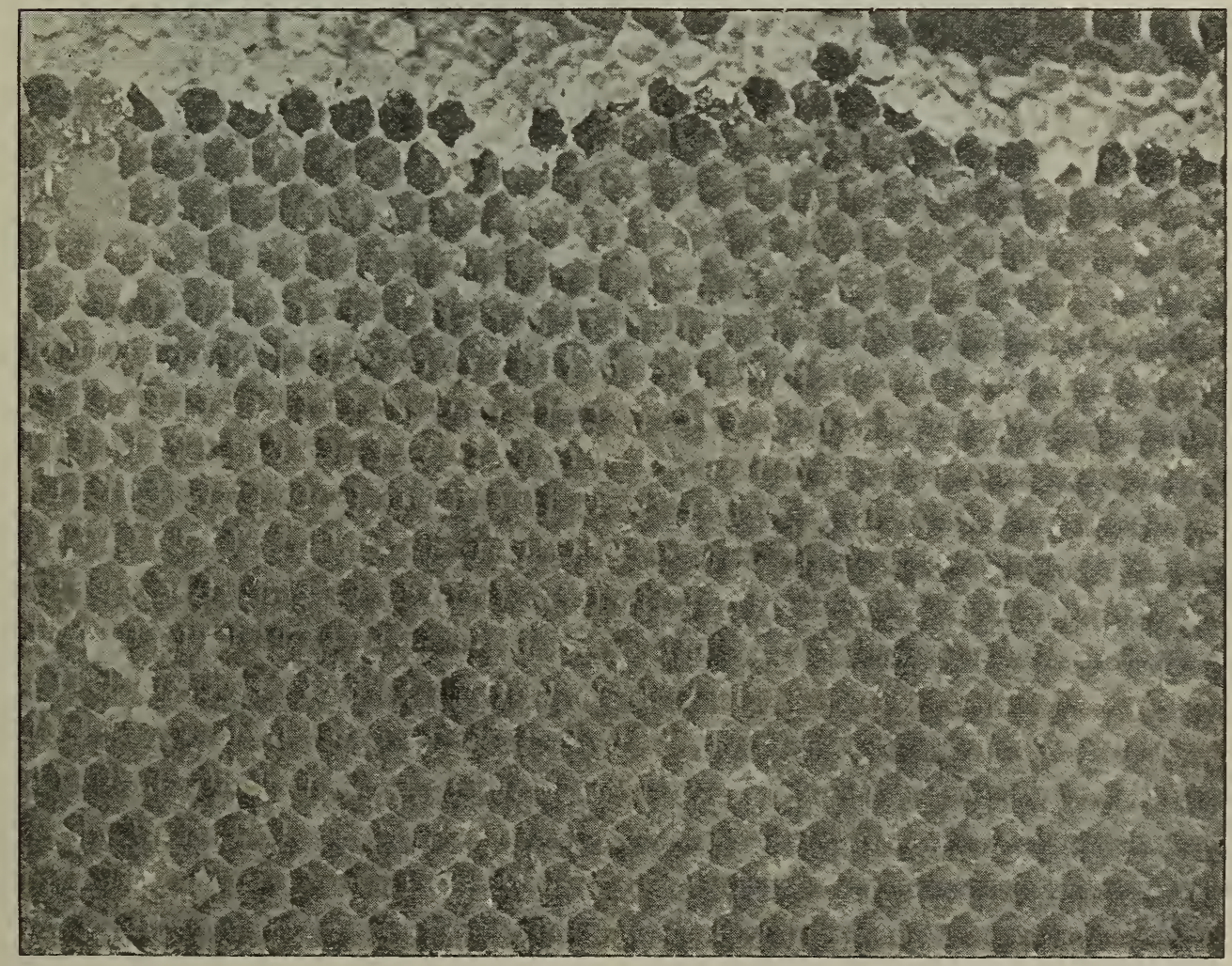

The coinb after being taken from the extractor is as good as new and is ready to be filled again by the bees. 
generally full of sediment owing to particles of wax, pollen, propolis, and dirt. The centrifugal honey-extractor throws the liquid honey from the cells, leaving the empty combs intact for the bees to fill up again. The extracted honey thus obtained is not strained from the comb in the old way, but thrown out by centrifugal force. It is clear and free from impurities-moreover, the flavor is not impaired by bits of pollen and propolis. Practically all the liquid honey on the market today is separated from the combs by the use of the extractor, and is, therefore, extracted honey. Occasionally there is a honey-for example, the farfamed heather honey of Scotland-that is so thick that it cannot be readily separated from the comb by centrifugal force, unless it is placed in a warm room for twenty-four hours before extracting.

There are as many varieties and flavors of honeys as there are of apples and other fruits. Extracted honey may be divided into two general classes, one suitable for table use and the other for manufacturing purposes. Among the first named are the light-colored honeys, such as the clover, basswood, alfalfa, sage, orange, tupelo, palmetto, and raspberry, all of which are of fine body and flavor, and of course suitable for use on the table. While it is not invariably true, yet generally the light-colored honeys are mild and delicious. The darker honeys are nearly always stronger in flavor and must be marketed in a locality where the consumers are used to the flavor, or they must be sold for baking purposes. Hundreds, yes, thousands, of carloads of dark honeys are used by the large baking concerns, for no artificial product* that has ever been produced quite takes the place of honey for keeping cakes soft and moist for months. Some cakes, like honey jumbles, contain a larger percentage of honey than others. Honey is also often used along with molasses and a cheaper syrup in baking. See Honfy AS A FOOD.

\section{THE FLAVOR OF EXTRACTED HONEY.}

As has been pointed out under ComB HoNey there is some difference in flavor between comb honey and extracted, owing to the fact that the latter, especially if im-

\footnotetext{
* Invert sugar, when it is cheaper than honey, is sometimes used as a substitute, but it lacks flavor. See INVERT SugAR.
}

properly handled, loses some of its aroma and because it usually has to be heated one or more times, as explained under BoTTIING. Overheating, even for a very short time, impairs the flavor of honey. Moreover, some producers in their eagerness to obtain all the honey possible extract it from the combs before it is fully "ripened." Honey when it is first stored in the cells is thin and watery, and does not have the exquisite flavor that it has when evaporated and changed chemically by the bees and sealed over. Honey which has been allowed to stay in the hive some time after it is sealed or capped acquires a body and a richness that honey only partially sealed does not have. Some producers who use specially constructed evaporating tanks maintain that unripe honey may be evaporated by artificial means and made just as heavy in body as that evaporated by the bees. If an extensive equipment is used this is probably true, but the flavor is not as rich as tho the honey had been left on the hive, fully evaporated and capped over by the bees before being extracted. Most beekeepers who have tried to ripen honey artificially have not succeeded, and the thin honey which they attempt to sell not only lacks in flavor and body, but in many instances actually sours, irreparably damaging future sales and injuring the reputation of the producer. Unless honey is coming in so fast that there is not a reserve of combs to take care of it, it is penny-wise-andpound-foolish to extract unripe honey. It is not possible to produce an extracted honey that will have all the delicate aroma that it possessed before being removed from the comb, and every extracted-honey producer, therefore, should err on the safe side by letting the bees do their part fully.

In 1870 A. I. Root extracted over three tons of honey from an apiary of less than fifty colonies. During the fore part of the season it had been allowed to become capped over; but during the basswood bloom, when the bees were fairly crazy in their eagerness to bring in the nectar, some of it was extracted that was little better than sweetened water. This granulated when the weather became cold, and nearly all of it had to be sold at a loss. Almost all honey will granulate; but an unripe honey will do so also, leaving a thin watery part, which, if it does not sour, acquires in time a dis- 
agreeable brackish flavor. Unripe honey will often show the peculiar quality of pushing the bungs out of barrels, corks out of bottles, and it may actually burst cans, to the discomfiture and disgust of every one who has anything to do with it.

New honey, even that which is fully capped over, often has a peculiar odor and taste. Sometimes where there is a great amount of goldenrod a disagreeable smell is noticeable in the apiary while the goldenrod standing, especially if left in the hives, it greatly improves.

One season we could not attend to extracting when the honey was capped over, and so the filled supers were raised up and super's of empty combs placed under them next to the brood-chamber. This occupied little time, and the bees were not hindered in their work. This was continued until the latter part of the summer, before any honey was extracted. Thile such honey is some-

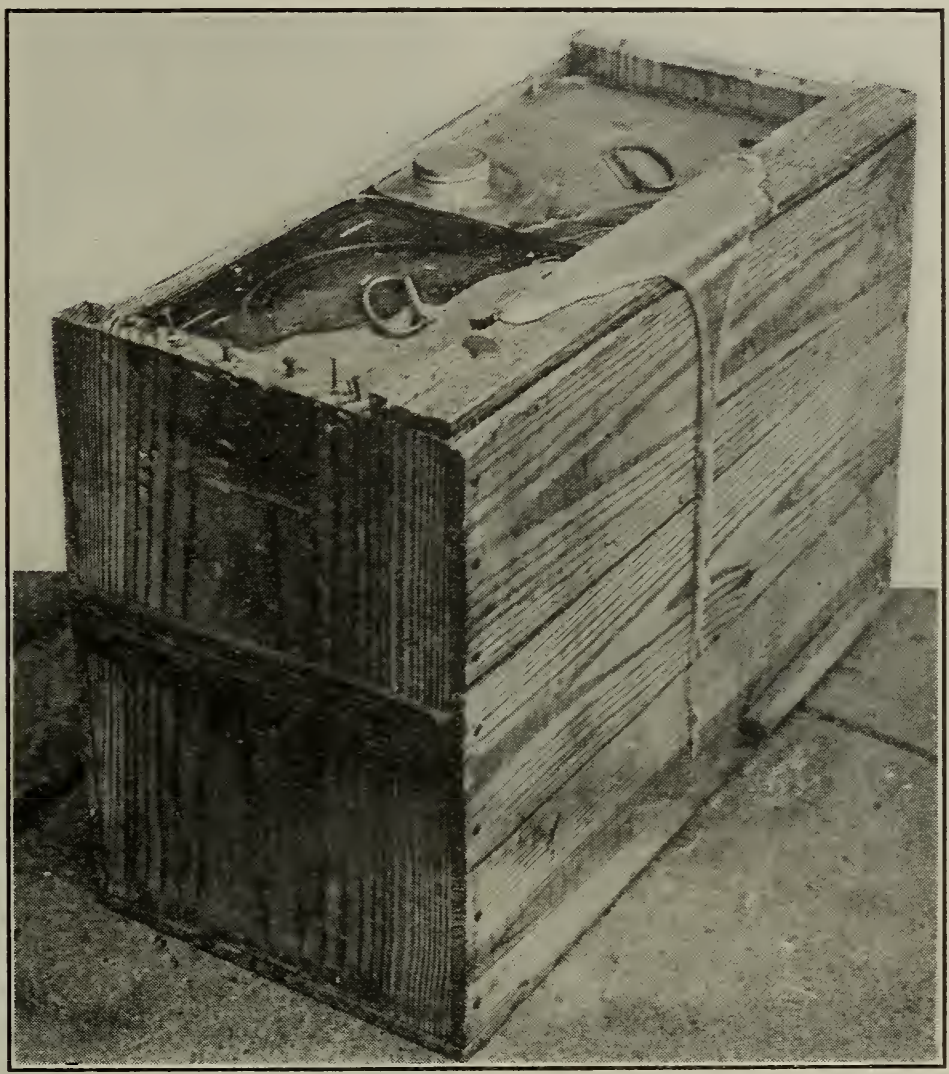

Unripe honey. Fermentation and consequent expansion caused the honey to leak out around the screw-caps.

honey is ripening. This is also true to a certain extent in case of aster honey. At times the honey actually smells sour. In a few weeks, however, all this passes away and the honey shows nothing of the former disagreeable odor or flaror. In certain localities where onion seeds are raised for market, the honey, when first gathered, has so strong a flavor of onions that it cannot be used. Later on, however, much of the disagreeable quality disappears.

Even basswood honey, when first gathered, is so strong, and has such a pronounced "twang" that it is often unpleasant. After what thicker and harder to extract. it has a richness of flaror that can be obtained in no other way. Of course, in localities where there are honey-flows from two or more sources it is necessary to extract after each flow if one desires to keep the flarors separate.

\section{HOW TO KEEP EXTRACTED HONEY.}

It is usually best to sell the crop at once when the market is good; but sometimes it is adrisable to hold, awaiting a further higher price. It is impossible to recommend any invariable rule, for conditions are dif- 
ferent in different seasons. It is pretty safe to assume, however, that honey brings a better price before the holidays than after.

Comb honey cannot be kept indefinitely, because there is danger that it may granulate:* but if extracted honey is properly cared for it may be kept for years without deteriorating. All honey should be kept in a room as near summer temperature as possible. The thermometer should not go below 70 degrees Fahrenheit, and no harm is done if it goes as high as ordinary summer temperature permits, even 90 or 100 degrees in the shade. Extracted honey keeps perfectly when stored in tin cans or in large tanks. Tanks holding more than 500 pounds are ordinarily made of galvanized iron. Some objection has been made to this metal because of the zine contained in the spelter; but in the large-sized tanks no injury to the honey has ever been noticed; but it would be a mistake to leave a very thin layer of honey for a long time in the bottom of a large galvanized tank, as the honey might take on enough of the zine to be poisonous. In California and other western states where great quantities of extracted honey are produced it is customary to store honey in large galvanized tanks, some of them practically good-sized cisterns above the ground, as will be found illustrated on page 14:1. In hot climates the honey will remain liquid for some time, and can be kept perfectly clear until cool weather comes on. If the honey has a tendency to granulate soon after extracting, it is not advisable to store it for any length of time in large tanks, but it should be drawn off into smaller cans of convenient size to handle after it granulates. In such cans it is not difficult to liquefy it, if desired. (See Bottling Honey and Granulated Honey.) It is an expensive matter to dig granulated honey out of a large tank. Some have attempted to supply heat by means of a steam-jacketed tank, or by means of coils of steam-pipes; but in most instances this, too, is expensive, and it is better to get honey into smaller cans as soon as possible.

In some localities barrels are extensively used for storing. They require careful watching, however, on account of the danger of leaking. The hoops need to be driven down occasioually to compensate for the

\footnotetext{
* See Coxb Honey, subhead "Granulated Comb
}

slight shrinkage of the wood, of which there is danger, especially in a hot climate. The barrel should be thoroly waxed on the inside as described under BARRELS. The bung should be left out and the honey stored in a dry room. When ready to ship, the bung should be driven in, a piece of tin tacked over it, and the hoops tightened.

\section{NO ADUIJERATED EXTRACTED HONEY.}

Years ago adulterated extracted honey was marketed in considerable quantities; but in late years, owing to the enactment and enforcement of pure-food laws the adulterated product has been practically eliminated from the market. One may be practically certain, therefore, that any liquid honey that he buys will be the pure product of the bees. Some may be of poor quality, it is true; but that does not signify that it is adulterated. See Adulterated HoNer, also LABELS, for a further discussion of this question.

\section{PACKAGES FOR SHIPPING AND SELLING EXTRACTED HONEY.}

By far the most popular package for shipping extracted honey in bulk is the five-gallon 60-pound can. These are usually shipped two in a wooden case as shown.

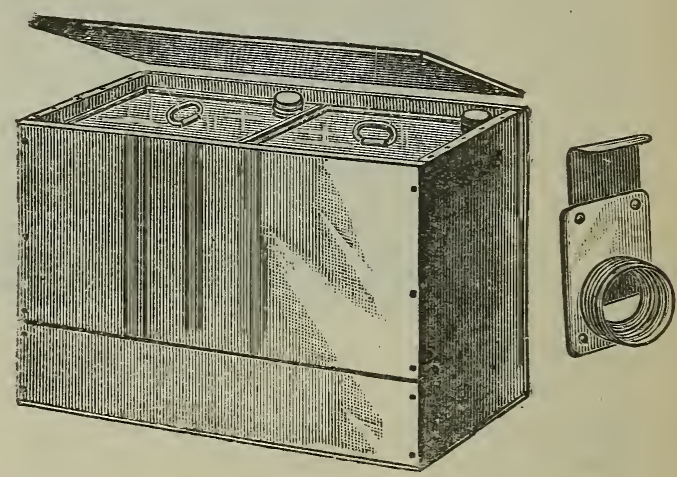

Case of two 60-1b. cans and honey-gate.

Especially in the West these cans are about the only shipping-packages that can be used, for the dryness of the climate causes wooden packages, such as kegs or barrels, to shrink to such an extent that they would be entirely useless. If these tin cans are tight in the first place they will remain tight, and no degree of dryness will affect them. While they are somewhat more expensive, yet this disadvantage is more than offset by the convenience in handling the honey. 
There is still another point in favor of tin; namely, there is never any loss by honey soaking into the package. In case of barrels or kegs the loss is sometimes 2 or even 5 per cent, and this is considerable. Such loss is greatly reduced by waxing; but that, in turn, involves much additional labor.

A very convenient device to use in connection with the five-gallon cans is the screw-cap honey-gate, as shown. This simple gate may be made by any one. Take a piece of heavy tin, $21 / 2 \times 3$, and make a square bend $1 / 4$ inch from each long edge. A heavy piece of sole leather, $2 \times 3$ inches, will just fit into this, and should be riveted firmly at the four corners. Solder to it a screw-cap the right size to fit the cans used, and with a tinner's punch cut a hole thru
HOW TO CLEAN SECOND-HAND CANS.

Opinions vary as the advisability of using second-hand cans. Frequently gasoline or kerosene cans may be bought for about half the price of new ones. Unless one is very careful in cleaning, however, honey placed in them is likely to be ruined. The general consensus of opinion is that bright new cans are the cheapest for fine light honey. Honey that is dark or ill flavored may be shipped in second-hand cans if they are carefully inspected and rigidly cleaned. If a can has held oil of any kind it may be cleaned by putting a handful of unslacked lime into it with three or four quarts of boiling water. After the lime is slacked, shake well and afterward rinse out twice with cold water.
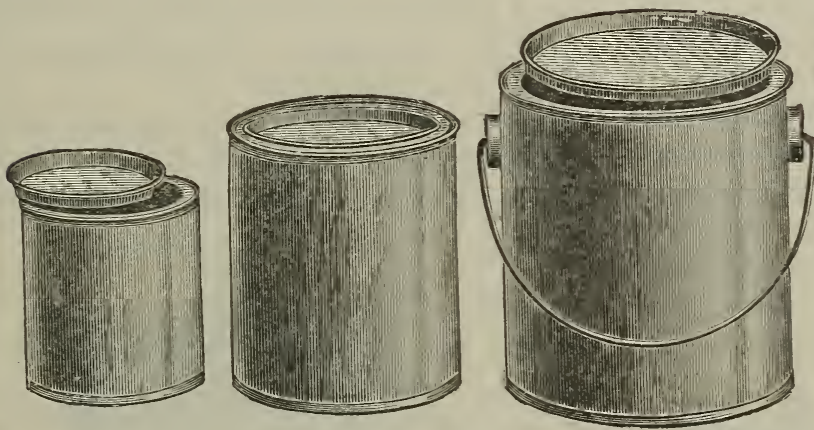

Friction-top cans and pails.

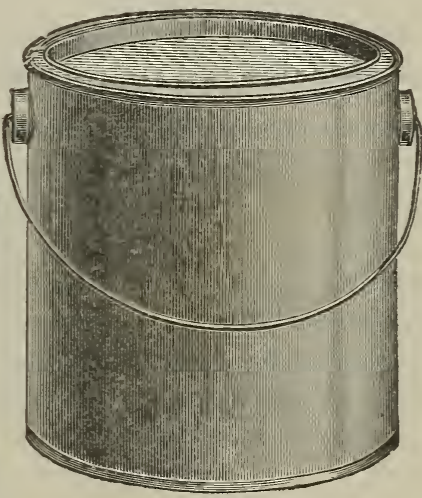

Rusty cans must never be used for honey. The rust not only discolor's the honey, but it indicates weak spots in the tin, which may cause leaks almost any time.

Some beekeepers insist that even new cans should be rinsed out with boiling water before the honey is put in them, to remove the dust or any other foreign matter. Other's claim that it is so difficult to dry the cans after they are thus cleaned that it does not pay. If the cans are not carefully dried the moisture left is almost sure to cause rusting. We have rarely found new cans that require rinsing.

Honey is one of the purest and best of foods, and at the same time one of the most inexpensive. On this account it does not pay to economize by using second-hand containers. There is no way of telling whether a second-hand can is clean enough to use, and no one would eat honey from a dirty package. 


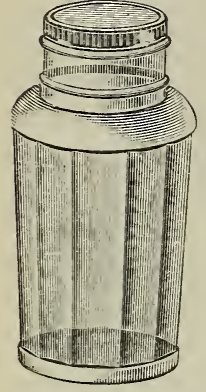

Taper-panel jar

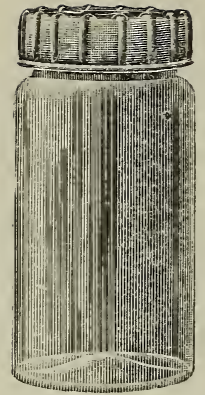

Federal jar

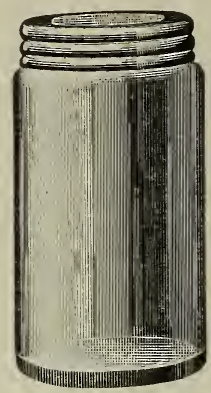

Round jar

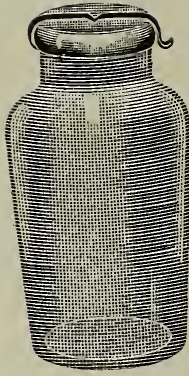

Tip-top jar

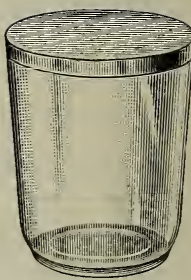

Tumbler
FRICTION-TOP PAILS.

Since the friction-top cans and pails have been perfected the style shown on previous page has become popular. 'The opening at the top is very large, and this adds greatly to the convenience in filling. The caps, when they are properly pressed into position, are absolutely tight and will not work loose.

\section{GLASS PACKAGES FOR EXTRACTED HONEY.}

The appearance of extracted honey is beautiful. For this reason the lighter grades should not be retailed in tin but in glass. A tin package must depend upon its label for its attractireness. Honey in clear white glass speaks for itself. The label does not need to be gaudy; in fact, it should serve
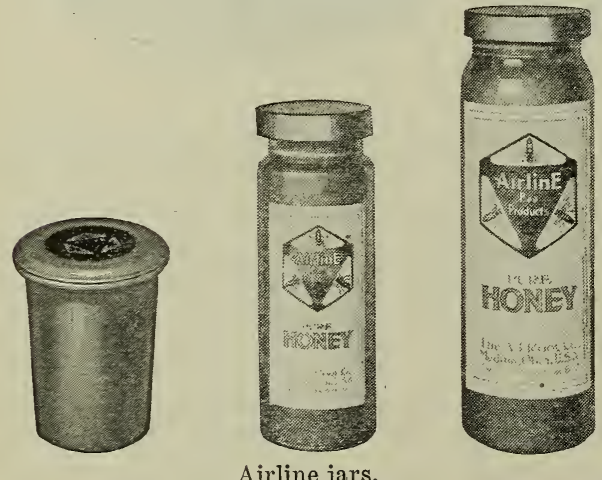

only to call attention to the honey. There is a great variety of different types of jars, from the smallest tumbler to the large twoquart Mason jars. Square bottles with large mouths using corks were very popular a few years ago, and are still used quite largely. These are obtainable with a picture of a straw skep pressed in the glass on the front.

Mason fruit-jars are popular because they can be bought anywhere, and no one objects to buying them with honey, since they are always useful. Whenever possible select crystal-white glass rather than that which has a greenish tint, for green does not show the honey to the best advantage.

Paper milk-bottles have been used for honey to some extent; and while these are very satisfactory for granulated honey they do not answer for long shipments of honey that is not granulated. For this reason they are not very popular.

Extracted honey is one of the purest and best foods. It should not be classed with cheap syrups, and therefore it deserves the best and most attractive package.

EXTRACTING.-As shown under ExTRACTFD HoNey the liquid honey is thrown from the combs by centrifugal force. This process is known as extracting, and the machine used, the extractor. When one realizes that the bees consume from five to fifteen pounds of honey in producing one pound of wax some idea is gained of the economy brought about by saving the combs.

\section{HONEY-EXTRACTORS.}

There are several inventions that have revolutionized commercial beekeeping. One of these is the movable frame; another, the honey-extractor. Like many other great inventions the first idea came as a discovery. In the year 1865 Major D. Hruschka, of Venice, accidentally discovered the principle which led to his invention of the extractor in that year. His little boy while playing was whirling a basket around his head by means of a short piece of rope. He happened to have a piece of honeycomb in the basket and the centrifugal force caused a few drops of honey to be thrown out into the air. His father grasped the principle which led him to construct a rude machine that actually extracted the honey without 
crushing the combs. Shortly afterward he perfected the device which was the first honey-extractor.

Among the early extractors made in this country was one constructed by J. L. Peaborly. In this machine the whole can revolved, and the honey ran out thru a hole in the center of the bottom. The same force that threw the honey from the combs, however, held it to the sides of the can and none would run out until the machine was stopped. In 1869 A. I. Root constructed what he called the Novice honey-extractor. This was so great an improvement over all that liad preceded that it found a ready sale at once. The inside framework for holding the rombs revolved: and in order to combine lightness with strength it was made of folded tin bars, and tinned wire screen. The crank was geared so that one revolution marle three revolutions of the combs.

\section{REVERSIBLE ENTRACTOR.}

When the honey from one side of the comb was extracted in the Norice machine the comb had to be pulled up and turnert

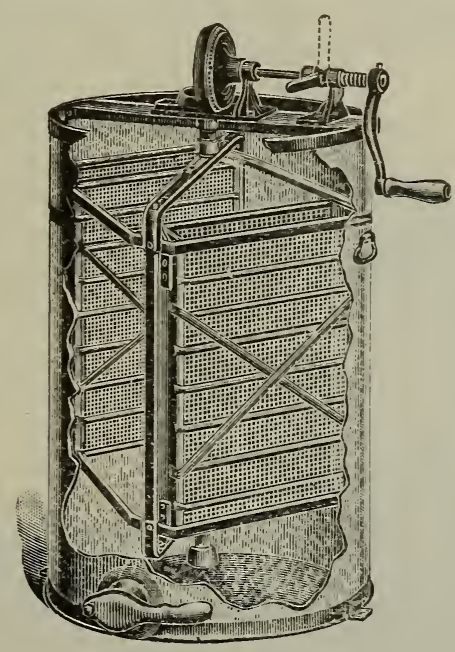

Two-frame reversible extractor.

around in order to throw the honey out of the other sicle. About the time that A. I. Root was experimenting along this line Thomas William Cowan, editor of the British Bee Journal, constructed what was then known and is still called the Cowan reversible extractor. Several "baskets" holding the combs were hung on hinges like a door, so that they could be swung from side to sirle so that either side of the comb could be next to the outside. Tha first side could be extracted and then the pocket, or basket, swung around so that the honey could be thrown from the other side without taking it out and reversing it.

The illustration does not show the original extractor made by Mr. Cowan, but the Americanized machine. The original mechanism has been greatly improred in workmanship and desig'n.

Shortly after the two-frame Coran extractor was introduced into this country (1890) there came a demand from the beekeepers of the west who produce honey by the carload for a larger machine. In response to this, four, six, and eight frame Cowan extractors were made. The same principle of the swinging pockets was used in these large machines with this difference. that all the pockets were geared together so that when one of them was swung around they would all more at the same time.

THE ROO'T AUTOMATIC REIERSIBLE EXTRACTOR.

In using the Cowan extractor when one desires to reverse it is necessary to stop the machine, and with the hand catch hold of the pockets and swing them around to the other position. The Root automatic extractor, as its name indicates, reverses the pockets automatically when the brake is applied. The lever acts as a brake until the extractor has been reduced in speed to a certain point when the hub of the reel is held stationary by the brake, and the reel, which continues to turn, accomplishes the reversing of the pockets by means of the reversing lever located on the top of the reel. This action is always positive and reliable. The strain of reversing is borne entirely by the brake, thus relieving the friving mechanism of all stress.

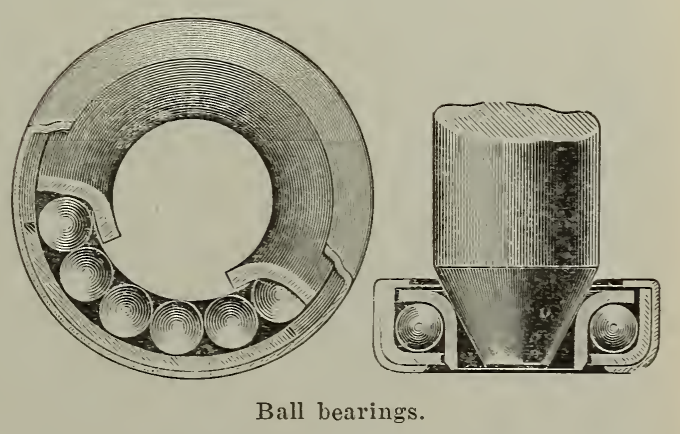

Practically all extractors built are now equipped with ball-bearings to reduce friction. In the hand-driven machine this feature is of considerable inmportance. 
Another improvement is the slip-gear device. The function of the slip-gear is tn disengage the crank and iarge gear wheel from the small pinion that drives the extractor reel. After the machine has been brought up to full speed the slip-sear lever, shown by the dotted line in the illustration, is thrown down to a horizontal position. This permits the coiled spring to disengage

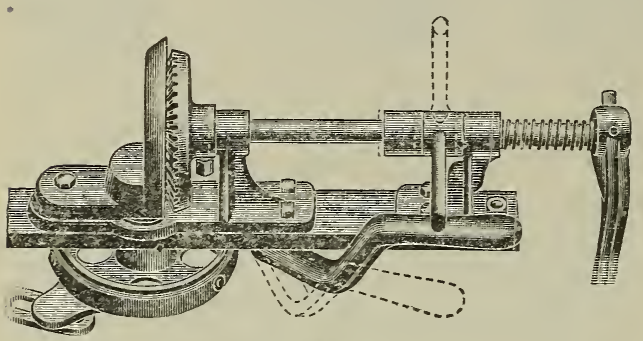

Slip gears.

the gear, and the reel, now free from the drag of the crank, may hum like a top. Mounted on ball-bearings as it is, it will whirl for a considerable time, continuing to throw out the honey without any effort on the part of the operator, who can meanwhile be uncapping more combs. As soon as the honey is all out of one side the pockets may be reversed, the gears thrown into mesh again, and the process repeated.
POWER-DRIVEN IIONEY-EXTRACTORS.

A few years ago a power-driven extractor was a curiosity, only one or two such outfits being in use. Within a period of ten years large extractors driven by gasoline-engines hare become very common. Where access cani be had to electric current, electric motors are also used, and in some localities water-motors. However, on accouv: of the fact that extracting plants are usually $i: !$ isolated places the gasuline engine is $1 \mathrm{y}$. the most commor source of jower. The engines have becn perfected to such a point that they are very reliable and efficient. Twenty years ago it took an expert to start a gasoline-engine, and sometimes another one to keep it rumning. Refinements in design brought about by experience of designers of automobile engines have rendered the farm gasoline-engine a really practicable and reliable source of power. There are a number of makes of rery good engines that can be bought for about $\$ 35.00$; and since a $1 \frac{1}{2}$-horse-power engine driving the larg-

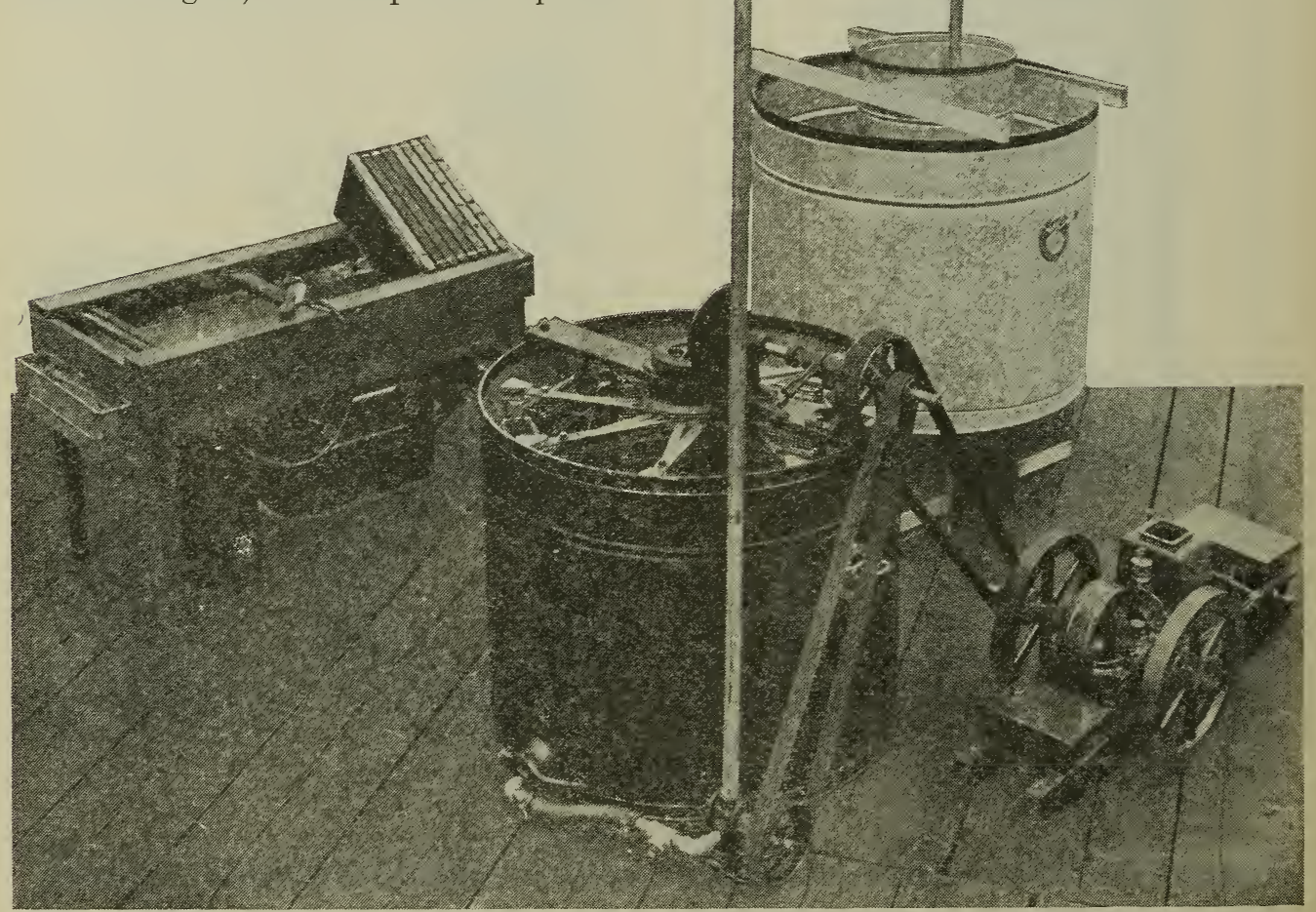

Iilal swrangement of extractor, pump, engine, tanks, etc. 
est extractor would not consume more than two or three quarts of gasoline in a day, it can be sien that such machines are very economical.

The method of transmitting the power of the engine to the extractor is shown in the accompanying illustrations.

In view of the fact that it is not practicable to stop and start the gasoline - engine every time the combs are put in and taken out of the

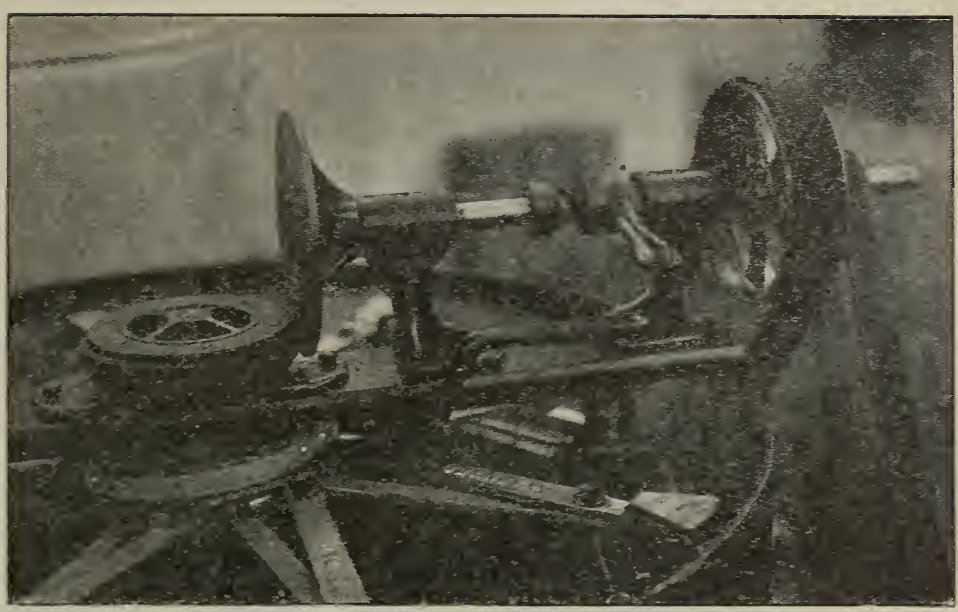

The cam-lever in a horizontal position, the extractor at rest. extractor, a friction-drive is employed with means for engaging the power, so that the extractor can be stopped and started. In fact, any speed desired is obtained simply by the movement of a cam lerer on the horizontal shaft of the extractor. The engine and the horizontal shaft of the extractor run all of the time, the reel being started as the metal dise on the horizontal shaft is mored into engagement with the paper pulley on the rertical shaft of the reel.

When the small handle is in a horizontal position no pressure is exerted on the horizontal shaft, and the metal disc does not touch the paper-rimmed pulley on the reel. As this lever is moved upward into a vertical position the cam gradually exerts a lateral pressure on the spring, which forces that is, toward the metal disc-so that the spring does not push against it so hard. The lever may then be thrown into its rertical position instantly, and yet the reel will start slowly and pick up speed gradually. not reaching full speed until the bulk of the honey is thrown out.

Where the honey is rery thick and the combs are new and not strengthened, therefore, by layers of cocoons always found in the cells of combs used for brood-rearing. it is often necessary to start the extractor slowly and let it run a few rerolutions until perhaps two-thirds of the honey is thrown out of the first side of the comb; then rererse, and extract all of the honey from the other side of the comb, finally rerersing back again to the first side and extracting the rest of the honey there. This plan does ihe disc into engagement with the beforementioned paper - rimmed pulley. The reel starts smoothly without a $n \mathrm{y}$ jerk. In case of new fragile combs when it is necessary to start rery slowly at first so that the bulk of the honey will be thrown out before the reel reaches full speed the cam lever may be moved very slowly into its rertical position, or the adjusta b l e collar, against which the spring pushes, may be set to the left-

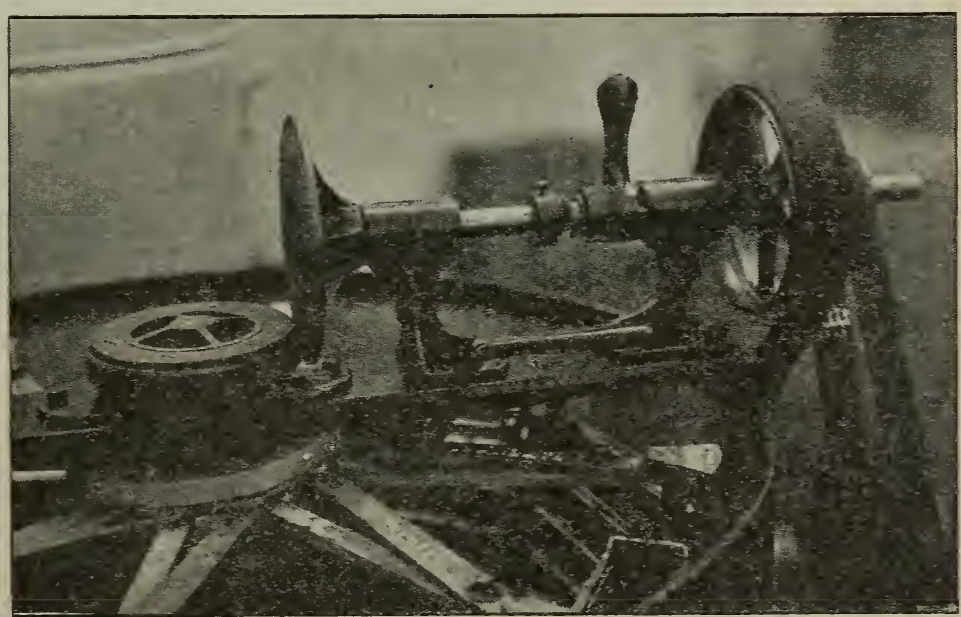

The cam-lever in a vertical position. The disk is thus crowded.orer against the paper wheel on the $v$ ertical shaft so that the reel turns. 
away with the danger of comb breakage. Under such conditions requiring great care it can be seen that if all the honey were extracted from the first side, which would necessitate rumning at full speed, the entire amount of honey on the other side would probably crack the comb. On the other hand, if the combs have been used for brood-rearing for a time before they are put into use for extracted honey, they are greatly strengthened by the fibrous cocoons. With such combs, and especially if the extracting is done in hot weather, when the honey is not likely to be thick and waxy, it is not necessary to observe so much caution.

The friction drive has been in use several years, and has been found the most satisfactory form of drive for a honey-extractor. It is not adapted, however, for a hand extractor, as the ratio of drive is about 1 to 1 -that is, equal. It is true that the paperrimmed pulley on the rertical shaft may be raised or lowered, thus changing the ratio of the speed; and while this is of great advantage in case the engine speed is not exactly right, or the size of the pulley is too large or too small, nerertheless it is not possible to "gear up" enough to drive the extractor by hand with a crank. In other words, it would be impossible to tur'n the crank fast enough to extract the honey sufficiently. For this reason some of the smaller producers who desire a large extractor, but who do not wish a gasolineengine, prefer the older beveled-gear drive, with the ratio of 2 to 1 -that is, one revolution of the crank shaft means two revolutions of the reel carrying the comb. Beveled gears are not as well adapted for power, however, since they necessitate a loose belt and idler, a mechanism that is not quite as easily controlled. The friction drive has practically supplanted all bevel-gear drives for power purposes.

Many beekeepers having less than one hundred colonies use power outfits, but when there are more than a hundred colonies to be extracted a gasoline-engine and eightframe extractor will almost pay for themselves in one season. A hand-driven extractor requires a good strong man, whose services cost at least $\$ 2.00$ a day.

A power outfit, moreover, will do quicker and more thoro work. It is impossible to extract all the honey by hand; and the result is, the combs go back to the hives very wet. Some of this honey will be saved by the bees, but a large part of it is consumed and thereby as good as wasted.

\section{HONEY-PUMPS.}

Along with the adoption of power honeyextractor's came the demand for pumps that would elevate the honey into tanks, for it is not always possible to build a honey-house on a side hill where the extractor can be located on a floor and the honey run into the tanks by gravity on a floor underneath. The earliest experiments with honey-pumps revealed the fact that very few waterpumps, even the rotary pumps, are suitable for pumping honey, for honey is very different in consistency from other liquids usually pumped. However, pumps especially designed for honey are now obtainable, and they are perfectly satisfactory. Belted direct from the cross-shaft of the extractor they run all the time that the engine is running. Consequently, the extractor can is kept empty, the honey being elevated as fast as extracted to the tank. It is not practicable, ordinarily, to elevate thick honey more than eight to ten feet.

The use of the honey-pump permits placing the extractor right on the floor where it may be firmly anchored, and where it is far more convenient than if elevated on a platform, even tho the platform be low.

Some have attempted to drive a honeypump by means of a chain. We do not regard this as advisable, for occasionally a bit of wood such as a broken corner of a frame or other foreign material may be thrown from the pocket of the extractor into the extractor can where it will find its way to the pump. In case the pump were positively driven something would be sure to break. With a belt drive the belt merely slips off. Then the pulley may be turned backward a few rerolutions until the foreign material, whatever it is, is removed. Usually, if the pump is worked by hand, back and forth, the bit of wood may be broken up and work may proceed at once.

\section{WHAT EQUIPMENT TO USE.}

A beekeeper who has only a few colonies, or one who runs most of his bees for combhoney production and extracts but a little honey, therefore, does not need a large power extractor. A light hand machine that can be put into service at any time is not only more economical but better in every 
way. Ordinarily. one who hiss less than twenty-five colonies. or who extracts not more than two or three thousand pounds of honey in a season can get along rery well with a two or four frame Norice extractor. For one who has more than twenty-five colonies a rerersible extractor is preferable because of the great saring in time. As has been pointer out. when the combs are new the peckets of which do not reverse, requires a sreat deal more time to operate. Beekeepers who number their colonies by the hundred find that there is a material saring in using a power-driven extractorat least the six-frame size. Some use porrer. even for the four-frame extractor.

An important adrantage of the larger extractors is their greater stability. With

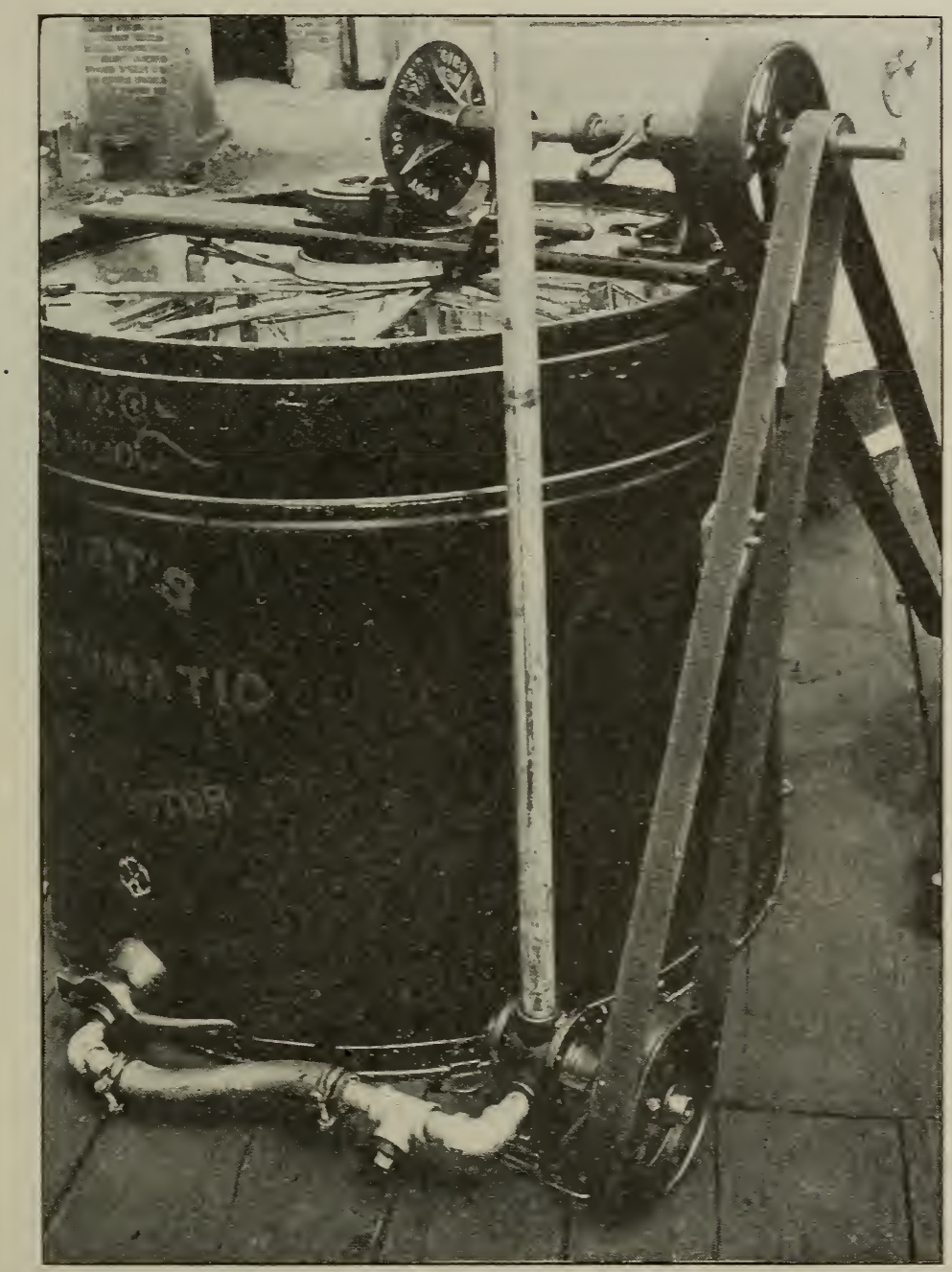

A closer riew of the pamp, showing the construction.

and fragile. or the honey thick, it is not best to attempt to extract one side of the comb thoroly before reversing to the other. It is better to run the extractor a ferr turns to throw out about two-thirds of the honey from the first side, then reverse to the second side and extract all of the honey, and finally going back to the first side, extracting all of the honey there. An extractor. the two or evell four frame size. it is necessary to put combs of equal weight opposite each other. Ereu then much bracing must be done or else the can will tear i:salf loose from the floor. In cas of the larger sizes. the difference in the weight of the combs does not throw the cans out of balance appreciably, hence no bracing or equalizing is necessary. 
THE LOCATION OF THE EQUIPMENT.

As is pointed out under BuILdings there are great advantages of the honey-house built on a side hill where there are different floor levels. The simplest arrangement of all is to have the honey from the extractor run by gravity into the straining or settling tank, which must be, of course, in a lower ruom. Where this is impossible the honeypump is a necessity for a complete equipment. When extracting in a small way with a hand extractor one can get along very well by having the extractor elevated just high enough to permit a good-sized pail to stand under the gate, the honey being lifted by the pailful up into the straining-tank. gate does very well, but a far more convenient arrangement is to have the wet cheesecloth tied over the top of the tank into which the honey is emptied. The cheesecloth soon becomes filled with bits of cappings so that the honey strains slowly. It is necessary, then, to untie the string that holds the cloth to the top of the tank and to put on a fresh cloth. The cloth should always be wet first to facilitate the straining.

A rather more convenient arrangement is to have a large piece of heavy wire screen attached to the top of the tank. This should be pressed down in the middle so that it is four or five inches lower than the top of the tank. The wet cheesecloth may then be laid

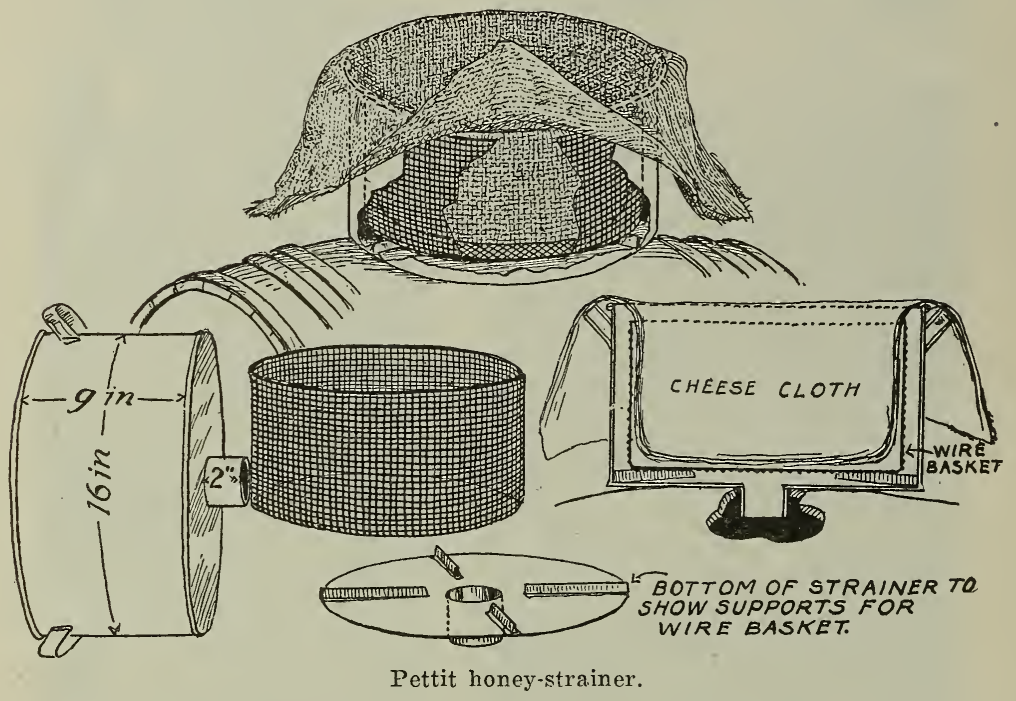

When this plan is followed it is always best to keep the gate of the extractor closed until the honey comes almost up to the reel in the extractor; then when the gate is opened the pail will fill quickly and almost no time need be lost. Leaving the gate of the extractor open so that the honey may run into the pail as fast as it is extracted is bad practice, for sooner or later one will let the pail run over on to the floor. In any event a shallow tin tray, or, at best, a large piece of tin should be laid on the floor for the honey to rest on. Then if the honey should run over, or if there should be some drip from the gate while the pail is being emptied, it is easier to clean up.

STRAINING HONEY.

For extracting in a very limited way a wet cheesecloth bag attached to the honey- on this screen without the necessity of tying around the top of the tank. When one cloth is clogged so that the honey strains too slowly it may be drawn over to one side and left to drain while another cloth is placed in position without delay.

S. T. Pettit, of Aylmer, Ont., Can., devised a very convenient can strainer having a large surface of cloth supported by a coarse wire-screen basket as shown.

We have used such a strainer, but find it is a little more convenient to have instead of the opening in the center of the bottom of the strainer a gate soldered to one side near the bottom. If the strainer is used for filling cans the stream of honey may be shut off by means of the gate when the can is full. Fresh cloths can be substituted for those that are clogged at any time. 
To do away with cloth strainers Mr. E. IV. Alexander used an ordinary ten-quart milk-pail, cutting off the sides and bottoms. These were united by upright tin braces, as shown in the illustrations.

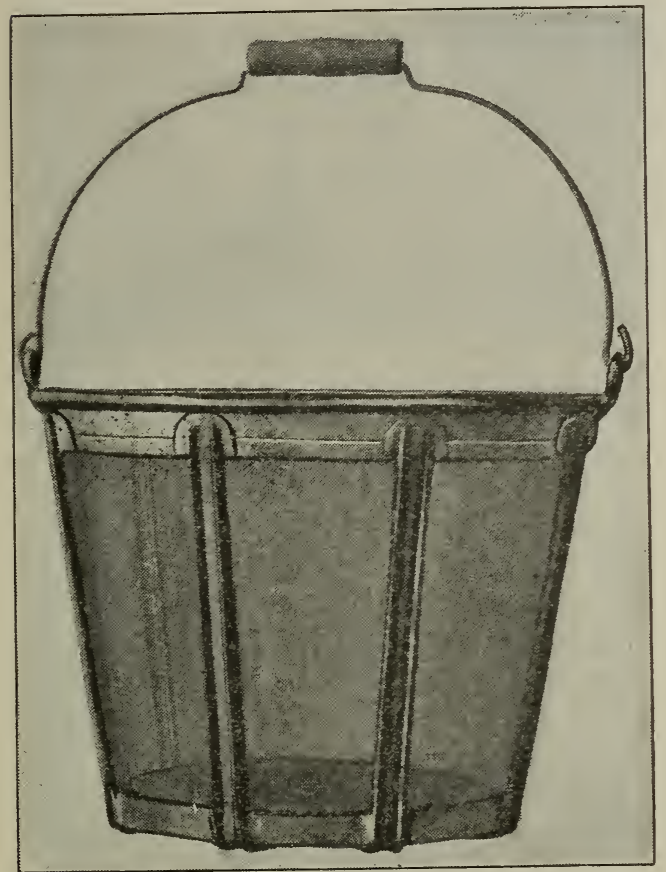

Alexander honey-strainer.

The open spaces were filled in with a fine mesh of brass wire cloth securely soldered in place. The honey is poured thru such a straining-pail into the tank. It is necessary to have two or more pails so that one may be in use while the other is being cleaned.

THE GRAVITY METHOD OF STRAINING AND CLARIFYING HONEY.

Of late the gravity principle of straining has received much aitention on the part of honey-producers on account of its simplicity and freedom from vexatious delays necessitated by changing filled-up cloths and washing straining surfaces. Briefly, the plan consists in the use of a relatively tall tank containing nothing by way of equipment except a suitable gate at the bottom and a float to break the current of the honey when it-is poured in at the top, thus preventing an active circulation of the new honey with the rest of the honey in the can. The plan is to draw no honey from the bottom until the tank is nearly full. If the honey is not allowed to circulate so that the particles of cappings and bits of comb are carried down to the bottom, the honey when drawn off at the gate is found to be very clear.

In extremely hot weather when the honey is comparatively thin the gravity system alone leaves little to be desired, but in cool weather, or whenever the honey is quite thick, it is found that, in order to be clarified sufficiently, the tank must stand for several days. This makes necessary a somewhat elaborate outfit of expensive cans in order that the work may not be hindered. For a small outfit one tank alone would be sufficient.

\section{THE GRAVITY SETTLING-TANK AND STRAINER} COMBINED.

Mr. R. Powell, of Riverside, Cal., uses a strainer; but on the grarity principle all

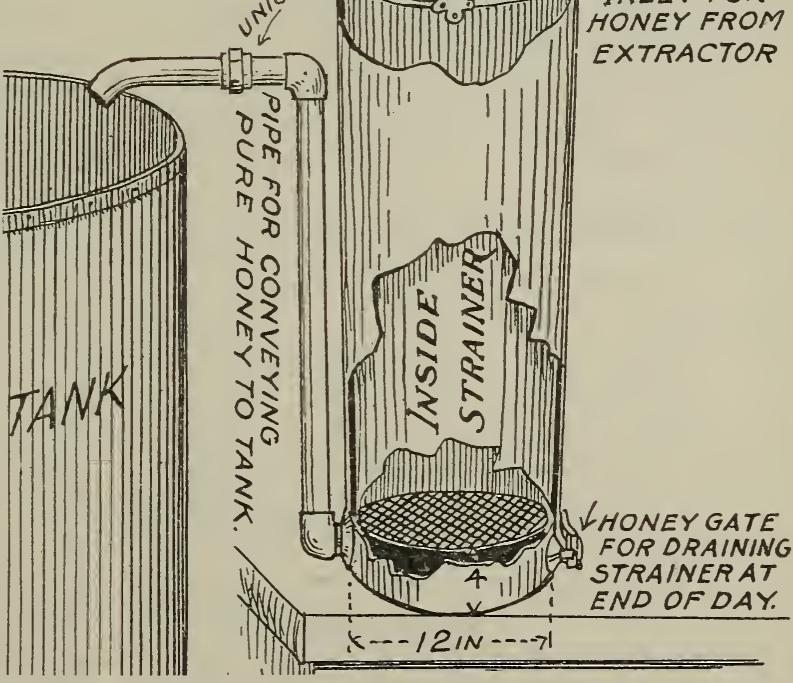

Powell's improved gravity strainer; capacity eight tons of honey per day.

particles of capping, pieces of wax and propolis which might clog the straining surface are kept at the surface of the honey, the strainer serving only to separate the very fine particles that the gravity plan alone would not get rid of. Mr. Powell 
makes a galvanized iron can a little deeper than the loney-tank, 12 inches in diameter at the bottom and 14 at the top.

Inside of this can is another, having a strainer at the bottom. When the work is started for the day the can should be filled about half full of strained honey; then the honey from the extractor may be poured in at the top, or led in thru a pipe, as shown. All foreign material thus floats near the surface of the honey, and the screen at the bottom has nothing to do but strain out the fine particles. Mr. Powell says that this strainer will handle from four to eight tons of honey a day without attention.

During the last few seasons we have used a modification of this Powell plan which is shown in the illustration of the ideal extracting plan, page 262. In this illustration the honey from the extractor is pumped to the strainer, but the plan works just as well if the loney is poured into the strainer, provided a wooden float is used to break the current.

The only additional equipment necessary beyond a regular storage tank is an additional can without a bottom, a little higher than the regular tank preferably, and smaller in diameter, altho no exact ratio between the two diameters is necessary. Orer the lower end of the smaller can cheesecloth is stretched and tied firmly.

The straining-can is set inside the large tank, the cheesecloth resting on the bottom of the latter. Two or three inches of clear honey should be poured in at the start to prevent the cheesecloth from becoming clogged. As the new honey is poured in it gradually percolates thru the cheesecloth into the main tank outside, the level in the two cans always remaining the same, or practically the same. As the work progresses the inner can should b? raised so that the cheesecloth will be several inches from the bottom of the tank. This should not be done, however, until the main tank is half full. It will be seen that all foreign material that will flnat will be kept away from the cheesecloth. When the work is over the inside tank may be raised so that all of the honey in it will strain out. However, as long as the cheesecloth does its work the process is continuous, for the honey may be drawn out of the main tank as soon as it becomes full. From this time on it should be drawn off only fast enough to keep it from running orer. The greater the depth of honey about the cheesecloth strainer the less the probability of the cloth becoming clogged.

When the work is over and the main tank finally emptied the cheesecloth will strain the last of the honey inside the straining-tank without clogging appreciably. One cloth will last much longer without clogging than if all the honey were poured thru it in the regular way, for by this plan the refuse floats to the top and the strainer really has comparatively little to do.

\section{HFATING THE HONEY TO FACILITATE STRAINING.}

In some localities the honey when extractecl is so cold and thick that it is almost waxy, and straining or clarifying even on the principle above described becomes something of a problem. Under such conditions it is necessary to do the extracting in very hot weather, or else in a room artificially leated. If the extracting is done late in the season when the weather has turned cool it is sometimes necessary to keep the combs in the heated room twenty-four hours or longer before the honey is thin enough to extract and strain quickly.

By means of power extractors, even very thick honey may be extracted, but a power extractor does not help much on the straining problem.

Several large producers have used an extractor having a double wall, the space between filled with hot water or steam. As the lioney runs down towazd the outlet it is warmed to such an extent that it strains easily. If an engine of fairly good size is used (two to three horse power) the hot water surrounding the cylinder may be piped to the extractor. In other words, the space between the two walls of the extractor serves as a water-tank, and the waste heat of the engine is made use of for warming the honey.

Ordinarily, a simpler and better plan is to run the lioney from the extractor thru a pipe, either by gravity or by means of a pump, which pipe in turn passes thru a larger pipe containing hot water heated either by the cylinder of the engine or by means of a stove.

E. L. Sechrist, of Fair Oaks, Cal., pumps his honey into a special tank. which is water-jacketed, heated by a stove under- 


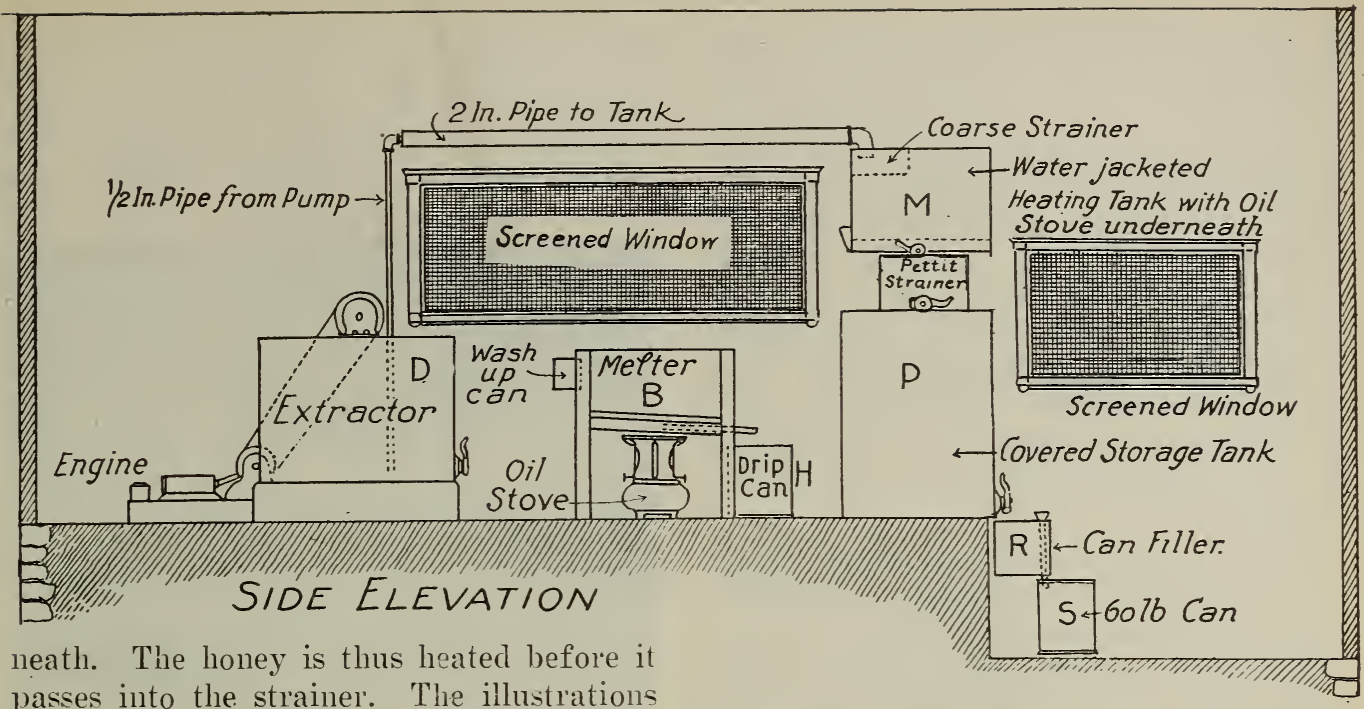
show the location of this equipment.

Some beekeepers have tried rumning the honey as it comes from the extractor thru a trough having a store underneath to warm the surface of the trough and thus raise the temperature of the honey. This plan is a little dangerous, for it is necessary to have considerable heat, since the honey runs thru the trough rapidly, and there is danger the honey along the edges may burn. A better way is to rum the honey thru a pipe submerged in water heated by a stove.

GETTING THE BEES OFF THE COMB.

Probably the majority of extracted-honey producers free the combs of bees by a com-

bination of the smoke, shake, and brush methor. The hive is opened; smoke is blown down thru the super's liberally, driving the bees down out of the way, and each capped comb held by the top-bar or end-bar as preferred, and given a sharp jarring shake so that the bees fall off, not back into the super, but on the alighting-board in front of the hive. If they are shaken back into the super they would get on to the other combs and would have to be shaken off again. After shaking. the few remaining bees are brushed off. The combs should be lield by one end of the top-bar in the left hand. and both sides brushed. The frames should be held with the top-bar toward the

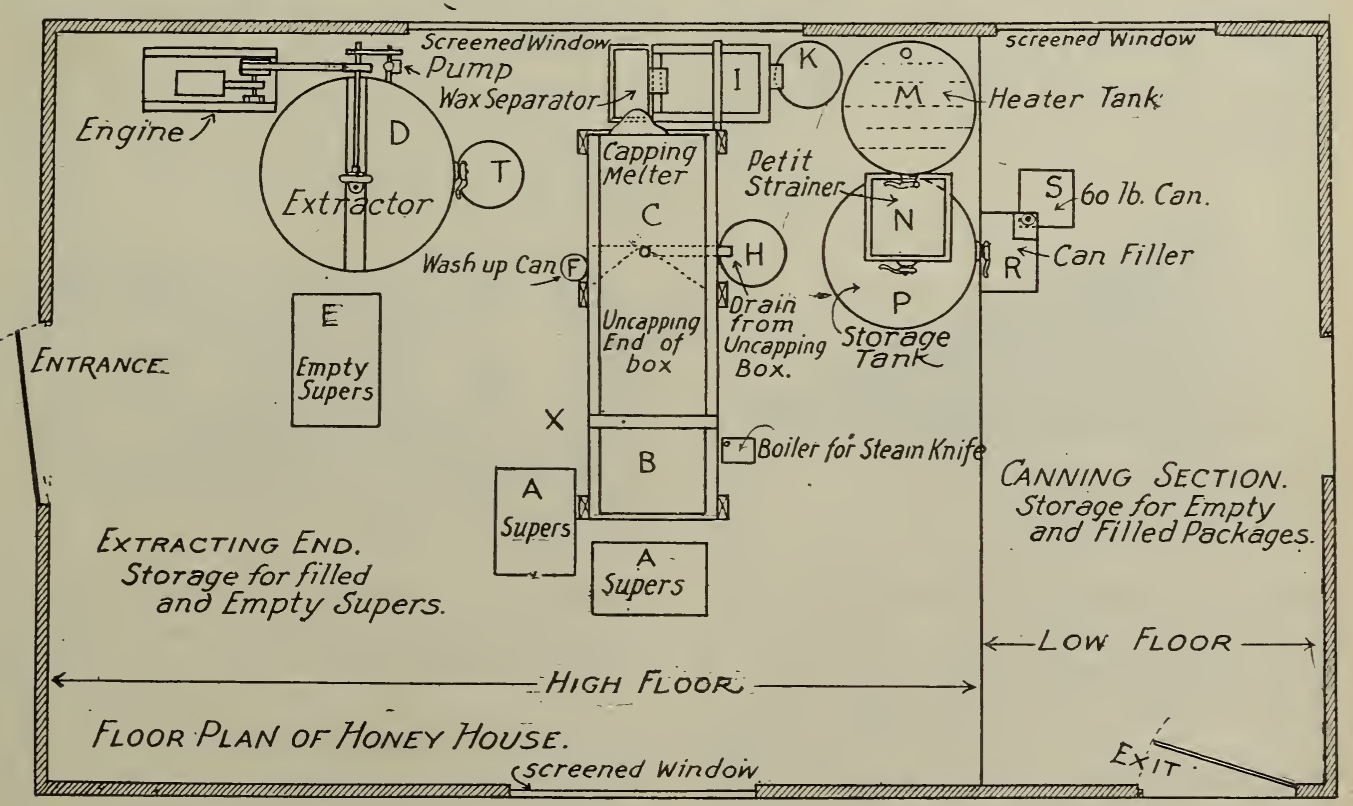


brush so that either side of the comb may be brushed without turning the frame around.

If there is but one super of combs to be removed some prefer to shake one or two combs in front of the entrance, and then shake the bees from the other into the empty space made vacant by the removal of the first one or two. This avoids getting so many bees on the ground, altho if they are shaken right on to the alighting-board they commence crawling in at once so that it really does not make a great deal of difference.

When so many combs are being shaken and brushed, it is advisable to have the trousers tied around the ankles, or else to wear trousers-guards as are worn when riding bicycles. Some producers during this process tuck their trousers inside their stockings. Many take the additional precaution of wearing fingerless gauntlet gloves in order to prevent bees from crawling up the sleeves.

\section{WHAT KIND OF BRUSH TO USE.}

When brushing bees from extracting combs a serviceable brush is necessary. A

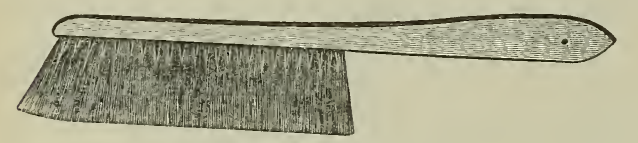

The German bee-brush.

makeshift is never economical. Either the German or the Coggshall brush answers every purpose, and, what is of prime importance, they may be washed when they become sticky with honey.

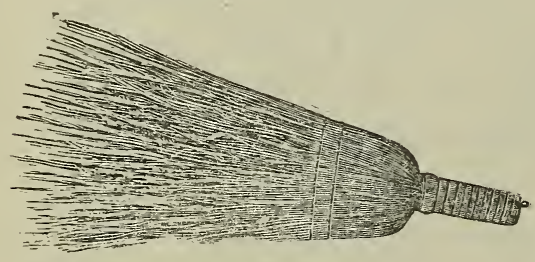

The Coggshall bee-brush.

In case any colonies are diseased, especially with American foul brood, it is of the utmost importance to let no honey be exposed where robbers might get at it. A bunch of grass or weeds should never be used as a brush, for when thrown away robbers would be sure to find it. Under such conditions the brushes should be carefully washed and the sweetened water should not be left around where the bees can find it. If disease is suspected the combs should not be shaken at all, as some

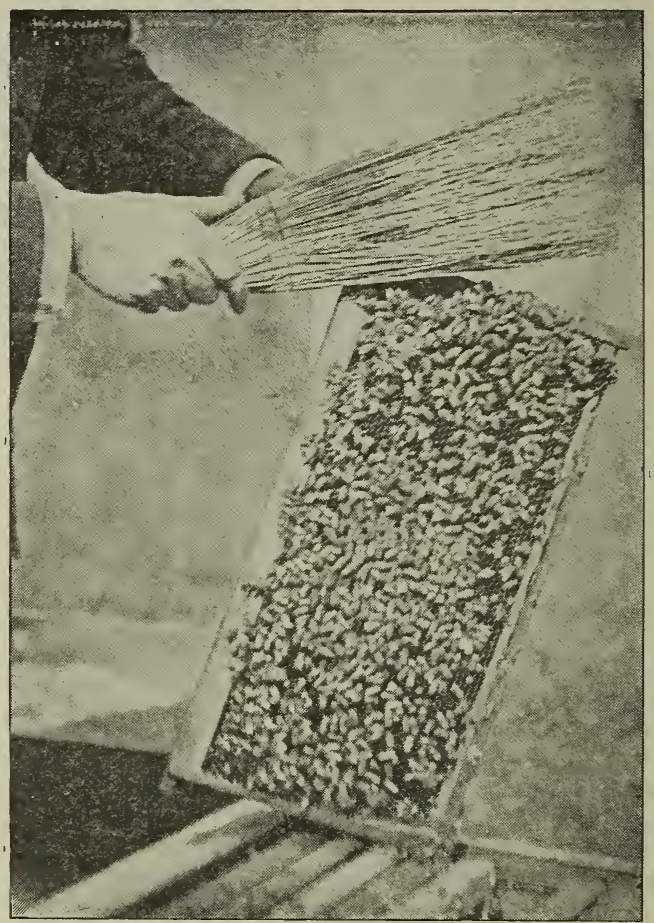

How to hold the Coggshall bee-brush.

honey might be shaken out, especially if there were any uncapped cells, and such diseased honey on the alighting-board would be sure to make trouble.

\section{THE USE OF BEE-ESCAPES FOR FREEING BEES.}

In comb-honey production the use of the bee-escape for removing bees from the su-

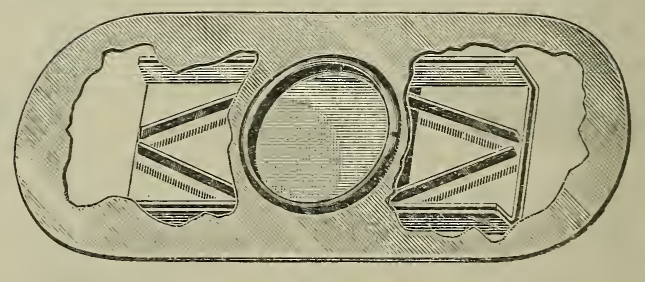

Double bee-escape.

per is almost universal. In extracted-honey production the escape-boards have not been so popular, principally because the honey in the twenty-four or forty-eight hours required for the bees to pass down into the brood-chamber has time to become cold 
so that it is much harder to extract. A second objection is that bees do not leare extracting-combs quite as readily as they do comb-honey sections on account of the fact, probably, that there are always some uncapped cells, and the bees are slow in leaving thru the escape on this account.

For many producers the first objection has been largely orercome by what is known as the rentilated or screened escape-board. As the name implies, the bee-escape, instead of being placed in the center of a solid board. is placed in the center of a screen bound with a wooden frame. The warmth of the bees below rises and keeps the honey warm, almost as warm as tho the bees were on it, so that it extracts easily.

The second objection has been overcome by the use of the double bee-escape. If the combs are entirely capped orer the super may be taken off in the morning if the escapes were put on the night before.

The rentilated escape-board which is the invention of Mr. Arthur Hodgson, of Jarvis, Ont., has brought the escape into more general use among extracted-honey producers.

\section{THE CARBOLIC CLOTH FOR DRIVING BEES FROM} SUPERS.

A comparatively new method for freeing supers of bees that bids fair to supersede either the shaking plan or the bee-escape is the carbolized-cloth method that seems to be meeting with much faror. The beekeeper provides himself with five or six pieces of cotton cloth a little larger than the common super. These are soaked in a solution of one part of pure carbolic acid to nine parts of water. The surplus moisture is wrung out and the damp cloth is laid directly on the super after the bees have been smoked somewhat first. The hire-cover, or other board, is then put on top to prevent the cloth from drying out too rapidly. When one hire is thus prepared the beekeeper goes to the next, and so on, until the cloths are all on. By that time the bees are practically out of the first super, and that cloth may be placed on another super, and so on.

This method works best on shallow extracting-supers, but is rery effective on the deep supers.

If the crude carbolic acid is used, the odor is stronger, and there is a little more danger of tainting the honey. Unsealed honey, especially, takes on this odor easily, and for this reason the liquid used should not be too strong.

The advantage of the carbolized-cloth method over the others is that there is no danger of starting robbing, even if the honey-flow is orer and the honey may be removed from the bees almost immediately while it still holds all the heat from the bees. Eren with the ventilated escape-board the honey is not quite as warm, of course, as it is when just taken from the bees.

\section{TAKING THE COMBS TO THE EXTRACTOR.}

There are various methods in use for transporting the combs of honey from the hive to the extracting-room. In small apiaries the tin comb-buckets with a tight-fitting cover holding half a dozen combs are rery satisfactory.

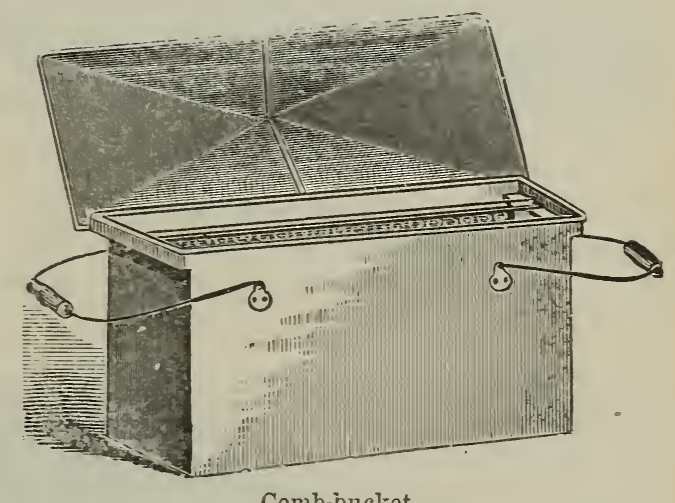

Comb-ibucket.

Others use larger comb-carriers consisting of a full-sized super, with tin nailed on the bottom, a haudle across the top, and a tightfitting corer in two halves hinged together in the center.

Probably the majority of producers use a wheelbarrow with a specially constructed box or platform to hold sereral supers. Some apiaries are located where the ground is too rough for a wheelbarrow, but by a little work the rough places may be smoothed up enough to answer very well. Certain it is that it is easier to move several supers with a wheelbarrow than by any other plan.

Sometimes a cart haring two large wheels can be handled easier on rough ground than a wheelbarrow. L. E. Mercer, of California, uses such a cart which is equipped with pneumatic-tired wheels and a long box in which to receive the combs.

With either a wheelbarrow or a cart it is advisable to nse a specially constructed box 


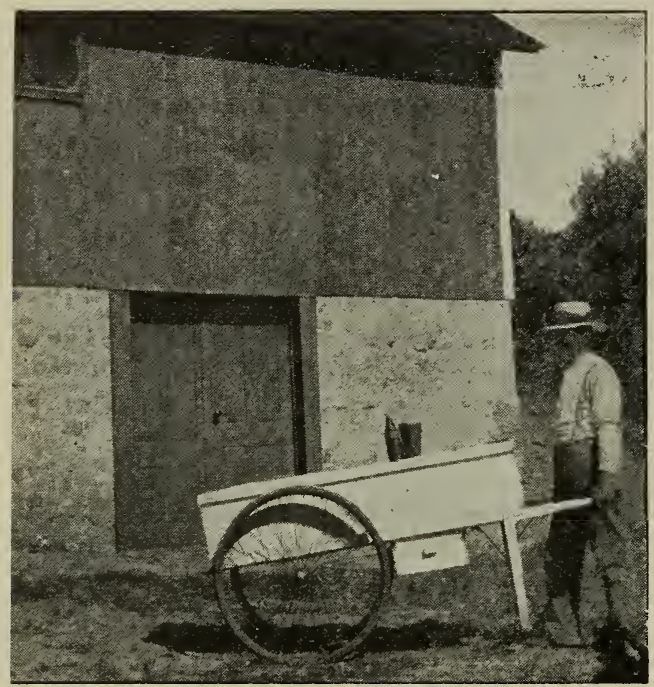

Mercer's cart.

or platform, for by so doing almost double the ordinary load may be carried with but little additional exertion.

Where the hives are at some distance from the honey-house so that it is an advantage to take considerable of a load at a trip light spring wagons have been used with good success.

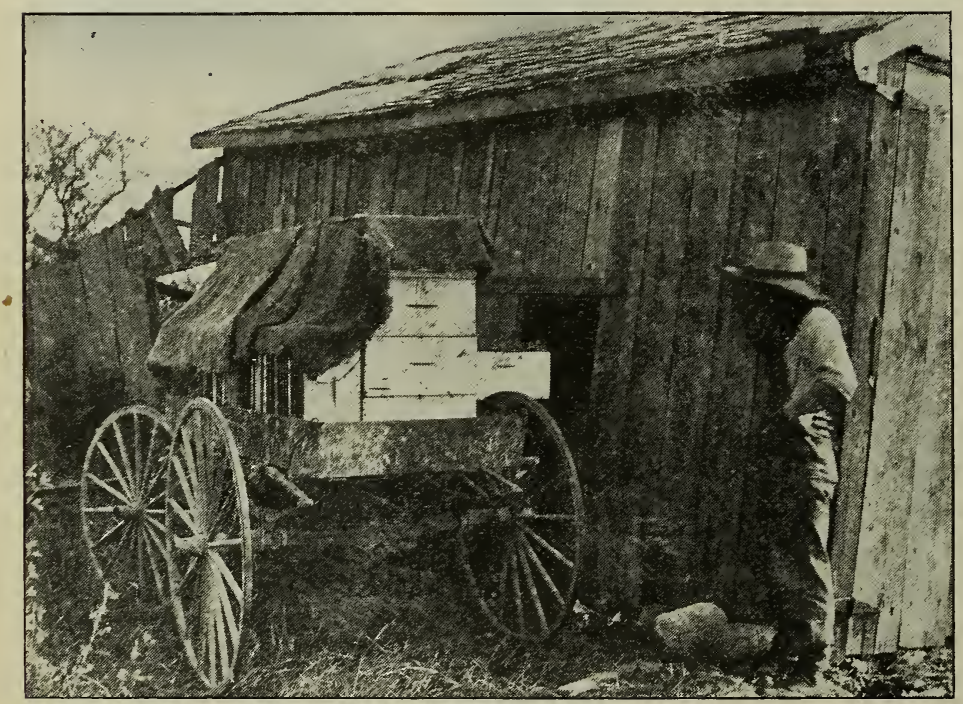

"Democrat" used to carry supers to and from a distant extracting-house.

It is usually unsafe to have a horse in a bee-yard, but two men can usually move quite a load without much trouble, one between the shafts to pull and steer, and the other behind to push. Sometimes an auto truck is used. See Moving Bees.
R. F. Holtermann, of Canada, lays a wooden track at each cxilacting yard from the building down thru the hives.

A light four-wlieeled truck is loared up with eight or ten full supers and pushed along with little effort to the extractingroom where the supers are slipped thru an opening in the side of the building.

\section{UNCAPPING THE COMBS.}

In dry climates under certain conditions honey may be ripe enough to extract when it is but half capped over-that is, when only the upper half of the combs is capped; but under ordinary circumstances it s much safer to wait until the combs are almost entirely sealed or capped, for the honey will be thicker and richer. See the discussion on this subject under ExTracted Honev.

There are various sizes and shapes of knives used for cutting the cappings from the combs. Some begin at the top of the comb and cut down, while others, the majority, perhaps, begin at the bottom and cut upward. No definite rule can be laid down; for the way that might be the easiest for one operator might be the hardest for the next. Each producer should uncap with the kind of knife and stroke that seems the most natural. Some use a common butcher knife with a long blade.

For the benefit of beginners it may be well to point out that the very great majority of producers use a knife originally designed by T. F. Bingham.

The shank connecting the blade with the handle has circular projections on each side folded at right angles to afford a good grip for the thumb and forefinger. As the blade is on a different plane from the handle one can get a better hold and in a position to exert more leverage by grasping the shank itself with the thumb and forefinger, the rest of the fingers encircling the flat handle, as shown. 


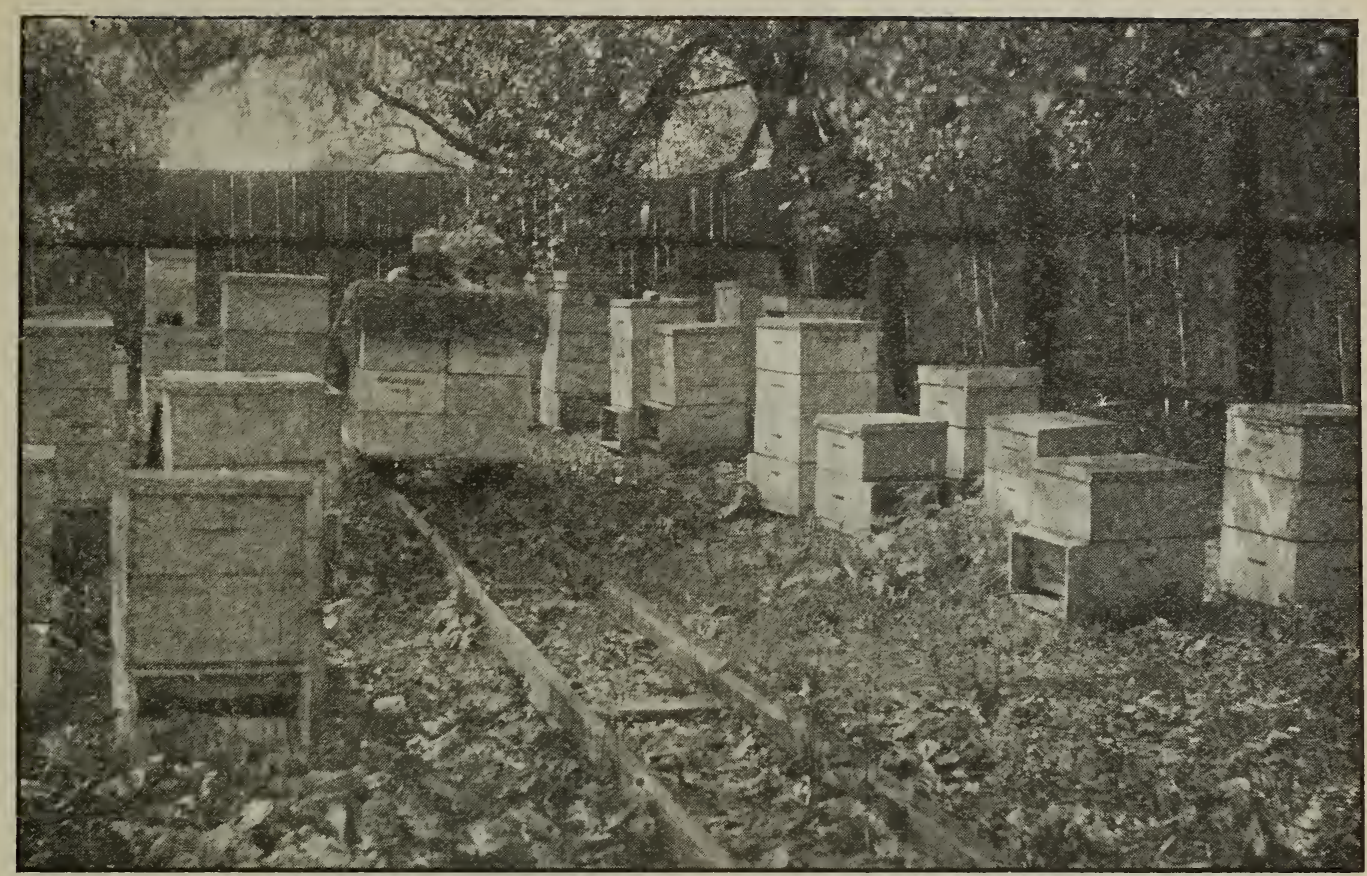

The supers of honey loaded on a car, ready to be pushed to the extracting-house, on the wooden track.

A right-handed operator, to uncap, should stand the frame on one end-bar on a nailpoint sticking up about an inch from the center of a cleat nailed across the top of the

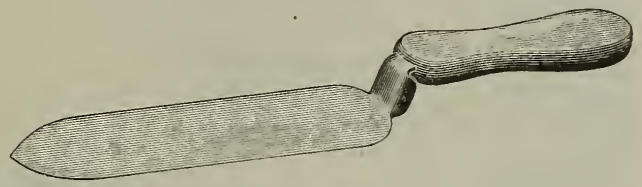

Bingham improved uncapping knife.

receptacle to hold the cappings. The combs should be held by the left hand on the upper end-bar and top-bar. When the knife first starts cutting the cappings on

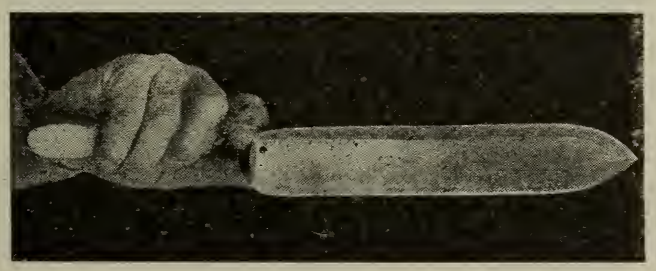

the lower end of the comb, the frame should be held about vertical. As the knife is pushed upward toward the upper end-bar the frame should be leaned to the right so that the cappings as they are sliced from the comb may fall direst into the reeptacls underneath as they drop from the knife. If the frame is held straight or leaning slight- ly to the laft a sheat of capring may slide back on to the comb and be held there by capillary attraction of the honey, and it requires extra time and fussing to scrape it off again.

After one side of the comb is uncapped it may be swung around on the nail-point to expose the other side. Many prefer to tur'n the frame end for end rather than to swing it around in order to keep the top-bar always to the outside, the idea being that, the end-bar being rar'swer, it is not so much in the way of the knife.

Then uncapping one should not try to take off merely a rely thin layer of capping, for it does no harm to uncap deep, since the wax and honey cut off are by no means wasted. A good rule is to uncap down to a level even with the side of the top-bar. Combs which have been used for brood-rearing are a little harder to uncap the first time, owing to the layers of cocoons, but when these have once been shaved down even with the side of the top-bar they are rery easy to uncap on subsequent extractings. The cocoons toughen the comb so that it is not so easily crushed out of shape by the knife nor broken in the extractor.

The point of the knife should be started on the nearest lowest corner of the comb 
and pushed toward the top-bar until the cappings are cut from the end of the comb. Then the knife should be started toward the other end-bar by a sawing motion. It is much easier to uncap bulged combs. Therefore, in a ten-frame super, for instance, it is not a good plan to put in the full ten combs. Fight combs equally spaced in an extracting super contain the same amount of honey, or even more, and the comb, being bulged, can be much more quickly uncapped since there will be few depressions.

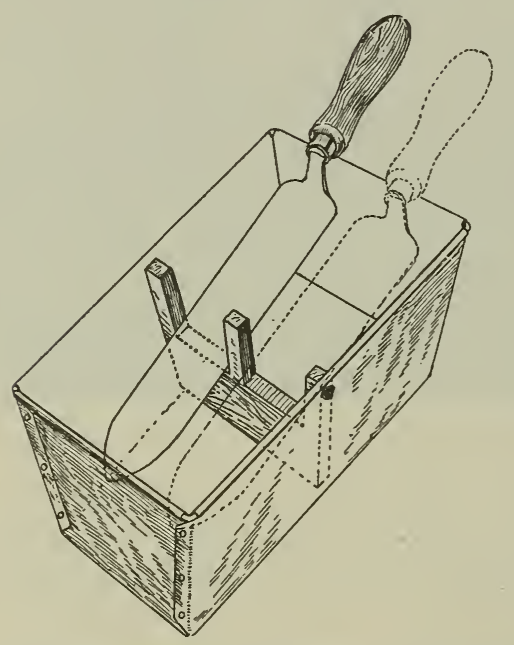

A cold knife must be kept very sharp, and there is need of constant scraping to keep the wax from gumming up the sharp edge, thus interfering with the work. A dull cold knife or one that is badly gummed up and very dirty does not make a clean cut, but tends to crush the comb.

Because of the necessity for frequent cleaning and sharpening an increasing number of producers prefer to work with a hot knife, and especially in case of thick honey there is no question but that a hot knife will do quicker and faster work with less strain on the wrist. When ordinary knives are used it is customary to have two of them, one to be left in hot water over a small stove, while the other is used to uncap both sides of a comb.

Where the honey is thick and cold sometimes a knife heated in hot water will be cooled off by the time it is half way thru the cappings of one side of the comb, so that it is little better than a cold knife. In fact, the wax has a tendency to gum up a warm blade even more rapidly than it does one that is entirely cold. The blade should be either hot or cold, therefore, and not lukewarm.

Because of the necessity of frequent changes in and out of the hot water a knife heated by steam, popularly called the steam uncapping-knife, has become very popular in the last few years.

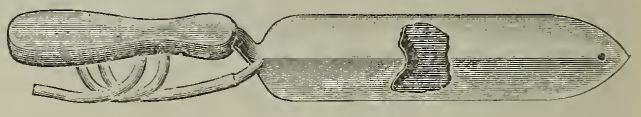

Steam-heated uncapping-knife.

A piece of non-rusting metal is soldered on top of the knife-blade, and steam is introduced thru a tube near the shank of the

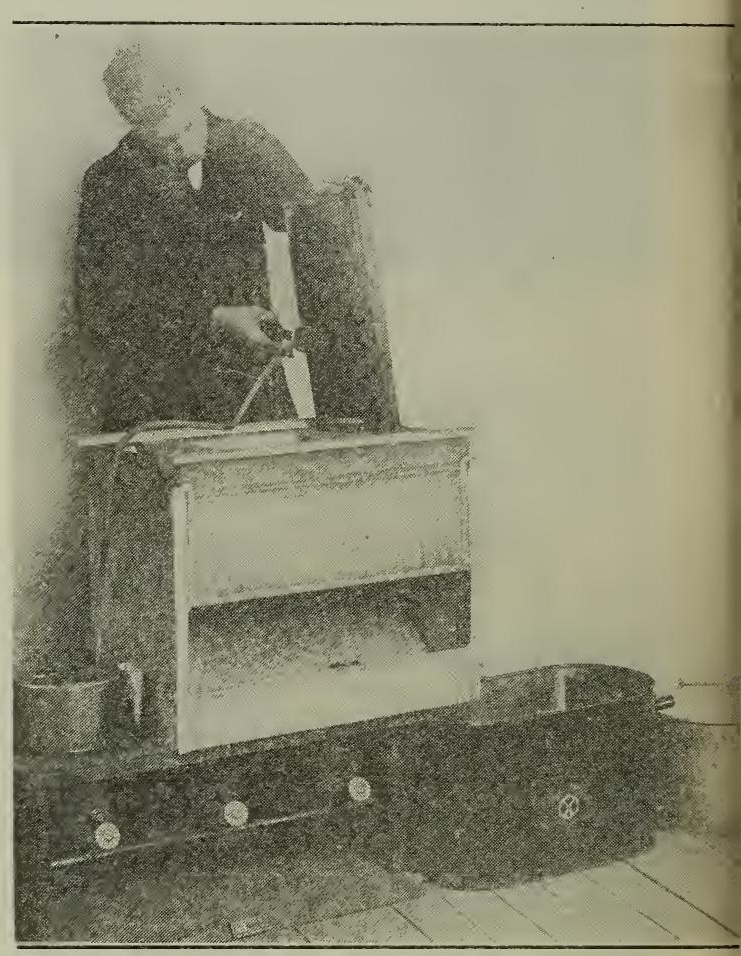

Steam knife in use. The boiler holds enough water for half a day's work.

knife, circulates over the blade, and blows out thru a small opening at the point. This knife keeps hot continuously, the wax melts off, hence there is no gumming up nor delay necessitated by scraping and cleaning the edge of the blade. A piece of rubber tubing containing some fabric in its make-up conveys the steam to the knife from a small boiler over a stove. Tubing, known as airpressure tubing, carries the steam satisfactorily, and yet it is flexible enough not to interfere with the action of the knife. 
A tea-kettle makes about as good a boiler for a steam uncapping-knife as anything that can be used. Tape should be wound around the end of the rubber tubing so that it will just crowd into the spout of the teakettle, and then more tape should be wound around the spout, tube, and all, to make the joint steam-tight. No steam will leak around the lid if the latter is crowded in with sereral thicknesses of cheesecloth so that it is a tight fit.

There is practically no danger of getting up too much steam in a tea-kettle, providing the opening in the end of the knife is clear for the escape of the steam. In case this opening should become clogged the lid of the kettle will be forced up by the pressure to allow the excess steam to escape.

In case a regular copper boiler or other can is used for a boiler it is a good plan to take the precaution of making a safety valve as shown in the illustration below.

Any tinner can make such an arrangement with a super spring and small tin cap, and it furnishes a very convenient opening' for filling the boiler, besides.

\section{DISPOSING OF THE TIET CAPPINGS.}

When the cappings fall from the uncapping-knife they are saturated, of course, with honey. There are two different methods in use of separating the wax and the

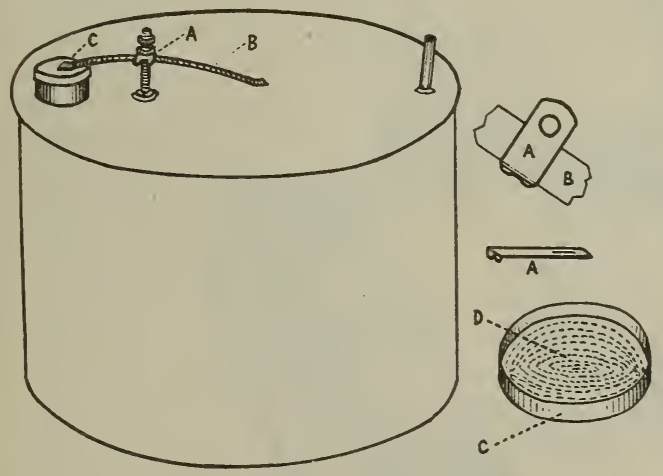

Steam honey-knife boiler, showing construction of safety-valve. A, cliip which holds super-spring to adjusting-screw. $B$, super-spring. $C$, tin cap covering one-inch brass tube. D, rubber packing within tin cap.

honey. The first embodies the principle of draining the cappings until practically all of the honey is separated; and the second, an entirely different principle, which contemplates melting the cappings as fast as they are sliced from the combs so that the melted wax and the honey by reason of their different weights separate at once, the wax floating on top of the honey. The devices which operate on the draining principle are usually caller uncapping boxes or cans, while those which melt the cappings are called capping-melters. We will consider first the uncapping-can.

One of the simplest and cheapest arrangements for disposing of cappings is a plan originally described by IT. Z. Hutchinson. From his grocer he bought up a number

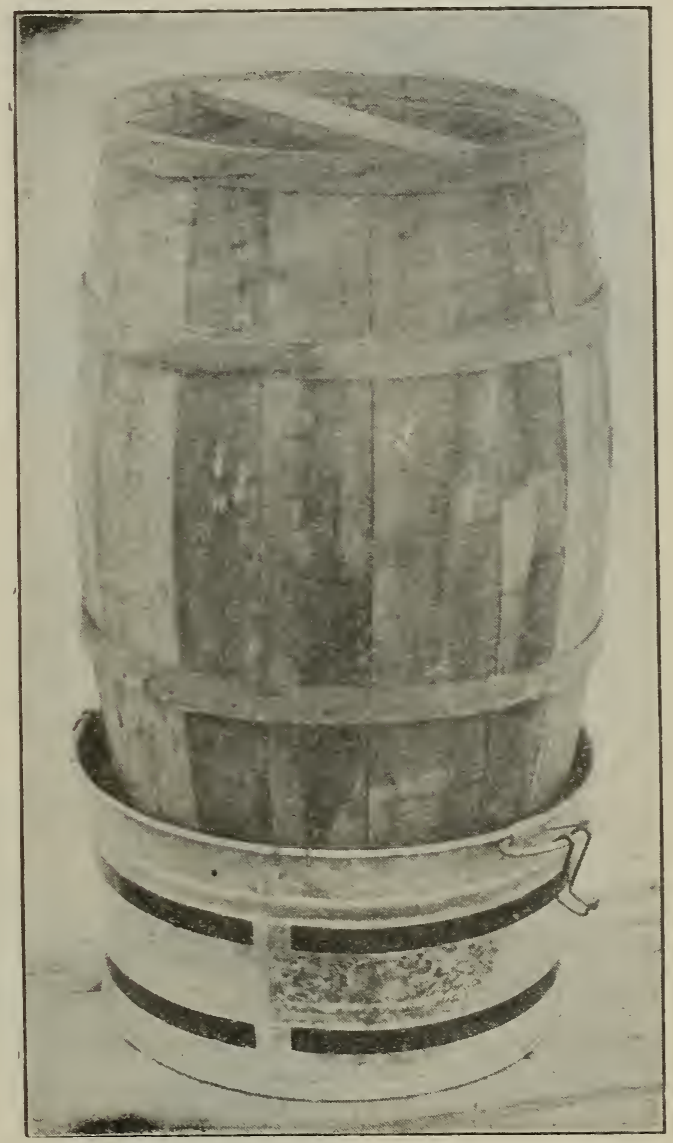

of cracker-barrels, as many as he thought he would need for the season, and in the bottom of each one bored three or four holes.

Inside the top of the barrel a cross-cleat is nailed, as shown in the illustration, with a nail-point in the middle for the end-bar of the frame to rest on.

The barrel is supported orer a galvanizediron tub by means of four hooks made out of heavy wire. One of these hooks is shown in the handle of the tub. A simpler way of supporting the barrel is to nail a couple of cleats to the side of the staves at the 
right point just long enough to go across and rest on the edges of the tub. The cleats have the advantage that they furnish handles with which to lift the barrel when it is full so that an empty one may be put in its place.

Of course, when one barrel is full it is set ofi' to one side to drain over another tub, and another one put in its place. No hur'y

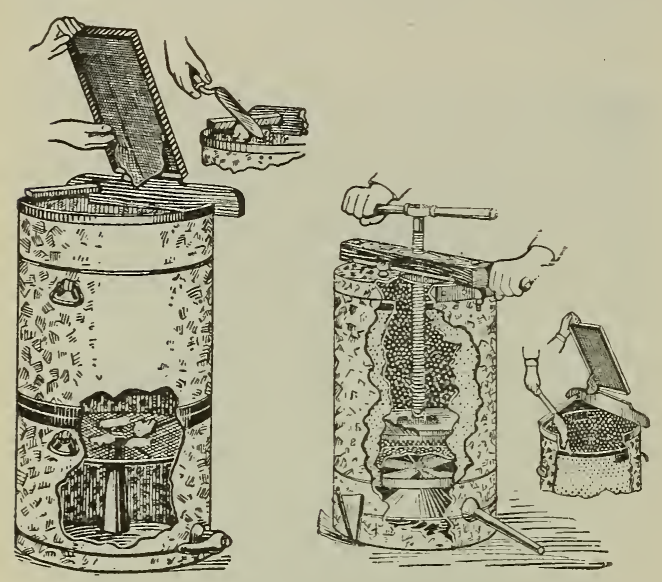

Dadant uncapping-can and the German press.

about emptying the bar'rels, for they are cheap, costing not orer five or ten cents.

In any method of draining cappings it is very important to stir up the cappings frequently with a stick. This sirves to break
The Dadant uncapping-can, as ean be seen from the illustration, operates on the same principle as the cracker-barrel and tub. The upper can containing the cappings has a screened bottom, however, so that the honey may escape mole easily. The honey, as it rrops into the lower can, may be drawn off from time to time thru the gate at the bottom. The cappings in the upper part after draining over night are supposed to be dumped out into some other receptacle for the further draining of the small amount of honey still left in the cappings.

An uncapping-can which is provided with a plunger and screw by means of which great pressure can be applied to the semidry cappings, is the German press.

A burlap sack is supposed to be hung in the can held in place by the comb-rest, which has notches cut to fit the top of the can. When the bag is full the top is pinned together with nails, the comb-rest removed, and the cross-arm carrying the screw and plunger put in position. The plunger is run down slowly, the honey gradually being pressed out so the cappings are made nearly dry. The plunger and screw are removed; a circular cleated division-board put on top of the first bag of cappings; another empty sack put in and the process repeated. At

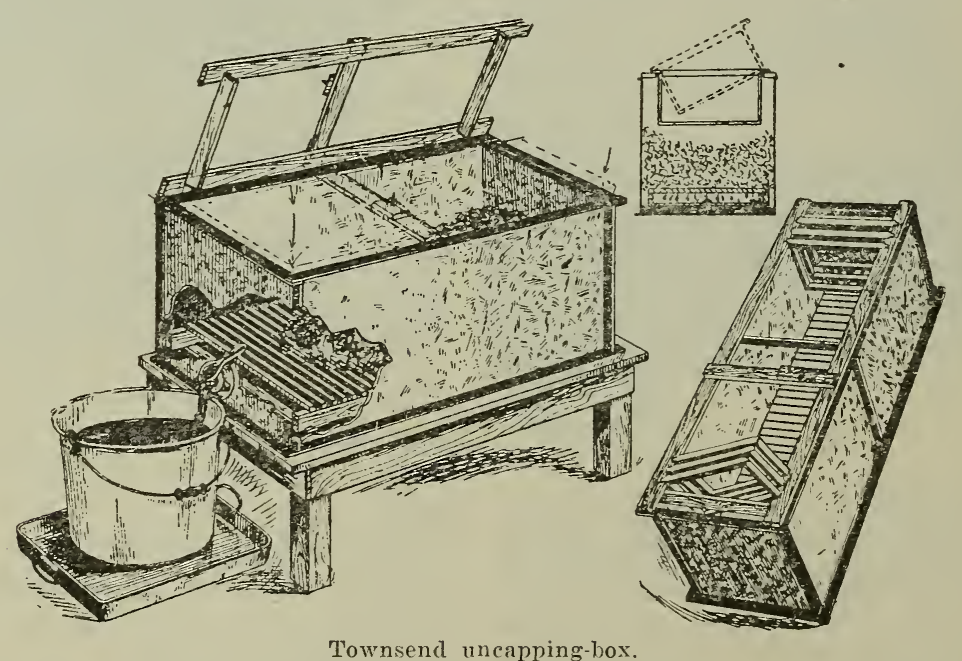

up the small particles of comb, which would otherwise hold the honey and prevent it from draining out freely. The efficiency of the draining method depends upon the thoroness with which the cappings are stirred and punched with a good heavy stick. the end of the day the pressure may be applied to two or eren three sacks of cappings and left on all night. In the morning the bags of practically dry cappings may be remored, and later on if desired the cans may be set orer a stove, steam generated in 
the lower part, and the cappings melted into wax.

Mr. E. D. Townsend, of Michigan, uses for an uncapping-box a long square tank made of galvanized metal. It is six feet long, two feet high, and two feet wide.

The slatted framework at the bottom is marle a little smaller than the can so that it may be easily removed for washing. There is only $1 \frac{1}{2} 2$-inch space under the cleats, so the gate at the end of the tank is left open all the time. In this way nearly all of the space inside the tank is available for the storage of cappings.

A tank of this size will hold all the cappings for one whole extracting of the average-size vard. A short-handled fork is used for handling the cappings, and each day the accumulation from the day before is pitched toward one end of the tank, and in this way the honey from the new cappings does not have to drain thru the dry ones again.

Still another plan that has come into use recently consists of a series of cleated tıars. One tray is supported just high enough so that one end can rest on the top of a common wash-boiler to catch the honey. The rappings fall from the knife directly on to the tray, and are spread around occasionally. When the first tray holds all the cappings that can be put on without falling off they are spread out somewhat and another tray put on top of it, and the process repeated. The weight of the trays above presses the honey out of the cappings below. The longer the work continues the greater the weight on the lower trays. Finally, the under trays may be remored, the dry cappings scraped off, and the trays used over again.

Fach tray has a solid tin bottom, two sides and one end of which are turned up to prevent the honey from dripping off. The open end, which should be the lowest, is placed orer the wash-boiler. The cleats are erenly spaced and rigidly held by perforated metal nailed on top. When one tray is full and the next tray put on top it should be so located that the open end is perhaps a half-inch beyond the end of the tray beneath, so that the honey may drip directly into the boiler, and not on to the end of the tray beneath.

The total outfit of trays is not very expensive, but this plan, of course, does not lend itself very well to a portable outfit.
CAPPING-IELTERS.

There is no plan of draining cappings which secures all of the honey. I small percentage is always left, for the process of draining cannot be kept up indefinitely, owing to the tendency of the honey to granulate. The cappings after several days, tho they may look hard and dry, really contain considerable honey, the exact amount depending upon the efficiency of the plan used. Of course, when these cappings are transferred to a solar wax-extractor the honey and wax are separated, but the honey is darkened and injured by the process.

To separate the honey and wax immediately so that everything can be cleaned up when the extracting is over, capping-meltess have gradually come into use. It can not be denied that it is a great convenience to have the cappings gotten rid of as fast as the work progresses, for it is hard work to handle cappings that are heary with honey. When the day's work is finished, nothing is left but a layer of melted wax, which, after it has cooled over night, needs only scraping to be ready for market, the honey meanwhile being in shape to strain and empty into the main tank with the rest. Honey that has been taken from the capping-melter strains quickly because it is warm.

If the capping-melter is crowded too fast, or if one having a too limited capacity is used, it may clog up so that a quantity of the honey will be confined and thus subjected to the heat for a considerable length of time. Under such circumstances it is likely to become darkened and scorched slightly in flavor. With a properly designed melter, howerer, or one that is large enough for the work on hand there is scarcely any difference to be noted between the honey that has gone thru it and that which has been extracted from the combs in the regular way. It is true that if honey has been allowed to cool under the wax it takes on a waxy flavor, which, while not disagreeable, is ret pronounced enough to enable one to distinguish it from the rest of the honey. On this account a separating can should be used so that the honey may be separated from the hot wax as soon as possible.

There are some localities where honey in cappings candies rely quickly-sometimes 
in twenty-four or forty-eight hours, and undor these conditions a capping-melter is almost a necessity. By the way, whenever one desires to melt up granulated honey or granulated coml honey a capping-melter is the very best arrangement to use because there is practically no danger of scorching the honey, and yet the work may be done quickly.

One of the simplest capping-melters is a hot-water jacketed can having a gate at th? bottom for an outlet on the principle of a double boiler. The melter is not adapter for the largest apiaries as it is designed for a single-burner stove only.

The Peterson capping-melter shown in the illustration, is a simple construction, the long shallow trough having a double bottom, the space between being filled with hot water. The water compartment is extended beyond the edge of the table, as shown, so, if desired, knives may be placed in the water to heat.

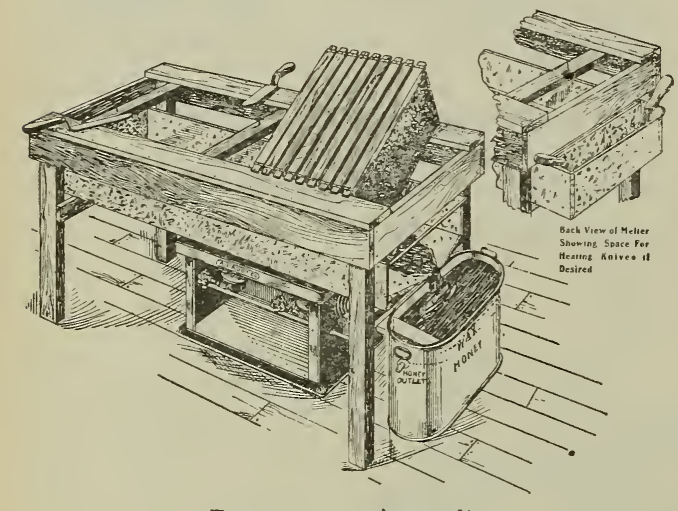

Peterson capping-melter.

This melter is large enough to be heated by a two-burner stove, hence it has a much greater capacity than the round-can design described above. Furthermore, there is space at the end of the table for the uncapped combs to rest upon before they are placed in the extractor. The open end of the long trough is about an inch lower than the other end so that the honey and melted wax run down into the separating-can beneath.

A third form of melter which has a greater capacity than either of the other two is that shown at the top of the next page.

A number of different beekeepers have made suggestions on this design, the original principle being worked out by $\mathrm{Mr}$. F. R. Beuhne, of Australia. Mr. Beuhne's construction was improved by E. L. Sechrist, of California, and still further improved by Mr. H. Bartlett-Miller, of New Zealand. The cappings of honey strike the sharp steam-heated triangular tubes and are melted at once, dropping on to the steam-heated curved bottom beneath, and from then out at the opening in the end of the can. It is impossible to confine the honey in a melter of this construction; and while its costs considerably more than either of the other designs, we believe it has a greater capacity than any other design ever used.

\section{DISPOSING OF THE WAX AND HONEY THAT} RUN FROM THE MELTER.

When capping-melters first came into use the stream of hot wax and honey was run directly into a pail or can, and as soon as it was full another was put into its place. This plan is objectionable in that it requires too many cans of hot wax standing around in the way. Furthermore, the honey underneath takes on a taste of the wax to some extent if it is allowed to remain in contact with it until the wax cools. To overcome this difficulty a gate may be provided at the bottom of the can so that the honey may be drawn off at intervals as fast as the can becomes full. Care must be taken, of course, to shut the gate before any wax begins to run out. In this way the wax remains in the can until the next day when it is emptied out in the form of a solid cake.

A much better arrangement, however, is a separating-can made according to a principle first described by R. C. Aikin, of Colorado. As shown in the illustration of the Peterson capping-melter an ordinary wash-boiler may be used with a tin partition soldered near one end coming to within one-half inch of the bottom of the can. Some honey should be left in the boiler before the work is started. When the new wax and honey run in the wax floats on top of the honey in the larger compartment of the boiler, the honey alone escaping into the small compartment, since the levels in the two compartments will be nearly the same. When the boiler is full the honey will escape continuously from an outlet in the end of the boiler while the wax will remain in the large compartment.

In actual use this separating-can should be insulated by being placed inside a wooden box, having a cover fitted over the top with a funnel to receive the wax and honey. 


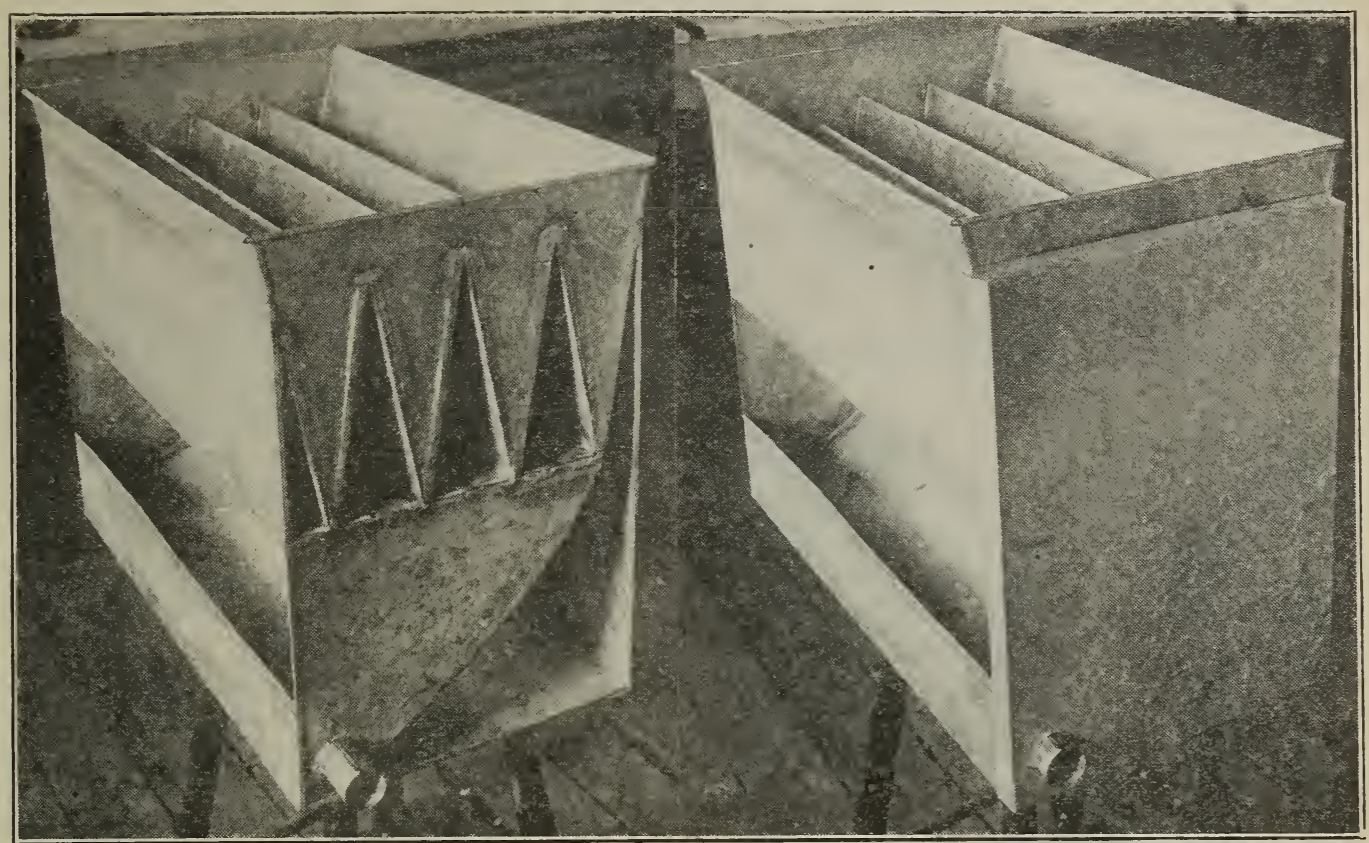

Bartlett-Miller capping-melter. The first view was taken before the end was soldered on, to show the interior construction.

It would be all the better if some insulating material could be wrapped around the boiler before it is enclosed in the box.

F. L. Sechrist, of California, uses a specially made separator as shown herewith. He provides a wax outlet, but if the separator is large enough this is not necessary. A small stream of drizzling wax is a nuisance. If a can as large as a washboiler is used it will hold all the wax for the average day's run even in an extensive yard, and the wax part of the outfit requires no attention, therefore. When the work is over

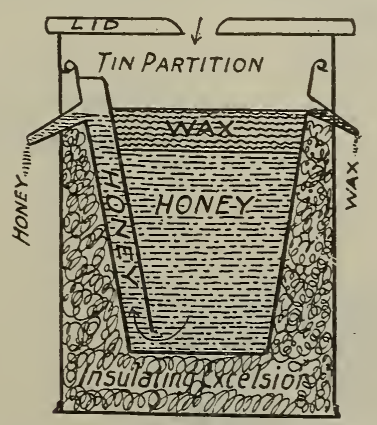

Sechrist's honey and wax separator.

for the day, the cover of the box is removed so that the wax will have a chance to harden, and the next morning it may be lifted out, the honey drained off, the under side of the cake scraped to get rid of the refuse, and the wax will be ready for market.

\section{SHALLOW OR FULI-DEPTH EXTRACTING COMBS.}

Those contemplating the production of extracted honey are often undecided as to whether to use the shallow or the full-depth extracting combs. This depends a good deal on the honey-flow and general conditions. Other things being equal it takes about as long to handle a shallow comb as a fulldepth one, and nearly as long to uncap a shallow comb. So far as the cost of handling is concerned, therefore, it is more expensive to handle and uncap the shallow combs to extract a ton of honey than it would if the honey were in full-depth. combs. However, other conditions are not always equal.

Shallow combs have the especial advantage that bees enter the super quicker than they will a full-depth super. There is less room in a shallow super for the bees to keep warm at a time and during a light honey-flow. Therefore they may fill a set of shallow combs when they would hardly get started in a full-depth super.

Many producers use both the shallow and full-depth combs. Nevertheless, there are far more full-depth extracting-combs in use than shallow. 
AUTOMATIC DEVICES FOR RINGING A BELL WHEN A CAN IS FULL.

In drawing honey into a 60-pound can from a tank it is a great convenience to have an automatic alarm that will give due notice when the can is nearly full. Several beekeepers have gone still further and worker out ingeniors devices to shut the gate on the tank automatically when the

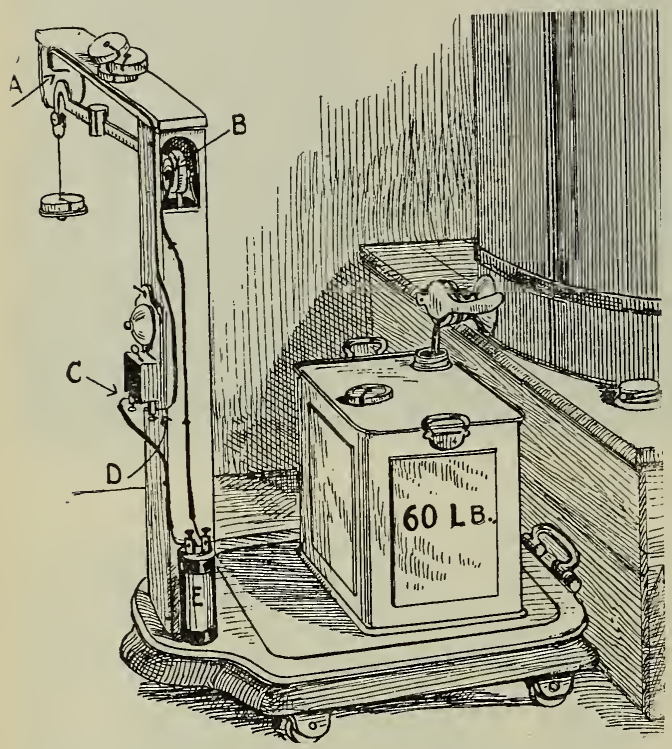

E. D. Townsend's arrangement of strainer and sealer, illustrating the Hutchinson automatic alarm.

can is full. These are quite complicated, however, and unless one is a natural-born mechanic they are likely to be more of a bother than help. A simple alarm, on the other hand, is of practical benefit.

W. Z. Hutchinson user regular platform scales with the weight set at about 58 pounds exclusive of the weight of the can. When the beam rises the electrical circuit is completed and the bell rings. The operator shuts the gate off at just the right time.

The bell is an ordinary door-bell, and the current is furnisled by any dry battery. The method of making the connection is very simple. In brief, two wires run from the binding post on the battery to those on the bell. One of them, however, is broken, and one of the ends fastened to the scale beam at the pivot, and the other located just above the outside end of the beam.

It can be seen that when the can is full the scale beam rises and comes in contact with the copper wire just above it, and the bell rings. All the connections must be kept tight, and occasionally the end of the scale beam must be brightened with a bit of sandpaper, also the wire where it makes contact on the scale beam. Any corrosion at these points would result in failure of the bell to ring.

In case one has no scales a simple balance may be used of hard wood at least an inch thick, about 39 inches long, and 12 inches wide, and balanced on hinges or a knife edge in the middle. A can filled with honey to within an inch and a half of the top should be put on one end and an empty can on the other under the loney-gate. When the empty can under the gate fills to the same point - that is, an inch and a half from the top, it will overbalance and sink down a couple of inches until it strikes a block containing the arrangement to complete the electrical circuit and ring the bell. A mark should be placed at the proper place on the board, and the empty can always put in exactly the same place. A rather large funnel is necessary with th:s arrangement; otherwise, when the can overbalances and settles down the honey might be spilled,

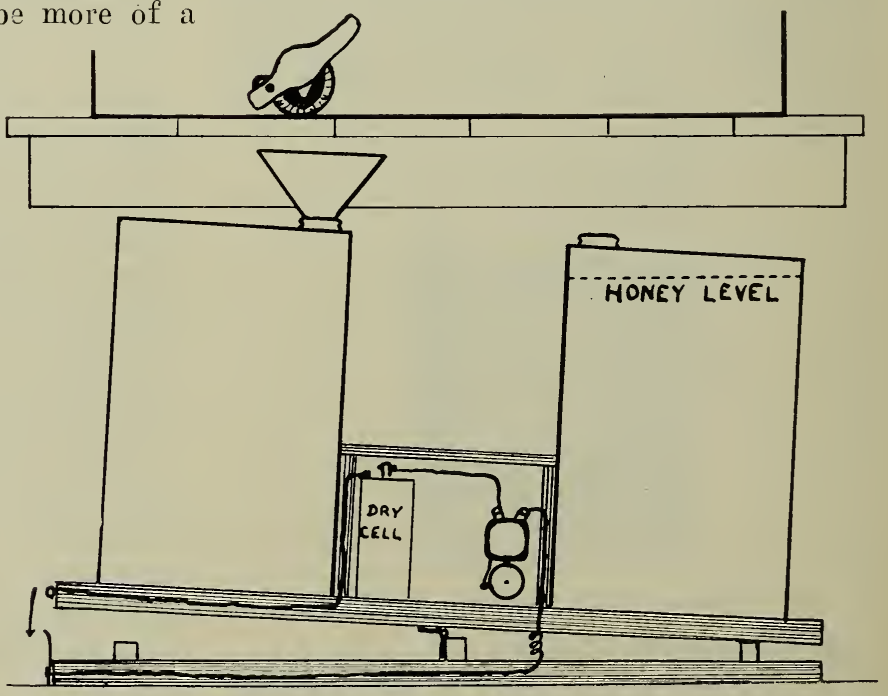

An electric alarm to give warning when the can is nearly full. $A$ can nearly full of honey is placed on one side of the balance, up close to a box in the center containing the dry battery and bell. When the can at the left overbalances the one on the right, the circuit is completed and the bell rings. 


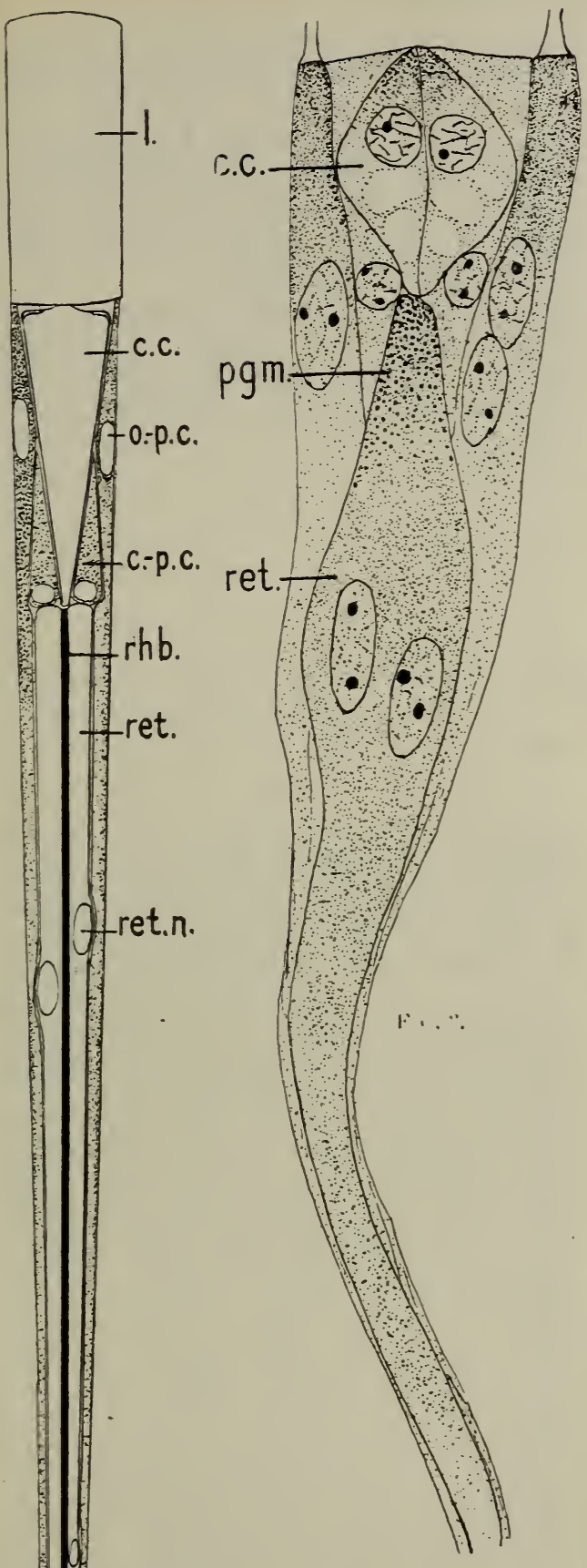

FIG. 1.-Ommatidium of adult eye of bee; l. lens; c. c.. crystalline cone: o. p. c., outer pigment cells: c. p. c.. corneal pigment cells, which, in the early stages, secrete the lens: r. h. b., rhabdome: ret.. retinula: ret. n., nuclei of retinula cells; b. m., basement membrane.

FIG. 2.-Ommatidium of pupa: lettering as in Fig. 1; p. g. m., pigment

F. G. 1. forming in retinula

In Fig. 1 the pigment is not shown in the center portion of the retinula cells. because the opening would not be exactly in line with the gate. A good stiff board is necessary that will not curve out of line with the weight of two 60-pound cans of honey.

\section{EXTRACTING-HOUSES.-See BUILD-} INGS.

EYE, COMPOUND.-An examination of the large compound eyes of a bee will show that the outside is made of hexagonal areas. thousands in number. Each of these hexagons is the outside of one of the elements of which the compound eye is composed: and, since they are all constructed alike, a description of one will serve for all. Each of these elements is called an ommatidium. If, then, we take a section thru one of the compound eres parallel with the top of the head of the bee we shall get some of them cut lengthwise, thereby showing best the structure. altho it is also necessary to cut other sections at right angles to this plane in order to get the shape of some of the parts. The figures which accompany this show the ommatidium cut lengthwise. Another figure shows an ommatidium from the pupa stage.

The outside portion, already mentioned. is the lens layer $l$, and is composed of chitin, as is all the rest of the outside corering of the bee. The section shows this cut open, so that only two sides of the hexagon are shown.

The next lower structure is the crystalline cone $c, c$, which is composed of four cells. of which only two show in the long section. In the pupa stage the boundaries are much clearer. and the nuclei larger than they are in the ardult eye. This cone is clear, and, like the lens above it, gathers in the lightrays so that they can act on the nerves below just as the lens in the human eye gathers together rays of light so they can affect the nerves behind it.

Directly in line with the cone is a long rodlike structure which runs clear to the bottom of the ommatidium, called the "rhabdome," rhb. This probably contains the end of the nerves, which are sensitive to light.

Around the rhabdome are eight retina cells ret, which have poured out a secretion while in the pupa state to form the rhabdome. 
Around the cone and retina cells there are pigment cells $o . p . c$. and $c . p$. $c$, that keep the light from passing from one ommatidium to the other, and thus making a confused image, just as the inside of a camera is painted black to avoid reflections. In the human eye we also find pigment, which is also located just behind the nerveendings, and answers the same purpose. There are two kinds of these pigment-cells. The ones at the base of the cone, o. p.c., are two in number, and do not extend below the base of the cone. The other pig- ment cells, c. p.c., extend from the lens to the base of the ommatidium, and are generally twelve in number. The pigment in these cells is located principally at the outer portion of the eye; and the retina cells also contain a pigment, thus making a complete sheath of pigment around the nerve and nerve-endings in the middle.

The nerve lines in the eye extend down along the eight retina cells, and at the bottom come together, and the united nerve extends toward the brain. See cut on preceding page.
FAIRS, EXHIBITS AT.-See HONEY EXHibits.

FARMER BEFKEFPERS.-Sometimes the professional class of honey-producers have a feeling of antipathy if not disgust toward the farmer who keeps a few bees, especially if he is in the immediate neighborhoor. In some cases, at least, there is some justification for that feeling. Some farmers have too many irons in the fire. They do a little of everything to make a little money, but they do nothing particularly well.

A farmer of this class usually has hard luck. His buildings are in a tumble-down condition, machinery out in the weather, his fences down, his stock ill fed, and, on top of it all, he is in debt. When he keeps bees he allows them to take care of themselves, his swarms get away from him, hives are robbed out, and, if weakened by disease, foul brood is scattered far and wide. $\mathrm{He}$ does not take any agricultural paper, much less a bee-journal, and sells his honey at any old price.

He never gets any honey unless the season is extraordinary. It is no wonder that the real progressive beekeeper finds such a farmer a menace to his business.

Fortunately the majority of our farmers are well-read, comfortably well off, and if they keep bees they secure fair returns from them. Thre is nothing that will yield for him larger returns for the money invested than bees. His wife and children may just as well get a little money on the side by keeping bees as in the keeping of chickens; and the chances are two to one that they will make more money, and at the same time keep the home supplied with the most delicious sweet that the world has ever known. Such a class of farmers are adding dignity and strength to their calling; and when they keep bees they get a better seeding from their clover-fields; more and better fruit from their orchards (see Frurt-BLOssoms and PoIIIINATION); plenty of honey for the family, and a little extra clean cash.

It is not an uncommon thing for a few hives on the farm to bring in a net return of five and even ten dollars per colony. Fol' the money invested there is nothing like it.

of course it is only fair to say that some years on the farm the bees will not do much; but it is a poor farmer beekeeper who cannot make the bees pay their own way during poor seasons, and even make handsome returns when the season is good. The farmer who has an orchard, raises alsike, sweet clover, or alfalfa will be able to keep his few colonies more than busy.

$W^{\top}$ e contend that every up-to-date farmer, especially if he raises clover seed or fruit, should keep bees. See Fruit-BLossoms; Backiot Beekefing; The Beekeeper and 
the Frutr-grower; Fiees axd Poultry; A B C of Befkefpisg.

\section{FEEDING AND FEEDERS.-Feeding} is practiced for one of two purposes-to stimulate brood-rearing at times of the year when no honey is coming in from natural sources, or to supply food to colonies that are short at the approach of winter. These will be referred to later under separate heads. Whenerer possible, feeding should be avoided; for at best it is a messy job, expensive, and, in the case of the beginner, liable to cause robbbing. In a good locality it may be possible to avoid feeding altogether. Especially would this be true in those places where there is plenty of buckwheat or fall flowers. To buy sugar by the barrel every fall is very expensive, and the beekeeper should lay his plans to avoid it as far as possible. In many cases fall feeding is made necessary by extracting too close, in some cases even from the brocdnest. This is bad practice and decidedly poor economy. But there are times when it is necessary to give the bees food either to keep up and stimulate brood-rearing or io prevent actual starvation.

When the honey already in the hives at autumn is of good quality, and nicely sealed, it would be folly to extract it, put it on the market, buy sugar, make syrup, and feed it to the bees. There would be very little gained by it, even if the honey sold at a higher price, and the sugar syrup were cheaper. Where the natural stores are dark, of poor quality, or bad honey-dew, it might be advisable to extract and put in their place sugar syrup. Yet of late years it has been our practice to let the bees have everything of their own gathering, provided it is nicely ripened and sealed in the comb, no matter what the source; and it is very seldom we lose bees in outdoor wintering by reason of poor food.

Where one does not have combs of nice stores sealed, it will be necessary to feed sugar syrup. The cheapest and best food for this purpose is ordinary white granulated sugar. Some of the brown sugars may be used; but experience has shown that they are not as good, and not as cheap in the end, altho selling at a lower price.

Sugar syrup when capped over makes an excellent food for winter. It does not cause dysentery, and is cheap; but it is not the equal of good honey for breeding, as it is lacking in some of the necessary food elements in honey. (See Honer as A Food.) On the other hand. sugar syrup is a little better as a winter food. It is less stimulating-that is, less inclined to start up premature breeding in late winter or early spring.

It is usually poor practice to extract good honey out of the brood-nest. While at times the natural stores might bring twice as much as the same weight of sugar syrup, the labor of extracting and wear and tear on the colony itself in feeding and evaporating the syrup down, is so great that no economy is effected. Ordinary sugar stores should be supplied only to make up the deficiency, if any.

In mid-winter, if the bees are short of food, they should be given candy made of. granulated sugar. (See CANDY.)

The difference in cost between a first quality of extracted honey and sugar syrup when sealed in the comb is so little that, if there are combs of good natural stores, rather than extract them it would be better to set them aside, and then in the fall give these combs to such colonies as had an insufficient supply. But in any case it would be wise not to use all such combs, because, during midwinter, it is sometimes very handy to have them ready, so that they can be placed right down in the center of a brood-nest of a colony, for the simple reason that it is impracticable to give liquid food to bees during midwinter. If combs of sealed stores are not to be had, it is advisable to give cakes of candy, as described under CANDY elsewhere.

\section{HOW TO MAKE THE SYRUP.}

Something will depend on whether the bees are to be fed for the purpose of inducing brood-rearing or to give a supply for winter. For stimulating, a syrup made of one part of sugar to one of water by bulk is about right. If the water is bot the sugar will dissolve more readily. For a winter food giren early in the fall the proportion should be about two parts of sugar to one of water. For late feeding, just before cold weather comes on, the ratio should be about two and a half to one. When made as thick as this the syrup is liable to go back to sugar to some extent, and sometimes it is necesary to put in about a tea- 
poonful of tartaric acid to every 20 pounds of sugar. Others find it better to use honey. The proportion then of honey will be about one-third by bulk of the amount of water used. If honey is used care should be taken to see that it comes from hives where there has never been any foul brood. In our own practice we have never found it necessary to use either honey or acid.

A syrup made by mixing sugar and water in equal parts does not necessarily require heat. The water may be poured into a receptacle cold, and sugar stirred in until the volume of the sugar equals that of the water. The stirring will have to be continued until the sugar is dissolved. If there is any quantity to be mixed in that way, an ordinary honey-extractor serves as a very excellent agitator. The machine is filled nearly half full of water, when the sugar is poured in little by little while the reel is being turned. It will have to be revolved until the sugar is all dissolved. After a vigorous turning of the crank, even after the sugar is thoroly mixed, there will be a number of small air-bubbles. These will all disappear if the syrup is allowed to stand for a while. When the proportion of the sugar is two to one or two and a half to one, it is advisable to use hot or boiling water.

Syrup can be mixed in a common washboiler where heat is employed. In that case the boiler is put on the stove and filled with the requisite quantity of water. After it has come to a boil, the sugar is slowly stirred in, a little at a time. While on the stove the mixture must be kept thoroly stirred to prevent the undissolved sugar from settling on the bottom and burning. Care should be taken about that, because burnt sugar or syrup is liable to be fatal to the bees.

In many cases syrup has to be prepared at the outyard. Or perhaps the good wife objects to having her stove messed up. While on oil or gasoline stove will heat the water, either one is very slow. Some use and recommend a good-sized common galvanized wash-tub, such as can be obtained at any hardware store at a comparatively low price. This is placed on four or five stones of suitable size outdoors. The right proportion of water is poured into the tub. A fire is then built under, and when the water comes to a boil the granulated sugar is slowly stirred in. After it is all dissolved, the fire should be scraped out from under the tub to prevent overheating or burning. This work should be done on a cool or rainy day when the bees are not flying; otherwise one would start robbing.

\section{FEEDERS.}

There have been hundreds of feeders invented and put on the market. Some of them are very complicated, and the more so the less useful. If one desires to keep down his investment he may use common tin pans. These can be placed in the upper story of the hive, and filled with syrup. On

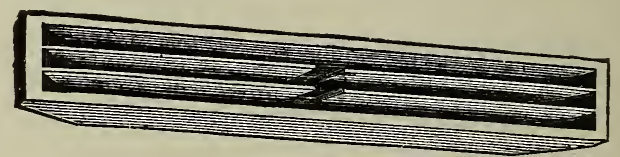

Simplicity feeder.

top of the syrup should be laid a strip of cheesecloth that has been dampened in water. The bees will crawl up on the eloth and appropriate the syrup without danger of drowning. One objection to pans is that it litters them up; and after the feed is all taken, the cloth is likely to be stuck down by the dried crystals. Boiling water will, however, very soon clean them.

A feeder that has been used very largely is the Simplicity trough feeder. It is an excellent feeder, cheap in price, and occupies very little room on top of the broodframes; or it may be used in front of the entrance at night when the weather is warm. It should not, of course, be placed there during the day on account of the danger of robbing.

Another feeder that has been used very largely consists of a common wooden butter-dish, or pie-plate, such as one gets at the grocery when he buys butter. A hundred of these can be nested together so as to take up but very little room, and the price is insignificant. It is not necessary to use cheesecloth with the butter-dish. Set it on the top of the frames, and fill it with syrup.

\section{FEEDERS ON THE ATMOSPHERIC PRINCIPLE.}

The principle of giving chickens water on the atmospheric principle has been applied to feeders for bees. A common Mason jar, for example, filled with syrup, and covered with a common saucer, when inverted will 
make a very good feeder for bees. But in order to provide for a proper flow, three or four toothpicks should be put between the jar and the sancer. At this time the saucer will be right side up, and the jar upside down. As fast as the bees take out the srrup a bubble of air will enter the jar. when syrup will take its place in the saucer.

The device is rather crude and unhandy. A better atmospheric feeder may be made ont of a Mason jar, and cap in this way. Break or remore the porcelain in the top of the cap, and then punch two or three holes about the size of a common pin. Fill the jar full of syrup, screw on the cap, and invert. In that position it will have to be held by some kind of contrivance where it will be secure from robber's and where the bees can go under and take the syrup thru the abore-mentioned perforations.

Manufacturers malie a special Mason jarcap with perforations: and with this cap they supply a block of wood into which has been bored a hole large enough to receive a Ma-on jar when inverted. This hole is of the diameter to hold the jar 3/s of an inch above the bottom of the hole in the block. Thru the bottom is a mortise or slot that communicates with the entrance of the hive when the feeder is attached to the hive. This is done by inserting the projection into the entrance.

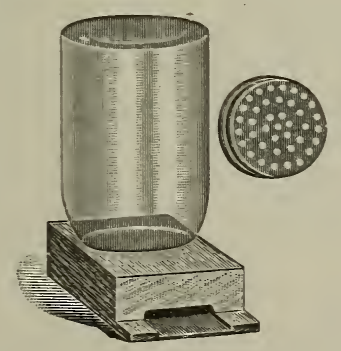

Boardman entrance-feeder.

The Boardman, of all the feeder's here shown, is the handiest. It does not require the opening of the hive, and, what is of some importance, permits the apiarist to see at a glance by looking down a row of his hives what feeder's are empty or nearly so. One can take a wheelbarrow load of filled cans, lift the empty ones out of the block, and substitute filled ones. It is the work of but a few minutes to supply erery colony in the apiary with a filled can of syrup. This is especially convenient during a dearth of honey when it is desired to keep up brood-rearing for increase. For further particulars regarding this feeder see FEEDiNg to Stimelate further on.

The pepper-box feeder is another form of atmospheric feeder that has been adrertised quite extensively. While this can be

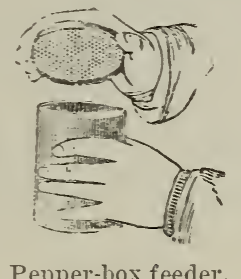

inserted into an entrance block like the Boardman, it is not so easy to determine when it is empty. Ordinarily it is used in an upper story or super abore the broodchamber.

\section{THE ALEXANDER FEEDER.}

This is a very popular feeder. and some prefer it to anything else. It is on the principle of the Simplicity: trough feeder and is a little longer than the width of the hive. The bottom-board is shoved forward by the width of the feeder, and into the space left racant is placed the feeder. The projecting end is used for filling, after which it is closed by a wooden block.

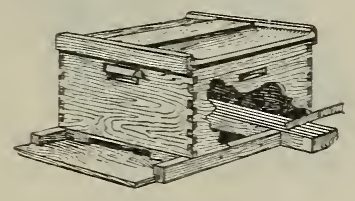

Alexander feeder.

While this fecter is rery handy, it does not. like the Boardman, regulate the supply of feed. The bees will empty it in an hoir of two, and then be inclined to rob. because the large amount given stirs them up to the point of excitement. One serious objection to the Alexander feeder is that it is sometimes difficult. owing to the unevenness of ground, to adjust the feeder to the back end of the hive. See FeEdisg to Stinulate further on.

\section{THE DOOLITTLE DIVISION-BOARD FEEDER.}

For cool-weather feeding. or fall or winter feeding. the Doolittle is superior to those previously mentioned.

It las the same outside dimensions as an orcinary brood-frame, but is two inches 
wide. It will hold about 6 lbs. of syrup, and usually about four feederfuls will supply a colony with enough stores for winter, provided the syrup is made two and onehalf to one as already described. We use

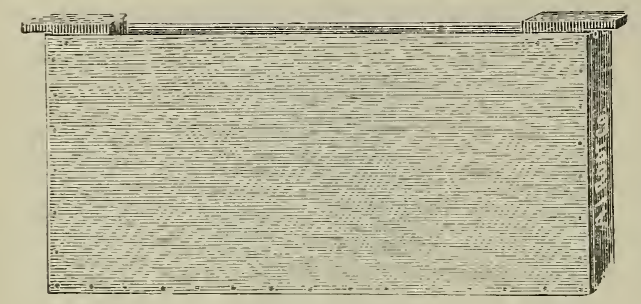

Doolittle feeder.

the Doolittle feeder almost exclusively during the cool weather or in the fall, and as a general thing we fill it with warm syrup. It may be used as a dummy or a division-board.

\section{THE MILLER FEEDER.}

Where one desires to feed 20 to $25 \mathrm{lbs}$. of syrup at a time, all in one feed, the Miller feeder is the best of anything we have ever tried. It is a little less in dimensions than the inside of an ordinary super to a hive,

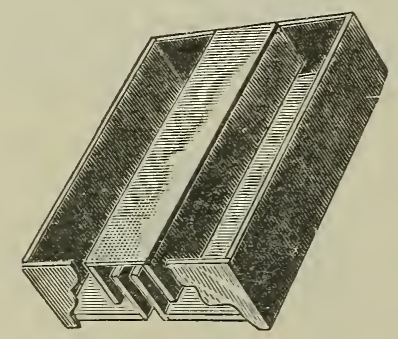

Miller feeder.

and is always used in connection with a super or upper brood-chamber. For late feeding, where one desires to do the work all up at one time, he can feed with this

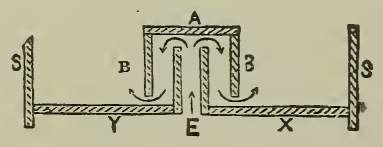

feeder 25 lbs. of thick syrup. If the weather is cool the syrup should be hot when the bees will take it down in a single night. The feeder can then be transferred to some other hive.

The peculiar merit of this feeder is the fact that the entrance to it is directly over the center of the brood-nest. Bees can rise up thru the space $\mathrm{E}$ shown in the sectional drawing, follow the direction of the arrows, and reach the syrup. If the feeder is full, the syrup in the compartmenets $\mathrm{BB}$ will rise to a coresponding level in the two outside passages under $\mathrm{A}$.

\section{FEEDING WITHOUT A FEEDER TO PREVENT STARVATION.}

One year two or three of our outyards were on the verge of starvation. Broodrearing had progressed very heavily in the hives, and the expected honey-flow, on account of continuous rains and chilly weather, had not come on. There was not time to put on feeders-in fact, there were none at the yard. We had on hand some very heavy Porto Rico honey which we knew to be free from any bee disease. We took a couple of cans of this to the yard and emptied them into a common tin pail. The honey was very thick; and while an attendant lifted the cover and smoked the bees down we poured a small stream of about threeeighths inch in diameter back and forth along the top-bars of the frames. Some of the honey we allowed to drip down between the frames. The cover was then replaced. In this way we went thru every colony without disturbing the brood-nest or using a feeder of any sort. As there would be plenty of honey coming in provided the sun would ever shine, we fed the bees in this way to tide them over. Some of the stronger colonies we gave a second feed because they would take the honey, smeared over the top-bars in the space of five or six minutes. We then went back and smeared the top-bars again. While the amount of honey given in this way was not large, it was sufficient to prevent the bees from starving before we could get down and give them another feed, or until the honey-flow should come on.

Ordinarily we would advise the use of the Boardman entrance feeder; but when one does not have a supply of these, nor any other feeders, he can very easily tide the colony over for a day or two by smearing the top-bars as explained.

It is not advisable to pour the honey over the brood-nest of a weak colony. A strong colony will clean up the syrup, even if some of the bees are daubed. Care should be taken, of course, not to give a colony too much, or enough so that it will run down 
over the combs on the bottom-board and out of the entrance, as this would start robbing.

\section{FEEDING TO STIMULATE BROOD- REARING.}

As previously intimated, feeding to stimulate brood-rearing is a very different proposition from feeding to supply the bees with the necessary winter stores. In the case of the former, our desire is to get as large a force of bees (not stores) for the approaching harvest or the approaching winter, the method of procedure being the same in either case. To stimulate broodrearing, we will feed approximately half a pint of syrup daily; but if we give that amount in an ordinary open feeder, such as the Simplicity, Doolittle, or Alexander, the bees will take it all up in about an hour's time. The result, if the syrup is given in the morning or during even the middle hours of the day, is to excite the colony unduly. Bees will rush out into the open air to ascertain where the sudden supply of food may be obtained. If a whole apiary is fed in this way, there is a general uproar of excitement, often followed by robbing of some of the weaker colonies and nuclei, for the bees in the field will pry into everything. An entrance unguarded is immediately attacked; and unless there is sufficient force to repel the onslaught, robbing will get so far under way that it may result in the robbing-out of the attacked colony. But this is not all. When the supply of syrup in the feeders fails, bees are apt to be cross, sometimes attacking passers-by or stock in the fields. This is particularly so if robbing gets under way. For these reasons it is usually advised to feed toward night.

Happily we are able to avoid all this trouble by using a feeder that will make a quart or a pint of syrup last during the entire twenty-four hours of the day. In the case of a nucleus, the amount can be so regulated as to last thirty-six or fortyeight hours.

When the supply of food comes in very slowly, about as it would come in from a very moderate honey-flow, enough to give the bees and queen encouragement to keep up brood-rearing, they will rear more brood than if the supply is intermittent. All excitement-that is, uproar in the air-as well as robbing is avoided. It is impossible to fix the Simplicity, Alexander, and Doolittle feeders so that they will not give out the syrup too fast; but we can regulate the pepper-box and Boardman entrance feeders. This is accomplished by soldering up all the holes or perforations except one or two. Any tinsmith can do this with a solderingiron in a very short time. The feeders are then filled with syrup and given to the colonies.*

For outward feeding this slow feeding is a great convenience, because one can gire his bees a supply of food to keep up the normal functions of the colony that will last for two or three days. For very slow feeding one hole is better than more. A strong colony will require more openings than a weak one; and in all cases syrup for stimulating should be in the proportion of about 66 per cent water and 33 per cent sugar, thoroly stirred until the sugar is dissolved.

Perhaps the reader does not own any pepper-box or Boardman feeders, and yet would like to practice slow feeding as herein directed. All he needs to do is to procure a quantity of self-sealing tin cans that can be readily obtained at the ordinary grocery. Thru the top punch a hole just large enough to admit a common pin. If this hole does not prove to be large enough to let out sufficient food, two holes may be used, or even three, depending upon the size of the colony. The can should then be filled with syrup, and the top pushed firmly in place.

Experiments have shown that this scheme of slow feeding will raise more brood for the sugar used than where the same amount is given intermittently in the open feeders like the Simplicity, Alexander, and the Doolittle. For our work, we prefer the Boardman entrance feeders because we can see at a glance thru the glass when the syrup has been used up. If the supply has been taken, it is very easy to put a filled can in the place of the empty without disturbing the hive or the bees.

Where one desires to feed rapidly, in small doses, the Simplicity, Alexander, or the Doolittle feeders are better than the onehole feeders referred to; but one can use the Boardman feeders by having an extra supply of tops with the full number of perforations.

* Boardman feeders with only three or four holes can now be purchased of the dealers. 


\section{FEEDING UP FOR WINTER.}

If colonies are to be wintered on sugar syrup mainly, the general practice is to feed some time in September, and, as a rule, this is, perhaps, the best time to feed. Still, in many localities in central United States, there is warm weather in October sufficient to start brood-rearing, and much of the stores fed in September may be consumed so that what is left is not sufficient to last until the new honey-flow. For this reason it is often unsafe to feed in September and give no further attention to the bees. There are other cases when, for one reason or another, feeding may be delayed until cold weather begins. If one is rumning a number of outyards it is impossibls, without hiring a large force of men, to feed all these yards at once, and by the time the last yard is reached it may be rather late.

But before we begin the actual work of feeding we make a preliminary canvass of the whole apiary. This we do by "hefting" each hive; that is, we lift up either the front or back of the hive. A little practice will enable one to determine approximately the amount of stores in each hive, provided there is not too large a force of bees. In that event, we must allow for a corresponding increase. As ve go over each hivo we mark on the cover with a piece of chalk the number of pounds that will be required. If the colony is a strong one we allow for a total of $25 \mathrm{lbs}$. if it is to be wintered outdoors; for indoors, about two-thirds that. We aim to have each colony strong enough so that it will require an average of about 25 lbs. each for outdnor wintering. After all the hives are marker up we proceed to the actual work of feeding.

For this late fall feeding we know of no better feeder than the Miller. This will hold at least $25 \mathrm{lbs}$. of feed at a time, and it can be quickly put on and taken off without much disturbance to the brood-nest. On the other hand, if the colonies are not quite as strong as they should be, so that some contraction is necessary, the Doolittle divisionboard feeder holding about 6 lbs. of thick feed at a time may serve a better purpose. During the season, any combs which are found that are too old, or which, for some reason or other, are not perfect, whether due to drone-cells or irregularities, can be gradually pushed to the outside of the brood-frames; then in the fall, when it is time to put in the feeder, provided the division-board feeders are used, these defective combs can be very easily taken out to be melted up later, and with no loss of brood. Furthermore, if the colonies need feeding, these outside combs will not contain much honey. On a cool day an outyard can be looked over very quickly, and the old combs that are on the outside of the brood-nest removed with very little trouble. If a follower is used, the removal of one comb and the follower makes room for the feeder; but if the combs completely fill the hives, two combs must be removed.

The best time of day for putting feed into the feeder is toward the close of the afternoon. It is not advisable to do the work in the morning or early in the day, for' the reason that the bees are always excited, and robbing might be started, especially if it were warm enough for the bees to fly. Right here is a point in favor of the chilly-weather feeding, for there is no such danger of robbing, of course, when the bees cannot fiy on account of the cool temperature.

We prepare the feed at home and carry it to the yards in the regular five-gallon honey-cans hot, as these are about the largest-sized cans that can be handled conveniently by one person. If two were doing the feeding a larger can might be used.

While the syrup is still lot we load it into the wagon or auto truck, six or eight cans at a time, and carry it rapidly to the yard. When we reach the edge of the apiary, we take the cans, one at a time, and locate them thru the yard where the markings on the hives show that we shall need them. If the cans have good strong handles we are able to carry two at a time, one in each hand; but the difficulty is that the handles are liable to tear loose from the can at one end and drag thru the hand, cutting the fingers. For this reason we prefer to carry one can at a time in the arms. If a small rope sling were used, two cans could be carried witlout danger.

When we are ready to commence feeding we fill a large sprinkling-can, with the rose removed, and then proceed at once to pour the syrup into the division-board feeders in every hive. Each feeder, as mentioned before, will hold about six pounds of thick syrup. By the time we have emptied one 
of the fire-gallon cans we are ready for another. On the covers of the hives are marked the number of pounds of syrup which each hive is to receive. It is likely that not all of the hives will need feeding a second time, so the second day the work can be done even more quickly than the first time. When it is not too cool the bees will have taken the syrup in one feeder in 24 hours' time; but if the weather is very cold they will require 48 hours; but this time can be materially reduced if the syrup is given hot. We would always give it hot if it is cold enough so that the cluster is contracted. After all the hives have been fed up we go over the hives again, this time making a careful examination of the broodnest. If more syrup still is required we mark the hive again and later on feed it and all others that may be short.

\section{FEEDING IN FREEZING WEATHER.}

Tho colonies have been wintered well when fed after cold or freezing weather much the safer plan is to have it all done during fall not later than October, for the northern states, that they may have the syrup ripened and entirely sealed. If the weather is not too cold one can feed with the Miller feeder as previously intimated. If one has been so careless as to have bees that are in need of stores, at the beginning of winter, we would advise frames of sealed honey if they can be obtained; and if not, candy. See Candr.

If the syrup is covered up with warm cushions or something equivalent, it may be fed at any time, altho it does not seem to be as satisfactory under all circumstances as stores sealed up in their combs.

When feeding in cool or cold weather, one is very apt to uncover the cluster, or leave openings that will permit the warmth of the cluster to pass off. We have several times had colonies die in the spring after commencing feeding, and we imagined it was from this cause alone. When they first commence raising brood in the spring, they need to be packed up closely and snugly. Making a hole in the quilt or cushions above the cluster, and placing the feeder over this so as to close it completely, does very well. but is not, after all, as safe as giving the feed from below. For feeding in early spring, where the colony is weak, we would prefer candy or combs of sealed stores.

10
FEEDING IN THE SPRING, OR FEEIING FNOUGH IN THE FALL TO IAST TIIL THE NEXT HONEYFLOT.

Some years ago it was the general practice to feed in the spring to stimulate broodrearing, such feeding taking place as soon as settled warm weather came on. The purpose of this was to get a large force of young bees for the harvest when it came: but in later years the tendency on the part of our best beekeepers has been toward feeding copiously in the fall enough to last not only all winter but during the spring and until the honey-flow. Experience seems to show that spring feeding very often does more harm than good by over-stimulation. Brood is expanded beyond the capacity of the bees to hover and keep warm. Robbing is often induced. Beginners especially are apt to overdo it; and even a veteran will sometimes get his colonies so strong before an extra supply of nectar comes in, that swarming will be brought on prematurely.

This question of feeding heavily in the fall to last until the next honey-flow the following year, or feeding moderately in the fall and stimulating the following spring, depends somewhat on the locality, and very largely on the man himself. Many beekeepers of experience, especially in some localities, can doubtless practice spring feeding to advantage; but as a rule beginners will do better to give all their colonies enough in the fall.

WHEN ROBBERS ARE BAD, FEEDING AT NIGHT.

During the early fall of 1887 we found our apiary almost on the verge of starvalion, the previcus summer having been very dry. Robbers were unusually vigilant, and it was almost impossible to perform any manipulation with the hives without getting a perfect storm of robbers in the broodnest. Feeding during the day was out of the question, and yet the colonies must be fed in order to prepare them for winter. Accordingly, to circumrent the robbers we fed at night by the light of lanterns. Contrary to what we might expect, the bees gave us but very little trouble by flying against the lanterns. As the bees took up all the feed in the feeders during the night, and the robbers had had no opportunity to investigate during the feeding, everything was comparatively quiet the next morning 
and also during the following day. We fed very successfully in this way some three or four barrels of sugar. Altho we have recommended feeding toward night, in the preceding paragraphs, in the case above mentioned we fed from about 7 P. M. in some cases until 10:30 P. M. Perhaps we should also remark, that, if it is inconvenient to work at night, feed on the first rainy day. Put on a rubber hat, coat, and rubber boots. As long as it rains, bees will not molest. Rain does not interfere with work as much as one might imagine.

For particulars regarding feeding back to fill out sections, see

FEEDING BACK.-This subject is one interesting a large number of beekeepers in the comb-honey class, the main object, perhaps, being to prevent unfinished sections. At the same time much can be done toward preventing swarming as well, if the sections are removed from the colonies before they are capped and finished up after the danger of swarming is over by the feeding-back process, for it is well known that a great amount of capped honey in the hives is very conducive to swarming.

Many who attempt to feed back, fail on account of the many difficulties encountered. Mr. J. E. Hand, of Birmingham, Ohio, has made a thoro study of this subject, and he finds that, while the work can be profitably done, much attention must be given to the details, since there are many things to take into consideration.

It is more practicable, he says, to use a feeder in which the honey can be given below the brood-chamber instead of on top, as this is the more natural way for the bees, and they take it more readily. The Quinby feeder has a tin tray, 2 inches deep, enclosed by a wooden frame of the same depth, which is the same width as the hive, but $2 \frac{1}{2}$ inches longer. The tin tray is exactly the same length as the hive, and when in use is pushed to the back end of the frame surrounding it, leaving a space of $2 \frac{1}{2}$ inches in front for the bees to pass out and in the hive. The other end of the tin tray projects $2 \frac{1}{2}$ inches beyond the hive at the back to allow space for filling it. A framework of slats lengthwise of the feeder sits in the tray for the bees to travel over while working in the feeder so that they may not be drowned. The feeder rests squarely on the bottom-board, and the hive covers the feeder except the $2 \frac{1}{2}$ inches at the back end, which space is covered by a little board. The bees cannot get into the place where the feed is poured in, and the honey (about six quarts) flows evenly under all parts of the hive, where it can be quickly taken up by the bees.

Many fail in their attempt at feeding back for the reason that they do not select the right time of the year. It is best to begin right after the main honey-flow has ceased before the work in the supers is over, and use fresh honey the day it is extracted. At this time the bees naturally go right on as tho the flow had not stopped. It is best to give about six quarts of thinned-down honey to each colony every other day. The interval between the feeding allows the bees time to remove the honey, which is first placed directly in the brood-cells, to the supers. No definite rule can be given for thinning down the honey, since the density varies so much. For average honey enough water must be added so that the syrup will be 75 per cent honey and 25 per cent water. Very thick honey needs more water, while thin honey needs less.

It is necessary to have the brood-chamber well occupied by brood, for bees never do well in supers over brood-chambers containing much capped honey. The first requisite, then, is a good queen, which will be able to hold her own against any amount of feeding. The brood-chamber must be contracted, furthermore, so that the queen will be able to keep every comb filled with brood. In this connection the sectional hive is very convenient for the reason that one section may be removed, thus contracting the brood section and still allowing brood in the shallow frames to be under the entire super. It is quite important, however, to have the combs in the brood-chamber as new as possible, for the bees are quite apt to carry up bits of comb to be used in capping cells in the supers, and old dark comb will discolor the super-cappings to quite an extent.

The thinned-down honey should be put into the feeder just before sundown, so that there may be no uproar that may be likely to cause robbing. It is not desirable to have more than two supers of sections on the feeding colonies at a time. As soon as the combs in the super next the broodchamber are nearly capped, this super 
should be raised up and the upper one placed under it next to the brood-chamber. As soon as the top super is finished and capped solid to the wood, it may be removed and a fresh super placed next the broodchamber. Of course it is not essential that combs be built out and capped solid to the wood. The combs all capped over, except cells next to the wood, would grade Nc. 1.

\section{CAUTION : FED-BACK COMB HONEY LIABLE TO GRANULATE.}

Under Comb Honex, How to Produce, subhead "Bait Sections," reference is made to the fact that bait sections or fed-back comb honey is more liable to granulate than urdinary comb honey. Dealers have complained that the former granulates very rapidly on their hands; and when they know it they will not accept it unless for immediate sale. It should be sold in one's own locality; and sold as early as possible. While not all of it will granulate, the history of such honey is decidedly unfavorable.

FEEDING OUTDOORS.-After what we have said elsewhere in this work regarding the danger of exposing sweets in the open air during the robbing season, it may seem the height of folly to recommend what appears to be the same thing that we have been condemning; but, as we shall show, this outside feeding may be practiced without any bad results that follow from the exposure of sweets under other conditions. It is well known that, when bees are busy in the field in a natural honey-flow, hives can be opened without any robbing. Now, then, if we can keep the bees busy by making them go after food, set outdoors, that is of the consistency of raw nectar, we shall accomplish artificially much the same result.

But as we proceed further the question may be asked, "Why feed outdoors at all if the proper stimulation can be given by placing the food inside the hives that need it, rather than supply all colonies alike, irrespective of whether they need stores or not?"

While it is ordinarily better to feed each individual colony according to its reeds, there are times when one can feed a whole apiary by placing a weak syrup in an outdoor feeder. At any time when robbers in- terfere with the manipulations of the colonies sweetened water outdoors diverts the meddlers by making a sort of artificial honey-flow. When the bees can gather anything from the fields they are not disposed to rob. In the same way if we can keep the bees busy artificially we can accomplish much the same results. This we can do with an outdoor feeder and sweetened water, to be explained further on. If one engages in queen-rearing, or desires to extract when bees will ordinarily rob, an outdoor feeder can be started so that the necessary work can be performed easily and secure from pilfering bees. Again, it will sometimes happen that the whole apiary is on the rerge of starvation, and outside feeding can be used to tide the bees over until the expected boney-flow starts, or until feeders can be installed on the hives and colonies can be fed in the regular way.

Outdoor feeding can also be employed to advantage to "call the bees off" when robbing the neighbors' preserves during the canning esason. The same calling-off process can be used when the bees are robbing candy-stands or stands where lemonade or cut melons are on display for sale.

Within a quarter of a mile of our home yard there is a fairground, and sometimes we find it necessary, if bees are inclined to rob, to start outdoor feeding the day before the fair opens, and keep it up during the fair. If there is a severe dearth at the time, bees are inclined to meddle with the candystands and soda-fountains. While the amount they actually steal is insignificant, their presence "drives away trade."

\section{DISADVANTAGES OF OUTDOOR FEEDING.}

Having said this much in favor of outdoor feeding a whole apiary, it should be clearly and emphatically stated at the outset that it is an expensive way of feeding bees. When a colony can take the syrup from an ordinary feeder, either at the entrance or on top of the hive, and place it in the combs, the wear and tear on the bees is nothing as compared to that which takes place when the bees are compelled to leave the hives, fly to the feeder, scuffle with each other, and then rush back in pellmell haste to their hives to unload. Nor is this all.

One year, when robbing was very bad, and when we desired to keep on with our queen-rearing operations, we fed for sever- 
al weeks in outdoor feeders. It was very noticeable that the field bees had their wings badly worn, and at the end of the queen-rearing operations the fielders were conspicuous by their absence, and nothing but young bees were left. While outdoor feeding stimulates brood-rearing, it does so at a large cost. Besides the wear and tear on the wings themselves there is the labor of reducing a ten-to-one sugar syrup or sweetened water (nine parts of water to one of sugar) to a well-ripened sugar syrup of two and one-half parts of sugar to one of water. When feeding in the hive, the syrup is never weaker than one part of sugar to one of water; and it is often two parts or even $2 \frac{1}{2}$ parts of sugar to one of water. It will be readily seen that outdoor feeding of bees involves an mormous drain on the colony.

There is another serious drawback to outdoor feeding. It naturally feeds all the bees in the vicinity, the neighbors' included. It also causes a disproportionate amount of syrup to be given to the colonies. The strong ones will have a great deal more than their share, and the weak ones considerably less. By feeding within the hive, one can regulate the supply for each colony or nucleus.

\section{HOW TO FEED OUTDOORS.}

While an expert can set out unfinished sections for the bees to clean, as spoken of under the head of COMB HONEY, TO ProDUCE, subhead "Unfinished Sections," the practice on the part of the beginner should be discouraged. But he can feed outdoors without stirring up an uproar by feeding a very thin syrup, about nine parts of water to one of sugar. As already explained, this is virtually sweetened water. At the beginning a little stronger syrup will have to be made in order to start the bees. Then it can be weakened down to the nine-to-one basis.

We prefer the regular trough feeder for the purpose-either the Alexander or the Simplicity. Twenty-five or fifty of them will be required all set out in a row on a couple of $2 \times 4$ scantling properly leveled up. When these feeders are not available, two or three common washtubs can be used, but the surface of the sweetened water should be covered over with sticks or corncobs to prevent the bees from drowning; and there should not be much more than an inch of liquid to the tubs or at least not more than will be required to supply the bees all day or as long as it is desired to keep them busy. If the sweetened water is left out over night during warm weather it is liable to sour, so that a supply should never be given greater than the bees can take up for the day.

To prevent the bees from crowding, it is desirable to use a large amount of surface; hence it is recommended to use two or three tubs with an inch of sweetened water rather than one tub with three inches of liquid. When the surface is comparatively small, the bees crowd each other in a way that is injurious to their wings; and by spreading the feed no bee will be compelled to crowd against its neighbor.

\section{FENCE.-See Comb Honey.}

\section{FERTILE WORKERS.-See LAYING} WORIEERS.

\section{FERTILIZATION OF FLOWERS BY} BEES.-See Pollination.

\section{FIREWEED.-See WILLOW-HERB.}

\section{FIXED FRAMES.-See Frames, SELF-} SPACING.

FLIGHT OF BEES.-The distance bees go in quest of stores varies very greatly according to conditions. Usually on level country, more or less wooded, they do not go over a mile and a half. If, however, there is a dearth of pasturage within that distance, and plenty of it along some river bank three to five miles away, they may or may not go that far. When bees go out after stores they evidently try to find their nectar as near the hive as possible. They will not go over half a mile if they can get ‡ sufficient supply within that distance; but in most cases that range does not supply enough pasturage, and it is evident they keep increasing their flight until they go as far as a mile and a half. If they are unable to secure enough, and if there is forage on beyond, they often go further.

Bees will sometimes fly over a body of water or a valley from an elevation three or even five miles, particularly if there are fields in sight that are somewhat showy. Whether they have a long-range vision or not has not been proven; but the fact that 
they will find white patches of buckwheat five miles away across a valley is somewhat significant. In a like manner they will go four or five miles to orange bloom in California across a valley. Whether they are guided by sight or smell in either case is difficult to prove; but it is quite probable that a breeze will carry the odors of a buckwheat-field or of an orange-grove in full bloom to bees five miles away. IVhile we might not be able to detect odors at such a distance, the scent organs of the bee are much more acute than ours; and they might and probably would get a knowledge of its presence in a given locality.

As a general rule, as stated at the outset, bees do not fly much over a mile and a half. Where they have to go greater distances their wings sometimes show wear, especially if they have to pass thru shrubbery.

We once had one yard located in an aster district. The supply of nectar gave out in the nearby fields; but we traced some of the bees of that yard to asters five miles away. That fall there was a very rapid decimation of the bees. Colonies that were strong just before the asters came into bloom dwindled down to three and two frame nuclei. The surviving bees had their wings badly frayed. The presumption is that in dodging thru and over shrubbery in their long flights they tore their wings more ur less, with the result that large numbers of them never got back home.

When bees are going to and from the field, they fly as low as possible to avoid the wind. Instead of flying over shrubbery they will dodge thru it for forage on the other side. At other times they will fly over it. We have observed, however, that bees would go no further than a piece of woods half a mile arvay at one of our yards. The probabilities are that, on rising to the height of the trees, they encountered a current of wind in the opposite direction. It is a well-known fact that bees cannot fly against a strong wind.

\section{THE RANGE OF FLIGHT AND ITS RELATION TO OUTYARDS.}

In the location of outyards one should take into consideration the general lay of the land and the character of possible beeforage. In ordinary white-clover regions where there are patches of wocds, buildings, or much shrubbery, bees do not fly much over a mile and a half; but when clover ceases to yield, and basswood can be found two or three miles arvay, those same bees will fly further; and when conditions are right, they will fly from three to five miles, and eren seven miles across a body of water. But locations that furnish such long ranges are very rare.

The flight of bees will determine somewhat the size of the beeyard. If they do not go further than a mile and a half probably not more than fifty colonies can be kept in the location, and possibly thirty would be better.

In some parts of the country as many as 500 colonies can be kept in one place. The late E. W. Alexander kept 500 colonies at Delanson, N. Y., on a hill overlooking a ralley. He traced his bees five miles from home many times, and secured large crops of honey. J. F. McIntyre, at his celebrated Sespe apiary near Ventura, Calif., kept over 500 colonies. See ApIary. In both of these cases it is evident that the bees would have to fly at least five miles in order to get the proper yield per colony. When an apiary of fifty colonies secures a good yield, the presumption is that the bees do not fly very far; and it sometimes happens that thirty colonies will do better than fifty. In that case they should be located about three miles apart, making a radius of flight of a mile and a half.

FIGWORT (Scrophularia marilandica L.).--Also called heal-all, square-stalk, and carpenter's square. A strong-smelling herb, 3 to 6 feet tall, with square stems, opposite leaves, and small greenish purple flowers, growing in woodlands and hedges from Massachusetts to Kansas and Louisiana. The abundant nectar is secreted in two large drops by the base of the ovary. In 1879 a small field of figwort at Medina, Ohio, made a remarkable showing. Honeybees visited the flowers from morning until night during the entire period of blooming. On the average a flower was visited once a minute. After the nectar was removed other drops would exude in about two minutes. At one time this plant excited a considerable furore among beekeepers, as it was thought that for artificial pasturage it would exceed anything then known. The honey obtained would not warrant, however, 
the large expense of its cultivation. The flowers are also very frequently visited by wasps. Several other species of figwort occur in this country. S. nodosa is a European species.

FOOD VALUE OF HONEY.-See HONEY AS A FOOD.

FOUL BROOD.-Under DisEases OF BeES we reforred to the fact that there are two classes of the disease-one that affects the mature or adult bees, and one that affects the brood. The former we considered under Disf:ASES of BEEs, and the latter we will now take up under this head.

The term foul brood covers likewise two brood diseases-one known as American, or the old-fashioned diseased brood, caused by Bacillus larvae, and one the European, a disease of comparatively recent introduction, caused by Bacillus pluton. There is some evidence to show that the European type was present in this country as early as 1890 ; but it was not until 1899 that the author discovered that there are two distinct types of foul brood. See. Gleanings in Bee Culture, page 858, for 1899. Shortly after, others, including the foul-brood inspectors of New York (where the European type of foul brood was first found), also recognized the difference.

The American form of foul brood, often called the "ropy" type, because the dead matter assumes a gluey, sticky, tenacious character, was well known in Europe, and has been referred to by Dzierzon and other writers. But Mr. Moses Quinby, of St. Johnsville, N. Y., was the first one to recognize it in the United States and prescribe for its cure.

The Quinby cure is the basis of the only successful mode of treatment known and recognized today, altho some have, since Quinby, proclaimed themselves as the original discoverers of it.

Foul brood, either American or European, is (unless it be the Isle of Wight disease) the most serious enemy, not even excepting severe winters, with which a beekeeper has to contend. So serious is it that the old-time box-hive beekeepers-the kind who take no bee journal and who read no bee book-are being practically eliminated. Localities that once had bees on every farm have practically no bees today except some in the hands of specialists who keep bees for the bread and butter they can get out of them. There is another class who are still represented, and they are the progressive farmer and the professional man of the towns and cities (the backlot class) who are well enough posted to know how to combat foul brood successfully in either one or both of its two forms.

Foul brood, chiefly the American type, has wrought such destruction in this country that the United States census for 1910 shows a large falling-off of bees on the farms. While there has been an increase of beekeepers among the professional class in our cities and towns, there is no denying the fact that the farmer beekeeper in the Northern states has been practically driven out of the business by disease. No more can it be said that "bees work for nothing and board themselves." They might have done so under the old box-hive system, before foul brood had made its fearful inroads, but they can do so no longer. While the loss of so many farmer beekeepers is to be deplored, there is some satisfaction in the fact that the industry of beekeeping is now being placed on a higher plane-in the hands of the intelligent and progressive backlotters and farmers. The reader of these lines belongs to this class; and we wish to assure the reader that he need have no real dread of any disease that affects bees if he will follow the simple directions for their treatment that are given in these pages. While, of course, he will and should fear foul brood (not because it can put him out of business, but because it can annoy him) he should not get the idea that he can not control it, nor that it can prevent him from securing a crop of honey. Foul brood does, however, cause some apprehension in the mind of the queen-breeder and of the man who sells bees; for under our state laws there are severe penalties for shipping diseased bees or infected combs into territory where no disease exists. In this connection it is proper to remark that some thirty-five states and provinces have stringent foul-brood laws. See Laws RELATiNG To Bres.

But perhaps the most important thing for the reader now to consider is how to know foul brood when it shows itself in the yard. It is comparatively easy to hold the disease in check at its very start, but quite 


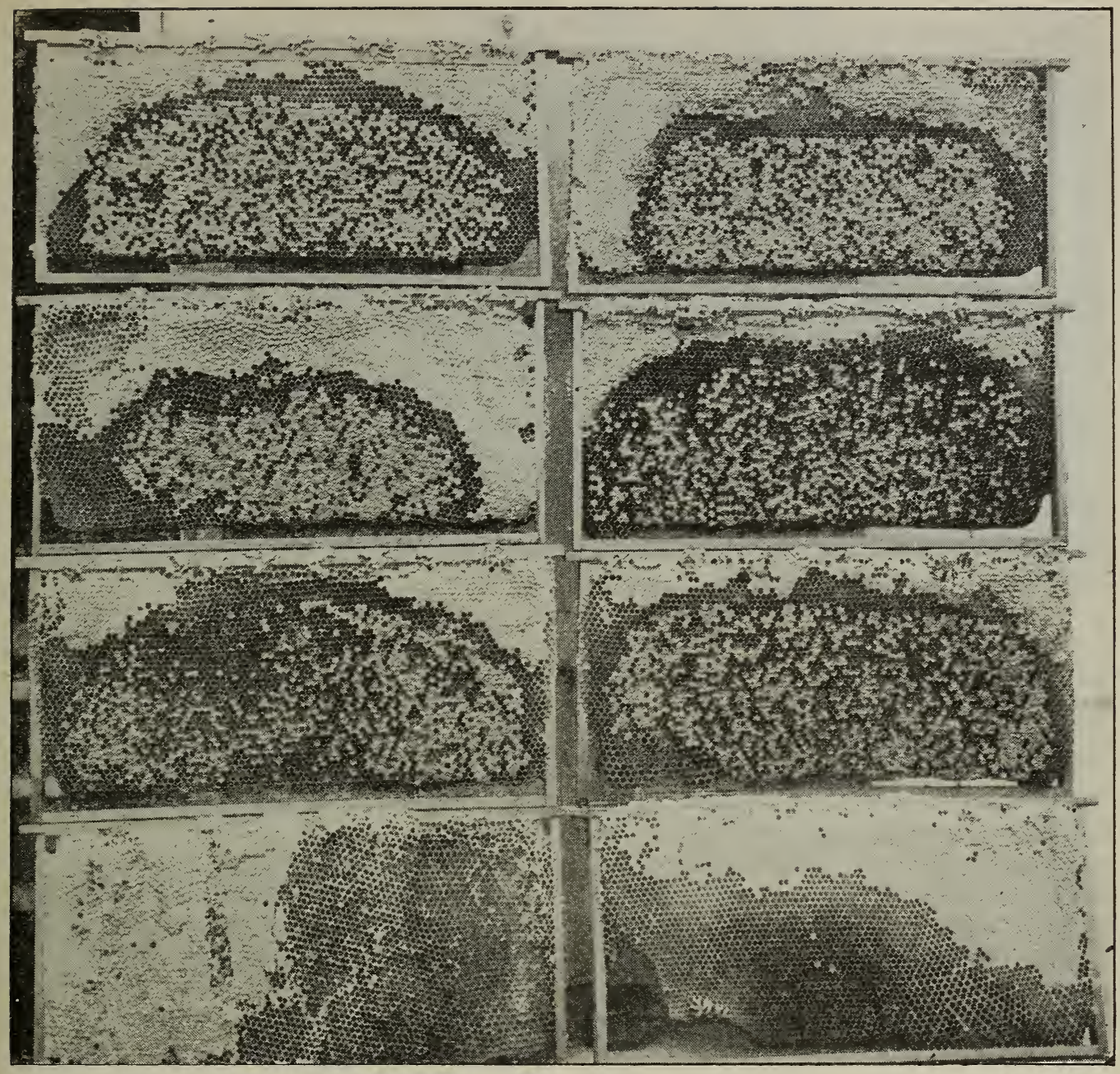

Combs showing the irregular, mottled, scattered cells with their perforated and sunken cappings of American foul brood.

another proposition after it gets a strong foothold. Every beekeeper, therefore, should know the important symptoms of both American and European foul brood. After he actually sees combs affected with either disease, he will have a much better knowledge of them of course; but as that involves considerable danger, especially if the combs are sent by express or mail, he will have to depend on photographic representations and a description of the symptoms.

In the first place, we may say that Arnerican foul brood had a run in our own home apiary some 30 years ago; and so severe was the attack before we learned how to cure it that we lost over half of our colonies and a honey cròp, to say nothing of the ruin of a very profitable trade in bees and queens which had to be summarily discon- tinued. During the two or three years that we combated the disease we acquired an experience that was valuable-of the kind that Josh Billings told about when he said that " Egsperiense teeches a good skule, but the tuishun kums rather hi." And it was "hi" with us. In addition to this "experience" we have traveled extensively over the United States, visited apiaries where foul brood, both American and European, was present and under treatment. We have seen the two diseases, each in its incipient and advanced stages, and we have seen how they can be successfully combated by the simple methods that are now recommended by our foul-brood inspectors. Besides this, we have had hundreds and hundreds of specimens of affected brood sent from all parts of this country; and at one time our 
office seemed to be the only place to which samples of brood could be sent for diagnosis. But in later years the United States government, thru its Bureau of Entomology, has been making a study of foul brood; and its corps of apicultural experts are now prepared to render assistance in the way of information,. so now it is no longer necessary nor advisable to send samples to our office. Indeed, we advise against it, because the Bureau, having trained experts and a bacteriologist, with microscopes and laboratory, are able to make a much more accurate diagnosis of all samples of affected combs or diseased brood sent in.

\section{AMERICAN OR ROPY FOUL BROOD.}

As a general thing the beekeeper will not discover it in its incipient stages. $\mathrm{He}$ is not expecting it, and, if it comes, does not see it. His first intimation of its presence will be occasional cells of sealed brood showing sunken, greasy cappings and cells with irregular perforations. American foul brood is confined mainly to brood that has died after the cells have been sealed; but 25 or 30 per cent of unsealed cells will show dead brood, and the dead larvæ in both sealed and unsealed will vary in color from a yellowish brown to a dark brown, and finally to a brownish black. The larva that has just died holds its shape. As the disease advances it begins to shrink, and the dead matter become so rotten and putrid that the skin breaks, and we see on the lower side of the cell a melted-down mass of matter that is very ropy-that is to say, sticky and tenacious. The worst specimens are usually found in the cells that have been sealed, altho the melted broken-down form of larva will be found in some unsealed cells.

The initial stages of foul brood are usually confined to the sealed cells. After the disease has advanced so that 75 per cent of all the sealed brood in a comb is affected, there will be found quite a sprinkling of stray cells of young larvæ that have never been capped over that are dead. But usually the grub will be almost fully grown before it dies in the unsealed cell, tending to show that American foul brood does not usually kill the larva until after it is sealed in the cell, or just before that sealing.

European foul brood is usually confined to the unsealed cells. The dead larva of this disease will have a light-yellow color instead of a brownish-dirty one verging on to very nearly black. The American may be found at any time of the year when broodrearing can take place; but the European type usually shows up at its worst early in the season, and before the main honey-flow.

One may find occasional dead brood just before sealing that does not indicate disease of any sort; but the one crucial test that is usually employed to distinguish American foul brood from brood dead from starvation, chilling, or overheating, and brood dead from European foul brood is the roping test. A common wooden toothpick, sometimes a spear of grass or a broken sprig, or even a pin, breaks thru the skin of a suspicious larva. If the dead matter adheres like spittle or stringy glue to the end of a toothpick, or whatever is used, and strings out from half an inch to two or three inches, one may be almost sure that it is a case of foul brood of the American type-especially if the dead matter strings out two or three inches and finally breaks, the two ends flying back to the points of attachment.

It is very seldom that we find all the cells in the comb affected, even in an advanced stage. American foul brood seems to attack a comb in spots. This is due, probably, to the fact that young larvæ are fed with a pap or honey containing the germs of the disease. As this affected food is fed by a bee or bees recently in contact with affected material, only the small area so fed is affected. Other small areas are given a food that is not contaminated; and all such brood matures and is healthy, and is as perfect as any normal brood. As a rule, in the worst-affected cases half of the brood will hatch out perfectly healthy and normal bees, so that foul brood, either American or Furopean in its very worst stages, does not necessarily kill a very large part of the brood; but, of course, if the colony containing it is neglected, every cell in the comb will ultimately become diseased. We will refer to this again under the head of "Treatment of American Foul Brood."

The name foul brood would indicate that it is foul-smelling. In a very advanced stage one can detect a strong odor like that from an old-fashioned glue-pot while the glue is hot. The odor is not necessarily foul nor nauseating; but there is a stage (and 


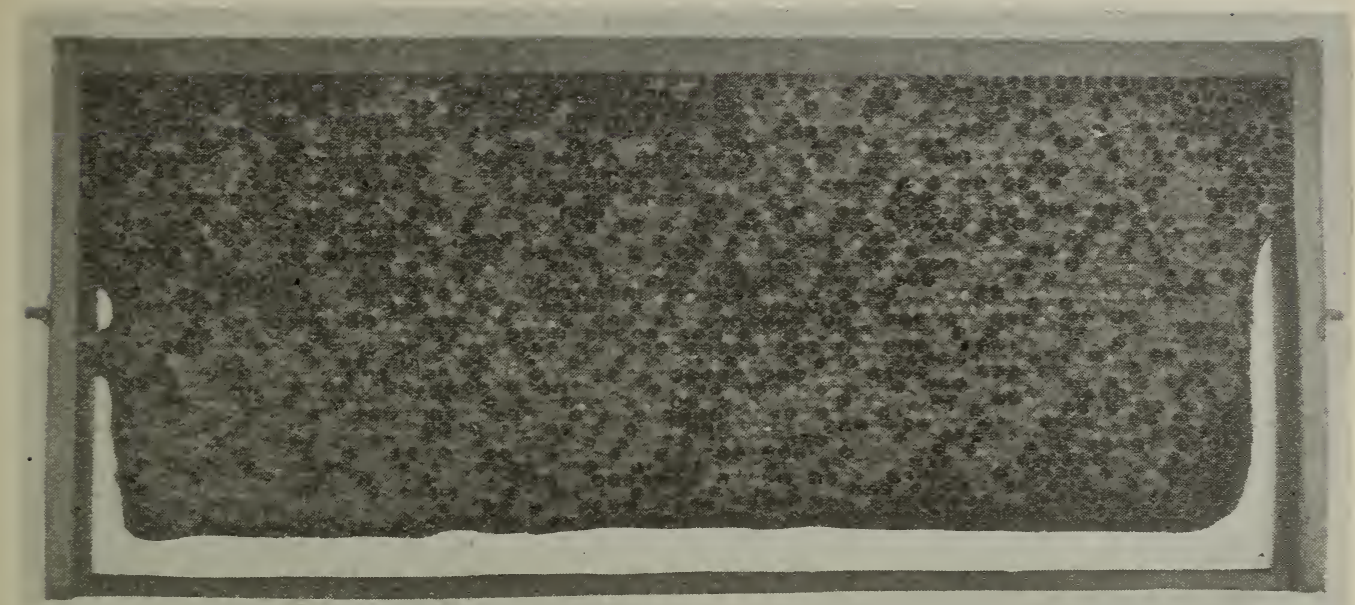

A comb badly affected with foul brood of the ropy or American type.

that is when almost every cell is affected) when the odor is distinctly foul-so much so that one feels he cannot continue to smell it without its turning his stomach. After one has once had a whiff of genuine foul brood he can very often detect the odor by placing his nose at the entrance of the hive. The author has frequently located colonies having the disease by simply getting down on his hands and knees and placing his nose close to the entrance and taking a number of deep inhalations thru the nostrils. In fact, we would advocate going thru an apiary where we suppose the disease to exist, especially if robbers are present, and locating the colonies having foul brood by the peculiar odor that may be detected at their entrances. Often this odor caunot be detected at the entrance, especially if it is a mild case. All colonies where the odor is found, however, should be marked; and then toward night, or under a robber cage, as described under RoBbixg (which see), one can then examine the combs carefully one by one to determine whether there are any cells, sealed or unsealed, containing dead ropy matter. As soon as a single cell has been discovered, that hive should be immediately closed and held for treatment. It is of the utmost importance that not a robber should be allowed to get into an infected hive or taste any honey containing disease germs. While foul brood is often spread by a general exchange of combs during extracting or for equalizing the strength of the colonies, in most cases it is spread from hive to hive and from one apiary to another thru robbing. American foul brood often starts in a few weak hives on a farm. The colonies become weakened during the summer because disease does not destroy them immediately. In their weakened condition they die during winter, and the following spring bees in the neighborhood rob out these dead colonies, thus carrying the infection to their hives. In this way foul brood spreads all thru a locality. No wonder that the farmer beekeeper is being eliminated. See FArMer BeEkeEpers.

But to return to the odor at the entrance. On one particular occasion we located a colony having foul brood by an occasional whiff we could catch at the entrance; but it was nearly a week after that when we found one coll containing ropy dead matter. Apparently the colony had nearly cured itself. But there still remained a characteristic odor which could not be eliminated. Experience shows that a colony which cures itself does not stay cured. The stock may be vigorous enough to keep the disease down; but an occasional cell will manifest itself for the ensuing ten or twelve yearsand in the mean time be a constant source of infection to all the rest of the apiary. There would be some colonies that would not be able to resist, hence the danger.

Sometimes one can detect a glue-pot odor at the entrance of one of the hives. $\mathrm{He}$ will be horror-stricken and conclude that, because he has run across the unmistakable smell, the disease is surely present in his apiary. This fear will be dissipated if he understands that the same foul-brood 


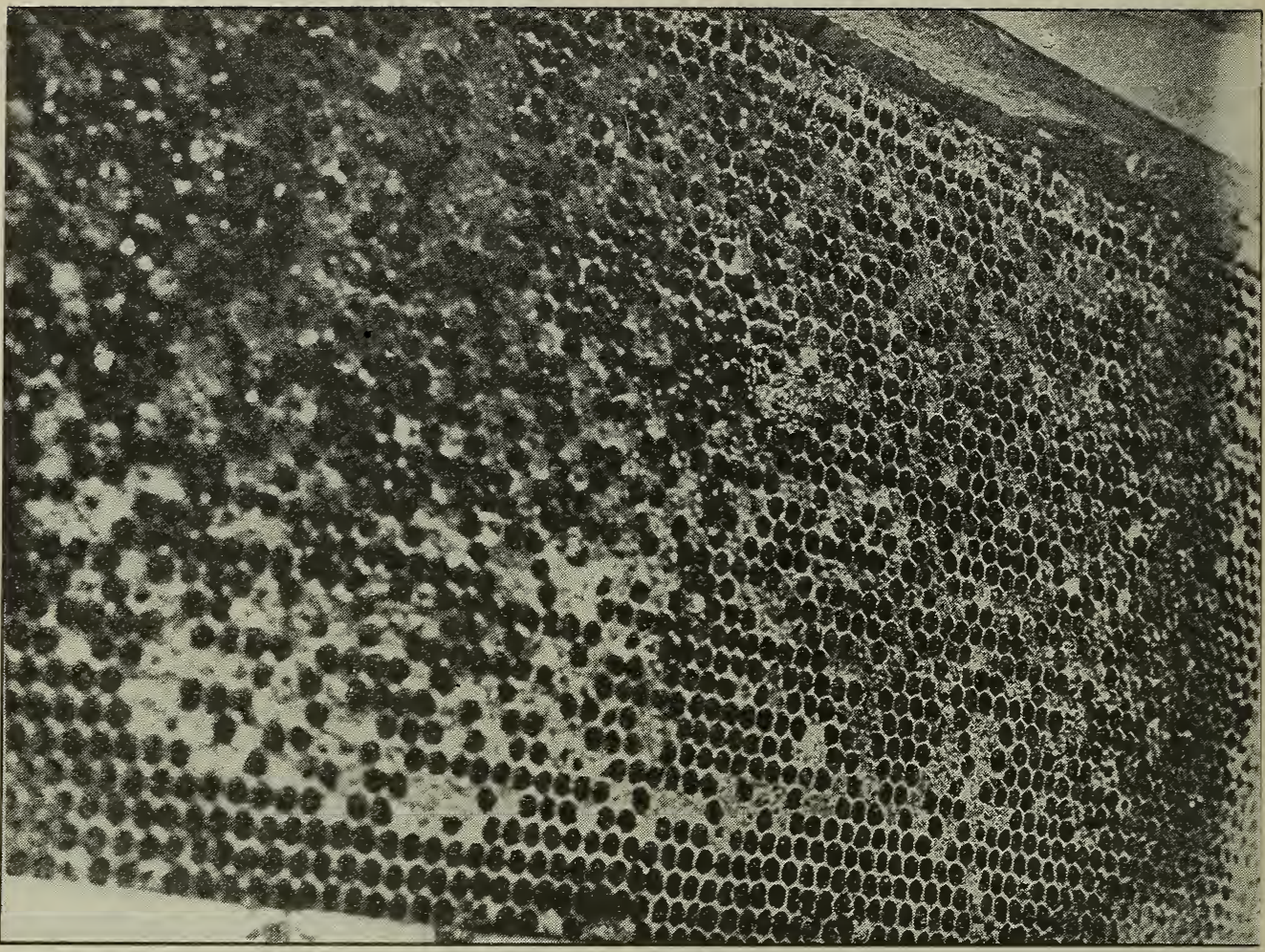

A COMB OF AMERICAN FOUL BROOD.

[Notice the characteristic sunken and perforated cappings at the left. Notice that these cappings showing the presence of the disease are scattering.]

odor, or at least one very much like it, may have come from a lot of putrid dead bees after a severe winter. These dead bees may be in the hive or at the entrance. Again, overheated brood or chilled brood, if neglected until it fairly rots, will give off a similar odor. The reader will understand, therefore, that the odor test is by no means final; but it is very suggestive, provided no dead bees are found, and provided that one knows that the brood of the hive from which the odor emanates has not been chilled nor overheated.

\section{HOW FOUL BROOD IS CARRIED TO NEIGHBOR-} ING HIVES.

When a colony is badly affected the disease has progressed to such a stage that the probabilities are that other colonies in the same locality are affected, especially those having entrances pointing in the same direction or similarly located. At this point the beekeeper should be warned that colonies next to the one badly affected are very apt to show the disease. This is explained on the ground that young bees and even the adult ones become more or less confused at their entrances, and so get into the wrong hive. As they do not show any of the manifestations of ordinary robbers, they are admitted. If they carry honey from an infected colony, as many of them do, they will transmit the disease as soon as they give pap made out of such honey to young brood; and that explains why there will be only a single cell or a group of cells perhaps, or one square inch that will have foul brood, while all the rest of the brood in the hive is perfectly normal. We generally expect to find in one or more neighboring hives with entrances facing in the same direction a cell or two of foul brood. If one can be sure that the comb containing the diseased cell or cells is the only one affected, the removal of that comb may effect a permament cure. As will be stated further on, all such colonies should receive a thoro treatment.

There is a kind of pinhole perforation that does not signify anything wrongindeed, quite the contrary. As bees seal up their brood, there is a stage when there will 
be a small round hole in the center of the cap. Sometimes these holes are not closed up, and then we have what is called bareheaded brood. But the perforations in bareheacled brood are very different from the perforations in cells containing foul brood, either American or European. The bad cells should have sunken cappings. The perfor'ations are ragged, triangular, and the edges appear to be somewhat greasy, while in the perforations in barehaded brood the cappings are slightly convex, and the hole is circular.

\section{TIE TREATMENT AND CURE OF AMERICAN FOUL BROOD.}

At the outset we spoke of the Quinby method as being the basis of the most successful treatment for American foul brood. This plan involved the melting-up of the old combs (shaking bees into clean hires) and compelling the bees to start anew. As this treatment was described before foundation was known, of course no mention of it was made. Practically the only improvement orer the Quinby treatment is giving the bees starters or full sheets of foundation instead of empty frames with mere wooden guides. In more recent times the late D. A. Jones, of Beeton, Ont., gave out what he called the "starvation" plan. It involved the same principle as the Quinby treatment, with this difference, that he shut the combless bees after shaking, in a large wire-cloth box, or a box with wire-cloth cover, and set it in a cool place until the bees had consumed all the honey in their honey-sacs. This idea was to eliminate all possible sources of infection before the bees were put on frames of foundation and fed. The treatment worked admirably; but it was found in later years that it was not necessary to starve the bees-that they would use up any infected honey that they might have in their sacs in drawing out foundation, providing the hive has no combs. About this time, Mr. William McEvoy, of Canada, who had then recently been appointed foul-brood inspector for Ontario, had been very successful in shaking the bees into their own hive, and giving them frames of foundation starters. They were allowed to build combs on these for four days. His idea seemed to be to let the bees use up the infected honey in building the combs and storing it in the built comb. These combs supposed to contain infection were then removed, when they were given full sheets of foundation. But experience has shown in thousands of cases that it is not necessary to remove the first set of combs built on foundation starters, and that such removing involves a large amount of waste; and that, when the second set of foundation is given, the bees are in a demoralized condition, and quite inclined to swarm out.

Years ago, when the authors had foul brood, we shook 80 colonies and gave them only one set of frames with full sheets of foundation in clean hives. The treatment was a success in every case. Altho we have prescribed this same treatment in hundreds if not thousands of cases, we have nerer yet had one report saying that the disease had returned. The bees, as a matter of fact, will either consume or use up all the infected honey in drawing out the first set of foundation; and it is very important to give the bees either a clean hive or disinfect the old one. When we shook into the old hives the disease came back in some cases. This disinfecting may be best accomplished by burning it out with an ordinary blow torch, such as is used by telephone men and painters to remove paint from a house; or it may be accomplished by smearing the inside of the hive with kerosene, touching a lighted match to it, and letting it burn until the inside of the hive is charred to a brown or black. The fire may be easily arrested by using a little water and putting on the cover immediately. The steam, generated when the ccver is clapped down, immediately puts out the fire. But there may be an objection to kerosene leaving an offensive odor in the hive. Another plan is to use a handful of common dry straw, setting it on fire, and then with a stick polze the burning straw around the hive so that every portion of it will be slightly scorched. The straw should be dumped out, and a little water dashed in the hive.

The shaking treatment, to be carried out as it should be, requires some precaution to prevent absconding. The Bureau of Entomology has recommended a mode of procedure which we most thoroly indorse. As government experts have made foul brood a more careful study than any other men in the United States, we cannot do any better than to advise our readers to follow faithfully the treatment recommended in Farm- 
ers' Bulletin 442, entitled "The Treatment of Bee Diseases," by Dr. E. F. Phillips, in Charge of Apiculture, Bureau of Entomology. For convenience of the reader we give it here.

\section{SHAKING TREATMENT.}

The shaking treatment consists essentially in the removal of all infected material from the colony, and in compelling the colony to take a fresh start by building new combs and gathering fresh stores. This is done by shaking the bees from the old combs into a clean hive on clean frames.

Time of Treatment.-The shaking treatment should be given during a flow of honey, so that other bees in the apiary will not be inclined to rob. If this is not possible the operation may be performed under a tent made of mosquito netting. The best time is during the middle of a clear day when a large number of bees are in the field. It is sometimes recommended that shaking be bees cannot crawl as they move to the top of the hive after shaking. This largely prevents them from getting on the outside of the hive. If self-spacing frames are used, a couple of thin boards laid on the top-bars on either side will accomplish the same result. The runway (D) is put in place in front of the entrance. The old hive is now opened for the first time. The frames are removed one at a time, lowered part way into the new hive, and with a quick downward shake the bees are dislodged. The frames are then put into the extra hive body (C) and immediately covered to prevent robbing. After all the frames are shaken the bees remaining on the sides of the old hive (A) are shaken out.

If honey is coming in freely, so that thin honey is shaken out of the combs, cover the runway (D) with newspapers and shake the bees in front of the new hive (B), leaving all frames in place and the cover on. After the operation the soiled newspapers should be destroyed. In shaking in front of the

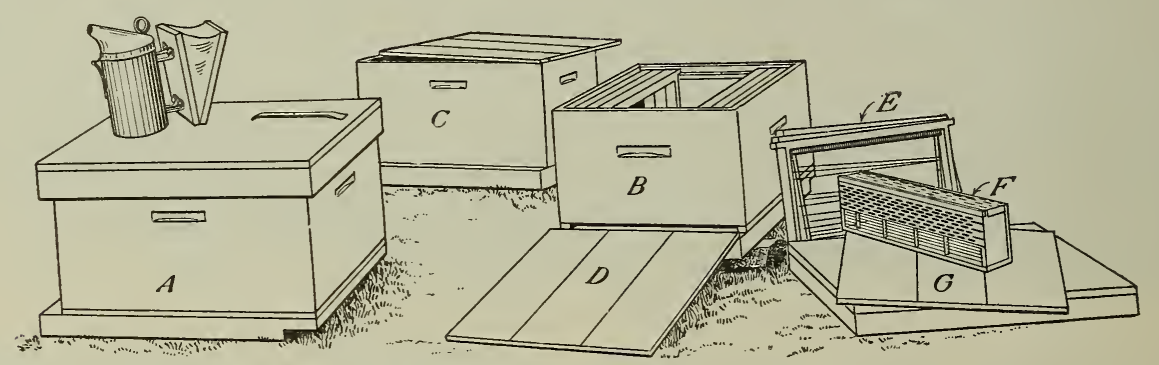

FIG. 6.-Apparatus for the shaking treatment: $A$, Hive containing diseased colony (formerly in position of $B) ; B$, clean hive; $C$, empty hive to receive combs after shaking; $D$, hive cover used as runway; $E$ frames removed from $B$ to give room for shaking; $F$, queen and drone trap; $G$, cover for clean hive, $B$.

done in the evening, but this is impossible if many colonies are to be treated. The colony can be handled more quickly when the field force is out of the hive.

Preparation.- All implements that will be ueeded, such as queen and drone trap, hive tool, and lighted smoker, should be in readiness before the operation is begun. A complete clean hive with frames is provided, as well as a tightly closed hive body in which to put the contaminated combs after shaking. An extra hive cover or some similar apparatus should be provided to serve as a runway for the bees as they enter the new hive. "The new frames should contain strips of comb foundation from one-fourth to 1 inch wide. Full sheets are not desirable, and if combs built on full sheets of foundation are desired they may be built later.

Operation.-The old hive containing the diseased colony (Fig. 6, A) is now lifted to one side out of the flight of returning field bees, and the clean hive (B) set exactly in its place. The cover $(G)$ is now taken off and a few frames ( $E$ ) removed from the center of the hive. If unspaced frames are used, those remaining in the hive should be pushed tightly to either side of the hive, thus making a barrier beyond which the entrance the first one or two frames should be so shaken that the bees are thrown. against the entrance, where they can locate the hive quickly. They then fan their wings and the others follow them into the hive. If this is not done the bees may wander about and get under the hive or in some other undesirable place.

After the bees are mostly in the new hive a queen and drone trap (F) or a strip of perforated zinc is placed over the entrance to prevent the colony from deserting the hive. The queen cannot pass thru the openings in the perforated zinc and the workers will not leave without her. By the time that new combs are built and new brood is ready to be fed, any contaminated honey carried by the bees into their new hive will have been consumed and the disease will rarely reappear. If it should, a repetition of the treatment will be necessary.

Saving the Healthy Brood.-The old combs are now quickly removed. If several colonies are being treated at one time it may pay to stack several hive bodies containing contaminated combs over a weak diseased colony to allow most of the healthy brood to emerge, thereby strengthening the weak colony. After 10 or 12 days this colony is 
treated in turn and all the combs rendered into wax. If only one or two colonies in a large apiary are being treated it will not pay to do this.

Saving the Wax.-Any but a very small apiary should have included in its equipment a wax-press for removing wax from old combs. After the contaminated frames are taken to the honey-house the combs should be kept carefully covered, so that no bees can reach them until the wax can be rendered. This should not be delayed very long or the combs may be ruined by wax-moths. The slumgum or refuse remaining after the wax is removed should be burned. Contaminated combs should not be put into a solar wax-extractor for fear of spreading the disease. The wax from contaminated combs may safely be used for the manufacture of comb foundation.

Cleaning the Hive.-The hive which has contained the diseased colony should be thoroly cleaned of all wax and honey, and it is desirable that it be carefully disinfected by burning out the inside with a common gasoline blue-flame torch. If this piece of apparatus is not available several hive bodies may be piled together on a hive bottom and some gasoline or kerosene poured on the sides and on some straw or excelsior at the bottom. This is then ignited; and after burning for a few seconds a close-fitting hive cover is placed on top of the pile to extinguish the flames. The inside of the hive bodies should be charred to a light brown. The careful cleaning and disinfection of frames always costs considerably more in labor than new frames would cost, but these also may be carefully cleaned and used again. Frames may be cleaned by boiling in water for about half an hour, but this frequently causes them to warp badly. The disinfection of hives and frames with chemicals is not recommended, as the ordinary strengths used are valueless for the purpose.

Disposal of the Honey.-If there is a considerable quantity of honey in the contaminated combs it may be extracted. This honey is not safe to feed to bees without boiling, but it is absolutely safe for human consumption. If there is a comparatively small quantity it may be consumed in the beekeeper's family, care being taken that none of it is placed so that the bees can ever get it.

To place such honey on the market is contrary to law in some states. There is always danger that an emptied receptacle will be thrown out where bees can have access to it, thus causing a new outbreak of disease. It can be safely used for feeding to bees provided it is diluted with at least an equal volume of water to prevent burning, and boiled in a closed vessel for not less than one-half hour, counting from the time that the diluted honey first boils vigorously. The honey will not be sterilized if it is heated in a vessel set inside of another containing boiling water. Boiled honey can not be sold as honey. It is good only as a food for bees, and even then should never be used for winter stores, as it will probably cause dysentery.

The Second Shake.-Some beekeepers prefer to shake the bees first on to frames containing strips of foundation as above described, and in four days to shake the colony a second time on to full sheets of foundation, destroying all comb built after the first treatment. This insures better combs than the use of strips of foundation, but is a severe drain on the strength of the colony. Since it is desirable to have combs built on full sheets, the best policy is to replace any irregular combs with full sheets of foundation or good combs later in the season.

The Cost of Shaking.--If the treatment just described is given at the beginning of a good honey-flow, it is practically equivalent to artificial swarming, and results in an actual increase in the surplus honey, especially in the case of comb-honey production. The wax rendered from the combs will sell for enough to pay for the foundation used if full sheets of foundation are employed. Since a colony so treated actually appears to work with greater vigor than a colony not so manipulated, the cost of treatment is small. If treatment must be given at some other time, so that the colony must be fed, the cost is materially increased. In feeding, it is best to use sugar syrup, or honey that is known to have come from healthy colonies.

\section{TREATMFNT WITH BEE-ESCAPE.}

As a substitute for the shaking treatment just described, the bees may be removed from their old combs by means of a beeescape. The old hive is moved to one side and in its place is set a clean hive with clean frames and foundation. The queen is at once transferred to the new hive and the field bees fly there on their return from the field. The infected hive is now placed on top of or close beside the clean hive and a bee-escape placed over the entrance, so that the younger bees and those which later emerge from the cells may leave the contaminated hive but cannot return. They therefore join the colony in the new hive. If desired, the infected hive may be placed above the clean hive and a tin tube about 1 inch in diameter placed from the old entrance so that the lower end is just above the open entrance of the new hive. The bees follow down this tube and on their return enter the new hive. When all of the healthy brood has emerged from the infected combs the old hive is removed. This treatment induces less excitement in the apiary and is preferred by many experienced beekeepers. Care should be taken that the old hive is absolutely tight to prevent robbing. The old hive and its contents of honey and wax are treated as indicated under the shaking treatment. 


\section{FALL TREATMENT.}

If it is necessary to treat a colony so late in the fall that it would be impossible for the bees to prepare for winter, the treatment may be modified by shaking the bees on to combs entirely full of honey so that there is no place for any brood to be reared. This will usually be satisfactory only after brood-rearing has entirely ceased. Unless a colony is quite strong, it does not pay to treat in the fall, but it should be destroyed or united to another colony. In case a diseased colony dies outdoors in the winter there is danger that other bees may have opportunity to rob the hive before the beekeepers can close the entrance. In case bees are wintered in the cellar it is more advisable to risk wintering before treatment, for if the colony does die the hive will not be robbed.

\section{DRUGS}

Many European writers have in the past advocated the use of various drugs for feeding, in sugar syrup, to diseased colonies, or the fumigation of contaminated combs. In the case of American foul brood, of which the cause is known, it has been found that the drugs recommended are not of the slightest value.

FORMALDEHYDE FOR CURING FOUL BROOD.

In 1903 and ' 4 discussion arose in Gleanings as to the possible value of formaldehyde or (formalin) for curing American foul brood. Some of the experimenters who had subjected several combs of honey and brood from infected colonies to the fumes of the gas in a tight box reported it a success. Others tried the same thing only to find that such combs would transmit the disease the same as before. Experiments conducted in the.Bureau of Entomology, Department of Agriculture, Washington, D. C., showed that, when combs were subjected to the fumes of the gas for 48 hours in a Novy anaerobic jar, all germs of the disease would be destroyed; but as the average beekeeper could not have the requisite facilities, skill, and knowledge to carry on such work, he had better not take his chances of transmitting any infectious disease thru combs fumigated under conditions such as he is able to provide. In all probability the work would not be complete enough to rake disinfection sure. If any infection at all were left, the disease would spread again, and so the work might just as well have not been done-or not attempted; because melting up the combs and boiling, or, better, burning up the frames, would remove all possible traces of disease,
EUROPEAN FOUL BROOD DIFFERENTIATED.

As we have already explained, this is a disease that has some symptoms that are the same as those of American foul brood; but it has other symptoms that are quite different. In its general appearance, especially in its advanced stages, a comb affected will look somewhat like those of American foul brood; but a more careful examination will show a decided difference.

1. Larvæ affected with European foul brood is seldom if ever ropy. The dead matter has more of a jellylike consistency; and if it clings to a toothpick, the roping will not extend more than half an inch at most.

2. The disease comes on mainly in the early part of the season, and it is confined largely to the unsealed brood. The dead larvæ first turn gray, then light yellow. Sometimes a yellow spot shows in the center of the grub before it turns yellow all over. It does not finally assume a shapeless melted-down mass as we find it in the American type of the disease. It retains its shape without a break in the skin, finally shriveling up into a dry scale which the bees easily remove. The dried scales on American foul brood, on the contrary, stick to the side of the cell like so much glue; and it is very easy to detect combs previously affected with this disease, altho it may be a year or so afterward, because the lower sides of the cells look as tho they had been daubed over with some sort of gluey substance with a remnant of larval skin.

3. The ordinary glue-pot or foul-brood odor is almost entirely lacking in combs affected with European foul brood. There is, in place of it, a sour, musty, or rottenegg smell that is not easily recognized as the odor of the other brood disease. In the later stages it takes on a foul odor something like that of the American disease, in which stage the sour smell seems to be lost or obscured by the more pronounced odor of decay. The color of European foul brood in its earlier stages is a bright yellow. The yellow color may be taken as its chief characteristic.

4. European foul brood seems to spread much more rapidly than American. If an apiary is affected at all, more colonies will be involved; but in the American type of 
the disease, honey seems to be the main source of infection. In the European type, honey may be the source, but certainly it does not seem to be the only means for its transmission.

5. Black and hybrid bees are much more subject to the ravages of European foul brood. If the disease is not too far adranced, the mere introduction of a vigorous strain of young Italian queens may cure the whole apiary. There are some localities in New York and Virginia where Italian apiarics are surrounded by apiaries of black and hybrid bees; and yet the remarkable fact is that these Italian yards are free from disease while the yards of common bees around them are affected with it in spite of treatment by shaking.

6. There also seems to be a general agreement among authorities that weak colonies are the ones that are the first attacked. It is, therefone, very important, where this disease gets into a yard, that all the weak be doubled up; for it is only the strong and extra strong that will be able to combat it, even when they are given every assistance possible on the part of the owner.

7. Again, it has been noticed that, as soon as a good honey-flow is on, European foul brood begins to disappear; and sometimes as soon as there is a dearth of honey it breaks out again, particularly when broodrearing is well under way in the spring, for that is the time of year when it usually makes itself manifest.

8. In the case of American foul brood it has been proven that combs of honey are sources of infection. While all the honey could be extracted out of the combs, it has been demonstrated over and over again that it is impossible for a colony of bees to remove the germs by any process, for the simple reason that the dead matter* sticks like glue to the sides and bottoms of the

* I think the disease will not be transmitted by a diseased larra even tho still undried, if it is so far decayed that the nurse bees will not eat it. By the way, this theory, original with me, has never been advanced by any one else, and as it has never been objected to by any one, it is safe to say that it is the best theory yet advanced to explain how the disease is convered, and at the same time to explain how and why the dequeening or caging cures. Here's the theory in brief: When a diseased larva dies, the nurses suck its juices, feed them to the young larvæ, and thus the disease is transmitted; but after the diseased larvæ become so far decayed as to be offensive, the nurses will no longer suck their juices, but leave them to become dried, or remove them without sucking them. So a break in brood-rearing that leaves no longer any eatable diseased larvæ stops the contiuance of the disease-C. C. MILLER. cells. On the other hand, the combs of European foul brood, because the dried larræ do not stick, can be readily cleaned up by a vigorous colony of Italians and used over again. Before they have been cleaned up they may transmit the disease. Hybrids and blacks, for some reason, do not effect this clean-up; and hence it is either necessary to melt up the combs, or, better, Italianize.

To recapitulate, combs of American foul brood must be melted up or burned. Combs of European foul brood need not necessarily bo destroyed, and can be used again, when giren the proper environment.

9. American foul brood seems to be no respecter of persons, or, more exactly, no respecter of strains or races. European foul brood, on the other hand, yields rapidly to a resistant strain of Italians without the destruction of combs. But not all Italians are equally resistant. Some strains, especially of the extra yellow, inbred until their vitality has been weakened, are no better than the ordinary blacks and hybrids. Conversely, some extra-yellow bees are very resistant-as much so as any leather-colored strains.

It seems to be apparent that bees that are good workers, and stand wintering well, are usually found to be very resistant to European foul brood, altho the rule does not universally hold true. When Italians, therefore, are spoken of as "resistant," it should be remembered that there are Italians and Italians-some better than others.

10. While the shaking or brushing on to frames of foundation in clean hives is almost sure to cure American foul brood, it is only partially effective with European. In many cases, European foul brood will reappear after skaking. It is, therefore, apparent that, if shaking is employed, additional curative measures must be applied.

\section{TREATIIENT AND CURE OF EUROPEAN FOUL} BROOD.

Having suggested some of the salient characteristics of the European disease as compared with the American, we are now ready to discuss methods of cure. From what has already been said, it is apparent that the same treatment that applies to the American will be only partially effective with European foul brood. When, therefore, shaking is applied in connection with 
dequeening for a time, and introducing a queen of vigorous Italian stock, a cure is usually effected. But as shaking involves a large expense, the destruction of brood and combs, the practical beekeeper can usually dispense with it. The author has seen comb after comb that has been fairly rotten with European foul brood contain as healthy brood as one could wish to see after the introrluction of a vigorous strain of Italians.

In 1899 and the early 1900's, when European foul brood, then known in New York as a foul brood that was different from the old-fashioned kind, the shaking method was applied exclusively. It was soon discovered that the disease was continually coming back. Later it was learned that shaking was effective in most Italian colonies. Then it was discovered that some Italians were more resistant than others. Finally the inspectors advised that shaking and Itatianizing should be applied. If colonies were not strong it was recommended to double up until they were. Then a few beekeepers began to notice in some cases that the mere introduction of a resistant strain of Italians would effect a cure.

In 1904 Mr. E. W. Alexander, of Delanson, N. Y., referred to in many places in this work, reported to the author that one of his neighbors had blundered on to a cure which he thought was effective. At that time he was not prepared to state whether it would bring about a cure or not; but after he had experimented with it on some 500 colonies he gave out what has since been called the Alexander cure, and which is now the basis of all the modern methods of treatment for the European type of the disease. In brief the Alexander treatment is as follows:

Every diseased colony in the apiary not very strong is doubled up or united with other weak colonies until all are made. strong. In some cases building up or strengthening of the weak can be effected by taking frames of hatching brood from the stronger and giving them to the weaker. The next procedure is to remove the queen from every infected colony, and in nine days destroy every mature queen-cell, or any virgin if hatched. In the meantime a quantity of cells are to be reared from the best Italian breeder in the yard. These cells, when ripe, are given to the colonies made queenless 20 days before. During this interim of queenlessness the bees clean out the combs, polish up the cells, and whell the new queen starts laying, which will be on the 27th day, approximately, the new brood will be healthy from that time on. It is not necessary to remove any combs from the hives nor apply any kind of disinfection. The old queens that were removed in the first place are to be destroyed.

In a series of articles which Mr. Alexander wrote defending his treatment-for he encountered all sorts of opposition from those who failed-he laid strong emphasis on the importance of making all colonies extra strong, using a vigorous resistant strain of Italians and keeping the colony queenless for at least 20 days, at the end of which time a ripe queen-cell or a virgin just hatched was to be given.

Large numbers were successful in applying the treatment. Others failed; but for what reason is not known unless they did not follow directions or were unfortunate in not securing the right strain of Italians. There is another possible reason. When European foul brood is scattered all thru an apiary it is important that every colony be treated at the same time. In this way all sources of infection in the yard are removed before the new queens begin to lay. When some colonies are treated at one time and some another there is a constant source of infection.

Mr. S. D. House, of Camillus, N. Y., told the author that a vigorous strain of Italians would almost alone clean out European foul brood after the colony had been queenless for a period. He showed colony after colony that had been rotten with the disease, and which at the time of our visit were entirely free of it. He stated that European foul brood was rampant all around him in the black and hybrid colonies. In spite of the fact that it was within reach of his bees he had no fear of it. He wrote a series of articles for Gleanings in Bee Culture in 1911, and among them was one, on page 330 , giving his method of treatment that is similar to Miller's. This attracted considerable attention at the time. The editor of Gleanings was severely criticised by some of the state inspectors for giving publicity to such heresy; but old Father Time has demonstrated that Alexander and Mr. House were nearly right. 
In later years European foul brood broke out in the apiary of Dr. C. C. Miller, of Marengo, Ill., an authority referred to in many places in this work. The author adrised him to follow the Alexander or the House treatment, which he did, with marked success. By accident he discovered that it was not necessary to have the colonies queenless more than ten days. That a vigorous strain of bees would do a good cleanup job in the period named. After experimenting with the disease for two or three years he finally announced the following modified Alexander-House-Miller treatrnent, that is much the same as that used by S. D. House. Dr. Miller says:

First, no matter whether the case be severe or mild, make the colony strong. In a severe case, kill the queen; and as soon as the colony recognizes its queenlessness, say within 24 hours, give a ripe queen-cell, or, immediately at the time of killing the queen, give a virgin not more than a day old or a cell in a protector. That's all; the bees will do the rest. In a mild case, make the colony strong, and cage the queen in the hive for a week or ten days-only that. But don't expect the disease to be at once and forever stamped out. Last year I had the disease in a mild form in about one colony in four; this year in about one in twenty.

It will be noticed that Dr. Miller, like Mr. Alexander, emphasized the importance of making all colonies strong, either in the treatment of a severe case or a mild one. Later on, after considerable discussion, he added this:

A correspondent asks, "What do you do to save the combs?" Nothing. Just use them the same as if there had been no disease. Vigorous bees with a vigorous queen will clean them out. Spores may be left, and here and there the disease may break out again; but in the long run the loss will be less than if the combs were destroyed, and possibly the returns of the disease will be no more frequent than if all combs are destroyed. In my own apiary I think there were no more fresh outbreaks where the old combs were left than where the bees were thrown upon foundation."'

A large number have followed Mr. House and Dr. Miller and have been very successful. This does not mean that every trace of the disease will be wiped out after treatment; but it does mean that the disease will be brought so nearly under control that a case only here and there will show up, and even then in a very mild form. It is possibly true that some queens of a resistant strain are not quite as resistant as others. In that case dequeening for ten days and requeening again will complete the cure.

Mr. Morley Pettit, provincial apiarist for Ontario, Canada, carried on some quite extensive experiments in the treatment of European foul brood. His recommendation is practically the same as that of Dr. Miller, with this difference: If a colony shows more than 50 per cent of diseased brood he recommends, in addition, shaking.

It is the author's belief that beginners (if only one or two colonies are involved) would do well to apply both shaking and dequeening.* The more adranced can follow the Miller plan with comparative safety, with the possible exception that where a colony shows more than 50 per cent of dead brood they can apply shaking in addition.

\section{SACBROOD.}

For many years back there has been recognized a form of dead brood under the name of pickled brood that is neither European nor American foul brood. It comes and goes at certain seasons, but is never a destructive agent like either one of these diseases. Sometimes it has the appearance of foul brood so far as color is concerned; but it is nerer ropy like the American type; and, while similar to the European, it seldom gains very much headway in a colony.

It is mildly infectious, and the infected larvæ turn yellow and then brown. Sometimes the color is gray. The dead specimens may be in unsealed cells, but are generally in the sealed ones. The dead larvæ, says Dr. White in Circular No. 169, Bureau of Entomology, are "almost always extended lengthwise in the cells, and lying with the dorsal side against the lower wall. . . The form of the larvæ dead of this disease changes much less than it does in foul brood. The body wall is not easily broken, as a rule, and on this account often the entire larva can be removed from the cell intact." . . . "When removed they have the appearance of a small closed sac. This suggests the name of sacbrood."

\section{CAUSE OF SACBROOD.}

So far no microbe or fungus has been discovered as the cause of the disease.

* I never shook and dequeened in a single case, and $I$ would not advise the rawest beginner to do so. -C. C. Miller. 
Whatever it is, it is so very small that it will pass thru a Berkfield filter. Sick and dead larvæ of sacbrood have been macerated and diluted with sterile water. The product was then passed thru a Berkfield filter; but it was found that the filtrate would transmit the disease to a healthy colony. Colonies fod with this filtrate would again give the disease to other colonies. It is evident that the disease is infectious. Dr. White concludes that "sacbrood is an infectious disease of the brood of bees caused by an infecting agent that is so small or of such a nature that it will pass thru the pores of a Berkfield filter."

This led us to the conclusion that the foul-brood inspectors of the country might be compelled to quarantine an apiary where sacbrood might be found; but Dr. E. F. Phillips, in Charge of Apiculture in the Bureau, does not think that this would be necessary. The disease at its worst is not very destructive; and when it does make its appearance it affects so few larvæ in a colony that it need cause no great alarm. While he might at times advise treating or isolating colonies, he does not believe it would be necessary to quarantine an apiary where it was found.

\section{STARVED OR NEGLECTED BROOD.}

There is another form of dead brood that very greatly resembles sacbrood; and that is, starved or neglected brood. Early in the spring, when natural pollen is scarce, and brood-rearing is well under way, some of the brood will die for the lack of the nitrogenous element in their food as obtained from pollen. It is starved, not from a lack of honey, but from a lack of proper breadand-milk diet made up of pollen and honey. Considerable of this dead brood will be found in the early spring. The bees readily pick it out of the cells; and as soon as natural pollen comes in, the trouble will disappear.

DEAD BROOD FROM DRONE-LAYING QUEENS OR LAYING WORKERS.

Under BROOD, reference is made to the fact that drone brood or laying-worker brood will often be found dead, and a stinking mass. The cells will be perforated, and the odor will be very much like that from American fcul brood in an advanced stage. The fact that it does not rope rather sug- gests to the inexperienced that it may be European foul brood; and many times A B C scholars write us, describing this trouble, and asking whether it is foul brood.

The remedy is, of course, to remove the drone-laying queen or break up the layingworker colony as described under LAYING WORKERS.

One may rest easy if he finds all worker brood healthy, and nothing but drone or laying-worker brood dead.

\section{FOUNDATION.-See Comb FOUNDA- TION.}

FRAMES.-These are devices for holding combs while in the hive; are sometimes called racks. They make possible modern manipulation by which every comb can be inspected, removed, transposed-in fact, the whole internal economy of the hive can be determined. The straw skep and the box hive of olden days had no frames, and neither does the same hive in use today in parts of Europe and the mountainous parts of the United States. See Box Hives.

As shown under Hives, Evolution of, there were many crude ways of making combs movable - some better than others. Perhaps the crudest of all was to cut them out and put them back again. Later on, combs were built from bars. This necessitated cutting the combs from the sides of the hive to effect a removal. To these bars were later attached other members, making up a complete frame. But such frames were almost immovable. While they could be taken out of the hive it required a great amount of patience and time, to say nothing about bee-killing.

It remained for the Rev. L. L. Langstroth, of this country, then a Presbyterian minister, to discover a principle that would make every comb or frame removable. To construct a frame that will inclose a comb required no great act of invention; but to make a frame so it could be readily removed from its fellows, without smashing or irritating bees, required the work of a s'enius, and that genius was Langstroth.

Under the head of A B C OF BeEkeEPING, Hives, Evolution of, and BeE-SPaCe, it is explained that he discovered the principle of a bee-space-a space that bees respect, and never fill with comb or bee-glue. (See BEE-SPACE.) Taking advantage of this prin- 
ciple, Langstroth saw that, in order to make his frame morable, he must provide a beespace all around. The next problem that he met was how to support and hold his frames so that there would not only be a bee-space all around between it and the top, bottom, and end of the hive, but a bee-space between each and all of the frames. It is just as important to have every frame separable from its neighbor as separable from the hive. This he accomplishes rery nicely in making the top-bar of his frame long enough to have a projection at each end. These projections as a means of support were made to rest in rabbets in the upper ends of the hire. (See Hives and A B C of BeEkeeping.) Langstroth, therefore, went ahead of his predecessors in two important points-by providing a bee-space and a means of support so that the frames would not be glued fast to cach other nor to the hive. His prodecessors, as will be seen by a perusal of Hives, Evolutior of, made their frames close-fitting like drawers in a bureau, and each frame came in contact with its neighbor. (See the Huber hive under Hives, Evolution of.) These early derices, perhaps, would have been all right had it not been for two things-the ever present bee-glue sticking everything fast with which it came in contact, and the crushing of the bees when the parts of the frame come together. A few crushed bees, many of them squealing with pain, will infuriate a whole colony; and it is no wonder that our forefathers resorted to the use of brimstone and refused to accept the so-called morable frames that were invented before Langstroth. The so-called movable combs of Dzierzon made it necessary to cut every comb loose. This process necessarily caused a great deal of dripping honey. During a dearth of nectar this would cause robbing. (See RobBing.) When, therefore, Langstroth by his great invention of a really morable frame demonstrated that he could make every comb movable-that he could take the hive all apart without killing a bee and without receiving a sting-he revolutionized for all times the methods for handling bees. While bees will sting, and always will sting, and do sting, yet it is now possible, by the proper use of smoke, to open up a Langstroth hire without a sting with favorable conditions. See Manipulation of Hives and Fraires, and Stings.
The various crude attempts to make combs morable are set forth under the head of Hives, Evolution of. The methods of adjusting modern Langstroth frames in modern Langstroth hives are described under Hives and A B C of Beekeepivg.

Langstroth desired to bring out a frame that would be really movable, and in doing so went to the limit. His frames had no point of contact with each other. They were simply hung or suspended in the hiverabbet. They often hung out of true, and, worse still, were often badly spaced; but in spite of all this, many beekeepers prefer the principle today. There are cthers who consider it an advantage to have projections on the frames, such projections being half bee-space beyond the comb. These selfspacers will always hang true and the proper distance apart. See Spacing Frames. The advantages of these self-spacing frames are shown in the article on Franes, SELFSPACING.

SIZE AND SHAPE OF FRAMES

There has been endless discussicn as to the best size of frame. Some prefer one that is square-approximately a foot wide and a foot deep. Others consider 12 inches too great a depth, and prefer to have the extra comb area extend laterally. A great majority of modern beekeepers prefer today a frame longer than deep, such as we find in the Langstroth dimensions. As the dimensions of the frame determine the size and shape of the hive itself, a further consideration of the subject will be found under Hives.

Whether a frame should be made reversible is discussed under the head of ReversING. Whether a frame should have the endbars come in contact the entire length or only part way is discussed in the next subject.

FRAMES, SELF-SPACING.-By these are meant frames held at certain regular distances apart by some sort of spacingdevice, forming either a part of the frame itself or a part of the hive. Under SPACING of Frames, elsewhere, and under ExtractING, we have discussed the distances that frames should be apart. Some prefer $11 / 2$ inches from center to center; but the majority, supported by the best of reasons, prefer $13 / 8$ inches. Self-spacing frames, then, are 
those that, when put into the hive, are spaced automatically, either $13 / 8$ or $1 \frac{1}{2}$ inches from center to center. Loose or unspaced frames differ from them, in that they have no spacing-device connected with them, and are, therefore, when placed in the hive, spaced by eye-or, as some have termed it, "by guesswork." Such spacing results in more or less uneven combs; and beginners, as a rule, make very poor work of it. The advocates of self-spacing frames claim that they get even, perfect combs, comparatively few burr-combs, and that, without any guesswork, the combs are spaced accurately and equally distant from one another. Selfspacing frames are always ready for moving, either to an outyard, to and from the cellar, or for ordinary carrying around the apiary. Loose frames, on the contrary, while they are never spaced exactly, often of the best beekeepers, all these onjections lose their force.

There are a good many styles of selfspacing frames. We will describe, first, those most comonly used in this country and then show some of the others that are or have been used in Europe. Among the first mentioned we might mention the closed-end Quinby, the Danzenbaker, the Heddon, the Hoffman, the thick-top staplespaced, metal-spaced Hoffman, and the nail-spaced.

The closed-end Quinby is, as its name indicates, one whose end-bars are wide their entire length. The top and bottom bars are one inch wide. These closed uprights, or ends, when they come in cirect contact, cause the combs which they contain to be spaced accurately from center to center. The eut at A shows one such frame. Several

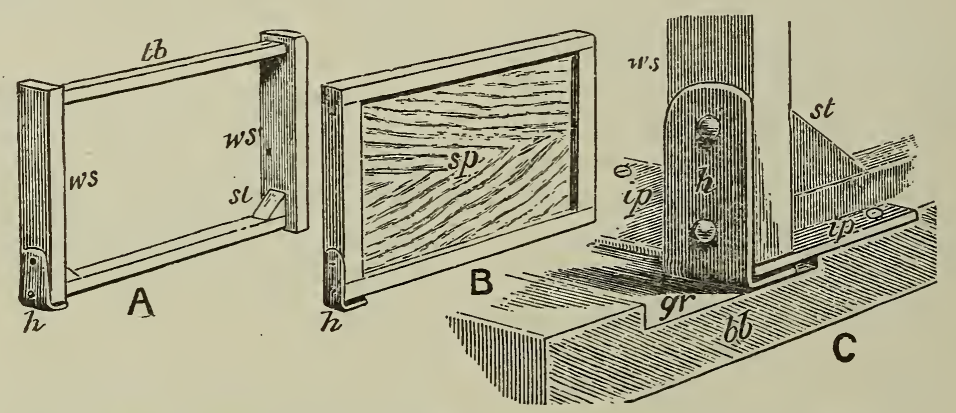

How the Quinby frame hooks on to the bottom.-From Cheshire.

cannot be hauled to an out-apiary, over rough roads, without having sticks between them, or something to hold them in place. It is contended by some, also, that spaced frames can be handled more rapidly. See Manipulation of Hives and Frames. On the other hand, the advocates of the loose frame urge, as an objection, that the selfspacers kill the bees.

This depends. The careless operator may kill a good many bees. If he uses a little common sense, a little patience, applying a whiff or two of smoke between the parts of the frames that come in contact, he will not kill any bees. The fact that sime of the most extensive beekeepers of the world are using self-spacing frames, and the further fact that the number of self-spacing-frame users is constantly increasing, shows that this supposed bee-killing is more fancied than real. When frames are handled but once a year as it is now the practice of some of the closed-end frames are made to stand, and have very often been called "standing frames." Mr. Quinby, in order to keep such frames from toppling over, invented the strap-iron hook on one corner, as shown re-engraved from Cheshire; $h$ is the hook that engages the strap iron ip in the bottomboard; $g r$ is a groove to admit of the hook, and at the same time render it possible to catch under the strap iron.

These hooks are on the outside of the hive proper, and hence they do not kill bees, nor are they filled with propolis as they would be if made on the inside of the hive. $A$ and $B$ are respectively the frame and the follower, altho they are drawn somewhat out of proportion.

The ordinary closed-end frames come together laterally. The Quinby frames may be placed laterally up against each other; but the usual practice is to bring them together by sliding the end-bars past each 
other. The movement is endwise, and, if it is properly performed, all bees that may be on the edge of either of the frames will be brushed aside. The bottom hook permits of an endwise as well as sidewise movement.

The Quinby frame is considerable of a departure from the Langstroth principle, because the Quinby hive and frame have no bee-space back of the end-bars. None is needed, for the reason that the combined end-bars make the end of the hive; but the frame does have a bee-space between the hive-bottom and the cover or the next set of frames above. Without the top and bottom bee-space Captain J. E. Hetherington could never have handled 3000 colonies as he did on the Quinby frame for years in the Mohawk Valley, New York. Mr. P. H. Elwood is at the present time using a large number of colonies on the same frame in Herkimer Co., New York, and using them successfully.

With a panel on each side, a cover and a bottom-board, the Quinby-Hetherintgon hive is complete, the ends of the frames forming the ends of the hive; altho, for additional protection in the spring the users have an outside case to set down over the whole. This makes a very cheap hive that has many desirable features in it. For fuller details in regard to this frame and its manner of construction, the reader is referred to "Quinby's New Beekeeping."

\section{THE DANZENBAKER CLOSED END-FRAMIES.}

The end-bars are pivoted at the center, the pins resting on hanger cleats secured to

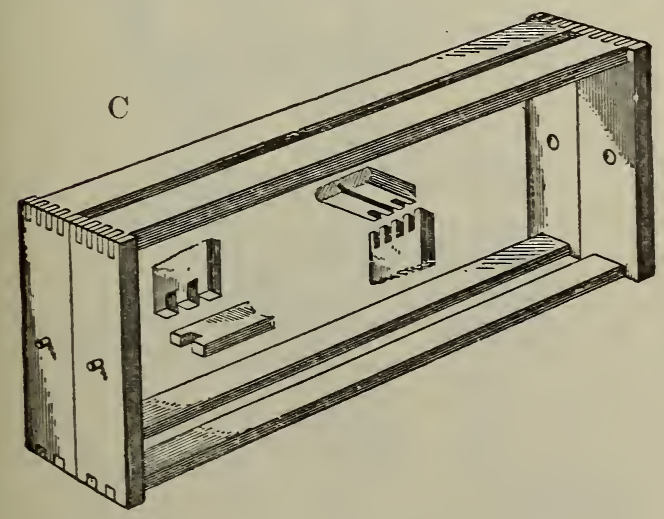

Danzenbaker closed-end frames.

the ends of the lives. These pins make a very small line of contact, whereas the ordinary standing closed-end frame resting on tins secured to the bottom edge at the ends of the hive will crush a good many bees. The pins hare the further advantage that, if there is any reduction in the depth of the live due to shrinkage, the bee-space above and below the frames will be affected only half as much as if the frame vere standing.

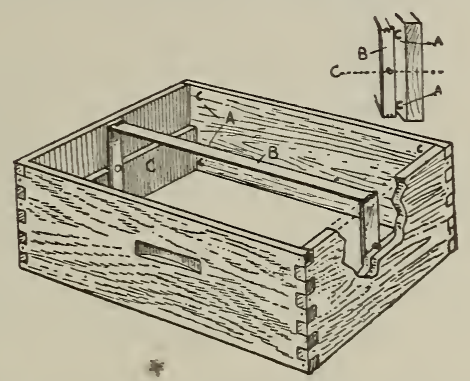

Many beekeepers prefer what is known as the "hanging frame." This has many very decided advantages orer the standing frame; and there is no doubt that. for this reason, the unspaced frame is used so generally; but the hanging frame is also used as a self-spacing frame.

\section{IMPROVED HOFFMAN FRAMES.}

This is a modification of the original frame used by Julius Hoffman, then of Canajoharie, N. Y. The top-bars had projecting edges at the ends as well as end-

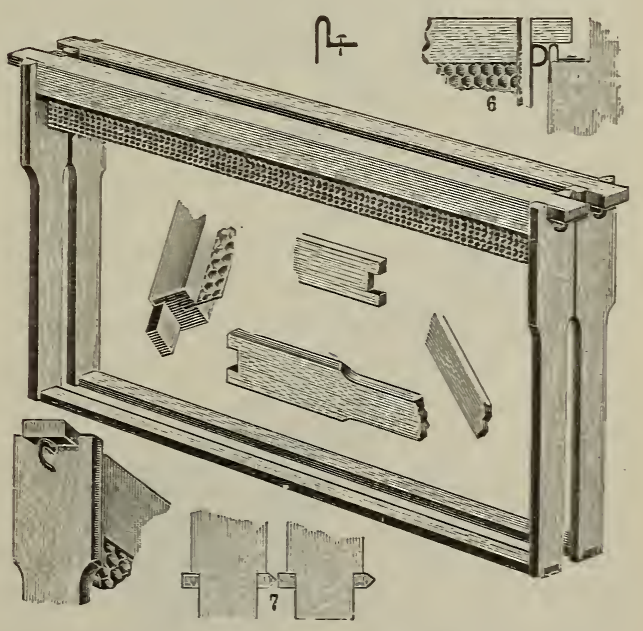

Improred Hoffman frames.

bars; but as he used a special hive without a bee-space at the top, that construction was perfectly practicable. When the Hoffmanframe principle was applied to the regular Langstroth hive, with a bee-space on top, it was found that closed top-bars at the ends 
were impracticable because they permitted the bees to ge on top of the frames. The result was, the $y$ glued the tops together and to the rabb' $t$ s. In the Hoffman hives the bees were siut out from the tops, and, of course, couli not stick the parts together. The moder'n Hoffman frames are, therefore, made liaving only the end-bars wide at the top. This greatly facilitates rapid handling, and preserves at the same time the essential feature of the original Hoffman by which it was possible to handle numbers of frames in lots of two, three, and four at a time, or space them all at one operation against the hive side. While the act would kill some bees, yet this can be avoided by blowing smoke down between the end-bars, shoving the frames all together. In this respect the modified Hoffman has the great advantage over the original frame. This will be shown more clearly under MANIPUlation of Hives and Frames.

Another feature of this frame is the endspacing staple that abuts agoinst the tin rabbet shown at 6 , in the cut. The ends of the top-bars are cut off so as to leave a beespace around them. With the old-style frames the bees could sometimes glue the ends of the top-bars to the rabbet. This has been overcome in the style shown.

When the top-bar is long enough to reach and almost come in contact with the ends of the rabbets, the bees would chink in beeglue between the ends of the top-bars and the rabbets. After the ends of all the frames have been thus glued, it was somewhat difficult to remove any one comb, because the fastening of each frame must be loosened before the comb sought could be lifted out; but when the top-bar is shortened, as at 6 in the illustration, and the staple is used, there is none of this kind of gluing, the only fastening being that between the upright edges of the end--bars themselves; and this fastening, for the majority of localities, so far from being a disadvantage, is useful in that it holds the frames together while the hives are being moved, and yet does not hold them so as to prevent easy handling.

The Hoffman is the most extensively used self-spacing frame in all the United States, and there is even a possibility that it is used more generally than any other frame whether spaced or unspaced. Most of the hive- manufacturers supply it as a part of the regular equipment of their standard hives.

For details concerning its use, see MaNipulation of Hives and Frames.

\section{METAL-SPACED HOFFMAN FRAMES.}

All that has been said in favor of the regular Hoffman will apply with equal force to the metal-spaced frame here shown. In some localities where propolis is very

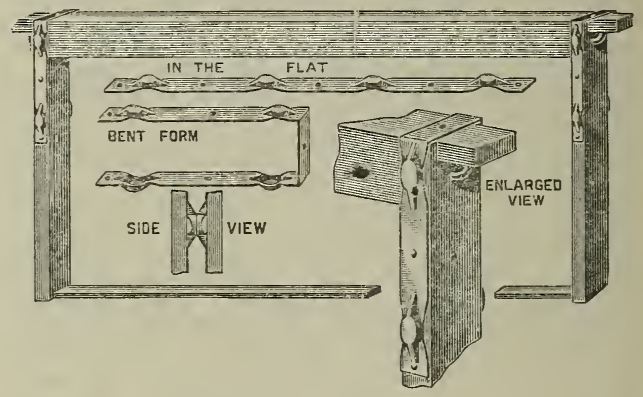

abundant, sticky, or hard, the wooden projections of the regular Hoffman sometimes split off when the frames are pried apart. For localities where this condition prevails the metal-spaced is recommended It can be used interchangeably with the regular Hoffman. The spacers on this frame are stamped out of metal and must necessarily be accurate. The form of its construction in the shape of the letter $U$ bending over the top-bar projection prevents the latter from breaking thru careless handling.

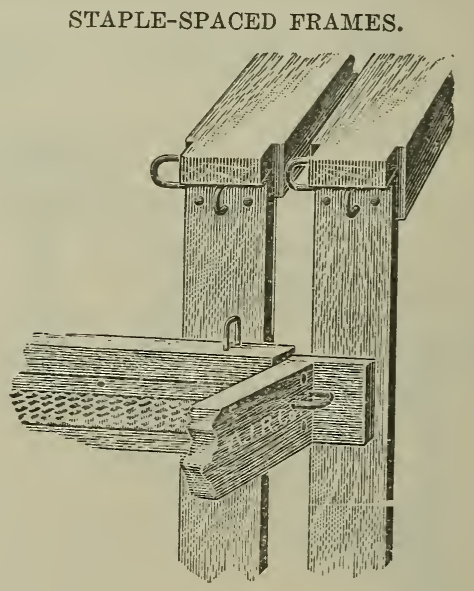

There are some others who prefer frames with staples for side-spacers as here shown. Others use nails in place of staples; but the latter with their rounding edges allow the frames to slide past each other more readily. 

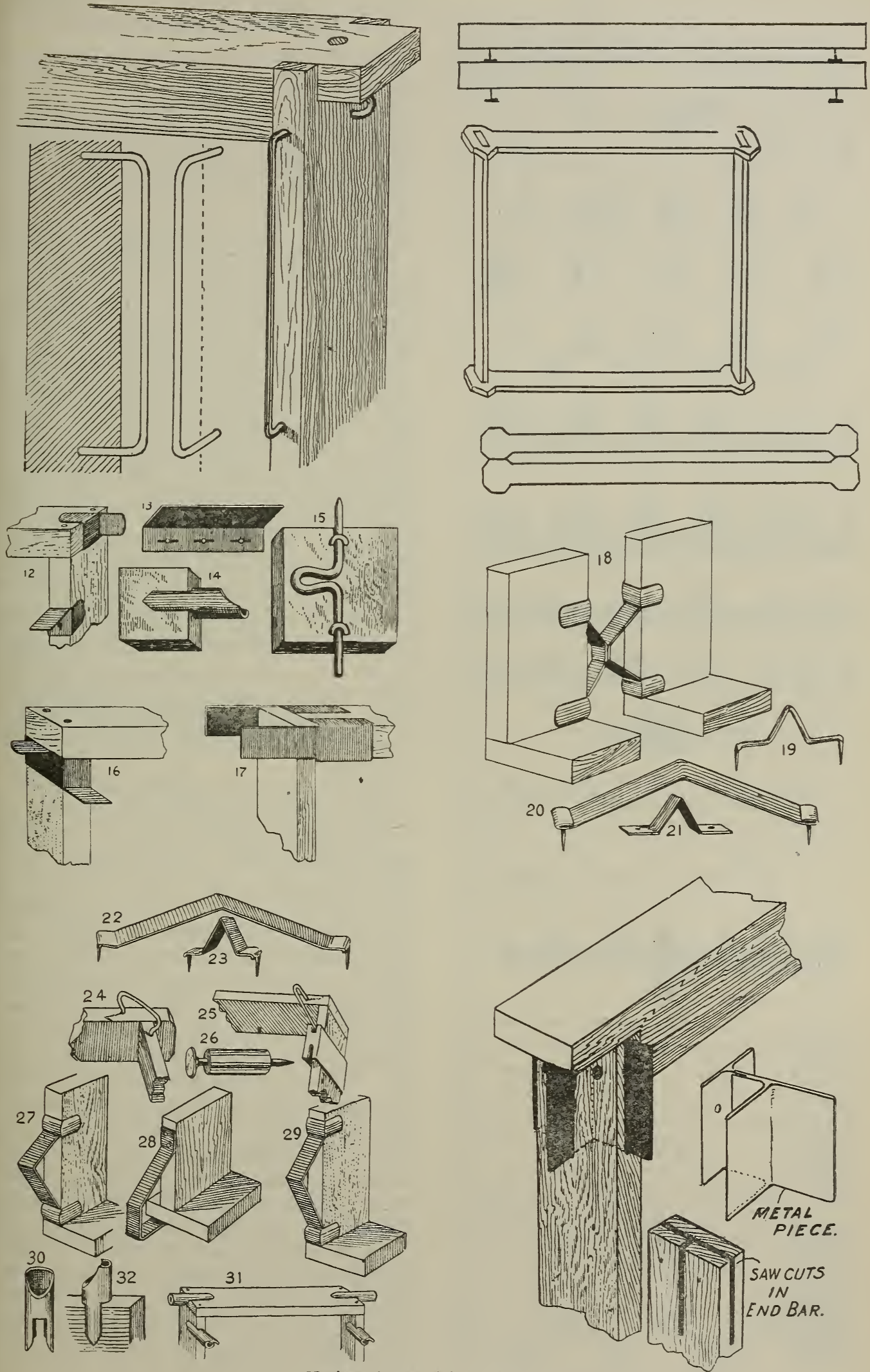

Various forms of frame-spacers.

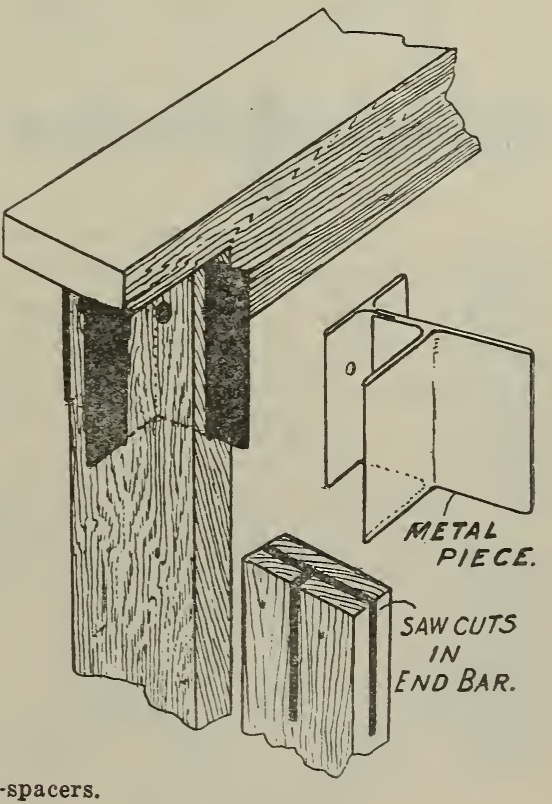



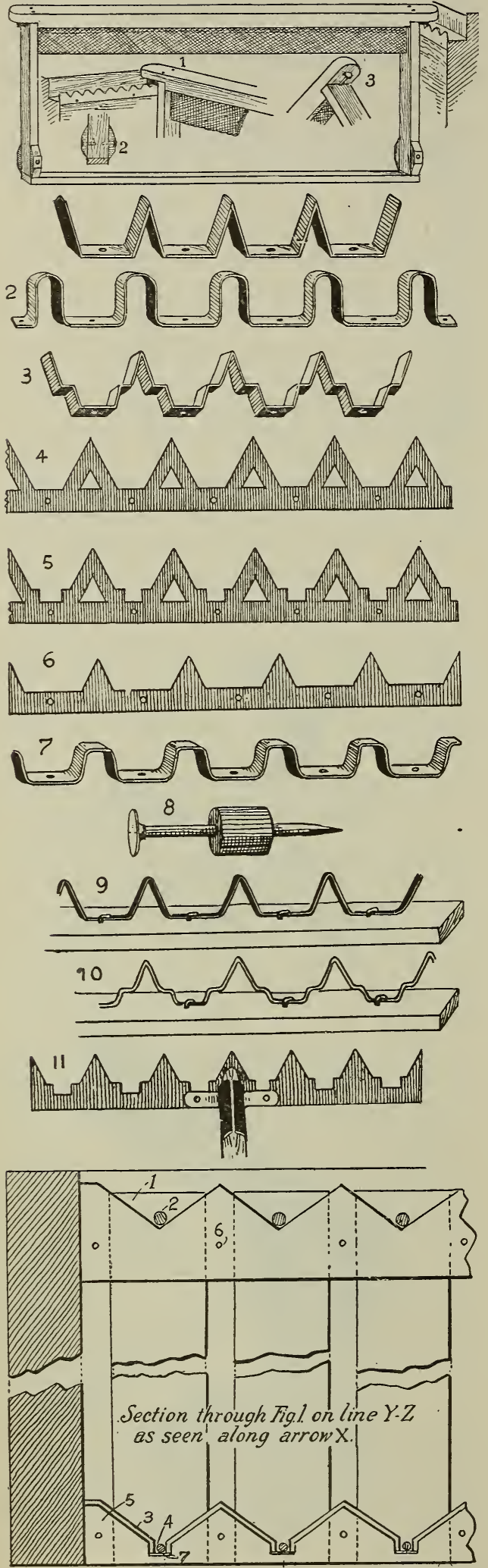

Hive-rabbet spacers.
OTHER SELF-SPACING DEVICES.

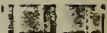

Various spacing-devices have been suggested at different times. A few of these we present here, leaving the reader to judge of their relative merits. It will not be necessary to describe them in detail, as the engravings make plain their manner of construction and use.

It will be noted that there are two kinds of spacing-devices. One is made a part of the frame and the other a part of the rabbet. It would seem at first glance that the latter would be a very happy solution of the problem of automatic spacing, as it would leave the frames without projections in the way for uncapping; but the fact is, rabbet or hive spacers have never been very popular, and therefore are very little used. The principal objection to them is that one cannot move the frames en masse or in groups, thus saving time in handling the brood-nest. The advantage of group handling is made more apparent under MaNipUlation of Hives aNd Frames.

The very fact that no extensive beekeeper is using these self-spacing devices as a part of the hive, and the further fact that all others who tried them in a small way sooner or later abandon them, should discourage would-be inventors from wasting any time over them.

\section{SELF-SPACING FRAMES-ADVANTAGES.}

They make possible straight, beautiful, and regular combs; are practically free from burr-combs; can be hauled without any special preparation over the roughest roads, turned upside down, and rolled over without disturbing the combs. They permit, to a very great extent, the handling of hives instead of frames. Under MaNiPULAtion of Hives aNd Frames is shown how they can be handled in pairs and trios-in fact, half a hive at a time. They can also be inverted, thus causing the combs to be built out solidly to the bottom-bar; and, when once completed, they can be restored to their upright normal condition. They can be handled as rapidly as the loose frame. Indeed, the late Mr. Julius Hoffman, of Canajoharie, N. Y., when owner of some 600 colonies on Hoffman frames, said he could work nearly double the number of colonies with his frame that he could on any frame not spaced or close-fitting, and he had used both styles of frames. But not 
every one will be able to do this; and very likely some people would handle them much more slowly than they could loose frames.

SELF-SPACING FRAMES FOR SMALL BEEKEEPERS.

Whaterer may be said regarding the adaptability of Hoffman frames for the expert, it is evident that, in almost every instance, they are better for the beginner, average farmer beekeeper, or any one who does not propose to make a specialty of the bee business, but desires to keep only a few colonies to supply himself and neighbors with honey. Such persons are apt to be a little careless, and, with ordinary loose unspaced frames, make bad spacing. It is seldom indeed that one can look into the hives of this class of beekeepers and find their loose frames properly spaced. In some instances the combs are so close together that opposite surfaces are gnawed down to give the bees sufficient space to pass between; and in others they are so far apart that small patches of comb are built between; since it is an invariable rule laid down in hive economy, on the part of the bees, not to leave more than proper beespaces.

\section{FRAMES, TO MANIPULATE. - See Manipulation of Hives and Frames.}

FRUIT-BLOSSOMS.-In the northern portions of the United States, where much fruit is grown, especially apples, pears, and peaches, there will be an occasional spring when quite a little honey is gathered from the blossoms. Nearly every season fruittrees yield a little honey, if not too cold, just when it is most needed to stimulate broodrearing; and altho the bees may not store much, they will gather enough to give the whole apiary a new impetus, so that, where fruit is grown extensively, beckeepers often receive considerable benefit.

As to its quality, the honey from fruitblossoms is among the very best. It is light in color, of good body, and in flavor not unlike the beautiful aroma one enjoys when going thru an orchard in full bloom. Such honey, if it could be gathered in sufficient quantities, would doubtless have an extensive demand; but it is very seldom that bees are able to get enough to store any in the supers or sections.
SPRAYING DURING BLOOM DESTRUCTIVE TO BEES AND BROOD.

Now that spraying with various poisonous liquids has come to be almost universal among fruit-growers, the question arises, "Shall such spraying be done during the time the trees are in bloom, or before and after?" If it is administered when the petals are out, bees are almost sure to be poisoned, much brood will be killed, and many times valuable queens are lost. About the first thing one notices during fruitblooming time, if trees are sprayed while in bloom, is that a good deal of the brood dies, until the beekeeper begins to wonder whether his bees have American or European foul brood, or sacbrood-unless the truth dawns upon him that they have been carrying in poisonous liquids from the trees that have just been sprayed. Experiment stations all over the United States have shown that it is quite useless-indeed, often decidedly harmful to the young fruit-to spray during the time the trees are in full bloom; and they have shown over and over again that just as good-nay, better results can be secured by spraying both before and after blooming, when there is no danger of bees visiting the trees in quest of pollen and nectar. Some experiments that were conducted at the Cornell and Gencra experiment station, New York, are particularly conclusive in showing that to spray in full bloom is decidedly injurious to the blossoms themselves, to say nothing about the great damage done to the beekeeper. The poison as ordinarily used is very harmful to the growth and development of the pollen. Again, the delicate organs of the flowers (stamens and pistils) are either killed or injured. Some of the pollen in the experiments above mentioned was taken into the laboratory and mixed with a thin syrup of about the consistency of raw nectar, and to this was then added a quantity of the spraying-liquid of the strength that is ordinarily used on fruit-trees. In every case it was found the pollen failed to derelop. In short, those in charge of these experiments gave any amount of proof to the effect that, irrespective of any interests of the beekeeper, the fruit-grower himself could not afford to spray during fruit-blooming time, because spraying-liquids that are sufficiently strong to kill insect pests are decidedly 


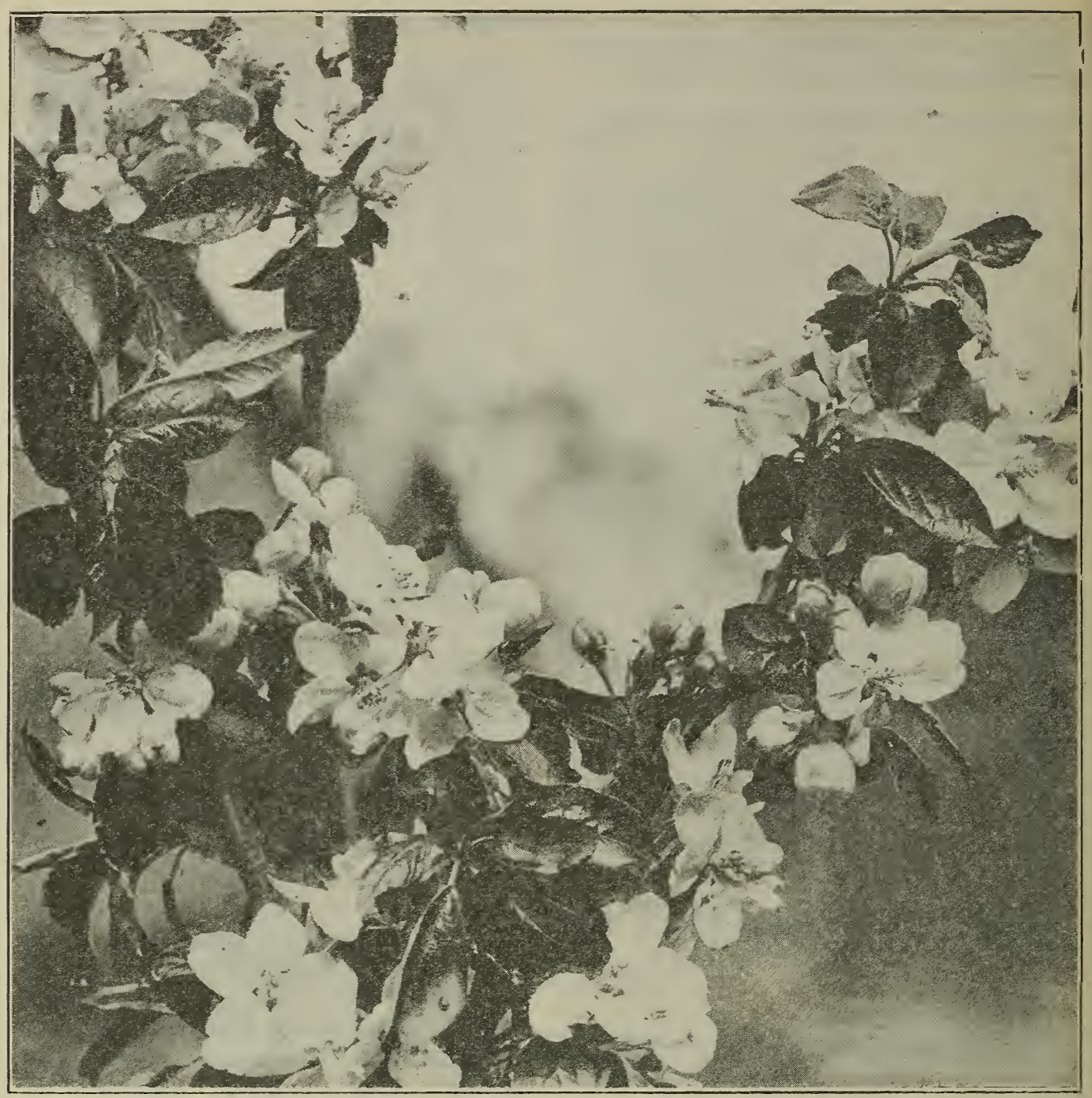

Apple-blossoms.

harmful to the delicate reproductive organs and to the pollen of the flowers themselves.

Some prominent fruit-growers who once were of the contrary opinion, and who sprayed during full bloom, have since found their mistake to their sorrow. In some instances they confessed to losing nearly one thousand dollars.

Some spraying-fluids are not poisonous, as, for example, the lime-sulphur washes, the kerosene, and other emulsions of crude oil; but even these should not be sprayed when the trees are in bloom. Hellebore, or any of the Bordeaux mixtures, especially if they contain Paris green, or any of the arsenites, will be poisonous, of course; but such fluids are also too strong for the delicate pistils and stamens of the flower.
Spraying is practiced to kill the fungi and injurious insects. The codling moth that is responsible in the main for wormy apples lays its egg in the bark of the trees. As soon as the larva hatches, it seeks out the blossoms about the time the petals fall and begins to burrow into them. If they have a coating of poison it dies before it can do any mischief. Otherwise it makes its temporary home in the maturing fruit.

\section{THE STATEMENT OF A HIGH AUTHORITY IN FRUIT CULTURE.}

"The American Apple-orchard" is the title of a book by F. A. Waugh, published by the Orange Judd Co., of New York. It contains over 200 pages of interesting and valuable matter. Price $\$ 1.00$. 
Those fruit-growers in the vicinity of our beekeeping friends, who insist on spraying at the wrong time in spite of the advice of experiment stations all over the United States, and up-to-date fruit-growers, should be shown a copy of this work. If they are so behind the times as to spray while the trees are in bloom they have much to learn and it would be dollars and dollars in their pocket to purchase a copy of this work and read it carefully. We are not sure but that beekeepers can afford to buy it and loan it out to their fruit-growing neighbors. We copy a portion of chapter 11, entitled "The Insect Campaign." Under the head of "Codling Moth," the worm that so often turns one's stomach as he bites into an apparently sound apple, he says:

This is one of the best-known and most widely distributed enemies of the apple. Newly settled districts have nearly always enjoyed a temporary immunity from this pest, but experience has shown that the moth cannot long be kept out of any commercial apple-growing district. Apparently the ravages of $t$ l? ? codling roth are more serious in centris and southern latitudes, where two or tr. c. or even is many as four, broods are hatched in a year. However, the campaign against this insect is an annual one, and has to be fought in practically all the commercial orchards in the country.

The principal preventive of damage is the spray-pump, using poison sprays. Paris green is largely used at the present time, but is being generally supplanted by lead arsenate. Thoro spraying at the right time with these insecticides will very greatly reduce the percentage of damage. Indeed, in many cases the work of the insect is practically eliminated. As in dealing with every other insect or fungous pest, thoro spraying at the proper time is highly essential. The proper time in this case is within one week to ten days after the falling of the blossoms. A longer delay cannot be made with safety. After about 10 days the calyx, or blossom leaves of the young apple, close and the apple turns to a pendant position. Before this time the newly set fruit stands erect with the calyx lobes open. A poison spray properly distributed falls into this calyx cup and the poison lodges there. As many of the young larvæ enter the apple by eating in at this blossom end they secure with their first meal a taste of poison which usually prevents any further apple-eating on their part.

Special attention should be called to the fact that apple-trees should not be sprayed while in blossom. Spraying at this time is not always totally without value, but in many instances it is not only unnecessary, but even highly dangerous to the crop. Under all circumstances it is very likely to poison the bees working on the apple-blossoms. 'This sort of damage is far-reaching in many cases; and as the bee is one of the fruit-grower's best friends we cannot afford to murder whole swarms in this way.

This early spraying, just after the blossoms fall, will not usually catch quite all the codling moths, even all the first brood. When the second or third brood hatches later in the year a still smaller percentage can be poisoned the arsenical spray; nevertheless, it pays to give additional sprayings for this purpose in case the second and third broods appear to be large.

\section{HOW THE SPRAYING OF COVER CROPS UNDER ORCHARDS KILLS BEES.}

But there is another kind of spraying which in some sections of the United States is terribly destructive to bees. There are many commercial orchards where clean cultivation is employed-that is to say, the ground under the trees is harrowed, and kept clean of all regetable growth. There is another class of fruit-growers who beiieve it is an advantage to sow some sort of legume under the trees, not only to protect the roots of the trees, but to hold the moisture in the soil. At the proper stage of growth these cover crops are plowed under to furnish a humus and a fertilizer. There is no question but that in many localities this scheme of green manuring is ahead of clean cultivation.

Various legumes are used for the purpose. In Colorado, red clover has been used extensively; in California, the retches and the annual yellow sweet clover (Melilotus indica). In Colorado, red clover usually comes into bloom about the time the trees are sprayed the second or third time, or after the petals of the fruit-trees have fallen. Unfortunately, this blooming of the red clover comes at a time when there is an entire scarcity of nectar. The result is that the bees get well started on the red-clover cover crop; and when the trees above them are sprayed, the arsenates and other poisonous mixtures fall on the clover, with the result that the bees are killed by the thousands.

In Colorado there is a law against spraying while trees are in bloom; and the up-todate fruit-growers of the state discourage spraying at such a time, because they know that it would kill the bees, their best friends, and at the same time injure the embryo fruit. 
In 1914 and ' 15 whole apiaries were destroyed on the western slope of Colorado, particularly in the vicinity of Montrose, where the sprays applied after bloomingtime fell on the cover crop of red clover beneath. At first the fruit-growers insisted that the bees were not destroyed. A thoro investigation was made, however, and it was pretty well proven that the bees were poisoned, not because they visited the fruittrees, but because they gathered the poisoned nectar from the red clover. Considerable feeling arose between the fruit-growers and beekeepers; and at this writing (May, 1916) the difficulty has not been adjusted. The fruit-growers are urged either to cut their red clover or plow it under before they apply the second and third sprays to the trees. And many of them, recognizing the valuable and almost indispensable work performed by the bees, are doing this; but some others, not so sure that the bees are a benefit, are compelling the beekeepers to move their bees away from their locality, and they have done so; but as history repeats itself it is reasonably certain that these fruit-growers will see their mistake, ask the beekeepers to bring their bees back, and follow the practice of their more progressive and more considerate neighbors to cut or plow under their cover crops before they spray.

Prof. C. P. Gillette, Entomologist at the Colorado Experiment Station, a friend of the fruit-grower and the beekeeper alike, and one of the best entomologists in the country, strongly urges the fruitmen, before they spray, either to cut their red clover or plow it under. Dr. A. J. Cook, formerly Horticultural Commissioner of California, holds that the whole difficulty can be solved by substituting the vetches or the annual yellow sweet clover, that comes into bloom when no poisonous sprays are applied to the trees.

It is possible and probable that the more progressive fruit-growers and beekeepers of Colorado will unite in asking for legislation that will prevent the wholesale destruction of bees as the result of spraying cover crops while in bloom, especially when there is a dearth of honey. Where clean cultivation is practiced, or where the vetches and the annual yellow sweet clover are used, or even where red clover comes into bloom at a time when the trees are not sprayed, no trouble will take place. The situation is somewhat serious from the beekeepers' point of view. Some, it is positively known, have been driven out of the business of honey production into something else.

\section{POLLINATION OF FRUIT BLOOM.*}

Not infrequently in the past beekeepers and fruit-growers came in conflict; the latter asserted that bees injured the bloom, punctured the fruit, and interfered with the packing, and consequently in some cases they asked the beekeepers to remove their bees on the plea that they werc a nuisance. The fruit-growers little rcalized that they were driving away the agency necessary for the proper pollination of fruit bloom. Happily at the present time the two factions understand that their industries are mutually dependent. Fruit-growers, indeed, derive very much more benefit from bees than the beekeepers themselves, as they have been repeatedly taught by costly experience. Some years ago a beekeeper in Massachusetts was obliged to remore bees from a certain locality on the complaint of the fruit-growers that they were a nuisance; but after a year or two had passed they were very glad to have the bees back again, because so little fruit set on the trees in proportion to the bloom. The beekeeper was recalled; and, as was to be expected, not only more but finer fruit was produced.

The practical application of the discovery of the agency of insects in the pollination of flowers in the cultivation of fruits and vegetables has been of inestimable value to agriculturists. It can be shown easily that there are many different kinds of plants which, in the absence of insects, would remain partially or wholly unproductive. In the work of pollination the services of the bees, or Anthophila (flower-lovers), are the most important; while among the bees the honey-bees, because of their highly specialized pollen-gathering apparatus, their great numbers and industry, far surpass all other species. Fruit orchards cannot be planted profitably on a very extensive scale without maintaining in connection with them numerous colonies of honeybees; and it is esti-

* In order to understand better the structure of the llower it is suggested that the reader turn first to the subject of POLLINATION OF FLOWERS. It will also serve to illustrate the different methods of pollination referred to in this article. 
mated by Dr. Phillips, of the Bureau of Entomology, that bcekeeping adds indirectly more to the resources of the country annually by flower pollination than by the sale of honey and wax. Several enthusiastic horticulturists have eren declared that for all practical purposes in pollination the honeybee is alone sufficient; but this assertion must be somewhat modified; for in the country as a whole domestic or hive bees are aided by wild bees, wasps, flies, butterflies, and to a less extent by beetles. At the time of its discovery honeybees probably did not occur on the Western Continent, and for many thousands of years its raried wild flora had been dependent for pollination on the native insects, especially the wild bees. Neither were honeybees found in Australia, New Zealand, or other Pacific islands when they were first visited by Europeans. The indigenous insects had in all probability more or less successfully pollinated the natural floras of these regions in the absence of the honeybee. In extensive areas of the unsettled wilderness there are still many flowers which rely chiefly on the wild insects, and everywhere they are helpful allies of the fruit-grower.

While it is true that the wild bees pollinated the wild flora, it is neverthcless true that the highly developed and cultivated fruits of modern times require the special agency of the honeybee. When a modern Burbank, for example, develops a new fruit by special hand pollination, and when those fruits are grown by the ton and carload, wild insects are utterly inadequate. The only pollinating insects under the control of man are the honeybees, and these have to be introduced in large numbers in order to make the growing of these fruits commercially possible.

In sections where immense orchards cover many square miles of territory, the wild insects are wholly inaciequate to pollinate the great expanse of bloom, and many apiaries must be established to obtain the best results. Fruit-growing has a great future before it, and must ever be associated with bee culture.

\section{THE NUMBER OF CULTIVATED PLANTS.}

Only about 44 species of cultivated plants were known to the ancient world. In his "Origin of Cultivated Plants," De Candolle enumerated 247 species cultivated for their roots, leaves, flowers, or fruit, of which the Old World furnished 199, America 45, and 13 were of uncertain origin. While De Candolle described the majority of plants most valuable to the human race, Sturtevant has enumerated in manuscript, according to Hedrick, 1113 domesticated species, which are cultivated today; and a total of 4447 which are partially edible. Not all cultivated plants are pollinated by insects; a part are pollinated by the wind and a part are self-fertilized. In order to avoid confusing these different groups it is desirable to describe briefly the common wind-pollinated and exclusively self-pollinated species.

\section{CULTIVATED PLANTS POLLINATED BY THE WIND.}

The wind is a much older agency in pollination than insects. See Pollination of Frowers. The edible nuts of North America, as the walnut, hickory, acorn, beech, hazel, butternut, pecan, and chestnut, are almost invariably pollinated by the wind; but the horse-chestnut in the temperate zone, and many tropical species producing nuts are insect-pollinated. The common anemophilous species not only have the stamens and pistils in different flowers, but in different flower-clusters, so that in the absence of cross-pollination, at least, by different clusters, the species are sterile. The pecan, chestnut, and hickory are the only nuts domesticated in this country; but since nuts afford a wholesome and nutritious food nut culture is rapidly extending, and it is predicted that in the South the pecan groves will rival the cotton fields in extent. The flowers of the wind-pollinated nut-trees yield pollen but no nectar.

The grasses, or Gramineae, which are all wind-pollinated, include the common cereals, corn, wheat, barley, ryc, rice, oats; also sorghum, sugar cane, and millet. The flowers are usually perfect, but self-pollination is prevented by the anthers and stigmas maturing at different times. But sometimes the stamens and pistils are in separate flower-clusters, as in Indian corn. Since human existence depends upon the grasses, they have been aptly termed the type of human beneficence. The sedges, rushes, and reeds are also wind-pollinated. Mythical stories of honey stored from anemophilous flowers are occasionally circulated: but these reports probably have their origin in 


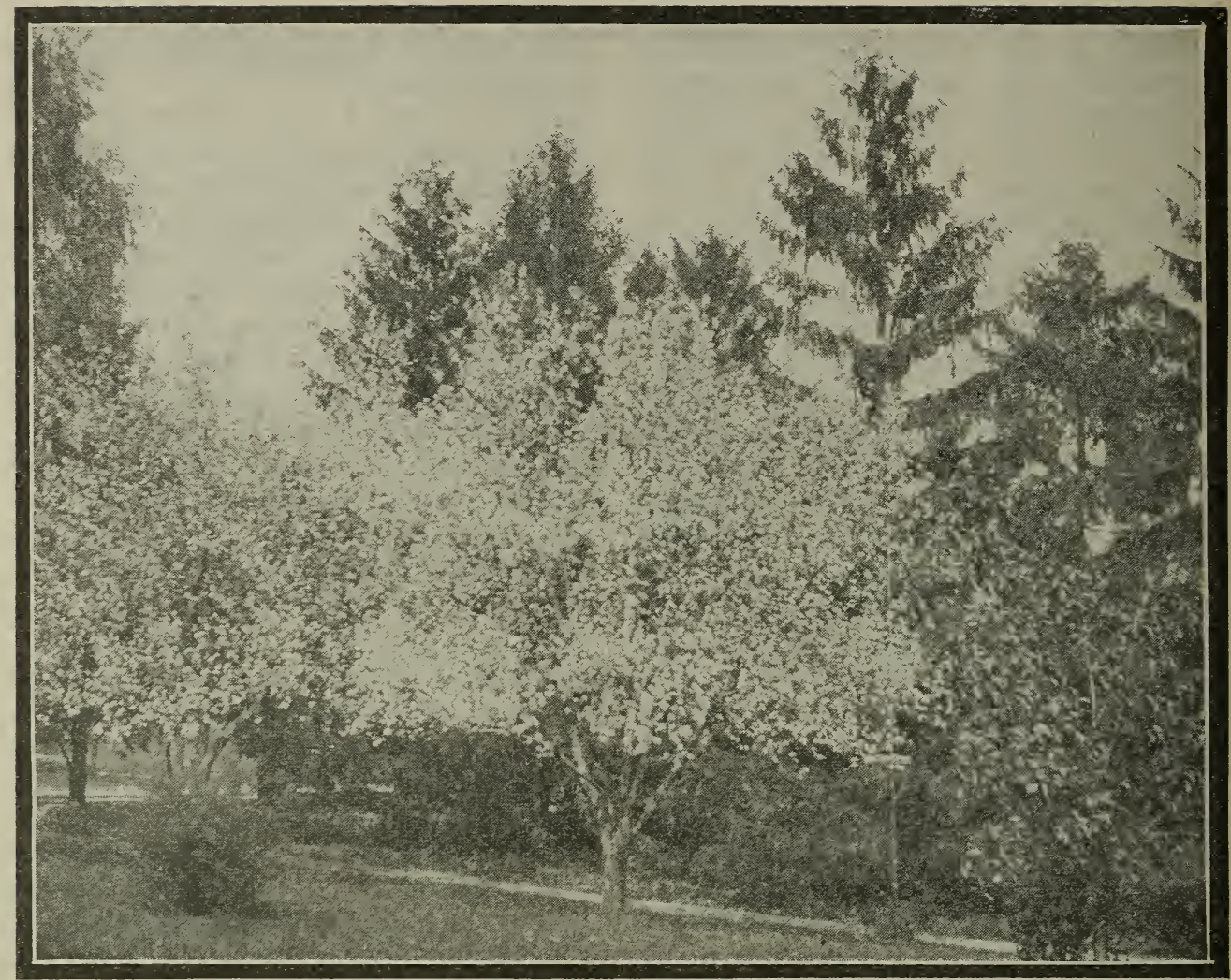

Apple trees in bloom in A. I. Root's orchard.

the collection of honey-dew which is common on the foliage of several species.

The hop-vine, the white and black mulberry, the date palm, and many other palms are also anemophilous or wind-pollinated. According to Swingle about one-half of the trees of the date palm in nature are staminate, or "male," and one-half pistillate, or "female," so that cross-pollination is a necessity. Under cultivation a single staminate tree will serve to pollinate artificially fifty or more pistillate trees. In each of the fruiting clusters a small branch of pollen flowers is tied. The cocoa-nut palm, a bountiful source of food in the tropics, is also wind-pollinated.

CULTIVATED PLANTS POLLINATED CHIEFLY BY WILD INSECTS.

Several widely cultivated garden and forage plants are pollinated chiefly by wild insects. Red clover is usually dependent on bumblebees for pollination, as is well illustrated by the history of its introduction into New Zealand, where the raising of seed did not become commercially profitable until three species of bumblebees were import- ed from England. The first consignment, which successfully established themselves in South Island, was liberated in 1885. Altho hundreds of tons of seed have been produced since that date further importations are believed to be desirable. According to an extensive series of observations, a description of which was published by the Department of Agriculture in 1914, honeybees trip few flowers of alfalfa. Bumblebees trip about 30 per cent of the flowers visited; but the most efficient pollinators are leaf-cutting bees belonging to the genus Megachile. Three of these bees were observed to trip flowers at the rate of 552 per hour. The flowers of the common garden beet, altho fragrant and nectariferous, are not often visited by bees; but about 30 per cent of the flowers are pollinated by thrips (Bull. Bureau of Plant Industry No. 104). The fig-trees, of which there are many species, have diclinous flowers; that is, the stamens and pistils are in different flowers and are pollinated by small wasps. But some varieties of fig produce large quantities of edible fruit without pollination. 


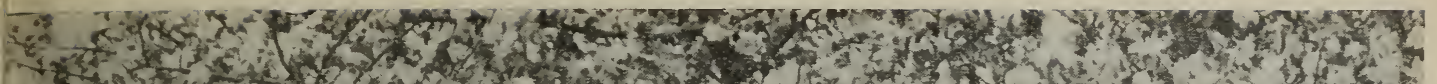
An

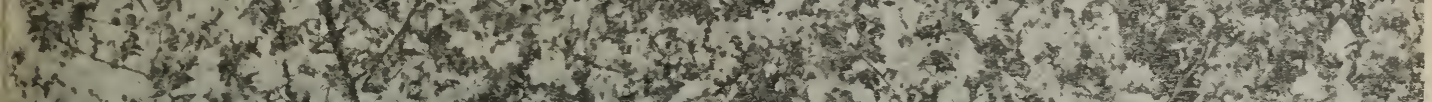

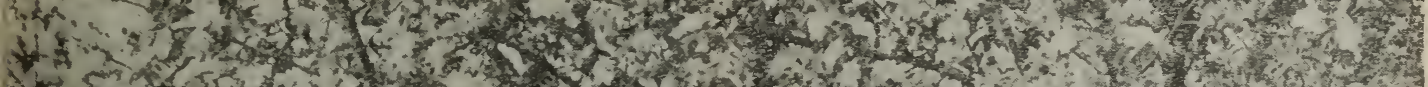

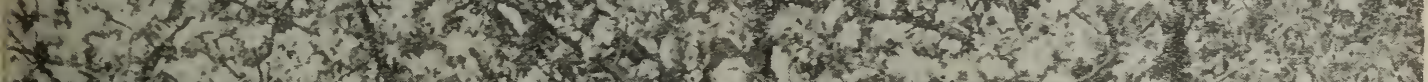
2. If

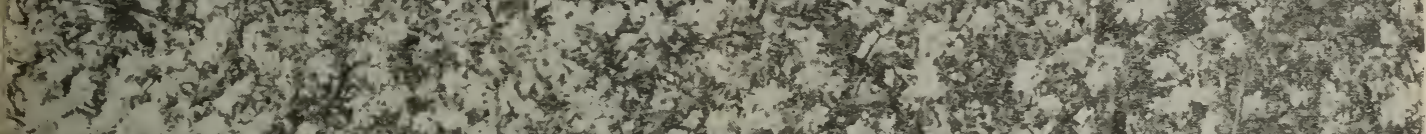

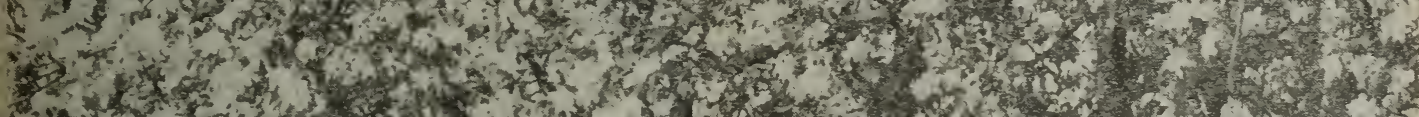

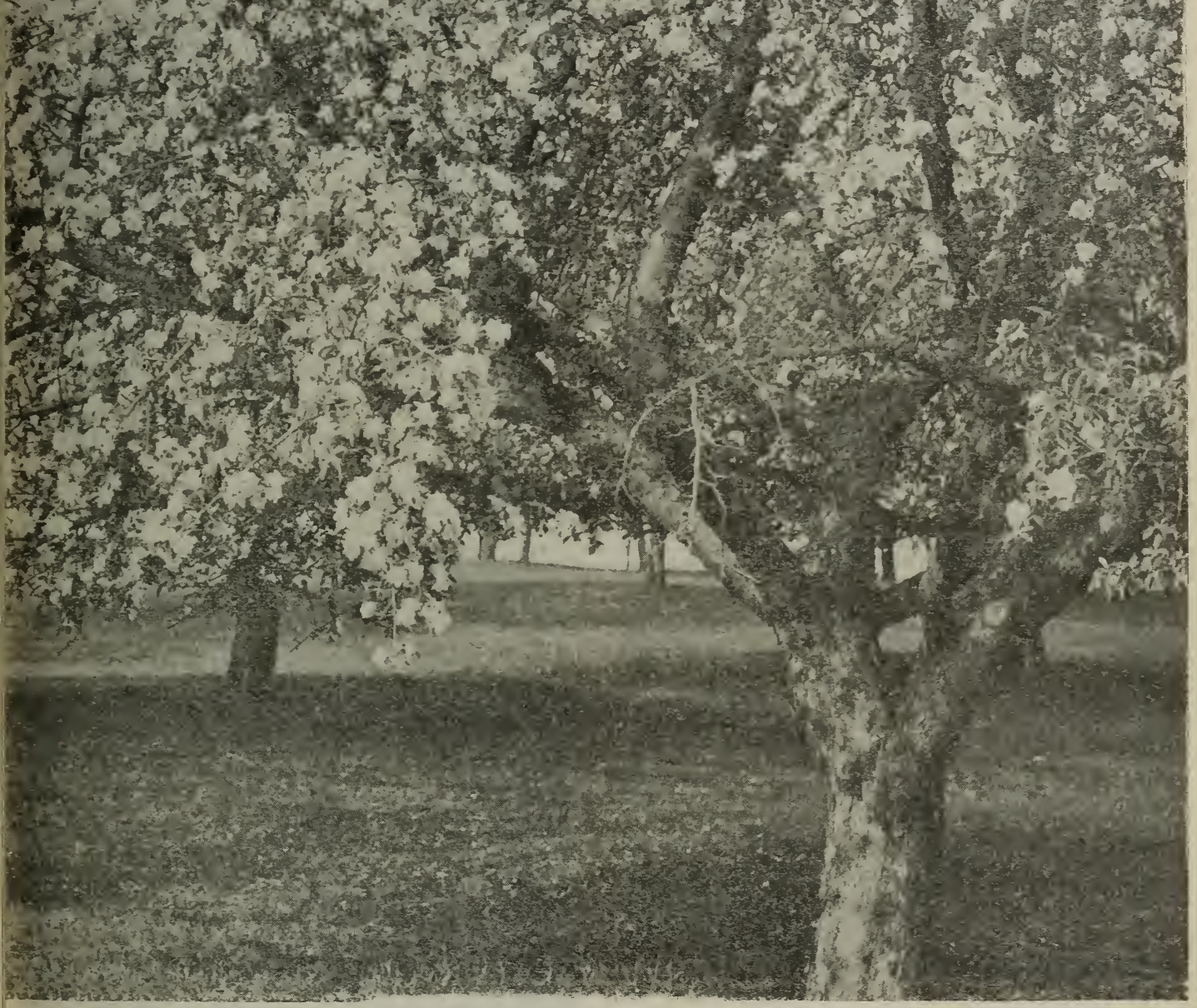

An apple orchard well loaded with bloom.

THE HONEYBEF AND FRUIT CULTURE.

Altho many nut-trees, the cereals, the date-trees, and cocoa-nut trees are pollinated by the wind, the fig-trees by wasps and several widely cultivated forage and leguminous plants are self-pollinated, or pollinated by bumblebees and leaf-cutting bees, it is still true that the honeybee is a most important visitor to the majority of culti- vated plants. It is an essential factor in fruit culture, and in the pollination of fruit bloom its significance becomes paramount to that of all other insects. When the value of the fruit crop is considered both from a hygienic and economic point of view, who can overestimate the services of the domestic bee to the human race? Numerous species and countless varieties of fruils are already under culture, and within the next 
century many new forms will be domesticated and improved or introduced from foreign lands.

A great variety of fruits were introduced into this country after its discovery, but wild fruits have always been abundant in the western continent. Hedrick calls North America a natural garden. "More than 200 species of tree, bush, vine, and small fruits were commonly used by the aborigines for food, not counting nuts, those occasionally used, and numerous rarities. There are now under cultivation 11 American species of plums with 588 varieties; 15 species of grapes with 1194 varieties; 4 species of raspberries with 28 varieties; 6 species of blackberries with 86 varieties; 5 species of dewberries with 23 varieties; 2 species of cranberries with 60 varieties; and 2 species of gooseberries with 35 varieties, or a total of 45 species of American fruits with 2226 varieties." This number is destined to be greatly increased in time by the domestication of other wild fruits. Coville has recently shown that blueberries can be cultivated; and it may be expected that improved varieties will be obtained of blueberries, huckleberries, juneberries, elderberries, wine-berries, ground-cherries, thorn apples, buffalo-berries, highbush cranberries, cloud berries, native mulberries, pawpaws, and persimmons. A beginning in the culture of the fig, the avocado, and the date has been made in California; while the mango, a delicious fruit, of which there are more than 500 varieties, has been introduced into Florida. Hybridizing can multiply new forms indefinitely and yield such anomalies as the loganberry and the blackberry-dewberry. In the vast and splendid future of fruit culture the importance of the honeybee will now be shown by an examination of the pollination of the more important fruits.

THE POLLINATION OF CUCURBITOUS FRUITS.

The flowers of the squash, cucumber, melon, and pumpkin are monoecious; that is, the stamens and pistils are in different flowers on the same plant. Self-fertilization is thus impossible, and in the absence of insects the vines cannot (unless they are artificially pollinated) produce fruit. The staminate flowers open a few days before the pistillate, are larger, and are often on longer stalks. The nectar is secreted within a fleshy cup formed by the fusion of the base of the calyx with that of the corolla. In the squash (Cucurbita maxima) and purnpkin (C. pepo) this cup is large, and, except for

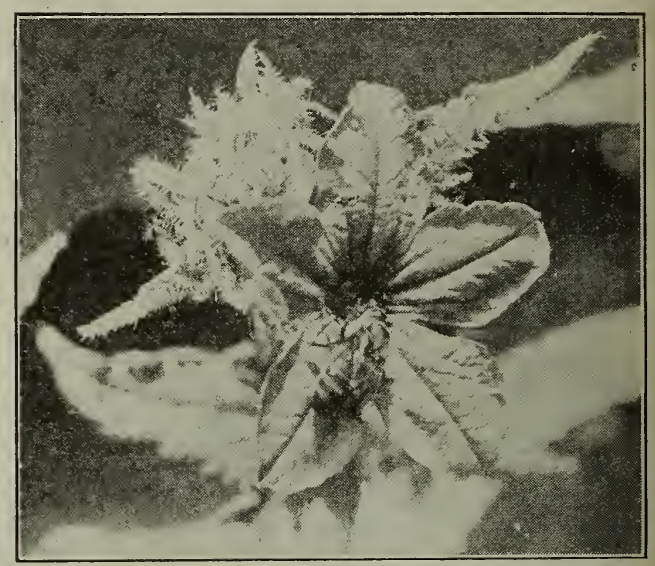

Cucumber-blossom with a bee on it; caught in the act.

three narrow slits, is covered in the staminate flowers by the column of stamens. The flowers are pollinated chiefly by honeybees and bumblebees, which visit them in great numbers and can reach the nectar with their

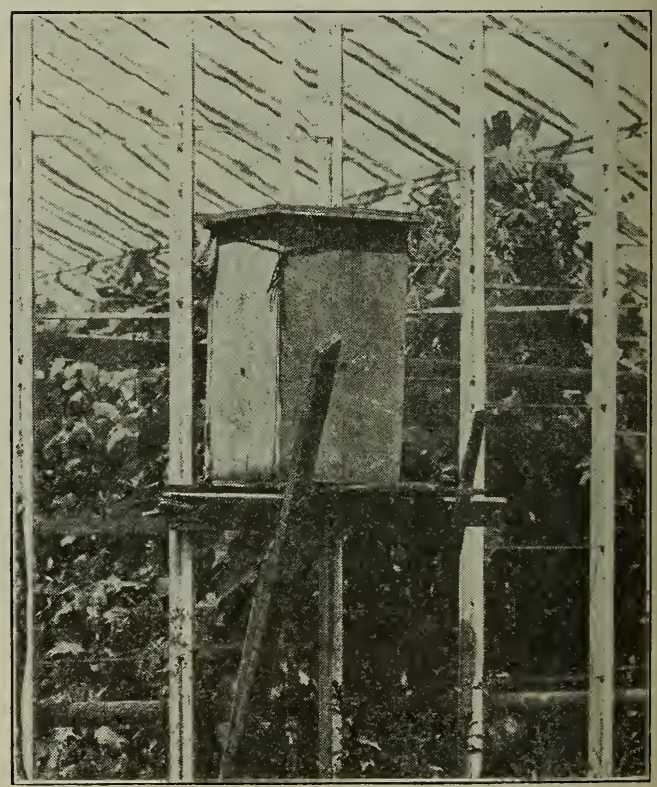

Interior of cucumber-greenhouse; hive with entrance inside.

long tongues. On a clear warm day in August the writer has seen a staminate flower of the squash visited in ten minutes by 8 honeybees and 4 worker bumblebees 
(Bombus terricola). Another flower in ten minutes received 6 visits from honeybees and 6 from bumblebees. One of the longtongued wild bees (Xenoglossa pruinosa) is said to risit only the flowers of the pumpkin. In the vicinity of pickle-factories there are usually from five to six hundred acres of cucumbers under cultivation, yielding 75,000 or more bushels of fruit. The immense number of blossoms require many colonies of honeybees for their proper pollination.

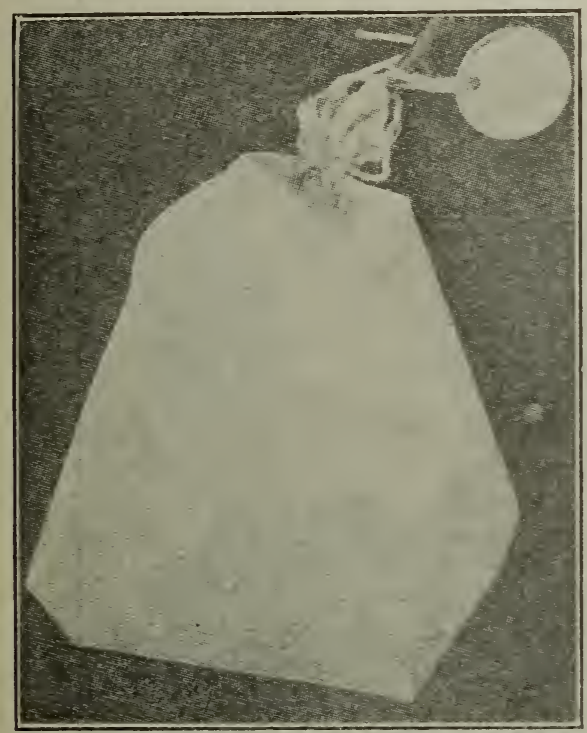

Method of bagging a cluster of flower buds to determine whether the variety is self-fertile or selfsterile.-(After Lewis and Vincent).

Honeybees are also largely used for pollinating cucumbers grown in greenhouses for early market. In Massachusetts some 2000 colonies are required annually to pollinate the cucumbers raised under glass, one large grower using 80 hires. For the crop of cucumbers, squashes, melons, pumpkins, watermelons, and kindred fruits we are thus wholly indebted to bees.

$$
\text { POLIINATION OF THE TOMATO. }
$$

The flowers of the tomato are nectarless, but are visited by bees gathering pollen. Cross-pollination is favored by the stigmas maturing two or three days before the anthers. The different varieties, as Champion, Ponderosa, and Peach can be easily crossed, but are largely self-sterile. At the Ohio Experiment Station, Green set out in August 200 plants of Dwarf Champion in a greenhouse, and by winter they had made a fine thrifty growth and were fruiting nice1y. A good crop of tomatoes was expected; but when January came and the fruit began to ripen, the bulk of it was about the size of hickorynuts and without any seeds. Fink also states that plants from which insects were excluded yielded few and small fruits.

\section{THE POLLINATION OF BERRY-PLANTS.}

GRAPE.-It is well established that many kinds of grapes are self-sterile; and, since in this country an immense area is devoted to the culture of this fruit, ignorance of the manner of pollination of the different species and varieties must result in great loss. Some 40 species of grapes have been described, of which about 20 occur in North America. They are widely distributed thruout the north temperate zone, but are especially abundant in the region of the Caucasus and in the eastern United States. There are now under cultivation some 16 species, 1194 varieties, of which 790, or threefourths, are hybrids. Foreign grapes do not succeed well in this country when planted outdoors, but grow satisfactorily in hothouses. Grape-growing on a commercial scale in America takes its beginning in 1849, when Nicholas Longworth, of Cincinnati, after 30 years of experiment with foreign grapes, turned his attention to our native species and planted extensively the Catamba, a variety of the common wild Vitis labrusca.

The flowers of the vine are small and green and occur in dense thyrsoid clusters. The calyx is minute, and the five petals cohere to form a little hood, which falls away entire when the flower opens. The five stamens produce only a small quantity of pollen; alternating with the stamens are five nectar glands. The flowers are very sweet-scented with an odor suggestive of mignonette, which can be perceived for a long distance. A part of the plants produce perfect or hermaphrodite* flowers and a part staminate flowers with a rudimentary ovary.

Many rarieties of American grapes are self-sterile. Of 169 cultivated varieties inrestigated by Beach at Geneva, N. Y., 37 were wholly self-sterile, and in the absence of cross-pollination produced no berries; 28

* See Pollination of Flowers for a definition of these terms. 
were so nearly self-sterile that the clusters were unmarketable, and thus from a commerical point of view of no more value than the previous group; 104 varieties produced marketable clusters when self-fertilized, but of this number 66 had the clusters loose, and only 38 yielded compact perfect clusters. Among the varieties wholly sterile were Aminia, Black Eagle, Essex, Oneida, Eaton, Salem, and Wilder; nearly sterile self-sterile varieties, therefore, there must be a sufficient number of strongly self-fertile vines to pollinate them properly. Care must be taken to select varieties which bloom simultaneously. Self-sterility is due to lack of potency of the pollen, the selfsterile varieties always having shorter stamens than the self-fertile forms.

The grape remains in bloom from six to ten days according to the temperature of

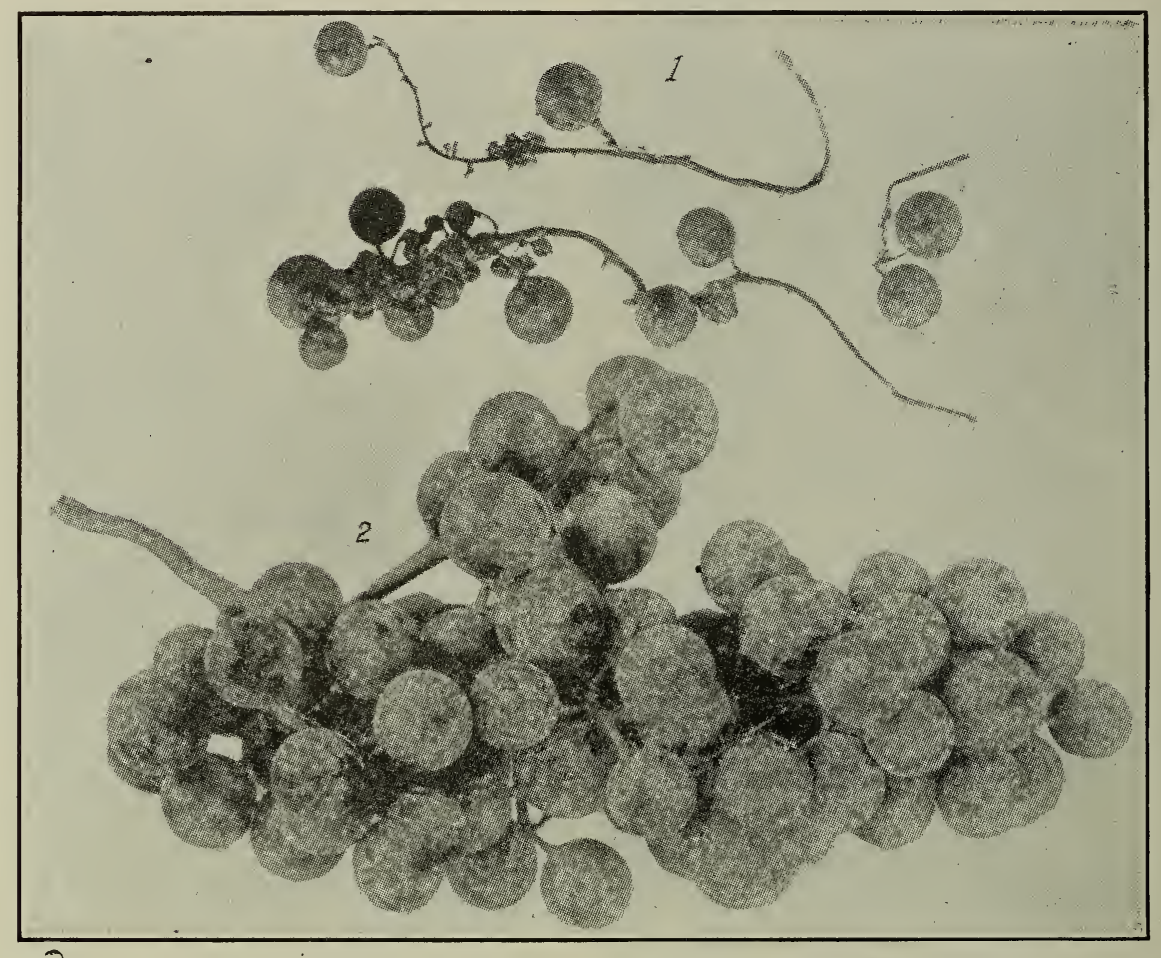

1, Brighton grape self-fertilized; 2, Brighton grape cross-fertilized.-(After Beach.)

varieties were Brighton, Canada, Geneva, Vergennes, and Woodruff; wholly or nearly self-fertile varieties were Delanson, Moore's Early, Niagara, Worden, Agawam, Catawba, Champion, Clinton, Concord, Isabella, and Victoria. The self-fertility of a cluster was tested by enclosing it in a Manilla paper bag before any of the flowers had opened, thus excluding pollen from all outside sources. (Beach, S. A., "Self-fertility of the grape," Bull. No. 157; "Fertilizing Self-sterile Grapes," Bull. 169, et cetera, N. Y. Agr. Exp. Sta.).

Nearly all the self-sterile varieties are hybrids; when pollinated by other self-sterile varieties they yield no fruit, but when pollinated by self-fertile varieties they produce marketable clusters. In a vineyard of the air. Both anthers and stigmas mature at the same time, and the pollen retains its vitality for at least two weeks. Species with the stamens longer than the pistils are usually regularly self-pollinated, and are, therefore, largely independent of insects. While occasional pollination by the wind may occur, the flowers are adapted to insect pollination. The strong fragrance compensates for their inconspicuousness. In central Europe the five fleshy nectaries secrete no nectar, but in warmer climates it is said to be abundant. The quantity of pollen is small, but it is gathered by honeybees, bumblebees, and wild bees. Beetles are sometimes very destructive to the inflorescence. But where the varieties are self-sterile, as is the case with the muscatine grapes (vari- 


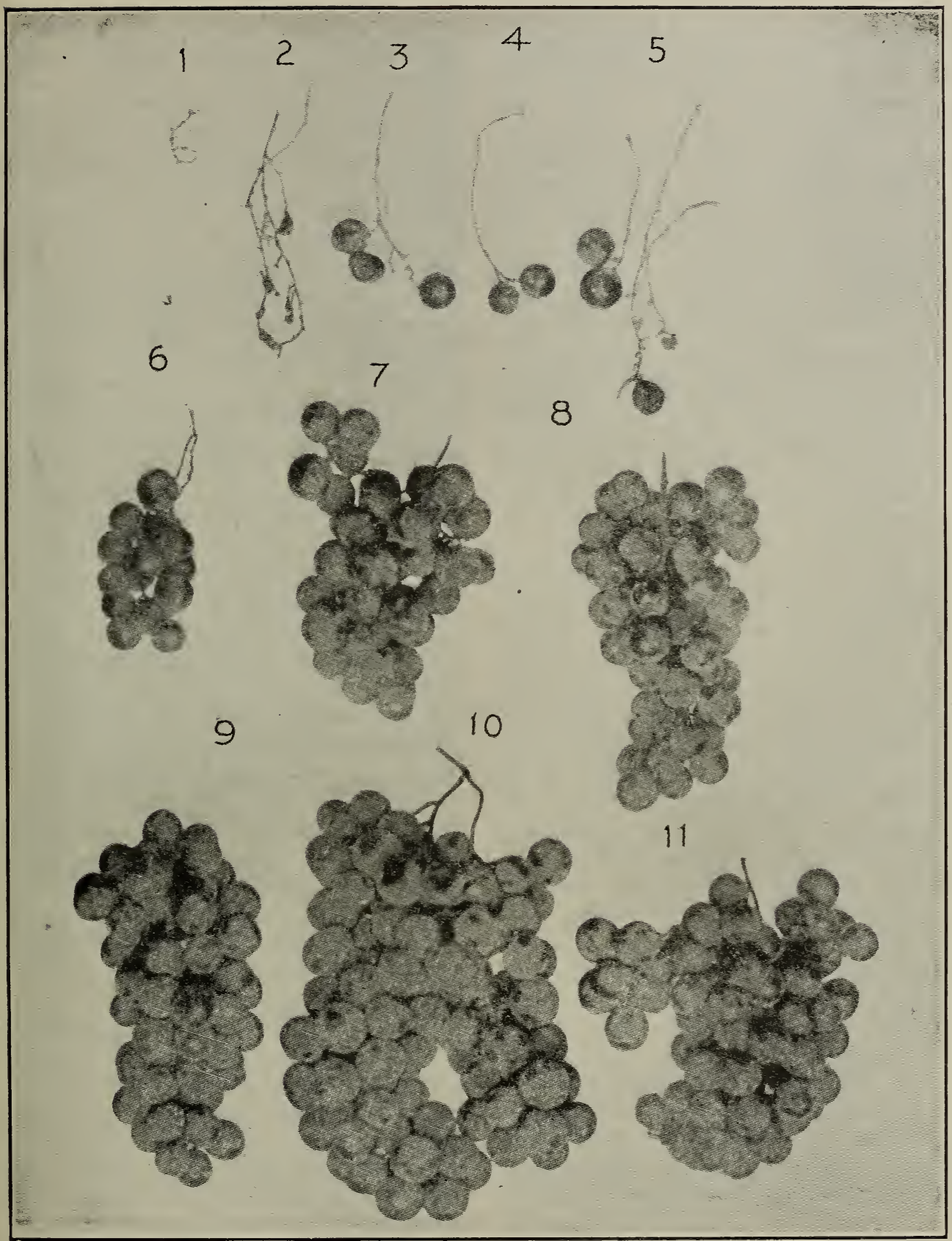

Brighton grape pollinated by 1 , Salem; 2, Creveling; 3, Lindley; 4, pollen of another vine of same variety; 5 , self-pollinated; 6 , by Nectar; 7 , Jefferson; 8 , Niagara; 9 , Worden; 10, Vergennes, 11, Rochester. - (After Beach.)

eties of Vitis rotundifolia) which have been extensively planted in the Southern states, bees do not visit the flowers as frequently as would seem to be desirable. Efforts should be made to obtain vines which secrete nectar freely, and also a bee-yard should be located in or near the vineyard.

STRAWBERRY.-A strawberry grower of great experience says that more trouble, failures, and dissatisfaction arise among fruit-growers-particularly among small growers-from ignorance regarding the sex of strawberries than from any other cause. In this genus there is a marked tendency for the stamens and pistils to occur in different flowers. A part of the plants produce staminate flowers, a part pistillate, and a part perfect or hermaphrodite flowers, as is 
especially well shown by the European strawberry, the hautbois, or highwood strawberry of Germany. Plants with staminate flowers are comparatively rare while the other two forms are common.

The strawberry grows wild thruout a large part of Europe, Asia, North America, and Chile, S. A. Little improvement was made in the fruit until after the beginning of the nineteenth century, when by crossing and selection hundreds of new varieties were obtained and the berries greatly improved in size and flavor. In eastern North America there are only two well-defined wild species, Fragaria virginiana, the common field strawberry, and the wood strawberry, F' vesca. On the western coast of both North and South America F' chiliensis is common. All the American species intercross easily.

Owing to their greater productiveness preference in field culture is often given to the pistillate varieties, which are marked (P.) in the catalogs of nurserymen. Pistillate varieties which have been extensively planted in the past are Crescent, Manchester, and Bubach; while the Sharpless is perhaps the best known of the older perfect varieties. Where pistillate plants are used in order to provide for their pollination every fourth row must be planted with perfect or hermaphrodite plants; otherwise the pistillate plants will be barren. It is not at all rare, according to Fuller, to find perfect plants which are largely sterile to their own pollen, altho the pollen is perfectly potent to fertilize other varieties. A variety may have both stamens and pistils, and yet, owing to self-sterility, ninety per cent of them be barren. It is of the greatest importance, therefore, to ascertain by growing individual plants under glass whether perfect flowers are self-fertile or not, or, where this is not known, to plant more than one variety. The best-flavored strawberry ever produced by Fuller was discarded because, altho hardy, freely blooming, and perfect, it was largely sterile both to its own pollen and that of other varieties.

The pistillate plants are entirely dependent on insects for pollination; no insects, no berries, except in instances where a few stamens may be present. The nectar is secreted by a fleshy ring at the base of the receptacle between the stamens and pistils.
It is not abundant, and there is no record of a surplus of strawberry honey. The stigmas mature before the anthers. The flowers are visited by honeybees and many wild bees, which gather both pollen and nectar. It is evident that all the flowers are benefited by cross-pollination and that an abundance of bees is most desirable in strawberry-growing.

R.ASPBERRY AND BLACKBERRY.-The raspberries and blackberries, which belong to the genus Rubus, are widely distributed thruout the north temperate zone of both hemispheres. The nectar is secreted by a narrow ring at the base of the receptacle. In the raspberry it is very abundant, and a large surplus of excellent honey is obtained annually; the blackberry, on the contrary, is a poor honey-plant even in Michigan where it covers large areas from which the forest has recently been cleared. The petals of the raspberry, which drop off on the second day, stand erect when the flower opens and hold the stamens closely against the convex mass of pistils, ensuring self-fertilization in the absence of insects. When insects visit the flowers, especially bees, they regularly effect cross-pollination by rubbing the pollen adhering to their bodies on the numerous stigmas. Since the flowers are visited by innumerable loneybees besides a great company of wild bees cross-pollination largely prevails. When the flowers are enclosed in muslin bags they are self-fertile, but the results are not as good as when they are unprotected.

The flowers of the blackberry are larger than those of the raspberry, and the petals spread out, affording a convenient landingplace for insects. The stamens bend away from the center; and as the outer anthers dehisce first the flowers are usually crosspollinated before the inner anthers, which may effect self-pollination, have opened. In the raspberry and blackberry the anthers and stigmas mature at about the same time. The flowers of the blackberry are visited by many honeybees, wild bees, flies, and beetles. On a small piece of cultivated blackberries growing near the apiary of the writer the insect-visitors were collected during a succession of days, and the wild bees were found greatly to outnumber the honeybees. The latter manifested a preference for collecting the pollen rather than the scanty supply of nectar. 
CURrant and Gooseberry.-The currants and gooseberries, which belong to the genus Ribes, all secrete nectar and are largely dependent on insects for pollination. The Journal of the Board of Agriculture, England, says that when insects were excluded from gooseberries, red and white currants, practically no fruit was formed. When artificially pollinated with pollen from the same flower or variety they all proved self-fertile, and set fruit perfectly; but the pollen is so adhesive that it is not readily transferred from the anthers to the stigma except by the visits of insects.

In the European gooseberry (Ribes grossularia) the anthers open before the stigma is fully grown and capable of pollination. Moreover, the flowers hang downward, and, as the anthers stand at the same level as the stigma, the pollen cannot, as a rule, fall on it, and thus in the absence of insects no fruit is produced. The flowers are adapted to bees, and honeybees, bumblebees, and wild bees are very frequent visitors. A bee while sucking nectar touches the stigma with one side of its head and the anthers with the other side, so that in a succession of visits it cannot fail to effect cross-pollination. The European gooseberries do not succeed well in this country; and our native northern gooseberry (Ribes oxyacanthoides) has been extensively planted in the Northern states under the name of Houghton. It is easily cultivated and enormously productive. At the Connecticut Experiment Station 72 species of insects have been listed as visitors.

The flowers of the red currant (Ribes rubrum) are also usually cross-pollinated by insects; but as the anthers and stigma mature simultaneously and the flowers often stand sidewise, self-pollination may occur by the pollen falling on the stigma. Honeybees, wild bees, and flies are very common visitors. In the black currant (Ribes nigrum) the pistil is a little longer than the stamens, and self-pollination may occur regularly in the absence of insects by the pollen falling on the stigma. In an Alpine species of currant (Ribes alpinum) the stamens and pistils are in different flowers so that no fruit sets in the absence of insects.

CranberRY.-The cranberries are adapted to pollination by bees. The anthers connive to form a cone around the single style, and are prolonged upward into long tubes, which open by pores in the ends, from which pollen falls on the head of a bee seeking nectar. The stigma projects beyond these tubes, and thus receives pollen collected by the approaching insect from other flowers. Individual flowers remain in bloom for more than two weeks. On a large cranberry bog the flowers are as numberless as the sands of the sea, and the indefatigable industry of bees is alone equal to the work of pollinating them.

The United Cape Cod Cranberry Company, which has some 700 acres of cranberries under cultivation, has discovered that the wild bees are not sufficiently numerous to do this work satisfactorily; and that the yield per acre can be greatly increased by placing colonies of bees near the bogs. "One test," says E. R. Root, "was significant. The cranberry bog at Halifax contains 126 acres. On one side of this there were three or four colonies of honeybees last year. It is evident that this number was inadequate to cover the entire field, and it is noteworthy that the yield of cranberries per acre was in direct proportion to the proximity of such acreage to the bees. The yield was heaviest close to the hives, and became thinner and thinner as the distance from the hives increased. The showing was so remarkable in this and other bogs that it is proposed to increase materially the investment in bees another year. A small area of cranberry bog was screened to exclude the bees. The screened portion had very little fruit, while that free to the visitation of bees had a large yield. In consequence many cranberry-growers are planning to go into the bee business for the purpose of obtaining a greater crop of cranberries. In our travels over the United States we never saw a situation that demonstrated more clearly the value of bees as pollinators than did this piece of cranberry bog."

Blueberry ANd HuCKLeberry. - The most valuable of American wild fruits are the blueberry and huckleberry from which there are annually gathered several million dollars' worth of fruit. It was long supposed that blueberries could not be domesticated, but Coville has recently shown that they can be cultivated in a suitable soil. There are in this country more than $\mathbf{1 5 0}$ species belonging to these two genera grow- 
ing in a great variety of situations, as dry rocky pastures, swamps, and woodlands. The inverted urn-shaped flowers, with concealed nectar, are adapted to pollination by bees, among which the honeybee is common; but in remote and obscure localities the wild bees are often the chief visitors.

\section{THE POLLINATION OF FRUIT-TREES. THE PLUM.}

The cultivated plums may be divided into three groups according to their origin: The European, the Japanese, and the American. Familiar varieties of European plums (Prunus domestica and P. insititia) are the Yellow Egg, Bradshaw, Lombard, German Prune, Damson, and Green Gage; of the Japanese plum ( $P$. triflora), Burbank, Abundance, and Red June; and of American plums, the wild plum ( $P$. americana), the Canada plum ( $P$. nigra), and the Wildgoose plum (P. hortulana). All the species, according to Waugh, hybridize, the Japanese plums crossing easily with the American, but the European and American varieties cross with difficulty. It is believed that hybrids of great value will eventually be obtained. The plum has also been crossed with the peach, cherry, and apricot.

The pollination of plum-trees is a matter of great economic importance. "When the native plum-trees first began to be cultivated in this country," says Waugh, "their general self-sterility was a drawback, which in many cases proved fatal to their success." Waugh's observations extended over five years and included many varieties, especially of native species. All the varieties of American plums proved self-sterile, with the exception of Robinson, and this variety is not wholly reliable when self-pollinated. The Japanese plums were also found to be generally self-sterile. Of the European plums a part seem to be self-sterile and a part self-fertile, but no satisfactory experiments are on record. All of the hybrids are self-sterile. The experiments made, says Waugh, show beyond question that the majority of plums do not bear well, and most of them set no fruit at all unless two or three varieties are mixed in the same orchard. The reason for this is that the blossoms of most rarieties do not pollinate themselves. In general the varieties in each group pollinate each other better than they do varieties belonging to another group.
( Waugh, F. A., "Plums and Plum Culture," also Bulletins 53, 67, 89, etc., Vermont Experiment Station).

Self-sterility in plums may be due to several causes. The stigmas may mature two, three, or even five days before the anthers. A part of the pistils may be defective, but usually there are enough perfect pistils to ensure a full crop. The pollen may be impotent. The stamens are shorter or at least do not exceed the pistils in length so that pollen cannot fall on the stigmas unless the flowers stand sidewise. The plums bloom profusely, and the limbs of the Japanese varieties are often completely wreathed with flowers. In small orchards the air is filled with insects hovering about the trees. In a little ovcr an hour the writer collected 100 specimens of wild bees, mostly species of Andrena and Halictus, and this was only a small part of the number present. Honeybees are frequent visittors, both sucking nectar and collecting pollen, and the placing of colonies in plum orchards is strongly recommended by horticulturists. Man cannot control, but he can raise honeybees, which he can place in large numbers in the orchards.

\section{THE POLLINATION OF THE CHERRY.}

The cherries belong to the same genus (Prunus) as the plums, and the structure of the flower is similar. Cultivated cherries are popularly divided into two groups, the sour cherries and the sweet cherries. The sweet, heart, mazzard, bird, Bigarreau are varieties of Prunus avium, a species found wild in Asia; while the sour, pie, and morello cherries are varieties of $P$. cerasus, also an Asiatic species. The two groups hybridize.

The sweet cherry (Prunus avium) is in bloom five or six days. The stigma and anthers mature simultaneously; but as the flowers are usually pendulous and the stamens diverge from the pistil self-pollination rarely occurs. Common visitors are honeybees and wild bees, and their value in pollination is well illustrated by the following experience. The crop of a sweet-cherry orchard in 1.912 was 13 tons. Acting on the advice of Gardner the owner in 1913 cut branches from seedling cherry trees at blooming time and placed them in buckets of water thruout his orchard. In addition several colonies of bees were placed in the 
orchard. With no better season and with the trees only one year older the crop was 39 tons.

Among the orchard trees of Oregon the cherry ranks fourth in importance, being surpassed only by the apple, prune, and pear in the order named. A poor cherry crop affects the income of many persons. The rapid increase of the area planted with cherries has been followed by complaints that in spite of the heary bloom there was not sufficient fruit to be profitable. In

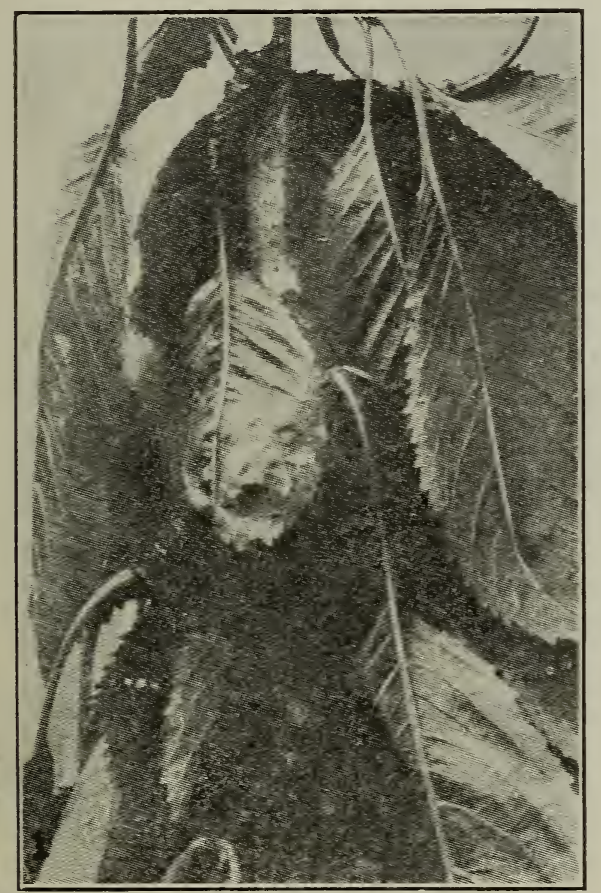

1, Bing sweet cherry crossed by Napoleon yields no fruit.-(After Gardner.)

some instances the new orchards have never paid expenses, while old orchards have become less productive. Altho sorely perplexed by these conditions the cherry-growers, unfamiliar with the mutual relations of flower's and insects, have been slow to believe that lack of proper cross-pollination is the chief cause of the failure of their trees to set fruit. But the cherry orchards of a decade ago were of small size and mixed varieties; while recently orchards of 10 to $10 n$ acres have been planted consisting wholly of one or more of the standard varieties. It has been commonly recognized that rain, fog, temperature, the condition of the soil, and the age of the trees were influential factors; but few in the absence of definite information have considered the possibility of self-sterility.

In order to determine the cause and remedy these failures Gardner in 1911-13 investigated the pollination of the sweet cherries. Thousands of flowers were pollinated with their own pollen and insects excluded by bagging. All of the 16 varieties tested proved self-sterile. The self-sterility was in no case due to the inability of the pollen to germinate, for in the case of each of the rarieties tested the pollen was potent

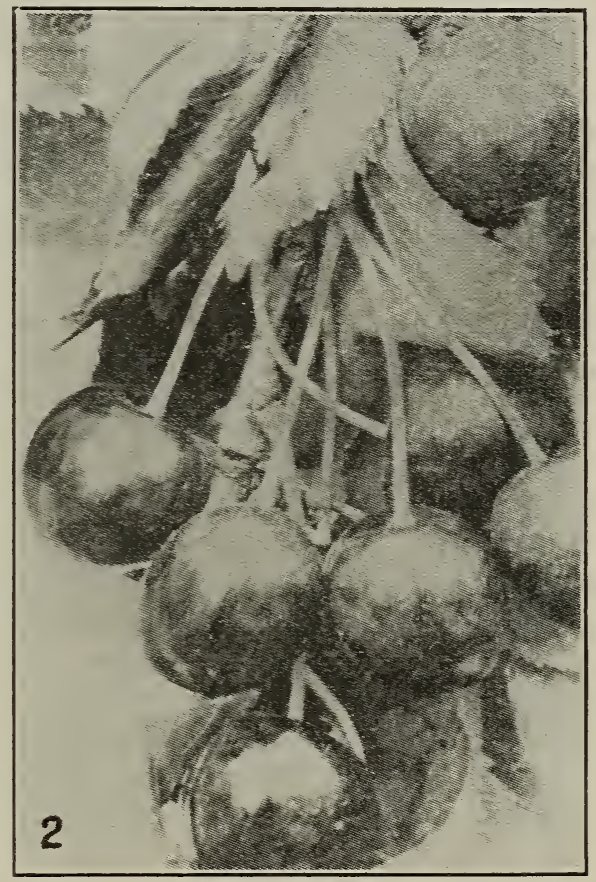

2. Arerace rincter of Bing crossed by Willamette. - (After Gurdner.)

in producing fruit with some other variety. Ninety per cent of the commercial plartings consist of the varieties Napoleon, Lambert, and Bing, all three of which are intersterile; that is. each of these varieties is sterile to the pollen of the other two varieties as well as to its own pollen. Napoleon where planted in solid blocks yielded little fruit altho interplanted with Lambert and Bing. But each of these three varieties is effectively pollinated by Black Republican, Tartarian, and Waterhouse. (Gardner, V. R., "The Pollination of the Sweet Cherry." Oregon Experiment Station, Bulletin 116, 1013.)

"The importance of honeybees as agents in cross-pollination," says Gardner. "cannot 
be over-emphasized." This is clearly shown also by the experience of cherry-growers in California. For several years the cherry crop of Vaca Valley, in Solano County, Cal., had not been good, altho it had formerly been quite sure. It was recollected that formerly, when the cherry crops were good, wild bees were very plentiful in the valley, and since most of the bees had disappeared it was thought that perhaps the lack of fruit might be due to imperfect pollination. To test the matter the Messrs. Bassford, therefore, placed several hives of bees in their orchard in 1890 . The result was striking, for the Bassford orchard bore a good crop of cherries; while other growers in the valley who had no bees found their crops entire or partial failures. In 1891.there were some 65 hives in the Bassford orchard, and H. A. Bassford wrote to the Fintomologist: "Our crop was good this season, and we attribute it to the bees. Since we have been keeping bees our cherry crop has been much larger than formerly, while those orchards nearest us, five miles from here, where no bees are kept, have produced but light crops."

The flowers of the sour cherry (P. Cerasus) closely resemble those of the sweet cherry, but the petals are flatter and the stigma matures before the anthers. Selfpollination is thus at first impossible. The position of the stamens and the opening of the anthers outwardly also tends to prevent automatic self-pollination. Not a single fruit set when insects were excluded from cherries, says the Journal of the Board of Agriculture, England. Neither did any fruit mature when the flowers were pollinated with their own pollen, but all the flowers pollinated from another variety set fruit. So necessary are the honeybees for cherry orchards that the growers have imported in one case a carload of bees from the South.

\section{THE POLLINATION OF THE PEACH.}

The peach also belongs to the genus Prunus ( $P$. Persica). The rose-red flowers appear in early spring before the leaves. Nectar is secreted within a cup-shaped receptacle and attracts both honeybees and wild bees. One cold rainy spring a colony of honeybees was placed in the center of a small block of peach-trees so that the bees could easily visit the flowers. The result was that this orchard set all the peaches the trees could carry thru the following dry season; while other peach orchards, which bloomed equally well, but were without bees, failed to set a crop (20th An. Rep. Mass. Fruit-growers' Assoc., 1914, p. 52). According to Fletcher, however, 2939 Gold Drop peach-blossoms showed no benefit to this variety when cross-pollinated with pollen from three other varieties.

\section{THE POLLINATION OF THE PEAR.}

The pollination of pear-trees has been studied by Waite who was the first in America to show that many varieties of orchard trees are self-sterile. In his earlier experiments clusters of buds were enclosed in bags of paper or cheese-cloth which were not removed until the blooming period was over; but in his later experiments the bags were opened and the anthers carefully removed and the flowers hand-pollinated. There were employed in these experiments 144 trees belonging to 38 varieties. More than one-half of these varieties when selfpollinated proved to be wholly or nearly self-sterile and produced little or no fruit. Among the wholly or nearly self-sterile varieties were Anjou, Bartlett, Clapp's Favorite, Howell, Lawrence, and Winter Nelis; self-fertile varieties were Angouleme, Bosc, Buffum, and Flemish Beauty.

A brief summary of Waite's conclusions is as follows:

Pollen from another tree of the same variety is no more effective than pollen from the same tree.

The pollen of a self-sterile variety may be perfectly effective when applied to another variety.

Even in those varieties which can be self-fertilized the pollen of another variety is prepotent, and when insects are not excluded most of the fruit seems to be the result of crossing.

Self-fertilized pears contain small vestigial seeds and are smaller and less perfect than those produced by crossing.

The ineffectiveness of the pollen in selfsterile varieties is due to no defect in the pollen.

In 1892 Waite visited the large pear orchard of the Old Dominion Fruit Company near Scotland on the James River. The orchard consisted originally of about 22,000 standard Bartlett pear-trees. It had been planted some 18 years previously, but 


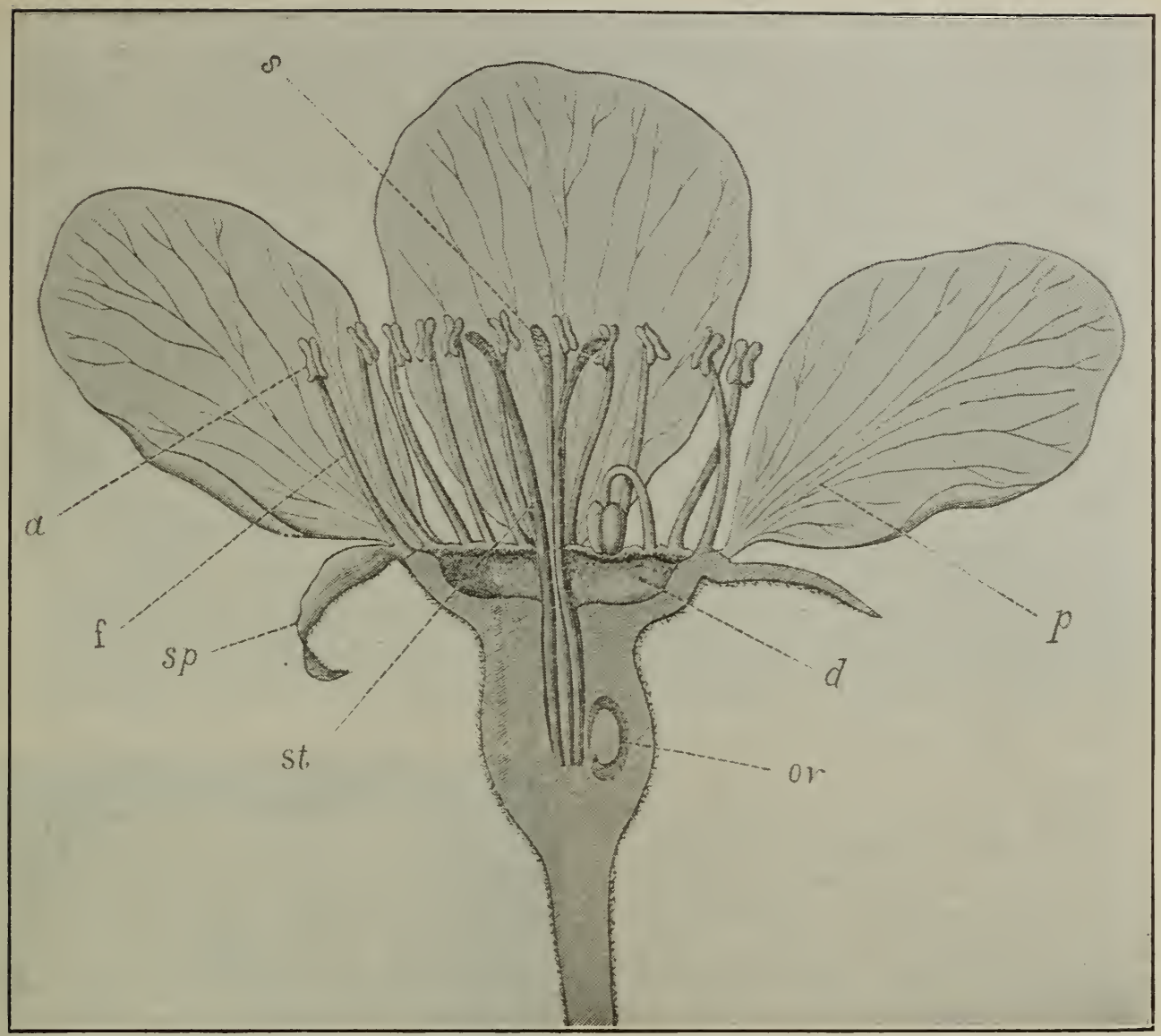

Enlarged section of the flower of a Bartlett pear; $s p$, sepal, the five sepals form the calyx or cup; $p$ petal, the five petals form the corolla or crown; the stamens consist of two parts, $f$, the filament or threadlike stem, and $a$, the anther, composed of two sacs which contain the pollen; the pistils consist of three parts, $o v$, the ovary, st, the style, and $s$, the stigma; $d$, the disc in which the nectar is secreted. Pollination is the transfer of the pollen to the rough sticky surface of the stigma. The pollen grains send out slender tubes, which pass down thru the style to the ovules. From the end of a tube a sperm cell passes into an ovule and unites with an egg cell-this is fertilization.-(After Waite.)

had never borne a full crop. The maximum crop was three-fifths of a peck per tree, while a standard Bartlett tree 12 years old should easily yield five times that amount. In 1892 the crop was less than 100 boxes of three pecks each. The trees in the orchard had always bloomed heavily, and were every year snowy white with blossoms. It was clearly indicated that something was wrong. In three places in the orchard, where the trees had died, two Clapp's Favorite and a Buffum tree had been planted by mistake, and in their vicinity the Bartletts fruited heavily. A small orchard containing a variety of trees had been very productive, and the Bartletts near this orchard also bore well. Bartlett pear-trees are largely selfsterile, and the failure of the great orchard was due to the want of pollen from another variety. (Waite, M. B., "The Pollination of Pear Flowers," Div. Veg. Path. Bull. No. 5, 1895. Also Yearbook Dept. Agr., 1898.)

A pear flower remains in bloom 7 or 8 days. There are 20 stamens in four cycles and five pistils. The stigmas mature two or three days before the anthers, at which stage self-pollination is impossible. In the bud the stamens are bent inward, but gradually bend backward after the flower opens, the anthers on the outer row opening first. Self-pollination may occur by the styles finally bending backward until the stigmas touch the anthers or in the case of flowers standing sidewise by the pollen falling on the stigmas. The quantity of nectar secreted within the concave receptacle is greatly affected by the weather; but sometimes it collects in large drops which overflow and fall to the ground. A great variety of insects, as honeybees, wild bees, wasps, flies, 
and beetles visit the flowers. Waite collected 50 and Mueller 30 species. At Washington, D. C., Rochester, N. Y., and the Connecticut Experiment Station the ground bees belonging to the genera Andrena and Halictus were found to outnumber all other insects. The writer observed a mediumsized pear-tree in full bloom for an hour and a quarter, but during this time saw no insects except honeybees, which were very abundant. A cluster of 7 blossoms received 8 visits in a quarter of an hour; and two other clusters consisting of 16 flowers received 16 visits. This was an average of a little more than four visits to each flower on the tree per hour.

The great service rendered by insects in the pollination of pear blossoms is well illustrated by the experiments of V. H. Lowe at the Geneva Experiment Station, New York, in 1889. A number of small peartrees were covered with a hood of sheeting which came down over the tree like a bag, and was tied at the lower end around the trunk of the tree. On all the trees so covered there was a large number of buds, and all the conditions were favorable for a good crop, except that the visits of insects were entirely prevented. As a result, on the whole lot of trees covered there was just one fruit. On another set of trees of the same sort and size there were 145 pears. In the case of another tree a large limb was enclosed in a bag with similar results.

Extensive experiments on the pollination of Bartlett and Kieffer pears have also been made by Fletcher. Thirty thousand and eighty-one Bartlett blossoms, carefully deprived of their anthers and pollinated with Bartlett pollen, produced only six small fruits as compared with 763 fruits produced by 7170 Bartlett flowers pollinated with Lawrence, Anjou, Dutchess, and Kieffer. Two large 18-year-old Bartlett pear-trees were completely covered just before the blossoms opened with muslin sheeting in such a way that all insect visitors were excluded; but two limbs on each tree were permitted to protrude beyond the sheeting and were open to insect visits. These two limbs were loaded with fruit; while the flowers under the sheeting, which were dependent on self-pollination, produced only ten small pears. One thousand two hundred and sixty-eight Kieffer pear blossoms pollinated with pollen of the same variety produced only five pears; while 2363 Kieffer blossoms pollinated with Bartlett pollen produced 446 pears. Kieffer is, therefore, almost completely self-sterile (Fletcher, S. W., "Pollination of Bartlett and Kieffer Pears," An. Rep. Va. Poly. Inst. Agr. Exp. Sta., 1909-10). As in the case of the other fruits the importance of the honeybees which can be imported is clearly apparent.

\section{THE POLLINATION OF THE APPLE.}

The apple is the most important of all fruits, and the value of the crop anuually in the United States is at least $\$ 100,000,000$. Every orchardist should know what varieties are self-sterile and how they can be properly pollinated. Of 87 varieties of apples tested by Lewis and Vincent in Oregon 59 were found to be self-sterile; 15 were self-fertile but gave better results

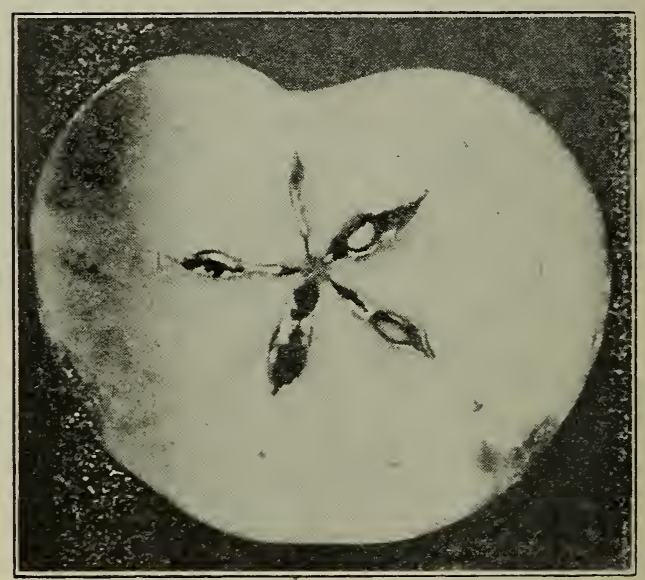

The result of imperfect pollination. Note the shriveled condition of the upper seed and the depression in the apple on that side.

when pollinated by some other variety; and 13 were partially self-sterile.* Among the self-sterile varieties were Bellflower, Gravenstein, King, Rhode Island, Greening, Tolman Sweet, Wealthy, and Winesap; among the self-fertile were Baldwin, Oldenburg, Shiawassee, Washington, and Yellow Newton; partially self-fertile were Ben Davis, Stark, Spitzenburg, and Yellow Transparent. The experiments showed that in the majority of cases cross-pollination is a necessity to ensure a profitable crop. Cross-

\footnotetext{
* The question whetler a variety is sterile to its own pol'en varies according to localitv. For example, the bellflowers in the Pejario Valley, California, are self-fertile; elsewhere they appear to be selfsterile.
} 


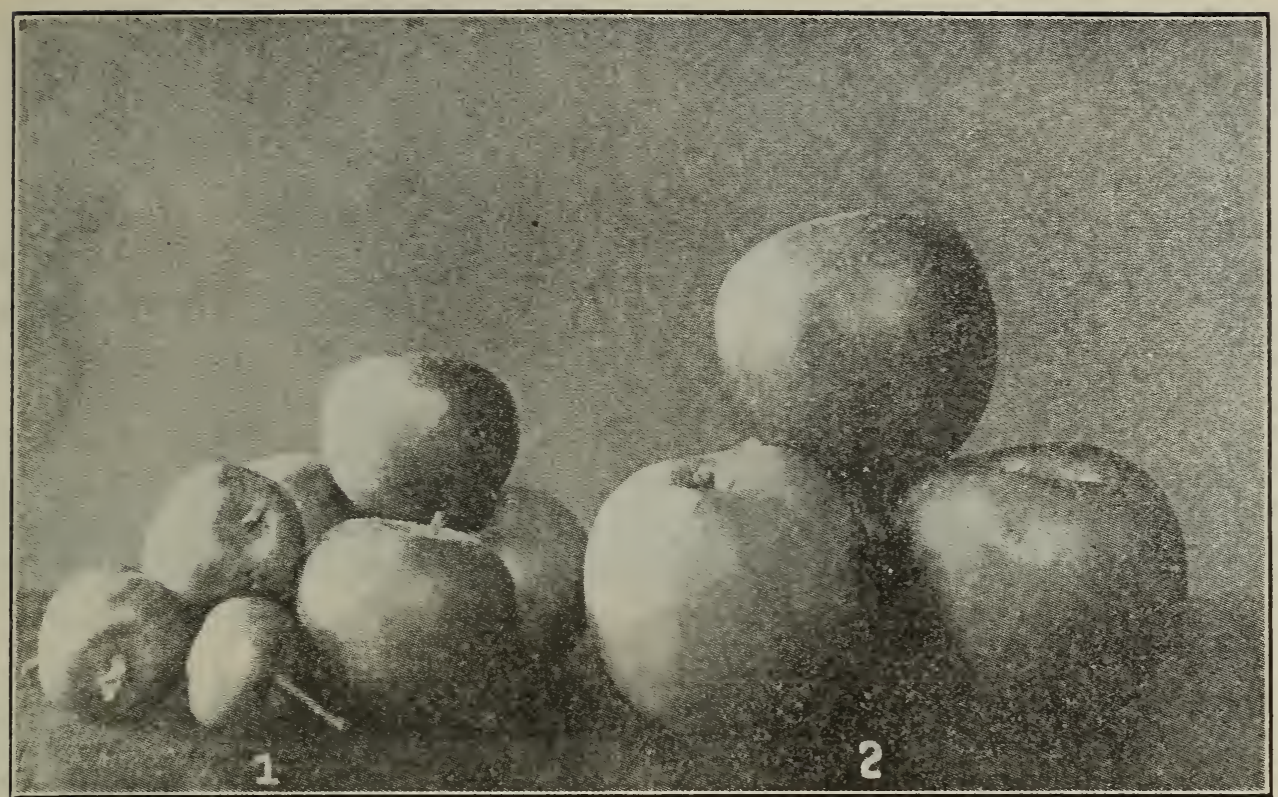

1, Self-pollinated Newtown apples, producing at least one-third of the apples under-sized. 2, Newtown apples pollinated by Grimes Golden; no small apples.-(1fter Lewis and Vincent.)

ing always gave better results than selfpollination, and is the rule, while selfpollination is the exception. Cross-pollinated trees gave larger and finer fruit with well-developed seeds; while self-pollinated trees gave smaller fruit with the seed usually wanting or abortive, as is shown in the following table:

EFFECTS OF SELF AND CROSS POLLINATION.

Oregon Exp. Station, 1908. Newtown Apple

$\begin{array}{ccc}\text { Pollinated } & \text { Av. wt. fruit } & \text { Av. wt. seeds } \\ \text { by Self } & 73 \text { grams } & .05 \text { grams } \\ \text { by Esopus } & 147 \text { grams } & .66 \text { grams } \\ \text { by Grimes } & 173 \text { grams } & .60 \text { grams } \\ & \text { Esopus Apple } \\ \text { by Self } & 100 \text { grams } & .13 \text { grams } \\ \text { by Nertown } & 126 \text { grams } & .65 \text { grams } \\ \text { by Baldwin } & 157 \text { grams } & .71 \text { grams }\end{array}$

Waite found that hand-crossed Baldwins were highly colored, well-matured, and contained many seeds; while the self-fertilized fruit was seedless, only slightly colored, and only one quarter to two-thirds of the regular size.

The Journal of the Board of Agriculture, England, says that out of 63 varieties of apples on which unopened blossoms were enclosed and left untouched the only one that matured fruit was Irish Peach. Of those enclosed and pollinated with their own pollen by brush, only a few matured fruit.
Others failed to yield any fruit when pollinated with pollen of the same variety. On the other hand, of the 64 crosses made, 43 were successful. In Illinois there were formerly many large orchards of 40 to 80 acres of a single varietty which seldom or never bore large crops; while mixed orchards in the vicinity often gave bumper yields (An. Rep. Mass. F. G. Assoc., 1914, p. 47). But under certain circumstances a single variety planted in large blocks has been kuown, according to Waite, to yield satisfactorily, as the Ben Davis at the Olden Fruit Farm in Missouri. In Oregon it has been the practice to plant two rows of one variety, then two rows of the variety used as a pollinator, followed by two rows of a third variety. Varieties must be selected, of course, that bloom at the same time.

The flowers of the apple are larger than those of the pear, partially rose-colored and pleasantly scented, especially in the evening, when they are attractive to moths. The stigmas mature two days before the anthers. The stamens stand erect, so covering the nectary that the nectar is not as easily accessible as that of the pear. Bumblebees which seldom visit pear flowers are common on apple bloom. At the Connecticut Experiment Station 52 insects were listed as visitors, among which were 26 species of bees. 


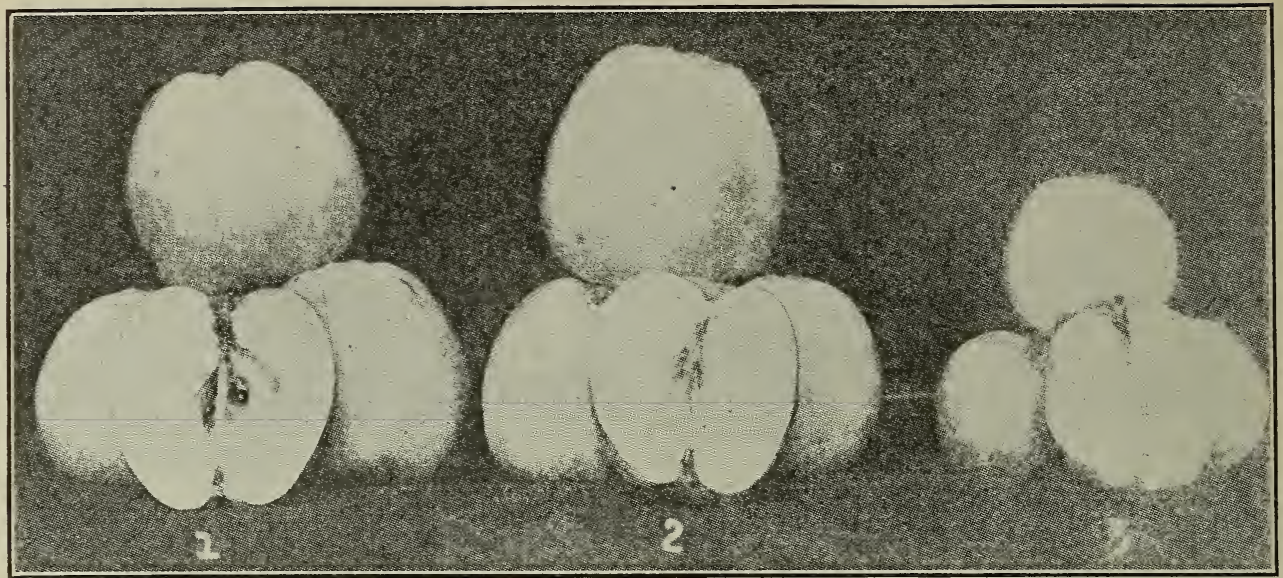

1, Keswick Codlin apple cross-pollinated; 2 and 3, self-pollinated. Notice the absence of seeds in the self-pollinated apples.-(After Lewis and Vincert.)

It is a matter of common observation that where an apiary is located near an apple orchard honeybees are frequent visitors to the bloom, and often appear to be the only insects present. Waite observed that in large orchards covered with blossoms there were not sufficient bees to pollinate the trees; and this is no doubt often the case in sections where apple-growing is the principal industry. The president of the Vermont Horticultural Society found on examination that in orchards which failed to produce abundantly there were no bees or too few to be of much use. Wherever there were large apiaries there was in every instance a large apple crop (Gleanings in Bee Culture, March 15, 1912). Plant mixed orchards, says Waite, or at least avoid planting solid blocks of one variety. Be sure that there are sufficient bees in the neighborhood to pollinate the blossoms properly, while a large fruit-grower in California declares: "Bees and fruit go together. I can't raise fruit without bees." (Waite, M. B., "Cross-pollination of Apples," Year-book Dept. Agr., 1898, Lewis, C. I., and Vincent, C. C., "Pollination of the Apple," Oregon Exp. Sta., Bull. No. 104, 1909.)

\section{THE POLLINATION OF THE QUINCE.}

The common quince (Pyrus Cydonia) has solitary flowers, which are larger and bloom later than those of the apple or pear. The stigmas mature before the anthers, but selfpollination occurs regularly. The flowers yield nectar, and 30 species of insects have been enumerated by the Connecticut Experiment Station as visitors.
Experiments in crossing were made by Waite at Rochester, N. Y., in 1892-93. Pollen from Orange, Rea, Champion, and Meach were used, and the flowers (from which the anthers had been removed) were enclosed in paper and cheese-cloth bags. Both the crossed and self-pollinated flowers produced a fairly good percentage of fruit and practically an equal quantity. The experiments showed no striking benefits from crossing as did those with the apple and pear. (Waite, M. B., Yearbook of Dept. Agr., 1898, p. 178.)

\section{THE POLLINATION OF THE ORANGE.}

Numerous crosses have been made by the Department of Agriculture between the common orange and other species for the purpose of obtaining hardy and improved varieties with promising results. The white flowers of the orange secrete nectar so freely that at times it drips upon the foliage and grass beneath the trees.

Formerly the orange-growers of Florida opposed the placing of colonies of honeybees in the groves, believing that they injured the flowers and fruit. Beekeepers were obliged to pay for this privilege. But with a better understanding of the value of bees in pollination their presence is now recognized as desirable. Around Bradentown the citrus men are actually offering bee-yard sites free of rent, and in many instances even buy bees to place among the trees. The Manatee Fruit Company of Palmetto has established three bee-yards in connection with their groves and wish for more. They declare the nearer the bees to 
the groves the larger the quantity of fruit and the better the quality. An orangegrower of Terra Cea for six years or more has had 40 colonies of bees in his grove and every year during this time has had a fine crop of fruit which has attracted wide attention. The marked increase in the quantity and quality of the oranges raised around Deland is largely attributed to the greater number of bees kept near the groves. Twenty years ago there were not ten hives and now there are hundrerls. There should be at least five hives to the acre. (Baldwin, E. G., The Deland News, Dec. 23, 1914.)

\section{CONCLUSIONS.}

Many nut-trees, cereals, and a few fruittrees are pollinated by the wind; but the majority of berry and larger fruit plants in North America are either pollinated by insects or self-pollinated. The few pollen grains distributed by the wind are of no importance. This is clearly shown both by the structure of the flowers and by repeated experiments. A noteworthy example is given in the bulletin of the Oregon Experiment Station for 1909. From 1500 blossoms on a seven-year-old apple tree all the petals were removed in order that they might not attract insects. The result was that only eight bees were seen to visit the flowers, while another tree about 20 feet away, which bloomed profusely, received forty visits from bees in half an hour. The stamens were also removed to prevent selfpollination. Only five flowers set fruit. Evidently wind did not pollinate a blossom.

Self-sterility is very common among cultivated fruits. It is partly due to the separation of the stamens and pistils in different flowers and partly to the impotency or ineffectiveness of the pollen in self-pollination. Hybrids, as among the grapes, are usually self-sterile. A variety may be sterile to its own pollen and also to the pollen of another variety, e. g.. the Napoleon and Bing sweet cherries are self-sterile and mutually inter-sterile. A knowledge of self-sterility is, therefore, of the greatest importance in fruit-growing.

Among cultivated fruits cross-pollination by insects usually prevails, even among spe- cies possessing the power of self-fertilization. Pollen from another variety is generally prepotent over pollen from the same rariety. Self-pollination in the early stages of most fruit-blossoms is prevented by the stigmas and anthers maturing at different times (dichogamy), also by their relative position. Fruits resulting from cross-pollination are usually larger, better formed, and contain fully developed seeds.

\section{(4)}

In the absence of cross-pollination many fruit-blossoms may. be self-pollinated by the stigmas at the close of the blooming period, bending backward until they touch the anthers. According to Waite self-pollinated and cross-pollinated flowers of the quince were equally productive, but this statement may be modified by further observation. Fruits from self-pollinated and self-fertilized flowers are usually smaller, less perfect, and contain only vestiges of seeds. Automatic self-pollination is as effective as selfpollination by hand. At the Oregon Experiment Station two sets of flower-buds of different varieties of apples were enclosed in bags. One lot was left untouched. The bag's of the other lot were opened, the flowers pollinated by hand, and the bags then replaced. Both lots gave practically the same results.

Beetles, flies, butterflies, and moths, sawflies, wasps, and bees are all useful agents in pollination; but sometimes certain beetles and flies do more harm than good. Ants are invariably hurtful. The bees and wasps are the most beneficial, next come the flies, followed by the butterflies and moths, while the beetles stand last.

In wild or thinly settled regions and in small orchards the wild bees are very beneficial; and their visits to plums, cherries, blackberries, and in some instances other fruits greatly outnumber those of the honeybees. But many of the wild bees fly only from 30 to 90 days; a part are vernal and a part autumnal; and as they build their burrows largely in the ground they are destroyed or driven away by intensive culture. They cannot, therefore, be relied upon in extensive fruit plantations for pollination. 


\section{(7)}

The pollination of cultivated fruits can be controlled with certainty only by the aid of honeybees. This has been repeatedly pointed out in the preceding pages. It is confirmed by the practical experience of hundreds of fruit-growers. As these are essentially similar and all agree that honeybees are a necessity it will be sufficient to give a few examples. In a remarkable statement of Albert Repp, of Repp Brothers, owners of an 800-acre fruit farm at Gloucester, N. J., he says:

"I could not do without bees. I never take a pound of their honey. All I want them to do is to pollinate the blossoms. I'd as soon think of managing this orchard without a single spray-pump as to be without bees. I've got fifty colonies now, and am building up the apiary each year."

About nine miles north of the plant where this work is published is a fifty-acre apple-orchard operated by J. L. Van Rensselaer. This orchard for a number of years had been neglected in that it had not been sprayed nor pruned. Mr. Van Rensselaer finally leased it, sprayed and pruned the trees, and asked the publishers to put some bees on the place, which was done. The first year, 16,000 bushels of perfect apples were harvested, when, prior to that, scarcely 500 bushels were obtained. Every year since that, from 10,000 to 15,000 bushels have been secured. Mr. Van Rensselaer enthusiastically says the bees play a very important part in securing these results.

The apple-growers of the country are waking up to the fact that there must be bees in the orchards; and beekeepers are now having a considerable demand from the large fruit-growers for bees to put in their orchards.

The editors of the various fruit-journals, among them The Fruit-grower, of Rochester, N. Y., and Better Fruit, Hood River, Oregon, have a number of times published strong editorials in favor of putting bees in orchards. Among the leading agricultural journals is the Rural New-Yorker. Its editor made the statement, "I have seen the certain results of the good work of the honeybee in a neighbor's orchard. Those bees break the trees down just as truly as tho they climbed on the trees by the million and pulled on them. The appearance of those trees after a few years of beekeeping would have convinced any fair-minded man that our little buzzing friends are true partners of the fruit-grower."

Mr. E. Whitcomb, of Nebraska, a former president of the National Beekeepers' Association, reports how the bees helped to secure a cherry crop in 1915 when other growers without bees secured none. Writing for the Independent Farmer he says:

We had 300 bearing cherry-trees close to our apiary. During the blooming season there were two days during which our bees worked on these cherry-blossoms profusely. As a result we harvested 300 bushels of cherries when our neighbors two or three miles away, who had no bees, and whose trees bloomed as profusely as did ours, were compelled to come to our orchard for cherries.

It is the unanimous opinion of all progressive fruit-growers that honeybees and fruit culture are inseparable.

\section{(8)}

Besides pollination the fruit crop is influenced by the weather, temperature, the condition of the soil, and the age of the trees. Insect pests, fungous growths, diseases, and spraying the trees while in bloom, are also injurious. Cold rainy weather, by preventing the flight of insects, interferes with the proper pollination of the blossoms.

The usual manufacturer of chemicals for spraying and spraying outfits not only tells how to mix the chemicals for the sprays, but how to apply them. Only one, so far as the author knows, advocates spraying when the trees are in bloom. The reader will, of course, patronize the others, who follow recommendations of experiment stations to spray before and after the petals have fallen.

The suggestion has been made that the difficulty can be overcome by making a spraying solution that will be repellent to insects. It is recommended to add sulphur (which is said to be repellent to insects) to the arsenate of lead or copper sulphate. Full directions for doing this can be secured from experiment stations; but it is not proven that sulphur is repellent to bees when there is a dearth of honey. The author believes they would help themselves to the poisonous nectar in the blossoms. If so, it behooves the fruit-growers for their own interests to spray before the blossoms open, and after the petals fall. 


\section{G}

GALLBERRY (Ilex glabra(L.) A.Gray). $-\Lambda$ lso known as inkberry and evergreen winterberry. The common gallberry is one of the best honey-plants in the United States. It grows in sandy soil near the coast from Massachusetts to Georgia and Florida and westward to Louisiana. In southern Georgia it covers hundreds of

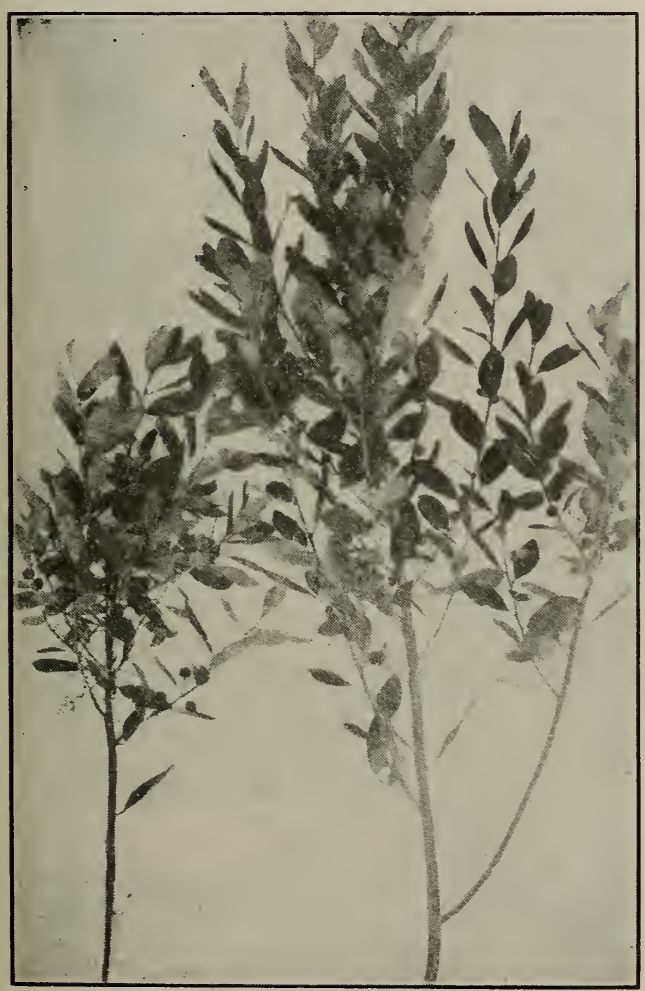

Common gallberry (Ilex glabra).

acres of the sandy coastal plain, but it will not flourish in a limestone soil. The gallberry is an evergreen shrub, with shining dark green, small obovate leaves. It multiplies both by offshoots and from seed; and is rapidly extending over the new land from which the pine forest has been recently cleared. The diffusely branched bushes form dense thickets which withstand the encroachments of all other plant growths and can be passed thru with difficulty.
The blooming period lasts for about a month beginning with May and closing early in June. The small flowers, in a multitude of little clusters, are produced in the greatest profusion, and 3000 have been counted on a bush with a stem only half an inch in diameter. Innumerable sprays of white bloom, variegated with green leaves,

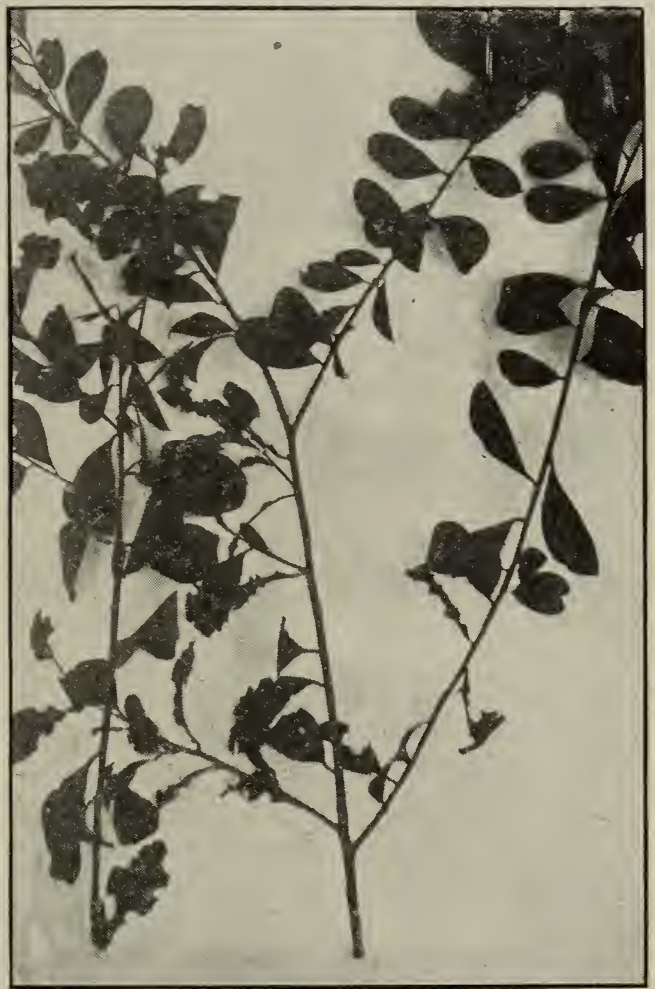

Swamp gallberry (Ilex lucida.)

toss and wave in the wind like a great foam-crested sea. Except in one of the vast northern apple-orchards in June no more attractive sight can be found. The flowers are largely dioecious, i. e., a part of the bushes produce chiefly staminate and a part mostly pistillate flowers; and they are, therefore, dependent on insects for pollina-. tion. The sterile flowers are in clusters of 3 to 6 , while the fertile are solitary. The bushes begin to bloom the second year. 
In Georgia the gallberry is the most important and common honey-plant. We have never failed, says J. J. Wilder, to get a surplus from it even during the most unfavorable weather conditions. In over half a century there is no record of its ever once disappointing the beekeeper. The largest surplus that has been obtained from a single colony is 147 pounds. During the honey-flow the bees disregard all other bloom, working until about 8 o'clock in the morning for pollen when the flow begins and continues for the remainder of the day. The honey is light amber, very heavy, and very mild and pleasant in flavor. When it is pure and well ripened it has never been known to granulate. Altho the honey is produced by the hundred tons it is rarely shipped north as it is impossible to fill the demand for it in the Southern markets. Wilder declares that he has never known a gallberry section to be overstocked, and in one location 362 colonies did nearly as well as 100. In 1907 good gallberry locations in Georgia were, in his opinion, nearly numberless, and large quantities of this fine honey were annually lost for want of bees to collect it. In North Carolina many beekeepers give the gallberry as one of the leading honey-yielders in the eastern part of the state.

The berries (drupes) are shining black, and are sometimes used for dying wool or in making a substitute for ink, whence the name inkberry. They are also called winterberry because they remain on the bushes in great numbers during the winter and afford a never-failing food supply for birds.

Swamp gallberry (Ilex lucida (Ait.) T. \& G.).-This species is also an evergreen shrub, resembling the common gallberry in leaf, flower, and fruit; but it is a little larger, blooms a little earlier, and grows in swamps. It extends from Virginia to Florida and Louisiana. The honey is also very similar to that of $I$. glabra, but, according to Livingston, is milder. (A synonym is $I$. coriacea.)

\section{GLOVES FOR HANDLING BEES.-}

Altho a good many apiarists work with bare hands and bare wrists, there are a few who prefer to use gloves with long wrists, and quite a large number who use them with fingers and thumbs cut off. If the bees are hybrids, and extracting is carried on during the robbing season, it is a great convenience to use something that protects the back of the hands and wrists, leaving the fingers bare, so that, for all practical purposes of manipulation, one can work as well with protectors as without.

Women beekeepers and men who are at all timid, and a very small number who seem to be seriously affected by even one sting, might use gloves to great advantage - especially the last-mentioned class, where two or three stings might prove to be serious.

As to the kind of gloves, some use buckskin or dogskin with loose flowing sleeves sewed on at the wrists, with a rubber cord

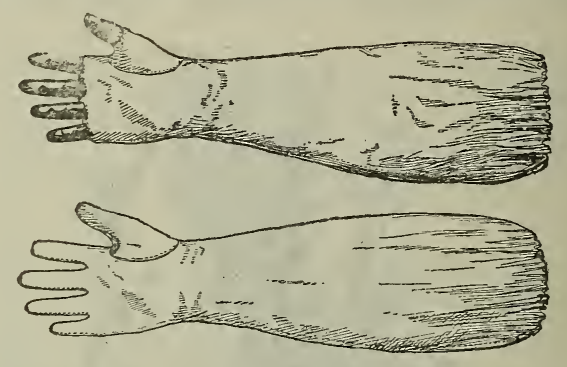

Bee gloves.

gathered in the end to fit over the elbow. Then there is a kind of glove made of heavy drilling soaked in linseed oil or white-lead paint, made specially for the purpose, shown in the illustration. As sent out by the supply-dealers they are not coated, as some prefer to use them plain; but where the bees are especially cross, the fabric will need to be further reinforced with paint or linseed oil.

For further particulars regarding beedress, see VEILs.

GLUCOSE.-This name is applied to the thick viscous liquid obtained by the concentration of a solution coming from the incomplete hydrolysis of starch. The word is misapplied by a great many, especially in the sugar-cane belt, for the reducing sugars present in the cane. From a purely chemical side, glucose means the sugar dextrose, so with these various applications of the word some little confusion exists. In the commercial world, however, the first is the accepted meaning of the word. In the United States the source of glucose is corn starch, with a little made from potato starch, but in Germany all is made from potato starch. 
Its manufacture consists in the heating of the freed starch with water and a small percentage of hydrochloric acid under pressure. The process is carefully conducted and stopped at the proper point of hydrolysis. The liquid is neutralized with soda and concentrated to the desired consistency, which is a liquid of about 15 to 20 per cent water. Formerly sulphuric acid was the acid used for conversion; but on account of its carrying arsenic its use was stopped. The solids of commercial glucose consist of about one-third dextrose and two-thirds dextrin. The dextrins present in commercial glucose are of a different character from those present in floral honey or honey-dew, and by this property its presence in honey can be easily detected.

By increasing the amount of acid, and also lengthening the time of heating, products are made which contain more dextrose and less dextrin. These are known commercially as "70, "80, and "anhydrous "starch sugar." They are, for the most part, solid. Their use in honey adulteration is very rare, and, if used, their detection is comparatively easy for a trained chemist.

Commercial glucose is sometimes known as corn syrup.

The ease with which commercial glucose can be detected when mixed with honey has led to its disuse except in mixtures so labeled. See Adulteration of Honer.

Analysis of American commercial glucose, according to Bryan, published in the Journal of the Franklin Institute for October, 1911, shows the following average, maximum and minimum figures:

\begin{tabular}{|c|c|c|c|}
\hline & & & \\
\hline & & $0 \%$ & \\
\hline & & & \\
\hline Matter & & & \\
\hline Undetermined & 47.50 & & \\
\hline \multicolumn{4}{|c|}{ Direct Polarizations: } \\
\hline & +17 & & \\
\hline At $87^{\circ} \mathrm{C}$. & +16 & & \\
\hline \multicolumn{4}{|c|}{ Invert Polarizations: } \\
\hline At $20^{\circ} \mathrm{C}$. & +17 & & 100 \\
\hline At $87^{\circ} \mathrm{C}$. & +16 & +174. & \\
\hline
\end{tabular}

The undetermined matter, so reported, is composed of dextrose and partially converted starch products.

The percentage of dextrose given is really the percentage of reducing (of Fehling solution) bodies calculated as dextrose. It may contain the sugar maltose and some of the reducible dextrin.
German glucose, according to Herzfeld, published in the above article, shows the following:

\begin{tabular}{|c|c|c|c|}
\hline & & $\mathrm{Ma}$ & \\
\hline & $19.7 \%$ & & \\
\hline & 40.7 & 47.4 & 36 . \\
\hline & .267 & .404 & \\
\hline $\begin{array}{l}\text { Direct } \\
\text { Invert }\end{array}$ & $\begin{array}{r}+1 \\
+1\end{array}$ & $\begin{array}{r}+181.2 \\
+161.2\end{array}$ & \\
\hline
\end{tabular}

Starch sugars show the following composition according to Bryan (also given in same paper).

Crystalline sugars (often referred to as Anhydrous Sugar) :

$\begin{array}{lccc} & \text { Arerage } & \text { Maximum } & \text { Minimum } \\ \text { Water } & 7.42 \% & 9.94 \% & 5.04 \% \\ \text { Dextrose } & 86.33 & 90.70 & 81.52 \\ \text { Dextrin } & .39 & .54 & .16 \\ \text { Mineral Matter } & .73 & 1.06 & .48 \\ \text { Undetermined } & 5.13 & 7.53 & 2.77\end{array}$

Polarization:

10 grams to $100 \mathrm{ec}-$

$$
+27.89+28.65+27.50
$$

Dextrose calculated from polarization$91.59 \% \quad 94.08 \% \quad 90.31 \%$

"Climax sugar" or 80 sugar:

$\begin{array}{lccc} & \text { Average } & \text { Maximum } & \text { Minimum } \\ \text { Water } & 9.84 \% & 10.61 \% & 9.06 \% \\ \text { Dextrose } & 77.54 & 77.84 & 77.24 \\ \text { Dextrin } & 1.04 & 1.15 & .96 \\ \text { Mineral Matter } & 1.18 & 1.18 & 1.17 \\ \text { Undetermined } & 10.40 & 10.96 & 9.83\end{array}$

Polarization:

10 grams to $100 \mathrm{ec}-$

$+27.45+28.40+26.50$

Dextrose calculated from polarization$90.12 \% \quad 93.20 \% \quad 87.03 \%$

"Nabob sugar" or 70 sugar:

$\begin{array}{lccc} & \text { Average } & \text { Maximum } & \text { Minimum } \\ \text { Water } & 16.43 \% & 18.03 \% & 13.77 \% \\ \text { Dextrose } & 69.81 & 73.16 & 66.60 \\ \text { Dextrin } & 1.17 & 2.42 & .57 \\ \text { Mineral Matter } & .80 & 1.12 & .45 \\ \text { Undetermined } & 11.79 & 14.35 & 9.30\end{array}$

Polarization:

10 grams to $100 \mathrm{ce}-$

$\%$ dextrose calculated $+33.45+24.90$

from the polarization

$\begin{array}{lll}95.05 & 109.85 & 81.77\end{array}$

In these tables it is noted that the two percentages of dextrose given do not agree. That one calculated from the polarization is always high on account of the influence of the amount of dextrin (this having a larger polarization influence than dextrose).

GOLDENROD (Solidago).--The goldenrods and asters are the most common and conspicuous of autumnal flowers in eastern 
North America. Both genera belong to the Compositae, the great family which stands at the head of the plant kingdom. The inflorescence of the Compositae represents Nature's greatest triumph in flower-building. Intercrossing by insects, economy of time and material, a large number of seeds well adapted to germinate, and their wide in the common whiteweed, or daisy, the number of florets may exceed 500, in the head of the goldenrod there are only from 16 to 30 , according to the species, e. g., in the cream-colored goldenrod ( $S$. bicolor) there are about 16 ray and 14 disc florets, and in the tall hairy goldenrod ( $S$. rugosa) about 8 ray and 6 dise florets.

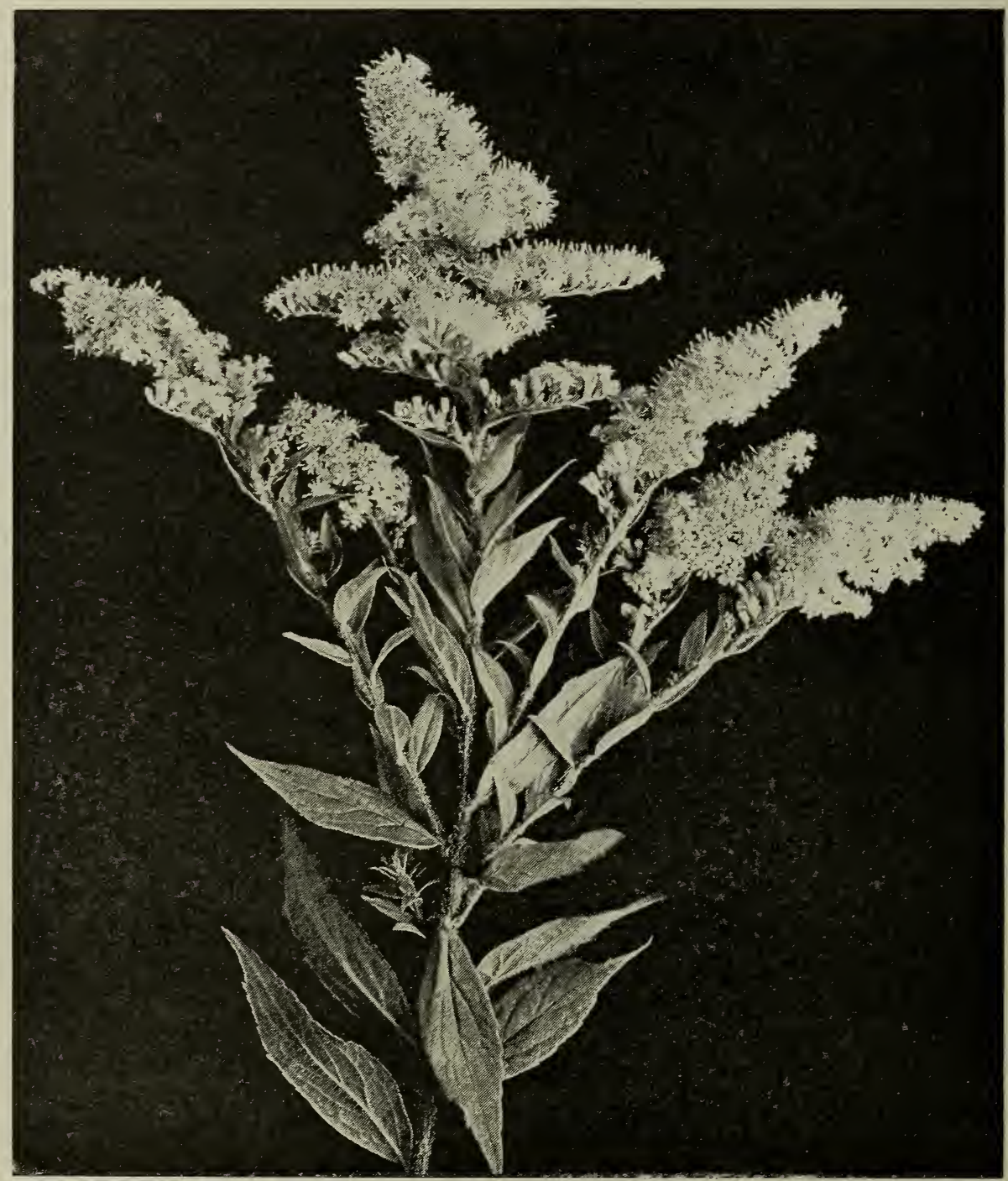

Hairy goldenrod.

distribution have all been very perfectly secured. The individual flower is small and of little significance as compared with the community. Conspicuousness is gained by massing a large number of flowers in a head or capitulum, an arrangement which permits insects to visit them very rapidly. While
The stately and beautiful genus of goldenrods begins to bloom at midsummer, or earlier in the case of the early goldenrod, and in November there is still visible the flower clusters of the Canada goldenrod and the tall hairy goldenrod, while the salt marsh goldenrod may prolong the season 
until December. There are about 85 described species, confined chiefly to North America, with a few in South America and Europe. Fifty species occur north of Tennessee and east of the Rocky Mountains.

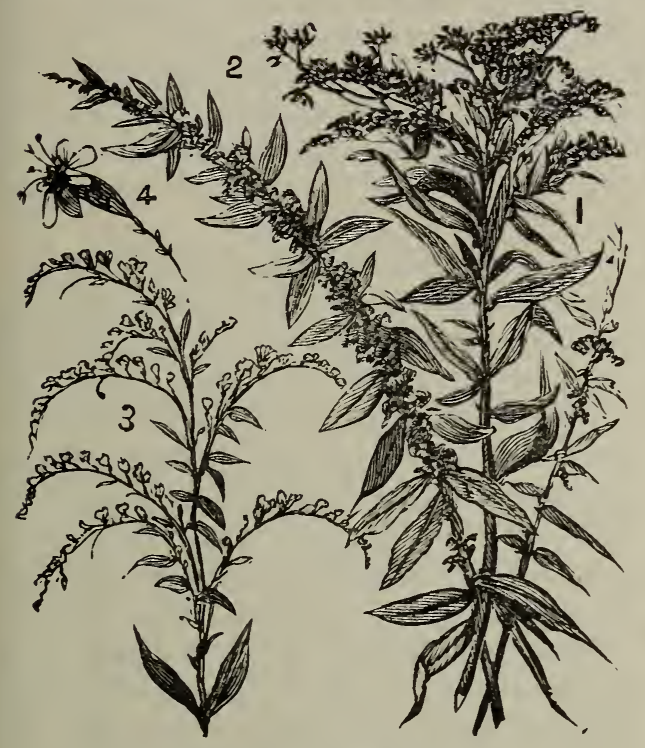

Three species of goldenrod.

They are closely allied, often hybridize, and are difficult to distinguish. There is a form adapted to almost every kind of location. The woodland goldenrod ( $S$. caesia) is found in open woodlands, the field goldenrod ( $S$. nemoralis) is very common in dry fields, the rock goldenrod ( $S$. rupestris)

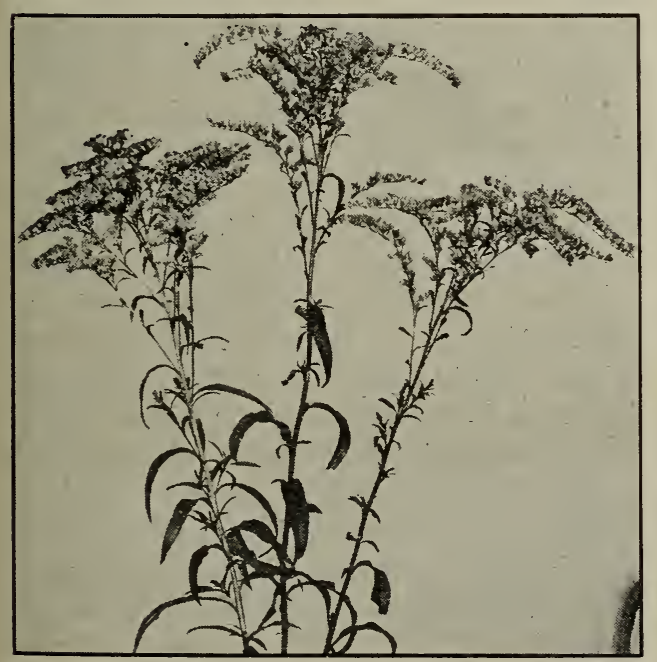

Sweet goldenrod (Solidago odora).

prefers rocky situations, the swamp goldenrod $(S$. neglecta) lives in swamps, while the seaside goldemrod ( $S$. sempervirens) thrives in salt marshes.

Altho the individual heads are so small conspicuousness is gained by massing them in great plume-like clusters or panicles. Their bright yellow color renders them visible both by day and evening; and as the temperature at night is several degrees above the surrounding air they sometimes serve as a temporary refuge for insects. The floral tube is very short, seldom over one millimeter in length so that there are few insects which are unable to gather the nectar. In Wisconsin Graenicher has taken on the

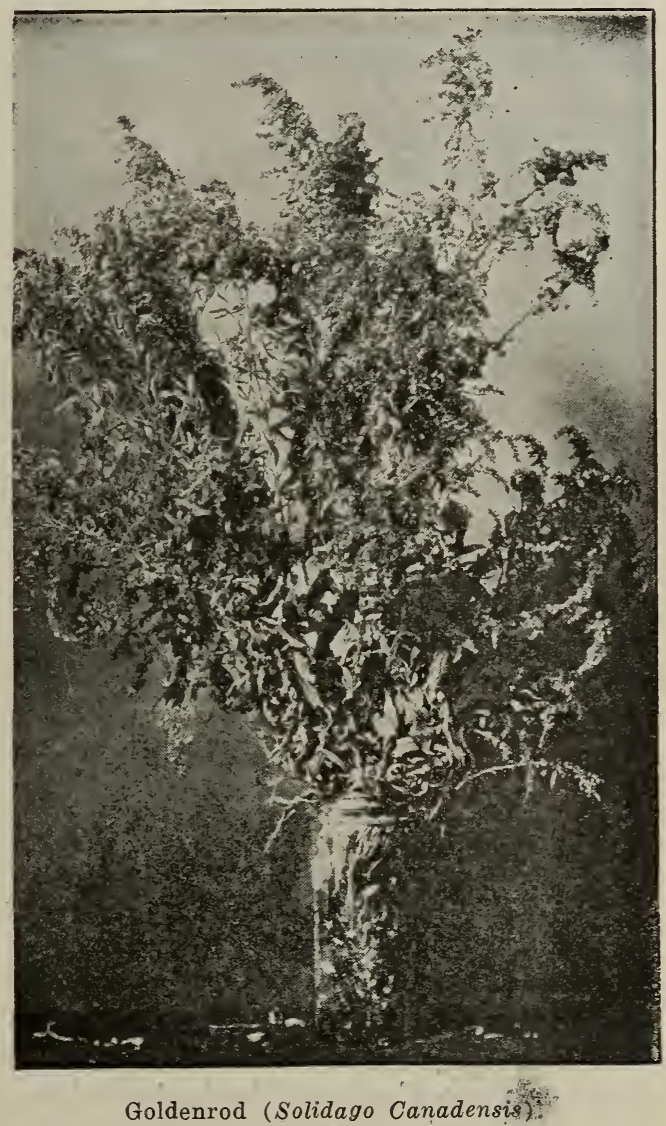

early goldenrod ( $S$. juncea) 182 different species of bees, wasps, flies, butterflies, and beetles either sucking or collecting or feeding on pollen; and on the Canada goldenrod ( $S$. canadensis) 141 visitors. The honeybee visits the florets so rapidly that the number of visits per minute cannot be counted. A large amount of pollen is gathered both by the domestic bee and by wild bees. So abundant, indeed, are the flowers, and so ample the stores of pollen and nectar that 
four or five of our native wild bees, which fly only in autumn, never visit any other plants. Some of the goldenrods are pleasantly scented. Others are nearly odorless.

In New England many species of goldenrod grow luxuriantly in pasture and waste lands and are almost the sole dependence of the beekeeper for winter stores. The bees work on the flowers with great eagerness, and the activity in the apiary equals that of the midsummer honey-flow. In Massachusetts a marketable surplus, according to Burton N. Gates, is often taken in September. Allen Latham states that once in three or four years strong colonies in his apiary on Cape Cod would store upward of a hundred pounds from fall flowers. In southern Maine the bees never fail to fill many frames with goldenrod honey, which because of its golden yellow color and fine flavor is preferred by many persons to white honey. In other sections, as the South and West, it is of less importance; but it comes at a time of the year when it helps to keep the bees busy, and at the same time serves to make up the loss in stores during the latter part of the summer.

The species most common and valuable to eastern beekeepers are the sweet-scented goldenrod ( $S$. odora), early goldenrod ( $S$. juncea), field goldenrod ( $S$. nemoralis), Canada goldenrod ( $S$. canadensis), late goldenrod ( $S$. serotina), tall hairy golden$\operatorname{rod}(S . r u g o s a)$, and in great abundance in salt marshes and along sea-beaches the seaside goldenrod (S. sempervirens). Unlike most of the other species the inflorescence of the common bushy goldenrod ( $S$. graminifolia) is in large flat-topped clusters or corymbs. It is one of the best nectar-yielders, and a favorite with honeybees. Once in a woodland pasture largely overgrown with the hairy goldenrod ( $S$. rugosa) a dozen or more plants of the bushy goldenrod were found. Honeybees were the only insects present, and they showed a marked preference for the bushy goldenrod. They were repeatedly seen to leave the latter species; and after flying about, but not resting on the flowers of the hairy goldenrod, return to the plants they had left a few moments before. A plant of each of the above species was bent over so that their blossoms were intermingled, appearing as a single cluster; a honeybee alighted on the bushy goldenrod and it seemed very prob- able that it would pass over to the flowers of the hairy goldenrod, but such was not the case, for presently it flew away to another plant of the former. The flowers have a sweet fragrance, and are visited by over a hundred different species of insects. All the goldenrods in New England yield nectar, altho the early goldenrod ( $S$. juncea) seems to be of less value than some of the later kinds; but, singularly enough, at Marengo, Illinois, they are of little importance to the beekeeper.

While the bees are bringing in the nectar, the whole apiary is filled with a disagreeable sour smell, which on a calm evening can easily be perceived at a distance of one hundred feet. The odor observed during a goldenrod honey-flow has sometimes been likened to that of decaying carrion, but this is a mistake. When such an odor is present in the apiary, it is caused in most cases by one or more stink-horn fungi (Phallus impudicus). Where there is decaying organic matter, as near old stumps, these fungi frequently spring up in the fall. They exhale a strong fetid scent similar to that of dead carrion, which may easily mislead the beekeeper, as we have learned by experience. The stem is hollow, and the cap-like top deliquesces into a sticky, semiliquid mass, filled with spores, which is very attractive to carrion-flies. The flies feed on the thick syrup and thus become an agent in distributing the spores. As soon as the fungi are removed the carrion-like odor disappears. The sour smell of the nectar also vanishes in a few days.

Goldenrod honey is very thick and heavy with the golden-yellow color of the blossoms. The quality is poor when first stored, but when capped and thoroly ripened the flavor is rich and pleasant. It is the general testimony of New England beekeepers that many persons prefer this honey to any other. They regard its color, body, and flavor as the qualities of an ideal honey. When cut up into cubes for table use it is hardly less attractive than white-clover honey. Its genuineness is never questioned. But the flavor is stronger than that of white clover, which would probably be given the preference by the majority as the great universal staple to be used with bread and butter. Extracted goldenrod honey crystallizes with a coarse grain in about two months. 
We have neve known goldenrod to fail to yield freely even in cold wet weather, but it does exceptionally well during a warm dry fall. The honey has always proven an excellent winter food for bees, and without it there would be little hope for bee culture in New England. So far as the beekeeper is concerned goldenrod is well named, and it would be a want of gratitude on his part not to uphold its claims as our national flower.

GR.ADING COMB HONEY.-The average comb-honey man either does not grade his honey at all, or else does it so poorly that it is not worthy of the name of grading. One large dealer in honey, who buys and sells hundreds of thousands of dollars' worth every year, told us that practically all the comb honey that comes into his hands has to be regraded before it is fit to send out; and, of course, he has to charge this up to the producer. Even beekeepers who are supposed to be up to date, he says, apparently pay very little attention to this allimportant matter. A poorly graded honey, or one that is not graded at all, brings two to three cents less per pound on the whole shipment. The producer himself could easily find some one who would be willing to do such work for him, if he hasn't the time himself, for about half a cent a pound. As a rule the grading should be done by some member of the family, or some one interested in the sale of the honey. A hired man is inclined to be careless, and poor grading reacts on his employer.

Ordinary marketable comb honey can be divided into about three classes: Fancy, No. 1 , and No. 2, or choice. Nothing but fancy should be put into the fancy, and nothing but No. 1 in No. 1. We have personally inspected thousands of pounds of comb honey that had gone to market, and it is certainly surprising how some of the intelligent producers will mix the fancy among the No. 1 and the No. 1 among the fancy, and even go so far as to put choice among the fancy. This disgusts the buyer or the commission merchant, and, of course, he charges up the cost of regrading to the producer. Or if. he does not grade the honey over at all, it is sent out directly to the consumer or retail merchant, who will pay anywhere from two to three cents a pound less because the honey is of such uneven quality.
In order to get the largest price possible for comb honey, it will be necessary to grade it; and the more thoroly and honestly the work is done, the higher will be the price secured. If one is careless in grading there will be inferior sections mixed in with sections of a higher grade; and if the commission man or buyer discorers this he is likely to "knock down the price" of the whole caseful to the price of the inferior sections. It is very important to have every section in a case of the same grade.

Not much will be accomplished if there are a dozen different systems or rules of grading. Various rules have been adopted by the National Beekeepers' Association; but they have never been accepted by the large buyers and commission men of the country; nor have they received the general indorsement of even the beekeepers themselves. The great difficulty encountered has been the diversity of conditions and variety of notions on the part of the producer. For example, one section of the country will have only white honey; another will have largely amber and dark. One locality prefer's double-tier shipping-cases; another, single-tier. Some beekeepers prefer plain sections, and others want beeway. The Colorado beekeepers prefer double-tier cases and $17 \% 8$ beeway square sections. Under these diverse conditions it is a little difficult to get an agreement on one set of rules covering the whole country. However, the Colorado beekeepers have adopted a set of rules which, with some slight modifications from time to time, have been accepted and used by the beekeepers thruout the great West and to some extent in the East. After the new net-weight law went into effect, the rules were modified in that provision was made for weight of honey in a section exclusive of section and shippingcase. The latest revised rules, as put out in February, 1915, by the Colorado Honeyproducers' Association, are as follows:

\section{CONB HONET.}

Fancy.-Sections to be well filled, combs firmly attached on all sides and evenly capped except the outside row next to the wood. Honey, comb, and cappings white, or slightly off color; combs not projecting beyond the wood; sections to be well cleaned. No section in this grade to weigh less than $121 / 2 \mathrm{oz}$. net or $13 \frac{1}{2}$ gross. The top of each section in this grade must be stamped, " Net weight not less than $121 / 2$ oz." 


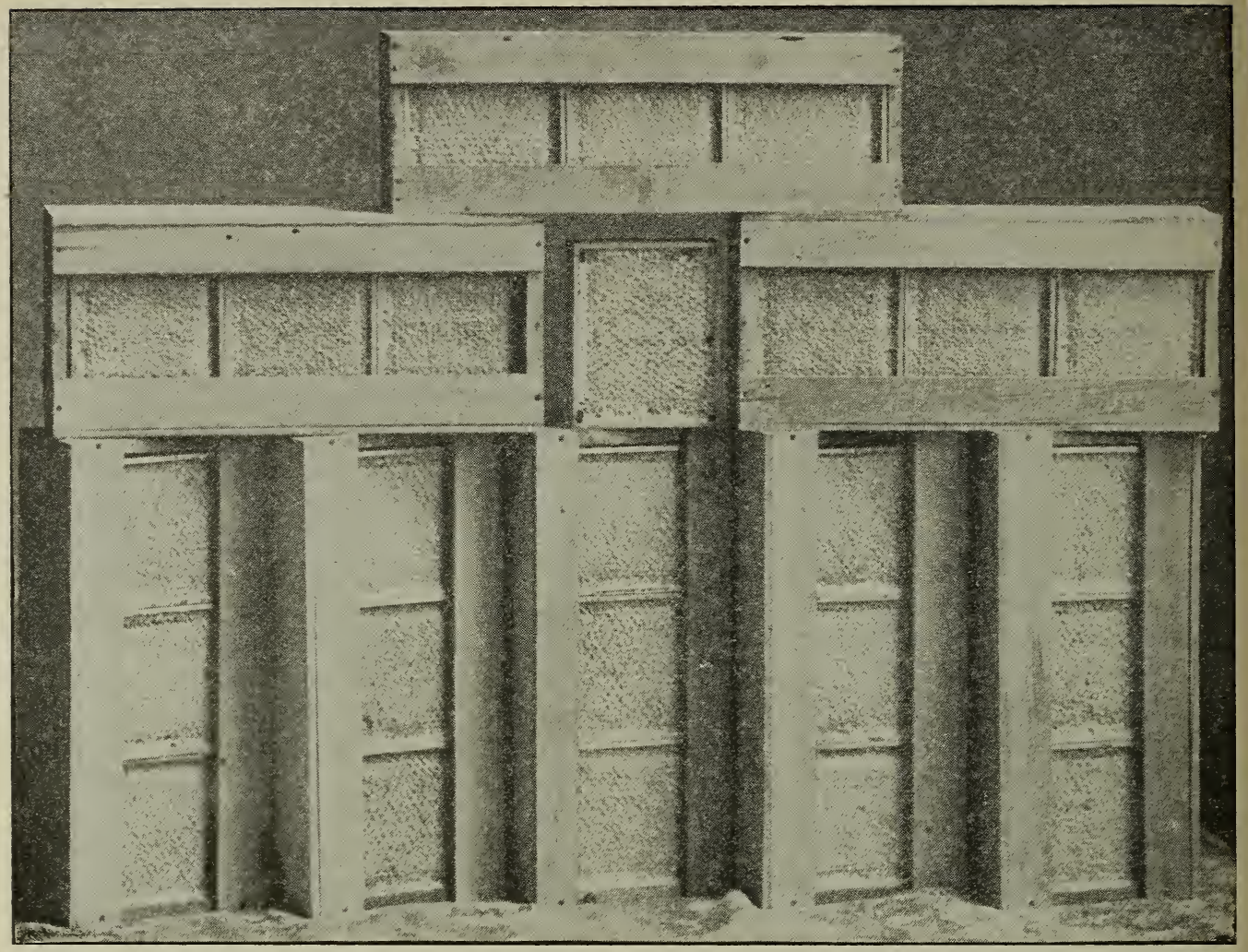

Honey sent by the Ontario Beekeepers' Association to the late King Edward. Note.-This would grade as Extra Fancy by the Root grading rules.

The front sections in each case must be of uniform color and finish, and shall be a true representation of the contents of the case.

Numher One.-Sections to be well filled, combs firmly attached, not projecting beyond the wood, and entirely capped except the outside row next to the wood. Honey, comb, and cappings from white to light amber in color; sections to be well cleaned. No section in this grade to weigh less than 11 oz. net or $12 \mathrm{oz}$. gross. The top of each section in this grade must be stamped, "Net weight not less than $11 \mathrm{oz} . "$ The front sections in each case must be of uniform color and finish, and shall be a true representation of the contents of the case.

Number Two.-This grade is composed of sections that are entirely capped except row next to the wood, weighing not less than 10 oz. net or $11 \mathrm{oz}$. gross; also of such sections as weigh $11 \mathrm{oz}$. net or $12 \mathrm{oz}$. gross, or more, and have not more than 50 uncapped cells all together, which must be filled with honey; honey, comb, and cappings from white to amber in color; sections to be well cleaned. The top of each section in this grade must be stamped. "Net weight not less than 10 oz." The front sections in each case must be of uniform color and finish, and shall be a true representation of the contents of the case.
Comb honey that is not permitted in shipping grades:

Honey packed in second-hand cases.

Honey in badly stained or mildewed sections.

Honey showing signs of granulation.

Leaking, injured, or patched-up sections.

Sections containing honey-dew.

Sections with more than 50 uncapped cells, or a less number of empty cells.

Sections weighing less than the minimum weight.

All such honey should be disposed of in the home market.

\section{FXTRACTED HONEY.}

This must be thoroly ripened, weighing not less than 12 lbs. per gallon. It must be well strained, and packed in new cans; 60 lbs. shall be packed in each five-gallon can, and the top of each five-gallon can shall be stamped or labeled, "Net weight not less than 60 lbs.',

Extracted honey is classed as white, light amber, and amber. The letters " $W$," " $\mathrm{L}$. A," "A" should be used in designating color; and these letters should be stamped on top of each can. Extracted honey for shipping must be packed in new substantial cases of proper size. 


\section{STRAINED HONEY.}

This must be well ripened, weighing not less than 12 lbs. per gallon. It must be well strained; and, if packed in five-gallon cans, each can shall contain 60 pounds. The top of each five-gallon can shall be stamped and labeled, "Net weight not less than 60 lbs." Bright clean cans that previously contained honey may be used for strained honey.

Honey not permitted in shipping grades:

Extracted honey packed in second-hand cans.

Unripe or fermenting honey weighing less than 12 lbs. per gallon.

Honey contaminated by excessive use of smoke.

Honey contaminated by honey-dew.

Honey not properly strained.

As stated, the revised rules are modified to conform to the federal net-weight law; which specifies that only the comb and honey inside of the section and not the section and honey shall be the measure of the quantity sold by weight. Formerly the section surrounding the comb was included. Under the old rules it was permissible to sall the gross weight of the section and the honey at so much per pound. It will be noted, therefore, that the new Colorado grading rules specify the minimum weight, net, and one ounce more gross, as the sections weigh approximately one ounce.

Before a limit was placed on the weight of the sections, producers put up their honey in any old way. Heary and light sections-good, bad, and indifferent in other respects-were all put together in one case. This caused no end of complaint. Under the new set of rules, this is impossible.

Producer's of the country, after the new net-weight law went into effect, September 1914, were compelled to mark every section by weight. Sections that are approximately of the same weight are put in a class by themselves. But no section in that weight shall be less than a certain definite figure in ounces. For instance, under the Colorado grading rules, for " Fancy," no section may weigh less than $121 / 2$ ounces net or $131 / 2$ ounces gross. In grade No. 1 the figures stand respectively 11 and 12 ounces; in No. 2, 10 and 11 ounces.

The operation of the federal net-weight law at first caused a general grumbling on the part of the producer and the dealer alike: but the result has been salutary, because the dealer and the consumer now know exactly what their money is paying for. While the producer at first lost a little because any weight in excess of the minimum figure was given to the consumer, the producer soon learned that it was necessary for him to charge enough more for his product to cover one ounce per section.

The "fancy" grade provides that the comb shall be "firmly attached on all sides and evenly capped;" No. 1 grade provides that comb shall be "firmly attached, not projecting beyond the edge." The No. 2 grade makes no statement as to how the combs are to be attached, but still provides that "it shall be entirely capped except the row of cells next to the wood."

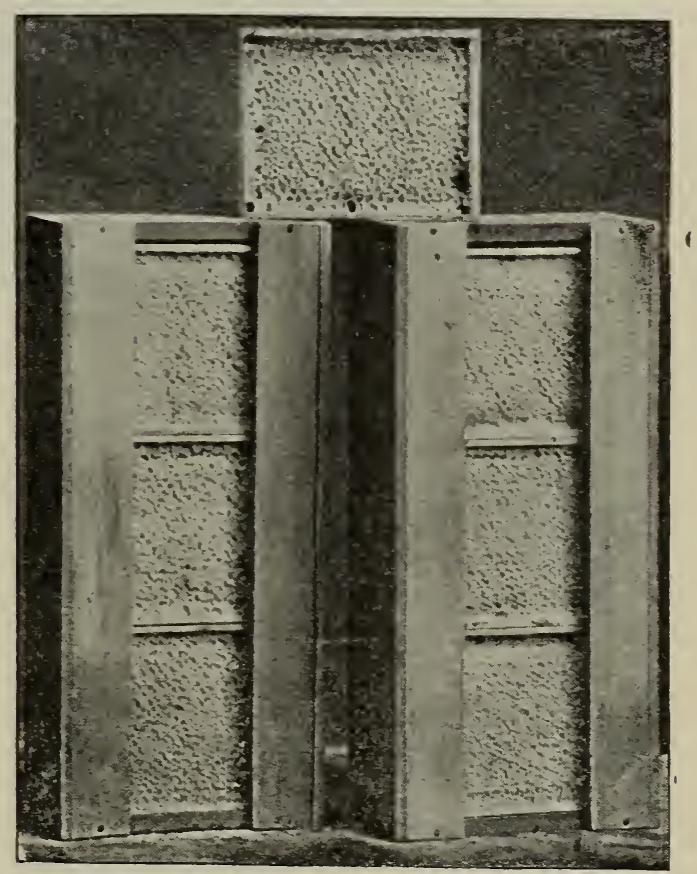

Fancy. comb honer in $4 \times 5$ plain sections.

The revised rules proride, also, that honey must not be packed in second-hand cases nor in badly stained or mildewed sections. It must not show any signs of granulation or leaks; must contain no honey-dew, and must not have an undue amount of cells uncapped.

While these rules are perhaps adequate for the great bulk of comb honey produced, they are not quite flexible enough to take in honey that will be abore the Colorado "Fancy" and No. 1 grade. The A. I. Root Company have the following set of rules which, it will be observed, provide for "extra fancy" and No. 1 and No. 2. 
In harmony with the Federal net-weight regulations and the statutes of many states, all comb honey we handle is figured with the weight of the section box as well as the case excluded. To get the net weight, deduct the weight of the empty case and $1 \mathrm{lb} .8 \mathrm{oz}$. for the weight of 24 sections ( $1 \mathrm{oz}$. each).

\section{COMB HONEY.}

Extra Fancy.-Sections to be evenly filled, combs firmly attached to the four sides, the sections to be free from propolis or other pronounced stain, combs and cappings white, and not more than six unsealed cells on either side. No section in this grade to weigh less than $14 \mathrm{oz}$. net. Cases must average not less than $22 \mathrm{lbs}$. net.

Fancy.-Sections to be evenly filled, comb firmly attached to the four sides, the sections free from propolis or other pronounced stain; comb and cappings white, and not more than six unsealed cells on either side exclusive of the outside row. No section in this grade to weigh less than 13 oz. net. Cases must average not less than 21 lbs. net.

No. 1.-Sections to be evenly filled, comb firmly attached to the four sides, the sections free from propolis or other pronounced stain; comb and cappings white to slightly off color, and not more than 40 unsealed cells, exclusive of the outside row. No section in this grade to weigh less than $11 \mathrm{oz}$. Cases must average not less than $20 \mathrm{lbs}$. net.

No. 2.-Combs not projecting beyond the box, attached to the sides not less than twothirds of the way around, and not more than 60 unsealed cells exclusive of the row adjacent to the box. No section in this grade to weigh less than $10 \mathrm{oz}$. net. Cases must average not less than 18 lbs. net.

CULI, COMB HONEY.

Cull honey shall consist of the following: Honey packed in soiled second-hand cases or that in badly stained or propolized sections; sections containing pollen, honey-dew honey, honey showing signs of granulation, poorly ripened, sour, or "weeping"' honey; sections with combs projecting beyond the box or well attached to the box less than two-tbirds the distance around its inner surface; sections with more than 60 unsealed cells, exclusive of the row adjacent to the box; leaking, injured, or patched-up sections; sections weighing less than $10 \mathrm{oz}$. net.

\section{EXTRACTED HONEY.}

This must be well ripened, weighing not less than 12 lbs. per gallon. It must be well strained; and, if packed in five-gallon cans, each can shall contain 60 lbs. The top of each five-gallon can shall be stamped and labeled, "Net weight not less than 60 lbs." Bright clean cans that previously contained clean light honey may be used for extracted honey.

EXTRACTED HONEY NOT PERMITTED IN SHIPPING GRADES.

Extracted honey packed in second-hand cans, except as permitted above.
Unripe or fermenting honey, or weighing less than 12 lbs. per gallon.

Honey contaminated by excessive use of smoke.

Honey contaminated by honey-dew.

Honey not properly strained.

It will be noted that while these rules are somewhat similar to the Colorado rules, they go further in providing an "extra fancy" or sections weighing not less than 14 ounces net, and a case not less than 22 lbs. net. That of course means some of the combs will weigh more than 14 ounces in order to bring up the entire weight to 22 pounds. The "fancy" grade goes a little further than the Colorado fancy in making the net weight $1 / 2$ ounce higher, and providing that the weight of all sections in the case shall not be less than 21 pounds net. This means that the average weight will be exactly 14 ounces. This provision of the net weight per case puts the grading where many producers will not or cannot meet it; but if they can they will get paid for it, as there is a fancy trade that is willing to pay for a high standard.

There is no doubt that the Colorado rules as written will cover 95 per cent of all comb honey produced; but they do not cover special lots that will meet certain requirements, and for which a correspondingly higher price will be secured.

\section{GRADING BY PICTURES.}

Some effort has been made to grade honey by means of pictures; but nothing definite has been accomplished, as it is difficult to make photos flexible enough to take in the various comb surfaces and cappings of honey that can be included in one grade It is possible true plates may be used in connection with the rules, to enable one to determine what section will grade Fancy, No. 1, and No. 2; for it must be understood that different persons would have a different idea as to whether one section should be graded as No. 1 or Fancy, and a set of pictures showing the idea of an expert on grading might be helpful to a novice. We have given here a few plates that may give an idea of what is meant. But it should be understood that in the pictures the unsealed cells show black-much more in contrast than in the actual combs themselves; or, to put it another way, in any thing but an extra fancy, where no empty 


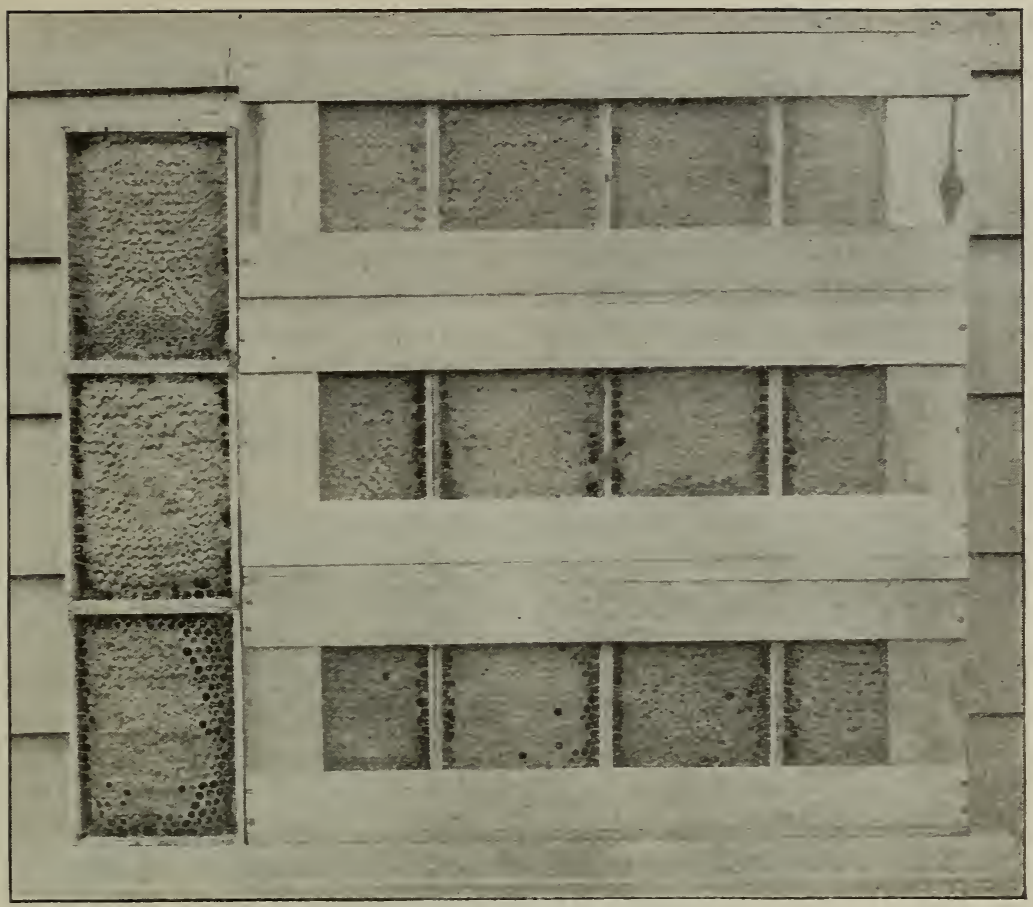

Grading rules illustrated.

cells show, the pictorial representations do not show up as well as the real article.

The honey sent to the late King Edward would be what is called "extra fancy white," according to the Root grading, for it is white honey put up in plain sections, and, as the illustration shows, it is evenly and nicely filled. When cells next to the wood are all sealed, or nearly so, it should be designated as " extra fancy ;" but as such are the exception rather than the rule there will be very little "extra fancy" on the market, altho such honey is generally shown at exhibitions when competing for a prize.

In the half-tone engraving above shown the honey in the top case, with its sample section opposite, would, by the Root grading grade Fancy; that in the middle case Fancy or No. 1, according to the amount of soiled surface, and that in the bottom case would be about No. 2.

\section{TRAVEL-STAINFD AND OTHER SOILED SECTIONS.}

There are really four classes of discolored sections, each due to a distinct and separate cause. First there is what is called the real travel-stained section. As its name indicates, the cappings are soiled because the bees have gone over the surfaces of the cappings with their dirty feet.
Then there is another lot that are stained because the boxes are capped over in the vicinity of old comb, dirt, or propolis. If the faces of such sections are examined carefully it will be found that the stain or discoloration goes clear thru. These discolorations are due to the bees taking up pieces of old black wax, propolis, or anything that will answer as a substitute or filler for pure wax. The cappings of some sections of this sort are filled with bits of old rope, lint from newspapers, small hard chunks of propolis, fine slivers of wood-anything and everything that is handy. Sections of this class often look like those of the first class, hence the frequent confusion.

In the third class are those with soiled cappings, due to the pollen dust or possibly a thin layer of propolis stain.

The fourth and last class takes in all those that are called "greasy" or "watersoaked," having cappings that lie on the honey. The covering to each cell is more or less transparent, or water-soaked-the transparent part being half-moon shaped, or in the form of a ring encircling a white nucleus center that is not greasy or transparent. Some of the trareled sections can be improred by bleaching. See Bleachixg Coms Honer. 
GRANULATED HONEY.-Nearly all liquid honey, and most romb honey, if given time enough, are liable to cloud and partially solidify at the approach of or after cold weather; that is, it assumes a granular mealy condition, something like moist Indian meal, and again like moist fine white granulated sugar. The granules of candied honey are about the size of grains of ordinary table salt, but may be much finer with some grades of honey. Comb holley granulates less readily than extracted, and only after a much longer period. While cold weather is much more conducive to granulation, yet in some localities, and with sorne honeys especially, it takes on the semi-solid form even in warm weather. Some honeys will candy in a month after being taken from the comb, and others will remain liquid for two years. The honey most likely to granulate is extracted alfalfa, which does so in from three to five months. Mountain sage from California and tupelo from Florida remain liquid for a year or longer. Ordinary comb honey in sections, if well ripened, will usually remain liquid as long as the weather is warm. After that time, especially if it has been subjected to cold, there are likely to be a few scattering granules in each cell. These gradually increase in number until the comb, honey, and wax become almost one solid mass. In such condition it is unsuitable for the market, the table, or for feeding back, and should be treated by the plan we will describe presently. See Comb Honer, how to Produce.

\section{IS GRANULATION A TEST OF PURITY?}

In the eyes of the general public, granulated honey is not pure, many thinking it has been "sugared," either with brown or white sugar. But the very fact that it granulates solid is one of the best proofs of its purity. If honey granulates only partially, in streaks, it may be evidence that it has been adulterated with glucose. But even pure honey will assume this condition, while honey that is nearly two-thirds or threequarters glucose granulates very little. Here, again, it must not be taken as positive evidence that, because honey refuses to granulate, or does so only slightly, therefore it is adulterated. The purity of any honey can usually be determined thru the taste by an expert beekeeper who has tested various grades of honey, and knows their general flavor. But here, again, even taste must not be considered an infallible test. Doubts can be removed only by referring a sample or samples to an expert chemist. See AduLTERATION OF HONEY.

\section{HEATING LIQUID HONEY TO PREVENT GRAN-} ULATION.

There is no plan that will act as an absolute preventive; but by a method which we will describe, granulation can be deferred for one and possibly two years. Even after treatment, if the honey is subjected to a freezing and thawing temperature for a series of days it will be almost sure to start candying again. Continuous cold weather with the mercury slightly above zero is not as favorable as alternate cold and warm weather.

$\Lambda$ fter the first few days the honey will appear slightly cloudy. This murky appearance grows more pronounced, and granulation proceeds more rapidly, until the point of solidification is reached. But there is no excuse for having honey at any time, either comb or extracted, kept in a zero or freezing temperature; for all practical purposes we can prevent extracted honey candying for a year on the average.

\section{HEATING TO LIQUEFY GRANULATED HONEY.}

There are two methods commonly in vogue to heat honey. One is, to put it in a double boiler or vat, and gradually raise the temperature to 150 or 160 degrees Fahr., holding it at that point till all the honey is melted. It should then be put into bottles or tin cans, and sealed while hot. Another plan is to liquefy the granulated honey slnwly.. and keep it at a temperature of 130 degrees Fahr. for three days. It should not go ahove 135 degrees. The process of melting will be very slow, and a continuous slow heat so acts on the honey that it will remain liquid much longer than when the heat is applied more rapidly and raised to a higher point. It is then sealed hot, as in the other case.

For full particulars on bottling honey to keep it in a liquid condition, see BotTLING HONEY.

To liquefy honey in the granulated state, or to heat it to prevent its getting into that condition, the honey should be placed in a double boiler-that is to say, a tank with double walls, having the space between the 
walls filled with water. This may be placed on the stove and filled with honey. The double boiler used by the Rauchfuss brothers, of Denver, Col., is shown in the engraving, and its construction will be apparent.

Where one doesn't have such a boiler, and cannot afford one, he can make a very good substitute by taking a common wash-boiler. Into this he puts some blocks about an inch square. On these blocks he places two or three tin pails, or as many as will go into five cents apiece. He cuts off the top at a convenient height, then washes out the cans thoroly. For the purpose of liquefying he uses eight on top of an ordinary cook-stove. To keep the honey from burning he gets some band iron, $3 / 4 \times 3-16$, at some hardware store, and makes a series of hoops on which the cans are to stand while heating. Eight of them are placed together as shown; then, to conserve the heat further, a tin cover large enough to slip down over the whole.

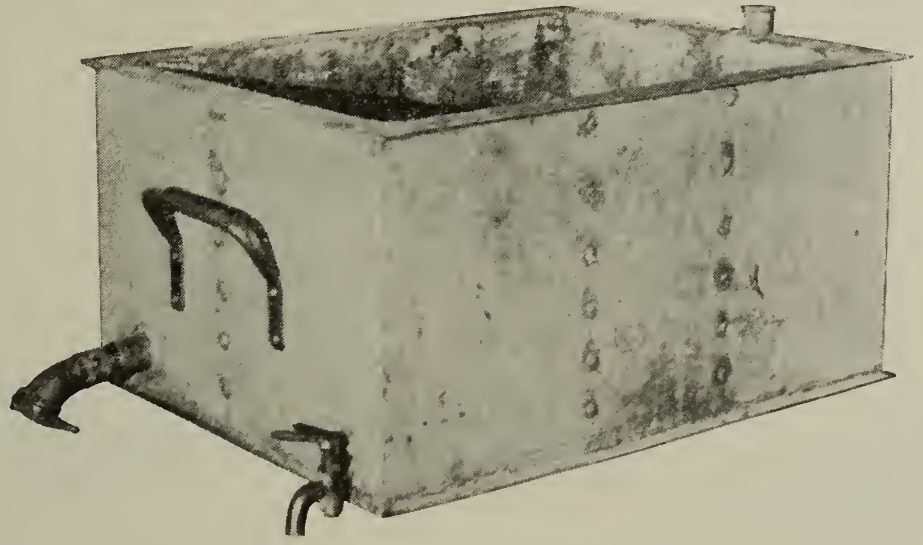

Rauchfuss double boiler for liquefying honey.

the boiler. Should he have something larger than a wash-boiler it would be all the better. The honey is then poured into the tin pails. If granulated solid it may be handled with a spade. Water is poured into the washboiler until it comes within two inches of the top of the pails. The whole is then placed on the stove, and subjected to a slow heat. When the water reaches a temperature of 160 , or nearly that, the fire is checked; the honey should not become any hotter because it may otherwise injure the flavor as well as the color. Honey should never be brought to a boiling temperature except to kill the germs of foul brood, when all such honey may be fed back provided it has boiled at least two hours with a cover on, after having been first thinned down with water so it will not burn.

Mr. C. W. Dayton, of Chatsworth, Cal., has another and very simple out fit to liquefy honey. As it can be made out of materials fourd in any beekeeper's yard, at very sinall cost, many will, perhaps, prefer it to the Rauchfuss double boiler just described.

As will be seen from cut, second colımn, Mr. Dayton makes use of second-hand kerosene-cans, which may be purchased for
With the help of this outfit Mr. Dayton says he can melt up $200 \mathrm{lbs}$. of honey in a very short time. These cans would be more convenient to handle were he to take heavy

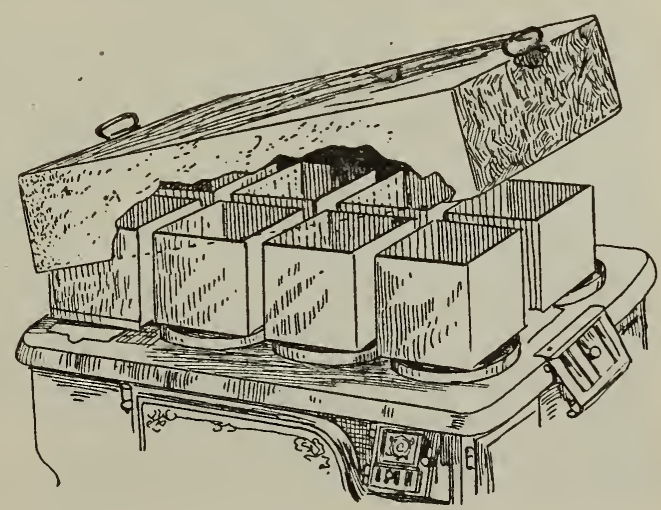

Dayton's oufit for liquefying granulated honey.

wire, make some bails and hook them into holes punched on two opposite sides. He would then have a very serviceable pail at a small cost: and, when the honey is melted, he could lift it off the stove and pour it into some other receptacle from the corner of the cans. This corner makes the finest kind of pitcher mouth. 


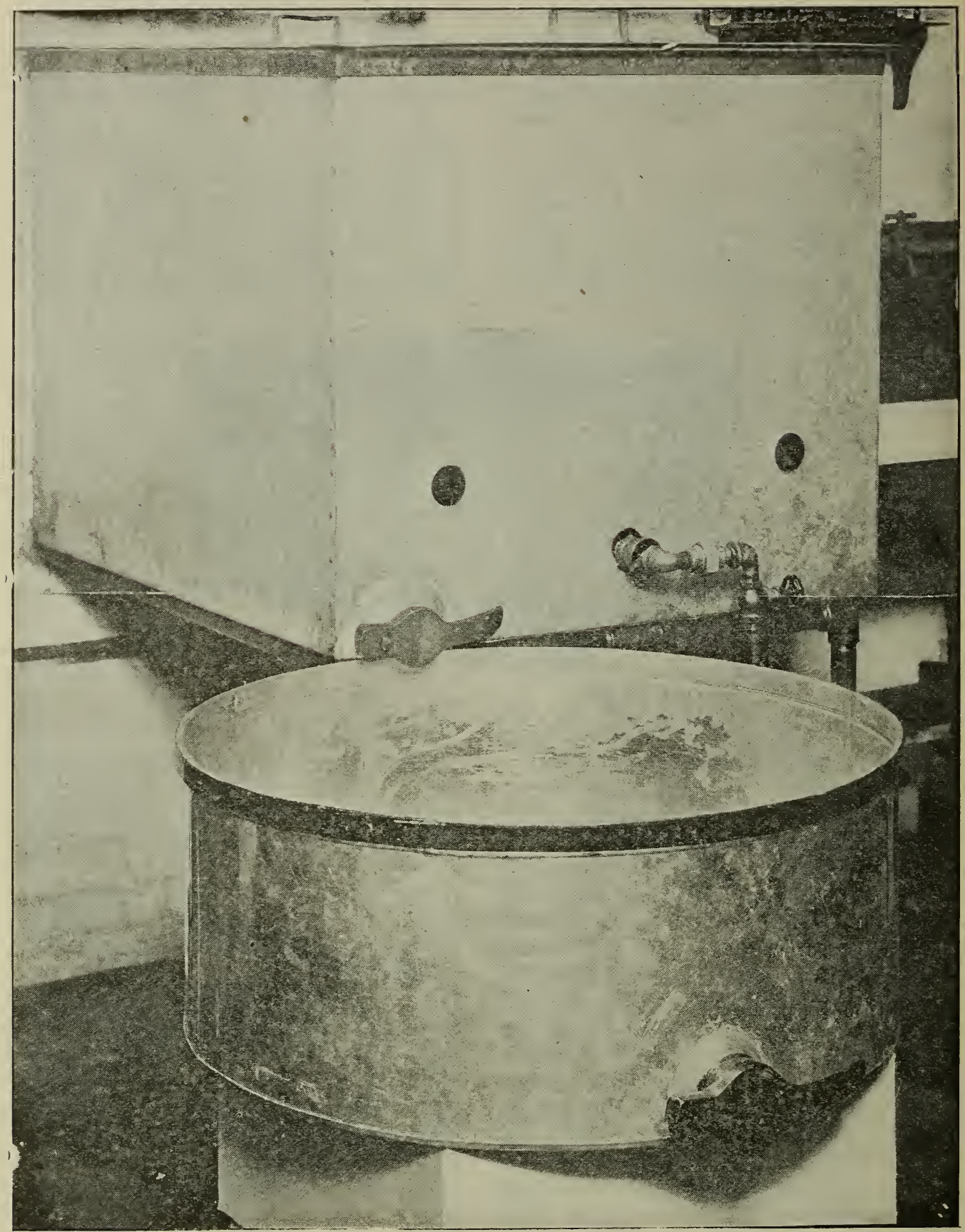

FIG. 1.- Pouder's hot-air oven for liquefying honey in sixty-porund cans. The cans are held upside down, as shown in Fig. 2 ; and the honey, as fast as it becomes liquid, runs down to the bottom of the oven and from thence out the gate, away from the heat.

POUDER'S METHOD OF LIQUEFYING.

Undoubtedly the best arrangement for liquefying granulated honey in square cans is that used by Walter S. Pouder. Here is what he says of it:

- For years I have depended upon the hotwater tank for melting five-gallon cans of granulated honey, but have found many inconveniences connected with the method, and have been obliged to adopt a safer and speedier method. To take care of the expansion I have used syphons, coal-oil pumps, funnels soldered to perforated screw caps, and other methods, but have always found a lack of tidiness; and in some instances we have ruined very superior honey by over- 


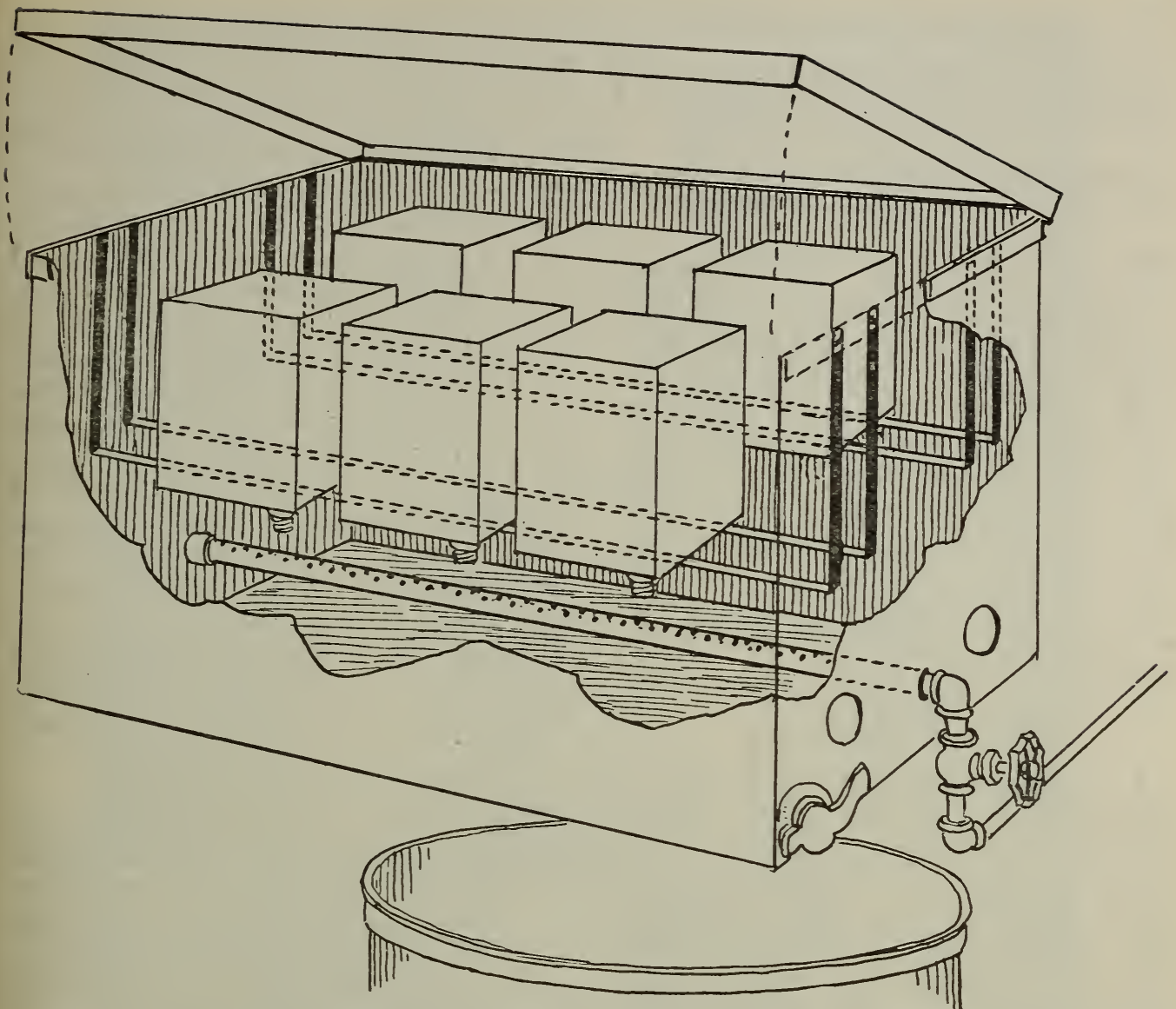

FIG. 2.-Pouder method of liquefying granulated honey, showing the position of cans and gas-burner in the oren.

heating. If we overlooked a nail-hole near the bottom of the can we would find a can of sweetened water instead of honey; and in lifting heated cans from the water I have had the handles pull off; and the can, in falling back, would cause the hot water to slop over and scald my toes till I have seriously wished I did not have to dabble in honey at all.

I have longed for a method in which the liquid honey would flow away from the heat as fast as it became fluid, and at last I have such a device in use, and I believe many readers of this work will be interested. It is simply a gas oven, made of heavy galvanized sheet iron, and of a capacity for six cans, three on each side of the gas-burner, cans to be suspended on brackets in an inrerted position with caps removed. When in use the honey-gate at the bottom of the oven is left open; and as fast as the honey becomes liquid it flows to the outside tank. Considerable experimenting was required in order to maintain proper temperature, and we have learned to regulate the temperature by using a thermometer before we place any honey in the oven. Naturally the highest temperature is nearest the top of the oven, and we are able to keep within 180 and 190, and the temperature declines toward the bottom of the oven, hot air being circulated thruout. Some heat is slightly radiated against the lower part of the cans, and I find this in my favor, as it tends to prevent openings of cans being clogged with granulated honey.

The two round openings in the front are for ventilation, and to secure perfect combustion. There is a three-inch space between the burner and the bottom of the oven; cans are suspended with a 1-inch space between the bottoms of the cans and and the bottom of the oven, and a two-inch space over the tops of the cans; and there is also a 12-inch space between the two rows of cans. We also find the device very convenient in melting jars of granulated honey without so much as injuring the label by simply inverting the open jars on a heavy wire screen.

Such an oven could be constructed for any capacity-for two, four, or six cans at one time, and could be used over a gasolinestove where gas is not obtainable. A thermostat could be added, thus making it an automatic arrangement; but in my business I have not found it necessary. The honey, as it flows into the outside tank, is just right to be strained into our bottling-tank, and there 
is no deterioration, because it could not be overheated.

Visiting beekeepers pronounce the entire arrangement a model of perfection, and I submit the above description by request.

Under Botruing Honer will be found a description of a similar oven using steam.

\section{MELTING UP HONEY IN A CAPPING-MELTER.}

Under the head of Extracting and Comb HoNey the use of a capping-melter is described with a set of illustrations. This outfit is also well adapted for melting up granulated comb honey. Ordinarily granulated extracted will run thru it very readily without any danger at all of impairing the flavor, and, what is more, it will be strained in the process. In the case of candied comb honey, the wax and honey will be very nicely separated by the device shown under Extracting, subhead "Capping-melters."

\section{CAUSE OF GRANULATION.}

As already stated, the primal cause is alternation of cold and warm weather. During any very cold temperature, prolonged for days, honey probably would not candy at all, but chill into a hard waxy mass, readily softening again in a warm atmosphere. Honeys that contain a larger amount of dextrose granulate more readily than where the reverse is true. Stirring or violent agitation hastens granulation; and if some granulated honey is mixed with ordinary liquid extracted, the latter will granulate much more rapidly; for when honey once starts to granulate, the process goes on very rapidly, altho it may take from ten days to six months for the honey to pass entirely from the liquid condition into solid.

Under BotTLING we spoke of there being two ways to prevent honey from granulating. The first method employs artificial heat. The second one uses the actinic rays of the sun, that probably have some effect in preventing granulation, aside from the heat itself from the direct rays of the sun. For full particulars regarding this, see Bottling Honey.

\section{THE SCIENCE OF GRANULATION.}

While we do not know very much as yet about the theory of honey granulating, yet we do know that, while the nectar of flowers may be, chemically, cane sugar, yet after it has been stored in the hive by the bees, and partially digested or worked over as explained under HONEY elsewhere, it is known to science as invert sugar. Ordinary honey is a combination of dextrose, levulose, in approximately equal proportions, with a little water. "Honey candies upon standing," says Dr. Headen, of the Colorado Experiment Station at Fort Collins, "because of the ability of its dextrose to assume a crystalline form much more readily than the levulose." At the Colorado state beekeepers' convention, he showed samples of free dextrose and levulose. The former looked like very nice light-colored brown sugar; the latter appeared like a cheap grade of dark-colored molasses. The doctor explained that, if granulated honey were subjected to a sufficient pressure, the greater portion of the levulose could be obtained, leaving the solid mass largely dextrose. The levulose of honey candies slightly, but is very different in appearance from its dextrose constituent.

\section{FREAKS OF HONEY-GRANULATING.}

This problem of honey-granulating is very interesting. It sometimes transpires that of two lots taken from the same barrel or can, and placed in two self-sealing packages, the honey in one will soon granulate while in the other it will remain liquid, notwithstanding that both packages have been subjected to the same temperature and general conditions. If this happened in the case of sealed packages only we might suppose that the sealing of one package was less perfect than the other; but that the candying does not depend on the sealing altogether is shown by the fact that the two lots of honey may not be sealed at all, and yet one of them turns to a solid while the other remains liquid. These instances are by no means frequent: indeed, they are rare; yet they occur just often enough to excite curiosity.

We have seen alfalfa honey after it had been in glass jars seven years, and were told that it had candied solid within a few months after being taken from the extracting-cans. At the time re saw it (seven years after), it was going back to the liquid condition. Some cans were almost entirely liquid, and others had streaks of granulation reaching out like the branches of an evergreen-tree all thru the package. There was every evidence to show that so far it had undergone a slight chemical change. This change was doubtless due to the con- 


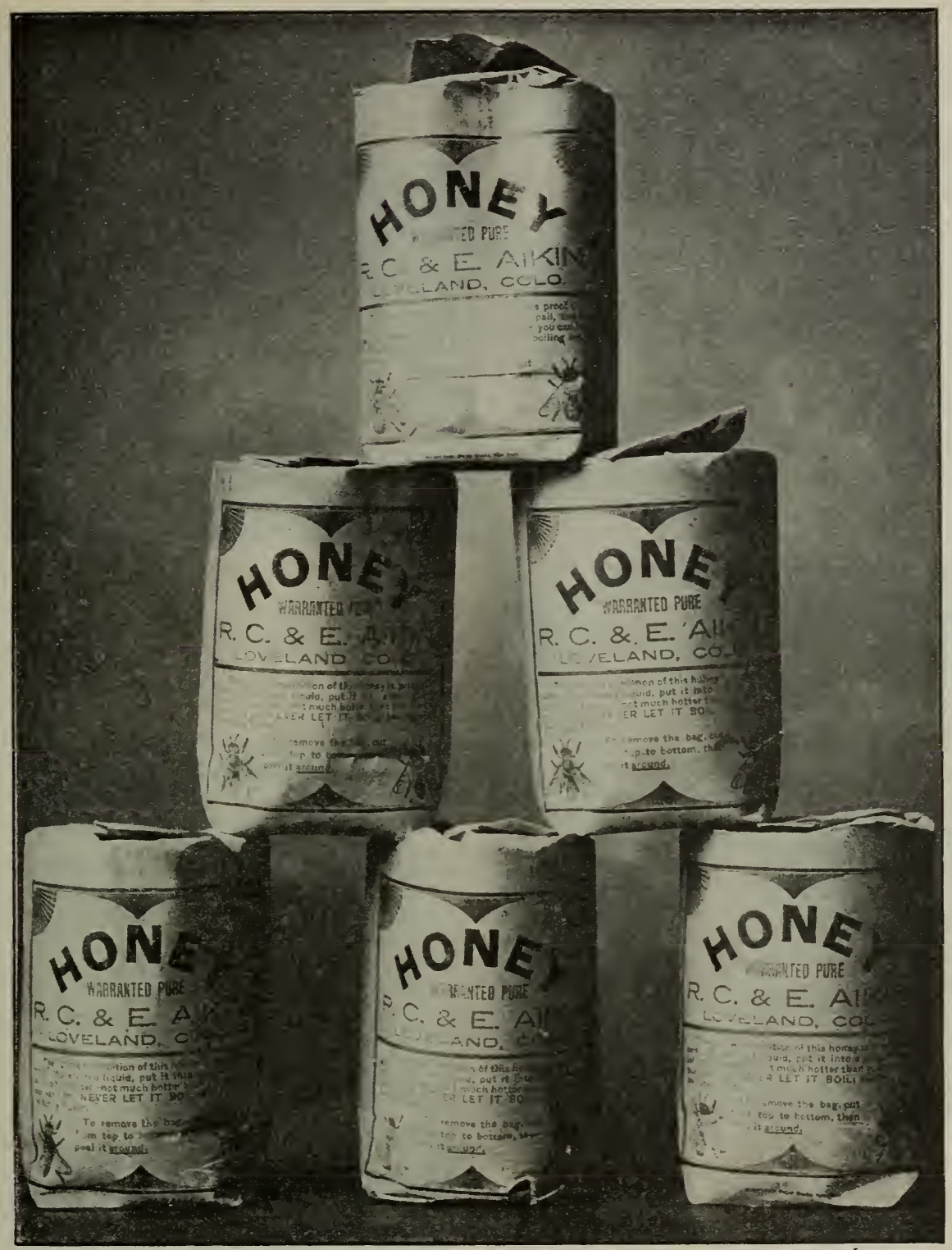

Aikin's paper-bag honey-parkage for granulated honey.

tinued effect of light upon the granules. See "Sunlight to Prevent Granulation." under Bottuing.

\section{HOW TO GET GRANULATED HONEY OUT OF BROOD-COMBS AND YET SAVE BOTH.}

Where honey granulates at all in broodcombs, it will usually be only partially. After uncapping, M. M. Baldridge, of St. Charles, Ill., recommends placing all such combs in the extractor, and throwing out any portion of the honey remaining liquid. He next lays the combs in the bottom of a clean wash-boiler, and, from an elevated dipper, pours water slowly into the cells.
He then turns the comb over and treats the other side the same way. As fast as the combs are splashed with water he places them in a hive or super. After they have all been doused he takes them out and sets them over strong colonies. He says the bees, by aid of the water, liquefy the whole mass, clean the combs, and save both the combs and honey.

Granulated comb honey in sections can scarcely be treated in this way, as it would be impracticable to uncap the cells. These should be treated in a capping-melter, as directed a couple of pages back. 


\section{HOW TO MARKET GRANULATED HONEY.}

Some years ago attempts were made to put up granulated honey in small packages for retail purposes; but it was not until the year 1901 that any real progress was made. At that time R. C. Aikin, of Loveland, Col., began to put up his honey in cheap lard-pails. He allowed it to granulate, and then sold it direct to consumers. As the packages were cheap he could afford to put the honey on the market at a price that would compete with ordinary sugar. A little later on he conceived the idea of using stout paraffine-paper bags instead of pails, and made a complete success of it.

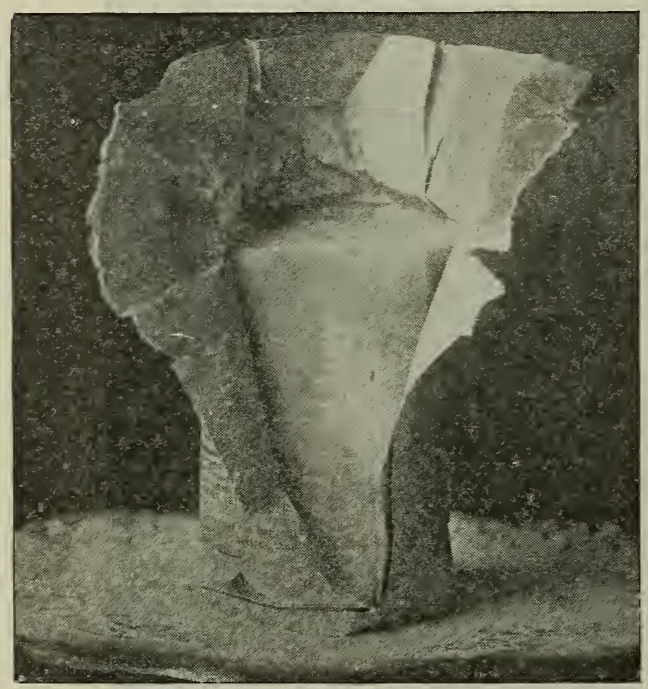

Aikin's paper-bag package dissected for the table.

Alfalfa honey, as is well known, granulates very rapidly. As soon as the graining begins to show he draws the honey off into the bags, and allows them to stand in a cool place, when it soon candies. The illustration shows the solid cake of granulated honey after the bag is torn away preparatory for the table. It readily granulates into bricks, and will stand all kinds of rough treatment. The only expense is for bags, which can be bought of supply-dealers, in 2-lb. size, for $\$ 7.00$ per 1000 and other sizes in proportion. It was thought for a time that Eastern clover and basswood honeys would not granulate solid enough when put up in this shape; but experience shows that they can be handled in that package as well as alfalfa, provided they are already graining when the bags are being filled, or if a little old candied honey is mixed in to expedite the process. This is very important in the case of honey granulated in bags or pails.

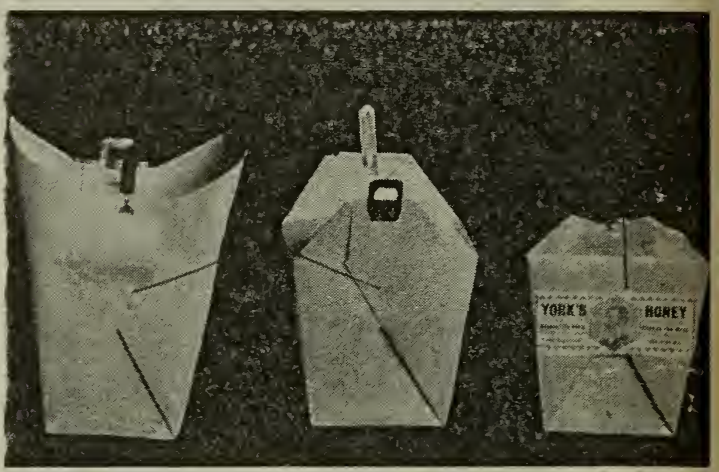

Square oyster-pails for granulated honey.

On each paper package are printed directions for liquefying, reading like this:

The solid condition of this honey is proof of its purity. If preferred liquid, put it into a pail, and the pail into warm water, but not hotter than you can hold your hand in. Never let it boil, for boiling spoils the honey flavor. To remove the bag, eut from top to bottom, then peel it around.

Granulated honey in paper bags should, if possible, be sold before hot summer weather comes on.

\section{GRANULATED HONEY IN OYSTER-PAILS.}

Another package, somewhat similar to the Aikin bag, is the ordinary oyster-pail. When honey begins to granulate it can be

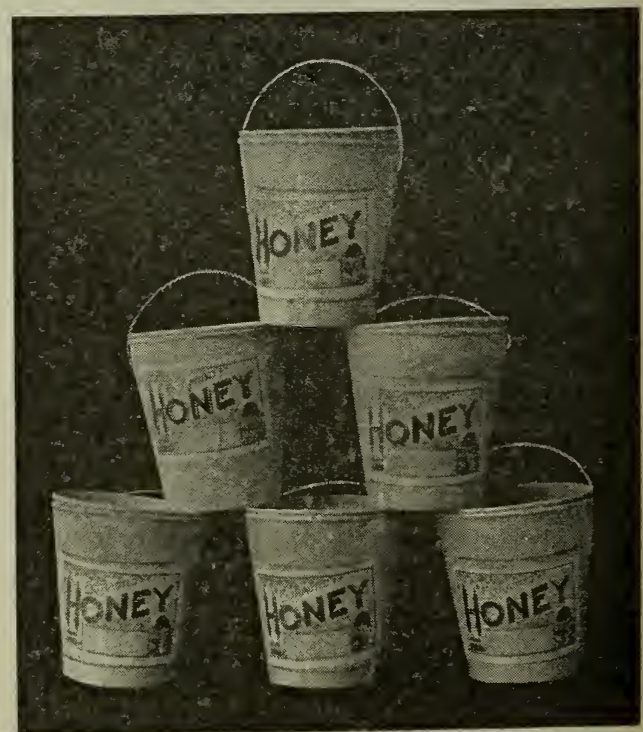

Round oyster-pails filled with granulated honey. 
drawn off into pails of proper sizes, the covers put on, and the honey allowed to stand. In the course of a few weeks in cool weather it should become quite solid; but it should be remembered that at an extremely cold temperature honey will not candy, but does so readily during alternately warm and cool weather. Oyster-pails have the advantage that beekeepers can buy them at any grocery, and they are almost as cheap as the Aikin paper bags. They have the merit, also, that honey can be sold in them in a practically liquid condition without fear of leaking. They can also be handled quite roughly. If the honey should granulate, so much the better.

\section{CUTTING GRANULATED HONEY INTO BRICKS.}

Honey in 60-lb. square cans that is granulated solid requires a considerable amount of treatment before it can be gotten out, put

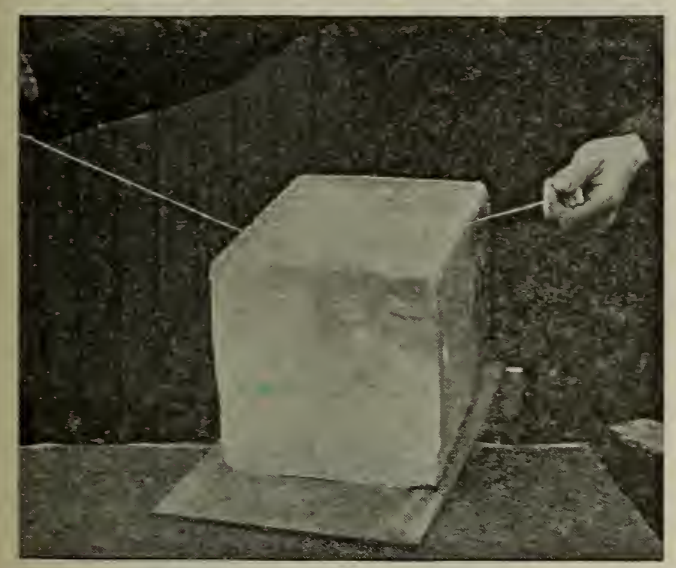

Slab of honey nearly cut thru by wire.

into bags, and candied again. The cans must be immersed in a boiler of water about 160 degrees, and kept there for hours at a time, before the honey melts enough to be poured out. Mr. Jesse A. Warren conceived the plan of stripping the tin away from the honey within, leaving it in the form of a solid cake. With a pair of snips he cuts off the top and bottom of the can, then slits it down at one corner. He next takes a strand of steel wire, attaching a handle to each end and slips it under the cake of honey about two inches. The wire is then folded around the cake, the two ends crossed, and with a handle in each hand the operator draws slowly, sinking the wire gradually into the cake from all four sides, until continuous 12 pulling causes it to pass clear thru. A thinbladed knife is now inserted in the slit where the wire entered, and slabs off a chunk like that shown in cut next page. Other pieces are slabbed off in like manner.

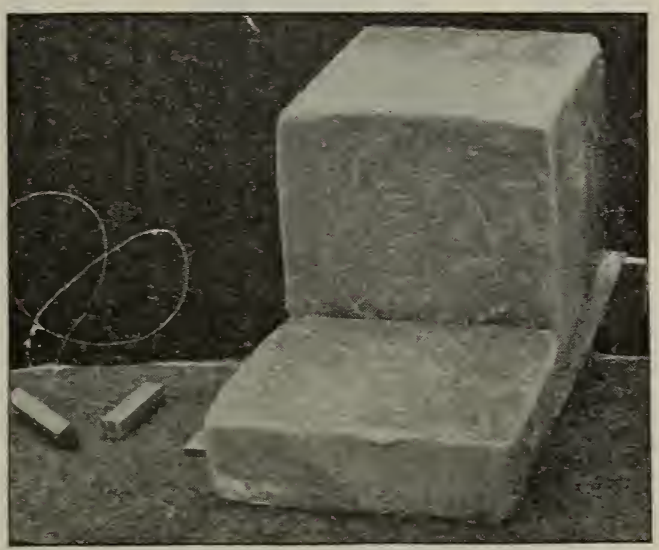

Slab of honey cut off.

These are then cut up into bricks, using the same general plan-bricks all the way from 5 oz. up to 2 lbs. They are wrapped in paraffine paper, on which are general directions explaining how to liquefy.

CUTTING GRANULATED HONEY WITH A MACHINE.

The plan just described can be used in only a very limited way. It has the further disadvantage that it is almost impossible to cut the cakes in regular sizes. A far better apparatus is the ordinary butter-cutter shown in the illustration, and sold by the Clereland Galvanizing Works, Cleveland. The same thing, or something like it, can be obtained of any dealer in dairy supplies. This butter-cutter employs the same principle-a wire drawn taut for cutting butter. Since butter has about the same consistency as hard-granulated honey, the same machine will slice up a cake of granulated honey in uniform bricks, and do it more quickly and neatly than can possibly be done with a single strand by hand.

In using the machine, care should be taken not to crowd the frame holding the strands of wire too fast, as it is a job that cannot be rushed without danger of breaking the wires. A gentle continuous pressure is what is required.

For the perpendicular cuts a couple of heavy weights are applied in such a way 
that, after the cake of honey is put in place, the horizontal frame and its wires gradually work their way thru the mass. When the

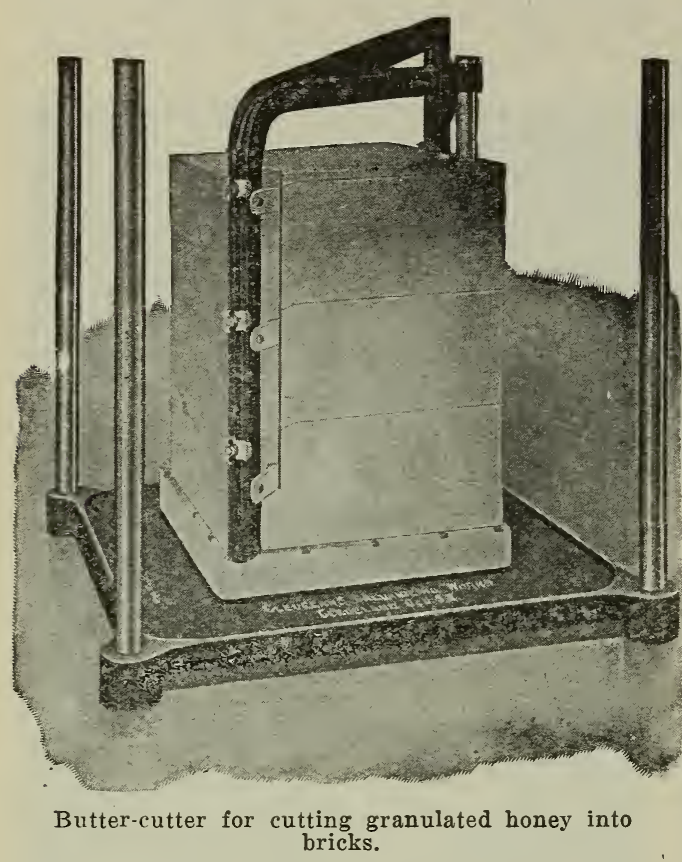

cake is cut the other way on the horizontal line, the operator takes hold of the gate, as it were, pulling gently.

All that then remains is to take a thinbladed knife, pick up each brick and lay it on a piece of paraffine paper. The brick is

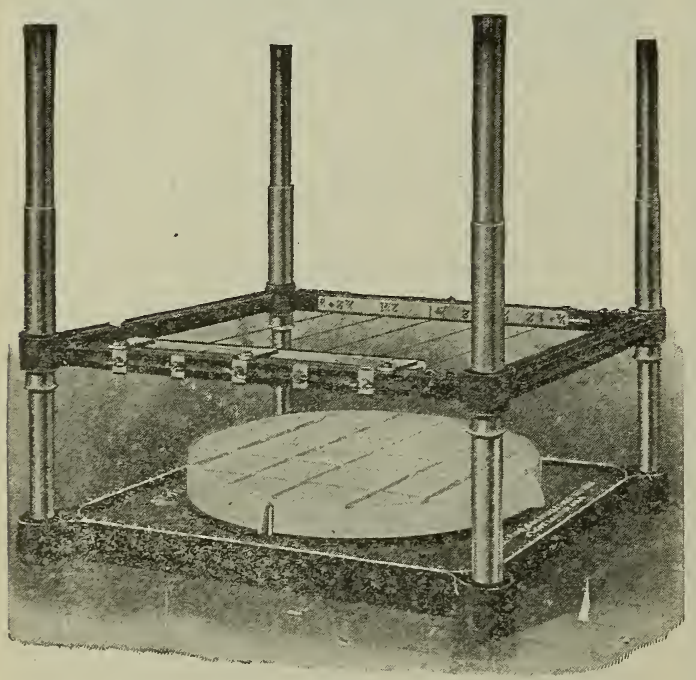

Machine for cutting granulated honey.

then neatly wrapped, when it is slipped inside of a special carton made just large enough to receive it. The carton is then covered with another wrapper, neatly lettered, and containing directions how to liquefy the honey when desired. As a rule, the consumer is advised to use the honey in the solid form by explaining that it can be spread on bread like so much butter.

It is advantageous to adopt the $11 / 4-\mathrm{lb}$. brick or 48 to the $60-1 b$. cake from the square can. It sells from 25 to 30 cents retail, thus making a good margin on 10 cent honey.

\section{CAUTION.}

The tin should not be cut off from the ean of candied honey unless the honey is very solid. If it is slightly mushy there will be trouble. The mass of granulated honey will squash out of shape, and run all over everything. There is no use in trying to cut up honey like this into bricks. It should cither be melted or put into oyster-pails, where the process of solidifying can be completed.

It may be questioned whether it pays to cut off square cans and take the honey in a solid chunk; but it enables one to fill rush orders for granulated honey on short notice. Second-hand cans are worth only a few cents; whereas to melt the honey out and re-candy is out of the question.

GENERAL REMTARKS ON HOW TO MAKE HONEY CANDY QUICKLY.

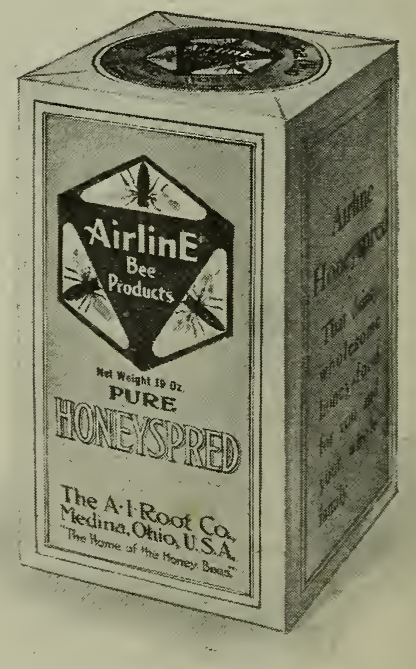

As we have already explained, continuous zero weather is not so favorable as weather somewhere near the freezing-point, now moderating up to the thawing-point, then 
freezing, then thawing again. When the weather remains continuously cold, set the honey out in pails or bags in a room where the temperature goes a little below freezing, leaving it for a day or two, then bringing it into a warm room. After it is thoroly warmed up, put it into the cold room again, and so continue with changes of temperature. Stir the honey occasionally, and always make it a rule to have some granulated honey mixed with that which is to be brought to a solid condition.

\section{EDUCATING THE PUBLIC TO GRANULATED HONEY.}

The question may arise whether it would be everywhere practicable to sell granulated honey in any one of the forms described. It could hardly be deemed advisable to furnish buyers or commission houses knowing neither the shipper nor the real character of such honey. The packer or producer must first introduce it to his own customerspeople who know him. The nature of the honey must be explained; how put up; that only the purest and best can be solidified in this manner; that it can be liquefied by putting the pail in water about as hot as the hand can bear, etc. In short, the trade must be educated to it. The fact that no unripe or glucosed honey can be put up in bags or bricks will be a strong "talking-point" on the purity of the honey. When the facts once become known, cld prejudices give way.

A short time ago we cut up some brick honey with a wire into packages weighing 5 ounces. These sold for a nickel. They went off so fast we could not supply the demand. For the sake of experiment we cut up one 60-lb. can of granulated honey into 160 cubes. The honey cost $6 \frac{1}{2} 2$ cents per pound. "We retailed these cubes at 5 cents each, or $13 \frac{1}{2}$ cents a pound-doubling on our money.

After the trade gets educated to buying honey in this form no effort at all is necessary to sell it. The cost of the package is practically nothing, and all trouble from the honey candying again is orercome, because the trade has been educated to know that such honey is the pure article.

The time may come when granulated honey will be known on the market as a common article of commerce; because when the public generally understands that such honey must be of the best quality, and absolutely pure, it will sell without any hesitation.

For particulars on how to prevent comb honey from granulating and how to dispose of it when it does granulate see Coзrв HowEr, HOW to Produce. 


\section{$\mathrm{H}$}

HANDLING BEES.--See MaNipulation of Colonies; Frames, Self-SPacing; Anger of Bees; also Stings, and Hives.

HAULING BEES.-See Moving BeES. naturalized from Europe, and widely distributed over eastern and central North America, particularly in Illinois, Kansas, and Nebraska. In the last-named state it reaches a height of from three to five feet.

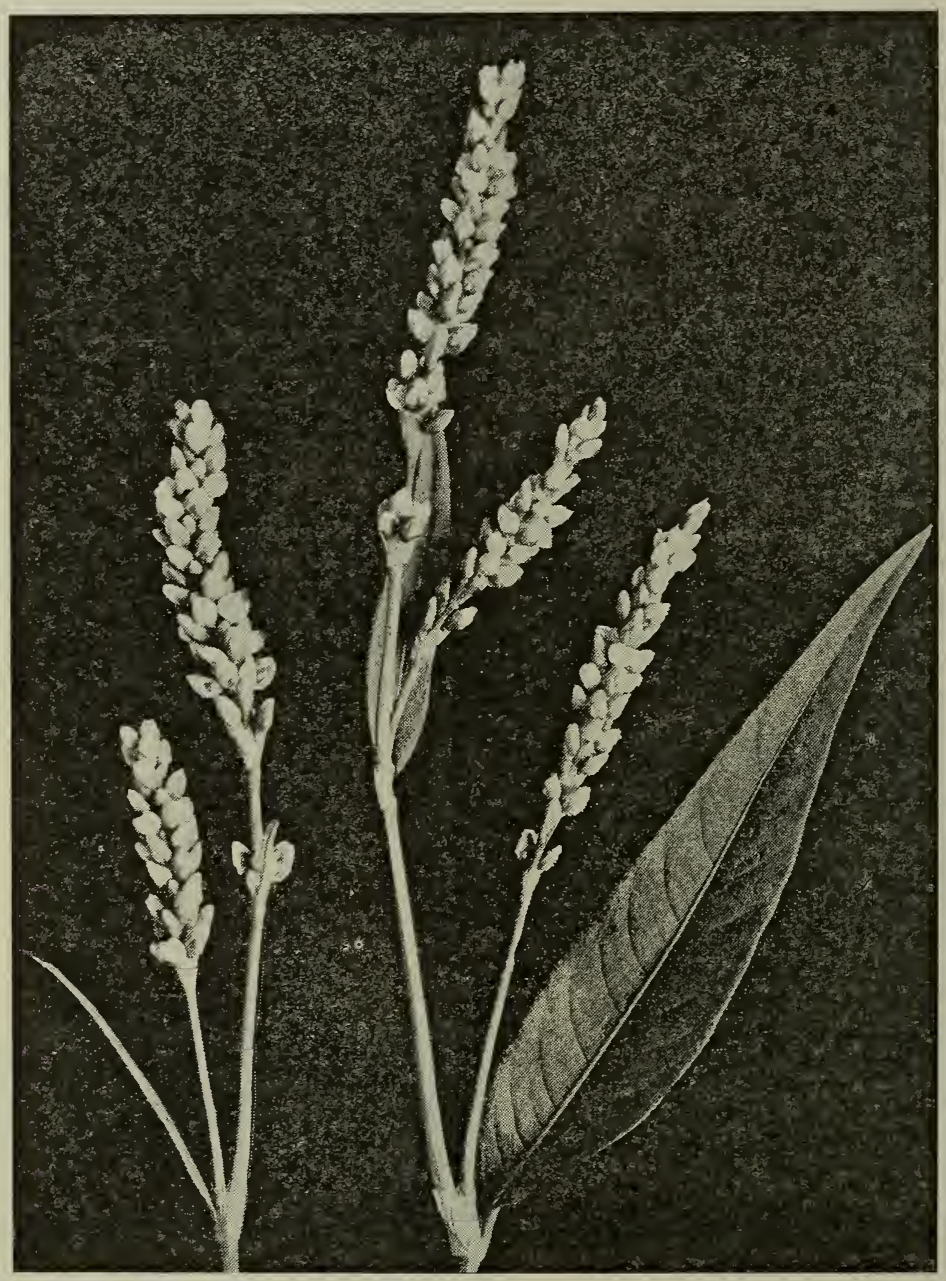

Heartsease or smartweed.

HEARTSEASE (Polygonum Persicaria L.). This is one of a large family of nectarbearing plants of which the common buckwheat is one. Heartsease, sometimes known as lady's thumb, knotweed, or heartweed, is and grows luxuriantly on all waste and stubble lands. The flowers in oblong clusters are generally reddish purple, and, in rare instances, white. It yields in Nebraska, and other states in that section of the coun- 
try, immense quantities of honey. One beekeeper, Mr. T. R. Delong, at the North American convention held in Lincoln, Neb., in October, 1896, reported two of his coloiies yielded each $450 \mathrm{lbs}$. extracted honey, ad that the average for his entire apiary was 250 lbs. per colony-all heartsease. While perhaps these yields were exceptionally large, quite a number of other beekeepers reported at the same convention an average of $200 \mathrm{lbs}$. from the same source. When we visited Nebraska last there were acres and acres of this honey-plant over the plains as far as the eye could reach; and as it yields honey from August till frost, one is not surprised at the enormous yields.

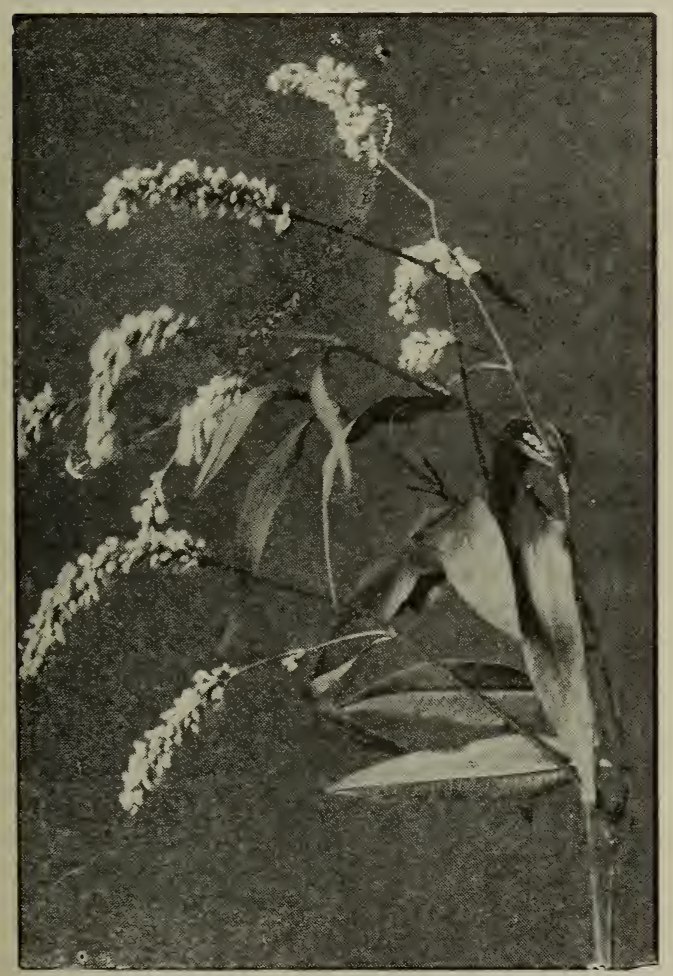

Heartsease.

The extracted honey varies in color from a light to a dark amber; and the flavor, while not quite up to that of white honey, is very good. Heartsease comb honey, in point of color, is almost as white as that of clover. The extracted granulates in very fine crystals, and looks very much like the candied product of any white honey. Care should be taken in liquefying, as heartsease honey is injured more easily, and to a greater extent, by overheating than any other.
HEAT.-See Artificial Heat.

HERMAPHRODITE BEES.-These are nothing more nor less than freaks of nature -that is to say, we sometimes see worker bees having drone heads and drones with worker heads. They are not very common, it is true; but about once a year there is sent in to the authors specimens of either the one or the other kind of bees that have, apparently, appropriated the wrong head. The beginner needs to be reminded that the head of a drone is very different in appearance from that of a worker or queen. The two compound eyes of the former are large and well developed, while in the latter they are much smaller.

Under the heading of Drones, to which the reader is referred, we mention another freak of nature-namely, drones with variously colored heads.

HIVE-MAKING.-Unless one is so situated that freights are high, and unless, also, he is a mechanic, or a natural genius in "making things," he had better let hivemaking alone. Hives can be bought usually, with freight added, for much less than the average beekeeper can make them himself, if we consider spoiled lumber, sawed fingers, and the expense of buzz-saws; moreover, hives made in the large factories, where they dre turnd out by the thousands, by special machinery run by skilled workmen, are much more accurately cut, as a general thing.

The following letter from a practical planing-mill man, who ought and does know what he is talking about, sets forth the actual facts as they are:

\section{ELIAS BAMBERGER} Manufacturer of SASH, DOORS, BLINDS Contractors' and Builders' Supplies including all kinds of Window Glass

Cor. Exchange and Adams Sts.

Estimates Furnished on Application

Freeport, Ills., June 11, 1907.

The A. I. Root Co., Medina, Ohio.

Gentlemen: - I received five of your $\mathrm{AE}$ 525-10 hives yesterday, and find that I can not make my own hives and supplies as cheap as yours and use the same quality of lumber. You can see by the head of this letter that if any one can make hives cheaper than your prices or any of the so-called "trust-hive", manufacturers, I ought to be able to do it; but, using the same quality of lumber, I can not. John H. Bamberger. 
But there is lots of fun in making things, even if they are not so well made; and there are some rainy or wintry days in the year, when, if one is a farmer, for instance, he can as well as not, and at little or no expense for time, make a few hives and other "fixin's." Again, if one lives in a foreign country he may not be able to get the hives that we shall recommend.

\section{REQUISITES OF A GOOD HIVE.}

While it is very important to have good well-made hives for the bees it should be clearly understood that the hive will not insure a crop of honey. As the veteran Mr. Gallup used to say, "A good swarm of bees will store almost as much honey in a.halfbarrel or nail-keg as in the most elaborate and expensive hive made, other things being equal." This is supposing we had a good colony in the height of the honey season. If the colony were small, it would do much better if put into a hive so small that the bees could nearly or quite fill it, thus economizing the animal heat, that they might keep up the temperature for brood-rearing and the working of wax. Again, should the bees get their nail-keg full of honey, unless more room were given them they would have to cease work or swarm, and either way a considerable loss of honey would be the result. The thin walls of the nail-keg would hardly be the best economy for a wintering hive, nor for a summer hive either, unless it were well shaded from the direct rays of the sun.

P. H. Elwood, of Starkville, N. Y., who owns over 1000 colonies, said in Gleanings in Bee Culture some time ago, "A good hive must fill two requirements reasonably well to be worthy of that name. 1 . It must be a good home for the bees; 2 . It must in addition be so constructed as to be convenient to perform the various operations required by modern beekeeping. The first of these requirements is filled very well by a good box or straw hive. Bees will store as much honey in these hives as in any, and in the North they will winter and spring as well in a straw hive as in any other. They do not, however, fill the second requirement; and to meet this, the movable-frame hive was invented."

Under Hives and Frames, a little further on, will be shown styles and the special features that belong to each. But there is only one hive that is used largely thruout the United States, and that is the Langstroth - that is, it embodies the Langstroth dimensions. The frame is $175 / 8$ long by $91 / 8$ deep, outside measure. This establishes the length and depth of the hive. As to width, that depends upon the number of frames used. It is the rule to allow $5-16$ bee-space between the ends of the frames and the inside ends of the hive. This will make the inside length of a Langstroth hive 181/4 inches, or the outside length 20 inches if made of $7 / 8^{-}$ inch planed lumber. It is the rule to make the depth of the hive $3 / 8$ inch deeper than the frame-1/8 inch under the frame and $1 / 4$ inch on top. For dry climates a greater allowance should be made on account of shrinkage. The selection of the frame, and the number to the hive, the distance they are spaced apart, then, determines the dimensions of the hive itself.

As stated, the Langstroth is the standard thruout the United States; but there has been a tendency on the part of a very few toward a frame of the same length, but two inches deeper. There is a tendency to go to the other extreme in adopting a frame of Langstroth. length, but two or three inches shallower, using two stories of such a hive for a single brood-nest.

On account of the diverse notions of beekeepers, and the peculiarities of locality, it would hardly be worth while to give generaldirections for the manufacture of any one hive; and, besides, no printed directions will give as good an idea of the construction of a hive as the very thing itself. For these and other reasons it would be far better for the one who intends to make hives to send to some manufacturer for a sample in the flat, all complete. With the several pieces for patterns he will then know exactly the shape and dimensions, how to make rabbets, and in general how the hive is constructed in every detail. If one does not find on the market just such a hive as suits his notion, of course he sees, or thinks he sees, "in his mind's eye" just what he wants to make; but in that case we would advise him to make a sample or two before he makes very many of them; for nine times out of tenyes, ninety-nine times out of one hundredhe will discard the one of his "own get-up," and adopt some standard made by manufacturers generally. 


\section{HIVE ON SCALES.-See Scale Hive.}

HIVES.-The word "hive," broadly speaking, covers any sort of inclosure in which bees make their home. In the primitive days these consisted of hollow logs two or three feet long with a board for the corer and another board for the bottom. Later, boxes were constructed. (See Box Hives.) In early times straw skeps were used, and are still used in parts of Europe today. (See SkePs.)

The modern hive consists, first, of a brood-body, a box without top or bottom, to hold a series of frames. (See Frames.) Fach frame incloses a comb. But no hive is complete without a roof or cover, and a bottom, usually called a bottom-board. In addition to the roof and hive-body, with its frames and bottom, there are upper stories, or supers. A super, just as its name indicates, is a story-a box without corer or bottom to hold either a set of frames, the same as in the brood-nest, or a set of holders to support section honey-boxes in which bees store honey. For a further descriptiou of modern hives, see A B C of Beekeepisg, especially the drawing showing the interior and exterior of the hive. For particulars regarding comb-honey supers, see CoмB HONEx, APPLANCES FOR. For directions to make, see Hrve-making. For a description regarding the hives of early days, leading up to the present, see Hives, Erolution of.

\section{DIMENSIONS OF HIVES.}

Hives based on Langstroth dimensions are the standard. Some thirty years ago there were in use the American, Gallup, Langstroth, Adair, and Quinby frames. All of these required, of course, hives of different dimensions. Between the Adair, the Gallup, and the American there was but very little difference, comparatively, as they were square, and very nearly of a size. The Langstroth was long and shallow-the shallowest frame that had then been introduced; and the Quinby, having about the same proportions, was the largest frame in general use. By consulting the diagram containing the different sizes of frames it will be seen that there are practically two classes - the square and the oblong. As there would be but very little difference, theoretically and practically, between the results secured with a Gallup, American, and Adair, we will consider the arguments for the square frame.
SQUARE FRAMIES.

In nature, bees have a tendency to make a brood-nest in the form of a sphere; patches of brood are more inclined to be circular than square or oblong. Theoretically, then, a circular frame would be the best; but as that would not be practicable, owing to the difficulty in the construction of the frame and hive, obriously the square frame would come the nearest in conforming to nature and a perfect cube for the hive. The square frame, as a rule, called

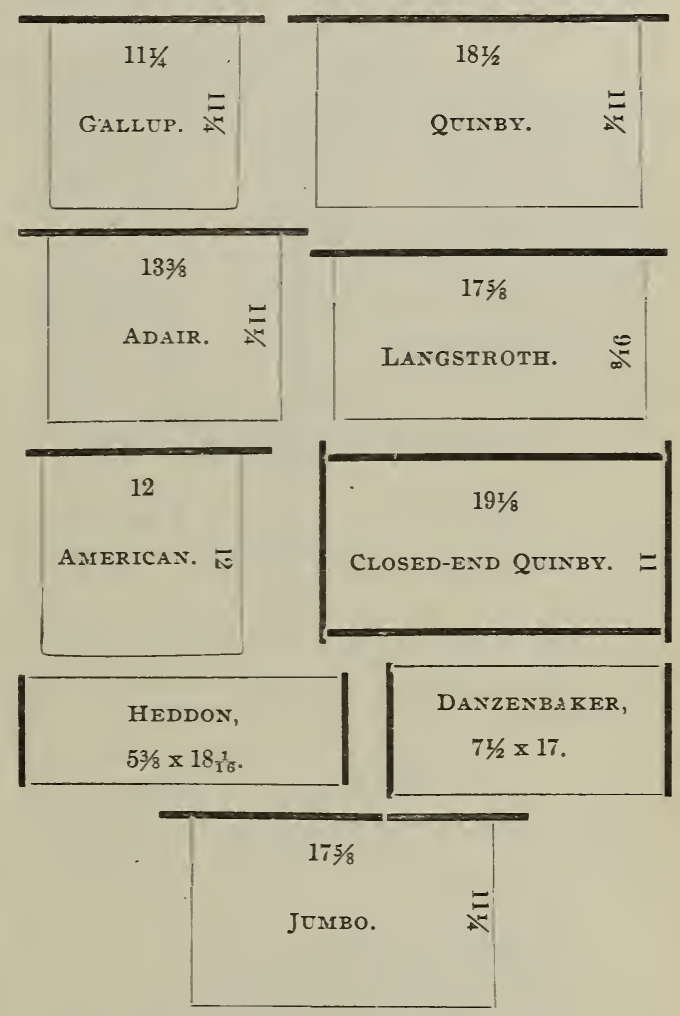

for a hire in the exact shape of a cube. If, for instance, the frame was 12 inches square, outside dimensions, then the hire, if the combs were spaced $13 / 8$ inches apart, and $123 / 4$ inches wide inside, should take in just nine American frames. Such a hive, it was argued, would conserve the heat of the bees to the best advantage, would give the greatest cubical contents for a giren amount of lumber-barring, of course, the perfect sphere. As it economized heat in winter, it would winter bees better than a hive having oblong frames.

All of this seemed to be very pretty in theory; and there are some users of square frames who insist that the theory is borne 
out by actual experience. But the great majority of beekeepers, after having tried the square and the oblong frame, finally decided in favor of the Langstroth for the following reasons :

THE LANGSTROTH FRAME AND HIVE AND WHY IT BECAME THE STANDARD.

1. A shallow frame permits the use of a low flat hive that can easily be tiered up one, two, three, and four stories high. This is a great advantage when one is running for extracted honey, as all that is necessary when the bees require more room is to add upper stories as fast as the bees require them, and then at the end of the season extract whenever it is convenient. Square or deep hives cannot be tiered up very high without becoming top-heavy and out of convenient reach of the operator.

2. The long shallow frame is more easily uncapped because the blade of the uncapping-knife can reach clear across it.

3. The shape of the Langstroth frame favors an extractor of good proportion.

4. A deep frame is not as easily lifted out of a hive; is more liable to kill bees in the process of removing and inserting frames.

5. The shallow frame is better adapted for section honey. It is well known that bees, after forming a brood-circle, are inclined to put sealed honey just over the brood. In a frame as shallow as the Langstroth, there will be less honey in the broodnest and more in the boxes; for bees, in order to complete their brood-circle in the Langstroth, will, with a prolific queen, often push the brood-line almost up to the topbar, and, consequently, when honey comes in, will put it into the supers or boxes just where it is wanted.

6. When bees are left to themselves they will generally form a cluster late in the season, immediately over the entrance of the hive, and down two or three inches from the top of the frames. As the season progresses the cluster eats into the stores above it; and on reaching the top it works backward. It therefore transpires that the cluster reaches the top of the hive where it is the warmest during the coldest part of the year. In the case of the ordinary square frame the bees will be found just over the entrance, but four or five inches from the top; but in the midst of the coldest weather the bees may not and probably will not be near the top of the hive; but on reaching the top they can progress backward only a comparatively short distance because the top-bar of a square frame is relatively short. In the case of the Langstroth hive, the bees during the entire cold part of winter stay in the top of the hive, where it is the warmest. As the stores are consumed they move backward and gradually reach the back of the hive, and by that time warmer weather will probably prevail.

But in actual experience bees seem to winter just as well on a Langstroth as any other; and as the shallow frame is better adapted to section honey, beekeepers naturally turned toward the shallower frame, with the result that now probably 99 per cent of all the frames in the United States are of Iangstroth dimensions; and whatever advantage there may be in favor of the square shape, the beekeeper is able to buy standard goods so much cheaper that he adopts the Langstroth frame.

FRAILES SHALLOWER AND DEEPEK I'HAN THE LANGSTROTH.

A few years ago there was a tendency toward a frame still shallower than the Langstroth, and what is called the Heddon; but as eight or ten of these frames, or one

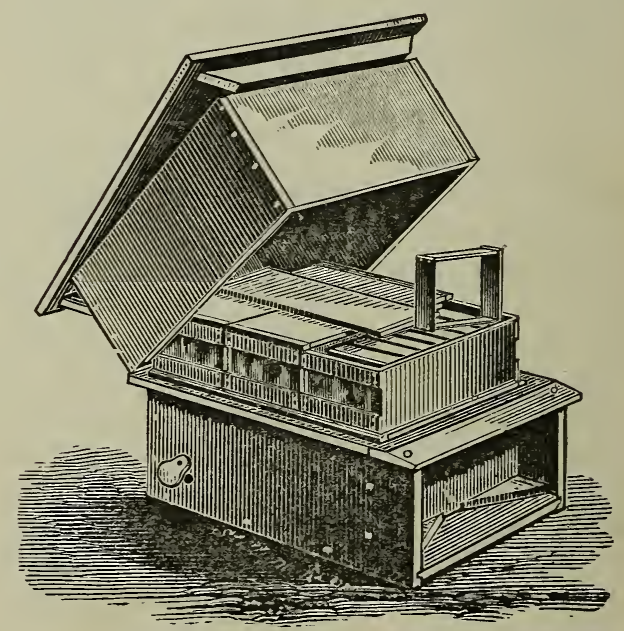

The original Langstroth hive.

section, make too small a brood-nest, two sets of such frames are used to accommodate a whole colony. Of the Heddon hive more will be given further on.

There is a very small class of beekeepers who feel that the Langstroth is not quite 
deep enough, and who, therefore, prefer th Quinby. They argue that ten such frames, or frames Langstroth length, and two inches deeper, are none too large for a prolific queen, and that these big colonies swarm less, get more honey, and winter better. Of these latter more will be said under the subject of "Large vs. Small Hives."

The old original Langstroth hive that the Rev. L. L. Langstroth put out contained ten frames $173 / 8$ × $91 / 8 . *$ Each hive had a portico, and cleats nailed around the top edge to support a telescoping cover, under which were placed the comb-honey boxes, or big cushions, for winter. There was a time when this style of hive was the only one

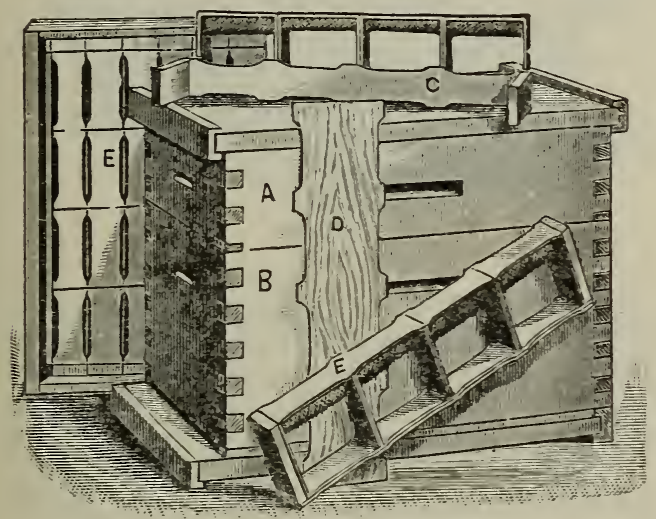

Modern hive based on Langstroth dimensions.

used; but owing to the fact that it was not simple in construction, that the portico was a splendid harboring-place for cobwebs and gave the bees encouragement for clustering out on hot days instead of attending to their work inside of their hives, a far simpler form of hive was devised. The Simplicity, first brought out by A. I. Root, having Langstroth dimensions, was the result. Instead of having telescope covers the contiguous edges of the hive were beveled so as to shed water and give in effect a telescoping cover. The cover and bottom of this hive were exactly alike, the entrance being formed by shoving the hive forward on the bottom, thus making an entrance as wide or narrow as seemed most desirable. The upper story was exactly the same as the lower one or brood-nest-so, taking it all in all, the hive was simplicity itself. But it

* The length for nearly 50 years has been $175 / 8$ instead of $17 \% / 8$. had one serious defect, and that was the beveled edge. It was found to be practically impossible at times, on account of the beeglue, to separate the upper story from the lower one without breaking or splitting the bevel. Finally there was introduced a hive very much the same, having straight square edges, and along with it came the feature of dovetailing or locking the corners, as shown in the hive previous.

This hive was introduced in 1889, and seemed to meet with the general approbation of beekeepers. It embodied in the main the Langstroth dimensions, but used eight

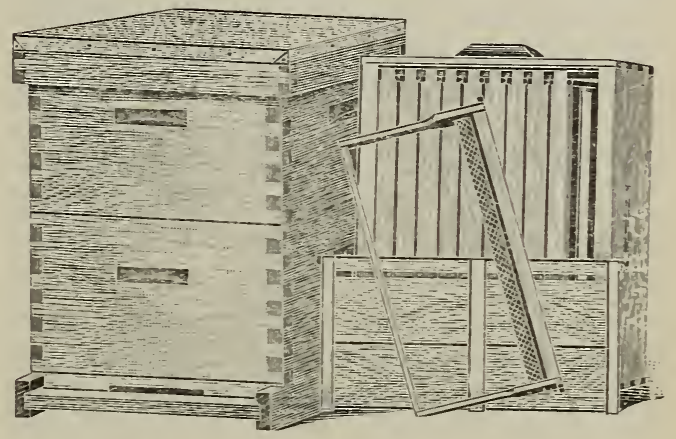

instead of ten frames; for at the time it was introduced, nearly every one preferred eight frames. The original Dovetailed hive had a flat cover, and a bottom-board made the same as the cover, except that there were side-cleats to raise the hive off the bottomboard.

Since that time there have becn modifications of the hive, and it is now made in eight, ten, and twelve frame sizes. While

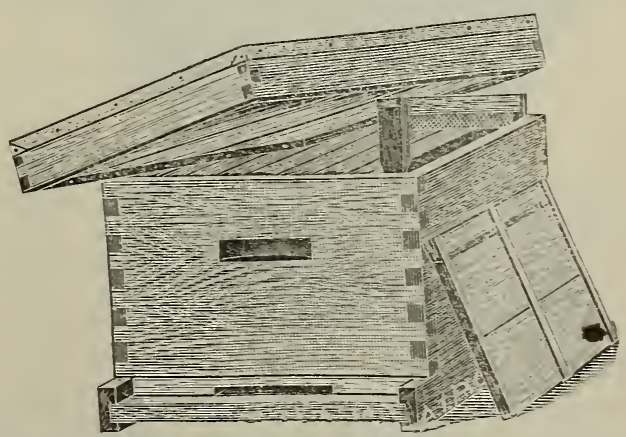

the eight was used almost exclusively, the ten-frame size now bids fair to run out both the eight and twelve frame widths.

The cover is made single or double. The body is locked at the corners, and the bottom-board is made in sereral styles. See ENTRANCEs. 
The Hoffman self-spacing frames, described under Frames, Self-Spacing, and Frames Manipulating, also Frames, is used in the Dovetailed hive almost exclusively. The supers for this hive are the same as those shown under Сомв Honer.

As now constructed the hive embodies the very latest developments in hives and hive-construction. It can be handled rapidly, and is especially adapted for out-apiary work, where frequent moving from one field to another is necessary. It is standard, being made by all the supply-manufacturing concerns, and is for sale everywhere. The lock corner is especially well adapted for hot climates; and for any place it is far superior to corners depending on nails alone. The ordinary miter or halved joint is inclined to pull apart in parts of California, Texas, Florida, and other portions of our country subject to extremes of heat, or hot dry winds.

A very important requisite of a good hive is a good cover. While the flat cover -one making use of one flat board and two

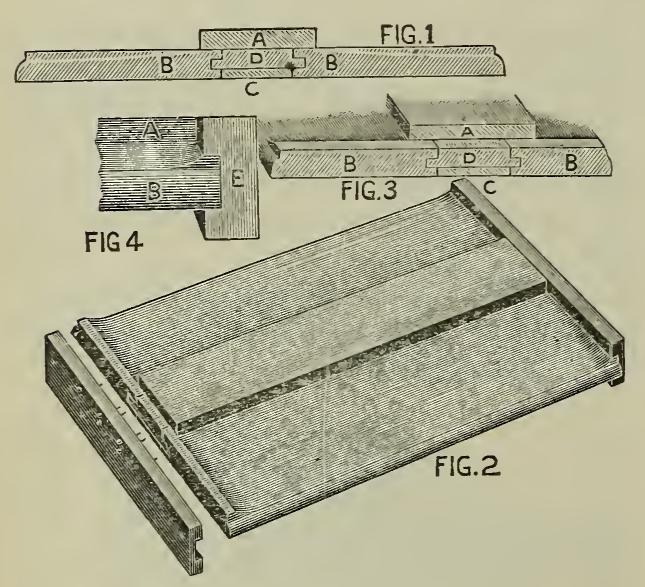

Excelsior flat cover.

cleats-was a good one, yet, owing to the width of the single board, and increasing scarcity of such lumber, something made of two or three narrow boards had to be used. Accordingly, the Excelsior was devised. It consists of boards not exceeding 6 inches in width, because narrow boards can be easily secured, and because they will not shrink and check under the influence of the weather like the wide ones. The two side boards, B, $\mathrm{B}$, are beveled or chamfered on one side so that one edge is left only about three- fourths the thickness of the other edge, but the ends are left full thickness of the boards to shed water away from the edge and to give more nail-room for the grooved endcleats, E, that slip over and bind the whole together. The purpose of the chamfering is to shed water to the sides of the hive and away from the center-piece, $\mathrm{AD}$, which is tongued and grooved to fit a corresponding tongue and groove edge of the two sideboards that were beveled to shed water.

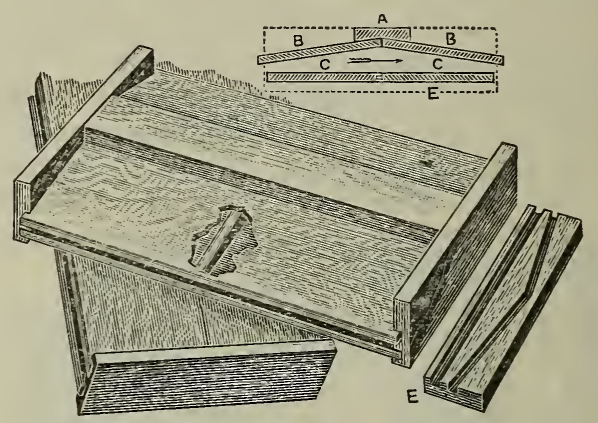

Gable cover.

The space under $\mathrm{D}$ is filled with a thin board $1 / 4$ inch thick, the ends of which project into the $7 / 8$-inch groove of the endcleats, $\mathrm{E}$, where it is securely held in place.

In very hot climates a two-thickness or gabled cover is used. The lower part of the cover is flat, and the upper part gabled, as shown in the accompanying illustration.

\section{TELESCOPE COVERS.}

There is a strong tendency at the present time toward a double or telescopic cover, as is shown in the illustrations below.

The lower cover consists of two or more tongued-and-grooved boards, $3 / 8$ inch thick, with rim of $3 / 8 \times 7 / 8$-inch wooden strip around the edge. At the center there is a

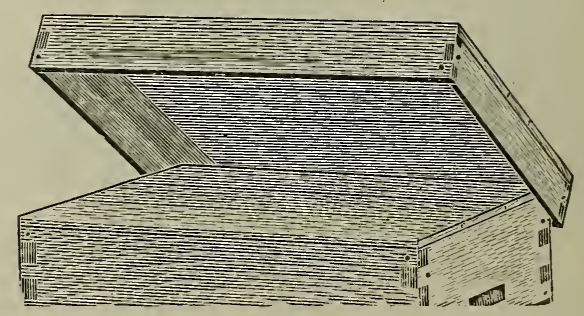

Telescope cover.

hole for a Porter bee-escape, so that by inserting the escape the inner cover can be used as an escape-board. This inner cover 
takes the place of the metal-bound supercover as used by some. It lies directly over the frames, and orer this is placed a shallow telescoping cover made of $3 / 8$ lumber, and corered with sheet metal or roofing paper.

A top protection of this sort is not only better than a single-board cover, but it shuts out the weather. The air-space between the two covers gives the bees better protection from the direct rays of the hot sun if the hives are out in the open, and, if kept painted, will last indefinitely. The lower cover will be sealed down by the bees, and the upper one cannot blow off because the downwardly projecting sides will hold it in place. Of course such an arrangement

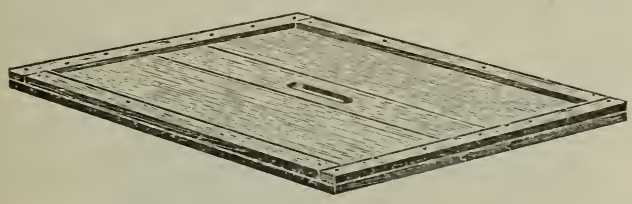

Inner cover.

makes extra handling in opening and closing the hive; but the majority of beekeepers are beginning to see that this is more than offset by the greater durability and better protection.

This cover is so far superior to all the other covers previously shown that it is rapidly superseding them. It is warmer in winter and cooler in summer. It is also more durable.

\section{HIVES WITH CLOSED-END FRAMES.}

Under Franes, Self-spacing, we have spoken of the Quinby, as that is the one used in central New York, especially in Herkimer and Otsego counties. But in this department we shall have more to do with the subject of closed-end frames, certain principles of their construction, and their adjustment in several of the best hives.

Closed-end frames may be divided into two classes-the standing and suspended. The Quinby, already spoken of under Frajees, Self-spacing, the Bingham, and the Heddon, are of the first-mentioned class; the Danzenbaker belongs to the latter class. It is generally considered that frames with closed uprights, while not as convenient, lerhaps, for general manipulation, are better adapted to wintering. Frames partly rlosed end, like the Hoffman, or open all the way up, like the ordinary loose hanging frame, permit of currents of air around the ends of the frames, and (it is claimed), as a consequence, bees are not so much inclined to bring their brood clear out to the end-bars as they do when closed ends are used. The difference is more theoretical than real.

\section{THE BINGHAM HIVE.}

Mr. Quinby was the first to apply Huber's principle of closed-end frames in this country (see Hives, Evolution of). This he introduced shortly after the appearance of the Langstroth hive. Not long after, Mr. Bingham in 1867 brought out his hive with closed-end frames with a narrow top-bar and no bottom-bar, but still embodying the chief features of Huber's hive of 1789. But the peculiar feature of the Bingham was that it made use of shallow frames only 5 inches deep, a series of them being lashed together by means of a wire loop and stretcher sticks, said loop drawing on the followerboards in such a way as to bring tight com-

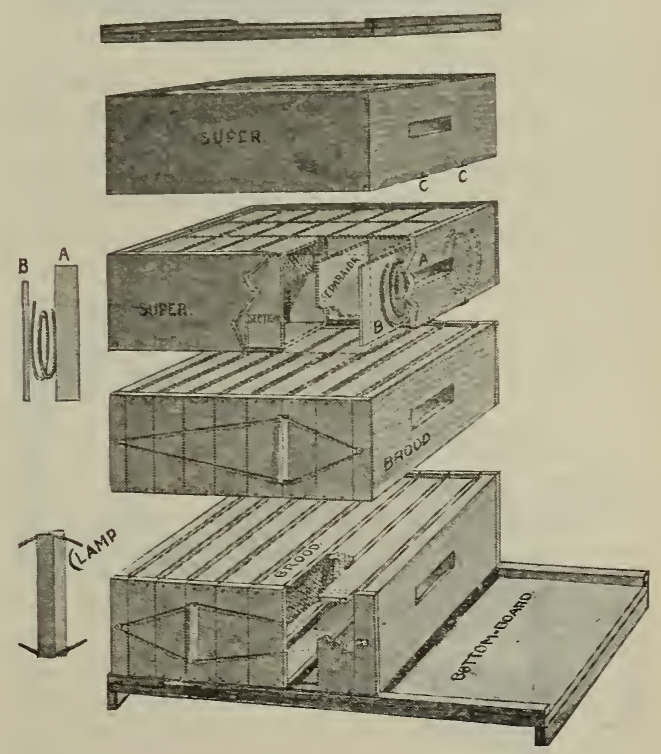

pression on frames inclosed in the manner shown. Seven of these brood-frames in the hire make up a brood-nest, and an entire brood-nest may consist of one or two sets of frames. The top-bar is dropped down from the top of the end-bars a bee-space, while the bottom-bars are flush with the bottoms of the end-bars. With a bottom-board having a $3 / 8$-inch strip on each side, the ordi- 
nary bee-space is preserved thru the several divisions of the hive.

The super is like any ordinary one adapted to comb honey, except that it uses coiled springs to produce the necessary tension.

Altho Mr. Bingham has used this hive for a great many years, and quite successfully too, no one else seems to have done much with it; but a modification of the hive is shown in the Danzenbaker and the Heddon.

\section{THE DANZENBAKER HIVE.}

The Danzenbaker consists of a broodchamber of the same length and width as ten-frame Langstroth Dovetailed hive, but deep enough to take in a depth of frame of

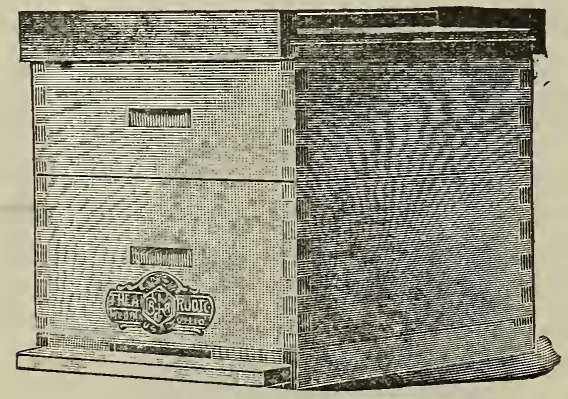

only $7 \frac{1}{2}$ inches. The rabbet, instead of being near the upper edge, is dropped down about midway; or, more strictly speaking, there is a cleat or board nailed on the inside of the ends of the hive, as shown in $\mathrm{F} \mathrm{F}$ in

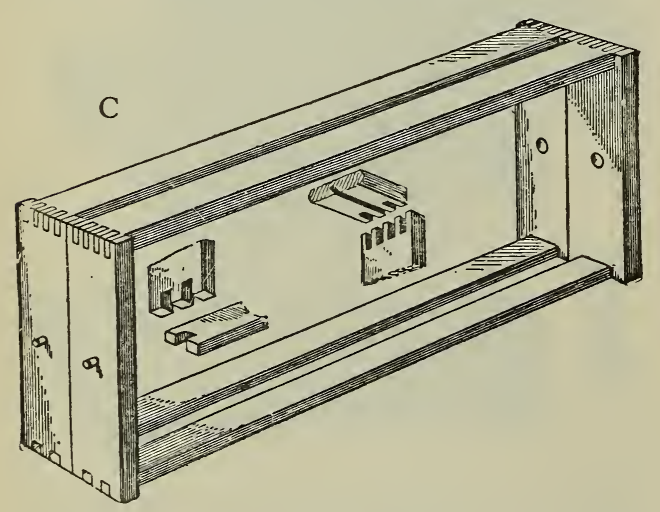

the diagram, next column. On this support hang the closed-end brood-frames, pivoted at the center of the end-bars by means of a rivet driven thru from the inside, as shown at $I$ in the diagram. Ten of these frames fill the hive; and when they are crowded together with a follower-board on the side, we have practically a double-walled hive- the ends of the frames with closed uprights forming one wall, and the ends of the hive the second or outer wall; the follower on one side wall, and the side of the hive the outside or secondary wall. As these frames are pivoted in the center, as shown at $\mathrm{C}$, they can be reversed; and this feature, while it costs nothing, is something to be desired, as it enables us to have all frames filled solid with comb.
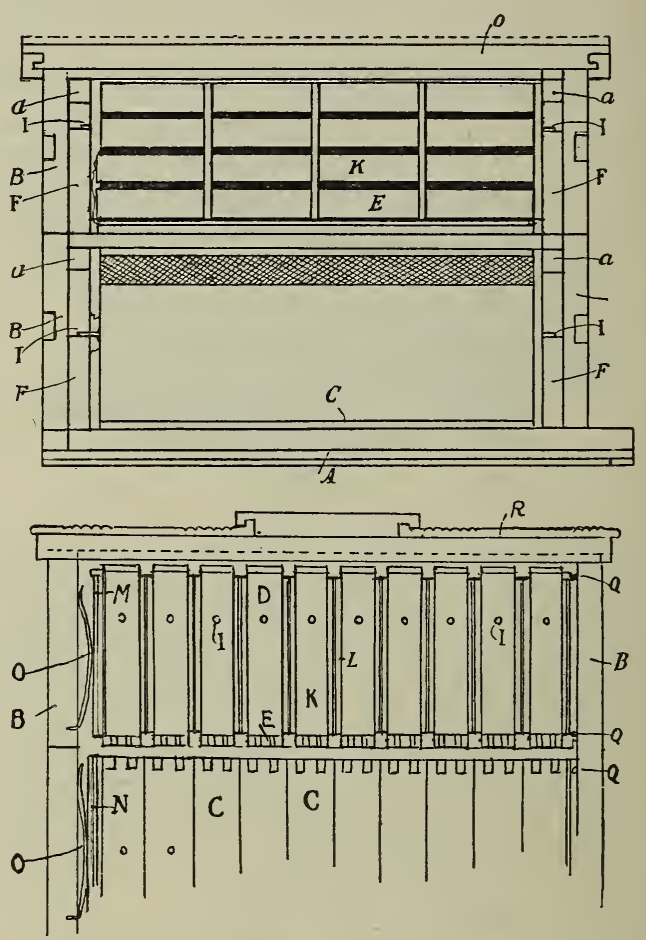

The bottom of the hive is the same as that for the Dovetailed hive, already described. The super for comb honey takes in the $4 \times 5$ plain section, and makes use of the fenceseparator system. The sections are supported in section-holders; indeed, the whole arrangement is the same as the sectionholder super already described in Сомв HONEY.

\section{THE HEDDON HIVE.}

This hive was patented and introduced in 1885. Its peculiar and distinguishing feature is in the use of one brood-chamber divided into halves horizontally, each half containing a set of eight closed-end closefitting brood-frames, $5 \%$ inches deep by 18 1-16. The end-bars, as already stated, are close-fitting-that is, the brood-frame slidels into the hive with just enough play to allow 
of its easy removal and insertion. On the bottom inside edge of the ends of each case are nailed strips of tin to support the frames, and the whole set of eight are squeezed firmly together by means of wooden thumbscrews as shown. Under the head of Coxrs HoNeY we have already spoken of the value of compression for squeezing sections or section-holders or wide frames. The more tightly the parts are held together, the less chance there is for bees to chink propolis into the cracks.

The bottom-board of this hive is much like that used on the standard hives, in that it has a raised rim on the two sides and end, to support the brood-chamber a beespace above the bottom-board, and at the same time provide for an entrance at the front. The cover is the ordinary flat oneboard, cleated at the ends.

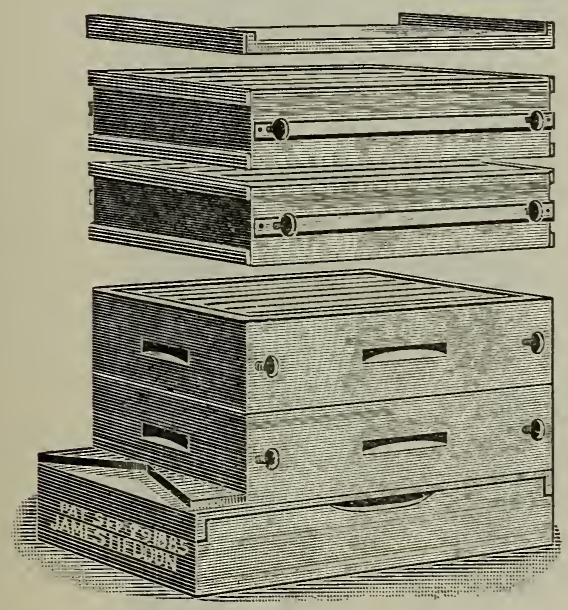

The purpose of the inventor in having the hive divided in this way was to afford more rapid handling, and to accomplish contraction and expansion by simply taking from or adding to the brood part of the hive one or more sections. This divisible feature of the hive, according to its inventor, enables him to handle hives instead of frames, to find the queen by shaking the bees out of one or both of the shallow sections. The horizontal bee-space thru the center of the brood-nest is considered an advantage in wintering, in that the bees can move up and down and laterally thru the combs.

The advantages of this hive are more theoretical than real. Like the Danzenbaker, it has been gradually going out of use, so that today there are but comparatively few that have it.

\section{THE DADANT HIVE.}

Almost the very opposite of the Heddon in principle and general construction is the Dadant hive. While Mr. Heddon divided the brood-chamber into one, two, or three separate portions, the Dadants have it all in one large complete whole. The frames are $181 / 2 \times 11 \frac{1}{4}$ - that is to say, they have the Quinby dimensions. There are nine or ten to the hive. Such a hive has about the equivalent capacity of a twelve-frame Langstroth, regular depth. The Dadants have always insisted that their ten-frame Quinbys, when compared with the ten-frame Langstroth, averaged up year after year, would gire far better results, both in honey and in economy of labor. This opinion is not based on the experience of two or three years, but on a period covering a good many years. The large hives, they claim, swarm less, produce more honey, and winter better. They claim they do not have to exceed two per cent of swarming, and this average has been maintained year after year. Apparently the colonies in these large hives have very little desire to swarm; but when they do swarm the swarms are enormous. In regard to this point, in an article that was published in Gleanings in Bee Culture, C. P. Dadant says :

Don't understand me to say that, with large hives, you will have no swarms, for this is incorrect; but if you want to prevent swarming to the greatest possible extent, you must, first of all, have large hives. Other things are required, such as the removal of the excess of drone combs, plentiful ventilation, a supply of surplus combs, etc.; but the sine qua non, in our eyes, is large hives.

With a little care it is not difficult to keep swarming down to such a point that the natural increase will barely make up for winter losses. In our case we find it insufficient, and we resort to artificial swarms, or dividing, which we find much more satisfactory, for we can breed from the queens that we prefer, and, at the same time, keep our best colonies for producing honey. Every practical beeman will agree that it is the large colonies that give the large crops, whatever may be his opinion as to the size of hive needed.

But if we must have swarms, with large hives they will be large, take my word for it.

The Dadants have claimed that the ordinary eight and ten frame hives are not large enough for good prolific queens: that a brood-frame of Langstroth depth is too shallow; that we never know what a good 
queen can do till we give her a large hive and a large frame. Again, in one of their articles for Oct. 1, 1898, in Gleanings in Bee Culture, Mr. C. P. Dadant says:

With the large hives we found queens that had a capacity of 4500 eggs per day. Exceptions, you will say? Certainly, but it is a very nice thing to give a chance for those exceptions. And I hold that you cannot do this as fully with a two-story eight-frame colonies for winter, which is in itself a great advantage, as the number of bees has much to do with their ability to keep warm, and their ability to retain the heat has also much to do with their honey consumption. A weak colony suffers much from the cold, and is compelled to eat more..... But to me the greatest advantage of the deep large frame is the greater ease bees have in reaching the honey while preserving a more compact cluster.

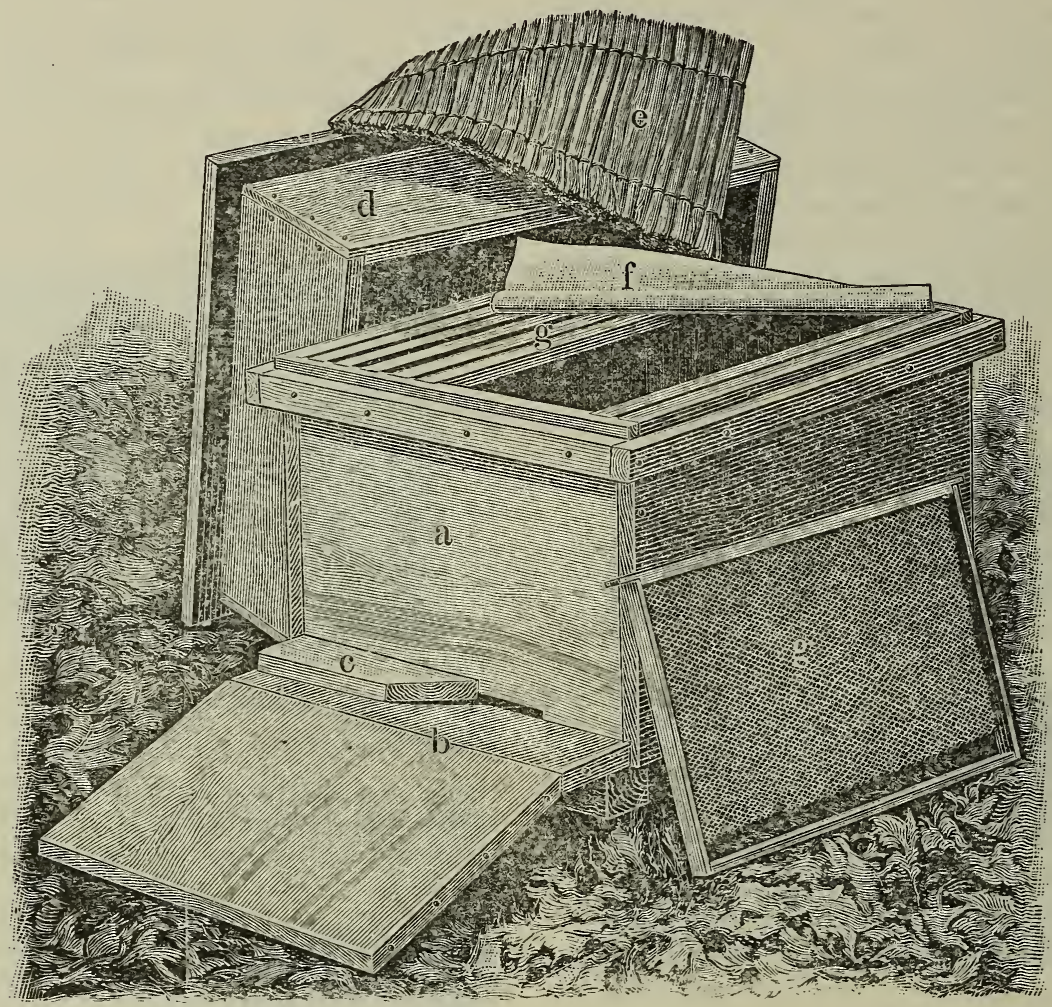

Dadant-Quinby hive.- "From Langstrath on the Honeybee," revised by Dadant.

hive as with a hive that may be enlarged, one frame at a time, till it contains all the room that the queen may need. Your eightframe hive gives her too much room at once when it is doubled in size. If the season is a little cool, there is a chance of delaying the breeding by chilling the combs. The bees will then concentrate themselves upon the brood and keep it within narow limits, for the queen will seldom go out of the cluster to lay.

As to the matter of wintering, these jumbo hives seem to offer exceptional advantages. Mr. Dadant, in one of his articles, says:

The facts upon which I base my conclusion are those facts that we have seen under our own eyes, of better success in wintering with the large deep hive. We have thus stronger
LARGE HIVES; WHERE AND UNDER WHAT CIRCUMSTANCES USED.

The Dadants have a considerable following in their vicinity; and in France the Dadant-Quinby has become almost the standard hive. But it should be remembered that the Dadants are extracted-honey producers; and in France liquid honey has rather the preference. There can be no sort of doubt that these large hives, for extracted honey, have some advantages over the smaller ones; but when it comes to the production of comb honey, there is a question, and a big one too: Is such a large hive as good as a smaller one? In some localities the bees might fill only a brood-nest in such a 
hive; whereas if a shallower one were used, like the Langstroth, the available comb space below would be filled with brood; and the honey, when it did come in, and what little there was of it, would be forced into the supers. In the selection of a large hive, then, a good deal depends on the locality, and whether one proposes to run for comb or extracted honey.

\section{THE LARGE HIVES NON-SWARMIERS.}

There is one very important feature in favor of the Dadant hive, and, in fact, any large hive; and that is, the reduction or almost entire control of swarming. There has been no satisfactory method proposed to accomplish this result with the singlestory Langstroth when run for the production of comb honey; and a great many give up the problem, stating that it is better to let the bees swarm once, and then somehow afterward control the after-swarms, arguing that more actual comb honey will be produced from the parent colony and its swarm than where other methods are employed. But if swarming is to be allowed, what is to be done at outyards? If an attendant has to be constantly on hand during the swarming part of the day, it means a big expense, and this might, in a poor season, balance the entire proceeds of the honey crop. If, on the other hand, swarms are allowed to go to the woods, then there is a loss. It is true that swarms will not escape if the queens' wings are clipped; and to a very great extent clipping does prevent this waste. But better-far better-is it to take away the desire for swarming altogether, if it can be done. In the production of extracted honey, at least, the Dadants have demonstrated that, with their large hives, they have practical control of swarming, because their hives are so large that the bees and the queens rarely feel cramped for room. The author believes in large colonies, and is hopeful that the time will soon come when we shall learn how to make these big colonies produce comb honey as well as, at the same time, remaining practically non-swarmers. At the present time shallow hives, like the Langstroth, have the almost exclusive preference for comb honey thruout nearly all the territory in the northern portions of the country-the territory where the main honey supply is almost entirely from clover and basswood.
LARGE COLONIES IN TWO-STORY EIGHT-FRAME

\section{LANGSTROTH HIVES.}

We have experimented a little with twostory colonies in Langstroth hives tiered one above another, raising brood in both stories. When we have a good queen, such colouies in these double chambers grow to be tremendously strong, and they show less inclination to swarm-no sort of doubt about that; and, what is more, in a few instances we have placed comb-honey supers on top of these same colonies, and had them fill two and three supers. But in a majority of cases the colonies will not be strong enough tc fill two stories and go into the supers besides; so, after getting the colonies up to good strength, and just at the approach of or during the honey-flow, we take away one story and place on one or two comb-honey supers. Such a large force of bees, of course, rush right into them. If there is any honey in the fields the supers are filled and completed in short order. We have thus far succeeded in getting stronger colonies in this way than in a single brood-nest alone. By thus breeding in double stories, and having prolific queens, or, perhaps, what may be better, working colonies on one full-depth story, and one half-depth story, we can get the bees into the sections at once. For particulars regarding this last, see the Barber plan spoken of under СомB HoNey.

\section{OBJECTIONS TO LARGE HIVES.}

Their size renders them both heavy and unwieldy. They cost more money-about twice as much if made as shown in the engraving of the Dadant hive. It is diffcult, in the first place, to get good clear lumber wide enough to make these deep hives; and then when they are made, and are full of bees and honey, it is not practical to move them about much. The $\mathrm{Da}$ dants, for instance, leave these large hives on their stands all summer and winter, both at the home and outyards. They find it more practical to do so. Even when wintered on their summer stands in singlewalled hives, the loss just about equals the slight increase they have in swarming.

These large frames are not nearly as easy to manipulate as the shallow Langstroth. It takes longer to get them out of the hive, and during the operation there is more danger of killing bees. The Dadants and others having the Quinby hive find it necessary to 
use another size that they call their shallow or half-depth frame, $53 / 8 \times 181 / 2$, for extracting. These are placed on top of the brood-nest, and are tiered up one, two, three, or four high. One is led to wonder why a compromise between a deep Quinby and these extracting-frames would not be better-a frame adanted for breeding as well as for extracting-as, for instance, one like the Langstroth; then when one wants a large hive he can tier up one brood-chamber on top of the other.

THE TEN-FRAME HIVE OF EXTRA DEPTH.

It was suggested by A. N. Draper, formerly of Upper Alton, Ill., one of Mr. Dadant's followers, that, in order to reduce cost, instead of making a hive after the Quinby dimensions, and on the Dadant pat-

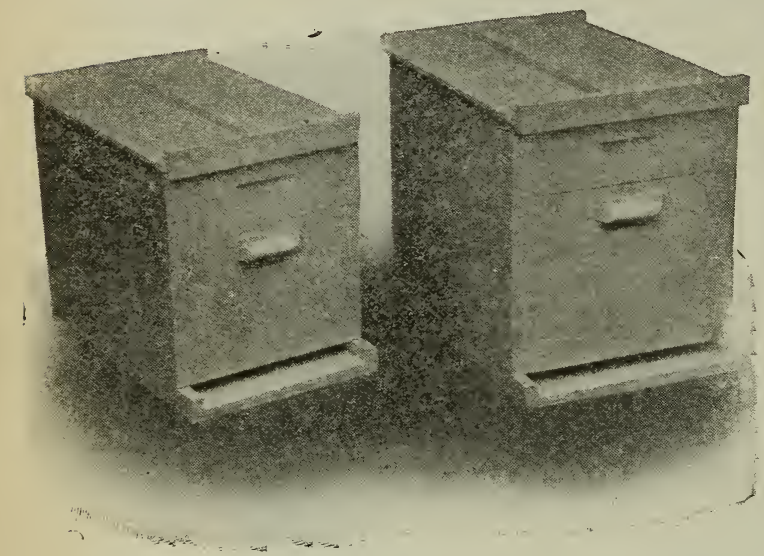

The comparative difference in size between a regular eight-frame hive and a ten-frame jumbo.

tern, a hive be constructed after the pattern of the regular ten-frame Dovetailed, having Langstroth dimensions save in one measurement--that of depth. He would add to the hive and frame $2 \frac{1}{8}$ inches. As the Dadants ordinarily use nine frames in their Quinby hives, ten frames $2 \frac{1}{8}$ inches deeper, with Langstroth top-bar, would give the hive equal capacity. Such a hive would take regular Langstroth ten-frame bottomboards, covers, supers, honey-boards, winter-cases-in fact, everything adapted to the regular ten-frame Langstroth Dovetailed hive. As the ten-frame hive is one of the standards, it seems reasonable to suppose that, if the large hive is really better, such a hive would be more simple and cost less than to adopt-regular Quinby-frame dimensions, and make the hive as the Dadants show it.
Indeed, we have been told that the Dadants would faror such a hive rather than the one they have adopted, if they were to start anew. The supply-dealer will make the brood-chamber for about 25 per cent more than the regular ten-frame Langstroth Dovetailed; the super, covers, and bottomboards would, of course, cost no more. Where one by reason of locality or preference desires such large hives, the Jumbo ten-frame Langstroth of extra depth, suitable for taking standard ten-frame fixtures, is the hive to select.

\section{THE TWELVE-FRAME LANGSTROTH HIVE.}

There are some others besides the $\mathrm{Da}$ dants who believe that the ordinary tenframe Langstroth hive-body makes too small a brood-chamber; that a good queen, such as ought to be in every hive of the up-todate honey-producer, will easily fill a twelve-frame hive with brood. There is no use in denying the fact that the ordinary nser of a common ten-frame hive often wishes he had a hive of two frames more capacity. To put on an upper story to take in the extra frames sometimes gives too much room.

Mr. R. F. Holtermann, of Brantford, Canada, operates something like 700 colonies on twelve-frame hives. He is one of the best and most extensive honey-producers in America. He tried out the ten and twelve frame hive side by side, and gives his verdict in favor of the latter.

The objection to a twelve-frame hive is that it is not well adapted to the production of comb honey. It is heavy to lift; and while it uses the regular standard Langstroth frame, it requires an odd-sized width of bottom-board and cover as well as of supers. On the other hand, the ten-frame Langstroth hive, with an extra depth of about the same equal cubic capacity, uses regular covers, bottoms, and supers, but requires an odd-sized frame. In favor of the deeper frame it may be said that a prolific queens seems to like large combs.

Taking everything into consideration, the ten-frame Langstroth hive is a happy medium between the very deep and the very shallow, and the very wide twelve-frame and the narrow eight-frame hive. The fact that it has become almost universal on the American continent is much in its favor. 


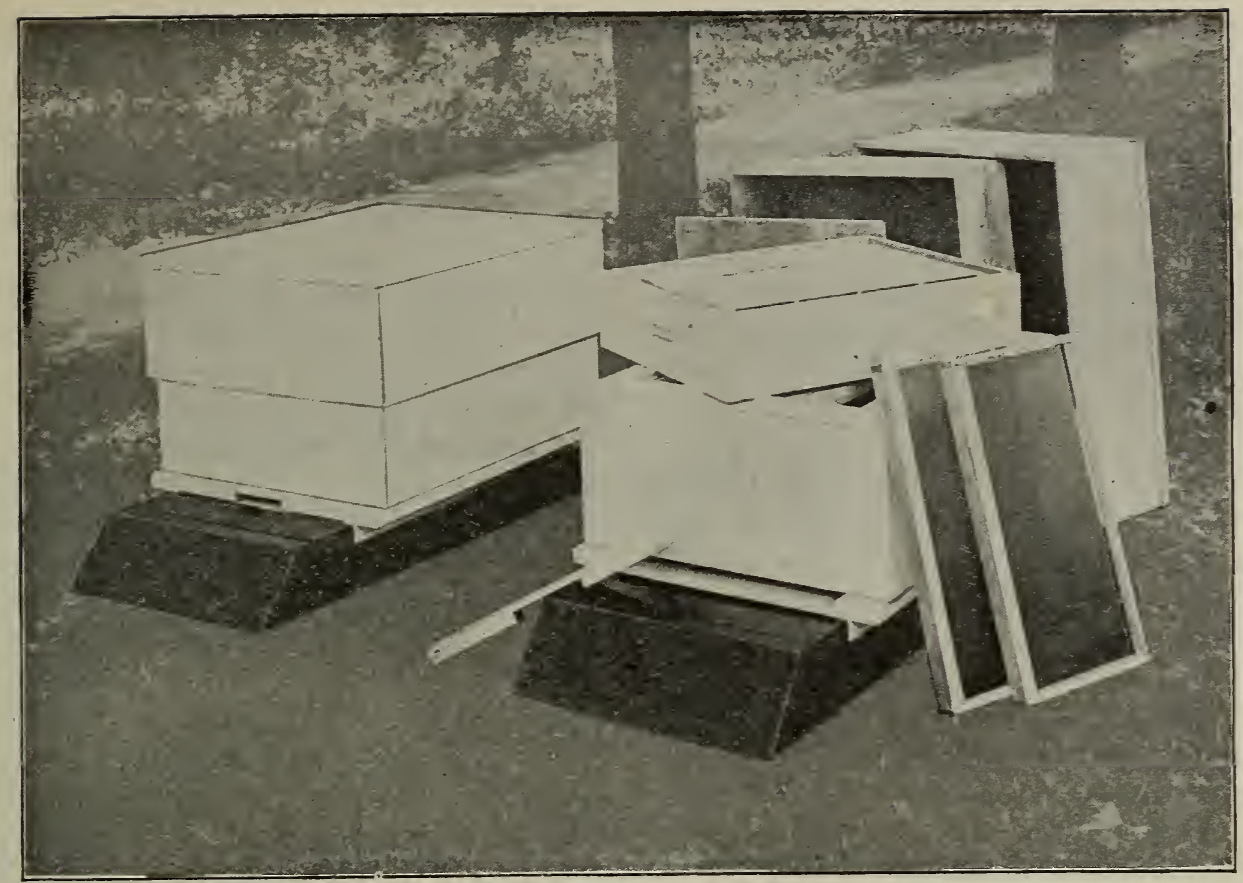

Root double-walled hive with removable bottom.

\section{DOUBLE-WALLED OR CHAFF HIVES.}

The hives that we have thus far described are what may be called single-walled hives; that is, the outer shell or case consists of a single-board thickness of lumber. Such hives, as a rule, cannot very well be wintered outdoors on their summer stands. They either have to be carried into the cellar at the approach of cold weather, or else have to be put in outside packing-cases, as the single walls hardly afford sufficient protection to enable the average colony to go thru the winter safely, or without great loss both in bees and in stores. The poorer the protection, the greater the consumption of stores. A colony poorly protected outdoors will probably consume twice as much as one adequately protected.

In the South, of course it is not necessary to carry the single-walled hives into the cellar or winter repository; but north of latitude 40 , hives of single-board thickness either ought to be housed or protected with winter cases. Where one from choice or necessity has to winter outdoors, what are known as double-walled hives should be used. These have the same inside dimensions as the single-walled hive, and are generally made to take the same supers and the same inside furniture. The first doublewalled hives that we used were two-story; but they were awkward and unwieldy things compared with the hives of today. The one shown in the illustration next following represents a ten-frame Langstroth single-story

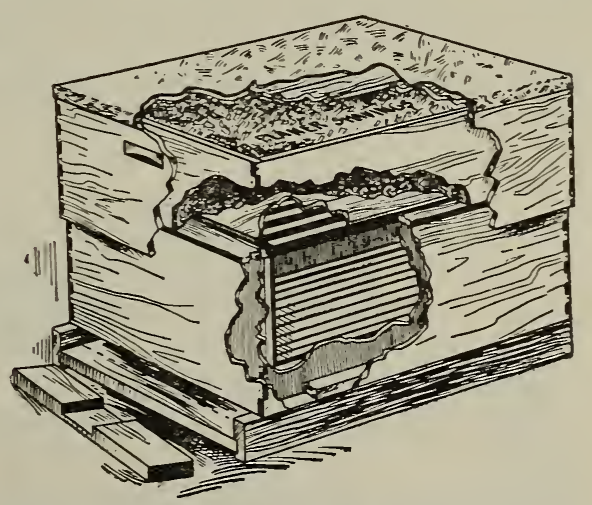

Buckeye double-walled hive with space between the walls filled with packing material.

double-walled hive; and as it represents the simplest form of wintering hive, we will describe this only, leaving the reader to adapt it to the dimensions of whatever frame he is using.

The space between the walls is filled with some porous material like dry leaves, planer shavings, cut straw or hay, ground cork, or any material that is light,loose, and porous. 
An examination of the illustrations on next page will show how this warm ideal hive differs from the others.

Bees are essentially warm-blooded animals, and if they are not warmly housed in our northern climates they will die during winter.

Careful observations have shown that these double-walled packed hives will yield larger returns in honey. For it is a wellknown fact in the domestic economy of a hive that comb-building cannot progress unless a temperature of 98 degrees is maintained night and day. Frequently in good honey-gathering weather the nights are cold enough so that the inside of the hive will be chilled, and comb-building will stop; for the bees are compelled to leave that work to hover around their brood to keep it warm. In doing this they consume largely of their stores in order to keep up the necessary hive temperature. In the double-walled packed hive brood-rearing and comb-building can continue, no matter what the temperature during ordinary summer weather may be outside.

But this is not all. While bees in singlewalled hives often do come thru the winter successfully, the result is attained at a considerable loss in stores. Overfeeding on the part of the bee in order to keep up the temperature of the cluster, causes overloading of the intestines, and this sooner or later brings on the fatal disease known as dysentery. (See Drsentery.). Nothing will use up a colony's vitality in the spring more than this dread disease. On the other hand, bees in double-walled packed hives unless the winter is severe will rarely have it. They come thru stronger, cleaner, and better, with a larger stock of stores in reserve to take care of the necessary brood-rearing that takes place as soon as warm weather opens up.

The reason for this is plain: Experiments show that the internal temperature of a single-walled hive outdoors during winter is only slightly higher than that outdoors. On the other hand, the internal temperature of a double-walled packed hive is anywhere from 25 to 50 degrees higher than the outside temperature. (See Gleanings in Bee Culture, page 78, for 1912.) The colder the atmosphere in which the bees are kept, the more they have to eat. Overfeeding plus cold causes dysentery.
Taking everything in consideration, if the double-walled hives cost more than the single-walled, they will save from 25 to 50 per cent of the stores, and anywhere from 50 to 90 per cent of the winter losses, year in and year out. During spring and summer a larger return in honey may be expected for the reason the bees are not obliged to stop their comb-building because their super is too cold nor stop brood-rearing in the spring. Neither are they forced to eat too much of the freshly gathered stores in order to keep up bodily heat.

Under WINTERING OUTtDOORS will be found a description of the quadruple winter cases. Bees in four single-walled hives packed in one of these cases will be as well if not better protected than bees in the double-walled hives referred to. In some localities, where migratory beekeeping is practiced, or where a scheme of out-apiaries is used, a single-walled is preferable to a double-walled hive, because it takes less room in the wagon or truck, is lighter, and more easily handled. Where such hives are used, they should be kept in a winter packing-case until settled warm weather comes.

The double-walled hive has the advantage in that it is more suitable for the backlot beekeeper, the farmer beekeeper, or those who desire to leave their bees on the same stand the year round, and who, on account of other duties, cannot fuss with putting: bees in the cellar and taking them out again, or packing and unpacking in large winter cases. Even when bees are wintered in the cellar, a double-walled hive is a great advantage in that it protects the brood and the bees after the bees are set out of the cellar in early spring. If they could be kept in the cellar until settled warm weather, the bees would not be subjected to the rapid and severe changes of weather conditions. But this is not practicable. In localities where the climate is very severe, many find it advisable to put these doublewalled hives in the cellar and set them out in the spring. Bees need protection, not only during cold winter weather, but in the spring, when changes are often frequent and severe.

\section{CONSTRUCTION OF THE BUCKEYE HIVE.}

The brood-rhamber is made up of an outer and inner rim of select $3 / 8$ lumber, lock cornered together for strength. The space 
between the two walls is covered over with a sort of picture-frame water-table. This is secured to the inner chamber in the manner shown; cleats I I as well as the water-table are then nailed to the inner and outer chamber. The two chambers are turned upside down before the bottom cleats are nailed in and then filled with packing material.

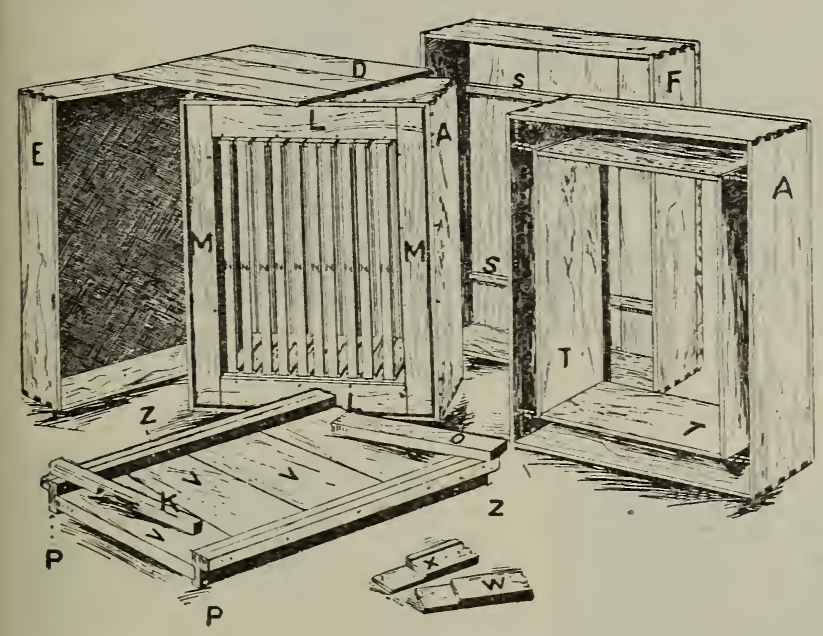

Buckeye hive dissected, showing separate parts, and how the brood-chamber packing is shut in by cleats $M$ and $L$. A, outer wall brood-chamber; $T$, inner wall brood-chamber; $\mathrm{X}$, $\mathrm{W}$, packing space cover; $\mathrm{L}$, M, packing space bottom; $\mathrm{F}$, telescope cover; $E$, chaff-tray; $D$, super-cover.

Experience shows that the top needs protection more than the sides. Hence we have tray $\mathrm{E}$ made of $3 / 8$-inch lumber with a bottom of common burlap. Cover D is put in place after the frames and the bees are in the hive, then tray $\mathrm{E}$ is put on top of the whole. This is filled level full of packing material, such as leaves or planer sharings, and orer this then is placed the large cap or cover that goes orer the whole.

It will thus be observed that we have something on the style and lines of an ordinary refrigerator, or an ordinary safe that sometimes has to go thru a fire. Anything that will keep ice from melting will in like manner keep water from freezing. The principle is the same as the thermos bottle, so well known on the market. The thermos bottle will keep water cold or hot for hours and hours. The double-walled hive here shown will keep a cake of ice, if the entrance is closed, almost as well as a refrigerator. It will also hold a pail of boiling water and keep it hot for hours on the principle of a fireless stove.

The general features that go to make up a refrigerator or a safe apply equally well to a beehive.

Some have the idea that a hive having. so-called dead-air space will winter bees as well as one having space filled with packing: material. This is a mistake. In the first place, there is no such thing as "dead air" space in a beehive or in anything else. Air is bound to circulate. The air next to the outer wall that is cold cools and necessarily circulates orer to the other side or inner side where it is warm. The cold air rushing orer to the warm side cools the warm side, thus making the inner wall almost as cold as the outer. When a hive is so designed that it can hold packing material, this material holds an infinite number of pockets of air in little compartments. As the air in these compartments cannot circulate, it follows that the outer wall may be comparatively cold, while the inner one will be warm. The fact that all refrigerators have the space between the walls packed with material, goes to show that the theory of "dead air" space between two walls is all wrong. Not only that, but actual practice shows a big difference between the so-called double-walled

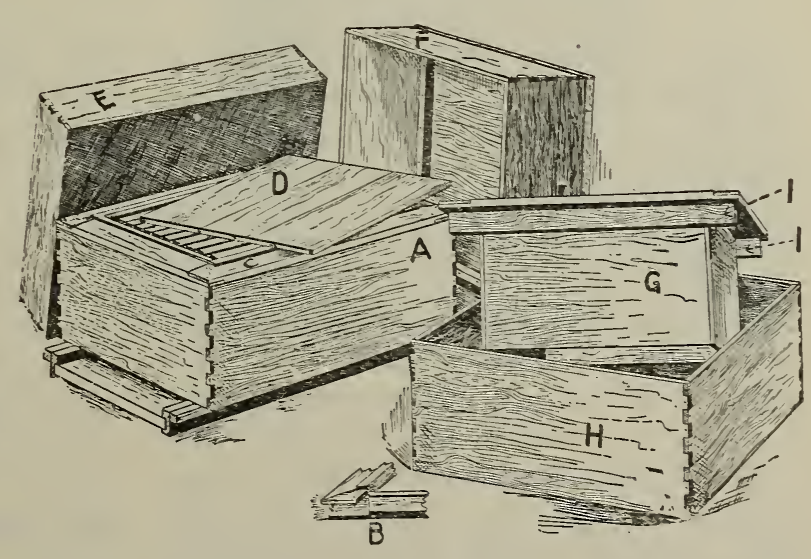

Buckeye hive dissected, showing the inner walls detached from the outer walls of the brood-chamber.

dead-air-space hive and a real double-walled hive, the spaces between which are packed. This hive has a loose bottom and loose 
cleats, front and rear. In the spring refuse and propolis will accumulate on the bottomboard. All that is necessary is to lift the hive body off the bottom, loosen front and rear cleats $K$ and $O$, scrape off and clean the dirt, replace the cleats and put the hive back on its bottom.

But the question may be asked why cleats $\mathrm{K}$ and $\mathrm{O}$ are loose. During hot weather it is recommended that cleat $K$ should be removed entirely. If the colony is very strong, remove cleat $\mathrm{O}$ also, and this makes a draft between front and rear of the hive.

The question may be raised: If such ventilation is needed, why is it necessary to have the hive so warm with double walls? For the simple reason that the upper part of the hive should be kept warm while the bottom should be cool. If the weather ually began to use planer-shavings, which we can get more easily. These, we find, answer every purpose, and we now use them exclusively. Forest leaves, if dry and well packed, will do just as well, and they have the advantage that they make the hive, when packed, lighter-that is, easier to lift and handle.

If the locality is cold enough to warrant wintering in the cellar, we should, of course, use single-walled hives exclusively.

HIVES, EVOLUTION OF.-Primitive hives were simply the trunks of hollow trees in which bees were lodged, cut down, and carried wherever the beekeeper desired. This plan of beekeeping is still practiced in some parts of Europe, in southeastern United States, and is common enough in Africa.

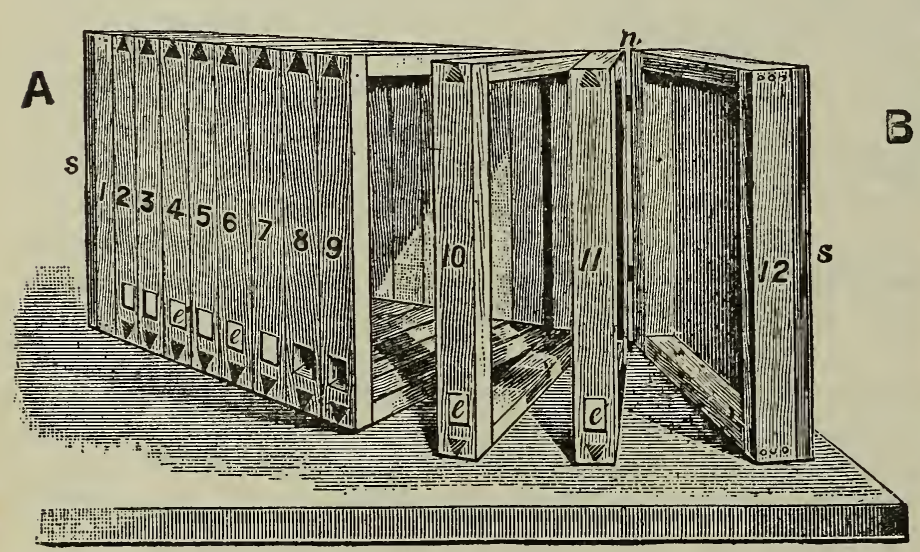

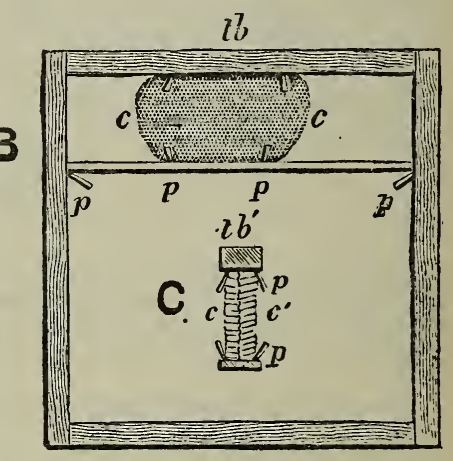

Fig. 1.

Fig. 2.-Huber's leaf hive, 1789.-From Oheshire.

changes sudderily at night, or if it turns cold or chilly as it often does during midsummer, the double walls and the packing keep the colonies warm and conserve the brood and the honey when otherwise some of the brood might be chilled and the stores consumed.

Every now and then beginners will write us, asking what was the matter with their brood and inquiring whether the disease known as foul brood has got into their hives. While it is possible for bees to have disease, it very often happens that the brood is chilled because the small cluster in a single-walled hive is not able to keep the brood warm.

\section{PACKING MATERIAL.}

We formerly used wheat or oat chaff; but as we could not secure this readily we grad-
The stingless-bee apiaries of South Ameirca have hives of this description.

The next step was to construct a cylinder resembling the trunk of a tree, either of wood or earthenware. In northern climates straw came into use, but had to be fashioned in the shape of a bell to make it easy of construction. This is the kind of hive which was so highly praised by poets. It has the merits of extreme simplicity and cheapness. Usually it had cross-sticks added inside to keep the combs from falling down on critical occasions. See SkePs.

Not all beekeepers were satisfied with these hives; and as early as the 17th century some few began to cast about for something better. Della Rocea, who wrote a book on bees in the 18th century, mentions bar hives as in vogue in the islands of the Grecian 
Archipelago, where he lived for many years.* Such hives were known even to the ancient Greeks. They resembled large flower-pots with wooden bars on which the bees were to fasten their combs. The shape of
Maraldi, about the same era as Mewe, invented a single-comb observation hive made with glass sides, which contained the germ of the movable-comb frame. $\mathrm{He}$ allowed too much space for one comb, and

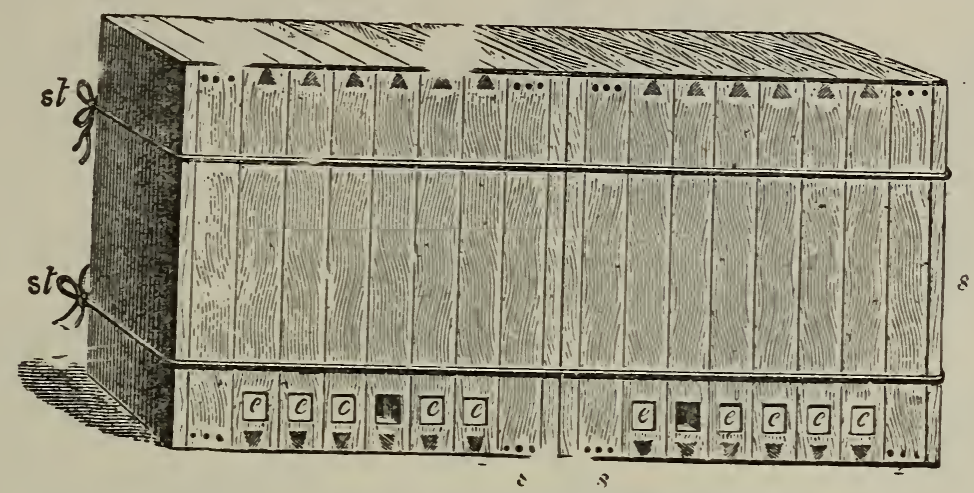

Fig. 3.- Huber hive, showing how he artificially increased the number of his colonies. E, E, E are entrance holes.-From Cheshire.

the hive made it practically impossible to cause a breakdown of the combs except by heat.

The plan of a morable roof was another step in advance, as it gave the beekeeper an opportunity to put on an upper story or a super to liold the surplus honey where it should be, and remore it at the end of the honey harrest.

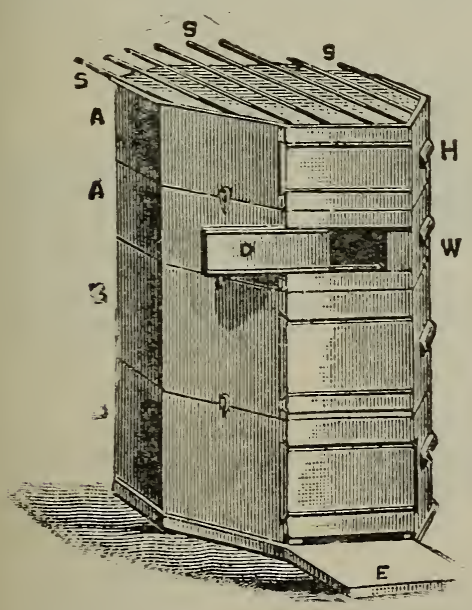

Fig. 4.-The Stewarton hive, 1819; shallowbar hive with glass strips between bars. - From Cheshire.

Newe, in Great Britain, constructed hives of wood on somewhat the same plan as early as 1652, and these were gradually improved by various inventors.

\footnotetext{
* Bar hives and morable combs are referred to in a book published in Italian in 1590. The author was Gicranni Rucellai,-A. C. Miller.
}

frequently the bees built their comb crosswise. Still there was in the Maraldi hive the important advantage of handling one

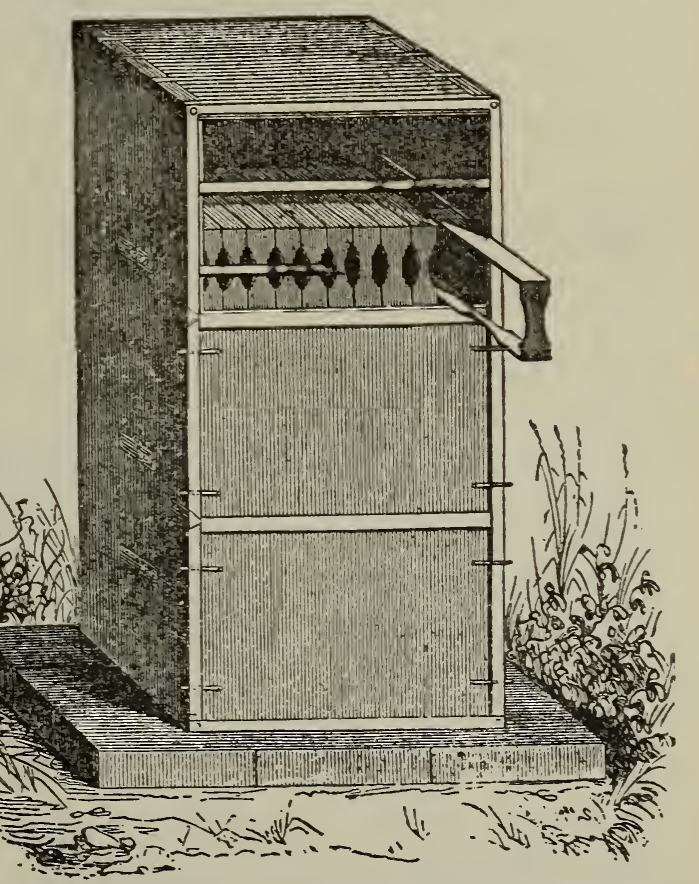

Fig. 5.-Prokoporitsch's hive, 1830.-From Framiere.

comb at a time, and by this means to get a far better conception of what was going on inside the hive. Huber extended this idea by his improvement, Fig. 1, which came very near to the hanging morable frame invented by Langstroth sixty years later. 
To Huber belongs the credit of inventing hives with movable frames, ${ }^{*}$ and it was by the use of these that he was able to make the discoveries in apiculture which so aston-

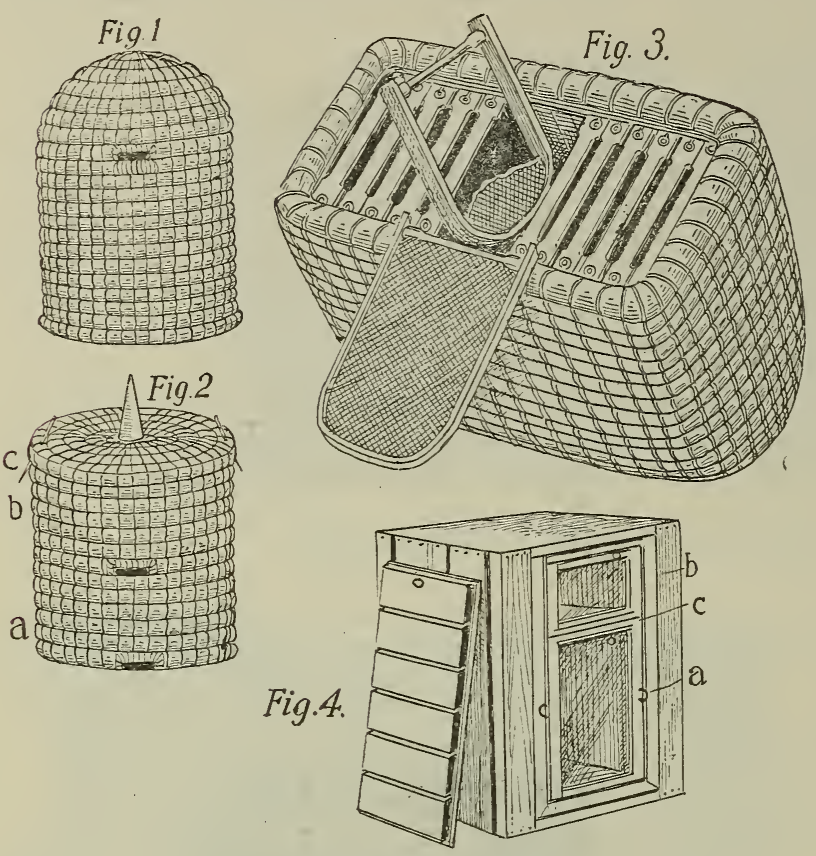

Varieties of the skep. poses. Fig. 3 (previous page) shows how he increased his apiary by artificial means. In this case he divided a strong colony by slipping a board between the frames, thereby splitting it in two. His plan of providing a part of each frame for surplus honey is excellent. It is very evident from this that Huber invented some of the principal features of our movable-comb hives. The Heddon and Bingham hives are on the movable-comb. plan. (See Hives.)

About 1819 Mr. Robert Kerr, of Stewarton, Scotland, invented a bar hive of considerable merit, shown in Fig. 4. This hive was used very successfully, and is still in use, but with movable frames instead of mere bars. It was still further improved by Howatson, also of Scotland, about 1825. Here we have the tiering principle clearly comprehended; and had this author and inventor grasped the idea of movablecomb frames instead of bars he would have invented a hive on the Heddon principle.

ished and delignted the scientific world (see Fig. 2). Huber invented these hives about 1789 , or perhaps a little earlier. It has been contended by some writers that Huber's hive was not practical; but some of the most practical beekeepers the world has yet produced used modified Huber hives, notably Quinby and Hetherington, beekeepers of New York State, whose names are revered by American beekeepers.

An examination of the illustrations of $\mathrm{Hu}$ ber's hive makes it plain that he had a clear idea of what was required in a hive for practical pur-

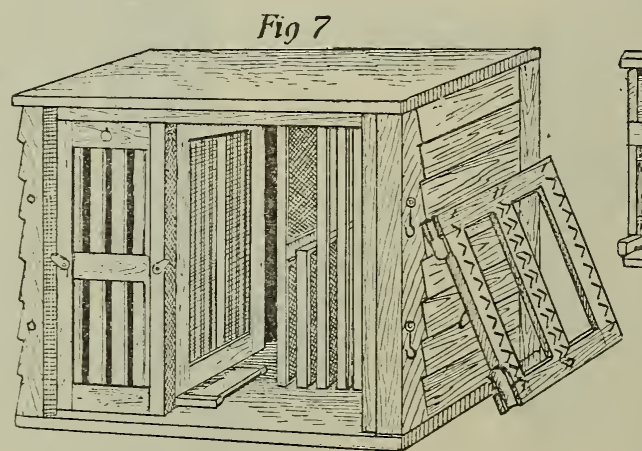

Prokopovitsch, a Russian, about 1830, invented and made in large numbers a mov-

\footnotetext{
* This honor is usually ascribed to Langstroth, for, indeed, he was the first one to invent an allround practical hive and frame-a frame that provided a bee-space all around it; but he did not invent the first movahle frame (see FraMes).
}

Fig 8

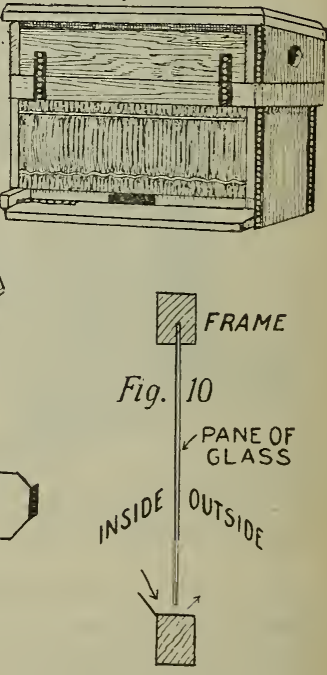

able-comb hive of great merit. See Fig. 5 . In his own apiaries, of which he had many, were over 3000 of these hives in actual use. 
His pupils (for he established a school of beekeeping) had many more in use.

It may be noted that his surplus frames bear considerable resemblance to our beeway sections, and that his hives were dovetailed. Prokopovitsch was certainly a beekeeper of remarkable abilities. $\mathrm{He}$ employed means and methods far ahead of his time.

It has been claimed by some writers that Dzierzon, of Germany, invented movable frames in 1845; but it is evident he has no claim whatever to this distinction. As a matter of fact, according to his own statements, he used bars until 1855, when he was persuaded by Baron Berlepsch to use movable frames, which had just been introduced from America. (See Dzierzox: also Dzierzon Theory.) Dzierzon's bar combs were removed by using a long knife to cut the attachments from the back of the hive

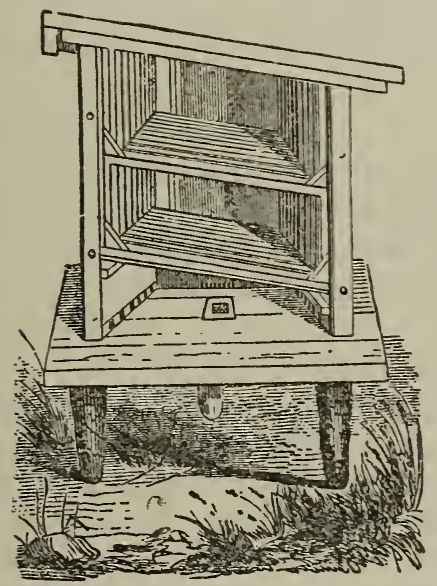

Debeauroy's hire, 1845; inrented in France before Langstroth's hive appeared.

one by one; for, to reach the comb at the front of the hive, all the other combs had first to be removed. His hive was far inferior to those already mentioned. When he adopted frames he did not change the construction of his hives in the least.

Next came Langstroth with his epochmaking movable-comb hive with movable roof, which combined the essential requirements of a hive. All the combs in the Langstroth hive are readily removable without the slightest annoyance either to the beekeeper or the bees. Langstroth did his work so well that he left very little for future inventors to do. Many have tried to improve his hive, but in most cases the so-called improvement has proven to be a backward step. The striking feature of the Langstroth hive is the provision for a beespace on all sides of the comb. This beespace cannot be less than one-sixth of an inch nor more than one-third. This alone was a great discovery, and placed Langstroth far above the mere inventor. (See Frames; also A B C of Beekeepixg.)

From his writings it is evident that Langstroth knew nothing about what others had done before him in this line; and it is apparent that his invention was the result of a very profound study of the bee and its habits. To some extent he was misled by others into thinking that the principle of the Langstroth hive had been discorered by Dr. Drierzon independently, whereas it is now proren that the German beekeeper had no claim to the invention of the hanging morable comb, to say nothing of the beespace and the movable roof, which are essential features of the hive.

Langstroth's invention, accompanied by an excellent treatise* on the art of keeping bees, created a rerolution in beekeeping in a short time, linking his name with that of Huber as the two founders of modern apiculture.

HIVES, MANIPULATING.-See MANiPULATION OF Colonies.

\section{HIVE-STANDS.-See APIARY.}

HOLLY (Ilex opaca Ait.).-American holly. A small tree, 20 to 50 feet tall. with a trunk sometimes six feet in circumference. Bark smooth and grayish white. The coriaceous, spiny-toothed, elliptical leares, with red berries in the axils, are familiar to every one. As in the common gallberry, which belongs to the same genus, the flowers are small, white, and polygamo-diœcious, the staminate being clustered and the pistillate solitary. It extends thruout the southern states west to Texas and north to Pennsylvania, whence it follows the coast northward to Massachusetts.

American holly is widely distributed in Georgia, but is seldom very common in one locality. The flowers expand in April, and altho the honey is never obtained pure. it is undoubtedly excellent. In Florida it is con-

* A reprint of the original work has been published by The A. I. Root Company; price $\$ 1.00$. 
fined to the northern part of the state, where it blooms a little earlier than in Georgia. The honey is always mixed with that of other early spring flowers. For example, on the eastern coast it forms a fine blend with the honey of the saw palmetto. In South Carolina the holly is also considered a valuable honey-producer, and the odor of the flowers is very noticeable in the apiary when the trees are in bloom. In Massachusetts the holly does not flower until June. There is in this state a variety with yellow fruit.

There are several species of Ilex with red berries which are liable to be confused with American holly, as they are valuable as honey-plants, and may attain the size of small trees, but they may be easily distinguished by their smaller leaves which are never spiny-toothed. The myrtle-leaved Ilex (I. myrtifolia) is fairly common in cypress swamps in the wire grass region of Georgia. It blooms at the same time and usually in the vicinity of the common gallberry, and the honey is believed to be equally good, for the bees gather the nectar most eagerly. The yaupon (I. vomitoria) and the dahoon (I. Cassine) may grow twenty feet or more tall, and in the southern states are helpful in building up colonies in early spring. In New England the black alder ( $I$. verticillata) is a common shrub in swamps and is much visited by bees.

HONEY.-Every reader of a work of this kind, no doubt, has a good idea of the physical properties of a honey, and he may be able from the taste to determine somewhat the kind of honey, viz., the predominant food of the bees, and it may be possible that he has an idea of the chemical composition. He may also be able to supply a good definition of a honey. But for the benefit of others, a brief statement covering this extensive field may not be out of place.

As regards definition:

According to the Century Dictionary, "Honey is a sweet viscid fluid collected from the nectaries of flowers and elaborated for food by several kinds of insects, especially by the honeybee (Apis mellifica)." An accepted German definition is, "Honey is the nectar obtained from flowers by worker bees, which, after modification in the honey-stomach of the latter, is stored in the cells of the comb for the nourishment of the young brood." In this country the food standards consider "honey as the nectar and saccharine exudations of plants, gathered, modified, and stored in the comb by honeybees (Apis mellifica and Apis dorsata)." In the latter definition there is included, besides the nectar of flowers, also saccharine exudation of plants. This comes about in that many plants contain sugar in their saps, and, when an exudation of sap takes place, and the water in the sap is evaporated, a saccharine residue remains, which is gathered by the bees. Also, many trees exude a sweet sap when stung by some insect, and this is also gathered by the bees (see HoNEY-DEW).

Physically considered, honey may be a solid block resembling a pound cake of creamery butter or it may be semi-solid or decidedly liquid. The old idea that crystals of dextrose in a honey indicated beyond doubt that the product was badly adulterated with sugar should be and has been dispelled.

In color, honey may be water-white, or it may grade thru the yellows to the brown into the seal brown and nearly to the black. It has been known to be decidedly red in color, and again at another time have a greenish tinge - none of these indicating by any means the addition of artificial colors, but being due entirely to the source of the bees' food. Honey may be as mild or as strong in flavor as one can imagine, and may possess all the fragrant aroma imaginable, and again have a nauseous aroma. Yet in each case it is absolutely pure.

The consuming public are very apt to jump at conclusions as regards purity of this product on account of these various flavors and aromas. A person used to clover or alfalfa honey would immediately say buckwheat honey was not honey at all; and, vice versa, one used to buckwheat honey would say clover honey was nothing more than a mild-flavored sugar syrup.

As regards composition:

Honey belongs to the carbohydrate foods. It is practically a solution of the two sugars, dextrose and levulose in water with sucrose in varying small quantities, naturally flavored and containing aromas imparted to it by the flower and by the bee. Early analyses of honey were very incomplete. 
Hassall in his "Food-Its Adulterations and the Methods for their Detection," published along in the sixties, reports results of moisture, cane sugar, glucose, insoluble matter, and mineral matter on four samples which he states, "with the exception of these, so far as we are aware, no reliable analyses have yet been made."

Wiley in Part 6, Bulletin 13, Division of Chemistry, United States Department of Chemistry, published in 1892, gives a rather complete analysis of a number of American honeys. But by far the most complete and exhaustive study of American honeys was made by Browne and published in 1908 as Bulletin 110, Bureau of Chemistry, United States Department of Agriculture. Following this, in 1912, Bryan published results of examinations of imported honeys from Cuba, Mexico, and Haiti as Bulletin 154 of the same bureau and department. Miss Alice R. Thompson in 1908 published results of the examination of Hawaiian honeys as Bulletin No. 17, Hawaiian Agricultural Experiment Station.

Abstracting these, we obtain some interesting facts, and at the same time a fairly complete analysis of representative American honeys, together with those liable to enter the American market.

Browne made a classification of his samples according to floral origin; that is, placing all those supposed to be obtained from clover together, etc., and then attempted drawing some conclusions as to physical and chemical constants of each variety. While the results do show some conformity to type, they are not as close as could be desired for examination of the pollen found in the samples showed that the bees had gathered nectar from other flowers, altho the prevailing pollen was that of the species under which the analysis had been classified.

In this same bulletin is a rather exhaustive study of the several kinds of pollen found and the characteristics of the pollen of the various individual flowers. The quantity of pollen varied considerably in the samples, hence the examination for pollen cannot give any index of the percentage of adulteration. From the kinds of pollen found one can judge with some degree of accuracy the kind of flowers visited, but it is hardly safe to say that with the absence

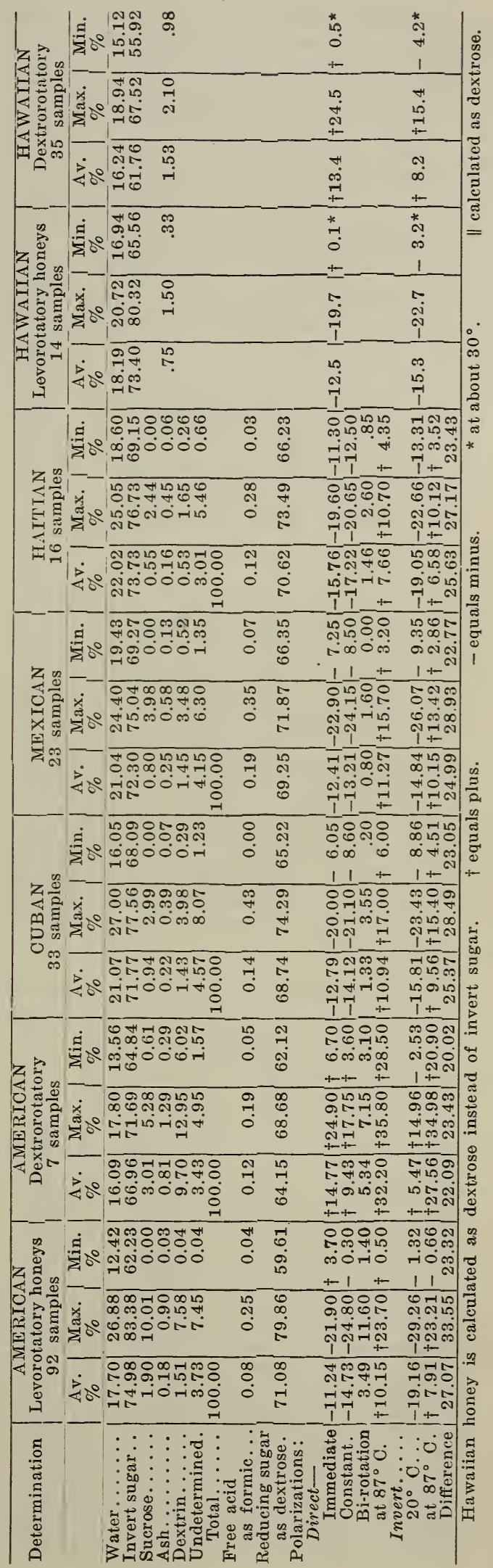


of a certain pollen, the nectar from that flower has not been gathered and stored.

In the preceding table are contained the analytic results of the examination, showing the average, maximum, and minimum figures for American, Hawaiian, Cuban, Mexican, and Haitian honeys. (Table preceding.)

It is noted that the American as well as the Hawaiian honeys are divided into two classes - levorotatory and dextrorotatory. The former may be termed honeys under the National Food Law, while the latter are honey-dew honeys. The standard of food products under the national law states that "Honey should be levorotatory, and should contain not more than 25 per cent water, not more than .25 per cent ash, and not more than 8 per cent of sucrose.

The quantity of ash stated is too low, as Browne's examination has shown 0.90 per cent ash.

The analytical figures given in the analyses are for percentage of moisture, invert sugar, sucrose, dextrin, ash, and undetermined matter. The acidity of the honey samples has also been given.

In American honeys there is an average of 3.73 per cent of undetermined matter. The composition of this material is the subject of much work now, and the substances found in this class by the chemist are often the deciding figure in determining the adulteration of honey with commercial invert sugar.

The composition of the sugars reported as invert sugar, viz., percentage of dextrose and levulose, are sometimes of value. Taking Browne's results for the average of the various species of honey we find:

\begin{tabular}{|c|c|c|}
\hline Kind of Honey & Dextrose & Levulose \\
\hline Alfalfa ....... & $36.85 \%$ & $40.24 \%$ \\
\hline White elover .. & 34.96 & 40.24 \\
\hline Alsike clover ....... & 36.06 & 40.95 \\
\hline Sweet clover ........ & 36.78 & 39.59 \\
\hline Catclaw ............. & 38.21 & 40.81 \\
\hline Mesquite $\ldots \ldots \ldots \ldots$ & 38.04 & 41.03 \\
\hline Locust .... & 35.98 & 40.35 \\
\hline Dandelion . & 35.64 & 41.50 \\
\hline Goldenrod & 34.45 & 37.85 \\
\hline Aster .... & 33.93 & 41.31 \\
\hline Apple .... & 31.67 & 42.00 \\
\hline Raspberry. & 33.57 & 41.34 \\
\hline Buckwheat ..... & 36.75 & 40.29 \\
\hline Wild buckwheat & 35.39 & 41.36 \\
\hline Cotton ......... & 36.19 & 39.42 \\
\hline Basswood & 36.05 & 39.27 \\
\hline Sumac ... & 33.72 & 37.61 \\
\hline Tupelo & 24.73 & 48.61 \\
\hline
\end{tabular}

In every case the levulose predominates. This is of value, as in commercial invert sugar the two are equal or the dextrose predominates. See Invert Sugar.

The distinction between honey and honeydew honey is only possible by means of the polariscope. If a solution of the honey turns a polarizer ray of light to the left it is levorotatory, and the honey is a true honey; but if it turns the ray to the right it is a honey-dew honey, provided no commercial glucose has been added.

For further consideration see GRANULATed Honey, Extracted Honey, Honey-dew, Honey as Food, Honey, Analysis of, and NECTAR.

\section{PHYSICAL CHARACTERISTICS OF HONEY.}

The amount of water present in honey depends upon the degree of eraporation to which the bees have brought the product in the hive. Honey which has been taken out of the hive prematurely is said to be "unripe." According to the committee on food standards and also the German standard, honey which consists of more than 25 per cent of water must be classed as immature. It is obvious that some standard percentage as this is necessary, even tho arbitrary, in order that a basis may be had for determining what honeys are unripe.

Honey which has not been capped over is sometimes ripe, but more often unripe; and the combs of unripe honey should never be placed on the market as anything but immature honey. It possesses poor keeping qualities. Honey extracted from uncapped combs should be exposed to evaporation before bottling.

The amount of moisture in honey is not conditioned by the nectar of the flower from which the honey is derived. It varies in some degree, however, with the environment of the apiary. Evaporation within the hive is promoted or retarded by local conditions of humidity. For this reason honey from arid parts of the country is thicker in general than honey from regions where rainfall is plentiful. The difference in average water content of ripened honeys between those from the humid states of the upper Mississippi and those from the Southwest, is 3.5 per cent, according to the tests in the Government sugar laboratory.

The degree of granulation which a particular sample of honey may reach, as well 
as the length of time it takes to granulate, is another physical characteristic worth noting and forms roughly an index to its purity. Honeys high in dextrose are prone to granulation. This characteristic of alfaifa honey is well known. Conversely, honeys low in dextrose do not granulate readily. Note that tupelo, a non-granulating honey, shows only 24.73 per cent of dextrose, while alfalfa, an early granulating honey, shows by the table 36.85 per cent. See science of granulation under Granclated Hoxey. Impure honeys, such as honey-dew honey and honey adulterated with glucose, do not granulate as readily as a pure honey. Sage and tupelo by nature seldom granulate. This characteristic is utilized by packers in preparing a product which will not readily crystallize on the market when exposed to changes in temperature. See Botrlisg.

Ordinarily honey is judged by its color, flavor, and density. There is an almost endless variety of flavors, making it practicable to suit the most exacting connoisseur. The flarors, like the eranescent aroma of honey, are very difficult to describe and really cannot be satisfactorily communicated thru printed description. Alfalfa, buckwheat, basswood, cotton, orange, and sereral other kinds of honey hare a characteristic flaror and aroma which any one accustomed to them can recognize without difficulty. The presence of honey-dew is usually detected by a burnt-sugar flavor. The flavors of some of the prominent honeys are described under the respective plants.

Color is a fair guide, but not always so, for the famous heather honey of Europe is quite dark, and yet no honey stands higher in popular esteem on that continent. The best honeys of this country are usually spoken of as white, and, tho this is not quite correct, still it is near enough for all practical purposes without coining a new word.

Clover honey may be taken as the typical white honey by which others may be conreniently judged. For the purpose of comparison some may be a little lighter, and others a little darker shade; but these nice points of distinction are risible only to an expert. See HoNeys AND their Colors.

It has been the custom of a number of honey producers to market their products under such names as "white-clorer honey," "sage honey," and "pure orange honey."
Tpon this practice, Bulletin No. 110 of the Bureau of Chemistry makes the following statement. "Bottled honeys are frequently labeled by some floral designation, and these honeys, even when within the standard, often show a suspicious variation from the analyses of such honeys of known floral origin, especially as regards sucrose content. The microscopic examination of these honeys frequently shows an almost complete absence of pollen from the flower in question. Beekeepers and bottlers of honey are sometimes extremely careless in the labeling of their products and apply the name of almost any flower, thinking that they keep within the requirements of the law so long as their product is pure honey. This is a mistake, as the product should be labeled exactly according to its origin." See LABELING OF HONEY.

HONEY, ANALYSES OF.-Outside of the determination of moisture or water content, the methods of analysis of honeys can hardly be carried on by the beekeeper or bottler, first, on account of the rather complicated procedures, and, second, on account of the expensive apparatus needed. The moisture determination described below for the beekeper or bottler is not as accurate as that one described for the chemist, but it will yield comparative results. It is the one in general use by makers of maple syrup, sorghum syrup, and also cane syrup.

The analytical procedure described for the chemist are all well-known methods and should yield accurate results. It is on the interpretation of analytical results that the chemist may fail if he has not had some little experience with honey. This latter phase of the question would easily fill many pages, and then it would be doubtful whether the whole field has been corered in such a way as to explain all cases and conditions. So one can give here only the outline of the general and special methods employed in honey examination and follow these with some remarks about detecting adulteration.

For sake of convenience and ease of presentation, the method of procedure adopted is to divide the matter into statements of the methods for the individual determinations: then follow with maximum and minimum figures obtained on pure honeys for each determination. Where no maximum or minimum figures are given, these may be 
obtained from the table of analysis given under HoNeY (page 377).

The first step in any analytical examination is the drawing of a representative sample. This is of greatest importance and prevents difficulties with honey on account of partial crystallization or candying of numerous honeys.

\section{SAMPLING.}

Сомв.-In comb honey it is necessary to either select a representative comb or better to take portions of a number of combs. Then by means of a knife cut across the top of the comb and allow the honey to drain from the cells. Should the honey have granulated in the comb, it will be necessary to heat the comb on a water bath at a temperature not above $160^{\circ}$ Fahrenheit until the wax liquefies, stirring, then allow the whole to cool. The wax will solidify in a layer on top. This can be removed and the sample is ready for analysis. Should the liquid so obtained be full of dirt, treat it as given below under "Extracted Honey."

ExtraCted HoNFy.-If the sample is free from granulation, and also clear and clean and in a perfectly liquid condition, no preparation is necessary. When the sample has granulated or shows partial granulation, it should be heated on a water bath (never over a direct flame) to a temperature never over $160^{\circ}$ Fahrenheit until the crystals are in solution. If the sample is dirty, it can be passed in this state thru a fine linen cloth to filter out this dirt. The heated honey is allowed to cool to collect and solidify the wax. It is then ready for analysis.

Drawing representative samples from large containers is a difficult proposition. The best procedure in such cases should be to liquefy the whole, then stir before taking the sample. Under these conditions only could one obtain an average sample.

\section{MOISTURE METHOD FOR BOTTLER.}

The necessary apparatus are a Baumé hydrometer graduated from $0-50$ which can be obtained from any wholesale druggist or chemical house, and a tin cylinder as shown in cut about two inches in diameter and twelve inches high.

\section{BY BAUME HYDROMETER.}

A hydrometer or spindle is an instrument for showing the density of a liquid. $\mathrm{Hy}$ - drometers are graduated to various scales and for various purposes. The one generally used for rough sugar work is the Baumé. The standard of graduation is an arbitrary one and varies somewhat with different makes. The usual Baumé hydrometer is made of glass and shows a graduation from zero to 50, divided into degrees, as shown in figure below. The density is measured by floating the hydrometer freely in the liquid, which is generally held in a tall

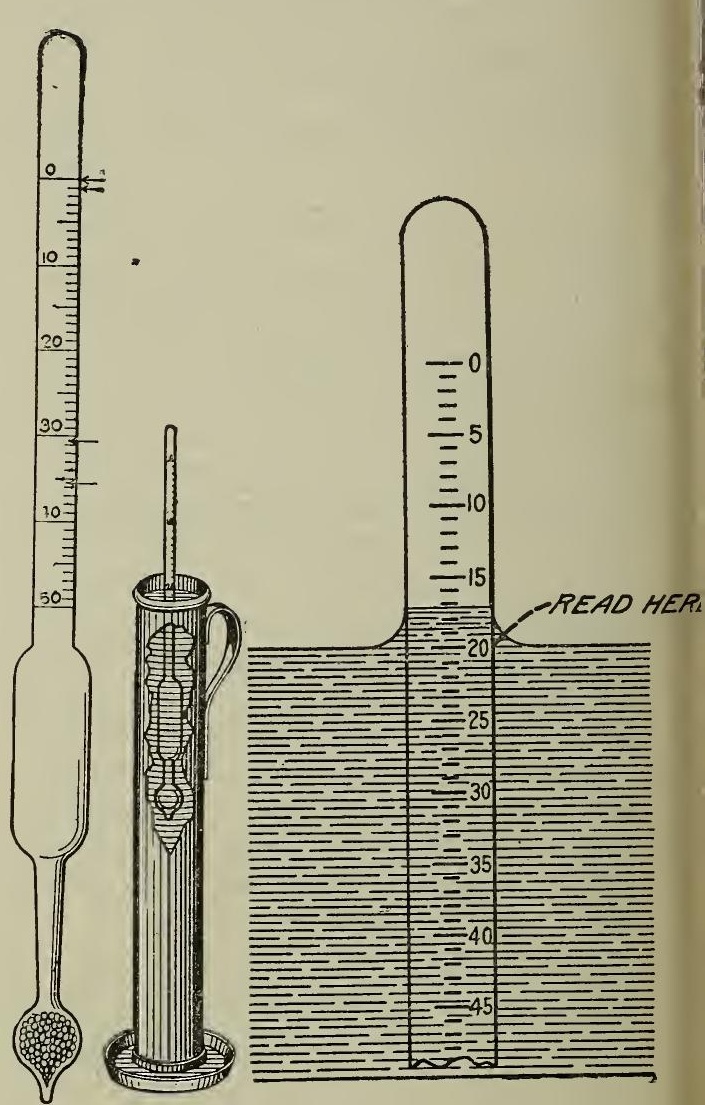

Hydrometer and its position in the liquid.

cylinder, as shown in the illustration. The point on the scale where the instrument comes to rest is considered the density. It will be noted that the surface of the liquid is curved up at the points of contact with the metal cylinder, and also with the hydrometer. The correct reading of the instrument is on a line with the surface of the liquid as shown in the cut and not at the upper edge of the curved portion. The temperature at which Baumé hydrometers are standardized is $60^{\circ} \mathrm{F}$., unless it is otherwise marked on the stem of the hydrome- 
ter, so for correct readings the honey should be cooled to that temperature. A honey of standard density has a Baumé reading of $40.9^{\circ}$, but if measuring the density of the warm honey by drawing some out into a cylinder the density will be somewhere about $37^{\circ}$ to $40^{\circ}$, and on cooling $40.9^{\circ}$ to $41.5^{\circ}$. This is readily understood when one considers that the zero of the hydrometer is at the upper end and the 50 at the lower end. On heating a liquid, there is an expansion and the liquid is lighter, so the hydrometer sinks further down than on cooling, when there is a contraction of the liquid. The accuracy of these glass hydrometers is very much affected by using them in hot liquids, hence it is not good practice to use the accurate instruments in the hot honey.

The following table shows the solid content and the water content for different degrees Baumé. These figures are only approximate. A gallon of the honey should be weighed to give accurate results.

DRY SUBSTANCE AND WATER CORRESPOND ING TO EACH DEGREE BAUME.

\begin{tabular}{|c|c|c|c|c|c|}
\hline 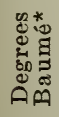 & 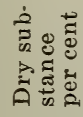 & 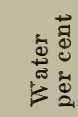 & 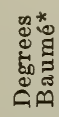 & 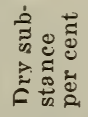 & 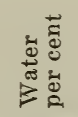 \\
\hline 1 & 1.7 & 98.3 & 26 & 46.8 & 53.2 \\
\hline 2 & 3.5 & 96.5 & 27 & 48.6 & 51.4 \\
\hline 3 & 5.3 & 94.7 & 28 & 50.5 & 49.5 \\
\hline 4 & 7.0 & 93.0 & 29 & 52.4 & 47.6 \\
\hline 5 & 8.8 & 91.2 & 30 & 54.3 & 45.7 \\
\hline 6 & 10.6 & 89.4 & 31 & 56.2 & 43.8 \\
\hline 7 & 12.3 & 87.7 & 32 & 58.1 & 41.9 \\
\hline 8 & 14.1 & 85.9 & 33 & 60.0 & 40.0 \\
\hline 9 & 16.0 & 84.0 & 34 & 61.9 & 38.1 \\
\hline 10 & 17.7 & 82.3 & 35 & 63.9 & 36.1 \\
\hline 11 & 19.5 & 80.5 & 36 & 65.8 & 34.2 \\
\hline 12 & 21.3 & 78.7 & 37 & 67.8 & 32.2 \\
\hline 13 & 23.0 & 77.0 & 38 & 69.7 & 30.3 \\
\hline 14 & 24.8 & 75.2 & 39 & 71.7 & 28.3 \\
\hline 15 & 26.6 & 73.4 & 40 & 73.7 & 26.3 \\
\hline 16 & 28.4 & 71.6 & 41 & 75.7 & 24.3 \\
\hline 17 & 30.3 & 69.7 & 42 & 77.7 & 22.3 \\
\hline 18 & 32.1 & 67.9 & 43 & 79.7 & 20.3 \\
\hline 19 & 33.9 & 66.1 & 44 & 81.8 & 18.2 \\
\hline 20 & 35.7 & 64.3 & 45 & 83.8 & 16.2 \\
\hline 21 & 37.5 & 62.5 & 46 & 85.9 & 14.1 \\
\hline 22 & 39.4 & 60.6 & 47 & 88.0 & 12.0 \\
\hline 23 & 41.2 & 58.8 & 48 & 90.1 & 9.9 \\
\hline 24 & 43.1 & 56.9 & 49 & 92.2 & 7.8 \\
\hline 25 & 44.9 & 55.1 & 50 & 94.4 & 5.6 \\
\hline
\end{tabular}

It is not to be understood that a degree Baumé corresponds to 1.7 per cent of sugar, for the hydrometer measures other dissolved solids also.

\footnotetext{
* Taken at $60^{\circ} \mathrm{F}$.
}

In order to determine relatively the number of degrees Baumé of the cooled honey when the reading is made with the hydrometer at a high temperature, it is necessary to take the temperature at the same time that the hydrometer is read. Subtract 60 from the number of degrees Fahrenheit of the heated honey (this being the normal temperature) and multiply the difference by 0.0265 . This figure (which is the temperature correction expressed in degrees Baumé) is added to the Baume reading of the hot honey; and the result is the Baume reading of the cooled honey. For example, a heated honey shows a reading of 38 at a temperature of $160^{\circ} \mathrm{F}$. Then-

$160^{\circ}$ minus 60 equals 100

100 times .0265 equals 2.65

38 plus 2.65 equals 40.65

The cooled honey would read 40.65 , or by above table have about 25.5 per cent water.

\section{MOISTURE FOR THE CHEMIST.}

Weigh 2 grams of the sample in flatbottom aluminum (or platinum) dish $2 \frac{1}{2}$ inches in diameter) containing from 10 to 15 grams of fine quartz sand which has been thoroly washed and ignited. A small glass stirring rod is weighed out with the dish and sand, and after the addition of the honey and weighing dissolve the latter in 5 to 10 cc. of distilled water and thoroly incorporate with the sand by stirring with the rod. Then place the dish in a vacuum oven and dry to constant weight at from $68^{\circ}$ to $72^{\circ} \mathrm{C}$. under a 20 to 24 inch vacuum.

\section{ASH (MINERAL MATTER).}

Carefully weigh 5 grams of the honey in a tared platinum dish, add a few drops of olive oil, and heat the whole over a flame, using care not to lose any honey by spattering. Then ignite in a muffle or over direct flame at a low red heat. Cool, weigh, and calculate percentage. Should the ash run around .1 per cent it would be well to check the result by using 10 grams of the honey. The greatest care is necessary in ashing a product not to overheat.

\section{DEXTRIN.}

Transfer 8 grams of the honey to a 100 CC. flask with $4 \mathrm{CC}$. of water and add sufficient absolute alcohol to bring up to the mark. (The transfer is best made by de- 
canting as much as possible of the liquid honey into the flask, then adding $2 \mathrm{CC}$ of water to the dish (from a burette) to take up adhering honey and again decanting. By using $1 \mathrm{CC}$ more of the water in two successive washings and adding a few cubic centimeters of the absolute alcohol each time before decanting the honey can be completely transferred without the necessity of using more than $4 \mathrm{CC}$ of water. Finally rinse out the dish with absolute alcohol and then add it to the flask with continual agitation until the volume has reached $100 \mathrm{CC}$. Allow this to stand until the dextrin has settled out on the sides of the flask and the supernatant liquid is perfectly clear.

Then decant the clear solution thru a filter and wash the precipitated residue with $10 \mathrm{CC}$ of cold 95 per cent alcohol to remove the adhering liquid, pouring the washings also thru the filter. Dissolve the residue adhering to the flask and the particles which may have been caught upon the filter in a little boiling water and wash into a tared platinum dish. Evaporate the contents of the latter and dry in a vacuum oven to constant weight as for the moisture determination. The alcohol precipitate is liable to carry sugars with it so it is necessary to determine the weight of these and therefore correct for them.

After determining the weight of the dried alcohol precipitated, redissolve the latter in water and make up to a definite volume. If the alcohol precipitate weighs as much as 0.5 gram, the volume should be $50 \mathrm{CC}$; from 0.5 to 1.0 gram, it should be $100 \mathrm{CC}$; from 1.0 to 1.5 grams $150 \mathrm{CC}$ and so on. Determine the sugars in aliquots from the filtered solution of the alcohol precipitate, both before and after inversion. The total alcohol precipitate less the weight of invert sugar and sucrose gives the weight of dextrin, from which the per cent can be obtained.

\section{REDUCING SUGARS.}

Take 10CC of the solution used for the immediate polarization determination (see later) before inversion and make up to $250 \mathrm{CC}$ in a flask with water. Use $25 \mathrm{CC}$ for reduction according to Allihns' method. Calculate the results expressed as dextrose to invert sugar by the factor 1.044. If Munson and Walker's method is used for reducing sugar determination, use $25 \mathrm{CC}$ of the above sugar solution and $25 \mathrm{CC}$ of water. Allihns' method and also Munson and Walker's methods are given in detail in the Official Methods of the Association of Agricultural Chemists, in various hand-books for sugar chemists, such as Browne's, Spencer, and in most works on food analysis as Leach, etc.

\section{SUCROSE.}

Determine the total sugars after inversion by transferring $10 \mathrm{CC}$ of the $55 \mathrm{CC}$ solution (see later) used for the invert polarization to a $250 \mathrm{CC}$ flask and making up to the mark with water. Take $25 \mathrm{CC}$ for a reduction by either Allihns' or Munson and Walker's method. Calculate to per cent invert sugar. Subtract the per cent of invert sugar before. inversion from this figure and multiply the difference by the factor 0.95 to obtain the per cent of sucrose. The percentage of sucrose cannot be determined accurately from the polarizations.

\section{POLARIZATIONS.}

Transfer 26 grams of honey to a $100 \mathrm{CC}$ (true CC) flask with water, and add 5CC of alumina cream; make up the solution to volume at $20^{\circ} \mathrm{C}$, and filter and polarize the liquid at once for the "immediate polarization." Transfer 50CC of this filtrate to a 50-55CC flask; add 5CC of concentrated hydrochloric acid, and allow the whole to stand over night for inversion. Place the remainder of the filtrate in a flask, after removing the quantity necessary for the reducing sugar determination, and allow to stand over night. On the following day again polarize the two solutions at $20^{\circ}$ and also at $87^{\circ} \mathrm{C}$, making a total of five different readings.

The polarization at $87^{\circ} \mathrm{C}$ is a rather difficult one to make. It is necessary to have a water-jacketed tube and run water of about $95^{\circ}$ thru at first to bring quickly the temperature up to around $85^{\circ}$, then run the water at about $90^{\circ}$. When the solution itself has reached $87^{\circ}$, make a reading. If much time is necessary to bring the solution up to $87^{\circ}$, it might be well nearly to neutralize the invert solution before making the reading. This practice will give different results, and also the solutions will turn much darker, making a reading more difficult.

The purpose of the $87^{\circ}$ reading is to obtain a reading after the invert sugar has 
become optically inactive. With substances nther than honey dextro readings at $87^{\circ}$ on the inverted solution would indicate the presence of commercial glucose. In honeys the reading is due to the excess of dextrose plus the natural dextrins. Many chemists have fallen into this mistake.

\section{ACIDITY.}

Dissolve 10 grams of honey in water and titrate with tenth-normal sodium hydroxide, using phenolphthalein as indicator. Express the acidity as formic acid.

It is known that the sting of a bee is due to formic acid, so all analyses are calculated to formic acid. Experimental work on the acids of natural honey has shown that there are two groups of acids present, volatile and non-volatile acids. Of the former, formic acid forms about one-half, the others being butyric, valeric, caproic, and capric. Of the non-volatile acids lactic acid predominates, then malic acid, succinic, and oxalie have been recognized. Where the honey has soured or fermented the acid formed is acetic.

\section{DEXTROSE AND LEVULOSE.}

The percentage of these sugars can be calculated from the polarizations and reducing sugar contents. The results are only true. when the reducing sugar content has been determined by Allihns' method. The calculation is as follows:

Multiply the direct polarization at $87^{\circ}$ by 1.0315 (100CC of solution at $20^{\circ}$ expands to $103.15 \mathrm{CC}$ at $\left.87^{\circ}\right)$. Subtract this figure from the direct constant polarization at $20^{\circ}$, and then divide by the factor 2.3919. The figure thus obtained is the grams of levulose in the normal weight of honey. Hence to find percentage, this must be divided by 26 .

The percentage of levulose, so found, if subtracted from the percentage of invert ugar obtained by reduction will give very losely the percentage of dextrose if these wo sugars were present in nearly equal mounts. If these two sugars differ widely 1 percentages an error is introduced into he original calculation of invert sugar, and ence in the percentage of dextrose. The lost accurate procedure is to reduce the vulose to its dextrose equivalent in copperreducing power by multiplying by the factor 0.915 , This subtracted from the total reducing sugars as dextrose will give the true percentage of dextrose. The results then of this determination, viz., per cent of dextrose plus per cent of levulose, will be greater than the percentage of invert sugar found by reduction, but such results are correct.

\section{UNDETERMINED.}

The sum of the percentages of water, sucrose, levulose, dextrose, ash, dextrin, acidity, subtracted from 100 gives the percentage of undetermined matter. This consists of wax particles, pollen grains, albuminoids, proteids, tannin, essential oils, combined acids, and a number of other substances.

\section{PROTEIN.}

Weigh out 2 grams of the honey and transfer to a 500CC Kjeldahl flask; add 10 grams of powdered potassium sulphate and 25CC of C. P. sulphuric acid. Place the flask in an inclined position, and heat below the boiling-point of the acid for from 10 to 15 minutes, or until frothing has ceased (a small piece of paraffine may be added to prevent extreme foaming). "This part of the operation is tedious on account of the sugars in the honey. Gradually increase the heat until boiling is obtained, then continue boiling until the mixture is colorless or nearly -so, or until oxidation is complete. This may take over five hours. Cool. Add $200 \mathrm{CC}$ of. water, then neutralize with sodium hydroxide solution (a few drops of phenolphthalein may be added to the liquid to determine easily when enough soda has been added). Connect immediately with a condenser and distill into half or tenth normal acid. Titrate this with tenth normal alkali, using cochineal as an indicator. A blank should be run with the reagents and the results subtracted from those obtained from the honey before calculating the percentage of nitrogen. The per cent of nitrogen times 6.25 gives the per cent albuminoids or protein.

American honeys run from 0.1 to 1.0 per cent, and even higher. German honeys average about 1.08 per cent with a range from 0.30 to 2.42 per cent.

\section{DETFCTION OF COMMERCIAL GLUCOSE.}

The dextro rotation of a honey at 87 is due to honey dextrins. These are dif- 
ferent in character from those dextrins obtained by the acid hydrolysis of starch, or such as occur in commercial glucose. One point of difference is the fact that honey dextrins are not colored by iodin solution, while the dextrin of glucose, exsept those of high-conversion products, are colored by iodin. Due to this fact Beckman has proposed the following test, which is qualitative in nature.

Prepare a one-to-one solution of honey with water and add a few drops to $2 \mathrm{CC}$ of iodin solution. If commercial glucose be present the solution turns red or violet. The depth and quality of the color depend upon the quantity and nature of the glucose employed for adulteration.. A blank test with a pure honey of about the same color, using the same quantity of iodin solution, should be made at the same time for the purpose of securing an accurate comparison of color.

If the original honey is dark in color or the test is not delicate enough, one can take the honey solution, add absolute alcohol until all of the dextrins are precipitated, allow these to settle (never filter), decant liquid, and dissolve the dextrin in hot water, then treat with iodin. By this means as low as 2 per cent glucose can be detected.

To determine the quantity of commercial glucose the following method by Browne gives fair results. It is better than other proscribed methods.

\section{METHIOD FOR ESTIMATING GLUCOSE FROM THE POIAARIZATION.}

The invert polarization at $20^{\circ}$ is subtracted from the invert polarization at $87^{\circ}$, and the result multiplied by 77 (the average per cent invert sugar after inversion in pure honeys). This product is divided by the per cent invert sugar after inversion found in the sample under examination. This figure is multiplied by 100 and the result divided by 26.7. The result so obtained is the percentage of pure honey in the sample under examination. This percentage subtracted from 100 gives the per cent glucose.

The table at bottom of page gives results by this method on mixtures of honey with varying percentage of glucose.

The percentages actually found agree fairly well with those added. However, it is not safe to say the percentage of glucose in mixtures with less than 10 per cent. Its presence in small quantities is easily told thru the qualitative test described above.

\section{ENZYMES.}

Enzymes are bodies of varying chemical nature (considered to be albuminous in nature) which occur in the constitution of animals and plants and effect decomposition of certain chemical compounds occurring in association with them without being used up themselves. They are all destroyed by high heat, but at lower temperatures are more or less affected. In honey, both invertase and diastase are present and are the principal ones. Invertase is capable of breaking up sucrose into dextrose and levulose while diastase is capable of changing starch into dextrose. All honeys contain these enzymes. Boiling a honey destroys them. Heating a honey to $170^{\circ}$ or $180^{\circ} \mathrm{F}$. (a temperature above that recommended for liquefying a honey) destroys the action of invertase and weakens but does not destroy disastase. To destroy the activity of the latter it is necessary to bring the temperature up to $200 \mathrm{~F}$.

The test for enzymes is then important in assisting in the determination of adulteration with commercial invert sugar. A colnw reaction (with Browne's or Bryan's moo'

\begin{tabular}{|c|c|c|c|c|c|c|c|c|}
\hline 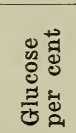 & 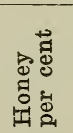 & 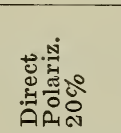 & 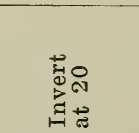 & 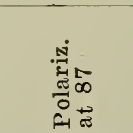 & 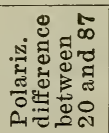 & 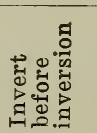 & 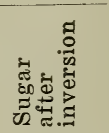 & 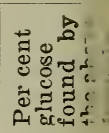 \\
\hline 100 & & +153.8 & +153.34 & +144.32 & & 30.02 & 30.45 & \\
\hline 50 & 50 & +67.0 & $\begin{array}{l}+65.67 \\
\end{array}$ & $\begin{array}{l}+73 . \\
\end{array}$ & 8.14 & & & 56 \\
\hline 20 & 80 & +15.4 & +13.42 & +33.00 & 19.58 & 69.0 & 70.35 & 19 \\
\hline 10 & 90 & $-\quad 2.4$ & $-\quad 4.84$ & $\begin{array}{r}+ \\
+\quad 18.59\end{array}$ & 23.43 & 74.42 & 74.12 & $\varepsilon$ \\
\hline 5 & 95 & -11.5 & -14.30 & +11.66 & 25.96 & & 80 & \\
\hline 3 & 97 & -14.2 & -16.94 & $\begin{array}{r}+\quad 9.13 \\
+\quad\end{array}$ & 26.07 & 76.62 & 78.01 & \\
\hline 2 & 98 & -16.0 & -18.70 & 8.14 & 26.84 & & 78.34 & 1.2 \\
\hline 1 & 99 & -18.2 & -20.90 & 6.93 & 27.83 & 77.20 & 78.87 & \\
\hline 0 & 100 & -19.5 & -22.11 & $\begin{array}{l}+\quad 5.94 \\
\end{array}$ & 28.05 & 77.68 & 78.93 & \\
\hline
\end{tabular}


see below) and a posisuld signify commercial

carrying on the test is as sau method."

Thin noney with 2 to $3 \mathrm{CC}$ of water
1. op by drop, shaking constantly to 1 ibsolute alcohol. Allow to stand, ant, and add cold recently boiled $i$ water to the precipitate and filter. it this process on a second 10 grams le honey, boiling the filtered solution a is minutes (another method uses the same .mount of honey, but adds it to $250 \mathrm{CC}$ of 95 per cent alcohol, then shaking and centrifuge, then wash the precipitate repeatedly with 75 per cent alcohol to remore all sugars, then dissolve in cold water). Neutralize the solution to methylorange, using tenth normal sodium hydroxide. then add 1.5CC of one per cent formic acid.

The invertase is determined by adding $5 \mathrm{CC}$ of ten per cent sucrose solution to a portion of the honer-extracted solutions, made to $100 \mathrm{CC}$ with cold recently boiled distilled water and determine the reducing portion of each of the honey-extracted solution. To the remainder of the solution, add 5 drops of toluene to prevent growth of micro-organisms; place in an oren at 25 to $30^{\circ}$. C. for four days and again determine reducing sugars. For diastase, use the same procedure as described above, starting with 10 grams of honey, except that a solution of starch, equivalent to 0.25 grams of potato starch is substituted for sucrese and the solution is kept at 45 to 50 degrees C. for 24 hours in place of 4 days at 25 to $30^{\circ} \mathrm{C}$. The results in each case are expressed in grams of reducing sugars per 100 grams of boney.

The following figures for diastase on pure German honeys have been obtained: 0.60 to 3.68 , and for invertase 1.05 to 12.02 . There are no figures so far published for American honeys.

\section{ALBUMINOID PRECIPITATE. "LUND'S TEST."}

In the undetermined matter of honey, there are rarying quantities of substances precipitated by the addition of tannin and also phosphotungstic acid. The quantity of the precipitate so obtained has been used as a measure of adulteration. Commercial invert sugar contains none of these mate- rials, hence no precipitate, so that a figure for this test below the minimum of a pure honey in conjunction with the disastase test and color test strongly indicated adulteration.

For these tests a special glass tube is necessary, similar in form to a Horvet maple tube. The tube should hold over $40 \mathrm{CC}$, and hare a mark at the $40 \mathrm{CC}$ point. The lower portion of the tube should hold $4 \mathrm{CC}$, and be $8 \mathrm{MM}$ in diameter and be graduated into tenths of a cubic centimeter. The upper portion should be $16 \mathrm{~mm}$ in diameter. The lower portion of this part should be graduated into half cubic centimeter up to 20 $\mathrm{CC}$ : from $20 \mathrm{CC}$ to $40 \mathrm{CC}$ there need be no graduation.

LUND'S TANXIN TEST.

Take 20CC of a filtered ten-per-cent honey solution in the tube and add $5 \mathrm{CC}$ of a fire-per-cent tannin solution (in distilled water), then add distilled water to the $40 \mathrm{CC}$ mark and shake thoroly. Allow the tube to stand 24 hours and then read off the rolume of the precipitate. Results in Germany on this test show pure honeys never go below $0.9 \mathrm{CC}$ of the precipitate and seldom below 1.2CC and may go as high as 4.0 CC. Adulterated honeys show figures from nothing up to 0.30 and ligher, but seldom above 1.0CC.

\section{IUND'S PHOSPHOTUNGSTIC-ACID TEST.}

In a tube described above, add $20 \mathrm{CC}$ of a filtered ten-per-cent honey solution and then $5 \mathrm{CC}$ of the following reagent. (Phosphotungstic acid, 2 grams. sulphuric acid (1 to 4), 20 grams, water, 80 grams), then water to the 40CC mark. Shake as before and allow to stand 24 hours. Pure honeys show from 0.3 to $40 . \mathrm{CC}$ of a precipitate, while adulterated honey much less. This latter test has been used more than the tannin test. Results from American honeys by American chemists have not been published.

\section{COLOR TESTS.}

In the commercial manufacture of invert sugar there is more or less decomposition of a small percentage of the levulose, giving rise to furfural or oxymethyl furfural. This latter body when treated with various reag'ents develops brilliant colors. This, then, is the basis of a color test for com- 
mercial invert sugar. As levulose and dextrose are present in pure honey, it is claimed that by over-heating these same furfural bodies will be formed. Much has been written pro and con on this point, possibly mainly to cast doubt on these very delicate color tests. Heating as carried on by the beekeeper (up to $160^{\circ} \mathrm{F}$.) will never develop furfural in a pure honey. Heating to boiling and then cooling will not develop this substance. Boiling a very acid honey may give a very slight test, but taken along with the strength of color shown by commercial invert sugar when present in as low as 5 per cent no one would be confused by the test.

The number of these color tests proposed are too many to be given in one place. The following are easily worked.

\section{BROWN'S ANILIN ACETATE TEST.}

Prepare fresh each time it is used the following reagent:

To 5CC of anilin (this should be waterwhite) add 5CC of water, shake, and then add glacial acetic acid to clear the emulsion (generally about $2 \mathrm{CC}$ is necessary). To 5CC of a 1-to-1 solution of the honey with water in a test tube add 1 to $2 \mathrm{CC}$ of the above reagent. Allow the lafter to flow down the walls of the test tube to form a layer. In the presence of commercial invert sugar a red ring forms at the junction of the two liquids.

BRYAN'S MODIFICATION OF FIEHE'S TEST.

Prepare the following reagent fresh at each time of testing:

Five-tenths gram of resorcinol in $50 \mathrm{CC}$ of hydrochloric acid (Sp. Gr. 1.19). Place 10CC of a 50-per-cent honey solution in a test tube and run $5 \mathrm{CC}$ of redistilled ether on top. Shake contents gently (taking care not to form an emulsion), and allow to stand until ether layer is perfectly clear; transfer 2CC of the clear ether solution to a small test tube, and add a large-sized drop of the reagent. Shake, and note the color immediately. In the presence of commercial invert sugar the drop in the bottom assumes an orange-red color, turning to a dark red. Most pure honeys show this coloration when allowed to stand anywhere from half to one hour, but never on the immediate application of the reagent. Heated honeys do not develop an immediate coloration.
FEDER'S ANILIN CHLORIDE TE. ST.

Prepare freshly each time it is use $x$ the following:

To $100 \mathrm{CC}$ of C. P. anilin add $30 \mathrm{CC}$ of $2: 5$ per cent of hydrochloric acid. For the test, 5 grams of the honey are mixed directly in a porcelain dish with $2.5 \mathrm{CC}$ of the anilin reagent. A bright-red color indicates commercial invert sugar. Pure honeys may show a faint pink color at the start, but on standing this very often disappears.

\section{SUMMARY.}

To form a conclusion on a sample of honey it is necessary to make most of the determinations described above. A moisture determination gives the data as to whether a sample complies with the United States standards in this particular. The determination of reducing sugars before and after inversion gives the only reliable data as to sucrose content. In this connection it should be noted that a fresh honey may show a high percentage of sucrose, but on standing show less, little or none depending on the activity of the enzyme invertase in the honey. The polarization figures, together with the reducing sugar content, furnishes the data along with the Beckman test for the presence or absence of commercial glucose. The presence of large quantities of sodium chloride in the ash would also help in deciding on commercial glucose. Too much dependence cannot be placed on the chlorine content of a honey unless it is known that the honey was not produced near salt water.

For commercial invert sugar the percentage of dextrose and levulose, the amount of ash and composition of the ash, the amount of tannin and phosphotungstic acid precipitate, the diastase and invertase reaction, the percentage of nitrogen, and the color tests are all helpful and needed. The presence of tartaric, phosphoric, hydrochloric, and sulphuric, also acetic acids in appreciable quaritities are extra, and are valuable determinations. The quantity and kind of pollen, also appearance, are sometimes of value in deciding on a honey.

For the further consideration of this subject see Granulated Honex, Extracted Honey, Honey-dew, Honey as Food, and NeCtar. 
HONEY AND ITS COLORS.-The various kinds of honey differ very much in color, flavor, and density. One variety may be practically colorless, while another produced in the same locality, under the same conditions, by the same bees, but from different flowers, may be a dark brown. One kind may contain less than one-sixth of water, while another may contain a fourth. The proportions of dextrose, levulose, and sucrose vary considerably; but as the extent of the variation is known to chemists they are compelled to take this into account in forming an opinion from the analytical figures.

Ordinarily honey is judged by its color, flavor, and density. There is an almost endless variety of flavors, making it practicable to suit the most exacting connoisseur. Color is a fair guide, but not always so, for the famous heather honey of Europe is quite dark, and yet no honey stands higher in popular esteem on that continent.

The best honeys of this country are usually spoken of as "water-white," and, tho this is not quite correct, still it is near enough for all practical purposes without coining a new word.

Clover honey may be taken as the typical white honey by which others may be conveniently judged. For the purpose of comparison some may be a little lighter, and others a little darker shade; but these nice points of distinction are visible only to an expert.

Taken by this standard, in the North we have all the clovers-white, alfalfa, crimson, mammoth, alsike, sweet-and the European sainfoin; basswood, raspberry (wild), willow-herb (or fireweed), Canada thistle, apple, cucumber (pickle), and Rocky Mountain bee-plant. In the South we have white honey from the following: Gallberry (holly), sourwood, tupelo, mangrove, cotton, palmetto, huajilla, catclaw, huisache, mesquite, California sage, and some others of less importance. From the American tropics the chief white honey are logwood, or campeche; campanilla (Cuba), and the mangrove (courida), on all tropical seashores.

Amber-colored honey comes from many sources. Among them, only the more familiar ones can be noted in a popular book of this kind; namely, goldenrod, wild sunflower, heartsease, Spanish needle, sumac, milk- weed, poplar, gum, magnolia, lima bean, marigold, horsemint, horehound, carpetgrass, and the hog plum (hobo), rose-apple, and royal palm of the West Indies.

Of dark honeys we take two great examples-the buckwheat of the United States and Europe, and heather, which is confined to Europe alone. The latter, tho dark, is a rich, strong-fiavored, thick honey, so dense that the extractor is not used to take it from the combs. That produced in Scotland commands a very high price, while that of England is cheaper, being gathered from another species of heather. In North Germany the heath or heather honey commands a good figure. It is largely produced by migratory beekeepers, their bees existing on white clover during summer, and in the fall being moved to the heaths.

Buckwheat honey is not nearly as good as clover, either in flavor, density, or color; but it is so liberally produced in buckwheat localities that it is a paying crop to the beekeeper. It blooms late, hence the bees can be prepared in ample time to profit by its bloom. This feature alone makes it very valuable to the beekeeper who is fortunate enough to live in a buckwheat-growing section. In those parts of this country where buckwheat is grown largely, consumers are willing to pay as much, or almost as much, as they will for fine white honey. Indeed, many prize it more highly.

In France there is a great demand for buckwheat honey from bakers of a kind of bread which has been made for centuries. No other sort of honey is desired by these bakers, who derive nearly all their supply from Brittany, where buckwheat is commonly sown. Attempts have been made to get the bakers to use other dark honeys, but without success.

In Europe there are some prominent honeys which are almost or quite unknown in this country. Heather has been mentioned. Sainfoin is another which is quite common, being almost the same as alfalfa honey with us. Narbonne honey belongs to this class. In southern Europe romarin (rosemary) is very highly spoken of; and in Greece there is the classically famous honey of Mount Hymettus, from wild thyme. In Australia the honey of eucalyptus is highly appreciated, but attempts to sell it in England have always ended in failure, altho it ought to be useful for persons suf- 
fering from coughs and colds. Instead of the eucalyptus flavor proving to be an attraction it proved to be a drawback. In California, eucalyptus has a limited demand.

HONEY AS A FOOD.-Nearly eighty pounds of sugar on the average is annually consumed by every man, woman, and child in the United States. It is only within the last few centuries that sugar has become so low in price as to come into general use even among the poorest families. Formerly, honey was the principal sweet, and it was one of the items sent as a propitiatory offering by Jacob to his unrecognized son, the chief ruler of Egypt, 3000 years before the first sugar-refinery was built.

The health of the present generation would be greatly benefited if honey could be at least partially restored to its former place as a common article of diet. The almost universal craving for sweets of some kind shows that the system demands food of this kind, but the excessive use of sugar brings in its train a long list of ills. Prof. A. J. Cook, of Sacramento, Cal., says, "If cane sugar is absorbed without change, it will be removed by the kidneys and may result in their breakdown. . . . There can be no doubt but that in eating honey our digestive machinery is saved work that it would have to perform if we ate cane sugar. . . . . We all know how children long for candy. This longing voices a need and is another evidence of the necessity of sugar in our diet.... Children should be given all the honey at each meal time that they will eat. It is safer and will largely do away with the inordinate longing for candy and other sweets, and in lessening the desire will doubtless diminish the amount of cane sugar eaten." Dr. Nuttall, a physician of the Pacific Medical Institute, Los Angeles, Cal., has stated that honey is a most valuable food, and that he is recommending it to patients suffering from impaired digestion.

Dr. Talmadge, of Salt Lake City, Utah, is using honey very successfully in the treatment of typhoid-fever patients, and he finds that it is readily absorbed even by those whose digestion is very weak. Dr. J. H. Kellogg, Battle Creek, Mich., endorses honey as the best form of sweet. In fact, all doctors and physicians who have made a study of honey as compared to sugars or syrups, strongly recommend its use.
Honey, like fruits and other foods with a high percentage of sugar, is to be classed with those furnishing the carbohydrates, and comparison should be made upon this basis. The carbohydrates are energy-formers, as contrasted with foods containing protein (the tissue-forming element), with those largely fat, and with those containing the small amount of mineral matter which is necessary in bone-building. As a carbohydrate it ranks one-fifth less than sugar, the difference between them being due to the presence of the water in honey. The energy value is 1485 calories per pound, a calorie being the unit of heat required to raise the temperature of one gram of water one degree centigrade. This exceeds the caloric contents of every other food but dates, being far ahead of meat, eggs, bread, milk, or vegetables. Its value for furnishing energy without going thru a prolonged digestive process has given it a place in army rations. Immense quantities of honey were used by the armies in the great war of Europe because at the time honey was actually cheaper than sugar and because it is naturally more delicious and convenient a spread for bread than raw sugar.

Basing food value upon the amount of energy in calories to be derived from a food; and taking the average prices into consideration, honey is a more economical food than pears, oranges, figs, bananas, strawberries, and grapes, other foods in the the same class of energy-producers. Of foods in other classes, honey is more economical as an energy-producer than celery, tomatoes, canned corn, and all the meats, with the possible exception of pork chops. On the other hand, it is less economical than bread, cereals, potatoes, baked beans, and apples.

These comparisons were made from studies and tables from the U. S. Department of Agriculture and other sources. The diagram below illustrates graphically the constituents of an average jar of honey. The flavor of honey depends largely upon the presence and proportion of the elements bracketed as "undetermined matter."

\section{*INORGANIC ELEMENTS PRESENT IN HONEY.}

"The animal body requires for its well being the following inorganic elements:

\footnotetext{
* Condensed from an article by Dr. Fehlman in the Schweizerische Bienenzeitung, by J. A. Heberle.
} 
Phosphorus, P.; iron, Fe.; calcium, Ca.; magnesium, Mg.; chlorine, Cl.; sodium, Na.; potassium, K.; sulphur, S.; manganese, Mn.; and silicon, Si. As to the importance of manganese and silicon, opinions differ; but both of these elements are present in the ash of the honey. Until recently the inorganic parts in honey had received but little attention. Some are of the opinion that the ground on which the plani grows would influence the amount of inorganic elements in the nectar; for instance, that land with much iron would produce nectar or honey with much iron content. Others hold that certain plants have a special affinity for some of the inorganic elements, and will take these up while they partly or entirely neglect others. .... The above enumerated inorganic elements that the animal body requires are all found in the ashes of honey of various origin. The only exception is silicon.

"It is generally known that iron is very important to the human body. It is an important constituent of the red blood corpuscles. Chlorosis is a sign that the body is suffering from a lack of iron. For such persons honey is a very valuable medicine. Why not in such cases eat honey regularly, which supplies the iron in the most assimilable form, instead of artificial iron preparations? Besides iron, manganese seems also to influence favorably the building of blood.

"Phosphoric acid with calcium is the principal constituent of the skeleton, but is also found in the brain and nerves. It is often prescribed in chlorosis and for convalescent persons, especially in preparations which are closely related to the form in which it is present in the brain, as ovalecithin, phytin, glycerin phosphates, etc.

"Calcium is an important part of the skeleton and teeth, but is also found in the soft tissues of the body, and is probably a necessary part in the protoplasm of most cells. It is continually exchanged, and therefore an indispensable part of our food. Calcium and potassium seem also to influence the work of the heart.

"Sugar, altho a valuable food, has no trace of inorganic matter. It consists of carbon, hydrogen, and oxygen only. Considering the excellent qualities of honey, and

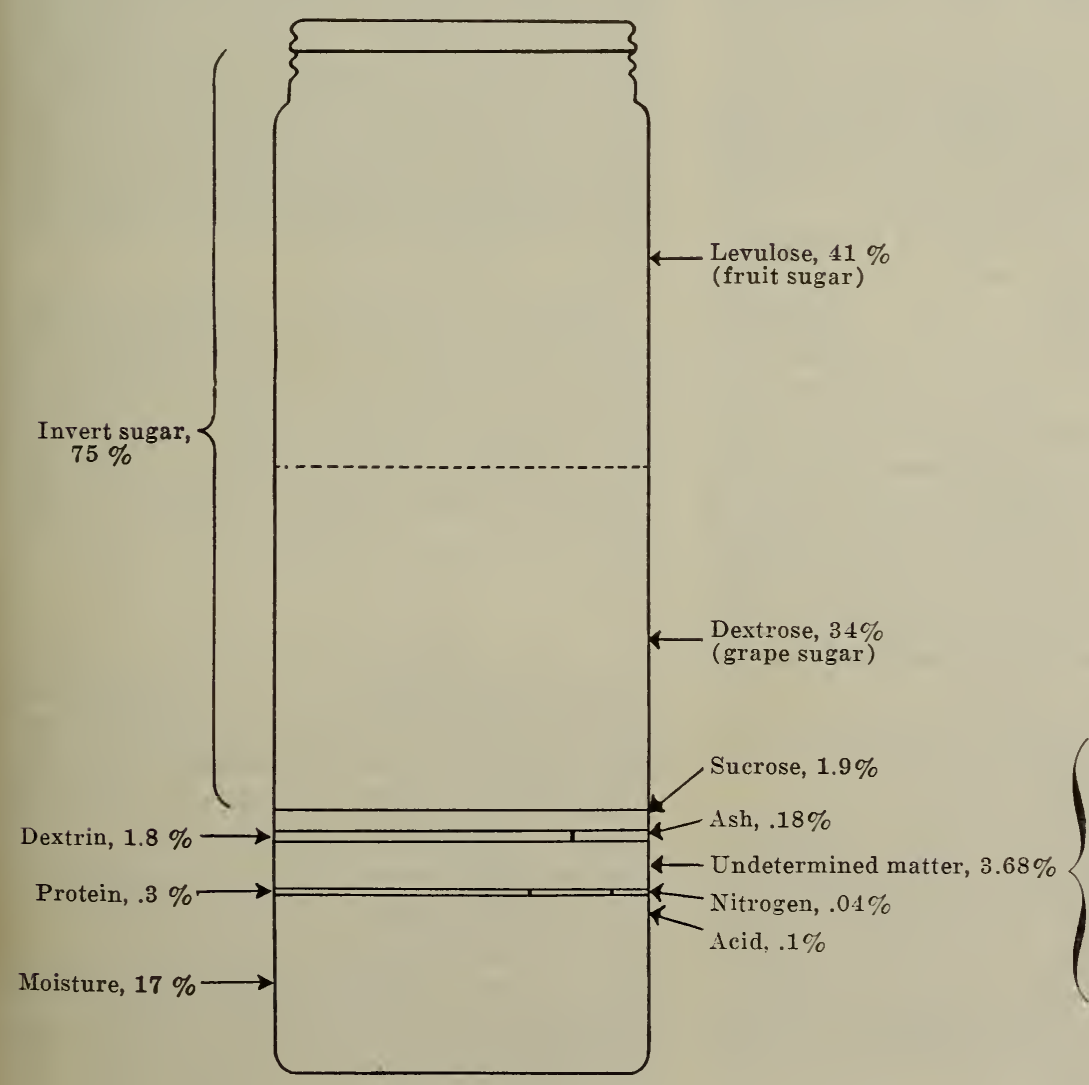

Iron, lime, sodium, sulphur, magnesia, potassium, manganese, phosphoric acid, polen grains, albumen, aromatic bodies (terpenes, etc.) higher alcohols (manitol, etc.), and various other bodies of indefinite or unknown character. 
its moderate price, it should be used far more extensively."

\section{THE USE OF HONEY IN COOKING.}

The simplest way to serve honey is the most common-just spread it on bread or rolls, either in the form of comb or liquid. It goes as far as jam in this way. Honey is often served with rice, breakfast cereals, pancakes, and similar foods. Honey and cream is an ideal combination. Honey can be used to advantage in flavoring ice cream, gelatine creams, and delicate blanc-manges. Honey combines particularly well with oranges, apples, bananas, peaches, and dried fruits. A delicious substitute for maple syrup is made by honey diluted with hot water, and the same syrup cold is superior to undissolved sugar for sweetening summer drinks. This method of flavoring goes well with carbonated water.

Fruits cooked in honey keep indefinitely. Bar-le-Duc currants, which sell ordinarily at a high price, are nften made by cooking currants in honey. A brighter color is present in fruits so preserved than in those bottled in the usual way as honey is a preservative.

Indiscriminate substitution of honey for corresponding amounts of molasses or sugar in recipes does not always give the expected results. The cook should keep in mind the difference in chemical nature between honey and syrup before making up a recipe Better bake a small amount as a test before entirely filling a new recipe.

Less soda is required when substituting honey for ordinary molasses. Experiments in the government nutrition laboratory have shown that one level teaspoonful of soda is generally the amount required with a cupful of honey. In baking with sour milk and soda it is well to add a pinch of bakingpowder to every pint of flour. Cakes will be lighter and finer grained if this is done. When baking powder is substituted for soda use a little more.

When honey is used in a recipe less milk is required on account of the water in the honey. Compared with some of the "corn syrups" on the market, honey is sometimes considered, pound for pound, more expensive, but where two or three cups of svrup will be required in a recipe only one of honey is necessary. The cake or cooky is improved in flavor and healthfulness with no increase in cost.
Baked foods keep much better when prepared with honey instead of with sugar. It was formerly believed that cakes baked with honey absorb moisture from the air, but experiments have been made in the government nutrition laboratory which seem to show that the softness of the honey cake is due to the presence of the levulose in the honey. The fact that such cakes, tho soft, never become soggy, even tho exposed to moist air for a long time, seems to bear out this conclusion. Cakes should be allowed to "ripen" for a day or two at least, to develop the honey flavor. Honey fruit cakes, hermits, and the like are better at the end of two or three weeks.

Cakes made with honey and butter will keep until the butter grows rancid. Cookies made with honey will not dry out. Dough itself containing honey will stay fresh indefinitely. The remarkable merits of goods baked with honey have led large wholesale bakers and cracker manufacturers to use quantities in their product. Some big firms buy honey annually by the carload. The same power in retairing moisture and freshness is present in icings made with honey. The icing will last for months unimpaired in consistency and taste, and is especially valuable for such cakes as fruit cakes which are to be kept for a long time. Orange, bitter almonds, lemon, and fruit flavors generally blend well with honey, as do also anise, cardamon, coriander, and other spicy seeds.

Contrary to directions for cooking honey, as given in some of the old cook books, it is seldom necessary to bring honey to the boiling-point and then skim and cool it. Bringing honey to the boiling-point is sure to give it a burnt flavor. It should not be kept unnecessarily hot for any length of time.

\section{THE HONEY RECIPES.}

All of the recipes here given have been thoroly tested; but any recipe, while it may be successful in the hands of the originator, often needs modification when it is tried by others. All will give good results, but the following 20 recipes (pictured on page 392) are especially fine. In this connection wa wish to call particular attention also to the one for making cereal coffee. The ingredients used are so simple and the work of preparing consumes so little time that 
there is no one who should miss trying this delightful drink. It has a very rich flavor, especially when cream is used, without the scorched, bitter taste that most cereal coffees have. The expense, of course, is so little as to be practically nothing. The honey and egg used allow the bran to brown to a rich color without burning, so that the final result is surprising. Try it.

\section{1. - OATMEAL COOKIES}

2 cups rolled oats

2 cups flour

1 teaspoon soda

1 tablespoon grated chocolate or cocoa

$1 / 2$ teaspoon cinnamon

$1 / 2$ teaspoon cloves

$$
\begin{aligned}
& 1 / 2 \text { teaspoon nutmeg } \\
& 1 / 2 \text { teaspoon salt } \\
& 1 \text { cup chopped raisins } \\
& 1 / 2 \text { cup chopped nuts } \\
& 1 \text { cup honey } \\
& 1 \text { cup sour cream } \\
& 2 \text { eggs }
\end{aligned}
$$

Sift the dry ingredients together (except the rolled oats) and add all other ingredients, the soda dissolv. ed in the sour cream. Stir well, and drop by teaspoonfuls into cooky pans, or bake in gem-pans. Nuts niay be omitted.

\section{2.-HONEY RUSKS}

3 cups flour

2 cups milk

1-3 cup honey

$1 / 2$ cup warm water

1 cup compressed yeast

$1 / 4$ teaspoon salt

Dissolve the yeast in the warm water. Mix the flour, milk, honer, yeast, and salt and set in a warm place to rise. When very light, add the beaten egg. butter, and enough flour to make a stiff dough. Knead lightly and mold in small biscuits or twists. Raisins, currants, or cardamon seed may be added at discretion. Rub the top with beaten egg; cover, and let them rise again until they are double in bulk, and are very light and fluffy. Bake 20 to 25 uninutes in a moderate oven, glazing them with sugar and water just before removing them from the oven.

\section{3.-HONEY BAKED BEANS}

Soak over night one pint of small white heans. Bring to a boil, adring baking-soda the size of a bean, and allow to simmer for half an hour. Drain, and cook till tender in salted water, but not long enough to break the skins. Drain and rinse the beans, and put them in an earthern bean-pot. Pour over them a pint of milk, adding a tablespoonful of butter, 2 tablespoonfuls honey, and a pinch of cayenne pepper. Cover closely, and bake in a slow oven till the milk is absorbed.

\section{4.-IADY FINGERS}

1 cup honey

2 eggs

$1 / 2$ cup butter

$1 / 2$ teaspoon baking powder

4 cups flour

$1 / 2$ teaspoon soda

1 teaspoon salt Sugar

Blend the honey warmed with butter, add heaten eggs and flour sifted with the dry ingredients. Cut in strips. Roll in sugar. Bake in a quick oren.

\section{5.-MARSHMALLOW CREAM \\ $1 / 2$ cup honey \\ 1 teaspoon gelatine \\ $y_{72}^{\prime}$ cup cold water \\ $1 / 2$ cup boiling water \\ Whites 2 eggs \\ 1 teaspoon vanilla \\ 1 teaspoon lemon extract}

Dissolve gelatine in the usual way, heating it over a teakettle until thoroughly dissolved. Cool, hut do not chill; stir in the honey, and add to the whites of the eggs bcaten very light, a few spoonfuls at a time, beating constantly. Divide into 2 parts: to one part add a color and flavor with vanilla, about 1 teaspoon; to the other part add 1 teaspoon lemon extract. Mold in layers, adding nuts to one part and maraschino cherries to the other. Serve with or without whipped cream.

\section{6.-FRUIT CANNED WITH HONEY}

Prepare fruit as usual in canning. Put on to boil. When the fruit is ready for canning add honey, about as much of it as one would use of sugar. Be sure to let the fruit come just to the boiling-point; but after adding the honey do not boil, as this is liable to damage the fine flavor of the honey. Have the jars ready, clean, and very hot; put in the fruit and seal. Fruit canned thus keeps better than by the old method of canning with sugar; it lias in addition the delicate flavor of the boney. Only those who regularly use honey in canning and preserving can appreciate the rich flavor and the fresh natural calor of the fruit thus prepared.

\section{7.-SOUR-MILK CAKE}

3/4 cup lard or butter

$1 / 2$ cup sugar

$1 / 2$ cup honey

$1 / 2$ cup sour milk

$1 \mathrm{egg}$

$12 / 3$ cups flour

$1 / 2$ teaspoon soda

2 teaspoons baking powder

$1 / 2$ teaspoon cinnamon

$1 / 2$ teaspoon cloves

Pinch salt Nutmeg

Beat the sugar and lard to a cream and then add the egg well beaten and the other ingredients. Use little nutmeg and mix the soda with the flour. Bake in either jelly-tins or loaf in a moderate oven, and put together with caramel frosting.

\section{8.-GRAHAMI PUDDING}

$\begin{array}{ll}1 / 4 \text { cup butter } & 11 / 2 \text { cups graham flour } \\ 2-3 \text { cup honey } & 1 / 2 \text { teaspoon soda } \\ 1 / 2 \text { cup milk } & 1 \text { teaspoon salt } \\ 1 \text { egg } & 1 \text { cup seedless raisins }\end{array}$

Melt the butter; add the honey, milk, and egg, well beaten; dry ingredients mixed and sifted, and raisins. Turn into buttered mold; cover and steam $21 / 2$ hours. Serve with pudding sauce.

\section{9.-HONEY NOUGATINES}

1.3 cup honey

1.3 cup pure corn syrup

Paraffin

1 cup sugar

$1 / 4$ teaspoon salt
$1 / 4$ cup water

1 teaspoon ranilla

Whites 2 eggs

$1 / 2$ pound chocolate

1 cup almond or walnut meats, chopped fine
Mix the honey, corn syrup, or glucose, sugar, paraffine (piece size of pea), and water and boil until a drop makes a hard ball when dropped in cold water $\left(248^{\circ}\right.$ F.) Stir occasionally while boiling. Pour part of the syrup gradually on to the whites of the eggs, beaten dry. Add the salt. Beat constantly in pouring. Boil the remainder of the syrup until it is brittle when tested in cold water ( $\left.290^{\circ} \mathrm{F}.\right)$, and aggain pour on the eggs, this time all of the syrup, and beat constantly while pouring. Then boil the mixture and beat constantly until it is crisp when tested. Cool in a buttered tin. Cut in oblong pieces and coat with chocolate.

\section{0.-HONEY DROP CAKES}

1 cup sugar

2 tablespoons honey

2 or 3 eggs

$2-3$ cup shortening

1-3 cup buttermilk sour cream

$1 / 4$ teaspoon soda

2 teaspoons baking powder

Pinch salt

$1 / 2$ teaspoon vanilla.

or orange, or lemon, to taste

About $3 \frac{1 / 2}{2}$ cups flonr

Cream the sugar, shortening, and honey, add the eggs well beaten and then the buttermilk. Sift the dry ingredients in flour enough to make a stiff batter to drop from spoon. Bake in moderate even. 


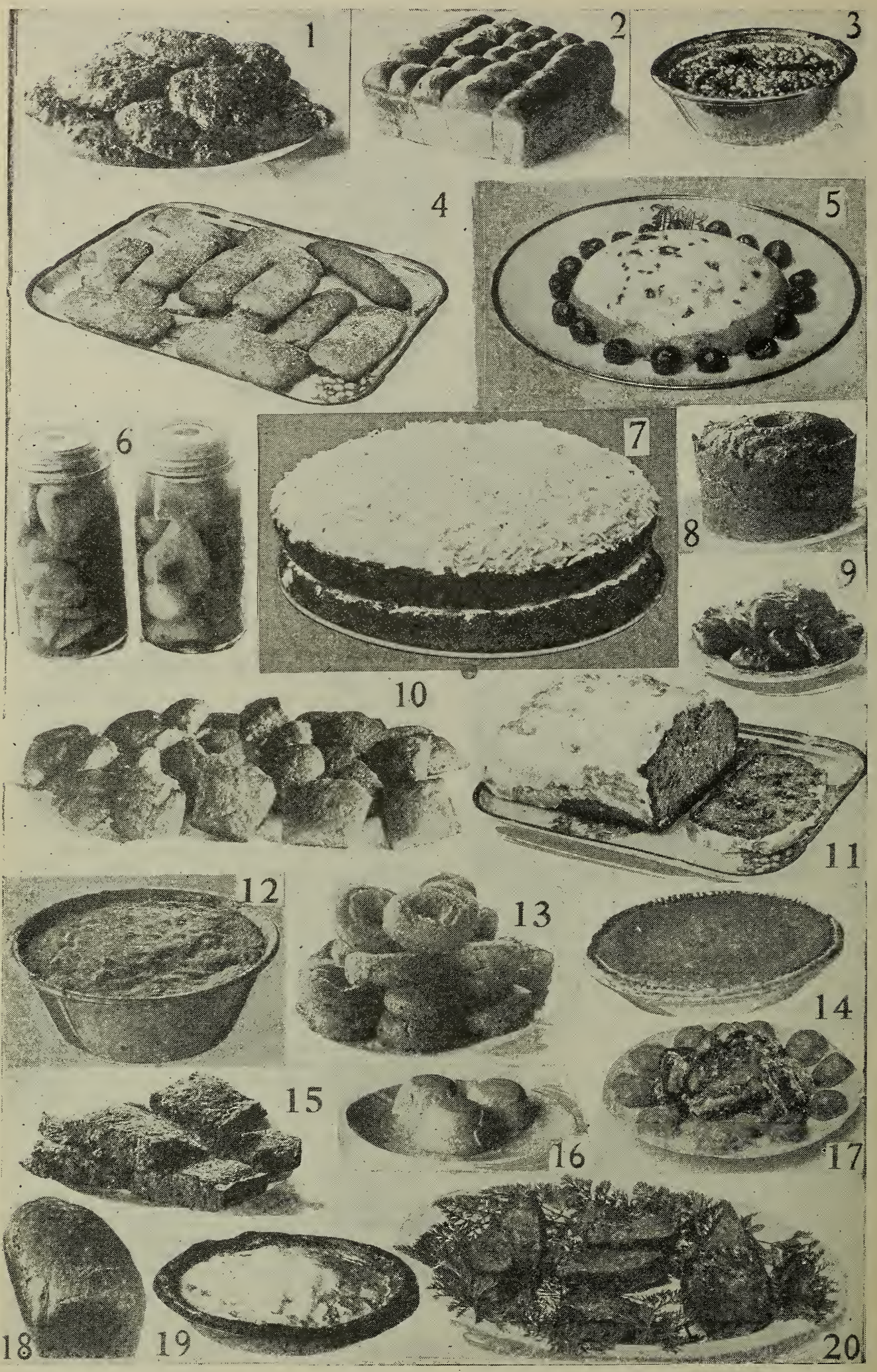

The results of twenty of the recipes selected as the best. See preceding and following pages. 
These cakes will run together in baking, and must be cut apart with a knife, but are much better than rolled, and much less trouble to bake.

$$
\text { 11.-FRUIT CAKE }
$$

$3 / 4$ cup honey

$1 / 2$ cup butter

2 eggs

$1 / 4$ cup milk

1 cup raisins

$1 / 2$ cup chopped citron

Warm the butter, honey, and milk over a slow tire; cool, and add the well-beaten eggs, the salt, and the ginger. Sift the baking powder with the flour; dredge the fruit with flour, and add these alternately. Mix well and bake in greased loaf-tin about an hour.

$\begin{array}{ll} & 12-\text { APPLE PUDDING } \\ \text { Apples sliced fine } & 2 \text { eggs } \\ 1 / 4 \text { cup honey } & 1 / 2 \text { cup water } \\ \text { Cinnamon } & 3 \text { or } 4 \text { slices bread. } \\ \text { Butter } & \text { crumbled } \\ 1 \text { teaspoon salt } & 1 \text { cup rice }\end{array}$

The rice should be cooked for several hours previously. Beat into this the yolks of the eggs. In the bottom of the pan place a layer of crumbs with dots of butter here and there; then a layer of apples, with honey and cinnamon on top. The third layer is a mixture of rice, egg, and salt. The fourth and fifth layers are a repetition of the first and second. Add water and bake in a moderate oven. Cover with meringue.

\section{DOLGHNUTS}

1 egg

1 cup sweet milk

1 teaspoon cream tartar

1 cup honey

1 teaspoon soda

Flour

2 tảlespoons shortening Pinch salt

Cream the honey and shortening together and add the egg, well beaten, and the other ingredients. Mix well, and add flour enough to roll out and cut easily. Roll out on baking board, and cut with doughnut-cutter. Fry in hot lard. The honey in this recipe makes the doughnuts a delicious brown, and also keeps them moist for a long time.

\section{4.-PUMPKIN PIE}

2 cups sifted pumpkin

¿-3 cup sugar

1 cup honey

4 tablespoons flour
2 teaspoons ginger
1 teaspoon cinnamon
3 cups milk

Mix the flour with the sugar and add to the pumpkin. Then stir in the honey, the spices, and the milk with all its cream. Recipe makes 2 pies.

$$
\text { 15.--GINGER DROP CAKES . }
$$

1 cup sugar

1 cup honey

$$
\begin{aligned}
& 3 / 4 \text { cup sweet milk } \\
& 1 \text { tablespoon ginger } \\
& 1 / 2 \text { teaspoon salt } \\
& 1 \text { teaspoon soda }
\end{aligned}
$$

1 cup lard

1 teaspoon soda

Cream the sugar, lard, and honey together. Dissolve the soda in a little hot water. Add the egg well beaten and the milk. Use enough flour to make the batter stiff enough to drop from sponn. Bale in greased gem pans in moderate oven, or drop on greased pan from spoon.

\section{6. - HONEY CORNSTARCH PUDDING}

\section{1-3 cup honey}

$1 / 4$ teaspoon salt

\section{$41 / 2$ tablespoons corn starch}

4 cups scalded milk

Mix the honey, salt, and cornstarch. Stir in the hot milk gradually, stirring until smooth. Stir and cook over boiling water until the mixture thickens. Cover and cook 15 minutes. Turn into a wet mold, chill, and serve with cream and sugar.

\section{7.--HONEY FONDANT}

2 cups granulated sugar 1-3 cup honey $1 / 2$ cup water

Mix, put over fire, and stir only until the sugar is dissolved. Boil carefully until able to shape a very soft ball when tested in cold water (about $238^{\circ} \mathrm{F}$.). Do not stir while boiling and do not scrape off sugar which adheres to the side of the pan. When done pour into greased platter and partially cool. Beat and stir with a wooden spoon until it begins to crumble and then knead with the hands like dough. Pack in a bowl, cover with cloth, and set aside until needed. When ready for use the howl of fondant may be set in hot water until soft enough to handle. Any flaroring may be added when shaping into candies. The honey flaror alone is delicious when the fondant is used to stuff dates.

The use of honey in fondant obviates the necessity of using cream of tartar. The slight acidity of the honey keeps it from graining too soon. If the fondant is boiled too hard, pull until white; the result will be a fine taffy.

\section{8. - WHOLE-WHEAT BREAD}

1 quart wholewheat flour 1 large cooking spoon (may be $1 / 2$ graham or 1.3 rye)

1 pint water (may be $1 / 2$ scalded milk cold) honey

$1 / 2$ compressed yeast cake, or the equivalent

$11 / 2$ teaspoons salt

Butter, size of an egg

Dissolve the reast thoroughly in the water; have the water siightly warm in cold weather. Add the honey; mix well; add the salt, and stir until dissolved. Mix the flour and water thoroughly by means of a large cooking spoon, putting all together at once. The dough should be rather sticky and soft. If the dough is too stiff with a pint of water, more may be added, a teaspoonful at a time thoroughly incorporated, until the right consistency is obtained. If the bread is wanted rather dry, leare the dough stiffer.

Cover closely, keeping in a warm place in cold weather, aud vice versa. In the morning turn the dough out on the board, and knead into it the butter, flouring the board and hands as lightly as possible. Make 2 loares in narrow pans, cover, and keep warm to rise. It should about double in bulk. If the dough is not covered closely the surface will dry so as to form a skin. This will cause streaks in the bread. Bake 30 to $40 \mathrm{~min}$ utes in an oven not too hot. This bread does not become stale for several days if kept as other bread. It contains all the vitalizing elements of the grain.

\section{9.-TIP-TOP LEMON PIE}

\section{3 eggs $1 / 2$ lemon}

$1 / 2$ cup honey 1 teaspoon melted butter 1 tablespoon flour $\quad 1 \frac{1 / 4}{4}$ cups rich milk

Combine thoroughly the yolks of the $3 \mathrm{eggs}$ beaten light, the honey, flour, the juice, flesh, and grated rind of half a lemon, and the butter. Mix thoroughly in the order given and add the milk; pour into a pie-plate lined with a good crust, pricked to prevent air blisters. Bake until set. Cover with a meringue of the whites, beaten with 3 tablespoons honey and a few drops of lemon juice, and brown lightly.

Many prefer to bake the crust separately and also cook the filling in a double boiler before putting it in the shell.

\section{0.-BAKED SQUASH}

Peel and slice the squash into piecss about $1 / 2$ inch thick. Place slices in the bottom of a large bread pan. Dot each slice with a generous piece of butter; strew honey over squash, 1 teaspoon - to each slice; then pour in enough hot water to 
cover the bottom of the pan. After cooking on top of the range for 10 or 15 minutes, turn each slice with a knife and boil until tender. More hot water may have to be added. Place the pan in the oven and let the squash take on a delicate brown. Serve at once after removing from the pan.

\section{HONEY CAKES.}

LEMON CAKES.-Bring 1 $1 \frac{1}{2}$ cupfuls of honey to a boiling-point. Skim if necessary. Add $1 / 4$ cupful of butter and cool. Add 2 cupfuls of pastry flour, stirring it in carefully. Let this mixture stand over night. When ready to bake, stir in the grated yellow rind of 1 lemon, 2 tablespoonfuls of lemon juice, $1 / 2$ cupful of chopped blanched almonds; add $1 / 2$ teaspoonful of soda dissolved in a little lukewarm water, and bake in small round tins. Ice when cool.

NUT CAKES.-Beat to a cream $1 / 2$ cupful of butter and 1 cupful of powdered sugar. Beat into this 1 gg well beaten and $1 / 2$ cupful of honey. Stir in 2 cupfuls of pastry flour, previously sifted, with 2 teaspoonfuls of baking powder, and last stir in $1 / 2$ cupful of finely chopped filberts. Let the mixture stand where it is very cold (do not freeze) over night. When ready to bake, roll the dough very thin, cut into fancy shapes, brush them over with the white of an egg diluted with a teaspoonful of warm water. Sprinkle the cakes with granulated sugar and chopped filberts. Bake in a hot oven until a golden brown.

SHORT CAKE.--Three cups flour, 2 teaspoonfuls baking powder, 1 teaspoonful salt, $1 / 2$ cup shortening, $1 \frac{1 / 2}{2}$ cups sweet milk. Roll quickly, and bake in a hot oven. When done, split the cake and spread the lower half thinly with butter, and the upper half with $1 / 2$ pound of the best-flavored honey. (Candied honey is preferred. If too hard to spread well it should be slightly warmed or creamed with a knife.) Let it stand a few minutes, and the honey will melt gradually, and the flavor will permeate all thru the cake. To be eaten with milk.

SoUR-MILK CAKE.- $1 / 4$ cup lard or butter, $1 / 2$ cup sugar with a little salt mixed in; beat the sugar and lard to a cream, then add $1 / 2$ cup of honey, $1 / 2$ cup sour milk, 1 egg, 12 -3 cups flour, $1 / 2$ teaspoonful soda in flour; also 1 small teaspoonful making powder; $1 / 2$ teaspoonful cinnamon, 1/4 teaspoonful cloves, a little nutmeg. Bake either in jelly-tins or loaf and put it together with caramel frosting.

NUT CAKES.-Eight cups sugar, 2 cups honey, 4 cups milk or water, $1 \mathrm{lb}$. almonds, $1 \mathrm{lb}$. English walnuts, 3 cents' worth each of candied lemon and orange peel, 5 cents' worth citron (the last three cut fine), 2 large tablespoonfuls soda, 2 teaspoonfuls cinnamon, 2 teaspoonfuls ground cloves. Put the milk, sugar, and honey on the stove, to boil $15 \mathrm{~min}$ utes; skim off the scum, and take from the stove. Put in the nuts, spices, and candied fruit. Stir in as much flour as can be done with a spoon. Set away to cool, then mix in the soda (don't make the dough too stiff). Cover up and let stand over night, then work in flour enough to make a stiff dough. Bake when you get ready. It is well to let it stand a few days, as it will not stick so badly. Roll out a little thicker than a common cooky. Cut in any shape you like.

This recipe originated in Germany, is old and tried, and the cake will keep a year or more.

HARD CAKE.-Take $6 \mathrm{lbs}$. flour, $3 \mathrm{lbs}$. honey, 11/2 lbs. sugar, 11/2 lbs. butter, 6 eggs, 1/4 oz. saleratus; ginger to your taste. Direction for mixing: Have the flour in a pan or tray. Pack a cavity in the center. Beat the honey and yolks of eggs together well. Beat the butter and sugar to cream, and put into the cavity in the flour; then add the honey and yolks of the eggs. Mix well with the hand, adding a little at a time, during the mixing, the $1 / 2 \mathrm{oz}$. saleratus dissolved in boiling water until it is all in. Add the ginger, and finally add the whites of the 6 eggs, well beaten. Mix well with the hand to a smooth dough. Divide the dough into seven equal parts, and roll out like gingerbread. Bake in ordinary square pans made for pies, from $10 \times 14$ tin. After putting into the pans, mark off the top in $1 / 2$. inch strips with something sharp. Bake an hour in a moderate oven. Be careful not to burn, but bake well. Dissolve sugar to glaze over top of cake. To keep the cake, stand on end in an oak tub, tin can, or stone crock-crock is best. Stand the cakes up so the flat sides will not touch each other. Cover tight. Keep in a cool dry place. Don't use until three months old at least. The cake improves with age, and will keep good as long as you will let it. I find any cake sweetened with honey- does not dry out like sugar or molasses cake, and age improves or develops the honey flavor.

SoFT CAKE.-One cup butter, 2 cups honey, 2 eggs, 1 cup sour milk, 2 teaspoonfuls soda, 1 teaspoonful ginger, 1 teaspoonful cinnamon, 4 cups flour.

EGGLess CAKE.-One cupful sugar, $1 / 2$ cup honey, 1 cupful sour milk, 2 tablespoonfuls of butter, 1 cupful chopped raisins, 1 cupful chopped dates, 1 teaspoonful soda, $2 \frac{1}{2}$ cupfuls flour. Spices may be added to taste.

Sponge CAKE.-One coffee-cup honey, 1 cup flour, 5 eggs. Beat yolks and honey together. Beat whites to a froth. Mix all together, stirring as little as possible. Flavor with lemon juice or extract.

"RAILROAD" CAKE.-One cup honey, 1 heaping cup flour, 1 teaspoonful cream tartar, $1 / 2$ teaspoonful soda, 3 egos, and a little lemon juice. Stir all together ten minutes. Bake 20 minutes in quick oven.

LFMON CAKES.-One cup butter, 2 cups honey, 3 eggs well beaten, 1 tablespoonful essence of lemon, $1 / 2$ cup sour milk, 1 teaspoonful soda. Flour enough to make as stiff as can well be stirred. Bake at once in quick oven.

JELLY RoLL.- - Yolks of 6 eggs or 3 eggs, 1 cup of white sugar (scooped), 1 cup of flour (heaped), 1 teaspoonful of butter, 2 tablespoonfuls of sweet milk, 2 teaspoonfuls of cream tartar, 1 teaspoonful soda or 2 of baking powder. Bake in an oblong pan, spread with granulated honey, and roll at once. Set where it will cool quickly.

SwISS CAKE.-Melt 4 ounces butter; add $1 \mathrm{lb}$. of honey, stirring well; take it off the fire and let it cool. Add the minced rind of a large lemon, 4 ounces sweet almonds chopped fine, a little nutmeg, 2 scant teaspoonfuls of carbonate of soda, dissolved in a little water. Mix these well and add flour until very stiif, and set in a cool place 12 hours. Roll out $1 / 2$ inch thick, eut into squares, decorate with nuts and chopped citron. Bake in hot oven. Make two dozen cakes from this amount.

PORK CAKE.-One pound fat pork chopped fine, 1 pint boiling water poured on pork; 2 cups honey, 3 teaspoonfuls soda, 2 cups raisins, 2 teaspoonfuls each of cloves, cinnamon, and nutmeg; about 7 cupfuls of flour.

COFkEn CAKE. - 1 cup of honey, $1 / 2$ cup of sugar, shortening size of an egg, 3 cups flour, 1 teaspoon- 
ful soda dissolved in 2-3 cup of cold coffee (scant), 1 teaspoonful of cinnamon, $1 / 2$ teaspoonful of cloves, $1 / 2$ teaspoonful of nutmeg, 1 cup of raisins (floured). If too thin, add a little more flour.

Fruit CAKE.-Two cups of honey, 2 cups of raisins, 1 cup of shortening, $1 / 2$ cup of sour milk, 1 teaspoonful soda, $1 / 2$ teaspoonful cloves, 1/2 teaspoonful cinnamon, $1 / 2$ teaspoonful nutmeg, 4 cups flour. Bake 40 minutes.

Frut CAKe.-Ore and one half cups honey, 2-3 cup butter, $1 / 2$ cup sweet milk, 2 eggs well beaten, 3 cups flour, 2 teaspoonfuls baking powder, 2 cups raisins, 1 teaspoonful each of cloves and cinnamon.

FrUIT CAKE.-One-half cup butter, $3 / 4$ cup honey, 1-3 cup apple jelly or boiled cider, 2 eggs well beaten, 1 teaspoonful soda, 1 teaspoonful each of cipnamon, cloves, and nutmeg; 1 teacupful each of raisins and dried currants. Warm the butter, hones, and apple jelly slightly; add the beaten eggs, then the soda dissolved in a little warm water; add spices and flour enough to make a stiff batter, then stir in the fruit and bake in a slow oven. Keep in a covered jar several weeks before using.

Fruit CAKe.-Two eggs well beaten, 1 cup butter, $1 / 2$ cup sour cream, 1 cup hones, 1/2 cup sugar, 1 teaspoonful soda dissolved in warm water, 1 teaspoonful cinnamon, $1 / 2$ teapsoonful clores, 1 cup raisins, 1 cup currants, 2 cups flour.

Honey TEA-CAKe-One cup honey, $1 / 2$ cup sour cream, 2 eggs, $1 / 2$ cup butter, 2 cups flour, scant $1 / 2$ teaspoonful soda, 1 tablespoon cream of tartar. Bake 30 minutes in a moderate oven.

Fruit CAKE.-Four eggs, 5 teacups flour, 2 teacups honey, 1 teacup butter, 1 teacup sweet milk, 6 teaspoonfuls baking powder, $1 \mathrm{lb}$. raisins, $1 \mathrm{lb}$. currants, 1 teaspoonful cloves, 1 teaspoonful cinnamon, 1 teaspoonful nutmeg. Then bake in slow oven. The abore will keep moist for months.

CITRon CAKE.-Two eggs, 1 cup dark honey, 4 tablespoonfuls butter, 1 cup milk, 3 cups flour, 1/4 lb. citron chopped fine, 2 teaspoonfuls baking powder, 1 teaspoonful lemon.

RAISIN CAKF.--Three eggs, 1 cup honey, 4 tablespoonfuls melted butter, 1 cup sweet milk, 1 1-3 cups raisins chopped fine, 3 cups flour, $1 / 2$ teaspoonful salt, $1 / 2$ teaspoonful soda, 2 teaspoonfuls baking powder, 1 teaspoonful vanila extract.

Ammonia Cake--(Pain d'epice, or Leb Kuchen). -Use $3 \mathrm{lbs}$. of honey, $3 \mathrm{lbs}$. of flour, $1 \mathrm{oz}$. powdered ammonia, a small teacupful of ground cinnamon, $1 / 2$ teaspoonful of ground cloves, $6 \mathrm{oz}$. orange peel (or citron) cut very tine; $4 \mathrm{oz}$. sweet almonds cut very small. (The ammonia evaporates in baking.) Directions: Pour the honey in a graniteware or copper sauce-pan, and set on the store. When it boils, draw it aside and remove the scum. (As honey boils and burns very quickly, great care must be used.) Then pour the honey into the ressel in which the paste is to he made; leare it to cool; then add flour and other ingredients, except the ammonia, which latter must not be added till the flour and honey have been mixed up and the paste has become cold. In preparing for use, place the ammonia in a cup; pour on a few drops of cold water and stir it well, so as to form a thick paste, then mix it up with the rest. Then take a piece of the paste, roll it out into a cake not over $1 / 4$ inch thick, and cut up into convenient sizes. Put these on a flat tin and bake in a hot oren 12 to 15 minutes. The above is made by the monks of Buckfast Abbey, England.

DROP CAKES.-Two eggs beaten without separating, 3 tablespoonfuls softened butter, 1-3 cup honey, 1 1-3 cups flour, 1 1-3 teaspoonfuls baking powder.
Drop on buttered baking-sheet about $1 / 2$ teaspoonful of batter to a cake. Put them well apart; spread slightly with the bowl of a tin spoon, dipped in cold water; press one pecan nutmeat on the top of each.

Drop CAKES.-One cup honey, $1 / 2$ cup sugar, $1 / 2$ cup butter or lard, $1 / 2$ cup sour milk, 1 egg, $1 / 2$ teaspoonful soda, 4 cups sifted flour. Flavor to taste.

Chorce Drop CAKES.-One gallon honey (dark honey is best), 15 eggs, 3 lbs. sugar (a little more honey in its place may be better); $1 \frac{1 / 2}{o z}$. baking soda, 2 oz. ammonia, 2 lbs. almonds chopped up, 2 lbs. citron, 4 oz. cinnamon, 2 oz. cloves, 2 oz. mace, $18 \mathrm{lbs}$. flour. Let the honey come almost to a boil; then let it cool off, and add the other ingredients. Cut out and bake. The cakes are to be frosted after. ward with sugar and white of eggs.

Drop CAKES. - Take $1 / 2$ cupful of butter, $1 / 2$ cupful of sugar, and blend them; after which add 1 cupful strained honey, the beaten yolks of $2 \mathrm{eggs}, 3$ tablespoonfuls of lemon juice, and the whites of 2 eggs beaten dry. Mix well, and add $31 / 2$ cupfuls of flour and 1 teaspoonful of soda; 1 teaspoon baking powder, a little nutmeg. More flour may be added, if needed, and often is, for the dough should be stiff enough so that it will drop by spoonfuls on to a tuttered kakingpan. Shape round, and bake in a moderate oven.

TEA CAKES.-Biend 1-3 cup honey, 1 teaspoonful butter, 1 egg well beaten, 2-3 cup flour, sifted with half a teaspoonful of baking powder, and a pinch of salt. Drop br teaspoonfuls on a tin, and bake in a quick oven. These proportions will make about 20 cakes.

Griger CAKe.-One cup honey, $1 / 2$ cup butter, or drippings, 1 tablespoonful boiled cider, in $1 / 2$ cup of hot water (or $1 / 2$ cup sour milk will do instead). Warm there ingredients together, and then add 1 tablespoonful ginger and 1 teaspoonful soda sifted in with flour enough to make a soft batter. Bake in flat pan.

GINGERBREAD.-Warm together $1 / 2$ cup of brown sugar and hones, with 1-3 cup of shortening. Remove from stove; add $3 / 4$ cup sour milk and 2 eggs; pour gradually into bowl containing 2 cups of flour sifted with a tablesponnful of ginger, a scant teaspoonful of soda, and a little salt. Other spices may be added. Bake in moderate oren.

GiNg inbread.-One egg, 1 cup honey (dark), 1 cup milk (sour), 2 tab!espoonfuls butter, $1 / 2$ teaspoonful soda, 1 teaspoonful ginger. Flour to make rather stiff batter.

Alsatian Gixgerbread.-One pound honey, 1 pound flour; ginger to suit; $2 \frac{1 / 2}{2}$ drams bicarbonate soda. The honey is first brought to a boil, preferably in a double boiler. It is then remored from the fire, and the flour well stirred into it, and then the soda (or baking powder); bake. If sweet gingerbread is wanted, add the white of an egg, well whipped, and more honey. The above will keep well for a vear if kept in a cellar.

GIXg:R CAKE.-Put 1 cup darkest honey into a dish with $1 / 2$ cup brown sugar; 1 teaspoonful salt, 2-3 teaspoonful vanilla, $1 / 4$ teaspoonful ground cloves, $1 / 2$ teaspoonful cinnamon, $1 / 2$ teaspoonful ginger. To this add 2 tablespoonfuls soda dissolved in 1 cup boiling water. Stir together well; $1 / 2$ cup cold water. Nearly 1 cup shortening. Stir in flour un'il thick as molasses. Break in 1 large egg; leat thoroly with egg-beater. Pour into two 9-inch iellytins and tuck in raisins. Bake in an even, brisk oven.

Griger CAKn.-Three cups flour, 1/2 cup butter; rub well together. Add one cup brown sugar; 2 
large tablespoonfuls ginger; same of caraway seeds if you like: 5 eggs, 2 cups honey, 3 teaspoonfuls baking powder. Beat it well, and bake in an iron pan an hour or more.

LAYER CAKE.-Two-thirds cup butter, 1 cup honey, 3 eggs beaten, $1 / 2$ cup milk. Cream the honey and butter together, then add the eggs and milk. Then add 2 cups flour containing $1 \frac{1}{2}$ teaspoonfuls baking powder previously stirred in. Then stir in flour to make a stiff batter. Bake in jelly-tins. When the cakes are cold take finely flavored candied honey, and, after creaming it, spread between layers.

\section{HONEY COOKIES.}

Aunt Milule's Cookies.-One cup butter beaten light, 1 cup sugar beaten to cream with butter, 1 cup honey. Let honey warm; put 1 teaspoonful of soda in the honey. If you have fermented honey, use that with soda, as it is as good as cream tartar. If you have not the fermented honey, then use 2 teaspoonfuls of cream tartar and 1 teaspoonful of soda, or 2 teaspoonfuls of baking powder. When the honey has cooled, beat light and add to the br.t. ter and sugar. Then add 1 cup cold water, 1 teaspoonful vanilla, flour to make a very stiff dough. Eill a salt-shaker with powdered sugar; shake over the sheet of dough after it is rolled; press the sugar by rolling the pin over it once more. Then cut out and bake brown in a moderate oven.

CreaM Cooḱtes.-One teacupful extracted honey, 1 pint sour cream, scant teaspoonful soda, flavoring if desired; flour to make a soft dough.

Fowls' CookiEs.-Three teaspoonfuls soda dissolved in 2 cups warm honey, 1 cup shortening containing salt, 2 teaspoonfuls ginger, 1 cup hot water; flour sufficient to roll.

VINEGAR COOKIES.--One cup of butter and lard mixed; 1 cup of sugar, 4 eggs, 2 cups of honey, 3 teaspoonfuls of soda in $1 / 2$ cup of boiling water: spices to taste; flour to roll out; $1 / 2$ cup of vinegar.

HARD-TIME COOKIES.-One pint of honey, 1/2 teacupful of granulated sngar, $1 / 4$ pint of melted lard and butter mixed; 1 even teaspoonful soda dissolved in $1 / 4$ cup of warm water; $1 / 2$ teaspoonful of ginger, $1 / 2$ teaspoonful nutmeg, a little salt. Roll rather thin, and bake quickly.

SwIss Cookies.-Prepare some dough as for the gingerbread, and mix with it 1-3 lb. crushed almonds, orange and lemon juice, and cinnamon; and, if desired, cloves to suit the taste.

ThinNessef Cookifs.-Melt together 1 cup of honey and 1 cup of lard or butter. When cold, add 1-3 of a cup of sugar, a pinch of salt, a tablespoon of soda and $1 \mathrm{egg}$. Stir in flour enough to make a stiff dough; roll, and cut into small cakes, and bake on greased tins, in a moderate oven.

Grrman Christmas Cookies.-Warm 1 pint molasses, 1 pint extracted honey, 1 pint brown sugar, 1 tablespoonful each of butter and lard; add 2 tablespoonfuls soda in 1 pint of sour cream; 10 cents' worth mixed and ground candied orange and lemon peel and citron: 1 cup nut-meats, 1 ground nutmeg, 1 tablespoonful ground cinnamon, 1 tablespoonful ground cloves, 1 tablespoonful salt; add flour until dough is stiff as cooky dough, or a little stiffer. Leave until morning; then roll out a little thicker and cut in shape and bake in hot oven. If the dough is too soft to roll in the morning add more flour. Frost with lemon icing made from powdered sugar and water. Pack in stone jars; cover with paprss, and tie and put down cellar a month before Christmas,
Sugarless Cookies.-Two cups honey; 1 cup butter, 4 eggs (mix well); 1 cup buttermilk (mix); 1 good quart flour; 1 level teaspoonful soda or saleratus. If it is too thin, stir in a little more flour. If too thin it will fall. It does not want to be as thin as sugar cake. Use very thick honey. Be sure to use the same cup for measure. Be sure to mix the honey, butter, and eggs well together. You can make it richer if you wish by using clabbered cream instead of buttermilk. Bake in a rather slow oven, as it burns very easily. To make the cookies, use a little more flour, so that they will roll out well without sticking to the board. Any kind of flavoring will do.

Ginger Cookins.-One cup honey, $1 / 2$ cup of sugar, 1/2 cup shortening, 1/2 cup warm water, 1 teaspoonful soda, 1 teaspoonful ginger, 5 cups flour, pinch of sait.

HoNey-Jumbles.-Two quarts flour, 3 tablespoonfuls melted lard, 1 pint honev, $1 / 4$ pint molasses, $1 \frac{1}{2}$ lerel tablespoonfuls soda. 1 level teaspoonful salt, $1 / 4$ pint water, $1 / 2$ teaspoonful vanilla.

GiNGER COOKIES.-Two cups honey, 1 cup sugar, 1 cup lard, 3 eggs, 1 tablespoonful ginger, 1 teaspoonful cinnamon, 2 tablespoonfuls soda, 6 tablespoonfuls vinegar, a pinch of salt; flour enough to roll.

GINGRR Cookies.- One cup honey, 1 cup sugar, 1 cup buttermilk, 1 cup lard, 1 teaspoonful salt, 1 teaspoonful cinnamon, 1 teaspoonful ginger, one teaspoonful soda, heaping; 1 teaspoonful lemon extract. Stir stiff with flour; for gingerbread, mix stiff and ro:l out and cut and bake in quick oven. Also very good with caraway seeds instead of spices.

Gingersnaps.-One pint honey, $3 / 4$ lb. butter, 2 teaspoonfuls ginger. Boil together a few minutes, and when nearly cold put in flour until it is stiff. Roll out thin, and bake quickly.

DART CoOKIES.-One cup brown sugar, $1 / 2$ cup sour cream, 1-3 cup butter, 2-3 cup dark honey, 1 egg, 1 tablespoonful rinnamon, 1 scant teaspoonful. soda. Flour to make thick batter. Improved witl chopped nuts sprinkled over and pressed in with the bowl of spoon.

German Christmas Cookies.-One quart honey, 1 quart sour cream, 1 tablespoonful ground cloves, 1 tablespoonful ground cinnamon, 1 nutmeg, grated; 4 tablespoonfuls soda, 1 pint of chopped nuts, 5 cts.' worth of citron chopped fine; 1 pinch of salt, $1 \mathrm{lb}$. of brown sugar. Flour to roll. Cut, and bake like cookies.

German Christmas Cookres.-One quart honey; let come to a boil; then set away to cool. Add 1 pound brown sugar, 4 eggs, juice and rind of 2 lemons, $1 / 4$ citron chopped fine, 2 teaspoonfuls soda, 1 tablespoonful of cinnamon, 1 tablespoonful of cloves, 1 taklespoonful allspice, 1 tablespoonful of nutmeg. Flour to stiffen. Make dough as stiff as you can. Chopped nut-meats can also be added if desired.

LeMON SNAPS.-Mix 1 quart honey, $1 / 2$ lb. powdered sugar, $1 / 2 \mathrm{lb}$. fresh butter, and juice of two oranges or lemons. Warm just enough to soften the butter. Beat the mixture very hard. Add a grated nutmeg. Mix in gradually $2 \mathrm{lbs}$. or less of flour. Make a dough hard enough to roll out easily. Beat it well all over with rolling-pin. Roll $3 / 8$ inch thick; cut with tumbler dipped in flour. Bake well on buttered tins.

OAtmeal Cookies.-Cream together 1 cup sugar, $1 / 2$ cup honey, $3 / 4$ cup lard or butter, 6 tablespoonfuls milk, $1 / 2$ cup raisins, 2 cups rolled oats, 2 eggs; sift together 2 or more cups flour, $1 / 2$ teaspoonful 
salt, 2 teaspoonfuls cream of tartar, 1 teaspoonful soda; 1 teaspoonful cinnamon. Mix together, and roll quite thick.

DoughNUTS.-One egg, 1 cup sweet milk, 1 cup hones, 2 tablespoonfuls shortening, 1 heaping teaspoonful cream tartar, $1 / 2$ teaspoonful soda. Flour to roll and cut easily. Pinch of salt.

Doughnuts. - Take two eggs; butter, the size of an egg; $1 \frac{1}{2}$ cupfuls alfalfa honey; 1 cupful of sour milk to which has been added 1 teaspoonful of soda and flour to roll, to which add 2 teaspoonfuls of cream of tartar.

Gexuixe Nurearberg Lebkuchex. - (German (hristmas cookies.) Boil a quantity of honey till it forms pearls as it drips from a spoon, then pour out and cool off somewhat. Mix with flour until it forms a stiff dough. Let the dough stand 8 to 14 days. For $10 \mathrm{lbs}$. of this dough (for a smaller quantity use proportionately less), add 2 heaped tablespoonfuls of baking soda dissolved in water; 1 heaped tablespoonful cinnamon, 2 teaspoonfuls ground cloves, 1 teaspoonful crushed cardamon, 2 tablespoonfuls anise seed, finely chopped rind of two lemons, $3 / 4 \mathrm{lb}$. chopped almonds, $1 / 4 \mathrm{lb}$. citron. Work the dough until it becomes soft enough to be easily rollea out with a rolling-pin. Roll flat cakes of any desired shape. Dissolved baking soda must be added gradually, otherwise dough will become sticky.

Sugar Cookins.-One and one-half cups sugar, $1 / 2$ cup hones, $1 / 2$ cup butter or lard, $3 / 4$ cup sour milk, 1 level teaspoonful soda, $1 / 2$ nutmeg, grated, 1 pinch of salt. Add flour to make a rather soft dough. Roll out to $3 / 4$ inch thick, and bake in quick oren.

\section{BREAD, GEMS, ETC.}

BROWN BREAD.-One heaping coffee-cup of coln meal; 2 cups graham flour; sift closely together, then leat together with 1 cup of hones, 2 cups sweet milk, 1 cup sour milk, 1 dessertspoonful soda and 1 teaspoonful salt. Place in form, and steam $31 / 2$ hours.

BROWN BREAD.-One cup corn meal, 1 cup rye meal, 1 cup sour milk, $1 / 2$ cup or less of honey; a teaspoonful of sa!t and a teaspoonful of soda. Steam 1 hours, and then dry in the oven 15 minutes. It may le added that most of the molasses now sold is not fit to eat, and in any case honey is much better.

STEAMEd BRown BREAD.-Two cups graham flour, sometimes heaped, depending on condition of milk, 1 cup meal, 2-3 cup dark hones or sugared honey, 2 cups sour milk, 1 teaspoonful salt, 2 teaspoonfuls soda dissolved in one tablespoonful boiling water, stirred into the milk and honey; $1 / 2$ cup raisins. Stir thoroly; fill pound baking-powder cans half full; corer tight, and steam 3 hours.

GrAHAM BREAD.-Three cups graham flour, 1 tablespoonful salt (scant), 2-3 cup honey, 2 cups sour milk, 1 teaspoonful soda dissolved in warm water; pinch baking powder; a few nuts chopped fine. Bake 1 hour and 15 minutes.

GraHAM BREAD.-One pint sweet milk, $1 / 2$ cup extracted honer, 1-3 cup sugar, 1 teaspoonful soda, a pinch of salt, $2 \frac{1}{2}$ cups graham flour. Stir all into a batter in a vessel in which it shall be steamed for

3 hours. Then remove from the steamer and bake $1 / 2$ hour.

GRAHAM BREAD.-One and one-ha'f cups sour milk, $1 / 2$ cup shortening, 2-3 cup hones, 1 egg, 1 teaspoonful soda, 3 cups graham flour.

HONFy GRAIHAM BIscuits.-Use 2 cups graham flour, 2 cups white flour, $1 / 2$ cup butter, 1/2 cup honer, 2 teaspoonfuls baking powder. Sift the flour and baking powder well together; rub the butter into the flour thoroly. Add the hones, and just enough sweet milk to make a soft dough. Roll out and bake in a quick oren.

French MUfFins.-One and one-half pints flour, 1 cup hones, $1 / 2$ teaspoonful salt, 2 teaspoonfuls baking powder, 2 tablespoonfuls butter, 3 eggs, and a little over half pint mik or thin cream. Sift together the flour, salt, and powder; rub in the butter cold; add beaten eggs, milk, and honey. Mix smoothly in batter as for pound cake. About half fill sponge-cake tins, cold and fully greased, and bake bread in good steady oven for eight minutes.

Gexs.-Two quarts flour, 3 tablespoonfuls melted lard, $3 / 4$ pint honer, $1 / 2$ pint molasses, 4 heaping tablespoonfuls brown sugar, $1 \frac{1 / 2}{2}$ level tablespoonfuls soda, 1 level teaspoonful sa?t, 1-3 pint water, 1/2 teaspoonful extract vanilla.

Cormarad Cake.-One cupful cornmeal (yellow), $3 / 1$ cupful white flour, putting both in flour sieve; add one level teaspoonful soda and a rounding teaspoonful cream of tartar, and sift all together; then add 1 cupful of hones, $1 / 2$ cupful of shortening; add enough sweet milk to mix to a batter that will not run, but drop from spoon in a lump. Bake onehalf hour in hot oven.

Gears.-Take 1 cup buttermilk, $1 / 4$ cup sour cream, 1/2 cup lest quality extracted honey, 1/4 cup white sugar, 2 well-beaten eggs, 4 tablespoonfuls cottolene or lard, 1 teaspoonful of salt and soda. Sift together cornmeal and flour, one-half of each, with 2 tablespoonfuls of cornstarch-enough to make a good batter, not ton stiff. Butter may be used for shortening, leaving out salt. Bake in gem-pans.

BRAN GeMs.-Take 2 cups bran, 1 scant cup wheat flour, 1 large pinch salt, $1 \frac{1 / 2}{2}$ cups buttermilk, 1 level teaspoonful soda, 3 tablespoonfuls strained honey. Mix the bran, flour, and salt thoroly, add buttermilk, in which soda has been dissolved; lastly, add honey. Bake until (crusty) thoroly done in greased gem-pans in a hot oven.

\section{MISCELLANEOUS}

HoNey Cereal Coffee.-Use 1 egg, 1 cup honey (preferably dark), 2 quarts wheat bran. Beat the egg, add honey, and lastly the bran, and stir until well blended. Put in oven and brown to dark brown, stirring frequently, keing careful the oven is not too hot. To prepare the coffee, allow one heaping tablespoonful to a cup of hot water, and boil for at least ten minutes.

PeAch Preservis.-Pare and halve nice large peaches the night before. Pour 1 pound of honey to evers $1^{1 / 2}$ pounds of fruit.

Plum ButTeR.-Take 4 quarts of plums after being rubbed thru the colander. Let it come to a boil; then add 1 quart of honey and 1 quart of sugar, or 2 quarts of hones, and boil until it crusts on top when cooled, or about fifteen minutes. Stir frequently to prevent burning.

APPLE BUTTER.-One gallon good cooking apples, 1 quart honey, 1 quart honey vinegar, 1 heaping teaspoonful ground cinnamon. Cook several hours, stirring often to prevent burning. If the vinegar is very strong, use part water.

BAR-LE-DUC PRESERVES.-These presertes are beliered to be the finest of their kind, and have hitherto been imported at extravagant prices. Other fruits kesides currants may be treated in this way, as hones is of itself a preservative. These preserves da not require to be kept absolutely air-tight. 
Take selected red or white currants of large size, one by one; carefully make an incision in the skin $1 / 4$ of an inch deep with tiny embroidery scissors. Thru this slit remove the seeds with the aid of a sharp needle; remove the seeds separately, preserving the shape of the fruit. Take the weight of the currants in honey, and when this has been heated add the currants. Let it simmer a minute or two, and then seal as for jelly. The currants retain their shape, are of a keautiful color, and melt in the mouth. Care should be exercised not to scorch the honey; then you will have fine preserves.

Custard.-Use 1 egg, 1 tablespoonful honey (or more to suit individual taste), 1 cup rich milk, nutmeg or other flavoring. Beat the eggs, and add the honey and other ingredients.

HoNey BeANs (NAvy).-Place 1 onion, $1 / 4$ pound bacon, and kutter the size of an egg in the bottom of a tean-pot or iron spider. Pour over the beans 2 tablesponfuls olive or cooking oil, and 2 tablespoonfuls best quality extracted honey. Lay sliced Greening apples to cover over the top of beans. Soak the beans and bacon over night. Keep moist while baking. Bake until well done. Add pepper to suit taste.

BAKED BEANS.-Boil 2 pints of keans in slightly salted water until tender; then add 1 cupful of extracted honey and $1 / 2$ cupful of butter, with salt and pepper to suit taste. Bake in a covered baker until solid, kut not dry.

Summer Drink.-One spoonful fruit juice and 1 spoonful honey in $1 / 2$ glass water; stir in as much soda as will lie on a dime, and then stir in half as much tartaric acid, and drink at once.

FilliNg For LAYer CAKe.-Take 1 tablespoonful of lemon-juice, 2 heaping tablespoonfuls of granulated honey; stir to a smooth cream. When cake is done, lay on a plate hot; spread with the honey whie hot.

Picklen Grapes in Honey.- - Seven pounds good grapes (wine grapes if possible) on the stalks, carefully packed in a jar without bruising any of them. Make a syrup of 4 pounds of honey, a pint of good vinegar with cloves, etc., to suit the taste. Then koil the syrup, carefully skimming it, for twenty minutes. While boiling hot, pour the syrup over the grapes and seal up. This will keep perfectly for years, as the honey is a preservative.

Honey Crab-apple Jelly.-Boil fruit with as little water as possible; squeeze thru a jelly-bag. Add $1 / 2$ cup of honey and $1 / 2$ cup of sugar to 1 cup of juice; then boil about twenty minutes, or until it begins to jell. Pour into glasses. Do not cover up until cool.

BAKED APPLES.-Split some sour apples, cut out the core, and fill pan. When they begin to soften, fill the cavity with some honey and lemon juice. Set back in store to finish baking.

SALAd Dressing.-Take $1 \mathrm{egg}$, well beaten, with 2 dessertspoonfuls honey. Add a pinch of salt; pepper to taste; 1/4 teaspoonful of mustard. Stir well together, and add $1 / 2$ cup of vinegar. Let come to a boil, stirring constantly. Cool, and add $1 / 2$ pint of sweet cream just before using.

Salad Dressing.-Take the yolks of $4 \mathrm{eggs}$, beat well, add 4 tablespoonfuls cider vinegar, 2 tablespoonfuls butter, 2 tablespoonfuls honey, 1 teaspoonful mustard. Mix thoroly together, and cook in a double boiler to a smooth paste, stirring constantly. Mix with thick sweet cream, when ready to use. It will keep two weeks in a cool place.

Steamed Pudding - Use 2 eggs, 2-3 cup honey, 1 cup chopped raisins, $1 / 2$ teaspoonful salt, $1 / 2$ tea- spoonful soda, $1 / 2$ teaspoonful cinnamon; $1 / 4$ teaspoonful cloves, $1 / 2$ teaspoonful allspice, 2 teaspoonfuls baking powder, 2 tablespoonfuls ground chocolate, 1 cup sweet milk, $1 \frac{1}{4}$ cups flour; more if needed. Steam three hours.

Mince Meat.-Four pounds of apples, pared, cored, and minced; $1 \frac{1 / 2}{2}$ pounds of raisins, stoned and minced; 4 pounds of keef suet shredded, or 2 pounds butter; 1 pound honey and $1 / 2$ pound sugar; $1 / 4$ pound of mixed spices, minced rind of 4 lemons and juice of two lemons. Make a month before using. If apples are very sour, use more honey.

Buckwheat Pancakes.-Take scant 2 quarts of water at a little below blood heat-cooler if weather is warm; dissolve salt in the water till it tastes almost briny; 2-3 compressed yeast cake, thoroly mixed in water before flour is added. Mix in the water a large tablespoonful of liquid honey; add the buckwheat flour thru a sieve. The batter should then be stirred or beaten a long time. If any batter is left, set away in a cool place, not too tightly covered. When ready for the next batch add the necessary quantity of salted warm water and the honey; stir thoroly, and then add the buckwheat as before. It is better to mix a little too thick rather than too thin. Water can be safely added before baking, if necessary. If sour in the morning from being kept too warm, use a little baking soda, dissolved in warm water. The old batter is useless after the soda treatment.

BuckWheat Pancakes. - When buckwheat pancakes are raised over night and the soda is put in when ready to bake, add one or two spoonfuls of extracted honey. It makes them bake nice and brown, and gives them a fine flavor.

JUNKET.-To a pint of milk, just warm, add 2 dessertspoonfuls of honey and $1 / 2$ junket tablet, dissolved in cold water; flavor to taste. Set in a warm place until firm.

\section{HONEY CANDDY.}

CARAMELs.-Take 1 pint honey, 1 teaspoonful cinnamon or vanilla, $1 / 2$ pound cocoa, $3 / 4$ pound pecan nuts, 2 pounds sweet almonds. Cut the nuts fine, and boil them with other ingredients until thick. Cool and roll out. Cut in squares and dry in the oven.

CARAmfls.-One cup extracted honey of best flavor; 1 cup granulated sugar; 3 tablespoonfuls sweet cream of milk. Boil to "soft crack," or until it hardens when dropped into cold water, but not too brittle-just so it will form into a soft ball when taken in the fingers. Pour into a greased dish, stirring in a teaspoonful extract of vanilla just before taking off. Let it be $1 / 2$ or $3 / 4$ inch deep in the dish; and as it cools cut in squares and wrap each square in paraffine paper, such as grocers wrap butter in. To make chocolate caramels, add to the foregoing one tablespoonful melted chocolate, just before taking off the stove, stirring it in well. For chocolate caramels it is not so important that the honey be of best quality.

TAFFY.-Boil some honey until it hardens when dropped into cold water. Pull it becomes white. Any quantity may be used. A pound requires twenty minutes' boiling and stirring. Great care must be exercised not to burn the honey. It makes very fine taffy.

Peanut Honey Candy.-Take 1 cup butter, 2 cups honey, 2 cups sugar, 1 cup boiling water, $1 / 4$ teaspoonful cream tartar, $1 / 2$ teaspoonful glycerin, a tiny dash of soda. Boil ten minutes to a soft ball, and set in cool place. When it has cooled slightly, stir in one or two tablespoonfuls of peanut butter, 
or to suit the taste; keep stirring till creamy; then pour into buttered pans; mark in squares.

PeAnut CANDY.-Use 1 cup honey, 1 cup granulated sugar, 4 tablespoonfuls sweet cream. Boil until it cracks when dropped in cold water. Remove from the fire and stir in a pound of peanuts that have been previously shelled and well erushed with the rolling-pin. Pour into a greased pan and set to cool.

Peanut Rolls. - Take 1 cup butter, 2 cups honey, 1 cup boiling water, $1 / 1$ teaspoonful cream tartar, $1 / 2$ teaspoonful glycerine, a tiny dash of soda. Boil ten minutes; pour over a layer of rolled peanuts which have been scattered evenly orer the bottom of the buttered pan. When nearly cold, mark off in long strips and roll up tight; then slice across with a sharp knife, before it gets quite cold

HoNey Chocolate.-Chocolate sweetened with honey rather than with sugar is excellent. Here is how it is made: Melt 1 pound of gelatine in a pint of water; add 10 pounds of honey, thoroly warming the same, and then add 4 pounds of cocoa. Flavor with vanilla when taken off the fire, and then pour into greased dishes or molds.

French CaNdies.-In an enameled sauce-pan melt 1 part of gelatine in 1 part of water, stirring well. When at the state of a soft paste, add 4 parts of honey previously warmed, stirring lively. Take from the fire; add the desired flavor and color, mix ing carefully, and pour into a shallow lightly greased dish. Let it dry for a few days.

Nougat.-Take 3 cups granulated sugar, 11/2 cups any kind nut-meats, 2-3 cup honey, 2-3 cup hot water, white of one egg beaten stiff. Boil the sugar, honey, and water together until they make a rather hard ball when dropped in cold water. Remore from the fire, pour in the beaten white of the egg, and beat briskly with a silver fork. After beating a while, pour in the nut-meats and beat until it begins to form a hard creamy mass, then pour into a buttered tin to cool.

TAFFY.-Use 3 cups sugar, 2-3 cup extracted honey, 2-3 cup hot water. Boil all together till it spins a thread when dropped from a spoon, or hardens when dropped into cold water. Pour into a greased ressel. When cool, pull until white.

POPCORN BALLs.- Use 2 gallons of corn, 2 cups granulated sugar, 3 tablespoonfuls honey, 2 tablespoonfuls apple vinegar, $1 / 2$ cup of water. Stir together and boil until it will rattle in water. Then pour over the corn, and mix well. Dampen the hands in cold water and form into balls.

POPCORN BALLS.-Take 1 pint extracted honey; put it into an iron frying-pan, and boil until very thick; then stir in freshly popped corn, and, when cold, mold into balls. These will specially delight the children.

Good Candy.-Use $2 \frac{1}{2}$ cups sugar, $1 / 2$ cup honey, $1 / 2$ cup water. Boil until thick syrup. Pour one cupful of syrup on the beaten whites of $2 \mathrm{eggs}$, stirring meanwhile. Boil remainder of syrup till it hardens when dropped in water; then pour it into the syrup and eggs, stirring briskly. Add a cupful of peanuts. Stir until it begins to harden; then spread in a pan and cut in squares. Flavor to taste. If properly made it will be soft and pliable.

Crystallized Honey Popcorn.-Take 1 teacup ful water-white honey, 1 teacupful white sugar, $1 \frac{1 / 2}{2}$ tablespoonfuls butter, 1 tablespoonful water. Boil until brittle on being dropped in cold water. Have ready 2 quarts of nicely popped corn, and pour the candy over until evenly distributed over the corn, stirring briskly until nearly cool.
Honey CANox.-Take 1 cup sugar, 2 tablespoonfuls honer, 2 tablespoonfuls of water, walnut meats. Cook and test like molasses candy.

CANDY.-Granulated sugar 1 cup; strained honey 1 tablespoonful; butter, size of walnut; sweet cream enough to dissolve the mixture. It does not need much cooking. When taken from the fire, beat with a spoon until smooth.

\section{HONEY REMEDIES:}

Cotgir Syrup.-One-third teaspoonful of powdered ipecac dissolved in 1 teaspoonful of cold water. Add a teacupful of warm water, a tablespoonful of extracted or strained honey, and boil down half.

HoNEY-AND-TAR Cotgh-CURE.-Put a tablespoonful liquid pine tar into a shallow tin dish and place it in boiling water until the tar is hot. To this add a pint of extracted honey and stir well for half an hour, adding to it a level teaspoonful pulverized borax. Keep well corked in a bottle. Dose, teaspoonful every 1,2 , or 3 hours, according to severity of cough.

Cough Syrup.-Buy a five-cent package of lobelia herb; put about $1 / 8$ of it in a large cup of good cider vinegar; put it in a granite dish to simmer on the stove for not less than $1 / 2$ hour, but do not let boil after the strength is well out of the herb. Strain, put back on the store, stir in about as much honey as rou have used vinegar. See that the honey is well mixed while hot. Bottle ready for use. Dose, about $1 / 4$ teaspoonful every 15 minutes if the cold is bad.

Cough Syrup.-Make 3 pints of strong tea by boiling a good-sized bunch of old field balsam in a covered ressel; strain, add $11 / 2$ cups of sugar; boil to 2 pints; take from the fire; add a small teaspoonful of pine tar; let cool five minutes, then add $1 / 2$ cup of strained hones. Dose: 1 teaspoonful as often as needed-2 to 4 hours, according to the case.

For Colds.-Boil 2 ounces of flaxseed in a quart of water; strain, and add 2 ounces of rock candy, $1 / 2$ pint of honey, juice of 3 lemons. Mix, and let all boil well. Let cool and bottle. Dose: One cupful on going to bed; $1 / 2$ cupful before meals; the hotter the better.

Tمотн-PASTE.-Eight ounces precipitated chalk, 4 oz. powdered castile soap, 4 oz. orris-root powder, 2 oz. essence of wintergreen, and honey to make a paste.

HONEY FOR FRECKLES.-Half a pound of honey, 2 oz. glscerine, 2 oz. alcohol, 6 drams citric acid, 15 drops ambergris. Apply night and morning.

Baly of Gilead Salve.-Four ounces mutton tallow; 1 pint balm-cf-Gilead buds; 3 ounces loaf sugar; 1 ounce castile soap; 1 ounce rosin; 3 ounces beeswax; 1 ounce alum; 1 pound lard. Put the buds in a kettle with the lard, and boil slowly for half an hour, stirring often. Strain, and take the buds out. Put in the rest of the ingredients, and cook slowly until done. This usually takes from one-half hour to an hour; excellent for chapped hands or lips, sores, or cuts, frost bites, and piles.

HoNey AS A SOFTENER OF THE HANDS.-Many are unaware that the very best cosmetics are made with honey as a prime ingredient. Here is one for the hands, which is said to be very fine: Rub together $1 \mathrm{lb}$. of honey and the rolks of $8 \mathrm{eggs}$; gradually add $1 \mathrm{lb}$. oil of sweet almonds, during constant stirring; work in $1 / 2 \mathrm{lb}$. bitter almonds, and perfume with 2 drams each of attar of bergamot and attar of cloves. Of course, the quantities may be reduced if necessary. 
HONEY SOAP.-Cut 2 pounds of yellow soap in thin slices and put into a saucepan with sufficient water to prevent the soap from being burned. Place on the fire, and as soon as all the soap has dissolved add 1 pound of honey and stir until the whole begins to boil. Then remove from the fire, add a few drops of essence of cinnamon, pour into a deep dish to cool, and then cut into squares. It improves by keeping.

Honey-PASte for Chapped HANDS.-An excellent paste for chapped hands is made as follows: The white of $1 \mathrm{egg}, 1$ teaspoonful of glycerine, 1 ounce of honey, and sufficient barley flour to compose a paste.

Cold Cream.-One cup of honey, $3 / 4$ of a cup of beeswax, 1 cup of cottolene. Melt all, take it off the fire, and stir till it is cool. Rose or violet perfume may be added. It should be well protected from the air. The blending should be well done. This is fine for chapped or rough hands, if they are slightly moistened before applying.

POLISH FOR KID SHOES.-Beeswax softened with neatsfoot oil. The composition is made by mixing the oil with the melted wax so as to be, when cold, about like butter, soft enough to "spread." A small portion of lampblack is also mixed in while the mass is melted. If there is any ordinary shoe polish on shoes, it should be washed off and the surface allowed to dry. An old toothbrush can be used to apply a thin even coat, which is then polished with a soft woolen rag, see-sawed across the surface.

WATER-PROOFING FOR IJATHER.-Take 2 pounds tallow, 1 pound resin, $1 / 2$ pound beeswax. Melt over a slow fire; and before applying to the uppers of boots or shoes, fill the leather with neatsfoot oil, as there is less danger of burning the leather, and they will keep soft and pliable longer. For the soles use the tallow and resin in equal parts. Be careful not to burn the leather.

\section{BIBLIOGRAPHY.}

In Bureau of Chemistry Bulletin No. 13, Part VI. (out of print), page 871 , will be found a bibliography of honey literature for the years 1867 to 1891, inclusive. In Bulletin No. 110 , page 89 , will be found a continuation of this up to the first part of 1907 . In Bulletin No. 154, page 17, the bibliography takes the literature up to the close of 1911. These bibliographies were compiled by A. H. Bryan, chief of the sugar laboratory, and are complete.

Browne, C. A. Chemical Analysis and Composition of A.merican Honeys. Bul. 110, U. S. Dept. Agr. Bureau of Chemistry. 1908.

Browne, C. A. Methods of Honey-testing Hawaiian Honeys. Bul. 17, Hawaii Agr. Bureau of Entomology, 1911.

McGill, A. Strained Honey. Bul. 217, Inland Revenue Dept. Ottawa, Canada, 1911.

Van Dine, D. L., and Thompson, A. R., Hawaiian Honeys. Bul. 1, Hawaii Agr. Exp. Sta. 1908.
Root, H. H. The Use of Honey in Cooking. A. I. Root Co., Medina, 1916.

Hunt, C. L., and Atwater, H. W. Honey and its Uses in the Home. U. S. Dept. Agric., Farmers' Bul. No. 653, 1915.

Honey for Cooking, special number of Gleanings in Bee Culture, Medina, vol. 42, Oct. 1, 1915.

Michaelis, Reinhold. Deutsches Honigbuechlein. 1911.

\section{HONEY - BOARDS. - See EXTRACTED} HoNer, and Hives.

HONEYCOMB.-A beautiful thing in nature is a piece of comb honey with its snowy whiteness and its burden of sweetness. Aside from its whiteness and sweetness, the marvelous structure of the comb compels our admiration. The walls of its cells are so thin that from 3000 to 4000 of them must be laid one upon another to make an inch in thickness, each wall so fragile as to crumble at a touch, and yet so constructed that tons of honey stored in them are transported in safety thousands of miles.

Formerly the word "honeycomb" meant both the comb and the honey contained in it; in other words, what we now call " comb honey" was called "honeycomb." Wherever the word "honeycomb" is found in the Bible, it means " comb honey."

It is only in comparatively recent years that the real source of the wax of which comb is constructed has been known. In 1684 Martin John discovered that with the point of a needle he could pick scales of real beeswax from the abdomen of a bee working at comb-building.

These wax scales may be found plentifully on the floor of a hive at a time when much comb-building is going on; and, in fact, more or less of them may be found at almost any time of the year. They are somewhat pear-shaped, as shown next page, where is shown also the powerful jaw of the worker by which the wax is worked. These wax scales are much more brittle than the wax that has been worked into comb, and are transparent, looking somewhat like mica. Some say they are white, some say pale yellow. Likely enough both are right, the color depending upon the pollen consumed. 
These wax scales are secreted by eight wax-glands on the under side of the abdomen of the worker bee, as seen in the cut below.* Examine a swarm lately hived, and you will find plenty of bees showing this appearance. When first secreted, wax is liquid. It is derived from the blood of the bee by cell action. So it is an expensive

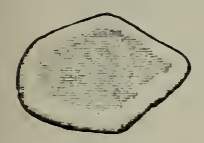

Wax scale.

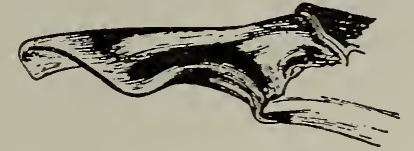

Jaw of a worker bee. product, and one might well say it is derived from the "sweat and blood" of the bee, for it is sweat out from the blood by the wax-glands. Just how expensive it is seems a hard matter to learn. For many years the stereotyped expression was, " Every pound of wax requires 20 pounds of honey for its production." Later investigations have cut down that estimate greatly. But there is no agreement. Some esti-

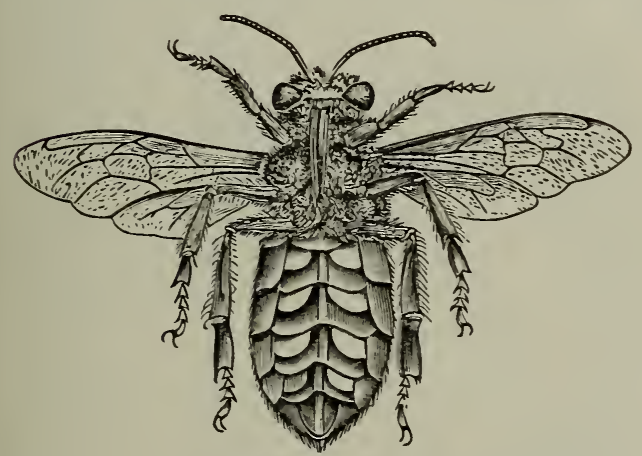

Wax scales on the under side of the abdomen of a worker.-After Cheshire.

mate as low as 3 or 4 pounds of honey to one of wax. Others say 7,15 , or some other numbers.

Some hold that the secretion of wax is involuntary, and that, if not utilized, there will be so much dead waste, and so nothing can be gained by trying to save the bees the work of secretion. But this is by no means the general view. Cowan says, in "The Honeybee," page 171, "Wax is not produced at all times, but its secretion is voluntary." The practically unanimous agreement among beekeepers, that a very much larger quantity of extracted than of comb honey can be obtained, is hard to explain without admitting that the furnishing of drawn

* For description of how these are removed by the bees see WAx. combs saves the bees much labor in the way of wax-production, and that that production depends on conditions that come largely under the control of the beekeeper.

A high temperature farors the secretion of wax, and when it is produced in large quantities the bees hang inactively in clusters or festoons.

"Wax is not chemically a fat or glyceride," says Cheshire, in "Bees and Beekeeping," Vol. I., page 160, "hence those who have called it 'the fat of bees' have grossly erred; yet it is nearly allied to the fats in atomic constitution, and the physiological conditions favoring the formation of one are curiously similar to those aiding in the production of the other. TVe put our poultry up to fatten in confinement, with partial light; to secure bodily inactivity we keep warm, and feed highly. Our bees, under Nature's teaching, put themselves up to yield wax under conditions so parallel that the suitability of the fatting-coop is vindicated.

"The wax having been secreted, a single bee starts the first comb by attaching to the roof little masses of the plastic material, into which her scales are converted, by prolonged chewing with secretion; others follow her example, and the processes of scooping and thinning commence, the parts removed being always added to the edge of the work, so that, in the darkness, and between the bees, grows downward that wonderful combination of lightness and strength, grace and utility, which has so long proroked the wonder and awakened the speculation of the philosopher, the naturalist, and the mathematician."

A chief use for the honeycomb being to furnish cradles for the baby bees during their brood stage, the problem is to find what arrangement will accommodate them in the least space and with the least expenditure of wax. If a bundle of leadpencils be tied tightly together, they .will assume the arrangement of a series of circles, and no other arrangement can possibly accommodate them in less space. That gives us the hint, then, to scoop out cylindrical holes in a mass of wax, with the same arrangement, leaving only very thin walls at the places corresponding with the points where the pencils touched each other.

That complies with the requirement to have the cells in the least possible space; 
but it requires a great amount of wax. There is no need to have the walls thicker at one point than another, so all the wax

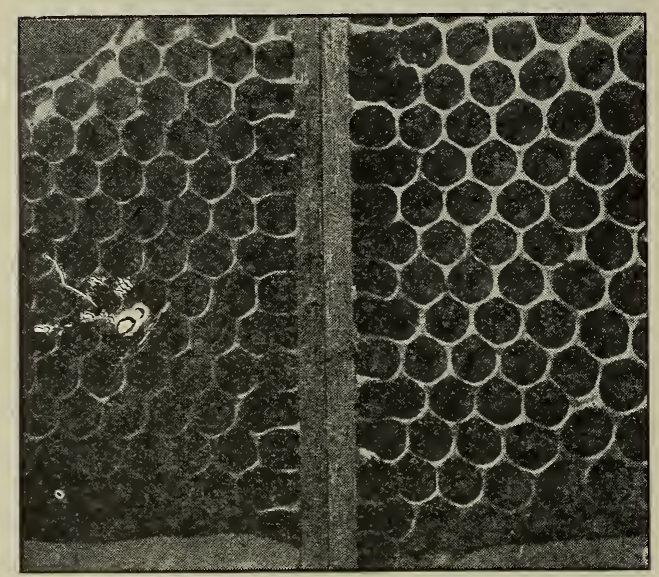

How combs are attached to a vertical support.

may be scooped out until the entire walls shall be as thin as at the thinnest part. That leaves us a hexagon-precisely the thing the bees have adopted.

Having settled the arrangement of cells on each side of a honeycomb, the next ques-

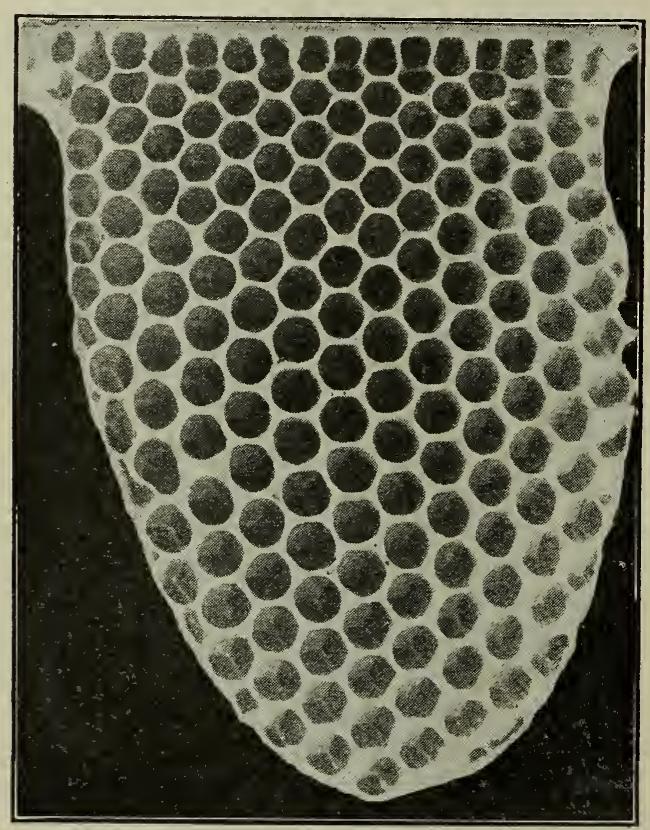

A characteristic spur of natural comb built from a horizontal support.

tion is how to let the two sets abut one against the other with the least waste of room and wax. Let a single layer of marbles fill a plate. Then these marbles may in a crude way represent the bottoms of one series of cells, or the cells on one side. How shall another layer of marbles be placed upon these with the best economy of room? Place a single marble upon the layer, and it will at once settle down, resting upon three of the lower marbles. Add other marbles, finishing out the second layer, and we have the least possible waste of space between the two layers. This gives the cue for the best way to have the cells of one side abut against the cells of the other side. Scoop out all unnecessary wax, leaving a thin wall that shall lie tangent to the circumference of each two marbles at their point of contact, and we have at the bottom of each cell three lozenge-shaped plates, these three lozenges helping to form the bottoms of three of the cells on the opposite sides. But without all this trouble we might have found the same thing by examining a honeycomb, for this arrangement is exactly the one used by the bees in building the septum, or middle wall between the two series of cells.

By far the larger portion of the cells in a hive will be found to measure about five to the inch. These are called worker-cells, and may be used for rearing worker-brood, or for storing honey or pollen. A smaller number of cells will be found to measure about four to the inch. These are called drone-cells, and may be used for rearing drone brood, or for storing honey-seldom for pollen.

If the worker-cells were exact hexagons measuring five to the inch, there would be exactly 28 13-15 cells to the square inch on one side of a comb. But there is not this exactness, as will be shown by careful measurement, altho the eye may detect no variation. Count the number of cells in a given length in a horizontal row of cells, and then make the same count in one of the diagonal rows, and you will find they are not precisely the same. That shows that the cells are not exact hexagons. Measure the cells in a number of combs built by different colonies, or even by the same colony, and it will be found that they are by no means all of them five to the inch.

This, of course, refers to natural comb built by the bees without any comb foundation being supplied to them. Comb foundation is generally made with cells of such size that worker comb built upon it contains about 27 cells to the square inch. 


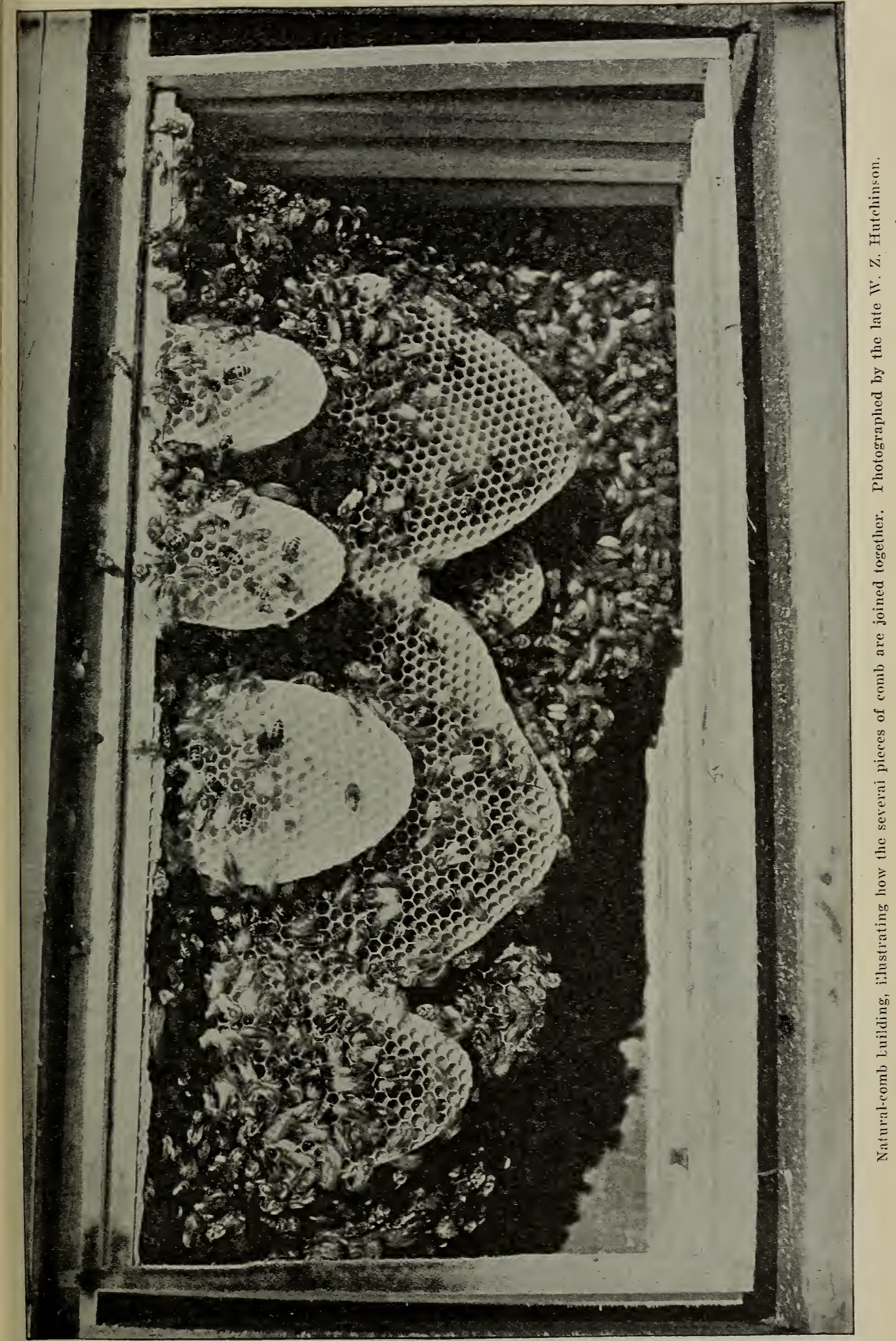


Instead of lessening our admiration, the slight variation from exactness in the work of comb-building, when the bees are left free to take their own course, rather increases it, just as a piece of "hand-made" work is often more admired than that which is " machine-made." The marvelous ingenuity displayed in adjusting the work to rarying circumstances is something far beyond machine-like exactness. Cut a few

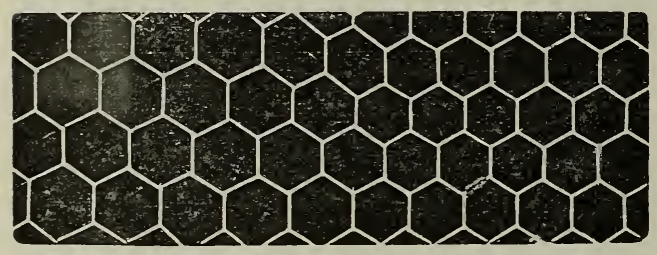

The merging of drone to worker comb

square inches of comb out of the middle of a frame of worker comb in the middle of a honey-flow, and the chances are ten to one that the bees will fill the hole with drone combs. A few cells will be built that are neither drone-cells nor worker-cells, and these are called accommodation cells; but so skillfully are the adjustments made in passing from worker to drone cells that at a hasty glance one would likely say that all were either worker or drone cells. Observe the small pieces of comb started at different points on the same top-bar on previous page. They may be at such distances apart that, when the two combs meet, if built with rigid exactness, the center of

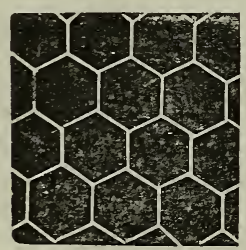

FIG. 1.

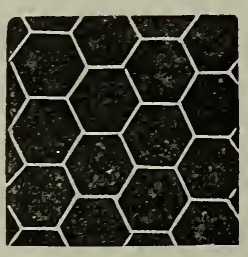

FIG. 2. a cell in one comb will coincide with the edge of a cell in the other comb. Yet so skillfully are measurements made, and so gradual the change as one comb approaches the other, that the unaided eye can detect no variation from an unbroken comb of worker-cells, and the whole is such an exquisite work of skill as no human expert can equal. Who taught the bees to make such measurements? Besides the worker and drone cells, queen-cells are built at times, as described.
In general, comb is built so that an angle is at the top and bottom of each cell, as in Fig. 1 ; and this is believed to give greater strength than if the cells were built like Fig. 2.

When combs are built upon foundation. the rows of cells run in a horizontal line with exactness. But when the bees build at their own sweet will, there is no little rariation from the horizontal.

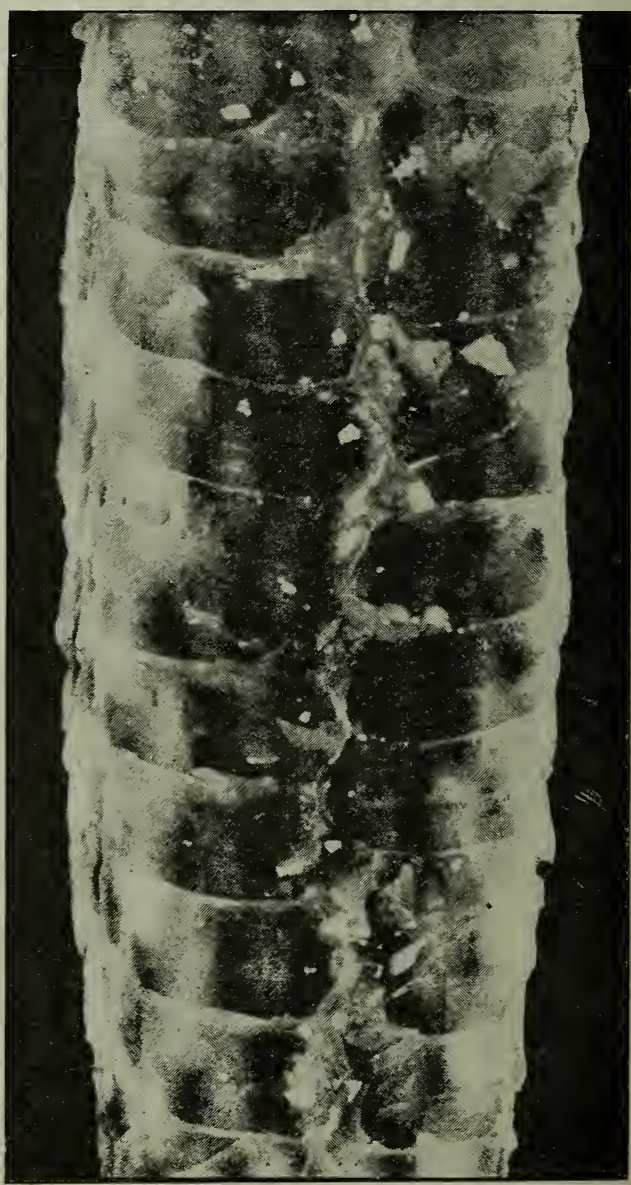

Cross-section of honeycomb, enlarged view. The cells are partly filled with honey. This illustration shows that the cells are not straight and horizontal, but curved and slanting upward.

While the cell-walls vary from $1-3000$ to $1-4000$ inch in thickness, the septum is thinner, sometimes being as thin as 1-5000 of an inch when first built. But as successive generations of young bees are reared in the cells, cocoons and secretions are left at the bottom of each, and in time the septum may become $1 / 8$ inch thick. From this it happens that, altho worker comb is ?'8 inch thick when first built, specimens of 


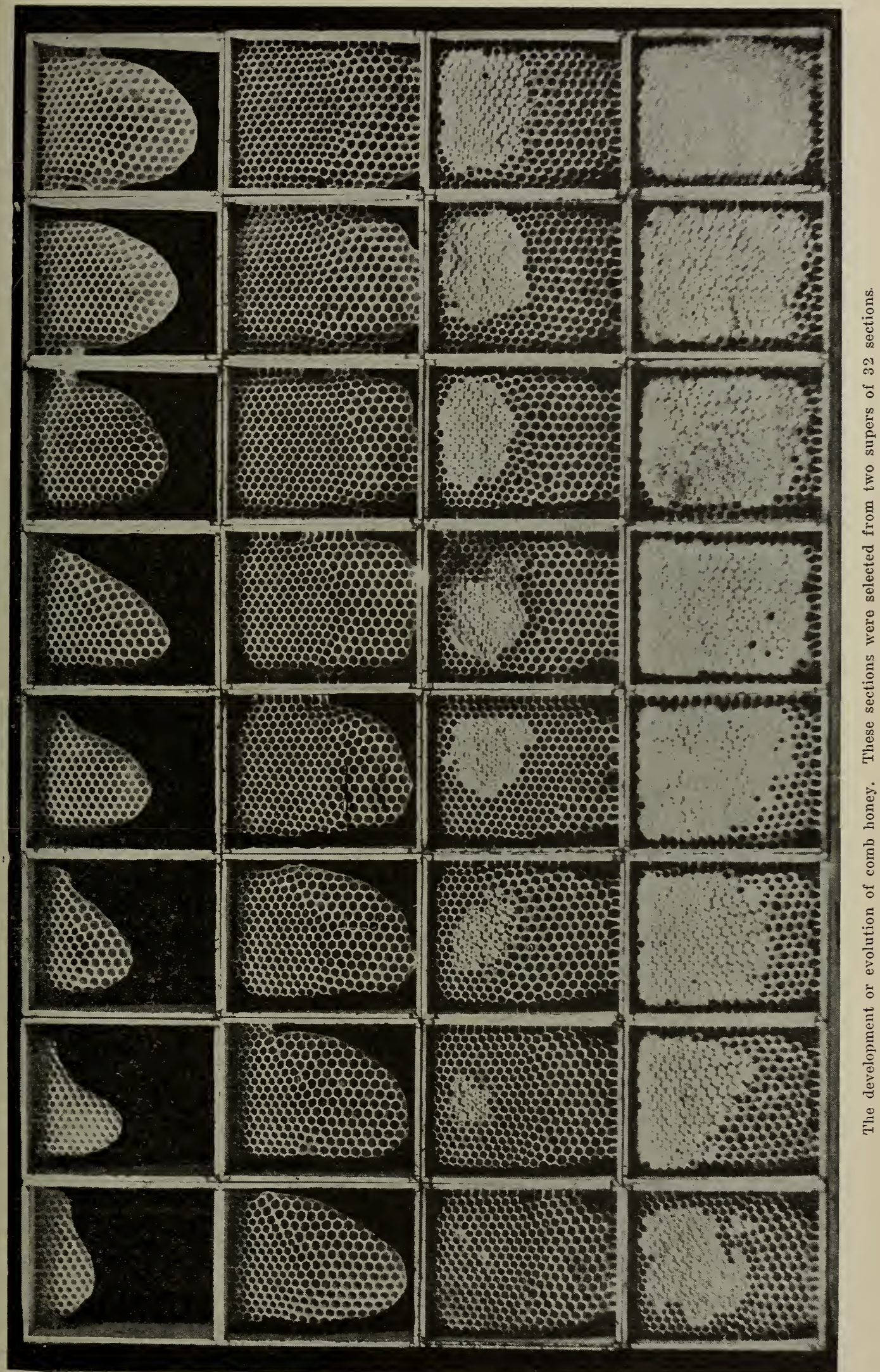


old comb may be found measuring an inch in thickness, since the bees draw out the cell-walls at the moutl of the cell to balance the additions made at the bottom of the cell, so as to maintain the same depth in an old cell as in a new one.

When, however, worker-cells are used for storing honey, if there be room for it, the depth of the cells may be so increased that the comb may be two or three inches thick. Drone comb is even more likely to be thus built out. The cells of both kinds slant upward from the center to the exterior of

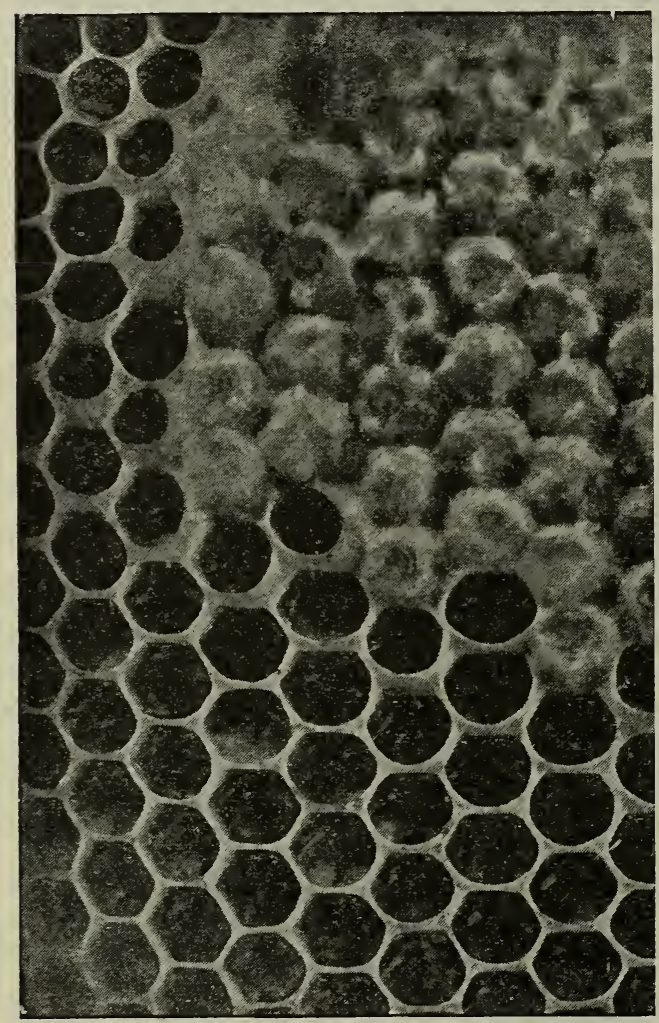

Drone calls used for honev storage. It will be seen that the lower part of the opening is capped first. This, with the slant of the cell, keeps the new honey from running out.

the comb, yet so slightly that to the casual observer they appear entirely horizontal. Yet when the comb is so greatly thickened for the storing of honey, the slant may be much increased, giving the cell a curved appearance. See page 404 , second column.

Formerly it was taught that the cappings placed over honey are air-tight, and this in spite of the fact that it is a common thing to see white comb honey become watery and dark when kept in a damp place, the thin honey finally oozing out thru the cappings. Cheshire, who at one time held that the sealing of honey-cells is air-tight, says (Bees and Beekeeping, Vol. I., page 174), "By experiments and a microscopic examination, I have made evident that former ideas were inaccurate, and that not more than 10 per cent at most of the sealing of honey is absolutely impervious to air." The sealing of brood-cells, however, is very much more porous still (see Broon), no doubt for the sake of allowing proper air for the brood. The brood-cell cappings seem to be made up of shreds of cocoons, pollen, and almost anything that comes handy, with only enough wax to weld the whole together.

The beautiful white color of honeycomb becomes dark with age, so as to become nearly black.

Drone comb measures just about four cells to the inch, but the bees seem less particular about the size of it than with the worker. They very often seem to make the cells of such size as to fill out best a given space; and, accordingly, we find them differing from worker size all the way up to considerably more than $1 / 4$ of an inch in width. Drones are raised in these extralarge cells without trouble, and honey is also stored in them; but where they are very large, the bees are compelled to turn them up, or the honey would flow out. Now, as honey is kept in place by capillary attraction, when cells exceed a certain size the adhesion of the liquid to the wax walls is insufficient, of itself, to hold the honey in place. Where drones are to be reared in these very large cells the bees contract the mouth by a thick rim. As an experiment, we had some plates made for producing small sheets of foundation, having only $31 / 2$ cells to the inch. The bees worked on a few of these, with these same thick rims, but they evidently did not like the idea very well, for they tried to make worker-cells of some of it, and it proved so much of a complication for their little heads that they finally abandoned the whole piece of comb. apparently in disgust. Bees sometimes rear worker brood in drone comb, where compelled to from want of room, and they always do it in the way we have mentioned, by contracting the mouth of the cells and leaving the young bee a rather large berth in which to grow and develop. Drones are sometimes reared in wrrlzor-cells also, but 
they are so much cramped in growth that they seldom look like fully developed insects. (See LAIING Workers; also Brood.)

Several times it has been suggested that we enlarge the race of honeybees by giving them larger cells; and some circumstances seem to indicate that something may be done in this direction, altho there is little hope of any permanent enlargement in size unless is combined with it the idea of selecting the largest bees to propagate from, as given a few pages back. By making the cells smaller than ordinarily, we get small bees with very little trouble; and we have seen a whole nucleus of bees so small as to be really laughable, just because the comb they were hatched from was set at an angle so that one side was concave and the other convex. The small bees came from the concave side. Their light, active movements, as they sported in front of the hive, made them a pretty and amusing sight for those fond of curiosities. Worker-bees reared in drone-cells are sometimes extra large in size; but as to whether we can make them permanently larger by such a course is very doubtful. The difficulty, at present, seems to be the tendency to rear a great quantity of useless drones. By having a hive furnished entirely with worker-comb, we can so nearly prevent the production of drones that it is safe enough to call it a complete remedy. (See Comb Foundation.)

\section{HOW BEES BUILD COMB.}

In this day and age of bees and honey it would seem that one should be able to describe how our bees build comb, with almost as much ease as one would tell how cows and horses eat grass; but for all-that, we lack records of careful and close experiments, such as Darwin made many years ago. In our house-apiary there were dozens of hives where the bees were building right up close to the grass; and all one had to do, in order to see how it was done, was to take a chair and sit down before them. But the little fellows have such a queer sleight-ofhand way of doing the work that we hardly know how they do accomplish it.

If we examine our bees closely during the season of comb-building and honeygathering, we shall find a good many of them with wax scales protruding between the rings that form the body, and these scales are removed from their bodies as described at the beginning of this article. If a bee is obliged to carry one of these wax scales but a short distance, it takes it in its mandibles, and looks as business-like with it thus as a carpenter with a board on his shoulder. If it has to carry it from the bottom of the honey-box, it takes it in a way that it is difficult to explain any better than to say it slips it under its chin. When thus equipped, one would never know it was encumbered with anything, unless it chanced to slip out, when it will very dextrously tuck it back with one of its fore feet. The little plate of wax is so warm from being kept under its chin as to be quite soft when it gets back; and as it takes it out, and gives it a pinch against the comb where the building is going on, one would think it might stop a while, and put it into place; but not it; for off it scampers and twists around so many different ways one might think it was not one of the working kind at all. Another follows after it sooner or later, and gives the wax a pinch, or a little scraping and burnishing with its polished mandibles, then another, and so on; and the sum total of all these maneuvers is, that the comb seems almost to grow out of nothing; yet no one bee ever makes a cell.

The finished comb is the result of the united efforts of the moving, restless mass; and the great mystery is, that anything so wonderful can erer result at all from such a mixed-up, skipping-about way of working as they seem to have. When the cells are built out only part way they are filled with honey or eggs, and the length is increased when they feel disposed, or "get around to it," perhaps. It may be that they find it easier working with shallow walls about the cells, for they can take care of the brood much easier, and put in the honey easier too, in all probability; and, as a thick rim or coping is always left around the upper edge of the cell, no matter what its depth, they have the material at hand to lengthen it at any time. This thick rim (see next page) is also very necessary to give the bees a secure foothold, for the sides of the cells are so thin they would be very apt to break down with even the light weight of a bee. When honey is coming in rapidly, and the bees are crowded for room to store it, their eagerness is so plainly apparent, as they push the work along, that they fairly seem to quiver with excitement; but for all that, 


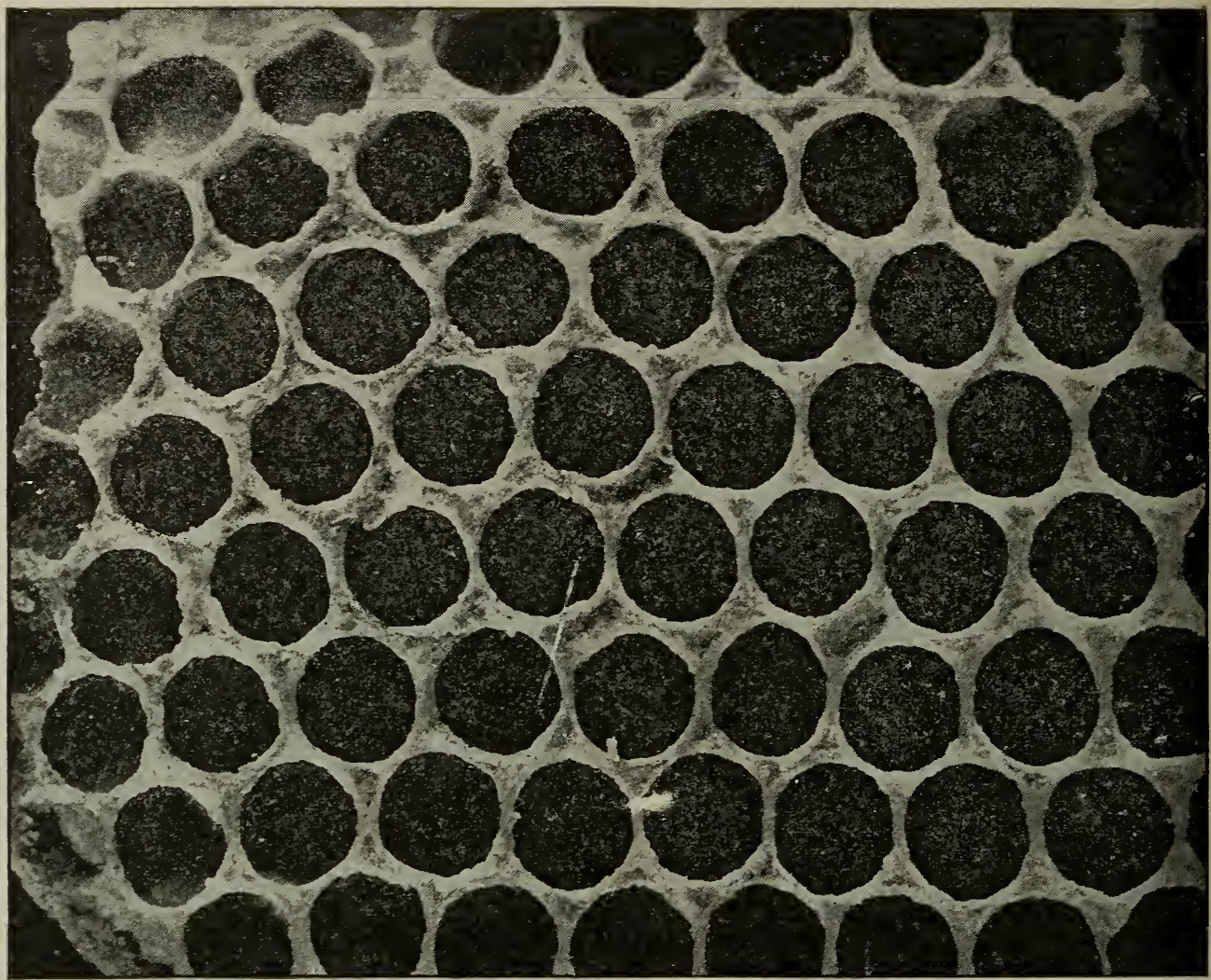

Top view of honeycomb greatly enlarged, showing the thick circular rim or coping at the top of the cell.

they skip about from one cell to another in the same way, no one bee working in the same spot to exceed a minute or two, at the very outside. Very frequently, after one has bent a piece of wax a certain way, the next tips it in the opposite direction, and so on until completion; but after all have given it a twist and a pull, it is found in pretty nearly the right spot. As nearly as we can discover, they moisten the thin ribbons of wax with some sort of fluid or saliva. As the bee always preserves the thick rib or rim of the comb at the top of the cell it is working, the looker-on would suppose it was making the walls of considerable thickness as shown; but if we drive it away, and break this rim, we shall find that its mandibles have come so nearly together that the wax between them, beyond the rim, is almost as thin as tissue paper. In building natural comb, of course the bottoms of the cells are thinned in the same way, as the work goes along, before any side walls are made at all.

When no foundation is furnished, little patches of comb are started at different points, as shown in the engraving (page 402). Then as these patches enlarge, their edges are united so perfectly that it is sometimes difficult, when the frame is filled solid, to determine where the pieces were united, so perfect is the work. At other times there is, perhaps, a row of irregular or drone cells along the line of the union.

The midrib of natural comb becomes thicker as it approaches the line of support. and tapers toward the bottom. Why this is so is evident. That there should be it gradual gradation in thickness from top to bottom seems wonderful when we remember the haphazard, skip-about work on the part of so many different bees.

For the consideration of the thickness of combs and how far to space them apart see Frames, Self-spacing; also Spacing ow Frames; also Comb Foundation.

\section{NO ARTIFICIAL COMB HONEY.}

No one is so fooljsh as to claim that a suit of clothes made on a machine is any more "artificial " than one sewed by hand. It is simply economy of labor. Yet hundreds of 


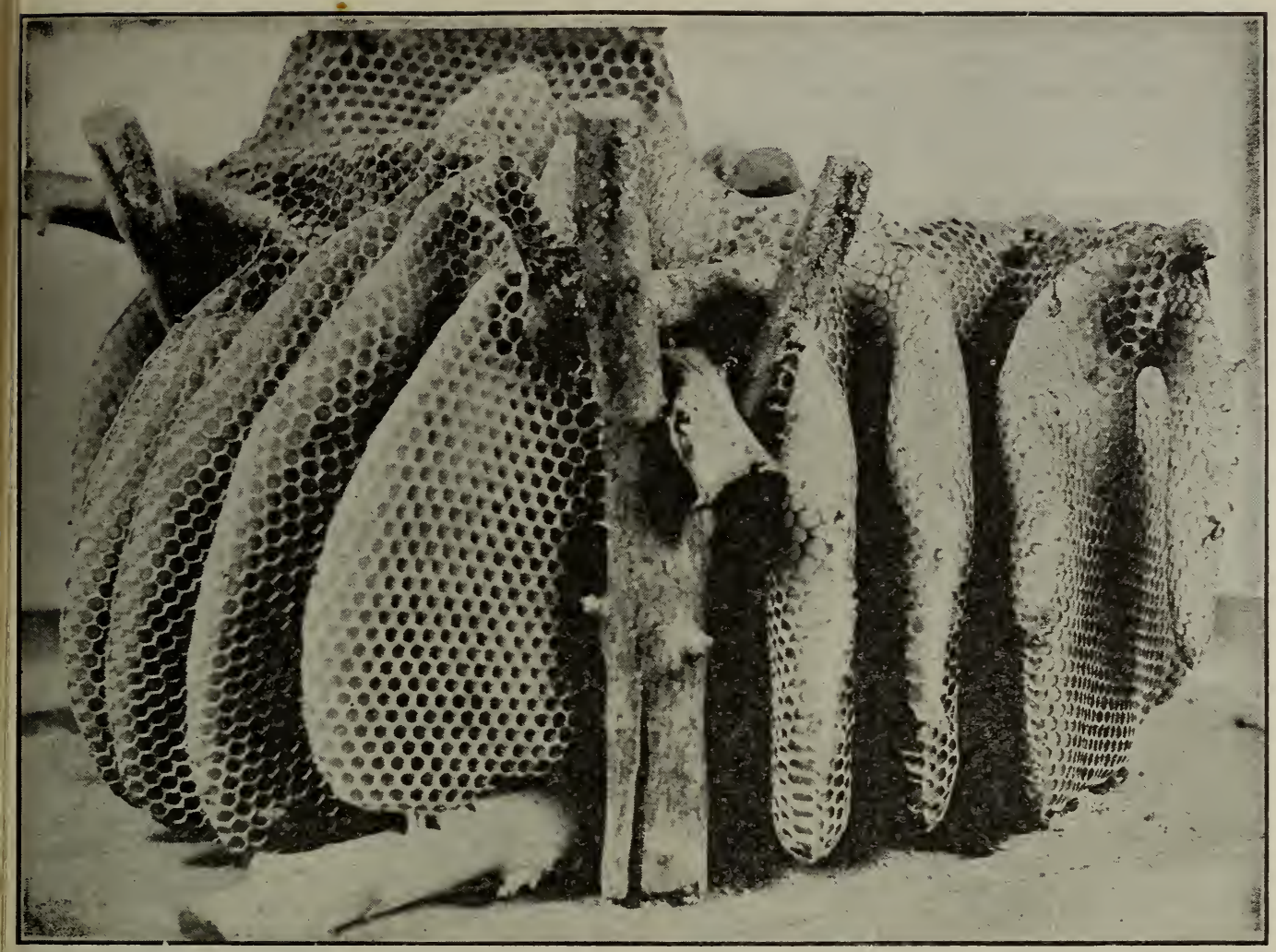

Natural-comb building in a hive made entirely of glass.

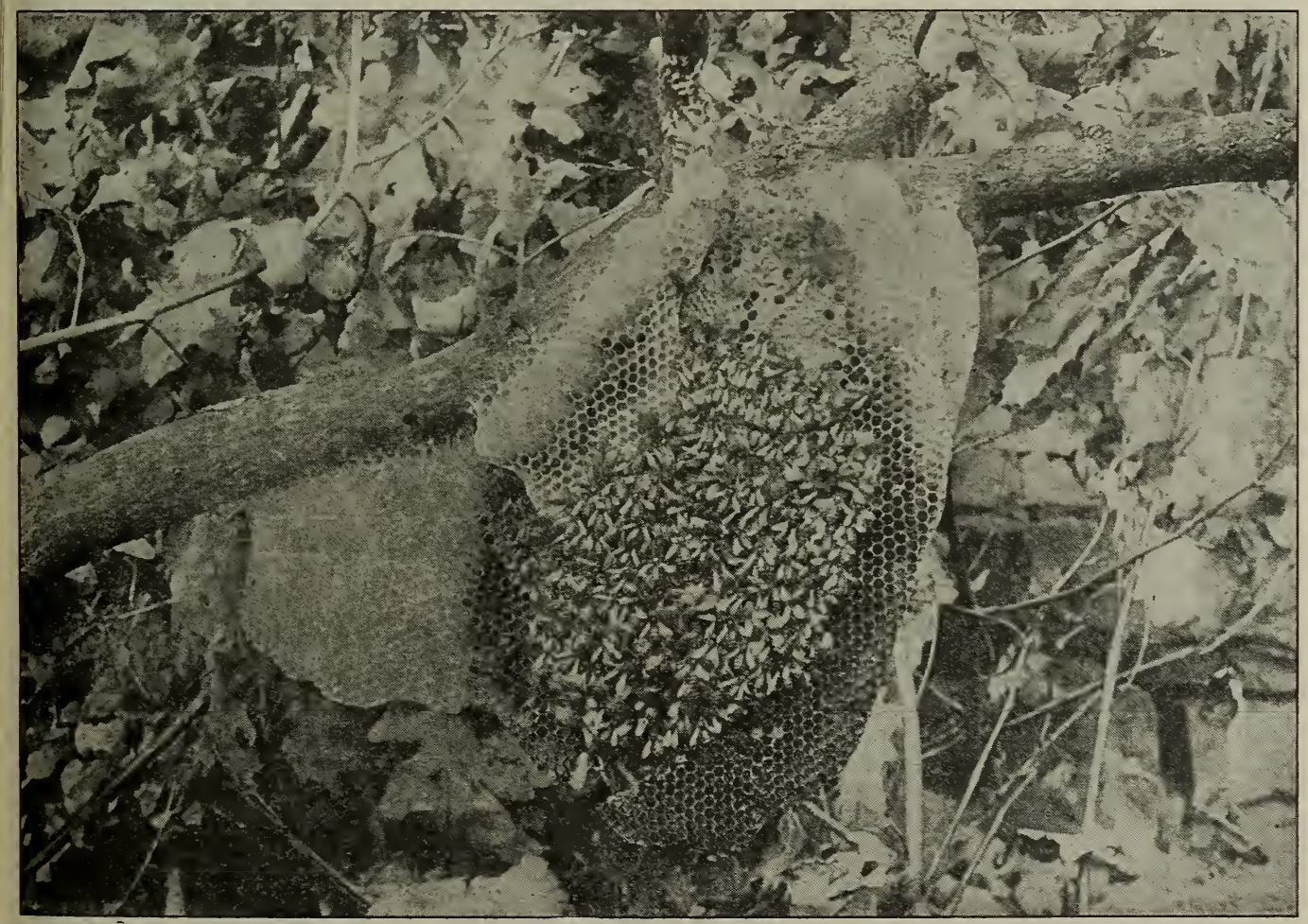

Bees living on combs built in the open air. 
persons have the incorrect notion that there is a honeycomb made fro mwood pulp, punk, putty, paraffine, or perhaps material other than wax. We say "foolish enough" advisedly, because a wise man changes his mind (when it becomes necessary); but a fool, never. It would not be surprising in these days of sensational journalism and of false nature-stories if one should get the notion that artificial comb honey really exists; but the foolish part comes in when a person, totally inexperienced with bees, stoutly and smilingly maintains that there is such a thing as manufactured honey in the comb. We feel sure that the inimitably foolish expression of such a person is the origin of the colloquialism, "The smile that won't come off." No use. Do not argue. It won't come. "Why, I've seen it at the stores. Grocer told me all about it-was several cents cheaper. I tried it; we didn't like it as well as the genuine." And then the beekeeper goes away, not a wiser but a madder man, and wonders why the foolkiller doesn't do his duty, and why every one except the beekeeper knows all about bees and their products. See Comb Honey, also HONEY FiXHibIts.

HONEY-DEW.-So named because it was formerly supposed to come down from the heavens in the form of a saccharine spray, settling on the leaves of trees and low shrubbery. Honey-dew such as beekeepers usually encounter is largely the product of aphides, plant-lice, or coccidsscale insects. These are sometimes found on the top limbs of a tree, and honey-dew which they secrete is thrown out as a spray, which falls on the lower limbs and on the sidewalk* $^{*}$ or grass. Observers, seeing the leaves of the lower limbs of trees and the grass covered with a sort of saccharine varnish, naturally came to the conclusion that this substance was a real honey-dew, and hence the name.

There are certain plants, provided with special glands outside of the flowers, that exude a sort of saccharine substance; but, strictly speaking, this not a honey-dew. The ordinary "stuff" that is gathered by the bees, commonly called honey-dew, is nothing but a secretion from plant-lice. There are several species of honey-dew lice, among which

* Sometimes the sidewalks in our town, in July and August, are spotted all over near the trees. may be named Lecanium tiliae, that attack the basswoods; Lecanium tulipifera, of the tulip-tree, often called "poplar," and the scale or bark louse that attacks maple-trees, Pulvinaria innumerabilis (Rath.). Prof. Cook, formerly of the Michigan Agricultural College, and later Horticultural Commissioner of California, professor of entomology, and a beekeeper of long experience, thus describes these lice:

The maple-tree scale or bark louse (Pulvinaria innumerabilis Rath.) consists of a brown scale five-eighths of an inch long, which is oblong, and slightly notched behind. On the back of the scale are transverse depressions, marking segments. The blunt posterior of the insect is raised by a large dense mass of fibrous cottonlike material, in which will be found about 800 small

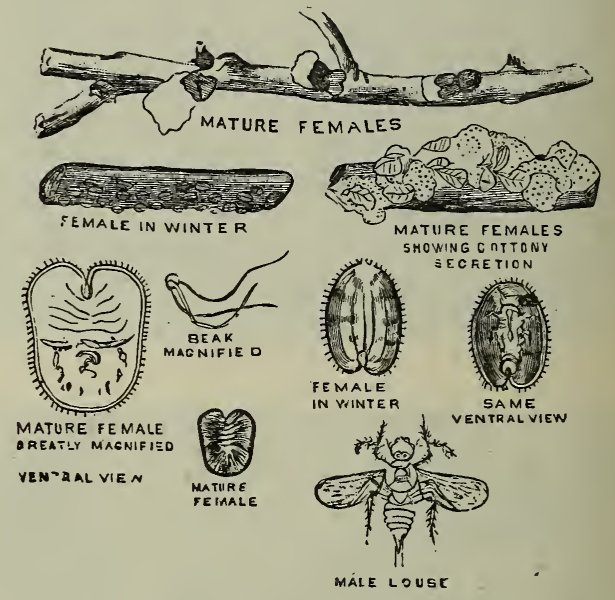

white eggs. These eggs falling on to a dark surface look to the unaided eye like flour; but with a lens they are found to be oblong, and would be pronounced by all as eggs, at once. This cottonlike egg-receptacle is often so thick as to raise the brown scale nearly a fourth of an inch. The scales are found on the under side of the limbs of some trees, and are often so thick as to overlap each other. Frequently there are hundreds on a single main branch of a tree. I find them on basswood, soft and hard maple, and grapevines, tho very much more abundant on the maples.

Another feature, at this mature stage of the insect, is the secretion of a large amount of honey-dew. This falls on the leaves below, so as fairly to gum them over, as tho they were varnished. This honey-dew is much prized by the bees, which swarm upon the leaves. If such honey-dew is pleasant to the taste, as some aver, I should have no fear of the bees collecting it.

From the middle to the last of June, the eggs begin to hatch, tho hatching is not completed for some weeks after it begins, so 
we may expect young lice to hatch out from late in June till August.

The young lice are yellow, half as broad as long, tapering slightly toward the posterior. The seven abdominal segments appear very distinctly. The legs and antennæ are seen from the other side. As in the young of all such bark-lice, the beak, or suckingtube, is long and thread-like, and is bent under the body till the young louse is ready to settle down to earnest work as a sapper. Two hair-like appendages, or setæ, which soon disappear, terminate the body.

Another authority, Prof. H. A. Surface, President of the Pennsylvania State Beekeepers' Association, and formerly State Zoologist, has this to say on the subject of the origin of honey-dew :

Honey-dew in this state is never found excepting on plants that are infested with certain scale insects, plant lice, or similar insects. It is true that it will be seen on the lower leaves of a tree before the insects get there; but this is because they often leave the trees by flying thru the air and commence to feed on the tender new leaves of the upper part and drop their sweet secretions on the leaves below. Later they drop to the leaves below, or crawl down the tree, and may be seen on the lower leaves. This does not mean that honey-dew was on the leaves before the insects were there.

Honey-dew attracts ants, wasps, flies, bees, and other insects that feed on sweets; but the plant-lice do not feed on the honey-dew nor on sweets, as they draw all their living from the sap of the trees or plants that are infested. No one has ever seen plant-lice feeding on the sweet liquid called honeydew; but, on the other hand, we have frequently observed this liquid coming from the cornicles or honey-tubes of plant-lice, as well as from the vent or digestive tract. No one can watch plant-lice during the summer without seeing the honey-dew appear first in small globules, and then increase to larger drops on the cornicles or honey-tubes, especially when ants are stroking the plant-lice with their antennæ. There can be no possible doubt about the source of this liquid.

As to whether the honey-dew is a benefit to the beekeeper depends upon how he winters his bees, and upon locality. If the bees can be wintered on their summer stands, or where they have flight as frequently as they need it, and the locality and season are such that they can fly frequently, say once every two or three weeks, they will winter all right on honey-dew; but if they are to be put into a cellar, or otherwise kept from flying for six weeks or two months, they will doubtless perish with dysentery. Honey-dew makes far more waste material to be voided from the system than any other food that the bees can take, and it is known that this voiding is done only when in flight. This explains why bees must be given an opportunity for flight if they are forced to feed on honey-dew. If such opportunity be not given, it is better to feed the bees abundantly as soon as possible with sugar syrup after having removed the honey-dew, and save this for stimulative feeding next spring.

THE UNPRECEDENTEDLY HEAVY YIELD OF HONEY-DEW DURING THE SUMMER OF 1909.

The year 1909 was remarkable for the immense quantities of honey-dew produced in almost every section of the country outside of the irrigated region where alfalfa and sweet clover are grown. In the eastern portions of the United States there was almost a failure of clear white clover or basswood. What little there was produced was so mixed with honey-dew that much of it was not suitable for table use.

Most of the honey-dew for 1909 came from the leaves of the hickory and oak. Contrary to what many have supposed, this saccharine matter found on the leaves came from aphides located higher up on the trees. But the ordinary observer not finding the insects, even after a search, might naturally conclude that they were not present, and that the sweet, sticky, gummy stuff on the leaves was an actual exudation from the leaves themselves; but in every case a more careful and scientific search has shown somewhere the aphides.

Oddly enough, the honey-dew of 1909 made the bees unusually cross. They worked heavily on the dew during the early morning hours, and as soon as the sun dried the gummy substance down toward noon, so they could get no more of it, they became furious; in fact, they would act very much as if they had beeu robbing, and the supply of stolen sweets had suddenly given out. For further particulars regarding this, see ANGER OF BEES.

\section{QUALITY OF HONEY-DEW.}

Prof. A. J. Cook says that much of the honey-dew is "deliciously wholesome." While there are samples that are fairly palatable, the great majority of them, according to our experience, are dark and of very poor flavor, and in some cases positively nauseating. There is almost no market for them. Even the large baking concerns will not have them, for, as a matter of fact, they require good table honey, even tho it be of very strong flavor. 
We do not know what to do with homeydew of poor quality but to hold it over and feed it out to the bees in the spring for stimulating brood-rearing - see FEEDING. It is not always safe to use as a winter food; but for raising bees it seems to be as good as the best honey known.

HONEY EXHIBITS, and how they may be used in the development of the bee and honey industry.-Of late, very much indeed has been accomplished by the exhibits of bees, honey, and apiarian implements at state and county fairs. Several of the larger fair associations have had very pretty buildings erected on the fairgrounds for these displays.

Such exhibits have a decidedly educational influence on the public. They show how honey is produced; and not only that, but that it can be produced by the ton and carload. On account of newspaper yarns, there seems to be a general impression among people that comb honey is manufactured, and that the extracted article is adulterated with glucose. It is absolutely impossible to manufacture comb, fill it with honey, and cap it over with appropriate machinery-just as impossible as it is to manufacture eggs. The publishers have had for many years a standing offer of $\$ 1000$ to any one who would show where comb honey was manufactured, or even procure a single manufactured sample which could not be told from the genuine. Altho this offer has been published broadcast in the daily papers, no one takes it up. We have also had the conditions of this offer printed on a neat little card, the same distributed by beekeepers at fairs and other honey-exhibits, so that, if such a thing were possible, there would be a bonanza for somebody. As to extracted honey, there was a time when it was adulterated somewhat, but owing to the action of state and national laws there is very little of it now. See AduLterATION OF HONEY, also the last paragraph on HoNeYCOMB.

Beekeepers, besides educating the general public as to the genuineness of their product, can create a larger demand for honey. As a usual thing, exhibitors are allowed to sell their honey, distribute circulars, and do a great deal of profitable advertising. This not only helps the individual, but helps the pursuit in general.
The following engravings will give an idea of how model exhibits should be arranged.

There should be shelving arranged in the form of pyramids, octagons, and semicircles. The honey should be put up in tin and glass, in large and small packages, and the whole should be neatly "set off" with appropriate labels. As a general thing, glass packages should have a very small label, so that as much of the liquid honey as possible will show. T'in receptacles should have labels to go clear around the can. Comb honey should be put up in cartons and shipping-cases; and yellow cakes of wax should be shown in a variety of shapes.

In one of the illustrations will be seen a large pyramid of beeswax, supporting on its several shelves packages of honey, the whole surmounted by the bust of a goddess. Make a series of square shallow boxes of such varied sizes that, when piled one on top of another, they form a perfect pyramid. These are to be completely covered with sheet wax having the edges that come in contact nicely cemented together with a hot iron. The letters are cut out of inch boards with a jigsaw, after which they are dipped in hot wax, and secured with nails to the pyramid. The next thing to make is the goddess of liberty, or the bust of a prominent man. These in plaster can usually be purchased at any of the stores for a small sum of money, and, after being dipped in hot wax, give a very fine wax figure.

A correspondent has suggested dipping $a$ teddy bear in melted wax. It might muss up his fur a little, but he ought to look like a bear; and as this animal is known to be a connoisseur of good honey, his presence surmounting the pyramid would be very appropriate.

Besides the exhibit of honey in various styles of packages, there should be a moderate collection of bee-supplies, so that, when the eager public come along with their string of questions, they can be shown step by step the process of producing honey and its final putting-up for market. A good many questions will be asked in regard to the extractor. It will be called a churn, a washing-machine, and everything else except what it really is. There should be one or more observatory hives to show how 


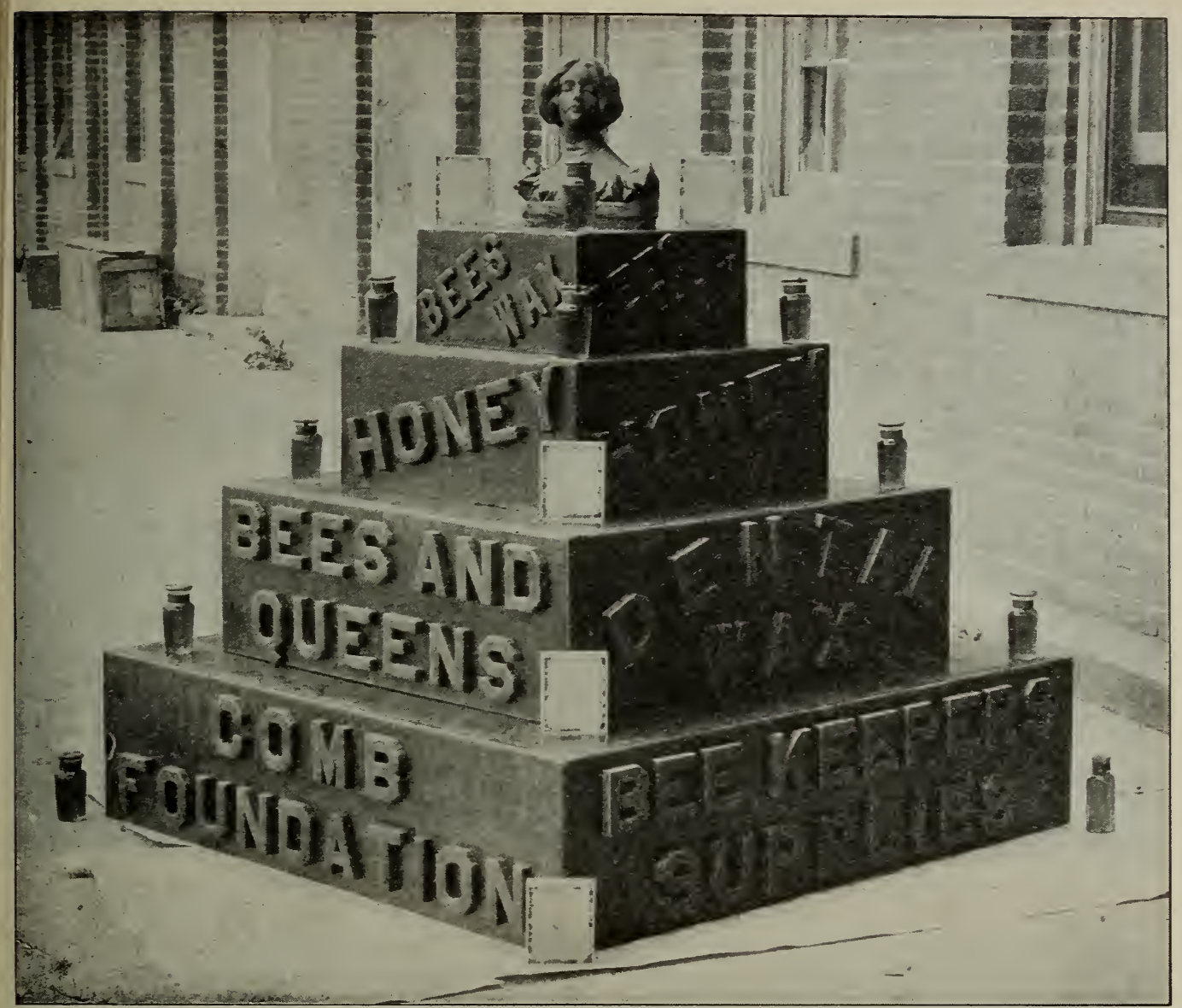

Suggestion for a beeswax exhibit at state fairs.

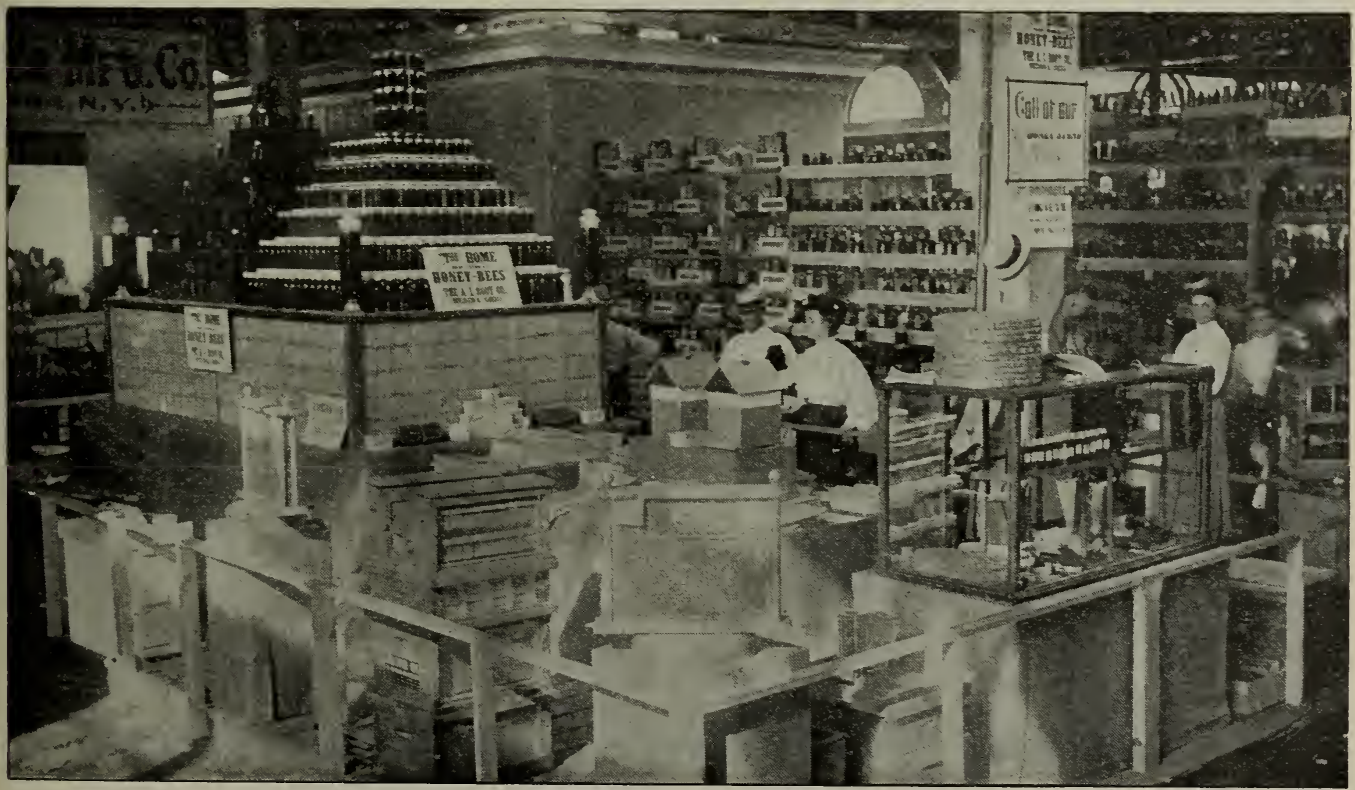

The apiarian exhibit at the Columbus State Fair, in September, 1906. 


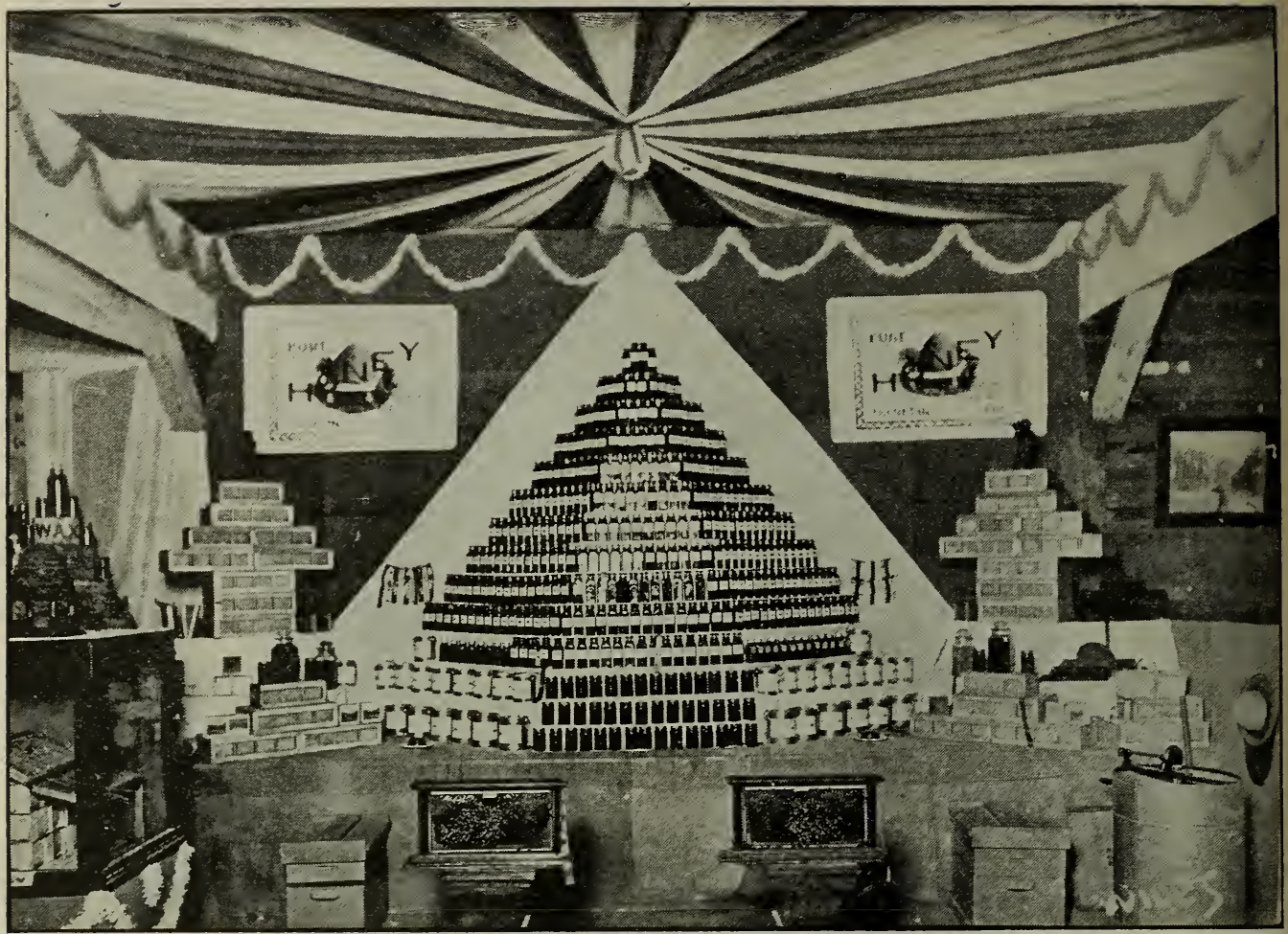

Exhibit of J. M. Buchanan, Franklin, Tenn., at Tennessee State Fair,. Nashville, October 9, 1909.

bees behave when at home. A good many will ask to see the "king-bee."

Very much can be done by having a glass hive and live bees, with an entrance communicating outdoors thru the sides of the building where the exhibit is made. What

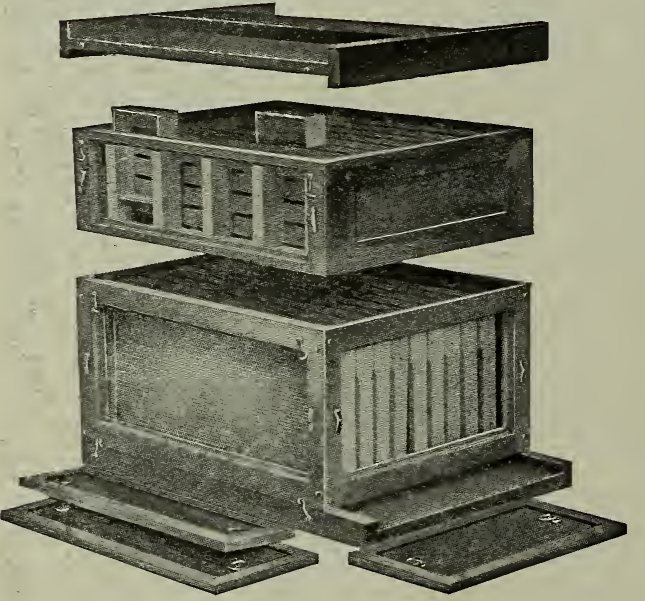

Observation hive and combhoney super.

is equally good, or perhaps better, is a oneframe nucleus having glass sides, making, as we call it, an observatory hive. This should contain one frame of nice healthy brood, regular and perfect comb, finely marked bees, and a bright-yellow queen. Hundreds of people will stop and examine, and ask a variety of questions about the bees and the queen. By this means one can convey to the consumer some knowledge of the habits of bees, and how honey is produced, thus indirectly creating a demand.

It should be stated in this connection that bees in an observatory hive will stand confinement for two or three days or even a week. Ordinarily at fairs and other places, where the show lasts only two or three days, the confined bees will do very well. But at expositions, where they are shown week after week, it is necessary to give them a flight every two or three days. Some arrangment should be made with the management by which these glass hives may be placed next to the wall of the building, the entrance communicating with a hole thru the building.

The usual plan is to have two or three observatory hives, and keep one or two on exhibition all the time while the other is being freshened up by a flight outdoors. After these latter have had two or three 


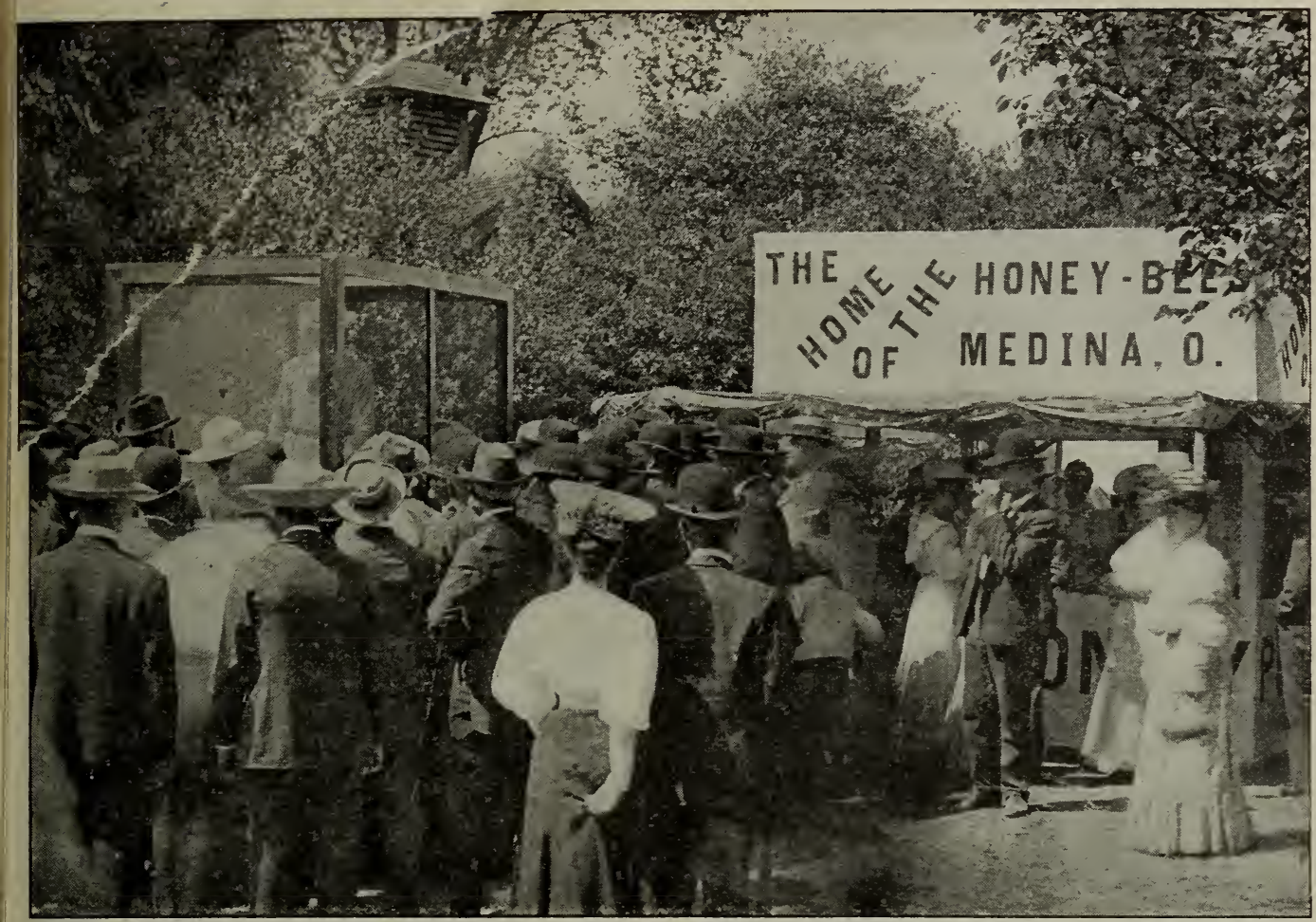

Demonstration work at the Ohio State Fair, Columbus.

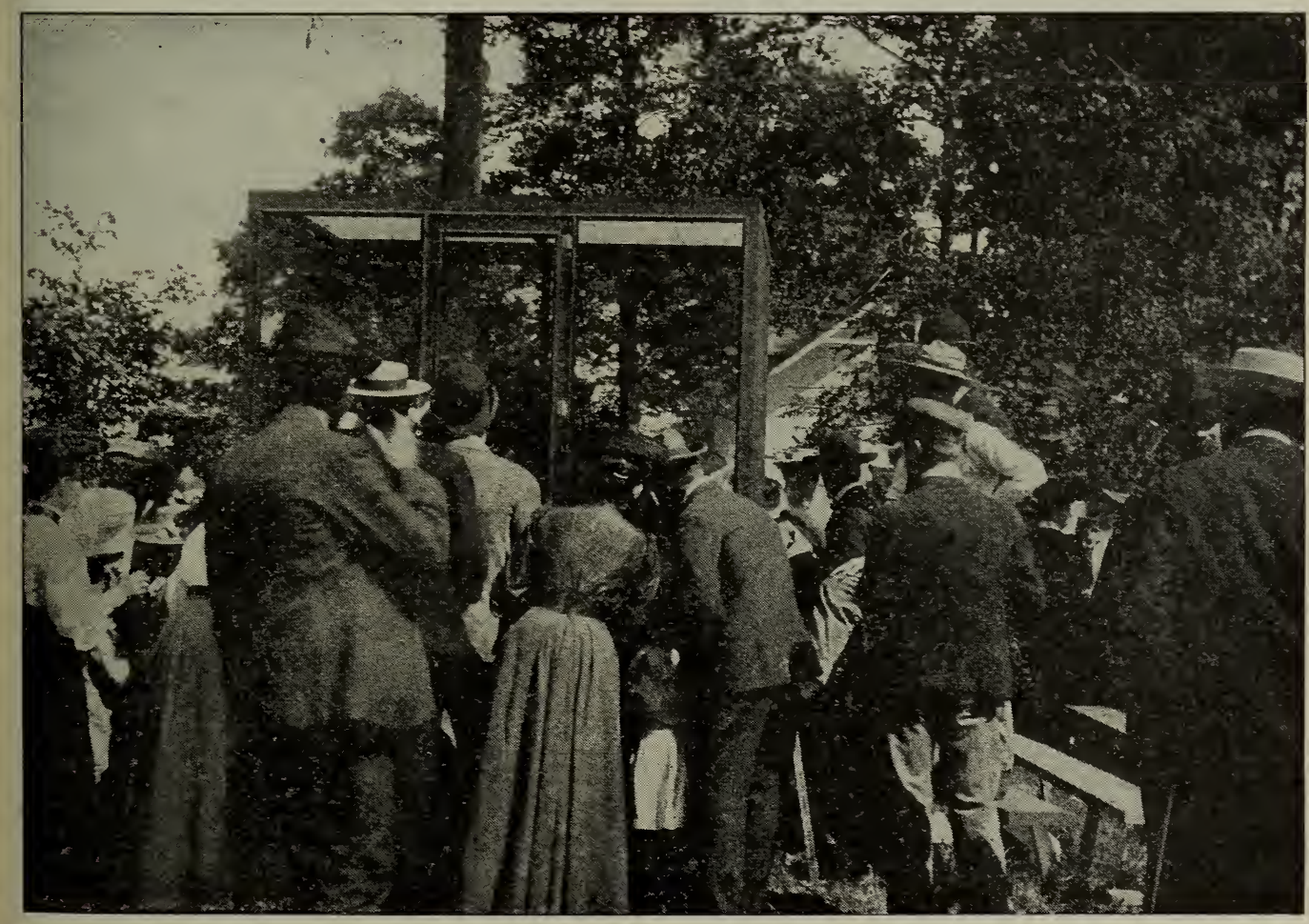

The A. I. Root Company's demonstrating-cage at the Medina County Fair. 
days in which to cleanse themselves $t_{L}$ entrance should be closed at night, when the hive can be put back on its stand, and another observatory hive take its place. So in alternation each one of the two or three lots of bees can be freshened up.

Where it is impossible to place the observatory hive next to the outside wall of the building, a long tube from the hive communicating with the outside wall of the building can sometimes be used. But the distance must not be over eight or ten feet.* 'The bees, strange as it may seem, will pass out thru the tube to the outside and return to

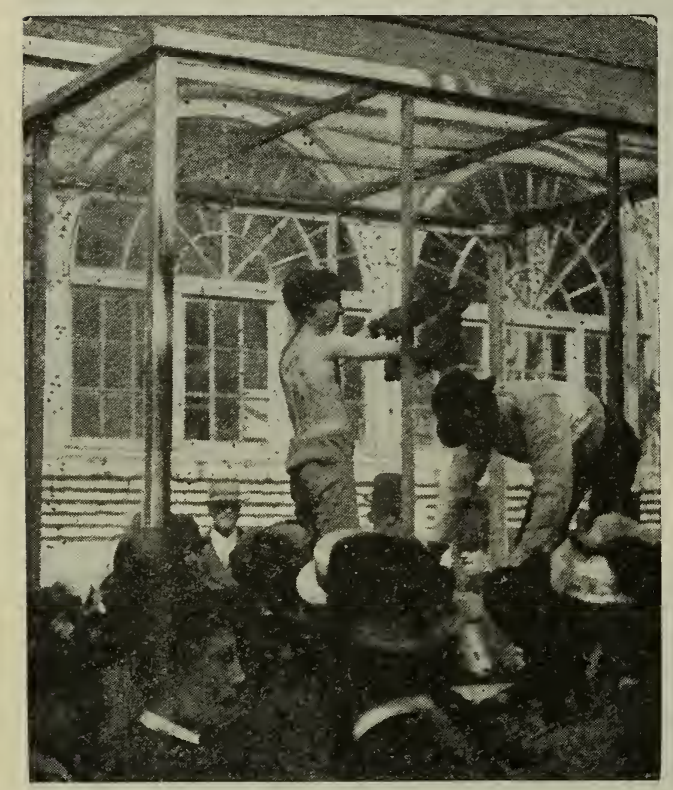

Charles Mondeng and his son Norman demonstrating Adel bees at the Minnesota State fair. Mr. Mondeng and his son were awarded the first prize for bee demonstration; first prize on golden Italian bees; first prize on leather-colored Italian bees.

their hive. This avoids a replacement of bees, and permits the normal work of the colony to go on uninterruptedly. Bees coming in with loads of pollen can he seen; and their rejoicings, with a quick nervous wagging of their bodies, attract the attention of the visitors.

\section{THE ADVERTISING VALUE OF OBSERVATORY HIVES IN SHOW-WINDOWS OF GRO- CERIFIS AND DRUGSTORES.}

In the fall, when the active selling season for honey naturally starts, a beekeeper can very often to advantage place a single-comb

* The exit from the building should be above the heads of pedestrians. To make this possible the tube will have to slant upward from the hive.

\begin{abstract}
"towindows of
is
his honey
the 1 .

additiol.

general pur

on sale in the

The sidewalk wils ... stien bu l. nive be crowds to see the " $\mathrm{k}$ we her $n=i l=$. nall il and the bees making s.msin

comb and extracted are $d_{1}$ ages of various sizes in show-witc with the exhibit of live bees the $3+3 \ldots$ mines will naturally step inside and buy a age of honey. The first package will $i$. so good that it will call for another anc. another. The advertising value of live bees can scarcely be cverestimated, especially in localities where such exhibits have never been made before. When sales of honey are once started they will keep on and on. (See Marketing Honey; also Bottling HoNEY.)
\end{abstract}

LIVE-BEE DEMONSTRATION WORK TO ADVERTISE HONEY AT THE FAIRS.

In connection with an exhibit inside of the building, there should be a placard directing the visitor to a bee-show outside, as near the building as possible. This should be a demonstration of the method of handling live bees inside a wire cage, the operator taking them up by handfuls and forming artificial swarms. Where the two exhibits, one of honey anid bee-supplies, and the bee-show itself, can be located outdoors, it will be better. The former should then be in a temporary booth or tent, since it would not be advisable to have the exhibits of wax and comb honey exposed to the direct action of the sun. The bee-demonstrating cage should be located close by, within ten or twenty feet. It consists of a wirecloth structure large enough to take in a man, a hive of bees, and leave room enough to practice ordinary bee-manipulation. This cage should be elevated on a stand four or five feet above the ground-the higher the better, because there will be a great jam of people around to see the man inside pick up live bees by the handful.

Announcement should be made from outside of the cage that, during certain hours, an operator, bareheaded and barearmed, will perform some wonderful stunts in handling bees. When the performance begins, the 
people will surge around the stands, and that is just what is desired in order to sell honey at the other stand a few feet away.

The operator begins his performance by stepping inside the cage of live bees, and shutting the door behind him. He then tells the crowd that he is going to handle live

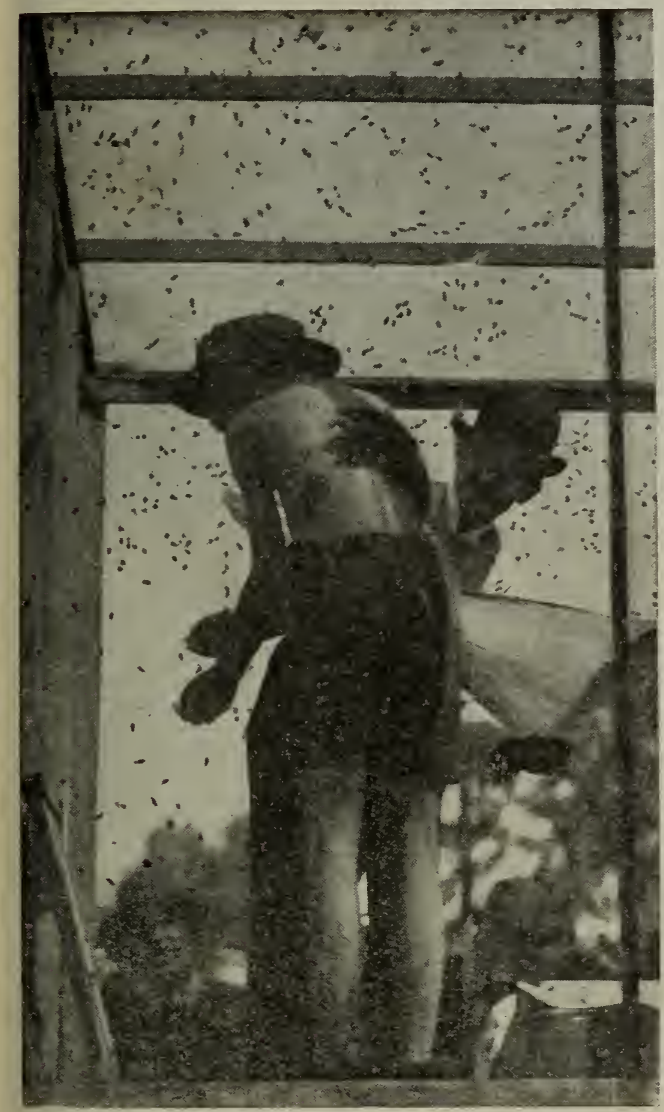

Norman Mondeng is only eleven years old, yet he handles kees without fear. His entire clothing was a bathing suit.

bees, every one of which is armed with a sting; and if any one doubts it to come forward and he will furnish the "proof." He then proceeds to take off his coat and rest and roll up his sleeves, take off his collar, and tuck down his shirt-band. It will then be necessary for him to put on bicycle pants-guards, or slip his trousers into his stockings. The crowd will quickly appreciate this part of the performance, because the operator tells them the bees will sting if they get inside of his clothing. With a lighted smoker he opens up the hive. After pulling out the frames he shows the bees and queen on the comb; then he calls out for everybody to wait and see the next stunt, for he is going to make a swarm. With a large dishpan, which he has previously provided, he shakes two-thirds of the bees off the combs into this pan. Then he takes it up and turns to the crowd, saying, "The bees are not real mad yet, so I'll begin to shake them up to make them so." The people wonder what he is going to do, seeing him barearmed and bareheaded. He keeps on shaking until he has the bees all in one big ball, and to the uninitiated it looks as if they would sting him to death. But, no! the continual shaking is the very thing that makes them gentle instead of cross. He now rurs his hand under the ball of bees, pushing it under gently, being careful not to pinch any. The movement must be very deliberate-so slow indeed that the hand scarcely scems to move. He picks up a handful and holds them up for the crowd to look at. If he has good nerves he can put three or four bees in his mouth; shake a handful of bees on top of his head, and

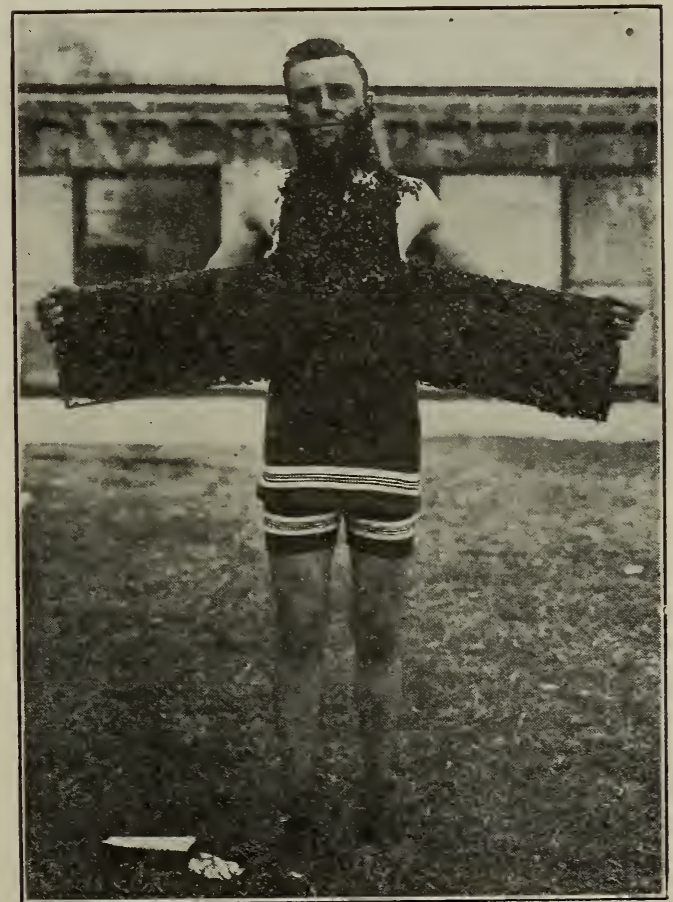

William $H$. Crowson demonstrating bees at the Tri-state Fair, Memphis, Tenn.

in the mean time pick up another handful.

At the next performance there will be big crowds around to see the work. While the man is doing his stunts with the bees he tells what honey is, saying that it is a wholesome sweet, and that there is no such 


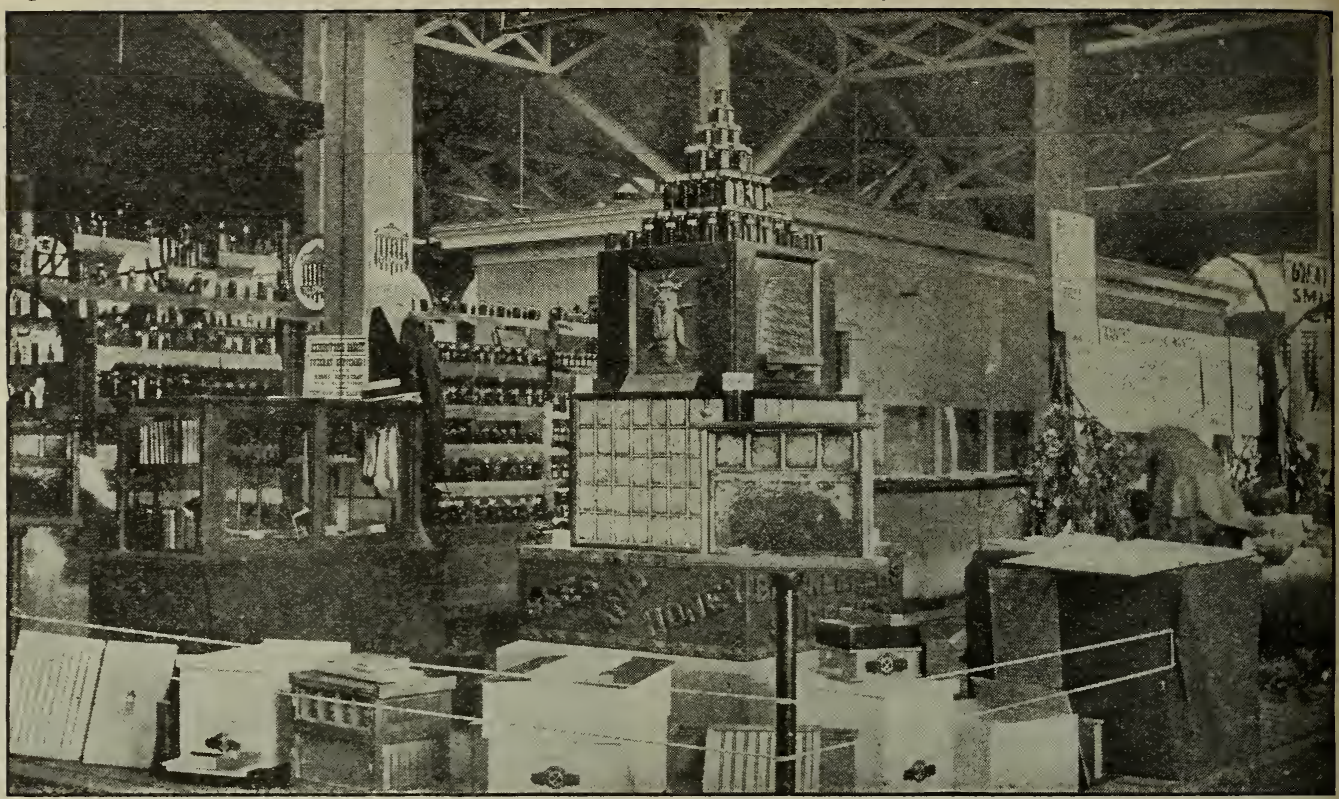

The A. I. Root Company's exhibit at the Ohio State Fair.

thing as manufactured-comb honey, and that he will pay $\$ 100$ for a single sample of it. At that psychological moment he draws attention to the fact that he has some good honey at the stand opposite or in the building yonder. The crowd will then go round to the stand and buy the honey.

The preceding illustrations show the exhibits of bees and honey, the exhibit of the live-bee cage, and the crowd that assembled around it, both at the Ohio State Fair held at Columbus, and the Minnesota State Fair.

After the exhibitor gets his questioner interested, he can hand out one of his advertising cards, and at the same time give him a little sample of honey to taste. This can be done very readily by handing out some strips of strong manila paper, which are to be dipped in the honey and then transferred to the mouth.

HONEY-HOUSES. - See EXTRACTINGHOUSES.

HONEY, METHODS OF ANALYSES. - See Honey, Analisis of.

HONEY ON COMMISSION.-See MARKETING HONEY.

HONEY-PEDDLING.-Under EXTRACTED HoNer, which see, we have already told something about selling direct to consumers.
But there are many who say they "haven't the gall or cheek to go around and ask folks to buy," and prefer to be excused from any such disagreeable experience. But there are ways in which one does not need to lose either his dignity or self-respect. A peddler may, it is true, call at unseasonable hours, or steal valuable time from a prospective customer in trying to force a sale. In such ways one may make himself very obnoxious, and render a second visit utterly useless. The late Dan White, of New London, Ohio, a progressive and practical beekeeper, has hit upon a novel plan that entirely eliminates all objectionable features. He thus describes his plan.

\section{PEDDLING MADE EASY.}

I packed my grip and took two 12-pound cans of honey and started out. About all I had in my grip was a good supply of those leaflets published by the A. I. Root Co.; also 50 postals addressed to myself.

I got into the town just before dinner time; and after eating a good meal at a boarding-house I filled my pockets with leaflets and took one honey-can and commenced business. I started down a street and did not miss calling at every house. After ringing the bell, or rapping, a lady would open the door and look at me with more or less suspicion. I would say, "I made the call to ask you if your family were fond of honey."

They generally answered yes, but believed they would not buy any.

"Well," I would answer, "but I am not selling honey today. I am giving it away, 
and should be glad to give you some in a sauce-dish.',

Some would look astonished, others would smile, and say, "That's funny," but in every instance I was invited in. I would pour out the honey, then hand out a leaflet, telling them to read every word of it. "You will find it very interesting; it will tell you all about honey-how and why we extract it, etc. Then here is a postal card addressed to me; and should you decide to want a 12 pound can, put your name, street, and number, on the card; drop it in the office; and when I deliver in about ten days you will get a can of honey.",

Well, there were enough cards put in the mail within five days to take thirty cans of honey. I promptly made the delivery on time, taking along twenty extra cans that sold about as fast as I could hand them out; and since then I have received orders for 50 more cans from the same town. I tell you, it has got all over town that a honey-man had been there selling real honey, 12 pounds for one dollar. I am certain that this one place will take over 2000 pounds, all in onegallon cans. Now, then, 18 pounds of honey given away from house to house, 50 postal cards, 200 leaflets left at houses and handed to people on the street, and one day walking over a very small portion of the town, has found a place for at least 2000 pounds of honey. Then think what I can do next season should I secure a good crop. All I shall have to do is to take a big load and go up there and hand it out.

By the way, the honey sold there was thrown out of clean white combs, over every inch of whose surface the uncapping-knife had to go. It weighed strong 12 pounds to the gallon-just as good as the best comb honey, only it was out of the combs. Of course, I can go back just as often as I choose; yes, and the people will be glad to see me.

\section{New London, Ohio.}

\section{Dan White.}

It would appear that one of the prime requisites is a first-class article of wellripened extracted honey. Very many make a mistake right here, and, of course, if the honey is poor, one is not likely to make a second sale. Mr. White's scheme is to have the honey taste so good that, when it is gone, the good people will drop that postal for more. At present prices a 12-lb. can of honey should retail for not less than $\$ 1.50$.

In a similar way Mr. Herman F. Moore, of Chicago, retailed large amounts of honey. His plan, like that of Mr. White, was to go around and solicit orders. In the cities of Cleveland and Toledo, or even those of smaller size, he would start out on foot, exhibiting a sample of his honey in a quart Mason fruit-jar. His reason for using this package was that almost any family would be willing to take a household article of this kind, for the simple reason that it would not have to be thrown away when it had served the purpose of holding the honey.

With this jar of honey Mr. Moore would call at private houses, one after another, and ask for a dish and spoon, saying that he had some very nice honey, and that he would like to give the women-folks a sample to taste. He then held up the beautiful transparent goods to the light, told them he was a beekeeper, and dealt only in pure honey; explained how it was produced, and finally named the price. If the lady of the house cared to take any he would take her order and deliver the next day. As a rule he took an order.

In this way he made the rounds of a certain section of the city. When he first began he took the orders one day and delivered the next; but his business grew so rapidly that he was finally obliged to take on a helper, his brother, and, a little later on, two more men and a man and his wife. The two last named washed the jars and filled them. Two of the men delivered while he and his brother took orders. In this way they sold enormous quantities of honey; and as it was always the finest quality, and guaranteed to be pure, they built up a large trade.

There is another plan, providing one can trade honey for other useful articles too numerous to mention. Even if one did not sell much he would get a day of royal sport.

TR.ADING HONEY FOR DUCKS, PIGS, PUPS, ETC.

In all the literature on bees and honey, we are urged to develop the home market. Acting on the advice, after $I$ had traveled over my regular route this fall I went into an entirely new locality. After enjoying the scenery and the sunlight for about a fivemile dive I called at a farmhouse and inquired of the good lady if she would like some honev.

"Well, yes, I should like some, but I have no money.",

Seeing some ducks, I offered to trade honey for ducks; and for a pair I gave four pint jars of honey.

Calling at another house, I sold $\$ 2.00$ worth for cash; and while I was talking with the man one of the ducks gave a quack, which led to an inquiry as to what I had. I told them I had traded honey for ducks.

"Well, now, look here; can't I trade you some hens for honey?", 


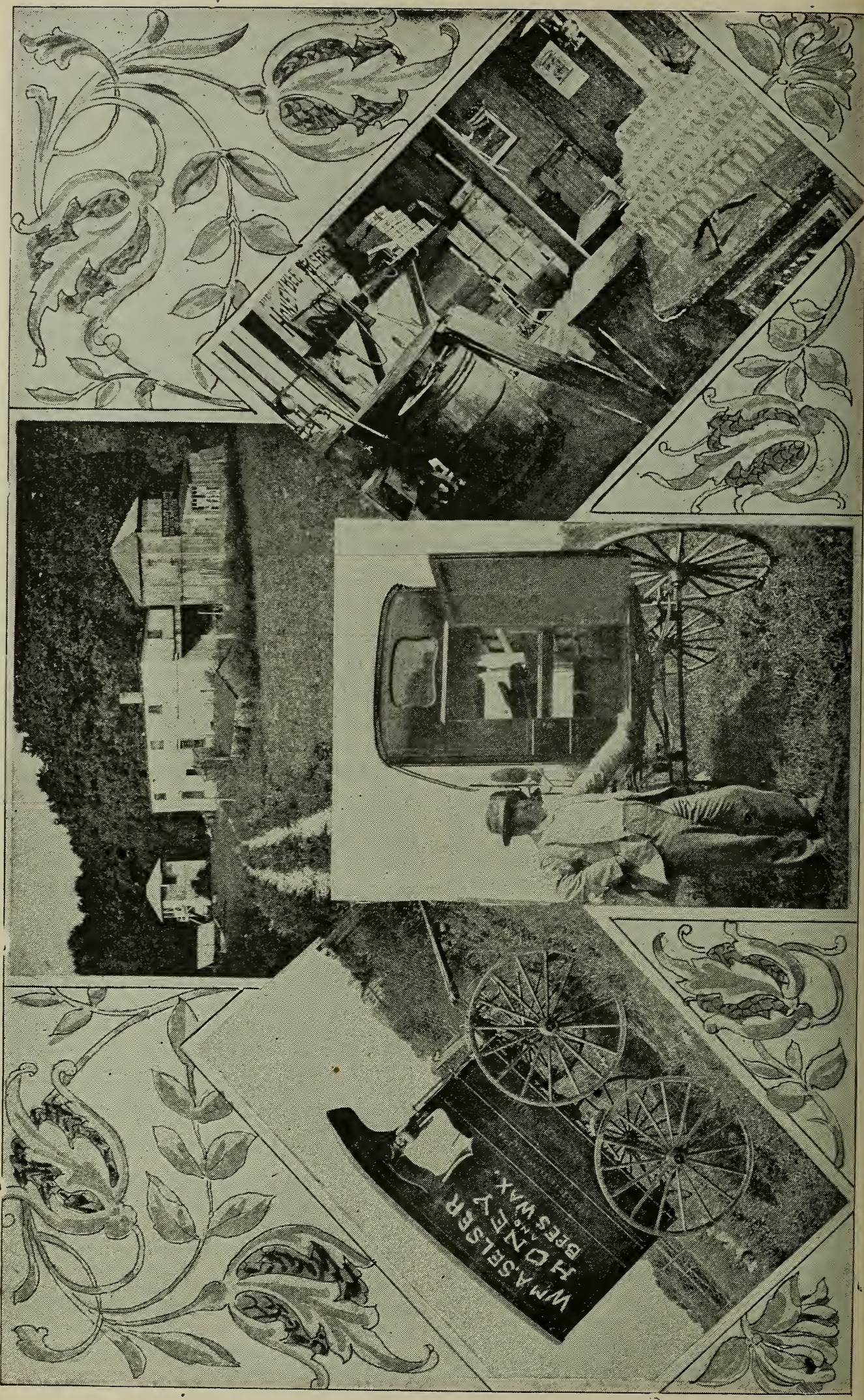


I traded for half a dozen, and made the children, I hope, happy (I was). In this way I passed the day, and on my drive home I was trying to figure out my profits. I had disposed to two gross of pint jars, and 120 pounds of comb honey. For the pint jars I received 25 cents; also 25 cents each for the sections of comb. I had had a royal day's sport; and as I listened to the quack of the ducks and geese, the cackle of the hens, and squeal of the pigs, and looked at the large box of eggs that I had in the wagon, I thought I would have to send for some of Dr. Mason's egg-preservative. After getting home I took account of stock. I had $\$ 54.40$ cash, 108 dozen eggs, 8 ducks, 1 goose, 2 pigs, 24 hens, and 1 bullpup. (The pup is for sale.)

Charlton City, Mass.

Another experience is thus given by $G$. C. Greiner, of La Salle, N. Y.:

Peddling honey has, like everything else, its ups and downs. We don't always strike it rich. Some days it may seem like terribly steep uphill business, while other days the money may roll in by the handfuls. As an illustration, and a proof that the latter sentence is almost literally true, let me give you one days's experience.

Late last fall I chanced to take a trip to Niagara Falls with the intention of making a display of my goods at the city market. At first things looked a little gloomy. Purchasers did not flock in as I had hoped, until after some ninutes of patient waiting. One passing lady, in looking at my honey, asked, "Is your honey pure?" The reply I made must be inagined, for it would fill more space than the editor would be willing to allow. But let me emphasize-here is where the blabbing came in. In answering her question I delivered a good half-hour lecture in less than two minutes, trying to convince her of the purity, and all the good points of my honey. In the mean time, passing people had stopped to listen; and by the time my lady friend was ready to buy one of my quart cans I had quite a crowd around me. To cut the story short, for quite a few minutes J handed out cans, mostly quarts, as fast as I could make change (many of the purchasers promising to buy more the next time I attended the market, if the honey proved to be what I had recommended it to be).

When the market closed, at 11 a. m., I had a few cans left. With these I drove to Main Street and tied my horse in front of one of the stores, where I had a little business to transact. A few minutes later, while I was conversing with the storekeeper inside, some one opened the door and inquired:

"Hello! where is this honey-man?"

After introducing myself he requested me to show hin what I had to sell. It did not take very long to convince him that I carried the genuine article; and what pleased me still more was the fact that he ordered two cans to be left at the corner drugstore across the street.

When I delivered the cans they were closely scrutinized by the clerks and some other parties who happened to be present, and one of the clerks asked:

"What guarantee have we that this is pure honey?",

Here another lecture-like conversation, too long to be repeated, took place, the substance of which may be concentrated in my reply:

"First, pure honey and my name and address are on every package; and, second, back of this is the New York state law that prohibits all honey adulteration.',

Before I left the place I sold two more cans to those other parties.

A great help in selling honey on the road is a proper traveling-outfit, which enables us to present our products in clean, neat, and inviting appearance. I know from experience that at least one-fourth of my sales of honey can be traced back directly to this feature.

PEDDIING HONEY AT GROCERIES AND OTHER RETAIL STORES.

Mr. W. A. Selser, of 10 Vine St., Philadelphia, is not only a practical beekeeper, but he was also a large buyer of honey. In addition to the amount he produced in his own apiaries, he bought up every year the product of several large yards. All of this, mostly extracted, he peddled out from a honey-wagon to the retail trade.

The secret of his success in selling and in getting good prices was in putting up always a first-class article in a neat and attractive form. He advertised liberally, and every one knew him about Philadelphia as "the honey-man."

After several gross, perhaps, were put up, Mr. Selser loaded all he could carry in a special wagon shown at the left, and in the central view at the bottom. He then visited the city stores and replenished their stock. After he had supplied all the city retail places he then went into the country, visited the suburban towns, and even drove as far as the city of New York, supplying some stores.

In these days of light automobile delivery cars the territory can be greatly extended; in fact, a bottler can make several outlying towns, and follow up the trade, taking care of a large line of fancy grocery stores. Light automobile trucks with top of the familiar Ford type are now being used for this very purpose-to sell and distribute honey. 
HONEY-PLANTS.-The importance to American beekeepers of a thoro knowledge of the honey-producing flora of this country cannot be overestimated. A beginning in this work has already been made by several states. An excellent preliminary list of Texan honey plants by Louis H. Scholl was published in 1908, and in 1911 there appeared a carefully prepared bulletin on the honey plants of California by M. C. Richter. In both these lists much attention is given to the geographical distribution within the state limits of the species enumerated. More or less complete lists of the chief mellifluous plants of Massachusetts, North Carolina, Iowa, Oklahoma, and Arizona have also been prepared. So helpful have these publications been to beekeepers that there can be little doubt that similar bulletins will soon be issued by other states. Such investigations promise to bring to light many interesting and valuable facts. No one should enter extensively upon the production of honey without first investigating the flora on which he must depend for a marketable surplus. Success or failure may often depend upon such information.

The geographical distribution of honeyplants in the United States presents many striking peculiarities. While some occur over the entire country, others are restricted to a small area. The sumacs extend from the Atlantic to the Pacific; so do the carrot and carpetweed, tho the latter is commercially most valuable in central California. Sweet clover is spreading everywhere; and the goldenrods and asters know no north nor south. While heartsease grows thruout nearly all North America, the wild sunflower is confined chiefly to the West, cotton to the South, white clover to the East, and willowherb to the North. Much narrower are the limits of many other species. The white-tupelo region is a tract of land along the Appalachicola River; manchineel occurs in the extreme south of Florida; the black mangrove in tide-water marshes in the southern half of the same state; our native acacias belong to Texas, the sages to southern California, and scores of other honey plants are equally restricted in their distribution. But it is not only in individual states that they are very variable in their range, but in almost every township; for example, within less than a mile of each other, yet without invading each other's territory, there may be found the salt-marsh goldenrod, the field goldenrod, and the wood goldenrod.

Honey-plants are likewise very variable in the preference they exhibit for different soils. The tupelo and willows grow in wet swamps, the tickseed in marsh lands, the smooth sumac prefers a rocky soil, the mesquite and cacti are dwellers in the desert; the gallberries in Georgia avoid a limestone region, while sweet clover will grow nowhere else. The spikeweed and the alkali-weed thrive in an alkaline soil; the Rocky Mountain honey-plant in a dry saline soil; the salt-marsh goldenrod in a soil and atmosphere impregnated with salt, while the fireweed springs up in profusion on burnt lands, and the production of nectar in wild alfalfa is greatly stimulated by a mountain fire.

Undoubtedly the secretion of nectar is often if not always correlated with the character of the soil, the temperature, and water supply. Alfalfa, which, in irrigated sections of California, is a large and most reliable yielder, is of little value along the coast or in the East. A heavy thundershower followed by a sudden fall in the temperature may bring a successful honeyflow from buckwheat or basswood to a premature end. Wild alfalfa may produce nectar abundantly on one side of the Coast Ranges, and very little on the other side. Heavy rains are likely to lessen greatly and light rains may either stimulate or retard the quantity of nectar secreted by a honeyplant. The last honey obtained from lima beans and alfalfa is darker than the first. On a sandy soil the honey obtained from alfalfa is lighter in color than on a heavy soil, and lime in a soil is also reported to render a honey lighter. A prolonged drouth is apt to bring loss and disappointment, tho it shortens the tubes of the red clover so that part of the nectar is available. Black sage requires a clear warm season preceded by abundant rain. Blue gum and red clover are very reliable yielders, and are largely independent of the weather.

Nor must the periodicity of honey-plants be overlooked. The orange-tree and the cabbage palmetto in Florida can be depended upon only about one year in three. Sage does its best one year in five, and is a partial failure every other year. The rules which govern the blooming of white clover 
have not yet been formulated. Manchineel does not afford a heavy flow every year. The different species also vary greatly in the length of time they are in bloom. In many cases they are in flower for only a few weeks; but carpet grass yields from May until frost; pepper bush from July to September; pin clover in California begins in February and continues thru the summer, and alfalfa from April to October. Nor does candying take place at the same time in the different kinds of honey. After ten years white tupelo is still liquid, while the honey from blue curls granulates in the cells before they are sealed. Usually a honey granulates within six months after it is extracted.

Even where there is a good honey flora fair weather is essential, or the bees can not bring the nectar into the hive. The willows and the gallberries, which bloom in the spring when there is much rain and foggy weather, are, therefore, not so desirable as species which flower later. The succession of honey-plants should also be considered. In California, after the orange trees have ceased to bloom for the rest of the season in that locality, the bees bring in only a "dribble" of dark honey from pepper and horehound. Fortunate is the beekeeper to whom the autumn months bring a heavy flow of nectar from fall flowers.

More information about the honey-plants of foreign countries should be obtained. Who can say what happy surprises Africa, Asia, and the Pacific islands may yet afford the beekeeper? It should not be forgotten that sweet clover, alfalfa, pin clover, borage, eucalyptus, horehound, carrot, catnip, wild marjoram, thyme, and red, alsike, and crimson clovers are all introduced plants. Our agricultural and horticultural explorers are successfully seeking new fruits, grains, and flowers; but do they ever look for new honey plants?

The possibilities of artificial pasturage are only partially recognized. In many localities the apiarist might greatly increase the number of nectariferous flowers by sowing each season a few pounds of sweet clover in waste places and along the roadside. There are many plants which produce paying crops, and are at the same time valuable to the apiarist, such as cotton, alfalfa, mustard, onions, lima beans, the orange, and a great variety of fodder-plants and fruit trees. When it is remembered that more than one-half of the principal honey-plants of Florida are arboreal, and that many shade and timber trees yield nectar freely, there would seem to be good reason to expect that in the future forestry and bee culture may be united.

By hybridization and selection many new varieties of fruits and flowers have been originated; and the laws of heredity and breeding are studied more zealously today than ever before in the history of biology. Why should not plants, especially those valuable for fruits and seeds, be developed with a greater capability for secreting nectar? Insects have shown us what is possible in this direction. It is probable that there would have been very few nectar-producing flowers but for their agency. There may yet be an apple-tree that, in addition to excellent fruit, will yield nectar as freely as does the orange or basswood. The orchardist of the next century may obtain a crop of honey from fruit bloom which will rival in value the later harvest of fruit. No effort has yet been made in this direction, and many of the achievements of the horticultural experimenter appear to have offered greater difficulties. There may yet be plants of which it may literally be said that they flow with nectar.

\section{POLLEN-PLANTS.}

An ample supply of pollen is of even greater importance to honeybees than large stores of honey. In limited areas nectar famines not infrequently occur, when in some localities, at least, the bees are able to obtain partial supplies from honey-dew, the sweet juices of broken or decayed fruits, and the sap of various plants. But there is nothing in nature which can be used as a substitute for pollen, tho bees sometimes collect the spores of fungi and mosses to a small extent. Pollen famines do occur in Australia, according to $\mathrm{R}$. Beuhne, when the brood dies in the hive, and no artificial substitute gives satisfactory results. The same scarcity of pollen occurs in many of the southern states at times.

Of the true flowering plants called angiosperms, because they have their seeds enclosed in a seed-case, and receive the pollen on a prepared surface known as the 
stigma, there have been described in North America north of Mexico about 14,600 species. Of this number, at least 3000 are nectarless, but of necessity produce pollen. Very many of them have small green or dull-colored flowers, and are pollinated by the wind, as the alders, birches, poplars, elms, beeches, oaks, and hickories ; the grasses, sedges, and rushes; many homely weeds like the pigweeds, ragweeds, nettles, pondweeds, sorrels, hernp, and meadow-rue. Usually the stamens and pistils are in separate flowers, which are borne on the same plant (monœcious), or on different plants (diœcious). They are commonly without nectar, since they depend on the wind for pollination; but they produce great quantities of pollen, and are consequently often valuable to the apiarist. See PoLLen.

Others are large handsome flowers like the roses and poppies, which are pollinated by insects, and are called pollen flowers; they contain no nectar, and insects visit them for pollen alone. Mistakes are often made in regard to these flowers, and bees are reported as bringing in nectar when such is not the case. Possibly some of these errors have arisen from the presence of honey-dew on the leaves. A list of the more important pollen-plants is, therefore, given separately. No attempt has been made to include all nectarless flowers, but only those of importance to beekeepers. A great number of flowers vield both nectar and pollen; but these are placed under HoNEY-PLANTS. The species in the following list are nectarless unless otherwise stated.

PLANTS THAT YIELD POLLEN ONLY.

Alder (Alnus).--Wind-pollinated; the small brownish flowers appear in early spring. The aments (staminate) of the common or hoary alder (A. incana) are visited by honeybees for pollen.

Anemone (Anemone quinquefolia).-Large white pollen flowers; pollen gathered by bees in spring.

Ash (Fraxinus).- Some species are pollinated by insects, others by the wind; small greenish flowers.

Bayberry (Myrica).--Shrubs blooming in spring; flowers small, greenish, wind-pollinated.

Beech (Fagus).-Large trees, with small windpollinated flowers. Honey-dew is found on the leaves.

Birch (Betula).-Small greenish or golden-yellow flowers, appearing with or before the leaves in spring; wind-pollinated; mostly trees.

Bloodroot (Sanguinaria canadensis). - Large handsome white pollen flowers in April or May. Visited by honeybees in large numbers, which remove nearly all the pollen.

California Poppy (Eschscholtzia californica).Large orange-ycllow pollen flowers; great numbers of bees visit them for pollen.
Castor-oil Bean (Ricinus communis).-The small flowers are wind-pollinated; stamens very numerous; an abundance of pollen; extra-floral nectaries at the base of the leaves.

Chestnut (Castanea).-The chestnut tree $(C$ dentata) has small, pleasantly scented, pale yellow. pollen flowers; but chinquapin (C. pumila), a spreadshrub is reported to be a valuable honey-plant in the South.

Clematis.-A part of the wild species and the large handsome flowers of the cultivated varieties of C. Jackmanni are nectarless, but are visited by bees for pollen. Other species yield nectar includ. ing the common wild Clematis (C. virginiana).

Cockle-burr (Xanthium canadense).-Small flowers from which bees obtain pollen in the fall. They contain a little nectar.

Corn (Zea mays).-Wind-pollinated; bees gather pollen from the spindles; are reported to obtain sap from the stalks, but this should be confirmed.

Cone-trees (Coniferae).-Fir, spruce, pine, cedar, juniper, and many other cone-trees. While they produce enormous quantities of pollen, it is not much used by bees-probably too resinous. From the foliage of pine trees and spruces bees obtain much honey-dew. See Honky-DEw. Gymnosperms.

Date Palm (Phoenix dactylifera).-Large areas of California and Arizona are adapted to date culture. There are extensive plantations of great age in Lower California and Mexico. In southern Asia and northern Africa this tree is of inestimable value. The staminate and pistillate flowers are produced on different trees, or the trees are partly "male" and partly "female." In nature pollination is effected by the wind, but under cultivation by binding a sprig of staninate flowers among the pistillate. Flowers small, in large clusters; in California bees visit the staminate flowers freely for pollen. Bloom in early spring.

Elder (Sambucus).- Sinall white pollen flowers in large clusters; bees sometimes gather the pollen.

Elm (Ulmus americana).-Small purple flowers which appear in the spring, and are wind-pollinated. They are visited by great numbers of bees for pollen.

Grape (Vitis).-Valuable for pollen; yield some nectar. Honey-dew occurs on the foliage.

Grasses (Gramineae).- Small greenish flowers, with a great abundance of pollen; wind-pollinated; sparingly visited by insects. About 429 species in North America.

Hazelnut (Corylus americana).-Small yellowish flowers, valuable for pollen in early spring; wind. pollinated.

Hepatica (Hepatica triloba).-Handsome blue or white pollen flowers; attractive to bees in early spring.

Hemp (Cannabis sativa).- Small flowers pollinated by the wind.

Hickory (Carya).-Pecan, mocker-nut; large trees with small wind-pollinated flowers; valuable for pollen; much honey-dew on the leaves.

Hop (Humulus Lupulus).--Small greenish flowers, wind-pollinated; common.

Hornbeam (Carpinus caroliniana).-Large tree, with small wind-pollinated flowers.

Loosestrife (Lysimachia vulgaris).-Medium-sized yellow pollen flowers.

Lupine (Lupinus).-The flowers are nectarless, but are frequently visited by honeybees and other bees for pollen. Honeybees sometimes vainly attempt to suck nectar from the flowers. Blue lupine ( $L$. subcarnosus) is very abundant in Texas, and is often visited by bees for pollen. 
Meadow-rue (Thalictrum).-Common; white or greenish pollen flowers risited by honeybees for pollen. Rue anemone (Anemoneila thalictroides) produces a great abundance of white flowers in low land; wind-pollinated.

Mullein (Verbascum).-Common; bright-yellow pollen flowers. A part of the species are nectarless. Others contain some nectar.

Mulberry (Morus rubra).-A tree with small wind-pollinated flowers.

Nettle (Urtica).-Greenish flowers in summer; wind-pollinated.

Oak (Quercus). - Small greenish or reddish flowers; wind-pollinated. Honey-dew is found on the foliage of many species.

Pigweed (Chenopodium).-Goosefoot. White mealy garden weeds, with small greenish sessile flowers in large clusters, wind-pollinated. Also amaranth; also called pigweed (Amaranthus retroflexus); coarse wind-pollinated weeds in cultivated ground; flowers in large clusters, of some value for pollen.

Poppy (Papaver).-The poppies are very large showy pollen flowers visited by honeybees. The scarlet color does not repel bees, as has been reported.

Plantain (Plantago).-Partly pollinated by the wind and partly by insects; flowers contain a little nectar, and have a pleasant odor; very common weeds, visited by honeybees.

Poplar (Populus). - Aspens. Small purplish flowers, wind-pollinated; pollen abundant, forcibly expelled from the anthers; said to be valuable; nectar-glands at base of leaf-stalks. Honey-dew sometimes occurs on the foliage. It should be distinguished from the white poplar (Liriodendron Tulipifera).

Prickly poppy (Argemone).-Large yellow or white pollen flowers. A. platyceras in Texas blooms in June, and honey-bees gather large quantities of its pollen.

Ragweed (Ambrosia).- Small green flowers pollinated by the wind; valuable in the fall for their abundant supply of pollen. Two common species are Roman wormwood (A. artemisiifolia) and great ragweed (A. trifida).

Rockrose (Helianthemum canadense).-Large, solitary, yellow pollen flowers; common in the Eastern states.

Roses (Rosa).-These handsome well-known flow. ers are nectarless, but yield much pollen which is gathered by honeybees and many wild bees.

Rushes (Juncaceae).-Small green lily-like flowers; wind-pollinated.

St. John's-wort (Hypericum).- Small yellow pollen flowers; common; attractive to bees after pollen.

Sedges (Cyperaceae).-A large family of grasslike plants; flowers small, green, wind-pollinated The so-called "tule honey" has been reported to be gathered from species of Scirpus growing along the Sacramento River, California; but this is undoubtedly a mistake.

Sorghum (Sorghum vulgare).-Pollen very abundant; a grass.

Tick-trefoil (Desmodium).-Flowers resemble those of the field-pea, or vetch; many species are nectarless, and do not appear to be visited by honeybees, tho the pollen is gathered by bumblebees. Sometimes listed as honey-plants.

Walnut (Juglans).-Large trees with small windpollinated flowers. Valuable for stimulating early brood-rearing in the spring.

Many handsome garden exotics, as pelargonium and hybrid petunias, are nectarless.

\section{PLANTS THAT YIELD NECTAR.}

$A$ honey-plant may be defined as a plant which secretes nectar accessible to honeybees, in quantities sufficiently large to be of practical importance to beekeepers. This, of course, implies that in some locality it is a common plant. If a list of all plants secreting nectar were desired, it would be easy to enumerate thousands of species; but very few of them are of practical importance in bee culture. Many are rare, others grow in the deep recesses of forests and swamps, while still others yield so little nectar that the larger bees pass them by unheeded. The bunchberry (Cornus canadensis) is very common in open woodlands; but the small flowers contain so little nectar that bumblebees ignore them entirely, and honeybees visit them only occasionally. They are left to flies, beetles, and the smaller bees. Then there are many flowers adapted to moths, butterflies, bumblebees, and humming-birds, which have the nectar so deeply concealed that it cannot be reached by honeybees. Many a beginner in beekeeping has fondly imagined that his flower garden would supply his bees with a rich harvest, wholly unconscious that the gaudy exotics of cultivation are often nearly or quite nectarless. In the following list the more important honey-plants in North America, so far as known at present, either wild or cultivated, hare been briefly described.

Acacia.-A large genus of shrubs and trees, most abundant in Australia; honey white, of fine quality. The most important species in this country are $\boldsymbol{A}$ Greggii, southeast Texas, New Mexico, and Arizona - see CATCLAW; A. Berlandieri, along the Rio Grande-see HUAJILI.A; A. Farnesiana (huisache), along the lower Rio Grande and Gulf Coast; $A$. Roeheriana, southern Texas; $A$. dealbata (silver wattle), and A. decurrens mollis (black wattle) in California.

Agave.-See Century Plant.

Alfilerilla.-See Pin Clover.

Alfalfa (Medicago sativa).-One of the most valuable honey-plants in irrigated regions of the West; honey water-white to amber; thick, and of superior quality.-See ALFALFA.

Alsike.-See Clover.

Andromeda.- Shrubs, in northern Florida yielding a reddish-yellow pungent honey.

Apple (Pyrus Malus).-Often yields a small surplus; honey light in color and of good quality. Crabapple ( $P$. coronaria) is also of value.

Apricot (Prunus armeniaca).-A small yield of honey.

Asters (Aster).-Common fall flowers. honey medium in quality and color. See AsTER. 
Artichoke, Globe (Cynara Seolymus). - Freely visited by bees, but honey unknown. Cardoon ( $C$. Cardunculus) is very common in Argentina.

Artichoke, Jerusalem (Helianthus tuberosa).-A good honey-plant, cultivated for tubers.

Banana (Musa Sapientum and Musa Ensete).The flowers produce large quantities of pollen and nectar. Cultivated in Florida.

Barberry (Berberis vulgaris, Eastern states; $B$. pinnata, Cal.; B. trifoliata, Texas).-Shrubs yielding both pollen and nectar; honey amber-colored, sometimes a surplus.

Basil (Pycnanthemum virginianum).-Mountain mint; Minnesota to Georgia and Alabama. Bees visit it freely.

Basswood (Tilia americana and T. heterophylla). -Among the most valuable honey-plants of North America; a white honey with an aromatic flavor. Central-Northern states, and as far south as Texas. The European basswood, or linden, is equally valuable, and is widely planted as an avenue tree. See BASSWOOD.

Beans, Lima (Phaseolus lunatus).-From lima beans in California there is obtained a thick waterwhite honey of delicious flavor. Horse-beans ( $P$. nanus) in British Isles and Holland are also valuable.

Bearberry (Arctostaphylos).-Gives a surplus in parts of California. In Placer County, according to Gleanings in Bee Culture, it is the best honeyyielder: blooms in December; honey amber-colored, of fine flavor.

Bee-balm (MTelissa officinalis).- In gardens, sparingly wild.

Beggar-ticks (Bidens frondosa).-Commonly listed but value as a honey-plant not certainly known.

Blackberry (Rubus).-Yields very little nectar either wild or cultivated; more frequently visited by wild bees than honeybees.

Black Gum.-See Tupelo.

Blue Curls (Trichostema lanceolatum).-A white honey that granulates very quickly, often before it is sealed.

Black Mangrove (Avicennia nitida).-Tide-water marshes on the east and west coasts of southern Florida and on the Keys; honey very white, of mild flavor, equal to that of orange or palmetto

Blackheart, or Water Smartweed (Polygonum acre).- In wet lands in Illinois and southward. For other species see Heartsease.

Black Haw (Viburnum prunifolium).-Of value for early brood-rearing.

Blueweed (Echium vulgare).-Viper's bugloss. Showy bright-blue flowers, very frequently visited by bees. A weed from Europe, common in places.

Bokhara.-See SweEt Clover.

Boneset, Thoroughwort (Eupatorium perfoliatum). -A honey plant of considerable importance.

Borage (Borago officinalis).-Cultivated from Europe, an excellent honey-plant.

Box-elder (Acer negundo).-Manitoba to Texas. The small greenish flowers yield nectar.

Buckeye (Aesculus glabra).-Ohio to Kansas and southward. Considerable honey is obtained from the California buckeye (A esculus californica).

Broomweed (Gutierrezia texana).-Plains of Texas and Arkansas. Honey dark amber and strong flavored, but gond for winter. September to October.

Buckthorn (Rhamnus cathartica).-This species is found in the middle states. Cascara sagrada (R. Purstiana), according to Gleanings in Bee Cul- ture, is the main honey-plant at Sonora, Cal. Comb honey from this p!ant is so dark that it sells poorly where not known, but is highly valued for its medicinal properties; does not granulate; a profusion of flowers on which the bees work for about twentyfive days. The coffee-berry ( $R$. californica) yields a heavy amber honey.

Buckwheat (Fagopyrum esculentum).-A dark purplish honey of heavy body. Extensively grown in New York and Pennsylvania. See BuckwheAt.

Buckwheat, Wild (Eriogonum fasciculatum).-In parts of southern California the most important honey-plant; honey light amber, of good flavor; granulates.

Burr Clover (Medicago denticulata).-Closely related to alfalfa. Common in California; occasionally yields a surplus.

Button-bush (Cephalanthus occidentalis). - Important on the overflowed lands of the Mississippi, and in swamps in other states. A mild light-colored lioney.

Buttonweed (Senecio glabellus).--Several species of Senecio, or groundsel, appear to be of value as honey-plants.

Cabbage (Brassica oleracea).-Cabbage, rape, turnip, radish, cress, horseradish, mustard, and many other species o fthe mustard family (Cruciferae) are of value. See MUSTARD.

Cactus, or Prickly Pear (Opuntia Engelmannii). -Southwestern Texas, and southward and westward. Sometimes a surplus of honey, of light-amber color; body heavy and "stringy," of rank flavor; flowers yellow inside, red outside.

Campanilla (Bidens frondosa). -Christmas bells, Christmas pop, campanilla. Honey pearly white, equal to alfalfa in flavor. Mexico, Cuba, and $\mathrm{Ja}$ maica. See Campanilla.

Canada Thistle (Cirsium arvense).-A common weed from Europe; honey of good color and quality.

Carpet-grass (Lippia nodiflora).-One of the principal honey-plants of central California, also valuable in the West Indies; honey light-colored, of mild flavor. $L$. lanceolata and $L$. repens are likewise much visited by bees, but are less important. See CARPET GRASS.

Carrot (Daucus Carota).-From Maine to California, naturalized from Europe. A white honey; candies in a few months.

\section{Cascara sagrada.-See BUCKTHORN.}

Cassia.-The species of cassia bear pollen flowers. The partridge pea (C. Chamaechrista), however, has extra-floral nectaries on the leaf-stems, which yield large quantities of nectar for more than 100 days. This species is common in the southern states, and in northern Florida the woods for miles are yellow with the blossoms; honey light amber, very clear and thin, but with a strong flavor. Wild senna ( $C$. marylandica) also possesses extra-floral nectaries.

Catalpa (Catalpa speciosa).-Not important; honey of medium quality; a handsome shade tree.

Catclaw.-See ACACIA and CATCLAw.

Catnip (Nepeta Cataria).-Secretes nectar very freely under cultivation. See CATNIP.

Century Plant (Agave americana).-Cultivated; yields nectar copiously. See Century Plant.

Cherry (Prunus).-The cherries, of which there are many species, yield nectar quite freely.

Christmas Berry (Heteromeles arbutifolia).Common in the Coast ranges of California; honey amber-colored, thick, candying in a few months; often a surplus. 
Clorer, White (Trifolium repens).-The most important honey-plant in the eastern and central states; honey white, of the finest quality. A part of the nectar of the red clover is available in dry seasons (T. pratense). The honey of alsike clover ( $T$. hybridum) is equal to that of white clover, as is also that of crimson clover ( $T$. incarnatum). The sellow clovers are of much less importance. Sour clover ( $T$. fucatum) is the source of considerable honey in the alkaline regions of central California. See Clover.

Clorer.-See Steet Clover, SAINFoin Clover, PiN Clover, JACK Clover, and Burr Clover.

Cotton (Gossypium herbaceum). - Important in the cotton belt; honey light, of fair quality, not equal to that of white clover. See Cotron.

Cow-pea (Vigna sinensis).-From China, widely cultirated for forage. In Georgia it is under cultiration in all parts of the state, blooming from June to September; but it yields a surplus in few places; honey lighi-colored, but of inferior flavor.

Cucumber (Cucumis sativus). - In the vicinity of pickle-factories this plant yields quite a harvest of honey after clover is orer. Poor flavor.

Currant (Riles).-The many species of currants and goosebcrries, both wild and cultirated, are widely distributed and are of some ralue.

Coral-berry (Symphoricarpos orbiculatus).-Indian currant. New Jersey to Texas. Yields considerable nectar, and blooms for a long time.

Cow-itch (Cissus incisa).-A vine growing on sandy shores from Florida to Texas. Sometimes there is a small surplus of honey.

Crownbeard (Verbesina virginica).-Pennsylvania to Texas. The white flowers appear in the fall, and are the source of much honey of fine quality. The sellow-flowered $\nabla$. occidentalis is valuable in Tennessee.

Dandelion (Taraxicum officinale).-Eurasia, North America, and many other parts of the world. Valuable in spring for both pollen and nectar. Honey golden sellow, thick, strong flarored, crystallizing in a few weeks.

Eryngo (Eryngium articulatum).-A dark hones of good flavor. California.

Eucalyptus.-A genus embracing many species of trees which are a rery important source of honey in Australia; many species have been introduced into California. Blue gum (E. globulus) and E. leucoxyton, melliodora, and robusta yield a great abundance of nectar. The honey varies from water-white to amber, and from a most agreeable to a peculiar acid taste in blue gum, which renders it unsalable at retail.

False Indigo (Amorpha fruticosa).-Ohio southward to Florida. Not important.

Figwort (Scrophularia).-The figworts would be excellent honey-plants if they were more common. In $S$. marilandica (Simpson's honey-plant) the nectar is secreted in two large drops by the base of the ovary. Honeybees are constant visitors. Massachusetts to Kansas and Louisiana. In southern California $S$. californica is a valuable honez-plant.

Furze (Ilex europaeus).-Belongs to the pulse family; introduced from Europe; a good honey-plant.

Gallherry (Ilex glabra).-Georgia and other southern states. A reliable yielder; honey white, of superior quality; also several other species. See HOLLY and GALLBERRY.

Germander (Teucrium canadense). - Central states. Honeybees common on the flowers.

Giant Hyssop (Agastache nepetoides).-Vermont to Nebraska and southward In bloom about six weeks; many honeybees.
Goldenred (Solidago).-Numerous species. Surplus in New England; honey golden or dark amber; thick, of fine flavor. See GOLDENROD.

Gooseberry.-See Currant.

Greasewood (Adenostoma fasciculatum).-In drs saline localities in the West; frequently visited by bees.

Gum-plant (Grindelia squarrosa).-Many acres of the dry plains of Manitoba and Minnesota are covered with the yellow flowers which are very attractire to bees.

Hawthorn (Cralaegus).-A great number of closely allied species, blooming in May; valuable for both nectar and pollen.

Heather (Calluna vulgaris).-Locally on the eastern coast; a prolific source of honey in Europe and the British Isles; honey rich amber, of pronounced flaror and pungent aroma.

Hedge-nettle (Stachys).-Many species secrete nectar freely, and attract a large number of bees.

Horsemint (Monarda punctata).-New York to Florida and Texas. One of the main yielders in Texas; honey of good quality, but rather strongflarored. $M$. clinopodioides is likewise very valuable; honey has been compared to that of basswood. See Horsemist.

Heartsease (Polygonum Persicaria).-Naturalized from Europe thruout a large part of North America; honey varies from light to dark amber; flavor very good. Water smartweed ( $P$. punctatum) occurs in wet lands thruout North America; honey dark, and of poor quality. Many other smartweeds are of more or less ralue: about 70 species in North America. See HEARTSEASE.

Hop-tree (Ptelea trifoliata).-Florida to Texas and northward; nectar abundant; honerbees common.

Horehound (Marrubium vulgare).-Good yields of dark honey, but it is so bitter as to be almost worthless except for medicine.

Holly (Ilex).-Common or American holly ( $I$. opaca) and white holly (I. myrtifolia) are eagerly visited by bees in Georgia; and the honey, tho not obtained unmixed, is regarded as excellent. The gallberries belong to the same genus. See GALLBERRY.

Honeysuckle (Lonicera).-Honeybees suck the nectar in the flowers of several species of bush honersuckle, as Sullirant's honersuckle ( $L$. Sullivantii). The nectar of the climbing garden honeysuckie ( $L$. periclymenum), adapted to moths, and of the trumpet honeysuckle ( $L$. sempervirens), adapted to hummingbirds, is beyond the reach of hive-bees.

Horsechestnut (Aesculus Hippocastanum). Adapted to bumblebees; but honerbees obtain both pollen and nectar.

Huajilla.-See ACACIA and GUAJILLA.

Jack Clorer (Wislizenia refracta).-A most prom. ising honey-plant, rapidly spreading in California. Blooms in the fall; honey white, mild; a large surplus.

Judas-tree (Cercis canadensis).-Redbud. From the red-purple flowers honesbees gather both nectar and pollen.

Knotweed.-See Heartsease.

Lemon (Citrus Limon L., or C. Limonium Rossi). Valuable for honey in San Diego Co., Cal.

Linden.-See Basswood.

Iocust, Common or Black (Robinia Pseudo-Acacia).-Widely planted; blooms in Mas; hones white; a surplus. See I.ocust.

Logwood (Haematoxylon Campechianum).-Common in the states bordering on the Bay of Cam. 
peche; introduced into Florida, Jamaica, and in the West Indies; honey nearly water-white, of good body, and unexcolled in flaror and aroma. See LOGWOOD.

Loquat (Eriototyra japonica).--Sometimes wrongly named Japan plum; south and in California; valuable because it flowers late.

Lucerne.-See Alfalfa.

Modrona (Arbutus Menziesii).-Nectar and pollen.

Magnolia.-Trees with very large white flowers; not rery important.

Mallow (Malva).-The flowers of several species are very frequently risited by honeybees for nectar and pollen, but not important except perhaps locally.

Manchineel (Hinpomane Miancinella).- Southeast Florida and on the Keys. Nectar very abundant. Small trees with apetalous, greenish flowers.

Maples (Acer).-The different species are of much value, yielding both nectar and pollen for early brood-rearing. The sugar maple (Acer saccharum Marsh) produces a profusion of flowers.

Marigold (Gaillardia pulchella).-One of the main honey-producing plants of Texas. Honey rich golden, and of good quality. See MARIGOLD.

Marjoram (Origanum vulgare).-Introduced from Europe: in gardens, and sparingly escaped. A favorite of honeybees, but not common enough to be of much value.

Melilot.-See SweEt Clover.

Melons (Cucumis Melo).-Melons of all kinds are valuable to apiarists.

Mesquite (Prosopis julifiora).- Southwest in semiarid regions. Main source of honey in Texas; a white honey of good quality. See Mesquite.

Milkweed (Asclepias).-Honeybees visit many species for nectar, but the pollen-masses often become attached by dry membranous clips (corpuscula) to their claws or tongues; sometimes they are unable to extract the pollinia, and finally perish; dead bees are often found on the flowers. See MILKWEED.

Mayweed (Anthemis Cotula).- - Honey light yellow, and very bitter.

Milk-vetch (A stragalus). - The various species are visited by honeybees, and the more common are valuable in favorable seasons.

Mint (Mentha).-Honey amber-colored.

Mistletoe (Phorodendron flavescens).-Yields nectar and nollen; valuable in Texas for early broodrearing; llooms in January and February.

Mustard (Brassica).-Honey light, or mild flavor; not as heavy as alfalfa; candies quickly; a large surplus in Lompoc Valley, California. See MusT'ARD.

New Zealand Flax (Phorrnium tenax).-Sometimes grown in the South; covers thousands of acres in New Zealand; a valuable honey-plant.

Onion (Allium Cepa).-Surplus yields of honey are obtained from fields of onions cultivated for seed; the peculiar onion odor and flavor disappear as the honey ripens.

Orange (Citrus Aurantium).-Yields a surplus in Florida and California. Honey nearly transparent, of delcious flavor, with the aroma of the blossom; candies after a few months. See Orange.

Palmetto (Sabal Palmetto).- Southern half of Florida; honey light-colored, very mild, but not as fine as that from saw palmetto; grows in the hummock lands thruout Florida; honey lemon-yellow, thick, of the finest flavor. See Palinetro.
Scrub Palmetto (Sabal mesacarpa) is very abundant in the hummock lands of Florida. Honey lemon-yellow, thick, of good flavor.

Partridge-pea.-See CAssia.

Peach (Prunus persica).-Sometimes a small surplus.

Pepperidge.-See Tupelo.

Pear (Pyrus communis).-Yields nectar more abundantly than does the apple, sometimes a surplus. See Fruit Bloom.

Pepper-tree (Schinus molle). - California and Florida; honey amber-colored, and of pronounced flavor. See PEPPER-TREE.

Pepperbush (Clcthra alnifolia).-White alder. On the coastal plain of Georgia and in northern Florida it yields a surplus; honey white and of superior quality; blooms from June to October. Maine to Florida near the coast.

Pepper-vine.-See Snowvine.

Pennyroyal (Satureja rigida).- - A small surplus in the southern half of Florida, where it blooms in January; honey is clear, and of good flavor and body.

Persimmon (Diospyros virginiana).-Connecticut to Florida and Texas. A large tree; blooms-in spring; valuable.

Phacelia.-At Ventura, California, a water-white honev is obtained from Phacelia hispida; it has a fine flavor, but candies soon after extracting. In central California $P$, tanacetifolia yields a mild lightamber honey. See PHACELIA.

Pigeon-cherry (Prunus pennsylvanica).-Considerable nectar is obtained from the flowers.

Pin Clover, or Alfilerilla (Erodium cicutarium). - Maine to Texas and California, but most abundant in the West; honey of good quality and flavor. $E$. moschatum is also a raluable honey-plant; honey similar to that of the preceding species.

Plums and Prunes (Prunus).-All kinds of plums yield nectar.

Prairie Clover (Petalostemum candidum).-Belongs to the pea or pulse family; reported as valuable.

Pumpkin (Cucurbita Pepo).-Cultivated; honey amber-colored; candies quickly.

Raspherry (Rubus idaeus, variety aculeatissimus.) - Very common in northern Michigan; a white hon ey of the finest flavor. See RASPBERRY.

Rattan (Berchemia scandens).- - In Texas, in favorable seasons, yields a surplus of dark-amber honey used for manufacturing purposes.

Redbay (Persea Borbonia).-A southern tree with small yellowish flowers growing near the coast. Redbud.-See Judas Tree.

Red-gum (Eucalyptus rostrata).-Nectar abundant; a promising species. See Eucalyptus.

Rhododendron and Kalmia.-The flame-colored azalea (Rhododerdron calendulaceum) and the mountain laurel (Kalmia latifolia) when in bloom in the mountains of North Carolina give a distinctive color to the landscape. The honey has been reported to cause nausea and dizziness. See Porsovóus HONEY.

Rocky Mountain Bee Plant (Cleome serrulata).Very attractive to bees; handsome rose-colored flowers. See Rocky Mountain Bee Plant; also SpiDER PLANT.

Sage (Salvia).-Black or button sage ( $S$. mellifera) is one of the chief honey-plants of California; honey thick, white, of delicious flavor, not inclined to candy. Purple or white-leaved sage (Salvia leucophylla) yields a similar honey, but is less abun- 
dant. White sage ( $S$. apiana), tho one of the commonest. does not yield nectar as freely as the two abore-named species, but the honey is equally good. Creeping sage ( $S$. sonomensis) is common in the mountains and Sierra foothills. The honey is of about the same quality as black sage. Annual sage (S. columbariae) yields a surplus of excellent honey in Monterey County, Cal. The lance-leaved sage ( $S$. lanceolat $\alpha$ ) is listed as a honey-plant in Nebraska, and the blue sage ( $S$. azurea) in Texas. Many species of sage are adapted to bumblebees, or in South America to honey-sucking birds, but the nectar cannot be obtained by honeylues. See SAGE.

Sainfoin Clorer (Onobrychis sativa).-Cultivated for hay or fodder. Honey resembles that of white clover. See SAINFOIN Clovir.

Sensitive Pea.-See CAssia.

Serradella Clover (Ornithopus sativus). $-\mathrm{A}$ fine honey-plant, similar to sainfoin.

Shadbush (dmelanchier canadensis).-Honeybees gather hoth nectar and pollen; of minor importance.

\section{Smartweea.-See Heartshase.}

Sneezeweed (Helenium autumnale).- Swamp sunflower; in wet land thruout the eastern states. Hon eybees suck nectar and gather pollen. In Texas, bitterweed (H. tenuifolium) yields a golden-yellow honey of heavs body, but rery bitter, "as if 50 per cent quinine and some pepper were added."

Sourwood (Oxydencron arboreum). -1 splendid honey-producer. The nectar is so abundant that it can be shaken from the blossoms; a superior honey which does not readily candy. See Sourwood.

Sow Thistle (Sonchus oleraceus). - In waste places; yields some nectar.

Spanish Bavonet ( $\mathbf{u c c a ) . - H o n e y b e e s ~ s u c k ~ t h e ~}$ nectar of $Y$. filamentosa and of $Y$. Whipplei, and the latter is said sometimes to yield a surplus.

Spanisl Needles (Bidens aristosa).-Marshy lands of Mississippi and Illinois Rivers; honey golden, of exquisite flavor, and good body; not inclined to. granulate.

Spider-plant (Cleomie spinosa, formerly called $C$. pungens).--Introduced from tropical America; cultivated; escaped in waste places from Illinois to Louisiana. Thirteen flowers have yielded a spoonful of nectar. "Under favorable conditions one of the most remarkable honey-plants in the world." The Rocky Mountain hee plant (C. serrulata, formerly called $C$. integrifolia) grows in dry saline soil from Minnesota to Kansas, and westward among the mountains.

Spikeweed (Centromadia pungens).- "On the alkaline plains of the upper San Joaquin (Cal.) this species covers tens of thousands of acres; honey amber, of good quality, but granulates quickly."

Squash (Cucurlita maxima).-Nectar abundant in a little reservoir at the bottom of the flower.

Sumac (Rhus glabra).-New England and southwestward. A surplus in Connecticut; honey bright amber; very heavy, but at first has a bitter odor and flavor which disappear as it ripens; waxes instead of granulating. Monntain sumac ( $R$. copallina) yields a surplus in Georgia and Texas. $R$. diversiloba is common thruout California. See SuMAC.

Sunflower (Helianthus annuus).-Common, wild in the West; yields a surplus of amber-colored honey with a characteristic flavor.

Sweet Clover (Melilotus alba and $M$. officinalis).Introduced from Europe; white and vellow sweet clover are spreading thruout the entire country. Honey white with a slight greenish cast, hardly equal to white clover. See Street Clover.

Snowvinc (Cissus arborea), Pepper Vine.-In wet land, Virginia and southward. In southern Georgia it blooms from June to September; honeybees give it the preferenre to cotton. Honey not as light-colored as that of cotton, but of fair quality.

Sweet Fennel (Foeniculum vulgare).-Cultivated from Europe, and escaped in waste land. Honey light amber.

Thistle.-See Canana Thistle and Sow This. TLE.

Thyme (Thymus vulgaris).-The classical honey of Mount Hymettus was from this species.

Titi, White (Cyrilia racemiflora).--Ivory bush. An evergreen shrub or small tree that grows in pine swamps from Virginia to F'lorida and Texas. It blooms in Florida in mid-February; honey red, strong in flavor; used by bakers. A surplus is obtained only in northwest Florida, and there it is small, as the weather is usually rainy. In Georgia white titi extends up to the middle of the state. It is not a very sure nor a very abundant vielder; but it comes at a time when there is little else to keep the bees buss, and so is raluable. The quality of the honey is rather poor.

Titi, Black (Cliftonia monophylla).-This is also an evergreen shrub found in pine swamps. In Georgia it is very common along the streams of the Altamaha River region. It blooms in March and April; the honey is in fair quantity, and of fair quality.

Tarweed (Hemizonia fasciculata). - Along the coast oi southern California. Honey dark amber, with a strong tarweed odor; granulates in a few months; said to be used in the manufacture of chewing tobacco. Yellow tarweed ( $H$. virgata) yields in central California a heavy light-yellow honey of gnod flavor.

Tulip-tree (Liriodendron Tulipifera).-White popiar, whitewood. A dark thick honey of rather in. ferior quality. In the South it blooms in April. See TUIIP TREe.

Tupelo, Black (Nyssa Ogeche).-Northwestern Florida and southern Georgia. Honey white to am. ber in color; of good flavor, but rather thin. White tupelo ( $N$. aquatica) is most abundant along the Apalachicola River. Honey is white, or with a slight rellowish tinge in the sunlight; thick, unsurpassed in flaror by any other honey in the state. It does not candy, eren after years. See Tupelo.

Simpson Honey-plant (Scrophularia marilandica). S. nodosa is a Europaan species. Nectar abundant. See FIGTORT.

Tobacco (Nicotiana Tabacum). - In Connectient the nlants are permitted to flower and seed. From the first of August to frost there are hundreds of acres of tobacco flowers corered with bees. The honey is reported to be of fair quality.

Varnish-tree (Allanithus glandulosa).-Tree of heaven, Chinese sumac. Small greenish flowers: the staminate are ill scented, and the honey has a bad flavor.

Verbena or Vervain (Verbena).-In California $\nabla$. prostrata is of some value along the coast, but the species are mostly" unimportant.

Vetch ( $\nabla$ icir $\iota$ ).- Several species are risited by honeybees for pollen and nectar.

Viper's Bugloss.-See Bluetreed.

Wild Cherry.-See CHERRY.

Wild Senna.-See CASSIA.

Willow (Salix).-Valuable in early spring for both nectar and pollen. In New York the honey is said to resemble that of apple bloom, and to have a pleasant aromatic taste; but in California it is described as hitter-flavored and amber-colored. See WIILOW. 


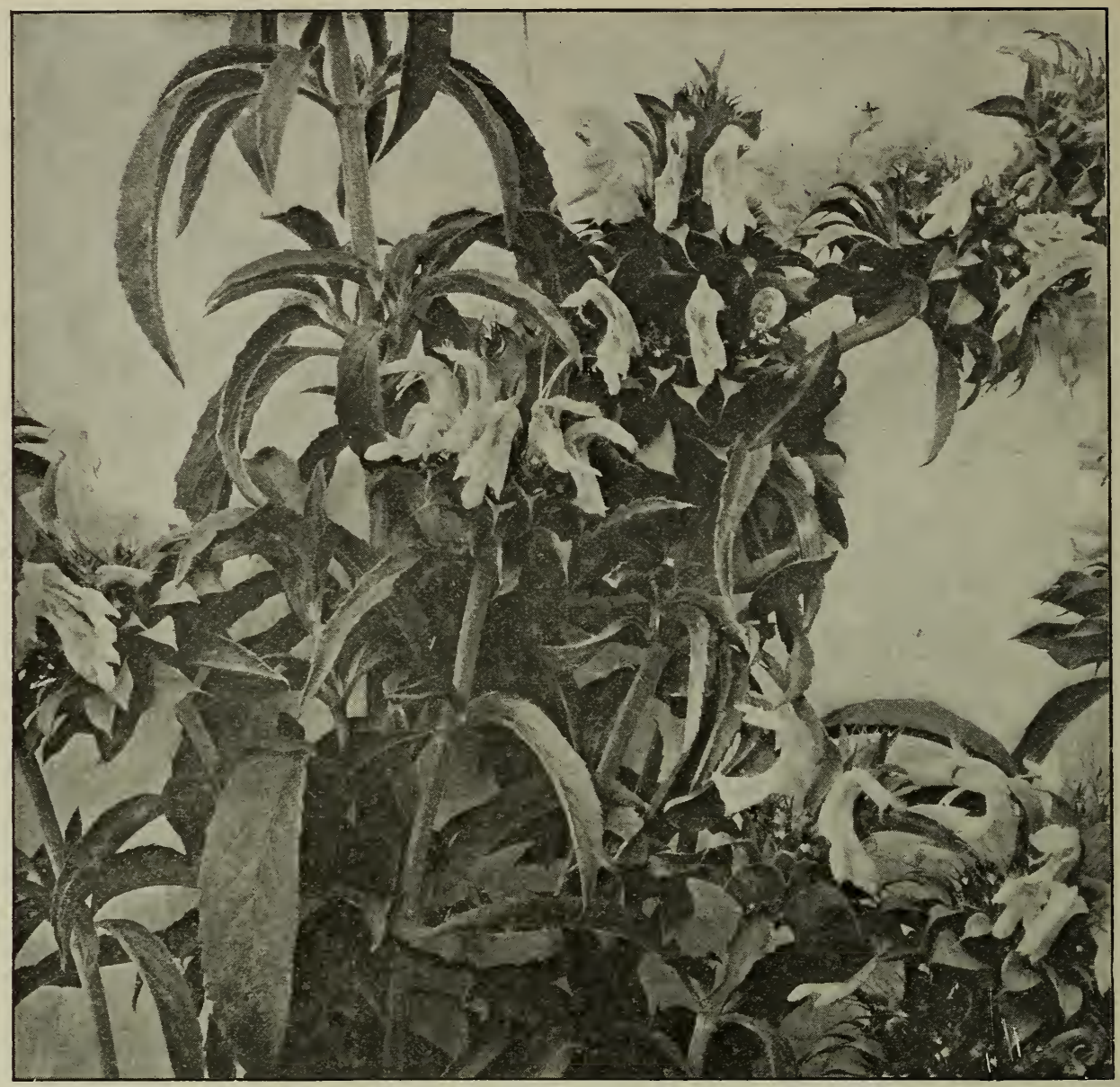

Texas horsemint.

Willowherb (Epilobium angustifolium).-Canada, Michigan, and northern states. Flowers red-purple; honey clear, limpid, literally water-white; very sweet; aromatic. See WILLOWHERB.

Wild alfalfa (Lotus glaber).-An important honeyplant in the Coast Ranges of California; honey white to amber; the yield is very variable in different years.

\section{HONEY VINEGAR.-See VINEGAR.}

HOREHOUND (Marrubium vulgare L.). -This is quite an important honey-plant in Texas and California. In Texas, Scholl says it yields nectar freely and steadily from February to July. It has been claimed that the honey is very bitter; but he declares that this is hardly the case in his locality; that it has a very sweet taste liked by some, but nauseating to others. In California, according to Richter, it is a splendid yielder of dark-amber honey, too strong for table use, but largely used in medicine. In Ventura and Ios Angeles counties hore- hound is quite a common plant; but it is considered a pest on a sage range; for if even only a small quantity of its nectar is gathered, the color and flavor of sage honey are impaired.

HORSEMINT (Monarda punctata L.). -A perennial herb with lance-shaped leaves and two-lipped yellowish flowers spotted with purple. Like the sages it belongs to the mint family or Labiatae. It grows in sandy fields and prairies from Florida to Texas and northward to Wisconsin and New York, blooming from midsummer until fall. Many species belonging to this genus have, very long floral tubes, and are adapted to insects with much longer tongues than the honeybee, so that even when common they are of little value to the apiarist for nectar. Wild bergamot (M. fistulosa), for example, is a bumblebee flower, with a tube three times the length of the tongue of the domes- 
tic bee. But in the horsemint the floral tube is scarcely longer than the calyx; and, as honeybees can easily suck the nectar, they resort to the flowers in immense numbers. Along parts of the Mississippi River and in Texas it is a leading honey-plant.

Horsemint was first brought into notice a few years ago when it was highly recommended to beekeepers and the seeds sold quite extensively. It was subsequently dropped and almost forgotten until reports of large crops of honey, said to be from this source alone, began to be published. It first attracted attention again on the low alluvial lands bordering on the Mississippi River. Afterivards wonderful reports came from different parts of Texas-one man reporting as high as 700 pounds gathered by one colony in a single season. The bees that performed this remarkable feat were Cyprians, or, at least, were crossed with Cyprian blood.

Horsemint is of more value to beekeepers in Texas than in any other state. It begins to yield in June, and is the source of a large amount of light-amber honey. The extracted honey is a clear light amber, a little darker than the comb, and of good body. Like buckwheat honey it has a pronounced flavor, and for this reason has been compared with the basswood honey of the North. By persons who prefer a strongly flavored honey horsemint honey is liked better than that of white clover; but the general opinion seems to be that while the taste is good it is a little too strong.

Monarda clinopodioides Gray is also very common on the dry plains of Texas. The form of the flower, the time of blooming, and the quality of the honey are very similar to those of the preceding species. Horsemint is thus the source of one of the main honey crops of Texas.

\section{HOUSE-APIARY.-See APIARY.}

HUAJILLA (A cacia Berlandieni Benth.). -No portion of Texas is so well adapted to beekeeping as the southwestern section where the most important honey-plants are the mesquite (Prosopis), catsclaw (Acacia Greggii), and, most valuable of all, the huajilla (pronounced wa-he-yah). This shrub grows in dense thickets on dry bluffs along the Rio Grande and also in Mexico. It requires only a scanty amount of rain early in the spring, and survives in semiarid regions where chiefly desert plants abound. The blooming period is in April and lasts for about two weeks and the flowers are the source of a large quantity of a beautiful water-white honey. Almost as

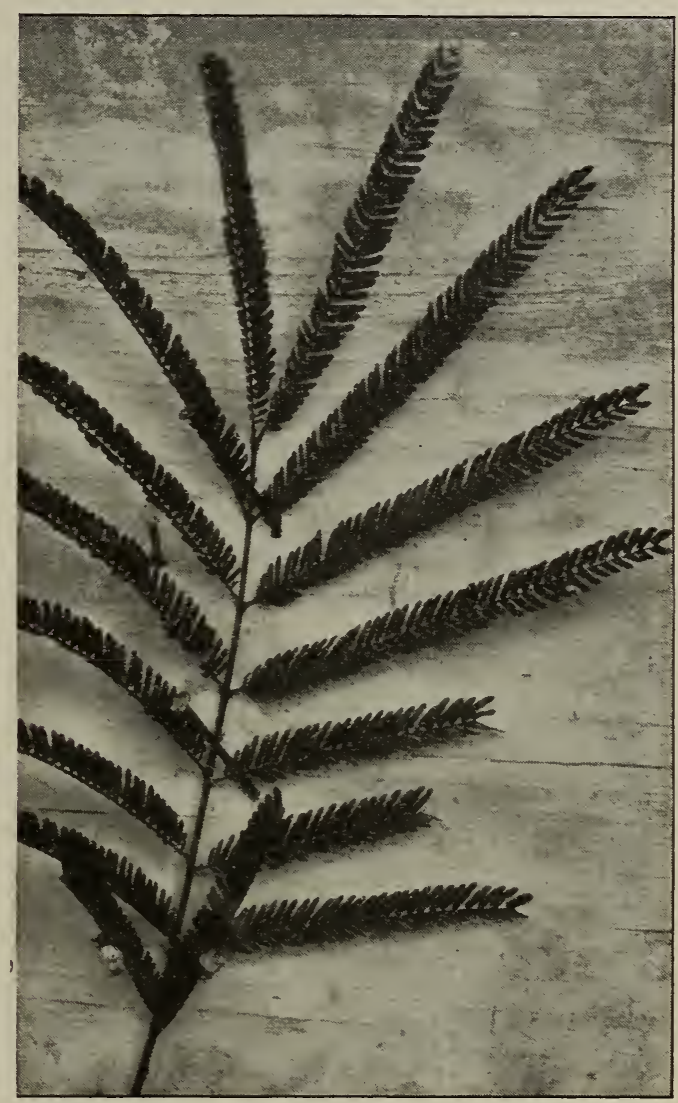

Huajilla.

clear as water, mild in flavor, delicate in aroma, buajilla honey is considered the finest produced in Texas.

The leaves are bipinnate like those of a fern. The leaflets, as is shown in the figure which is natural size, are very numerous.

\section{HUMBLEBEES.-See BUMBLEBEES.}

HYBR.IDS. - A hybrid may be a cross between species or between varieties of a species. Bees mentioned under this head belong to the class last mentioned-a cross between varieties, and usually between Italian and common black bees. Everybody who has had Italians very long probably knows what hybrids (a cross between Italians and common black bees) are, especially if he had kept bees when the honey crop 
was very suddenly cut short during a long and severe drouth in the fall. They are very much crosser than pure Italians or blacks. Many of the old veterans in the business have concluded, even tho the hybrids will secure as much honey, and sometimes even more, that it pays to Italianize. A good strain of leather-colored Italians* will be almost as gentle as flies, and will gather fully as much honey as hybrids. Very often the half-bloods can be handled, when weather conditions are right, nearly as easily as Italians; but as a rule they require a great deal more time in that the operator must proceed much more cautiously in order not to stir up their excitable and vindistive temper.

While hybrids are by no means as hard to handle as pure Cyprian and Holy Land bees, they are bad enough. The very fact that hybrid queens, if sold at all, bring only about one-fourth the price of pure Italians, gives one some idea of their relative value in the open market.

But the most serious objection to hybrid and black bees is the fact that they are an easy prey to the ravages of European foul brood (see Foul Brood, sub-head "European Foul Brood"). While hybrids are more immune than the blacks, pure Italians seem to be able to resist the disease much better than the crosses. In some parts of the country the hybrids and blacks are dying off for the simple reason that they cannot stand the ravages of European foul brood as do the Italians; and it will not be long before there will be nothing but pure Italians where this disease has had its full sway. Of course, not all Italians are immune; but good vigorous strains will resist the disease provided other curative measures are applied. All they need is a little help from their owner. It follows, therefore, that the up-to-date beekeeper will eliminate his hybrids as soon as possible before European foul brood starts in his locality.

In many large apiaries thruout the country hybrids are tolerated simply because their owners do not take the time to Italianize. Where one owns a series of outyards, comprising from 500 to 1000 colonies, it would be rather expensive to buy Italian queens; but if he will follow directions given under QueEn-REARing in this work he

* For test as to what constitutes a hybrid, see ITALIAN BEES. can rear his own queens; and this brings up the question whether the blacks and hybrids in a locality will not make it impossible to rear pure stock. If one will use drone-traps on all colonies where there are black or hybrid drones, and then insert a drone comb in the center of the brood-nest of the best Italian colonies, he will soon have a great preponderance of pure Italian drones. The result will be that the most of the young virgins will meet drones of their own race. (See Drones; also QueEn-Rearing.)

It goes without saying, that the A B C scholar should at least start with a gentle strain of bees. Hybrids of Italian and common black bees should be avoided. The beginner may have to purchase hybrids because there are no other bees in the locality; but he should, as soon as possible, Italianize. (See Introducing.) Nothing will be more discouraging to one just starting than to be stung viciously by one of the old-fashioned hybrid colonies. If he should happen to open a hive of one of these half-bloods, without smoke, during cool or chilly weather, he might get terribly stung; and the result would be that he would conclude that the bee business was a life-and-death affair. While it is unwise for a novice to open any hive of bees during bad weather, no matter what the strain, he should not undertake to do anything with a hybrid colony until weather conditions are suitable. The outdoor temperature should be not less than 70 degrees; and if the bees should be working in the fields they may be handled without much difficulty.

A beginner should never open a hive of hybrids without smoke. A little should be blown in at the entrance, and each movement should be preceded by a light puff of smoke. If the beginner is a little timid it would be well to have an attendant operate the smoker while he, with a pair of gloves, proceeds to manipulate the colony. (See Manipulation of Colonies; Smokers; also Strings.)

\section{HYBRIDS OF CARNIOLANS AND CYPRIANS WITंH ITALIANS.}

In this country, at least, we have as yet done very little to determine with accuracy the value of different crosses which can be made very easily. A cross between Italians and Caucasians has been spoken of very favorably by Mr. J. J. Wilder, of Cordele, 
Ga., one of the most extensive beekeepers of the country. Mr. Wilder says this cross will rear brood under conditions and at seasons of the year when pure Italians will do practically nothing. In some parts of the South it is very desirable to have a strain that will rear brood in and out of season, because of certain honey-flows that may follow shortly after. A pure Italian stock has a tendency to stop brood-rearing almost entirely after the main honey-flow. If there be another flow two or three weeks later, without brood-rearing in the meantime, the force will be greatly reduced, and the bees that are left will be of little value in a honey-flow.

In the same way a cross between Carniolans and Italians has been found to be equally profitable. Every beekeeper should, therefore, study his locality very carefully, and be prepared for every honey-flow that may come on. He should then test his various strains; and if he cannot get just what he desires from a pure race, a crossing of two or more races may be found adrantageous.

It may be well to observe that there are two ways of making crosses. For example, a large number of Carniolan or Caucas:an drones may be reared, and all other drones, such as Italians, held back by means of drone-traps. If, as is generally supposed, the male has the greater potency in transmitting his qualities, it will be desirable to make a cross in this way: For example, Caucasians or Cyprians have a tendency to swarm and breed excessively. If these traits are too much of a good thing for the locality it can be toned down by crossing with Italian drones of another strain that is more conservative in both respects.

Other hybrids may be considered by the beekeeper who bas in mind to produce a superior strain of bees for some particular purpose. We know that crossing, as a general rule, increases the size, courage, and stamina of our domestic animals; and it is probably so in bees, yet we hare made but little progress along this line, because it is so difficult to distinguish between the crosses and pure breeds in many cases.

We have an imperfect control over bees when mating, hence it is rery difficult to effect mating just as we desire to have it. There is a grand field for practical experiments, such as would prove useful to beekcepers.

See Droxes; Parthexogenesis; DzierzoN THEORY, subhead "Recent Evidence in Support of the Theory." 
INCREASE.-Under the head of NUCLEUS several methods of forming nuclei are explained; but under this head we shall deal with the subject more from the standpoint of the honey-producer who actually desires increase and at the same time produce a crop of honey. One can divide up a strong colony into three or four nuclei; but in doing so he would probably destroy all his chances of securing a crop of honey, and at the same time be almost sure to cause some brood to die. It should always be borne in mind that the field bees will go back to the old stand. The nucleus left will necessarily receive more than its proper proportion of bees, while those moved to the other locations may or may not (depending upon circumstances) have too few bees to take care of young brood. The loss of brood may be minimized somewhat by putting most of the sealed brood on other stands and a large part of the unsealed at the old stand; but if the division be made during chilly weather even the sealed brood may die from chilling.

The following plan avoids all this loss of brood, and at the same time enables one to make a moderate increase as well as secure a honey crop. It was practiced and recommended by one of the most extensive beekeepers in the United States, the late $\mathrm{Mr}$. E. W. Alexander, who was recognized as an authority on general practical apiculture, for indeed his crops of honey went up into the carloads. He first made the plan public in 1905 , after having tested it many years. So many favorable comments were received of beekeepers who had tried it and found it to be a success that we republished it with some slight modifications in 1906 . We here present the plan as it was given in Gleanings, page 423, 1906 :

When a colony is nearly full enough to swarm naturally, and you wish to make two from it, lift it from its stand and put in its place a hive containing frames of comb or foundation the same as you would prepare a hive for a swarm. Remove the center comb from this new hive, and put in its place a frame of brood from the old hive, and be sure to find the queen and put her on this frame of brood in the new hive; also look it over very carefully to see that it contains no eggs nor larvæ in any queencells. If it does, destroy them. Put a queenexcluding honey-board on top of this new hive that contains the queen and frame of brood with their empty combs, then set the full queenless colony over the excluder; next put in the empty comb or frame of foundation taken from the new hive, and close the upper hive except the entrance they have thru the excluder into the hive below. Leave them in this way about five days, then look over the combs carefully, and destroy any larvæ you may find in the queen-cells unless they are of a good strain of bees that you care to breed from, for they frequently start the rearing of queens above the excluder very soon after their queen was placed below the excluder. If so, you had better separate them at once; but if they have not started any queen-cells above, then leave them together ten or eleven days, during which time the queen will get a fine lot of brood started in the lower hive, and every egg and particle of larva that was in the old hive on top will have matured, so it will be capped over and saved; then separate them, putting the old hive on a new stand. It will then be full of young bees mostly, and capped brood, and in about twenty-four hours they will accept a ripe cell, a virgin, or laying queen, as they will then realize that they are hopelessly queenless. I would advise you to give them a laying queen, as I never like to keep my full colonies for even a day longer without a laving queen than $I$ can help.

In this way you secure two strong colonies from one, without losing a particle of brood or checking the laying of this queen; and with me it almost wholly prevents swarming. This is the way we have made our increase for several years, and we like it much better than any other method we ever tried. In doing so we keep all our colonies strong during the whole summer, and it is the strong colonies that count in giving us our surplus.

The mere fact of having a large number of colonies does not amount to much unless they are strong in bees and are well cared for at all times. This is a fact that many have sadly overlooked; and when the season comes to a close, giving them a small surplus, they feel disappointed and lay the fault on many things that have had but little to do with their failure. 
In making increase in the above way the new swarm on the old stand is in fine shape for a super of sections, as it has a large working force backed up by having its hive nearly full of brood, and but little honey, as the bees have been in the habit of storing their honey in the old hive that was on top, so they will soon go to work in the sections with no notion of swarming. Then the old hive that has been set a way can usually spare 15 or 20 lbs. of honey, which can be taken with the extractor, giving its new queen plenty of room to lay, and in a short time will be one of your best colonies, and also have no desire to swarm.

If you have followed directions as I have recommended in the above, keeping them snug and warm, and feeding them a little thin warm syrup nearly every day for the first thirty days after they have commenced to fly, you can have two good strong colonies in the place of one ready to commence work on the clover harvest, which here commences about June 15.

From an extensive experience a'ong this lime I find I can get nearly twice the amount of surplus by dividing as above stated over what I was able to acquire either by letting them go undivided or dividing in a way that caused the loss of a greater part of their brood. This losing of brood we must guard against at all times if we expect to secure a fine surplus. It costs both time and honey to produce it, and it is the princinal factor in obtaining those strong colonies that give us tons of honey.

I find that nearly all who have made a failure of the method have taken colonies that had already made some preparation for swarming by having eggs or larvæ in their queen-cells.

During the summer I received a few letters from parties who had made a failure of this method in about the same way. Some had taken colonies that had capped queencells in their hives at the time they put the queen in the under hive, and, of course, they swarmed in a day or two. I cannot see that these failures are any proof of fault in the method. When we work with our bees we must always use some discretion in such matters. If a colony is very strong in bees it certainly requires different management from one rather weak.

Several jears ago one of $\mathrm{my}$ sons bought nine colonies of bees in common box hives, about the first of June. He brought them home and transferred them at once to movable-frame hives, and in about three weeks divided them, making 20 colonies of the 9 he bought, using some queen-cells I had on hand for his surplus colonies. He then attended to those 20 colonies so they were all strong at the commencement of our buckwheat harvest. I then lent him 20 hives of empty combs to put on top of his colonies to extract from. He took 2849 lbs. of extracted honey from those 9 colonies and their increase, and left them in good condition so every one came out the next spring in fine order.

Another son, the same season, took one colony, divided into three, and received 347 lbs. of extracted honey. They also came thru the following winter in good condition. I speak of these cases simply to show that it is not necessary to keep hundreds of colonies in order to get a little honey. If you will keep only strong colonies and give them the best of care you will soon find both pleasure and profit in bee-keeping.

Perhaps no one article that was ever published in Gleanings in Bee Culture called forth more discussion than this. A few did not succeed with it to their entire satisfaction; but the great majority made a success of it. It is a fact today that large numbers of some of the best beekeepers in the country practice the method, believing that there is no other encual to it. It is evident, howerer. that the article must be read with some poetic license. That is to say, it should be modified to suit peculiar conditions. $\mathrm{Mr}$. Alexander had a remarkable locality. $\mathrm{He}$ had a fair clover flow in June, and this was followed in August by a heary flow from buckwheat, goldenrod, and aster. The locality was so exceptional that for years he maintained 500 colonies in one location. Usually it is not practicable to have more than 100 in one place.

The basic principle of placing the brood into an upper story for a few days orer an excluder before making the division is acknowledged by all to be good. The saring of all the brood and conserving the heat are factors that make this superior to any other method of dividing.

Dr. C. C. Miller, to whom reference is made in various portions of this book, however, says that if he were to divide his colonies before the clover flow as recommended at the close of Alexander's sixth paragraph it would be only at a loss of the honey crop. It can generally be set down as an axiom in beekeeping that it is not practicable, ordinarily, to secure increase and a full honey crop at the same time: and therefore Mr. Alexander's statement that he can secure by this plan "two good strong colonies in the place of one, ready to commence work on the clover harvest," seems impossible of accomplishment if we take with it the other statement in the next sentence that he secured nearly twice as much of clover as he would have secured without dividing. 
The trouble seems to hinge on the point of having two good colonies in place of one at the opening of the clover harvest by June 15. If the reader will turn to the article, sixth paragraph, he will see that Mr. Alexander recommends that the directions be followed exactly-that bees must be kept snug and warm, and that they must be fed a little thin syrup nearly every day. The two colonies must be given every help possible.

Note that he did not say that he secured by this method "nearly twice the amount of surplus" from clover as might be inferred from the last sentence of the preceding paragraph. To one who knows his locality it is clearly evident that he meant of all honey-buckwheat, goldenrod, and aster as well as clover. He could have meant nothing else.

It will be noticed that Mr. Alexander began his work of increase about April $1 . \overline{3}$ with queens not over ten months old. Hle does not claim that both colonies will ie equal in strength, nor that one colony will gather as much as the other.

Many beekeepers will have to substitute the word "alfalfa" for " clover," or " buckwheat" for "clover."

This method of making increase, if the testimony of some of the best beekeepers in the country is to be believed, gives the largest returns, becanse all the brood is saver. The expert beekeeper will be able to make his own modifications; but the beginner will do well to follow Mr. Alesander, not forgetting the importance of young queens, daily feeding, and keeping bees in a warm hive, preferably double-walled, or singlewalled hives in packing-cases.

INSPECTORS. - Under the head of "IJaws Relating to Foul Brood" will be found references to bee-inspectors, whose duties are to discover and eradicate bee diseases. Under this head we shall attempt to give the qualifications of a bee-inspector. First of all, he should be an experienced beekeeper; second, he should have a theoretical and practical knowledge of all bee diseases, particularly those relating to brood; third, he should be intelligent, broadminded, and tactful.

Taking up the first requirement, a beeinspector will be very seriously handicapped if he does not have both a theoretical and a practical knowledge of bees, One of the most important factors in the elimination of disease is the instruction given the beekeeper on how to keep bees in the first place, on the principle that prevention is better than cure. The inspector should explain the normal conditions in a hive so that the owner of the bees will be able to recognize at once those that are irregular and abnormal. A large number of those who keep bres have but little knowledge of the business. In many cases swarms alighted on the premises and were hived. In other cases the bees were bought at auction because they were cheap; and still others, some of the family may have gotten the bee-fever, and, after building up the apiary to four or five colonies, left home. The rest of the family have but little or no interest in the bees, but are glad to get the honey if there is any. These little yards of bees, no matter how acquired, are left to shift for themselves, and the result is they afford favorable places for the attack of bee disease. Their owners are not apt to read bee-books, but will receive personally any amount of instruction on how to take care of them. A good bee-inspector, one who thoroly understands his job, can be the indirect means of putting all these little yards that would otherwise be neglected in nice shape. The owners will be getting a revenue; and if bee disease does make a start they will be able to arrest it in time.

The second requirement implies a theoretical and practical knowledge of bee diseases. If the owner of the bees discovers that a man sent out by the state does not thoroly know disease when he sees it, he is under a big handicap. If the beekeeper is himself a practical man, and discovers that $\mathrm{Mr}$. Inspector is not familiar with his job, he will probably do just as he pleases, thinking he knows niore than the representative of the state. As a general rule the bee-inspectors are thoroly informed in regard to bee diseases before they are sent out.

The third requirement is sometimes hard to meet. It is not difficult to get a man who understands bees and bee diseases; but it is not so easy to add to those qualifications the third one-intelligence and tactfulness. An inspector who goes out on tours of inspection meets all kinds of people. He should be able to size up his man at a glance. If he should approach the beekeeper and say, "T am the state inspector, and 


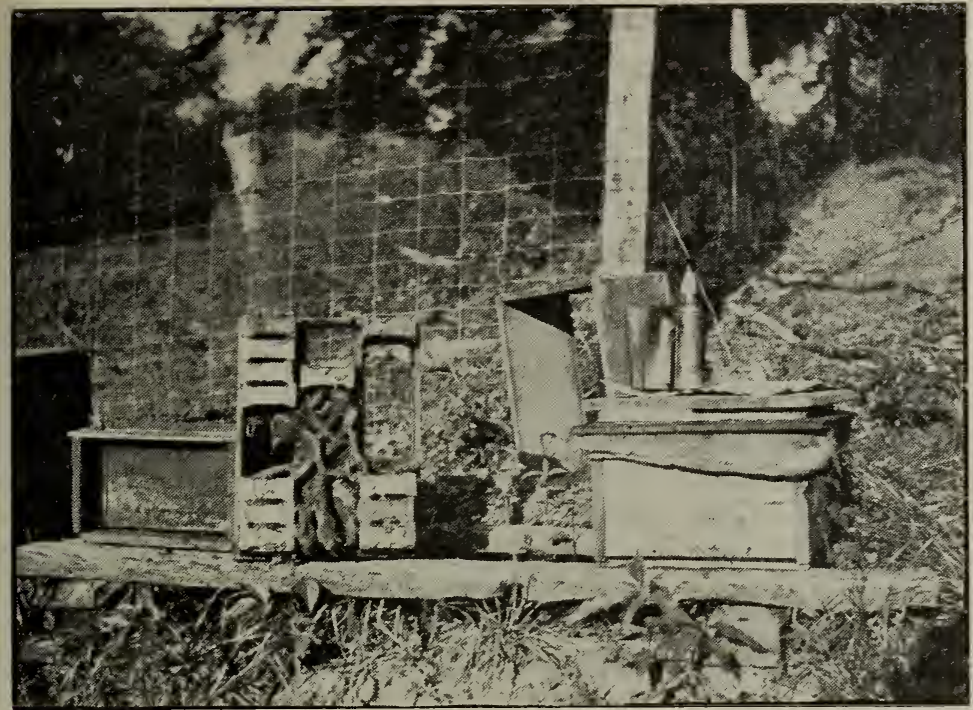

Too frequently inspectors meet conditions like this.

hardly be secured for less than $\$ 3.00$ a day and expenses. In some cases it may sometimes be necessary to pay as high as $\$ 5.00$, because a competent beeman can hardly leare his own bees and work for three months for the state at $\$ 3.00$ a day and then find his own bed and board for the remaining nine months of the year. But a good man can usually be secured for $\$ 3.00$ a day provided the state can give em$\mathrm{ployment}$ the year round. If he is a gond beekeeper and a good

I require to see your bees," he might meet with some opposition; but if, on the other hand, he approaches his man with smiles and a hand-shake, and asks him if he bas any bees, and how they are doing, he will usually meet with a pleasant response. The inspector can then say that he is sent by the state to give instructions on how to keep bees, and that if he can be of any help he is free to command, etc. Then the beekeeper will be interester. Mr. Inspector can very gracefully volunteer the statement that there is considerable bee disease in the country, and if any is present in the hives he will be glad to tell how to eradicate it. If he is tactful, he will not put forth any show of "authority," nor invade the premises without finding some member of the family. If the owner is not present he can ask permission from some one in the house to see the bees, explaining the matter in a tactful way. Usually the good housewife is rerfectly willing to tell him where the bees are, and even go with him.

\section{PAY OF INSPECTORS.}

At this day and age a good inspector can talker he can be used to give lectures and demonstrations at farmers' institutes during' winter, and he can be used to assist in various ways in the general state work outside of bee culture provided he is a man of some education and of ordinary ability.

Students from apicultural schools that are scattered over rarious parts of the country can usually be secured for a very moderate sum. These men, after haring taken an apicultural and agricultural course, have a theoretical and practical knowledge of general farm problems, such as soils, fertilizers, fruit-growing, and the like. And when it is not possible to use an inspector in the

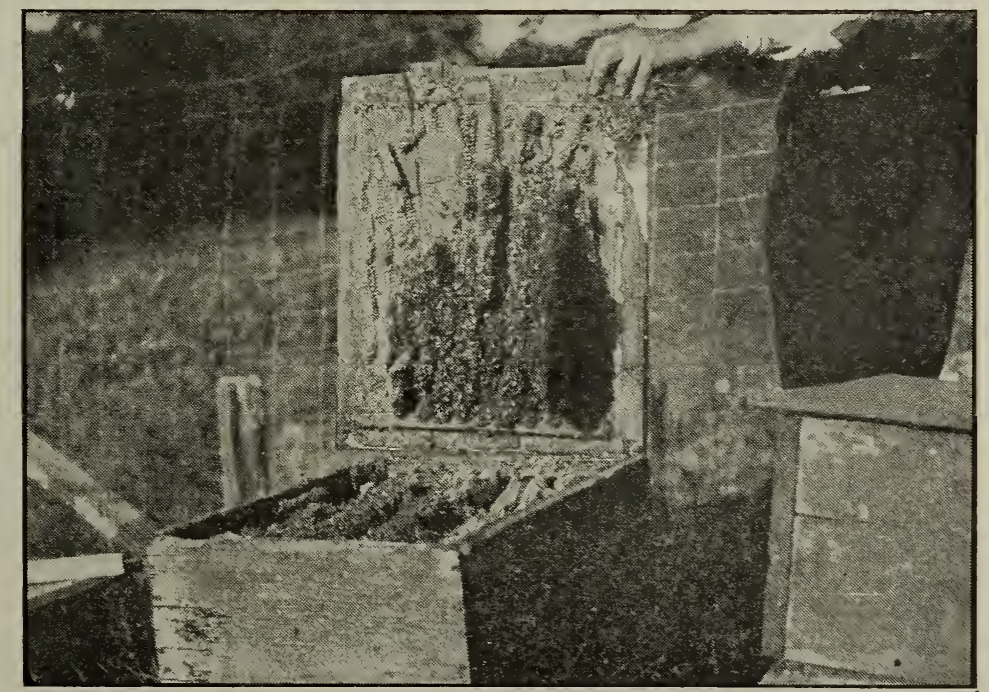

But what can the poor inspector do? 
eapacity of beework, his talent can be turned to very profitable account along other agricultural lines. It is, therefore, desirable to have a bee inspector who not only understands bee culture but agriculture in general.

The nursery inspectors who are sent out over the country are rendering excellent aid by telling farmers how to handle their fruittrees in order to keep down blight, San Jose scale, and, in general, how to secure a large amount of fruit. These men are rendering their respective states most valuable service, because there is nothing like a practical demonstration in the orchard of how to treat the trees and how to trim them so as to secure the maximum results. This kind of actual field demonstration work is invaluable, not only in urchard work but in actual beekeeping. If possible, a bee-inspector should be one who understands both orchard and bee work, as they naturally go hand in hand.

INTRODUCING.--Under normal conditions only one queen will be tolerated in a colony at a time. Should there by accident be two, when they meet there is likely to be a royal battle, until one of them is killed. So it happens that queens are, as a rule, jealous rivals; but there are exceptions. Under certain conditions, as when an old queen is about to be superseded, the young daughter may be tolerated in the hive along. with her mother--both laying side by side; but in the course of a few days or weeks the mother will be missing. Whether she dies of old age or the daughter kills her we do not know. There are other conditions where two and sometimes a dozen laying queens will be found in the hive, but under circumstances which seem to be abnormal.

Again, it may be stated that a normal colony of bees will not accept a strange queen, even tho they have no mother of their own, much less will they accept an interloper when there is already a queen in the hive. We may, therefore, lay it down as a rule that has exceptions* like all other good rules, that we cannot let loose any queen, young or old, in a colony that al-

* If a virgin queen, on returning from a matingtrip, enters by mistake a hive where there is an old laying quecn she may, and very often does, supplant the old queen. The virgin is young and vigorous, and more than a match for the old queen full of eggs. Even though the colony odor be lacking, the bees in this case accept the supp?anter. ready has one. Moreover, bees that are queenless will not, under ordinary conditions, accept another, no matter how much they may need one, until she has been "introduced." It follows, then, in the process of requeening we are compelled to put a new queen in a wire-cloth cage and confine her there (where the other bees cannot attack her) until she has acquired the same colony odor or individual scent as the bees themselves. This usually takes two or three days, at the end of which time the queen may be released and they will treat her as their own royal mother. We do not know how bees recognize each other, or how they can tell a strange queen from their own, except by scent factor.

It is a fact well recognized that a dog can pick out his master from hundreds of others thru the agency of scent; nay, further, he can track him if he loses sight of him by catching the scent of where he has walked, in spite of the fact that hundreds of other people may have gone over the same ground. This scent that is so acute in a dog is undoubtedly highly developed in the bee, otherwise we should be at a loss to account for some of the phenomena in the domestic economy of the hive. See SCENT OF BeEs.

Hence we naturally conclude that, by the sense of smell, bees recognize their own mother from a new or strange one.

Again, we learn that, if two queens have exactly the same colony odor after being caged for two or three days in a queenless hive, either one may be liberated, and the bees will accept one just as readily as the other. If both be liberated at the same time, one in one corner of the hive and the other in the opposite corner, both will be tolerated by the bees; but once the queens come together themselves there is danger of a royal battle* resulting in the death of one. From this fact we infer that the bees, providing a queen or queens have the requisite colony odor, will accept at any time one or more such queens under many conditions; that, further, when two queens have the same colony odor, if they can be kept apart by means of perforated zinc both will

\footnotetext{
*We say "danger" of a battle. Queens will not always fight when so put together. The relative ages of the queens makes a great difference. If one queen be an old one there probably will be no fight, and even if there is, the young queen will be more than a match for the old one.
} 
continue to lay eggs in the same hive without interference. This condition will be allowed so long as the colony prospers, or until a dearth of honey comes, when the bees show a disposition to rob. They may then destroy one of the queens.

Bees that have been thrown into a box or pan, and then shaken or bumped again and again until they are demoralized or frightened, are much more tractable than those not so disturbed. Such bees if made queenless just prior to the shaking, and confined without combs or brood in a cool place for a few hours, will usually accept a queen at once. The factor of colony odor then apparently does not operate, for the bees are put out of their normal condition.

Very often the queens of two colonies may be made to exchange places. The two hives are opened, and before either colony can discover that it is queenless, the queens are exchanged; but when this exchange is made, the precaution must be taken to open the hives very quietly, using but little smoke. The idea seems to be to disturb the colony as little as possible, so that their normal condition may continue. Not suspecting any change in queens, the bees are not looking for any, and allow the new mothers to go right on where the previous queens left off. On the other hand, if either colony is queenless long enough so that it sets up a loud buzzing or a cry of distress. it will be pretty sure to ball any queen that may be given it.

Young bees just hatched will at any time accept any queen. Therefore, it comes about that, when one desires to introduce a valuable breeder on which he desires to take no chances whatsoever, he causes her to be released on a frame of very young or hatching bees; but consideration will be given to this later.

Virgin queens, if just hatched, will usually be accepted by a colony, if not too long queenless, without the process of introducing or even of caging; but when one of these queens comes to be four or five days old she is very much more difficult to introduce than a normal laying queen.

When a little honey is coming in, it is much easier to introduce and unite bees than during a dearth.

A queen in the height of her egg-laying will be accepted far more readily than one that has been deprived of egg-laying, as in the case of one that has been four or five days in the mails.

Some colonies are more nervous than others. To open a hive of such on an unfavorable day might arouse the inmates to a stinging fury. Indeed, such colonies will often ball and sting their own queen when the hive is opened if the day is unfavorable.

It is easier to introduce toward night, or after dark, than during the day. The reason of this is that after dark the excitement of the day has subsided. There is no chance for robbing and no reason for vigil. In short, bees are not expecting trouble and are not inclined to make any.

A fasting queen, or, rather, a queen that is hung'ry, will usually ask for food, and hence will generally be treated more considerately than one that shows fear or fight.

A colony queenless long enough to have ripe queen-cells, or long enough to have laying workers, will not accept a queen as readily as one that has been without a mother for only a few hours. Reference to this will be made later.

Having stated, therefore, the basic principles governing the relation of the queen to the bees we can now more intelligently proceed to the methods of introduction, most of which are based on the theory that the queen to be introduced must first have acquired the colony odor of her new subjects.

The cages are supplied with bee candy (see CANDY), so that, in case the bees do not feed the queen, she will not starve. In some cases the bees release the queen by eating away the candy and letting her out. In others they tunnel under the cage by tearing away the comb, and releasing her. In still other cases the apiarist himself liberates her after she has been confined the requisite length of time, or until such time as she has acquired the colony odor.

Most of the cages are sent out by queenbreeders with directions how to perform this operation; and it is usually safer for the beginner to follow these directions implicitly.

IIALLING AND INTRODUCING CAGE.

The mailing and introducing cage that has been used over the country is called the Benton, and is shown in the accompanying illustration. This consists of an oblong block of wood with three holes bored nearly thru, one of the end holes being filled with 
soft candy (see CANDY), and the other two are left for' occupancy by the bees and queen. On the back of the cover are printed full directions for introducing, and at each end of the cage is a small hole bored thru lengthwise the grain of the wood. One hole (next to the bees) is covered with a piece of perforated metal, secured in place with two small wire nails driven thru the perforations. The other hole (that is, at the candy end) is covered over with a piece of pasteboard perforated by a line of pinholes running thru the center. The object of these perforations is to give the bees an

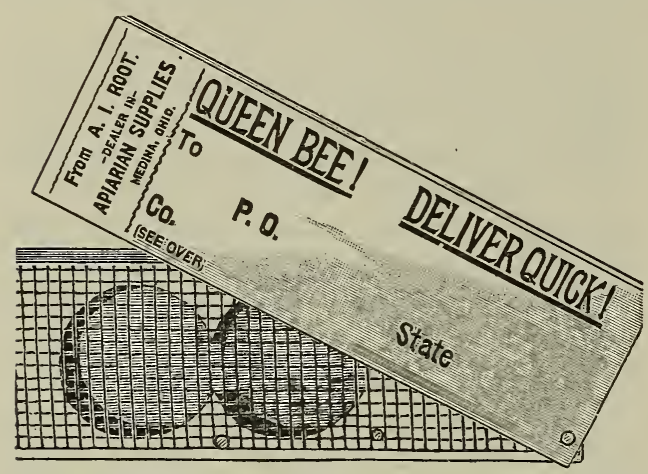

Benton mailing-cage. Postage on this cage is one cent. A larger size for longer distances, as shown next page, requires two cents.

opportunity to taste the candy thru the holes of the pasteboard; and once having gotten a sip they will gnaw the holes larger, and pull away the pasteboard entirely.

Very often, after the cage has been thru the mails, and been on the journey for several days, the bees in the cage will have consumed two-thirds or three-fourths of the candy. If those in the hive to which the queen is to be introduced gain access to the candy direct they would eat out what little there is of it in five or six hours, liberate the queen, and probably kill her. In order to accomplish introduction safely the cage should be on the frames (where the bees can get acquainted with the queen) for at least 24 hours, and longer wherever practicable. As it takes anywhere from 12 to 24 hours for the bees to gnaw away the pasteboard before they can get at the candy, and from 6 to 24 hours to eat out the candy, we are assured of at least 18 hours before the bees can release the queen; and generally the time is longer-anywhere from 24 to 48 hours. The pasteboard has another advantage, in that it makes the introduction en- tirely automatic. The one who receives the queen pries off the cover protecting the wire cloth, and then by the directions which he reads on the reverse side of this cover he learns that all he has to do is to lay the cage wire cloth down over the space between two brood-frames of the queenless colony, and the bees do the rest. It is not even necessary for him to open the hive to release the queen; indeed, he should let the colony entirely alone for three or four days, as opening the hive disturbs and annoys the bees to such an extent that very often they will ball the queen, seeming to lay to her door what must be to them a great disturbance in having their home torn to pieces.

There are several sizes of these Benton cages-the larger ones being used for longer distances. The one shown is good for 1000 miles thru the mails, altho very often used for twice that distance. This may be called a combination mailing and introducing cage. Ordinarily, if we have much introducing to do we prefer something especially adapted to the latter purpose alone; we have, therefore, used with a great deal of satisfaction the Miller introducing-cage.

As many of the readers of this work may possibly do something at mailing queens, it might be well to add a word about making the candy for Benton cages. This should be prepared as directed under Candy. It should be made several days in advance of. the time it is expected to be used; for after it has been made it will soften down and become quite sticky. If put in cages in this condition it will result in the death of the bees and queen before accomplishing half their journey. After the candy has stood several days it is likely to become soft again, when more sugar should be kneaded in. It would be better then to let it stand two or three days, and then, if necessary, knead in more sugar until it holds its consistency so that the dough is stiff, moist, and mealy. This is important. It is almost equally important to have the candy hole coated over with hot paraffine. This is for the purpose of preventing the absorption of the honey out of the candy into the wod. The candy should then be crowded into the candy hole, and then the hole in the end over which the pasteboard is to be tacked should be plugged full of candy, after which the pasteboard is nailed on. 
The manner of filling a cage with bees and queen for mailing is to pick it up with the left hand in such a way that the thumb covers the hole over which the perforated metal has been nailed, but which, before the time of filling, should be revolved around on one side or taken off entirely. The queen is first to be picked up by the wings, her head pushed into the holo as far as possible.

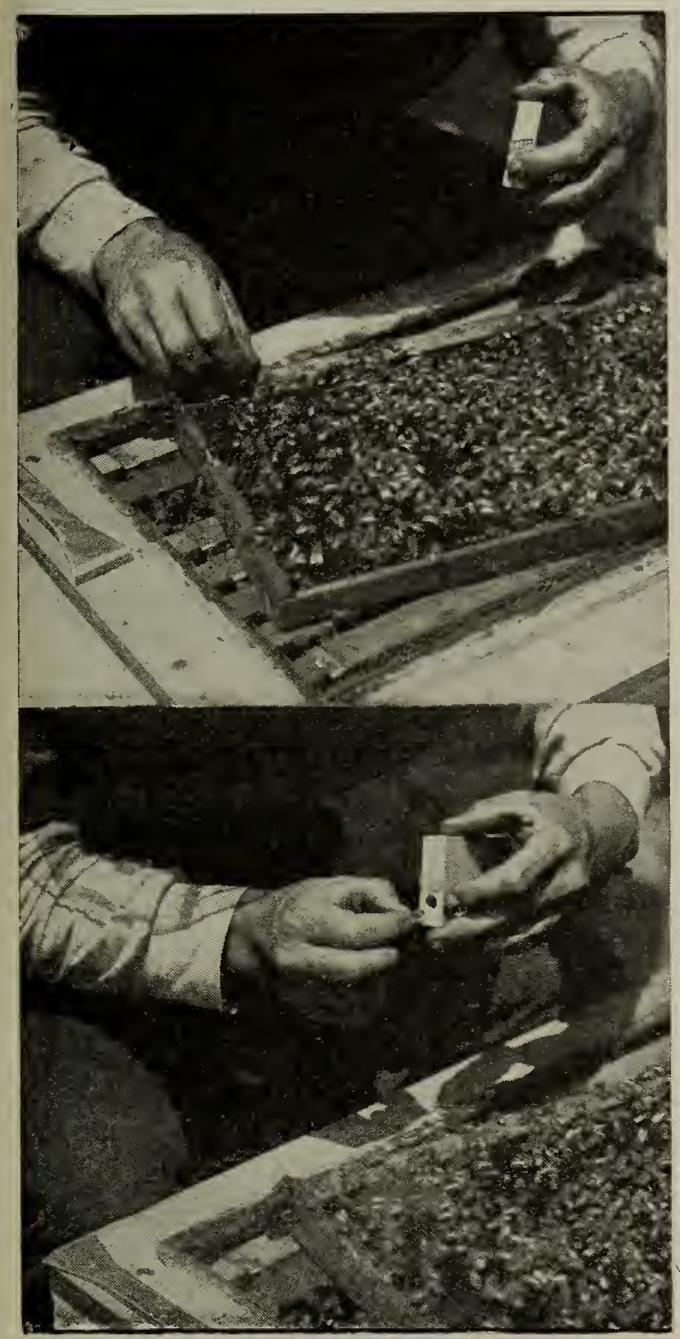

How bees and queens ore put up in a mailing-cage.

After she runs in, the thumb is placed over the hole. Worker-bees are next picked up in a similar manner, and poked in, selecting those that are filling with honey from open cells until there are a dozen bees. If the cage is larger, two dozen may be used; and if it is extra large, four or five dozen. When cages are mailed during cold weather there should be more bees put in, to help keep up the animal heat. During hot weather a dozen bees are quite sufficient in the smallest Benton cage.

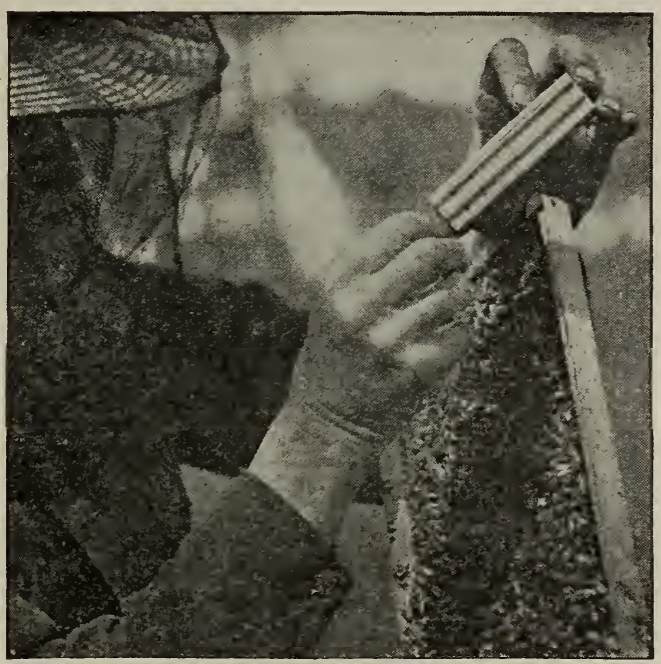

Putting queens and bees in export Benton mailing-cage.

It is very convenient to have in the apiary small special cages for introducing and holding queens that come out with swarms until they ean be introduced or disposed of. The one illustrated below is an excellent one. It is especially handy for introducing young virgins. The cage is so flat it can slide in at the entrance without even removing the cover of the hive, and the bees will release the queen by the candy method. Yet for introducing fertile or valuable queens we recommend inserting it between two combs and drawing them to-

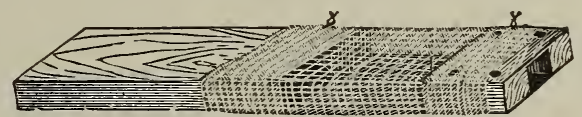

C. C. Miller's introducing-cage.

gether until they hold the cage. The queen thus acquires the scent of the combs, brood, and the cluster, and hence when released will be more likely to be accepted.

This cage, like the Benton, will give very much better results if a piece of pasteboard is nailed over the end. This the bees will gnaw away, gaining access to the candy, which they eat out. Since we discovered the value of the pasteboard used in the manner stated, with either the Benton or the Miller cage we are able to introduce a larger per cent of all queens, provided, 
of course, the colony has not been queenless more than four or five days. One that has been without a mother longer may get to depending on cells; and when the work has so far progressed they are liable to destroy the introduced queen and await the hatching of one of the virgins.

Another feature of this cage, of great importance to beginners, is as a queencatcher. It can be put down over the queen after the wooden slide is removed, and when she crawls upward the plug is replaced.

\section{THE MILLER SMOKE OR DISTRESS METHOD OF INTRODUCING.}

In 1913 Mr. Arthur C. Miller, of Providence, R. I. (who wrote the article on BEE BEHAIIOR and NUCLEUS in this work), introduced to the beekeeping world a new method of introducing queens. While one feature of it was old, the general procedure was original with Mr. Miller. Many years ago Mr. Henry Alley introduced queens by smudging the colony and queen with tobacco smoke. While the plan was successful in many instances, it was too often a failure and for that reason it seems to have been dropped. Mr. A. C. Miller's method, while similar only in the use of smoke, is enough different to make it practically new, and fairly reliable when directions are followed. There are conditions under which it is superior to any other plan of introducing queens; and some of our best beekeepers and queen-breeders use it at times to the exclusion of all other methods. It has an advantage in that virgin queens of any age can be introduced to colonies that would kill them nine times out of ten by the old methods as soon as released. Moreover, the Miller plan is found to be superior in introducing even laying queens to a colony that has been long queenless, and when the chances of successful introduction would be somewhat doubtful. Indeed, it works so well in some cases that safe introduction can be accomplished even when there is a laying queen already in the hive. If the alien queen is younger or more prolific than the old queen, the latter may be superseded automatically. The plan has been used for requeening box hives with a considerable degree of success, and that, too, without finding or removing the old queen. But the success of this method of requeening without dequeening will depend on the superior- ity of the alien over the old queen; for by the smoke method both queens will be equally acceptable to the colony; and so far as the colony is concerned it appears to be a choice between the two, resulting in favor of the better queen.

HOW TO INTRODUCE BY THE MILLER SMOKE METHOD.

The colony to receive a queen has its entrance reduced to about one square inch. Strips of wood, entrance cleats, or even grass or weeds, may be used for the purpose. The smoker bellows is worked until it turns out a white smoke - not a hot transparent smoke, as that would be destructive. Three or four long puffs are then blown in at the entrance. The amount may vary according to the size of the colony, the condition of the fuel, and the fuel itself. At all events, enough smoke is blown in at the entrance until the colony sets up a roar, which will take place in ten or twenty scconds. If the roar does not take place it shows not enough smoke has been used. The queen to be introduced is now run in, either from the fingers or from a queen-cage, and followed by a gentle puff of smoke, when the entrance is entirely closed, and left so for ten or fifteen minutes. At the expiration of that time it is reopened and the bees allowed to ventilate and quiet down, but the opening should not be wider than the original contraction of one inch, as the idea is to let the colony quiet down slowly from its distress. A full entrance is not given for an hour or more, and better not till the next day. Where grass or leaves are used they may be left to wilt and be pushed out by the bees. They are handy at outyards.

In order to make the plan work successfully there are several important requirements.

(1) The colony should not be larger than one story and the frames and bees should occupy the whole of the story. It has been found impracticable to use this plan of introduction when only a third or a half of the hive is occupied with bees and combs, for the simple reason that the bees and queen may get out of the smoke and thus be remote from the smoke that induces the necessary condition-distress.

(2) The hive must be smoke-tight. If it has gaps at the corners, or if the covers do 
not fit tightly, the bees will recover from their distress too quickly, and may kill the queen. All possible chance of ventilation must be prevented except at the entrance, and that should be opened by using only the narrow opening thru which the smoke is introduced.

(3) The smoke must be such as to create the greatest distress, and at the same time the least danger of overdoing it. There is no need of torturing the colony by causing the individual bees to curl up and lie on their backs. Just enough smoke should be given to give a general roar.

(4) Enough smoke should be used to fill every portion of the brood-chamber. This is important.

(5) The bees should be confined for ten or fifteen minutes.

(6) The whole entrance should not be opened up at the end of the fifteen minutes.

While a portion of these directions may seem like a repetition, yet the number of misunderstandings and failures that have occurred show that the essential features of the method cannot be stated too strongly.

The theory of this method is based on the principle that bees in distress know no enemy or alien. Each is looking to the other for help or food. The colony spirit is entirely broken up, and every bee that comes under the influence of the uproar is seized with the same emotion, to be relieved of her distress. It is important, also, that the queen be under the same spell or influence; hence the directions to follow her up, after she goes into the hive, with a puff of smoke.

This method can be used for introducing virgin queens five or six days old. Such queens are usually rejected by a colony, or even by a nucleus. These six-day-old queens after introduction by this plan have been known to take a flight the very next day, and to be laying shortly after.

The question might be raised here, why the smoke or distress method is not used in the directions for introducing sent out by queen-breeders in the mailing-cages containing queens. The reason of it is, there are some very nice points in introducing by the distress method, and the average beginner will succeed better by the cage plan. As a general thing, queen-breeders use the cage plan for introducing virgins, which are usually quite young, because it takes less time to go thru the procedure of introduction. An introducing-cage is inserted between the frames and left there. That is all there is to it. The smoke method of introducing requires considerable time and a great exactness of procedure, or the plan will fail.

But the general scheme is so useful that experienced beekeepers can use it to very great advantage. The beginner or veteran should understand that, when he tries it for the first time, he must follow exactly the method outlined.

PUSH-INTO-COMB-CAGE PLAN OF INTRODUC-

ING.

During 1911 and '12 there was considerable discussion in the bee journals concerning the method of introducing known as the push-into-comb-cage plan-that is to say, a plan which permits of a queen being caged over a few cells of honey and brocd. This is accomplished by taking a square of wire cloth of suitable size and cutting a small square out of each of the four corners. The projecting ends are then folded down so as to make a wire-cloth box without bottom. This is pushed into a broodcomb with the queen under it. If it is not pushed in too deep, the bees will usually release her in 24 to 48 hours by gnawing under or tunneling under the wire cloth. Reports of this method of introducing have been uniformly favorable, and one reason for this is due to the fact that the queen has immediate access to cells of honey; and if she should lay a few eggs in the comb before she is released she will have the odor of a laying queen, and this odor is one of the elements that go to make up successful introduction.

Some years ago one of our prominent queen-breeders offered to replace all queens that he sent thru the mails, providing this plan of introduction were followed. $\mathrm{He}$ reported that it was so successful that he scarcely ever had to replace a queen; and he believed that these replacements were due mainly to the fact that the recipient failed to carry out his instructions.

But one difficulty with a plan like this is that not every one will have on hand the proper material nor have the necessary skill for making up a cage of this sort. Another and more serious difficulty is the problem of getting the queen transferred 
from the maiting-cage to the introducingcage pushed in the comb, without injuring her or allowing her to get away during the process. Another difficulty is that some push the cage into the comb so far that the bees fail to release her, altho in such cases no harm results, because the apiarist can remove the cage and release her.

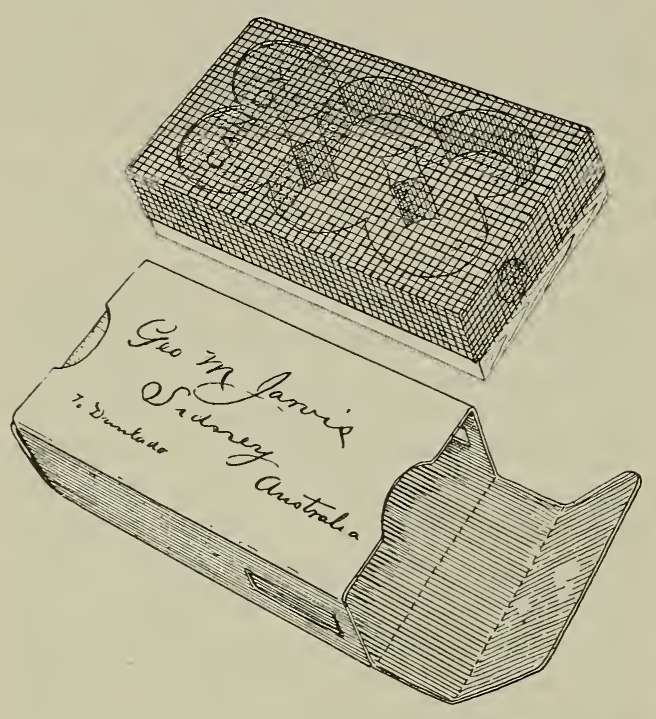

The mailing and introducing cage with carton.

The difficulty of making a combination cage so that both can be sent in the mails, and at the same time not increase the postage, is solved by making the introducing-cage of just the right size to telescope over the mailing-cage. Both can then be slipped into a neat carton to stand the rough usage of the mails. The accompanying illustrations will show how this scheme can be carried into execution.

The following are the directions that are used in cages of this kind:

On receipt of the queen go to the hive where she is to be introduced, and remove the old queen, and, before the bees discover that the old mother is gone, cage the new queen among them. To do this, select a comb containing hatching brood, eggs, and cells of honey. Find a spot on the comb where there is hatching brood, eggs, and cells of honey contiguous in a spot about the size of the cage. If there is no hatching brood, cells of pollen and honey will do very well. Shake the bees off the comb and carry comb and queen received from the mails into the house before a window.

Gently raise the wire-cloth top that telescopes over the wood part until it is almost off. Wait a few moments until the queen works her way upward on to the wire cloth; then quickly lift the wire-cloth cover, with queen on it, off the wood part and shove it on to the selected spot on the comb. If, dur-

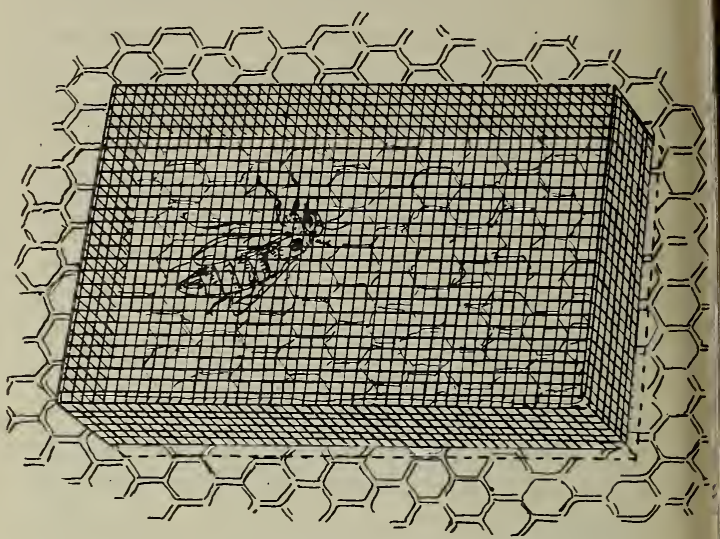

Cage pushed into the comb, showing the manuer of introducing the confined queen.

ing the operation, she flies, don't get excited. She will quickly go to the window, where it will be easy to cage her by gently slipping the wire-cloth introducing part over her.

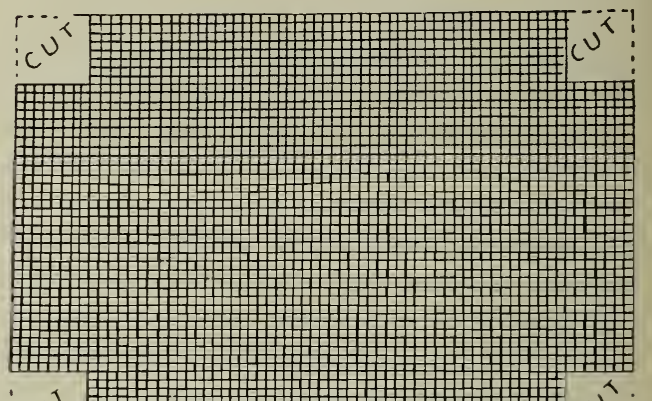
$\iota^{v} \nu^{v}$

The manner of folding the cage.

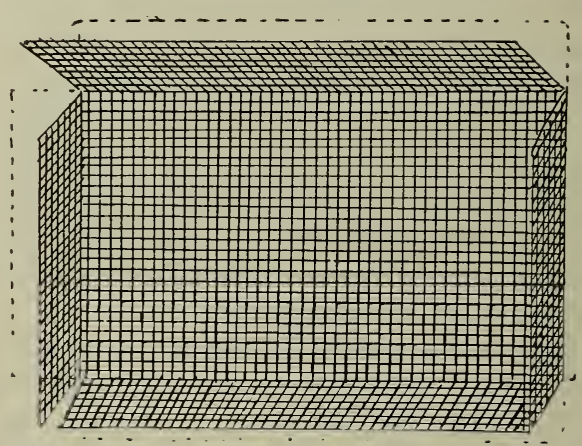

Wire-cloth corners cut out before folding to make the introducing cage that telescopes over the wooden part.

The next operation is to slide a postal card between the wire-cloth cage and the window, being careful not to pinch the queen in the operation. Lift cage and all with the postal card away from the window, and lay both on the comb. Gently draw out the postal 
card until the queen prawls on the comb, then shove the wire-cloth cage down into the comb about a quarter of an inch. In doing this, care should be exercised so there may be no gaps at the corners where the wirecloth sides and endis are folder down.

In from 24 to 48 hours the bees may tunnel under and release the queen. If at the end of 48 hours the queen is not out, she may be released by pushing a pencil thru the comb from the side opposite where the queen is caged. In an hour or so the queen will find her way out easily. It is important that she should have her liberty when conditions in the colony are entirely normal. A disturbed colony, or one that is opened up and pulled to pieces, is much more apt to ball a queen than one that is going on with its regular routine.

One very great advantage with this form of introducing is that it avoids the possibility of transmitting bee diseases thru queen-cage candy. See Foul Brood. If the candy is made of honey that has come from a hive infected with foul brood, it would be the means of carrying the disease thru the queen-cage to the hive, provided the candy method previously describsd were used. To offset this difficulty the Postoffice Department. during the early part of 1912. issued a ruling (which ruling is still in effect) that no queen should be sent thru the mails unless accompanied by a copy of a certificate from a bee inspector or a copy of a sworn statement to the effect that the queen-breeder boiled his honey that he used in his queen-cage candy for thirty minutes in a closed ressel; but not every one would do this work properly, and perhaps not every queen-breeder would be conscientious in carrying out this regulation. If the push-into-comb-cage plan were used, it would eliminate all possible carrying of disease in this way unless the recipient of the cage were careless enough to throw it outdoors where his bees could get at it; and he would hardly do that. See CANDr.

\section{A SURE WAY OF INTRODUCING.}

There is one perfectly sure way of introducing a very valuable queen, such as an imported one, if the conditions are observed carefully. Two or three frames of hatching brood are removed from several hives: every bee is shaken off, and the brood put into an empty hive closed down to a small space; and unless the weather is very warm. the whole is placed in a warm room, or over the hive of a strong colony with screen wire cloth between the two. The queen and her attendants are let loose in this hive, and the young bees, as they hatch out, will soon make a colony. As several who have tried this plan have been so careless as to leave the entrance open and let the queen get out, the beginner is warned especially to have the hive closed, so that no bee can by any possibility get out.* If the frames selected contain no unsealed brood, there will be very little loss; but otherwise the larvæ, having no bees to feed them, will mostly starve. As soon as a few hundred bees are hatched, the queen will be found with them, and they will soon make a cluster. When the combs hare been taken from strong colonies, where the queen is laying hundreds of eggs in a day, the colony will become strong in a week or two. Three frames will do very well at first, and one or two more may be added in the course of a week or two. No live bee is to be given to the queen, and the hive must be kept in a warm place-the nearer $: 0$ degrees $F$. the better.

\section{INTFODUCING TO YOUNG BEES.}

There is another way that has proved to be good. In order to describe it we can do no better than to make an extract from an editorial in Gleanings in Bee Culture, page 539, Vol. XXI.:

We have just received a consignment of 30 imported Italian queens, direct from Italy, by express. Every queen came thru in good order, and they are now introduced into the apiary without the loss of one. Our method of introducing with this lot was something we had not tried before on so large a number of queens. We took four or five strong colonies, and divided them up into 30 one-frame nuclei. This was done in the forenoon. In the afternoon we transferred the imported queens, without any attendants, to Miller introducing-cages, placing one in every nucleus above mentioned. Most of the queens were out at the expiration of two days, in good order, and they are now all out.

You see, the point is here: These newly divided nuclei will have old and young bees, and more or less hatching brood. Before the imported queen is released, the old bees will have returned to the old stand, and it is these old bees that always make trouble in introducing. $\mathrm{By}$ the time the queen is released, there are none but young bees, including those that were brought to the nucleus-stand and those that are hatched out in the interim. These, of course, all being

* The entrance can be opened in four or fire days. 
young, will accept their new mother, without any trouble. The plan has proved to be so satisfactory that we shall employ it hereafter for all valuable queens.*

\section{DIRECT METHOD OF INTRODUCTION.}

Where it is desired to introduce a queen from a nucleus to a queenless colony, both in the same yard, the operation can usually be performed with safety and with very little labor, as follows: The colony to receive the queen should be made broodless a few hours in advance. Go to the nucleus and lift out two frames, bees and all, with the queen in between. Put these down in the center of the queenless colony; close up the hive and don't go near it for several days. The bees that have been queenless and broodless are crying for a mother. When she is given them with a large force of her own subjects, she seems to be protected, even if she does not have the odor of the new colony which, by the way, has been modified by the bees and brood given them from the other hive.

This is a modification of the Simmins direct method of introducing. It could not be used in the case of a queen sent thru the mails.

\section{THE SIMMINS FASTING METHOD.}

While this has been discussed to a greater or less extent in the bee-journals, the plan, while very simple, is not one that we would recommend in the case of a valuable queen, or in any event to a beginner. It is as follows: The queen to be introduced should be put in a cage at night without attendants and without food. She should thus be confined for thirty minutes when she must be released at dusk over the frames of the queenless colony. The hive is not to be opened again for 48 hours.

\section{DUAL PLAN OF INTRODUCING.}

Another plan is to introduce two virgins or laying queens at one operation to save the necessary time it takes for the bees to get acquainted with the queen. This is described in detail under the head of QUEEN-REARING, to which the reader is directed.

* I've used the same plan with a full colony. Set the colony on a new stand, leaving the old stand a hive with a frame of brood to catch the fielders. After introduction the hive may be returned.-C. C. MiLLer.

\section{HOW SOON WILL AN INTRODUCED QUEEN BEGIN TO LAY?}

As a general thing, we may expect her to begin laying in a couple of days; but sometimes, if the queen has been a long time prevented from laying, as in the case of an imported queen, she may not lay for three or four days, or even a week. If introduced in the fall, she may not commence laying at all until spring, unless the colony is fed regularly every day for a week or more. This will always start a queen that is good for anything if the weather is warm enough.

\section{HOW TO TELL WHETHER A COLONY IS QUEEN- LESS OR NOT.}

Having discussed mailing and introducing cages, it may be pertinent at this point to give one of the prime essentials in successful introducing. The very first thing to be determined before an attempt to introduce is made, is to determine that the colony is certainly queenless. The fact that there may be no eggs nor larvæ in the hive, and that the queen cannot be found, is not sufficient evidence that she is absent, altho such a condition points that way. But during the earlier part of the summer there should be either brood or eggs of some kind if a queen is present. Yes, there should be eggs or brood clear up until the latter part of summer. In the fall in the northern states, or after the honey-flow is over, old queens generally stop laying, and shrivel up in size so that a beginner might conclude that the colony is queenless, and therefore he must buy one. In attempting to introduce the new queen, of course he meets with failure, as she is stung to death, in all probability, and carried out at the hiveentrance. If eggs or larvæ cannot be found at any season of the year when other stocks are breeding, and the supposedly queenless colony builds cells on a frame of unsealed larvæ given them, it may be concluded as a general rule that the colony is probahly queenless, and it will be safe to introduce a new queen. But when eggs, larvæ, and sealed worker brood are found, the presence of queen-cells simply indicates that the bees are either preparing to supersede their queen or making ready to swarm. See Swarming.

We said old queens would stop laying in the fall if no honey was coming in. It 
should be noted that young queens will lay, flow or no flow.

HOW LONG SHALL A COLONY BE QUEENLESS BEFORE ATTEMPTING TO INTRODUCE?

Colonies that have not been queenless more than a couple of days are to be preferred - just long enough to determine whether cells start, and just long enough so the bees begin to recognize their loss, but not long enough for them to get cells under way. Cells nicely started or capped over are quite apt to make the colony act as if it wanted something of its own; and when a laying queen is introduced to them they take a notion sometimes that they won't have anything but their own raising.

The worst colony to introduce a laying queen to is one that has been queenless long: enough so that there is a possibility of one or more virgin queens being in the hive. It is hard to decide definitely in all cases when such colonies are queenless. Most virgins, after they are three or four days old, are very apt to be mistaken for workers, especially by a beginner.

\section{WHAT TO DO IF BEES BALL THE QUEEN.}

When queens are introduced in the oldfashioned way-that is, before cages were constructed so as to release queens automatically-much trouble was encountered by bees balling queens. If they were not ready to accept her when she was released by the apiarist, they were pretty sure to ball her. But here is a point that it is well to observe: When the bees let out the queen they very rarely ball her. But when it is necessary for the apiarist to perform the work, opening the hive, accompanied by general disturbance, is apt to cause them to ball her as soon as released. Suppose they do. The ball should be lifted out of the hive and smoke blown on it until the bees come off one by one; but hot smoke must not be blown on the queen. When the queen is found, get hold of her wings and pull the rest of the bees off from her by their wings. Put more candy in the opening, and give her another trial. The advice has been given to drop the queen, when she is balled, into a vessel of water. The angry bees will immediately desert the queen, when she can be easily taken out of the water, and recaged.
Another way of saving the queen without having to recage her is to carry a small oilcan with a spring bottom, such as is used on a sewing-machine, filled with thin syrup. When the bees are found balling her, saturate the ball thoroly by pressing hard upon the bottom of the can, causing the syrup to penetrate thru the ball. Close the hive and the bees will turn their attention to cleaning themselves and the queen, when she will be accepted without further trouble.

It may be well to explain in this connection that bees are very much more apt to ball a queen that shows fear than one that behaves as if she expected kind treatment. If a new queen just introduced throws up her feet, and squeals, she is pretty sure to get into trouble.

WHAT TO DO WHEN THE QUEEN FLIES AWAT.

Sometimes a beginner is rery nervous, and by a few bungling motions may manage to let the queen escape from the hive where he expects to introduce her. Or this may happen: The queen may take wing right from the frame - become a little alarmed because there are no bees about her, and fly. In either case, one should step back immediately after opening the hive, and in fifteen or twenty minutes she is quite likely to return to the same spot and enter the hive. If she is not discovered in the hive in about half an hour, she may be found in other hives near by. If a ball of bees somewhere down among the frames is found, it may be surmised that here is the queen that flew away, and that she has made a mistake, ard entered the wrong hive.

\section{INTRODUCING VIRGIN QUEENS.}

As previously explained, a young virgin just hatched, generally weak and feeble, can usually be let loose in a queenless colony without caging, and be favorably received; but one from two to six days old is, as a rule, much more difficult to introduce than a laying queen; and one ten days old, more than old enough to be fertilized, is most difficult. Such queens can be introduced to a strong vigorous colony by using the Miller smoke or distress method. Better by far give them a cell or a virgin just hatched, thus saving time and rexation; for even should the old virgin be accepted, she may be deprived of a leg, or be so deformed from rough treatment as to 
become in a large measure impaired for usefulness. Under head of QUEEN-REARING is described "baby nuclei;" and, as already stated, it is much easier to introduce any queen, either virgin or laying, to a nucleus or weak force of bees than to a strong vigorous colony; so if one would attempt to introduce four or five day-old virgins, give them to nuclei--the smaller and weaker the better, or use the Miller smoke method.

INVENTIONS RELATING TO BEE CULTURE.-It would be quite impossible in the limits of an article in this work to record all the inventions relating to bee culture; but it is perfectly feasible to include those that have been adopted, and which are in r.se more or less by the progressive beekeepers of the country.

There are four inventions that revolutionized the methods of work with bees, and which really form the basis of all modern methods of management today. First and foremost was the invention of movable frames by I. L. Langstroth in 1851. No one today, either in Europe or this country, questions Mr. Langstroth's right to the honor of this great invention, for practically all hives and frames in use today are Langstroth. (See Frames; also HiveIIAKING.)

Next followed the invention of comb foundation by J. Mehring, in 1857. But the foundation he made had no side walls, and so it remained for Samuel Wagner, twenty years later, to develop the product that we now use with side walls.

The next was the invention of the honeyextractor, by Major Francisco Hruschka, in 1865. The fourth was the invention of a bellows bee-smoker by Moses Quinby.

There have been a large number of improvements that have made the inventions of Langstroth, Mehring, and Hruschka much more workable than they were originally. However, it is but fair to say that Langstroth came very near making his hive and frame almost perfect at the very start; and there are possibly thousands of our readers who would consider the later improvements made in the Langstroth frame and hive of doubtful value. It is, nevertheless, a fact that the old movable frame, as first made by Mr. Langstroth, both as ble extractor was put on the market. The Cowan principle was applied to the regards dimensions and styles, is still in use all over the world. For extracting purposes some of our large honey-producers will have no other. They regard anything in the way of a self-spacing attachment, either as part of the hive or frame, as unnecessary, and a backward step. (See Frajes, Self-Spacing.)

The original comb foundation by Mehring was a rery crude product; and it may be questioned whether or not Wagner should not share equal honor in the invention. The great improvements that were made in this article had more to do with the machinery for making the product than the thing itself. A. I. Root did more to perfect comb foundation than perhaps any other man unless it was his colaborer and mechanic, Mr. Alva Washburn. He certainly introduced it to the beekeeping public. The first foundation was turned out on plates, and was, therefore, a very crude article; but $\mathrm{A}$. I. Ront conceived the idea of having it made by means of a pair of rolls. This suggestion came to him when noticing the wet clothes as they came out from a common wringer in his own home. After consulting his friend and mechanic, Mr. Washburn, a pair of rolls were made, the product of which was fully the equal of any comb foundation made on modern machines. To Mr. Washburn belongs the credit of making perfect foundation on rolls that were mechanically correct. The only improvement made on the Washburn mills was in the methor of making them, by which they could be turned out for one-fifth the cost, thus enabling every beekeeper to own a comb-foundation machine. Later improvements were made by E. B. Weed, which will be referred to later.

As regards the invention of ${ }^{\circ}$ Hruschka, several machincs were made and put on the market. The one made by J. L. Peabody consisted of a can that revolved without gearing. The limitations of this were such that very few of them were ever sold. To A. I. Root belongs the credit of making some of the first all-metal extractors that use gearing, a stationary can, a reel with baskets to hold the combs, said reel connected to the gearing, and mounted to revolve independently of the can. Thousands and thousands of these machines were sold, and very little in the way of improvement was made until the reversi- 
ble extractor was put on the market. The Cowan principle was applied to the two-frame machines, and later came the Root principle of a series of baskets geared together in such a way that the reversing of one pocket reversed all at the same time. Again came the invention of Mr. Frank G. Marbach, by means of which the pockets could be reversed automatically by simply applying a brake and slowing down the speed of the machine. This was followed by a slip gear and better mechanism, by which the extractor of today has from two to ten times the capacity of the earlier machines. In this connection mention should be made of the honey-pump that is now being used successfully on the large-sized extractors to delirer the honey from the extractor to a tank abore or anywhere else.

The fourth important inrention is the bee-smoker. Quinby was the inventor of the bellows bee-smoker, which he brought out in 1875. This was further improved by T. F. Bingham, L. C. Root, and H. H. Root, younger son of A. I. Root. The modern bee-smoker is almost as indispensaable as an extractor and morable frames; for without smoke, applied by means of a convenient instrument, the work of handling bees would be disagreeable if not impossible at times. The invention of father Quinby forms the basis of all the modern smokers. But to T. F. Bingham belongs the credit of devising a smoker that blows air into the fire-cup without sucking any smoke into the bellows. Mr. Bingham's invention consisted in leaving out the tube connecting the two parts of the instrument. While that at first thought might seem to be no invention, yet it made all the difference in the world between a workable tool and an unworkable one. The latter would go out and clog up with creosote, while the former would continue burning, burn any kind of fuel, and not clog up.

E. B. Weed, formerly of Medina, was the inventor of what is known as the "Weed New Process" for making comb foundation of a very superior kind in large quantities. His automatic machinery, with Washburn's and Howk's improvements for turning out the product, is now used in nearly all civilized countries of the world. This invention almost ought to be classed among the four great inventions.
An inrention which is now in almost unirersal use, in this country at least, is that of the late Julius Hoffman, in what is known as the Hoffman self-spacing frame. While the old-style Langstroth non-spacing frame was once the leader, vet during late years the Hoffman-Langstroth is one that is listed by large and small manufacturers and dealers all over the country. It is an invention that has come to stay. Howerer, the present Hoffman frame is not the same as the original Hoffman; or, to put it in another way, the modern Hoffman retains only the self-spacing end-bars of the original, and not the Hoffman top-bar.

Another improrement was suggested by Mr. Francis Danzenbaker - namely, the lock cornering on hives. This feature has now come to be adopted by all modern hive-makers thruout the United States, and, to a great extent, thruout the world.

The inrention of the sectional honey-box is not attributable to any one person; however, A. I. Root was the first to make one holding one pound. His first pound sections were doretailed all around. Later on came the inrention of the one-piece section, on which J. H. Forncrook secured a patent; but after long litigation from one court to another, the Supreme Court finally declared it "null and roid for want of novelty." It was shown that one J. Fiddes and a number of others had made and used sections of this kind; so in the matter of one-piece sections the honor will have to be divided among four or five different people. The late James G. Gray, of Medina. made the first practical machine for making one-piece sections. Later. machines for turning out section honey-boxes in lots of one hundred thousand a day were the invention of Mr. George L. Howk.

The Porter bee-escape is one of the best little inventions that have been brought out. It is one of the few patented inventions that survived. It is used very largely by comb-honey producers.

Queen-excluders in the form of perforated zinc and spaced wires are inrentions of merit. In connection with these we find entrance-guards and Alley traps that are useful. The Alley trap is another patented invention that survived.

The new steam uncapping-knife (see ExtractiNG) is an invention that is coming more and more into use. The capping- 
melter for melting cappings as fast as they come from the knife gives promise of being one of the inventions that will last; for it enables a competent man who follows directions to melt his cappings and separate the honey from the cappings immediately, so that when the day's work is done he will have his honey free from cappings, and the cappings converted into wax ready for use.

Mr. Arthur C. Miller was the discoverer or inventor of the principle that is now used in all modern foundation-fasteners using a hot plate; yet, strangely enough, not one of these fasteners bears his name. Mr. Miller was also the inventor of two or three different uncapping-machines, and of the steam-heated uncapping-knife. If he had applied for letters-patent on this kind of knife it would have been granted him, and he would be today considered the inventor, as he really is, of the steam-heated uncapping-knife.

Mr. T. F. Bingham and Mr. Hetherington were really the inventors of the modern uncapping-knife popularly known as the Bingham. The Bingham - Hetherington shape is now used in all uncapping-knives, whether steam-heated or plain.

No one seems to have invented the double - walled packed hive for outdoor wintering; but A. I. Root was, perhaps, in connection with Mr. J. H. Townley, the first to apply the principle of chaff packing in double walls. As chaff is not now obtainable, other packing material is used. Langstroth in the early '50's used double hives but not packed.

In the early ' 80 's there were a hoard of inventions relating to feeders, foundationfasteners, and reversing attachments for movable frames, nearly all of which died a natural death because they were impracticable and only increased the cost of management.

Among the later hive inventions that have merit is the Aspinwall hive, based on the principle designed to prevent swarming. (See Swarming.) Whether this will ever come into general use remains to be seen; but its cost of construction, and the large number of extra parts that must be manipulated at intervals, will probably prevent this hive from displacing the standard hives in use to any great extent. The swarming problem is not a serious one in the production of extracted honey; and while probably three-fourths if not fourfifths of all the honey produced in the world is extracted, it will be seen that there will be a very limited demand at best for non-swarming hives.

In the way of minor inventions or improvements mention should be made of the omission of porticos on hives by A. I. Root, and of bevel edges between the parts of the hives. A hive plain and simple, with a detachable bottom-board and a plain simple cover, is much more workable than some of the complicated domiciles of the early days with moth-traps, porticos, etc.

It is another improvement to have the hive body and supers of the same dimensions and the same depth, except in the case of half-depth supers. In a word, the modern hive is made up of multiples of parts that will fit each other in any combination, permitting of any degree of expansion and contraction to accommodate a large or small colony. This feature of interchangeability is prized almost as much as any one single invention, barring only the four great inventions first mentioned.

It might be interesting and perhaps enlightening to some would-be inventors to record here a list of the inventions that have died a natural death. Some of these at the time were heralded as revolutionary; but they never "revolutionized," but, on the contrary, sickened and died, as thousands of others had done. It is well that they did.

It is but fair to say to inventors that a patent or patents on any invention or improvement relating to bee-feeders, methods of wiring frames, or foundation-fasteners, are generally a waste of time, and can only lead to disappointment. There is a large list of patents in the Patent Office covering all forms of bee-feeders, not one of which is equal to any of the unpatented feeders described under the head of FEeDERS. In the same way it is a waste of time to try to invent a beehive, something new and better than those that are generally accepted by the fraternity at large. Every conceivable form of hive has been made the subject of a patent. With perhaps a dozen important exceptions there is hardly a patent on bee-fixtures that is worth the paper on which it is printed; and the beginner, 
at least, will be very wise if he accepts the standard hive and appliances which are described in this or any standard work on bees. It is true, patents will be granted on almost anything; but any one who is familiar with patent claims knows that they can be and usually are so loosely drawn that they are worthless. The poor inventor supposes that because he has been granted a government parchment a fortune awaits him. But he is doomed to disappointment as sure as fate. (See Patents, elsewhere.)

\section{INVERTING.-See REVERSING.}

INVERT SUGAR.-Chemically considered, this is a mixture of equal parts of the two sugars, dextrose and levulose, coming from the inversion or breaking down of sucrose. In common terms, sucrose is the ordinary white sugar of commerce, such as beet sugar or cane sugar. This breaking down of sucrose occurs when it is dissolved in water and boiled. The action then is very slow; but by the addition of a very small percentage of any acid the action is made more rapid. Hence, in the commercial preparation of this product white sugar is dissolved in water, then tartaric, acetic, phosphoric, or hydrochloric (muriatic) acid is added and the whole boiled. Of the two sugars of invert sugar, dextrose is easily crystallizable, while levulose remains a liquid under most conditions, but on long standing and under concentration the dextrose will crystallize out. As regards sweetness, dextrose is not so sweet as sucrose, while levulose is much sweeter; hence invert sugar is generally said to be sweeter than sucrose.

The preparation of invert sugar from sucrose by using water and tartaric acid was patented a number of year's ago by Herzfeld in Germany. The proportion he uses is approximately as follows: cane sugar, 25 lbs.; tartaric acid, 1/2 oz. (avoirdupois); water, 1 gallon. Bring to a boil and keep at that temperature for $1 / 2$ to $3 / 4$ hour.

When prepared as above the product is liable to be yellow or brown in color, but it is perfectly possible by concentrating in vacuum or under reduced pressure to produce an invert sugar water-white. It can be made to appear like a high-grade clover honey. Its analysis is very similar to that of a clover honey.
During the preparation of this sugar, a small amount of the levulose is broken down into furfurol or methylfurfurol. This product even in very small quantities gives strong color reactions with some reagents as resorcin-aniline acetete which forms a partial test for invert sugar.

Attempts have been madc to make invert sugar which would not give these color reactions, but on a commercial scale they have not been altogether successful. The enzyme, inrertase (from yeast) will break down sucrose into dextrose and levulose without the formation of these furfurol bodies, but on concentration these bodies are formed. Other ways have been tried. It is true, tho, that invert sugar can be made commercially that gives only slight color reactions, and improvements in manufacture of late years have vielded a product which has rery much less of these furfurol bodies present, but the chemist does not need these color reactions altogether to prove the presence of commercial invert sugar in honey.

Commercial invert sugar is generally put ou the market as a water-white liquid at the same price as granulated sugar. It has anywhere from 50 per cent to 75 per cent invert sugar, from 1.5 per cent to 30 per cent of sucrose, and from 1.8 per cent to 30 per cent of water. If a mineral acid as phosphoric, muriatic, sulphuric is used for the inversion, this is generally partially neutralized with soda, and hence the product will have anywhere from 0.5 to 3.08 of ash. Where acetic acid or phosphoric acid unneutralized is used, or where tartaric acid is used, there is practically. no ash unless the sucrose carried some. For the detection of commercial invert sugar see Honey Analysis and Adulteration.

\section{ISLE OF WIGHT DISEASE. - See Diseases of BeEs.}

ITALIAN BEES.-At present the Italians, and eren hybrids, have shown themselves so far ahead of the common bee that we may safely consider all discussion of the matter at an end by the great majority of beekeepers. Many times we find colonies of bybrids that go ahead of pure stock; but as a general thing (taking one season with another), pure Italians, where they have not been enfeebled by choosing 
light-colored bees to breed from, are ahead of any admixture. There has been a great tendency with bees, as well as other stock, to pay more attention to looks than to real intrinsic worth, such as honey-gathering, prolificness of the queens, hardiness, etc.

Even if it were true that hybrids produce as much honey as pure Italians, each beekeeper would want at least one queen of absolute and known purity; for altho a first cross might do very well, unless he had this one pure queen to furnish queen-cells he would soon have bees of every possible any time and their queens removed, scarcely disturbing the cluster, and, as is sometimes the case, without the use of any smoke, by one who is fully conversant with the habits of bees. A good many hybrids will not repel the moth as do the half-bloods and the pure Italians. For these reasons and several others we would rear all queens from one of known purity.

The queens, and drones from queens obtained direct from Italy, vary greatly in their markings, but the normal worker bee shows three yellow bands.
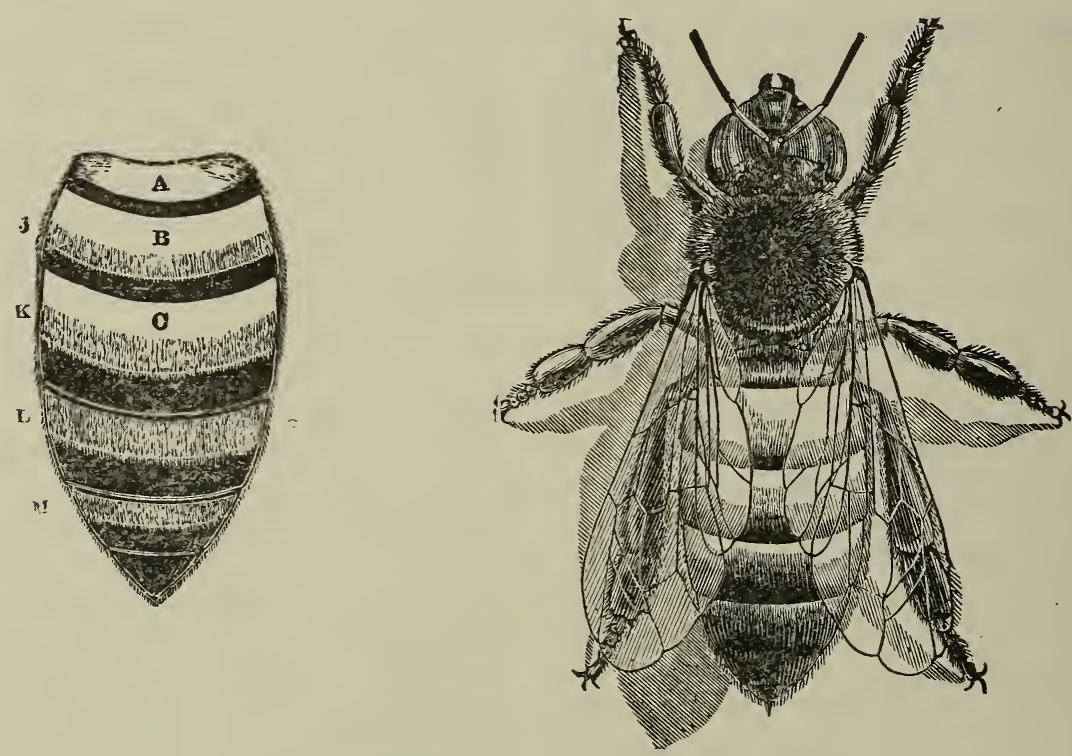

Characteristic markings of pure Italians.

grade, from the faintest trace of Italian blood, all the way up. The objection to this course is that these blacks, with about one band (with the exception of the Eastern blood), are about the worst kind of bees to sting, being very much more vindictive than either race in its purity; they also have a very disagreeable way of tumbling off the combs in a perfectly demoralized state whenever the hive is opened. Neither will they repel bee disease like pure Italians. See Foul Brood, subhead "European Foul Brood;" also "HrbRIDs." If for no other reason, one can well afford to Italianize because in no other way can European foul brood be controlled. This disease, in some sections of the country, is cleaning out the blacks and hybrids, while the Italians are nearly immune to it.

Our pure Italian stocks can be opened at
While the presence of three yellow bands has for many years been supposed to be an absolute test of purity, recent work by Prof. Wilmon Newell, then of College Station, Texas, shows that this may not be entirely correct. But reference to this is made later.

Every worker-bee, whether common or Italian, has a body composed of six tubes, or segments, one sliding into the other, telescope fashion. When the bee is full of honey these segments slide out, and the abdomen is elongated considerably beyond the tips of the wings, which are ordinarily about the length of the body. Sometimes we see bees swollen with dysentery spreading the rings to their fullest extent, and in that condition they sometimes would be called queens by an inexperienced person.

On the contrary, in the fall when the bee is preparing for its winter nap, its abdo- 
men is so much drawn up that it searcely seems like the same insect. The engraving on the left shows the abdomen of the bee detached from the body, that we may get a full view of the bands or markings that distinguish the Italians from our common bees. It is important to observe particularly that all honeybees, common as well as Italian, have four bands of bright-colored down, J, K, L, M, one on each of the four middle rings of the body, but none on the first and none on the last. These bands of down are very bright on young bees, but may be so worn off as to be almost or entirely wanting on an old bee, especially on those that have been in the habit of robbing very much. This is the explanation of the glossy blackness of robbers often seen dodging about the hives. Perhaps squeezing thru small crevices has thus worn off the down, or it may be that pushing thru dense masses of bees has something to do with it. We often see such shiny black bees in great numbers, in stocks that have been nearly suffocated by being confined to their hives in shipping, or at other times.

These bands of down differ in shades of color from nearly pure white to a rich orange and down to a brown, many times, and this is the case with the common bee as well as with the Italian. Under a common lens the bands are simply fine soft hair, or fur, and it is this principally which gives the light-colored Italians their handsome appearance. One may have noticed the progeny of some particular queen when they first came out to play, and pronounced them the handsomest bees he ever saw; but a few months after they would be no better looking than the rest of the bees. This is simply because they had worn off their handsome plumage in the "stern realities" of hard work in the fields. Occasionally will be found a queen whose bees have bands nearly white instead of yellow, and this is what has led to the so-called albino bees. When the plumage is gone, they are just like other Italians. These bands of down have nothing to do with the yellow bands that are characteristic of the Italians; for, after this has worn off, the yellow bands are much plainer than before. A, B, C, are the normal yellow bands of which we have heard so much, and they are neither down, plumage, nor any thing of that sort, as will be seen by taking a careful look at an Italian on the window. The scale, or horny substance of which the body is composed, is yellow, and almost transparent, not black and opaque, as are the rings of the common bee, or the lower rings of the same insect.

The first yellow band, A, is down next the waist. It is very plain, when one knows what to look for, and no child need ever be mistaken about it.

At the lower edge of this first yellow band is the first black band; this is often only a thin sharp streak of black.

The second, B, is the plainest of all the yellow bands, and can usually be seen in even the very poorest hybrids. The first band of down is seen where the black and yellow join, but it is so faint one will hardly notice it at first in some specimens.

We have at the lower edge of the scale, as before, a narrow line of black; when the down wears off, this shows nearly as broad as the yellow band.

When we look at hybrids, we shall find a greater diversity; for while the bees from one queen are all pretty uniformly marked with two bands, another's will be of all sorts, some beautifully marked Italians, some pure black, others one or two banded. Some will sting with great venom, while others with only one or two bands will be as peaceable as the best Italians. Without a doubt, many queens have been sent out as pure that produced only hybrids; but since our recent studies in the matter we are quite well satisfied that several queens have been sold as hybrids that were really full-bloods.

In the matter of rearing queen-cells, either the Cyprians or Holy Lands will rear more queens than any Italians, Carniolans, blacks, or hybrids.

As many as a hundred natural cells are not infrequently found on one frame. One instance is recorded where 25 cells from a Holy-Land queen hatched within a few minutes of each other; and so vigorous were these young queens that some of them actually flew the moment they popped out of their inclosures.

The recent craze for five-banded bees, golden bees, and yellow-all-over bees, has complicated the marking problem somewhat. For instance, a colony that produces four or five banded bees, when crossed with a black or Carniolan drone, may produce 
the same kind of bees; but the second cross, at least, will show three-banded bees that are in reality hybrids but still showing the typical three yellow bands.

Under the Dzierzon Theory, subhead "Recent Evidence in Support of the Theory," it will be found that the first cross between an Italian queen and a Carniolan drone may have generally the markings of the yellow bees. The second cross will make one, two, or three banded Italians, and the bees will be distinctly hybrid, showing characteristics of the two races.

While the presence of three yellow bands does not necessarily prove the purity of Italian stocks, the test is fairly reliable in an Italian apiary that has not been run to color to get four and five bands, or in a yard where there have not been raised Carniolan, Caucasian, or black drones for several years previously.

FOUR AND FIVE BANDED ITALIANS.

Reference has already been made to the extra-yellow bees. For a good many years back there has been a demand for beautiful bees, and in all probability there always will be such a demand. A large number of queen-breeders in the country have been endeavoring to meet it. The time was when breeders guaranteed to furnish queens that would furnish "yellow-all-over bees" and "five-banded bees." While an occasional queen may produce a majority of such bees, it should be said that the most of the extra yellow stock does not show more than four bands; and the yellow-all-over bee is a "rare bird " indeed. It may be said that there is no such thing as a five-banded Italian or yellow-all-over Italian. The nearest approach to it is the very yellow threebanded bees and four-banded-perhaps the fourth band showing a predominance. As to the real practical value of these bees there is considerable discussion. While it is true that some of these very yellow bees are also good workers and good bees to winter, the facts are that very many of them, at least, are worth very little in the field, and die early in the winter. Many breeders, in their efforts to get color, have lost sight of other desirable qualities; and it is, therefore, coming to pass that very many extra-yellow bees are poor workers, very cross, and lacking in hardiness. On the other hand, it is only fair to say that there are some very yellow bees that combine to a remarkable degree other desirable qualities.

A good many readers of this will prefer good bees and those that are gentle. Usually the typical Italians that have been bred for business will be found to have not more than three yellow bands, often not more than two showing distinctly. These are usually called "leather-colored" Italians because they are typical of the native bees in Italy. These two-banded Italians, however, will show a third band if full of honey and placed on the window. These may often be confused with the ordinary two-banded hybrids. There is, in fact, a very marked difference in their general deportment and general behavior.

\section{HOLY-LAND AND CYPRIAN BEES.}

In 1882 considerable excitement arose over two new races of bees brought over from the Old World by D. A. Jones, of Beeton, Ontario, Canada, who was the leading beekeeper of his country. They were called Cyprian and Holy-Land bees, from the places where he found them. The former, from the Isle of Cyprus, seem to have been for many vears isolated, and are a very distinct and uniform race.

While they look like Italians, and might be classed as such by beekeepers not familiar with their peculiarities, they have a few distinct characteristics. Holy-Land bees show whiter fuzz-rings, and the bodies are slimmer than those of the ordinary Italians. They are more like the ordinary albincs. In fact, most of the albinos formerly sold were of Holy-Land extraction. The Cyprians look very much like the four and five banded Italians. The yellow bands are of a deeper orange than those of the Italians, slightly wider, and sometimes more than three in number. Just at the base of the thorax, and between the wings, there is a little yellow spot that is quite distinct and prominent, called the "shield." This is seen on some Italians, but less distinctly.

When Italians are crossed with Cyprians or Holy Lands it is a little difficult to see the difference except by their nervousness.

\section{TEMPERAMENT OF EASTERN BEES.}

These bees are more nervous, especially the Cyprians. Sometimes smoke seems to have no power over them. They will fly up 
twenty or thirty at a time without warning, and sting the moment they touch the apiarist. The more they are smoked, the more enraged they become. Cyprians especially are the crossest bees ever brought into this country-so cross, indeed, there is scarcely a breeder in the United States who has them for sale. The same objection, tho to a less extent, applies to the Holy Lands.

Te once sold an imported Crprian queen; and our customer, after he had kept her for a while, returned her, saving that her bees were so ricious that on one occasion they stung ererything in sight, and drove the family down cellar. We bought the queen back; but after we had had her for a few weeks and her bees had begun to hatch out we found it would be hardly safe to keep them in the yard. They would become so enraged at times that the whole colony would rush out in battle array. While the progeny of this queen was exceptionally cross, the general run, both of Cyprians and Holy Lands, is so disagreeable to handle that they are now well nigh discarded in the United States.

The only possible redeeming feature is that they are good brood-rearers: but they breed to excess after the honey-flow, using up all their arailable stores in raising bees. when Italians would conserve their energies and leave enough honey for winter.

ITALIANIZING. - Few questions are asked oftener than. "How shall I Italianize?" and "When shall I do it?" There is generally a loss in removing a queen and substituting another, eren where we have laying queens on hand; and where we are to use the same colony for rearing the queen, there is still greater loss. Under the heads of NtCLEI and QLEEN-REARING these points will be found fully discussed. There one has an apiary of black bees, his cheapest way, especially if he has plenty of time to derote to the subject, is to purchase three or four choice tested queens. and rear his own queens from them after the honey-flow. He should then put drone-traps on all his black and hybrid colonies, leaving only the Italian drones the freedom of the air. See DRONEs. If the breeders are bought in the spring or summer months, we would not remove the old queens until the summer crop of honey is orer: only, instead of allowing natural swarming, take two or three frames from each old stock about swarming time, and make nuclei, giving them cells from the breeding stock.

Then these queens are hatched and laying, the nuclei can be built up, with frames of brood given one at a time until they are full stocks. By such a course one will have the full benefit of old queens during the honey-season, until the new ones are ready to take their places. After the honey-yield the old queens can be removed, new ones introduced, and the now small colonies giren queen-cells. This does the swarming for the season, and the Italianizing, at one and the same time. See Ircrease; also NUCLETS.

If one has more money than time to spare, and wishes to have the work done up quickly, he can purchase as many queens as he has colonies, and introduce them at any season of the year, as directed in IxTROdecixg QueExs. He can purchase all tested queens, but we would adrise taking untested Italian queens during the months of July and August, when they are the cheapest, as this is also the best time of the year to Italianize. If done in the spring it is liable thru change of queens to cut off brocd-rearing, and, hence, cause too few workers when the harrest comes on. Some find it more conrenient to change queens during the suarming season, first for the purpose of stopping swarming. and, second. because there are plenty of cells usually at this time from choice stocks. See cellprotector under QUEEN-REARING.

After the stocks have all been prorided with Italian queens, by either of the plans giren abore, if one wishes the bees to become pure Italians he is toscommence replacing all queens that prove to be hybrids, as soon as the young bees are hatched in sufficient number's to enable him to decide. See Italiax BeEs. If honey only is the object these hybrids should not be replaced until after the honey-flow; for they will arerage nearly if not quite as good honeygatherers, and will raise just as pure drones as pure Italians. If the bees of any particular queen are too cross to be endurable she can be replaced. These hybrid colonies should not be allowed to swarm naturally; for if they raise a queen she will produce hybrid drones;* and this is something we wish most scrupulously to guard against.

\footnotetext{
* To get rid of black drones, see Droxes.
} 
IABELS FOR HONEY.-The Federal Food and Drug Act has been amended by the "Gould Amendment," which changes the wording of the original act regarding the labeling of net weight and makes it compulsory for food in package form to bear a statement of its net weight, etc. The section as amended reads:

That, for the purpose of this Act, an article shall be deemed to be misbranded:

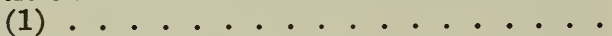

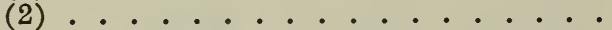

(3) If in package form, the quantity of the contents be not plainly and conspicuously marked on the outside of the package in terms of weight, measure, or numerical count. Provided, however, that reasonable variation shall be permitted, and tolerances and also exemptions as to small packages shall be established by rules and regulations made in accordance with the provisions of section three of this act.

In the case of extracted honey, packages holding two ounces or less weight, or one fluid ounce or less by measure do not have to have the contents stated on the label, but for larger ones the statement must be on the label in a conspicuous place. The net weight so placed must be the actual net weight, and the variations in individual packages must be as often above as below to relieve one of prosecution under this act.

In the case of comb honey, "The net weight of the comb honey is considered to be the weight of the honey and comb, exclusive of the wooden section. As it is not practicable to mark the exact net weight on each, the sections are sorted into groups and on each section in the group should be marked its minimum net weight. See Cомв Honey, to Produce. This may be marked in accordance with paragraph (h) of Food Inspection Decision No. 154 (a copy of this can be obtained by addressing the Bureau of Chemistry, United States Department of Agriculture, Washington, D. C.).

"The individual units must be marked, and the shipping-case may be if desired. The marking should be done before their introduction into interstate commerce.
"While the regulations a no not prescribe the manner of marking, as to whether a rubber stamp may be used, the law requires that the statement shall be plain and conspicuous. Stamping by means of aniline ink is frequently illegible, owing to failure to print or to the running of the ink. If such a stamp is used, care should be taken to make the statement plain and conspicuous, as required by the act."

The above is a letter signed by the Secretary of the Committee on Regulations, Net Weight, and Volume Law, and represents the committee's views as to which weight be considered final.

LARVAE.-Brood while in the worm state. See Brood and Brood-REAring; BEHavior of Bees; and Development of BEES.

LANGSTROTH. - Lorenzo Lorraine Langstroth was born in Philadelphia, Pa., Dec. 25, 1810. He graduated at Yale College in 1831, in which college he was tutor of mathematics from 1834 to 1836 . After his graduation he pursued a theological course of study, and in May, 1836, became pastor of the second Congregational Church in Andover, Mass., which position ill health compelled him to resign in 1838 . He was principal of the Abbott Female Academy in Andover in 1838-'9, and in 1839 removed to Greenfield, Mass., where he was principal of the High School for Young Ladies, from 1839 to 1844 . In 1844 he became the pastor of the Second Congregational Church in Greenfield, and after four years of labor here, ill health compelled his resignation. In 1848 he removed to Philadelphia, where he was principal of a school for young ladies from 1848 to 1852 . In 1852 he returned to Greenfield; removed to Oxford, O., in 1858, and to Dayton, O., in 1887.

At an early age the boy Lorenzo showed a fondness for the study of insect-life; but "idle habits" in that direction were not encouraged by his matter-of-fact parents. 

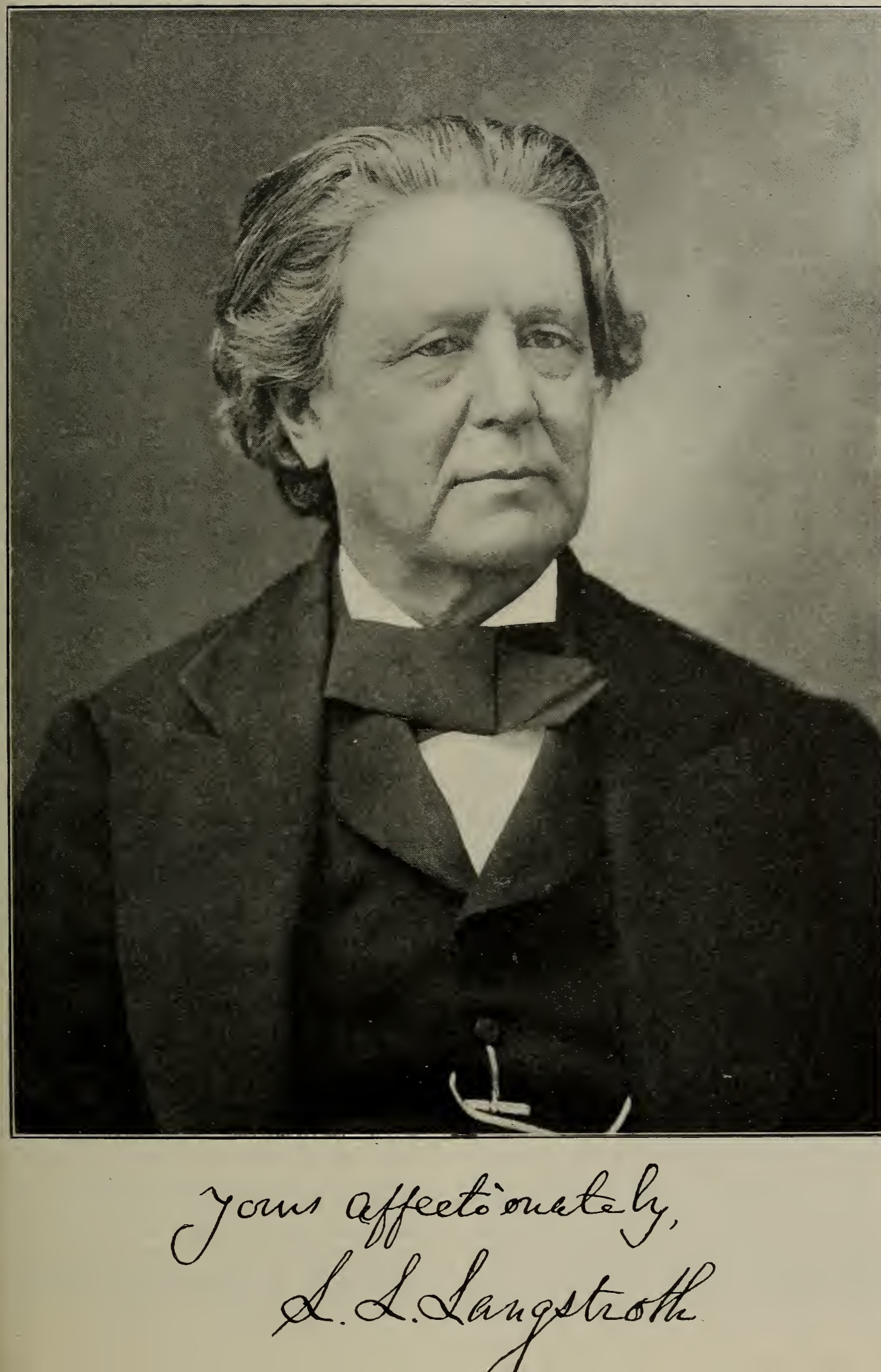
In 1838 began his real interest in the honeybee, when he purchased two stocks. No such helps existed then as now, the first bee-journal in America being issued more than twenty years later, and Mr. Langstroth at that time had never seen nor heard of a book on bee culture; but before the second year of his beekeeping he did meet with one, the author of which doubted the existence of a queen! But the study of the bees fascinated him, and gave him the needed outdoor recreation while engaged in literary pursuits, and in the course of time he became possessed with the idea that it might be possible to construct a hive so that its contents in every part might be easily examined. He tried what had been invented in this direction, bars, slats, and the "leaf-hive" of Huber. None of these, however, was satisfactory, and at length he conceived the idea of surrounding each comb with a frame of wood entirely detached from the walls of the hive, leaving at all parts, except the points of support, space enough between the frame and the hive for the passage of the bees. In 1852 the invention of the movable-comb hive was completed, and patented October 5 of that year. See Franies, Hives, and BeE-space.

It is well known that, among the very many hives in use, no other make is more popular than the Langstroth; but it may not be so well known that, in a very important sense, every hive in use among intelligent beekeepers is a Langstroth; that is, it contains the most important feature of the Langstroth-the movable comb. Those who have entered the field of apiculture within a few years may faintly imagine but can hardly realize what beekeeping would be today, if, thruout the world, in every beehive, the combs should suddenly become immovably fixed, never again to be taken out of the hive, only as they were broken or cut out. Yet practically that con-dition of affairs existed thru all the centuries of beekeeping up to the time when, to take out every comb and return again to the hive without injury to the colony, was made possible by the inventive genius of Mr. Langstroth. It is no small compliment to the far-seeing inventive powers of $\mathrm{Mr}$. Langstroth, that, altho frames of different sizes have been devised and tried, and improvements, so-called, upon his hive have been made by the hundred, yet today his hive and frame still stand, and their use is almost universal thruout this country and over a large part of Europe.

As a writer Mr. Langstroth takes a high place. "Langstroth on the Hive and Honeybee," published in May, 1853, is considered a classic; and any contribution from the pen of its author to the columns of the bee-journals was read with eagerness. Instead of amassing the fortune one would think he so richly deserved, Mr. Langstroth at the time of his death was not worth a dollar. He sowed, others reaped. At the date of his invention he had about 20 colonies of bees, and never exceed 125 .

In August, 1836, Mr. Langstroth was married to Miss Anna M. Tucker, who died in January, 1873. He had three children. The oldest, a son, died of consumption contracted in the army. Two daughters survive.

After his twentieth year, Mr. Langstroth suffered from attacks of "head trouble" of a strange and distressing character. During these attacks, which lasted from six months to more than a year (in one case two years) he was unable to write or even converse, and he viewed with aversion any reference to those subjects which particularly delighted him at other times. Mr. Langstroth was a man of fine presence, simple and unostentatious in manner, cheerful, courteous, and a charming conversationalist.

In reply to a question, he wrote, under date of March 26, 1888: "I am now a minister in the Presbyterian Church. Altho not a settled pastor, I preach occasionally, and delight in nothing so much as the Christian work. My parents were members of Mr. Barnes' church, in Philadelphia, the motber Presbyterian church in the United States."

Mr. Langstroth died Oct. 6, 1895, at the Wayne Avenue Presbyterian Church, Dayton, Ohio, where he was preaching that day. Before he began, the pastor of the church, Rev. Amos O. Raber, moved the pulpit to one side and placed a chair in front where Mr. Langstroth could sit while speaking, for his enfeebled condition would not permit him to stand. After a few preliminary sentences, and requests for prayer on the part of the congregation, he said: "I am a firm believer in prayer. It is of 
the love of God that I wish to speak to you this morning-what it has been, what it is, what it means to us, and what we ought--"

His daughter, Anna L. Cowan, who was present, thus describes the last scene:

"As" he finished the last word he hesitated; his form straightened out convulsirely; his head fell backward, and in about three minutes he was absent from the body, at home with the Lord.

"There was no scene of confusion in the church. Tears were running down every cheek, but there were no screams, no loud sobbing. As one person remarked, 'Heaven never seemed so near before. It seemed but a step." "

Then, with no fiery throbbing pain, No slow gradations of decay,

Death broke at once the vital chain

And freed his soul the nearest way.

Thus was finished the remarkable career of one of the great men of the country. $\mathrm{He}$ would have been great had he nerer known anything about bees; but his contributions to bee literature, and his basic invention that revolutionized beekeeping thruout the world, place him in the very front if not the greatest beekeeper who ever lived-not in the money he made, but what he did in making money for others who followed the directions given in his delightful book, "The Hive and the Honeybee." (The publishers of this work have published a reprint just as he wrote itprice $\$ 1.00$.)

For further particulars regarding his invention, see Frames, also Hives.

The statement was made that Mr. Langstroth was a great man. Some interesting sidelights showing the greatness of his character are set forth in an article by his old friend A. I. Root in Gleanings in Bee Culture for Oct. 15, 1895, just after $\mathrm{Mr}$. Langstroth's death.

A. I. ROOT'S PERSONAL RECOLLECTIONS OF THE REV. L. L. LANGSTROTH.

In the introduction to our A B C book you will find some mention of the incidents of my first acquaintance with the honeybee, and how I came into possession of Langstroth's hook.

I made the acquaintance, by letter, of Samuel Wagner; got hold of Vol. I. of the American Bee Journal. I. wonder whether there is anybody living now who will enjoy reading the first edition of Langstroth and the first volume of the American Bee Jour- nal as I enjoyed it then. Why, the very thought of those old days of enthusiasm makes the blood even now tingle to my fingers' ends.

As soon as I found that Mrr. Langstroth was living at Oxford, Butler Co., O., I commenced correspondence. Then I wanted the best queen-bee to start with that the world afforded. It was pretty well along in the fall, but I could not wait till spring, as some of $\mathrm{my}$ friends advised me to do. I soon learned to look up to friend Langstroth with such confidence and respect that I greedily read again and again erery word I could find from his pen-even his advertisements and circular in regard to Italian bees. When the book was read thru once I read it again. Then I read certain chapters over and over; and when summer time came again, and I had little miniature hives or nuclei under almost every fruit-tree in our spacious dooryard, each little hive containing a daughter of that $\$ 20$ queen, then I read Langstroth's book with still more avidity and eagerness, finding new truths and suggestion in it each time.

I think I met him first and heard him talk at a convention in Cincinnati. $\mathrm{He}$ was a wonderful talker as well as writer-one of the most genial, good-natured, benevolent men the world has ever produced. He was a poet, a sage, a philosopher, and a humanitarian, all in one, and, best of all, a most devoted and humble follower of the Lord Jesus Christ. His fund of anecdotes and pleasant memories and incidents was beyond that of any other man I ever met; and his rare education and scholarly accomplishments but added to it all. No one I ever saw could tell a story as he would tell it. A vein of humor and good-natured pleasantry seemed to run thru it all. I think he elljoyed telling stories-especially stories with good morals; and they all had to have a good moral or they could not come from L. J. Langstroth. Not only the play of his benerolent face and the twinkle of his eye, but the motion of his hands as he gave emphasis to the different points in his narration, showed how thoroly he entered into his topic.

It was my good fortune to listen to him one or more times from the pulpit. He preached to us once here in Medina. The church was full, but I hardly believe any one else in that large audience enjoyed his talk as I did. They did not know him as I did.

You must not think from what I have said that our good friend always agreed with everv one else. He had opinions of his own, and he could be stubborn and almost contrary when he got "hot" in a discussion. But the gentle spirit was back of it all. I remember once being out in the apiary, explaining to him some wonderful improvement I had just been working out. He, however, did not see it as I did, and stoutly maintained that the old way-his way, in 
fact-was better. All at once I stopped and concluded we had better give up the subject. Pretty soon he laid his hand on my arm, and said:

"Friend Root, will you not forgive me? I was rude and uncourteous. You have practiced this thing, and are succeeding. Very likely you are right and I am wrong.",

Mr. Langstroth paid us a visit. He told us a long story about his patent. This poor man had dwelt on it so long that even he, a minister of the gospel, and a successful one, had lost his peace of mind; and if he had not lost his faith in God it shook his faith in humanity. I called his attention to the hopeful text, "But I say unto you, Love ye your enemies; do good to them that hate you; bless them that curse you, and pray for them that despitefully use you." But even he did not catch on. I urged until he seemed annoyed, and I was afraid of a return of his malady. With a sad heart I gave it up. As it was getting to be late and toward bed time I went with him to his room. He said very little, altho he was naturally exceedingly talkative, and I felt I had offended him by my importunity. In the morning, when breakfast was ready, as he had not put in an appearance Mrs. Root thought I had better go to his room. It was warm weather, and the door was wide open. The old gentleman was awake and partly sitting up, leaning on his elbow. As soon as he saw me he beckoned me to come up near him, with his finger. I was really afraid he was going into one of his "spells." He took his watch out from under his pillow and asked me to listen. As I was a watch repairer I supposed there was something wrong with the beat; but when I told him that it seemed to be in perfect order, and that it beat clearly and regularly, what do you think he said? He asked me what the watch said to me. I replied that it did not "say" anything, and now felt sure that he was losing his mind. This is what he said:

"Mr. Root, that watch has been saying 'Quinby! Quinby! Quinby!' all night long, and I can't stand it any longer. I am going to start today. I am going to see Mr. Quinby. I am not going to say a word about the patent or about the hive. I am going to him as tho we had always been friends."

Friend Langstroth went to see Mr. Quinby, as he declared he would do, and they had "the best time in the world.",

His last public talk to beekeepers, if I am correct, was the one given at Toronto; and I felt anxious at the time that some shorthand reporter might be at hand who could give all his words, and even his little stories, just as he gave them to us. Perhaps others did not enjoy this talk as $I$ did, because they did not know him as I did. Why, that history of long ago, telling of the troubles, blunders, and mistakes in introducing the Italian bees from Italy to America, should be handed down to coming generations. It should be embodied in some of the standard works on bees, in order to secure its preservation.

Langstroth and Quinby-those two old pioneers-have now both passed away, but " their works do live after them," and shall live for a thousand years or more. I feel anxious that the first edition of both Langstroth and Quinby should be preserved. There is something to me more interesting in their first efforts-Quinby's book, for instance, telling how to keep bees with a box hive, and Langstroth telling his first experiments with the movable-frame hive. Those early editions should be preserved.

When quite a child I was greatly interested in reading the life of Benjamin Franklin. When I first became acquainted with Langstroth I could not resist the suggestion that he was much like Franklin. The maxims of Poor Richard suggest the thought. Mr. Langstroth was remarkably well read in ancient literature. He was familiar with the writings of great men in all the ages. It rejoices my heart now to know that he has been remembered for many years at our national conventions, and to know that he was even present with his daughter at the one that occurred so short a time before his death. He never seemed to have a faculty for accumulating property; but what is millions of money compared to the grateful remembrance with which Langstroth's name will be spoken in every civilized land on the face of the earth?

LAWS RELATING TO BEES. - The subject of bees takes up but little space in law. The old law writers, the men who really laid down the basic principles of our law during its formative period, classified bees and defined the rights of the keepers of bees in a few brief paragraphs, yet they seem to have covered the subject as fully as was necessary at the time at which they wrote.

As to legal opinions handed down in cases that have been adjudicated by a court of last resort, and which opinions form the bulk of our law of today, those pertaining to bees are very meager in volume. There have been, no doubt, many cases in the minor courts, but the decisions in such cases are binding only on the courts that decided them, and then only where there is a lack of higher authority. It matters not how much was involved in a case nor how ably it was presented and argued, nor how learned and scholarly was the opinion handed down by the trial judge, nor what the verdict of the jury was, provided it was a jury case; unless the case was appealed to a court of last resort the decision is not available law. 
For it is only the decisions that have been handed down in cases that have been appealed to a court of last resort that are published, and available to the lawyers and the courts in general and can be considered as law by them.

\section{GENERAL PRINCIPLES OF LAW PERTAINING TO} BEES.

But the fact that but little litigation concerning bees has reached the courts of last resort does not mean that the laws governing bees and their keeping was in an undetermined state. Law deals primarily with principles; the subject matter is secondary. To ascertain what the law is in a giren instance, all that is really necessary to do is to apply an established principle of law to the facts in the case. For example, to steal the property of another person is larceny, and it matters not whether the subject matter stolen be an automobile, a caged lion, an aeroplane, or a hive of bees, as it is the act that constitutes the offense.

The law as laid down by Blackstone and other law writers of his time and of times prior is briefly as follows:

That bees are wild by nature; therefore, tho they swarm upon your tree they are not yours until you have hived them, any more than the birds that have their nests in your trees or the rabbits that run wild thru your fields. But when they hare been hived by you they are your property the same as any other wild animal that you may have reduced to possession. Animals that are wild by nature and have been captured by you, should they escape, you still have a right in them if rou follow them with the idea of recovery. A swarm of bees that has left your hive continues to be yours so long as you can keep them in sight and under any probability of recovery; 2 Blackstone Com. 392; Coopers Justinian Inst. Lib. 2, tit. 1. No. 14; Wood's Civil Law, bk. 2, chap. 3, p. 103; Domat's Civil Law, vol. 1, bk. 3, pt. 1, Subd. 7, No. 2133: Puffendorf's Law of Nature, 4, chap. 6, No. 5; Code Napoleon No. 524; Bracton's Law, 2, chap. 1. No. 3 ; and see notes in 40 L. R. A. 687; 62 L. R. A. 133.

During the early derelopment of our Eastern states the general principle of law relative to ownership of bees was adjudicated in a number of cases. The question raised and the decisions rendered are briefly as follows: Where bees have escaped and so properly may be considered as wild bees and without any owner at the time of their discovery, it has been held that such bees in a tree belong to the owner of the soil where the tree stands. Merrills vs. Goodwin,.1 Root 209; Ferguson vs. Miller, 1 Cow. 243; 13 Am. Dec. 519; Goff vs. Kilts, 15 Wend. 550 .

That bees are ferae naturae, that is, wild by nature, but when hired and reclaimed may be a subject of ownership. State vs. Murphy, 8 Blackf. 498; Gillet rs. Mason, 7 Johns. 16; Rexroth vs. Coon, 15 R. I. 35 ; 23 Atl. 37.

But the finding of a swarm of bees in a tree on the land of another, marking the tree and notifying the owner of the land does not give the finder such property in the boney as will entitle him to maintain trover for the honey. Fisher rs. Steward, Smith 60.

Where one discovers wild bees in a tree, and obtains license from the owner of the land to take possession of them, and marks the tree with his initials, he gains no property in them until he takes them into his possession. Gillett vs. Mason, and Ferguson rs. Miller, supra.

Where bees take up their abode in a tree, they belong to the owner of the soil even tho they are reclaimed; but if they have been reclaimed and their owner is able to identify them as in a case where he followed the bees and saw them enter the tree, they do not belong to the owner of the soil, but to him who had former possession, altho he cannot enter upon the land of the owner of the tree and retake them without subjecting himself to an action for trespass. Goff vs. Kilts, 15 Wend. 550.

In a case decided in 1898 and entitled State of Iowa rs. Victor Repp, 104 Iowa, 305,40 L. R. A. 687 , it was held that the mere finding of bees in a tree on the land of another did not give the finder any title to the bees or to the tree. The facts were. one Stevens who found the bees trespassed on the land and hived the bees in a gum belonging to another. The defendant Repp removed the bees from where they had been hived and was for that act arrested and tried for larceny, Sterens, the man who hived the bees, being the complaining witness. The trial court convicted Repp, and the case was appealed to the Iowa Supreme 
Court. That court reversed the trial court, and in rendering the decision Justice Ladd said: "The title to a thing ferae naturae cannot be created by the act of one who was at the moment a trespasser, and Stevens obtained no interest in the bees by the mere wrongful transfer of the bees from the tree to the gum. Having neither title nor possession he had no interest therein, the subject of the larceny. As the information alleged ownership in Stevens, and the case was tried on that theory, we need make no inquiry as to any taking from Cody (the owner of the land)."

\section{WHERE BEES SHOULD BE LOCATED.}

Bees should be located by their owner so that in the natural course of events they will not molest others. If a keeper of bees locates his bees so that they will be prone to attack other people or their horses he is guilty of negligence. A case in point is Parsons vs. Manser, 119 Iowa 92, 62 L. R. A. 132, decided in 1903, the facts of the case being that the beekeeper had a hitching-post in front of his house. This post was located in the public highway; about twenty-five feet from the post, but in the beekeeper's yard, there were two beegums. The plaintiff, Parsons, was a medicine-peddler. He called at Manser's house and tied his horses to the hitching-post. The bees attacked the horses and stung them to death. The beekeeper was held liable for the death of the horses, as the evidence showed that he was aware of the fact that the bees would attack horses when hitched to the post. A beekeeper is not liable, however, unless he has been negligent. In other words, the beekeeper must bave been at fault, and if thru no fault of the beekeeper some other person is injured, the beekeeper is not liable. It was so held in a New York case, Earl vs. Van Alstine, 8 Barb. 630, which was an action for damages caused by plaintiff's horses being stung, resulting in the death of one of the horses.

\section{FARL VS. VAN ALSTINE.}

The facts in this case were: That Van Alstine was the owner of fifteen hives of bees. The bees were kept in his yard adjoining the public highway. Earl, the plaintiff in the case, was traveling along the highway with a team of horses, and when he passed Van Alstine's place the bees attacked his horses and stung them so severely one died.
Action was brought in the Justice's Court and Earl secured judgment for the sum of $\$ 70.25$ and costs. The case was appealed to the County Court of Wayne County where the judgment was reversed. From the County Court the case was appealed to the Supreme Court, Seventh Judicial District, which court affirmed the decision of the County Court, the decision being of date June 4, 1850.

The opinion was written by Justice Selden, and he discussed very thoroly the questions involved, the opinion being in part as follows:

This case presents two questions:

1. Is any one who keeps bees liable, at all events, for any injury they may do?

2. Did the defendant keep those bees in an improper manner or place, so as to render him liable on that account?

It is insisted by the plaintiff that, while the proprietor of animals of a tame or domestic nature (domitæ naturæ) is liable for injuries done by them (aside from trespasses upon the soil) only after notice of some vicious habit or propensity of such animal; that one who keeps animals feræ naturæ is responsible at all events for any injury they may do, and that as bees belong to the latter class, it follows, of course, that the defendant "s liable.

In order to determine this question, upon which no direct or controlling authority exists that $I$ have been able to find, it becomes necessary to look into the principles upon which one who owns or keeps animals is liable for their vicious acts. It will be found upon examination of the authorities upon this subject that this classification of animals by the common law into animals feræ naturæ and domitæ naturæ has reference mainly, if not exclusively, to right of property which may be acquired in them; those of the latter class being the subject of absolute and permanent ownership, while in regards to the former only a qualified property can exist, and the distinction is based upon the extent to which they can be domesticated or brought under the control and dominion of man, and not at all upon the ferocity of their disposition or their proneness to do mischief. For instance, the dog, some species of which are extremely savage and ferocious, is uniformly classed among animals domitæ naturæ, while the hare, rabbit, and dove are termed feræ naturæ, altho completely harmless. It would not be natural to suppose that a classification adopted with exclusive reference to one quality of animals could be safely used to define and regulate the responsibilities growing out of other and different qualities; nor would it accord with that just analysis and logical accuracy which distinguishes the common law, that it should be resorter to for that purpose. 
Chitty, under the head of actions on the case for negligence, gives the following rule: "'The owner of domestic or other animals, not naturally inclined to do mischief, as dogs, horses, and oxen, is not liable for any injury committed by them to the person or personal property unless it can be shown that he previously had notice of the animal's mischievous propensity.', (Chitty Plead. 82). This accurate elementary writer did not fall into the error of applying the rule to the whole of the class of animals domitæ, but adns the qualification, "not naturally inclined to do mischief." By his arrangement of the subject, too, he confirms the view of Peake that the liability is based upon negligence.

These authorities seem to me to point to the following conclusions:

1. That one who owns or keeps an animal of any kind becomes liable for any injury the animal may do, only on the ground of some actual or presumed negligence on his part.

2. That it is essential to the proof of negligence and sufficient evidence thereof that the owner be shown to have notice of the propensity of the animal to do mischief.

3. That proof that the animal is of a savage and ferocious nature is equivalent to proof of express notice. In such cases notice is presumed.

..... Having shown then, I think clearly, that the liability does not depend upon the classification of the animal doing the injury, but upon its propensity to do mischief, it remains to be considered whether bees are animals of so ferocious a disposition that any one who keeps them, under any circumstances, does so at his peril. If it is necessary for the plaintiff to aver and prove the mischievous nature of the animal, nothing of the kind has been done in this case; but if the courts are to take judicial notice of the nature of things so familiar to man as bees, which I suppose they would be justified in doing, then I would observe that however it may have been anciently, in modern days the bee has become as completely domesticated as the ox or cow. Its habits and instincts have been studied, and thru the knowledge thus acquired it can be controlled and managed with nearly as much certainty as any of the domestic animals; and altho it may be proper still to classify it among those feræ naturæ, it must nevertheless be regarded as coming very near the dividing line, and in regards to its propensities to do mischief, I apprehend that such a thing as a serious injury to person or property from its attacks is very rare, not occurring in ratio more frequent certainly than injuries arising from the kick of a horse or the bite of a dog.

There is one rule to be extracted from the authorities to which I have referred, not yet noticed, and that is that the law looks with more favor upon the keeping of animals useful to man than such as are noxious and useless. And the keeping of the one, altho in some rare instances they may do injury, will be tolerated and encouraged, while there is nothing to excuse the keeping of the other. In the case of Vrooman vs. Lawyer, 13 John. Rep. 339, the court says: "If damage be done by any animal kept for use or convenience, the owner is not liable to an action without notice.", The utility of bees no one will question, and hence there is nothing to call for the application of a very stringent rule to the case. Upon the whole, therefore, I am clearly of the opinion that the owner of bees is not liable at all events for any accidental injury they may do. The question is still left whether the keeping of bees so near the highway subjects the defendant to a responsibility which would not otherwise rest upon him. I consider this question substantially disposed of by the evidence in the case. It appears that the bees had been kept in the same situation for eight or nine years, and no proof was offered of the slightest injury having ever been done by them. On the contrary, some of the witnesses testified that they had lived in the neighborhood and had been in the habit of passing and repassing frequently with teams and otherwise without ever having been molested. This rebuts the idea of notice to the de. fendant, either from the nature of the bee: or otherwise, that it would be dangerous to keep them in that situation; and of course upon the principles already settled, he could not be held liable.

The judgment of the county court must be affirmed.

The two cases last mentioned (Parsons rs. Manser and Farl rs. Van Alstine) are in perfect harmony. In the first case the evidence showed the beekeeper was at fault; in the second, no negligence of the beekeeper was provell. From these cases it can be seen that the law governing the location of bees is rery simple. For a beekeeper not to be liable for any injury that his bees may inflict on some other person who is acting within his rights the bees should be located in such a way that the beekeeper knows or should ordinarily know that they will not be troublesome, for if he has knowledge that in the course of ordinary events the bees in the position where they are located are liable to molest others, he can be held to answer for whatever damage they may commit, and that means not only actual but punitive danages should the facts warrant.

\section{BEES NOT A NUISANCE.}

The liability of a beekeeper for any injury done by the bees to another person or the property of another rests on the doctrine of negligence, and not on the doctrine 
or theory that bees are a nuisance per se; that is, in themselves a nuisance. In the case of Petey Manufacturing Co. vs. Dryden (Del.) 5 Pen. 166; 62 Atl. 1056, the court used the following language: "The keeping of bees is recognized as proper and beneficial, and it seems to us that the liability of the owner as keeper thereof for any injury done by them to the person or property of another rests on the doctrine of negligence." Also see Cooley on Torts, 349 .

\section{CITY ORDINANCES DECLARING BEES A NUI- SANCE.}

The right to follow any of the ordinary callings of life, to pursue any lawful business vocation, is one of the privileges of citizens of this country; but it must be done in such a manner as is not inconsistent with the equal rights of others. Butchers Union vs. Crescent City, etc. 111 U. S. $746 ; 28$ L. Ed. 591.

A city has a right under what is termed in law "Police Power" to pass ordinances for the public welfare, even tho the thing prohibited limits and restricts some person in the exercise of a constitutional right, if the act is for the public health and welfare. For example, laws prohibiting the maintaining of slaughter-houses in certain districts and the prohibiting of livery stables on certain streets have been held to be valid police legislation. But the act specified in the ordinance must, in the particular instance mentioned therein, be a nuisance. The mere fact that the city has passed an ordinance declaring the keeping of bees a nuisance does not of itself make it so unless the bees are in fact a nuisance.

\section{ARKADELPHIA VS. CLARK.}

Arkadelphia vs. Clark, 52 Ark. 23; 11 S. W. 957, is a case in point. This particular case was decided in 1889, and a report and history of it was published by Thomas G. Newman, then General Manager of the National Beekeepers' Union, for free distribution to the members. From the history of the case as given by Newman it seems that Z. A. Clark, the defendant in the case, was not in political harmony with those in power. He was a beekeeper, and it was sought to punish him and get rid of his presence by prohibiting the keeping of bees within the corporate limits of the city of Arkadelphia. So in May, 1887, the Arkadelphia city council adopted an ordinance which read:

Be it ordained by the Council of the City of Arkadelphia, That it shall be unlawful for any person or persons to own, keep, or raise bees in the City of Arkadelphia, the same having been declared a nuisance.

That any person or persons keeping or owning bees in the City of Arkadelphia are hereby notified to remove the same from the corporate limits of Arkadelphia within thirty days from the date hereof.

The ordinance also provided a penalty of not less than $\$ 5.00$ nor more than $\$ 25.00$ for violation of the ordinance.

In June, 1887, Clark was given notice to remove his bees. This he did not do, and he was arrested on January 2, 1888, and fined day after day for ten successive days. He did not pay his fines, so was committed to jail by the order of the mayor of Arkadelphia. Being a member of the National Beekeepers' Union, he apppealed to it for protection; and as it was considered that Clark was in the right the National Beekeepers' Union engaged attorneys to defend the suit.

The decision as handed down by the Supreme Court was that "Neither the keeping, owning, or raising of bees is, in itself, a nuisance. Bees may become a nuisance in a city, but whether they are so or not is a question to be judicially determined in each case. The ordinance under consideration undertakes to make each of the acts named a nuisance without regard to the fact whether it is or not, or whether the bees in general have become a nuisance in the city. It is therefore too broad and is invalid.

The argument of Judge S. W. Williams, one of the attorneys for the defense in the foregoing case, covered very fully the subject of nuisance per se, and the power of a city to prohibit under the police power. That part of his argument, with some late citations added, being as follows:

This case discloses a most flagrant violation of the property rights of the citizen. It seems that Clark, who lived in the outskirts of Arkadelphia, a village of some two thousand inhabitants, scattered over territory enough for one hundred thousand-a ruse in urbe-had a few bees, as the record shows (page 1), 35 stands. This gave rise to a persecution unparalleled since the days of the boot and thumbscrew, to force Clark to give up his property.

Those running the city at the time, not content to make a test case, and have the 
question settled by this Court-after passing this sweeping ordinance, commenced a system of daily arrests, trials without jury, judgments and imprisonments, resulting in appeals; and this is one of a numerous spawn of cases from the same oppressive hot-bed.

At last Clark was compelled, at a great loss, to give up his property, and quit his business of bee-raising and honey-production in Arkadelphia-a principal source of his support-as an alternative to indefinite imprisonment.

When the case came to the Circuit Court, one test case was tried, upon motion to dismiss, and the Court below held the ordinance void, because it did more than regulate the keeping of property -it forbade the owning, or keeping a valuable and useful property in the town; in effect holding that the bee was, per se, a nuisance. For if it was not, then its presence in a town could not be prohibited by any law.

Before proceeding to argue the case we call attention to the statement of Counsel, at page 9 of their Brief, that it is a matter of common knowledge that they are liable to sting children, etc. It is not a matter of common knowledge, because it is not true; unless children molest them at their hives, or catch them. But because a domestic insect may sting or hurt under some circumstances, no more makes it a nuisance-per se-and liable to prohibition, than the fact that a horse may kick, may run away in harness and kill a child; or an ox may gore persons with its horns, would make these animals nuisances per se.

I venture the assertion that there is not a town or city in the United States where hees are not kept. I know they are now kept in Little Rock, and have ever been. My nearest neighbors have them. I have kept them in my yard while rearing a family of children, and I cannot recall any instance of an injury from bees. I speak this in line of common knowledge, which the Court must recognize.

I can recall the kick of a pony, and a cow running over a child-shall keeping horses and cows be forbidden by ordinance? And while bees have been kept for centuries in towns, it is an argument in their favor that Arkadelphia is the first on record to forbid them. I respectfully submit that, while the Court must judicially know the habits of all animals, the "little busy bee"' should have a chance with the cow, the horse, the sportive dog, the gentle, purring cat, and even the festive chicken cock-on a par with counsel's skunk-farm story-a pure fiction of Bill Nye.

I may be allowed to refer to the fact that last year two instances are given in newspapers, one authentic at Hot Springs, one elsewhere, not so well establishedwhere children were killed by a chicken cock attacking them. For this reason can the keeping of chickens be forbidden? The bee has no such record of homicidal or infanticidal results. Will these instances, or the fighting of mother-hens over their broods, make chickens per se nuisances? Unless bees, under all circumstances, however kept and tended, and in any quantities however small are per se nuisances-this ordinance cannot be sustained; for it does not regulate the quantity, or manner of keeping, or make the keeper responsible, as in case of other dangerous animals, and punishable for consequences, but assumes to destroy property in them in Arkadelphia altogether, or compel a man to leave his home and buy another or quit his business.

The provisions of Sections 751 to 764 , Mansfield, does not give the city of Arkadelphia power to take a man's property for public use, without compensation, under the power to prevent injury or annoyance. Section 751 invests them with no such quia timet jurisdiction.

Because bees may sting or annoy, therefore we prohibit. It would follow that, because cows may gore, dogs annoy the sensitive by barking or biting or running mad, we will also prohibit them. Because vehicles may annoy, by raising a dust, or making a noise, or animals may run away in harness, therefore we prohibit them. No such autocratic or despotic power is necessary to preserve the citizen from real harm and annoyance; and the legislature could not prohibit the keeping of bees, and could not delegate such power under the Bill of Rights. For the right to acquire, possess, and protect property is secured by Section 2, Article 2, of the Constitution, beyond legislative and municipal control: and bees are the subject of property. Nor can the citizen be destroyed or deprived of his life, liberty, or property, except by the judgment of his peers, and the law of the land.

Ib. Section 21. Nor shall property be taken or damaged for public use without just compensation. Ib. Section 22. This propertyright is also protected by the 14th Amendment to the United States Constitution. Stockton laundry case, 26 Federal Rep. 611. In re Hong Wah 82 Fed. 623. The last cited is a case in point. The general law regulating governments of cities does not give every town council, when, in their judgment, they fear that the keeping of certain kinds of property may annoy or injure, to declare it an annoyance and prohibit it. It must be a nuisance, per se, like a mill-pond or slanghter-house. Many things annoy, and may injure, that are not nuisances, and cannot be prohibited. Bell-ringing, vehicle-running, steam-whistles, and railroad trains are often annoying; so are privies and stables. This would not give power to prohibit them, to prevent quia timet-the possibility of annoyance or injury. The viciousness of this ordinance will be manifest, if we keep in view the difference between the power to regulate and keep possession of property, in due bounds, which power is conceded-and 
the power to prohibit keeping property altogether.

These general clauses of the statute granting powers to towns are to be strictly construed, and this Court has repeatedly held ordinances void which have been passed under a liberal construction of the general powers given. The first is Waters vs. Leech, 3 Arkansas, 114. Thus the right to regulate and license keeping of a dram-shop does not authorize them to prohibit. Tuck vs. Waldron, 31 Arkansas, 462. Saloam S. Springs vs. Thompson, 41 Arkansas, 456. Nor did the power to suppress gaming-houses empower a city to license them. State vs. Lindsey, 34 Arkansas; Goetler vs. State Use, etc.; 45 Arkansas, 454-and the power given in the act did not give power to declare that which is not a nuisance per se, to be one-which was attempted. Little Rock vs. Ward, 41 Arkansas, 527. 48 Am. Rep. 46. Even the legislature cannot, by declaration, makie anything what it is not. 3 S. W. Rep. 425. 12 Western Rep. 760. 11 Central Reporter, 219.

We may sum up this result: The power to regulate does not give the power to prohibit, tho it does give power to license. Russellville vs. White, 41 Arkansas, 485; and that the power to prevent and abate nuisances does not give power to declare that a nuisance which is not per se such; and no presumptions are indulged in favor of the rightfulness of an ordinance. A City Council, with full power to declare a nuisance does so at its peril: Americus vs. Mitchell, 5 S. E. Reporter, 201. Persons abating a nuisance under a state law must show its existence. Newark \& South Horse-car Co. vs. Hunt, 11 Central Reporter 219.

In keeping with the decisions of our own court, to the effect that a City Council can not by ordinance make that a nuisance which is not such; see the following authorities: Horr \& Bemiss, Mun. Pol. Ord. Sec. 252. 24 M. J. Eq. 169.

There is a recent case decided by the Supreme Court of Michigan, in which a city attempted by ordinance, under penalty of one hundred dollars, to punish and prohibit the distribution of hand-bills and cards on any street or alley. The ordinance was held void, and that it was not a proper exercise of the power to clean streets, etc., and to prevent the incumbering of the same, and to regulate the manner in which the streets should be used, and to prohibit and prevent the flying of kites, and all practices, amusements, and doings therein having a tendency to frighten teams or horses, as dangerous to life or property. This was held void in case of People vs. Armstrong (73 Mich. 288) by the Supreme Court of Michigan, Jan. 18, 1889 , and is reported and commented on in the Albany Law Journal, March 9, 1889, with approval.

In that case there was much more pretense for the power than there is in this case; for bees are not named-and the power is claimed here under the general power to prevent injury or annoyance, etc. Mansfield's Digest, Sec. 751 .

An ordinance of Grand Rapids, which forbade the marching, parading, riding, or driving upon public streets with musical instruments, banners, flags, torches, flambeaux, or while singing or shouting, without the Mayor's permission, was void, as prohibiting a thing lawful in itself, and leaving it to an unregulated official discretion. See Frazee's case, 63 Michigan, 396.

All ordinances arbitrary in their terms, and unreasonable, and unnecessarily abridging private rights, are void. 1 Dillon Municipal Corporation, Sec. 253, Clinton vs. Phillips, 58 Illinois, 102. Kip vs. Patterson, 26 N. J. Law 298. Commissioner vs. Gas Co., 12, Penn. St. 318. Commonwealth, vs. Robertson, 5 Cush. 438.

This ordinance not only does not come within the power granted, but it is also unreasonable and unwarranted; either is sufficient to make it void. Lynn vs. Freemason Building Association, 117 Penn. 1.

Municipalities have only such powers as are expressly granted to them, or such as are necessary to carry those powers into effect. United States vs. Ludlow, 9 Central Reporter, 517. Johnson vs. District of Columbia, 6 Mackey, 21. It is well settled that the general power to prevent annoyance does not give power to declare everything which may annoy or arouse the fears of the sensitivea nuisance. Nor does the existence of that fact give power to prohibit. See authorities above cited.

It is equally well settled that a city cannot, under general power, declare that a nuisance which is not so in fact. Des Plaines vs. Poyer, 123 Ill. 348. Cuba vs. Mississippi; Cotton Oil Co. 10 L. R. A. (N. S.) 310 . Stockton Launary Case, 26 Federal Reporter, 611 -where it is held that an ordinance is unconstitutional and void which forbids a laundry in the heart of the city; yet a drying up of stinking soap-suds might become dangerous to health, and annoy, and infected clothing would be more frequent than beestings. See also 9 Pacific Reporter, 141.

Mr. Wood, in his work on Nuisance, in the index at page 1021, refers to bees with a reference to title-Dangerous Animals. Under that head, at page 1025, he refers to cases of animals which, by their owners, may be known to injure, referring to page 871 et seq., which recognizes fully the right to keep animals subject to responsibility (on scienter) for injuries by those known to be of vicious character.

Strangely enough, of all the cases cited, not an instance of injury by " the little busy bee" or the silk-worm is found, showing how harmless these little insects really are. The habits of the bee lead it to wood, field, and orchard, for pasture, and if it enters a house it is because carelessness has left some sweet uncovered, and exposed, to attract it, and rarely then does it enter a house. Those who thus invite it are guilty of contribu- 
tory negligence, and have no right to comp'ain.

I am employed in this case by the National Beekeepers' Union, and this is probably about the only known case in America or England where a town has attempted to prohibit bee culture; and this is a test case to determine the extent of their powers. The burden of showing the nuisance is on the city. Railey's onus probandi, 233, ib. page 460 .

A city ordinance cannot be leveled at a mere private nuisance to one or more persons. The nuisance must be public and general in its character, and must be an actual nuisance. Horr \& Bemiss, Sec. 252, 254. 4 Blackstone's C'onmentaries, 167. 1 Bishop Crim. Law, Sec. 243. Wood on Nuisance, pages $24,25,26,80,81,82$. Dillon on $\mathrm{Mu}$ nicipal Corporation, Sec. 308.

I undertake to say from a knowledge of the habits of the bee that it would be impossible for it to become more than a private nuisance, for which the person injured has his remedy, as in case of injury from a vicious animal. The nuisance must not nnly be public and actual, but substantial. "It is not a mere trifling annoyance with which the law deals in public nuisances,", but "real, substantial injuries that are calculated to offend the sense of men of simple tastes and habits." Conveniences are not balanced. Wood on "Nuisance," page 81 .

Even in those acts which are admittedly nuisances, an ordinance is void and umreasonable where it trenches on private rights and property without corresponding public necessity. Thus, while slaughter-houses mav be regulated, an ordinance is roid which prohibits one from killing an anjmal on his own premises, unless in a slaugbterhouse-an attempt to drive everybody to one slaughter-house. Treford vs. People, 14 Michigan, 41. Cannot compel removal of a steam-engine from a city not per se a nuisance. Baltimore vs. Palecke, 49 Md. 217. 33 American, 239. Nor can a city require the owner of a theater to pay a police officer for attendance at every performance. Waters vs. Leech, 3 Ark. 110. In the last cited case Judge Dickinson, delivering the opinion of this Court, says: "The corporate powers are not only limited, but must be reasonably exercised in sound discretion, and not only strictly within the limits of the Charter but in perfect subordination to the Constitution and the general laws of the land, and the rights dependent thereon.",

In short, I refer the Court to Horr \& Bemiss on municipal police ordinance, Sec. 131. for a full review of this point.

Where the instances are given wherein unreasonable ordinances and those in violation of private rights are given, the ordinances must accord with the Federal Constitution and laws, and with the legislation of the state.

It is misleading to follow English decisions, because in that country municipal power rests often upon proseription, a source not recognized here. Horr \& Bemis, Sec. 123.

We do not dispute that if there was express $\mathrm{p}$ wer given to enact an ordinance of a certain kind, if constitutional, the discretion or propriety of enacting it is left to the judgment of the Council, and its decision is final. Horr \& Bemiss, Sec. 128. But here is no "express power'" given by law to forbid bees; but merely a general power to prevent "'annoyance," "'injury," etc. Whether an ordinance is within the terms of the power, and is reasonable, the courts must determine, and have determined in this state, and elsewhere, again and again.

So much for the contention of counselthat the action of the City Council was final; invoking a correct principle applied to a wrong state of facts. I say to them, show your express power to prohibit keeping bees, or any other animal, or insect, for fear somebody may get hurt, and I will surrender the case, and even waive the constitutional question. There is no such express power given; that is the full extent to which the decisjons go. If a power is expressly given by the legislature, within the Constitution, the decision of the Council, that the power should be exercised by ordinance, is final. Yet this is inroked to bolster up this sweeping antibee ordinance; about as much akin to the question as a Choctaw Treaty to a Psalm of David.

You cannot stable bees like a horse, but the Court must judicially know to do that would destroy their value as property, and the Court will judicially know that unless the owners of houses, groceries, etc., are careless in leaving attractions for them, they will not annoy them; and if they do so attract them by carelessness, they camnot complain. The bee, even with these attractions, prefers to pasture among forests, fields, and amidst flowers; so much so, that its habits are crystallized in song, and made subject of poetic simile.

If the people of Arkadelphia will keep the sugar and molasses barrels closed, and the grocers will keep their premises clean, no bee of Clark's will visit them; and from the well-known habits of the housewives of Arkadelphia-in perfect order and cleanliness having no superiors-no bee visits a private house there; and hurting young fruit and the like. as suggested in the ordinance, raises a suspicion that here is a pretext, and behind the ordinance is a concealed motive. Was it that Clark was making too much out of honey and bees? or was he competing too sharply with somebody?

The power given cities must harmonize with constitutional property rights, and must be reasonable and lawful, and not contravene common right. Dillon on Mun. Corp. Sec. 258, 259. And "wherever an ordinance seeks to alter a rell-sertled and fundamental principle of the common law," or to establish a rule interfering with the rights of individ- 
uals, or the public, the power to do so must come from plain legislative enactment.", Taylor vs. Griswold, 2 Green, N. J., 222. Dillon on Municipal Corp. Sec. 55 and Note.

I have already shown that by no possibility can the power be derived from the powers contained in Mansfield's Digest, Sec. 751; which is nothing but a power to punish or abate a public nuisance; and while the named and defined powers are very full, we look in vain for any power or authority to abate or remove bees, as such; nor would it be constitutional if there was such a statute. It is only when bees by the place or manner of keeping, or the like, become a public nuisance, and to that extent, and no further, does the general power go. Dillon on Mun. Corp. Sec. 261. Horr \& Bemis, Sec. 252, last paragraph. Emmett vs. Council Bluffs, 46 Iowa, 66. Pye vs. Peterson, 45 Texas, 312. State vs. Matt, 61 Md., 292. Davis vs. Clifton, S N. C. C. P., 236. Horr \& Bemis, Sec. 144.

The power cannot be given in general terms to abate that which comes under the general definition of a nuisance, in advance of a judicial determination. Dillon on Mun. Cor. Sec. 308; and in Gates vs. Milwaukee, 10 Wallace, 497. Judge Miller says: "This would place every house, every business, and all the property in the city at the uncontrolled will of the temporary local authority. So the words "injury", and "annoyance," used in Sec. 751, Mans. Dig. have been too often defined in like Charters to need further explanation here. It simply gives a power over nuisances, and does not mean any injury or any annoyance that sensitive or timid or nervous people may imagine or fear.

The bees must be per se a nuisance to justify this sweeping ordinance, under which according to its letter, a man cannot live in Arkadelphia, if he owns bees, no difference where he keeps them; for personal property, wherever kept, is in law with the owner. In Harvey vs. Dewoody, 18 Arkansas, 252; where the Mayor and other town officers were sued in trespass for tearing down an old house which the owner had permitted to remain vacant and open, and to be used as a privy, until it became unhealthful and dangerous, an ordinance was passed to abate it. To a plea setting up the ordinance and facts on which it was based as a defense, on demurrer to this plea, it was held a good defense.

The counsel for Arkadelphia try to gather comfort from this case, but it would be parallel if the Des Arc Council had passed an ordinance requiring all wooden houses to be torn down, without regard to condition or occupancy, or compensation to the owner. We would then have a case like the sweeping ordinance prohibiting bees, and requiring their removal for public good, without compensation. Would a plea setting up an ordinance requiring all wooden buildings to be destroyed have protected the officers in the Dewoody case?
I shall not attempt to follow the learned counsel, nor review their authorities; as far as they have any bearing on the case, they sustain my position: 1 . That the power is not given to prohibit bees by the statute. 2 . That bees must at the time and place, and under all circumstances, be a nuisance per se, or the ordinance violates property right, and is not sustained by law.

Another instance where a city tried to prohibit beekeeping within the city occurred in 1.901, when the city of Rochester, New York, enacted an ordinance similar to the one enacted by the city of Arkadelphia.

W. R. Taunton, a member of the National Beekeepers' Association, was living in Rochester. The National Association had an investigation made, by which it was ascertained that Taunton was handling his bees in sucli a manner as not to annoy his neighbors, and that he ought to be protected, so advised him not to remove his bees, and assured him that in case of trouble the association would defend him.

Taunton was arrested for refusing to comply with the ordinance and was tried in police court. The defensc was that the ordinance was unconstitutional and void, and it was so held by the court, and the defendant was discharged.

A case where the bees were, from the evidence given at the trial, declared to be a nuisance, is that of Olmsted vs. Rich, $25 \mathrm{~N}$. Y. S. R. $271 ; 6$ N. Y. Supp. 826, which was an action for an injunction prohibiting the keeping of bees in a certain place and for $\$ 1500$ damages. At the trial the evidence showed that the beekeeper had a large number of hives of bees on a village lot adjoining the man who desired the injunction, and that during the spring and summer the bees interfered with the enjoyment of his premises. The bees drove him and his servants and guests from his garden and grounds, stinging them, and otherwise making his dwelling and premises unfit and unsafe for habitation, constituting a nuisance. The verdict was against the beekeeper for six cents damages and a permanent injunction was granted, which was affirmed on appeal.

\section{SHIPPING BEES BY RAIL.}

The general rule is, that it is the duty of a common carrier to carry all freight that is tendered to be carried. As to the right to refuse shipment, in Porcher vs. Northeast- 
ern R. R. Co. 14 Rich. L. 181, the court quoted with approral from Story, Bailments: "If he (the carrier) refuses to take charge of the goods because his coach is full or because they are of a nature which will at times expose them to extraordinary danger or to popular rage or because he has no convenient means of carrying such goods with security, etc., these will furnish reasonable grounds for his refusal, and will, if true, be a sufficient legal defense to a suit for the non-carriage of goods." In Boyd vs. Moses, 74 U. S. 7 Wall 316; 19 L. Ed. 192 , it was held that "A carrier may refuse to take lard which is packed in such a condition that it cannot be carried without injury to the rest of the cargo." Also see note in 36 L. R. A. 649.

The law, therefore, appears to be that if bees are properly packed for shipment it is the duty of a common carrier of freight to take them, but should they be not properly packed for shipment so that the carrier could refuse the shipment on any of the previously stated grounds he could legally refuse to accept them.

\section{LIABILITY OF RAILROADS FOR LOSS IN SHIP- MENT OF BEES.}

It is the duty of a railroad to furnish a proper car when they undertake the transportation of bees; and the railroad company with which the contract for shipment is made is liable for injury caused by a defective car, even tho the car has left the initial road and was in the possession of a connecting railroad. This was held to be the law in the case of International and $G$. N. R. R. Co. vs. Aten, a Texas case reported in 81 S. W. 346, in which case the station agent was informed that the car was desired for a shipment of bees. The car furnished was not suitable, and by reason of the car not being suitable the bees were injured on a connecting railroad.

\section{BEES INJURIOUS TO FRUIT.}

That bees are an essential agent in the pollination of fruit blossoms, and that they are never injurious to sound fruit, or in any way injure fruit-trees are matters that are firmly established.

That bees do not injure fruit or fruittrees has also been established in a court of justice to the satisfaction of a jury. It was in the case of Utter rs. Utter, tried at Go- shen, New York, in 1901. As the case was not appealed from the trial court, the decision is not to be found in the reported cases. In the Utter case, like the Arkadelphia case, the bees were merely incidental. The facts were, that there had been years of previous trouble between the parties, and the suit over the supposed or alleged injury caused by the bees was but the culmination of the long-continued quarrels.

It was claimed by the plaintiff that the bees of defendant ate and destroyed plaintiff's peaches, and the trial was to ascertain if such were the case.

At the trial there appeared as witnesses for the defense A. I. Root and E. R. Root, of Medina, Ohio; Frank Benton, of Washington, D. C., and several others prominent in the world of apiculture. Frank Benton, at that time Assistant Entomologist of the Department of Agriculture, Washington, D. C., by reason of his standing as a scientist and his general knowledge of matters pertaining to apiculture, was a very important witness.

The testimony of Mr. Benton established the following facts:

That the honeybee has a soft, pliable tongue, and could not puncture sound fruit; that the inner tongue of the bee is spoonshaped and covered with hairs: that the tongue of the bee cannot become rigid; that the bee laps up the nectar; and that the feelers of the bee are soft and cannot pierce anything, being only organs of touch and smell. Mr. Benton's further testimony was to the effect that birds and other insects do the puncturing, and that then the bees may suck the wasting juices.

The jury found the bees not givilty of injuring the fruit and returned a verdict for the defendant, J. W. Utter.

\section{FRUIT DRYING.}

Where fruit is being dried is another matter, and there is no doubt but that damage is done by bees to drying fruit if they are allowed to work upon it. The sugar that bees carry away from the drying fruit is deducting just that amount of weight from the fruit, besides injuring its appearance. Bees can also make themselves a nuisance to those at work where fruit is being dried. In one instance known to the writer a beekeeper in California by reason of there 
having been a poor season in the mountains brought his bees to the small town where he lived. The principal erop in and about this town was fruit, and when the apricot drying season came on the bees became so thick on the newly cut fruit that a large force of girls who were cutting the fruit had to be laid off and operations stopped for the day. That night the beekeeper removed his bees some three miles away, and the next day made a satisfactory settlement with the fruit-dryer, and so the trouble ended.

\section{LAWS RELATING TO FOUL BROOD.}

--In controlling bee diseases in a community, past experience has shown that it is necessary that every beekeeper do his part; otherwise the work done by individuals is largely nullified by the carelessness or neglect of a few. Where all the beekeepers are progressive, a simple plan of co-operation would be enough; but, unfortunately, there are in almost all communities some beekeepers who are either ignorant, careless, or willfully negligent. If any of these will not voluntarily care for their bees there must be some legal means of compelling them to abate a public nuisance when disease appears among their colonies.

Laws providing for inspection of apiaries with the object of controlling diseases are, therefore, drafted primarily for the beekeeper who does not voluntarily treat diseased colonies. The progressive beekeeper needs no such law to compel him to do his duty. The inspector of apiaries, however, in actual practice, is much more than a police officer; in fact, his police duties are but a small part of his work. However the law may be worded, the good which an inspector does is due in the greater part to his work as an educator. It is the duty of the inspector, specified in the law in most cases, to instruct the beekeepers how to know disease and how and when to treat. The great good which has been done by the various inspectors in the past has been due almost entirely to this part of their work.

It would, however, be unwise to set the inspector to work merely as an educational officer without any power to enforce his orders. This has been tried, and appears to be a failure. There are, unfortunately, in almost all communities, beekeepers who, from obstinacy or spite, must be driven to their duty. Most men, however, when once they learn that they must treat disease will accept the teachings of the inspector.

The following states and territories now have laws of some kind providing for inspection: Arizona, California, Colorado, Connecticut, Hawaii, Idaho, Illinois, Indiana, Iowa, Kansas, Kentucky, Massachusetts, Michigan, Minnesota, Missouri, Nebraska, Nevada, New Jersey, New Mexico, New York, Ohio, Oklahoma, Oregon, Pennsylvania, Rhode Island, South Dakota, Tennessee, Texas, Utah, Vermont, Washington, Wisconsin. Somewhat similar laws exist in New Zealand, some states. in Australia, Ontario, Ireland, and parts of Europe. The beekeepers in several other states are now agitating the passage. of similar laws.

These laws may be divided into two groups-those in which the work is done by men employed by the state, and those in which the county authorities appoint inspectors for the county only. Of these the work by the state officers has proven much more effective. In states where the counties are small, as in the East, county inspection is practically of no value. In states where the counties are large it has been found practically impossible to get competent inspectors in every county; and, furthermore, there is not enough work or enough money available to induce a good man to take the work, unless he is doing it merely for the good of the industry. In the West, where some counties are as large as some of the Eastern states, there is more reason for county inspection; but even in these cases the results are, as a rule, not equal to those obtained in states having state inspection.*

The chief weakness in county inspection is the lack of co-operation among the inspectors in neighboring counties. There is in most cases not only a lack of co-operation, but too often a jealousy between them which results in a lack of co-ordination in the work. This might be remedied by the appointment of a competent state inspector to whom the county inspectors would be responsible; but county officials prohably object to the appointment of officers over whom they have no direct jurisdiction. A much better plan is to appoint enough state inspectors to cover the state.

* The county law in California is not satisfactory. 
A special tax on colonies to bear the expense of inspection is sometimes made. When this tax applies to every beekeeper in the state, no objection can be found to it. The plan of requiring each beekeeper to pay for the work of the inspector in the actual inspection of his own apiary is unjust, and always causes trouble. Inspection is instituted for the benefit of all beekeepers in the state, and they should pay for it. To compel the beekeeper who is unfortunate enough to have disease among his bees to pay for work, the object of which is to protect other beekeepers in the comminity and state, is unwise, unjust, and shows lack of foresight on the part of the framers of such a bill.

Practically all laws in force, whether state or county, provide for inspection of apiaries; penalties for resisting the entrance of the inspector on the premises; penalties for failing to comply with instructions for treatment if the hives are found to be diseased, and penalties for selling or bartering bees, hires, or appliances before the apiary has been pronounced free of disease. Usually additional provision is made for more than one inspection of queen-rearing yards. This is very wise as they might spread infection far and wide.

Every state in the Union where bees are kept to any extent should have a foul-brood law. In some cases, where it does not seem practicable to have a law applicable to every portion of the state, a county law is enacted; but for reasons already mentioned a state law should be secured if possible. The chief difficulty lies in getting the legislature to provide sufficient funds to carry a statewide law into effect. The average member of a general assembly will vote to pass any bill provided such bill does not call for a special appropriation of $\$ 500$ or $\$ 5000$. The ordinary tax-payer is inclined to criticise a legislature because its members rote for excessive appropriations that are wasteful and extravagant. It comes to pass, therefore, when a state representative or senator is asked to lend his support to a bee bill that calls for a special appropriation of one or two thousand dollars he immediately loses his interest. The difficulty of funds can be very nicely solved by placing the administration of the law in the hands of the State Board of Agriculture or any other body that already has a regular annual appropriation. In most states there is a nursery-inspection law in force. If the provisions of the nursery law are already carried out by the State Entomologist, that same official, with the machinery of his office and a very little additional appropriation, can also look after bee-inspection work. All that is necessary is to pass a law that will create a division of apiary inspection under the regular Department of Agriculture, or under the Bureau of Fntomology if there be such. This puts the onus or responsibility for the additional funds upon a properly organized body that is supposed to know its own requirements. The arerage member of the General Assembly will be perfectly willing to rote for any reasonable appropriation asked for by the State Board of Agriculture when he would refuse to rote for a law calling for a special appropriation.

In the case of Ohio, there was already a Department of Agriculture, and so all that was necessary was to pass a bee-inspection law, the administration of which naturally fell into the hands of the State Entomologist. The following is a copy of the law, and is here presented because many other states have passed th same law with the same general prorisions.

\section{APICULTURAL-INSPECTION LAW OF OHIO.}

Section 1155-1. The Ohio State Board of Agriculture is hereby authorized to establish a division of apiary inspection in the Ohio department of agriculture, and to appoint a competent entomologist as the chief inspector of said division, and the necessary assistants, who shall, under the direction of the board, have charge of the inspection of apiaries as hereinafter provided; he may investigate, or cause to be investigated, apiaries as hereinafter provided; he may investigate or cause to be investigated outbreaks of bee diseases and cause suitable measures to be taken for their eradication or control.

Section 1155-2. The inspector or his assistants shall, when notified in writing by the owner of an apiary, or by any three disinterested tax-payers, examine all reported apiaries, and all others in the same locality not reported, and ascertain whether or not the diseases known as American foul brood or European foul brood, or any other disease which is infectious or contagious in its nature, and injurious to honeybees in their egg, larval, pupal, or adult stages exists in such apiaries; and if satisfied of the existence of any such diseases he shall give the owners or care-takers of the diseased apiaries full instructions how to treat such 
cases, as in the inspector's judgment seems best.

Section 1155-3. The inspector or his assistant shall visit all diseased apiaries a second time, after ten days, and, if need be, burn all colonies of bees that he may find not cured of such disease, and all honey and appliances which would spread disease, without recompense to the owner, lessee, or agent thereof.

Section 1155-4. If the owner of an apiary, honey, or appliances wherein disease exists shall sell, barter, or give away, or move without the consent of the inspector any diseased bees (be they queens or workers), colonies, honey, or appliances, or expose other bees to the danger of such disease, said owner shall, on conviction thereof, be fined not less than fifty dollars nor more than one hundred dollars, or imprisoned not less than one month nor more than two months or both.

Section 1155-5. For the enforcement of the provisions of this act the state inspector of apiaries or his duly authorized assistants shall have access, ingress, and egress to all apiaries or places where bees are kept; and any person or persons who shall resist, impede, or hinder in any way the inspector of apiaries in the discharge of his duties under the provisions of this act shall, on conviction thereof, be fined not less than fifty dollars nor more than one hundred dollars, or imprisoned not less than one month nor more than two months or both.

Section 1155-6. After inspecting infected hives or fixtures or handling diseased hees, the inspector or his assistant shall, before leaving the premises or proceeding to any other apiary, thoroly disinfect any portion of his own person and clothing and any tools or appliances used by him which have come in contact with infected material, and shall see that any assistant or assistants with him have likewise thoroly disinfected their persons and clothing and any tools and implements used by them.

Section 1155-7. It shall be the duty of any person in the state of Ohio, who is engaged in the rearing of queen bees for sale, to use honey in the making of candy for use in mailing-cages which has been boiled for at least thirty minutes. Any such person engaged in the rearing of queen bees shall have his queen-rearing apiary or apiaries inspected at least twice each summer season; and on the discovery of the existence of any disease which is infectious or contagious in its nature and injurious to bees in their egg, larval, pupal, or adult stages, said person shall at once cease to ship queen bees from such diseased apiary until the inspector of apiaries shall declare the said apiary free from all disease. Any person engaged in the rearing of queens who violates the provisions of this section shall, on conviction thereof, be fined not less than one hundred dollars nor more than two hundred dollars.
Section 1155-8. The Ohio State Board of Agriculture shall make an annual report to the governor of the state concerning the operations of the division of apiary inspection, which shall give the number of apiaries inspected, the number of colonies treated and destroyed by the direction of the chief inspector, and such other information as may be deemed necessary.

Section 2. That sections, 5853, 5854, 5855, $5856,5857,5858,5859,5860,5861,5862,5863$, 5670 , and 13368 of the General Code be and the same are hereby repealed.

The above is a correct copy of the apiaryinspection law now in force.

Effective May 21, 1910.

The few years that this law has been in force has shown that some changes might be made to advantage. Section 1155-3, where the funds are somewhat limited, has not been found to be workable. It would make a large expense for the inspector to come back in ten days and reinspect. The section should authorize the inspector or assistant to use his discretion. In ninety-nine cases out of a hundred the average man is very willing to act on instructions for treatment.

In section 1155-4 the owner of bees having disease shall not sell, barter, nor give away, without the consent of the inspector, any diseased bees, colonies, hives, nor appliances, including honey. There is really no objection to one selling honey in the general market. To require the owner of a diseased apiary not to sell his crop, that might be worth several thousand dollars, would be an unnecessary restriction and hardship. The presumption is that honey in supers will be free from disease anyway; and even if it were diseased it could not possibly affect human beings. However, the Ohio law allows the inspector to give his consent to sell either the honey or the bees. So the matter is up to his discretion.

There is one provision left out of the Ohio law; and that is one giving the inspector or his assistant the power to treat or burn diseased hives or bees when the owner refuses to obey instruction. In a general way the first section gives the State Inspector authority to cause suitable measures to be taken for the eradication or control of disease. While this might and probably would be sufficient it would be better to have a special section giving the inspector or his assistant the stated author- 
ity to burn or treat disease in case the owner failed to treat as ordered. It will seldom be necessary to enforce this provision; but the moral effect on the owner of the bees would be such that he would not be inclined to disobey the order of the state.

With these exceptions the Ohio law is nearly perfect, and the fact that it does not call for a special appropriation makes it easy to pass.

THE EDUCATTONAL VALUE OF BEE INSPECTION.

If the entomologist or chief inspector is not a beekeeper he can very easily appoint competent beekeepers to do the general work under his direction. Such persons, aside from their regular duties of inspection, can and do render valuable instruction on how to take care of bees and how to produce a crop of honey.

\section{MORAL SUASION VERSUS FORCE.}

As a general thing it will not be necessary to make forcible entrance on a man's premises nor to burn his bees and hives if diseased. Such measures should be used only when the owner refuses to carry out instruction. If by moral suasion he can be induced to treat of his own free will it will be far better than to enter forcibly his premises and, if need be, destroy his property. Some man of vicious tendencies might, out of pure revenge, if his bees and hives were burned, scatter bee disease thruout the neighborhood. While, of course, this would be against law it might not be easy to prove that he did it.

I.AYING WORKERS.-These queer inmates, or, rather, occasional inmates, of the hive are worker-bees that lay eggs. Aye, and the eggs they lay hatch too; but they hatch only drones, and never worker-bees. The drones are rather smaller than the drones produced by a queen, but they are nevertheless drones, in every respect, so far as we can discover. It may be well to remark, that ordinary worker-bees are not neuters, as they are sometimes called; they are considered undeveloped females. Microscopic examination shows an undeveloped form of the special organs found in the queen, and these organs may become, at any time, sufficiently developed to allow the bee to lay eggs, but never to allow of fer- tilization by meeting the drone as the queen does. See QueEns.

\section{CAUSE OF LAYING WORKERS.}

It has been over and over again suggested that bees capable of this egg-laying duty are those reared in the vicinity of queencells, and that by some means they have received a small portion of the royal jelly necessary to their development as bee-mothers. This theory has been entirely disproved by many experiments; and it is now pretty generally conceded that laying workers may make their appearance in any colony or nucleus that has been many days queenless, and without the means of rearing a queen. With Cyprians, Syrians, and their crosses the laying workers are common, even tho the colony has a good queen; and a case is known of a yearling queen in full vigor, a queen a few weeks old and reared in the same colony, and scores of laying workers, all busily laying on the same combs. The stock was Cyprian. Not only may one bee take upon herself these duties, but there may be many of them; and wherever the beekeeper has been so careless as to leave his bees destitute of either brood or queen for two or three weeks, he is liable to find evidences of their presence, in the shape of eggs scattered about promiscuously; sometimes one, but oftener half a dozen in a single cell.

Sometimes the eggs will be found stuck on the sides of the cell. In that case it is evident the laying worker cannot reach the bottom of the cell. Very often there will be found several eggs in a queen-cell.

If the matter has been going on for some time, he will see now and then a drone larva, and sometimes two or three crowding each other in their single cell; sometimes they start queen-cells over this drone larva; the poor motherless orphans, seeming to feel that something is wrong, are disposed, like a drowning man, to catch at any straw.

\section{HOW TO GET RID OF LAYING WORKERS.}

Prevention is better than cure. If a colony, from any cause, become queenless, be sure it has unsealed brood of the proper age to raise a queen; and when this one is raised, be sure that she becomes fertile. It can never do any harm to give a queenless colony eggs and brood, and it may be the saving of it. But suppose one has been so 
careless as to allow a colony to become queenless and get weak, what is he to do? If he attempts to give them a queen, and fertile workers are present, she will be pretty sure to get stung; it is sometimes difficult to get them to accept even a queencell. The poor bees get into a habit of accepting the egg-laying workers as a queen, and they will have none other until they are removed; yet we cannot find them, for they are just like any other bee; we may get hold of them, possibly, by carefully noticing the way in which the other bees deport themselves toward them, or we may catch them in the act of egg-laying; but even this often fails, for there may be several such in the hive at once. We may give the bees a strip of comb containing eggs and brood, but they will seldom start a good queen-cell, if they start any at all; for, in the majority of cases, a colony having laying workers seems perfectly demoralized, so far as getting into regular work is concerned.

It is almost impossible to introduce a laying queen to such colonies; for as soon as she is released from the cage she will be stung to death. No better results would follow from introducing an ordinary virgin; but the giving of a queen-cell, or a just-hatched virgin, if the colony has not been too long harboring laying workers, will very often bring about a change for the better. In such cases the cell will be accepted, and in due course of time there will be a laying queen in place of the laying worker or workers; but often cells will be destroyed as fast as they are given. The only thing then to be done is to scatter brood and bees among several other colonies, perbaps one or two frames in each. From each of these same colonies take a frame or two of brood with adhering bees, and put them into the laying-worker hive. The bees of this hive, which have been scattered into several hives, will for the most part return; but the laying worker or workers will remain and in all probability be destroyed in the other hives. Of course, the colonies that have been robbed of good brood will suffer somewhat; but if it is after the honey season, no great harm will have been done. They will proceed to clean up the combs; and if they do not need the drones as hatched they will destroy them.

See that every hive contains, at all times, during the spring and summer months at least, brood suitable for rearing a queen, and you will never see laying workers.

\section{HOW TO DETECT THE PRESENCE OF LAYING} WORKERS.

If we do not find any queen, and see eggs scattered around promiscuously, some in drone and some in worker cells, some attached to the side of the cell, instead of the center of the bottom, where the queen lays them, several in one cell and none in the next, we may be pretty sure we have laying workers. Still later, we may see the worker-brood capped with the high convex cappings, indicating clearly that the brond will never hatch out worker-bees. Finding two or more eggs in a cell is never conclusive, for the queen often so deposits them in a feeble colony where there are not bees enough to cover the brood. The eggs deposited by a fertile queen are usually in regular order, as one would plant a field of corn; but those from laying workers, and usually from drone-laying queens, are irregularly scattered about.

\section{LAUREL.-See PoIsonous Honey.}

\section{LINDEN.-See BASSWOOD.}

IIVE-BEE DEMONSTRATION. -- See HoNey Exhibits.

LOCALITY.-This has a great influence in beekeeping. Many of the manipulations recommended in one locality will not answer for another. A hive well adapted to one place might give indifferent results elsewhere with different conditions. The length of the honey-flow, the time-it comes on, whether the nectar comes in a rush for three or four weeks at a time as it does in the East, or whether the flow extends over a period of three or four months, coming in very slowly, are all conditions the beekeeper must study and be able to meet as they are. A slow honey-flow, continuing over a period of four or five months, may require an altogether different hive or management. It may render the production of comb honey impracticable, for the reason the combs will be travel-stained, and therefore not fit to compete with honey from other localities. On the other hand, a short rapid honey-flow, as in the basswood regions, and where the honey is mainly white, 
and of good flavor, makes the production of comb honey more profitable than extracted as a rule.

Locality has a bearing on the kind of treatment the bees should receive. If there is no honey after the first or middle of July, and the beekeeper is located in a region where snow falls in winter, and where cold winter prevails for five or six months, he will have to make some plans to keep down brood-rearing after the honey-flow, and arrange to get the bees in the best possible condition for cold weather. He will probably have to feed, and then in the spring he will be compelled to stimulate broodrearing to a high pitch as soon as the bees can fly; thus getting the colonies strong at the beginning of the honey-flow. If, however, one is located in the South he must see that his bees have a large amount of stores; for in a warm climate they will consume more than in the North, where it is cold. While the beekeeper of the colder regions tries to prevent his bees from dying during the winter, he who is located in the South endeavors to prevent his bees from starving until the next honey-flow.

\section{THF BEST STATES FOR KEEPING BEES.}

We are very often asked the question as to the best location in the United States for keeping bees as a business. We usually advise the inquirer to stay right where he is. While beekeeping in good seasons may be rery profitable in California, yet experience has shown that the honey-producers of the Golden State hare only one good year in from three to five. Taking everything into consideration they do not average any better than their brethren of the East where the market is certainly better.

There are certain parts of California, however, where the seasons are more regular. An example of this is found in Imperial Valley, in Imperial County. This was formerly a desert, and parts of it constituted the old Salton Basin, which was formerly known as "Death Valley," as nothing could live there. But all this section has been opened up by means of irrigation, and now it is one of the finest and best alfalfa districts in the world. In fact, for productiveness it is said to equal the Nile Valley of Egypt. Beekeeping in Imperial County is very profitable, and the seasons are fairly regular. Most of the available territory is, howerer, at this time mostly taken up; but sometimes one can buy a bee-range to very good advantage.

The color of the alfalfa honey in Imperial Valley is not quite as light as that in Colorado, Nevada, and Idaho; but the flavor is rery good. On account of the difference in color the alfalfa of Imperial Valley does not bring as high a price as that of the other districts mentioned.

Northern and central California offer conditions that are a little more suitable than the mountain-sage region of the southern part of the state. While the yield per colony is not as great, during a good year where sage and alfalfa both are grown it is fairly regular.

Colorado, Arizona, New Mexico, Utah, Idaho, in the irrigated portions, sometimes show wonderful results in honey; but in all the states named, where the bee-range is at all good, the country is orerstocked with bees and beekeeper's, and one can scarcely get into one of the places without buying out somebody already in the field.

Texas as an all-around bee proposition is one of the best bee states in the Union. It is not orer-populated yet, and there are very many desirable bee-ranges within its borders, but some seasons it has severe drouths resulting in a failure of the honey crop and the death of many colonies from starvation.

Kansas and Nebraska are good bee states, having usually good fall flows; but sometimes either or both have fearful drouths that kill down nearly all vegetation, rendering farming as well as beekeeping, for that season, almost a failure.

Oklahoma as a bee state is coming forward very rapidly. The climate is mild. and soil conditions good.

Among the eastern states, New York is one of the best because it has, in addition to clover and basswood, immense acreages of buckwheat, which on those hills yields imnense quantities of honey. Wisconsin and Minnesota were formerly good localities for basswood; but that desirable tree for timber as well as honey is now being rapidly cut off, and the main stay will be, as with the other states, white clover, with a large sprinkling of sweet clover along the roadsides and railways.

Most of the north-central states have conditions that are practically the same, reach- 
ing away from Minnesota to Maine, and continuing down the Ohio River and Chesapeake Bay. While the amount of honey secured in these localities is less per colony, the price it brings is higher, because in this portion of the United States the centers of population are located. Thruout the South, east of the Mississippi, the honey secured is very good, mostly extracted, and the flow covers a long period; but the quality is not quite equal to the honey of the North.

There is some desirable bee territory in Florida, but as in California the seasons are not always dependable. In a good year large quantities of tupelo honey are produced in northern Florida, particularly along the Apalachicola River. Palmetto and orange blossom yield a light crop in central and southern Florida; and in a good year along the Florida Keys mangrove is a good yielder. Migratory beekeeping is found to be fairly profitable on the Florida Keys. See Migratory Beekeeping. In general, beekeeping in Florida is no more profitable than in some of the northern states. The great advantage of Florida is from the standpoint of health, and on this account much of the available bee territory is overstocked.

LOCUST (Robinia Pseudo-Acacia L.).Variously called common locust, yellow locust, white locust, and false locust. This is one of the finest honey-trees of the eastern and southern states. It belongs to the great family of the Leguminosae, which includes many of the best honey-plants, as the clovers, acacias, vetches, peas, and beans. It is a native of the mountains from Pennsylvania to Georgia, and westward to Missouri and Arkansas; but it has become extensively naturalized in Canada, New England, and the eastern states. Large plantations of it have been made for timber. The wood is hard and very durable, and is much used for posts. There is a saying that stone will crumble before locust will rot. The tree grows to great size, and is long-lived except when attacked by borers. It spreads rapidly by sprouts rising from the roots, which run for long distances near the surface. When the trees are cut or killed by borers the roots send up a great many sprouts, which grow very rapidly and flower within two or three years.
The white fragrant flowers resemble peablossoms, but are in pendent clusters like those of wisteria. It blossoms in May and June, remains in bloom for about ten days, and yields an immense amount of waterwhite honey, of heavy body and mild flavor. Two other species of locust occur in eastern America. The clammy locust or $R$. viscosa is similar to the above, but its flowers are tinged with pink and are inodorous. It is a native of the mountains from Virginia to Georgia, but it has been introduced in the North, where it seems perfectly hardy. The other species, bristly locust or rose acacia ( $R$. hispida) is a shrub growing from three to ten feet high. The stems are covered with bristles, hence the name. The flowers are large, rose-colored, and not fragrant, and are few in a cluster. It is a native of the mountains from Virginia to Georgia, but has also been introduced and become established in the North. While of no particular value as a honey-plant, it is very beautiful as a cultivated shrub.

LOGWOOD (Haematoxylon campechianum).-A tree found in the West Indies and Central America. It is primarily a dyewood. The dye is extracted from the heart of the tree. In its early stages, this heart is only a small colored core; but as development continues, it enlarges, until in full maturity there is but little sap between heart and skin. The dyewood is prepared for shipment by digging up the tree, roots and all, chipping away the outer sap, thus leaving the colored core ready to be rendered into dye.

There are large areas in the tropics where this tree is the predominating growth. When the full bloom is on, many square miles of country become suffused with the mellow beauty of its golden blossoms, the delicate and pleasing perfume of which is everywhere paramount. We know no finer honey than that of the logwood blossom. It is almost water-white, very dense, and possesses a peculiarly pleasing flavor-in fact, it seems to embody the primal fragrance of the bloom.

In Jamaica logwood is the principal source of honey. This is true both as regards quality and quantity. One may usually count on two main flowerings-one occurring in November, and the other about Christmas time. The first is not so much to 
be depended on, as it is usually light, and besides there are about that time other honey sources productive of inferior quality"bitter bush," for instance-so that the finished combs held up to the light reveal
Here lies the hope of the apiarist. Two factors then contribute to his crop. The first is the condition of his colonies. They must be ready. or the finest of the year goes to brood and brood-combs. Even if barrels

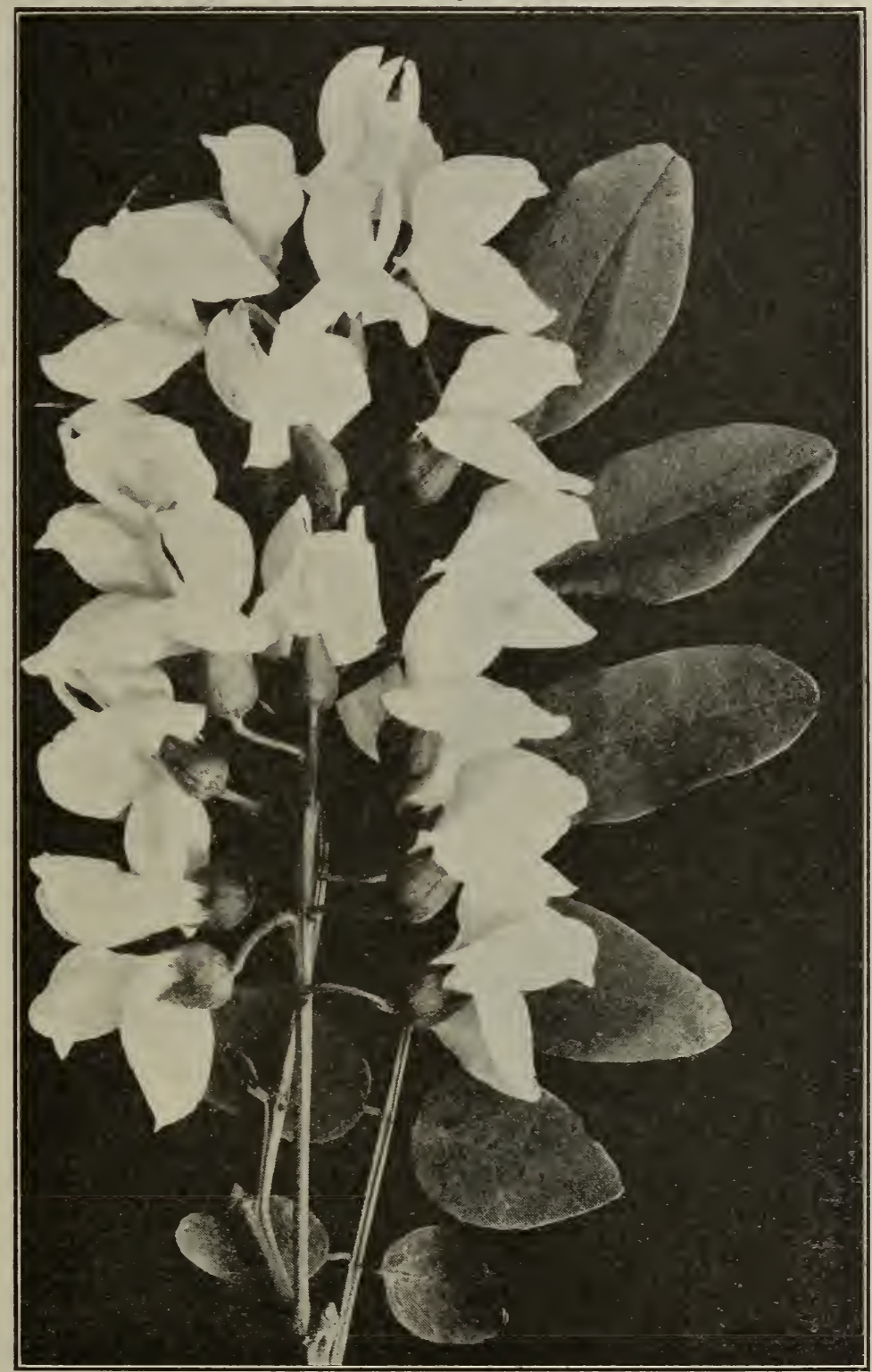

Common locust.

a patch-work of various colors. Even in extracted honey, it is almost impossible to effect a separation. This mixed flow, however, is peculiarly valuable as it enables the beckeeper to fill his brood-nest and eatch the main logwood flow in the supers.

The second or main flow occurs about Christmas, and may last all thru January. of sugar have to be fed, a super should be on every hive, and bees in the supers by the middle of December. This done, the beeman's end has been accomplished. But there is another factor: Rain. We have watched the great strings of buds drooping heavily downward, and while forests beaded with folded blossoms all ready to burst-one 
factor was missing-rain. We have seen, while full apiaries waited, the untempered torrid sun burn the blossoms into crumbled dust. But, let the rains fall at the proper juncture, and thousands of acres burst into fairyland. We have seen erenings when everything looked hopeless. That night a shower fell. At daybreak the apiary was a-roar, and the clear atmosphere was black with bees. Of course, the duration of the principal bloom is also dependent upon light intermittent showers. There have been seasons when the main bloom lasted for six weeks, and individual colonies made as high as five hundred pounds.

Is there no danger of the logwood forests being depleted? Hardly, unless by intentional transfer of industry. The tree grows of its own accord, and the growth is so abundant that the planter, so far from planting trees, has to thin out the yearly natural propagation. Otherwise the logwood estate needs little attention. The main expense is to prepare the mature stock for market, and this consists in paying laborers so much per ton for " chipping." Owing, however, to the rapid introduction of aniline dyes, the logwood industry is being supplanted by others that are more profitable - such as sugar-cane, bananas, ete. But where a genuine logwood estate can be found, the beekeeper can afford to establish apiaries of some five hundred colonies.

LUCERNE.-See ALFALFA. 


\section{M}

MAGNOLIA (IIagnolia foetida (L.) Sarg.).-English names are laurel bay and bull bay. The noblest tree of all the magnolia family grows to a height of forty feet in its native habitat, the deep hammocks, straight and heavily branching. The leaves are dark, rich green, smooth and glossy on the upper side, of a rusty-velvety nature below. The blossoms are the crowning glory. They are large and showy, like huge creamy-white saucers, gradually turning brown as they mature and fade. They are rich in pollen, and the bees become fairly steeped in the dust as they gather the nectar from the stiff yellow stamens at the center of the white saucer-like flower. $\Lambda \mathrm{n}$ analysis of samples of honey sent to the government experts at Washington, from the ricinity of DeLand, Florida, always reveals the presence of pollen grains from the magnolia, showing that it is a good yjelder of honey. It comes along with holly, and often with scrub palmetto, so that it is never secured alone. Even back from the hammocks it is extensively planted for shade and arenue trees, and the number of these trees used for ornament is so large that they make considerable showing in the activity of the bees in localities that would not otherwise feel their influence.

MANGROVE, BLACK (Avicennia niti$d a$ Jacq.).--Never in the history of honeyproducing plants has any single source yielded the results or attracted the attention of the public as has the black mangrove of southern Florida. Of the vervain family, the black mangrove is an evergreen maritime shrub or tree-shrub in northern limits, tree further south. It flourishes best on the small islands and keys that fringe the shore on both eastern and western coasts. where the salt water keeps its feet seasoned with brine, tho not necessarily under water. It does not grow much north of the 29th parallel-that is, about the range of Ormond, on the east coast. It needs to be kept distinct in mind from the red mangrove
(Rhizophora Mangle, L.), and the white mangrove (Laguncularia recemosa, Gaertn) whose habitat is similar to that of the black mangrove, only it does not need salt water to flourish. The white mangrove belongs to the pomegranate family, and is also called buttonwood, which see. The black mangrove, when a tree, much resembles a scraggy old oak, the bark being a gray hue and

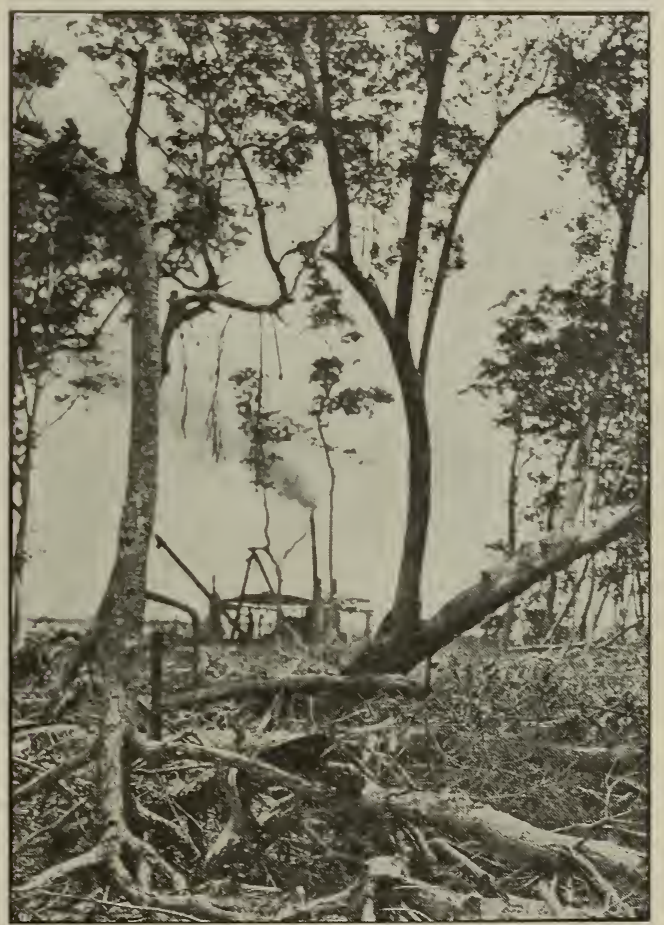

Black mangrore on the right; red mangrove on the left.

the surface rough and uneren. It attains a trunk diameter of four feet at its best, and cren greater in the extreme southern portions of the state and on the Keys. It usually grows back of the red mangrove, if both grow together, the red being a soil gatherer, on the fringes and shell reefs, and the black forming soil back of that. Both are valuable in this particular of catching drift and lodging humus and gradually transforming the shallows into reefs and 
islands, and ultimately into solid earth. It dues not, like the red, require a sea-bath every day, but must have salt water in the subsoil. The leaves are short-stemmed, fuzzy in appearance when young, soon beroming smooth and tough. The shape is oblong, a little larger just above and below the middle. The leaves are bright green above, pale beneath, speckled with fine specks that gleam with a peculiar metallic glint. The flowers are inconspicuous, of a yellowish-green hue, blossoming on a spike or head, the same flower-stalk carrying both old and new blossoms at the same time. This peculiarity lengthens out the bloom-period very considerably, which lasts from six to eight weeks in most favorable seasons. The wood closely resembles ebony in color and weight, and, when used as fuel, makes an intense heat and burns with a peculiar crackling sputter. The stove-door must not be tightly closed in burning the wood or it will not burn steadily. On the small islands thick set on the Indian River, and even further north, along the east shore of Florida from Ormond south, are thousands of acres of the black mangrove, now from six to ten feet high, shrubs of considerable size. This is the paradise of beemen, or was before "the freeze" of 1894. But if the name is "black," the honey is white. It is the whitest honey in Florida, with perhaps the single exception of cabbage palmetto. The body is rather thin, tho better in that on the Keys than on the mainland. In flavor it is very sweet and mild, and has just the barest suggestion of brakishness about it, due either to the soil or the vicinity of the salt marshes. The brakishness is not at all objectionable. The honey is usually pronounced first class, and ranks with the four best honeys of Florida -namely, the white tupelo, the orange, the scrub palmetto, and the mangrove. Up to the year of the "big freeze" in 1894 it was without exception the greatest yielder of honey of any plant or tree in the world. As much as $400 \mathrm{lbs}$. from one hive in one season from black mangrove has been recorded. The severe cold of the year named froze down all the mangrove on the coasts, and it has taken them 18 years to recover. They are now coming into bearing or yielding again, and there seems no reason why they should not become as great producers again as they were before. It began to yield honey again in small quantities first in 1909. Since that time the bushes have been increasing in size, and the yields have grown also, tho it has not yet shown anything like its former secretion. Like most sea-coast yielders it seems very sensitive to temperature and humidity changes and conditions. In 1911, for example, in the vicinity of the 29th parallel it started in to yield well, and all seemed prosperous: The bees began to show their old-time zeal, leaving their hives for the marshes almost before dawn, and lingering there till after dusk, roaring across the intervening coves incessantly; but after about two weeks of such work, weather conditions suddenly altered, and hardly a bee was seen again on the blossoms, altho they continued to grow and fade as before. When conditions are just right the honey can be seen in large drops, shining in the tiny cups, and a bee can load up from a single blossom. Overstocking could never be a bugbear in a mangrove section if conditions were just right. The cabbage palmetto usually blooms at the same time as the black mangrove, so that the two honeys usually blend. See PalmetTO, CABBAge. In earlier days " migratory beekeeping' " to the vicinity of Hawks Park was practiced from many points up and down the coast, and from inland localities, from fifty or more miles distant. The severe cold weather of one or two years put an end to that practice. Whether or not former conditions will return remains to be seen.

\section{MANIPULATION OF COLONIES. -}

Success or failure in the bee business depends very largely on manipulation. Colonies can be so handled as to make the business an entire failure. Sometimes improper handling so disgusts the would-be beekeeper that he never becomes one. Temperamentally he may not be fitted for the business, or else mentally he may be incapable of acquiring the art of handling them. A great majority of persons, however, who love honey and who enjoy outdoor work, have no difficulty in learning to handle what perhaps a few erroneously regard as a "mighty dangerous proposition." Over and over the statement has been made, "Bees would sting me, even if I were half a mile away from them. The further I am away from them, the better I like it." There is a 
sort of silly fear, on the part of a few at least, that bees are "mighty dangerous animals," and that their disposition is to rule or ruin, and to take. possession of the field because they are possessed of that small but mighty reapon, the sting. Nothing could be further from the truth.

There is probably not one person in a hundred who is not perfectly capable of handling bees. Whether he can make money or honey out of them is not a question so easy to answer, but that he can learn to handle them-that he can overcome all natural fear and prejudice-has been demonstrated by thousands who have commeneed beekeeping, and know no fear of them.

Under the head of ANGER OF BEES and under Stings we have shown that bees are not the irascible little creatures that many people suppose; that they are, on the contrary, when their nature is carefully studied, as gentle as kittens; and when one goes about them right they can be handled almost as safely. (See A B C of BeEkeepING at the beginning of this work.) But one cannot thoroly know this until he has actually opened a hive or seen it opened, and actually handled the combs for himself. This is not saying bees will not sting when handled improperly or at the wrong time.

The beginner should understand that bees can be worked very much better when weather conditions are right. The day should be warm, the sun shining, and the time selected for the manipulation between ten in the morning and three in the afternoon. Fxperienced beekeepers can handle them at any time under practically all conditions; but even the reterans endeavor to do it when they can work to the best advantage. In early spring or late in the fall, or when the atmosphere is chilly, or at any time immediately following a rain, or after a sudden stoppage of the honey-flow, bees are inclined to be cross. When it is cold, the bee-glue in the hives is brittle. In order to open a colony at such times it is necessary to break this bee-glue with a snap or jar. This always has a tendency to irritate the bees, even when weather conditions are favorable. The beginner at least should select his time, and of course will endeavor to make his movements very deliberate, avoiding very quick jerky actions, all snaps or jars. There are times when one will be compelled to open hives when the bee-glue snaps and when the bees sting; but he will then have the experience and proper appliances for doing the work.

Before we attempt to go into details of manipulation it will be necessary to consider tonls and conveniences, without which the handling of colonies would be difficult or even impossible at times. There are several essentials which may be mentioned in the order of their importance: A bee-smoker (see Srrokers) for quieting the bees; a beeveil (see VEILS), and suitable clothing for protection against stings, and some form of knife, screwdriver, or hive-tool to separate the frames and parts of the hive from each other that are usually stuck together

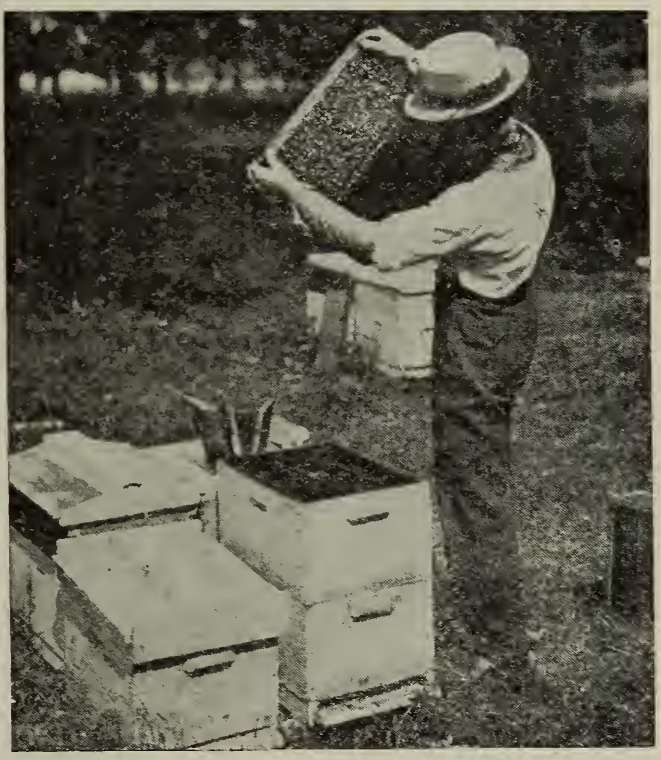

with bee-glue. Without the smoker and its intelligent use one would feel almost inclined to go back to the days of our forefathers when they brimstoned their bees (see Box Hives). But with smoke properly applied, one can render bees that would be otherwise nervous and hard to handle perfectly tractable. Even when conditions are bad, weather chilly and propolis hard, they can generally be brought under perfect control. The intelligent use of the smoker will often render the use of the veil unnecessary; and not a few experienced beekeepers do not use a veil constantly, but have it conveniently hanging from the hat, whence it can be pulled down whenever necessary. A bee-veil, however, is generally worn by veterans and beginners alike all the time while at work among bees. It is annoying 
and disconcerting to have cross bees buzzing around the face with the possibility of a sting in the eye, nose, or mouth. The beginner will always have a greater sense
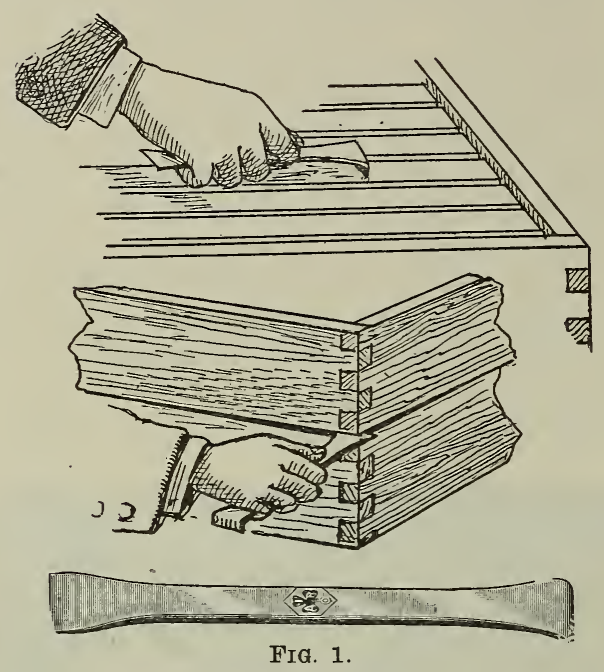

of security when his face is protected, and the old hand works with less interruption.

Gloves (see GLOvES) are recommended to the norice when he opens a hive for the first time. After he has learned the habits of bees he may dispense with them, because he will at most receive only an occasional sting on the hand. Very often experienced beekeepers wear a long gauntlet that reaches from the elbow to the wrist. This should be made so that no bees can get up the sleeve. It should fit tightly around the wrist, or, better yet, reach far enough to cover the hand, leaving the ends of the fingers exposed.

If one is very timid, or is unusually susceptible to stings, he can wear gloves that protect the fingers as well as the whole hand, wrists, and forearm. (See Gloves.)

In the line of tools a common jack-knife or a common screwdriver may often be used in lieu of something better. But a hive-tool made for the purpose is far superior.

The subjoined illustrations show a form of tool that has given general satisfaction among beekeepers.

It is something that any blacksmith can make out of an old buggy-spring or any good piece of spring steel. It must not be
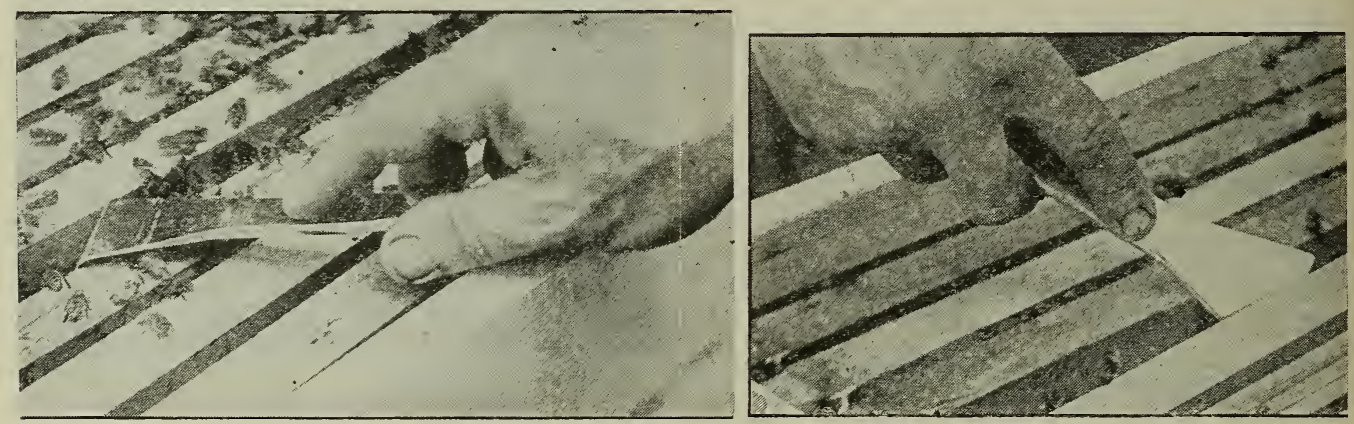

FIG. 2.-A side twist of the tool affords a strong leverage by which the frames are separated easily and without jar.
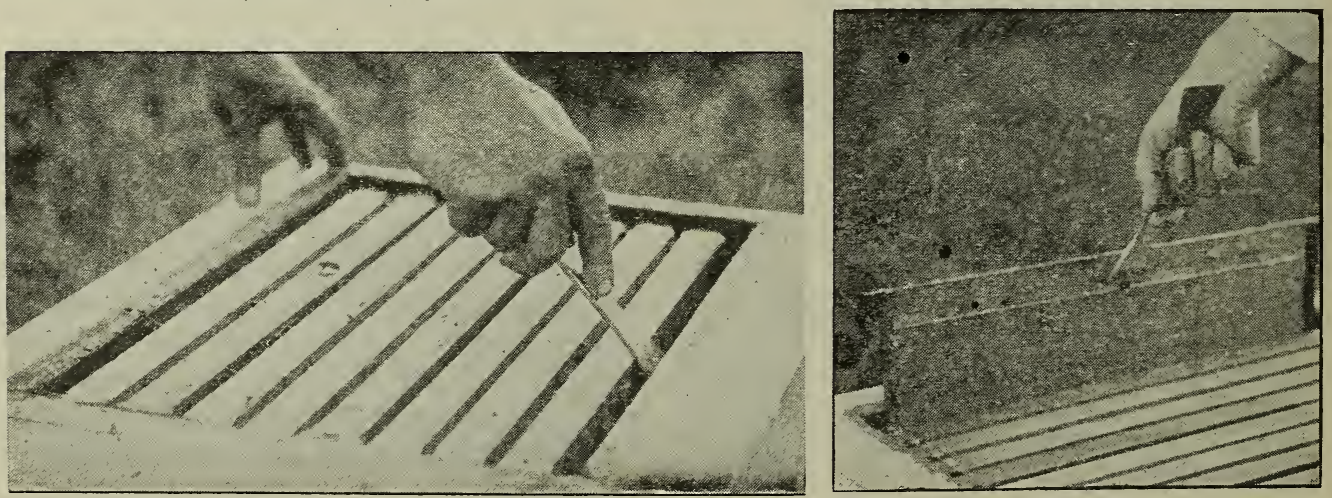

FIG. 4.-The proper way to pry all the frames over at one operation.

FIG. 5.-How the hook end is useful in fishing out frames and division-boards. 


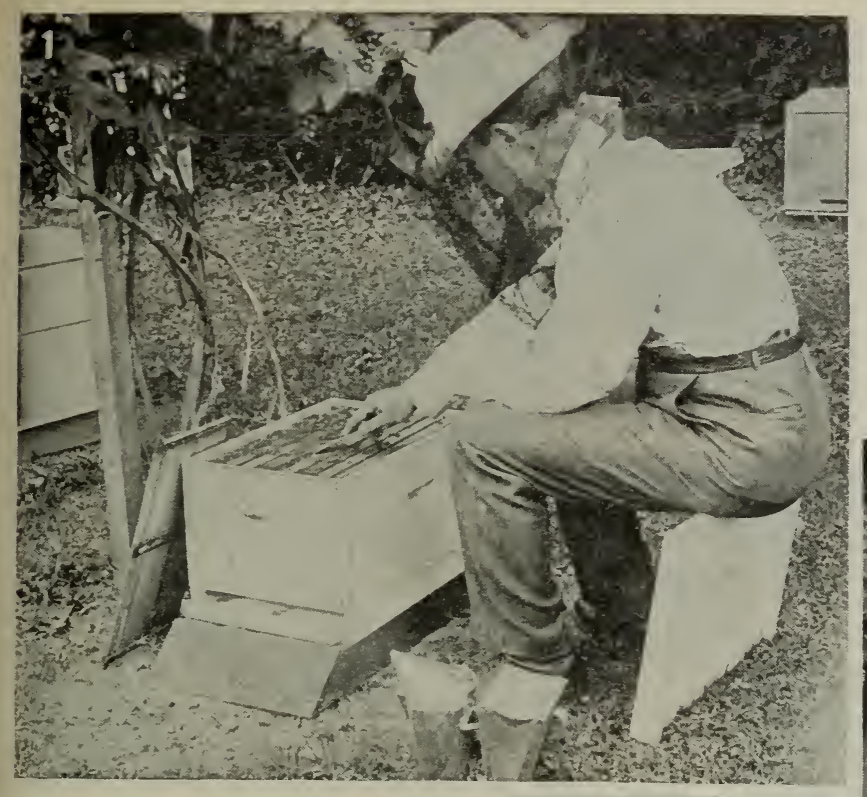

Fig. 2 exerts more of a leverage, and, at the same time, is less liable to crush bees.

Fig. 4 shows how the tool may be used for crowding all the frames over to one side in one block; or one can, if he prefers, use the plan shown in Fig. 2; but it will generally be found that the one shown

FIG. 6.-Making a gap between the frames so that one can be easily removed.

tempered too hard or it will break. Each end should be flattened out while hot, and brought to an edge. One end is bent to a right angle, and the other is left straight. The tool is then taken over to an emery wheel or grindstone and finished up. Care should be taken to have the edges straight and square.

The hooked end is ordinarily used for scraping propolis or wax off the frames or bottom-boards, while the other end (also useful for scraping) is pushed between the two parts of the hive. The drawing (Fig. 1) shows the tool held improperly. The bent or curved end should be placed directly against the palm in order that sufficient pressure may be exerted to shove the other or straight end between the two hive parts.

Either end of the tool may be used for separating Hoffman frames, or, in fact, any style of frame that one happens to use; but our men prefer the hook end. This is inserted between the frames to be separated, as shown in Fig. 2, when a side twist of the wrist will exert considerable leverage, forcing apart the frames very gently. However, there are some who prefer to use the straight end of the tool in the manner shown in Fig. 3; but the method given in

in Fig. 4 is more convenient. In Fig. 5 the curved end is used to good advantage in lifting the division-board out of the hive. See also, in this connection, Fig. 9.

Some prefer a hive-tool having a narrowed end like a screwdriver; but the continuous use of a tool like this abrases the edges of the hives so that, after a time, it leaves bruise marks and cracks, inviting winds and storms, and robbers when they are prowling about. For separating two hives heavy with honey there is nothing better than a wide thin blade made of good spring steel, tempered just enough to have the resilient qualities of a buggy-spring.

HOW TO WORK OVER HIVES.

Many yard men prefer to work with a sort of stool and hive box combined; yet others wish to have nothing to lug around 
except the bee-smoker and the hive-tool. As most hives are placed on or near the ground, one must either sit down on some object or kneel in front of the hive, to bring himself to the proper working distance. We usually use a hive-cover as shown in Figs. 6, 7, 8, 9. It is always handy and has
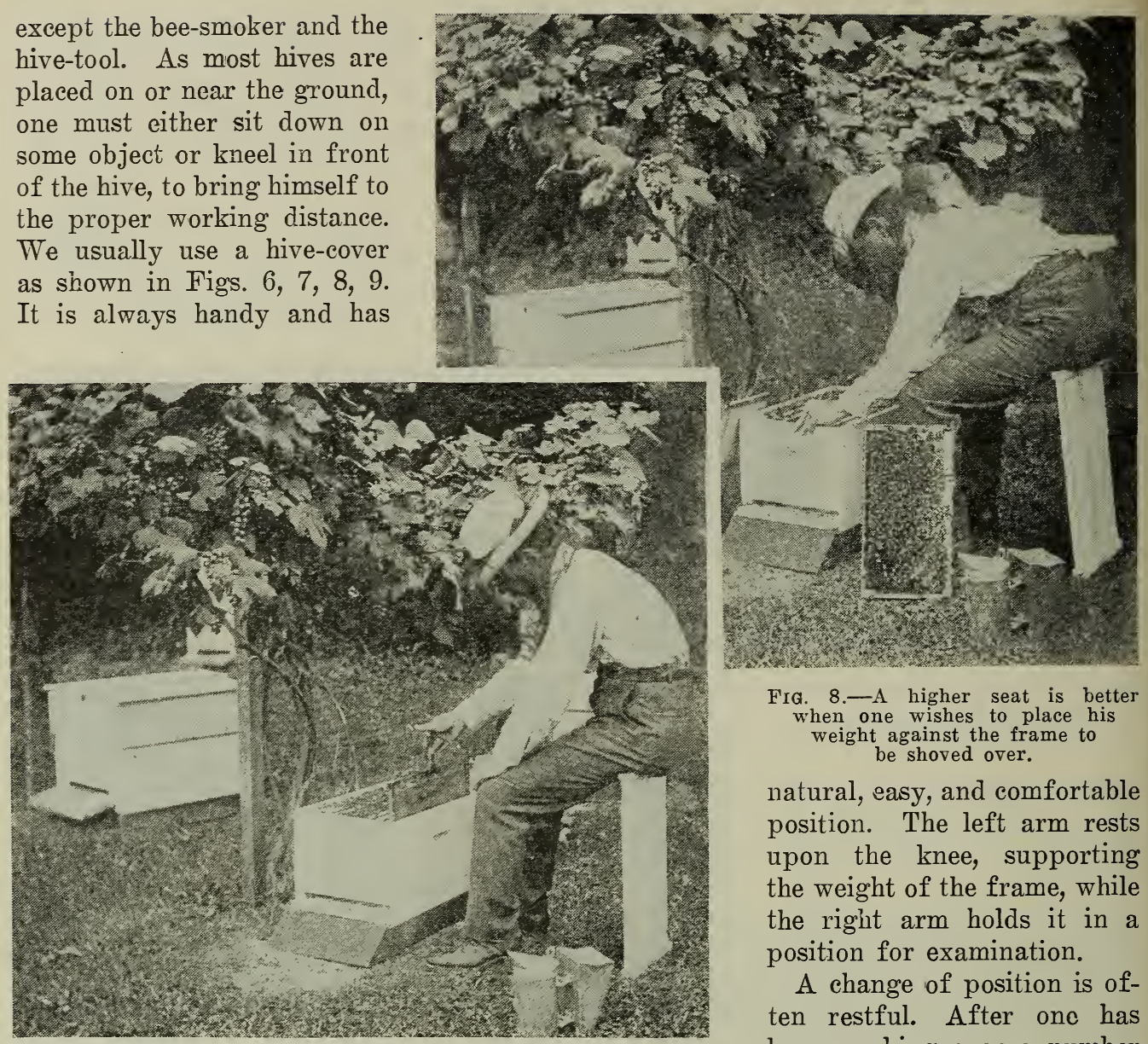

FIG. 8.-A higher seat is better when one wishes to place his weight against the frame to be shoved over.

natural, easy, and comfortable position. The left arm rests upon the knee, supporting the weight of the frame, while the right arm holds it in a position for examination.

A change of position is often restful. After one has been working over a number FIG. 9.-Pulling out a refractory division-board that resists removal. of hives, sitting down on the

the further advantage of a milk-stool in that one can shift his body back and forth on the hive-cover in order to reach frames toward the near or far side of the hive, as the case may be. A seat that does not allow one to shift his body back and forth, necessarily requires more stooping or bending of the back.

Occasionally it will be found desirable to turn the cover up lengthwise, and the author always uses it in that manner when he desires to place the weight of the body against the frame that is crowding over against its fellows. See Fig. 8. In pulling out a division-board, one has a little more leverage if he sits high rather than low. See Fig. 9. But if he merely wishes to separate the frames, then spend several minutes hunting for the queen or looking over the brood, as shown in Fig. 7, one should sit on the narrow side rather than on the end. In this the operator assumes a very hive-cover, he finds it convenient to vary the position by resting on the knees close to the hive; and still again he may find it comfortable to vary the monotony by standing upright, bending over only when it is necessary to remove a frame.

Perhaps it may seem that the operator in Fig. 9 is taking things easy. There are times when only one hand can do good work. If one can assume a comfortable attitude, even tho it be only momentary, he ought to do so.

Some of our apiarists will say they have no time to sit down, much less "loaf on the job," as might appear in Fig. 6. The more one can save his legs and arms the more he can actually accomplish in a day. In hunting for a queen one cannot afford to stand up on the job, but should get right down where the eyes can do their best work, as seen in Fig. 7, always holding the frame in such a way that the sunlight will strike 
it squarely. In looking for eggs this is very important, especially if the operator is getting old when eyesight is not at its best.

Where one is working over bees day after day, a special hive-seat is a great convenience. The illustration shows what is being used in our bee-yards. It was shown in one of the early editions of this work, but was

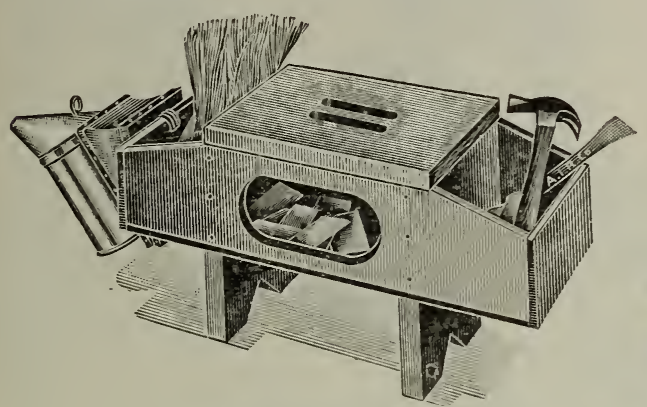

Hand seat and tool-box for yard work.

dropped out because it was thought hardly of sufficient importance to occupy space. During all the years that have intervened, our apiarists have seemed to find it very handy. In fact, they consider it almost indispensable. If one were to come to any one of our yards he will find the men carrying one around as they go among the hives.

The top is made of $7 / 8$ lumber, having two oblong holes in the center to provide a handle by which to carry the box. The legs are also of $7 / 8$, while the sides, ends, and bottom are of $3 / 8$. The compartment in the side, reached by the oval hole, is very handy for holding broken section pieces for record work, and other small articles, while the two compartments on each end usually hold the smoker fuel, hive-tools, hammer, bee-brush, queen-cages, and other articles of like nature. The smoker has a hook on the bellows so that it can be carried in the manner shown. With this whole outfit one has practically all the tools he needs, including smoker fuel, for a day's work.

The exact dimensions of the seat are not important. The one we use is 13 inches high by 22 long, outside measurement.

\section{HOW TO OPEN A HIVE.}

The prospective beekeeper should approach the hive and blow smoke into the entrance. This is not always necessary, but it will be found to be a wise precaution for the beginner and for an experienced man on a bad day. After the beginner learns the individual temperament of his different colonies, and also discovers that on certain days, and certain times of days, the bees can be handled much better than others, he will of course use his judgment in the matter. If he has reason to believe that a colony would be irritable he should send two or three puffs of smoke into the entrance. He will now push the screwdriver, or special hive-tool already shown, under the cover. He should do this gently, working the thin edge of the blade between the two hive parts until the cover is raised about the thickness of the blade, but not wide enough to allow any bees to escape.

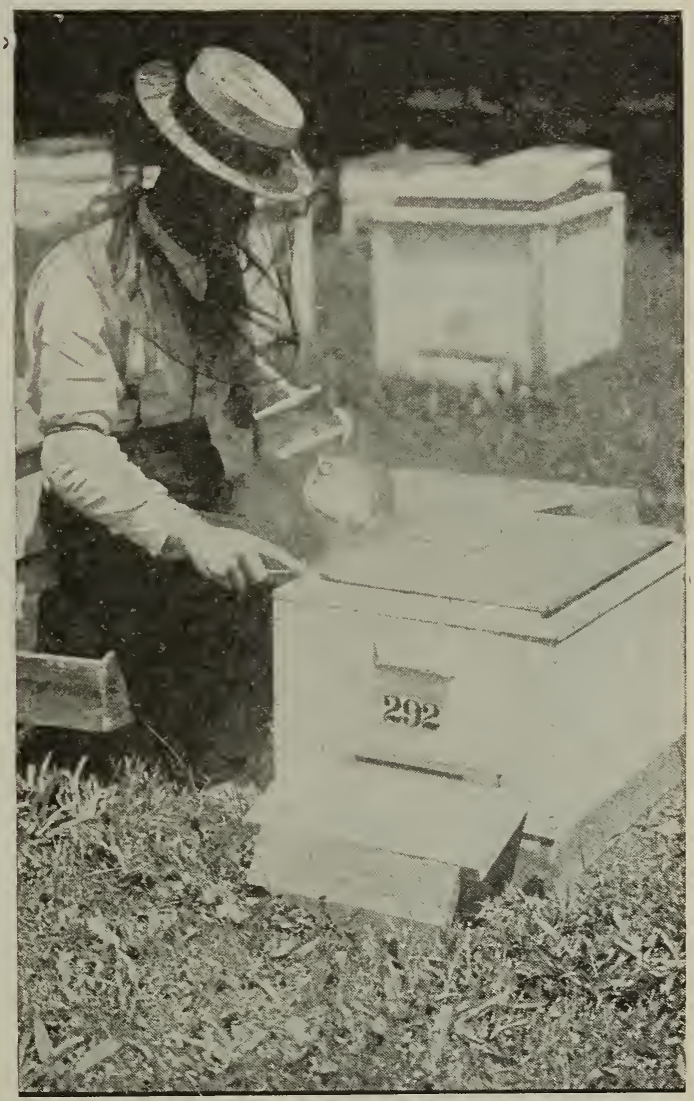

FIG. 9.-Method of inserting the hive-tool under the cover; blowing smoke in the gap thus made.

Thru the gap thus made he will blow three or four puffs of smoke. He then shoves the tool a little further, increasing the gap, following it up with some more smoke. He now lifts or lowers the hand holding the tool so that the cover is raised an inch above the hive. The smoker is next set down upon the ground, when the cover is gently lifted off. We say "gently" because 


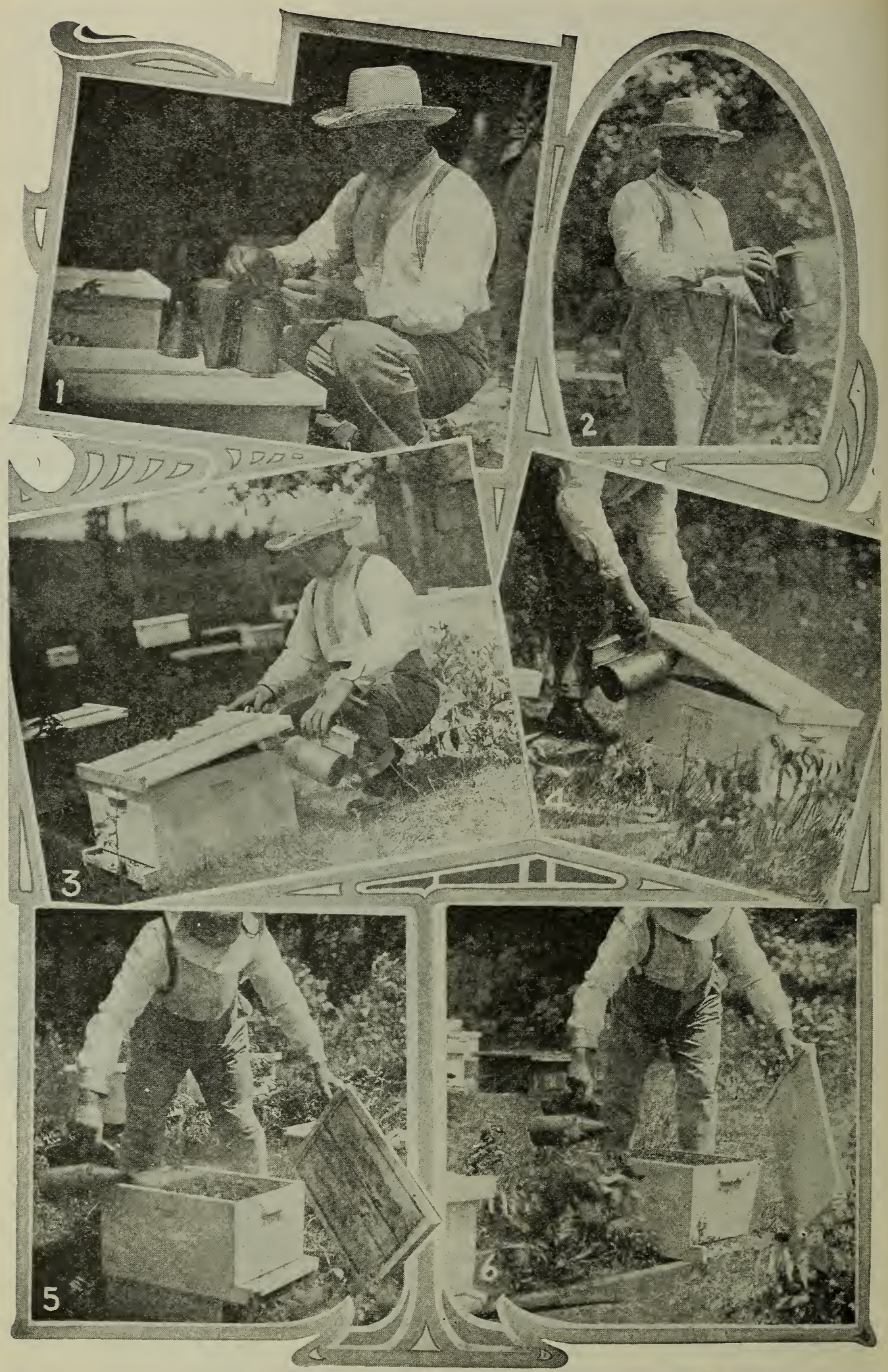

E. D. Townsend illustrating for beginners the proper use of smoke in opening a hive. 
this is important. Slam, bang, rip, and tear methods won't work with bees.

Sometimes much more smoke will be required than others. If the atmosphere is a little chilly, or if it be immediately after a rain during a honey-flow, much more smoke will be needed than on a warm balmy day when bees are at work in the fields. If they are at all nervous the smoker should be brought into play again; indeed, at such times we would advise putting it between the knees. (See SMokers.)

This nervousness may not immediately be recognized by a novice; but for his special benefit we may say that, when bees are subdued and require no more smoke, they will be down between the frames almost out of sight; but if they are inclined to "resent the intrusion," dozens and dozens of them may have their heads sticking up; and as the apiarist proceeds to lift out a frame he may meet with a "warm reception." But before this takes place he will usually see on the part of the bees a nerrous, quick
HOW TO HANDLE UNSPACED FRAMES,

To get at the center frame, crowd the frames, one at a time, adjacent to it, toward the sides of the hive. This will give room to lift out the desired frame. Beginners are very apt to pull the frame out without spacing the frames apart. This rolls the bees over and over, enrages and maims them, and moreover runs a pretty good chance of killing the queen. Lift the frame out carefully, and be careful not to knock the end-bars against the sides of the hive. If it is one's first experience he may be nervous, and do things a little hurriedly. As a reward, the bees will quite likely sting him and make him still more nervous. To avoid this, proceed very cautiously and make the movements deliberate. Having removed the frame, hold it up as shown in Fig. 1, which we will call the first position.

Perhaps the queen is not to be seen on this side, so it may be necessary to turn it over and see the other side. If the comb is

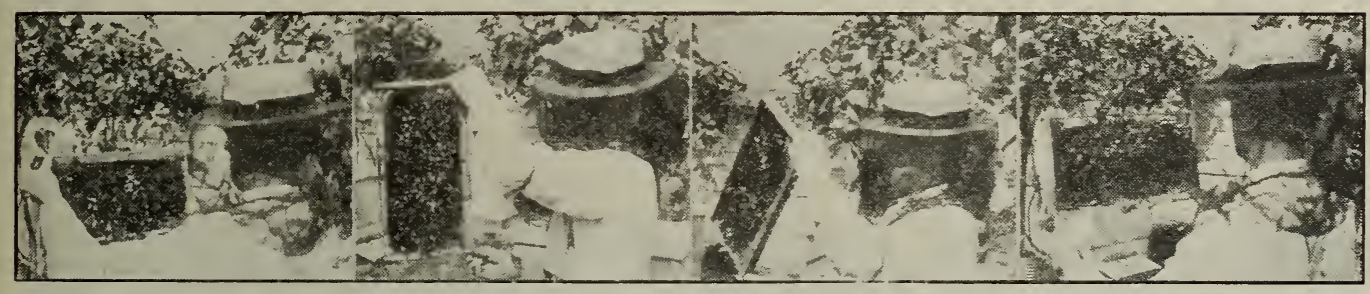

FIG. 1.

FIG. 2.

FIG. 3. movement, their bodies turning either to the right or to the left, apparently ready to take wing. When they do so, it will be a quick sharp dart, without warning, for any exposed part of the beekeeper's anatomy. But even if the bees do make a general onslaught, and grab as if about to strike, stings may be averted if the operator is quick enough to brush the bee or bees off. There is an interval of a fraction of a second, not very long, it is true, in which, after the bee shoves its claws into the flesh, it can be brushed off, just before the sting gets into action, for a bee, when it stings, must have a good strong hold, and it is while it is taking this hold that the apiarist can often save himself many a wicked jab.

If, then, the bees seem inclined to fly up, they should be smoked just enough to keep them down. If an attendant is present, let him use the smoker. See Stings, subhead "How to Avoid being Stung." not heavy with honey, it can be turned right over with the bottom-bar resting horizontally. But a better way, and a good habit to fall into, and one that beekeepers usually adopt, is to raise the left hand until the top-bar is perpendicular, as in Fig. 2.

Now revolve the frame like a swinging door, or the leaf of a book, so that the opposite side is exposed to view (see Fig. 2). Lower the left hand as in Fig. 3 until it reaches the position as shown in Fig. 4. To examine the other side follow the exact reverse order.

Having examined this frame, lean it up against the side of the hive, and remove another frame next to the one already taken. Examine this in like manner. Lean this also against one corner of the hive, or return it to its place; lift out another, and so on until all have been examined. Should the queen not yet have been found, look the frames all over again, being careful to ex- 
amine the bottom edge of the combs. See QueENs, subhead "How to Find."

If the queen is not found on the first examination it may be advisable to go over the frames once more; but very often it is better to close the hive and wait an hour or two, after which one can go back and search the frames as before. By this time the colony will have recovered itself, and the queen, in all probability, have shifted her position from the bottom or sides of the hive to one of the combs. Nine times out of ten she will be found at the second going-over of the frames, without any trouble. When the queen cannot be found the second time going over, as a rule we would not advise hunting longer, because one is liable to waste a good deal of valuable time; and it is, therefore, better to wait till the queen comes out of her hidingplace back to the brood-frames themselves.*

In the case of black colonies, especially where very populous, it is sometimes necessary to lift the hive off the stand and put it down at one side. On the old stand place an empty. hive, affixing an entrance-guard. See Drones. Take the frames one by one out of the old hive, and shake them in front at the entrance of the empty hive on the old stand. Black bees fall off very readily; and as they crawl toward the hive the queen can be easily seen; but if she eludes scrutiny she will be barred by the perforated zine where she may be readily discovered trying to make her way thru. After all the frames are shaken, if she cannot be found, take the old hive, now empty, and dump it, causing the bees to be thrown before the zinc. She will soon be seen trying to pass the guard.

We have told how to find the queen; but the reader must not imagine that it is going to be as difficult as this every time. She is usually to be found on the center frames; and, especially with Italians, is likely to be found on the first or second frame handled.

When loose frames or frames without spacing shoulders are put back in the hives they must be spaced carefully $13 / 8$ inches from center to center as near as it is possible. It is not practicable by the rule of thumb or finger to get them all exactly this distance so that there will be some combs a little thicker than others, even when the

* If the bees are inclined to rob, use an empty body to hang half of the frames in, placing them in pairs, and pair-off the rest in the hive being worked on.-A. C. Miller. greatest of care is used. If one is a little careless (as most people are) there will be considerable variation in the thickness of the combs, and the thicker ones will have to be shaved down with an uncapping-knife at the first extracting. If the combs are left thick and thin there will be danger of killing a good many bees in inserting and removing the frames, especially when the position of the frame is changed. All of this nuisance of irregularity in thickness of combs can be avoided by the use of selfspacing or Hoffman frames.

There is no cut-and-try spacing as with unspaced frames, no big and little fingers to get the distances wide and narrow, and the beginner has no difficulty in determining just how far to place the combs; for if he places the shoulders in contact they will always be the right distance apart.

There is not much danger of killing bees provided one proceeds carefully, using a little smoke in blowing the bees away from the contact edges of the frames. When the hive is ready to close up, all that is necessary is to shove the frames together, that are separated two and three inches apart, or put in the groups of two, three, or four frames at a time, as the case may be, and crowd the whole together, after putting on the cover. On the other hand, when unspaced frames are handled, each frame must be put back into position one by one. This takes a large amount of time whatever we may say of the time consumed in separating spaced frames apart. See Frames, Self-spacing; also Frames.

It is important to observe in the handling of Hoffman frames that smoke can be used to very good advantage. Just a little blown down between the contact edges or where the edges are to come together will drive the bees away so they can be shoved together. Mr. Hoffman, the inventor of the frames, stated that the judicious use of a smoker would save time, avoid bee-killing, and, taking it all in all, he could handle twice as many colonies on his spaced frames as he could on the ordinary old-style frames without spacing attachments.

There are some localities where propolis, or bee-glue, is much worse than others. In such places the Hoffman metal-spaced frame has the advantage. The illustrations will show their special features. They are somewhat more expensive, but they are 
stronger; and as they have only points of contact there is less danger of killing bees.

\section{HOW TO MANIPULATE HOFFIIAN FRAMES.}

The manner of opening hives containing Hoffman or any other self-spacing frames, is just the same as that for hives contain-

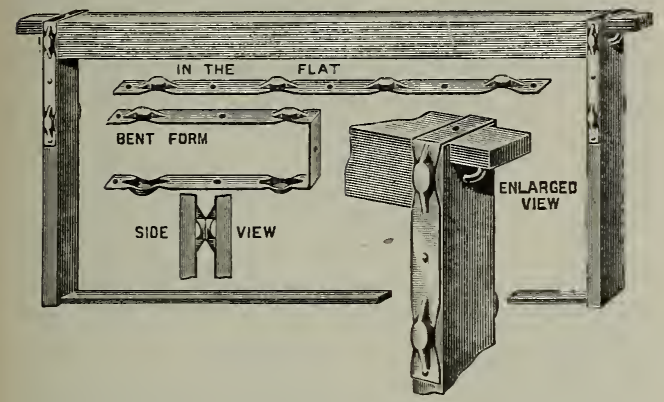

Metal-spaced Hoffman frame.

ing loose or unspaced frames already described, but the manner of handling the combs is somewhat different.

If there is a division-board in the hive this is first removed in order to give room for the handling of the frames themselves. If there is none the outside frame is pried over to the side of the hive and lifted out very carefully. This will then make room for the removal of any two, three, four, or five frames all in blocks. As an ordinary Hoffman or self-spacing frame will be somewhat glued together by propolis it will be necessary to use the hive-tool to separate the frames in the group. They should be left together because they can be put back in one block.

In removing self-spacing or Hoffman frames from a brood-nest, it is not necessary to scatter them all around the outside of the hive, leaning them up against each other in such a way that it kills bees, but each group of frames, two, three, or four, as the case may be, can be left sticking together stationed on the outside of the hive. There is no danger then of killing the bees between the frames, and the necessary information can be secured from the one or two surfaces of combs examined. When the ordinary unspaced frames are used, it is necessary to handle each frame individually, because they cannot be picked up very well in groups of three or four like the Hoffman or any other good self-spacing frame. See Frames, Self-SPacing.

In ordinary practice it is not necessary to hunt up the queen. The examination of the surface of one or two combs will show whether eggs are being laid. If eggs and

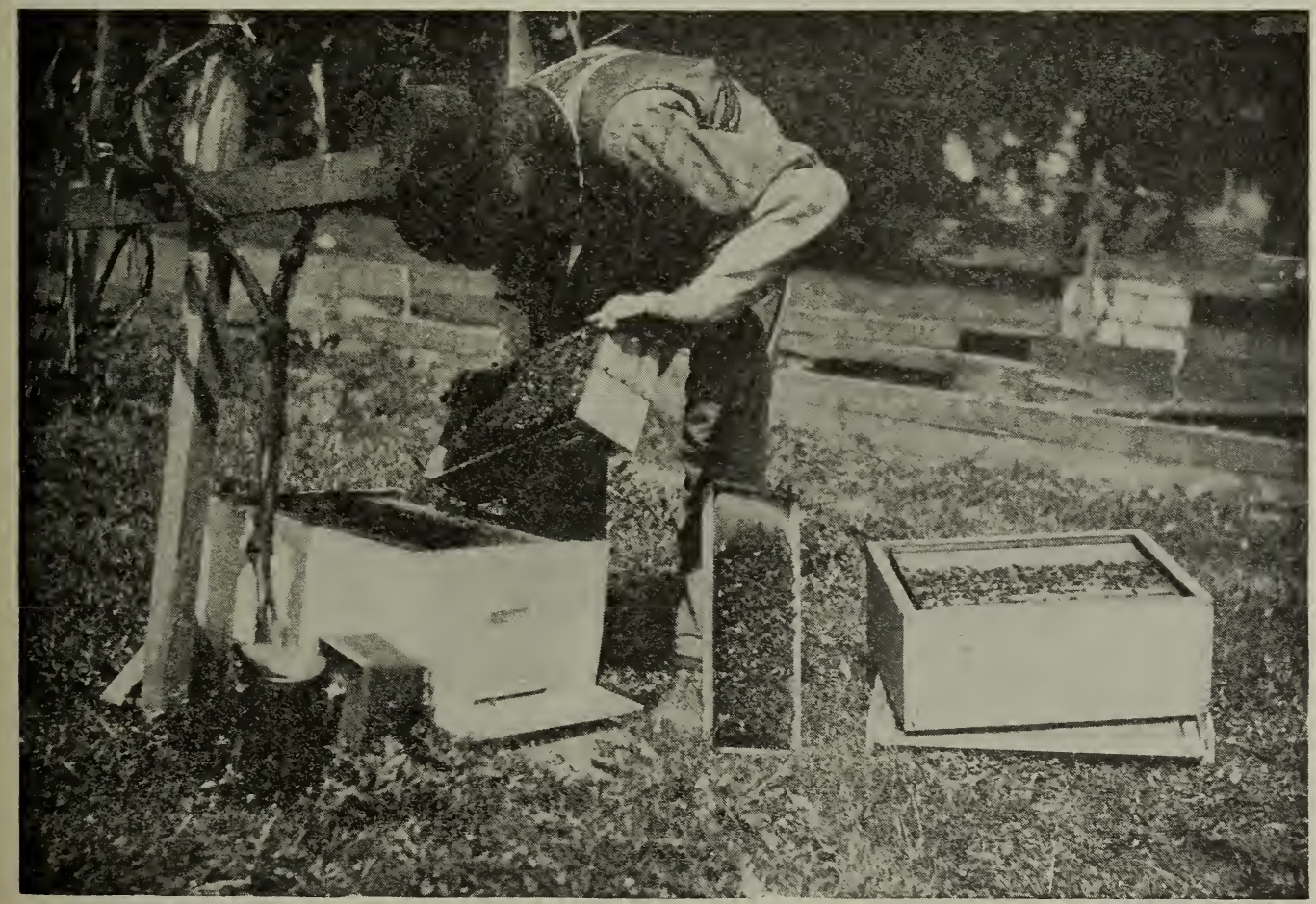

Handling closed-end frames in groups of three at a time. 

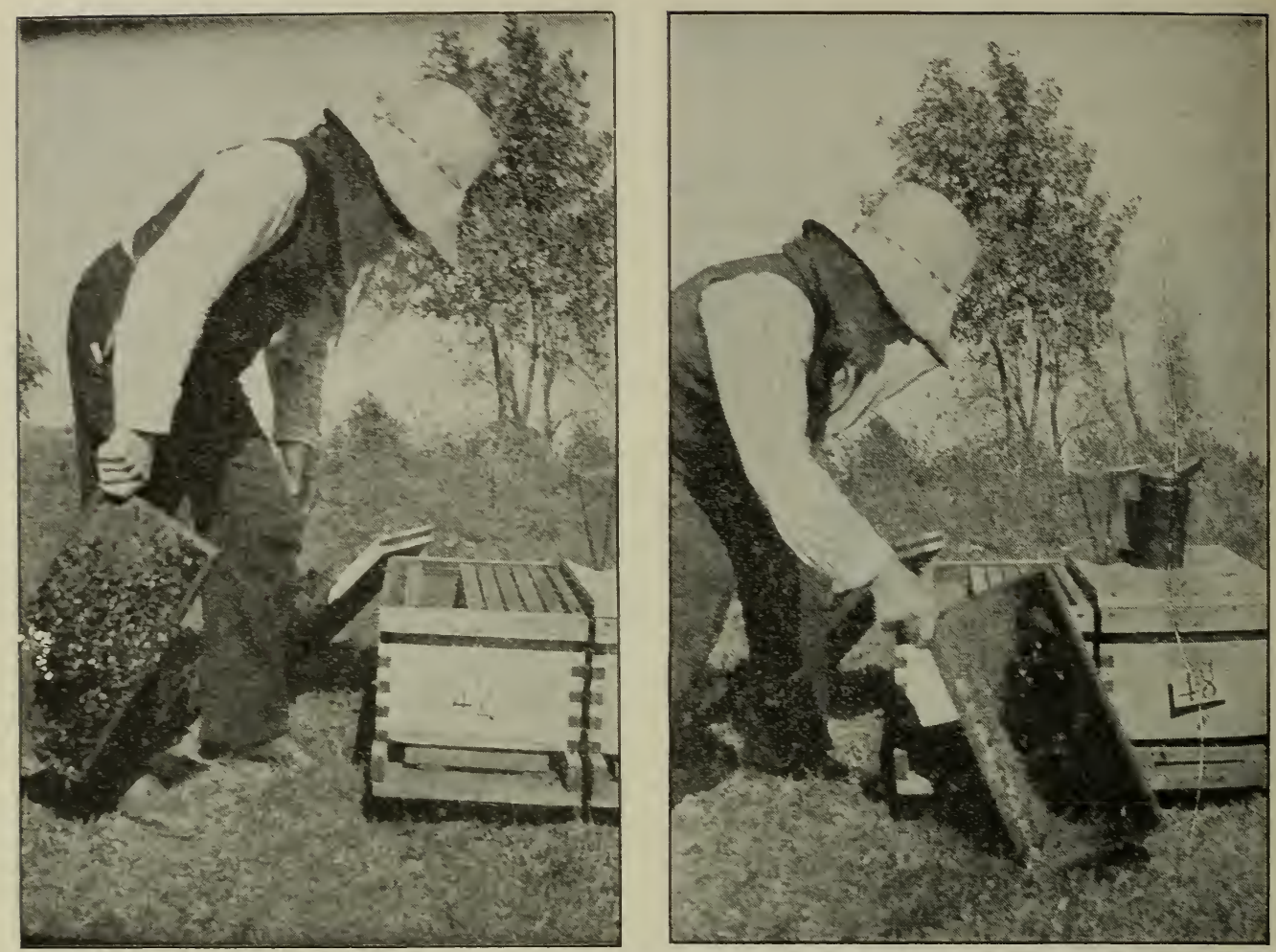

Dr. Miller's method of jarring bees off the combs.

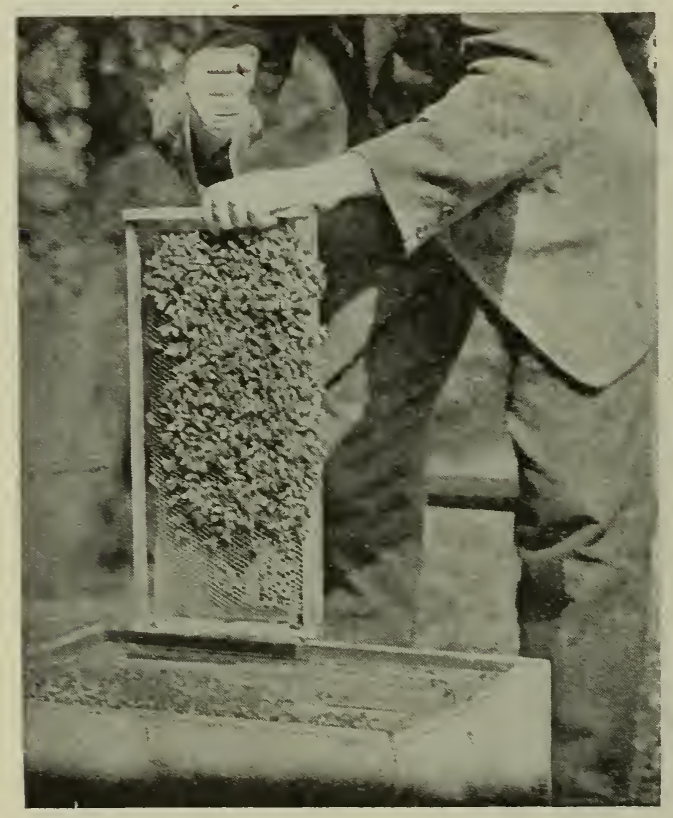

How to bump the bees off a comb.

brood in rarious stages are found in regular order it may be assumed that the queen was in the hire within three days at least.

The location of the queen can be determined somewhat by the manner in which the eggs are laid. If the examination of one comb shows no eggs and an examination of another shows that there is young brood, the position of the queen can be traced by the age of the brood until eggs are found, and the queen may at the time of the examination be at one side of the brood-nest rather than the other. After she goes clear across she is quite liable to jump from one side clear to the other.

Sometimes the behavior of the bees is such as to indicate where the queen is. Her location can generally be determined immediately after releasing the queen when introducing, because the bees will have their heads pointing in one direction; and sometimes by a hum of rejoicing the queen can be traced, especially if she has been well receired.

\section{DISLODGING BEES FROM COMBS.}

For many manipulations like giving brood to another hice, or for the purpose of extracting, it becomes necessary to dislodge the bees from the frames. This can be done by brushing them off as shown under ExTRACring, or they can be pounded off with a blow of the fist on the back of 

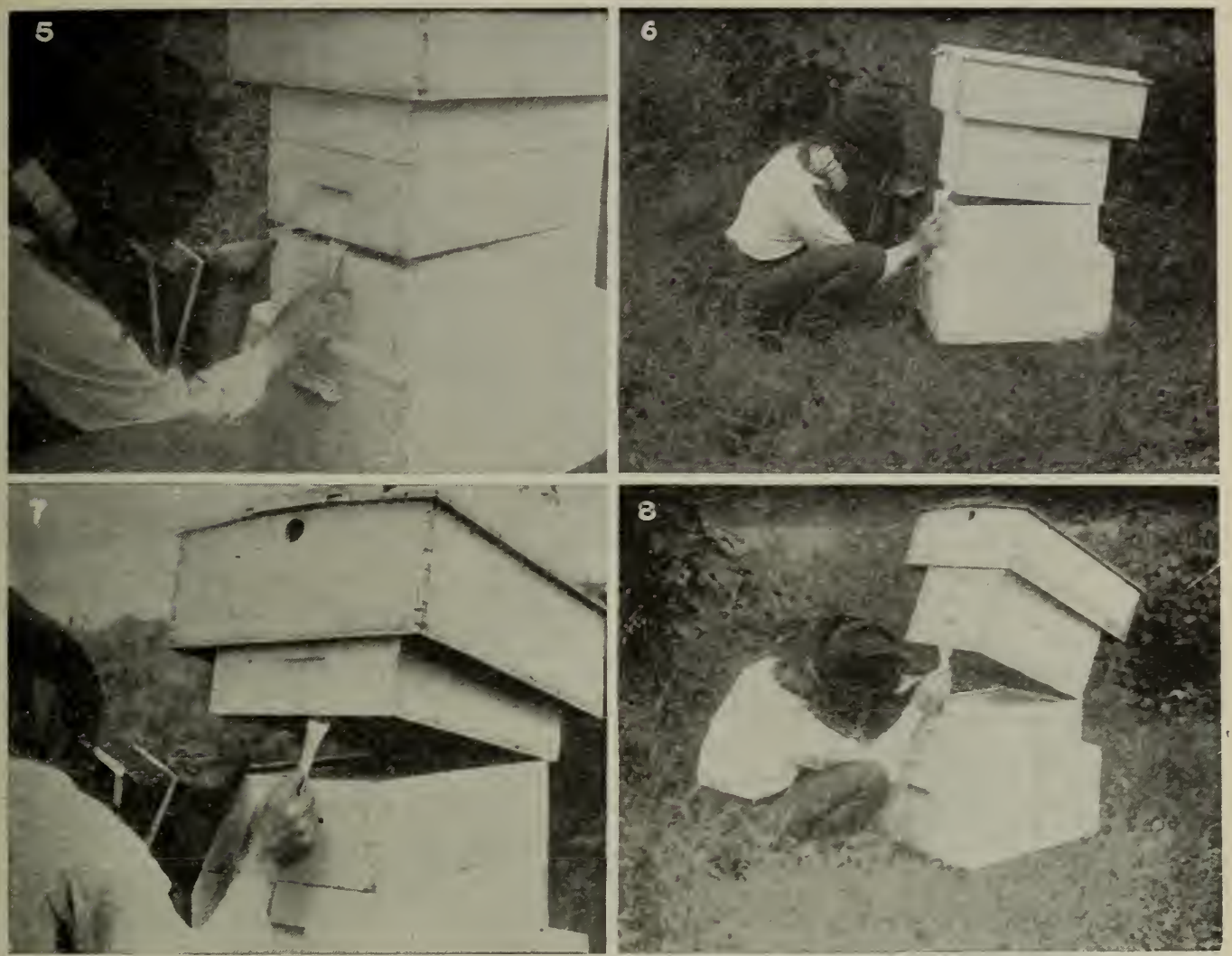

Learning condition of hire without removing cover or pulling to pieces.
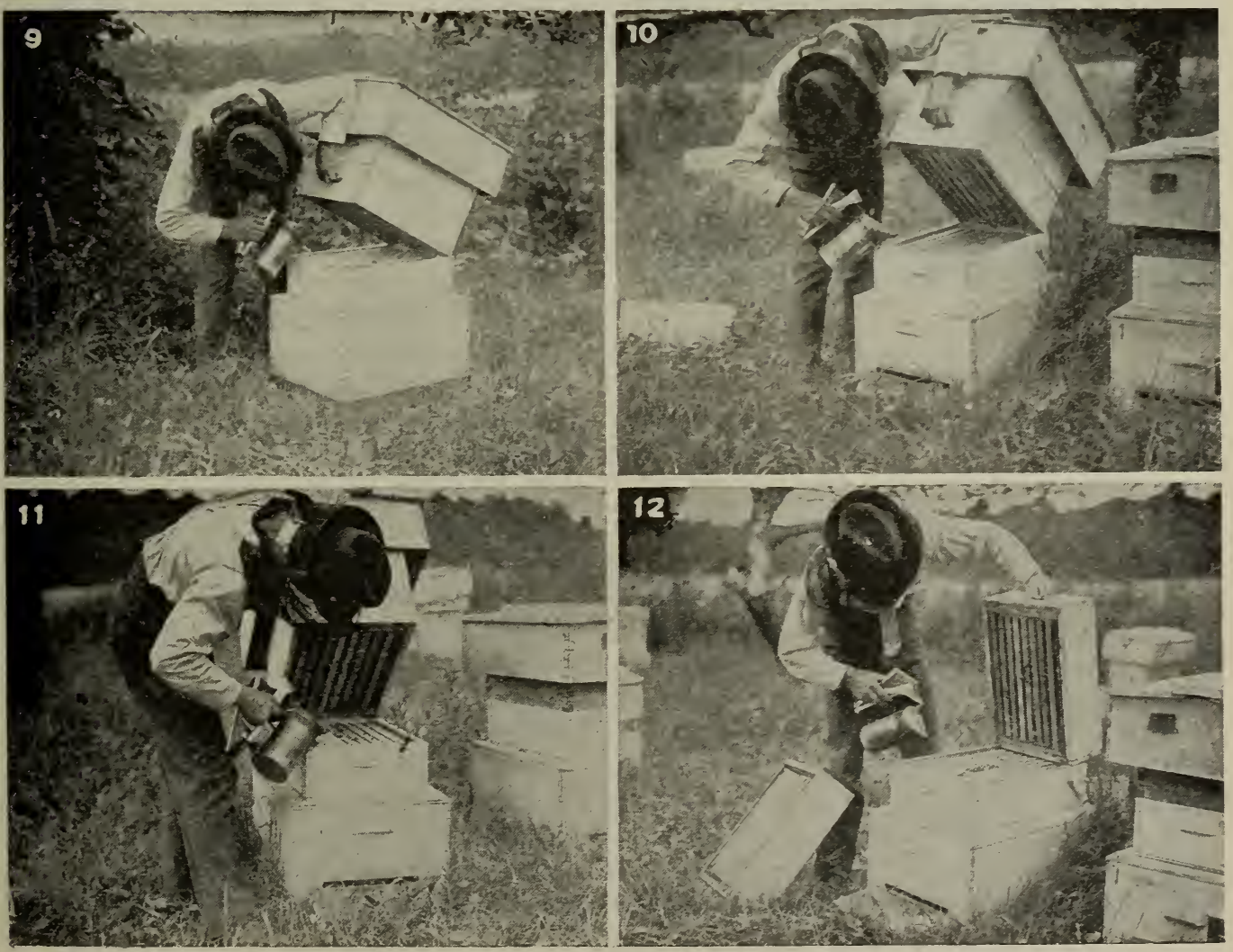

Determining the filling of the supers and whether ready to come off. 
the hand, grasping the end-bar as shown bottom of p. 490. Or one may grasp the end-bars solidly, and with a quick downward jerk remove all or nearly all of the bees. When more convenient one can swing the frame, pendulum fashion, with one arm, letting the corner drop violently against the ground while the other end is held in the hand. See top of page 490 .

HOW TO ASCFRTAIN THE CONDITION OF THE HIVE WITHOUT HANDLING FRAMES.

A good many, in working for extracted honey, operate on the tier-up principle, leaving the supers all on the hives until the season is over. By that time it is important that robbers be given no opportu-

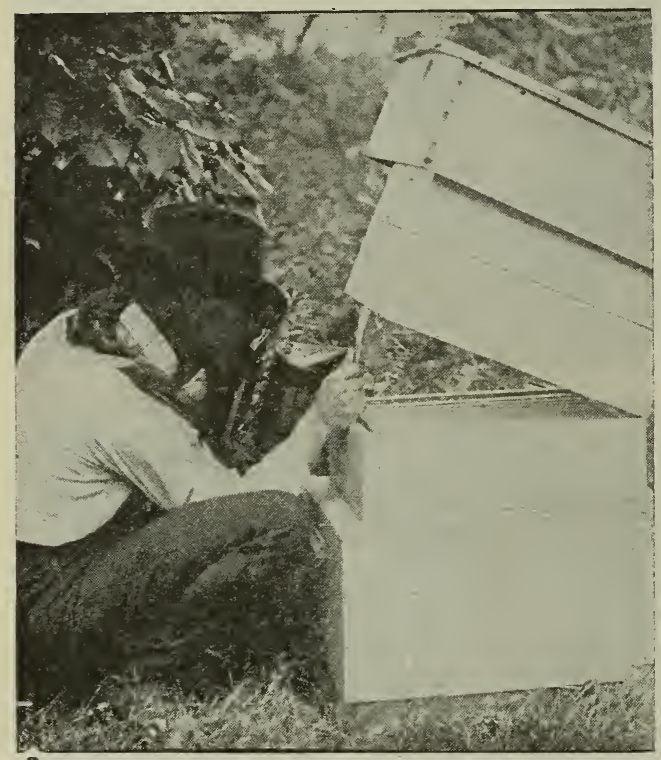

Fi 13. - How a smoker and a hive-tool will enable one to learn the condition of the supers at one glance.

nity to help themselves to sweets, when the honey is taken off; but before doing so the condition of the supers should be determined in advance. In order to keep ahead of the bees it is necessary to make an examination from time to time. Toward the early part of the season it is customary to place the empty supers under those partly filled. As the season begins to draw toward its close, the process is reversedthat is to say, the empties are put on top of those partly filled.

In order to determine the amount of honey in any super, it is not necessary to take off the cover and pull the hive apart.
If it is tiered up four and five stories high, it involves a large amount of labor and considerable lifting to pull the supers off one by one, inviting the attention of robbers in the operation. If one is supplied with a good strong steel hive-tool and a smoker, he can get a fair idea of the filling of any super, without even removing the cover from the hive. In the series of snapshots on previous page, the reader will be able to gather, almost at a glance, the exact method to be used in determining what the bees are doing.

Let us take an example. We will start with the hive shown in Fig. 5, previous page. It has three supers. The middle one is the one on which the bees began work first, and at the time of this examination it should be completely filled. The bottom super was placed under after the middle one was about half filled. The third super was put on top because there would probably not be more than a week more of honey-flow.

At this time we desire to know what the bees have actually done; so, without removing the telescope cover on top nor the super cover directly beneath, we extend the thin blade of the hive-tool. broad end, between the two lower supers at the back end of the hive; for one should always endeavor to keep out of the flight of the bees. This is gradually shoved in until the blade has been pushed in anywhere from $1 / 2$ to a full inch. A gap is now formed, of approximately 1-16 inch, just wide enough so that a little smoke will drive back the bees. A slight pressure downward separates the two upper supers about an inch at the back end, when more smoke is blown in. The tool is pushed down a little further, making the gap a little wider. See Fig. 6 . But we are not quite satisfied as to the condition of the supers, so we push the tool and supers upward, as shown in Fig. 7, until we have the hive-tool in position as shown in Fig. 8. Here it acts as a prop, when, with the intelligent use of the smoker, we can drive back the bees enough so that we can see the condition of the two supers, or enough to determine whether the bees need more room.

But suppose we are not quite satisfied. We turn to the position shown in Fig. 9, disregard the hive-tool, and lift the two supers higher, the hive-tool falling on the ground. When doing this we slide the two 


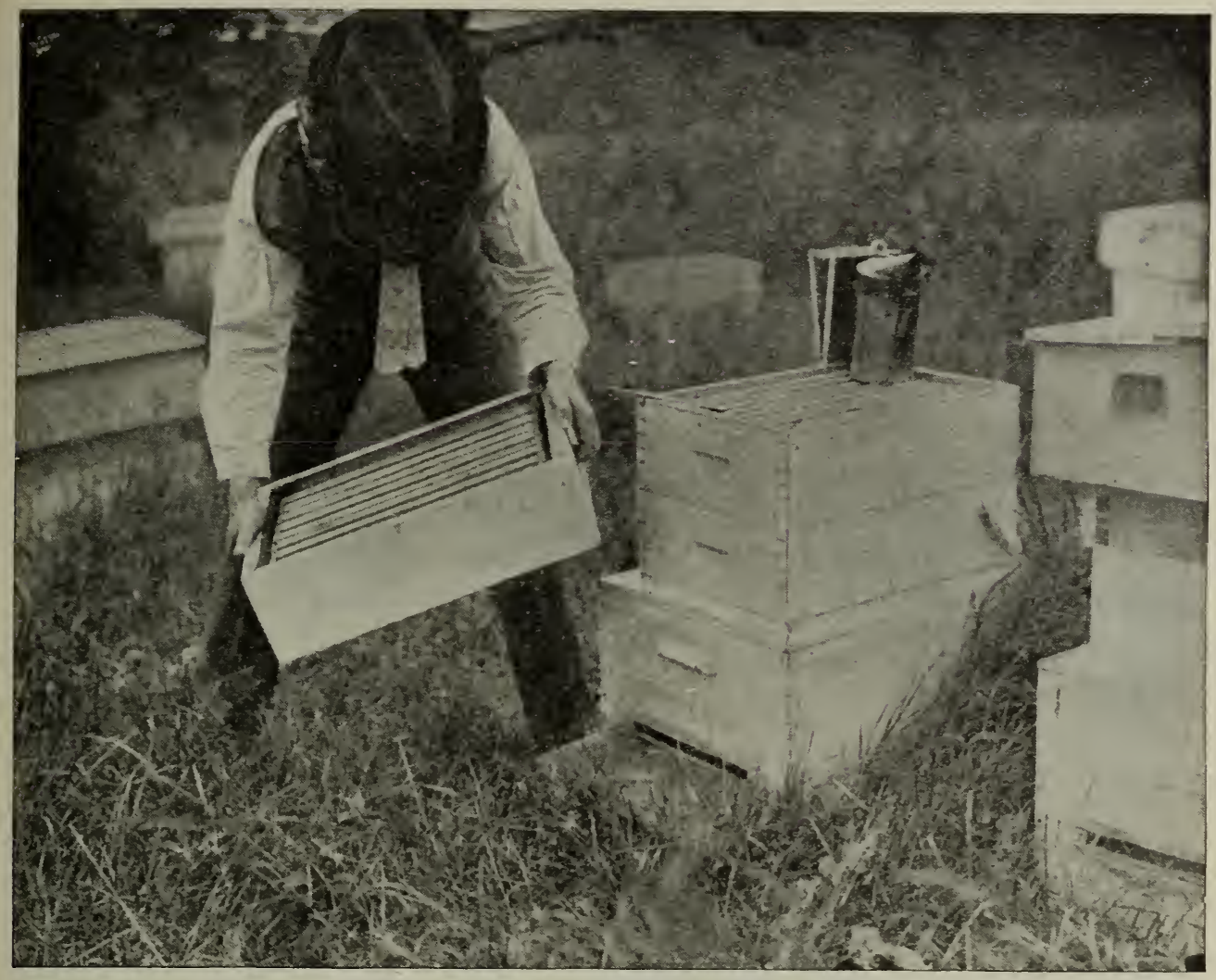

FIG. 14.-Shaking bees out of a super.

supers about an inch backward so that the other end will fulcrum on a safe bearing. If the super is slipped forward, as shown in Fig. 7 , it can be readily seen that it cannot be tilted up very high without sliding off in front. See Figs. 9, 10, 11.

Usually an examination of this sort is quite sufficient. If the supers are not filled they are quietly let back into place, using sufficient smoke to drive the bees away so they will not be crushed as the hive parts come together again. The operation shown in Figs. 5, 6, 7, 8, 9, 10, 11, is then repeated with other hives, taking from 30 to 60 seconds per hive. At no time have we lifted but a part of the dead weight. When the supers are held at an angle the load is on the fulcrum point of contact, while the hand sustains only a small part of the weight.

Fig. 12 shows the method employed when supers are apparently well filled and ready to come off. The top super is removed and leaned up against the leg of the operator. The middle super that has been filled can now be taken off; but before doing so a second examination is made as shown. It is set oft. when the bottom super may also be removed if ready. If so, the top super is put back, the idea being to confine the bees to as small a super capacity as possible as the season draws to a close, in order to make the bees finish their work.

Fig. 15 shows a slightly different pose from that indicated in Fig. 8. While the position of the operator is somewhat cramped, it is true, yet it is much easier than tearing down the hive, super by super, and replacing them.

In Fig. 14 we have a case where the season is closing abruptly. The bees have only partially begun work in the top super. To leave it on would mean that all the supers would have honey in, and none of them quite completed. Accordingly we shake the bees out of the top super, place a thin super cover on the two lower supers, place the super just shaken on top, and the regular cover on it. The hive is now left until we can determine a little more about the season. If there should be some good rains and warm weather, the season may 


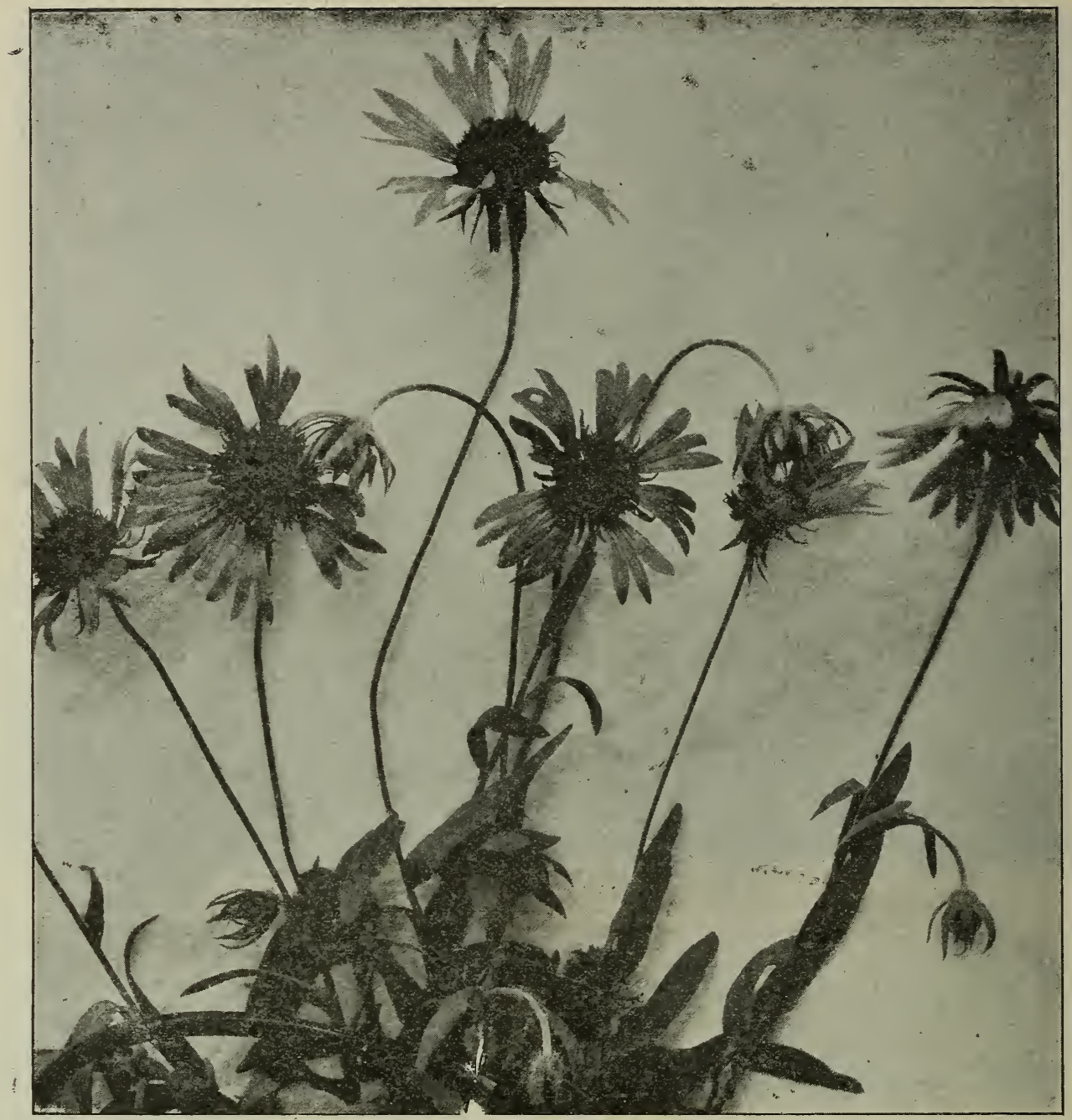

Marigold, great honey-plant of Texas, but found all over the United States.

take another start. In that case the super cover that was placed between the top super and the two below is removed, when work will be resumed in the third super. If we were sure that the season was drawing to a close, the top super should be removed in the first place.

HOW TO PUT ON ESCAPE-BOARDS.

In going thru bee-yards we have noted the fact over and over that some beekeepers have an awkward way of putting on escapes. They will pull the hive apart, super by super, place the escape on the broodnest or on a super partly filled, then one by one put back the supers. If no honey is coming in, this will probably mean that robbers will get started.

There is no need of removing any super, nor a cover, for that matter. All that is necessary is to apply the principles illustrated in Figs. 5, 6, 7, 8, 9, 10, 11 . See also illustration under CoMB Honey, ProDUCTION OF, showing how to put on an escape-board.

M A R I G O D (Gaillardia pulchella Foug.).-This is found all over the United States, but, so far as is known, it does not yield any great amount of honey except in Texas, where it is considered one of the main honey-producing plants. It begins to yield in May or June, giving a rich golden honey. While it is praised greatly by many connoisseurs in the South, it would not rank well with the clover and basswood of the North. The comb honey is golden yellow, not white. 
MARKETING HONEY. - Everything, nowadays, depends on having goods neat, clean, and in attractive shape, to have them "go off" readily; even our hoes have to be gilt-edged, for we noticed some once at a certain hardware store, and it seemed that those that were gilt, or bronzed, perhaps, were selling in advance of the plain ones. We've been told of gilt-edged butter that sold for fabulous prices, but we hardly think it will be advisable to put our honey up in that way, altho we do wish it to look as well as any of the other farn products.

In order to get a fair price for his honey, one should watch the markets. To obtain this information, he should take one or

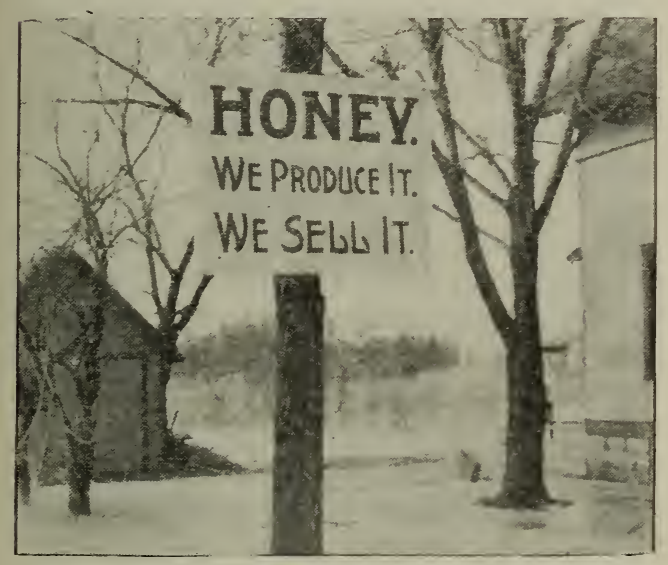

The silent salesman.

morc bee-journals. Thru the medium of these he will learn whether the honey crop is going to be small or large. This he can not determine from his own locality. If one has secured a good crop of honey, and learned that the crop thruout the country is small, he must not be in haste to dispose of it to the first buyer. In any case he must exercise judgment.

\section{HOW TO MAKE HONEY SELL IN THE LOCAL MIARKETS.}

The grocer should be supplied with a lot of the choicest extracted, in tumblers and bottles and best comb honey in shippingcases. Some of it should be set off in paper cartons, and some of it should be plain. When customers come in, there should be strips of paper about $1 \frac{1}{2}$ by 2 or 3 inches. Dip one of these pieces of paper, curled in the shape of a trough, into the extracted. Twirl it around till all the drip is off, and pass it quickly to the customer, that he may sample. If he would like another taste, hand him another slip of paper, which he is to fold as nearly as possible in the form of a spoon. If the honey is ripe-that is, good and thick-the taster will want some. There is one thing that is very important. Something should be done to draw a crowd. Prepare a nucleus in a glass hive, and put it up near the window where the crowd can see the bees. Sometimes the crowd will be so great as to block the street to see the queen or "king-bee;" but the producer will be the gainer, because his honey is inside.

This nucleus or glass hive should be $1 \frac{1}{2}$ stories high, with glass panels on the sides. It should contain a single comb of bees, brood in all stages, a queen, and just over the frame four sections of honey, filled or partly filled. The purpose of the sections is to show the relationship of the combhoney production to the brood-nest. In fact, the nucleus will be a vertical section of a $1 \frac{1}{2}$-story hive run for comb honey. See ObSERvatory Hives.

There should be on hand for a day or two an expert to explain about the honey, how it is produced, how good it is, etc., and to show that it is the most wholesome sweet in the world for children. He should then reinforce his arguments by handing out honey-leaflets that contain cooking-recipes, and that tell why the doctors recommend honey in preference to cane sugars, or why some invalids can eat honey when they can not eat other forms of sweet. Perhaps the producer himself will be the best man to do the "talking;" and therefore he had better stay with his grocer a day or two, or at least be on hand when he is likely to have a run of customers. He should charge the grocer nothing for his services, telling him that he will take his pay out of the increased sales.

If one succeeds well in one market, and the novelty of the thing wears off, let him try another in a neighboring town, and so on complete the circuit of towns around about. After one has done all this he will not need to ship much if any to the city markets, save commission, save freight, and have his honey within a few miles of where he can look after it, without being at the mercy of a city commission house. See SHIPPING-CASES: HoNEY-PEDDLING; also Exhibits of HoNer, subhead "Selling Honey at County Fairs." 
SENDING HONEY TO COMMISSION HOUSES.

We believe commission houses thruout our cities are great aids to beekeepers in disposing of their honey; notwithstanding, we want to enter a word of caution right here against being in too great haste to lump off one's honey to these places. One may argue that he would not have time to dispose of his product in small amounts; but many a beekeeper has found to his sorrow the mistake he made in contributing to the flood of honey at a certain commission house. The consequence is, that at that place honey is a "glut on the market."

But it very often happens that one can get a higher price by sending to these commission men. The general trade looks to them for supply, and they make it their business to find a market.

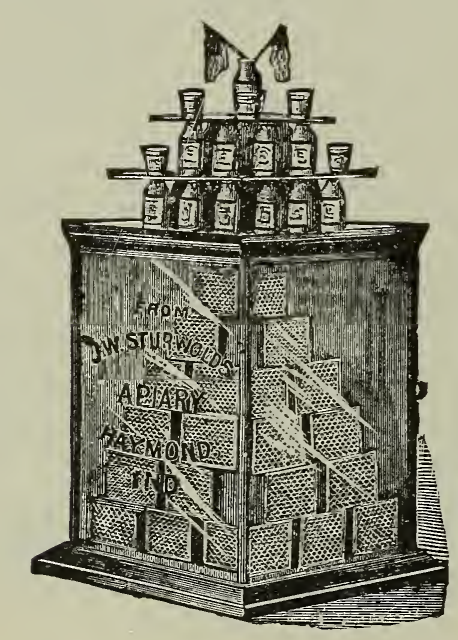

Sturwold's show-case for honey.

One should never send honey on commission or outright sale to a new firm, no matter what it advertises, how big it talks of its financial standing, nor what promises it makes. He should go to the bank and find out its responsibility, and ask the commission house to send the names of beekeepers who have dealt with it. But we would not advise even then to consider this an evidence of good faith. We would take time to write to the parties and ask if their dealings were entirely satisfactory, and whether they would advise shipping to the commission house in question. The temptations in the commission business are very great; and if the broker is not honest he may take advantage of the producer. Commission men charge all the way from 5 to 10 per cent commissiorf; and in addition to this the shipper is required to pay freight, drayage, and to stand all breakage.

Most commission houses will make advances in cash on receiving the honey; and a few of them will make payments as fast as it is sold; but a majority make no remittance until the honey is all sold, and sometimes not even then until the beekeeper writes complaining, and inquiring regarding his honey or his money.

We have said that commission men should be strictly honest; but some of them yield to the temptation of quoting a higher price in the bee-journals than they are actually realizing in every-day sales. The beekeeper complains when he receives his returns, and he is met with the statement that his honey was of poor quality, and had to be sold for less money; or that the honey came badly broken, and had to be lumped off as chunk honey; or he may be told that the "market suddenly fell" (which may be true), and it was not therefore possible for the house to realize quotations given in the bee-journals. It is a common trick on the part of dishonest commission men to quote high prices if they can get their names in the bee-journals, then sell for lower prices in order to "move off stock." We have had reason to believe that sometimes, from complaints that have come in, and from certain evidence placed in our possession, honey has actually sold at several cents higher per pound than was shown by the account of sales rendered to a beekeeper, and on which commission was based. In this way commission men practically take two commissions. Say, for instance, the honey sold for 12 cents. The broker makes returns to the beekeeper of 10 cents, and then charges 10 per cent commision on this 10 cents. He thus makes the 2 cents which he actually steals, and then the 10 per cent which is rightfully his.

In the foregoing we have endeavored to set forth some of the tricks that are practiced by some of the unscrupulous commission houses. But we are glad to say that all, or nearly all, of the men who quote prices in the bee-journals are responsible and honest men, especially those who have been doing business for years; for no commission man can hold his name in the advertising columns of the average bee-jour- 
nal today if there are complaints entered by beekeepers against him. And right in this connection we wish to say that the mere fact that one's bank says a certain commission house has good financial rating should not be considered as evidence that the house is also honest. We would rather trust the man who is honest and not responsible than the one who is financially good and yet "up to the tricks of the trade."

At the time of making shipment, send bill of lading to the commission house, and name price below which the honey must not be sold. A commission house has no right to sell at a lower figure until it is given instructions. Before the honey is packed it should be carefully weighed so that one will know exactly how much honey he has sent. Large shipments should not be sent at first. If in any case honey is sent, and the commission house fails to make returns, or refuses to do so, it is a criminal act. Such house has no right to appropriate one's honey without rendering some sort of returns. Never take a note in payment from an irresponsible firm or individual, for legally a note is a settlement.

\section{SELLING FOR CASH.}

If the producer can sell for cash and the party is responsible, he should do so, providing he can get market prices. He should look out for firms wanting to buy for cash with no rating, in Dun's or Bradstreet's commercial agencies. To make himself secure he should ship to his name at the point of destination, and then send bill of lading to some bank in the city with instructions to turn over bill of lading to purchaser on receipt of cash. Banks will charge a small fee for doing the business, but the shipper will be safe. The law gives the producer greater protection when his honey is sold on commission than when sold for cash, provided money is not received before honey is turned over. We wish to reiterate the point again: Never deliver honey to a concern on an outright sale or deal till the banks say the broker is entirely responsible; then if everything is in writing producer is able to collect by due process of law; but if buyer is irresponsible, producer will be throwing away money in trying to do anything with him in a legal way. For further consideration see Peddling Honex, Honer ExHIBITS, and SHIPPING-CASES.
MATING OF QUEEN AND DRONE.See Drones.

MESQUITE (Prosopis juliflora D. C.) - A leguminous tree common in southern Texas, New Mexico, and Arizona, and important in old Mexico, more particularly in Sonora, where it grows to the dignity of a fine timber tree in the valley of the Yaqui River. Growing in a semi-arid country it is always possible to get a yield of honey from the mesquite except where it grows so far north that the cold injures it. In Uvalde Co., Texas, it is regarded by the beekeepers as a great tree for honey. There it is little more than a shrub; but further south in Mexico, around Monterey, it becomes of far more economic importance. The Texans class the mesquite honey high; but we should be inclined to rate it among the ambers. There are several species of mesquite, but the foregoing is the one usually referred to by beekeepers. The others are probably equally good for honey.

"One of the main sources of nectar," says L. H. Scholl, "for the Texas beekeeper is the mesquite brush and trees that cover a very large area of the Lone Star State. As unimportant in appearance as this bushy tree is, it is of greater importance to the beekeeeper than most people suppose."

The mesquite (pronounced mes-keet) has two separate and distinct blooming periods during the year. The first comes during April, and the other during the last of June or the beginning of July. These periods are sometimes a week or so earlier or later, according to the conditions of the season, the lateness or earliness of the spring, cold weather, and the quantity of rain during the preceding fall and winter. In this last respect the mesquite is peculiar in that, if rain has been plentiful in the fall and winter, no matter how dry the following spring or summer may be, there will be a profusion of bloom and a heavy flow of nectar. This is due to the ability of the plant to store up water, from which it is enabled to put forth its growth, and also to the fact that its roots penetrate the soil to a great depth, spreading out quite a distance in the soil. It is remarkable how large the roots of a very small shrub of mesquite are in proportion to its size. It shows at once that it is well adapted to a dry region. 


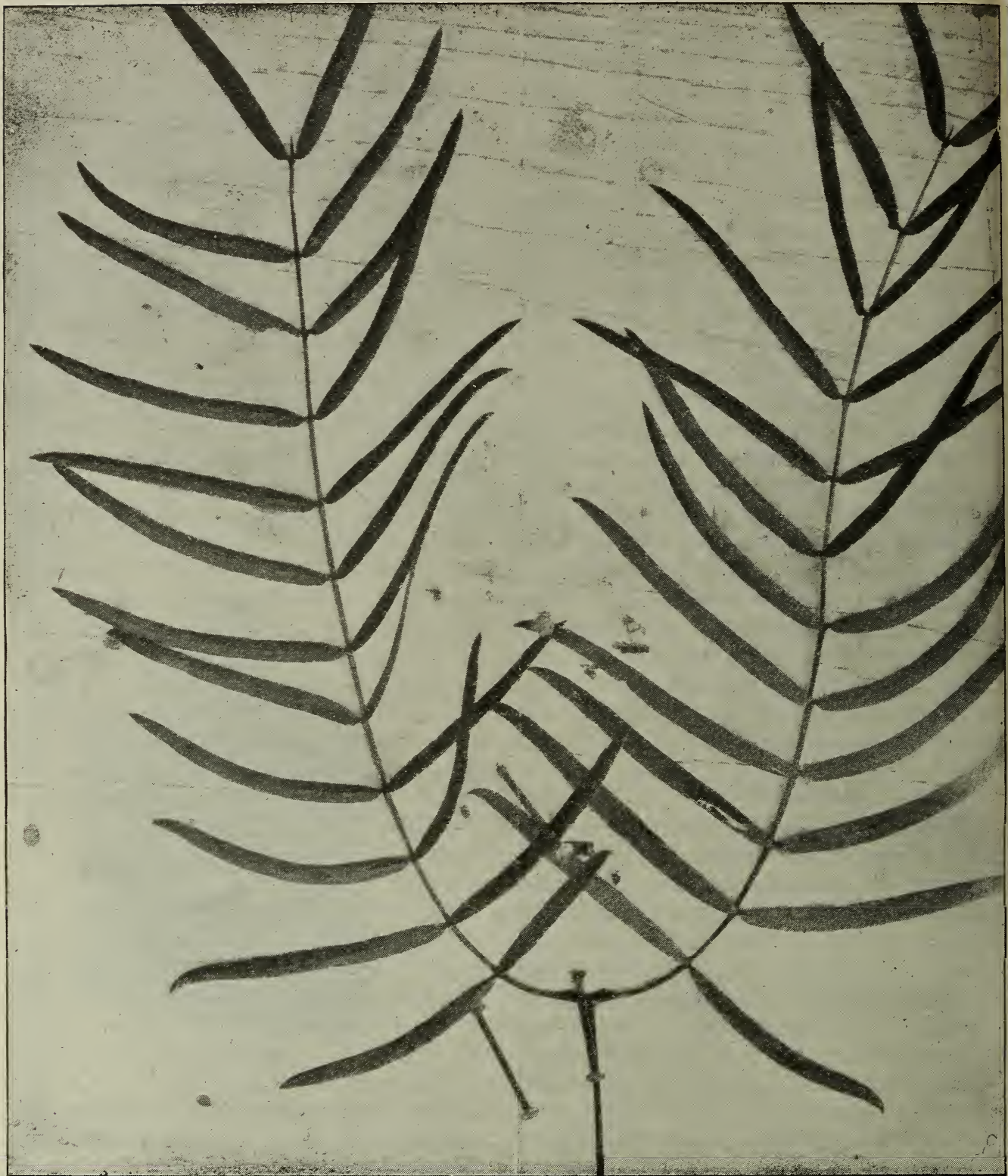

Mesquite leaf.

The quality of the honey is good, and of a light-amber color. It has been said many times that mesquite honey could be used better for an every-day table honey than any other of the Texan honeys, since one never tires of it, as he is apt to do of honey that has a particular flavor that may be more pleasing at first.

The long spikes of feathery blossoms measure from three to five inches in length. When the second blooming time arrives, the beans from the first blooming, which are from six to eight inches long, will be in all stages of ripening. These are greedily eaten by all kinds of stock and cattle, and are of considerable value in this way. Even human beings find that these beans have a good taste, and children particularly relish them each season as they ripen. They vary considerably, however, in taste, some being so bitter that they cannot be eaten, while others are very sweet and agreeable. The wood of the mesquite is valuable for furniture and cabinet work, as it takes a fine polish, and mesquite posts are used very extensively. 
METAMORPHOSIS OF BEES. - See DeVFLopMeNT OF BEES.

MIGRATORY BEEKEEPING. - Experience has shown that the secretion of nectar in a given locality varies sometimes, even within a distance of only a few miles. It will happen sometimes that the homeyard bees will be gathering no honey when an outyard eight or ten miles away will be securing a fairly good crop. This is due to the fact that the character of and moisture in the soil makes possible the growth of some plants that will not take root in other locations only a few miles away. For example, a bee-yard may be situated in a valley close to a stream, along which there will be a heavy growth of honey-yielding plants. Within a few miles from there, perhaps on higher ground, and soil less productive, there will be nothing.

Sometimes we find conditions like thisin one locality a large amount of buckwheat will be grown; ten miles away from there, there will be none whatever. The same is true of red clover, alsike, and a number of other artificial-pasturage crops.

Again, it will happen that in one year when there is an excess of rainfall the location in the valley will be too wet for the proper growth of plants yielding nectar, while on the higher ground, a few miles away, conditions will be just right for a fine flow of honey.

The knowledge of these varying conditions in localities only a few miles apart has led some beekeepers to practice what is known as migratory beekeeping. For example, in one yard it is evident that bees are not getting any honey, and there is no flora of any sort that gives any promise of any. On the other hand, there is another yard that is doing well, and there are still other locations without bees where there are immense quantities of alsike or red clover, or of buckwheat. Evidently it is a part of wisdom and business sense to move the yard that is yielding no returns to the location in which the honey can be secured.

In 1.913, and again in 1914, for example, we found that our bees at our Medina yard were on the verge of starvation. We had one small yard in a swamp in Summit Co. where aster and general fall pasturage were abundant, and where the bees were building up well. We moved over there 200 to 300 colonies, and the same bees that required to be fed near Medina when placed in their new environment began to store honey, rear brood, and build up. It looked as if the scheme were going to be a great success; but the aster honcy for that season for some reason (see AstER) proved to be a bad winter food, and we lost a good many bees during that winter. But the next year the aster did not kill the bees, and the result was we had some fine colonies in the spring.

While migratory beekeeping is not practiced to any considerable extent in this country, largely because of the expense of moring, yet there are some sections in the country that make the practice exceedingly profitable. In Germany migratory beekeeping is carried on somewhat more extensirely than in this country, and vecasionally we hear reports of a whole beeyard being put on an immense raft on a river. This raft is secured near the shore, and when the honey crop is taken the raft is let loose, when the raft, bees and all, are towed to pastures new. These floating apiaries have never been much of a success. Too many bees appear to drop in the water and drown. Mr. C. O. Perrine, many years ago, tried out this experiment on the Mississippi River, but the experiment was a financial failure. For further particulars see Moving BeEs, sub-head "Shipping Bees in Carlots."

Mr. O. O. Poppleton, of Stuart, Florida, used to practice migratory beekeeping on quite an extensive scale down on what is known as the Florida Keys. The base of his operations was at Stuart. He owned a gasoline-launch capable of carrying some 40 to 50 of his big colonies in what is known as the Long Idea hive. As soon as the season failed in one locality he put the bees on the launch, went down the Indian River, and located them at a place previously determined on, where mangrove would soon be out in all its glory. In this way he operated a series of outyards, moving the bees about from place to place for a number of years. But after he had passed the age of 75 he found it would be impracticable to carry on the bee business on so extensive a scale, and so he sold out.

MILKWEED. (Asclepias syriaca L.).There belong to the milkweed family, or Asclepiadaceae, some 1900 species, widely 
distributed in the temperate and tropical regions of both hemispheres. About 22 species occur in eastern North America, and 25 more in the southern and western states. The common milkweed, or silkweed (A. syriaca) is the most common species in the northern states. It is a stout plant, four or five feet tall, with oblong leaves and purple flowers, growing in fields and waste land. In California $A$. mexicana and $A$. speciosa are of interest to beekeepers. Milkweed has been listed as a valu-

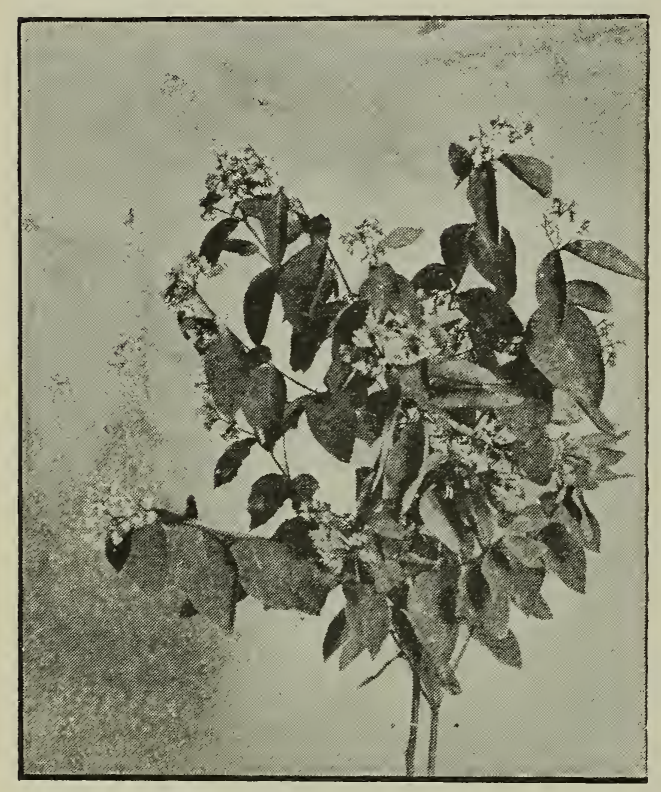

The foliage is similar to that of the Rose of Sharon.

able honey-plant over a large part of the United States, namely, in Massachusetts, North Carolina, Tennessee, Texas, Nebras$\mathrm{ka}$, California, and Michigan. The honey is usually mixed with that of other flowers blooming at the same time. In Michigan milkweed is abundant in sections of Charlevoix, Emmet, Grand Traverse, and Antrim counties, and a fine surplus of milkweed honey is obtained. When the weather is favorable the nectar is secreted very rapidly, and a large colony will sometimes gather 13 to 17 pounds in a single day. A colony has been known to bring in an average of 11 pounds per day for 10 successive days; and in one apiary a yield of 95 pounds per colony was obtained. The honey is excellent, has a fine flavor and good body, and compares well with that obtained from the raspberry. It is so thick and heavy that it is necessary to warm the combs before extracting. The color is almost water-white.

The small flowers are in flat-topped clusters or umbels, and are green, white, yellow, red, or purple, but never in our species blue. They are called pinch-trap flowers since they possess a remarkable clip-mechanism found in no other family of plants in the world.

Many species of milkweed are probably harmless to honey-bees-only $A$. syriaca and $A$. mexicana, indeed, have been reported as causing much loss. In the case of these species the bees probably seldom perish except when several legs or other organs become entangled at the same time. More often the activity of the bee is crippled by the many clips and pollinia attached to its tongue, legs, or antennae. Butterfly-weed (A. tuberosa) and purple milkweed ( $A$. purpurascens) are butterfly flowers.

In South America Araugia albens, another member of the milkweed family, attracts hosts of moths to its sweet-scented flowers. The tongues of the moths are caught in the slit-like notches, and as they

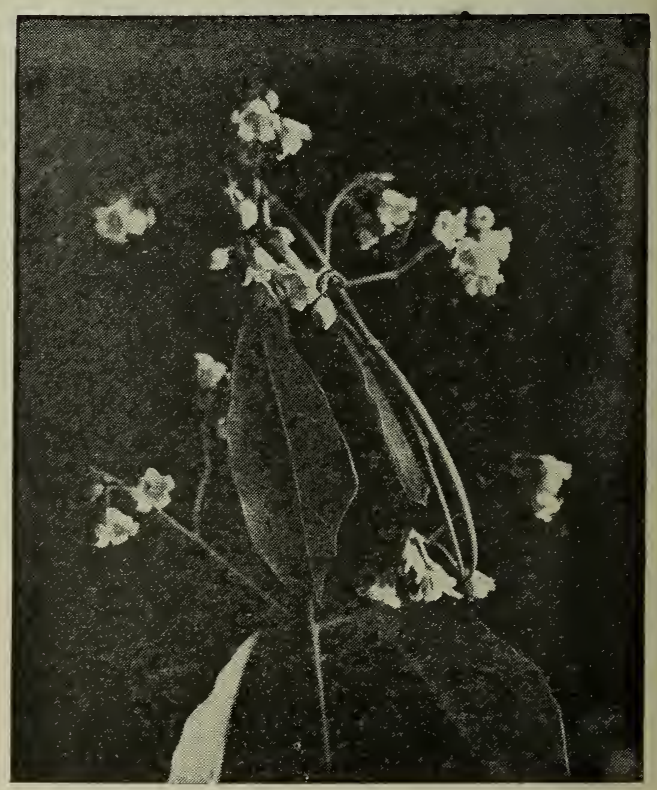

It bears umbels of small bell-shaped flowers.

are unable to free themselves they die a lingering death. Some years ago it was seriously proposed by an economic entomologist to employ this plant in the extermination of the codling moth, so injurious to 
apples. But this well-laid scheme went a-gley, as the moth would not visit the flowers.

The way in which the pollen masses are clamped to the feet or legs of insects is of much interest to beekeepers, and every season there are many inquiries in regard to this queer phenomenon. The five anthers stand close together, forming a sheath around the stigma. Each anther is provided with two lateral wings; and where the wings of two adjacent anthers touch, there is a narrow slit, larger at the base than at the top. The anther, it will be recalled, usually consists of two sacs containing the pollen. But in the milkweed the grains of pollen are not separate, but are bound together in waxy flattened masses called pollinia. Two of these pollinia, or club-shaped masses of pollen, belonging to two different anthers, are attached by flexible bands to a small dry membrane, or disc, midway between them. In this flat triangular dise there is a wedge-shaped slit at one end. The dise stands directly back and above the slit between the two anther wings. This is the pinch-trap ready for action.

Let us now observe what happens when bee alights on the flower in search of nectar. In its efforts to obtain a foothold

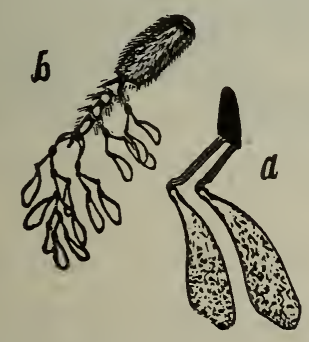

Pollen of the milkweed attached to a bee's foot.

on these small smooth flowers it thrusts a claw or leg into one of the slits between the anther wings. Presently its leg is drawn upward into the wedge-shaped slit in the ittle membranous dise, which soon becomes irmly clamped to its leg, or in some cases to one of its antennæ. The harder the bee pulls, the tighter does the little pinch-trap hold. When it flies away to another flower the pollen masses which, as described above, are joined to the little dise by straps, are forcibly torn from their pouches. Exposed to the air the strap-like stalks dry and draw the pollinia close together. Then as the bee alights on another flower they are easily thrust thru the slit between two of the anther wings; but once inserted, and the insect's leg drawn upward, they can not again be withdrawn. The bee can obtain its liberty only by breaking the conneeting bands. If this happens, the pollen masses are left in a chamber near the stigma, and the bee bears away the membranous dise with its empty stalks. Dise after dise may thus become attached to an insect until it is crippled or helpless.

It is stated on the authority of Gibson that one season an English beekeeper lost thousands of bees from the effects of strings of these clips. It was at first supposed that they were being destroyed by a fungus. Many different explanations have been given of these curious structures by persons not familiar with the flowers of the milkweed. Some think them a parasite, others a protuberance growing on the bee's foot, and others a winged insect enemy of the bee. We give here an engraving of this curiosity, magnified at $a$, and also a mass of them attached to the foot of a bee. If the insect is not strong enough to pull out the pollinia, or later to break the connecting bands, then it perishes slowly and miserably of starvation. These dry membranous dises are often described, even in botanical works, as glands, or as being glutinous or sticky, but this is not the case.

MOTH-MILLER. - In the old box-hive days and the early days of the movable frame, the bee-moth or wax-worm was regarded as the most serious enemy with which the bees had to deal. Many of the beekeepers of those times were driven out of the business because their bees were cleaned out by the pest. So serious was it regarded that numerous moth-traps and moth-proof hives were invented. These were worse than useless, as they had all kinds of "retreats," cracks, and crevices for the very purpose of trapping moths. Instead of catching them they made the finest kind of breeding-places for the pest.

In this day and age the modern beekeeper regards the bee-moth as more of a joke than a pest. In fact, it is almost a disgrace for one to allow it to get a start among his colonies or among the combs. It has been practically eliminated from all modern apiculture, and it is only occasion- 
ally that it gets in its work among good combs; and when it does, the owner is or should be ashamed of his own carelessness.

The bee-moth does not exist as a real beeenemy anywhere in the United States except in some of the southern states where black bees are kept in box hives exactly as they were in the days of our forefathers (see Enemies of BeEs). They are just as ignorant of modern principles; and so today the bee-moth, or, rather, the larvæ of the wax-worm, eliminate all except their very strong colonies (see Box Hives).

There are two species of wax-moth--the larger one, Galleria mellonella, and the lesser wax-moth, Achroia grisella. The former is much the more general, and, because of that, more destructive. Either species possible a very fair living (see Box Hives). The statement was made at the outset that the bee-moth is regarded as a joke by the modern beekeeper, and so it is. Since the introduction of the Italian bee and the movable frame there is no excuse for having the pest among colonies or combs. In the first place, the Italian bees themselves will eliminate it, whether it be in a nucleus or a strong colony. Even an admixture of Italian blood will keep it under. control. Black bees, on the contrary, are an easy prey to the bee-moth.

\section{HOW TO DETERMINE THE PRESENCE OF THE WAX-WORMS.}

The eggs hatch, and soon the larvæ begin their chank, chank, chanking. If one will

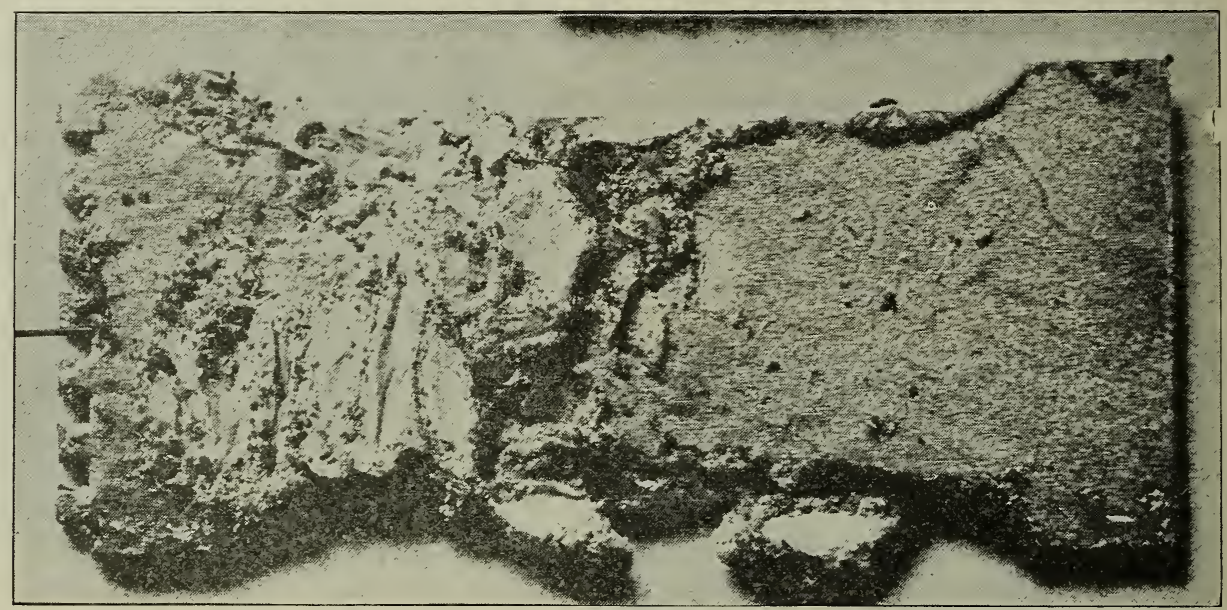

A sample of how the eggs and cocoons of the bee-moth are deposited on wood. Sometimes the wood is grooved or eaten out. The illustration fails to convey the real filthiness of the mass.

thrives among the ignorant and superstitious beekeepers, and particularly in box hives of black bees. In some of the southern states the bee-moth is a serious enemy in that it destroys all second, third, and fourth swarms, leaving only the first swarm. Even the parent colony goes down with the rest. If it were not for the bee-moth these old time beekeepers would probably be keeping three times as many bees, and, of course, getting a proportionately larger amount of honey. Unfortunately, some of this class will not be the ones who read a work of this kind; and it is to be hoped that the extension workers sent out by the United States Government will soon be able to teach them modern methods-methods that will eliminate the bee-moth and render listen he will be able to hear these loathsome worms eating their way thru the combs. Their presence can be easily determined also by a sort of webwork spotted with their excreta just beneath the surface of the comb, where, evidently, they try to keep out of sight, and away from the bees. As they become more numerous they fill the space between the combs with web. In the earlier stages a few young Italians will keep out the worms and carry them out of the entrance; but black bees, unless the colony is a strong one, will let them go on until all the spaces between the combs are filled with the web, and these ugly wriggling worms. Brood-rearing will be brought to a standstill, and the elimination of the colony will take place about the time 
the old bees begin to die off. Usually a colony of black bees will prevent the waxworm from making very much progress in the hive, but not always; and here comes in the advantage of movable combs, which the owner can inspect. When he finds unmistakable traces of the wax-worm he can help out the bees by cutting out the webs and worms with a knife or a stick; but it will be very difficult for him to eliminate all the eggs of the moth which may be scattered all thru the hive in cracks and crevices beyond the reach of the bees. The old patent moth-proof(?) hives of early days were full of these cracks and crevices, and of course much worse for their propagation than the regular simple hives without moth "contraptions."

In modern apiculture the moth, or, more properly speaking, wax-worm, can do no damage except among combs which are laid aside for the time being. Combs from colonies of Italian bees will usually be safe when they are put away in bee-tight extracting-supers for the season.

In this connection combs in unspaced frames-that is, frames without shoulders -are much more subject to damage from the wax-worm than those in spaced or Hoffman frames. The former when put away for the season are generally put into the super and placed together in close contact. Combs that are spaced like the Hoffman, the ordinary distance apart- $13 / 8$ inches from center to center-are much safer, because they cannot be placed in close contact. If they are set 2 inches apart, the damage, if any, will usually be confined to one comb.

It is generally regarded as perfectly safe to take the combs out of the hive right after the season is over, and confine them in hivesupers stacked up. If these stacked supers are covered so as to make them bee-tight there will be practically no danger from the bee-moth. All combs should be put into supers so that neither the moth-miller nor robber bees can gain access to them. As a general thing, some combs will contain a little honey; and the first warm day during a dearth of honey these combs, unless put into bee-tight compartments, will invite the worst kind of robbing. Not only this, there will always be danger of the bee-moth. Combs confined in bee-tight hives or supers, if they have eggs of the moth in the first place, may develop the wax-worm later; but in an Italian apiary this will rarely occur; and even when the moth-eggs are in the comb they will be killed by the first winter freezing. Right here is one explanation of why the bee-moth is much more destructive in the South than in the North. All stray eggs or larvæ are killed by ordinary freezing weather. Combs stored away in the fall in bee-tight supers will usually

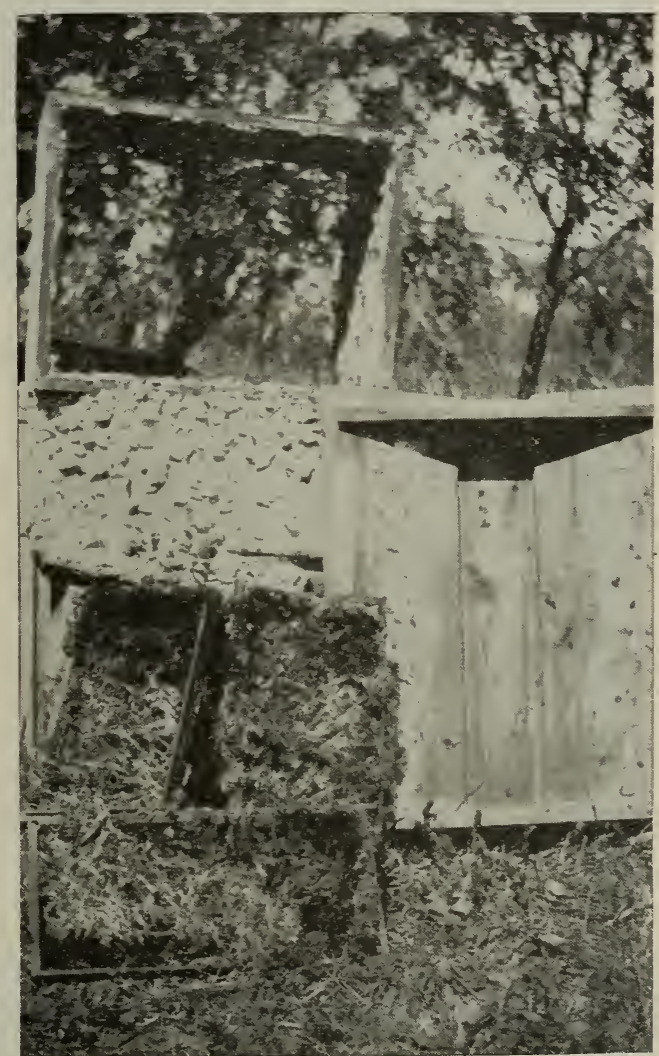

How moths ruin combs that are not taken care of.

be safe if freezing weather follows shortly after. They can also be rendered safe from the depredations of the moth-worm by the use of carbon bisulphide, mentioned further on.

\section{TWO OTHER SPECIES.}

The work of the lesser wax-moth is somewhat similar to that of the larger species; but the galleries are smaller, and the webs are finer and more on the surface of the comb. The photo, by J. W. Teft, shows the characteristic nest of the lesser wax-moth.

There is still a smaller species that infests combs, known as the Mediterranean flour-moth. This is not really a wax-worm, 


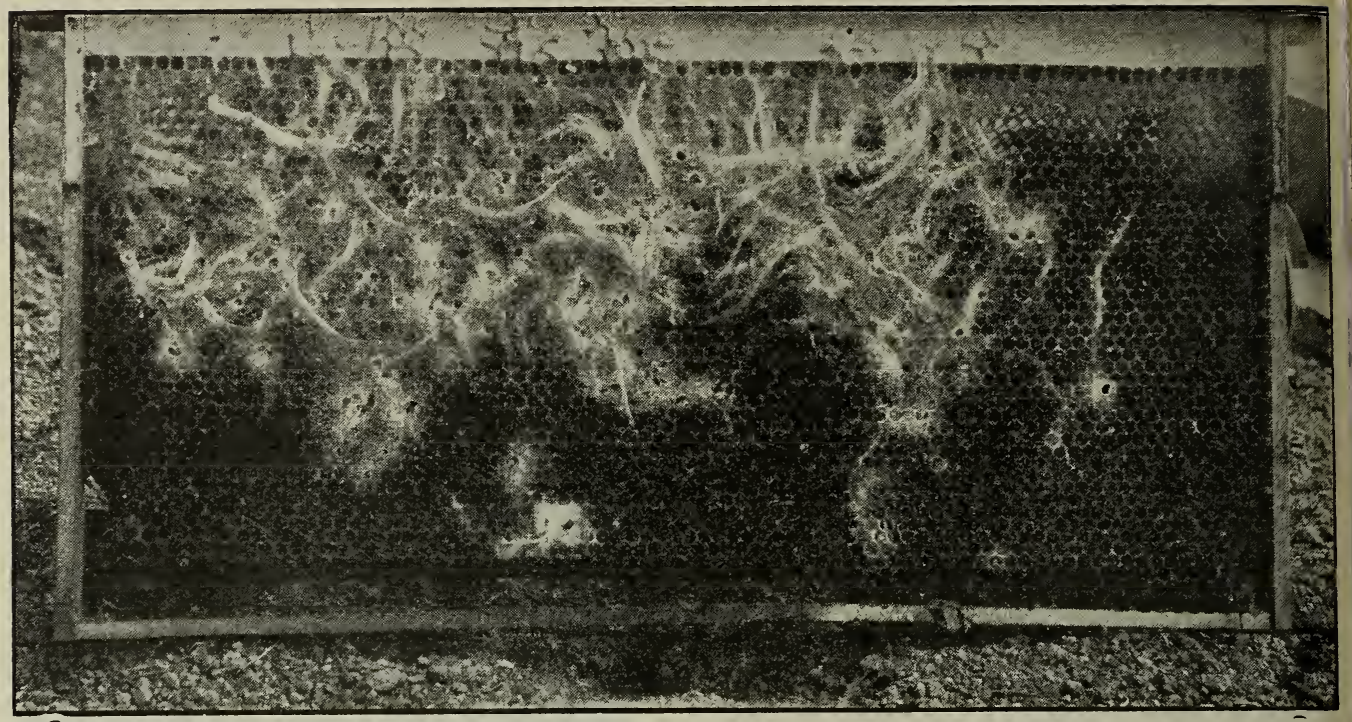

Combs infested by the lesser wax-moth. This photograph was sent us by George W. Tebbs, Hespeler, Ontario, Canada, who wrote that the frame was taken from a hive which had originally contained an Italian colony, but which had been empty during the winter.

and its presence is due to the fact that it eats the pollen in the comb; but it leaves in its wake a lot of webs as shown in the illustration below.

BEE-MOTH IN HIGH ALTITUDES.

In Colorado, at least in the region of Denver, where the elevation is fully a mile above the level of the sea, the ordinary wax-moths are unknown. The great elevation seems to be more than they can stand. There is, however, a very small wax-worm, but it is not the same that ordinarily troubles beekeepers.
THE MOTH-MILLER SOMETIMES A BLESSING IN DISGUISE.

The moth-miller is not altogether an unmitigated nuisance. This pest, as already explained, seldom troubles the professional or up-to-date beekeeper. It is only the slipshod, careless, don't - read - the - papers class that it annoys. Their bees become weaker and weaker, and finally die in the winter, leaving combs more or less filled with boney, and smeared over with the dead matter from foul brood. Unfortunately, these "old gums" containing diseased

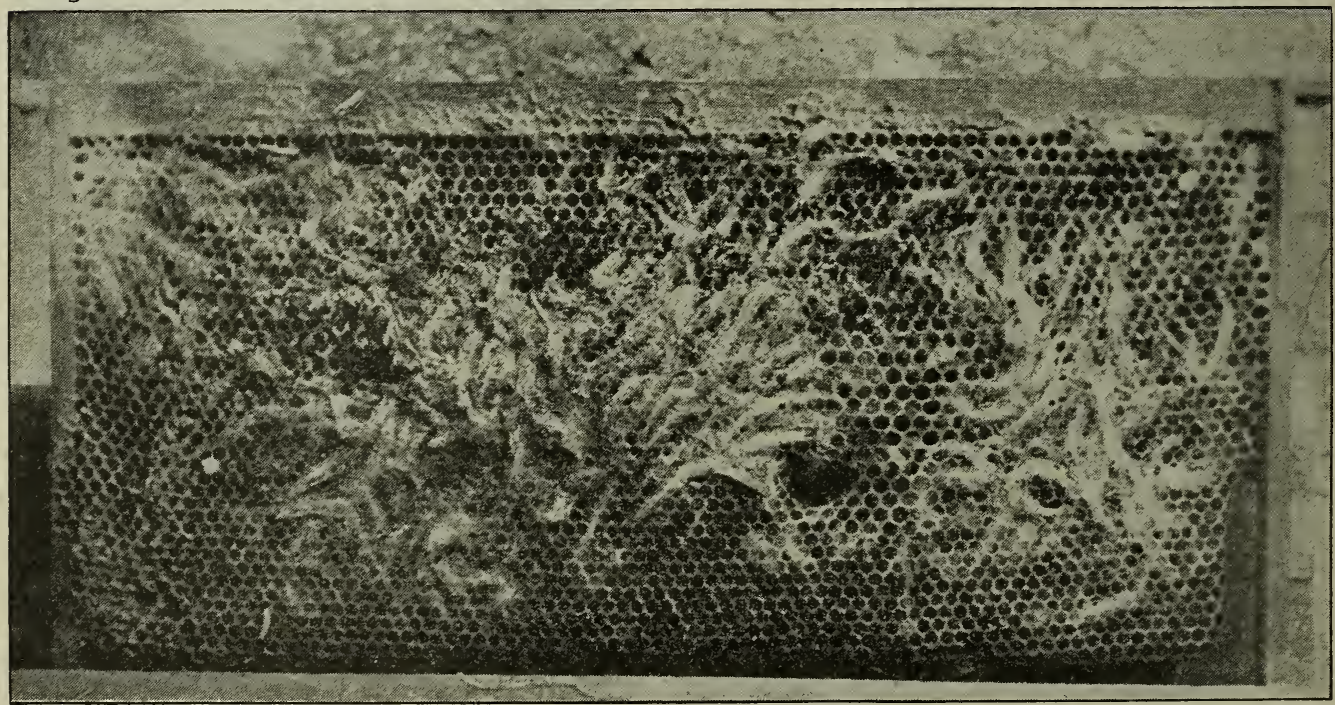

Work of the Mediterrean flour-moth. 
honey are a constant source of infection to all the bees in their vicinity. The healthy bees within range rob them out. In the mean time the moth-millers, if present, get in their work. Their larvæ destroy the

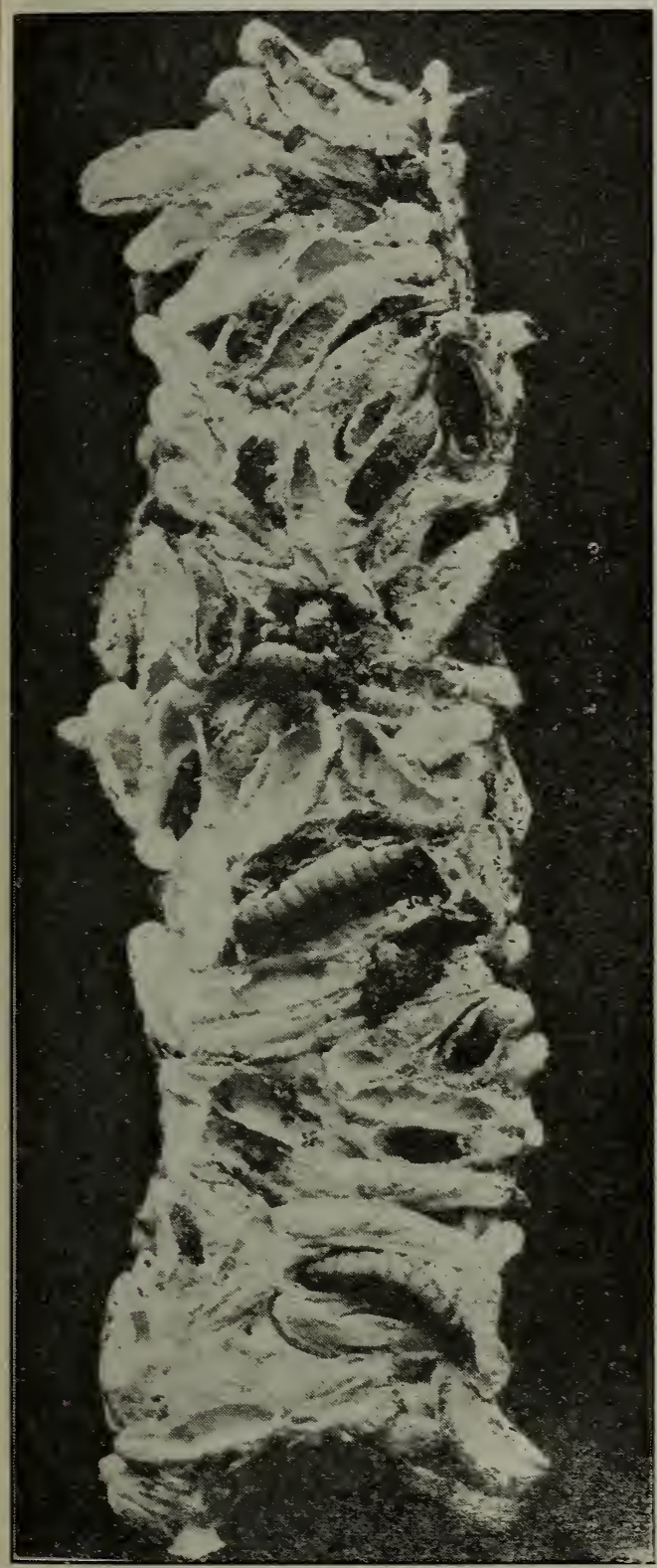

Cluster of bee-moth larræ photographed exact size. -Texas Agricultural Bulletin No. 158.

combs so that no future swarm will find these old hives a suitable abiding-place. It is right here that the moth-miller proves to be a blessing in disguise. These old combs smeared with foul-brood scales would, unless destroyed by some agency, attract swarms; for experience has shown that they are frequently occupied by stray swarms. The bees get nicely started in housekeeping, begin to fill the combs with honey and brood, when, lo! bee disease begins to make its appearance. The colony dwindles, of course, dies in the winter, and is again the source of infection to the neighboring bees. They rob it out once more; but if there are moth-millers in the locality they soon destroy these old combs and leave in their place a mass of webs that is so repellent that no swarm of bees will make a home there. Said one of our Ohio bee-inspectors, "The moth-miller, after all, may be a friend to the progressive beekeeper in that it destroys one great source of infection-old diseased combs and "gums" in his neighborhood that might otherwise remain in bee-trees and old hives for years

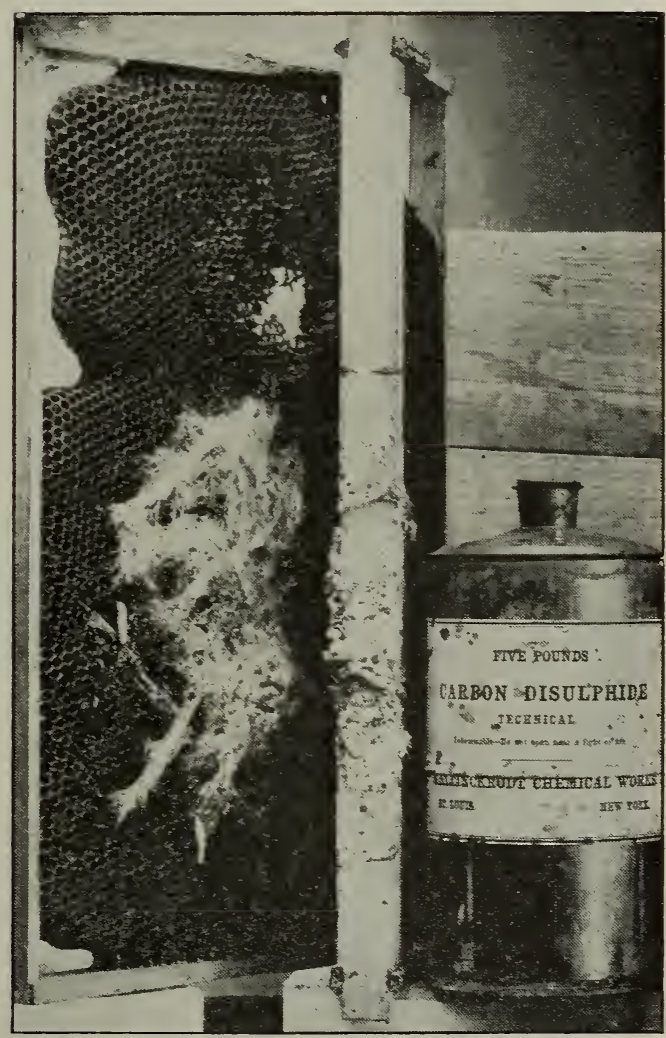

Web and cocoons in the center of a brood-frame. -Texas Agricultural Bulletin No. 158.

and years, and for years and years spread the disease."

One of the most thoro treatises on the wax-moth or wax-worm is a bulletin issued by the Texas Agricultural Experiment Station, No. 158, June, 1913. Among other things it discusses the life-history of the 


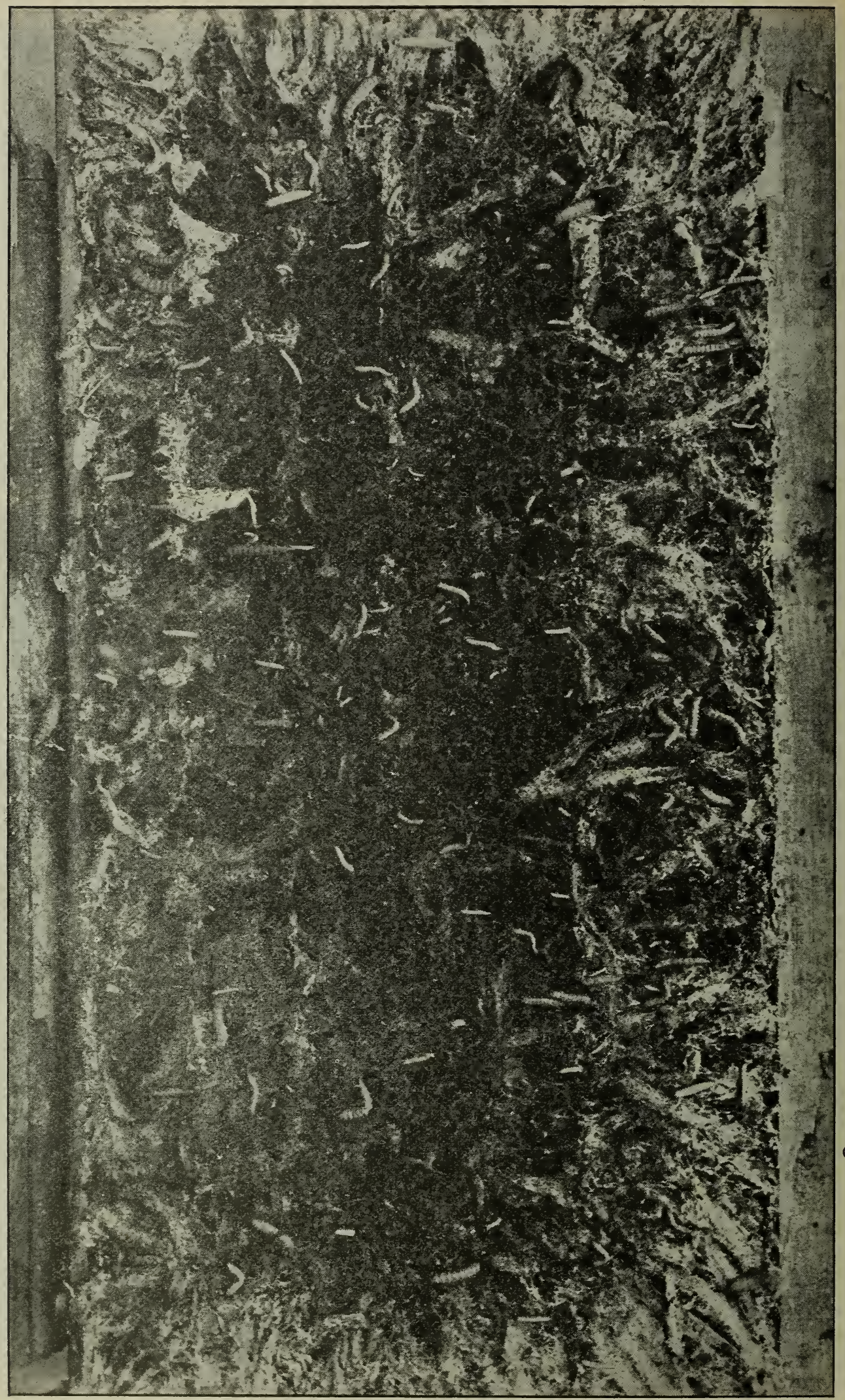


bee-moth or wax-worm. The author, Mr. F. B. Paddock, made a very exhaustive study of the larger species, Galleria mellonella. As this bulletin covers the development, life-history, and the control of this pest, we are glad to place extracts, including the engravings, before our readers.

ORIGIN AND DISTRIBUTION OF THE BEE-MOTH. THE ADULT MOTH.

There is some dispute and no little uncertainty about the origin of the bee-moth. Dr. A. J. Cook has this to say in regard to its origin: "These moths were known to writers of antiquity, as even Aristotle tells of their injury. They are wholly of Oriental origin, and are often referred to by European writers as a terrible pest." ,*

The bee-moth was introduced into America about 1805, tho bees had been introduced some time prior to this. The time of the introduction of the bee-moth into Texas is not known. The insect is now found in Italy, Germany, France, England, Ireland, India, Australia, and in most of the beekeeping sections of the United States. This insect is distributed practically all over Texas.

The larva ("web-worm"), upon reaching maturity, constructs a cocoon by means of silken threads which it is able to spin. After the cocoon is completed the larva changes to the pupal stage. This is the stage in which the form of the larva is reconstructed to make the moth which will emerge later from the cocoon. The moths mate and the females deposit the eggs which hatch into the larvæ. This is called the "life cycle.",

\section{THE ADULT MITH.}

The adult bee-moth (Plate II, a) is about five-eighths of an inch (15 millimeters) in length, with a wing expanse of about one and one-quarter inches ( 30 to $32 \mathrm{~mm}$ ). The moth with its wings folded appears ashygray in color, but the back third of each front wing is bronze colored, and this wing is thickly covered with fine scales which rub off easily when the moth is touched. On the outer and rear margins of the fore wing is a scanty row of short hairs. The hind wings are uniform in color, usually gray, with traces of a few black lines extending from the outer margin inward toward the base; on the outer and rear margins is a thick fringe of hairs on which is a dark line running parallel with the border of the wing. The body is brown, the shade varying, with a covering of scales. These scales rub off easily and are not always present on the older moths. The male is slightly smaller than the female. A difference between the sexes is noticed in the fore wing, which, in the case of the male, is deeply scalloped

* "Manual of the Apiary," A. J. Cook, page 485. on its outer margin. This scallop carries a heavy fringe of hairs, almost black in color. Another difference is in the mouth parts, the palpi of the male being rudimentary.

\section{HABITS.}

The moths emerge entirely at night; and in the cases observed, no moths emerged after 9 p. m. They at once seek some protected place in which to expand their wings and dry, and by the next morning they are able to fly. During the day the moths seek a sheltered place away from light and enemies, where they apparently settle down and draw their wings around them, remaining very still and quiet. Usually they are well protected by their color, which resembles weather-beaten wood. If disturbed during the day, the moths will make a dart or short flight, acting as tho blinded by the light. When an object is met, the moth quickly settles down and seenis very anxious to avoid flight. That they are hard to disturb in the daytime is shown by the fact that in several of the cages used in the experiments small ants attacked the moths and killed them without any apparent struggle on the part of the moths. Only by close examination could it be detected that the moths were dead and not resting in the usual manner. It is only during the latter part of the oviposition period that the females are active during the daytime.

The male moths emerge a few days earlier than the females and are much longer lived. In several cages, closely observed, the males lived an average of twenty-six days, which was fourteen days longer than the average life of the females. The male moths are very active thruout their existence. Just how long the males are functional has not yet been determined. In some matings under artificial conditions one male fertilized two females at an interval of ten days. During the first part of the emergence period the males are in excess of the females, since the males emerge first as a general thing. Later on, the number of males and females reaching maturity at the same time is about equal. During the latter part of the emergence period the females predominate. However, for the brood as a whole, taking sometimes as long as a month for all of the individuals to reach maturity, tine males and females are about equal in number.

The first and the last emerging individuals of the brood are smaller in size than the average, regardless of the sex. The quality of the food has a great deal to do with the size of the adults. The last larvæ of the brood are always undersized, but are almost always able to pupate and reach maturity. Several matings have been made with oddsized individuals, such as large males and small females, and vice versa. The results of these matings indicate that those larvæ which were forced into pupation prematurely may transform to functional adults. 


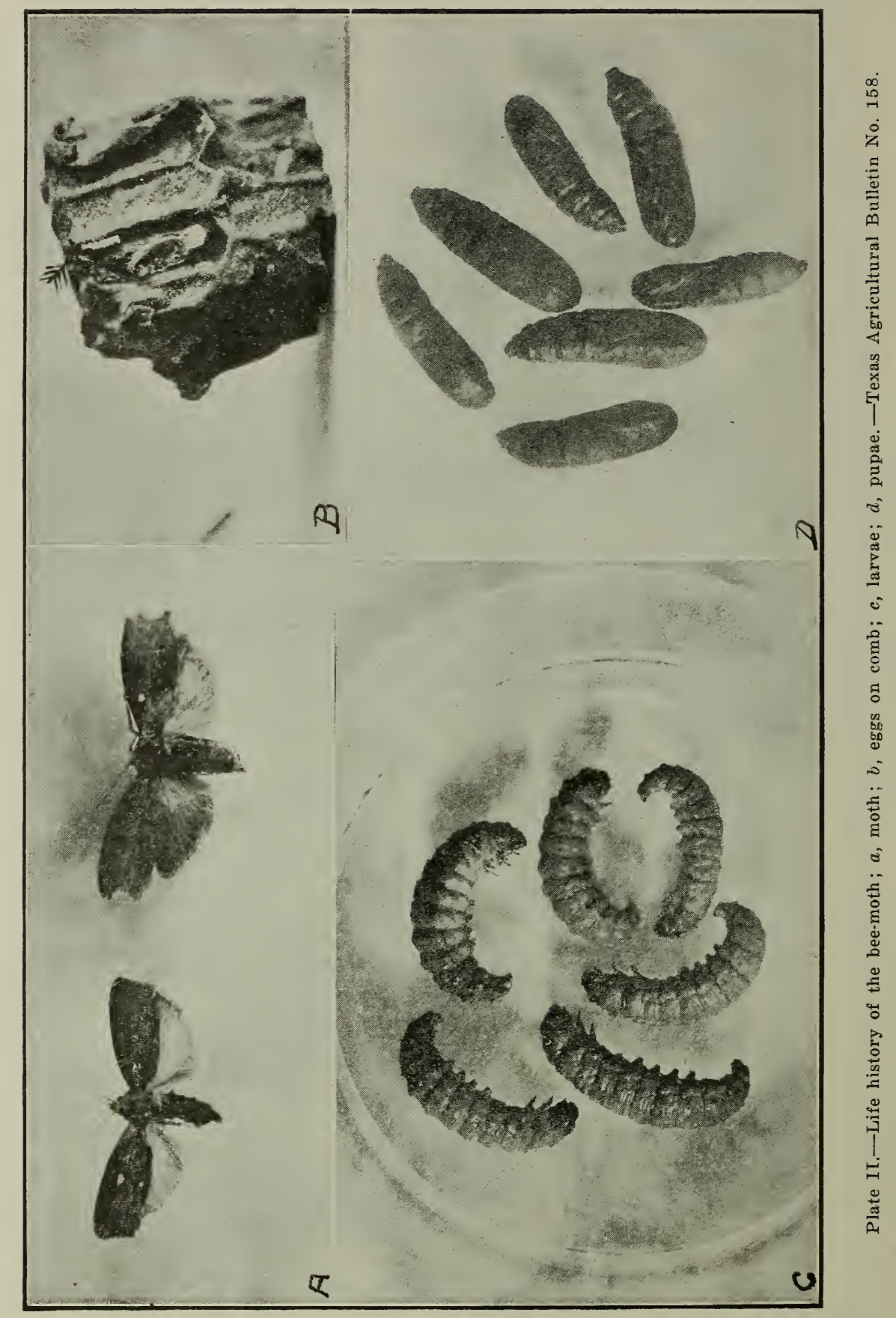


MIATING AND OVIPOSITION.

During the mating period the males are more active than the females; and at this time can be noticed "drumming" with their wings, the vibrations of which are, at times, sufficient to produce a low hum.

The moths probably mate very soon after emergence, tho no direct observations have been made upon this point. However, females only one and one-half hours old were killed and their ovaries examined. It was found that, at this time, fully two-thirds of the eggs were of full size and well down in the oviducts, tho not packed closely, as was found to be the case in the older moths. The eggs had the appearance of being ready for deposition.

Mating takes place at night, as would naturally be expected from the nocturnal habits of the species. In one cage a pair of moths was observed in coitu early in the morning, but this was no doubt an abnormal condition, as the female died in a short time. Another case was observed where the moths were in coitu from $7 \mathrm{p}$. m. till 10:30 p. m. The next morning no eggs had been deposited, but the following night the female began ovipositing. This was an exceptional case, as the female had been confined for a week after emergence before having the opportunity to mate.

It would seem that the female commences to oviposit in a comparatively short time after emergence. However, in the cages, an average of six days elapsed between the time of emergence and the first egg-laying. This period varies with the different broods of the year. Oviposition usually take place at night and the moths generally start laying the eggs soon after dark. In the cages they have been observed busily engaged in ovipositing as early as $7 \mathrm{p}$. m. While depositing eggs the female seems mindful only of the task she is performing, and is not easily disturbed, tho she is active, seemingly nervous, darting in and around the comb. While thus engaged the antennæ vibrate continuously and perhaps are used to locate suitable crevices in which to place the eggs. The ovipositor is long, equal in length to the last two abdominal segments, and is very slender. It is constantly moving over the comb to detect a roughened spot wherein to deposit the egg. It thus has the appearance of being dragged after the female in her travels over the comb.

Having found a suitable place for the egg, the ovipositor is spread at the tip, the female braces berself as tho pushing backward to force the ovipositor into the comb, and then, after a quick jerk of the abdomen, an egg is forced down the ovipositor to its destination. In many instances females have been observed depositing their eggs at the rate of one every minute for a period of thirty minutes, and then, after a short rest, have continuerd again at the same rate. The eggs are always securely fastened to whatever object they are laid upon. The eggs are always laid in cavities. In the cage experiments this was on the side of the comb, often where the walls of a cell had been turned in. An example of this is shown at Plate II, b. Only one egg is deposited at a time, altho in working over the comb a female often places the eggs close together. On the smaller pieces of comb, furnished to moths confined in cages, as many as seven eggs were found in a single cavity. The number of eggs actually deposited by one female has not been determined, but females which had not deposited eggs were killed and the eggs in their ovaries were counted. The largest number of eggs found in ovaries of a single female was 1128 , and the average number was 1014 .

In the cages, under artificial conditions, if comb was not supplied for the female, she would deposit her eggs in any rough place detected by her ovipositor. In many instances the females would refuse to oviposit on cappings which were furnished in some of the cages, but would go around the base of the lamp globe in which they were confined and fill every crevice with eggs. Sometimes these eggs would be fastened on the ontside of the glass, and in such cases the globe would be fastened to its restingplace.

The average time consumed in depositing the full quota of eggs varies with the brood. In the first brood it is nine days, but in the second only seven days. During the last part of the egg-laying period the female appears to be in a great hurry, and during the last few days she oviposits during the day as well as during the night, at times stopping to rest. If disturbed during the resting periods, she vigorously resumes her egg-laying. The females usually die while ovipositing, and the last three or four eggs are barely extruded from the ovipositor. If a female is being killed or injured, she will attempt to oviposit even after she is unable to walk.

The females will deposit their eggs even when they have not had the opportunity to mate. In all cases where the sexes were not properly paired, the females would finally oviposit, the period of oviposition being, however, much shorter than the natural one. Altho many females which did not mate were confined in cages, and altho they deposited eggs, none of these unfertilized eggs ever hatched. It seems a fairly safe conclusion that parthenogenesis does not occur with this species.

\section{THE EGG.}

The egg (Plate II, b), is elliptical, measuring about one-fiftieth of an inch $(.48 \mathrm{~mm}$.) in length and .43 in width. The shell is pearly white in color and slightly roughened by wavy lines running across it diagonally at regular intervals. If the egg is not deposited on dark comb it is very diff. cult to see, and even then experience is necessary to detect all of the eggs present.

The embryonic development of the egg has not been studied, but a few observations 


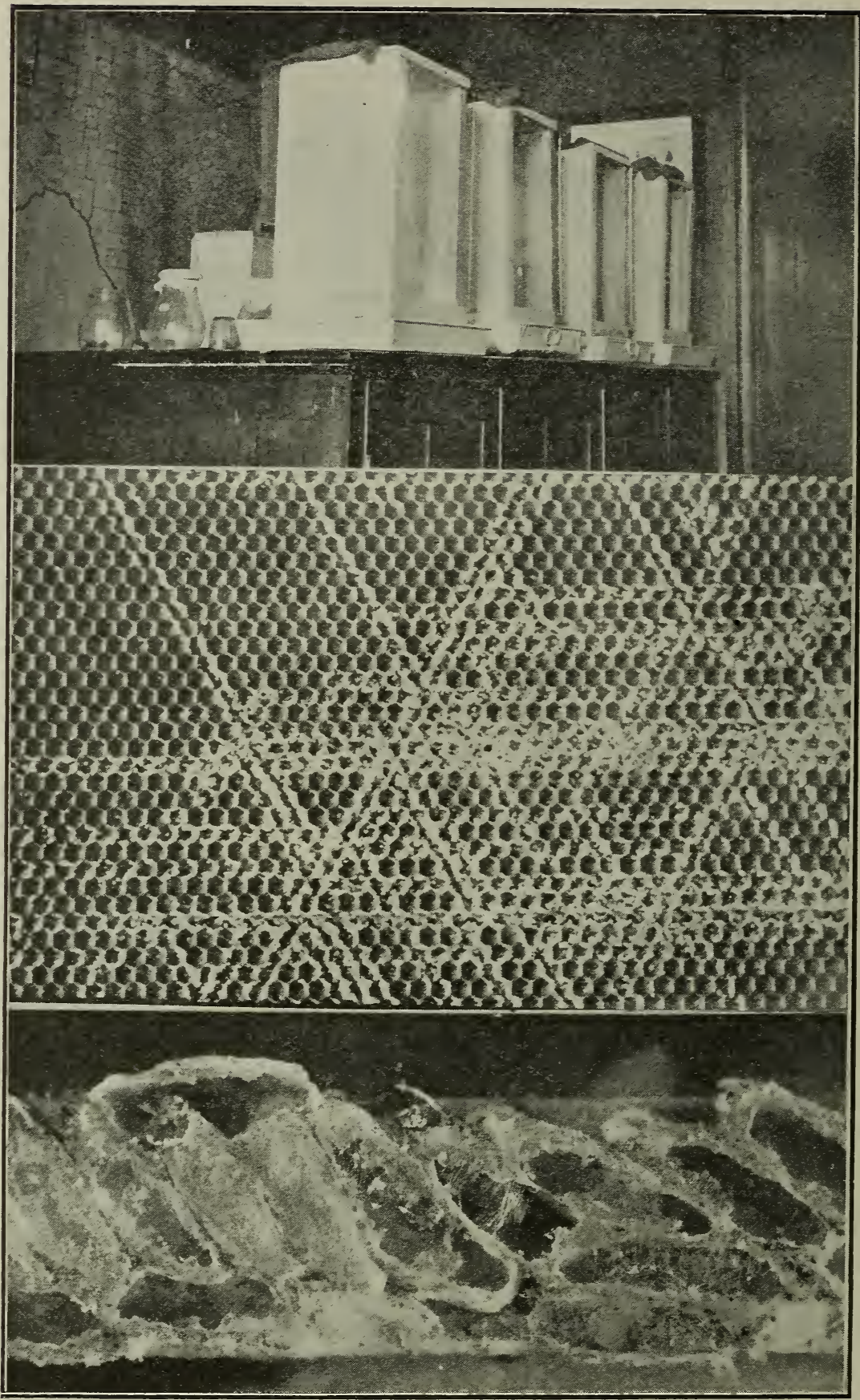

Plate III.-Above, cages used in study ing the development of the bee-moth; at center, work of wax-worm, or larva, on comb foundation; below, mass of cocoons, one of which shows larvæ repairing damaged cocoon.-Texas Agric. Bulletin No. 158 . 


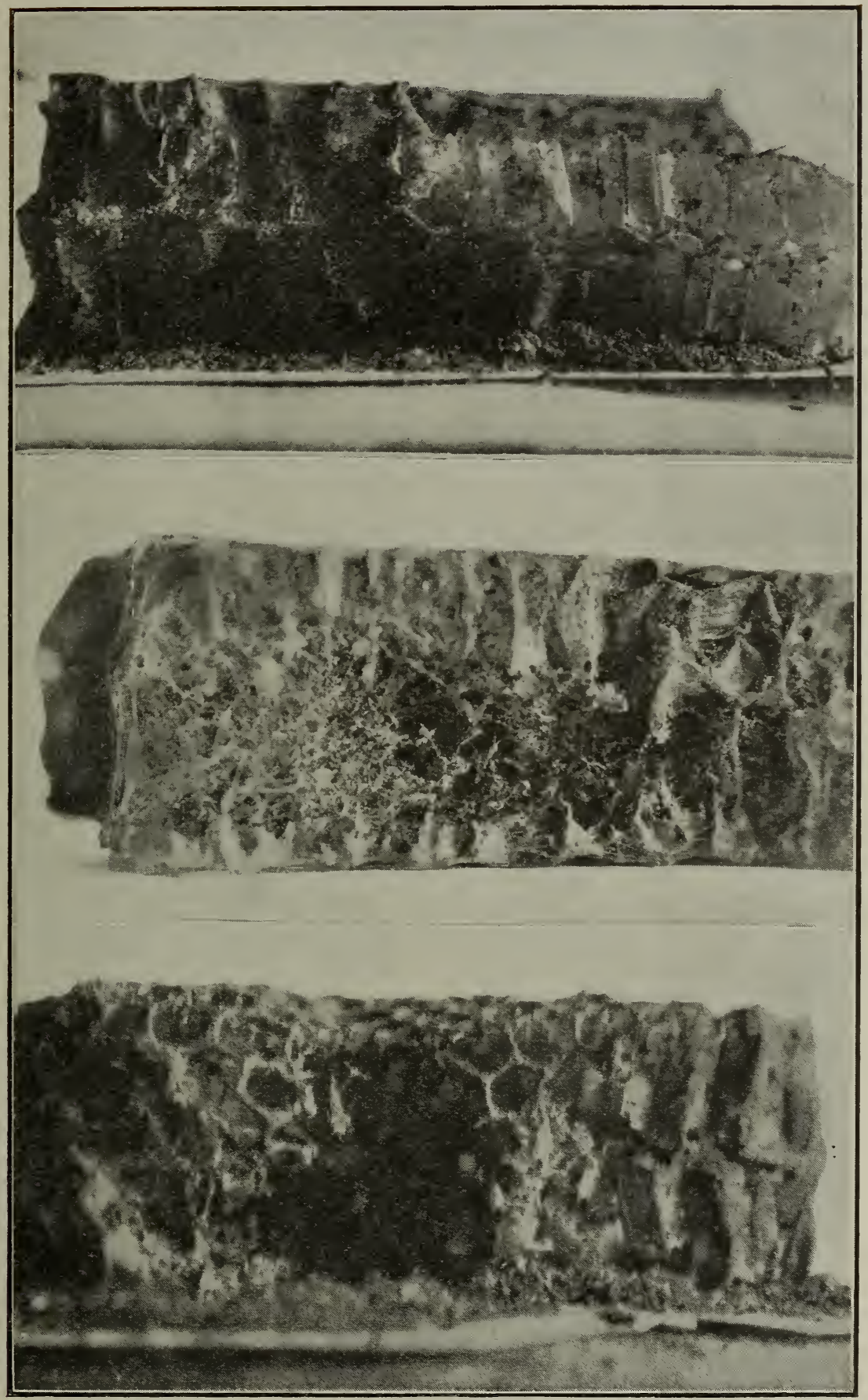

Plate IV.-Characteristic work of the wax-worm on empty comb.-Texas Agricultural Bulletin No. 158. 
have been made upon the incubation period. During this period the egg gradually changes from a white to a yellow color. About four days before hatching, the developing larva becomes visible as a dark ring inside of the shell. The perfectly formed larva can be distinctly seen for at least twelve hours before the shell bursts. During this time the larva is engaged in cutting an opening in the shell and its final emergence from the egg is made thru a ragged hole in the top. After the larva is out of the shell it appears white and clear.

The egg stage of the first brood averages twelve days and of the second only ten days.

\section{THE LARV Æ.}

The larvæ ("worms") when first hatched are white in color and very small, only oneeighth of an inch $(3 \mathrm{~mm}$.) in length. After emerging from the shell they are quiet for a short time while they are apparently drying and stretching in preparation for their work of destruction. Soon they become very active, but only upon close examination can they be seen hurrying over the comb in their attempt to gain an entrance before being detected by the bees.. During this short period of one or two hours they are at the mercy of their enemies. Within a short time after hatching, the first meal is taken, and this consists of scales of wax which they loosen from the comb in their attempts to gain an entrance. The entrance is made at the top of the cell-wall between the cells.

The entrance is extended by the larvæ into tunnels directed toward the bottom of the cells. Their presence is now noticeable, for in their work the bits of chewed wax not used for food are pushed back of them and out of the tunnel, making the surface of the comb appear rough and poorly kept. This tunnel affords protection and food for the larvæ and also leads to their desired feeding place, the center of the comb. Usually four days are consumed in reaching this point.

When the center of the comb is reached, the larvæ leave their tunnels and wander over the bottom of the cells or, in the case of comb containing honey, tunnel along the midrib from cell to cell. If disturbed, they seek their tunnels for protection. At first only small holes are eaten thru the bottoms of the cells, thus affording a passageway from cell to cell thru the center of the comb, so that, if disturbed, they can pass into threads of silk spun by the larvæ in their attempt to escape. In two or three days these openings are enlarged and outlined by threads of silk spun by the larvæ in their travels from ceil to cell. These threads soon become numerous enough to form a silken gallery, which gives almost complete protection from the bees or other enemies. From this central gallery the feeding is extended out along the bottoms of the cells or the middle of the comb. The silk is spun wherever the larvæ go, so that very soon the bottoms of the cells are replaced by a layer of silk thread covered with excrement of the larvæ and particles of chewed wax. This condition is shown in Plate IV.

After the midrib has been eaten, the larvæ start on the walls of the cells, the ones furthest away from the light being the first that are destroyed. As this feeding continues out along the cell-walls, the threads of silk are extended to cover the new feeding-ground, and not only serve to protect the larvæ, but also act as a scaffold to support the damaged cells. Soon the center of the comb appears as a mass of tangled refuse and discarded wax. This condition is also shown at Plate IV. The feeding continues until the walls are entirely eaten, but the top of the cells is never eaten, perhaps because this would expose them to outside influences and enemies. An example of this is shown at Plate IV, lower photo. The area of feeding is gradually extended from the point of infestation to include finally the entire comb. If the comb does not furnish sufficient food for the larvæ that are present, they will begin to feed in the refuse under the comb in which there is considerable wax in small pieces. In this they construct such a large amount of web that they are absolutely protected from enemies.

The length of the larval period for the first brood is forty-five days, or about six and one-half weeks. In the second brood this period is shortened to thirty-five days, or five weeks.

The full-grown larva, shown at Plate II, $c$, is about three-fourths of an inch $(18 \mathrm{~mm}$.) in length. The body is large and the head is small and pointed. The general color of the body is a dirty gray, with the first segment brown on top and a broad line across it. The head is brown in color, with a light V-shaped line on top, this "V"' opening toward the front of the head.

Having completed its growth, the larva seeks a place in which to pupate, tho sometimes the end of the feeding gallery may be enlarged and closed to serve as a cocoon. The cocoon may also be spun in the refuse under the comb and this mass of webs affords an excellent protection to the pupa. The most common place is in some crack or corner about the hize, as shown in Plate $\mathrm{V}$, below, or between the frames and the hive or in the "bee space" at the end of the top-bars, as is shown in Plate VI, right. The larva prefers to get into a place which it can chew in order that a cavity may he constructed and the cocoon thus be better protected.

Having prepared for the location of the cocoon, the larva begins to spin the silk thread about itself, starting just above the head and working backward more than the length of the body. A thin layer of silk is spun in the general shape of the cocoon; and this framework is covered with fine silk from the inside. The larva is able to reverse itself within the cocoon, which it does inany times during its construction. The 


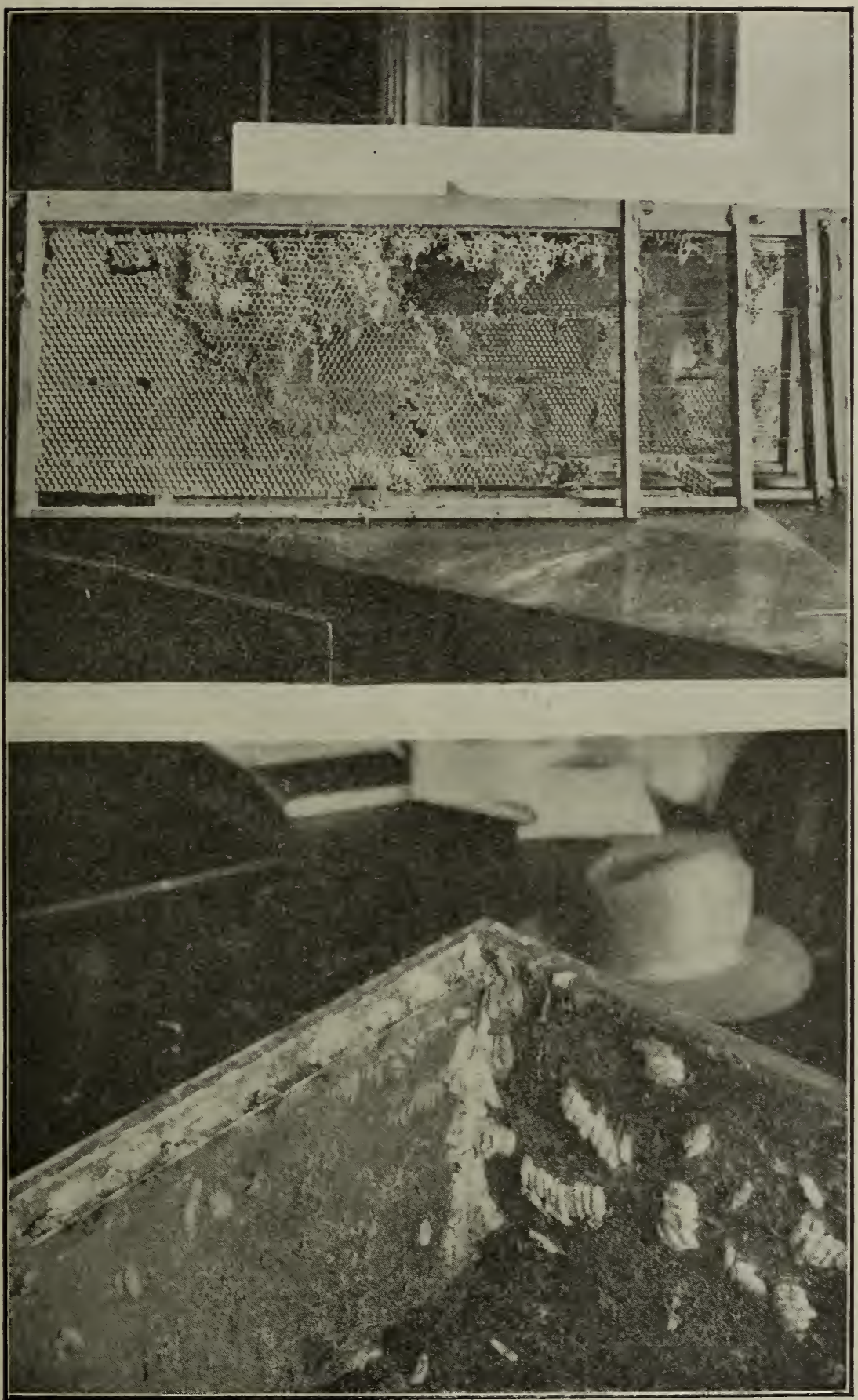

Plate V.-Above, comb and foundation destroyed by wax-worm; below, characteristic appearance of cocoons inside of beehive. - Texas Agricultural Bulletin No. 158 
outer layer, upon hardening, becomes very tough and even like parchment, while the inner layer remains soft and fluffy. Cocoons, both whole and broken open, are shown at Plate III, below, and in Plate VI, left. The average time consumed in the construction of the cocoon was two and one-fourth days in the case of the larvæ observed in our cages.

\section{THE PUPA.}

As the cocoon nears completion, the larva becomes very sluggish and the body shortens. The last act of the larva is to make an incision in the cocoon near the head end which provides for the easy emergence of the moth at maturity. The average time elapsing from the completion of the cocoon to the formation of the pupa was three and three-fourths days in the cages of the experiments.

The change to the pupa takes place during the night. The newly formed pupa is white. At the end of the first twenty-four hours it turns to a straw color, very light at first, deepening slowly. By the end of the fourth day the pupa is light brown and this color gradually deepens, so that by the end of the pupal period the insect is a dark brown. (Plate II, d.) The male pupæ average 14 millimeters (about two-thirds of an inch) in length and the female pupæ are fully 16 millimeters in length. A row of spines arises just back of the head and extends to the fifth abdominal segment; the body line is somewhat curved downward. The time from the formation of the pupa to the emergence of the moth was seven and three-fourths days in the cage experiments.

The total time from the starting of the cocoon to the emergence of the moth averages two weelss.

\section{LIFE HISTORY.}

From the work which we have done in trying to identify the different broods, or generations, of this insect, it appears that there are three broods in the extreme southern part of the United States. The third brood is not nearly as large as the first two, due to the fact that some of the second brood of larvæ do not pupate until late fall. There is a decided overlapping of the generations, which makes it difficult to determine the exact number of broods a year. At almost any time, from early spring until December, examination of a colony of bees is likely to reveal this insect in all stages. It is often assumed that the life history is short and that there are several generations each year.

In well-protected hives the development may continue thruout the year without interruption. Usually the winter is passed with about one-third of the insects in the pupal stage and the remainder in the larval stage. Warm spells during the winter cause some of the moths to emerge from their cocoons; in the laboratory many moths emerged when the temperature was main- tained constantly at 60 degrees $\mathrm{F}$. It is not unusual to see moths on the windows of the honey-house, trying to escape, during the warm spells in December and January. Their presence may be accounted for on the supposition that they have just emerged from their cocoons or they may have been in hiberation as adults and become active with the rise in temperature. Such moths do not reproduce in localities where freezing temperatures are frequent. Even the most vigorous moths cannot withstand a freezing temperature for more than three days. Moths in well-protected places can survive an outside temperature as low as 26 degrees F. for as long as five days. The moths are never active during the day when the temperature is below 50 degrees F., so at such times reproduction does not take place.

\section{NATURAL ENEMIES.}

Of the natural enemies of the bee-moth, the most important is the honeybee itself. It is a well-established fact that if the colony be kept strong, healthy, and with a vigorous queen, it will defend itself against the bee-moth. This is particularly true in the case of "Italian", bees. "In the Ohio Cultivator for 1849 , page 185 , Micajah T. Johnson says: 'One thing is certain: if the bees, from any cause, should lose their queen, and not have the means in their power of raising another, the miller and the worms soon take possession. I believe no hive is destroyed by worms while an efficient queen remains in it.' This seems to be the earliest published notice of this important fact by an American observer.",*

This fact is of vital importance in the fight against the bee-moth, for if the pest can be kept from its favorite food, control measures are made much easier. The fact that the bees under natural conditions are able to defend themselves should leave the problem of control to such means as will destroy the pest in places other than the hives. Recently it has been found advantageous to introduce Italian blood into the colony, as the workers of this race seem to be more efficient fighters of the bee-moth. In most cases this is sufficient for the control of the pest in the colonies, but it must be remembered that the colony cannot be kept under close observation and maintained at full strength unless domiciled in a frame hive.

A small red ant, Solenopsis sp., $t$ has been found to be an enemy of the bee-moth, as many of our cage experiments were destroyed by this ant killing the moths and larvæ. The attack is made on the moths during the day or when they are at rest. Usually the ants crawl under the wings of the moth and begin the attack upon the abdomen. There is no apparent struggle on the part of the moth, for close examination is necessary to

* Langstroth on the Hive and Honeybee, by Chas. Dadant, p. 469 . 


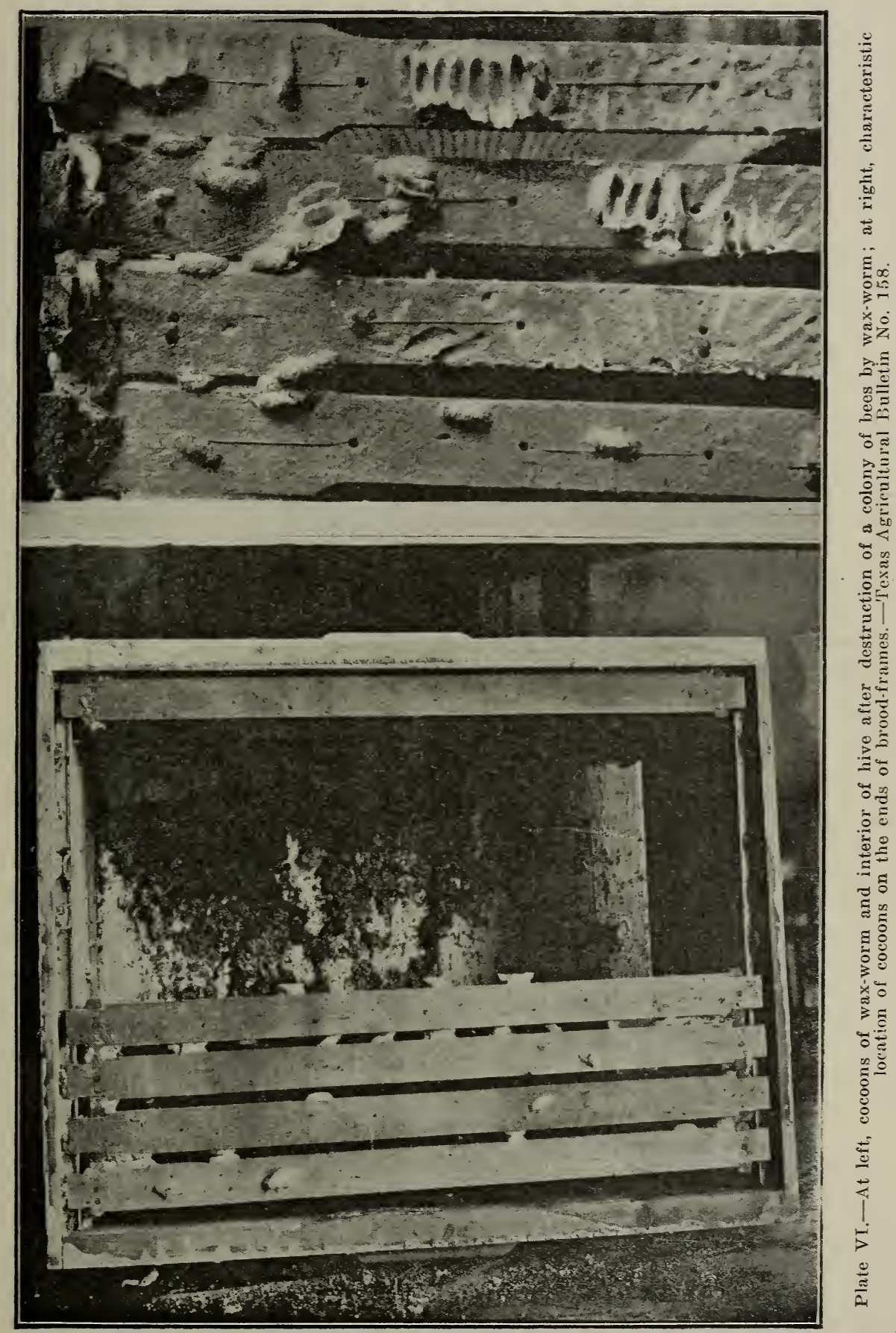


determine that the moth is dead and not resting. The abdomen seems to be all that is desired, and this is carried away in small pieces to the nest of the ants. This same species of ant also destroyed moths which had recently been prepared for exhibits. At such times only the abdomen was taken by the ants. In their attacks on the larvæ the ants entered the cages and crawled over the comb and wax in search of their prey; and if any larvæ were exposed they were attacked. The larger larvæ are more frequently attacked, as they are less active and usually feed in more exposed places than do the smaller ones. Unless the larvæ were well protected by webs in the refuse, they were destroyed by the ants. Apparently there are days and even parts of days when the ants are most active in their destruction. Never were the ants present in sufficient numbers to attempt tracing them to their nests. No observations have been made upon this ant in or about the apiary, and, while it proved very destructive under artificial conditions, the moths and larvæ might be better able to protect themselves under natural conditions.

Three hymenopterous parasites have been recorded from the bee-moth. One is a chalcid, Eupelmus cereanus, found by Roudani in Italy; another is Bracon brevicornis, which was found by Marshall in France, and a third species, Apenteles lateralis, was recently found by A. Conté in France.* This last species was found near Lyons, where it spread very rapidly. It is apparently of considerable importance since it has also been reported to attack the larvæ of several other moths in England and Germany. The adult parasite is about one-sixth of an inch (4 mm.) in length, very lively, and avoids light; the body is black and the wings are transparent. with black specks. The larvæ of the bee-moth are attacked while quite young and never attain a large size. A single parasite develops in each larva. The bees are said to pay no attention to the presence of the parasite, so that it can easily enter the hive in search of the bee-moth larvæ. It was artificially introduced into hives by Conté with very satisfactory results.

\section{ARTIFICIAL CONTROL.}

Unfortunately, the only natural enemy of the bee-moth that is present to any great extent is the honeybee itself. In the absence of any other natural enemies of importance, the measures of artificial control must be made all the more effective if the beekeeper is to free his apiary of the pest. If the moths are driven from the hives by strong colonies of Italianized bees, they will surely seek scraps of comb and wax about the ground and stored comb and honey in the honey-house. It seems quite likely that

* "A Hymenopterous Parasite of the Bee-moth," A Conté (Compt. Rend. Acad. Sci. Paris, 154 pp. 41,42 ). in such cases the eggs are deposited as near to the comb as possible, as along the cracks between the supers, and the larvæ, after hatching, find their way to the comb thru crevices much smaller than the moth could enter.

One of the best methods of artificial control, and one upon which many beekeepers depend, is fumigation of combs and honey. Gas is able to penetrate material that it is not possible to treat in any other manner. The fumigation process is not difficult, for, when once started, no further attention is necessary until the treatment is complete. It is not necessary to watch the entire process. Stored material, such as comb honey and empty combs, should be examined from time to time, and at the first evidence of the wax-worm they should be fumigated. Stored material of this kind should be examined at least once every week during the summer and once every month during the winter season, so as to detect the infestation at the start.

\section{FUMIGATION.}

In the present investigation two materials have been used in the fumigating experiments. These were selected because almost every beekeeper is acquainted with them and they can be obtained in practically every locality at a reasonable price. They are sulphur and carbon bisulphide, or "' high life.',

\section{SULPHUR.}

Dry powdered sulphur, or "flowers of sulphur," is a light-yellowish powder, with which every one is familiar. When sulphur is burned it unites with the oxygen of the air and forms a poisonous gas known as "sulphur dioxide." This gas is quite effective in killing some kinds of insects, including the wax-worm. A common method of burning the sulphur is to place it on a pan of red-hot coals and immediately tier up the infested supers over the burning sulphur. The bottom super should not contain any infested material, and the pile should be covered as quickly as possible. A number of experiments were made with sulphur for fumigating combs containing the wax-worms. The results of these experiments are given in the following table:

Tab?e I.-Results of Fumigating Infested Combs with Sulphur Dioxide.

Larvæ.....1/4 oz...... One hour..... Killed

Larvæ.....1/2 oz...... One hour......... Killed ${ }^{*}$

Larvæ..... $2 / 3$ oz....... One hour........ Killed*

The larvæ which were used for these experiments were ten to twenty days old, and in every case they were well protected by the webs and refuse.

From the experiments with sulphur dioxide it is evident that only extremely large doses will affect the eggs of the bee-moth

* Eggs which were present on these combs were not killed by the sulphur dioxide as larvæ were found hatching a few days after the fumigation. 


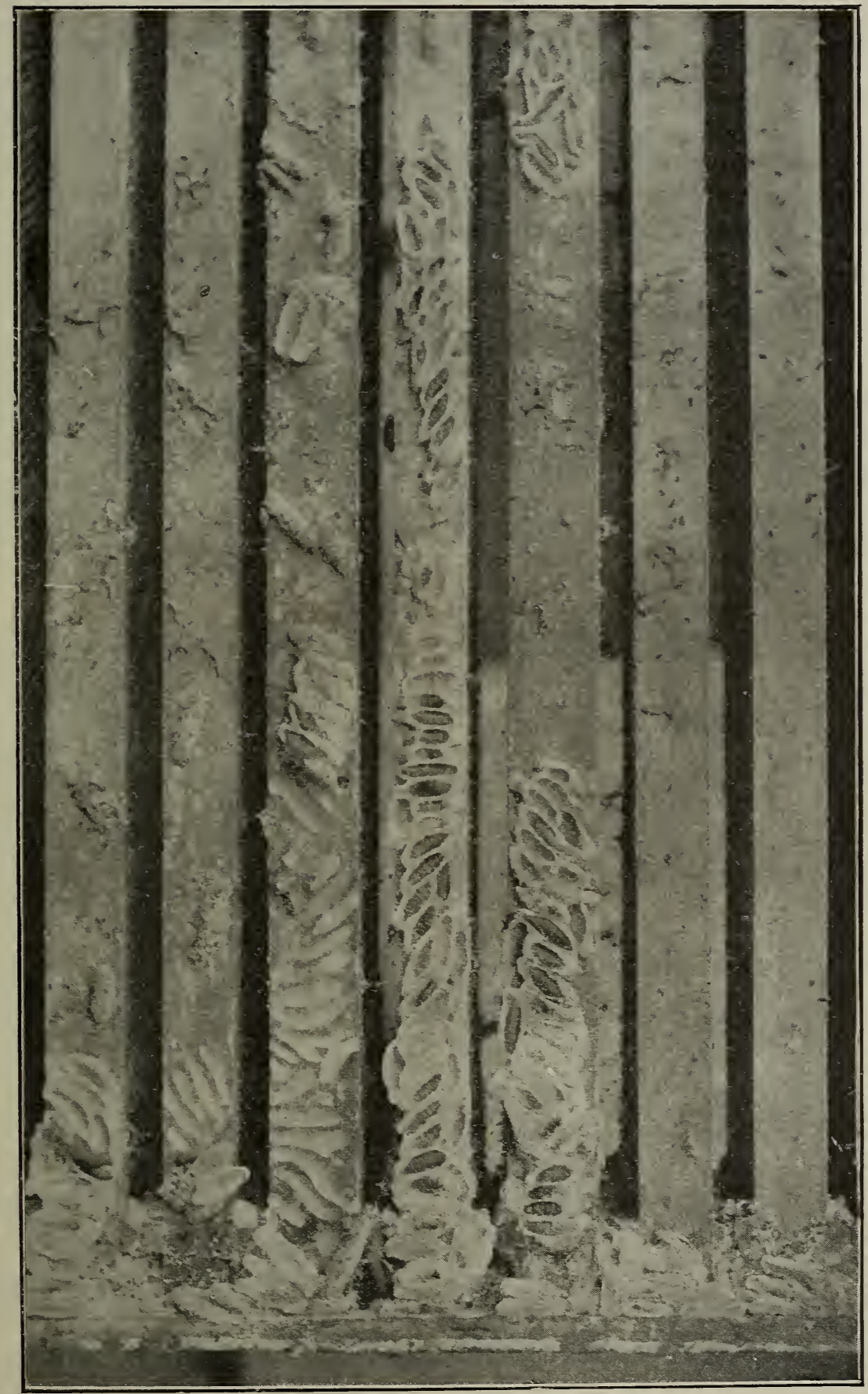

Plate VII - Appearance of infested hive with cover remored, showing cocoons broken open and the larvæ inside of them. - Texas Agricultural Bulletin No. 158. 
-so large, in fact, that such fumigation would not be practical.

The larvæ which were used in the experiments were of different ages and some were better protected than others. When the larvæ are not very well protected they are quite susceptible to the gas, but the larger larvæ, which are often enclosed in a mass of webs, are not killed except when extremely large doses of sulphur are used.

These results seem to indicate that the sulphur fumes are not ordinarily penetrating enough to affect the eggs, and only when the larvæ are young and not well protected will the gas affect them. While the method is simple, there are minor details upon which the success of the operation depends. The sulphur must be burned at a high temperature in order to generate the most effective gas. While the method is generally effective under proper conditions, it cannot be recommended in preference to fumigation with carbon bisulphide.

\section{CARBON BISULPHIDE ("HIGH LIFE").}

The commercial bisulphide is an oily liquid, very volatile and exceedingly foul-smelling. It is cold to the touch; and because of its rapid evaporation it produces a freezing sensation when dropped on the skin. When exposed to air at ordinary temperatures the bisulphide changes to a gas quite rapidly, and this gas, or vapor, is a little more than two and one-half times as heavy as air. This is a point to be remembered in its use, since it goes first to the bottom of whatever it is confined in. When mixed with air it becomes highly inflammable and sometimes explosive. Such a mixture of air and bisulphide gas may be exploded by even a spark, such as might be made by hitting a nail with a hammer. The liquid, on evaporation, leaves a residue of impurities. Its rate of evaporation is in proportion to the temperature and the area of the exposed surface. Its efficiency is greatest with rapid evaporation, and this is secured in relatively warm weather, but artificial heat must never be used to hasten its change into gas. Carbon bisulphide is obtainable from practically every druggist.

When carbon bisulphide is to be used for fumigation of infested material, the greatest precaution should be used to keep all fire, such as lights, cigarettes, etc., away from the liquid and where it is being used. For this reason it is well to take the material that is to be fumigated to some place out of doors and at least a hundred feet away from any building. The infested material should be placed in supers or hivebodies if possible. These are piled as high as is convenient and all cracks between the supers made as nearly gas-proof as possible. Especially should the bottom be tight. A good plan is to place an inverted hive cover on the ground, lay a piece of canvas over it, and then tier up the supers on this. After the pi.e has been comp'eted, an empty super should be put on top. In this should be placed a large shallow pan into which the bisulphide is to be poured. When all is in readiness, pour the bisulphide into the pan and immediately put a hive cover on the top of the tier to confine the gas. This operation is best performed in the evening, and the pile of supers should be left intact until the following morning. When the supers are taken down the confined gas will escape from them immediately, even before they can be carried, separately, into a building.

MOVING BEES. - Young bees, when they first start out, or old ones on the first flight of the season after a winter's confinement, hover in the air about the hiveentrance, take a careful survey of surroundings, making wider and wider circles, each time taking in new objects by which they may familiarize themselves with the home. When the location is once carefully marked they will go back and forth without taking any note of distinguishing objects. But when the hive is moved only a few feet there is apparent consternation and confusion.

One cannot, therefore, move his bees a few feet or a quarter of a mile without having the great majority of them go back to the old spot unless treated by the plans here described. Some strains of black bees when moved will find their hives. See "Black Bees," under head of RACES of BeEs. The bees lost perish, or possibly get into some other hive near their old location, with the result that there is a fight, and many bees killed.

If one desires to move his bees, and wishes to take them at least a mile and a half or two miles away, the problem is quite easy, for then they will stay wherever they are placed. As soon as they are liberated in their new position they will mark the location as thoroly and carefully as when taking their first flight. After that they will go to and from the same spot as if it had always been their home.

But to move bees from the front to the back yard, or from a fourth to half a mile, is not so easy. They are familiar with the whole range of flight within a mile of the old stand; and when they go over their old hunting-ground, so to speak, instead of returning to the hive from which they have just come they will return to the old location. How, then, shall we make them stay where placed? One way, and the very best 


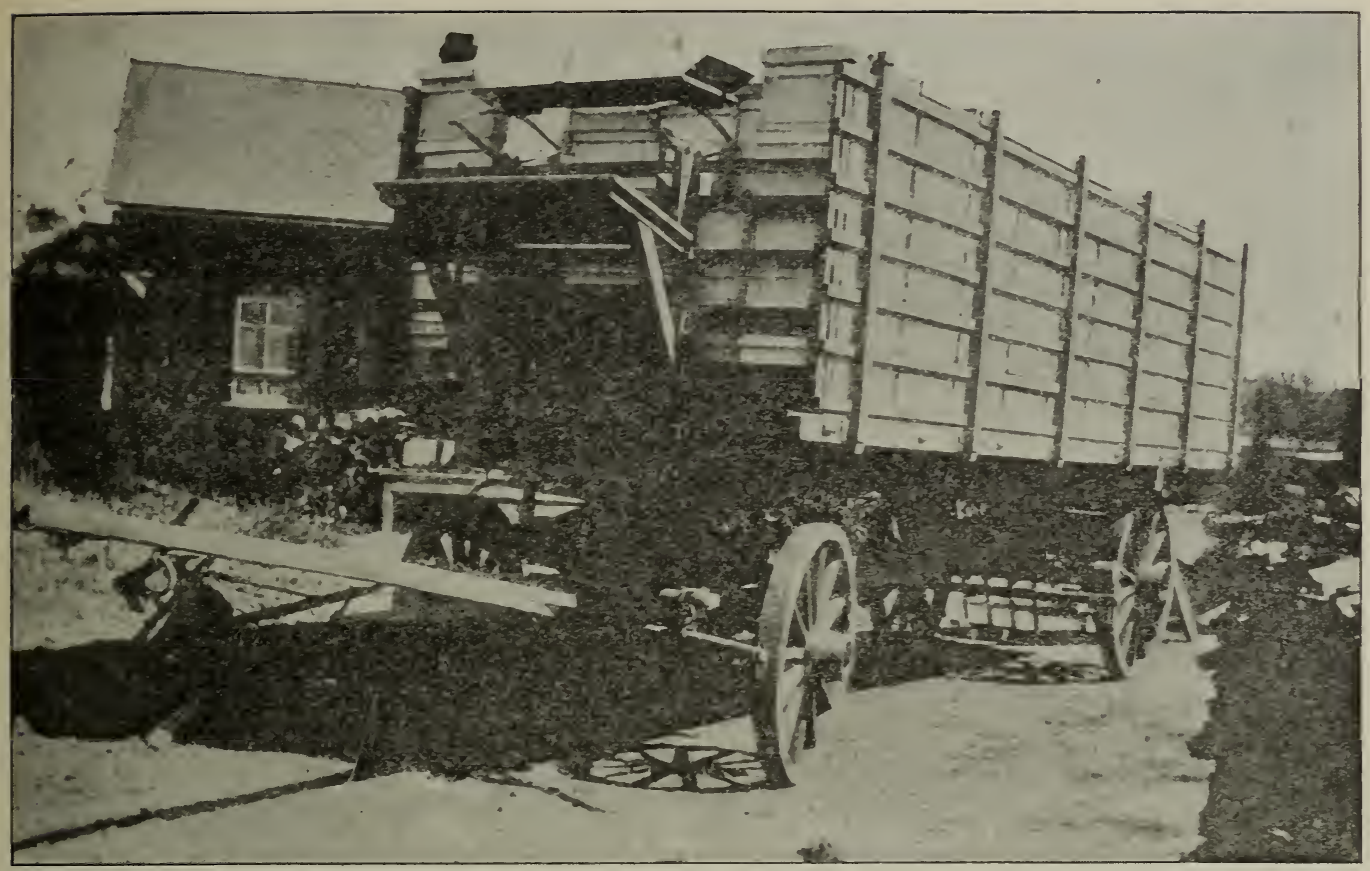

Rack made in California, especially for hauling bees.

one, is to wait till fall or winter. After they have quit flying for the season, more them to the spot desired. If they are confined a week or two weeks by cold weather, or longer, they will mark their new location and go back to it as their regular and permanent home. It will be better still if they can be confined for several months in the cellar; then when they are put out again in the spring, place them in the new location; for it is well known that cellared bees can be placed anywhere the following spring without reference to their old stands. Wherever they are placed they will mark their location, and that must be their fixed position for the season.

But suppose it is the midst of summer, and for some reason the bees must be moved a few rods from their old location. Perhaps complaint is made that the bees in the front yard are interfering with passersby, and to avoid trouble it seems desirable to move them to the back yard. In an emergency of this kind the following plan may be used:

Tack wire cloth over the entrances, carry the hives down cellar, and keep them there for at least five days, and longer if they appear to be quiet. While the bees are in the cellar, change the surroundings in the front yard or in the old location as much as pcssible. After the becs have served out their allotted time of confinement, put them in the back yard in the same order as before if it can be done conveniently. While some of the bees may, perhaps, go back, the great majority will stay in their new location. Those that do return should be given a frame of brood in a hive; and when they have clustered on it they should be taken to the new location and dumped in front of the entrance to the hive. If the bees are confined during cool or rainy weather, when they cannot fly, there will be no loss of honey that might be gathered from the field. While the bees are confined in the cellar a sharp watch should be kept on them to see that they do not suffocate; and, if practicable, the whole top of the hive should be covered with wire screen.

There is still another method; and wherever it is practicable to carry it out it is better than carrying them into the cellar; that is, move the bees to a point a mile and a half or two miles from the old location. Let them stay there two or three weeks, then more them back. But this involves considerable labor, so that the average person would not think it practicable.

Another plan that has been spoken of very farorably, and possibly may be better than any of the others mentioned heretofore 


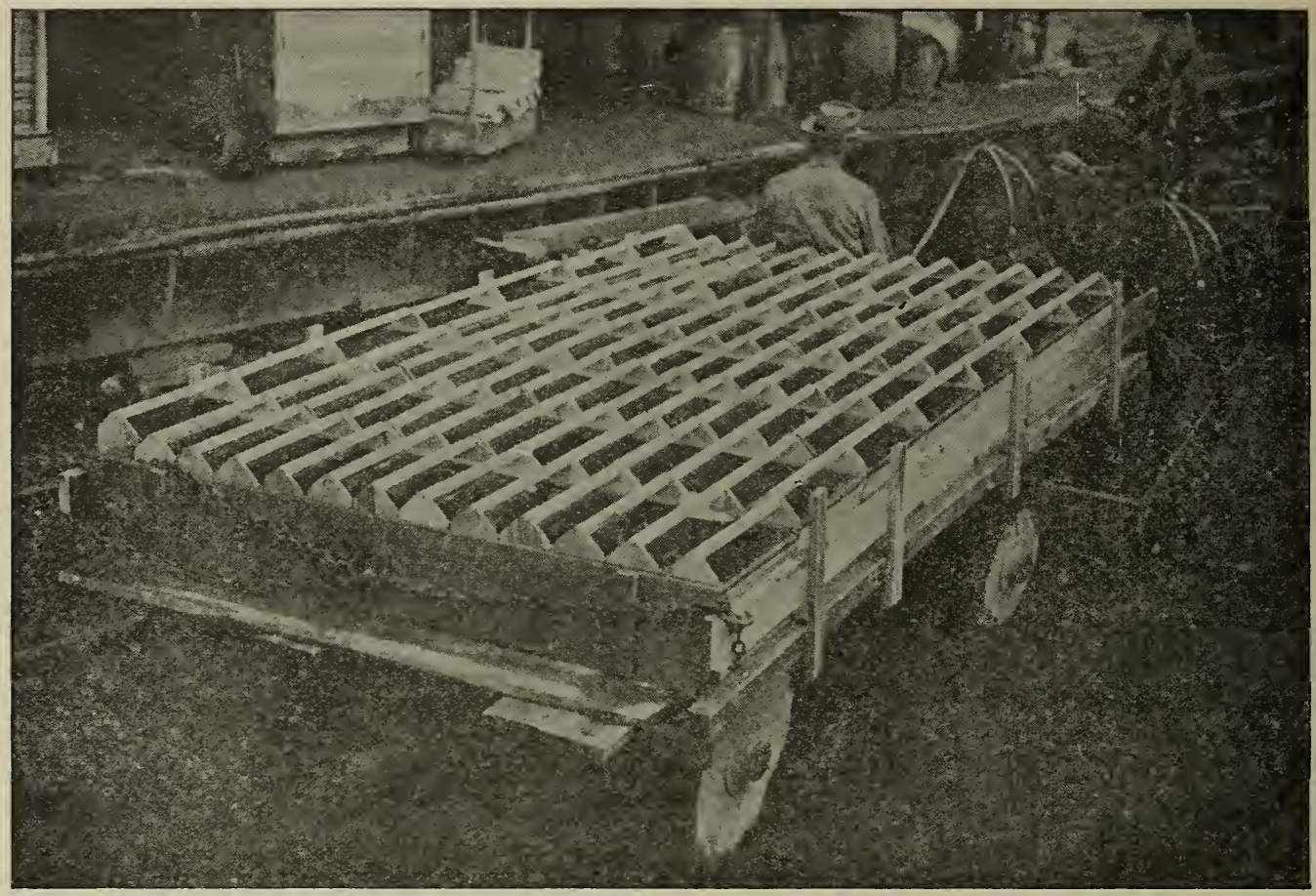

Wagonload of 91 nuclei en route to the Basswood yard. A low-wheel wide-tired wagon is just right for loading and unloading, and for carrying bees from one yard to the other. The wide tires make it possible to get over soft sod when the ground is wet.

except the plan of moving to an outyard and then moving back again, is this: In the cool of the morning, at a time of year when no honey is or has been coming in, colonies may be moved a few feet or a few rods with very little trouble. The hives are put on a wheelbarrow early in the morning, and trundled as roughly as possible after smoking at the entrance clear over to the new location, for it is important that the bees get a general shaking-up in moving. If the frames are self-spacing there will be no damage done to the combs nor to the hees. The hive is set down on its new stand, when it is given a little more smoke. Any number of colonies can be moved in this way; but the moving should be done at once, and the old location should be changed in appearance as much as possible. Very few bees will go back when so treated. The author has tried it in a limited way, and found that it works admirably. But right here a caution must be entered. The bees should not be moved. a short distance when a honey-flow is on or has been on for two or three days. When they have been going regularly to the fields for a number of days they get their location well fixed, and it is almost impossible to move them at such times short distances without a general returning of field bees to the old stands. A correspondent reported that he attempted to move bees to a neighboring lot when the honey-flow was on, and he says he never saw bees crosser in his life. When, therefore, a neighbor complains that the bees are interfering with public traffic along the highway, and they must be moved at once, one must take into consideration whether there is a honey-flow on. If so, an explanation should be made that moving bees at such times will only make the trouble complained of much worse. See Bees as a Nuisance; also Apiary.

We have tried another plan that has given good results; but this, like the other, must not be attempted when a honey-flow is on. Move the hive a few inches a day, and each time make a bigger jump than the one preceding. After the bees have been moved in this way from two to five times they learn to expect a change in location, and therefore will hunt out their hive wherever it may be. Sometimes in such moving it is advisable to put up a board against the entrance just after moving, in 


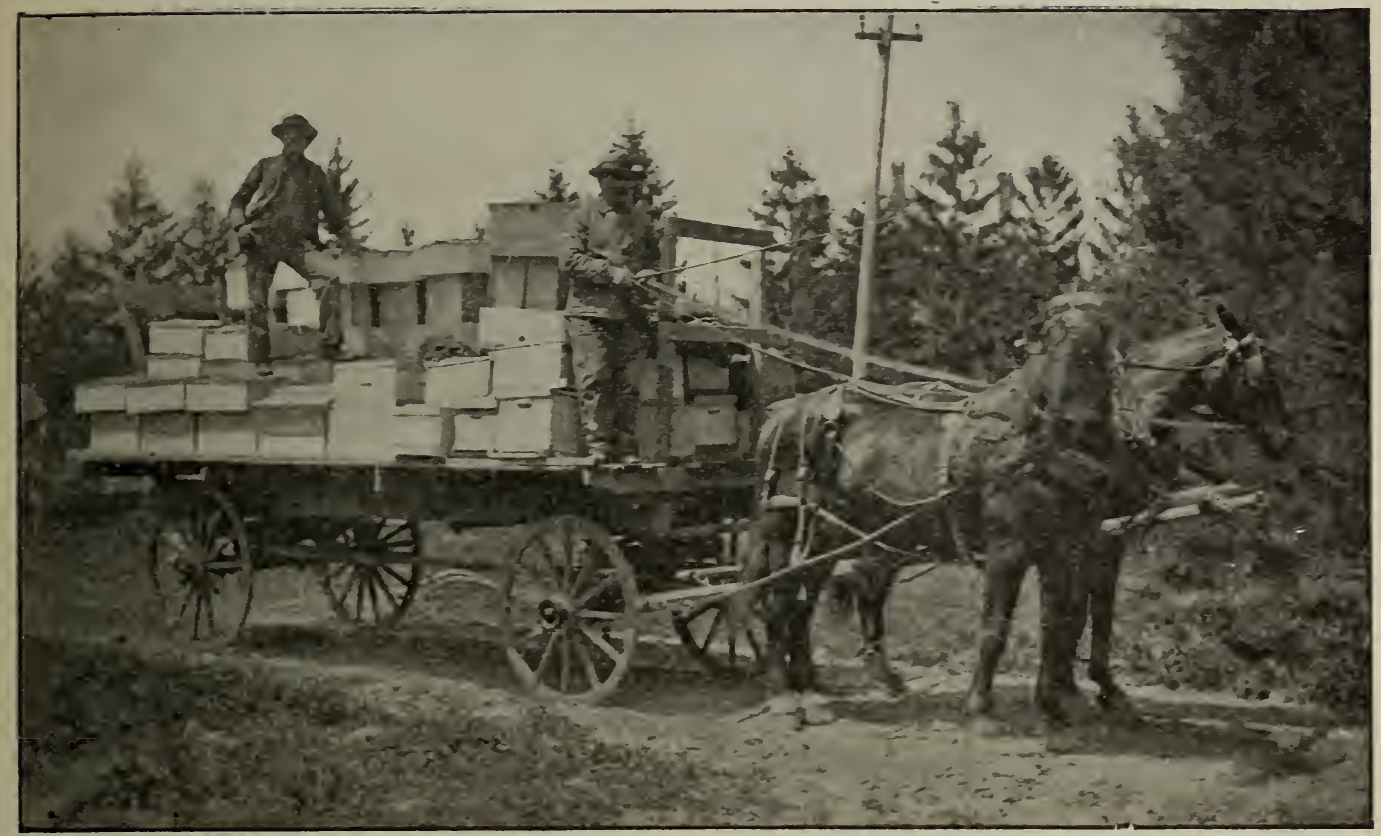

The Root Company's men ready to move bees to one of the outyards.

order to arrest the attention of the bees when they come out. This forces them to mark their location anew.

Ordinarily, as a matter of convenience, the bees should be moved in the cool of the morning, when no honey-flow is on, giving the bees as much of a shake-up as possible, but of course not violent enough to break the combs.

\section{HOW TO MOVE BEES A DISTANCE OF SEVERAL MILES.}

The remarks that have been made heretofore apply to moving bees only a short distance; but when they are to be carried a considerable distance, and jolted over rough roads, they require more ventilation than can usually be afforded by an ordinary entrance. If they are shut up during the middle of the day, those in the field are liable to be lost. Ordinarily they should be confined at night or in the early morning -better at night.

If it is desired to more bees during the daytime, while many are in the fields, they can nearly all be gotten in by smoking them at intervals for about half an hour. This will give those that are out time to come in, and the smoking will prevent any more going out. If the colony is very strong, a hive should be left with a comb of brood on the old stand, when the owner can start a nucleus very conveniently with the returning bees.

Many beekeepers fasten the bottoms to their hives permanently, so all that is necessary in such cases is to secure the corer and put a wire-cloth screen orer the entrance. A very good plan is shown in the next engraving, consisting of two cords or ropes.

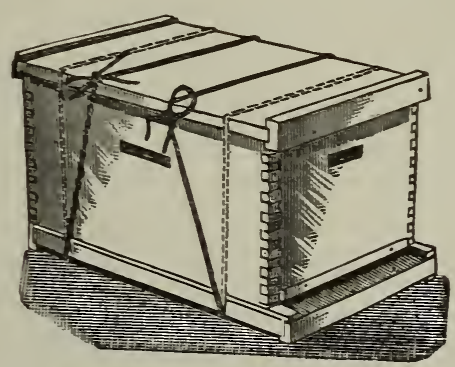

Fastening bottom-board and cover.

One rope is drawn around as tight as possible at one end, and the other is put on the other end. The cords are then drawn together at the top in such a way as to produce a strong tension.

Another plan, somewhat similiar, is to use one cord or rope. It is drawn around the hive, and tied loosely. A stick is then slipped into the cord and giren a halftwist in such a way as to draw the loop up very tight. 


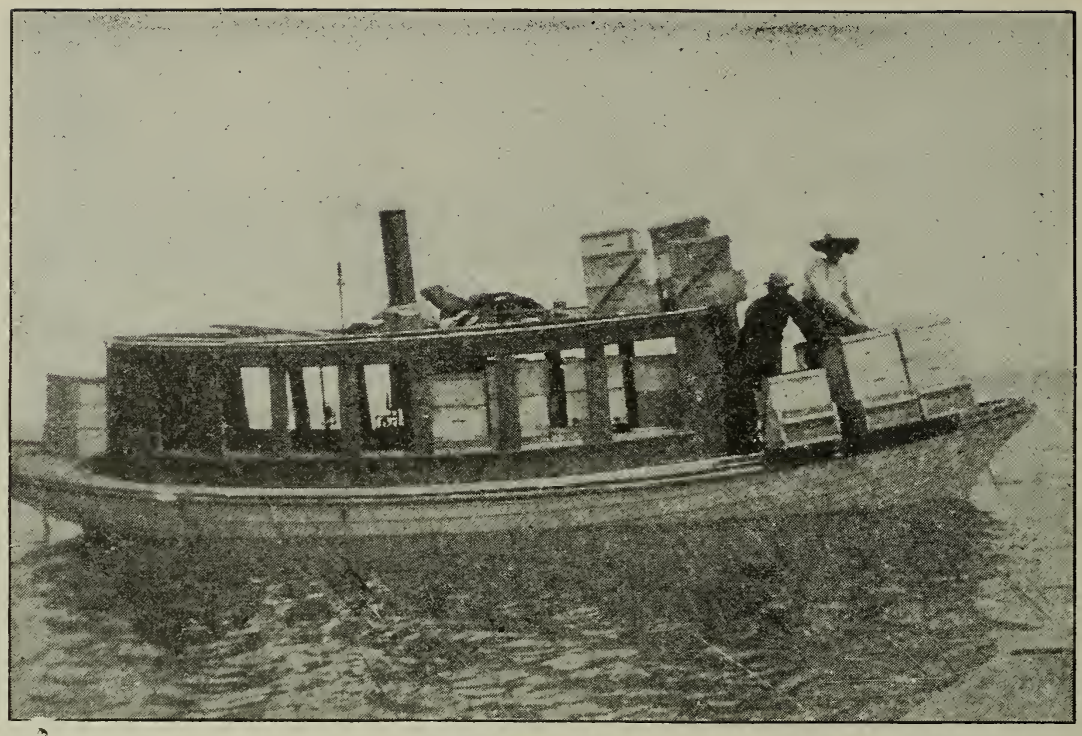

Moving bees by boat.

But by far the most satisfactory plan, certainly the safest, and the authors adopt it in their moving, is that of using a special staple (obtained at the hive-factories) shown in the accompanying illustrations. One leg of the staple is driven into the

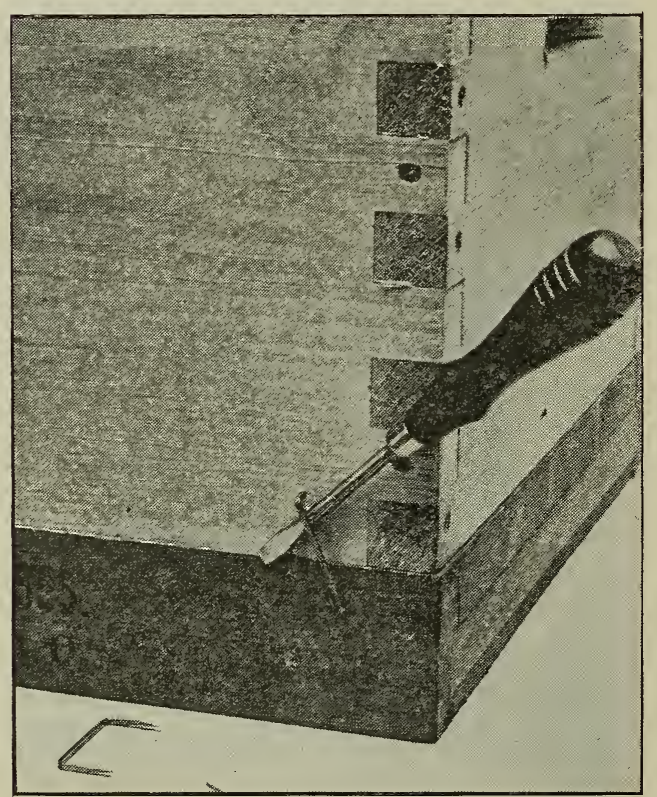

Removing the staples.

bottom-board, and the other into the hivebody. Two staples on each side will be sufficient to hold the bottom-board. The cover is fastened in the same way. The staples are very easily removed with a screwdriver at least a foot long, if they are not driven down too tight. The tool is shoved under one side, close to a leg of the staple, and given a quarter twist, and then it is moved over to the other side, and twisted again. When the staple is raised high enough so the screwdriver can get under and give it a good pry it can be easily removed.

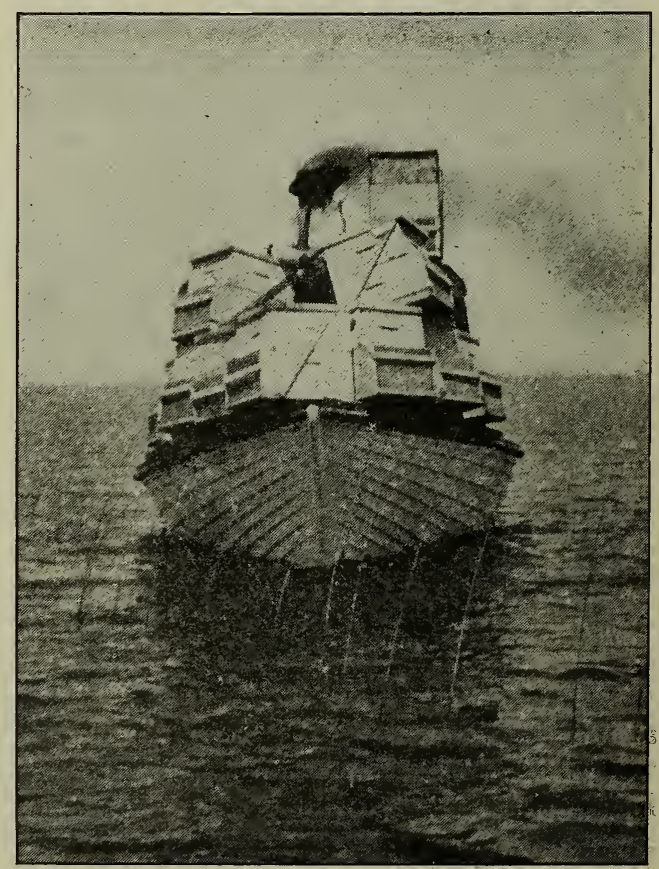

Under way. 


\section{PREVENTING BEES FROM SMOTHERING.}

In the early part of the season, in the spring or fall, or any time when the weather is cool, it is not necessary to have any more ventilation than will be secured with an ordinary entrance covered with wire cloth. As the weather warms up, additional

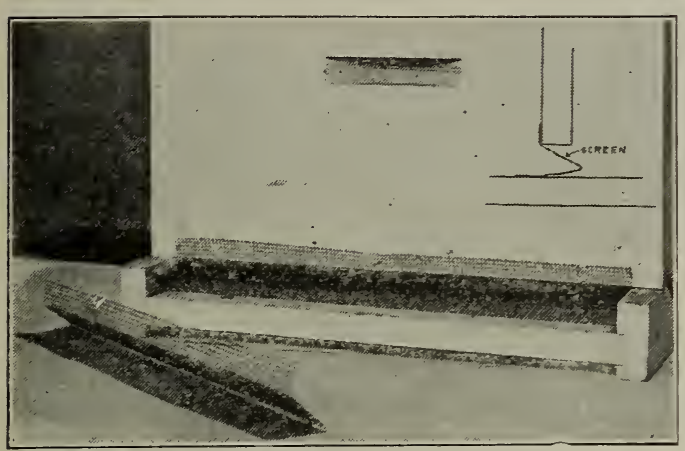

air will have to be provided. Sometimes this can be accomplished by taking pieces of section stuff $1 / 8$ in. thick, and placing one at each of the four corners between the hive and cover. The latter should be secured by' ropes or staples, as previously shown. This makes a crack all around $1 / 8$ inch wide, but not quite wide enough to let bees thru.

A far safer and better arrangement is to use wire screen in place of the covers. A wooden frame $1 \frac{1}{2}$ or 2 inches deep should be made of $7 / 8$ lumber, the same length and width as the hive. A piece of wire cloth large enough to cover it is tacked on, and over the marginal edges are nailed strips of wood $7 / 8$ inch wide and $1 / 2$ of an inch thick. The purpose of the $1 / 2^{-}$ inch strip is twofoldto help hold the wire cloth in place and raise the next hive that may be piled on top crosswise at least one - half inch above wire cloth.
The screen is held on the hive by the use of crate staples as shown on the previous page. They are quickly applied, and easily removed with a screwdriver. It is always advisable to use wire screens in moving bees during hot weather. It is hardly safe to depend on the ventilation at the entrance or thru narrow $1 / 8$-inch slots between the covers and hives.

When hires of bees are loaded on to a wagon or truck they should be placed in such a way that ventilation thru the top screen will not be shut off. In the case of an ordinary hay-rack the hives may be spread out over a large surface in the bottom of the wagon and over the rack. In this way it will not be necessary to pile one hive on top of another.

\section{LOADING ON AUTO TRUCK.}

When using an automobile truck, where hives have to be piled on top of each other, an open framework of $2 x 4$ 's should be placed between the several tiers of hives. Without some scheme of separating the

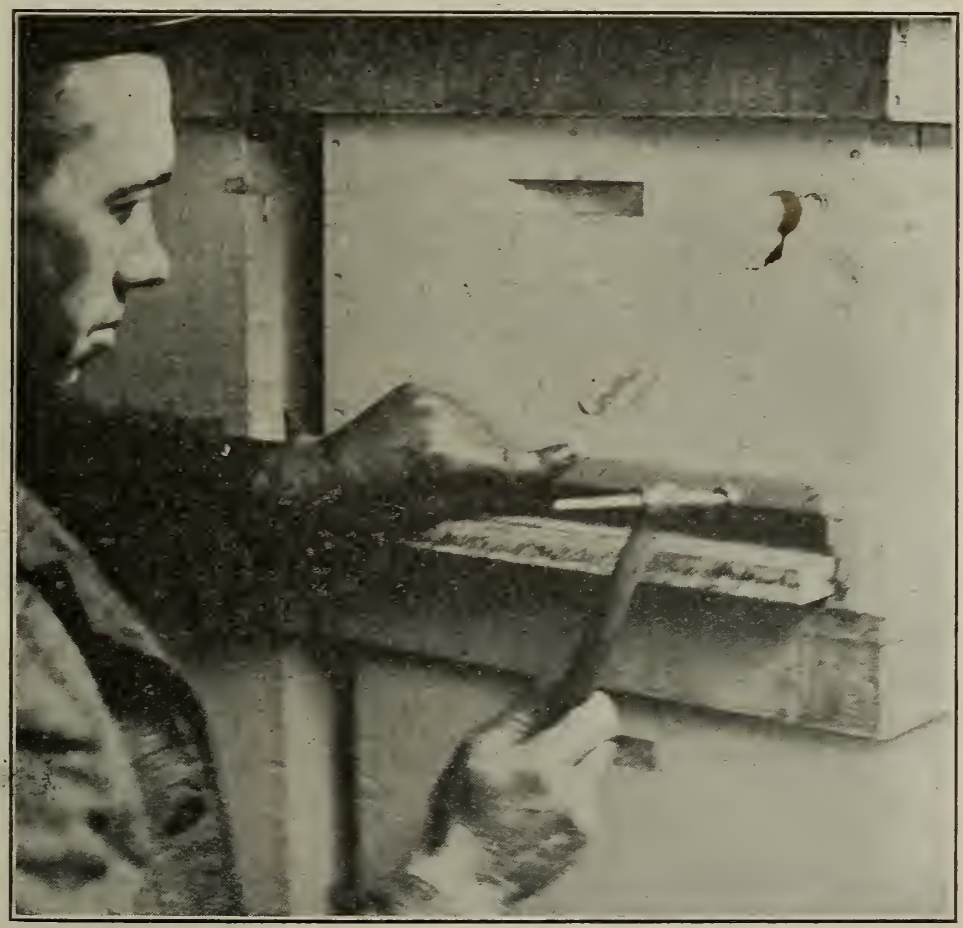

FIG. 7.-Tacking on the entrance screen. These screens hold their positions by friction, and do not need to be tacked until just before hives are loaded. A wide piece of galvanized wire cloth is bent in the shape of a long $V$ or wedge, with a right-angle bend half an inch from one of the edges. The point of the $\mathrm{V}$ or wedge is pushed in until the right-angle bend comes flush with the front of the hive, the other edge lying flat on the alighting-board, thus affording plenty of surface for tacking. This plan gives much more surface than a plain vertical screen, and the bees cannot crowd down, shutting off the air at the bottom. 
hives apart, the bees in all except the top tier of hives would smother.

The most satisfactory entrance-closer is a piece of wire cloth, the length of which is the inside width of the hive, and bent in the form shown in the next diagram.

This is easily placed in the entrance of the hive by tacking the upper right-angled piece against the upper part of the entrance. (See cuts previous page).

The main feature of this is that it holds its place without any tacks, altho one or two are needed to prevent its jolting loose when on the automobile truck or wagon. Moreover, the angle that projects into the entrance increases the amount of ventilation just in proportion as more wire cloth is used.

\section{MOVING BEES BY TRUCK OR WAGON WITHOUT SHUTTING THEM IN THE HIVE.}

This can be done very often without the necessity of using wire screens at the top, nor even entrance screens. Before the hives are loaded, smoke is blown into the entrances to prevent rushing out and stinging when the hive is disturbed. Just before the start is made, the entrances are smoked again. The subsequent jolting over the roads, so far from making the bees ugly, quiets them. If the weather is exceedingly warm the bees will crowd out and cluster around the front of the hive rather than smother to death.

The objection to this plan is that some bees get out all over the hives. For this reason it should not be used with an ordinary horse-drawn wagon. It has the further disadvantage that there will be a lot of flying bees around the hives, some of which will be lost as the truck moves forward. But when one is not provided with screens of any sort he can very often pick the bees up, put them on the auto truck, and land them at the outyard without any further trouble.

\section{WHEN TO LOAD BEES.}

No bees should be loaded on a wagon or truck during the middle hours of the day, since many field bees would be lost. They should be loaded very late in the day or early in the morning while all the field bees are in. Entrance-screens can be put on at night, and the bees may be moved any time the following day, altho on account of rising temperature they should be started as soon as possible. If it is necessary to move the bees during the middle hours of the day when they are in the field, the colonies can be smoked, and all the field bees as they go in will remain. But the practice is not to be recommended, as there will be some fielders left out notwithstanding. Some will be gone two hours; and it is a waste of time to fuss around that length of time trying to get bees in when with a little forethought they can be caught when they are all in the hive for the night. In warm weather it is better to move at night after all the bees are in.

\section{AUTOMOBILE TRUCKS OR HORSE-DRAWN WAGONS.}

In this day and age, on account of the danger from stings the self-propelled wagons are to be preferred. They will make a trip to an outyard and back in about a fifth of the time; and when bees are removed to an outyard on a warm day quick moving is far better than slow moving with a team. Moreover, speed develops air-currents that are highly important in moving. Ordinarily it takes a team of horses nearly half a day to get to a yard four or five miles and back, and that spoils the whole forenoon or afternoon. A motor truck, on the other hand, in the same time can make three or four such trips.

In our outyard work we use a light Ford runabout with a small wagon-box on the rear to make trips to the yards. This will easily carry two men and 12 hive-bodies with empty combs, or half that number when the combs are filled with honey. This wagon-box is just right to carry tools and appliances, including hives, so that for ordinary outyard work one can make quick trips and carry back and forth all he practically needs. A light Ford truck will do general out-apiary work at about onefourth the cost of a larger machine capable of carrying a ton and moving correspondingly slower. Our experience shows that the small machine will make a run to outyards for from three to five cents a mile, while the larger ones cannot do it for less than ten cents. This includes wear and tear, depreciation and interest. Where one is engaged extensively in the business he 


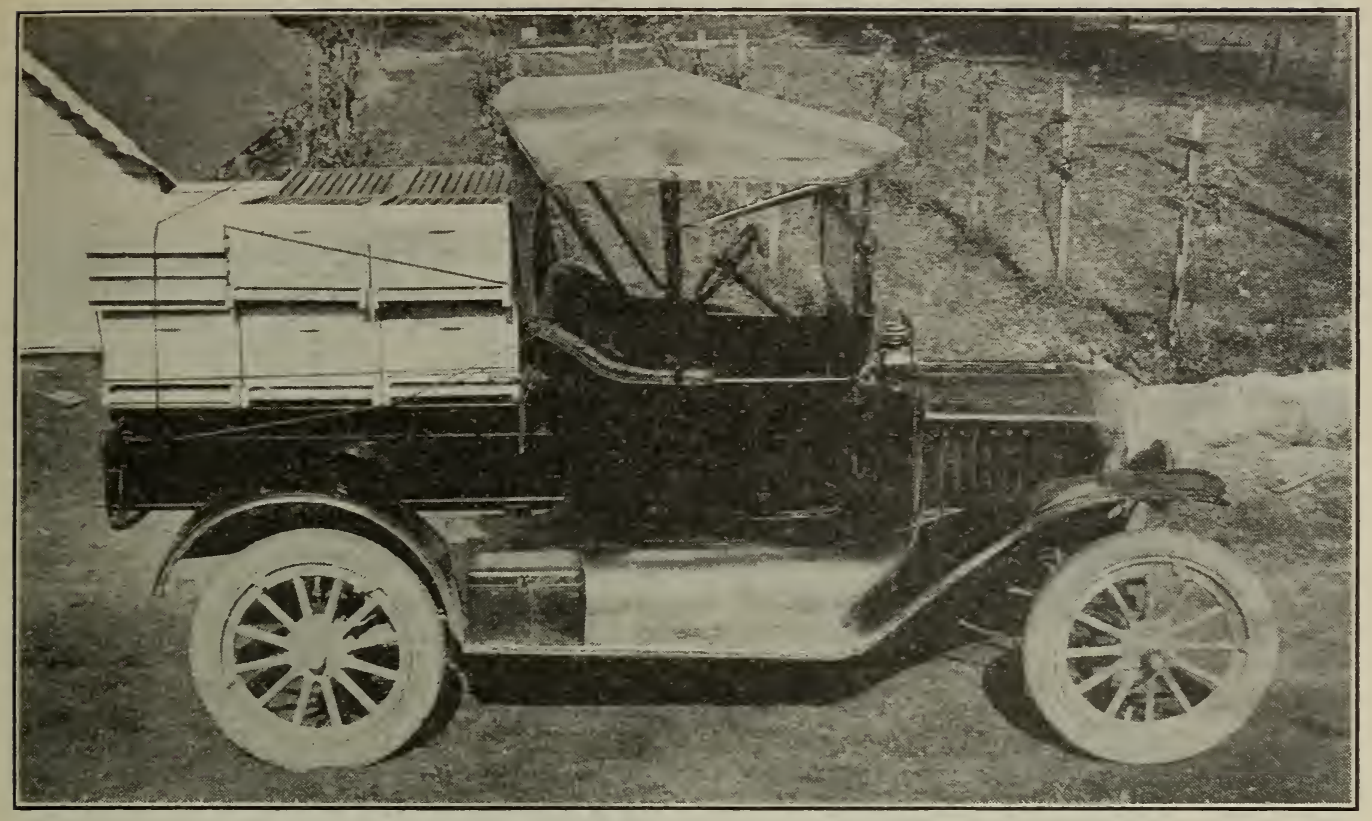

Our Ford runabout converted into a light truck.

can afford a light motor truck and a large one besides. But as a general thing a small machine will do 95 per cent of the moving, and the other 5 per cent can be moved on hired machines of large capacity.

The illustration shows a light two-passenger Ford with a light wagon-box, which can be secured at one-third or one-half price of a larger truck costing twice or three times as much to operate per mile. Moreover, the Ford can be operated by any ne on account of its simple gear shift, while the large two-ton trucks requiring the use of sliding gears are complicated.

\section{SHIPPING BEES LONG DISTANCES BY EXPRESS.}

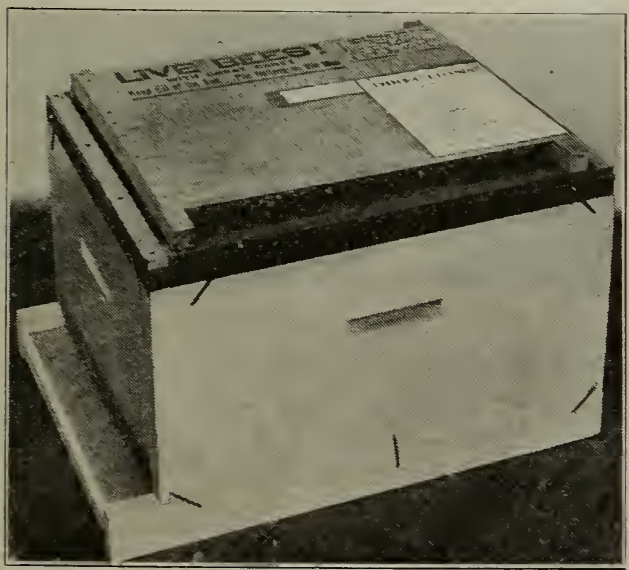

The Dovetailed hive prepared for shipping bees.
During warm weather it is advisable to have the shipping-boxes or hives with wire screen at bottom as well as top. The express agents are usually careless, and, in spite of instructions to the contrary, will leave bees out in the hot sun or in a small express room with all kinds of packages piled on top. For that reason additional rentilaticn should be provided. Provision

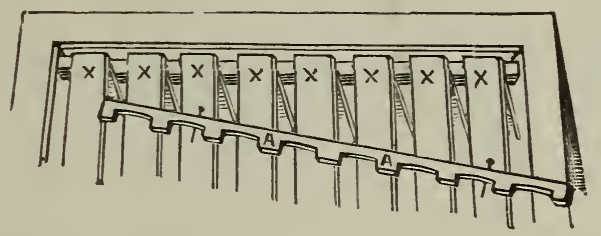

should be made so that the bottom screen will be protected so that ventilation can be secured at all times.

The illustrations herewith show packages of bees in colonies and nuclei put up as they should be for shipment. If unspaced frames are used they should be secured by notched cleats as shown.

There should be a label on top of every shipment of bees, cautioning agents against leaving the bees out in the hot sun or piling anything on top of them, thus shutting off the rentilation; that bees are perishable property, and should be moved without delay, and that on arrival at destination the owner should he informed by telephone or messenger. 
SHIPPING BEES WITHOUT COMBS.

Under the head of Buring BeEs the combless packages of bees are illustrated and described. The cages should be provided with a large amount of ventilation; and when one or more cages are sent by express they should be crated apart so as to provide ventilation. When only one crate is sent the cleats should project in such a way as to make it impossible to shove the package close up to something else and thus shut off the ventilation.

Quite an extensive business is carried on in shipping bees in one, two, three, and five frame nuclei. The illustrations show a light shipping-box, the sides and top of which are made of good strong lumber only 3-16 inch thick. The ends are 3/8. The bottom is covered with wire cloth, then two cleats are nailed across the ends to raise the nucleus off the floor. For the sake of convenience the wire cloth is secured on the

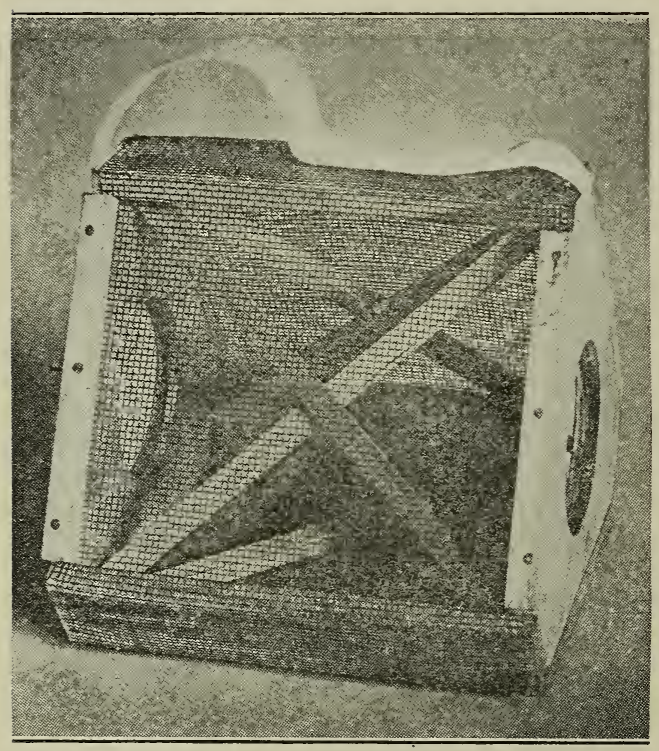

Half-pound cage for shipping bees.

special cover shown above, which, when set down in place, leaves a space of an inch between the cover proper and the wire cloth. The thin board over the wire cloth protects it from the direct rays of the sun, and from sharp projections of any object. It also affords a convenient place to attach the address, and to put on the caution, "With Great Care." See Shipping Bees.

Bees go at a rate and a half by express, hence it is very necessary that the packages be as light as possible; and for that reason the combs should hold no more honey than just enough to carry them thru to their destination. Neatly printed directions on

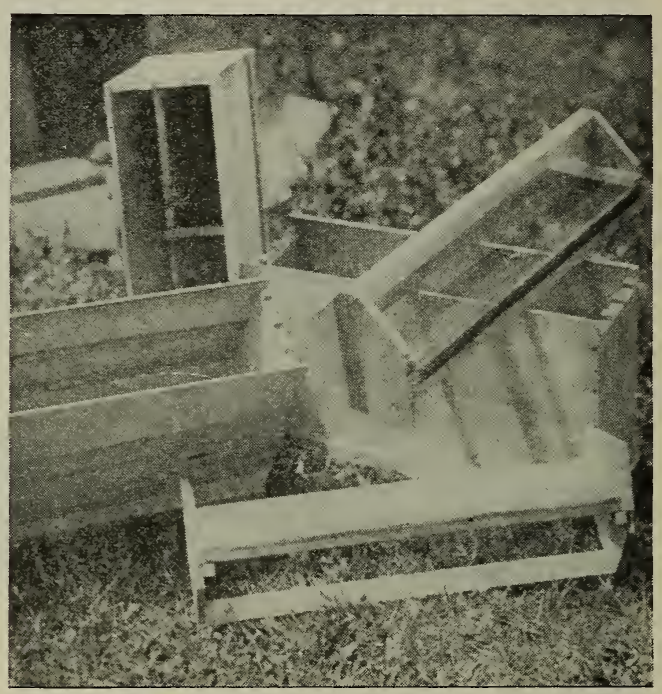

Empty three-frame nucleus shipping-boxes. Note that the boxes are made of light thin stuff, and screened top and bottom.

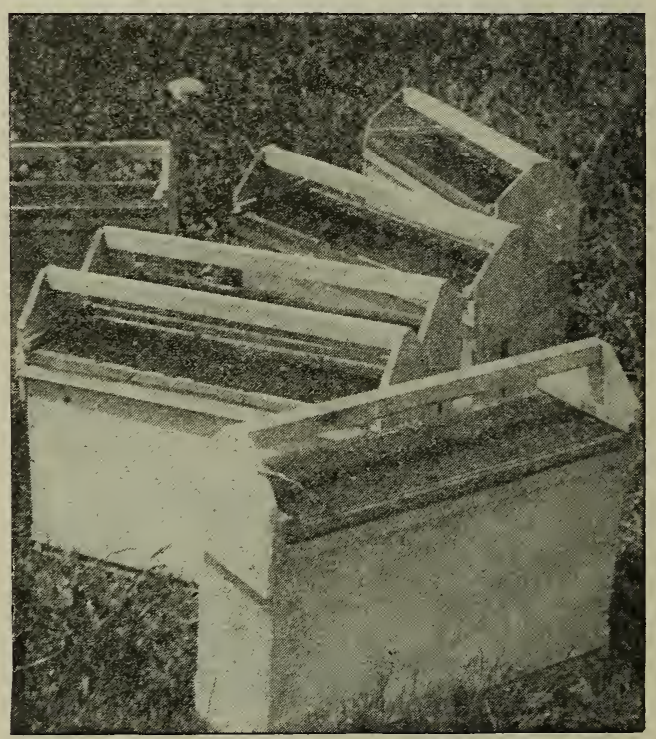

Three-frame nucleus shipping-boxes filled with bees. The screen tops (with the convenient crossrail for a handle) are secured to the nucleus box proper with two screws at each end. Such boxes are very handy for moving bees, either for shipping or carrying from one part of the yard to the other. They are also very handy for carrying combs.

the outside explain stimulative feeding so that a nucleus may be made into a strong colony. See Buying BeEs. 
M U S T A R D (Brassica arvensis (L.) Ktze.).--Wild mustard, or charlock, belongs to the same family (Cruciferae) as the turnip, cabbage, radish, and rape, all of which secrete nectar while in bloom. Introduced from Europe it has become naturalized over all the United States, and is often very abundant in grain-fields, where it sometimes presents an almost unbroken expanse of yellow. Almost equally common is the black mustard (B. nigra (L), Koch), a good crop of honey from it, he will then be so much ahead, and there is little chance of any great loss.

The seed should be sown very early in the spring, either in shallow drills so far apart that the cultivator can be used between them, or broadcast. The former plan is, of course, the better one for nearly all honeyplants, but it is more trouble. From 6 to 10 lbs. per acre will be needed, sown in drills, and from 15 to 20 when sown broad-

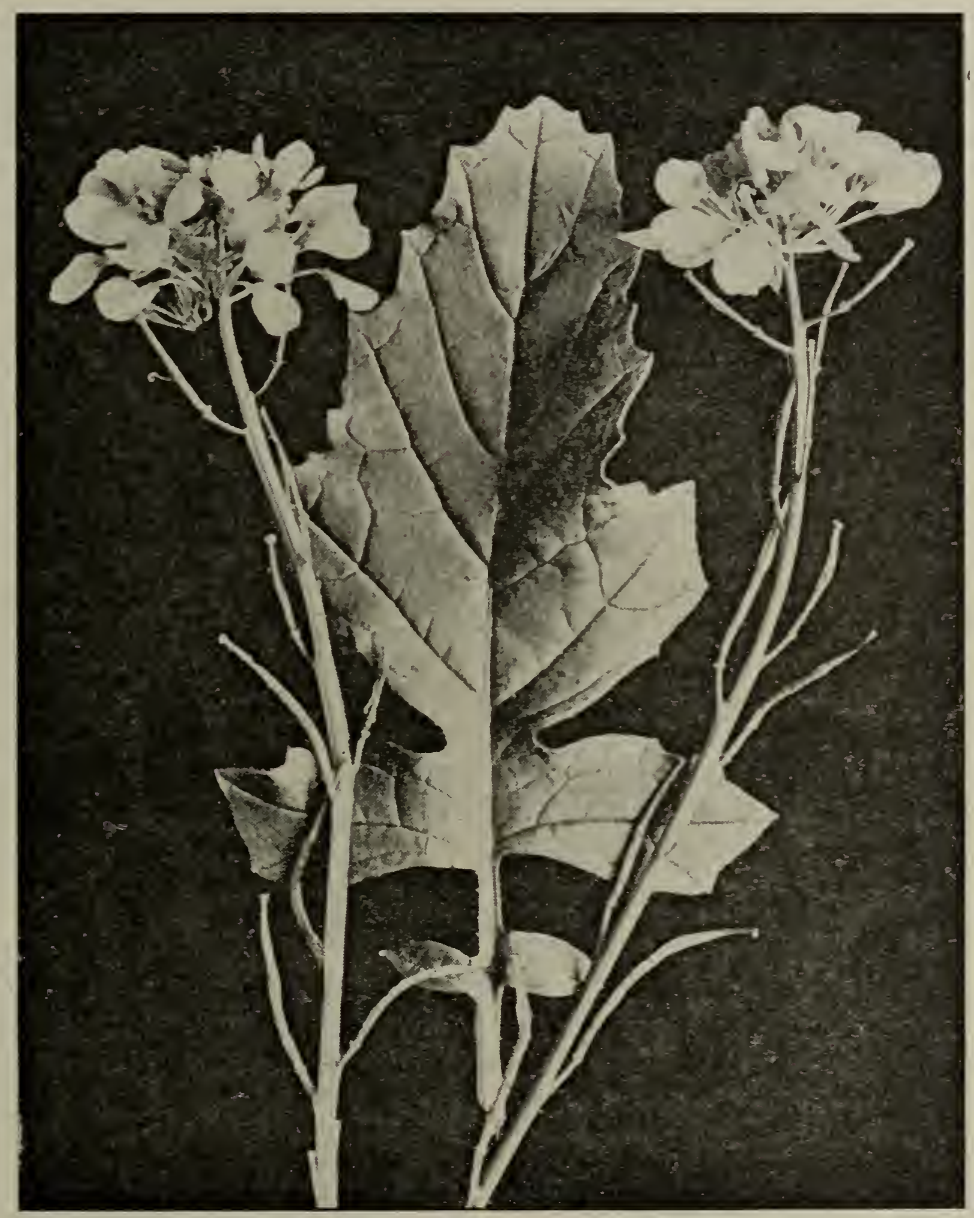

Black mustard.

which flourishes everywhere in waste places. We have had a good opportunity of testing many of these plants, because acres of them are raised for other purposes than the honey. It will be a hard matter to determine which is best for a locality without trying every kind. One should find out what market there is for seed, and then proceed to raise it as if it depended on the seed alone to pay expenses. Should one secure cast. If the seed is to be saved it should be sown not later than July 1 .

Two kinds of mustard-the English yellow and the Trieste or red-are extensively cultivated in the Lompoc Valley, California. The latter comes from Austria, and gets its name from a town in that country where it is grown on a large scale. From this crop alone in a single year the farmers of this valley have realized a quarter of a 
million dollars. The average yield per acre is from 800 to 1000 pounds. The average price of seed is 3 cents per pound, tho as much as 8 cents has been obtained.

The cultivation of mustard in the Lompoc Valley, says E. A. Oates, is easy and inexpensive; but it must be grown in rotation with other crops, as it will not produce bountifully two years in succession on the same land. When a majority of the pods are ripe it is ready for the reaper, and should be cut early in the morning or late in the afternoon, when there is moisture in the air to prevent the seed from shelling out of the pods.

The bees work alike on both yellow and red, which indicates that there is no difference in the amount of nectar they secrete. The period of flowering lasts about a month; and where the sowings are made at different intervals it can be prolonged for a period of ten weeks. The honey is mild in flavor and light in color, and commands the same price as sage. Tho not as heavybodied as alfalfa, it has the same tendency to candy quickly. It may candy in the tank in four or five days, but this may be prevented by using a tank with a glass top, protected by a wooden shutter, which is removable at will, exposing the honey to the sunlight.

When sage is in bloom, bees appear to prefer its nectar to that of mustard. When it is not necessary, it has been observed by M. H. Mendleson that they will not gather from an inferior source. In 1884, he 'says, one colony out of 200 gathered exclusively from an abundance of mustard bloom; the 199 gathered from the sages. This was an exceptional case.
NECTAR.-Strictly speaking nectar is a cane sugar (sucrose) gathered from flowers by bees. It is thickened and transformed by them into honey. See Honer. Many times has honey been analyzed by competent chemists, but very seldom has there been an attempt to analyze nectar, owing to the difficulty of securing a sufficient quantity for experimental purposes.

The only satisfactory experiments of the kind which have yet appeared are those of Prof. Planta, of the University of Zurich, Switzerland, who was not only one of the best chemists in Europe, but also a competent beekeeper besides.

It will be noted he experimented with the nectar of two American plants, Agave Americana (century plant) and Bignonia radicans (trumpet-creeper). The former is a prodigious yielder of honey, far excelling any plant we know of in the North, and excelled only by some tropical trees such as Protea millifera, Hakeas, and Leucodendron, and perhaps others not yet known. It grows in the southwest part of the United States, and is common in Mexico.

Several transiations of Dr. Planta's article on nectar analysis have appeared, and we give one which we deem best for our purpose.

In the Zeitschrift fuer Physiologische Chemie, Band X., Heft 3, Dr. A. de Planta describes his researches on the chemical composition of some of the nectars in plants. He says it was a great pleasure for him during his researches on the life of bees to have established the relation which exists between nectar and honey, nectar serving for the preparation of honey. There was a great difficulty in getting a sufficient quantity of nectar, as plants yield it usually in small quantities, but there are some exceptions. Among these are Protea mellifera, Hoya carnosa, and Tacoma radicans, or trumpet-creeper, which contains such large quantities of nectar that it is easily collected. Thunberg says in his "Flora Carpensis" of Protea mellifera (Zuykerbosches, Zuykerboom, Tulpboom) that it flowers in autumn; that is to say, in March and the following months. The flowers are often half filled with watery honey which furnishes an excellent syrup after it has been 
filtered to rid it of insects and impurities, and slightly evaporated by gentle heat.

This syrup is an article of commerce at Cape Town. Two bottles of it were produced, the specific gravities being 1.375 and 1.372. It has a slight acid reaction, but contained no albuminoids or nitrogenous matter. It contained 73.17 per cent solids, 10.08 being glucose and 1.31 per cent cane sugar. By glucose is meant a mixture of crystallizable grape sugar (dextrose) and uncrystallizable grape sugar (levulose), both having a similar chemical composition. This glucose may already be formed in the nectar by the action of the ferments it contains upon the cane sugar, transforming it into glucose; and this inversion can be continued in new honeys, owing to the action (which he had already demonstrated in 1879) of the saliva of bees which also transforms cane sugar into glucose.

Grape sugar from the syrup was also obtained in a crystallized form. No trace of formic acid could be detected in the syrup, tho quantities of pollen were found in suspension, determined by Professor C. Cramer to be that of Protea mellifera, testifying to its genuineness.

Wishing to compare this with fresh nectar, he succeeded, after great difficulty, in getting three bottles. The specific gravity was $1.078,1.079$, and 1.077. These contained 17.66 per cent of solids, of which 17.06 was grape sugar. They contained no cane sugar. There was not the least trace of formic acid. A comparison of the two shows that the difference was due only to the extra quantity of water contained in the fresh nectar.

Besides these he also examined the nectars of Hoya carnosa and Bignonia radicans, both in the fresh and evaporated states. The following table gives the results:

$\begin{array}{lrrr}\quad & \text { Sugar } & \text { Cane } & \text { Grape } \\ \text { Nectar of } & & \text { sugar } & \text { sugar } \\ \text { Protea mellifera, fresh } & 17.06 & & 17.06 \\ \text { Protea mellifera, dry } & 96.60 & & 96.60 \\ \text { Hoya carnosa, fresh } & 40.64 & 35.65 & 4.99 \\ \text { Hoya carnosa, dry } & 99.68 & 87.44 & 12.24 \\ \text { Bignonia radicans, fresh } & 15.27 & .43 & 14.84 \\ \text { Bignonia radicans, dry } & 99.85 & 2.85 & 97.00\end{array}$

Dr. de Planta has also made aqueous extracts of various flowers, among others those of Rhododendron hirsutum and Onobrychis sativa. In order to obtain 1 gram of sugar (equal to 1.3 grams of honey) the bees must visit at least 2120 flowers of Rhododendron hirsutum and 5530 of sainfoin (Onobrychis sativa).

As honey is almost entirely formed from nectar, he gives the following table, comparing the quantity of water he has found in nectars and also in old and new honeys:

\section{Nectar of}

Protea mellifera, Hoya carnosa,
Nectar Old 82.34 59.23
Bignonia radicans

84.70

Fritillaria imperalis, 93.40 Honey from

Department of Landes

Senegal,

Melipona,

Canton Grisons (alt. $600 \mathrm{~m}$.), $\quad 18.61$

Sainfoin

Canton Grisons (alt. 1395 m.).

Canton Grisons (high Alps),

Buckwheat,

Acacia from Ingoldstadt,
19.09

25.59

18.84

19.41

17.52

21.74

20.41

21.68

33.36

20.29
Whereas the nectars vary between 59 and 93 per cent, the quantity of water contained in old honey varies only between 17 and 21 per cent, and that in new honeys 20 to 21 per cent, with the sole exception of buckwheat honey, in which he found 33 per cent.

From these observations he thinks that the bees throw off a considerable quantity of the water while it is in their stomachs. $\mathrm{He}$ does not admit that it is evaporated entirely in the cells, for the analyses he has made of honey newly deposited in the cells show that it already reaches them considerably concentrated. The following table shows the relative proportions of sugar contained in different honeys:

A-Old hontity oneys from- Present formed by

Department of Landes $\quad 87.00 \quad \begin{gathered}\text { inversio } \\ 1.00\end{gathered}$

Senegal

$85.40 \quad 3.70$

Canton Grisons

(alt. $600 \mathrm{~m}$.)

80.60

Sainfoin

88.70

0.00

Canton Grisons

(alt. $1395 \mathrm{~m}$.)

B-New honeys from-

Canton Grison

$\begin{array}{lrr}\text { (Alpine region) } & 81.60 & 10.60 \\ \text { (alt. } 600 \text { m.) } & 81.60 & 9.30 \\ \text { (Alpine region) } & 87.20 & 00.80\end{array}$

Altho most of the nectars contain a considerable quantity of cane sugar it is found in very few of the honeys of the Alps. Some honeys contain a little, while in others it is entirely absent. It is clear that, during the formation of honey, the cane sugar in the nectar is converted into grape sugar by the saliva of the bees, which contains a ferment endowed with this property (see his researches on this subject in Deutsche Bienenzeitung, 1879, No. 12).

Another difference between honey and nectar consists in the former containing nitrogenous substances and formic acid. Mullenhof has shown how this last is deposited in the honey, and E. Erlenmayer has proved its antiseptic properties.-British Bee Journal.

Probably nectars do not all analyze alike; but Dr. Planta's analysis will be found, until we get something better, sufficiently near an average to satisfy all practical requirements. 
It will be observed Dr. Planta attributes the inversion of nectar to the saliva of the bees. It seems on the face of this to be only a "guess," and yet it has been repeated by many writers on the honeybee ever since. We know inversion is taking place even while the nectar is still in the corolla of the flower, and it occurs long after the honey has been made and deposited, for new honey contains quite a large percentage of sucrose (sugar) whereas old honey contains little or none. We are very sure this change is caused by minute microorganisms similar to those in soft sugar or rum. For this reason the composition of honey is quite variable-so much so as to baffle many chemists in making a true standard by which to judge honey. Old honey therefore is actually superior to new, for the process of inversion is complete. If kept in a dry place it also contains less water, and, besides, loses the ethereal essential oils or essences of the flowers from which it was gathered; therefore nectar collected even from poisonous plants may become quite innocuous if allowed sufficient time to ripen. See HoNEy.

NUCLEUS.-This word, when applied to bee culture, means just what the name signifies-a small colony of bees. It may mean a hundred bees with a queen, and as such it is called a small baby nucleus; but, as shown in QUEEN-REARING, so small a number will not hang together. Reference will be made to this later. The term "baby nucleus" more properly means a larger force-anywhere from five hundred to a thousand bees with a queen-a force large enough to set up housekeeping in real earnest. Usually these babies are put on miniature frames in miniature hives. (See BABY NuCLeI under the head of QUEENREARING.)

Generally speaking, the word "nucleus" signifies one or two full-sized frames of bees, either in a full-sized hive or one just large enough to hold two frames and no more. When it has five or six frames of bees and brood it is usually called a light or a weak colony.

These small aggregations of bees must be built up to full-sized colonies in order to make them useful for honey production; for it requires a strong colony of not less than eight or ten frames in size to produce honey. While a two or three frame nucleus will furnish a little extracted honey, the amount that it will produce in comparison to a large colony is relatively small. Or, to put it another way, five two-frame nuclei will not begin to produce as much honey as one ten-frame colony. How to build up these nuclei into colonies so they will be of some use is fully described under the head of BuILding UP Colonies, and INCREASE.

Nuclei are used for one of two purposes -for making increase and for the mating of queens. It is a waste of time and bee force to have virgins mate from a full colony. While cells should be raised in such colonies, the queens should be mated in miniature hives having anywhere from five hundred up to one thousand bees, For particulars regarding this phase of the subject, see QUEEN-REARING.

Nuclei may also be useful for the purpose of instruction. A beginner can handle a light force of bees much more freely than a big powerful colony. The small babies or the two-frame nuclei can be manipulated by the average A B C scholar very readily. Queens can be introduced much more easily than to the large stocks. As the nucleus grows in size, the beginner, who is constantly watching them, grows in experience; and by the time the colony reaches the full size he is perfectly capable of handling them, provided, of course, he has read articles on A B C of BeEkeeping; MaNipulation of Hives and Frames; Stings, and RoBbing.

\section{BABY NUCLEI REQUIRE WATCHFUL CARE.}

At the very outset mention was made of the fact that baby nuclei of only a hundred bees are not practicable. Some years ago the late E. L. Pratt, of Swarthmore, Pa., found he could mate queens from very small nuclei. Sometimes he used a single section of honey, placed it in a little box, and gave it about a hundred bees and a cell or a virgin. $\mathrm{He}$ had a large number of these in use, and found it possible to mate his queens, using only a very small number of bees. While he succeeded, and we succeeded with them, we found, as did practically all others, that these little babies of 100 bees were too fickle; that many times, when the virgin went out to mate, all of her bees would follow her. They were 
constantly swarming out-so much so that it was found to be much more practicable to use at least five hundred bees, and, better, a thousand. A hundred does not make up a strong household, and the bees know it. They know that something is wrong, and so they swarm out on the least provocation.

Moreover, it was discovered that these little babies of a hundred bees are robbed out. The powerful colonies in the vicinity made their lives miserable. Even contracting the entrance to a passage large enough for only one bee was not found to be sufficient; and the poor little chaps had to give way to the superior numbers of their enemies, with the result that their homes were despoiled and the nucleus broken up.

A pound of bees consisting of approximately five thousand makes a very nice nucleus. As mentioned under the head of Buring BeEs, the selling of bees in pound packages without combs is getting to be quite an industry. When bees die in the spring, a pound of bees, or two or three pounds, as the case may be, will give a new lease of life to a nucleus that is all but gone, but having a good queen. A little later in the season, the beginner can take half a pound of bees, and by feeding have a good colony at very small expense by fall. (See Feeding AND F'eeders.) Indeed, the expert can do much better if he starts early enough. We once took five half-pound packages of bees, each with an untested queen, in July, and built them up to fine colonies by November. (See Increase, Building up Colonies, and Buring BeEs.)

\section{FORMING NUCLEI FOR INCREASE.}

As already explained, dividing colonies into nuclei for the sake of increasing the number of hives with bees in, is a mistake if honey is the object. But after the main honey-flow, increase can be made by splitting up the colonies into units of two and three frames, supplying each with a cell, virgin, or laying queen. The process appears to be much simpler than it really is. The question often comes up in the inind of a beginner, "What can be easier than to take a ten-frame colony and divide it into five two-frame nuclei on as many hivestands?" If the bees moved from the parent stand would stay where placed, the problem would be very much easier. Unfortunately the old field bees, especially right after a honey-flow, will go back to the parent stand, leaving nothing but the young bees to take care of the brood, and which, in a great many cases, is neglected and dies. This is not all. Robbers, ever present, will be ready to invade the entrances of these deserted nuclei with just a few young bees; and before Mr. Beginner knows it he has a perfect uproar, and the loss of some thousands of bees, and perhaps trouble with the neighbors on account of robbers smelling around the entire neighborhood after they have wrought havoc with the nuclei formed. See RobBing.

If the beginner buys a colony of bees from some farmer or beekeeper two or three miles away he can bring it home and make the divisions before the bees mark their location, and the bees of each nucleus will stay where they are placed. This will effect an equal division, and everything will be easy, provided, of course, that the entrances are contracted and the beginner uses ordinary caution. At the time the nuclei are formed, each should be supplied with a cell, virgin, or a laying queen. If it is desired to make increase rapidly, the nuclei will make greater progress when supplied with laying queens. If it is desired to let each nucleus raise its own queen, precaution should be taken to see that eggs or very young larvæ are in each nucleus; but it should be understood that the progress will be very much slower.

In many cases the colony or colonies to be divided have grown so strong the beekeeper desires to make increase and to keep down swarming at the same time. How shall he do it and avoid having many bees going back? This can be accomplished after forming the nuclei by putting wire cloth over the entrances, and keeping them closed for three or four days. In the mean time, if the nuclei are not already shaded and the weather hot it would be well to put a shade-board over the hives to prevent any danger of suffocation. At the end of the third or fourth day the wire cloth can be removed.

Usually it is better not to make too great a division after the first of July or August. If the beginner splits his colonies up into halves, the problem will be very much simpler. In that case he should remove most of the bees, all sealed brood as far as possible, and the old queen, to the new 
location, leaving the unsealed brood and about a third of the bees on the old stand. The latter should be given a cell or virgin. Most of the flying bees will return to the old home, making the division somewhere near equal, with the chances that the old hive will have the larger force of bees in twenty-four hours. But the split-off, or nucleus, on the other stand, will have all the sealed brood and hatching brood, and will soon be more than able to match forces with the parent colony. The old queen which will act as an attraction to hold the bees will soon supply it with eggs and young larvæ as fast as the bees can take of it or as fast as the brood hatches out.

In a similar way three colonies can be made out of one; but most of the sealed brood and most of the bees should be given to the nuclei on new stands, always keeping in mind that most of the flying bees will return to the old stand. If, however, the entrances are kept closed for three or four days there will not be so much returning. Of course, the nucleus on the old stand will not need to have its entrance closed. If it is discovered that one of the nuclei, or both of them, are short of bees, a frame or two of bees from some other colony can be shaken in front of the entrances of the nuclei on new stands. When doing this, it may be advisable to cage the queen for a day or two.

If the nuclei are formed immediately after the honey-flow, all the old bees will go back to the old stand; but if two or three weeks or a month elapses, during which little or no honey has been gathered, there will be very much less returning.

The beginner should take this fact into account when he forms his nuclei, and in a day or two afterward he should see that there are bees enough in each division so that the young brood at least is not neglected. This is the reason why the advice is given to put the sealed brood on the new stand and the unsealed brood on the old stand. For a few days, or until the brood hatches out of the new stands, some of the young brood may be neglected; and this is a point that should be carefully taken into account.

The Alexander plan of increase, as given under INCREASE, explains how nuclei can be formed on another plan that is excellent.
Under the head of Feeding ANd Feeders, subhead Feeding to Stimulate, will be given full particulars on how to feed up these nuclei if there is no nectar in the fields. The Boardman one-hole feeder should be used for the purpose, and the entrances should be kept contracted down to the space so that only two or three bees can pass at a time. If the division is made on the basis of five nuclei out of one full colony, the respective entrances should be closed down to an opening that will permit only one bee to pass at a time.

As soon as the nuclei begin to prosper, an extra comb may be added on the outside. Except in very hot weather it should not be placed between the two frames of brood, as this will split the cluster, and result in the killing of some brood.

If the nuclei are formed in the first place as early as the first of June, when they are built up to about five-frame strength they can be divided again, and built up again to a strong colony by November, altho in most localities cold weather will come along by Cctober 15. In the southern states one can keep on dividing, as already explained, much later.

In 1892 , on the principles already outlined, the writer, without any special effort, increased an apiary from ten colonies, some of which were almost nuclei, to about eighty-five good colonies, and obtained about 2000 lbs. of honey. These were not fed, but depended entirely on nectar gathered from the fields, for the season was not a good one. Colonies were divided in the latter part of May, and given frames of foundation and laying queens. They were given every possible advantage, and by fall we had eighty-five nice colonies with plenty of winter stores gathered from fall bloom.

SOMERFORD METHOD OF FORMING NUCLEI.

Mr. W. W. Somerford described a method of forming nuclei that has worked very satisfactorily, especially when the work is done at outyards. While it involves some of the principles already described, it is enough different to warrant giving it a place here.

To begin with, remove the queens or eage them in all your fancy stock, after getting the brood-nest well filled with brood (the more brood the better- 8 or 10 frames in a hive if possible). Wait ten days after removing the queen, when the bees will generally have cells on each and every comb, and 
be in a broody or listless condition, waiting for cells to hatch. Divide and remove the frames quietly, giving each new hive two frames of brood and all adhering bees, and one good frame of honey, using it for a division-board (and, by the way, such division-boards are to my notion the best in the world): put the two frames of brood and bees next to the wall of the hive, and let the honey-frame be the third from the side of hive. Be sure to see that you have at least one good ripe-looking cell in each new hive, or division, and don't forget the frame of honey. As soon as each division is made, stop the entrance of the hive by stuffing it full of green moss. If you haven't any green moss, use green grass or leaves, and be sure to stuff them in tight-as tight as tho you never intended the bees should gnaw out, and be sure there are no cracks or holes that a single bee could get out at; for if there are, your division will be ruined by all, or nearly all, the bees that can fly leaving it. Each parent colony should make four or five good divisions that will make booming colonies in 40 or 50 days, and I have had them the best in the apiary in less time. Leave or loose the old queen on the old stand (if not too old), and the bees from it will work straight ahead, as they don't have to be confined to make them stay at home.

Don't be uneasy about the divisions that are stopped up, unless you failed to stuff the entrances well, for they will not smother, but busy themselves gnawing at the moss or grass for two or three days, possibly four or five, if you have done an extra good job at stuffing the entrance. At the end of that time you will find they have all gnawed out so as to secure egress and ingress. Then you can move enough of the grass or moss to give them a clean entrance, $1 \frac{1 / 2}{2}$ or 2 inches wide; and by looking into them you will be astonished at the quantity of bees you have in each hive (and they, too, well satisfied), having consumed so much time in gnawing out that the queen had time to hatch and kill off her rivals and be ready for the wedding-trip by the time the entrance is cleared. So, instead of, in a week's time, having a worthless weak division with a chilled inferior queen, as is the case in the old-style way of dividing, where nine. tenths of the bees return to the old hive, you have a strong vigorous queen and a nice little satisfied swarm of bees, ready for business in the way of pulling foundation before they are three weeks old.

I have succeeded with nineteen out of twenty divisions made in the above way, when I did not even see them until the third veek, after dividing as above; and for the average beekeeper who has out-apiaries I think there is no better way in the world to make increase. If there is I'd like to see or hear of it while the expansion question is being aired.

In the above method of increasing, you have no queens to buy, no robbers to bother with, and but little time lost, as an expert can make 20 divisions an hour.

Navasota, Tex.

In the first paragraph, Mr. Somerford mentions removing or caging the queen. It should be explained that usually any queen can be caged in her own hive for weeks at a time, and her bees will take care of her thru the wire cloth. If a queen is remored entirely it is implied that she is to be caged in another hive, or introduced. She may, however, be put in a cage supplied with queen-cage candy, and kept for a week or ten days in a warm room. But there would be danger of losing her, as she might die, because, under artificial conditions, she cannot get the "balanced rations" that she needs to keep up her bodily functions.

Another plan of making two colonies out of one is given under the head of INCREASE. For full consideration of the subject of Baby Nuclei, see QueEx-REaring.

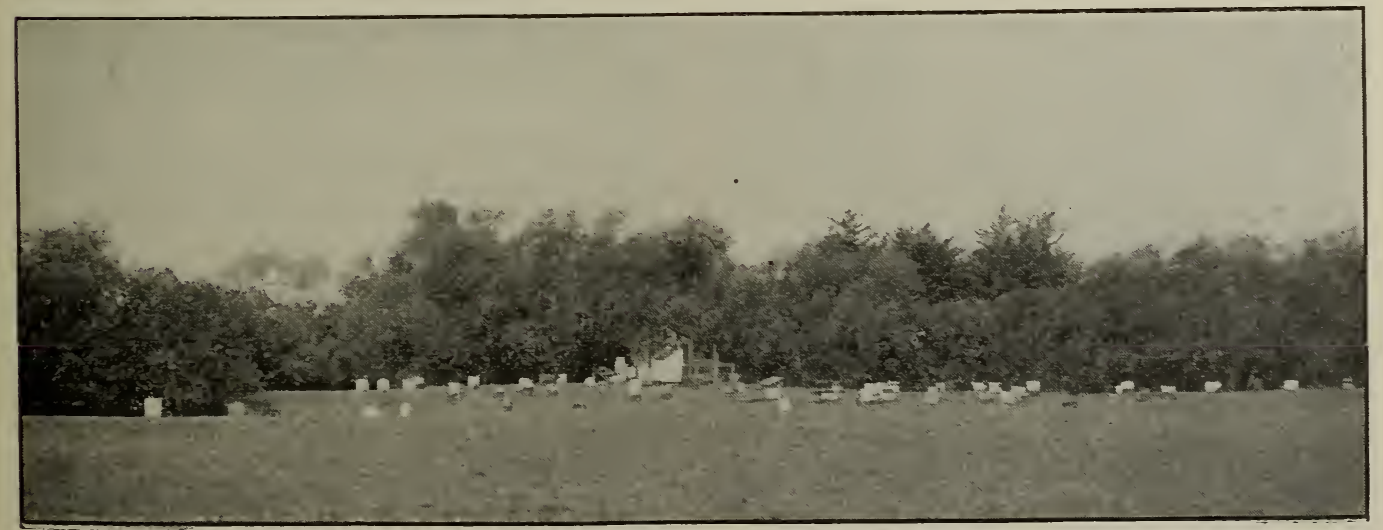

A portion of Mr. Stewart's apiary, Contra Costa County, California. 


\section{O}

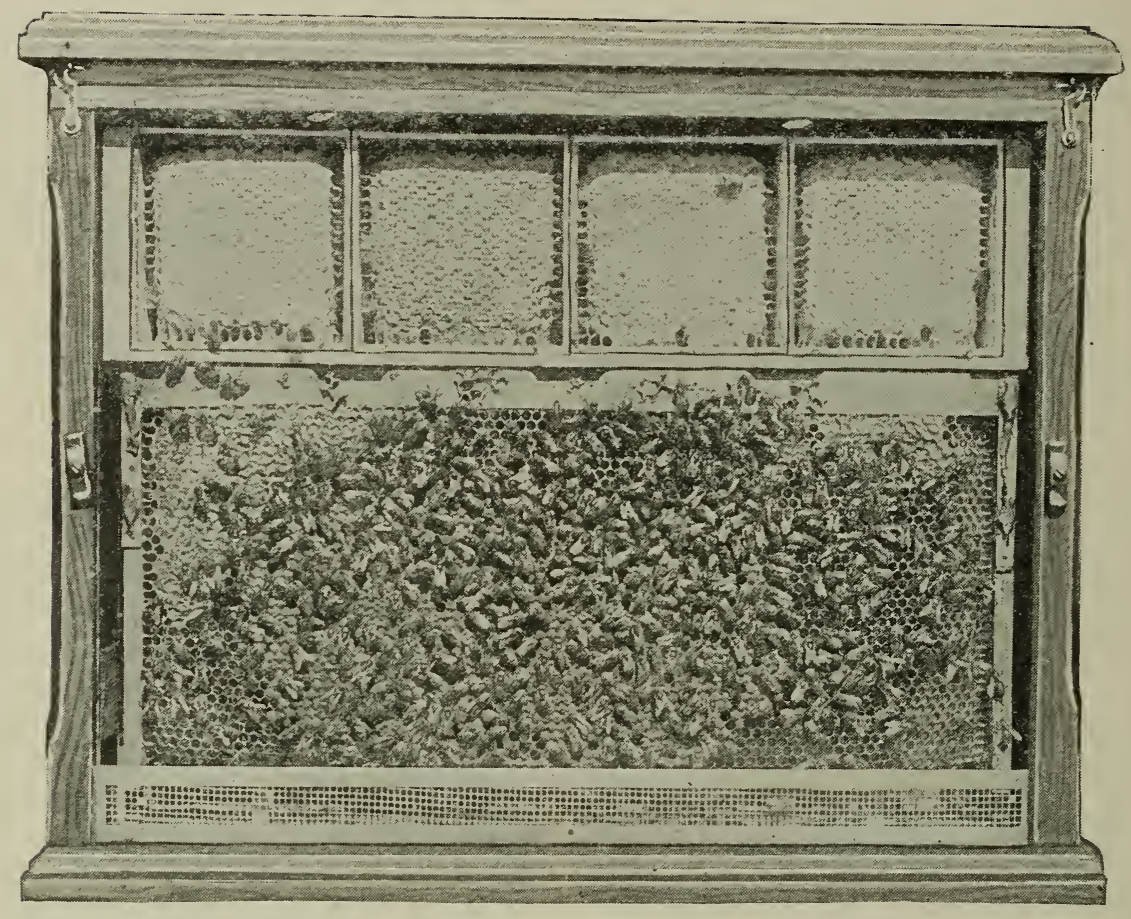

Ordinary observatory hive for showing a single comb and a set of sections as they appear in a regular hive. This form of glass hive is often on display in grocery windows where honey is for sale, or at fairs and expositions to illustrate the relation of combs to sections.

OBSERVATORY HIVES.-The origin of hives with windows or transparent sides is lost in the mists of antiquity. In very ancient times pieces of transparent substances such as horn, isinglass, mica, etc., were let into the sides of the hives that the work of the bees might be observed. Such windows, however, afforded but meager opportunity for studying the behavior of the bees in the hive. The first approach to the modern type of observatory hive was invented by Mr. W. Mew, of Easlington, Gloucestershire, England, about 1650. This appears to have been but little more than a hive with glass windows. At about the same time, Mr. John Thorley, of Oxon, England, put bees in a bell glass and used bell glasses as surplus chambers on his hives. No practical advance was made from this until about 1730, when Reaumur the eminent
French naturalist established a swarm between two panes of glass. These panes were so far apart that the bees could build two combs between them, hence much of the work of the bees and queen was hidden. Bonnet the Swiss naturalist recommended a hive with "doors" only so far apart as to permit the bees to build one comb between them; and Huber, about 1790 , adopted this suggestion, and the result was the wonderful advance which he and his faithful assistants, his wife and his servant Burnens, made in the knowledge of bee life. From that time until the present, little change has been made in observatory hives, except in so far as the use of movable-comb hives changed the methods of stocking them.

The usual type of observatory hive consists of a single-comb hive with glass panels. Sometimes there is a row of sections on top 
to show the relative positicn of the sections to the brood-nest while they are being filled by bees in the regular way. Of course it would not be possible to produce section honey in a single-frame nucleus; but when an observatory hive with sections is displayed in a window where honey is on sale, it not only attracts prospective buyers but it educates them, in that it shows a part of the brood-nest with the bees and the brood, and the sections of honey just as they are on the hive. It advertises honey as nothing else does. Great crowds congregate on the street watching the bees on the comb " making honey."

The bees are usually left in the widow for about a week. By that time they will need to be renewed or they will soon die; and by that time, also, the most of the people in the vicinity will have seen it.

Experience shows that this display hive of bees will immediately increase the sales of honey, both comb and extracted, and grocers who have had it are loud in their requests to have bees put in their windows -especially if their neighbor across the street has them in his window.

The single-comb hives can be studied to good advantage in the home or in the school. In either case they are placed on a shelf on a level with the window-sill so that the entrance will pass under the window-sash. The space on each side is closed with a stick. The bees will set up housekeeping, go to the fields, and enter upon their ordinary work as tho there were no one on hand to see why and how they do it.

Sometimes an observatory hive can be placed some ten or twelve feet from the window or side of the building. In that case, a tube connects the hive to a hole thru the side of the building. Strange as it may seem, the bees will learn to go thru this long tube to the outside. At the San Francisco Fixposition in 1915, an observatory hive was arranged in this way, and the bees used this long tube entrance the entire season. This, of course, made it unnecessary to replace the bees every so often.

Where nature study is being taught in schools these observatory hives are used to a considerable extent; and very often beekeepers themselves who desire to become more intimately acquainted with the habits of the bee find pleasure and profit in keep- ing one of these hives up next to the window of the living-room.

When the bees come in with fresh loads of pollen or new honey, they show the usual signs of rejoicing by shaking their bodies, apparently to attract attention, and thus induce other bees to find the treasures that they hare brought home. A great many other interesting things can be discorered with one of these hives where the comb is parallel with the glass panel. But what transpires in the cells and behind the cappings cannot be determined with this kind of glass hive.

Mr. Arthur C. Miller, of Providence, R. I., an ardent student of bee culture, and one who has watched the bees for many hours at a time, discovered a plan by which he can see the bees at work and the larræ spinning their cocoons as well as if he had $\mathrm{X}$-ray eyes.

It was his desire to see what the bees were doing in the cells; and one day when a small burr of comb was found built against the glass, and a bee seen at work in it the idea was conceived of fixing in an observatory hive a small comb or several of them, so that a whole row of cells was parallel to the glass. It is not necessary to describe the many and crude attempts before success was achieved, but at last a stage was reached where a row of combs was fixed between two panes of glass about four inches apart, and a small colony established therein.

The hive was placed indoors before a window, the bees passing in and out beneath the partly raised sash. The little colony started at work nicely, and soon honey and pollen were being stored in the cells against the glass. By accident the wooden shutters were left off the hive for two or three days, and when it was observed at the end of that time the bees were found at work in a perfectly normal manner and no running over the glass was noticeable. Obviously, the shutters were not necessary, and their abandonment seemed to mark a distinct advance. A cold storm which occurred shortly after nearly destroyed the colony, and the shutters were again used. Matters improved, and the colony gained until another storm put them back again despite the shutters. Investigation showed a sharp draft thru the hive from the entrance to the sundry ventilators. These 
were closed, but the entrance did not furnish sufficient air, and other troubles appeared. Then followed long experimenting with ventilation until at last a relatively large area at the bottom of the sides of the hive was opened for ventilation, and screened to confine the bees. This was all below the combs, and the bees could have as much

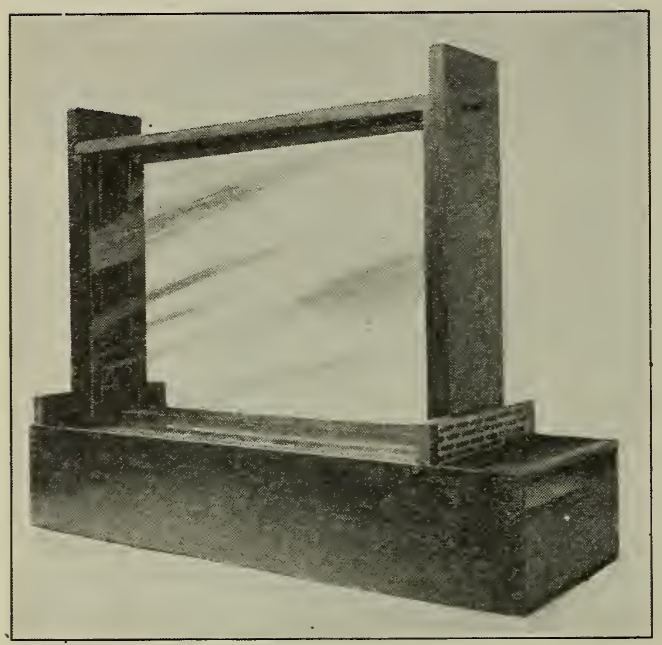

Miller's observatory hive.

or as little air up among them as their instincts dictated. That was a success, but it developed another trouble, for every time the door of the room was opened or closed, or if the wind was strong toward the window, the bees were blown out of or into the entrance in a most troublesome way. A short passage or tunnel considerably larger than the hive entrance and having a wirecloth top was put betwcen the entrance and window opening, and that trouble stopped.

This was not all done in one hive or in one season, but extended over several years. The colony would seem thrifty for a time, then it would meet with some reverse, and it would often take a season or two to find the cause of the trouble.

There came a day when eggs were seen in cells next to the glass, and in due time they hatched and the larvæ were fed and grew until they touched the glass, then the bees pulled them out. The shutters were tried but with not much advance. Then "storm sash" in the form of an extra pane of glass on each side were applied and the hive was a success. A quarter of an inch confined air space was left between the panes.

From then on, the bees used the cells next to the glass as readily as the others. Almost every action was observable; the bees could be seen every way except face to face. Another hive was made and stocked and a piece of comb was put in which was less than half a comb, for it was only the cell walls from one surface of the comb. The glass wall of the hive was to and did form its new base. The bees used it as readily as the other combs, and the queen laid in it and bees were raised in it. The book of nature had been opened at a new page. Thereafter the development of the hive was a matter of detail. As now made it has a base about six inches wide and deep enough for a grooved feeder block to be slid into it under the floor of the hive. Access to this feeder is obtained thru several holes bored in the floor and guarded with excluder metal to keep the queen from wandering in. A similar guard is adjustable at the hive entrance to prevent the loss of a swarm if the colony has to be left to itself for an extended period, for if thrifty it soon becomes overcrowded. The uprights are approximately three inches wide and grooved for four panes of glass, the inner panes being about one inch apart

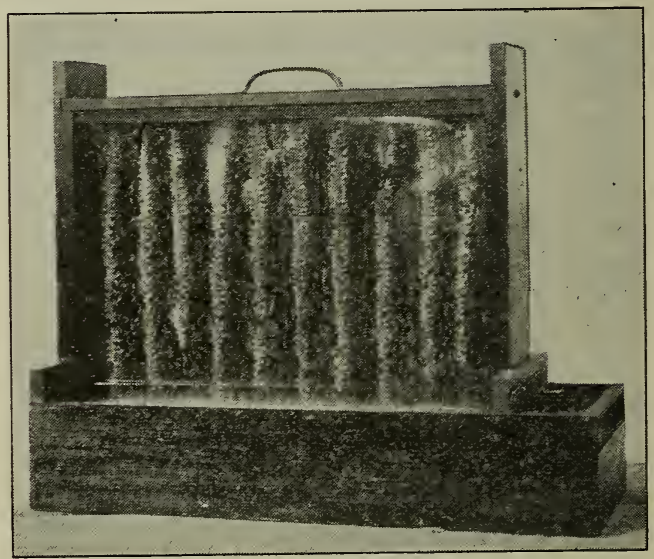

Miller's observatory hive.

and the outer ones a quarter of an inch from the others. Panes fifteen inches long by ten inches wide have been found to be a very satisfactory size. The uprights are fastened to two horizontal pieces extending across the base. These latter pieces each have a groove one-half inch above the floor. Into these grooves are slid two strips of glass to close the space at the bottom between each pair of panes. Between these 


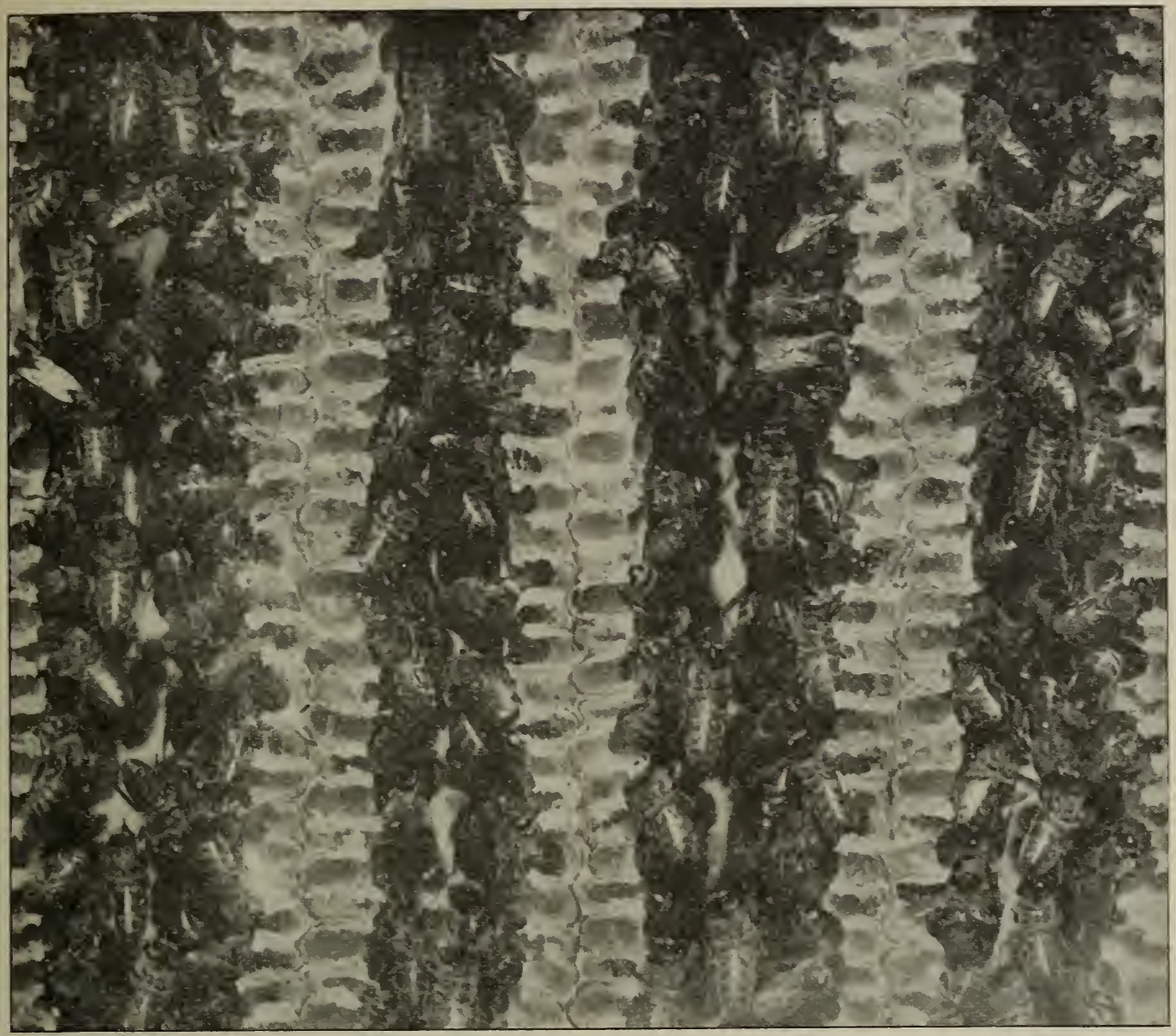

A close view of comb built against the glass of the Miller obserratory hive. This form of hive enables the observer to see the bees at work in the cells, the hatching of the egg, and the derelopment of the larræ.

strips and the raised sides of the base, strips of wire cloth are put and furnish the ventilating area. Galvanized wire cloth of fine mesh has proved preferable to ordinary painted wire cloth. The woodwork of the hive and the wire cloth is painted a dead black, both inside and out. This gives a sharp contrast with the combs, and is advantageous when taking photographs. The outside of the hive may be finished in natural wood, but the inside of uprights and under side of top should be dull black.

The distance between the inner panes has been varied from half an inch to three inches. The former is too close and the latter unnecessarily wide. An inch to an inch and a quarter is best, and then no bee can completely escape observation.

To stock this type of observatory hive is a bit troublesome. The two panes of one side of the hive are removed and the hive is laid on its side in a box prepared for the purpose, the "tunnel" of the hive connecting with an entrance in the side of the box. If this box arrangement is not used, trouble will be experienced by bees clustering on the outside of the ventilators. A sheet of new comb has previously been given to a colony; and as soon as it has larvæ one to three days old it is ready for use. It is cut vertically into strips just a little narrower than the space between the inner panes. These strips are then laid in the hive, spacing them about an inch and a half from center to center. It is desirable that comb containing some honey be used also, and if there is not any honey in the upper part of the brood comb, a strip or two of comb containing honey should be cut from some other sheet. If cells with the ends against the glass are also desired, a little more delicate work is necessary.

From a new dry comb a strip somewhat wider than needed is cut, then with a hot 
knife the cells are cut from the base. These baseless cells are very delicate and must be cut to the required dimensions with the hot knife. They are then lifted on a cool knife or piece of card-board and slid into position in the hive. No gluing or waxing is needed, for the bees will do that perfectly.

The other pair of panes are next carefully slid into place. If any of the strips were cut too wide the glass will hit and move them and cause a lot of trouble, but otherwise the operation is easy. The entrance guard is lifted, a queen put in and the guard replaced, and the cover put on the box. On a wide board in front of the entrance are now shaken the bees from two combs taken from any hive. The older bees will go home, the others will crawl into the hive. They go in better if the hive is dark; hence the putting of the cover on the box; but it may be opened from time to time to watch matters. If they are a little slow to enter they may be hurried by a gentle puff of smoke now and then, but on the whole it is better to let them take their time.

This operation is preferably done near the close of the day, and at a time when nectar is being secured, then robbing is not troublesome.

The hive is left in its horizontal position for a couple of days, the box being shaded from the direct rays of the sun. If it is found that not enough bees are in the hive to fill the spaces fairly between the strips of comb, more may be shaken in front at any time. In about two days all of the combs will be seen to be attached to the upper one of the inner panes. The other side certainly is. The hive may now be taken from the box, set in an upright position and taken away.

\section{MAINTENANCE AND OPERATION.}

As soon as the hive is in its place syrup should be given in the feeder and feeding continued for several days, for the little colony has virtually no field force, and will soon exhaust the honey in the combs. Also the feeding will stimulate wax production and enable the bees to complete the combs. During a heavy honey-flow these little colonies will gain stores, but in a light flow their field force is too small and help may be needed in the shape of syrup or honey in the feeder.

By coloring syrup (using a candy color) it is easy to see just where it is put first and more or less of it moved afterward. An ounce of deeply colored syrup is enough to use at a time for this experiment.

If feeding is necessary in cold weather, use a hot syrup, nearly filling the feeder (a half pint). It will warm the hive and arouse the bees, and as soon as the syrup cools sufficiently they will take it. Use for this purpose a syrup made of two parts sugar and one of water. If the weather is very cold, close the hive and remove it to a warm room, keeping it there until the bees have taken up all or most of the syrup. If, however, the combs were packed with stores before settled cold weather, and the room temperature keeps between 35 degrees and 60 degrees $F$. as the extremes the bees will not need feeding until spring.

If the hive becomes over-populous remove it at night to some other window and in its place put any convenient box containing a piece of comb with unsealed brood, or a caged queen. The next morning the field force will start out as usual, but will return to the old location where the brood or queen will hold them. As soon as the population of the observatory hive seems to be reduced enough, close its entrance to prevent the escape of more bees. Within two or three hours the box on the old location may be closed and taken away and the hive put back and the entrance opened. The removed bees may be destroyed or kept confined for a few days, and then at nightfall be dumped into some hive in the yard.

If the colony in the observatory hive becomes weak, it is most easily strengthened by turning in a lot of young bees. An easy way to do this is to shake into a box the bees from a comb from some thrifty colony in the apiary, and cover the box with a piece of wire cloth. Carry it to the observatory hive and fix it so the edge of the box is close to the opening to the tunnel. Remove the wire cloth over the box and the bees will soon enter the hive.

The same manner of weakening and strengthening may be followed with the prevailing types of observatory hives, but it is often easier with them to remove the comb and bees and restock the hives completely.

The new type of observatory hive is good for about two years without renewing the 
comb, but after that the comb becomes dark and opaque and the glass more or less coated with wax lumps, propolis, cocoons, etc., it has proved more satisfactory to restock the hive every year.

Bees winter nicely in these little hives provided the temperature of the room decis not go to freezing or stay below 40 degrees $\mathrm{F}$. very long at a time. A room temperature up to 65 degrees or even 70 degrees does not cause trouble in the winter, provided the hive entrance is wide open. A few bees may venture to go out; but by the time they reach the outer end of the tunnel they meet the cold air and turn back. A window facing south is the best for winter; but any exposure will do for summer, tho one not facing the prevailing winds is to be preferred.

All types of observatory hives should have the ventilating space solely at the bottom of sides or ends, and with double glasses with a confined air space between them. Extra space into which the bees may spread and yet not build comb is greatly to be desired, particularly in single-comb hives. This and ideal ventilating conditions are secured by having the floor wider than the hive and having such extension covered by wire cloth spaced half an inch above it.

ORANGE (Citrus Aurantium L.).-The orange is a native of southeastern Asia, whence its cultivation has extended since the tenth century thruout the warmer regions of both worlds. It is beliered that the Arabs carried it into Africa and Spain, and that the early Spanish settlers introduced it into Florida. Later colonists found large groves of wild orange-trees. It has been estimated that there are in this state 10,000 square miles adapted to orange culture. There also belong to the genus Citrus the grapefruit ( $C$. Decumana), the lemon (C. Limonium), and the lime (C. Limetta) and the mandarin or tangerine $(C$.nobilis). All the species are evergreen trees or shrubs with fragrant white flowers, or those of the lemon are purplish outside, which yield nectar.

While in certain seasons, and under special artificial care, in cold winters, the trees will do well as far north as Jacksonville, Fla.; still, it remains true that the home of the citrus is in the southern half of the peninsula. The blossom period va- ries. It is very erratic, owing to rainfall, soil, variety of fruit, degree and extent of cool weather in the winter and early spring, etc. For instance, in the middle of the state blossoms have been seen on the round orange as early as Feb. 6; and in 1912 the first bloom appeared on normal trees March 15. As a rule, for that locality Feb. 20 will be about an average time for the appearance of the rrinute balls that are to be the snowy-white blossoms. The bloom period lasts about four weeks if the weather is not too hot and dry. The later the bloom appears, as a rule, the shorter the period of its blooming. A cool or frosty period during the bloom will prolong it, unless the frost is so severe as to damage the blossoms; then it shortens the bloom as it did, for instance, in 1911. No more beautiful sight can be imagined than an orange-grove in full bloom. The air is redolent for a quarter of a mile around in all directions with the perfume, and the white blossoms among the green leaves are a sight not soon forgotten. The bloom is as sensitive to weather conditions as that of the mangrove. Too hot, too dry, too wet, too cool, all these make the secretion very fickle. As a result, orange is not to be counted on for nectar in paying quantities oftener than one year in three, on an arerage. A warm damp day, with sun and cloud alternating, seems best for nectar secretion. Then the nectar can be seen in early morning shining in the white petals, ready for the visits of the bees; and they lose no time in getting at it, either! Then the bees come tumbling down on the edge of the alighting-boards, too tired to do more than crawl heavily into the hives, and that often after a brief rest if the day is windy. Those blossoms deep within the shade of the trees linger on latest, and then, suddenly, without a sign of warning, the nectar will cease as suddenly as it began. The honey is light amber, clear, and crystalline, with none of that thick opaque tint sometimes visible in even clear amber palmetto honey. The body is not so heavy by any means as that from the scrub palmetto, tho it is heavier than that from the cabbage palmetto. But the flavor is the thing! It has a delightful "fruity" aroma, when pure, that cannot be auplicated by any other honey. The bouquet of the blossoms seems preserved in the honey. Ernest R. Root once said of a 
sample of pure orange-blossom honey sent him by Edwin G. Baldwin, of DeLand, Florida: "We are inclined to think the flavor is a little finer than anything of the kind we have ever tasted." But it is not easy to get "pure orange honey" for the reason that there is only a limited area where the trees are sufficiently abundant to yield a surplus unmixed with nectar from any other source. There must be thousands of trees within an area of six miles in diameter, and little else in bloom at the time.

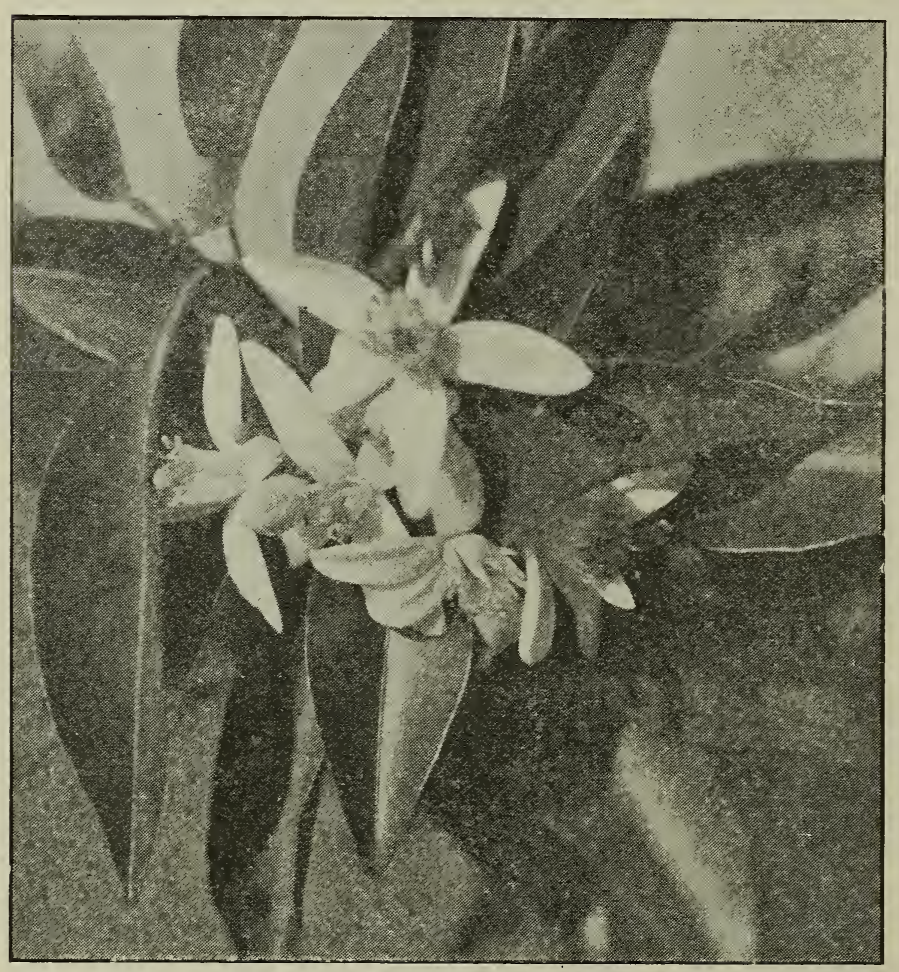

Orange-blossom

W. S. Hart, of Hawks Park, Fla., sums up the matter thus: "Pure orange honey is unexcelled in color, body, and flavor. But it is, and always will be, scarce." But in California there seems to be, notwithstanding, a large amount of orange honey produced. Wild cherry, andromeda, and other sources often give a dark tint and pungent taste to the sweet orange honey. A very little admixture of either of these two will spoil the pure article. There are many thousands of orange-groves, from the north to the Keys, from the east coast to the western shores; but they are not always grouped about a common center closely enough to make profitable foraging for bees. For this reason there are not many good orange-blossom localities. Probably Volusia Co. has more sections where pure orange honey can be obtained than any other single county in Florida, unless possibly it be Manatee Co., on the west coast. Wauchula, in De Soto Co., and Orlando, in Orange Co., are also inviting sections for orange honey. Near Eustis, Fla., are extensive groves that seem attractive and promising. Palmetto, Fla., is in a good location, and there are one or two beemen there who are improving it. E. B. Rood, of Bradentown, is one apiarist who secures a good lot of fine orange honey if the season is at all favorable. E. G. Baldwin, of DeLand, is saving all the precious nectar that a hundred colonies or more can extract from the snowy petals each year.

It is hard to state an average yield per colony of this honey. It might be better to say that, in a good year, an average of $40 \mathrm{lbs}$. would be satisfactory, and in poor yearswell, anything would be better than none! It is certain, however, that, as scientific beekeeping be. comes more and more widespread in Florida, and the good locations are discovered and exploited, orange honey will become better known than it is now. The white fly is damaging the groves to a certain degree, and that always shortens the bloom; but spraying with red fungus is slowly but surely making itself felt, and no doubt that enemy to the fruitman, and hence to the beeman, will disappear altogether in time.

The orange is also extensively cultivated in California, Louisiana, and Texas. About forty miles below New Orleans on the western bank of the Mississippi River there are many miles of almost continuous orange groves. The first orange trees were planted in this section more than one hundred years ago. In recent years thousands of orange 
trees have been planted in the coast country of Texas, bordering on the Gulf of Mexico, which it is expected will presently become an important source of orange honey.

The orange was introduced into California by the early Catholic missionaries, and today it rivals or surpasses Florida in the production of citrus fruits. The citrus belt includes the southern portion of the state, especially the counties of Riverside and Orange, and extends northward to the San Joaquin and Sacramento Valleys. As with many other honey-plants, the secretion of nectar varies in different localities and is greatly influenced by weather conditions. In the cool regions near the coast there is little nectar. Fog also often interferes with the flight of the bees so that there may be very few days which are ideal for field work. Near the foothills it is occasionally very cold; and an apiary at an elevation of a few hundred feet has been snowed under for a few hours while in the valley below the orange trees were also white-but with flowers, not snow. At Redlands the weather is very warm and there is little fog. with the result that four years out of five orange bloom yields a fair crop, in proof of which may be cited the experience of a beekeeper who states that he has shipped one or more carloads of pure orange honey every year except 1904. Yet even here the weather is sometimes so cool that tons of nectar are lost because the bees are forced to remain in the hives. Even in fair weather the flowers have been known to yield only a scanty supply of nectar. But when the conditions are suitable there is probably no other honey-plant in the United States which secretes nectar so copiously. At times the clothing of pickers and pruners is wet by the dripping nectar, and the horses and harness require washing at the close of a day's cultivating among the trees; while even the ground is dampened by the many falling drops.

In southern California the trees are in bloom during the last of March and thruout April, or about six weeks. It would be for the advantage of apiarists if the honey-flow was later, for while it aids in building up the colonies, the latter are often not sufficiently strong to bring in all the nectar, or the cold compels them to remain inactive. With large colonies and clear warm weather the nectar comes in very rapidly. At
Redlands a hive on scales showed a gain of 119 pounds in 17 days from April 7 to 23 . The honey was secured in about five hours of each day from 11 to 4 o'clock. During the morning the bees brought in pollen from various flowers, but before noon they were all at work on the orange bloom. A surplus of from 60 to 120 pounds per colony is obtained. The nectar is frequently very thin when first gathered, and naturally after irrigation is thinner for a few days; but toward the end of the flow, if the weather is warm, it becomes much thicker.

The very heavy water-white honey is unsurpassed in flavor; but as it usually crystallizes in a few months many dealers prefer to buy sage honey. It is very easy to obtain orange honey pure, for sage does not blossom until the weather is warmer. At Pomona the land for miles is entirely occupied by groves, and it is difficult to obtain room for an apiary. Here after the honey-flow is over the bees bring in nothing for the rest of the season except a dribble of dark honey from pepper and hoarhound.

A large acreage in California is devoted to the cultivation of the lemon and grape fruit, but these trees do not yield nectar as freely as does the orange. The other citrus trees are not common.

OUT-APIARIES.-Within late years this term has been used to apply to a beeyard remote or distant from the home yard by some two or three miles. It is a well-known fact, that only a limited number of colonies, comparatively, can be accommodated in any one locality, different places being able to support widely different numbers of colonies.

\section{NUMBER OF COLONIES IN AN APIARY.}

The number of colonies of bees that can be profitably kept in one locality is limited by the amount of pasturage. Of late years quite a number of beekeepers have established one or more out-apiaries, for the sake of keeping more bees than the bome pasturage would support. Just how many bees can be supported in a single locality has probably never been ascertained, and it is just as probable that it never will. One field may support five times as many as another, and the same field may support five times as many this year as last. Most 
beekeepers, however, think it inadvisable to keep more than 75 to 100 colonies in one apiary, while a few think their locations so good that 200 or more can be profitably kept together. As many as 500, and in one case even 700, have been kept in one yard. These cases are very rare, however, as it is seldom that bee pasturage will be strong enough to support so many. The man who has only a few more colonies than he thinks best to keep in one apiary may find it better to have his bees just a little crowded at home before he goes to the extra expense of an out-apiary. Indeed, it depends somewhat upon the man, whether, having been successful with one apiary, he will find any profit in the second. But having gone so far as to have one or more apiaries away from home, it is not best for him to have any crowding in the least. If 100 colonies will do well in each apiary, the probability is that 75 will do better; and while there is unoccupied territory all about him he had better keep on the safe side and have so few in each place as to feel sure of not overstocking. His own convenience should have much to do in deciding. For instance, if he has, in all, 300 colonies, and thinks that 100 can find enough to do in a place, but can get thru the work of only 75 in a day, then he will keep the 300 in 4 apiaries of 75 each, rather than in 3 apiaries of 100 each. For it will make one less travel to have in each apiary just what he will do in a day's work. If he can do 50 in a day, then he may just as well have 100 in two apiaries as in one, for in either case he must make two trips to get thru with them.

As a general thing, most localities will not support to the best advantage over fifty colonies to the yard. In a series of outyards owned by the authors we find it an advantage to have not more than thirty to forty, altho there are some seasons when a larger number could be operated to advantage.

The number of hives per apiary will depend very much on the amount of available forage for the bees. A locality that has large acreages of alsike, some red clover, as well as white clover, will support twice as many colonies as one where there is only white clover. The presence of considerable sweet clover will help materially.

In western territory where alfalfa is grown, the number of stocks will depend on the number of acres grown as well as on the time when the alfalfa is cut. Some ranchmen cut their alfalfa earlier than others. Some grow alfalfa for seed. Where seed is raised, a much larger number of colonies can be handled to advantage.

It is almost impossible to give a definite number per apiary. One may have to experiment to determine how many he can keep. In an eastern locality if there have been early spring rains and there is a considerable amount of alsike, sweet, and white clover, and especially if there is some basswood, 75 colonies to the yard could be operated to advantage. If there is only white clover available, probably not over 30 could be placed. In that case the farmers should be urged to put in alsike. If they can be induced to give it a trial on the basis of the beekeeper furnishing the seed at half price, they will probably continue to use it year in and year out, with the result that the locality wiil be measurably improved. (See "Alsike" under Clover.) As a general rule it is better to have too few colonies than too many to the yard; and it should always be borne in mind that strong powerful colonies will gather relatively more than the weak or medium. (See BuILding UP Colonits.)

In these days of automobiles, by which one can cover three or four yards in the afternoon, it is not so necessary as it was in the olden days of the slower horse and wagon to have so large a number of colonies per yard. For that reason, if for no other, it is safer to err on the smaller number.

Some yards will show up much better than others year after year. In that case a larger number can be placed in such yards.

DISTANCE BETWEEN APIARIES, AND LOCATION THEREOF.

A location for an out-apiary must, of course, be far enough distant from the home apiary not to interfere much; but just how far is best, it is not easy to decide. Perhaps, all things considered, a good distance is something like three miles apart. As the area of flight is a circle, the ideal plan of locating out-apiaries so as to occupy fully all adjoining territory is to put them in hexagonal form, in which case a circle of six will surround the home apiary. 
In the diagram, $A$ represents the home apiary, and $\mathrm{B}, \mathrm{C}, \mathrm{D}, \mathrm{E}, \mathrm{F}, \mathrm{G}$, the out-apiaries, at equal distances from $\mathrm{A}$ and from each other. If more than seven are needed then a second series may be started, as at $\mathrm{K}, \mathrm{M}, \mathrm{L}$, indicated by the letters. The circles representing the area of flight from each apiary are seen to overlap each other; but this is at the outer parts, where the ground is more sparsely occupied, and the doubling on the same ground is compensated by the convenience of the shorter distance to go from one apiary to another. But this ideal plan, altho a good thing to work from as a basis, is not likely ever to be fully carried out. Many reasons will

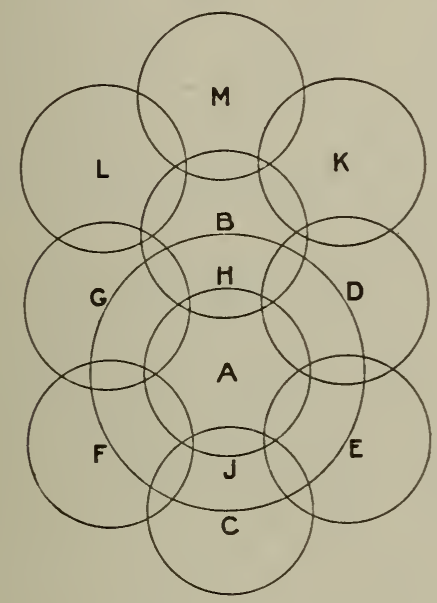

make it desirable to vary. The roads may run in such directions as to make a difference; no good place may be found for any apiary at some of the points. It may be remarked that the area of flight is not always a circle. An apiary placed in a valley between two ranges of hills might have an oblong area, the bees perhaps flying twice as far along the line of the valley as in the other direction. When an apiary is on a hill overlooking a valley bees will fly further than when on a level. See Flight of BEES. If only a single out-apiary is to be planted, it is probably best to go in the direction of the best pasturage - a thing not always easy to determine. Sometimes one location proves to be better than another, year after year, altho no apparent reason for it can be seen. It may even be worth while to vary a location a mile or more for the sake of having it where pleasant people live. But one can do much toward making the people pleasant by be- ing pleasant himself. As iittle trouble as possible should be made, and one should be still more careful than at home to avoid everything that may incite robbing, for robbing begets cross bees on the place.

Since the days of the automobile and the automobile truck it is feasible to locate beeyards much further apart than was practicable under the old plan of horse and buggy or team. While it is true that bees often do not fly more than a mile. and sometimes not orer half a mile, it is equally true that some seasons they will go five miles in the same location. As already stated, the general lay of the land, the condition of the roads, etc., will determine to a great extent the location of the outyard. As far as possible, apiaries should be located just off from stone or brick roads. They should also be placed in sight of some dwelling-house. While this is not absolutely essential, yet the fact remains that thieves are less inclined to meddle with the bees when the apiary is in sight of some dwellinghouse.

It is desirable to have the apiary located where there are suitable windbreaks. (See APIARY and WINTERING.) This is especially important if the bees are wintered on their summer stands; for good wintering cannot ordinarily be secured outdoors when the hives, no matter how well packed, are exposed to piercing winds. Some years ago the late Edwin France had an article on the location of out-apiaries. As he was a very successful producer, as is also his son N. E. France, who followed him, it has been thought best to reproduce what he says:

I have taken pains to make a correct diagram of the territory that we occupy with our bees; and I must say that I was surprised myself when I saw the exact position of each yard. They are clustered together more than I had supposed. The accompanying diagram will show how they stand, and I will give some facts and figures that will make quite an interesting study about setting out out-apiaries and overstocking our pasture. Of course, it is impossible to locate a set of out-apiaries just so far from the home apiary, in a circle, each one in its proper place, just as nicely as we could make it on paper. We have to take such places as we can get, and many of the places that we can get won't do at all, for some reason or other; and when you have six or eight yards planted you will be likely to find, as in our case, some of them badly crowded-too much so for profit. 
The circles in the diagram are three miles each, or $1 \frac{1}{2}$ miles from center to outside, which is a very short distance for a bee to go in search of honey. If the bees fly three or four miles, as I think they do in poor seasons, it is plain to see how it works in a poor season. The outside apiaries may be getting a fair living, while the inside yards are nearly starving. In first-class seasons, when

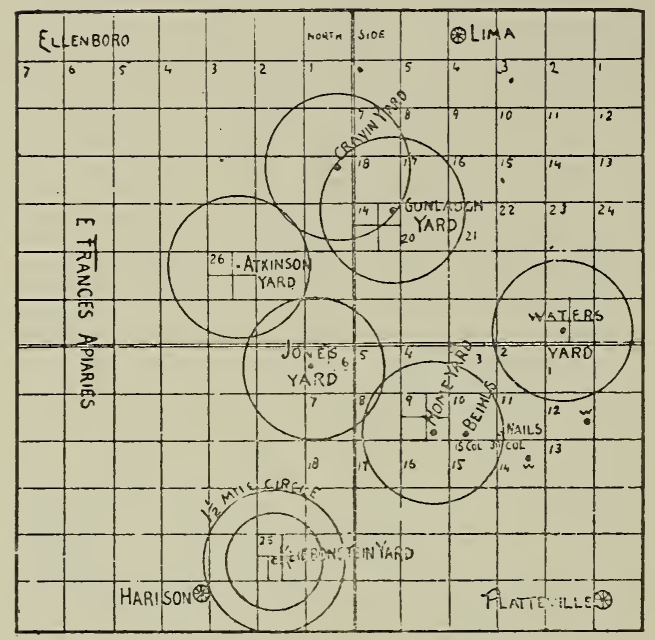

honey is plentiful everywhere, and very few bees go over one mile, there is enough for all. I here give the number of bees in each yard this spring, the amount of honey taken, and the amount of feeding this fall to put the bees in trim for winter.

Atkinson yard. Colonies, spring count .......100 Craven yard. Colonies, spring count..........990 90 Kliebenstein yard. Colonies, spring count......96

Waters yard. Colonies, spring count........ 88 Jones yard. Colonies, spring count........... 80 Gunlauch yard. Colonies, spring count....... 90 Home yard. Colonies, spring count...........

Total

649

No increase to speak of.

Honey extracted:

Atkinson yard ...........190

Cravin yard........................

Kliebenstein yard.............740

Waters yard $\ldots \ldots \ldots \ldots \ldots \ldots 497$

Jones yard ..................60

Gunlauch yard............350

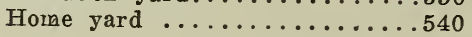

Total

3125

Fed back:

Atkinson yard...............000

Cravin yard ...........................

Kliebenstein yard............000

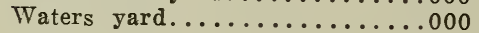

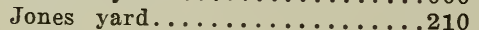

Gunlauch yard .............486

Home yard ..........................

Total

1932

Surplus after feeding

1193

Now, notice the Kliebenstein yard, how it is located away by itself, as, for instance, from other yards. It has a great advan- tage; and then there is plenty of basswood all around it. It has no bees belonging to other parties on its territory. It gave the most honey, no feeding, and is in the best condition of any yard for winter stores.

We will now notice the Atkinson yard. It is pretty well hemmed in on the north and east sides by the other yards, but has an unlimited field on the west, of good pasture. We took but little honey there, but it is in good condition for winter, without feeding.

Now, away over on the east side we have the Waters yard. It is two miles from basswood, but a splendid white-clover rangeplenty of basswood two miles north and east. This yard gave some honey, and required no feeding for winter.

Then there are the Cravin and the Gunlauch yards, each 90 colonies in spring, only $1 \frac{1}{2}$ miles apart-too close, with very little basswood north of them. Both of these yards were fed more honey than we took from them. There were a few acres of buckwheat near them that helped them a little. The Jones yard did fairly well, considering its surroundings. It had the least number of bees, an abundance of basswood near, and then had eleven acres of buckwheat just over the fence.

We will now notice the home yard. There were 105 colonies. The Jones yard is rather too close. Then there is an apiary of 20 colonies a little over half a mile east, at a point marked Beihls; another apiary 11/2 miles east, 30 colonies marked Nails; another apiary southeast, marked $\mathrm{W}$, about 40 colonies; another apiary still further to the east, and a little to the north, marked W, about 40 colonies. So you see the honeyyard territory is overstocked the worst of all, and had to be fed $360 \mathrm{lbs}$. more than was taken from them. The home yard has the best clover field of any, but basswood is scarce within two miles. In looking at the diagram, one not acquainted with the ground would naturally ask, "Why don't you use that open space southeast of the home yard?"' It is all prairie land. Corn and oats don't yield much honey.

We will now just look back to the record of a year of plenty, 1886, and see how the yards averaged up then.

\section{COLONIES, SPRING OF 1886.}

Atkinson yard, 72 cols.; average lbs. per col., 106 Cravin yard 80 cols.; average lbs. per col., 1061/4 Kliebenstein yard 60 cols.; average lbs. per col., 109 Waters yard 72 cols.; average lbs. per col., 107 Gunlauch yard 50 cols.; average lbs. per col., 100 1/2 Home yard 61 cols.; average lbs. per col., 117 Jones yard not planted then.

FOR 1885.

Atkinson yard 56 cols.; average lbs. per col.,90 Cravin yard 53 cols.; average lbs. per col., 74 Kliebenstein yard 46 cols.; average lbs. per col.,62 Waters yard 57 cols.; average lbs. per col., 57 Gunlauch vard 46 cols.; average lbs. per col., $771 \frac{1}{2}$ Home yard 62 cols.; average lbs. per col., $71 \frac{1 / 2}{2}$ FOR 1884.

Atkinson yard, 51 cols.; average lbs. per col., 107 Cravin yard, 41 cols.; average lbs. per col., 113 
Kliebenstein yard, 51 cols.; av. lbs. per col., 109 Waters yard, 41 col.; average lbs. per col., 130 Gunlauch yard, 41 col.; average lbs. per col.,1061/2 Home yard, 61 cols.; average lbs. per col., $113 \frac{1}{2}$ FOR 1883.

Four rards, average for the whole......105 lbs. Number of colonies, 35, 48, 33, 60 .

In 1887 we kept no record. It was a very poor season, and we got but little honey.

The year 1888 was a very poor one also.

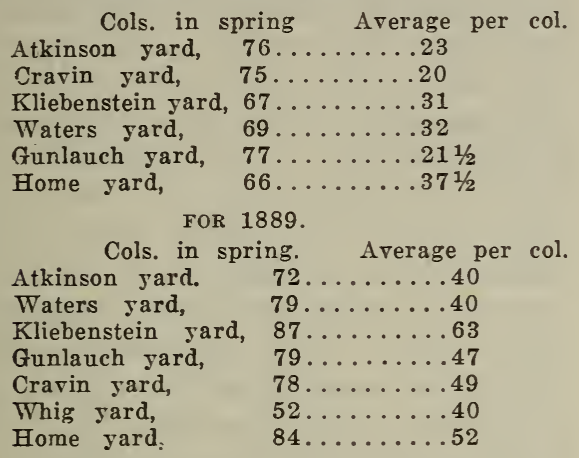

Now, friends, you have the figures and the map of the ground that our bees are on. Study it for yourselves. But if you plant out-apiaries, don't put them less than five miles apart if you can he'p it. If you are going to keep help at the separate yards, to run the bees, six miles apart is near enough; then, if the pasture is good, you can keep from 100 to 150 colonies in each place. If you go from home with your help every day, then you want to gauge the number of colonies so as to work one whole yard in one day; or if you have but three or four apiaries in all, you will have time to work two days in each. But don't go over the roads for less than a full day's work when you get there; and remember, when rou are locating an apiary, that, when you are hitched up and on the road, one or two miles further travel will pay you better than to crowd your pasture. Don't overstock your ground.
Platteville, Wis.
E. France.

Soon after the appearance of $\mathrm{Mr}$. France's diagram, there appeared in Gleanings another valuable article from the pen of C. P. Dadant. It substantiates what Mr. France has said, and shows the relation that apiaries bear to each other along the banks of the Mississippi.

The very interesting article of Mr. France, on out-apiaries, has induced us to give you our experience in this matter, not because we can throw any more light on the question, but because our practice, which extends back to 1871 , in the matter of outapiaries confirms the views of both Mr. France and Dr. Miller, and will add weight to their statements.

Under ordinary circumstances it is not advisable to place apiaries nearer than four miles apart; but Dr. Miller is undoubtedly right when he says that the configuration of the land has a great deal to do with the greater or lesser distance that bees trave] in certain directions.

In the accompanying diagram you will perceive that these apiaries are all located on land sloping toward the Mississippi River, and are separated from one another by creeks, and groves of timber land. The Grubb apiary is owned by D. W. MeDaniels, who has had charge of our apiaries also for

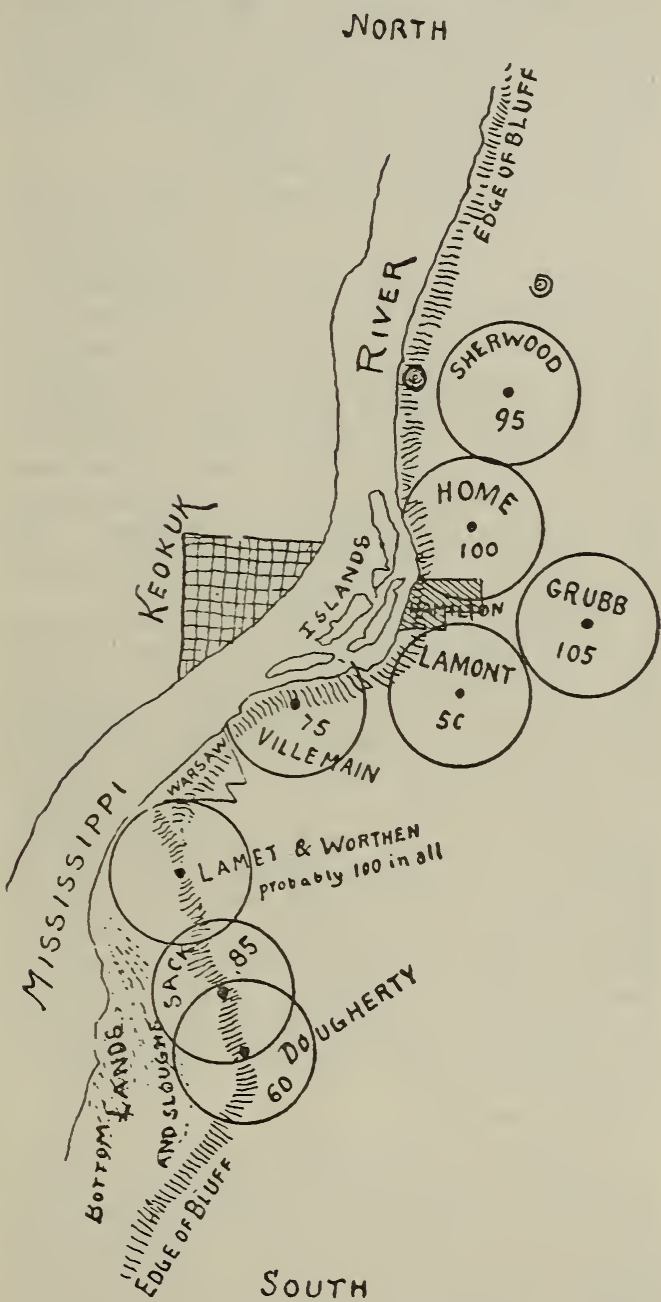

'The Dadant system of out-apiaries along the Mississippi River.

a few rears past. Of all these apiaries, the Sherwood is the best in the product of both spring and fall crops, altho there are seasons like the past when the fall crop fails there altogether.

The Villemain apiary has the poorest iocation, to all appearances; but it is located near the only basswood grove there is in the country, and has also quite a fall pasture from blossoms that grow on the islands near it. But what will you think of the Sack apiary, which is located a little over two miles south of the Lamet apiary, with an- 
other apiary close to the latter, but not shown on the diagram, and only one mile and a quarter north of another apiary of 60 colonies, owned by A. Dougherty? Yet this Sack apiary gives us the best average of honey of all, excepting the Sherwood apiary. The reason of it is, that the pasturage is all west of it on the river bottoms, and very abundant. It is probable that the bees in this apiary go as far west as the river, about three miles, while they perhaps do not travel over a mile east on the bluffs. Their course north and south, in the direction of those other apiaries, is over a hilly country covered more or less with timber which makes their flight more difficult.

The two small circles in the northern part of the diagram show the spots where we had apiaries formerly, and which, you will perceive, were further away from home than the present. At that time the Sherwood apiary did not exist, nor did the Grubb apiary; and yet we must say that we can see no difference in the yield of the home apiary. We are satisfied that the Grubb bees go east, the Sherwood bees and the home bees northeast, for their crop. When we say the bees go in a certain direction, we do not mean all the bees, but the greater part of them. We can give you one convincing instance of the correctness of this opinion.

By glancing at the diagram you will notice that the home apiary is just about a mile and a half from the north point of an island in the river. In certain seasons the islands are covered with water in June; and after the waters recede they become covered with luxuriant vegetation, and the yield of honey from them is very large. In one of these seasons we found a colony, belonging to a neighbor, located half way between us and the river, harvesting a large yield of honey from this source, while our bees harvested nothing. Is it not evident that our bees had not gone that far? Yet we have seen them two miles and more from home in another direction.

Hamilton, IIl.

C. P. Dadant.

In 1890 , and also 1897, the author visited a number of extensive apiarists in the states of New York and Vermont. Among others called upon was Mr. P. H. Elwood, who occupies a territory for his system of outapiaries not many miles from that formerly occupied by Mr. Quinby. Mr. E. runs about 1000 colonies in a series of eight or ten out-apiaries, and they are located in the valleys in the midst of those York state hills. These hills are anywhere from 500 to 1000 feet high, and are covered with basswoods and clover. The former, scattered over the hills from top to bottom, prolong the duration of the honey-flow very considerably. Instead of there being only ten days or two weeks of basswood, it some- times lasts a whole month. The first basswoods to blossom are at the foot of the hills; and as the season advances, those higher up come in bloom; so the flow does not entirely cease until the trees at the very top of the hills have gone out of bloom. The bees will commence flying on the horizontal; and as the season progresses, they keep flying higher and higher, until they have scaled the top of the hills. Beekeepers who are situated in such a country, or in swamp land, are in the best localities for honey. It might be well to observe in this connection, that these hills form excellent windbreaks for apiaries in the valleys. In Vermont, a colder climate, this feature cuts quite a figure. Mr. J. E. Crane's apiaries were located among the hills, in some cases on the sides of the mountains; but, unlike Mr. Elwood, he had no basswood there.

\section{RENT FOR OUT-APIARIES.}

The agreement between the beekeeper and his landlord, for rent, is as varied as the cases that occur. Some pay a fixed sum, five or ten dollars per year; some pay ten cents per colony; others agree to pay a per cent of the crop; some make a bargain to pay so much for every swarm hived by some one of the landlord's family, and so on, while some cannot get the landlord to agree to take any rent whatever. In this latter case it is only right to make sure that the landlord has a good supply of honey for his family to use during the coming year. In any case, be sure to do a little better than is expected.

HAULING BEES AND BEE-SUPPLIES TO OUTYARDS.

Out-apiary management demands some sort of conveyance, not only to carry the beeman and his helpers to and from the outyards, but to haul the bees and the supplies. Formerly a horse and buggy or a team and wagon were used exclusively for the purpose; but the rate of travel was so very slow that the time lost on the road was considerable of an item. With a horsedriven vehicle it is not practical to handle more than one or two outyards in one forenoon or afternoon, and generally about half the time is spent on the road. If a beeman's time is worth in the height of the season 50 cents an hour, and his helper half that, and if the time of the team is worth 
$\$ 4.00$ a day, it makes the net cost $\$ 1.15$ an hour. On the basis of $2 \frac{1}{2}$ hours for time actually spent on the road, this would make a net cost of $\$ 2.88$ of dead or non-productive time.

\section{AUTOMIOBILE FOR OUT-APIARIES.}

On the other hand, an automobile will make the trip to the yards in one-fifth or one-seventh of the time. A safe average running speed is about 15 miles an hour, altho on good roads one can run as high as 20 or even 25 miles. On the other hand, it costs anywhere from 5 to 20 cents* a mile to operate an automobile if we include depreciation of the machine itself, wear and tear, tires, gasoline, and oil. But even on this basis the automobile is considerably cheaper, provided, of course, there is a series of not less than three or four outyards, or, better, five or six. The self-propelled vehicle makes it possible to have yards further apart; and this makes it feasible to have a lesser number of colonies to the yard, and a larger average yield. If a yard is overstocked it will not, of course, give as large an average per colony.

It is not necessary to buy an expensive truck. An ordinary light machine selling for less than $\$ 400$ with a wagon-box on the back will handle practically 95 per cent of the out-apiary work provided there are not more than four or five yards. For very heavy hauling, a big truck can usually be hired at an expense of about 20 cents a mile, including driver; and this will be far cheaper than for the beekeeper to own the machine. Or a trailer can be hitched on the light machine and carry $750 \mathrm{lbs}$. in addition to 500 or $750 \mathrm{lbs}$. on the truck itself. The automobile without a trailer can carry $750 \mathrm{lbs}$. to the trip, and thus do practically all the work, even to hauling the bees home in the fall, altho there is an increasing tendency on the part of out-apiary beekeepers to winter their bees at outyards in large quadruple winter cases. (See Wintering Bees Outdoors.) In that case the small machine can do all the hauling provided the owner manages to take a light load at each trip, both going and coming.

If there is a series of eight or ten yards one can well afford to have a light machine to carry the men to and from the yards, and

* A Ford will run for from 3 to 5 cents as against a ton automobile truck at 15 to 20 cents per mile. a trailer capable of carrying $750 \mathrm{lbs}$. more, altho it is surprising to see how much work can be accomplished with a Ford alone.

The illustration of a Ford truck under the head of Moving BEES shows a little machine that the authors have been using at our outyards with considerable success. We have actually loaded on to it at a time twelve to fifteen colonies, and two or three trips will carry a whole yard of bees from one point to another. Twenty-five empty hives and supers with combs can be piled up and roped on to the machine; for so long as the weight is kept down to about $750 \mathrm{lbs}$. one may pile on to it is much as he can get on.

The upkeep of an automobile costing less than $\$ 400$ is about a third of the cost of operating the larger machines costing $\$ 1000$ or more. The former use small tires, and, what is of great importance, the first cost is much lower. Beekeepers should understand that the main expense of operating an automobile is depreciation, which cannot be figured at less than 33 per cent the first year; 25 for the next, and 10 per cent for each succeeding year. The depreciation is the largest item; and as the cost of the lowpriced machine is less than half the ordinary machines, the depreciation is correspondingly less.

But there is another item to be considered. The little high-speed engine in the small machine will give about twice the milage per gallon of gasoline of the heavier machines, and this is no inconsiderable item.

By lengthening the wagon-box a much larger bulk of hives can be carried at a load; and, generally speaking, we would advise having the wagon-box stick out at the rear at least two feet or more, because a great deal of the stuff carried to the outyard is bulky but not heavy. But when the wagon-box is enlarged, precaution should be taken not to put on a load of more than $750 \mathrm{lbs}$. While the chassis of a light machine will carry 1000 lbs., such a load is rather hard on the tires, and we recommend, therefore, making an extra trip rather than trying to do the whole job in one load.

A large heavy automobile truck costing from $\$ 1000$ to $\$ 1500$ with a maximum

*E. L. Hoffman, Zanesville, Minn., handles 1000 colonies with one assistant, a Ford, and a trailer. He secures big crops of honey, and with his Ford he sells and delivers his crop in his locality. 
speed of only fifteen to twenty miles an hour is an expensive and wasteful proposition for the average beekeeper. What he needs is something that will make quick trips at a minimum expense.

Whatever the kind of hive used, some plan must be adopted for fastening in the bees, so that they may have abundance of ventilation while being hauled. As, however, the hauling is done in spring and fall, less ventilation is needed than during hot weather. The ordinary entrance, say 14 inches by $3 / 8$, covered by wire cloth, will answer, as that gives a ventilating surface of about 5 inches, altho more would be much better. (See Moving Bees.) Of course, the bees should all be shut in when not flying, and in spring it is a good plan to shut up in the evening all that are to be hauled the next day. In the fall the weather may be such that bees will not fly at any time in the day, otherwise one must get to the out-apiary early enough in the morning to shut in all the bees he will haul that day. If one is to take bees to an out-apiary in the spring, the sooner it is done the better, as pasturage is then apt to be rather scarce at best. Where bees are to be brought home in the fall to be cellared, they may as well be brought just as soon as heavy frost occurs, or as soon as they stop gathering; at least they should be brought early enough to have a good fly before going into winter quarters. After being unloaded from the wagon the bees may be liberated at once by blowing a little smoke or dashing in some cold water; or, if loaded too late in the evening to fly, they may be left till the next morning when they will be quietly settled down; and if carefully opened, no smoke need be used. For full particulars on the difficulties in hauling bees see Moving BeEs.

TOOLS FOR OUT-APIARIES, AND WHERE TO KEEP THEM.

Whatever tools one uses in the home apiary, he is liable to need the same in each out-apiary. If a different person is in charge of each apiary, then each one must have his own set of tools; and even if the same force go in succession from one apiary to another, it may be the more convenient to have a separate outfit kept at each place. There is nothing in the line of tools needed for an out-apiary, different from those that are needed at home, unless it is a robber-cloth. It is not safe to be without one of these in the home apiary, but they are especially valuable in out-apiaries where, sometimes, notwithstanding robbers are troublesome, one's plans are such that he desires to force thru a certain amount of work. By having two or three robber-cloths we have sometimes been able to go on with our work when, without them, we should have been obliged to desist.

\section{HOW TO MAKE ROBBER-CLOTH.}

Take about a square yard of stout sheeting or cotton cloth; if the hives are small, less will do. Lay one of the cut edges on a piece of lath, about the length of the bive. Lay a similar piece of lath on top of it, and drive wire nails thru both, at a distance of perhaps three inches apart. Let the nails be long enough to reach thru and clinch. Then treat the opposite edge the same way, and the robber-cloth is complete.

This robber-cloth is exceedingly convenient to throw quickly over any hive or super that it is desired to cover up temporarily. One can grasp a lath at the side with one hand, and, with a single fling, throw it over the hive, making it instantly bee-tight. It does not kill bees, if any happen to get under it. If one hand is occupied with something else, the other can very quickly uncover and cover it.

We have sometimes worked with a weak colony when robbers were so bad they would pounce into every opening; but a robber-cloth on each side covering the frames allowed us to make an opening at the frame we wished to take out. As a general rule, of course, we would try to manage not to work the bees at such times.

But, to return. It is very convenient to have a little tool-house at each yard. It is almost a necessity. A hive or box covered over water-tight answers very well. There should be one or more of these at each apiary in any case, for there are some things one must be sure of having on hand, as smoker fuel. Matches should also be kept under cover in such a place, in a tin box. A baking-powder box does well. Beehats, smokers-in fact, a full set of everything can be kept in the same way.

GENFRAL MANAGEMENT OF OUT-APIARIES.

The management of outyards will depend very largely on the man, the locality, and 
the general conditions. Sometimes up in the mountain country where the roads are very poor, and a very large number of colonies can be supported per apiary, it is more practicable to have a man at each yard who camps on the job night and day until the main honey-flow is over. Of course it is not necessary to have a man at the yard during the dormant season; but when warm weather sets in some one should be on hand to build up the colonies and put them in proper condition to catch the honey-flow.

As a general thing, however, a man at each yard is too expensive, and it is, therefore, better to have one force operate all the yards, using an automobile, even if an occasional swarm does get away. This plan has the advantage that the owner of the bees can always be present with the men, directing the work, thereby securing efficiency and at the same time better service. The helpers usually work better when the boss is around; and the boss who does not see to his own job will soon run himself out of business. One who is capable of operating a series of outyards is capable of directing his men, and usually he is a man who has gradually grown into the business, increasing it from year to year as knowledge and experience permit. It follows, therefore, that when the owner can keep his eye on every colony at every outyard, and direct the individual treatment, he gets far better results than if he has a hired man out of his sight at each outyard.

The owner of the bees, when he takes his helper or helpers, should make his plans well in advance before he starts for the yard. He should not only know what he is going to do, but whether he has the proper equipment with him to work out the plans for the day or trip. He should go further and have his plans matured a week in advance so that he can take care of each yard at a definite period. He should see to it that he has sufficient supplies on hand of every description; and if he does not have enough equipment at each yard he should so arrange his work that he can carry what is necessary at each trip; otherwise he will be working at a great disadvantage.

It is not essential that a helper should have experience. The beeman who uses his brains can take a comparatively raw man or boy and almost double his own capacity for work in a day. Our yardman takes along anywhere from one to two helpers. The helper with smoker opens up the hives in advance, so that all is ready when the boss makes his inspection. His practiced eye will see almost at a glance what treatment is required, and he will, therefore, direct his helper or helpers to bring him the necessary equipment to put the colony in proper condition. An experienced man who has his plans well.worked out will be able to keep one man bringing him stuff. As the men acquire more experience the boss simply tells them what to do with a colony. In the meantime he studies the needs of the next colony.

A good beeman who is capable of getting along with help will be able to take care of seven or eight hundred or perhaps a thousand colonies with one or two men as helpers. When conditions are right, and with the proper system, he sometimes may be able to handle twice the number with the same help.

Of course it goes without saying that the owner or boss should know how to operate his automobile. As already pointed out, he cannot afford to waste time with a horse and buggy, as he will thus kill valuable time.

But perhaps it may be urged that the roads are bad and almost impassable for any automobile, and that a horse and buggy must therefore be used. But usually a Ford with a good driver will go where any horse can.

In this connection it may be said that out-apiaries should be located on paved or stone roads as far as possible and as close to the road as conditions will permit. This is quite important during the early part of the season when early rains would make an ordinary clay road muddy and slippery for a machine. Good management, therefore, requires not only a definite plan for each day and each week, but an arrangement of outyards along highways that will be passable during the months of the year when bees will ordinarily be handled.

No beekeeper should go to an outyard without a spare inner tube and an outer casing, with a boot to providłe against blowouts, and patching stuff to make repairs to inner tubes. In the rush of the season it is the height of folly to get caught on the road with a blowout or a puncture 
without means for making repairs. To run on an uninflated tire is the ruination of the inner tube and a damage to the casing. As a general thing we would recommend having a Ford equipped with a detachable rim. With this extra rim carrying a tire already inflated, one can get started in a very few minutes.

An extra box should be provided on the running-board of the machine to hold smoker, smoker-fuel, hive-tools, bee-brush, grasshook, or anything else that may be required at the outyard. These tools will be needed on every trip, besides the combs, supers, and other equipment that will ordinarily be loaded in the wagonbox for that special trip.

Sometimes it is necessary to take along a scythe, and while the boss is making an inspection of colonies his helpers can be employed in cutting down grass and weeds and leveling up the hives. This last item may not seem to be essential; but if a hive is on a tilt it will have its combs in the section-supers built out of plumb. If the season happens to be a good one, and there are four or five supers on the hive, a stiff wind just before a thunderstorin may blow the whole thing over. It is important, therefore, to have a good foundation for each hive at the yard.

At every outyard there should be a small collapsible building (See BuILdings). This is to hold extra combs, supers, and equipment; and if the extracting is performed with a small hand machine it can be done in a building of this sort.

As given under Extracting, the authors advise one large extracting-outfit at the home yard, where the work can be done inside of a bee-proof building. It is not advisable ordinarily to extract at outyards, on account of the danger of robbers, and because conditions usually are not favorable for putting up an extracting-outfit.

In the case of bee disease it is sometimes necessary to extract at the outyard, in order to avoid mixing the combs, and danger of carrying disease to the home yard. But even in that case, if one plans rightly he can arrange to take his combs off, load them on the machine, carry them home, extract, and return. There should be a drip-pan in the wagon-box to catch any drip from the supers after extracting. And it may be advisable to throw a large canvas over the load to keep any bees in the home yard from getting a taste of the honey. In any case the extractor should be thoroly washed out after extracting from diseased or suspected combs. Such work cannot be done too carefully.

\section{WINTERING OUT-APIARY BEES.}

In former times it was the practice to haul the bees home from the outyard and put them in a large cellar; but the present tendency is to winter the bees in large quadruple winter cases at the outyard. (See Wintering OUtdoors, subhead "Quadruple Winter Cases.") If there is any danger that the bees may be tampered with during winter by thieves or naughty boys we advise hauling the bees home and wintering them under the eye of the owner. Usually an outyard can be located in sight of some house. If the land is rented from the owner of the house he will be willing to keep a watch on the bees; but as a usual thing bees may be left out of doors year in and year out without disturbance.

If the bees at the outyards are well supplied with stores in the fall, and put into large winter cases they will not require much attention except to see that the entrances do not become clogged with dead bees, which may happen along late in the winter. Usually some one near the outyards can be hired to rake the dead bees out of the entrances, as it may not be practicable for the owner to make a visit when roads are bad.

For building up outyard bees the reader is referred to BuILding UP Colonies; NUCLEI, and INCREASE.

\section{FAILING LOCATIONS.}

Experience has shown, in many instances, that a yard which in years gone by has furnished tons of honey is now practically worthless, or so nearly so that the moving of the bees to some more favorable location is a necessity. For instance, four or five years ago an apiary furnished an abundance of basswood honey; but the basswoods have all been cut off; there is no clover and the field is worthless. Again, a locality has once furnished immense quantities of white clover; but intensive agriculture has set in, and clover pasturage has given way to immense wheat-fields. The inroads of civilization sometimes cut off 
the honey-resources of a locality; at other times they augment them very considerably. There are a few locations in York state that formerly gave very little honey until the farmers in recent years introduced: buckwheat to such an extent that these are now splendid buckwheat countries; and the yield of this dark rich honey plays a considerable part in the net profits of the season.

\section{A SCALE HIVE AT AN OUT-APIARY.}

It is a well-known and established fact, that one yard may yield quite a crop of honey while another, only a few miles distant, requires to be fed. It is highly important to be able to tell just what the bees are doing at stated periods during the season. One beekeeper kept a hive on scales at each yard; and every time he visited one he consulted the scales. If they indicated an increase of several pounds, he knew the bees in this apiary needed more room, and were also liable to swarm; but if they indicated a loss of several pounds, he inferred that the whole yard was losing likewise, and that some colonies needed to be fed. Of course, the hive on the scale should contain a fair average colony. In many cases it is not always possible to visit yards at regular periods, and in that case some resident near the apiary can be employed to watch the scale, and report by postal card. (See Scalf Hive.)

\section{A CAUTION ABOUT ENTERING INTO THE OUT- APIARY BUSINESS.}

While there are many beekeepers who have brains and capacity enough to manage a series of out-apiaries, there are also more who would better never think of going into the business. To be a keeper of several out-apiaries means great perseverance and a good deal of system, besides ability to manage not only the bees, but the help who are to take care of them. If one cannot make fifty or sixty colonies pay in one location, he should not delude himself by the idea that he can make bees pay by establishing a series of out-apiaries. The man who can not make a small business pay probably will not make a large one do so. When one can manage successfully his home apiary, it may be profitable, as soon as the increase is sufficient, to take a part of it to an outyard.
OVERSTOCKING.-This means putting more colonies in a locality than can be supported profitably. Sometimes a local beekeeper makes the mistake of putting too many bees in a place; but it more often happens that another, observing that the locality is good, brings in one or more yards, thus crowding the territory that was already overstocked in the first place. (See APIARIES and BACKLOT BeEkEEPING, FARMER BeEkeepers, and OUt-APIARIES.)

A given locality with only ten colonies to gather the nectar in it may show a wonderful arerage per colony-perhaps 200 or 300 pounds. When the number is tripled or quadrupled, the average will be cut down a half. The locality should be carefully studied, and only that number of colonies used which on an average, one year with another, will give the largest results in honey, with a minimum of labor and capital. If 75 hives during an average season would furnish an average of 150 pounds to the hive, then, perhaps, the number might be increased to 100 or even 150 . If, on the other hand, the average is, say, only $50 \mathrm{lbs}$. of extracted honey, and there are only 50 colonies in the apiary, then, clearly, 50 would be all there could be kept with profit in that spot; and it could be questioned whether or not 35 might not be just as profitable, and at the same time save a little in the investment and some labor in gathering and harvesting the crop.

But in some locations, notably California, Colorado, Cuba, and in some portions of Florida, one can have as many as 300 or 400 colonies, and in some rare instances 500 colonies in one apiary. The late E. W. Alexander, of Delanson, N. Y., had some 700 colonies in one beeyard; but he had immense acreages of buckwheat and goldenrod. The celebrated Sespe apiary, in Southern California, owned by Mrs. J. F. McIntyre, has, in one yard, some 600 hives of bees; but the great mountains on either side, the fertile valley, and the great abundance of honey flora, make such a number possible. See APIARIES; also OUT-APIARIES.

\section{OVERSTOCKING AND PRIORITY RIGHTS.}

A new phase of overstocking has been developed within recent years, bringing up a rather difficult and serious problem. In good localities such as, for example, the ir- 
rigated regions of Colorado, the keeping of bees is much more profitable, or at least once was, than in some of the less favored localities in the central and northern states of the Union. It has come to pass that, in recent years, certain beekeepers, learning of the wonderful yields in Colorado, in the irrigated alfalfa regions, have started apiaries within less than a mile of some other beekeeper having 100 or 200 colonies in that locality. When the new comer establishes another apiary of 100 colonies, the place becomes overstocked, with the result that beekeeper No. 1 has his average per colony cut down very materially. There is only a certain amount of nectar in the field to be gathered; and if all the colonies get a proportionate share, then beekeeper No. 2 practically robs beekeeper No. 1 of a large percentage of honey that he would have obtained had not other bees been brought into the locality to divide the spoils. But there is no law against such a procedure. The only protection that the original squatter has is the unwritten moral law that is observed among the better class of beekeepers, to the effect that no beekeeper should locate an apiary so close to another as to rob him of a certain amount of nectar in the field which is his by priority of location. In a good many localities in Colorado, unfortunately this unwritten moral law is only loosely observed. Locations that once afforded an average of 100 or 150 pounds per colony now afford only about 50 or 75 pounds.

For the other side, on this question of priority of right it may be said that the first-comer beekeeper has in no sense leased, bought, or borrowed the land growing the plants from which the nectar is secreted; that any and every one has a right to the product from the flowers. Legally the second comer has just as much right to the field as his neighbor.

We will not attempt to define moral distinctions which may be involved in this question any more than to state that, if a beekeeper has by luck, careful observation, or at great expense, discovered a locality that yields large amounts of honey, he ought to be left in the peaceful enjoyment and free possession of his discovery, to the extent that no one else should locate an apiary nearer than a mile and a half from any of his apiaries; and right here it would appear that the principle of the golden rule ought to be used to settle all such problems; for it is practically certain that beekeeper No. 2, who comes into an already occupied field to divide the profits, would not regard with very much favor such action on the part of another if he were in the position of the one having prior rights.

In many localities there is a very strong sentiment on the part of local beekeepers established in good territory against new comers putting more bees into a place already overstocked. 'This sentiment is so pronounced and strong that the new man is often glad to sell out or move away of his own accord. Sometimes he is stubborn, and attempts to fight it out; but usually he is the loser in the end, because he does not know the locality as do the old-established beekeepers, and his yields per colony will be considerably less. While the policy is not here advocated, local beekeepers sometimes agree on the plan of freezing out, or, more exactly, starving out, the new comer. The latter enters the territory with a yard of bees. Immediately the old-established beekeeper or beekeepers will place around that yard, within a quarter of a mile of it or less, a lot more bees-enough to overstock the place very greatly. The old residents, knowing the locality, build up their colonies, and are ready for the nectar when it does come in. But there is not enough to go around by considerable; and the result is, the bees will not secure an average of ten pounds per colony. But the old resident beekeepers will secure more than the new comer because they know the locality and how to meet the conditions. After Mr. Newcomer has tried it out one season, and finds he cannot make anything, he will move out. This freezing-out or starving-out game has been worked to a finish in a good many places in the West. As a general rule the resident beekeepers in the locality will agree among themselves to divide up the territory and put no more bees to the yard than the locality will support. This policy prevails in many of the alfalfa districts of the West. A good feeling exists, and in some places they co-operate among themselves to sell their honey, perhaps picking out one of their number to visit the big markets. Such a policy is much more sane than for every one to grab territory and compete against his neighbor 
with the result that no one can make a fair living:

In one or two localities Mr. Newcomer has been met by, a shotgun proposal. $\mathrm{He}$ is told to get out or "take the consequences." As such a policy is, of course, indefensible, a milder and gentler means should be employed.

As a general rule the new comer can find territory if he will make some inquiry be- fore he attempts to squat his yard or yards. By making a personal visit, and becoming acquainted with the beekeepers in any given locality, he can usually make satisfactory arrangements, and open territory may be assigned if there is any. Sometimes none is available. In that case, Mr. Newcomer should not attempt to crowd in, for he may find some one beekeeper who will resort to the shotgun argument.
PALMETTO (Sabal palmetto (Walt.) R. \& S.).-Also called cabbage palmetto and cabbage tree. This is the most picturesque tree in all Florida. Like all the palmettos, the cabbage palmetto belongs to the order Palmales and the family Palmaceae. The leaves are fan-shaped, in length about five or six feet, in width about three or four; color of leaves, bright green. The name "cabbage palmetto" is from the cabbage that forms the bud at the top of the growing trunk, and from which all the leaves grow. It grows from 20 to 30 feet high, at its best even higher, and is found in profusion along the east and west coast, and on all river courses and hammocks thruout the southern half of Florida. In general its habitat is the south two-thirds of the state, tho it is found as far north as Jacksonville. The trunk is straight, and, as the tree ages, is bare and gray in hue, looking like a weatherbeaten pine board. The wood is fibrous, and impervious to water, resisting decay when entirely submerged, though it quickly decomposes when exposed to dampness and hot sun alternately. The sheathing bases of the leaf-stems are imbricated and form a boot-like lacing of bark about the trunk for many feet below the top; these, the socalled "boots," gradually fall away, leav- ing the trunk bare, with slight perpendicular ridges, showing the fibrous corrugations, due to the nature of the wood. Its blossoming time varies according to locality. In the extreme south it begins to bloom about the first part of July; as late as August in northern portions. The blossom-stalks shoot out from the bud at the top, among the leaf-stems, and at first look like huge "blacksnake whips," only they are greenish-brown in hue. These gradually unfurl, forming a profusely flowered raceme resembling a giant ostrich plume. The resemblance to a plume is intensified when the racemes open in a mass of greenish-white petals that fill the air with a delicate aroma, as pronounced as apple blossoms. One such raceme, in full flower, is a sight to be long remembered.

The flowerets are very sensitive to atmospheric conditions. Too much dampness blights, and too dry hot air blasts the delicate blossoms. As a consequence, it can not be counted on as a good yielder oftener than one year in three, on an average. When it does yield, it is profusely. It yielded well in 1907, again in 1909, and fairly well in 1912. The roar of the bees during a good flow from the cabbage palmetto is like that in locust or basswood bloom. The honey is almost water-white, 
clear, and translucent. The aroma is distinctive, tho not at all resembling that from saw palmetto. In body it is rather thin, under normal, never thickening up,

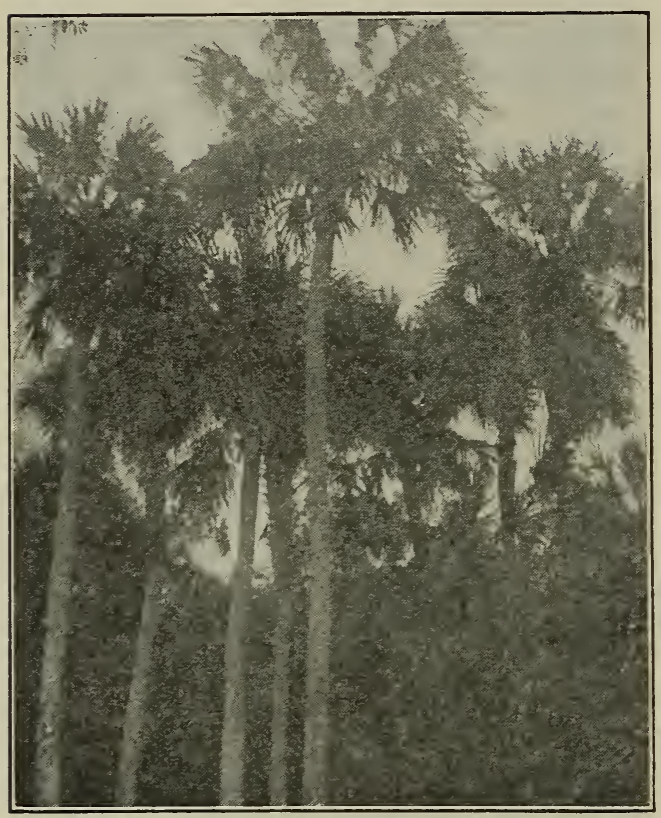

Cabbage palmetto.

even in cool weather, to a very heavy consistency. In warm weather it runs almost like water. It often froths considerably on extracting - just after uncapping, in fact - - tho that all disappears after the honey has stood for a few days. It requires rather careful handling to keep at its best. While it does not rank as high as the honey from saw palmetto, it would still come about fifth or sixth in the entire list of honeys from Florida. The flavor is extremely mild. It is an excellent honey to "blend" with other honeys. In the vicinity of Hawks Park, Fla., it blooms almost simultaneously with the mangrove, so that the two are always secured together, never separately, in that section. Further south they are secured separately. For example, on the southwestern coast there is little mangrove, so that the palmetto honey is obtained in its purity. The combination of this honey and the margrove, however, is, fortunately, a fine one, and won signal praise from the father of modern apiculture, I. L. Langstroth himself. Mr. W. S. Hart, of Hawk's Park, had sent a sample of the blended honeys to Mr. Chas. F. Muth, of Cincinnati. Mr. Langstroth later received a smaller sample of it from $\mathrm{Mr}$. Muth, and wrote him the following interesting letter:

Friend Muth:-I have delayed giving you my opinion of that Florida palmetto honey till I got the verdict of others as to its merits. In color it is unexceptionable, and its flavor is very pleasant. I am not sure but the majority of consumers will consider it the equal if not the superior of white clover. Our southern friends are to be congratulated on being able to supply our market with such a choice article.

Oxford, O., Nov. 16, 1882.

L. L. Langstroth.

\section{SCRUB PALMETTO.}

The scrub palmetto (Sabal megacarpa (Chapm.) Small) is a low shrub with thickset branching leaves that grow from a trunk that is long and crooked, erect early, later prostrate, and half submerged in earth. The branches, like the entire family of Palmaceae, grow from a central bud at the end of the trunk, and are imbricated in the bud. The stems, supporting the light-green fanshaped leaves, are about four feet tall on

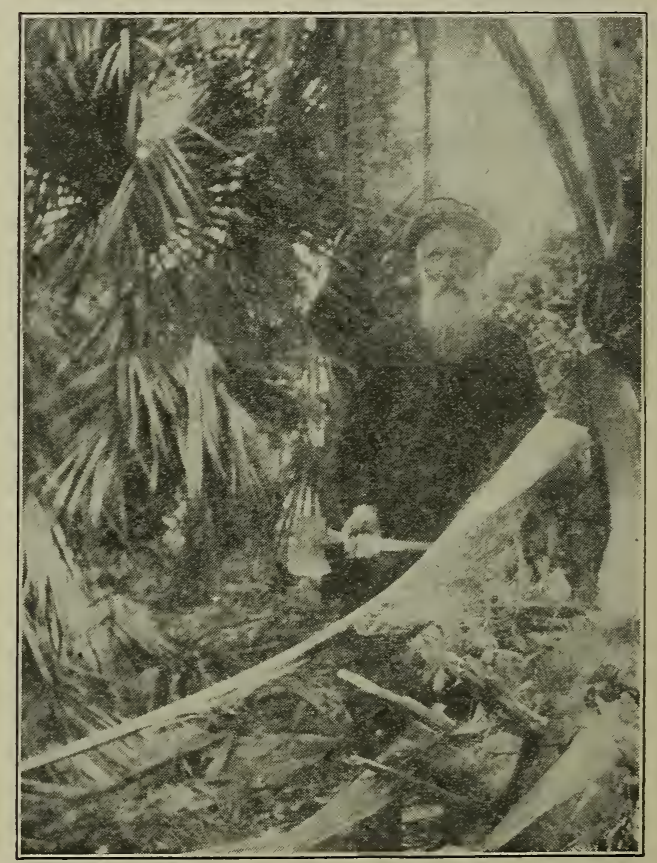

Scrub palmetto.

the northern limits, but reach six or seven further south, where the plant is at its best. In shaded portions or damp sections, perhaps owing partly to the soil, the leaves are often bluish in color. The trunk, when it 
falls over, sends up fresh clusters or clumps of shoots that form a new shrub. One trunk may thus send up many clumps of leaves resembling distinct plants, but really attached to a single trunk. The flowering blossoms are carried on a plume-like stalk that shoots out from the base of the stem at the central bud. The blossoms are generally white, creamy, at times with a half-greenish cast to them; single flowerets of the racemes small and delicate, with a decidedly sweet aroma. These single flowers on the racemes resemble somewhat the delicate "lily of the valley." It is these racemes, from two to four feet in length, that secrete the nectar. The plant grows freely on sandy soil over the southern two-thirds of the peninsula of Florida, becoming scarcer toward the northern boundaries, and smaller as well. It reaches its finest form from a line east from Tampa to the coast, southward, and flourishes on the Keys. It begins to blossom in the vicinity of Fort Myers and Miami, about April; further north, May is the flowering time. May is the time for blossoms about midway of the state. The edges of the stems of the leaves show on either side serrated points, or teeth, that give the name "saw palmetto" to this species. But the real saw palmetto ranges much further north, even extending into the Carolinas, and is the Serenoa serrulata, not the Sabal megacarpa. The serrations of the saw palmetto are deeper and more rasping. On the west coast of Florida, from about Tampa, north and south, the scrub palmetto extends for miles eastward in an unbroken sea of green. On the Seaboard Airline Railroad it is possible to ride for miles without being out of sight of the scrub palmetto that makes such an impressive sight, seen in such masses. Usually pine trees grow scatteringly among dense hammocks of the scrub palmetto. These form what are commonly called "the flat-woods." On the edges of heavy, damp hammocks, where the soil is richer, the scrub reaches much greater density, size, and vigor. There are still wide areas of scrub-palmetto hammocks and flatwoods yet unoccupied by any beemen, that offer an attractive field for apiculture. There is one objection to such areas, however: The palmetto is usually the only nectar-secreting plant in such territory, and colonies have to be watched or they will run out of stores in seasons when the palmetto does not bloom. But there is no honeyplant in Florida that is more reliable, year in and year out, than the same scrub palmetto.

The product ranks among the four best honeys of the state, and, tho forest fires destroy much of the bloom for that year, still the sections burned one year produce the most honey the second year, so the loss is not without some advantage. The honey is clear, amber, almost lemon-hued; body thick and waxy, and aroma exquisite. Almost all are enthusiastic over such honey, once they taste the pure article. In many localities it is disguised by the admixture of other honeys gathered by the bees either during the flow or just prior or subsequent to it. Once known, it is always popular with consumers. It candies pretty early, but not so promptly as orange honey. Mr. O. O. Poppleton pronounces it the best honey in Florida, with possibly the exception of that from white tupelo.

(See Tupelo.)

PARTHENOGENESIS.-In the great majority of cases the sex cells disintegrate unless they unite with the products of the opposite sex of the same species; but in some cases of the animal kingdom cells are given off from the ovary, which, without fertilization, are able to undergo development. That these cells arc true eggs is evident from their origin, appearance, behavior, and fate, while the only difference between these eggs and eggs requiring fertilization is that the former are able to divide and grow without receiving the stimulus given by the male sex cell. To this phenomenon the name "parthenogenesis" is applied.

The word parthenogenesis (virgin development) was first used in this sense by Professor v. Siebold in his classic paper, "Parthenogenesis in Lepidoptera and Bees," in 1856.

However, earlier writers described the phenomenon under various other names.

In 1745 Charles Bonnet described the parthenogenetic development of plant-lice; and Prof. Oscar Hertwig, the great German embryologist, designated this work as marking one of the milestones in the history of the seience of development.

Just one hundred years later the Rev. Johannes Dzierzon, of Carlsmarkt, Ger- 
many, put forth the theory that the drone or male bee is produced from an egg which is not fertilized. This work, published in the Eichstadt Bienenzeitung, may well be looked on as the starting-point of the theory of parthenogenesis, since it began a very important discussion, and marked the origin of a host of works along similar lines. Dzierzon based his views on the following facts observed by him and since confirmed by many others: 1. An unmated queen occasionally lays eggs, but these produce only drones.

2. Workers, under certain peculiar circumstances, lay eggs, but these develop only into drones. Worker bees have never been known to mate.

3. Old queens may exhaust their supply of spermatozoa received in mating, and thereafter produce only drones. As the supply diminishes they lay an ever increasing percenage of drone eggs. (See Dzierzon ThFory.)

While this theory is based on the work of Dzierzon, it must not be forgotten that its establishment is due in no small part to the researches of Professor Leuckart and von Siebold, of Germany.

The facts brought out in an examination of this work have an important bearing on the practical work of the apiary, and it is necessary for the queen-breeder, at least, to know the application. If, for example, a Cyprian queen is mated to an Italian drone, the resulting workers are a cross between the two races, or Cyprio-Italians. Any queens reared from this colony are also Cyprio-Italians; but the drones of this cross-mated queen are pure Cyprians, the Italian drone in the cross having no influence on the male offspring of the Cyprian mother. If, therefore, but one purely mated queen is obtained, her daughters produce pure drones, regardless of mismating, and the race may be established in an apiary.

The conclusion frequently drawn from this theory is that the queen can voluntarily control the sex of an egg by withholding or allowing its fertilization. It is sometimes further held that all eggs in the ovary are male, and the sex changed by fertilization. These conclusions are not based on observation, and proof is entirely lacking. In a statement of the theory, therefore, it is necesssary to stick to facts.
The Drierzon theory has been combated by many different scientists, more recently by Dickel, a German beekeeper with scientific aspirations. While the theory has been somewhat modified by recent work, it remains the prevalent view today, and Dickel generally receives the condemnation so richly deserved.

Parthenogenesis occurs in many other orders of both plants and animals, and a comparison of the various results is most interesting. Merely to cite some cases for comparison: In the bee, only males are produced parthenogenetically; in certain lepidoptera, only females are so produced; while in plant-lice and certain small crustacea, both males and females are produced from unfertilized eggs. Ants were formerly supposed to have a parthenogenetic development identical with that seen in the honeybee; but more recent work makes this doubtful as a general statement. The silkworm is occasionally parthenogenetic.

PARTRIDGE PEA (Cassia Chamaechrista L.).-Also called sensitive pea. A tough hardy weed of the pulse family (Leguminosae), growing plentifully in the high pine woods of central and northern Florida. In summer the ground is yellow with it for miles. It is scraggly in form, branching low to the ground, and reaching a length of two and three feet on good ground; limbs tough and woody when dried. The yellow flowers are slightly clustered, and the petioles bear one or two glands at the base, from which the bees gather the nectar. We have seldom seen a bee on the blossoms proper. The stems are brown, and often branch out as low as an inch above the ground. As the branches grow they widen horizontally, sometimes lying almost parallel to the surface of the ground. The bloom period is long, lasting from July to mid-September. Unless the summer rains are too heavy and continuous, it yields nectar every season. In rainy seasons the nectar is washed out of the plants before the bees can gather it. The honey has a pretty hue, being light amber. The body is thin, even exceptionally so, and the flavor is disappointing. It is far inferior to ordinary sorghum. A good teaspoonful of pure resin or turpentine would hardly shock the palate more, especially if fresh from sampling palmetto or orange honey. 
The late H. IT. Herlong, of Fort White, Fla., secured all his surplus from this source and chinquapin, which yields a bitter honey. He produced almost exclusively comb honey; and, poor as the flavor is, he managed to sell his crops at paying figures. The fine appearance of the capped article doubtless was the secret of this. As an extracted honey, it is valuable only for baker's use. It is a safe and sure crop in its locality, and quantity partly atones for lack of quality.

The partridge pea is also common thruout the other southern states and extends northward to New England. In many dry sandy sections of the South it is the chief dependence of the beekeeper, making beekeeping possible in most unfarorable localities. A surplus of 100 pounds per colony is obtained. The honey, according to J. J. Wilder, is nearly water-white with a fine flavor. In the morning the cup-like glands on the leaf-stems hold large drops of nectar which shine in the sunlight like dewdrops. It is a very reliable yielder for more than 100 days. The flowers are pollen flowers, devoid of nectar, and visited by bumblebees only for pollen.

PASTURAGE. - See ARtificial PasTURAGE.

PATENTS RFLATING TO BEE CULTURE.-Under the head of Inventions Relating to Bee Culture is given a list of all the useful ideas and inventions, patented or otherwise, that have been accepted by beekeepers. It is but fair to state that there is hardly a hive covered by patent not expired in use today that is worth much. The field of apicultural invention has been so thoroly covered by some 2500 patents on file in the Patent Office that it is practically impossible to secure a patent on any hive or bee-appliance today that will have claims of any ralue. Even if the patent is granted, the claims are generally so loosely drawn, and so complicated to avoid conflicting with other patents, that they will be worthless. As already pointed out at the close of the article on inventions, no patent granted today on beehives or bee-feeders will be worth anything to the inventor. The unpatented hive has so far reached the point of utility and perfection that it would be practically impossible to make any improvements; and the improvements, if any, would not be fundamental.

When the field was wide open, as in the days of Langstroth, it was possible to secure fundamental patents; but even with a fundamental patent Langstroth was robbed of the fruits of his brain, and died almost penniless, notwithstanding the fact that his invention was so useful that it was accepted, at the time of his death, practically thruout the whole known world, but ling years after his patent of 1852 had expired.

In the early days of bee culture the country was full of patent-right venders who sold county or state rights. Some of these sharks reaped a harvest in selling moth-proof hives. (See МотH-MIILLER elsewhere.) Practically all of these patentright venders sold useless contraptions, and most of them were men without principleso much so that the business of selling out county and state rights has come into ill repute.

PEDDLING HONEY.-See HoNEY-PEDdLING; also Extracted Honey.

PENNYROYAL (Satureja rigida Bart., a synonym is Pycnothymus rigidus).-This very interesting plant, a member of the Labiatae or mint family, grows over the southern half of Florida in sandy pine land. The stalks are square, with many spreading branches; the leares are small and very numerous, stiff, and spear-like, attached close to the stalk with almost no stems. The blossoms are light purple, with darker blotches of color on the middle of the lower lip, and are very minutely pubescent-that is, are covered with a fine furze. Undoubtedly that "Nestor in apiculture," O. O. Poppleton, of Sterart, Fla., first called the attention of the beekeeping world to the wild pennyroyal as a honey-plant. In 1882 he remarked on the abundance of the plant and the quality of the honey from it. $\mathrm{He}$ discovered its good points when he was on a visit at Tampa. It is just as common, he has discovered, on the east coast. Beginning to bloom in Norember or December it does not yield nectar well till after New Year's, then gradually increases its flow up to the first of March, when it generally goes out of bloom. Mr. Poppleton has secured as much as $50 \mathrm{lbs}$. per colony from this source alone. But it seems to be an erratic yielder, 
in good seasons producing abundantly. Any year it is a fine help in brood-rearing. It finds the hives light in honey, and, perhaps, in bees. It leaves them full of both honey and bees. The beeman so fortunate as to be in a pennyroyal district can begin extracting palmetto honey much earlier than where no pennyroyal exists. It acts much the same as fruit-bloom in the North does to the clover flow, for it allows the very first palmetto honey to go into the surplus chamber that would otherwise have to go into the brood-chamber. And so, while it is not of so much apparent commercial importance as some of the other nectars in Florida, it is in reality a much more valuable honey-plant than is usually believed or known. The honey is clear, and light in color, perhaps the whitest of all honeys in the state, the body and flavor both being fine. Some beemen here maintain that pennyroyal honey is the finest in the state.

PEPPER-TREE (Schinus molle L.). From Peru. This is really not a peppertree at all; its flowers and the honey have a peppery flavor, and the seeds resemble pepper. It is a magnificent shade-tree, and in California has been very largely planted. The honey is thick and dark, but it serves a very useful purpose in helping the bees to tide over bad times without feeding. It is under a ban now, as it is supposed to harbor injurious insects; but it seems probable these pests would still exist even if all pepper-trees were destroyed.

\section{PERFORATED ZINC.-See DRONES.}

PHACELIA (Phacelia tanacetifolia Benth.).- Introduced from California into Europe, where it has been highly praised both as a honey and forage plant. Some, however, deny its value as a forage plant, and not until 1804 did any Californian ever mention it as such. It has blue flowers much resembling heliotrope, the beauty of which makes it worthy of a place in the flower-garden, where the bees may be found on it in great numbers. One season in California, M. H. Mendelson extracted a carload of phacelia honey, but never before nor since has he extracted as much. The honey is stated to be amber-colored, and pleasantly aromatic in flavor. In his list of honey-plants of Texas, Scholl mentions two other species of phacelia.
PICKLED BROOD.-See Foul BROOD; subhead "Sacbrood."

PLAYSPELLS OF YOUNG BEES. Under the head of ROBBING mention is made of the playspells of young bees as being very similar to the performances of robbers as they toy around in their efforts to find an entrance into a hive which they are robbing. As soon as settled warm weather comes on in the spring, especially after a few days when the bees have been shut in, there will be a very pronounced demonstration of hundreds of bees flying around in front of the entrances of a number of hives. They fly up and down and back and forth, some coming out of the entrances, some going in, and all apparently having a good time. Some of this behavior is not unlike robbing. The numbers and commotion increase until in front of the strongest colonies there will be seen quite a little swarm in the air. The demonstration will keep up for perhaps a few minutes and then gradually subside.

If these playspells occur at a time when no nectar is coming in, they sometimes cause a little apprehension on the part of the owner of the bees. Sometimes these frolies are so much like a genuine case of robbing that the best experts are puzzled. However, there are two important distinctions: 1 . When bees are playing, there are no fighting bees, as is the case when robbing is going on. On the other hand, when a colony has been overpowered, robbers will perform in front of an entrance like a lot of bees at play. They will cavort all around in front of the entrance, apparently to determine whether the coast is clear-that is, whether they can dart in at the entrance without opposition. If it is a case of robbing, the colony has been overpowered; and the actions of the robbers are for all the world like those at play.

2. A playspell is of short duration. With robbing there is no let up. If the demonstration of flying bees begins to subside, and finally stops altogether, one may rest easy. But if the flight keeps up for half an hour or more, something is going wrong. The entrance should be contracted, and the colony should be treated as recommended under Robbing. See Drifting.

POISONED BROOD.-See FRUIT-BLOSsoms and FOUL BROOD. 
POISONOUS HONEY.-There are cases on record, apparently authenticated, which seem to show that honey gathered from flowers of plants that are in themselves poisonous is also poisonous either to human beings or to the bees themselves, or both. Xenophon tells how, in the memorable march of the ten thousand Greek soldiers to the sea, some of them were taken seriously ill after eating poisonous honey. The facts are so carefully and minutely recorded as to leave no doubt of the honeypoisoning.

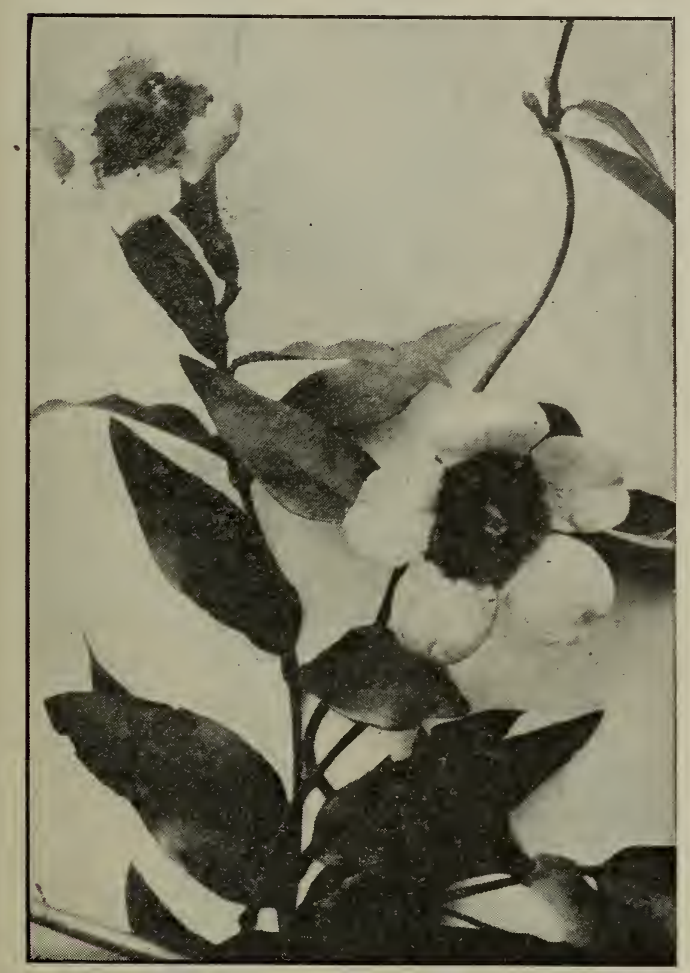

Yellow jessamine.

The wild honey in one or two of the southern states, in some very isolated localities, is reported to produce sickness, and in some instances this is so sudden and violent that it has given occasion for alarm. In certain regions of Virginia, especially near Halifax Court-house, there is grown quite extensively in the mountains mountain laurel. The bees are very fond of it; and while it does not seem to affect them particularly, it is dangerous to human beings, or at least is so reported. The plant itself is an extremely distressing narcotic, varying in effects according to the quantity taken into the stomach. Dr. Grammer, of Halifax Court-house, reports that, during the late civil war, himself and quite a number of comrades were poisoned by eating honey from this plant. There was, he says, a queer sensation of tingling all over, indistinct vision, with an empty, dizzy feeling about the head, and a horrible nausea that could not be relieved by vomiting. This lasted for an hour or so, while the effects did not wear off for several days.

The lambkill (Kalmia angustifolia) and the mountain laurel ( $K$. latifolia) are abundant over large areas, and in the mountains of Carolina the mountain laurel often presents an unbroken sheet of bloom. If the honey were deleterious frequent reports of illness might be expected, but nothing of the sort happens. Kalm, the Swedish traveler, after whom the genus Kalmia is named, says that if domestic animals eat the leaves they fall sick or die, but that they are harmless to wild animals. The belief that the leaves are poisonous seems to have extended to the honey. But Dr. Bigelow states in his Medical Botany that he repeatedly chewed and swallowed a green leaf of the largest size, without perceiving the least effect in consequence. A powder made from leaves recently dried in doses from ten to twenty grains produced no perceptible effect. The taste of the leaves is perfectly mild and mucilaginous. Dr. Bigelow believed that the noxious effect of the leaves on young domestic animals was due to their indigestible quality. The probability is that the honey is entirely harmless; the matter should be tested, using, of course, proper caution.

In Georgia and Florida the yellow jessamine (Gelsemium sempervirens) is very abundant, and the bees visit the yellow blossoms from February to March. But a surplus of jessamine honey seems never to be obtained, and it is useful chiefly for spring stimulation. According to E. G. Baldwin no injurious effect has ever been observed either from the nectar or the honey in the hives.

POLLEN.-The anthers of flowers are composed of four sacs, which contain numerous small dust-like grains called pollen or microspores. Pollen is a highly nutritious food which is eagerly eaten by many insects, and is gathered in large quantities by bees as food for their brood. A pollen 
grain is protected by an inner and an outer coat (in a few species there is but one coat), and is filled with a semiliquid in which float many minute granules. Its contents form a complete food, consisting of

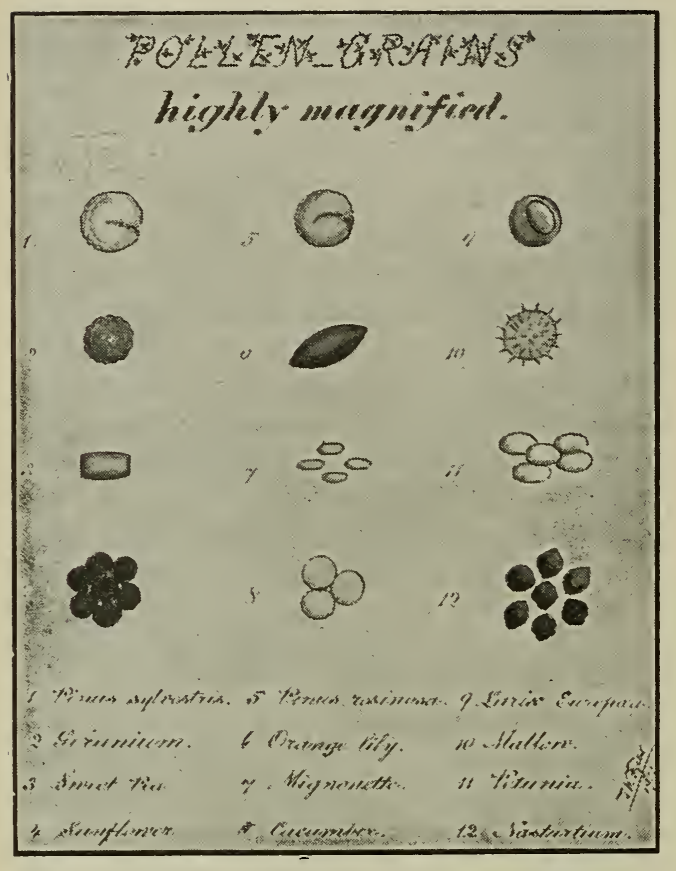

-After Fletcher.

proteids, substances rich in nitrogen, sulphur, and phosphorus; and carbohydrates, or starch, oil, and sugar. Pollen thus offers a rich supply of easily obtained nourishment to all insects, especially to those which are not predaceous.

Pollen grains vary in size from $1 / 100$ of an inch in Iris to $1 / 3000$ of an inch in some saxifrages. The number of pollen grains is also very variable but is usually large. Each anther of the peony has been estimated to produce 21,000 grains; and if there are 174 stamens to a flower there would be $3,654,000$ grains. In wisteria there are said to be 7000 grains to each ovule. The excess of pollen is thus so large as to permit of much waste. In shape the grains may be globular, ellipsoidal, polyhedral, or of the form of a dumb-bell in the borage family; or in some Polygalaceae they have the sbape of "a wickerwork basket." The outer coat may be banded, ribbed, or checkered, and beset with sharp teeth, points, spines, prickles, or knobs; variation in the sculpturing is, indeed, almost endless. The air in the numerous little pits and hollows on the surface of the grains protects them from contact with water. The projections enable them to adhere to insects. While yellow is the prevalent color, red, blue, brown, and green hues also occur.

\section{THE BEHAVIOR OF BEES IN COLLECTING POLLEN.}

The behavior of bees in collecting pollen is of great interest to both beekeepers and fruit-growers. Bees are the only insects which feed their brood on pollen, to obtain which in sufficient quantities they are compelled to visit a great variety of flowers, and incidentally are thus most valuable agents in pollination. The small primitive bees of the genus Prosopis have nearly smooth bodies, and the pollen-brushes on the hind legs are so feebly developed that they are little better adapted for carrying pollen than the wasps. The common ground bees of the genera Halictus and Andrena show a much greater advance. The body is hairy, and the hind legs are entirely covered with collecting hairs, which become filled with loose, dry pollen grains. A further step in the development of the pollen-collecting apparatus of the hind legs was the acquisi-

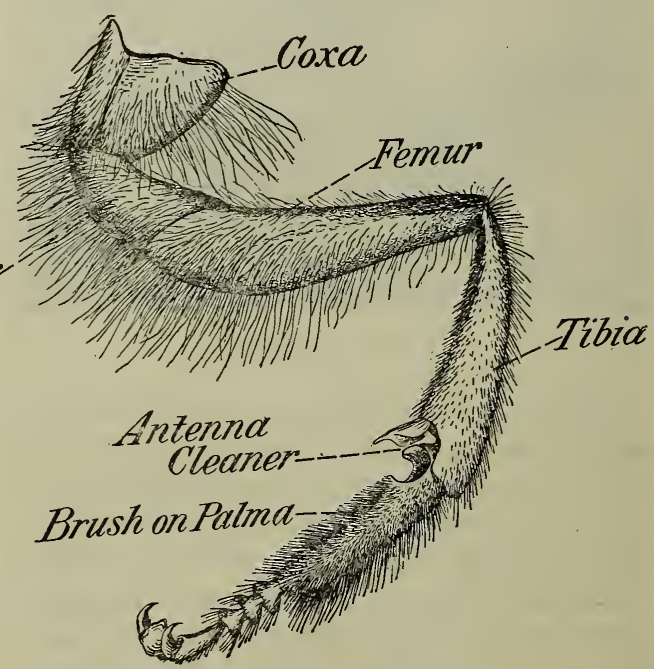

FIG. 1. - Left fore leg of a worker bee.Bulletin No. 121, Bureau of Entomology.

tion of the habit of moistening the pollen with honey. Among the solitary bees, Macropis and the Panurgidae carry in this way large balls of damp pollen moistened with freshly gathered nectar. Finally among the 

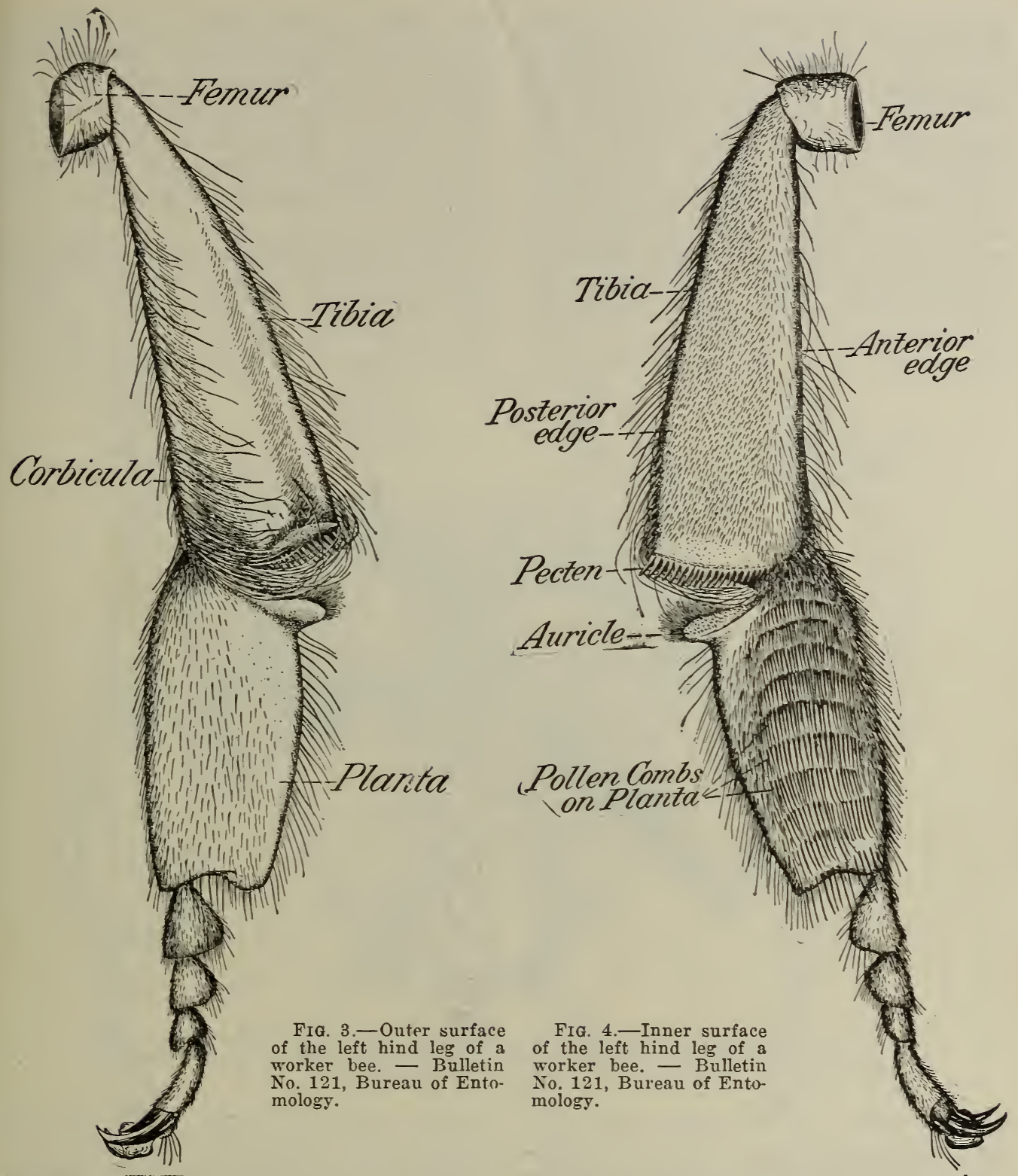

bumblebees and honeybees there occur on the hind legs structures called corbiculæ or pollen-baskets in which the damp pollen is packed, while the tarsal brushes are highly specialized. In honeybees the tibial spurs on the hind legs, used by the wasps and solitary bees in digging holes in the ground, have been lost because no longer useful.

In another series of bees the Megachilidae, or leaf-cutting bees, the pollen-collecting hairs form a stiff brush on the under side of the abdomen. These hairs slant backward and vary in length and color in the different species. As the bees crawl over level-topped flowers, like the sunflower

and other species of Compositae, which have a large amount of free pollen on the surface, the abdominal brush becomes filled with dry pollen. The leaf-cutting bees are also very common visitors to leguminous flowers, as the vetches and clover, which have an apparatus for placing pollen on the under side of the bodies of insects. This large family of bees has become adapted to collect pollen chiefly from these two groups of flowers. None of the species moisten the pollen with honey.

The behavior of the honeybee in collecting pollen has been carefully investigated and described by Casteel. ("Behavior of the 
Honeybee in Collecting Pollen," D. B Casteel, Bur. Ent., Bull. 121.) Honeybees collect pollen from flowers by the aid of the mouth parts, the three pairs of legs, and the dense coat of long plumose hairs. The feather-like structure of the hairs enables them better to retain the pollen which falls upon them. The mouth parts are especially serviceable in the case of small flowers, or of those which produce little pollen. The mandibles are actively used in biting and scraping the anthers and freeing the pollen, which is brushed up by the Maxillae and legs bears a dense brush of unbranched hairs, which on the plantae of the hind legs has become modified into a regular series of transverse combs. The palmar brushes of the fore-legs take away the mass of wet pollen from the mouth parts, and collect the dry pollen from the pubescence on the head.

The metatarsal brushes of the midlde leg's receive the pollen from the first pair of legs and transfer it to the plantar brushes of the hind legs. This transfer is effected by drawing each of the middle legs between the

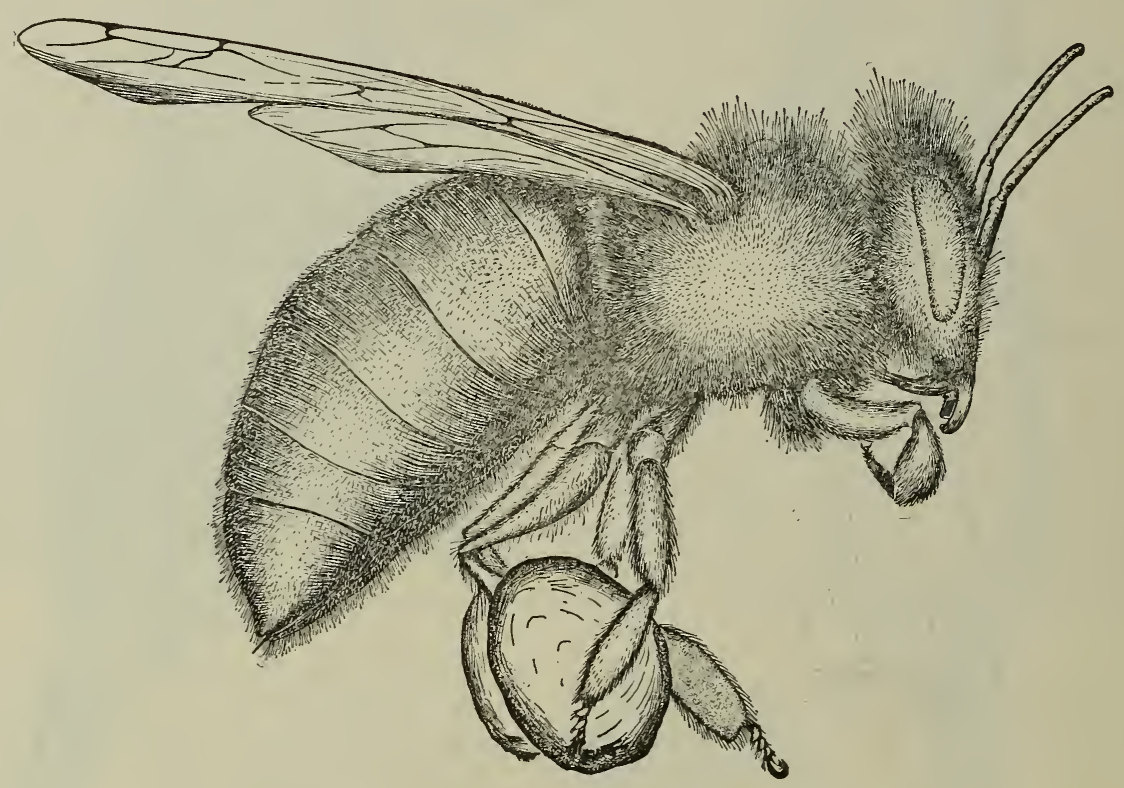

FIG. 6.-A bee upon the wing, showing the position of the middle legs when they touch and pat down the pollen masses. A very slight amount of pollen reaches the corbiculae thru this movement. -Bulletin No. 121, Bureau of Entomology.

slender tongue. All the pollen gathered by the mouth parts is very thoroly moistened with nectar or honey which comes from the mouth. It is, indeed, so wet that in its transfer to the pollen-baskets the hair on the breast and the brushes of the legs becomes so damp that it easily moistens the dry pollen swept from the bee's body.

The leg of a bee is composed of nine segments: The coxa, by which it is attached to the body; the trochanter, femur or thigh, tibia or shin, and the five tarsi. The first tarsal segment, or metatarsus, is as long as the four tarsal segments together. This segment of the fore-legs is called the palma (palm), and of the middle and hind legs the planta (sole). The inner side of the metatarsal segments of all three pairs of plantae of the hind legs. In this way the pollen on the left middle leg is scraped off on the pollen combs of the right hind leg, and the pollen on the right middle leg is scraped off on the pollen combs of the left hind leg. The middle legs also brush off the pollen entangled in the hair on the thorax, which is moistened by coming in contact with the wet pollen from the mouth parts. The middle legs are further used to pat down and compact the pollen mass in the pollen-baskets, to which they sometimes add a small amount of pollen.

The hind legs are very highly specialized for carrying the pollen masses. The tibia is dilated at its lower extremity and the metatarsal segments (plantae) are much thinner and wider than the corresponding 
segments of the fore and middle legs. The pollen-basket or corbicula is a longitudinal groove on the outer side of the tibia. It is broadest at the lower end and is nearly surrounded by a salient rim. On the front edge of the tibia there is a fringe of hairs overarching the pollen-basket, and on the hind edge a row of hairs slanting backward. The floor of the basket is nearly smooth except for a few small spines near the entrance. The moistened pollen is held in spines. Its inner edge, when the leg is straightened, slips along the spines of the pecten, while its outer edge which is fringed with hairs projects into the entrance of the pollen-basket. The end of the tibia and the auricle have the appearance of a pair of jaws or pincers; and in the older works on bee culture are erroneously described as being used for taking scales of wax from the wax-pockets. The inner side of the planta, or metatarsus, is covered with about
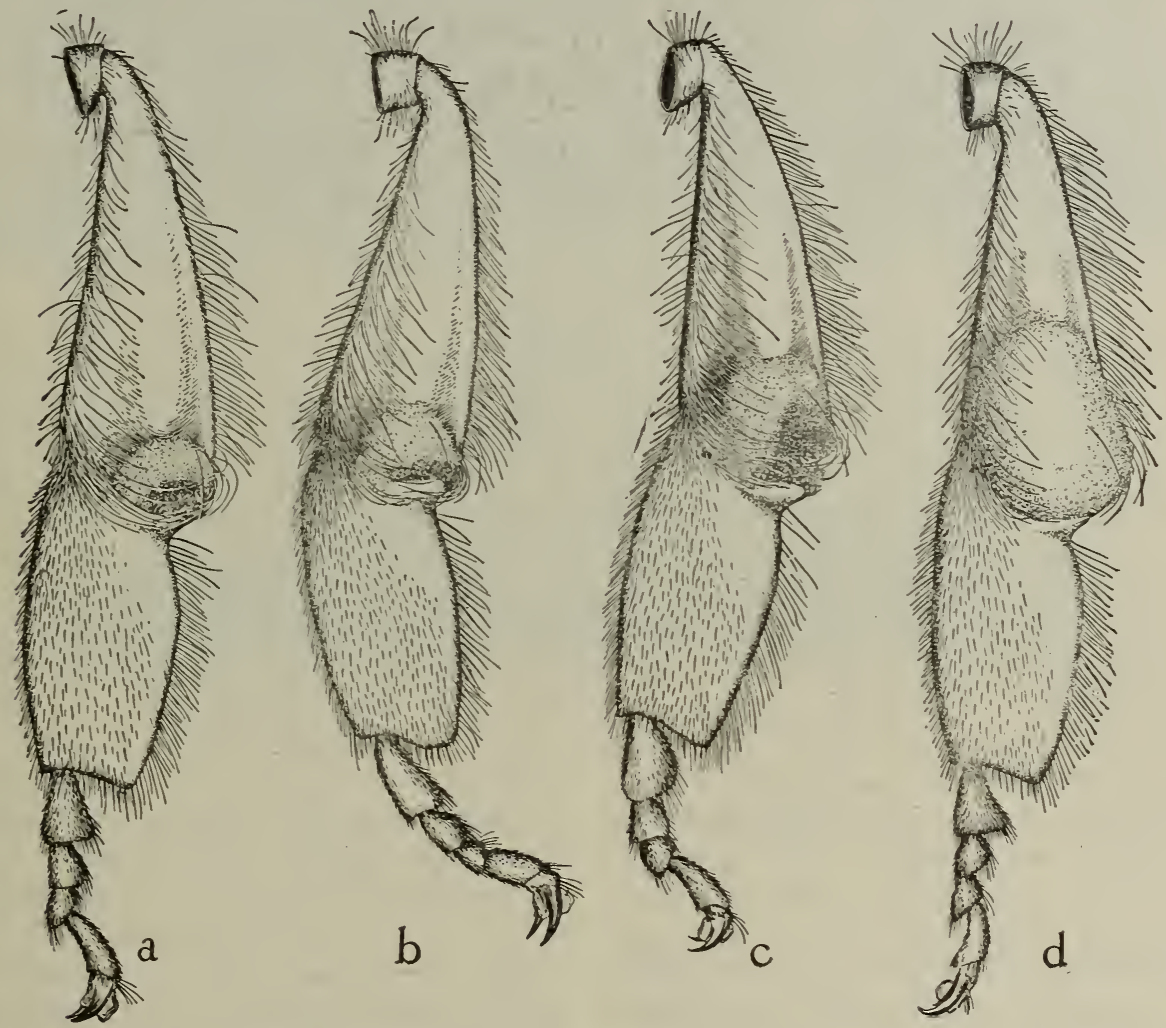

FIG. 8.-Camera drawings of the left hind legs of worker bees to show the mamner in which pollen enters the basket. $a$, shows a leg taken from a bee which is just beginning to collect. It had crawled over a few flowers and had flown in the air about five seconds at the time of capture. The pollen mass lies at the entrance of the basket, covering over the fine hairs which lie nlong this margin and the seven on eight short stiff spines which spring from the floor of the corbicula immediately above its lower edge. As yet the pollen has not come in contact with the one long hair which rises from the floor and arches over the entrance. The planta is extended, thus lowering the auricle; $b$, represents a slightly later stage, showing the increase of pollen. The planta is flexed, raising the auricle. The hairs which extend outward and upward from the lateral edge of the auricle press upon the lower and outer surface of the small pollen mass, retaining it and guiding it upward into the basket; $c$, $d$, represent slightly later stages in the successire processes by which additional pollen enters the basket. - Bulletin No. 121, Bureau of Entomology.

position largely by its adhesiveness. The lower end of the tibia, except the articulation, is truncated, slightly concave, and fringed along its inner margin with 15 to 21 stiff spines, inclined backward, called the pecten. Immediately below the flattened end of the tibia on the upper edge of the planta is the auricle. This ear-shaped structure is concare and covered with short eleven transverse rows of stiff spines which serve as pollen combs. The spines of the lowest comb are the largest and are used for picking up wax scales. This highly specialized apparatus receives the pollen and loads it into the pollen-baskets.

Most of the pollen on the plantar combs of the hind legs is received from the middle legs as has been described, but a portion of 


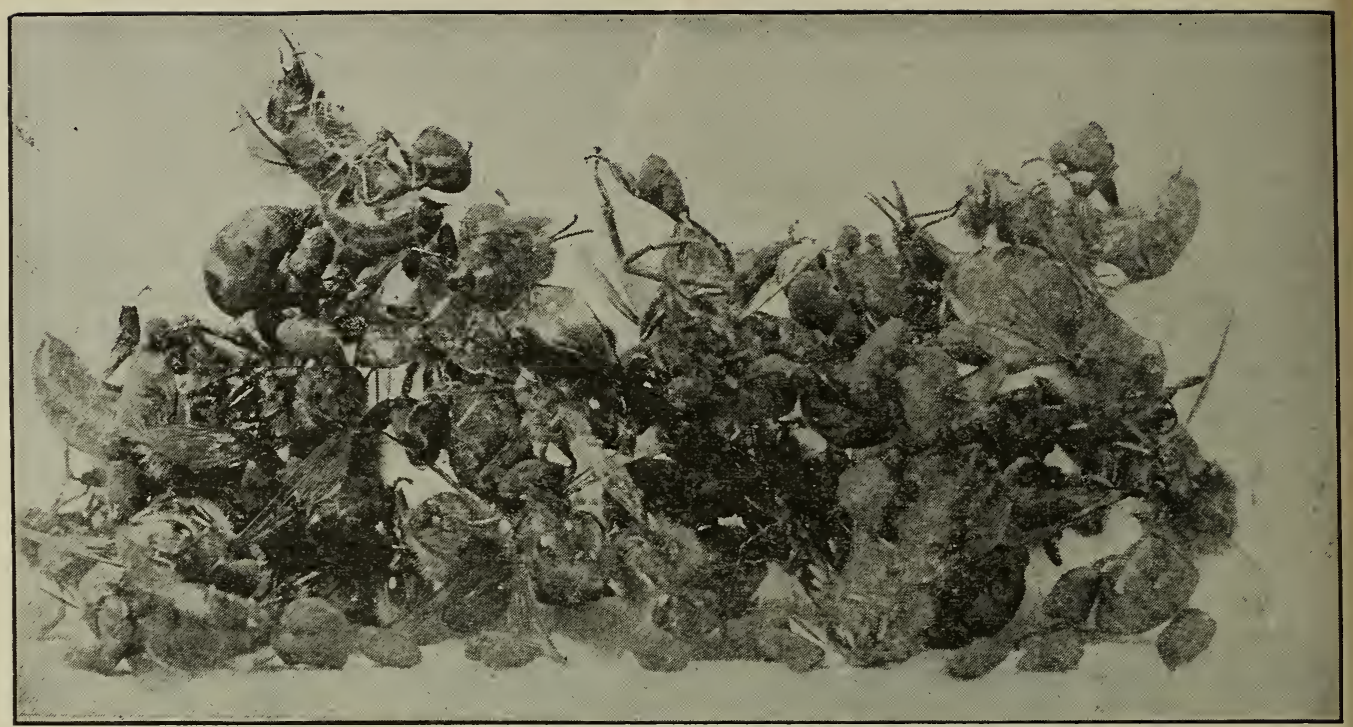

Bees with masses of pollen on their legs.

it is swept from the abdomen. During the act of loading the pollen into the corbiculæ, which has been described in much detail by Casteel, the hind legs hang downward beneath the abdomen, and the plantar combs are in contact for most of their length. If pollen is to be loaded into the left pollenbasket the right planta is drawn upward, scraping against the pecten of the left leg. A small portion of the pollen will be left on the spines and the end of the tibia. The left leg is then flexed, pushing the auricle against the flat end of the tibia, squeezing out a thin layer of pollen. The spines of the pecten prevent this layer of pollen from escaping on the inner side, but an the outer side there is a way open to the pollen-basket. In a similar way pollen is transferred from the plantar combs of the left leg to the right pollen-basket. The movements alternate very rapidly, the legs rising and falling with a pump-like motion. As the amount of pollen loaded at each stroke is very small a great many strokes are required.

The pollen at first lies at the extreme lower end of the pollen-basket, but as successive layers are added it is gradually pushed upward. If pollen from different species of flowers and of different colors, which occasionally happens, is collected, the mass will have a stratified appearance. The shape of the pollen mass is largely determined by the hairs which fringe the sides of the basket. The hairs on the front edge, which curve inward, prevent it from projecting far forward; while the hairs on the posterior edge, inclined outward, permit it to extend backward far outside of the tibia. Casteel found it possible to manipulate the legs of a recently killed bee with a pair of forceps, and artificially load the pollenbaskets with thin layers of pollen as has been described. It was formerly believed that in loading the pollen-baskets the hind legs were crossed, and the plantar combs scraped over the edges of the baskets and the fringes of hair. On trial it is found that this method yields wholly different results.

Chemical analysis shows that the liquid with which the pollen is moistened is chiefly honey or nectar recently gathered. In pollen taken directly from the anthers of corn the sugar content was 11 per cent, while in pollen from the pollen-baskets the sugar content was 28 per cent, showing that a large amount of sugar had been added. Since the pollen from the corbiculæ contains three times as much reducing sugar as sucrose it is indicated that the liquid added is honey (largely a reducing sugar) rather than nectar which contains more sucrose. The wild solitary bees, however, certainly make use of freshly gathered nectar in collecting pollen from nectarless flowers. If any saliva is used by the honeybee it is so small as to be of no significance.

Honeybees make their collecting trips more frequently in the morning than in the latter part of the day. Young bees return- 
ing with their first loads are said to show great excitement, while the older bees more about leisurely. After a suitable cell has been selected, which may take some time, the bee grasps, according to Casteel, one edge with its fore-legs, while the apical end of the abdomen rests on the other side of the cell. The hind legs hang free within the cell, the pollen masses about eren with its margin. The pollen masses are then forcibly thrust out of the baskets by the plantæ of the middle legs. The bee then usualis departs, learing to another worker the fore legs, and within easy reach of the autennæ.

If flour is dusted upon these organs the bee will immediately slip this notch orer the antennæ, push the spur orer to place, cleaning every portion of the antennæ at two or three sweeps. Some hare thought that the same derice is used for cleaning the tongue in a similar manner, but this is hardly probable. The tongue, unless at the extreme end, is too large to go in this opening. If it could be used for cleaning the tongue the delicate cleaner would become smeared

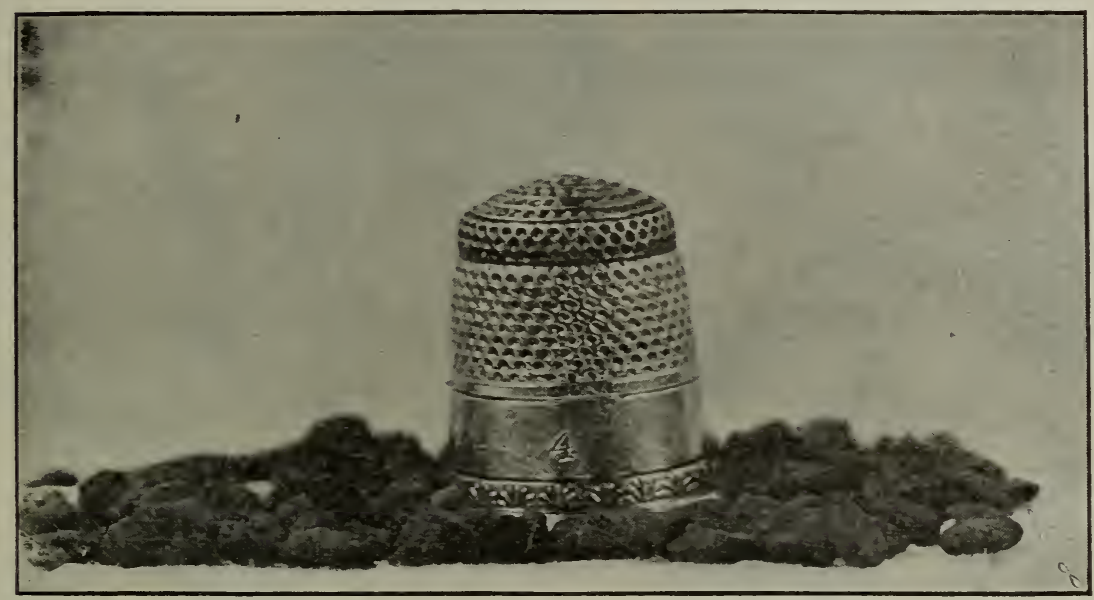

Masses of pollen taken from legs of bees. These were photographed with a thimble to show the relatice size.

packing of the pollen in the cell. The pellets are broken up and pressed downward, and sugar and perhaps some other liquid is added to preserve them.

If one desires to witness some of these comical sleight-of-hand performances, for, indeed, they are little short of real legerdemain, he needs to dust only a few bees with common flour and note what happens.

Reference was made to the fact that the bee cleans its antennæ with its fore legs. If these delicate organs of sense and hearing be in any way impeded by a smearing of pollen the bee is unable to communicate with its fellows or perform satisfactorily the functions of the hive. See SExse Orfrans of BeEs. By referring to the cut shown on p. 560, left fore leg of the worker bee there will be found a little notch. Just over this notch is a spur. This opening is fringed on the inside with a row of hairs. It will be noted that this cleaner is located, we might say, in the "elbow" of the with honey, and thus what would appear to be its primary function as an antennæcleaner would be destroyed.

NECESSITY OF POLLEN FOR BROOD-REARING.

We are interested about pollen, because bees cannot rear brood without either that or some substitute for it. Bees kept in confinement, and fed on pure sugar and pure water, will thrive and roid little or no excrement; but as soon as pollen, or food containing the farinaceous element, is given them, their bodies will become distended; and instead of a transparent fluid they will void a liquid of a darkish tint which will soil their hives and emit quite an unpleasant smell. We once kept about 300 bees in a cage with a queen, and gare them only pure sugar and water. They built comb, and seemed quite contented, the cage emitting no smell whatever. In order to start broodrearing we gave them some sugar candy containing flour, and they soon became un- 


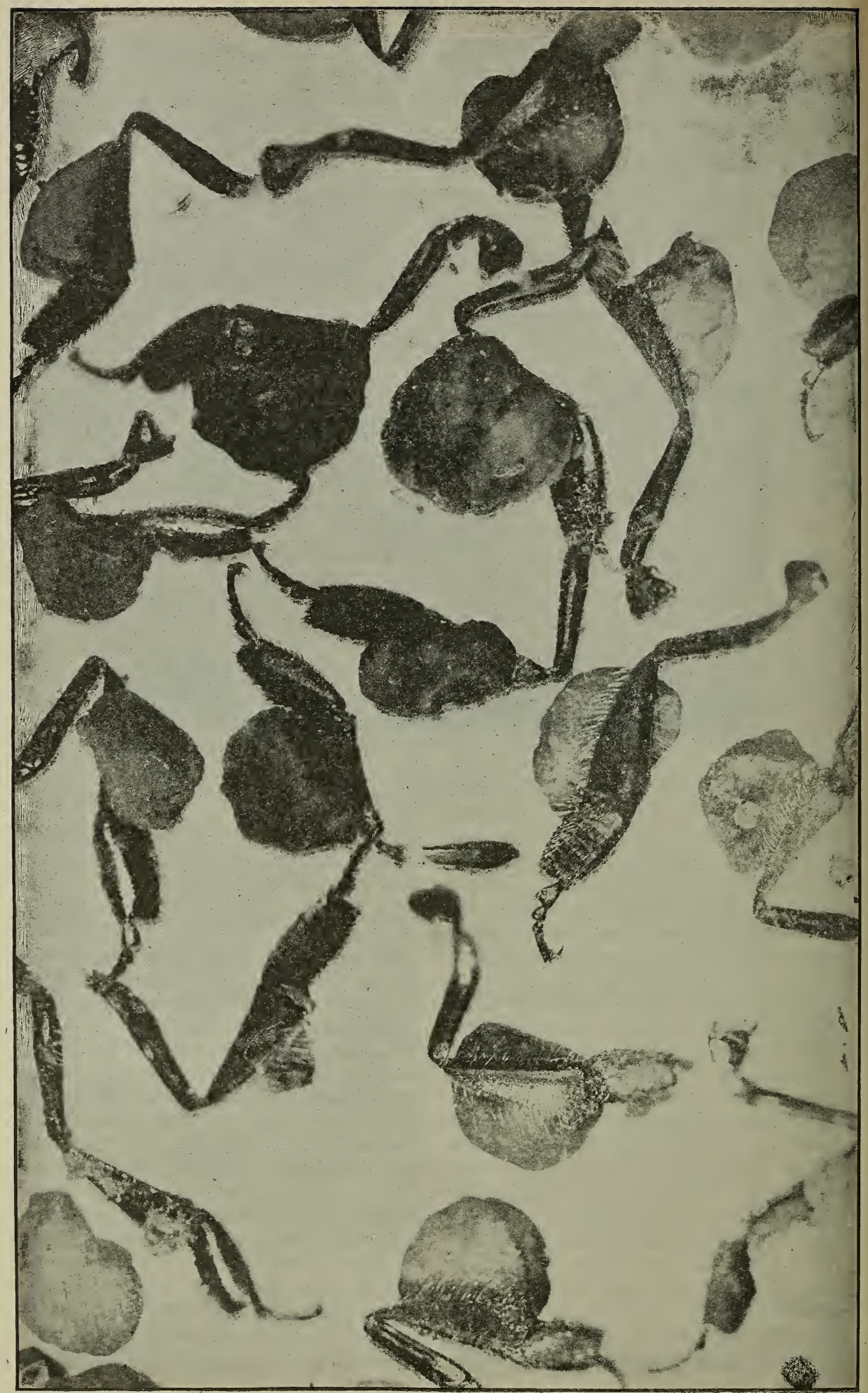

Pollen masses on legs of bees,-Photo by E. F. Bigelow. Several show side hairs (like stakes on a hay. wagon) to hold tho load. 
easy and tried in vain to get out. At this time the cage gare off quite an unpleasant smell, and so they were allowed to fly. Had the pollen element not been given them, it is probable they could have endured the confinement a month or more. We once wintered a fair colony of bees on stores of pure sugar syrup, and when they flew in the spring there was no perceptible spot on the white snow about their hives. They had no pollen, and so, of course, no brood-rearing could go on without it. A few years ago we made some experiments with bees confined in a large room under glass. As it was late in the fall, after brood-rearing had ceased, we did not know whether we should succeed in starting them again. After feeding them for about a week, eggs were found in the cells, but none of them hatched into larræ. A heap of rye meal was placed in the center of the room near the feed, and anxiously we waited to see them take notice of it. After several days a bee was seen hovering curiously about it. In breathless suspense we watched it until it finally began to dip its tongue into the heap, and then to pad it on its legs. It carried home a small load. We had the hive open, and the frame out. as soon as it was among its comrades, and watched the behavior of the rest while it shook itself among them, until it deposited its treasure in a cell, and hurried away for another load. Very shortly some of the rest followed it, and buzzed about the room until they found where it was loading up, and soon they were at work on the meal, as merrily as in spring. Of course, the eggs were very soon, now, transformed into unsealed larvæ, then into capped brood, and, in due time. we had young bees hatched out in the month of December.

By warming the room with a stove for sereral days in succession, we found we could start brood-rearing and pollen-gathering eren in the month of January. It may be well to state here, that, altho we succeeded in rearing bees in midwinter, as strong and healthy, apparently, as those raised in summer time, the experiment was hardly a success after all; for about as many bees died from what we suppose was the effect of confinement as were hatched out.* It was a decided success in determin-

* In the very large greenhouses covering acres of ground, where bees are used as pollinating agents, we have been informed that they do not bump against the glass and die by the hundreds. ing many unknown points in regard to bees, aside from the office of pollen; and we presume, if it ever should be necessary, we could overcome the difficulties of flying bees under glass. Under the head of FruitBLOSSOMS will be found further facts on this matter.

\section{ARTIFICIAL SUBSTITUTES FOR POLLEN.}

It has been known for many years, that in the spring time bees will make use of the flour or meal of many kinds of grain, and many beekeepers feed bushels of it every season. The favorite seems to be rye; and as the bees are apt to fall into it and sometimes get so corered as to perish, we have been in the habit of having the rye ground up with an equal quantity of oats. A great many plans hare been devised for feeding it withcut waste; but, after all our experiments, a heap of meal on the ground is about as satisfactory as any way. Of course, it should be protected from rain; and as there is usually much high wind in the spring, which is, to say the least, very annoving to the bees, it is well to have it in a spot sheltered as much as possible, always aiming to give them as much sunshine as may be. By way of experiment, we have concentrated the rays of the sun on the meal heap by mirrors, that the bees might work on days otherwise too cold; we have also made glass-corered structures for the purpose, and have even kept their meals hot by means of a lamp; all these plans hare succeeded, but we are inclined to doubt whether stocks pushed along in brocd-rearing, by such means, were really in adrance of some that were left to take their chances. It is amusing to see the little fellows start from their hires on days so cold that they would not otherwise stir out, hie to the warm meal and load up, and then go home so quickly that they do not hare time to get chilled.

Is there any danger of feeding them too much meal? There is. Reports and our own experience have shown that bees will sometimes get their combs packed with this inferior substitute for the real article: and we would advise giving it only during those seasons when there seems to be a lack of natural pollen. As a general thing, nature supplies bees with all the nitrogenous food they require, and quite early enough. If rye meal be given on a warm day when the bees can fly in mid-winter they will store 
some of this meal and start brood-rearing; then when cold weather comes on again, the brood is deserted and dies. Nature, on the other hand, will not supply this food before the proper time for brood-rearing to come on. But the question may arise, "How is the owner of the bees to know when nature is not supplying them a farinaceous diet?" If the bees seem to be hovering around chicken-houses, barns, and stables, then it is apparent that they are not getting sufficient pollen to feed, and they should be supplied artificially as already explained.

Not a few of our readers have been perplexed and astonished, doubtless, by seeing the bees, in early spring, greedily appropriating sawdust, just as they do rye meal. We have seen them at the sawmills, so thick on a large heap of fresh sawdust as to attract a large crowd of people; and when we caught them, and tasted of the pollen from their legs, we were somewhat amazed to find it sweet and very much like pollen from the flowers. They doubtless had plenty of honey but no pollen, and these fine particles of wood contained enough of the nitrogenous element to answer very well, mixed with honey, as they have it when packed in their pollen-baskets. The pollen substitute from common sawdust contains an essential oil, besides some gummy matter, that gives an odor doubtless reminding the bees of the aroma of opening buds. Not only do they thus collect (to us) tasteless sawdust, but they have been found at different times on a great variety of substances. A friend in Michigan at one time found them loading up with the fine black earth of the swamps, and they have been known to use even coal-dusí ; but the strangest thing of all was told us by the owner of a cheese-factory near by. He said the bees were one day observed hovering over the shelves in the cheese-room, and, as their numbers increased, they were found to be packing on their legs the fine dust that had accumulated from handling so much cheese. Microscopic investigation showed this dust to be embryo cheese-mites, so that the bees had really been using animal food as pollen, and living animals at that. If one might be allowed to theorize in the matter, it would seem this should be a rare substance to crowd brood-rearing to its uttermost limit. HOW TO START BEES AT WORK ON RYE MEAL.

A beginner hears the feeding of oatmeal highly recommended as a substitute for pollen. He places some near the entrances of the hives, but not a bee touches it. He is told again to wait until early spring, before the bees have access to natural pollen, and then they will take it. He does so, but, as before, not a bee notices it. He is next told to put a heap of it in the sun, a few rods distant from the hives. This time he may succeed; but it would not be strange if he should once more report that his bees would have nothing to do with it. Finally he is directed to take a piece of honey and get some bees to feeding on it, then to set it on the heap of meal.* The bees soon gather over it in great numbers; those that go home loaded start out many more searching all about the vicinity, to see where the treasure comes from. The hum of the busy ones on the honey soon attracts them, and, in snuffing about the pile of meal, some bee discovers that it can be used as a substitute for pollen; the others soon follow suit, and, in a little time, both the bees and their owner are happy, and the pile of meal quickly disappears. After this he never has any more trouble in getting the bees to work on meal, for he knows how. The bees and their owner have both learned a valuable lesson about pollen. Is there any very great difference in the way they have been taught? Did they not both learn by practical experiment?

\section{BEES ROBBING ARTIFICIAL POLLEN FROM BARNS AND STABLES.}

There are times when bees will not only find sawdust but delve down into chop feed for cattle. On such occasions they will raid barns, stables, and chicken-houses in a way that seems almost like a regular case of robbing. In the spring of 1909 numerous reports from all over the country told how bees had invaded premises of farmers, driving cattle out of the stables, and causing annoyance generally. One of our own

* Even this does not always suffice; but if a little lycopodium powder-just a spoonful-be scattered on the meal the bees will very quickly begin work. They seem passionately fond of this powder, which is the spores of a club-moss, Lycopodium, those beautiful evergreens so much used for Christmas decorations. It is often adultered with pinetree pollen, which of course does not hurt it for the beekeeper. If one desires he may cut the tassels from a lot of corn just when the pollen begins to drop, and lay these on papers in some dry room. In a week or so they may be put in a box and saved for the following spring, and used as directed for lycopodium. They contain sufficient pollen to start the bees on the meal.-A. C. M. 
neighbors telephoned us one day, saying that a swarm of bees had taken possession of his chicken-house, and that he would like to have us come and take the bees out. Investigation showed there was no swarm, but the inside of the building was filled with bees. At first we were inclined to think that syrup of some kind had been stored there, as it looked like a genuine case of robbing; but careful examination of the floor where the chickens had been fed showed the desire of the bees for nitrogenous food was so great that they had invaded this chickenhouse and helped themselves to the bran and screenings.

A few days later a farmer located near one of our outyards complained that our bees had taken possession of his cow-stables, saying that the cows were stung, and that it was impossible for man or beast to enter the barn. We sent a man down to investigate, and he found, as in the former case, that the bees were after chopped feed.

The spring had been very peculiar-so peculiar, in fact, that warm weather came on without any natural supply of pollen. The time for rearing brood had come; and the poor bees, thru dire necessity, were compelled to help themselres to anything they could find. Wher a few of their number found a substitute for pollen they were wild with excitement, and rushed pellmell into every stable and barn where there was any trace of meal of any sort. It is in seasons like this that the apiarist should be forehanded enough to supply them with all the rye meal they can use. But this supply should be cut off just about as pollen from natural sources begins to come in.*

During that spring a great deal of dead brood was reported, and it was believed at the time to be due to a lack of nitrogenous food.

POLLEN IN SFCTION BOXES AND COMB HONEY.

We do not mean to convey the idea that we should be satisfied with pollen in our honey, for a very good and useful thing is sometimes a very bad one, if out of place. When pollen or meal is brought into the hive, it is taken at once very near the brood; in fact, it is placed in the comb opposite, if possible. When opening hives in the spring, we find pollen scattered all

* Indeed, it will be found that bees will disregard the substitute as soon as pollen can be had. C. C. M. thru the brood-combs to some extent; but the two combs next the two outside broodcombs are often a solid mass of pollen. Should a few stormy days intervene, however, this will disappear so quickly that one who has not witnessed the rapidity with which it is used in brood-rearing would not know how to account for it. When it is gone, of course the brood-rearing must cease, altho the queen may continue to lay. The amount of brood that can be reared by keeping a stock supplied with pollen artificially, during such unfavorable weather, is a very important item where rapid increase of stock is desired.

Some of those who use shallow hives have complained that pollen would go up into the sections. It has been claimed by the users of shallow frames that this can be usually obviated by putting a comb of pollen in the brood-nest* The presence of this below will usually induce the storage of more pollen in the same place, leaving the sections clear for the storage of honey only. The same principle will apply of course to deeper hives; but it is very seldom that pollen will be found in the sections where the brood-nest is as deep as the Langstroth. It is where there is less depth that there is danger.

QUEEN-EXCLUDING HONEY-BOARDS DO NOT NECESSARILY EXCLUDE POLLEN.

It is said that the strips of perforated zine in the slatted honey-board will largely prevent the storage of pollen above. From what experience we have had, we are inclined to think the zine will discourage it to some extent; but if contraction be carried too far, the bees will put the pollen where they please, zine or no zinc.

For a further consideration of this subject see Fruit-BLOsSoms also.

POLLINATION OF FLOWERS.-Before we consider the wonderful little schemes by means of which flowers are pollinated, we should become acquainted with the names of the different organs or parts of the flower. In the accompanying illustration we have a figure of what is known as an hermaphrodite flower-that is, one containing both stamens and pistils. Many of the specimens shown deviate from a perfect flower. If some common flower,

\footnotetext{
* I seriously question this.-C. C. M.
} 
as a rose or buttercup, is selected for examination, it will be seèn to consist of numerous small thread-like organs surrounded by two whorls of leaves. The outer circle of leaves is green, and forms the calyx, or cup, each leaf of which is called a sepal. The office of the calyx is to protect the inner and more delicate organs, especially in the bud, when the calyx alone is visible. The second circle of leaves is large and bright-colored-red, white, or yellow in the rose, and yellow in the buttercup; this is

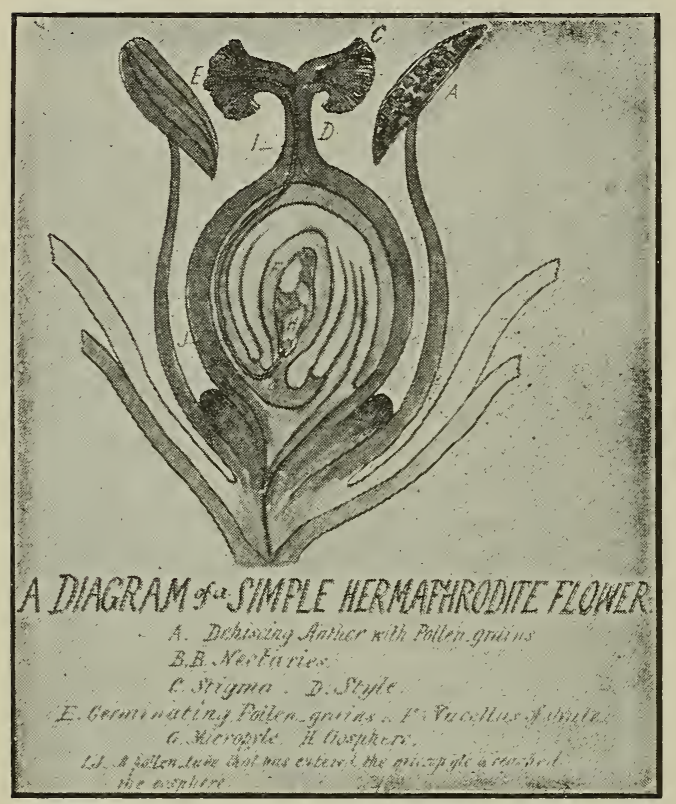

-After Fletcher.

the corolla, or little crown, and each leaf is known as a petal. The brilliant hues of the corolla are designed to attract the attention of insects. Within the corolla are the stamens, composed of slender stems, and the filaments, bearing the four-celled anthers, which contain fine grains of powder known as pollen. In the center of the flower stand the pistils. Usually a pistil consists of three parts-the ovary, style, and stigma; but the style is sometimes wanting. The base of the pistil is the ovary, and is a capsule containing the nascent, unfertilized ovules; the style is a porous stalk rising from the ovary, and bearing at its upper end a glutinous receptive surface called the stigma. Pollination is the transference of pollen from the anthers to the stigma. If the pollen is from the same flower it is selfpollination; but if from a different flower of the same species it is cross-pollination. Cross-pollination between the flowers of different species is hybridization.

Soon after a grain of pollen has lodged on the stigma, if the proper conditions exist, it sends out a slender tube which grows down thru the porous style, by which it is nourished, until it comes to one of the ovules in the ovary. It enters the ovule by a little orifice (micropyle, meaning little gate), and there passes from the end of the tube a male cell or germ, which unites with an egg cell in the ovule-this is fertilization. Fertilization does not always occur immediately after pollination; for instance, the flowers of witch-hazel are pollinated in the fall, but fertilization does not occur until the following spring. It would be well to bear in mind these botanical terms in the descriptions which follow, in order to understand how beautiful and perfect is the design in nature in bringing about cross-pollination.

Before we consider a few of the mutual relations of flowers and insects for the purpose of ensuring cross-pollination, something should be said about the importance of crossing, both in the animal and vegetable kingdom. The effects of self-fertilization and cross-fertilization were first clearly pointed out by Charles Darwin. He was experimenting with two beds of toadflax, or butter-and-eggs (Linaria vulgaris), one set being the offspring of self-fertilization and the other of cross-fertilization. The plants had been raised for the purpose of studying heredity, and not the results of cross-breeding. To his astonishment he observed that the plants which were the result of cross-breeding were far more vigorous than the others. He temporarily abandoned all his other investigations and devoted himself to making numerous experiments in interbreeding, and to acquiring information as to the practical experience of horticulturists and breeders of animals.

As the result of his inquiries he laid down the general law that no species of animal or plant can fertilize itself thru numberless generations, and that an occasional cross is indispensable. The evil effects of interbreeding had, indeed, long been known in a general way, and are even instinctively recognized by barbarous races. The deterioration goes on so slow- 
$1 y$ at first that it is not easily discovered; but finally results in loss of size, vigor, and fertility, and may be accompanied by deformity. The good effects of intercrossing are immediately manifest. When plants were crossed, their offspring were larger in size, grew more vigorously, bloomed a little earlier, and yielded more seed than their parents. The two parent plants, or animals, must not, however, be exactly alike. Since then, says Dr. Fletcher, endless observations have confirmed the accuracy of Darwin's law, and it has been found that, in the vast majority of plants, special appliances exist which will secure more or less frequent intercrossing.

A summary of the more important ways in which self-pollination and consequently self-fertilization are prevented in plants is given in the following table.

\section{A. SEPARATION OF STAMENS AND PISTILS BY SPACE.}

1. Stamens and pistils in different flowers, but on the same plant.

2. Stamens and pistils in different flowers and on different plants.

3. Stamens longer than the pistils, or pistils longer than the stamens.

4. Stamens bent away from the pistils, or pistils bent away from the stamens.

\section{B. SEPARATION OF STAJIENS AND PISTILS BY} TIME.

1. Anthers mature before the stigmas.

2. Stigmas mature before the anthers.

C. MECHANICAL SEPARATION OF THE STAMENS AND PISTILS.

1. Absolute separation. Anthers or pollen masses held in a fixed position, and never set free unless the flower is visited by insects.

2. Partial separation. Self-pollination may occur during the latter part of the blooming period.

\section{PHYSIOLOGICAL SEPARATION OF THE STA-} MIENS AND PISTILS.

1. Stamens aborted in some flowers, pistils in others.

2. Pollen from a different flower prepotent over pollen from the same flower.

3. Pollen from the same flower is sterile or impotent on the stigma.

But while there is wide provision for cross-pollination among flowers, they very generally retain the power of self-pollination, so that, in the event of the failure of cross-pollination, before the period of blooming closes self-pollination may occur.
The more common ways are as follows:

a. The stamens lengthen, contract, or bend so that the anthers touch, or drop pollen on the stigmas.

b. The pistils lengthen, contract, or bend so that the stigmas receive pollen from the anthers.

c. If lobed, the lobes of the stigma roll back so that they touch the anthers.

d. The filaments and styles become twisted together.

e. The corolla in wilting closes, causing the stigmas to be pollinated.

f. Self-pollination caused by the growth or movement of the petals.

g. Change in the position of the flower caused by the curving of the flower-stalk.

But while there are many plants in which self-pollination is a secondary result, there are also many which are regularly self-pollinated, and, consequently, self-fertilized. When the flowers expand, the anthers rest directly against the stigma, which thus necessarily receives the pollen. Many plants produce, besides conspicuous flowers, small green flowers, which never open, and which (though invariably self-fertilized) are very fertile. Many of these self-fertilized plants are very common, very vigorous and fertile, and extend orer a large portion of the earth, as the chickweed, shepherd's-purse, and doorweed. They prove conclusively that, though nature may abhor perpetual self-fertilization, she does not abhor selffertilization. On the contrary, it is a most valuable principle which is carefully preserved, and upon which the plant world is largely dependent. The contrivances, says Kerner, to bring about self-fertilization, are no less numerous than those which favor cross-pollination. "That flowers should be adapted at different times to two such diverse purposes as cross and self pollination is one of the marvels of floral construction."

These facts have led certain botanists to question Darwin's conclusions as to the evil results of continual self-fertilization, and to assert that the good effects of intercrossing are only a temporary stimulant and are not permanent. In only about five cases did Darwin carry his experiments beyond the third generation. In the opinion of Henslow, self-fertilized plants are best fitted to survive in the struggle for life. To sum up, he says they are very numerous, increase very rapidly, are very vigor- 
ous, flourish in the most neglected ground, and, being independent of insects, are best able to establish themselves in foreign countries, and are, therefore, of world-wide distribution.

It should, however, be noted that the forms which are continually self-fertilized are admittedly degraded or retrogressive species, or at least are not advancing in development. Like certain groups of animals they are adapted to certain places or conditions in nature where they appear able to maintain themselves indefinitely. But for races of plants which are rapidly evolving, cross-fertilization appears to be essential. Darwin showed that, when the offspring of cross-fertilization were brought into competition with the offspring of selffertilization, the former always gained the mastery and survived. It would, therefore, appear that intercrossing in an advancing race of plants would be indispensable in enabling it to overcome its competitors.

Flowers according to the ways in which they are pollinated are divided into three groups.

Flowers pollinated by the wind (Anemophilae, wind-lovers).

Flowers pollinated by water (Hydrophilae, water-lovers).

Flowers pollinated by animals (Zoidiophilae, animal-lover's).

Flowers pollinated by animals may again be subdivided into

Snail-pollinated flowers (Malacophilae).

Bat - pollinated flowers (Chiropterophilae).

Bird-pollinated flowers (Ornithophilae).

Insect-pollinated flowers (Entomophilae).

Flowers pollinated by insects are divided into:

Flowers visited by miscellaneous insects, fly-flowers, moth-flowers, butterfly-flowers, bee-flowers, bumblebee-flowers, wasp-flowers, ichneumon-fly flowers.

Flowers may be divided into pollen flowers and nectar flowers according as they contain nectar or only pollen; or they may be divided into flowers with the nectar fully exposed, partly concealed, or deeply concealed.

Flowers pollinated by the wind.-If in- dividuals and not species are considered, there are more plants pollinated by the wind than in any other way. The conetrees (Coniferae) are all wind-pollinated. Vast forests, covering many millions of acres, of pine, spruce, cedar, larch, and fir occur in the north-temperate zone of the Old and New World. Pollen is produced in enormous quantities. Sometimes it rises in clouds, and is mistaken for smoke; the air is filled with myriads of grains which powder the foliage of the trees and even the ground. The so-called "showers of sulphur" are the falling pollen grains of the cone-trees.

In all the Coniferae the stamens and ovules are in different cones. Cross-pollination is here, therefore, an invariable rule, and furnishes a strong argument in favor of intercrossing. There is no stigma, style, nor ovary; but the ovules are unprotected, except by the scales of the cone, and the pollen comes directly in contact with them, instead of being deposited upon a stigma; hence the name gymnosperms, or naked seeds. The young cones are often very handsome, and are colored red or purple, or the scales, as in the fir, may be a very delicate shade of green.

Wind-pollination existed long before insect-pollination, for fossil cone-trees are found in the rocks long before there is any evidence of the existence of the true flowering plants. The wind offers an excellent medium for intercrossing. It levies no toll for its services, and it is seldom that there is not sufficient air stirring to carry pollen. In the pines the grains of pollen are provided with little wings. A gentle breeze is much better than a strong wind, which sweeps the pollen away too quickly and too forcibly. When the weather is stormy (and this is often the case when the wind is high) the anthers do not open; and if they have already dehiisced they close again to protect the pollen.

It is better not to apply the name flower to the cones of the Coniferae. It is true that Asa Gray and the older botanists often speak of "the flowers" of the fir and pine; but botanists are not agreed as to what constitutes, among the gymnosperms, a flower and what an inflorescence, or flowercluster. There is, moreover, no stigma, style, or ovary, but the ovules are borne on an open leaf or scale called a carpel. The 
word "flower" should, therefore, be restricted to the higher flowering plants or angiosperms.

The grasses, sedges, and rushes are also all pollinated by the wind with the exception of a few cases of self-pollination. In all parts of the world grass clothes the land; "should its harvest fail for a single year famine would depopulate the earth." Who would eren attempt to estimate the countless hosts of flowers? Many species bloom at dawn, when the sun is just rising above the horizon, when, their anthers loaded with pollen, they exhibit an attractiveness very different from their appearance at noonday. The stamens and pistils often occur in the same flower; but self-pollination may be prevented by the stigmas ripening before the anthers. Common corn is an illustration of a grass which has the stamens and pistils in separate flowers. The blossoms that bear the seed are low down, and are
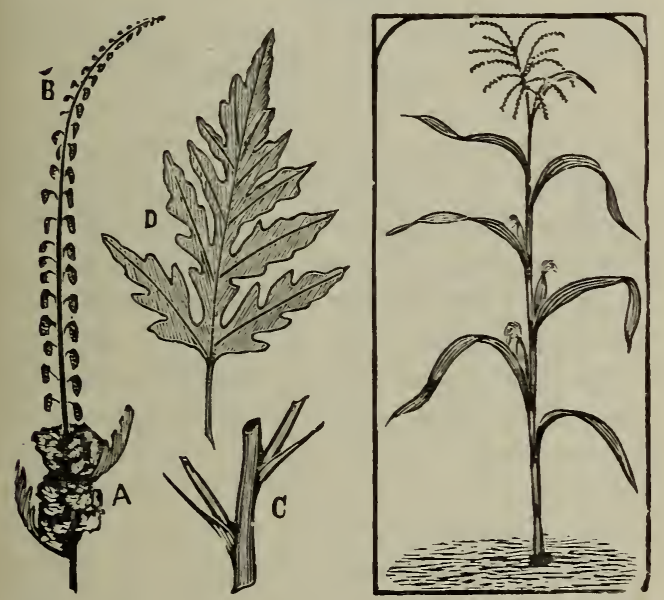

Ragweed and corn, showing the two kinds of blossoms on one stalk.

what we commonly term the ear; the pistils are the silk. The flowers that bear the pollen are at the rery summit of the stalk, and are known as the spindle. When ripe the pollen is shaken off and falls on the silk below, or, what is still better, it is wafted by the wind to the silk of neighboring stalks, thus preventing in-breeding.

Very many deciduous-leaved trees and bushes are wind-pollinated, as the alders, birches, oaks, hornbeams, elms, walnuts, hickories, and beeches. Usually the stamens and pistils are in different flowers, either on the same plant or on different plants. Trees the world over more often have the stamens and pistils separated, and consequently the sexes, than herbaceous plants. Anemophilous trees bloom in early spring: before the foliage has appeared, in order that the leaves may not intercept and waste the pollen.

Many coarse homely weeds are pollinated by the wind, as pigweed, ragweed, nettle, hop, pondweed, sorrel, dock, hemp, and rue. anemone. Their flowers are sunall and green or dull-colored. The common ragtweed (Ambrosia artemisiaefolia), also sometimes called bitterweed, bears two distinct and entirely unlike flowers. On the ends of the tall racemes, as at $B$, the pollen-bearing blossoms are seen very conspicuously; and many of you who are familiar with the weed perhaps never imagined that it had any other blossom at all. If so, will you please go outdoors and look at them again? Right close to the main stem, where the branches all start out, you will find a very pretty little flower, tho it possesses no color except green. These little green flowers bear all the seeds, as you will see on some of the branches where they have matured. Now, if you will get up early in the morning you will find that these flowers, when shaken, give off a little cloud of fine green dust, which is the pollen of the plant of which we have been speaking. As these plants are in no way dependent on bees for the pollination of their blossoms, they contain no nectar. During two seasons, however, we have seen bees busily engaged in gathering pollen. Both the ragweed and the corn insure intercrossing with other plants of the same species. A stalk which succeeds in pushing itself above the others, and producing a profusion of pollen, will probably be the parent, so to speak, of a multitude of the rising generation. This process repeated for generations would develop a tendency in corn and ragweed to send up tall spires, clothed with an abundance of pollen-bearing blossoms. The tallest plants also are most likely to shed their pollen on the neighboring plants, and this, too, fosters the tendency mentioned.

Flowers pollinated by water.-Flowers pollinated by the agency of water are comparatively rare. There are, however, four common species, two growing in salt water and two in fresh water, which deserve mention. The two marine species are ditch 
grass (Ruppis maritima) and eel grass (Zostera marina), both of which are very abundant in shallow streams and bays along the eastern coast. The two fresh-water forms are waterweed (Elodea canadensis) and tape grass (Vallisneria spiralis), which grow in ponds and canals thruout much of eastern North America. Tapegrass is also called "wild celery" because it is the favorite food of the canvas-back duck. The pollination of tapegrass and waterweed is so very remarkable that it must be briefly described. The flowers are diœcious, that is, the staminate and pistillate flowers grow on different plants. Both kinds of flowers are formed under water near the base of the plants. The pistillate rise to the surface, upon which they float, anchored by a long thread-like stem. The staminate flowers while still in bud break away from their stems, and rise to the surface, where they float about like little boats. Presently they expand; and when they drift against a pistillate flower the anthers come in contact with the broad leaf-like stigmas and pollinate them. Then the fertile flower is again drawn down into the water by the spiral coiling of its stem, where its fruit is matured.

Flowers pollinated by birds.-In Brazil there are many hummingbirds and honeysuckers which visit a great number of flowers and play an important part in their pollination. The color of bird flowers is almost invariably scarlet, crimson, or bright red. The only bird in North America which visits flowers is the ruby-throated humming bird. The cardinal flower, the scarletpainted cup, the trumpet honey-suckle, and the trumpet-creeper are common hummingbird flowers. The nectar in these flowers lies at the bottom of long tubes, where it is beyond the reach of hive-bees, yet the cardinal flower is sometimes listed by mistake as a honey-plant. The wild columbine and the spotted touch-me-not are also very often visited by hummingbirds, but they are likewise much frequented by bumblebees, to which they seem better adapted than to hummingbirds.

Honeybees obtain both nectar and pollen from the flowers of the spotted touch-menot. Did you ever notice the spot of fur, or down, on the back of the bee, just between the wings? Well, bee-hunters sometimes put a small drop of white paint on this spot, so that they may know a bee when it enmes back. Several years ago bees were going into many of the hives, with a spot of white on this fur that looked at first sight almost like a drop of. white paint. For several seasons we hunted in vain to see where they got this white spot. At one time it seemed to come from working on thistles; but we were obliged to give this up, for we found it most on bees one season when they did not notice the thistles at all. One swarm of beautiful Italians that filled their hive nicely in September had a white back on almost every bee. We lined them

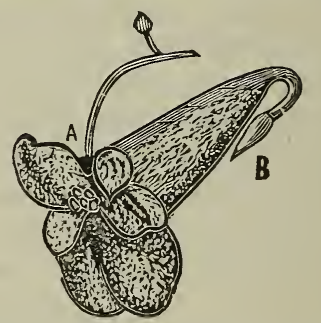

Flower of the wild touch-me-not, showing the manner in which the bee gets the pollen on its back.

from the hive, and followed them. They went toward a large piece of wild woodland, and we scanned the tops of the trees in vain. Finally, over between the hills, beside a brook, we found acres of the wild touch-menot (Impatiens), the same plant that we have often played with in childhood, because the queer little seed-pods will snap all to pieces when ripe if they are touched never so carefully. The nectar is secreted in the spur of the flower, shown at B.

The bee can reach this only by diving down into it almost out of sight; and when the coveted treasure is obtained it backs out with a ludicrous kicking and sprawling of its legs, and in so doing the down on its back is ruffled up the wrong way. Now, this would be pretty certain to get the pollen dusted all over it; but nature, to make sure, has planted a little tuft that bears the pollen just on the upper side of the entrance to the flower, at A; and as the bee struggles to get out, white pollen is brushed on its back most effectually, to be carried to the next flower, and so on.

Flowers pollinated by insects.-It is estimated that there have been described in the world up to the present time 132,584 different kinds of flowers. Kerner places the number of species pollinated by the 
wind at about 10,000; but this, undoubtedly, is an underestimate. But even if it is twice that number, there must be over 100,000 different species of flowers that are pollinated by insects. Insect flowers are usually bright-colored, often sweet-scented, and commonly yield nectar as well as pollen. The pollen, unlike the dry dusty pollen of wind flowers, is thickly beset with teeth, spines, knobs, pits, and grooves, which cause the grains to adhere together, and to the bodies of insects. Water is always hurtful to it, and there is an astonishing number of devices provided for its protection, the mere description of which would fill many pages. It is probable that insects first visited flowers for the sake of the pollen, and that the function of secreting nectar was developed later.

Any part of the flower may secrete nectar, as the bracts, sepals, petals, stamens, and pistils; but most frequently it is secreted near the base of the styles. Its quantity varies from an almost imperceptible layer to several drops or even a spoonful. In a tropical orchid Coryanthes there collects in the hollow lip over an ounce avoirdupois.

Insects which are of importance as flower-visitors belong to four orders: the beetles (Coleoptera); the flies (Diptera); the moths and butterflies (Lepidoptera), and the bees, wasps, and their allies (Hymenoptera). Beetles appear to prefer pollen to nectar. Only a comparatively few of them live on a floral diet. The flies are more common, but a great many of them are predaceous. All the butterflies and moths are adapted to sucking nectar, but many of the latter in the adult state never take any food at all. The bees, especially the honeybees, far surpass all other insects in importance as pollinators, for they are almost entirely dependent upon a floral diet, both for food for themselres and their offspring. The honeybee is on the wing very early in the spring, and continues to fly until late in the fall. Its great numbers, its general size and shape, the special construction of its tongue and legs, all together make it especially well adapted for collecting and carrying pollen.

Fly-flowers are malodorous, as the carrion-flower, purple trilium, and skunk cabbage. Notwithstanding their nauseous odors honeybees visit certain kinds for pollen, as the skunk cabbage. Sometimes they serve as temporary prisons, holding the flies in captivity until they are completely dusted with pollen, as Indian turnip and Dutchman's-pipe. The nectar in many moth and butterfly flowers cannot be reached by honeybees. Common butterfly flowers are the pinks, various primroses, lilies, and orchids, and some species of phlox. Among moth flowers are the evening primrose, the climbing honeysuckle of cultivation, some species of cacti, as the night-blooming cereus, the night-flowering catchfly, and the thorn-apple. The pollen may, howerer, be accessible to honeybees, as in the evening primrose. There are also many bumblebee flowers from which honeybees are commonly excluded. The best known is, of course, the red clover. The columbines are sometimes listed as honey-plants; but honeybees are unable to obtain the nectar in the normal way, tho they rob the nectaries freely after bumblebees have bitten holes in them. So, too, there are various species of aconite, larkspur, and sage, besides many other flowers, which do not yield nectar to honeybees.

Thruout the animal and regetable kingdom there seems to be a constant struggle for the perpetuation of their species, which is secured only by ripening good seeds. Notice how the weeds in our garden will struggle and fight, as it were, to get a foothold until they can get a crop of seeds ripened, and then notice the numerous ways they adopt to scatter this seed as widely as possible. If the plants were animated beings, we might almost call it tricks and sharp practice; some of the seeds have wings, and are blown about; others have hooks, and catch on our clothing, and on the fur of different animals, in the hope of being carried to some spot where they have a better place to germinate. Fruits and berries (when the seeds are fully ripened), instead of clothing themselves in the sober green of the foliage surrounding them, affect scarlet red and other bright colors, and, sometimes, fancy stripes, which induce the birds to take them in preference to the fruit of other trees. Why do they want their fruits to be eaten by the birds, if it is their purpose to secure a place for their seed? Well, if you examine you will find that the seed is encased in a horny shell that is proof against the digestive organs of the bird, and these seeds and stones are, therefore, voided frequently or invariably while on the wing, 
in just the condition to take root in the soil wherever they may be cast. Bear this in mind while we go back a little to the bees and flowers.

We have suggested that the nectar is placed in flowers to attract the bees. After a bee has found nectar in one flower it will be very likely to examine others of a similar kind or appearance. If the flowers were all green, like the leaves of the plant, the insects would have much more trouble in hunting them up than they now do, because contrasting colors, such as the white and red of the clovers, make them conspicuous. If you look back to what we said about corn and ragweed you will see that the flowers of both are a plain green, for they have no need of bees to insure pollination.

It is easily proven that bees have a sort of telescopic vision that enables them to perceive objects at long distances. When a bee starts out in the morning it circles up aloft, then takes a view, and starts out for business. If one field of clover should be more conspicuous than the rest, it would probably give it the preference-at least, so far as to make an examination. If it has been at work on a profitable field the day before, it will, doubtless, strike for it again without any preamble. That bees look for honey, and hunt it out, we have proven to our full satisfaction; and we are well convinced that what is often called instinct, and allowed to drop there, is only profiting by experience and an excellent memory of past events, as human beings do. We say that bees instinctively go to the flowers for honey. We have watched them in the spring when the blossoms first open, and many a bee, very likely a young one that has never before seen a blossom, will examine the leaves, branches, and even rough wood, of the trunk of the tree, intently smelling and sniffing at every part, until it finds just where the coveted treasure is located. After it has dived deep into one blossom, and tasted the nectar, it knows pretty well where to look next time.

The touch-me-not has learned, by ages of experiment, to produce a bright orange flower, to secure nectar in the spur, to place the pollen-bearing stamens at the point where the bee must rub against them in getting the nectar, to construct those wonderful seed-pods, which explode and scatter the seed far and wide, just that it may reproduce and multiply its species. We should judge it had succeeded pretty well in a waste piece of woodland near our home, for there are now acres of it as high as one's head, and it is quite a valuable acquisition to our apiary. As nearly as we can make out, the plant has much increased since the advent of the Italians, as might be expected. This is true of dandelions as well ;* and the large, brilliant, showy blossoms that now line our roadsides and waste places, instead of unsightly weeds, should remind one how much an apiary of bees contributes to fulfill the words of sacred prophecy:

The wilderness and the solitary place shall be glad for them; and the desert shall rejoice, and blossom as the rose.-Isaiah 35:1.

Now, we cannot positively affirm that flowers were given their gaudy colors thru bees selecting the brightest and most conspicuous, thereby inducing such blossoms to bear seed in preference to those less gaudily attired, neither do we know that cherries became red because the birds selected those that showed a disposition to that color, year after year, for many centuries; nor can we prove that the bright plumage of male birds came about in the course of time, simply because the female encouraged the attentions of and showed a preference for those most handsome. We can only suggest that the actions of birds, bees, flowers, and fruits, seem to point that way. You all know how quickly we can get fancy-colored flowers, yellow queen-bees, or birds of almost any shade of color, by careful selection for several generations. Have not the bees so colored the flowers, and birds the berries, etc., altho they did it all unconsciously?

It is significant that so many of the flowers have a form of construction and depth of flower tube that would indicate that it had adapted itself to the bee. While, of course, there are many exceptions, it appears that nature caters more to the bee than to any other insect. Just see how she makes a convenient doorstep of a flower tube of just the right size and shape, so that the bee can get the nectar which it has to offer. Cheshire has pointed out that so intimate and so perfect is the relation between the flowers and the honeybees that there would be no advantage in breeding

\footnotetext{
* See Dandelion.
} 
larger bees or of changing their general structure, because to do so would necessitate changing practically the whole of the floral kingdom. While it undoubtedly would be an advantage to breed bees with longer tongues, that advantage would be manifest only in the case of red clover, and apparently old Dame Nature has designed that the common bumblebee shall perform the work here that cannot fully be accomplished by the honeybee. It should be mentioned, however, that the honeybee does gather quite a little nectar from the red clover, and of course accomplishes to a considerable degree the work of pollination.

POLLINATION OF FRUIT-BLOOM.See Fruit-BloOM.

\section{PRIORITY RIGHTS.-See OvERSTOCK-} ING.

PROFITS IN BEES.-This question is a hard one to answer, as so much depends on the locality and the man, and the number of bees to the area.

On the average, perhaps, in the northern states, in what is known as the rain-belt, one might expect to get anywhere from 25 to $50 \mathrm{lbs}$. of comb honey, and perhaps from 25 to 50 per cent more of extracted. There will be some seasons when he might secure as much as 100 lbs. or more on an average, and occasional seasons when there would be neither comb nor extracted, and the bees would require to be fed. Taking one year with another, the ordinary beekeeper ought to average about $35 \mathrm{lbs}$. of comb honey, on a conservative estimate, providing he has reasonable skill and love for the business. The comb honey might net him, deducting the expense of selling, from 10 to 15 cents; the extracted, from 6 to 10 . These figures do not include the labor of producing the honey nor the cost of the fixtures. The cost of the supplies, exclusive of sections and foundations, ought to be sufficient to cover 10 to 20 years if no increase is made. Suppose we put the comb honey at $35 \mathrm{lbs}$. as the average, and the price secured 14 cents net. The actual money he would get from the commission merchant or grocer might be about $\$ 5.00$ per colony; but out of this he must deduct a certain amount for labor, and 10 per cent on the cost of supplies, to be on the safe side.

With only a few bees the labor would count for nothing, as the work could be performed by some member of the family or by the man of the house, who should, during his spare hours, do a little with bees, and work in his garden. In case of one, two, or three hundred, the labor item must be figured. The larger the number crowding the available territory the smaller the profit per colony. A rough estimate for an apiary in a locality not overstocked, not including the labor on the $\$ 5.00$ actually received for honey sold, ought to leave a net profit of somewhere about $\$ 4.50$. This would be on the basis that the locality did not require much feeding in the fall. If feeding was found to be necessary, 50 cents more might have to be deducted, making a net profit of $\$ 4.00$. On this basis it will be seen that the profit in one season ought to pay for the hives and supers in one year, or come very close to it, leaving the investment good for ten or more years. If we figure it that way the ten per cent need not be added. For a professional man, or one who has other business, eren these returns are not bad; for if he secures only enough for family use, the diversion or change to relieve the tired brain is worth something.

The question as to whether one should keep few or many bees will depend upon many conditions; but the principal one is the ability of the man. Many a person can handle a few chickens, and get good results; but when he runs the number up into the hundreds he meets with failure. Some have done remarkably well with a few colonies; but when they have attempted to double or treble the number they entered into a business proposition that proved to be too much for them.

Many vears ago a neighbor cleared a thousand dollars from one acre of onions. It made him wild. He bought ten more acres of the same kind of onion land, going into debt for it, and expected to clear the following year $\$ 10,000$. When he managed the one acre he did all the work himself; but when he worked the ten acres he had to hire help. The help was incompetent, or did not understand. Onions fell in price; and at the final roundup that year he had a great stock of poor onions without a buyer. They rotted. He became discouraged, and lost all he had.

A few persons, on account of a lack of experience or perhaps business ability, not 
understanding their own limitations and those of their localities, will plunge into beekeeping too deeply and meet with disaster. Many can keep more bees by scattering them in outyards; and if they have the requisite training and business ability they can make more money. But where we find one person who can manage 500 colonies or more successfully, there will be more who cannot go beyond the 200 or 300 mark. The same rule applies to any business.

Let us look at the other side of the question--the side of expansion. Here is a beekeeper who has 300 colonies. During the busy season he is comfortably busy. But during six months in the year his time is not very profitably employed-a distinct loss; for it will take him only a short time, comparatively, to get his supers ready for the next season, nail his hives, repaint them, or do other preliminary work that can easily be done indoors, and yet his interest, or his rent and his living expenses are going right on. Suppose, for example, that this beekeeper has 600 colonies, or 1000 ; that he has good business ability; that he has plenty of bee-range. Suppose he scatters this number in 15 different yards, none further than 15 miles from his home, and a good part of them not over four or five miles away. In the busy season he will, of course, have to employ help. If he has the right kind of executive ability he will see that that help is profitably employed. When the rush of work is over he will look after the marketing of the crop, put the bees into winter quarters, perhaps doing the work himself with the occasional help of one man and a machine. In cold weather he can devote all of his time profitably in preparing for the next season. While he is operating 1000 colonies it costs him no more to live; the same automobile that will carry him to two or three hundred will carry him to the other seven or eight hundred. If he is running for extracted honey, the same extractor, uncapping-knives, and smokers can be used at a central extracting-station. He is thus enabled to put his invested capital where it will be earning money for him all the time in the busy season instead of eating up interest part of the time. We will suppose that some of his swarms get away from him; we will also suppose that some of the work is not done as well as when he had only 300 colonies; but he has increased his honey crop by three times, possibly, and has increased his actual operating expenses only to the extent of the help that he has to pay for, extra hives, and sugar to feed. A couple of men and a boy three months in the year-the men at $\$ 3.00$ each and a boy at $\$ 1.25$ per day-would make his expense $\$ 565$, counting 26 working days to the month. To this we will add $\$ 50$ for extra team or automobile truck hire. The cost of the extra 700 colonies with hives and supers divided by ten (assuming that they would last ten years) would be $\$ 500$ more, or $\$ 1115$. But we must add $\$ 350$ more for sugar for feeding and $\$ 250$ for sections, foundation, and shipping-cases, making $\$ 1715$ as the total added expense for the 700 extra colonies. Say he is producing comb honey, and that he can average $35 \mathrm{lbs}$. per colony. If this nets him 12 ets. he would get from 300 colonies $\$ 1260$. If he has 1000 colonies his gross income will be $\$ 4200$ by adding only $\$ 1715$ to his gencral expenses.

This is a supposable and a possible case. The most that we would show is that the operating and overhead expenses will not be proportionately increased if the number of colonies be doubled or trebled-all on the assumption, of course, that the beekeeper has the necessary skill and business ability.

PROPOLIS.-This is a sort of resinous gum that bees collect for coating over the inside of their hives, filling cracks and crevices, cementing loose pieces of the hive together, and for making things fast and close generally. It is not generally gathered in any great quantity until at the close of the season, when it seems to be collected in response to a kind of instinct that bids them prepare for cold weather. They are seen almost every day, during a dearth of honey, collecting propolis from old hives, old quilts, and pieces of refuse wax, when one is so wasteful and untidy as to leave any such scattered about. That the principal part of it comes from some particular plant or class of plants; or tree, is probably true, for almost the same aromatic resinous flavor is noticeable. no matter what the locality or season of the year. Bees gather propolis with their mandibles, and pack and carry it precisely as they do pollen. It is never packed in the cells, however, but 
applied at once to the place wanted. It is often mixed with wax to strengthen their combs, and is applied to the cells as a varnish, for the same purpose. In the absence of a natural supply, the bees frequently resort to various substances, such as paints, varnishes, resins, pitch, and the like; and the superstition, popular in some sections, that bees follow their owner to the grave, after his death, probably obtained credence from seeing the bees at work on the varnish of the coffin. To save the bees the trouble of waxing up the crevices in their hives, it has been suggested that a mixture of melted wax and resin be poured into the hive and made to flow along the cracks and corners. This may do very well, altho bees can do this better and cheaper than we can. The principal trouble has been to get rid of the surplus propolis, and it would be better to have some device to keep it out of the way than to add more. It has been said that grease, lime, chalk, or tale applicd to the parts will prevent bees from depositing propolis, for the reason that they camnot make it stick.

\section{HOIV TO KEEP PROPOLIS FROM SURPLUS} HONEY.

Of course, the readiest means is to remove all sections just as soon as a single one is capped over; and as but little propolis is gathered during a strong yield of honey, but little will be found on the honey unless it is left until the yield has ceased. Some bees not only cover all the woodwork of the sections if left on too long, but they also varnish over the whole surface of the white capping, almost spoiling the looks and sale of the honey.

It is next to impossible to keep propolis from the sections entirely. Bees will deposit at least some in the interstices between the sections. As Nature abhors a vacuum, so do the bees dislike a crack or crevice. The nearer surplus arrangements can be made so as to leave but few crevices or places of contact accessible to bees, the less propolis will be deposited. Some surplus arrangements are made so as to produce compression upon the sections, thus reducing the space formed by contact with sections to a minimum. Some prefer to have the outside of the sections covered entire. This can be accomplished either with the wide frames or with holders having the top and bottom to correspond with the outside of the sections.

\section{HOW TO KEEP PROPOLIS FROM S'TICKING TO} THE FINGERS.

At certain times of the year, notably in the fall when bee-glue is very abundant and sticky, after the honey-flow is over and the bees have nothing else to do, they will sometimes gather a great deal of resinous matter which they chink into every available place, smearing over the brood-frames. When these latter are handled the fingers gather up a great deal of the sticky stuff, making the work unpleasant, not to say hampering. At such times one may wear gloves; but as many do not like them, the trouble can be overcome to a great extent by dipping the fingers in vaseline, lime, or taleum powder.

HOW TO REMOVE PROPOLIS FROM THE FINGERS.

$\Lambda$ variety of substances have been suggested. Alcohol is perhaps the neatest, but is rather expensive; gasoline or common lye for soap-making answers nearly as well, and is cheap; soap will answer if a little lard be rubbed on the hands first but will have little elfect on it otherwise. A correspondent says he has a pair of light cotton gloves which he slips on when handling his waxy frames, and his hands are left clean whenever he is obliged to stop work.

For removing it from glass, alcohol is perhaps best. When we have much glass soiled, it can often be cleaned most expeditiously by boiling it in a kettle of water with a quantity of wood ashes, or, better, lye. Right here we can not do better than to reprint an article by Miss Emma Wilson, from Gleanings in Bee Culture.

When I cleaned the $\mathrm{T}$ tins with concentrated lye, I felt pretty sure that hives, supers, separators, etc., could be cleaned in the same way, but was so busy I could not take time just then to experiment, hence concluded to say nothing about it till I could find time to test the matter. This morning, May 5 , being the first opportunity I have had, I concluded to experiment a little.

I put on my wash-boiler with water and lye, then went to the shop and selected the most badly propolized supers and separators that I covld find as fit subjects on which to experiment. I dropped a few separators into the boiler while the water was yet cold, to see what effect it would have on them. I 
could not see that it affected them in the least until the water almost reached the boiling-point, when the propolis disappeared.

What I was most afraid of was that the separators while wet would cling so closely together that the lye would not reach every part, and hence they would not all be perfectly clean. I was glad to find these few did not bother at all, but came out perfectly clean. I stirred them with the poker while boiling, altho I don't know that it was necessary as I tried another lot without stirring, and they came out just as clean. I next tied up a bundle of 59 separators, that being the number I had handy. Of course, they were tied loosely. I dropped them in, having a strong cord tied around the middle of the bundle to lift them out by. I let them boil two or three minutes, and took them out; 32 of them were perfectly clean. The rest, in the center of the bundle, still had some propolis left on, and were treated to a second dose.

Taking a very large quantity of the separators at one time, there might be more trouble than I think about getting them clean, but I don't believe there would be if the water were kept hot enough, and enough of the lye used. I don't think any harm would come from having it unnecessarily strong.

I next tried dipping the $\mathrm{T}$ supers. My boiler was large enough to clean only half a super at a time, so I had to dip in one half, reverse it, and dip the other half. Had I been able to dip one all at once, I think I could have cleaned one a minute. And they are beautifully cleaned. I don't know of any other way they could be cleaned so nicely-quite as clean, I think, as when new. We scraped all our supers before the lye was thought of; and while they are much improved by the scraping they are not nearly as nice as when cleaned with lye, while the scraping is harder work.

I did not have anything large enough to dip a hive into, but of course a hive would clean as readily as a super. With convenient apparatus to work with, a large number of such articles as separators could be cleaned at a time with no very great amount of labor. It is such a comfort to have everything clean! Wood separators are so cheap that we have always thought it did not pay to clean them. I rather think we shall conclude that it does pay, after this, providing we can get them satisfactorily dried in good shape.

DO THE BEES NEED PROPOLIS?

Much discussion has arisen in regard to the habit bees have of making all openings tight with bee-glue. Theory says, if allowed to follow their bent, or instinct, they will smother themselves to death. Practice says they do, at least at times. so prevent the escape of moisture that their home gets very damp and wet, filled with little icicles, so that they suffer; or, at least, such is the case in the hives we have provided for them. Who is right-the bees or the enlightened beekeeper? The greater part of the fault lies in the hive we have given them. The enameled cloth which we formerly used for covering bees is as impervious to air and moisture as the propolis they collect with so much pains and trouble. If the outside of this is allowed to get frosty, it will condense the breath of the bees on the inside; and if the outside is but thinly protected from the weather, icicles will certainly form on the inside, and freeze the bees fast in a lump.

Under the head of Wintering OUTDOORS will be found a discussion regarding the value of packing material, the purpose of which is to keep the outer walls from becoming cold and condensing the breath of the bees into moisture and the moisture into ice. So far as it is possible, the hive should be packed warm enough so that the moisture will not condense in the hive-much less, ice form around the side walls.

\section{VALUE OF PROPOLIS.}

The gum has been used to some extent in medicine: also in the preparation of certain leather polishes. It is claimed that propolis for this purpose possesses a property that renders it superior to any of the pitches or resins. 
QUEEN-REARING.-As a general rule, extensive honey-producers believe that it is better and cheaper for them to buy their queens than to attempt to raise them. First, when they buy queens they introduce new blood in their yards; and, second, in order to raise queens it takes a large amount of skill, time, and equipment, which, if devoted to the production of honey, would yield larger results in dollars and cents. There are other large producers who do raise some queens of their own, such stock coming from colonies showing the best average in honey production year in and year out. When swarming is controlled by caging the queen, requeening can be effected without very much loss of time. Moreover the best of cells can be reared during the swarming season.

There are certain of the smaller producers who raise their own queens, if for no other reason than for the fun of it. The whole process, from start to finish, is interesting if not wonderful. For the benefit of these and others we shall attempt to show some of the fundamental principles as well as the methods that are used by our best queen-breeders. But before the breeder launches into this general subject, he should first turn to QuEENs. After having read that he may then consider queen-rearing.

\section{CONDITIONS FAVORABLE AND UNFAVORABLE FOR REARING QUEENS.}

When a colony from some cause or other becomes queenless, the bees will set about rearing another.

Some hold that the best queens are those that are reared either during the swarming-time or when the bees are about to supersede an old queen soon to fail. At such times we see large beautiful queencells, reminding one of big peanuts, projecting from the side of the comb. The larvæ in such cells are lavishly fed with royal jelly; and when the queens finally hatch they are usually large and vigorous.
We said there is one class of cells that bees rear when they are about to supersede an old queen. When she is two or three years old she begins to show signs of failing. The bees recognize the fact that their own mother will soon die, or at least need help from a daughter, and very leisurely proceed to construct a number of cells, all of which are supplied with larvæ, and fed in the same lavish way as those reared under the swarming impulse.

But we can never determine in advance when the bees will rear supersedure cells, and it may be true that the queen about to be superseded is not desirable stock from which to rear. In this case such cells should not be utilized. For a like reason, also, it may be that cells reared under the swarming impulse should be rejected; because it is certainly penny wise and pound foolish to rear queens from any thing but the very best select stock. All swarming-cells from good queens should be reserved by placing them in West queencell protectors; then hunt up queens two or three years old, pinch their heads off, and replace them with one of these cells in cach colony. One may have good queens eren two or three years old, but it is hardly probable. The majority of our honeyproducers think it profitable to replace all queens three years old, while a good many make it a practice to requeen all colonies having queens two years and over, and of late years there is a tendency on the part of a few to requeen every year.

While these swarming-cells produce the very best queens, yet it may not be convenient to requeen during the swarming season, which in some localities may be a rery bad season to do so, owing to the interruption that it makes in the regular production of honey; for some believe that a good many colonies will not do as well in honey-gathering when they are queenless. Swarming-cells may, however, be given to nuclei, for they ought not to be wasted. 


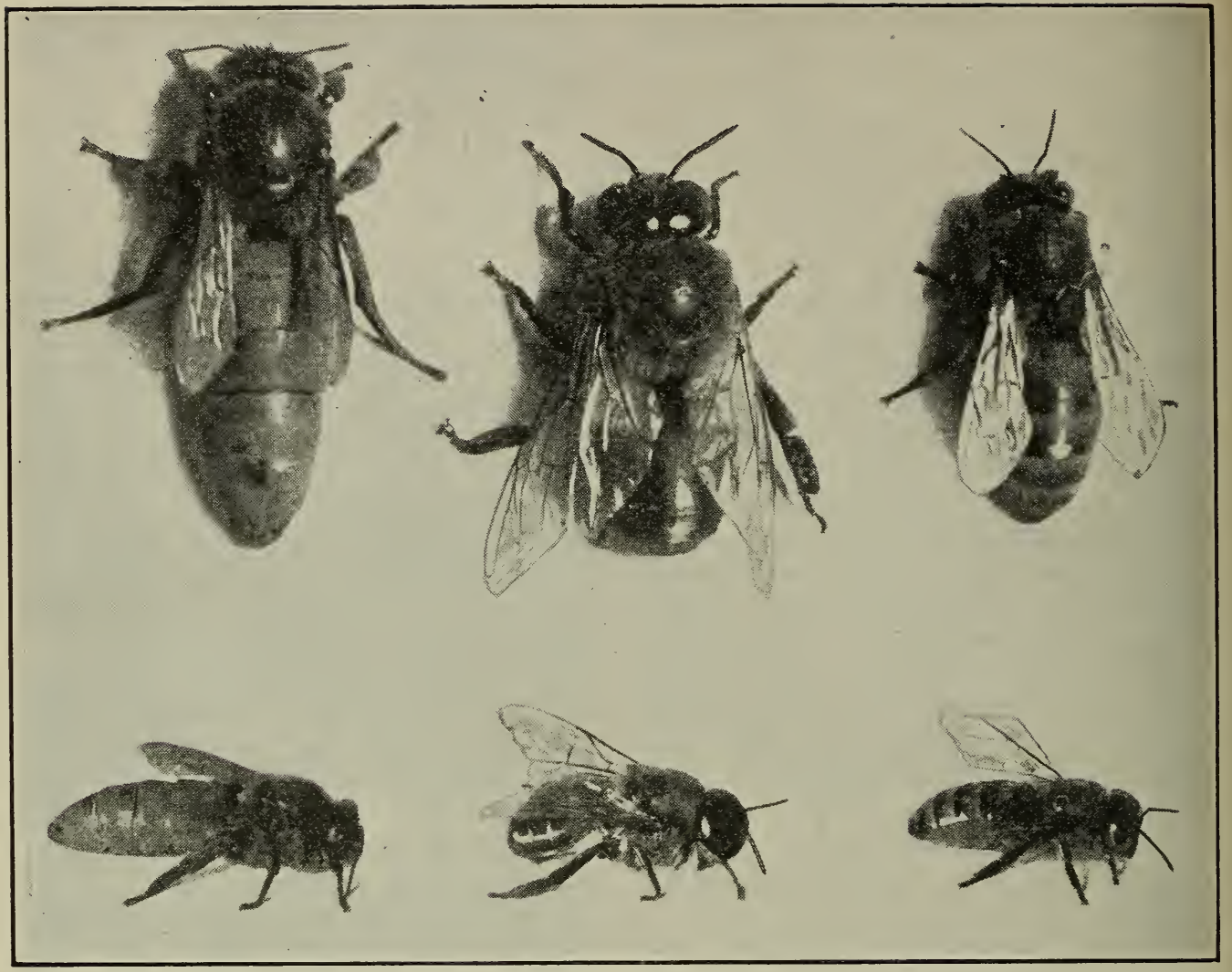

Queen, drone, and worker.

Among the several systems of rearing queens, the one put out by Mr. Doolittle a few years ago forms the basis of some of the best now in vogue. It is very simple, requiring no special tools more than one can improvise for himself. Thoroly understanding this, the reader will be in position to carry out the more advanced ideas put forth by Samuel Simmins, E. L. Pratt, Henry Alley, and others.

THE DOOLITTLE METHOD OF REARING QUEENS.

While Mr. Doolittle's system is slightly artificial yet he endeavors to make his methods conform as nearly as possible to $\mathrm{Na}$ ture's ways. It is of prime importance in the rearing of queens to bring about conditions that will approach, as nearly as possible, those that are generally present during the swarming season at a time when the bees supply the cell-cups lavishly with royal food. One of the first requisites, then, for cell-building is strong powerful colonies; second, a light honey-flow, or a condition almost analogous, viz., stimulative feeding if the honey is not then coming in. Queens reared during a dearth of honey, or queens from cells reared in nuclei, are apt to be small. The mothers that do the best work are those that are large, and capable of laying anywhere from 2000 to 3000 eggs per day.* A queen that is incapable of this should not be retained. A colony with a good queen might earn for its owner in a good season $\$ 5.00$ in clean cash. In the same season the same colony (or, perhaps, to speak more exactly, the same hive of bees), with a poorer queen, would bring in less than half that amount. A queen that can lay 2000 or 3000 eggs a day at the right time

* It is not necessarily the large queens which do the best work. Also 2000 to 3000 is hardly the maximum of "best" queens. A Langstroth comb mas approximately 6000 cells, and good queens will not infrequently fill all of one and part of another in twenty-four hours. This summer I saw fourteen colonies, each with two 12 -frame chambers for the queen; and in several which I inspected, the queens had the whole 24 frames filled with hrood in various stages. This figures out like this: 24 times 6000 equals 144,000 cells of brood. Divide this by 21 the time from egg to mature bee, and the result is 6857 for a day. Allowing for some pollen (and there was not much in those 24 combs) the figure 6000 could not have been far from what those queens were doing.-A. C. MILLER. 
of the year, so that there will be a large force of bees ready to begin on the honey when it does come, is the kind of queen that should be reared.

The old way of raising queens was to make a colony or a nucleus queenless; wait for the bees to build their own cells, then distribute them to colonies made queenless beforehand. This plan is very slow and wasteful, and, worst of all, results in the rearing of inferior queens. Mr. Doolittle takes advantage of Nature's ways to such an extent that he is enabled to rear a large number of queens from some selected breeder, in that he makes it possible to increase the number of cells ordinarily built; for the prime requisite in queen-rearing is cells -plenty of them-that will rear good strong healthy queens.

The first step in queen-rearing is to provide queen-cups. Many times, when an apiarist is going thru his yard he can cut out embryo cell cups, such as bees make. These can be utilized at some future time for the purpose of grafting. But such cells, after they are gathered, are exceedingly frail, irregular in shape, will not bear much handling, and most of the time one cannot înd enough.

\section{HOW TO MAKE DOOLITTLE CELL-CUPS.}

Mr. Doolittle was among the first who conceived the idea of making artificial cellcups that should not only be regular in form but of such construction as to stand any reasonable amount of handling. Contrary to what one might expect, such cells are just as readily accepted by the bees as those they make in the good old-fashioned way; and, what is of considerable importance, they can be made in any quantity by one of ordinary intelligence.

Mr. Doolittle takes a wooden rake-tooth, and whittles and sandpapers the point so that it is similar in size and shape to the bottom of the ordinary queen-cell. Two or three other sticks are then fashioned of the same shape and pattern. Preparatory to forming the cells Mr. Doolittle has a little pan of beeswax, kept hot by means of a lamp; also a cup of water. Taking one of these cell-forming sticks he dips it into water, after which he plunges it about 9-16 of an inch into the melted wax. He then lifts it up and twirls it at an angle (waxed end lower) in his fingers. When cool he dips it again, but not quite so deep, and twirls it as before. He proceeds thus until the cup is dipped seven or eight times, but each time dipping it less deep, within 1-32 inch of the previous dipping. The main thing is to secure a cup having a thick heavy bottom, but which will have a thin and delicate knife edge at the open top, or at that point where the bees are supposed to begin where man left off work. After the last dipping is cooled, a slight pressure of the thumb loosens the cell cup slightly. It is then dipped once more, and before cooling it is attached to a comb or stick designed to receive it.

\section{GRAFTING CELLS.}

A small particle of royal jelly is inserted in every queen-cell. The amount in each should be about equivalent in bulk to a double-B shot, says Mr. Doolittle. But we have found that a much less quantity will answer. Out of an ordinary queen-cell well supplied with royal jelly we get enough to supply 20 cups. If we took a quantity equal in bulk to a $\mathrm{BB}$ shot we would have to rob two or three cells to supply that many. This royal jelly should come from some queen-cell nearly ready to seal, as that will contain the most. It should be stirred to bring all to about the same consistency, after which it may be dipped out of the cells by means of a stick whittled like an ordinary ear-spoon, or a toothpick.

The next operation is to take a frame of young larvæ just hatched from the eggs of the best breeding queen. Each little grub should be picked up with the aforesaid earspoon, and gently laid on the royal food previously prepared in one of the cell cups. A larva should be given to every one of the cell cups in this manner, and when all are supplied they are to be put into the cellbuilding colony, to be explained later.*

\section{REARING QUEENS IN LARGE NUM- BERS.}

Thus far we have considered the original Doolittle system of rearing queens; and where one desires only a few for his own use he may find this method more convenient than the one now to be described. But if he has any number to rear he should carry out the following plan. The methed

* This work should be done in an atmosphere of $80^{\circ} \mathrm{Fahr}$, 
of preparing the colonies for cell-building will be the same.

Instead of dipping the cells one by one with a stick, or dipping several sticks at once, compressed cell cups are made on a plan originally devised by E. L. Pratt. With a suitable die, cells more nearly per-

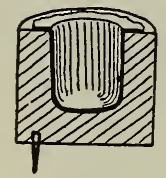

A

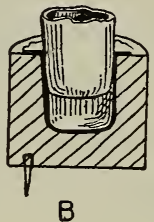

B
Cross-section of wooden cell-holder; cell cup partially pushed into place.

fect than can possibly be dipped by the slow process already deseribed are punched out at the rate of 2000 an hour. These are furnished by dealers, and, generally speaking, it would be better to buy cell cups than

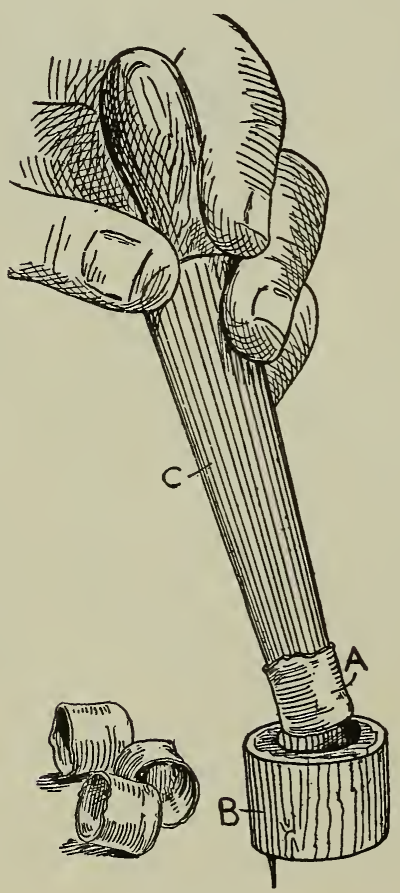

Manner of inserting cell cups in cell-holders.

to attempt to make them by the dipping process.

To facilitate general handling, the modified Doolittle system calls for wooden cellholders, which may, under certain circumstances, bc used as direct cell cups.

These are cylindrical pieces of wood, $3 / 4$ inch in diameter, $5 / 8$ inch long. A suitable drill bores out one end of the right size to receive one of the compressed cell cups. These wooden cell-holders can likewise be purchased by the thousand.

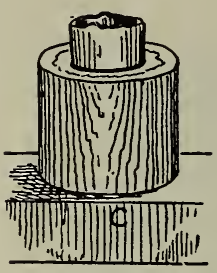

Cell-holder with cell in place.

The compressed cups are forced into the hole in the cell-holders by means of a little plunger-stick. When enough of them have been prepared, and secured to a cell-bar by means of nail-points forced into the soft wood, they are ready to be grafted. This process is much the same as that already described in the Doolittle method, except that a much smaller quantity of royal jelly is used, and special tools are provided for the purpose, these being obtained of the dealers. Sufficient royal jelly is gathered up from a series of cells, and the same is stirred with a special jelly-spoon. A spoon-
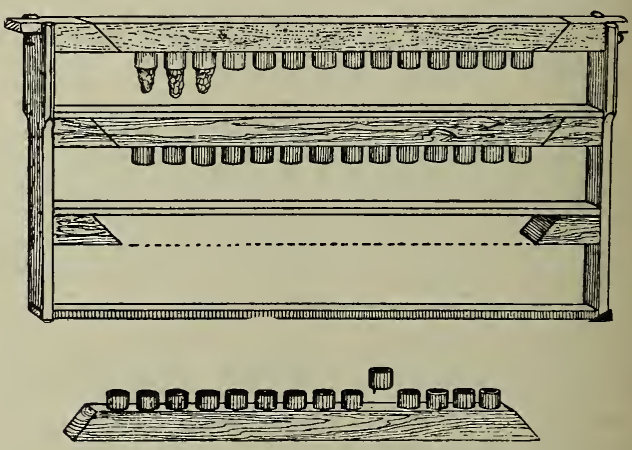

Hoffman frame with removable bars for cell-holders.

ful is then held in the left hand, while the right hand uses the grafting-tool to take a speck of the royal jelly, about the size of the head of a pin. This is then placed in the bottom of one of the compressed cups. Other cups are treated in the same way until the whole series of cells is provisioned.

If one should run short of compressed cups he can, with a keen-edged knife, cut off the old cell, from which the queen has hatched, even with the wood, and then with the plunger-stick ream out the hole in the cell-holder. This hole can be grafted in the manner already explained; but it will 
be found preferable to use the compressed cups, as better results will thus be secured.

The next operation is to take a comb of very young larvæ, just hatched, from a
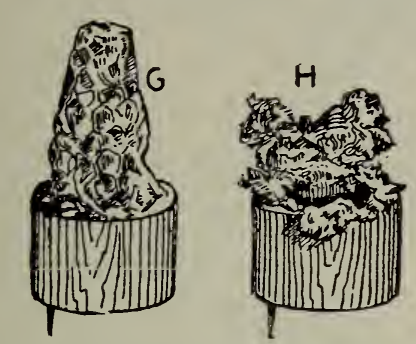

G, fully completed cell from holder; H, partially built cell torn away to get at the royal jelly.

breeding queen. In an atmosphere not cooler than 75 or 80 degrees (the warmer the better) a young larva is scooped or lifted up out of a worker-cell with the flattened end of the grafting-tool, and deposited in the royal jelly of one of the compressed cups. This is repeated until all the cups are grafter. This royal jelly serves a

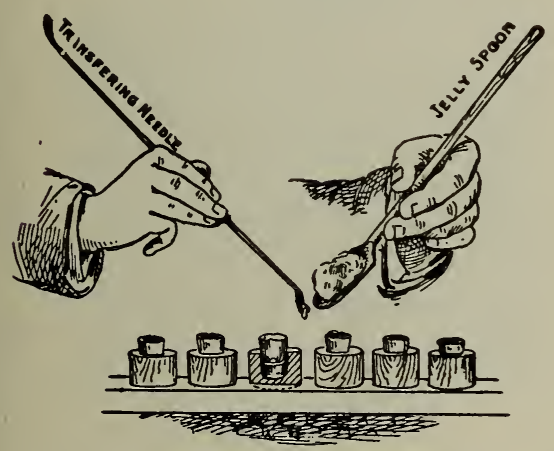

Supplying cells with royal jelly.

double purpose. It affords a downy bed, so to speak, in which to lay the larva, and at the same time provides food until the bees can give it a fresh supply. Despite the claim that royal jelly is not necessary one will get more cells accepted by using it.'

\section{GETTING CELLS ACCEPTED AND BUILT OUT.}

The average beginner will probably succeed best by giving grafted cells to a queenless strong colony. In about two days after making it queenless a bar of 15 cells (not more) inserted in a frame may be given. If no honey is coming in from natural sources, the colony should be fed in a manner to be explained. When conditions are right, nearly every cell, if not every one of them, will be accepted. By " accepted" is meant those artificial cups on which the bees have begun work, and to which they have added their own royal jelly. After being accepted they are given to the upper story of a strong colony to be completed with an excluder between the two stories.

The question might be raised right here, "Why not make these upper stories start as well as complete the cells?" For the simple reason that they will not start work of this sort except under the most favorable conditions; and the average queenbreeder has decided it does not pay to try to make the attempt. There should be one colony to start the cells and another to complete them after they are accepted in another colony.

After the first batch of fifteen grafted cups have been accepted and removed, another batch of fifteen may be given, and so on the process can be repeated. But such cell-starting colonies should not be kept for such purpose more than three weeks, on account of the danger of laying workers. See LAYING WORKERS.

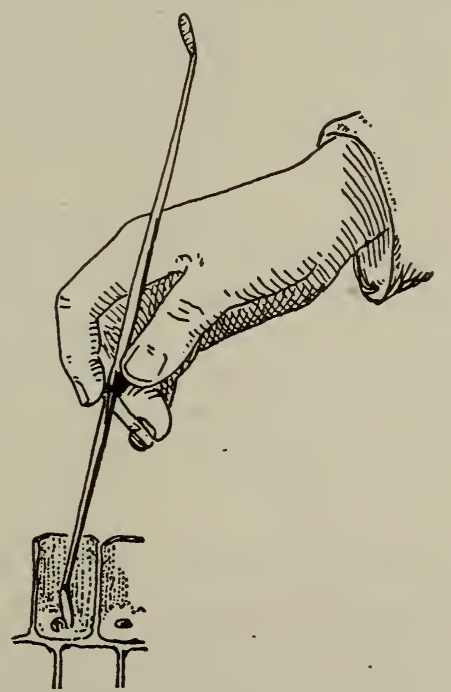

Lifting a larva out of a worker-cell.

In eight days after giving the first batch of grafted cells, it will be necessary to go over the combs very carefully and destroy any natural cells of their own; for if these are left in the hive the bees will do no work on the second batch of cells. In the mean time a virgin would hatch and trouble happen. Even after the first batch of natural cells are cut out, it is advisable to go over the combs again in eight ảays, because a 
colony like this may steal an egg or two from some other colony.

Another excellent cell-building colony outside of the swarming season is one having a queen which it is trying to supersede. One or more such colonies will be found in a large apiary, but as a general rule the queen is hardly good enough to use as a breeder. Having found such a colony, begin giving it daily feeds at once, this being a requisite for the best results in cell-building with any colony, either with a queen or without one. This supersedure cell-building colony will not only draw out and complete one set of cups but several sets in succession; but it is best not to give any one such colony more than a dozen or a dozen and a half prepared cups at a time. Allow it to finish up one batch, and then, if necessary, give it another.

To one of our supersedure colonies, as we call them, we gave one batch of Doolittle cups after another until they had completed over 300 fine cells; but we were careful to take away each lot before any could hatch, of course, for a young virgin would very soon make havoc of the other cells unhatched, and besides would get the colony out of the notion of trying to supersede the old queen.

Just how far supersedure bees will continue to build out batches of cell cups one after another is not known, but if they are fed half a pint of syrup daily they appear to be willing to keep up the work indefinite$l y$, in the hope that they will some day be able to rear a virgin that will supplant the old queen that appears to be failing.

\section{THE FORCED-CELL-STARTING COLONY.}

There is still another plan used by queenbreeders to get cells accepted or started in a more wholesale way; and that is, make up a forced-cell-starting colony. This is done by making a strong colony queenless and broodless excepting the few combs of honey it is allowed to have. The combs are taken out one by one, and shaken in front of the entrance. When combs are cleaned of bees it will be very easy to see any eggs. Combs containing honey are set back in the hive, and with them two division-board feeders. One is placed on each side and half filled with syrup; and an hour or two after the bees have been made queenless they will set up a roar; for without any brood or any possibility of producing it, they are in dire distress, and in just the right condition, psychologically, to rush upon grafted cups that may be given them. The nurse bees are already supplied with pap; and with no young brood of any kind to feed they have royal jelly in any quantity to give the cups. A colony in this condition may be given 100 cells on two frames, which are placed in the center of the colony in places previously left vacant. If everything has been done right, nearly every one of the cells will be accepted; but the attempt should not be made to make such a colony start a second batch. When the cells are accepted they are taken out and placed in an upper story of a cellbuilding (or, rather, cell-completing) colony next to be described.

While queenless bees will complete any cells given them, yet such cells will not be as good as those built under the swarming or supersedure impulse. A two-story colony with an excluder between the stories is prepared. The lower hive contains the queen, but the brood is lifted into the upper story. The queen and bees below will begin rearing more brood. If no honey-flow is on, it is important to feed, because otherwise these cell-builders will tear down the work so nicely started in the other hive.

Under FEEDING is described the Boardman feeder for slow feeding. After one feed is given another must be given the next day. If a day is skipped in feeding, the colony begins to feel that the honey-flow has stopped, and apparently comes to the conclusion that there will be no necessity for continuing the work of cell-building. When feeding stops, it will often destroy work nicely under way.

Such cell-builders will take care of and build out about fifteen cells at a time. When the first batch is sealed, another batch of accepted cells may be given, and so on the process may be continued thruout the season-provided, however, the colony is kept up to the swarming-pitch by continuous feeding.

In about twenty days brood is again lifted from the lower to the upper hive and the combs from which brood has hatched above is put below. Brood must be kept above to keep cell-building going on. 


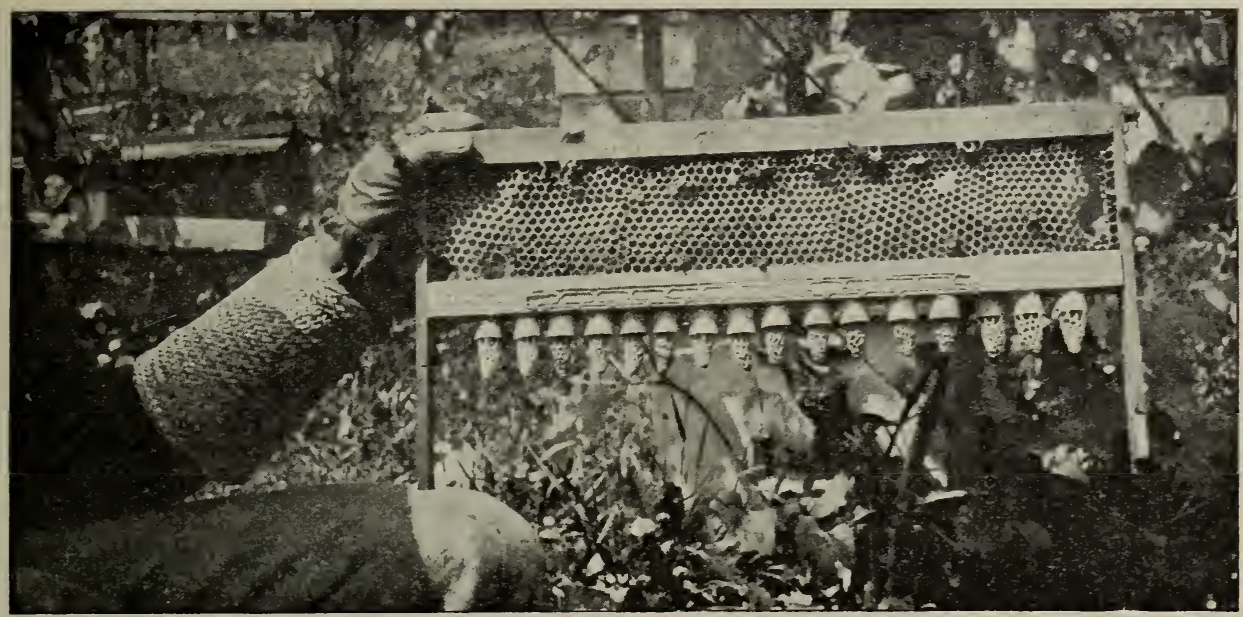

Fully completed queen-cells built on wooden cell-cups here described.

\section{NURSERY CAGES.}

The illustration shows a batch of cells taken from one of these cell-builders. In carge queen-breeding establishments there

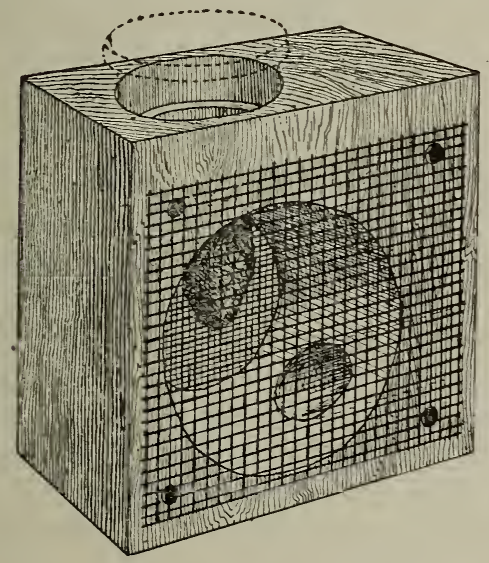

Nursery cage for cells and virgins.

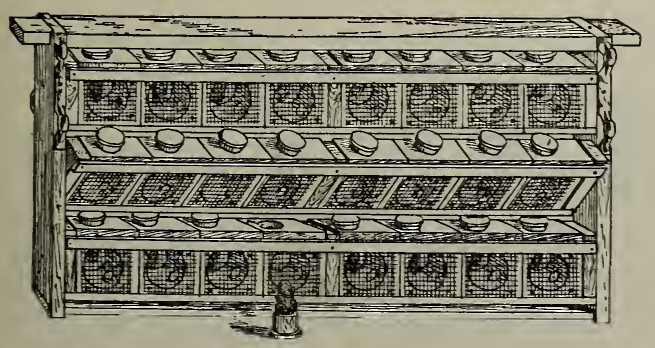

A nursery frame.

will be a dozen or more cell-building colonies kept constantly at work; but the ordinary beekeeper who desires a few queens of his own will not need to keep more than one such colony more than a few days.

The cells are now ready to be placed in nursery cages. This, it will be seen, is practically a modified Alley cage. A surplus of cells often occurs in queen-rearing - that is to say, a lack of queenless nuclei or colonies to take them. One should arrange to have more than he will probably be able to use, to provide for bad weather, when cells will be destroyed or young hatched virgins will be missing. At such a time, if one has extra cells or virgins that he can take out of a nursery, he can quickly make good the loss.

The nursery cage here shown has a large opening at the top to receive the wooden cell cup; the small hole in the lower righthand corner is filled with queen-cage candy to supply the young miss after she hatches. Twenty-four of these cages, supplied with cells that are capped over, can be put in a nursery-frame having holders which may be tilted on an angle so that any one cage can be easily removed from a holder without disturbing the rest. There are three of these holders in each frame, piroted at both ends as shown. When the nurseryframe has been filled with cages, each containing a capped cell, it should be put down in the center of a strong colony.

While various artificial-heat incubators using kerosene-lamps have been devised, experience has shown a majority of breeders that nothing is quite so good as a strong cluster of bees. What is still more, when the young virgins hatch, some of the bees will be inclined to feed them thru the wire cloth, providing a stimulus that they cannot receive from the queen candy in the cage. After the virgins have hatched 
they should be transferred to Miller cages, and introduced as soon after hatching as possible. The younger the virgin, the more successful will be her introduction. After she becomes four or five days old, even if she be accepted by the bees they are likely to mistreat her so that her usefulness thereafter will be greatly impaired. While it is possible to introduce these virgins to fullsized colonies it is not practicable except by the smoke or distress method described under Introducing. It is much easier to introduce to baby nuclei.

\section{DUAL PLAN OF INTRODUCING VIRGIN QUEENS,} FOR EXTENSIVE BREEDERS.

It sometimes happens that a breeder will have a great surplus of cells, or more virgins than he bas queenless nuclei or colonies. In such cases it has been found practicable to introduce two queens at a time. First a virgin, the younger the better, is introduced in a Miller cage to a baby nucleus. After two or three days she should be released; in about four days more, being seven days from the time of caging the first queen, another virgin may be caged among the same bees; but the candy of the second cage thru which the bees liberate the queen must be covered with a little strip of tin or the bees will liberate her prematurely. In two days more the first virgin will be mated, and within two or three days will begin to lay if the weather is favorable. Then she is removed and sent out to fill an order; the strip of tin covering the candy of the second cage is opened to let the bees release virgin No. 2, and, having already acquired the colony odor, she will usually be accepted in less than a day's time. In about seven days from the time she was caged, a third queen, if there is still a surplus of virgins, may be put into the nucleus while No. 2 is taking her mating-flight, and so the progress may continue so long as there is a surplus of virgins.

This is really high-pressure queen-rearing, and should be practiced only when there is a surplus of virgins, or when there are rush orders for cheap queens-cheap queens, because the queens introduced on the dual plan may or may not be the equal of those introduced in the regular way where a single queen is introduced at a time and is confined in a cage not more than a couple of days. If the virgin is very young, just hatched, and the nucleus has been queenless a couple of days, she can be let loose quietly over the top of the frames without any eaging; but care should be taken not to allow her to touch the hands, for the scent of the human body sometimes causes the bees to attack and kill her.

\section{INTRODUCING QUEEN-CELLS INSTEAD OF VIRGINS.}

Some queen-breeders prefer to give ripe queen-cells to their nuclei direct, claiming that too many of the virgins that they introduce anywhere from one to four and five days old are lost. It is true, the average beginner will succeed better with cells than with virgins; but if cells be given the nuclei should be made strong in bees. In some cases it will be necessary to use West queen-

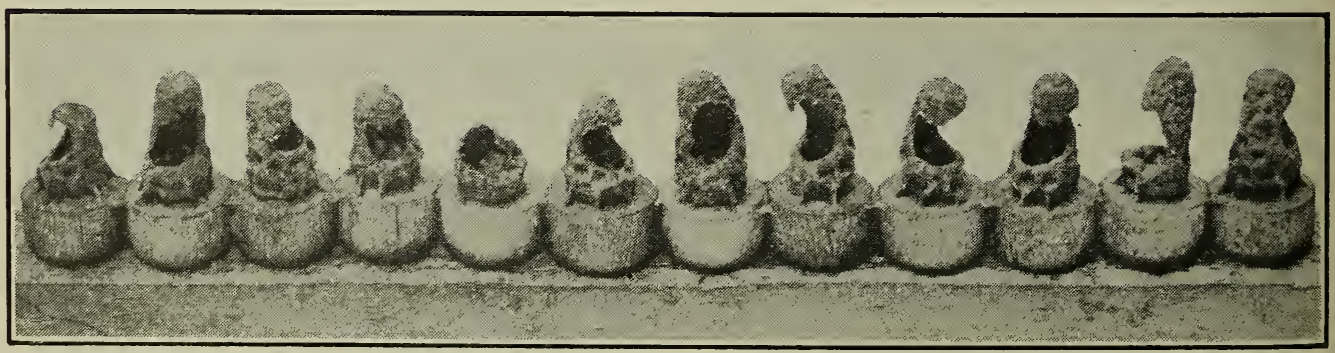

After the battle. By accident a batch of cells were left for a day or so too long in a cell-building colony. The first virgin that hatched, true to her nature, waged an unfair war upon her helpless sisters still in their cradles. Every cell was ruthlessly torn open, and the little white queen inside killed. A virgin queen will not stand for competition. This inborn instinct of hatred against a rival does not end with youth. Two laying queens-old enough to know better-will usually fight if placed together even in strange and unnatural surroundings. Place two queens under a drinking glass in the hot sun. If they could reason, we might expect them to forget their hatred of each other in view' of their common predicament of being confined away from the care of nurse bees. But the powerful instinct of hatredi is so strong that they will usually fight-fight until one or the other is stabbed by that poisoned weapon that is never used except against a rival. 
cell protectors to keep the bees from gnawing holes into them.

The long spiral cage is designed to slip under the queen-cell protector, and when

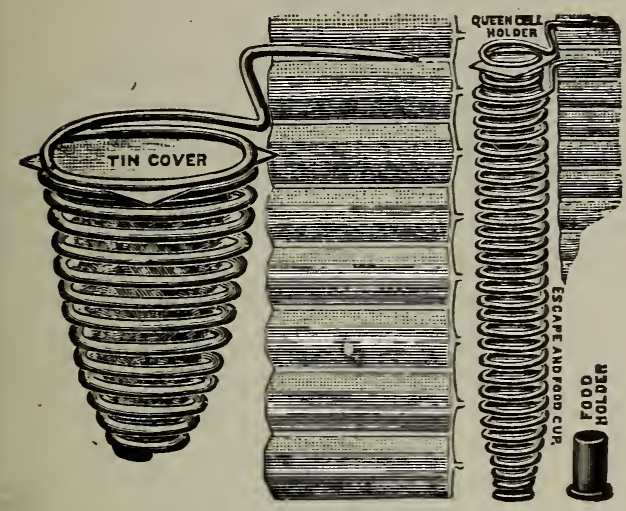

West queen-cell protector.

the young queen hatches out she will pass into the long cage, where she can be held secure from bees or other virgins in the colony that might kill her.

\section{DIVIDING AN UPPER STORY INTO THREE MIAT- ING NUCLEI.}

After securing a large lot of nice cells in the cages already shown and described. it is next in order to consider the mating box or hive. As already explained, one can use one or two full-sized Langstroth frames and put them in a three-frame box or hive, or in a full-sized hive, by using a division-board to reduce the space; or, better still. he can take an eight-frame hive-body and divide it off into three equal compartments by inserting two tight-fitting division-boards lengthwise that will reach clear up to the cover, and close the holes of the nive rabbets. Each compartment will then be just wide enough to take two full-sized Langstroth frames. The under side of this hive should have a wire-cloth bettom. for reasons to be given later. The two outside compartments should each have an entrance, one on each side of the hive along the center. The center compartment should have one at the rear of the hive-body. These entrances should be made with a half-inch bit, and have a cleat nailed just below, forming a narrow door-step.

When complete it will be an ordinary eight-frame hive-body with wire-cloth bottom, having three two-frame divisions with an entrance on each side and one in the rear. Each of these compartments is to receive two frames of brcod and bees, after which it is set over a strong colony of bees. The heat passing from the bees beneath will keep the three clusters above perfectly warm, no matter if the weather should be a little cool. Queens or cells may be given to each one of these nuclei, and

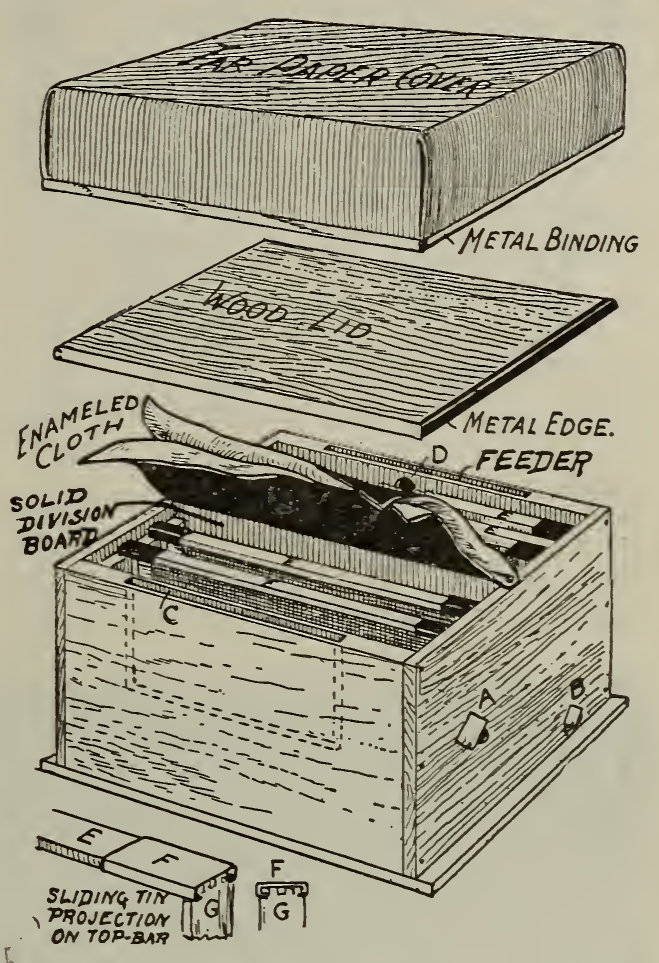

Fig. 1.-Twin mating-box.

queens will be mated from the upper story in the regular way. Where the climate is a little uncertain and the season short, there is nothing better than this divided-off upper story.

\section{PABY NUCLEI, AND HOW TO MATE QUEENS IN LARGE NUMBERS.}

There one desires to secure the largest number of queens possible from a given force of bees, twin-mating nuclei on a much smaller scale are to be preferred.

The illustration shows one the authors use. It is just right so that one of its compartments on either side will take two frames of such size that three of them will just fit the inside of a regular Langstroth frame, the division being made on vertical lines. The baby hire itself is on the same general principle as a full-sized one, having rabbets at the ends to support the 
frame projections. A division-board thru the center lengthwise, $1 / 8$ inch thick, divides the hive off into two bee-tight compartments. Tacked to this board is a square of enamel cloth which, when spread, covers

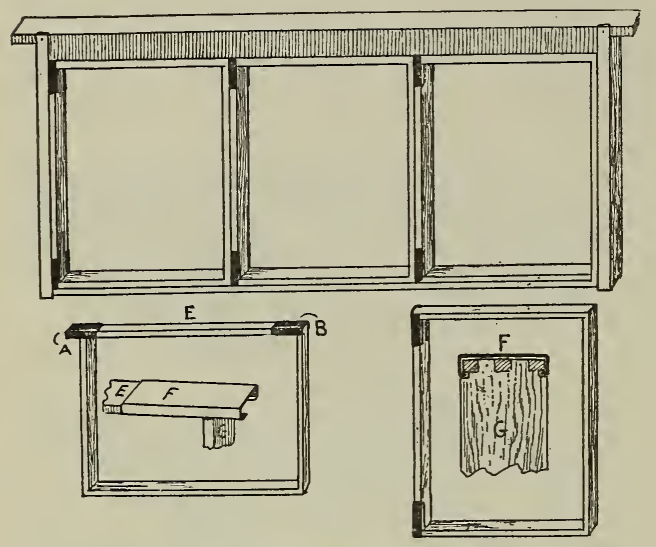

Twin-nuclei frame.

both sides. In order that the little frames may hang in the rabbets and yet at the same time be fitted inside the full-sized Langstroth frame, projections or supports are made of metal, and so constructed that they can slide forward to form a projection, or be shoved back out of the way.

Farly in the season these little frames are filled with full sheets of foundation; or, from a lot of old defective combs can be cut pieces which can be fitted in these thirdsized nucleus-frames. When filled with comb or foundation three of them are inserted in a common Langstroth frame, which inay be put down in the center of a good colony. Where preferred a colony may be supplied exclusively with these three-in-one frames. When filled they can be given bees and all to the baby hives by being taken out of the large frame, and the metal projections shoved forward or outward, as shown at $\mathrm{F}$ and $\mathrm{A}$. When shoved out they are ready to hang in the nucleus-box; but before this is done each division of the twin box should be supplied with about half a pint of bees. While the bees may be taken from the same yard in which the matingboxes are to be stationed, it is strong!y advised to procure them from an outyard;

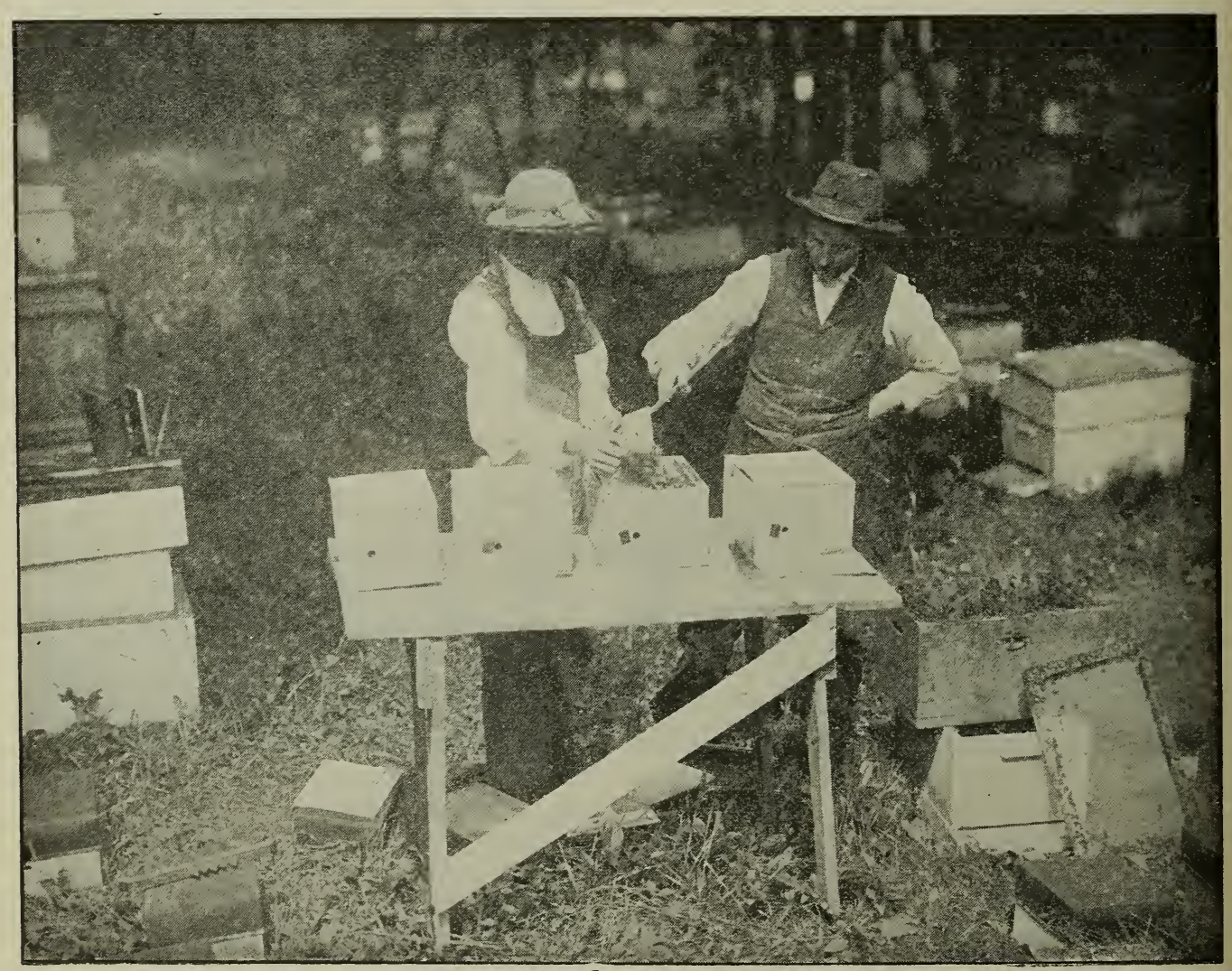

Fig. 2.-Scooping the bees with a small dipper into baby nuclei, 
or, if one does not have one, to purchase three or four colonies of black or hybrid bees from some farmer. All their drones must first be captured with perforated zine.

\section{FORMIING BABY NUCLEI.}

A regular hive-body that has a wire-cloth screen bottom and a removable wire-cloth screen top is prepared. Into this box some ten or twelve pounds of bees are shaken from some other yard. These may come from four or five colonies, but generally from a dozen or more hives. This box of bees is then taken to the queen-rearing yard, where the nuclei are to be formed. Four of the twin baby hives are first placed upon a little light stand, each filled with empty combs ready to receive the bees, entrances closed, and ventilators opened. The hive-body containing the shaken bees is then placed conveniently near. They are wet down with a spray, then given a jar so as to get the bees down in a mass in the bottom. With a little tin dipper are scooped up approximately four ounces of bees, making anywhere from a thousand to twelve hundred individuals. As the bees have been previously wet down they can not fly very readily, and can therefore be scooped up a la Pratt and dumped in one of the compartments as shown in Fig. 2. An attendant stands ready with a number of virgin queens. He remores one of the frames of one compartment, and, while the apiarist is scooping up a dipperful or two of bees and dumping them in the space made vacant by the removal of the frame, he drops in a virgin queen that has previnusly been dipped in honey or syrup. $\mathrm{He}$ now puts in the removed frame and folds back the enamel cloth. The operation is repeated in the other compartment of the box, and so on the process is continued until all of the twin mating-boxes are filled with bees and virgin queens. The baby hives are then set to one side for about 48 hours, when they are placed on their permanent stands for the summer. Their entrances are opened at night. The next morning, as the bees come out they will mark their location and begin housekeeping with their baby queen.

After the baby nuclei are in full operation ripe queen-cells in place of virgins are given. The two frames are spread a little apart when the cell is placed in position.
At the time of forming these baby nuclei, a thick syrup of aboui $21 \%$ parts of sugar to one of water is poured into the feeder compartment at one side. At other times, if it is a little cool it is given at night, hot, when it will all be taken up before morning. This feeding may be required off and on during the season. In some years the baby nuclei will gather enough to supply their own needs. At other times they will require a little help.

These little twin nuclei serve only the purpose of mating. No cells are reared in them, and the comparatively small number of bees in each compartment makes it easy to find a laying queen or virgin if present. If in doubt as to whether the nucleus has a virgin, another cell is given; and even should the virgin come back from her flight she will take care of that cell by gnawing a hole in its side and killing its occupant. Should she be lost in one of those flights the cell will provide another virgin, which will come on in due course of time. It is better to have a surplus of cells than to lose time.

These baby nuclei have been carefully tested in one of the author's yards, and have given good results; but one needs to remember a few things in handling them or he may become disgusted with the whole plan.

1. If the force becomes a little weak, a frame of hatching brood should be given, but not eggs or larvæ; or if this cannot be had, after the last queen is taken out a few more bees may be dumped in from a strong colony of the main yard. While some of these will go back, many will remain.

2. After the young queens begin to lay they should be taken out almost immediately, otherwise they will fill the two small combs with eggs and lead off a little swarm if there is a honey-flow on. If not convenient to take the queen out at once, the perforated zine slide should be shoved around to shut her in.

3. It is preferable to make up these little nuclei with bees from some outyard.

4. One side of the nucleus box should not be allowed to become empty of bees. The combined heat of the two clusters brings about a better state of contentment. Where there is only one compartment of bees in a mating-box they cannot do as well as when there are two. 


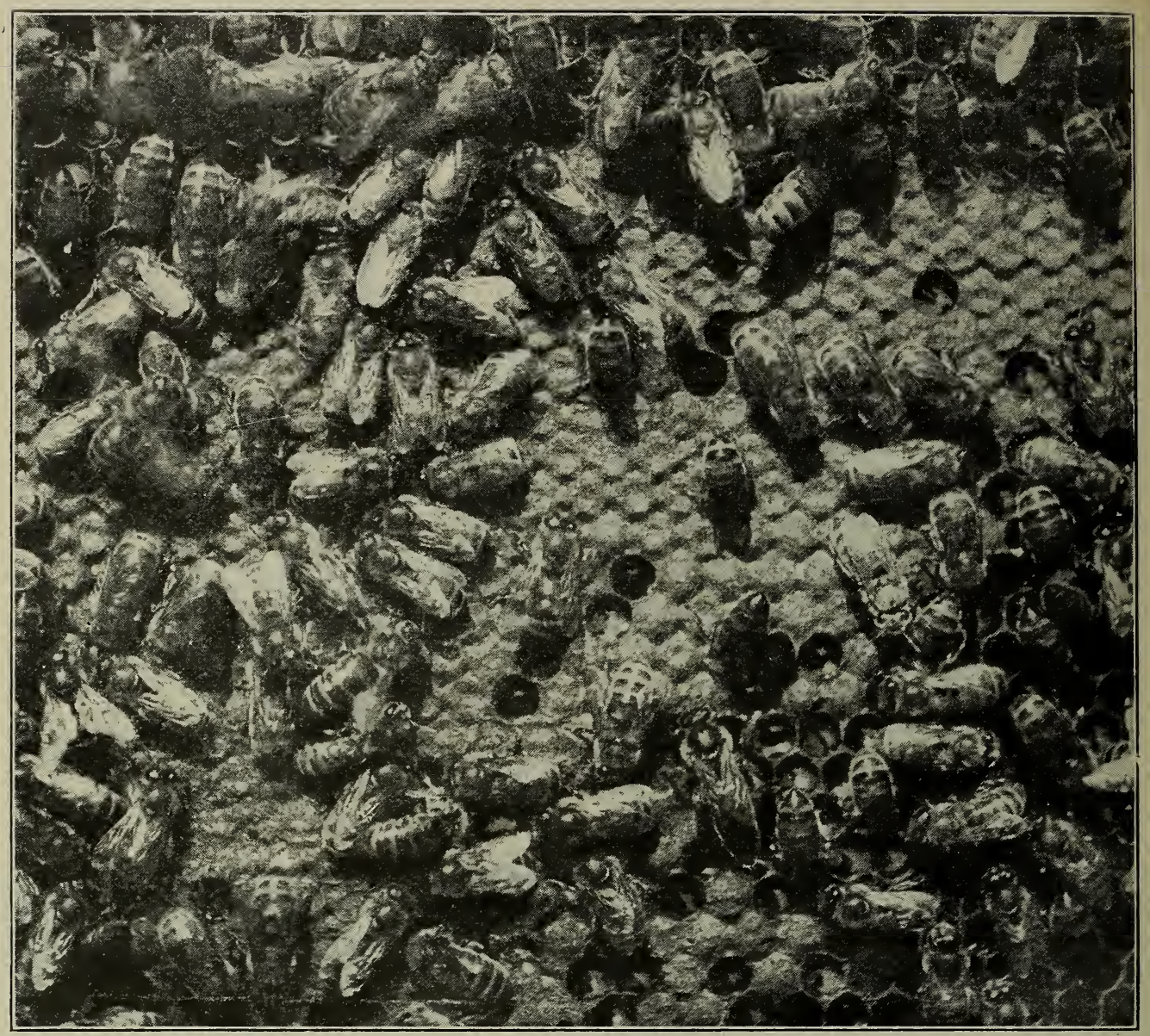

Find the queen.

QUEENS.-The most important personage in the hive is the queen, or mother-bee. She is called the mother-bee because she is, in reality, the mother of all the bees in the hive.

Structurally she is the same as the worker bee. The same egg that will produce a worker will also produce a queen. While a worker will lay eggs only under stress of abnormal conditions, and these only drone eggs (see LAYING Workers), the queen-bee, after she has met a drone (or male bee), will lay two kinds of eggs-worker and drone. While the worker bees have all the organs of the queen, those organs are undeveloped. The workers instead of being neuters are all females but incapable of reproducing more females. The queen is the only true female. So far from being a ruler or sovereign she is little more than an egg-laying machine subject to the caprices of her sisters.
When a colony is deprived of its queen, the bees set to work and raise another so long as they have any worker-larvæ in the hive from which to do it. This is the rule, but there are some exceptions-so few, however, that it is safe to assume that a queen of some kind is present in the hive whenever they refuse to start queen-cells from larvæ of a proper age.

\section{UNDERSIZED OR IMPERFECTLY DEVELOPED QUEENS.}

Some queens are small,* unusually dark in color, and sometimes become fertilized. They lay eggs for a little while (from a week to several months), but never prove profitable. Sometimes they will not lay at all, but remain in a colony all thru the season, neither doing any good nor per-

* Small queens are not necessarily inferior. One of the most marvelous egg-producers I ever saw was a "bantam" from Golden stock. She could run thru perforated zinc and back again. before a worker could get started thru.-A. C. MiLler. 
mitting any other queen to be either introduced or reared. A wingless queen, or one with bad wings, will produce the same result. The remedy is to hunt them out and remove them. Where they are so nearly like a worker-bee as to make it hard to distinguish them, they can often be detected by the peculiar behavior of the bees toward them. See woodcut below. In the fall, after the queen has ceased laying, she will usually look small and insignificant even tho she be an extra good one. But if it is

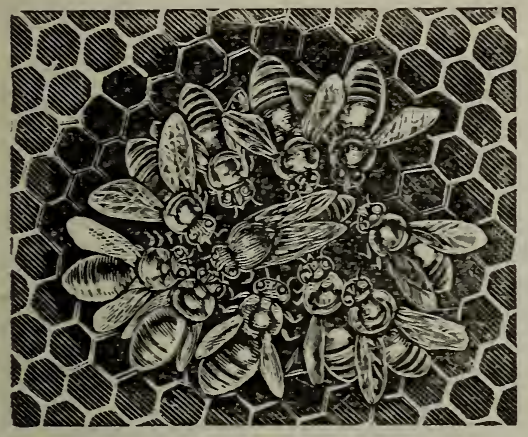

The queen and her retinue.

during the laying season, when all fertile queens are laying, and the queen looks small, she should be removed, ard another put in her place. It doesn't pay to keep anything but the very best stock. The loss in honey would pay for sereral of the best queens.

\section{DEVELOPMENT OF BABY QUEENS.}

HOW $\perp$ WORKER-EGG IS MADE TO PRODUCE A QUEEN.

This is a question that puzzles novices about as much as any question they can ask. To answer it we will try an experiment and let the bees tell their own story. We will get a frame of eggs, and put it into a colony having no queen. The tiny eggs will hatch into larræ as before; but about as soon as they begin to hatch, we find a few of the cells supplied with a greater profusion of milky food than others. Later these cells will begin to be enlarged, and soon at the expense of the adjoining ones. These are queen-cells, and they are something like the cup of an acorn in shape, and usually occupy about the space of three ordinary cells. In the cuts will be seen cells in different stages of growth.

There are some queer things about queen- cells, as will be noticed. After the cell is sealed, the bees put a great excess of wax on it, make a long tapering point, and corrugate the sides something like a thimble, as shown at C. This corrugation, or roughness, when closely examined, will be seen to be honeycomb or, rather, an imperfect representation of honeycomb on a very small scale.

It is very handy to be able to tell when any queen-cells will be likely to hatch; and the bees are rery accommodating in this respect also; for, about the day before the queen hatches, or may be two days, they proceed to tear down this peak of wax on the tip of the cell, leaving only a thin covering. IVe don't know why unless they are anxious to get a peep at their new mother. It has been said they do it that she may be better able to pierce the capping; but sometimes they omit the proceeding entirely, and apparently she has no difficulty in cutting the cap off. If the cell is built on new comb, or on a sheet of foumdation, and be held up before a strong light at about the fifteenth day, or a little later, the queen can be seen moving about in the cell. Afterward, by listening carefully, she can be heard gnawing her way out. Pretty soon the points of her sharp and powerful mandibles will be

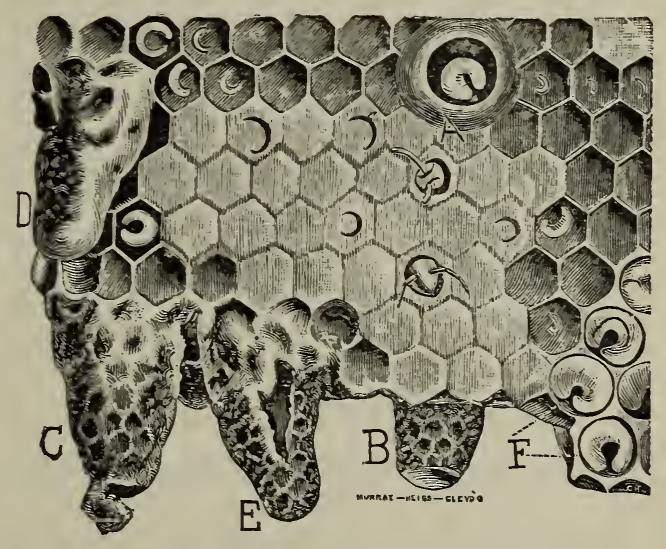

Queen-cells.-After Cheshire.

seen protruding, as she bites out a narrow line. Since she turns her body in a circle while doing this, she cuts out a circle so true that it often looks as if marked by a pair of compasses. The substance of which the cell is made is tough and leathery, and, therefore, before she gets clear around her circle, the piece springs out in response to her pushing, and opens just about as the 
lid of a coffee-pot would if a kitten should happen to be inside crowding against the lid. They may often be seen pushing the door open and looking out, with as much apparent curiosity as a child exhibits when it first creeps to the door on a summer morning; often, after taking this look, they will back down into their cradles, and stay some time. This is especially the case when other queens are hatching, and there is a strife as to who shall be sovereign.

We will now consider the strange substance, royal jelly, on which the baby queens are fed while in the cell.

The milky food before described, which is given to the young larvæ, and which is supposed to be a mixture of pollen and honey partially digested, is very similar, if not identical, in composition with the royal jelly. Bees are not the only examples in the animal kingdom where the food is taken into the stomach by the parent, and, after partial digestion, regurgitated for the use of the offspring. Pigeons feed their young precisely in this way until they are able to digest their food for themselves. It has been stated that bees use a coarser food for the worker larvæ, after they are a few days old, and also for the drone larvæ during the whole of their larval state. By " coarser food" is meant a food not so perfectly digested; in fact, drones are said to be fed on a mixture of pollen and honey, in a state nearly natural. It has also been said, that queens receive the very finest, most perfectly digested, and concentrated food that they can prepare. This we can readily believe, for the royal jelly has a very rich taste-something between cream, quince jelly, and honey-with a slightly tart and a rank, strong, milky flavor that is quite sickening if much be taken.

\section{WHAT DOES THE QUEEN DO WHILE SEALED UP?}

We have opened cells at every stage after they were sealed until they were ready to hatch. One day after being sealed they are simply ordinary larvæ, altho rather larger than worker larvæ of the same age; after two or three days, a head begins gradually to be "mapped out," and, later, some legs are seen folded up; last of all, a pair of delicate wings come from somewhere. See Development of Bees. Two days before hatching we have taken them out of the cell, and had them mature into perfect queens, by keeping them in a warm place. We have also taken them out of the cell before they were mature, held the white, still, corpselike form in the hand while we admired it as long as we chose, then put it back, waxed up the cell by warming a bit of wax in the fingers, and had it hatch out three days after, as nice a queen as any. Mr. Langstroth mentions having seen the whole operation by placing a thin glass tube, open at both ends, into the cell, so as to have it inclose the queen, the bees being allowed to

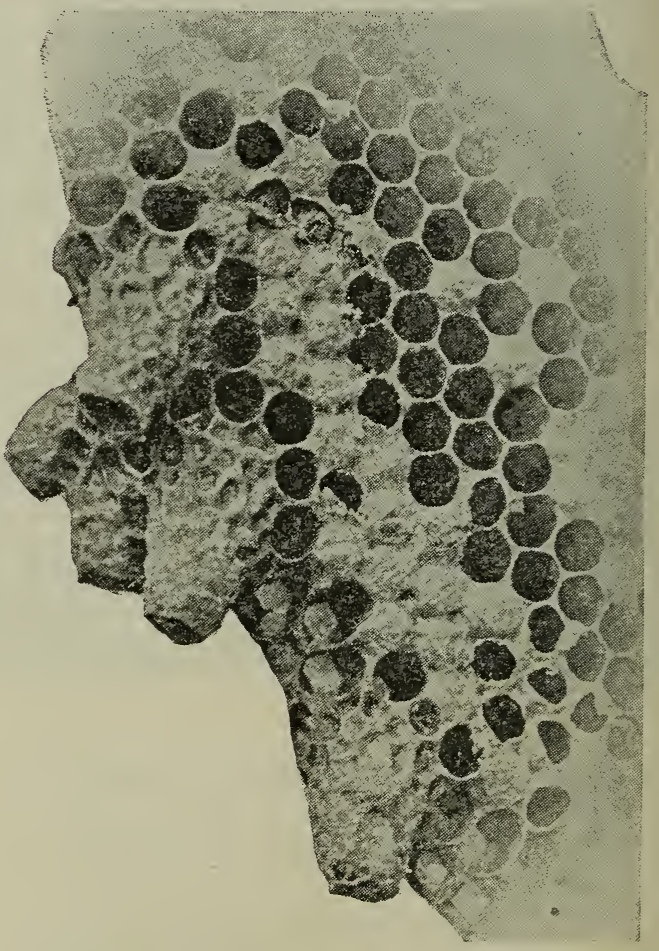

Natural-built queen-cells, life size.-Photographed by W. Z. Hutchinson.

cap it as usual. This experiment was first made by Huber. With several such glass queen-cells the whole operation could be watched from beginning to end. See $\mathrm{OB}_{\mathrm{B}}$ SERVATORY HIVE.

\section{WHAT BECOMES OF THE QUEEN AFTER SHE LEAVES THE CELL?}

After she pushes open that hinged door, which will be found illustrated at $\mathrm{C}$, second column, page 593, she generally begins by poking her head into the cells until she finds one containing unsealed honey, from which she takes a sup that, at least, indicates she likes that kind of provision. 
After she has had her supper she begins to crawl about, partly to enjoy using the long strong legs God has given her, and partly because she knows that it is her allotted task to tear down the remaining queen-cells, if such there are. If. other queens have hatched before her, it is one of her first and foremost duties to look them up, and either reign supreme or die in the attempt. When all other cells have been removed, as they usually are where queens are wanted for other purposes, she has nothing to do but to promenade over the premises, monarch of all she surveys. If she ever sits down to take a rest, or takes a rest in any other position, during the first week of her life, we have never been able to discover it.

But suppose she does find another cellwhat then? She sometimes runs around awhile; sometimes the bees tear it down, and sometimes she tears it down herself, with the same strong mandibles that she used to cut her way out of the cell at first. She usually makes the opening in the side of the cell, as shown at $\mathrm{E}$ in the woodcut on page 593 and again on page 588 .

It is said that the queen immediately stings her helpless immature sister to make a sure thing of her destruction, but of this we are not certain, for we never have caught her in the act. Te have seen spots in the side of the queen that looked as if she had been stung; we have also rescued cells and put them into a wire-cage nursery after they had been torn open, and had them mature into nice queens. As these immature queens are very soft, the workers will soon pick them out of the cell, piece by piece, and we have sometimes placed them in the nursery and had them mature, minus a wing, or leg, or whatever portion the mischievous worker had pulled away. From many observations the queen generally tears a hole in the cell. or bites into it in such a way that the workers take hold of it, and tear it all down, much in the way they do any mutilated or broken piece of comb. When queen-cells hare been cut out, all the larvæ that are in any way injured are at once thrown out, and none but the perfect cells preserved. Bees nerer fuss with cripples, nor try to nurse up a bee that is wounded or maimed. They have just the same feeling for their fellows that a locomotive might be expected to have for a man whom it had run over. They battle against anything that threatens the extinction of the colony, it is true. We have never been able to discover any signs of their caring for one of their number, or even having compassion on their helpless brood when it is wounded and suffering. If a hole is made in a queencell by the queen or by any person, they are almost sure to tear it down and throw it away. When a queen hatches, the remaining cells are very soon torn down, as a general thing, but there are many exceplions. Where two queens hatch out at about the same time they also generally attempt to kill each other; but we have never heard of both being killed. This probably results from the fact that they can sting their rivals only in one certain way; and the one that, by strength or accident, gets the lucky position in the combat is sure to come off victorious. This explains how a very inferior rirgin queen, that has entered the hive by accident, may sometimes supplant an old laying queen. Two queens, when thus thrown together, generally fight very soon, but this does not always happen. Several cases are on record where they have liven in peace and harmony for months, cren when hatched at about the same time, and it is quite common to find a young queen helping her mother in the egg-laying duties of the hive, especially when the mother is two or three years old. If the season is good, and the hive populous, they may divide up their forces, and we have AFTER-SIVARMING, which see.

Sometimes the queen will pay no attention to the remaining cells, but will let them hatch out, and then their "little differences" are adjusted afterward, eitber by swarming or by the usual "hand-tohand" conflict "until death." We once looked for a queen, and, not finding her, concluded she was lost. Another cell was inserted, and in due time hatched out. We were much surprised to find this new queen laying when only one day old; but a little further looking revealed two, both on the same comb. Many losses in introducing queens have resulted from two queens being in the hive, the owner being sure his hive was queenless-because he had remored one. See Introducing.

QUEENS' VOICES.

Queens have two kinds of roices, or calls, either one of which they may emit on cer- 
tain occasions. It is almost impossible, on the printed page, to describe these sounds. One of them is a sort of z-e-e-p, z-e-e-p, zeep, zeep. Some call it piping, others teeting. Whatever it is, it consists of a prolonged tone, or a long zeep followed by several much shorter, each tone shorter than the preceding one. This piping is made when the queen is out of the cell, either virgin or laying, but usually by a young one. The older ones are generally too dignified, or too something, to give forth any such loud squealing; but they will squeal, and lustily, too, sometimes, when the bees ball them and grab them by the legs and wings. They shout just as we would when surrounded by enemies on avery side, and in mere fright give an exclamation of alarm.

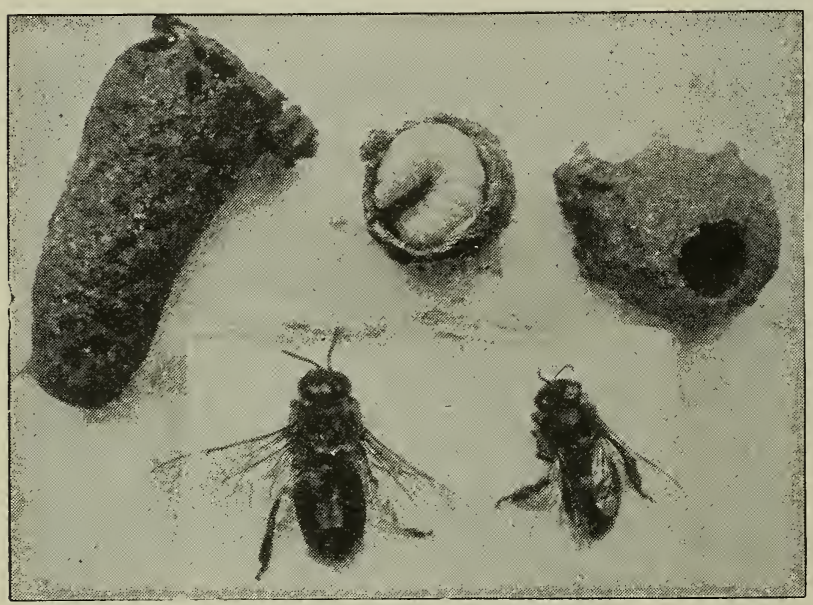

Natural queen-cells at different stages.-The capped cell on the left has been detached from the comb, and is ready to give to a colony; cell in the center, five or six days old, has been shaved down to show the queen larva just before it is ready to stretch out lengthwise of the cell; cell on the right shows the mouth of a cell just before capping.

The other note that queen-bees are known to give forth is what is called quahking, for that more nearly describes the actual sound than any other combination of letters we can put together. If we mistake not, it is emitted only by a young queen in the cell, before she is hatched, and is made in answer to the piping or zeep, zeep, of one of the virgins that has already hatched, and is trying perhaps to proclaim aloud her sovereignty. The quahk will be heard, then, only when there are queen-cells in the hive. At others times the note will be a series of long z-e-e-p, z-e-e-p, followed by shorter tones, as explained.
While a young queen is being introduced she frequently utters a note of alarm, a zeep, zeep, etc. The bees are almost always stirred by these notes of the queen, and they will often turn and run after her and eling around her like a ball, when they would have paid no attention to her had she not uttered this well-known note. When once heard it will be recognized ever afterward. Queens, when placed near together in cages, will often call and answer each other, in tones that we have supposed might be challenges to mortal combat.

Some queens received one summer from the South called so loudly when placed on the table that they could be heard clear across a long room. One voice would be on a high, shrill key and another a deep bass, while others were intermediate. On watching closely a tremulous moveof the wings was noticed while the queen was uttering the note, and one might infer from this that the sound is produced by the wings, but this is probably not the case. Some one reported having heard a queen squeal, both of whose wings had been entirely clipped off.

\section{VIRGIN QUEENS.}

The newly hatched queen is termed a virgin simply to distinguish her from queens that have been fertilized by the drone and are laying. Virgin queens, when first hatched, are sometimes nearly as large as a fertile queen, but they gradually decrease in size, until when three or four days old they often look so small and insignificant that a novice is disgusted with their appearance, and, if hasty, pronounces them useless. For the first week of their lives they crawl about much as an ordinary young worker does, and it is often very difficult, if not almost impossible, to find them, unless an amount of time is taken that is more than a busy apiarist can well afford to spare. It is a waste of time to look for them. It is better to insert a frame having some unsealed larvæ just hatched from the egg; then if no cells are started, one can decide the queen is there without looking further. This plan answers a threefold purpose: It tells at a glance whether 
the queen is in the hive all right or not; for the rery moment she is lost they will start more queen-cells on it; keep them from going out with the queen in case the queen is lost by any accident on her wedding-flight, which is frequently the case; and, lastly, it serves as a sort of nucleus to hold the bees together and to keep them from going out with the queen on her wedding-trip, which they are much disposed to do, if in a small nucleus containing no brood. Unsealed brood in a hive is a great safeguard against accidents of all sorts, and we hare often started a young queen to laying by simply giving the bees some eggs and unsealed brood. Whether it caused her to rouse up and take her wedding-flight, or whether she had taken it, but was for some reason idle, we cannot say; but this we know, that young queens that do not lay at two weeks of age will often commence, when eggs and larræ are giren to their colonies. It may be that the sight of eggs and larræ suggests to them the next step in affairs, or, what is more probably true, it may induce the workers to feed them, as they do a laying queen, an unusual quantity of food.

AGE AT WHICH VIRGIN QUEEXS TAKE THEIR WEDDING-FLIGHT.

Some go so far as to say that the queen goes out to meet the drones the day after learing the cell. Others fix the weddingflight from two to ten days after birth. It is quite likely that some difference arises from the fact that queens often stay in the cell a day or two after they are strong enough to leave it. Sometimes a queen will be found walking about the combs when she is so young as to be almost white; we hare often seen beginners rejoice at their beautiful yellow queens, saying that they were yellow all over, without a bit of black on them; but when looked at again, thèy would be found to be as dark as the generality of queens. At other times when they come out of the cell they will look, both in color and size, as if they might be three or four days old. The queens in our apiary generally begin to crawl about the entrance of the hive, possibly looking out now and then, when 5 or 6 days old. The next day, supposing of course we have fine weather, they will generally go out and try their wings a little. These flights are usually taken in the warmest part of the afternoon.
There is no prettier or more interesting sight to the apiarist than the first flight of a queen. She runs this way and that, somewhat as does a young bee, only apparently much more excited at the prospect of soaring aloft in the soft summer air. Finally she tremblingly spreads those silky wings, and with a graceful morement that we can not remember to have seen equaled anywhere in the whole scope of animated nature, she swings from her feet, while her long body sways pendulously as she hovers about the entrance of the hive. A workerbee horers also about the entrance and carefully takes its points when trying its wings for the first time; but she, seeming to feel instinctirely that she is of more value to the colony than many. many workers, with the most scrupulous exactness notes every minute point and feature of the exterior of her abode, often alighting and taking wing again and again, to make sure she knows all about it.

By and by she rentures to circle a little way from home, always rerging back soon, but being gone longer and longer each time. She sometimes goes back into the hive satisfied. without going out of sight at all; but in this case she will be sure to take a longer flight next day or a half-hour later in the same day. During these seasons she seems to be so intent on the idea she has in her head that she forgets all about surrounding things, and, instead of being frightened as usual at opening the hive, she will pay no attention; but if the comb she is on is lifted up she will take her flight from that as well as from anywhere else. We have caught them in the hand at such times, without their being frightened; but as soon as they were allowed to go, they were off as if nothing had happened.

After the queen is satisfied that she will know the place, she rentures out boldly; and from the fact of her circling right up in the air, it was once supposed that fertilization took place above the ken of human eyesight. This has been shown to be a mistake. See Drones.

After a successful flight she returns with the organs of the drone remaining attached to her body. See Droxes. This is a white substance, and is frequently so large as to be plainly seen while she is on the wing. A queen is usually gone half an hour, but we have seen them return fertilized after an ab- 
sence of not more than 10 or 15 minutes, and there have been reported instances where she has been gone not more than three minutes. This accomplished, she goes quietly into the hive. The bees are much inclined to chase after her, and they sometimes pull at the protruding substance as if they would drag it away. That they do so, is pretty well proven.

Entil recently it was generally believed that the queen met the drone only once, notwithslanding the fact that Francis $\mathrm{Hu}-$ ber, in his book, "New Observations," published in 1814, made the statement that queens might or might not take more than one wedding-flight before beginning to lay. But this seems to have been overlooked until 1904, when considerable proof was adduced to show that the same queen before laying (not after) may not only take several wedding-flights, but come back on different occasions with sure evidence of having met a drone.

While it seems to be pretty well proven that the queen may take more than one marriage-flight prior to her laying, it is very much doubted whether she ever takes a second flight to meet the drone after laying, altho there are some facts that seem to point that way. Against the belief that the queen meets the drone after once beginning to lay is the fact that she may receive on one of her wedding-flights enough spermatozoa-more than enough, in fact, to supply her fully for all the eggs that she can ever lay, even tho she lives to be five or six years old. The number of spermatozoa has been variously estimated at from two to twenty million, which she receives at one mating. Even if we accept the lesser figure, a good queen can scarcely lay more than two hundred thousand eggs in a season, even in a southern climate; and she then would have to live ten years, which she never does, to use up all the spermatozoa she receives at her one mating.

For further particulars on this subject of mating, see Drones.

The next day after a successful mating one will, as a general rule, find the queen depositing eggs. The average age at which queens begin laying is about nine days; we generally wait ten days from the date of hatching, and are then pretty sure of finding them ready to send off. Between im. pregnation and the time the first egg is laid a remarkable change takes place.

After the queen has been out and fertilized, her appearance is much the same as before. She runs and hides when the hive is opened, and looks so small and insignificant that one would not think of calling her a fertile queen. A few hours before the first egg is laid, however, her body increases remarkably in size, and, if an Italian, becomes lighter in colcr, and, instead of running about as before, she walks slowly and sedately. She seems to have given up all her youthful freaks, and comes down to the sober busines of life in supplying the cells with eggs.

HOW OLD A QUEEN MAY BE AND STILL BECOME FERTILIZED.

As before stated, queens usually begin to lay when 8 or 10 days old, on the average; but during a spell of bad weather, or when drones are scarce, they may fail to lay until three weeks old. The longest period we have ever known to elapse between the birth of a queen and her laying worker-eggs was 25 days. All queens that do not lay at the age of 20 days should be destroyed, when the season, flow of honey, flight of drones, are all right. There is one important exception to this. Many times queens will not lay in the fall at all, unless a flow of honey is produced either by natural or artificial means. Queens introduced in the fall often will not lay until the ensuing spring, unless the colony is fed regularly every day for a week or ten days. Likewise young queens that are fertilized late in the season will often show no indications of being fertilized until the colony is fed. A lot of young queens that we thought might be fertilized but did not lay were once wintered over, just to try the experiment; and altho they went into winter quarters looking very small, like virgin queens, nearly all proved fine layers in the spring.

\section{DRONE-LAYING QUEENS.}

If a queen is not fertilized in two weeks from the time she hatches, she will sometimes commence laying without being fertilized at all. She is then what is called a dronelaying queen. Usually her eggs are not deposited in the regular order of a fertile queen, neither are there as many of them; by these marks we are able to guess that 
she may not be all right, and so keep her until some of the brood is capped, when the extra height of the cappings, as we have explained under Drones and BRoOD, shows. At times, however, the eggs are deposited so regularly that we are deceived, and the just as good to furnish supplies of drones for the apiary as the drones reared from a fertile queen, is a point not fully decided; but if the queen lays the egg's in drone comb, and the drones are large, fine, and healthy, they are probably all right. Drones reared

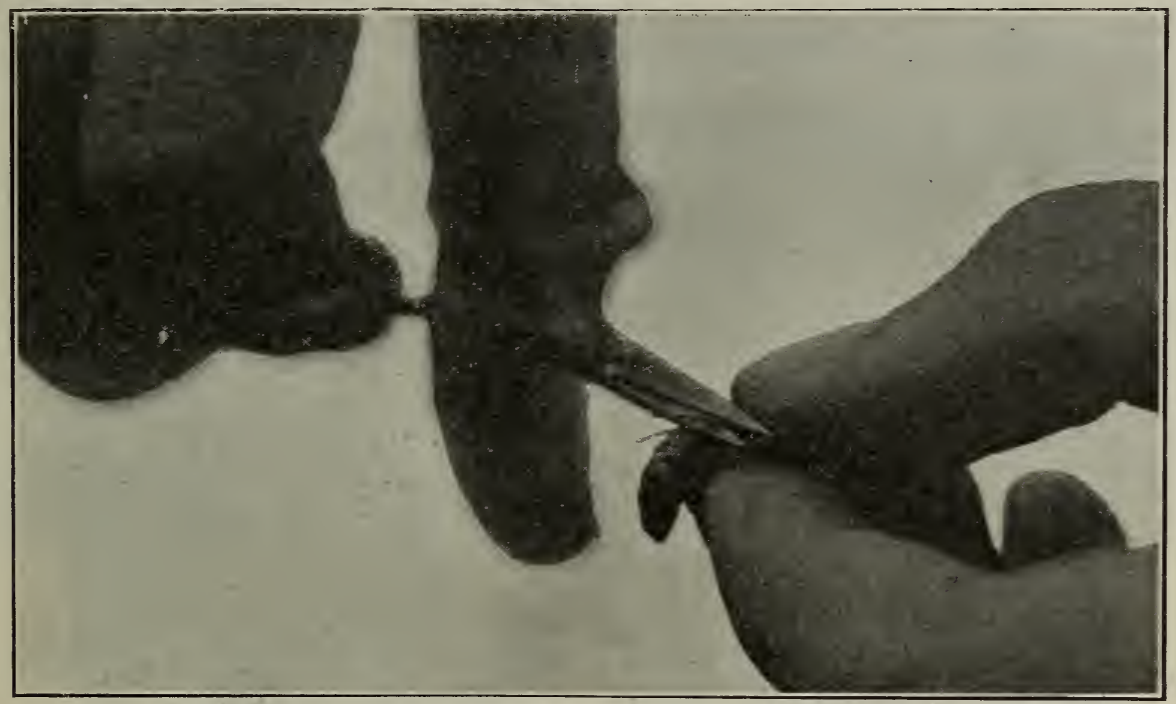

The easiest way to clip a cuecn.

queen may be sold for a fertile queen, when she is only a worthless drone-layer; but this can be determined after the brood is capped.

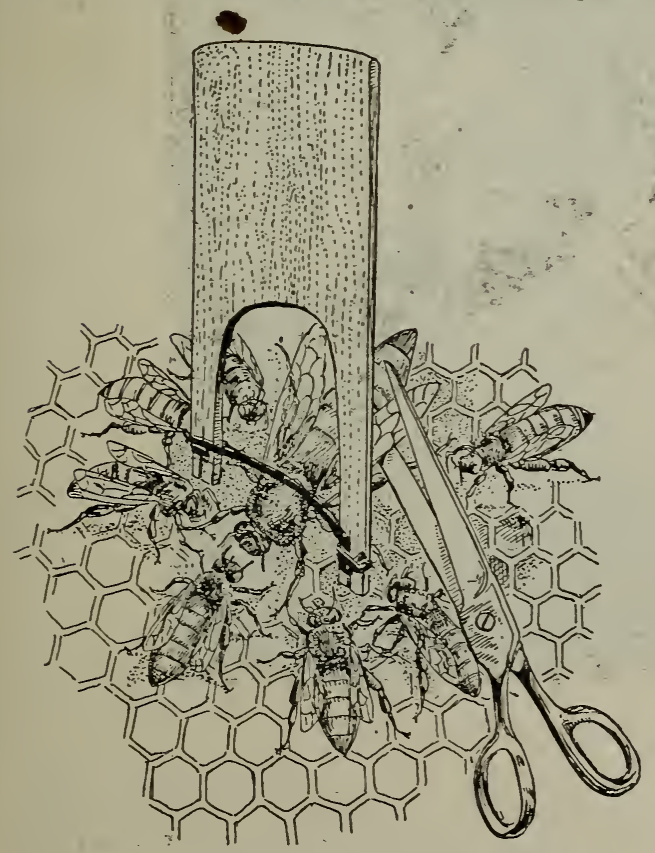

Willis queen-clipping derice, and how used.

Such a case occurs, perhaps, once in a thousand. Whether these drone-layers are from fertile workers, and drones reared in worker-cells, as those from drone-laying queens sometimes are, should not be used.

How to find queens, see MaNipulation of Colonies, subhead "How to Manipulate Hoffman Frames," also "How to Handle Unspaced Frames."

\section{SHALI WE CLIP QUEENS' WINGS?}

The majority of honey-producers practice what is known as clipping; that is, two wings on one side are cropped off, leaving merely the stumps of what were once wings. The object, of course, is to prevent swarms from going off by making it impossible for the queen to follow. See BEE BEHAVIOR, also SWARMING.

There are very few who believe or profess to believe that clipping is injurious to the queen. The fact that queens after being clipped seem to do good service for two or three years, and sometimes four, and the further fact that such queens do as well as those not clipped, would seem to show that no detrimental results follow.

\section{HOW TO CLIP A QUEEN'S WINGS.}

There are sereral ways of accomplishing this. One plan is to grasp the queen by the 
wings with the right hand, in the usual manner. With the thumb and forefinger of left hand, take hold of her waist, or thorax, as shown in the cut at the top of previous page. In this way she can be held very securely and safely, leaving her legs as well as her wings entirely free. With a pair of slender-pointed embroidery scissors (or any case let her fall more than an inch; for a queen during the height of the egg-laying season is liable to be injured if handled roughly. Some prefer, after picking up the queen, to grasp her by the legs; but this is liable to pull one or more legs off unless done just right, and therefore the first mentioned plan is recommended.

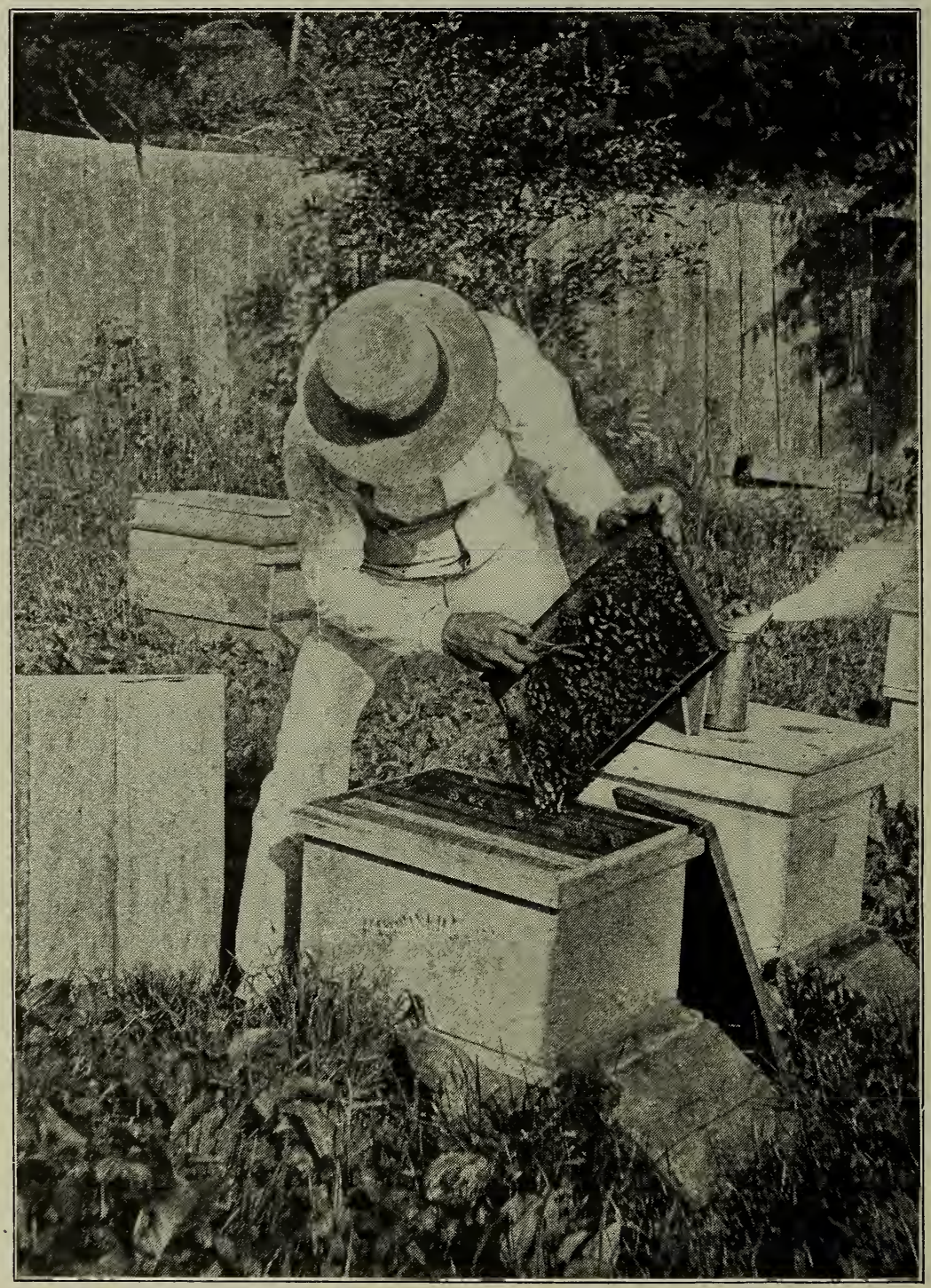

Greiner's method of clipping without handling the queen.

kind of scissors if these are not obtainable) clip off the two wings on one side, leaving anywhere from one-eighth to one-sixteenth of an inch left, being careful not to cut too close. This accomplished, drop her gently between two frames of brood; but in no
Before any one of these plans is attempted, if one has had no experience he should first practice on drones. If these are not to be found, worker bees should be picked up by the wings until one becomes reasonably expert; but a worker should not 


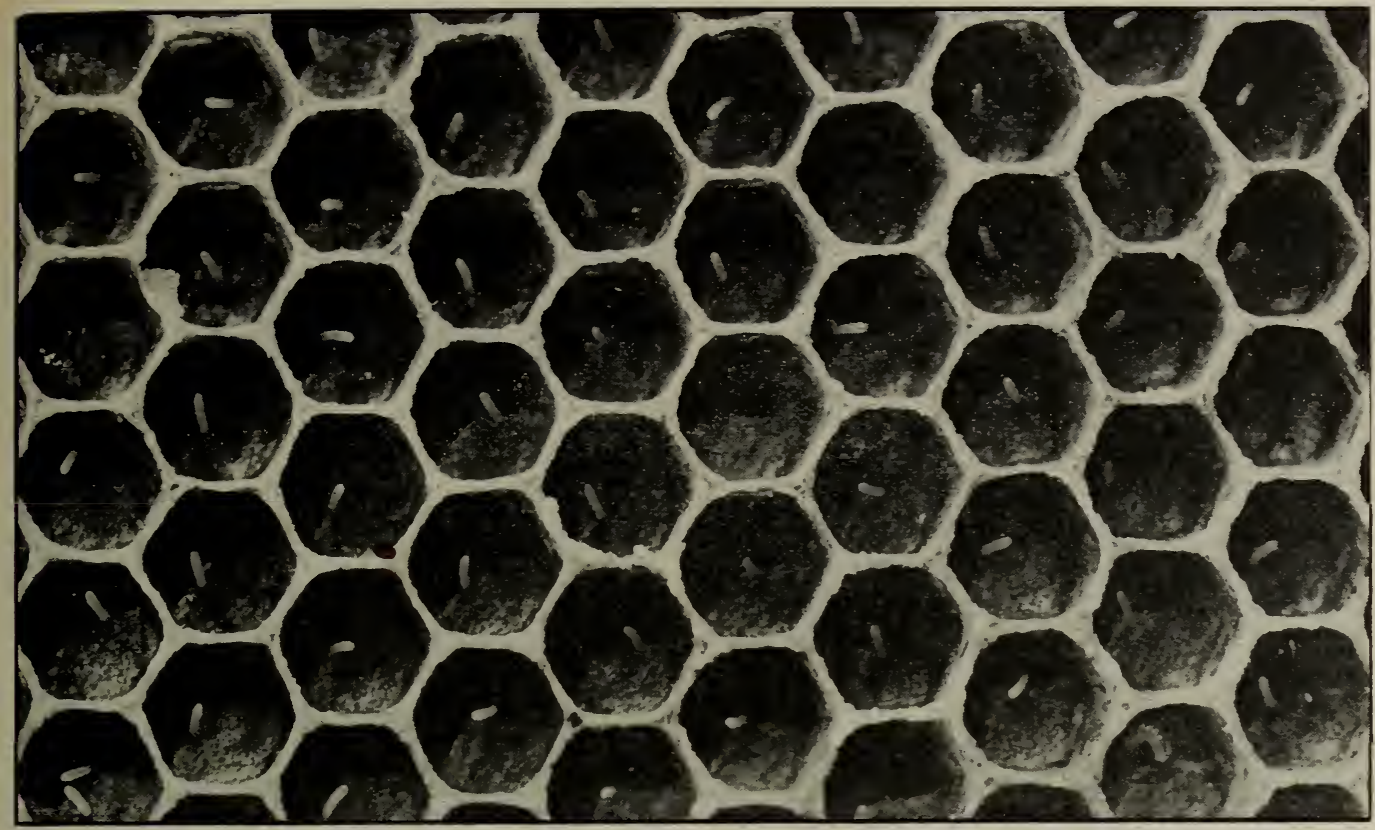

Close view of eggs. Notice the cell in the lower left-hand corner contains two eggs, while that at the righthand corner has a larra.

be put between the thumb and finger of the other hand, as one will run a good chance of being stung. For this part of the work drones should be procured. Then, when one can do both operations well, he can try a queen. Eyen then we advise the attempt on one of not much ralue, as it is a nice piece of work to do it well.

Sometimes in an outyard, when.a pair of scissors is not to be had, we use a sharp blade of a penknife. This is passed under the two wings in such a way as to cause them to bear directly upon the edge of the blade. The thumb is now pressed down upon the wings over the blade, and then drawn back and forth seesaw fashion, perhaps two or three times. If the knife is sharp, the wings will be severed with two or three strokes. If it is dull, the queen should be laid on her back, still holding her between the thumb and finger of the left hand so that her wings will bear directly upon a hive-cover or any other piece of board or wood. The edge of the knife should be brought to bear upon the wings, when a slight pressure will cause the blade to pass thru them.

During these operations care should be taken to handle a queen only by the wings or the thorax. This way avoids all danger of hurting her. One should be careful not to press the abdomen of any queen.
HOW QUEENS LAY TWO KINDS OF EGGS.

That queens lay two kinds of eggs no one now is inclined to dispute, since the experiments with the microscope have decided the matter so clearly, as given under Drones. Suppose a young queen goes out to meet the drones so late in the fall or so early in the spring that there are none; what is the consequence? Sometimes she will nerer lay at all; but frequently she commences to lay when three or four weeks old, and her eggs produce only drones. In fact, she can produce no other eggs, having never been fertilized. How shall we distinguish such queens from fertile ones?

We cannot decide positirely concerning them, by any means we know now, until their brood is ready to seal up; then we will know by the round, raised cappings of the brood, like bullets laid on a board, as we explained under Drones. See Brood, particularly large illustration of worker and drone brood. One can give a pretty good guess by noticing the way in which the queen lays the eggs; if they are few and scattering, and somletimes, or often, in drone-cells, coupled with the fact that she did not commence laying until two weeks or more old, she should be replaced. A young queen, if properly fertilized, never, or very rarely, lays an egg in a drone-cell; 
and when she commences to lay, she fills cell after cell in regular order, as men plant hills of corn; her work also has a neat and finished appearance that says at once to the expert, "She is all right."

In rare cases a young queen begins with all, or nearly all, drone eggs, but, after a while, lays entirely worker eggs as regularly as one could wish.* We do not know why this is; perhaps she has not yet got used to the "machinery." Again, any queen is liable any day of her life to begin laying drone eggs altogether, or in part. A nice laying young queen, taken from a hive, and shipped to a distance, may prove to be a drone-layer shortly after or immediately after she is received. Such things are not very common, but they do occur. Out of three or four hundred colonies one may find one drone-layer, on an average, each spring. During the summer, perhaps one more will be found. It may be that the queen was not fertilized sufficiently, and that the supply of spermatozoa gave out while she was in full vigor, thus reducing her to the condition of a virgin queen. Microscopic examination has shown an entire absence of spermatozoa in at least one or two instances where queens of this kind were killed and dissected. Similar experiments given by Dzierzon show that the spermatozoa may be injured beyond recovery by chilling the queen, and yet the queen herself be resuscitated. Hardship and being shipped long distances may produce the same results.

Queens not only turn suddenly to dronelayers, but they sometimes produce about an equal number of each kind of eggs. In all these cases, where the queen lays drone eggs when she evidently intended to lay worker eggs, they are in worker-cells; at the same time the number of eggs laid usually rapidly decreases. The bees, as well as queen, evidently begin to think that something is wrong; queen-cells are soon started, and after the young queen is hatched she becomes fertile, and begins to help her mother.

Very early in the spring, late in the fall, or at any time when forage is not abun-

* It has been suggested that this phenomenon may be accounted for by the fact that fertile workers were in the hive before the young queen began to lay; and the drone eggs are not from the queen but the fertile workers, and that, when the queen begins. she lays worker eggs at the very start, while the fertile workers are destroyed, and hence the drone eggs disappear. This is possible. dant, a queen will pass right by drone-cells, taking no notice of them. We have often tried to get eggs in drone-cells by feeding, but conclude that the queen knows what an egg will produce, and just how to have every egg laid in a drone-cell produce a drone. Possibly the workers have something to do with this matter, but we.have never been able to make out by what means they signify to the queen that some eggs in drone-cells, or even queen-cells, would be desirable. There seems to be a constant understanding in the hive as to what is going to be done next, and consequently there is no clashing. In our apiary there seems to be, in strong stocks, a kind of understanding that eggs shall be laid in drone-cells about the last of March, and we have drones, therefore, some time in April, ready for the first queens that may, by any accident, make their appearance. Those who insist that there is only one kind of eggs can satisfy themselves very easily by taking an egg from either a drone or worker cell and placing it in the bottom of a cell of the other kind. They will get a drone in a worker-cell, or a worker in a drone-cell. Again: If we give a young laying queen a hive supplied only with drone combs, she will rear worker brood in these drone-cells, and the mouth of the cells will be contracted with wax.

When bees get ready to swarm they build shallow queen-cells, in which the queen then lays a worker egg. Altho we never saw her lay an egg in a queen-cell, we are satisfied that she does it, from the way in which it is put in. Like the rest of the eggs, it is fastened to the center of the bottom of the cell by one of its ends, and we suppose, when first deposited, it is covered with a sort of glutinous matter that makes it stick firmly where it first touches. We know that bees have the skill to remove both eggs and larvæ, for we have several times known them to take eggs and brood to an old dry comb when no queen was present in the hive.

Occasionally a queen is found that will never lay at all; again, queens that laid egg's which never hatched into larvæ have been several times reported. We have had several such, and they were in appearance fine nice-looking queens.

After having related some of the faults and imperfections of queens, it should be 
stated for their credit that, when once properly installed in a good strong colony, they are about as safe property as anything, because, in the great majority of cases, they live and thrive for years. While a worker lives only a few months, queens often live three or four years. One that was imported from Italy furnished us brood and eggs for queen-rearing for four summers. IVe then sold her for $\$ 2.00$, and she died in being sent less than 50 miles. She was very large and heavy, and, probably, being so old could not cling to the sides of the cage like a younger one.

\section{LOSS OF QUEEN.}

It is a very important matter to be able to know at once when a queen is lost. During the months of May and June the loss of a queen from the hive a single day will make quite a marked difference in the honey crop. If we assume the number of eggs a queen can lay in a day to be 3000 , by taking her away a single day we might be just that number of bees short right during a yield of honey. To put it very moderately, a quart of bees might be taken out of the hive by simply caging the queen for a single day. Beginners should remember this, for their untimely, or, rather, inconsiderate tinkering, just before the flow of honey comes, often cuts short their income to a very considerable degree. Whatever is done, it is very important not to drop the queens off the combs when they are handled at this time of the year, nor should we needlessly interrupt the queen in her work by changing the combs about so as to expose the brood or upset the little household matters of the bees.

With a little practice one will be able to detect a queenless hive simply by the way the bees behave themselves in the hive and on the outside. When they stand around on the alighting-board in a listless sort of way, with no bees going in with pollen, when other colonies are thus engaged, it is well to open the hive and take a look at them. If egg's and worker-brood are found one may be sure a queen is there; but if not, proceed at once to see if there is not a queen of some kind in the hive, that does not lay. If one is not found they should be given a frame of eggs to see if they build queen-cells. Incipient ones should be found in about twelve hours if the bees have been some little time queenless. If these are found a queen should be given. If no queen is to be had, they may be allowed to raise one, if the colony has bees enough. If it has not, they should be united witl some other stock.

\section{THE CRY OF DISTRESS FROM A QUEENLESS} COLONY.

Mention has been made that a queenless colony will reveal its condition by the behavior of the bees in the hive. It will set up a peculiar cry-that is to say, the bees all thru the hive will be buzzing as if in distress, and they surely are, because they have no queen. As soon as a hive of this kind is opened they will begin this cry of distress. Sometimes only a part of the bees will be involved, and at other times apparently every bee in the colony. This buzzing of the wings is so marked that the practiced beekeeper recognizes it as an indication of queenlessness; and if he finds no eggs nor young brood at a time of the year when both should be present, he is quite sure that the hive has no queen. If he finds queencells, all doubt will be remored. Sometimes a colony that is not queenless will set up a buzzing as if they were without a mother. It is then evident that the show of distress is not because they have no queen but because of the disturbance. Too much smoke, for example, with most colonies and a little smoke with some colonies will cause them to make this sign of distress. It must therefore be regarded as not an infallible sign of queenlessness.

\section{ODOR OF A LAYING QUEEN.}

After bees have been some time queenless they usually become, if no fertile or laying workers make their appearance (see LAYING WORKERS), very eager for the presence of a queen; and we can in no way describe this eager behavior, if we may so term it, so well as to describe another way of testing a colony that is thought to be queenless. Take a cage or box containing a laying queen and hold either the cage or simply the cover of it over the bees, or hold it in such a way as to let one corner touch the frames. If queenless, the first that catch the scent of the piece of wood on which the queen has been, will begin to move their wings in token of rejoicing, and soon nearly the whole colony will be hanging to the cage or cover. 
When they behave in this manner we have never had any trouble in letting the queen right out at once. Such cases are generally where a colony is found without brood in the spring.

There is something very peculiar about the scent of a laying queen. After having had a queen on the fingers, we have had bees follow and gather about the hand, even when we had gone some distance from the apiary. By this strange instinct they will often hover for hours about the spot where the queen has alighted for even an instant, and, sometimes, for a day or two afterward. Where clipped queens get down into the grass or weeds or crawl sometimes a considerable distance from the hive, we have often found them, by watching the bees that were crawling about along the path she had taken. When cages containing queens are being carried away bees will often come and alight on the cage, making that peculiar shaking of the wings which indicates their joy on finding the queen. See Sense Organs of Bees.

\section{QUEENS' STINGS.}

There is something rather strange in the fact that a queen very rarely uses her sting, even under the greatest provocation possible, unless it is toward a rival queen. In fact, they may be pinched or pulled limb from limb, without even showing any symptoms of protruding the sting at all; yet as soon as they are put in a cage or under a tumbler with another queen, the fatal sting is almost sure to be used at once. There seems to be a most wise provision in this; for if the queen used her sting on every provocation as does the worker, the prosperity of the colony would be almost constantly endangered.

We said a queen very rarely uses her sting; but it is the exception that proves the rule. The following will explain:

One very young virgin queen that stung me was well developed and later proved to be a good queen for business. The other virgin, also very young, that stung me was from a good-looking cell, and I suppose was all right. As it was so much easier to crush her than to endure her continued stinging till I could yet her out of my clothing, she was killed without knowing positively what kind of a queen she would have proven herself to be.

Ceres, Cal. W. A. H. Gilstrap.
CAUTION IN RFGARD TO DECIDING A STOCK TO BE QUEENLESS.

As a rule it may be said that absence of brood or eggs is a pretty sure indication of queenlessness; but it should be borne in mind that all hives, as a rule, are without eggs and brood in the fall and early winter months, or, in fact, at any time when there is a considerable dearth of pasturage. At such seasons, beginners are more apt to think their hives are queenless, because the queens are much smaller than when they are laying profusely. In weak colonies queens often cease laying during the whole of the winter months. They will not lay much when their colonies are in the cellar except during the last month in the cellar.

For further particulars regarding queens, see Drones, Queen-Rearing, and Bee BeHAVIOR.

QUEENS, HOW TO FIND.-See MANipulation of Colonies, subhead, "How to Manipulate Hoffman Frames;" also "How to Handle Unspaced Frames."

QUINBY.*-Moses Quinby was born on April 16, 1810. During his boyhood his family removed to Coxsackie, Greene Co., New York.

In 1828, at the age of 18 , he earned his first money, working in a sawmill, and with it purchased his first swarm of bees and began the twenty-five years of study and experiment which prepared him for the writing of his book, published in 1853. In 1832 he married Miss Martha Powell Norbury, also of English extraction, and, like Mr. Quinby, a Quaker. They were married at the Norbury homestead. From this time till his removal to the Mohawk Valley he lived at the home. There was a mill on the place, and he earned the support of his family in these early years running the turning-lathe and doing cabinet work, many specimens of household furniture made by him being now the valued possessions of his granddaughters. Here also he made his hives and the first honey-boxes.

I have reason to believe that at this period there were more bees kept in this section than in any other part of the United States. For years after Mr. Quinby's death I have been to this location to buy bees to

\footnotetext{
* Written by his son-in-law, L. C. Root.
} 
replenish my home apiaries. On a recent visit I saw small apiaries, many of them using the form of hive Mr. Quinby had recommended.

He says he "commenced without any knowledge of the business to assist him, save a few directions about hiving, smoking them with sulphur, etc." Beekeeping was considered a matter of luck. His friends and neighbors on all sides discouraged him. One wise old man predicted failure for him because he pottered with them too much, boring holes in the top of the hives and disturbing them. All of this advice only stimulated him to greater action. He prefixed to the word "luck" a big $P$, and underlined it.

Here he spent twenty-five years experimenting and writing, with a determination to place beekeeping on the same successful financial basis with other branches of agriculture. All his experiments during this period were made with bees in box hives, there being no better ones at that time.

His first move to avoid destruction of the bees in securing the honey was by boring holes in the top of the hives, for he found that the bees would fill large boxes put over the hive. These were the forerunner of the super and section.

Another menace to success in beekeeping was foul brood. Rereading the chapter in his first book, in the light of modern science of contagious diseases and bacteriology, shows it to be a marvel of careful observation and accurate reasoning that would do credit to the present day. The principles of his treatment of the scourge can never be changed. These and many other facts $\mathrm{Mr}$. Quinby found had never been published; so, being by nature philanthropic, and having an unselfish desire to help others in a practical way by sharing his knowledge, he wrote this accumulated experience of twenty-five years into his "Mysteries of Beekeeping Explained, being a complete analysis of the whole subject," as the title-page quaintly states. As I reread the book I realize how fully up to date it was for 1853 , and how fundamentally correct were his statements and deductions on many points. It bears evidence of being entirely the author's own work. He started with no knowledge of the subject, but with an inquiring and open mind; had no help from others, and only theoretical information from the limited literature on the subject of bees.

The keynotes of its success appear to me to be the scientific attitude of its author, unusual at that period-the clearness and plainness of its style, and the effort to help and instruct the reader rather than impress him with the accomplishments of the writer.

We do not know just when he was able to make beekeeping his sole business and the support of his family; but he certainly did so after his removal to St. Johnsville, Montgomery County, New York, in 1853, the year his first book was published. During the next ten years he owned the largest number of colonies at any time during his

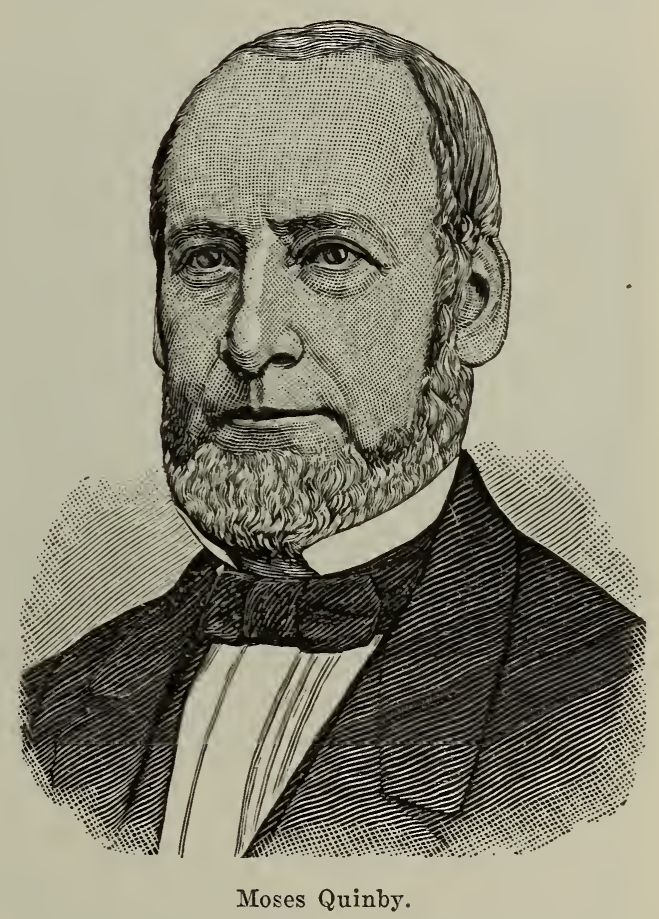

business career. He began to send large amounts of honey to the New York market, even while still using the box hive. There being only a moderate demand at that time he nearly glutted the market. This was, indeed, the beginning of the reconstruction period in beekeeping. In $1856 \mathrm{Mr}$. Quinby's attention was called to Mr. Langstroth's invention of a movable-comb hive. He saw its advantages, and at once adopted it in a modified form. Then followed the introduction of Italian bees, honey-extractor, comb foundation, single sections for comb honey, and his own invention of the beesmoker. These were indeed gratifying days 
to Mr. Quinby. Who was there in all of the beekeeping world so well prepared as he from the standpoint of practical experience to meet the needs of this wonderful forward movement?

Mr. Quinby's non-swarming standingframe hive enabled him to accomplish large results under his management. Much might be said in regard to Mr. Quinby's preferring the larger frame. Marked success can be secured only by extremely populous swarms. I have proven the larger frames very advantageous to that end.*

I shall never forget the enthusiasm which was cansed at our home when the words "centrifugal force for removing honey from the combs" were received in the report of

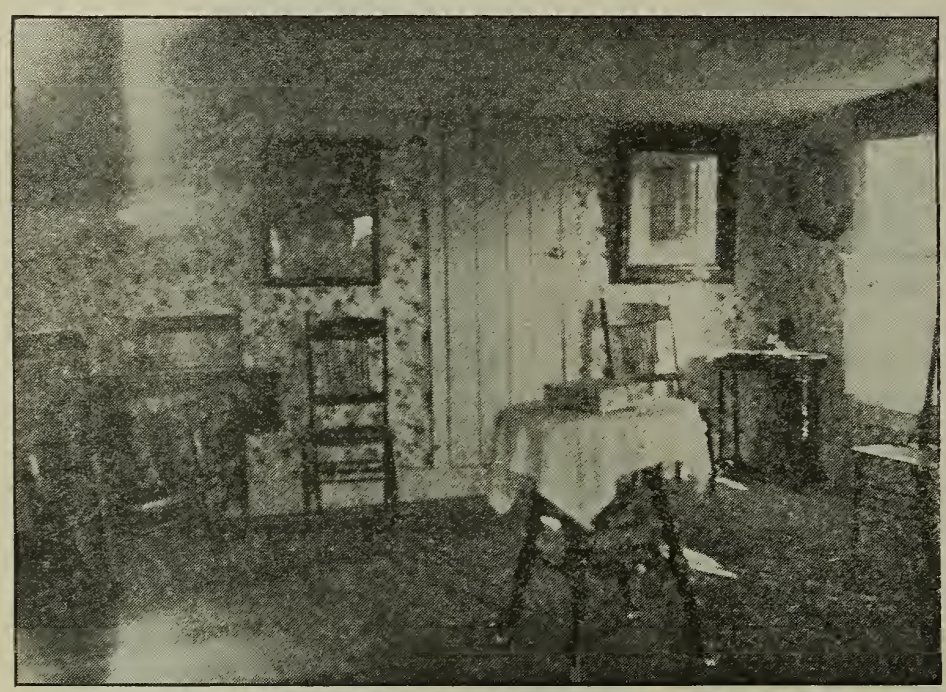

The room where Mr. Quinby wrote the 1853 edition of his book.
Mr. Quinby realized that, tho fearless himself, people were deterred from keeping bees by fear of being stung. Smoke had keen used in various crude ways; but he knew that, if it could be easily and conveniently adapted, it would be a great boon, especially to the amateur. His invention of the bee-smoker did this, being so arranged with upright bellows and fire-tube as to burn standing upright, but to go out when placed on the side, and to be easily manipulated with one hand. The principle of it has never been improved upon.

New York state, where Mr. Quinby's influence was most in evidence, became the largest honey-producing center in the world. One of the first articles he ever wrote on bees for publication was for a Philadelphia paper, expressing doubts as to the possibility of a writer having secured a gain of twenty pounds of honey from a swarm in two weeks. In these later days he had seen that amount gathered in two days, and five hundred pounds of extracted honey taken from one colony in a season. Mr. Quinby sent in these days anywhere fion 5000 to 30,000 pounds of honey to the New York market annually.

While essentially a scientist and teacher, his

the invention of Major de Hruschka, of Vienna. An old fanning-mill, which had been used for cleaning grain, was at once taken apart, the fans removed, and wire cloth stretched around its four sides. A larger box was made, inside of which this frame was arranged to revolve, and with the gearing of the fanning-mill it was set in motion. The gratification with which Mr. Quinby saw the honey thrown from the first combs cannot well be described. He soon made an extractor in more workable form, which was afterward perfected by A. I. Root, and known as the Novice extractor.

* See Frames, Self-spacing, for a description of his self-spacing frame; and Hrves, subhead "Dadant-Quinby Hive," for a description of the merits of the large hive and frame. first object was to enable others as well as himself to make beekeeping a commercial success by knowing how to gather in quantity this useful, natural food-stuff and delicacy. As Mr. Quinby became well known from his books and articles in agricultural papers, his home was quite a center for those seeking the information he so gladly imparted. Mr. Quinby was never so happy as when passing on his knowledge and experience to others. Few people who were not personally acquainted with him can realize how devoted he was to his questioners, whether in person or by mail or thru the press. From the start to the last evening of his earth life he never proved a principle in bee culture the benefit of which he did not give to the public. Two hours 


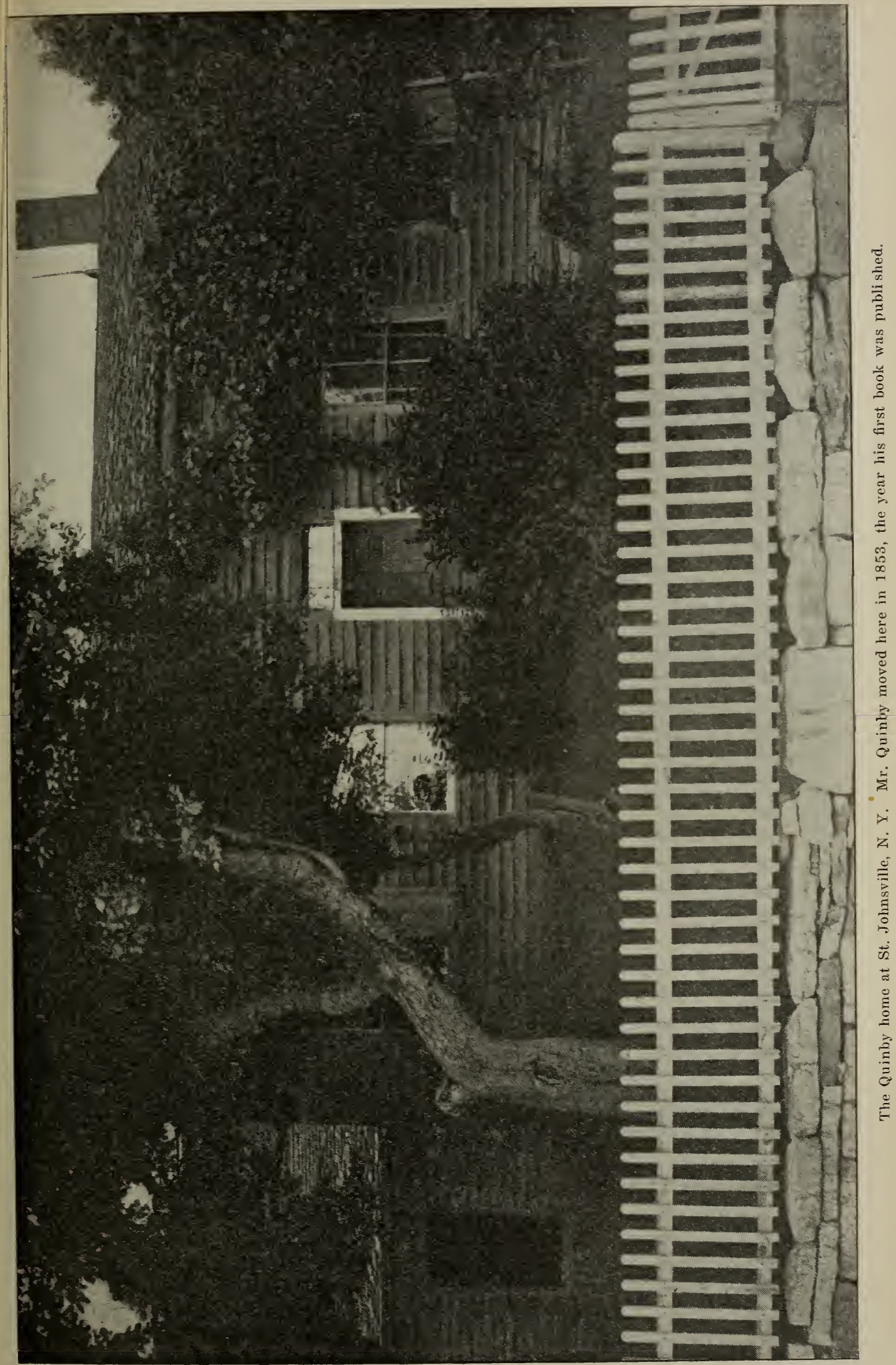


bəfore he passed away he was at his desk, where he left an unfinished article.

The late Captain J. E. Hetherington was one of his most energetic pupils. It is still a joy to me to recall his enthusiasm during his frequent visits to Mr. Quinby's home, and the eager way in which he asked questions and received answers. He soon became one of the large bee-owners, first of box hives, but, as improvements followed, always up to date. Of these early visitors, almost the only one living is P. H. Elwood, of Starkville, New York, then as now the intelligent, thoughtful worker and genial friend.

In $1865 \mathrm{Mr}$. Quinby published a revised edition of lis book, and from the tone of the preface it is gratifying to see his pleasure in the success and popularity of this first edition.

In March, 1870, the Northeastern Beekeepers' Association was organized at Albany, with Mr. Quinby as its first president, an office he lield for five years, declining re-election at the meeting preceding his death. $\mathrm{He}$ was elected president of the North American Beekeepers' Association, at Cleveland, in 1871, and served one year.

Thus with modest honors and much satis- faction in his work and in the fruit-growing on his place, a happy home life and wide outside interests in the anti-slavery cause, temperance work, and all good and progressive endeavors, the years went by. Death came suddenly on the night of May 27,1875 , and a life of usefulness was over.

I am writing this article with the extreme desire to show Mr. Quinby's devotion to his chosen calling. It would be impossible for any one who did not come in daily contact with him in his manipulation of bees, in the beekeepers' conventions, and, most of all, in his home, to have a full appreciation of how completely his work filled his thoughts. How well I remember the emphasis he gave the words when he once said to me, "I want it distinctly understood that I cannot afford to spend my time making money!"

He gave forty-seven years of constant application in honest effort to place beekeeping on a firm business basis. I am somewhat acquainted with the history of the beekeeping of the past, and I feel justified in pointing with pride to these fortysiven years of devotion which should warrant the name of "Father of practical commercial beekeeping in America." 


\section{$\mathrm{R}$}

R.ACES OF BEES.-Thruout this work we deal particularly witl Italians, the common black bees of this country, and the crosses between the two, because they are used almost exclusively by the beekeepers. The crosses are often given the name "hybrids;" and as that name has been generally adopted, we retain it. For particulars regarding these bees the reader is referred to Hririds, which see. The Italians are spoken of specifically, also, under the heading of ItALIANs, elsewhere in this work.

\section{BLACK OR GERMAN BEES.}

Black bees are so common in nearly every vicinity that very little description is necessary. As the name indicates, they are black. One variety in the South is of a brownish black; another distinctly black, and, if anything, a trifle smaller.

Comparing the Germans with the Italjans, they are more inclined to rob, are not as good workers, but are equal when nectar is abundant, or when there is dark honey like that from buckwheat to be gathered. They are much more nervous; and when a hive of them is opened they run like a flock of sheep from one corner of the hive to another, boiling over in confusion, hanging in clusters from one corner of the frame as it is held up, and finally falling off in bunches to the ground, where they continue a wild scramble in every direction, probably crawling up one's trousers-leg, if the opportunity offers. Their queens are much harder to find, the bees are not so gentle, and, worse than all, they have a disagreeable fashion during robbing time of following the apiarist about from hive to hive in a most tantalizing manner. This habit of poising on the wing in a threatening manner before one's eyes is extremely annoying, and some bees will keep it up for a day at a time unless killed. We generally make rery short work by smashing them between the palms of our hands, or batting them to death with little paddles we keep near. It is useless to strike at individual bees while they are in the air, for one is much more liable to miss than to hit them. Our practice is to take two sticks, one in each hand, and work them back and forth in front of our face very rapidly, just about as one would operate a fan on a hot day. This rapid movement excites anger in the bees, with the result that they make a dive for the whirling sticks; and in less time than it takes to tell it, one by one they get their heads rapped, and go down into the grass. *

Comb honey from the blacks is a little whiter, if anything, than that made by pure Italians, becausc the capping is raised up, leaving a slight air-gap between it and the surface of the honey in the cell. But this difference in the whiteness of capping is so very slight as compared with that on comb honey made by the Italians that it really cuts no figure in the market. The blacks are also much easier to shake off the combs than pure Italians, which can hardly be shaken off, and some prefer blacks or hy-brids, when extracting, for that reason alone.

Blacks, when their hires are mored a short distance, will find their entrances much more readily than Italians. In fact, we have been enabled to move our black colonies all over the apiary, and yet we have discorered time and time again that the returning bees will nose around every hive until they find their own, when they will enter as tho they had always lived there. On the other hand, Italians cannot be moved in this way. Many of them will be found on the ground on the old location, and die, only a few of them, comparatively, finding homes in other nearby hives. See Moving BeEs.

Many believe that blacks are more persistent than the Italians in that they will stand unfarorable weather conditions better than Italians; but it has been proven over

* A piece of wire window-screen three or four inches square, tacked to a stick, is more effective. It creates no draft, and the bees cannot dodge it.A. C. MILler. 
and over again that they will not resist brood diseases as do the yellow bees. Indeed, they rapidly succumb under the ravages of European foul brood where some strains of Italians will seem to be almost immune to it. Practically all Italiams will resist brood disease of both European and American foul brood better than the average strain of black or hybrid bees. See Foul BROOD.

\section{CARNIOLANS.}

The Carniolans, evidently a variety of black bees, which they very much resemble, were introduced into this country in 1884 . They are said to be very gentle; but the few colonies we have tried are no more so than arerage Italians, and in one case they were more vindictive than the Cyprians. As stated, they resemble blacks, and might little propolis as any bees ever known. Some colonies that we had, actually deposited almost none. In the production of comb honey this is quite an important item. See Crosses of Bees under Hrbrids.

\section{CAUCASIANS.}

This is a race that looks very much like Carniolans and the common black bee of this country, but it resembles the latter more than the former. So close is the general resemblance that even experts in some cases have been unable to distinguish them. But there is a vast difference in their general habits and temperament.

The claim has been made that Caucasians are the gentlest bees known; and this claim, in part, at least, has been established, altho they are no more so than some good strains of pure Italians. Beemen are not agreed,

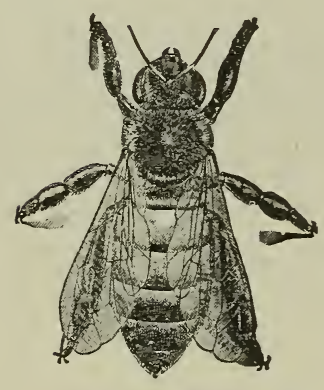

Worker.

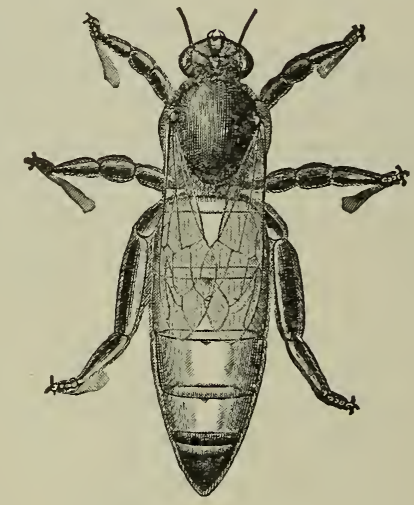

Queen.

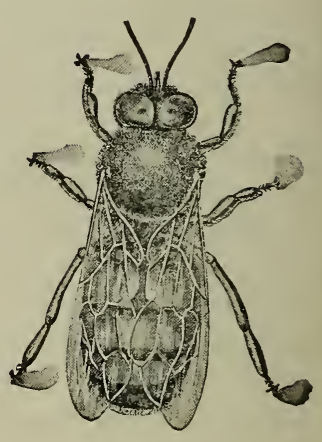

Drone easily be mistaken for them; but there is a difference. They are larger, and their abdomens are of a more bluish cast, the fuzzy rings being very distinct. They are gentler, and do not, like the blacks, boil over in confusion when the hive is opened. They have not the fixity of character of the Italianscolonies of the same race differing quite widely. The general verdict is, that they are excessive swarmers, and this trait alone makes them very undesirable for combhoney production, altho some like them for the production of extracted honey. Their close resemblance.to black bees makes it difficult to detect the crosses of the two races. This fact, coupled with their great swarming propensity, will largely prevent their meeting with general favor.

But the Carniolans have one good trait in their favor, and that is, they deposit as however, as to their honey-gathering qualities. Some consider them very inferior while others believe they are equal to any race in this respect. All admit that they are bad propolizers, sticking large chunks of gum in all parts of the hive-a trait that becomes more manifest as cold weather comes on. In this one respect they differ radically from Carniolans.

The most serious objection we have found to them is their propensity to swarm. It is even more pronounced than with the Carniolans. In our apiaries we have been unable to control them by the ordinary methods that have worked successfully with Italian bees. We had so much trouble with their swarming that we finally abandoned them altogether. Some others, however, and among them J. J. Wilder, of Cordele, Ga., say they have had no trouble from them in 
this respect, any more than from ordinary Italians. Whether Mr. Wilder's experience is due to the fact that he has a different strain of Caucasians, or whether it is due to environment, we are unable to say.

\section{BANAT BEES.}

These are named from a district of Hunyary from which they were imported. They much resemble the Carniolans in appearance and habit but with less inclination to swarm. They are gentle, and impart this trait to their offspring when crossed with Italians. Even after several generations this character is in evidence. The queens are dark tan color, are no more prolific than good Italians, but they build up the colonies more rapidly in the spring. They are worthy a more extended trial both in their purity and in their crosses.

\section{TUNISIANS.}

This black race, natives of North Africa, are sometimes called "Punics." They have been tested to some extent in this country, but so far have not been able to establish any claim in their favor that would entitle them to consideration on the part of American beekeepers. They are cross, and so inclined to smear everything with a red beeglue that they are entirely unsuited for the production of comb. honey. They are no better honey-gatherers than gentler races.

\section{EGYPTIANS.}

The Egyptian bee is reputed the most beautiful species of Apis. It has been named Apis fasiata by entomologists; has been cultivated for thousands of years by the Egyptians, and was probably the first species reduced by mankind to domestic purposes.

In the time of the ancient historian Herodotus, apiaries werè transported up and down the Nile so as to keep pace with the seasons in Upper and Lower Egypt. This practice is continued at the present day to a limited extent. Inscriptions on tombs show the practice in use 4000 years ago, at least, and that the honeybee was highly reverenced by the people of that age.

The Egyptian bee is so much smaller than the Italian that the two do not hybridize very well; on the contrary, the queen, if compelled to mate with a European drone, frequently dies soon after fertilization. It is probably, however, the mother-species of the Cyprian, Holy-Land, and Grecian bees. It is a fast, excellent worker, but reputed to possess an irritable temper tho kept domesticated for thousands of years. Possibly in a climate similar to that of Egypt it would exhibit a better temper than in Northern Europe. It could hardly be otherwise.

In color Egyptians are almost identical with Italians, but in addition have a coat of white hairs, which adds to their appearance. There are varieties, or races, of the same species in countries next to Lower Egypt. One feature of these bees would please Americans, namely, their ability to keep themselves pure and uncontaminated with other races. There is a similar species in Senegal known as Apis Adansonii, of which we know but little.

\section{ALBINOS.}

Albinos are either "sports" from Italians, or, what is more generally the case, a cross between Holy-Lands and Italians. After testing them in our own apiary we find them little different from common Italians. The fringe, or down, that appears on the rings of the abdomen of young bees is a trifle whiter than usual, yet no one would observe it unless attention were called to it. The queens are very yellow, while the workers, as honey-gatherers, are decidedly interior, even in the second generation; and when we select light-colored bees or queens for several successive generations, unless careful we develop only a weaker progeny lacking ability as honey-gatherers and endurance. By selection we can get almost anything we want, and that quite speedily with bees; for we can produce several generations in a single season if need be.

\section{EASTERN RACES OF BEES.}

Cyprians, Holy-Lands, or Syrians, are mentioned elsewhere under head of ITALIANS. Of other Eastern races we can do no better than to quote what Mr. Frank Benton, formerly Apicultural Expert of the United States Department of Agriculture, has said of them in a special bulletin issued by the Department, entitled "Honeybees," containing 118 pages. Mr. Benton spent some months in the jungles of India, in search of new bees. For this reason, if for no other, he is able to give us authoritative information. From the bulletin above mentioned we make the following extracts: 
THE COMMON EAST-INDIAN HONEYBEE.

(Apic Indica, Fab.)

The common bee of Southern Asia is kept in very limited numbers and with a small degree of profit in earthen jars and sections of hollow trees in portions of the British and Dutch East Indies. They are also found wild, and build when in this state in hollow trees and in rock-clefts. Their combs are composed of hexagonal wax cells, and are arranged parallel to each other like those of A. mellifica, but the worker brood-cells are smaller than those of our ordinary bees, showing 36 to the square inch of surface instead of 29 ; while the comb where workerbrood is reared, instead of having, like that of A. mellifica, a thickness of seven-eighths inch, is but five-eighths inch thick. (Fig. 1.)

The workers. - The bodies of these, threeeighths inch long when empty, measure about one-half inch when dilated with honey. The thorax is covered with brownish hair, and the shield or crescent between the wings is large and yellow. The abdomen is yellow underneath. Above it presents a ringed appearance, the anterior part of each segment being orange yellow, while the posterior part shows bands of brown of greater or less width, and covered with whitish-brown hairs; tip black. They are nimble on foot and on the wing, and active gatherers.
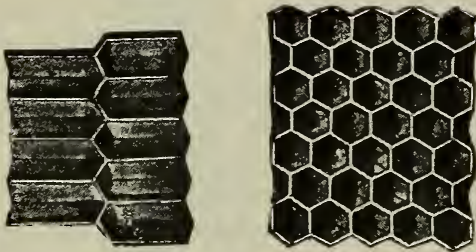

FIG. 1.-Worker-cells of Common East-Indian Honey-bee (Apis Indica), natural size.

The queens.- The queens are large in proportion to their workers, and are quite prolific; color, leather or dark copper.

The drones.-These are only slightly larger than the workers; color, a jet-like blueblack, without yellow, their strong wings showing changing hues like those of wasps.

Manipulations with colonies of these bees are easy to perform if smoke be used; and, tho they are more excitable than our common hive bees this peculiarity does not induce eexcessive stinging, but seems rather to proceed from fear. The sting is also less severe.

Under the rude methods thus far employed in the management of this bee no great yields of honey are obtained, some 10 or 12 pounds having been the most reported from a single hive. It is quite probable these little bees would yield more if imported into this country, since they could no doubt visit many small flowers not frequented by the hive bees we now have, and whose nectar is, therefore, wasted; but very likely they might not withstand the severe winters of the North unless furnished with such extra protection as would be afforded by quite warm cellars or special repositories.

Here is something exceedingly interesting regarding the smallest honeybees in the world. Just take a look at the size of the cells as shown in the figure, natural size,

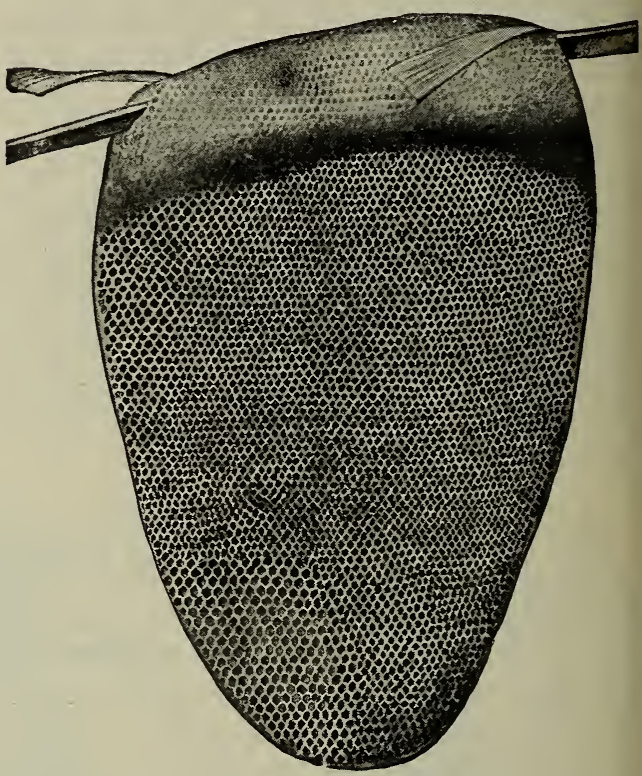

FIG. 2.-Worker-cells of Common East-Indian Honey-bee (A pis Indica), one-third natural size.

and then compare them with comb of the ordinary hive bees.

Here is what Mr. Benton has to say:

\section{THE TINY EAST-INDIAN HONEYBEE.}

(Apis florea, Fab.)

This bee, also a native of East India, is the smallest known species of the genus. It builds in the open air, attaching a single comb to a twig of a shrub, or small tree. 'This comb is only about the size of a man's
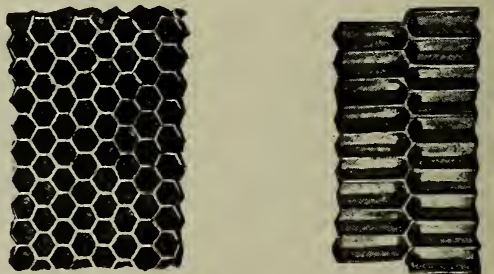

Fig. 2.-Worker-cells of the tiny East-Indian Honeybee (A pis florea), natural size.

hand, and is exceedingly delicate, there being on each side 100 worker-cells to the square inch of surface (Figs. 2 and 3 ). The workers, more slender than house-flies, tho longer-bodied, are blue-black in color, with the anterior third of the abdomen bright 
orange. Colonies of these bees accumulate so little surplus honey as to give no hope that their cultivation would be profitable.

\section{GIANT BEES OF INDIA.}

(Apis dorsata, Fab.).

A few years ago a great deal used to be said regarding the East Indian "giant" honeybees, Apis dorsata, and the possibilities of having them imported and domesticated in this country. Much truth and nonsense have evidently been circulated in regard to them. Mr. Benton, having been in their native land, describes them.

This large bee, which might not inappropriately be styled the Giant East-Indian bee, has its home in the far East-both on the continent of Asia and the adjacent island. There are probably several varieties of this species, more or less marked, and very likely Apis zonata. Guer., of the Philippine Islands, reported to be even larger than Apis dorsata, will prove on further investigation to be only a variety of the latter. All the varieties of these bees build huge combs of very pure wax-often 5 to 6 feet in length and 3 to 4 feet in width, which they attach to overhanging ledges of rocks or to large limbs of lofty trees in the primitive forest jungles. When attached to the limbs of trees they are built singly, and present much the same appearance as those of the tiny East-Indian bee, shown in the accompanying figure (Fig. 3). The Giant bee, however, quite in contradistinction to the other species of apis men. tioned here, does not construct larger cells in which to rear drones, these and the workers being produced in cells of the same size. Of these bees-long regarded as a myth by beekeepers of America and Europe-strange stories have been told. It has been stated that they build their combs horizontally, after the manner of paper-making wasps; that they are so given to wandering as to make it impossible to keep them in hives, and that their ferocity renders them objects greatly to be dreaded. The first real information regarding these points was given by the author. He visited India in 1880-81 for the purpose of obtaining colonies of Apis dorsata. These were procured in the jungles by cutting the combs from their original attachments, and it was thus ascertained (as might have been expected in the case of any species of apis), that their combs are always built perpendicularly; also that colonies placed in frame hives and permitted to fly freely did not desert these habitations, and that, far from being ferocious, these colonies were easily handled by proper precautions, without even the use of smoke. It was also proved by the quantity of honey and wax present that they are good gatherers. The execution at that time of the plan to bring these bees to the United States was prevented only by severe illness contracted in India.
These large bees would doubtless be able to get honey from flowers whose nectaries are located out of reach of ordinary bees, notably those of the red clover, now visited chiefly by bumblebees, and which it is thougbt the East-Indian bee might pollinate and cause to produce seed more abundantly. Even if not further utilizable, they might prove an important factor in the production, thruout the Southern states, of large quantities of excellent beeswax, now such an expensive article.

There are a few in this country who believe the introduction of the giant bees here would result disastrously to the business; that, as the English sparrow has driven out some of our American song birds, so Apis dorsata might drive out the Italians and black bees by taking the nectar that would otherwise go to Apis mellifica, and thus indirectly rob the beekeeper. It is also stated that -1 pis dorsata could not be domesticated, but would run wild all over the country; but from all the information we can gather we have no fear of any of these things. The facts prove that they have not run out $A$ pis indica, Apis florea, and other Eastern bees in their own habitats; furthermore, it is doubtful whether they would be able to stand our changing climate, even in the South; for it must be understocd that India and the Philippines have a much warmer climate.

In late years we do not hear much about these giant bees. The difficulty of getting them is such that it is impracticable to import them.

R.ASPBERRY (Rubus idaeus L., variety aculcatissimus).-Where the raspberry is cultivated on a large scale for market it is an important honey-plant. Bees work on the flowers closely, and the honey is of the finest quality. Langstroth says of raspberry honey: "In flavor it is superior to that from white clover, while its delicate comb almost melts in the mouth. When it is in blossom, bees hold eren white clover in light esteem. Its drooping blossoms protect the honey from moisture, and bees work upon it when the weather is so wet they can obtain nothing from the upright blossoms of the white clover." The raspberry begins to flower just after fruit-bloom, and just before clover, so that large fields of it are a great acquisition indeed. The red varieties (especially the Cuthbert) are said to furnish the most honey. 
WILD RASPBERRY IN NORTHERN MICHIGAN.

More than one-half of northern Michigan was once covered with white and Norway pine, according to E. D. Townsend. Nearly all of this in recent years has been cut off for lumber. During the first dry season after the cutting, fire burns over this stump land, and two or three years later it is covered with willow herb. From these pine barrens raspberry bushes are either entirely
But the rapidly growing young trees and underbrush soon smother the raspberries and the beekeeper is forced to seek a new location. If, however, the land is occasionally burned over the average yield of honey is less, but the bee pasturage lasts much longer. Thus we find, says Townsend, the raspberry district always changing, and the shrub not a permanent source of nectar in one locality like clover. As new areas are lumbered off "new pastures are offered to new comers." Mlost of the good locations are today occupied. There is only one way, says Hutchinson, to find a desirable location, and that is to hunt for it.

The flowers begin to yield nectar from the first to the middle of June, according as the weather is warm or cold. Connois-. seurs have pronounced the honey superior to any other table honey in the world, for it partakes somewhat of the exquisite flavor of the berry itself, with all the added qualities that are so much prized in clover. The berries will not bear shipping, and must be used soon after being picked.

RATS.--Rats may and can do a great deal of damage in a honey-house. Raspberry.

absent, or they are short, stunted, and scattering, and of little value as honey-producers. It is upon tracts from which hard-wood timber has been lumbered that we must look for a luxuriant growth of raspberry. After the once magnificent forest of beech, maple, and elm has been removed there speedily springs up a vigorous growth of wild red raspberry, which completely covers the ground, and which, says Hutchinson, is simply incomparable as a honey-producer; it never fails to yield nectar even in cold, rainy weather. If such land is not burned over the rich loam, mulched with brush, produces large thrifty bushes, which yield great crops of this celebrated honey for several years.
There are some old fellows clever enough to avoid traps and poison. The only thing to do with such is to shoot them by watching when they congregate about five o'clock in the afternoon in and about the outbuildings. A 32-caliber Flobert rifle with shot cartridges, or, better, a taxidermist's 44-caliber shotgun, will do good execution.

One of the best traps that was ever made is the old-fashioned rabbit-trap with grain spread on the bottom of the box. The trigger to close the trap should extend down to the grain. The rats in eating will bump against the trigger and set it off, when they are imprisoned alive, after which they can be drowned. 
Poison can be given in the form of dough made of one-fifth part of barium carbonate, or barytes, and four-fifths meal. This poison has no odor nor taste; and it is better than strychnine because its action is slower, giving the rats a chance to get off the premises before they die.

RECORD-KEEPING OF HIVES.-Almost every apiarist has a plan of his own, whereby he can record the condition of the hive at the time of its examination, so that, in future, without depending on memory, he may tell at a glance what its condition was when last examined.

Many of the large honey-producers, Dr. Miller among them, have what they call a record-book. This book has a page for each colony, the number of the page corresponding with the number of the colony. The book should be small and compact, just about right to carry in the hip-pocket, and securely bound. It should always be carried when at work among the bees. On each page is supposed to be a record of each colony's doings within a year-when it became queenless, when it had cells or brood, when it swarmed, and, toward winter, the strength and quantity of stores it had when last examined.

There is an advantage in the book method-and that is, the book can be consulted in the house, and the work mapped out beforehand for the day. If the record-book be for an out-apiary, the work can be planned while riding to the yard; and, upon arriral, the plans formulated can be executed. It is thus possible to know in advance just where to get cells to give to queenless colonies; just which colonies will be likely to have laying queens; which ones may cast swarms, and which ones will be likely to need more room in the way of sections or surplus combs.

There is one objection to the record-book, howerer. It is liable to be lost, or to be left out in the rain; and if the book is lost, the whole knowledge of the apiary, except so far as the apiarist can remember, is gone. Another thing, only one can use the book at a time.

Others prefer card indexes. Each hire in the apiary will have a number, and corresponding to that number will be a card. Boxes of these card indexes can usually be obtained at the stationer's or at the bookstores at a moderate price. The adrantage of such index is that, when some particular card for some hive is full, it can be replaced by another card bearing the same number or added data. But the most important adrantage is that one can look thru his inder at home; and when he comes across a card, the corresponding hive of which requires some particular attention, he can remove that card entirely from the index; and so on he can remore the cards of all other colonies of the yard requiring special attention. These cards can then be slipped into the hip pockets and carried to an outyard or handed to an assistant with proper instructions; and after the hives have receired the requisite attention, the necessary record can be attached. On returning home the cards can be put back.

Where there is a series of outyards, one should hare one index for each yard. As there will seldom be more than 200 colonies to the rard, one can have an index of 200 cards. For example, yard No. 1 will have cards up to 199; yard No. 2 from 200 to 399 ; yard No. 3 from 400 to 599, and so ov. If any of the cards should get mislaid or get mired with another index, the first figure of the number will indicate to what yard or index it belongs. For example, we would know that card 346 would belong to yard No. 2, or the Jones yard, as the case might be.

For the purpose of queen-rearing, the card index is invaluable because it enables one to keep a complete record of a queen, even her pedigree for several generations back. When she is sold, the record can be made, showing to whom she was sold, so that, if the purchaser complains that her bees are not pure, or that the colony is rliseased, the breeder can easily go to the identical colony from which she came, and prove or disprove either assertion.

The value of the card indes can be materially increased by the use of colored cards, to slip into the index here and there to indicate immediate or early attention to some particular number. As the apiarist goes orer his records the colored cards will indicate just where the cards are, referring to a specific colony. Let us suppose a case. No. 241 at the time of our examination lcoked suspicious. We fear the presence of foul brood. A red card is put right in front of card 241, for red indicates danger. Blue, 
green, and yellow cards may be used to indicate other conditions such as queenlessness, short of stores, failing queen, about to swarm, etc. If one is making preparations to feed he will hunt over the blue cards. Either pull the cards back of them ont of the index or note down on a slip of paper the numbers of the hives that require feeding.

In this connection it should, perhaps, be stated that one can purchase, at very small expense, loose-leaf note-books with an alphabetical or numerical index. These books are so constructed that any particular page can be removed and another page substituted or added, on the principle of looseleaf ledgers. Such books can be used in place of a card index. In other words, it will be a pocket card index that can be carried to and from the yard; and as such books are usually bound in leather they will stand rough usage.

Of course, with any books or eard index it goes without saying that every hive in the yard should be numbered. These numbers may be applied on the hive with a brush, using black paint. But it is preferable to use a detachable number. Such a number may be stenciled on a sheet of tin and the tin tacked on the hive. The objection to these is the expense. Fortunately there can now be secured of supply dealers numbers printed on heavy manila tags that are afterward soaked in boiling paraffine so they will stand the weather. These numbers can then be tacked on the cover, or on one side or end of the hive. As a general rule it is better to use the front end just over the entrance. In the course of two or three years it may be necessary to replace the old number with a new and fresh one. As these card numbers are very cheap the expense of renewal is small.

\section{RECORD-KFEPING IN OR ON THE HIVE.}

There are many beekeepers who think they cannot afford to fuss with books, card indexes, nor anything of that sort. Some of them simply write the record inside of the cover; but in most cases the form or make of cover renders this impracticable.

One of the best schemes to accommodate this class of beekeepers is what may be called, for want of a better name, wooden writing tablets. These are made out of broken sections, $1 \frac{1}{2}$ or 2 inches wide, by
4 or 5 inches long. But these, unless dipped in white lead, will soon weather-stain so that the lead-pencil record will be blurred if not entirely obliterated. To coat a thousand of these, dip in thin white lead, and lean against something until dry. In every case after they are painted they will hold leadpencil records the entire season. At our yards we used both the card index and the wooden tablets coated with white lead. The tablets are for a temporary record, which record is later transferred to the card index. In connection with the white tablets we use some painted different colors to indicate different conditions of the colony. For instance, one can stand in one position in the yard, and at a glance can easily locate one colony having a blue, red, yellow, or green tablet, each color carrying its own special significance.

But these wooden tablets will blow off the hives, and become lost. This difficulty is easily overcome by the use of little spring clips made of brass; and in lieu of anything better, the ordinary steel super springs coated with paint make a very good substitute. Each spring clip should be fastened down with a staple. The advantage of these clips is that they not only hold the tablets fast to the hive, but they enable one to place the tablet in front or on top. Where a colony needs attention at the next visit, a red tablet is placed on top of the white one bearing the record. If a colony needs feeding, a blue tablet will be used; if it is queenless, a green one; and so on one can use a great variety of colors to indicate as many conditions of the colony. But in most cases a red tablet may be used to show anything that requires immediate attention. For example, here is a colony that is starting to build queen-cells. They should be cut out. At the next trip those cells will need to be cut out again to forestall swarming. Again a red eard may indicate a failing queen, or a poor queen which needs replacing soon; a colony that is on the verge of starvation, a colony that has suspicious-looking brood, that will need another examination a week hence before its nature can be fully determined; and so on a red card may be used to indicate any conditions that need rectifying at the time of the next visit.

The spring clips should usually be made out of brass, and those we use are made of that material, 24 gauge, $1 / 4$ inch wide, and 
about 4 inches long, bent as shown in the illustration.

The whole outfit-brass clips, brass staples, wooden tablets of different colors, etc., can be obtained of the dealer. But where

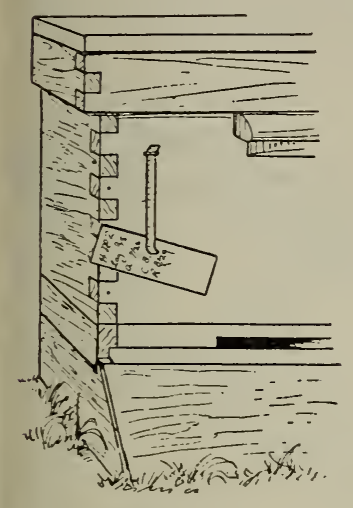

Spring clips.

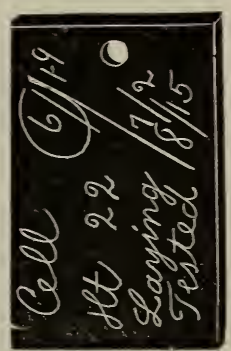

Slate tablet. one is a producer of comb honey he will have many pieces of broken sections, which, when dipped in white lead, will be equal to any to be obtained of his dealer.

Some years ago we used small slate tablets. They were nothing more nor less than miniature slates without frames cut as shown in the illustration. An ordinary slate or lead pencil was used to make the

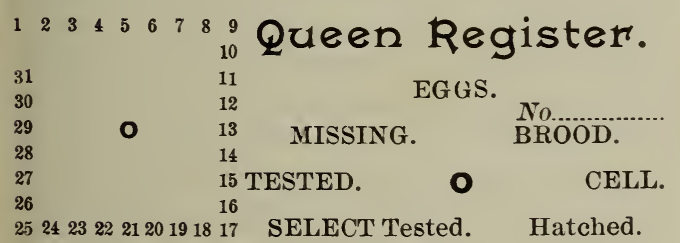

MARCH.

LAYING.

OCT. APRIL.

SEPT, O MAY DIRECTIONS.-Tack the card on a conspicuous part of the hive or nu-
cleus; then, with a pair of pliers, force AUG. JUNE. $\begin{aligned} & \text { cleus: then, with a pair of pliers, force } \\ & \text { circle, after whinto the center of each is bent in such a }\end{aligned}$ circle, after which it is bent in such a
manner that the head will press se-

JULY. curely on any figure or word.

record. These have one advantage over the wooden tablets on account of their weight. They can usually be laid on top of a hive cover without danger of their being blown off. But the serious difficulty with them lay in the fact that they were expensive. Another objection to them is that the pencil records would wash off in the first hard dashing rain, and the lead-pencil records would become almost illegible.

\section{QUEEN-REGISTER CARDS.}

Another system of record-keeping that is popular with some is what are called register-cards. The accompanying plan shows how they are used. To indicate the date, the pin heads are revolved so as to point to the proper place. There is no writing, and nothing to do except to turn the pointers to the right place. This was preferred by the late W. Z. Hutchinson and others.

\section{RED CLOVER.-See Clover.}

REVERSING.-This, as the term signifies, is the process of inverting, or turning over, the combs; and this may be accomplished by inverting the frames individually or the whole hive at one operation. The subject began to be discussed in 1884; and for three or four years following there was much said on the subject. Reversible frames and reversible hives were invented by the dozen. Some of them were quite ingenious, while other's were clumsy and impractical.

Taking into consideration the fact that the bees store their honey just immediately over the brond, and that, as a consequence, their combs at this point are much better filled out, certain beekeepers conceived the idea of turning the combs upside down at frequent intervals. "Why," said they, "when the combs are reversed, bringing the bottom-bars uppermost, the combs will be built clear out to the bottom-bars, and the honey now in the bottom of the combs will be carried up into the supers, just where it is wanted." This seemed very nice in theory, and even in practice it seemed to be partially carried out; for a good many beekeepers reported that, when the combs were reversed, the bees, rather than have the honey in the bottom of the combs, near the entrance, and accessible to robbers, would uncap it and take it up into the sections. But the result was, that often poor and dark honey went up above; more often the bees allowed the honey to stay at the bottom of the hive, and the only real advantage secured was getting the combs filled actually to the bottom-bars, now at the top.

A very few claimed that reversing, when done at the proper time, would destroy queen-cells, and so control swarming. But it did not in most cases. 
After all, the real and direct advantage of reversing is in the matter of getting combs filled out in brood-frames as solid as a board. See Manipulation of Colonies. When hunting queens it is much easier to find one where there is no horizontal space between the edge of the comb and the bottom-bar, and no holes to furnish her hidingplaces. Moreover, having combs filled out solid gives better fastening to the frame and increases the capacity of the hive just in proportion to the new comb built after reversing. Nearly every frame that is not reversed is liable to have a space of $1 / 2$ inch or $3 / 8$ between the bottom of the bottom-bar and the comb; and this is a waste that ought to be utilized if possible. To a certain extent this space can be filled in non-reversing frames by having sheets of foundation reach from frame-bottom to top-bar, wired in with perpendicular wires; but even such combs are never as well filled as those reversed:

Several good reversible frames have been proposed; but no one should think of adopting any of them unless it has some points of merit outside the one exclusive feature of reversing. A reversible frame that is not good for all-around use-easy to handle -would be very unprofitable.

One of the first practical reversing frames was the Van Deusen, having metal corners or ears. This was essentially a standing frame, and could be used just as well one side up as the other. The frames were spaced apart by "spacing-ears," and these very ears offered some distinctive advantages in

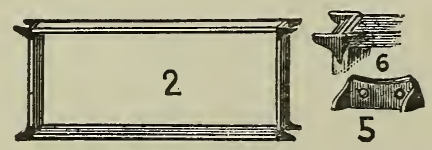

The Van Deusen reversible frame.

the way of handling the frame. This frame was used very largely by the one-time most extensive beekeeper in the world, the late Captain J. E. Hetherington; also by his brother in Michigan. Outside of its reversing feature it offered one very decided advantage; namely, the facility with which it could be handled like the leaves of a book. By taking out one or two frames the rest could be thumbed over without lifting them out of the hive. Notwithstanding, it is not now used.
Two other very excellent reversible frames are the Danzenbaker and the Heddon (see Hives; also Frames, Self-spacING; and Manipulation of Colonies), either one of which can be used as well one side up as the other; in fact, any closed-end standing frame can be used as a reversible

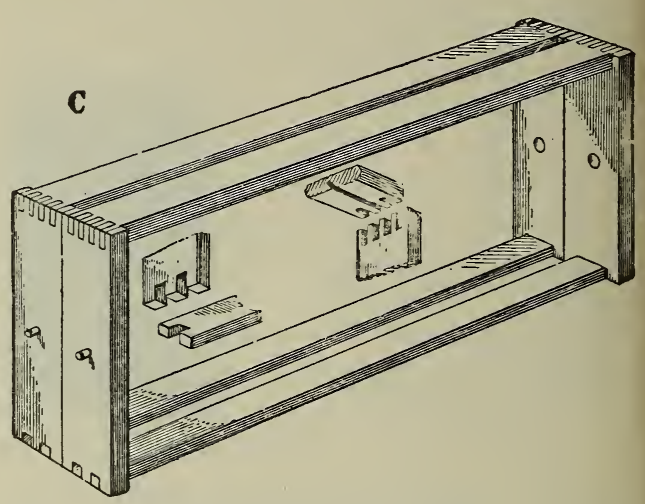

Danzenbaker reversible frame.

frame, except the Quinby. The fact that none of these frames are in use to any extent would seem to argue that the advantages of reversing are more theoretical than actual.

ROBBING.-As the term signifies, "robbing" is an act or series of acts where bees pilfer or steal from each other, or from any source where sweets in the form of jam, jellies, syrup, or honey, are left exposed. Like some human beings when the opportunities are given, bees find it easier to steal than to work. The passion for stealing or robbing, if neglected, becomes a habit-a habit that is exceedingly hard to break up.

When bees discover that a large amount of sweets can be secured without working for it, they are quick to profit by the chance; and in the space of a few minutes they may start an uproar of excitement. This not only means pillage, but death to the bees and stings to their owners.

Paul says that the love of money is the root of all evil; and similarly the love of honey on the part of the bees is a root of a great deal of the evil that takes place in bee culture. In this respect bees are not greatly different from some human beings. When they find it easier to help themselves to the results of the honest toil of others they will enter into the business of plundering without scruple. 
One of our A B C class has said that he found bees making visits to over 100 cloverheads before they obtained a load sufficient to carry to their hives. It is probably true that during a great part of the season a bee will be absent a full hour, or, it may be, during unfavorable spells, as much as two hours, in obtaining a single load. The time during which they may be absent is very variable. If the nectar secretion is heavy they will return much quicker than where it is light. Is it at all strange that a bee, after having labored thus hard during the fore part of the day, should, in the afternoon, take a notion to see if it could not make a living in some easier way. Would it be very much worse than many types of humanity? As the bee noses around to other hives it catches the perfume of the clover honey they have gathered in a like manner, and, by some sort of an operation in its little head, it figures out that, if it could abstract some of this, unperceived, and get it safely into its own hive, it would be so much the richer. It has no sort of care whether these other bees die of starvation or not. That is none of its concern.

With all their wonderful instincts, we have nerer been able to gather that the bees of one hive ever have any spark of solicitude as to the welfare of their neighbors. If, by loss of a queen, the population of any hive becomes weak, and the bees too old to defend their stores, the very moment the fact is discovered by the other colonies they rush in and knock down the sentinels, with the most perfect indifference, plunder the ruined home of its last bit of provision, and then rejoice in their own home, it may be but a yard away, while their defrauded neighbors are so weak from starvation as to have fallen to the bottom of the hive, being only just able to attempt to crawl feebly out at the entrance. Had it been some of their own flock, the case would have been very different indeed; for the first bee of a starving colony will carry food around to its comrades, as soon as it has imbibed enough of the food furnished to bave the strength to stagger to them.

Suppose the bee mentioned above, in prowling around in the afternoon or some other time, should find a colony so weak or so careless that it could slip in unobserved, and get a load from some of the unsealed cells, and get out again. After it has passed the sentinels outside it usually runs little danger from the inmates, for they seem to take it for granted that every bee inside is one of their number. There is danger, tho; for should it betray too great haste in repairing to the combs of honey they often suspect something; so it assumes an indifference it is far from feeling, and loiters about very much as if it were at home, and finally, with a very well-assumed air of one who thinks he will take a lunch, it goes to the cells and commences to fill up. Very often, when it gets pretty well "podded out" with its load, some bee approaches, apparently to see if all is right. When the robber once gets its head into a cell, however, it seems to have lost all sense or reason; and if it is discovered at this stage to be a stranger and a thief, it is often pounced upon and stung with very little ceremony. How do they know a stranger from one of their own number, where there are so many? It is said they tell by the sense of smell; this may be the principal means, perhaps, but apparently they depend greatly on the actions and behavior of a bee, murch as we do when judging of the responsibility of a man who asks to be trusted. The can give a very good guess, simply by his air or manner, or even by the sort of letter he writes. If a robber is suspected. and a bee approaches for the purpcse of satisfying itself, it is a very critical moment, and one becomes intensely interested in watching the performance. The robber will stand its ground, if it is an old hand, and permit itself to be looked over with wonderful indifference; but one who has watched such scenes closely will detect a certain uneasiness, and a disposition to move slowly toward the entrance, that it may be the better able to get out quickly. when it discovers things to be too hot for it inside. If the bee that first suspects it concludes it is an interloper, it begins to bite it. and grab hold of its wings to hold on until other's can come to help. The thief has now two chances to escape, and sometimes it seems meditating which to adopt; one is, to brave it out until they shall perhaps let it alone, and then slip out unobserved. The other is, to break away and trust to its heels and wings. The latter plan is the one generally adopted, unless it is a very old and "hardened sinner" in the business. One that has been many times in 
such scrapes will usually get away, by the latter plan, by an adroit series of twists, turns, and tumbles, even tho three or four bees have hold of it at once. Some of these fellows, by a sudden and unexpected dash, will liberate themselves in a manner that is also wonderful, and then, as if to show their audacity, will wheel about and come back close to the noses of their captors of a minute before.

In case the bee secures its load and makes its way out unobserved, it gets home very quickly, and, under the influence of this new passion for easily replenishing its hive with the coveted sweets, it rushes out with a vehemence never known under any other circumstances. Back it goes and repeais the operation, with several of its comrades at its heels. Does it tell them where to go?

We wish to digress enough here to say that we do not believe in a so-called languase among bees, or animals in general, further than certain simple sounds which they utter, and which we may learn to interpret almost if not quite as well as they.

When a bee comes into the hives in such unusual haste, podded out with its load in a way also rather unusual when obtained from ordinary stores, its comrades at once notice it, and, either from memory or instinct, they are suddenly seized with the same kind of passion and excitement. Those who have had experience at the gamblingtable, or in wild speculations of other kinds. can understand the fierce and reckless spirit that stirs these little fellows. The bees, when they see a comrade return in the way mentioned, seem to know, without any verbal explanation, that the plunder is stolen. Anxious to have "a finger in the pie," they tumble out of the hive, and look about, and perhaps listen, too, to find where the spoil is to be had. If they have, at any former time, been robbing any particular hive, they will repair at once to that; but if it is found well guarded, those used to the business will proceed to examine every hive.

\section{INTELLIGENCE OF THE HONEYBEE.}

One afternoon, the door of the honeyhouse being left open, the bees were soon doing a "land-office" business before the mischief was stopped by closing the door until they had clustered on the windows in the room, which were then opened, and the process repeated until all were out. All the rest of the afternoon they were hovering about the door. Toward night they gradually disappeared; and when we went down, about sundown, to try a new feeder, not a bee was near the door. We put the feeder in front of a hive where the bees were clustered out; and as soon as a few bees had got a taste, and filled themselves, they of course went into the hive to unload. We expected a lot to come out, as soon as these entered with their precious loads, but were much astonished to see an eager crowd come tumbling out as if they were going to swarm, still more when they rushed right past the feeder and took wing for-where do you suppose? the honey-house door, of course- How should they reason otherwise. than that it had again been left open, and that was where these incomers had found their rich loads? On finding it closed, back to the hive they came, to repeat the maneuvers over and over.

As another evidence of the wonderful intelligence and almost reasoning power of the honeybee, we will give another instance.

Some years ago in September a carload shipment of honey came in 60-pound cans so badly damaged that the contents had leaked out and run thru the floor of the box car. The railroad company had agreed to take the car away at half-past ten; and as the weather was cool the bees had not discovered it at that time. Unfortunately the company failed to move the car as agreed, and we knew nothing of it till we were apprised something was wrong by the unusual number of bees swarming around the windows and doors of the factory. We carried a hose over to the leaky car and washed away the honey, cleaning it from the gearing, ironwork, and under side of the car until the bees were pretty well satisfied there was nothing more to get, altho they were hanging around in great numbers. To prevent the bees from getting the honey inside the car, our boys covered the floor pretty well with sawdust. About three o'clock the engine came around and pulled the car away. A little after four, some men who were loading wheat informed us our bees were making them a great deal of trouble. We at once jumped to the conclusion that the company, instead of taking the car entirely away, as agreed, had only removed it to another location in the yard, and that the sticky car was still enticing our 
bees. IVe saw the sawdust on the floor on which they were dumping bags of wheat, and concluded it was the honey-car; but, while we were puzzling to account for the fact that the ironwork under this car showed no trace of honey or water either, a man called and pointed to another car in still another location, just swarming with bees around its door, inside and out. Then we "caught on." There was not a particle of honey in or around either of the two cars we were looking at. After the honey-car had been pulled clear out of town, the bees, not willing to give up, proceeded to "leave no stone unturned," and were investigating every car having an open door that, in their judgment, might be the one that had been pulled away. When they found one with sawdust spread over the floor they naturally concluded that was the car, and got down on their hands and knees searching in the sawdust for honey. The other bees, seeing them thus employed, naturally concluded this was the place. Others, having learned that one box car contained so rich a find, concluded that a search thru all the cars in the yard might possibly reward them for their investigation; and it was only in the cool of the evening that they were willing to stop digging in that sawdust, and be convinced there were no more honey-cars.

It may not be true that bees recognize colors, but they certainly do take in the general makeup of objects. They are not only able to recognize a hive, but they know a box car at sight; and even if it is moved to a different location they take in its general appearance so that they know pretty well how to find it in case of removal. We are not prepared to prove that they read the letters "Big Four" on the side of that car, nor that they remembered there was an enormous figure 4 printed in white on the red door of the car they wanted; but they came pretty close to it.

\section{HOW BEES COMMUNICATE.}

Of course, bees have particular notes, as for joy, sorrow, anger, despair, etc., which are produced by the wings, usually when flying; but we are quite sure they are unable to communicate to each other more than a single idea. In other words, they have no faculty of telling their fellows that a lot of honey is to be had in a feeder at the entrance, and that it would better be brought in quickly or other bees may find it. A bee goes out in the spring, and, by smelling around the buds, discovers honey and pollen; when it comes into the hive the others see it and start out to hunt up the source of supply in a similar way. For further information on this subject, see SwARMING.

\section{WHEN BEES WILL NOT ROB.}

By turning back and reading ANGer of BEEs, one will get a very good idea of the causes that start bees to robbing. Read, also, Bee-hunting, Feeding, and Bee BeHAVIOR. As a general thing, beas will never rob so long as plenty of honey is to be had in the fields. During a bountiful flow we have tried in vain to get bees to take any notice of honey left around the apiary. At such times we can use the extractor right in the open air, close to the sides of the hives, if need be. On one occasion we remember leaving a comb of unsealed honey on the top of a hive from morning until noon, and not a bee touched it. It seems they preferred to go to the clover-fields in the regular way rather than to take several pounds from the top of a neighboring hive. We can readily suppose that they did not have to visit anything like a hundred blossoms at this time, and perhaps they secured a load in going to not more than a dozen.

After the season begins to fail, one must expect that every colony in the apiary will be tried. As a rule, any fair colony will have sentinels posted to guard the entrance as soon as there is any need of such precaution. The bee that presumes to think it may enter for plunder will be led off by "the ear," if we may so express it, and this will be repeated until it learns that there is no chance for peculation at that house. At the close of the honey harvest precaution should be taken that there are no weak colonies, especially if they are queenless, that may be overpowered, for one such may start the fashion of robbing, and make it much harder to control. An apiary, like a community, may get so demoralized that thieving becomes a universal mania. "A stitch in time will save" a great many more than nine in this case. The space occupied by the bees also should be in proportion to their numbers. They should have only as many combs as they can cover if they are to defend themselves properly from either moths or robbers. Colonies without either 
queen or brood are not apt to fight for their stores very vigorously, so it will be well to see that they have either one or both, should there be an attack made on them. It is hardly necessary to repeat what has been said about Italians being better to defend themselves than the common bees. A few Italians will often protect the hive better than a whole swarm of black bees.

\section{HOW TO KNOW ROBBER-BEES.}

It sometimes puzzles beginners exceedingly to know whether the bees that come out are robbers, or ordinary inmates of the hive out for a general playspell. Indeed, there are times when a playspell looks very much like robbbing. See Playspells of BEES and DRIFTING.

When the robber-bee approaches a hive, it has a sly, guilty look, and flies with its legs spread in a rather unusual way, as if it wanted to be ready to use its heels as well as wings if required. It will move cautiously up to the entrance, and quickly dodge back as soon as it sees a bee coming toward it. If it is promptly grabbed on attempting to go in, never fear. When a bee goes in and it cannot be determined whether it is a robber or not, a close watch should be kept on all the bees coming out. This is a very sure way of telling when robbers have got a start, even at its very commencement. A bee, in going to the fields, comes out leisurely, and takes wing with but little trouble, because it has no load. Its body is also slim, for it has no honey with it. A bee that has stolen a load is generally plump and full; and as it comes out it has a hurried and "guilty look;" besides, it is almost always wiping its mouth, like a man who has just come out of a beer-shop. Most of all, it finds it a little difficult to take wing, as bees ordinarily do, because of the weight. In BEEHUNTING is related how a bee, laden with thick undiluted honey, would stagger under its load before it could take wing for the final trip home. The bee, when coming out of the hive with honey it has very likely just uncapped, feels instinctively that it will be quite apt to tumble unless able to take wing from some elevated position, and therefore crawls up the side of the hive before launching out. When first taking wing it falls a little by the weight of its load, before its wings are fully under control, and therefore, instead of starting out as a bee ordinarily does, it takes a downward curve, coming quite near the ground before rising safely and surely. With a little practice one can tell a robber at first glance by its way of coming out of the hive, particularly by that fashion of running up the side of the hive before taking wing.

HOW TO TELL WHERE THE ROBBERS BELONG.

If one is a bee-hunter he will probably line them to their hive without any trouble; but if he is not, he can easily find from which hive they come by sprinkling them with flour as they come out of the hive being robbed. Watch should be kept on the other hives, to see where the floured bees are going in. If the robbing is confined to one or two colonies, as is aften the case, they should be put down cellar and kept there for several days where they can not incite other colonies. References will be made to this further on.

\section{HOW TO STOP ROBBING.}

As to the best mode of procedure, a good deal will depend on circumstances. When bees in the whole apiary are robbing in a wholesale way from the honey-house, or from any place where a supply of honey or syrup is kept, the obvious remedy is to shut the door of the dwelling to cut off the supply. If the bees have entered a barrel thru the bunghole, the chances are we shall find, after the head of the barrel is taken out, that there is a peck or more of bees swimming around in the honey. If robbing has become very bad we would drive the bung into the barrel, and then, after the uproar has quieted down, remove it and run the honey thru a strainer.

Bees soon stop robbing when all sweets within their reach are removed or so protected that they cannot get at them; but even then the apiary will be out of balance for the rest of the day, and more or less for two or three weeks following, because the bees will be trying to find where they can find more sweets.

Sometimes robbing is started by some one in the neighborhood making sweet pickles, canning fruit, or doing anything that causes a strong odor of sweet or sour during its preparation; then the only thing the beekeeper can do is to have the house screened; or if the case is very bad, and the bees keep 


\section{ROBBING}

on "sticking their noses into other people's business," the entrances of all the hives should be smoked with tobacco smoke. Half a dozen whiffs of smoke should be blown into each entrance, one after the other. In half an hour the dose should be repeated. This will cause the bees to quiet down until such time as the canning-work or the picklemaking is over at the house where bees are "making themselves too familiar."

The best treatment for a general robbing thruout the apiary is prevention. The screen door and other openings into the honeyhouse should be self-closing. Unless they are, some one will be almost sure to forget and leave one of them open. If the doors are not self-closing, all the honey or syrup stored in the building should be put ints hives, shipping-cases, cans, barrels, or any receptable where bees can be kept from helping themselves; then if perchance the door is left open no harm will be done.

\section{ONCE A ROBBER, ALWAYS A ROBBER.}

After robber bees once get into a building it is a mistake to let them out again; for no sooner are they out than they are at their old tricks again. It is better to confine them, and then after they have been imprisoned for 24 hours they may be brushed down into a box from the screen or from whatever portion of the building they may have clustered in. They should then be carried to an outyard. It is not advisable to let them loose again in the same yard where they have learned their bad tricks of stealing; for if allowed their liberty they will be continually prowling around for days to see where they can effect an entrance to the honey-house or an unguarded hive. It may be cheaper in the end to kill them outright, especially if there are not more than half a pound of bees. If there are many more, it may be desirable to save them; but they should not be let loose again in the same yard-taken to another yard they will cause no trouble.

\section{ROBBING OF NUCLE] OR WEAK COLONIES.}

There is another kind of robbing that is much more common, and which is apt to perplex the beginner more than anything else, and that is the onslaughts that are often made on weak colonies or those that are disinclined to make a defense, especially if queenless. Nuclei with large entrances are especially subject to the attacks of bees from strong stocks, and will very often be cleaned out entirely before the apiarist discovers the mischief. By that time the whole apiary will be in a perfect uproar; and as soon as the supply of honey has been exhausted in the one nucleus the robbers will hover around all other entrances, and on finding one poorly defended they will get in more bad work. During a dearth of honey there are always some bees that make a business of smelling around, and it is a wise precaution always to have the entrances of nuclei contracted to $\approx$ width where only one or two bees can pass at a time.

One of the most prolific causes of robbing is a warped cover or an old hive, the corner of which has split open. All such makeshifts should ultimately be replaced, but in an emergency a handful of mud plastered into the opening or crack, or some cotton stuffed in, will go a long way toward preventing serious trouble later on. During a good honey-flow small cracks large enough for bees to get thru do no particular harm, but during a honey-dearth extra precautions must be taken. Weak colonies especially cannot defend several entrances, and that is why poorly fitting covers or leaky hives must not be tolerated. The robbers seem to realize that the regular entrance is more likely to be well guarded, and that is why they are often seen trying to crawl thru some unguarded crack.

We will suppose that a hive has been overpowered, and that its own bees are making no defense, realizing, probably, that resistance is useless. If anything is to be done to save the colony it must be done quickly. One way is to grasp up a handful of long grass, strew it closely around the entrance, and then spray or sprinkle a dipperful of water on it, and scatter more wet grass over the entrance. A very little carbolic acid added to the water makes the spray more offensive to robbers. The invaders will not, as a rule, crawl thru the wet grass to get into the hive, while on the other hand those that have already entered the hive will get out and return to their homes. In the mean time the regular inmates of the hive, as soon as they are given a little assistance, will begin to set up a defense. The grass should be kept wet for at least an hour or two, and possibly till sundown; but before strewing the grass the 
entrance should be contracted down so that only one or two bees can pass at a time. The entrance should never be closed up entirely, no matter how bad the bees are robbing. On a hot day the large number of robbers in the hive, together with the regular inmates, would be almost sure to smother to death.

Another and a better way to treat colonies or nuclei that are not making a good defense is to carry them down cellar or put them in any cool place where they will have an opportunity to recover themselves, and where, too, robbers cannot continually keep un the nolicy of nestering the life out of

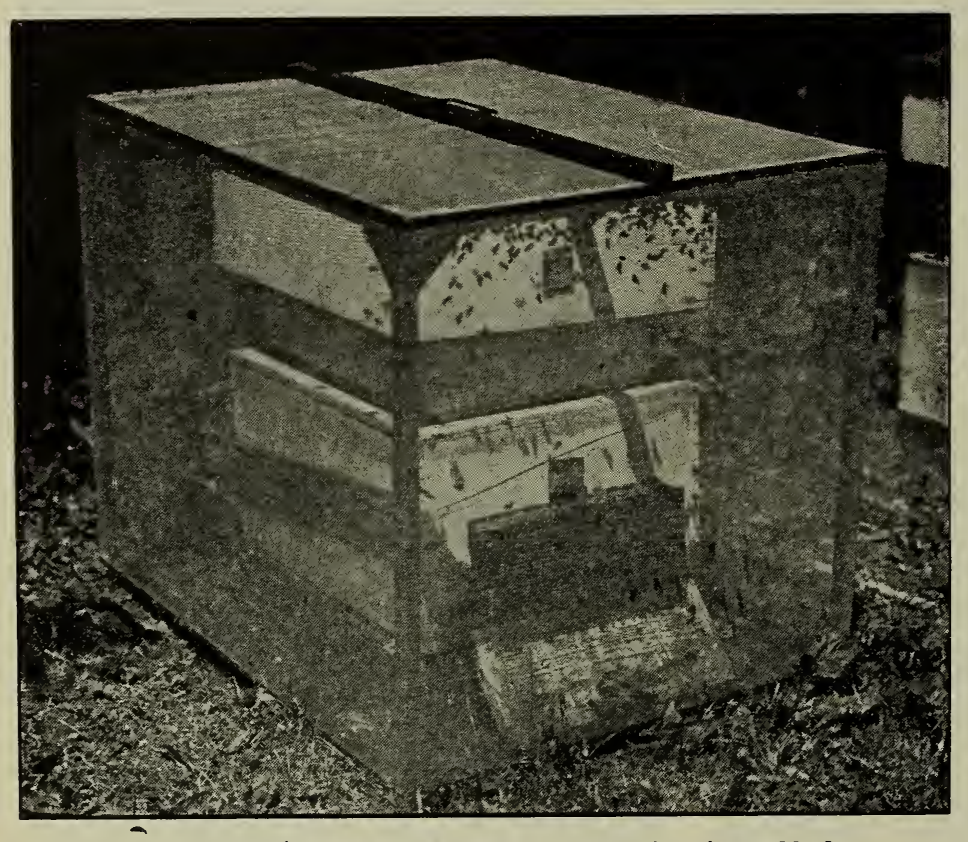

Convenient cage to set over hive that is being robbed.

new man has been left in charge. Such a man or boy will sometimes let robbing get well under way, not knowing that trouble is brewing. In very short order it will be apparent that the colony or the nucleus is not making a defense. Sometimes even a strong colony will be taken by surprise, and before it is aware of what is up the robbers will be piling into the hive at a furious rate. At other times there are not enough bees in a nucleus to make a respectable defense. Such colonies or nuclei need help, and that right speedily. If we have one of these wire cages, we set it right over the hive, and that immediately stops any more robbers from getting in. As soon as the marauders in the hive fill up, they will rush out of the entrance pellmell; but instead of going back to their own hive they are imprisoned in the cage. In the mean time there will be a big horde of robbers outside of the cage. It is our practice to raise this cage up for three or four seconds, when all the outside robbers will pounce on the entrance. Right here the reader may think we are making a mistake. Our policy is to eatch every robber that has been carrying on the business of stealing for the last

them. In 24 hours the robbers in the yard will have quieted down, when the nucleus or robbed colony can be taken out and set back on its stand. But at this time the entrance should be contracted down to a space just wide enough so that only two or three bees can pass at a time.

A still better plan for the treatment of a colony that is being overpowered by robbers is to set a wire-cloth cage or tent over it. This cage need not be larger than will cover the hive. The illustration shows the style used by the authors. We have three or four of such cages in the yard ready for an emergency of this kind.

We do not have robbing except when the regular apiarist is temporarily away and a few minutes or half-hour, so as they return from their hive we lift their cage at intervals and let them in. The bees that have been imprisoned will cling to the top of the cage, even tho it be lifted for the moment. In the mean time their number will be reinforced by more robbers coming out of the hive. In the space of about thirty minutes, if the robbing has not been going on too long, every robber will be in the top of the cage. and there they will stay. It is a serious mistake to let such bees loose again, for they will immediately go back to their hives and return to attack the colony that has been overpowered.

Toward night we lift the cage off the hive; set it down carefully till the next 
day, when they will be found clustered up in the top of the cage, perhaps in one corner. We now scoop them all off with a dipper, after using a little smoke, and dump them into a box. We next take them to an outyard, where everything will be strange to them, and give them to a colony that needs a few more bees, taking the precaution, however, to cage the queen, as the new bees might kill her.

It has been said, "Once a thief always a thief;" and while the statement applies to the human family, it is true of robber bees - "Once a robber always a robber." We them around easily and squat over a hive to be manipulated. The cages that we have used are made in the same way as the small cages, of $7 / 8$-square stuff braced at the intersections by three-cornered blocks. Crossrails on each side two feet from the bottom serve as convenient handles, so that the man on the inside can pick up the cage and walk from one hive to another. We have found the use of cheese-cloth quite as effective as wire cloth for these large cages, and much cheaper; and we discovered, also, that it is not necessary in most cases to have the top corered. The average robber

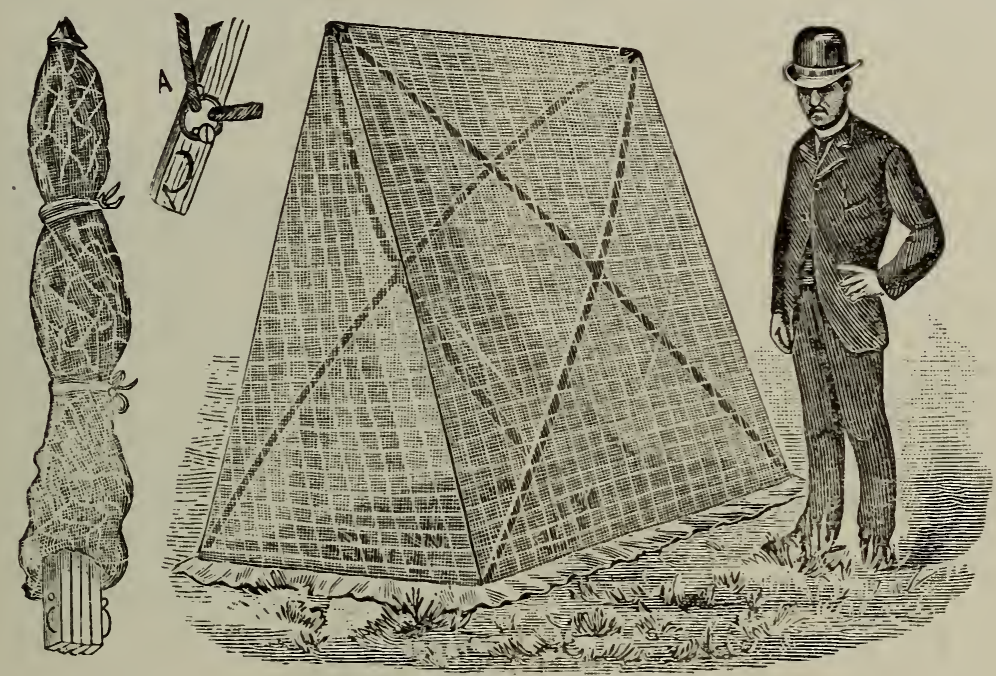

Tent folded.

Folding bee-tent ready for use.

have sometimes doubted whether it is best to let these robbers loose after they have once been trapped. Where there are very many of them it would be too bad to destroy them. If only a few they should be killed.

\section{ROBBER-CAGES; HOW TO MAKE.}

A little way back reference was made to a wire-cloth cage large enough to be set - over a hive to protect it from robbers.

They consist of a light framework of $7 / 8$ square stuff held together at the intersections by means of three-cornered blocks. The whole is then covered with wire cloth, and across the top a strip is nailed to provide a handle so the cage may be lifted up with one hand. In our own apiaries we find it best to have in addition one or two larger cages-big enough to take in a man while he is operating over the hive. These cages may be of various sizes, but they should be light enough so that one can carry that is supposed to make trouble will hover along on a level about the top of the hive that is being. operated. It does not have sense enough to rise up and dive down over the top; but in the mean time bees that belong to the hive that is being manipulated will easily escape. On the other hand, the cages that have tops will cage the bees so they will be bumping around the head of the operator. Unless they are actual robbers, it is better to let them loose; and as soon as the operator has left the hive they will go into their own entrance.

For raising queens these topless cages are very convenient when the robbing season is on. The queen-breeder, while he is on the inside of one of these cages, can work over a hive as long as he pleases, secure from robbers. If he uses the cage continually, robbers will seldom get a taste of honey; and therefore there will be little or no trouble. 
We have used with considerable satisfaction anothar form of cage that is collapsible - that is to say, it folds up into a small compass. It is shown on the previous page.

\section{EOBBER-TRAPS.}

Their purpose is to catch the hardened "old sinners"-bees that are professionals in the art of robbing, and which are of but little practical value for the purpose of getting honey honestly from the fields: We catch these shiny-backed bees and kill them. While some protest has been raised on the ground that they might be made over into a colony, yet the kind of "old sinners" to which we have referred are useless for any purpose. In a queen-rearing yard the sooner they are out of the way the better for all concerned. As long as they are allowed to prey on their honest neighbors they will continue to make work in the yard disagreeable by keeping every colony stirred up and more or less cross, despoil baby nuclei, and make trouble generally. But this is not all. They incite other bees to rob. The force of example is very potent among bees as well as human beings.

While one does not need to use traps continuously, they are required on occasions; for if a few bees once get started to robbing they will day after day pounce on the combs every time a hive is opened, and render life miserable for their owner and for the baby nuclei. Time and time again in our yards we have restored everything to absolute order and quiet by the use of the trap. It works like magic; and after the rascals are caught, one will be surprised to note how few bees can make such an uproar as is evidenced by the number in the trap. Their intrinsic value is practically nothing, even if they were good honest bees. To let them loose would only invite more trouble. The amount of honey that they might gather if they could be "reformed" would be a very insignificant item. But the amount of damage that they can do in interfering with our queen-rearing operations is no small item.

It has been suggested that, if a robbertrap will catch robbers, it will also catch honest bees, and why destroy good property? There is no need for catching anything but the hardened old sinners-those that we consider hopeless beyond redemption. As explained, we do not run the trap continuously thruout the season-perhaps one or two days in a whole year, and not even then if no robbers show up.

How do we avoid eatching honest bees? Easy enough. The traps are put in operation only when the prowling thieves are around. They are constantly on the alert, skilled as they are in the art of stealing and finding any exposed sweets; that is to say, they are ever following one about, while the honest bees are either in the field or hive.

Let us assume a case. After we have been working in the yard a few days there are a few robbers that accumulate. But we do not let them continue on with their nosing into other people's business till they make work in the yard exceedingly disagreeable, and the colonies that are being worked, cross. Before they become very numerous, two or three robber-traps are put into operation; and in an hour absolute peace is restored-not a prowler is in sight.

The value of the traps depends on the fact that it stops a would-be bad case of robbing before it has progressed to any extent. A little syrup (and a very little) is put into one or two traps. The robbers, because hunting for sweets, are caught long before any honest bees think of looking for them.

\section{CONSTRUCTION OF ROBBER-TRAPS.}

An ordinary hive, such as is used in the yard, two wire screens such as are employed for moving bees, a super-cover, and a wire-cloth-cone bee-escape, make up the complete outfit. (The ordinary Porter spring escapes for this purpose have not been found to be as satisfactory as the wire-cloth cones.) We open up the robber-trap hive, and just over the entrance of it we find a wire-cloth cone tacked up against the inside hive-front. This is made by cutting and folding a piece of wire cloth in the form of a triangle. The large end fits over the entrance, while the other end, gradually tapering to a small orifice (about $3 / 8$ inch square), reaches nearly to the top of the hive, or within an inch of the rabbet on which the frames rest; it is then secured by double-pointed tacks as shown at the top of Fig. 1. As an additional precaution we find it desirable to have a smaller wire cone 
of the same construction under the larger one. Where there is only one cone the bees are liable to go back out thru the entrance. Other forms of cones are shown in the two lowerr views of Fig. 1.

One of these traps is placed at a conven-
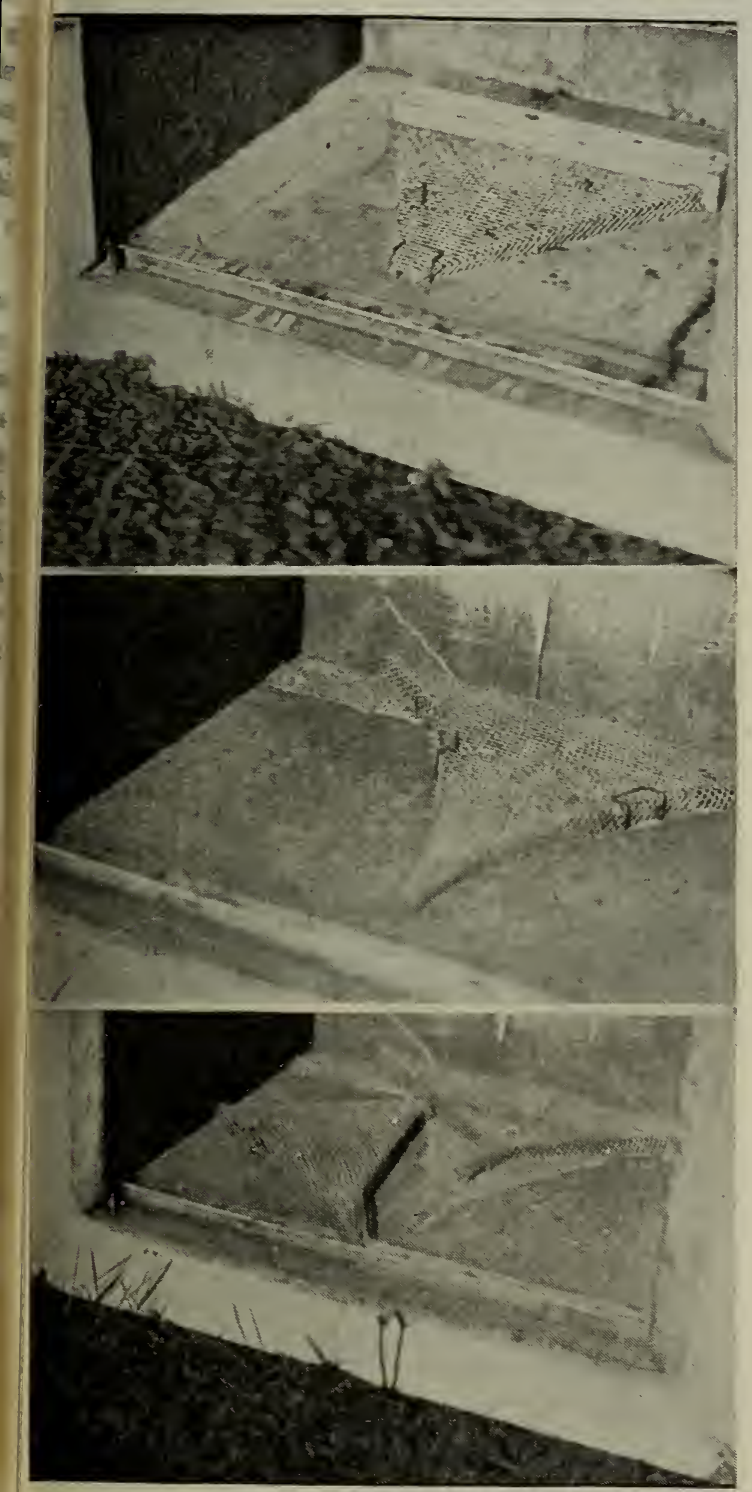

Fig. 1.-Wire-cloth-cone bee-escape on the inside of robber-traps. Note that the large end of the cone communicates with the regular entrances of the hive. Robbers pass in at the entrance up thru the cone into the hive and are caught.

ient location in the yard, when one of the wire screens for moving bees is laid on top. With a brush we smear a little diluted honey (honey is better than syrup) over the wire cloth at one end-the back oné. This film of honey is spread over an area of about two inches wide by the width of the screen. Another screen is placed on top of this, and over the whole is placed a supercover, as at the left in Fig. 2. It will be noticed that this super-cover is set back about two inches, leaving a portion of the wire cloth-the part smeared with honeyexposed where the bees can get a smell of it, but not touch it, because the upper screen keeps them from it. A robber-bee, if a "hardened sinner" or a professional, when it smells honey in this way will immediately begin to "investigate." It will hover around the wire cloth (not covered by the supercover) for a minute or two, and then, like a duck to water, it will make a dart for the entrance. There are no guards there to stop it; it rushes in pellmell, crawls up thru the two wire-cloth cones shown in the previous illustration, and ont thru the apex, when it is a prisoner. It may take a sip of honey, and when it gets its fill it will go toward the light at the point where the super-cover is slid backward. The chances are only one in a thousand that it will get back thru the wire-cloth cones as mentioned, and it soon worries itself to death. Thus the trap works after it catches all the criminally inclined bees. The small amount of diluted honey on the inner wire cloth is used up, and antomatically the robber-trap goes out of commission. The old robbers are all caught; and as there is no more honey to attract honest bees, none will be caught.

The question may arise, "Is the robbertrap of any use to the honey-producer?" Certainly not to the same extent that it is useful in a queen-rearing yard; but during a period of extracting there are times when it might be used to good advantage, especially if some careless employee should happen to leave the door of the honey-house open or allow a colony to be robbed to death.

As has already been pointed out, if robbers can be caught at the very start they will be found to be mainly from one hive, and a little later from two or three. If they get well agoing they will attract other bees by their uproar; but if robber-bees be floured, and followed back to their hives, it will be seen that the great bulk of them go to only two or three hives. A yard-man has to be extremely careless to allow robbing to get started thruout the yard. 


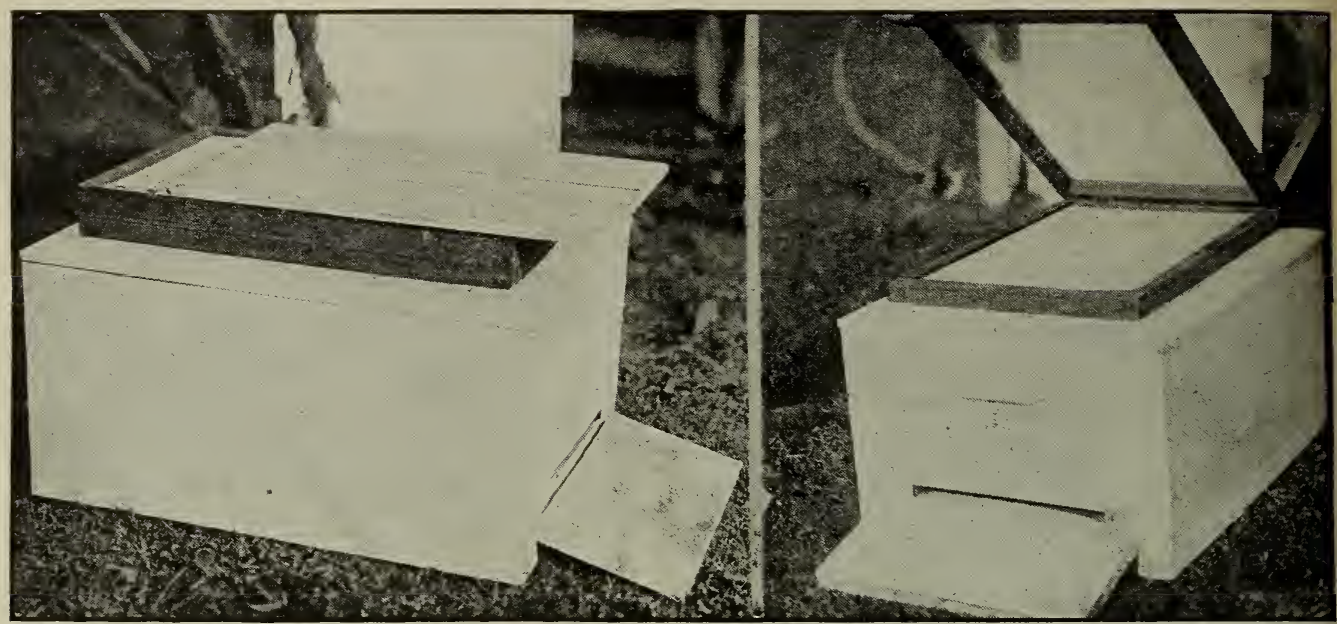

FIG. 2.-Outside detail of the robber-trap. A double screen is used, and honey is painted on the inner screen. Robbers are attracted by the odor of the honey. As they can not reach it from the outer screen they enter the hive and are trapped.

HOW THE ROBBER-TRAP CAN BE MADE TO CURE THE ROBBING NUISANCE.

It often happens that a colony will be nearly conquered by robbers, and it may be a fairly good-sized one too. The thing to do then is to take it off its stand and put a robber-trap in its place, when, presto! the thieves will be imprisoned. In the meantime the attacked colony is taken down cellar where a window has been left open. The marauders that don't belong there will pass outward thru the window, which then should be closed. In very short order the robber-trap on the stand of the hive thai was being robbed will have collected all the robbers. When everything becomes quiet in the yard, put the trapped bees down cellar and keep them there for some days as already directed. If confined more than two days they will have to be fed.

The robbed colony, after its despoilers are caught, may now be put back on its stand, when the entrance should be contracted to about the space that one bee can pass at a time. The bees in the trap down cellar can not of course molest it; and, during the time that they are held in confinement, it will have recovered itself, and with its contracted entrance will be able to put up a very stiff defense in case another onslaught is made.

\section{SWAPPING PLACES WITH THE ROBBING AND ROBBED COLONIES.}

Trying to people our house-apiary in the fall, when it was first built. we had trouble with one certain colony. In fact, when robbing was going on anywhere it was sure to be these hybrids that were at the bottom of the mischief. After we had tried every plan recommended, and still finding these fellows would persist in pushing into every new colony we started, the idea occurred to us that, on the principle that it takes a rogue to catch a rogue, it would be well to try to see how these would repel other robbers. We simply took the greater part of the combs from the robbers, bees and all, carried them into the house apiary, and put them in place of the colony which they had been robbing. The effect was instantaneous. Every laden robber-bee that went home with its load, on finding the queen and brood gone from the old stand at once showed the utmost consternation, while the passion for robbing was instantly changed to grief and moaning for the lost home. The weak colony which they had been robbing, and which had only a queencell, was carried to them, and they soon took up with it and went to work. The robbers newly domiciled in the houseapiary repelled all invaders with such energy and determination that the rest seemed to abandon the idea which they, doubtless, had previously formed; viz., that the house-apiary was a monster hive but ill garrisoned, so we had very little trouble afterward. Before we transposed them, as mentioned, we had serious thoughts of destroying their queen, simply because they were such pests; but the year after- 
warr, this colony gave in the house-apiary over $100 \mathrm{lbs}$. of comb honey.

HOW TO KNOW WHEN A HIVE IS PUTTING UP A GOOD DEFENSE.

The half-tone shown below is a good illustration of how a powerful colony will deploy its sentinels or guards during the time when other colonies near by are being robbed. This colony is prepared for any kind of an onslaught; for the minute that a robber hovers over the entrance it is promptly met in mid air by one of the sentinels. They immediately clutch in a

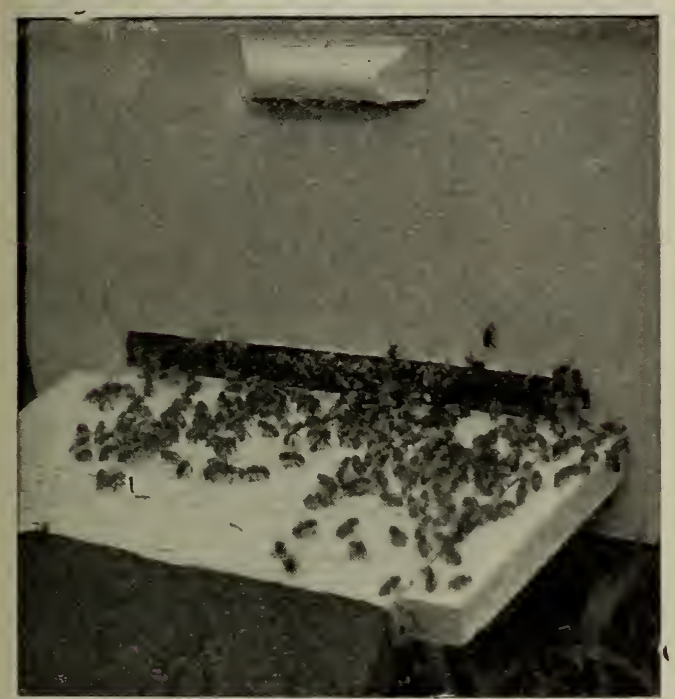

A colony that is ready to meet any kind of on. slaught from robbers. Robbers had hovered around the entrance. The result was, the guards were out in good force to repel the attack.

rough-and-tumble fight, drop to the ground, roll over and over, and lucky is the rohber if it gets away without having its hair or legs pretty vigorously pulled. Such "a warm reception "will discourage any wouldbe robber from tackling that colony again. The entrance is rather wide open and the colony is strong enough to put up a defense and a vigorous one at that. If the colony were not so strong it would be proper to contract the entrance as shown under ENtrances and WINTERING elsewhere.

WORKING WITH BEES BY LANTERN LIGHT WHEN ROBBERS ARE TROUBLESOME DURING THE DAY.

Some years ago, when we sold our bees down so that most of the colonies were not much more than two or three frame nuclei, we found it recessary to build them up by means of stimulative feeding. No honey had been coming in, and the bees were very troublesome about robbing. The moment the hive was opened, robbers would pounce down on the combs. Feeding by day was quite out of the question. We finally decided to try going thru the colonies by lantern light; and, quite to our surprise, we found that we could go into hive after hive, and get a pretty accurate idea of their condition. Of course, no robbers would bother at such a time. We gave the bees some weak syrup at the time of the eramination, and by morning it would be all taken up. By working a few nights in this way by lantern light we built up the whole apiary without any trouble from robbers, and by late fall we had a lot of nice colonies well supplied with stores and young bees.

The only difficulty one will experience will be the disposition on the part of a few bees to fly out toward the light. Some of them will buzz around against the lanternglobe. But the trouble from this source is not very great. Other bees will have a tendency to crawl up one's sleeve or his clothing. To prevent this the ordinary fingerless gloves as described under GLoves should be worn.

HOW TO REMOVE THE ROBBING TENDENCY BY OUTDOOR FEEDIXG.

When honey is coming in there is no robbing: but as the nectar supply stops, bees begin to pry around to find what they can steal. At such times, when hives are opened for examination robbers will be about, and if the combs are exposed very much by such handling they will pounce upon the hive and combs in great numbers, and then attack the entrance after the hive is closed up. If one is trying to rear queens the results will be discouraging. Bees get cross, refuse to start cells, or, if built out, tear them down, and kill off drones, and destroy drone brood.

The fact that there is no robbing when honey is coming in suggests the remedy; riz., feed outdoors a thin syrup of the consistency of raw nectar. See Feeding OutDOORS.

HOW TO FEED OUT UNFINISHED SECTIONS OR WET EXTRACTING-COMBS.

While these can be scattered out in the open, it is quite sure to result in fearful 
robbing and stinging after the supply is exhausted. To forestall this, the combs and sections should be put in hives or supers, one tiered above another on a regular bottom-board, and then the entrance should be contracted so that not more than one or two bees can pass at a time. To make it wider results in a scramble and robbing of weak colonies in the yard. The top of the tier of hives or supers should, of course, be covered.

These tiered-up hives with small entrances are much used to clean up scraps of honey, extracting-combs, and to empty out partly finished sections. See ComB Honey. This slow robbing also has a tendency to draw off robbers from the nuclei and weak colonies and therefore serves a double purpose.

WHAT HAPPENS IF ROBBING IS NOT STOPPED.

When robbing is under genuine headway, the honey of a strong colony will disappear in from two to twelve hours; the bees will then starve in the hive, or go home with the pillagers, or scatter about and die. This is not all; when the passion is fully aroused they will not hesitate to attack the strongest stocks, and bees will be stung to death in heaps before the entrances. This may put a stop to it, in time, but we have seen them push ahead until every hive of the apiary was in an uproar, and it seemed as if every bee had certainly gone crazy. At such times the robbers will attack passers-by in the streets, and even venture an attack on cats, dogs, hens, and turkeys. Like the American Indians when infuriated at the sight of blood, every bee seems to have a demoniacal delight in selling its life while inflicting all the torments it possibly can, feeling sad only because it can not do any more mischief.

The worst robbing time seems to be after the heaviest or main honey-flow is over, when bees become especially crazy if they get even a smell of honey left carelessly anywhere near the hives. One who has never seen such a state of affairs can have but little idea of the furious way they sting every thing and everybody. The remedy is to get a good smoker and put in enough fuel to insure dense smoke; then, using one hand to work the smoker bellows, with the other, contract the entrance of every hive that shows any symptoms of being robbed. Shut up every bit of honey where not a bee can get at it, and do the work well; for at such times they will wedge into and get thru cracks that would make one think inch boards were hardly protection enough. Be up betimes next morning to see that all entrances are close and small, and that all the hives are beetight. An experienced hand will restore peace and quietness in a very short time to such a demoralized apiary. Black bees are much worse than Italians, for the latter will usually hold their stores against any number of assailants ; good, strong, well-made hives, filled with Italians, with plenty of brood in each, will be in little danger of any such "raids," altho we have seen the wounded and slain piled up in heaps before robbers would desist and give up trying to force an entrance. See ANGER OF BEES.

\section{BORROWING.}

Before closing this subject of robbing there are a few more points to be mentioned. There is a kind of pillaging called borrowing, where the bees from one hive will go quietly into another, and carry away its stores as fast as gathered; but this usually happens where the robbed stock is queenless, or has an infertile queen. As soon as they have eggs and brood, they begin to realize what the end of such work will be. This state of affairs seldom goes on long; for it either results in downright robbing, or the bees themselves put a stop to it.

Caution to Beginners.-The first year we kept bees there was constant fear that they would get to robbing, as we had read so much about it. One afternoon in May we saw a large number of bees passing rapidly out and in a particular hive, and the more they were examined the more we were persuaded that they were being robbed. We contracted the entrance, but it seemed to make little difference. We finally closed it almost entirely, compelling the bees to squeeze out and in, in a way that must have been quite uncomfortable, at least. After awhile they calmed down, and we had only the ordinary number of bees going out and in. "There," thought we, "had we not read the books and known how, we might have lost out bees," and we undoubtedly felt very wise if we did not look so. On turning the head, behold, the robbers were at another colony, and they had to be put thru the 
same program; then another and another; until we concluded a host of robbers had come from somewhere, and made a raid on the apiary, and that, had we not been on hand, the whole of them would have been ruined. We had got very nervous and fidgety, and, when we found the whole performance repeated the next day, we began to think bee culture a very trying pursuit. Well, in due course of time we figured out that there was no robbing at all, but that it was just the young bees taking their afternoon playspell, for, as we have already stated, a playspell of young bees often looks like a case of robbing. See Playspelus of BEES.

ROCKY MOUNTAIN BEE-PLANT (Cleome surrulata Pursh).-This is a beautiful plant for the flower-garden, to say nothing of the honey it produces. It grows from two to three feet in height, and bears large clusers of bright pink flowers, as shown in the cut.

It grows naturally on the Rocky Mountains and in Colorado, where it is said to furnish large quantities of honey. Altho it succeeds easily under cultivation we can not learn that it has ever been a pecuniary success in our locality. With this, as with all other plants, it must be borne in mind that a fair test would require acres instead of little patches in the garden.

The engraving was copied from a largersized picture, in Prof. Cook's "Manual of the Apiary." During the season of 1879 we had a number of the plants growing in our honey-garden. It was, however, so much inferior in looks, as well as in the amount of honey produced to the spiderplant, that we did not take the pains to save any of the seed. The two plants very much resemble each other, but the latter is a much stronger and finer-looking plant, and has a rank luxuriance of growth that the Rocky Mountain bee-plant lacks.

The Michigan Agricultural College experimented, in 1891, with several acres of this plant, for the sole purpose of testing its honey-producing qualities. They found it exceedingly difficult, however, to get a good stand of plants. In fact, we do not know how a perfect stand can be obtained

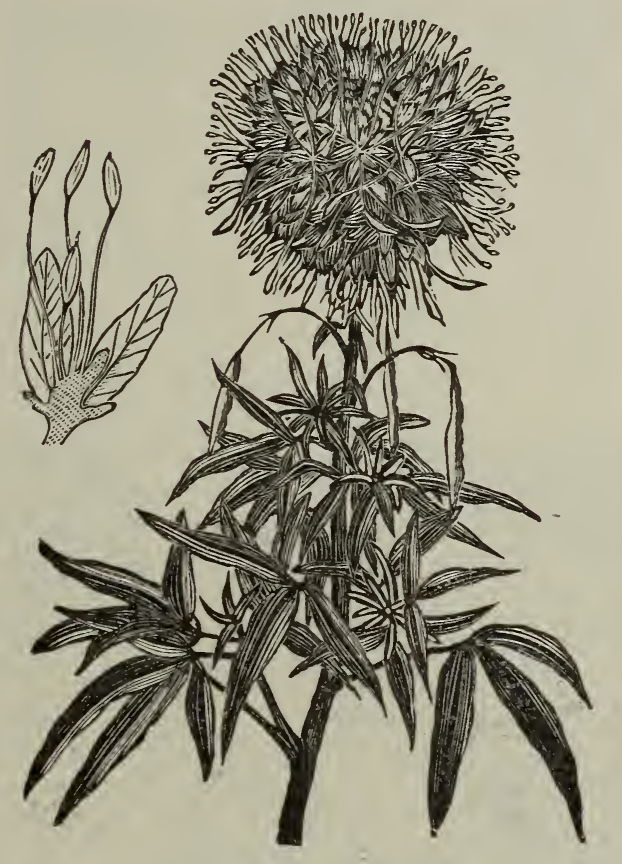

Rocky Mountain bee-plant.

without transplanting; and as this makes the expense equivalent to a field of cabbages or strawberries, of course the honey produced did not come anywhere near paying expenses.

ROYAL JELLY. - See QUEENS; also QUEEN-REARING. 


\section{S}

SAGF.--Sage honey, which is widely known for its delicious flavor in Europe as well as in America, is a product peculiar to California. Practically the entire sage region of this state lies south of a line drawn from the coast thru San Luis Obispo and Tehachapi. Sage honey is obtained principally from the black and white sages, altho there are several other species which yield a surplus in certain localities; but the black sage, also known as ball, button, and blue sage, is by far the most important, ard ranks as the chief honey-plant of California.
Black SAgE (Salvia mellifera Greene) is so called because after the blooming season is over the flowers and leaves turn dark and adhere to the bush until the next season. It is abundant in southern California in sunny canyons and on the slopes of the Coast Ranges and the San Bernardino Mountains. Richter says that it ascends to an elevation of 5000 feet. It is a shrubby plant with many herbaceous branches, from three to six feet tall, bearing narrow leaves which are green above and woolly beneath. The flowers are in dense whorls, of which there

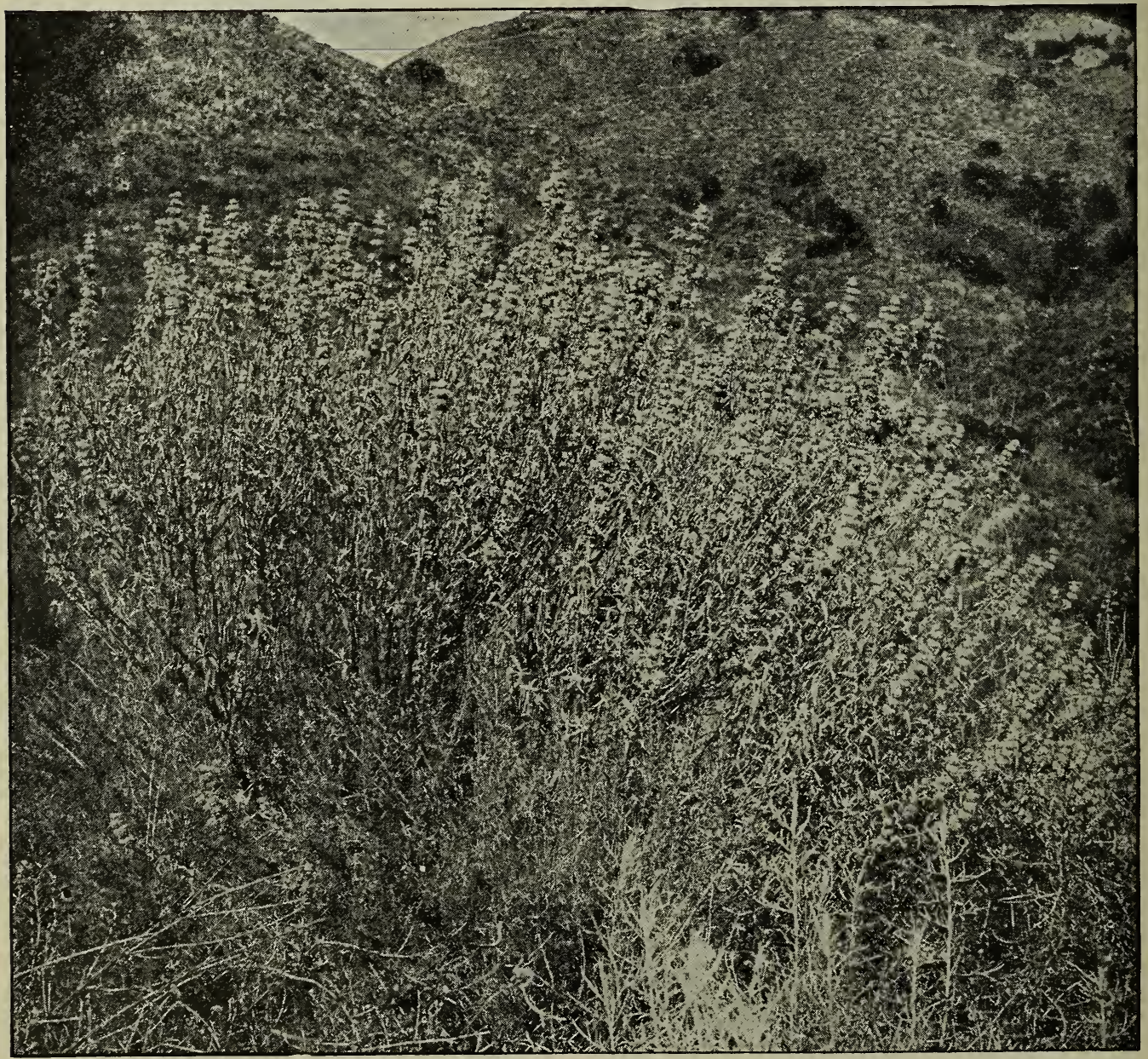

A bush of California button sage. 
are from three to five on each branch as shown in the illustration. These whorls, the larger of which are an inch across, are known as buttons, and diminish in size toward the tip of the stalk. The flowers are white, or tinged with violet, two-lipped, and begin to open first on the outer edge of the whorl or cluster of buds, and the plant continues in bloom until each "button" has wholly flowered out. A tiny drop of nectar can be squeezed from each corolla tube in the same way as from red clorer.

The honey-flow lasts from the middle of March, or the first of April, until about the first of July. The crop is unreliable every other year, and a total failure once in three or four years. Every fifth year a large crop may be expected, and if the rainfall has been ample a fair surplus is sometimes obtained three years in succession. The black sage does not yield nectar freely unless there has been at least ten inches of rain during the winter, followed by a clear warm spring. The rainfall varies greatly in different years, presenting great $\mathrm{kx}$ tremes; in 1882, Chadwick says that there was only 2.94 ins., while in 1905 it amounted to 22.12 inches. Altho the plants are well adapted to live in semi-arid regions. if there is a long-continued drouth, they dry up and are valueless to the beekeeper. The flowers are often injured by the sage worm, and the foliage by rust. The honey is water-white, thick and heavy, and does not granulate.

White SAge (Salvia apiana Jep.) begins to flower during the latter half of May, and the blooming period lasts from six to eight weeks. It is very abundant on the dry plains, or mesa lands, and foothills of southern California. There are thousands of acres of this beautiful shrub, and one may ride thru arenues of it for miles. One range is described as a mile wide and two miles long consisting practically of unbroken white sage. The shrubby plants are four or five feet tall, the foliage and stems are light green, and there are numerous flower-stalks loaded with long racemes of bilabiate, white flowers. The lower flowers on the stems expand first:

A flower of the white sage secretes much less nectar than does one of either the black or purple sage. In districts where both the black and white sages were abun- dant beekeepers have estimated that the black yielded ten pounds of honey to one from the white species. To produce a vigcrous growth and a profusion of flowers there must be a sufficient rainfall. The honey is white and heary, does not candy; while the quality is nearly as fine as that of black sage. Much of the white-sage honey, so-called, comes from black sage.

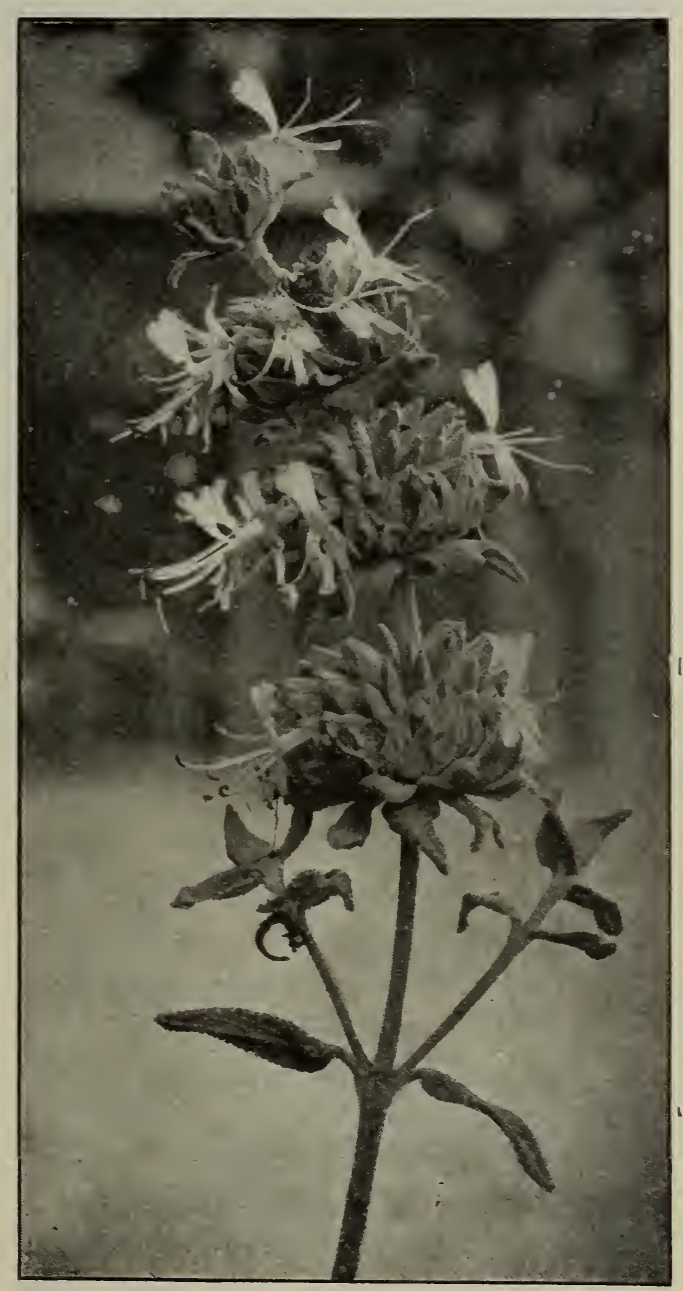

A stem of California button sage with blossoms.

The purple sage (S. leucophylla) has its purple flowers clustered in whorls, or " buttons" similar to the black sage. Thlis species is not so abundant as the black and white sages, and is found chiefly in southern California westward of the Coast Ranges. None of the sages yield nectar more freely. The honey is water-white, does not crystallize, and its flavor is described as superior to that of all other sage hon- 


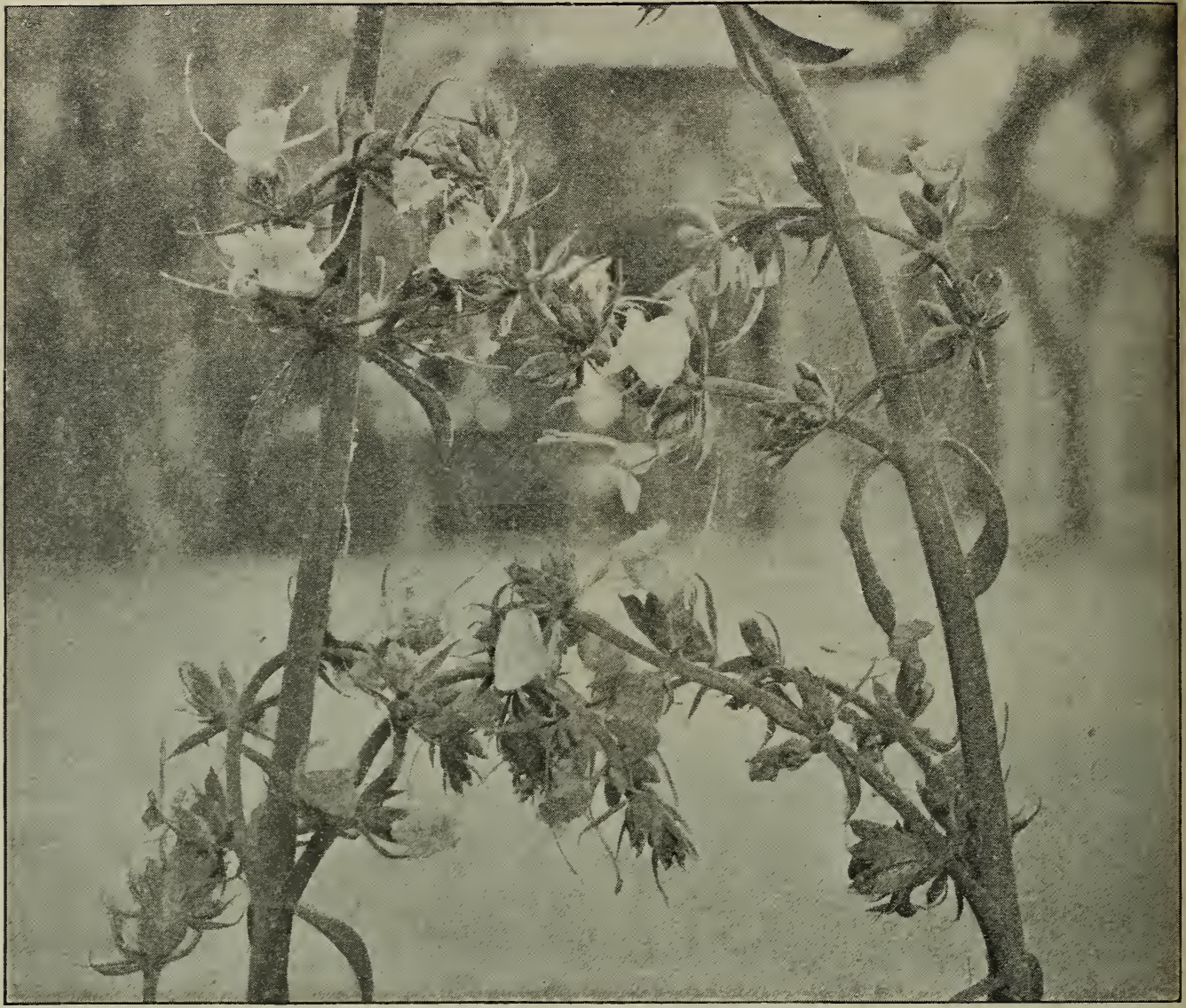

Stems and blossoms of California white sage.

eys. The creeping sage ( $S$. sonomensis), or ramona, covers the ground with a matlike growth, from which arise flowering stems four or five inches tall bearing light violet flowers. The species is widely distributed in the Sierra Nevada and Coast Ranges, and in some localities is important. The honey is like that of the other sages.

Annual sage (S. columbariae), or chia, is also common on the foothills and mountains of the Coast Ranges, and in some districts yields a surplus. The seeds were formerly used for food, and were also considered of medicinal value in cases of fever. The three above species bloom in April and May.

\section{LANGSTROTH'S OPINION OF SAGE HONEY.}

The crops of honey secured from black sage within the past 25 years have been so immense that fine sage honey is now offered for sale in almost all the principal cities of the world, and a nice sample of well-ripened California honey, whether comb or extract- ed, is enough to call forth exclamations of surprise and delight from any one who thinks enough of something good to eat, and pleasant to the taste, to commit himself so far. We well remember the first taste we had of the mountain-sage honey. $\mathrm{Mr}$. Langstroth was visiting us at the time, and his exclamations were much like our own, only that he declared that it was almost identical in flavor with the famed honey of Hymettus, of which he had received a sample some years before. Well, this honey of Hymettus, which has been celebrated both in poetry and prose for ages past, is gathered from mountain thyme, and the botany tells us that thyme and sage not only belong to the same family, but are closely related. Therefore it is nothing strange if Mr. Langstroth was right in declaring our California honey to be almost identical in flavor with the honey of $\mathrm{Hy}-$ mettus. The California sages grow along the sides of the mountains, and blossom successively as the season advances; that is, 
the bees first commence work on them in the valleys, and then gradually fly higher up, as the blossoms open on the mountain side, giving them a much longer season than we have in regions not mountainous.

A peculiarity of this honey is that it is not inclined to candy, but remains limpid during the severest winter weather. We have taken a sample so thick that the tumbler containing it might be turned bottom upward without its running at all, and placed it out in the snow, in the dead of winter, and failed to crystallize it.

\section{SAINFOIN.-See Clover.}

SCALE HIVE.- Many of our most prominent beekeepers have in their yards during the season when honey is coming a sort of barometer of the daily honey flow or, more exactly, a scale hive. This consists of a hive mounted on ordinary platform spring scales with a dial to indicate any increase or decrease in the weight of the colony. As the honey-flow begins, it will be apparent that the hive will gain slightly in weight. This weight will increase during the day that there is a fair honey-flow on and decrease somewhat during the night owing to evaporation of the nectar. As the season continues it is rery easy to determine the strength of the honeyflow, what days are best, what conditions are best for a honey-flow, and when the season nears its close the dial will show a smaller and smaller increase until nothing is shown at all.

For the scale hive it is advisable to select a strong colony-one of the very best in the yard, because a medium or indifferent one might not show any increase in weight, while the stronger colony would be able to record whether any honey at all were coming in. While of course it is understood that this strong colony would not be a fair average of all the others in the apiary, it would indicate some idea of what the nectar secretion was in the field. If, for example, the best colony would record a pound or two pounds in a day, it might be assumed that the poorer or weaker colonies would show proportionately anywhere from a half to a full pound of nectar increase in weight. Still again, our best colony on the scale might not show more than a quarter of a pound increase.
Correspondingly the other colonies of the apiary might not show any gain if they were on the scale. Therefore, it is important to have the best colony in the yard.

One might naturally ask why it is important to have a scale hire. It might be argued that an expert beekeeper would be able to determine by the flight of the bees going into the hives whether a honey-flow was on, whether there was a good flow, whether it was increasing, or whether it was letting up. Very true, but the actual record of the best colony in the apiary, together with the observation of the flight of the bees at all entrances, gives an experienced beekeeper a much more accurate idea of what is going on. In a practical way, the scale hive enables the apiarist to determine whether he should put his extra super on top of those partly filled, or whether he should place it under. See Comb Honer, Production of.

We will suppose that it is at the beginning of the honey-flow and that the bees have partly filled the first super given. If the scale hive shows a good record day by day, it would be advisable to place the next empty super under the one partly filled. If, on the other hand, the season is getting toward its close and the scale shows a gradual daily decrease, then it would be advisable to put the extra super on top of the one partly filled, or perhaps, better still, not put it on at all.

The scale hive is rery useful also in determining how far it is advisable to continue extracting in the yard. If the season is drawing toward a close and one desires to leare enough stores in the hive for winter, or to take care of brood-rearing, in anticipation of another honey-flow to follow in another month or six weeks, then obriously it is not adrisable to extract if such extracting would leave the hives without any stores, making it necessary later on to feed sugar syrup.

The scale hive is of value to the honeyproducer by enabling him to determine what policy to pursue during the season, so that in producing comb honey he will not have too many unfinished sections on his hands; or, if he is running for extracted, he will not leave his brood-nests bare of honey, if he extracts at all from the brood-nest as some beekeepers do. Again, there are some producers who, tho they do not extract from below, desire to have left over 
for winter a large number of extracting combs well filled with sealed honey so that at the close of the season they can give the bees the necessary stores by simply giving these combs. In cool or cold weather they are invaluable. They save all feeding, and considerable extra time, besides the cost of sugar.

The yield per day for a strong colony of bees may vary all the way from half a pouná to ten or even more pounds.

\section{SENSE ORGANS OF THE HONEY-} BEE.-At first thought it is only natural to think that the sense organs of the honeybee are located in parts of its anatomy similar in position to the corresponding parts in which our sense organs are located, but when we recall that the bee is not organized like the higher animals we should not expect to find such a similarity. Of the various known sense organs in the bee, only one of them is located in a place similar to the corresponding one in us. While our eyes are situated in the front of the head, the large compound eyes of bees are located both on the sides and front of the head. We are also inclined to think that the structures of the sense organs of the bee should be similar to those of ours; but since bees live different lives from us we have no right to draw such conclusions; and, furthermore, after studying the sense organs of the bee we find little or no similarity between their structures and those of ours. Owing to the preceding differences between bees and the higher animals we must be cautious in drawing conclusions from the various activities of bees, because we are liable to interpret their activities in the same manner in which we interpret our own, and, furthermore, on account of these differences all kinds of views have already been advanced in regard to the senses of the honeybee. The correct views are those which comply with the fundamental principles involved and agree with the experimental evidence. To illustrate this point, taste organs must be located in or near the mouth, and they must be of such a structure that when the food comes in contact with their nerves they are stimulated. The organs of smell are most advantageously located when they are constantly in contact with moving air, and they must be of such a structure that the air can come in contact with their nerves.

\section{THE SENSE OF SMELL.}

Both beekeepers and scientists are agreed that bees have an acute sense of smell, and this belief is borne out by many experiments on this subject. McIndoo thinks that bees smell many times better than people, and perhaps even better than the bloodhound.

(a) LOCATION OF THE OLFACTORY ORGANS.

Of the sixteen structures advanced for the location of the organs of smell, only four of them are of interest to beekeepers. The oldest view is that these organs must be located in the spiracles or breathing-pores on the sides of the body in order that they be constantly in contact with moving air. Another old view is that they must be located in the "snout" in order that their position correspond to the nose of a higher animal.

Since 1838 many observers have tried to prove experimentally that the organs of smell in all insects are located in the antennæ (feelers). Not until 1880 were scientists convinced that the olfactory organs really lie in these appendages. At this date appeared Hauser's large and comprehensive paper which seemingly settled all doubts on this subject. When we critically examine this paper, however, it is easily seen that his results are not infallible. Hauser studied the behavior of various insects before and after the removal of the antennæ. When these appendages were cut off many individuals soon became sick and died, altho some of them lived thereafter for many days. In regard to insects with the antennæ dipped into melted paraffin, the behavior was similar to that of those with the antennæ amputated.

After performing many experiments with a certain genus of beetles, he concluded that these insects lose the olfactory sense by the removal of the antennæ. Experiments with several other genera of insects gave the same results, but other beetles belonging to three genera gave less satisfactory results. These never completely failed to respond to strong-smelling substances. Experiments with Hemiptera (bugs) gave a still less favorable result. After the loss of the antennæ these insects reacted to odors almost as well as they did before their antennæ were amputated.

The following results were obtained by MeIndoo. To study the behavior of bees 
and to test them with odors under conditions which permitted of their close observation, triangular cases were used. These were made of three narrow wooden strips, two of which were 10 and the third 6 inches long, each strip being half an inch thick. Cheesecloth served as a bottom and glass as a top for each case. Nine middle-aged workers,

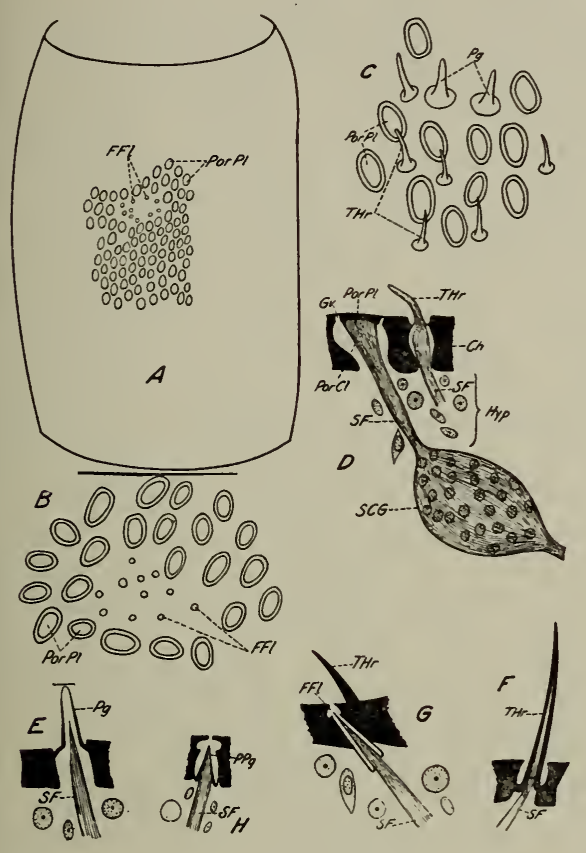

Fig. 1.-Antennal organs of honeybee copied from Schenk after McIndoo. A, an antennal segment of a drone, showing a few of the many pore plates (PorPl) and a group of Forel's flasks $(F F l)$; B, pore plates and Forel's flasks from a drone's antenna; C, pore plates (PorPl), pegs $(P g)$, and tactile (touch) hairs ( $T H r)$ from a worker's antenna; D, structure of a pore plate and of a tactile hair; E, structure of a peg; F, structure of a tactile hair; $G$, structure of a Forel's flask; $H$, structure of a pit peg.

a queen, now and then one or more drones, a lump of candy, a small piece of comb, and a piece of cotton wet with water were put into each case. Thus confined, workers live on an average of 9 days and 3 hours; queens $16 \frac{1}{2}$ days, and drones 3 days and 9 hours. The following sources of odors were used: Essential oils of peppermint, thyme, and wintergreen, honey and comb, pollen, flowers of honeysuckle, leaves and stems of pennyroyal, spearmint and sage, and bee-stings. After testing mary workers, queens, and drones with these odors, it was found that they have an acute sense of smell. Drones smell slightly better than workers, and workers smell considerably better than queens.
To study the behavior of workers with mutilated antennæ, and to see if the antennæ carry the olfactory organs, the following experiments were performed: One antenna of each of many workers was pulled off. Thus mutilated bees are not entirely normal in behavior. They live only twothirds as long as unmutilated ones, and seem to smell one-half as well as normal workers. Workers with one antenna pulled off and with two to eight joints of the other one cut off are still more abnormal in behavior and respond less slowly to odors. Workers with both antennæ pulled off, cut off, covered with shellac or celloidin are entirely abnormal in behavior and live less than one day. They fail to respond to all odors. The antennæ of 95 workers were burned off with a rer-hot needle. These workers were also abnormal and lived only 17 hours on an average. Seven of them which lived longest were tested with odors. They responded one-half as rapidly as normal workers. The antennæ of many workers were covered with liquid glue. Twenty-one were obtained which were fairly normal in behavior, but they lived only 24 hours on an average. They responded to odors practically as well as unmutilated workers.

From the preceding experiments it is evident that bees with mutilated antennæ are not normal, and that their slowness in responding to odors or their entire failure to react when tested is due to the injury caused by the mutilation. It seems, therefore, that the antennæ have little to do with the sense of smell. Since bees have an acute sense of smell, and as the antennæ do not carry the olfactory organs, we must look for them elsewhere.

Mc.Indoo has confirmed the preceding results by using many ants, hornets, and beetles. Some beetles with the antennæ cut off smell just as well as they do with them intact, and they are apparently normal in other respects, and live about as long as other beetles not operated upon.

Of cour'se nearly every beekeeper believes that bees smell with the antennæ, but let us consider the structures of the various antennal organs to determine whether the air can come in direct contact with these organs. Figure 1 represents the antennal organs as copied from Schenk. Two of the five organs have been called olfactory organs. These are the pore plates (D, PorPl) 
and pegs $(\mathrm{F}, P g)$; it is to be noted that the end of each nerve $(S F)$ is covered with a hard substance, called chitin, thru which air cannot pass. Each pore plate is really surrounded by a double groove $(G v)$, instead of one, as shown in the figure. Such an arrangement allows the heavy plate to move inward and outward, and the most reasonable use advanced for this organ is that it prevents the insect from striking

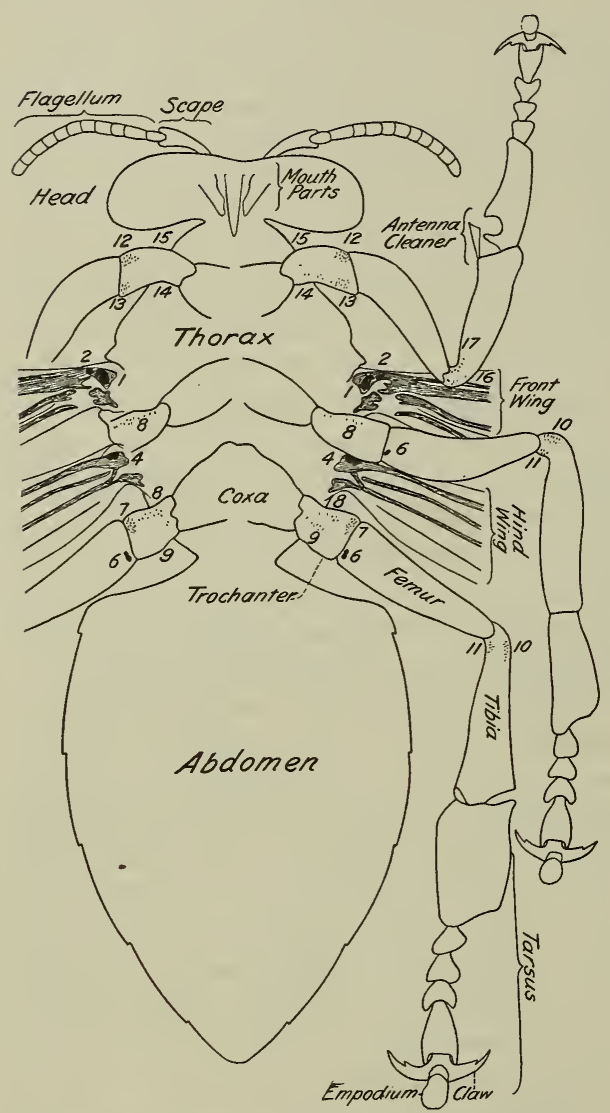

Fig. 2.-Diagram of under side of a worker bee, showing location of groups of olfactory pores as indicated by the numbers. (After McIndoo.)

objects which the bee cannot see while flying. As the bee flies toward an object the air between the antennæ and object is compressed whereby the plates are pushed inward. These plates might also be useful in detecting the air currents made by the fanners, and therefore be a means of regulating the ventilation in a hive. The pegs are certainly useful only for organs of touch because similar hairs are common on the mouth parts of the honeybee, and they have been found on all the appendages of certain other insects. The pit-pegs $(H$,
$P P g$ ) and Forel flasks (G, FFl) have been called organs of hearing; but since they are not common to other insects, and as they are few in number, it would seem that they are rudimentary tactile (touch) hairs which do not come to the surface as do the other tactile hairs, marked $T H r$ in the figure.

In 1857 Hicks discovered some peculiar pore-like sense organs on the legs and wings of various insects. During the last few years McIndoo has thoroly investigated these organs in the honeybee, ants, hornets, wasps, butterflies, moths, beetles, and spiders, and Baker has recently studied them in plant-lice. McIndoo proved that they serve as olfactory organs, and consequently called them olfactory pores. In the honeybee they are found on the wings, legs, stings, on all the mouth-parts, on the "neck," in the cavity (buccal cavity) leading to the mouth, on the sides of the head, and 6 or 8 on the extreme base of each antenna. Drones as an average have about 3000 olfactory pores; workers about 2800, and queens about 2200. Two-thirds of these pores lie on the bases of the wings and are near the large breathing-pores in this part of the body, while about 600 are present on the legs, 100 on each sting, and about 300 . on a pair of mandibles ("jaws"), leaving comparatively few on the other enumerated parts of the bee. The location of the groups of olfactory pores present on the wings and legs are indicated by numbers in Fig. 2; on the opposite sides of the same appendages they are similarly located; on the stings, mandibles ( $M d$, Figs. 5, 6 , and 7, Por ), in the buccal cavity, and on the sides of the head they are widely distributed, but on the other mouth parts (Figs. 5 and 6, Por), "neck," and bases of the antennæ they are arranged in group.

Under the microscope an olfactory pore appears as a bright spot; it is surrounded by a dark border, and at its center there is a transparent area which is an opening thru the hard outside covering, and this opening is filled with the end of a nerve which comes in direct contact with the outside air. Figure 3 represents a typical olfactory pore with its nerve $(S F)$ passing thru the hole $(\operatorname{Por} A p)$ in the outside covering of a worker bee.

To determine the function of these organs the wings, legs, and stings of many workers 
were mutilated. The behavior of the mutilated bees was carefully studied, and they were tested with odors in the same manner as already described. The stings of 100 workers were pulled out. These bees lived 30 hours on an average. Twenty of them were tested with cdors. They responded only slightly more slowly than unmutilated bees. The wings of 28 workers were pulled off. When tested with odors, these bees responded one-eighth as rapidly as normal bees. The bases of the wings of 20 workers were covered with glue. When tested, these bees responded also one-eighth as rapidly as normal bees. The organs on the legs of 20 workers were covered with a mixture of beeswax and vaseline. When tested, these bees responded two-fifths as rapidly as unmutilated workers. The wings were pu'led off, and the organs on the legs of 20 workers were covered with the beeswaxvaseline mixture. When tested with odors these workers responded one-twelfth as rapidly as unmutilated workers. All of the workers with mutilated wings and legs lived just as long in the observation cases as did unmutilated workers, and they were absolutely normal in all respects except they reacted to odors more slowly. Many similar experiments have also been performed by using various other insects, and all the results confirm the ones obtained when bees were employed.

\section{(b) USES OF THE OLAFACTORY SENSE.}

Von Buttel-Reepen, from his wide experience with bees, believes that there are eight normal odors in a colony of bees which influence behavior. They are as follows: (1) queen odor; (2) family odor, or an odor common to all the offspring of the same queen; (3) individual odor for each worker; (4) drone odor; (5) brood odor; (6) wax odor; (7) food odor, a particular odor for each kind of food, namely, honey, pollen, and larval food; (8) hive odor, which is a combination of all or a part of the other odors. At various times one or more abnormal odors may also be present in a hive which influence the behavior of the bees. Von Buttel-Reepen produces almost no experimental evidence in support of his views, and McIndoo, who is a firm advocate of his theories, has spent considerable time trying to prove them, but has not been able to devise experiments to prove most of them, altho the following results may be regarded as having considerable weight.

It is certain that a queen gives off an odor, and it seems reasonable that the odors from any two queens would be slightly different. It is also quite probable that all the offspring of the same queen inherits a particular odor from her. This odor, called the family odor, perhaps plays little or no use in the lives of bees, for it is certainly masked by the other odors. Drones seem to emit an odor peculiar to their sex, but little can be said about it. It seems certain that each worker emits an individual odor which is different from that of any other worker. It is also probable that the combbuilders, nurse bəes, and those secreting

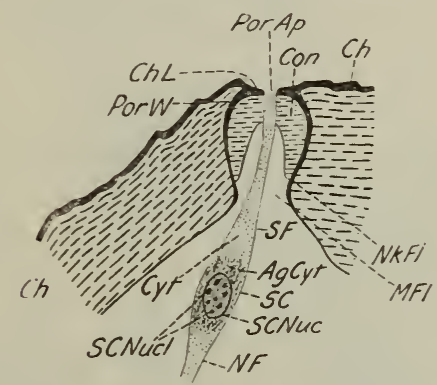

Fig. 3.-Cross-section of typical olfactory pore, showing end of nerve ( $S F)$ filling the opening $($ PorAp) in outside covering $(C h)$ so that it comes in direct contact with outside air. (After McIndoo.)

wax emit odors slightly different from those of the field bees. Such a statement is easily made, but perhaps beyond our means of proving it.

Of all the odors produced by bees, the hive odor is probably the most important. It seems to be the fundamental factor or principle upon which the social life of a colony of bees depends, and perhaps upon which the social habit was acquired. It is the same as the nest odor among ants. Without it a colony of bees could not exist. Since it is so important, of what does it consist? It is composed chiefly of the individual odors from all the workers in a hive, and is supplemented by the odors from the queen, drones, combs, frames, and walls of the hive, etc. In brief, the odors emitted from all the objects within a hive make up the hive odor. From this definition it is easily understood why no two colonies have the same hive odor. The hive odor of a queenless colony is perhaps considerably different from that of a queen-right colony. 
The absence of a queen odor in the hive odor probably explains why the workers in a queenless colony are irritable and never work normally. All the bees-workers, queen, and drones-in a colony carry the hive odor of that colony on their bodies among the hairs. This odor serves as a sign or mark by which all the occupants of a hive "know" one another. Since the queen and drones are "aristocrats," they seem to disregard the sign that has been thrust upon them; but whenever a queen enters the wrong hive, she soon "realizes" that she wears the wrong badge. Bees carry the hive odor wherever they go. Bees re-. turning to the hives from the fields pass the guards unmolested, becarse they carry the proper sign, altho the hive odor that they carry is fainter than when they left the hive, and it is also partially masked by the odors from the nectar and pollen carried by these bees. A nectar-carrier from a strange hive is often admitted because the bees are willing to tolerate a worker carrying a foreign hive odor for the sake of getting its load of nectar.

Bees kept in the open air for three days lose all the hive odor carried on their bodies, but each bee still emits its individual odor. When a colony is divided the hive odor in each half soon changes so that by the end of the third day one-half of the original colony possesses a hive odor so different from that of the other half of the colony, that when the workers are removed from the two new colonies and are placed together in observation cages, they fight one another as tho they had been separated all their lives.

When bees are united the most important factor concerned is the hive odor. The success in uniting seems to be due to two reasons; (1) the bees are confused and excited when the two or more hive odors are mixed with one another, and particularly when smoke is added to them, and (2) the bees busy themselves in taking honey instead of attacking those carrying strange hive odors.

While a foreign hive odor calls forth the fighting spirit in workers, the queen odor always seems pleasant to workers regardless of whether the queen belongs to their hive or to another hive. This is shown in introducing queens by the cage method. By the time the introduced queen has emerged from the cage she has taken on the hive odor of the workers around her so that she is perhaps accepted chiefly owing to her peculiar odor, which by this time is not partially masked by a foreign hive odor. Even if the queen odor forms a part of the hive odor, it is probable that this odor to the workers stands out quite prominently from the hive odor. That workers do not miss their queen for some time after she has left the hive, indicates that her odor thoroly permeates the hive odor and that whenever this odor grows faint the workers "know" that she is not among them.

When a queen is introduced by the smoke method, the hive odor is changed by the smoke, the workers are confused and exciten, and by the time they have become reconciled, the introduced queen has taken on enough of their hive odor to allow her to remain in their hive without being attacked.

Perhaps every beekeeper has witnessed what happens to queens when they are held too long between the fingers. Odors from the fingers change the hive odor on the queen, and as a result the workers ball the queen. In such a case only a little foreign odor is needed to overbalance the pleasant queen odor. This is further shown when a finger is rubbed over the back of a worker. In observation cages the worker thus treated is immediately attacked by its hive-mates.

There has been much speculation concerning the ruling spirit or power in a colony of bees. The opinion of MicIndoo is that a normal hive odor serves such a purpose. The hive odor is a means of preserving the social life of the bees from without, and the queen odor which is a part of it insures continuation of the social life within. As already stated the workers "know" their hive-mates by the hive odor they carry. This odor insures harmony and a united defense when an enemy attacks the colony. The queen odor constantly informs the workers that their queen is present. Even if she does not rule, her presence means everything to the bees in perpetuating the colony. Thus by obeying the stimuli of these two odors and being guided by instinct, a colony of bees perhaps could not want a better ruler.

That a colony of bees possesses a queen odor, a family odor, individual odors, and a drone odor, implies that bees have special scent-producing organs. Such an organ has been found in workers and queens but 
as yet none has been discovered in drones. The external portion of this scent-producing organ is a fold or canal (Fig. 4, Can) in the articular membrane on the upper side between the last two segments of the body. Just beneath the thin membrane lie many large gland cells $(G l C)$, each one of which forces its secretion thru a tube $(T u)$ to the exterior where the liquid rapidly evaporates, thereby giving rise to what is probably the queen odor in queens and to the family and individual odors in workers.

In conclusion under this heading it may be said that the sense of smell of the honeybee is much keener than that of man; and perhaps no other animal, except ants, can compare with it in this respect. The ability of the bloodhound to follow scented trails is only one of the many uses of the sense of smell in the bee. Bees do not follow scented trails as much as do ants, but it is quite probable that queens in flying leave scented trails behind them and these trails may aid the drones in orertaking the queers. Since drones have only one duty to perform, it would appear that their highly developed sense of smell is used primarily in mating, and as a queen is more or less an egg-laying machine such an acute sense of smell is not needed; and comparing her ability to smell with that of a worker. it seems that she has slightly degenerated in this respect.

\section{(c) COMBINED SENSE OF SMELL AND TASTE.}

The honeybee, as well as many other insects, is supposed to have a true sense of taste, but this belief is not supported by experimental evidence. McIndoo, who has recently investigated this subject, says the following:

In the higher animals the senses of smell and taste are not sharply separated, and in the honeybee it will be shown that these two senses are not separated at all. For this reason the honeybee may be said to possess a combined sense of smell and taste. The mouth-parts cannot be removed, nor can they be covered with any sticky substance without making the bees abnormal while eating; therefore such operations are useless in trying to find out how bees distinguish differences between foods. On account of the abnormal conditions resulting from any kind of operation, it was decided to find out whether bees have likes and dislikes in regard to foods and to make a careful study of all the sense organs on and near the mouth-parts.

In determining the first point more than 5500 bees were used in their normal state. Foods fed to them contained repellents, and those having the four attributes of human taste-sweet, bitter, sour, and salty. The following substances are the most important ones used; carbolic acid, oil of peppermint, whisky, rarious acids, formaldehyde, kerosene, lime-sulphur, seven different kinds of sugars, quinine, strychnine, lemon juice, and 11 different salts, including our com-

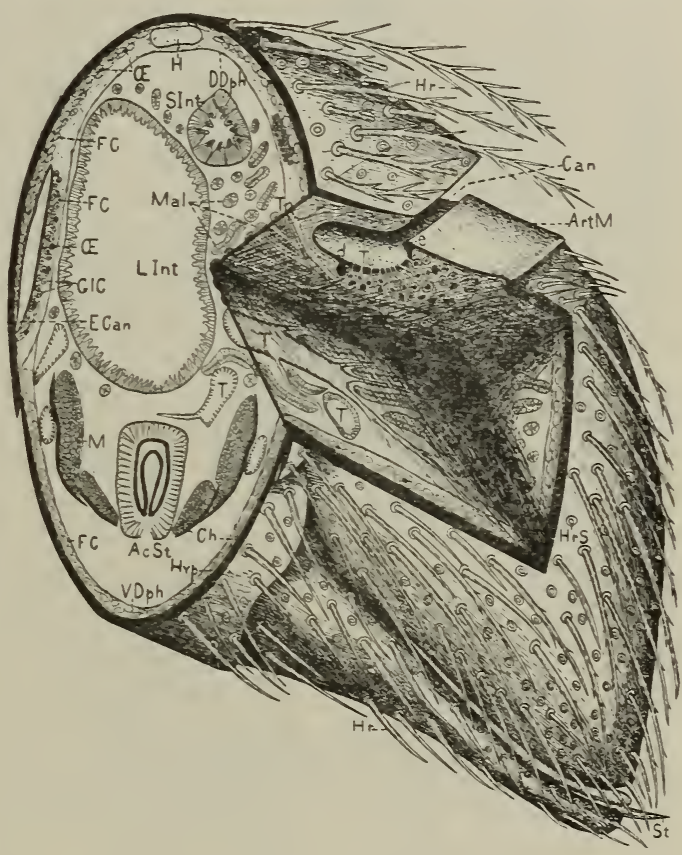

Fig. 4.-Diagram of a transverse-longitudinal view of end of body of a worker, showing internal anatomy, and the scent-producing organ composed of articular membrane $(A r t M)$, and canal (Can) and tubes $(T u)$ connected with gland cells. In the live bee the only part observed is the white membrane (ArtMI) and the canal is never seen. (After McIndoo.)

mon table salt. Some of these substances were mixed with honey, others with canesugar candy, while the various sugars were made into candies. Cane-sugar candy, three varieties of honeys, sugar syrup, honey and pollen mixed, and honey and sugar mixed, not containing any of the above substances, were also fed to bees.

It was found that bees generally avoid foods containing repellents unless they are forced to eat them by the pure foods being removed. Then in such cases the bees show preferences between the foods containing 
the various repellents. They freely eat their favorite food flavored with whisky, but they do not like it as well as pure honey.

Bees show decided preferences between candies made of various sugars. They cannot be forced to eat saccharine (a sugar 500 times as sweet as cane-sugar) candy, but greedily eat mannose (a simple sugar) candy which kills them as quickly as strychnine. They are particularly fond of canesugar, levulose (fruit sugar) and maltose (malt sugar) candies, but care little for dextrine (a starch gum and not a sugar) and lactose (milk. sugar) candies. They care little for raffinose (a sugar found chiefly in a certain Australian eucalyptus plant) candy when they have the preference of cane-sugar, levulose, or maltose candy, but much prefer it to dextrose (grape sugar) candy. Bees can be forced to eat any one of these candies, except saccharine, when no other food is present, but these experiments were not aimed to determine what candics agree with them best. Of these eandies, they like cane-sugar best, altho levulose candy is a close second.

The bees liked fresh basswood honey much better than an old dark-colored honey given to them. The source of the latter honey was unknown. It was taken in the crystallized form from old combs and was then melted. Bees care little for either sugar syrup (half and half), or for basswood honey and pollen (4 parts honey to 1 part pollen), or for basswood honey and sugar (half and half) when they are given pure basswood honey at the same time.

In these experiments bees also showed narked preferences between foods containing bitter and sour substances and between foods containing the various salts. They could scarcely be forced to eat chinquapin honey, and in a few instances showed decided differences between certain foods while the experimenter could detect only little or no differences between the same foods.

The preceding results clearly demonstrate that bees have likes and dislikes in regard to foods, and they can discriminate between some foods better than we can. As a general rule, foods agreeable to us are also agreeable to bees, but there are a few marked excentions. Substitutes for honey as food for bees may be better than honey in a few instances, but these investigations show that no substitute can be had which will be liked by bees as well as the best pure honey.

That bees must first eat more or less of the foods before being able to discriminate differences between them, unless they contain repellents, indicates that bees have a sense of taste, providing this discrimination is not accomplished by means of the sense of smell. This point was decided after making a study of all the sense organs on and near the month-parts. Only two types

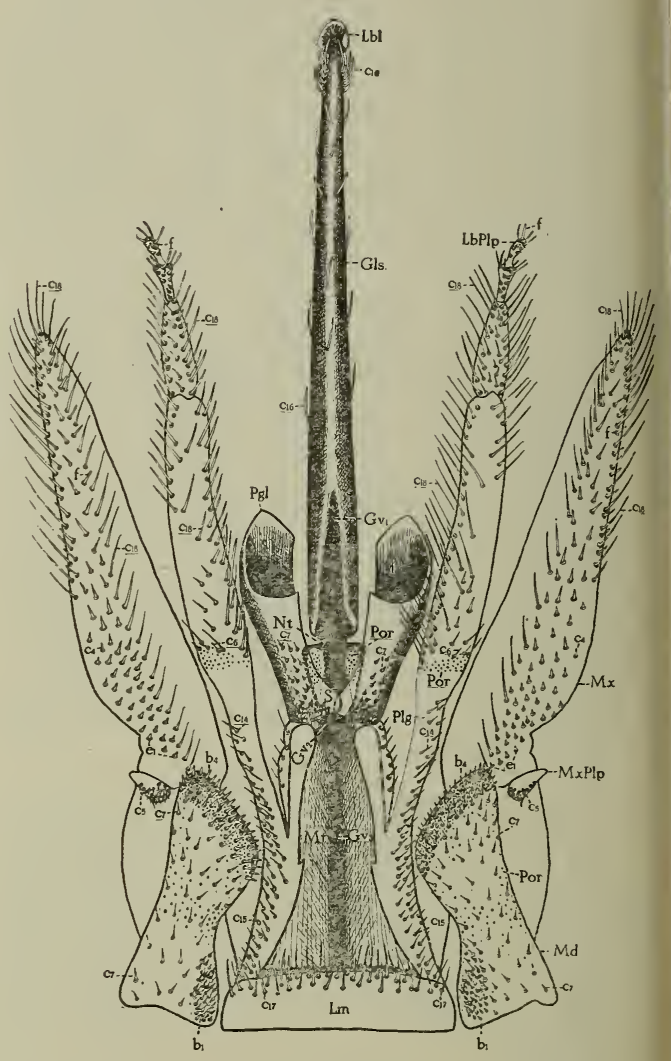

Fig. 5.-Diagram of mouth-parts of a worker spread out flat, showing location of sense hairs ( $b 1$, $b 4, c 4$ to $c 7, c 14$ to $c 18, e 1$ and $f$ ) and olfactory pores (Por) on upper sides of tongue (Gls), paraglossa (Pgl), palpigers (Plg), mentum (Mt), and labrum $(L m)$ on inner sides of labial palpi $(L b P l p)$, and on outer sides of maxillæ $(M x)$ and mandibles $(M d)$. All the hairs shown are connected with nerves, and the long hairs on the tongue so easily seen have been omitted. (After McIndoo.)

of serise organs were found. The organs of smell, already briefly discussed, make up the first type. These cannot be used as taste organs because they rarely, and perhaps never, come in contact with the liquid food being eaten. Sense hairs form the second type. These also cannot serve as taste organs because the liquid foods cannot 
pass thru their walls in order to stimulate the nerves attached to them. More is said about this subject under the following heading.

\section{THE SENSE OF TOUCH.}

Since bees are corered with a hard outside corering, they cannot feel weak pressures, and for this reason certain hairs hare become connected with nerves. Nearly all the hairs on the mouth-parts (Figs. 5, 6, i) are connected with nerves. The tongue is quite sensitive to touch, because it has about 35 sense hairs (Figs. 5 and $6, C$ 16) which lie among the long hair's so easily seen on this appendage. These long hairs are not true hairs and are not connected with nerres. The mandibles ("jaws") are literally covered with sense hairs (Fig. 5, 6, and $7, b 1, b 2, b 4, c 7$,$) and olfactory pores$ (Por). These hairs are irregularly scattered, except there is a curved row (Figs. 5 and 7,34 ) at the tip of each mandible on the outer side. The hairs in this row curre slightly over the edge of the mandible toward the biting surface or inner side. These hairs may be roughly compared to the fingers at the tip of an elephant's trunk, altho they are certainly many, many times more sensitive. In fact the tips of the most sensitive human fingers imaginable cannot be compared in sensitiveness to the mouthparts of a worker bee. Figure 7 gives a good idea of how well the mandibles are prorided with nerres. Such a keen sense of touch easily explains how workers can handle the eggs and larvæ without injuring them, and why workers are able to mold the walls of their cells of a uniform thickness. The sense hairs on the mouth-parts and also those on the antennæ enable the bees to communicate with each other merely by touch.

There are a few sense hairs in the cavity leading to the mouth; and the fleshy threelobed "tongue" hanging in front of the mouth bears two large groups of sense hairs. In the mouth just in front of the pharyns there are two more large groups of sense hairs.

All over the head, on the throat, on the legs, and even on the body of the bee, there are sense hairs so located that it is impossible for a person to touch a bee without touching some of these hairs.

We are now ready to explain how bees eat solid and liquid foods. By means of the sense hairs on the mandibles, these appendages can separate the pollen or bee bread into pieces small enough to be swallowed. These pieces are then dropped upon the extreme base of the tongue which resembles a small crane in that it may be mored up and down, backward and forward and from side to side. The upward move-

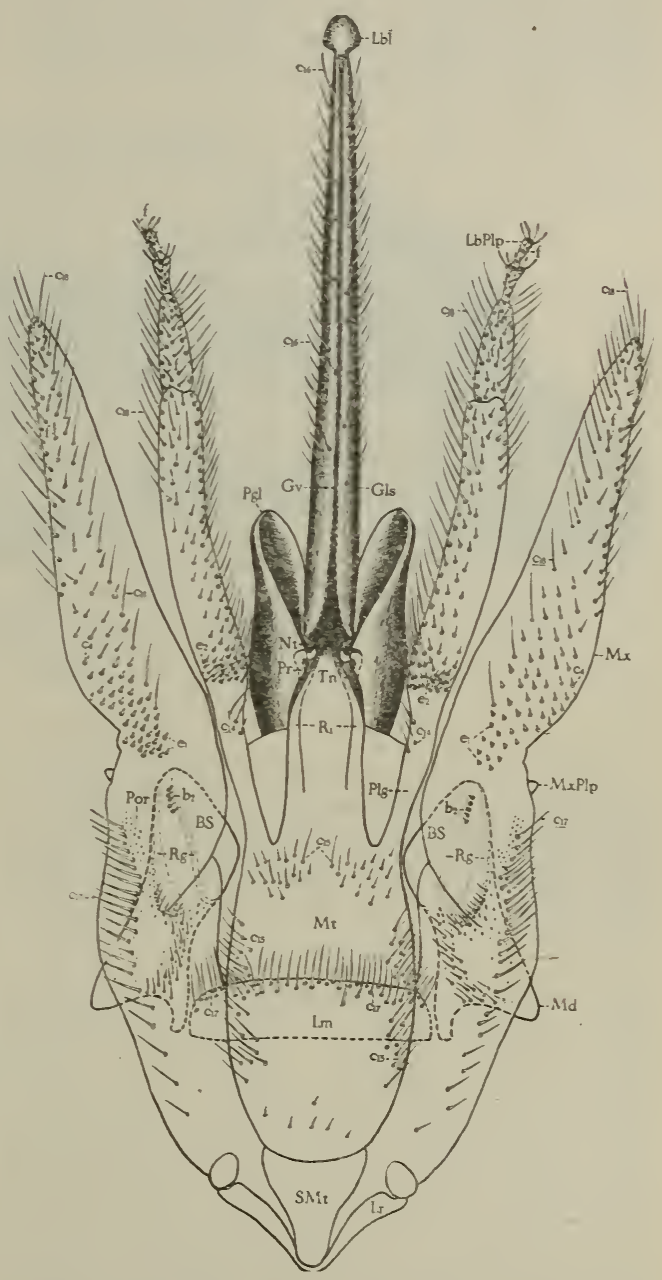

Fig. 6.-Diagram of mouth-parts of a worker spread out flat, showing location of sense hairs ( $b 2$, $c 4, c 14$ to $c 18, e 1, e 2$, and $f$ ) and olfactory pores (Por) on opposite sides to those stated under Fig. 5. The mandibles (IId) and labrum $(\mathrm{Lm})$ are seen by looking thru the other appendages. (After McIndoo.)

ment carries the pollen to the mouth, where it is pushed into the mouth by means of the fleshy "tongue" corered with sense hairs already mentioned. Should a piece of pollen be too large to pass thru the esophagus, it could not pass between the two groups of sense hairs just in front of the pharynx without touching them. In such a case 
these hairs would cause the muscles attached to the sides of the mouth to contract, whereby the pollen would be thrown to the exterior. It is thus seen that these sense hairs serve as a safety device to prevent the bee from swallowing pieces of solid food too large to pass thru the esophagus.

When a bee smells food it at once extends its tongue and touches the food. The sense hairs at the tip of the tongue inform the bee as to whether the food is liquid or solid. If liquid, it is immediately eaten. But sup-

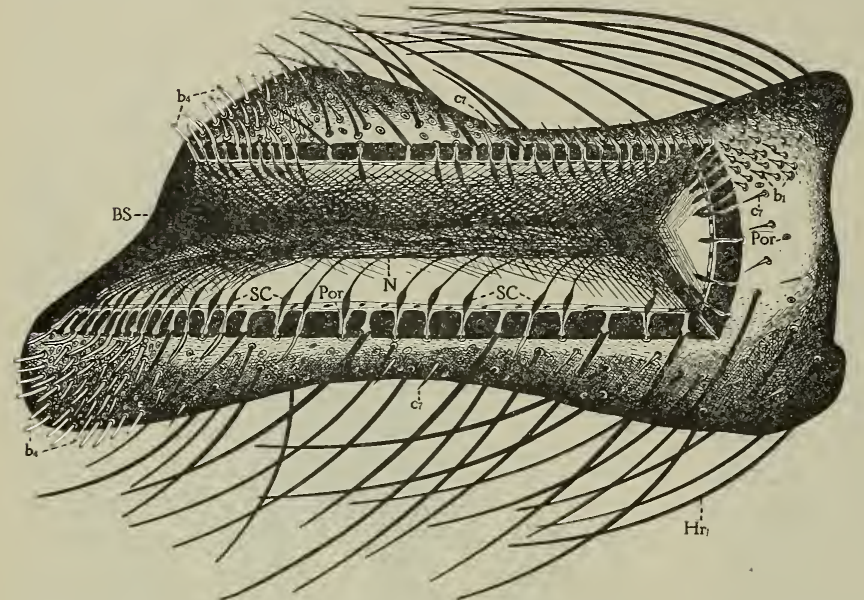

taste, altho it is easily seen that the sense of taste really plays no part in the reactions shown by bees while eating. To us sometimes a food, before being eaten, emits only a faint odor or no odor at all; but when we eat it, we perceive a pronounced odor. In such a case the odorous particles are not given off until the food is taken into the mouth and mixed with saliva. The same principle is certainly applicable when bees eat candies which contain undesirable substances emitting extremely weak odors. The liquid food now lying on the upper side of the tongue is raised to the mouth opening where it is sucked into the mouth by means of the pharynx acting as a powerful pump. The pharynx is able to do this because it is supplied with several large muscles.

\section{OTHER SENSES.}

Excluding sight, little is known about the remaining senses of the bees. Since the eyes of the honeybee are discussed elsewhere in this book, only a few remarks will be made about this subject here.

The sense of sight of the honeybee is poorly developed compared with that of smell. It is still a disputed question as to whether bees can distinguish colors, but from the many experiments performed it seems that they can, altho perhaps not as we do. It is also doubtful whether they can tell whether objects are round, square, flat, rough or smooth by sight, altho this is easily done by touch when the objects are small. It is certain that bees see long distances, but how distinctly we do not know. The only use of sight inside the hives is perhaps to tell light from darkness; outside the hives it is probably the most important sense used in mating, in finding flowers, and in returning to the hives. McIndoo believes that bees find flowers by seeing them from considerable distances, but when within a few feet of them the bees are able to select the ones they want primarily by smelling the odors from these flowers.

We still know practically nothing about the sense of hearing in the bee. Every beekeeper has perhaps heard queens pipe the bee has a combined sense of smell and 
and workers squeal. A worker is almost sure to squeal every time it is pinched or caught in a tight place and cannot escape. When the wings are pulled off the workers continue to squeal, showing that they have special organs for producing these sounds. No such organs have ever been described, but three special organs said to receive sounds have been found. The pore plates in the antennæ have been called organs of hearing, besides olfactory organs and special devices to prevent the insect from flying against objects that it cannot see. A second so-called organ of hearing is found in the head at the base of each antenna, and a third one in the tibia (fourth segment) of each leg.

Bees can usually tell when a thundershower is coming up and they seem to have a sense of humidity. Unless humidity is sufficiently connected with temperature, bees need a special sense organ to tell dry air from humid air because they cannot feel moisture thru the hard outside covering, concluding from the fact that water does not pass thru this covering.

Bees seem to have a sense of temperature, but since heat readily passes thru the outside covering they do not need special sense organs for this sense.

Bees, like people, need a sense of direction, but they probably do not have such a sense. Instead of this sense, the landmarks that they "know" seem to answer this purpose.

SCOUTS PRECEDING SWARM.-See Absconding Swarms, also Swarms.

SECTIONS.-See CoMb Honer, APPLIANCES FOR and HIVES.

SELLING HONEY. - See BotTLING Honey, Extracted Honer, Comb Honey, Shipping-Cases, and Specialty in Bees.

SELF-SPACING F R A M S . - See Frames; also Frames, Self-spacing, and Hives.

SEPARATORS.-See COMB HONEY, APPLIANCES FOR.

SHADE FOR HIVES.-See APIARY.

SHIPPING BEES.-Under MIGRATORY BEEKEEPING mention is made of the advantage of moving bees from one locality to another to catch the honey-flow. The practice has been extended so that bees are sometimes moved from one state to another in carlots. This enables the owner to gather two or three crops of honey; whereas if he were to remain in one locality he would secure only one.

Shipping bees in carlots from one place to another has been practiced more in the West and North than in the East; but some beekeepers in the northern states, just before winter sets in, move their bees to the extreme South, build them up during the early winter or spring, catch a crop of honey, then move them back north to catch the clover flow.

The publishers of this work have moved several carloads of bees in this way. In our first two shipments we succeeded; but later shipments were not as successful, for the reason that the seasons both south and north were unfavorable. Unless there is a fairly good crop of honey to be secured at both ends of the route the practice of moving bees in carlots is not a paying one; and as the seasons are somewhat uncertain, the movement of bees from north to south and from south to north is attended with considerable risk.

Usually the freight alone on a carload of bees from Florida to Ohio will run somewhere about $\$ 1.00$ per colony provided there are 350 colonies to the car. The larger the number of colonies, the lower is the freight relatively. Unfortunately the railroad companies require that the attendant who goes with the bees pay regular railroad fare. This ruling is decidedly unjust, because the attendant in a carload of horses can go free. The freight rate on the bees themselves, the loss of some bees and brood during shipment, railroad fare of attendant, his time on a basis of twenty hours a day, ${ }^{*}$ makes the expense of moving from the extreme South to the North about $\$ 2.00$ per colony. If the bees are moved back to the North there must be entered a charge of about $\$ 4.00$ against each colony. In order to cover this expense the season will have to be good at both ends of the route to yield a profit.

Taking everything into consideration, the shipment of bees in carlots long distances is a doubtful venture. In some cases the

\footnotetext{
* He won't get much sleep, as he will have to be on the alert almost night and day.
} 
weather is extremely hot when the bees are moved. If the temperature ranges around 80 or 90 in the shade, the loss of bees and brood will be considerable in spite of the precautionary measures on the part of the attendant in spraying the bees with water, as will be explained further on. This loss may amount to nearly 50 per cent of the bees and brood. If colonies are worth, with the queens, $\$ 5.00$ each, it will be seen that in addition to the charge of $\$ 2.00$ there will have to be entered another of $\$ 2.50$.

It sometimes happens that the car is unnecessarily delayed en route; and every day of delay means the loss of bees as well as brood. Ordinarily a car of bees will not stand more than four or five days of hot weather.

As a general proposition carload shipments should not be made when the weather is very warm. Usually a crop of honey can be secured in Florida long before hot weather sets in in the North. At this time the bees can be moved with some degree of safety. In the same way, bees moved south in the fall can be sent thru without much loss.

The success or failure of long-distance migratory beekeeping will depend very largely on the man who undertakes it. One cannot hire somebody else to do it, because no hired man can feel the same interest in making the thing a paying investment as the man who owns the bees, and who takes all the risks. Where one has good health, can stand being up night and day, plenty of brawn and muscle, and last, but not least, is a good beekeeper, one who knows something of the conditions south as well as north, he will stand some chance of making the thing a success, provided, of course, the movement of bees takes place in reasonably cool weather.

Where one desires to move his bees not more than one or two hundred miles there is not much danger of losing the bees en route; but if there are good roads, and motor trucks are available, we recommend moving the bees by motor truck. Even tho one has to pay at the rate of ten or fifteen cents a mile, the cost of moving will be less than moving by rail. Usually a motor truck with a trailer can be secured that will move one or two hundred colonies at a trip. The cost of loading will be very much less, because when bees are shipped by rail they must be securely fastened to take care of the severe end jolts of a freight train that are heavy enough to jar every colony loose from its moorings and let loose the bees. The motor truck, on the other hand, will he under the direct control of the owner of the bees. It can start gradually, and be run slow enough to avoid jolts over the "thank-you-ma'ams" and chuck-holes.

\section{HOW TO PREPARE A CARLOAD OF BEES FOR} SHIPMENT.

An important requisite is to get the local agent to make arrangements all along the line to see that the bees are moved with all possible speed. At transfer points it is especially important to get an order from - the operating lines to have the bees transferred without delay. Arrangements should be made at least a week or two in advance, as it takes time for the correspondence to get over the lines. It is also important that the rate of freight be determined in advance.

If there are not more than 250 colonies to be moved, a small car should be secured, in order to reduce the minimum weight on which freight must be paid. Usually the average gross weight of the hives of bees will be below minimum freight; therefore the more bees there are loaded on to a car the less the relative cost per colony. The average 36-foot car will take about 350 colonies, piled four tiers high, two rows on a side, leaving a small alleyway between the tiers of colonies and an entrance-way opposite the car doors, for there must be room for the attendant to place a cot-bed where he can sleep, when conditions will permit, either night or day. The minimum weight on a 36-foot car is $14,000 \mathrm{lbs}$. The average shipping weight of a colony is about $50 \mathrm{lbs}$., including the crate. This will make the gross weight $17,500 \mathrm{lbs}$., or $3500 \mathrm{lbs}$. in excess of the minimum. If one were to ship only 200 colonies he would have to pay freight on the minimum of $14,000 \mathrm{lbs}$., and on this basis he would be paying for 4000 lbs. of freight, with nothing to show for it. Hence it is important to load up to the minimum.

Arrangements for securing the car should be made at least a week in advance. During warm weather or when the weather is not cold, a cattle-car should be secured. For fall shipment an ordinary box car should be 
selected. Not all cars furnished by the railroad company will be strong and well built.

Formerly it was thought necessary to build a series of shelving made of $4 \times 4$ 's and $2 \times 4$ 's to hold the hives one tier above another, as it was supposed that some colnies might need individual treatment en routc. But experience shows that this is

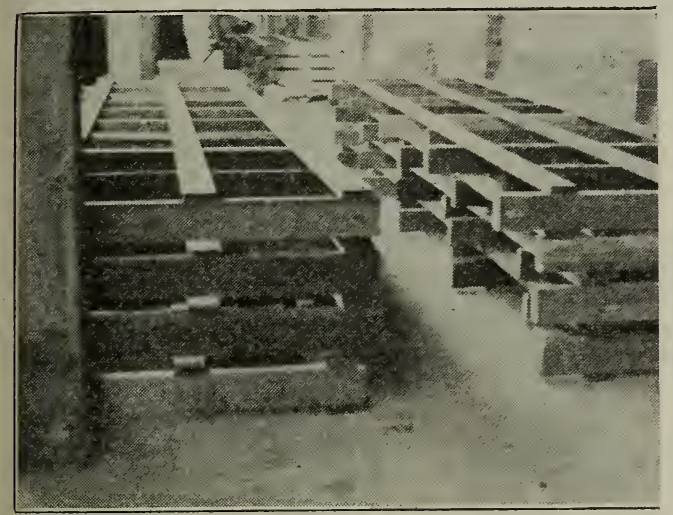

FIG. 1.-Crating on platform ready to load.

impracticable. Moreover, the arrangement of shelving wastes space, and makes the loading and unloading rery difficult and expensive.

On our later shipments from north to south and back we discovered a better plan. A series of cratings were made of $2 \times 4$ 's and long $7 / 8$ - inch strips 4 inches wide. The cratings were put together in such a way that the $2 x 4$ 's stood on edge. The long strips were nailed on each side, making in all a framework 4 inches thick plus two $7 / 8$-inch strips, or a total of $5 \frac{3}{4}$ inches.

Figs. 1 and 2 show how the crating is put together. Each crate should be long enough to run from the car door to the end of the car, and wide enough to take two tiers of hives side by side. The $7 / 8$ -

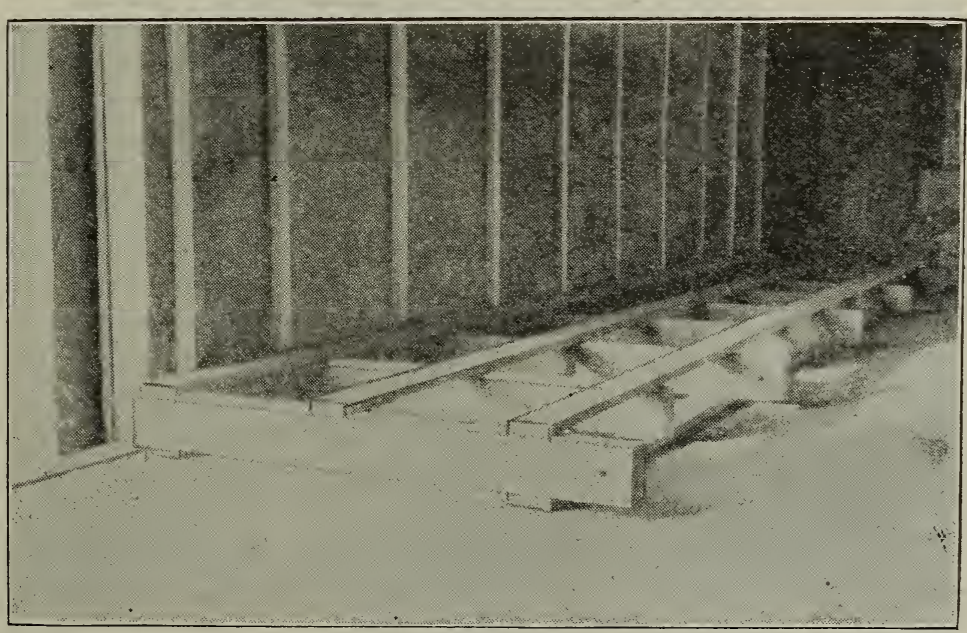
inch strips are nailed on each side at intervals, center to center, equal to width of hive. The two by fours are spaced a distance equal to the length of the hive. A crate is set down on the car floor to provide bottom ventilation. Two rows of hives are piled on the crate side by side, with the front and rear of the hives pointing to the front and rear of the car. If everything has been done right the inside edge of each hive will rest upon the middle of the center strip. Every other $2 \times 4$ in the crate is made a little longer so that it can be bolted to an upright $2 \times 4$ that binds the four tiers of hives together. The operation of loading is as follows:

One crate is placed on the car floor. Two rows of hives with screens at top and bottom are loaded on the crate. Over the first tier is then placed another crate; on top another tier of hives until there are four tiers. The other sides of the car are loaded in precisely the same way. When all are in place, the upright $2 \times 4$ 's as long as the height of four tiers are bolted to the projecting ends of the horizontal $2 \times 4$ 's in each crate. Bolts are used because they are more easily removed than nails and are stronger. The two tiers of hives on each side forming an alley way between are then braced from each other by means of ties across the top and bottom. To stand the end shocks the two sets of tiers in each end of the car are securely braced apart by $4 \times 4$ 's. These ties or braces must be at the top and bottom so that the operator can reach every colony with a watering-pot. 


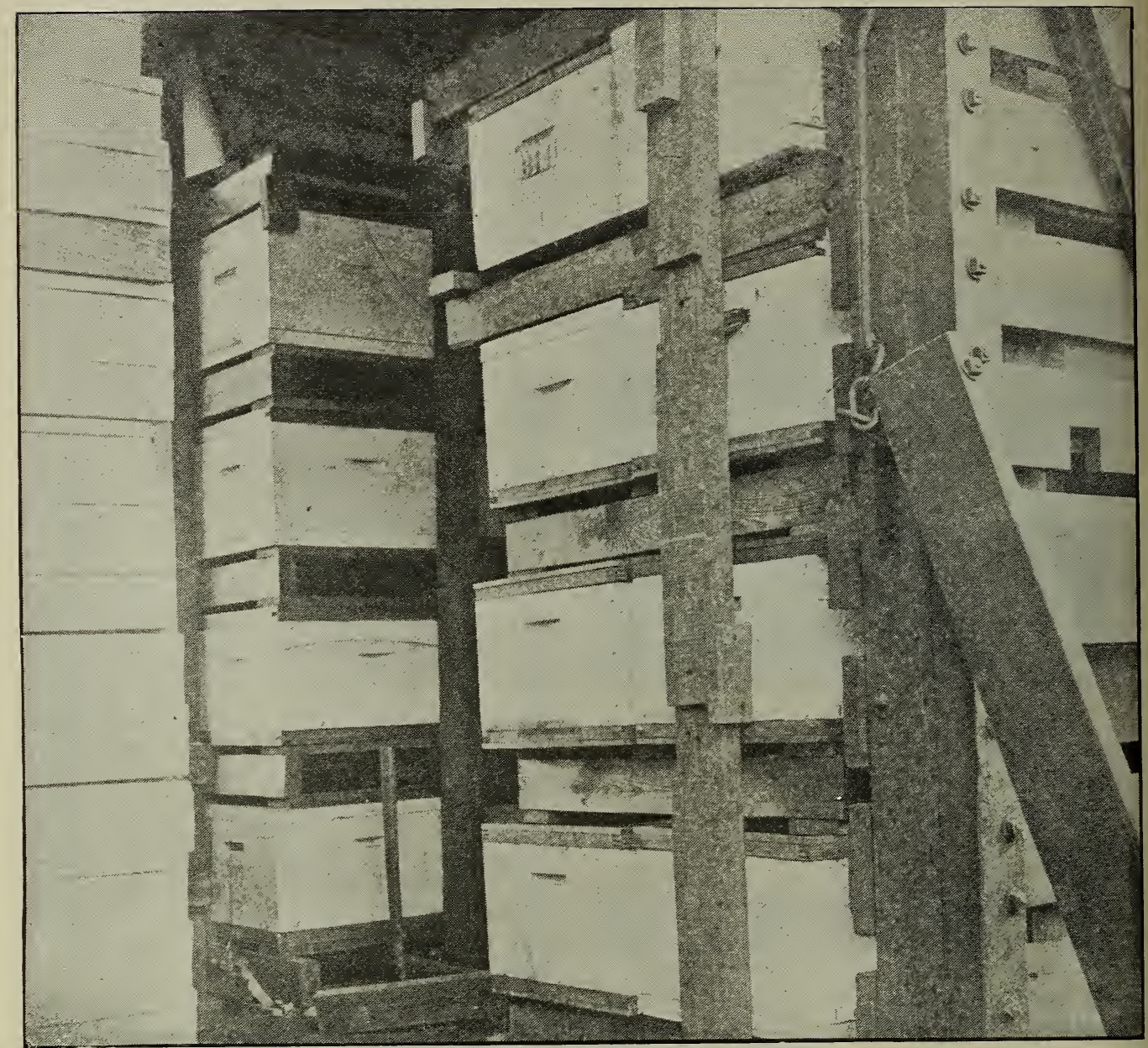

Fig. 3.-Interior of first car of bees from Virginia, May 21, 1915, just before the work of unloading.

bed-clothing, lanterns, hammer, saw, nails, a few extra bolts, a brace and bit, and a little extra lumber. Usually it is an advantage to carry along a little oil-stove to heat water for coffee or do a little light cooking, as one gets a little tired of all "cold grub" on so tedious a journey. It is important that each of the hives should be screened top and bottom as explained under Moving Bees Short Distances. That makes it necessary to remove covers and bottoms. These should be piled on top of the tiers of hives just under the car roof. They should be secured by means of a rope or wire.

Where a cattle-car is used the crates can be wired to the frame of the sides of the car. This helps to hold each tier to itself.

SPRAYING THE BEES TO KEEP THEM COOL.

Mention was made of the fact that the operator should have room enough so he can go back and forth between the hives to sprinkle them with a watering-pot or forcepump. It is important to have in each car at least one or two barrels of water along with the bed and tools. During hot weather on a trip of six days bees will use up several barrels of water en route. When the car stops and the weather is hot, bees will be thickly clustered over the wire cloth; and to prevent their becoming overheated the wire cloth should be sprayed. Care should be taken not to overdo it, as the young brood will be chilled. As a general thing, unsealed brood, either on account of too much heat or chilling in bad weather, will be killed, altho we have brought shipments thru from the South with all the brood in good condition; but the weather was cool, and the hives were sprayed only when the car was not moving.

The attendant must make up his mind 


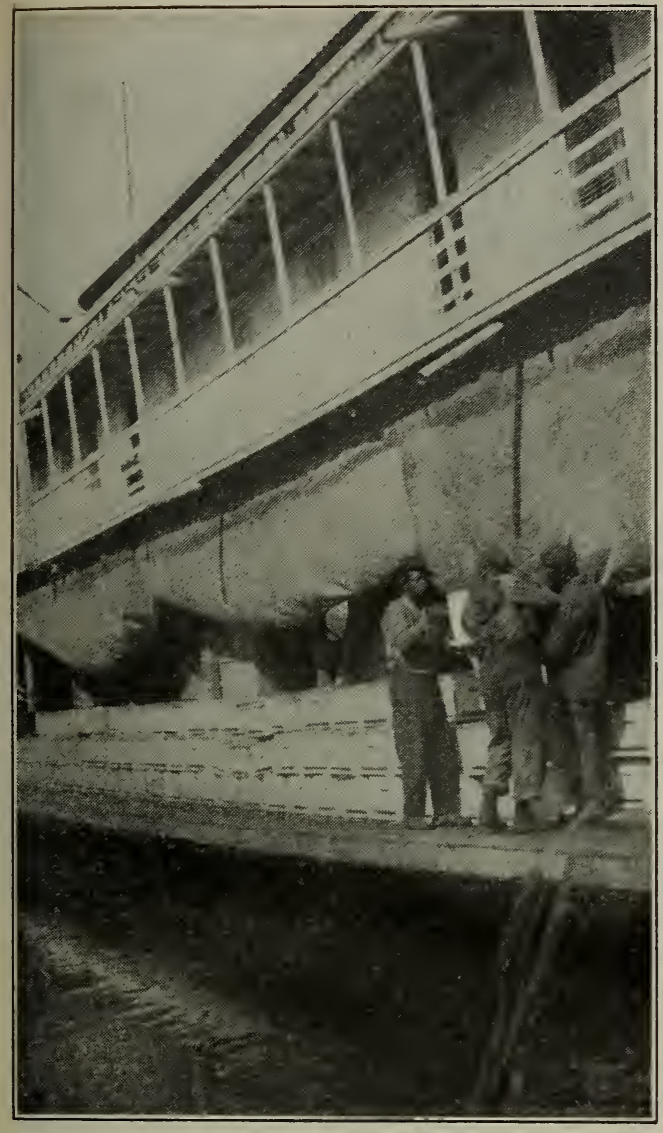

Loading the bees on the steamer.

that a trip with a carload of bees is not a Pullman ride. He will have to watch the framework very carefully, especially after each end shock. Whenever the car stops he will have to look after the spraying. When the car has to stand on a side track for a few hours he may be compelled to tack some sheeting on the exposed side of the car to shut out the hot rays of the sun.

While one can get 350 single-story colonies of bees in a 36-foot car, he can load as many as 400 colonies, or, more exactly, 200 two-story colonies, in the same space. This saves some crating and time in handling individual units. But as a general thing we advise against the shipment of two-story colonies. Colonies that are very strong will not go thru as well as those that are lighter. Ordinarily $3 \mathrm{lbs}$. of bees and six or seven frames of brood are enough for a hive. Colonies, however, may be proportionally stronger in cool or cold weather.

\section{SHIPPING BEES IN CARLOTS WITHOUT COMBS.}

Under the head of Buring BeEs, mention is made of bees being sent by express without combs. Some experiments have been made showing that, even tho express rates are considerably higher, a 3-lb. package of bees, or, rather, a crate of 12 of them, can be sent by express cheaper than the equivalent capacity of bees and brood in the regular hives by freight, and the time on the road will be very much less. But during extremely warm weather, such packages of

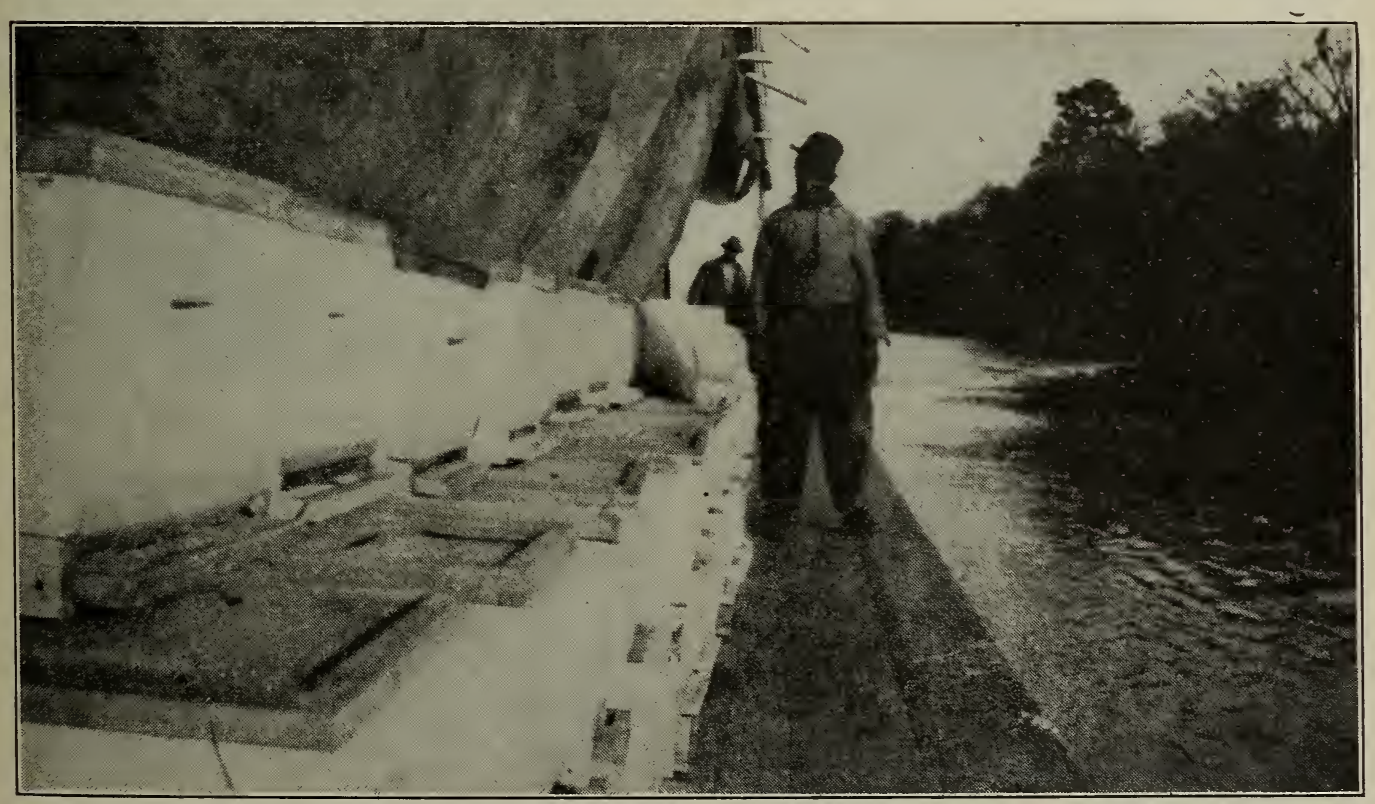

On the boat down the Apalachicola River, between Bainbridge and Randlett's Landing. 


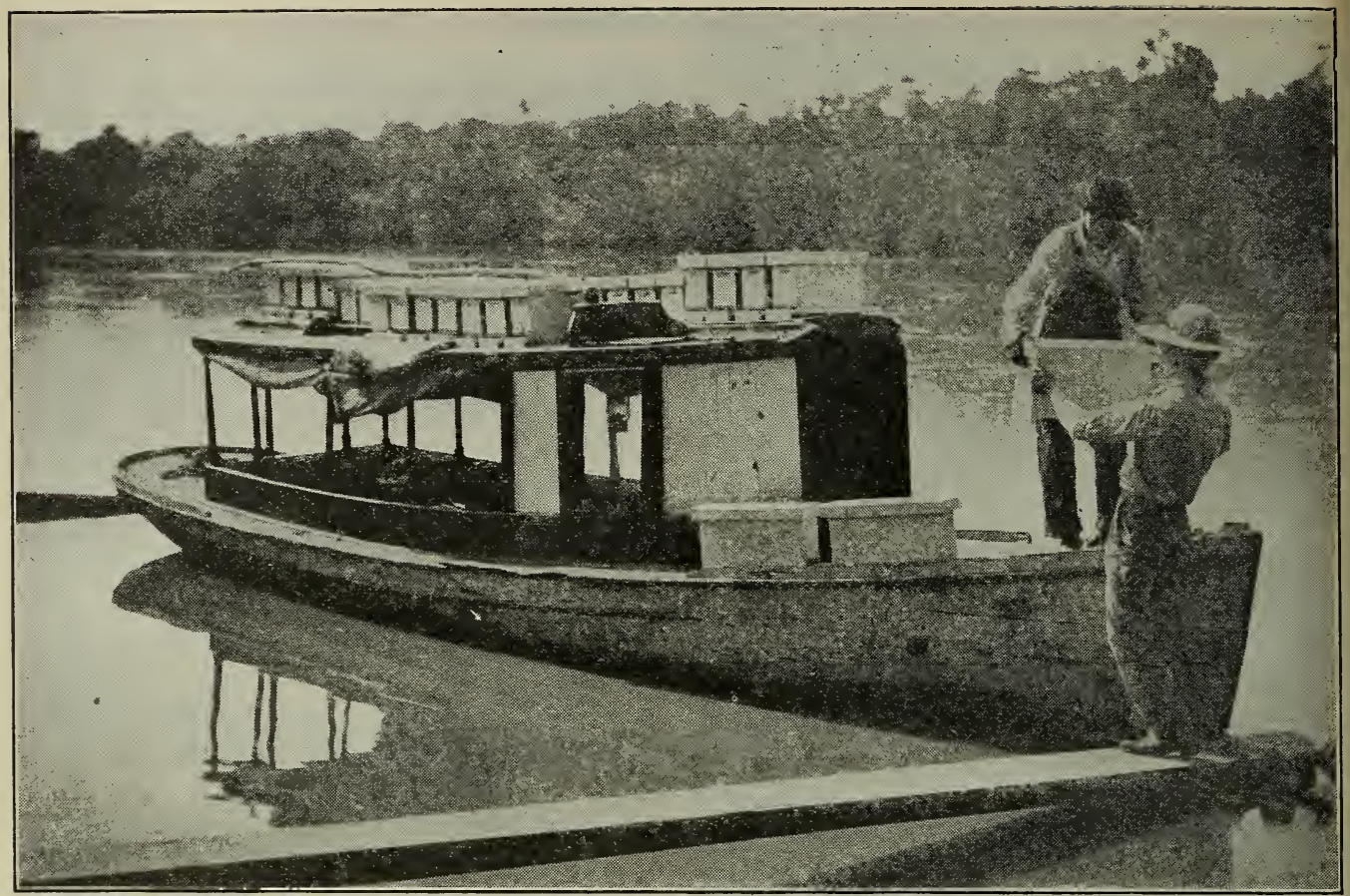

Loading three-frame nuclei on launch preparatory to trip five miles up the river to the Nucleus yard.

bees, possibly a dozen or more, do not go thru in good order. But in early spring they can be sent from the South to build up colonies in the North very nicely.

A large business has developed in shipping bees by express in one, two, and three pound packages without combs, and this business is proving to be highly profitable. See Buring Bees.

SHIPPING BEES BY BOAT.

Where water privileges are available, bees can often be shipped best by boat, either up or down river or down bays. In 1914 we shipped bees up the Apalachicola River. The ordinary flat-bottom boats used on those shallow rivers answer a very excellent purpose. The hives are loaded on the outside platforms; and as there is no jolt, the individual hives do not need to be braced together. Bees on boats like this can be carried one or two hundred miles very easily. As the air on water is usually cooler, there is but very little danger from suffocation, but they will need to be sprayed at intervals.

For migratory beekeeping small boats can be used, carrying forty or fifty colonies at a time for ten or fifteen miles. The illustrations show bees that we loaded and moved on the Apalachicola River in 1914.
SHIPPING-CASES FOR COMB HONEY.- It is one thing to produce a fine crop of comb honey with sections nicely filled out, well scraped and graded, and another thing to deliver that honey to market without leakage or breakage. It should be borne in mind that a section of honey is exceedingly fragile, much more so than a bottle containing pickles, syrups, or any other commodity. For many years back comb-honey producers have been putting their nicely built sections in poorly designed cases, and the result has been a large amount of breakage and leakage. This loss is usually assessed against the producer, and sometimes the item alone is enough to wipe out the entire profit of the season. When he gets his returns he is so disgusted that he either quits the business entirely or produces extracted honey only thereafter.

If beekeepers would be as careful in packing their product as the manufacturer of bottled goods, there would be very little complaint of broken-down combs or leaky sections, and the result would be a much larger consumption of comb honey because the dealer would then be willing to take it and push its sales. Unfortunately, there has been so much ignorance and carelessness on the part of comb-honey producers that 
many dealers say they will not handle comb honey again. This is most unfortunate, because the consumers demand comb honey. Some years there is an over-supply of extracted and a great deficiency of honey in the comb. In 1915 and 1916 the reverse was true.

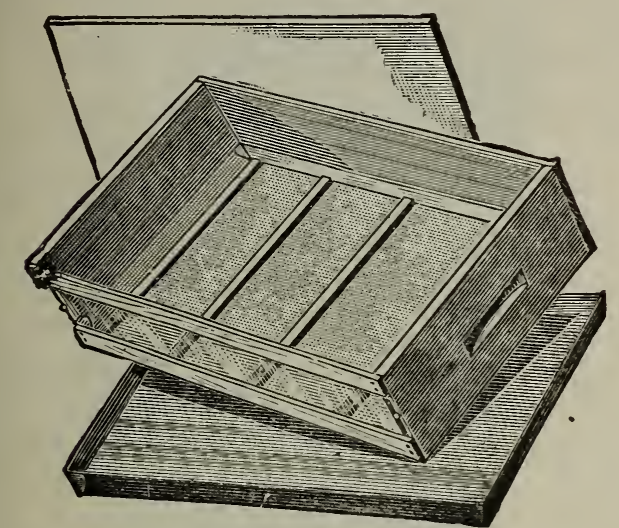

Old-style shipping case with paper drip pan and no drip cleats.

The old style of shipping-cases were made of light thin stuff having a glass front with a paper tray in the bottom and cross-cleats to support the sections of honey. This case was altogether too light to protect its fragile contents; and the bottom of the case, or, rather, the cleats supporting the sections, were rigid, so that whenever the case received a bump or jar from any cause, some sections were liable to be broken. The pat- ing foundation for the sections to rest on; namely, the wooden cross-cleats. The next two illustrations show a much more strongly built case. It will be noticed in the lower cut that the bottom is padded with ordinary corrugated paper, the same material that is used by the patent-medicine men in packing their bottles of medicine. In fact, the shippers of all bottled goods are using corrugated paper, not only around the bottle, but in the bottom. This material makes an excellent cushion, not only under the sections but at the tops, ends, and sides as well, so that when the case is dropped or receives a sudden jar the cushion of the corrugated paper absorbs a large part, if not all, of the shock. Comparative tests show that sections in a case having corrugated paper will stand much rougher usage without breakage than similar sections placerl in a case having rigid cleats across the bottom that of course cannot absorb any of the concussion. Experience has also demonstrated that it is wiser to use narrower glass. It shows off the honey to better advantage, and at the same time permits of the use of wider cleats and more nails in the front. When these are properly nailed, the case is much stronger.

Sometimes cross-partitions of corrugated paper are used, and at other times cartons, making use of cheap strawboard, are used, such cartons slipping around each individ-

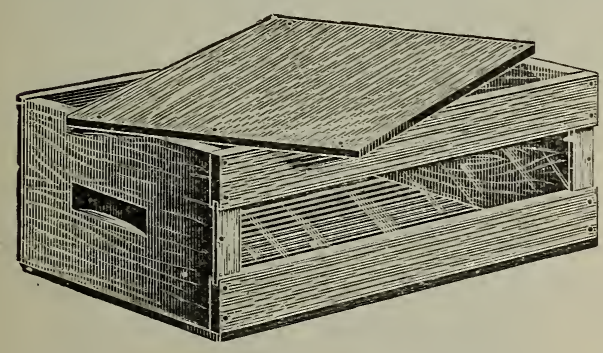

Regular 12-1b. shipping case.

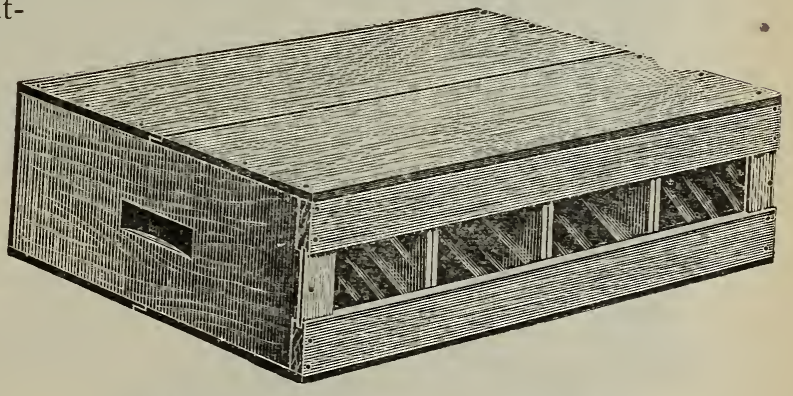

Regular single-tier 24-lb. shipping case.

ent-medicine men and bottlers of canned goods as already mentioned put up their product in such a way that each separate bottle will be cushioned or protected from the ordinary rough usage that the whole box receives in the hands of the truck men and the express handlers, to say nothing of the damage received when shipped by freight.

The cut at the top shows one of the oldstyle cases that provided a rigid or unyield-

ual section. If these are a little larger than the sections, and especially if a little deeper, they will sustain all the weight that may be placed on top of the case, leaving the sections which they contain without any strain upon them. The cartons have the further advantage that they can be sold with the individual sections. Thus, the delicate comb is protected, not only during shipment, but while in the market basket from the grocery to the home. 
If there is anything that disgusts the housekeeper, it is a leaky section of honey that besmears all her other groceries, making a broken, sticky mess of everything. If, therefore, the comb-honey producer would have the consumer pleased as well as the large dealer and buyer, he must make sure that his goods are protected clear to the consumer.

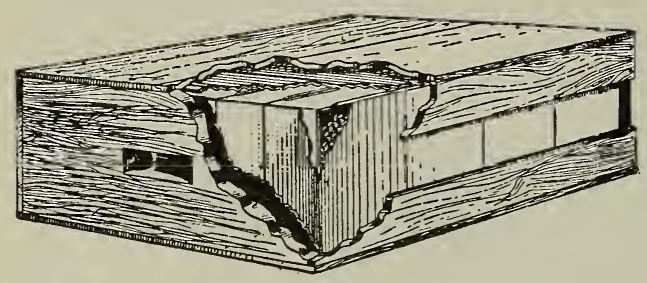

24-lb. Safety shipping-case.

The subjoined illustrations show the details of what are called safety cases. These contain the cartons already mentioned, and also the corrugated paper at the bottom, top, sides, and ends.

The other illustrations show how the cover-boards are halved together, and how the glass is let into the strips top and bottom. The strips should be thoroly nailed, two nails in each end; in fact, the case complaint, and, besides, avoid practically all trouble with the commission merchants or the dealers who buy the goods. It generally happens when the comb honey goes thru in bad order that there is considerable correspondence as to what would be a proper adjustment. Sometimes the services of an attorney are called in, and if a suit is brought this makes all the more expense.

\section{WHY IT PAYS TO USE BETTER SHIPPING-CASES.}

One large buyer of comb honey who buys honey in car lots made the statement that his breakage carefully figured up in one season showed a loss to the producer of not less than 11 3-10 per cent. If we were to take into consideration the shipments that are made from all parts of the country, in all kinds of shipping-cases, this loss would reach nearer 25 per cent; but call it 20 per cent. The safety cases with cartons and corrugated paper cost about 6 or 7 cents more than the ordinary old-style cases that result in a breakage of about 20 per cent. If the breakage and leakage amount to about 20 per cent on the average, and if an allowance is made for about 50 per cent for salvage on the broken product, there is still a loss of anywhere from 35 to 50 cents per case of honey when the investment of a better case of 7 or 8 cents will save practically all of it. Let it be assumed that the loss from leakage and breakage in the ordinary case is 35 cents per case of 24 sections. On a crop of 20,000 pounds it would mean a loss of $\$ 300$, while the extra cost of using the safety cases or those equally good would amount to only about $\$ 50.00$. Plainly, here would be a saving of about $\$ 250$. Moreover, the beekeeper using these better The covers are halved at the joints to keep out ants and other insects.

Note that the pieces holding the glass are fastened securely to the ends by two nails in each. should be well nailed all over. So far as possible it should be made very rigid, so that it will not spring nor twist, for if the case is at all frail the sections are almost sure to receive damage, particularly so if corrugated paper and cartons are not used.

While shipping-cases containing cartons and corrugated paper built on scientific lines cost more, as a matter of course, than the old-style cases, yet the producer can well afford to use them, and he will save a considerable breakage, leakage, and no end of cases would get quick returns, and a satisfied customer for another year's business.

But there are a large number of beekeepers who feel that they cannot even afford to purchase the cheap factory-made cases. If the loss is anywhere from 10 to 20 per cent with the cheap cases we may reasonably figure that the loss would be anywhere from 25 to 50 per cent with the ordinary homemade cases or cases made at planing-mills. The great trouble with the home product is the poor sawing, inaccuracy, and their mis- 

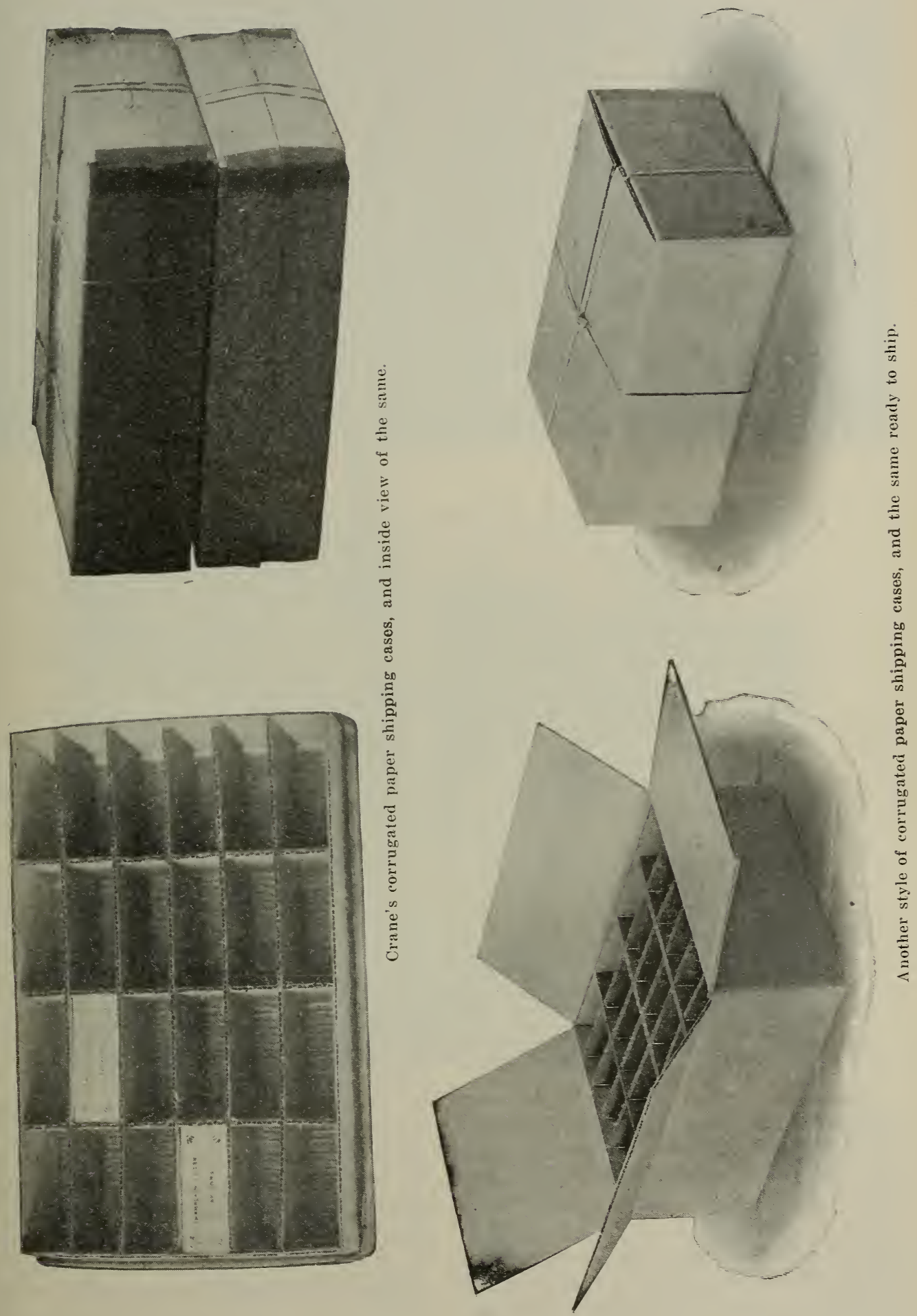

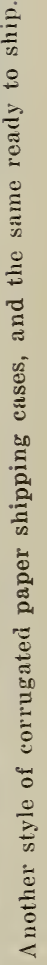


erable appearance. Hen if the honey goes thru safely the cases look so cheap and poor that the average buyer will deduct anywhere from 1 to 2 cents per pound on the honey. The honey may be ever so nice; but if it is put up in a roughly made container it will bring a correspondingly lower price. The most serious objection to home-made cases is their variation in size. Some of them will be too shallow, and the result will be that when the cover is nailed down it will break nearly every section in the case. Another case will be too deep and too long, with the result that the sections will rattle about in the case and break down nearly as badly. The average planing-mill man does not understand the importance of making the case it is not practicable to put glass in them, the fragile contents of the package is not understood, and, as a result, they receive a much rougher handling. Again, it has been claimed that the paper cases will not stand rain or wet like the wooden cases. If a single section is broken down it is liable to cause the bottom of the case to soak up with honey, and this weakens the case so that it is of but little use to protect the rest of the sections.

Various styles of these cases have been proposed. Those shown at the top of the last page are those used by Mr. Crane. Those shown at the bottom can be purchased at the ordinary paper-box factories, for putting up egg's and bottled goods.
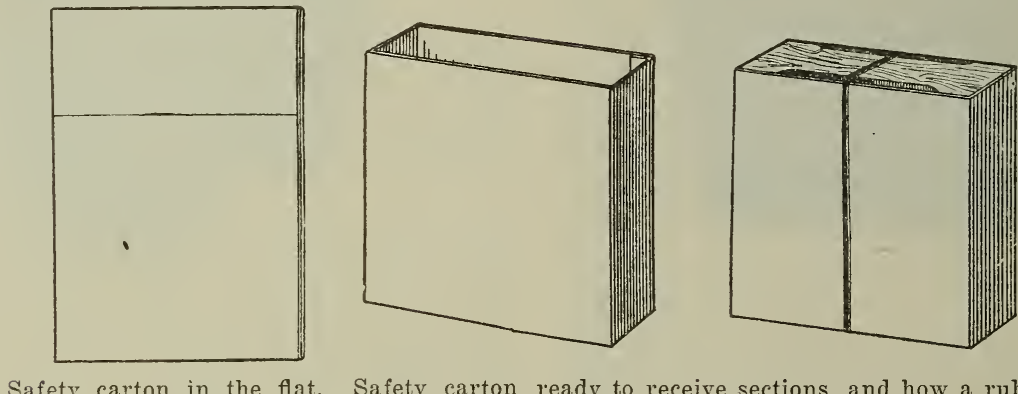

Safety carton in the flat. Safety carton ready to receive sections, and how a rubber band is slipped over section and carton.

absolutely accurate. The saws have very coarse teeth making rough edges, and his gauges are not accurate. His product will be anything but satisfactory for shipping so expensive and fragile a product as comb honey. When a good factory-made case with cartons and corrugated paper can be bought for 32 cents in lots of a hundred, it is folly to pay a planing-mill man 20 cents a case that will bring a loss in breakage and leakage amounting to 50 per cent on the honey.

\section{SHIPPING-CASES MADE OF CORRUGATED PAPER.}

During the last few years some effort has been made to use shipping-cases made out of corrugated paper or strawboard-the same material that is used in the safety cases, to cushion the sections. Mr. J. E. Crane, of Middlebury, Vt., has used this kind of case for several years, and is well pleased with them; but some of our large commission houses and buyers of honey protest against their use. They claim that they are not strong enough to stand the rough handling of the railroad men; that as
The last named provide a double thickness under the bottom and over the top of the sections, and in the knockdown or flat take less room. The design also makes a stronger case.

While such cases seem to answer very well for honey in bottles, it should be remembered that a bottle of honey or a bottle of syrup or pickles will stand very much rougher handling than the ordinary section of honey. Paper cases can be bought for less money than the wooden ones, especially those of the safety kind; but experience of the last two years has shown that it would perhaps be wise not to use too many of them at the start at least. They may come into general use in time, but comb honey is so fragile an article that a wooden box is none too strong. See Botruing Honey; also Marketing Honey.

\section{SIZE OF FRAMES.-See HIVES.}

SKEP.-The term "skep" is often used by old-fashioned beekeepers to refer to a colony of bees in any kind of hive; but more 


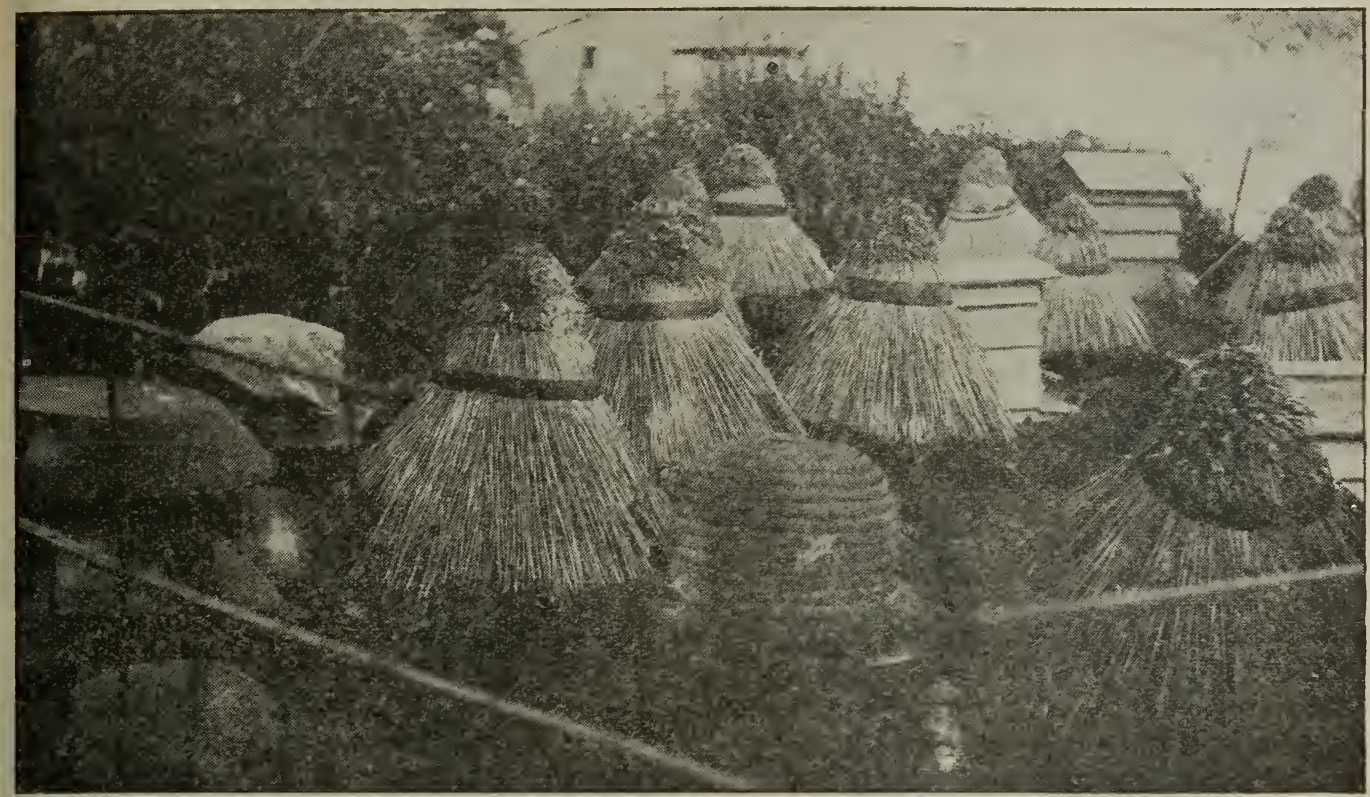

Straw keeps the hives cool in sumer and warm in winter.

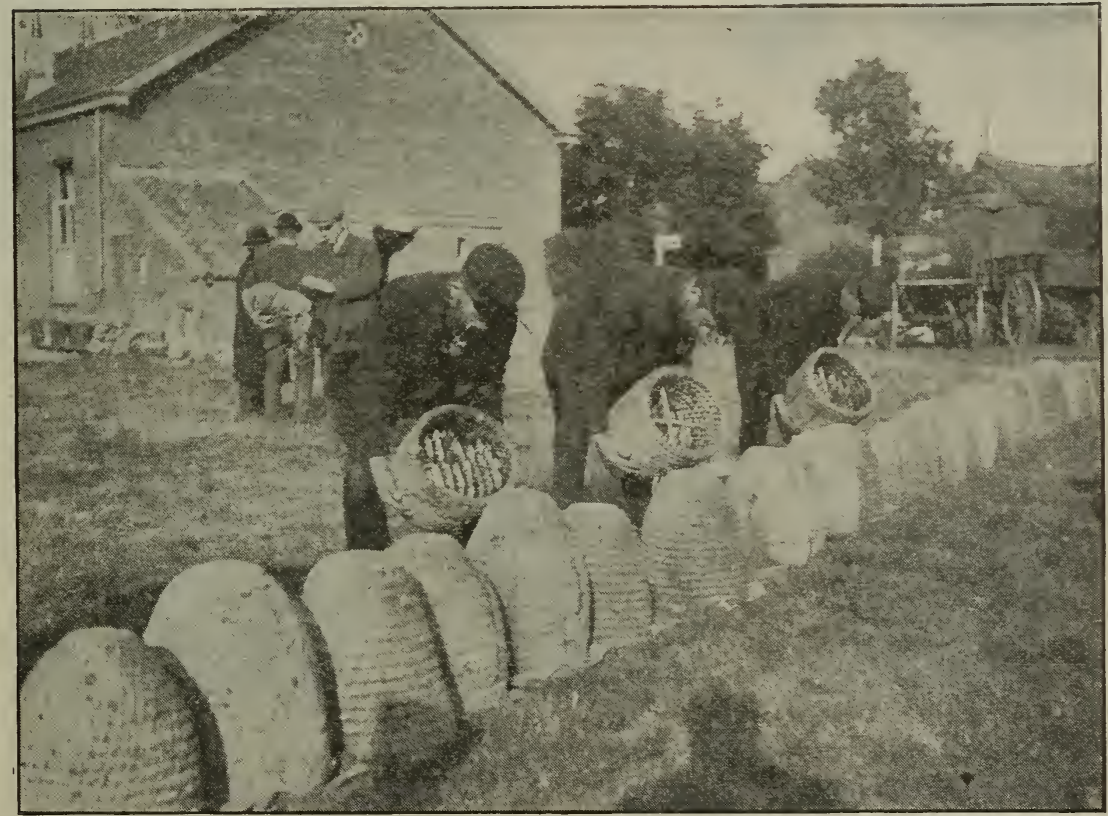

Dutch swarm specialists inspecting bargains at the bee-market in Holland.

properly it applies to box hives and straw skeps-the last named meaning basket in old English. In England and even many of the countries on the continent of Europe, the old straw skep is still used quite largely, because lumber is expensive and straw cheap. The bees are allowed to build the combs just the same as mentioned under the head of Box Hives; also Hives, Evolution oF. On top of the flat-top type of skeps, modern supers containing sections are sometimes used. The making of straw skeps for cottagers is quite a little business of itself -requiring a certain degree of skill and industry.

Straw skeps are not used in this country at the present time; and if it were not for the familiar pictures of "ye olden times" we Americans would know but little about them. See Box Hives. 


\section{SMARTWEED.-See Heartsease.}

SMOKE AND SMOKERS.-We . can drive cattle and horses, and, to some extent, even pigs, with a whip; but one who undertakes to drive bees without smoke will find to his sorrow that all the rest of the animal

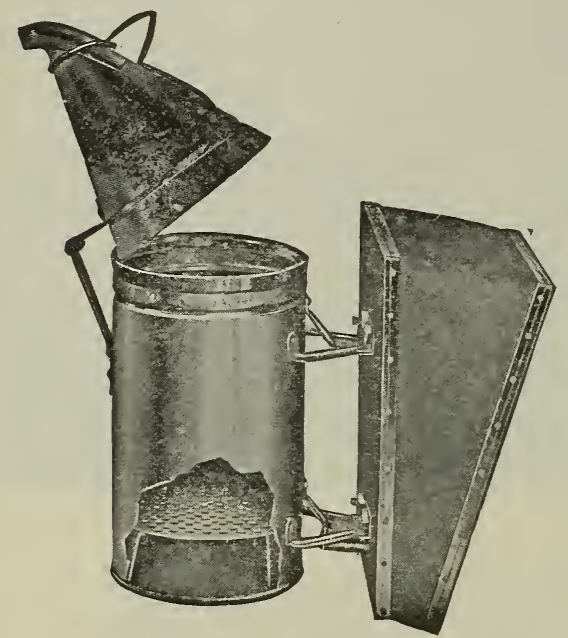

Bingham smoker.

kingdom are mild in comparison, especially so far as stubbornness and fearlessness of consequences are concerned. We may kill them by thousands; we may even burn them up with fire, but the death agonies of their comrades seem only to provoke them to new no such potent power as smoke known? See Bee Behavior.

There have been various devices for getting smoke on to the bees, such as, for instance, a common tin tube having a mouth-piece at one end, and a removable cap with a vent at the other end for the issue of smoke. By blowing on the mouthpiece, smoke can be forced out. Others, again, have used a tin pan in which was some burning rotten wood. This is put on the windward side of the hive so as to blow smoke over the frames. All of these, however, were crude makeshifts in comparison with the smokers of today.

It is to the eredit of Moses Quinby for first giving us a bellows bee-smoker. This was a most decided step in advance over the old methods of introducing smoke among the bees. In principle his original smoker did not differ essentially from the Bingham and the L. C. Root, which were introduced later. It had, however, one serious defect; and that was, it would go out, the fire-pot not being properly ventilated to insure a good draft. Some years after, Mr. T. F. Bingham, of Farwell, Mich., and Mr. L. C. Root, son-in-law of Quinby, then of Mohawk, N. Y., but now of Stamford, Ct., introduced bee-smokers to the world on the principle of the original
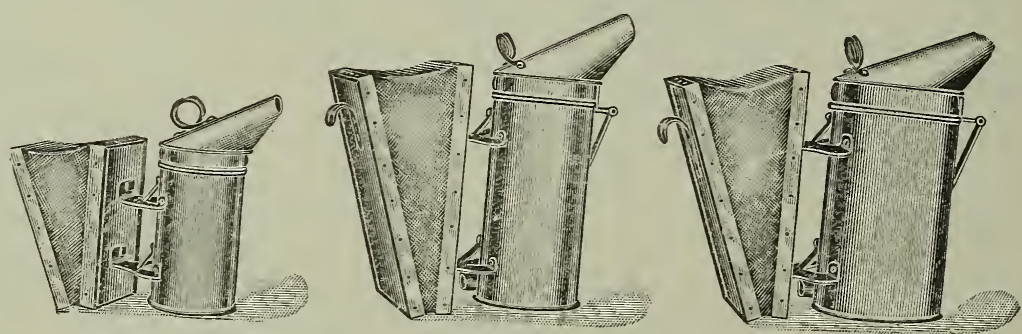

Three sizes of Root smokers.

fury, and they push on to the combat with a relentlessness which can be compared to nothing better than a nest of yellow-jackets that have made up their minds to die, and to make all the mischief they possibly can before dying. It is here that the power of smoke comes in; and to one who is not conversant with its use, it seems simply astonishing to see them turn about and retreat in the most perfect dismay and fright, from the effects of a puff or two of smoke from a mere fragment of rotten wood. What could we beekeepers do with bees at times, were
Quinby bellows smoker, but with several decided improvements. The fire-cups, at the same time, were made rather larger, and were ventilated in such a way that a continuous draft could be maintained, even when the smoker was not in use, thus preventing them from going out like the original Quinby.

Of the two smokers, the L. C. Root was taken off the market some years ago. The Bingham is still sold, and is now furnished in various sizes along with the Root smokers, by all dealers. 
was a time when the cold-blast bid fair to displace the hot-blast. The former was thought to have the advantage of being cheaper, using the fuel more slowly, and

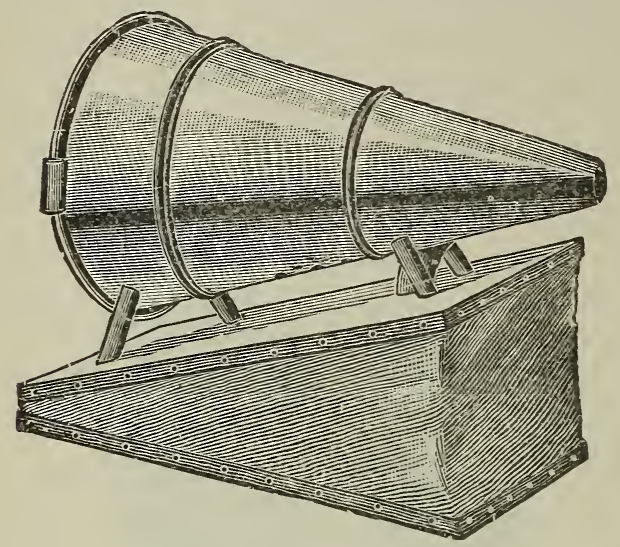

Clark cold-blast smoker.

sending a cold blast of air upon the bees. The fact that the smokers of this type have almost disappeared from the market shows that they are not as effective as those using the hot blast.

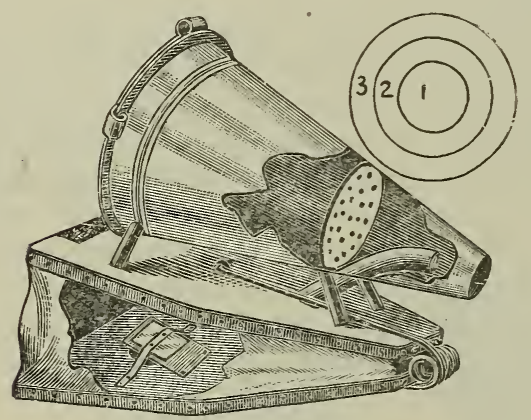

Cold-blast principle illustrated.

One must work the bellows of a coldblast almost constantly in order to get a smoke dense enough to subdue bees. Even then the force is too strong; while a hotblast furnishes a gentle breath of strong smoke that will conquer.

\section{FUEL FOR SMOKERS.}

It will be unnecessary to give directions for using these hot or cold blast smokers, as printed directions accompany all smokers sent out by each manufacturer; yet it may be well to allude to the different kinds of fuel that have been used. Rotten wood is good, and accessible to all, but it burns out too rapidly. Mr. Bingham recommends sound har'd wood for his smoker. Dr. Miller and some others prefer turning-lathe hardwood shavings, or, if these are not available, planer shavings. In certain localities peat can be obtained very cheaply, and it makes an excellent fuel. Some use old rags; others old discarded hive-quilts that are covered with propolis. These last make a very pungent subduing smoke. In some parts of the South, dry pine needles are used.

IV. L. Coggshall, one of the most extensire beekeepers in the world, uses a special fuel made out of old phosphate-sacks rolled around a half-inch stick, tied at regular intervals, and then chopped into convenient longths with a sharp ax. The rolls should,

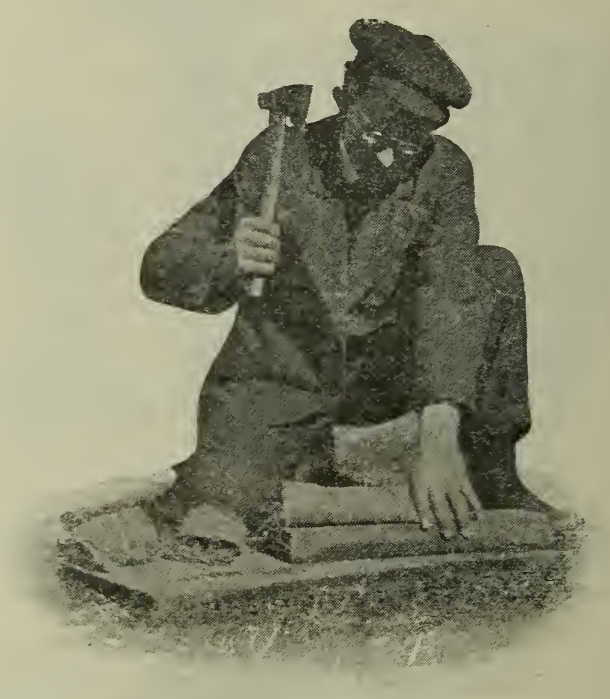

Chopping up rolls of burlap for smoker-fuel. An old sack is rolled up, tied at intervals, and then cut in pieces between the strings.

of course, be of the right diameter and length to fit inside the smoker used. The sacking must not be rolled too tightly nor made too snug a fit, or else it will choke the draft and put out the smoker. The reader is, therefore, recommended to make a few experimental rolls before he makes up a lot for a season's use.

To facilitate lighting with a match, one end of the roll is dipped half an inch into a solution of saltpeter, and allowed to dry. If a little red lead be sprinkled in the solution it will be very easy to tell which end of the roll is for lighting.

A quantity of old sacking, says Mr. Coggshall, will be sufficient for one season's use, and the fuel gives a lasting smoke without 
sparks. He further says that he can take a cold smoker, and in ten seconds have all the smoke he requires, as the saltpeter ignites instantly.

When old sacking cannot be obtained, old carpets or old burlap can doubtless be used. Even new burlap would not be expensive, altho Mrr. Coggshall says the fabric should be partly rotted to give the best results. He lays his old phosphate-sacks out in the weather for about three months, and then rolls them up.

\section{THE BEST SMOKER FUEL.}

We have been using greasy waste in a smoker with great success. It requires no treatment with any chemical to make it

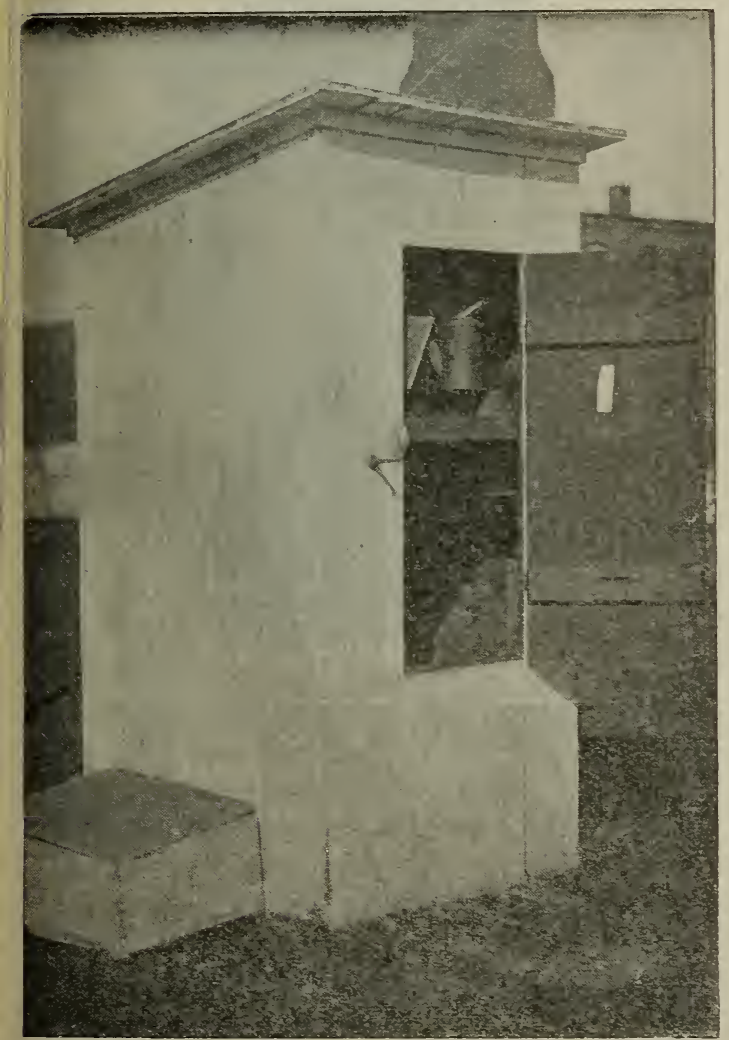

A tool-house for smokers, tools, reils, and fuel. The fuel is kept in the lower part under the shelf.

light easily, and it is almost impossible to extinguish it after it is once lighted, even tho it be stamped in the mud. There is no question but that this is perhaps the very best smoker fuel, altho in some places it may be somewhat difficult to obtain. It furnishes a strong subduing smoke, and is almost free from creosote. It can usually be had for the asking at any machine-shop or printing-shop, and it may be picked up along railroads, altho as a rule it would take too much time to hunt up greasy waste in this way. A piece could be found here and there, but generally not enough to pay for the trouble. A supply can be obtained at any factory to last a whole season; and we always advise its use, therefore, when it can be obtained. It gires a strong, pungent smoke; does not make a hot fire; is easily lighted; will not go out, even tho the smoker be left standing for four or five hours at a time.

\section{ABUSES OF A SMOKER.}

A good smoker should last a number of seasons, but it will very quickly cease to be a good implement if it is not well taken care of.

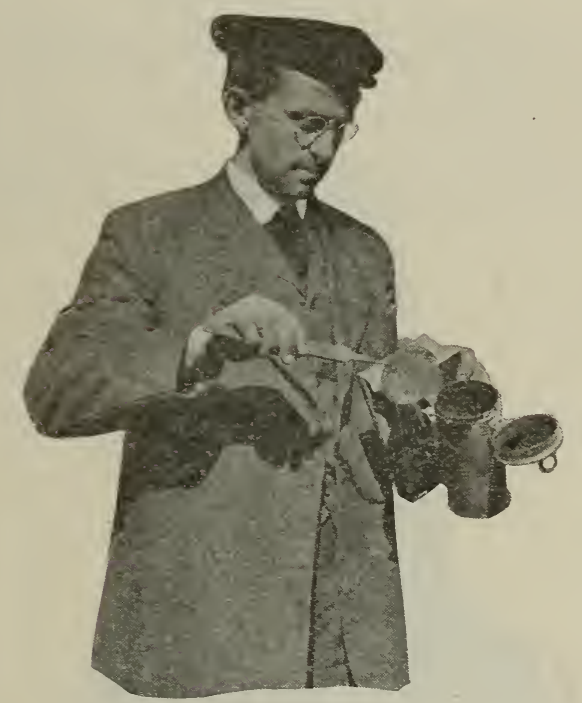

It is very seldom the grate becomes so filled up that it has to be cleaned; but when this does happen it is the work of only a moment to insert the point of a file in one of the holes and lift out the grate, as here shown. It pays to keep the grates clean. There are a larger number of holes near the outside of the grate than in the center, consequently the fuel burns evenly and does not throw sparks until it is all consumed.

One of the most common abuses of a smoker is to leave it out in the rain. We have seen many smokers left out in all kinds of weather; and it is needless to say that the bellow's leather soon becomes hard, and cracks, and the fire-box gets rusty. A good many beekeepers keep their smokers in an empty hive and thus avoid the danger of a costly fire. If the whole hive should burn, the loss would not be so very great. 
A better plan than this is to build a small tool-house like that on preceding page. This need not be over five or six feet high. There

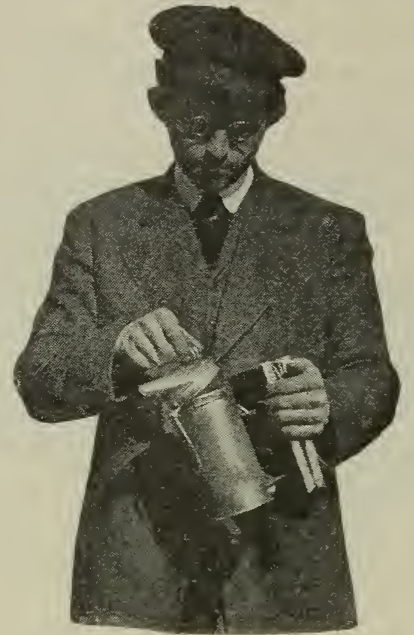

FIG. 5.-How to hold the smoker when raising the cap. Compress the bellows in order to give the fingers a firmer hold.

is a substantial shelf as shown, on which smokers, hive-tools, veils, etc., may be kept. It is a good plan to provide a piece of heavy

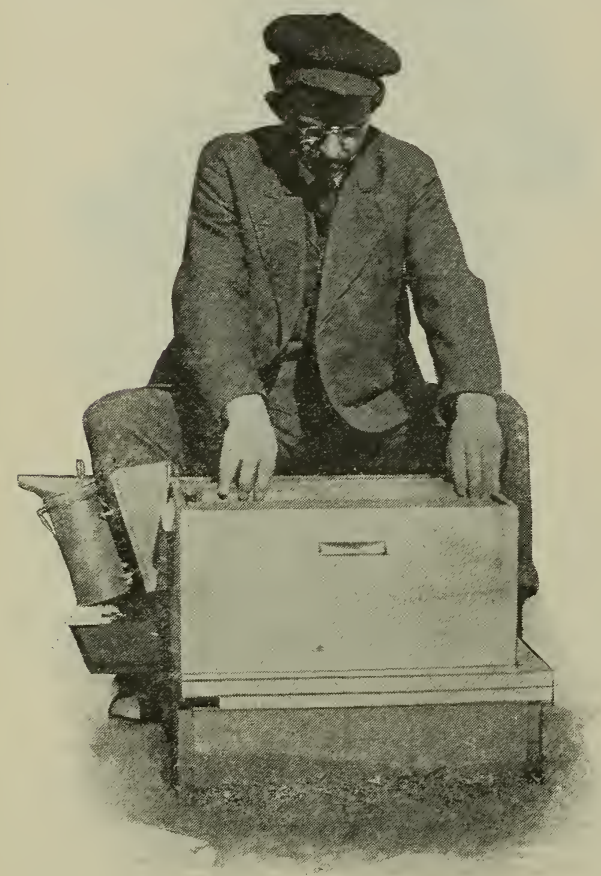

Fig. 6-The convenience of a hook in the back of the bellows. The smoker is always at hand at a second's notice.

sheet iron about half an inch above the shelf for the smokers to stand on, so that there will be no danger of setting fire to anything.
The fuel is kept below this shelf. There is room enough usually to hold a supply for a whole season; and when it is kept in this way it is always dry and ready for use. We have such small buildings at all our outyards, and consider them almost indispensable.

Another common abuse of the smoker is to allow creosote to collect at the top until the cap will not fit down over the fire-box.

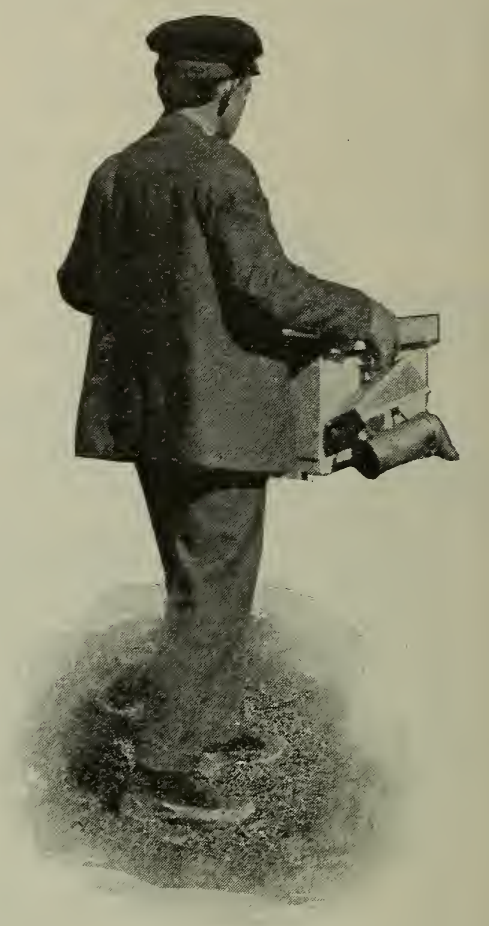

FIG. 7.-Carrying a smoker with the little finger when the hands are full.

In a new smoker with the flexible hinge there is not apt to be so much trouble in this way, but at the same time it is well to spend about ten seconds once a week or so with a screw-driver in cleaning off this accumulation. We have seen smokers with caps or nozzles so filled with creosote that they would not fit down over the fire-box at all, and of course leaked smoke very badly or else had to be pounded on the top with a stick. It takes but little time to remove the greater part of the creosote so that the parts will fit. Most smokers are made with the caps a trifle large; and while they leak smoke at first the collection of creosote will stop this in a short time.

Sometimes beginners in their eagerness to test new smokers work the bellows so 
vigorously as to blow fire from the nozzle, and before they know it the fire-box is redhot. This means, of course, that the tin is all burned off, leaving the bare iron to rust thru in a short time. There is usually no need of having a hot flame in the firebox. for this implies perfect combustion;

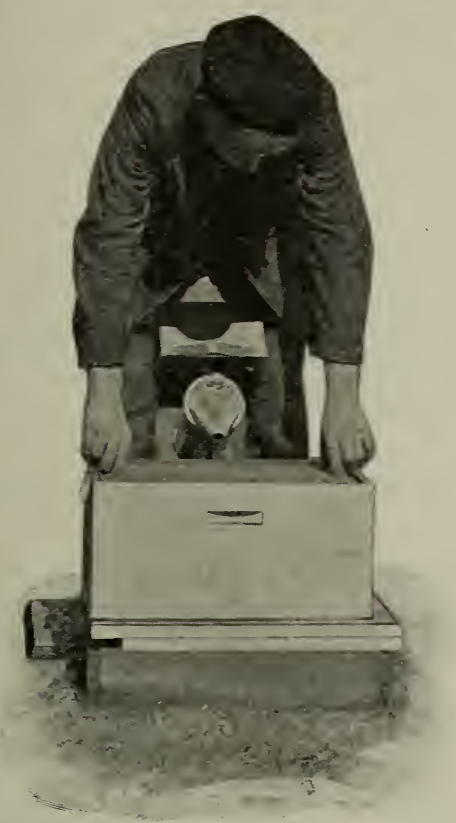

FIG. 8.-Holding a smoker between the knees while manipulating frames.

while the secret of getting lots of smoke is to have imperfect combustion. Sometimes this is a fault of the fuel. It is best to use fuels that burn slowly.

While it is impossible to aroid dropping a smoker once in a while, as a rule beesmokers are handled pretty roughly. It does not take long to learn to use reasonable care in handling a smoker, whereby it will last enough longer to pay.

When a fuel is used in which there is a good deal of pitch it is sometimes difficult to raise the cap or nozzle after the fire is out and the metal has become cold. We have known of instances where the cap had been battered almost out of shape after being stuck down solid. It is always best where such fuel is used to raise the cap when putting the smoker away. If it is left open there will be no sticking.

The grate will usually keep clean; but in some cases when it gets stopped up, insert the point of a file into one of the holes and lift it out as shown on page 659 . It can then be easily cleaned and replaced.
HOW TO USE A SMOKER.

Perhaps the majority of beekeepers understand using a smoker without any special instructions, but we believe that, as a rule, too much smoke is used. It is best to use just as much as is necessary and not any more. A beginner so often stupefies the bees that they become practically demoralized. It is needless to say that this is a very bad plan. Very often colony after colony can be opened, especially when the bees are working, without the use of smoke; but at the same time it is well to have a smoker near at hand.

It is not considered good practice to smoke bees out of comb-honey supers. as they are frightened at the smell of smoke, and, in their desire to save honey, uncap some of the cells and thus spoil the appearance of what might otherwise be fancy honey.

In looking for a queen, use little or no smoke, as it is rery easy to set the bees

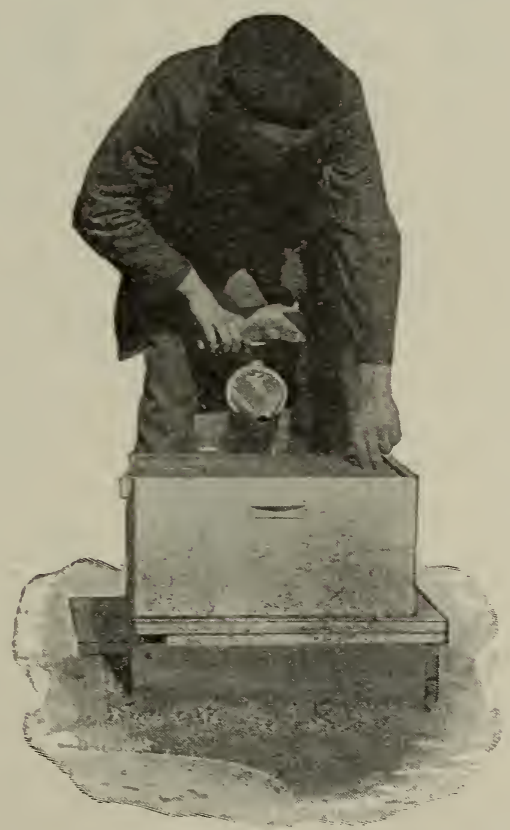

FIG. 9.-Working the bellows of the smoker while holding between the knees manipulating frames.

running all over the combs, making it next to impossible to locate the queen. At such times the frames should be handled slowly and carefully, the beekeeper doing nothing to disturb or excite the bees.

Fig. 5 shows the most natural way of holding the smoker when the cap is opened. A better hold is secured with the left hand 
if the bellows is compressed as shown. Take hold of the coiled-wire handle with the right hand and it will be seen that the cap can be raised very easily without the least danger of burning the fingers. The coiled-wire handle remains cool, no matter how hot the fire is. It saves knocking the top loose with a hammer or hive tool.

SOLAR WAX-EXTRACTOR. - See Wax, also Bottling Honey.

SOLITARY BEES.-The bees, or $A n$ thophila, according to their economy, may be divided into two groups, the social bees which live in communities, as the honeybees, bumblebees, and stingless bees; and the solitary bees, among which each female builds her own nest and provides alone for her brood. The social bees are described elsewhere in this work.

Up to the present time there have been recorded in North America over 2000 species of native bees. This is about one-quarter of the described species in the world, which are estimated at 8000 . In Europe there also occur about 2000 species, 200 are known in England, 440 in Germany, 510 in Hungary, and 413 in Algiers. The majority are solitary forms, since the social families do not include over 500 species. But the indigenous bees of North America are as yet only partly known. Immense tracts still remain, so far as their bee fauna is concerned, terra incognita. Manitoba, British Columbia, the whole tier of southern states along the Gulf of Mexico, as well as many western states, are as yet practically unexplored, and will doubtless afford a rich harvest to the diligent collector. The number of species found in any one locality is usually not large, and is greatly influenced by the climate and soil. In Maine there are about 200 species, in Illinois 300 , and in New Mexico 500. The Anthophila may be classified in fourteen or more families according to the conception of family adopted by the mellitologist. In this division the more important characters employed are the structure of the mouth-parts, and the pollen-brushes, and the veining of the wings.

SOLITARY BEES AND FLOWER POLLINATION.

In their relations to flowers bees may be divided into two series, the short-tongued forms and the long-tongued forms. The long-tongued bees are able to reach the nectar in nearly all flowers except those adapted to butterflies, moths, and birds, but they confine their attention chiefly to bee flowers which have the nectar more or less concealed, such as the columbines, larkspurs, clovers, vetches, many mints and figworts, thistles, and many other Compositae with long corolla tubes. The short-tongued bees are compelled to visit open, rotate flowers with the nectar exposed or only slightly concealed, as the plum, strawberry, blackberry, raspberry, pear, apple, and basswood, or to flowers with very short corolla tubes like the goldenrods. In North America the more common genera of short-tongued bees are Prosopis, Colletes, Sphecodes, Halictus, Andrena, and Macropis.

\section{THE SHORT-TONGUED BEES AS FLOWER VISITORS.}

The most primitive bees belong to the genus Prosopis, and are closely allied to the sand wasps from which probably they are

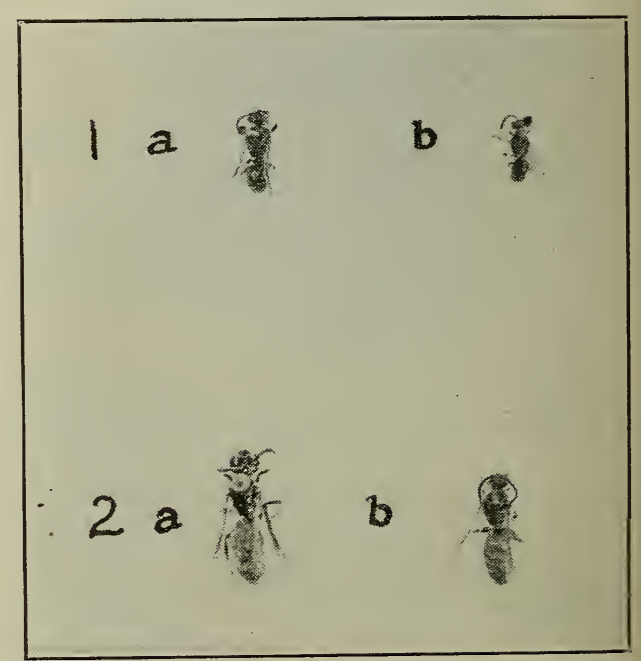

Fig. 1.-Primitive bees: 1. Prosopis modesta; $a$, female; $b$, male. 2. Sphecodes ranunculi; $a$, female; $b$, male. Tongues short, bodies smooth and nearly hairless, without pollen-brushes. The pollen and nectar are masticated as collected, and the regurgitated liquid is stored in the cells as food for the larvæ.

derived. Among these small coal-black bees there are no adaptations for visiting flowers. Their nearly hairless bodies are destitute of pollen-brushes, and they have short, broad, emarginate tongues like the wasps. Were it not that they feed their offspring on a paste of pollen and nectar and conse- 
quently visit flowers more frequently. they would be of no more value than the wasps as pollinators. The semi-liquid paste stored in their cells consists of partially digested pollen and nectar, which has been regurgitated. The bees of this genus tunnel in the pithy stems of brambles, and naturally are common on the flowers of blackberries. but they are also often found on the blossoms of the stone-crop (Sedum acre), prickly sarsaparilla (Aralia hispida), goldenrod. mignonette, and collecting pollen on wild roses. Almost equally primitive is the genus Sphecodes, except that they hare ac- riduals as fialictus and Andrena. They show a marked advance over the preceding genera in their adaptations to flowers. The tongue is longer, the thorax is thickly pubescent, and the hind legs for nearly their entire length are covered with a dense scopa of hairs. They carry the pollen dry and chiefly on the thighs, while the honeybees moisten it with honey and pack it on the tibiæ. The ground bees are very important in wild regions where there are no honeybees, and before the discorery of America probably played the chief role in the pollination of fruit bloom. On warm days in

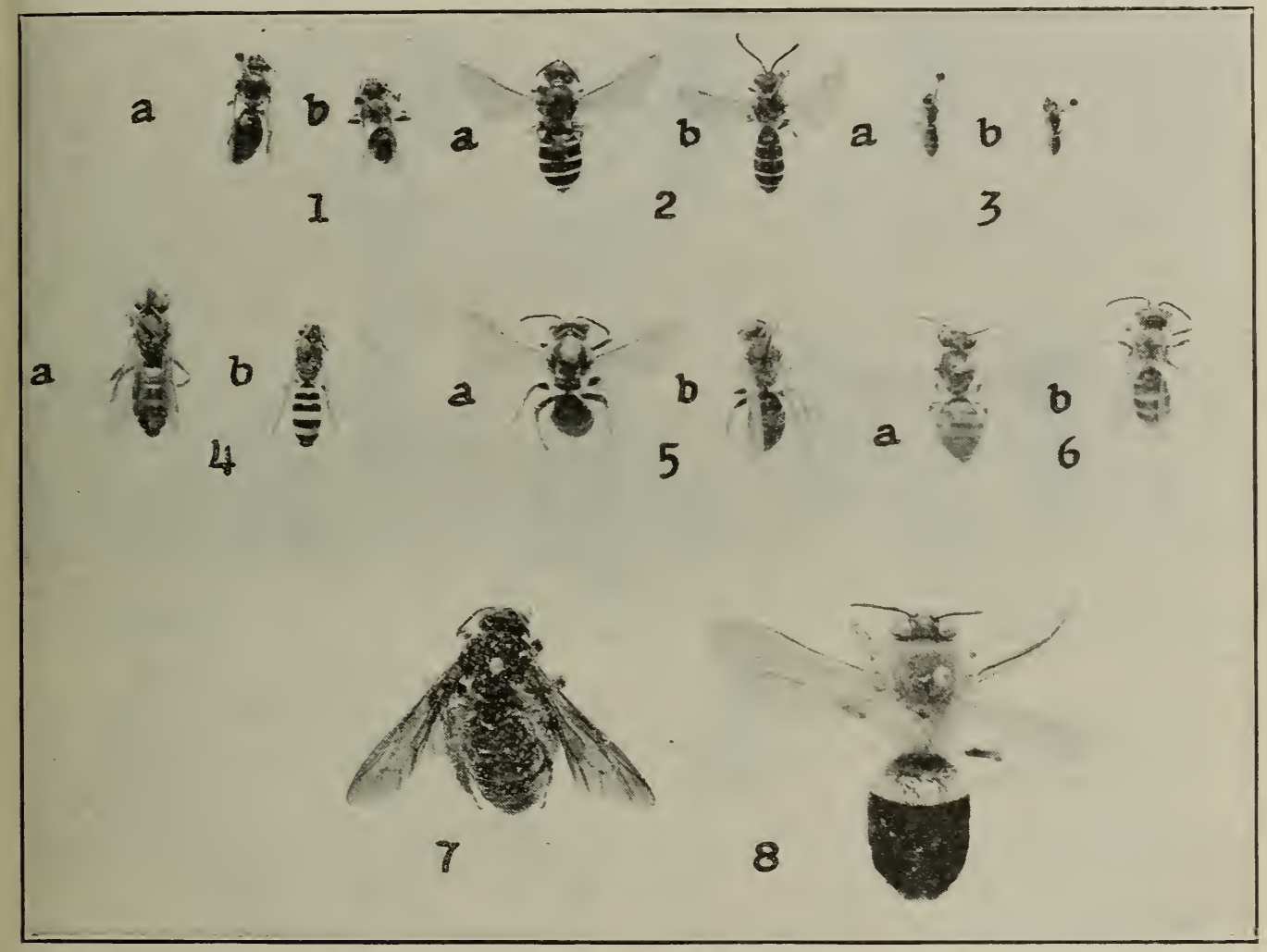

Fig. 2.-Short-tongued bees. 1. Macropis ciliata; $a$, female; $b$, male. 2. Halictus lerouxii; a, female; $b$, male. 3. Halictus hortensis; $a$, female; $b$ male. 4. Agapnstemon radiatus; $a$, female; $b$, male. 5 . Andrena crataegi; $a$, female; $b$, male. 6. Andrena erythrogaster; $a$, female; $b$, male. 7. Nomia heteroptera, female. 8. Megacilissa electa, male.

quired a short pointed tongue. They are nearly hairless and are without pollenbrushes, and the food supply furnished their brood is similar to that of Prosopis. Great interest attaches to these two genera since they show the early stages of bees before they were much modified as the result of flower visits, and doubtless closely resemble ancestral forms of the honeybee (Fig. 1).

No other genera of the solitary bees are represented by so many species and indi- spring clouds of these bees fill the air around the blnom of the willows, plum-trees, cherries, blackberries, and at times nearly all fruit-trees and shrubs. Observations made at the experiment station of Connecticut showed that in that locality they were by far the most common visitors to the apple, pear, quince, gooseberry, currant, blackberry, and raspberry. For instance, out of 359 Hymenoptera taken on the sweet cherry 349 belonged to Andrena and Halic- 
tus. But in very large orchards and in gen$\epsilon$ ral, honey-bees are the most valuable. The ground bees are also common on blueberries, cornels, Viburnum, roses, sumacs, goldenrods, and hundreds of others (Fig. 2).

All of the genera of short-tongued bees, thus far described, carry the pollen dry; but Macropis is the first genus to moisten it with honey. The brush on the hind tibiæ is long and dense and is often heavily loaded with damp pollen. A common species of this genus is $M$. ciliata, or the loosestrife
The leaf-cutting bees (Megachile), the mason bees (Osmia), and the cotton bees (Anthidium) have on the under side of the abdomen a stiff brush of unbranched hairs inclined backward. When they move over level-topped flower-clusters, like the sunflower and many other Compositae, this abdominal brush sweeps up the pollen while the bees are at liberty to suck nectar. They are also well adapted to pollinate leguminous flowers, as the pea, bean, vetch, and their allies, where the anthers lie on the

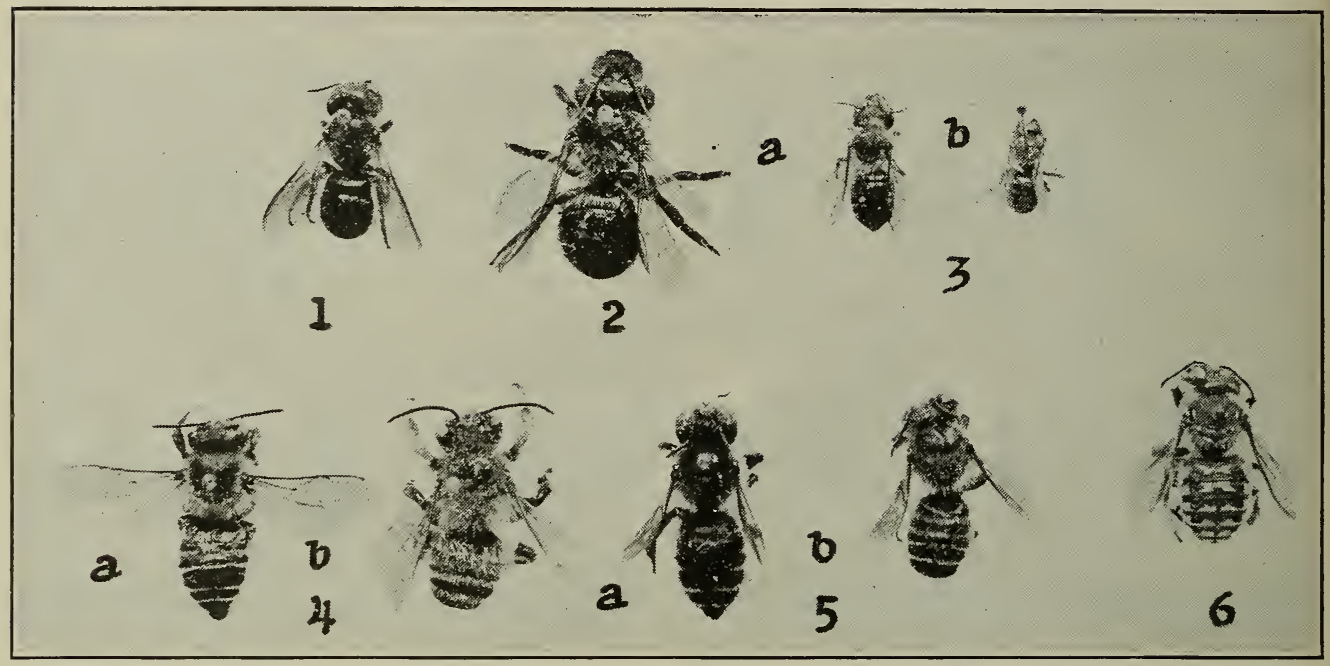

Fig. 3.-Long-tongued bees with abdoninal pollen-brushes. Mason bees: 1. Osmia mandibularis, fomale; 2. Osmia megacephala, female; 3 . Osmia atriventris; $a$, female; $b$, male. Leaf-cutting bees: 4. Megachile latimanus; $a$, female; $b$, male; 5 . Megachile vidua; $a$, female; $b$, male; 6 . Anthidium cognatum, female.

bee, so called because it is usually found on the flowers of the common loosestrife (Lysimachia vulgaris), a pollen flower (Fig. 2).

\section{THE LONG-TONGUED SOLITARY BEES AS FLOWER VISITORS.}

The long-tongued bees include all the social bees as well as many genera of solitary bees. The length of the tongue varies greatly, the medium length being $6 \mathrm{~mm}$., as found in the honeybee, and the extreme length 21 to $22 \mathrm{~mm}$. in some female bumblebees. They restrict their visits chiefly to bee flowers and thus avoid the competition of many short-tongued insects and are likely to find a more ample supply of nectar. The long-tongued solitary bees may be divided into two series in accordance with the way they collect and carry pollen. One series has the pollen-brushes on the hind legs, and the other on the under side of the abdomen. under side of the irregular flowers and come directly in contact with the abdominal scopa. The tongue in this group is usually less than $6 \mathrm{~mm}$. long, and the pollen is, of course, always carried in the dry state. (Fig. 3.)

A part of the long-tongued bees with polleniferous scopa on the hind legs carry the pollen on the femora, or thighs, as Panurginus and the carpenter bees (Xylocopa); while a part carry it on the hind tibiæ. The Anthophoridae, or cliff bees, have a worldwide distribution, and in their senses and general appearance resemble bumblebees, but are smaller in size, and there are no flowers especially adapted to them. The collecting hairs in some genera are extremely long, as in Dasypoda, and great balls of pollen, half the size of the abdomen, are carried on them. The common genera Anthophora and Melissodes visit the same flowers as bumblebees (Fig. 4). 
Many bees with a short term of flight visit only one or a few allied species of flowers, which are abundant and in bloom during the time the bees are on the wing. Certain vernal species of Andrena visit only the flowers of the willows, while other autumnal flying species confine their visits to the goldenrods and still others to the asters. There are indeed a number of bees which obtain their supply of nectar and pollen exclusively from the Compositae. These flowers, as in the case of the golden- skill, and provisioning them with food for the use of the brood. The brood parasites on the contrary neither build nests nor gather stores for their offspring, but in the case of the solitary bees they lay their eggs at a favorable opportunity in the cells of the nest-builders. The latter are often called host bees and the former guest bees.

HABITS OF THE NEST-BUILDING BEES.

The genus Prosopis, says Knuth, stands at the lowest level among bees and belongs

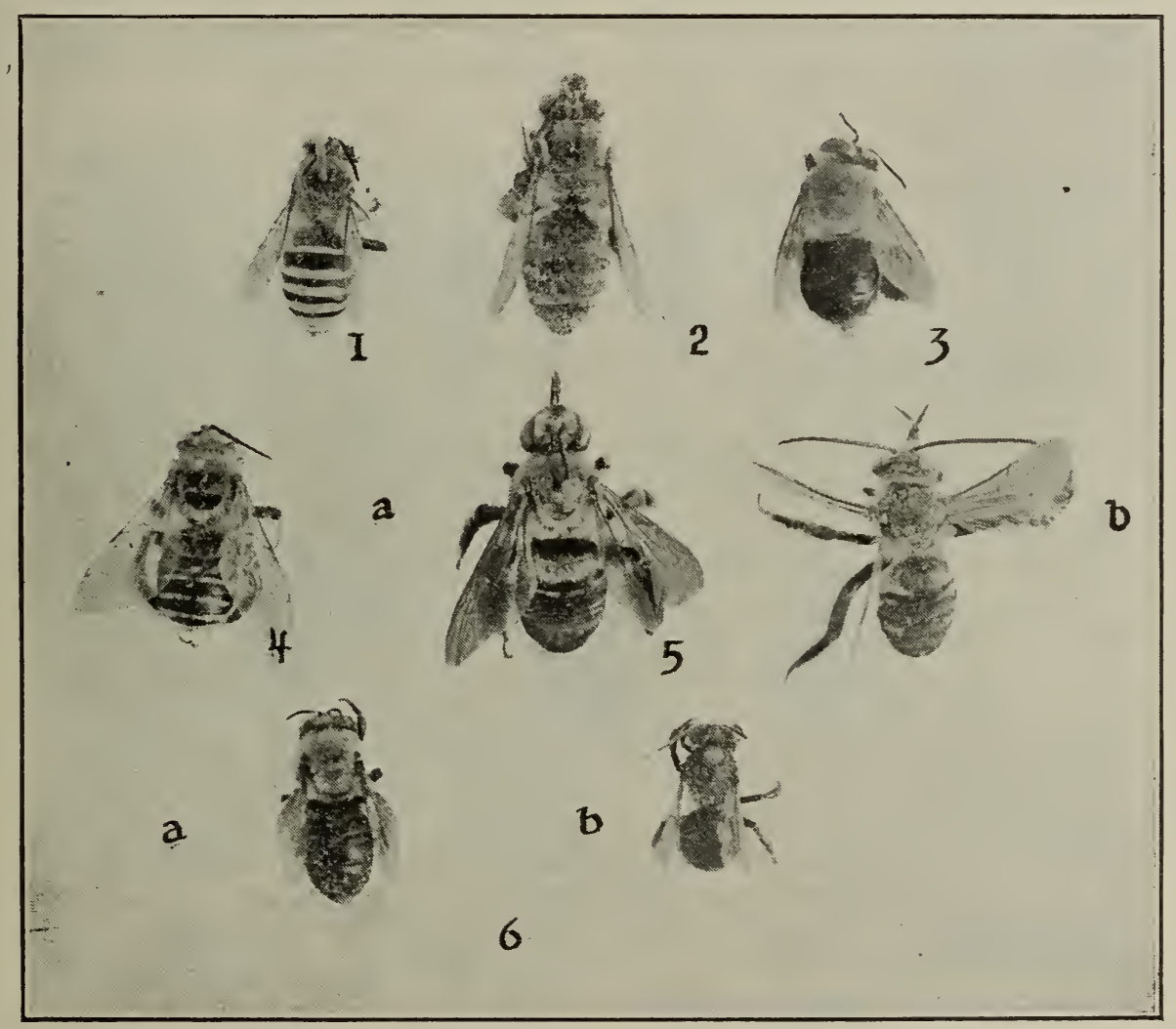

Fig. 4.-Long-tongued bees with pollen-brushes on the hind legs. Anthophoridae: 1. Anthophora smithii, male. 2. Anthophora occidentalis, female. 3. Centris apicalis, female 4. Melissodes obliqua, male. 5. Melissodes atripes; $a$, female; $b$, male. 6 . Mrelissodes dessponsa; $a$, female; $b$, male.

rods and thistles, are very common, yield ample food supplies and are easy to visit. This habit has arisen because of the advantage thus gained by the bees and is called oligotropism.

\section{HOST BEES AND GUEST BEES.}

According to the way in which they provide for their young, bees may be divided into nest-builders and brood parasites. The nest-builders are industrious insects, constructing their nests with great care and to them only because it feeds its young on pollen and nectar. The female builds a row of cells in the hollow stems of blackberry bushes from which she has excavated the pith. The cells are lined with a thin coating of saliva, which hardens into a smooth cement, and are provisioned with a semiliquid paste of partially digested nectar and pollen. An egg is laid in each cell. After the tunnel has been closed the mother bees still linger in the vicinity (Fig. 1).

The two commonest genera of the short- 
tongued bees are Halictus and Andrena. The species of Halictus, often called "sweat bees," vary in size from some of the smallest bees known to forms as large as the honeybee. The sexes mate in the fall, and the females (like the queen bumblebees) hibernate during the winter. They reappear in the spring and dig burrows in the ground which are five or six inches in depth and have several short branches, in each of which and at the lower end of the tunnel a cell is built. In each cell a little ball of beebread, composed of pollen and honey, about the size of a small pea, is stored for the use of the larvæ. Halictus does not close the tho unable to mate, yet produce by parthenogenesis both sexes, and in like manner the cycle is repeated from year to year. (Fig. 2.)

Andrena is our largest bee genus, and more than 250 species have been described in America. Thousands often tunnel in the same sandy bank of earth until the ground appears as tho filled with shot-holes. It is, says Smith, a village or city of homes. A part of the species are vernal and fly only in the early part of the season, and a part are autumnal and fly only in autumn. Each burrow has a number of short lateral branches, in which and in the enlarged low-

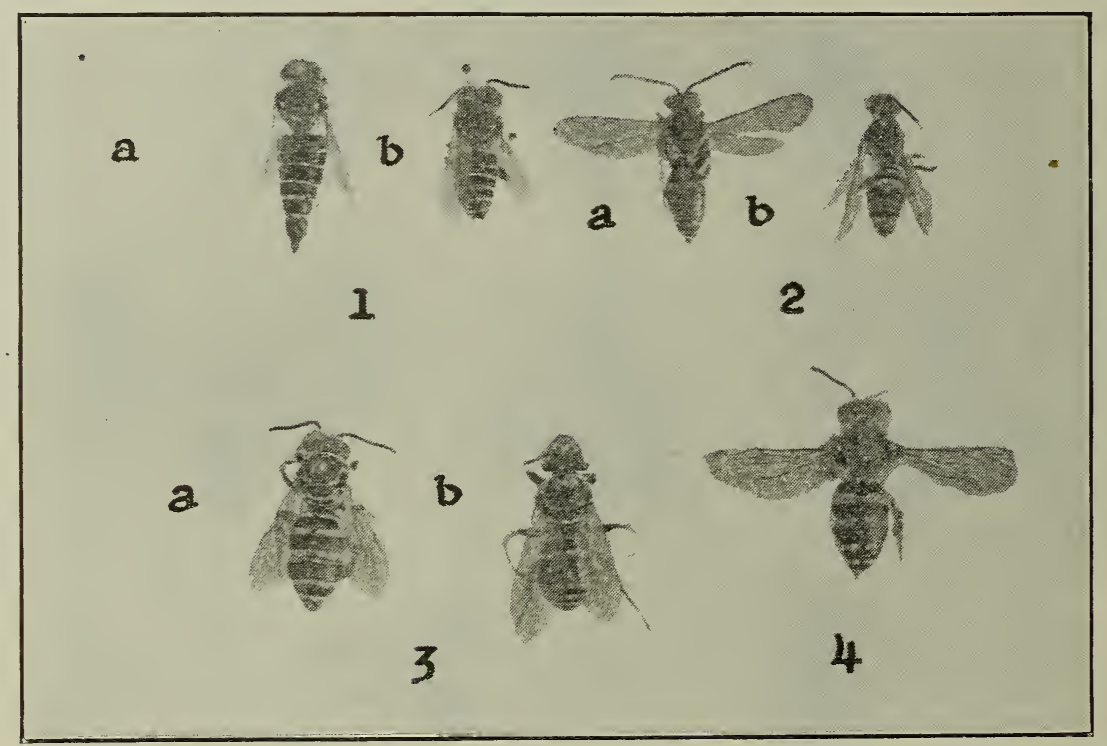

Fig 5.-Parasitic bees: 1. Coelioxys rufitarsus; $a$, female; $b$, male; 2. Nomada bella; $a$, female; $b$, male; 3 . Triepeolus donatus; $a$, female; $b$, male; 4 . Melecta mi. randa, female.

entrances to the cells. Fabre has shown that the first generation of several species (and this is probably true) consists wholly of females. The eight or ten sisters, the offspring of one mother, continue to return to their cells at night and to share together their old home. Beginning with the cell in which she was born, each female digs a new group of cells connected with the main tunnel. Altho there are then no males in existence, she provisions her cells with balls of bee-bread and lays eggs, which by parthenogenesis give birth to both males and females. There are thus two generations among the Halicti. The autumnal generation, consisting of both sexes, produces the following spring only females, which, al- er end of the burrow the female stores a small mass of pollen and honey and lays an egg. The species are closely allied and are called ground bees. (Fig 2.)

The mason bees of the genus Osmia vary greatly in the manner of building their nests. Some make use of the stumps of hollow reeds, tubes, or empty snail shells, while others build their cells in small cavities in stone walls or posts. Several American species build earthen cells about half an inch in diameter which, tho rudely fashioned of mud on the outside, are beautifully polished and glazed within. In France, according to Fabre, the Sicilian Chalicodoma builds its clay cells beneath projecting tiles which in the course of years cover five or 
six square yards, and with their great weight threaten the destruction of the roof. (Fig. 3.)

The observations of Fabre show that the mother Osmia determines the sex of her offspring and can lay at will either a male or female egg. The males of Osmia are much smaller than the females, and their cells are consequently smaller and contain a less amount of stores than those of the latter. When an old nest is used a second time female eggs are invariably laid in the large cells and male eggs in the small cells. Fabre induced a large number of females to build their cells in glass tubes of various sizes. When the tubes were sufficiently large the bees always laid first a series of female eggs and then male eggs. By varying the size of the tubes he succeeded in obtaining series in which the order of laying was reversed and began with males; or in which the entire laying contained only males. "The egg, as it issues from the ovary, has not yet a fixed səx. The final impress that produces the sex is given at the moment of laying, or a little before."

The leaf-cutting bees of the genus Megachile build their cells of round and oval pieces of leaves or flower petals. They do not dig burrows for themselves, but make use of the burrows of other bees or of the straight tunnels of large earth-worms. If the shaft is longer than is needed the approach from below is blocked by fragments of leaves piled in irregular order. After this barrier comes five or six pockets or cells composed of elliptical and round sections of leaves which the female Megachile cuts out with her mandibles. The sides of the cell are formed of six or eight oval pieces in one or two overlapping rows, with the lower ends bent inward to form the bottom. Any little crevices are covered with small ovals to render the leaf-pot water-tight. The top of the cell is closed by two, three, or six, or even ten circular pieces which, by some marvel of geometry, are the exact size to fit the cell. The sections of leaves are taken from a great variety of plants, and no special preference is manifested for any particular species. The cells are provisioned with pollen and honey. (Fig. 3.)

The thimble-shaped cells of the cotton bees of the genus Anthidium are made of white cottony hairs gathered from various kinds of thistles, mulleins, and the cotton rose. Only dried hairs from dead plants are used since hairs containing sap would be likely to mildew. The little packets of cotton, the results of many journeys, are felted or matted into a layer which forms the entire cell. So firmly are these little bags woven together that they may all be removed without separating. The cotton bees make use of the tunnels of Anthophora, or the holes of earth-worms, or the stumps of hollow reeds. Other species of Anthidium employ empty snail shells, and are called resin bees since they divide the hollow spiral into cells by partitions of gum gathered largely from conifers, especially the juniper. (Fig. 3.) The economy of the carpenter bees is described under IYLOCOPA.

The Anthophoridae, or cliff bees, are distributed over the entire globe and are one of the largest of bee families. The females of Anthophora drive tunnels six inches or more in length in the sides of precipitous cliffs, extensive colonies selecting the same location. In the chalk-pits at Northfleet, England, there was a colony so large that in the month of April the countless numbers assembled cast a dark flickering shadow on the ground. The inner walls of their cells are glazed with a thin cement of saliva applied with the tongue which, on hardening, becomes impervious to moisture. An egg is laid on the surface of the stores, which are in a semi-liquid condition. The larvæ pass the winter in the cells and change to pupæ the following spring. Common genera are Anthophora, Melissodes, and Xenoglossa. (Fig. 4.)

\section{THE PARASITIC SOLITARY BEES.}

Notwithstanding that the bees are proverbial for industry beyond any other group of insects except, perhaps, the ants, there are many parasitic genera which no longer gather stores of pollen and nectar, but rear their brood at the expense of the nestbuilding genera. They are rariously called guest bees, brood parasites, inquilines, or cuckoo bees while their unconscious victims are known as host bees. The guest bees are usually allied in structure with their hosts. and both are probably derived from the same primitive stock. Thus the bumblebees (Bombus) and the false bumblebees (Psithyrus) doubtless have a common ancestry. Common genera of parasitic bees are $\mathrm{No}^{-}$ 
mada (parasitic on Andrena), Coelioxys (parasitic on Megachile), Stelis (parasitic on Anthophora). (Fig. 5.)

The manner in which a cuckoo bee enters the nest of her host varies greatly with different genera. Melecta boldly enters the burrows of Anthophora, even when the female is present, and the latter seems wholly unconscious of the danger. Triepeolus more prudently waits until her host Colletes has departed for the field before entering the tunnel. In France, according to Fabre, Stelis nasuta opens with great difficulty the hardened cells of Chaticodoma, sealed with clay cement, lays several eggs and again closes the opening with a pellet of clay. The American parasite Stelis sexmaculata lays her eggs in the nests of Alcidamea producta, which are found in the stems of the blackberry or sumac. The lawful owner Alcidamea lays her egg on the top of a conical mass of bee-bread, but the parasite Stelis places her egg near its base where it is likely to escape notice. There may be as many as four cells, each closed with a felt-like mass of chewed strawberry leaves.

Graenicher has observed and described the tragic end of the host larva. The larva of the parasite is armed with long sharp mandibles; but those of the host larva are blunt and bifid and not well adapted either for defense or attack-so the latter is doomed from the beginning. When the two larvæ, while feeding on the bee-bread, meet, the parasite seizes the body of the host larva between its sharp mandibles. The hostlarva may struggle a little but soon succumbs, and after sucking out its liquid contents the parasite again turns to the beebread. If there are two larvæ of the parasite Stelis sexmaculata a combat between them is sure to occur, and the victor is the larva obtaining the first hold on the body of the other; but two larvæ of Alcidamea can not injure each other.

The handsomest parasitic bees belong to the genus Nomada, and Smith calls them the most beautiful of all the bees found in Great Britain. They are often called waspbees, because of their gay coloring. They are dark red in color, often suffused with black, and maculated with bright or pale yellow. Their larvæ are often found in the nests of Andrena.

In the pollination of flowers the parasitic bees are of much less importance than the nest-builders. Since they have no occasion to gather pollen, they have largely lost their pollen-brushes and visit flowers only to procure nectar for themselves. A part of the species restrict their visits largely to the Compositae which yield nectar freely.

\section{SOURWOOD (Oxydendrum arboreum} (L.) DC.).--Also called sourgum and sorrel tree from the acid leaves. A tree growing 60 feet high, belonging to the heath family (Ericaceae) with very numerous small white flowers in racemes. The corolla is urn-shaped, closely resembling that of

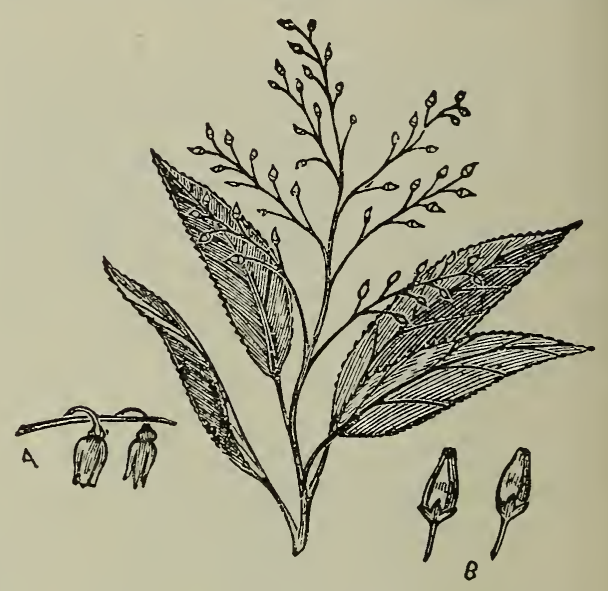

Sourwood leaf, flowers, and seed-pods.

the huckleberry; pendulous, and contracted at the mouth so that the ample supply of nectar is protected both from rain and undesirable insects. It grows in rich woods from Pennsylvania southward to Florida and Louisiana. In Georgia it flourishes chiefly in the northern part of the state, where it blooms in June and July, and is one of the best honey-producers. The honey is medium amber in color, and of excellent quality.

Sourwood is considered a great honeybearing tree in some localities, especially in the South. It is sometimes called sorrel, and is a fine tree from 40 to 60 feet in height, and about a foot in diameter; altho it sometimes reaches 70 feet in height and a foot and a half thru. The popular name, sourwood, is derived from the odor and the peculiar sour taste of the leaves and small twigs. The tree commences to bloom the latter part of June, and the harvest from this source lasts until the middle of July. 
It is entirely distinct from the black-gum and sour-gum, or pepperidge, with which it has been unwittingly classed by some writers on honey-plants, much to the injury of sourwood. The former are honey-producers to a small extent, but are not worthy to be compared with sourwood, which, we are convinced, after living where bassivood, poplar, clover, buckwheat, goldenrod, persimmon, and aster abound, has not its superior among the honey-producing plants of America, either in the amount of yield, or in its beautiful appearance. Basswood is more important only because of its widely extended growth. Bee-masters are familiar with the flora which abounds where those who have written our books on bee culture reside, yet few are aware of the merits of sourwood, outside of the regions where it is found.

It abounds in the native forests from southern Pennsylvania into Georgia and Mississippi. It seems to be more abundant along the whole mountainous tract of country on both sides of the Alleghenies and the Blue Ridge, reaching, in places, even as far as the tide-water on one side, and to central Tennessee on the other. In many sections where poplar abounds and much buckwheat is raised, sourwood is considered the honeyplant, and yields the largest amount of surplus honey. It seems to flourish best on high, dry soil, and is often common on poor woodland ridges, which ean be purchased at a nominal price; tho the forests along the rivers, in rich cultivated soil, are often beautifully checkered with the white blossoms in July. Being a forest tree, it is tall and generally spare of branches along the trunk, except when it grows in the edges of fields, where it yields the greatest amount of honey. The trunk preserves its uniformity of size for some distance up from the ground. The wood is white with straight grain, which splits nicely. It is brittle and quite fine-grained, and is used for posts by cabinet-makers.

The flowers (see engraving) are produced on racemes five or six inches long, which hang in clusters on the ends of the branches. Many of these flower-bearing racemes are thrown out from one central stem, and are all strung with white, bell-shaped flowers, rich in honey. The flower is midway in size and appearance between the whortleberry blossom and the lily of the valley.
Unless there is a failure of the blossom, the honey-yield is sure to be abundant; for, being in the woods with good roots, the flow is not checked by ordinary drouths, nor do the rains wash out the honey from the pendant, cup-shaped flowers. Often have we regaled ourselves, while riding along the road, by breaking off a bunch of blossoms, shaking out the honey in the hand, and licking up the delicious nectar. Each flower, as it dries up, produces a brown seed-pod about the size of a large grain of wheat, which separates, when ripe, into five parts, and permits the very fine seed to fall to the earth.

We are inclined to think that the tree would thrive in our more northern latitudes; perhaps anywhere in our land. It is found abundantly in many parts of the Allegheny Mountains, where it is very cold, the thermometer often indicating several degrees below zero.

SPACING FRAMES.-In nature combs will be found spaced from $1 \frac{3}{8}, 1 \frac{1}{2}, 15 / 8$, and sometimes up to two inches from center to center. Dzierzon, one of the very first to conceive the idea of a movable comb, gave $1 \frac{1}{2}$ as the right distance until Wyprecht made accurate measurements in straw hives having straight combs built in them. Out of 49 measurements, the average distance was scant $13 / 8$ inches. Baron von Berlepsch, by 40 other measurements, verified this result. In the United States, prominent apiarists have found the distance of naturalbuilt combs averaged $1 \frac{1}{2}$ inches from center to center. It has been observed that, in the center of the brood-nest, the combs are spaced more closely than those on the outside, the latter ranging anywhere from $15 / 8$ to 2 inches to centers.

It has been urred that nature be followed in the spacing of brood-frames. But it seems a very poor guide, inasmuch as there is such a diversity of measurements. The beekeeper should adopt that spacing which will give him the best results-the most brood and surplus honey. Quite a number of beekeepers are using $1 \frac{1}{2}$ spacing for their frames. The reason for this is, principally, because they happened to start with this spacing. But those who have given special attention to the matter, trying both spacings, agree almost uniformly that the right distance is $13 / 8$, or, if anything, a trifle 
scant, and some use quite successfully $1 \frac{1}{4}$ - $^{-}$ inch spacing. Many, indeed, who had selfspacing frames adapted for $1 \frac{1}{2}$ inches, have gone to the enormous expense of changing' over to the $13 / 8$. The advantages of this latter spacing are so evident that very few deny that better results can be obtained with it. Brood comb is found to be, on an average, 7/8 inch thick; capped brood, one inch thick. On $13 / 8$ spacing, this will allow $1 / 2$ inch between uncapped combs and $3 / 8$ between capped brood combs.

The following paragraph is taken from an article published in Gleanings in Bee Culture, page 673, Vol. XVIII., written by Mr. Julius Hoffman, inventor of the Hoffman frame, and it applies here exactly:

If, for instance, we space the combs from center to center so as to measure $1 \frac{1}{2}$ instead of $13 / 8$ inches, then we have an empty space of $5 / 8$ inch between two combs of brood instead of $1 / 2$, as it ought to be; and it will certainly require more bees to fill and keep warm a $5 / 8$ than a $1 / 2$ space. In a $1 / 2$ space, the breeding bees from two combs facing each other will join with their backs, and so close up the space between the two broodcombs; if this space is widened, however, to $5 / 8$, the bees cannot do this, and more bees will be required to keep up the needed brooding temperature. What a drawback this would be in cool spring weather, when our colonies are still weak in numbers yet breeding most desirable, can readily be understood.

Where wider spacing is adopted, there is apt to be more honey stored in the combs. and less of worker (but more drone brood). Close spacing, on the contrary $(13 / 8)$, tends to encourage the rearing of more worker brood, the exclusion of drone brood, and the storage of less honey below. This is important.

Under the head of SwARMing, subhead "Dadant on Swarm Control," it will be seen that Mr. Dadant and Mr. Allen Latham believe that $1 \frac{1}{2}$-inch spacing tends to reduce swarming, and that the regular $13 / 8$ spacing is too close. On the other hand, it may be said that the self-spacing Hoffman frame adapted to $13 / 8$ spacing will gradually, on account of propolis accumulations, increase to $1 \frac{1}{2}$. For further information on the spacing of frames see Frames, Self-spacing; Hive-Making; Hives; Honeycomb.

SPANISH NEEDLES, large-rayed ( $B i$ dens aristosa (Michx.) Britton.-This spe- cies should not be confused with the smallrayed Spanish needles Bidens bipinnata $\mathrm{L}$. The plant with the showy, large-rayed heads yields immense quantities of honey along the low bottom-grounds of the Mississippi and Illinois Rivers. The following from Gleanings in Bee Culture, page 162, Vol. XVI., is from the Hon. J. M. Hambaugh, and tells all about the plant, and the immense quantities of honey that are often produced by it.

Something over a year ago I wrote a letter for Gleanings, claiming that the honey gathered from this plant is superior to that produced from other fall flowers, and that it should rank among the very best grades, and command the same price in the markets as clover and linden honey. My peculiar location has, fortunately, placed me in a position to understand pretty thoroly the nature of this plant, and the quality of the honey it produces. Located at the foot of the bluffs of the Illinois River, there is a broad expanse of low marshy lands to the east and south, from three to five miles in width. These lands are subject to overflows from the river once a year, which usually take place in early spring. This renders a large portion of the soil unfit for tilling purposes; and the consequence is, the Spanish needles have secured a permanent foothold, almost to the exclusion of nearly all other plants. Early in September they begin to open their beautiful bright-yellow rays, and in a short time whole districts are aglow, and their darzling brilliancy reminds one of burnished sheets of gold. It is now, should the weather prove favorable, that the bees revel in their glory, and the honey comes piling in; and the beauty about this kind of honey is, it needs but little "boiling down," and the bees no sooner fill their cells than it is cured and ready to seal. This is one great advantage, and saves the bees lots of labor, making the storage of honey more rapid. I had one colony of bees that stored $631 / 2 \mathrm{lbs}$. of honey in six days; another one, $86 \mathrm{lbs}$. in nine days, while 43 producing colonies netted me 2021 lbs. in ten days-an average of $47 \mathrm{lbs}$. to the colony. Tho not quite as clear as clover or linden, the honey has a golden hue, an exquisite flavor, and a very fine body, weighing fully $12 \mathrm{lbs}$. to the gallon, and, as previously stated, I can not see why it should not rank on the market in grade and price with clover and linden honey.

SPECIALTY IN BEES.-The question of making beekeeping a side line or hobby has already been pretty thoroly discussed under the head of BeginNing with BeEs, Out-apiaries, Profits in Bees, OverstockING, and BeES AND Poultry. On the other hand there are farmers who produce potatoes only. Others grow small fruits; still 
others, onions and celery. In the line of professions there are physicians who make a specialty of the eyes, some of the ears, and others both of the eyes and ears. Others gire their whole time to the treatment of the lungs or the throat, and others to diseases of the skin. While it is true that some beekeepers specialize on queenrearing and others on extracted honey, the number who confine their attention solely to the keeping of bees is not large and mainly in the West.

Whether one shall keep more bees and drop all other pursuits will depend on a good many conditions. First is the question of locality; second, the man; third, the state of his finances.

\section{LOCALITY.}

No one should attempt to make a living entirely from bees unless he has a locality that is eapable of supporting a large number of bees. See Locality and OverstockING. Ill some places, probably not more than twenty-five or fifty colonies could be maintained to a yard. Two hundred parceled out in five or ten apiaries two miles apart would increase the expense of operation. To put a man at each yard would be out of the question. A horse and wagon would be too slow, because the apiarist would thus be one-third of the time on the road. An automobile truck is expensive. If one has a locality that will support five hundred to a thousand colonies in from ten to twenty yards, the gross earnings would warrant the purchase of an automobile truck and a runabout, perhaps, for making quick trips. See Moving BeEs and OurAPIARIES. As a rule, a few bees as a side line can be kept profitably almost anywhere; and therefore if one has a notion of making beekeeping an exclusive business he should seek some locality where there is an abundance of flora capable of furnishing a good table honey that will bring a good price, and a locality which, at the same time, is not already occupied by other beekeepers, thus overstocking. See OverSTOCKJNG.

\section{THE QUESTION OF THE MAN.}

Some men who do well with a small business would make a failure with a large one. Going into beekeeping extensively not only requires capital and brains but a large amount of business ability. With the ele- ment of business ability comes the question of experience. Certainly no one should engage in the bee business in an extensive way unless he has had a large amount of practical knowledge of a kind that starts from the bottom and works upward. See Beginniag with Bees; also Backlot BeeKEEPING. A large business gradually built up from a small beginning is much more sure of success, especially if the man who made the start is still the presiding genius of the large business. While one can sometimes buy a man of successful experience, it is better for the boss to have the know how himself; otherwise, if his man leaves him for any cause he would be sadly crippled. Moreover, if he knows the business himself, his help can not impose on him by pretending to "know it all."

\section{CAPITAL.}

Capital is another important requisite. This need not, however, be a serious obstacle if one would be willing to start with a small beginning and make the bees pay their own way, as we have taught all thru this work. One would be much more likely: to meet with success if he gradually enlarges his business, bearing in mind the danger of trying to expand too fast.

SPECIALIST BEEKEEPERS; WHERE LOCATED.

The number of persons who make beekeeping a specialty is constantly increasing: but most of the specialist beekeepers are located west of the Mississippi. Where alfalfa is grown extensively we often find beekeepers who number their colonies by the thousand. The mountain-sage districts of California sometimes make specialized beekeeping a possibility. As a general proposition, howerer, it may be stated that where there is one specialist beekeeper there are a thousand who combine the business of honey production with some other profession or business. See BACKLOT BEEkeeping; Farmer Beekeepers; Beekeeping and Fruit-growing; Bees and PoulTRY.

\section{SPECIFIC GRAVITY OF HONEY.-} Ordinary extracted honey when ready for the market should run about 12 lbs. to the gallon at normal temperature. If, however, it is heated to $1350: 140 \mathrm{Fahr}$., to prevent granulation (see Granulation of HoNer), the specific gravity while at this temperature will be about $11 \mathrm{lbs} .10 \mathrm{oz}$. to 
the gallon. As the average gallon can will not hold $12 \mathrm{lbs}$. of honey at a temperature sufficiently high to prevent granulation, the consumer will not get a gallon of honey.

There are some honeys that run about $111 / 2$ lbs. to the gallon, but they should never be put in sealed cans nor marketed when as thin as that, as they are almost sure to sour. They should rather be stored in open vats or cans in a dry room for a few weeks, so that the excess of moisture can escape. Honey exposed in a damp atmosphere will take on more moisture. It is, therefore, important that the artificial ripening process take place in a warm $d r y$ room, heated artificially if necessary. As a rule it is not wise to extract honey in the eastern states unless three-fourths of all the cells are capped over; and sometimes then the honey should be left on the hive until all the cells are sealed. In the western states where there is a drier atmosphere, or during extremely hot dry weather in the East, a larger percentage of unsealed cells may be permissible at the time the combs are extracted; but it is best to store in open cans for a short time before shipping. See Honey, Analysis OF.

When honey is not thoroly ripened that is to say, when it runs a little short of $12 \mathrm{lbs}$. to the gallon, the thinner portion is apt to rise to the top while the heavier part will settle to the bottom (see ExTRACTED HoNEY). The top will have a tendency to sour, and it will not be long before the whole mass will be involved. If the souring or fermenting process has not gone too far, the honey may be saved by heating, thus destroying the yeast plant. But if it has gone too far, nothing can be done but convert the honey into vinegar. See Vinegar.

\section{SPRAYING FRUIT - TREES. - See Fruit-Blossoms.}

SPRAYING DESTRUCTIVE TO THE BROOD.-See FrUIT-BLOSSOMS.

SPREADING BROOD.-As is very well known, queens are inclined to lay their eggs in circles in the comb, the circle being larger in the center combs and smaller in the outside ones. The whole bulk of eggs and brood in several combs thus forms practically a sphere which the bees are able to cover and keep warm. When the queen has formed this sphere of brood and eggs she curtails her egg-laying for the time being until enough brood is hatched out to increase the size of the cluster; when she will gradually enlarge the circles of brood to keep pace with the enlarged ball of bees.

Yet the queen very often is overcarefulthat is, she errs on the safe side, so that when warm weather has fully set in she sometimes lays fewer eggs than she should in the judgment of the apiarist, and accordingly he inserts a frame of empty comb in the center of the brood-nest. In this comb the queen may commence laying at once to unite, as it were, the two halves of brood. More often she does not. In that case more harm than good has been done. If the queen does fill the first one given she will be likely, if the weather is not cold, to go into the second comb and fill it with eggs on both sides; for nice clean empty cells are very tempting to her. In a word, this operation of inserting empty combs in the center of the brood-nest is called "spreading brood," its object being to increase the amount of brood, and thus insure a larger force of workers for the prospective harvest. While this spreading of the brood may be done by practical and experienced beekeepers, because it stimulates the queen to greater egg-laying capacity, yet when practiced by beginners and the inexperienced it generally results in much more harm than good as already stated. A beginner without previous experience might, on a warm day in early spring, think it high time to put empty comb in the center of the brood-nest. The queen, we shall say, immediately occupies it, filling it with eggs. This, of course, requires a large force of nurse-bees to take care of the young bees and hatching larvæ. A cool spell of weather is almost sure to come on, with the result that the cluster of bees is contracted, leaving the brood that was forced outside, out in the cold, where it chills and dies. The outside edge of the cluster, in its effort to take care of this brood, is likewise chilled, and the colony suffers a check and setback far worse than had it been left to its own devices.

Ordinarily the spreading of brood can be practiced safely only after settled warm weather has arrived. The beginner who desires to give extra combs for egg-laying, 
especially in early spring, would do well to put those extra combs at the outside; but after settled warm weather has come, when the temperature does not go below 60 degrees Fahrenheit at night at any time, he may insert a frame of empty comb at the center of the brood-nest.

It should be borne in mind that the practice of spreading brood has been largely abandoned, even by experienced beekeepers. Where the queen has plenty of room somewhere in the brood-nest (and that "somewhere" should be outside the broodcluster), both bees and queen will ordinarily rear as much brood as they can safely and profitably care for.

SPRING DWINDLING.-This is confined to bees outdoors or those just set out of the cellar, and appears only in springhence the name. It was once supposed to be a disease; but it has now been definitely determined to be only the natural result of a severe winter on a colony too weak or a normal one not protected to stand the cold. Gradually the individual members die off until the original bunch of bees is reduced to a few dozens. This decimation may be due to a low vitality on the part of the old bees that are inclined to die off any way before spring, or it may be due to dysentery. See Dysenterry. If it is caused by the first mentioned, it shows that the colony went into winter quarters with almost no young bees; that is to say, the great force representing the colony was made up of old bees whose length of days would naturally expire at the beginning of the spring, even under good or the best conditions; when, therefore, the conditions are not favorable, naturally enough these old bees die off much the sooner.

On the other hand, if spring dwindling is due to dysentery, the condition of the colony in the fall previous, if it could be known, would probably show an insufficient profection, or a cluster too weak in the first place to stand even an ordinary winter, to say nothing of one that is exceptionally cold. Under Drsentery it is shown that this disease or malady, rather, is the result of overfeeding. Overfeeding is caused by an attempt on the part of the bees to keep themselves warm. A cluster too small, or a normal cluster in a single-walled hive, in a cold climate, will overeat; and as the bees have no opportunity for flight, their intestines become orercharged, resulting finally in purging, and this purging fouls up the whole hive. An examination down in the brood-nest at about this stage in the spring shows a small weakened cluster, bees uneasy and somewhat scattered, and combs emitting a nasty ill-smelling odor of excrement. The bees have greatly distended abdomens, showing that they are orerloaded with fecal matter, as explained under DrSentery. A normal colony should show a compact quiet cluster of bees.

A good flight in warm weather will enable diseased bees to cleanse themselves and make a new start. In fact, continuous warm weather is a relief for spring dwindling. But, unfortunately, in many localities there will come a week or two of warm weather at which time bees will start broodrearing. When a cold spell comes on, the already greatly attenuated force attempts to hover its brood, with the result that both brood and bees die. A changeable condition of weather, therefore. is hard on nuclei that are suffering from spring dwindling.

In this connection, spring dwindling caused by dysentery may be due to bad food; but in most cases it is caused by insufficient housing-that is, a lack of proper packing. See Spring Managemient.

\section{RFMEDY FOR SPRING DIVINDLING.}

Sometimes several of the nuclei that have been reduced by spring dwindling may be united; but in most cases this does little or no good. While the combined force of bees all in one hive look well at the time of uniting, yet in a few days this large force seems to have diminished very rapidly, and, unfortunately, it is no better so far as strength or appearance is concerned than any one of the several nuclei that went to compose it in the first place.

Probably the best way to unite is on the Alexander plan, as given under the head of UNiTing. If practiced early it will prevent spring dwindling.

As a further prevention colonies should be made to rear brood as late in the fall as possible. If there is any fall flow, bees will rear brood naturally, and the hives will be filled with a large force of young bees. If there is no fall flow, stimulation should be practiced. See Feeding. This stimu- 
lative feeding may not start up brood-rearing if the queens are two or three years old. As a rule it does not pay to keep queens longer than two years; and many think that they should not be older than one year. Young queens will lay readily in the fall if given stimulative feeding, while old queens may require considerable coaxing. It follows that one of the best preventions for spring dwindling is a young queen in the fall. Such queens will lay until a large amount of stores is used up in August and September, in the northern states, and the beekeeper should, therefore, see to it that they have sufficient after they cease broodrearing. This brings up another important matter; and that is, there is nothing better than good sugar stores for the prevention of spring dwindling or dysentery; and these should by all means be given in the fall early enough to be sealed over, rather than in the spring.

For particulars on how to protect the colonies to avoid spring dwindling, see Spring MaNagement and Wintering. For the causes that induce dysentery in colonies that spring dwindle, see Dxsenterx. For particulars on how to feed in the fall, see Feeding and Feeders, subhead, "Feeding to Stimulate." For the consideration of the question of uniting, see the Alexander method under the head of UNITING.

SPRING MANAGEMENT. - All colonies should be gone over very carefully as soon as bees can fly, to determine their stores. Unless they have two or three combs of honey, stores should be taken from some other colonies that can spare them. If no hive has a surplus, the needy should be fed a thick syrup consisting of two parts of sugar to one of water. See FEEDING, especially those instructions urging fall rather than spring feeding.

Feeders should be placed on top of the frames, and covered with packing. It may turn cold shortly after; and even if the syrup is left in the feeder, starvation will be averted, for the bees will cluster around it and help themselves as they have need. When the weather is cool or cold the syrup should be given hot.

If colonies have been well housed and fed in the fall as they should be, there will be no occasion for feeding or equalizing of stores. Of course, there is liable to be occasionally a colony which, by reason of bad stores, may have dysentery. In that case the front of the hive will be soiled with dark-brown spots, and there will be a quantity of dead bees in front of the entrance and on the bottom of the hive. Such a colony, even with the best of nursing, may die before settled warm weather comes on. If considerable honey-dew has been gathered during the previous summer, one is likely to find some spring dwindling and dysentery in some of the hives. Some honey-dews will make a very fair winter food; but the majority of them, especially those gathered from hickory and oak, are bad. If this is the case as much of it as possible should be used in brood-rearing in the summer, and then sugar syrup should be fed.

Some springs the weather will open up warm very suddenly with no natural pollen available. The warm weather may last several days. During this time brood-rearing will start up rapidly; and if there is no pollen in the hives the bees will be hunting around in the barns and stables

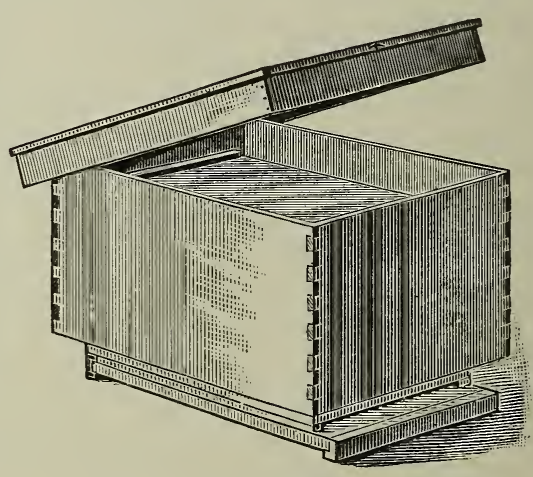

Outer case used for spring protection.

and chicken-coops for bran or chopped feed. It is necessary at such times to give artificial pollen. Trays should be set out in sunny places, under cover if possible, containing a few quarts of rye or pea flour.

Unless bees can have natural or artificial pollen when brood-rearing starts, considerable brood will be found dead. On seeing this the beginner is apt to conclude his bees have some form of bee disease-possibly foul brood. If the brood dies shortly after a sudden warming-up spell, during which there is very little natural pollen in or out of the hives, the owner of the bees should 
await further developments. See Pollen, subhead, "Bees Robbing from Barns and Stables."

It may be necessary in some climates, after the bees are set out of the cellar on their summer stands, to provide some sort of protection.

Where colonies are very weak it may be advisable to unite; but this uniting, if the bees are in the cellar, should take place before they are set out. See Unitivg.

One difficulty in uniting outdoor bees is that those moved to a new stand are quite inclined to go back to the old hive. This can be overcome to a great extent. See UNITING. Uniting in the spring is often unsatisfactory. Never unite two weak ones, but add a weak one to a medium, and thus make it strong. Unless the colony is very weak take out the surplus of combs that it does not occupy or use, and crowd the little cluster on as few frames as it can occupy. In that case, division-boards should be moved over, and the frames set over on the other side. The hive should be warmly packed, and the entrance contracted down to one inch wide to prevent robbing and to conserve heat.

In going over the yard in early spring one is likely to find, if the bees are wintered outdoors, one or more dead colonies. Their entrances should be shut up beetight, for on the first warm fly day they will be robbed out by the other bees, resulting in a general disturbance of the whole yard. See Robiing. Combs on which bees have died may be used later on by putting fresh bees on them. Unless they are very badly soiled with dysentery so they are fairly smeared over with a brown excrement, or the stores are very bad, they can be used again. But badly soiled comb, or otherwise undesirable, should be put thru the wax-extractor. See WAX; alșo Dysentery.

In early spring it may be necessary to rake out the dead bees in the entrances of some colonies. If a colony is strong it will usually do its own house-cleaning; but sometimes the dead accumulate in such numbers as actually to block the entrance. In all such cases there is danger that the few survivors may die outright.

Some very weak colonies will be found with queens, while there will be some other colonies fairly strong without any queen. In that case it is best to unite these two, moving the weak colony over to the strong one. See Uniting; also Introducing.

Some experienced beekeepers can "spread brood" in early spring; but the beginner will do well not to practice it. See SpREADING BROOD.

It sometimes happens that there will be weak and strong colonies in the same yard. The latter will be too strong and the weak too weak. Some have practiced exchanging places with the two colonies. If they are next adjoining, this can be done very nicely; but the exchange should never be made except during warm weather. The flying bees of the strong colony can enter their old stand where the weak colony has been placed. This will build it up while the old colony on the stand of the weak one will be depleted of bees. No harm to the brood will be done if the weather is warm.

This plan is practiced to a considerable extent by some of our large beekeepers and particularly by Ira D. Bartlett, of Michigan.

\section{STATISTICS CONCERNING THE BEE AND HONEY BUSINESS. - It is} regretable that there are no accurate figures concerning the number of beekeepers and number of colonies of bees in the whole United States. While the census reports beekeeping among other industries of the country, yet an examination of the figures for 1900 and 1910 show that they should not be taken too seriously. They may be accurate for some individual states, but it is nevertheless a fact that they are very inaccurate for other states. Attention to this will be called a little later.

But why should we not take the census bureau figures too seriously? In some states at least it is apparent that the census enumerators were much more careful in gathering their data than in others. Take a case in point. In 1900 the United States census figures showed that one of the states in the Union, namely, North Carolina, where beekeeping is a comparatively neglected industry, was actually reporting more bees and more honey than the great state of California, where it is known there is more honey produced than in almost any state in the Union, in a good season at least. The explanation of this is doubtless due to the fact that the census enumerators for North Carolina were careful to get in their record every beekeeper and every farm where bees 
were kept, while in the more important state of California, where beekeeping is a large and flourishing industry, the census enumerators did their work very poorly. Many of the largest bee ranches in the United States are located up in the mountains in the sage district of California. The enumerators probably did not get track of these. In a general way, it may be said in this connection that many of the most extensive beekeepers of the world are located in out-of-the-way districts apart from the general public, and for that reason the enumerators probably failed to get any record of them. But in these same districts sometimes honey is produced by carloads. We should therefore judge that the census people did not get any record of some of the largest bee ranches in the world.

Again, it is well to call attention to the fact that the census for both 1900 and 1910 take into account only bees on farms. There are a very large number of people who keep bees, that are located in the towns and cities, and some of these are quite extensive producers of honey. Attention will be called to this later.

Let us take-another case in point that shows the Cnited States census is not to be taken seriously. At one of our principal state beekeepers' conventions it was found that approximately three-fourths of the bees there represented had not been included in the 1910 census account. A similar condition has been found in other conventions, and if this is true it is no small wonder that the United States census does not adequately represent the bee and honey industry in the United States.

It is to be hoped that ere another ten years rolls by the United States Census Bureau will appreciate the importance of the beekeeping industry and will see to it that its employees or enumerators in every state alike take as much pains in getting data concerning bees and honey as they do of the other larger industries in the country. Unfortunately, the census people appear to have had the impression that the keeping of bees is a very small industry, and hardly worth taking into account. It is time they knew that there are millions in the business.

Fortunately, the authors are in possession of data showing the amount of the beekeepers' supplies sold thruout the United States, and these data enable us to form a fairly accurate idea of the relative importance of the industry. When we find that the United States census figures are very much at variance with our data, we know there must be some mistake, and this mistake is due rather to the manner in which Uncle Sam has secured his figures.

Knowing that the census figures for 1900 were grossly inaccurate, all the manufacturers of beekeepers' supplies in the United States agreed to turn over a record of their complete output of sections to Dr. C. C. Miller, of Marengo, Illinois. As there would necessarily be some rivalry between the various manufacturers, it was agreed on the part of all that the relative output of each factory would be kept entirely secret, and that only the total or gross aggregate should be given out to the public. The figures were duly turned over to Dr. Miller, and he subsequently made public the total aggregate, showing that there is annually manufactured in the United States sixty million section honey-boxes. As these figures were based upon an average taken from a period of years, the actual annual output of sections as here given is fairly accurate. As each honey-box holds slightly less than a pound on the average, it is fair to assume that the actual yearly output of comb honey in the United States is somewhere around fifty million pounds. So much for comb honey.

At the time these figures were taken by Dr. Miller it was generally estimated that there was three times as much extracted honey as comb, but at the present time it would be conservative to say that there is at least five times as much. If we use the multiple of three, the total amount of extracted honey would be one hundred and fifty million pounds of this product; or if we used the multiple of five, the total would be two hundred and fifty million pounds. But let us take the lower figure and consider that the actual amount of extracted honey produced in any one year is one hundred and fifty million pounds. To this should be added the fifty million pounds of comb honey, making a total of two hundred million pounds.

Extracted honey sells anywhere from five to ten cents per pound, and comb anywhere from ten to thirty cents per pound. But let us take the conservative figure of ten cents as an average price that honey 
sells for, both comb and extracted. This would make twenty million dollars' worth of honey that is annually produced in the United States in any single year. As the average mind cannot comprehend these figures we will load these two hundred million pounds of honey into freight cars of thirty thousand pounds to a forty-foot car. Let us put all these cars together into one solid train and we will have a train fifty miles long. The arerage person when he considers these figures, especially when it is loaded into freight cars like this, thinks there must be some mistake, and that it cannot be possible that any amount of honey like that was produced in the United States alone. Even if we accept the United States census figures (which we are satisfied take into account only about half the amount of honey produced in the United States) we will still have as the annual production ten million dollars' worth of honey. Considering the fact that the census enumerators skip large areas, and in many cases omit to take into account the product from extensive apiaries located in out-ofthe-way districts, as well as the large number of bees located in towns and cities, it is fair to assume that our own figures of twenty million dollars' worth of honey annually produced in the United States are much more accurate than those given us by the government.

Now the question arises, how many colonies of bees are there, and how many beekeepers in the United States? If we estimate for convenience that the arerage output per hive each year, taking one year with another, is somewhere about twenty pounds ; if we accept the figures of two hundred million pounds as the total aggregate production in the United States, we would have in the neighborhood of about ten million colonies of bees. If we estimate that each beekeeper in the country has on the average about ten colonies, we would then have a million beekeepers in the United States. The United States census shows that there were nearly six hundred thousand farms reporting bees in 1910, and seven hundred thousand in 1900, showing a falling-off of one hundred thousand during the ten years. Attention will be called to this later. As these figures do not take into account the large number of persons keeping bees in cities and towns, many of whom produce honey by the carload, it is safe to estimate that the total number of persons keeping bees in the United States is somewhere around one million, or the same number arrived at by the other calculation based on the total aggregate of honey produced in the country.

Thirty or forty years ago, most of the honey in the United States was produced east of the Mississippi from clover. In many parts of this section of the country the pasture lands have given away to intensive agriculture, and while it is no doubt true that more clover honey is produced now east of the Mississippi than during an earlier time, because there are more bees, yet it is safe to say that the clover area is becoming less and less. Howerer, this reduetion in white clorer is being offset to a great extent by the sowing of alsike clover on farms where red clover grows only sparingly. See Clover. In the mean time, irrigation has opened immense tracts where alfalfa is being grown, so that at the present time most of the honey being produced in the United States comes from the country west of the Mississippi. At all events, the markets are better supplied with mountain sage and alfalfa than they are with clover honey. Over against this we must take into consideration that the great centers of population are east of the Mississippi, and the probabilities are that most of the clover honey produced in that part of the country is consumed locally. In the West the country is much more sparsely settled, but, on the other hand, beekeeping is carried on in a much more extensive way. The result is that the West produces more than it can consume, and it is shipped eastward. Even when we take all these factors into consideration the fact remains that the great bulk of the honey comes from the West. For example, in a good year California would doubtless lead off. Indeed, there has actually been shipped out of that state after a good season as high as five hundred cars of honey. This does not take into account the large consumption of honey within the state. Texas would follow as a close second. Then we would place next in order Colorado, Arizona, Idaho, and, in general, those states where alfalfa is grown very largely. According to the United States census figures which we will reproduce shortly, Missouri and Illinois fol- 
low very closely after the two great states of Texas and California in the matter of honey production. This may or may not be true; but if Illinois, Missouri, New York, and Pennsylvania produce as much honey as is credited to them by the census, there are certain other states with conditions practically as good that should produce almost as much. But a comparison of the table shows in most cases that they are away below. If the census enumerators did their work as faithfully in these states where the showing is light, as was done in Illinois, Missouri, New York, and Pennsylvania, it would show that the poor states mentioned were much better. But the facts are that the soil, conditions, climate, and all are about the same in a number of the states, and there should not be such a difference as we find between Kansas and Missouri, for example, or between Minnesota and Wisconsin, or Minnesota and Illinois.

In respect to the amount of beeswax annually produced in the United States, the Bureau of. Entomology has estimated that there is about two million dollars' worth, or about one-tenth of the value of honey annually produced in the country. But beeswax sells anywhere from 30 to 35 cents per pound, and that is two and a half or three times as much as honey brings, if we figure 10 cents as the average price of both comb and extracted. On this basis, for every pound of wax produced there would be from 25 to $30 \mathrm{lbs}$. of honey; and this proportion would not be far from correct. The presumption is that the census enumerators were more careful to get the exact account or the amount of beeswax on hand at the farms because of its larger relative value.

\begin{tabular}{|c|c|c|c|c|c|c|c|c|c|}
\hline \multirow[t]{2}{*}{ State } & \multicolumn{2}{|c|}{$\begin{array}{l}\text { Farms } \\
\text { reporting }\end{array}$} & $\begin{array}{l}\text { Per } \\
\text { cent } \\
\text { of } \\
\text { gain }\end{array}$ & \multicolumn{2}{|c|}{$\begin{array}{l}\text { Colonies } \\
\text { reported }\end{array}$} & \multirow[t]{2}{*}{$\begin{array}{c}\text { Per } \\
\text { cent } \\
\text { of } \\
\text { gain } \\
\text { or loss }\end{array}$} & \multicolumn{2}{|c|}{ Value in dollars } & $\begin{array}{l}\text { Per } \\
\text { cent } \\
\text { of } \\
\text { gain }\end{array}$ \\
\hline & & & or loss & 1910 & 1900 & & & & \\
\hline Alabama .... & 23,911 & 32,100 & -25.5 & 135,140 & 205,269 & -34.2 & 213,000 & 288,000 & -26.0 \\
\hline Arizona .... & 441 & 489 & -9.8 & 23,770 & 991 & $\dagger 25.2$ & & 00 & $\dagger 56.7$ \\
\hline kansas ... & 19,692 & 22,182 & -11.2 & 92,7 & 11 & $\dagger 16$ & & 00 & 2.1 \\
\hline 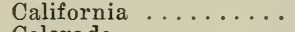 & 6,869 & 6,915 & -0.7 & 200,7 & 12 & $\dagger 55$ & 00 & 00 & $\dagger 100.1$ \\
\hline Colorado .......... & 3,563 & 4,518 & -21.1 & 71,4 & 56 & $\dagger 19.5$ & 30 & 000 & $\dagger 58.5$ \\
\hline Connecticut $\ldots \ldots \ldots$. & 1,798 & 2,252 & -20.2 & 9,445 & 11,438 & -17.4 & 00 & 40,500 & † 3.2 \\
\hline Delaware ........ & 1,119 & 1,684 & -33.6 & 6,4 & 10,187 & -37.1 & 13,600 & 20,244 & -32.8 \\
\hline District of Columbia.. & 1 & 7 & $\dagger 85.7$ & & $\begin{array}{r}59 \\
759\end{array}$ & $\dagger 155.9$ & & 99 & $\dagger 297.0$ \\
\hline orida $\ldots \ldots \ldots \ldots$ & 4,345 & 4,521 & $-\quad 3.9$ & 38,8 & 753 & -2.2 & 00 & 83,800 & $\dagger 17.5$ \\
\hline rgia ... & 23,167 & 32,246 & -28.2 & 130 & 919 & -30.5 & 18 & 000 & -22.9 \\
\hline$\cdots$ & & 87 & -0.8 & & & $\dagger 13$ & & 00 & $\dagger 54.1$ \\
\hline & & 32 & -14.9 & 155 & & -13 & & 00 & 0.3 \\
\hline Iowa & & & -31.9 & & & -30 & & & -17.4 \\
\hline Kansas $\ldots \ldots \ldots$ & 16,869 & 18,295 & $\begin{array}{r}0.1 \\
-\quad 7.8 \\
\end{array}$ & $\begin{array}{r}160,0 \\
73,7\end{array}$ & 138,811 & $\begin{array}{ll}\dagger & 15 \\
-16 & 0\end{array}$ & & & $\dagger 16.5$ \\
\hline tucky $\ldots \ldots$ & 36,854 & 44,974 & -18.1 & 152,9 & 203,820 & -24.9 & 000 & 00 & $\begin{array}{l}-21.4 \\
-20.4\end{array}$ \\
\hline $\operatorname{sian} a \ldots \ldots . . .$. & 4,928 & 6,148 & -19.8 & 29,5 & & -16.0 & & 300 & $\dagger \quad 7.1$ \\
\hline & 1,371 & 2,496 & -45.1 & 7,5 & & -30.1 & & & -21.0 \\
\hline land. & 4,186 & 5,098 & -17.9 & 23,156 & 28,013 & -17.3 & 300 & 00 & $\dagger \quad 1.0$ \\
\hline chusetts ..... & 1,597 & 1,799 & -11.2 & 7,464 & 8,381 & -10.9 & 700 & 300 & 11.0 \\
\hline$n \ldots \ldots$. & 16,892 & 18,122 & -6.8 & 115,274 & 100,397 & $\dagger 14.8$ & 44 & 500 & 26.7 \\
\hline . & 9,522 & 6,078 & $\dagger 56.7$ & 56,6 & 45,877 & $\dagger 23.5$ & 22 & 300 & 32.6 \\
\hline ssippi . & 16,028 & & -10.9 & 74,3 & 95,257 & -21.9 & 144 & 000 & 9.1 \\
\hline $1 \mathrm{ri} \ldots$ & 40,110 & 41,145 & -2.5 & 203,5 & 205,110 & -0.8 & 585 & 508 & 15.0 \\
\hline$\ldots \ldots$ & 795 & 234 & $\dagger 239.7$ & 6,3 & & $\uparrow 250.5$ & & 00 & $\uparrow 294.5$ \\
\hline ebraska ........... & 12,538 & 12,130 & $\dagger \quad 3.4$ & 45,625 & 52,143 & -12.5 & 153 & 200 & -23.5 \\
\hline rada $\ldots . . . .$. & 176 & 278 & -36.7 & 8, & 5,692 & $\div 47.6$ & 00 & 00 & $\dagger 140.7$ \\
\hline New Hampsh & 1,002 & 1,288 & -22.2 & 644 & 5,520 & -15.9 & 00 & 700 & -4.3 \\
\hline New Mexico. & & 410 & $\dagger \quad 2.0$ & & & $\dagger 63.1$ & & 00 & $\dagger 122.6$ \\
\hline New Jersey & 1,627 & 2,327 & -30.1 & & 14,118 & -25.7 & 00 & 200 & $\dagger \quad 6.0$ \\
\hline New York & 5,279 & 22,738 & -32.9 & 156 & 08 & -16.5 & 00 & 594 & 8.9 \\
\hline North Carolin & 36,258 & 41,051 & -11.7 & 188,9 & 244,539 & -22.7 & 387 & 430,000 & -10.1 \\
\hline North Dakota. & 79 & 30 & $\dagger 163.3$ & & 79 & $\dagger 77.4$ & & 474 & $\dagger 109.4$ \\
\hline &, 203 & 34,458 & -32.7 & 98,241 & 151,391 & -35.1 & 000 & 403,000 & -31.5 \\
\hline $\mathrm{na}$ & & 3,438 & † 40.1 & 19,4 & 37 & -3.7 & & 400 & $\dagger 41.5$ \\
\hline . & 8,861 & 8,895 & -0.4 & 47,285 & 585 & -14.9 & 150 & 160 & -6.4 \\
\hline & 22,297 & 28,962 & -23.0 & 124,830 & 161,670 & -22.8 & 478 & 532 , & -10.0 \\
\hline $\begin{array}{l}\text { Knode is } \\
\text { South Ce }\end{array}$ & $\begin{array}{l}285 \\
598\end{array}$ & 370 & -23.0 & 1,267 & 1,681 & -2 & & 300 & 9.7 \\
\hline uth Dakota. & $\begin{array}{r}12 \\
1\end{array}$ & 16,272 & -23.0 & 75,422 & 93,958 & -1 & 13 & 143 & 5.6 \\
\hline nessee ..... & $\begin{array}{r}1,347 \\
30,712\end{array}$ & $\begin{array}{r}387 \\
38,225\end{array}$ & +248 & & & +21 & $\begin{array}{l}600 \\
600\end{array}$ & & $\begin{array}{r}7213.1 \\
-30.0\end{array}$ \\
\hline xas $\ldots$ & 37,875 & 60,043 & -36.9 & $\begin{array}{l}144,4 \\
238,1\end{array}$ & 2,644 & -39.4 & 00 & 000 & $\begin{array}{r}-9.9 \\
\end{array}$ \\
\hline & 1,873 & 3,037 & -49.5 & 26 &, 818 & -22.6 & 12 & 1,500 & $\dagger 10.9$ \\
\hline$\ldots \ldots \ldots$ & 1,124 & 1,878 & -40.2 & 10,2 & 12,836 & -20.4 & 00 & 47,000 & -5.5 \\
\hline & 22,437 & 25,774 & -12.8 & 104,005 & 139,064 & -25.2 & 30 & 000 & -1.9 \\
\hline & & 4,435 & $\dagger 32.7$ & 33,884 & 30,870 & $\dagger \quad 9.8$ &, 000 & 107,000 & $\dagger 18.8$ \\
\hline t Virginia .. & 24,0 & 25,240 & -4.8 & 110,673 & 111,417 & -0.7 & $3.88,900$ & 375,600 & $\dagger \quad 3.5$ \\
\hline consin $\ldots \ldots$ & 10,391 & 10,535 & - 1.4 & 95,638 & 106,090 & -9.9 & 360,500 & 377,000 & -4.4 \\
\hline oming $\ldots$. & 579 & 153 & $1 \div 278.4$ & 4,090 & 1,020 & $1 \div 350.6$ & 20,493 & 5,322 & $\uparrow 285.1$ \\
\hline Grand total....... & 590,907 & & & $3,462,52$ & 258,239 & & $10,372,978$ & 179,839 & \\
\hline
\end{tabular}

A dash (-) before a number indicates a loss; $\uparrow$ shows a gain. 
A little way back reference is made to the fact that the United States census for 1910 should not be taken too seriously; but it should be said that it is valuable for the purpose of comparison, as both were taken by the same method. We herewith present a comparative table of the census for 1900 and 1910. The student will be interested in comparing the figures. For instance, there has been a marked falling off in the number of farms where bees were reported. That there has been a decrease in the number of farmer beekeepers there can be no question. Whether the table showing the decrease by states is accurate cannot be proven; but decrease there surely has been in the aggregate. This is probably due to two causes; viz., 1 . To a reduction in the amount of clover grown, either because intensive agriculture has crowdied it outh, or because soil that once grew elover luxuriantly has become "clover-sick" - that is, too acid. Clover is the main dependence for honey in most of the states east of the Mississippi and north of the Ohio. It is a notable fact that clover has not yielded as it did in the olden days before the lime had been exhausted from the soil. See Clover. When "bees don't pay" on the farm, they die off because the farmers won't feed them. We shall have more to say about this at a later time. 2. The other cause for reduction in the number of farmer beekeepers is clearly traceable to bee disease that has made such rapid spread. The obvious remedy is to work for more extensive bee-inspection work, and, besides, preach the doctrine of putting lime in the soil. That can be done cheaply, and make clover grow as before. While lime can have no effect on bee diseases it will make clover grow as it did in old days.

Attention should be called to the fact already mentioned, that these data are for bees on farms only, and that bees in towns and cities are not included. The official designation of a "farm " actually includes many apiaries in towns; but, as is well recognized, most of the large town apiaries have not been included in the enumeration.

The only states showing any increase in beekeepers worthy of consideration are Minnesota, Oklahoma, South Dakota, Washington, Montana, Wyoming, and North Dakota-all western states. The greatest reported loss is Utah, where 49.5 per cent decrease is shown in the number of farms reporting bees. It is worthy of mention that the loss in number of farms reporting bees is usually greater than the number of colonies, indicating that those now in the business are keeping more bees. On account of bee diseases already mentioned, farms that used to keep bees in a small way have now been obliged to give up the business because bee disease will not allow bees to work for nothing and board themselves as they used to do in the olden days. The result is now that there is a smaller number of beekeepers in the country, perhaps, but a larger number of colonies of bees. In some of the western states there are not a few beekeepers who count their colonies by the thousand and who produce honey by the carload.

Taking everything into consideration, the beekeeping industry is certainly growing. The bee-supply factories all over the country show a healthy increase; and the business of selling honey is being organized and developed now as it never was before. While there are fewer bee journals in the United States than there were ten years ago, yet these bee journals are of a much higher class with a much larger circulation. This would indicate a larger interest in bees, not on the part of everybody, but on the part of those who are making the business more of a study.

STINGLESS BEES.-See BeEs, StingLESS,

STINGS. - Many persons, doubtless, would keep bees were it not for the natural fear of stings; but when their habits are thoroly understood this fear disappears almost entirely. The average beekeeper pays no more attention to a sting or two received on his fingers than the mechanic who bruises his knuckles when a wrench slips. When bees are properly handled the number of stings can be reduced down to a very low percentage. Very often one can work all day among his bees and not receive a single jab; and at other times, if he is a little careless, or if he takes chances, he may get a regular onslaught of a dozen at a time. When, however, one exercises ordinary precaution he will receive only an occasional sting; and eren the effects of that, if he is quick enough, can be minimized to such an 
extent that it will be difficult for him to find it an hour afterward. The writer once worked a whole month without a sting.

As will be pointed out later, the moment a sting is received it should be removed instantly-the sooner the better. If it is left in the wound it will gradually work

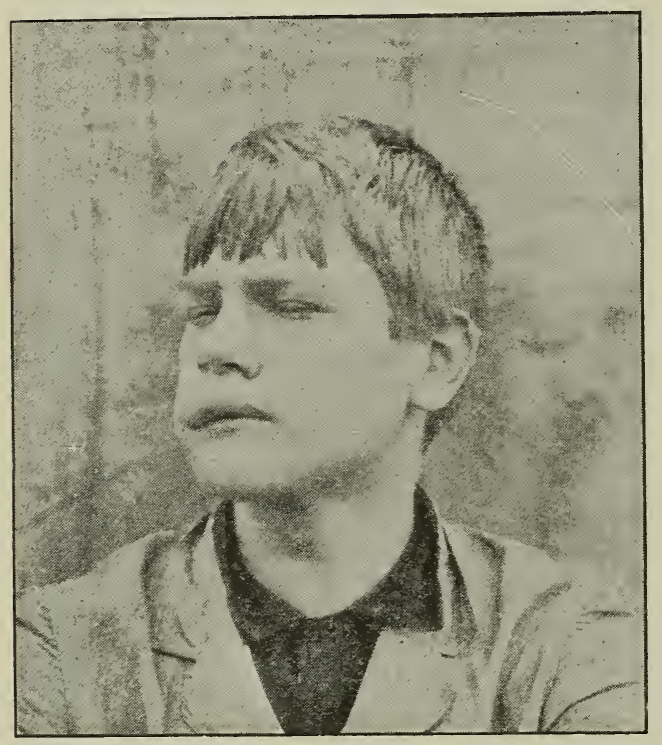

Effect of one bee-sting on the lip of a novice.

itself into the flesh by muscular contraction, discharging the contents of the poisonsac, and the result will be far more severe than if it had been removed immediately, care being taken, of course, not to squeeze the poison-sac during the operation.

It is always advisable for the beginner to wear a bee-veil and a pair of gloves at the start. A good bee-smoker, with the fuel burning well, should be at hand. The time selected for handling the bees should be between 10 o'clock in the morning and 4 in the afternoon. The operator should never stand in front of the entrance-always to one side. A little smoke should be blown in the entrance. The cover should next be lifted gently and more smoke blown between the cover and the hive before the hive is opened. More particulars in regard to opening the hive are given further on under this head, and also under MANIPULATION of Colonies, subhead "How to Open a Hive."

Even after one does receive a sting he should go about his work as tho nothing had happened. If he does not allow his mind to dwell upon the pain he will not feel it. If a sting is received thru the clothing or a glove, it will be a mere prick, and can be instantly removed without getting very much of the effects of the poison.

If one expects to be a beekeeper he should make up his mind that he can overcome his natural fear. $\mathrm{He}$ should understand that when properly handled, the directions being carefully followed out as to time and conditions, bees will be as gentle as kittens; that even when their hive is torn to pieces, and their combs scattered here and there, they will not make a protest. If, however, Mr. Beginner thinks he knows it all, and proceeds to open up a hive without suitable protection, he may be severely stung, with the result that he will conclude beekeeping is an exceedingly hazardous business. On the contrary, it is one of the safest that one can enter into. The average young horse or a Jersey cow is more dangerous than a colony of bees; for either one of them, unless their habits are thoroly understood, can cause loss of life. If one attempts to step into a stall on a dark night, surprising the horse without saying "whoa!" or giving notice of his presence, he may be kicked clear across the barn. In the same way, a stranger who does not know the pranks of a Jersey cow will be dealt with so severely that he may conclude that the animal ought to be slaughtered rather than to be allowed to live. In the same way street cars, automobiles, rowboats, are all sources of danger; and it would be just as reasonable to avoid horses, cows, street cars, and automobiles as it would be to avoid bees because some people have been stung or even have lost their lives thru gross carelessness. Any one of them is safe when properly handled.

Perbaps it may be urged that the pain of the sting could be endured provided there were no further swelling or disfigurement of the features. If one will wear a bee-veil carefully fitted to his clothing, there will not be the slightest excuse for having a swollen eye or a distorted lip. As a matter of fact, after one has been stung a certain number of times his system will become hardened or immune so there will be but little or no swelling. The average beekeeper ean be stung on his face or hands a great many times; and beyond the mere momentary pain there will be no after-effects ex- 
cept a slight soreness for a few hours at the point where the sting was received. The number of stings that one must get before he becomes immune depends somewhat on the individual himself. A very few never have any swelling, and others will become immune after a comparatively small number of stings. Usually in a season's operations one will become proof against swelling after a sting.

Too much emphasis cannot be placed on the absolute importance of removing the sting the moment it is given. This can be done by a quick rubbing or mashing motion, and rery often one can parry or prerent a

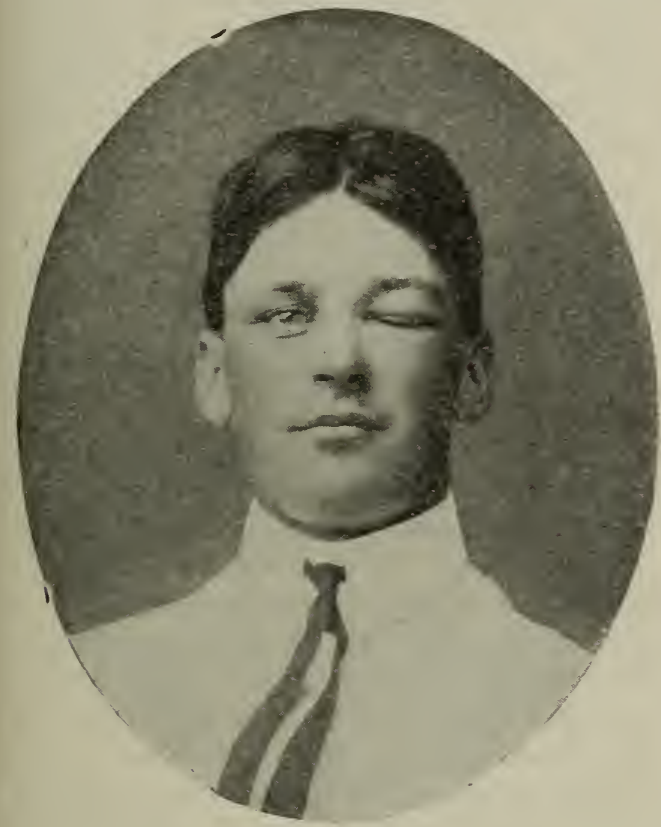

Be proud of your swollen eye!

It isn't the fact that you're licked that counts; It's how did you fight-and why? EDMUND VAXCE COOKE.

sting altogether by smashing the bee or brushing it off before it can get in its work. The bee, in order to sting, must take time enough to sink in its claws before it can force its weapon thru the epidermis of its foe. At the precise instant that one feels the claws of a bee sinking into the skin he should dislodge it if he is in position to do so. Sometimes when he is holding a frame with a valuable queen on it he must "stand and take;" but eren then the frame can be set down gently and the sting removed. Usually, if there is just a mere prick of the skin there will be little or no swelling, and the pain will be hardly noticeable.
THE PROPER WAY TO REMIOVE A STING.

With the blade of a knife, scrape the sting loose, being careful not to break it off nor to press on the poison-sac. A pressure on the latter will force the poison into the wound, making it much worse.

When a knife is not handy, push the sting out with the thumb or finger nail in much the same way. It is quite desirable that the sting be taken out as quickly as possible, for if the barbs (to be described further along) once get hold of the flesh, muscular contraction will rapidly work the sting deeper and deeper. Sometimes the sting separates, leaving part (one of the splinters, so to speak) in the wound. It has been suggested that care should be taken to remore erery one of these tiny points; but after trying many times to see what the effect would be, we have concluded that they do but little harm, and that the main thing is to remove the part containing the poisonbag before it has emptied itself into the wound. When very busy, or haring something in the other hand to make it inconvenient to remove the sting with a knife or finger-nail, we have rubbed the sting out against the clothing; in such a way as to push the poison-bag off sidewise; and altho this plan often breaks off the sting so as to leave splinters in the wound, we have found little if any more trouble from them than usual.

\section{REMEDIES FOR BEE-STINGS.}

Medicines of all kinds are of so little avail, if of any use at all, that the best way is to pay no attention to any of them. This has awakened a great deal of arguing, and the remedies that have been sent, which the writers knew were good, because they had tried them, have been enough to fill this whole chapter. We have tried a great many of them, and, for a time, we imagined they were of value; but after giving them a more extended trial, we have been forced to conclude that they were entirely futile. Nay, further, they not only did no good, but if the directions with the remedy were to rub it in the wound, they did positive harm. The friction would diffuse the poison more rapidly into the circulation, and make a painful stvelling of what would have been very trifling, if let alone. It should be borne in mind that the poison is introduced 
into the flesh thru a puncture so minute that the finest cambric needle could by no manner of means enter where the sting did, and that the flesh closes over so completely after it as to be practically impossible for the remedy to penetrate this opening. Even if there is a remedy that will neutralize the poison in something the same way that an alkali neutralizes any regular acid, how is it possible to get it directly in contact with the poison? There is no way of doing it unless resort is had to a surgical operation. There is no remedy except to remove the sting immediately, and then let the wound alone, and going on with the work without even thinking about it. But, suppose we get a sting under the eye-one that closes up that very important organ; shall we go on with our work? That depends. If it brings on headache or causes great discomfort, rest a while, and in the mean time apply a cold wet cloth until the local fever is allayed. Sometimes applying a hot and cold wet cloth alternately brings relief.

Kerosene was suggested as a remedy, and two of our friends regarded it of such importance that they almost got into a controversy about who was entitled to the honor of the discovery. After having received a very bad sting on the hand, we went for the oil-can and dropped oil on the spot for some time. As kerosene will remove a rusty bolt or screw when nothing else will avail, and as it seems to have a wonderful power of penetrating all cracks and crevices, we began to have faith that it might follow the sting of the bee, and in some way neutralize the poison. But the only result was one of the most painful and lasting wounds we ever had.

WHAT TO DO WHEN HORSES ARE STUNG A GREAT NUMBER OF TIMES AT ONCE.

Severe cases of stinging are usually the result of carelessness, either from allowing combs to be scattered, causing robbing, or because a hive has been bumped over by careless driving, or by some animal allowed the range of the apiary. There are a number of cases on record where horses have been stung to death; and it is hardly safe to hitch such animals within a ferv feet of a hive, nor yet to let them run loose in a beeyard, altho a few sheep may be let in to keep the grass down to advantage.

Mr. Chalon Fowls, of Oberlin, Ohio, left a horse hitched near some hives of what he thought were gentle Italians; but by some means or other the animal bumped one of the hives, irritating the bees, causing them to rush out and sting. The horse, of course, began to plunge and kick, with the result that he demolished completely all the hives within reach. Mr. Fowls said the horse, when he could get to him, was almost literally covered with stings. He unhitched and led him away, and immediately called for a boiler of hot water. This was brought out as soon as it could be heated. Cloths and blankets were immersed in it, almost boiling hot, wrung nearly dry, and laid over the animal, now writhing in the severest agony. The moment Mr. Fowls applied the hot blankets he says the horse quieted down. During the escapade he himself was terribly stung in the face and on the hands; and he says that, as soon as the hot cloths were applied to his face he felt almost instant relief. The cloths were applied to the horse on every portion that was stung, and $\mathrm{Mr}$. Fowls had the satisfaction of knowing that he could save his horse, which was soon as well as ever.

During the summer of 1902 at one of our outyards we had an experience which we thought at the time would be fatal to both man and beast. It came about somewhat in this way. A neighbor of ours who had a field of timothy near our yard had allowed his horse to eat grass within a few feet of the yard while he went to the further end of the field to look after some work. In the mean time the horse had managed to get over among the bees. The result was, she knocked over five hives, and was literally covered with stings when our neighbor came up. Being a practical beeman as well as a borseman himself, he rushed into the fray, freed the horse, and started her for the barn. The animal was beginning to swell badly, and it was evident to him that she would die before relief could be given by a veterinary, even if called. He accordingly rolled up about a pound of common table salt in a paper, opened the animal's mouth, and with the left hand grasped her tongue, pulling it out as far as he could. He then with his right hand shoved the salt clear down her throat, reaching to his elbow. This done, he quickly closed her mouth and elevated her head until he saw the wad of salt go down the gullet. In a short time the 
horse showed relief, for the salt probably neutralized, to some extent, the effect of the acid poison. It also acted as a physic; for when a horse is sick at the stomach he can not vomit, and it is necessary to give him something at once to keep the bowels open. In three or four hours the horse was greatly relieved.

Our neighbor did not apply wet blankets wrung out of hot water; but the veterinary who was consulted afterward, said that the giving of the salt was one of the best things that could have been done, and added that he would have wrapped the animal up in a blanket wrung out of hot water. If to this water was added a small quantity of ammonia, all the better. We suggest, then, if a horse is badly stung, it be given a dose of common salt, and treated to applications of hot blankets, and that the blankets be renewed often. Where hot water cannot be obtained, use cold.

The moral of this is to keep bee-yards fenced off so that no stock or horses can get in. It is also advisable to locate the apiary a few rods from any line fence or hitchingpost. See APIARY.

HOW ONE WHO IS SERIOUSLY AFFECTED BY A SINGLE STING MAY BECOME COMPARATIVELY IMMUNE TO THE POISON.

There are some who are so seriously affected by the bee-sting poison that even a single sting will cause the body to break out in red blotches. Only one person in ten thousand is thus affected. So rare are the reported cases that the editors of Gleanings in Bee Culture, a journal with a circulation of over 20,000 do not hear of them once in ten years. But there are quite a number of others who are less affected but who inform us that a single sting produces great discomfort. While there is no danger of loss of life, the results of a sting are such that they have been obliged to give up the delightful pastime of keeping bees, very much to their regret. We have formerly advised all such persons when going among bees to be veiled and to wear gloves. But in late years we have found a better remedy. It was suggested by the fact that the average person becomes less and less affected by the bee-sting poison: and it occurred to us that, inasmuch as the human system has the power to withstand increas- ing doses of many poisons, after the first one, why should it not be able to immunize itself to a certain extent against the virus of a bee-sting? It is a well-known fact, opium and morphine fiends are able to take doses of those drugs in amounts that would kill ten people who are not in the habit of aking them. The same thing is true of alcohol. It is evident if one who is very seriously affected by bee-sting poison would just merely prick himself with a sting and then brush it off before it has had time to throw much of its virus into the wound, the after-effects would not be very serious; and that if the dose were repeated some four or five days afterward, or about the time the effect of the previous sting had passed away, one could, by continuing this process, ultimately apply the dose at more frequent intervals until in time his system would be 110 more affected than that of an ordinary person.

An interesting case came under obserration. A boy, when stung, became so affected that his body would break out in great red blotches; his breathing grow difficult, and his heart begin to pound like a sledge hammer. It was really a question whether there was not danger of losing his life. Nevertheless he was very desirous of engaging in beekeeping, and determined to work with them. A live bee was pressed on the back of his hand until it merely pierced his skin with the sting. It was removed immediately; and since no serious effect followed another sting prick was administered inside of four or five days. This was continued for some three or four weeks, when the patient began to have a sort of itching sensation all over his body. The hypodermic injections of bee-sting poison were then discontinued. At the end of a month they were repeated at intervals of four or five days. Again after two or three weeks the itching sensation came on, but it was less pronounced. The patient was given a rest of about a month, when the doses were repeated as before. He then went to school and was not back for eight or nine months. On his return the applications were given again, when it was plainly noticeable that the after-effects were becoming markedly less. He then went out into the bee-yard and was stung occasionally, but, beyond a small swelling locally, there was no unpleasant effect. 
Some months afterward he was assisting one of our men at one of our yards, when, without warning, a colony of bees that was being dissected made a most furious attack on both the men. The young man who had been taking the immunizing doses of beevirus received, he estimates, ten or a dozen stings all over his body. He had no veil nor gloves, for the other man was doing the work with the bees. He expected serious consequences; but, greatly to his surprise and gratification, no unpleasant effects followed. What was more, there was no swelling. It should be remembered that this person used to be so seriously affected that a single sting would cause his parents to worry, for they feared he would not be able to survive the attack. He now handles bees with the same freedom that any experienced beekeeper does.

\section{WHAT TO DO WHEN A PATIENT SUFFERS SE- VERELY FROM ONE OR MORE STINGS.}

In the foregoing, allusion was made to the fact that a person not used to stings may suffer severely from one or more stings. It is rare indeed that one sting causes any more than a local pain. Red blotches may break out all over the body. In other cases there may be shortness of breath, a faintness, some nausea, and a weak heart action. When the heart is affected it is very important to keep the patient quiet and cool, and to get the services of a physician at once to administer some heart stimulant. If the patient has been stung a great many times, cloths should be wrung out of hot water and applied to the body. Feet and hands should be kept warm, and the patient, if he has a weak pulse and difficulty in breathing, should be placed near an open window, or, better still, out on the porch where the cool breezes can strike him. If there is no air stirring, it would be well for some one to keep up a vigorous fanning of the face. The body should be warmly covered and protected until the doctor arrives. Where electricity is available an electric fan may be made to play across the face of the patient.

Where one suffers a shock and shows a weak pulse (and these cases are rare) he should be very careful after he recovers from attempting to do any hard manual labor for two or three weeks as he will probably suffer from the shock. He should avoid becoming overheated, and for a day or two after being stung he should be very quiet, keeping as cool as possible. Any exertion may bring back the old trouble of weak pulse, and this of course introduces an element of danger, if not the danger of leaving a permanent legacy of a bad heart.

Where there is no weak action of the heart, that is, the pulse seems to be good, but one suffers from a general fever over the body with red blotches all over, applications of cold cloths wrung out of water sometimes is sufficient to bring relief. Sometimes hot applications are better still. and very often it happens that hot and cold in alternation proves beneficial. In all cases of severe stinging the patient should lie down and keep very quiet, and under no consideration should he attempt to do any manual labol until he is sure he is clear past the shock.

\section{HOW TO AVOID BEING STUNG.}

If the reader will turn to the $\mathrm{A} B \mathrm{C}$ of Beekeeping, also Manipulation of ColoNIES, subhead "How to Open a Hive," and if he has read carefully the beginning of this article, he will have a general knowledge of how to avoid stings. It will be proper at this point to amplify some things already said, and to add others not already covered. The subject is so important that we cannot go over it too fully, even at the risk of repetition. Whether one shall keep bees or not, whether he will be able to make a success of them or not, will depend very largely on how carefully he follows the directions given by number below.

1. He should have a good bee-smoker with the fuel well ignited. The author prefers greasy waste, as it is procurable at almost any machine-shop or garage, and can usually be had for the asking. (See SMokERS.)

2. He should have a bee-veil that is sesurely attached to the hat and to the waist or shirt (see VeILS).

3. His clothing should be loose, not fitting closely to the body; a blouse waist or shirt with sleeves buttoned or tied securely around the wrists should be worn. If he is shaking bees from the combs, he should have his trousers stuck in his socks or folded around the ankles, holding them in place by means of strings or bicycle pantsguards. The shoes should be high enough to 
project under the trousers; and in the case of a woman the skirt should be long enough to reach the tops of the shoes. When bees are shaken on the ground care should be taken not to allow them to crawl up on the feet. If perchance they do get on the foot, it should be stamped on the ground, jarring them off. When the weather will permit, the man should have both his coat and vest off. A very good suit is that worn by garage men and railroad engineers in the form of a union overalls suit. Those who are very timid should wear gloves or gauntlets. (See Gloves.)

4. He should never stand in front of a hive - always at one side or in the rear. When bees are flying to the fields back and forth they are more liable to sting, apparently working on the assumption that the obstruction has no business to be in the way.

5. A good hive-tool is important. In the absence of a special tool, a screwdriver or a knife with a strong blade may be used.

6 . The middle hours of the day, if one is a beginner, should be selected for the manipulation of bees. The novice should never attempt to open a hive on a cool or chilly morning, or late in the afternoon, and nerer after a chilly rain.

7. One should avoid opening a hive or going out into the apiary-in fact, immediately after a heavy rain or after any other cause that suddenly checks or stops the honey-flow. Either a rain or a cold spell may stop the secretion of nectar. The more sudden the stoppage, the crosser will be the bees; and when they work on buckwheat or honey-dew, they are apt to be cross when the flow stops along during the middle hours of the day, until it begins again during the afternoon.

8. Having selected a favorable time for the manipulation, the beginner, at least, should blow one or two puffs of smoke into the entrance of the hive. With a hive-tool, screwdriver, or knife, he should separate the cover from the hive by merely entering the blade, leaving a gap wide enough for the entrance of smoke, but narrow enough to exclude the exit of bees. A couple of puffs of smoke should be forced into the crack made by the hive-tool, after which the cover may be lifted and more smoke blown over the frames. The cover may be set down by the side of the hive. However, it is usually advisable to jar the bees from the corer by giving a sharp blow on the ground just in front of the entrance, when they will quickly run in. This is important, because the crawling bees on the ground are quite liable to get under the clothing; and a crawling bee always moves upward.

9. Before proceeding further, the operator should carefully note the behavior of the bees. If they crowd up closely between the frames, making quick movements, and one or two start flying up as if about to attack, more smoke should be blown orer the combs. If, however, a few of them crawl leisurely orer the combs, apparently paying no attention to anything, the frames may be separated with a hive-tool or a screwdriver; but the smoker should be kept conveniently in the other hand; and if at any moment the bees show a disposition to rush out or sting, more smoke should be used.

10. If there is a division-board in the hive it should be remored. The frames should be separated on either side of the one that is to be taken out. If the operator or beginner is timid he should blow smoke over the top of the frames, and then very quietly lift the frame selected, being careful to avoid jerks or quick movements, and especially careful not to roll the bees over when pulling it out. This cannot be emphasized too strongly. Crushed or maimed bees may stir up the colony to a fighting pitch. This should be avoided by all means. After the first comb is remored, the others may be taken out very easily.

11. The operator should not only avoid mashing or killing bees, but he should never jerk the hands back, even if two or three bees do rush out and make a bluff as if they were about to sting, which they will frequently do. If the hand is held stationary when they make these onslaughts they will seldom sting; but if the hand is jerked backward it may be stung by two or three bees. Just the moment that a bee inserts its claws the hand should be withdrawn. and. when away from the hive, quickly rubbed against the clothing in such a way as to brush the bee off before it can sting.

12. One should learn to distinguish between bees that are angry and those that are flying about aimlessly. Cross bees will be detected by their high keynote and their quick darting movements in flight. A bee that nervously flits back and forth on the 
wings before the face, giving out a high keynote, is cross, and will sting unless the operator has his face protected by a veil. The best thing to do with such bees is to pay no attention to them. When they become troublesome, especially as is the case with hybrid bees, they should be struck down with a paddle, or else they will follow one about for an hour or two, angrily buzzing against the veil, striking against the clothing or the hands and stinging if they can:

13. When replacing the frames, they should be put back in the same order they were in originally, being careful not to pinch any bees. In fact, the process of putting the combs back should be the reverse of that described under No. 10.

14. Bees are much more inclined to sting during a time when there is a dearth of honey, and when robbing has been allowed to get started. (See Robbing.) One should not leave a hive open very long when stray bees from other hives are hovering over the tops of the combs, now and then darting into the hive or on to the combs and stealing more or less of the sweets. (See Robirng.)

15. After the hive has been opened up and has stood for a while without any manipulation, the remainder of the frames left should receive two or three puffs of smoke before handling. This is to drive down the guards.

16. Hot breath from a human being or an animal when combs are handled very often starts bees to rush off the combs by the dozen and alight on the veil. If one has no face protection he may receive a ozen stings in the fraction of a second.

17. Ordinarily bees will sting a man or an animal when he is sweaty and gives off a strong odor. However, the practical beekeeper pays but little attention to what his condition may be. His experiences will determine what to do if the bees show a disposition to be cross. At such times the smoker should always be ready. It is the indispensable implement in the yard, and should be in condition to give off a volume of smoke at any instant-not that one's life depends on it, but rather to save time and to avoid stings.

18. Children should not be allowed to race thru a beeyard when bees are busy in going to the field, or at any other time when they might be a little cross. They should be cautioned to go around the apiary; and while the children of beekeepers become careless they should avoid, as far as possible, doing anything that will cause unnecessary stings.

19. Never hitch a team or a horse near a hive of bees. A single sting will sometimes cause a horse to break loose, rush thru the yard, knocking over hive after hive. If for any reason he becomes entangled in his harness ho will be stung to death, and at the same time the life of the owner may be in danger in trying to save the animal. When hives are ruthlessly knocked over as the result of a runaway horse or team, there is liable to be a general stinging fracas. The owner should not be tempted to go into a yard at such times without veil and gloves, and a smoker well ignited. To do so without protection is only inviting disaster.

WHAT KIND OF BEES STING WORST.

The general decision now is, that pure Italians, Caucasians, and Carniolans are the most easily handled. (See RACES of BeEs.) Not only do they sting less, but as they keep their places on the combs without getting excited* when the hives are opened properly, they are far less likely to get under one's clothing than common bees. A great many stings are received from bees that are in no way badly disposed at all, simply from getting pinched accidentally while on the person of the beekeeper. The pure races may be handled all day, with no such mishap; but after working among the old-fashioned blacks or hybrids we often find a dozen or more under the coat, in the sleeves, if they can get up, and, worst of all, up the trousers, unless the precaution has been taken to tuck them into the boots or stockings when wearing low shoes. (See VeILS.) This one thing alone would decide one in favor of the Italians, if they were simply equal to the blacks in other respects. Hybrids, as before stated, are worse to sting than either of the races when pure; while Cyprian and Holy-Land bees are so much worse still, that sometimes smoke has no effect on them. (See Crprians, under Italians; also Races of Bees.)

* Queenless bees are not as quiet. It may be because they seldom work with energy, and have therefore no fresh accumulation of stores, which tend so much to put bees on their good behavior. All bees are much worse after a sudden stoppage of nectar secretion, especially after a basswood or buckwheat flow. 
BEE-STING POISON.

When bees are very angry and elevate that portion. of their bodies containing the sting, a tiny drop of some transparent liquid can often be seen on its point. This liquid is the poison of the bee's sting. It has a sharp, pungent taste; and when thrown in the eyes, as sometimes happens, it has a stinging, acrid feeling, as if it might be a compound of cayenne pepper, onionjuice, and horseradish combined; and one who tastes it or gets it in his eyes concludes it is not so strange that such a substance, introcluced into the circulation, should produce severe pain and local fever for a few hours.

\section{HOW IT IS DONE.}

It is quite an interesting experiment to let a bee sting one on the hand, and then observe the whole performance without disturbing it. After the bee has worked the sting so deeply as to be satisfied, it begins to find itsclf a prisoner, and to consider means of escape. It usually gets smashed at about this stage of proceedings unless successful in tearing the sting-poison-bag and all-from the body; however, if allowed to work quietly it seldom does this. After pulling at the sting to see that it will not come out, it seems to consider the matter a little, and then commences to walk around the sting, in a circle, just as if trying to twist a screw out of a board. If one can be patient and let the bee alone, it may work it out, but in most cases the sting either tears out from the body of the bee or breaks off. In either case it should be removed from the victim at once.

\section{ODOR OF BEE-STING POISON.}

After one sting has been inflicted, there seems a much greater chance, when about in the apiary, of getting more stings. Mr. Quinby has suggested that this is owing to the smell of the poison, and that the use of smoke will neutralize this scent. We very often blow smoke on the wound. The heat relieves the pain somewhat, and the smoke obscures the bee-sting odor. There is no doubt about that.

POISON OF THE BEE-STING AS A REMEDIAL AGENT.

For some years past there have been running in the daily press many reports in regard to the agency of bee-stings in the cure of certain forms of diseases, especially rheumatism. From the facts put forth, any candid reasoner will have to admit that being stung frequently does have the effect of relieving certain forms of rheumatism, paralysis, and perhaps dropsy.

Numerous accounts have also appeared of various persons affected with rheumatism being greatly relieved by stings, especially on the affected parts. Some others have reported that they could discover no appreciable effect one way or the other.

It has happened at various field-day gatherings of beekeepers that certain parties who read these reports, haring suffered severely because of rheumatic pains, presented themselves and asked to have experts cause the bees to sting them on the affected parts. The operator picks a bee off a comb by the wings and presses it against the flesh until the sting is driven into the skin. This has been done on several occasions, and in each case the parties who came forward for this kind of treatment have said they experienced relief. At the Jenkintown field-day meeting, June 26, 1906, an old gentleman got up on the platform, and, before something like a thousand people, stings were applied to his arm until something like a hundred were imbedded deeply in the flesh. Did it hurt? $\mathrm{Oh}$, yes! But the induced ferer of the stings, he said, seemed to bring a warmth and toning of the muscles that was after all a relief; for, strangely enough, this large number of stings does not seem to affect a rheumatic leg or arm as it does a healthy member.

It is a well-known fact that the homeopathic school has for many years used beesting poison in a remedy called "apis mellifica." There are large wholesale drughouses that have made a business of buying stings taken from live bees, being dropped, as they are extracted, into small vials containing sugar of milk. We have.filled orders from our apiaries for bee-stings to the extent of 10,000 in one lot. From a frame of live bees placed in a convenient position a bee is picked up with a pair of broad-nosed tweezers and immediately crushed. This act forces out the sting, when it is inmediately grasped by another pair of fine-pointed tweezers. These are then given a sharp rap over a wide-mouthed bottle containing sugar of milk. In this 
way the stings are extracted one by one until the whole number has been pulled. But the operator, after having extracted four or five thousand, experiences a sort of tingling and itching sensation in the face, and finds he has to take a rest of some days before he can renew his work. At other times it happens that he can extract only a few hundred a day when that itching sensation will reappear. This is probably due to the fact that he inhales some of the fumes of the poison, which, entering the lungs, is absorbed by the blood and carried thru the system.

At other times a pound or so of bees is put into a large wide-mouthed bottle or jar of alcohol. But the poison of the stings extracted in this way must necessarily be mixed with the other juices of the bees.

Homeopathic physicians have "apis mellifica," thus made from bee-stings, supplied to them in the form of a liquid. It smells not unlike bee-sting poison, and is often given internally to relieve the pain of rheumatism or swellings in general. But it is evident that a hypodermic injection of the bees, given directly on the affected part, would be a hundred times more productive of good results, assuming, of course, the poison does have a remedial effect.

DOES A BEE DIE AFTER LOSING ITS STING?

It has been stated that the loss of the sting results in the death of the bee within a very few hours; but this is not always true. Colonies have at times become so enraged as to sting everything within reach, even plunging their little javelins into fence-posts and other inanimate objects, the results being that nearly every bee of the hives in the fracas would lose its sting, and yet these same colonies live and prosper. One correspondent in particular relates the following incident:

Thru carelessness he allowed a certain one of his colonies to become so infuriated as to sting everybody and everything within reach. He declared, upon a subsequen $乞$ examination, that there was scarcely a bee in that whole colony which did not show unmistable evidence of having lost its sting in the uproar just mentioned. Now, the singular fact was that these bees actually lived, gathered honey, and prospered.

That some bees die after losing their sting, may be true; but that they invariably do so is a claim now thoroly disproved.
SMOKE NOT ALWAYS A PREVENTIVE OF BEE-STINGS.

There are some colonies that, under some conditions, can not be conquered, even with smoke. If the atmosphere is a little chilly, or immediately after a rain, or if the supply of nectar has suddenly stopped short off, a few colonies may be very hard to handle. While most bees under these conditions will yield to smoke, it seems to infuriate others. The only thing to do is to let them alone for the time being; then the next day or two, when the weather is favorable, blow a little smoke in at the entrance, raise the cover very gently, blow in a few whiffs more, when, presto! the fiends of the day before are as gentle as one could wish.

\section{MECHANICAL CONSTRUCTION AND OPERATIION OF THE STING.}

After a bee has delivered its sting, and torn itself away from the sting, a bundle of muscles near by, and partly enveloping the poison-bag, will be noticed. The curious part of it is that for some considerable time after the sting has been detached from the body of the bee, these muscles will work with a kind of pump-like motion forcing the sting further into the wound, as if they had a conscious existence and burned with desire to wreak vengeance on the party attacked. Nay, further, after the sting has been pulled from the flesh, and thrown away, if it should stick in the clothing so the flesh will come in contact with it, it will commence working again, pull itself into the flesh, and empty the poison into the wound, precisely as if the living bee were itself working it.

We have suffered many times from a sting unconnected with any bee. A sting would hold life enough to give a very painful wound, for some minutes afterward. Muscular contraction of the sting has taken place under the field of the microscope 20 minutes after being detached from the bee. This phenonienon is wonderful, and we have often, while watching the sting sink into the rim of a felt hat, pondered on that wonderful thing, animal life. Why should that isolated sting behave in this manner, when the bee to which it belonged was perhaps far away, buzzing thru the air? Why shonld this bundle of fibers and muscles behave as if it had a life to throw away? 
Under the microscope the sting is found to be a beautifully fashioned and polished instrument, whose delicate taper and finish make a most surprising contrast with any instrument man has been able to produce. In shape it appears to be round; but it is, in reality, egg-shaped, and is of a darkred color, but transparent enough to show the hollow.

The sting proper is composed of three parts-the outer shell, or husk, D, and two barbed spears that slide partly inside of it. Fig. 2 shows the spears. The barbs are much like those on a common fish-hook; and when the point of one spear, A, penetrates far enough to get one barb under the skin, the bee has made a hold, and has no difficulty in sinking the sting its whole length into the wound; for the pumping motion at once commences, and the other spear, B, slides down a little beyond $\mathrm{A}$, then $\mathrm{A}$ beyond $\mathrm{B}$, and so on. With a motion like that of a pair of pump-handles, these spears are operated by small but powerful muscles attached thereto. These muscles will work, at intervals, for some time after the sting has been torn from the bee, as we have explained. They work with sufficient power to send the sting thru a felt hat or into a tough buckskin glove. We have often watched the bee while attempting to get its sting started into the hard cuticle on the inside of the hand. The spears often run along the surface diagonally, so that it can be seen how they work down by successive pumps.

It was formerly supposed that the duct $0 \mathrm{O}$ was for the purpose of conducting the poison from the poison-bag up the barbs; but Snodgrass, of the Bureau of Entomology, has shown that this is a mistake.

Fig. 3 is a transierse section, sliced across the three parts, at about the dotted line $\mathrm{D}$. $A$ and $B$ are the barbed spears; $F$ and $G$, the hollows to give them lightness and strength; $\mathrm{H}, \mathrm{H}$, the barbs. It will be observed that the husk, $\mathrm{D}$, incloses but little more than one-third of the spears. The purpose of the main shaft $\mathrm{C}$ is to hold the spears in place, and to allow them to slide easily up and down, also to direct them while doing this work. To hold all together, there is a groove like a sliding dovetailed joint in both spears, with a corresponding projection in the husk, which fit each other as shown. This allows the barbs to project to do their work, and yet holds all together tolerably firm. We say tolerably firm, for these spears are very easily torn out of the husk; and after a sting is extracted they are often left in the wound, like the tiny splinters we have before mentioned. When torn out and laid on a slip of glass they are scarcely visible to the naked eye; but under the microscope they appear as in Fig. 2.

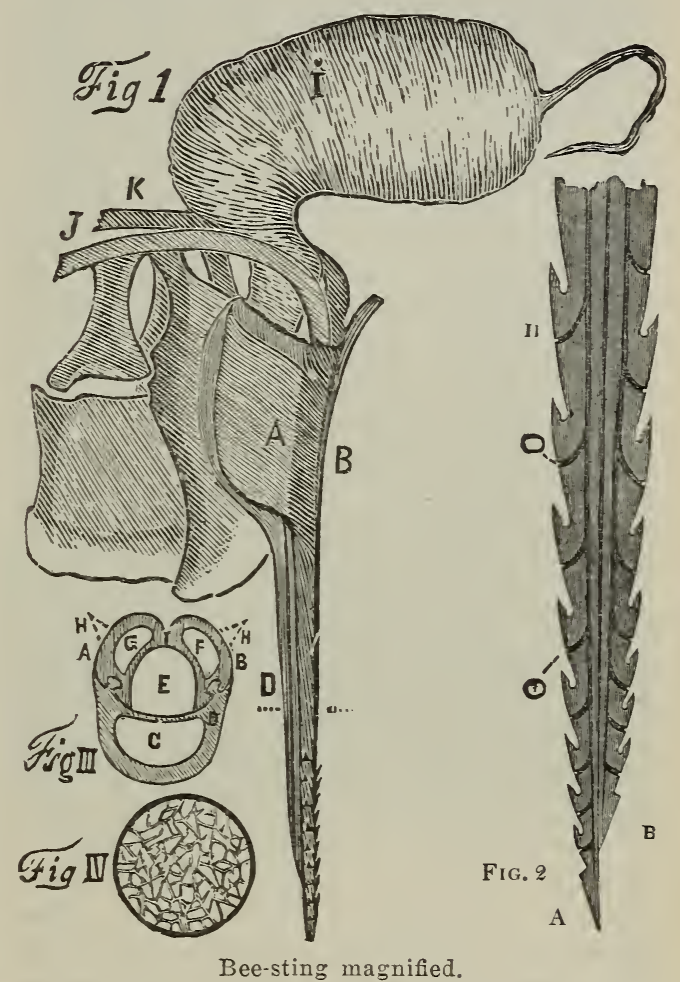

Stings do not all have the same number of barbs. We have seen as few as seven and as many as nine. The two spears are held against each other as shown in Fig. 3, and you will observe that the shape and the arrangement of the three parts leaves the hollow, E, in their center. The working of the spears also pumps down poison, and quite a good-sized drop collected on their points while we saw them working under the microscope. J. R. Bledsoe found a valve that lets it out of the poson-bag into this wonderful little pump, but prerents it returning. We have not been able to see this, but hare no doubt that it is there. The drop of poison, after lying on the glass a few minutes, dries down and seems to leave a gummy substance that crystallizes, as it were, into strange and beautiful forms, a diagram of which is shown in Fig. 4. 
SUCROSE.-See Cane SUgar.

SUGAR.-The term sugar is applied by common consent to the white sugar commercially prepared from the sugar cane and the sugar beet, or sucrose. To the layman, and possibly to the chemist, the word "sugar" means white granulated sugar; if it is powdered, the adjective "powdered" is added to sugar as "powdered sugar;" if it is moist and soft, and either white or only slightly yellow in color, it is termed "soft sugar;" while if it is brown in color, moist and soft, it is termed "brown sugar." In distinction the word "sugars" refers to the whole class of sugar, of which there are some 150 or more, many of which are rare and some of more common occurrence. Grape sugar is the sugar dextrose, while fruit sugar is the sugar levulose. (See INvert SUGAR.)

Common sugar is composed of the elements in the following proportions: Carbon, 12 parts; hydrogen, 22 parts ; oxygen, 11 parts. It is found free in nature in many roots, as beets, turnips; in the stems of plants, as sorghum, sugar cane, cornstalks, and in the sap of trees like maple, birch, etc., and in many fruits. It has never been commercially prepared from the elements.

A white sugar or granulated sugar is practically pure sucrose, while the varying off-colored sugars ranging from light yellow to brown are mostly mixtures of crystals of sucrose surrounded with molasses. These yellow or brown sugars are all produced by the refineries from the liquors after the production of the white grades. Formerly one had brown sugars direct from the cane, but now these are not produced to any extent in this country. Louisiana sugars in hogsheads used to be these old brown sugars.

There has always been a discussion as to whether white sugar made from beets was the same in every particular as that made from sugar cane. Both contain practically the same amount of sucrose, also water and mineral matter, but the organic impurities which may amount to from .05 to .1 per cent are often different in beet white sugar than in cane white sugar. These impurities may play a part in some manufacturing processes, and prevent the use of beet sugar in all places where cane sugar has been used. However, as a sweetener and for table use or for jelly or preserving work it is doubtful whether there is any notable dif- ference between beet and cane sugar. (See CANE Sugar.)

SUMAC.-There are about 15 species of sumac in the United States: Shrubs, small trees, or vines, with handsome trifoliate or pinnate leaves, and not infrequently poisonous sap. The small white or green flowers are massed in large clusters. The stamens and pistils are often in separate flowers, and in the case of some species on different plants.

In southern New England, especially in Connecticut, Rhus glabra L., called smooth, upland, or scarlet sumac, is very common in hillside pastures and along stone walls. It is an irregularly branched shrub, seldom more than ten feet tall; but its graceful foliage is very attractive. The blooming period lasts for about three weeks from July 8 to the beginning of August. The flower secretes nectar most freely on hot clear days, but in cloudy weather the flow ceases entirely. Strong colonies will bring in 20 pounds during an ideal day, and will store a surplus of from 20 to 100 pounds according to the weather. At its height the flow is very rapid and heavy. While the bees are busy on the bloom there is a bitter odor about the apiary, and the new honey is more or less bitter to the taste. Fortunately, the bitterness is only transient, and by winter the honey is edible.

One must eat sumac honey to appreciate it, says Latham. There is a richness but at the same time a mildness about it that will suit the most sensitive taste. Once a customer, always a customer, if one buys sumac honey. When pure the honey has a golden color. If properly ripened, it has no noticeable odor, but is very heavy, and, like appleblossom honey, waxes instead of candying. It is safe to say that much of Connecticut would be worthless to beekeepers but for this plant.

R. typhina L., staghorn sumac, widely distributed thruout the eastern United States, is a small tree 10 to 40 feet tall. The young shoots are covered with velvety hairs like a stag's horn; hence the name. If more common, it would be important. $R$. toxicodendron L., poison iry, poison oak, is a vigorous climbing vine. It is said to yield a surplus in certain localities.

In Georgia there are sereral species of sumac which are valuable; but the most 
important is $R$. copallina L., known as dwarf sumac and mountain sumac. This species extends from Maine to Florida and Texas and westward as far as Minnesota. In a few localities in north Georgia it is the main source of marketable honey. In Texas in favorable seasons, depending upon rain, it also yields a surplus. In California $R$. diversiloba $T$. and $G$. is found thruout the state and yields an excellent grade of white honey which, however, granulates very readily. In southern California $R$. laurina Nutt. is common and yields one or more extractings of amber-colored honey of fine flavor but strong odor.

Rhus Metopium L., coral sumac, poison wood, doctor gum, is a tree 40 or 50 feet tall, growing commonly on the extreme southern part of the Florida peninsula and on the Keys, but found as far north as Palm Beach. Its common names are very numerous and misleading. It is often, but erroneously, termed "manchineel," from confusion with the tree of that name, which it closely resembles in many particulars: but it is much mole common than the real manchineel, which is much more poisonous.

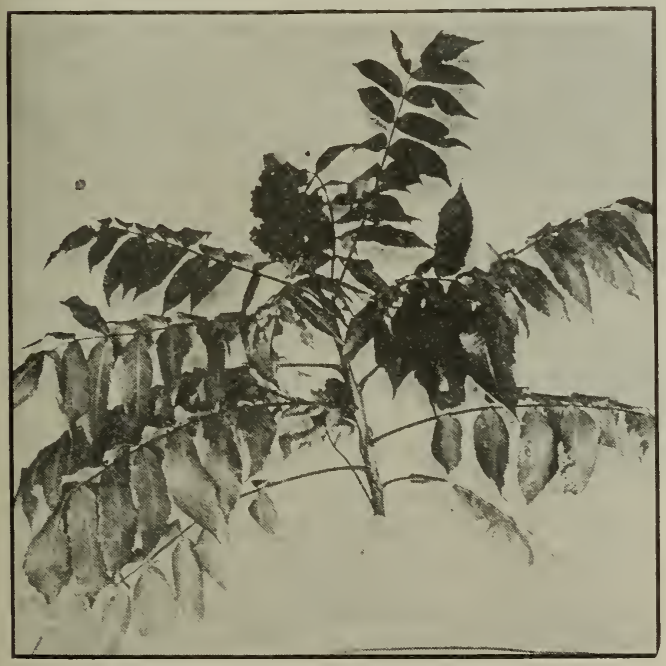

Sumac, smooth (Rhus glabra).

Both have an acrid sap which heightens the danger of confusion between them. Of the sap of R. Metopium Professor Rolfs says: "The juice is poisonous to a great many people." It resembles poison ivy in being harmful only to certain skins.

Coral sumac, or poison wood, yields honey of a high order and in great quantities. In some seasons the bees are said to go fairly wild with excitement over it. While the lioney is of good quality, its exact color, body, and flavor can never, probably, be determined with exactness, for it blossoms simultaneously with several other honey-bearing plants or trees (notaably with the dogwood and also the pigeon

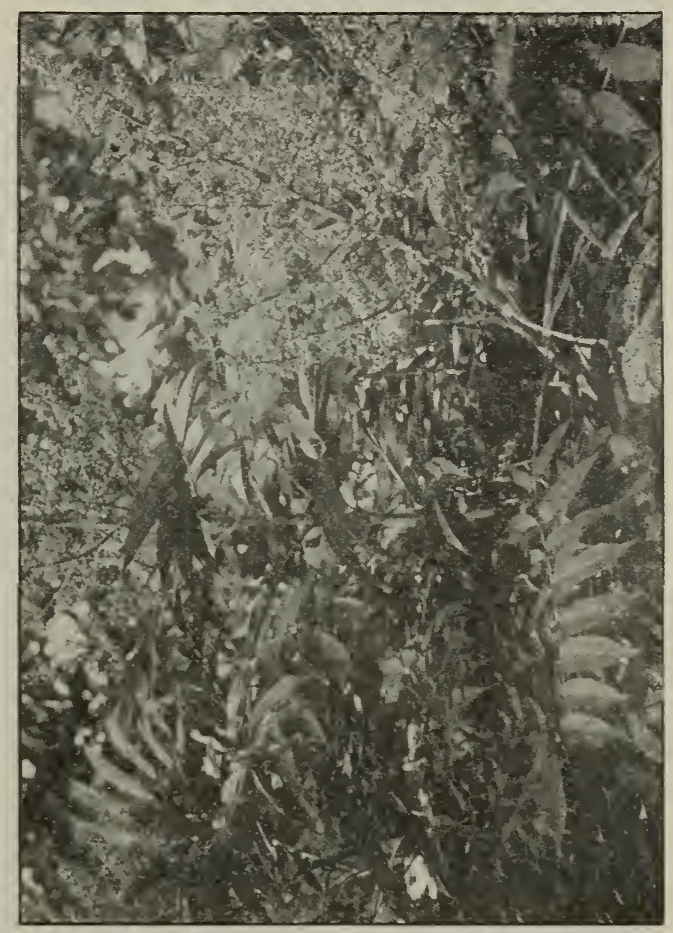

Sumac flowers and leaves (Rhus glabra).

plum), so that only a blend of several honeys is possible. The blend of the three is thick and appetizing, of good color, and usually brings good prices in the northern markets. It constituted most of the surplus of O. O. Poppleton, of Stewart, Florida, whose crop in 1909 was 28,000 pounds.

SUNFLOWER (Helianthus annuus L.An extensive American genus embracing sixty or more species. The common sunflower grows wild thruout the West, especially from Minnesota to Texas on the prairies and waste lands lying between the Rocky Mountains and the Mississippi River. In Nebraska it becomes "a veritable herbaceous tree," and completely takes possession of large waste areas 10 to 25 or more acres in extent. The tall plants also grow along the roadsides and about cities and towns. This species is likewise common in California, and one year M. H. Mendleson, of 
Ventura, extracted a carload of wild sunflower honey, but the yield had never before been so large. According to Richter, the honey is amber-colored, with a characteristic flavor not disliked by many. Scholl says that in Texas bees gather much propolis both from the flowers and leaves. The stems yield a textile fiber, the seeds oil, and the flow'ers a yellow dye. Many other species of sunflover are exceedingly common both in the West and South. The Jerusalem artichoke (H. tuberosa L.) is a good honeyplant, and bees visit the flowers in myriads. In Contra Costa County, California, there are acres of this plant growing wild. The tubers are used as a vegetable.

\section{"WILD SUNELOWER OF FLORIDA."}

This name is rather loosely applied by beemen of Florida to various species of Compositae that grow over the southern half of the peninsula, including Gaillardia lanceolata, Helianthella, Coreopsis, and burr-marigold. South of a line drawn thru Stewart and Osprey, the one on the east coast and the other on the west, there are thousands of acres of these beautiful plants, which rasemble the Spanish needles and Chrysopsis of the North. They extend as far north as Osceola, but beemen of the southern third of the state are most enthusiastic over them. The "savannas" about the edges of the Everglades seem to be their best habitat, while they. are not common on high pine land. The blooming period is in September and October. The yield is rather unreliable, and nectar is secreted only during very dry falls. A fair crop can be counted on about every two or three years; a "burnper" about once in five years. The honey is amber, fairly good body and rather mild; but it is, after all, a fall-flower crop, and by no means ranks with the best honeys. It is fine for putting the colonies in good condition for the close of the year.

SUPER.-See CoMb Honer, APPLIANCES FOR; also Hives.

SWARMING. - All animated nature seems to have some means of reproducing its kind, that the species may not become extinct. Among the insect tribes we find a great diversity of ways and means for accomplishing this object. In the microscopic world we find simple forms of animal life contracting themselves in the middle until they break in two, and then each separate part, after a time, breaks in two, and so on. With bees we have a somewhat similar phenomenon. At the approach of the honey-flow a combination of conditions will cause a colony to subdivide-that is to say, swarm. By a sort of mutual agreement a majority of the old bees with the queen and perhaps a majority of the young bees rush out of the hive until the air is full. They will continue to pour out of the entrance until two-thirds or three-fourths of them have deserted the hive, and then circle about in the air for a few minutes when they will probably alight on a bush or on a limb of a tree, forming a large cluster.*

The term "swarm" itself may mean an aggregation of bees while in the air, or the same bees after they have been put into a box, hive, or skep; but technically it is a swarm until it settles down to its regular routine of work. After that, it is a colony. In modern bee culture, at least, there is a sharp distinction between a swarm and a colony; and this fact should be noted in the general discussion which follows.

The bees left in the hive called the "parent colony" appear to be mainly young ones-enough to take care of the young brood that is unsealed, and to keep the brood warm for the time of the year.

The popular impression has been that the queen leads forth the swarm; but this has been shown to be a mistake. While she may, under extraordinary conditions, precede the swarm, as a virgin going out to mate, she is usually among the last to leave. Reference will be made to this later.

What induces the bees to leave the hive at any precise moment no one seems to know. That there is a concerted action in which all the inmates of the hive, except the very young ones, suddenly take a notion to leave, no one denies. One observer states that one or more bees in one portion of the hive will commence their hurly-burly rush back and forth. More bees join in the general pow-wow, until the whole hive is in a furore of excitement. Those nearest the entrance proceed to rush out like shot from a gun, followed by a stream of bees for all the world like a spray of water issuing from the nozzle of a hosepipe.

\footnotetext{
* In rare cases swarms will abscond without clustering.
} 
The time taken for them to evacuate the hive depends somewhat on the size of the entrance, but usually it does not take more than three or four minutes. If the owner happens to be on hand at the time of the first onrush, he may eatch the most of them by setting down over the hive a wire-cloth cage (see Robbing); but as a general thing he is nowhere around; and even if he is, he may not be able to reach the hive with his cage before half of the bees are out.

At the outset it was stated that the queen does not, as a rule, lead out a swarm; as a matter of fact she probably has but very little to do with it. Her presence at the entrance may, howerer, excite the bees. If she is a virgin, and about ready to make her weddingflight, she may or may not utter the sound of zeep, zeep. These miniature squeals sometimes excite the swarming propensity of the bees; and if the colony is only a small one, the entire force may rush out with her. On the other hand, an old queen, or a queen that has been doing regular egg-laying work, seldom or never resorts to such jurenile pranks; and we may set it down as a rule that has exceptions that a laying queen has little or nothing to do with starting $\mathrm{up}$ the swarming furore prior to the entrance of the swarm into the air. But when the general excitement is rife thruout the colony, she joins with the bees as a matter of course, usually going out with the last.* If her wings are clipped she is usually found coming out with some stragglers, when she may be readily caught at the entrance. Her capture makes it easy to catch the swarm.

\footnotetext{
* Dr. C. C. Miller holds that the queen may be among the first, among the last, or anywhere between, perhaps on an average issuing when the swarm is about two-thirds out. Others say the queen is usually the last.
}

THE CAUSE OF SWARMING.

In order to understand the swarming problem, which is one of the most difficult to solve of all with which the beekeeper of today has to contend, a few facts should be presented that we may discover, if possible, whether there is a fundamental cause of swarming or a series of them. These facts may be summed up about as follows:

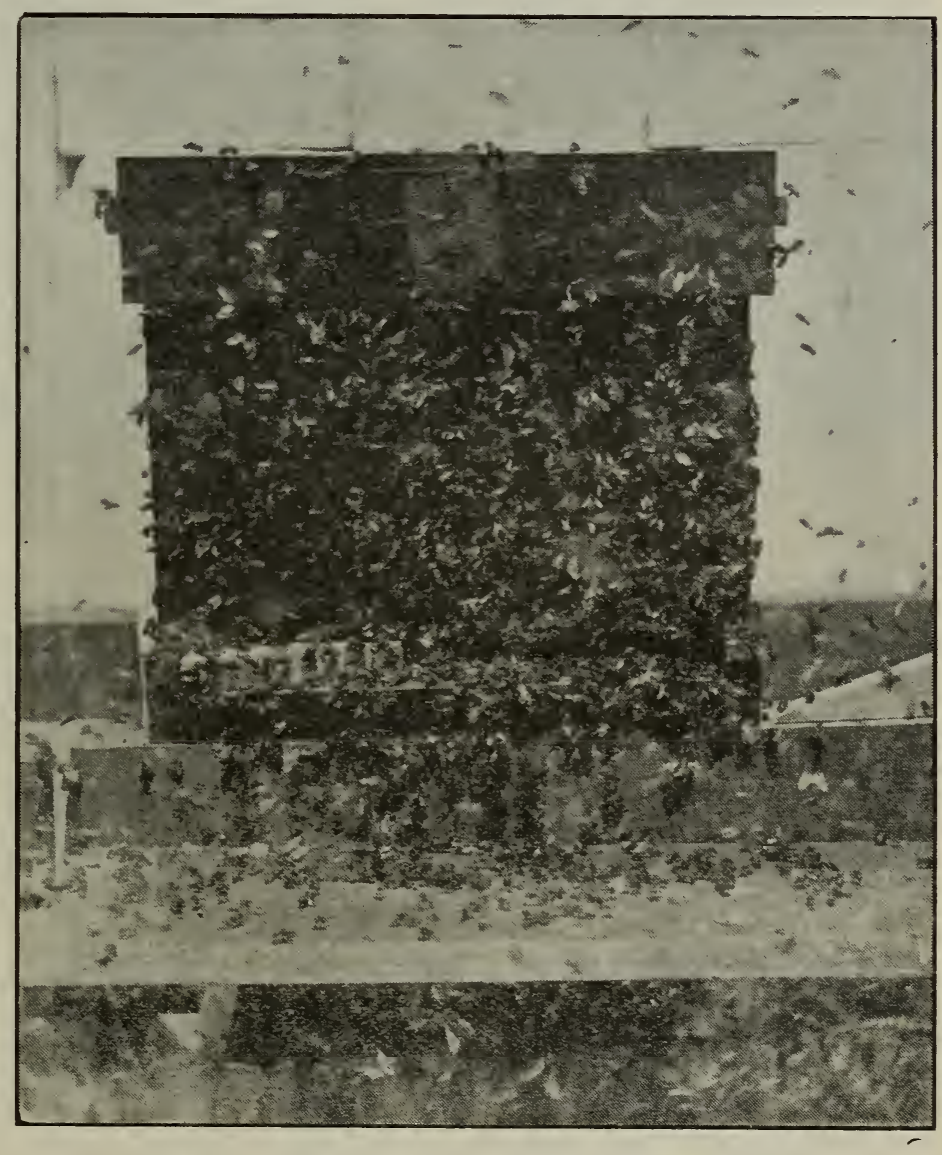

hht in the act of learing. $-P h o t$
Chas. I. Halie, Iork, Pa.

1. Colonies with young queens are much less inclined to swarm than those with queens a year old or more.

2. A colony crowded for room, when the swarming season is on, and when every comb is filled with brood and honey, will probably cast a swarm, altho it may go thru the whole season and store honey, without swarming, if enough super room is given. It follows that lack of room is often a contributing cause.

3. Colonies are more likely to swarm with a small and restricted entrance than with 


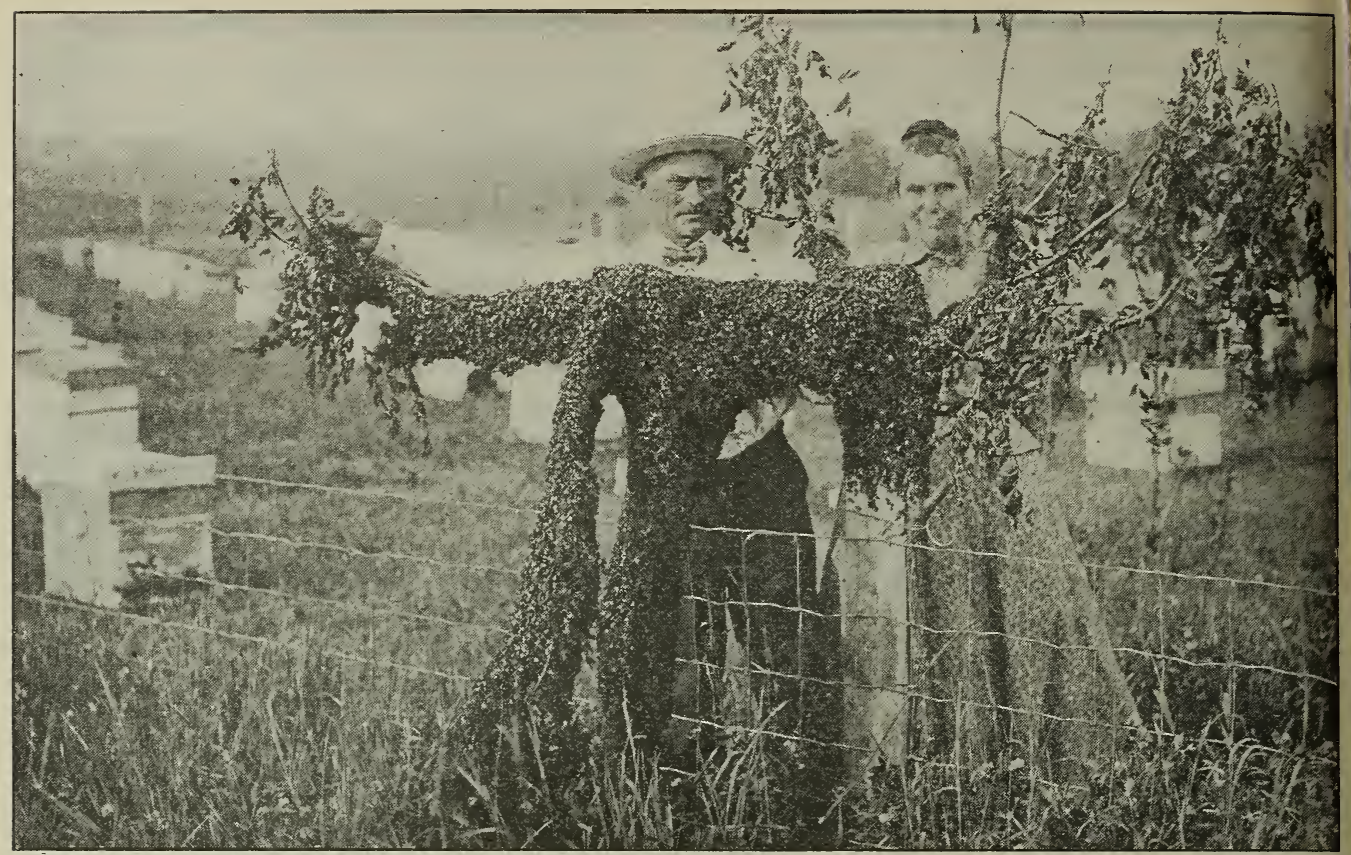

This mammoth swarm was the product of one queen on 24 combs. The swarm issued June $11,1913$. From J. W. Davidson, Yorktown, Ind.

a large one; altho, as in the case of No. 2, colonies with such entrances may store honey thru the entire season without making an effort to swarm. It follows that an overheated brood-nest may be a contributing cause.

4. The presence of queen-cells at the opening of the honey harvest, if they are allowed to remain, will usually be the indirect cause of swarming, and hence the practice of cutting out or "killing" cells every eight or ten days. On the other hand, it must be admitted that cell-cutting or cellkilling does not always stop swarming, especially some seasons. It follows that the prospect of a new queen may be a cause of swarming.

5. Taking away the brood from a colony and hiving it on frames of foundation or empty combs will usually stop swarming, for the time being, but it does not always do so. In other words a large amount of brood and constantly emerging young bees incites swarming.

6. Caging the queen or removing her for a period of ten days will usually stop swarming. Bees will not swarm without a queen because they must have something from which to make a new generation in their new home. But checking egg-laying may have its influence.
Clearly, then, while the things mentioned may be considered as contributory causes, there must be something back of them as the real cause of swarming. What that something is has been the cause of some theorizing, but it can hardly be said to be a settled question. German authorities, among them Gerstung, hold that when brood is reared in large quantity, the nurse bees constantly on the increase, there comes a critical period when the number of nurses is too great for the amount of brood to be fed. They are gorged with the food prepared for larvæ, and these are in too small number to receive it, and this condition brings on the swarming fever.

Geo. S. Demuth, of the U. S. Bureau of Entomology, has advanced a rule which is given in Farmers' Bulletin 503, where he says: "Any manipulation for swarm control, whether applied after the colony has acquired the 'swarming fever' or applied to all colonies alike previous to the swarming season, is based upon a single principle - a temporary distuibance in the continuity of the daily emergence of brood. This disturbance should occur just previous to or during the swarming season."

If that "temporary" in the last statement may be considered as occupying sever- 
al days, then it is possible that in practice the two theories may coincide.

In support of the theory that there is a preponderance of nurses as compared with the brood to be fed, attention is called to the fact that at the time of swarming a large amount of brood will be found in the hive, but only a small part of it unsealed; and this state of affairs having continued for several days must inevitably result in a large number of bees of the proper age to prepare food for larvæ without a sufficient number of larvæ to consume the food prepared. It is also advanced that if for a time the queen is absent (see No. 6), so that no brood at all is to be fed, the swarming fever will disappear, and this is counted as support of the theory that there had been too many nurses for the amount of brood to be fed, the amount of food prepared having become less because not needed, and perhaps a portion of the nurses having turned their attentions afield earlier than they would have done under usual conditions.

The brood interruption rule fits in well with natural swarming and shook* swarming, since the swarm will have no brood until it can rear it. In the meantime there is no swarming from the swarm. Thle parent colony continues to send off afterswarms because the hatching brood continues to emerge. The rule fits well with the dequeening method of swarm control and also with the plan of removing the brood. It is also in harmony with the scheme of decapitating the brood which was once advocated but which was quite effective:

Whether we accept the rule as correct or not, it would seem that practice in accord with it brings results. While it may be the main or basic cause, it is probable that the other causes have a strong influence and that while any one cause may force a swarm it will generally require a combination of them to do so.

Dr. Phillips, in his book entitled "Beekeeping," in commenting on the swarming problem, says: "The methods described in Demuth's bulletin are those which have proved reliable in the hands of reliable beekeepers thruout the United States."

However, Mr. Demuth, in conversing with the author late in the summer of 1916 ,

\footnotetext{
* See Artificial Strarming.
}

stated that during the previous year his bees in producing comb honey in Indiana swarmed so furiously that summer that they violated many of the fundamental rules of swarming. In answer to some questions he writes:

My observations on swarming, during the past season, do not conflict with the rule that an unbalanced condition of the colony as to young and old bees is an important factor in the cause of swarming. On the contrary, most of the evidence furnished by the past season is in support of the youngbee theory. The fact, however, that some colonies swarmed that were made up entire. ly of older bees makes it necessary, in order to retain the young-bee theory, to assume that under peculiar conditions older bees, or at least middle-aged bees, may become a factor in the cause of swarming.

When the field bees are confined to the hive at intervals during the honey-flow by rain or by irregular secretion of nectar, as was the case last summer in some portions of the clover belt, it is not unreasonable to expect the resulting congestion of bees in the brood-chamber to have some effect on swarming. In this connection it is interesting to note that the records in the bee-journals show that the seasons of excessive swarming in the clover belt have occurred when a protracted period of rainy weather immediately preceded the swarming season. In addition to this, last summer the clover vielded only during the afternoons, and the field bees were packed in below the frames during the forenoons.

The theory as to the effects of an excessive supply of larval food fits in well with the brood interruption rule, but it does not adequately explain why a colony that is preparing to swarm can be induced to give up swarming by removing all their combs that contain larvæ and substitute in their stead empty combs or combs partly filled with honey. The removal of all larvæ should as an immediate effect greatly increase the excess in the supply of larval food, and, as a result, according to the theory, the desire to swarm should be increased.

An unusual season brings up the point that there must be a contributing cause outside of the hive itself; and this cause is the peculiar conditions of the locality or the scason itself, for bees certainly have a way of forgetting or ignoring all proprieties set forth in text-books, some seasons. It must be stated, however, that these peculiar seasons occur only once in ten or fifteen years, and, therefore, only the general averages and not the abnormalities of the season or the locality should be considered.

However, when these abnormal seasons come on when the honey-flow is light-a 


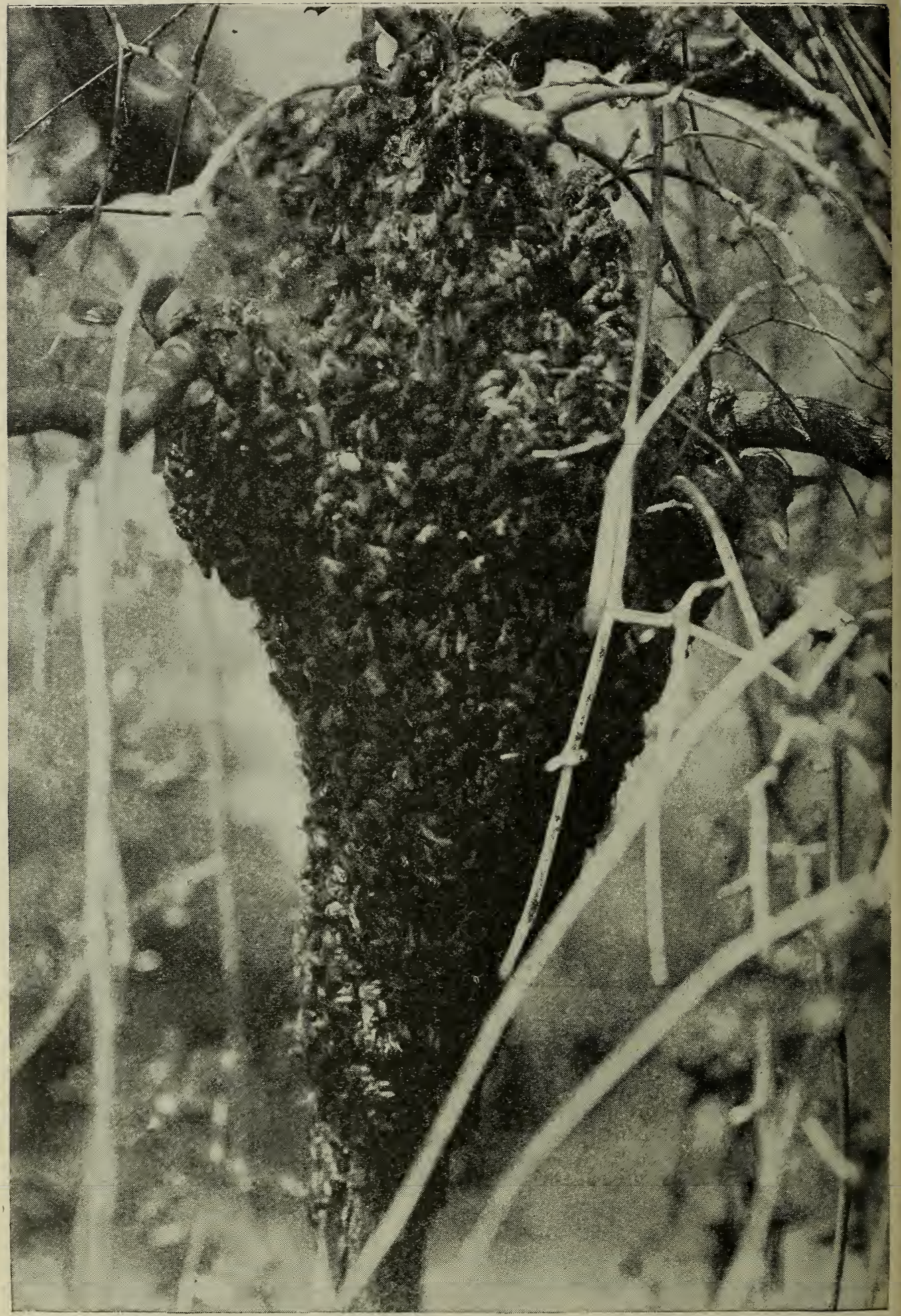

A fine large swarm ready to shake into the swarm-catcher. 
little honey coming every day-but heavy enough to force brood-rearing, swarming will be fast and furious just as it is in parts of Texas. When such seasons occur, if one is producing comb honey, ${ }^{*}$ practically all control measures except dequeening may fail. On the other hand, when the honey comes in with a rush, crowding the queen so that she is honey-bound, swarming almost entirely stops. In either case Demuth's rule fits in very nicely. In the first case there is no interruption of the brood; in the second, there is a decided cessation of it. In this connection it will be proper to discuss-

\section{SWARMING MODIFIED BY LOCALITY.}

Commencement of the swarming season varies, of course, according to the locality, and it may be said that the swarming propensity itself is modified very materially also by the same cause. In places where the honey-flow is very heavy and continues so for some time, swarming seems to be checked, for the bees are all intent on gathering honey. Indeed, they have no time to waste on such foolishness. In such localities the swarming season comes on when the first or light honey-flow begins, and continues so long as it is light; but just as soon as the secretion of nectar becomes heavy, then just that soon swarming stops.

It sometimes happens that a beekeeper residing in one of these localities wonders why his brethren in the craft make so much fuss in the bee-journals about swarm control when he has almost no trouble. The other party, on the other hand, cannot understand how the first-mentioned beekeeper can perform certain manipulations with his bees, and not have excessive swarming. In reading the following pages treating on this general subject one must bear in mind this question of locality. - It should, therefore, be said that much of the matter that follows relates to conditions as we generally find them in the northern states, and not as they are found in parts of Texas, California, and some portions of the tropics. In these localities there may or may not be swarming after the main flow begins.

Having discussed some of the underlying factors that cause swarming, we may now proceed more intelligently to discuss-

* In the production of extracted there are no special difficulties in swarm control.
THE SYMPTOMS OF SWARMING.

From what has already been said the reader will have some idea of what are the symptoms of swarming. Clustering out has hitherto been considered one of the sure signs; but it is by no means reliable.

If the weather is very hot or sultry, or if the entrance is too small, bees may cluster out at any time with no intention of swarming. (See ENTRANCES.) If a colony has been busily at work, and then for some reason slows down until it is doing almost nothing when others are at work, and if the bees in addition begin to cluster out, swarming is probably in contemplation.

The most common and perhaps the most reliable symptom is the presence of queencells containing eggs or larvæ at the beginning of or during the honey-flow. These may be in various stages of completion. As will be explained further on, they should be cut out every eight days; for if they are allowed to be sealed, a swarm may issue the first favorable opportunity, and again it may come forth, cells or no cells.

\section{PREPARATIONS FOR SWARMING.}

Every beekeeper should have on hand extra hives, combs, or supers; and, if combs are not available, frames of foundation or supers containing sections with full sheets. In the production of extracted honey at least, empty combs are about the best property one can have. There should be enough on hand to supply every colony with a full set. Where empty combs are not to be had there should be an equal number of frames with full sheets of foundation; but for the purpose of producing a crop of extracted honey, and at the same time prevent swarming, fully drawn combs are far superior to foundation. If the bees have to stop and draw it out they will often sulk and swarm out.

Before the swarming season is anywhere near-in fact, as early in the season as possible, when the colonies are not strongthe queens should be found and their wings clipped, as explained under QueEns. All modern beekeepers today consider it important to have queens of all honey-producing colonies clipped, because it is very much easier to handle the swarms when they do come out. A swarm with a queen in the air is a difficult proposition at best, especially if there are any tall trees in the vicinity. 
Sometimes swarms will cluster on high limbs, where it is practically impossible to get them. On the other hand, if the wings of the queen are clipped she can be easily picked up at the entrance of the hive and caged just after the swarm has issued. She may then be placed at the entrance of a hive on the old stand, when the swarm will hive itself automatically, coming back to its queen. If the wings of all the queens are clipped in advance, there will not be much likelihood of losing stray swarms providing an attendant can be on hand to pick up the clipped queens and hive the swarms in the manner to be explained. This matter will be given more fully further on.

But there are some who do not care to clip, fearing it will mutilate the queens and mar their appearance; and where there are such they can use the Alley trap as described under Drones. The objection to the traps is their expense and their obstruction of the entrances when they should be open and free.

It sometimes happens that the clipping of queens' wings is delayed until the swarming season has begun, when it will be almost impossible for the beekeeper to take the time to go thru the hives, find the queens, and clip their wings. He should then have on hand a number of Alley traps. The exact procedure for handling swarms with clipped queens or by the use of Alley traps will be explained further on.

\section{PREVENTION OF SWARMING.}

Under this head methods for the restriction or prevention of swarms will be considered and at the very outset it should be made plain that there is no infallible method for accomplishing this except by dequeening. All other methods are restrictive, and, to a certain extent, afford absolute prevention only in some colonies some seasons.

From what has been already said on the causes that induce swarming, one can form some conception of the proper means for restricting or preventing it.

Before proceeding further, it should be made clear that the control or prevention of swarming is comparatively easy when running for extracted honey. Unless perforated zinc is used to restrict the queen to the lower brood-chamber, the giving of room by adding supers or upper stories with fully drawn combs* will so reduce swarming that there will be scarcely one per cent during the season.- See Extracted Honey, How to Produce; also Hives, subhead "Large Hives Non-swarming." See Dadant on swarm control further on.

In running for comb honey the problem is very much more complicated. The different methods employed may be summed up briefly as follows: (1) Introduction of young queens at the beginning of the harvest. (2) Cell-cutting or cell-killing. (3) Dequeening and requeening. (4) Hiving on starters, frames of foundation, or empty combs and giving the brood to other colonies. (5) Giving additional room and manipulation of supers. (6) Providing abundant ventilation. (7) Giving shade. (8) Breeding from non-swarming strains. (9) The elimination of too many drones.

Except for absolute dequeening, any and all of these methods combined may fail some seasons with some colonies; and,again, some colonies will keep on storing honey even when no such preventive measures are employed beyond giving plenty of super room. If we could breed a strain of nonswarming bees that would store honey and never swarm, the problem of comb-honey production would be greatly simplified; but at the present time we are obliged to confess that there is no strain of non-swarmers, altho something in that direction has been accomplished.

It will now be in order to explain more fully the various methods as indicated above.

INTRODUCING YOUNG QUEENS AT THE BEGINNING OF THE HARVEST.

Long experience has shown in apiaries all over the country that colonies headed by young queens are much less inclined to swarm than those having queens a year or more old. Those with queens only three months old swarm less than those that are two years old, and where one expects to requeen because he needs better stock he should do so just before the beginning of the honey harvest. This should be done by the introduction of laying queens. If virgins are given they are likely to lead out a swarm on their mating-trips, and, more-

\footnotetext{
* Frames with full sheets of foundation may an. swer some seasons, but they sometimes cause the bees to sulk and swarm.
} 
over, valuable time will be lost in broodrearing. Just before or at the beginning of the harvest, breeding should be kept up without a break, especially if the honeyflow is likely to last more than a month.

Why are colonies with old queens more inclined to swarm than young ones? There is no satisfactory explanation unless the old ones are more inclined to lay drone eggrs. It is difficult to get a young queen to lay in drone-cells. Queen-breeders know that if they desire to raise drones they must use old queens. Some argue that the presence of a large number of drones in a colony is conducive to swarming; and this is probably true if there are also initial queencells. It is probable also that young queens do not lay in initial queen-cells like old ones.

\section{CUTTING OUT CELLS.}

Of all the methods employed to hold swarming in control, this is perhaps the most common. While it is not always the most effective, it is very clear that, unless the cells that contain young larvæ or eggs are cut ont every eight days, bees will swarm, other conditions being favorable. While cutting out the cells does not necessarily check swarming it goes a long way toward it. There are some very nice points in cell-killing. As Dr. Miller has had the largest experience of any man in the United States, if not in the world, the author has asked him to give his views; and the reader will do well to go over very carefully what he has to say.

I have yours asking some questions about cutting out cells to combat swarming, and proceed to reply. We don't call it cutting cells here, but "'killing cells,", the term "cutting cells", being applied to cutting out ripe queen-cells that are to be used for rearing queens. When we find queen-cells constructed as a preparation for swarming, we never cut them out. If a cell contains a larva several days old, it is simply mashed with the end of the hive-tool. If an egg or a small larva is in the cell, it may be mashed or the egg or larva may be dug out. In either case the work is very quickly done, and a very slight defacement will cause the bees to reject the cell.

We begin looking for swarming-cells just as soon as we think there is any danger of their being started, or a little before. The first time we look in a few of the strongest colonies-perhaps the first of June, before the bees begin to store from white cloverand if we find no cells started in these we go no further, for if the strongest have not thought of swarming the weaker ones may be trusted for a time longer. After that we try again in 8 or 10 days. Ten days may be as well as a shorter time. Indeed, as the young queen will be started from the egg there is no danger that she will go off with a swarm under fifteen days. But if we go beyond ten days, complications may arise by means of swarming with the old queen, and as there is some danger of delays from rainy weather or other cause, it is not a bad plan to make eight days the period. Then if it is delayed a day or two for any cause we are still all right.

The second time we look again in the strongest colonies, and if no cells are found in these we go no further. But whenever we find one or more cells started in any one of these strongest colonies, then every colony must be examined. At least that will be the way early in the season; later on there will be exceptions.

Some one may ask at what stage of the growth of queen-cells they are destroyed. At any or all stages. In fact, no thought is given to whether advanced cells or only eggs are to be found. Every eight or ten days we go thru each colony and kill all cells found.

At the first overhauling and at any subsequent one so long as no cells have been found at a previous overhauling, the bees are shaken from each comb. One sharp shake will usually leave the comb clean enough. This allows the cells to be more easily seen, whereas if all the bees are left on, some cells may escape detection. If no cell is found, then the page of the colony is found in the record-book, and the entry "no c." is made after the date. Some years we have omitted such entry so long as no cells have been found in the colony that season, leaving it to be understood that so long as no entry as to cells appears, no cell has been found. But it is a little safer to make the entry, for then we can be sure that we have not killed cells and forgotten to make the entry.

When at any time cells are found, they are of course killed, and the entry of that killing is made with some degree of particularity. The entry " $\mathrm{k} 1 \mathrm{eg}$ " means killed one egg; "k 2 eg", means killed two eggs; "k 1 c", means killed one unsealed cell; " $\mathrm{k} 1 \mathrm{~s}$ c" means killed one sealed cell. Often there will be killed one or more eggs and one or more grubs, when the short but comprehensive entry will be made, "kc," meaning killed cells. Indeed, that is the most common entry made.

After the first time around, before opening a hive, the book is always consulted as to previous history, and if cells have been previously killed it is a matter of some judgment as to what is to be done. If the previous entry was " $\mathrm{kc}$ ", there is a good chance that the bees are bent on swarming, and it will not do to shake the bees off the comb, for we may want to find the queen, and stirring up the colony by shaking the bees would make the finding difficult. So 
the combs are carefully examined without shaking the bees off. If no cells are found after thus looking over the combs, or at least a good part of them, then the bees are shaken off the combs and a thoro examination made. Instead of this, we are more likely to find a number of cells well advanced, in which case some sort of treatment that involves finding the queen will usually be decided upon, and the queen will be found before any combs are shaken. This shows the importance of examining the record before opening the hive, for without that we would not know whether to shake the combs or not.

The beginner is very likely to think that all that is necessary to prevent swarming is to continue regularly killing cells, believing that there will be no swarming so long as no cells are allowed to approach the sealing stage. But it doesn't work out that way. After a colony once fully gets into the notion of swarming, it seems only to make it more stubborn to have its cells killed, and finally it may swarm with nothing further than eggs in queen-cells, if indeed there is that much preparation.

So it is a matter of some nicety to decide when it is wise to continue to depend upon killing cells and when to resort to some other measures. Suppose a colony had cells killed.June 10, and it is again visited June 18, 19 , or 20 , and at this time nothing further than eggs are found in queen-cells. No trouble to decide in this case. Kill the eggs, and continue killing them each time no further advance is made. It sometimes happens that eggs are found upon one or two visits, and then the bees go thru the rest of the season without any further thought of swarming.

Suppose, however, that in the same hive, upon visiting it June 18 or 20 , we find queencells in number, some of them well advanced or even sealed. In this case it will be useless to think of depending upon any further cell-killing.

Between these two extremes, only eggs and many advanced cells-come all degrees of advancement, and it is not easy to know where to draw the line. If only small larvae are found, they may be considered the same as eggs, and killing cells continued. Something depends on the number of cells found. If not more than 3 or 4 , even tho quite well advanced, it may be counted safe merely to kill them. Something, too, depends upon the time. Early in the season the bees are more persistent about swarming, whereas later the killing of cells may be more relied on, even tho well advanced. Also, cells late in the season may mean superseding the queen, especially if the cells be few in number.

It is no little trouble to keep killing cells every 8 or 10 days, and the question as to how efficient the plan is is a fair one. Also it is a matter of some consequence to know what bearing this sort of management has upon the crop. These questions may be fairly well answered by quoting from Gleanings in Bee Culture for 1905, page 1174, where I reported:

"Of 160 colonies run for comb honey that were fair subjects for comparison, $13 \frac{3}{4}$ per cent went thru the season without ever offering to start queen-cells; $121 / 2$ per cent started cells one or more times, but gave it up when their cells were destroyed; and $733 / 4$ per cent seemed so bent on swarming that they were treated by being kept queenless 10 or 15 days. The colonies that were left with their queens all the time averaged $361 / 2$ per cent more sections than those that were treated. But that's better than they would have done if left queenless for 21 days, which would have been the case practically if swarms were shaken.' Altho it is mentioned that treatment was given that left colonies queenless 10 or 15 days, it should be said not often did the time extend beyond 10 days.

Of course seasons differ; but likely enough 1905 was about the average. It should be remembered that this was with 8-frame hives run for section honey. With larger hives, or with extracted honey, the result would have been better.

One trouble with so much shaking of bees off the combs is that it sometimes happens that on a certain visit we find a colony with no cells and then at the next visit queenless, the queenlessness in some way no doubt caused by the operator.

I said that early in the season every colony must be examined and cells killed, but later in the season there were exceptions. Those exceptions become more numerous as the season advances, and occur whenever a young queen of the current season's rearing is introduced. We then write in the record-book the word "Pass," and for the rest of the season that hive will not again be opened. It is possible that a colony with such a young queen may swarm, but it so rarely happens that it is not worth while to keep watch for it. When a colony is treated for swarming, if its queen is not a little better than the average, it is always desirable that she shall be replaced by a young queen, and thus the ranks of the "Passers", are constantly recruited, and the work of killing cells lightened.

When it is best to stop the business of killing cells it is not easy to say; but hardly much before the waning of the fall flow. If continued too late it may interfere with those colonies that want to supersede their queens. But killing cells in the later months is by no means so important as earlier, for a swarm in August will interfere very little with the crop as compared with one in June.

\section{DEQUEENING AND REQUEENING TO PREVENT SWARMING.}

Dequeening is, perhaps, the only absolute means that can be employed. It is used by some of the largest and most successful beekeepers in the world, including Dr. Mil- 
ler, at times. It is effective because a colony will rarely swarm without a queen. It comes about as near being an absolute rule as any in beedom. During some seasons when swarming is particularly troublesome and the apiarist is almost in despair because the swarms come out in spite of him, dequeening is about all he can do.

Mrs. Wilber Frye, of Sand Lake, Michigan, is one of the best comb-honey producers in her state. She has been very successful in the control of swarming by dequeening the colonies and then cutting out cells nine days afterward. After having used the plan for a number of years she says she cannot discover that the queenless colonies, so far as honey production is concerned, are much inferior to those operated by other methods. By dequeening, she and another woman do all the work of running a series of outyards, producing a very fine grade of comb honey, and that, too, without swarming. In the production of comb honey, especially at outyards, the one great problem is swarm control. With that difficulty solved the expense of producing comb honey will be greatly reduced. Mrs. Frye feels that dequeening is the solution.

Not all persons who have tried this dequeening method are successful. They find two main objections. 1. That a queenless colony or one having a queen caged (which amounts to the same thing) is not as energetic as one having a queen. 2. Even when one dequeens or cages he must resort to cell-killing in eight or nine days; otherwise the bees will swarm with the first virgin that hatches.

It has the further advantage that it checks brood-rearing, thus preventing a large force of bees from coming on after the harvest is orer, when they would have to be fed in lacalities where the honey-flow is short and no supply of nectar comes in until the fall. Dequeening simply reduces the size of the colony, thus avoiding the rearing of useless consumers, when they could do no good. Following this there should be fall breeding. If there is no fall flow, the bees should be fed to stimulate brood-rearing. See Feedivg and Feeders, subhead "Feeding to Stimulate."

SHAKING ON EMPTY FRAMES OR STARTERS.

This is virtually shake or "shook" swarming as described under Artificial Swarm-
ING, to which the reader is referred. During some seasons, and with some strains, it is quite effective. It has the advantage that the professional man who is compelled to be away from his bees during the middle hours of the day can shake his swarms at his convenience, either in the morning or in the afternoon, rather than have them come out when he is away. In practice it comes very near taking the place of natural swarming.

Of course bees shaken on frames of foundation may swarm out. A natural swarm may do the same thing.

Mr. Chalon Fowls, of Oberlin, Ohio, uses very satisfactorily a modification of the plan in that he does not shake but makes the old bees do the swarming. He thus describes it:

Let us consider for a moment the difference between a natural swarm and a" shook", swarm. A natural swarm is made up of the bees old enough to fly; but a shook swarm consists of bees of all ages-nursebees, cell-builders, all sorts. We have made many "shook" swarms previous to 1912 (when we adopted the new plan), and I often thought the bees acted uneasy and dissatisfied, which I attributed to the presence of so many young bees. No doubt many of these were cell-builders primed with royal jelly, which would go right to building another batch of cells.

In 1911 we had a poor season here, the bees getting just enough honey to induce them to swarm, and we practiced "shook", swarming until we became convinced that the plan was wrong in principle for the aforesaid reasons.

About this time Dr. Miller answered an inquiry in Gleanings, Aug. 15, page 490, 1911, explaining that the presence of queencells above a comb-honey super would not have enough effect on the lower story to start swarming there. Probably I got the illea from this, and the next year (1912) we put it in practice, making over forty swarms by the new plan. The next year (1913) we had a bumper crop, and the bees directed their energies to storing, so we did not need to make as many swarms; therefore I decided to wait another year before reporting, as I wanted to try the plan out thoroly under different conditions; so last year we made about fifty swarms by this plan, and I don't remember that we had a single failure.

Having found a colony with queen-cells we begin our treatment. If the hive has a loose bottom so it (the hive) may be used as an upper story, so much the better. In this case, find the queen and place her on a comb containing but little brood and a few bees, and place in an empty hive, filling the rest of the hive with empty combs, 
and place on the stand after setting the hive of brood aside. Frames of foundation may be used, but are not as good. In case foundation is used I would take (in addition to the one comb with the queen and a little brood) two frames containing little or no brood from the hive of brood, first brushing off the bees so they will be with the brood. Now place a queen-excluder on the new brood-chamber and two or more extracting-supers of empty combs on top (we use shallow supers) with the hive of brood put on last. Fill any extra space with dummies and leave till the next visit in seven or eight days, when they are moved to a new stand. To insure that no young queens hatch during the time, at the time of making the change tear out the capped cells, leaving all those not capped. Of course the swarm in the lower hive will be made up of returning field bees all old enough to fly. It will be seen that this result is radically different than in the case with a shaken swarm with bees of all ages, and therein is the secret of its success, in my opinion.

The first year I practiced this plan, there were some cases in which cells were built in the lower story; and as there often were a lot of young bees left sticking to the sides of the hive, or adhering to the two outside frames of honey sometimes left below, I believed those fellows did the work. As most of our hives have tight bottoms I was obliged to leave them on the stand, lifting the brood out to raise up. Therefore since that first year's experience I have taken more pains to get those fellows out of the lower story. Rather than leave a quantity of young bees in the hive below I would brush them out into the hive of brood to be put on top, as I feel that is much safer.

\section{GIVING ADDITIONAL ROOM TO PREVENT SWARMING.}

The precise methods for doing this are described under the head of ExTRACTED Honey and Comb Honey, How to ProDUCE. The more-room principle involves one of the fundamental features in the prevention of swarming. While it is true that some colonies will not swarm, even in contracted quarters, there is no better way to force swarming than to keep the colony in a single brood-nest without giving supers or upper stories. If, therefore, one would check swarming, the practice should be reversed.

There is one point to consider, and that is that room should be provided before the bees are crowded. If they are allowed to fill every available cell with honey or brood, the chances are they will start cells; and when cells are once begun it is sometimes difficult to get the swarming notion out of the colony. Better by far make the conditions so the bees will not build cells than to try to stop swarming by killing cells afterward.

\section{PROVIDING ABUNDANT VENTILATION.}

This is a very important factor especially in a hot season. It is so simple to apply that all colonies at the beginning of the honey harvest should have their entrances very much enlarged or their hives lifted up

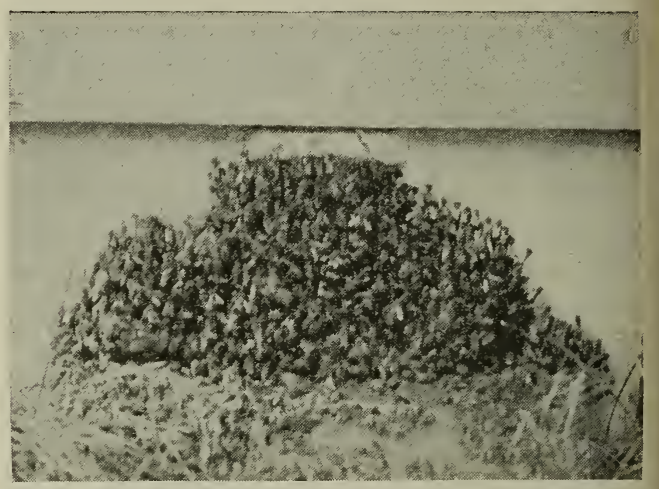

FIG. 1.-A case of too small an entrance. It was a warm day when this picture was taken. The bees, being unable to ventilate thru the small entrance ( $8 \times 3 / 4$ in.) clustered out.

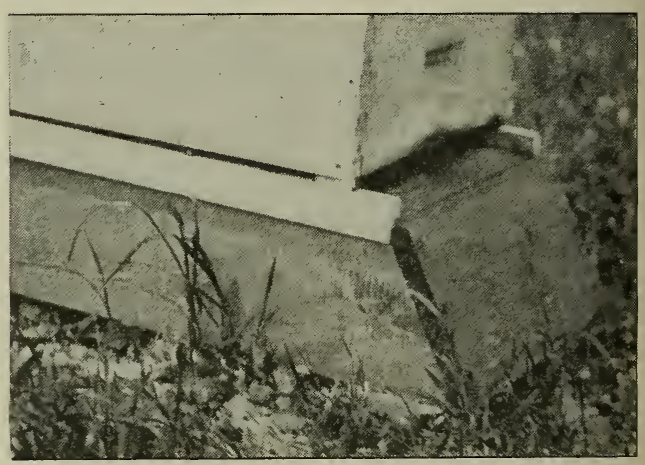

FIG. 2.-A hive with proper ventilation at the bottom to prevent clustering out at the entrance.

on four blocks, as described under ENTRANCES. If the entrance is very much contracted it makes it extremely difficult for the bees to ventilate the hive properly.

During the swarming season the weather may be very hot or even sultry; but, no matter what the outside temperature, it is very important that the internal temperature be kept down to about 96 . If it goes much higher, much of the brood will be destroyed, and a large portion of the bees will be forced outside. 
By giving plenty of bottom ventilation it will take less bees to keep the hive cool than when a restricted entrance is used. In this connection it may be well to explain that one set of bees will place themselves in such a position that they force a current of air into the hive, and another set forces the warm moist air out of it. If one will, after the bees have been heavily at work in the field, light a match and hold it in front of the entrance, he will find there is a strong

\section{GIVING SHADE.}

Practically the same reasons that apply for giving an abundant ventilation also apply here. A colony any season that is exposed to the direct rays of the sun has a much more difficult problem in keeping the interior of the hive cool than when the hive is in the shade. Under the head of APIARIES; various means for shading the hive are illustrated and described. If a hive is exposed to the hot sun it requires a

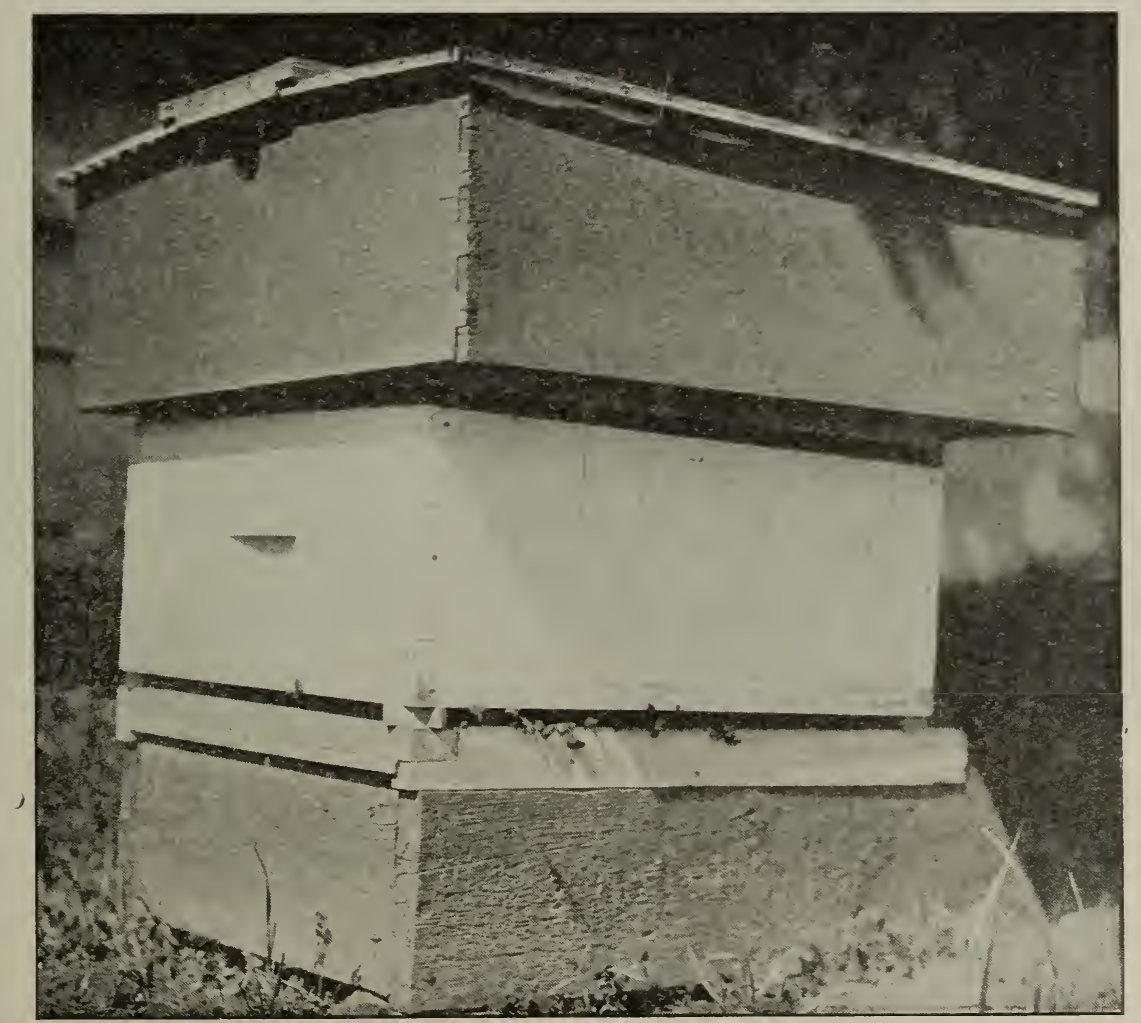

FIG. 3.-One of Vernon Burt's hives for the production of comb honey. Mr. Burt sars this scheme of putting his brood-bodies upon four blocks so as to provide entrances for all four sides goes a long way in eliminating swarming.

current of air going in on one side and another strong current going out at the other side. Sometimes the air seems to go in at both sides and come out in the center. (See Ventilation.)

Of course a restricted entrance must mean that the bees will cluster out in front of the hive and that starts the loafing habit - a habit that is not easy to break up, even after larger entrances are provided. While clustering-out is not necessarily an indication of swarming, it may be. Very often bees will cluster out worse after a honeyflow when the weather is extremely hot than during it. See Ventillation. good many bees to keep up the ventilation, and these bees might otherwise be in the field at work.

\section{BREFINTG FROM NON-SWARMING STOCK.}

The usual tendency on the part of beekeepers is to raise queens from swarmingcells because they are abundant, and because vigorous queens can be reared from such cells. But the question has been raised whether such queens will not inherit more of the swarming tendency than those reared under other impulses as in supersedure.*

\footnotetext{
* One queen-breeder says for this reason he raises
} all his queens under the supersedure impulse. 
No definite proof has been adduced to show that colonies headed by queens from swarming-cells will swarm more than colonies from queens reared from supersedure cells; howerer, Dr. Miller and some others have made some progress in breeding from nonswarming strains of bees. For years his queens have been bred from those colonies that keep on storing honey thru the season without swarming. While he does not claim that the colonies from such queens will not swarm, he feels that the effort is not in vain.

The very fact that Dr. Miller has produced some of the largest yields of comb honey per colony that have ever been known -yields taking the apiary as a whole that have broken the record-shows that his views can be taken with some degree of authority.

THE PREVENTION OF SWARMING WHEN RUNNING FOR EXTRACTED HONEY.

As already stated, swarm control is comparatively simple in the production of extracted honey. While the principles already set forth apply more particularly to comb honey, they have considerable force in the production of extracted. It should be borne in mind that comb-honey supers with their little square boxes containing only foundation are unnatural, and for that reason there is apt to be a period of sulking or hesitation before the bees go into them. During that time preparations for swarming may begin.

In the production of extracted honey, the mere giving of empty combs in which to store the freshly gathered honey goes a long way toward keeping the bees contented. If room is given fast enough, and if sufficient ventilation is provided, and the queen not cramped for egg-laying room, the amount of swarming will be very little, comparatively. The extra room in the case of the ordinary Langstroth hive can be given by adding extra supers as fast as the bees require them. While the same thing can be done in the production of comb honey, the extra supers, as already stated, are unnatural, requiring the bees to build comb in the small compartments more or less remote from the brood-nest or queen.

We have been able to keep down swarming by adding extra supers from time to time containing fully drawn empty combs. If a queen-excluder is put on at the very beginning of the season, the queen may be cramped for egg-laying room, especially if an eight-frame hive is used. If, however, she is given all the range of two stories thru the breeding season, there will be little or no preparation for swarming. A week before the actual honey-flow the sealed and hatching brood should be put in the upper story, and the unsealed in the lower story, with a queen-excluder between. As the brood hatches out in the upper story it will leave room for the storage of the first new honey. Before the bees are cramped for room another story should be added, always keeping in mind the importance of keeping well ahead of the bees. If the bees seem disposed to cluster out, the hives should be raised up on four blocks, because ventilation is very important. If they are exposed to the direct rays of the sun, a shade-board may be required. (See APIARY.) As fast as combs are filled with honey they may be extracted, or held till later in the season, a reserve of empty combs being given instead.

\section{THE DADANT SYSTEM OF SWARM CONTROL.}

Under Hives mention is made of the large Quinby hive used by the Dadants, and of the fact that they have very little swarming. During 1916, from 525 colonies in Quinby hives run for extracted honey they had only 30 swarms. Their scheme of swarm control in connection with these large hives may be briefly summed up as follows:

1. An ample brood-chamber as provided by the Quinby hive.

2. Plenty of super room filled with foundation or fully drawn combs. The Quinby hive is so large that the average queen does not require a queen-excluder, and therefore will not go into the upper story. No effort is made at any time to cut out queen-cells every seven or eight days, and on this point the Dadants make strong claims for their system.

3. Ventilation is provided by raising the hive up on four blocks above the bottomboard. If the season is hot and the colony very strong the space may be increased to two or three inches.

4. Protection from the sun or hot weather is regarded as important; and to that end shade-boards or a moderate shade from trees is provided. 


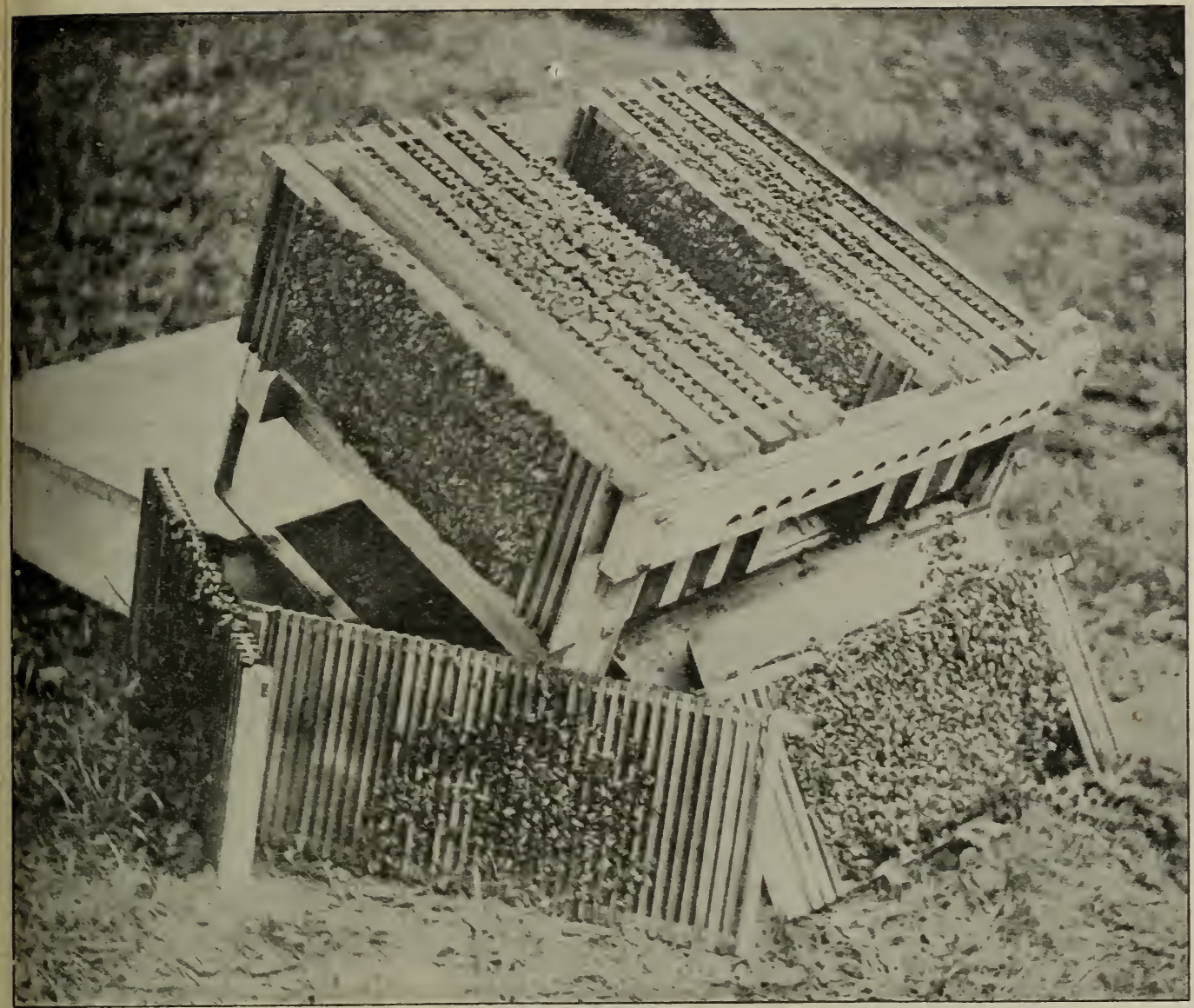

Aspinwall hive dissected, showing brood-frames and slatted dividers.

5. The queen must be young. While some queens are used the second year, usually a rery prolific queen will fail at the end of the first year.

6. No drones should be allowed in the hive. To that end, all drone comb should be excluded by the use of combs drawn from worker foundation.

7. Frames should be spaced $1 \frac{1}{2}$ inches from center to center. Mr. C. P. Dadant regards this wider spacing as quite important because it gives more room between the combs. The fact that the Dadants secured a crop of 125,000 lbs. from 525 colonies during 1916, one of their best year's, without the use of queen-excluders, without cutting out cells, and with only 30 swarms, shows there must be something in their system. The hives were operated almost entirely on the let-alone plan, and all they did beyond what is stated was to take off the honey after the super's were filled.

Whether or not practically the same results can not be secured with Langstroth 23 hives on the tiering-up principle is something of a debatable question. It is apparent, howerer, that the queen-excluder must be used at some stage of the proceedings, because an ordinary ten-frame Langstroth brood-chamber will not hold a good queen; and unless restrained she will go up into the extracting-supers. The plan, however, of giving the queen the range of two hives during the fore part of the season and then confining her to a lower story by the use of a queen-excluder will probably accomplish practically the same result, altho it would necessitate a little extra labor in shifting sealed brood to the upper story and the unsealed to the lower after excluders are put on. The ordinary Langstroth hive is about as much as one can lift in these days when whole apiaries are moved from time to time. The Quinby hive is too much of a lift for most men. This together with the extra cost is doubtless the reason why the smaller hive is used almost universally. 
The main feature of swarm control in the Quinby hive rests in the fact that the queen has unlimited room for laying. This can be given in two brood-chambers of Langstroth size.

\section{NON-SWARMING HIVES.}

All the systems thus far described, both under this heading and under the head of "Artificial Swarming for the Prevention of Swarming," relate to methods of man-

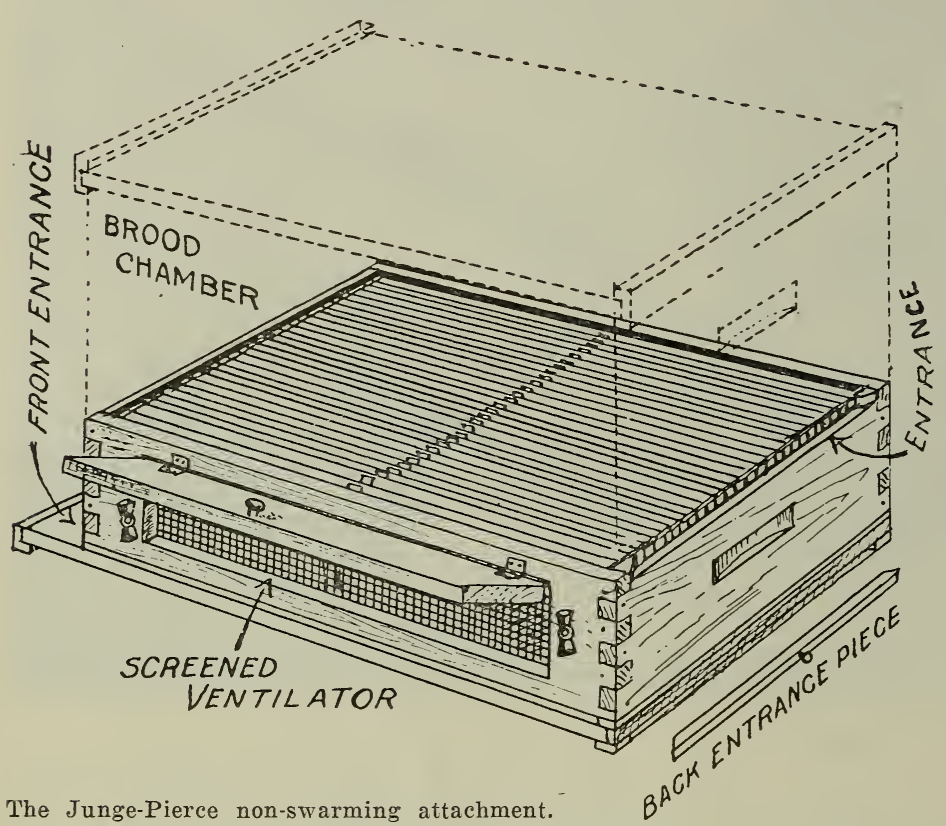
surplus bees will be clustered in the dummies between the frames; and as the dummies consist of a series of slats a bee-space apart, there can be no comb building. L. A. Aspinwall has tried out this principle, and it has worked so well in his hands that he thinks he has solved the problem of a non-swarming hive. But there have been some reports showing that it failed in the hands of others. The chief objection to the hive is its expense. JUNGE-PIERCE HIVE.

There are others who tried the principle of agement of the hives or colonies themselves. For a number of years much has been said about non-swarming hives. Within the last two or three years progress has been made.

Mr. L. A. Aspinwall goes at the problem by increasing the clustering space between the combs during swarming. To that end he has devised a hive cosisting of a series of brood-frames, and during the swarming season a series of slatted wooden dummies or separators placed in alternation between the frames. These slatted dummies made up of quarter-inch vertical slats spaced a bee-space apart provide a clustering space between the brood-combs, thus relieving the congestion that naturally arises because a large force of bees cannot be crowded into the small space between the combs such as are found in an ordinary hive. The Aspinwall frames, instead of having one end-bar, have a series of extra end-bars bee-spaced apart that provide a clustering-space at the making a clustering-space formed of a series of dummies a bee-space apart under an ordinary hive or in front of it. In the cut will be noticed that it consists of an ordinary super having ventilating sides covered with wire cloth and shutters, and a detachable entrance strip at the upper back end. This super is filled with ordinary fences such as are used in a comb-honey super. These fences are so constructed as to provide a series of slats and bee-spaces where the bees can build no comb, and at the same time provide a large amount of clustering-room between the brood-nest proper and the bottom-board with its entrances beneath.

Both Mr. Junge and Mr. Pierce feel that this non-swarming attachment, when rightly applied, will discourage if not altogther stop swarming. But they insist that it must be placed under the hive before the swarming fever is under way. 
METHODS FOR HIVING SWARMS.

In the foregoing, methods have been given for preventing, checking, or controlling swarming. It will now be in order to take up the other problem of restricting swarming down to one swarm per colony, and hiving that one swarm when it does come out. A large number of beekeepers believe that a natural swarm has much more energy in the production of either comb or extracted honey than a colony whose efforts to swarm have been checked or balked. Sometimes swarms that have been thwarted will begin to sulk and then the problem is how to get them to work. While perhaps the great majority of beekeepers will find it an adrantage to use preventive measures, believing that the bees will cast their first swarms in spite of them, there are those who hold that they can secure more honey by letting the bees satisfy their natural desires by swarming once-that is to say, the parent colony and the swarm together will produce more honey than if they have been kept in one hive. While this is, of course, a debatable question, it is a matter that should receive careful consideration; for no one method or set of methods will work with all beekeepers and in all localities.

For the purpose of the present discussion it will be assumed that it is an advantage to manipulate the colonies so that they will cast a swarm, after which repressive measures will be applied on the parent colony.

Some of the advocates of the one-swarm scheme find that the artificial plan of shaking, as advised under the head of ARTIFICIAL SWARMING, is quite satisfactory, while others believe it is better to let bees have their own way, so far as the first swarm is concerned. The advocates of the one-swarm plan practice clipping the queens' wings, as already described under the hear of QueENS.

HOW TO HIVE A STARM WITH CLIPPED QUEEN.

Under the general head of QueEns, subhead "Clipping," intimation is given how swarming can be controlled to a certain extent by clipping. Where the plan of forcing the swarm ahead of time by brushing or shaking* is not practiced, clipping has come to be almost universal among * This plan is described under ARTIFICIAL
SwARMING. comb-honey producers; for where queens' wings are clipped, or they are prevented from leaving the hive by the use of Alley traps or entrance-guards (see Drones), a great amount of labor will be saved.

It will be assumed that all queens in the apiary have their wings clipped. A swarm comes forth. After the bees are nearly all out the queen will be found, in all probability, hopping around in the grass near the entrance, vainly endearoring to fly with the rest of the bees. She should be caged, and the cage slipped into a pocket or some cool place, temporarily. The super or supers in which the bees have already started work should be set on the ground near the hive. The brocd-chamber should now be removed just as it is, to an eatirely new location. In its place on the old stand a hive containing frames of foundation or empty combs should be set and on top of this a queen-excluding honey-board. Some prefer having only starters of foundation. The supers, placed on the ground temporarily, are now put on the new hive containing these frames of foundation or combs. The caged queen is laid in front of the entrance.

All this may be done while the bees are in the air, and it will not be long before they discover that the queen is not with them, return pellmell to their old location, and rush into the new hive. After they are well started going in, the queen may be released, when she will go with them.

The work already begun in the supers will be pushed on and completed with more vim and energy than before, because, as already stated, a new swarm works with new energy. If only frames containing starters have been given them, what honey does come in is forced into the supers, for the bees have no other place to store it, at least until foundation below has been drawn out; but as soon as this takes place it is occupied immediately by the queen.

The old hive containing frames of brood and queen-cells now in another location may cast a second or third swarm; but if queen-cells are cut out, even second swarming may, to a very great extent, be checked.

This method of handling swarms where natural swarming is allowed commends itself especially to the women-folks, who are generally at home. All they have to do is to hunt up the clipped queen, cage her, and 
then put an empty hive containing frames of foundation in place of the old one. As it might not be practical for the women to carry the old hive to another location, they can simply drag it over to one side, and change the entrance so that it will face to the rear. When the "man of the house" returns, he can lift the supers from the old stand on to the new one, then take the old

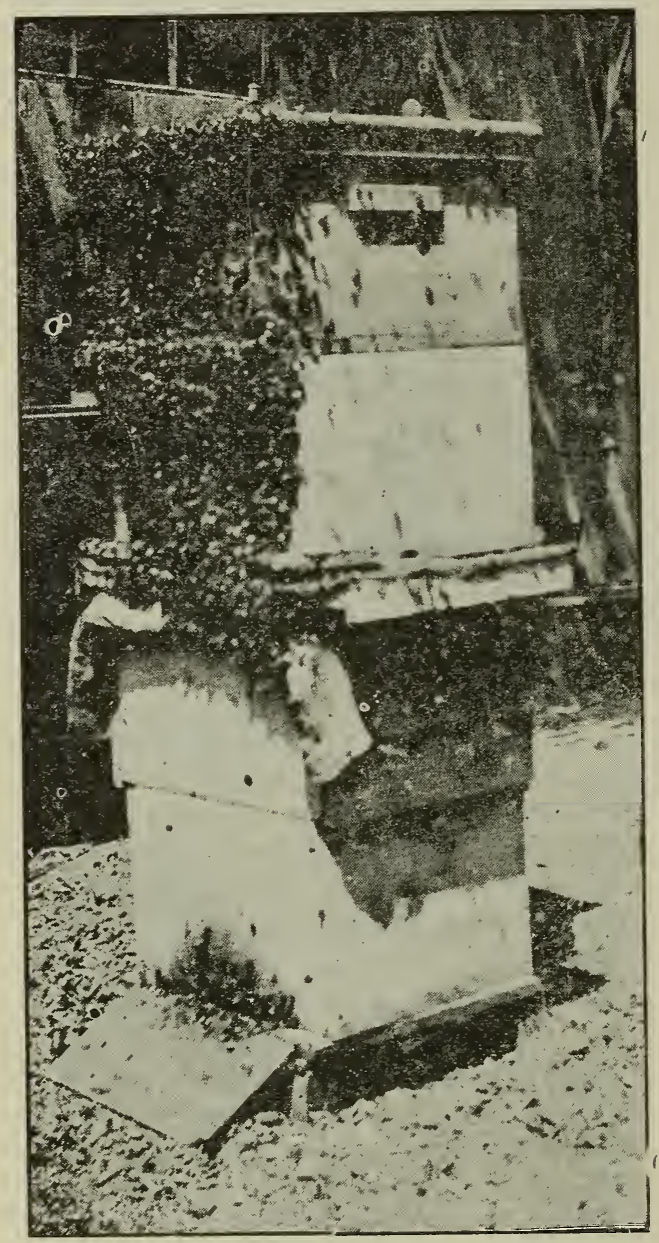

A self-hived swarm.

brocd-nest orer to another location. This may be done any time within a day; or, when preferred, the old hive can be left alongside the new one, providing the entrance is reversed.

If two or more swarms come out at the same time, and one of them has a virgin queen, all the bees will be iikely to unite with the one having the queen; then, of course, this plau of bees returning will come to naught. But in a well-regulated apiary of Italians there will be few such occurrences.

PERFORATED ZINC TO RESTRAIN QUEENS.

The employment of perforated zine will not prevent swarming-it only hinders the bees from accomplishing their purpose; that is, absconding and taking their queen with them. The perforated zinc simply takes the place of clipping the queen's ving's. In some cases it may be desirable to use the zinc.instead of clipping. Usually, it is preferable to clip the queen's wings rather than to cause the bees the inconvenience of crawling, during the continuance of the honey-flow, thru narrow perforations of zine or wire bars, simply to hold back the queen should a swarm issue.

While we recommend clipping in place of using perforated zinc, yet.in the case of very strong colonies in the height of the honey-flow, especially when such colonies are in two-story hives, it is more practical to put on entrance-guards or Alley traps. (1) Attaching the traps can be done in a tenth of the time it takes to find the queen: (2) pulling the hive all apart to find her majesty causes more or less interruption; but of course the queens should be clipped early in the season when it is easy to find them.

THE ALLEY TRAP IN HIVING STARMIS.

While the trap can be used as menticned under Dnones for catching the queen as she issues with the swarm, yet it shuts off rentilation, so vitally necessary during the swarming season. It impedes the ingress and egress of the workers, and during the honey-flow it must necessarily eut down the efficiency of the colony. It should therefore be used cnly in a case of emergeney, either to prerent a valuable queen from getting away or to hold her until such time as the apiarist can go thru the colony, hunt her up, and clip her wings.

\section{SWARMING - DEVICES VARIOUSLI CONSTRUCTED.}

Every apiarist engaged in the production of honey should certainly have the wings of all his queens clipped. He cannot afford not to, unless he uses perforated zinc. It is much more difficult to take care of swarms when queens are allowed to go with the swarm. But as there are some 
who dislike to "disfigure" or "mutilate" their queens, and as some swarms in any case will get out with a virgin queen, it has been thought best to describe the various devices for capturing swarms with unclipped queens. See QueEss, subhead, "Clipping."

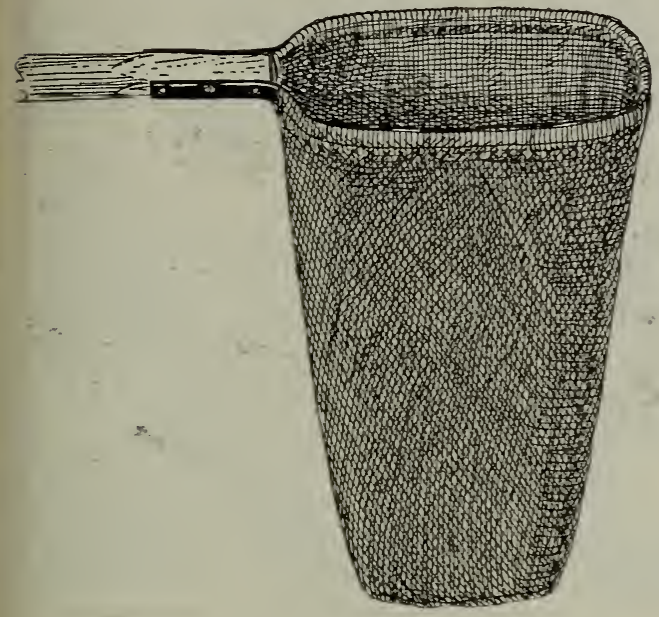

Almost every apiarist has his own peculiar notion as to how a swarming-device should be constructed. Some of these implements are rery ingenious, and of raluable assistance during the swarming season. Their particular use is to remove a swarm after it has clustered, and place it in the hive where it is desired that it take up a new abode. The first one to which attention is called, not because it is the best. but because it is the simplest, is a sort of butterfly-catcher.

The hoop is made of band iron, and is about 20 inches in diameter. The ends are secured, as shown, to a suitable pole. The bag is to be put up under the swarm. and the hoop is then made to cut off the cluster so that the bees will fall into the bag. It is then turned edgewise, so as to confine them while being taken down and carried to the hive. It may be necessary to hold the bag in the air to catch the flying bees. These will shortly cluster on the outside. As the bag is made of cheese-cloth. the bees inside have plenty of air. To empty the bees turn it inside out.

\section{A. E. MANUM'S SIVARMING-DEVICE.}

This consists of a wire-cloth basket made in the shape of an inverted pyramid, and pivoted at the opposite corners so as to hang always in an upright position. When a swarm is captured the basket may be grasped by the ring at the small end, and inverted, dumping the bees into the hive prepared for them.

As soon as the cluster beginning to form on a tree or bush is half or nearly completed, the basket is shored up to and around the cone of bees. An assistant, if present,

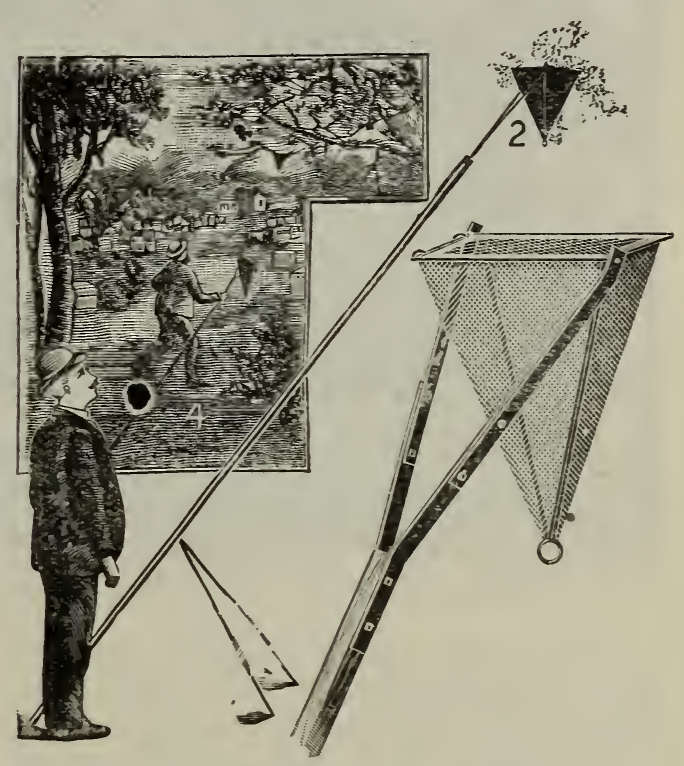

Manum's swarm-catching device.

gives the limh a jar, so as to disengage the bees into the basket. In case no one is ready to assist, a sliding morement will precipitate the cluster into the wire-cloth cage, when it is quickly lowered. This operation, in passing down thru the limbs, will usually catch the wire-cloth lid, and close it with a slam. In case it is not closed, the apiarist steps forward and does it himself. Half or two-thirds of the bees are generally confined. In all probability the queen is there also. As the bees can not get out, those still flying in the air will very readily cluster on the wire cloth, surrounding the majority of their companions inside. To make this more expeditious the tripod is adjusted and the cage suspended in the air right where the bees are flying thickest. In five or ten minutes the remainder of the bees will be clustered on the outside. At this stage of the proceeding the apiarist comes forward. folds the two short legs against the pole, grasps it at its center of gravity and walks off to the hive, which he has previously prepared. 


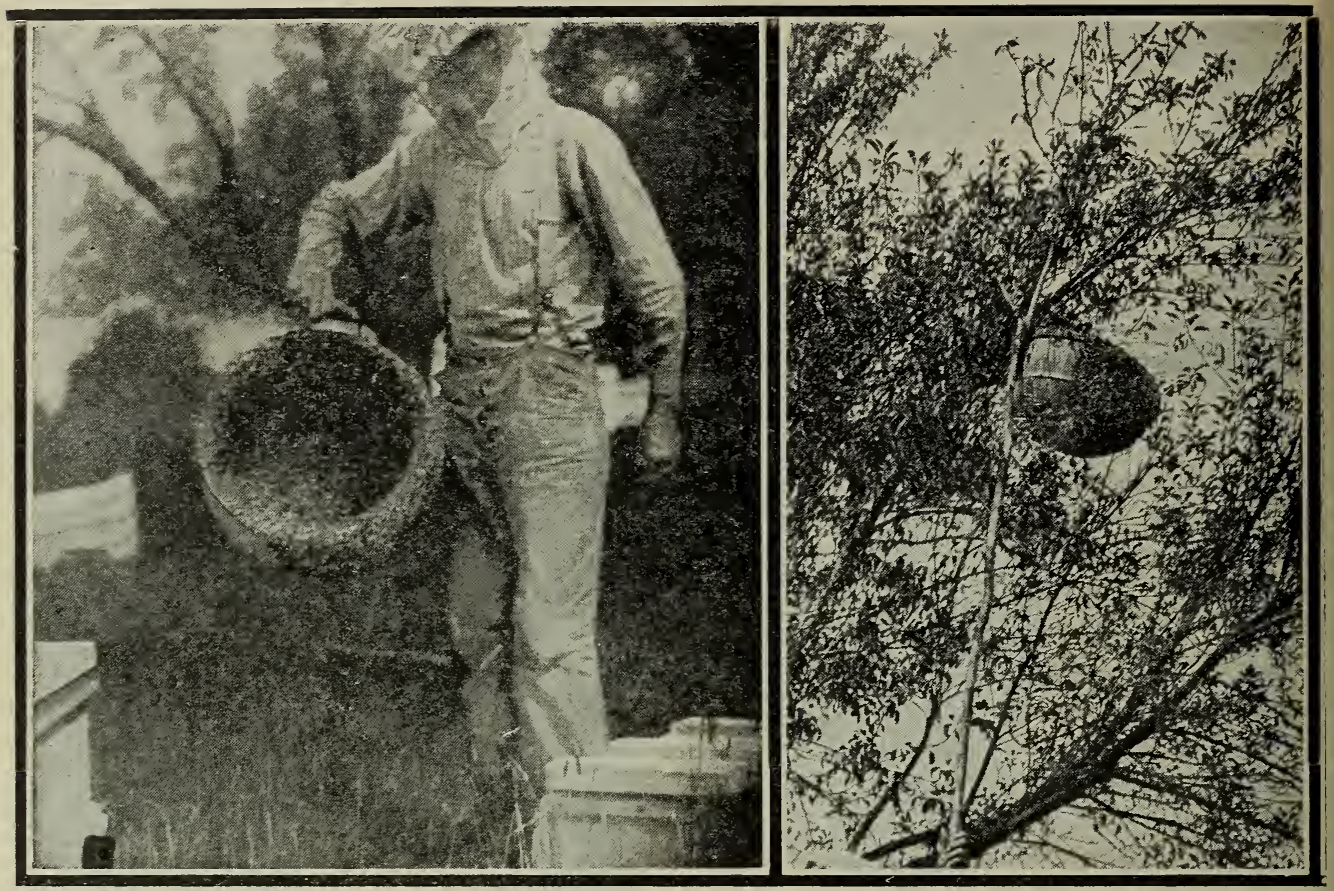

S. D. Chapman, of near Mancelona, Mich., and his method of hiving swarms with a forked pole and a bushel basket.

One of the special features of the Manum arrangement is that the basket can be adjusted to almost any position, all the way from two to ten feet off the ground. All that is necessary is to adjust the tripod so that the basket will be held where the bees are flying. In the mean time, unless the hive is already prepared, the apiarist has ample time to get it ready. After this he can return to the swarm just now clustered. Most of the devices require to be held until the cluster has settled. It is a tedious job to hold a pole at arm's length, with face upturned. If the swarm clus. ters very high, some other arrangement, perhaps, would be better than the Manum; but for moderate heights it's just the thing.

In the absence of any special tools or appliances one can extemporize a swarmcatching device out of the ordinary material at a farm in a very few minutes. A small sapling is cut, long and slender. All the branches are trimmed off, care being taken to leave a fork or crotch in the end. This extemporized swarming-pole should be anywhere from 12 to 15 feet long. A common bushel basket is hooked into the fork at the end of the pole. The combination is almost as good as the one just described, with the further advantage that the basket can be detached from the further end of the pole as soon as the swarm is caught.

After the basket is hooked on to the end of the pole, the basket is elevated to a point just below where the swarm is hanging on the tree. It is gradually pushed up until the swarm is nicely placed therein. The pole is given a sharp push upward, care being taken not to unhook the basket. This sudden jar will dislodge the swarm; and before the bees have an opportunity to take wing, the basket is lowered and unhooked from the end of the pole. It may now be dumped in front of the hive where it is to be placed. In all probability a few more bees may cluster back on the old spot. If so, the operation is repeated, after which the second bunch of bees is placed where the first was dumped.

\section{THE SWARM-HIVING HOOK.}

With most of the hiving-devices a hivinghook can be used to considerable advantage at times. It is simply an iron hook mounted on the end of a long pole, and resembling, somewhat, a shepherd's crook. One of the hiving-devices is passed beneath the swarm. This hook can be used to reach over, grasp the limb on which the swarm is clustered, and by one or two smart jerks jar the bees into the basket, bag, or box. 
HOW TO GET A SWARM FROM AN INACCESSIBLE LIMB.

Sometimes a swarm will alight upon a limb beyond the reach of any ladder. Possibly, also, the limb upon which the bees are clustered is so far out from the body of the tree that it would not sustain the weight of any one climbing after them. Such a swarm can usually be reached in the following manner. A stone about as large as the single fist is tied at the end of a good line. If one is not a good thrower

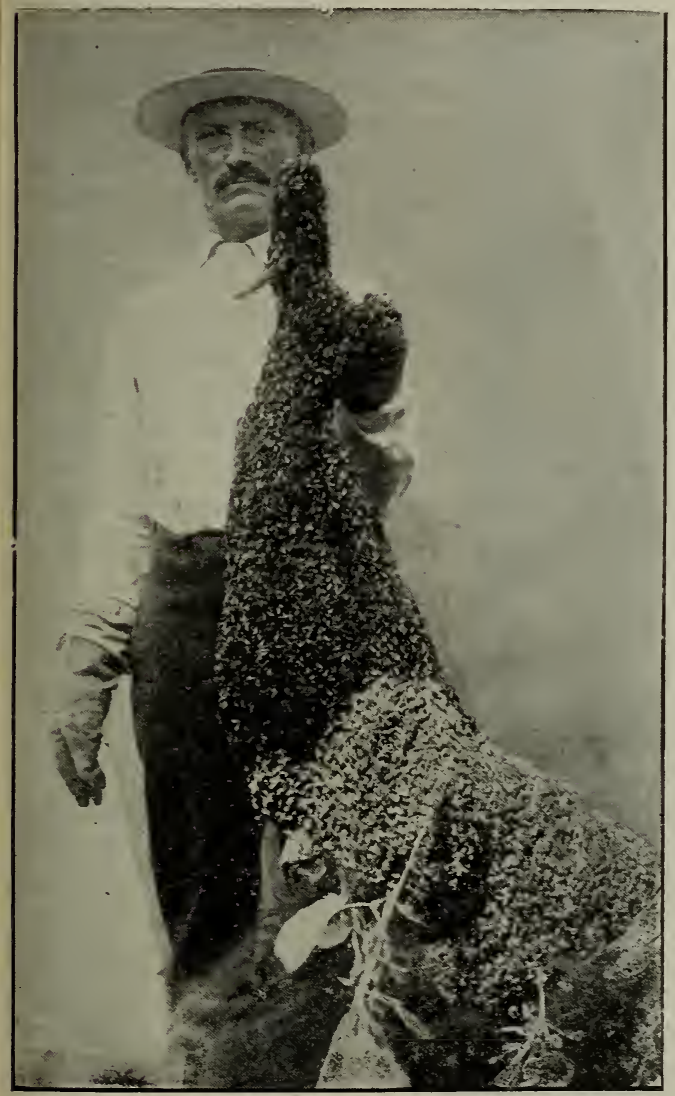

This swarm of bees issued June 7 from a colony of bees that produced 180 pounds of comb honey the same season.

himself he can get some boy who is a good ball-player to perform the throwing act. He should uncoil a considerable quantity of the line, then throw the stone into a crotch if one is near the swarm. If he is lucky enough to land the stone in the crotch, he should draw gently on the line until the stone catches in the fork. One quick jerk will dislodge the bees, and after that the limb should be kept in a tremble until the bees cluster on some other spot which they will do presently if the limb is kept agitated for five or ten minutes. They may cluster bigher up, but the probabilities are they will seek some other spot more accessible.

If there is no convenient crotch at the right point, the stone should be thrown so it will pass over the limb, taking about one foot of line. The string should be given a good jerk, causing the stone with the line to whirl around the limb a couple of times. If one does not succeed in doing this the first time or two, a third or fourth attempt may be successful. It is not a very difficult trick; but the main thing is to get the line attached to the limb at some point near the swarm. Then the rest is easy.

\section{SPRAY-PUMP FOR CONTROLLING SIVARIIS WHILE IN THE AIR.}

One of the most useful implements in the apiary when queens are not clipped is a good hand force-pump. A swarm of bees in the air with a queen that might otherwise circle about for fifteen or twenty minutes can usually be made to cluster in from two to five minutes by its use. Whether the fine particles of water dampen the wings, and so impede their flight. or cause the bees to think it is raining, or both, and that therefore they had better cluster at once, can not be proven; but certainly the spray has a very decided effect. One who becomes moderately expert will be able not only to make the bees settle but to compel them to cluster on some point easily accessible to any of the ordinary hiving-devices just described. Occasionally a swarm will make for the top of a tall tree. With a pump they can be headed off, causing them to settle on a lower branch. Even when a swarm is clustered twenty or thirty feet from the ground, by adjusting the stream nozzle and letting it play directly on the swarm itself, it can, many times, be dislodged, thus causing them to take wing and finally settle again upon a lower point of attachment. Again, several swarms will come out simultaneously, and two or more attempt to cluster together. By the timely use of the spray, each swarm can be kept separate by dampening the wings of the stragglers of the two swarms about to come together. A good many times a swarm that is about to abscond can be headed off and made to cluster; in fact, 
during the summer of 1889 the author could drive a swarm about like a flock of sheep. It is very annoying and inconvenient to have a swarm pass from one's premises over to those of a neighbor.

\section{SWARM-CATCHER.}

This is simply a large wire-cloth cage, in the shape of an oblong box, about three or four feet high, by 12 or 15 inches square, one end being open, and made to fit against an ordinary hive-front.

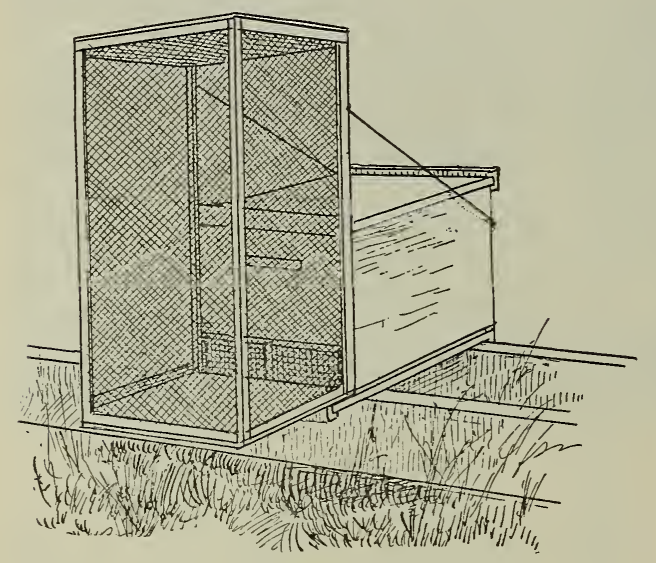

Swarrn-catcher.

It very often happens that the apiarist is on hand just at the time the swarm pours out the entrance like hot shot. With one of these wire swarm-catchers handy he simply attaches the mouth to the entrance, and the outpouring bees fly pell-mell into the top of the cage, and are there confined. When the apiarist succeeds in eatching twothirds of the bees, the rest will cluster on the outside. The cage is set very near where the bees come forth, mouth end down. Meanwhile he prepares his hive, if he has not already done so, and then brings the cage of bees and dumps them into the hive, replaces the cover, and the swarm is hived without having had any swarm in the airno, not even giving them a ghost of a chance to fly all over the neighborhood, and possibly finally alight upon the limb of a tree 40 feet from the ground. But it should be borne in mind that the swarm-catcher is serviceable only when the apiarist happens to be on the ground just as the bees are beginning to pour forth.

A large cage that comes down over the whole hive is much better than something adjusted to the entrance. The one shown in the half-tone, under RoвBing, is more quickly applied, because it can be set down over the hive and proceedings stopped. As soon as the bees are all out, the cage is lifted gently, and carried to the hive where it is proposed to dump the swarm. The eage is held squarely over the prepared hive with its cover off, and given one quick jounce. This will dislodge the bees so that most of them will land in and around the hive. As soon as they have settled, the cage is removed and the cover put on.

\section{THE AUTOMATIC HIVING OF SWARMS.}

For many years back there has been an effort on the part of beekeepers of an inventive turn of mind to get up an arrangement that would automatically hive swarms in the absence of an apiarist or attendant; and since out-apiaries have begun to assume such importance where the production of honey is carried on extensively, some sort of device that will hive automatically the swarms-yes, do the work just as well as if the apiarist were present himself, is something greatly to be desired. Several devices have been introduced; but most of them have been proven to be more or less a failure.

The general plan contemplates some scheme having an empty hive placed near the colony expected to swarm. This empty hive may be alongside, in front of, or below the other one. In the case of the first-mentioned plan, an entrance-guard is placed in front of each hive; and connecting the two is a tube of wire cloth or perforated zinc. When the swarm comes forth, the queen, finding herself barred by the perforated metal, runs along until she finds the tube communicating with the entrance-guard of the other hive. In this tube she runs up against a bee-escape or wire-cloth cone. She passes this; but, being unable to return, is compelled to enter the entrance-guard of the new hive. Upon discovering that the queen is not with them, the bees rush back to the old stand; a part of them find the queen in front of the new hive, enter with the queen and "set up housekeeping." But the plan fails because the majority fail to find her, and re-enter the parent colony.

The author has tried these plans to some extent, but, taking everything into consideration, it is cheaper and more practicable to hive the swarm on the clipped-wing plan, 
or, better, practice shook swarming, as described under Artificial Swarming.

HOIV TO HIVE SWARMS WITHOUT SPECIAL DEVICES.

If the apiary is located in a locality where there are no tall trees, but only lowgrowing shrubbery, or, at most, dwarf fruittrees, or, better still, if the wings of all queens are clipped, the special tools already described will not be found necessary, and perhaps not even a convenience. The author's home apiary located at Medina, and shown in connection with other yards under the general head of APIARY, page 60, as will be seen, has no trees. Outskirting it are rows of bushy evergreens furnishing the only place for the bees to cluster in the immediate vicinity of the apiary besides grapevines in the apiary itself. Rarely do swarms cluster elsewhere. When a swarm alights on one of the two places just mentioned a frame of unsealed larvæ is selected. As the swarm is but rarely more than four or five feet from the ground this frame is gently thrust among the bees. A large majority of them will very soon crawl upon the frame. This, together with the adhering bees, is placed in a hive in company with three or four frames immediately under where the swarm is clustered, if possible. The limb on which the cluster is hanging is jarred, causing the bees to fall on the frames below. Those bees which have already clustered on the frames will begin to call their companions. The hive is then left until the bees have all entered, then they are removed to their permanent stand in the apiary before they have had time to fix a location. Of course they can remain where they are.
HOW TO BRING HOME A SWARM A MILE OR SO FROM THE APIARY.

A swarm will sometimes escape and be traced a mile or so from the bee-yard. At other times a farmer will report that a swarm of bees is hanging to one of his trees, and that, if the bee-man will come and hive them, he can have them. A good swarm is

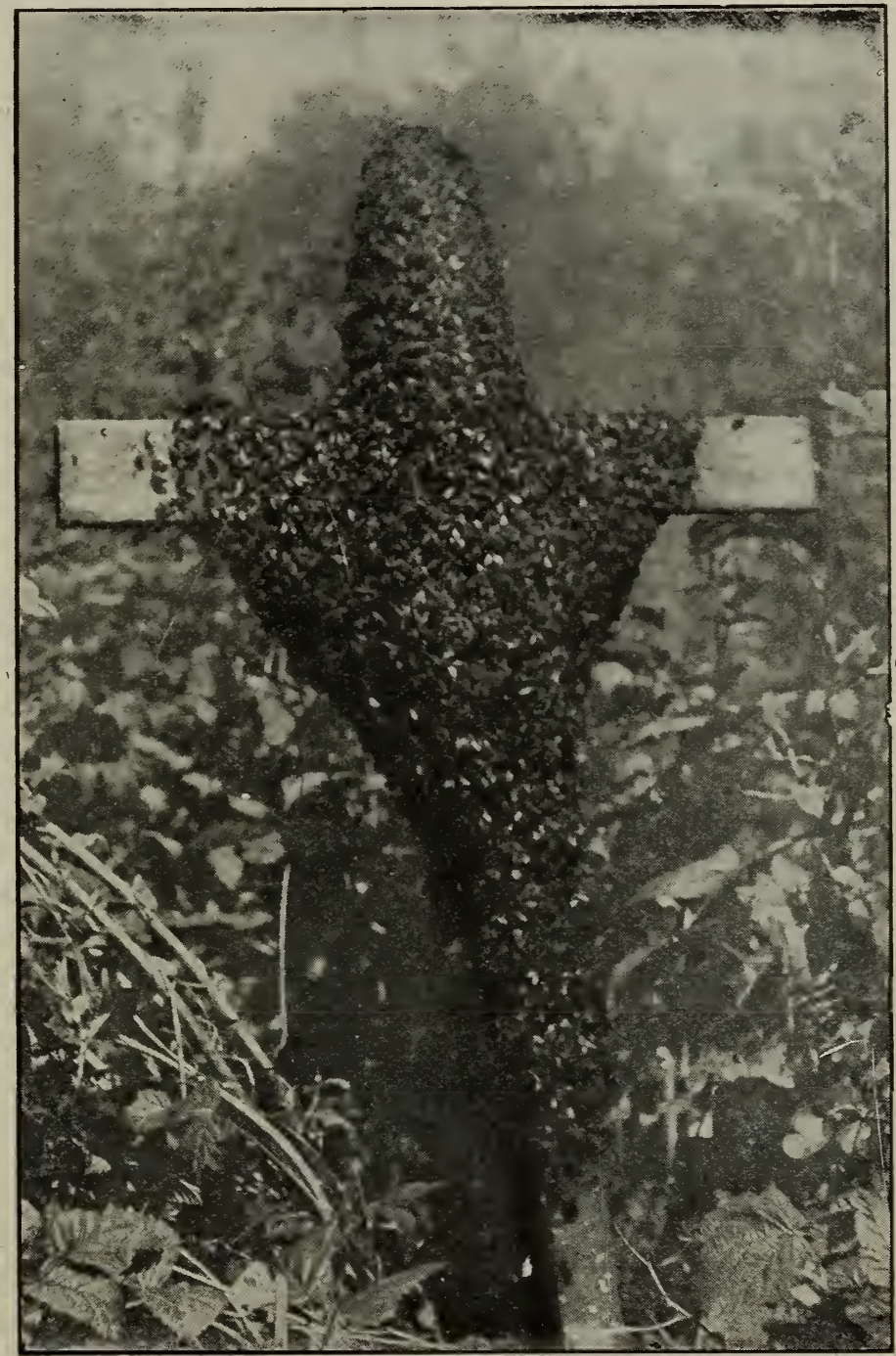

A cross of bees that are not cross.

sometimes worth going after; but how shall it be brought back with the least expenditure of time when bees are swarming at home? A boy can be sent on a bicycle, equipped with a burlap sack, a pair of pruning-shears and a smoker, these latter fastened to the rider. The bicycle enables him to make a quick trip, and on arrival the bag is quietly 
slipped around the cluster of bees, if attached to a limb of a tree, and tied. The pruning-shears cut the limb, when the bag and all is slung over the handle-bars, or carried in one hand while the other guides the machine home.

\section{PLURAL SWARMS UNITING.}

When the swarming-note is heard in the apiary it seems to carry with it an infection. In no other way can swarms issuing one after another be accounted for while the

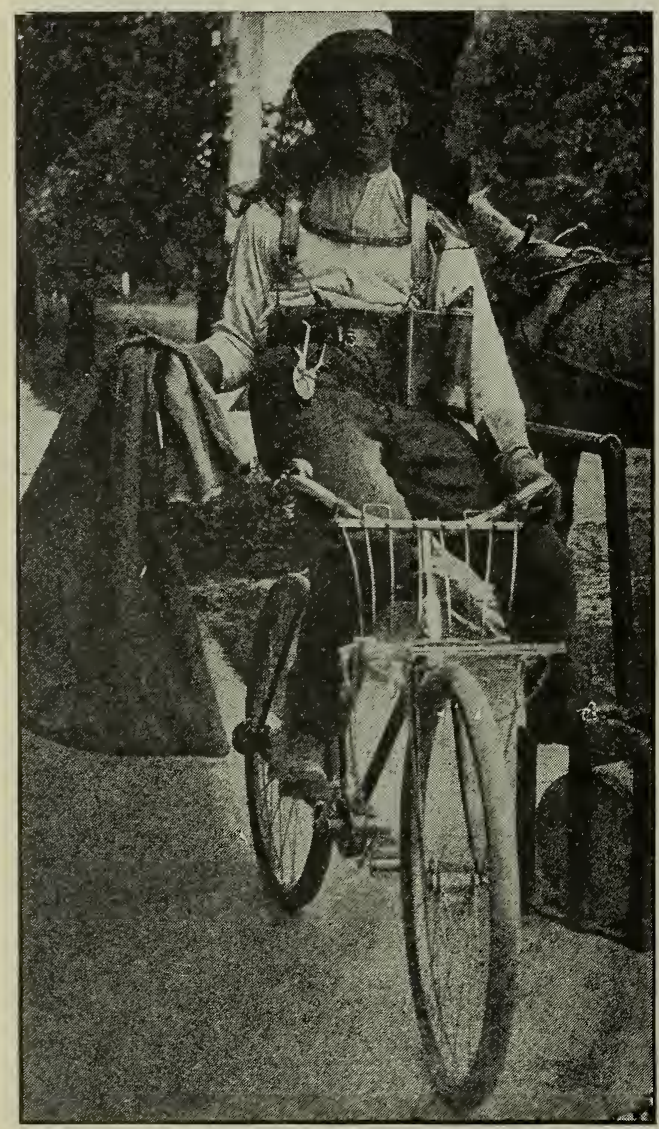

Carrying a captured swarm on a bicycle.

first is in the air, unless they hear the sound and hasten to go and do likewise. Of course if the wings of the queens are not clipped they will all unite in one, and as many as a dozen have been known to come out in this way and go to the woods before anything could be done to stop them. If for no other reason the wings of all queens should be clipped. Even then if a stray virgin is present all the bees may unite as one swarm, taking her along.
SWEE'T CLOVER.-Half the states in the Union have laws classing sweet clover among the noxious weeds. In these same states, while legislation remains technically in force, farmers are planting acre after acre in sweet clover.

A former Ohio statute required road superrisors to cut it, along with the Canada thistle, common thistle, oxeyed daisy, wild parsnip, wild carrot, teasel, burdock, and rockleburr. They were even given the right to enter private lands where it was growing and cut it down. Bee pastures near Delaware were destroyed at one time under the provisions of this law. Similar laws are still in force in other states. That they will soon follow Ohio in removing it from the list of noxious weeds is evident.

Its peculiar odor, the somewhat bitter taste of the leaves, the fact that cattle have to learn to like it, the tendency of the stalks to become woody, and a habit of appropriating land upon which other plants cannot even get a foothold, were the sources of this ill favor. Within the memory of every one, the virtues of this innocent plant have been so forcefully brought to the attention of the public that much of the former odium has been removed.

Sweet clover meanwhile is rapidly reaching a position of importance as a staple American farm product. At the present time, its seed is the highest-priced crop seed on the market-a situation which could not obtain were it a weed.

In spite of the fact that not a single state experiment station has failed to recognize the real worth of the plant, there still remain occasional uninformed or prejudiced farmers who see nothing but danger in its growth and nothing but damage in its spread. In parts of Ontario, farmers are said constantly to neglect important work in order to cut it down.

\section{VARIETIES.}

Three species are common, the white biennial (Melilotus alba), the large yellow biennial (Melilotus officinalis), and the small yellow annual (Melilotus indica). When the plant is referred to simply as "sweet clorer," the white is usually meant. The biennials store up in their large roots supplies of food for rapid growth in early spring of the second year. 
The yellow variety never grows as high nor with as thick stems as the white. The third variety, the yellow annual, is seldom considered of much value except in southern California, where it is grown in orchards as a cover crop to shade the ground and prevent the moisture from drying out. In regions where the biennials will succeed, its growth should not be encouraged.

The sweet clovers have been known to the world for thousands of years. Their value as pasturage for both stock and bees seems to have been understood first in central Asia. From there the seed was introduced into Europe at a very early date. According to the Iliad, upon these plants the steeds of Menelaus and Achilles pastured before Troy.

A number of other names have been used for sweet clover, among the most common of which are melilot, melilotus, and Bokhara clover. Ree clover and honey clover are names indicating its value as a honey-plant.

\section{WORID-WIDE ADAPTABILITY.}

The range of its growth has now encircled the globe. It has been planted on every continent, and is at present one of the most widely, tho not the most extensively, cultivated crops in the world. In parts of this country, Australia, and South Africa, its success has heen remarkable.

From Florida savannas to the sandy mesas of Colorado, from the deserts of Arizona to the pine woods of Ontario, sweet rlover has succeeded. It seems to be fond of gullies and eroded banks, lands wasted by mining operations, abandoned quarries, and greasy oil lands. While alfalfa will not succeed above 6000 feet, sweet clnver thrives from the level of the sea beach aloft as far as the timber line.

The acid soils of the East and the alkali regions of the West seem equally its home. In soils rich in lime it appears to be most successful, yet lands too acid for clovers will grow it. The range of this vigorous plant is wider than that of the clovers and probably even than alfalfa.

Sweet clover grows spontaneously along the roadsides, even in abandoned wheel tracks. Where the weather has washed away the humus it starts, and in time replaces the humus and restores the land to its former value.
It has been reported successful as a crop in peaty swamp soil and in loose and ashy ground too deficient in potash to grow corn without fertilizer. As Judge Quarton, of northern Iowa, says, "It will grow on absolutely any soil except that which is waterlogged. Clay hillsides, sand, rocky points, quarries, alkali-it will grow anywhere."

\section{AS SOIL IMPROVER.}

Its power of renewing the fertility of eroded ground has been suggested. By its vigorous growth and the decay of the large roots it will replace humus where it has been weathered away, and by its power of taking nitrogen from the air will bring up in fertility poor, run-down soils.

The plant takes nitrogen from the air by means of the nitrogen-gathering bacteria which inhabit nodules about the roots. This adds more nitrogen to the soil and makes possible the growth of other plants. The bacteria which inhabit the root-tubercles of sweet clover and alfalfa are identical, or at least capable of living on either plant, and for this reason sweet clover is valuable as a pioneer crop for alfalfa, insuring proper inoculation of the soil.

Besides, the large fleshy roots of the biennial swcet clovers store up a great deal of plant food the first year of growth, in order to get an early and running start in the spring of the second year. This supply of food, not altogether used up, goes back to the soil on the death of the plant, adding to and enriching the humus.

The roots being fleshy instead of fibrous decay more rapidly and so hasten the increase of fertility. Their rapid decay moreover releases the stored-up nitrogen about the ends of the rootlets sooner than do the roots of the clovers.

The exceeding rapidity of the decay makes plowing an easy operation-much easier than plowing an old alfalfa-field.

In contrast to the other legumes which gather nitrogen in the same way but which need considerable humus, sweet clover thrives where humus is quite absent. This emphasizes its value as a pioneer crop.

The long taproots, piercing the lower layrrs, make way for roots of other crops which are not able to penetrate where the around has not been broken up. The continual growth and decay of the heavy roots slowly converts sand into fertile soil. 
Where it is planted as a fertilizer, the application of manure or straw will help it to get a start and will hasten the work of soil restoration.

"It is best to relay the sowing of other grass two or more years after the sweet clorer has been seeded. Areas should not be pastured, but the sweet clover allower to fall down and form a surface mulch. On badly eroderi areas, sweet clover and the yellow locust form an excellent combination." *

Sweet clover's valuable power of soil renewal the Ohio Experiment Station sums up as follows: "It belongs with the clovers, :nd it may be used to improve the land on which it grows. This appears to be its mission. It occupies lands which have become unfit for good growth of other forage plants. Its rank then is as a useful forage plant, eapable of increasing the fertility of land."

\section{RUN-DOWN LAND RESTORED.}

One of the most characteristic examples of this service to the land is its work in alkali regions of Colorado. In some places irrigation and the growth of alfalfa for a number of years had forced the alkali out of the earth and on to the surface. The alfalfa roots, piercing the layers of the subsoil, brought up saline and other deposits which in turn destroyed the life of the plants.

Nothing but a kind of salt grass could be made to grow. Whole farms and towns were deserted. Finally farmers accidentally discovered that sweet clover would grow where nothing else would, that cattle could be pastured on it successfully, and that it could be used for hay or harvested for the seed.

Finally-and this is most important--the alkali deposits on the surface and in the subsoil somewhat began to disappear. Now alfalfa again is grown. The crops are rotated with sweet elover and the soil maintained in its fertility.

Lands of this nature, formerly unfit for alfalfa, corn, or wheat, now yield immense crops of all three. In some cases the value of farms in Kansas, Oklahoma, Missouri, Nebraska, Colorado, Wyoming, and Montana, where sweet clover lias been grown, has risen nearly fifty per cent.

\footnotetext{
* Ohio Experiment Station, circular 129.
}

Sweet clover has transformed King Island, off the coast of New South Wales, from an island of useless sand dunes into one of the best grazing regions in the commonwealth. Sown on white beach sand, sweet clover changed the character of the soil until at the end of five years much of it had become dark brown in color, and in some places almost black. Each year it is improving the value of the land. At present the export trade of King Island consists of fat cattle, dairy produce, and horses, and by far the most extensively used grass is sweet clover.

In northern Kentucky, farms in Pendleton, Bracken, and Robertson counties had been planted in tobacco for a century. It was once the custom, when the soil gave out entirely, to allow the tobacco lands to grow up in brush for six to ten years, and then to plow and plant again. During the years of abuse, this heavy waste seemed to be necessary.

By some means, sweet clover was introduced, but for a long time was fought as a weed. Finally farmers began to realize its value. The old soil, tobaccoed almost to death, received new vigor.

Today sweet clover flourishes in those counties. Land which formerly brought from five to ten dollars an acre is worth from forty to sixty dollars. At that time farmers were abandoning their homes and seeking employment in the cities. They did not have the means to buy suitable clothing. At present there is on deposit in the banks of Pendleton County money aggregating over $\$ 100$ per capita, most of which belongs to the farmers.

\section{AN EXCELLENT PASTURE.}

As a pasture, sweet clover is very satisfactory. According to an analysis by the Wyoming Experiment Station, it does not differ greatly from alfalfa in food content.

Altho cattle will sometimes refuse grass in order to feed on sweet clover, it is sometimes a little difficult to get them to acquire an appetite for its rather bitter leaves. For this reason it is sometimes a little difficult to get them started. To create this appetite, they should be turned into the field early.

"A man prominently identified with livestock interests in the Middle West once told me that no self-respecting animal would eat sweet clover. I wish he could see my 


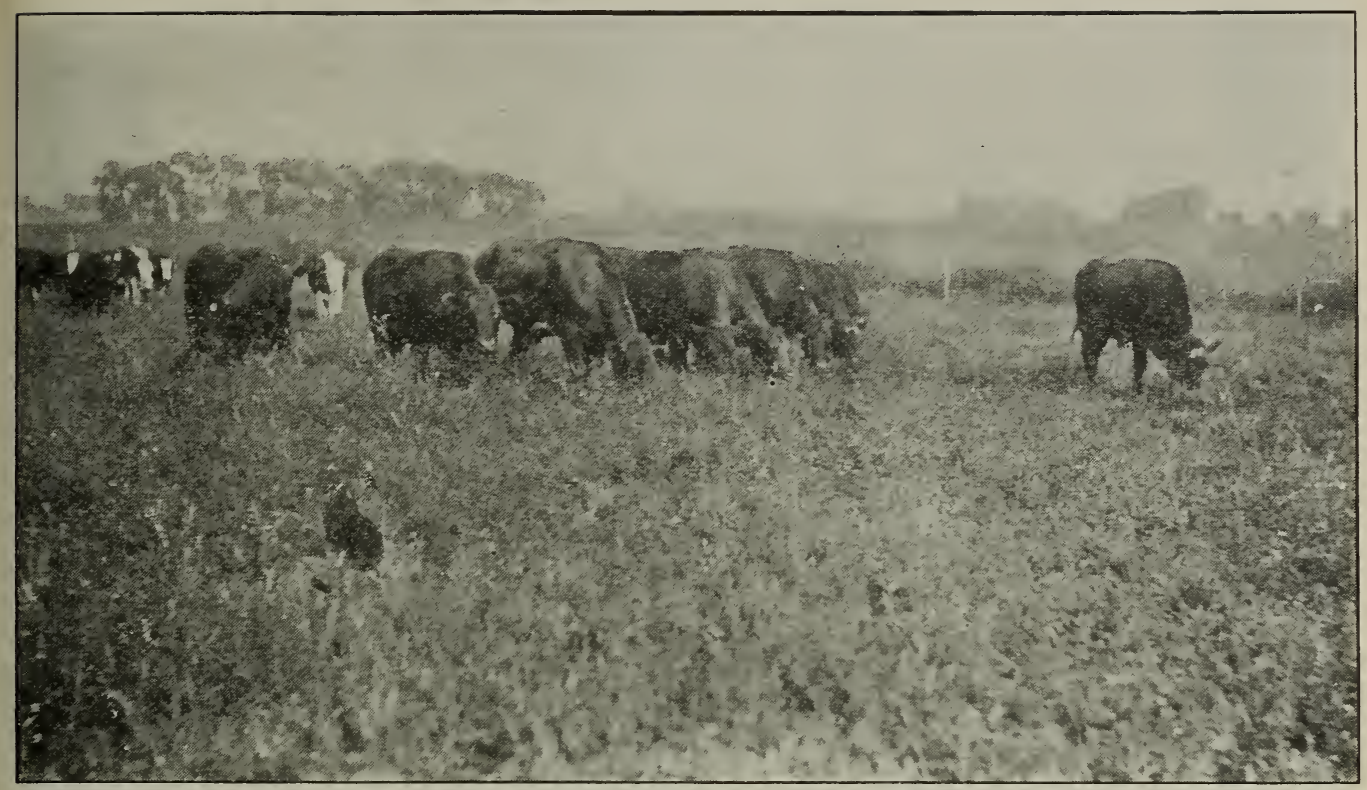

Frank Coverdale's field of sweet clover with cattle grazing on it.

steers today," wrote C. E. Gapen in the Country Gentleman, interviewing W. P. Graham, an Illinois sweet-clover grower and authority.

Mr. Graham pastures three head of cattle to the acre with success, instead of the traditional "one head to the acre." He maintains, by the way, that sweet clover is a better soil renovator than alfalfa.

For pasture for cattle, seeding it with timothy or any of the native grasses gires best results. The sweet clover acts as a nurse crop for the timothy. The former is richer in protein and the latter in carbohydrates, two constituents as necessary in a stock ration as in human. Then, too, if one fails, the other is likely to take its place.

In pasturing hogs, an acre of sweet clover will do for about twenty shoats. A superior pasture is secured by seeding with oats on good ground. These fields will provide an immense feed for two seasons, and, if enough is left to reseed itself, the pasture will be perpetual.

In regard to this, $\mathrm{Mr}$. Coverdale, the authority already mentioned, says:

\section{SWEET CLOVER FOR HOG PASTURE.}

Nine years ago I sowed a sixty-acre field to white sweet clover, and also a forty-acre field. Altho the plants started, not a single one lived until winter, and the whole undertaking was a failure because of the poor and impoverished condition of the soil. Many others around here lost their seed in the same way. The tables have turned, however, for we are now securing perfect stands of this legume, as shown by the picture of one of my neighbor's fields. His hogs enjoy a continued feast, and they keep it down to about six inches high by continual browsing. My neighbor has a field of alfalfa arljoining this, and he has been changing the hogs from one to the other, but he is much better pleased with the results from the sweet clover, as it is so much more hardy. He has now bought seed to change his alfalfa-field into sweet clover, as the alfalfa won't stand being pastured. A few more farmers in this neighborhood have secured seed, and will have hog-pastures just like this one.

The field sown is identical with our own, especially our hog-pasture. I have come to the conclusion that every farmer can and should have a hog-pasture like it. Every one around here who has come to my knowledge is very enthusiastic over the success, and is securing new supplies of seed to be sown next spring. This fact speaks louder than any other. My seed is all sold.

One authority adrises mowing the second season if the white clover threatens to get too tall and grow woody. The guards on the mower should be turned very high in order to prevent killing any of the plants.

No injurious effects on the stock can be noticed. On the contrary, it prevents bloat in cattle. After feeding it a number have reported that their cattle were troubled rery little with digestive disorders.

"At one time when we fed our three Jerseys for sereral weeks on sweet clnver and bran, we decided that it made a little 


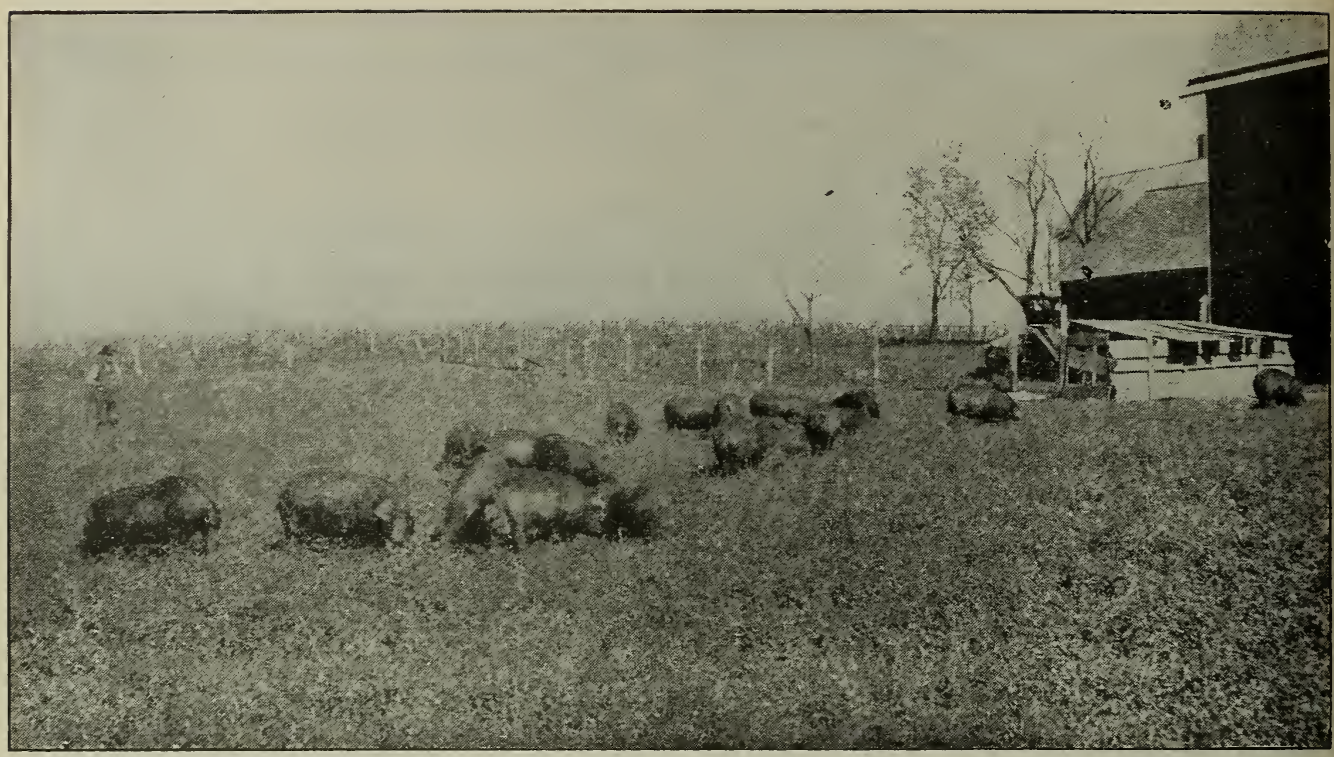

Hogs pastured in a field of white sweet clover near Delmar, Iowa,

nicer butter than anything else." This from J. A. Green, Boulder, Col.

Care should be taken in pasturing stock on sweet clover that they do not crop it so closely that it has no chance to bloom. They should be given a field so large that the plants will be able to reseed themselves. Fortunately the plant, particularly the yellow biennial, is not easily discouraged.

\section{VALUABLE FOR HAY.}

Hay made from the sweet clover when the plant is in the right stage of growth, and properly cured, some farmers think equal to the best quality of hay from the cowpea vine or any of the clover family. It does not bring as much on the market per ton as clover or clean timothy, but it is often used instead of these.

The quantity of hay to the acre is remarkable. The Utah Experiment Station found in 1892 that sweet clover produced more than double the yield of the clover and grasses compared with it. Other stations have reported phenomenal yields.

Very complete directions for handling sweet clover for hay have been given by Frank Coverdale, of Delmar, Iowa, who is perhaps the best authority on sweet clover in this country.

\section{SWEET CLOVER AS A HAY CROP.}

When I first began to grow sweet clover I had little thought of ever using it for a hay crop; but as time passed I began to see that it would answer very well as a dry feed. We experimented with one patch, and, contrary to what I had expected, a fine hay crop of superior quality was secured. This first field that we tried had been sown about the first week in May, and had been pastured to hogs until August, when all hogs were taken off. By October 10 the sweet clover stood 22 inches high, and then the mower was started. Just as soon as the hay was well wilted (but not dry enough to put in barns) it was raked into windrows and shaped into well-formed small cocks. These cocks, by the way, were just large enough so that they could be thrown on the rack in one good fork-load all at one time. This avoided scattering the leaves. which are as valuable as so much wheat bran. From this the reader will see the importance of putting up the hay so that it is not too dry when handled. All the handling, in fact, should be done while it is green and tough, when it can be gotten into the cocks before any leaves will be scattered around. It should stand in cocks until it is sufficiently cured to keep in the mow. We have always found that this clover has kept well when managed in this way.

White sweet clover is the worst of any of the clovers that I know of to scatter its leaves when overdry; and the leaves being thick and meaty are surpassed by those of no other legume. A dairyman is lucky who has a good winter supply of first-year sweetclover hay for his cows.

The cocks referred to will stand many rains and still be very good feed.* Sweet clover sheds water better than common clo-

* The authors have had sweet clover exposed to rainy weather for several weeks after it had been cut. After it stopped raining it was gathered up and put into the barn. Strange to relate, the cows and horses, after all this wetting down, preferred it to good timothy hay. 


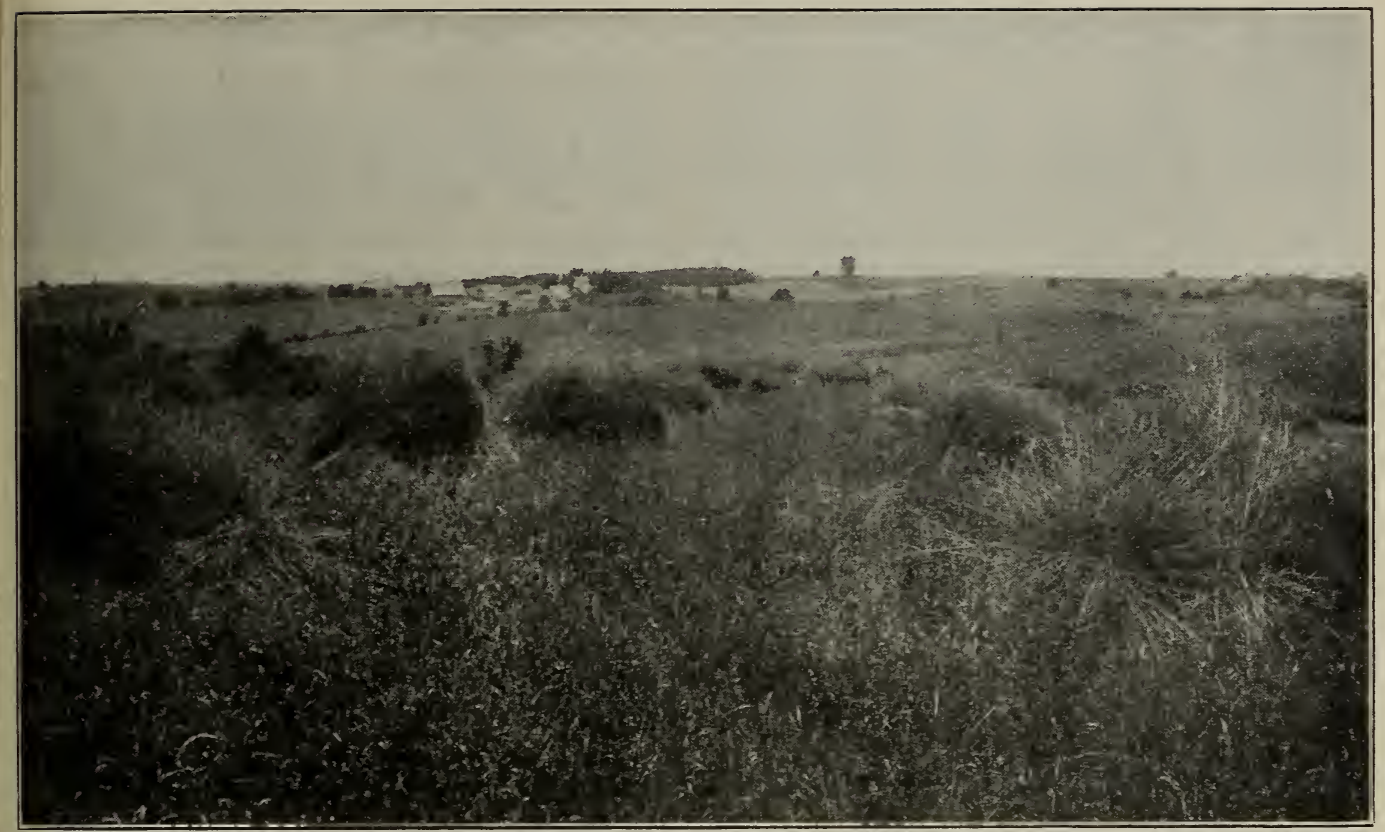

Sweet clover harvested for seed by a self-binder.

ver, and it has a smooth stem. The common red clover, because of its hairy stem, holds moisture, and quickly turns black and becomes unfit for feed. I have been happily surprised to find that this first-year hay cures the nicest of any that I have ever made.

I know of no other clover that can be depended upon to make a good hay crop the same year as sown. It has often been tall enough to mow in July; but at this time it would be very dangerous to mow it unless care were taken; for as yet there are no crown sprouts started; and if one mows the clover close to the ground in July, much of it will be killed outright. On this account, if one wishes to mow the first clover in July, or before the crown sprouts start, the machine must be set so as to cut high enough to leave stubbles that have a few leaves to make a start for the next crop. When the crown sprouts are started, the mower may be run close to the ground with perfect safety. These crown sprouts on the firstyear crop will be seen close to the roots after removing about an inch of dirt. This is the reason, by the way, why this clover will not winter-kill. The crown sprouts are about an inch below the surface of the ground, so that a covering during the winter is a certainty - a point of vast importance to one who is depending upon this clover the coming season.

\section{MAKING HAY FROM SECOND-YEAR GROWTH.}

Handling the second-year growth is, perhaps, a more difficult problem, as the clover gets very rank early in the season before good curing weather arrives. In this respect it is just like alfalfa. We have never dared to try to cure the hay until along in June; but at the same time every effort that we have made has been successful; we have never yet made a forkful of poor sweetclover hay. With the improved variety of white sweet clover that we now grow, I am not sure but that we might cure the hay even as early as the first of June. If we could do this, the problem of making hay from second-year's white clover would be solved, and two good cuttings could be easily made during the second year, and a seed crop secured late in the fall.

There are many ways in which this clover can be handled for hay. One plan, which is very successful and easily carried out, is to wait until the clover is in bloom, and just beginning to form seed. This is just before the leaves begin to show yellow. While the foliage is still on, go over the field with a self-binder and set in shock rows, two and two. These bundles will cure nice and green, and will dry very quickly. They should be hauled and stacked like oats until winter, when the bands may be cut and the bundles thrown in the mangers for any kind of stock. It will keep perfectly dry if well stacked, and will make very satisfactory feed. The binder should be run high enough to leave behind a stubble which contains a few leaves, otherwise it will die out. If the leaves are left on, a nice crop of seed of excellent quality can be cut later in the fall.

Another plan is to pasture the second-year clover with some kind of live stock until late in May or the first of June. The hay will then be just about right in good hay weath. er, and can be made just as tho it were a first-year crop. The stubble should be left 
high, as shown in the illustration. It will be seen that some of the clover in the picture has not been cut well. In explanation, I will say that, just before we started to cut this hay, a new pitman arm had been put on the mower, and it drew the sickle too far one way, and hardly cut at all on the return stroke. If this had not been the case, there would have been a smooth top.

The cocks of hay shown were out in two showers, but nothing was colored except the outside. The middle cured to perfection, and went to the barn as green as tea leaves. This field was mown when just coming into bloom, and the stubble grew up and made a seed crop.

The reader may be interested to know that clover of any kind in this part of Iowa was very rare last year, as severe drouth had killed all other clovers except a little alsike here and there. Sweet clover grew as tho there had been no drouth.

An Alabama farmer who owns 640 acres grows 160 acres a year of oats and sweet clover, and cuts the combination crop expressly for hay. He says the hay when baled and marketed in Birmingham, Ala., sells readily at $\$ 15$ a ton.

Sweet clover should be cut as soon as the first blossoms appear. If left longer, the stems become woody and a great many leaves fall off when it is cured. The mower should be started in the morning as soon as the dew is off. Great care should be taken to prevent sun-burning as this destroys its palatableness and nutritive properties.

Sometimes the plants are high enough in May for mowing; but since hay cannot be cured at that time, the field may well be used as pasture until haying weather comes.

Care should be taken against feeding too much of the hay. Stock may become cloyed and go "off feed."

Sometimes, just as in pasturing on sweet clover, it is a little difficult to get stock started to eating it. The taste for sweet clover is an acquired one. By moistening the hay with brine they can usually be made to eat it. This should no more be urged as an objection to the use of sweet-clover hay than the fact that western cattle will sometimes refuse corn is an argument against the use of corn as a feed.

Cut while young and tender the fall of the first year, sweet clover may be put into silos just as corn. During the winter it may be fed to stock just as other silage. In 1914 W. P. Graham, of Ogle County, Illinois, fed steers with seventy tons of sweet clover which he had put up in a tile silo.

\section{AS A HONEY-PLANT.}

It is one of the most important horleyplants in the world. Widely distributed all over the United States, it is becoming more and more abundant. While it does not yield any surplus in the East except in limited areas, the bees are always busy on it when in bloom, which is from the close of white clover clear on up to fall. It is therefore invaluable for brood-rearing, particularly as the beekeeper can depend on it every year, wet or dry. In the West, carloads of almost pure sweet-clover honey are produced. We say, "almost pure" because there are other plants usually in bloom at the same time. This very fact makes it more salable, because a strictly pure sweet-clover honey is a little too strong, and a slight admixture of other honey improves it very much. Conversely, a little sweet clover in any other honey adds a quality or flavor that is very delightful. For that reason bottlers of honey like to get it to mix with other honey. Taking it all in all, sweet-clover honey will always have good demand as a blender. This will be better understood when it is stated that cumarin, a substitute for vanilla, is extracted from the sweet-clover plant. It is this vanilla flavor in sweet-clover honey that makes it so desirable for blending purposes.

The plant furnishes nectar for a long season. A clear, light-colored honey. lighter even than the honey from white clover, is its product; the greenish tinge which has been reported seems to be found only in certain parts of the East.

Pendleton, Bracken, and Robertson counties in northern Kentucky, where sweet clover grows more than anything else, are a famous honey-producing section. In one of these counties are more than 4000 colonies. The honey crop is not always a success, however, even there, since sweet clover must have plenty of moisture for nectar. It is not as dependable a yielder as alsike clover.

Sweet clover is almost the only plant which it pays the beekeeper to cultivate for its nectar alone. Other plants have been recommended-Quinby suggested catnip if he were going to grow any plant for this purpose-but only sweet clover has established its right to this distinction. It has been extensively distributed by beekeepers who planted for bee pasture. 
Farmers who keep bees should be first to try it out and urge their neighbors to plant it. Unless beekeepers advertise the value of its qualities, it is doubtful if it will not be some time before the agricultural world fully realizes its worth.

\section{SEEDING SWEET CLOVER.}

At almost any time of the year the plant may be sown and will mature, on aceount of the hard seed coat which makes germination slow.

In December, January, February, and March the seed may be sown broadeast on the snow or on ground honercombed by frost. Spring rains soften the seed coat and bring about germination in the spring. Spring sowing is the plan most popular in northern Kentucky where sweet clover makes its greatest success.

Sowing in March allows the seeds to be covered by the rains and alternate freezes and thaws.

Spring sowings take place in April or May. At that time it is corered lightly and the soil firmed with a roller or drag. Some authorities believe this spring sowing the best, all things considered.

In a country where the winters are mild. seed may be planted in the fall. Part of the clover comes up before winter but the growth is not so heary the second season since the roots do not have time for derelopment. What seed fails to germinate during the fall usually does so in the spring.

Alfalfa must be sown between Ang. 15 and Sept. 1 for proper derelopment before winter, while sweet clover may be delayed as late as Oct. 1 with fair results. This makes it possible for sweet clover to be planted in fields in which crops are too late in maturing to admit of alfalfa.

One of the peculiar characteristies of sweet clorer, and one which, more than any other, has caused difficulty in its cultivation is its demand for a hard seed bed. Farmers have often been amazed to see the apparent ease with which the plant will appropriate railroad banks and flourish without any care whatever; yet in their own fields where it is planted as a forage crop it would do only indifferently.

SOWING SWEET CLOVER WITH OATS.

With regard to this, Mr. Coverdale, already referred to, says:
Secure from a druggist a few sheets of litmus paper. Stick a spade three inches into moist surface soil; withdraw the blade and put in a sheet of blue litmus paper and press the soil tightly against the paper for ten minutes. After removal, if the litmus paper has turned pink, lime is needed for best results. However, if there is only a slight pink color on the paper it is possible to get along without the lime.

In either case, Early Champion oats is the best variety to seed with. Sow a third less than the usual seeding of oats. It is a pretty good plan to inoculate the seed. I prefer the glue and dust method when it is done right. Select some soil three inches under the surface, where sweet clover has grown for years. Dry it in a cellar-not quite dry, but so it will pulverize nicely. Moisten the seed well with glue water that is just a little sticky when put between your finger and thumb. Mix thoroly, allowing all the dirt possible to hang to the seed. I have had the best results by sowing this inoculated seed by hand, because in this way the dirt sticks to the seed, whereas a seecrer rubs and grinds it loose. None of the extras need be put on where sweet elover has been growing in late years. Do not allow the sunlight to strike the seed before covering.

It will pay to make a seed-bed on the surface, cultivating it quite well, as the white sweet clover always makes a stronger growth on such prepared land. It is always the poorly cultivated as well as the corners that are missed that do the poorest.

If the scil cuts in well, one good harrowing will be suffieient. If not, double and harrow. It probably would not pay to plow unless the land is a tough sod. I always plow such fields with good results, and secure a good deal of seed or hay the first season.

If one does not want to disk or plow the ground I would advise sowing the seed in MIarch just as the snow is going off.

NEEDS SOLID SEED-BED.

A firm seed-bed is necessary. Otherwise plants will be heared out by the frost in the winter intervening between the first and second seasons of growth. Just enough loose earth should be placed on top to cover it.

Frank Corerdale gives some valuable notes on seeding:

"Sow sweet clorer on ground well prepared, on a gocd mellow seed-bed. A sod field that has been plowed the previous fall is best of all. Spring-plowed sod is all right, and will answer nearly as well. but work into a good seed-bed. Where the rainfall is sufficient, harrow the seed in shallow. But in arid sections a drill is best, putting the seed sufficiently deep to insure 
moisture enough to make sure of a good come-up.

"Sweet clover sown on such ground will grow a heavy crop of nodules on its roots; and by the end of the second season this ground will be thoroly inoculated, and can be depended upon for all time to come for routine methods, as these bacteria will live in the soil for several years.

"A good stand of alba is usually sure when sown on land that would grow 60 bushels of corn per acre, and a nurse crop sown with it of barley, wheat, or early oats, seeded somewhat thinner than usual. After the ground is inoculated from growing previous fields, a fair cutting of excellent hay can be mown in October after the grain has been harvested, making a crop of small grain and a cutting of hay the same season."

\section{SWEET CLOVER-SOWING THE SEED AMIONG} GROWING CORN.

Considerable has been written in various farm papers in regard to sowing sweetclover seed in cornfields just after the last cultivation. Ordinary broadcast seed-sowers cannot be used, because the cornstalks and leaves are so much in the way. It has been several times suggested that sowing the seed while going thru the corn on horseback would answer better; and no doubt this plan is giving fair results.

About three years ago a machine was advertised for the express purpose of sowing clover and other seeds between the rows of corn. One was purchased and given a trial with excellent results. This machine has some cultivator teeth to work the seed into the soil. We had a splendid stand of sweet clover, sown 1916. We also had a splendid catch in a field of corn where the corn was about ready to cut.

The only trouble with the machine for sowing is that it sows more seed than is needed; and there is no way of controlling the amount of seed very accurately. The cultivator teeth work well; and with the rains we had after the seed was sown, it seemed that almost every seed had germinated. As a result, there were about four times as many plants as were needed between the rows of corm.

The machine for sowing is a revolving cylinder made of galvanized iron, and the whole thing is pulled by a horse.
SWEET-CLOVER STRAW AFTER THRASHING OUT THE SEED.

Horses and cattle after they get a taste of sweet-clover hay will eat the dry stalks from which the seed has been thrashed; and even after these dry stalks have been out in repeated rains, so that any other kind of clover or hay would be ruined, the sweet clover seems to be hurt but very little.

\section{INOCULATION.}

Sweet clover is unable to grow without the help of nitrogen-gathering bacteria in nodules about the roots. These bacteria, if they do not already exist in the soil, must be placed there with the seed. The process of starting the growth of the proper bacteria is what is known as inoculation. The bacteria are usually present on lands where sweet clover has been grown before.

Inoculation may be accomplished easily by gathering soil from about the roots of roadside sweet clover, moistening the seed with a thin solution of commercial glue, and mixing a few handfuls of the soil with a peck of seed. Unless the seed is thoroly dried it may spoil.

Another form of the soil-transfer method is to scatter between two and three hundred pounds of soil to the acre, the soil taken from a field in which the plants show an abundance of tubercles on the roots. The government bulletin suggests that the seed be mixed with a small proportion of the soil and the remainder of the soil scattered broadcast and immediately harrowed in.

The work should be done on a cloudy day or during the evening, or else the soil in which the bacteria are growing should be turned under before the sun's rays have time to penetrate the particles. Sunlight destroys bacteria of all kinds.

The soil may also be inoculated by the pure-culture method. A bottle of the pure culture of the proper kind of bacteria is opened and mixed with water. This solution is then mixed with the soil and the soil distributed over the field immediately after it has dried. The drying should be done in a shaded room away from the sunlight. This gives the sun no chance to kill the bacteria in the seed. 


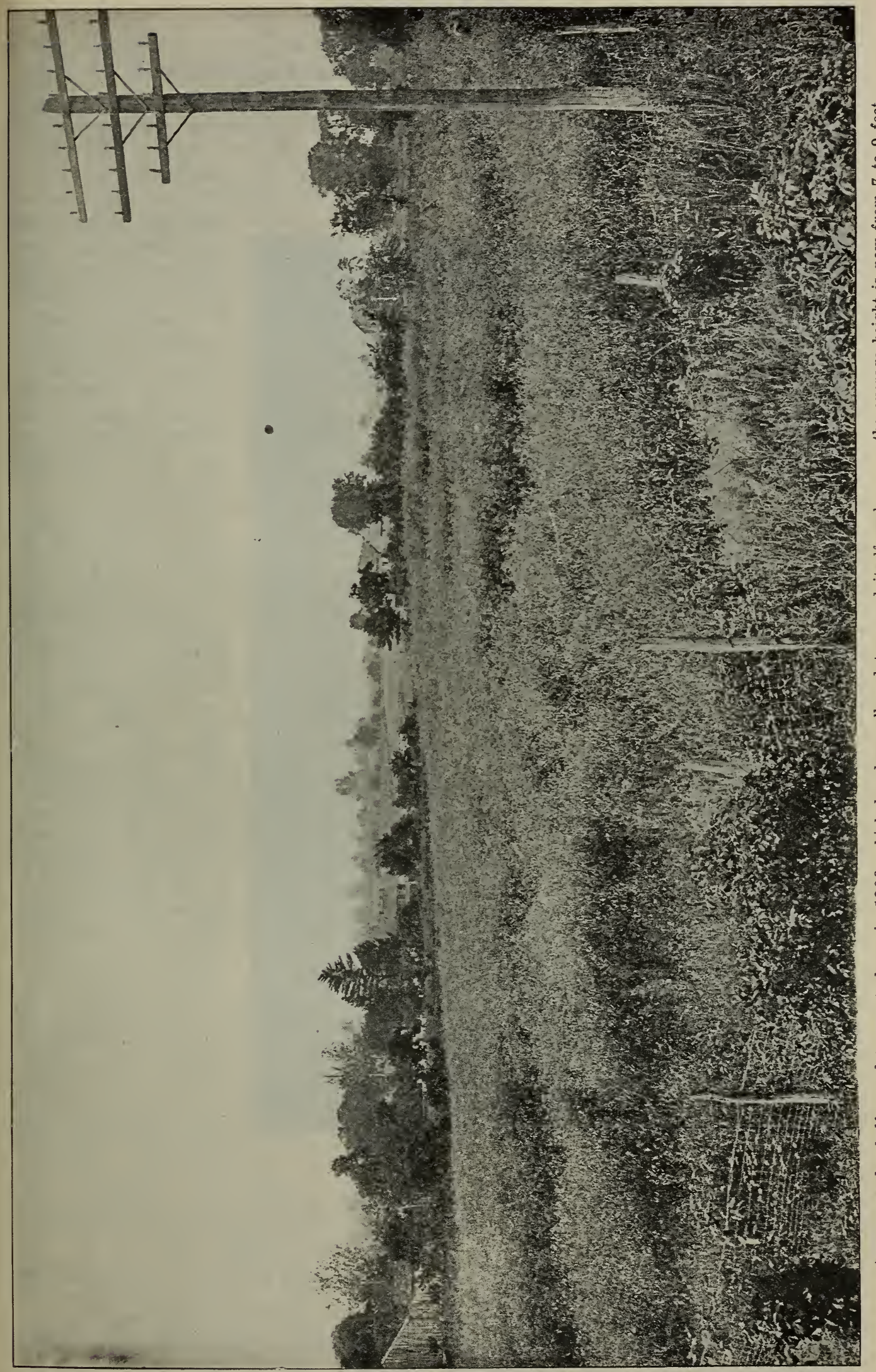


MAKING MORE SEED GERMINATE.

One of the great obstacles which have been found hitherto to the successful growing of sweet clover has been the uneven germination of the seed. At the price of sweet-clover seed this has been indeed a fault. Some farmers have report-

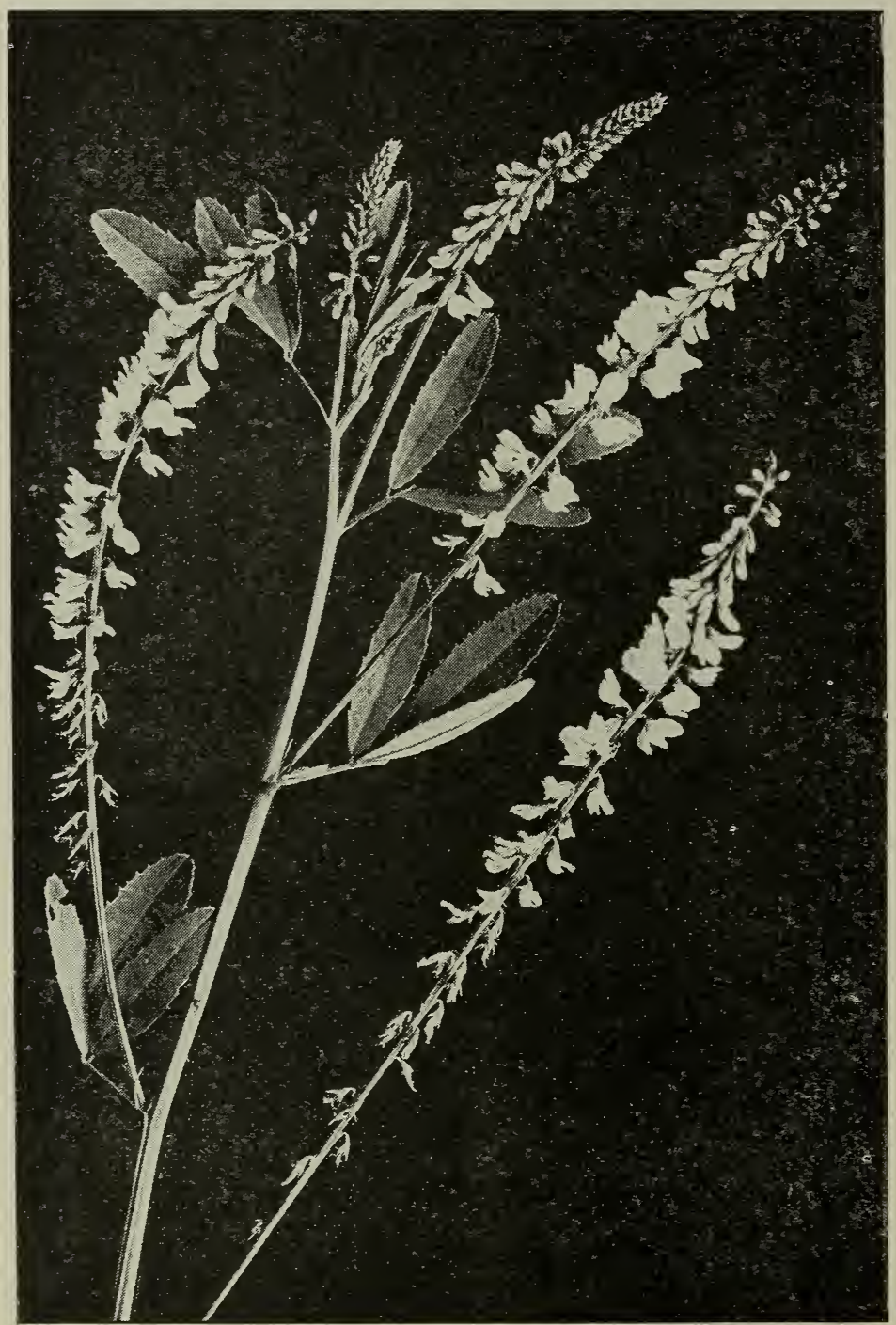

White sweet clover.

ed decided success in getting a stand while others have hardly been able to get a fair amount.

Sweet clover often grows apparently of its own free will in the most unexpected places, but efforts at starting it have been hindered by the lack of germinable seed. This has been due not to the infertility of the seed itself, but to the hardness of the cellulose case which surrounds the germ.

Sweet clover shares this fault with alfalfa and the true clovers. A large proportion usually fails to come up the first year and much of it never sprouts at all. In the wild state it has its advantages where seed falls in September and October and does not sprout until spring. By that time the rains and freezes have softened the seed coat so that moisture can get thru.

Several schemes for reducing the loss dure to difficult germination have been tried with rarying success.

In the national bulletin on sweet clorer directions are given for soaking the seed in comme r cial concentrated sulphuric acid for half an hour, a plan which has been successful, albeit somewhat dangerous. The acid eats away the impermeable seed coat sufficiently to enable the seed to absorb enough moisture to germinate. Tests made in the Department of Agriculture gare an increase in germination of $\leq 0$ to 45 per cent.

After the acid is poured off, the seed should be quickly washed, using running water if possible, is sulphuric acid becomes very hot when mixed with a small proportion of water. The seed should then be dried out quickly by spreading it on a board or canvas and stirring at intervals of two or three minutes.

Since sulphuric acid burns flesh and wooden objects, great care should be taken in working with it. Vessels used for treating the seed should be of earthen or enamelod ware. 
After testing, seed should preferably be planted at once, as it has a tendency to dry out. Where the air is not too dry, however, it may be held two weeks or a month if necessary.

A new but highly promising method consists of scratching sweet-clover seeds in what is called the Ames hulling and scarifying machine, brought out in April, 1915, by the Iowa Experiment Station. By its use the germination of legume seeds is reported, after extensive tests, to be increased to over 90 per cent.

The first machine of this efficiency was constructed in December, 1913. No announcement was made at that time, however, in order to allow time for field tests, comparing treated and untreated seed, in addition to extensive germination tests. A large number of plots were seeded on the station field in 1914, comparing treated and untreated sweet-clover seed from various sources. In a large number of cases, stands which were, if anything, too thick. were secured from the treated seed, when the same seed planted at the same time, but not treated, failed to produce any stand at all.

The machine as constructed has a capacity of approximately twenty-five bushels per hour, and requires about four-horse power to operate it. It is estimated that it can be put on the market at a price not to exceed $\$ 90$ to $\$ 100$.

The construction of the machine represents eight year's' work on the part of H. D. Hughes, Chief of Farm Crops at the Iowa Experiment Station.

During the spring of 1914 and 1915 several thousand pounds of sweet-clorer seed were treated for individual farmers. A farmer for whom the section treated some 3000 pounds of seed in the spring of 1914 states that the seed germinated approximately 50 per cent when sent to Ames, but germinated 98 per cent when returned.

Another reports using 5 pounds per acre of treated seed, from which he secured a perfect stand, while the usual rate of seeding ranges from 15 to 20 pounds per acre with many failures and uncertain stands resulting from poor germination.

\section{HOW MUCH TO SOW.}

The amount of seed to sow to the acre depends upon what purpose the sweet clover is grown for. Moreover, the promising invention described above is likely to make necessary a revision of the estimates usually given.

Not less than 20 pounds of unhulled seed and not less than 12 to 15 pounds of the hulled should be sown to the acre. Ordinarily 20 to 30 pounds of the hulled and 5 pounds more of the unhulled are adrised.

For sowing on waste lands, about one bushel to six acres is enough. Altho the plant spreads rapidly, it is well to sow enough to insure a good stand. To secure continuous growth, sow the second year also.

Can sweet clover be gotten rid of after a crop has been grown, and small grains sown the next rear? This is a question which has worried farmer's wherever the plant is being introduced. One reported that he had planted wheat the spring following a crop of sweet clover in the same field, and that the clover has choked out the wheat. The experience is unusual. to say the least. The best crop to put in immediately following sweet clorer is corn. The effect of the sweet clorer will be noticed only in increased growth of the coriv. sometimes as much as twenty bushels hearier than on land not previously planted in sweet clorer. Sometimes corn is grown two years in succession, and then followed by wheat. No trouble with smothering is reporter.

The farmer need fear no difficulty in getting rid of sweet clover after he las once sown it. The fact that the plant grows abundantly along the roadsides and seldom appears in cultivated fields, is evidence that it can be easily destroyed if necessary.

Another point on which there is question is the amount of sweet-clorer seed to be mixed with oats in seeding them together. Some sow ten pounds to the acre, others as much as trenty. A good arerage is fifteen.

Care must be taken in mixing the seed in the drill, and in not having so much in at once that the clover will work down under the oats in the drill-box. This would mean uneven proportions in the field. With care the seeding can be made even. Hulled sweet clover is more satisfactory in such a mixture, since some of the unhulled is not likely to come up the first year.

Rye or spring barley are other crops often sown with sweet clover. The grain is harvested while the clorer is coming on, 
and the field used for pasture or for hay after the grain has been taken off.

Here is where sweet clover again is superior to alfalfa. Grow oats, wheat, or barley as a nurse crop and you get the grain besides, but best results with alfalfa are obtained by planting alone.

There is no better way to fit a piece of ground for alfalfa than to seed in sweet clover, cut off a crop of hay the first season, and plow under the second season when the clover is about a foot tall. Cultivate with a drag and harrow until the first of September. Then seed in alfalfa. This inoculates the soil for alfalfa besides fertilizing the ground by the addition of humus.

\section{GROWING FOR SEED.}

Before harvesting sweet clover for seed, it is always best to take a cutting of hay first. Much better seed and shorter and finer straw will result. The crop should be harvested like oats with a self-binder about the time most of the seed is showing black.

In moving, care must be taken to prevent shattering of the hulls. A canvas covering for the hay-rack will save what drops off.

For thrashing small amounts of the seed, an old-fashioned flail or similar primitive instrument will do. But for larger amounts the thrashing-machine is necessary. The process results in a lot of broken stalks and leaves being mixed with the seed. These can be removed with a fanning-mill.

\section{MORE VIRTUES OF SWEET CLOVER.}

Among minor merits of this all-around plant is the tendency of wild sweet clover to drive out weeds. Growing luxuriantly in waste places and reseeding itself, it will even choke out the dreaded Canada thistle.

On the other hand the plant is not hard to get rid of, as suggested above. When the land is broken up, the plant is gone. Pasturing the land so no seed matures has the same effect if kept up one or two summers.

Add to these advantages its freedom from pests, both insect and fungous. A species of aphis has been reported but no appreciable damage noticed. This absence of enemies is one of its most peculiar characteristics, partly explained by the presence of cumarin, the bitter element in the leaves.

\section{SIVEET CLOVER AS A COVER CROP.}

In many parts of the West, in some of the large orchards sweet clover is used as a cover crop-that is to say, the ground under the trees is harrowed when sweet clover is sown in the regular way. As soon as it reaches two-thirds of its growth it is plowed under. In a similar way red clover, alsike, and other clovers are sown and plowed under. When alsike and red are used, the clover is often allowed to come into bloom. If the trees are sprayed at this time the nectar in the clover will be poisoned and bees that gather it will be killed by the thousands. (See FruIT-BLOOM, subhead; "How the Spraying of Cover Crops Kills the Bees.") On the other hand, sweet clover will come into bloom, especially Melilotus indica, when the trees are not sprayed. It grows rapidly, and, when plowed under, makes excellent fertilizer.

\section{IN SUMMARY.}

While much information has had to be omitted from this article enough evidence is in to show that sweet clover is one of our most valuable forage plants. Long despised as a weed, sweet clover is rapidly breaking down prejudice and ignorance and taking the place it has long deserved. "The new sensational grass" it has been called. Sweet clover is new in the sense that only lately has its full value been getting recognition.

As a soil renewer, it is unexcelled. As pasture and for hay, it is nearly equal to alfalfa in feeding value. As a honey-plant, furnishing nectar over a long season it is unsurpassed. These are not the only merits, only a few of them. Within this sketch it has been possible to suggest only some of its characteristics and its value.

A much more complete treatment may be found in "The Truth about Sweet Clover," published by the A. I. Root Company, Medina, Ohio, and sent postpaid for ten cents.

The agriculturist who fails to inform himself on the value of sweet clover, whether he concludes it is suitable for his own purposes or not, is falling behind the times.

\section{AUTHORITIES.}

In the preparation of this subject the following authorities have been consulted: Lloyd, W. A., Sweet Clover. Circular No. 129, Ohio Agricultural Experiment Station.

Root, A. I. The Truth about Sweet Clover. A. I. Root Company, Medina, 1913.

Westgate, J. M., and Vinall H. N. Sweet Clover. Farmers' Bulletin 485, U. S. Dept. Agric. March 12, 1912.

Also the files of Gleanings in Bee Culture. 
TEMPERATURE.-In bee culture, temperature is one of the most important factors with which we have to deal. The more nearly we can hold it to the exact point the better we shall be able to bring about certain desired results in the business.

Under the heads of Vextilation and SwARMING it is shown how the bees keep down the internal temperature of the hive during hot weather by an elaborate scheme of forced ventilation. One set of bees, by means of a vigorous fanning of the wings, force air into the hive; and another set, working in collaboration, drive foul and heated air out. Under Moving Bees, the importance of giving plenty of ventilation, by means of wire screens to keep down the internal temperature of the hive, is shown.

Under the head of Botrling Honey it will be seen that temperature plays an important part in preventing the granulation of liquid honey. If it is too high, the delicate flavor of the honey will be injured. If it is too low, granulation will take place soon.

Under the head of Cellar WINTERING, subhead "Temperature of the Cellar," it is explained that, in order to get the best results, the temperature should show a reading not below 40 nor above $60 \mathrm{~F}$. In some cellars 45 degrees gives the best results; in others, 50 ; and still others, 55 and 60 .

\section{THE TEMPERATURE OF THE CLUSTER IN WINTER.}

Up to the year 1911 various erroneous notions were current. Some authorities stated that the internal temperature of a colony in winter was blood heat; that when the cluster was broken into, no matter how cold the day, the individual members would rush out, apparently just as active as at any time during the summer. Others held that bees went into a winter sleep, somewhat analogous to a condition of semihibernation or even perfect hibernation.
Still others maintained that bees during winter could and do go into a state approximating death; that they had broken into their clusters and found them lifeless; had carried them into the house and put them near a stove, and found that they soon revived and flew about the room as lively as ever. From this they argued that bees were like ants in that they went into a state of perfect hibernation.

Others, again, helä that the winter temperature of the cluster dropped down to about 60 degrees $F$. and remained at that point until the weather warmed up, when the bees- would arouse.

The fact is, there is truth in all of these assertions. The different observers had taken the temperature of the clusters at different times during the winter and under different conditions. The temperature of the honeybee cluster varies all the way, according to conditions, from $32 \mathrm{~F}$., which would shortly result in death, to 97 , which would be summer temperature. Whenever the cluster is chilled thru, so that each individual member of it is stiff and cold, and apparently lifeless, that cluster of bees will die soon, unless the weather warms up or the temperature outside of the hive or inside is raised. If one were to dig down into such a brood-nest and find such a condition, he would naturally argue that bees hibernate like ants and flies.

There was quite a school of beekeepers who, in the early days, argued in faror of reducing the surrounding temperature until the bees were chilled thru, because they said that in such a state they would consume almost no stores. Unfortunately for this argument experience shows that in a chilled condition bees cannot live more than a week or ten days. Any time within that period they may or may not be revived by placing them in a warm room. If a cluster is chilled clear thru in an outdoor colony, and it warms up outside enough so that the internal temperature of the hive reaches between 60 and 70 , the bees may revive, move to the portion of the brood-nest where their stores 
are, and may, if the winter is not too severe from that time on, live thru.

When the conditions are such that a cluster will chill thru during the middle or early part of the winter, the owner may rest assured that the bees will die. When he comes to open up the hive in the spring he will find a perfectly formed cluster with every bee dead.

On the other hand, when a colony is properly housed, and strong enough, there will be no danger of the cluster chilling. thru. It behooves the apiarist, therefore, to have strong colonies and then place them in a good cellar or in warm double-walled hives or packing-cases. (See Wintering Outdoors and Wintering INDOORs.)

When one desirous of getting the temperature of a colony of bees during midwinter thrusts a common thermometer down into the cluster, he is misled. In an hour or two after inserting the instrument he will probably find the mercury standing at about 97 , for the very act of breaking into the hive and thrusting something down into the cluster of bees arouses them so that the temperature rises rapidly till it reaches 97 . $\mathrm{He}$ concludes that the temperature of the winter cluster is 97 , for has he not seen it with his own eyes?

If, again, he were to put a dairy thermometer into the center of the cluster, allowing the upper part of the instrument to project thru the packing-material, and allow it to stand, he would get a more correct reading, but not until the bees have gone back into their quiescent state previous to their disturbance. They might never go back; but in most cases a temporary disturbance does no harm, and a cluster of bees will resume its normal course. If in a day or two after the insertion of the thermometer the cover is lifted gently so as not to disturb the bees, and if the thermometer sticks up thru the packing, so that it is not necessary to uncover the cluster, a fairly correct reading may be secured, provided the cluster in the meantime has not moved. The temperature may then show as low as 57 . If it is lower, the bees will proceed to raise the temperature of the cluster in a manner that will be explained later.

In this connection it should be stated that the common mercurial thermometers are not always correct; and, what is more, it is not always possible to place them so that they will be in the exact center of the cluster; and even when they are so placed, the bees may move from one portion of the broodnest to another. As fast as stores are consumed in one portion the cluster will move to a fresh supply, provided it is not too cold.

It is not difficult, with these general facts before us, to understand how various observers have been deceived in forming conclusions in regard to the temperature of the honeybee cluster during winter. It is also very evident how one might jump to the conclusion that bees hibernate like ants.

It was not until the Bureau of Entomology, Washington, D. C., attacked this problem in 1912, 1913, and '14 that the matter was definitely cleared up. Dr. Burton N. Gates, then Apicultural Assistant in the Bureau of Entomology, Washington, D. C., made a series of experiments in determining the temperature of the bee colony in winter, in Bulletin 96, U. S. Department of Agriculture. These experiments were carried on further by Dr. E. F. Phillips, Apicultural Investigator in the Bureau, and by Geo. F. Demuth, as shown in Bulletin No. 93, Department of Agriculture. Dr. Gates worked with mercurial thermometers, but because of the limitations of these instruments he was unable to carry his work to a finish.

Dr. E. F. Phillips and Mr. Demuth conducted a series of experiments in wintering bees in a constant-temperature room at the University of Pennsylvania, Philadelphia, during the winters of 1912 and 1913 and 1913 and 1914. Several colonies variously prepared were placed in a constant-temperature room, where the temperature was held by means of coils of pipes containing a brine solution-much the same apparatus that is used in cold-storage plants. On the roof of the building containing this room there were placed several colonies of bees where the conditions of outdoor-wintered colonies could be observed. A series of electric thermometers, or " thermo couples," were placed in these colonies in the room before mentioned, and in colonies on the roof outdoors. By an elaborate system of wiring, these electric thermometers were connected to an observation room in the building, entirely separate and distinct from the constant-temperature room. Here Dr. Phillips, with his assistant, could follow 
with the greatest precision the temperatures of every part of the hive and clusters of the several colonies inside and outdoors.

By these temperature readings it was possible to determine the exact state and size of the cluster, when it moved, and the various reactions that took place as the result of feeding, disturbance, and the rising and lowering of the temperature outside the hives. The purpose of using electric thermometers was to aroid the disturbance incident to the use of mercurial thermometers that require the entering of the bee-room and the opening of the hive to get the readings. Moreover, it would be practically impossible for an observer to stay in a bee-room with a temperature of $42 \mathrm{~F}$. day and night, taking readings every fifteen minutes; and even if he could do so, the constant disturbance would naturally cause a rise of temperature that would be above the actual normal of a colony not so molested.

The outside-wintered colony had 19 electric thermometers, with connections to the observation room below. Bees were placed on the roof early in November. From then on until along in March the inside and outside temperatures were taken. It was learned that the temperature within the cluster is far from being uniform, as is generally supposed by beekeepers. "At the temperature at which other insects become less active (begin hibernation) the honeybee becomes more active, and generates heatin some cases until the temperature within the cluster is as high as that of the broodnest in summer." During the fore part of the readings in November and December the internal temperature of the cluster of this outside colony had a tendency to drop as the outside temperature went down until it reached $57 \mathrm{~F}$. At that point the reaction. took place; that is, the generation of heat began, and from this point it began to rise in spite of the fact that the outside temperature continued to drop. The cluster heat continued to rise until the center of it registered nearly 90 degrees. After the coldest outside temperature was reached, the outer air began to get warmer, and simultaneously the temperature of the cluster began to sag.

Dr. Gates tried these experiments at an carlier period, as reported in Bulletin No. 96 , and discovered a similar inverse ratio; but he did not find the exact point when the colony temperature ceased to drop with that of the outside. Dr. Phillips and Mr. Demuth learned that this point is $57 \mathrm{~F}$. When the colony is without brood, and the bees are not flying, the bees generate practically no heat until the coolest point among the bees reaches a temperature of $57 \mathrm{~F}$. "At this point the bees begin to form a compact cluster; and if the temperature of the air surrounding them continues to drop, they begin to generate heat." Between 57 and $69 \mathrm{~F}$. the bees do not do much in the way of heat generation.

Apparently, it is desirable to have the surrounding temperature at such a point that the internal temperature of the cluster will not go below 57 nor above 69 ; but, as will be shown, the questions of food and syrup are additional factors to be considered.

Attention will now be directed to the colonies, or one of them at least, in the constant-temperature rcom, where the mercury was kept at about 42 or 43 degrees F. "This temperature was chosen as being nearly the one generally considered best by beekeepers." There were two colonies-one fed on honey stores and another on an inferior grade of honey-dew honey, that are particularly mentioned in the bulletin. Colony No. 1, fed on honey stores, was in a constant-temperature room for 163 days, during which readings were taken hourly. At first the internal temperature of the cluster according to the chart hovered around 64 and 68 . It rose gradually clear thru the winter. The colony fed on honeydew stores showed a higher temperature at the beginning; when up to about $76 \mathrm{~F}$. it began to take a sharp rise, going up to 91 above, and on Nov. 23 the temperature began to show a sharp drop, the line running down as low as 48 on Dec. 10, when the colony died. Clearly the poor food caused uneasiness by reason of the accumulation of fecal matter that the bees could not digest, and this uneasiness caused activity; and activity called for a greater consumption of stores. The one condition operated against the other, finally ending in the destruction of the colony. The other hive fed on good honey pursued its normal course thru the season.

It is interesting to observe that the normal temperature of the cluster of the colony fed 
on good stores only gradually increased, and this increase was doubtless due to the slight accumulation of feces. This accumulation was markedly less than that in the case of the colony on honey-dew stores, not because the bees became uneasy, but in proportion as the feces increased, the activity and temperature of the colony increased. This increase was not enough, however, to cause the death of the colony, but a slight reduction in the force in the spring. These observations explain the importance of good food-a food that will not clog the intestines. It also explains a common cause of dysentery.

Phillips and Demuth also discovered that the length of the life of bees either during summer or winter depends on the activity of the bees. The greater the activity, the shorter the term of life.

They also found that when brood-rearing commences or is in progress, the temperature of the cluster will rise to about that which takes place in summer or spring. This was to be expected, of course.

During these experiments a remarkable thing was learned-namely, that there can be, and actually is, activity inside of a cluster of bees during winter. When the temperature of a cluster goes down to 57, and the outside temperature surrounding the hive is dropping, the bees by actual muscular exercise can raise the temperature of the cluster. This activity may consist of a few bees tugging at each other, moving their bodies back and forth, or actually fanning with their wings. One bee may set up an active fanning inside the cluster during the dead of winter. Bees actually fan to cool themselves in summer and to warm themselves in winter, paradoxical as this may seem. It is difficult to comprehend that bees can warm themselves up by exercise, like their owners; and the idea that their little electric fans, so to speak, can raise the cluster temperature as well as cool it seems at first ridiculously absurd; but that it is true the author proved to his entire satisfaction by the experiments he conducted during the winter of 1914 and 1915.

In this connection it is proper to state that this fact was learned thru the use of a hive that had double glass sides. The bees were compelled to form their winter clusters against these sides. It would thus be possible to watch the internal movements that actually take place inside, and what was seen was indeed a revelation.

Various observers have opened up clusters of bees in mid-winter, and found the bees inside in many cases as active as they ever are. Certain thermometric readings were taken, showing the temperature was nearly the same as during the summer. In the light of these observations just taken by the Government it is very easy to explain this, notwithstanding that there are times when the temperature of the cluster is below 60 to 70 . One has only to remember that, when the inside temperature of the cluster goes as low as 57 , the bees raise the temperature of the cluster even tho the outside temperature is becoming colder and colder. The presumption is that, when the cluster is large enough, they keep up these "daily exercises" in order to keep the cluster warm. A prolonged cold spell, especially that down to zero, is nearly always disastrous to good wintering. This cold weather puts the bees in the cluster in a state of activity; and activity causes an abnormal consumption of stores, with no means of voiding their feces, and then dysentery follows; hence we commonly find after a prolonged spell of cold weather that has lasted for weeks, combs spotted with dysentery, and no wonder.

At the close of this bulletin the authors make the statement that "bees in winter, either in cellars or outdoors, should be disturbed as little as possible." This is a very natural conclusion; yet for two or three winters back we have had good results in making increase in cellars by pursuing just the opposite policy. We fed bees on hard candy, and disturbed them as much as possible. This caused brood-rearing and increase at times when the temperature of the cellar was 55 to 60 . While this mcde of wintering is not advocated for novices, and while such increase is not made without some corresponding disadvantage, we know we have made increase in the cellar; but we advise the average person to follow Dr. Phillips' advice. Fussing with bees in the cellar is usually attended with disaster; but that does not argue that the expert may not pursue the practice to advantage.

THISTLE.-See Canada Thistle. 


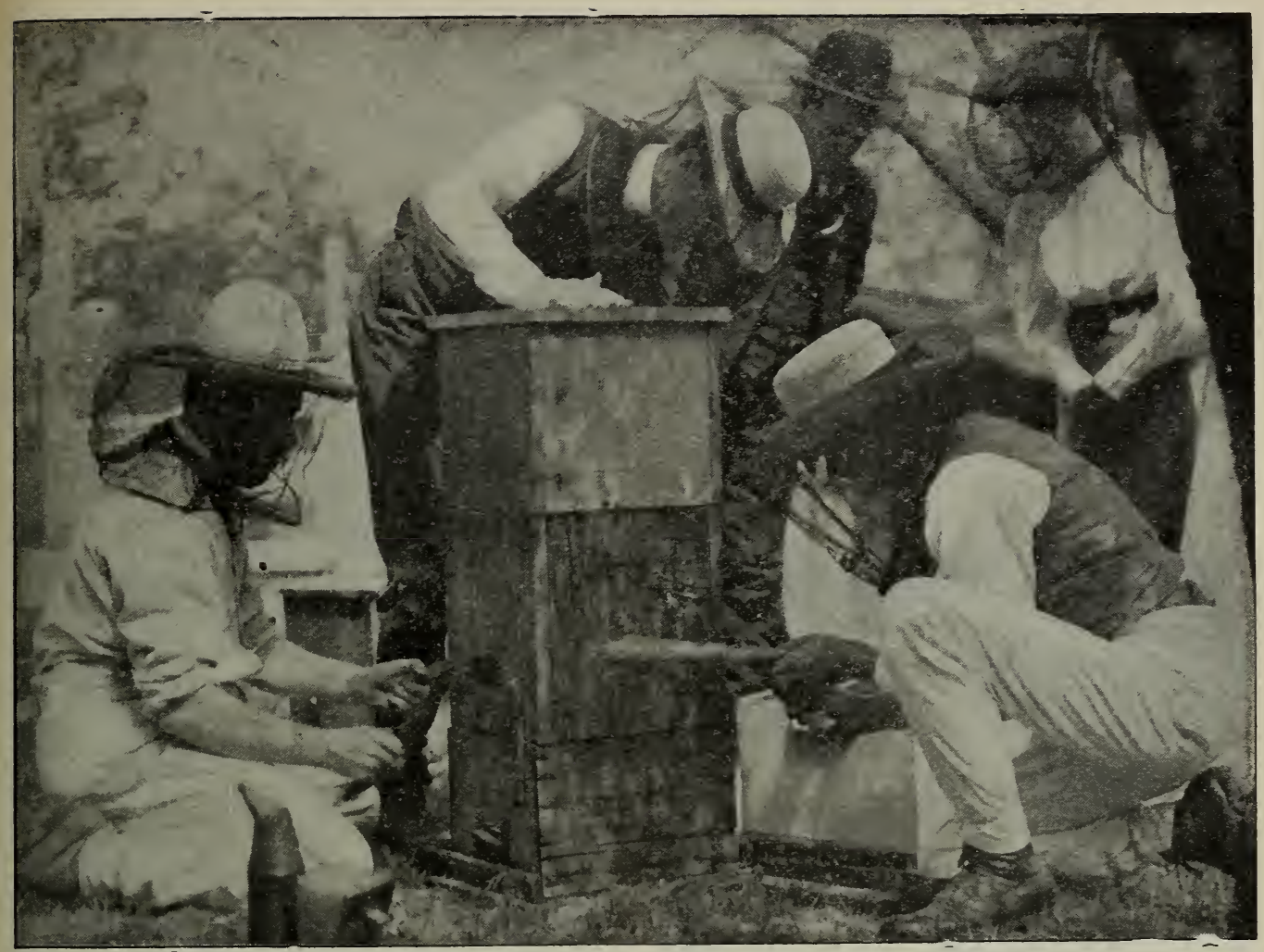

Box hive turned upside down preparatory to drumming out the bees.

TITI (Cyrilla parvifolia Raf.).--Ironwood, leatherwood, and red titi. An evergreen shrub, 6 to 10 feet tall, growing in swamps and along streams in northern Florida. The leaves are oblong, leathery, shining green above but paler below. The flowers are numerous, small, white, and in racemes, appearing in February and March. As the weather is rery likely to be unpleasant during the blooming period, very little surplus is obtained from it. The honey is red-colored, rather strongly flavored, and good mostly for bakers' use. 'A surplus is obtained only in the extreme northwestern part of the state.

C. racemiflora (L.), or ivory bush, is also found in wet land in Florida, but is more widely distributed, extending northward to Virginia and westward to Texas. The white flowers open in May and June. In middle Georgia it is not a very sure or abundant vielder, but it is valuable as it comes at a time when there is little else for the bees to work on. The honey is only fair in color and quality.

Black titi (Cliftonia monophylla (Lam.) (Britton), also called buckwheat-tree and ironweed, is a small evergreen tree growing in pine swamps from Florida to Louisiana. In southern Georgia it is rery abundant along streams. The fragrant small white flowers appear in March and April. A small quantity of honey of only fair quality is obtained.

TRANSFERRING. - This term might mean moving bees from one yard to another, or bees from one hive to another. In the strict technical sense, however, it means moring bees from box hives, log gums, or straw skeps into modern movableframe hives. The process involves the act of cutting the combs out of an old hive and fitting them into movable frames, after which they are placed in an up-to-date hive. When one by purchase or otherwise acquires a lot of old gums, he must transfer them into modern hives before he can do anything. To do this he must provide himself with as many. hives, with a full equipment of frames, as he has gums or old box hives to transfer. He will need, in addition, a hammer, a coldchisel, a fine-toothed saw, some tacks, a ball of string, a big butcher- 
knife, a small box a little larger than the top of the gum, and a large board or cover on which to place the combs when cutting them to size to fit the frames. He will also require a pail of water to wash up his hands and tools every now and then, as they will become intolerably sticky with honey.

\section{HOW TO TRANSFER.}

A little smoke should be blown into the entrance of the gum or box hive, at which time it is lifted off its stand and a modern hive put in its place to catch the returning bees. The old hive should now be turned

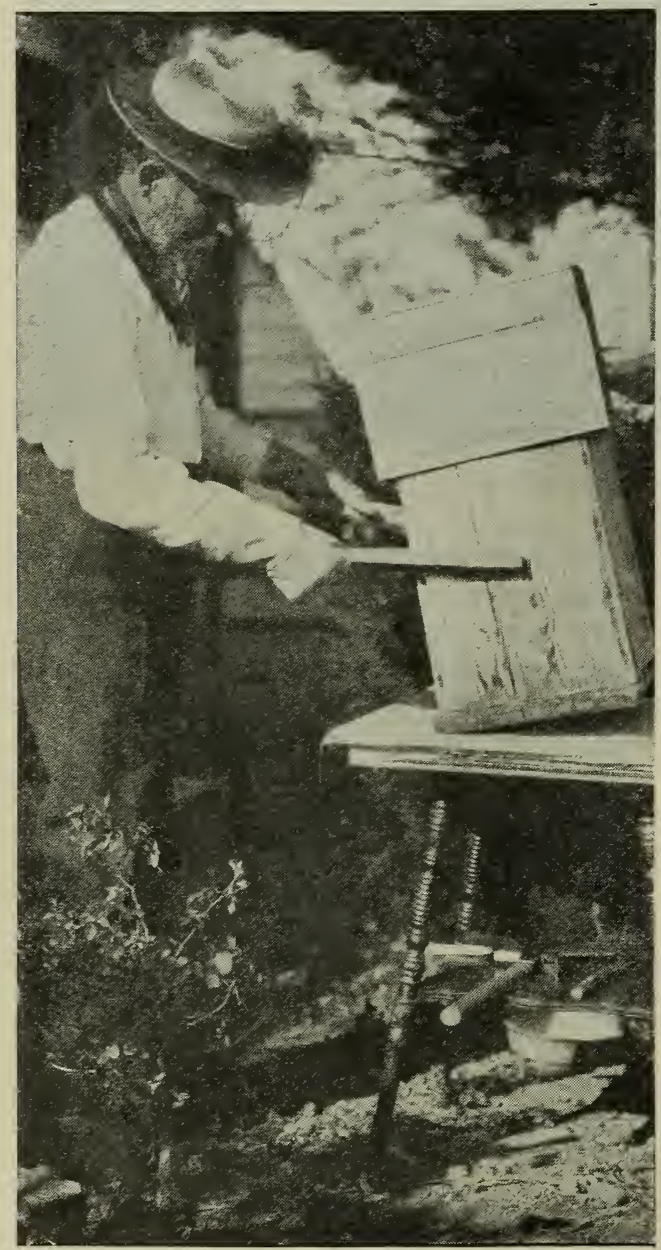

Drumming bees up into the empty box.

upside down, and smoke blown down between the combs, and the small box (above referred to) placed over. The operator should now, with a couple of sticks or clubs, drum on the outside of the gum. If it is an old $\log$ he can use a couple of hammers.
This drumming should be kept up incessantly until all or nearly all the bees have crawled up into the empty box placed on top. This should now be emptied in front of the entrarice of the new hive. The sides of the old gum are now removed with coldchisel and hammer; and the combs, the largest and best of them, are cut out with the long-bladed knife and laid in a pile. Every now and then the tools and the hands will have to be washed in the pail of water.

The next problem is to cut the best of the pieces of comb so they will just fit in the frames. This is best accomplished by laying a slab of comb on the board or hivecover, and over it a frame. The knife is next drawn along next to the inside of the frame, marking its exact size and shape on the comb. The frame is lifted off, when the comb is trimmed to the required size and fitted into the frames. Care should be taken to cut the comb large enough to make it a snug fit. If it is a loose fit it is advisable to wind a string around the frame and comb, going around it two or three times, and then tying; but if the work is done properly the combs will not need to be fastened.

No comb, unless large enough to fill a frame, and unless it contains brood, should be inserted in the frame. It is a question whether it pays to use good worker comb unless it contains brood. Certainly all irregular pieces, and all drone comb of any size whatever, should be rejected and melted up into wax, as it does not pay to fuss with them. Small pieces of comb containing worker brood should be saved, and a series of them placed on the board and fitted together as tightly as possible. A frame should be laid over the pieces and the exact size marked. The surplusage on all sides is then cut away, and the frames slipped over the pieces. It will take considerable care in handling this patchwork of comb to keep the pieces from falling out. The bcard should be lifted to a vertical position and then deftly pulled away. A string may now be wound around the frame in such a way that the several strands will come opposite the small pieces, holding them in place. After the brood has hatched out, such comb should be rejected.

Some prefer to use narrow strips of wood. Wooden separators such as are used in comb honey can be cut up into narrow 
strips and tacked to top and bottom bar's of the frame and across the face of each piece of comb. The frame is then turned the other side up while another set of strips is tacked to the other side. The comb may now be put in the hive. As soon as the bees

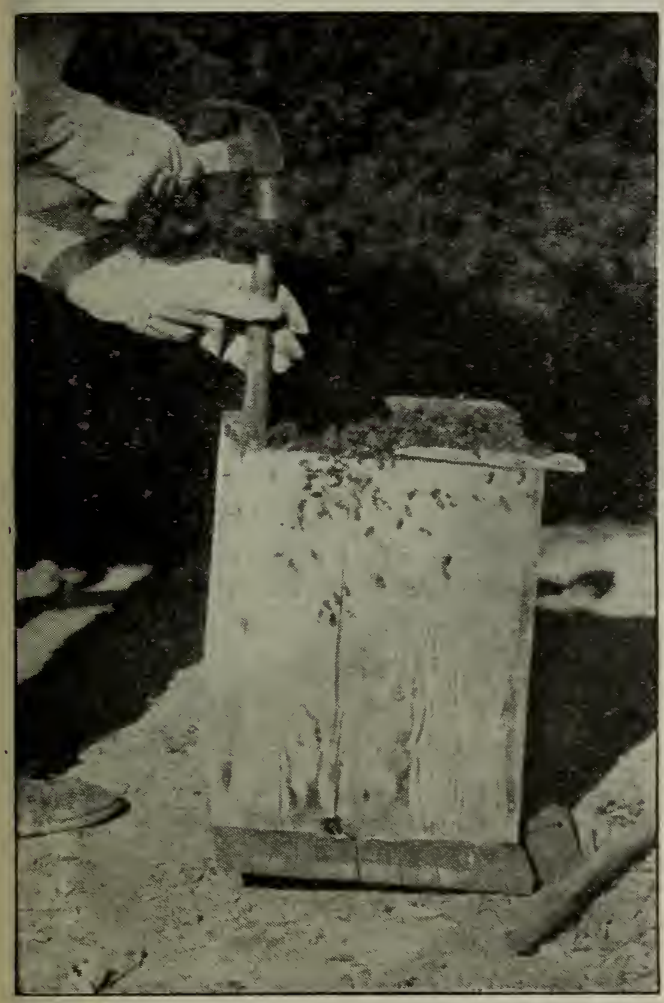

FIG. 1.-Remoring cne of the sides of the box hires.

have fastened the pieces to the frame and to each other, the string* or strips of wood should be removed; otherwise, some brood will be destroyed.

All scraps of every sort, as soon as they are cut out of the hive, should be dumped into a closed box or hive to keep them away from robbers; and each comb, as soon as it is fitted into a frame, should be put into the new hive on the old stand. At the close of the work everything should be washed up clean to prevent robbing. (See RobBirg.)

If all combs are rejected unless they contain worker brood, there will be extra space in the new hive. This should be filled either with good combs from other hives, or with frames of foundation. It is usually poor policy to try to save any combs in a

* The string is preferable to the strips of wood for the reason that the bees will remove the former if the apiarist neglects to do it. box hive unless they contain worker brood. In the directions already giren, no mention is made of the possibility of robbers "interfering" with the "operations." If the work is performed at a time when no honey can be secured, robbers would enter into a free-for-all help-themselves proposition, and in the course of a few minutes there would be a general uproar, and the bees cross enough to drive every one off the premises. The beginner should understand that, when he undertakes to transfer, he should be careful to prevent a general robbing fracas, else he may have a damage suit on his hands from some irate neighbor whose children, horses, or cattle have bsen stung. Where there are no other bees in the yard or immediate vicinity, there will be no danger of robbing, and $\mathrm{Mr}$. Beginner can proceed without fear of molestation.

The danger of robbers brings up the question of--

WHEN TO TRANSFER.

Usually the best time to do this work is in the spring during fruit-bloom when the

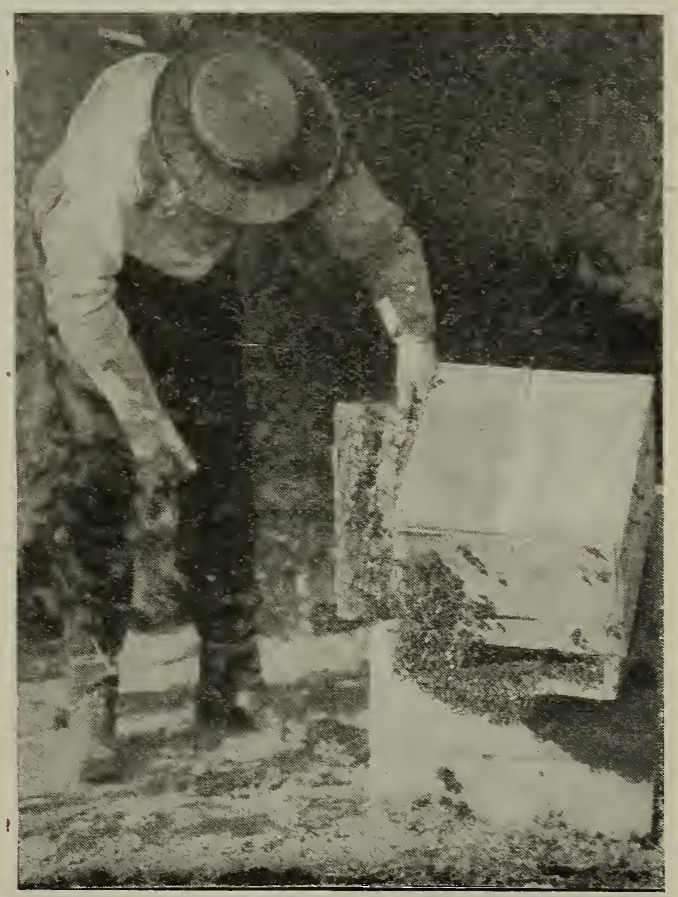

FrG. 2.-Box of bees placed in front of the entrance of the hire.

combs are light and without much honey, and when the bees will work on the bloom rather than rob. Transferring can be done 


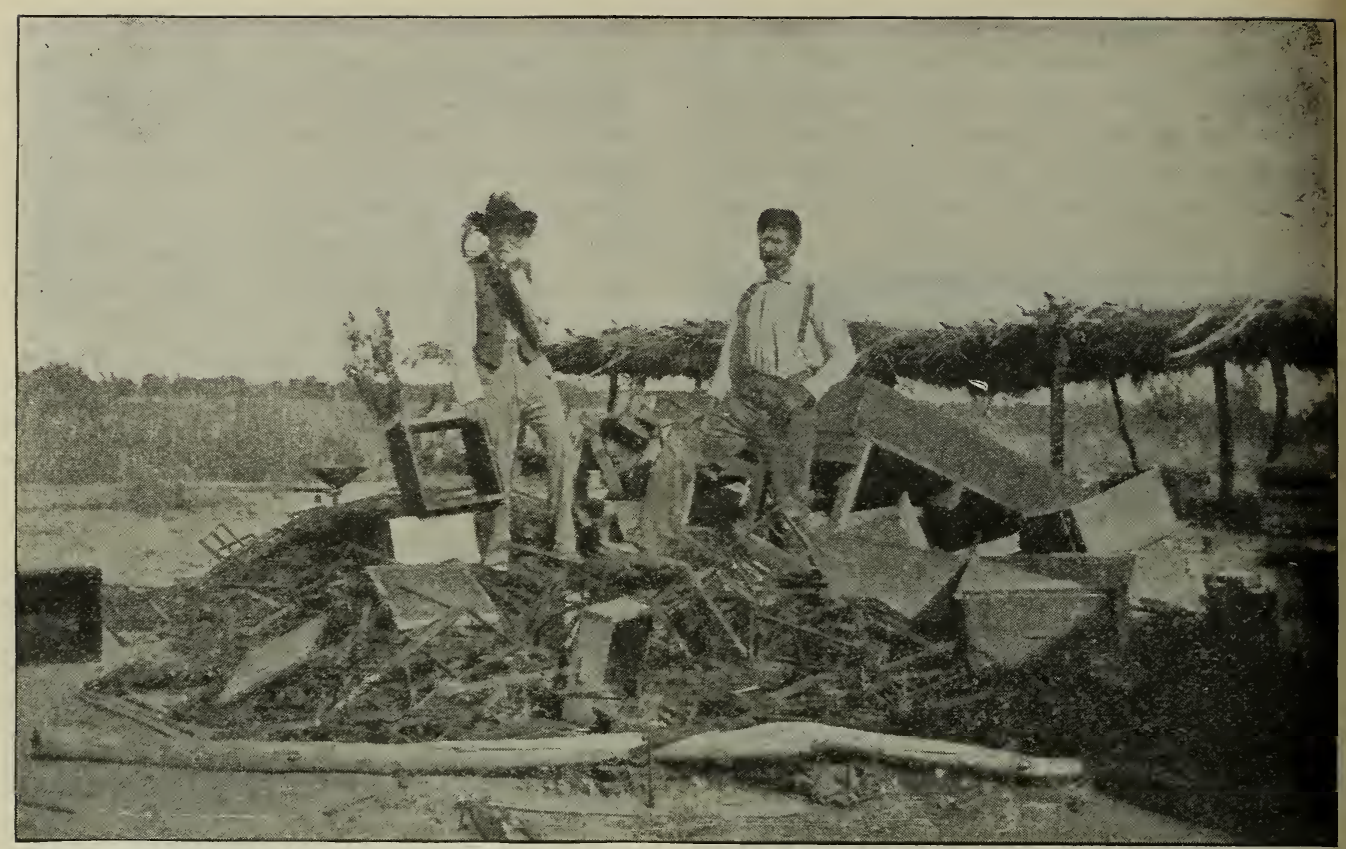

Mike Wall, Tempe, Ariz., and pile of odd-sized frames from which he had cut the comb and fitted them into Langstroth frames.

at any time when there is a honey-flow on; but if it is undertaken during or following the main honey harvest the combs will be very heavy, and awkward to handle.

When, however, one desires to transfer at some particular time, irrespective of robbers, he can take the whole equipment, bees and all, into a screened building. The objection to that procedure is that the bees will get all over the building and on to the windows, many of them wearying themselves to death in trying to get out. A far better way is to use a large wire-cloth cage, such as is illustrated under RobBing. The new hive and the old one, including all the tools, should be crowded on to as small an area as possible. The operator is then to pick up the cage and set it over the whole, with himself inside. If he proceeds carefully he can do the work of transferring with the help of an assistant on the outside to hand him the necessary tools for the completion of the work.

\section{A SHORT WAY OF TRANSFERRING.}

A little before swarming time the top of the box hive is pried off, and a single-story hive containing empty combs is placed on top. All joints between the two hives are made tight. After the queen starts laying in these combs a large portion of the bees will soon move up into it. After brood-rearing is well under way the upper story with its movable frames is lifted off and placed on the stand occupied by the box hive. In the mean time much of the brood from the latter will have hatched out, and what remains can be cut out and fitted into the frames as already described. The rest of the bees are either drummed out or smoked out of the old hive when the old combs are melted up.

THE GUERNSEY METHOD OF TRANSFERRING.

This is very similar to the one already described. An upper story with a full set of empty combs is placed on top of the old box hive after the top has been pried off. As soon as the queen takes possession above, which can be determined by the presence of eggs, a queen-excluding honey-board is slipped between the two hives. In 21 days, or as soon as the brood is hatched out of the combs in the old hive, the upper story is lifted off, the box hive is removed, when the upper story with a bottom-board is placed on the old stand. Any bees left in the old gum may be drummed out, after which the remaining combs can be put in a solar wax-extractor, and both honey and wax will be put into separate receptacles; or the old hive can be set to one side, when 


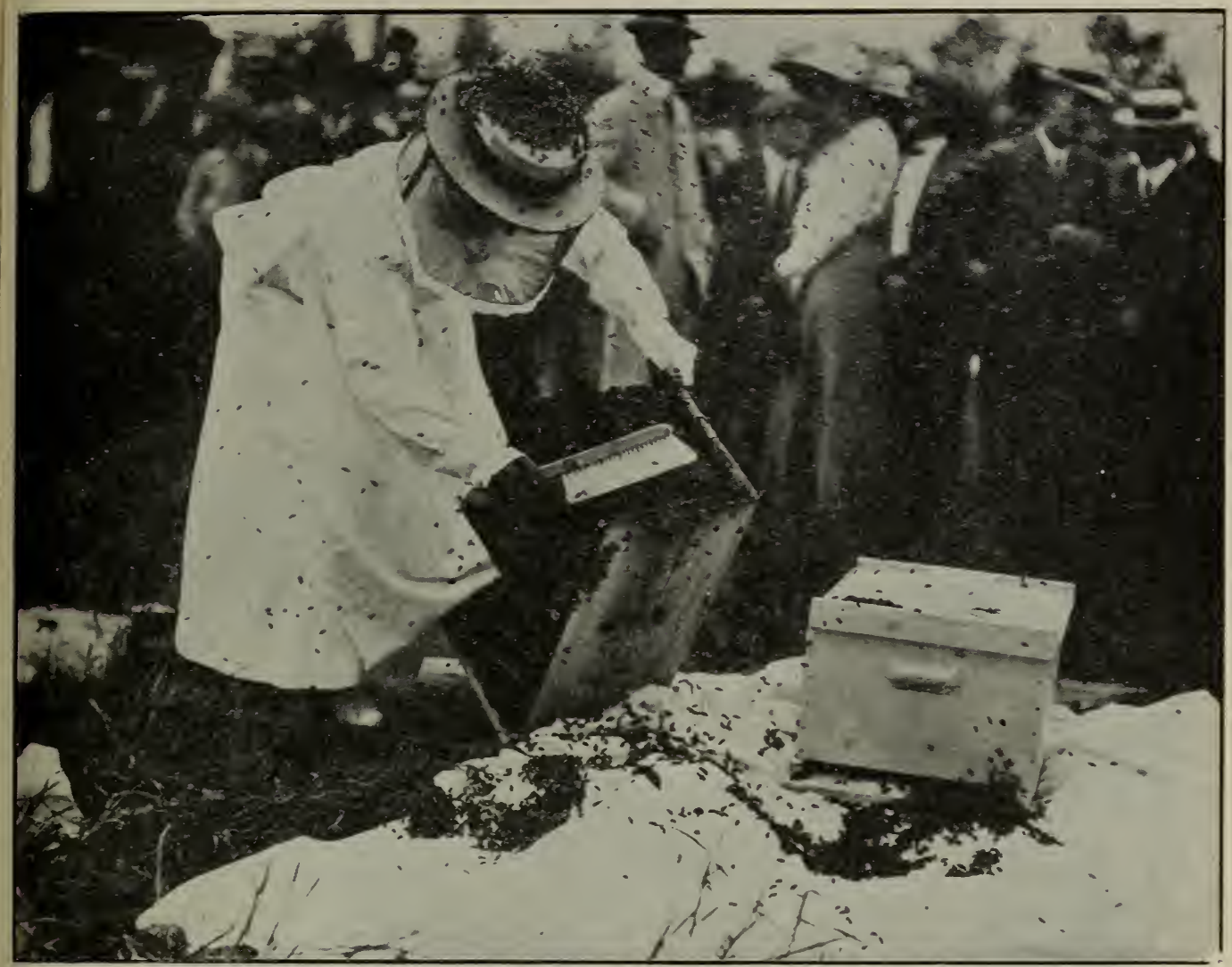

Transferring not impossible for women to undertake. Brushing the few remaining bees from the combs in the old box-hire.

the bees will rob out the honey left in it, after which the combs can be cut out and melted up. The objection to letting the bees rob out the honey is the danger of bee disease.

THE HEDDON SHORT WAY OF TRANSFERRING.

This is a plan that has been used considerably and preferred by many, because it does away with all robbing, the messing up of hives and tools, and leares nothing but perfect combs built from full sheets of foundation in the hive in which the transfer is made. Combs built from foundation are much superior to those made out of pieces and fitted into frames by the old plan. The plan of procedure is as follows:

The old box hive is moved back four or five feet, when the new hive, with a full set of combs or foundation, is put in its place. The old hive is turned upside down, after which about two-thirds of the bees are drummed into a small box placed above, in the manner already explained. In doing this drumming it is important that the queen enter the box. This can be determined by dumping the bees from the box in front of the entrance of the new hive. By watching carefully, it can be seen whether the queen goes in. If she is not discovered, more bees are drummed out of the box hive, and the second lot is dumped in front of the entrance. If the queen is found this time the old box hive should be giren enough bees to take care of the brood. It is then turned right side up, and put two feet back of the new hive with its entrance turned in the opposite direction. It is allowed to stand for 21 days, at the end of which time all brood will have hatched out, and nothing will be left but a little drone brood. All bees in the old box hive are drummed out in front of the new hive having an entrance-guard. The combs in the old hive are melted up, and the hive itself burned or used for kindling-ाvood.

At the time of making the second drive after all the brood has hatched it would be advisable to smoke both lots of bees before 


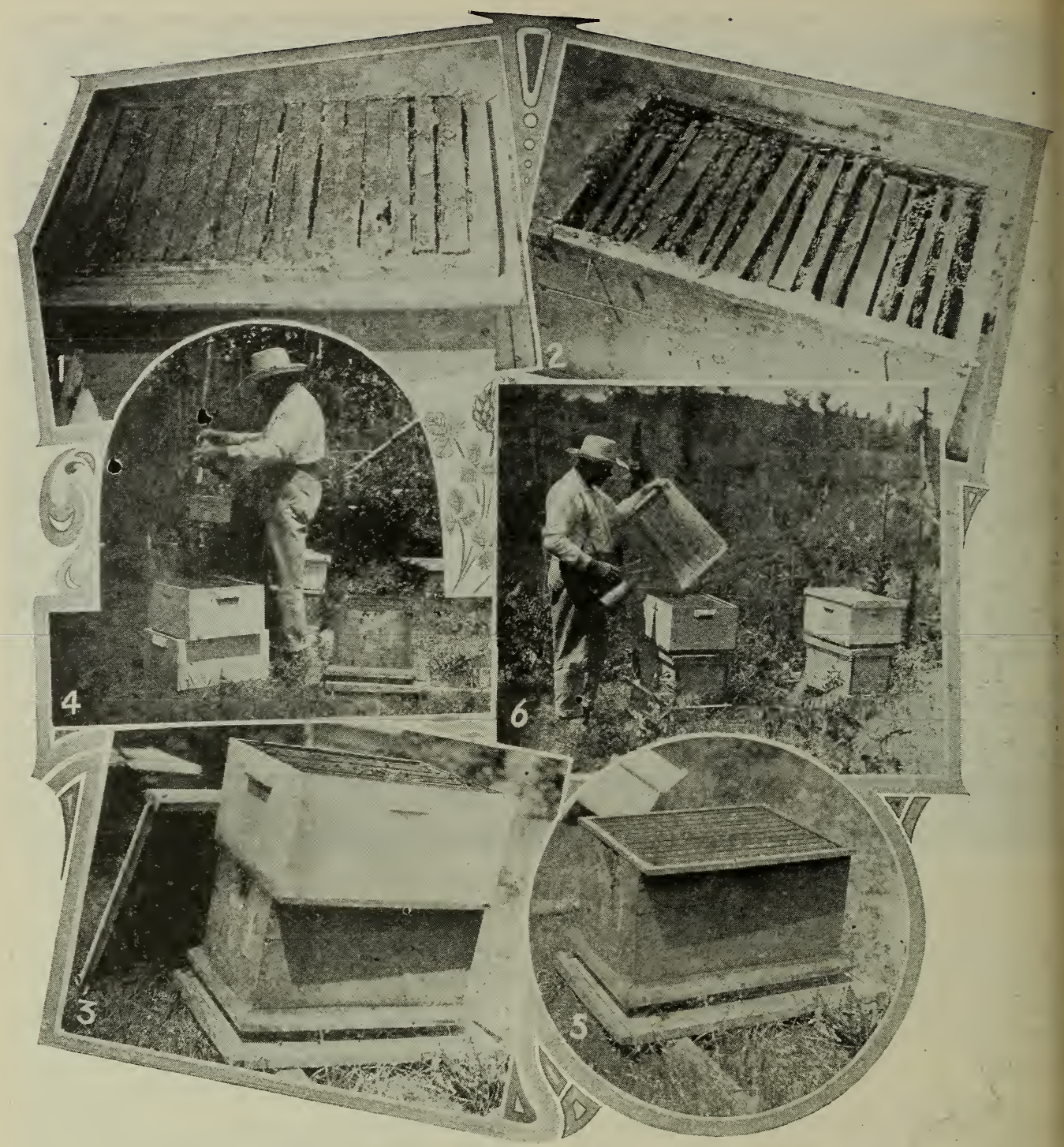

Method of transferring as carried out by E. D. Townsend.

uniting them, otherwise there may be considerable fighting. (See Uniring.)

If there is no choice between the queen in the old box hive, which will be the young one, and the old queen in the new hive, the entrance-guards will not be needed. On the general principle of uniting, one queen will be saved, and probably the younger one, or the better one of the two. (See UNITING.)

There is one objection to the Heddon method. If it is practiced during or after the honey season, combs in box hives may be heavy with honey. They can be extracted in an ordinary extractor, or they can be put into a solar wax-extractor; or still again they can be put into a wax-melter, described under the head of Extracted HoNEY and under WAx, when the two can be separated, the wax going into one compartment and the honey into another. If the work is done right, the quality of the honey will not be affected very much, or at least not to be noticeable.

TRAVEL-STAIN.-See Comb HoNEY.

TULIP-TREE (Liriodendron tulipifera (L.).--Other vernacular names are white poplar and whitewood; a handsome stately tree, sometimes exceeding 150 feet in height, growing chiefly in the forests of the south- 
ern states, but extending northward to Michigan. The large greenish-yellow flowers are bell-shaped. The tulip-tree is very common over all Georgia. It blooms in April, and secretes a very bountiful and reliable supply of nectar. The honey is dark and thick, and, when pure, is of inferior quality, but it nearly always improves by an admixture of holly honey.

After writing the foregoing, we concluded we did not know rery much about the whitewood, especially the blossoms. So we traveled off into the woods, where we found a tree; but there were only buds to be seen, not blossoms. It must be too early in the season; but hark! whence come those sounds of hummingbirds and humming bees? our clumsy boots slip, or a dead limb break unexpectedly. Now we were at the very summit of the tree, and, oh what a wonderful beauty we saw in those tulip-shaped blossoms that peeped from the glossy-green foliage all about us! No wonder there was humming. Bumble - bees, gaudy - colored wasps, yellow Italians, and last, but not least, beautifully plumaged hummingbirds. were all rejoicing in a feast of sweets. Every now and then one of the latter paused before our rery face, and, as it swung pendulously in mid air, winked its bright little eyes, as much as to say, "Why, what on earth can you be doing away up here in our domain?"

We picked off the great orange-colored,

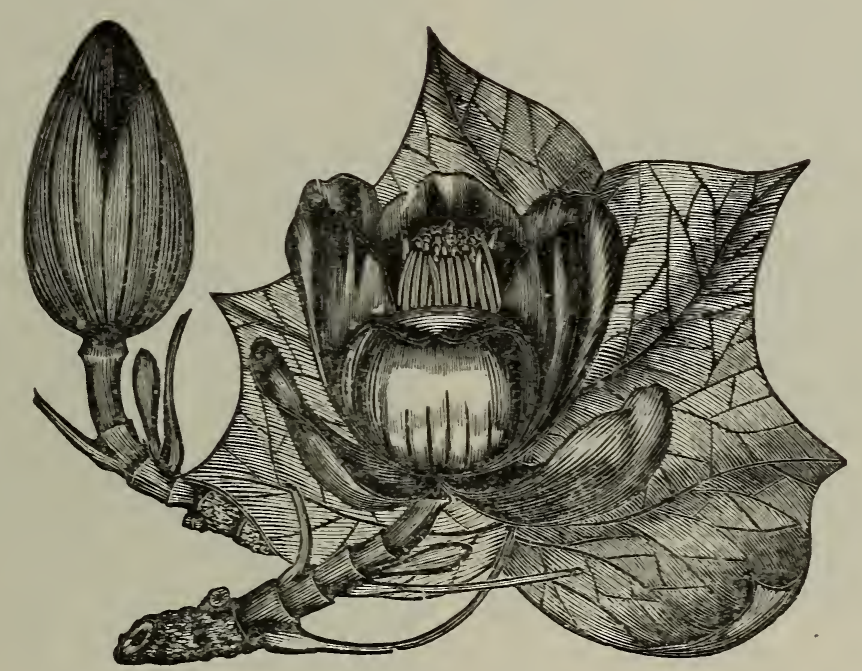

Leaf, bud, and blossom of the tulip-tree or whitewood.

Thence, too, that rare and exquisite perfume? We looked higher, and away in the misty top of the tree discerned, by the light of the setting sun, multitudes of bess flitting about. Oh that we were just up there! We looked at the rough trunk of the tree, and meditated that we were a boy no longer, but forty years of age, or would be in a few months more. We might get up to that first limb; after a good deal of kicking and puffing, we did. The next was a harder pull yet; but soon the limbs were smaller, and finally we began to crawl upward with about as much ease as our year-and-a-half-old baby girl goes upstairs whenerer she can elude maternal vigilance. Up. up, we went, until, on looking down, we really began to wonder what that blueeyed baby and her mamma would do should 24 mottled blossoms, and looked for the honey. We presume it was the wrong time of day to expect much; but inside, those large petals seemed to be distilling a kind of dark dew that the birds and insects were licking off. It tasted to us more like molasses than honey. In the cut our engraver has tried to show you what we saw in the tree-top.

As the sun had gone dorn, we commenced in a rather undignified way to follow suit, and after resting a little limped home. Altho stiff and sore, we carried an armful of whitewood blossoms to surprise the good folks who, probably, had never dreamed of the beauties to be seen orly in the tree-tops.

Our friends in the South have a great deal to say about what they call "poplar honey;" and, if we are correct, the poplar is the same tree which we call whitewood. 
It blossoms with them in April and May. We know what time it blossoms here, for we thought about its being the 27th of May when sliding down out of that tree. Shortly after, we received some bees from G. W. Gates, of Bartlett, Tenn. The combs were filled, even bulged out with a dark honey, such as we have described, and the bees had built fins of snow-white comb on the cover of their shipping-box. From this we infer the honey must be yielded in great abundance in those localities. We have seen it stated that the large flowers sometimes yield a spoonful of honey each. As the tree is often used for ornament, we make the following extract from Fuller's ForestTree Culturist :

\section{LIRIODENDRON TULIPIFERA}

(Tulip-tree, whitewood).

Leaves smooth, on slender petioles, partially three-lobed, the middle one appearing as tho cut off; flowers about two inches broad, bell-shaped, greenish yellow, marked with orange; seeds winged, in a large coneshaped cluster which falls apart in autumn. The figure shows a single seed as it appears when separated from the mass. It blooms in May and June, and the seeds ripen in late summer or early autumn, and should be sown as soon as ripe, in good, moderately dry soil. They may remain in the seed-bed two years if desirable, but should receive a slight protection the first winter; tree of large size, sometimes 130 feet high, with a very straight stem; wood light color, greenish white, soft and light, not hard enongh to receive a polish. It is much used in cabinet work, and for making panels for carriages, and for any inside work where toughness or a hard surface is not required. There is perhaps no native wood that will shrink more in seasoning than whitewood, for it not only shrinks sidewise but endwise as well; yet when once thoroly seasoned it remains fixed, and does not warp or twist like many of the hard and tough kinds of wood. There is also much difference in the character of the wood coming from different sections of the country, and mechanics who are conversant with the various kinds and localities will readily tell whether specimens came from the West or East. The latter is of a light greenish color, grain not so smooth and soft, and sometimes rather tough. The wood is but little used, except for the purposes mentioned above, and consequently it is only large trees that are of much value. It is one of the most beautiful ornamental trees we possess, growing in a conical form, and producing an abundance of beautiful tulip-shaped flowers in spring. The roots are soft and sponge- like, and it requires great care in removing to insure success.

The question is often asked, "Is whitewood good for bee-hives?" It may do for sections and brood-frames, but it is very unsatisfactory for hives, for the reasons given in this extract.

TUPELO OR GUM (Nyssa).-The tupelos are the most valuable honey-producing trees in Florida, not to say the entire United States. They are, at the same time, the most tantalizing. While the four native species are all clearly defined (tho some authorities claim that they hybridize), the duplication and complication of common names applied to the gums has given endless trouble to those trying to classify these trees thru the local names only.

Aside from the identification of the tupelos by the characters of their respective woods, they are readily distinguished by their botanical characters. There are four native species, as follows:

1. Nyssa sylvatica (synonym Nyssa multiflora), which is variously named black gum, sour gum, and pepperidge, is a highland species, a large forest tree growing, at its best, from 100 to 150 feet high, in rich upland woods of northern Florida and westward. The leaves are small and entire-that is, are not notched or lobed. The bark of this gum, as it grows older, finally breaks into hexagonal blocks. This is the giant of the tupelos.

2. Nyssa biflora called locally water gum or water tupelo. It is very common in the estuarine swamps of the mouth of the Apalachicola and other northern rivers of Florida, but does not grow down to the river banks, perhaps because the water is too swift or too muddy for it there. It grows from 100 to 120 feet high, with a trunk diameter of from five to seven feet at base. Its favorite habitat is in swamps and on the margins of ponds, and can be recognized by its bark, which is from $3 / 4$ to $11 / 4$ inches thick.

3. Nyssa aquatica (synonym Nyssa uniflora) is named, locally, tupelo gum, white tupelo, and cotton gum. This is, as its name implies, also a low-ground species, reaching a maximum height of 90 or 100 feet in its best habitat; but in pine-barren ponds it is a small tree, a mere shrub, 
and is often taken for a different species by those not familiar with its habits. It is, when thus stunted, often called locally, "scrub tupelo." (The term "scrub" is not a definite nor accurate name.) It is occasionally found as far south as the middle of Florida, but is not of commercial importance except in the northern and western

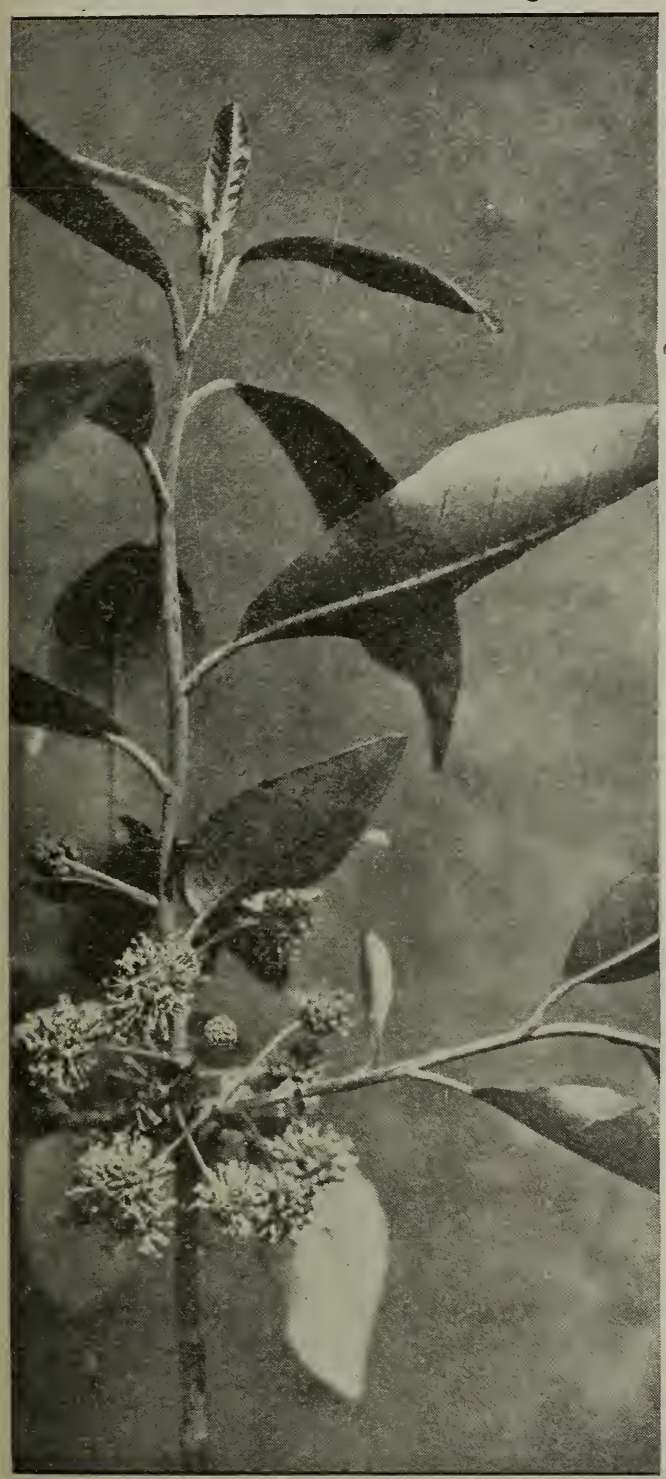

Sprig of scrub tupelo, showing the shape of the leaves and blossoms.

part of the state, and thence on into Georgia and further. It has large leaves, which are usually irregularly toothed, with a bark comparatively smooth and thin, only about $1 / 4$ inch thick. The fruit, called drupes, is a dark purple. This tupelo, with the fol- lowing, is the source of the "tupelo honey" of commerce, and this special variety is the greatest honey-producer of all the tupelos.

The country along the lowest part of the Apalachicola River is so thinly settled that the effects of civilization are hardly noticeable except for the removal of large quantities of cypress for timber by the lumber-

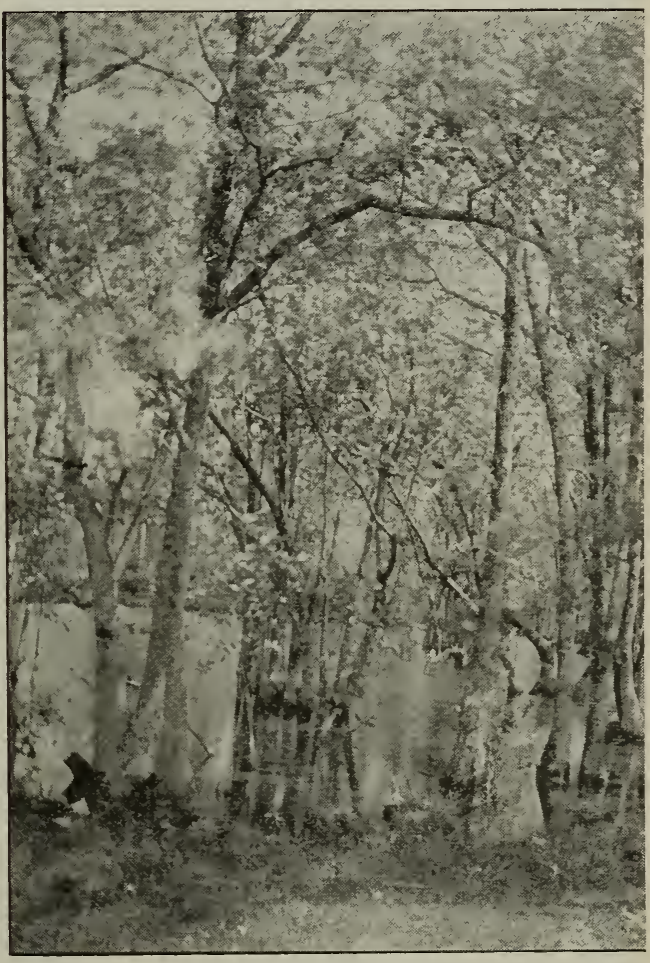

Scrub tupelo of Georgia.

men. Almost the only works of man that are visible from a boat, on this part of the river, are lumber-camps and apiaries, the latter to take advantage of the abundance of fine honey secreted by the Nyssa aquatica and-

4. Nyssa Ogechee (synonym Nyssa capitata), Ogechee lime, black tupelo, and Ogechee plum, is only a small tree, but grows in deep swamps from central Florida to the north and west part of the state. It is of commercial importance, however, only in the northwest. The maximum height of this species is about 60 feet, usually much less, say thirty or forty feet, and the bark is irregularly fissured. The leaves are large, and the drupes red and very acid. The stems of the leaves are short. The blossoms grow under the leaves. The honey is white and the body thin, much resembling that 


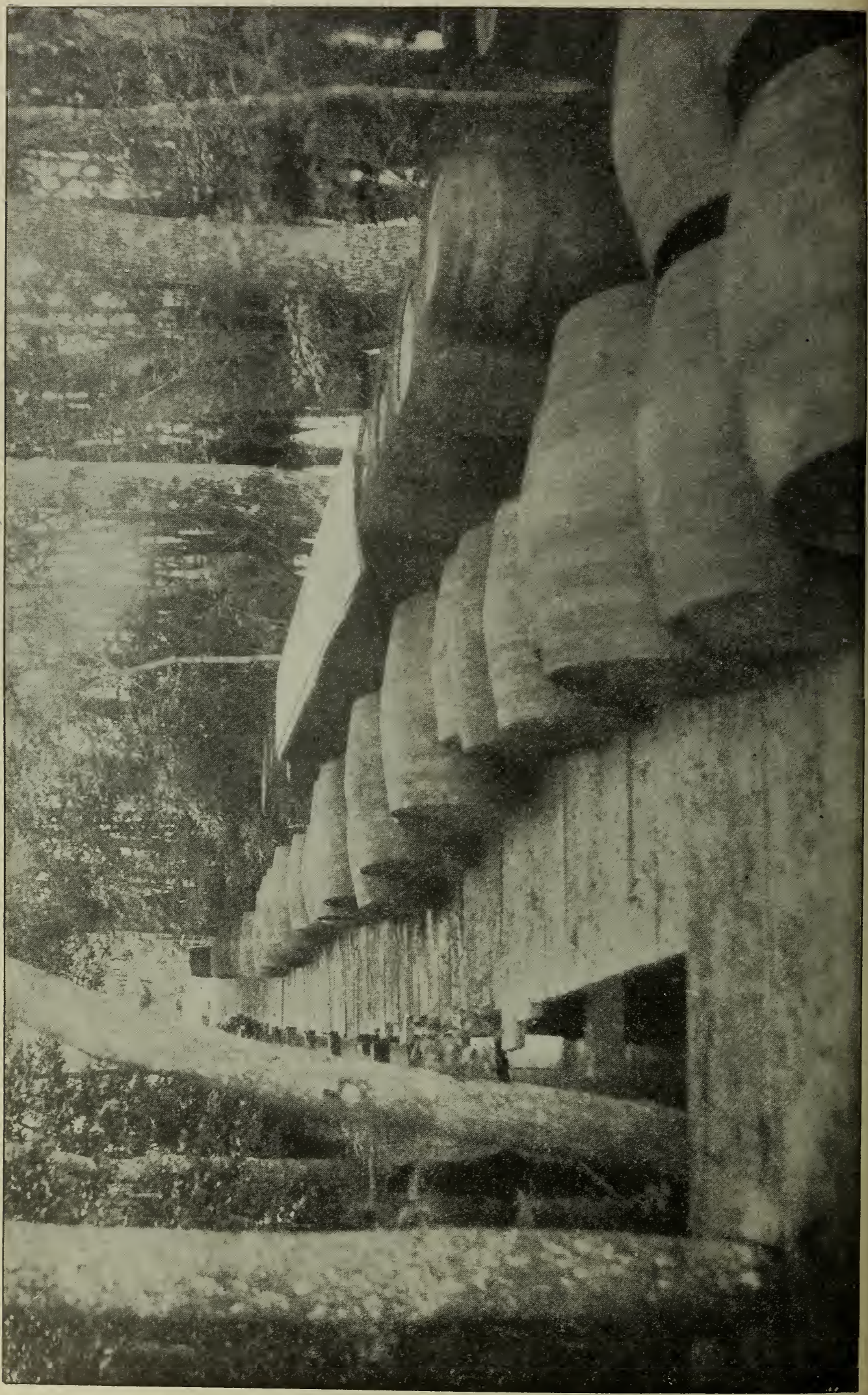


from cabbage palmetto. It comes into bloom in March, after the titi, but just before the Nyssa aquatica.

Calhoun Co., which forms the western boundary of the Apalachicola River for many miles at its southern part, is the banner honey county of Florida, producing

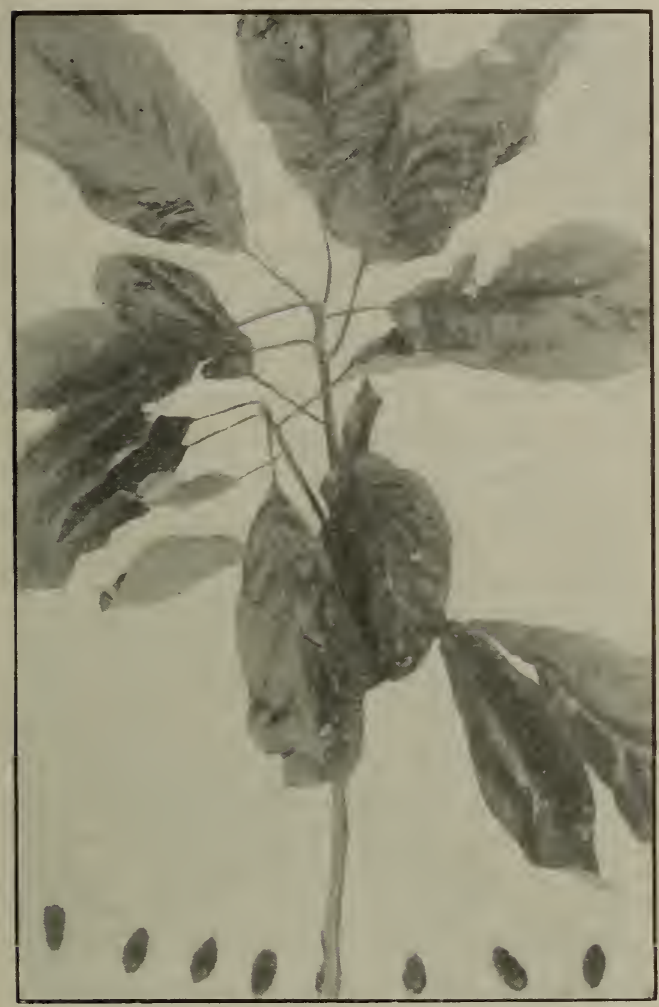

Black tupe!o or gum with berries.

annually about one-third of the honey crop of the entire state. The source of this honey is the Nyssa aquatica and the Nyssa Ogechee (commonly called "white tupelo" and "black tupelo"). These are the two great honey-yielding trees of the tupelos.

Note.-There is a fifth species of tupelo, called Nyssa acuminata by Small, which appears only in Georgia, a mere shrub, growing not more than seren or eight feet tall. It has smooth bark, branches and twigs red, and tops spreading. The honey closely resembles that from the Nyssa aquatica in body and color, being white and thick, but having a greenish cast to it. It is often called, locally but rariously, "scrub tupelo," as are some forms of the Nyssa aquatica.

The best honey of all is, as indicated, that from the Nyssa aquatica. It is white and rery thick, and of delicious flavor. When unmixed with other honeys it will not candy. It deserres to rank with the four best honeys of Florida, and with any of the best honeys of the world.

In the wonderful tupelo regions along the Apalachicola Riv"cr in northwestern Florida there has actually been produced nearly 2000 barrels of honey, each containing from 300 to 500 pounds. in a strip of territory not orer 100 miles in length, and perhaps a mile or a mile and a half in width on each side of the stream.

What about this honey? What is it? It comes mainly from the tupelo, both white and black. If one goes into southern Florida the local beekeepers will confidently assert that the palmetto is the finest honey produced in the state. In other regions they will say that mangrove carries off the palm; but when one goes into the northwestern country the beekeeper will assuredly assert that a pure white tupelo without other honey excels them all. It is of heary body. and rery mild in flavor. 


\section{$\cup$}

UNITING BEES.-This term is used to refer to the putting together of two or three nuclei or weak colonies, either from the same yard or from other yards, to make up one good colony. The operation is just the reverse of dividing, where a colony is split up into several smaller units. (See Dividing, INCREAse, and Nuclei.)

When several families of bees are put together they may or may not quarrel, derending on circumstances. If the weather is warm, and the bees are hybrids or blacks, they may, at the moment of uniting, enter into a free-for-all fight. The result may be, unless stopped by the timely use of smoke, almost the entire annihilation of one cr both lots of bees. As a general rule there will be no quarreling where gentle strains of bees are used, like Italians; and even when they have these "family disturbances" they can be "adjusted" very nicely by the use of a little smoke. Sometimes more smoke will be needed than at others, especially if the two lots of bees are of fairly good strength, and persist in stinging each other to death.

There is another difficulty in uniting; and that is, that the old bees, if taken from the same yard, are quite apt to go back to the old stand. This is especially true if the uniting is performed during or immediately following a honey-flow. Young bees that have never been out of the hive will stay where they are placed, and perhaps a majority of the old ones.

The old-fashioned black bees can be moved about from one part of the apiary to another with less trouble than ordinary Italians because they will find their location better.

In these days, when out-apiary beekeeping is practiced on so large a scale, the weak colonies or nuclei of two separate yards can be united very easily without any returning. Where one finds, toward fall, a number of undersized or weak colonies in two or more of his yards he can put the weaklings of one yard with the undersized or medium-strength colonies of another, thus bringing them all up to normal strength either for honey-gathering in early summer or for wintering at the close of the season. (See BuIlding UP ColoNIES.)

When there is only one yard of bees, as in most cases, one can unite even then if he will follow the directions we are now about to give.

HOW TO PREVENT THE BEES FROM THE SAME YARD GOING BACK AFTER UNITING.

After inclement or cool weather, during which the bees have been confined for several days, they may be united with little or no returning, when, if they have been going to the fields for nectar for several days, they will be almost sure to go back. It is, therefore, advisable to wait for a spell of rainy or cool weather when the bees cannot fly much, during which time they will have been confined for at least four or five days. Then in the cool of the morning the nuclei can be moved to their permanent winter stands. At the moment of uniting it is advisable to use plenty of smoke, not only to avoid any possible fighting that may occur, but to disorganize them so that, when they seek flight from their new home, they will mark their entrance anew. It is also important to remove the old hives after taking the bees from them to unite with other bees.

It very often happens that late in the fall one will have a lot of nuclei without any brood. If these should happen to be queenless, the bees of several of them can be shaken into a swarming-box and confined over night in a cellar or in a cool place. The intermingling of several families of bees, and confinement in a box without combs, breaks up the old family spirit that formerly existed, and almost entirely eliminates all knowledge of the old home. This lot of bees can now be apportioned out to colonies that are not quite up to standard of strength as follows: 
In the cool of the morning, before any bees are flying, the swarming-box should be taken into the apiary. Previous to this, all hives to be strengthened should be marked in such a way that the apiarist can at a glance determine how many bees he shall give to each individual stand. $\mathrm{He}$ approaches hive No. 1. The marking on the cover shows that it can take two dipperfuls of bees. He gives the swarming-box a jounce on the ground so as to pile the bees up en masse on the bottom. If they are disposed to fly up, he wets them down with a little spray--just enough to dampen their wings, and thus impede their flight. Before they can crawl up on the sides of the box he now scoops up a bunch of the bees with a little tin dipper and dumps them in at the front of the entrance. If the hive in question requires two dipperfuls, then two dipperfuls of bees it gets; and so on he distributes bees to every hive that needs them.

As a matter of precaution, every hive receiving bees like this should have its queen caged for 24 hours at least, in such a way that the bees can release her by eating out the candy or gnawing away the comb. As a further precaution, after the bees have been distributed in front of the various hives, an examination should be made in about 25 minutes to see that there is no fighting between the new family and the old.

By uniting in this way there have been accomplished two things-strengthening up the colonies that are not quite up to the standard, and disposing of all the weaklings in the apiary. If the swarming-box will not hold all of them at the first time, it can be filled the second or third time until all nuclei that are too weak to winter are cleaned up.

There is still one more way of uniting to prevent bees returning, and this may be practiced even when bees are flying to the fields if the weather is not too hot. The moved hive with its bees is put on top of another with a single thickness of newspaper between. By the time the bees above gnaw a hole thru, some time elapses. The confinement and the gradual uniting of the bees thru the hole in the paper averts all fighting and all returning of bees to the old stands, says Dr. Miller. During hot weather there is danger that the bees in the upper story may suffocate.

\section{UNITING NEW SWARMS.}

This is so easily done that directions are hardly needed; in fact, if two swarms come out at the same time, they are almost sure to unite, and two such swarms are not likely to quarrel. One of the queens will very soon be killed, but the extra one may be easily found by looking for the ball of bees hat will be seen clinging about her, very soon after the bees hare been joined together. A swarm can as a rule be given, without ary trouble, to any swarm that has come out the day previous; and if one will take the trouble to watch them a little, he may unite any swarm with any other new swarm, even if it came out a week or more before. If inclined to fight, they should be smoked as before explained to make them be good to the new comers.

\section{TINITING BEES IN THE SPRING.}

As has been pointed out elsewhere, uniting two weak colonies in the spring is usually unprofitable.* When there are two little reak colonies, or nuclei, one having a queen, it would seem the most natural thing in the world to put the two together for additional warmth and to provide a queen for all the bees; but, unfortunately, theory is not here borne out by facts. One can unite nuclei in the spring; and while at the very time of uniting they will seem to make up a fairly good colony, yet in two or three days there will seem to be just about as few bees as there were before the uniting took place.

A nucleus from an out-apiary can be brought home and united with a nucleus at the home yard, or at any other yard. There will be no returning of bees then, and the two clusters will stay together, sharing each other's heat and enjoying the privilege of having a queen over all.

\section{THE ALEXANDER PLAN OF UNITING WEAK COLONIES.}

During the year 1905, and again in 1906 and '07, a good deal of interest was manifested thru Gleanings in Bee Culture in the Alexander plan of uniting a weak colony to a strong one in the spring. Many of those who followed the method were very successful. A few, however, failed. To these latter reference will be made later. The

* Uniting a weak to a medium colony is quite a different thing, as will be presently explained. 
Alexander plan of uniting is given by $\mathrm{Mr}$. Alexander himself as follows after he had carefully revised it.

ALEXANDER METHOD OF BUILDING TP WEAK COLONIES IN EARLY SPRING.

About six or seven days after taking the bees from their winter quarters, pick out and mark all weak colonies, also the strongest ones, marking an equal number of each; then all weak colonies that have a patch of brood in one comb about as large as your hand. Set all such on top of a strong colony with a queen-excluder between, closing up all entrance to the weak colony except thru the excluder. Then there are those that are rery weak that have only a queen, and perhaps not more than a handful of bees with no brood. Fix these last named in this way: Go to the strong colony you wish to set them over, and get a frame of brood with its adhering bees, being sure not to take their queen; then put the queen of the weak colony on this comb with the strange bees, and put it into the weak hive; leave them in this way about half a day; then set them on top of the strong colony where you got the brood with a queen-excluder between. Do all this with very little smoke, and avoid exciting the strong colony in any way. If a cool day, and the bees are not flying, I usually leave the strong colony uncovered, except with the excluder, for a few hours before setting on the weak colony. The whole thing should be done as quietly as possible, so that neither colony hardly realizes that it has been touched. When the weak colony has been given some brood, and put on top in this careful and still manner, hardly one queen in a hundred will be lost, and in about 30 days each hive will be crowded with bees and maturing brood. Then when you wish to separate them, set the strongest colony on a new stand and give it also some of the bees from the hive that is left on the old stand, as a few of the working force will return to the old location, especially if they are black bees or degenerate Italians.

In every case that has come to my notice where this method has been reported a failure it has been from one of two causeseither lack of brood in a weak colony to hold the queen and her bees in the upper hive, or smoking the strong colony so that, as soon as the weak one was set on top, the bees from below would rush up and sting every one above. Therefore avoid using smoke or doing anything to excite the strong colony.

If done in a careful manner the bees in the lower hive never seem to realize that any strangers have been put above them, and they all work in harmony together.

At the outset mention was made of those who met with failure in following the method. As Mr. Alexander says, the difficulty doubtless arose from the fact that they failed to put brood along with the weak nucleus to hold the queen and her few bees, or else they did the work so clumsily that it stirred up both lots of bees, with the result that they came together before they had the same scent. Mr. Alexander's injunction is to put the bees together so carefully that the clusters do not really unite for some two days, at which time there is a peaceful union, and the two queens go on laying so as to make up one rousing colony, which can be divided, making two strong colonies where before there would have been only one, since the nucleus left to itself would have died.

Where one desires to proceed with extreme caution he is advised to put a wirecloth screen between the two lots of bees at the time of uniting, and keeping it there for two or three days, after which its place is taken by a perforated zine honey-board. In this connection it should be said that the wire-cloth screen should be mounted in a wooden frame about $3 / 8$ inch thick.

While this plan of uniting contemplates performing the act in early spring, something can be done at it in the fall. Mr. Josiah Johnson, in a communication sent to Gleanings in Bee Culture, tells how he unites on the Alexander plan in the fall.

Some have had trouble in following the Alexander plan of building up weak colonies. I think the trouble in many cases is due to rousing up the bees and getting them uneasy before the weak colony is put over the strong one. Then the two colonies have war for a while. I always use wire cloth between the two hives and never have any trouble from the lower colony going up and killing the bees in the upper hive. For some time I have wintered my weak colonies this way, on the summer stands. Last winter I had several weak colonies, and I put them all over strong colonies, making an entrance in the back with my knife thru the handhole of the upper hive. This should be just large enough to allow two or three bees to pass out at a time. This is done on some cloudy day after very cold weather comes.

Isast year I had a weak swarm of bees. There was just one frame of bees and a young queen. I put this frame of bees in with nine frames of honey, and put the frames in a hive and set it on top of one of the strongest colonies I had, and in February they got pretty strong, and I left them on till April; and when I set them off I had two strong colonies.

Milan, Ill. Josiah Johnson.

See Building up Colonies, Spring Dwindling, and Spring Management. 


\section{V}

VEILS.-The necessity of using face protection will depend largely upon the race of bees to be handled. When dealing with hybrids, Cyprians, or Holy-Lands, a veil is a necessity. With Italians, Carniolans, cr Caucasians it is not so important; still we prefer to have one on the hat ready to pull down. Its use in any case gives the apiarist a sense of security to enable him to work to much better advantage than he would if continually in fear of every cross bee that chanced to buzz near his eyes.

The two objections that have been made against the use of veils are that they obstruct the vision more or less, and interfere with the free circulation of air in hot weath- rision but little if any. The top of the veil is gathered with a rubber cord, so that it may be made to fit closely around the crown of the hat.

There is a special broad-brimmed cloth hat, costing about 20 cts. each, that is sold by dealers. These hats are very light, will fit any head, and can be folded and put in a coat-pocket. The under side of the brim is green; the upper side of the crown is a drab color. This broad brim is supported and held out by means of a steel hoop, and when the reil is placed orer the hat and properly drawn down it cannot touch the face or neck, and hence leares no possible chance for stings. During hot days when

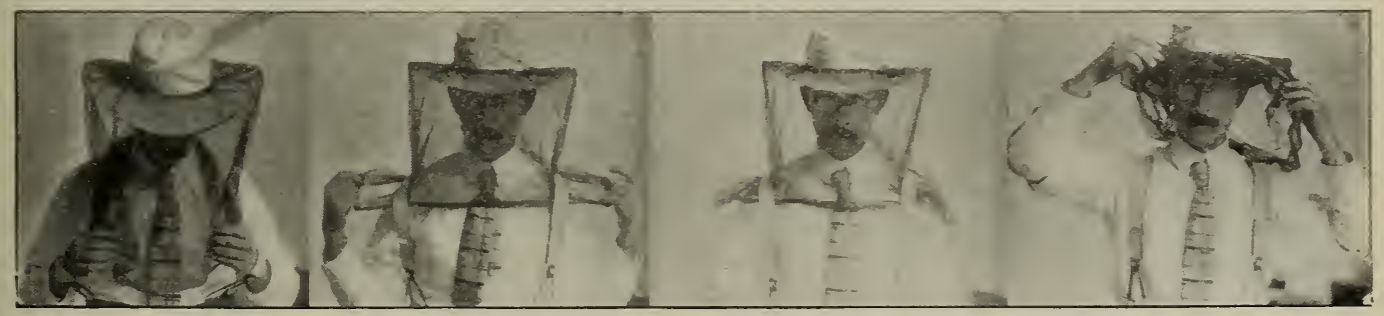

Manner of adjusting a bee-reil under the suspenders where there is no elastic cord in the bottom.

er, thus tending to make the wearer sweaty and uncomfortable; but these objections with a good veil are not very serious. Our best beemen, as a rule, wear a veil constantly when among the bees, and it is best to do so.

The very nicest veil is one made entirely of silk tulle, altho somewhat expensive. The material is so fine that a whole veil of it can be folded to go in a small vest-pocket. The author carries one of these constantly during the working season of the bees, and it is always ready for an emergency. It neither obstructs the vision nor prevents the free circulation of air on hot days. A cheaper one, tho not so light nor cool, is made of grenadine with a facing of silk tulle net sewed ir. The grenadine is strong, and the brussels-net facing obstructs the bees require the most attention in the apiary, a coat or rest is simply intolerable. In the absence of either one of these garments the corners of the reil may be drawn under the suspenders. The four plates herewith show successively this manner of drawing the veil under the suspenders, and its position when in use. The last riew of the series shows how easily it can be drawn out from under the suspenders and raised above the hat while not in use. A few apiarists work a good part of the time with the reil raised. When the suspender method of holding is used one can raise or lower and fasten the veil in a moment's time.

But there are many who prefer a reil with a rubber cord inserted in the bottom, fastening the same by means of a large safety-pin to the clothing. Unlike the other 
veils shown with no elastic in the bottom of the fringe, this veil can be used by a man or woman, because the safety-pin can be secured to the clothing of either. But in putting this on, care should be taken to draw the elastic clear down near the bottom of the waist, securing it with a pin as shown in the first illustration. No. 2 looks very nice, but the movement of the arms will soon push the cord above the shoulders, leaving it so loose that bees can readily crawl up. No. 3 is better; and if the elastic the country. It is a plain wire-cloth cylinder having a circular gathering of muslin at the top, and a sort of skirt of the same material sewn to the bottom edge. With this outfit one will be required to go bareheaded or wear a small cap. Much of the work in the apiary is done during the hottest weather, and this veil is very cool because the wire cloth rides on top of the shoulders, leaving a free circulation of air over the top of the head. In passing among trees or shrubbery it does not get " hooked,"

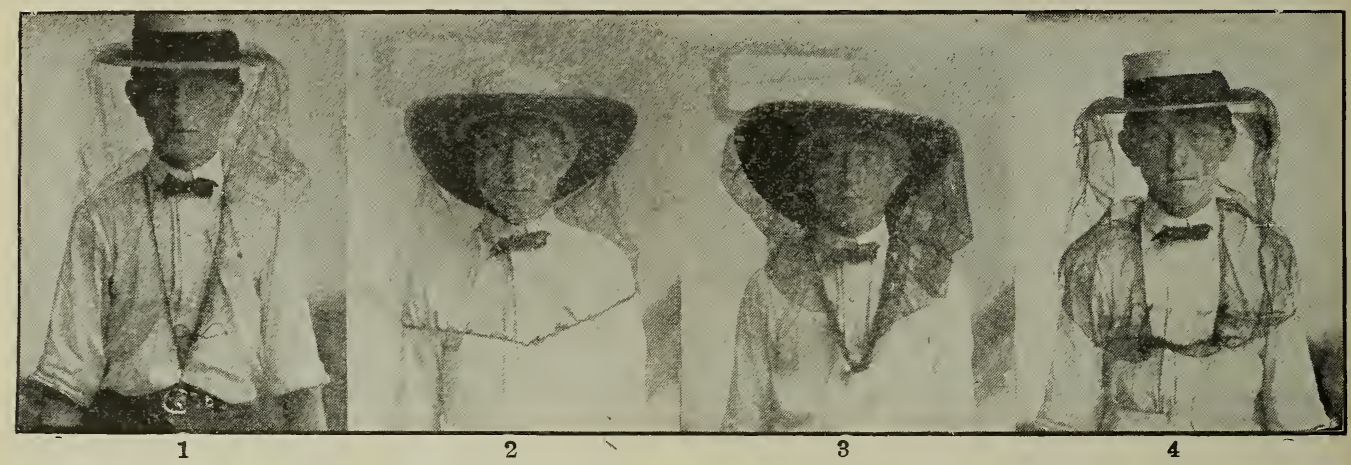

Right and wrong way to fasten a bee-veil having a rubber cord inserted in bottom.

is stiff enough very good results will be secured. But if not, the veil must be drawn ajown as shown in the view at the extreme left, or No. 1.

No. 4 shows a good method of fastening by means of a long string inserted in the bottom edge of the veil. The ends are crossed in front of the waist, brought to the rear, pulled clear around to the front again, and tied. (See cut of Woodman veil further on.) This holds the veil very securely as shown, and some seem to prefer it. An objection is that one cannot very well push his hand up under the veil to get at his face to wipe off the perspiration as he can where rubber cord is used as shown in No. 2, or where the edges of the veil are tucked under the suspenders. It is very important to have a protection that will secure freedom and ready access to the face. While a stray bee may get under without much danger of being stung, it is annoying to have it crawl around promiscuously. With the veil properly adjusted, one can easily reach his hand up under, pick up the bee, and at the same time be very little discommoded in his work.

The Alexander is a headgear that is used by some of the most extensive beekeepers in nor torn like some of the veils of fabric. It has the further advantage that it can be removed in an instant without breaking any fastening, and is quickly put on again. The muslin skirt fits loosely yet fairly snug around the shoulders and neck. There are many practical beemen who prefer wirecloth head-protectors to anything else.

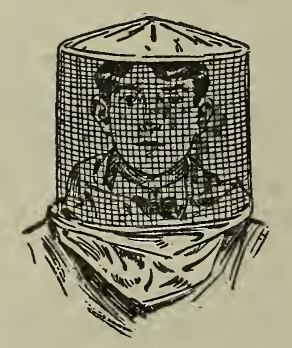

The Alexander bee-veil.

When first used they seem a little awkward; but the extreme comfort that one enjoys more than compensates for its apparent outlandishness.

The one shown in the cut uses a strip of wire cloth approximately a foot wide and a yard long. A yard of muslin completes the material required. Where one uses a coat, the skirt of this head protection can 
readily be tucked inside; but even without coat or vest, the loose folds of the cloth fit with a fair degree of snugness around the shoulders and neck.

Some use with much satisfaction a sort of chopping-bowl or basket inverted. It is a hat that is worn in India and other hot countries, and is slowly working its way into this country, particularly in the South. It is made of palm-leaf, and it is supported abore the head in the manner shown below. to bee-veils is the obstruction to the eyesight. To overcome this, Mr. John C. Capehart, of St. Albans, West Virginia, g]ued a piece of glass in front of the veil. The diffieulty with this was, that the glass would hardly ever be in range with the eyes, on account of its weight, and then it would be covered with steam from the breath; and, worse than all, it would get broken. The brussels net is open to none of these objections, and is almost as transparent as glass.

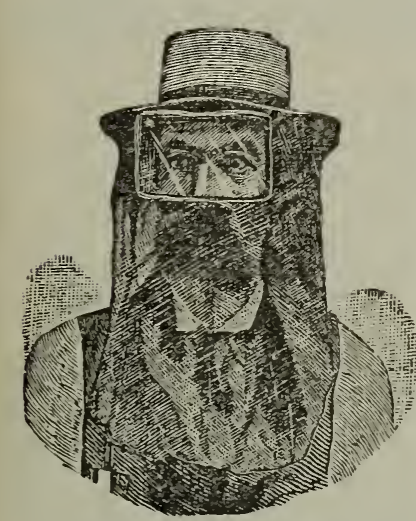

Capehart's glass-front veil.

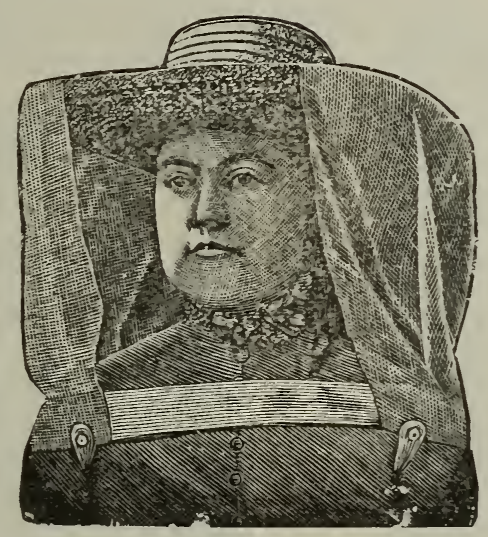

Mrs. R. H. Holmes' bee-hat.

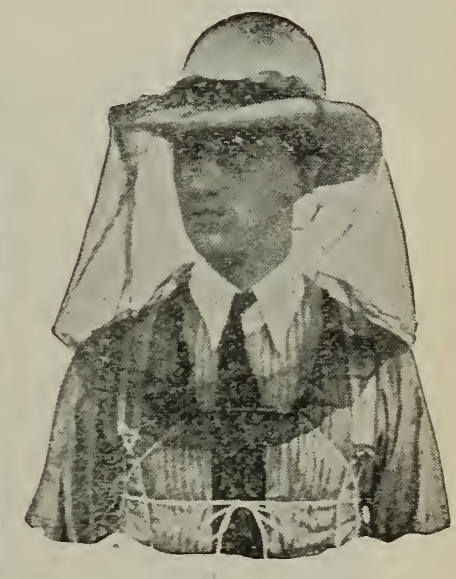

Woodman's adranced bee-reil.
The cut will render further description unnecessary.

As light breezes can circulate above and around the head, it is perhaps the coolest sun-shade of any herein illustrated and de-

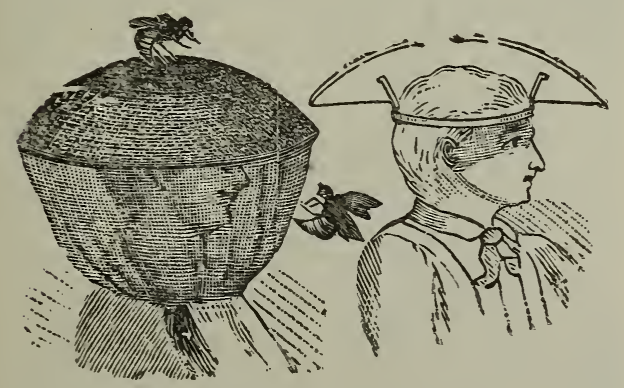

Hopatkong veil and hat.

scribed. If one cannot secure one of these, and would like to get the ventilating feature, he can take an ordinary palm-leaf hat several sizes too large. On the inside of the hat-band sew four or five $3 / 8$-inch corks that have been cut in halves lengthwise. These, if spaced at regular distances, will keep the hat from the head, and permit ventilation.

As has already been said, one objection
Mr. Walter S. Pouder made an improvement on this way by substituting celluloid film such as is used for photographic film negatives. While this overcomes the objection of weight it does not prevent the moisture of the breath from accumulating on it. Moreover, it is very inflammable-so much so that if a hot spark from a smoker should alight upon it, the face might be seriously burned. So far we have found nothing better than nor as good as silk tulle.

\section{THE GLOBE BEE-VEIL.}

This is a veil that has had a very large sale, and is preferred by a great number.

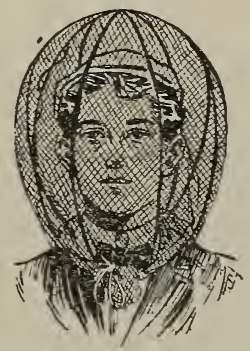

because it is large enough to extend down over an ordinary hat or cap; and it is so constructed that it cannot get against one's 
face at any point. Sometimes an ordinary veil will touch one's nose or the back of his neck. At these points a bee can insert its sting thru the meshes of the veil. The globe veil is made so as to fold up compactly so that it can be carried in the pocket. With cross bees to handle, this is by all odds the best veil in the lot.

The Holmes veil is simply a straw hat with a broad rim, the veil being made of mosquito-bar, and the facing of brussels net. A strip of cloth lines the lower edge

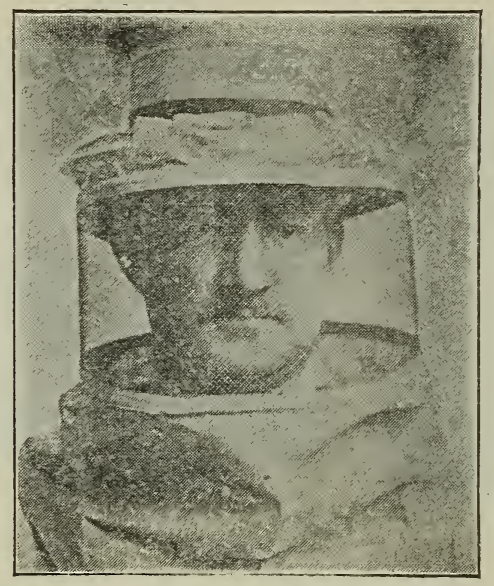

The Muth bee-veil.

of the veil, and is made just large enough to fit snugly around the shoulders. A couple of cloth straps hitched to buttons pass under the arm-pits, and button on in front. While this arrangement is good, the rubber cord and safety-pin is better.

HOW TO GET AIONG WITHOUT A VEIL.

It is a very great convenience to be able to dispense with a veil altogether, when circumstances permit it. The only obstacle is natural dread that a bee may possibly sting the face if it has a chance. This fear will wear off as one becomes more and more accustomed to handling bees. When without a veil, if a bee comes up, and, by its hum, reveals anger, one should not dodge nor strike at it, but control the muscles of the face as perfectly as tho he were not at all aware of its presence. A little wince of the cheek or of the eye encourages its fighting qualities. One can often put up his hand to the face when one of these rascals persists in its annoyances. Should it actually begin to sting, he can smash it.

\section{BEE DRESS OR CLOTHING FOR BEEKEEPERS.}

Under the head of GLoves, following in its alphabetical order, will be found some long-sleeved gloves or gauntlets that reach away up above the elbows. Many beekeepers use these to keep bees from getting up the sleeve, and at the same time protect the

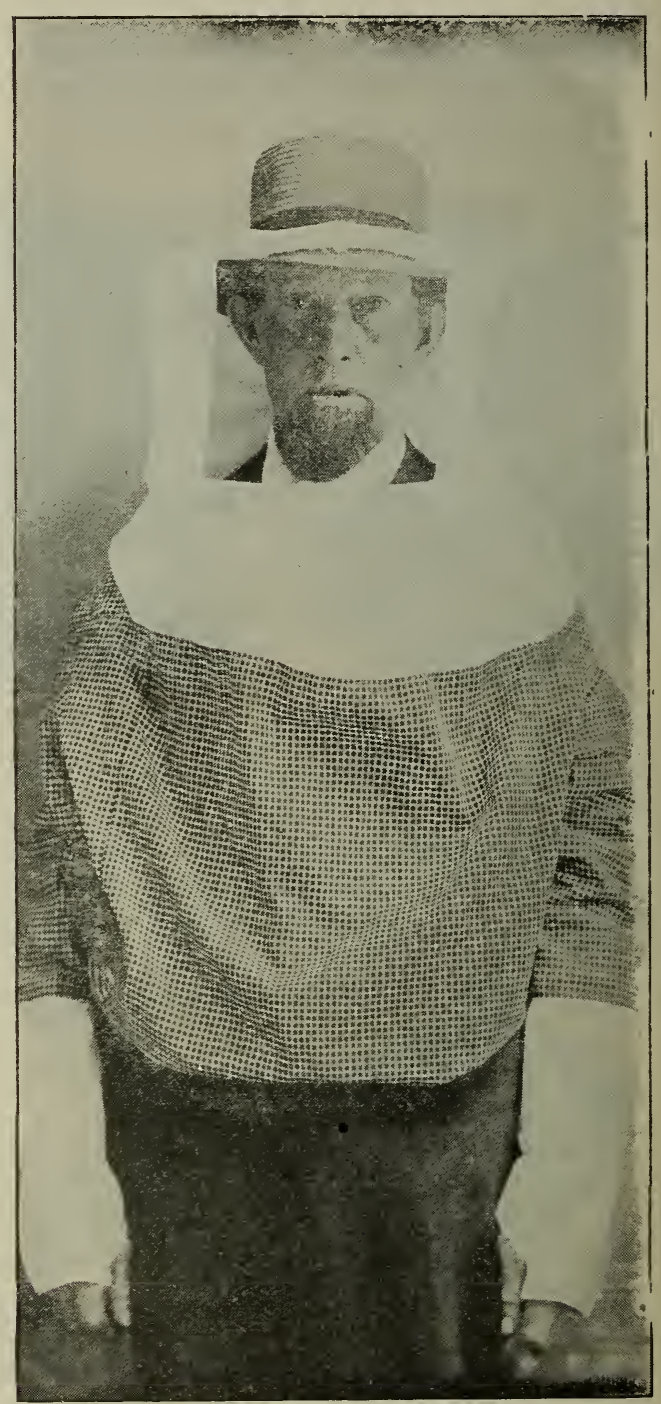

The Coggshall bee-veil and suit.

wrists, especially the inside fleshy portions of them where they are very sensitive. Others carry this same principle further, combining the gloves and headgear all in one. The accompanying illustrations show the outfit worn by Mr. David Coggshall, of West Groton, N. Y. The lower part of the blouse is taken up by a string hemmed in 


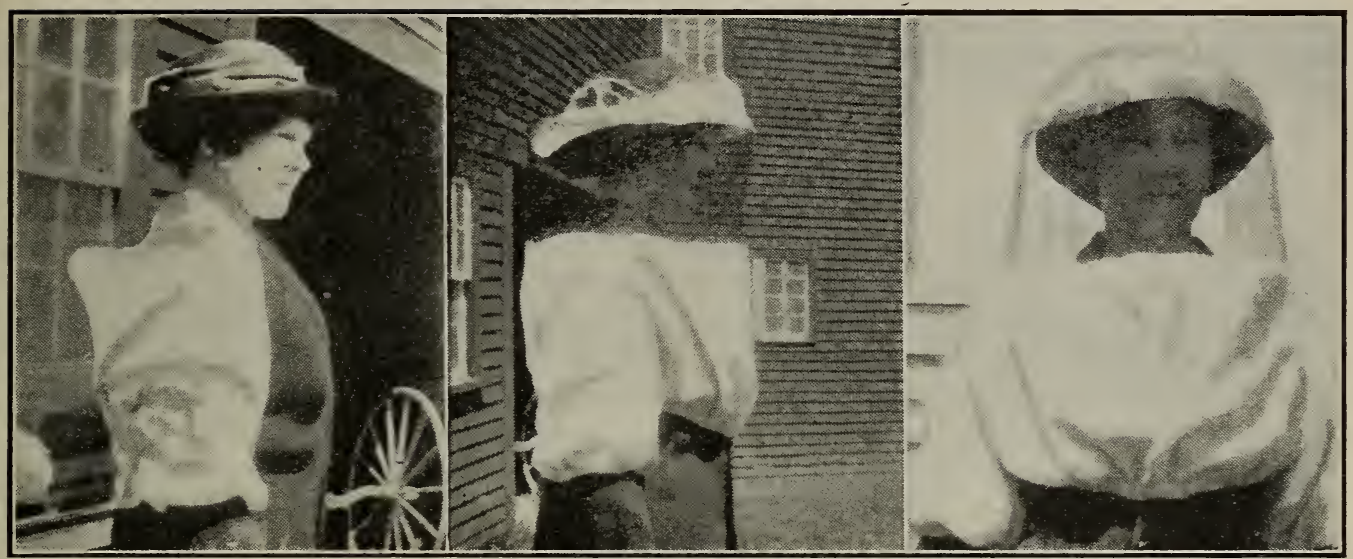

The reil worn by Emma Strout is something on the same order.

at the lower edge, which is drawn and tied. When not desired to use the veil it is pulled down from the hat as shown in the second illustration. The veil worn by Emma Strout is something on the same order.

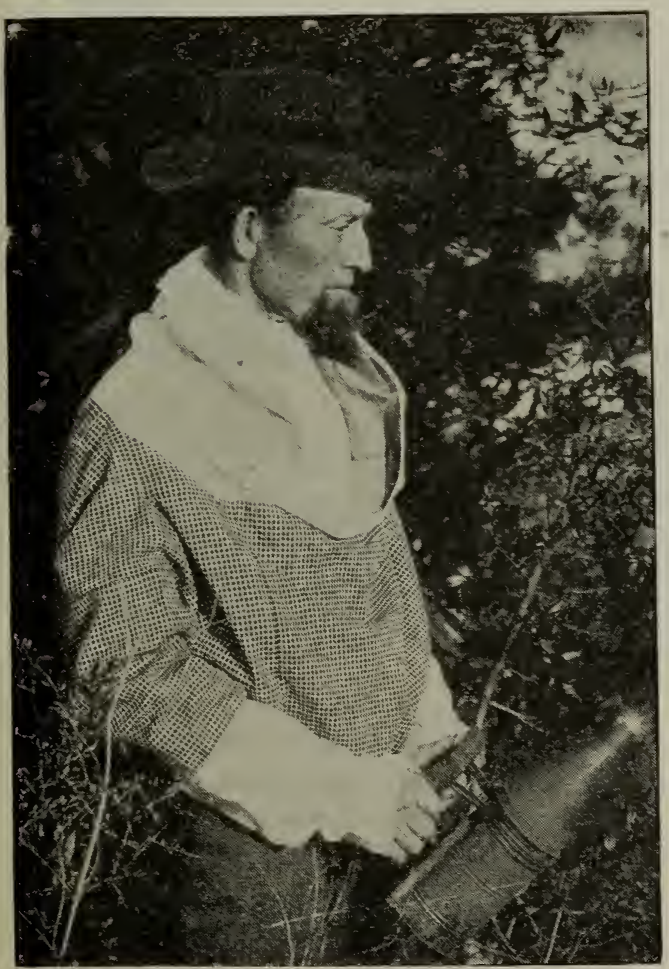

The Coggshall reil when not in use. but ready for emergency.

As for trousers, one can get a pair of overalls at any clothing-store, and it is suggested that he get outfits such as are used by machinists and engineers. These have numerous handy pockets, large and small, in which various tools may be placed.
Bicycle pants-guards can be used to very good advantage during extracting and all other times, when one is shaking or brushing bees off combs. The bottoms of the trousers should be neatly folded around the ankles, and the guards slipped on to hold the folds in place.

A woman should ordinarily work in short skirts or walking costume. Such a dress with hightopped shoes makes a very neat and becoming outfit. Some women go so far as to dress in what are called "divided skirts," the lower end of

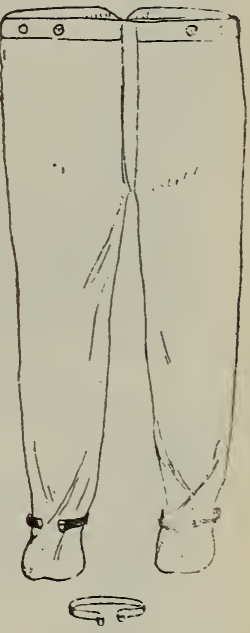
which are fastened below the knee; and a few go even a little further and wear regular man's attire, and one can scarcely blame them for it.

VENTILATION.-Bees that are outdoors in their regular hives generally receive at the entrance all the ventilation they require. There should be, except in very hot weather, no other openings. Occasionally hives are so poorly made that they will have gaping cracks; but these, unless too large, will be closed up with bee-glue-usually along toward fall; and some strains of bees, notably the Caucasians, will close them up early in the season. Indeed, they will sometimes obstruct the entrance by means of little chunks of propolis.

In olden times it was customary for the patent-right men to furnish their patrons 
with hives having all kinds of ventilating holes and little trapdoors; but the modern hive, as a rule, has no openings of any sort except at the entrance, which is contracted or enlarged according to the season. In hot weather it will be opened to its maximum, and in cool weather it will be reduced to one-fourth or even less of its largest capacity. See Entrances and Wintering.

During extremely hot weather, especially during swarming time, it is sometimes necessary to provide upward ventilation in addition to that provided at the entrance. a vertical line over the bottom super; and in rare cases it may be necessary to go even further by tipping the cover up in addition. It is much better to provide ventilation in this way for extremely hot weather than to bore holes in the sides or ends of the hives or supers. The amount of ventilation that may be required thru the top of the hive by staggering the supers back and forth will depend on how hot the weather may be at the time, and whether the hive in question is shielded from the sun. So long as the bees cluster out in front, it is an indication

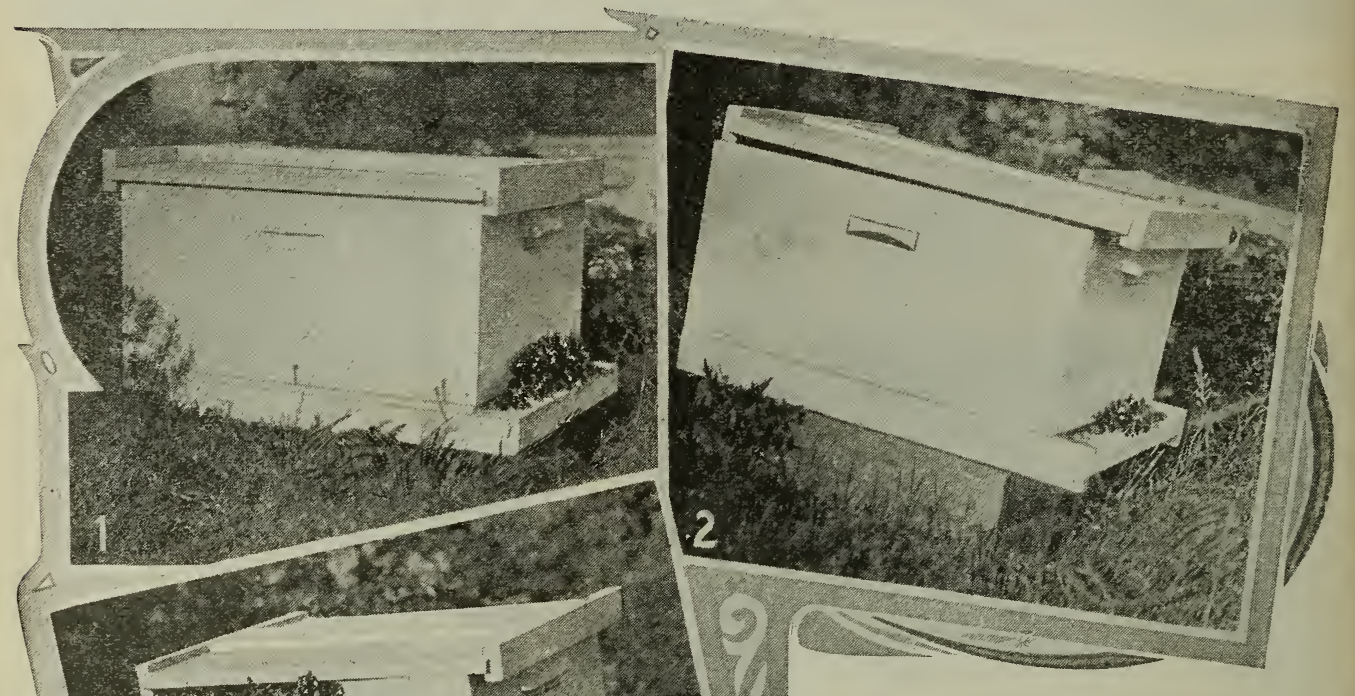

FIG. 1.-Hive with bees clustered in front for want of ventilation. FIG. 2.The same hive after the cover had been tilted forward, and the bees had gone in. FIG. 3.-Another hive where even the back ventilation was insufficient to draw the bees in, for they clustered out at both places. In this case another super should have been given in addition to tilting the cover forward.

The cover may be lifted up in such a way as to leave a crack at the back end. This will allow a current of air to circulate from the top clear down thru the hive. But sometimes loosening the cover is insufficient. It is, therefore, necessary to provide ventilation for one or more supers that may be on the hive at the time. In that case, the second super is shoved forward on the lower one-just enough to leave a crack, front and rear. If that is not enough, the third super is staggered back so as to be in that there is a lack of ventilation. Sometimes a great cluster of bees will be clear over a large entrance, practically closing it up except what little air can filter thru the mass of bees. In cases like this, it is advisable to lift the hive up on four blocks as shown under Swarming, subhead "Control of swarming by means of large entrances." If this does not draw the bees into the hive, additional ventilation should be provided at the top of the super or supers, in the manner already explained. But one should be careful not to overdo this, because combbuilding cannot progress very satisfactorily in supers when chilling blasts go back down 
over the bees, and this is liable to occur at night, even after a hot day.

Under SWARMING it has been shown that ventilation and swarming often stand in the ratio to each other of cause and effect; that is to say, not enough ventilation overheats the brood, causes the bees to cluster in front, induces loafing, cell-building, and finally swarming. Time and time again this loafing on the part of a big bunch of bees in front has been stopped by providing ventilation. When a colony in the height of the season can earn anywhere from five to ten dollars, it is folly to compel the poor bees to loaf and cut down their earning capacity simply because of a lack of means to keep their domicil cool enough so that they can go inside and go to work.

\section{VENTILATION DURING THE WINTER.}

Under Wintering, also under ENTRANCES, it is explained that bees outdoors on their summer stands do not require nearly the amount of ventilation that is needed during the summer. Even in cold weather a strong colony should have a larger entrance than one for a weak one. See EnTtrances.

When bees are wintered in a cellar it is highly important that the atmosphere be dry, and that there be means provided for supplying with fresh air the room where the bees are kept. Insufficient ventilation causes uneasiness; uneasiness induces overfeeding, and overfeeding brings on dysentery. See DYSEnTERY. It is important, therefore, that the cellar have plenty of ventilation during the entire period of confinement, and more air toward spring than late in the fall.

Authorities disagree somewhat as to the size of entrance that bees require while in the cellar; but the author's experience indicates that the same size of entrance that is used during moderate summer weather is better than a large one. When we gave a large amount of bottom ventilation in the cellar we had some severe winter losses, and lhat was the experience of the late W. Z. Hutchinson. Dr. C. C. Miller favors a large entrance.

In severely cold weather it is highly important to see that the entrances of the hives outdoors are not clnsed up with wet snow or ice. A closed entrance is almost sure to be fatal to the colony sooner or later.
It sometimes happens that dead bees clog up the entrance, and the colony dies simply because a few of its dead shut off its means of ventilation.

\section{SMOTHERING BEES BY CLOSING THE ENTRANCE.}

Altho bees manage to get along with even a very small entrance, one should be on the guard against closing it entirely, in warm weather, even for only a few minutes. Many are the reports we got almost every season, of bees destroyed by simply closing their entrance while undertalking to stop swarming for a few minutes, until some other colony can receive attention. See Swarding and Entrances.

When bees have the swarming ferer, as a general thing they are gorged with honey and in a feverish state. They are like a man who has been taking violent exercise after a hearty meal, and require more than an ordinary amount of air. Their breathingtubes are in different parts of the body, under the wings and on each side of the abdomen (see ANatomy of the BeE); hence as soon as the entrance is clcsed, and they crowd about it, the heat of so many becomes suffocating in a very few minutes; the honey is involuntarily discharged, wetting themselves and their companions, thus most effectually closing their breathing-tubes in a way that causes death to ensue very quickly. Heavy swarms have been known to be killed in the short space of fifteen minutes, when the hive was thus closed on them. The heat generated by the smothering mass often becomes great enough to melt down the combs, enveloping bees, brood, honey, and all, in a mass almost scalding hot. Bees are sometimes smothered in this way, in extremely hot weather, even when they have very large openings covered with wire cloth. In fact, bees shipped by railroad, in July and Angust, have been known to be smothered, when the whole top of the hive was covered with wire cloth.

\section{HOW BEES DO THEIR OTN VENTILATING.}

If one will watch a colony of bees during a warm day, he will see rows of bees standing around the entrance, and far inside of the hive, with their heads pointing one way, all making their wings go in a peculiar manner, much as they do in flying; but in- 
stead of propelling their bodies along, they propel the air behind them, and a pretty strong "blow" they get up too, as may be felt by holding the hand near them. If the air is very hot and close inside the hive, so that there is danger of the combs melting down, they manage to send cooling currents clear to the furthest parts of the hive.

The most prosperous colony we ever owned was one that was so completely enveloped in chaff that they sent a stream of warm air out of their hive during frosty nights in March strong enough to melt the frost about one side of the entrance. Of course a stream of fresh air went in at the opposite side as fast as the warm air went out.

For further particulars on the subject of ventilation, see ENTrances, Comb Honex, Swarming, and Wintering.

VINEGAR.-This is one of the legitimate products of honey; and when properly made it has a quality quite superior to any other vinegar, especially for making pickles. It will not lose its strength like most other vinegars; and one can have light or dark vinegar by taking light or dark honey -at least so says R. R. Murphy, of Fulton, Ill., who has made and sold large quantities of honey vinegar.

Mr. G. W. Gates, of Bartlett, Tenn., says: "We have used no other vinegar for two years; and nearly every one who tastes our pickles asks my wife for her recipe for making them. When told that we use nothing but honey vinegar, they are surprised."

Mr. E. France, of Platteville, Wis., asked the wife of one of the merchants why she always bought his vinegar; and her reply was, that the stuff from the store always ate up her pickles; but that, when she used honey vinegar, her picklez kept, and had a beautiful fine flavor.
Notwithstanding the fact that vinegar from honey is the finest in the world, the very low price of the ordinary product from cider makes it impossible to get a very high price for honey vinegar. The length of time it takes to make it, and the quantity of honey required, would make the vinegar too high-priced to compcte with the other kinds on the market. But every beekeeper has some poorer grades of honey, some from broken combs, washings from honey-barrels, honey-cans, etc., that will be practically wasted unless made into vinegar. Mr. France always used the washings of his honey-barrels; and this sweetened water he converted into vinegar. When one can utilize honey that would practically all go to waste, and convert it into cash, he is just that much ahead.

\section{HONEY VINEGAR, HOW TO MAKE.}

The honey-water and honey-washings should be put into a barrel with the top head taken out. To determine whether the water is sweet enough, a fresh egg should be dropped in. If the egg will just float so as to leave a spot above the liquid, about as big as a ten-cent piece, then it is "all right," according to Mr. E. France.

Another beekeeper, Mr. G. D. Black, of Brandon, Ia., uses an ordinary hydrometer, which he says he bought for 35 cents. When this sinks into the liquid so the scale registers at 11 , it is of the right consistency. The top of the barrel is covered with cheesecloth, and the whole allowed to stand in a warm place where it can work and sour. In winter it should be put into the cellar. It will take anywhere from one to two years to make good vinegar. But the process can be greatly hurried by putting in " mother" from another vinegar-barrel.

VIRGIN QUEENS.-See QUEENS. 


\section{W}

WATER FOR BEES.-Like all other live stock, bees need water. The amount required depends largely on how much brood-rearing is going on, and whether nectar is coming in to a considerable extent from the fields. Brood requires a great deal of water as well as pollen and honey. On the other hand, when new honey is coming in but little water is needed.

About the time the bees are breeding heavily they will be found around wateringplaces, ponds, creeks, and rivers, especially during a dearth of nectar. They seem to prefer to get water where they can take a

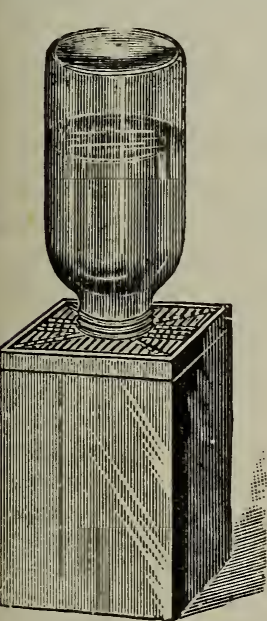
big drink without any danger of being subm e r g e d. Sometimes when creeks, ponds, and rivers are at some distance from the apiary bees may be somewhat of a nuisance around nearby watering-troughs and outside pumps. Hence it is important for the beekeeper to have a watering-font in the beeyard itself. A tub of water with chips or corncobs floating on the surface, a Mason jar filled with water inverted over a small plate, or, better, a crock placed over a dinner-plate, will furnish bees water on the atmospheric principle all day or several days, in fact. A better arrangement is a wooden block or board with transverse sawcuts as shown in the illustration. A large glass jar filled with water and inverted over one of these boards will keep the saw-cuts filled with water, where the bees can get all they require without even wetting their feet. If one of these is furnished in the apiary the bees will not be likely to bother the neighbors. A closed vessel containing water is much better than a tub or pan of water, as the water cannot become stale and bad. Sometimes when one of these special fonts is first set out the bees will pay no attention to it, especially after they have been in the habit of visiting the neighbors' pumps and watering-troughs. They can as a rule be started by sweetening the water or by adding a little salt, for bees are fond of salt also. When bees are compelled to go a distance for water they wear themselves out unnecessarily, and, during chilly weather in the spring, they never get back.

When bees are in the fields, bringing in new honey, they require less water than at times when no honey is coming in. It is probable that the excess of water removed during the ripening process, as explained under Ventilation, supplies the bees with the proper amount of moisture.

Bees also need some water during midwinter; but usually the moisture produced by condensation from the breathing of the bees will be sufficient. It was once argued that they should be supplied with water while in the cellar. If a wet sponge is placed on a cluster they will take up the water quite rapidly. This would seem to prove that they should have an artificial supply; but general practice has shown that no special provision need be made. It would be impracticable to give bees water when wintered outdoors; and it would hardly be necessary, because if one will examine down into a brood-nest during winter he will see considerable moisture around the inside of the hive and on the under side of the cover.

In bringing carloads of bees from south to north and from north to south, it will be found impracticable to make these long trips without a barrel of water in the car. If the weather is hot and sultry, bees, on account of their excitement, often require a large amount of water. But this water must be supplied at intervals of every few hours or many bees will die. In some shipments of bees from south to north during hot or warm weather, a carload of bees has been known to take up seven or eight barrels of water. The water allays thirst and cools the cluster by evaporation. 
While bees seem to gather water at times, they also appear to have a delicate apparatus of some sort for extracting water from nectar, and of discharging it or a part of it in flight. When they are fed outdoors with sweetened water, as described under OuTDOOR FEeding, they will immediately, on taking flight, discharge a fine spray of water. If one will station himself between the feeders and the sunlight he will be able to perceive these bees, on rising from the feeder, discharging this thin fine spray.

That it is pure water and not sugar can be proven by tasting it. That bees also discharge water when gathering thin nectar from the fields was proven by A. I. Root many years ago. When bees are gathering a large quantity of nectar from a single blossom they will, on rising from the plant, discharge the excess in the form of a thin spray. Enough of this spray fell on some dinner-plates to be distinctly perceptible, but the taste showed nothing but water.

WAX.-This is a term that is applied to a large class of substances very much resembling one another in external characteristics, but quite unlike chemically. The wax of commerce may be divided into four general groups: Beeswax, familiar to us all; mineral wax, or by-products from petroleum; wax from plants, and wax from insects other than bees. But the first two are by far the most important commercially, in this country. Of the mineral waxes the most common are paraffine and ceresin. Beeswax is the most valuable, and has a specific gravity of between .960 and .972 , and melting-point of between 143 and 145 degrees $\mathrm{F}$. The mineral waxes vary so much in hardness, melting - point, and specific gravity, that it would be useless to name exact figures. As a rule, however, the fusing-point of paraffine is much below that of beeswax, while that of ceresin may be either above or below, or practically the same. In general the specific gravity of both commercial paraffine and ceresin is below that of beeswax; which fact renders it an easy matter to detect adulteration of beeswax with either paraffine or ceresin, by a method that will be explained further on, under the head of Adulteration of BeEswax.

There are also known to commerce Japanese wax and China wax, both of which may or may not be the product of insects or plants. As they are so much more expensive than either paraffine or ceresin, little fear need be entertained of their use as adulterants of beeswax.

\section{BEESWAX.}

For the bees and their keeper, no product has ever been discovered that can take the place of that which the bees themselves furnish. Real beeswax retains ductility and tenacity under greater ranges of temperature than any mineral, plant, or insect wax. Combs made from foundation containing 25 to 50 per cent of adulteration of paraffine or ceresin are very liable to melt down in the hive in hot weather. Paraffine is ductile enough to make beautiful foundalion, but does not stand the heat of the hive. Ceresin, on the other hand, while more closely resembling genuine beeswax in point of specific gravity and fusibility, is too tough and brittle, under some conditions, for bees to work. Work it? Yes, they will, and construct combs; and in Germany considerable ceresin foundation has been and perhaps is being sold; but our experience leads us to believe that it is poor economy, and will lead the beekeeper or the poor bees to grief sooner or later. Practically, then, genuine beeswax is the only product that ought to go into foundation; and it is the only article that foundation-makers in this country use.

\section{BEESWAX IN THE ARTS.}

Under the action of the United States pure-food law that went in effect June 30, 1906, beeswax has had much larger use than ever. The new food law will have no effect one way or the other on the use of paraffine, ceresin, and the like in any compound or mixture that does not belong either to the food or drug classes. Electrotypers can use a substitute for taking impressions, altho the great majority, we understand, prefer pure beeswax, even at a higher price. Natural-wood finishers can still use paraffine and ceresin; but most of them assert that there is nothing to compare for that purpose with pure beeswax. The first mentioned gives a greasy, smeary finish, while the product from the hive yields a highly polished surface-one that stands wear as nothing else will; a finish cheaper than hard oil-not by the gallon, but to apply. 
A very satisfactory floor finish can be made by melting a pound of beeswax, and while it is cooling; stirring into it some turpentine. An exact proportion of the two ingredients is not necessary-in fact some workmen prefer the paste thick, others want it thin. When cool, if the mixture is too thick it is a simple matter to thin it down by working in more turpentine.

The Roman Catholic Church uses large quantities of beeswax in the form of candles. She does not tolerate paraffine, ceresin, nor any of the mineral waxes, all of which give off an offensive greasy odor while burning, whereas candles made of beeswax leave a delightful perfume. Moreover, the burning of mineral wax causes a deposit that injures pictures, while beeswax mellows and preserves them.

Certain grades of blacking, harness oils, and lubricants require pure beeswax in their manufacture. A blacking containing beeswax will withstand more dampness than that made of any other substance.

The electrical-supply business is a consumer of our product. The windings of the wire are soaked in paraffine or beeswaxpreferably the latter, because it seems less affected by extremes of heat and by moisture. Pattern-makers also use beeswax. The profession of dentistry consumes large quantities of pure wax every year to take impressions in the mouth. Last, but not least, the beekeeper is a large consumer as well as a producer of wax.

In all the arts, paraffine, ceresin, and certain other mineral waxes can be used; none of them have all the desirable qualities furnished by the product from the hive.

\section{HOW THE BEES "MAKE" WAX.}

If the bees are watched closely during the height of the honey harvest, or if at other times a colony of bees is fed heavily on sugar syrup for three days during warm weather, there will be found toward the end of the second or third day little pearly dises of wax somewhat resembling fish scales protruding from between the rings on the under side of the body of the bee. These when examined with a magnifier reveal little wax scales of rare beauty. Sometimes these scales come so fast that they fall on the bottom-board and may be scraped up in considerable quantities seeming for some reason not to have been want- ed. During the season for the natural secretion of wax where a colony has plenty of room, wax scales are seldom wasted in this way. At swarming time there seem to be an unusual number of bees provided with wax scales, for when the bees remain clustered on a limb for only a few minutes bits of wax are attached as if they were going to start combs.

The way the bees remove these wax scales from their bodies and construct them into comb is not so easily seen. There were many wild guesses as to how this was done. The so-called "wax-pinchers"* on the hind legs were supposed to play an important part. The matter was definitely cleared up by Sladen and Casteel. In circular No. 161 Dr. D. B. Casteel of the Bureau of Entomology, Washington, D. C., made the whole process plain.

Briefly stated, it is this: The wax scales are scraped off by one of the large joints, or planta, of one hind leg, the spines of the planta piercing or catching into the scale; then the leg, by a peculiar maneuvering, is moved up to where the fore legs may grasp the scale. At this point of proceedings the scale is manipulated or masticated in the mandibles, when it is applied to the comb. During the process, the bee stands on three legs (the two middle legs on either side, and one hind leg not in action), while the other hind leg and the two fore legs; in connection with the mandibles, perform the manipulation. Casteel says that the so-called "wax-pinchers" in the hind legs have nothing to do with the manipulation of wax, but are designed for another purpose, and that each individual bee removes its own wax scale.

It has been popularly supposed that the bees remove the scales from each other; but Casteel shows that this is not the case. The scales are sometimes found scattered thruout the hive and on the bottom-board as already stated. In some instances they show the marks of the spines of the planta of the hind legs. In others they were probably dropped accidentally by the bees in that wonderful sleight-of-hand performance by which they transfer the scale from one portion of the body to the other. In still other cases the scales show no markings

\footnotetext{
* The real purpose of these is explained under Pollen, subhead "Behavior of Bees in Collecting
} 
whatever, and the presumption is that they simply fell off the bees when they reached a certain stage of development.

Dr. Casteel also confirms the observation of Dreyling, that there are certain ages and certain seasons when the bees will develop these wax scales more than others. From this it would appear that there are times when the bees cannot construct combs to any great extent, even tho they are liberally fed. In a practical way it has been found that sometimes even when the bees are fed they will not build combs; and the probabilities are that they simply can not, because the colony is made up of bees too young, too old, or both. Usually the condition of a honey-flow can be supplied artificially by feeding.

\section{WAX-RENDERING.}

SOLAR WAX-EXTRACTORS.

It is said the sun wax-extractor was originated in California about the year 1862 . At that time it was used for extracting honey from the combs. The honey-extractor of to-day being then unknown, it is related that the early Californians extracted their honey largely by means of the sun's heat. They simply placed their cards of comb in

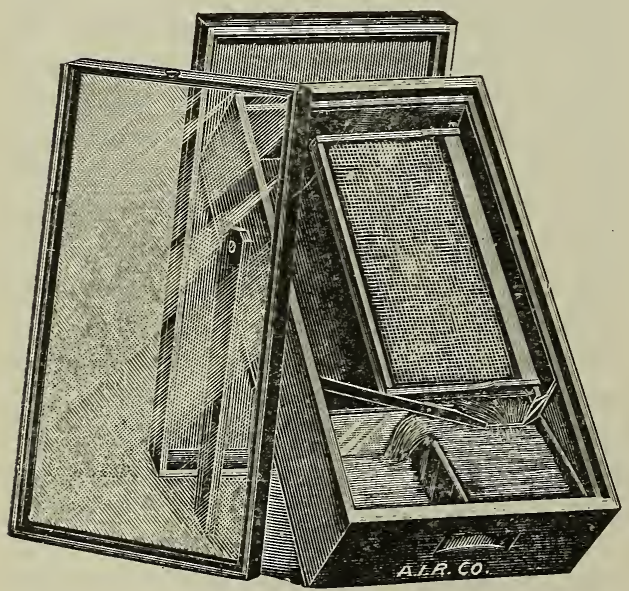

Doolittle solar wax-extractor.

large trays covered with glass, where old Sol, by the mere beaming of his countenance, did the work. As the combs melted, the honey and wax ran together into a receptacle. In the evening the wax, by reason of its lighter weight, floated on the surface of the honey, and hardened. The
Californians thus practically accomplished two objects at one and the same operation -extracting both honey and wax-the latter already in marketable shape. As to the quality of the honey so separated from the combs, it is much better than one would suppose, but inferior to the ordinary extracted. Recently the use of the solar extractor has been restricted to the melting of wax.

To a casual observer it seems almost incredible that wax can be melted by the aid of the sun. It is well known to the beekeeper that little scraps of wax in summer weather will melt on a hive-cover exposed to the direct rays of the sun. If a shallow box is covered with a sheet of glass, and a piece of comb is placed therein, it will utilize a much larger percentage of heat. Still further, by collecting more rays of the sun, and casting them into the box by means of a reflector (a sheet of tin, for example), a correspondingly greater increase of temperature may be expected. The reflector, however, is unnecessary, as sufficient heat is obtained without it.

\section{THE DOOLITTLE SOLAR WAX-EXTRACTOR.}

This machine has had a very large sale. Its general design is after a pattern made and used by the well-known beekeeper $G$. M. Doolittle. The only objection to it is that it is rather small, but just the right size to take pieces of burr-comb and other bits of wax that accumulate in every-day working of the apiary. These accumulations can be thrown into the machine whenever one happens to pass by it; and instead of having a lot of little scraps scattered here and there thru the apiary, to be melted up at some future time, they may be converted at once into a marketable product.

These small machires are not suitable for melting up combs. For that, something as large as the Boardman should be used.

This is built very much on the same general plan as the one just described, but is larger. The rockers, or runners, affor ${ }^{r}$ facility for transportation, and also for tilting the machine at the proper angle to the sun. Common greenhouse sash may be used; but a large glass, say $30 \times 60$, is better for the reason that the sash cut off a good deal of the sun's rays, making shade-lines along which the wax fails to melt. The size of glass that one is able to buy will, of 
course, regulate the size of the extractor;* the depth of the box or tray may be anywhere from 6 to 8 inches, the bottom being made of cheap lumber. This box or tray

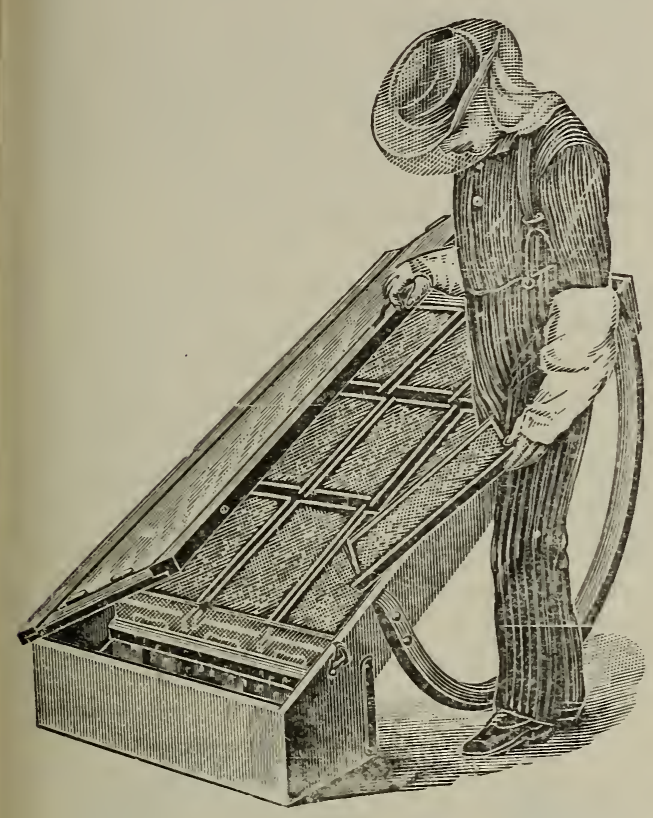

Boardman solar wax-extractor.

should be lined with common black sheet iron. Tin should not be used, because it reflects back too much of the sun's light. The whole tray, including the frame for the glass, should be painted black; and the glass, while the machine is in use, kept scrupulously clean.

SOLAR WAX-EXTRACTORS NOT SUITABLE FOR OLD COMBS.

Solar wax-ertractors have their use to handle new combs, particles of fresh wax, pieces of burr-combs, and the like, and can be used to clarify and bleach to a certain extent wax already caked, but are not adapted to the handling of old black combs that have several generations of cocoons in them. Large sun extractors like the Boardman will get the bulk of the wax out of such combs, but they do not get all of it. If sun heat is used at all for melting, the slumgum (or refuse) should be further treater.

\footnotetext{
* If the large glass can not be had, better purchase three sheets of $20 \times 30$, and put them in the frame crosswise-the sheets butting tight up against each other.
}

RENDERING WAX FROM OLD COMBS.

For new combs the problem of rendering wax is a comparatively simple one, since the operation consists simply in melting them in hot water and dipping the wax of the top. This is true also of cappings where the total amount of refuse or impurities is so small that there is practically no difficulty in getting all the wax. Here a solar wax-extractor is satisfactory, altho not to be depended upon for speed nor great capacity unless very large, which would be expensive.

When old comb is to be rendered, on the other hand, the problem becomes much more difficult, as the many layers of cocoons found in the cells used for brood-rearing confine the $\max$ and make it hard to remove. It can be readily seen that, if old

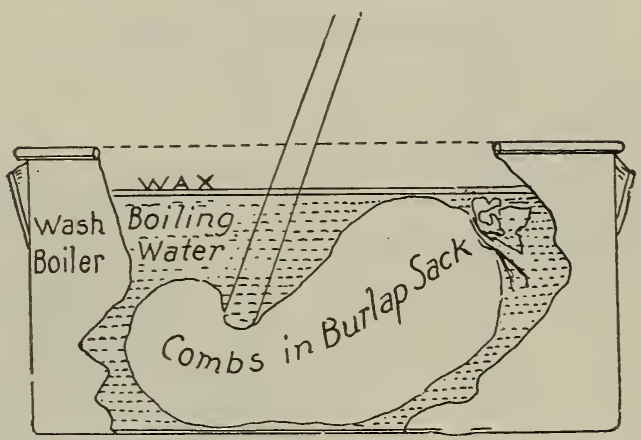

FIG. 2.-A very crude and wasteful method of rendering.

comb is simply melted in hot water or steam, these cocoons will become saturated with wax, making the loss very great. The following discussion, therefore, will have to do especially with the difficulties encountered in rendering wax from old combs.

There are many different methods practiced by beekeepers all over the world to obtain the wax from old brood-combs; and it is needless to say that, in many of them, the loss is considerable. One of the crudest methods is to throw the combs into a large iron kettle of water and then build a fire and boil the contents for several hours, skimming the wax off the top of the water meanwhile. More comb is added from time to time, and the process is continued perhaps all day. Finally a piece of wire screen is weighted down on the refuse to keep it out of the way and facilitate dipping the wax. Careful experiments have shown that this method wastes from 25 to 
40 per cent of the total amount of wax, while a great deal of time is required to clean and refine what little wax is secured.

Another plan which has been advocated to some extent is that shown in Fig. 2. A sack of comb is held under the surface of the water, and agitated or punched with a stick for a long time until much of the wax is released and floats to the surface, where it may be dipped. off. This method results in somewhat cleaner wax; but there is apt to be waste nearly equal to the plan before mentioned.

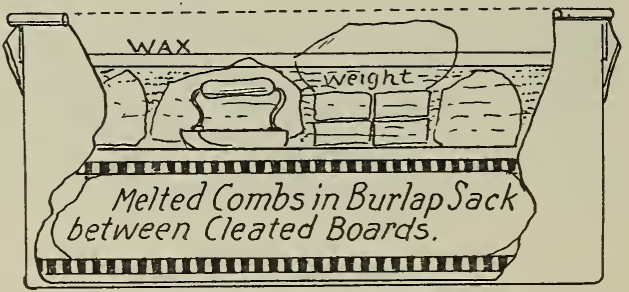

FIG. 3.-A popular but wasteful and slow method of obtaining wax.

There is another method that is used more, perhaps, than the two which have just been described. It is a somewhat better plan, for the amount of waste is not so great. It is shown in Fig. 3. In order to get the best results the weights should be so arranged that they can be lifted up a few inches in order to give the refuse in the sack a chance to become saturated again with hot water. The weights should then be lowered, and this process kept up for several hours, the water meanwhile boiling vigorously. The wax should be dipped off almost as fast as it rises to the surface.

In 1904 Mr. T. J. Pennick, of Williston, Tenn., suggested the use of centrifugal force applied to hot slumgum just taken out of boiling water. It was his opinion that the free wax, when hot, would by this means readily separate from the solid matter in a very short time. Extensive experiments have developed the fact that there would be a great deal of wax which would not escape from the refuse, no matter how fast it might be whirled in an extractor, showing that even great centrifugal force could not separate the wax from the refuse. Wax nearest the outside might be thrown out; but that nearest the center would be held back and not escape.

* It released all the wax, and lots of dirt and coloring-matter..-A. C. M.
Mr. A. C. Miller, of Providence, R. I., some time ago devised an agitator* and applied it to the rendering of wax. The old combs in such an agitator are thoroly stirred and rubbed under hot water so that the wax is liberated, and rises to the surface, where it is drawn off thru a spout. As will be seen, this is somewhat similar to the plan shown in Fig. 2, before mentioned, altho it would be of course a great improvement on that very crude method.

From experiments and from reports received from hundreds of beekeepers, it would seem as tho the wax-press were by all means the most satisfactory wax-extractor yet devised. It is doubtful whether anything but pressure combined with heat can remove all of the wax. In saying this, we realize that there will probably never be a wax-extractor of any kind that will economically remove the last particle of wax; but if the amount of waste can be reduced to less than one per cent, the loss is an item that can be neglected.

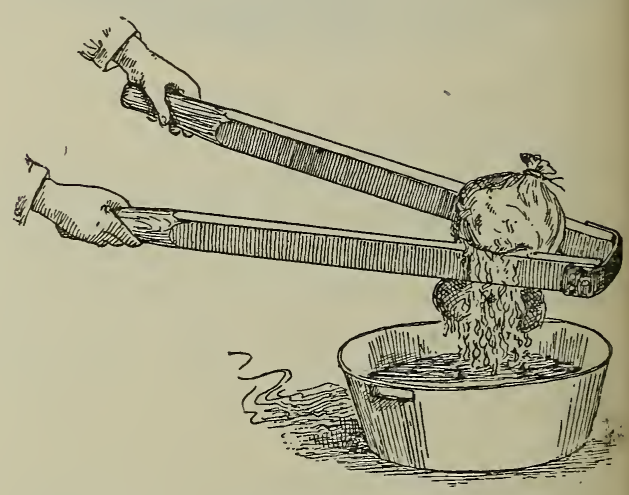

FIG. 4.-An unhandy and unsatisfactory plan.

Before entering the discussion of waxpresses it may be well to add a word of caution to beekeepers who are sure that the particular method they are using enables them to obtain all the wax or practically all. If the refuse, when they are done, has not been put thru a well-constructed press there will be no way of determining the amount of waste, for it might contain as much as 20 per cent of wax and still look perfectly clean and show no traces of it when examined. On a small scale it is possible to get some idea of the amount of wax left in refuse by the following very simple plan:

Thoroly heat in boiling water the refuse to be tested, then allow it to cool slightly; 
seize a large handful, and squeeze it as hard as possible in the fingers. If fine lines of wax appear in the creases between the fingers a good deal of wax is left-perhaps from five to ten per cent or more, depending upon the amount of wax shown: The hand will not be burned in the very short time necessary to make this test. But, as before stated-the most conclusive method of determining the waste is to run the refuse thru a well-constructed press.

\section{HOT-WATER WAX-PRESSES.}

In these presses the pressure may be continued without the least danger of chilling the combs. This method has also a decided advantage in that the screw can be raised after having been turned down, and the cheese allowed to become saturated
The quality of wax from hot-water presses is usually not very good, because of the long-continued high temperature. In the Hershiser press more hot water is introduced at short intervals into the lower part, causing the melted wax to overflow thru the outlet at the top. In this way the wax is not left for any great length of time on the boiling water, so that the color is not darkened.

Perhaps one objection to hot-water presses is the cost of the outfit; but for extensive beekeepers they are the most practical, as somewhat cleaner work can be done, owing to the long-continued intermittent pressure on the refuse surrounded by hot water. In other words, old combs rendered in a hotwater press may be pressed as many as fifteen or twenty times, so that it is possible

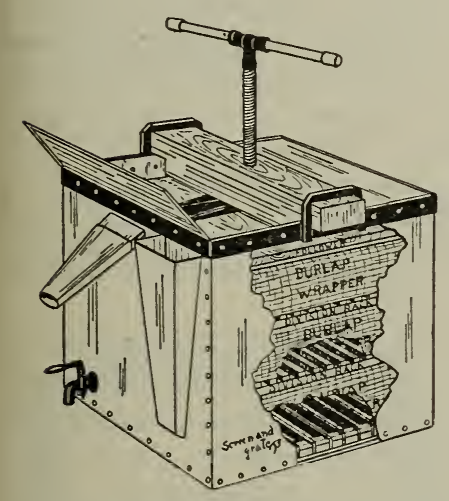

FIG. 5.-Hershiser hot-water wax-press.

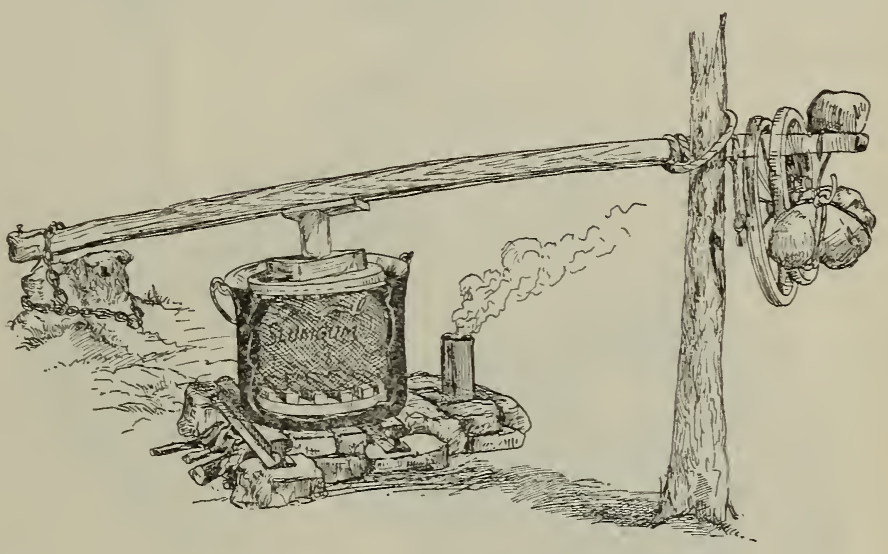

FIG. 6.-Use of the lever in pressing wax. again with boiling water. This is quite an advantage. The screw may then be lowered, and this hot water forced out of the refuse, carrying with it more of the wax. This operation must be repeated as often as found necessary by experience. It is thus seen that there is no disagreeable handling of the refuse until all the wax is out. Furthermore, the work, if necessary, may be confined to the one tank.

Mr. Orel L. Hershiser, of Buffalo, N. Y., devised the hot-water press shown in Fig. 5. The capacity of this is large, so that it is possible to obtain as much as 75 pounds of wax in one day over a -common stove. One great objection to hot-water presses heretofore has been their relatively small eapacity of wax per day. Mr. Hershiser, by making the press very large, overcomes this difficulty. to reduce the final loss to only a fraction of one per cent.

If one wishes to try the hot-water method by using an outfit constructed at home he can follow the plan shown in Fig. 6. An ordinary kettle may be used, altho it would be advisable to have one with a flat bottom. As it would be rather difficult to construct a cross-beam over the kettle rigid enough to stand the pressure exerted by a screw, a lever may be used as shown, tho some means will have to be employed to keep it from falling over sidewise, such as a loop around a tree or post. In using a lever it is important to have it so adjusted that the pressure will be uniform and directly downward. Any pressure exerted from a point not directly over the kettle will result in pressing the refuse to one side, so that the "cheese" will be very thin on one edge and 
very thick on the other. If this were the case there would, of course, be too much wax left in the thick portion. To get the best results the cheese should not be over an inch or an inch and a half thick after pressing.

Cleaner work can be done by an intermittent than by continuous steady pressure; and so, whether using a lever or screw, it is well to relieve the pressure about every ten minutes, allowing the cheese two or three minutes in which to become thoroly saturated again with boiling water. Pressure should be applied slowly at first in order to avoid bursting the burlap.

With the outdoor kettle plan the wax will be discolored on account of the long-continued heat unless it is dipped off the surface of the water almost as fast as it rises. About three hours of intermittent pressure for one batch of combs in a kettle will render out the wax.

\section{STEAM-PRESSES.}

Methods of rendering wax, embodying the principle of applying great pressure to combs surrounded by steam, are quite old,

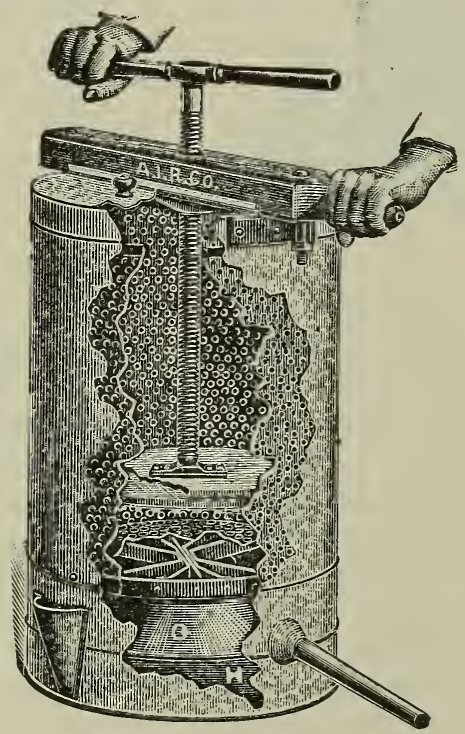

FIG. 7.-German steam wax-press.

both in this country and in Germany, where they originated. In many ways steampresses have advantages over other methods; but the quality of wax is usually not so good, because of the high temperature to which the comparatively thin surfaces of melted wax are subjected; altho the wax, as it leaves the refuse, falls down out of the way so that the work can be much more conveniently carried on, since there is no great depth of water in the way.

A steam-press of popular design is shown in Fig. 7. Steam is generated under the false bottom $\mathrm{G}$, of the compartment $\mathrm{H}$, and, passing upward thru an opening in the center of the false bottom, surrounds the combs beneath the plunger in the perforated metal basket. As the wax falling from the refuse cannot get into the water on account of the false bottom, it passes out of the tube shown.

Steam-presses are very convenient as uncapping-cans; for when the perforated metal basket is full of cappings the crossarm can be placed in position, the screw run down, and practically all honey forced out. Then steam may be generated, and the wax melted into marketable shape without any second handling and with little extra trouble; or the "cheese" of cappings, pressed nearly dry of honey, may be stored away to be rendered into wax at a more convenient time later.

These presses are also very useful in pressing honey from broken combs, unfinished sections, etc., and rendering the pressed comb into wax.

Mr. Edward G. Brown, of Sargeant Bluff, Iowa, has described an excellent plan for rendering wax on a large scale, making use of an open press heated with a steam-jet. Where one has access to steam this is a very practical method. His plan in full is as follows :

The wax-rendering apparatus which I use is somewhat beyond the reach of many beekeepers; but it gets the wax, and I think a little nearer all of it, than most of the various outfits in use. I will give the figures of the wax rendered, and later describe the apparatus.

The best results which we have secured were from a lot of combs, many of which were 25 years old. There were 400 of these combs in the lot, and we obtained $164 \mathrm{lbs}$. of wax, or a little over $4 \mathrm{lbs}$. of wax to every 10 combs. There were two working at the job, and the total time for rendering, including firing up the boiler, etc., was a little less than five hours. We have made a few full-day runs on combs varying in age from one to twenty-five years, and the results average about 250 to $375 \mathrm{lbs}$. of beeswax to the thousand combs. In a day we can usually render from 800 to 1000 combs, the number depending, of course, upon the condition of the combs, etc. 
When I buy old combs I usually figure on about $\because 1-2$ lbs. of wax to the hive of ten combs, Langstroth size.

In the last two years we have rendered something like 8000 or 9000 combs on account of foul brood, and I believe that this is the only way to eradicate the disease completely from a yard when it once gets a start. There is just one other way; and that is, to build a bonfire and burn up all the supplies, etc., in connection with the yard. Incidentally the latter plan is somewhat expensive, for it leaves the apiarist at the foot of the ladder, ready for a new start.

The figures given above may seem a little large to some; but the apparatus is of fair size, and requires two to work it at full speed, and a part of the time there were three of us. Our work-shop is an old cheesefactory which I also use for storage room; and the heat for the wax-rendering is furnished by a big boiler from which I also get the power for running my buzz-saws, as I make all my own bives and heavier supplies.

The engraving shows the various parts of the tank, which is 2 feet wide, 7 feet long, 16 inches deep. It is divided into tro parts, as

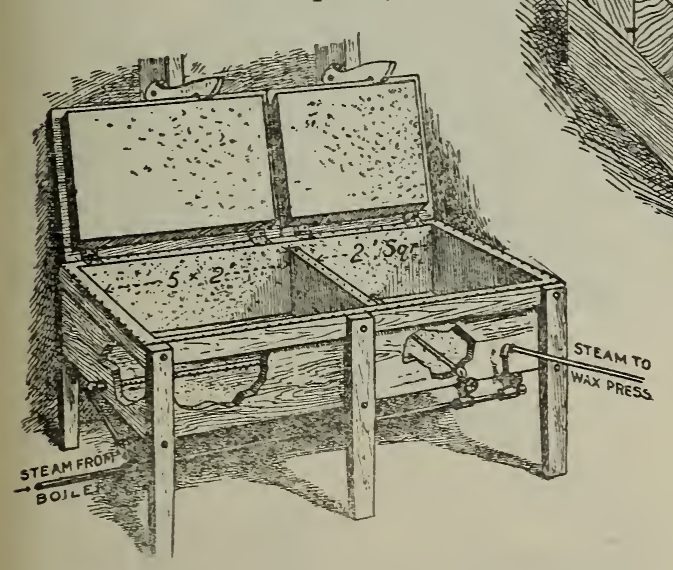

FIG. 8.-Steam-heated vat for melting old combs.

shown, both parts being lined with galvanized iron, and fitted with a cover of the same material. Each part is about half filled with water; and steam for boiling the water is introduced by means of a 3-4-inch pipe, on the under sides of which holes are drilled so that, when the steam is turned on, the contents of the tank are kept in motion. Fach division of the tank has a separate pipe controlled bv a valve so that heat can be applied wher wanted, and as hard as desired. The press as shown in the second engraving is inade from an old cheese-press. The construction is sufficiently clear, hence no detailed description is necessary. A pipe is arranged under the press in such a way that steam may be forced between the cleats of the bottorn of the press, thus keeping the slumgum hot.

Two pieces of heavy burlap are used for holding the slumgum, the outer one being about 30 by 30 inches, and the inner one about 20 by 20 . These are laid over a form

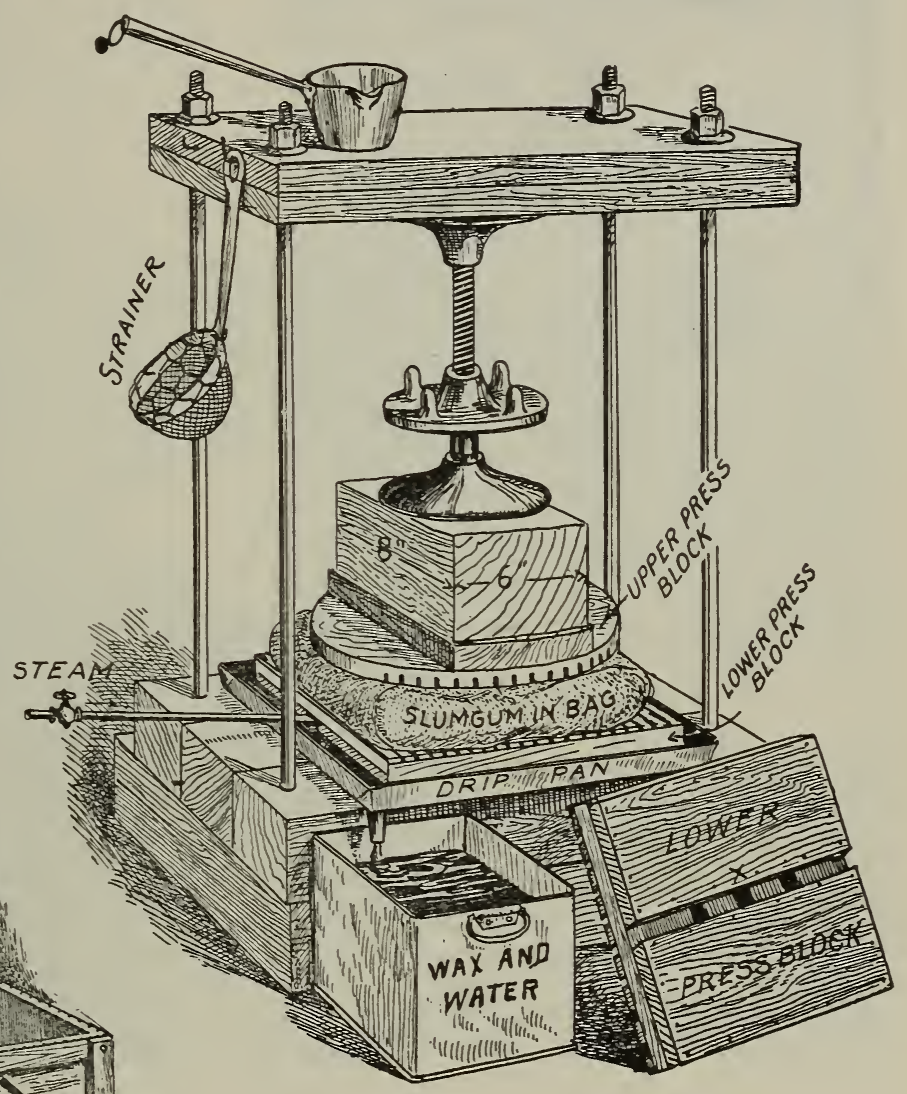

FIG. 9.-Brown's wax-press for wholesale work.

10 inches square and 4 inches deep, which will hold about two gallons of the melted combs. After the comb is dipped in, the sides of the cloths are folded together, then the form is removed, the upper block placed in position, and the pressure applied. Unless these sacks are of extra good quality they do not last longer than eight or nine times, and even the best ones usually burst after fifteen or twenty pressings. A short-handed pitchfork, a wire strainer, and a number of 50-1b. honey-cans with the top cut out, to be used as molds, complete the apparatus.

When rendering, the tanks are filled about half full of water brought to a boil by the steam. The larger compartment is then filled with combs still in the frames. About 50 frames of combs can be put in at once. The cover is then shut down and the steam turned on, From three to five minutes is re. 
quired to do the work, and when the contents are boiling thoroly the cover is raised and the steam partly turned off so that the frames may be swished about in the water and finally picked out with the pitchfork. The steam is then turned off, and the slumgum skimmed by means of the strainer into the small division of the tank, when a new

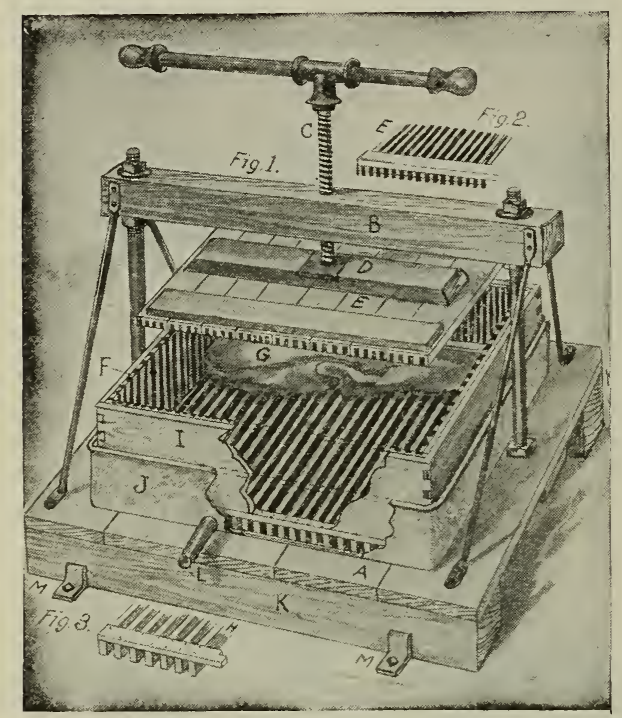

FIG. 10.-The original Hatch-Gemmill wax-press.

batch of frames containing combs may be put into the first or larger compartment.

While one man works at melting up the combs and tending the fire under the boiler, the other is kept busy working the press. The room is so hot and full of steam that the operators can wear but few clothes, and even then it is rather hot work.

The slumgum which is kept boiling is dipped from the small compartment of the tank into the burlap in the press, and the wax is run into square cans or molds. The frames as they come from the tank are cleaner than they could be scraped with a knife, and from experiments which I have made they are entirely free from any disease. We have not been able to make it pay to rerender the refuse from the press.*

\section{UNHEATED PRESSES.}

Mr. C. A. Hatch, of Wisconsin, was probably the first one to make extensive use of this method of wax-rendering. He had used for a short time a press designed by

* It is reasonably certain that a great deal of free wax is left in the slumgum or " cheese" that comes from a steam wax-press. In fact it may be said that no press where steam is the heating agent will get all the wax. When, however, the "cheese" is intermittently squeezed under hot water the free wax is washed out as well as squeezed out. The author unqualifiedly recommends the hot-water press.
W. W. Cary, of Massachusetts, in which the combs were pressed while submerged in hot water; but he believed that he could improve on this plan by applying pressure in a different receptacle without the use of so much hot water. Later Mr. F. A. Gemmill, of Ontario, Canada, also used such a press, which finally came to be known as the Hatch-Gemmill wax-press.

Mr. F. A. Salisbury, is an enthusiastic advocate of the unheated press. The form which he likes best is shown herewith. It will be seen that the loss of heat is prevented by having no circulation of air; hence, since wood is an excellent non-conductor, the combs remain hot for a considerable length of time. The construction is sufficiently clear from the illustration.

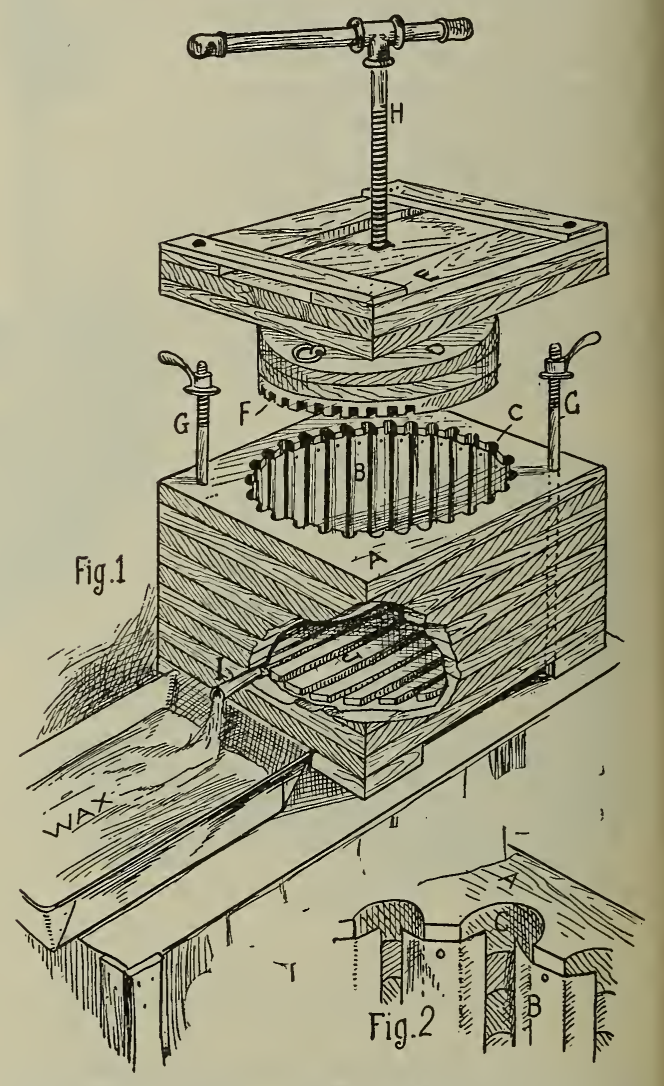

FIG. 11.-Salisbury's press, constructed almost entirely of wood.

The particular form of press preferred by the authors is shown in Fig. 12 . It will be noticed that a round can, constructed of tin, is used instead of the square wooden box and tray. The principal reason for this change is that it is easier to keep the cheese from bursting out sidewise when a round 
box or can is used, for the square box tends to bulge out in the middle, thus allowing the burlap to burst. If a round can is used, the pressure sidewise is always in a direction directly away from the center, and the horizontal pressure is thus equalized.

\section{WAX-RENDERING.}

In using this press we formerly advised a tube at the bottom of the can, left open during the pressing so that the hot water and wax would run away immediately. It is better, however, to have no opening at with a long curve at the upper end This is applied to the wax-press can as shown in Fig. 12. As will be noted the pipe goes down between two of the vertical cleats on the side of the can and is then bent over toward the center between two of the horizontal cleats at the bottom, under the screen. While the pressure is being applied the water and wax keep up a general boilingan ideal condition. No matter how long the pressure is kept on the slumgum, nor how many times the screw is raised to allow the hot water to saturate the refuse again, the

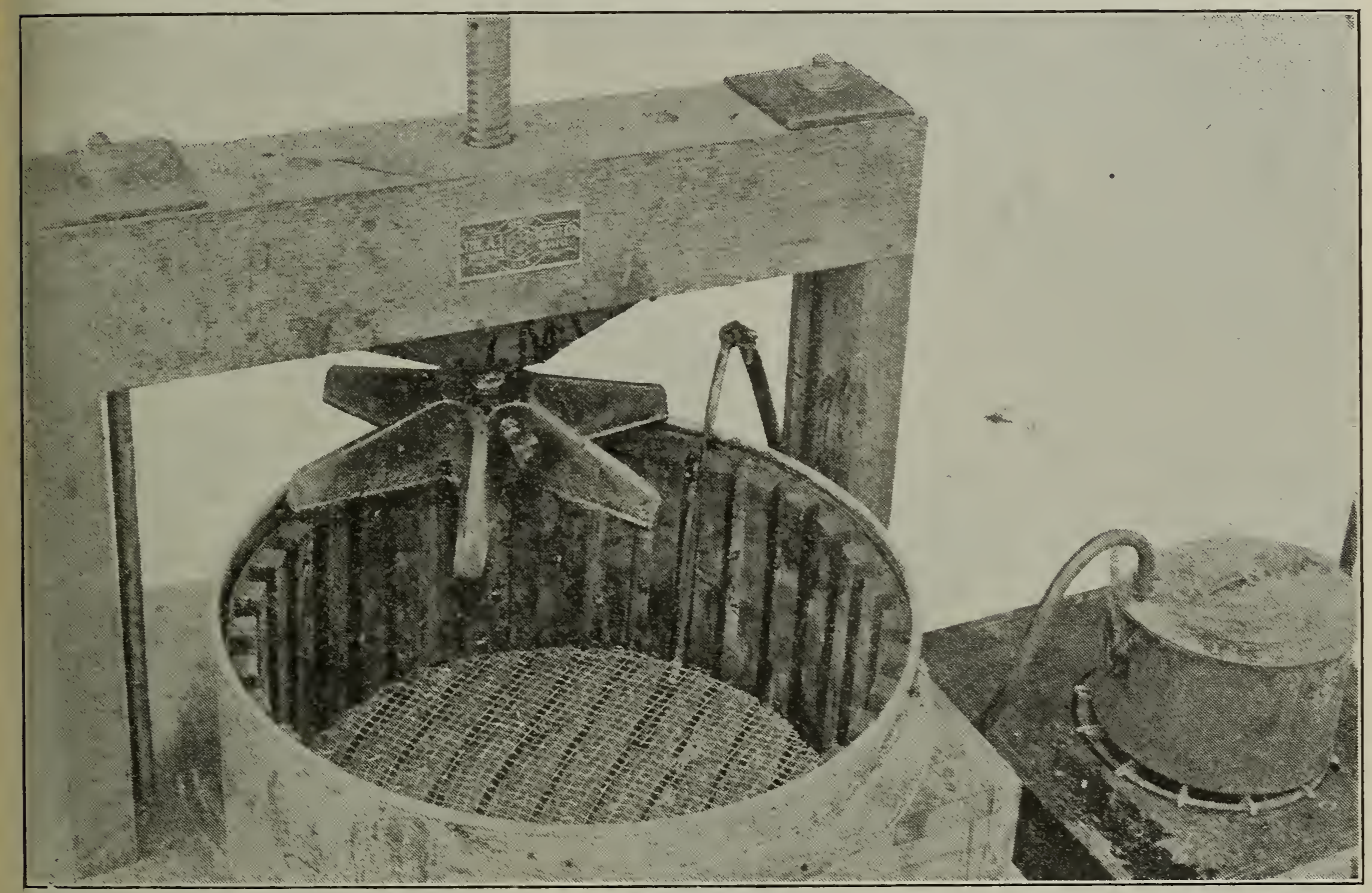

FiG. 12. - Steam from a small boiler introduced between the slats in a wax-press can. The water and wax keep up a continual slow boiling, insuring constant circulation.

the bottom of the can, but to confine the hot water and wax, thus preventing chilling as much as possible.

If no heat is applied to the combs during the pressing it is necessary to do the work in warm weather or in some room that can be kept hot by the heat of the stove used for melting, for when the air is cold the wax chills and the work is hindered. The efficiency of the press is greatly increased, therefore, if a very small jet of steam is introduced from a steam-knife boiler or teakettle, carried by means of a rubber tube to a one-quarter-inch copper pipe about fourteen inches long, with a right-angle bend five or six inches from the bottom and water keeps up this gentle boiling, so to speak, and the wax on top shows no tendency to cool. We formerly recommended running the refuse thru the press a second time; but if steam is introduced as explained, the second melting and rendering is unnecessary unless the work has been very carelessly done. If there is any doubt as to the thoroness of the work, it is a good plan to run the refuse thru a second time to make sure that it is clean. The second rendering takes about half the time that the first did.

\section{AN IDEAL EQUIPMENT.}

Fig. 13 shows the complete outfit which we recommend, including stoves, press, cans 


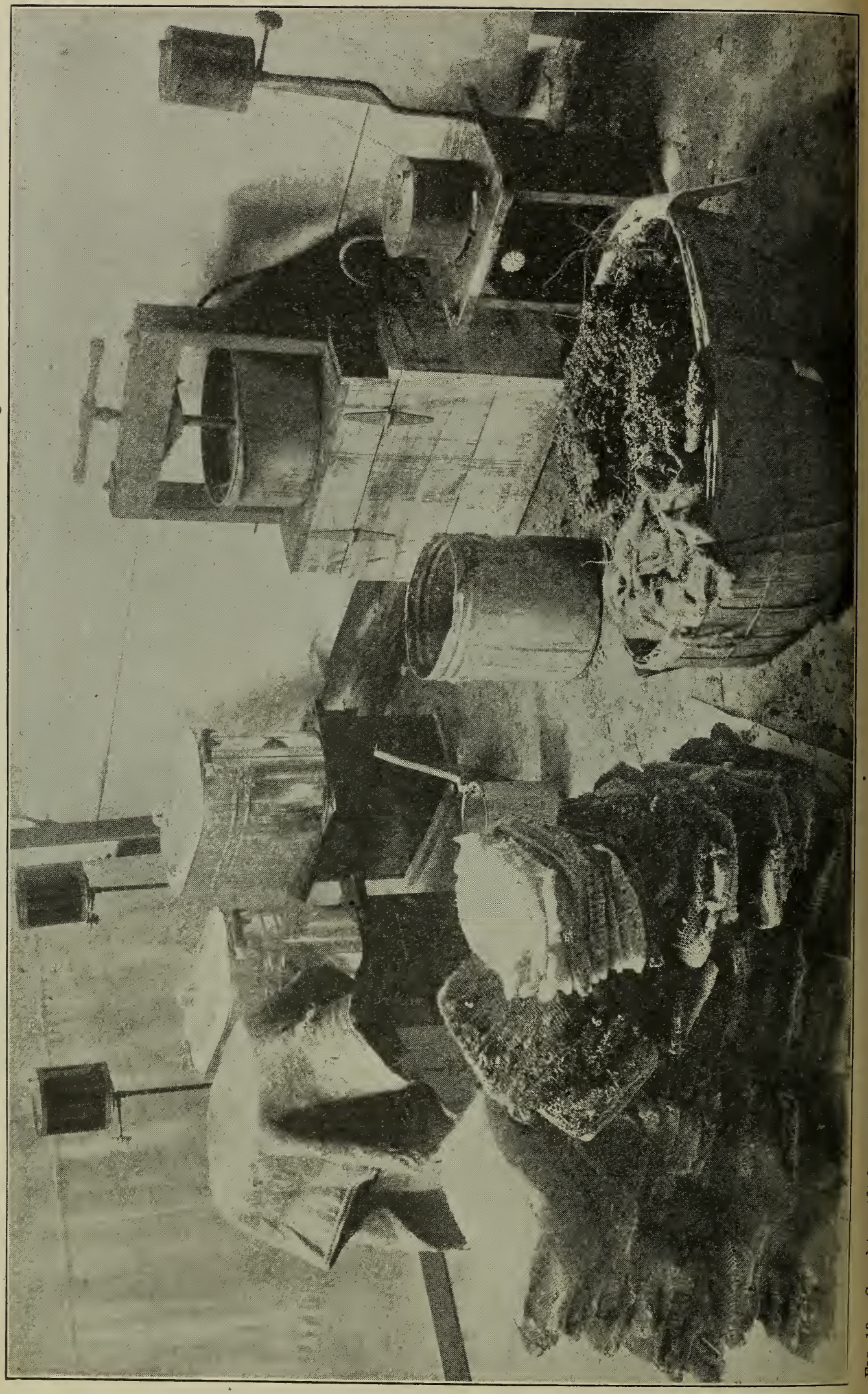


for melting the combs, boiler for steam, etc. A cook stove with a top large enough to hold two good-sized wash-boilers is ideal, but frequently it is inconvenient to provide such a stove in a basement or out-building where the wax-rendering is done. Two double-burner gasoline-stoves, one for each

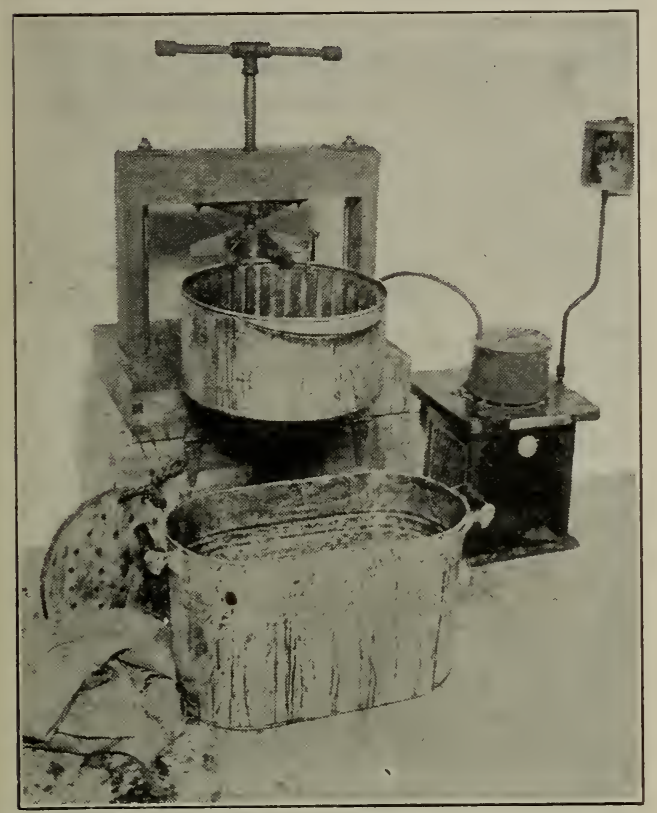

FIG. 14.-The press can pulled forward ready for filling.

wash boiler, will do as well. Oil-stoves would answer the purpcse for melting the combs but are not quite so convenient owing to the difficulty in turning down the oil burners in case the combs get to boiling too hard. Wash-boilers cannot be cleaned very easily after being used for melting combs, hence should be kept for this purpose only. Many prefer to rise a large square tank of galvanized iron, possibly orer a brick furnace out of doors. Or a stock-feed cooker may be used costing from $\$ 3.00$ to $\$ 15.00$.

The press should stand on a solid box that is firmly sacured to the floor, and it should be hinged in front so that it may be tipped over to run the hot water and wax into the can beneath. A large box or basket must be provided to hold the refuse after it is pressed.

\section{DIRECTIONS FOR RENDERING.}

When ready to begin work light one of the stoves and put on a boiler a little over half full of water. If the water is very hard add a little vinegar. When the water boils throw in the old combs. Thirty-five to forty combs (about half a barrel) may be put in gradually provided they are carefully pushed down with a paddle and stirred as they melt. When all the comb has been put in that the boiler will hold conveniently put on the cover and allow the mass to cook thoroly. About this time light the other stove and put on another boiler of water; also set going the burner under the steamboiler on a third stove to supply steam to the press-can.

It facilitates the work if a quantity of straw, preferably rye straw, is cut up in two-inch lengths and stirred into the melted combs. It makes the "cheeses" more porous so that less wax is left in the slumgum.

It is a mistake to begin pressing as soon as the comb is melted. Continue the cooking process with frequent stirrings until the combs are reduced to a steaming mushy mass. There must be no hard chunks.

When the contents of the first boiler are ready for pressing and the steam begins to issue from the pire in the bottom of the

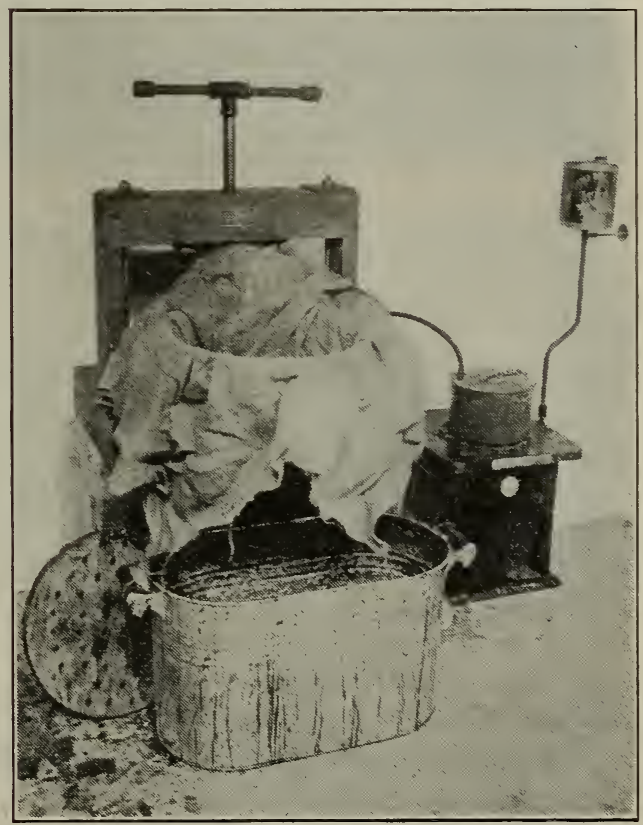

Fig. 15.-A large piece of stout burlap is the best material to use for holding the melted comb.

press-can, pull the can forward on the platform, holding it in position by means of the spider on the lower end of the screw resting on the top of the can, as in Fig. 14. Have ready a few pieces of good strong burlap, at least 40 inches square. Place one of 
these in the press-can; put the follower on top of it and throw a few dipperfuls of hot water from the other boiler into the can to heat thoroly all the parts. Pour this off and spread the burlap down into the can as in Fig. 15. Dip about two gallons of the melted comb and water into the press and fold the burlap neatly over it, as carefully

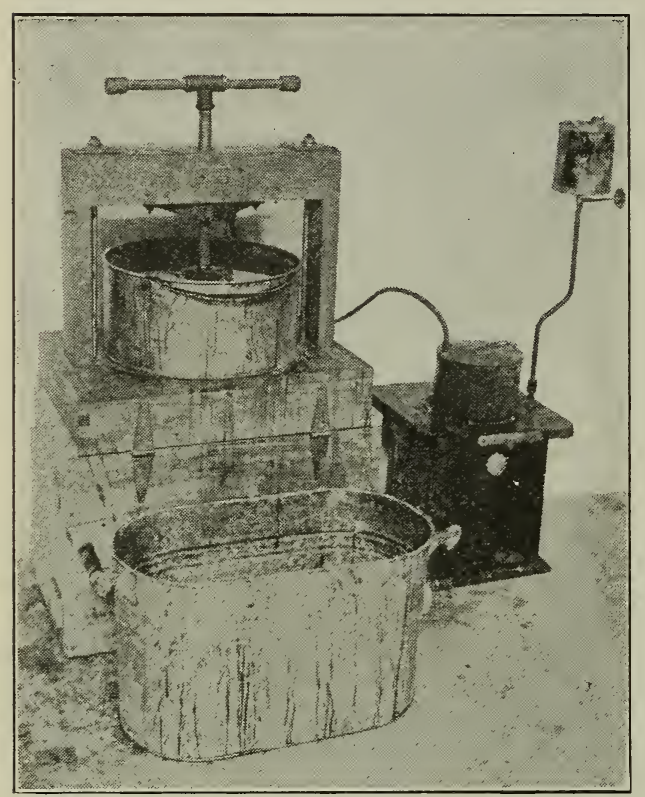

FIG. 16.-Applying the pressure. The wax rises to the top of the water. As much time may be given to the pressing as desired-no danger of chilling, because of the jet of steam.

as tho tying up a package. This is very important; for if there are thick rolls of the cloth in any one part of the "cheese," other parts of the refuse will not receive as much pressure as needed. To fold the burlap over, fold the back edge over toward the front, being careful to get the sides straight, then push the front edge over on top of it; lastly, fold in the sides neatly. Place the cleated circular follower in position (cleats down of course); push the can back exactly in the center of the platform and run the screw down very slowly-Fig. 16.

At this time it may be necessary to turn down the gasoline-burners under the first boiler in order that the contents may not get too hot; or, if it is on a stove, pull it over to the edge. Always use the utmost care to prevent the wax from slopping over. If it does, there is danger of having a serious fire. As soon as the water in the second boiler boils, begin filling that with combs.
Always turn the screw down slowly. If it is run down rapidly before the liquid in the mass inside the burlap has time to squeeze out, the burlap and the contents inside are likely to squash up around the follower, interfering seriously with the escape of the water and wax. Turn the screw only when it turns easily. Of course, when it is clear down it may be turned tight; but there is really more danger in applying too much pressure than in not applying enough.

Sufficient water should have been dipped in with the comb so that the water and wax when the screw is clear down will just about submerge the iron spider on the end of the screw. It ought to take two or three minutes to get the screw clear down. When it is down about as far as it will go, release the pressure until the cast-iron follower is nearly out of the liquid; pull up on the rope handle of the wooden follower until it is free from the burlap, thus allowing the hot water to saturate the refuse again. After a minute or so apply the pressure slowly once more. This process should be repeated two or three times.

When the screw is finally down as far as it will go, place a wash-tub or a large can

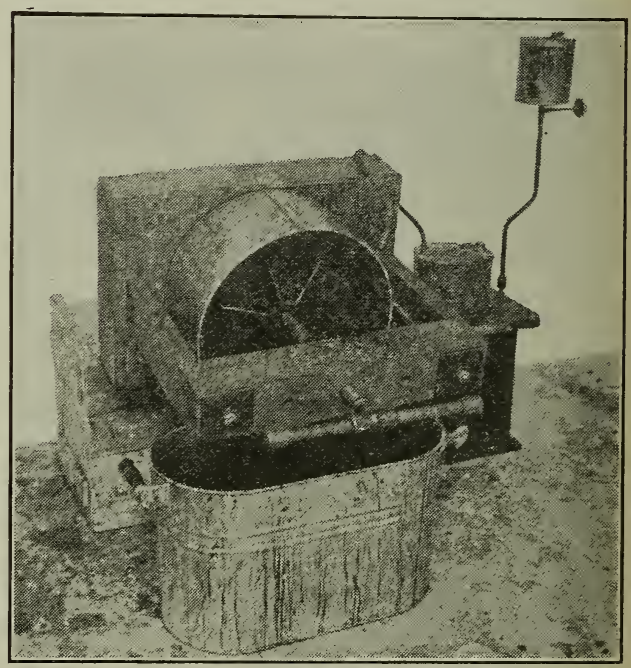

FIG. 17.-When the pressing process is completed the whole outfit is tipped up on its hinges to pour off the hot water and wax.

on the floor in front of the press and tip the latter over, pouring all the water and wax out. Leave the press tipped over a few moments until wax drains out-Fig. 17.

When no more wax will drain out, tip the press back into its regular position and pour the hot water and wax into an empty 
can or barrel having a faucet at the bottom. If a barrel is used which is smaller at the top, the hot water must first be drawn off after the work is over, and the wax run into previously soaped molds to harden. It is more convenient to use an oval-shaped can or round can that is larger at the top, so that the wax may be left right in it to harden in one large cake. There is no difficulty in lifting the cake out even tho it be 8 or 10 inches thick.

The idea of the faucet at the bottom is to permit drawing off the hot water, so that it may be used over and over again. There is no object in using fresh water each time; therefore when the first boiler is empty enough hot water may be drawn off from the supply-can to fill it half full again for a fresh lot of combs. When first starting out, it is a good plan to fill the boilers a little more than half full so that there will always be enough water for subsequent meltings.

If the work has been carefully done, when the screw is raised after the water and wax have been drained off, and the follower taken out, the "cheese" will be dry, comparatively speaking; and when it is dumped out into the box or basket, if a handful is taken up and pressed momentarily between the fingers, no great amount of wax will show. If only a very fine line of wax appears in the ridges between the fingers the work has been done thoroly. It is convenient, if not absolutely necessary, to wear a pair of canvas glores during the whole process; for when the burlap is shaken out the refuse is exceedingly hot. When shaking out the burlap, if the refuse does not shake out clean, lay the cloth orer the box, inside down, and quickly rub it between the hands. This will dislodge the refuse still clinging. Now place the burlap over the press again and repeat the process. The same burlap should last for a dozen pressings. Each time, however, look it over quickly to see if there is any sign of a weak spot or the beginning of a tear. If there is, discard it and use a new cloth.

A heavy cloth or old sack should be thrown over the unheated can containing the supply of hot water and wax poured in from the can under the press; for the more this heat can be conserved the shorter time it will take to start a new boilerful of combs,
The final waste of wax by this process need not be over 3 per cent. There is no practical process that we know of that secures all the wax. The quality of wax from this press is the very best, needing only a little scraping on the bottom to be ready for market. The color is good, and there is no need of refining it afterward.

When diseased combs are rendered, especially those containing some honey, every precaution should be taken to prevent the bees from robbing. If the buildings cannot be made bee-tight, the work must be done at night, and every tool and utensil used thoroly scalded. The refuse from the diseased combs should be burned, and the water which was used poured where the bees cannot possibly get access to it.

\section{THE AMOUNT OF WAX IN COMBS.}

The question is often asked how much wax can be rendered from comb holding a given amount of honey; but it is quite diffcult to answer such questions, as it makes considerable difference whether full sheets of foundation were used, and also whether such foundation was thick or thin. In general, however, it requires about $4 \mathrm{lbs}$. of wax in comb to hold $100 \mathrm{lbs}$. of honey, or, in other rords, a pound of new comb will hold about 25 lbs. of honey.

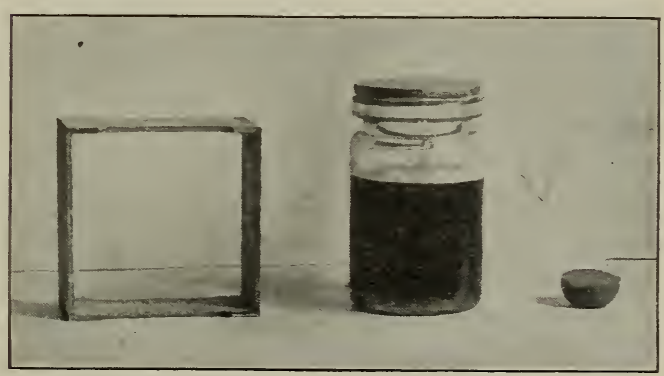

FrG. 21.-Hones pressed from a section; result orer 14 ounces honey, $1 / 2$ ounce wax, and 1 ounce of wood.

A sixteen-ounce section of honey consists approximately of $141 / 2$ ounces of honey-a little over one-half ounce of wax and about one ounce of wood. Fig. 21 shows the results after separating the honey, wax, and wood, in a sixteen-ounce section. Of course, these results, as before mentioned, are not always the same, and the different amounts vary considerably.

On one occasion we melted over $600 \mathrm{lbs}$. of candied comb honey. Keeping careful account of the weights, we found that the 
percentages of honey, wax, and wood were approximately 88,5 , and 7 , respectively.

HOW TO REFINE WAX WITH SULPHURIC ACID.

Wax cakes, as they are bought up, are usually of all grades and colors. The difference in color is due largely to the amount of impurities the wax contains. With all of the plans for bleaching or clarifying there seems to be no practical or satisfactory way of bringing the wax to a yellow colorthat is, to its original state of purity, except by treating it with acid.

The method, in brief, is as follows: A wooden tank or barrel is filled a quarter full of water, when cakes of wax are added until nearly full. The water is then boiled until all the wax is melted, when a quantity of commercial sulphuric acid is poured in, and the boiling continued until all is thoroly mixed. The heat is then removed and the impurities allowed to settle.

For a detailed account it may be well to describe a modern wax-refining plant. The tank is a little over $3 \frac{1}{2}$ feet in diameter and about 5 feet high. Water is run into it to a depth of 12 inches, and then 1500 lbs. of wax is thrown in, making it about full. The mass is then heated by means of a jet of steam from a pipe projecting down into the water from the top. When all the wax is melted, the acid is poured in. Dark wax to make brood foundation requires three pints of acid; but if light enough for surplus foundation, not more than $1 \frac{1}{2}$ pints is used. If the wax is already of good quality, so small an amount as one pint of acid will answer. On the average, therefore, one quart of acid is used in 80 gallons of water for $1500 \mathrm{lbs}$. of wax. Soon after this is poured in, the color of the boiling wax will be seen to grow lighter, and, after a minute or so, the boiling is stopped.

The steam-pipe is now drawn out, the tank covered with a cloth or carpet, and allowed to stand as long as the wax will remain liquid, or about 24 hours. At the expiration of this time the water and acid will have settled to the bottom by reason of their greater specific gravity. The consequence is, that the wax itself, after being purified, is entirely free from any residue of acid and dirt accumulation. The melted wax is now drawn off from the top, and poured into any sort of receptacles with flaring sides. When the wax is nearly all removed or shows evidence of coming near the dirt, the rest is allowed to stand. As soon as it cakes in the tank it is lifted out, and the dirt clinging to the bottom scraped off.

Acid for refining wax on a small scale is not to be recommended, for, without proper receptacles and facilities for heating, the wax is more often injured than benefitted.

\section{BLEACHING BEESWAX.}

There are methods by which beeswax can be bleached by the use of chemicals; but for practical purposes it is unwise to attempt them. Moreover it has finally been discovered that, for the economic uses of the beekeeper, foundation made of bleached wax is no better than, if as good as, that having the natural yellow color, refined by the use of sulphuric acid. Yellow wax is more ductile, and therefore more easily worked by the bees; and even when used for section honey-boxes, the combs from yellow wax are about as white as those from the bleached; so that when capped over no one can tell the difference. But very often dealers have a call for bleached beeswax; and the only practical way of getting it is to convert the product into thin sheets or small particles, and then subject them to the sun's rays for a suitable length of time. When sufficiently bleached it may be melted up and caked.

\section{HOW TO DETECT ADULTERATED WAX.}

Mention has already been made that beeswax is liable to adulteration with paraffine or ceresin, and sometimes with ordinary grease or fat.' Some unscrupulous box-hive beekeepers, after brimstoning their old "skeps," and melting up the wax,* add just enough tallow to increase the weight, because grease is cheap compared with the ordinary product of the hive. But such adulterations are very easily detected, both by smell and sight. The cakes have a greasy smell and feeling; and when subjected to the float test, presently described, will immediately rise to the top of the liquid. Paraffine and ceresin adulterations are not so easily recognized; but nearly all pure beeswax, when chewed for a few minutes, will crumble in fine particles, while wax

* See Box Hrves and Straw Skeps. 
containing a small percentage of paraffine or ceresin will chew like sealing-wax and ordinary chewing-gum.

The simplest and most reliable test is the float or specific-gravity test. The specific gravity of our ordinary commercial paraffines and ceresins is below that of beeswax. As an ordinary article of pure beeswax is lighter than water (wax standing 965 and water at 1000), of course it will float in water.

Into a jar partly filled with water pour alcohol until a small piece of beeswax of known purity settles to the bottom, taking care not to pour in too much alcohol, for the wax should barely sink to the bottom; that is, we desire the alcoholic liquid and the wax to be of the same specific gravity. If a piece of adulterated beeswax containing, say, 50 per cent of paraffine or ceresin is now put into the liquid it will float on the surface of the liquid. Another piece of wax that contains only 10 per cent of adulteration should be tested. It still floats, but has a tendency to sink almost under the surface. If another piece containing only 5 per cent is tested it may float or gradually settle to the bottom of the jar, perhaps standing upon a single point.

For all practical purposes this float is entirely reliable; that is, it has so far shown every adulterated sample. A large shipment of beeswax was sent us. It was very beautiful, and the cakes were all of a uniform size; but the price was very low. It was suspicious, and accordingly we subjected it to the float test. Sure enough, a small piece of the wax stayed nicely on top of the test liquid without the least effort. We then put it into a liquid that would let a 25 per cent ceresin adulteration sink. After hovering near the surface it gradually sank, and behaved like the piece of wax that we knew contained 25 per cent of ceresin. We wrote to the shipper that we did not want adulterated wax; that we must have the pure article; that he would have to take the stuff off our hands. He did it very promptly, without even trying to defend himself, any more than to say that he thought we were not very particular. He knew better, but thought he could unload the stuff without our being any the wiser.

CLEANING WAX FROM UTENSILS.

Perhaps the readiest means is to immerse the utensils in boiling water until all the wax is thoroly melted off, then drain, while hot. They can then be wiped off with soft newspaper. Where the article cannot be easily immersed benzine or a solution of sal-soda will readily dissolve the wax so it can be cleaned off with a cloth. Benzine dissolves wax almost as readily as water dissolves sugar.

\section{WAX-WORMS.--See BEE-MOTH.}

\section{WEIGHT OF BEES.-Some very in-} teresting experiments were conducted by Prof. B. F. Koons, of the Agricultural College. Storrs, Ct., to determine the weight of bees and the amount of honey they can carry. The results of these experiments were given in Gleanings in Bee Culture; and the article is so valuable we have thought best to preserve it in permanent form:

Some two years ago, in a leisure hour I went to my apiary and captured one outgoing bee from every hive and subjected them to fumes of cyanide of potassium for a few moments to render them inactive, and then weighed each bee upon our chemical balances - a pair of scales so delicately adjusted that it is an easy matter to weigh the one-millionth part of a pound or the one-thousandth part of a bee. From the weight of each separate bee it was a very simple problem in arithmetic to compute the number of bees in a pound. The results showed that mine, which perhaps are a fair average in size and weight, ran from 4141 to 5669 in a pound. These results you published in Gleanings, and there expressed a wish that $I$ would also determine the amount of honey carried by a homing bee. In my research for the weight of bees I took those just leaving the hive, which naturally would represent the normal weight, without extra honey or pollen.

During the present summer (when the bees were very active) I have undertaken to carry out your request as to the amount of honey carried by a bee. My method was this: From the chemical laboratory I secured a couple of delicate glass flasks with corks, marking them A and B. Each was very carefully weighed, and the weight recorded. I then went to a hive, and, with the aid of a pair of delicate pliers, or pincers, I captured a number of incoming bees and dropped them into flask $A$. I then secured about an equal number of outgoing bees in flask B. These were then taken to the laboratory immediately, and each flask again weighed, after which the bees were carefully counted and released. This operation was repeated quite a number of times, not on the same day, but as opportunity offered, and when the bees were bringing in an abundance of honey. I captured from 20 to 45 bees for each flask at each trip, aiming to have, as 
nearly as might be, the same number in each flask on any particular trip. I always weighed the flasks before starting out, lest some little bit of soil or stain, or even moisture on the glass, would render the results less accurate; I also always allowed any moisture condensed upon the inside of the flasks, while the bees were confined, to evaporate before weighing for another trip. I then treated my results as follows: From the weight of flask and bees I deducted the weight of the flask; the remainder I divided by the number of bees confined on that trip. This gave me the average weight of the bees captured at that time. The average weight of the bees in flask $A$, or loaded bees, was always greater, as it should be, than the average weight of the bees in flask B, or unloaded bees. The difference between these two weights gave me the average amount of honey carried by that lot of bees.

Mine are Italian and hybrid bees, but I made no attempt to determine the difference in the amount carried by the different swarms or breeds. I kept no record of the swarms except that I guarded against going to the same hive for a second lot of bees. A considerable difference does appear, but probably that arises in part from the abundance or scarcity of honey on any particular day when the colony was visited. My aim was to secure reliable results, as nearly as possible representing the average amount of honey carried by bees.

The following is the result of weighing several hundred each, of returning and outgoing bees. The smallest number of bees necessary to carry one pound of honey, as shown by my results, is 10,154; or, in other words, one bee can carry the 1-10154 (one ten thousand one hundred and fifty-fourth) part of a pound of honey; and the largest number, as shown by the results, required to carry a pound is 45,642 ; and the average of all the sets weighed is 20,167. Perhaps, then, it is approximately correct to say that the average load of a bee is $1-20,000$ (one twenty-thousandth) of a pound; or, in other words, if a colony has 20,000 bees in it, and each one makes one trip a day, they will add the pound to their stores. Of course, not all the bees in a colony leave the hive, the nurses remaining at home, hence necessitating more trips of those which do "go a field."

I also repeated my observations of two years ago on the weight of bees, and found that my numbers ran from 3680 to 5495 in a pound, and the average about 4800 , the same as in my former test. I likewise secured the following on the weight of drones: Of a dozen or more weighed, the largest would require 1808 to make a pound and the smallest 2122, or an average of about 2000 drones in a pound, over against nearly 5000 workers.

B. F. Koons. 1895 .
In a nutshell, and speaking in round numbers, we may say that it takes 4800 bees to make a pound; and that, while 10,000 bees may carry a pound of nectar, twice that number, or 20,000 , is probably more nearly the average. During basswood bloom, the first figure should be considered as the nearer correct one because the bees drop down at the entrance; but from almost all other sources of nectar the twenty-thousand mark is the one to accept.

Let us now look at these interesting figures another way: A bee can carry half its weight in nectar; and perhaps, under certain circumstances, a trifle more; but, generally speaking, one-fourth its weight is the amount. A single strong colony has been known to bring in a trifle over $20 \mathrm{lbs}$. of nectar from basswood in one day; ${ }^{*}$ but usually four or five pounds is considered a reremarkably big day's work. (See SCALF Hive.) If we figure that there were, say, in the first instance 20 lbs. gathered in one day, and $8 \mathrm{lbs}$. of bees, there would be 38,400 bees. If 20,000 of these were field bees (estimating 10,000 necessary to earry a single pound of basswood nectar), those bees must have made ten trips. On the same basis of calculation, a colony of equal strength that brought in $5 \mathrm{lbs}$. would make one-fourth as many trips, or two and onehalf trips. This would leave for each trip one hour for $20 \mathrm{lbs}$; ; or, in the case of $5 \mathrm{lbs}$. a day, two and one-half hours.

Both Profs. Gillette and Lazenby, the former of the Colorado Experiment Station and the latter of the Ohio State University, conducted a series of experiments which closely approximate figures of Prof. Koons, so we are sure they are correct.

WEAK COLONIES, TO STRENGTHEN.-See Uniting, sub-head "Alexander Plan," also Nucleus and BuILding UP Colonies.

\section{WHITE CLOVER.--See CLOVER.}

\section{WHITE HOLLY.-See GaLLBERRY.}

\section{WILD CHERRY (Prunus serotina),} known locally as black cherry. Few trees of Florida are more stately and more symmetrical in their growth than the wild cherry. It is native all over Florida, on high

* We had one colony that brought in over $43 \mathrm{lbs}$. in three days; and Doolittle $66 \mathrm{lbs}$. in the same time from basswood. 
pine lands and in low hammocks. The wood is a beautiful red, with a fine grain, and is very valuable for cabinet purposes. The wood is, however, somewhat softer than that of the wild cherry of the North (Prunus Pennsylvanica). In appearance it closely resembles the wild cherry of more northern latitudes. It seldom fails to yield honey, and bountifully too. Coming as it does just before the orange-trees bloom, it gives a final spurt to brood-rearing that is valuable indeed. As a surplus honey it is more of a pest than a benefit, as the honey is dark red, and as bitter as wormwood. The flavor of a cherry pit is about that of this honey. It does not take a great deal of it to spoil the flavor and color of the first orange honey of the season, and many beemen in orange sections must extract their supers of all traces of wild-cherry honey or have their fancy orange honey touched and tinged. In the vicinity of DeLand, Fla., it is a real nuisance after the orange honey commences to come in. Up to that time it is a bonanza and a blessing to the apiarist. The writer has in many cases placed a halfdepth super on the strong colonies when they were storing from wild cherry, which was removed when the wild cherry was over and orange began. Then he would extract the supers and put back on the hives for the flow of orange honey.

\section{WILD SUNFLOWER-See SUNFLOWER.}

WILLOW (Salix).-This is a very natural or clearly defined genus of shrubs and trees found chiefly in the north temperate and arctic zones. Of the 161 described species, about 78 occur in North America, more than 30 of which are in eastern America. So variable are the species, and so freely do they hybridize, that any entirely satisfactory treatment from a systematic standpoint is impossible. The Swedish botanist Anderson, whose monograph, published in the Prodromus of De Candolle, was the work of nearly twentyfive years, declared that he never saw two specimens of Salix nigricans, which has one hundred and twenty synonyms, that were exactly alike. In Great Britain the number of species of willow has been placed all the way from twelve to eighty.

The very small flowers are naked, or deroid of both sepals and petals, and are crowded together on an elongated stem or axis forming a cluster called an ament or catkin. The stamens and pistils in all species are in separate flowers, which are borne on different individual plants, some producing only staminate flowers, others only pistillate ones. In a staminate ament of the pussy willow ( $S$. discolor) the writer has actually counted 270 flowers, and in a pistillate ament 142 flowers. The multitude of bright-yellow anthers render the staminate blossoms very conspicuous. As an evi-

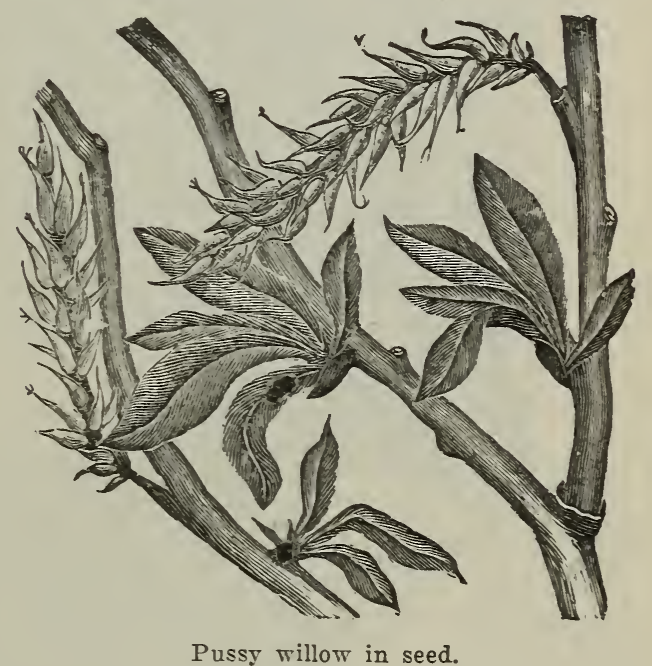

dence of their attractiveness, it may be mentioned that they are used in England for decorating the churches on Palm Sunday, and are offered for sale in New England cities by street flower-venders. The flowers are formed the preceding season, and appear in early spring before or with the leaves.

All of our species furnish both pollen and nectar, but it would, of course, be useless to look for pollen on pistillate shrubs or trees. The nectar is freely secreted in both kinds of flowers on the tips of minute flat glands, which in the pistillate flowers may be found at the base of the ovary. As our early willows attract great numbers of insects, the supply of nectar may be temporarily exhausted; but it should not be concluded, therefore, that it is wholly absent. If a branch of flowers be broken off and carried into the house and placed in water, and the nectaries examined after twenty-four hours under a microscope, nectar will probably be found in abundance. 
The earliest willow to blossom in New England is the glaucous or pussy willow (Salix discolor Muhl.). On a calm warm day the sweet odor may be detected several rods away, and a swarm of insects may be seen hovering about the bright-yellow sprays of bloom. Besides honeybees there are female bumblebees, the only form of bumblebee then on the wing, and great numbers of wild bees belonging to the genus Andrena gathering pollen for brood-

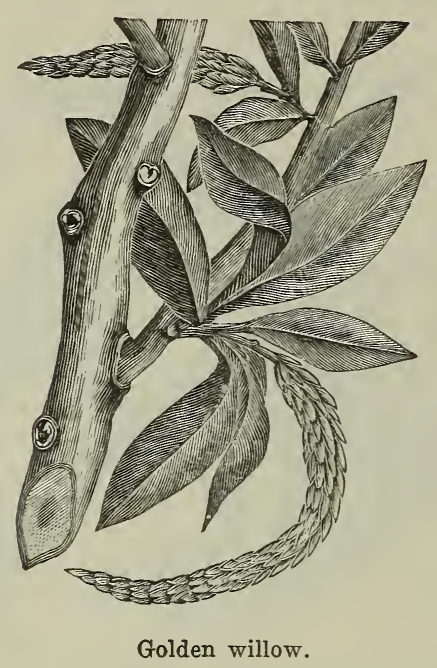

rearing. Several species of these bees are never found on any other flowers than the willows. Then there are many flies and a few butterflies and beetles. Ants often climb the stems and rob the flowers of the nectar, which is quite plentiful. In England some willows are said to be visited by moths in the evening.

The early-blooming willows are visited by large numbers of honeybees, both for pollen and nectar, and are of great value to the beekeeper. One of the commonest willows in the Eastern States is the pussy willow, which is a large shrub growing on river banks. In Massachusetts it blooms along the last of March and early in April. In Georgia the black willow ( $S$. nigra Marsh) grows along the streams thruout the state. It blooms in March, and in a few localities yields a surplus of honey of medium quality. The black willow is also common in Texas, where it is valued both for pollen and honey. Other willows which are common in the eastern states are $S$. sericea Marsh (silky willow); S. rostrata Richards, and S. cordata Muhl. In Cali- fornia, Richter says, the willows yield a surplus in several counties. It is a darkamber, bitter honey.

Among the willows introduced from Europe, and cultivated, are the osier willow ( $S$. viminatis L.) ; the Kilmarnock willow (S. caprea L.) ; the white willow ( $S$. alba L.), of which there is a variety with yellow twigs called viellina, and the weeping willow ( $S$. baylonica L.).

A honey-flow from the willows at Borodino, N. Y., is described by G. M. Doolittle as follows:

We have three kinds of willows-the golden, the white, and the weeping willow, which are of much value as honey-producers in the order named. When these willows are in bloom, and the weather warm, the bees rush out of their hives at early dawn, and work on the flowers all day long as eagerly as they do on clover or basswood. The blossoms often secrete nectar so profusely that it can be seen glistening in the morning by holding the blossoms between you and the sun, while the trees resound with that dull busy hum from morning till night, so often heard when bees are getting honey. As this is the very first honey of the season, I consider it of the greatest value to the bees, for brood is now crowded forward with great "vim," giving us the bees which work on white clover, while the honey often very greatly helps the depleted stores of the hive.

From the few trees along a small creek near here, my bees frequently make a gain of from six to ten pounds of honey while the willows are in bloom, and one season they made a gain of fifteen pounds. This spring some of my best colonies gained eight pounds, while on apple bloom they did not get more than a living from apple orchards white with bloom all about. The honey from the willow is quite similar to that from the apple bloom, and has a nice aromatic flavor. As the willows give the first pollen, and also the first honey each season, it will be seen what a great help they are to all who have them in profusion near their bees. The only drawback is the weather often being unfavorable, for I do not think that more than one year in three gives good weather all thru the time willows are in blossom. As it is often too cold, rainy, cloudy, or windy for the bees to get to the trees at this season of the year, honey and pollen from this source are not at all certain.

WILLOW-HERB.-(Epilobium angustifolium L.) ; also often called fireweed, and sometimes Indian pink and rose bay; occurs in the northern part of Europe, Asia, and North America; in eastern America it extends southward along the Appalachian Chain to North Carolina, and in the West 


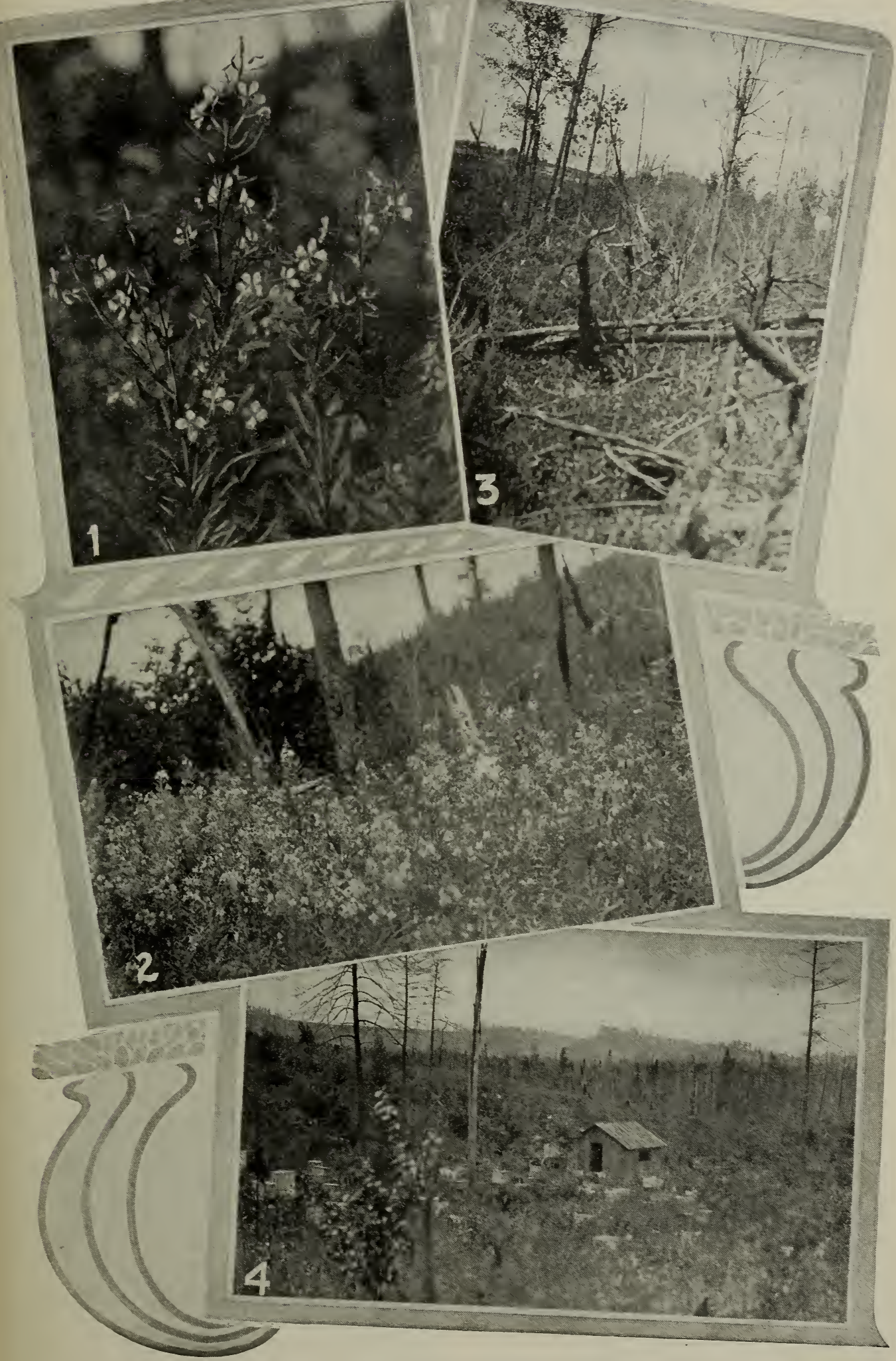

The willow-herb of northern Michigan.-No. 1, the blossom; No. 2, the plant; Nos. 3 and 4, its habitat. 
it follows down the Rocky Mountains to California. Its growth is confined, however, largely to the lumbering regions of northern Wisconsin, Minnesota, Michigan, Canada, Washington, and New England, upon areas that have been burned over; hence the name, "fireweed." After forest fires it seems to spring up spontaneously, monopolizing the soil itself. Sometimes it grows in localities never so devastated.

It is a handsome plant, usually only a single stalk growing from two to six feet high. The flowers are dark pink, arranged in clusters around the stalk. As the season advances, the first bloom goes to seed; and as the stalk extends upward, more blossoms appear, so the plant keeps in bloom from July till frost. Thus appear on each stalk buds, blossoms, and seed-pods at the same time.

Willow - herb, or fireweed, yields large quantities of white honey. Some of it is so light-colored as to be actually as clear and limpid as water, having a flavor simply superb-at least so we thought after eating some at one of the Michigan conventions which we attended at Grand Rapids. Mr. Hutchinson styles it the whitest and sweetest honey he ever tasted, and says the flavor, while not very pronounced, is suggestive of spice. The quality of the honey, its unfailing supply from year to year, following right after clover and basswood, and blooming from then till frost, make it one of the most valuable honey-plants known. Unfortunately its growth is confined almost exclusively to the regions where forest fires occur. But beekeepers situated in its vicinity are enabled to secure immense crops of fine white honey. Another remarkable feature of the plant is, it yields every year-at least so continuously that a failure has scarcely been known, even by the oldest inhabitants in the vicinity where it grows.

Mr. Hutchinson estimates there are thousands of acres in northern Michigan where this plant grows, without bees to gather its delicious nectar. But 'his condition certainly can not long exist; for where one can produce anywhere from 100 to 125 pounds of comb honey per colony, unoccupied fields will soon be covered by beekeepers, after the manner of the rush of the gold-seekers to the Klondike.

In Figs. 2, 3 and 4 will be seen the straight black shafts of dead pine-trees that stand out alone as the only survivals of their class from the fires. While we can not but deplore the loss of the pines that furnish the only timber fit to make hives, we rejoice that they have been succeeded by so valuable a honey-plant as the willow-herb.

Probably more than half of northern Michigan was once covered with white and Norway pine, which has now been nearly all cut off for lumber. During the first dry season after the cutting, fire burns over this stump land, and two or three years later the willow - herb comes to maturity. There was a time when this produced large quantities of very fine honey; but as the pine is now all cut, or nearly so, the prospect is that willow-herb in Michigan has had its day.

WINTERING.-Whoever has gone over faithfully the preceding pages is now nearly ready to sum up the matter of wintering. Under head of ABsconding Swarms, in the opening of the book, and under the subject of Uniting, he has been cautioned against dividing, and trying to winter weak colonies. See "Absconding in Early Spring," under the head mentioned. In regard to keeping bees warm thru the winter with Artificial Heat, see that head; also TemPERATURE. Concerning the effects of different kinds of food or stores on the welfare of bees during winter, see ASTERS, DYSENtery, Honey-Dew, Spring Management, Feeding and Feeders, Candy for Bees, and Spring Dwinding. On the subject of fixing the size of the entrances; see ENTRANCES to Hives, Ventilation, and Swarming. Some very important information is given under ENTrANCES; and it would be advisable to reread that article before one takes up the matter further here. For management in the spring, see SPRING Management, Dysentery, and Spring Dwindling. For a consideration of the different sizes and shapes of frames for wintering see Hives, also Frames. For the discussion of double-walled or chaff hives, see HIvEs. For stimulation in the spring, see Feeding, subhead "Feeding to Stimulate." For the consideration of windbreaks, see "Windbreaks," under APIARY. For the effect of honey-dew on wintering, see HoNEY-DEW. 
TWO METHODS FOR WINTERING BEES.

There are two methods in vogue. One is called the indoor plan and the other the outdoor. Which one the reader shall use depends entirely on the locality. Where the winters are extremely cold, with continuous freezing weather, without a break thru the months of December, January, February, and March, the indoor plan has hitherto prevailed; and while it is still very common. the outdoor plan is coming more and more to be used. The ordinary double-walled hives are bardly warm enough in these very cold localities unless such hives are covered ing toward the large winter cases already mentioned. In a general way it may be said the indoor plan should never be used where the winters turn from mild to severely cold, the variations taking place every week or two weeks.

Thruout the southern states it has been the practice to winter bees in single-walled hives on their summer stands. It has generally been considered that extra packing or double-walled hives were a useless expense; but experiments conducted by the Bureau of Entomology, Washington, D. C., in 1913 and 1914 go to show that extra packing,

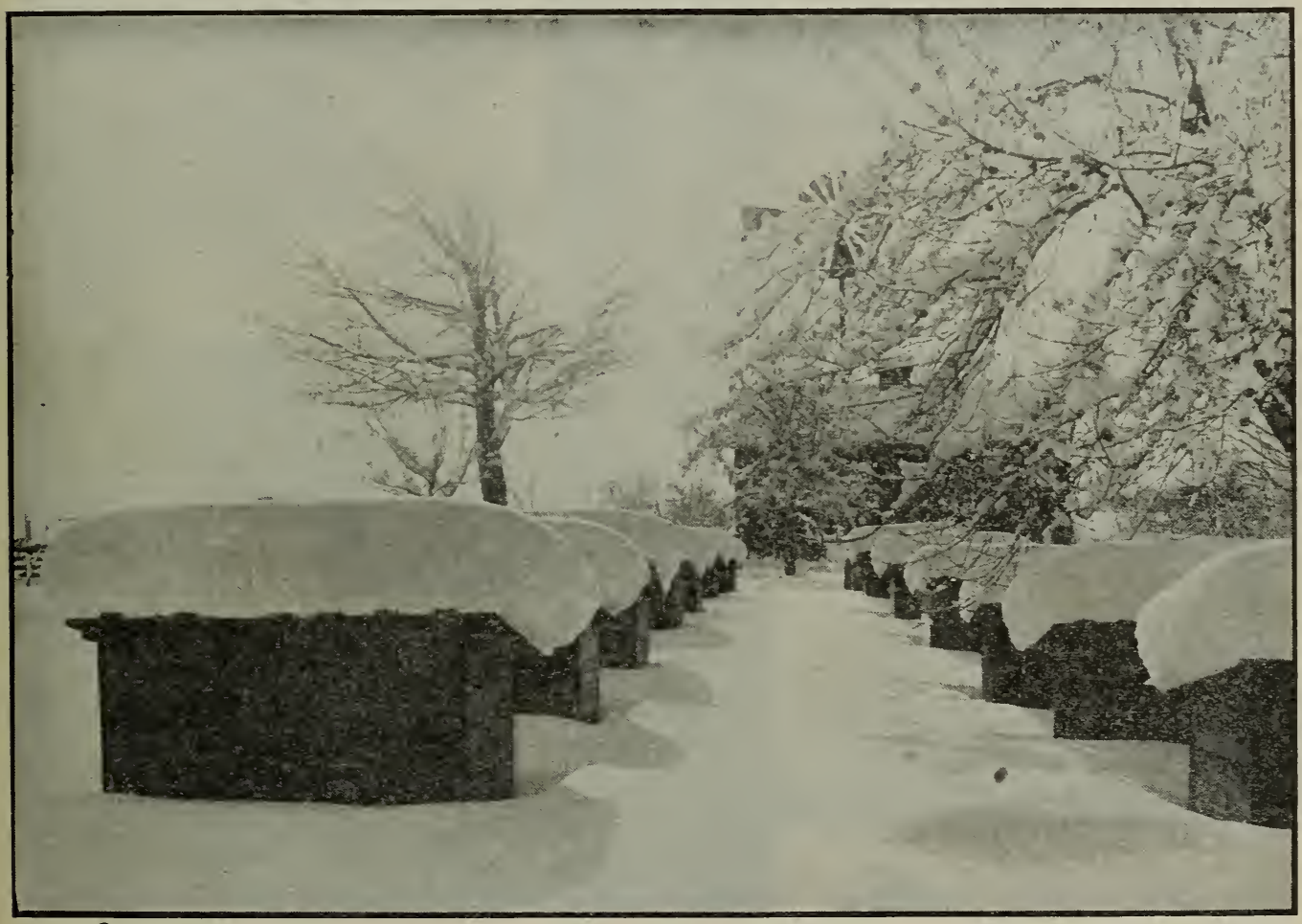

Outdoor wintering at the apiary of F. J. Miller, of London, Ontario, Canada.

with deep snow that does not thaw and freeze during winter. Thruout Canada there is a tendency to use large winter cases capable of holding four or more hives with at least six inches of packing all around; and the bees are kept in these cases till some time in May.

In the milder climates, such as may be found south of the Great Lakes and north of the Ohio River, outdoor wintering is almost universal. In such localities the ordinary double-walled hives give excellent results, altho there is a tendency at this writ- even in the southern states, may be used to advantage. Reference to this, will be made further on.

Altho cellar wintering requires less expensive hives, it involves more skill-especially so if the cellar or winter repository does not afford all the favorable conditions. Just what these are will be referred to later. While the outdoor method, on the other hand, demands double-walled hives, winter cases, or something to protect the hives on their summer stands, and a shielded location protected from the prevailing winds, it does 
not require that degree of skill made necessary when the bees are confined in the cellar. Therefore the majority of beginners, especially where the climate is not severe, are advised to winter outdoors. But it is important to observe that the spot where the bees are kept must be sheltered from prevailing winds.

With either the indoor or outdoor plan it is fair to state that, after a very severe winter in which the mercury plays below the zero-point for weeks at a time, and when spring is very late, with a warm spell followed by a very severe cold one, losses bees winter after winter with a loss not exceeding five per cent, if we throw out of calculation the one year in ten which proves abnormally severe.

WINTERING OUTDOORS. - This is simpler for most beginners, and the principles involved help to lay the foundation for the more difficult problem of indoor or cellar wintering. The prime requisite for both methods of wintering is a large force of young bees reared during the latter part of summer or early fall. A colony made up of old wornout bees with very few young, no matter how strong, will be almost sure to succumb before spring, or reach such a weakened condition as to become practically worthless for the following season. As a general rule, in the northern states brood-rearing ceases right after the honey-flow. This is perfectly normal where there is no late sum-

FrG. 2.-A deep telescoping cover to set over the packing-trays for outdoorwintered colonies is preferable.

are likely to be heavy, even among the most experienced beekeepers. But these losses can to a very great extent be minimized, even in bad years, provided one makes a study of his locality, regarding the average weather conditions that prevail. It will be the object of this article to set forth as nearly as possible some of the difficulties to be encountered, so that the reader may intelligently undertake the problem. It is well to state, tho, that the very severe winters referred to do not occur more than once in 10 or 20 years, when for some reason the whole year seems to be thrown entirely out of balance; but at all other times, if one follows carefully the directions here given his losses will not exceed ten per cent, and he may keep them down as low as two per cent. Indeed, some have wintered their

mer or fall pasturage as in the case of buckwheat; but during the latter part of August and the early part of September, broodrearing should begin again; and unless there are natural sources of nectar the bees will require feeding with thin syrup given in small quantities daily to stimulate. This stimulative feeding should be continued long enough to get a lot of brood in the hive so there will be a strong force of young bees to go into winter quarters. In many localities colonies will be able to gather enough nectar daily to supply themselves with 
young bees without any special feeding. So far the scheme of raising a large force of young bees is an important requisite for either method of wintering, but especially important where bees are wintered outdoors subjected to extremes of temperature requiring a large consumption of stores in order to keep up necessary heat.

It is unwise to attempt to winter bees outdoors in single-walled hives north of 40 degrees north latitude. While the colonies may come thru after a fashion, the shock of the exposure will be so great that they probably will not be good for much to gather sary animal heat; for it should be remembered that, the warmer and better protected the cluster, the less honey they require to eat. It is desirable to have the bees, so far as possible, enter a quiet state of sleep. But an extremely cold spell will make it necessary for this cluster to raise the temperature as explained under TEMPERATURE OF THE Honer-bee Cluster. When, therefore, a colony is so poorly protected that it has to go into a state of activity and overeat. the bees will become distended, and dysentery or purging is almost sure to follow. This condition occurring in mid-winter or early spring means the death of the colony, as there is no cure for it but warm weather.

A hive having double walls well packed with a warm cushion on top, and a good corer, or a singlewalled hive in a winter case makes about as good a winter home as it is possible to construct.

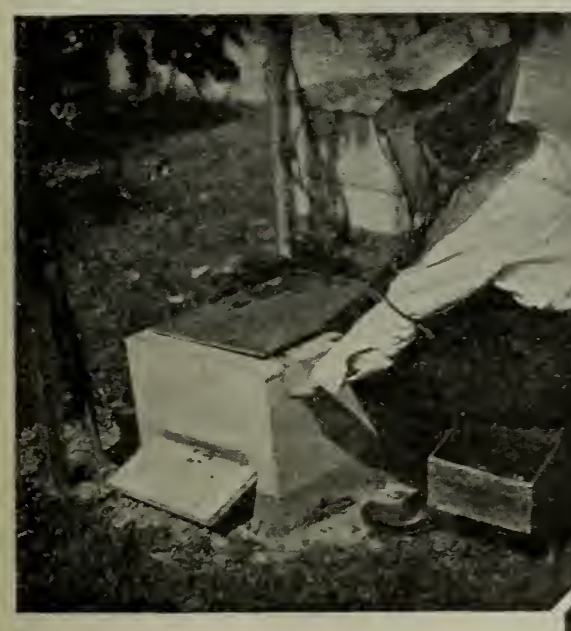

FIG. 4.-The super-cover is made of $3 / 8$ lumber, tin-bound at the ends. This is put on the hive, and covered with the tray shown in Fig. 3.

honey. It is also highly important that the hives be protected from high winds, and that the walls surrounding the hive be double and warm. Colonies in double-walled hives out in the open, and where there is a strong windsweep, may not survive, while those in single-walled hives screened by buildings, woods, or dense shrubbery, may winter well. It would appear that protection from the prevailing winds is just as important as having the walls of the hives double. Special doublewalled hives are manufactured, having the space between filled with chaff, planer-shavings, leaves, or other suitable material. The cover or roof should also be double so that the heat of the cluster will not too readily radiate away, thus causing a great consumption of stores in order to keep up the neces-
FIG. 5.-Manner of pouring in feed from a common watering-pot into a Doolittle division-board feeder. After sufficient syrup is giren, the feeder is remored, the combs are shored syrup is giren, the feeder is remored, the combs are shor
orer, a division-board inserted, and hire closed for winter.

The extra packing and double walls not only sare in the consumption of stores, but eliminate to a great extent winter losses.

Because double-walled hives are somewhat expensive, many and perhaps a majority of beekeepers start with hives made of single-thickness lumber. These during winter can be placed in the cellar or in winter cases. But if one adds the price of a winter case to that of a single-walled hive he will find the combined expense is about the same as the expense of a double-walled hire. 


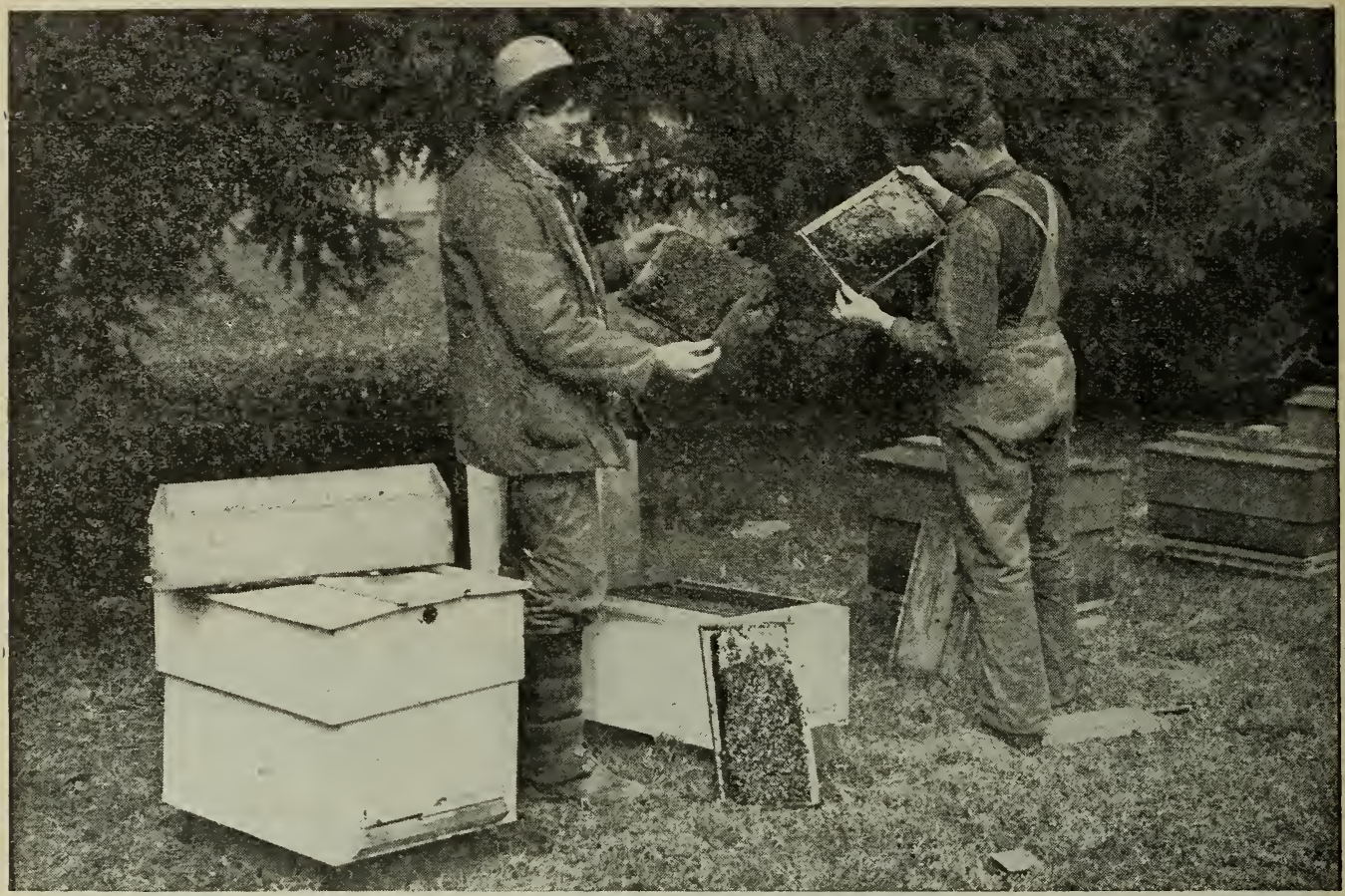

Examining a colony in a double-walled chaff hive; the chaff-tray containing packing-material is shown at the left.

Where economy is an important factor one is almost forced to adopt cellar wintering; but unfortunately in many and perhaps in a majority of cases the cellars are not suitable. Resort must, therefore, be had to

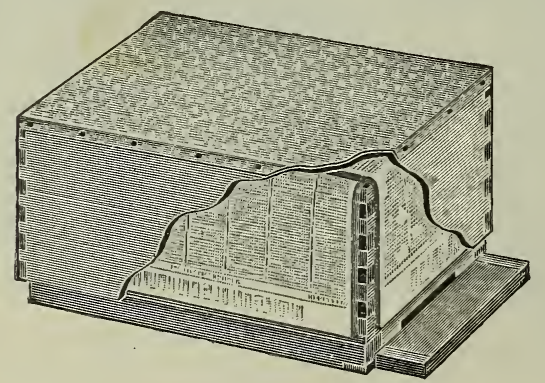

Telescope Cap.

some other niethod. Hives can be packed in drygoods-boxes; but the difficulty with such boxes is their variety and size. Attempts have been made to fold newspapers around the hive as shown in the accompanying illustration, and slip a telescope cover over it. But here, again, the cap adds expense. Resort is then had to the use of heavy paper which is wrapped around the hive in the manner shown in the next illustration.

A greased manilla paper about like flour- sacking, gives very good results; any paper which will stand weather, and yet fold up flat again in summer after the cold winter and spring are over, will answer.

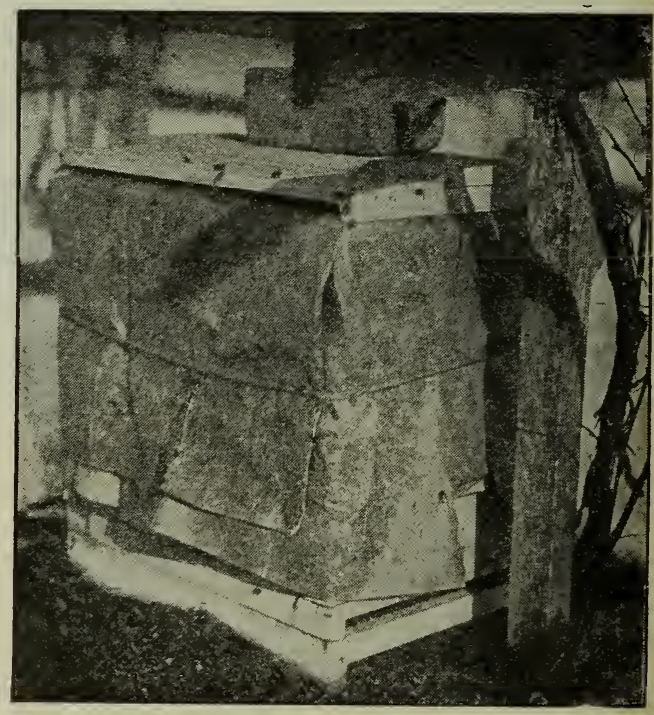

Combination paper and wooden winter case.

It is but fair to state, however, that, while hives wrapped in paper do very well in a mild climate, they will not stand the colder climates. 


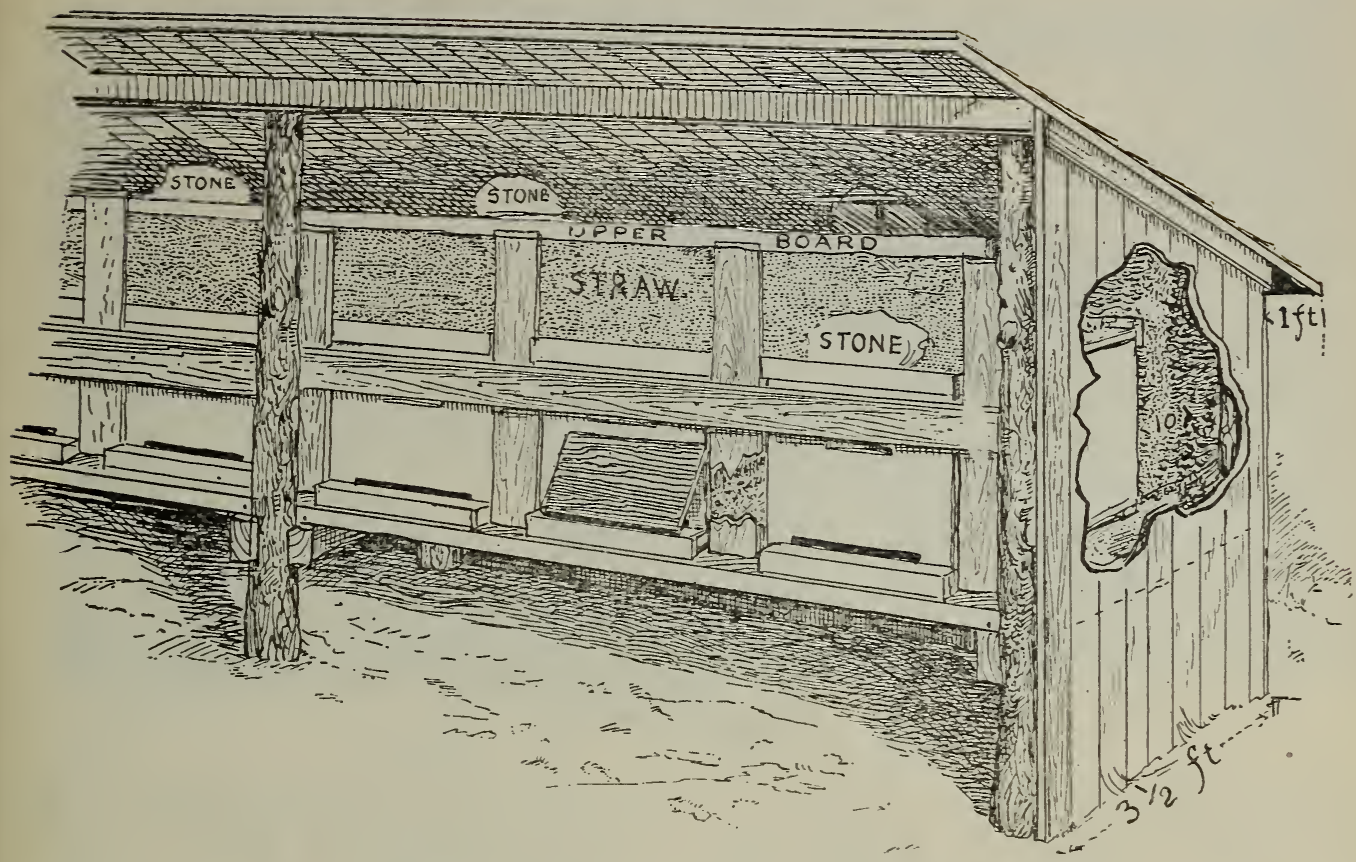

W. T. Davison's method of packing bees in straw for outdoor wintering.

Another scheme is to put the hives in a row under a shed, leaving the point of least exposure in front. Where there is no protection of the buildings or trees to screen in the apiary, a shed with the back to the prevailing winds is a great help. Under such a shed straw is then packed in between the hives and in the rear, after which it is covered with boards to shed water.

The one objection to the shed is the expense again. Another method is to put the hives together in rows of ten or twenty in a section and cover with straw or cornstalks. If the straw is piled right it will shed water; otherwise it should be protected by means of boards lapped in such a way as to keep out wind and rain.

WINTERING PEES IN TENEMENT WINTER CASE.

A tenement winter case, as its name indicates, is one large case capable of housing anywhere from two to a dozen colonies in single-walled hives. It is usually composed of large cleated panels made of cheap lumber for the sides and ends, and with a roof of like material covered with roofing paper. The whole is held together at the intersecting corners by means of Van Deusen hiveclamps, or hooks and eyes or common wood screws. When the bees are unpacked in the spring the panels are remored and laid away until the following September or October, when they are brought into use again.
The tenement hive finds its adrocates and users in colder climates-that is, climates where the ordinary double-walled hives do not give quite enough protection, and where cellar wintering is practiced. But indoor wintering has its disadvantages, as we will show a little later. Many cellars are poorly adapted for keeping bees over winter. Special repositories for the purpose are expensive; and even when the best conditions are provided it requires skill to bring the bees thru successfully from fall to spring. And this is not all. The cellar plan of wintering requires the moving of the bees in and out of the cellar, and more or less attention during the winter to provide for the varying degrees of temperature and the necessary ventilation. Mr. R. F. Holtermann, for example, whose bee-cellar is shown a little later on, gives the following reasons why he abandoned this $\$ 1000$ bee-cellar, and has now adopted the tenement-hive scheme of wintering.

When wintering in my special concrete cellar my method was to remove the bees from the cellar and place them on stands. They were next taken to clover pasture, sometimes a distance of thirty miles. Next they were taken to buckwheat, and finally returned to the bee-yard in connection with the cellar.

There are various styles of tenement hives, One of the simplest and best is the 


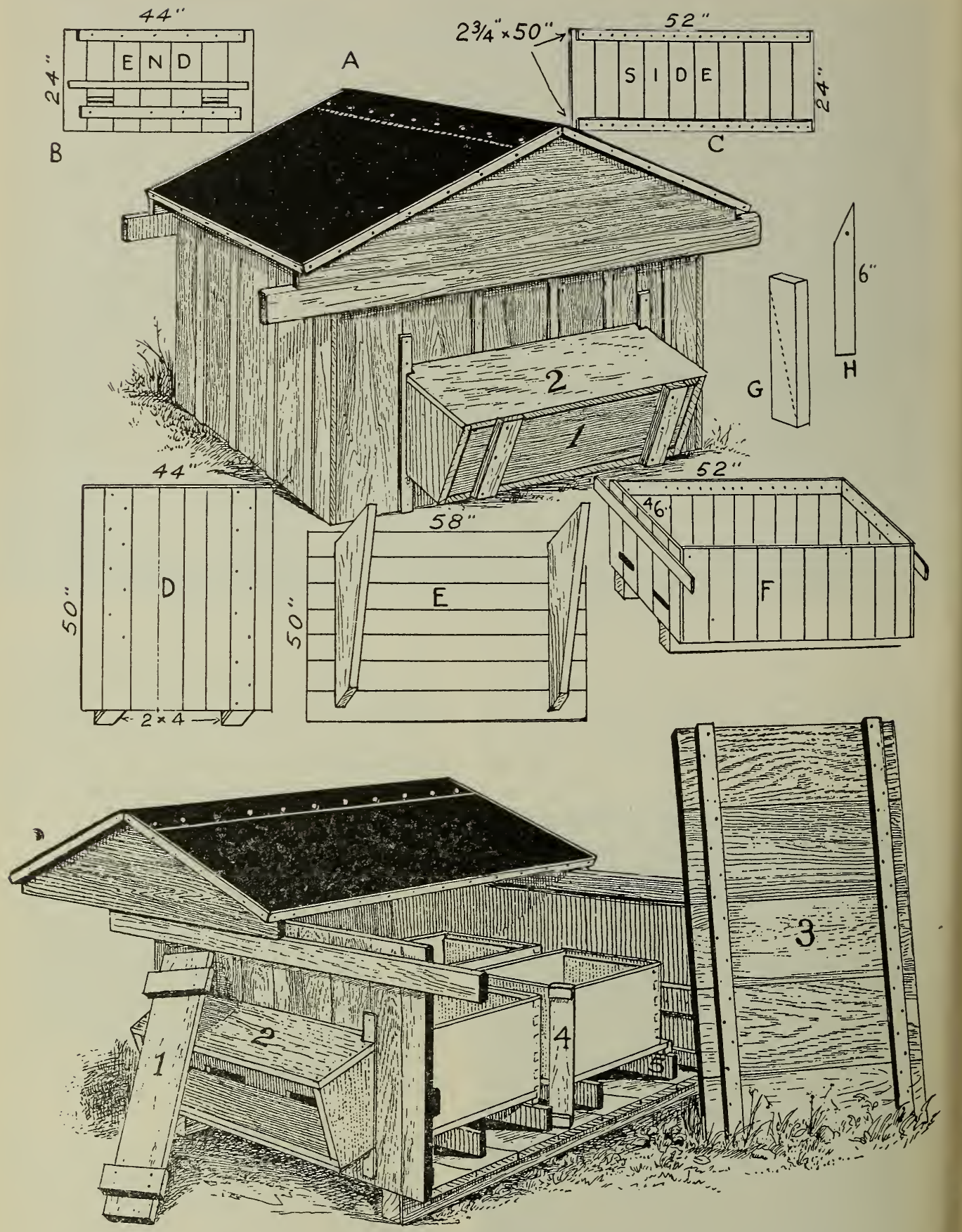

Bartlett's winter case for holding four ten-frame colonies; lower illustration showing interior.

Bartlett. The cut above renders the mode of construction so plain that further description will be unnecessary except that the several panels are held together by means of wood screws. The four hives are placed in contact with each other (for the purpose of conserving the heat of the clusters) when the space between the group of hives and the winter case is filled with packing material, consisting of planer shavings, forest leaves, straw, or chaff. Mr. R. F. Holtermann makes his tenement out of cheap half-inch boards, and he thus describes it:

I want the first case with entrances to the side, the next case no entrance on that side, thus breaking the rows for flying all thru, 


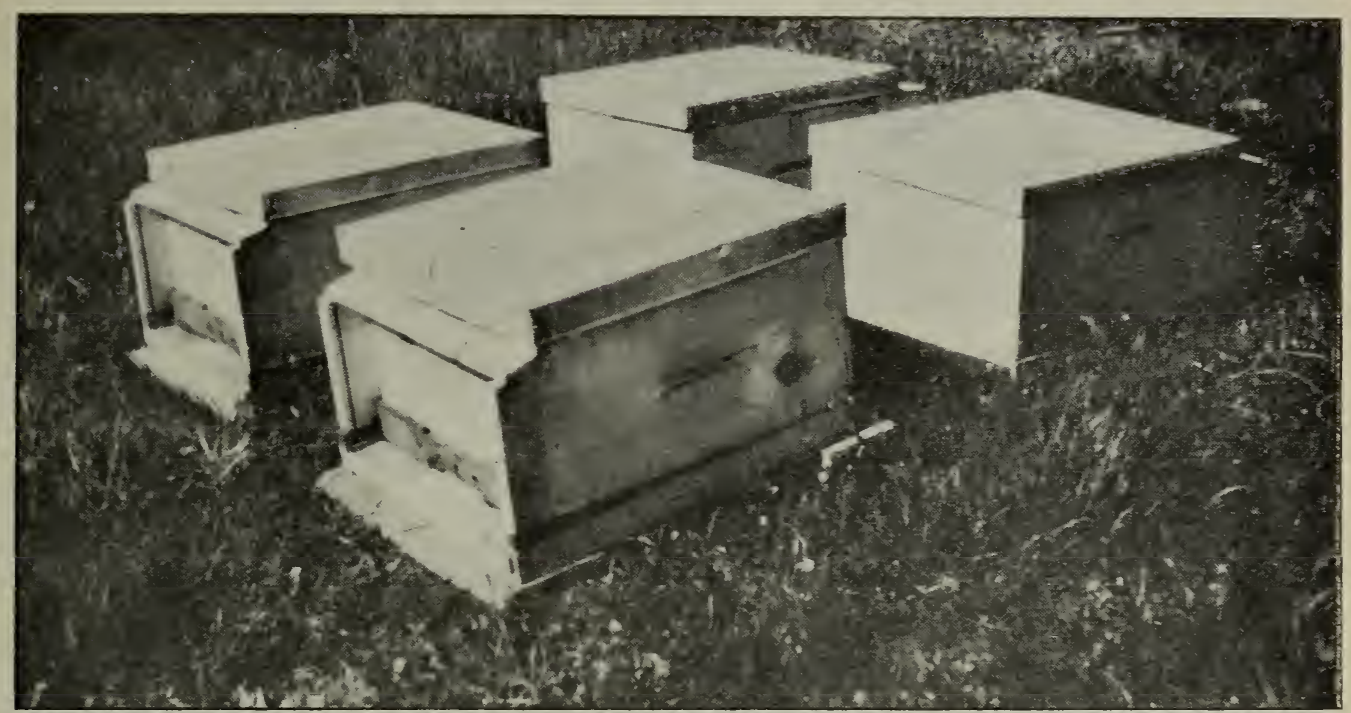

FIG. 1.-Four of Mr. Holtermann's colonies on their summer stands, in which position ther are easily brought more closely together for putting into the winter case.

and preventing drifting. I set the winter cases on blocks six to nine inches from the ground. About the apiary I put a fence 8 feet high.

\section{METHOD OF PROTECTING FOR WINTER.}

Fig. 1 illustrates four colonies of bees before putting them into the winter case, showing their position in summer, two side by side, and the pair back to back. During summer they should be far enough apart to permit one to get around them when the supers are on. In the packing-case they are close together so one hive protects the other from cold on two sides. There is about two inches of packing at the bottom, and four to six at the front and sides. Fig. 2 shows the packing-case with basket of forest leaves standing by it. The basket is made out of a rooden framework covered with burlap, and large enough to hold the top packing. It is made of light material for convenience in carrying. In the case where the cloths are partly removed, two 12-frame Langstroth hives can be seen. Two covers are also shown set at the side of the hives against the outer case where they act as packing. For the 12-frame hives the sides are made of 4 -ft. walls high enough to permit a super and queen-excluder on the hive.

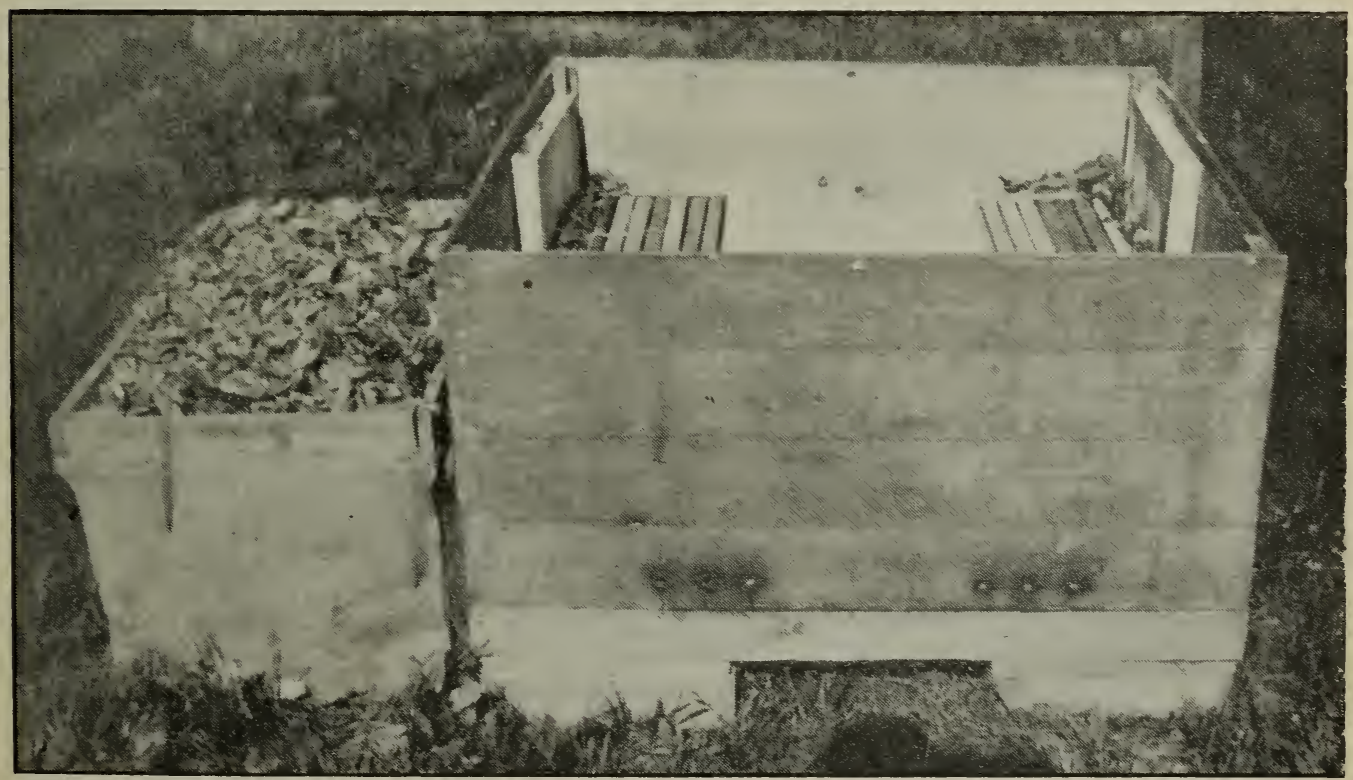

FIG. 2.-One of the Holtermann cases for four twelve-frame hires with top packing remored. The basket at the side holds the forest leaves which go to make up the rest of the packing. 


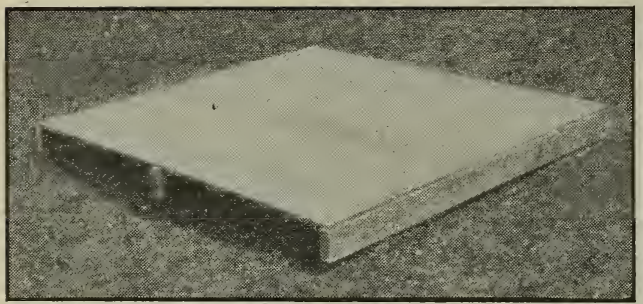

FIG. 3.-Bottom of Holtermann's winter case.

Fig. 3 shows the bottom of the case. Notice there are three one-inch by four-inch foundation pieces. In length each end projects $3 / 8$ inch beyond the platform board, and the outside 1 inch by 4 inch pieces for their entire length also project $3 / 8$ inch beyond the end of the platform boards, giving only $5 / 8$ inch of a nailing surface for the boards resting on them. The object of this is to let the side pieces of the case drop over

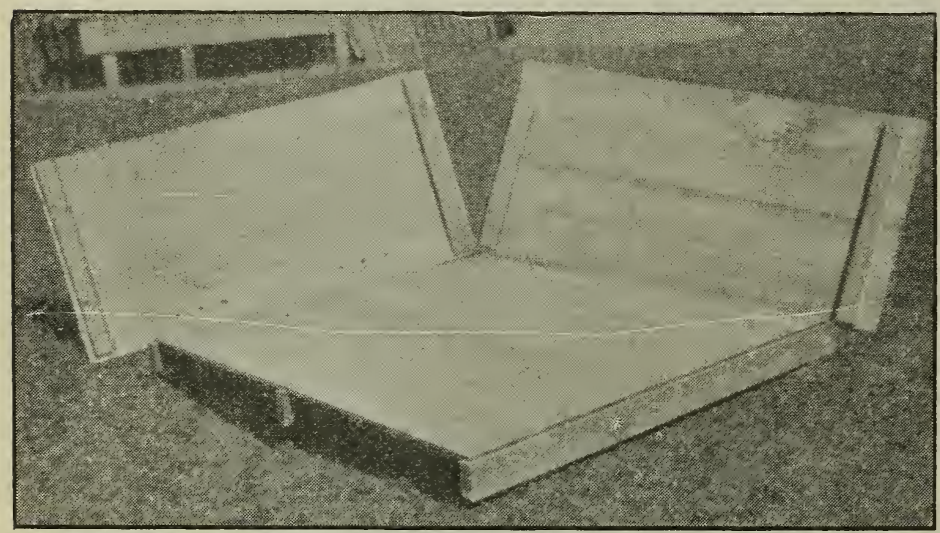

FIG. 4.--The end and sides of a case to assemble. roofing-paper. used for barns.

on the cleats. The latter fit outside of the case. The wooden cover made of one-inch boards is made water-tight by covering with

The winter cases are packed and mounted on concrete blocks not shown. These blocks are 9 inches high, 9 square at the base, and taper to 6 inches at the top. These blocks are a new thing for me; but I have found where the winter case is close to the ground the ice, during the winter, and particularly in early spring, is close to the entrance of the case, resulting in many bees chilling

I have no block nailed to the outside of the case and under the entrance, because it becomes a platform for snow, and tends to conduct snow into the entrance. The case is painted a dark red, with a paint commonly

This arrangement of blocks places the hives a good way from the ground; and unless there is considerable snow the cold winds will sweep under the case, chilling the bottom. The general practice is to place the cases on or very close to the ground; then a slanting board from the ground to the entrance renders it possible for the bees flying out on cool days and falling short of the entrances to crawl in.

The authors have used with some satisfaction the Holtermann the floor of the case, thus shedding water, the sides resting on the projecting platform supports.

Fig. 4 shows the end and side of a case and its relative position on the platform.

Fig. 6 shows the under side of the cover and the method of nailing the cover-boards

scheme of packing hives four in a case. Our case is very similar, the only difference being in detail. The series of illustrations pages 784 and 785 will explain. The crosscleats in Fig. 1 should be 4 inches deep instead of $1 \frac{1}{2}$, as there shown, as it has been

\section{-}

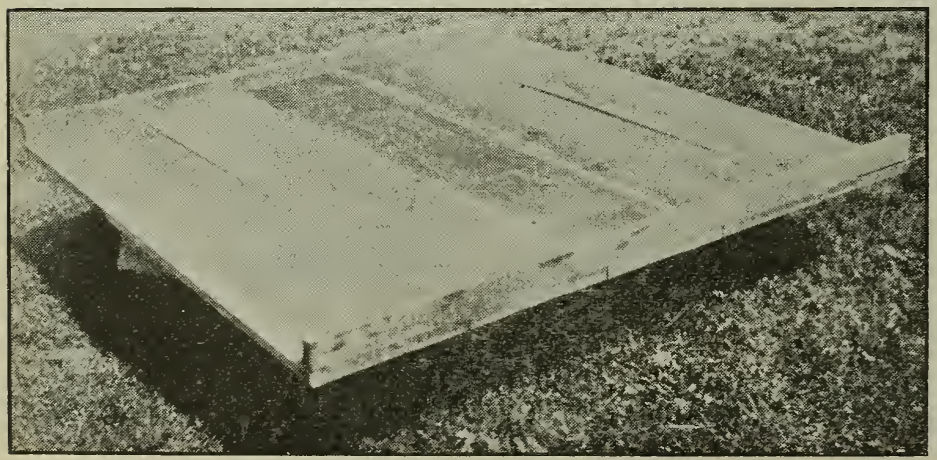

FIG. 6.-The under side of the cover. The cleats telescope over the sides of the case. found quite important to put packing beneath the hive as well as on top and at the sides. The hives are then set in place as shown in Fig. 3, after which the case as illustrated in Fig. 4 is slipped down over the whole. It is then filled with planer-shavings or leaves as shown in Fig. 5. The cover is made up of one large panel, as shown in Figs. 1 and 


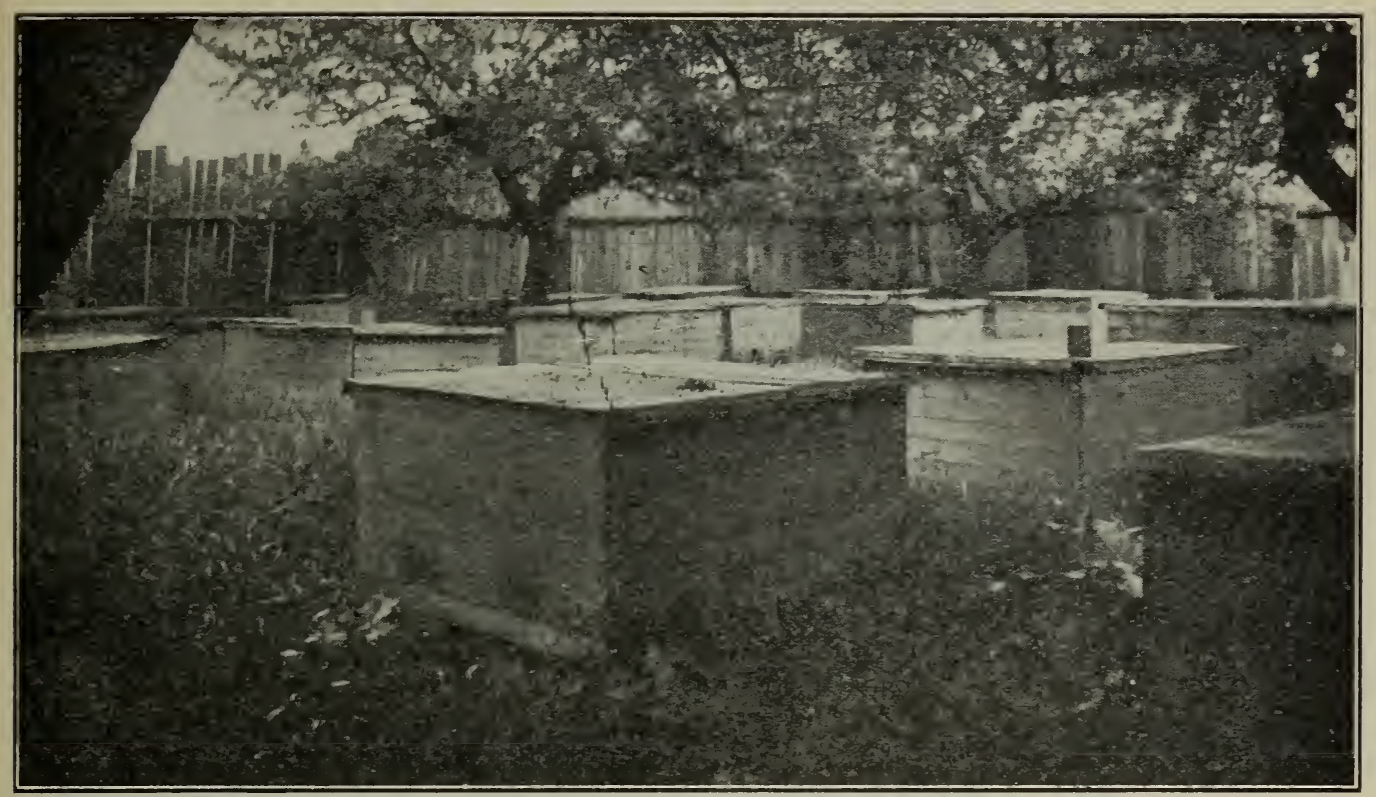

View of one of the Holtermann yards; the colonies are often left in these tenements until clorer bloom.

2 , and then covered with roofing-paper. The four side panels making up the case are beld in place with common wood screws. These can be easily taken out so that the cases can be put in knock-down and carried from yard to yard.

The top of each hive should be covered with a bee-escape board with the bee-escape removed. The hole should be left for the escape of moisture from the center of the cluster, altho we have wintered bees very successfully with the hole closed. A good deal will depend on conditions.

The size of these winter cases will depend on the size of the hive to be packed. We make our cases large enough to provide a six-inch packing space around the four hives placed in direct contact, 4 inches of

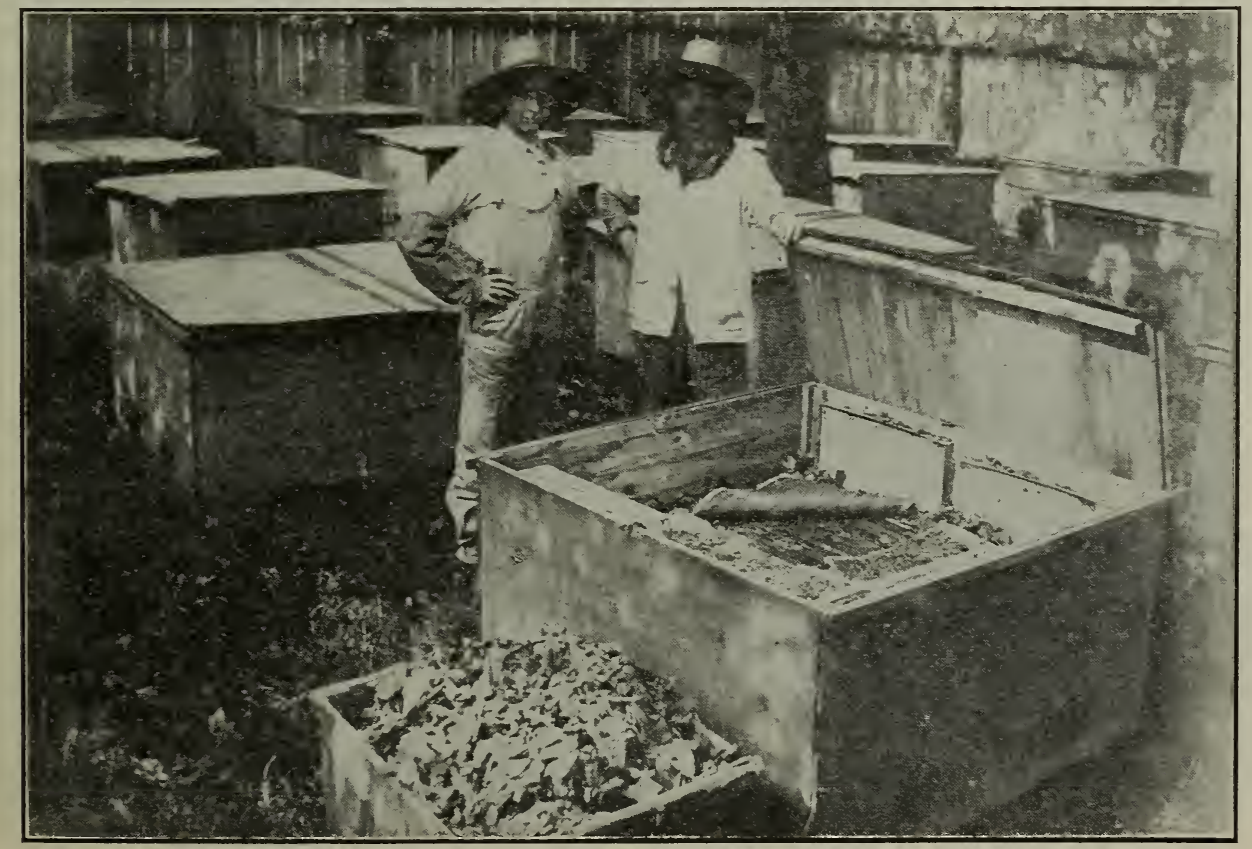

The cover of Holtermann's tenement hive removed, and leaves taken out to show the hives underneath. 


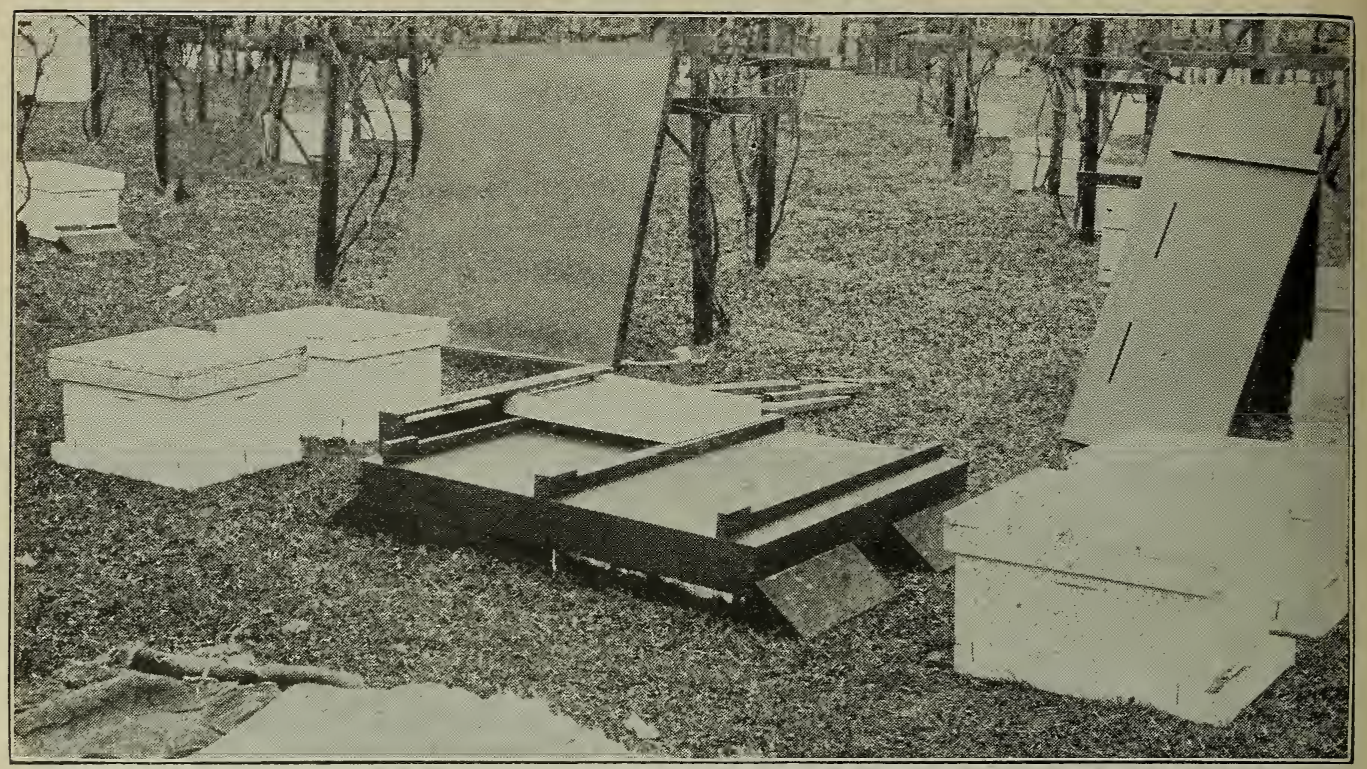

FIG. 1.--Each pair of hives moved out, and the winter-case floor set in place.

packing under the hive and 10 inches on top. This leaves room enough for an upper story if necessary, but it will not provide packing space above the upper story.

It is desirable to have large cushions made of burlap filled with packing, to cover the four hives. These cushions should be large enough to fill the top of the winter case after the four hives are in place. This will render it possible to make an examination

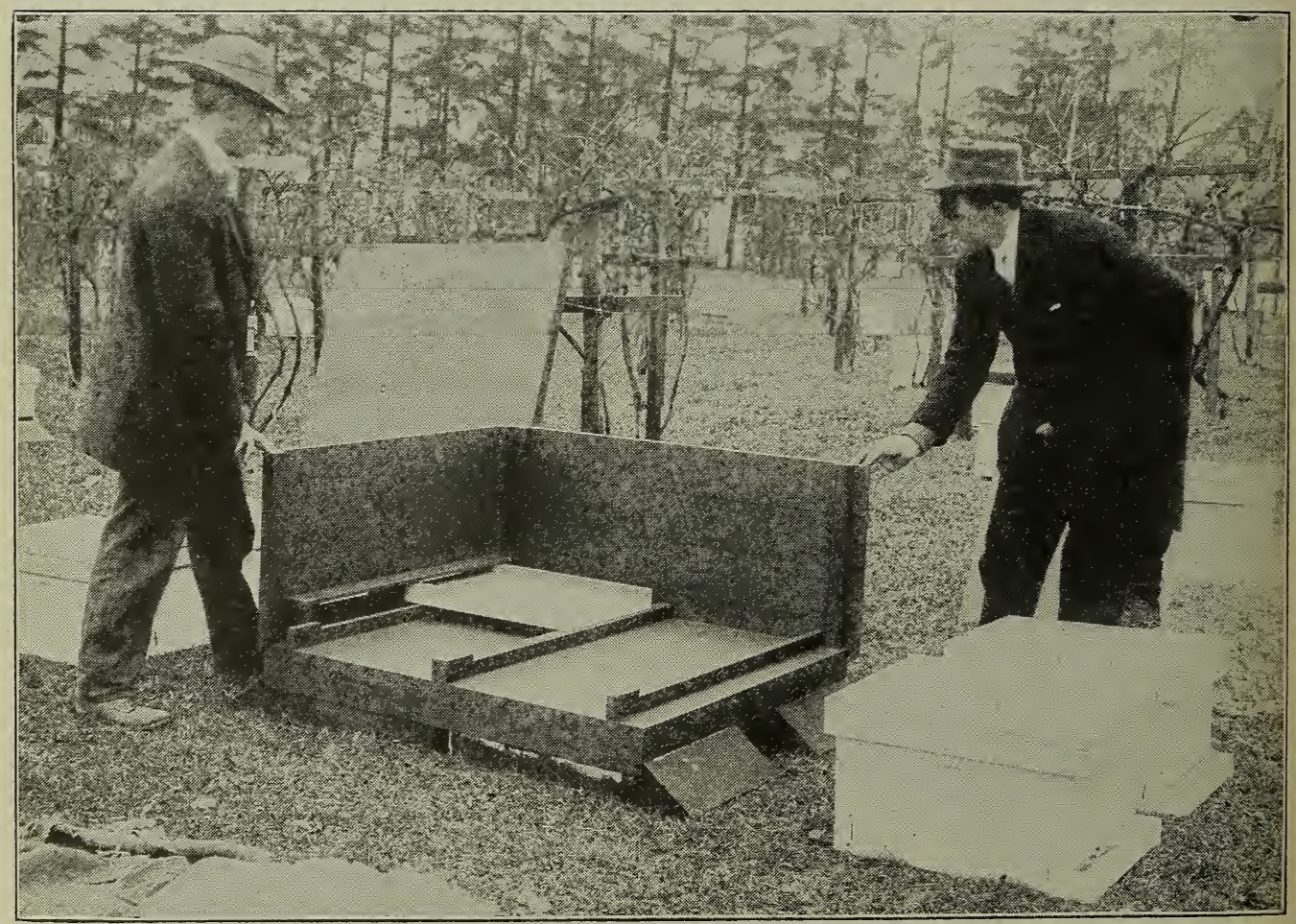

FIG. 2.-Two panels held in position to show the relation of the outside entrance to the hive entrance, and the "bridge" for keeping the packing material away from the entrance. 


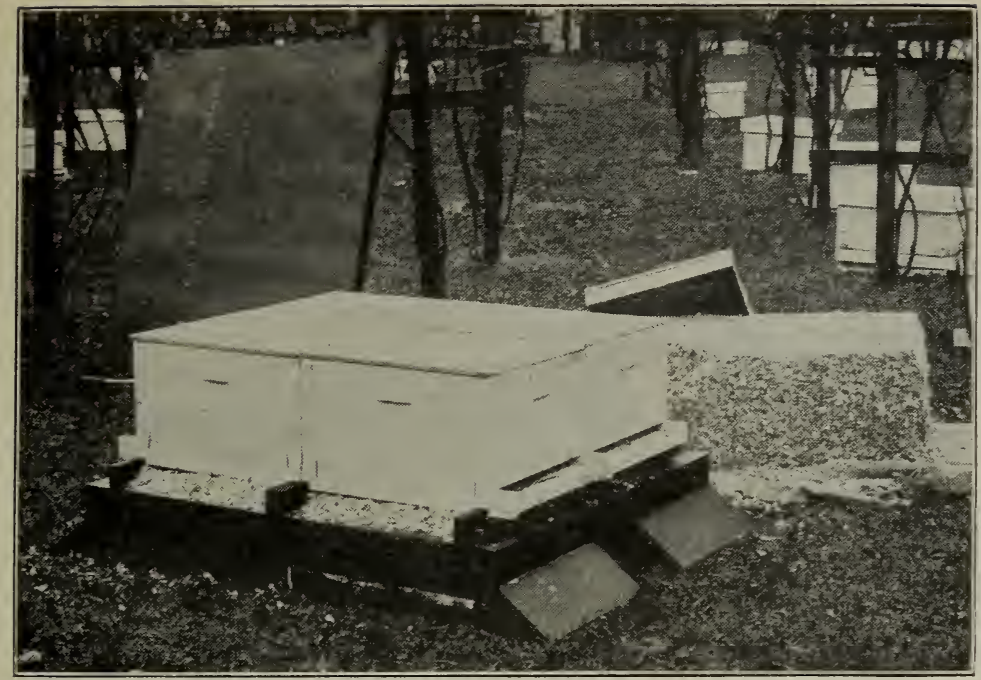

FrG. 3.-The four hives in position, the regular covers remored, leaving only the super corers so that the hives may be close together.

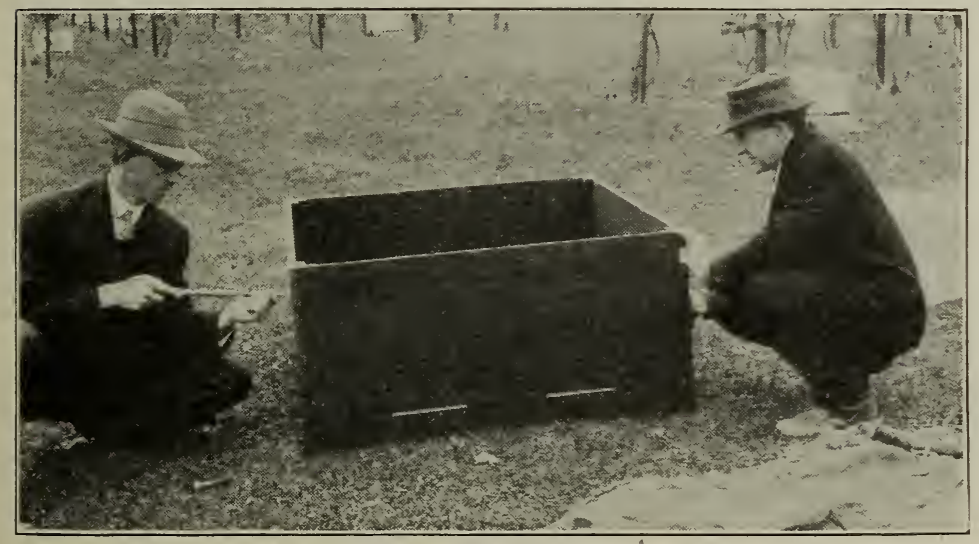

FIG. 4.-An automatic screwdriver for putting in the screws at the corners.

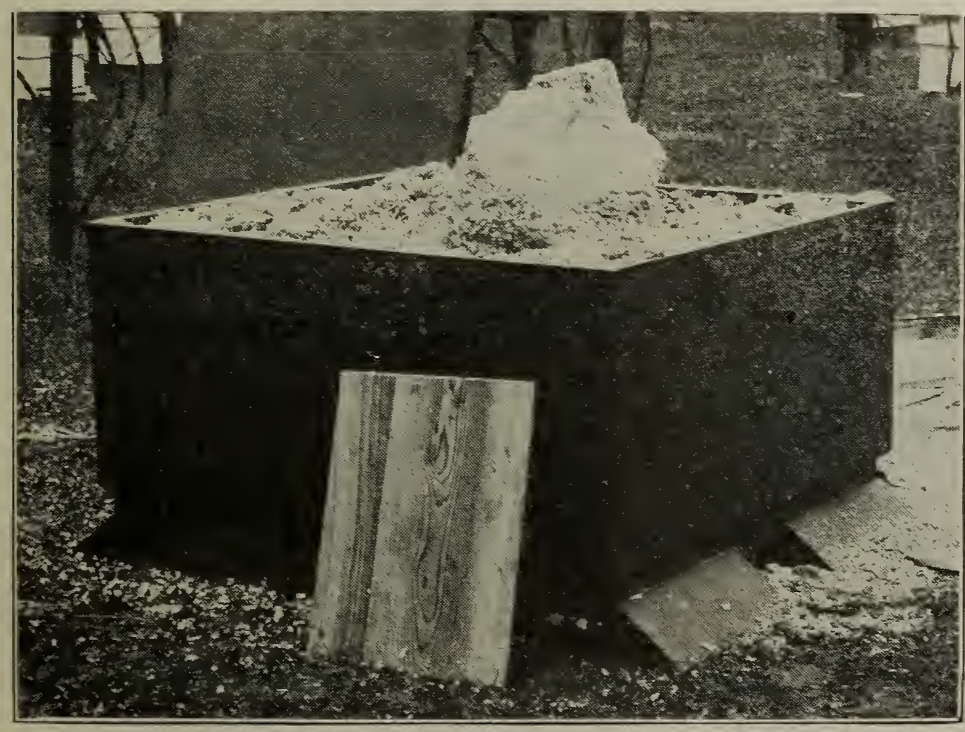

FIG. 5.-The case set down orer the hives, and the packing material put in. of the individual colonies in early spring to see if any of them are running short of stores. or require other attention. When the packing is poured loosely on top one cannot very well make an examination without making use of a scoop-shorel and then providing a series of baskets to hold the packing material in the mean time. When a large cushion is used it can be lifted out at one operation.

THE GREINER TENEMENT HIVE.

Mr. G. C. Greiner goes one step further, in that he winters five hives in a tenement.

It contemplates removing the hives from their summer position to the winter position, so that they can be covered by the tenement sheds. The method of making that shift Mr. Greiner explains as follows:

To explain fully the proper way of moving bees successfully-that is, without any loss-I refer the reader to next page. The upper row shows ten colonies as I work them for extracted honey during the season. They are equally spaced with two feet in the clear between the hives.

The second row shows the same hives after the first shift is made. The four hives, $2,4,7,9$, are moved $t h$ eir width toward the center hives 3 and 8. After two or three days (and, of course, I mean flying days), when these shifted colonies have again become accustomed to their new location, the end hives of each section of five represented by 
the figures $1,5,6,10$, may then be slightly moved toward their respective centers. Under no consideration should these latter be shifted at the same time when the first shift, Fig. 2, is made. That would bring their new stand too near the stands of those just moved, so that more or less mixing up would be encouraged.

The third row shows the ten colonies in position ready for the sheds. If carefully managed, and if the shifting has been done according to the hints here given, they should arrive at these places without the loss of a single bee.

This form of tenement, however, we do not regard as quite the equal of the Bartlett or the Holtermann. Relatively it has a greater amount of exposed surface to the colony. Then, moreover, it is an advantage to place the hives in tight contact in order that the bees may borrow warmth from each other. Mr. Holtermann and Mr. Bartlett, if we are not mistaken, keep their hives
OBJECTIONS

\section{CASES.}

There are two or three objections to these big four-hive winter cases. They involve a large amount of labor in packing and unpacking. The packing material gets all over everything, and at best it is mussy to handle, especially if planer-shavings are used.

The expense of these large winter cases plus the cost of four single-walled hives is about equal to four regular double-walled hives. While the latter may not afford as much protection, the labor of preparing for winter in such hives is almost nothing.

The labor of packing and unpacking in the fall and spring can be very greatly lessened by leaving the packing-cases assembled without taking them apart. All that is necessary in the spring is to lift out the

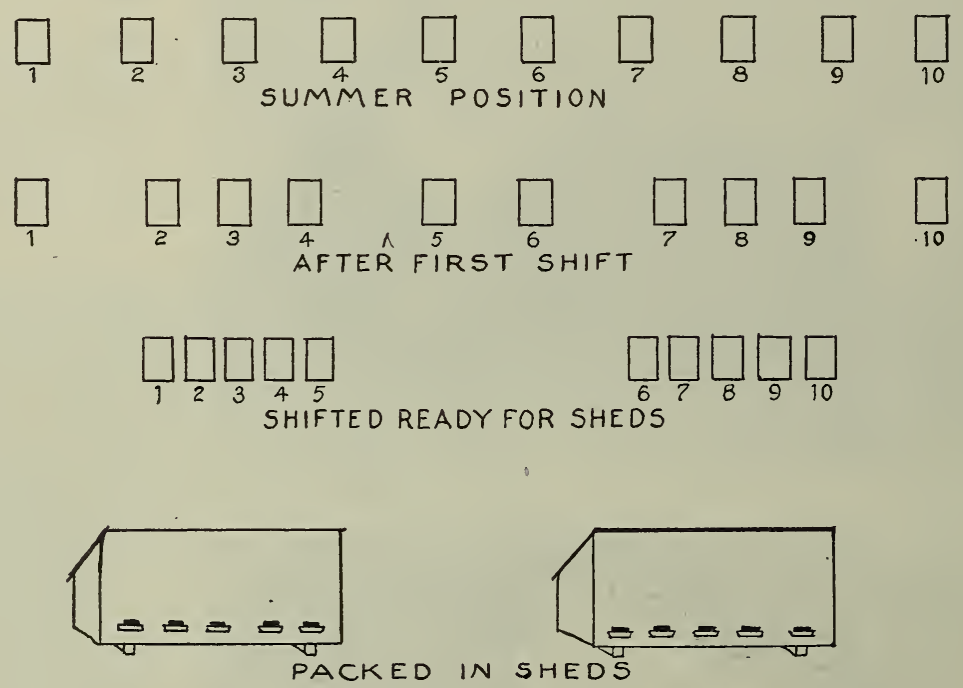

G. C. Greiner's arrangement of hives before and after putting in winter-cases.

running all summer in groups of four a few inches apart. This avoids all shifting from one season to another, and yet allows the owner to have one side and one end as a means of approach in handling. When it comes time to put the bees into winter quarters, there is no lifting nor shifting, except to place the hives in direct contact, when they are ready to pack for winter.

The average beginner in the colder climates will succeed better with the tenement plan of wintering than he would with the inost up-to-date bee-cellar or special repository under ground. hives and put them in their relative positions after the cases are removed. The packing is put back, and the case is moved to the edge of the yard with others. In the fall, on some cool day when the bees are not flying, the cases can be put back where they were the winter previous, the packing removed, and the four hives set down in the case and repacked.

\section{IMPORTANCE OF WINDBREAKS.}

In various places leading up to this, we have mentioned the importance of windbreaks to screen the hives from a strong 
windsweep. A bad location for wintering bees outdoors is on top of a hill with a clear stretch of country for a mile or two in the direction of the prevailing winds. Altho the bees may be nicely housed in doublewalled hives, the high winds during cold or chilly weather may and probably will have a disastrous effect on the bees. Many of them, lured out by a bright sunshine on certain days, will be caught by a chilling blast. They will drop on to the ground; and unless there is a change in the temperature or the wind for a few days they will never come back. On the other hand, a yard screened in by farm buildings, by a growth of woods or dense shrubbery, will be able to withstand the cold much better. While the bees may fly out on bright sunny days, experience shows that they quickly seek the protected inclosure where their hives are, and soon enter.

Likewise there are certain spots in an apiary where some hives are exposed to a long windsweep, while others are in a more protected position. Observation covering a period of years has shown that the latter winter much better than the former.

Again, it has been shown that colonies in single-walled hives may winter comparatively well in a sheltered location, while those in double-walled hives out in the open air will die. To say the least, the matter of protection and the matter of prevailing winds are of vital importance in outdoor wintering.

Windbreaks of woods or dense shrubbery ten or twelve feet high are better than high board fences. Farm buildings like barns and sheds at least twelve or fifteen feet high afford excellent screens. The objection to a high board fence is that the wind strikes it and glances upward, when it is caught by the blast of air from overhead. It may then dive downward and strike the third or fourth row of hives from the fence. Repeated observation has shown that this row of bees may die when other rows winter comparatively well. In the case of woods or shrubbery the wind cannot glance upward and dive downward. The blast filters thru, and by the time it penetrates the inner inclosure its force is broken.

It therefore is of the greatest importance in locating an apiary to find a spot that is protected, not only in winter but in early spring and late fall, and even in summer weather. The author had one apiary located on a side hill and another in the open. The side-hill bees faced the south. During a cold spell in fruit bloom the last-named bees worked freely on the blossoms, while in the yard exposed to the windsweep there was nothing doing. The side-hill bees continued to rear brood, while the exposed bees brought everything to a standstill.

The question has been often asked, "Which is more important-a sheltered location or winter packing?" If the beekeeper can have only one he should select the former; but it is better to have both packing and windbreaks to shut off the prevailing piercing winds. When bees are well packed and are in a sheltered location, with plenty of good stores, the chances of loss will be very slight.

\section{IMPORTANCE OF LETTING BEES FORM A WINTER NEST.}

What is meant by "winter nests"? A space of empty brood-cells in one or more combs, such space approximating the form of a flattened sphere in an ordinary Langstroth brood-nest. These empty cells surrounded by sealed stores constitute the winter nest where bees cluster when conditions are ideal. As the stores are consumed, the number of empty cells increases either backward or forward, but always upward. As a general thing the ball of bees will be located near the front of the hive and regularly over the entrance. As the stores are consumed they move upward and backward; but the cluster in no case extends over the sealed honey when the bees can have their own sweet will.

Very often a well-meaning A B C scholar finds three or four combs in the center of the hive, having, a space of empty cells as large as the hand spread out. He thinks this is all wrong and will remove the combs containing such spaces, and put in their place solid combs of honey. What has he done? He has compelled the bees to cluster upon sealed honey. The cluster is broken up into slabs approximately $3 / 8$ inch thick, each slab of bees separated by approximately an inch of solid honey. Instead of having one solid cluster separated by only the midrib of the combs, he has made a series of clusters, each within itself trying to maintain its own body heat but at very great disadvantage. 
To illustrate: Two people on a cold winter's night require less bed clothing than one person would in the same bed. Suppose that, instead of having those two bed-fellows separated from each other by only their night clothing, we have a slab of metal or even wood between them. If they are compelled to place their warm bodies in contact with that cold surface they lose a great deal of their body heat because the cold surfaces carry away (that is, dissipate) the warmth.

There is precisely that condition when combs of sealed honey are set down into a bunch of bees. They are compelled to divide up into four or five clusters. The result is, that colonies tampered with in this manner perish or come out in the spring very weak because of their inability to maintain the requisite temperature. Where outside bees become stiff with cold they can not long endure that condition.

If a colony is fed gradually during October and November they will form this winter nest. If, however, they are on the verge of starvation and they are fed $30 \mathrm{lbs}$. in a single night toward the last end of the fall, or when it is quite cold, they do not have the opportunity of forming this nest. They will carry the syrup down while it is hot; then for a few days after that, if it is so they can fly, or, rather, so the cluster can move freely about the brood-nest, they may or may not rearrange the stores. The cluster, when it actually forms up for winter, will be practically one homogeneous mass of bees separated by only thin cell walls and the midribs of the combs.

If anybody doubts that bees try to have a winter nest, let him break into several clusters of bees when the temperature is down to about 5 above zero, in an outdoor colony. The author has done this repeatedly. If the arrangement of combs has not been disturbed in the fall, we will probably find the bees tightly jammed into the cells. And, again, we will often discover as we go over our colonies in the late winter or early spring, that some of them have actually starved to death. In all such cases we will see dead bees tightly packed in the cells of the winter nest, and a solid mass of bees between the several spaces between the combs. Starvation is often due to the fact that cold weather has continued so long without a let-up that the bees are left high and dry, so to speak, in the center of the winter nest. They actually starve, notwithstanding that sealed honey is within two inches of the cluster. The long-continued cold has given them no opportunity to warm up and shift the cluster over in contact with the sealed honey. We have seen this condition almost every winter in our yard.

Still again, we have often found dead colonies where some of our newer men in the bee-yard had disturbed the combs, putting a solid comb of honey down thru the center of the winter nest. This made two bunches of bees; and both, being too small, died.

When it comes to indoor wintering, especially where the cellar temperature does not go below $40 \mathrm{~F}$., a winter nest is not so vitally necessary. But if the temperature goes down below 40 , then the absence of a winter nest may mean the death of a colony.

Nature has worked out this problem of wintering bees; and when the bee man tampers with her plans he tampers with his pocketbook. While he can do certain things contrary to nature, he can not interfere with her plan in the arrangement of the stores.

\section{NON-POROUS COVERS OR ABSORB- ING CUSHIONS.}

There has been considerable discussion in the bee-journals over the question of whether there should be loose porous absorbingcushions or other material placed above the cluster of bees so that the moisture from a cluster can pass up into the packing, or whether, on the other hand, the top of the hive should have a thin board or super cover on top. In the milder climates it seems to be pretty well proven that the wood cover over the bees brings the bees thru in better shape. In the colder climates, such as Northern Michigan, Canada, Northern Wisconsin, Minnesota, and Northern New York, a porous covering seems to have somewhat the preference, altho there are advocates of the solid-cover principle in these localities. If there is danger of the entrance becoming closed by deep snows or ice for weeks at a time, upward ventilation thru porous packing would probably be safer, for bees must have air.

When the top of the hive is closed tight, the moisture from the bees collects on the under side of the cover, drips down, and passes out at the entrance. The absorb- 
ing cushions, on the other hand, in our climate often become damp and soggy before spring. When in that condition they will sometimes freeze; and, so far from being a protection, they are a positive detriment. But where the climate is cold and dry, temperature going down to 10 or 20 below zero, the absorbing cushions will be less damp than in a milder climate subject to more or less humidity on account of moist or rainy weather. When absorbing cushions are used, there must be a space of at least one inch over the top of the packing. In addition, there should be ventilating-holes so that the moisture can escape. But these holes should be so situated as to prevent rain or snow from blowing in.

When non-porous covers are used, it takes less packing than when the absorbing plan is employed; but the entrances must be kept clear. If one has not decided which scheme to adopt, let him try the two side by side. The author has tried sheets of glass the exact size of the tops of the hives. These are imbedded in putty, making a tight sealing between the glass and the hive. The packing material is then placed on top. We have wintered most successfully anywhere from one to a dozen colonies, during successive winters, under these sealed glass covers-not because there was any merit in the glass, but because we could better observe conditions. We could never see that this moisture that collects and drops at the corners ever did any harm.

\section{BEST KIND OF PACKING MATERIAL.}

Wheat or oat chaff, preferably the former, has been recommended as being the best material to use; but since the advent of new methods of separating the chaff from the wheat by means of a suction-fan, it is not now easy to obtain the chaff. Dry forestleaves, plenty of them, or planer-shavings are recommended. Cut straw does very well. In milder climates, two thicknesses of old carpeting or burlap sacking will do.

In colder climates not less than six inches of packing should be used. If the absorbing schome is used, eight inches will be better.

\section{SIZE OF ENTRANCES.}

It has been shown that the entrance should be reduced down so as not to be larger than $3 / 8 \times 8$ inches; and in the case of some of the smaller colonies it would be better to have the openings $3 / 8 \times 3$ or 4 inches. In all cases of outdoor wintering it is important to keep these entrances clear, and it may, therefore, be necessary to rake out the dead bees now and then which may accumulate: for should the entrance become clogged the death of the colony must follow.

WINTER STORES - QUALITY AND QUANTITY.

Having now considered the inclosure, or the hives themselves, for holding a colony for outdoor wintering, something should be said about the quality and quantity of the stores. It is fair to say that bees outdoors consume nearly twice as much as those indoors; but it is argued, on the other hand, that while the former consume this larger proportion of food they keep stronger numerically and will be in better condition at harvest time than those wintered indoors on half the amount. The opinion of the beekeeping world is somewhat divided on this whole question; but certain it is that he who winters outdoors should provide twice the amount of stores, or at least see that his colonies, after the main brood-rearing has ceased, have from 25 to $30 \mathrm{lbs}^{*}$ of sealed stores. The beginner will need to weigh up his combs for the first colony or two, to he able to estimate approximately the stores of other colonies.

As a general thing an eight-frame colony should be crowded on six combs, and a ten on an eight. The division-board must be shoved up close to the frames, and empty space, if any, filled with leaves or other packing material. It is desirable that bees have stores given to them at least a month before they go into their winter sleep, so they may have a winter nest around which will be sealed stores within easy reach. As to quality, there is nothing better than good honey. If there is a shortage thick granulated sugar syrup should be given. It is believed by some good beekeepers that honey will go further pound for pound than syrup. Honey is a natural food, and, besides, contains other food elements such as protein for the bees. Many beekeepers pursue the

* In very cold climates from 30 to $40 \mathrm{lbs}$. may be needed. 
policy of extracting all the honey and feeding sugar syrup. At the present price of sugar and honey one can not afford to do. this.

Altho a colony may have sufficient stores by the middle or latter part of August it may run considerably short by the first of November, especially if a fall flow induces brood-rearing. In any case it is well to go over the colonies just prior to the final preparation for winter, and make sure they do not run short. This is very important as many a colony has been lost thru starvation when their owner supposed they had enough to last till spring.

\section{BEES FLYING OUT ON CHILLY OR COLD DAYS AND APPARENTLY DYING ON THE GROUND.}

In a late fall or early spring, bees will very often fly out on a bright day, whether it is very warm or not. They alight on the ground or some object, become chilled, and apparently die. Cases are on record where bees have flown out, alighted on the ground, become still and cold, and were apparently dead. There was one instance in particular of this kind where thousands of bees had flown out and lay on the ground apparently never to return. A cold rain set in and then it began to freeze, followed by some snow. This freezing weather lasted for a couple of days. This was followed by warm sunshine, when, wonderful to relate, those dead (?) bees came to life, took wing, and flew back to their hives. Other authentic reports, showing something similar to this, have been sent in. It seems almost unbelievable, but the facts are, that bees can fly out, alight in the snow, chill thru, and seem to be dead. If the snow is not too deep it melts away so that the bodies of the bees can become warmed up, when they will often revive; they always revive, if it is warm enough, and they have not been chilled too long.

Beekeepers have written in at many different times, fearing that their bees had flown out in late fall, and, becoming chilled on the ground, were utterly lost; but when a warm day comes on a little later, these bees, if it has not been too cold, will return to their hives.

Old Dame Nature seems to have made some wonderful provisions to preserve beelife. We are therefore constrained to be- lieve that bees can stand, under some conditions, chilling cold for some days without killing them. See page 803.

WINTERING IN CELLARS.-In discussing methods for wintering bees outdoors, some principles have been given that apply to cellar wintering. In the first place, bees do not require more than 10 or $15 \mathrm{lbs}$. of stores per colony, altho it is an advantage to have more, because it is diffcult to feed bees in the spring. With a strong force of young bees and good stores one is well equipped to winter bees in the cellar, provided he has reasonable control of temperature and means for ventilation. Before we go into the general subject of cellar wintering it is, perhaps, important to specify two or three

\section{IMIPORTANT REQUISITES FOR A GOOD BEE- CELLAR.}

First is the control of temperature. The ideal temperature is about 50 degrees $\mathrm{F}$. It may go up to 55 or 60 or it may go down to 40 ; where possible the extreme should not exceed these figures. A greater variation early in the winter does less harm than later. As the winter approaches spring it becomes increasingly important that the temperature be held as nearly as possible at 50 . By 50 is meant the reading of a tested thermometer. Cheap thermometers are often worthless for cellar use. If the temperature goes too high the windows should be opened at night-never in day time-to let in air, and closed just before daylight. If it becomes too cold, so the temperature goes down below 40, or near freezing, artificial heat must be used. To that end a small stove connected with a chimney may be used to advantage. Build just enough fire to raise the temperature to 50 or a little more. As a general thing it will not be necessary to have a stove; for enough bees in the cellar will keep up the temperature by their own body heat. If a repcsitory during the winter can not be kept cool enough by opening the windows at night, and closing them in the morning, it goes to show very plainly that the beekeeper should adopt outdoor wintering, as his climate is not cold enough to keep a cool cellar.

Many modern homes are now being heated with a furnace. If the general climate is cold enough, a room in the cellar shut off 
from the furnace-room by means of a brick wall and a door will afford an ideal place for wintering bees. During extremely cold weather the furnace-room door may be left open part way. This will modify the temperature and at the same time afford excellent ventilation.

Some of the best beekeepers in the country, including Dr. C. C. Miller, leave the bee-room door open, and then open the door or a window in the furnace-room to outdoors. In this way the finest kind of ventilation is secured. After the fresh air goes into the furnace-room, the temperature is modified; and when it finally works its way into the bce-room the bees have warm fresh air and plenty of it.

But a bee-room off from a furnace-room is not an ideal place for wintering bees if the climate outside is such that it may be warm, and then below freezing a part of the time during mid-winter. As already explained, the indoor plan should never be followed unless the temperature in the beecellar can be kept down to a point as low as 55 degrees F. Sixty will do no harm for a few days provided there is a large amount of ventilation.

If the door leading from the bee-cellar into the furnace-room is left open, of course it would let in some light. With plenty of ventilation this may not and probably will not do much harm. If it is discovered that the bees fly out into the furnace-room the windows to that room should be darkened.

A further advantage of a furnace-room next to the bee-room is that it keeps the whole cellar dry.

\section{VENTILATION.}

The question of air change depends almost entirely on the temperature of the cellar and its control. If the mercury can be.kept uniformly 45 thruout the entire winter with not more than two or three degrees variation it may be said that very little ventilation of the cellar will be needed; but if it has a tendency to go to 55 or more, then down, and especially if the bees begin to roar, showing uneasiness, it is very important to let in large quantities of fresh air by opening the cellar-windows at night, or thru sub-earth rentilators, as used by some. But if windows are opened they must be closed before daylight in order to shut out light. Some have found it better to let fresh air into an outer cellar and from there into the inner cellar where the bees are. It has been argued that air directly from outdoors has a tendency to stir up the bees; yet we have not found it so. Our experience is that, when bees are uneasy by being too warm, it is also because the air is foul. The obvious remedy is to let in cool air from the outside to reduce the temperature, and at the same time supply fresh oxygen.

Cellars should be large in proportion to the number of bees kept in them. A room 12 by 12 , and 7 feet deep, will winter 50 colonies much better than 100 . Ten colonies will come thru in better condition than 50 . The reason of this is simply a question of pure air. In some cases one may have access to a larger cellar that opens up into other compartments. If these compartments are not used, the doors should be left open so that the air of the entire cellar can be available for the bees. A bee-cellar only 10 by 10, 7 feet deep, should not be used to winter more than 100 colonies, and will give better results with 50 . A larger number may, of course, be crowded in, and will winter properly if enough ventilation can be given both day and night, keeping the temperature down to about 50 .

Where there is a furnace-room off from the bee-cellar room, more colonies can be accommodated in a given space, provided there is a large amount of ventilation secured in the manner explained. When air from outdoors is let into the furnace-room, it passes, after being warmed, into the beeroom with the door opened.

\section{SUB-EARTH VENTILATORS.}

The sub-ventilator should be from four to six inches in diameter, made of glazed tile, about 100 feet long, and from four to six feet below the surface of the ground. The outer end is brought to the surface of the ground, and the inner opens near the bottom of the cellar. Cold air entering the ventilator is warmed in passing under ground and until it enters the cellar, not only supplies the latter with pure air, but at the same time raises its temperature several degrees.

Sub-earth ventilators are not used to any great extent at this writing. The plan of using a furnace under the house, placing it in a room by itself adjoining the cellar, is preferable, provided, however, that outdoor 
air is allowed to go into the furnace-room from a door or window.

SPECIAI REPOSITORIES OR A CELLAR UNDER THE HOUSE.

Ordinarily a special repository built for the purpose is better than a cellar under a house or under a living-room. A repository should be wholly under ground, with about two or three feet of packing material on top. A hatchway on one side, with steps, will provide for putting in and removing the colonies or the repository can be built in a side hill. The advantage of the special repository is that the temperature is more uniform. A regular cellar under a house usually has about two feet of wall above ground, with one or more windows and about four feet under ground. The exposed outside portion of the wall is subject to variations of temperature.

The difficulty of ventilating a special repository is greater than that of a house cellar, especially if a furnace is used in an outer room. The ideal place for wintering bees indoors is a house cellar adjoining a room with an ordinary furnace for heating the upper part of the house, the same as Dr. Miller uses; but a house cellar with a furnace in an adjoining room should not be used in a climate that warms up every few days so that the temperature of the cellar varies from 40 to 65 or 70 . In such a cellar it will be almost useless to attempt to winter bees. It will probably be better to winoutdoors in single-walled hives, or, better yet, in double-walled hives or winter cases, the same as described a few pages back.

Objection has been raised that the noise overhead in the house cellar disturbs bees: but no absolute proof has been adduced to show this. The author has had some excellent results in wintering in a bee-cellar under a machine-shop where rumbling machinery every now and then was accompanied by the bumping of heavy castings. We have never been able to discover that this noise interfered with good wintering in that cellar.

But where a house cellar is damp, too small, too cold, too warm, or too something else, it may be well to construct a special repository for the bees. This may or may not be located in a side-hill. A little later on will be given illustrations of cellars used by some extensive beekeepers.
ARRANGEMENT OF HIVES IN A BEE-CELI,AR.

They may be piled up one on top of another in such a way that any one can be removed without disturbing more than the one or two above it. The reason for this will be apparent later. Strong colonies should be put in first, and placed on a $2 \times 4$ scantling. On top of these may then be placed the weaker ones. This has no special advantage except the convenience of having the heavy ones at the bottom and the light ones on top. The entrances of the hives should be left about the same as they were during the late fall $-3 / 8$ deep by 8 inches wide. Some consider it essential to remove the bottom of the hives entirely. Others consider it good practice to have a deep space under the frames by raising the hive off the bottom in front and supporting it there by a couple of blocks. But some disastrous results in wintering seem to show $u s$, at least. that too much bottom ventilation is bad unless the cellar is kept at a temperature of about 60 and thoroly ventilated. The bee is essentially a warm-blooded animal. We have uniformly secured the best results with a reasonably small entrance, or one about the size used during the fall or late spring. The larger the colony, of course the larger the entrance that will be required. In the case of a strong populous colony the entrance should be $3 / 8$ deep by the full width of the hive. The colonies of medium strength should have the entrance reduced accordingly.

INSPECTING THE BEES DURING MID-WINTER; AND DEAD BEES ON THE CELLAR BOTTOM.

Experience has proven that, when the temperature is maintained at 50 degrees, very little attention need be paid to the bees, especially in the fore part of the winter. But during the last month or two of confinement the bees require watching more carefully; for if they get to roaring many of them will be lost. It then becomes necessary to make frequent examination to determine the temperature and the quality of the air. It will also be found, perhaps, that a good many dead bees will be found on the cellar bottom. While this is not necessarily a cause for alarm, it is not as it should be. If the cellar and temperature are right there will be very few dead bees; but if they accumulate, their dead 
bodies should not be allowed to stench the living bees, but should be swept up perhaps every two or three weeks and removed.

A disposition to roar should be met by more ventilation, and at the same time the temperature should be reduced. If all the colonies in the cellar should become uneasy during mid-winter it is evident that something must be done at once or the whole lot of bees will be lost. They ought not to become uneasy until late in the spring. If they can not be quieted by infusion of fresh air it may be best to give the uneasy colonies a flight on the first warm day by setting them outdoors and letting them stay there for 24 hours or until they can clean themselves. Dysentery or diarrhea in the bee-cellar is generally the result of too much cold air or too high a temperature, either of which will induce too large a consumption of stores; and where bees are not able to void their feces, the intestines become distended, resulting in purging. A colony so affected should be removed as soon as a warm day comes and given a flight, when it may be put back.

WHEN TO PUT BEES IN THE CELLAR, AND WHEN TO TAKE THEM OUT.

This is a question that depends entirely on locality. Most bees go into the cellar in the northern states anywhere from the last of November until the first of January; but usually it is advisable to have all bees in before Christmas. As to when the bees should be taken out of the cellar, authorities differ. Some set them out in March, and then put on winter cases. Others believe it is better policy to keep bees in late or until the last cold weather is past, and then set them out. The authors advise taking the golden mean, waiting until the time natural pollen comes, or, in our locality, soft maples bloom. But when bees are uneasy in the cellar it is advised to set them out earlier than would be done otherwise.

TIME OF DAY TO TAKE BEES OUT.

The usual plan for taking bees from a cellar in the spring is to wait until fairly settled warm weather has come, and then on some warm bright day all the colonies are removed at once. The difficulty with this method is that the bees are likely to become badly mixed, owing to their eager flight without carefully marking the location. This results in a bad state of affairs, and should be aroided. Another method followed to some extent is to put some of the colonies out during an evening when all appearances indicate that it will be warm and bright the next day. A third of them, perhaps, are taken out, and these fly quite well the next day. The next evening another third is removed, and the last third the night following. The objection to this plan is that the bees removed first get to flying well and then start to rob colonies taken out later, thus making a fearful uproar.

Mr. E. W. Alexander, in Gleanings in Bee Culture, page 286, Vol. XXXIV., gave a plan open to none of these objections.

"First, get everything ready for a big job, and watch the weather closely, especially after a few nice days, for it is quite changeable at this time of the year. Then when the wind gets around in the east, and it commences to become overcast with heavy clouds, and has every appearance of bad weather for the morrow, we commence about sundown and carry out all our bees-yes, even if it takes not only all night but into the next day; and if it commences to rain before we are done, all the better, for we don't want any to try to fly until they have been out two or three days if we can help it. By this time they will have become nice and quiet; and when a fair day arrives they will commence to fly, only a few at a time, and get their location marked, so there will be no mixing up or robbing, because they all have their first fly together. Then when the day is over we find by examining our hives that nearly every one has apparently retained all its bees."

The plan here given avoids "drifting" on the part of the bees. See Drifting in its alphabetical order. When bees drift from one hive to another it means that the strong become stronger and the weak weaker. Morenver, there is danger of robbing. When bees are set out two or three different times, those first set out having marked their locations, and having quieted down, are quite liable to rob those set out afterward, because the last lot of bees are more or less demoralized until they can mark their locations and recover from their excitement. 
SHALI M'E PUT THE COLONIES BACK ON THE OLD STANDS IN THE SPRING?

After bees have been shut up in the cellar over winter they can be placed back on the old stand they formerly occupied or they can be put anywhere in the yard, or, in fact, anywhere on the premises. Bees after long confinement apparently lose all knowledge of their former location, and will stay anywhere they may be placed. If one finds it necessary or desirable to move his bees a short distance, it is a good time to wait until they are taken out of the cellar the following spring, when they may be placed anywhere.

\section{CARRIERS FOR HIVES.}

A wheeled vehicle is not as good for moving bees in and out of a cellar as some sort of carrier.

A wheelbarrow, if the paths are smooth, does very well. If the cellar steps are not too steep, a plank runway can be provided so that the load of bees can be delivered into the cellar itself. There are several good carriers and we here show a few. For hives without projections a pair of U-shaped wires bent to form a sort of bail with hooks on the ends answers nicely. The bottom hooks eatch on to the bottom of the hive.

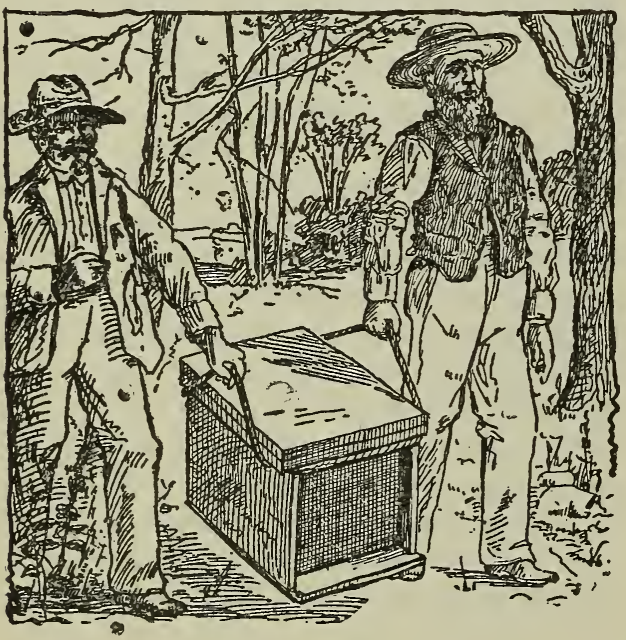

Miller's rope carrier.

Dr. Miller uses a rope as seen in the next cut. Of course, it can be used only when the hives are cleated at the ends.

Where hives are carried any distance, and help is scarce, the yoke can be used. One man can carry two heavy hives quite easily, descend cellar-steps, and go thru doors. The only objection is the rigging, and loading and unloading.

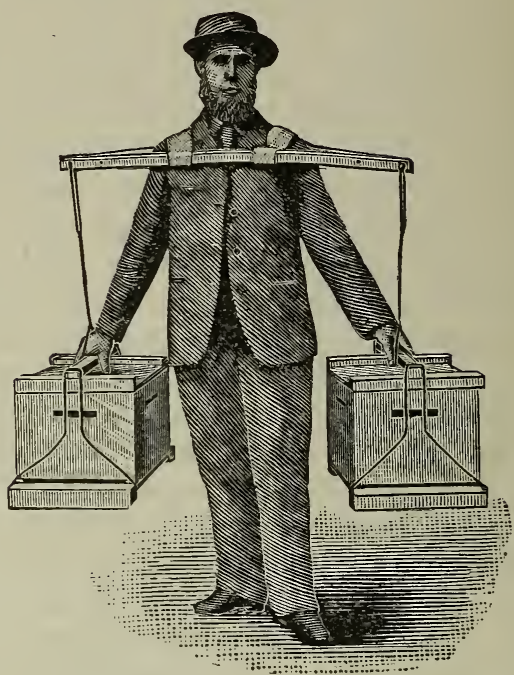

McFarland's neckyoke for carrying.

The particular form of hive-carrier preferred by many is the one described by Mr. G. C. Greiner and several others in Gleanings in Bee Culture. This is presented in the following illustrations.

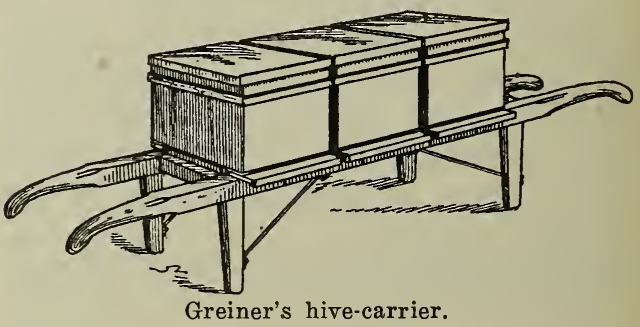

Two men can easily carry as many as five hives in this way. Where the cellar is located some little distance from the apiary this is the most convenient method yet devised.

Instead of constructing a regular hivecarrier as shown, it is possible to get along quite well by the use of two poles, as shown by illustrations on next page. These should be about two inches square and six or eight feet long. . They are placed on the ground in a parallel position, and as many hives placed on them as can be carried; perhaps three hives would be all that could be managed easily with the poles. It is much more satisfactory, however, to have the poles nailed together with a framework, making a regular hive-carrier. 


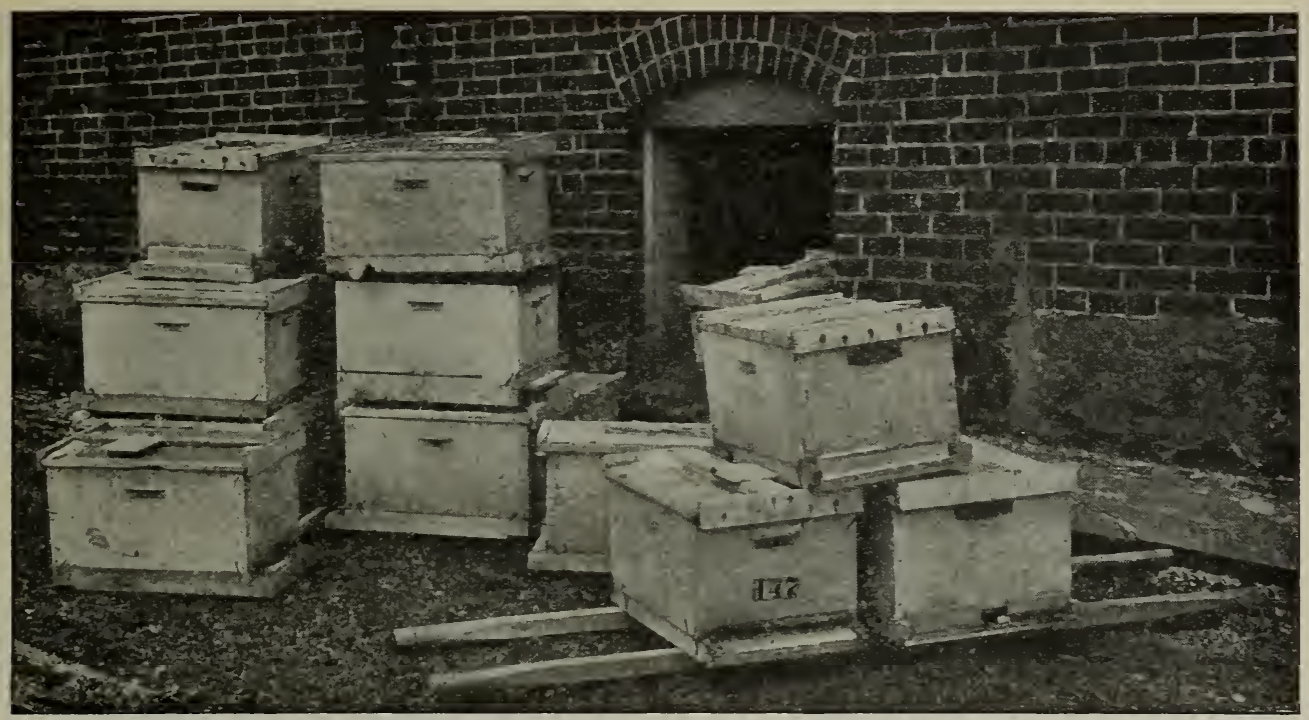

Carrying hives from the cellar at "The Home of the Honeybees."

A FEW CONCIJUDING FACTS ON INDOOR WINTERING WELL TO BEAR IN MIND.

1. Too low a temperature (below 40 Fahr. if long continued) in a bee-cellar will kill bees.

2. An excess of dampness in a cellar does no harm, necessarily, providing that the temperature is high enough, not lower than 45 or 50.

3. A low temperature, lower than 40 Fahr., and an excess of dampness, is a very bad combination, and will kill bees almost invariably. A high temperature, above 50 , but little or no ventilation, will cause the bees to be uneasy. If the temperature is above 45 there should always be some ventilation. It should be continuous rather than intermittent at night, but better intermittent than no ventilation.

4. Bees can be wintered in a cellar without much ventilation, providing the temperature is held uniformly between 43 and 45 , but they will winter much better if there is some fresh air and a temperature of 50 .

5. A cellar may be too dry, for bees in a cellar require a little moisture. If there

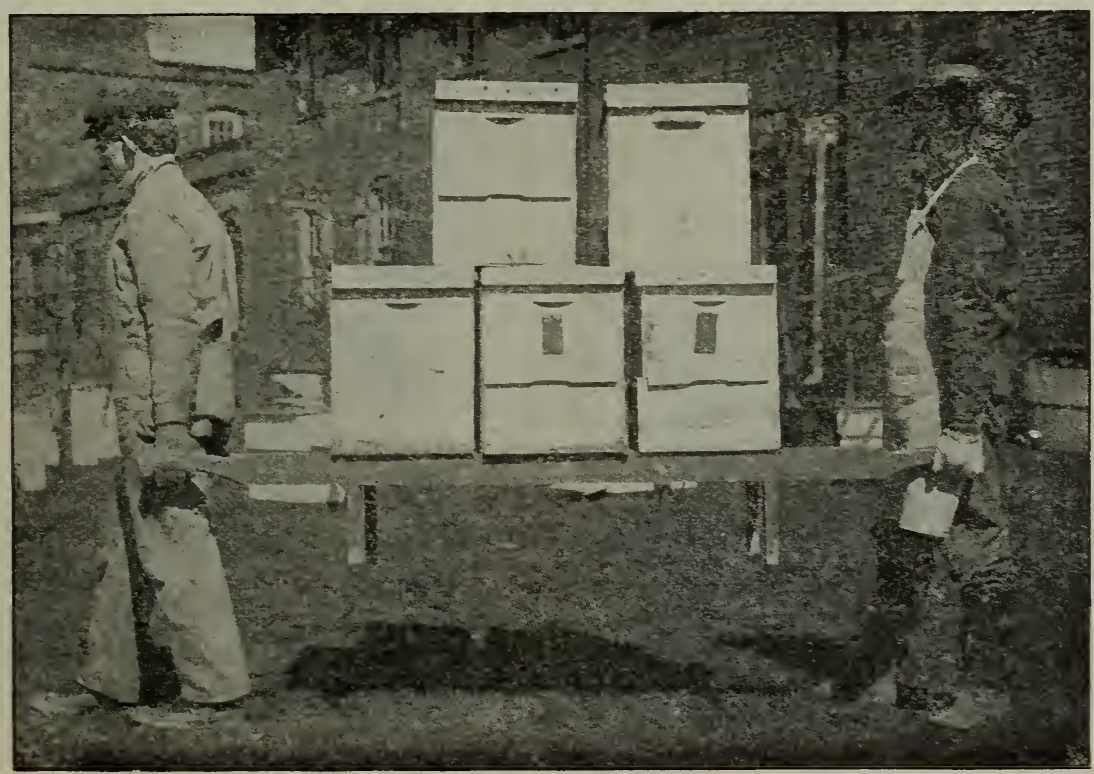

Carrying hives on two poles. 


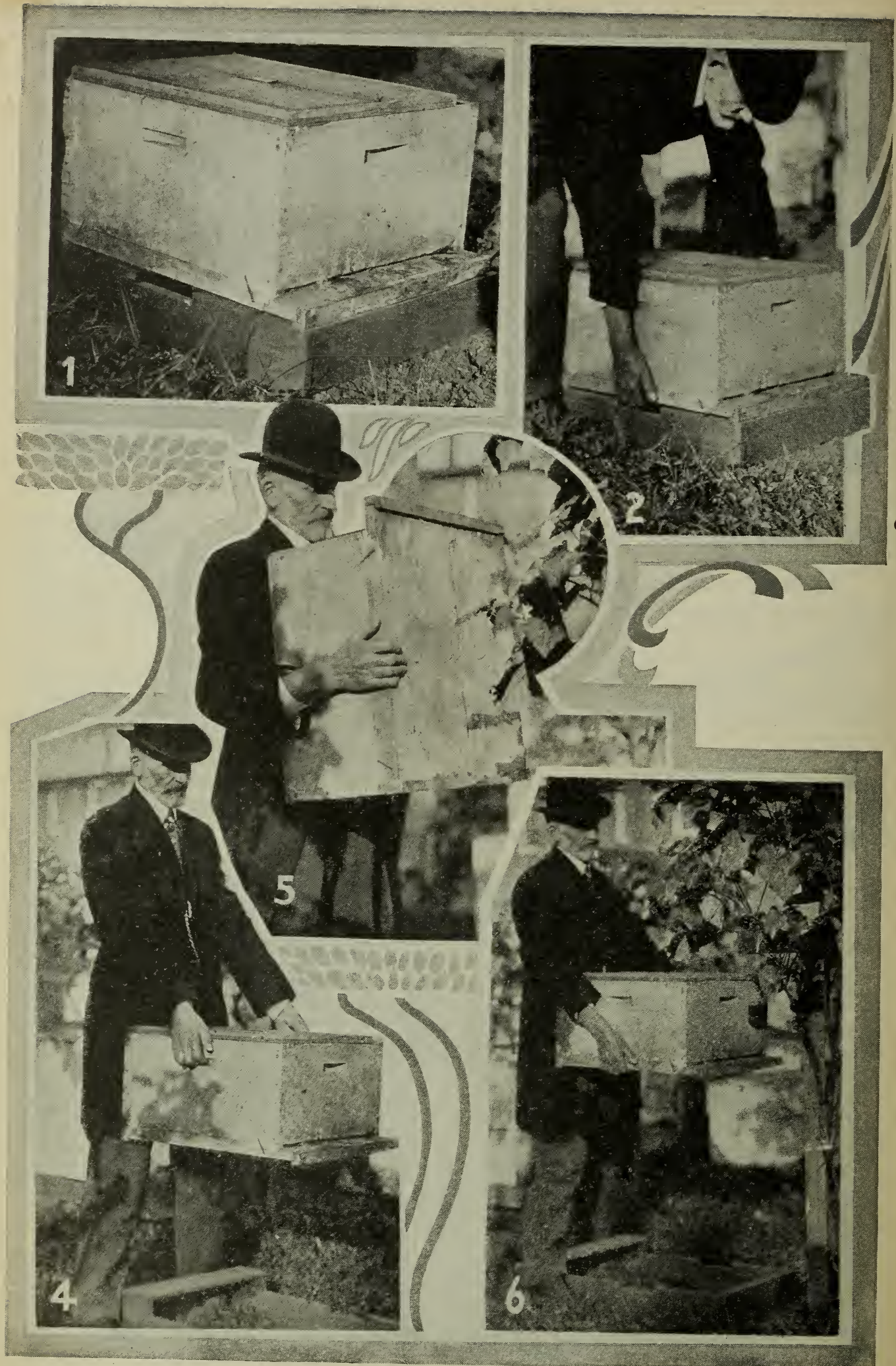

How R. F. Holtermann carries his twelve-frame hives into the cellar. He lifts the hive as shown in Fig. 2, and then brings it up against his body as in Fig. 5 . Positions in 4 and 6 put an unnecessary strain
on the back, and interfere with walking. 
is no moisture, possibly a wet sponge should be put in front of the entrances of some colonies.

6. Ideal conditions are, a nearly uniform temperature of $50 \mathrm{Fahr}$., a slight amount of moisture, continuous ventilation, and absolute darkness.

7. A very bad combination is a constantly varying temperature that goes down nearly to the freezing-point and then rises sometimes to 55 and 60 degrees. Such a rariation is almost sure to cause disastrous losses before spring.

8. A high temperature, between 60 and 70 , requires a great deal more ventilation than a temperature of 45 . The higher the thermometer the more fresh air there should be. Too much can not be given when the thermometer shows 65 degrees.

9. The statement has gone out that bees do not need rentilation in a bee-cellar. Fair results are sometimes secured with only the air that percolates thru the walls when the mercury can be maintained at 45 degrees, or within two or three degrees of it; but far better results are obtained when there are continuous infusions of fresh air thru ventilators, doors, or windows.

10. Occasional disturbance from the beekeeper entering the cellar does no harm.

11. Where the conditions in a cellar are such that there will be anywhere from three to four or even six inches of dead bees on the cellar bottom in the spring the owner of that cellar ought to investigate and ascertain the trouble. No matter if he does bring his colonies thru alive, it could hardly be said that he is wintering his bees successfully. An ideal cellar is one that will bring the colonies thru the winter in practically the same strength as when they went into winter quarters. The authors hare seen many cellars where all the dead bees that would fly out on to the cellar bottom would not in the spring make a coal-hodful to the hundred colonies. We have wintered bees at Medina time and time again in one of our cellars so successfully that one could walk across from one end of the cellar to the other in the spring and scarcely step on a single dead bee. No beekeeper should get it into his head that these old bees are superannuated and would die anyway. In any cellar where the conditions are such that there will be two or three inches of dead bees on the cellar bottom in the spring, there is something wrong.

12. Honey-dew, unsealed aster honey, o: very inferior or an unpalatable or poorly ripened honey may cause dysentery before spring, even when all the other conditions are ideal.

13. Pollen in the combs does little or no harm. The old theory that pollen was the cause of much of our winter losses is now an exploded myth.

14. The size of entrances will depend upon the character of the cellar.

15. Shutting bees in the hives with wire cloth is usually attended with uneasiness; and, unless remored, there will be severe mortality.

16. A furnace-room just off from a beecellar affords an ideal means of ventilation.

\section{HOW AND WHAT TO FEED BEES DURING MID-TVINTER.}

It is advisable to avoid feeding any syrup during mid-winter, because it has a tendency to stir up the bees, causing them to consume too largely of their stores; and, as they can not take a cleansing flight, dysentery is likely to follow. Moreover, the feeding of a single colony in a cellar is apt to stir up, by its roar, the other colonies near it.

When an outdoor colony is running short it should be given a comb of sealed stores. To avoid disturbing the winter nest this should be given directly on top of the brood-frames laid upon a couple of sticks. On top of the comb should be placed two other strips and then the packing-material. A comb may be given in the same way in the cellar, but it would be more practicable to take out an empty frame and put the one containing the stores in its place.

If one does not have any combs of honey he may give rock candy, provided it has not been scorched or burned, or any kind of candy. If the candy is the same as that used in queen-cages, or what is called Good candy, it should be put in shallow trays like paper or wooden pie-plates, so that, in case it becomes soft, it will not run down orer the combs, thus daubing the bees, and ultimately destroying the colony. There is always danger that a soft candy may do this, and hence the advice to use a hard candy. The use of a little honey makes a better candy; but not too much. One pound 
or a pound and a half of honey to $20 \mathrm{lbs}$. of sugar will be about the right proportion. It is very important that the mixture be not heated to a higher temperature than 280 ; and for this purpose a candy-thermometer should be used. See CANDY.

It is a nice art to make hard candy, and perhaps some would not care to undertake it. One or two reports seem to show that loaf sugar may be laid on top of the frames. In winter there would be enough dampness to keep the sugar moist. For summer feeding it would have to be dampened perhaps.

The giving of candy to bees in a cellar has a tendency to start brood-rearing. If

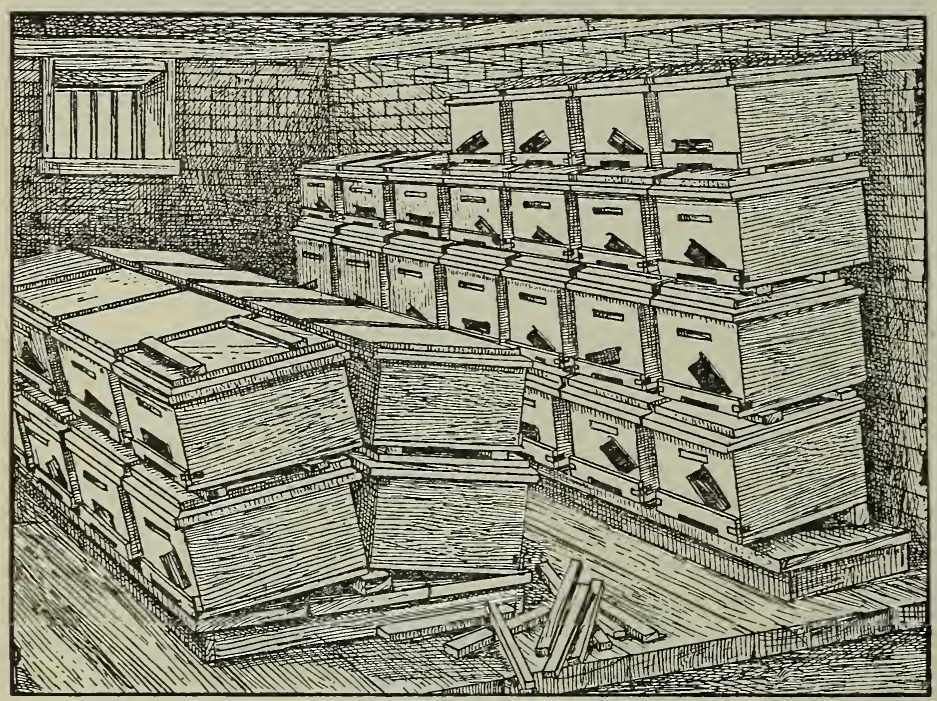

How N. D. West arranges his hives in the cellar.

the cellar is well ventilated, no harm will be done. If the ventilation is poor, with a temperature below $40 \mathrm{~F}$., it may result in dysentery. One year the author placed a yard of bees in the cellar, the colonies of which were weak and short of stores. Each was supplied with a slab of hard candy. Brood-rearing started up, and, remarkable as it may seem, those colonies built up to fair size by spring and as nice a lot of bees as we ever had. But cellar brood-rearing is attended with many dangers, and should usually be avoided by beginners, for sometimes it induces dysentery, especially when cellar conditions are not ideal.

\section{BEE-CELLARS VARIOUSLY CONSTRUCTED.}

The general principles of cellar-wintering, views, and descriptions are here given of some of those used by men who are very successful in wintering in this country and Canada.

Mr. N. D. West, of Middleburgh, N. Y., has been very successful in wintering bees in ordinary cellars under dwelling-houses. He prefers to have the bee-room separated from the outside door by another room, possibly a regetable-room, so that the temperature may be controlled more easily. The door between the two rooms may be left open most of the time, altho it can be closed when necessary. An outside ventilator is used thru an opening in one of the windows. A wooden box is made 8 inches square and about 2 feet long. This extends thru the window, and the outer end is built up so that the whole ventilator assumes the form of an elbow. The outer opening, which may be about 3 feet from the ground, is then covered in such a way as to keep out the rain and snow, but still allow space for foul or warm air to escape from the bee-room. Any openings $t \mathrm{hat}$ would admit light are closed so as to make the room dark and warm. Mr. West uses a spring of running water in one corner to keep the temperature constant.

In placing his hives in the cellar, he does not take off the bottom-boards. He makes a platform about four inches above the cellar-floor, and puts one row of hives on this with the back ends resting on a $2 \times 4$, so that they are four inches higher than the front ends. The next row of hives is placed on top of this row, altho set back just a little so that the tiers will not fall over. As will be seen, all the hives will be so placed with the entrances at least four inches lower than the back ends of the hives, so that any dead bees may be easily cleaned out. See illustration.

Harry Lathrop, of Bridgeport, Wisconsin, uses a stone bee-cellar built in a side hill. There are two rooms in the cellar, or, more properly speaking, a main room for the bees and a smaller one used as a vestibule. $\mathrm{He}$ thinks that, in some cases, it is advisable to 
have a stove in the vestibule. If there is a small opening at the top of the vestibule leading into the bee-room, and another opening at the bottom, artificial heat will cause a circulation. The air can be kept fresh by opening the outside door at intervals. An oil-stove should not be used, ordinarily, for the resulting bad air will be worse for the bees than the cold.

With a properly constructed bee-cellar, there should be no need of artificial heat; but, nevertheless, it is best to have the cellar so arranged that a stove can be used if necessary.

The illustration shows Mr. C. A. Hatch's plan for a bee-cellar. It will be seen that drop of five degrees does no great harm unless continued more than 24 hours. Mr. Hatch agrees with Mr. France in thinking that the three essentials for safe wintering are good feed, proper temperature, and young bees.

\section{HOLTERMANN'S BEE-CELLAR.}

One of the largest bee-cellars, as well as one of the best designed, is owned by Mr. R. F. Holtermann, of Brantford, Ont., Canada, an extensive beekeeper of that province. The cellar is made wholly of concrete, and, what is of particular interest to beekeepers, has a scheme of ventilation that is almost ideal. It is not only theo-

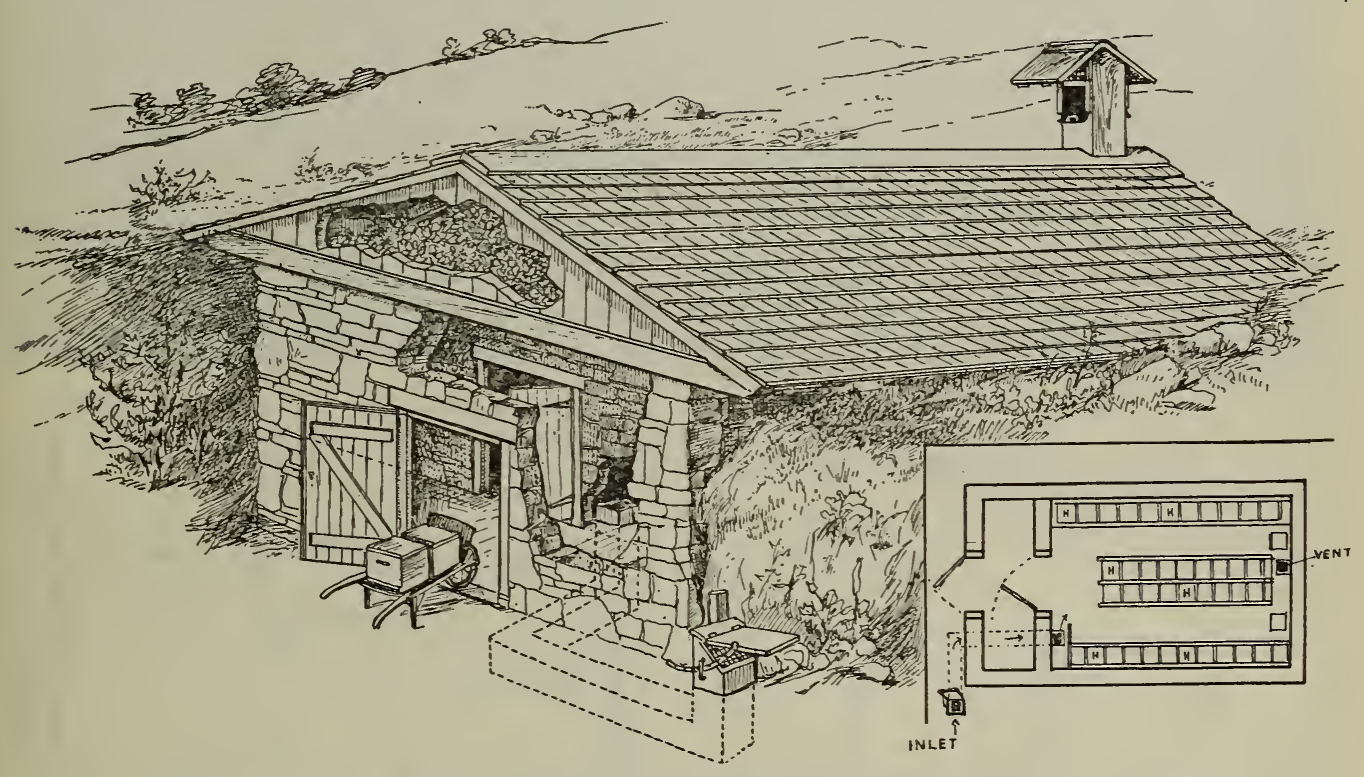

Hatch bee-cellar-dimensions of (ventilator) inlet, $6 \times 8$ inches; outlet, $8 \times 10$ inches.

the bee-room is almost entirely under the ground. The space between the ceiling and the roof is filled with leaves.

Mr. Hatch thinks it is advisable to have a cellar near the apiary, and built in a side hill if possible. If the entrance is on the level it is very easy to wheel colonies in and out. He believes that a cellar 12 by 16 feet, inside measure, would be ample for 100 colonies in ten-frame hives, or for 120 colonies in eight-frame hives.

An important point connected with the Hatch bee-cellar is the double entrance, or vestibule. In this way the temperature can be regulated very easily. A temperature of 50 degrees Fahrenheit is considered ideal, but it is probable that a rise or that is almost ideal. It is not only theoretin wintering that can scarcely be surpassed.

The authors have seen this cellar, and, notwithstanding there were about 500 powerful colonies in it at the tinie, there was perfect quiet and apparently perfect wintering. The temperature was about 43 , and the air was pure and sweet. Scarcely any dead bees were found on the floor.

The bottom illustration on page 802 shows how his big twelve-frame colonies are piled up, having the ordinary entrance and a honey-board on top.

The sub-earth ventilator, in the diagram next page, extends under the ground several hundred feet away from the building where it comes to the surface. At the 
other end it passes under the floor of the cellar, then up into a small room in which is placed a stove. From this compartment or room the air is distributed all around the cellar by means of a square wooden pipe suspended from the ceiling. Foul air is taken out at the bottom of the cellar by means of flues reaching down from the roof of the building to within a foot of the cellar floor. The upper story of the building is filled with hives and supers, being, in fact, the place where general shopwork connected with the yard is done.

Right here we can do no better than to give Mr. Holtermann's description of this cellar, which has given him such perfect results.

\section{DESCRIPTION OF THE CELLAR.}

The bee-house is of concrete-even to the chimney. This has a cowl on top, which veers its back to the wind to assist in getting a draft. On each side of the chimney is a box ventilator projecting thru the peak of the roof. This is 12 inches square, with a slide to regulate the amount of air passing thru. These shafts enter the cellar at the ceiling above, and are for warm weather. The building is $50 \mathrm{ft}$. long by 25 wide. The cellar walls are below the level of the ground, in order to get a more uniform temperature from the earth, and less liability for moisture to condense on its walls.

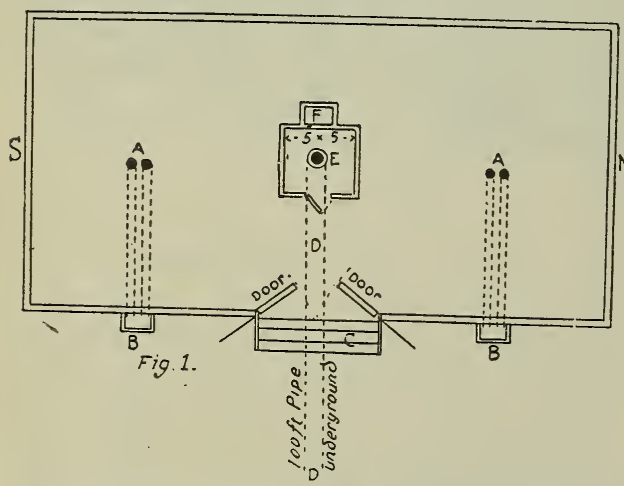

Ground plan of cellar. Inner compartment $\mathrm{E}$ has solid concrete walls extending to ceiling. Opening $\mathrm{E}$ communicates with a sub-earth ventilator, D. When in-rushing air is too cold a fire is built in the stove, tempering the air; then it passes upward to the ceiling, and into the square-box wooden flues shown at D D D D, in Fig. 3 , where it is distributed to every point in the cellar.

The cellar-ceiling, to seeure uniformity of temperature and prevent condensation, has, as seen in the perpendicular-elevation plan, Fig. 2, G, a tongue-and-groove floor; E, felt paper; D, air-space; C, tongue-and-groove floor; $F$, floor of the cellar is concrete. The only openings from the outside into the cellar are seen in Fig. 1. From B to A are two glazed waterlime-jointed tiling, coming above ground just outside of the bee-house at $\mathrm{B}, \mathrm{B}$, the wall going down $8 \mathrm{ft}$. into the ground; then passing under the cellar-wall and fioor, entering the cellar at points A, A. Then there is a stairway, $\mathrm{C}$, which is covered by two doors at the level of the ground, and

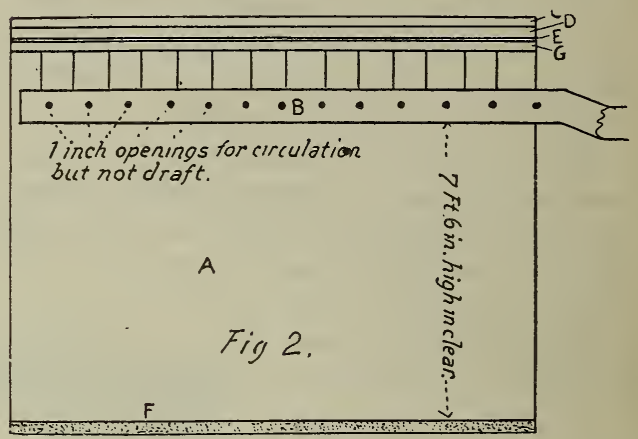

Perpendicular elevation of bee-cellar, showing the square-box ventilating-flue with its one-inch holes as shown in diagram 3.

again closed from the cellar by two doors. Thru these doors the bees are brought in and out.

$\mathrm{D}$ is a 12 -inch glazed pipe with waterlime joints $8 \mathrm{ft}$. under ground. This enters the cellar in the compartment $\mathrm{E}$, a coal stove standing over this opening. In this compartment, if the air is not sufficiently tempered

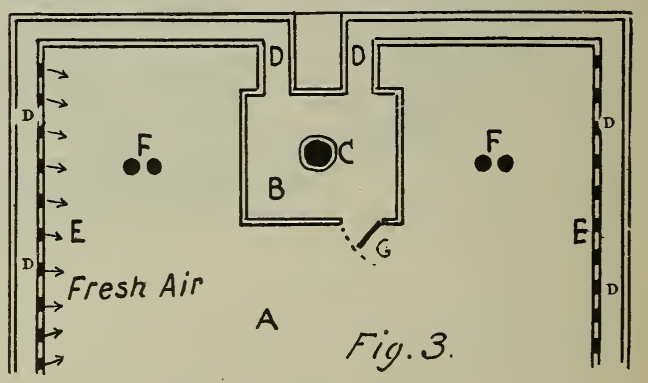

Horizontal plan showing scheme of ventilation. Room B has solid concrete walls to prevent danger from fire from the stove at $C$. Under the stove is the sub-earth ventilator opening that supplies fresh air, which, if too cold, is warmed and then forced thru the distributing-flues. D D D D, which are perforated by one-inch holes. The flues $D$ D are closed at the ends, and all air must pass out at the holes indicated by the arrows. F F are ventilators carrying foul air and moisture by means of flues extending thru the roof.

by its passage under the ground it can be warmed before it passes into the cellar.

In Fig. 3 the system of distributing fresh air is shown. The illustration is not quite correct as to the central compartment, how. ever. B is supposed to be the same central compartment as E in Fig. 1, and the distance between it and the west wall should be greater. At the top of this compartment, on the west side, are pipes, D, D, D, which carry the fresh air to the north and south end of the cellar, E E respectively being the north and south ends. From there thru many one-inch openings (see arrows also, in B, Fig. 


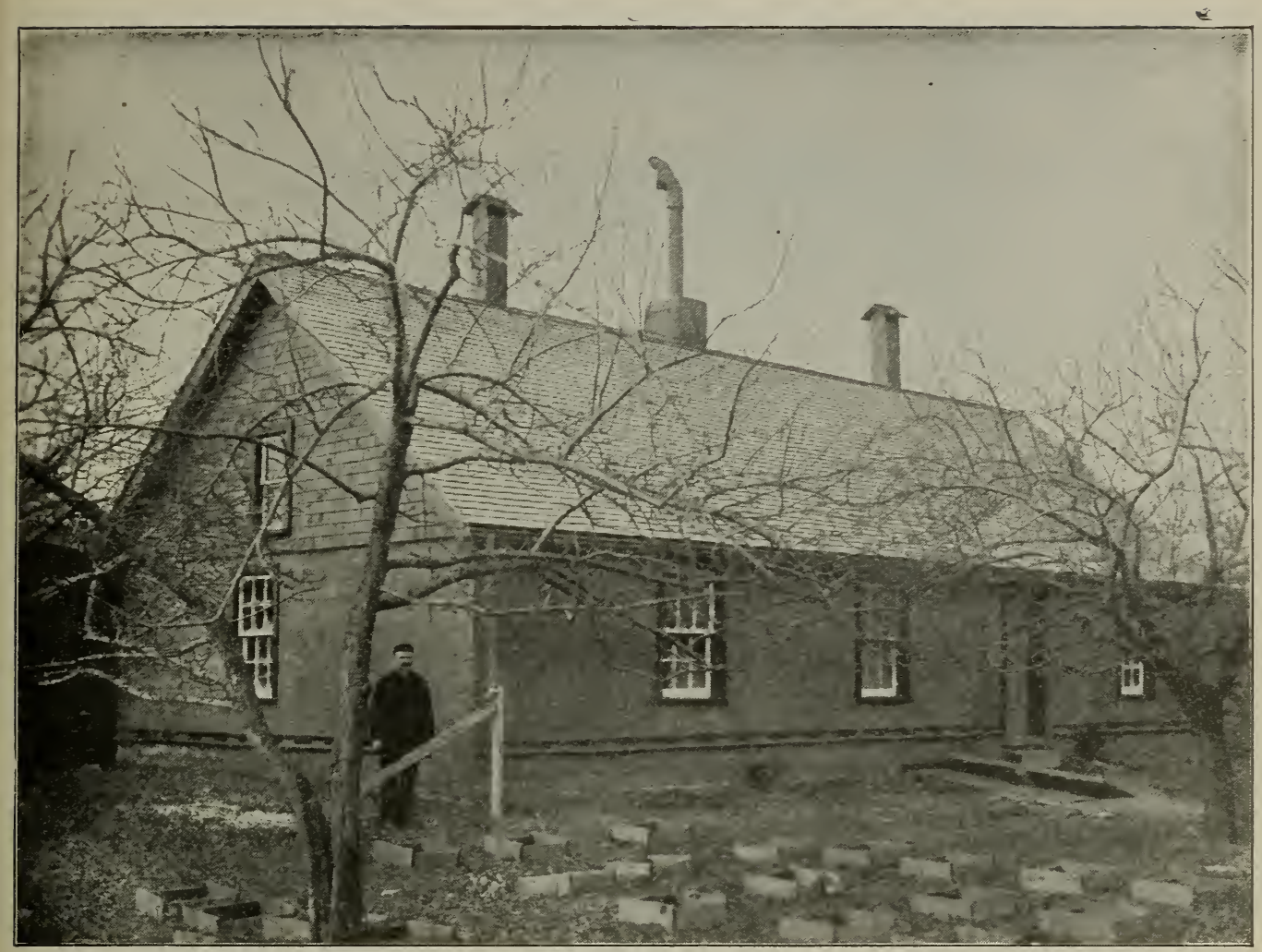

Holtermann's concrete bee-cellar and work shop.

2 , and the method of turning the corner of the wall), the fresh air is evenly distributed thru the cellar and carried off in a more or less foul condition thru openings in the bottom of chimney F, in Fig. 1, and at ventilators F, F, in Fig. 3, said ventilators showing thru the roof on either side of the chimney shown in the exterior half-tone view of the cellar.

I have a curtain this winter on the north, south, and west walls, and find it assists in equalizing the temperature. This winter I have had more or less air passing thru all the air-passages, yet have kept up a sufficiently high temperature half the time without a fire.

Two years ago I darkened all the windows in the bee-house above, and partially opened a trap-door which leads by means of a stairway alongside of the center compartment to the cellar floor. This, however, gave too rapid variations in temperature and was abandoned. During the last strong gale, with the wind reaching a velocity of over 60 miles an hour, within 24 hours a change from 59 to 12 degrees was experienced; while there was a variation of only $2 \frac{1}{2}$ degrees in the cellar without any alteration of the ventilating dampers.

A few pages back it is explained that Mr. Holtermann is not now using this bee-cellar. The reason for this is not be- cause he could not winter successfully, but rather because he was away from home all winter. He was compelled to adopt a method that would permit him to put the bees into winter quarters in October, and leave them there without further attention until the following spring.

But in view of the fact that the Holtermann cellar is the most elaborate and bestappointed bee-cellar that was ever constructed in this country or Canada, its description with illustrations is here preserved because there are doubtless some who may be compelled to winter indoors where even the tenement plan of outdoor wintering would not be adequate to protect the bees from the serere cold that might prevail in the locality.

\section{TINTERING BEES IN CLAMPS.}

In parts of the country where the soil is sandy and porous, bees are sometimes wintered in trenches dug in the ground. These are about 18 inches deep, large enough to hold two rows of ten hives each. The hives are set upon $2 \times 4$ 's to keep them off the ground. Three of these are used, one at each side and one in the middle, 
with the flat or wide side down. The plan as practiced by E. D. Townsend, of bottoms are removed from the hives, and North Star, Michigan. The first engravthe covers raised half an inch or so to ing shows the dirt partly shoveled away

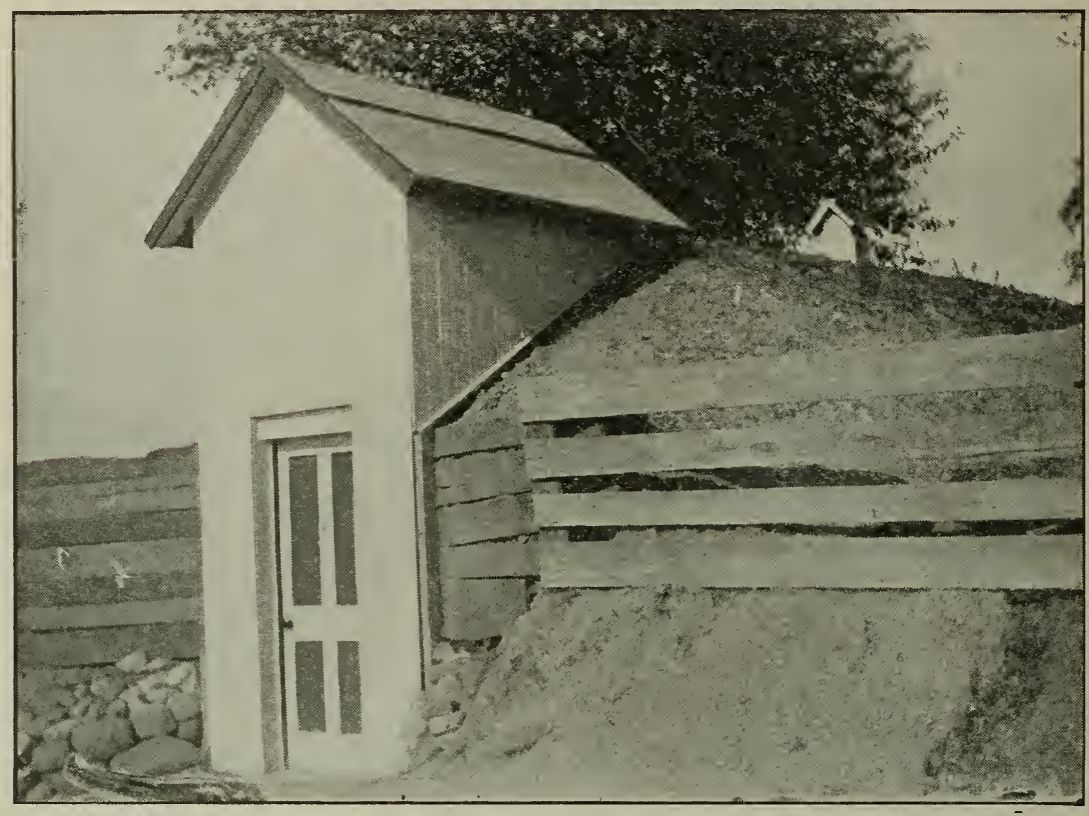

Davidson's concrete bee-cellar.

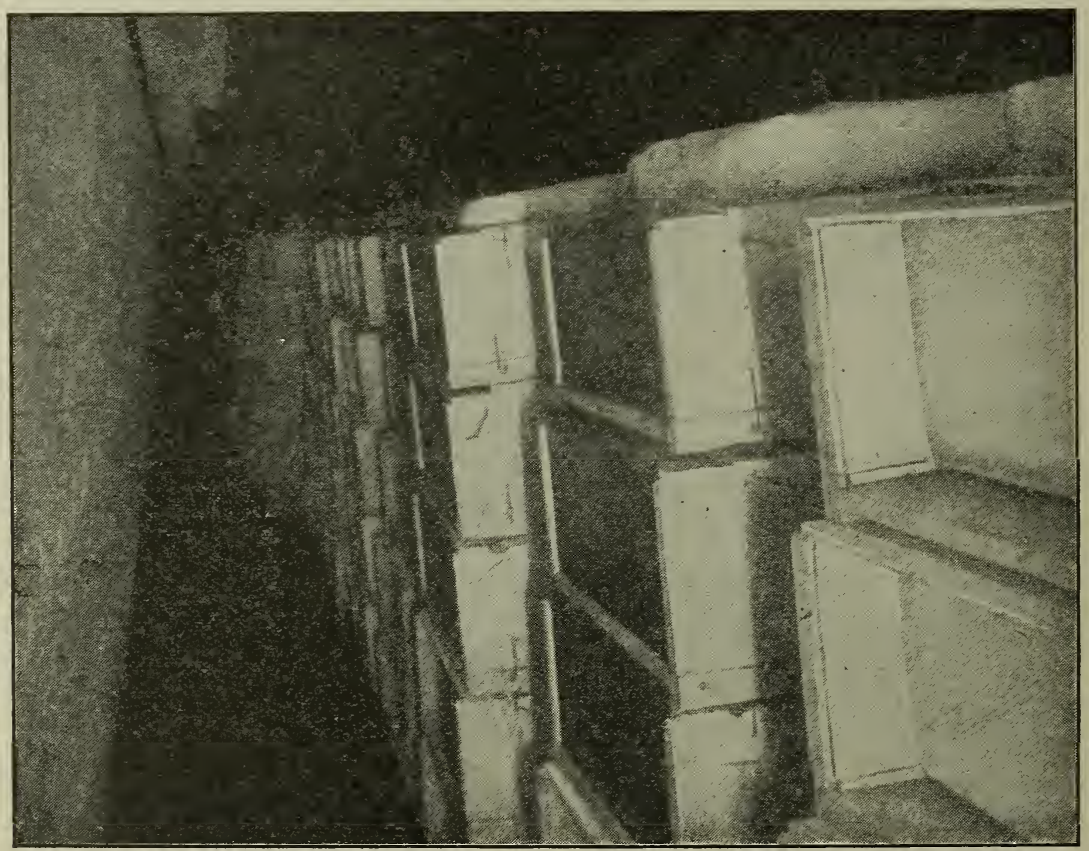

Interior view looking down the aisles of the Holtermann bee-cellar.

provide upward ventilation. About 18 inches of straw is thrown over the hives, and then the dirt is shoveled on. The engravings shown on next page illustrate the and some of the hives removed. The next illustration shows all of the hives removed in the spring from the pits or clamps, and set on their summer stands. It would seem 


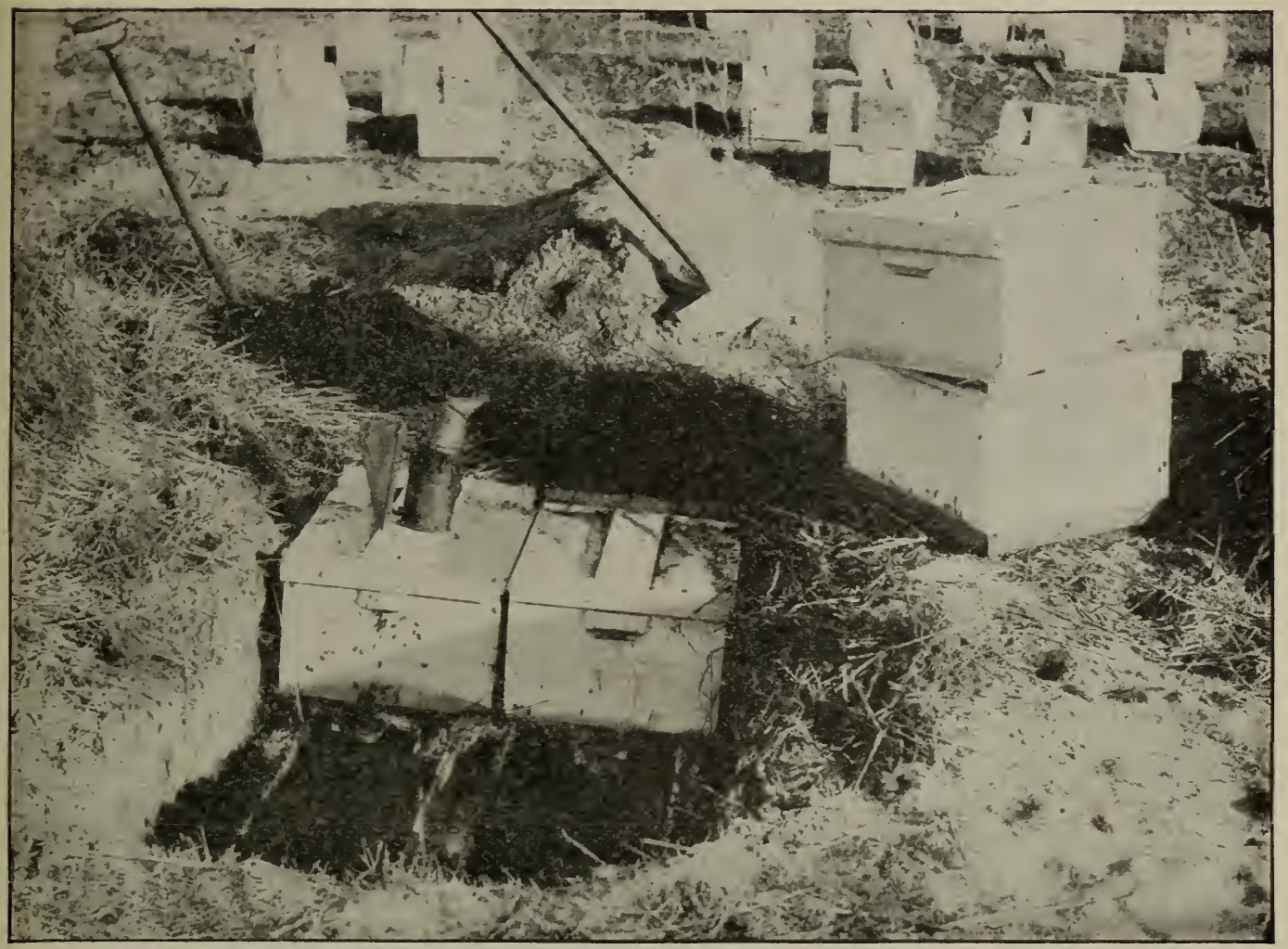

Wintering colonies in clamps or trenches dug in the ground.-From Beekeepers' Review.

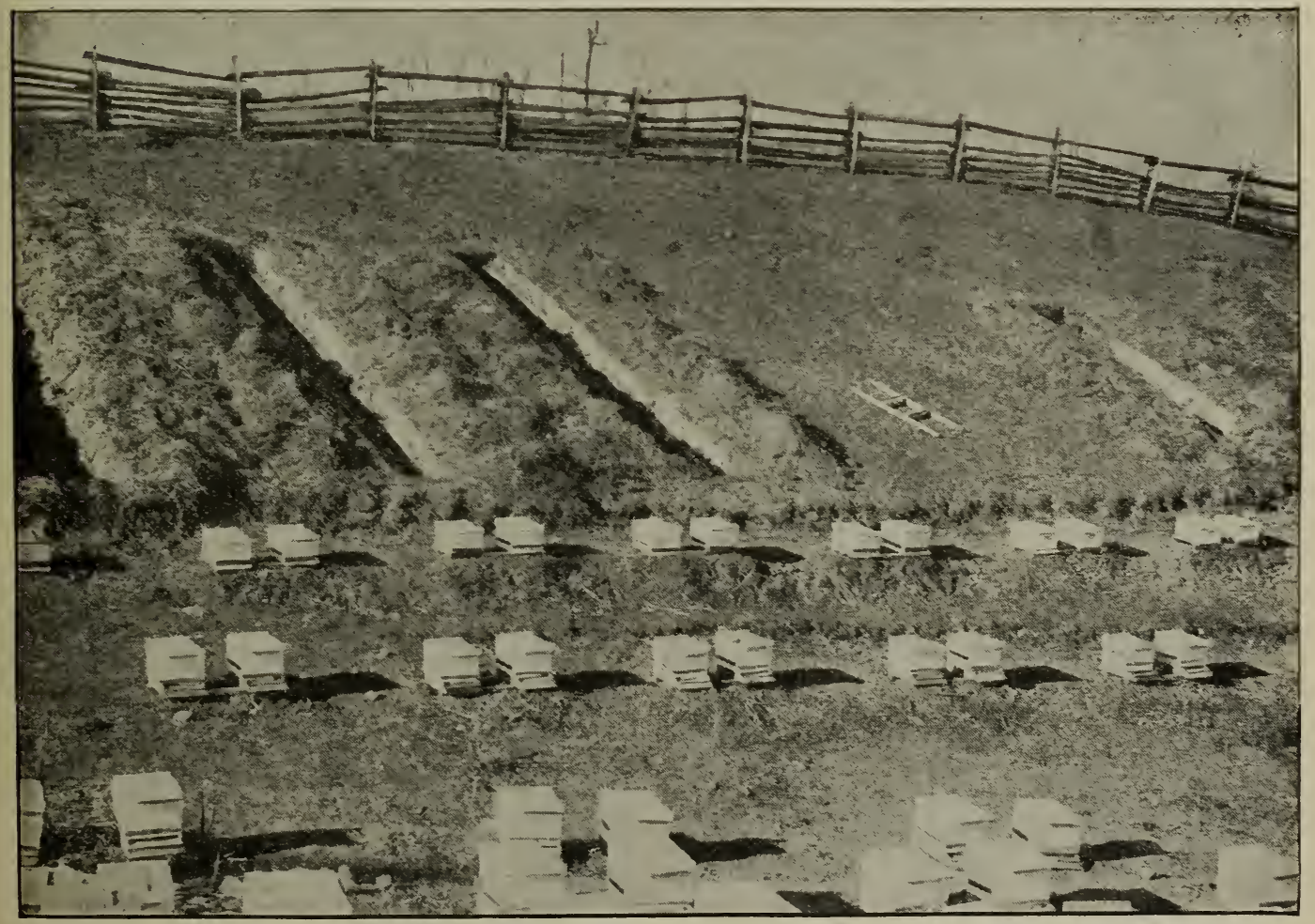

Colonies just removed from the trenches in the spring.-From Beekeepers' Review. 
as tho there ought to be some provision made for ventilation; but when it is remembered that the soil is sandy and very porous, it is seen that this is not necessary. This can not be made use of in a location where the soil is composed largely of clay. Mr. Townsend thinks that it is well to have surface drains along each side of the pits to carry off any water that may come that way.

\section{DO BEES HIBERNATE?}

The quiescent state or sleep into which bees enter when the wintering conditions are ideal, has been spoken of. In this period the bees seem merely to exist. With no activity the consumption of stores is very light.

As shown under TeMperature, particlilarly the temperature of the winter cluster during winter, bees are the quietest when the thermometer shows about 60 degrees F. If it goes below 57, the bees, instead of clustering, become active, and in the manner explained under TemperaTURE they raise the heat of the cluster sometimes almost to the brood-rearing point. When, therefore, the temperature is either below or above $60 \mathrm{~F}$., the bees are in anything but a state of sleep or what some have called semi-hibernation. Strictly speaking, bees do not hibernate, and perhaps do not even enter into the condition called semi-hibernation when they are the quietest. It all depends on what is meant by that term. But there are some interesting facts showing that bees can for a short time stand low temperatures, and revive like ants and flies that are true hibernators. In the diseussion which follows, however, one must not be misled. However, it is evident that nature has provided means by which bees can stand the temperature of freezing, or below, for a short time. In order that the reader may understand what hibernation really is, a few facts should be presented.

Hibernation was exploited about 30 years ago, when it was generally decided, and rightly, ton, that bees do not hibernate in the ordinary sense of the term (see American Bee Journal for 1885). But they do enter a quiescent state when the temperature has been lowered; and this state is somewhat analogous to the torpor cxperiencer by some animals in a state of true hibernation, during which no food is taken, and respiration is considerably reduced. Dr. Marshall Hall has stated that "respiration is inversely as the degree of irritability of the muscular fiber." If the respiration is reduced without this irritability being increased, death results from asphyxia. Hibernation is usually induced by cold, and the animal under its influence attains nearly the temperature of the surrounding atmosphere, yet can not resist any amount of cold, altho its capacity for doing so varies according to the animal. Sume animals bury themselves in holes, like snakes and frogs; others, like the bear, crawl under a pile of leaves and brush where they are still further covered with snow. Thus buried they will go all winter without food or water; but there is a waste of tissue. Fish may be incased in ice and still live, it is said. A lively frog may be dropped into a pail of water four or five inches deep, and exposed to a freezing temperature. Indeed, there may be a thin coating of ice formed over the animal. The next morning, that frog, though stiff and cold, can be warmed up into activity, but to freeze solid will kill the creature.

Flies, as is well known, will secrete themselves in window-frames and other hidingplaces, subject to cold atmosphere, for weeks at a time, and yet revive on exposure to warmth. As is well known, also, ants have been repeatedly dug out of logs, frozen solid-in fact, fairly enveloped in frost; yet on exposure $t_{0}$ warmth they will come to. Some hibernators can endure a freezing temperature, while others, like the bear, woodchuck, and the like, can not. Other rery interesting incidents may be taken from natural history; but the purpose of this article is to consider whether bees gc into a quiescent state that approaches hibernation, in which there is low respiration and a small consumption of stores.

Two or three years ago we put a number of cages of bees with some queens (laying the cages down on cakes of ice) in a refrigerator. The bees were chilled to absolute stiffness. Every day we would take out a cage, and each time the bees would revive, including the queen. This thing was continued for several days, and yet the bees would " come to" each time.

The strange part of it was, that the queens went on laying normally when put 
back in the hives, instead of laying drone eg'gs as we expected. Just what the temperature to which these bees were subjected was we can not say-probably something below 40 and something above 35, for the doors of the refrigerator were frequently opened, and the ice was constantly melting.

During one winter, when a very cold snap came on-the temperature going down to zero-we put out some cages of bees, exposing them to the cold wind, which was then blowing a pretty good gale, when the temperature was 5 above zero. We had expected that the bees possibly might be able to survive the shock for a number of hours, and yet revive; but 20 minutes of zero freezing was sufficient to kill them outright. If we had taken the bees and gradually acclimatized them to the cold, first subjecting them to 40 , then to 35 , and gradually down to the zero point, they would possibly have withstood the shock.

When the weather warmed up a little we took several cages of bees and buried them in the snow, leaving with them a thermometer so that we might know the absolute temperature. We went out and got a cage of bees about every two or three hours, and found that we could revive them without difficulty; but at the end of 24 hours the bees, when they "came to," seemed somewhat the worse for the experience. The temperature in the snow played around the 32 mark. But the experiments conducted during the summer would seem to show that bees might stand a temperature of 38 for a number of days.

Bees on the outside of the ball or cluster, in an outdoor-wintered colony, will often be chilled stiff while those inside have almost a blood temperature. During very severe weather, the outside bees may be gradually replaced by those within the cluster; for bees are in constant movement. Experiments show that a starved bee will not stand as much cold as one that is well filled. Beekeepers who have had any experience in wintering outdoors know how repeatedly they have taken clusters of bees that seemed to be frozen stiff, yet when warmed up before a good fire would revive and appear as lively as ever.

In view of the experiments thus far recorded it would appear that bees might be able to stand a temperature of 40 , or slightly below that, for a number of days; but if a warm spell does not come within a week, or less, those bees in their chilled condition may starve to death. But if it warms up, the cluster will unfold and the bees take food, and so be ready for another "freeze." The authors have repeatedly seen clusters of bees, after a zero spell, lasting a couple of weeks, that were stone dead; but the honey had been eaten from all around them within a radius of an inch or more. If a zero spell of weather continues more than a week or ten days, we always find some of the weaker colonies frozen to death in the spring.

If the bee were a true hibernator it would save the beekeepers of the world millions of dollars, because then all that would be necessary would be to establish a sort of cold-storage plant, where the climate was open or mild, and put the bees away for winter. In cold climates it would not be necessary to have cold-storage plants. The bees could be placed outdoors without protection, and left all winter; yes, they could easily be put on dry combs. Like the ants and flies they would remain in a dormant state; and when warm weather came on they would revive and resume their former activity. But, unfortunately, bees are not that kind of insect. That they will go into a quiescent state, or a kind of suspended animation, at a temperature between 57 and 69 F., has been clearly proven. During that period they consume the minimum of stores. If the time ever comes when we shall know enough to provide conditions so that a cluster will remain thruout the greater part of the winter at a temperature between 57 and $69 \mathrm{~F}$. it will certainly save a large amount of stores. But whether those conditions would indicate a state of semi-hibernation, or even an approach to it, the author is not prepared to say.

\section{WINTERING IN THE SOUTHERN} STATES.-The directions so far given apply particularly to localities that are subject to zero weather at times, that have more or less of snow during the greater portion of the year, and a large amount of frost in the ground, extending down perhaps two feet.

Where bees can fly almost every day in the year, and for ten months are able to 
gather a little honey or pollen, no special protection other than single walls has hitherto been considered necessary. The fact that the wintering problem in the South is not serious would seem to indicate that no special precaution is needed; but some experience that the author has had in wintering bees in Virginia and Florida indicates that, even where the bees can fly almost every day in the year, a moderate amount of protection can be given to advantage. This should be in the form of windbreaks to shut off the prevailing winds, and light packing-cases. While this may seem to be an unnecessary expense, the saving in brood and stores will pay for it in time. As will be seen under Temperature, bees, in order to keep up the proper amount of heat, must exercise, and this means a consumption of stores. Such activity causes the bees to fly out on a chilly day, and many never return. Again, where clusters are not large there is considerable brood in the Southland which chills and dies. This is a heavy drain on the colonies. While a colony can survive it, the beekeeper could well afford to furnish a little protection to save this brood.

Dr. E. F. Phillips, in charge of apicul- ture in the Bureau of Entomology, Washington, D. C., also believes that some winter protection in the South will prevent some loss of bees, if not of colonies.

Altho the advantages would seem to favor some packing in the Southland, it will probably be some time before its beekeepers below the Ohio River will realize its importance enough to providie the necessary winter protection.

One serious difficulty in wintering in the South is starvation. Bees require more stores per colony than in the North. When they can fly almost every day in the winter, breeding will be kept up more or less, with the result that the colony will use twice as much honey during the winter as a similar colony in the North, packed. It is important, for one to examine his colonies occasionally to see if they are running short; and if so, he should feed them with sugar syrup or honey.

WIRING FRAMES.-See COMB FouNDATION.

WOMEN AS BEEKEEPERS. - See BEEKEEPING FOR WOMEN.

WORKER COMBS.-See CoMBS.

\section{Y Z}

XYLOCOPA.-To this genus belong the carpenter bees, among which are the largest bees in the world. They are so called because they excavate with their powerful jaws tunnels a foot in length in solid wood. The cells are about an inch long, and are separated by partitions made of small chips cemented together in a spiral. The eggs are laid on masses of pollen, moistened with honey, about the size of of a bean. A common species in the eastern United States is $X$. virginica.

YELLOW SWEET CLOVER. - See SweET Clover.

ZINC, Perforated.-See Drones, ExtraCted Honey, and Swarming. 


\section{Beekeepers' Dictionary}

Abdomen.-The hinder of the three parts into which a bee is divided. See ANATOMY in text.

Absconding swarm.-A swarm which leaves for parts unknown. See ABSCONDING SwARMS in text.

Absorbents.-Materials more or less porous placed over the brood-chamber in winter, thru which moisture may escape without much heat escaping.

Adair frame. $-13 \frac{3}{8}$ inches long, $11 \frac{1 / 4}{4}$ inches deep.

After-swarms.-Swarms which come after the first swarm.

Albino.-A bee in which the coloring matter is deficient, making it lighter in color.

Alighting-board.-The projection before the entrance to a hive.

American foul brood.-See FouL BROOD.

American frame.-12 inches long, 12 inches deep.

Antenna (plural antennae).-Feeler; a horn-like appendage attached to the head of a bee; the organ of touch, and probably also of hearing and smell. See ANATOMY in text.

Anther.-The upper part of the stamen normally consisting of two sacs called the pollen-sacs, in which the pollen is produced. The anther at first is composed of four spore-cases or chambers, which at maturity are reduced to two by the breaking-down of the partition between the two sporecases on each side.

Aphis.-A plant-louse which secretes honey-dew.

A piarian.-Pertaining to bees or an apiary.

Apiarist.-A beekeeper.

A piary.-A collection of colonies of bees; also the yard or place where bees are kept. See APIARY in text.

A piculture.-Beekeeping.

A pidae. - The family to which the honey-bee belongs. See Solitary BeEs in text.

A pis.-The genus to which honeybees belong.

Artificial fecundation. - The impregnation of virgin queens in confinement (never accomplished).

Artificial fertilization.-Fecundation of virgin queens in confined spaces (not correct term).

Artificial pasturage.-Plants purposely cultivated for their nectar.

Artificial pollen.-Rye meal, pea flour, or other substances fed as substitutes for the pollen of flowers.

Artificial swarm.-A swarm made by dividing a colony of bees.

A utomatic hiver.-See SELF-HIVER.

Bacillus larvae.-Cause of American foul brood.

Balling a queen.-A number of bees clustering about a queen, sometimes making a ball an inch or more in diameter, sometimes releasing the queen unharmed; oftener continuing to ball her till she is dead.

Bar-frame.-A name sometimes applied to a movable frame in Great Britain.

Bee-bread.-The pollen of flowers gathered by the bees, mixed with a little honey, and deposited in the comb. See Polles in text.

Bee-brush. $-\mathrm{A}$ brush used in removing bees off their combs. See Pollen in text.

Bee culture.-The care of bees.

Bee-dress. - A suit or dress to wear while working with bees, preventing stings.

Bee-escape.-A device to get bees out of supers or buildings, so constructed as to allow bees to pass thru in one direction, but present their return. See COMB HoNEY in text.
Bee-gloves.-Glores worn to protect the hands from stings and from propolis.

Bee-glue.-Propolis, which see.

Bee-gum.-An old-fashioned name, now almost obsolete, to indicate a colony and the hive.

Beehive. $-A$ box or other contrivance for holding a colony of bees. See HIVES in text.

Bee-house.-A house constructed to contain colonies of bees. See House APIARy under APIARy in text.

Bee-line.-The shortest distance between two points. See BeE-HuNTiNG in text.

Bee-louse. - A commensal parasite common in $\mathrm{Eu}$ rope, and practically unknown in America; Braula coeca.

Bee metamorphoses.-The bee passes thru three stages before becoming a perfect insect-first the egg, then the larva, and next the nymph. The following will serve to show how this is accomplished:

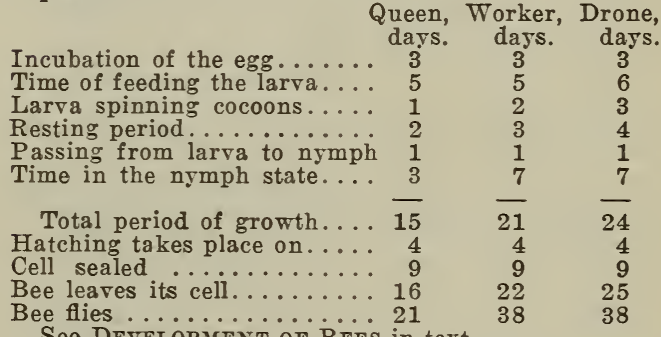

See DeVElopMent of BeEs in text.

Bee-moth.-A moth whose larvae destroy honey. combs, eating the wax; a wax-moth.

Bee paralysis.-A disease of adult bees in which the wings have a trembling motiun, and the bees have a shiny appearance; of littl? account in the North, but sometimes serere in the South. See DISEASES OF BEES in the text.

Bee-pasturage.-Flowering plants from which bees gather nectar.

Bee-pest.-Foul brood.

Bee-plants.-Flowering plants which produce nectar for bees.

Bee-space. - A space in which bees put the least amount of wax or propolis-about $1 / 4$ of an inch or a trifle more. See FrAMES in the text.

Beeswax.-The wax of which bees make their combs; excreted in small scales from the abdominal rings.

Bee-tent.-Tent of wire cloth or netting large enough to contain a hive and the operator, in which bees may be manipulated without being troubled by robbers. See RoBBING in the text.

Bee-tree.-A hollow tree occupied by a colony of wild bees. See BEE-HUNTING in text.

Bee-veil.-A net veil for protecting the head from the attacks of bees.

Beeway sections.- Sections having insets at the edges so as to make passages for the bees when the sections are crowded close together.

Black bee.-The German or brown bee; the bee first introduced into this country.

Bottom-board.-The floor of a beehire. See HIves in text.

Box hive.-A plain box used for housing a colony of bees.

Box honey.-Honey stored in small boxes.

Black brood.- See European Foul Brood.

Brace-comb. -The terms "-brace-comb" and "burrcomb" are often used indiscriminately as mean. 
ing the same thing. More exactly, a brace-comb is a bit of comb built between two combs to fasten them together, or between a comb and adjacent wood, or between two wooden parts, as between two top-bars; while a burr-comb is a bit of wax built upon a comb or upon a wooden part in a hive, seeming to have no object but to use up wax. See Hives in text.

Brimstoning.-The operation of killing a colony of bees with sulphur fumes. See Box Hives in text.

British standard frame.- 1 frame 14 inches long by $8 \frac{1}{2}$ deep.

Brood.-Young bees not yet emerged from their cells. See BROOD in text.

Brood-chamber.-That part of the hive in which the brood is reared.

Brood-comb.-One of the combs in the brood-chamber. See BROOD and COMBS in text.

Brood-nest.-That part of the brood-chamber occupied by eggs and brood. The term is also used to apply to that part where the bees are clustered when they have no eggs or brood.

Brood-rearing.-Raising kees from the egg.

Brushed swarm.-An artificial swarm made by brushing or shaking part or all of the bees of a colony into an empty hive, thus anticipating and preventing a natural swarm. It is also called "shaken swarm" and "shook swarm," altho some object to "shook swarm" as being ungrammatical. See Artificial Swarming in the text.

Bumblebee.-A large hairy social bee of the genus Bombus; humblebee.

Burr-comb.- See BRACE CoMB.

Button or bouton.-The enlarged part at the tip of a kee's tongue.

Candied honey.-Honey that has granulated and become solid.

Cap.-1. The covering of a cell containing brood or honey; the capping; the sealing. 2. To cover a cell with a capping; to seal. 3. A hive cover.

Capped brood.-Brood sealed over by the bees 8 or 9 days after the egg is laid; sealed brood.

Carniolan bees. - Bees obtained from Carniola, Austria. They resemble black bees with somewhat distinct whitish bands.

Carton.-A pasteboard box for holding a section of honey. See Comb HoNey, to Produce, in the text.

Cast.-A second swarm; also applied to any swarm after the first.

Cell.-One of the hexagonal compartments of a honey-comb.

Cell-cup.-A queen-cell when it is only about as deep as it is wide. Artificial cell-cups are made as well as natural. See QueEN-REARING in the text.

Cell-protector. - A receptacle made of wire cloth, which protects the sides of a queen-cell from the attacks of bees, but leaves the apex of the cell open.

Chaff hive.-A hive having double walls filled between with chaff.

Chorion.-The reticulated membrane or network that covers a bee-egg.

Chrysalis.-See pupa, the more usual name.

Chyle.-A milky substance prepared in the chylestomach of the nurse-bees, and fed to a young queen during its whole larval existence, and to other larvæ during their first three days of feeding.

Chyme.-Partially digested food to be further elaborated into chyle.

Clamp.-A winter repository for bees, made in sandy soil by digging a trench in which the hives are placed, and then covered with straw and earth.

Claustral hive.-Haring a covered-in entrance with ventilator for winter. See CLOISTER HIVE.

Cleansing fight.- The flight of the bees from the hive after long confinement, as in the spring, when they void their feces in the air.

Cloister hive. $\rightarrow$ A hive provided with a cloistered entrance, which excludes the light in winter weather to prevent the bees from flying.
Closed-end frames. - Frames with end-bars so wide that no space is left between them.

Colony.-A community of bees having a queen, some thousands of workers, and during part of the year a number of drones; the bees that live together as one family in a hive.

Comb.-An assemblage of hexagonal cells made of wax to contain eggs, brood, honey, or pollen; honey-comb. See Combs in text.

Comb-basket.-That part of a honey-extractor in which the combs are held. See Extracting in the text.

Comb-carrier.-A receptacle in which one or more combs may be placed and covered; so as to be easily carried, and protected from robbers.

Comb foundation. - Thin sheets of beeswax stamped to imitate comb, forming a base on which the bees will construct a complete comb.

Comb-foundation machine.-A machine for stamping the foregoing.

Comb-guide.-Strips of wood used as a guide in the construction of combs.

Comb honey.-Honey in comb together with the comb.

Cross.-When races of kees are bred together the resulting progeny is called a cross.

Cyprian bee.-The native bee of the island of $\mathrm{Cy}$ prus.

Decoy hive.-A hive placed with the object of attracting passing swarms.

Dequeen.-To take the queen from a colony of bees; to unqueen.

Dividing.-Separating a colony in a manner to produce two or more colonies.

Division-board.-A thin board of the same size as the inside length and width of the hive, used to contract the size of the brood-chamber or to divide it into separate compartments; often called dummy; see DUMMY.

Dovetailed hive.-A hive with Langstroth frames, the hive having interlocked corners after the manner of dovetailing. See HIves in the text.

Drone.-Male bee.

Drone brood.-Brood which matures into drones, bred in larger cells than worker bees.

Drone comb.-Comb having cells which measure 4 to the inch. Drones are reared in drone comb; also honey is stored in it, but not often pollen. Drone comb is about one inch thick when used for brood; when used for honey it may be very much thicker. Drone comb has about $181 / 2$ cells to the square inch on each side.

Drone egg.-The egg from which a drone hatches - an unimpregnated egg.

Drone-trap, see QUEEN-TRAP.

Drumming.-Pounding on the sides of an inverted hive to make the bees ascend into another hive placed over. In England it is called "driving." See Transferring in the text.

Dummy.-A thin board of the same size as a frame, or a little smaller, having a top-bar nailed on top. See DIVISION-BOARD.

Dysentery.-When bees can not fly, and an accumulation in the intestines causes them to discharge watery feces in the hive or on the outside front of the hive, they are said to have the dysentery or diarrhea.

Dzierzon theory.-A set of 13 propositions put forth by Rev. John Dzierzon (pronounced Tseer tsone) in the middle of the 19 th century, propounding the then novel idea of parthenogenesis. See DZIERZON THEORY in text.

Egyptian bee.-Apis fasciata. A smaller and more beautiful bee than the Italian, but exceedingly cross. See RACES of BeEs in text.

Embryo.-The germ of the bee in the egg.

Entrance.-The opening at the front of a live to allow the bees to pass out and in. In America the entrance is almost universally at the bottom of the hive. In Europe it is often higher up.

Entrance blocks.-Three-cornered pieces of wood for regulating the size of the entrance.

European foul brood.-See FOUL BROOD. 
Excluder, see QUEEN-EXCLLDER; also DRONES in text.

Extracted honey.-Honey obtained from combs by means of a centrifugal extractor.

Extractor.-See HONEY-EXTRACTOR and WAX-EXTRACTOR.

Extra-thin-super foundation. - Comb foundation running about $13 \frac{1 / 2}{2}$ square feet to the pound. See Comb Foundation in text.

Fdn.-An abbreviation for the words comb foundation.

Feces.-Excreta of bees.

Fecundate.-The queen is fecundated upon meeting the drone, and is then capable of laying eggs that will produce workers or queen; to fertilize; to impregnate.

Feeders.-Appliances for feeding bees artificially.

Femur.-Thigh of the honeybee. See Axatomy in text.

Fence.-A slotted separator resembling an ordinary wooden fence. It is used as a guide to compel the tees to build combs that are straight. See CoMB HONEY, APPLIANCES FOR.

Fertile.-A fertile queen is one that has mated with a drone.

Fertilize.-A queen's eggs that are intended to produce workers or queens are fertilized on their outward passage by receiving one or more of the spermatozoa contained in the spermatheca of the queen. Drone eggs are unfertilized.

Field bees. - When worker tees become about 16 days old, they begin the work of flying abroad to collect nectar, pollen, water, and propolis, and are then called field bees.

Fielders.-Field bees.

Fixed frames.-Frames that do not hang loose in the hive, but touch at one or more parts of the end-bars; self-spacing frames. See Frames, SelfSPACING, in text.

Formic acid.-A colorless corrosive liquid compound ( $\mathrm{HCO} . \mathrm{H})$, forming a rery small but important part of honey.

Foul brood.-A malignant contagious disease of bees affecting the brood. See FOUL BROOD in body of the work.

Foundation.-See CoMB Fouxdation.

Foundation splints. - Wooden splints about 1-16 inch square, emkedded vertically in the foundation of a brood-frame to prevent sagging. See Comb Foundation in the text.

Frame.-Four slats of wood to hold a comb, inrented by the late Rev. I. L. Langstroth, of $\mathrm{Ox}$ ford, Ohio. This frame requires a bee space 1/4 of an inch on all sides to be effective. Can te mored in any direction. See Frasies in text.

Fumigate.-To submit to the fumes of sulphur, carbon bisulphide, or other disinfectant. Combs are fumigated to kill the eggs or larræ of the beemoth, and bees are sometimes killed by fumigation. See Mотн Mrller in the text.

Galleria mellonella (formerly Galliera cereana.) The scientific name of the wax-moth. See MothMILLER in text.

Ganglion (plural, ganglia).-A nodular enlargement consisting of an aggregation of nerre-cells that receives and sends forth nerrous impulses and serres to stimulate organic and psychical action; a nerre center. See ANATOMY in text.

Go-lacks.-Unfinished sections which are returned to the hire to be finished.

Golden bees, or Goldens.-Bees in which the workers show as many as fire yellow bands.

Good candy, see QueEn CANDY.

Grafting:-Applied bs beekeepers to the process of removing a worker larva from its cell into a queen-cup, with the view of having it reared into a queen. See QUEEN-REARIXG in text.

Green honey.-Unripe honey.

II atching $t r o o d .-$ Young bees just gnawing their way out of the cells.

Tieddon frame. $-5 \frac{3 / 8}{8}$ inches deap by $18 \quad 1-16$ in length.
Hive. - 1. A lome for bees furnished by man; 2 . To put a swarm in a hive or to induce it to enter a hire. See Hrves in text.

Hive-tool.-A tool used to pry up supers, pry frames apart, etc. See MANIPULATION OF COLONiEs in the text.

Holy Land bees.-A variety of bees from Palestine. Somewhat resemble Italian bees, but are more irritable.

Honey.-The nectar of flowers gathered by the bees, and so changed by them that it becomes honey. According to the national pure-food law, "Honey is læro-rotatory, contains not more than 25 per cent of water, not more than 25 per cent of ash, and not more than 8 per cent sucrose (cane sugar.)"

Honey-bee.-The honey-bee belongs to the class Insecta, order Hymenoptera, superfamily Apoidea or Anthophila and family Apidae. In 1758 Linnaeus named the honey-bee Apis melljfera (honert bearer), and three rears later (1761) changed the name to Apis mellifica (honey-maker). A. mellifera has, therefore, the right of priority. Dalla Torre recognizes in the genus Apis orer 180 species, of which A. mellifera, dorsata, florea, and A. mellifera are fasciata, caffra, adansonii, japonica, ligustica, and unicolor. Races or rarieties of the domestic bee are also distinguished by the names of the geographical localities in which they occur and from which they hare been exported, as Italian, Carniolan, Syrian, Cyprian, Banat, Caucasian, and Tunisian.

Honey-board.-A slatted board placed between the brood-chamber and the honey-chamber to break the continuity of the two; formerly a board with holes in it to support the receptacles of comb honey. A queen-excluder is sometimes called a honey-board.

Honey-box.-A box for comb honey, closed on all sides, and provided with holes to allow the bees access. Almost obsolete.

Honey-comb.-Two series of waxen cells with a septum between them, which septum serres as the bottom for the cells of bath series. In the Bible honer-comb means comb honey. See Droxe COMB and TORKER COMB.

Honey-dew.-A sweet liquid similar to the nectar of flowers deposited on the leares and branches of plants.

Honey-evaporator. A machine for remoring water from honey deemed too thin.

IIoney-extractor. - A machine for throwing the honey from combs by centrifugal force.

Honey-gate.-An iron faucet used for drawing honey from barrels or other receptacles.

Honey-harvest.- 1 . Surplus honey taken from lees. 2. The time when bees are gathering a surplus, or more than $\in$ nough for their daily needs.

Honey-house. - 1 building for the purpose of hones extraction, storage, etc.

Honey-knife.-A knife used to share the cappings from combs of sealed honey preaparatory to extracting. See Extractisg in the text.

Honey-sac.-An enlargement of the bee's esophagus after it enters the abdomen; the sac in which a bee carries nectar or honey; honey-bag; honeystomach.

House apiary.-1. An apiary kept in a specially constructed building; 2 . The building itself which contains the hires, the walls of the building containing holes thru which the bees pass out and in.

Hybrids.-Usually used by beekeepers to designate a cross between the common black bee and the Italian.

Hymettus - A mountain district of Greece famous for its wild-thyme honer, and celebrated in classic poetry and history. See SAGE in the text.

Imago.-The fully dereloped bee or other insect.

Introduce.-To gire a colony a strange queen, taking precautions so that she will not be killed by the bees.

Introducing.-The manner in whicl a strange queen may be introduced to a colony of bees in the stead of a former one to which ther were accustomed. It is usually performed by hanging the queen in a 
cage in the midst of the strange bees several days until' she acquires the odor of the hive.

Introducing-cage.-A small box of wire and wood.

Inversion.-The process of turning a hive upside down to compel the bees to attach their combs to the bottom-bar, also to remove honey from broodframes into the supers.

Italian bee.-The native bee of Italy, the workers having three yellow bands. In America it has been bred to have four or five yellow bands.

Italianize.-To change a colony of any other race to Italians by introducing an Italian queen.

Jumbo frame. $17 \%$ inches long, $11 \frac{1}{4}$ inches in depth. See Hrves in the text.

Langstroth frame.-17\% inches long by $9 \frac{1}{8}$ inches deep. See Hives also Frames in the text.

Langstroth hive.-A hive having frames $17 \% / 8$ by $91 / 8$. In one sense, any movable-frame hive is a Langstroth hive, since Langstroth invented the movable-frame hive.

Larva (plural Larvae).-A bee in the worm state; unsealed brood.

$L$. frame.-Langstroth frame.

L. hive-Langstroth hive. See HIves in the text.

Laying worker.-A worker which lays eggs, such eggs producing only drones.

Light brood foundation.-Comb foundation running about 9 square feet to the pound.

Ligurian bee.-Italian bee, named for the district in which the best Italian bees are found.

Lining bees.-Watching the direction of the flight of bees so as to trace them to their home (usually in some hollow tree). See BEE-HUNTING in the text.

Loose frames or loose-hanging frames.-As opposed to fixed frames, those which have no provision for self-spacing, but must be spaced by the eye. See Frames, SELF-SPACING in the text.

Mal-de-mai-May-sickness; a peculiar disease of bees occurring mostly in May, and giving much trouble in Europe. See DISEASE OF BEES in the text.

Mandibles.-The jaws of the bee working like a pair of pliers, but sidewise, not up and down, as with ourselves.

May-pest.-Same as mal-de-mai.

Medium brood foundation.-Comb foundation running about 7 square feet to the pound.

Melipona bees.-A genus of stingless bee inhabiting South and Central America, comprising at least 50 species, some domesticated.

Mel-extractor.-Honey-extractor.

Movable frame.-A loose comb frame which can ke removed completely from the hive for the purpose of examination or use. A Langstroth frame. See FrAMES in the text.

Natural swarm.-A swarm of bees issuing spontaneously from the mother hive.

Nectar. - The sweet exudation secreted by glands in different parts of plants, ehiefly in the flowers.

Nectaries.-The parts of a flower wherein is secreted the nectar. See Pollen in the text.

Neuter.-A name sometimes applied to worker bees.

Non-swarming hive.-A hive so constructed as to control the desire to swarm.

Nucleus (plural Nuclei).-A very small colony of bees. The difference between a nucleus and a colony is much like the difference between a boy and a man. It is not easy to say just when nucleus kecomes large enough to be called a colony. Perhaps nothing larger than three combs with adhering bees should be called a nucleus, altho in the spring many called colonies have much less than three frames of brood.

Nurse bees.-The worker bees that feed the young, and do other work inside the hive. They are generally less than 16 days old.

Observatory hive.-A hive largely of glass to allow of the bees being observed at work.

Ocelli.-The three simple eyes of the bee. See EyE of BEES in the text.
Out-apiary.-An apiary kept at some distance (generally more than a mile) from the home of the keekeeper.

Overstocking.-A condition reached when there are too many bees for a given locality.

Paraffine.-A white translucent substance somewhat resembling keeswax, derived from mineral oil, and sold very largely in the form of candles. It is used by beekeepers to render honey-barrels tight.

Parent stock.-The mother of a swarm.

Parthenogenesis.-Production of a new individual from a virgin female without intervention of a male; reproduction by means of unfertilized eggs. In bees the unfertilized eggs produce only males. An unfecundated queen, and sometimes a worker, may lay eggs that will hatch, producing only drones. See Parthenogensis in the body of the work.

Perforated zinc.-Zinc sheet metal having oblong holes 1-6 of an inch in width to allow worker bees alone to pass, and excluding queens and drones. See DRONES in the text.

pickled brood.-Dead brood that has a sour smell. It may be dead from disease, or from cold or starvation. Now called sac brood which see.

Piping.-A series of sounds made by a queen, louder than any. sound made by a worker, consisting of a loud, shrill tone, succeeded by several others, each sound shorter than the one that precedes it. $A$ laying queen is seldom heard to pipe; a virgin perhaps always pipes at intervals after emerging from her cell, and in response to her piping may ke heard the quahking of one or several virgins in their cells, if such are in the hive, the quahking being uttered in a lower key and in a more hurried manner than the piping. Piping is also called "teeting."

Pistil.-The pistil is divided into the ovary, style, and stigma. The ovary contains the ovules which, after fertilization, become the seeds. See POILEN in text.

Plain sections.-Comb-honey sections with no insets or scalloped edges. See COMB HONEY, APPLIANCES FOR, in the text.

Pollen.-Dust-like grains formed in the anthers, within which are produced the male elements or sperms.

Pollen-basket.-A cavity on the hind legs of the bee wherein is deposited the pollen gathered from flowers.

Prime swarm.-The first swarm-the swarm with the old queen.

Propolis.-A kind of glue or resin collected by the bees and chiefly used to close up cracks and small spaces.

Pupa.-The third stage of the bee, during which it is inactive and sealed up in its cell; sometimes called "chrysalis."

Quahking.-The noise made by a young queen in her cell in response to the piping of the queen at large. See PIPING.

Queen.-A fully developed female kee; the mother bee.

Queen-cage.-A small box of wire and wood in which queens are held prisoners.

Queen candy.-Candy made by kneading powdered sugar into extracted honey until it forms a stiff dough; used in queen-cages; called Scholtz candy, because Rev. M. Scholtz introduced it in Europe. Afterward I. R. Good gave it prominence in America, and so it is often called Good candy. See CANDY in the text.

Queen-cell.-A cell in which a queen is reared, having an inside diameter of about 1-3 of an inch, hanging downward an inch or more in length. See QueEN-REARING in the text.

Quecn-excluder.-A device consisting wholly or in part of sheet zinc having oblong perforations about $1-6$ of an inch wide, allowing workers to pass thru but excluding queens and drones.

Queening.-The act of introducing a queen into a queenless colony of bees.

Queenless.-Having no queen. 
Queen-nursery.-A cage or set of cages in which to confine queen-cells or queens.

Queen-rearing.-Raising queens.

Queen-register.-A card to be attached to a hive with pointers that may be moved so as to indicate dates, and conditions relating to the queen, such as cell, hatched, laying, etc. See RECORD-KEEPING in the text.

Queenright.-Having a good laying queen.

Queen's voice.-A sound made by a queen. See PIPING.

Queen-trap.-A device provided with perforated zinc, to be attached to the entrance of a hive, allowing workers to pass, but trapping any queen or drone that attempts to issue. Called also drone-trap. See SwARMING in the text.

Quilt.-A cover for brood-frames made in the form of a thin cushion.

Qwinby frame.-The hanging Quinby frame is $18 \frac{1}{2}$ by $11 \frac{1}{4}$; the closed-end or standing Quinby is $191 / 8$ by 11 , is without lugs, and supported at the bottom. See Hives in the text

Quinby hive. - A hive invented by Mr. Quinby "based on Huber's leaf hive of the latter part of the 18 th century. See Hives in the text.

Rabbet.-Usually has reference to a narrow piece of tin folded in a peculiar manner to form a rest for the shoulders of the hanging frames. See Hives, in text.

Race. - The kinds of bees into which the species Apis mellifica is divided, the race being usually named after the place of nativity, as Italian, Ger man, Carniolan. Sometimes the word variety or breed is used with the same meaning.

Rendering wax.-The process of melting combs and refining wax from its impurities, usually done by means of hot water or steam accompanied by pressure on the mass of material. See WAT in the text.

Repository. - A room, usually upon a hillside, partly or wholly below ground, in which kees are wintered; a bee-cave; a bee-cellar. In a general sense the word may be used for any place in which bees are wintered.

Reversing.-Turning orer or inrerting a hire with bees to accomplish certain results.

Ripe honey.-Honey left in the care of the bees until it contains less than 25 per cent of water.

Robbing. As applied to bees, the taking of honey by stealth or force from the hires of other colonies.

Royal cell.-Queen-cell.

Royal jelly. - A rich food of whitish appearance placed by the nurse bees in queen-cells as food for the royal larvæ. See QUEEN-REARING in the text.

Sac brood. - A disease of brood. Slightly contagious but not serious. See FOUL BROOD at the close of the chapter.

Scholtz candy, see QuEEN CANDY.

Sealed brood.-Brood that has been capped or sealed over by the bees with a somewhat porous capping; mostly in the pupa stage. See BROOD in the text.

Section.-A small frame or box open on two opposite sides, that is placed on a hive to receive surplus honey; a section box. Also, the honey contained in a section box. See Comb HoNer in text.

Section box.-A sectionally constructed box for containing a small honeycomb.

Section holder.-A device for holding sections while in process of being filled on the hive.

Self-hiver-Anr derice by which the bees of a swarm are induced to enter of their own accord a hire prepared for them.

Self-spacing frames.-Frames so made that, pushed together, they will be spaced the proper distance apart from center to center- (usually $1 \frac{3}{8}$ inches); fixed frames.

Separator. - A very thin board or sheet of tin placed between sections to make sure that the bees will build the combs accurately.

Septum. The middle of a honey-comb.
Shaken swarm or shook swarm-An artificial swarm made by shaking bees from a rery populous colony into a fresh hive. By this means natural swarming is closely imitated. See BRUSHED SwARM. See ARTIFICIAL SWARMIING in the text.

Shipping-case.-A light box, usually with glass on one side, of varying size, in which section hones may be shipped. The sizes most commonly in use are those containing 12 and 24 sections each.

Skep.-A bee-hive without morable frames, especially one made of straw.

Skeppist.-An old-fashioned beekeeper.

Slumgum.-The refuse from a max-extractor. See WAX in the text.

Smoker.-An implement having a fire-box with bellows attached, by means of which smoke may be blown upon bees; a bee-smoker.

Solar wax-extractor.-A glass-corered box melting beeswax by the heat of the sun.

Sour brood.-Pickled brood, which see.

Spermatheca. - A small sac attached to the oviduct. of the queen, in which are stored the spermatozoa received from the drone in the act of copulation.

Spermatozoon.-One of the germs contained in the semen of drones. (Plural, spermatozoa.)

Spiracles. - Air-tukes thru which the bee breathes.

Spreading brood.-Putting a comb without brood between two combs of brood to induce the queen to lay in the former.

Stamens.-The organs of flowers producing pollen. See Pollex in the text.

Starter. A small piece of comb or foundation fastened in a frame or section to start the bees to luilding at the right place. See ComB FoundATION in the text.

Stigma.-That part of the pistil of a flower which receives the pollen for the fecundation of the orules; usually the end of the pistil.

Strain.-Altho scientists mav not all agree as to using this word, John Phin, in his excellent Dictionary of Practical Apiculture, says it "is one of the most useful, expressive, and legitimate words that we hare, and this is shown by the extraordinary difficulty of finding a synonym for it." Suppose one has a certain race of bees. Among them he finds some that are specially noted for some particular quality, good or bad, as gentleness or riciousness, and this quality descends with more or less certainty to their posterity. This quality does not differentiate them from others of the same race sufficiently to constitute them a different race or breed, but it is of sufficient importance to warrant their being called a strain. Moreover, the characteristics of a strain are not so fixed as the characteristics of a race, and without great care the particular characteristics will disappear, or, as we say, "the strain runs out." See RACES OF BEES in the body of the work.

Super.-A receptacle in which bees store surplus honey; so called because placed over the hire.

Supersede.-Then said of bees, to rear a young queen to take the place of the old one at other than swarming time.

Surplus or surplus honey.-Honey over and abore what the bees need for their own use, and which the beekeeper takes from them; honey stored elsewhere than in the brood-combs.

Surplus apartment.-The apartment in which surplus honey is stored.

Swarm.-A large number of tees with a queen leaving the mother colony to find new lodgings and found a new colony.

Swarm-catcher. - A net placed at the entrance of a hive, a basket at the end of a pole, or any other device intended to secure a swarm as it leares the hire or afterward.

Swarming season.-The period of the year when swarms usually issue in numbers.

Syrian bees, HoLY LAND bees, which see.

Tarsus.-The fire terminal segments of a bee's leg are called the tarsi; one of these segments is a tarsus.

Tested queen.-I queen whose progeny sliow she has mated with a drone of her own race. 
Thin-super foundation.-Comb foundation running about 12 square feet to the pound.

Thorax.-The middle part of a bee between the head and abdomen, and to which the wings and legs are attached.

Tiering up.-Adding supers on the top of a hive. See CoMB HoNey. in the text.

Transferring.-Ordinarily applied to the process of changing bees and combs from common boxes to movable-frame hives.

Transformations, see BEE METAMORPHOSIS; also DEVELOPMENT OF BEES in the text.

Transposition process.-Taking a young larva from a worker-cell and placing it in a queen-cell cup.

Travel-stain.-The darkened appearance upon the surface of comb honey when left long upon the hive; so called because it was formerly supposed to be caused by the bees traveling over the comb.

Trigona bees.-A genus of stingless bees in South America and Asia. Some species bite furiously.

Uncapping-knife, see HONEY-KNIFE.

Unqueening.-Removing the queen of a colony of bees.

Unripe honey.-Honey which has not been left in the care of bees long enough to be thickened until it contains less than 25 per cent of water.

Trealed brood.-Brood not yet sealed over by the bees. In a general way eggs are often included with larvæ under the term unsealed brood. See BROOD in the text.

Virgin comb.-Comb which has been used for honey only once, and never for brood.

Virgin queen.-An unfecundated queen.
Wax-extractor-An appliance for rendering wax by heat, or by heat and pressure.

Wax-pocket. The receptacles on the under side of the abdomen wherein the bees secrete their wax. See HoNEYCOMB in the text.

Wax-press.-A press in which the wax is squeezed out of the heated combs.

Wean.-To cease giving the highly concentrated food that is first fed to larvæ, and to give coarser food. A worker larva is weaned when three days old.

Wedding-excursion or wedding flight-The flight of the queen when five days old or older, to mate with the drone in the air.

Wild bees.-Bees that are living in hollow trees or other abodes not prepared for them by man. Strictly speaking, they are no wilder than bees in hives.

Wild queen-cells.-When queen-cells are being reared, those which are started on combs where they are not wanted are called wild.

Windbreaks.-Either specially constructed fences or barivers composed of growing trees to reduce the force of the wind. See APIARIES, also WiNTER ING OUTDOORS in the text.

Wintering.-The care of bees during winter.

Worker.-A female bee whose organs of reproduction are undeveloped; well named "worker," bacause workers do all the work of the colony except laying the eggs.

Worker comb.-Comb having cells which measure five to the inch, in which workers may be reared, and honey or pollen stored. See HoNEYCOMB in the text.

Worker egg.-A fertilized egg laid by a queen-bee, which may produce either a worker or a queen. 


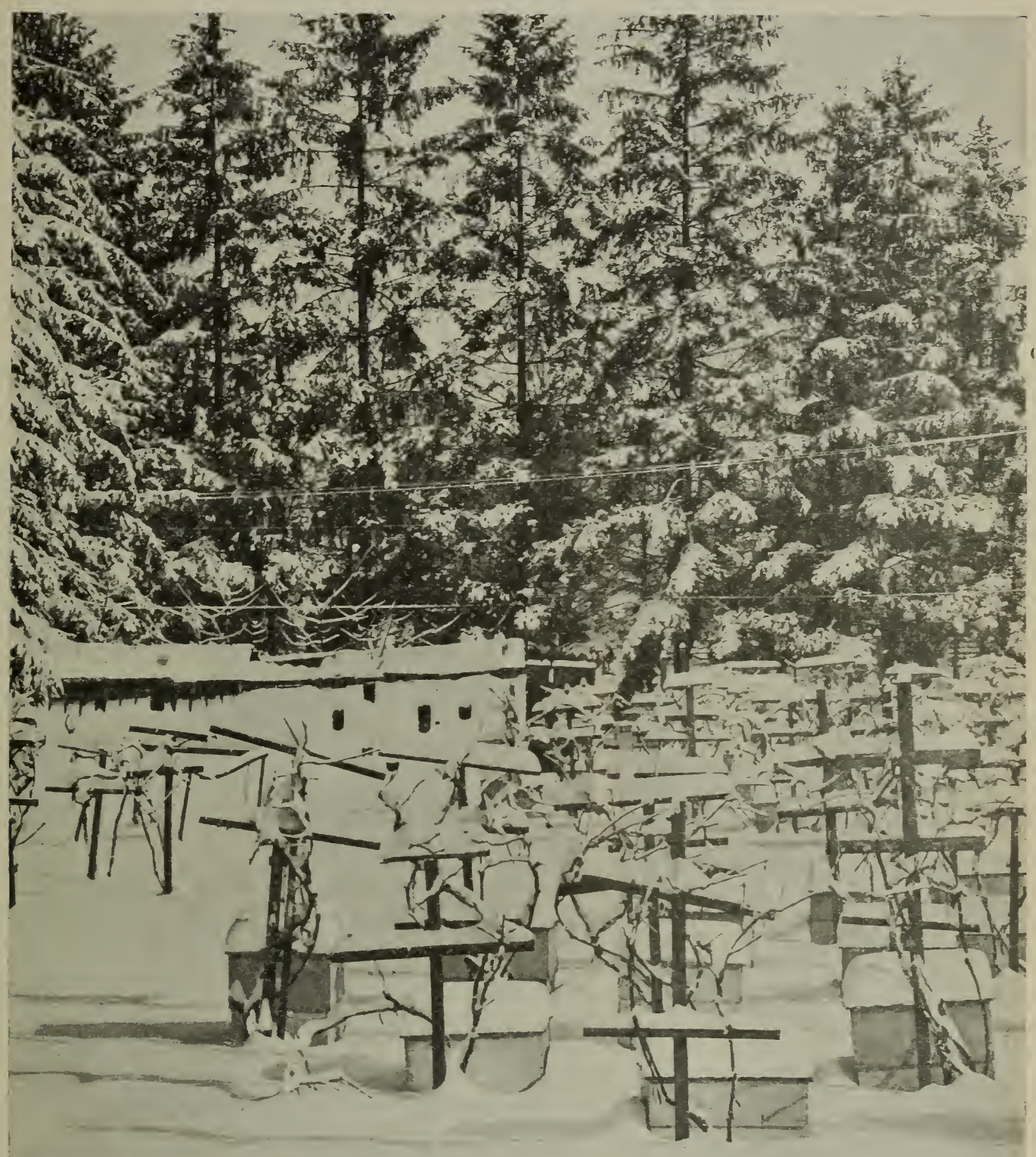

Such rest is here, and peace, and quiet breath, I scarcely know if this be sleep or death. There is no sign of anything alive, So solemn and so still is every hive. No murmur here, no eager flash of wing That thru the summer made our hearts to sing.

But every hive is still as some old tomb Of desolate dead dreams and withered bloom. The earth itself is white and still and cold And either dead or very, very o!d.
This bare dry twig was once a leafy rine Whose sap went mounting like some racy wine

That somehow made a miracle of green. Is this, then, all the miracle shall mean, This brown, unlovely, lifeless-looking thing? If so, why should we ever smile or sing? Yet smile we shall, and sing, because we know

A brave New Year is coming o'er the snow. -By Grace Allen. 

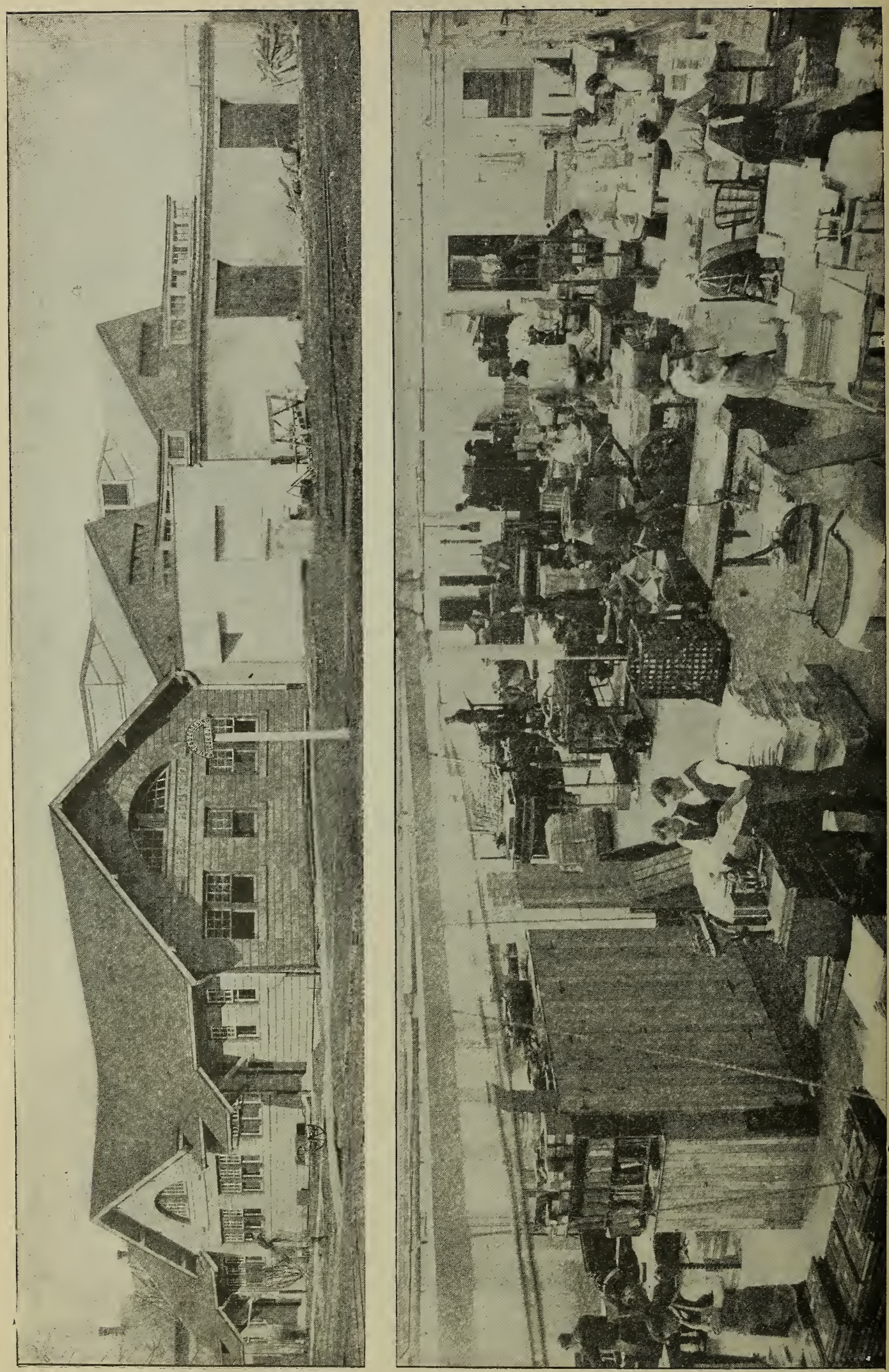


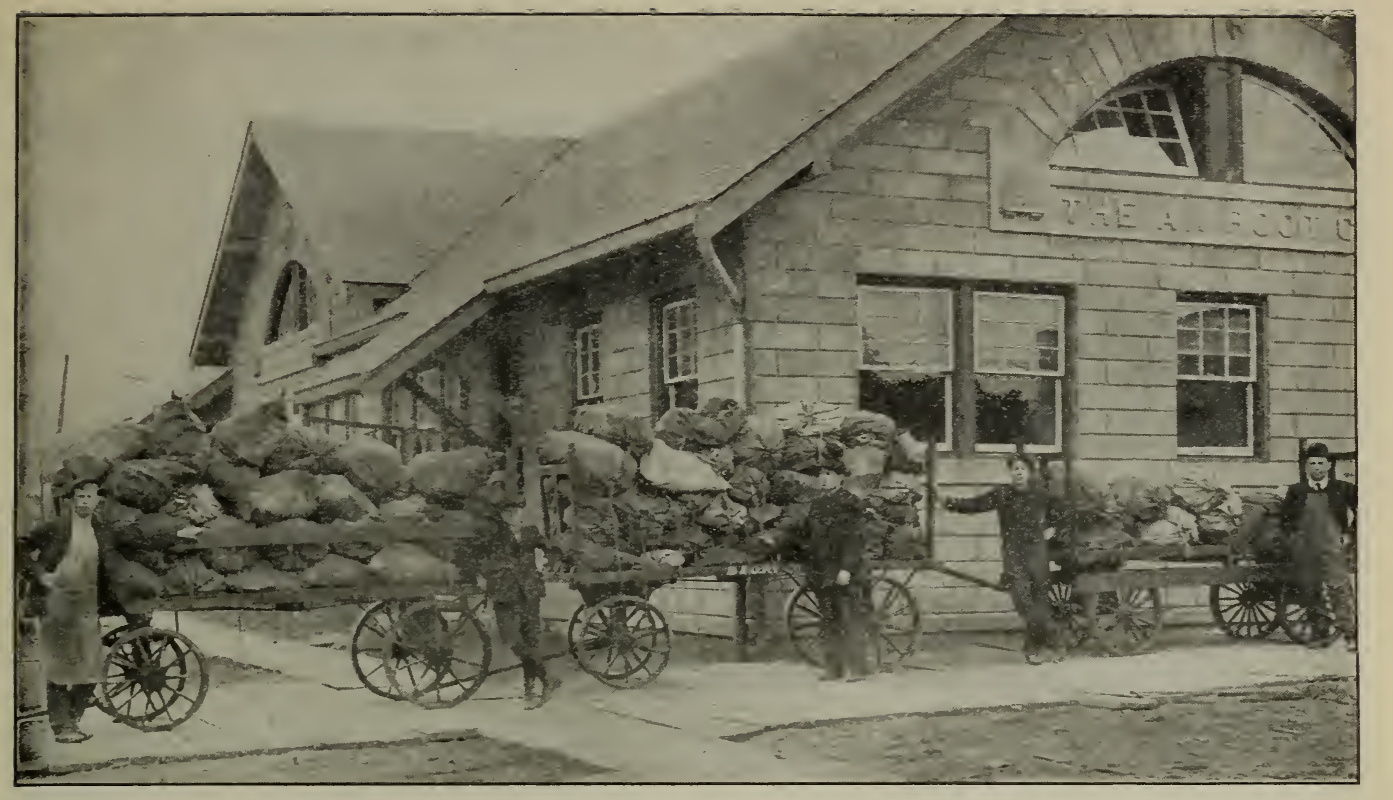

"Gleanings in Bee Culture" Ready for the Postoffice.
Note.-The view shows only about one-third of the list ready to mail.

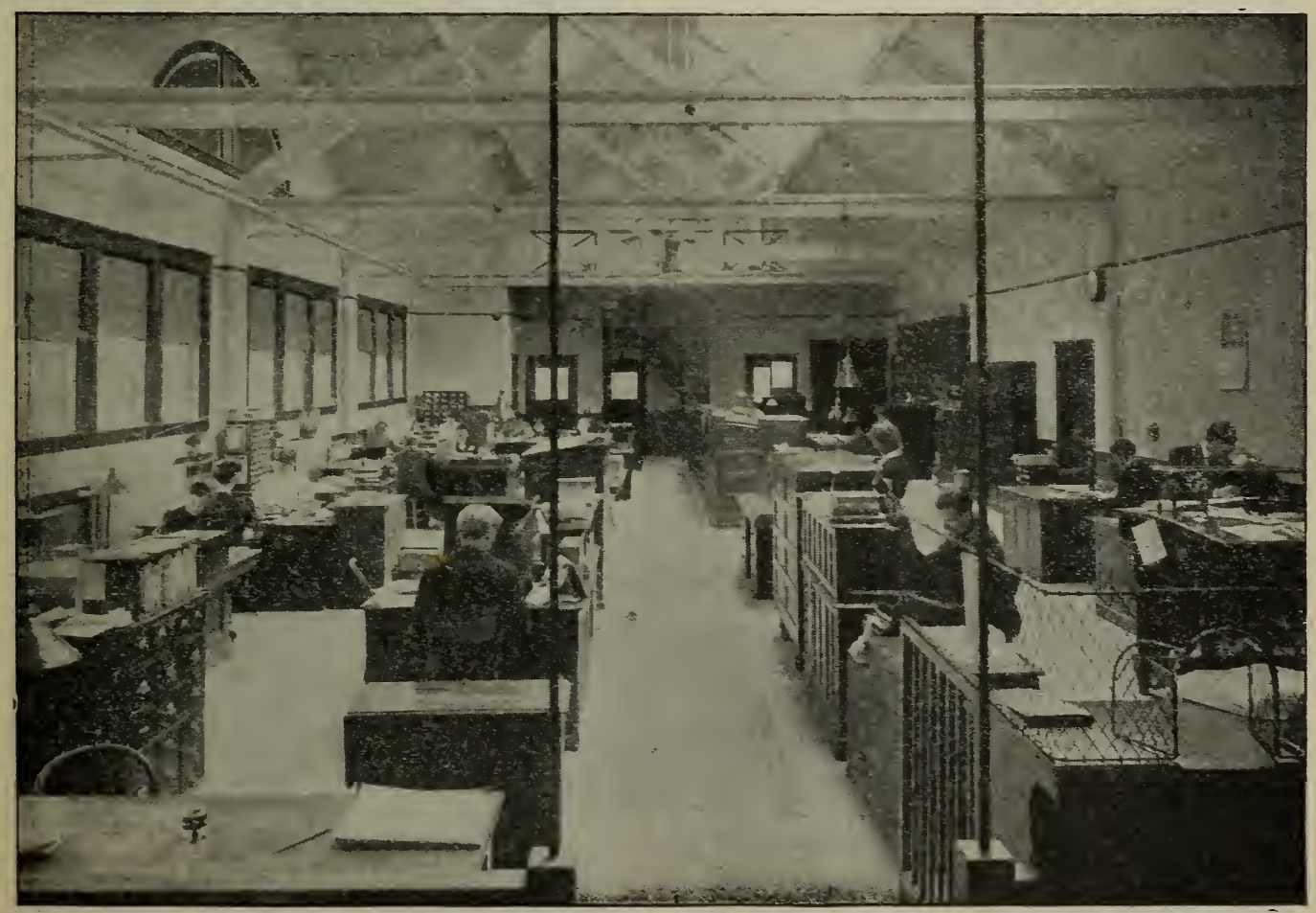

Interior View of The A. I. Root Company's Office. 


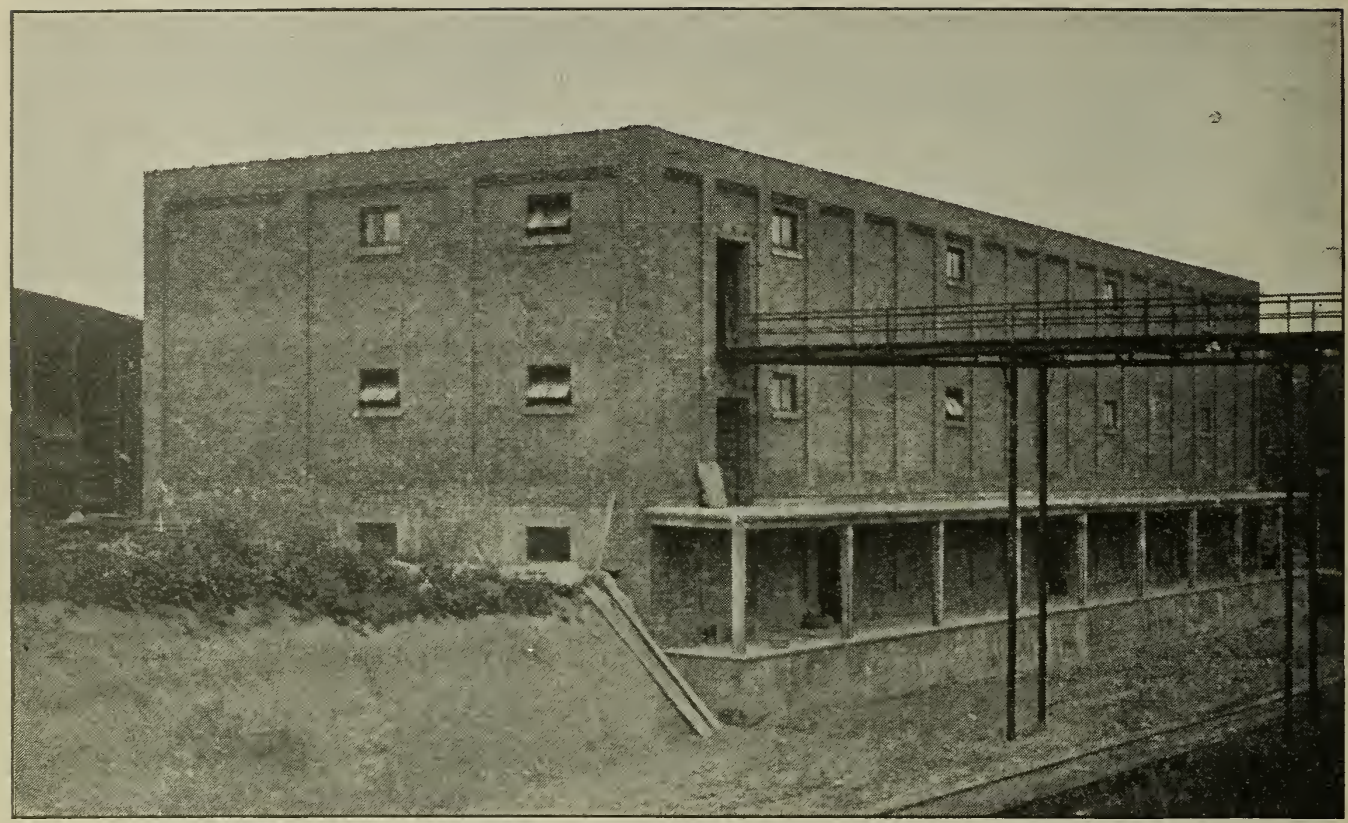

The A. I. Ront Company's Fireproof Warehouse, $148 \times 48$, three stories, with loading-platform and steel bridge connecting old Warehouse on the south.

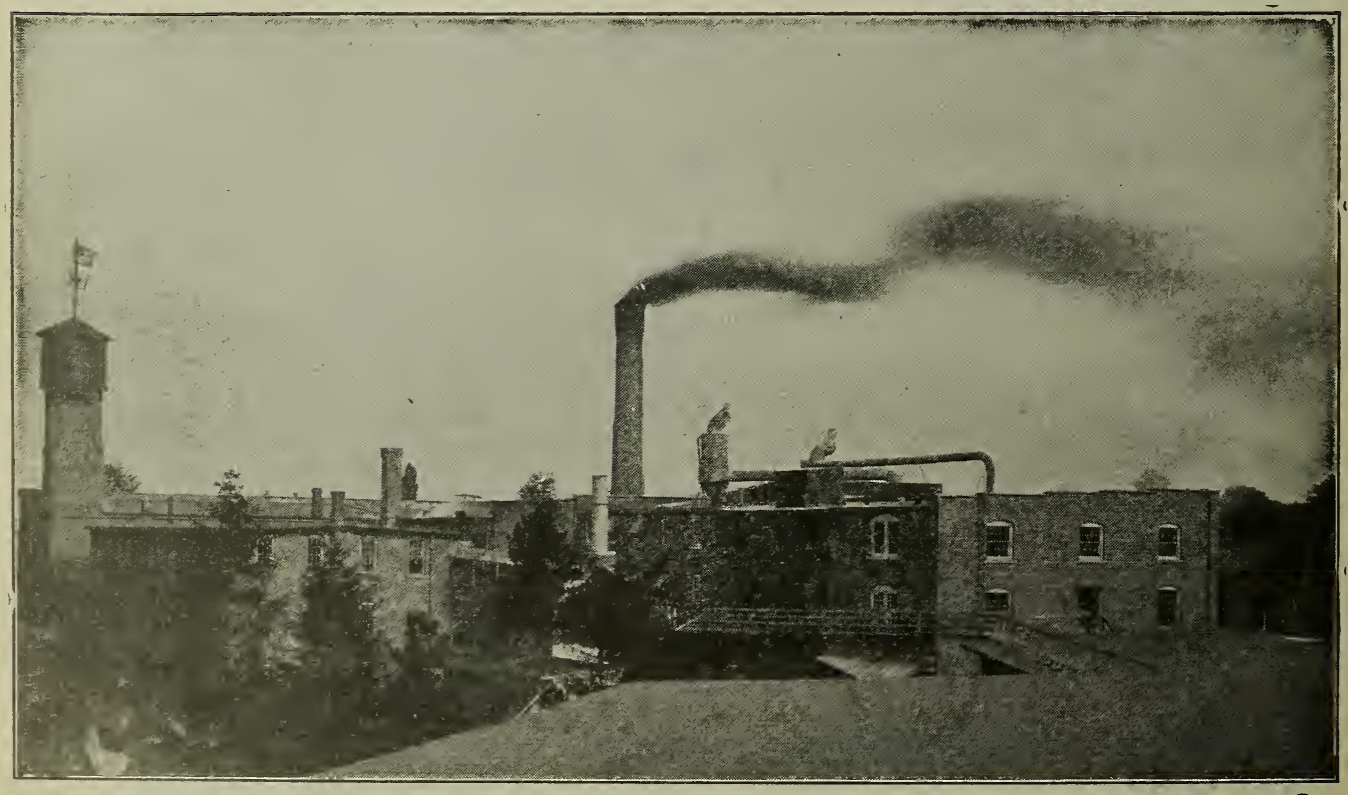

Partial View of the A. I. Root Company's Manufacturing Plant, looking from the south, 

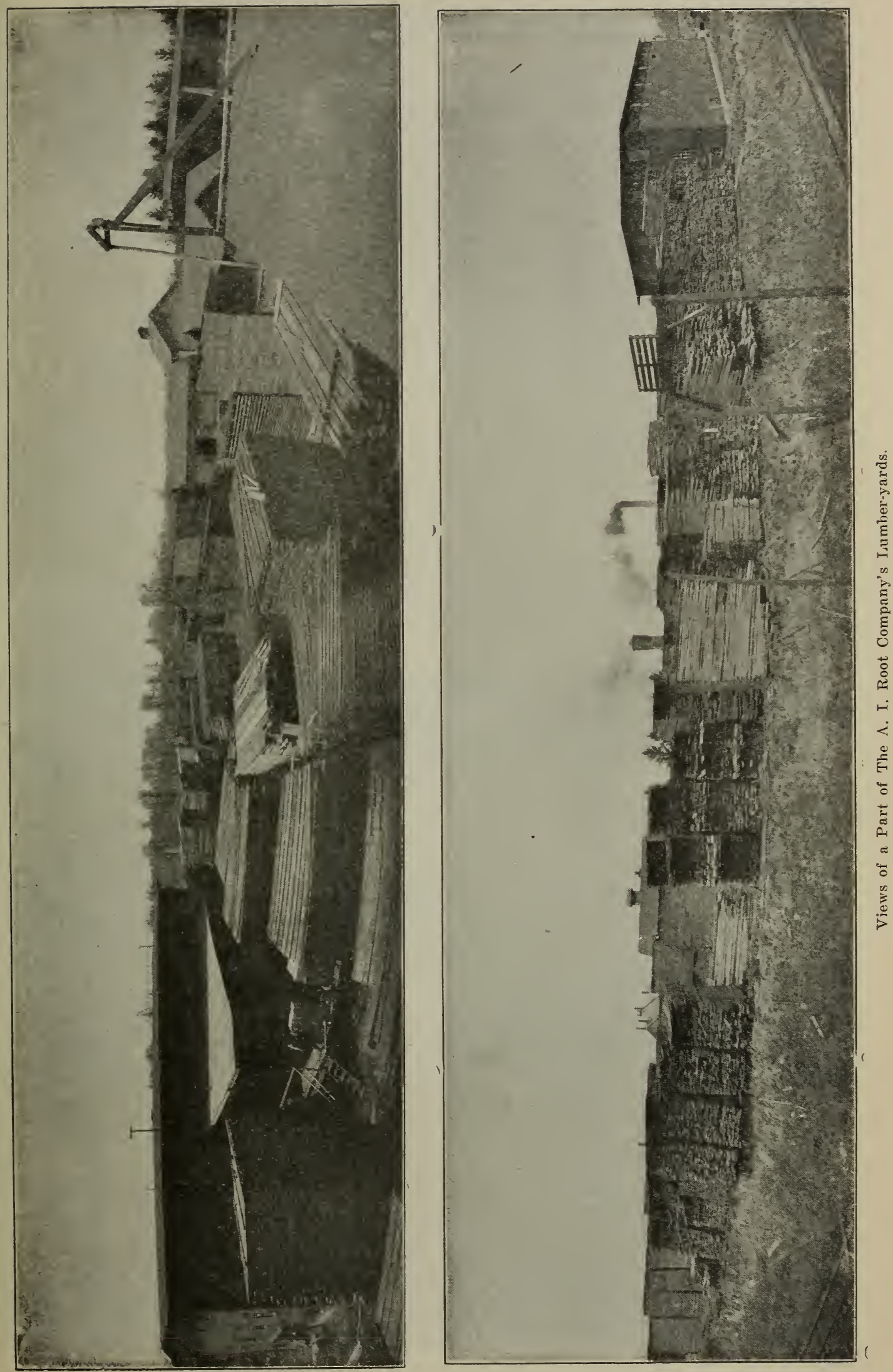


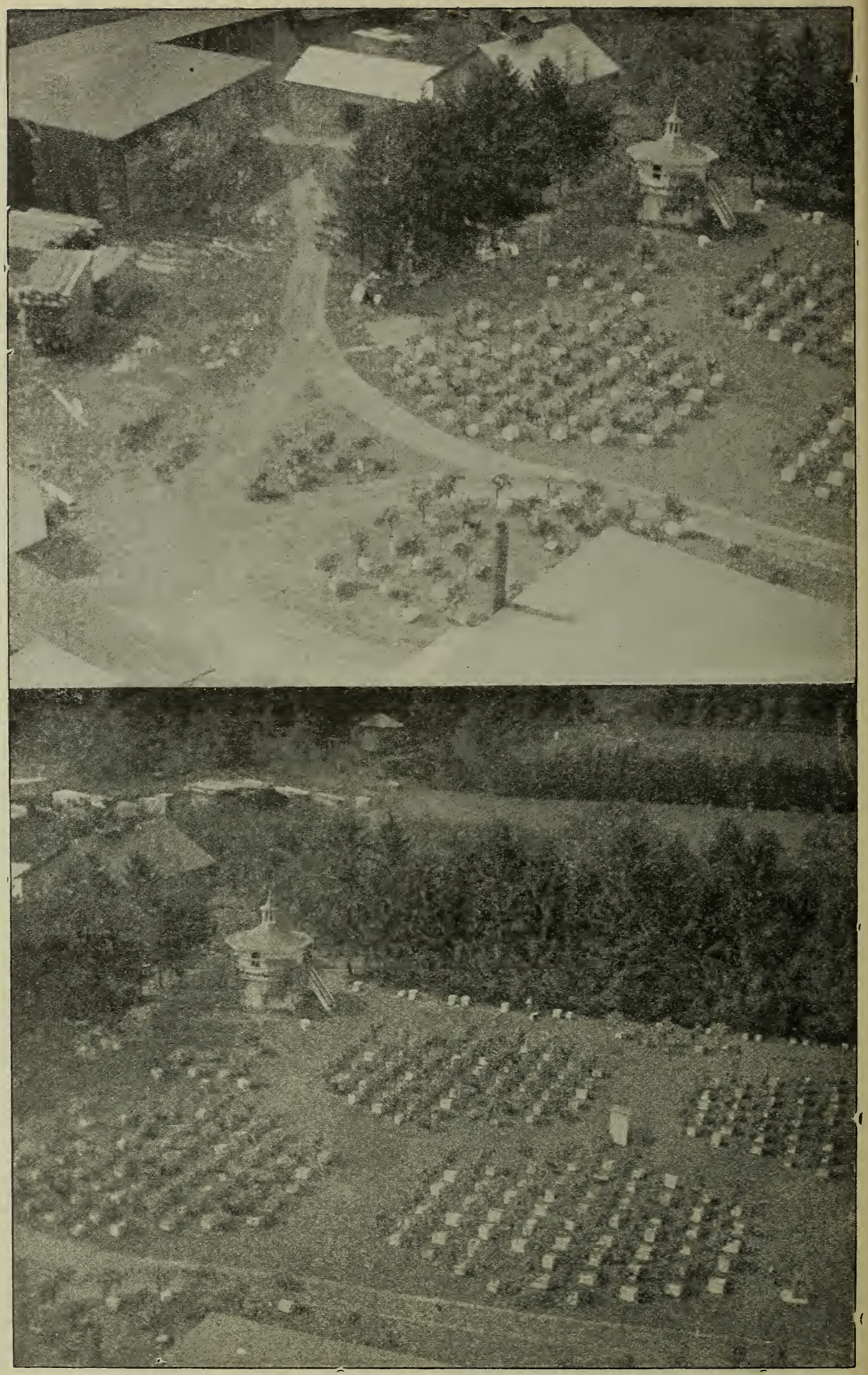

View from tōp of our Smoke-stack of a Part of our Home Apiary in 1906, Showing the Hexagonal Design and the Wall of Evergreens, as Planned by A. I. Root in 1877. 


\section{INDEX}

\section{A}

A B C-of Beekeeping,............ 11

How to Read the Book............ 4

Abdomen of a Bee ................. 31

Absorbents vs. Sealed Covers.........788, 789

Absconding-from Bad Quarters......... 13

for Want of Food............. 12

in the Spring.................. 13

Nucleus Swarms .............. 13

Swarms ..................... 11

Acidity of Honey .............. 383

Acreage to Keep Bees Busy............. 71

Adulteration - of Honey................. 14

with Invert Sugar ............14, 15

Advertising Value of Honey Exhibits....... 412

After-swarming-a Necessary Evil......... 16

Heddon Method................ 17

To Prevent...................16, 17

Ages of Queens, Drones, and Workers.....17, 18

Airline Granulated Honey............... 354

Albino Bees .................... 611

Alexander-Bee-veil ................ 746

Method of Increase..........434, 435

on European Foul Brood............ 304

on Uniting ................ 744

Alfalfa_as a Bee Pasturage................ 20

as a Pasture for Stock............ 26

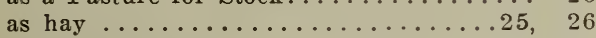

Authorities on .............. 28

Color of Honey.............. 19

Cultivation of .............. 20

Cutting Before Blooming..........25, 26

History of .............. 19

Honey $\ldots \ldots \ldots \ldots \ldots \ldots \ldots \ldots \ldots \ldots \ldots$

Pollination .................. 27

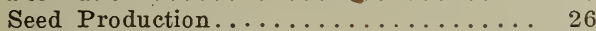

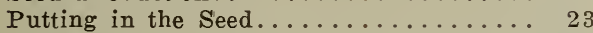

Soil Inoculation for. . . . . . . . . . 22

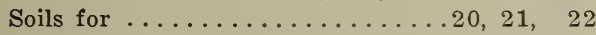

Sowing ..................... 24

Species of $\ldots \ldots \ldots \ldots \ldots \ldots \ldots \ldots \ldots \ldots$

Alfilerilla .................. 174

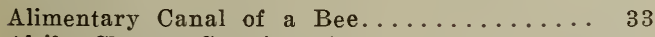

Alsike Clover-Growing of ............... 171

as Artificial Pasturage .............. 71

Seed, Furnished Free.............. 171

American Foul Brood. See Foul Brood.

Analysis of Honey. See Honey, Analysis of.

Analysis of Nectar................... 529

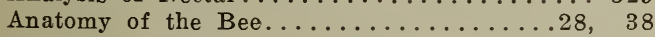

Anger-of Bees ................ 48

Cause of $\ldots \ldots \ldots \ldots \ldots \ldots \ldots, 41,411$

Stirred up by Honey-dew...........4 411

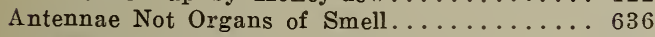

Ants-Carnivorous ................... 44

Enemies of Bees.............. 246

in the North ................ 42

in the South................. 45

Nests, to Destroy................ 43

Aphides One Source of Honey-dew. . . . .410, 411

Apiaries-Location of $\ldots \ldots \ldots \ldots \ldots \ldots \ldots 462$ Shielded by Shrubbery............. 42

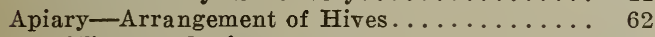
Hive-stands for ............57, 61 Inside of a Building ................ 67 Keeping Down Grass in..........63, 64
Location of $\ldots \ldots \ldots \ldots \ldots \ldots \ldots 45,48,49$

Shade for ............. 52

Apis mellifica Poison as a Remedy..........6 688

Appliances, Modern, .............. 2

Arkadelphia Case ................. 464

Artificial-Comb Honey, so-called.........408, 410

Fertilization ................ 69

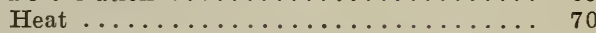

Pasturage ................... 71

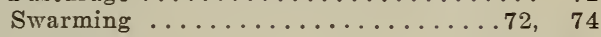

Ash in Honey.................... 381

Aspinwall Non-swarming Hive........... 706

Aster Honey-for Wintering............ 75

Pasturage .................. 499

Quality of ................. 75

Automatic Extractor. See Extracting.
Automobile-for Honey Peddling......... 421

for Out-apiaries .............. 547

vs. Horses ................. 524

B

Baby Nuclei for Queen-rearing. . . . . . . . 589

Backlot Beekeeping-for Whom Adapted...... 77

Rewards of ................... 79

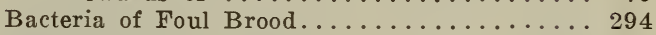

Ball Bearings for Extractor............. 261

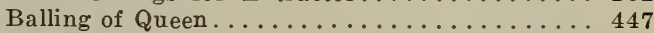

Banat Bees ....................6 611

Barrels-Frequent Cause of Complaints...... 80

How to test for Leaks. .............. 80

Removing Candied Honey........... 81

Suitable for Honey.............. 79

Waxing ..................... 80

Bartlett-Miller Capping-Melter . . . . . . . 279

Basswood-American ................. 82

Cultivation of $\ldots \ldots \ldots \ldots \ldots \ldots \ldots \ldots \ldots \ldots \ldots \ldots$

European .................... 83

Honey ..................... 82

Rapid Grower ................ 83

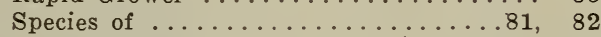

Baume Hydrometer ............... 380

Bee-Bread ...................... 88

Brushes for Extracting............270

Cellar, Different Types..........798, 801

Culture, its Scope............... 1

Escape, Invention of . . . . . . . . 449

Escape for Bee Hunting. . . . . . . . . . 92

Escape for Comb Honey.........201, 202

Glue. See Propolis.

Hunting, Best Time for.......... 88

Hunting, Box for................ 89

Hunting, Does it Pay?............ 94

Hunting, to Climb Trees............ 92

Hunting to Improve Stock............ 96

Hunting, Trapping Bees Out of Trees..... 92

in Modern Times................. 1

Inspection. See Laws Relating to Foul Brood Educational Value of............ 473 Legislation. See Laws Relating to Bees.

Line, Getting Started.............. 89

Load, Blossoms Visited............. 619

Moth. See Moth Miller.

Paralysis .................... 224

Paralysis, Immune Strain........... 225

Paralysis in Australia. ... . . . . . . . . 225

Paralysis, Symptoms ............. 224

Paralysis, Treatment ............... 224 
Smoker ...................9, 449

Space, Invention of .......98, 306, 307

Trees on Another's Property.......... 461

Unloading Pollen .............. 85

Veils. See Veils.

Young, Behavior .............. 84

Bees-Adjacent to Highway . . . . . . . . . 462

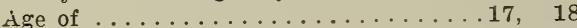

Albinos ..................... 611

Amount Can Carry................ 769

Andrena ..................... 666

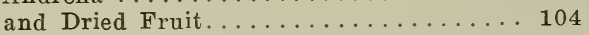

and Fruit .............3,4,98, 319

and grapes ..................... 104

and Other Pursuits.............. 110

and Poultry ............... 100

and Truck Gardening............. 100

a Nuisance .......100, 103,463,464, 468

as Scouts ................. 11

Attacking Fruit ..........103-106, 469

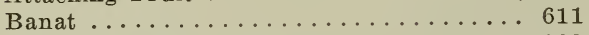

Beginning with .............. 109

Behavior Toward Each Other......... 619

Best Localities for. . . . . . . . . . . . 475

Black or German................ 609

Buying ................... 112

Carniolan .................. 610

Carrying into Cellar................ 794,796

Caucasian ................... 610

Controlled by Smoke............. 656

Cross, Cause of .............40, 41

Damaging Fruit .....103, 104, 105, 106, 469

Destroyed by Milkweed............ 501

Development of

Different Kinds of ................ 5

Distance They Fly..........246, 292, 293

Do they Hibernate?........... 803, 805

Driving with Carbolic Cloths........ 271

Dying on the Ground............. 790

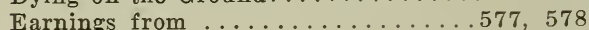

East Indian ................. 612

Eastern Races ...........454, 455, 611

Egyptians .................. 611

Exonerated by Jury.......... 106, 462 to 469

Few or Many................ 577

Flying out Chilly Days............. 790

Getting off the Combs............. 490

Getting out of Trees.............. 92

Giant, of India................ 611

Good-natured, Shielded by Shrubbery.... . 42

Hived on the Property of Another. . . . . . 461

Host and Guest. . . . . . . . . . . . . . . . . 665

How Build Combs...........407, 408

How Collect Pollen............560, 565

How Communicate ............. 621

How Know Each Other.............. 619

How Make Wax............... 755

How Recognize Each Other .......... 622

How Ripen Honey .............. 86

How Start Swarming .......... 88

How Unload Nectar ............ 86

How Ventilate Hives ............ 751

Immune to Bee Paralysis ......... 225

Improperly Handled . . . . . . . . . 480

in Ancient History .

in Carlots. See Shipping Bees.

in Cities $\ldots \ldots \ldots \ldots \ldots \ldots \ldots \ldots 4,468$

in Straw Skeps ............... 1

in United States .............6. 677,679

inspecting in Cellar ................... 792

Killed by Arsenic..............313, 316

Language Among ............... 620

Leaf-cutting . . . . . . . . . . . . . . 561

Likes and Dislikes ............ 642

Live-bee Display .............416, 417

Long-tongued ................. 664

Management in Spring. See Spring Management.
Manipulation ..........10,11,480,491

See also Manipulation of Colonies.

Mild Disposition ............... 38

Native, in Europe ............... 662

Native, in this Country ........... 662

Not Dangerous, Handled Riglıt.......4480

Not Humanitarian . . . . . . . . . . . . 619

Not a Nuisance ...........100, 464469

Number to a Colonv ............ 5

Number to Pound ............ 769

Number to Carry $1 \mathrm{lb}$. honey.......... 770

on the Farm .................. 282

on Shares ................ 106

Old Way of Keeping ............. 7

Ordinance Against . . . . . . . . . . . . . 564

Parasitic .................. 667

Profits in ............... 577

Raking out the Entrances . . . . . . . . 675

Resting Periods of ............ 86

Robbing Barns and Stable $\ldots \ldots \ldots \ldots 568$

Sent by Express ............ 525, 526

Shipped by Boat ............... 650

Shipped by Rail ............. 468

Shipping Without Combs ........526, 649

Short-tongued, Flower Visitors ...... 662

Smallest Race ................. 612

Smothered by Closing Entran'e ....... 751

Solitary. See Solitary Bees.

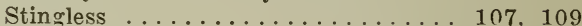

Studied in Observation Hives........ 535

Subject to Disease ................ 223

Taking French Leave ............. 12

That Gather Pollen, Different Species... 560

to Get Out of Sections .........200, 202

to Know When Cross ............... 685

to Manipulate. See Manipulation of Colonies

Tunisians ..................611

Weight of .............. 769

What Kind Sting Worse ......... 686

When to Handle . . . . . . . . . . . . . . 685

When Queenless ...............6 603

When to Take out of Cellar........... 793

When Will Not Rob ............... 621

Where to Locate . . . . . . . . . . . . . 462

Winter Sleep of ............... 80 3

Workers, two Divisions ........... 5

Worst Enemy of .............. 246

Young .................... 130

Beeswax. See Wax.

Beeway and Plain Sections . . . . . . . . . 192

Beekeeping-as an Avocation ............ 1

as a Side Line or Hobby....... .77, 670, 671

Conditions for ............... 671

for Women ................. 95, 98

in Back Yards ............... 77

Industry for .............. 671

Industry Growing . . . . . . . . . . 679

Migratory. See Migratory Beekeeping

Scope of ................. 5

Beekeeper-and His Liability to Neighbors... 463

in United States ............... 677

in Collecting Pollen .............. 560,563

Specialist .............670, 671

Too Many ................... 2

Beginning with Bees ..........109, 112

Behavior of Bees-in Building Comb ...407, 408 In Collecting Pollen ........ 560, 563 in Robbing .............. 620,621

Toward Each Other ............6619

Beharior of Young Bees .......... 130, 131

Behavior of Bumblebees ............. 151

Bell-ringing to Restrain Swarms ......... 12

Benton Cage for Mailing and Introducing. . . . 440

Bibliography of Honey .............. 400

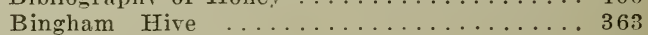

Bingham Smoker ............... 656

Birds, Not Bees, Destroy Fruit. . . . . . . . 104

Bite of Stingless Bees ............... 108 
Black or German Bees

Black Bee Subject to European Foul Brood

432,452

Black Sage ..................... 632

Blackstone on Bees ................ 461

Bleaching Comb Honey ............. 113

Blending Honey for Bottling ........... 118

Boardman Entrance Feeder ............ 285

Boardman Solar Wax-extractor........756, 757

Boomhower Knife-scraping Table ......... 203

Borage .....................113, 114

Borrowing Distinguished from Robbing .....6 630

Bottled Honey, Blend for . . . . . . . . 11,8 at Honey Exhibits ............ 413, 414

Bottles, Washing and Cleaning . . . . . . . 119

Bottling Honey, Inserting Corks . . . . . 119, 120

Labels for .................. 120

Large Scale ................ 116

Box Hive-and Mr. Quinby . . . . . . . 605

Beekeeping ............... 7,120

Cost of $\ldots \ldots \ldots \ldots \ldots \ldots \ldots \ldots \ldots, 112$

in Southern States ..............121, 122

Superstitions Concerning ......122, 123

Breeding-Drones, Importance of ....... 124

from Non-swarming Stock ......... 703

in the Fall ................673, 674

Importance of Pure Stock . . . . . . . . 124

Specifications .................... 124

Stock ................ 123, 124

Water for ................. 753

Brood-After it Hatches ........... 130 and Brood-rearing ......125, 130, 304, 565

Arrangement of ...........87, 125

Dead from Drone-laying Queen ....... 306

Development of ............ 129, 130

Drone ..................... 128

Drone, Looking Like Foul Brood ...... 306

Frames ................ 7

How it Looks .............. 125, 126

Index of Colony ............... 125

Killed by Spraying ..................... 315

of Laying Workers ..........473, 474

Spreading. See Spreading Brood.

Starved or Neglected ..........304, 306

What is it .................. 125

Brood-rearing-Dependent Upon Pollen .....565

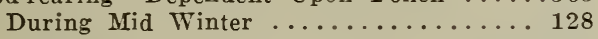

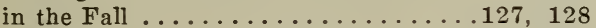

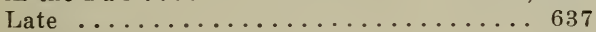

Too Early .................... 128

Water for ................. 753

Buckeye Hive, Construction of ......... 371

Buckwheat-a Paying Crop ..........133, 138

a Reliable Source ............... 132

and Crimson Clover ........... 136

Fertilizer for ............... 139

for Turning Under ............. 135

Honey, Quality of ............. 132

Preparing the Soil for ........... 134

Sowing in the Spring ........... 135

When it Yields Nectar ........... 133

Where Grown ................. 131

Bug Juice. See Honey-dew.

Building up Colonies for Comb Honey ....194, 195 Alexander Plan ............ 743, 744

Buildings-Location of ............ 141 on Wheels for Extracting .......... 143

Ventilation in Windows .......... 141

Bulk Comb Honey ................ 188

Bumblebee Parasitic .............153, 154

Bumblebees and Flower Pollination .....149, 150

and Mice ..................... 154

and Red Clover .............. 166

Growth of ............... 152

Imported to New Zealand ............ 166

Life History of .............. 151

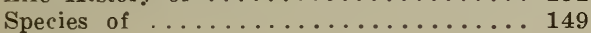

Button Sage ................... 633

\section{C}

Cakes and Cookies Made with Honey ..391, 400

Campanilla ................... 155

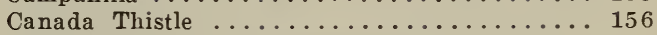

Candied Honey. See Granulated Honey.

Candy-Caution in Making ........... 158

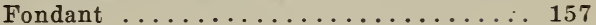

for Bees .................. 156

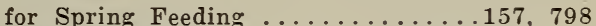

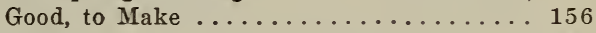

Cane Sugar .................. 158

Cans, Second-hand, to Clean ........... 259 to Test for Leaks ............... 259

Cape May Warblers Destructive to Fruit .... 104

Capping-melter for Melting up Honey ....... 350

Capping-melters ............... 277,279

Cappings, to Dispose of .............. 275

over Honey ................... 406

Card Index for Keeping Record .......... 615

Carlots of Bees. See Shipping Bees.

Carniolans .................. 610

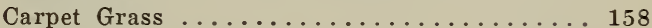

Carriers for Hives ............794, 795

Cartons for Comb Honey .... .......208, 654

Casteel on How Bees Gather Wax ....... 755

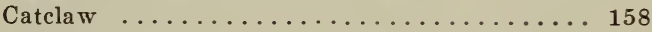

Catnip .................... 159

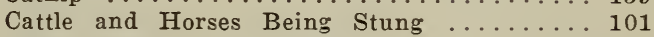

Caucasians ...................... 610

Cellar-Carrying Bees into .......... 794

Feeding Bees in .......... 797, 798

Inspection of Bees ............. 792

When to Put Bees in ............ 793

When to Take Bees out ........... 793

Wintering, Requisites ........790, 795

Various Constructions .........798, 801

Ventilation ................... 790

Cell Cups for Queen-rearing. See Queen-rearing.

Definition of ................. 219

Destroying to Restrain Swarming...669, 700

Walls, Thickness of ............ 404

Cells-in Honeycomb, Size of .......402, 404

of Drone Comb, Size of.......... 406

Relation to the Size of Bees .......... 407

Census not Reliable ..........6.6.6. 676

Chapman's Swarming-device ............ 708

Chemical Analysis of Honey . . . . 377,386

Cherry, wild .................. 770,77

Cider-mills and Bees .............. 105

Circulatory System of Bee ......... 35

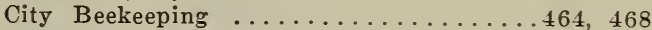

Climbers for Bee Hunters. . . . . . . . . . . . 691

Clipping Queens' Wings ......... 599,600, 698

to Prevent Swarming ............ 14

to Restrain Swarms .................. 12

to Stop After-swarming ............ 16

Clothing to Protect from Stings .......... 684

Clover-Alsike .................. 168

Food Value ................ 169

Seed Furnished Free .............. 171

Growing of ............ 170, 171

Saving the Hay .............. 170,171

Clorer, Crimson, Growing of $\ldots \ldots \ldots \ldots 172,173$

Crimson, in the Spring ......... 173

Clover, Failure of Crops ............ 161

Fall Conditions Favorable for ........ 161

Flowers of .............163, 165

Honey, Quality of ............. 160

Lime for .................... 161

Mammoth or Pearine ........... 168

Red, and Honeybees $\ldots \ldots \ldots \ldots \ldots 166,168$

Sweet. See Sweet Clorer.

Clover, White, Changing Condition of ...163, 165 Distribution of $\ldots \ldots \ldots \ldots \ldots \ldots \ldots 163$

How Propagated .............. 166

Clover Yield, Remarkable ............. 162

Clovers, Winter-killing of ........... 171

Cocoons of Moth-miller. See Moth-miller. 
Colonies-Building up in Spring 148, 194, 195, 744 Diagnosing .............. 491, 493 Few or Many .............. 577

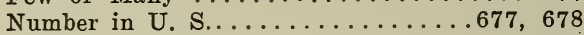

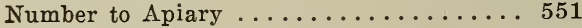
Profits in ................ 577 When to Handle ..............6685

Colony, Behavior of When Queenless ...446, 603

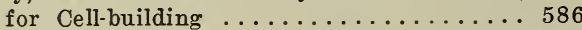
Manipulating ..........10, 11, 40, 481, 483 Records ................615, 617

Colorado Honey-grading Rules .......341, 343 Colors of Honey ............... 379, 387

Comb and Extracted Honey Both ......196, 199 and Extracted Honey, Quality of......256 Building and Honey-ripening . . . . . . . 86 Building, Variation in ........... 87 Building, Worker from Starters....... 212 Carrying-cart . . . . . . . . . . . 272

Comb-foundation-Fasteners $\ldots \ldots \ldots \ldots$ 183, 185

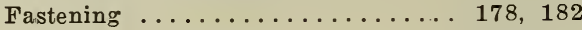
Fastening in Sections . . . . . . . 183, 187 Fastening to Wires ...........181, 182 Forerunners of Sections ........ 177 from Flat-plate Machine ........... 175

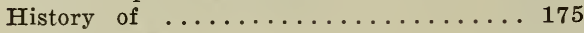
Invention of $\ldots \ldots \ldots \ldots \ldots \ldots \ldots 174,448$ Its Economic Uses ............ 177 Rolls ....................... 176

Starters vs. Full Sheets .......... 186 Weed Improvement ......... 176, 449

What it has Accomplished ......... 177

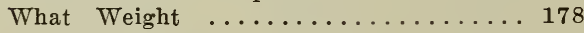

Wood Splints for ............... 180

Comb, How Bees Build ...........407, 408

Comb Honey-and Swarming ........195, 698

Appliances for . . . . . . . . . . 189, 194

Artificial ............... 408, 410

Bait Sections for ............ 199

By Feeding Back ................ 290

Cartons for ............... 208

Compared to Extracted ............ 188

Chunk or Bulk ............... 188

Defined ..................... 187

Divided into Three Classes ......... 341

Fences .................... 192

Grading of. See Grading Comb Honey.

Granulated ...................205

Granulated, Melting up ........350, 351

How to Keep ................. 208

Importance of Careful Packing ........6650

Importance of Strong Colonies ....... 194

Loss from Breakage ............... 652

Melting in Capping-melter ......... 205

Net-weight Law Affecting . . . . . . . . 456

Not Manufactured .......... 188, 408, 410

Objected to by Dealers ........... 188

Sections for ............. 189, 206, 207

Separators ..............8, 206

Shipping of. See Shipping-cases.

Super, Getting Bees out of........200, 202

Supers for ..................190, 191

Supers When to Put on .......... 196

Tiering up for ............. 200

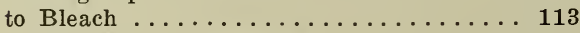

to Keep from Granulating . . . . . . . . . 208

to Produce ................ 194, 209

With Pollen in ................. 569

Combs-Attached to all Four Sides ...... 211 Better by Reversing ......... 617, 618

Carrying to the Extractors ......... 271

Damaged by the Wax-worm.......... 502,512

Diseased, Rendering ........... 767

Filled Out ................ 618

Getting Bees from ..............4490

Good, Bad, and Poor ............210

Importance of having a Large Stock ... 211

Not Affected by European Foul Brood .. 303
Poor, Bad Economy ............. 211 Old, Rendering into Wax.........757, 759

Strong, the Value of............. 211 Thickness of $\ldots \ldots \ldots \ldots \ldots \ldots \ldots 404,406$ to Manipulate. See Manipulation of Colonies. Uncapping ................. 272 Which Should be Transferred ....... 732 Commercial Beekeeping ...........6670,671

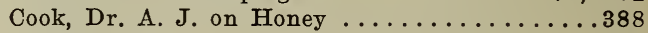
Compound Eye .................281 Contract for Bees on Shares .............. 106 Contraction ................213, 214

Court Decision Regarding Invert Sugar..... 15, 16 Relating to Bees .............. 106 Crimson Clover, Failures of ......... 173 Crop, Honey from ................ 214

Cross Bees ...................... 432 and Honey-dew .................... 411 Caused by Source of Honey ........ 42 Due to Improper Handling . . . . . . 480, 481 See Anger of Bees.

to Avoid. See Manipulation of Colonies.

What Makes Them so?.........4 40, 41

Cucumbers, Honey from ............. 216

Pollenized by Bees ..................... 216

Pollination of ............. 215

Cyprians and Holy Land Bees........453, 455

\section{D}

Dadant Hive . . . . . . . . . . . 365, 366 Dadant on Swarm Control .......365, 704, 705 Dandelion-a Forage Plant for Cows....... 218 a Nuisance ................... 219 Nectar and Pollen from .......... 216

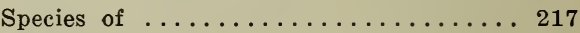

Distribution of .............. 216

Danzenbaker Closed-end Frame . . . . 309, 364, 618 Danzenbaker Hive ................ 364 Darwin on Pollination .............. 571 Dayton on Liquefying Granulated Honey .... 347 Davidson's Concrete Bee-cellar .......... 802 Demonstration of Live Bees ........... 416 Demuth on the Cause of Swarming ......665 Dequeening to Prevent Swarming . ...694, 698, 701 Development of the Egg and Larva 219, 223, 536, 537 Dextrin in Honey ................. 381 Dextrose and Levulose in Honey ........ 383 Diagnosing Colonies ............491, 493 Dimensions of Hives and Frames ......359, 361 Diseases ............ 223, 227, 294, 307 Affecting Census Figures . . . . . . . . 679 in May ................... 227

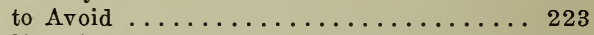
Two Classes for Bees ................... 224,225 Displays of Bees and Queens. See Honey Exhibits. Distance Bees Fly .............. 292, 293

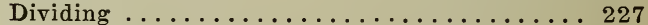

Doolittle Solar Wax-extractor ......... 756 Method of Shaking Swarms .......... 73 System of Queen-rearing ........... 582 Double Walls with Packing, Advantages of .... 370 Double vs. Single-walled Hives. . . . . . . . . 370 Dovetailed Hive, Extra-depth ............. 368 Dovetailing in Hives ............... 499 Drifting, Conditions favorable for.......... 228 Drone Bees ....................... 6

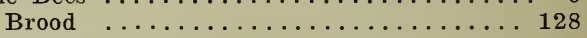
Brood Like Foul Brood $\ldots \ldots \ldots \ldots \ldots \ldots 306$

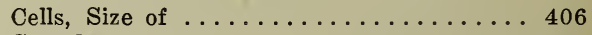
Guards ..................... 236, 237 Only One Parent? ............. 232 Laying Queen ...............598, 602 Traps .................... 236

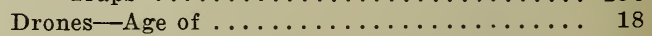
Behavior of .............. 87 Characteristics of $\ldots \ldots \ldots \ldots \ldots \ldots \ldots 229$ Destruction of in the Fall ........... 233 Distance they Fly............. 230 


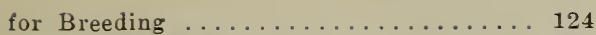

Economic Waste ................ 229

from Worker Bees............ 232, 233

from Drone Layers ............... 233

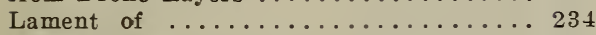

Mating with Queens .........229, 231

Preserved for Queen-rearing ........2 234

Restraining with Excluders ....... 235, 237

With Heads of Different Colors ........ 234

Dual Plan of Introducing Queens ........ 588

Dysentery-Cause of $\ldots \ldots \ldots \ldots \ldots \ldots 237,673$ Caused by Aphides ............ 238

Caused by Dampness and Cold ....... 239

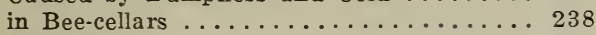

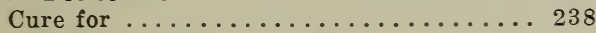

Result of Spring Dwindling .......6673

Prevention of .............. 238

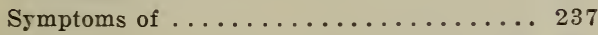

Dzierzon, Dr. ..............239, 241

Theory $\ldots \ldots \ldots \ldots \ldots 6,241,243,555,556$

Movable Frames ........... 307, 375

\section{$\mathbf{E}$}

Earnings from Bees .............. 577

Eastern Races of Bees .............6 611

East Indian Bees ................... 612

Egg of Bee-Derelopment

$129,130,219,223,536,537$

How Formed ................ 38

How it Produces Queen .............. 593

How Laid by Queen ...........125, 672

of Laying Workers ............. 473

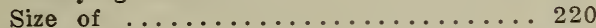

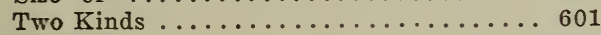

Egyptian Bees .................... 611

Electric Alarm when Can is Full......... 280

Electrical Wiring of Comb Foundation ....... 182

Elementary Beekeeping ............. 5-11

Enemies of Bees ............. 244, 247

Enemies of Moth-miller ............. 514

Entrance-contractor ................ 249

Entrances-Cleaning Bees Out of .......6 675

Closing of Dead Colonies ..........6675

for Indoor Wintering . ......... 251, 252

Grass and Weeds in Front of ........ 248

Large, Control Swarming ........... 251

Location of ...................... 247

Loss by Obstruction ......... 247, 248

Obstructed by Caucasians ......... 749

Plurality of ............250,251

Protected from Mice ............. 250

Size of $\ldots \ldots \ldots \ldots \ldots \ldots \ldots \ldots \ldots . \ldots \ldots, 789$

Enzymes in Honey ................ 384

Essentials for Handling Bees ........... 481

Eucalyptus-Different Species ......... 253

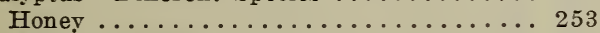

Where Distributed ............. 252

European Foul Brood. See Foul Brood.

Exhibits of Honey. See Honey Exhibits.

Extracted Honey and Comb Honey .... 196, 199 Clarified by Gravity ............ 267

for Cooking Purposes . . . . . . . 256

Glass Packages for ............. 256

Grading of .............. 343

Not Adulterated ......................... 258

Not Equal to Comb ............ 256

Not Fully Ripened ...........256, 257

Packages for .............256, 260

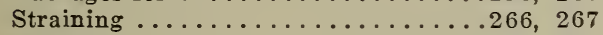

to Keep ........................ 257

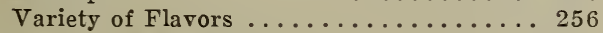

Extracting-Brushes for ............ 270

Cans, to Clean ...................... 259

Equipment, Location ............ 266

See also Building.

Getting the Bees off Combs ........... 269

House on Wheels .............143, 145

Houses and Buildings. See Buildings.
Supers Driving Bees with Carbolic Cloths. 271

Bail Bearings for ............. 261

Inrention of $\ldots \ldots \ldots \ldots \ldots \ldots \ldots \ldots 448$

Reversible ................. 261

Extractors, Power-driven ..........262, 265

With Honey-pumps .............. 264

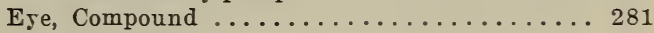

\section{$\mathbf{F}$}

Farmer Beekeepers ..........282, 294, 679

Driven out by Foul Brood ........... 294

Fastening Foundation with Steam........ 185

Fed-back Comb Honey Granulating ........ 291

Federal Net-weight Law..... 120, 343, 379, 456

Feeder-Boardman ............... 285

Doolittle ................ 286

Miller ................. 286

in Atmospheric Principle.........284, 295

Feeding-Night when Robbers are Bad.. 289

Back, Essential Conditions ........... 290

Back to Produce Comb Honey .... . . . . 290

During Mid-winter ........... 797, 798

for Winter, Best Time ........... 288

How to make the Syrup ............ 283

in Freezing Weather.............. 289

in Spring or Fall ............. 289

Outdoors ............. 291, 292, 629

Rapidly ................ 287

Slowly for Brood-rearing ............ 287

Variously Constructed ..........284, 286

When it Should be Practiced .......... 283

Without a Feeder ................ 286

Fence and Plain Section Srstem .......... 192

Fence Separators .............. 8, 206

Fertile Workers. See Laying Workers.

Fertilization, Artificial .............. 69

Figwort ..................... 293

Fireweed. See Willowherb.

Five-banded Italians . . . . . . . . . . . 454

Flavor of Comb Honey ............... 188

Flavor of Comb and Extracted Hones...... 256

Flight of Bee ...............292, 293

Flowers, How they Attract Bees ......575, 576 Pollinated by Birds ............... 574 Pollination by Water ........... 573

Flowers that Furnish Nectar ............ 576 With Gaudy Colors .............. 576

Fondant-for Queen-cage Candy ............ 157

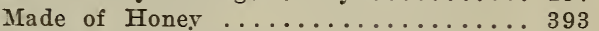

Food-Elements in Honey ............. 389 of Larval Queens ...............593, 594 That the Bee Likes ............6 642

Foul Brood-and the Moth-miller ......504, 505

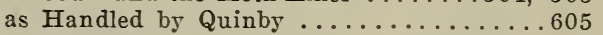
Bacterial Disease ............... 294 American ................... 296 American and European Differentiated

American, Symtoms of .........2962, 298 American, Treatment of ..........299, 302 Carried to Neighboring Hive ........ 298 Damage Done ................. 294 Disappears After Main Honey Flow .... 127 European, Alexander Treatment ........ 304 European, Attacks Hybrids and Blacks .. 452 European, Symptoms of ............ 302 European, Treatment of .............. 303,305 Importance of Knowing ............. 294 Laws. See Laws.

Penalties ................ 471

Two Classes of ............... 294

Under Control by Co-operation ........ 470

Foundation-Fasteners ......... 183,450 Press ................... 176 Rolls ....................... See Comb Foundation.

Fowls' Method of Swarm Control ........701 Frame-Inrented by Langstroth . ...306, 375, 448 
Invented by Dzierzon ............ 375

Movable, Invention of ...........448

Quinby's Closed-end .............66 606

Spacing of $\ldots \ldots \ldots \ldots \ldots \ldots \ldots \ldots 9,669$

Frames-Brood $\ldots \ldots \ldots \ldots .7,8,306,307,448,606$

How to Handle . . . . . . . . . . 482, 489

Langstroth Original . . . . . . . . . . 361

Reversing ........... ....6 617, 618

Self-spacing, ............306, 313

Shallower than Langstroth ............ 360

Size and Shape of ............. 307

to Manipulate. See Manipulation of Colonies.

Wiring for Foundation ......... 178, 181

Freight on Carload of Bees ........645, 646

Friction Drive on Power-extractors ...263, 264

Fruit-blossoms-Honey from . . . . . . . 313

Pollination of $\ldots \ldots \ldots \ldots \ldots \ldots \ldots \ldots \ldots \ldots \ldots \ldots, 335$

Spraying of ..............313, 315

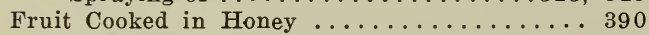

Damaged by Bees ..........103, 106, 469

Not Punctured by Bees ............ 469

Fuel for Smokers ............ 658, 659

Furnaces in Bee-Cellars ..............791

\section{G}

Gallberry. See Holly.

Giant Bees of India

Given Foundation Press

176

Glass Hives. See Observatory Hives.

Glass Packages for Extracted Honey ....... 260

Globe Bee-veil . . . . . . . . . . . . . . . . . 747

Gloves for Handling Bees . . . . . . . . 336

Glucose-Adulteration ................ 14

Detection of in Honey............ 383

Determined by Polarization ......... 384

Glue, Bee. See Propolis.

Goldenrod, Different Species ........338, 340

Goldenrod Honey . . . . . . . . . . . . . . . 340

Good Candy ................... 156

Grading-by Pictures ..................... 344

Importance of a Standard ............ 341

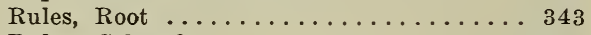

Rules, Colorado

341,342

Grafting Cells. See Queen-rearing.

Granulated Comb Honey, Melting up 205,350, 351

Granulated Honey-Airline ............ 354

Cutting up into Bricks .................. 353,354

Educating Public to .............. 355

How to Market............ 352, 354

in Brood-combs ................ 351

Liquefying .........115, 117, 346, 349

Liquefying with the Sun's Heat ....... 118

Granulated Sugar. See Sugar.

Granulation-Alfalfa Honey ............ 19

Cause of ....................... 350

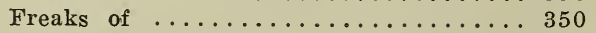

Not a Test of Purity ............ 346

Prevented by Heating ............ 346

Prevented in Comb Honey ............ 208

Science of .................. 350

Gravity Method of Clarifying Honey ....... 267

Groceries, Selling Honey in .......... 495

\section{$\mathbf{H}$}

Handling Bees. See Manipulation of Colonies.

Hatch's Bee-cellar ................ 798

Hatch-Gemmill Wax-press ............... 762

Hats for Bee-veils . . . . . . . . . . . 745, 747

Head of Bee ..................... 30

Heddon on Preventing After-swarming ....... 17

Heddon Method of Transferring ......... 735

Heartsease ........................ 356

Heat, Artificial ................. 70

Heating Honey to Facilitate Straining ....... 268

to Prevent Granulation .............. 346

Hermaphrodite Bees ................ 357

Hetherington, Pupil of Quinby ............. 608

Hibernation of Bees .................. 803
Hive-Aspinwall .................450

Bingham .................. 363

Carriers .................. 794

Dadant ....................... 365

Danzenbaker ............... 364

Double-walled .......369, 372, 777, 778

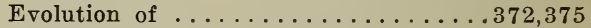

Heddon ...................... 365

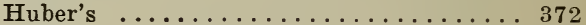

Jumbo .................... 368

Large, Obections to ............. 367

Making ................. 357

Modern, Dissected ............. 8

Non-swarming ............... 706

Prokopovitsch ............... 373

Records ...............6 615, 617

Scale ......................6. 635

Small, Swarming ............. 13

Stewarton ..................... 373

Tool and Its Uses . . . . . . . . . 10, 482,483

Twelve-frame Langstroth . . . . . . . . 368

Two-story vs. .Large Quinby Hive ...... 367

Hives, Arrangement of in Cellar . . . . . . 792

Definition of $\ldots \ldots \ldots \ldots \ldots \ldots \ldots \ldots \ldots \ldots$

Dimensions of ............... 359

for Stingless Bees $\ldots \ldots \ldots \ldots \ldots \ldots \ldots \ldots . \ldots \ldots$

How to Handle .........10, 11, 483, 485

Langstroth, Advantages of ......... 360

Large, to Prevent Swarming . . . . . . . 366, 368

of Early Construction ...........372, 374

Observatory. See Observatory Hives.

Requisites of .............. 358

to Open. See Manipulation of Colonies.

With Closed-end Frames . . . . . . . . . 363

to Handle .............. 488,489

Hivestands for Apiary ...........57, 61

Hoffman Frames-Invention of ........... 449

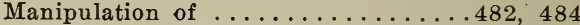

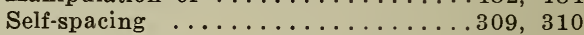

Holly ... . . . . . . . . . . . . . . . 375

Holtermann Winter Case ........... 780,782

Bee-cellar .............8800,801

Holy Land and Cyprian Bees .......... 454

Honey $\ldots \ldots \ldots \ldots \ldots \ldots \ldots .376,379,559$

Honey-a Carbohydrate ............ 376

Adulterated with Glucose ........... 14

Adulterated with Invert Sugar .... 14, 15

Alfalfa ................... 19

American and Hawaiian .......... 378

Amount Carried by Bee ............ 769

Analysis of $\ldots \ldots \ldots \ldots \ldots \ldots \ldots 377,386$

and its Colors .............. 387

as a Food .............2, 3, 388, 400

as an Energy Producer . . . . . . . . . 388

Aster, Quality of ............. 75

at Hospitals ............... 388

Bees to Carry Pound of .............

Bibliography of ............. 400

Bread ....................... 397

Cakes, List of .................. 394

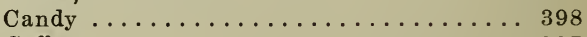

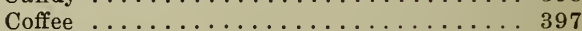

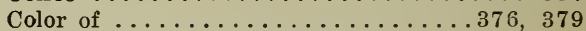

Comb, Cell Angle, How Placed ........... 401

Comb, Cells, Size of .........402, 404

Comb, Chief Use of . . . . . . . . . . . 401

Comb from Wax Scales ........400, 401

Comb in the Bible ............... 400

Combs ..................... 400,40

Composition of $\ldots \ldots \ldots \ldots \ldots \ldots 400,410$

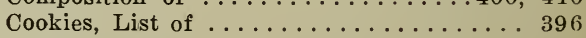

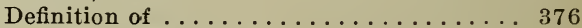

Dew for Wintering ........... 411

Dew, Quality of ..............

Exhibits ................. 412,418

Exhibits, Educational Effect of ........ 412

Exhibits, How to Arrange .......412, 415

Extractors $\ldots \ldots \ldots \ldots \ldots \ldots \ldots \ldots \ldots \ldots \ldots$ 
Extractors, friction Drive, ........ 263

Flow, Record of .............. 635

Flow, Slow or Rapid ............ 474

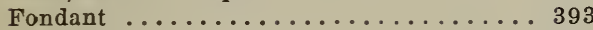

for Children ............... 388

for Invalids $\ldots \ldots \ldots \ldots \ldots \ldots \ldots \ldots \ldots \ldots \ldots \ldots \ldots \ldots \ldots$

Goldenrod .................. 340

Granulated. See Granulated Honey.

How Bees Ripen ............... 86

How it Differs from Sugar in Cooking... 390

How it Preserves Baked Foods ....... 390

How to Analyze .................... 379

In Cooking ...................... 390

Inorganic Elements in . . . . . . 388, 389

Methods for Analyzing . . . . . . . 383, 386

Peddling . . . . . . . . . . . . 418, 421

Peddling at Groceries ............. 421

Peddling Made Easy ............. 418

Physical Properties of ............. 376,378

Plants Affected by Soil Conditions ..... 422

Plants, Distribution of ........... 422

Plants, Hybridization of $\ldots \ldots \ldots \ldots \ldots 423$

Plants Modified by Soil ........4 422, 430

Plants of Foreign Countries .......... 423

Plants Yielding Pollen ......... 423, 425

Poisonous. See Poisonous Honey.

Preserves ........................ 397

Produced in the United States......677, 679

Pumps for Extractors ............. 264

Recipes ..................... 4900

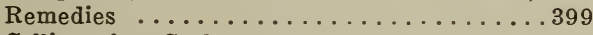

Selling for Cash . . . . . . . . . 496

Selling to Commission Houses ....... 496

Specific Gravity of ..........671, 672

Temperature of for Bottling ........... 115

to Prepare for Analysis . . . . . . . . 380

Trainload of $\ldots \ldots \ldots \ldots \ldots \ldots \ldots \ldots 6,676,677$

Weight of $\ldots \ldots \ldots \ldots \ldots \ldots \ldots 671,672$

See Extracted Honey. Also Comb Honey.

Horehound ................. 430

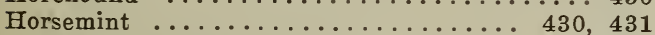

Horses, Protecting from Stings .......... 102

When Stung, to Treat ............ 682

House Apiaries, to Construct .......65, 66, 67

for Wintering ................... 69

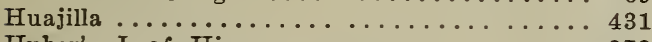

Huber's Leaf Hive ................. 372

Huber's Invention . . . . . . . . . 372, 374

Hybrids - of Carniolans . . . . . . . . 432, 433

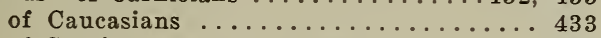

of Cyprians and Holy Land ........... 432

of Italians .................... 431,432

Subject to European Foul Brood........ 432

\section{I}

Imbedding Foundation in Wire........181, 182

Increase-Alexander Method ..........434, 435

by Forming Nuclei .............. 531

from the Honey-producer ............ 434

Index Cards for Bees ................... 615

Indoor Wintering. See Wintering in Cellar.

Inkberry. See Gallberry.

Inmates of the Hive $\ldots \ldots \ldots \ldots \ldots \ldots, 6$

Inorganic Elements in Honey .................. 388

Inspection of Bees. See Laws Relating to Foul Brood.

Inspectors-Nursery $\ldots \ldots \ldots \ldots \ldots \ldots \ldots \ldots 438$

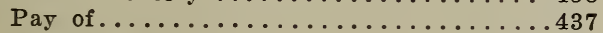

Qualifications of $\ldots \ldots \ldots \ldots \ldots \ldots \ldots 4,436,437$

Students for .................... 437

Intelligence of the Honeybees . . . . . . . . . 620

Introducing - a Sure Way ............. 445

Benton Cage for .....................

Cage, Miller's ................ 441

Candy Method of ....................

Conditions Favorable for . . . . . . 438,439

Direct Method of ................ 446

Dual Plan ................. 446
How Long Queenless for . . . . . . . . 447

Mailing-cage for ...............439,441

Miller Smoke Method ............. 442

Push-in-cage Plan ...........443, 444

Simmins' Method ............... 446

to Young Bees ................ 445

Scent Factor in .............. 438

To Young Bees .............. 445

Virgin Queens ............ 487, 588

Inventions Relating to Bee Culture .....448, 451

Invert Sugar, Court Decision Concerning .... 15

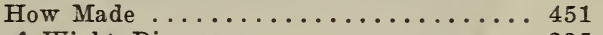

Isle of Wight Disease ............... 225

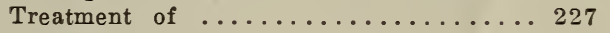

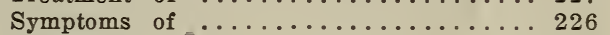

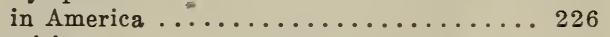

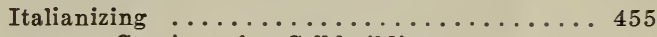

vs. Cyprians for Cell-building ....... 453

Italians-Five-banded $\ldots \ldots \ldots \ldots \ldots 445,454$

Markings of ................ 452, 453

More Resistant to Isle of Wight ......... 227

vs. Hybrids . . . . . . . . . . . .451, 452

\section{$J$}

Jumbo Hive . . . . . . . . . . . . . . . . 368

Junge-Pierce non-swarmer .......... 706

$\mathbf{K}$

Kegs .................... 79

King Birds Enemies of Bees............. 244

Labeling Honey .................. 379,456

Labels, Requirements of Law............... 120

Langstroth-and Quinby .............. 460

Frame, Origina ...........

Frame, Dimensions of . . . . . . . . . . 358

Biography of $\ldots \ldots \ldots \ldots \ldots \ldots \ldots 457,461$

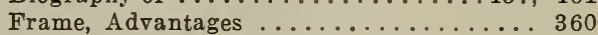

Hive, Original ............... 360

Standard Thruout the United States..... 330

on the Quality of Sage Honey......... 634

Patent on Hives.................. 557

Root's Reminiscence of.......... 459

\section{L.}

Lantern Light for Working Bees......... 629 Larvae, Development of ......220-222, 536, 537

Larval Bees, Behavior................ 84

Law-General Principles Relating to Bees.... 461

of Negligence Relating to Bees .....462, 463

Net-weight. See Net-weight Law.

Ohio .................... 471

Relating to Foul Brood........470,473

Laying Workers-Cause of ............ 473

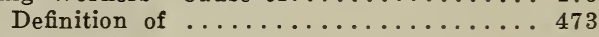

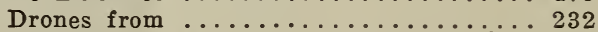

to Detect Presence............... 474

to Get Rid of .................... 4734

Laying of Queen................601, 602

Legislation Relating to Bees. See Laws.

Legs of Bees................. 560, 561

Liability of a Beekeeper. See also Laws...... 463

Lime for Alfalfa Soil................. 22

Lime for Clovers. . . . . . . . . . . . . 161

Live-bee Demonstration at Fairs . . . . . . . . . . 416,418

Locality-Effect on Swarming..........695, 697

Effect on Wintering.............. 775, 776

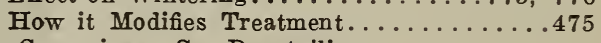

Lock Cornering. See Dovetailing.

Locust ................... 476

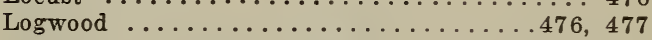

\section{$\mathbf{M}$}

Magnolia ................... 479

Mangrove, Black ..............477, 480

Manipulation of Bees-Dependent upon Weather Conditions ................ 481

Important Requisite ........... 40 
Essentials .................. 481

Tools .................481, 485

Manipulation of Supers..........491, 493

Manufactured Honey, So-called........188, 189

Manum Swarming-device ............ 709

Marigold ........................ 494

Marketing-Granulated Honey . .......352, 354 Honey Locally ................ 495

Mating Flight - of Queen.........597, 598 of Drone and Queen...........229, 231

May Disease .................... 227

Mehring, Inventor of Comb Foundation..... 448

Melting Honey in Capping-melter......... 350

Mice Destroying Bees................. 244

Migratory Beekeeping . . . . . . . . . . . . . 499

Milkweed ..................499, 501

Miller, C. C., —on Cell-killing .......669, 700

Smoke Method of Introducing......... 442

Treatment of European Foul Brood..... 305

Record-book ................ 615

Mosquito Hawks Destructive to Bees....... 246

Moth-miller-Adult ............... 507

Blessing in Disguise?............ 504

Control of .............. 516

Destruction of ............516, 518

Eggs .................... 509

Habits ................ 507

in High Altitude............... 504

Killed by Freezing.............. 503

Larvae of .................. 512

Natural Enemies of ............ 514

not a Dread to Modern Beekeeper....501, 502

Origin and Distribution of ......... 507

Prevalent in the South........... 503

Three Species ................ 502

to Determine the Presence of ......... 402

Movable Frame. See Frames.

Moving Bees-Automobile Truck for....... 524

How to Load............... 521, 522

Several Miles .................. 521

Short Distances ............519, 520

Shutting Bees in Hive.........523, 524

Mulberry Swamp .................. 336

Mustard, Two Kinds............... 527

\section{$\mathbf{N}$}

Nature's Way of Rearing Queens.

Nectar-Amount Carried by Bee

Composition of

Definition of

How Bees Deposit Their Load.

Secretion Due to Soil Conditions ...... 530

Nervous System of Bee............... 38

Net-weight Law, Federal........120, 343, 379, 456

Non-swarming Hive . . . . . . . . . 706

Nosema Apis ....................... 226

Nuclei-for Increase . . . . . . . . . . . 531

for Queen-rearing ........... 589,591

How to Feed..................... 532

Somerford Plan ............... 532

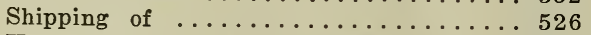

Upper Story for Queen-rearing. . . . . . . 589

Nucleus-Baby Hard to Handle........... 530

Boxes, Filling ............... 590, 591

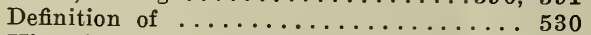

Hives in Grocery Windows........405, 535

Purpose of ................. 530

Nuisance, Bees Never...............464, 467

Number of Bees to Colony.............. 5

\section{0}

Observatory Hives-at Honey Exhibits....414, 416

First Used .................. 534 in Groceries .................. 505,535 in Public Schools................. 535

Maintenance of ............... 538

Miller's ................... 536

with Combs Crosswise ............. 535,538
Odor-from Honeybee ..........6640, 641 from Queens ................... 639

Ohio Foul-brood Law.............. 471

Olfactory Organs of Honey-bee........637, 639

Opening Hives. See Manipulation of Colonies.

Orange Bloom ..................539, 540 Distribution of $\ldots \ldots \ldots \ldots \ldots \ldots \ldots 540,541$

Honey, Quality of . . . . . . . . . . 541

Ordinances Declaring Bees a Nuisance....... 464

Out-apiaries-Automobile for ......... 547 Caution Concerning ............. 551

Definition of $\ldots \ldots \ldots \ldots \ldots \ldots \ldots \ldots \ldots 41$

Distance Between ............... 542

Distribution of ............543, 545

General Management of........548, 549

Hauling Bees to................ 546

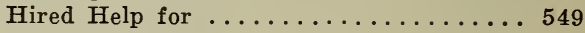

Number of Colonies in............ 541

Profits in .................. 578

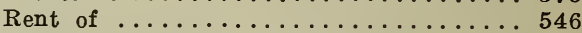

Robber Cloths for............... 548

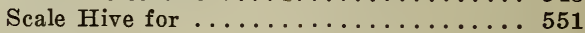

Tools for ................... 548

Wintering at ............. 550

Outdoor Feeding ..................... 291,292

Overstocking and Priority Rights......551, 552

\section{$\mathbf{P}$}

Packing-Bees in the Spring. See Spring Management.

During Winter, Advantages ......370, 450

Material, Best Kinds of . . . . . . . . 789

Needed in South ................. 805,806

Palmetto-Cabbage ................... 553,55

Crop, Quality of Honey............ 555

Palmetto-Honey of, from Cabbage........ 554

Scrub ................... 554

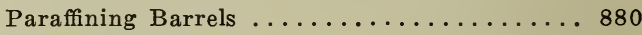

Parasites on Bees...............244, 245

Parthenogenesis $\ldots \ldots \ldots \ldots \ldots \ldots \ldots \ldots \ldots \ldots 5,556$

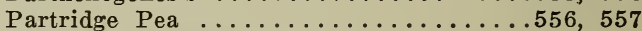

Pasturage, Artificial .............. 71

Patents Relating to Bee Culture............ 557

Peddling Honey. See Honey Peddling, also Shipping-cases.

Pepper-tree ...................... 558

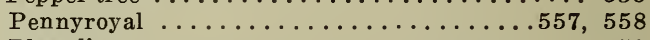

Phacelia ................... 558

Phillips and Demuth on Winter Temperature. 728

Phillips on Wintering in the South....... 806

Plain and Beeway Sections............ 192

Plant Lice One Source of Honey-dew . . . 410,411

Plants that Yield Nectar...........425, 429

Playspells-How Distinguished from Robbing.. 558

of Young Bees.................. 558

Poison of Beestings ................... 687

Polarization of Honey . . . . . . . . . . 382

Pollen-...........88, 330, 377, 559, 569

Basket of Bees ........... 561,563

Behavior in Collecting ......... 560

Characteristic in Honey .............. 377

Combs, Arrangement ............. 87

Definition of $\ldots \ldots \ldots \ldots \ldots \ldots \ldots \ldots \ldots 59$

from Milkweed .............. 501

Gathered from Stables.........567, 568

Grains, Size of ............. 560

in Comb Honey ................ 569

Necessary for Brood-rearing .......... 565

Substitutes for ............. 567

Plants ................... 423, 425

Pollination-Alfalfa $\ldots \ldots \ldots \ldots \ldots \ldots \ldots \ldots \ldots, 27$

Apple ...................... 330

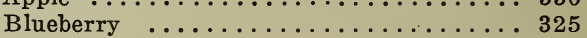

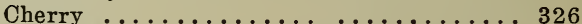

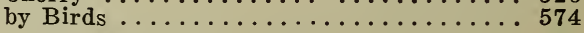

by Solitary Bees .................. 662

by Water ................ 573

by wind $\ldots \ldots \ldots \ldots \ldots \ldots \ldots \ldots \ldots \ldots \ldots \ldots \ldots \ldots \ldots \ldots \ldots, 572$ 
Conclusions on $\ldots \ldots \ldots \ldots \ldots \ldots, 333,334$

Cranberry .................. 325

Cross .............88, 331, 559, 571

Cucumbers ................. 320

Currant and Gooseberry ............ 325

Darwin's Conclusions ............. 571

Flowers ...............569, 577

Fruit Bloom .............316, 335

Immense Value of $\ldots \ldots \ldots \ldots \ldots 316,317$

Orange .................... 332

Peach ............................ 328

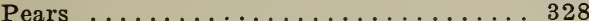

Quince ...................... 332

Raspberry and Blackberry .......... 324

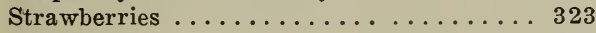

Tomatoes .................... 321

Poplar Honey ................ 737

Pouder's Method of Liquefying . . . . . . 348, 349

Pound of Bees, Number in . . . . . . . . . 769

Power-driven Honey-extractor . . . . . . 262-265

Presses. See Wax-presses.

Priority Rights and Overstocking ..... 551, 552

Profits in Bees ................. 577

Propolis-do Bees Need? . . . . . . . . . . 580

How Gathered ............. 85, 578

to Keep off Fingers ............. 579

Value of $\ldots \ldots \ldots \ldots \ldots \ldots \ldots \ldots \ldots 50$

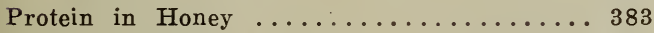

Pumps for Elevating Honey ........264, 265

Pupa of the Honeybee . . . . . . . . 222, 223

Quadruple Winter Cases .......... 780, 785 Quahking of Queens .............595, 596 Quality of Comb Honey and Extracted ..... 188 Queen-After Leaving Cell ............ 594

Age of ..................... 18

Cage Candy ........................ 157

Cells vs. Virgins .............. 588

Determining Whether Present ........ 446

Does She Lead the Swarm?...... 692, 693

from Worker $\mathrm{Egg} \ldots \ldots \ldots \ldots \ldots \ldots \ldots 593$

Getting Cells Accepted............ 585

How to Free from Ball .......... 447

Larva, Food for ............ 593, 594

Loss of .....................603

Mating Flight ............597, 598

Most Important Personage .......... 592

Nursery Cages for............ 587589

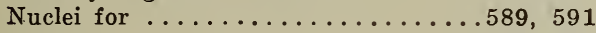

Odor of $\ldots \ldots \ldots \ldots \ldots \ldots \ldots \ldots \ldots 6,604$

Rearing, Cell Cups for ......... 583, 585

Rearing, Conditions Favorable for ..... 581

Rearing, Doolittle Method ........... 582

Rearing Extensive ............... 583

Rearing, Forced Cell Starting ....... 586

Rearing, Who Should Engage in?..... 581

Record-keeping of ............6 617

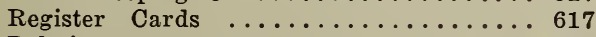

Relation to the Bees ................ 439

Structurally Like Workers . . . . . . . . 592

Turning to Drone Layer ... . . . . . . . . . 602

Queenlessness, Caution Concerning ........66 604 How to Detect.......446, 596, 603, 604

Queens-Age when they Mate ...... 596, 597 Behavior of $\ldots \ldots \ldots \ldots \ldots \ldots .67,595,596$ Breeding .................. 123, 124 Clipped ................. 706 Clipping . ............599, 600, 698

Development of $\ldots \ldots \ldots \ldots \ldots \ldots \ldots 593,595$

Finding on Good Combs ............ 618

Drone-laying ..................... 598

Finding on Good Combs ............. 618

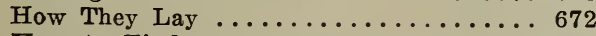

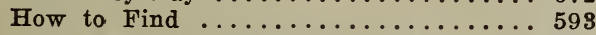

How They Lay Two Kinds of Eggs ..601, 602

Jealous Rivals ............... 438

only One in a Hive ............... 6
Reared from Swarming Cells ......... 581

Restrained by Zinc ............. 706

Stings .................... 604

Supersedure of $\ldots \ldots \ldots \ldots \ldots \ldots \ldots \ldots 438$

Two in a Hive ................. 595

Undersized .................. 592

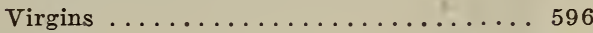

Voices .................. 595

While in Queen-cells ............ 594

Who Should Raise? .............. 581

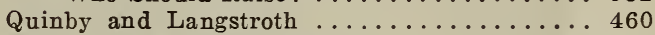

Quinby, Biographical Sketch of .........66 604

Book ........................66 608

Closed-end Frames . . . . . . . . . . . 606

Hive ...................... 366

Self-spacing Frame ........... 308

\section{$\mathbf{R}$}

Races of Bees

609,613

Raspberry-Honey, Quality ...........6 613

Wild, Northern Michigan ........... 614

Rats .................... 614

Rauchfuss Boiler for Liquefying Honey .... 347

Rearing Queens. See Queen-rearing.

Record-keeping of Hives .......551, 615, 635

Red Clover and Bumblebees ........... 166, 168

Reducing Sugars in Honey ........... 382

Rendering of Wax ............ 757, 765

Resinous Gum from Bees ............ 578

Respiratory System of Bee............ 35

Resting Periods of Bees ............... 86

Reversible Extractors ........... 261, 262

Reversible Frames ............... 617, 618

Rheumatism and Stings ............ 687

Ripening Honey and Comb-building ....... 86

Robber-Cages ..............6624, 625 Cloth for Handling Robbers ......... 548 How it Slips out of a Hive ........ 620 Once, Always a Robber ............6.623 Traps .................. 623,627

Robbers, How Recognized .......... 619,622 When Putting up Defense ..........6629 Where Belong ................. 622

Robbing-Cause of Crossness.........40, 41 Consequences When not Stopped .......6 630 Cured by Outdoor Feeding ........... 629

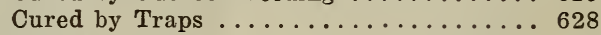
Defined ......................... 618 How Stopped .......... 622, 624, 628 of Nuclei or Weak Colonies .........6623 on Carload of Honey .............6 621 vs. Borrowing.

When Bees Will Not ............. 621

Working Bees at Night ............. 629

Rocky Mountain Bee-plant .............6631

Rolls for Making Foundation .......... 175

Root-Automatic Reversible Extractor ......261 Bee-veil ................745, 746 Grading Rules .................. 343

Reminiscence of Langstroth ........ 459

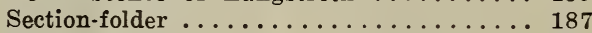

Smoker .................. 656

\section{$\mathbf{S}$}

Sacbrood ................... 305

Safety Cartons .................6654

Sage Honey, Source of ......... 632,633

Sage Honey, Quality of . . . . . . . 632, 634

Sage, Mountain ..............6632, 635

Salivary Glands ........................ 35

Sawdust a Substitute for Pollen ......... 568

Scale Hive ..................551, 635

Scales of Wax from Bees .........4 400, 401

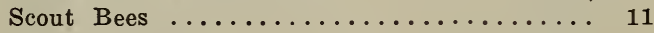

Scraping Sections ............. 202, 203

Sealed Covers vs. Absorbent .........788 789

Section-folder, Root .............. 187 
Section Honey-box, Evolution ............ 177

Invention of $\ldots \ldots \ldots \ldots \ldots \ldots \ldots \ldots 449$

Section Separators ..............8, 206

Sections-Bait, for Comb Honey . . . . . . . 199

Glass .................. 207

How to Keep Propolis from....... 579

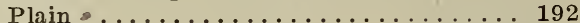

Scraping . . . . . . . . . . . 202

Tall vs. Square ...........206, 207

to Free from Bees ............... 200

Travel-stained .....................

Unfinished ................203, 204

What Size to Use ................. 206

Self-spacing Frames. See Frames, Self-spacing.

Selling Honey. See Marketing Honey.

Sense Organs of the Honeybee ......6.636, 645

Sense of Touch in Bees ............... 643

Senses, Other, of Bees ............... 644

Sentinels at the Entrance ............. 619

Separators, shall they be Used? ........... 206

Shade and Its Relation to Swarming ...... 703 for Apiary ..............50, 703 Boards ................. 51, 52

Shaken or Brushed Swarming ........72, 73

Shipments of Bees, Water for .......... 648

Shipping Bees ................6. 645, 650 in Carlots ............... 645, 649 Without Combs ............ 526, 649 See Moving Bees; also Migratory Beekeeping:

Shipping-cases-Better, and Why ........ 652 Economy to Use Good Ones .......... 652 for Comb Honey . . . . . . . . 6 650, 654 of Paper .............. 753,654 Old Style .................651

Shipping-cases, Various Styles .......6 651-653 Shrubbery, Effect on Bees' Temper ........ 42 Simmins' Method of Introducing ...........446 Size of Bees not Determined by Cells . . . . . . . 407 Skeps for Bees .................. 654 Skunks Destructive to Bees ..........245 Slate Tablets for Hive Records ......... 617 Slip-gear Device for Extractors . . . . . . . . 262 Smell and Taste of Honeybee ....6636, 638, 641 Smoke Method of Introducing Queens ..... 442 Smoke not Always Preventive of Stings .... 688 Smokers-Abuse of ........... 659, 660 Cold-blast . . . . . . . . . . . . 6 657, 658 Different Styles of ......... 656, 658 Fuel for ................ 658, 659 Hot-blast . . . . . . . . . . . 656, 657 How to Use . . . . . . . . . . . 659, 661 Importance of $\ldots \ldots \ldots \ldots \ldots \ldots \ldots 64$ Invention of . . . . . . . . . . . . 449

Smothering Bees by Closing Entrance ..... 751

Soil for Growing Buckwheat ........... 134 Improved by Sweet Clover . . . . 715,716 Inoculation for Alfalfa ............. 22 Inoculation for Sweet Clover . . . . . . . 722

Solar Extractor Not Suitable for Old Combs. . . 757 Heat for Liquefying ............. 118

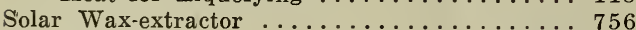
Solitary Bees ................662, 668 Somerford Method of Forming Nuclei ....... 532 Sourwood as a Honey-bearing Tree ........668 668

Spacing-and Its Relation to Swarming ..... 670 of Frames ........98, 307, 308, 669, 670

Spanish Needles ................. 670

Specialty in Bees............6670, 671 Specific Gravity of Honey .......... 671, 672 Spermatozoa of Drones............. 38 Spiders, Enemies of Bees ............... 246 Spraving Destructive to Brood ........... 313

Spray-pump for Controlling Swarms ....... 711 Spreading Brood ...............66 672, 674

Spring Dwindling .............6672, 775

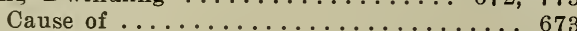
Remedy for .....................6. 673
Spring-Management ...........674, 676

Protection, Advantages of .......... 370

Square Cans, Automatic Fillers .......... 280

Starting in Bees .................. 109

Starvation During Winter in South . . . . . 806

States Best for Keeping Bees ..........475

Statistics of the Honeybee ....... $2,675,679$

Steam-for Fastening Foundation ...... 185, 186

for Bottling Honey ............. 117

Wax-presses .............760, 761

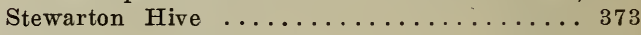

Sting-as a Remedial Agent ............ 687

Does Bee Die After Losing?........... 688

How to Remove . . . . . . . . . . . . 681

Odor of $\ldots \ldots \ldots \ldots \ldots \ldots \ldots \ldots 687$

Stinging of Horses, to Treat .......101, 682 Severe Cases .............. 682, 684

Stings $\ldots \ldots \ldots \ldots \ldots \ldots \ldots \ldots \ldots 33,679,690$ and Rheumatism ............. 687

Aggravated by Bee-killing . . . . . . . . . 685

Becoming Immune to ........... 683

Bugaboo of $\ldots \ldots \ldots \ldots \ldots \ldots \ldots \ldots \ldots 2,679$

Fear of ................ 679

Importance of Removing Immediately.... 681

Pain of ................ 680

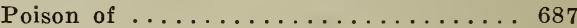

Queens' ...................... 601

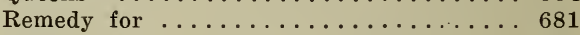

Structure of $\ldots \ldots \ldots \ldots \ldots \ldots \ldots \ldots 6 . \ldots \ldots$

to Avoid ...............6.680, 686

When Operator is Sweaty ..........6686

When Worse ............. 685, 686 See Manipulation of Colonies.

Stores for Winter . . . . . . . . . . 789

Straining Honey ................ 266

Straw Skeps. See Skeps.

Sub-earth Ventilators ................ 791

Sucrose .................... 382

Sugar ....................... 690

Sugar, Invert .................. 451

Sulphur for Bleaching Comb Honey ........ 113

Sumac ................6690,691

Honey of ...............6691

Sunflower . . . . . . . . . . . 691, 692

Supers for Comb. Honey ........... 190, 191

Comb Honey, to Put on ........... 196

Manipulation of ........... 491, 493

When Bees Refuse to Enter .......... 199

Supersedure and Swarming Cells for Queen

Rearing ................. 581

Superstitious Beliefs ................. 122

Swarm-Carrying on Bicycle.......713, 714

Catchers ............... 10, 712

Control by Clipped Queen ........... 707

Control, Dadant on ............... 704

Control Easier in Extracting Colony .... . 698

Control, Fowls' Method ............ 701

Controlled by Spray-pump .........711

Checked by Foundation ............ 694

Due to Crowded Condition .......... 693

Getting from Inaccessible Limbs ...... 711

Hiving-book ................... 709

Hiving With Clipped Queen......... 707

Hiving Without Special Devices ..... 709,713

is It Led by Queen? . . . . . . . . 6 692, 693

Led by Young Queen .............. 693

Occasioned by Queen-cells .......... 694

Stopped by Caging Queen ........... 694

Swarms, Absconding .............. 11

and Bell-ringing ............... 12

Plural, Uniting ................ 714

Restrained by Clipping ............. 12

Second ................. 17

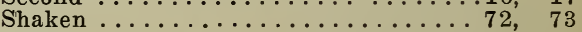

Swarming-a Means of Increase ........ 692 and Its Relation to the Spacing of Frames 670 Affected by Locality .......... 695, 697 
Artificial

Cause of

Cells for Queen-rearing ........... 581

Checked by Cell Cutting............699

Checked by Giving More Room ...... 702

Checked by Giving Shade .......... 703

Checked by Non-swarming Stock ....... 703

Checked by Ventilation .........702, 703

Checked or Controlled ............6.698

Defined ....................... 692

Derices Variously Constructed .... 708, 709

Fundamental Cause of ........... 694

Indicated by Cells ................ 602

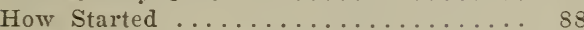

Less With Young Queens ............. 699

More Difficult with Comb Honey ......... 698

Natural rs. Artificial ............... 72

Preparations for ...........697, 698

Prevented by Dequeenin $\%$......... 694, 701

Prevented by Large Hires . . . . . . . 366, 368

Stopped by Dequeening ............ 701

Srmptoms of ............ 697, 698

Time for Bees to Get Out ........ 692, 693

Sweet Clover-Among Growing Coin . . . . . 722

as a Cover Crop ............... 726

as a Forage Plant .......

as a Honey-plant

as a Soil-improver

Character of

Feeding of $\ldots . \cdots$

General Summary of ............. 726

Growing for Seed .............. 726

How Much to Sow ............... 725

Hay of .............. 718, 720

Inoculation of Soil .............. 722

Laws Relating to ............... 714

Making Seed Germinate ........724, 725

Iore Virtues of .................. 726

Not Noxious Weed .............. 725

Pasture of .............. 716,717

Scarifying the Seed .............. 725

Seed .................... 721

Straw after Thrashing ........... 722

Varieties of ............... 714

with Oats .................. 721

World-wide Adap ability ......... 715

Symptoms of Foul Broct ......... 296, 302

Syrup, to Make ............. 283, 284

\section{T}

Taste Organs of Honeybee

Temper of Bees, Cause of

Temperature-of Honey for Bottling ........ 115

of the Winter Cluster .......... 727, 730

to Arrest Granulation ............. 209

Tenement Hire, Greiner's Method ........... 786

Bartlett's .............. 780, 781

for Wintering ............ 779,788

Thermometers for Testing Clusters . . . 7 728, 729

Thorax of a Bee .............. 30, 31

Tin Cans for Extracted Honey ...... 258, 259

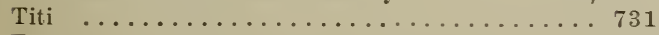

Tongue of a Bee .............. 31, 32

Tongue Reach of Bees for Red Clorer........ 168

Tools-for Handling Bees ............ 9, 10

for Manipulating Colonies ....... 481, 485

for Rearing Queens ............. 584, 585

Touch Sense in Bees ................ 643

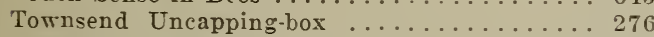

Trainload of Honey ..........6676,677

Transfer, When to ................... 733

Transferring-Definition of ......... 731

Guernsey Method ............... 731

How .................. 732, 733

Short Way of .............. 734

Heddon Short Method of ........... 735

Traps, Robber ..............6 626, 627

Trarel-stained Sections . . . . . . . . . 345
Trousers for Beework . . . . . . . . . . . 749

Tulip-tree $\ldots \ldots \ldots \ldots \ldots \ldots \ldots \ldots \ldots$ 736, 738

Tunisians ................. 611

Tupelo on the Apalachicola Rirer ......739, 741

Different Species of ........ 738, 739

Honer, Quantity and Quality ........ 741

\section{U}

Uncapping-Appliances .........274, 276

Box, Townsend's ............. 276

Combs ...................... 272,274

During Extracting ............ 273, 274

Knife, Steam, Inrention of . . . . . . 449

Melters ..............277, 279

Unfinished Sections ............... 203

Uniting-Difficulties of ........... 742

Alexander Plan ............... 743

Caging Queens for .................. 743

Colonies in the Spring ...........6 675

Definition of .................... 742

in the Spring ................ 743

to Prerent Bees Going Back . . . . . 742, 743

Two Swarms .................. 743

Weak Colonies, Alexander Plan ........ 743

Utter vs. Utter Case .............. 106, 469

\section{V}

Van Deusen's Reversible Frame

618

Veils

Coggshall's

Grass Front

$7+5-749$

Globe Bee ................. 747

Hot for .................. 745

Mrs. Holmes' . . . . . . . . . . . . 748

Objection to ............... 745

Strout's ................ 749

to Arert Stings ................ 684

Wire Cloth ................... 746

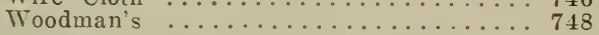

Ventilating, How the Bees do their Own....7751

Ventilation-Swarming ............. 702

by Lifting Hive on Four Blocks ....... 751

by Lifting Corers ............. 750

During the Winter ............... 751

of Cellars ............. 790, 791

Sub-earth ............. 790,791

Thru Entrance ........... 749,750

Vinegar ................... 752

Virgin Queens .............. 596, 597

to Introduce $\ldots \ldots \ldots \ldots \ldots \ldots \ldots 447,588$

\section{W}

Water-for Bees ............... 753

for Bees in Carload Slipments ......6 618

for Brood-rearing ............. 753

During Shipment ................ 753

Wax-Amount in Sections ........... 767

Cleaning from Utensils . . . . . . . . . 769

Crude Method of Rendering ........ 757

Different Kinds of ................ 754

Float Test for ............ 769

How Bees Make ............... 775

Used in Arts ................... 755

Press, Hatch-Gemmill ... . . . . . . . 762

Press, Hot-water . . . . . . . . . . . . . . 759

Press, Salisbury's . . . . . . . . . . 762

Press, Steam .............. 760, 761

Press Used for Cheese ............ 761

Produced in the United States ........6.678

Rendered by A. C. Miler Plan ........ 758

Rendered by Centrifugal Force ....... 758

Rendering, Crude Methods of . . . 757, 758

Rendering in Root Machine .... 763, 766

Rendering of Combs, Diseased ....... 767

Scales from Bees ............4400, 401

Secretion Favored by High Temperature. 401

Separation from Hones ....... 278, 279

Solar Extractor ................. 756 
Test for Purity of . . . . . . . . . . 769

Voluntary or Involuntary .......4 400, 401 Worm. See Moth-miller.

Weed Sheeted Foundation ............ 177

Weed Invention of Foundation . . . . . . 449

Weight of Bees ............. 769, 770

Weight of Honey ............. 671, 672

West's Bee-cellar .................. 798

White Clover ..................... 162

White on Peddling Honey ........... 419

White Poplar. See Tulip-tree.

White Sage ..................... 633

Whitewood. See Tulip-tree.

Wild Cherries ................... 770

Wiley on Honey ..................... 377

Willow ................ 771, 772

Willowherb .............. 772, 774

in Michigan ................. 774

Honey from .............. 774

Windbreak for Apiary ........... 53

Windbreak, Importance of $\ldots \ldots \ldots .543,786,787$

Wings, how they Determine the Age of Bees... 17

Winter-case, Holtermann's ... . . . . . 780,782

Case, Objections to ............ 786

Case, Quadruple ..............370, 780

Case, Size of $\ldots \ldots \ldots \ldots \ldots \ldots \ldots \ldots 78$

Entrances .................. 789

Feeding in Cellar.............796, 798

Flights of Bees ............... 790

Filling of Clovers ............. 171

Nest, Letting Bees Form . . . . . . 787, 788

Packing ................. 783

Packing, Best Kinds of .......... 789

Packing, Need of in South. . . . . 804,806
Sleep of Bees ............ 803, 805

Starvation ................. 806

Temperature of Cluster.........727, 730

Stores, Quality and Quantity ........ 789

Ventilation ...........751, 790, 791

Wintering-Aster Honey for .......... 75

at Out-apiaries .............. 550

Four Hives to Case . . . . . . . . 780, 785

in Cellars ................790, 802

in Clamps .................... 801

Indoor and Outdoor Methods of ...775, 776

Indoors, Important Requirements ... 795, 796

in Double-walled Hives ........ 777, 778

in House Apiaries . . . . . . . . . . 69

in Quadruple Cases ........370, 779, 788

in Single-walled Hives ........... 777

in Southern States .......... 805, 806

in Warm Room ............... 70

New Methods of .................. 775

Outdoors ...............776, 790

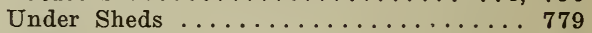

When to Put Bees in Cellar ........ 793

Windbreaks for ...........77, 786, 787

With Hives Packed in Papers ........ 778

Wiring-by Electricity ............... 182

Frames ................ 178, 181

Imbedding in Foundation ............ 181

Women Keeping Bees .............. 95, 98

Wood Splints for Comb Foundation ....... 180

Worker Bees, Duties of ............. 5

Combs from Starters ............ 212

\section{$\mathbf{X}$}

Xylocopa ...................8806 



